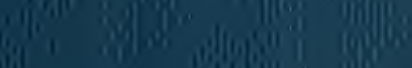

年,

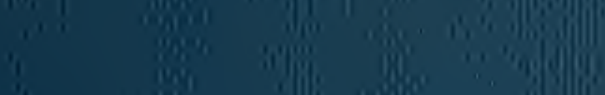

Iil

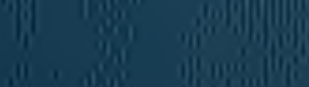

Sol

ind

20. 告, 3
5

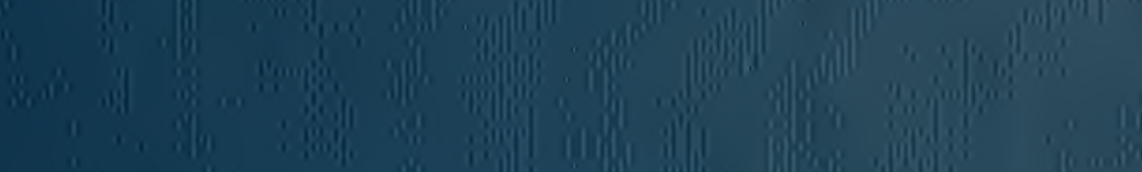

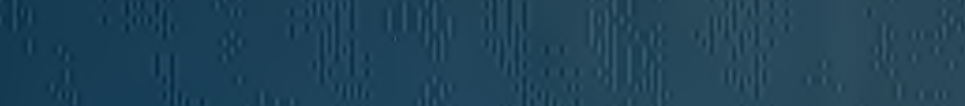

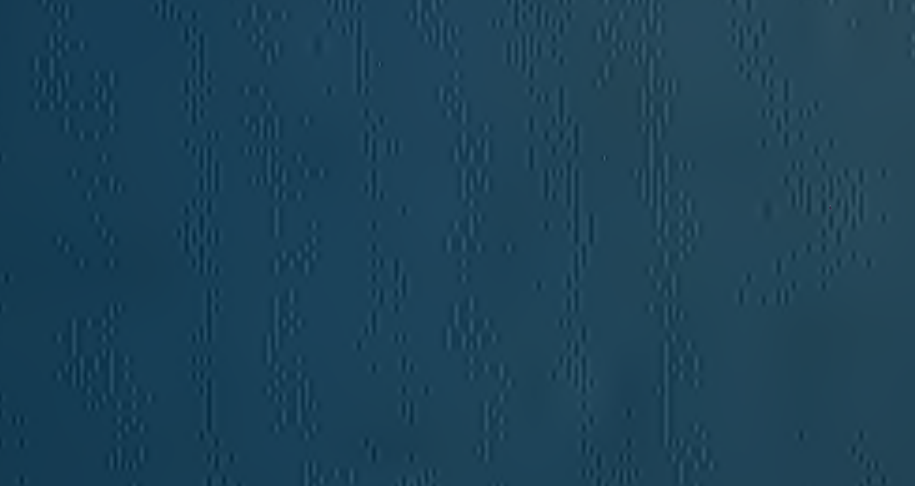
' ,

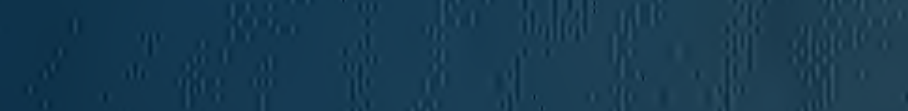

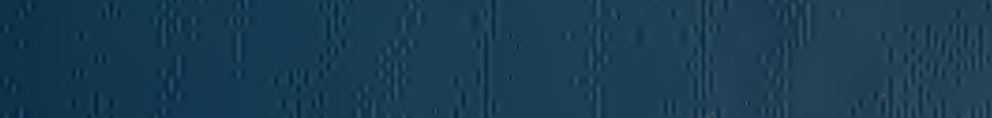
" i "

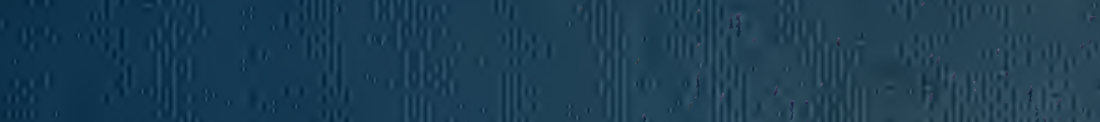

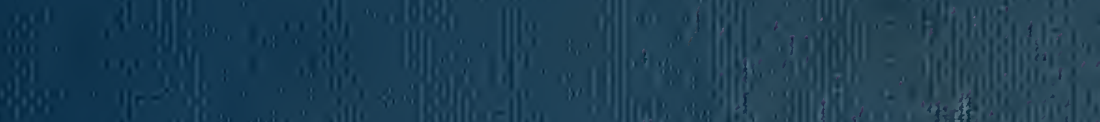
960" (i) ail 


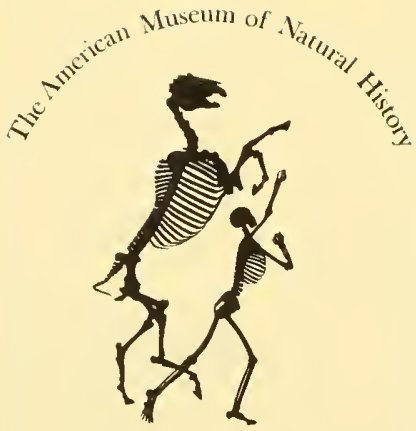

1869

THE LIBRARY

Gift

Sydney Anderson 






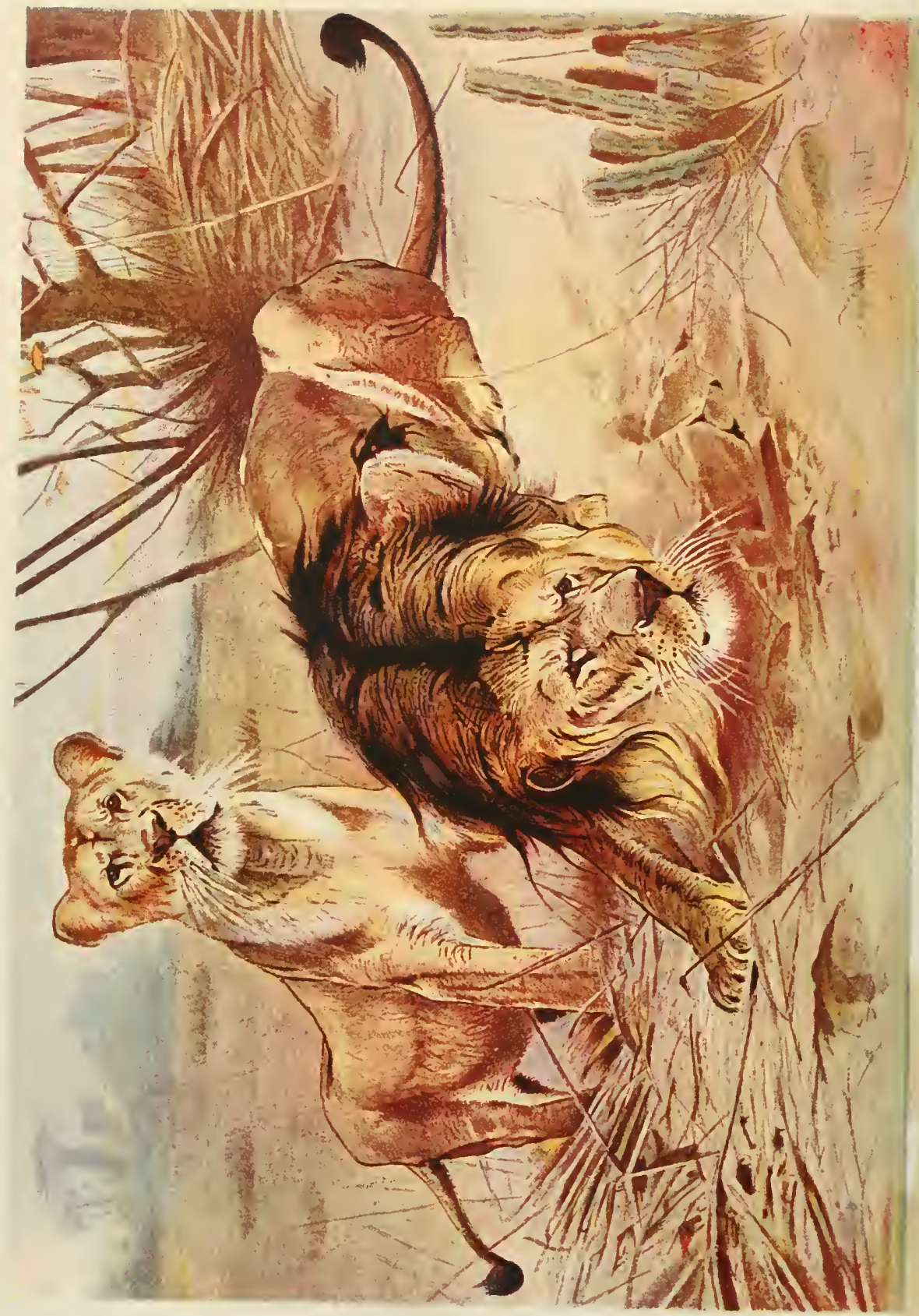




\section{THE ANIMALS OF THE WORLD.}

\section{BREHM'S}
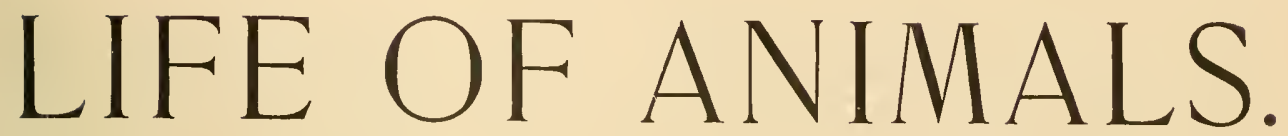

A COMPLETE NATURAL HISTORY FOR POPULAR HOME INSTRUCTION AND FOR THE USE OF SCHOOLS

BY

DR. ALFRED EDMUND BREHM.

COPIOUSLY ILLUSTRATED WITH WOOD CUTS AND COLOR-PLATES BY FR. SPECHT, W. KUHNERT, G. MÜTZEL, R. KRETSCHMER, W. CAMPHAUSEN, L. BECKMANN, E. SCHMIDT,

T. F. DEICKER, P. MENERHEIM, ETC., ETC.

VOLUME I.-MAMMALIA.

BROUGHT DOWN AND ESPECIALLY ADAPTED FOR THE USE OF ENGLISH READERS.

Transiated from the Third German Edition as edited by Prof. Dr. Pechuel-Loesche and Dr. William Haacke, and revised and abridged by Prof. Richard Schmidtlein.

CHICAGO :

A. N. MARQUIS \& COMPANY.

1895. 
Copyright i894 by A. N. Mlarguis \& Co., Chicago.

Copyright i895 by A. N. Marquis \& Co., Chicagá 


\section{INTRODUCTORY PREFACE.}

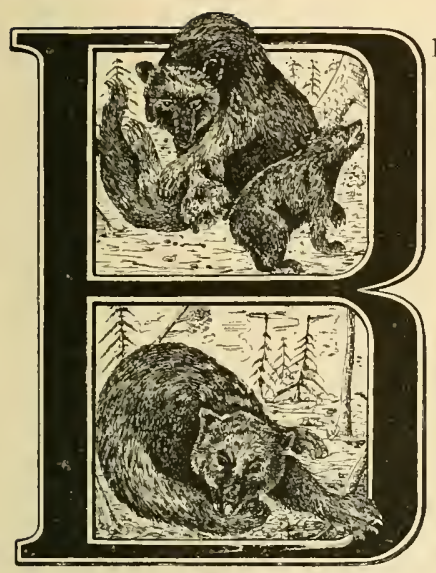
omitted details and descriptions of a strictly scientific nature, the object being to furnish a book for popular home instruction and for the use of schools. Professor Schmidtlein, in his scholarly and entertaining revision, made such changes as the progress of modern science demanded and perfected his work in a manner to call forth the highest praise from critics everywhere.

The present edition has been translated from the German by linguists of distinction who have in the happiest manner transferred to the English tongue the rich, exuberant and fascinating style of the original; while competent scholars have carefully revised the translation, making only such changes as were calculated to bring it closer to the mind of the English reader. These changes are either inclosed in brackets, or are set in smaller type than the body of the work. The short sketches introduced under the pictures, independent of the text, are also the work of the American editors. This edition is, therefore, practically a complete work brought down to date, containing substantially all the matter to be found in Brehm's "Life of Animals," adapted to meet and reach the popular taste, and rendered into English in such manner as to make it clear and intelligible to every one, the child as well as the adult, only those animals being omitted which are little known and of interest to none but specialists.

The book is designed to meet in the highest degree a great popular need, technical terms and long scientific descriptions being avoided, whenever possible, and it is invaluable as a work of reference and of study. It not only contains narratives of Brehm's exciting personal experiences and observations in forest and field, but also those of all other leading naturalists and explorers of the world, - whose intimate touch with animate nature inspired them to speak in words that glow with interest and that thrill the reader.

I most attractive feature of the present work is the superb illustrations, which include, with few exceptions, all that are contained in Brehm's complete work, and also numerous additions designed and executed at great expense and including the best efforts of the greatest artists in delineation of animal life. The work of these distinguished artists, supplemented with faithful mechunical reproductions, has resulted in the presentation of the various animals precisely as they appear in a state of nature, the figurcs being of a size to enable the student to obtain a most accurate knowledge of each creature, while parents and teachers can be assured that nothing is exaggerated, but that every detail is given with absolute fidelity. Too frequently it is the case that children are shown mere caricatures of beasts 
and birds, executed without artistic sense and in entire ignorance of the structure of the animals. The pictures in this work are faultless, all of them having been reproduced from living subjects and showing the hand of the master in every line. No such extended and comprehensive system of illustration of animals was ever before undertaken and this feature of the work alone must make it invaluable to every one who seeks acquaintance with those creatures, which, while they cannot speak, are so closely connected with the life of Man, contributing in some part at least to his support, his enjoyment and his amusement.

Interest in natural history is extending, as Man's scope of vision enlarges and he grasps more firmly the thought that the lower animals enter so closely into his own life and form so important a part in the great economy of nature. The great Scheitlin, as quoted by Brehm, has truly said, "The brute's fate is like ours. It is oftentimes made to share Man's fate, or Man shares its fate; it perishes with him in fire and water and battle. It is a pity that Man forgets that the higher animals, at least, know the difference between treatment that is good and treatment that is bad." Man is greatly in debt to the humbler creatures, which supply them with their flesh for food, their hide, their hair and their horns. It has been truthfully claimed that Man could not live in comfort if deprived of the service rendered by animals in life or death. They supply meat, milk, fat, perfumery, drugs, fur, wool, feathers, ivory, bone and a thousand other useful and ornamental commodities. They are companions, as the Dog, the Monkey and certain birds; beasts of burden, as the Horse, Ass, Ox, Camel, Llama, and afford endless sport and diversion for hunters, who, unfortunately, are too frequently cruel and make unnecessary slaughter of the defenscless. The student finds in the successive steps of animal life order and arrangement and takes delight in classifying the creatures according to their station, observing the points of difference, and determining the uses and adaptations of the individuals to their environment.

Extending the thought of imparting facts to the youthful mind, it might be shown that seven vertebre usually form the neck of the vertebrate animals, whether it be the Giraffe or the Mole; but that in the tail they vary from four to forty-six. It might also be shown that the muscles of animals set the bones in motion, and that these muscles form meat, which in certain animals is the food of Man It is interesting to note that Man alone of all the mammals walks erect; that the flight of swift bird: is far more rapid than that of the most fleet mammal; and that the Bat cannot really fly because bird: alone can do this, but that they flutter in the air. Men who have not been taught to swim, the Manlike Apes and the Baboons, are the only mammals which are unable to sustain themselves in water; while the Whale and the Sea-Lion, the Dugong and the Manatee, spend their entire lives in the se.. Take the eye of the animal, which is the most expressive part of its face, and there can be seen in it in many cases the character of its individual possessor, as the wicked eye of the Snake, the piercing eye of the Eagle; this being especially true among nammals, as the dull eye of the Cow, the mild one of the Gazelle, the stupid ones of a Sheep, the false ones of a Wolf, etc.

Characteristics, traits, etc., are thus observable in all the creatures, from the highest to the lowest, and may be pointed out, emphasized and indelibly impressed upon the mind of the young, especially by aid of the incomparable pictures contained in this work. The advanced reader and student will discover a complete and perfect system, extending from the highest Ape to the lowest creature, each in its place and every one well defined and accurately described.

It will be seen that the creatures are distributed all over the world and that America contains a larger variety and more interesting types, especially of higher animals, than the other portions of the globe. In the northern part are the Bison, the Prairie Dog and the Opossum, while in the southern portion are prehensile-tailed Monkeys, Vampires, Peccaries, Llamas, Alpacas and various Edentata, that are peculiar to these localities. In the representation of the various belts of earth the division made by Wallace is followed in this work. It will be seen that, as a rule, the color of an animal corresponds closely with its surroundings; that the majority of mammals live in flocks, each having a leader, that may be male or female; that when awake most animals are employed in search for food; that Birds eat more than mammals and that the former are much more active than the latter.

The comprehensiveness and interest of the work must be discovered in a perusal of its pages, as only brief and disconnected references have here been made as to its scope and general value. It covers a field not hitherto occupied in this country, embracing as it does the most thorough information with most graphic narrative, the whole embellished by artistic illustrations which so faithfully portray the lineaments of the animals as almost to make unnecessary the work of verbal description. Such a work as this, within the mental grasp of all, must enter the home and the school and result in a wide dissemination of additional knowledge concerning the beasts of the field, the birds of the air and all manner of creeping things. 


\title{
THE LIFE OF ANIMALS.
}

\author{
PRELIMINARY NOTES ON MAMMALS.
}

However superficially the student or reader may examine any subject, the necessity for some system in the arrangements of the facts will at once be apparent. This is especially true in connection with investigation into the truths of nature, and more particularly those connected with our globe. The most casual observer sees that the various natural objects, each different from the other, align themselves into larger and smaller groups having some one or more characteristics in common. The systematic arrangement of these classes, the division of then into smaller groups, the proper classification of names for these segregated assemblages of things, and the orderly presentation of the facts in regard to these divisions and the units of which they are composed, constitutes, in broadly generalized terms, natural science.

lin arranging the facts of nature that plan is best which is simplest: and science has begun its work of classifying the things on our globe by dividing them into three primary groups called the Animal, Vegetable and Mineral Kingdoms. Then, taking up the classification of the Animal Kingdom and looking for the first and most obvious division, it is found that one large group of animals is made up of species widely variant in other respects but agreeing in the fact that each is possessed of what is popularly known as a "backbone," consisting of a number of segments of bone or cartilage jointed together, which have been given the scientific name of "vertebre," the whole column of jointed segments being called the "vertebral column." Therefore the Animal Kingdom has been scientifically divided into two subkingdoms, known respectively as the Vertebrates (I irtebrata) and Invertebrates (Inicrtcbrata), the latter class including insects, mollusks, cephalopods, worms, snails, animalcules, protozoa and other classes of animals.

The Vertebrates have several characteristics in common besides the mere possession of a backbone. Between the backbone and the back is what is known as the vertebral canal, formed by arches of bone or cartilage extending from the vertebra, this canal being the receptacle in which is stretched, like a rope, the substance formed of nerve-tissue which is popularly known as the spinal marrow or spinal cord, and which is the main portion of the nervous system of the animal. On the other side of the backbone is placed the heart, the lungs and the stomach and other organs of digestion. The two jaws of Vertebrates are placed one above the other instead of being right and left, as is the case in insects. No vertebrate animal has more than four legs, while some of the invertebrates have a very large number. There are other physical characteristics common to all, or nearly all, Vertebrates, but their consideration involves technical explanations which would be out of place here.
Since Lamarck in 1797 suggested the division of the Animal Kingdom into the two sub-kingdoms of animals with and without backbones, this division has been generally accepted. In the subdivision of the Vertebrates there are usually recognized five classes: the Mammals (Mammulia); the Birds (Ar'es); the Reptiles (Riptilia); the Amphibious Animals, like the Frog, Newt, etc. (Amplibia), and the Fishes (I'isces).

The Mamnals, which form Class 1. among the Vertebrates, represent the hichest forms of life on our globe. Some have a much higher organization than others, but still, from the highest to the lowest, they have many characteristics in common. The primary distinction upon which the class Manmalia is founded, is the secretion in the glands of the female of a fluid for the nourishment of her young during the earliest period of infancy. In nearly all of the animals of this class the fluid secreted is milk, and the mammary glands are directly suckled by the young, which are born alive and in a more or less developed condition. In the lowest order of Mammals, however, - the egg-laying Monotremes,- the newborn, scarcely vitalized offspring is placed in a pouch and there sustained by a nutritive perspiration emitted from sweat-glands. In the order next above them - the Marsupials - the development of the animal at birth is only slightly more mature than that of the Monotremes, and the pouch for maturing the young places the infant in direct connection with the mamme of the mother, which thus supplies it with the milk needed to bring it to full life and vigor.

Mammals, besides being nurtured on mother's milk in their infancy, are also characterized by the possession of warm, red blood, circulated through the system by means of veins and arteries leading from a four-chambered heart. Fvery animal of the mammalian class agrees with the other in possessing a diaphragm muscle, or midriff, separating the cavity of the chest from that of the abdomen. For further statement of the general characteristics of Mammals we quote from the introduction to the German edition of Brehm's work, which says: "The skull is separated from the vertebral column, or backbone, in all Mammals; the upper jaw is united to the skull, and the teeth, though varying considerably in number and shape, show that in common they are in all species placed in hollows. Seven vertebra usually go to form the neck, be it long, as in the Giraffe, or short, as in the Mole. The chest or thorax part of the vertebral column (known as dorsal or thoracic vertebrx), consists of from ten to twenty-four vertebra; the lumbar vertebre, or those in the middle of the back, number from two to nine, the sacrum has from one to nine and the tail from four to forty-six. Ribs may be attached to different vertebre: but in speaking of ribs we usually 
mean the flat, eurved bones attached in the back to the dorsal or thoracic vertebre, and in front to the sternum or breast-bone and enclosing the chest cavity. The number of the true ribs reaching the sternum and of the false ones, which are either attached to it by cartilage or are not joined to the breast-bone at all, is subject to a great many variations. In the skeletons of the Mammals there is great diversity in the structure of the limbs, and in some Whales the hinder pair is totally lacking or the bony skeleton of the animal only reveals two stunted rudiments. In the fore-limbs the shoulders and the hand show the greatest variety; the clavicle (or collar-bone) may be very strong or it may be lacking; the fingers and tues may be all there, or may be stunted, according as the hands and feet become paws, hoofs or fins; the usual number of the fingers - five-may decrease to one. The bones of the leg are also variously developed.

"The bones of the skelcton are set in motion by muscles, which in some animals are for us the most important part, as they form our daily food. These muscles, which in plain, every-day speech, we call "flesh," are attached to the bones and move them in different directions. It may be sufficient to say that the muscles are developed to a close aceordance with the skeleton of the animal and the mode of life, which latter is closely allied to its form and general structure.

"The organs of digestion are very similar, yet they show some variations in their structure. The mouth is always furnished with soft, fleshy lips, plentifully supplied with nerves; the teeth reach their highest development in the Mammals, and are of great importance to the mode of life of the animal, and of special importance to naturalists in its scientific classification.

"The mouth is connected with the cesoplagus (or gullet), which never shows such a dilatation as in birds. The stomach is always more or less thinskinned, and may be plain or show as many as three compartments. Its arrangement is quite peculiar in those animals which, when time permits, comfortably ruminate their food and then send it to the digestive organs past the first storage receptacle.

"The chest cavity is completely closed by the diaphragm; the lungs float in it and do not conmunicate with any special pneumatic cavities. The trachea, or windpipe, usually divides into two branches, and has only one larynx, which lies at the upper end of the windpipc and is formed by a varying number of cartilages. A few Mammals have peculiar cavities connected with the larynx, but the vocal chords are lacking only in the Whales.

"The brain and nerves are variously developed. The former always fills its cavity in the skull, but this cavity may be very small, and the amount of brain is then accordingly slight. In no other Mammal does the brain so greatly exceed the spinal cord in bulk and weight as in Man, and in no other anjmal is the cerebrum (or the higher and front portion of the brain) so developed. This alone shows the structural superiority of Man to all other animals. The organs of sense are similar in all Nammals, the Whale alone showing a marked deviation from the general rule, for although it possesses a nose its sense of smell is certainly very deficient. The organs of hearing are usually perfeet, and the ear shows three labyrinths. The sense of vision is not, in Mammals, so greatly superior to the other senses as is the case with birds; the eyes are always two in number, usually small in size and never inwardly movable, as with the birds. The sense of taste is acute in Nammals, as may be concluded from the muscular tongue well supplied with nerves. The sense of touch is highly developed and may have its seat in the nose, in the hands or in hairs on the lips. Nearly all parts of the body are sensitive.

"As a bodily covering hair prevails; yet the coat may consist of scales, bristles, horny shields, horny callosities or simply the stin, which in such cases may have its outer layer developed so as to furnish the requisite protection. The nails may be flat and thin, round and thick, straight or curved, blunt or sharp, and may be nails proper or developed into claws or hoofs."

The variety in the life of the Mammals is very great, although with most species eating and sleeping comprise the daily history of their lives. Yet the lively Monkeys in Africa, the still more odd swinging, prehensile-tailed Monkeys of South America, the flitting Bats, the night-prowling beasts of prey, the diving Seals, the leaping Squirrels, the noble Horse, fleet Antelope and other animals lead lives which are peculiarly their own, differing greatly from those of other creatures and affording a most intcresting subject of observation. As a rule all the senses, except that of sight, (in which the birds excel) are more completely developed in the Mammals than in any other class of animals. The vocal expression of mammals is sometines remarkable for its volume but very seldom for its beauty, that of Man alone being really musical and superior to the voice of birds. The sounds made by different animals are quite varied, as is illustrated by a comparison between the mewing of Cats, the barking of Dogs, the lowing of Oxen and braying of Asses with the dismal howls of the Jackal and Coyote and the deafening noises of the Howler Monkeys.

The varied uses to which the tail is put forms an interesting subject of observation. In Man, the Man-shaped Apes and some varieties of the Sloth, the $\operatorname{coccyx}$, or vertebre forming the rudimentary tail, curves forward and does not project externally. In the other Mammals it varies from an invisible stump to a most extensive adornment. By most longtailed animals, the member is used as a weapon of defense against winged tormentors, and Cattle, which are especially subject to annoyance from Flies and Gnats, have a tail which is tufted at the end in such a manner as to afford an effective brush with which to fight thesc insects. Many South American Monkeys, some of the Marsupials, and other animals, have prehensile tails by means of which they can sustain their entire weight. To the Bats, and also to the Mammals having a membranous formation which enables them to flutter throtigh the air, such as the Taguan, the Assapan and some of the pouched animals, the tail serves as a rudder to steer its wearer while progressing through the air. Others have the tail so developed as to use it as an organ of touch, while the Kangaroo utilizes its tail as a third leg, which forms, with the others, a tripod upon which it supports its body when at rest. Some tails, like those of Rats, are nearly or quite bare of hair and are covered with scales, some have a covering of short hair, others are bushy. Somc bushy tails, like those of the Squirrel, arc what is called distichous, that is, they are arranged or parted into two rows of long hairs and make a pretty ornament, while the tail of the Great Ant-eater is draped into a long mane. 
In the classification of animals into species the tail is often useful, and the character of the animal's coat, especially if it be composed of spines or horny shields, or presents other peculiarities, also serves, quite often, to give a name to its wearer. The number, character and arrangement of the teeth, or what is called the centition, is the most usetul of all in making a scientific arrangement of the different animals into the various subdivisions. The teeth of an animal are so perfectly adapted to its mode of life that they especially serve to characterize it, and since the imperishable nature of their tissues preserves teeth for an indefinite time, they are particularly useful in affording an idea of the characters, liabits and affinities of extinct species of animals.

The number of species of Mammals which now live and have their being on earth is about two thousand, but this forms only a small minority of the aggregate number of species which inhabited the globe at earlier periods of its history. The study of fossil Mammals has revealed the fact that many animals of strange forms and characteristics formerly lived on this earth. Some were closely related to living species and genera, some are especially interesting because they furnish a connecting link between existing forms of animal life and structure, and some of the animals now living, like the Elephants, now represent, by a few species, families or orders of which many species are extinct. In its more extended form natural history includes the study of these fossil genera, and an elaborate system of classification has been created in recent years, as a supplement to the investigations and theories expounded by Darwin, which begins at I'rotozoa and ascends to Mian, including all the extinct gencra of which anything is known. This, however, is a classification involving so much of a technical character and for its proper appreciation requiring so great a degree of knowledge of comparative anatony, that it is obviously not adapted for use in treating of zoology from a popular standpoint. Therefore other systems of classification are used, and that followed by Brehm in this work divides the class Mammalia into fifteen main groups or orders as follows:

I. Apes and Monkcys (Pitheci).

2. Half-Monkeys or Lemuroids (Prosimii).

3. Wing-handed Animals, or lbats (Chiroptera).

4. Beasts of P'rey (Camizora).

5. Seals or lin-footed Animals (Pimipedia)

6. Insect-eating A nimals (Insectiona).

7. Rodents or Gnawing Animals (Rodintia).

8. Toothless Animals (Edentato).

9. Proboscis Animals or Elephants (Proboscidea).

Io. Odd-toed Animals (Perissodactytu).

11. Cloven-hoofed Animals (Artiodactyla).

12. Sea Cows (Sirviza).

13. Whales (Citacea).

- 14. Pouched Aninals (Marsufialia).

15. Egg-laying Mammals (Monotremata).

This is a very convenient classification, agreeing in the main with the arrangement gencrally in use in the study of zoology, although frequently the tenth and eleventh of these orders are regarded as suborders of an order named the Hoofed Animals (Ungulata).

Every scientific classification of the Mammals begins or ends with Man, for, zoologically speaking, the human being is only' a Mammal: that is, a warmblooded Vertebrate, with a four chambered-heart, nurtured in his infancy on mother's milk; and the anatomical differences which scparate him from the higher orders of $A$ pes are less marked than those whicli differentiate the latter from the South American monkey's. The first order in the classification of Linnacus was called Primat's, and included Man, all the Apes and Monkeys, the Lemurs and the Bats. Later zoologists by conmon consent excluded the IBats and made them a distinct order, and afterward the same was done with the Lemurs, but many still classify Man and all the Monkeys together in the order of Primates, dividing them into five familics: First, Men (Hominide) containing as a single genus Mlan (Homo); second, the Man-like Apes (Siminda); third, the remaining Old World Monkeys (Cercopithicide); fourth, the American Monkeys cxcept the Marmosets (Cebide), and fifth, the Marmosets (Hapulida).

The anatomical distinctions between Man and the nearest Apes are, principally, the greater size of the brain and brain case, as compared with the facial portion of the skull; the smaller development of the canine teeth of the male; the more complete adaptation of the structure of the vertebral column to the vertical position, Man being the only Mammal who habitually walks erect; the greater length of the lower as compared with the upper extremitics; and the greater length of the hallux, or great toe, with the almost complete absenec of the power of bringing it into opposition with the other toes.

Of course the mental difference between Man and the highest of the lower animals is so great as to be immeasurable, although the latter also have many traits which may compare favorably with those of human-kind. The devoted love of the mothers of most species is a trait which they share with humanity, and in their lives and daily doings they are also subject to many of the same physical conditions as mankind. Like us they are born, live and die; are subject to disease, to pain, to sorrow, and are capable of affection, sympathy and joy. Until they become old and weary of life's struggle most species of them find pleasure in association with their kind, although, like Man, they have their quarrels and their bickcrings.

The various orders are divided into more or less numerous families, these families into genera and each genus contains one or more species. Science has for convenience adopted a system of double names to describe each species of animals. Thus, the Tiger, which belongs to the Fourth Order or Beasts of Prcy (Camizora) is a member of the Cat Family (Fclicte) and of the genus of the Cats Proper ( $\left.F_{c} / i s\right)$ and the species Tiger (Tigris) the scientific name including both the generic and the specific designations, thus: Felis tigris.

Dr. Brehm, in the great work to which these remarks are appended by way of explanatory introduction, has exeluded Man from his consideration of the Natural History of Mammals. The book deals with the facts that pertain to the lives of the animals rather than with the anatomical details, only giving so much of the latter as is necessary to a complete portrait and biography. In the field of descriptive zoology the work is unique, and brings the various atrimals nearer to human comprehension and human sympathy than is possible by any other method of treatment; and for this reason this English translation of the work must be regarded as a valuable acquisition to the resources of the American student of zoology.

J. IV. L. 



\section{The Apes and Silsonkeys.}

FIRST ORDER: PITHECI.

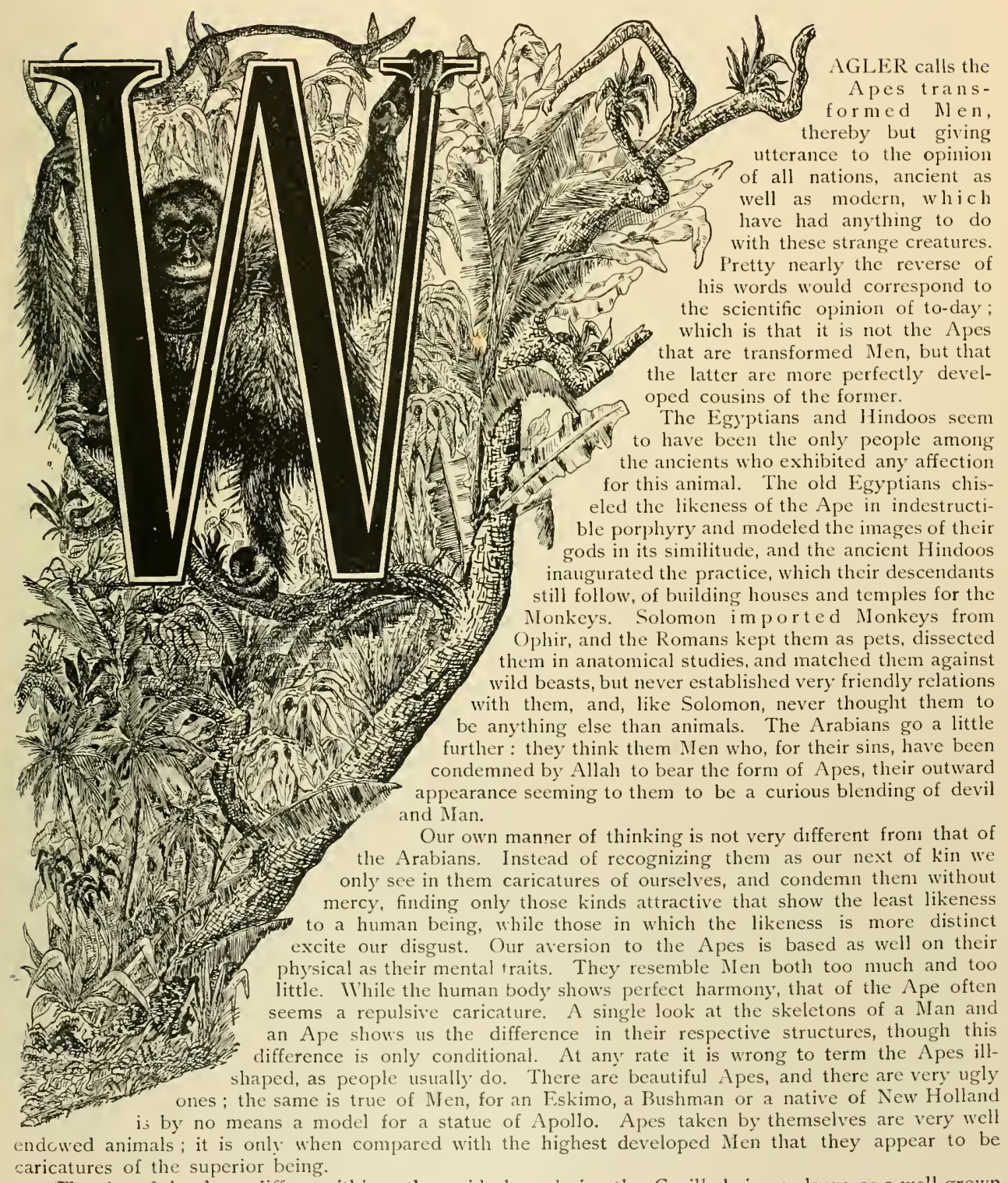

The size of the Apes differs within rather wide boundaries, the Gorilla being as large as a well-grown 
Man, while the Silky Monkey is not larger than a Squirrel. The shape of the body differs very much, also, as the names, "Man-shaped Apes" and "Dogshaped Monkeys," indicate better than would any long descriptions. There are bulky and slender Apes. They may be clumsy or graceful; most of them have long tails, some have short ones, and some none at all. Their growth of hair is varied: in some it is scant, in others plentiful, being mainly of a neutral tint, but sometimes the coloring is bright and pleasing. There are even some white ones. In Siam, the country of the white Elephant, where albinos from the animal world seem to be the fashion, beautiful white monkeys are prized as pets.

Anatomical There is greater similarity in the anaStructure tomical structure of the different kinds of Apes. of Apes than would be supposed from their outward appearance. The skeleton has seren cervical vertebræ, from twelve to sixteen dorsal, four to nine lumbar, two to five sacral, and three to thirtythrec caudal (going to form the tail); the clavicle is strong; the bones of the forearm are separate and movable, the wrist-bones are long, while the finger bones seem stunted in their growth. The feet are supplied with a thumb. The shape of the skull differs very much, according to the greater or lesser prominence of the jaws, and the size of the brain. The arches of the eyebrows are strong and prominent. The teeth are composed of all the different kinds: two incisors, one canine, sometimes as large as that of a beast of prey, two or three pre-molars and three grinders or molars form each side of a jaw. Among the muscles, those of the hand attract our attention, as, in comparison with those of a human hand, they seem to be so much simpler. The larynx is not capable of producing sounds that might constitute articulate speech, in our sense of the word; but the sac-like projections of the trachea seem to favor the production of shrill, howling sounds.

Special mention must be accorded the cheek pouches, that distinguish certain Apes. These open from the cheeks by a small aperture near the corner of the mouth and serve to store away food. They are most highly developed in the Guenons, Macaques and Baboons; they are entirely lacking in the Manshaped Apes and in al! the New World Monkeys.

The Ape Sometimes the Apes are called Quad-

compared numana, a distinction being made bewith Man. tween them and Man. But science declares that the difference in the structure of the hands and feet of Men and Apes is, though remarkable, by no means fundamental. In a careful comparison of the two it will be seen that their structure is essentially similar. The thumb put in apposition to the other fingers or toes is found in Man only in the hand, in the Arctopitheci only in the feet, while the rest of the Apes have it in both hands and feet. We are far from denying the difference of hands and feet in Man and the Apes, but we insist on this difference not being sufficient to be counted as a distinctive cause for differentiating the two.

In spite of the great resemblance between Man and Ape, there are characteristic differences between them; but no greater weight should be attached to this fact than is usually given to the comparison of other mammals. The lean body covered with hair, the thin legs devoid of calf; the long tail possessed by many, the callosities on the hinder quarters distinctive of certain species, and above all the head with its small, receding skull, and the thin lips, are distinctive features of the Apes.
Oken describes the Apes in comparison with Man in the following terms: "The Apes resemble Man in all bad moral traits; they are malicious, treacherous, thievish and indecent; they learn a number of tricks, but are disobedient and often spoil their performances, behaving like awkward clowns. There is not a single virtue that could be ascribed to the Apes, and still less any use to which they might be put. They have been trained to stand guard, to wait on the table, to fetch and carry, but they do these things only in the intervals of foolish spclls. They represent only the bad side of Man, in regard to his pliysical as well as his moral nature."

There is no denying that this description is, in the main, correct. Still we wish to give justice fair play, even in dealing with Apes, and therefore let us not forget to mention their really good traits. We cannot judge of their intellectual qualities in the aggregate, for the reason that the different species show so many contradictory features.

Nature, Habits $\mathrm{W}$ e must concede that the Apes are and malicious, cunning, choleric, vindictive,

Intelligence. sensual, quarrelsome, irritable and peevish; on the other hand, we must take into account their cleverness, their good humor, their gentleness, their trust in, and kindness to Man, their amusing social qualities, their cheering earnestness, their courage and their readiness to stand by each other in case of need, even against superior enemies, and their inclination to play and tease. In one respect they even rise to greatness, and that is in their love for their offspring, their pity for the weak and defenseless, not only of their own family and kind, but even of other animals.

The intellectual derelopment of which Apes are capable does not place them so high above all other mammals, Man excepted, neither does it place them so much below the level of Man, as is usually asserted. The possession of a hand places the Ape in so much more advantageous a position from a mechanical point of view than all other animals, that his accomplishments seem greater than they are. $\mathrm{He}$ is quick to learn, and the impulse to imitate everything, that is so strong in most of his kind, makes it easy for him to be taught certain tricks. After short practice he is able to do a great many things that can with difficulty be taught a Dog. But it must be mentioned that he always performs his tasks with a certain resistance, and never of his own accord, or with enjoyment. It is not hard to accustom an Ape to do certain things, but he will never be as conscientious and painstaking about it as a well-trained Dog. But it has taken several thousand years of breeding, cultivation and teaching to bring the Dog up to his present capabilities; while the Apes have had no opportunity of learning from Man. The capabilities of Apes will be seen in the course of this chapter, and will tend to prove that they are the cleverest among animals. Their memory is excellent, and they profit by cxperience. They have a surprising talent for dissimulation, know how to escape dangers and how to take good care of their own interests. There can also be no denying that they are affectionatc. They are capable of becoming attached to pecple, are grateful and show a certain amount of good-will to those who have done them a kindness.

It is remarkable, that in spite of their good sense, all Apes may sometimes be deceived in the silliest manner, their passions often getting the upper hand of their prudence. Once their passions are aroused 


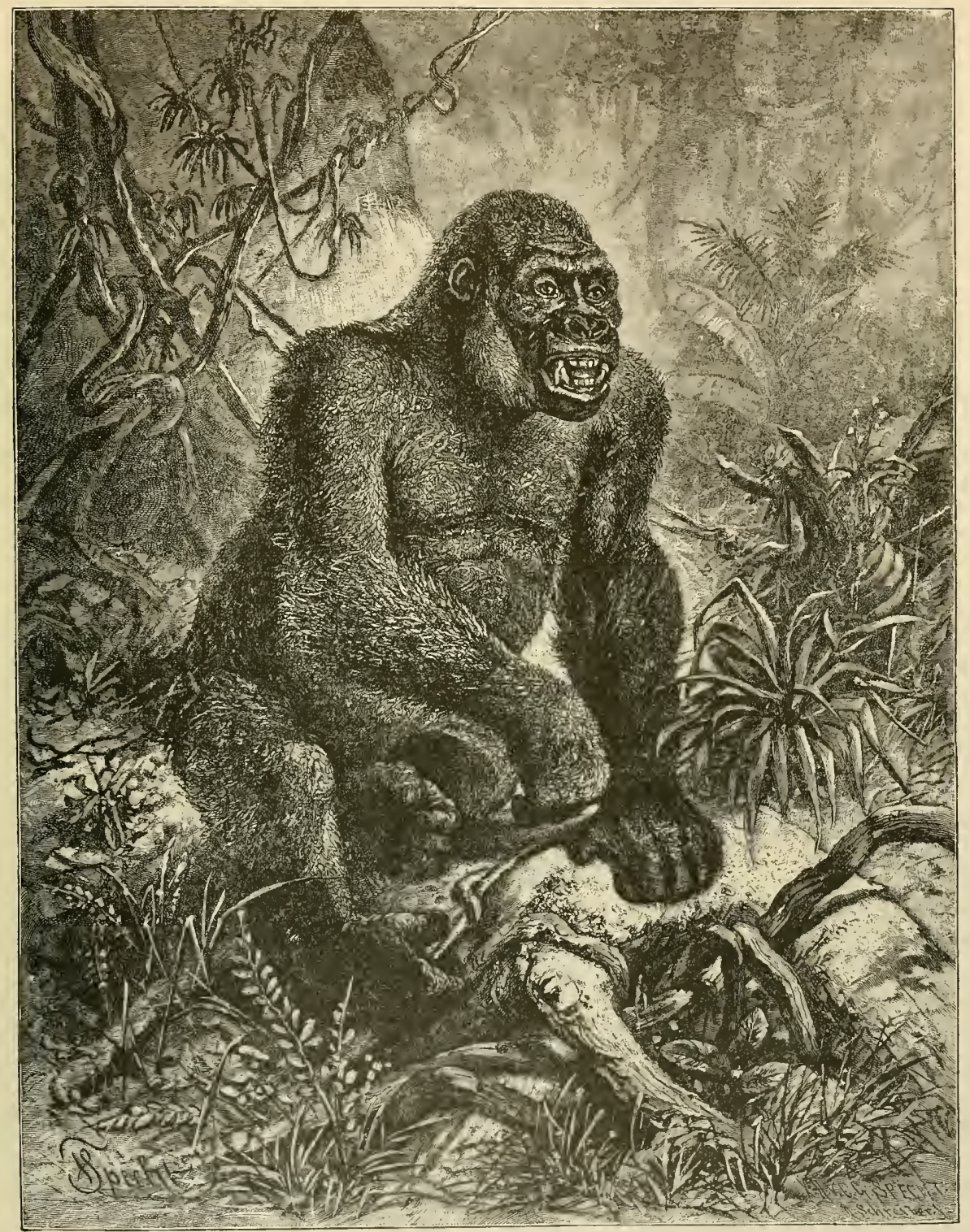

THE GORILLA. - This king of the African forests is tound only in the deepest fastnesses of Equatorial Africa ( 15 degrees north and 15 degrees south of the equator) and no adult of this family has been held in captivity, its great strength and ferocity preventing its capture alive. Several young Gorillas have been taken but did not long survive contact with Man. The artist presents the anmimal as it is secn mo may native forest with its terrible face, huge canine teeth, broad shonlders, great chest and immense hands, intently alert that no enemy may surprise it, and prepared for any emergency. Cnarm.
which even the lion might tremble. (Gorila gini.) 
they give no heed to anything and utterly forget safety in their eagerness to gratify their greedy appetites. In this way the cleverest Apes are governed by their passions precisely as many people are. It is doubtful whether this gives us a right to underrate their intellect.

Where Apes In former periods of the world the are Apes inhabited a larger portion of the Found. globe than they do at present. Now they are limited to the warm countries, a hot climate seeming to be a condition essential to them. Baboons are sometimes found rather high in mountains and appear to endure a lower temperature than is generally supposed; but nearly all the rest of the Apes are extremely sensitive to cold. Each continent possesses its own species, though Asia and Africa have one in common. In Europe there is only one kind, and that is limited to one troop which lives on the Rocks of Gibraltar, under the protection of the garrison. Australia has no Apes. Gibraltar is not the highest northern point where Apes are found, for a Japanese Nacaque probably extends his wanderings as far as the $37^{\text {th }}$ degree of north latitude. To the south the Apes go as far as the 35 th degree, but only in the Old IVorld. In America they occupy a belt of land extending as far north as Chihuahua in Mexico, and as far south as Catamasca in the Argentine Republic, inhabiting besides Mexico the Central American states and portions of all the countries of South America except Uruguay.

The home of an individual specics is usually within rather narrow boundaries, though it happens that there are corresponding varieties in two countries that are far apart on the same continent.

Vost of the Apes live in forests, but a few are sometimes found on rocky mountains. Their extremities are adapted to climbing, and trees are naturally their favorite haunts; the mountain Apes, however, climb trees only when compelted to do so.

Agility and Apes are doubtless the liveliest and

Predatory most agile of all mammals. While on

Traits. their hunt for food they do not know repose. The variety of their diet alone would call for great activity in the search, for almost every thing eatable comes handy to them. Fruit, onions, roots, seeds, nuts, buds, leaves and juicy plants form their staple food; eggs and young birds are dainties not to be despised. So there is always something to be caught, or plucked, something to be smelled or tasted, enjoyed or thrown away. Such investigations require a great deal of moving about. Their ideas as to personal property are extremely hazy. "We do the sowing, the Monkey's see to the reaping," is a common saying among the Arabians of East Soudan. Fields and gardens are regarded by them as extremely agreeable places of rest, and arc pillaged to the utmost. Each Monkey destroys ten times more than he eats. Neither locks nor bolts, fences nor walls, can keep these thieves out. They force the locks and climb the walls, and what cannot be eaten is taken away, including gold and jewelry. One must have seen a pillaging band of Monkeys to understand how a farmer can half die with rage over their visits, or, rather, risitations. To an onlooker a troop showing themselves at the climax of their agility cluring such a raid presents, indeed, a very interesting spectacle. They run, jump, climb, swing thenselves, and, in case of necessity, swim. The feats performed on trees are incredible. Only the Man-shaped Apes and the Baboons are clumsy ; all the others are perfect clowns; they seem nearly able to fly ; jumps of twenty-five or thirty feet are child's play to them. From the top of a tree they will jump down a distance of thirty-five feet, seize the end of a branch, which will go down with their weight; at its rebound they will give themselves a mighty impulse, and using the tail or their hind limbs as a rudder, go flying through the air like an arrow. The minute they land somewhere, they go on, paying as much heed to the sharpest of thorns as if they were disporting themselves on smooth parterre. A tree is to them a most comfortable pathway. They climb up and down, under a branch or over it; if they are thrown into a tree, they seize the first twig they can find, patiently wait till it is at rest, and then climb up on it, as if they were on tome fima. If the branch breaks, they take another; if this also breaks, a third one does for them, and if they have a fall they are not disconcerted in the least. If they cannot reach a thing with their hands they use their feet, and the Broad Noses (American Monkeys) have recourse to their tail. The tail is always used as a rudder in long jumps, and serves a variety of other purposes besides, sometimes forming a ladder for another Monkey. With the American Monkeys the tail may be considered as the fifth, nay, the first hand. The Monkey may twist it around the bough of a tree and rock to and fro on it; he may use it to get food out of narrow holes and crevices; he uses it as a ladder, and lastly, this useful member scrves its owner as a hammock for an after-dinner nap.

climbing Climbing is the only movement that and shows off the agility and gracefulness

Walking. of the Apes. Even the Man-shaped Apes are wonderful in this respect, though their climbing is more after human fashion. Their walk is always more or less clumsy. The Guenons, Macaques and Marmosets walk the best of all; the first mentioned can even run for a short time, and so fast that an ordinary Dog could not overtake them; but even the Baboons hobble along in the funniest sort of way. The walking of the NIan-shaped Apes is hardly deserving of that name. While the first walk on the soles of their feet, the latter lean on the knuckles of their lands, and bend their body oter in such a way that the feet practically have their position between the hands.

Apes in Some kinds are excellent swimmers,

the others sink in water like a piece of lead.

Water. Among the first are the Guenons, of which Brehm saw several specimens crossing the Blue Nile with the greatest ease; among the last are probably the Baboons and the Howlers. Those which cannot swim are remarkably afraid of water. A family of Howlers was once found on a tree, isolated by an inundation. They were half starved, yet did not dare start out for the nearest tree, that was barely sixty feet distant. Ulloa, a writer on Brazilian animals, has invented a pretty little bridge for the poor Monkeys that cannot swim and it would be of great service to them, if only they would use it. He tells us that each Howler grasps another's tail, the whole band forming a chain. The Monkey at one end holds fast to the top of a tree at one shore, and through the combined efforts of all, the chain is swung back and forth till the last Monkey at the other end is in a position to seize the branch of a tree on the other shore. On this artificial bridge the younger and weaker ones cross first, and then the first Monkey draws the others after him. Prince Wied, a rery conscientious observer, gives this story" its right name, calling it "a funny fable." 
Social Life The social of life of the Apes. Apes is a very attractive one for every observer. There are but few kinds which live singly; the majority prefer to live in small troops or bands. Each of these latter selects a permanent home of greater or less extent. The choice as a rule falls on a country that seems favorable in all respects. There inust be something to eat, or else they emigrate. In a poor country, forests near human dwellings seem to be regarded as paradisaical; the forbidden tree does not trouble the Ape's conscience, so long as the apples on it are toothsome. Plantations of sweet corn and sugarcane, fields of onions, orchards and banana trees are preferable to anything else; villages also are liked, where anybody chastising the robbers has to dread the superstition of the inhabitants. As soon as the band has come to a conclusion about a place of habitation, the real life of the Monkeys begins, with all its joys and sorrows, its quarrels and its cares. The oldest and strongest male is made the chief, this dignity is not conferred by universal suffrage, but by long and hard fights with the other aspirants, that is, with all the old males. The longest teeth and the strongest arm prevail. Whoever does not subject himself good-naturedly, is brought to his senses by a few cuffs, bites and scratches, and the crown is to the strong: in his teeth is wisdon.

The language of Apes is by no means a poor one, for each Ape has the most varied sounds for his differing emotions. Man soon learns to recognize the significance of these sounds.

The cry of terror, which also includes an invitation to flee, is especially expressive; it is hard to describe, and still harder to imitate; one can only say that it consists of a succession of short, vibrating and inharmonious gurgling sounds, whose meaning

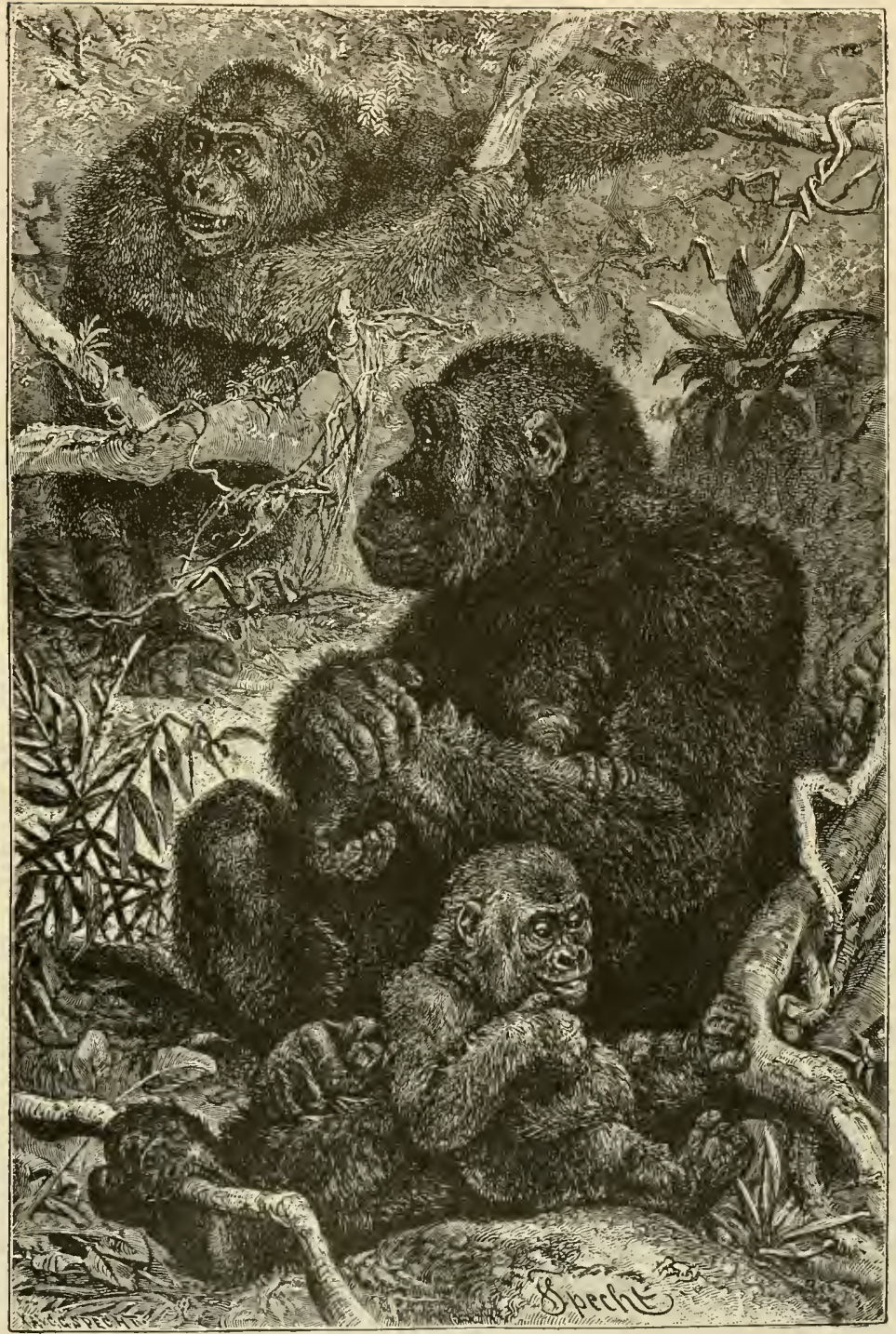

A FAMILY OF GORILLAS. - This picture represents a family of Gorillas, the month or two old haby in tha Aoreground, at the teet of its watchtul mother, whle the ever-alert fatner is keeping guard from a perch of will protect her and the helpless little one, whose dreamy face expresses entire satisfaction. It is a most graphic and faithful delineation of a Jite-like scene in the great hot torest in Equatorial Africa, and portrays in pleasing ineasure the home life of these creatures so greatly resembling Man. Fierce and intractable as is the Gorilla, he is kind to his the Monkey makes still clearer by grimaces. As soon as this note of alarm is sounded, the whole band starts to flee; the mothers call their children, and holding them fast, hurry on to the next tree or rock. It is only when the chief recovers his spirits that the band gathers again and returns.

courage and The Apes undeniably have courage. Fighting The stronger ones boldly resist the ter-

Qualities. rible beasts of prey and Man, and are 
not deterred from fights whose outcome is more than doubtful from the beginning. Even the graceful Guenons fight, when driven to it. The large sized Man-shaped Apes and the Baboons are endowed with fearful weapons in their teeth, and no mative wil] dream of attacking them without fire-arms. Against the Gorilla even fire-arms avail but little in a great many cases. At any rate the fury of the Apes, which redoubles their strength, and their agility that frequently prevents their opponents from striking them a decisive blow, are greatly to be feared. They fight with their hands and teetl, striking. scratching and biting. A great many stories about their other modes of defense have been disproved by careful observation. "It is said," remarks Pechuel-Loesche, "that the Apes defend themselves with broken branches; and it is generally conceded that they throw stones, fruit and picces of wood at their enemies, but this belief is based on inaccurate observations. The people who spread it probably saw only what they were prepared to see, not what really happened. Apes often break a dry branch in play, jumping on it, but they do not throw it at people standing below; neither do they throw fruit or other things they may happen to be holding, though they might drop it in their confusion when frightened. Neither do Baboons ever throw stones at their pursuers. Pieces of rock may crumble and fall down from the place where they sit, but that is all; the active animals are forever rolling stones from their places, Jooking for insects under them."

Conduct In captivity nearly all Apes live in harin mony together; still a certain relation of Captivity. dependence soon forms itself, just as in a troop in the wild state. The strongest Ape maintains his authority and torments the weaker ones until they recognize it. To be tenderly considerate of the feelings of others is not an Ape's character, though it is true that the stronger kinds, male as well as female, always protect the weaker ones; and strong females often go as far as to show a liking towards human babies or small, young animals, that they can carry in their arms. Badly as Apes treat other animals, they show kindness to their young and to children, naturally preferring their own to any others; this fondness has become proverbial.

Mother Ape The female Ape usually has one young and one at a birth; a few kinds have two.

child. The baby Ape is always an ugly little being, with arms and legs looking twice as long proportionately as its parents', and with a face so wrinkled and furrowed that it looks like that of an old man rather than of a child. This little monster is the mother's pet in a still higher degree than is the case with a human mother; she fondles it and takes care of it in a manner not only touching but bordering on the ridiculous. Soon after its birth the young A pe attaches itself to its mother, putting both arms around her neck and both legs around her hips, so as not to interfere with her in running. When it gets a little older, it sometimes jumps on the mother's back in times of danger. In the beginning the little Ape is naturally devoid of all sentiment, not appreciating the tenderness the mother bestows on it. She is forever playing with it; she licks its body, she hugs it, she holds it in both hands as if she were admiring it, and rocks it to sleep in her arms. Pliny assert: that Apes sometimes hug their little ones so close as to strangle them, but his statement has not been verified by modern observers. In a short time the young Ape begins to be independent and longs for a little freedom, which is granted it. The mother lets it play and romp with other little ones, but she dies not take her eyes off from it. following its every step and permitting only as much freedom as she deems proper. At the least danger she utters her sound of warning, inviting the little one to take refuge at her breast. If it is disobedient she slaps it, sometimes giving it a box on the ears. But she seldom has to resort to this, for an Apechild is very obedient and might serve as a model for many a human child. In captivity I have often seen Apes divide everything with their offspring: and the death of a young one is frequently followed by the death of its mother, she dying of a broken lieart. When a mother dies, leaving a child, the orphan is regularly adopted by some member of the troop, either male or female. The solicitude bestowed upon an adopted child is nearly as great as that of a mother Ape for her own offspring; although, when an Ape takes care of other animals, as it sometimes does, it is quite different. It will look after the adopted animal, cleaning and caring for it, but usually giving it nothing to eat; on the contrary, the food destined for the orphan is, without a scruple, devoured by its nurse, who meanwhile holds the hungry little beast at arm's length.

Maturity, It is not known how many years an Health and Ape requires for its growth. The GueLongevity. nons and the American Monkeys probably need no more than three or four years, while the Baboons might need from eight to twelve. In the wild state Monkeys seem to be subject to few diseases. At least we do not know anything about epidemics that are said to have occurred among them. It is also uncertain how long they live, but we may accept forty years as about the average life of the larger species, such as the Gorilla and Chimpanzee. [In North America] as well as Europe those in captivity suffer from the severity of the climate. Cold depresses them physically and mentally, and. as a rule, they soon die of consumption. A sick Ape is a spectacle that would move a heart of stone. The poor fellow, but recently so full of fun, sits miserable and sad, with a plaintive, really human look. The nearer he approaches death, the gentler he gets ; the animal side of his nature is lost, and the spiritual side shines brighter. He is grateful for every little help, soon looks on the physician as his benefactor, willingly takes medicines, and even submits to surgical operations without resistance. Apes that otherwise seem quite healthy, often get a disease of the tail, the end of which ulcerates and becomes gangrenous and the tail is lost by degrees.

Monkeys as I do not know whether I may advise

Domestic people to keep Monkeys as pets. The

Pets. merry animals give much pleasure, but also a great deal of annoyance. One must always be prepared for all kinds of pranks, but if he does not wish to study the intellectual resources of the animals he will soon grow very tired of them. The larger kinds sometimes become dangerous, for they bite and scratch furiously. It is not wise to give a Monkey the freedom of the whole house, for his active spirit requires constant occupation, and when he is not provided with it he finds employment for himself, which, as a rule, does not turn out to be very profitable to his master. Some kinds are not to be tolerated on account of their indecent beliavior.

The life of the tame Apes, which comprised several Gorillas, Chimpanzees, Guenons and others, at the 


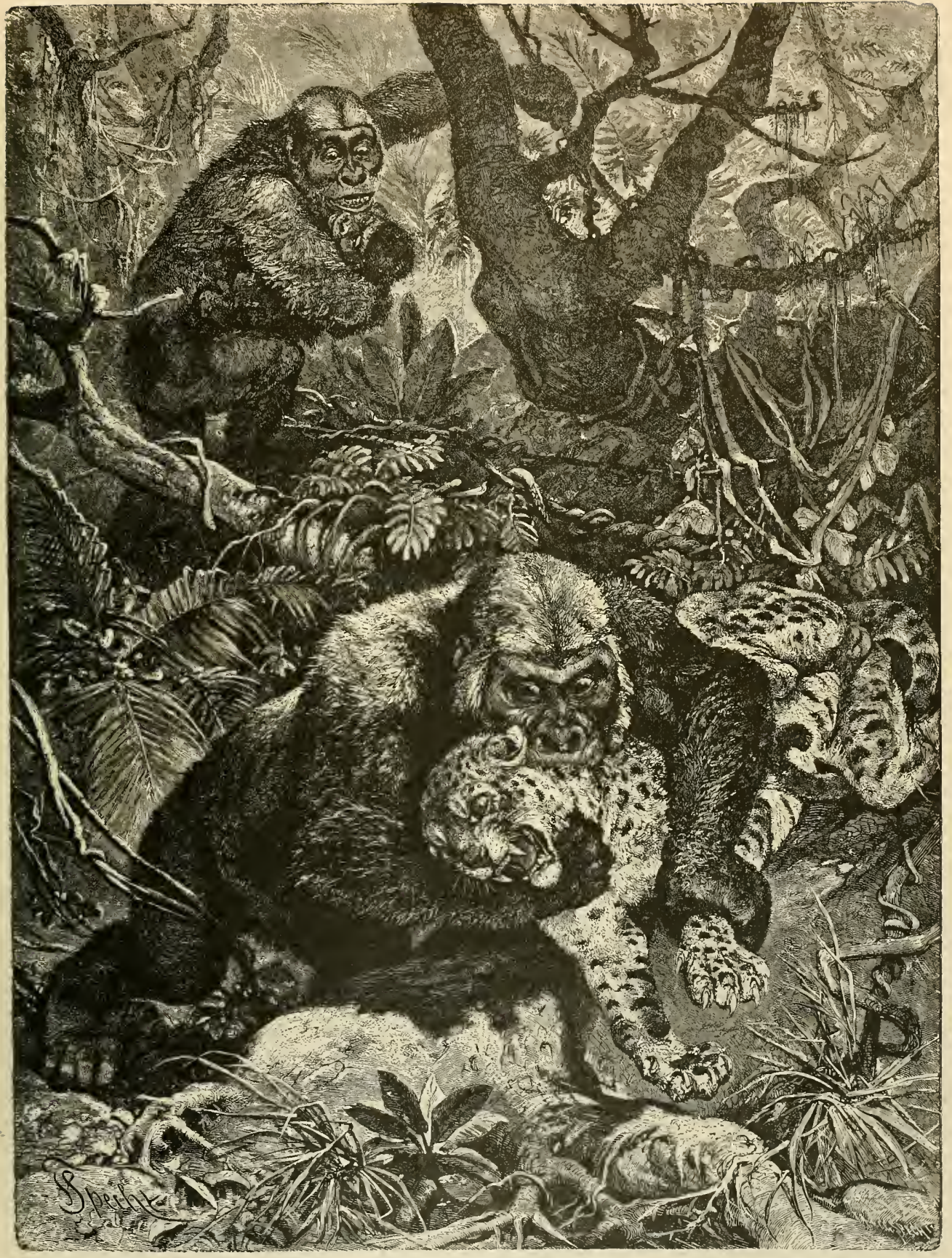

THE GORILLA AND THE LEOPARD. - The great strength of the Gorilla is clearly brought out in the above masterly illustration, which depicts the manner in which it attacks the Leopard. This treacherous animal dare not assail an adult Gorilla, but will prowl around the home of the latter, and. when an opportunity offers, seize and run off with a young one of the family. Being more fleet of foot than the Gorilla he easily escapes with his victim. In Interested spectator, from her perch on the tree-bough, of the deadly struggle beneath. 
station of the Loango exploring party, is described by Pechuel-Loesche as follows: "Our Apes used to select some animal or thing and become sincerely attached to it. In this way several of the strangest friendships came about. It is gencrally known that Apes adopt young animals, carc for them and cling to them even when they are dead. When our large collie, 'Trina,' gave birth to pups, and these became infested with fleas, we put the puppies in a cage with the Apes, where they were received with open arms carefully and tenderly clcaned and caressed, while the old Dog was sitting outside and attentively looking on. But there was always great trouble when we went to fetch the pups; they evidently had been distributed with a view to keeping them.

"Our mischievous Dog-faced Monkey struck up a friendship with the Gorilla and the tyrant of the yard, the smooth-coated Billy Goat, Mfuka. The Baboon, Jack, had selected a fat little Pig for his particular friend and performed the strangest equestrian feats on its back; later, a Dog took the place of the merry little Pig, and they played together in the drollest way. Forbidding lsabella had taken a liking to a parrot; but when she one day started to pluck out his scarlet tail-feathers, one by one, this remarkable friendship came to an end."

Taking into consideration the bad habits of the Ape and the tricks he plays, his usefulness counts as nothing. It is very easy to teach him; you show him what is required of him and beat him till he does it himself; that is all that is necessary! In an hour or two he will know how to do a thing, but he has to be kept in practice, for he soon forgets. His feeding is no trouble, for he eats anything Man eats.

In their native countries, in places that are not very fertile but more or less thickly settled, the harm done by the Apes more than outweighs their usefulness. The flesh of some kinds is eaten, and the skins of some of the others are used for various purposes, but this little profit is as nothing compared with the damage they cause in the fields and orchards, and it is hard to understand how the Hindoos can think them sacred and care for them as if they were demi-gods.

Classification IVe divide the Apes into three classes: of The Narrow-nosed (Caturrhini), the

Apes. Broad-nosed (Platyrhimi), and the Marmosets (Arctopithecini). The first two have nails on their fingers and toes; the Marmosets have nails only on the thumbs of their hind limbs, while their other fingers and toes are provided with claws. The Narrow-nosed and Broad-nosed are distinguished by a difference between their nasal septa and their teeth. The former have a narrow nasal bone, the latter a broad one, their nostrils being placed on the side. The Narrow-nosed are found only in the Eastern hemisphere. They are "Old World Apes," and are restricted, except a single species, the Barbary Ape, to Asia and Africa and the great islands of these continents. The two others are limited to Mexico and Central and South America.

\title{
The Illarow= Hosed Etpes.
}

\author{
FIRST FAMILY: CATARRHIN1.
}

The Narrow-nosed. Apes resemble Man in the arrangement of their teeth and the structure of the nose. Their upper jaw shows a gap between the incisors and canines, for the accommodation of the lower canine tooth, which is very strong. Not one of the representatives of this class has a prehensile tail. They are subdivided into two groups, the Man-shaped Apes (Anthropomorpha), and the Dogshaped Monkeys (Cynopithecini). The former step only on the extreme outer edge of the feet, the latter on the entire sole. The Mian-shaped Apes lack a tail and cheek-pouches, and very few of them have the callosities on their hinder quarters, that are always possessed by the Dog-shaped Monkey's, which also, as a rule, often have check-pouches and a tail.

\section{THE MAN-SHAPED APES.}

The Man-shaped Apes (Anthropomorpha) form the highest developed group of Apes, which in the structure of their skeleton, and also in the formation and position of the eycs and ears, come nearest to Man. Their upper extremities are longer than his, their lower extremities shorter. The tail is lacking. The face and toes are not covered with hair. Of the four known specics, two, the Gorilla and Chimpanzee, inhabit Africa ; the Orang-utan and Gibbon, the southeast of Asia.

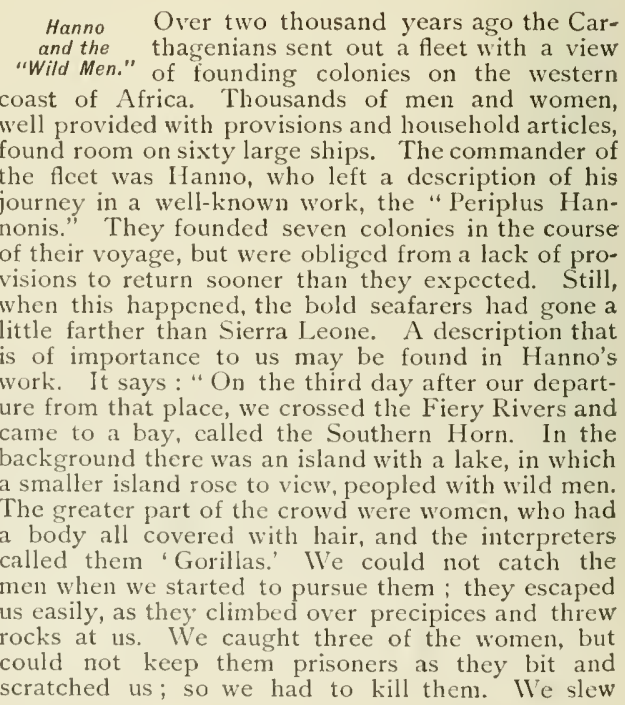

Hanno
and the

Over two thousand years ago the Carthagenians sent out a fleet with a view Thousands of men and women well provided with provisions and household articles, found room on sixty large ships. The commander of the flcet was Hanno, who left a description of his journey in a well-known work, the "Periplus HanThey founded seven colonies in the course visions to return sooner than they expected Still, when this happened, the bold seafarers had gone a little farther than Sierra Leone. A description that ure from that place, we crossed the Fiery Rivers and came to a bay, called the Southern Horn. In the background there was an island with a lake, in which a smaller island rose to vicw, peopled with wild men. creater part of the crowd were women, who had called them 'Gorillas' WVe could not catch the men when we started to pursue them; they escaped us easily, as they climbed over precipices and threw could not keep them prisoners as they bit and scratched us; so we had to kill then. We slew 


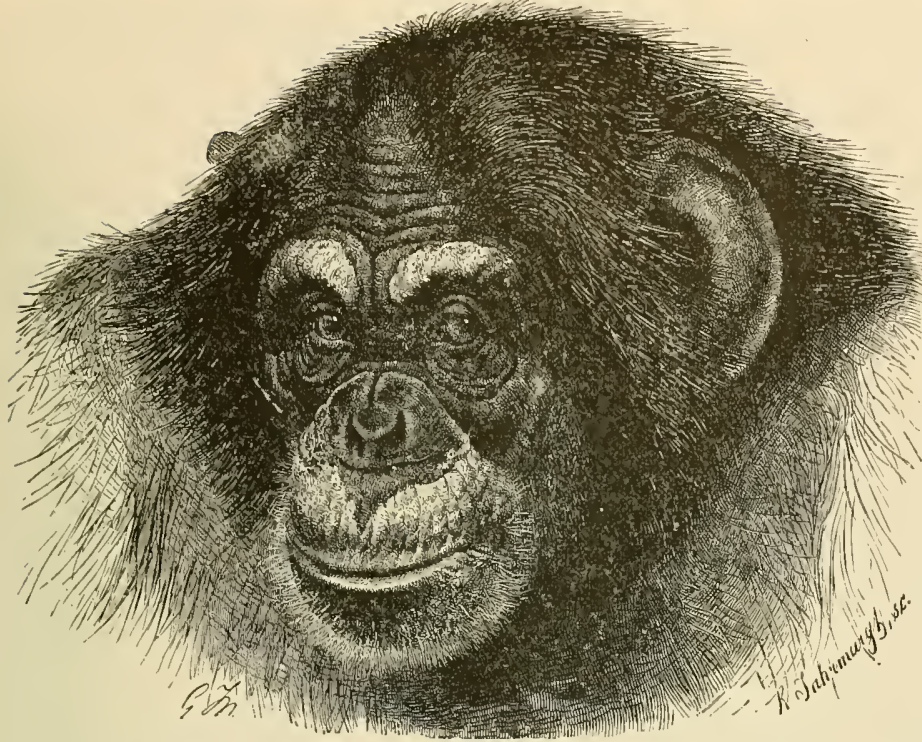

FACE OF A CHIMPANZEE.-This is an excellent picture of the Chimpanzee, displaying to the greatest advantage the immense frontal ridge above the eye as well as the great ears for which it is noted. The large, slit-like mouth with the extended lower lip, the length of the upper lip, the misshapen nose and the deep-set eyes, are all brought out with the most faithful exactitude.

them and conveyed the skins to Carthage." Pliny tells us that these skins were kept in the temple of Juno, in the latter city.

There is scarcely any doubt that Hanno, in speaking of wild men covered with hair, can only mean a Man-shaped Ape, and thougl he might have had the Chimpanzee in view, it is now known that the greatest of the Apes is the Gorilla.

\section{THE GORILLA.}

The Gorilla, Njina, or in the language of the natives, Mpungo, (Gorilla gina), the sole representative of the family of the Gorillas, is scarcely smaller but a great deal broader in the shoulders than a full-grown Man. The height of the male reaches on an average from sixty to seventy-two inches; the width of the shoulders thirtyeight inches. The females are smaller. The length and strength of the trunk and the upper extremities, the large size of the hands and feet, the middle fingers and toes of which are joined by membranes, form the most prominent characteristics. The most striking features in the large head, which because of the shortness of the neck and its powerful muscles seems to be set immediately on the trunk, are the prominent arches of the eyebrows, the eyes lying deep in their sockets, the broad, flat nose, and the large mouth, bounded by thick lips and provided with a fearful set of tecth The hair is rather long, shaggy, of dark colors, gray, brown or reddish. The face is left free from hair to the eycbrows, as also the ears and the hands and feet laterally and at the extremities

It is still impossible to determine the native country of the Gorilla exactly. It seems to be found only in a relatively limited part of western Africa, or, more definitely speaking, in Lower Guinea. It has been seen on the coast between the equator and the fifth degree of south latitude, and in the western parts of the adjoining mountains.

As it always lives in woods, it is not probable that it would be found to the south as far as the Congo or beyond the mountains to the east, though it might go to the north of the Ogowe and the Gaboon country, at least as far as Cameroon, as that part of the continent has more rain, and, in consequence, abounds in woods. It is possible that the Gorilla also lives in those parts of Upper Guinea that are equally favored.

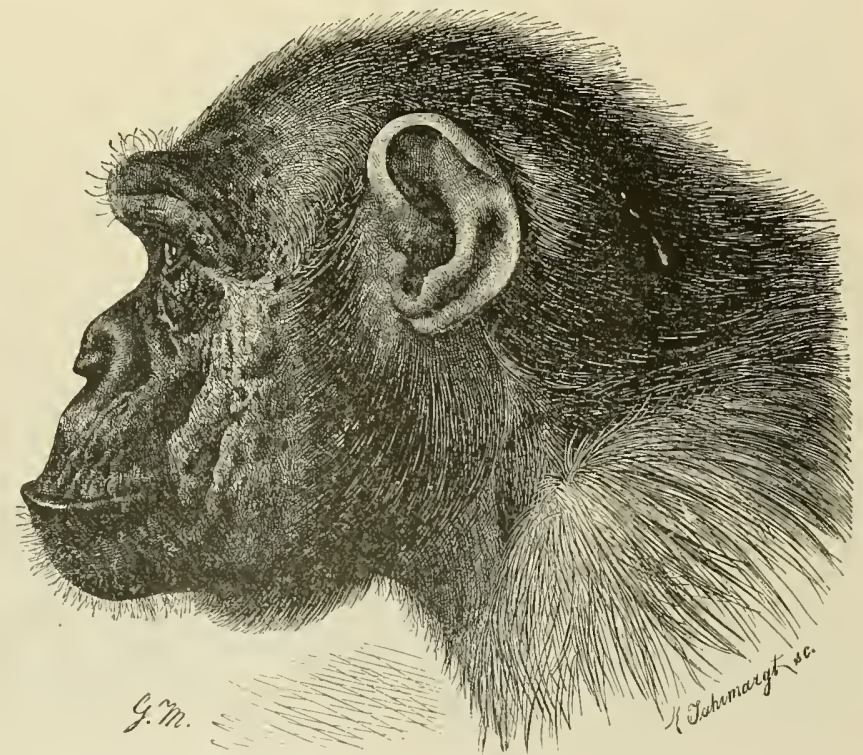

PROFILE OF A CHIMPANZEE. - This picture shows to good advantage the large and slit ike mouth the mild and gentle eve and the quaintly shaped nose that are peculiarities of the Chimpanzee. While decidedly unattractive there is absent the ferocity that marks the countenance of the Gorilla. Aud indeed the Chimpanzee has a disposition that is gentle and kind except when it has suffered from privation or age and infirmity overcone it. 


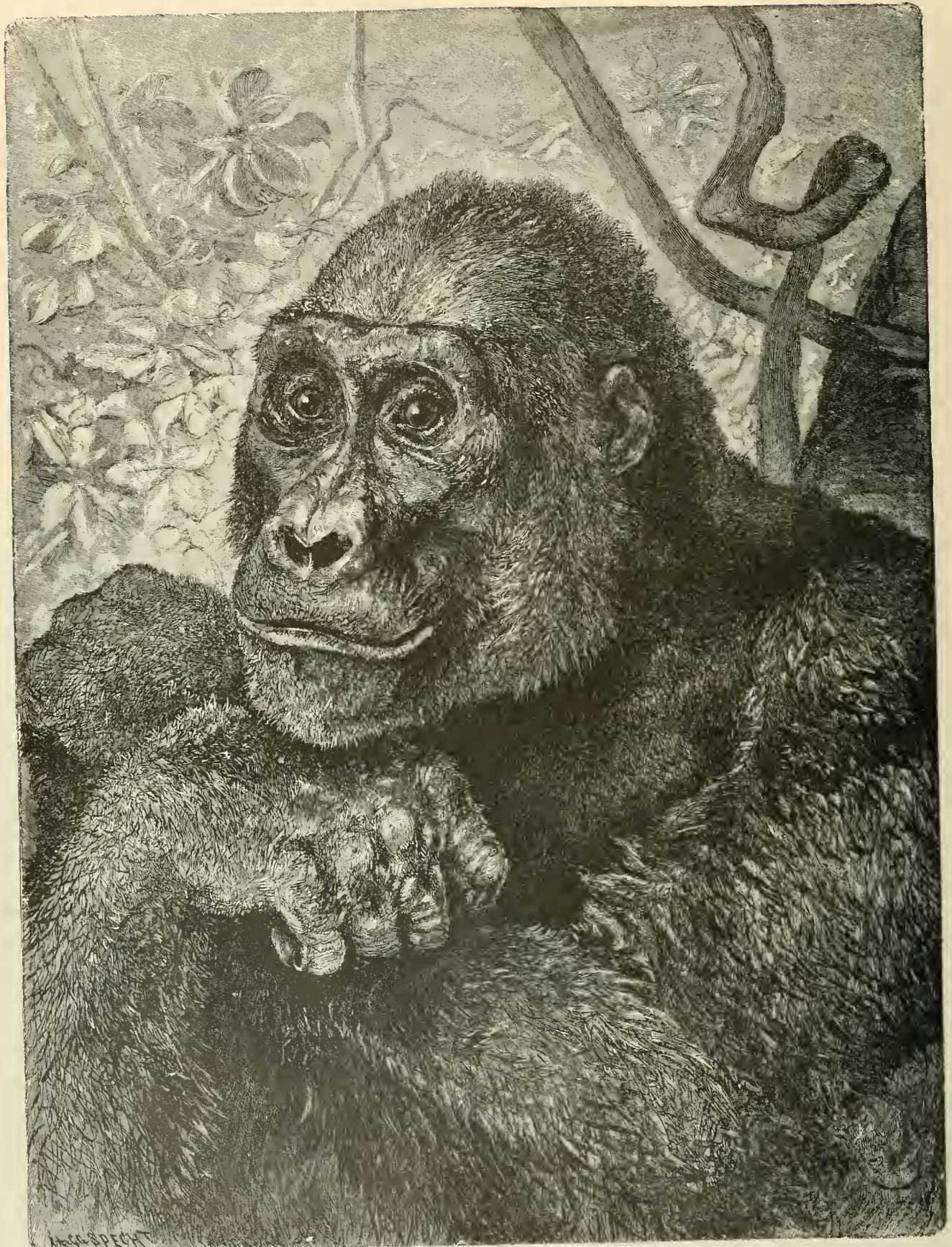

THE GOR great Ape is in a striking pose, being at rest, yet alert, as the keen, hazel eyes plainly show. The large nostrils are wide open, the wide mouth firmly closed, and the chin is resting upon the back of the huge muscular right hand that in turn lays upon the left fore-arm extended across the breast. At the fing proach of danger all would be changed; the hair of the forehead 


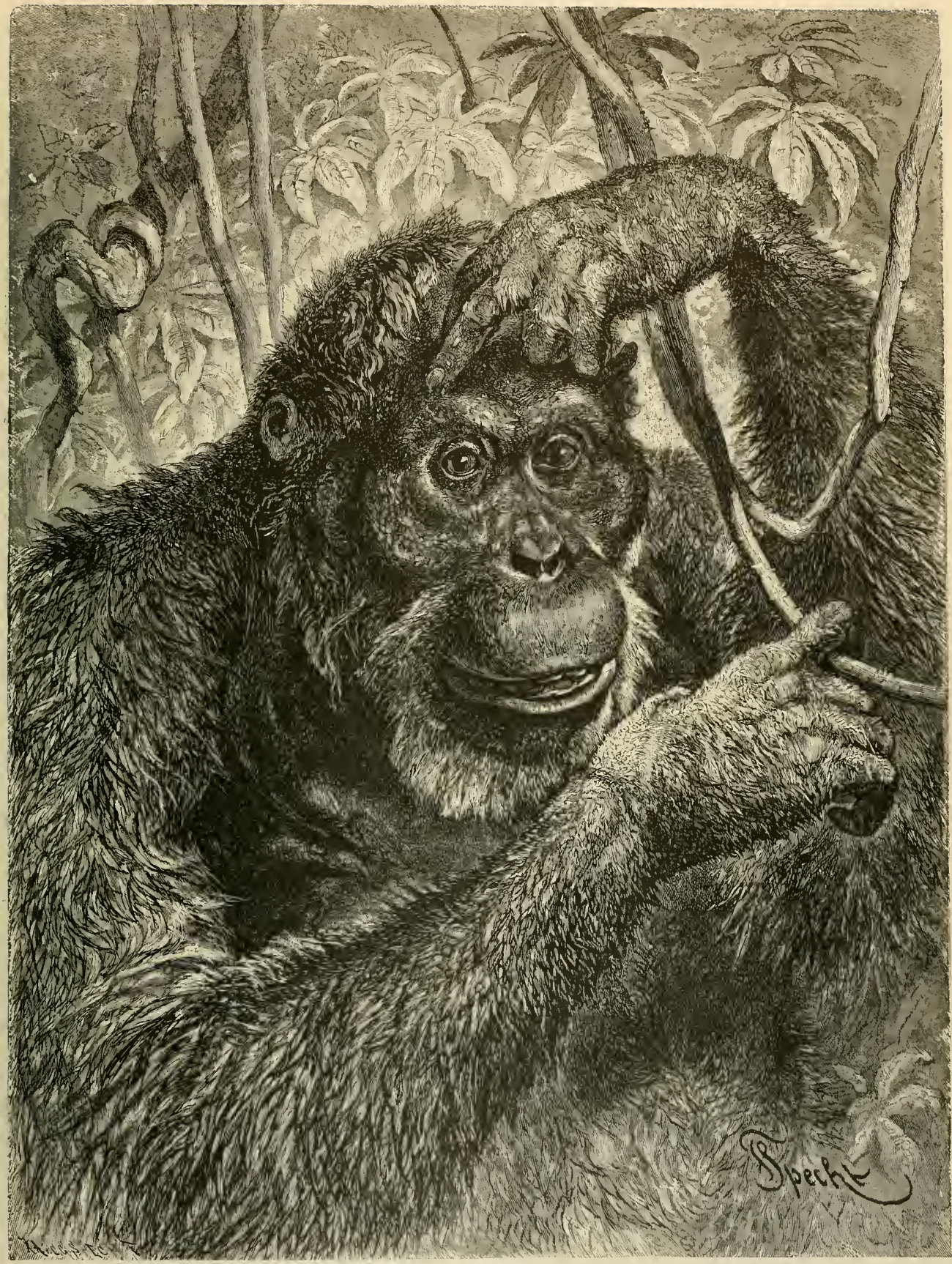

ORANG-UTAN. - The naturalists have given the name Satyr to this animal because of its resemblance to man and beast, the face, head, ears, beard and whiskers, the long arms and large hands all being wonderfully like those of a human being; while the shaggy coat of hair suggests the brute. It is not strange that the superstitious natives should think the Orang-utan a human being gone wild. The picture represents this Ape at rest in its forest home, both hands lightly holding to a vine, while the fingers of the left are laid upon the forehead. The great strength of the hands and arms, as well as of the broad shoulders, are distinctly shown and the face recalls that of human beings one has frequently seen. (Pithecus salyrus.) 
The Account Among the numerous accounts of the of Gorilla, where truth seems to be plenDu Chaillu. tifully mingled with exaggeration and tales of natives, the descriptions of DuChaillu have in their time made a great deal of stir. I would have used his works extensively, if they had not at the first perusal aroused a feeling of distrust. I an decidedly of the opinion that Du Chaillu's glowing descriptions are a wonderful blending of truth and fiction. Other travelers who have explored those parts and entered into communication with the natives have arrived at the same conclusion. Like his predecessors, Du Chaillu bases his narrative on hearsay, though he gives it the interest of a personal experience. So I will give here only a few words of Du Chaillu, in relation to a young Gorilla that came into his possession, though his observations were by no means confirmed by later and better ones:

"On the fourth of May several young Negroes, whom I had sent out for a hunt, brought home a young, living Gorilla. I cannot do justice in words to the emotions that overwhelmed me, when the little monster was brought into the village. The Ape was about two or three years old and twenty-four inches high, but as ferocious and obstinate as any full-grown brother of his might be. My hunters had caught it in the country between Rembo and Cape St. Catherine. According to their story, the hunters, five of them, had been noiselessly creeping through a wood near a settlement, when suddenly they heard a growl, which they at once recognized as the call of a young Gorilla for its mother, and they decicied to follow the sound. Their guns in their hands, the brave fellows crept on towards a gloomy place in the forest, thick with underbrush. They knew that the mother must be near, and expected the dreaded father to be not far away, but decided to try to get the young Ape alive at any risk. As they approached a sight new even to them met their eyes. The little one sat near its mother, plucking berries, and the old one was eating of the same fruit. My hunters got ready to fire immediately, and were barely in time; for the mother caught sight of them when they were lifting their guns. Fortunately they killed her with the first volley. The little one, frightened by the report of the guns, ran towards its mother, hugged her close and hid its face. The hunters hurried forward, but it then left the mother, ran to a small tree and climbing it with the greatest agility sat down on one of the branches and roared at its pursuers. But the Negroes did not get scared, nor were they afraid of being bitten by the furious little beast. So they cut down the tree, and as it fell they quickly threw a cloth over the head of the little fellow, and in that way were able to master it. Still the little Ape, who as far as age went was but a young child, showed itself to be amazingly strong and anything but good-natured; so that the men could not lead it, but had to put its head between the prongs of a pitchfork, and thus force it to be quiet. In this way he entered the village, and the news spread like wild-fire. As the prisoner was being lifted out of the boat, in which it had come part of the way, it roared and barked and stared wildly around, as if it was assuring us that it would take its revenge as soon as it could get a chance. I saw that the fork lad wounded its neck, and thercfore ordered a cage to be prepared for it. In two hours we had built it a strong cage of bamboo, in which we could observe it in security. It was a young male, independent enough to shift for him- self, endowed with extraordinary strength for his age. His face and hands were black; the eyes lay not quite so deep in their sockets as with the older ones; the body was thinner; the hair on the arms longer. The hair of the eyebrows and of the arms was of a reddish-brown color; the upper lip was covered with short hair, the lower one with a slight beard; light gray hair getting darker towards the shoulders covered his neck and back. I never saw so ill-natured an animal as this Ape. He raged at everybody who approached him, bit at the bamboo. palings, looked around with ferocious eyes and. showed his viciousness and ill-nature at every opportunity."

Later Lately our information about the Gorilla Account of has been vastly increased. German exGorillas. plorers, members of the Gussfeldt Loango. expedition, have succeeded twice in capturing live young Gorillas, in 1876 and $188_{3}$, and forwarded. them to Europe, where, under the care of Director Hermes, they lived long enough in the Berlin Aquarium to enable scientists to settle a few complicated questior.s. Furthermore Hugo von Koppenfels, a passionate hunter, has made several voyages to the Gaboon and Ogowe country within the last decade, with a view of finding the Gorillas in their native forests. So far Koppenfels has been the only European who can prove that he has observed Gorillas in the wilderness and killed them. He confirms many accounts that others have reported from hearsay, and completes them from his own stock of experience :

'As incredible as it may seem. I can affirm that even of the hunting tribes, hardly a third have ever met a Gorilla in the forests. The Gorilla - with the exception of old, hypochondriac males-lives with his family, and roams from place to place, as the demand for food impels him. He spends the night where he happens to be at the approach of darkness,

"This means that he builds a new nest every evening, and for this purpose selects strong young trees, having a circumference not over twelve inches. The nest is built somewhat like a Stork's, out of green twigs, in the embranchment of stronger boughs, at a height of fifteen to eighteen feet. It is used by the young ones, and if these still stand in need of warmth, also by the mother, while the father crouches down at the foot of the tree, his back against the trunk, and in this way protects his family from Leopards. In the dry season, when food and water begin to fail him in the inner depth of the woods, he makes raids on the plantations of the natives, where he, Ape-like, causes troublesome devastations.

"If let $a^{1}$ ne, the Gorilla does not attack Mien, but rather avoids them. If he is taken by surprise, he rises, utters a series of short half roaring, half grunting noises, that cannot be described ; beats his gigantic chest with his huge fists and shows his teeth with. an exceedingly ferocious expression on his face, while the hair on his head and on the nape of his. neck stands vibratingly erect. An old Gorilla in a rage is a sight to inspire terror. Y'et, if one does not irritate him and beats a cautious retreat before his. fury las reached its height, I do not think he would. attack anybody. But if one should have the misfortune to wound him slightly, then I, who it is trute have not been in such a terrible plight, am positive that he would turn on the huntcr, who is lost if he has not a second ball ready. Flight is impossible, as. is a defence with any weapon but fire-arms." 


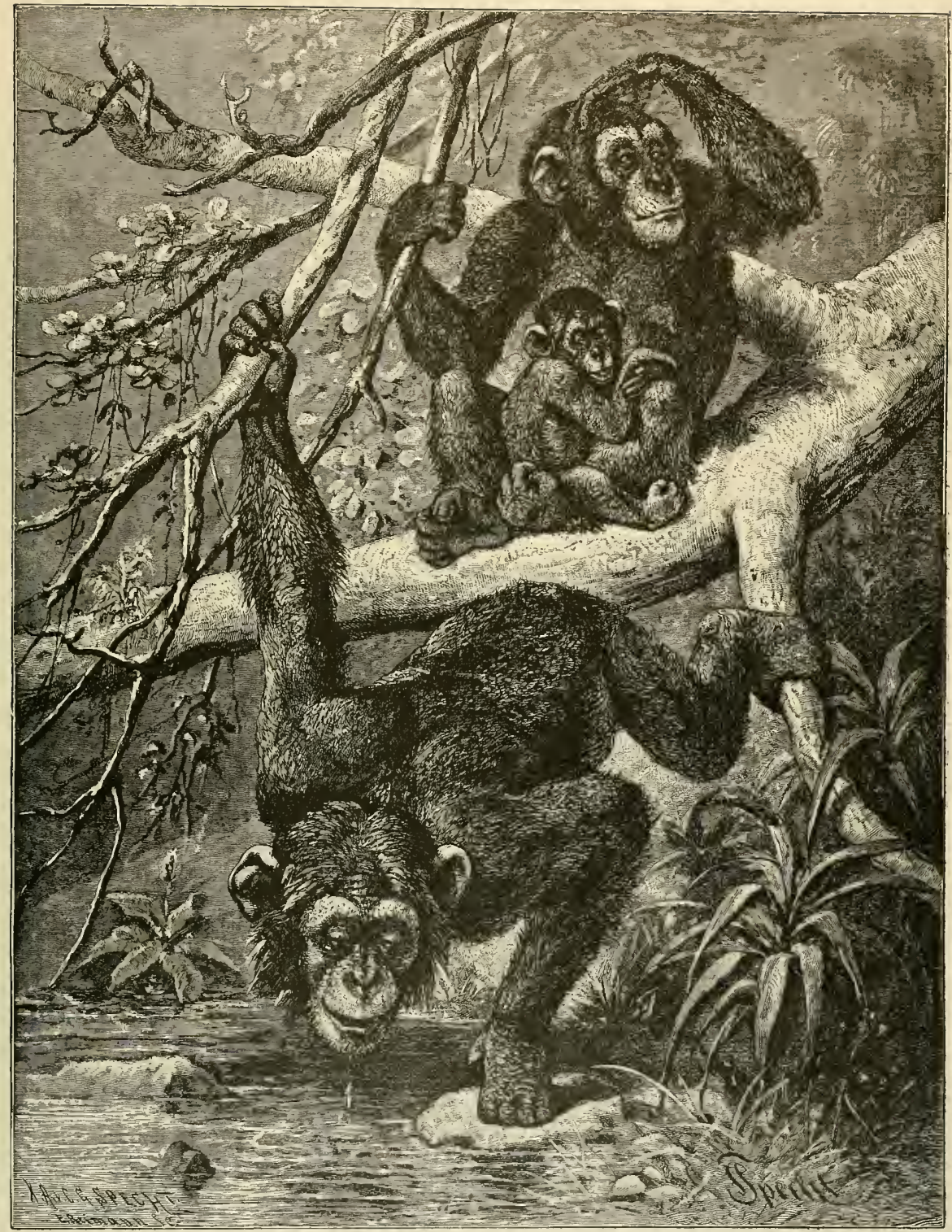

FAMILY OF CHIMPANZEES. - The great artist here represents a chaming scene in the home lite of the Chimpanzee. After having fed, the family-father, mother and child-are thirsty, and they have come to a cool and sparkling spring in the great Atrican torest, far away from the Man-hunter, who seeks their lives. But there are Leopards and Crocodiles that are to be dreaded, and while the father slakes his thirst, the mother, with her head thrown slightly back, shades her eyes with her large hand that she may more clearly discern a possible approaching enemy. The baby impatiently observes the movements of its father, because it, too, is thirsty, and it and the mother must wait until the father is fully satisfied. When he is done he will, in turn, take the place of sentinel while they drink. 
Koppenfels' H. von Koppenfels killed his first GoGorilla rilla Cliristmas, I874. He had taken Hunts. his position near an Iba tree, whose fruit is very much liked by that animal. "I had waited in vain for about an hour. Night was coming on; the Mosquitoes began to annoy me and I was just going to quit, when I heard the sound of breaking twigs near the Iba tree. Peeping from behind my tree, I saw a whole family of Gorillas, consisting of the parents and two children. Taking hunan growth as the standard, these latter might have been six years old and one year old, respectively. The solicitude of the mother for the baby was touching, while the father seemingly cared for nothing but the gratification of his own appetite. The best fruit within reach seemed to have been consumed, for the female climbed up the tree and shook it, to make the ripe berries fall to the ground.

At this time the male, his mouth still full, started for the river flowing near, evidently to get a drink. I did not take my eyes off him, for the stories of Du Chaillu and the fairy-tales of the natives had combined to throw me into a state of great agitation, when I first caught sight of the animals. But this gave way to a sudden calm, when the Gorilla, on his way to the river, seemed to grow distrustful and turning round, made for the tree that concealed me. It was too late-I kept track of his every movement, and had my gun in readiness. A few moments sufficed to take aim and shoot. Before the smoke cleared away I had put another cartridge in my.gun, anticipating an attack. My black companion stood trembling behind me, another gun in hand. The expected attack did not occur. The male Gorilla had fallen on his face, dead. The young ones, giving one scream, fled into the thicket; the mother jumped down from a considerable height and followed them. I was so excited that I forgot to shoot her. So my hunting luck had, at the same time that the Christmas candles were being lighted in Germany, given me, too, a magnificent present."

Not long after this Koppenfels shot, at a chance meeting, the strongest Gorilla it ever was his good fortune to kill Accompanied by his servants he had followed a narrow trail in the woods. "Suddenly the Galloa nearest me screamed: "Takc care, master, a large Gorilla !' and the cowards threw down the things they were carrying and took to their heels. I started at the cry, and just then a terrible growl coming from the side attracted my notice, and I saw barely fifteen paces away a gigantic mass standing erect. It was the largest Gorilla I had ever seen and the only one which ever stood awaiting me. If he had profited by my confusion, I would have been lost. I did not wait, though, to see how long our staring at each other might last. As I lifted my gun his roaring took on more of a barking sound; he beat his chest quicker, the shaggy hair on his head raised itself with a vibrating motion, and it seemed that my terrible opponent was going to attack me. If I had retreated in time, I am fully convinced that the Gorilla would not have approached me, but such was not my intention. Mastering my agitation, I took a steady aim at his heart, and pulled the trigger. The animal jumped high up, and spreading his arms, fell on his face. He had seized in falling, a liana, two inches in circumference, and so powerful was his grasp that he tore it down along with dry and green branches from the tree. His weight seemed to be about four hundred pounds, and he was six feet high."
H. von Koppenfels' plain, unvarnished tales, based as they are on personal experience, give us a more correct idca of this curious inhabitant of the forests, and do away with a great deal of the terror with which he has inspired us. To use the words of $R$. Burton : "He is only a poor devil of a Monkey, and not a fiendish freak of the imagination-half man, half beast."

The Gorilla The attempt to import young Gorillas in to Europe liad always been unsuccessCaptivity. ful, until the members of the German Loango exploring party tried it. Falkenstein, their physician and zoologist, by a lucky chance got hold of a young Gorilla, that was studied first in Africa and then in the Berlin Aquarium.

Director Hermes mentions the growth and further development of this Gorilla at great length in a lecture delivered at the meeting of German naturalists and physicians in Hamburg: "The Aquarium of Berlin has always set great value on the possession of Anthropomorphous Apes. During the last few years it has been able to procure specimens of all of the four species - the Gibbon, Chimpanzee, the Orang-utan and the Gorilla. In this way I had the best of opportunities to study them in captivity and compare them with each other.

The chief among all the Anthropomorpha is the Gorilla. It seems as if he was born with a patent of nobility among Apes. Our Gorilla, about two years old, is nearly twenty-eight inches high. His body is covered with gray, silky hair, the head alone having a reddish color. His thick-set, robust shape, his muscular arms, his smooth, shining black face with well-shaped ears, his large, black, clever eyes-all strike one as exceedingly human. If his nose was not so broad he would look like a Negro boy. What serves to heighten this impression is his awkwardness; all his movements seem those of an ungainly boy rather than an Ape. When he sits there like a Chinese pagoda, his gaze directed upon the spectators, and suddenly with a bright nod claps his hands, he lias conquered all hearts at a stroke. He likes company, makes a difference between young and old, male and female. He is kind to little children, likes to kiss them, and allows them liberties, witlout taking advantage of his superior strength. Older children he does not treat so well, although he likes to play with them, to race around tables and chairs which he frequently upsets, playfully slaps their faces sometimes, and also thinks nothing of trying his teeth on their legs. He is fond of ladies, likes to sit in their laps and hug them, or sit still, with his head on their shoulders. He also likes to play in the common cage, but conducts himself there as an unconditional autocrat. Even the Chimpanzee has to obey him, though the Gorilla treats him more as an equal, selecting him as his only playfellow and sometimes bestowing rather rough caresses on him, while he pays no attention to the smaller fry. Sometimes he gets hold of the Chimpanzee and rolls on the floor with him. If the Chimpanzee escapes, the Gorilla falls to the floor, on his hands, like an awkward boy. His gait resembles that of the Chimpanzee: they botll walk on the soles of their feet, supporting themselves on the back of he hands. But the Gorilia turns his toes out more, and holds his head higher, producing the impression that he belong to a better class of society. When he is in good humor-which is nearly always the case - he sticks out his red tonguc, which in that 


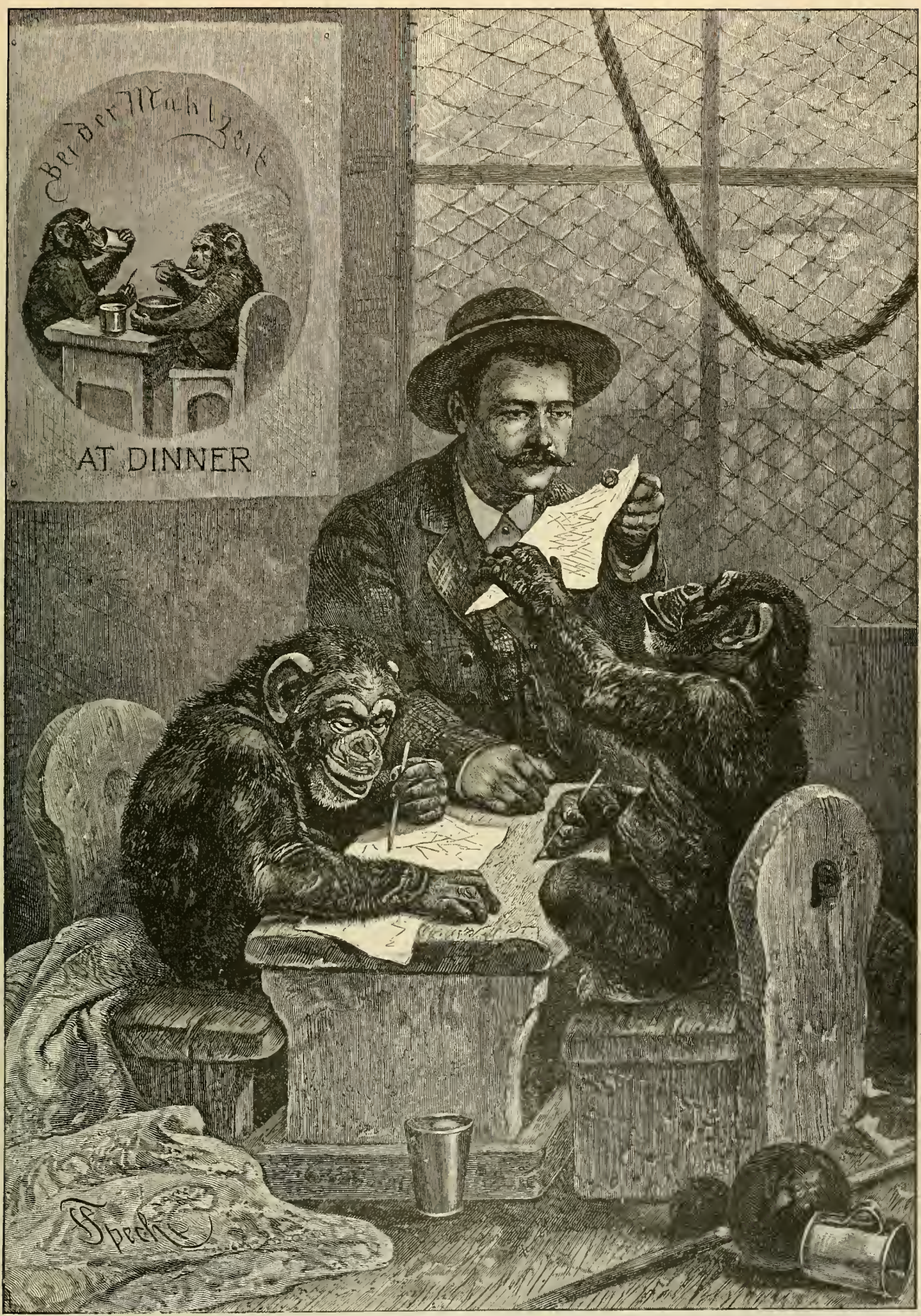

CHIMPANZEES AT SCHOOL. - The artist here presents two most amiable and accomplished young Chinpanzees that enlivened the famous zoological garden at Stuttgart for some years, and performed a number of delightful pranks, which made then favorites with everybody. The picture represents them. at school, the master examining the work of one of the pupils who is, unlike some school-boys, anxious to resume the task. The smaller sketch shows them at dinner and proves how cleverly they have mastered the accomplishments of eating and drinking like Girls and Boys. They were amiable, playful, knew scores of entertaining tricks, would sit in chairs, sleep in beds and walk around like hrman beings. 
black face of his, forcibly reminds one of a negro boy.

"His manner of life is just as human as his appearance. At about eight o'clock in the morning he wakes up, yawns, scratches himself in various places and remains sleepy and apathetic till his glass of morning milk is brought. That rouses hin. He gets up, peers around to see whether he cannot find something to destroy in the room, looks out of the window, claps his hands, and if he has no better company, tries to play with the keeper. The latter must always be with him. The moment he is left alone, he screams. At nine o'clock he is washed, a process in which he finds much pleasure, and expresses his satisfaction in grunts. Living with his keeper, he gets his meals at corresponding times with him. For luncheon he eats a couple of Frankfurt or Vienna sausages, or a sandwich with cheese, or smoked beef. His favorite drink is Weiss beer, and he looks remarkably funny when he tries to hold the large glass with his short, thick fingers and one foot. At one o'clock the keeper's wife brings in dinner. While he was living in.my house, last summer, he was evidently yearning for this hour. He always ran to open the door himself, when he heard the bell. As soon as the woman came in, he would investigate the dishes and sometimes help himself to a little of some dainty. She would punish him with a slap, and then he would behave and sit quietly. The first course is a cup of bouillon, which is emptied to the last drop. Then comes a dish of rice or vegetables, preferably potatoes, carrots or parsnips, cooked with meat. The woman insists on his eating properly, and he can handle a spoon quite well, but the minute he thinks he can do so unobserved, he puts his mouth in the dish. He likes it piece of roast fowl best at the end of his meal. At the conclusion of dinner he takes a nap of an hour or an hour and a half, and is then ready for new pranks. In the course of the afternoon he gets some fruit, while his evening meal consists of milk or tea with bread and butter. At nine o'clock he goes to bed. He has a nice mattress and covers himself with a blanket. The keeper stays with him till he is asleep, which does not take long. He likes best to sleep in the same bed with the keeper, hugging him and putting his head on some part of his body. He sleeps all night through and does not awaken until eight in the morning. A glass house in connection with a little conservatory adapted for palms, has been built specially for him, to take the place of the damp atmosphere of his tropical home. In this way I hope that aided by his robust nature, our Gorilla will be spared us and will long be the greatest ornament of our Aquarium, an honor to Germany, a joy to humanity, a glory to science."

This Gorilla died on the 13th of November, 1877 , after having been watched for nine months in Africa and for fifteen months in Berlin, and having successfully made a trip to England. The second Gorilla was taken to Europe by Pechuel-Loesche, the former companion of Falkenstein, who arrived with him in 1883 , on his return from the Congo, and was also presented to the Berlin Aquarium. He lived under the care of Director Hermes for fourteen months and died of the same disease as the first Gorilla. It is a notable fact that neither of the animals suffered from sea-sichness.

All other attempts to take living Gorillas to Europe and to keep them there, have been unsuccessful; [nor has one ever been brought to America.]

\section{THE CHIMPANZEE.}

Let us now consider the second species of the Anthropomorpha, the Chimpanzee (Simia troglodytes). $\mathrm{He}$ is considerably smaller than the Gorilla; old males reach a height of sixty-four inches; females, forty-eight inches. The skull is flatter, the arches of the eycebrows not so prominent and the expression of the face with its large, clear eyes a great deal gentler. The nose is flat, the upper lip long, arched and wrinkled; the lower lip, prominent. Both lips are exceedingly mobile and may be projected so as to produce a snout-like impression. The ears are larger and less human than those of the Gorilla. The arms are long, reaching a little below the knee, and possess great muscular power. The thumb in the hands is thin and short; the fingers are long, the middle finger being the longest. In the feet the large toe is separated from the others by a deep incision ; and the sole is flat. The hair of the Chimpanzee is smooth, that on the head usually showing a parting; it is long on the back part of the head, on the cheeks, the back, arms and legs; and shorter on the other parts of the body. The color usually is black; but in some specimens is a dull, reddishbrown. The lower part of the face has short, whitish hair. Chimpanzees walk on all fours, resting them. selves on the calloused back of their hands. The toes of the feet are sometimes drawn in when walking. There is a strong inclination in this species to show remarkably varying individual types which has led to controversies as to whether there were not several different species.

The Chimpanzee As a proof that the Chimpanzee was Long and known to the ancients, mention is

Well-known. usually made of the famous mosaic picture, which once adorned the temple of Fortuna in Preneste, [and which is still preserved in the Barberini Palace at that place, now the town of Palestrina in Italy.] This mosaic represents, among many other animals of the Upper Nile country, what is believed to have been the Chimpanzee. This Ape is often mentioned by the authors of the past few centuries, mostly under the name of "Inseigo" or "Nschiego," a name he still bears in Central Africa. A young Chimpanzee was taken to Europe in the beginning of the seventeenth century, dissected by Tulpius and Tyson and described by Dapper. He has been taken there repeatedly since and is a not infrequent feature on the European animal market. [Several have been brought to the United States and placed in museums and menageries.]

Formerly he was supposed to inhabit, exclusively, Upper and Lower Guinea and the country back of it, ranging from Sierra Leone to the Congo. He lives in the forests on the rivers of the coast and in the mountains. H. von Koppenfels has hunted him in the Gaboon and Ogowe country. To the south he was frequently seen by the German Loango expedition near the Congo. German explorers have established the fact that he is found in central Africa, deep in the region of the lakes, probably going as far as the oil-palm and the gray Parrot. Heuglin says: "In the thick foliage of the forests growing along banks of rivers in the country of the NiamNian the Mban (more correctly Baam) has made its home, an Ape the size of a Man and of a savage character, fearlessly turning on his pursuers. He lives with his family and builds large nests in the trees, making them water-tight and proof against 


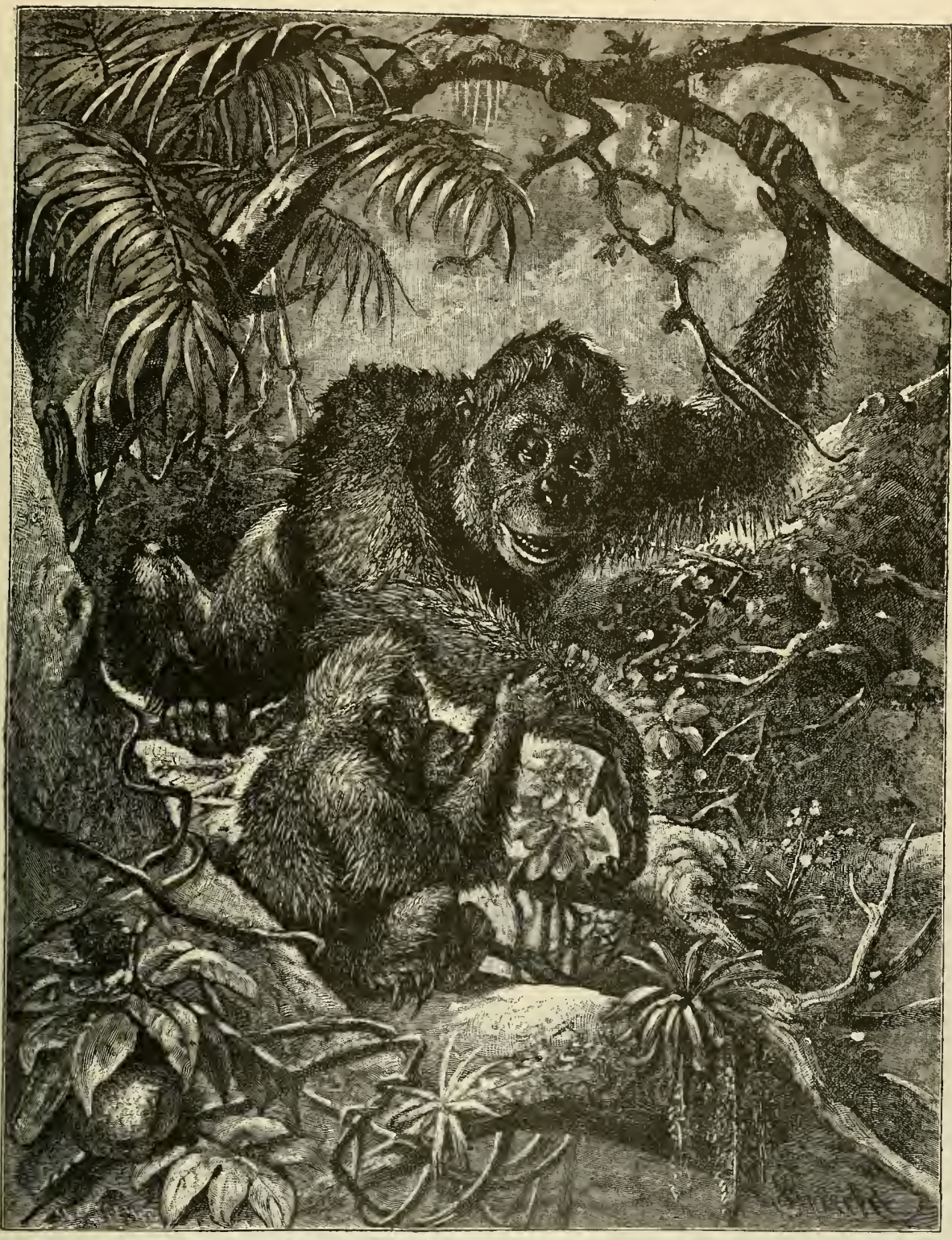

FEMALE ORANG-UTAN AND CHILD. - The artist here presents a home-scene in the life of the Orang-utan, a mother resting upon a tree-branch while her grotesque-looking child plays with her long fore-arm. These interesting animals are found in the islands of Borneo and Sumatra, and are sluggish creatures, who spend their lives in the trees, but are capable of greatest activity when pursued by enemies, their arms, which are much longer, proportionally, than those of the Chimpanzee, enable them to swing prodigious distances through the air. The enormous length of jaws of the animal is shown in the face of the baby The striking resemblance to Man is more apparent in the
face of the mother and explains why the nane, satyr " Wild man of the woods," is applied to the Orang-utatr. (Pithecus satyrus.) 
the rain. His hair is olive-black, his face hairless and flesh-colored, and his buttocks white."

character- Savage, who made his observations in istic Lower Guinea, writes: "We cannot say

Traits. that the Chimpanzee is a gregarious animal, as there are seldom more than five, or, at the utmost, ten living together. Relying upon trustworthy reports, I may say, though, that they sometimes gather in greater numbers for play. One of my narrators claims to have seen at one time about fifty of them which had assembled on trees and amused themselves with screaming and drumming on the tree-trunks. They avoid human habitations as much as they can. Their dwellings, which are more nest-like than hut-like, they build on trees, not at a great height from the ground. They break and twist and cross larger and smaller branches, and support the whole on an embranchment, or on a strong bough. Sometimes you find such a nest at the end of a bough, twenty or thirty feet from the ground, but I have seen some that could not be less than forty feet high. They do not care for a permanent home, but change abiding places often in looking for food or for other reasons. IVe frequently saw them in the mountains, probably because the valleys, more favorable to the agriculture of the natives, lacked the trees necessary for their nest-building. Two or more nests are rarely seen in the same tree or even in the same neighborhood, though five were once found together. Nests, properly so-called, consisting of interwoven branches, as Du Chaillu describes, have not been seen by any of the other narrators."

When in repose the Chimpanzee in the wild state usually assumes a sitting posture. He is often seen standing or walking, but the minute he is detected, drops on all fours and flees. As may be supposed from his nest building, the Chimpanzee is an adept at climbing. In his play he swings himself from tree to tree and jumps with amazing agility. His food probably is the same as that of the Gorilla,- fruits, nuts, buds and, perhaps, roots, forming the staple articles of diet.

The Chimpan: The Chimpanzee is made a captive zee in oftener than the other Man-1ike Apes,

captivity, but unfortunately does not live over two or three years in that state, although it is said that in west Africa he has lived over twenty year. in captivity. Captive Chimpanzees under observation have so far always shown themselves gentle, clever and amiable. Degrandpre saw on a ship a female which performed various tasks. Buffon relates that his Chimpanzee had a sad and serious look, and moved about in a dignified manner. He had not a single one of the nasty qualities of the Baboons, neither was he so playful as the Guenons. He was very obedient, shook hands with people, ate at the table, used his napkin, poured out wine for himself, got a cup and saucer when he wanted tea, put in the sugar and always waited for the tea to get cold. He never harmed any one, but had a very modest, gentle bearing, and delighted in being petted.

Out of all the numerous stories about the Chimpanzee we select here the accounts of the celebrated painter of animals, Fr. Specht, concerning one in Nill's Zoological Garden in Stuttgart. This Chimpanzee, as Specht affirms, could laugh like a human being: "I took notice of this, for no other animal can show its joy by loud laughter. When I would take this sympathetic fellow under the arms, throw him in the air and catch him, the cage rang with his merry peals of laughter. One day I brought a piece of chalk along, and sat down on a chair. In a moment he was sitting on ny knees awaiting. further developments. I put the chalk in his hand, and leading it, drew several figures on the wall. when I let go of his hand, he started to shade the drawings with such diligence that they soon disappeared, to the great amusement of the spectators. There are now two Chimpanzees in the Stuttgart Zoological Garden, which are the closest of friends. The female had been there before, and when the male arrived his box was put over night in her warm, roomy cage, the presentation being intended for the morrow. When the box, which, by the way, had been upholstered, was opened and the male got out, they both stood on their hind legs for a few minutes earnestly gazing at each other. Then they flew into each other's embrace and exchanged hearty and repeated kisses; and the female brought her blanket, spread it on the floor, sat down on it and by gestures invited the male to do likewise. It makes a charm. ing picture to see these two taking their meals at a table. They both use spoons and do not in the least interfere with each other. The female has the peculiarity of cautiously taking the male's glass and drinking a goodly portion out of that, too, after which she returns it. She evidently does not want him to drink too much. Both these animals laugh heartily when at play.

\section{Mr. Crowley" The same fate has befallen Chimpanzees of brought to the United States as was met by of those taken to Europe. All will readily New York. recall that most attractive fellow, "Mr. Crow.} ley," so long the chief object of admiration in the museum of Central Park, New York. This Chimpanzee was greatly attached to his keeper and displayed a readiness and agility in performing amusing tricks that won the attention of every one. He acquired a number of accomplishments in the way of eating and drinking, and displayed, until the ravages of disease spoiled his temper, a mildness of disposition that charmed his daily visitors. "Mr. Crowley" had two attacks of pneumonia before his final, fatal illness, consumption, that nearly certain enemy of all Apes in captivity. "Miss Kitty," a less amiable, and, therefore, less attractive Chimpanzee, was his companion for awhile, but she, too, shared the same fate as the idolized " Mr. Crowley." Two Chimpanzees which kept house in a cage in the zoological gardens at Cincinnati were very accomplished. They would sit comfortably eating together in a manner similar to that of the Anes of the Stuttgart II seum as illustrated on page 15. They would also disport themselves for quite long periods by rocking themselves in chairs, human fashion, but would then show their Ape nature by clambering over the backs of the chairs with great agility, besides performing many other tricks which made them the great attraction of the pleasant and well-stocked zoological gardens in which they were kept. Death severed the pair. Barnum, the American showman, had two Chimpanzees, "Xip" and Tuck," on exhibition in various towns and cities in this country, but they did not display the intelligence shown by "Mr. Crowley," nor did they live for a great while. Perhaus their narrow quarters in a cage and constant traveling combined to sour their tempers and linit their capacity for learning. Other attempts to introduce the Chimpanzee into this country have not been encouraging, lack of unclerstanding of the habits of the animal being in some measure the cause; but it is a fact that this Ape does much better in warmer and drier climates like Paris than in that of England and the colder parts of the continent of Europe and the northern states of this country. The experiment of keeping one has not been tried in the South, which is to be deplored, for there are doubtless cities in the southern states where the climatic conditions would prove to be especially favorable for keeping Apes much longer than is possible in the more northern zoological collections, which have never been able to keep specimens of the anthropomorphous Apes for any extended period.

\section{THE ORANG-UTAN.}

The most important Asiatic Man-like Ape is the Grang-utan (Man of the Woods), sometimes incorrectly called Orang-Utang, and named Mias or Majas in Borneo (Pithecus satyrus). He is distinguished by his disproportionately long arms, reach- 


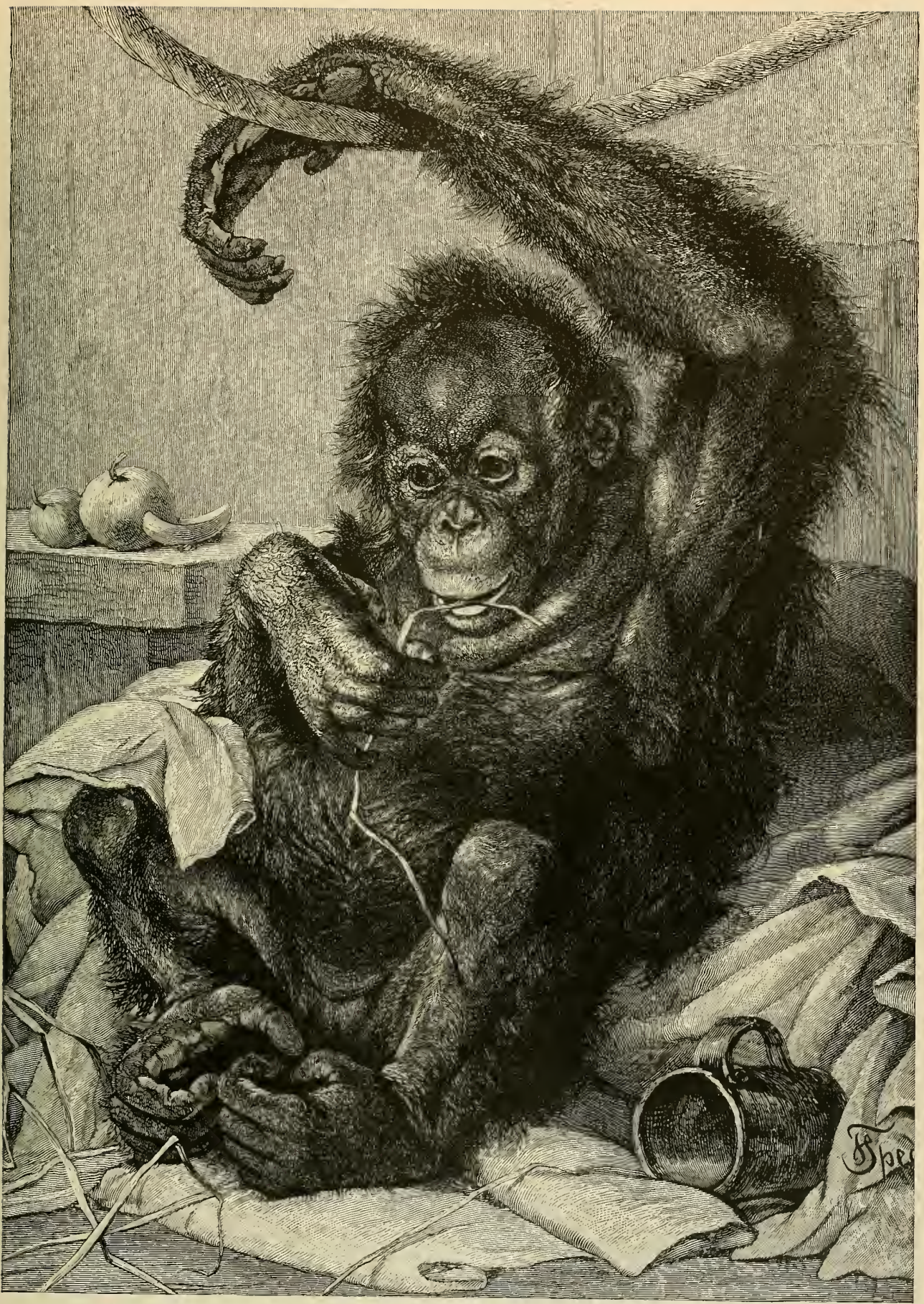

YOUNG ORANG-UTAN. - The baby-like face of the young Orang is clearly brought out in this picture which is an exact reproduction from life The expression is older than a child's, but the features are nearly identicl there being the rornd prominent forchead, full, clear and fearless eyes and large mouth and ears characteristic of the human child. and the wisp of straw held in the mouth and fingers show that like the human creature it is fond of play. This Orang has its own snug bed and sleeps restfully beneath the covers, drinks from its owr cup, runs and jumps, plays all kinds of mad pranks and enjoys life fully as much as mother's own baby in any one of ten thousand happy homes. ( $P$ uhecus satyras.) 
ing as far as his ankle joint, and by his conically shaped head and protruding jaws. He has only twelve rib-supporting vertebre. The skull of a young Orang-utan resembles that of a human child to a high degree; but as it grows older, the animal nature is developed and this likeness almost entirely disappears.

Physical The largest male Orang-utan killed by

character- IVallace was four feet two inches high, istics. but he could spread his arms to the width of six feet two inches. The face was thiiteen inches wide, and the circumference of the body was four feet. The abdomen of the Orang-utan protrudes and the hips are very wide; the neck is short and wrinkled in front, for the animal has a large pouch at his throat, which can be inflated; the nails are frequently lacking on the thumbs of the feet. The lips have a very unsightly appearance, for they are not only wrinkled, but also greatly swollen; the nose is pressed flat; the eycs and ears are small but resemble those of a human being. The canines are the most formidable among the teeth, and the lower jaw is longer than the upper. The hair is scanty on the back and breast, but is long and plentiful on the sides of the body. In the face it grows beardlike, and on the upper lip, on the chin, on the skull and on the fore-arms its position is upwards. The face and palms of the hands are bare, the breast and fingers nearly so. The color is usually red, sometimes merging into brown, darker on the breast and back and lighter in the beard. The bare parts look bluish or slate-gray. Old males are distinguished from females by their larger size, longer and thicker hair, thicker beard and peculiar callosities on the cheeks, spreading from the eyes to the ears and upper jaw, and giving the face a hideous aspect. The young Apes have no beard, but their hair is darker and longer.

Early Accounts The Orang-utan has been known for of the a very long time. Pliny avers that orang. there were Satyrs on the East-1ndian mountains, "very ferocious animals with human faces, sometimes walking upright, sometimes on all fours, and so agile that they could be captured only in old age or when sick." His story goes on down to our own times, receiving new additions every century, until one nearly forgets that they are animals concerning which the storics are told. They get to be treated like wild Mell. Exaggerations of all kinds disfigure the truth. Bontius, a physician living in the seventeenth century, spealis of his own experience, He says he has seen "the dwellers of the woods" several times, males as well as females. They sometimes walked erect and beliaved like human beings. One female in particular aroused his wonder. She was ashamed when strangers looked at her and covered her face with her hands; she would sigh and weep and do everything exactly like a human being; she only lacked speech. The Japanese affirm that $\Lambda$ pes coild talk very well if they were so inclined, but they are dumb through fear of being made to work. It is almost needless to state that in all these stories the Orang-utans walk crect, though it is sometimes added that they are also "able" to go on all fours. In reality the narrators of all these fables are innocent of deccption, only repeating what they heard from the natives.

Wallace's Owing to the excellent observations of Account of Wallace, we know more about the life the Orang. in a natural state of the Orang-utan than of any other of the Man-shaped Apes. This traveler had the best of opportunities to become acquainted with the animal and to compare his experiences with the tales of the natives. Some of his predecessors, especially Owen, Kessel and Brooke, had tried to get at the truth, and his accounts in the main go to prove their statements.

"We know," he says, "that the Orang-utan is a native of Sumatra and Borneo, and, we have cause to think, is limited to these two islands. But he seems to be much more frequent in the latter than in the former. He is found in extensive tracts of land in the southwest and southeast, northwest and northeast coasts, but occurs exclusively in marshy, low-lying woods. In Sadong he is only found in the plains covered with virgin forests and crossed by many rivers. Isolated mountains, inhabited by Dyaks and planted with fruit trees, rise here, and form a point of attraction for the Mias. They often visit them on account of the fruits, but always retire at night into their bogs. In all those parts of the country where the surface rises and is dry, the Orang-utan does not appear. An extensive plain of uninterrupted and level virgin forest seems a condition essential to the welfare of this $\lambda$ pe. These forests offer to him a ficld for as unimpeded progress as a prairie to an Indian or the desert to an Arab. He goes from tree-top to tree-top without ever alighting on the ground. A high and dry country, with the trees cleared away in places and the ground covered by underbush, may be better adapted for Nen, but not for this Ape with its peculiar mode of locomotion.

"It is an attractive and strange spectacle to see a Mias (Orang-utan) easily making his way through the forest. Without hurry he goes along one of the larger boughs, in a scmi-erect position, which the length of his arms and the shortness of his legs render obligatory; he does not use his soles, but walks on his knuckles, like so many of his cousins. He always seems to select trecs whose branches interweave; he stretches out his long arms, seizes the branches with both hands, seemingly trying their strength, and then deliberately launches himself forward upon the next tree, where he goes through the same performance. He never hops or jumps, or seems in the least to hurry, yet he proceeds on his way as quickly as anybody could run underneath." In another place Wallace says he thinks the Nlias could easily cover a distance of five or six miles an hour. "His long, powerful arms are of the greatest use to him; they enable him to climb the highest trees with ease, to pluck fruits and young leares of thin branches that would not hold his weight, and to gather leaves and twigs for his nest." An Orang-utan wounded by this explorer revealed to him the manner of building a nest. "As soon as I had shot," says Wallace, "the Mias climbed to the top of the trec. He started to break off branches and put them down crosswise. The place had been admirably selected. With surprising quickness he reached out in every direction with his unwounded arm, breaking strong branches and crossing them, so that in a few minutes he had formed a close wall of foliage, which effectually conccaled him from my sight. A similar nest is used by Orangs for their night's rest, but this is usually built on smaller trees farther down, as a rule not higher than thirty to sixty feet; probably because it is not here so much exposed to the winds. It is said that the Nias builds a new nest every night, but I think this improbable, for, if such were the case, the remains 


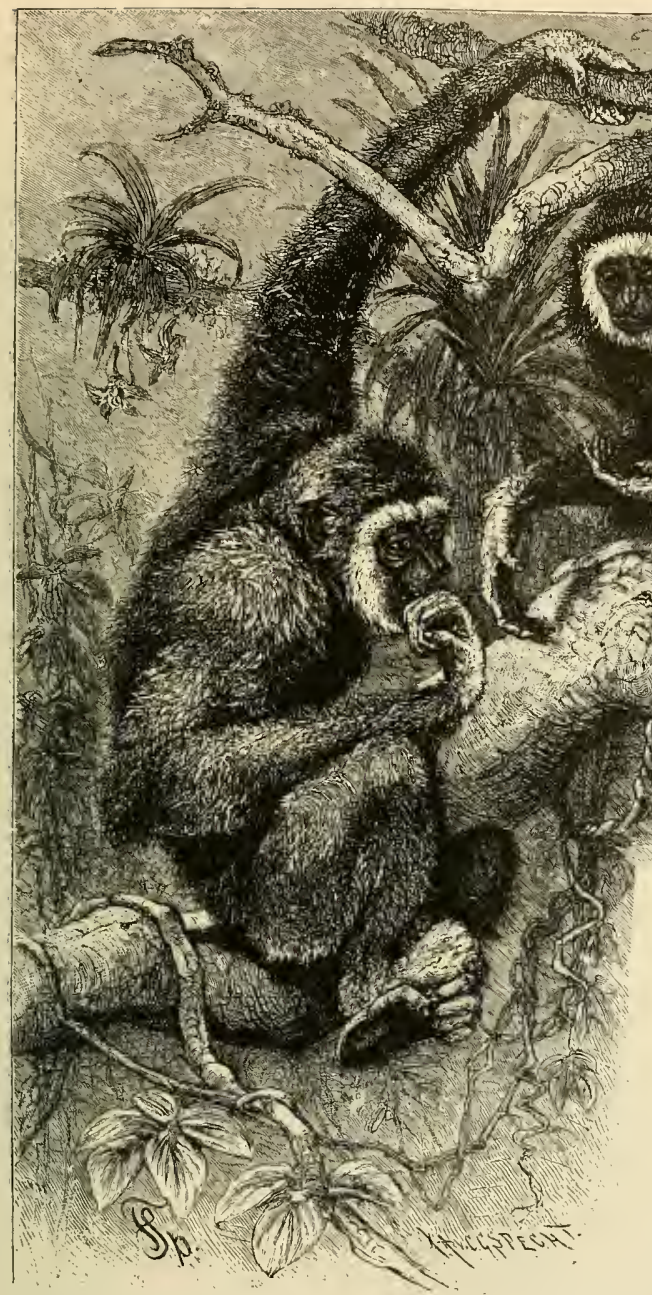

WHITE-HANDED GIBBONS,-These active and pretty animals are found in Terrasserim, southwest of Burmah, and are noted for their lond voices. Troops of them will get together in the deep forests and fill the air with their not unmusical cries for hours at a time. A white band of hair encircles the entire face and the body is black, dark-brown or ochre-brown. These interesting creatures drink water from the palms of their hands, are readily tamed in India but do not long survive foreign captivity. The artist represents them in the picture mounted on a favorite tree, suspiciously regarding some approaching object. (Hylobates lar.)

of these nests would be oftener found. The Dyaks claim that in wet weather the Mias covers himself with pandanus leaves or large ferns. Perhaps this is the origin of the belief that the Orang-utan builds a hut in the trees in which to live.

"The Orang-utan leaves his bed when the sun is well above the horizon and has dried the dew on the leaves. During the day he eats, but seldom visits the same tree two days in succession. As far as I could determine he feeds almost exclusively on fruit, but occasionally on leaves and buds. In very rare cases he descends to the ground; probably only when, driven by hunger, he looks for juicy young leaves on the banks of a river; or when in exceed- lives in a country where the Orang abounds. assured me that no animal was strong enough to hurt one, and the only animal he fights with is the Crocodile. When the Orang runs short of fruit, he descends to the river banks to look for young shoots and fruit. Then the Crocodile tries to seize him, but the Orang jumps on it, beats it with hands and feet and kills it.

"Rarely does it happen that an Orang fights with a human being. One day several Dyaks came to tell me that one of these animals had nearly killed a companion. His house was standing on the bank of the river, and he saw an Orang-utan making a meal of the young leaves of a palm. He frightened him, and the Ape beat a retreat into the woods. A 
number of Nen armed with spears and hatchets ran to cut off his retreat, and the foremost Man tried to spear the animal, but the Mias seized him and buried its teeth in the muscles over the elbow, tearing the flesh into shreds. If the others had not come to the rescue, he would have fared still worse, but they succeeded in killing the plucky beast. The wounded Nan was sick for a long time, and never recovered the complete use of his arm." The truth of this story was proven by IVallace, who on the following day, visited the field of battle, and cut off the head of the Orang-utan, for an addition to his collection.

The Orang. To complete this picture so exicellently Utan in represented by Wallace, we will draw Captivity. on several of the older reports. For the first correct observations we are indebted to the Dutchman, Vosmaern, who was in possession of a tame female. She was a good-natured animal and never proved herself false or malicious. One could without fear put his hand into her mouth. Her usual expression was that of sadness and melancholy. She liked all human beings without distinction of sex, but preferred those who took care of her. Her owner kept her chained, which at times made her desperate: she would throw herself on the floor, scream pitifully and tear all the blankets that were given to her. Once she was let loose, and immediately made her escape to the roof, where she climbed about with such agility that four persons spent an hour in trying to recapture her. On this same excursion she laid her hands on a bottle of Malaga wine, drew the cork and made haste to appropriate the contents, afterwards placing the bottle in its former position. She ate everything that was given to her, but preferred fruit and juicy plants to other food. She also liked boiled or fried meat and fish. Insects she did not hunt for, and a Sparrow that was offered her caused her great fright; still she finally killed it with a bite, pulled out a few feathers, tasted the meat and threw it away. Raw eggs she ate with pleasure, but strawberries seemed to rlelight her most. Her usual beverage was water, but she liked all kinds of wine, and especially Malaga. After drinking she would wipe her mouth with her hand, and she used tooth-picks in the same manner that human beings do. Slie was an accomplished thief and stole candy out of people's pockets in a masterly way. Before going to sleep she always made great preparations. She shook the hay and spread it fresh, put a bundle under her head and carefully covered herself; she disliked to sleep alone, for she dreaded solitude. Sometimes she took a nap in the day-time, but never a long one. the had been given some clothing, and this she alternately wrapped around her body and her head, without reference to the temperature of the room. When she saw the lock on her chain opened with a key, she got a little piece of wood and kept turning it in the lock. Once she was given a Kitten. While she was smelling it, Pussy scratched her arm. Then she.threw it away and never had anything more to do with Cats. She could untic the most complicated knots with her fingers or her teeth, and this secmed to afford her such pleasture, that she always untied people's shoes when she had a chance. Her liands were exceedingly strong and she could lift the heaviest burdens. She used her feet with the same dexterity as her hands. When she could not reach an article with her hands, she threw herself on her back and got at it with her feet. She never screamed unless left alonc. It first her screams resembled the howling of a Dog. She soon fell a prey to consumption.

An Orang- Another description comes to us from

Utan on a careful observer, who had an Orang-

shipboard. utan on a ship for three months. As long as the ship was cruising in Asiatic waters, the animal lived on deck, selecting a sheltered place for the night. During the day-time he always was in the best of humor, played around with little Monkeys that were on board, or disported himself in the rigging. Turning and climbing seemed to afford him especial pleasure, for he would practice it on different masts and cables His agility and muscular power were astonishing. Captain Smitt, the observer, had taken a few hundred cocoa-nuts. along, the Orang daily receiving two He was very expert in destroying the tough outer covering or the nuts with his teeth, though it was two inches thick and the sailors had to use a hatchet for the task. He would insert his formidable teeth into the tapering end of the nut, as the shell is very uneven there; then he would seize it with the right foot and in this way tear the tough covering to preces. Then he would pierce one of the natural apertures of the nut with his finger, drunk the milk, break the shell on some hard object and eat the kernel.

Besides the cocoa-nuts he liked salt meat, flour. tapioca, etc., and resorted to a great many tricks to get the greatest possible amount of meat at every meal. What he once procured he never released even though he was beaten for his obstinacy. The flour he daily received in the kitchen, and when the cook was absent, he never failed to open the flourbin, take out a good handful and then wipe his hand on his head, so that he often appeared on deck powdered. Every Tuesday and Friday he unfailingly made the sailors a visit when the dinner-bell rang, for on these days they had tapioca with sugar and cinnamon. Just as regularly he would make his appearance in the cabin at two o'clock, to get his share of the meal served at that hour. He was very quiet at meals, and, unlike other Apes, clean, though he never could be taught the proper use of the spoon. He put his plate to his mouth and simply drank the soup, without spilling a drop. He was very fond of spirits, and always received a glass of wine at dinner, which he emptied in a peculiar manner. He could project his lower lip in such a way as to form a cup three inches long and nearly as wide, and capable of holding a tumblerful of water. Into this curious cup he poured the wine, and never drank otherwise. After having carefully smelled of the wine, he projected his lip, poured the liquid in, and then proceeded to suck it in between his teeth, deliberately and slowly, as if he intended to make the pleasure as lasting as possible. Then he reached out his glass for more. He never broke a dish, thereby differing from the other Apes, who, as evcrybody knows, usually break everything.

He was never heard to make but two different sounds; a feeble, piping one, designed to express agitation, and a dreadful roar, resembling the lowing of a Cow, and denoting fear. Once he uttered the latter at sight of a Whale swimming near the vessel, and again when he cauglit sight of several Waterinakes that nis owner brought from Java. The expression of his face never changed. Unfortunately an accident, resulting from his love of liquor, ended his life before he renched Germany, which was his destination. He stole a bottle of rum, nearly cmptied it, became sick and died on the fourteenth day. 


\section{THE GIBBON.}

No other Apes show such a development of the upper extremities as the Gibbons or Long-armed Apes (Hylobates). They perfectly justify their name, for when they stand erect their fingers touch the ground. This one trait would suffice to distinguish the Long-armed Apes from all others of their class.

The Gibbons form the most numerous tribe of the Man-shaped Apes, there being about seven different kinds of these animals. They are all inhabitants of Asia, being found in East India and the adjoining great islands of Sumatra, Java and Borneo. They attain a considerable size, though none of them cxceed three feet, four inches in height. The body appears very slender in spite of the highly developed chest, for the hips are very narrow, reminding one of a Greyhound; the lower extremities are very much longer than the upper, and the elongated hands in some species show the forefinger to be connected with the middle finger by means of a membrane. The head is small and egg-shaped, the face very human, the callosities on the hind quarters are small and the tail not visible. Their fur is plentiful and sometimes silky; the coloring may be black, brown, brownishgray or cream. All the Gibbons are gifted with an exceedingly strong voice, which they use a great deal in the morning hours.

Leading The most Varieties of remarkable the Gibbon. of the Longarmed Apes are : the Siamang (Hylobates syndactylus), the Hoolock (Hylobates hoolock), the Lar or White-handed

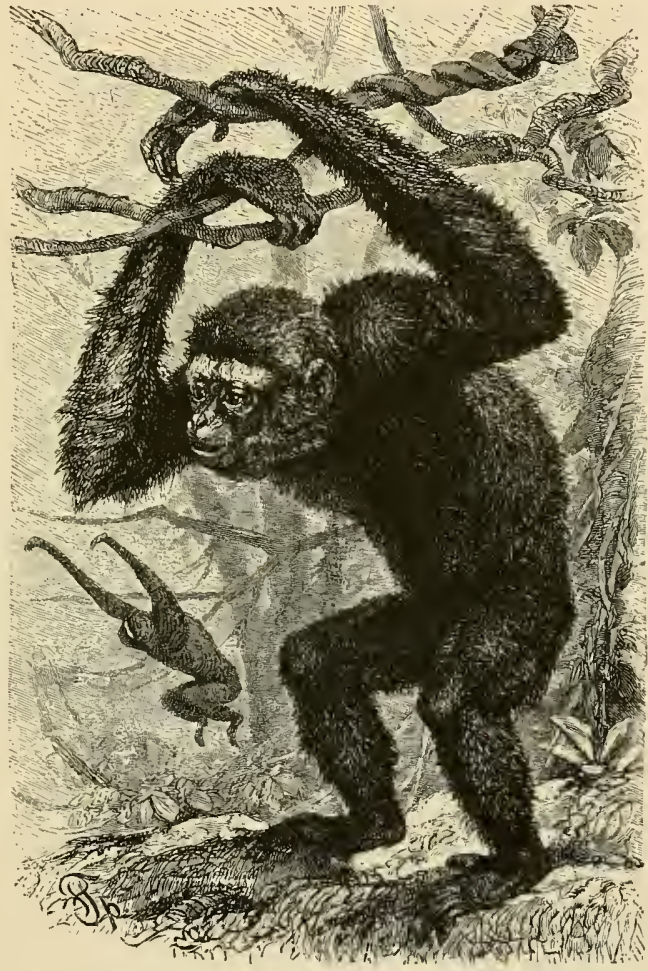

THE WAU-WAU,-Native of the great Asiatic islands, and is also known as the Sllvery Gibbon, from the coloring of its fur. It is among the most agile of all its group and can easily swing through the air from treebranch to tree-branch, a distance of fifty feet or more. The deepness of the chin and the two prominent ridges on the forehead give to the face a rather unpleasant appearance, but in captivity it is amiable and readily attaches itsel unpleasant appearance, but in captivity
to its master. (Hylobates variegatus.)
Gibbon (Hylobates lar), the Ungko (Hylobates raffesii) and the WVau-wau or Oa (Hylobatis rariegatus). The largest of the tribe is the Siamang, which possesses a soft black coat of fur, and a pouch at the throat, which he inflates in screaming, to strengthen his voice. His native country is Sumatra. The Hoolook, a trifle smaller than the Siamang, is usually black with the exception of a white band on the forehead; although there are several lighter kinds. $\mathrm{He}$ has no pouch and inhabits India. The Ungko, which has his home in Sumatra and is a rarer animal, shows still greater varieties of coloring. He, as well as the Siamang, is found sometimes as high as three thousand feet above sea-level in the mountain-forests. The Wau-wau has a face of a bluish-black hue, the head, the breast, and the inner sides of the arms and legs being dark brown, the rest of the body lighter. He inhabits the Malay Peninsula, together with the Lar, but is also found in Stmatra and Borneo. The frame of the Long-armed Apes is especially adapted for climbing. They are possessed of every qualification necessary for rapid, protracted and agile climbing and jumping. The large chest is endowed with capacious lungs, which do not tire or give out when the blood circulates faster during active exercise, the strong lower extremities give the necessary impetus for long Icaps, the long arms lend security in the seizing of a branch destined to be the next point of support, and which might easily be missed with shorter arms. How long these arms are proportionately is best seen by comparison with Man. The latter, extending his arms, takes in a width equal to his length; the Gibbon, double his length. A Man standing erect, touches the middle of his thigh; a Gibbon, his ankle-joint. Of course these arms are no fit instruments for walking: they are only intended for climbing. Therefore, the walk of a Long-armed Ape is but an awkward balancing of the hind legs, a clumsy waddling, while its movements in climbing a nd dancing among the branches are full of life and grace, seemingly knowing no bounds and ignoring the laws of gravity. On the ground the Gibbons are slow and extremely clumsy. There they are awkward and out of place; in the trees they are swift as birds. All narrators are unanimous in their admiration of the climbing accomplishments of the Longarmed Apes, in which they excel every other species.

Astonishing Duvaucel relates with what incredible Agility of rapidity and assurance the Wau-wau Gibbons. climbs a bamboo-cane, a tree top or a branch, swings to and fro on it, and then flings himself through space, covering distances of forty to fifty feet with the greatest ease, flying like an arrow or a bird It looks as if the consciousness of this incomparable agility gives him great pleasure, for he takes immense leaps that he could easily avoid ; sometimes changing his direction in the air, hanging on to the nearest branch and throwing himself forward again. It really produces the impression of magic, as if he could fly without wings, and lived more in the air than in the trees. What could such a being do on the ground? He is a stranger there, and only visits 
it to allay his thirst. His home is in the air, where he enjoys peace and security, easily escapes every enemy and, of a verity, lives and lusuriates in the enjoyment of motion.

The Natural Study of these animals in the wild state Traits is extremely difficult, as they are very

of Gibbons. shy and seldom leave the depths of their native forests. Only a good telescope - an instrument indispensable to the observer of all of the more timid an imals-enables one to see a little of their life. In this way it has been discovered that the mothers carry their little ones to the river, where, in spite of great screaming, they proceed to wash and afterwards diy them, taking as much pains in the whole process as we might desire to be lavished on some human children.

At sunrise and sunset they usually join their loud voices in such a conccrt as to dcafen a nearby observer, and frighten any one not used to this curious music. They are the alarm clocks of the Malay mountaineers, and the greatest an noyance of the town in li a bitants whose suburban summer life they manage to spoil. It is said that their cries are heard a mile away. Captive Long-armed Apes both with and sithout the cheek-pouches have been heard to utter very loud shrieks.

Bennctt, a careful observer, had a living Siamang in his possession, and noticed that when he was cxited he projected his lips like a funnel, inflated his pouches and made a sound rescmbling the gobble of a Turkey. He made cries denoting joy as well as anger. The female Ungko in London sometimes cried in a peculiarly harmonious manner. She began with $\mathrm{E}$, ascending and descending a full octave in cliromatics. In ascending the notes became slower and slower; in descending they followed in quick succession, the finale being a piercing yell. The regularity, assurance and rapidity of this performance invariably excited the enthusiastic admiration

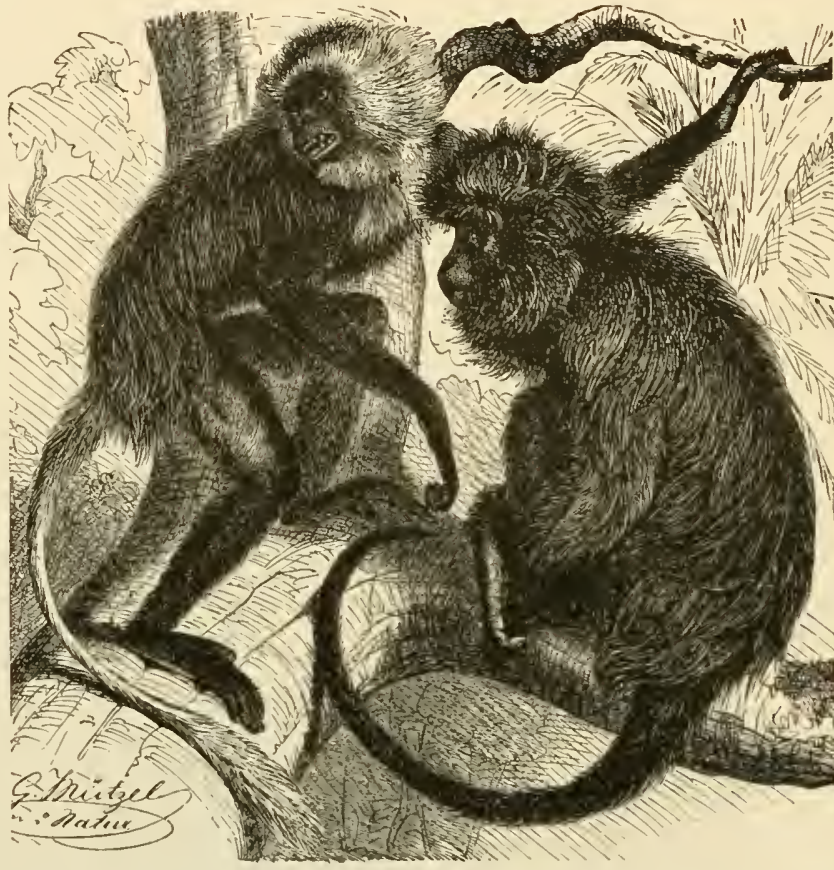

URSINE COLOBUS AND BLACK COLOBUS. - These monkeys are found in the deep woods of Africa. The Bear-like appearance gave to the Ursine Colobus its name. The cheek bones and chin are covered with long, white hair which stands onlward or downward as shown in the picture. It is very timid and fiees at the approach of Man. The Black Colobus, like the Ursine, has stunted chapter on "Dog-shiaped Jonkeys." of the audience. Opinions of observers as to the intellectual qualities of the Longarmed Apes aie divided. Duraucel calls the Siamang slow, stupid, awkward, lazy, cowardly and uninteresting, indifferent toward his keepers, a $n d$ incapable of af fection as well as revenge. Forbes, on the contrary; praises his tanjeness and familiarity: "The pretty, carcssing way he had of encircling my neck with his long a rms and leaning his head on my breast, cmitting a satisfied little grunt, was very prepossessing." B e nnett also judges him in a more favorable $\mathrm{light}$. He brought a Siamang nearly as far as Europe and says that in a short time he made his way into the affections of all his fellowtravelers. He died before they reached England and was mourned by the entire crew. Gibbons are ralcly seen in captivity, even in their native country: They cannot bear the loss of freedom, and when deprived of it they constantly long for their native forests and their plays and become more and more quiet and sad, until finally they die. 



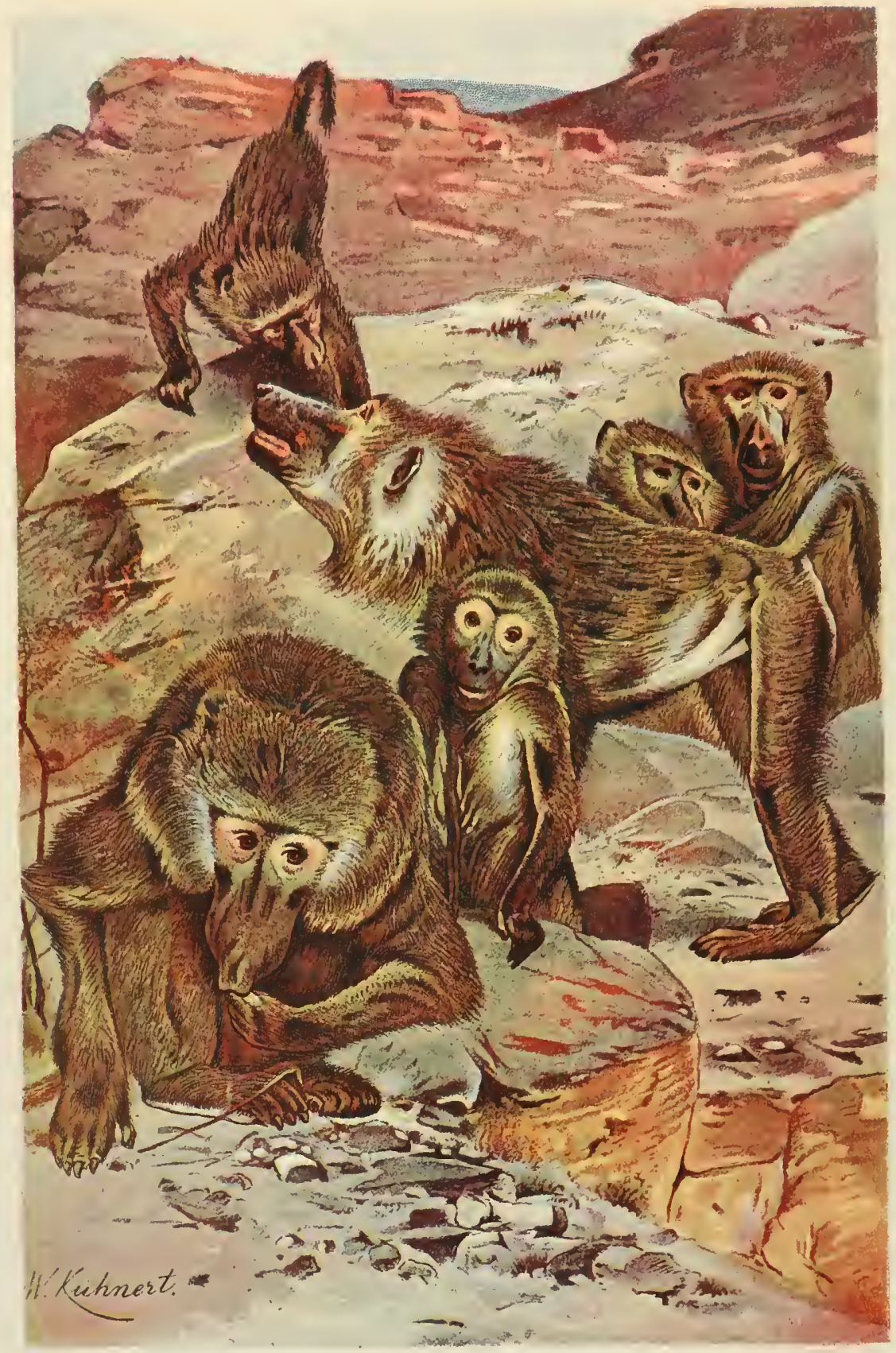




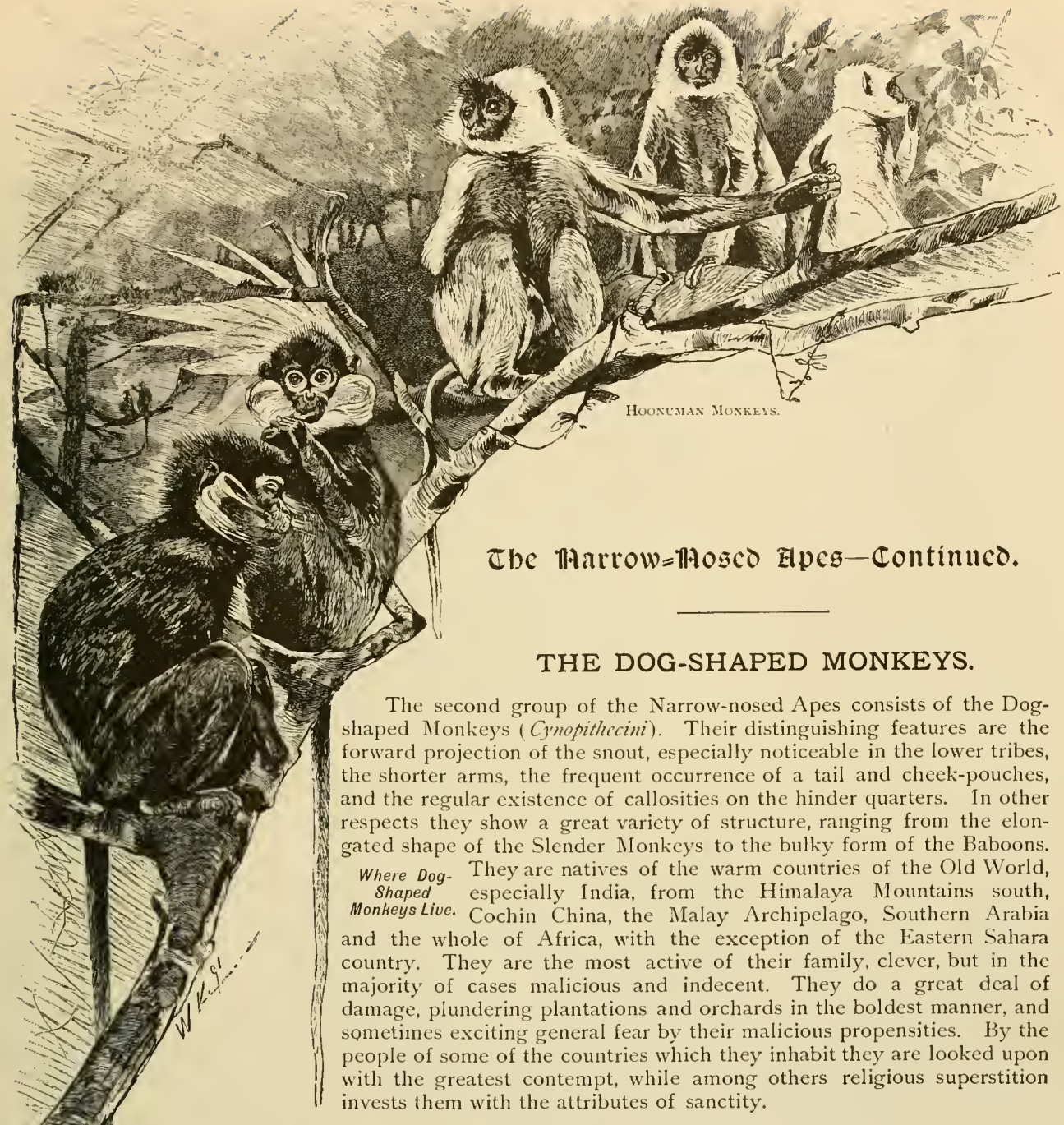

THE PRIAMUS MONKEY. - A native of Ceylon, very active and intelCeylon, very active and intel-
ligent, and is about sixteen
inches long, with a tail twen-
ty inches in length its color
is a deep gray, with tinges
of brown, and its lips, chin Ceylon, very active and intel-
ligent, and is about sixteen
inches long, with a tail twen-
ty inches in length its color
is a deep gray, with tinges
of brown, and its lips, chin Ceylon, very active and intel-
ligent, and is about sixteen
inches long, with a tail twen-
ty inches in length its color
is a deep gray, with tinges
of brown, and its lips, chin Ceylon, very active and intel-
ligent, and is about sixteen
inches long, with a tail twen-
ty inches in length its color
is a deep gray, with tinges
of brown, and its lips, chin and whiskers are nearly pure white. This ani-
mal makes prodigious swings through the air and easily escapes pursuit. (Semnopithecus nestor.)

\section{SLENDER OR SACRED MONKEYS.}

Among the Dog-shaped Monkeys we will first turn to the Slender or Sacred Monkeys (Semnopithecus), which are, as their name indicates, slightly built, and are endowed with long, fine extremities and a very long tail, a small, high head, a face devoid of hair, and a short snout, provided with small cheek-pouches. Their callosities are very small. The last molar tooth in the lower jaw is furnished with five cusps. Their skeleton in its slenderness reminds one of that of the Gibbons. The hands have long fingers, but the thumbs are short or very little developed, and not adapted for grasping. The hair is wonderfully fine, its coloring agreeable, and in one tribe peculiar; and the hair of the head is sometimes considerably longer than that of the body.

They are found in the southern part of the continent of Asia, Ceylon and the islands of the Indian Ocean. Here they live in more or less numerous troops in the forests, preferring the banks of a river or the neighborhood of villages or plantations, and being universally protected by the natives they lead an exceedingly enjoyable life.

The foremost place among the Slender or Sacred Monkeys belongs to the Hoonuman, or Hulman, the Sacred Monkey of the Hindoos (Semnopithecus entillus), which is the most common of all the Ape species 
in the greater portion of India. Ife continues to spread, as he is not only protected and petted, but is also imported into various parts of that country in order to perpetuate his species. His length is from three to four feet, and his tail is as long, or even longer, than this. The fur is cream-colored and the naked parts have a dark violet tint. The face, hands and feet - as much of them as is covered with hair and a stiff crest of hair over the eyes, are black, while the short beard is creamy.

The Hoonuman The Hoonuman occupies a very high in Hindoo place among the innumerable deities Mythology. of the Hindoos, and has enjosed this honor since time immemorial. Tradition holds that the giant Rama carried off Sita, the wife of Thri-Rama, and brought her to the Island of Ceylon; but a Monkey rescued the lady and brought her back to her husband, and ever since he has been considered a hero. There are a great many stories afloat concerning his remarkable intellect and his swiftness. For one of their most valued fruits, the mango, the $\mathrm{Hindoos}$ are indebted to him, as he stole it from the giant's garden. For this theft he was condemned to be burned alive - we are not informed by whom-but he extinguished the fire, badly burning his hands and face, which have ever since been black. These are the reasons assigned by the Brahmins for adoring him.

Hoonuman This Monkey Protected by has been studNatives. ied for a great nany years in his native country, and that is the reason why we came to make his acquaintance so late. Every person who visited India thought that so common an animal must certainly have been often taken to Europe[or America], and therefore each one neglected to stuff him and send him over. Besides, it is dangerous to kill this sacred animal; for only the Mahrattas, among Hindoos, hold it in low esteem; all the

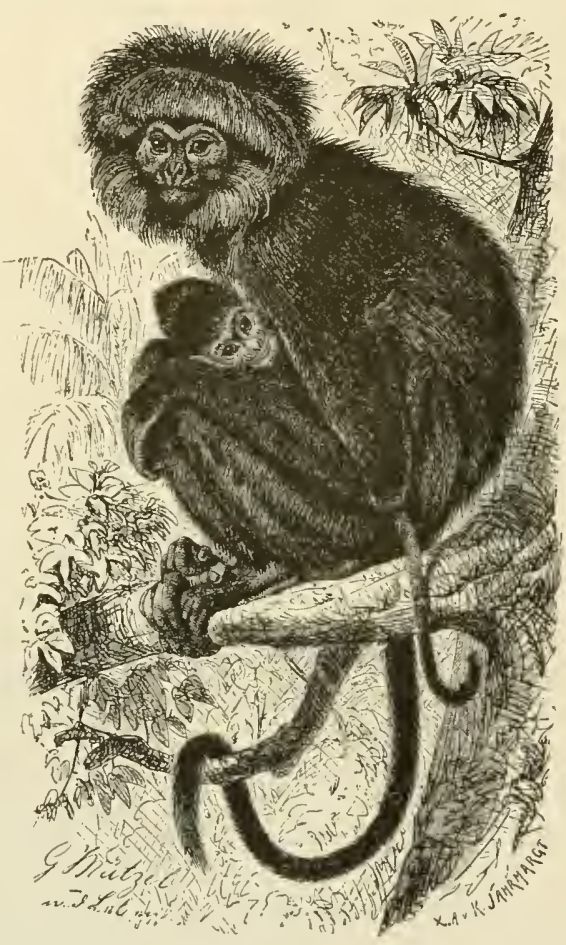

BUDENG OR NEGRO MONKEY, - Lives in large troops in the forests of Java and is hunted vigorously by the natives for it beautiful, long and silky black fur, which is used by the armies of Europe for decorating purposes. The Budengs build rude nests in the tops of the trees and live upon fruits and buds. The mop of hair surrounding the face gives them a peculiar expression. The care care and affection of the mother for her young is shown by the artist in the picture. The length of a full-grown Budeng is about hive feet, the tail coming in for more than half of the measurements.
(Scmopithecus maurus.) other Hindoos caring for and protecting it wherever they can. An European who dares attack a Hoonuman imperils his life, if he is the only foreigner in a Hindoo crowd, for the Monkey is sacred. A reigning family boasts descent from it, and its members style themselves "Tailed Ranas," as they maintain that their ancestor was endowed with this, to us, seemingly unnecessary appendage.

A High-Priced A Portuguese viceroy of India, ConMonkey's stantino de Braganza, had in his pos-

Tooth. session a Monkey's tooth, taken in war from the treasures of a prince of Ceylon; and a special embassy of the king of Pegu came to offer high a price was probably never before or since offered for a tooth. The more astonishing is it to ceroy held a meeting of his counselors; the lay. accept so oreat a sum, but a priest protested against it. He claimed that such a barter would promote heathen superstition, and his opinion prevailed. might have been of no iniportance to us, if the tooth had not been destroyed on this occasion and thereby lost a valuable clue to Indian theology and to natural science. This one tooth might have served very well for the classification of the Monkey to which it once belonged. Hindoo Vener. The sacred anation for the imal is held in Hoonuman. as high esteem to-day as in by-gone times. The Hindoos complacently look on when the impudent fellows plunder their gardens and rob their homes and regard with disfavor every one who dares to insult a Monkey. Tavernier relates how a young Dutchman, recently arrived from Europe, shot one of these animals from a window; whereupon there was a frightful commotion among the natives, which was with the greatest difficulty allayed. The servants at once handed in their resignations, being fully convinced that the foreigner would be killed and they probably along with him. Duraucel also say's that in the beginning it was very hard for him to kill one of these Monkeys, as the natives always contrived to prevent it. Forbes assures us that in Duboy there are as many Nonkeys as there are people. These creatures inhabit the top story of the houses and make life a burden to foreigners. When a native has a grudge against his neighbor, he puts some rice or corn on his enemy's roof, selecting the approach of the rainy season, when it is incumbent on every landlord to repair his housetop. As soon as the Monkeys see the prepared food, they not only eat what is within easy reach, but also tear up the tiles to get at the grains that have fallen into the crevices. As at this time of the year the roofers are in great demand, it is next to impossible to procure one, so the house stands open to the rain and the furniture is spoiled.

Hospital Not only the well Monkeys but also for sick the sick ones are cared for in that coun-

Monkeys. try. Tavernier found a hospital for Monkeys, Oxen, Cows, etc, in Ahmadabad. All the 
balconics are strewn from time to time with rice, millet, dates, fruits and sugar-cane-all for the Monkeys. These latter are so bold that they not only pillage the gardens, but sometimes enter the houses at meal-time and take the food out of people's hands. A missionary declared that only by constant watchfulness was he able to protect his clothing and other belongings from these thieves. It is very probable that the sacred character of the
The Budeng or This group has yet other remarkable Negro Monkey members. The Budeng or Negro of Java. Monkey of the Javanese (Scmnopithecus maunus) is a beautiful animal. In mature age he is black and glossy, his face and hands being like velvet, his back like silk. The head is covered by a peculiar cap of hair falling on the forehead and cncircling the cheeks. New-born Nonkeys of this species are of a cream color, and only the ends of

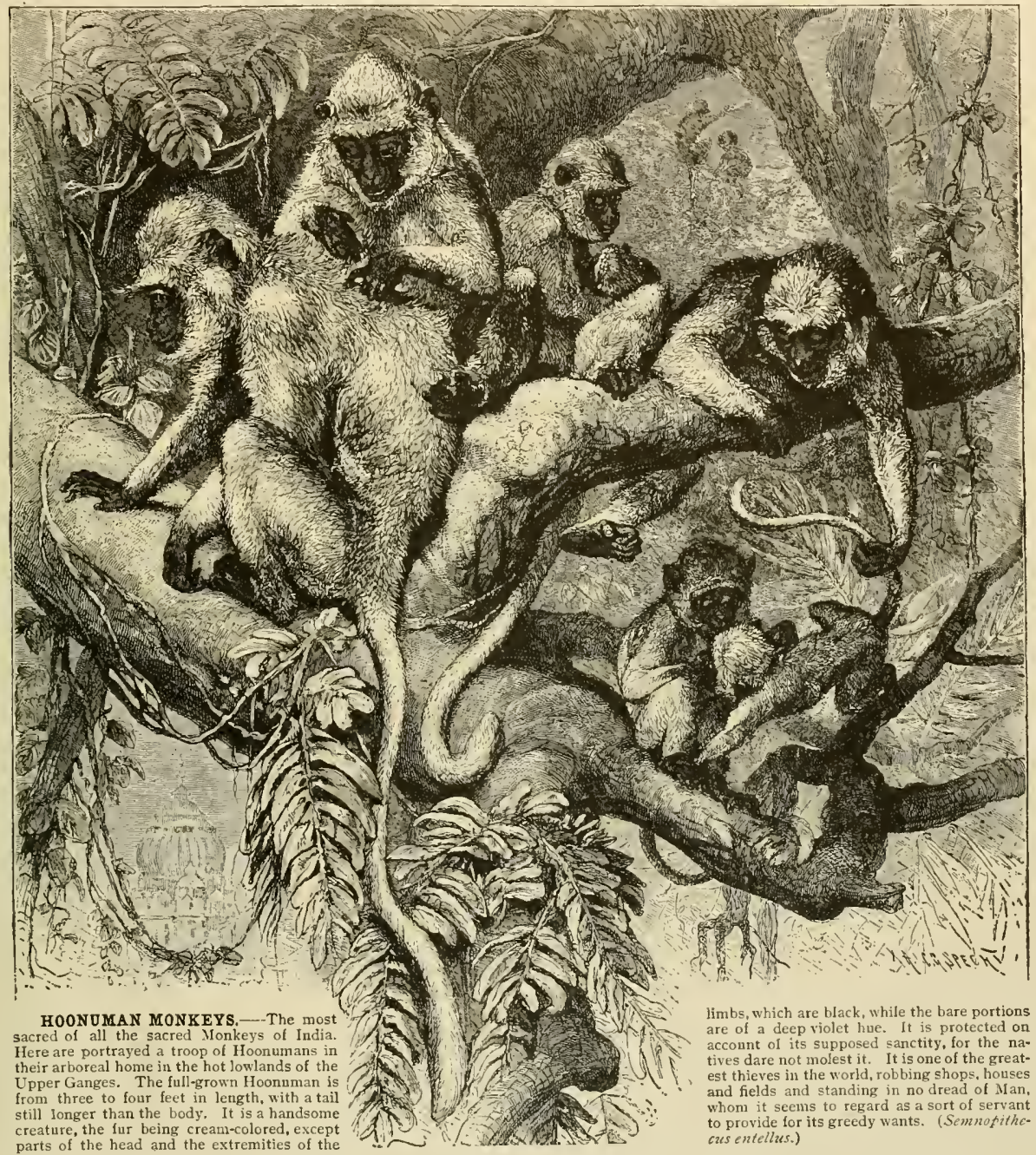

Monkeys is connected in some way with the belief in the transmigration of souls. It seems that the Hindoos think that after death their souls, as well as that of their king, enter the body of some Monkey.

Notwithstanding their impudence these animals are attractive and handsome creatures. The missionary, John, says that he never saw more beautiful Monkeys than the Hoonumans. Their friendliness towards each other and their enormous leaps attract the attention of every observer.

the hairs on the lower part of the back, the upper part of the tail and its tuft take a darker tinge. Soon the dark color begins to spread, and in a few months the hands, the head and the tuft of the tail are black, and then the whole coat gradually assumes the color of mature age. The length of this handsome creature is about five feet, the tail coming in for more than half of this measurement.

"The Budeng," says Horsfield, "is found in considerable numbers in the extensive forests of Java. 
One sees whole companies on the tree-tops, a single troop sometimes numbering more than fifty. It is best to study these troops at a distance. It the approach of Man they raise a terrible noise, jumping furiously from branch to branch, thereby often breaking strong boughs, which they throw down at the pursuer." The Budeng A captive Budeng is a quiet, gentle,
in
Captivity. patient creature. In Antwerp a Bulittle Monkeys, which were forever teasing and tormenting him, and he never thought of retaliating. The scene was very grotesque when a Guenon, barely a year old, compelled the big Monkey to attend him, and brought him to order by pitilessly boxing his ears and pinching him. (One cannot doubt that good-nature is the essential quality of the Budeng mind, and rery nearly misses that spirit of mischief and malice that appertains to all others of the Monkey tribe. The Budeng also seems to suffer much from a foreign climate. In captivity abroad he enjoys every glimpse of the sun, and is happy when he can bask but for a few moments in the rays of that life-giving orb, whose glow bestows on his native country all the splendor of the tropics.

The Long-Nosed There is another tribe that is now Monkey of separated from the Slender Monkeys Borneo. proper, the Long-nosed or Proboscis Monkey, or Kahau (Vasalis lameatus). In general this Monkey has the structure of the Slender or Sacred Monkeys; but the long nose, which is movable in every direction and capable of being projected or drawn in, lends his countenance a highly peculiar aspect. The body is slender, the tail very long, the extremities are nearly of equal length, the cheekpouches are lacking. The nose forms a hook-like projection over the upper lip, is rather broad in its micidle part, pointed at the end and shows a slight furrow in the median line; the nostrils are very large and can be considerably dilated. In the young animal this organ is small and blunt, and reaches its full size only in the adult Monkey. According to C. Bock, it is a peculiarity distinguishing only the adult male, and lacking in the female. The fur is thich and soft; the hair is short on the parting, longer on the back of the head and sides of the face, and on the neck it goes to form a collar. The color of this Monkey is red. The extreme length of the Longnosed Monkey is five feet. The females are smaller, but are said to be capable of reproduction before they have attained their complete growth. They live in bands in Borneo. Their life in the wild state is very little known. According to Wurmb, they assemble together in large troops at mornings and evenings and howl, the cry bearing some resemblance to the word "Kahau," whence they derive their name. Although at first glance the Kabau's nose looks like a burlesque of the same organ in Mlan, the real resemblance is slight, for the nostrils are at the extremity of the nose.

\section{THE THUMBLESS MONKEYS.}

The African relatives of the Slender Mlonkeys, the Thumbless Monkeys (Colobus), are striking animals, distinguished by their peculiar color, and queer but beautiful manes. India shows more life and color than arid Africa, and so the Slender Monkeys are of a lighter and brighter hue than the Thumbless Monkeys, though one cannot say that the latter are less pleasing to the eye than the former. On the whole, the differences between the two groups are but slight. The Thumbless Monkeys are mainly distinguished from the slender Monkeys in having the thumbs on the two fore-limbs docked or stunted. Their body is slender and graceful, the snout is short, the tail very long and the limbs also long and slight; the cheekpouches are lacking.

Guereza, Among these animals we ought to conHandsomest sider the Guereza (Colobus gurral first. of Monkeys. He is indisputably the handsomest of all Monkeys. His color is exceedingly pretty, and his hair as peculiar and, at the same time, striking in appearance as that of any other animal in the Monkey family. The merit of discovery of this beautiful creature belongs to the distinguished German, Ruppell, who found it on his Abyssinian tour, in the province of Godsham, and gave it the same scientific name as that employed by the natives. This Monkey was previously very little known. Hiob Ludolf mentioned it in his valuable work on Ethiopia. Ruppell saw a living Guereza and so could write about it from his own experience. After him several other naturalists have observed it. I found the skin of a Guereza on the lower White Nile, in the possession of a Hassanie, who used it as a tobacco-poucl, and who told me that farther south the Guereza was by no means a rarity. Heuglin also saw it frequently in Abyssinia and along the White Nile, and had reliable reports concerning the Monkey's existence in quite different parts of Central Africa; hence we may conclude that the animal ranges over a larger area than is commonly supposed. Thompson found it in the Massai country, and, according to Johnston. Hans Meyer saw it on the Kilima Nidjaro, at a height of three thousand feet above sea level, and also farther to the soutl in the Kahe country.

The Guereza is indeed a magnificent animal. On a beautiful black velvet body, a white head-band, a white neck, chin, throat, belt or mane, and tail-tuft stand out in magnificent relief. But each white hair has also brown ringlets on it, and this produces a silver-gray impression of the whole. The mane, if I may so call his side-belt, hangs on both sides like a beautiful Bedouin cape and serves as an indescribably handsome adornment.

Hunting The hunting of the Guereza is attended the with a great many difficulties. He is nearly

Guereza. secure from all dangers in his favorite haunts, the tops of high trees. A rifle in the hands of a native is a comparatively harmless thing, and it is lucky that such is the case; for if the Abyssinians knew how to handle a rifle, they probably would have already exterminated this fine animal. In former times he was much persecuted, for a shield covered with a Guereza skin was a thing much valued and consequently much sought after. The shields of the Abyssinians and of the other East African tribes were of oblong shape and were made of the lides of Antelopes or Hippopotami; and these were covered with the side and back skin of the Guereza and in this way showed the entire mane as their chief ornament.

In Gondar, the capital of Abyssinia, a Guereza shin used to command the price of one dollar, a sum which might have bought half a dozen fat sheep. Now their value has fallen, for fortunately the shields are no longer in use. I say fortunately, for in this way the attractive creature will be spared and escape the mania of persecution, which man evcrywhere exhibits against " his first-born brothers." So far as I know living Guerezas have only twice 


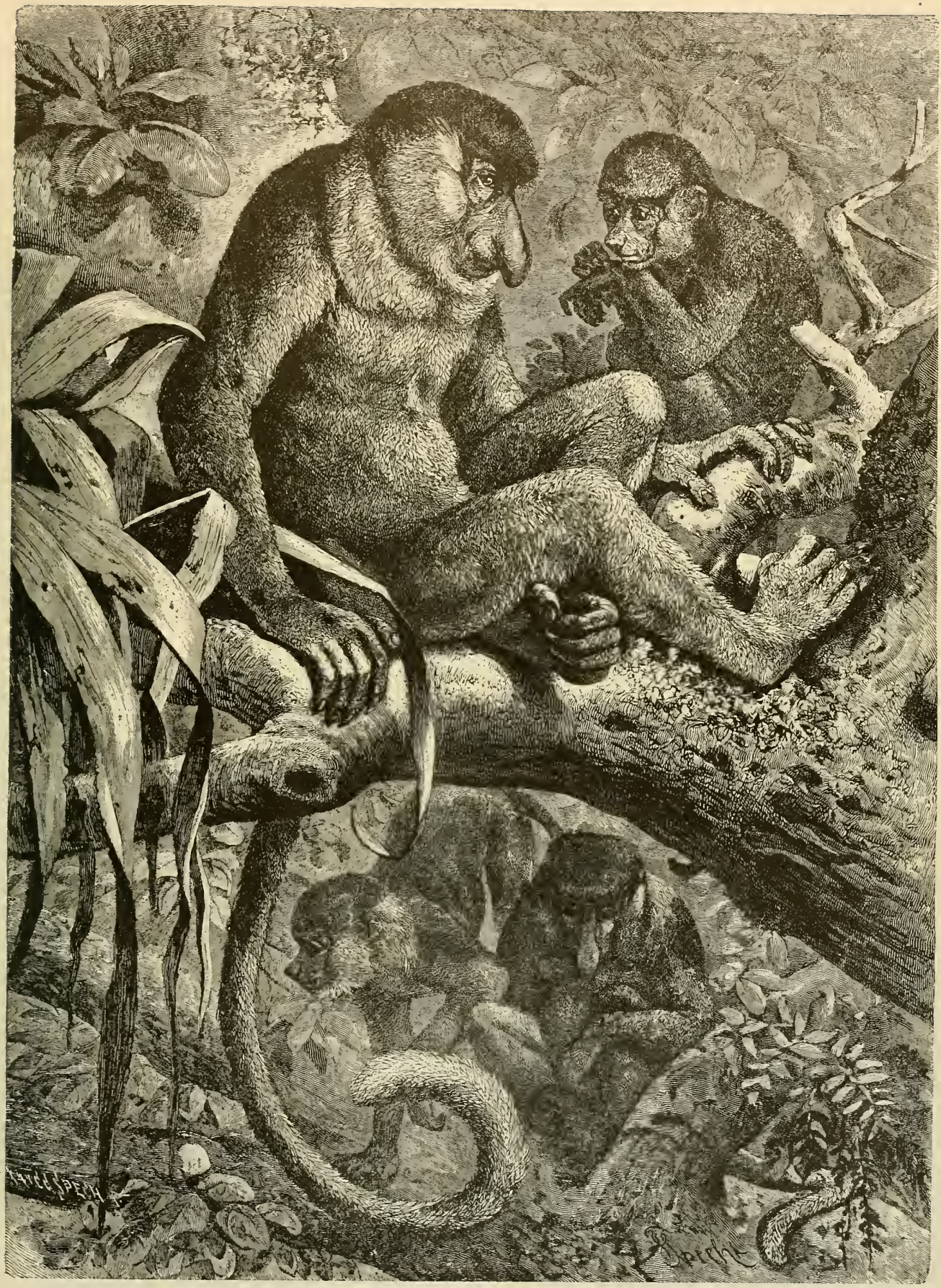

LONG-NOSED MONKEYS. - These grotesque looking Monkeys are natives of Borneo, and are sometimes called the Proboscis Monkeys, the organ from which this name is derived,being large and long and movable in every direction. This illustration is taken from life and shows them as they appear in the
zoological gardens in Batavia, the Capital of Dutch India, where they thrive as well as in their native forests. In their wild state, troops of these Ilonkeys assemble together mornings and evenings, and in this sketch they are apparently following the same custom. (N'asalis lazertus.) 
been taken to Europe [and none have ever reached America ].

other Further members of this group, of which Thumbless there are eleven in all, are the Ursine Monkeys. Colobus (Colobus ursinus) and the Black Colobus (Colobus Satanas). The first differs from the Guereza in the absence of the white mane, in longer hair and a nearly tuftless tail. He is a native of Upper Guinea and Fernando Po. The Black Colobus is uniformly black and is confined mainly to Fernando Po.

\section{THE GUENONS.}

Africa harbors not only the largest, the cleverest, and the ugliest of the Apes of the Old World, but also the most beautiful and the most sympathetic To the latter undoubtedly belong the Guenons. (Cercopithecus). We see this or that member of the family in every zoological garden, in every wandering collection of Monkey's and frequently as merry companions of people who are fond of animal pets.

Home Habits The native and Characteris- country of tics of Guenons. this group is the torrid zone of Africa, but they are never found on the islands of this continent. Wherever there are virgin forests, the Guenons are sure to be found in great numbers. Several species are found as well in the east as the west and the center of the continent, but the majority come from the west; although a great many have their home in Abyssinia and the Upper Nile country.

They are small, graceful creatures, have short, fine hands with long thumbs, a long tail devoid of tuft, capacious cheekpouches and large callosities. Their coloring is usually bright. There are about twenty different kinds in this group. In the Nile country they go as far north as the 16 th degree of latitude: in the west and east they are found nearly as far as the seashore. They always prefer damp woods, traversed by rivers, to the dry, mountainous regions. They also show a decided predilection for the neighborhood of cultivated fields. One may unfailingly count on finding Guenons where there are Parrots, and may also luok for the latter when these little Monkcys are around.

Merry and The Guenons are among the most Sociable Traits sociable, lively, merry and good-
of Guenons of Guenons. humored of the Nonkeys. They nearly alway's live in rather large troops; single families being scidom encountered. It is really anusing to fall in with a troop of these animals in a forest. The life, the noise, the fights, the quarrels, the jumping and running, thieving and pilfering, the faces and contortions are a sight to see. They have a government of their own, and the strongest of their own kind is the only master they acknowledge : no right is lawful but the one pertaining to the old Monkey patriarch, by virtue of his sharp teeth and strong hands. There is no danger from which they deem escape impossible. They make the best of every situation, never fear hunger or privation, and spend their life in perennial contentment and joy: They are possessed of an unlimited carelessness and a grotesque seriousness. No goal seems out of their reach, no tree-top too high for them and no treasure is secure in their presence, for they recognize no right of property. It is, therefore, not astonishing that the natives of East Soudan should refer to then with the greatest scorn and anger; neither is it surprising that outsiders think them the most amusing little creatures in the world.

It is impossible to miss a troop of Guenons in the forest. Even if one should not hear the varying call of the chief, he soon detects the noise produced by the running and jumping society in the trees, and if one should escape that, he is sure to see them run, jump, bask in the sun and seck cach other's fleas. for they never so much as think of hiding themselics. They are not met with on the ground unless something to eat is to be found there; they live in the trees and make them way from one branch to the other. Should their road lead through the thickest and sharpest of thorns, it is a matter of perfect indifference to them.

Guenons It is very on a Stealing interesting Expedition, to the observer to watch a troop bent on a stealing expedition. The boldness with
ays charned me as nuch which they procecd always charmed me as nuch
as it disgusted the natives. An old, experienced as it disgusted the natives. An old, experienced
male Monkey assumes the leadership and shows the way to the corn-field; the females with children carry them upon their backs, the little ones hooking their diminutive tails around the tails of their parents. In the beginning a great deal of caution is observed, and they use the tree-tops as far as possible. The old gentleman is always first, and the crowd follows step by step, selecting not only the same trees, but even the same branches as he. From time to time the wise leader climbs to the extrenie top of a tree and surveys the neighborhood. If the sight that meets his eye is favorable, he utters a few assuring, gurgling sounds, if not, he gives a note of alarm. The Monkey's alight from the tree nearest the cnosen field and scamper to their paradise. The activity 


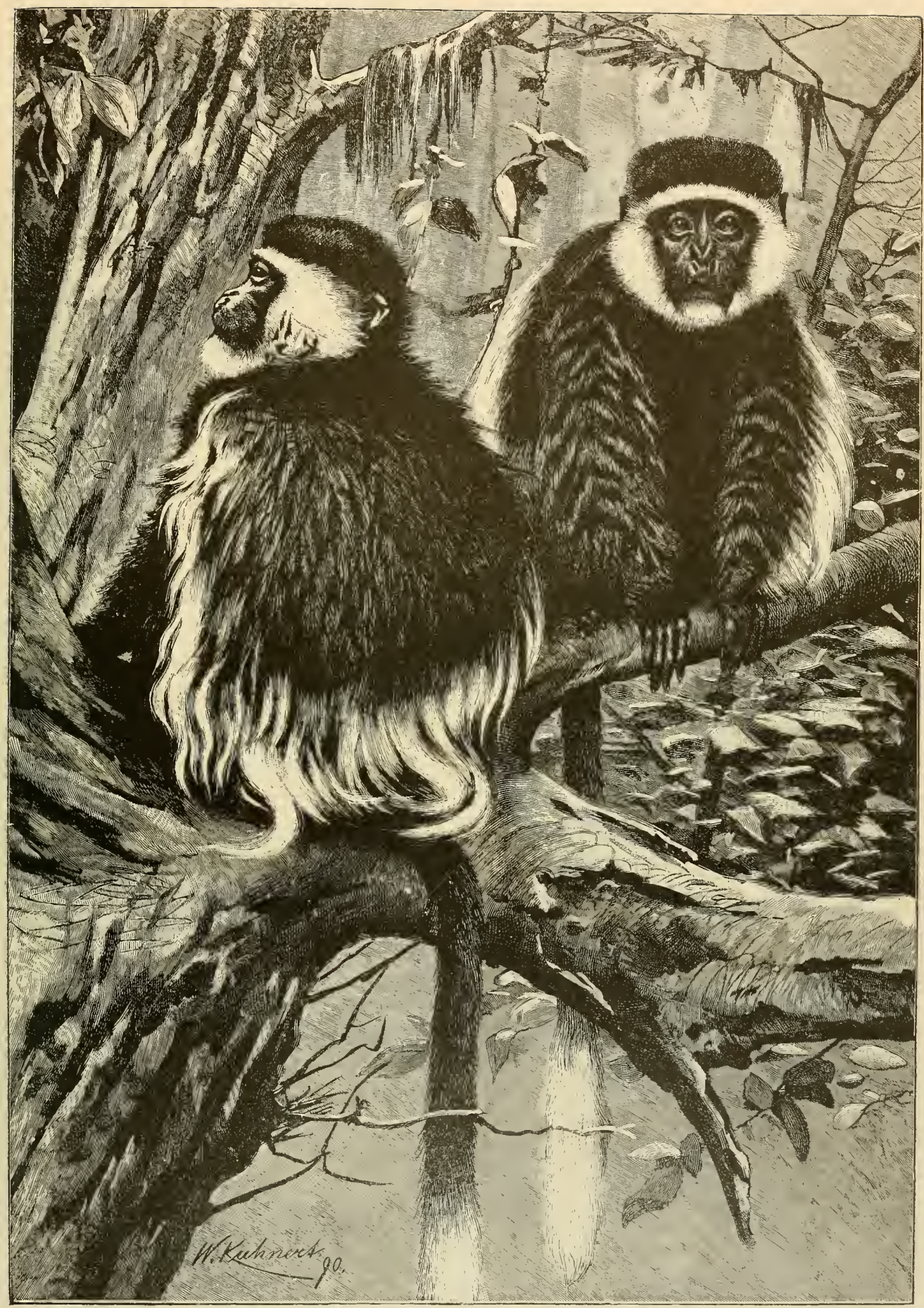

GUEREZA MONKEYS. - The most beautiful type of all the Mlonkey tribes and are natives of Abyssinia. Nature has given the Guerezas a most picture. This pair of strikingly handsome Guerezas are represented securely perched in their forest 
they display on their arrival is unparalleled. Rapidly they go to work, tear off ears of corn or durra, shell them and fill their cheek-pouches to the utmost. Then they begin to be more fastidious in their choice. All the ears and cobs are first carefully smelled, and if they do not come up to their standard, which happens rather often, they are thrown away, and the wastefulness that is a characteristic of all Monkeys is exercised to the highest degree. It may be estimated that out of ten ears one is eaten. As a rule, they take but a few grains from each ear and throw the remainder away. This is just what excites the wrath of the natives. If they feel themselves secure, the mothers let their children play with each other, without relaxing the extreme watchfulness they are accustomed to bestow upon their pets; not one thinks of looking out for danger that might befall the whole band, for all place implicit confidence in their leader. From tinse to time he stops in his meal, stands upright like a man, and survey's the ground. After each of these inspections one hears his assuring, gurgling sounds, if he has seen nothing that threatens. If he scents danger, he utters an indescribable, trembling note of warning. Immediately his subjects rally, each mother snatches up her child, and every one tries to grasp as much as he can in a hurry: I have seen a single Monkey bearing as many as five large ears of corn along, two being held in the right fore-arn and the others in the hands and feet, and the corn touching the ground as the Monkey ran along. If the danger becomes pressing, the load is thrown down with a wry face, though the last ear is kept until the pursuer is very near and they need both hands and feet for climbing.

Boldness Their way lies to the nearest tree. I

of the lave seen then climb up an isolated

Guenons. tree, and then descend from it and proceed on their way upon the ground when I pressed them hard. Once they reach the forest they are secure from all pursuit, for their agility in clinibing is nearly as great as that of the Long-armed Apes. There seems to be no obstacle that can stop them; not even thorns and hedges, nor long distances between trees. They are equal to anything. It is very astonishing, for we do not know of a single animal in our own temperate climate that could do anything approximating the feats which they easily perform. The leader is always in front, making the whole troop slacken or increase speed by his gurgling sounds. Fleeing Monkeys never show the slightest fear or discomfiture; and their presence of mind is really remarkable. One might say without exaggeration, that if they wish it, danger does not exist for them. Only Man with his long range rifles can overcome them; escape from beasts of prey is easy, and they know how to defend themselves from birds of prey.

Hunting In East Soudan the Guenons are not the liunted, but are caught in traps, consist-

Guenon, ing of nets enclosing some dainty food. The Monkeys try to take the bait and entangle themselves in the nets, so that they cannot get away. Europeans have no difficulty in shooting then, as they think of flight only after a number of their troop have been killed. They fear Men very little, or not at all. I have often seen then look very coolly at people on foot or on horseback. and at Horses or Camels, while they would utter their cry of danger as soon as a Dog came in sight.

I experienced what a great many others do on a Monkey hunt, and became thoroughly disgusted with it. I once shot a Guenon that was looking at me; it fell off the tree and sat on the ground, calmly. almost liumanly wiping the blood from its face with one hand, and the impression it made on me was so painful that 1 ran towards it and stabbed it twice with my hunting-knife, to relieve it from its suffering. Since then I never have shot another small Monkey, and advise nobody else to do so, unless it be for scientific research. I felt as if I had murdered a human being, and the face of the dying Monkey has haunted me ever since.

Guenons These Monkeys have little to fear Dread Nothing from beasts of prey. They are but Reptiles. much too quick for them; only the Leopard can sometimes overtake an incautious young Monkey. As to birds of prey, the Monkeys ward them off by their united efforts.

They have a great horror of everything that creeps, and especially of Suakes. I have forgotten to mention that these Monkeys ruthlessly destroy all birds' nests and are passionately fond of eggs and young birds. When they purpose robbing the nest of one of those birds that breed in caverns or hollows, they proceed with the utmost caution, for Sinakes are extremely likely to sleep in such a nest. I have often seen them carefully investigate a hollow trec, to sec if a Snake was, perchance, in hiding there.

First, they looked in as far as possible, then they listened, and then hesitatingly put in an arm. A Monkey never yet made a bold plunge in such a case, but he inserts his arm by degrees, all the time watching and listening, and dreading the appearance of a Serpent.

The time of reproduction seems not to be limited to a particular scason with the Guenons. In every troop one sees infants at the breast, children and half-grown Monkeys no longer in need of maternal supervision. Guenons reproduce well and thrive in z.oolosical gardens [in Europe or America] if they are well taken care of, though they are not as hardy as the Macaques and Baboons.

The Guenon During my stay in Africa, which lasted in several years, I always kept a great Captivity. many Monkey's, and among them several Guenons: and I may say that every one of them liad an individuality of its own, and was an attractive and interesting object for investigation. One Monkey would be quarrelsome and bite at every provocation; a second would be gentle and tame; a third might be peevish, a fourth always cheerful. One had a quiet and harmless disposition, while another was cunning, scheming and foreser plotting some nasty tricks. But they ail had this in common, that they liked to play practica: iokes on larger animals, while they protected and cared for little ones. They knew how to make the most of every situation. Daily they gave me proofs of good common sense and of cunning reflection, but also of great good-nature and the tenderest solicitude for weak or helpless animals, and several of them gained my sincere affection. Several groups anong the Guenons are very sympathetic.

The Green One of the best known species, ranging Monkey of from. Abyssinia to the sources of the Abyssinia. Nile, is the Green Monkey (Circopithcous sabacus), called Mbulandj by the Arabs and by others the Beautiful llaired. I le is four fect long the tail being more than half of this length. The hair on the upper part of the body is of a gray-green tint; the arms, legs and tail are gray; the short beard and the under and inner surface of the legs are 


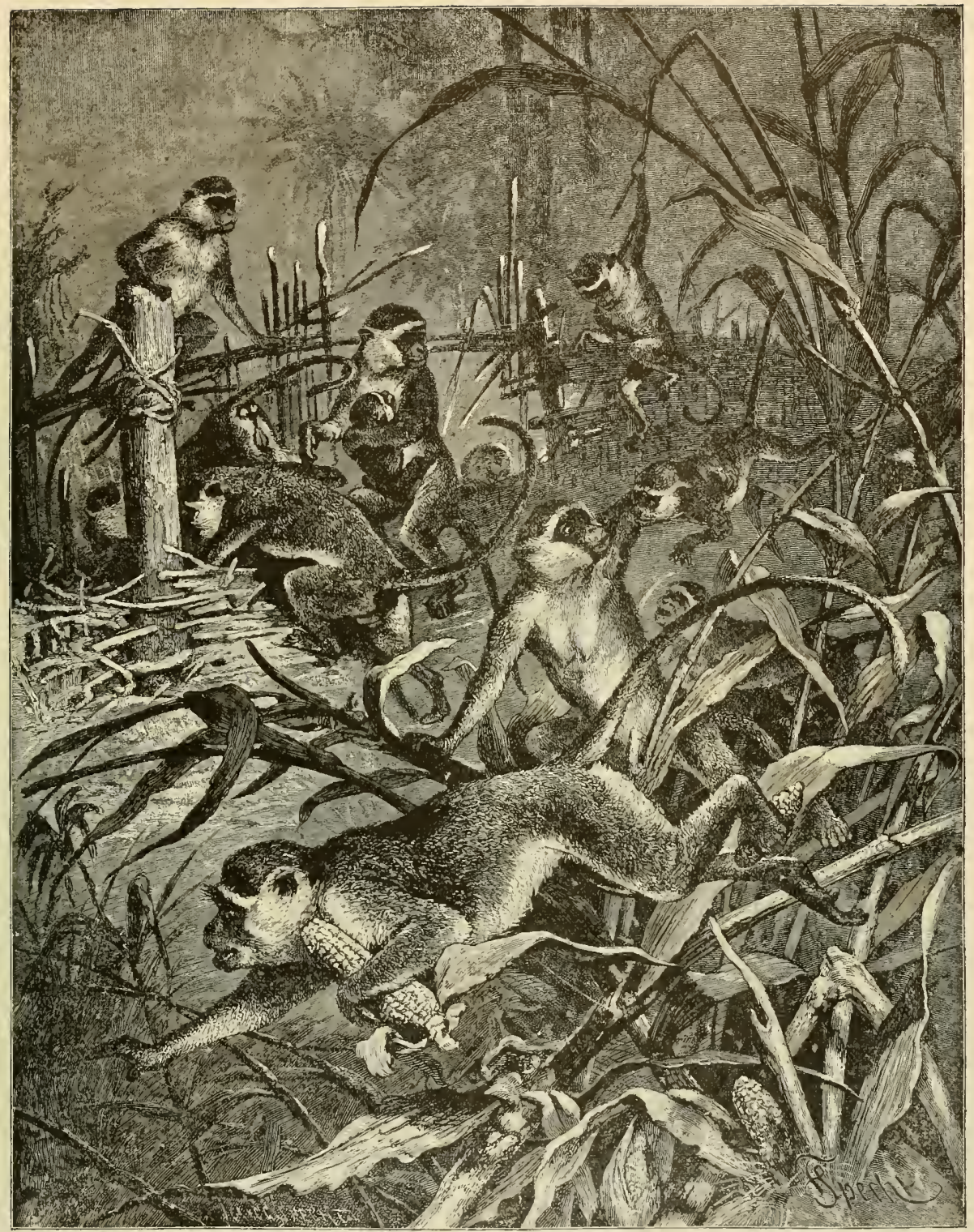

GREEN MONKEYS. - The artist has put Jife and action into the above picture, which shows a troop of Green Monkers fleeing from a field of grain they have been robbing, a species of thievery of which these monkevs are very fond. The knave in the foreground has an ear of corn in his left foot as well as in his left hand, and while making rapid progress is tenaciously holding on to his booty. Just behind him a mother is reaching out for her young one; and on the fence an old male stands guard, while the other members of the troop are escaping for their lives. The Green Monkeys are natives of Senegal and jealously protect their territory from other monkeys. Some of this family are said to have been hrought over to the lsland of St. Kitts, where they thrive, being the only OId II orld Monkeys living in a wild state in America, They are also sometimes called Beautiful Haired Monkeys, hecause of the delicate marking of each separate hair of their fur. The under portion of the body and limbs is nearly white, the outer part of the limbs is of a gravish shading, while the hair on the side of the face is a golden yellow. Mauy Green Monkeys have been taken to Europe and brought to the United States. (Ccrcofuthecus sabacus.) 
whitish; the nose, mouth and eyebrows are black, while the face is of a light brown color. The Diana Among the prettiest and most grace-
Monkey of ful of the Guenons is the Diana
Western Africa. Monkey. (Cimofithecus diama) whose color is slate-gray, merging into auburn on the back, while the under surface of the body and the beard are pure white. He is a native of IVestern Africa. The name is duc to a crescent-shaped white band of long hair stretching across the forehead. The length of its body is about eighteen inches, while its tail is longer. It is found in Guinea and Fernando Po. The Blue-Faced The Blue-faced Guenon (CiropithGuenon of couscephus), called Muido by the na-

West Africa. tives of Loango, is an inlrabitant of western Africa. He is of the same size as the Green Monkey, but his coloring is more vivid and pleasing. The back, upper part of the head and neck and the outer sides of the limbs are of an olive-green tint, here and there showing a golden gleam, white the under surface of the body and the imner side of the species of Guenon is so well fitted for domestication. "One Guenon that we called by the native name for the whole species, Muido, a female, lived in my possession for five years. the was very young when I got her, and I took good care to keep her in perfect health. In this Monkey I distinctly saw what an effect experienced care and kind treatment, practiced from earliest youth, have on the Monkey mind and how much ill-nature may be traced to thoughtless teasing and rude jokes. One would have much less cause for complaint of the malice and violence of Monkeys, if they were properly cared for during their childhood.

Uur Nonkey, whose childhood had been carefully guarded from all pernicious intluences, had the freedom of the whole house in Furope. She roamed through all rooms and went over tables and cupboards, but so cautiously that she never broke anything. She climbed out of the windows, performed gymnastics on the porch, ran over the whole roof, and was free to go into the yard and the garden.

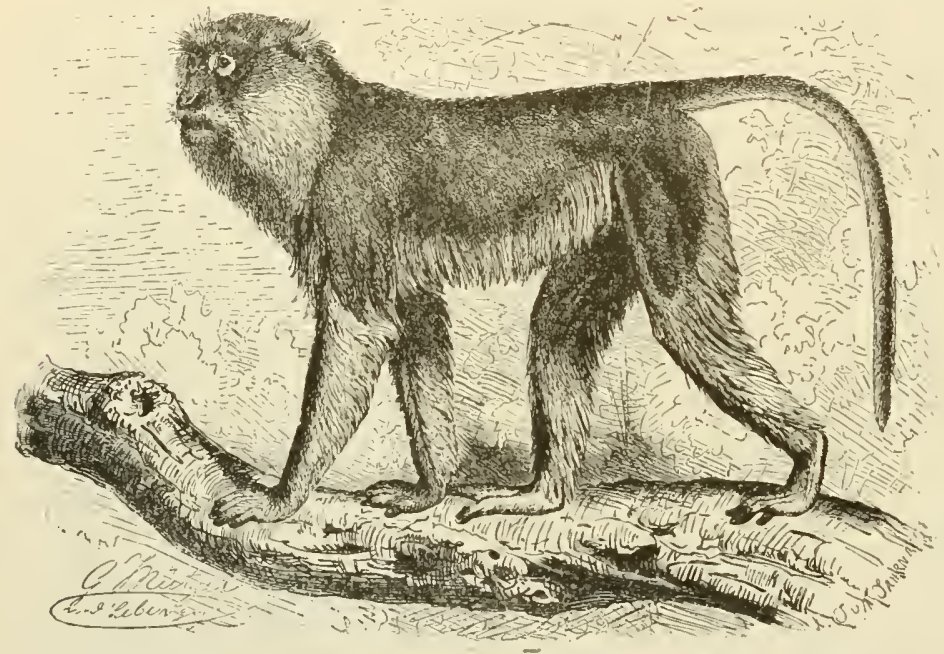

RED, OR PATAS MONKEY. - Native of Wist Ifrica, and its color is mainly a delicate yellowish red and its face is decidedly humanlike. It has a mustache and full whiskers and is a very pretty animal. Bruce, who studied it in its wild state, declares that a troop of Red Honkeys watched. from their home in the trees, while his boats were passing up the river, and that they finally became enraged and pelted the voyagers with bits of wood. He adds that when fired at they uttered the nost frightful cries but continued the fight, even after several of their comrades were slain. (Cercopithecus ruber.)

limbs are bluish-gray. The face is of a beautiful blue, showing a white spot on the upper lip, and encircied by a beard of flaming yellow, separated from the olive hair on the head by a black stripe. The tail is red from the tip nearly to its root. Robust, healthy Monkeys of this tribe, without distinction of sex, show this striking varicty of color in as perfect a manner as if they had been painted or stained.

They are plentifully found in I-ower Guinea, and south from lumba to the Congo, and are more numerous than any other species. Their favorite haunts are the forests along the coast and deeper in the continent in the dimin forests of the mountains.

The Blue-Faced Pechuel-Locsche, who studied this Guenon species, as well as a sreat many Domesticated. other's both in the wild state and in captivity, gives it as his opinion, that no ofl $l_{-1}$ she followed us like a dog on our walks in the woods and meadows, cat ching - piders, Butterflies and Grasshoppers (her favorite kinds of diet), and romped to her heart's content. I Her health was evidently much benefited by it, and her constitution became so hardy that she could roll about in freshly fallen snow without catching cold. On our walks she liked to invite attention to herself, and she had her likes and dislikes. She never harmed anybody, but delighted to hide in hedges at the approach of some unsuspecting farmer, and then suddenly appear and startle him. She was fond of little Dogs, but a voided large ones; yet, if they growled at her, she fearlessly jumped on their backs, boxed their ears, and bit and scratched to such good purpose that they hurriedly made their escape. She did not fear Frogs or Lizards, neither did she torment them. If she soiled her hands, she tried to clean them, and if she did not succeed, camc to us with a human-like request to perform that office for her.

Amusing Traits "The only thing we could not teach of the Blue. her was to be clean about the Faced Guenon. house. In everything clse she was obedient; she went to sleep in her basket, closed the door of her cage herself, and even when too noisy, would quict down at a single 'husln!' from us, She was fond of playing with dolls, balls, corks, little pieces of wood, ete. For a long time, she alway's took one little stick into her basket for the night, putting others carcfully away under cupboards, in the draperies, etc., and regarding them as her personal property, which nobody had any right to touch. She uscd her roomy check-pouches as a store-room for a great many trinkets. For several little articles she showed a great predilection, 
and if we missed them, we knew where they could be found. My wife early began the practice of emptying Muido's cheek-pouches every night. At the beginning, the Monkey resisted these operations but it was not long till she learned to disgorge these hidden treasures herself, as soon as my wife took her in her lap. Little stones, peas, coins, beans, nails, corks, thimbles, glass-stoppers and other things were brought to light, and the articles we did not inmmediately need we gave back, for she never lost anything. She took a great deal of pleasure in looking at pictures, especially colored ones, and attentively watched me turn the leaves, She would swoop down quick as a flash on the

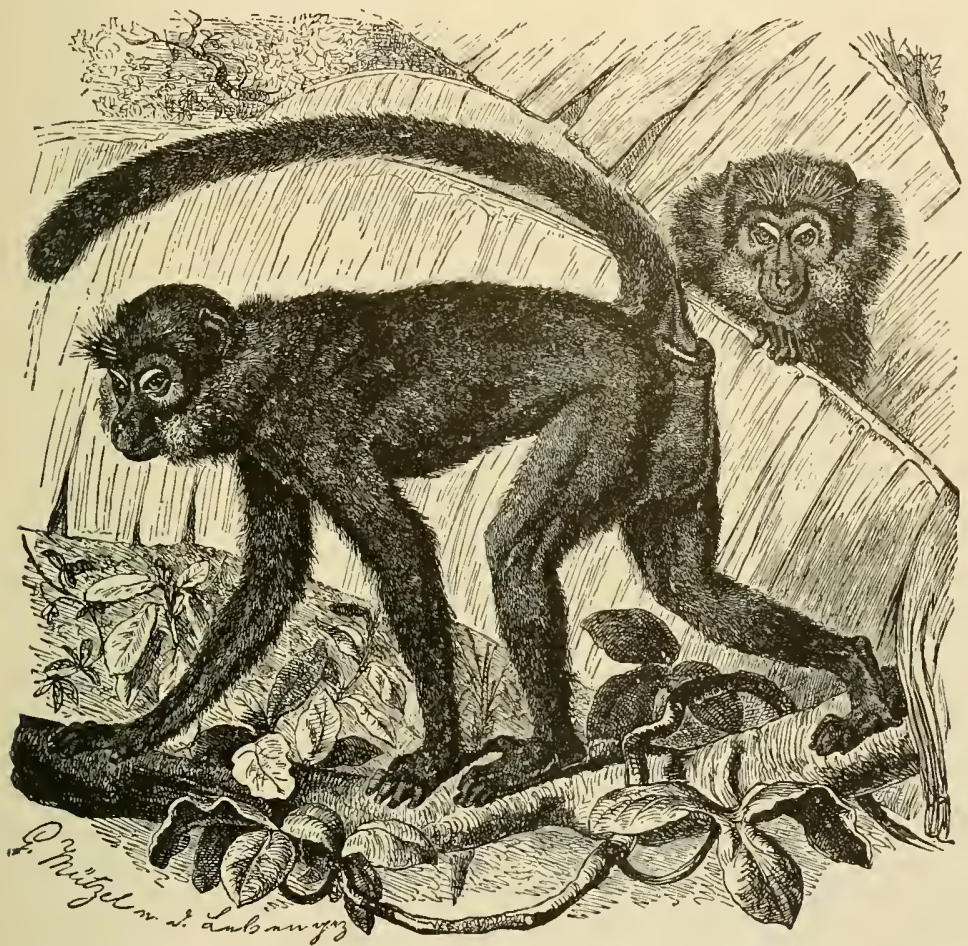

SOOTY MANGABEY.- This Monkey received its name from its color, and the mistaken notion that it came from Madagascar, where there are no true Monkeys It is a native of IVest Airica and, like all the class it represents, has the upper eyelid white, in strong contrast with its sooty color. This Mangabey is easily tamed, and, being the finest acrobat in the world, affords endless amusement to those who have the good fortune to observe it. Besides it has a fashion of raising its upper lip and showing its teeth, at the same time twisting its face into the most quaint of grimaces. It is fond of carrying its tail in the manner indicated in the picture, and also of sitting with its eyelids half closed, in the most affected manner possible. (Cercopithecus fuliginosus.)

picture of a Spider or Grasshopper, but soon came to know that they were not edible She would not show any fear at the pictures of Snakes, but knew them for what they: were, as we could see by the expression of her face and roice.

"Her food consisted of everything that came on our table, except milk and sandwiches, for which she had a decided contempt. She also liked ink and she would take the pen out of the inkstand, lick it and carefully put it aside; then she would dip her finger into the ink and lick that until she was satisfied. She was fond of wine and beer, but never drank too much, and gave the preference to beer-foam. Fruits of all kinds were welcome, especially currants, straw- berries and gooseberries. She did not care for eggs, and never destroyed a nest. A couple of little birds had their nest on our porch, and she was on quite intimate terms with them, as well as with several others, among which was a Woodpecker, to which the room. Her day's work always began at the breakfast-table. As soon as she awoke she threw aside the warm blankets, and hurried to the table, to be in time for the lighting of the lamp under the lighted and extinguished it with her hands. Then she would warm herself before the coffee-pot, and look at the blne flame of the alcohol, whose flickering fascinated her just as nuch as the boiling and singing of the water. After breakfast her mistress brushed her from head to foot, and this operation was so thoroughly agreeable to her that she took all the necessary positions herself. The daily bathing of the face was liked much less, and the weekly bath, with its soap and scrubbing, was lield in detestation. Muido's Judg- "She was
ment of invariably Human Nature. affect ed with predilection or antipathy on first meeting a stranger, never changing the attitude thus assumed, and she always recognized h im at subsequent meetings. Those that she liked she mited to play with her by gestures, sounds, or by touching their clothing; she would sit in their laps and take delight in being petted. Those that she disliked she treated with indifference; if they persisted in occupying themselves with her, she at first declined their attentions by violent gestures; if that was not sufficient, she would lie down, open her mouth wide, show her teeth, grunt and assume threatening positions. Then it became necessary to check her, lest she go farther and bite. It seemed that she formed her opinion of people from their appearance; a kindly face, a pleasant voice, calm, aristocratic manners, gained her heart forthwith; violent gestures, cold looks and a Joud, harsh voice were repulsive to her. As to children, she liked them all without exception. She romped and played with them, and when they became too wild she quietly retired. She never bit or scratched a single child; they were all as personal friends to her.

Her affection for my wife was really touching. She regarded herself as my wife's natural protector, and whoever approached the latter or shook hands 
with her always found the little Monkey ready to defend her in case of need, sitting on her shoulder or in her lap. Once her mistress was very sick, and the animal became sad and melancholy and would sit for hours at the door of the sick-room, demanding admission. After several weeks she was let in, when she immediately jumped on the bed, put her arms around my wife's neck, uttering a plaintive little sound, and could not be taken away again.

Muido's Vocal "This little Monkey had a very wide Accomplish- range of vocal sounds. We distin-

ments. guished thirteen different sounds, or groups of sounds, that she could utter, ranging from a low, musical chirping or purring, expressive of drawn 'o.' They were the strangest of sounds, and I never heard the like from any other Monkey."

[Other well-known members of the Guenon group are the Mona, Talapoin and Red-bellied Monkeys, all of which are distinguished for the beauty of their fur and their striking appearance.]

\section{MACAQUES.}

A great variety of Monkeys are comprised in the genus Macaque (Macacus) in Western Africa, but scientifically speaking there are only a few kinds having a right to this name, and they, with one exception, inhabit southeastern Asia. In general the Macaques have the following distinguishing traits: they are of sturdy build; the limbs are of moderate length: the snout projects about as much as that of the Guenons; and the tail may be as long as the body, or quite stunted. The cheekpouches and callosities are well developed. A further peculiarity of these animals is, that the hair on the head of some shows a decided parting, while in others it assumes the shape of a huge wig, and the beard, lacking in some, is of unrivalled growth in others.

In former ages they ranged over a great part of Europe, and even now they go farther north than other Monkeys. The short-tailed species inhabit the north of Africa, $\mathrm{Ch}$ in a and Japan; the long-tailed breeds are natives of the East Indies. They resemble both the Guenons and the Baboons, and live sometimes in forests like the former, sometimes on rocks like the latter. As to character, they seem to possess the impudence of both; in youth they are playful and good-natured like the Guenons; in old age they are $\mathrm{crabbed}$ and cross like the Baboons.

BONNET MONKEY.-Found in the hot regions of Asia and Africa, and is quite common in captivity, its amusing tricks making it very popular in muscums and zoolngical gardens. It has very large cheek-pouches and stows away in them the greatest possible number of nuts. It is fond of hugging and nursing other animals and of searching their bodies for vermin. Its color is an olive-gray and the hair of the head is parted in the middle. (Macacus sumcus.)

contentment or of a request for some favor, to the yelling and shrieking of anger ; from a softly uttered 'took took,' when she was alone in a dark room, and slightly nervous, to a loud 'tcck' that came with a violent fright. There were all kinds of crying, gurgling, screaming, grunting, each expressing different stages and kinds of excitement. The most wonderful of all was what we used to call her 'greeting to the sun.' When the sun shone bright in the morning, she would look up a specially luminous spot on the table or on the floor, make strange gestures, lift her arms with a slightly swinging motion, and then, addressing the sun, would give us in a loud, deep tone something like the greater half of a chromatic scale, always ending with a deep, long-
The Common The best known of this group is the Macaque of Common Macaque or Monjet (MacaJava. cus cynomolgus), a native of Java. He attains a length of three and a half feet, the tail being about twenty inches long. The hair on the head of the male is pressed down flat, while that of the female forms a crest. Their color is brownishgreen in the upper part, grayish-white in the lower; the hands, feet and tail are black. This animal is a native of Eastern Asia, cspecially of the great Sunda Islands, Nearly every ship that reaches Europe from the East Indies has a number of thesc Monkeys on board, as they can be purchascd rery reasonably from the natives[and many of them find their way to America]. The Monkey cages in zoological 


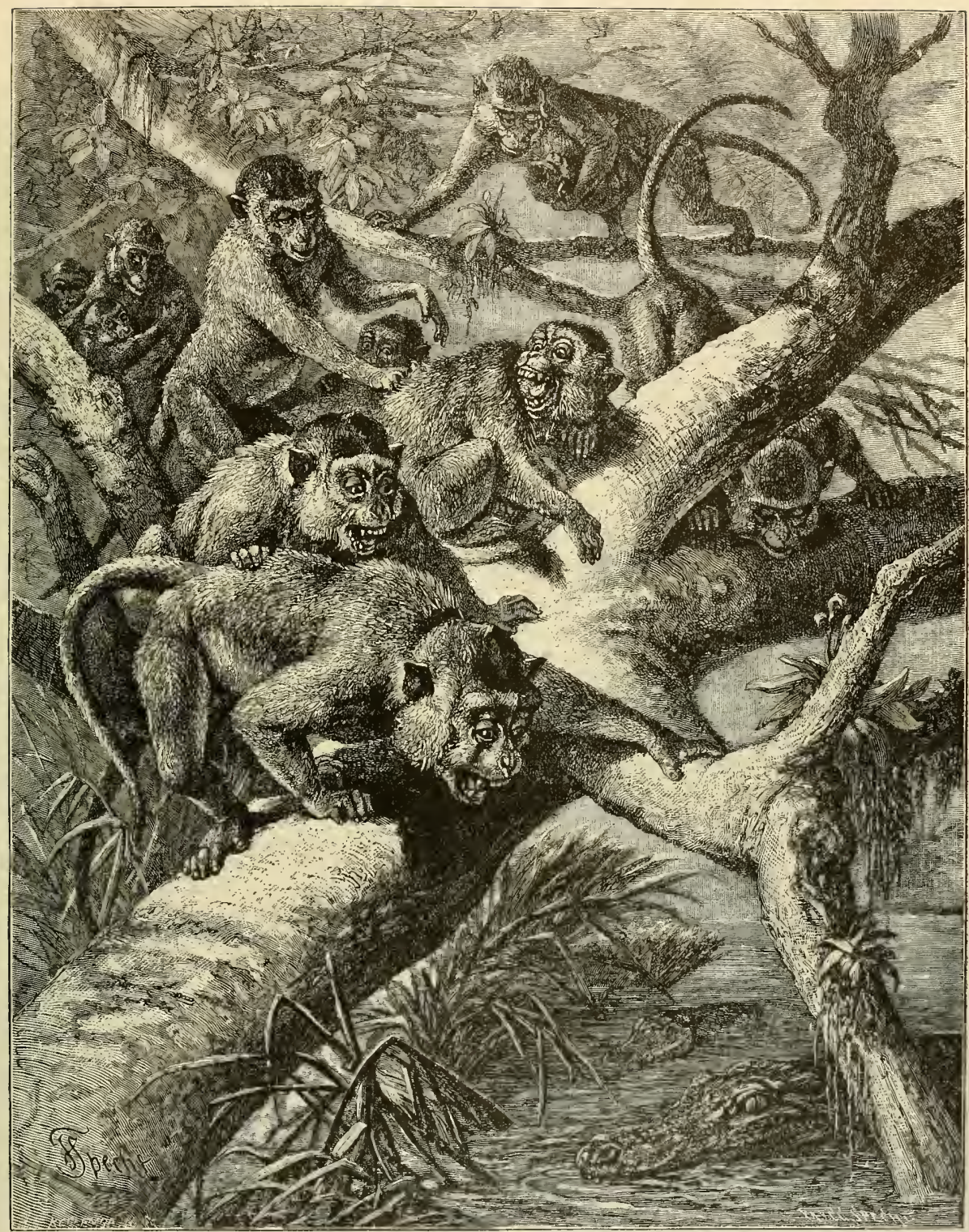

COMMON MACAQUE.-This picture illustrates in a striking manner the impudence that is so strong a characteristic of the Common Macaques as of many other species of Monkeys. The Crocodiles shown in the stream are the most feared of all the enemies of the Monkey tribes. But the mischievous troop in the trees know that they are beyond the reach of the reptiles, and they are having some fun with themthe oldest and boldest males just out of reach, the others at safer distance, but all evidently deriding their aquatic enenies with chattering glee. The Common Macaques are natives of Java, Sumatra, Borneo. Celebes and Batchian. They are great thieves, going out in large parties for the purpose of robbing fields of grain. They have very large shoulders and are clumsy animals. (Mlacacus cynomolgus.) 
gardens are, therefore, mainly dependent on this species for representing the group. He resembles the Guenon in shape as well as behavior. He is easy to feed in captivity, capable of reproduction, and is often used in Monkey theatres, being easily instructed and of a cheerful disposition; generally playing the part of waiter or servant of some kind.

The Bhunder, The Bhunder or Rhesus Monkey, also an Indian called the Markat (Hucacus rhosus), is Macaque. said to be held sacred in his native country. Captain Johnson says: "A man on whose veracity I can rely, tells me that the reverence shown this Monkey is nearly as great as that which the Hoonuman (Simnopithecus entellus) inspires. The natives of Baka leave one-tenth of their harvests piled in heaps for the Monkeys, which come down impression on them, and if one does them real injury, he endangers his own life.

Lady Barker's The story of Lady Barker's great din-

Feast ner in Simla, shows how peculiarly civ-

Demolished. ilized pleasures may sometimes run their course in India. Lady Barker had everything prepared for the reception of a great number of guests. She had herself decorated the table with flowers, and the choicest delicacies to be found in India and Europe were disposed about the table. When the time for dinner drew near, she retired to dress, while the servants, instead of watching the rooms, amused themselves more congenially. When she again descended, and went to cast a last glance at her work of art, she found the dining-room full of guests, but unfortunately not of the expected

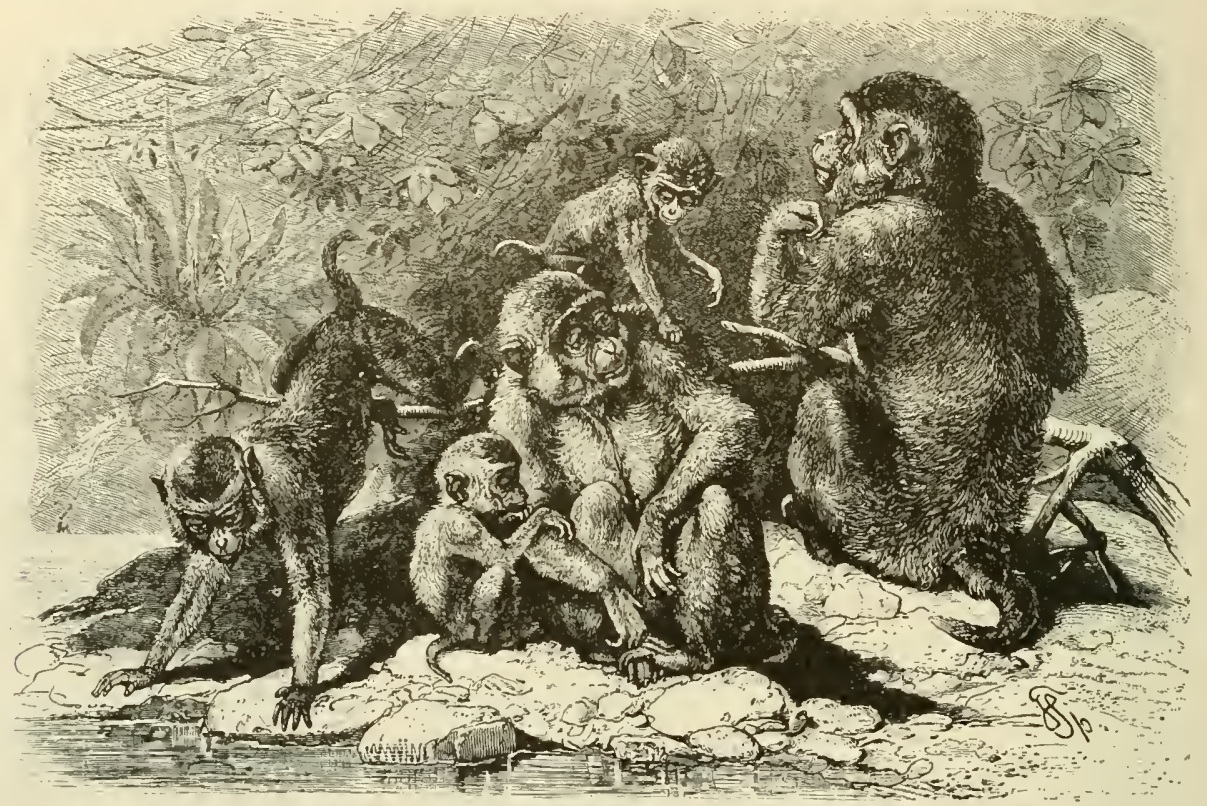

BHUNDER, OR RHESUS MONKEY, - This picture presents a very contented tamily of Bhunder or Rhesus Mlonkey's, which are natives of British India, wliere, in many localities, they are held in greatest reverence. On account of the protection thus afforded they are outrageous thieves and have not the slightest fear of Man. The mothers are at great pains to teach their young how to steal successfully and the pupils are very apt indeed. The Bhunders, like the Sacred Jonkeys, often crowd into viliages, where nothing that is edible is safe fron their pilfering fingers. When detected they escape punishment, because the poor natives dare not whip a creature that, in their belief, is favored of

their gods. (Ifacacus rhesus.)

from the hills in a large body and gather their tribute."

Every Hindoo willingly gives his share, and hereby shows a gentleness of spirit and goodness of heart which, though bordering on the ridiculous, does him so much honor, that we might well conform ourselves to his standard. Neither can I see anything grotesque in their protection of the animals from foreigners; I have always thought it but just that men should protect animals. Of course the Hindoos go too far in this. It is hard for a foreigner to live with these Monkeys without waging war on them. It is scarcely possible to have a plantation or a garden; for the protected rascals devastate it in the most relentless manner. If one puts out guards, they are of no avail, for driven away from one side, the Monkey's make their appearance at the other: burning fires, scare-crows and such things make no kind. A band of Monkeys had effected an entrance through the windows and were hugely enjoying themselves at the table. One may inagine the feelings of the hostess, who could offer her guests nothing but the soiled remnants of a splendid feast. It was probably the same troop of Monkeys that played another trick on Lady Barker. I Her Lap-Dog, "Fury:" waged a continuous war on the creatures and never missed an opportunity to drive them away. Out of revenge one of the unbidden guests took the poor thing along to its tree-top. There the pitifullyhowling little Dog went from hand to hand, shaken and tormented by all the Monkey's, and, at last, was dropped into a precipice. So "Fury" met with an untimely death, and the Monkeys were avenged.

The Bhunder reaches a length of about twenty inches, its tail measuring ten inches. He is of strong. sturdy build: the color of the fur is greenish or 
gray in the upper part, with a yellowish tinge over the hips and buttoclis; the lower part is white, the tail greenish above, gray below. The face, ears and

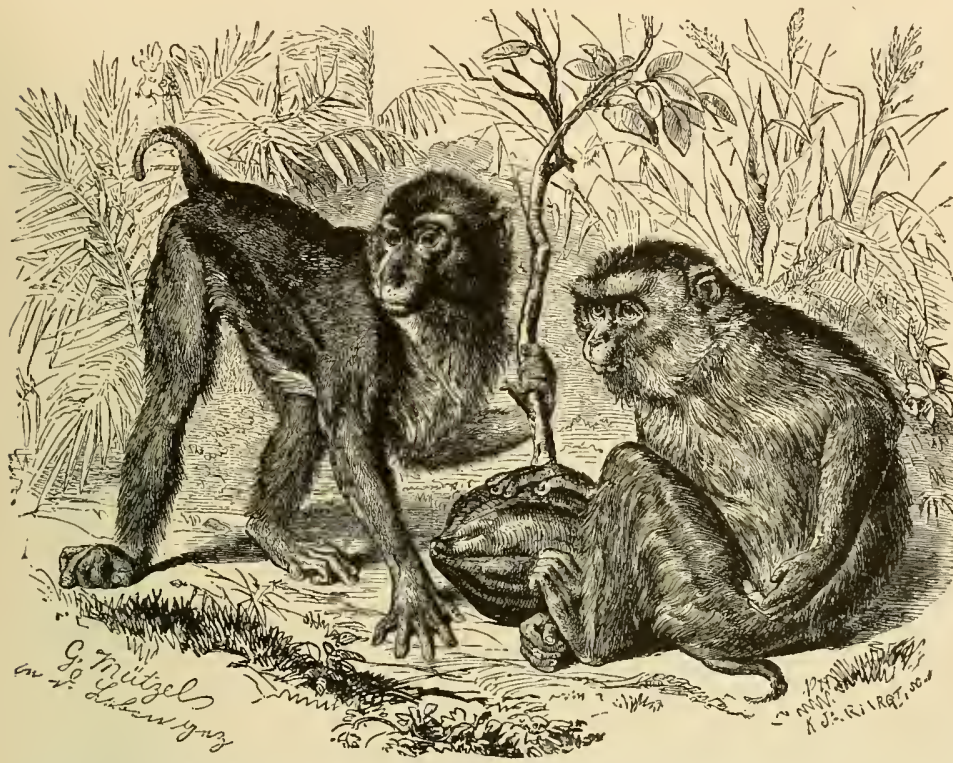

PIG-TAILED MACAQUES.- Natives of Sumatra, Borneo, and the Malay Peninsula, and are called Bruh, or "Climbers of Palms," by the natives, on account of their fondness for the Iruit of these trees. They are harmless and comfortably upon it. (Macacus nemestrinus.)

hands are of a light copper color ; the callosities of a vivid red. The female lets her tail hang down, while the male curves his laterally and inwardly.

The Magot, or The most important of all Macaques in

"Barbary a certain respect is the Magot, Barbary

Ape." Ape, or Tailless Ape (Macacus sylz'amus, or Imuns ccaudatus) the only Monkey living in the wild state in Europe. As he possesses no tail, he has lately been considered as a representative of a different species, but usually he is known as the Turkish or Barbary Ape. His frame is slight, his limbs slender, his fur and beard thick. The wrinkled face, the ears, hands and feet are flesh-colored the callosities bright red and the body is of a reddish-olive hue. The under surface of the body and the inner sides of the limbs are lighter and grayish. The length of a Magot is about thirty inches.

There is no doubt that this Monkey was known to the ancient Greeks under the name of Pithecus. Pliny tells us that it imitated everything, could be taught to play certain games, liked to be petted, and propagated in captivity, etc.

The Magot is a native of northwestern Africa. It would appear that the animal lives gregariously, in large troops, following the leadership of old expêrienced males. It is very clever, cunning and scheming, agile and strong, and, in case of emergency, defends itself excellently with its splendid set of teeth. When the creature is excited it distorts its face more than any other Monkey, moving the lips in all directions and chattering with the teeth. When it is frightened it utters a short, loud scream. Desire and delight, horror and anger, are only shown by grimaces and chattering of teeth. When it is angry, it moves the wrinkled skin on the forehead up and down, puts the snout forward, and presses the lips together in such a way as to form a small and perfectly round hole. The Magot inhab-

its mountainous regions, and is as much at home on rocks as on trees. It is said that it feeds on insects and worms like the Baboon, and therefore keeps lifting up stones, which occasionally roll down hill and endanger the safety of passers-by. It is also thought to be very fond of Scorpions ; very adroitly twisting off their poisonous tails, and eating them greedily. But it is also satisfied with smaller insects and worms, and the smaller the game the more zealously it is hunted, and the more voraciously it is eaten. The prey is carefully taken up, gazed upon with a satisfied chuckle, and speedily devoured.

The Troop of The Magot Magotsat is the only Gibraltar. M o n k e y that inhabits Europe in a wild state. I was told when I visited the south of Spain, that the band of these Monkeys at Gibraltar was rather numerous, but did not often show itself. One could see the animals looking for in-

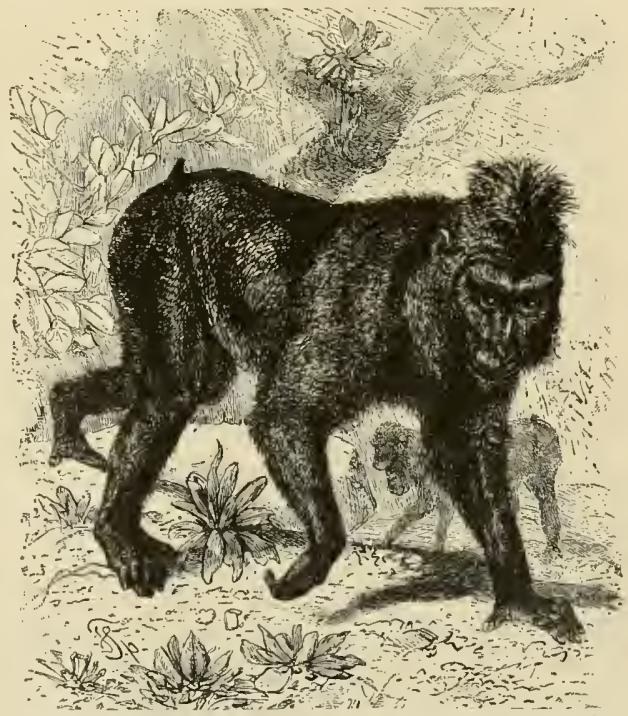

BLACK BABOON, - This picture presents the Blıck Baboon when in motion tupon the ground and shows its Dog-like action, a characteristic of its family. The thumbs spread out when it is walking or running and the crest and stubby tail are shaken when it is angered. (Cynocephalus niger.)

sects under stones, from the fortress, if he had a good telescope or field glass. They hardly ever 
came into the gardens. Even the Spaniards do not know whether the animals originally were natives of Europe, or whether they were imported from Africa. A. G. Smith's account of his personal experiences in this respect is very interesting. In the first place, he says that the existence of Monkeys in Europe had so often been doubted, treated as a silly story and denied by captains of ships frequenting Gibraltar, that he himself had lost all confidence in the reports. But he came to know better, when one day he made the ascent of the rock, to the flag-pole, to enjoy the magnificent view. The sentinel guard of the hag, in the course of conversation, chanced to remark that "the Monkeys were moving." This led to a careful questioning about them and he learncd the followine particulars:

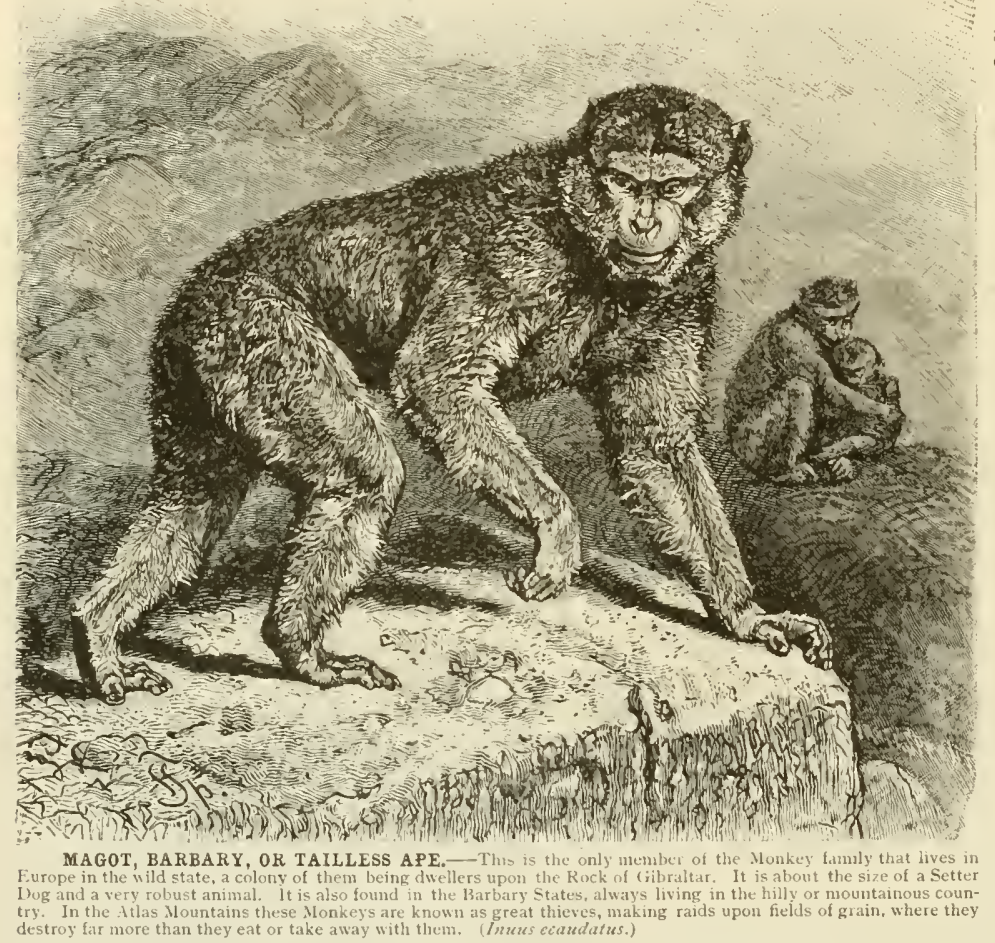

"The Monkeys gained a foothold on these rocks a great many centuries ago; how and when they crossed the water is not easily determined, and the Moorish story that to this day they pass to and fro between Gibraltar and Morocco, through a submarine passage, is a little too much for the credulity of any one. It is a fact, though, that they live upon the rocky elevation, although greatly reduced in numbers. For a long time there were but four of them. They are seldom seen, except when the wind changes and they move to other quarters. They are not very hardy animals and dread every change of temperature, especially the shifting of the wind from east to west and ifce a'ersa, and try to shelter themselves from it behind the rocks. They are active to a degrce and preferably dwell on steep, rocky walls, where they are the sole occupants of the many holes and uneren places in the loose ground. It does not seem that they have to work very hard for their living, for they look quite slick and well-fed. They are commonly supposed to be very shy and to flee at the slightest noise; but the sentinel denied this, and showed me a few rocks from which they had stared at him that very morning, without being in the least disconcerted by his English uniform and soldierly gaze. They remained for quite a little while at the distance of twenty or thirty yards and then retired very deliberately. Yet, as one sees them so little, chiefly when they are moving, it may be concluded that they are of a shy, unsociable nature, for nobody ever pursues them; they are carefully guarded from all intruders."

Posselt's Account A y e a r of Gibraltar later PosMonkeys. selt says about the same Monkeys: "On my passage from Cadiz to Gibraltar I had inquired after the Monkeys and an Englishman residing in Cadiz told me there were not any. Arrived in town, 1 learned that there were from three to fifteen Monkeys yct in existence; nobody knew the exact number, as they were shy and kept to the steepest and most inaccessible parts of the rocks. Without a guide, 1 slowly ascended the main road leading to the simnal station, and after having gone about twothirds of the way, I took to the left and made for the highest point on the northern peak. The magnificent view that spread out before my eyes quite engrossed my attention, and I forgot all about the Monkeys, until a sound resembling the distant yelping of a little Dog startled me. About two hundred paces in front of me was the first battery with its huge cannon pointing at Spain. On the brick platform of the battery an animal, about the size of a scotch Terrier, was stowly running away from ne, and from it the sound had come. I stopped and saw that it was a Monkey which had probably been standing guard ; for on the farther end of the platform, nearer the Mediterranean, two others were lying, lazily basking in the sunshine. Step by step I cautiously approached the interesting group, which drew together and attentively looked at me. At a distance of about one hundred paces I stopped, and they soon regained their composure. They resumed their former occupation, and then started to play. They hugged each other, ran around, and, sometimes, one would enter the mouth of a cannon and come out again. In a word, they seemed thoroughly tame, 
and bent on enjoying the beautiful, warm sunshine."

The Tribe My brother requested the comProtected by the mander of the fortress himself to Government. set us right in regard to these Monkey's and we received the following report from him: "The number of Monkeys at present inluabiting our mountain is eleven. As we have found that thicy have no trouble in finding sufficient nourishment on the rocks, we do not feed them, but leave them entirely alone. The guard of the signals as well as the detectives watch over them, and see that they are in no way molested or hunted. The guard of them, but last summer I saw as many as twentyfive together, and I think that we may safely claim as many as thirty. At this season they are not frequently seen, for food and water can be found in plenty on the top of the hills. During the hot summer lack of provision compels them to come farther down, and then they cause considerable damage in the gardens. In June or July of last year there were about half a dozen young ones. The adult male is of considerable size, being about three feet high; the largest females are also of good size, but more slenderly built, and not so strong. The

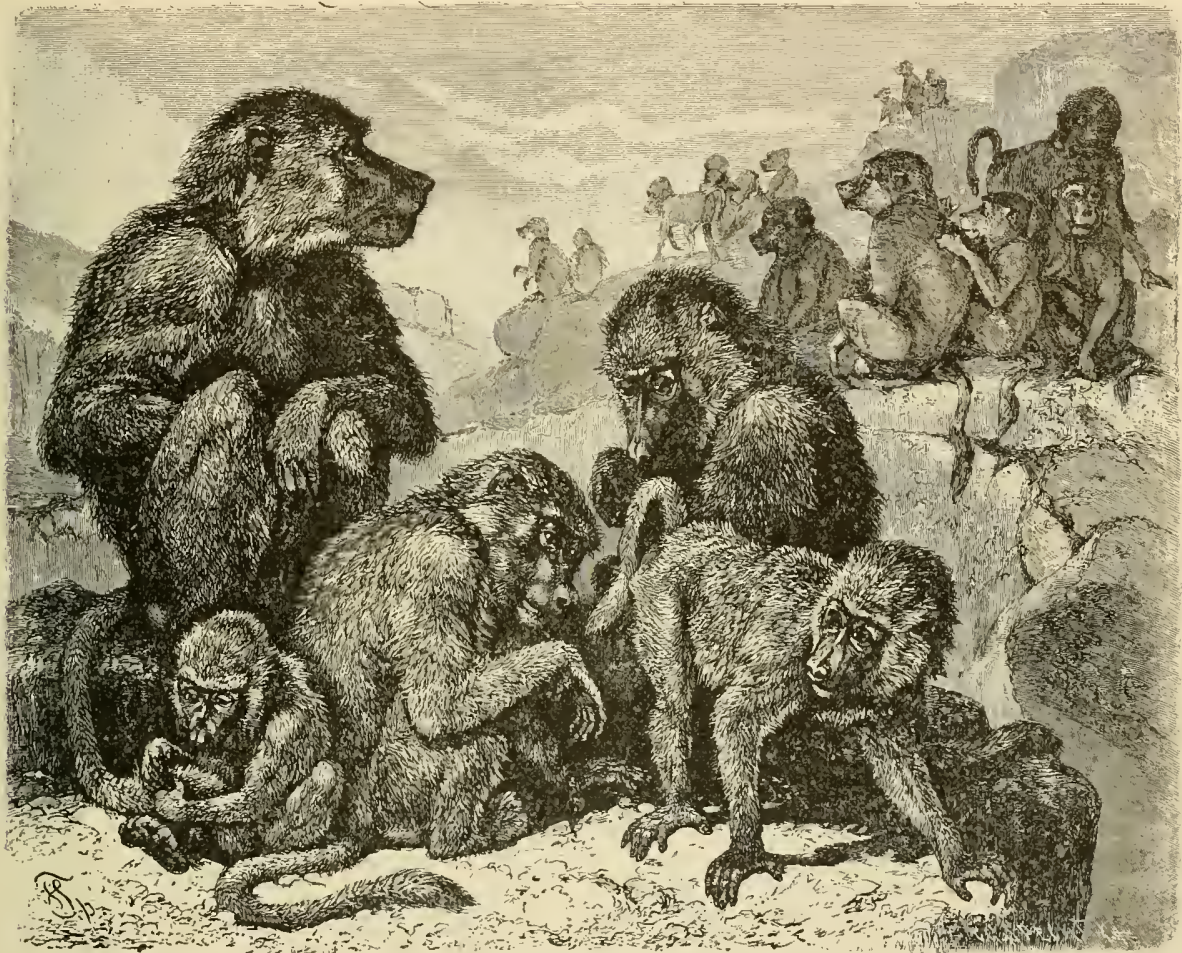

COMMON BABOON. - The group of animals here depicted are often seen in captivity in Europe and the United States. They are true Dog-headed Baboons, and their home is in the West Coast of Africa, Abyssinia and the Nile farther northward, and in eastern Equatorial Africa, They are large, and have hair of a uniform yellowish olive-green. This species is very strong and fierce when attacked, but the young are amiable and full of pleasing tricks. The playfulness of the little one is indicated in the picture, as well as the teasing propensities of those that are older. (Cynocephalus babuin.)

keeps an account of them and as they always keep together, he is soon made aware of an increase or a death in the family.

"Nobody knows how and when they got on the rocks, and the most divergent opinions prevail about it. Six or seven years ago their number was reduced to three; then Sir VVilliam Codrington, fearing they might die out, imported three or four from Tangier, and since then they have increased to the number named."

Lately this number has more than doubled itself. Ve wrote a letter of inquiry, addressed to some officer of the English garrison of Gibraltar, and Captain C. S. Shepard was kind enough to answer us, on the ISth of March, I889, as follows :

"It is hard to determine exactly the number of our Monkeys, Day before yesterday I saw a dozen strongest male usually keeps a little aloof from the band." According to these latest reports we may rest assured that Europe's last Monkeys are not going to die out just yet.

\section{THE BABOONS.}

The Baboons (Cynoccplatus) are one of the most remarkable groups of the Monkey family, but are by no means an attractive or pleasing one. We find its members to be the ugliest, rudest, coarsest and most repulsive representatives of the Monkey tribe. We may say that the Baboon stands in the lowest degree of development of the entire Monkey world. All the nobler shapes are effaced, and all the nobler qualities of the mind are drowned in the grossest passions. 
Like Aristotle, we call the Baboons Dog-headed Monkeys, for the shape of their heads resembles that of a rude, fierce Dog a little more than that of Man. In reality the resemblance between the two animals is but a superficial and unsatisfactory one, the head of a Baboon being as much a caricature of a Dog's head as the head of a Gorilla is a caricature of a Man's. But in comparison with the other Monkeys his snout is peculiar, and, therefore, we may safely leave the designation which old Aristotle gave to these animals.

Physical The Dog-headed Monkeys are the Characteristics largest in size, after the Man-shaped

of Baboons. Apes. Their body is of a strong, bulky make and their muscular power is enormous. Their thick head is provided with a large, long muzzle abruptly cut off at its end, often swollen or furrowed, and endowed with a prominent, blunt nose; the teeth resemble those of a beast of prey on account of the formidable canines, which on their inner side are furnished with sharp edges. The lips are very mobile, the ears small, the eves lie deep in their sockets and their expression fully reflects the Monkey's character in its true light ; it is cunning and brutal to the extreme. The limbs are short and stout, the fore-paws having five toes; the tail may be long or short, smooth-coated or provided with a tuft: the cheekpouches are large, the callosities are hideous and of an enormous size, and of a very vivid color. The long hair is sometimes developed into a mane and is generally of an undefined earthy or rocky color: gray, gray-green, yellow or brownish-green.

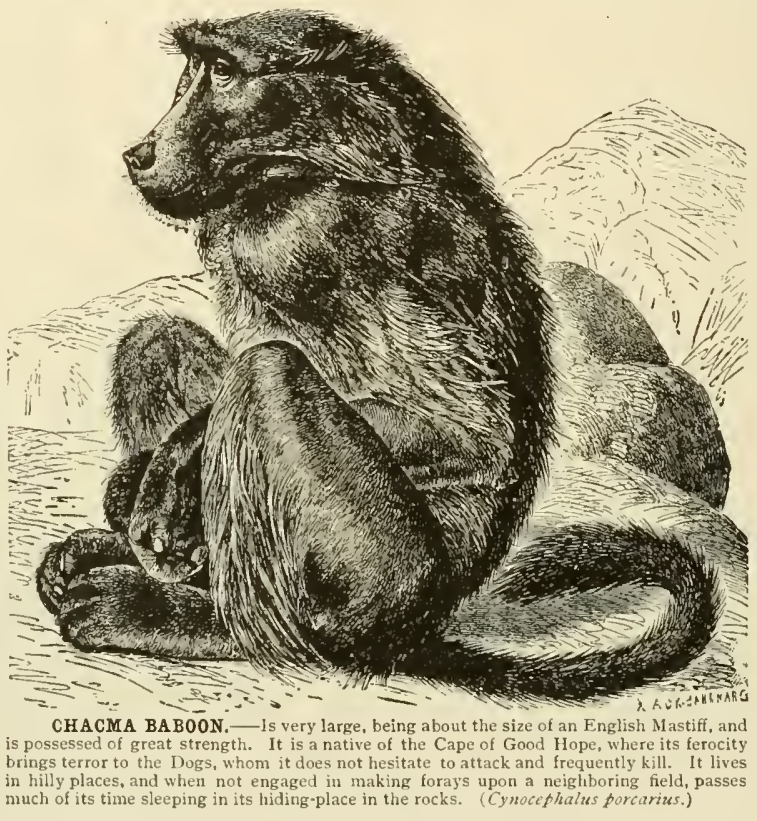

and in their greed of animal food also attack larger animals. According to Fisher, the Baboons in east Africa not only steal chickens, but kill the small Antelopes and even the larger Bosch-boks. In plantations, and especially vineyards, Baboons cause the greatest damage; they are even said to undertake their raids in an orderly, deliberate, and nearly military manner.

More than any other Monkeys, Baboons show, by their gait, that they are really quadrupeds. Their whole frame is adapted for progression on all fours. They resemble awkward Dogs in their gait, and even when they do stand erect they like to lean on one hand. When not hurried their walk is slow and lumbering; as soon as they are pursued, they fall into a singular sort of gallop, which includes the most peculiar movements of the body. Their walk is distinguished by a certain bold swagger, that has to be seen to be appreciated.

Morat Their moral Traits of traits do not Baboons. contra d ict their exterior in the least. I'e will begin a description of them in Scheitlin's words: "The Baboons are all more or less bad fellows, always savage, fierce, impudent and malicious; their muzzle is a coarse imitation of a Dog's, their face a distortion of a Dog's face. Their look is cunning, their mind wicked. They are more open to instruction than the smaller Monkeys and have more comnon sense. Their imitative nature seems such, that they barely escape being human. They easily perceive traps and dangers, and defend themselves with courage and bravery. As bad as they may be, they

Homes and The Baboons are found widely spread Habits of about in Africa, Arabia and India. Dif-

Baboons. ferent countries possess their individual species, but they may be common to several tracts of country.

The Baboons are, in the main, mountain Monkeys, but undoubtedly several kinds also live in forests and are better tree-climbers than one might suppose, seeing them in a country devoid of trees. In the mountains they go as high as 9,000 to 13,000 feet above the sea-level, sometimes reaching the snowregion; but they seem to give the preference to countries having an elevation of 3.000 to 4,000 feet. The oldest travelers assure us that mountainous regions are their true home.

The food of the Baboons consists principally of onions, tubers, grass, fruit, eggs and insects of all kinds. But we may safely assume that these strong and agile fellows are not satisfied with small fry, still are capable of being tamed in youth; but when they become old, their gentle nature disappears, and they become disobedient; they grin, scratch and bite. Education does not go deep enough with them. It is said that in the wild state they are more clever: while in captivity they are gentler. Their family name is 'Dog-headed Monkeys ; if they only had the Dog's soul along with his head!"

One cannot contradict Scheitlin; the picture he draws is correct. The mind of the Baboon seems to be the Monkey mind in its highest development, but more in the bad than the good sense. We cannot deny that they have a few excellent qualities; they are very fond of each other and their children; they also become attached to their keeper and make themselves useful to him. But these good qualities are in no way sufficient to counterbalance their bad habits and passions. Cunning and malice are common traits of all Baboons, and a blind rage is their chicf characteristic. Their anger is as easily aroused 
as a straw fire is kindled; but it passes away by no means as quickly. A single word, a mocking smile, even a cross look, will sometimes throw the Baboon into a rage, in which he loses all self-control. Therefore these animals are always dangerous, as their brutality may break out at any moment. As enemies they are really terrible.

Baboons The Baboons shun Man, but in case of and their necessity they enter into combat with Enemies, him as they do with a beast of prey. The Leopard seems to be their chief enemy, though he oftener attacks the little ones, having reasons for considering whether his fangs and claws are strong enough to cope with the teeth and hands of an adult

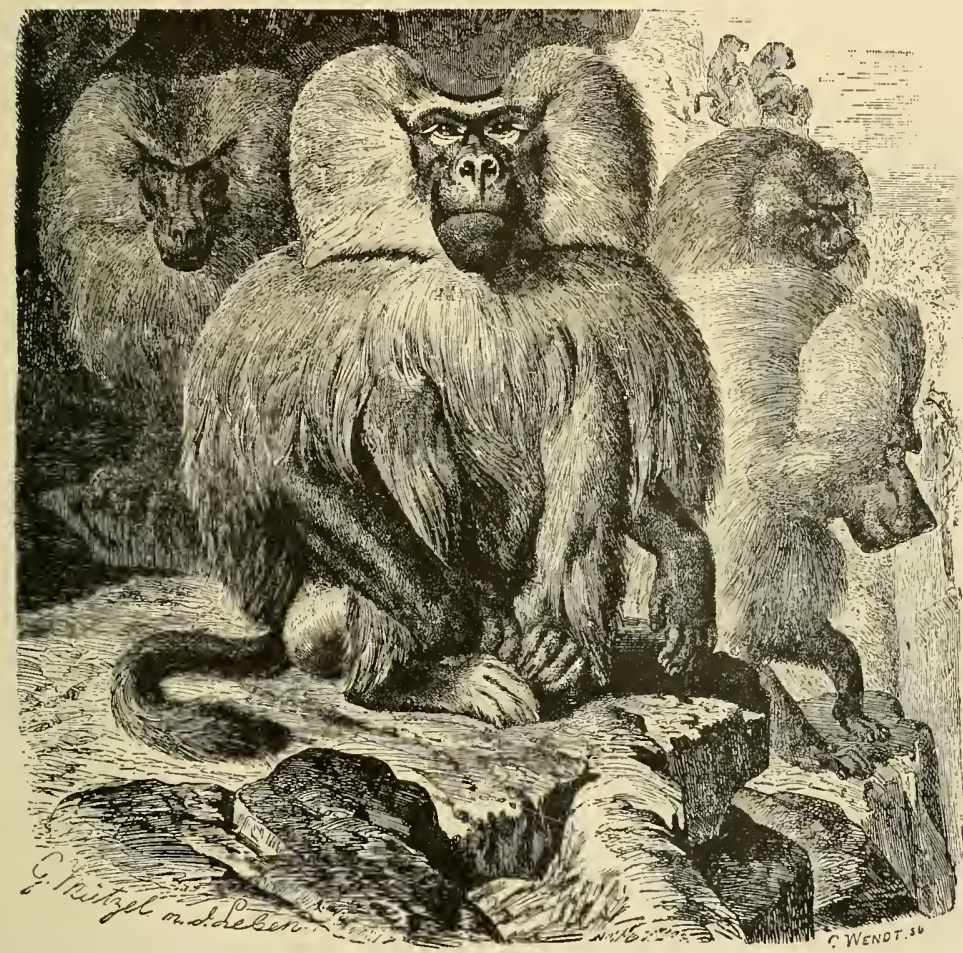

SACRED BABOON, OR HAMADRYAS,-The sacred Ape of the Egyptians. Native of Abyssinia, and a most extraordinary looking animal, with its curious adornment of hair, the head, neck, shoulders and all the fore parts of the body being covered with a long and shaggy coat; that of the back of the head and neck being more than hamadryas.)

Baboon. Dogs, as a rule, cannot successfully fight with the Baboons, and yet these noble and brave animals know of no greater treat than a Baboonhunt. With the exception of the Dog, the Leopard and the Lion, the Baboon has no enemies that are very dangerous to him; still it is to be supposed that his tribe have had some very disagreeable experiences in connection with the poisonous tooth of Serpents. A Baboon never rolls away a stone or investigates a bush without first making sure that no Snake is lurking there. Scorpions they do not fear, as they break off their poisonous tails with great skill and enjoy eating them as much as they do any other insect or Spider.

The usefulness of the Baboons is very slight. They are taught a great many tricks, and in South
Africa they are said to be made use of in searching for water in the desert. They are tamed and taken along into those arid regions, where even the Bushmen only know how to get water by drops. When the supply of the liquid is running low, the Baboon is given some food containing salt and a few hours later he is turned loose at the end of a line. The poor animal, crazed with thirst, runs hither and thither, sniffs the air, tears out plants and examines them, and finally either finds a place at which to begin digging for hidden water, or hurries forward to where he is sure of finding a running stream.

The first animal that we will consider in connection with this group, is a Monkey that by sonse is counted among the Baboons, by others among the Macaques. In his habits he is a true Baboon, but in his structure he differs from it considerably, and this is what gave rise to the difference of opinion among naturalists. We must consider him as a connecting link, possessing the peculiarities of both species. Those who count him among the Macaques cannot be accused of error; while those who believe him to be a Baboon are also in the right.

The Black The Black BabBaboon oon ( $C$ ynoccplatDescribed. Ius niger) differs from the others in having only the rudiment of a tail and also in his muzzle. His snout is broad, flat, and short, and the nose does not project over the upper lip, Baboonfashion, but ends about half way back on the upper part of the snout. For these reasons this Monkey is considered the representative of a special kind, the Dog-headed Monkeys proper ( $C_{y}$ nocephalus). Face and buttocks are devoid of fur, while the rest of the body is covered by long, woolly hair, which is the longest on the head, and so arranged as to form a crest. The color of the fur and face is black, while the callosities are red. In size this Monkey is inferior to all his relatives. His length is only about twenty-five inches, the tail being a little over an inch long.

$\mathrm{He}$ is a native of the Celebes, and though he is found there in numbers, his life in the wild state is very little known.

Lately he has been shipped to Europe[and America] and has lived for a considerable time in captivity. The Black Baboon which I saw in the Amsterdam Zoological Garden seemed to enjoy life very much. He was daily brought over to the Guenons; if these latter had been timid creatures, the imperious and haughty black Monkey would have tyrannized over them, but the agile crowd of Guenons 
was too quick for him. He seemed to be on friendly terms with the Macaques, and sustained very intimate relations with a female Baboon; at least, he was very attentive to the beauty, and, in return, allowed her to look over his fur.

According to Brockmann, no other Monkey is so eligible to membership in a Monkey theatre as the Black Baboon. He learns his part in play, retains what he has learned, and "works" with real pleasure. Yet he is not a regular member of the stage, as he is a rare and expensive Monkey, especially if one considers his frail health when in captivity.

The Common Among the Baboons proper, the and Sphinx. min) is the best known to me, though only in captivity. He is not easily taken for the Black Baboon, nor for other Monkeys that are pro-

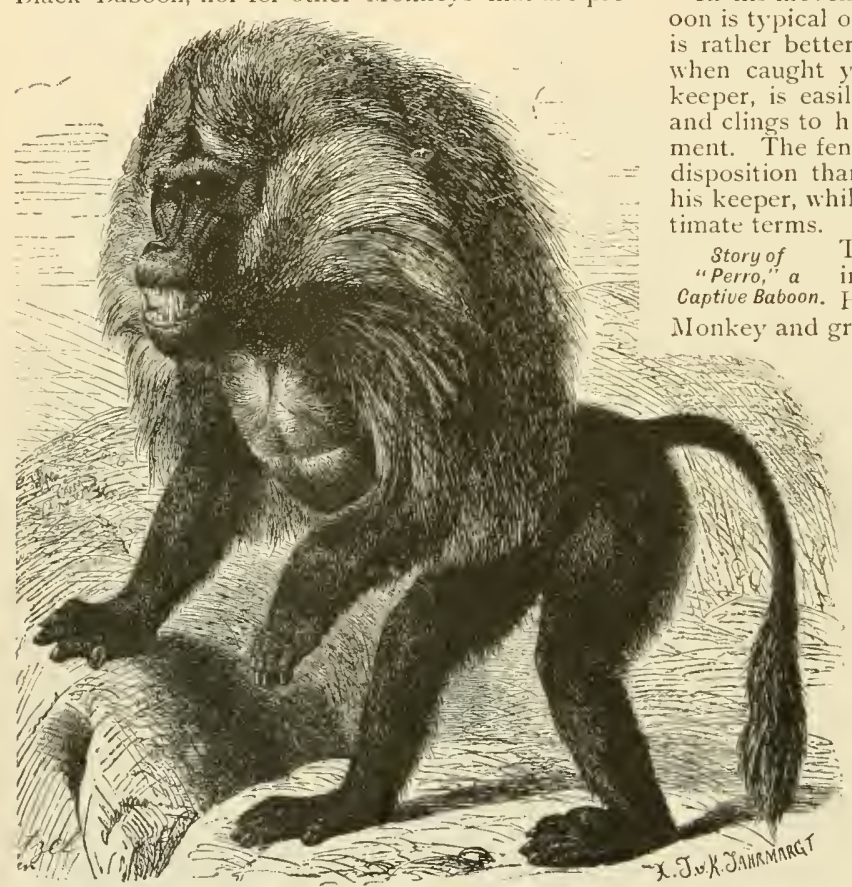

GELADA BABOON. - With its immense mane, great canines and fierce eye this animal presents a formudable appearance, and its looks do not belie its character. Sometimes a troop of these creatures encounters a body of Hanadryas when on a marauding expedition, and engage in desperat battle. The legs of the Gelada are black and the mane is a pale brown. (Cynocephalus gelada.) Story of Baboon, Chacma, Common Baboon (Cynocephalus bab-

Sphinx is smaller but of decidedly stronger frame; his muzzle is shorter and shows a peculiar thickening of the clieek-bones, and his hair has dark-gray and reddish brown ringlets.

The mode of life and behavior of these three Monkeys are very similar, and I therefore will speak only of the Common Baboon.

This Baboon is a native of the same belt of land as the Hamadryas, but penetrates farther into the centre of Africa. He inhabits Abyssinia, Kordofan and other countries of central Africa and he is found in troops. He is also common in German Eastern Africa, according to Bolim and Reichard, and goes as far to the southwest of Lake Tanganyika as the Upper Lualaba, if there is no case of mistaken identity in these reports.

In his movements and his gait the Common Baboon is typical of all the Baboons; but his character He is a very clever animal, and, ly trained to perform certain duties, me disposition than the male, which often turns upon his keeper, while she lives with him on the most in-

The first Common Baboon that came into my possession was named "Perro." He was a good-looking, pleasant w to like me after a short interval of three days. I made him guard our doors, chaining him to the yard gate. He soon selected a favorite spot, from which he watched the gate with extreme vigilance. Only we, or our friends, were given free access to the place; strangers were obstinately denied admission. When the latter were suffered to go in he would get very angry and he alway's had to be held back until the person had passed and gone beyond his reach. At every opportunity he showed himself to be a Baboon, from the top of his head to the sole of his feet, with all the characteristics, habits and nasty traits of his kind. When in a rage, he raised his tail, and stood on both feet and one hand; with the other hand he would beat the ground, reminding one of an angry Man bringing his hand down violently on the table, only that he did not make a fist of it. With flashing vided with manes; but he closely resembles the Chacma (Cynoceplualus porcarius) inhabiting South Africa, and the Sphinx (Cynoccphalus sphinx) inhabiting Western Africa. His smooth, even coat of fur is of a yellowish olive-green color, every individual hair being alternately dark and yellow, the under part of the body is lighter, and the cheeks are whitish. The face and ears assume a gray tint, the upper eyelids are white, the hands brownish-gray; the eyes light brown. Adult males reach a shoulder height of twenty-five to thirty inches, and counting from the tip of nose to the end of tail are four feet, eight inches long. WV must not forget, though, that the relatively thin tail comes in for one-third of this length. The Chacma is considerably larger, clumsier of motion and darker of hue, while the eyes and a loud yell he would then rush at his opponent. Not infrequently he would, with consummate art, take on a kindly look, smack his lips, something always intended as a token of friendship, and put out his arms towards one to whom he owed a grudge. If the intended victim would then approach him, he quickly seized his hand, drew it towards him and bit and scratched it. He was friendly to all our other animal pets, except the Ostriches, but these were really to blame for Perro's services as guard were not in demand, he would usually sit on the wall, holding a piece of straw matting over his head, as an umbrella. IIe took no special care of his long tail, simply letting it hang down the wall. Ostriches have a bad habit the enmity existing between him and them. When 
of snapping at everything that is not nailed or glued to a spot, and so it ofter happened that one of the birds would waddle up to l'erro, reach out for the hanging tail with its stupid head and snap it. In an instant the straw-matting was thrown away with a yell, and the Ostrich taken round its neck and given a thorough shaking. The Monkey often could not master his rage for a quarter of an hour after such an occurrence. It was not very wonderful that he administered a cuff or a blow to the birds whencver he liad the slightest chance.

Fondness of All our Baboons had, in common with Baboons for the natives, a passionate fondness for Strong Drink. Merisa, a kind of beer, manufactured from the grain of the durra or dolhen. They were

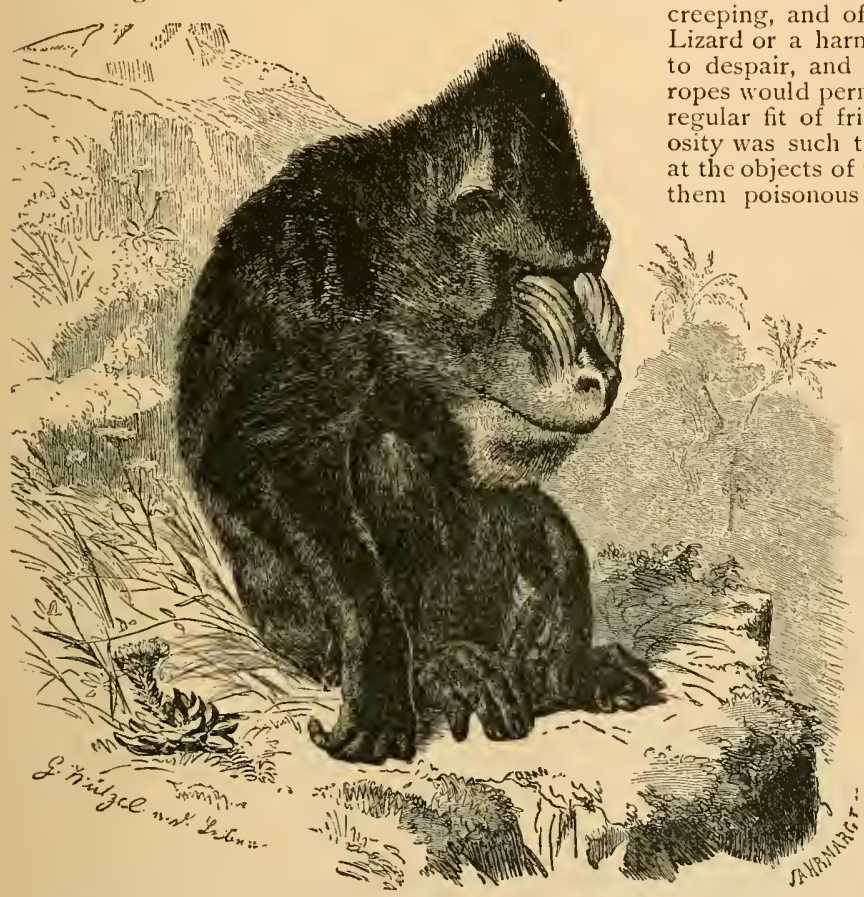

MANDRILL. - This is a native of the Gold Coast and inland regions of Africa, and is noted for huge callosities upon its cheeks, caused by swellings of the bones. The skin here is ribbed and has ridges that are alternately light blue, scarlet and deep purple in color. The male is five feet high when standing. The hair of the body is a black and olive-green above and silvery gray beneath. The Mandrill is frequently seen in captivity in this country as well as in Europe. In old age the animal is very brutal, and, in fact, under most favorable conditions it is very treacherous and likely for no cause to assail the hand that feeds it. (Cynocephalus mormon.)

often drunk and in this way proved to me that the Soudanese had told me the truth about the way Baboons are captured. My Monkeys also drank red wine, but whisky they scorned. Once we poured a little wineglassful of this liquor into their mouths by force. They had already been drinking some Merisa, and the effect of the combination soon showed itself. They became completely drunk, made the most fearful faces, and were boisterous and brutal in a word, they presented a degrading caricature of a brutish, drunken Man. The effects of the debauch on the following morning were most distressing, showing that with Baboons as with Men, strong drink is in the highest degree demoralizing and harmful
Great Courage Among my pets was a tame Lioness, of the who made the Guenons rather nervous, Baboons. but did not strike terror to the hearts of the courageous Baboons. They used to flee at her approach, but when she really seemed to be about to attack one of them, they stood their ground fairly well. I have often observed them as they acted in this way. My Baboons turned to flee before the Dogs, which I would set upon them; but if a Dog chanced to grab a Baboon, the latter would turn round and courageously rout the former. The Monkey would bite, scratch and slap the Dog's face so energetically that the whipped brute would take to his heels with a howl. More ludicrous still seemed the terror of the Baboons of everything progs. The sight of an innocent . Several times I brought nnakes in tin boxes. They knew perfectly well how dangerous the inmates of these boxes were, but could not resist the temptation of opening them, and then seemed fairly to revel in their own trepidation.

"Atile," a I took another memTamed Baboon ber of this family in Germany, a 1 o $\mathrm{ng}$ with me to Germany. It was remarkably clever, but also exceedingly mischievous. Our Dog had tyrannized over us all his life, and had become so sulky in old age that he lived in peace with nobody, and when he had to be punished he snapped even at me. But in Atile - that was my Baboon's namehe found more than a match. Atile thought it great fun to provoke the poor Dog on all occasions. When he was taking his nap in the yard, stretched at full length on the grass, the mischievous Monkey would softly creep up to him, get hold of his tail, and arouse him from his slumbers by a sudden pull at that esteemed member. The Dog would jump up in a rage and with a growl and bark rush at the Monkey. She (it was a female) would calmly await him, beating the ground with her hand. Greatly to his anger he never could get at her, for when he was near enough for biting, she would jump over him and was again pulling his tail. She would drive him perfectly insane through these repeated insults, but he always had to sneak away in the end, his tail between his legs.

Atile's Clever- Her cleverness was really remarkable.

ness and She stole in a masterly way; opened Affection. and shut doors and could untie intricate knots, when she thought it worth her while. Boxes she always opened and cleared of their contents. We sometimes frightened her by putting a little heap of powder before her on the floor, and setting it on fire. She would give a shriek, when she saw the flame leap up, and then jump as far back as 
her chain would permit. But she did not suffer us to practice this joke many times. After awhile she was shrewd enough to take the burning tinder and extinguish it with her hands before it had reached the powder, after which she made a meal of the whole.

Her affection for me was boundless. I could illtreat her and still she would show no resentment. It seemed that she considered me perfectly innocent of all the evil that befell her. When I had to chastise her, she never flew into a rage at me, but directed her wrath against the other people present, thinking, no doubt, that they were the cause of her punishnient. She preferred me to all her friends, and at ny approach would turn against those whom she had just been caressing.

She felt flattered at kind words, while laughter was revolting to her, especially when she thought she herself had provoked it. She responded to every call, and I could take her out on long walks without a chain. She followed me like a Dog, though she was fond of making little trips first to one side and then the other, extending them as far as she pleased, but never going very far from me.

The Hamadryas The Baboon which in virtue of his or Sacred shape, of his great sense, and also, Baboon. perhaps, of his unlovely character, played such a prominent part with the ancient Egyptians, is called the IJamadryas or Sacred Baboon (Cynocephalus hamadryas). How he came by the honor of bearing the name of a Greek nymph is a mystery to me, for surely his bearing shows nothing that is womanly. The ancients certainly did not bestow this name on him. Herodotus, Plutarch and Pliny call him Cynocephalus, Strabonius calls him Cebus, Juvenal gives him the name of Cercopithecus, Agatharchides that of Sphinx. The modern Abyssinians term him Hebe, the Arabians style him Robah, and in Egypt he is known as Khird. Among all these names there is not one that would recall a nymph, unless it be "Sphinx."

The Hamadryas The reverence accorded to the HaReverenced in nadryas by the ancient Egyptians Ancient Egypt. has been depicted by Dumichen. In all Egyptian antiquities and remains, this Baboon appears as chief of the Monkey tribe. Hieroglyphs often represent Monkeys, but the adult male of the Hamadryas is the only one that is shown sitting on an altar, adored by men. In some pictures he is shown as a judge of the good and bad actions of mankind; he is holding a pair of trembling scales and attentively looking at them. The deity which he represented occupies a very prominent place in all the pictures. Probably the deification of the Hamadryas had the same origin as that of the Crocodile, namely - fear; for even then there were people who feared their god, rather than loved him.

It is remarkable that the Egyptians were not the only ones to revere this Monkey. All the inhabitants of the steppes of Central Africa, as well as a great many Abyssinians, wear their hair combed and parted like the Hamadryas, and if they did not take the fashion from him, they did from statues of him. The Hamadryas is no longer held in particular esteem throughout those countries. The damage he does is too great to allow of any friendship between him and Man. In Egypt he is no longer found in a wild state. I did not meet the Hamadryas wild on my first African tour, but later I frequently saw him during my short stay in Abyssinia, and can speak about him from personal experience.
Home and The Hamadryas inhabits the whole Characteristics of coast of Abyssinia and of southern the Hamadryas. Nubia. The greater the abundance of plants in the mountains, the more he seems to appreciate the locality. The vicinity of water is a condition essential to the welfare of a troop of these Baboons. Sometimes a few troops descend from the higher mountains to the lower hills of Samchara or the strip of desert on the coast, but the great mass always stays in the high mountains. Every troop has its own territory, one and one-half to two miles in diameter. Small troops are more rarely met with than large ones. Once only did I see a troop of from fifteen to twenty; at all other times they were in flocks numbering at least one hundred and fifty head, and among them were ten to fifteen adult males (real monsters of large size and possessing teeth superior to those of the Leopard, both in point of strength and length); double this number were adult females. The remainder were young and half-grown animals of both sexes. Old males are distinguished by their huge size and a long, cape-like mane. The hair of the mane of a middleaged male that I killed measured eleven inches. The females have shorter hair and are of a darker brown color. The young animals resemble the mother. Every individual hair of the body is alternately greenish brown and yellow in tint, a blending of colors resulting which is hard to describe, but looks very much like dried grass. The sides of the head and the hinder limbs are always lighter, usually merging into ash-gray. The callosities are flaming red and the face devoid of hair and of a dirty fiesh color. The older a male gets, the lighter is his mane. In my opinion there are two species of this Baboon; the smaller kind, inhabiting Asia, provided with a gray mane, and the larger, found in Africa, whose mane remains a greenish blue gray, even in old age. The length of the adult male is about three feet, estimating the tufted tail to be eight or ten inclies.

In the carly morning hours, or when it is raining, one can find an entire troop in its sleeping places, which, in fact, are only holes of a larger or smaller size in inaccessible recesses of rocky walls. They are huddled together, the younger and smaller ones creeping close to their mothers and sometimes also their fathers. In favorable weather the troop leaves these rocks during the forenoon, and roams slowly about pulling out plants, whose roots seem to form their principal food, and rolling every stone from its place, to get at the insects, Worms and Snails that are hidden beneath, and that are esteemed special dainties. As soon as breakfast is over, they all return to the crest of the mountain. The males then sit on stones, grave and dignified, their backs turned to the wind; while the females look after the playing and romping young ones. Late in the afternoon the troop goes to the nearest river or lake to drink. After this they look out for another meal, and then retire to a suitable place for the night. If the locality is especially favorable, one can count on seeing the Baboons return to it every evening, if they are not disturbed in any way. Fields of durra in the vicinity of their abodes are counted as special attractions by them, and have to be carefully guarded if the owners expect a harvest; else the impudent robbers would go day after day, devastate a great deal more than they could consune, and finally ruin the entire field. 
Hamadryas When a troop of these Baboons are Watching for sitting still, they all keep perfectly Enemies. silent until something happens. The approach of a Man or herd of cattle, when perceived by one of them, is noted by a queer sound, which may best be compared to the barking of certain Dogs, and probably is uttered only with a view of attracting the attention of the troop. At the dangerously near approach of Man or of a beast of prey, entirely different and varying sounds are made by the members of the colony. The babel of voices in an excited band of Hamadryas is most fitly compared to the grunting and squeaking of a large number of Pigs. There are also a few deep sounds, reminding one of the roaring of a Leopard, or the low grumbie of an Ox. The Monkeys roar, growl, bark, shriek, grunt and squeal in chorus. All the see a Dog or a Leopard. Then the old males raise their terrible roaring noise, beat the earth with one fore-paw, show their teeth, and with flashing eves gaze down from the rock, ready to rush at the enemy.

Brehm's First The first troop I met was just restExperience with ing from a morning's wanderings. Hamadryas. The Monkeys were sitting on the crest of a mountain, the ascent to which was very steep on both sides. I had seen the large forms of the males at a great distance, but had thought them to be pieces of rock, for these Monkeys, in repose, present an impassive appearance. A repeated bark told me the truth. All the heads turned to look at our party. Only the young ones went on playing, and several females did not immediately give up their occupation, which consisted of carefully looking over the fur of one of the old gentlemen. Probably matters would not have gone any farther, if we had not had two Dogs along, beautiful, slender greyhounds, accustomed to hunt the Hyena and the Wolf. They answered the Monkey-cries by a loud bark, and immediately a commotion ensued among the Baboons. They seemed to know of a better and more secure abode, and slowly filed along the mountain-crest, till they disappeared from view. But at the next bending of the valley we saw the whole troop, all in a row, hanging on to a seemingly vertical wall of rock in a manner which I have been unable to solve to this day. This scene seemed too inviting to be left undisturbed. The pity that stirs the heart of every one who hunts small Monkeys because of their human-like appearance did not trouble us in the slightest, for the Hamadryas look like furious beasts of prey. Unfortunately the rock was too high for our bullets to reach them, but we determined to at least disturb them. The effect
of the first shot was indescribable. A deafening of the first shot was indescribable. A deafening
roaring, howling, barking and shrieking immediately followed; then the entire line began to move, as easily and securely as if the animals were on level ground. We could not understand how they obtained a foothold. But it would seem that a narrow edge of stone is considered safe and comfortable traveling ground by them. We fired about six shots in all; but we were unable to take good aim, because our surprise at the situation had robbed us of our equanimity.

Still our bullets were aimed well enough to increase the excitement of the creatures to a demonstration of terror. It was extremely ludicrous to 
see how, after every shot, the entire troop clung to the rock as if they thought the report alone was enough to precipitate them into the abyss. I believe that none of them was hurt. Still it seemed that fright had deprived them of their customary coolness and presence of mind, and at the next bend of the road we met the troop traversing the valley, trying to gain the opposite heights. A number had already succeeded in crossing, but the main portion were yet behind. Our Dogs were first startled at the spectacle, but then with a joyous bark rushed at the enemy. The scene we now beheld was a rare one. As soon as the Dogs made their attack all the adult males hurried forward, formed a circle around the Dogs, roared and showed their teeth, beat the earth with their fore-paws, and regarded their adversaries with such flashing, furious eyes, that the horrified animals shrank back and tried to gain our protection. We encouraged them to again proceed against the enemy, but when we succeeded in reviv-

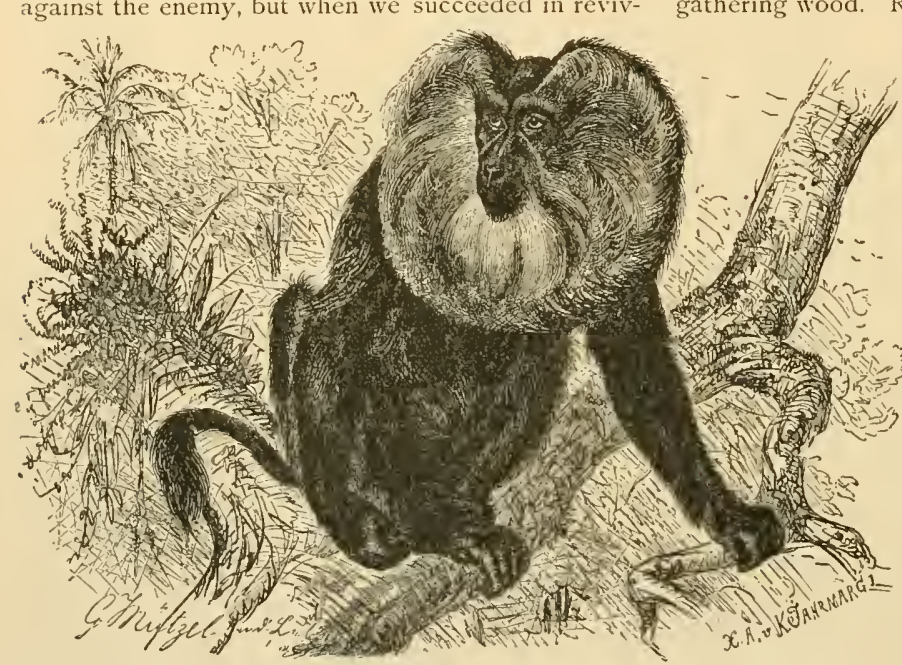

WANDER00.-This strange looking creature, which is very cunning and active. has soft and dull eyes and a long, black muzzle, which peer out from a great ruff, and beard of gray or white color. The body and tail are a deep black. The Wanderoo lives along the Mlabar coast, and has been introduced into Ceylon. It is easily domesticated, but does not long survive a residence in temperate climates. (Cynocephalus silenus.

ing their bravery, the aspect of things had changed, for the greater part of the Baboons had gone. Only a few of them were yet in the valley, and among them a half-grown Hamadryas. With a shriek it fled to the rock, and here our Dogs laid siege to it. IVe flattered ourselves that we would be able to capture the animal, but it was not to be Proudly, slowly and with much dignity, paying not the slightest attention to us, one of the strongest males made his appearance, and, casting looks at the Dogs, the meaning of which these latter were at no loss to understand, he ascended the rock, coaxed the young one to him, and with it made his way back, walking close to the Dogs, whicl were so dumbfounded that they let him completely alone. The courageous deed of the patriarch made such an impression on us that we forbore to hinder his retreat, though we might easily have shot him.

Tenacity, Boldness On other hunts 1 made a closer and Fierceness of acquaintance of the Hamadryas, Hamadryas. and learned of the wonderful tenacity with which they cling to life. If in shoot- ing our bullets failed to take effect in the head or in the heart, they were always lost to us, for however badly wounded they were still strong enough to escape. Small shot had no effect at all; they would simply rub the wounded place with their hands and proceed on their way.

Since I have seen the animals in the wild state, I do not think it at all improbable that they would, in case of danger, attack a Man, unprovided with firearms, as the Arabs and Abyssinians, and several good observers, notably Ruppell and schimper tell us. No experience of my own goes to prove this fact, but we have seen that even from well-armed people the Hamadryas beat a by no means hasty retreat, and which is accomplished under a very formidable showing of teeth and a loud roaring. Schimper told me that the Hamadryas not only attacked but easily killed Man, and that old males were known, without any provocation, to have killed young women gathering wood. Ruppell also say's that this hideous looking Monkey must be counted among the most dangerous enemies of mankind.

The Gelada, In the immediate Giant of the neighborhood of Baboon Family. the Hamadryas, we find the Gelada of the Abyssinians, (Cynocephalus gclada), the giant of the Baboon family, though his discoverer, Ruppell, denies his great size. Schimper, who lived in Abyssinia for over thirty years, and also Heuglin, both agree in telling us that the Gelada sometimes reached a man's height. He is easily distinguished from the Hamadryas at the first glance. The rich fur, longest on the neck and back, forms a cape and is of a blackbrown color, the hair in the face and on the throat being of the same hue; while the mane and the long tuft of the tail are yellowish-brown. There are two triangular places, deroid of hair, on the neck and chin, their points touching thus present the form of an hour-glass; they are framed in gray and white hair. Unlike the Hamadryas the Gelada's callosities are very small, completely separated and of grayish-black hue.

\section{MANDRILLS AND DRILLS.}

Not without cause the most monstrous of all Baboons is separated from the others, for he differs considerably from them. The body has a similar structure, but the head is disproportionately large; the small eyes are placed close together, and are surmounted by projecting ridges; on both sides of the nose is a large, prominent, furrowed, and as it were swollen projection. The limbs are powerful, the tail a short stub, standing upright; the callosities cover the entire buttocks. The fur is peculiar, and the chin is provided, at least in one species, with a pointed, vividly colored beard. Both the Baboons hereafter to be described, are natives of western Africa, and have frequently been brought over living to Europe and taken to America during the last three hundred years. 
The Mandrill, With the right that we call the GueUgfiest of the reza the most beautiful of Monkeys. Monkey Tribe. we may also eatl the Mandrill (Cynoceplatus momom) the ugliest. In mature age he is a hideous beast in every respect, and his moral nature completely harmonizes with his physical characteristics. The body is very strong, bordering on clumsiness, the head is horrid, the teeth are formidable, the fur is rough, the color of the hairless spots vivid and repulsive. Every hair is blaek and olive green, giving the fur on the upper part of the body the appearance of a dark brown tinge, washed over with green; on the breast the hair is yellowish, lower down whitish, on the sides light brown; the beard is of a lemon yellow; the hands and ears are
They are said to live in troops in the mountain forests, partly on rocks, partly in trees, and to often visit and devastate adjoining fields of grain. They are also said to enter the villages in the absence of the Men, and ill-treat the IVomen and Children. The natives fear the Mandrill more than the Lion, never enter into a fight with him, and shun the woods where this Monkey lives, except when a large and well-armed number of them engage in a regular crusade against him.

Fierceness and A young Mandrill is a lovely III-nature of the little ereature; in the common Mandrill. Monkey cage he is the comedian, always ready for merry pranks, alway's in good humor, and in spite of his unlinited impudence by

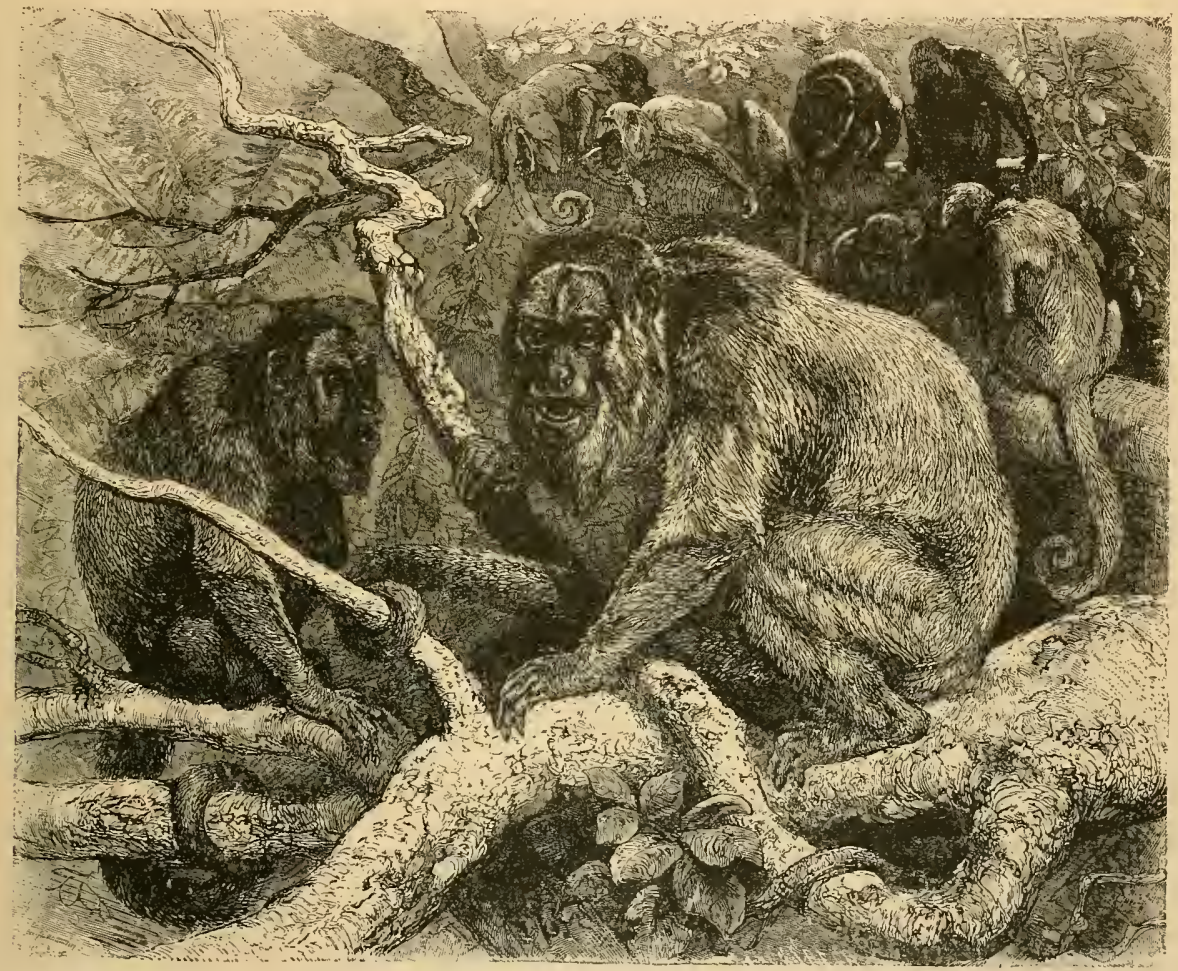

RED HOWLERS. - Like the other members of this numerous family these Honkeys possess extraordinary roices, the great travele Waterton saying of them, "Nothing can sound more dreadful than their nocturnal noises. You would suppose that one-half the wild beasts of the forest were collecting for a work of carnage." "This animal inhabits the tallest trees. The artist has faithfully portayed these interesting creatures in the very act of sending forth their discordant yells, in which they excel the noisiest of the Gibbons. The Red Howler, like its Black cousin, is rather sluggish for a Mlonkey. See page 52. (MIycotes seniculus.)

black, the nose and the immediate surroundings vermilion, the swellings on both its sides a bright blue, while the furrows in them are black. The callosities are blue and red. The usual height attained by males is a little over three feet.

The Drill, Similar to His cousin, the Drill (Cymoccphabut Smaller than lus lcucophatus), is a trifle smaller, the Mandrill. his fur is brown above, whitish below, the beard dull white, the face black, the hands and feet are a copper brown.

It is astonishing that we do not know anything about the life in the wild state of these two Monkeys, specimens of which have so often been captured. Both species are natives of Upper Guinea. no means repulsive. But all this changes very early, much earlier than with the other Baboons, and in a very few years the Mandrill reveals all the repulsiveness of his hideous nature. An English author says that the anger of other Monkeys compared to the rage of the Mandrills is but as a zephyr to a tornado earrying everything before it. His passions know no bounds. He rushes at his enemy, like one possessed, his eyes reflecting a demoniacal rage. One thought has hold of his brain : to tear his opponent to pieces, and he heeds neither whip nor knife. His mode of attack strikes one not as courageous, but as insane. No animal is more dangerous to a keeper than an angry Mandrill. Lions and Tigers 
are as Lambs compared to hin, for they have common sense and adapt themselves to circumstances. The Hamadryas and other Baboons are but timid beginners in wrath, as measured by this ugly brute. Doings of Pechuel-Loesche writes about the ManThree Captive drills that he observed for years in

Mandrills. Chinchocho: "We kept three Mlandrills in our yard, tied with ropes to the poles supporting their house ; they did not attempt to escape, provided they had sufficient exercise. They were true Baboons-cumning, ill-mannered, full of mischief, and well aware that they amused us by their pranks. Yet the character of the three was different. Pavy, a male, was amiable, affectionate and wheedling. Jack, a weak female, was a perfect humorist, and played with everybody but ladies, whom she hated. She was not very affectionate. Isabella was a very strong female, and she was presented to us because her wickedness made her unbearable at the trading post where she formerly lived. She furiously attacked people of every size, color and sex. It took us a long time, and required a great deal of kind treatment to persuade her that at least we Europeans were not her enemies. Her character was utterly spoiled. She accepted everything that pleased her, but was grateful for nothing.

"Pavy and Jack were like good watch-Dogs. They used to sit on the roofs of their high houses, scan the neighborhood, and apprise us of approaching visitors or of any extraordinary occurrence. On our walks we always tried to collect special dainties for our animal pets, such as fruit, sweet plants, leaves, Beetles or Grasshoppers. These two Mandrills, therefore, always watched for us, and greeted our return by crowing and executing the most daring jumps. When we called out to them they tried to surpass themselves. At the same time a Black Monkey would begin his peculiar sermon, and then all the other animals would raise their voices, including a Chimpanzee, whose vocal organs are so dis- agreeable to the ear. Sometimes the din greeting us was positively deafening.

Fondness of "It was new to me that Baboons seMandrills lected inanimate objects for toys and for Toys. took them to bed as children will take their dolls. Isabella put great value on a little tin can, and Pavy on a little piece of wood, that he would play 'toss' and 'cateh' with. Once it flew beyond his reach and Jack caught it. Immediately a fierce enmity sprang up between the two; but as the length of their ropes did not allow of a fight, they had to content themselves with chiding each other and making fearful faces. I returned the piece of wood to Pavy but the animosity continued. Jack had been seized with a passion for my insulated thermometer, and whencver she was let loose, tried to steal it. She evidently liked the lustre of the glass. She was so careful of it, however, that she did not break it, even when she had succeeded in taking it along with her on a walk over roofs and trees, and we had to coax her to give it back."

The Wanderoo, Another Monkey that is sometimes a Handsome counted among the Macaques is the

Monkey. beautiful IVanderoo or Nilbhandar (Cjnocephalus silemus). It has a slim body, a rich beard, enveloping the whole face, and a tufted tail of moderate size. The fur on the upper part of the body is of a lustrous black color; it is brownish-gray on the under part of the body, and the mane is white. The good-natured eyes are brown. This Monkey does not exceed three feet in length. An erroneous opinion as to the native country of this Monkey has prevailed until lately, Ceylon having been considered as its home. According to the latest investigations the animal is a native of Malabar, and is found in troops of from fifteen to twenty, exclusively in the high forests, ranging from the $I_{4}$ th degree of northern latitude to Cape Comorin.

\title{
Etmerican or Jbroad="lltosed Sildonkevs.
}

\author{
SECOND FAMILY: PLATIRRHINI.
}

The difference between the products of the tropics of the Old IVorld and those of South America is, as a rule, marked and striking. Everything in South America combines to produce the impression of fairyland; the rich variety of nature charms us and makes us forget the attractive features of the other half of the globe.

General View This impression of contrast is felt,

of American to a certain degree, when compari-

Monkeys. Son is made between the Monkeys of the Old and New IVorlds. The American or Broad-nosed Monkeys (Platymhini) are peculiar animals, but they are not beautiful; at least, not the majority of them. They are duller and more indolent than the Old World Monkeys, and also much more harmless and good-natured; which means that they are not really Monkeys. WVe are too nucl accustomed to look for a merry, mischievous disposition in a Monkey, and to think of Monkey nature as bold, impudent and good-for-nothing.

The structure of body, limbs and teeth in the American Monkeys differs from that of their Eastern cousins. Their body and limbs are as a rule slim. The tail is never lacking, and in only a few rare instances stunted; generally it is used as a fifth hand, as the end may be rolled up by a few strong muscles and it may therefore be used for grasping and holding. The thumb in the hands cannot be opposed to the fingers to the same degree as in the feet. Instead of thirty-two tecth, there are thirty-six, each side being furnished with six molars. Cheekpouches and callosities are never found. The partition between the nostrils is broad. No single nember of this family attains a large Monkey-size 
and none of then has a projecting muzzle. Their coloring is manifold, but never so bright and vivid as that of some of the Old World Monkeys.

Where Monkeys Their native country is South AmerLive in ica, Central America and Mexico.

America. To the north they are bounded by about the twenty-ninth degree of north latitude (as far north as Chihuahua, in Mexico), to the west by the Cordilleras, Sierra Madre and Andes Mountains, to the east by the Atlantic Ocean and to the south by the twenty-eighth degree of south latitude (line of Catamaica, in the Argentine Republic).

All the Broad-nosed Monkeys are essentially treeclimbers, and the virgin forests are therefore mainly their home. Marshy regions are preferred by them to dry localities. They leave the trees only in case of necessity, for they do not even drink like other animals; they climb to the water on boughs and branches overhanging it and drink without leaving them. It is quite possible that some of these Monkeys travel distances of hundreds of miles, without touching the ground. The trees supply them with everything they need to eat, their food being mainly vegetable, though they also eat insects, Spiders, eggs, young birds and honey. Few of them are guilty of devastating plantations.

Most species are active in the daytime, some come out in the gloaming, and some are awake only in the night. They are lively and active, with the exception of several exceedingly lazy species, representing, as it were, the American counterparts of the Orang-utans of the Old World.

Great Value They are all of the excellent Monkey's Tail. climbers and know how to make very good use of their tails. This tail is an indispensable all-in-all to some of them, their clumsiness being such that they would be helpless without its useful aid. In nearly every posture, even in deepest slumber, the Monkey twines his tail round something, even though it be only one of his own limbs. The muscular power of the tail exceeds that of the limbs, and the discriminating sense of touch with which the tail-end is endowed, enables them to put this remarkable gift of nature to the most varied uses and often serves them as a substitute for the greater quickness of mind and body possessed by their trans-Atlantic cousins. Yet the real tree-climbing Monkeys of the Old World are decidedly their superiors in climbing and jumping abilities. The walk of the American Monkeys is always clumsy and tottering and is performed on all fours.
The maternal instinct in the females of these species is as sublime as that of the Old World Monkeys. They have one and sometimes two young ones at a birth, and love, pet and protect their children with a solicitude and tenderness which cannot fail to win for then our admiration.

American The American Monkey's do very little, Monkeys Harm- if any, damage to Man. And the vast, less to Man. productive forests that form their home provide for them so generously that they stand in no need of help from him. A few of the American species sometimes make raids on plantations, but the little they eat and spoil is remarkably small in proportion to the robberies of the Old World Monkeys. They are hunted for their flesh and their fur. Many a traveler has had to subsist on Monkey

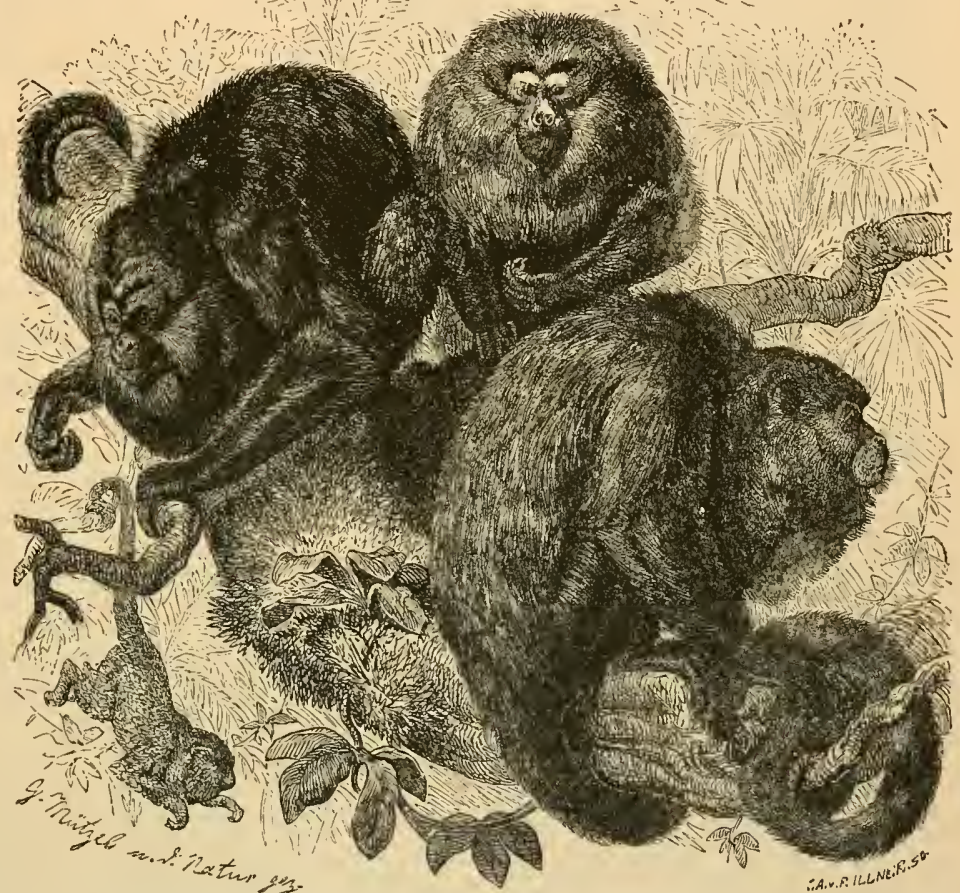

BLACK HOWLER MONKEYS. - Found in Guatemala and have prehensile tails but no cheek-pouches or callosities, as the Old World Monkeys. The Black Howlers are one of ten species, which extend from Guatemala to Paraguay, and this species is fonnd in the mountains as high as six thousand feet. Like all of the Howlers it has an unearthly yell, which can be heard at a distance of two miles, the great sounds being increased by a peculiar for-
mation of the hyoid bone of the throat. They are the largest of the New IVorld Monkeys, and the lndians are very roasts for weeks at a time, and did not find them bad fare. To the natives the Monkey is a very important animal, for its meat forms a great part of their food. They use bows and arrows on their Monkey hunts, usually steeping the arrow-heads in very strong poison. When a Monkey has been shot by them and feels that he is wounded he tries to pull the arrow out, but as the cunning natives take the precaution to cut the arrow-stem half-way through, beforc using it, the head usually breaks off in the wound.

How Indians The Indians also use bows and arrows Capture and to hunt Monkeys that they wish to Tame Monkeys. keep captive. Schomburgk tells us that the Areliunas, when they wish to tame an old, 
sulky Monkey, steep the arrow in weak Urari poison. When he falls down unconscious from the

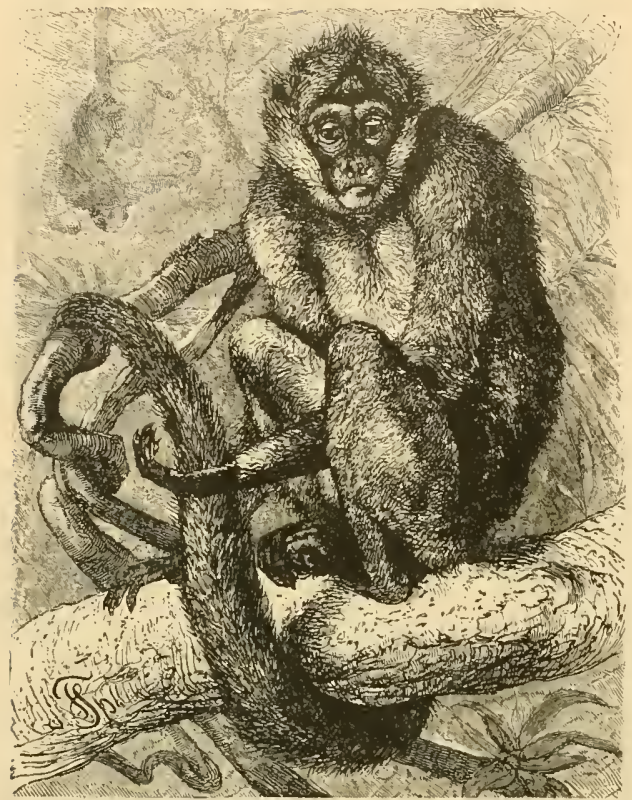

MIRIKI SPIDER MONKEY It is only in South America that Monkers are found objects about which they coil. The Spider Monkeys are especially gifted in this way, a particularly interesting family of these being the Miriki. They live in Southeastern Brazil, have fur of a woolly texture, rising to a tuft on the end and a beard surrounds the tace. They have very long tails, and one of their ways of using them is well brought to vew by the Nonkey in the of their ways of using them is well brought to view
background of this picture. (Atelos hypoxanthzes.)

effect of the poison they suck the wound: then they bury him up to the neck, and make him swallow some earth containing saltpetre or some juice of the sugar-cane. When the Monkey which has been sickened by this treatment begins to regain consciousness, they dig him out and swathe him in bandages In these bandages he is kept for several days, and the only beverage he receives is sugar-cane juice, while all his food is seasoned with saltpeter and plenty of red pepper. If this treatment does not tame him, he is smoked for some time-"like a ham." Soon his rage begins to abate, his countenance becomes placid and he is given milder treatment. The bandages are taken away and after such a cure the most aggressive Monkey forgets that he ever lived wild in a forest.

Few American Monkey h they may be secn in any museum or men- agerie in the United States. There are some rery fine specimens in Lincoln Park, Chicago, and in Central Park, New York City. The Capuchins are the species most frequently seen in the European animal markets; the Spider Monkeys are rarer, and the Saimaris one hardly ever meets. Very few lising Howlers have been brought to Europe.

The Broad-nosed or Amcrican Monkeys are divided into two groups: those whose tails are prehensile, the Cebidie, and those whose tails are not prehensile, the Pithecidre.

\section{THE HOWLERS.}

Chief among the Cebidæe is the Howler (Mycetes). The head of this animal is high and of pyramidal shape and the muzzle projects forward. The thumbs are thin. The chin is adorned with a beard. A remarkable peculiarity of the Howlers is their hyoid bone, or the bone in the neck from which the muscles of the tongue arise. Alexander von Humboldt was the first naturalist to dissect the Howler, and he says :

Where Howlers "The other American Monkeys, get their whose voice is piping like a Spar-

Strong Voice. row's, have a plain, thin hyoid bone ; but in this species the tongue rests on an extensive bony drum. Their upper larynx has six pockets which reflect the voice; two of these pockets are shaped like a pigeon's nest and resemble a bird's larynx. The plaintive sound peculiar to the Howlers is produced by the air forcibly streaming into the bony drum. If one considers the size of this drum, he is no longer astonished at the strength of the

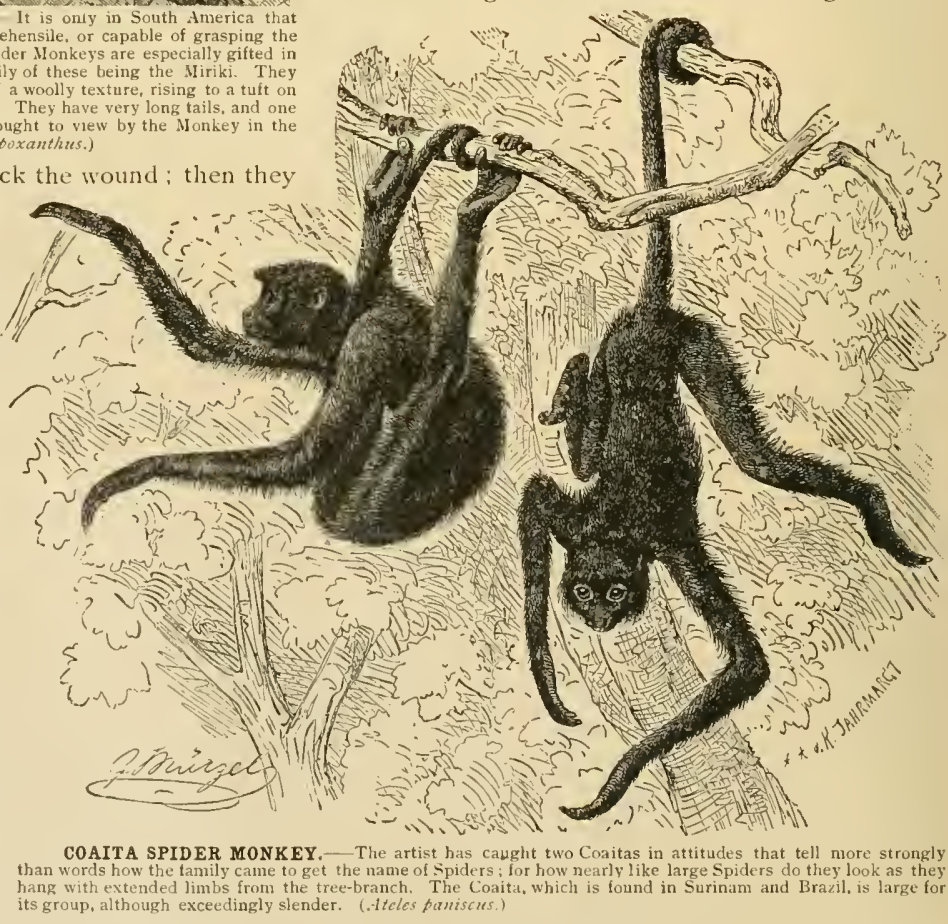
taken to Europe

COAITA SPIDER MONKEY. - The artist has caught two Coaitas in attitudes that tell more strongly than words how the family came to get the name of Spiders; for how nearly like large Spiders do they look as they hang with extended limbs from the tree-branch. The Coaita, which is found in Surinam and Brazil, is large for its group, although exceedingly slender. (.1teles paniscus.)

voices of these animals, which have earned for them a perfect right to the name of IIowlers. 
The tail of the Howler is very long; its end is bare on the under side, abundantly supplied with nerves and blood vessels of very strong muscular power, and therefore perfectly adapted to prehensile use.

Where the The Howlers are widely spread over Howler is all parts of South America. Thick,

Found. damp, virgin forests are their preferred haunts; they are only found in the prairies where, in close proximity to water, isolated groups of trees have in course of time developed into small woods. They shun dry parts of the country, but do not avoid the cooler regions if food and water are plentiful.

The Aluate or Red Howler (Mycetes scniculus), has a fur of auburn color, merging into golden yellow on the back; the hair is sloort and somewhat stiff. The average length of the male Red Howier is about four feet two inclies, counting the tail as from twenty-five to thirty inches. The female is smaller and darker. This family of Monkeys is found in nearly all the eastern portion of South America.

The Caraya or Black Howler (Ny'cetes niger), has much longer hair, of a uniform black color, reddish on the sides, and the under part of the body assuming a yellowish tinge, in the female. Its extreme length is four feet, one-half of which belongs to the tail. It inhabits Paraguay.

Travelers' The Howler Accounts of Monkey is an Howlers. animal that, since the earliest historical time, has been partially known to travelers, and many fictions have been circulated concerning its liabits and characteristics. Some of these are to this day believed by the unobserving whites and the Indians resident in the country inhabited by this creature; but we pay no attention to these doubtful stories, and recount only what is proven.

Schomburgk says: "For some time after my arrival I had, at sunset and sunrise, heard the fearful howling of the Monkeys in the neighboring virgin forest, but had never succeeded in seeing them on my walks. One morning 1 set out after breakfast, provided with my gun, and a dismal howl just then resounding made me eager to kill some of these noisy disturbers. I hurried on through thick and thin, and after prolonged efforts succeeded in approaching a whole troop, unperceived. There they were, right before me, in a high tree, and the concert they gave might have led people to believe that all the animals in the forest were engaged in deadly combat. Yet I cannot deny that there was some kind of harmony in the uproar, for sometimes the whole troop would pause, and then one of the singers would begin, and the dreadful howling would start afresh. The bony drum on the hyoid bone, which gives their voices such exceeding strength, could be seen moving up and down. For a few moments the sounds would resemble the grunting of a Pig; the next instant they would simulate the roar of the Jaguar rushing upon his prey, and then again came sounds like the deep and terrible snarl of the same animal, when, besieged from all sides, it recognizes its dangerous position. The dismal troop also had its ludicrous features, and the most confirmed misanthrope would have smiled if he had seen the grave and serious faces of the long-bearded vocalists. I had been toid that every band had its leader, which differed from all the deep basso voices, not only in his shrill tenor

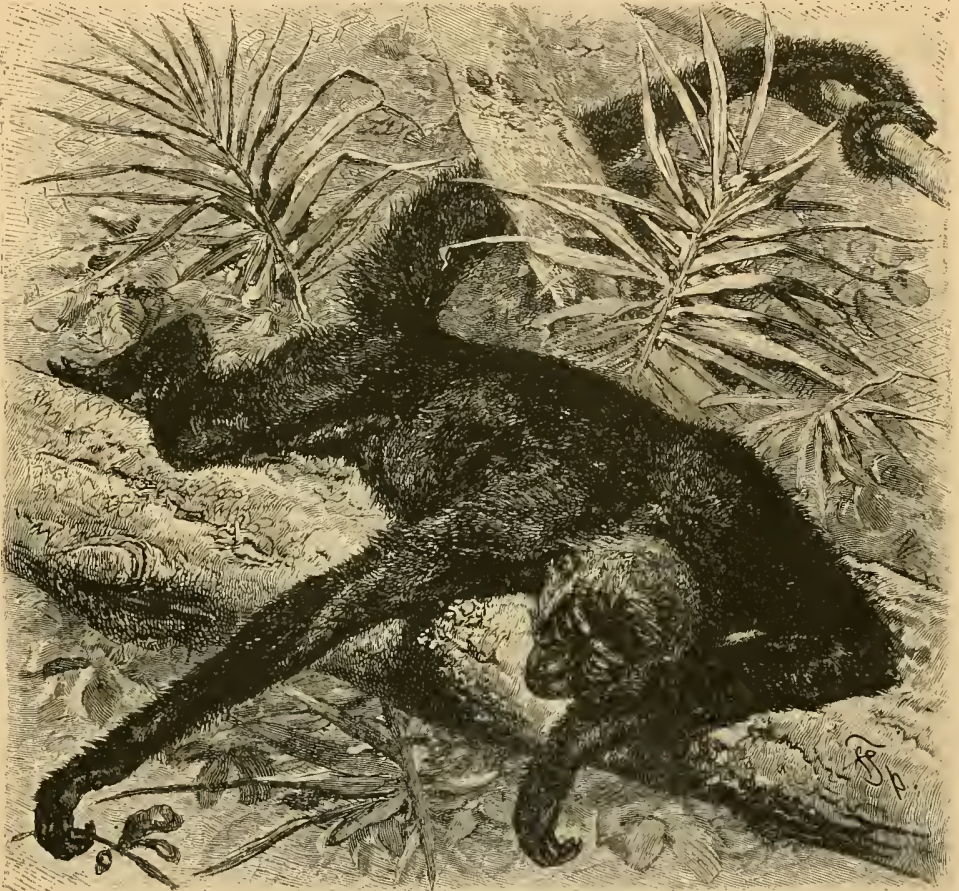

CHAMECK SPIDER MONKEY, - Belongs to the large family of Spider or Thumbless Monkeys, correponding to the Colobus of Africa, but the Chameck has the thumb slightly projecting, consisting of but a 作 ctylus.)

but also because of his slim figure. I can corroborate the first statement, but for a slim, graceful figure I looked in vain. On an adjoining tree I saw two silent Monkeys, which I took to be sentinels; but they certainly were bad ones, for I stood in the immediate neighborhood unobserved."

This description shows us sufficiently that the Howlers are highly peculiar animals. One can say without exaggeration that their whole life is a chain of peculiarities and richly repays observation; on the other hand it must be acknowledged that the Indians are pardonable in regarding the Howlers as melancholy and uninteresting, and as deserving of contempt. It is not even difficult to account for the calumnies that have been uttered against them when 
one realizes that the poor animals, neither in the wild state nor in captivity, show any graceful feature or anything to enliven the monotony of their lives.

General During the day the highest trees in the

Traits of forests are the favorite haunts of the

Howlers. Howlers; in the gloaming they retire to the lower trees, whose foliage is made thicker by creepers, and here they sleep. Slowly they climb from branch to branch, selecting leaves and buds,

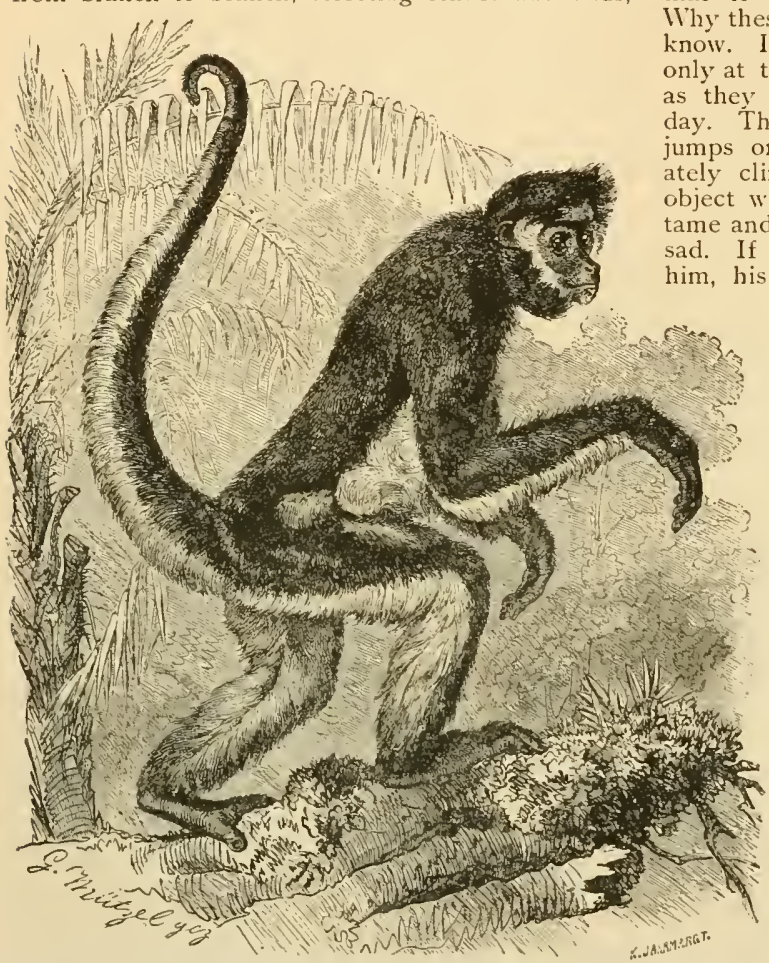

GOLD-FACED MONKEY. - This is a singular appearing animal, with its projecting crest of hair, its long-harred tail and strikingly marked coloring. It has a wide range in constantly using its prehensile tail in traveling. (Atcles bartlettii.)

slowly they pluck them and slowly they eat. W'hen they are satisfied, they crouch down on a bough, and sit there without moving, looking very much like old Men asleep; or they stretch themselves at full length on a bough, let their limbs hang down rigidly from both sides and only hold on to the tree with their tails. What one does, the other slowly and unconsciously does, also.

Kappler's Account Kappler, in speaking of the Red of the Howlers in Guiana, says: "They live

Red Howler. in small troops, composed of about ten individuals, always comprising one old male, who occupies a higher seat in the trees and conducts the concerts. Whenever I had the opportunity of observing the Howlers closely, an old male was sitting high up in the tree, holding himself on the tree with his fore-paws and tail, while other males, females and young ones, were grouped lower down in different positions. The old male would begin with a "Rochu," repeated five or six times and running into a roar, which would be taken up by all the others; and so loud were the cries that one was nearly deafened by them. The noise could be heard at a distance of two miles. The roaring of the Tigers which so terrified Pichegru and his friends on their flight from Cayenne to Surinam, probably was nothing but a concert given by Howlers, for the uproar they make may well frighten any one who hears it for the first time and does not know that it is created by these harmless Monkeys. Why these animals should howl so I really do not know. In Guiana it is believed that they howl $y$ at the rise of the tide; but this is not correct, will sometimes howl at any hour of the The Howler is lazy and melancholy; he ately climbs about, always holding fast to some with his tail. Captured young, he becomes ame and plays with Cats and Dogs, but is usually . If a person he has taken a fancy to leaves cries become a nuisance. Howlers emit a peculiar, ill-smelling odor, by which one traveling through the forests they inhabit can easily detect their proximity. The females never give birth to more than one young one at a time. Their chief enemy is the Eagle.

How the

Howler Acts

When Howlers are shot at they make their escape as quickly as possible. It is anusing sight when, in its fright, a halfgrown young one jumps on the back of an old male in order to escape with greater celerity, but is brought down by a sharp box on his ears, and thus taught that the service he covets does not belong to the duties of a father of a family.

In a great part of Paraguay the Howlers are hunted by the Indians; their fur is popular and their meat is a favorite food with the natives.

Howlers

Howlers are seldom tamed,

in and their domestication is

Captivity. very difficult. Rengger saw only two in captivity that were over a year old. They were fed leaves and preferred them to any other kind of food. They seemed very dull animals, paid no more attention to their keeper than to anybody else, and could not be taught to do anything. Wied relates of other tame Howlers, that they became so attached to their owner that they always cried when he left them but for a moment. Yet their laziness, sadness and disagreeable voice made them repulsive, even to him.

\section{THE SPIDER MONKEYS.}

An exceedingly slim body and long, thin, sprawling limbs distinguish the Spider Monkeys (Attes). The naturalist who first called them by this title found a most appropriate name, and one which naturally comes to every one who sees them. The head of the Spider Monkey is small, the face beardless and the thumb on the fore-paw lacking or rudimentary.

They are natives of South America, ranging to the twenty-fifth degree of southern latitude (as far south as Ascencion ). They live only on the higher branches of the tallest trees.

Spider Monkeys The lives of the different species of in Their Spider Monkeys seem to be very

Native Forests. similar, and exceedingly monotonous. Tschudi, agreeing with many other observers, 
says: "They live in troops of ten or twelve; sometimes they are found in couples, and not infrequently singly. The presence of troops of these Monkeys is easily detccted by the noise they make in bending branches when they are climbing. When one of them is wounded he gives a loud yell and tries to escape. When mothers are shot the very young ones do not leave them, but remain with them even after they are quite dead and stiff, persistently clinging to and petting the lifeless bodies. Spider Monkey's are easily tamed, are good-natured and affectionate, but do not bear captivity well. They are subject to skin diseases and diarrhea, and when sick are extremely miserable." The different species are very similas to each other.

Various Kinds There are two species which of Spider are found quite frequently Monkeys. in Guiana; the Coaita (Ateles paniscus), and the Marimonda or Aru (Ateles belacbuth). The first named is one of the largest of his tribe: his length is four feet, two inches, the tail taking more than half of this length ; and his shoulder height is about seventeen inches. The fur is harsh, longest on the sides, and forms a crest on the forehead, and is of a deep black. Only the face shows a reddisl tinge. Bright brown eyes give the goodnatured face a sympathetic look.

The only representative of the Spider Monkeys in Quito, Panama and Peru is the Chameck (Ateles pentadactylus). His fur is long and deep black in color and his thumb rudimental.

The Miriki (Atile's luypoxantluus), best described by Max, prince of IVied, inhabits Brazil. He is about four feet, four inches long, with a strong body, a small head, long limbs and thick, nearly woolly fur. As a rule the fur is of a dull yellow color, the inner sides of the limbs being lighter. The face, devoid of fur, is brown in youth and dark gray in old age. The thumb on the fore-paw consists of a short stub, devoid of nail.

The best-looking of all Spider Monkeys probably is the Gold-faced Monkey, which was discovered in Eastern Peru by Bartlett, Jr., and called Ateles Bartlettii in his honor. The long, soft, thick fur is deep black on the upper and outer parts of the body; the hands and the parts of the face that are not covered with hair are brownblack. The forehead shows a band of golden yellow, the whiskers are whitish and the lower part of the body and the inner side of the limbs are brownish yellow. The size of this magnificent creature is about the same as that of the other Monkeys of this tribe.

Life of the The life of the Spider Spider Monkeys Monkeys has been deDescribed. scribed by $\mathrm{Humbold}$, Prince Max von Wied and Schomburgk. In Guiana they are found only in the depth of the forests and never at a greater elevation than 1,600 feet ; and they shun cold forests on the heights. As a rule they are found in troops of six, more rarely in couples or singly, and still more seldom in greater numbers. Each of these troops quietly goes on its way without heeding other harmless creatures. In comparison with the miserable hobbling of the Howlers their movements may be called quick. The considerable length of the limbs is conducive to agility in climbing and jumping. Their arms are so long and, therefore, admit of such rapid progression, that the hunter must move quickly if he wants to keep up with them. They are quite agile when in the tree-tops. They climb well and at times take small leaps, but in every movement they throw their long limbs about in the queerest sort of manner. The tail is usually sent out first, to feel for a place of support, before the Monkey decides to leave the branch upon which he is sitting. Sometimes one finds whole troops hanging to branches by their tails

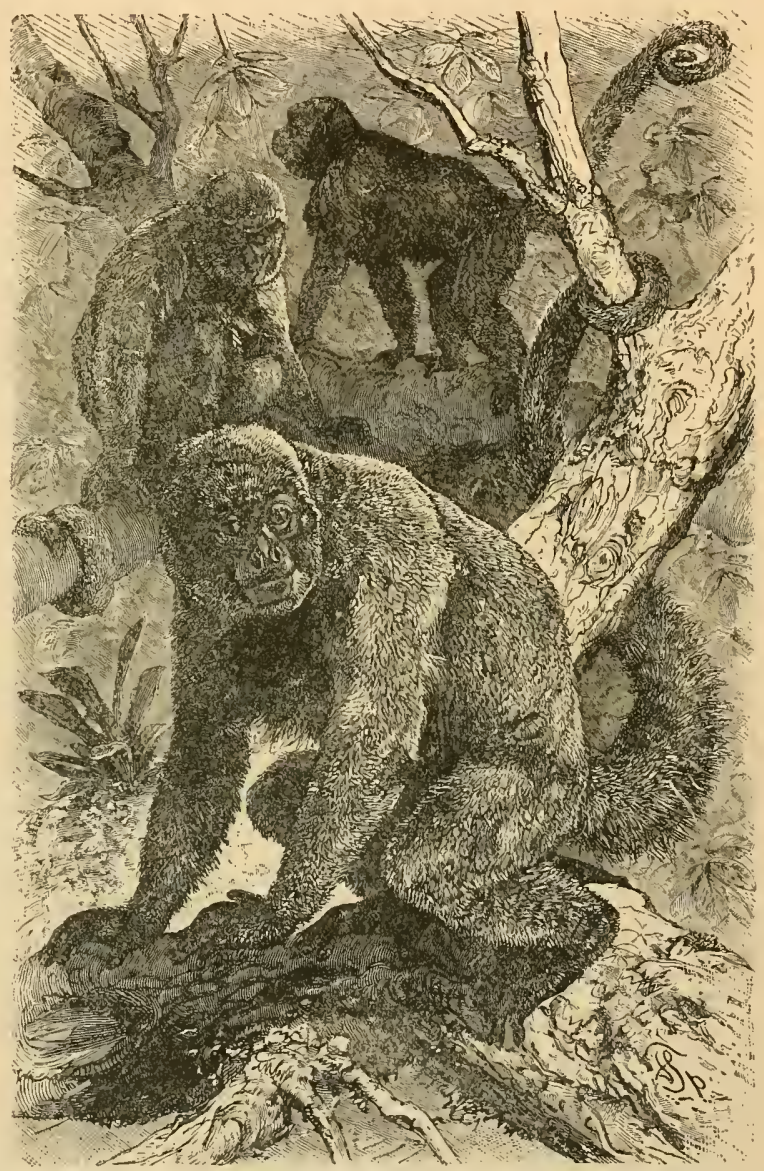

HUMBOLDT'S LAGOTHRIX MONKEY. - Was discovered by Humboldt up the viver Urinoco. It has fur like a hare, hence its name of Lagothrix, and its face is reniarkriver Urinoco. It has fur like a hare, hence its name of Lagothrix, and its face is reniarkLagothrix inhabits the dense forests, feeding on fruits and buds, chiefly, and lives in othrix inhabits the dense fore

only and forming the most striking groups. Not infrequently the whole family lazily lies on boughs, basking in the sun, with their hands on their backs and their eyes turned upwards. On the ground they hobble along so very heavily that it makes one feel quite nervous to look at them. The long tail, which they move despairingly to and fro in the endeavor 
to balance themselves, increases the ungainliness of their movements. European observers have never seen Spider Monkeys on the ground, and Prince Wied says that when in good health they never come to the ground, except when they cannot get to the water on low branches. They are hunted very much, for the Portuguese utilize their fur and the Indians prefer their meat to that of any other game.

These animals are seldom seen in captivity. One cannot help liking them, for they show neither mischicvousness nor malice, and their anger, though quickly aroused, is soon spent. They are amusing on account of their queer attitudes and contortions. They are very susceptible to kind treatment and acknowledge it by caresses.

\section{THE CAPUCHINS.}

The Capuchins ( Ccbus) differ from the American Monkeys described in the preccding pages in having a tail which is completely covered with hair, and is not capable of grasping anything, or, strictly speaking, is not prehensile, although it may be curled around a branch.

While the Monkey tribes we have just considered are rarely met with in the zoological gardens in Europe, a Capuchin is found in nearly every one of them. The arms of these creatures are of moderate size and the hands are always provided with five fingers. A more or less developed beard adorns the face and the fur is short and thick.

Capuchins the The Capuchins are sometimes Liveliest of

American Monkeys. They much rescmble those merry creatures, though more in their behavior than their physical characteristics. They are real Monkeys, that is, they are lively, docile, mischievous, curious and capricious animals. This is why they are so much more frequently kept as pets, and tamed ones so often taken to Europe. They also bear the name of Weeper Monkeys, and are indebted for it to their gentle, whining voice. Yet this voice is only heard when they are in good humor. The slightest excitement makes them utter abominable shrieks. They live exclusively in trees and are completely at home there. They inhabit all the larger forest regions of the southern portions of South America in rather numerous troops, often mingling with kindred tribes.

In captivity the Capuchins show all the qualities of the Guenons, besides several peculiar to themselves only. Notwithstanding their uncleanliness, extraordinary even among Monkeys, they are great favorites with the Indians and are frequently tamed by them. Like the Baboons, they are fond of narcotics and spirits. Schomburgk says that when one blows tobacco-smoke into a Capuchin's face, he rapturously closes his eyes and rubs his whole body with satisfaction. Tea, coffee, whisky and other stimulating drinks produce a similar effect on him.

The Cai, The best known of all the Capuchins Its Home probably is the Cai or Sai (Cibus and Habits. capucimus). Cai, in the language of the natives, means "dweller of the woods." The Cai belongs to the largest kinds of Capuchins and attains a length of twenty inches. In earliest youth he is distinguished by a wrinkled, flesh-colored forehead, devoid of hair. His coloring is a dark or light brown; the hairy temples, the whiskers, throat and breast, and the upper limbs are light brown. He is a native of Southern Brazil, and is widely spread from Bahia to Colombia. He prefers forests with- out underbrush, and spends the greater part of his life on trees, coming to the ground only to drink or to visit maize-fields. He has no permanent home. In the day-time he roams from tree to tree, at night he sleeps on an embranchment. Usually he is found in families of from five to ten, the females outnumbering the males. A solitary old male is sometimes met with. It is very difficult to study this animal in its wild state, as it is very shy. Rengger say's that he was only able to observe them a few times by chance. Once his attention was aroused by a few agreeable, flute-like sounds. I Ie looked up and saw, approaching him, an old male, followed by twelve or thirteen other Monkeys of both sexes. Three of the females were carrying young ones, either on their backs or under their arms. One of the Monkeys suddenly caught sight of an orange tree, bearing ripe fruit, and quickly uttered a few peculiar sounds. In a few moments the entire troop was gathered around the tree, plucking and eating so rapidly that the tree was soon bare of fruit. Then the stronger Monkeys tried to rob the weaker ones of their share of the booty, vigorously pulling their hair, the assailants making wry faces and showing their teeth in a spiteful way during the contention. Several of the party busily searched a dead part of the tree, breaking off the bark and eating the insects hidden beneath it. When they liad had enough to eat they laid down on a horizontal branch, in the position assumed by the Howlers, as described on a preceding page, and rested. The young ones played around, and showed themselves quite agile. They swung back and forth by their tails and climbed up on them as on ropes.

The young Cai is often caught and tamed. When older it cannot get used to captivity, but becomes mopish, refuses food, and usually dies in a few wceks. On the other hand, while quite young it will soon forget its freedom, become attached to people, and like many otlier Monkeys will partake of their food and drink. Of the senses of this animal, that of feeling is most acute: the others are dull. It is shortsighted and cannot see at all by night. It does not hear well, and for this reason can be easily surprised. The sense of smell is still more defective, and often deludes it into attempting to eat what its taste tells it is not fit for food.

Expressive The cry of the Cai changes according

Cries of the to its emotions. Most frequently it utcai. ters a flute-like sound, which seems to denote weariness. If it desires anything it groans; wonder and embarrassment are expressed by a halfwhistling note; when angry it cries in a deep, rough voice: "hee! hee!" When in fear or in pain it shrieks; when pleased it giggles.

It not infrequently happens that Capuchins give birth to young ones in captivity, and then their care of them seems still more tender than when in the wild state. The mother plays with her child all day, allow's nobody to touch it, show's it only to people of whom she is fond, and courageously defends it from everybody else.

The Cai is very sensitive to cold and damp and will never go into the water of its own accord. In captivity it is subject to many diseases, especially colds in the head and coughs, and it often suffers from consumption. According to Rengger, it attains the age of about fifteen years in the wild state.

The Cai The intelligence of the Cai is worthy of easily notice. From the very first few days Domesticated. of its captivity it learns to know its master and keeper, looks to him for food, warmth, 
protection and help and places implicit trust in him. It is pleased when the keeper plays with it, forgives him for teasing it, and when it has not seen him for a while, shows great pleasure at his return. It gets to be so devoted to its keeper that it entirely forgets its past freedom and becomes almost wholly a domestic animal. It not only becomes attached to people, but alsu to the domestic animals with. which it is brought up. It is no uncommon thing in Paraguay to rear the Cai in companionship with a Dog, which it utilizes as a Horse. When they are separated, it screams ; at the reappearance of the Dog it overwhelms it with caresses. Its love is so great that it is even capable of self-sacrifice, for if its Dog friend becomes engaged in a fight the Cai helps it with great zeal.

The Cai is entirely different when it is ill-treated. When it thinks itself strong enough, it opposes force even tries to make others give in to it, either by caresses or by threats. This retards its learning very much, for it acquires only so much as it deems profitable to itself, such as opening boxes, searching its master's pockets, etc.

The Apella The Apella or Brown Capuchin (Cibus or Brown apella) is a native of Guiana. Its colCapuchin. oring varies so much that it is hard to describe. The fur is glossy and some hairs stand straight up over the forehead and on both sides of the head, so as to form a crest. The face and throat are lighter than the body, while the back, tail and legs merge into black. The size of this Monkey is about the same as that of the Cai.

Schomburgk describes the life of the Apella in the wild state at greater length than other naturalists.

"Closely concealed behind a tree," he relates, "we awaited the troop of Monkeys. A vanguard

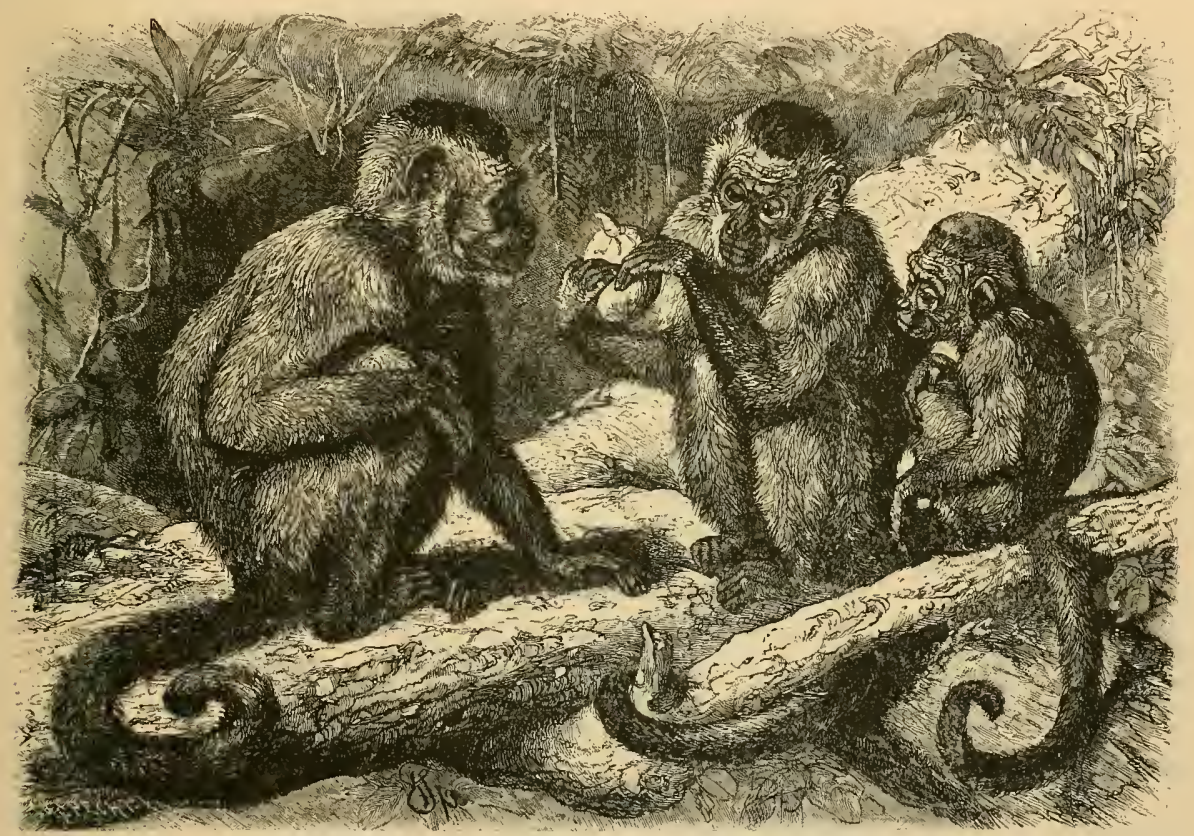

CAI WEEPER (CAPUCHIN) MONKEYS. - The artist presents a family of Cai Capuchins-father, mother and child-as seen in the open woods of Brazil and Colombia. The sorrowful expression of their faces is clearly shown. "The Weepers" live altogether in the trees, leaving them only for the purpose of obtaining water or to raid grain fields. They feed upon fruits, vegetables and insects. They are very timin but are frequently captured and are often seen in zoological gardens and museums of the United States. (Cebus capucinus.)

to force, and tries to bite those who offer it insult. If it fears its opponent, it resorts to dissimulation, and takes revenge as soon as the intended victim is off its guard.

The Cai is very fond of good things to eat, and soon becomes an adept at stealing. When caught in the act of theft it cries out with fear, before it is even touched; but if not detected, it looks very innocent and unconcerned. Small articles are hidden in the mouth, when it is disturbed, and are afterwards eaten at leisure. Its covetousness is very great. What it once gets, it does not give up, except to its master, when it happens to like him very much. Besides these qualities, it possesses a high degree of curiosity and destructiveness.

The Cai is very independent and subjects itself to a higher will than its own with great reluctance. It came first, then followed the main body, and a quarter of an hour later the rearguard came into view. I regret to say that I precipitated this latter into disorderly flight by bursting into a laugh at their peculiar antics. The weaker ones complained and whistled, and cast angry glances at the stronger, which bit and cuffed them when they were in their way. The young ones seemed perfectly glued to the backs of their mothers, and made the most precociously wise little faces imaginable, while the elder ones searched every leaf and every little crevice, on their way, for insects, with the utmost gravity. From four to five hundred Monkeys might have hurried on through the foliage above us (they travel from tree to tree and do not seem to know any other mode of progression), and they made such ludicrous faces that $I$ could not restrain myself and laughed 
heartily. The Monkeys in the trees immediately over us stopped for a moment as if struck by lightning; then they gave a shriek, which was re-echoed from all sides, and redoubling their speed the troop disappeared from view with a few mighty jumps."

The Apella as The Apella is often shipped to
$\begin{gathered}\text { Organ-Grinder's } \\ \text { Assistant. }\end{gathered}$
is a familiar figure in zoological gardens. Organ-grinders make use of this Monkey, as well as of the Guenon, to move people's hearts and purses. While some once popular tune is being ground out of the none too melodious instrument the little beggar, loosed from his leading-cord, clambers up door-steps, or climbs with wonderful agility to the window-sills of adjacent houses to peer through the panes. Some child is sure to see him, and then a gleeful time ensues both for the child and the

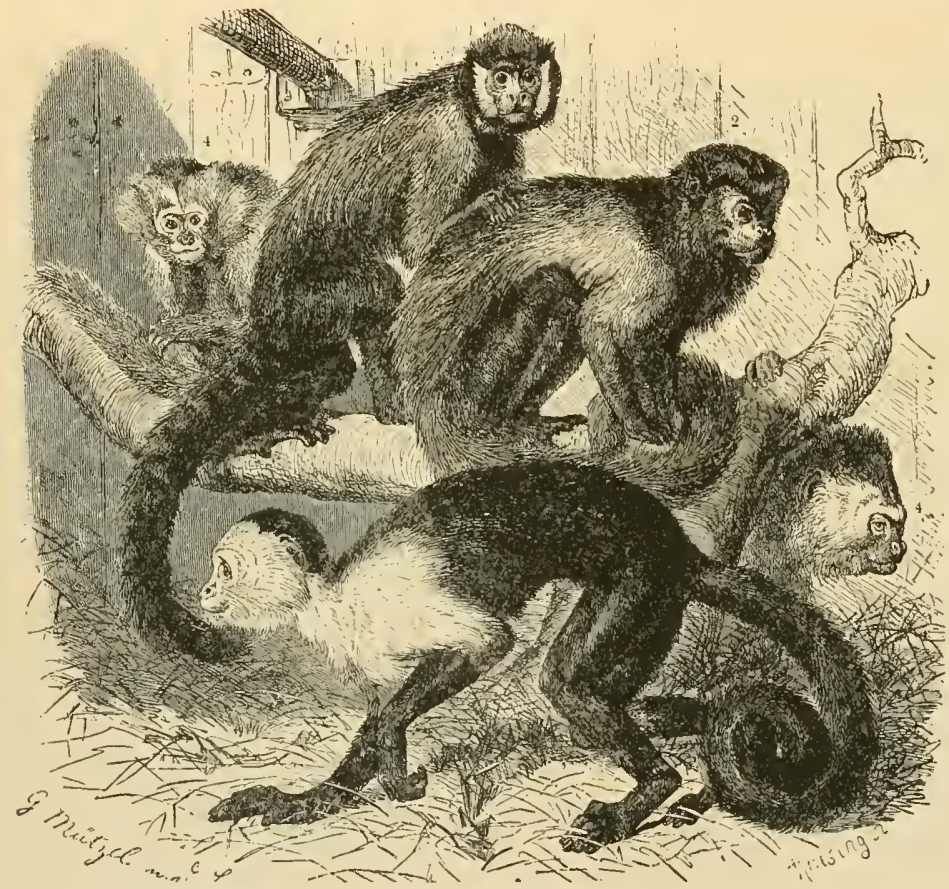

A GROUP OF CAPUCHINS.- - The artist here presents four of the eighteen species of Capuchin Mlonkeys, which differ chiefly in their coloring. These Monkeys are eagerly hunted in many parts of South America for their flesh. (1. White-Bearded Capuchin-Ccbus leucogenys, 2, Apella, or Brown Capuchin-Cebus apclia. 3. White-Faced Capuchin-Cebus hypolencus. 4. Green Capuchin-Cebus oliz'accus.)

The Pithecia have a short, stout frame, and the elumsiness of their appearance is increased by their long, loose hair, and their bushy tail, the hair covering of which is usually longest at the tip. The hair on their head shows a decided parting, and the chin and cheeks are covered with a full beard.

There are but few families in this group of Monkeys, and they are natives of the northern part of South America. They inhabit high, dry forests that are free from underbrush, and keep aloof from other Monkeys. Tschudi tells us that "their activity begins after sunset and lasts till dawn; during the day they sleep, and are hard to hunt, as they do not betray themselves by any noise. They are easily tanied, but stay morose and mopish in captivity, and are very lazy when awake in the daytime." Sehomburgk says that "wherever the foliage on the banks of the river was thick, troops of Monkeys gathered on the branches, and the Pithecia seemed the most numerous. Their long hair, beautifully parted, their magnificent be a rds and whiskers, and their bushy tails, gave the clever-looking animals a prepossessing but extremely ludicrous aspect.

Description The most comof the mon group of cuxio. this tribe inhabits the extensive forests on the upper Maranon and Orinoco rivers. The Indians call it Cuxio (Pithecia satanus), and it is twenty inches long, the tail being of equal length. The head is perfectly round and covered with a kind of a cap, consisting of not very long, thick hair, radiating from a common center, and parted in front. Kappler says that "no dandy could be more careful of his hair and beard than this beautiful animal." The upper part of his body is thickly covered with hair, while in the lower part it is more scanty. The general color of the aduit Nonkeys is black, speckled with rust-colored hairs; the young are grayish-brown. He lives in small families, consisting of from four to six

Monkey, and upon the latter candy and pastry are lavished in profuse supply. Oh, if he only had cheek-pouches! Besides toothsome dainties for himself the Monkey receives many small coins for his master, to whom he presently returns with them. llaving levied their customary tribute the pair, Monkey and Man, move on their way rejoicing, to repeat the same performance a few doors away. Monkeys with The sccond family of the Broad-
Non-Prenensile nosed Monkeys, the Pithecide, or Tails.

the non-prehensile tailed group, is composed in greatest part of small or mediumsized Monkeys whose tails are covered with hair to the tip and are incapable of grasping or holding anything. members, and seldom bears captivity well.

The White A second and well-known member of Headed Saki this group, the White-headed Saki of Guiana. (Pithecia lcucocephala), shows so many varieties, according to age and sex, that it is known under several different names. It lives in Guiana, in troops of from six to ten, prefers shrubs to high trees, and impresses one as a rather lazy creature. The food of this animal consists chiefly of berries, fruit and honey. The female brings forth but one young one at a birth, and carries it around on her back until it has become strong and independent of restraint. Kappler corroborates these statements, and adds that this Monkey is easily tamed, but is listless and timid in eaptivity. 
The Black- The life of the Black-headed Saki Headed Saki, (Brachu'unis melanoceplualus) is very litor Cacajao. tle known, though the many names by which it is called would indicate that it is frequently

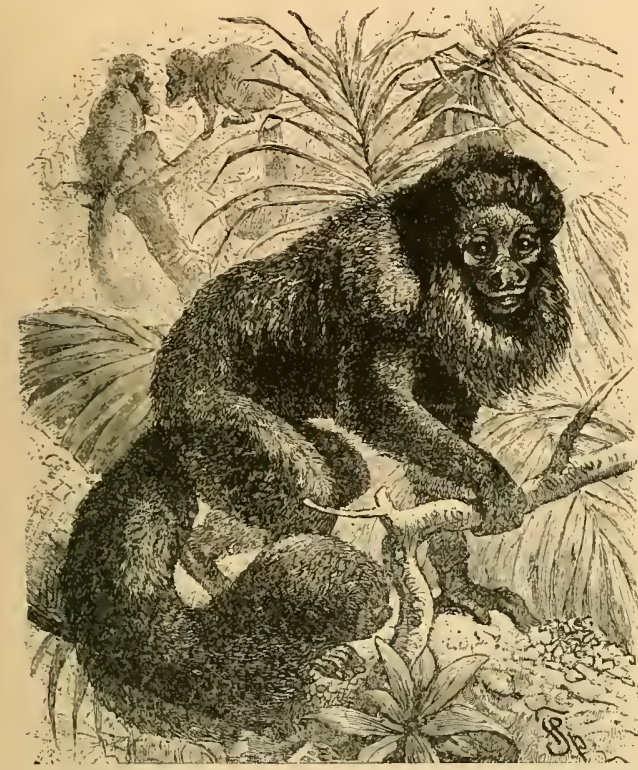

CUXIO MONKEY. - This remarkable looking animal exhibits a very hairy tall and an immense beard. It is extremely careful of the latter and so fearful of wetting it that it dips water up in its hand when it drinks. The Cuxio is chiefly nocturnal in habits and is found in Brazil. When angry it grinds its teeth in a savage manner. (Pithecia satanas.)

encountered by the natives. Besides the preceding names, this Monkey is also called Cacajao, Chucuto, Chucuzo, Caruari, MIono-feo or Ugly Monkey, and Mono-Rabon or ShortTail. The last name has been lately universally adopted; for the Cacajao, with a few other species having short, bushy tails, have been separated from the Pithecia, under the common family name of Short-tailed Monkey's (Brachyurus).

This Saki measures from twenty to twenty-seven inches in length, including the tail. Its thick, shining fur is longer on the shoulders and sides, and scantier on the under part of the body. The short, thin tail has a tuft on its tip. The fingers are exceedingly long and strong. Its color is grayish-yellow on the back and a rusty hue lower down. The hair of the head and fore-arms is shining black. In captivity it is greedy and obtuse, but not fierce. It trembles with fear at sight of a Crocodile or a Snake. This Monkey is a native of the northwest of Brazil, but does not seem to be very numerous. But a single living specimen has ever been brought to Europe although a number of live Short-tailed Saki Monkeys have been taken to the United States.
THE CALLITHRIX.

Another genus of American Monkeys, called Callithrix, is distinguished by a slim body, on slim limbs, a long, thin tail, a round head with a beardless face and a short muzzle; bright eyes and large ears; and the hands and feet each have five toes or fingers.

The Callithrix inhabit the quict forests of South America in small troops, and their presence is easily determined on account of their loud voices, which they are fond of using. In point of strength and loudness of voice they come next to the Howlers, and they betray themselves to the hunter at a great distance. The tenderness and agreeable flavor of their flesh cause them to be hunted vigorously by the natives. Their disposition is exceedingly gentle, and in captivity they become tame and affectionate to an extraordinary degree.

The Widow One of the most attractive nembers of Monkey and this group is the Widow Monkey ( Calits Beauties. lithrix hugens). Its length is about thirty-five inches, more than half of this belonging to the tail. According to Alexander von Humboldt, this little animal has fine, lustrous, black hair, a bluish white face, and small and well-formed ears. The neck shows a white collar, about one inch in width the feet are black; the hands white on the back and black on the palms. The missionaries have compared the white parts to the veil, collar and gloves worn by widows in South America, and this has given the name to the animal.

\section{THE CHRYSOTHRIX.}

We may consider the Saimaris (Chrysothrix) as the connecting link between the Monkeys with and those without prehensile tails. They have slender bodies, with long limbs, large heads, high foreheads, short faces, very large eyes standing close together, plain, large ears, and fur consisting of peculiar ringlets. Like the Callithrix, the tail is round and

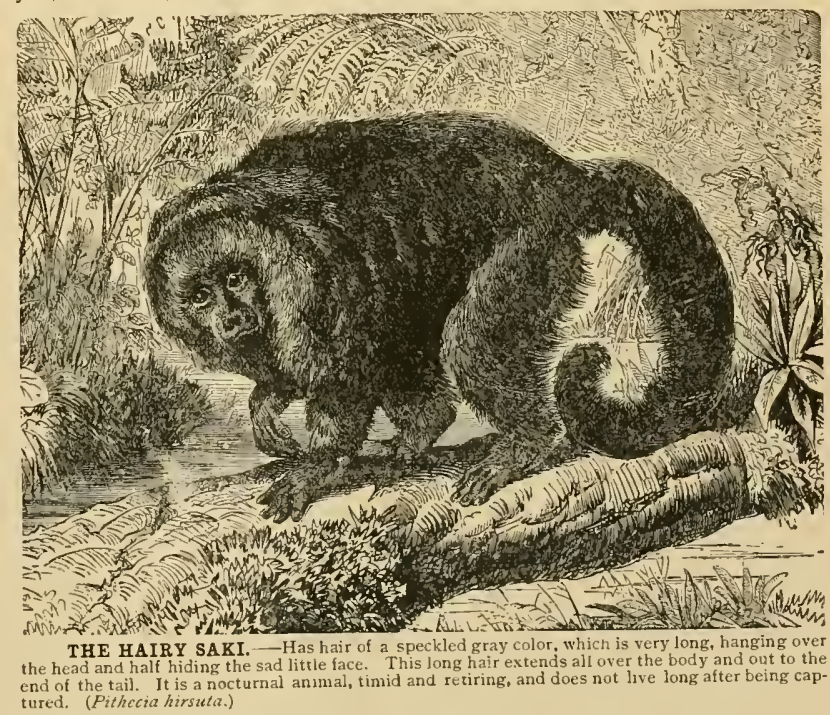

slender, and they have many peculiarities that are common to the non-prehensile tailed group. 
The Lively The best known nember of this Squirrel Monkey group is the Squirrel-Monkey, of Guiana. sometimes called the Golden-haired Monkey (Chrysothrix sciura), distinguished as much by a graceful body and agreeable color as by a merry, cheerful disposition. He may be counted one of the best looking of all the American Monkeys. The tail is very long; the body yellow above and whitish below. Sometimes the creature is gray with golden yellow limbs, or the head may be coal black. The length, tail included, averages about thirty-two inches.

This attractive little creature is a native of Guiana, and prefers the banks of rivers, which he haunts in large numbers. He does not inhabit high trees, but is found in the shrubs on the edges of the forest

purchase, and is thus able to speak with intimate knowledge concerning their habits and traits. According to him they are called Acalimas and Cabuanamas by the natives. He says: "The little Monkeys are very cheerful and ahways active, except that they sometimes take a nap during the day. They are very easily affected by changes of weather and dislike the cold. I always selected those that were quite young for my collection, and soon taught them to like bread, milk and ripe bananas. In the beginning I let them run at large in the room. They would sometimes suck their thumbs for hours, like babies. The dainty, white little face, black mouth, large bright eyes and engaging manners always produced a favorable impression on everybody. They are not so mischievous as other Monkey's; they easily show anger but soon for-

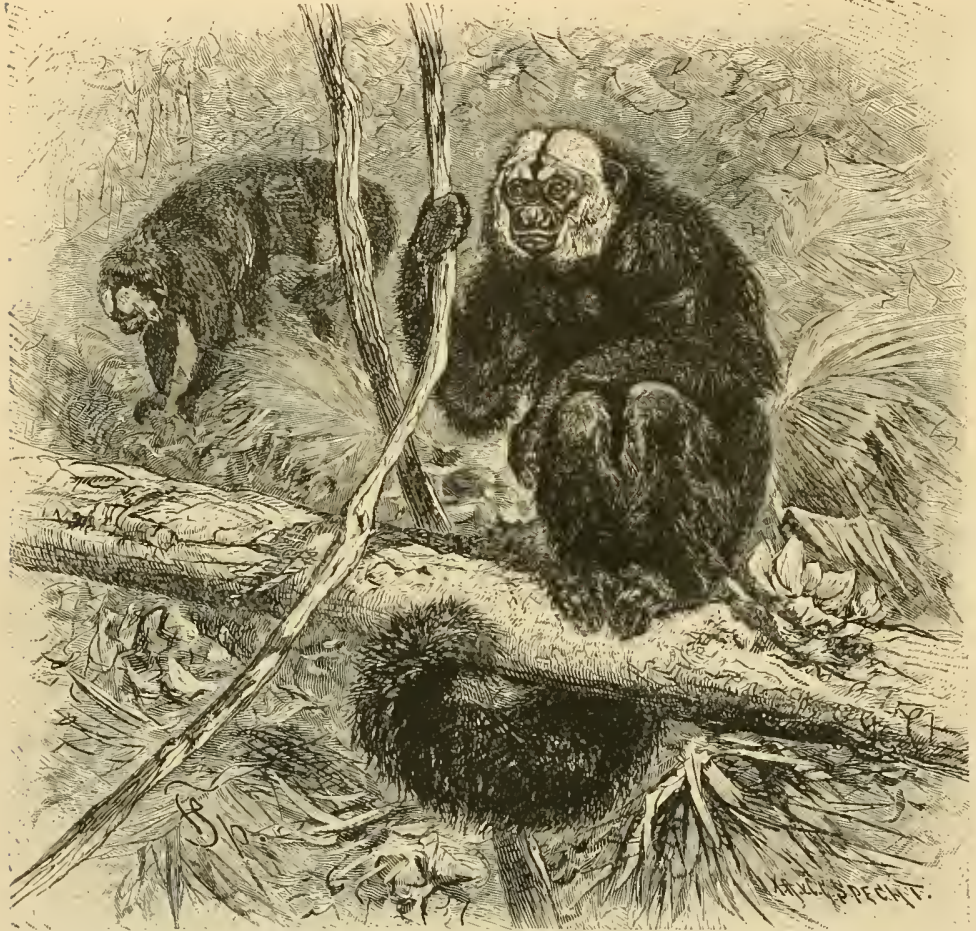

WHITE-HEADED SAKI MONKEY. A peculiarity of the "Saki" is that it strongly resembles Wan in the face, as the artist has clearly shown. Its white head and yellowish-brown body give it a striking appearance. The short and bushy tail is not prehensile. The creature is duli, quiet and rather stupid, and is easily nade content in short and bushy tail is not prehensile. The creature is dull, quiet and rather stupid, and is easily
captivity. Its life is spent in the trees and it feeds principally upon fruits. (Pathecia lencocephala.)

like the Capuchins and sometimes may be seen in company with a troop of those animals. The Squirrel Monkey is very active throughout the entire day, but at night he retires to the crowns of palms, where he finds a secure asylum for rest and sleep. He is very timid, never stirs at night, and flees at the slightest alarm by day. When frightened from any cause the troop moves in long rows, under the guidance of an old Monkey, which usually succeeds in leading them out of danger.

How Squirrel Kappler, during his twenty-six years

Monkeys Act stay in Guiana, always contrived to

in Captivity. keep three of these Monkeys in captivity, supplying each vacancy by death with a new get it. Except under provocation they never bite, and when kindly treated are the merriest little creatures in the world. Sometimes they steal a ride upon the backs of the Pigs which roam in the savannas. Every evening at five o'clock they were let loose in the yard and wildly romped and played around until dusk. when they would come in of their own accord to be locked up in their cage. They were fond of insects, but did not know how to distinguish between those that were poisonous and those that were harmless. Ignorance on this point caused three of mine to lose their lives. They are not docile, and are intellectually far below the Capuchin. IIhen they are comfortable, they purr like Kittens: when angry, their cries remind one of a Magpie. Most of them were brought to me from the sea-shore, where they jump around on the Awarra palms, which are quite full of thorns, sharp as needles and three inches long. The Indians shoot the mothers while bearing their littlc ones upon their backs, or they shake the young from the trees, where their dams have left them for a time that is intended to be brief. Rarely is one able to procure a male ; nearly all that were brought to me were females."

\section{THE OWL MONKEYS.}

Azara was the first naturalist who introduced to the world the Owl Monkey (Nyctipithecus), which is a most remarkable animal. A little later. Humboldt described it ; after him Rengger, Schomburgk and, finally, Bates gave interesting accounts of its habits and traits. To a certain extent the Owl 
Monkey is the connecting link between the Monkeys proper and the Half-Mlonkeys or Lemurs, being nocturnal in its habits like the latter and resembling them in many respects. The head and the expression of the face enable one to distinguish between then and all the preceding Monkeys at a glance.

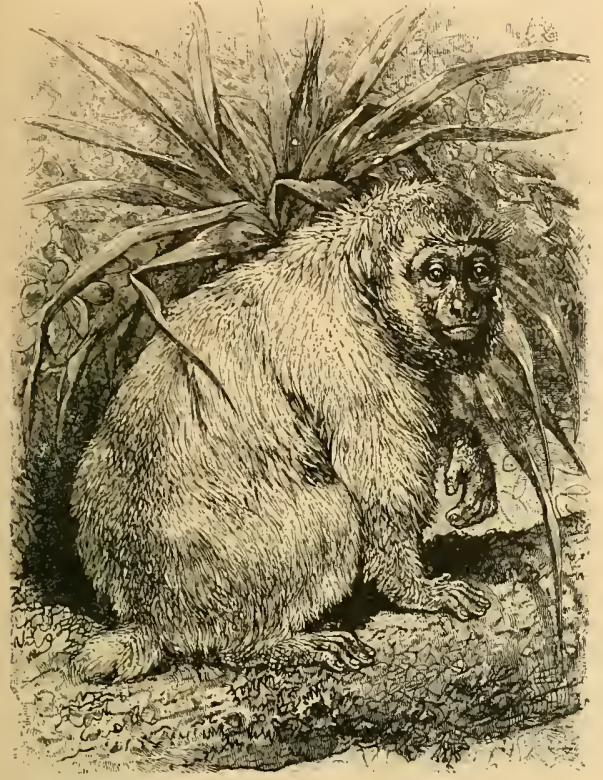

SHORT-TAILED MONKEY.-This strange looking Monkey has its home in the forests of the Upper Amazon, which are inundated through the greater part of the year, and from these trees it never descends to the ground. It does not show much activity in swinging or jumping, but runs very nimbly up and down the branches. It is of great interest to naturalists because of its having thirty-six teeth, instead of thirty-two, the number possessed by most of the Monkeys, as well as by thirty-two, the number posse
lan. (Brachyurus calvus.)

The small, round head has large, owl-like eyes; the muzzle projects forward but little and is broad and large; the nostrils open in a downward direction; the ears are small. The hair of the creature is soft and fluffy, and the bushy tail exceeds the body in length. The nails of the fingers and toes are compressed from side to side and curved, suggesting somewhat the idea of claws.

About the The Mirikina (Nyctipithecus trivergatus) is

Mirikina only fifteen inches long, but his tail

Monkey. measures twenty inches. This animal is thickly clothed with gray or brown fur, while the tip of the tail is black. The forehead is decorated with three black, parallel stripes and a wide, yellowish stripe runs from the neck to the root of the tail.

The Mirikina ranges over the eastern portion of the warmer parts of South America. Rengger asserts that in Paraguay he is found only on the right side of the river, as far as the twenty-fifth degree of southern latitude. "He spends his life in trees, commencing his hunt for food at night, and retiring early in the morning to a hole in a tree-trunk, where he sleeps through the day."

The servants of this naturalist while gathering wood once found a couple of these little Monkeys asleep. The frightened animals tried to escape, but were so dazzled with the sunlight that they could not climb or jump well. They were easily caught, though they made good use of their sharp teeth. Their bed consisted of leaves, covered with moss, and we may, therefore, conclude that they retire to the same place every morning. Rengger says that they are always found in couples, while Bates asserts that they are also met with in greater numbers.

The Mirikina A Mirikina caught young is easily in $a$ tamed, while an old one always reCaptive State. tains its fierce and wild nature. They easily bear captivity when well taken care of Negligence and uncleanness kill them. They should be kept in a spacious cage, or in a room, but not chained up, as they entangle themselves easily in ropes. When captive, they remain all day long in the darkest corner of their place of abode and sleep, sitting with their legs drawn up, the body bent forward, and the face hidden in their crossed arms. When one arouses them and does not keep them awake by petting, they go right back to sleep. On bright days they can distinguish no object, and their pupils are very small. When they are brought out of darkness into sudden light, their gestures and

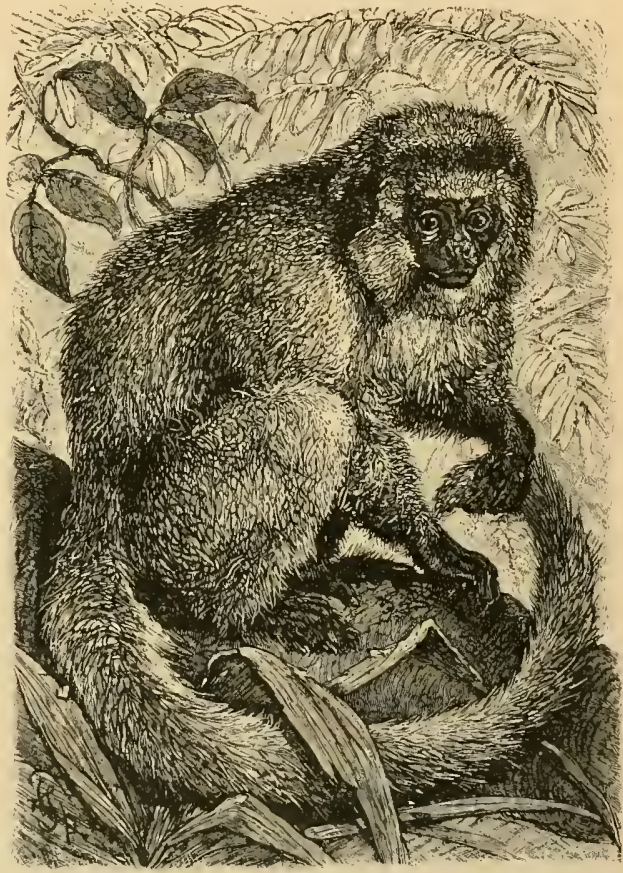

LOVELY-HAIRED MONKEY. - This really beautiful creature is scarcely larger than a Squirrel, and a native of Guiana. The tail is long and bushy, but not prehensile, 1t is somewhat nocturnal in its habits and feeds upon insects. The head is quite humanlike and the animal is very affectionate in disposition. In captivity it soon comes to know its friends and to distinguish them from strangers. It has a pleasing habit of turning its head to one side when spoken to, as though listening attentively to what is said. (Callithrex personata.)

plaintive sounds indicate that it is painful to them, but as soon as evening draws near, they awake, the pupil dilates gradually and finally the iris is hardly perceptible. Their eyes flash like a Cat's or an Owl's and they begin to walk around their cage and look for food. Their movements seem easy, though 
not graceful, for the hind limbs are the longest. They climb and jump to perfection. On their nocturnal wanderings they easily succeed in capturing sleeping birds. Insects are also welcome and caught very dexterously. From time to time they utter a hollow, loud sound, which has been likened by

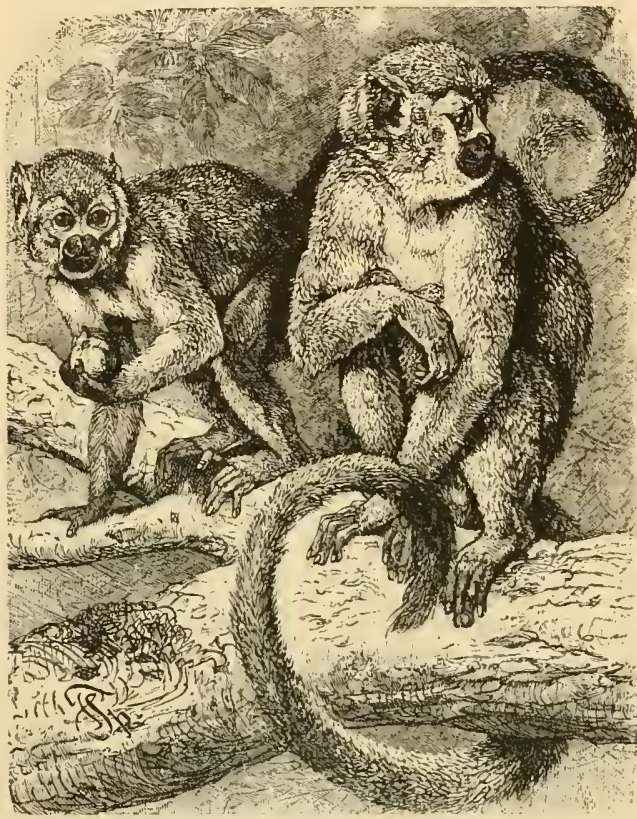

SQUIRREL MONKEYS,-Here are two of these merry and lively little creatures perched in a palm tree, the fruit of which one of them holds in his hands. They are exceedingly tımid, fleeing at the slightest alarm, and in this picture they are depicted as preparing to take flight from real or fancied danger. (Chrysothrix sciurea.)

travelers to the distant call of a Jaguar. They express anger by a repeated " grr, grr, grr, grr."

\section{Cbe IDarmoscts.}

THIRD FAMILY: ARCTOPITHECI.

Several naturalists see in the Marmosets only a variety of the preceding genus and class the two together: but we think that their distingusishing features are marked enough for us to treat them as two distinct groups.

The Marmosets have small, narrow claws on all fingers and toes, except the thumb-toes, whose claw is broad and nail-like. They have a round head, a short, flat face, small eyes, large ears, sometimes adorned with tufts, a slim body and short limbs; claw-like hands, whose thumbs cannot be opposed to the other fingers, although this can be done in the feet; a bushy tail and silky fur. The hands have really become paws in this tribe, and only the feet are similar to those of other Monkeys.

Haunts and The Marmosets have a very wide

Habits of range, being found in Mexico, Central

Marmosets. America and South America to the southern limits of Brazil. They occur in greater variety and numbers in Brazil, Guiana and Peru, Mlexico afforcling but two kinds. How high they ascend the mountains has not been determined;
Schomburgk saw them at an elevation of 1,600 feet, but it is believed they inhabit much greater altitudes in the Andes range.

All Marmosets are arboreal or tree-living, in the true sense of the word. They inhabit not only the damp, stately forests of the coast and the valleys, but also the stunted, bushlike woods in the inner parts of the continent. In their traits and habits they resemble Squirrels as much as they do Monkeys. They never sit erect as Monkeys frequently do but roam from tree to tree on the thick boughs, using their claws exactly like Squirrels. They have never been seen to go erect, and in walking they place the sole of the foot flat upon the ground. Still, in eating, they will often raise their bodies, like the Squirrel, when bearing food to their mouths. Special Traits In other respects they also resemble of the the Squirrels very much; possessing

Marmosets. the same restlessness and the same shyness and timidity. The little head of the Marmoset never rests, even for a moment, and the glance of the dark eyes wanders hurriedly from one object to another and seemingly with little understanding, the animal evidently thinking of something else all the time. 1 do not wish it understood that 1 thus credit the Marmosets with great ideas; on the con-

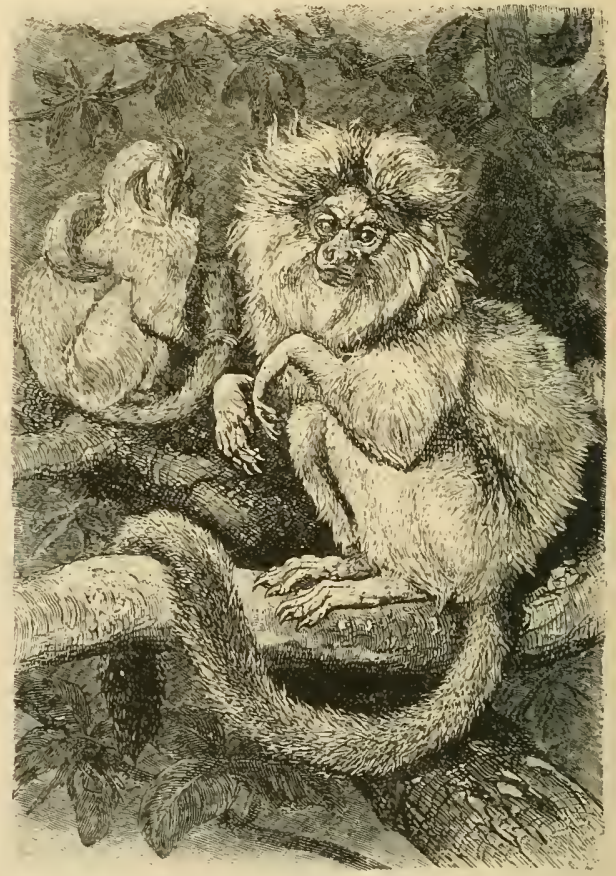

SILKY TAMARIN, - The Silky Tamarins are noteworthy for the beauty of their fur. Their hair is soft, long and of a chestnut color. and forms into two tufts over the ears; while the tall is long and bushy. They inhabit Brazil, and are about the size of a common Squirel. (Hapale Rosatha.)

trary, I believe them to be the dullest of all Monkeys, creatures with decidedly limited intellect, whose thinking capabilities are probably not any greater than those of the Squirrel. Timid, distrustful, reserved, petty and forgetful, the Mlarmoset seems to act unconsciously and to be carried away by mo- 
mentary feelings. He has all the qualities of a coward: the plaintive voice, the evident incapacity or unwillingness to give in to necessity, the complaining resignation, the morbid fancy that the actions of all other creatures in some way relate to him, the constant attitudes of either ostentatiously showing off or shrinking from observation, the inconstancy in his expressions, movements and actions.

Fruit, seeds, leaves and buds form the principal part of the food of the Marmosets, but they also hunt insects, Spiders, etc., with the greatest zeal, and eat them with evident relish. Indeed, one might say that they are animal feeders more than any other Monkeys, preferring $t h$ is to vegetable food.

The Three IVe rec-

Groups of ognize Marmosets. $\mathrm{t}$ h $\mathrm{re} \mathrm{e}$ distinct groups as belonging to the family Hapale : the Lion-like Monkey (Hapale le onina), having face and ears devoid of hair, a tufted tail, and a mane on the head, neck and shoulders; the $\mathrm{Tam}$ arins, to which belongs the Silver Monkey (Hapale Argentata), having a longer tail, but no mane, and the Silky Monkey (Hapale pygmaa) having tufts on its ears.

The most common member of the last named group is the Saguin Ouistiti or Common Marmoset (Hapale jaccluus). It is about ten inches in length and is clothed with soft, long hair. The coloring is black, white and russet, each hair being black at its root, and then alternately russet, black and white. The tail is black, showing about twenty white ringlets and a white tip. A whitish spot on the forehead, and a pure white tuft over each ear stand out in bold relief against the brown face.

In captivity they subsist on fruit, vegetables, insects, Snails and meat, and soon get familiar with

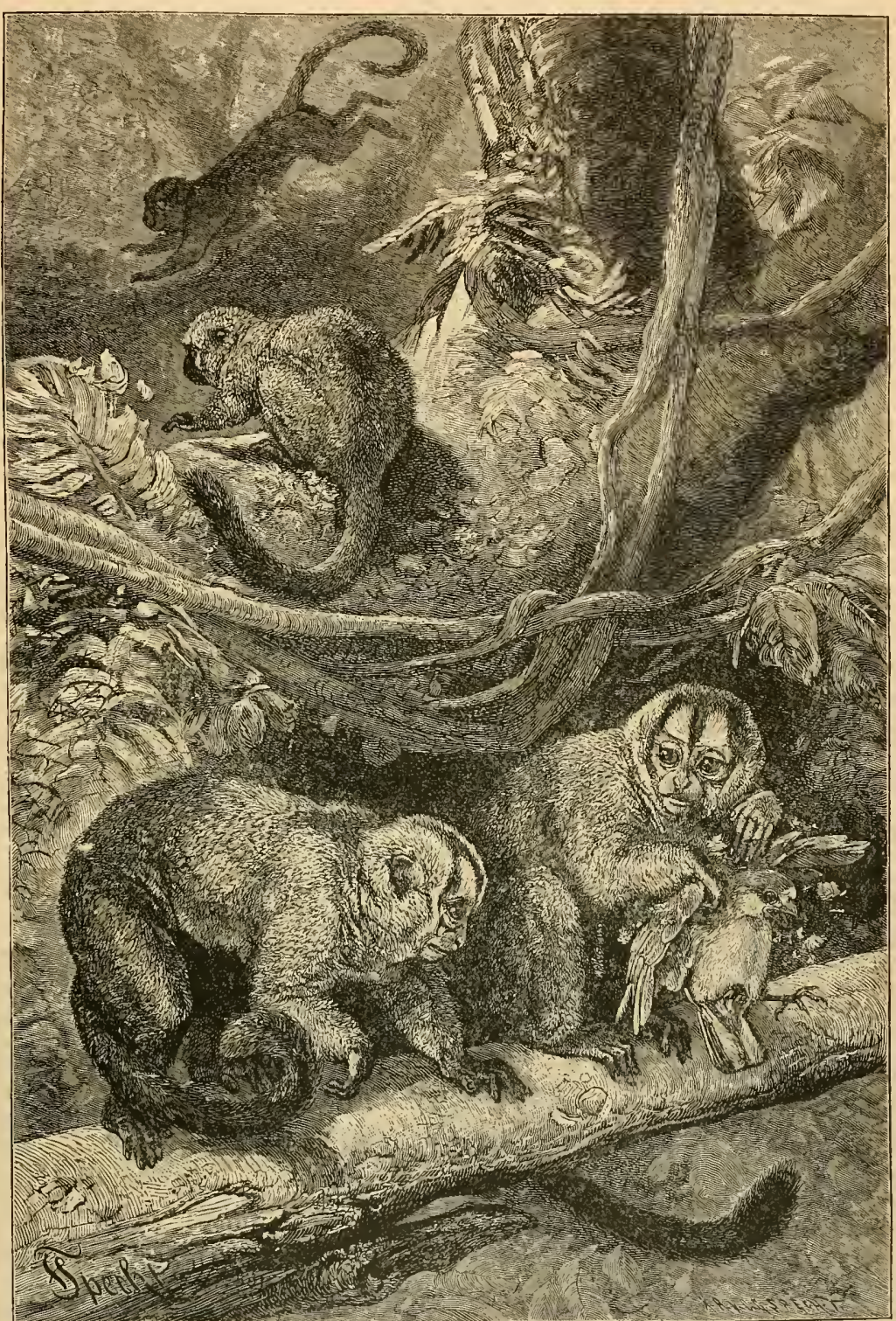

NIGHT MONKEYS. - The picture represents Night Monkeys of South America, one of which has just seized a little bird and it regards with disfavor the too near approach of its companion and evidently declines to share the toothsome morsel in its possession with the intruder. The entire family of Night Mlonkeys are noted for their small, round heads, lare eyes and long tails "Those indicat in the picture are sometimes called "Three-striped Owl Mlonkeys." on account large eyes and long tails, Those indicated in the picture are sometimes callon small birds, insects and fruits, are strictly of the three divergent black stripes on their forehead and face. They f those who take constant care of them. They show themselves distrustful and irritable towards strangers and are capricious like naughty children 
When angered they utter a few whistling sounds. Everything unfamiliar excites them strongly. They are so timid that the sight of a flying Wasp throws them into great excitement. When adult animals are

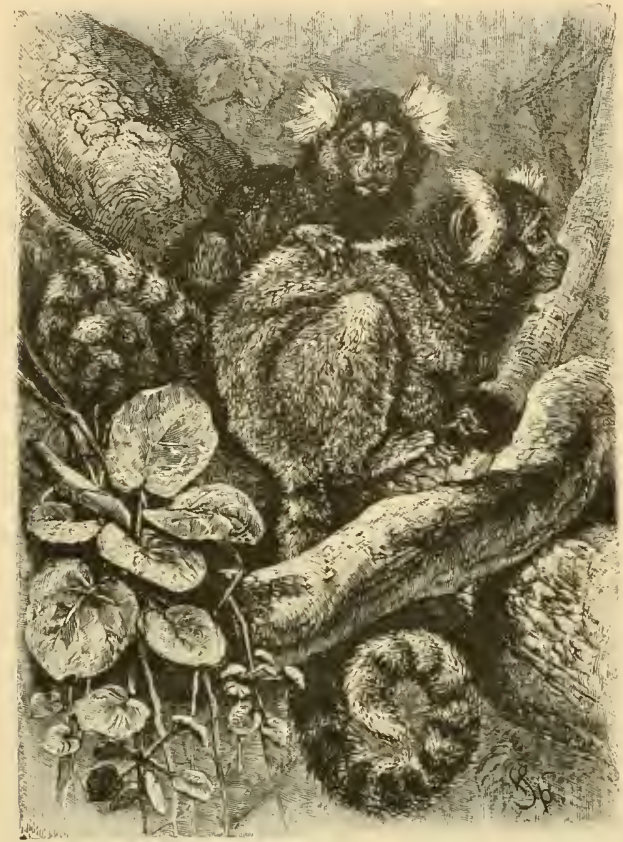

COMMON MARMOSETS. - These gentle little creatures belong to the same family shown in the preceding illustration, and are found in the tropical forests of Brazil. Their movements are so swift that it is difficult for the human eye to follow them as they travel through the branches of their native trees. Their size is about that of the common gray Squirrel.

made captive, they scream at the approach of every one, and it is a long time before they allow any one to touch them. Having been once tamed they soon become good friends with people and with other domestic animals, especially Cats, with which they like to play and to sleep, the latter probably because of the warmth afforded. They are forever protecting themselves against the cold, carrying all the cotton and rags they can get hold of to a corner of their cage, and covering themselves with it. A pretty sight is afforded when the little animal, lying on its bed, is approached by the keeper, bearing some sweet morsel, for which it extends its dainty head forward.

It has frequently happened that Ouistitis have bcen born in captivity, in Europe, as well as in the United States, and once, even in St. Petersburg though under very unfavorable conditions. The animals were ke pt in unheated rooms, even on cool days in Spring and Autumn, and were given no liberty at all, still they gave birth to young ones three times in two years and succeeded in rearing them, notwithstanding the small amount of care they received.

Pallas' Description We are indebted for their history of the Common to the naturalist Pallas, who say's:

Marmoset. "The Ouistiti, like all the other little, long-tailed American Monkeys, is much less Monkey than those belonging to families whose members attain larger size. It is quick and agile, but when in a state of contentment it may sit in the sun for hours without moving. It can climb with dextcrity, but does so with a peculiar phlegmatic pomposity. Sometimes it hangs from a bough by its fore-paws, and stretches itself, like a sleepy human being. Ouistitis like to remain in the warm sunshine searching each other's fur for vermin, Monkey-fashion, purring and cooing the while. With a similar cooing sound they retire on the stroke of six and are not seen nor heard again till six or seven the next morning. They are active and rather noisy in the day-time. Besides these cooing intonations they sometimes utter the combination of sharp whistling sounds represented by their name, "Ouistiti," quite distinctly, especially when food is in sight.

Many Types Besides the Ouistiti, naturalists have of the found over thirty distinct species of

Marmosets. Marmosets, differing greatly in size, color and general appearance, but all having the physical characteristics of the genus Hapale. Among them is the Hapale penicilata which is about the same size and ncarly as common as the Ouistiti.

The Pinche (Hapale adipus), belonging to the Tamarins, bears captivity still less than the Common Marmosets. These small, pretty animals are remarkable for their roices, which might be mistaken for a bird's, when the Monkey uttcrs its long, flute-like notes.

The Golden Marmoset (Hapule chrysoleucus) is also a small animal, taking its name from its bright yellow fur. The other families of the genus Hapale are all small creatures with the same general characteristics as those we have described, differing somewhat in the color and distribution of their furs

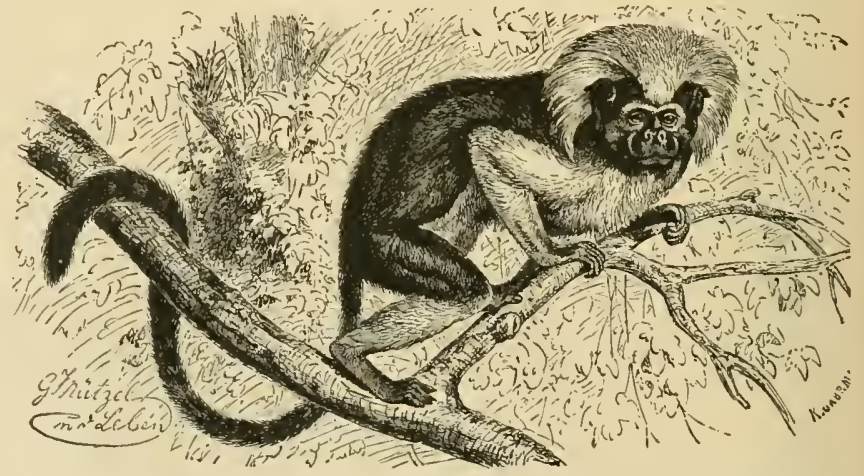

PINCHE MORMOSET--Distinguished for its large white tuft, which falls gracefully over and behind the ears. The throat, chest, abdomen and arms are also white, the rest of the body being a grayish brown. The voice of the Pinche is very sott and sweet, varying with the different moods of the
animal. It is a most delicate creature and does not live long in captivity. Its home is in the tropical animal. It is a most delicate creature and

and only designated by their scientific names, which rest only on slight variations. 


\title{
The Ibalt=lilsonkens or Lemuroids.
}

\author{
SECOND ORDER: PROSIMII.
}

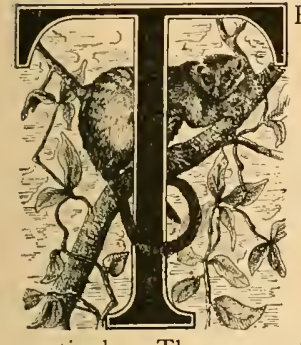

$\mathrm{HE}$ majority of naturalists have classified the Lemuroids with the Monkeys; but we see in them an entirely distinct order and accordingly here class them separately. In reality they bear but little resemblance to Monkeys. Their anatomical structure is entirely different, and their teeth do not correspond with the teeth of the Monkeys in any particular. The name of Quadrumana (four-handed), is a great deal more appropriately used in connection with Lemuroids than with the Monkeys, as the difference between the hand and foot in the former is very slight. One may take these animals to be the connecting link between Monkeys and the Marsupialia (pouched animals), imagining them to be successors of a genus of unknown animals of the same family as the Opossum; but they are not Monkeys.

Distinctive A generic picture of the Lemuroids Features of is not easily drawn. They differ

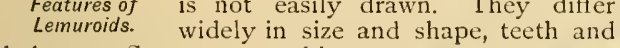
skeletonuroids. Some are as big as a large Cat, others as small as a Mouse. Most species have slim bodies; some are extremely thin. The muzzle of some reminds one of a Dog or Fox, while that of others may be Owl-like. The hind limbs are usually longer, and often considerably longer than the forelimbs. In some groups the anklebones are relatively short; but in some they are rather long. The tail may be longer than the body or may scarcely be visible; it may be bushy or partly devoid of hair. Large eyes adapted for use at night, well-developed ears and a soft, thick, usually woolly fur, characterize the Lemuroids externally as nocturnal animals. The skull is round in the back; the muzzle is narrow and short, and the orbits are large and close together, and have a projecting rim, high in the upper part, which does not surround the whole of the orbit but merges into the temple sideways.

The Homes The Lemuroids live in Africa, espeof the cially in Madagascar and the adjoining

Lemuroids. islands; but they are also found, although in much smaller numbers, in India and the South Asiatic islands. They all lead arboreal lives, some of them hardly ever coming to the ground. Some are remarkably quick and agile, while others are slow and deliberate and glide about as noiselessly as ghosts. Some are active and feed in the day-time, but the majority awake at sunset, and the dawn of day finds them already sound asleep. Fruit, buds and young leaves form the food of some kinds, while others subsist on insects, small vertebrata and vegetable matter. In captivity they soon become accustomed to all kinds of food.

\section{Tbe $\mathfrak{I c m u r s . ~}$}

FIRST FAMILY: LEMURIDAE.

The Romans applied the name Lemur to the souls of the dead, the good among whom protected the house and family from evil, while the wicked ones wandered about as evil spirits and worried poor mortals. Science also has its Lemurs, but these are by no means ghosts although they stealthily roam about at night, being creatures of flesh and blood and of a more or less prepossessing appearance. They are the center of the class of animals we propose to deal with, the family of Half-Monkeys, which comprises a number of groups of widely differing characteristics.

Habits The Lenurs possess all the peculiarities of

of the the Lemuroids, the two other groups of

Lemurs. Half-Monkeys differing from them mainly in their teeth, structure of hands and feet, and fur. 
rich in fruits and insects. They do not exactly shun Man, neither do they seek him. Nocturnal in their habits to a greater or less degree, they seek the darkest parts of a forest, crouch or roll themselves together and sleep a great deal. Their attitudes in sleep are very peculiar. Either they sit holding themselves with their hands, the head buried in the arms, and the tail rolled about the head and shoulders ; or else two or more will huddle close together. Sometimes two Lemurs will roll themselves together in a ball-like mass, with their tails curled around each other. If one disturbs such a ball of fur, two

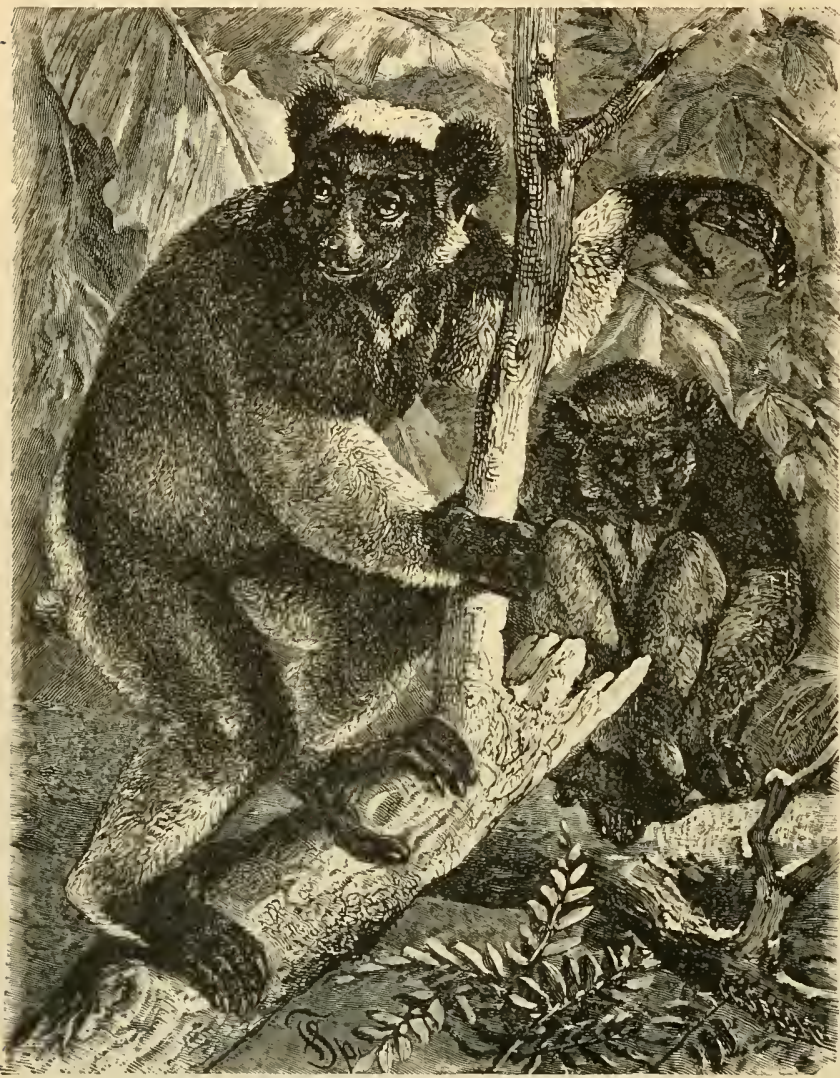

SHORT-TAILED INDRIS LEMUR.-The characteristics of this animal as it appears in its native Madagascan forest, are admirably depicted in this picture. The contrasts of light and dark in its fur, the stumpy tail from which it derives its name, the methods of grasping and climbing aided by the remarkable thumb, as well as the keen vision, are all brought out. The Squirrel-like attitude of the animal in sitting posture, as shown by the figure in the background, is another strong characteristic
of this type of the Lemur family. (Lichanotus brevicaudatus.)

heads suddenly make their appearance and stare at the intruder with large, displeased eyes.

The sleep of the Lemurs is very light. The humming of a Fly or the noise of a creeping Bectle is sufficient often to rouse many of them, when they prick up their ears and the large eyes look dreamily around; but only for a moment. They are extremely sensitive to light, more so than any other animals of the family of mammals. They seem to be as dead creatures in the day-time. In their wild state Lemurs awake only at dusk; but this is only partially true of those in captivity.
When in their forest homes they rouse themselves after sunset, clean their fur, exercise their usually rather loud and disagreeable voices, and then set out. The activity they display varies much in different species. The majority exert themselves in the first place to justify their spectral name, and raise a disturbance that strikes terror to the heart of a new-comer, who must attribute the indescribable noise to the "powers of darkness," though it slightly reminds one of the roar of dangerous beasts of prey, such as the Lion.

Some species, on the other hand, are entirely different in their actions and temperament. Stealthily and noiselessly they creep from branch to branch; their large, round eyes gleam in the darkness like fiery balls, and their movements are so deliberate and noiseless that not the slightest sound betrays them, even to an interested listener.

The Stealthy Alas! for the sleepHabits of ing bird that has Some Lemurs. attracted the notice of those fiery eyes. No Indian on the war-path moves with stealthicr tread; no bloodthirsty savage approaches with deadlier purpose than does the Loris, stealthicst of Lemurs, when creeping to his slceping prey. Without noise, nearly without visible movement, paw after paw is lifted till he has reached his victim. Then the hand is raised with equal silence till it nearly touches the bird, when with one movement, too quick for the eye to follow it, he has seized the poor thing, which is strangled before it regains consciousness. Nothing can equal the avidity with which the harmless looking Loris devours his prey after the murder is accomplished. Like the sleeping bird, the young ones, or the eggs, are lost if once the Loris discovers them.

All species belonging to this group move slowly and assure themselves of a safe hold upon a succeeding branch before relinquishing the one that supports them. A uniform and rather high temperature is a necessity to them; cold makes them peevish and brings on illness.

Their intellectual faculties are slight; but a few species present a noteworthy exception to this rule. They are all shy and timid, though they defend themselves courageously when attacked. When they become accustomed to people they are goodnatured and gentle, but rarely lose their timidity. A few species bear the loss of their freedom very resignedly; they may even be trained to render certain services to Man, such as hunting other animals. The tailless species usually retain their quict, melancholy temper, dislike of being disturbed, and they scarcely ever learn to discriminate between their keeper and other people, or show any gratitude for any kindness exiended to them. 


\section{THE INDRIS.}

The largest and most highly developed of all Lemurs are the Indris (Lichanotus) or, as they are called in Madagascar, Babacoto. There are two kinds, the short-tailed Lemur (Lichanotus brevicaudatus) being the better known. They attain a length of about thirty-five inches, inclusive of the tail, which measures but one inch. The medium-sized head shows a pointed muzzle, small eyes and small ears nearly hidden in the fur. The body and limbs are clothed in a thick, woolly fur; the forehead, throat, chest, tail, ankles and sides being white and the remainder of the body black and brown.

Sonnerat, who made the Babacoto known to the world, says that he is, like his relatives - the Monkeysa very good climber, that he sits erect, like a Squirrel, when eating, and carries his food, consisting chiefly of

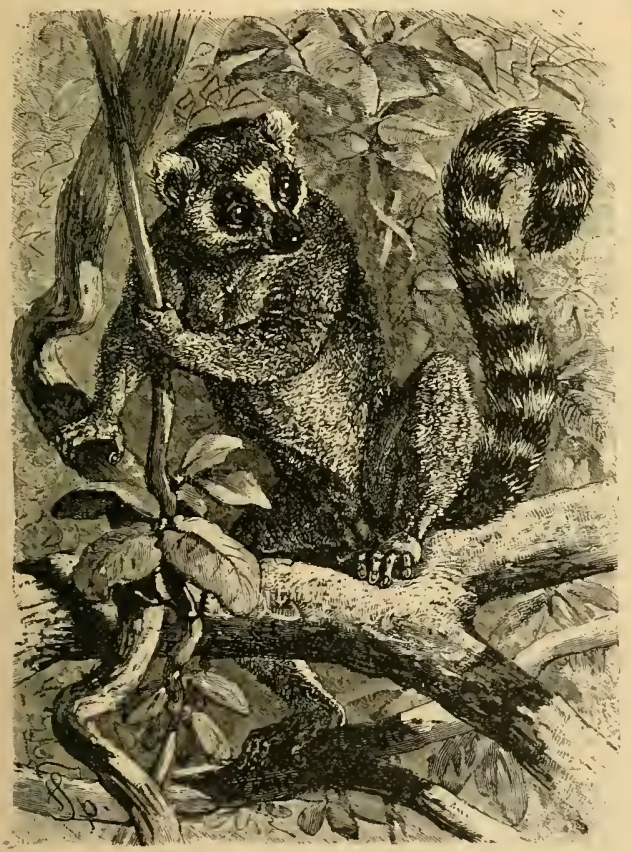

THE CAT-LIKE LEMOR. - In spite of the fox-like muzzle this picture shows ample justification for a name that compares this creature to a Cat. The tail in altemate rings of black and white is the most proma Cat. The tail in alternate rings of black and white is the most prom-
inent feature, not only because of its peculiar marking but also by reason inent feature, not only because of its peculiar marking but also by reason
of its length and bushy fur. The position shown in the picture displays to advantage the symmetrical and well formed limbs that give the animal the agility it displays in its nightly wanderings. (Lemur catta.)

fruits, to his mouth with his hands. His voice is of a melancholy, wailing cadence, resembling that of a crying child. He is gentle and good-natured, and numbers of his family are trained, and, like the
Dog, used for hunting purposes by the natives of the southern part of Madagascar.

"In certain parts of Madagascar," say's Pollen, "the Babacoto is trained for bird-hunts. He is said to be as serviceable as the best of Dogs; for, though he is a vegetable feeder, he by no means despises small

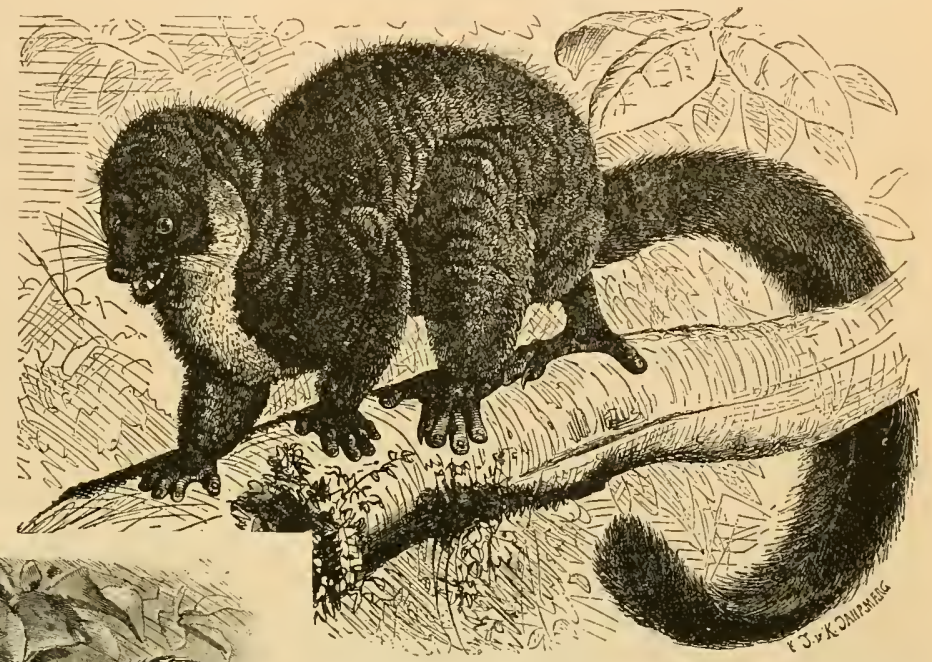

MONGOOSE LEMUR. - Has a remarkable, bushy tail that is longer than its body, and is reddish gray in color. It lives chiefly upon fruits and seeks food in the darkness of the nigh. The head is long and the forehead flat. It makes a very fine pet, doing well in captivity. (Lemur mongoz.)

birds, and catches them with the greatest dexterity, their brains being esteemed a choice dainty by him."

No Babacoto has been brought to Europe alive, which is very astonishing. Being more or less of a domestic animal in Madagascar, neither his capture nor his keeping can be attended with difficulties.

\section{THE MAKIS.}

The name of Maki bclongs to the most numerous family of the Lemurs, and this designation represents the peculiar cry they give forth. The Makis have a decidedly fox-like muzzle, with moderately large eyes and ears, well formed limbs of nearly equal length, the hands and feet showing a few scattered hairs on their backs; a tail longer than the body, and a soft fur of fine, and sometimes woolly, texture.

This group shows many varieties, but modern research has revealed the fact that many so-called varicties are not distinct species, the difference in appearance being based on sex, age, etc. The bestknown of the Makis is the Vari, or Ruffed Lemur (Lemur varius), distinguished by a black and white fur, the spots of the two colors being differently distributed in every specimen. The Vari is one of the largest of the Makis, equaling in size a large Cat.

The Catta (Lemur cattc) is distinguished by his graceful figure and his long tail, showing alternately black and white ringlets. His principal color is gray, the face, ears and under part of the body being whitish. Other kinds that we often see in zoological gardens, are the Mongoose (Lemur mongoz) and the Macaco or Black Maki (Lemur macaco). In the last named species the male is nearly pure black; while the female is of a lighter or darker 
rusty red, and for a long time was considered a distinct species.

Pollen's Pollen was the first to give us a clear Account of the and instructive picture of the Makis Matis.

in their wild state. They all inhabit the forests of Madagascar, sleeping by day and seeking their food at night in a lively and noisy manner. They live in troops numbering from six to twelve, and wander from one part of the forest to another in search of dates. As soon as the sun sets one may hear their loud wails. They are extremely agile and take considerable leaps with great ease. IVhen pursued by Dogs, they mount to the top of a tree, fix their eyes on the enemy, wag their tails and grunt. But as soon as they perceive the hunter, they make for the depths of the wood.

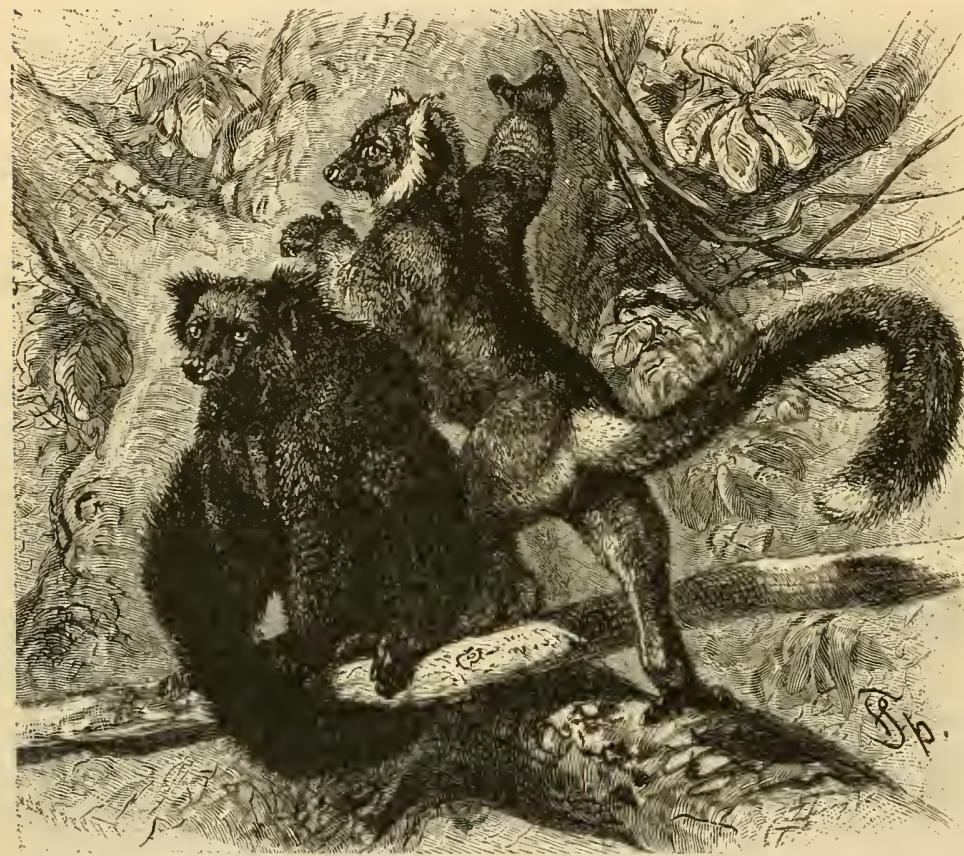

MACAC0, OR BLACK LEMOR, - Although called the Black Lemur, it is only the male specimen of the Macaco that is accurately described by this name, the female being of a light hue or russet color. It will be easily seen, therefore, that the figure in the foreground is the male and the other the female of this species. The picture also

Their intellectual capacities are not any higher than those of other Lemurs. Still they are usually gentle and prepossessing.

Makis in the Several specimens have been shipped

Captive to Europe and America and have with-

State. stood the strain of captivity for long periods of time. One Vari, for instance, lived nineteen years in Paris. Usually they become tame and familiar in a short time. They either employ their hands in bearing food to their mouths, or they take it up with their mouths without the aid of the hands. When contented they purr, and in this manner often sing themselves to sleep.

Buffon had a male Maki in his possession, which delighted him as much by its graceful agility as it annoyed him by its uncleanliness and mischicvous disposition. It was extremely sensitive to cold and damp and in winter always kept near the fire, somc- times standing upright in order to secure greater warnith from the flame.

The Maki which lived in Paris was also very partial to the fire. The poor, chilly southerner held not only its hands but also its face so near to the blaze that more than once its mustache was seorched. It was cleanly in its habits and took very good care not to soil its glossy fur. Its liveliness was only equalled by its curiosity. Everything was investigated by it, and in consequence it was forever spoiling, dropping or spilling something. The ereature was kind to all who petted it and would sometimes jump into the lap of a stranger.

\section{THE LORIS.}

While all the Makis show a lively, active disposition, the Loris (Stinops) are distinguished by the opposite qualities. One might call them the Sloths of their class. They are small, graceful animals, devoid of tail, having a large, round head and slender limbs, the hinder ones being a little longer than the fore-legs. The muzzle is pointed, but short; the eyes are very large and placed close together. The index finger is very much shortened, the third finger very long and the last finger shows a long and sharp claw.

There are but few varieties of Loris, and they are natives of India. The habits and traits of this animal in a wild state are nearly totally unknown.

A very dainty little animal is the Slender Loris (Stonops gracilis), which is barely as large as a Squirrel, being but ten inches long. It has large eyes, a pointed muzzle, a long fur, which is like plush to the touch, and is of a reddish brown above and gray or dull yellow below. Around the hazel eyes the fur takes a darker hue, contrasting with the light muzzle.

This pretty little creature, named Terangu and Una Happolava by the natives, inhabits the south of India and Ceylon. It sleeps all day in hollow tree trunks and makes its appearance in the evening. It has never been observed in its wild state.

Habits of a To my great surprise and joy I found Captive a living Slender Loris in the precincts slender Loris. of a wandering zoological garden. The delicate creature had come to Europe with three others about four years before, and had borne not only the voyage to Europe but the captivity of the colder climate. I purchased the animal at a high price, in order to have a picture of the species from nature and to study it, and gave it the best of care.

In the day-time the Slender Loris lies or rather hangs from a perch in its cage and sleeps, without 
being in the least disturbed by its surroundings. It sunset it awakes, stretches itself and noiselessly walks to and fro in its cage. It is very agile, but always makes sure before moving that the next branch is capable of sustaining its weight; sometimes stretching its limbs beyond seeming possi-

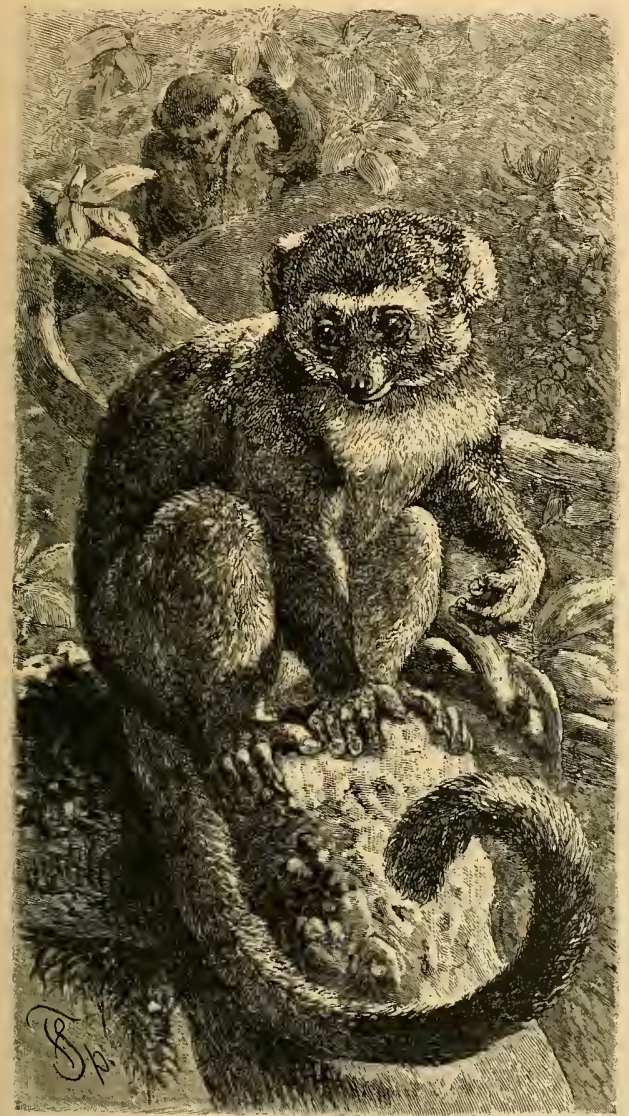

THE GRAY OR GENTLE LEMUR. This animal is a native of Madagascar, and has an aniable disposition. The tail and body are nearly of equal length, each being about fifteen inches. The prevailing color is gray, and the prominent eyes are soft and pleasing in expression. Its habits are nocturnal, and in captivity it is prone to seek the dark portion of its cage by day, but it is a most grateful little creature and one of the most popular pets of the entire family, (Hapalemur griseus.)

bilities. Sometimes it moves its head to and fro with wonderful rapidity. The eyes literally gleam like living coals in the dusk, and, being very close together and only separated by a pale streak, they make a peculiar impression.

When very angry, the Slender Loris vents its feelings in a deep snore, but it is by no means easy to disturb its equanimity. It likes to be petted, sometimes closing its eyes with evident pleasure when it is being car essed.

The principal food of this animal is bread soaked in milk. Fruit, meat and eggs it disdains to touch. This Loris of mine never has been tempted by living birds, but is very fond of insects and worms; yet it is so lazy and awkward that it does not catch them itself, and it requires the keeper to hold them while it eats.

The slow The Slow Loris, Sharmindi Billi, or

Loris or Bashful Billy (Stenops turtigradus), is Bashful Billy. better known than its slender cousin, perhaps because it occupies a wider area of country. It is a native of India, ranging as far west as the lower Brahmapootra. The animal has never been found in the Himalayas, but inhabits Assam and all the country to the south and southeast of it, as well as Sumatra, Java and Borneo. It is larger than the Slender Loris and shows a greater variety of coloring. The usual tint is a light or clark silver-gray, sometimes with a reddish tinge; a chestnut stripe runs the whole length of the spine, frequently ending

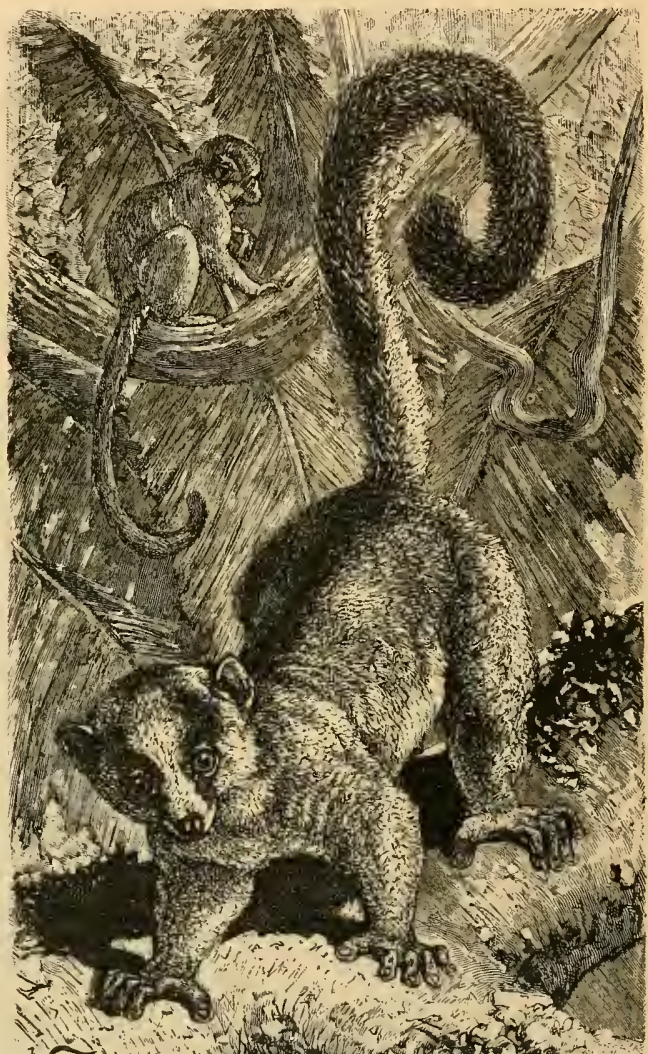

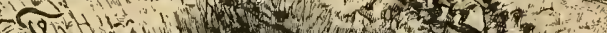

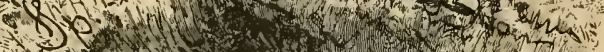

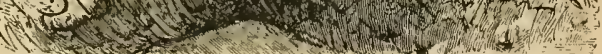

FORK-CROWNED LEMUR. - This animal is very abundant in the for the forests on the west side of ilidagascar, and is found in less numbers on ure in being near to Bees, whose honey it does not hesitate to steal. It utters sharp, piercing cry, very much like that of the Guinea-fow.

at the ears; in some cases it is prolonged by two ribbons to the eyes, in others four ribbons extend to the eyes and ears. The eyes are always surrounded by brown rings. The bald parts of the nose and soles are flesh colored. The length of the body 
is about fifteen inches; that of the tail, barely one inch.

The Slow Loris is difficult to study in its wild state, but we know that it lives with its family, sleeps during the day in hollow trees, and goes on its search for food at dusk. The animal has rarely been seen in its wild state by Europeans.

In captivity the Loris are gentle, patient and melancholy. All day long they sit crouching down and leaning their heads against their crossed arms. One of them was once tied to a rope and it would repeatedly lift the fetter with a sad little gesture of seeming complaint; but it never tried to break its bonds. At first it snapped several times at its keeper, but a few light punishments sufficed to teach it self-restraint. When petted it would take the hand which caressed it, press it to its breast and look up into the sympathetic face with half-closed eyes. At dusk it would rouse itself; first looking around with eyes yet full of sleep, rub them, and then begin to wander about the cage. Ropes had been ticd all ahout and it would climb upon them. It was fond of fruits and milk but had a special liking only for birds and insects. When such game was proffered, it would cautiously approach, as if on tiptoe, and at about a foot's distance would stand up, softly stretch its arm and then, with one movement, quick as lightning, make a dash for its prey and strangle it.

The Slow Loris I have seen and observed but two and its living Slow Loris; the first, only by

Peculiar Traits. day, in the Zoological Garden at Amsterdam. It was not quite so kindly a creature as I had expected. Either it was annoyed by our disturbing it, or else it was irritable by nature. In any event it was highly indignant at our intrusion. It spit like a Cat, and explained its meaning still

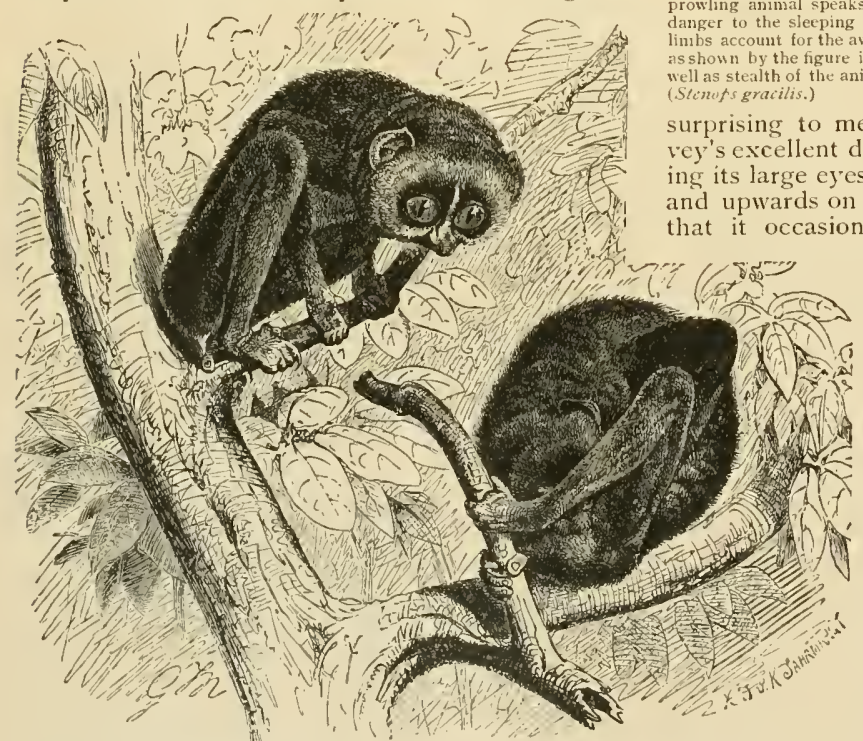

THE SLENDER LORIS,- The artist here shows the position of the Slender Loris at rest when awake, and aiso when asicep. It is curious to observe how in the first case it brings the hands and feet nearly together and presses the body against the upper legs; while in the other, the waking position is partly assumed, but the face is pressed down behind the left arm, while the body is nearly

further by trying to bite the keeper's hand, an offence it had been guilty of before. Failing in wreaking this revenge, it slowly retired suiking to its corner. Its retreat was performed in a manner

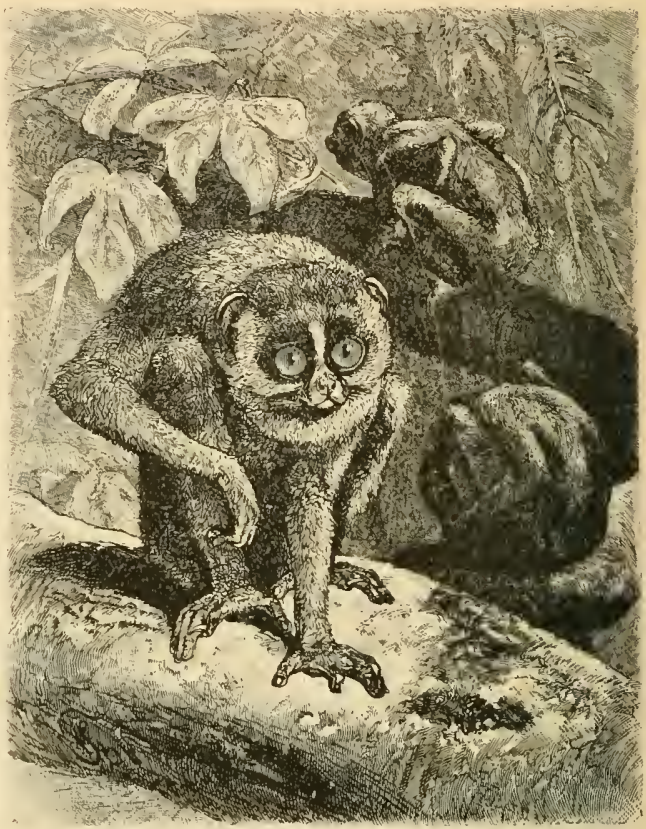

SLENDER LORIS LEMUR. - The stealthy character of this nightprowling animal speaks in its features and the large gleaming eyes bode danger to the sleeping bird it may choose for its prey. The long, slender animal are well shown by the other in the background. surprising to me, though I was familiar with Hare eyes upon us, it went back, step by step, and upwards on a nearly rertical pole. This means lity climbs upwards, with the face downwards. In my knowledge, no other animal does that. When it arrived at a point where two branches diverged from the main pole it stopped, and made the sketching artist's task an easy one.

\section{LARGE-EARED MAKIS.}

$A$ well-known species of the Half-Monkey tribe is the Largeeared Maki or Galago, which older travelers have frequently described. Their sense of hearing is most acute, as might be concluded from their large, membranous ears. The body of the Galago is slim, but does not look so, for the coat of fur is thick. The proportionally large head shows abnornilly developed ears that are destitute of hair. The large eyes are placed close together; the limbs are of moderate length; the hands and feet are well formed; the index finger and second toe, and in some the adjoining finger and toc, are furnished witl a claw; the others have flat nails. 
All the Galagos, which are inhabitants of Africa and some of its islands, must be looked upon as carnivorous, unlike the other Makis, for they eat fruit but incidentally. To describe them, I will draw on my own and Kersten's experience: "The Galagos are nocturnal animals, in the full sense of the word : beings for whom the moon takes the place of the sun, and for whom day passes unnoticed; for then these animals lie curled up and sleeping in some hiding-place, their eyes shut to the hated sunlight and their ears furled up to shut out all noise. If they are rudely awakened, their eyes first assume a dreamy, far off look, then the creatures gradually regain consciousness and show their displeasure at having been disturbed. After sunset they are altogether different. As soon as the forest is enveloped in darkness, the Galago wakes up, roused perhaps by the coolness of the air ; the tail which has been curled around his head is rolled back, the eyes are opened and his ears, which have been so folded as to completely cover the orifice leading into the inner ęar, are unfurled. He licks and cleans his fur, leaves his hole and begins his ghostly work, which, when its results are reviewed in the day-time, is seen to consist of nothing but murder and robbery, marked not only by insatiable thirst for blood but also by a degree of cruelty rarely to be found in animals. IV ith all the characteristics of a beast of prey, Lynx-eyed, sharp of hearing like a Bat, as acute in his sense of smell as a Fox, and quite as cunning though not so clever as that animal, agile like a Monkey, increasing the infallible precision of his attack by his boldness, the Galago is a formidable foe for all very little animals, therein differing from all his relatives."

These words narrate

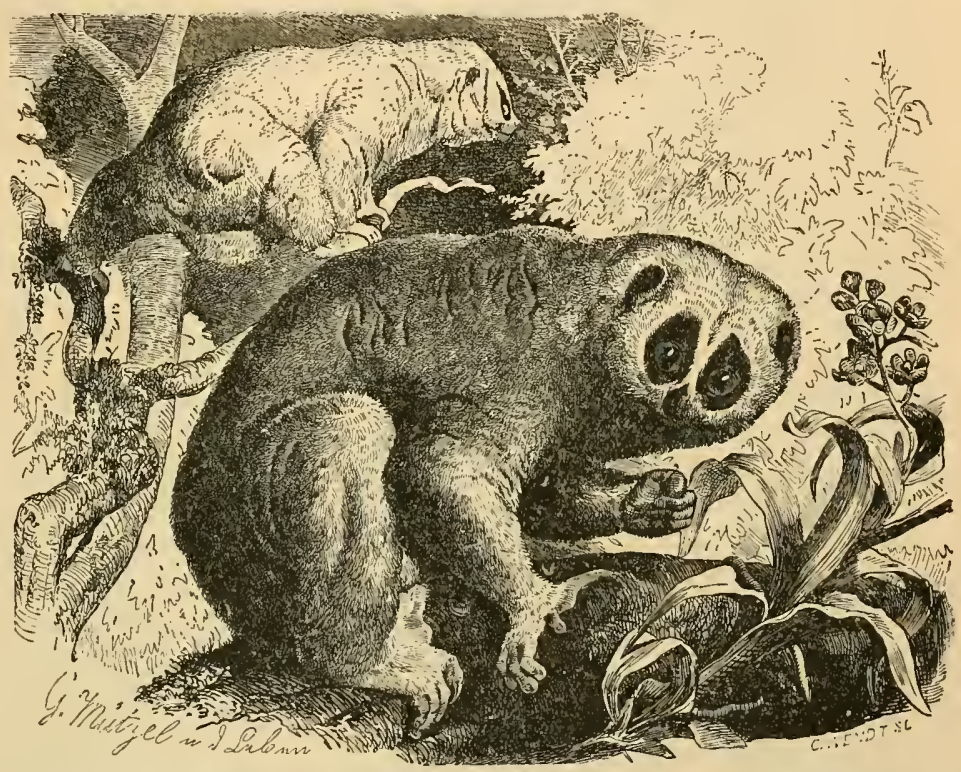

SLOW LORIS LEMOR. - This peculiar animal, which is also known as "Bashful Billy," is chubby and ponderous, as the picture shows, its large and heavy limbs making its movements so sluggish as to fully justify its name of "Slow." The brown rings that always surround its large eyes are well brought out in the picture, and the figure in the background shows the stumpy tail. scarcely an inch long. (Stcnofs tardigradus.)
Their belief is that he was originally a Monkey, but ways found him in mimosa forests, usually in couples. The animals we saw were sleeping on branches near the trunk, and always awoke at the sound of our footsteps. When we came too near, they dexterously climbed up the tree, never fleeing, but always sitting down and watching us with a certain degree of confidence as to their safety. They knew admirably, how to avoid the many sharp thorns of the nimosas, and they could leap considerable distances. We were told that at night they were very agile, and that then their eyes blazed "like living fire," to use the expression of the natives. It is said that the Common Galagos can be easily caught in traps ; and during the day-time good climbers need only use their hands to make the capture. The hunter only
has to shake the bough upon which the animal is became degraded through his sleepiness. We al- nearly everything that is known about the life of the Galagos in the wild state, and it will not be easy to learn more, as they are extremely difficult to observe in the night.

Accounts of Among the few known species of
the Common the Large-eared Makis, the largest
Galago. smallest barely exceeding the average Mouse, we will first consider the Common Galago (Otolicmus galago), a graceful animal, about the size of a Squirrel. His upper parts are gray, the under parts yellowish-white; the ears are flesh-colored and the eyes brown.

This species of Galago is a native of a large part of Africa. Adanson discovered him in Senegambia and later travelers observed him in South Africa and the Soudan. In this latter country I found him myself, but always to the west of the White Nile. The natives know him well under the name of Tendj. 
the above-mentioned traveler tells us, "the Comba not infrequently invites himself to partake of the feast. He drinks and experiences the truth of the saying, that an excess of spirits fogs the spirits. For the wonderful liquid streaming from the palm's crown is not only sweet, but also intoxicating, and

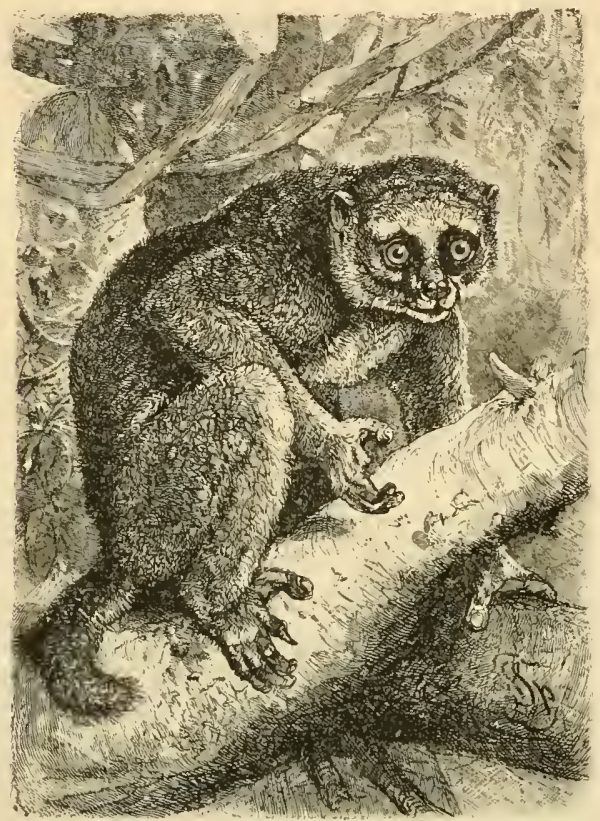

POTTO LEMUR, - This is a small animal, its body being only six inches long, and as the picture shows, has a short, stumpy tail and very small ears. Like other nocturna! animals its eyes are very prominent. it inhabits the West Coast of Africa and lives on fruits. (Peroducticus potto.)

gets more so the longer it remains exposed to the air. The thirsty guest loses consciousness, tumbles down from the tree upon which his hold is usually so secure, and lies on the ground, sleeping off the effects of his debauch. The Negro who comes the next morning to collect the palm wine that has flown out, finds the still unconscious dreamer, and either puts him in some improvised cage, or secures him with a rope fastened around the loins. The next day he brings him to town and offers him to some European, who regards the animal as a great prize. In the course of time he abundantly repays the trouble he gives while being tamed. In a room which harbors a Comba, there is no comfortable living for a Mouse. The room or ship he inhabits is also sure to get rid of the troublesome Cockroaches. We recollect with pleasure an experience we had on a tedious journey. Our ship was infested with Cockroaches, and this made the oeeasional unpacking of our trunks a necessity. As soon as the trunk was opened, the odor of these insects would attract our tame Comba. Though the time of day did not suit him for exploits of this kind, he carefully examined the contents of the trunk, and soon proved to us that he knew very well what was expected of him. He had ample scope for the display of his peculiar talents in looking after the disturbed army of Cockroaches. With surprising dexterity and lightninglike rapidity he made dashes at either a full-grown
Roach, or at a larva, and while one hand held the one he was chewing to his mouth, the other was hunting new game. In this way he kept on searching, working and eating till he completed his task."

\section{Tbe Tarsier.}

\section{SECOND FAMILY: TARSIDE.}

Another little animal, the Tarsier, has, with just cause, been made the representative of a distinct species. It has a large, round head, set close on the shoulders, a frog-like face, short fore-limbs and long hinder paws, and a tail surpassing the body in length. Its teeth resemble those of the Insectivora or Insect-eating animals. The name Tarsier (Tarsidte $)$ is derived from the animal's very long tarsus, or ankle-bones. By various naturalists it has been classed with the Mice, with the Marsupialia, or pouch-bearing animals, and with the Lemurs. Only one, or, at most, two families belonging to this group have yet been discovered, and these general characteristics apply to both.

The Spectre Tarsier (Tarsizs spectmm) attains a length of about seventeen inches, including the tail which is about ten inches long. The fur is brownish

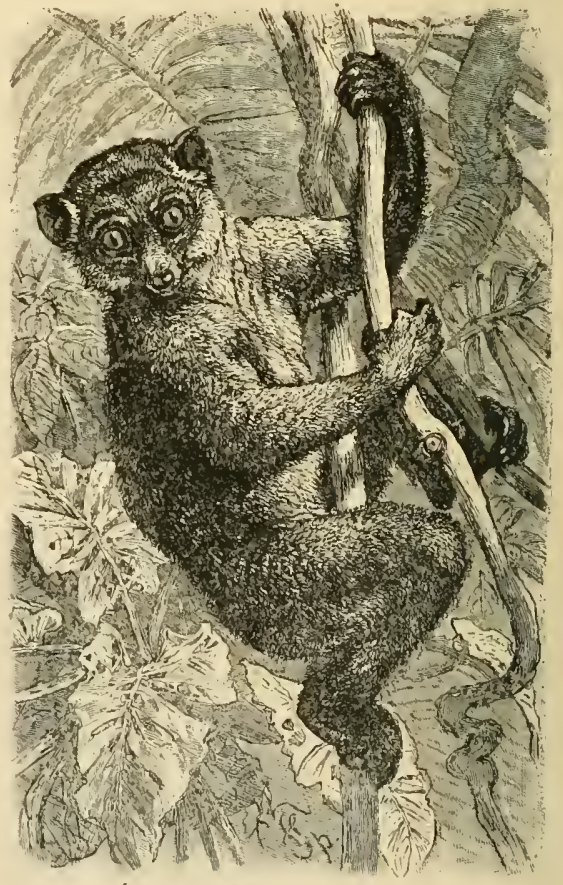

ANGWANTIBO LEMUR.-This is a small, symmetrica! animal resembling the Potto in some respects but having smaller hands and feet and only a rudimentary tail, and its ears are proportionately larger than those of the Potto. It is found in Cala-
bar, on the West Coast of Africa, and is very rare. (Aritocebus calabarcusis.)

gray, the ears are bald and the eyes are proportionately the largest of any mammal. Its finger-tips are provided with pads. The Spectre Tarsicr lives in the Malay Archipelago and is by no means common. 
The natives regard him as an enchanted animal and stand in great awe of him.

Jagor tells us about his captive Tarsiers as follows: "I lhad the opportunity of purehasing two Spectre Tarsiers. I was assured in Luzon, that these strange, pretty little animals inhabited only Samar.

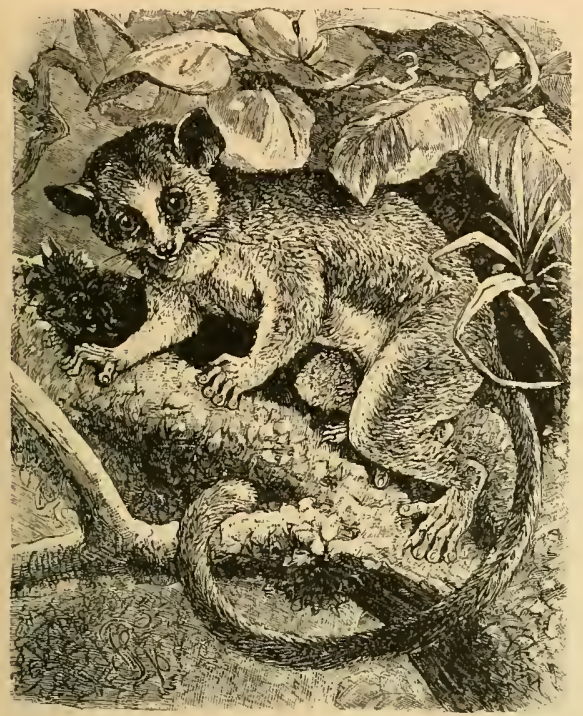

LITTLE GALAGO LEMUR.-This little creature is a native of Madagascar. Its well-formed head and ears, long tail and symmetrical limbs, of which the hinder ones are the longest, are brought out in the picture. It accumulates fat around its tail and in different parts of its body upon which it subsists durmg the dry season, when it coils itself up in a hole in a tree and practically hibernates. (M/iit coils itself up in a

My first pet had to go hungry for some time, as he scorned vegetable food, and I could not procure Grasshoppers at once. He looked very funny when I used to feed him. He would then stand on his two long, thin legs and his tail, and turn his round head, furnished with two huge yellow eyes, first one way, then another, looking for all the world like a lantern on a tripod. By degrees he would succeed in focusing his eyes on the proffered object; then would stretch out his arms like a child, quickly seize his prey and deliberately devour it.

In the daytime he was sleepy, dull and cross when disturbed; at dusk he awakened and his pupils dilated. At night he moved about noiselessly and rapidly, and generally sideways. He was easily tamed but died soon after I got him. A second pet of the same group also lived but a short time.

\section{$\widetilde{T b c} \tilde{E} p c=\tilde{E} p c$.}

THIRD FAMILY: LEPTODACTYLA.

About a hundred years ago the traveler Sonnerat received two animals from the western coast of Madagascar, animals of whose existence nobody had as yet been aware. Even on the opposite coast they were entirely unknown; at least the natives assured Sonnerat that they had never seen such creatures. They exhibited great astonishment and their exclamation, "Ayc, Aye?" was the name the naturalist chose for lis newly-discovered aninals.
The Aye-Aye brought to Europe by Sonnerat remained for a long time the only known specimen, and his description, dated 1782 , was the only source of information about the rare animal. Naturalists had begun to think the species had died out, when De Castelle proved the contrary in 1844 . This traveler had the opportunity of procuring a living young Aye-Aye, whieh he did, and he destined it for the Parisian Jardin des Plantes. Unfortunately the animal died before reaching Europe, but its skin and skeleton came into the possession of the Parisian Museum, and it was proved that it belonged to the same family as Sonnerat's Aye-Aye. The two specimens were the only ones known till I862. Then the Zoological Society of London received the glad news that two "Barefingered Animals" (Lcptodacty $(a)$ - that was the name science had given then in the meantime-had been caught in Madagascar and were on their way to Regent's Park. One of then reached the Zoological Gardens alive, the other in alcohol. Later a few more specimens followed, three of which were purchased by the Berlin Museum.

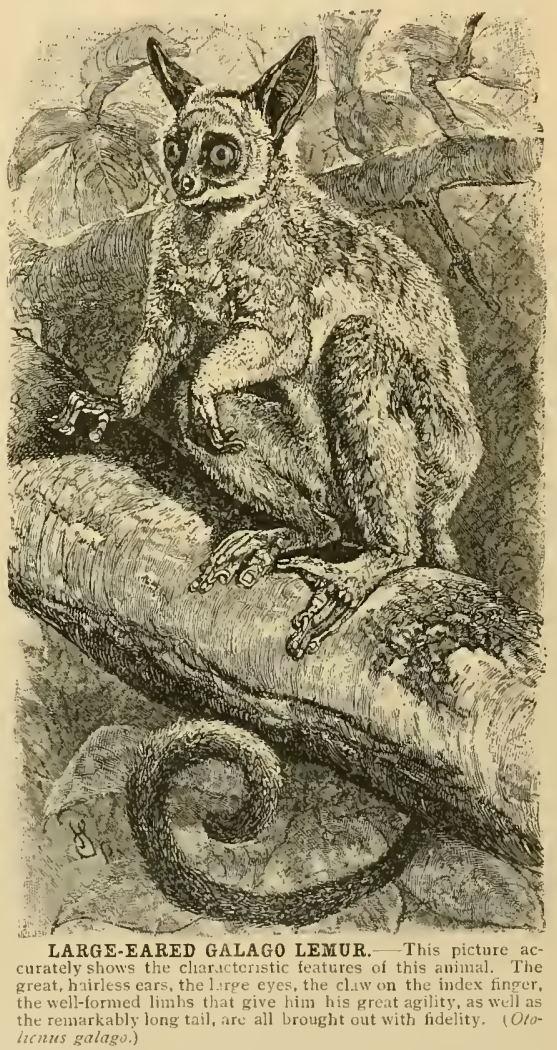

Then it was that naturalists were enabled to properly classify the Aye-Aye and give it a fixed position in their systems.

The Aye-Aye a Since the researches of Owen and Distinct Group of Peters the Aye-Aye (Chiromy's matthe Half-Monkeys. agasiariensis) has been regarded as forming a distinct group by itself among the HalfMonkey's. 
I had the opportunity of observing the Aye-Aye in London, though unfortunately but for a single evening. Yet I saw that Sonnerat's description requires not only additional details but correction. I will, therefore, give here an account of my own experiences and of what the keepers told me. a noticeable extent. It reminds one a little of the Galagos, but a naturalist would hardly think of classifying it with them. The thick, broad head, with its large ears, making it appear still wider;
The animal really resembles no one mammal to

able hands with their withered middle finger-all these peculiarities give the animal so strange an appearance that one vainly cudgels one's brains in the effort to classify it with creatures resembling it. Night is Day A cursory glance at the Aye-Aye is to the sufficient to tell the naturalist that he is Aye-Aye. dealing with a nocturnal animal. The Aye-Aye is more afraid of light than any mammal of which 1 know anything. A Half-Monkey can be awakened at least; he gropes around, looks wonderingly at the world in daylight, takes some interest

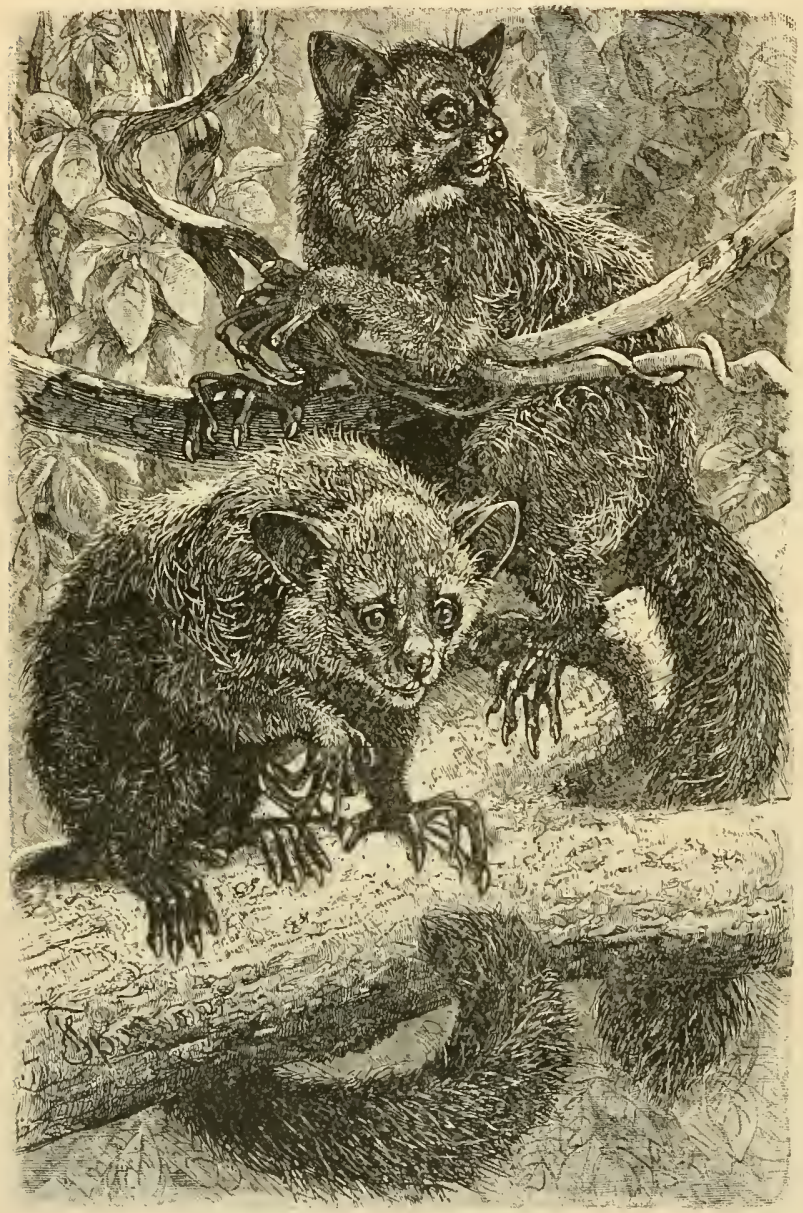
in a Beetle humming near by, even licks and strokes his fur; but when the AyeAye has been awakened in the daytime with a great deal of trouble, he seems to be perfectly absent in spirit. Mechanically he drags himself back into his dark corner, curls himself up, and covers his face with his thick tail, which he rolls around his head like a ring. Every movement, every action of this animal shows a laziness that is unequaled. Only in full darkness, long after sunset, does he creep out, evidently still laboring under the fear that a glimner of light might shine on him. The light of a candle, which passes unnoticed by all other nocturnal animals, makes hin beat a hasty retreat.

Personal If Sonnerat is correct in Observations of his description, he must the Aye-Aye, have had to deal with an exceptionally sweet-tempered AyeAye. The one I saw was anything but good-natured; on the contrary, he was an irritable, unsympathetic fellow. When he was approached, he spit like a Cat; when one held out one's hand he made a dash for it, uttering the same spiteful sound.

The only food the Aye-Aye in London gets is new milk, with the boiled and grated yelk of an egg stirred in. A little dishful is sufficient for his daily sustenance. He uses both his hands in eating; and with them he throws the liquid into his mouth. So far he has refused to eat meat.

These few facts I noted down in 1863 , and will now give the observations of Pollen, dated 1868 , as they afford a few particulars about the Aye-Aye in his wild state, He says : "This animal, so interesting to science, has a predilection for the bamboo forests in the inner parts of the large island. It feeds on the marrow of the bamboo and sugarcane, but also on Beetles and their larva. To get at the food, it gnaws an aperture in the stem of the plant, inserts its slender middle finger and scoops out the marrow or the insects it may contain. Its sleepiness by day equals its activity by night. From sundawn it from all others of that order, is the most peculiar known to naturalists. The picture shows from all others of that order, is the most peculiar knosyn to naturalists. The picture shows
many of its oddities-the long, sprawling fingers, all except the thumb having pointed claws many of its oddities - the long, sprawling fingers, all except the thumb having pointed claws
(the third finger being especially long), the loose straggling outer fur that covers a woolly undercoat, the large, naked ears, the long bushy tail, and even the rat-like teeth, are vividly portrayed. (Chtromy's madagascariensis.)

the small, fixed, stirring, glowing eyes, with a pupil smaller than that of any nocturnal Monkey; the mouth, which shows a certain likeness to a Parrot's beak, the considerable size of the body and the long tail, which, like the body, is clothed scantily with long, stiff, bristle-like hair, and, lastly, the remark- sleeps, hiding its head between its legs, and curling its tail around it. At night it climbs and jumps, investigating all crevices and openings in old trees in its search for food, and retires before daybreak. Its cry is a loud grunt, and is frequently heard during the night. 


\title{
The Tâing=ilbanded Inímals.
}

\author{
THIRD ORDER: CHIROPTERA.
}

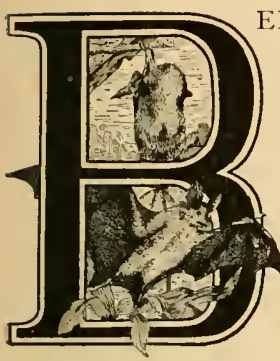

EFORE the setting of the sun on any beautiful summer day, some members of this remarkable order of animals begin their weird activity. Out of crevices and dark hollows creeps the strange, gloomy army of Bats, which has been hidden during the day as if it had reasons of its own for shunning the light, and sets out on its nightly travels. As the darkness becones more dense the number of these enigmatical beings increases until at midnight all have emerged and are flying hither and thither through the air.

Bats Inhabit The more closely we approach the torWarm rid zone, the greater is the number of Climates. Bats, and the richer their variety. The South is the native country of the majority of Winghanded Animals. Even in Italy, Greece and Spain the number of Bats is surprising. There, as evening draws nigh, they come out of their nooks and corners not by hundreds, but by thousands. Out of every house, every old stone wall, every rocky hollow they flutter, as if a great army was preparing for a parade, and the entire horizon is literally filled with them. The swarms of Bats one sees in a hot country are astonishing. It is extremely interesting to spend an evening outside the gates of a city in the Orient where the Bats literally darken the sky. One soon ceases to count them, for in every direction multitudes are fluttering through the air. Everywhere there is a living and moving mass flying through the trees of gardens and groves, fluttering over the felds, some low, others at a considerable height. Through the streets of the town, through houses and rooms flits the moving train. Hundreds are constantly appearing and disappearing and one is always surrounded by a hovering swarm.

PrincipalCharacteris- The IVing-handed Animals are tics of the Wing- mainly distinguished by their bodHanded Animals. ily shape. Almost uniformly they have a "stocky" trunk, a short neck and a thick, oblong head, with a wide mouth. In general structure they correspond nearest with the Monkeys, and, like the latter, have two mamme, but are totally different in every other respect. Their hands have to serve them as wings and are therefore enormously enlarged, while the trunk is of small size. Thus they give the impression of great size, while in reality they are among the smallest of mammals. The interior structure likewise shows characteristic peculiarities. The slieleton is light, but strong, the bones never contain air cavities, like those of birds. The formation of their hands is most peculiar, the arm, the fore-arm and the fingers being greatly elongated, especially the last three fingers, which exceed the arm in length. This arrangement renders them fit for the attachment of the flying membrane, but incapable of other service. The thumb, which stands outside the membrane, resembles the fingers of other mammals; it is short, has two joints, and is furnished with a strong claw, which is supposed to do duty for the whole hand in climbing and when the animal suspends itself. The thigh-bones are much shorter and weaker than the bones of the arm, the bones of the hinder limb in general being much inferior to those of the fore-limb. Their formation is

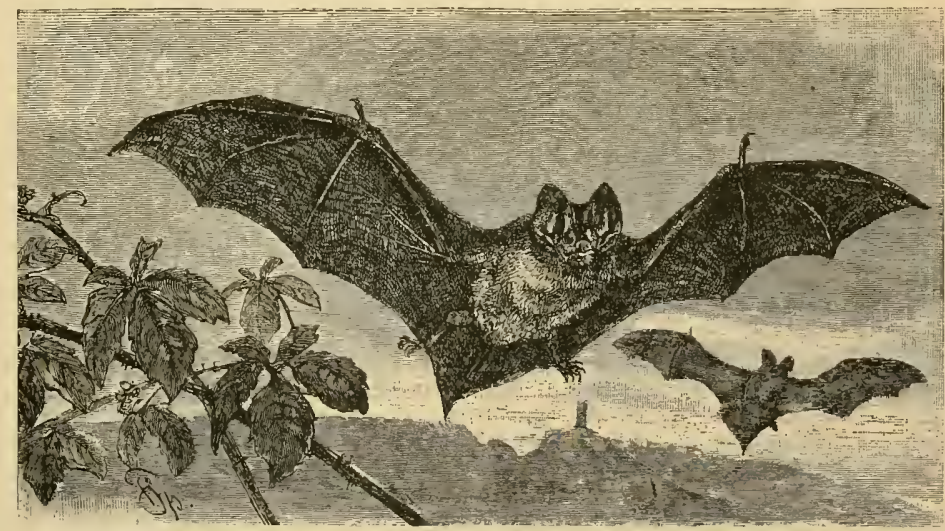

BARBASTELLE, OR PUG-DOG BAT.-When the evening comeş the Pug-Dog Bats flutter out in busy search for small Butterfies, upon which errand those in the picture are best, their sharp eyes looking eagerly about for these insects. They live in various parts of Europe and are numerous in the country of the Alps, where they or these insects. They live in various parts of Europe and

regular ; the foot is divided into five toes, and these have claws. A striking peculiarity pertains to the foot: a bone projecting from the heel and called the "spur." This bone is found only in Bats, and is used to stretch the membrane between the leg and the tail. The breast muscles are exceedingly strong, and possess one muscle that is lacking in other mammals, this being inserted into the back of the head on one side and into the hand on the other, serving to stretch the wings. The teeth re- 
semble those of the insect-eating animals, having all the various kinds in closed rows; but the number and shape vary greatly.

Some Pronounced The most pronounced of ail the
Peculiarities peculiarities is the skin, changing as
of Bats. it does the whole shape of the body as well as the expression of the face, sonetimes giving the latter a really monstrous appearance. The wide open mouth contributes to the repulsiveness; but the excrescences of the skin on the ears and nose really give the face its uncanny appearance and complete its extreme ugliness.

"No other group of animals," says Blasius, "shows such a development of the shin. I refer not only to the flying membranes but also to the ear and nose. The ears attain in all these families a striking growth. Their length in some kinds is nearly equal to that of the body: in width some show an extension of both ears into one. In some kinds the parts adjoining the nostrils and the crest of the nose show the most abnormal growth, and the results are faces such as we should be able to find nowhere else in the world. The strange development of the skin in the wings, ear and nose differs from that of all other animals and seems to regulate the movenents and mode of living of the Bats, even in details."

Features A feature of the wings, which has but of a lately been discovered, is a highly Bat's Wings. elastic, or, rather, contractile layer of skin. The outer layer is constantly kept pliable by anointings with an oily liquid, secreted by glands in the animal's face. The structure of the hair in Bats is also remarkable, as each thread presents a screw-like appearance under the microscope. The purpose of this arrangement seems to be the better retention of heat.

The Senses of the The senses of Wing-handed Ani-
Wing-handed mals are excellent, but developed
Animals. Some organs of sense show strange enlargements and appendages. The sense of taste is probably the least acute ; yet it cannot be called dull, judging from the structure of the tongue, the softness of the lips and the rich supply of nerves in both. Besides, this sense has been experimented on and proved to be acute. If one, for instance, puts a drop of water in the open mouth of a sleeping Bat, it will immediately swallow it; but if brandy, ink or some other illtasting liquid be given, it will cast out the draught. The eye is no less developed. In proportion to the size of the body, it is small, but the pupil is capable of considerable dilation. Some kinds have especially small eyes; and Koch calls attention to the fact that they are sometimes so hidden behind the hair of the face that they cannot be used for the purpose of seeing. These small-eyed animals are such as one sometimes sees flying about in the daytime, while the real, nocturnal Bats have larger eyes, lying quite free and unobstructed. let the eye may be destroyed without damaging its owner to any great extent. The sense of sight is supplemented greatly by the sense of hearing, of smcll and of touch. Bats have frequently been blindfolded by sticking a piece of court-plaster over their eyes; yet they flew about the room just as usual, avoiding in a dexterous manner obstacles placed in their path, such as strings stretched across the room, etc. The sense of touch may have its seat in the wings ; at least, this is the conclusion that has been reached after long and frequent observations. The senses of smell and hearing are very well developed.
The nose is perfect in all genuine Bats ; for not only can the nostrils be dilated, narrowed or entirely closed by special muscles, but the animais also possess large, leaf-like appendages, whose only use can be that of increasing the sense of smell. The ear, perfected in a similar manner, consists of a large shell, often extending to the corner of the mouth, provided with leaf-like expansions and extremely mobile. There is besides, a large flap, which may vary in shape, and which, if a noise be too loud, may be closed and thus spare its owner the pain of listening; while in very slight noises it serves to catch and increase the volume of the sound waves. It is doubtless true that the Bat may hear insects fly within a limited area, and that it is guided, to some extent, by the ear in its flight. If one cuts the leaflike appendages off, or the lobes or ear-flaps, the Bat gets confused and knocks against obstacles.

The The intellect of the Bats is by no Intelligence means as low as is commonly supposed, of Bats. and the creature gives the lie to the stupid expression of its face. The brain is large and has some convolutions, which alone indicates that its intelligence cannot be small. All Bats are distinguished by a rather high degree of memory and some by the presence of reasoning powers.

Kolenati tells us that a Bat, hunting in an avenue of linden trees, spared a femaic Butterfly, because she attracted a great many males of her kind, thus proving a lure for the game. If one tries to angle for Bats by using Butterflies on hooks, his labor is lost. They will approach and look at the hovering insect, but soon discover the fine tackle, and leave the temptation untouched, even if food is very scarce and they are hungry. It has been demonstrated frequently that Bats may be tamed and become strongly attached to their masters. A number of naturalists have trained their pets to take food from their hands or search for it in a glass. My. brother tamed a Long-eared Bat to such a degree that it followed him all over the house, and when he offered it a Fly, it instantly hastened to sit in his hand and take the morsel. The larger Bats are really possessed of amiable, social qualities; they become very tame and in many ways prove themselves very sensible.

About Blasius says: "The capacity for, and the the way special manner of, flying depends on the Bats Fly. shape of the wings. Whoever has studied Bats in nature, must have observed how the rapidity and agility of certain species correspond to the shapes of their wings. Those that have these members longest and slenderest fly highest and boldest; they can make the most varied and often sudden turnings, and are so confident that they will brave storms and winds, As a rulc the wing in flying describes but a small, acute angle, it being only at sudden turns that it takes a wider scope, while the flight is manifold and rapid with small wingmovements and apparently little exertion.

"The Vespertilio and Rhinolophus are the poorest flyers of all the liats. Comparing them with others, it will be found that their wings are the broadest and shortest; they describe a large, and in most cases. obtuse angle. Their flight is fluttering, slow and uncertain. Generally they fly low and in a straight direction, without quick turns or side-novements. fome seem to fairly skim the ground or water, flying but a few inches aborc it.

"It is not difficult to guess the gents from the height and manner of flight and the size of the 
animal; and one cannot err in determining the readiness and manner of flight after looking at the construction of the wings.

In general the flight of Wing-handed Animals is by short stages rather than by sustained motion. It the body. The strong breast muscles, the light lower part of the body, the elongation of arms and hands which sometimes reach three times the length of the body, and, lastly, the flying membrane itself, are all conducive to this mode of locomotion. Soar.

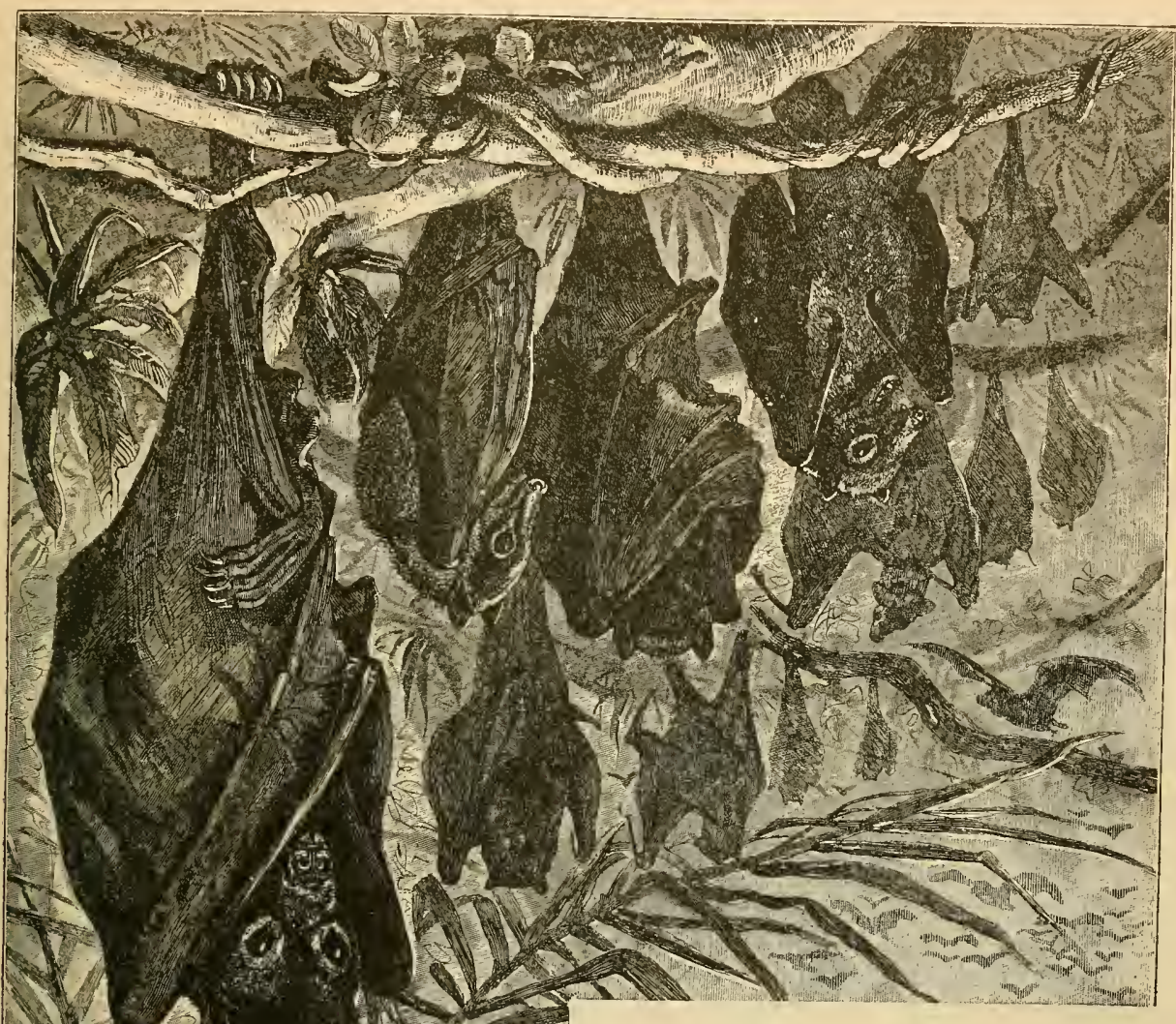

ing is impossible, for none of the bones of the Bat are filled with air, the body does not contain the large air cavities of the bird, and, which is the chief reason, the Bat does not possess the strong feathers that are used to give impulse and guide the course. Its flight is a constant beating of the air and never a long shooting or gliding about without motion of the wings. In order to be able to stretch their membrane and readily and quickly take to flight, all Bats while in repose hook the claws of their hind paws into some lofty place, and suspend thenselves from it, heads downward.

It must be said that their hands are not only used in flying, but also in running on the level ground. Their walk is not really so bad as one might be led to suppose : still, it is nothing but a wretched hobbling along. A few species make an exception to this rule and run nearly as fast as a Rat.

Peculiar Habits All Bats sleep by day and fly about and Character at night. The majority make their istics of Bats. appearance at dusk and retire to their hiding places long before dawn; some species come out between three and five o'clock in the afternoon and flicker merrily about in spite of the brightest sunshine.

is produced by a constant movement of the arms While the bird can soar, the Bat can only flutter Its fluttering is greatly promoted by the structure of 
Every kind has its own hunting-grounds in forests, orchards, avenues and streets, over stagnant or slowly-flowing water surfaces, etc. It is rare that Bats fly over open fields, for the simple reason that there is no game for them. In the fertile South they also haunt maize and rice ficlds, for these always harbor a great many insects, which are their lawful prey. Their hunting ground will not usually cover an area greater than a thousand feet; although some larger species might perhaps go one mile, and the prominent tropical species may fly over much greater distances, as they have been known to travel from one island to another several miles a part.

The Bats are gregarious, but only under certain conditions. There are species that are hostile to, and occasionally make a meal of each other. Bloodsucking Vampires will attack Long-eared Bats for the purpose of sucking their blood, and the latter will avenge the wrong by eating their assailants.

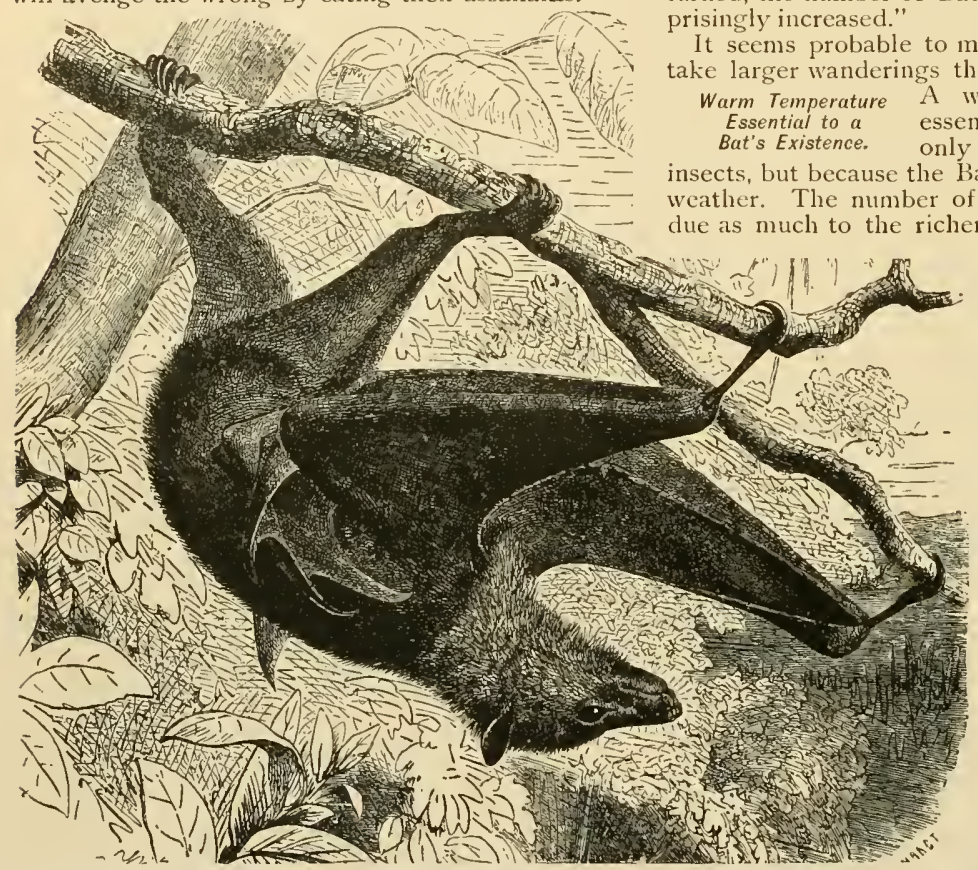

THE KALONG BAT. - This picture shows the great Kalong stalking out upon the branch of a tree in quest of truit of which it is so fond, the position being that always assumed by the Sloth. The great " spurs " of the creature are clearly shown as well as its gentle eye and small ear. The Kalong is gregarious and always moves in great swarms. (Pteropus edulis.)

The food of Bats consists of fruit, insects, small vertebrata, and blood sucked from larger animals. The Bats of Europe feed only on insects, especially Night-butterflies, Beetles, Flies and Mosquitoes. Their greed is exceptional, the larger ones devouring with ease a dozen Bectles, and the smallest ones eating several dozen Flies without having their hunger satisfied. The more active they are, the more food they require, and for this reason are exceedingly useful animals, meriting the favor of Man for ridding the world of so many pests. Of course such is not the case with Blood-sucling Bats, which may do a great deal of harm, nor with Fruit-eating Bats, which sometimes destroy orchards and vineyards.
Heuglin observed that African Bats followed herds of Cattle in their search for food. He says: "In the Bogos country there are a great many Cattle, and the herds will sometimes, in their search for good pasturage and water, remain from home for months. When we arrived at Keeren, all the horned beasts had gone into the valleys of Barka and myriads of Flies accompanied them. There were then but few Bats around Keeren, but at the close of the rainy season all the herds belonging to our Bogos were brought in and in their wake appeared incredible numbers of insectivorous Bats. When the last herd departed the Bats also disappeared. One night in the beginning of October we camped out on a plain, three miles from Keeren, near the fencedin places destined for Cattle. The animals then being in the mountains, we saw but one or two Bats, but on the following day when the herds had returned, the number of Bats toward evering had sur(t)

bering to the that all the bats under-

Warm Temperature A warm temperature is an Essential to a essential condition to Bats, not only because heat gives life to insects, but because the Bats themselves dislike cold weather. The number of Bats in warm climates is due as much to the richer insect life there as to the fact that the warmer atmosphere is conducive to their greater development. Most species stay in their hiding-places when the weather is cold, rainy or windy; others do go out on cold evenings, but for a short time only. WVe must also consider the circumstance that on cold evenings their flying about is to no purpose, as the insects likewise keep in hiding ; and, besides, wind makes flying very difficult to all but the Narrowwinged Bats.

On the approach of winter all Bats which do not migrate fall into a more or less sound sleep. They select for their hidingplace nooks or corners that are protected from the outside cold, as caverns, cellars, warm roofs, preferably places near chimneys, etc. Here one can find them in clusters, sometimes numbering hundreds, suspended by their hind legs and closely huddled together, in some cases different species being represented, but only such as are related to each other. It is very rare, indeed, that one finds two species together, which, in their active life, wage open war against each other. The heat of their blood sinks with the outer temperature, sometimes as low as four, or even one degree Reaumur, while the usual temperature is twenty-four degrees Reaumur. If the outer air gets so cold that the animals can no longer withstand it, they awake from their lethargy and begin to move about. Frequently they freeze to deatl, especially in captivity, when exposed to a very low temperature. II hile the cold 
weather lasts they remain in their pendant attitude, but on the warmer winter days sone species awake and fly about even in snow and thawing weather.

All Bats carry their young ones around with them when they fly, even when the little ones can use their wings fairly well and are able to temporarily

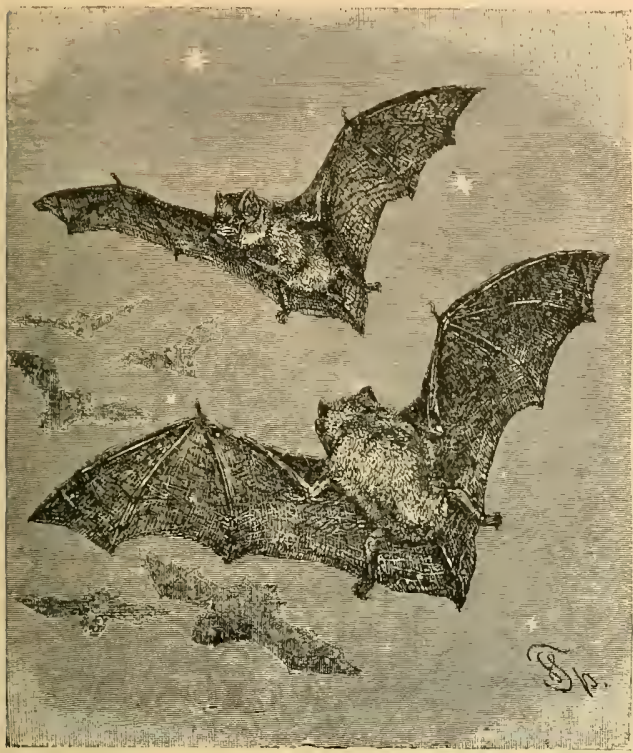

PIPISTRELLE BAT, - Out in the night in the light of the stars the little Pipistrelle busily llies, looking for such tiny insects as Gnats, Midges and other two-winged Flies, which form its food. This animal is found all over the British islands, temperate Europe and central Asia, and is of great usefulness in ridding those countries of the numerous little insect pests. (Vesperugo pisistrellus.)

leave their mother's breast. I have myself found young Bats hanging alone on trees in the virgin African forests. The young ones reach their full growth in from five to six weeks.

Strange Appear. The strange appearance and nocturance and Noctur- nal habits of the Bats have, since the

nal Habits. oldest times, given ample food for superstition, and the harmless animals still have to contend with the prejudice and antipathy of a large majority of people. We will not repeat the innumerable stories that have been told, many of which are still believed; but we wish to emphasize the claims of the Bats to consideration and good treatment. In our temperate climes they are all very useful, for they devour with great greed immense swarms of harmful insects. The few frugivorous Bats do not concern us in the least, neither do the blood-sucking Vampires, which latter, by the way, are not nearly so dangerous as they were once supposed to be. IVe may consider the whole class as a highly useful link in the chain of beings.

But Few The number of prehistoric IBats that Prehistoric has come to our knowledge is exceedBats. ingly small. Hair from these animals has been found in amber, and their petrified bones in stone quarries. There are about three hundred different species now living. The infinitely great differences in shape, in spite of superficial resemblance, render classification difficult, even for naturalists.

\section{fflving Dogs, or Jfuit=uEating JBats. FIRST DIVISION: PTEROPINA.}

The first grand division of the Bat family is formed by the Flying Dogs or Fruit-eating Bats, which may be again subdivided into two distinct groups, the first being the Flying Dogs proper (Pteropus), and the second group including the Night-Dogs (Cjnonyetcris).

All members of this family of Bats are found in the warmer countries of the Old World, especially in southern Asia, central and south Africa and Australia. Their large size is foundation for the many foolish tales which make of them living monsters. These harmless, good-natured animals have actually borne the reputation of being formidable Vampires, and people thought they saw in them those hideous creations of the imagination which attach themselves to sleeping human beings and suck their heart's blood.

Fruit-eaters have, in the main, a Bat-like shape, but their size is much larger than that of other members, and their head is that of a good-looking, sympathetic Dog or Fox; this having earned for them the name of Flying Dogs or Flying Foxes. The membrane, and consequently also the formation of the arms and legs, is similar to that of the other Bats; only that besides the thumb the index finger has a claw-shaped nail. The nose has no appendage, and the ears never show a flap. They are easily distinguished by their peculiarities from the remainder of the Bats.

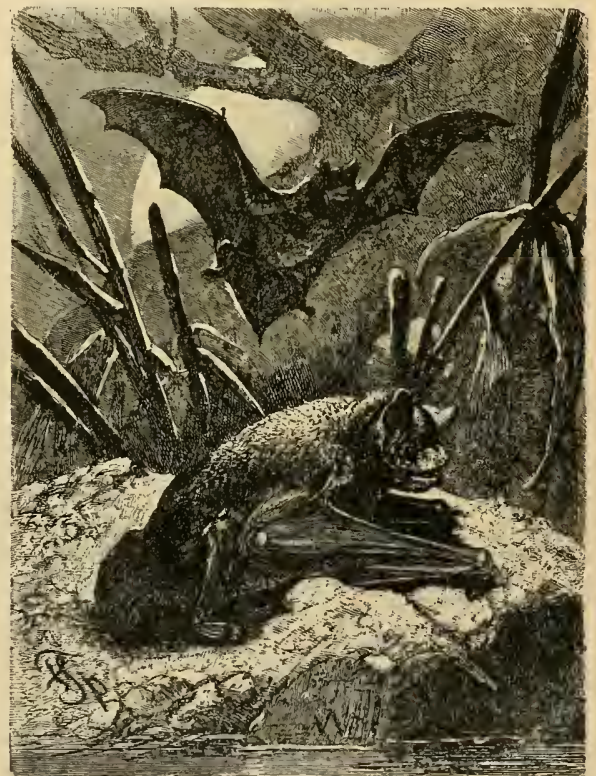

DAUBENTON'S BAT__ I tiny creature, but two inches long. I haunts church towers and other buildings in central Europe, and is always to be found near rivers and other bodies of water, where it easiest finds food at the gloaming and far into the night. As the artist represents it, it is an odd-looking and unhandsome animal, but useful because it destroys hurtfuh insects. (I'espertali daubentonii.)

Flying Dogs prefer dark woods for their haunts, and by day tenant the trees in large numbers, hanging in innumerable rows, wrapped up in thcir wings 
as in a cloak. One may find hundreds of them in hollow trees. They sometimes fly about during the day in gloomy virgin forests, although activity properly begins for them at dusk. Their keen vision and excellent scent direct them to trees possessing particularly juicy and ripe fruit; they come to it singly at first, but presently the swarm collects in large numbers and soon divests a tree of all its fruit. They often make raids upon vineyards, where they do great damage. They eat only the sweet, ripe fruit, leaving what is less developed for the other fruiteating animals. Sometimes they undertake migrations, flying from one island to another. They suck the fruit dry, rather than eat it; for they spit out the dry pulp. When they make a raid on an orchard they eat all through the night, making a noise that then about with her, bestowing upon them her tenderest care.

In captivity these Bats may be tamed and will then show a certain attachment for their keepers.

Because of their fruit-eating habits they do more harm than good; yet, in a country that is rich in fruit their devastations ought not to weigh heavily against them. Haacke finds that their flesh is delicate, and tastes like that of Rabbits and Chickens. Their fur is also sometimes uscd by the natives.

The Kalong, The largest of lie Fruit-eaters is the Largest of Kalong (Ptivopus edulis), his body Flying Dog Bats. being over fifteen inches long, while his spread of wings may be four feet, eight inches. His color is brown-black, the under parts assuming a russet tinge, much lighter than the upper portion.

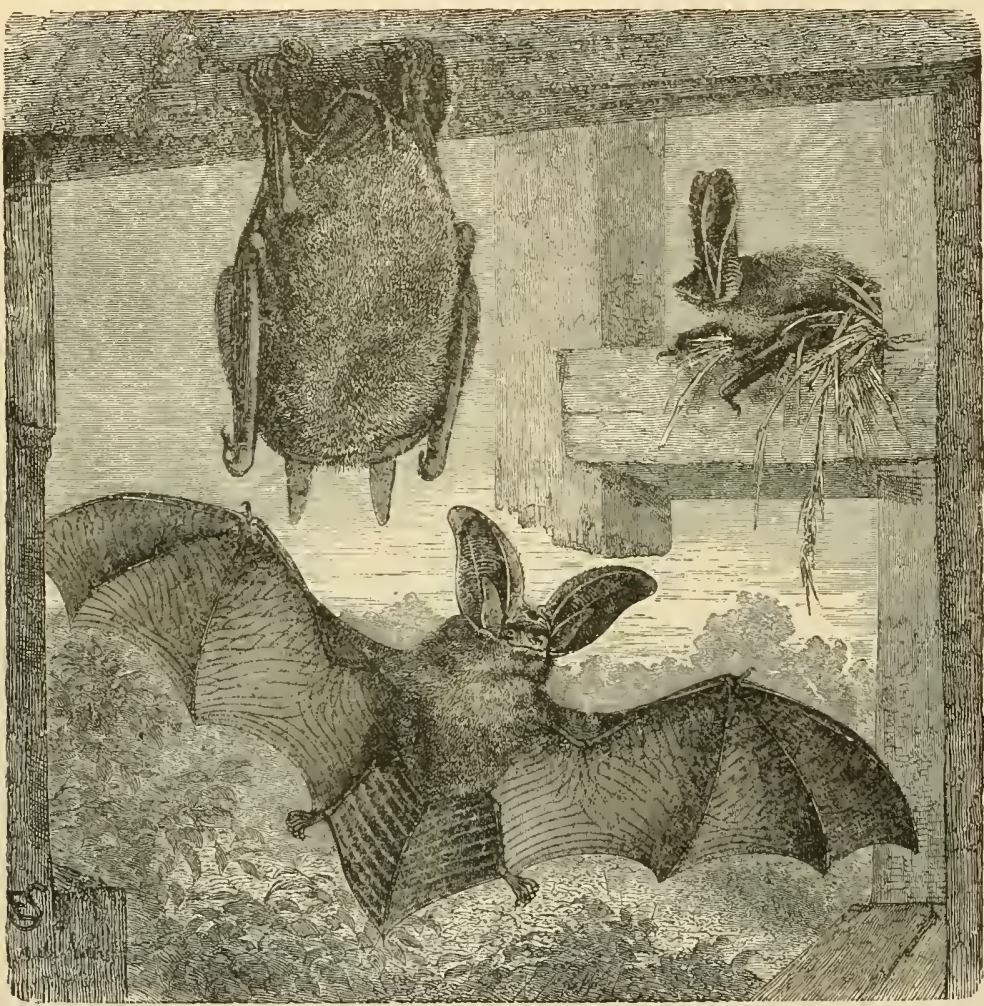

LONG-EARED BAT. - The picture presents these creatures, which are the common English Bat, although found in middle Europe and parts of Asia, in their favorite haunt, a great barn, and the nighty ears are strongly brought out in the flying and the crouching examples. These ears are nearly as long as the entire body. The nianne of sleeping is shown in the third animal, whose ears project far below the body although the head is well drawn up. (Plecotus auritus.)

may be heard at a considerable distance. The report of a gun does not disturb them, further than sometimes to cause them to flutter to an adjoining tree, where they resume their interrupted meal.

They scream a great cleal, even when movelessly suspended from the trees. Their voice has a peculiar creaky or shrieking sound and sometimes they hiss like geese.

The female gives birth to one or two young ones at a time, at intervals of a year. The infants attach themselves to their mother's breast, and she carries
The Kalong is a native of the Indian islands, especially Java, Sumatra, Band a and Timor ; living either in large forests or in the groves of $\mathrm{fruit}$ trees which surround all the Javanese villages, Occasionally these Bats cover the branches in such numbers as to conceal the bark. In the evening they a rouse from their sleep and flutter away, each flying a little distance from the other.

Rosenberg writes from Sumatra: "The Kalong is one of the commonest of animals, as well on the coast as in the depths of the island. These Bats live gregariously and fly in numerous flocks at sunset in search of food. During my stay at Lumut, a flock flew regularly by the little fort every evening, returning to its sleeping place before sunrise. I once fired a shot at a female flying rather low; a young one attached to her breast fell down, but before it could reach the ground the mother, which followed it with lightning-like rapidity, had caught it in her teeth, rose again in the air and hurried away with her little one."

The food of these Bats consists of all varieties of fruits, especially figs and mangoes, and they often do considerable mischief in the Javanese orchards. Yet they by no means confine themselves to regetable food, for they also hunt insects and small vertebrata. Shortt has, to his great surprise, seen them eating fish. "During my stay in Conlieveram," says he, "my attention was attracted by a little pond that owed its existence to a recent shower of rain. It swarmed with little fishes, playing in the water and 
pumping on the surface. The presence of fish in ponds that completely dry out and fill again during a shower, was not new to me; but my curiosity was aroused by a number of large creatures, fluttering rather clumsily over the water, until they succeeded in catching a fish, when they retired to a neighboring trec and devoured it. A closer investigation proved them to be Kalongs."

The Kalongs are hunted not so much because of the mischief they do, as for their flesh. In captivity they are easily tamed and kept. In the wild state they are very fastidious, eating only the juiciest of fruits, but when captive they are remarkably unexacting, eating any fruit that is offered to them and are also fond of meat.

Unfortunately they do not live long in captivity, in spite of the best of care. They can be given any privilege but the freedom of flying about. In
Old Flying Dogs of this genus attain a length of seven inches, their expanse of wing being thirty to thirty-five inches.

\section{The smooth=moscd TBats.}

\section{SECOND DIVISION: GyMnoRhina.}

This division of the Bat family comprises the Smooth-nosed Bats. The nose is smooth without any excreseence of the skin; but the inner part of the ear shows one small leaf-like appendage. In some species the ears are united by their inner margins over the crown of the head, in others this union is wanting. The nostrils in some open above the tip of the muzzle; in others below it. The family extends all over the globe, with the exception of the Arctic zone. The number of different species be-

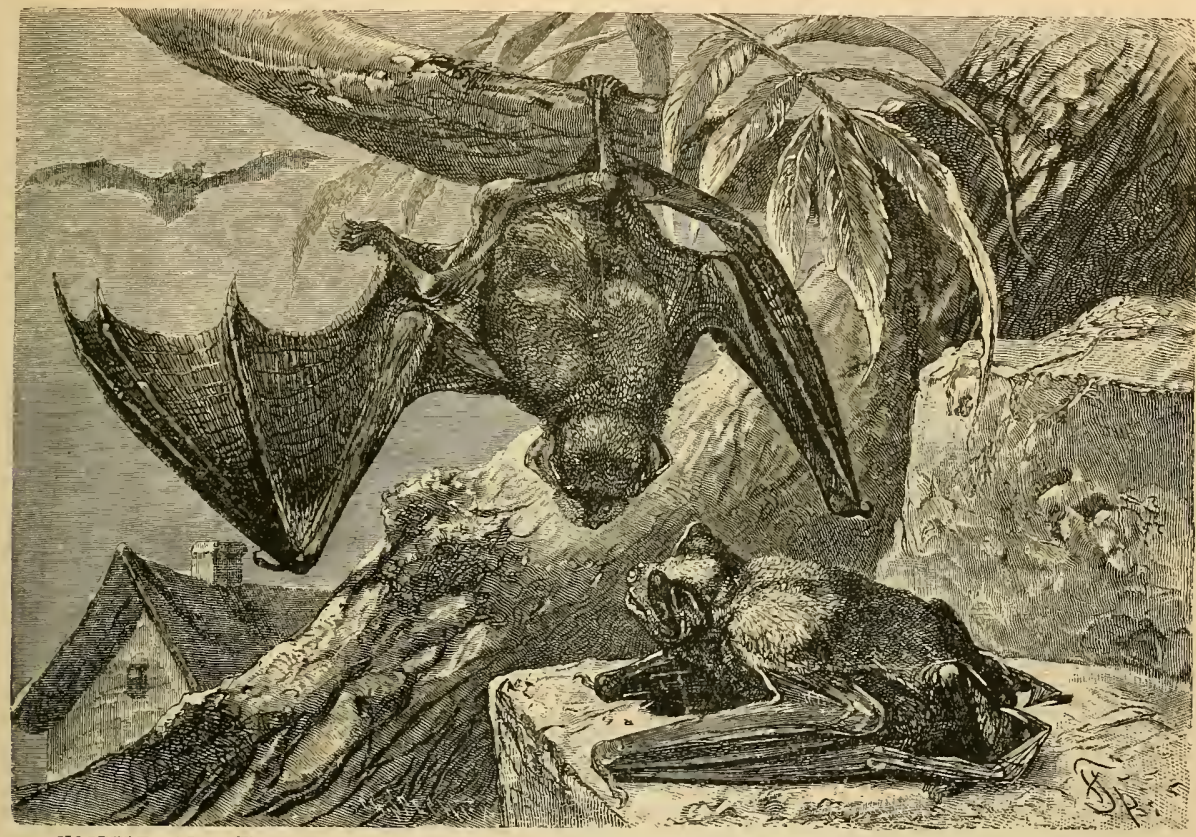

NOCTULE BAT. - This sketch accurately portrays the Noctules in the foreground at rest, while one in the distance is flying high in search of food. Although nocturnal animals they start out upon their hunts long before the setting of the sun. Bold and fearless they soar high

and are so active in their flight that the Falcon cannot capture them. How like a Frog is the crouching Bat in the foreground of the picture.
(Vesperugo noctula.)

consequence, sooner or later, abscesses form on their wings and finally cause their death.

Egyptian To the group Cynonycteris belongs

Flying-Dog the Egyptian Flying Dog (Cynoryctinis Bat. agyptiacus). It is spread all over Egypt and Nubia and is a regular frequenter of sycamore plantations. Some text-books say that it spends its days in the vaults of the pyramids. This is decidedly false, as it sleeps on trees like all its relatives.

The specimens I procured died in a short time. Other naturalists have been able to keep these Bats longer, and to train them to be very tame and familiar. Zelebor had a couple in Schoenbrunn, which he had taught to come to him instantly when he offered them a date, and which would submit to be stroked and petted by strangers. longing to this group is exceedingly large. The majority keep together in great swarms, especially during hibernation. One often finds hundreds and even thousands in one building. Many species live in perfect peace with each other and there are probably but very few of solitary habits. They are all sensitive to cold and retire early in autumn into their winter retreats, and do not make a reappearance until late in spring. Few fly about before dusk; the majority come out at the gloaming and remain only during the first hours of the night; at midnight they rest till the early hours of the morning, when they again resume their activity. Their flight is distinguished by strange zigzags, which make it impossible for birds of prey to catch then. Their attitude during sleep is the usual one; they run on the ground clumsily, but they climb 
with agility and quickness. They eat insects, only, and for the most part such as are very harmful to Man. They make a loud, whistling, chirping sound. The The Long-eared Bat (Plicotus auritus) Long-Eared cannot be mistaken for any other, beBat. cause of its long, large ears. It is one of the largest European Bats, measuring about four inches in length, its tail occupying about one and one-half inches, and the expanse of its wings being ten inches. The ears are more than two inches long, traversed by many furrows, and they curve bachwards. The inner margin of each is furnished with a tongue-like flap, and the entire ear is very mobile. The fur is brownish-gray, and the face is bordered with white hair. Young animals are darker than old ones.

The Long-eared Bat is distributed all over Europe, south from the sixtieth degree of latitude;

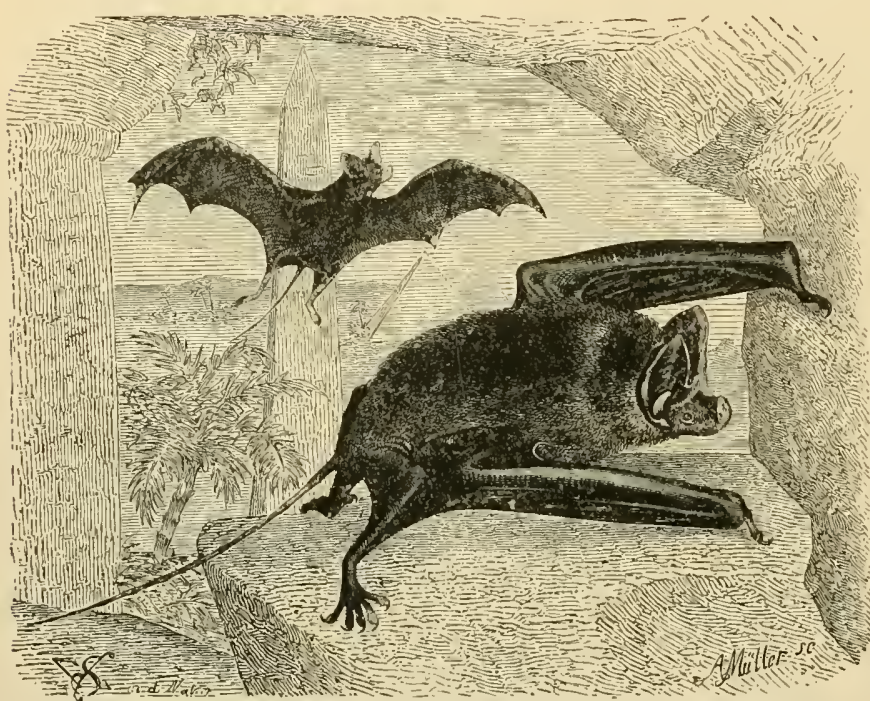

EGYPTIAN RHINOPOME. - What queer-looking creatures are here depicted, with their Hog like noses. great ears and long, Rat-like tails. They are African Bats and are found along the waters o the Nile, being fond of low places, and diligent hunters for food. (Rhmopoma microphyllum.)

and it has also been found in northern Africa, western Asia and the East Indies. It is very common, but lives singly, not in troops. It always keeps in the neighborhood of human dwellings, sleeping in summer as often in hollow trees as behind window-shutters, and in winter it visits cellars and basements as frequently as mines and quarries. In the city it likes squares grown with trees and shrubs, and, therefore, makes its appearance nearly always in rooms overlooking gardens.

Long-eared Bats bear captivity better than most of their relatives, and may live for montlis or even years, with very careful treatment. For this reason they are usually selected for the purpose of a study of the family in general. They may become more or less tame. Faber had one in his possession which he studied for several weeks. It was a very active little animal, especially at dusk, and often flew about in the day-time, but remained quict towards midnight. It could fly about in the rooms with the greatest ease, avoiding obstacles by whirring around then. It could climb upon the walls very well by the aid of its thumb. At the slightest noise it pricked up its ears, like a horse. In repose the ears were always folded back. It often turned its lread, licked itself with its tongue and sniffed. Like all Bats it suffered much from parasites, and often scratched its head with its nails.

The Mouse-colored The Mouse-colored or Common Bat or (I'espertilio mumims) inhabits all of Common Bat. eentral Europe, beginning with England, Denmark and middle Russia, southern Europe, northern Africa and the greatest part of Asia, up to the Himalaya Mountains. This is one of the largest of European Bats. It measures nearly five inches, two being occupicd by the tail, and the expanse of its wings is fifteen inches. Its upper part is light gray-brown, the lower a dingy white; young animals being lighter gray.

From March until October one is sure to see the Common Bat in localities favorable to its existence, and it is easily recognized by its flight, which, is clumsy and fluttering, but deroid of zigzag movements. It also lives in mountains and spends the day under the roofs of old buildings, or more rarely in caverns, hanging in clusters. The quarrelsome disposition and vicious biting of these Bats drive away all smaller varieties, except the Blood-suckers. Koch's observations of captive Common Bats lead him to think that the weaker kinds have good reasons for avoiding them, as they sometimes kill the smaller ones with a bite and then eat portions of them.

The Noctule The Noctule (T ispeor migo noctula) is an Great Bat. early flying Bat, and is popularly known in England as the "Great Bat." It is a eommon animal in Europe and is about four and one-half inches long, with an expanse of wing of fifteen inches. Its color is a reddishbrown, the ears and wings being brownish-black. The wings are long and narrow and its fight is very rapid, resembling that of a Swallow.

The Noctule is the strongest of the European Bats. It comes out earliest and flies highest. Not infrequently it is seen a few hours before sunset, dexterously eluding the pursuits of birds of prey. By its sudden turnings it escapes nearly all attacks, and not even the quick Falcon, which captures Swallows on the wing, ean harm it.

The Barbastelle A strange looking creature is the or Barbastelle (Synotus barbastillus),

Pug-Dog Bat. called in Germany the Pug-Dog Bat. The ears, united over the crown of the head, give to the face a remarkable expression. The wings are long and slender; the spur-bone at the heel shows a projecting, rounded fold of skin. The tail is a little longer than the body. This creature measures four and a half inclies in length, with an expanse of wing of ten inches. Its upper side is a dark brown, nearly black; bencath it is a little ligliter, being grayish-brown.

Blasius says that this Bat is common in England, France, Italy, Germany, Sweden and the Crimea. 
Hc has also seen it in Hungary and middie Russia and in the Alps as high as the cottages of the shepherds extend.

In summer the Barbastelle comes out as soon as the first shadows of evening fall, in fair weather as well as in rain or storm ; it prefers forest-edges and orchards to the houses of villages and confines its hunting chiefly to small Butterflies. Its flight is high and rapid, and full of zigzag movements.

\section{Icat $=$ H Hogco or BBlood=Fucking JBats. THIRD DIVISION: ISTIOPHORA.}

All sub-orders of this tribe are distinguished by leaf-like complications of the nose, which may assume the most varied shapes. but only under certain conditions; and this explains the conflicing stories that are told concerning them. IVe must also take into consideration the fact that it is very difficult to study their habits. It might be well to recount here a few instances of these blood-sucking traits, without ascribing the nocturnal deeds to any one species in particular, as is the practice of most travelers. These stories are very conflicting, and there is one species of Leafnosed Bats that I cannot connect positively with any one of these several accounts.

The Spaniard Azara, who calls this Bat "Mordedor," which in English means simply "The Biter," telis us among other things the following: "Sometimes they bite the combs of sleeping Chickens to suck their blood, and, as a rule the Chickens afterwards die, especially if the wound becomes inflamed,

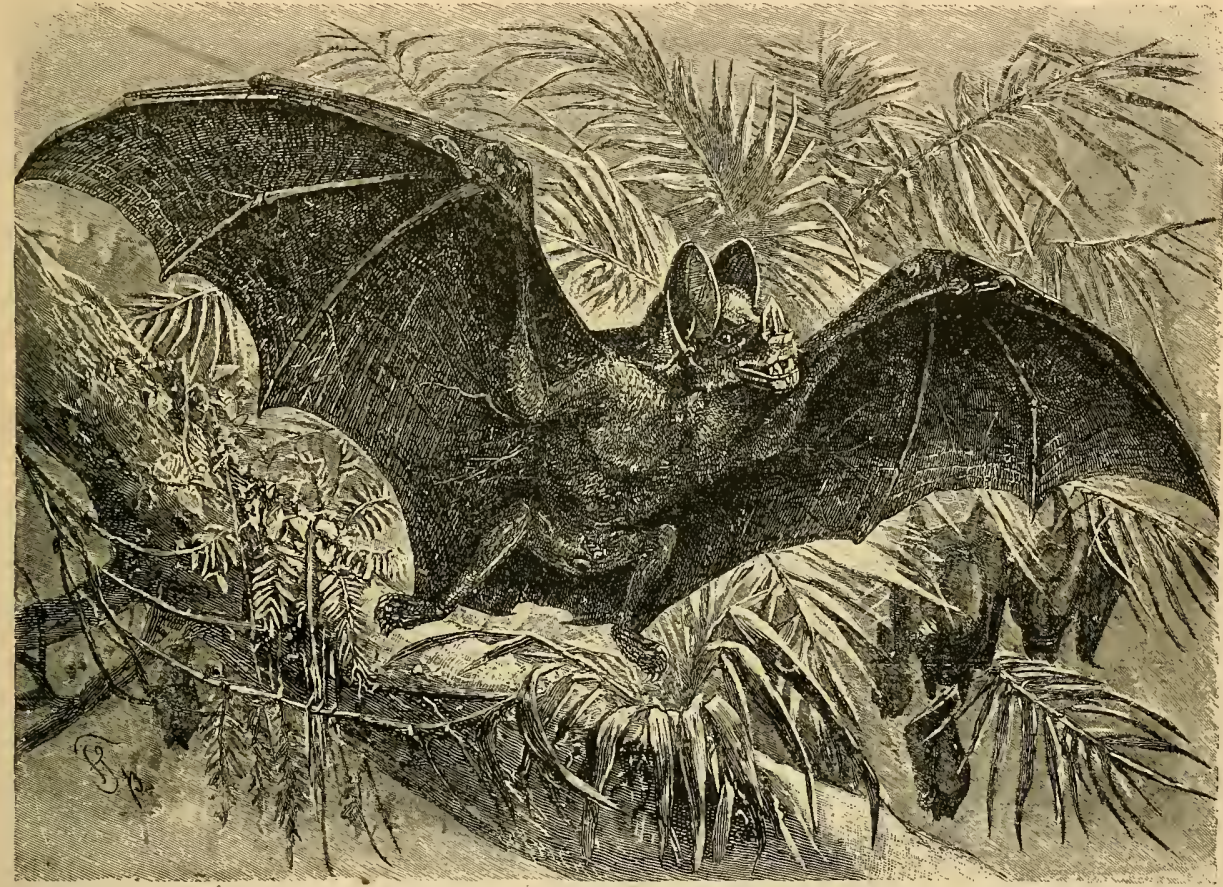

VAMPIRE BAT.- Here is presented a strikingly faithful picture of the Vampire with its enormous wings, great ears, lofty nose appendage and frightful grin. The Frog-like shape of the body is also clearly shown, as it is fluttering forth at evening time from its sleeping-place in the great forest. Monster as it seems to be, the. Vampire would not harm anything larger than a night insect. It is not a blood-sucker, like so many of its cousins, but is satisfied with the fruits and bugs it finds in its home in northern Brazil and Guiana. (Pliyllostoma spectrum.)

Blood-sucking Bats are distributed over all continents, but are confined to the torrid and temperate zones. Some are found hidden in the depths of great woods, in hollow trees, or among the large leaves of palm-trees or similar plants; the majority conceal themselves in rocky caverns, ruins and dark vaults or in the roofs of houses.

Their principal food consists of Butterflies, Beetles, Mosquitoes, etc.; and the majority, probably, also have blood-sucking propensities, attacking for this purpose sleeping birds and mammals, including Man. Though a gneat many facts have come to light pertaining to the blood-sucking habit, this peculiar trait is still steeped in mystery. The probabilities are that all Leaf-nosed Bats are blood-suckers, a thing that nearly always happens. They bite Horses, Donkeys, Mules and Cows in the sides, shoulders or neck, for to these parts they can easily attach themselves. I have been bitten in the toes four times, when sleeping in the open air. The wounds which I received in this way, without any pain, were round or oblong, and about one line in diameter, while their depth was so slight that they barely pierced the skin. They became visible through their raised margins. The blood that flowed from each bite would in my estimation amount to an ounce and a half. In Horses and other animals it might be three ounces, and I believe that their wounds would have to be deeper because of their thick skins." 
Rengger adds to these words of Azara the following: "A hundred times have I examined the wounds of Horses, Mules and Oxen without being able to determine how they were eaused. The incision is funnel-shaped, and has a diameter of a quarter of an inch, sometimes a little more; the depth is, according to the part of the body, from one to two lines. It never reaches through the skin to the museles. There is no impression of the teeth, as is the ease in wounds caused by a bite from any other animal; but the margins present a soft swelling. I cannot therefore think that the Leaf-nosed Bats cause these wounds by a bite, which, by the way, would awaken any animal. 1 think it probable that they first deprive the skin of its sensibility by sucking as is done in the application of a cupping glass, and when it is swollen, they make a small aperture with their teeth. That it is impossible for a Bat to suck and to move its wings at the same time is demonstrated by the structure of the latter. 1, at least, always saw them seated upon the Horses, and this
The following night several of them found their way into ny hammock; I seized a few that were crawling around on me and threw them against the wall. At daybreak I found a wound in my hip, undoubtedly caused by the Bats. That was a little too much for me, and I concluded to exterminate them. I myself shot many of them that were hanging on the planks of the roof and then had the negroes mount ladders into the garret and kill a few hundred old ones, together with the little Bats."

Hensel and happler have had similar experiences, and it is safe to conclude that many Leaf-nosed Bats are blood-suckers, that human beings are rarely bitten by them, and that the mischief they do varies with time and locality.

The The largest of the South American

Vampire Vampires proper is the Vampire Bat

Bat. (Phyllostoma spectrim). Its length is seven inches, its expanse of wing, according to Bates, is twenty-eight inches. The head is long and thich, the muzzle elongated; the large ears stand out

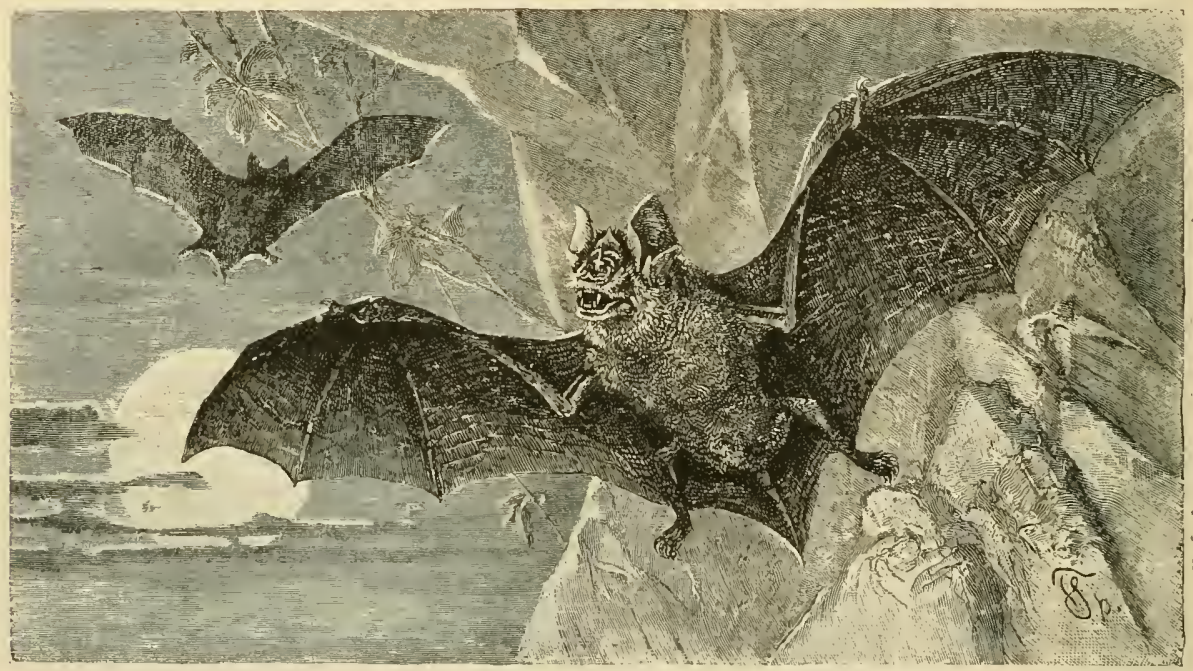

GREATER HORSESHOE BAT. What a hideous face is that of this uncanny creature, as the artist presents it, sallying forth towards sunset on the lookout for food. If naturalists tell the truth this Old World Bat is a blood-sucker, and sleeping Chamois, Squirrels and other animals should he on their guard. During the summer months it pursues insects up the mountains to a height greater than a mile. (R/hinoloflus forrem-equinum.)

necessitated the folding of their wings. The wound in itself is not dangerous, but as four, five, six or more Bats suck the same animal in one night, and often repeat the performance for several consecutive nights, the animals are much weakened by the loss of blood, especially as two or three ounces flow out after each visit."

Other travelers besides $\Lambda$ zara have been bitten by the Bats, among whom was Bates, who lived eleven years in Brazil. "The first night," he writes, "I slept soundly and perceived nothing extraordinary. The second night I was awakened at midnight by the noise of Bats flying back and forth in my room. They had extinguished my lamp, and when I relit it, I saw that the room was full of them. The air seemed black with the swarm flying around in it. I had recourse to a stick, and in a few minutes they disappeared. When everything was quiet, they reappearcd and again extinguished my light. I paid no further attention to them, and went to sleep. from the sides and top of the head; the leaf on the nose is small in proportion to the size of the animal; the soft, delicate fur is of a chestnut hue on the back and yellowish brown beneath, and the wings are brown.

The Vampire Bat inhabits northern Brazil and Guiana, being found in the forests as well as in buildings. Bates says : "Nothing in animal physiognomy. can be more hideous than the countenance of this creature when viewed from the front. The large, leathery ears, the ereet spear-shaped appendage on the tip of the nose, the grinning features and the glistening black eye, all combine to make up a figure that reminds one of some mocking imp of fable. No wonder that imaginative people have ascribed diabolical qualities to so ugly an animal. The Vampire, however, is the most harmless of all Bats, and its inoffensive character is well known to residents on the banks of the Amazon." According to older as well as modern observers, this much abused crea- 
ture is, although a Leaf-nosed Bat, by no means a blood-sucker. It zealously hunts nocturnal insects and does not disdain fruit. Waterton says: "In the broad moonlight I could see the Vampire fly to the trees and eat the ripe fruit. On its return from the forest it frequently brought a round fruit the size of a nutmeg into our yard, and when the Sawarri-nut tree bloomed it searched for nuts growing there. On moonlight nights I often saw Vampires flying around the tops of these trees, and from time to time a bud would fall into the water. This did not happen without cause, for all the buds that I examined were fresh and sound. So 1 concluded that they had been plucked by the Vampires, either for the young fruit or for insects that were concealed in them."

\section{THE HORSESHOE BATS.}

The representatives of this group in Europe are called Horseshoe Bats. The appendage of the nose covers the whole face from the forehead to the tip of the nose, and is the most remarkable feature in these animals. The wings are broad and relatively short, and the flight in conscquence is far from perfect. The fur of nearly all the Horseshoe Bats is light.

The Lesser There are four Horseshoe known EuroBats. pean species in this group, the most common of them being the Lesser Horseshoe Bat (Rhinolophus hippocrepis). it is one of the smallest of the Bats, for its entire length is only from two to four inches, with an expanse of wing of nine inches. The fur is grayish-white above and a little lighter below. This little Bat extends farther north than any of its kindred, inhabiting nearly all of middle Europe, and is also frequently seen in the southern portions of that continent. It is found in the mountains, in localities above the forest belt, and is the most gregarions of all Horseshoe Bats.

Though it is less sensitive to changes of temperature and climate than are the generality of Bats, still the Lesser Horseshoe Bat does not fly about in rough or wet weather unless compelled to do so. It always selects sheltered places for its habitation and sometimes, for this purpose, descends caverns and pits to a considerable depth. Its hibernation is of a rather long duration, but seems to differ in length according to circumstances. These Bats are among the first to retreat to their winter quarters, as well as among the last to leave their hiding-places. Some go to sleep later and rouse themselves earlier in the season than others, but this difference in the besinning and end of their hibernation does not seem to be due to the influence of age, but rather on account of sex, as Koch found that the males generally assumed a torpid state early in autumn, and that females continued their sleep until late in the spring. ln the same way some will temporarily awaken at times during their hibernation while others do not.

During the summer the Lesser IIorseshoe Bats delight in subterranean vaults, old and little frequented cellars, rocky carerns, old mines, and uninhabited houses. They are as gregarious then as in winter, but never assemble in such large groups as other Bats do; and they hang, not in clusters, but side by side, and far enough apart so that no one of the group touches another. When at rest this Bat always suspends itself by its hind legs and envelopes itself either partially or entirely in its flying membrane. During hibernation it wraps itself up so closely as to resemble a mushroom more than a Bat. In summer it is easily awakened so that one cannot well catch it without a net even in broad daylight, as the approach of Man causes it to quickly

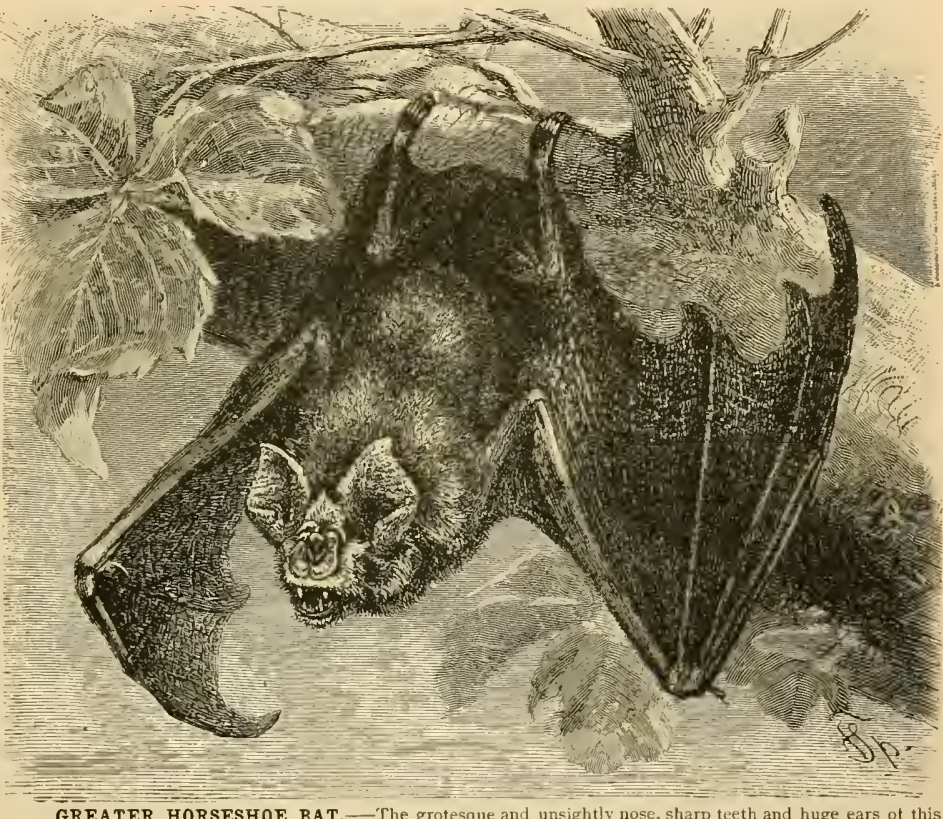

GREATER HORSESHOE BAT, The grotesque and unsightly nose, sharp teeth and huge ears ot this Bat are strikingly presented in this picture as the creature hangs in its peculiar sleeping posture from a tree-
branch. Partially aroused it would seem to scent danger and be preparing for escape by flight. (Rhinolophus fer. arouse and fly away. When not asleep, it moves its head to and fro with extreme rapidity, licks and cleans itself and searches for the innumerable parasites which infest its fur. In short, it belongs to the liveliest, prettiest and most attractive of European Bats, although it is clumsy and slow in flight, and, as a rule, does not rise high above the ground. Unfortunately it does not bear captivity. Lilie most nembers of its family, this Bat is easily excited, and when disturbed, or even when only touched, is liable to a violent hemorrhage of the nose, which often causes death.

The principal food of the Horscsloe Bats consists of insects that have no hard parts to their bodics. such as Flies, snall Night-Butterflies, etc. They are likewise genuine blood-suckers, as Kolenati's observa- 
tions show. This explorer one winter found fortyfive sleeping Bats in a cavern. They were, for the most part, Long-eared Bats and Lesser Horseshoe Bats all of which he captured and placed in a spacious room, where they were left to settle down at their own pleasure. A few days later the naturalist wished to introduce his collection to a friend, and found to his great surprise that six of the Horseshoe Bats had been devoured, nothing being left of them but the claws and the tips of their wings; while one had its head mutilated in a shocking manner. Numerous blood spots, bloody muzzles and swollen stomachs seemed to point out the Long-eared Bats as the murdercrs, and when one of them was killed and its stomach examined, every doubt on this score was set at rest. The wings of the Long-eared Bats

raised edges during the night, a thing he was at a loss to explain; Kolenati believes them to have been caused by the Horseshoe Bat. Hence we conclude that Europe also possesses genuine Vampires, though they are rather harmless on the whole, and do not inspire us with dread and horror.

The Greater The Greater Horseshoe Bat (RhinoloHorseshoe phus formm-cquimum) is still more comBat. mon. Its length is two inches, exclusive of the tail, which measures nearly an inch and a half. The wings have an expanse of thirteen inches. This Bat inhabits the greater part of central and all of southern Europe, and has been found in the Lebanon Mountains in Asia. In the mountains it is seen in summer at an elevation of 6,000 feet or even higher. Kolenati believes that it also is a blood-

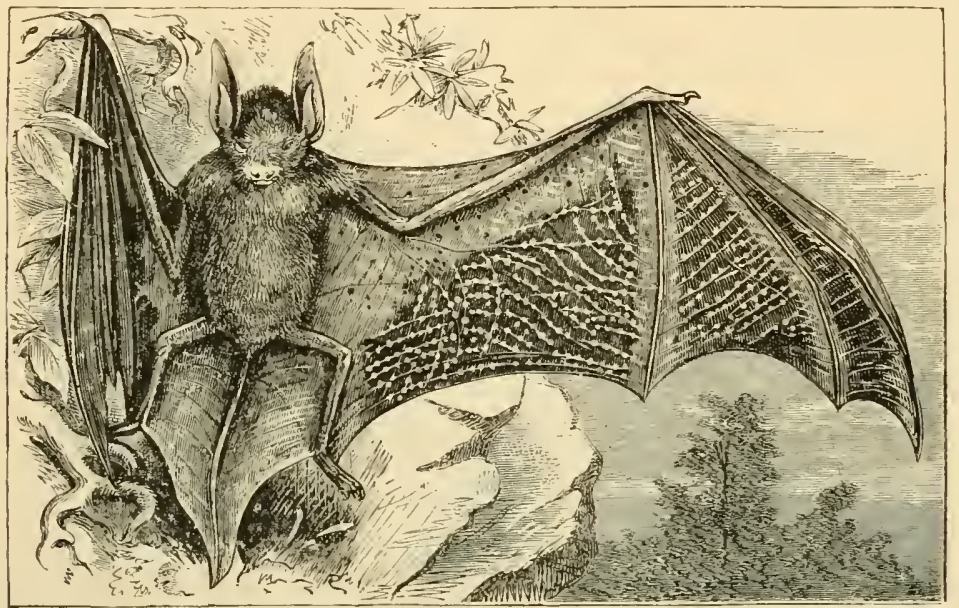

WELWITSCH'S BAT. - This Bat, first discovered by the late Dr. Welwitsch, is notesorthy for the bright and variegated coloring of its wings which near the body are brown dotted with black, and beyond this blackish brown with curved lines of yellow dots, while bands of dark orange dotted with black follow the course of the forearm and three of the fingers. It inhabits the vicinity of Angola. (Scolophalus woluztschu.) sucker. One sees it at night fluttering about in deep valleys, trying to attach itself to Roe-bucks and Chamois with this purpose in riew. It also roams about among sleeping squirrels, and though it has never been proven guilty of sucking blood, its actions are certainly highly suspicious.

other There are a few Groups other interesting of Bats. groups a mong the Bats. The Megaderma contain one species which is said not only to suck blood, but also ti feed upon small Frogs. These $\mathrm{Bats}$ are distinguished by a triple appendage on tha nose, by large ears united by their inner margins over the forehead, and by a long ear-flap.

The Lyre Bat (Higader-

showed fresh wounds near the body, whose margins had a swollen appearance; and these Bats were suspended from the ceiling in clusters, while the Horseshoe Bats had retired singly to the darkest nooks and cormers. The conclusion from these facts is very simple. The two species were not on friendly terms and had given each other battle during the night. While the Long-eared Bats were enjoying their first sweet slumber, the Horseshoe Bats had come and sucked their blood; the wounded Bats during the regular interval of their nightly slumbers had avenged themselves and devoured the culprits for their evil deeds.

In inhabitant of Grusia told the same naturalist that his pigeons often received small wounds with ma (yra), which may be considered one of the best typical examples of this genus, owes its name to its nasal appendage, which somewhat resembles a lyre.

Another group are the Rhinopoma. Their nasal ornament is simple, consisting of one erect, lancetshaped leaf. The ears are also united over the forehead and of moderate size, while the tail is very long for a Bat.

To this group belongs the Egyptian Rhinopome (Rlinopoma microphyllum). It is a very small animal, whose most remarkable feature is its long, thin tail. It consists of eleven vertebre and reaches far beyond the flying membrane. The creature is found in Egypt in great numbers, especially in deserted monuments and in artificial and natural caverns. 


\section{The JBeasts of IPrey.}

FOURTH ORDER: CARNIVORA.

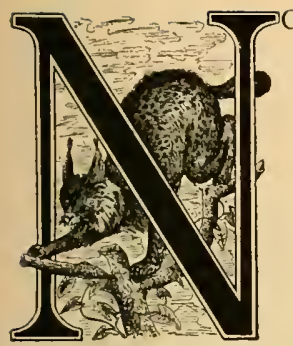

CLASS of mammalia presents a greater variety of forms than the Carnivora, nearly all sizes being represented, from the smallest to medium: while in external appearance there is infinite variety. How many intermediate connections are to be found between the powerful Lion and the tiny Weasel, the graceful Cat, clumsy Hyena, slender, dainty Civet with its fine, sleek skin, the strong, rough Dog, lumbering Bear and agile Marten -all these are members of one great family. One can but be astonished that they are united in one group, living as they do, some on the ground, some in the water and some on trees!

General All Beasts of Prey show in their phys-

Traits of ical endowments and mental capacities

carnivora. considerable uniformity, notwithstanding their superficial difference. Their modes of life, their habits, their food, all more or less similar, indicate that not only the structure of their limbs, their teeth and digestive organs, but also that their minds and nental capacity must, in some degree, be of the same cast. Caricatures and repulsive peculiarities are entirely absent in this class.

Their limbs are in harmonious relation with each other and the body, uniformly have four or five toes, and are provided with strong claws, which may be sharp or blunt, retractile in their sheaths, or without this covering. All the organs of sense show a high degree of development. The teeth are strong, sharp, often pointed, the upper ones fitting into or between those of the lower row, and all deeply fixed in powerful jaws which are set in motion by huge muscles.

The stomach is always simple in structure; the intestines are of short or medium length. Some species show peculiar glands, secreting a liquid of a pungent odor, which serves either as a defence against stronger animals, or to attract weaker ones; and which may be oily and used to keep the skin pliable.

A close examination of the Carnivora will show us the following general peculiarities of structure: the skeleton is strong, in spite of its light, graceful appearance; the skull is elongated, its solid ridges and crests and the strongly curved zygomatic arches affording ample room for the attachment of power- ful muscles. The orbits are large, and the nasal bones and cartilages are long, so that the organs of sense have room for perfect development. The processes of the vertebræ are long, and those of the lumbar region are often united; but the number of vertebra forming the tail is subject to great variation. The structure of the limbs may also vary according to the mode of life, but always shows a combination of strength and mobility.

Many Carnivora have the nose lengthened into a trunk and furnished with special cartilages and small bones; with these the trunk serves for digging up earth. The limbs of some are short and thick and these species are adapted for a subterranean life. In others the limbs may be long, giving the capacity for quick running, or they may be connected by webs and enable the animal to live in the water. The claws may be retractile, in which case they are protected in walking, and may serve as excellent weapons; or else they are blunt and immovable, in which event they serve only to protect the foot and to dig up the ground. The canine teeth are as formidable as the grinding teeth, and may, therefore,

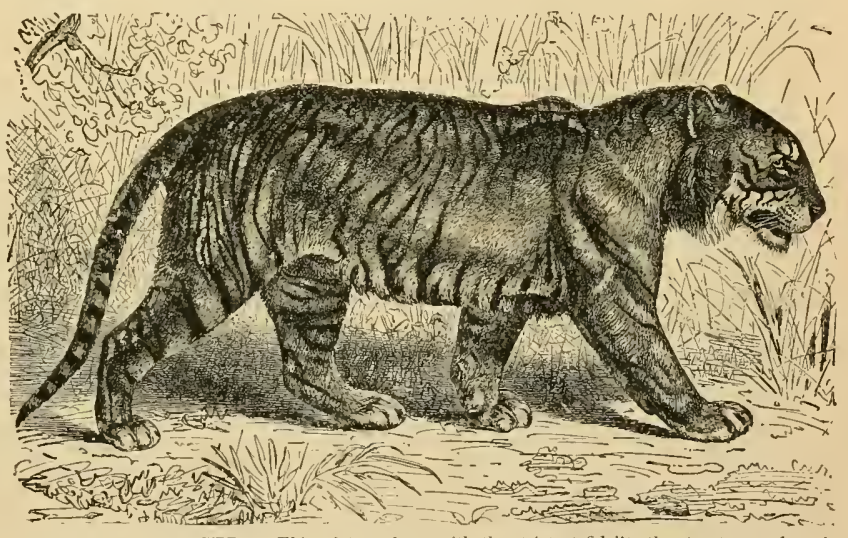

THE ROYAL TIGER. - This picture shows with the strictest fidelity the structure and markings of this great feline. The curved outline of the head with its stripings and shadings, the nuscular limbs and the powerful padded paws, the ringed and tapering tail, and the soft and stealthy movement be used with equal effect in fighting and for the holding and tearing of prey. Large muscles and tendons give strength and endurance, and are so arranged as to permit of wide-sweeping, easy movements.

Development of In addition to all this their senses are Senses in acutc to a high degree. In exceptional Carnivora. cases one sense may be weak, but the others are then sure to make up for the deficiency by special keenness. It cannot be said that any one sense is a distinguishing feature of all alike; for some show a wonderful development of the sense of 
smell, others of the serise of hearing, others again of the sight; and in some the sense of touch plays an important part. As a rule two of the senses are very acute, being usually those of smell and hearing; more rarely hearing and sight.

The mental faculties are in harmony with the physical structure. We find animals of wonderful sagacity among the Carnivora and, therefore, it is but natural that they should be adepts in all the arts of cunning and dissimulation, for their destructive and thievish natures call for this. Consciousness of their strength also gives them a courage and boldness such as other animals never attain. But these very qualities have others behind them, which do not show these animals in such favorable light. The Carnivora are accustomed to conquest, and their imperiousness often degenerates into cruelty and an unquenchable thirst for blood.

How Carnivora Differing mental and physical qualities

Live und in an animal indicate a certain mode of

Hunt. life in a given locality. But Carnivora live and govern everywhere: on the level ground, in the tree-tops, in the water, in the mountains and on the plains. In this order of animais are included some of perfectly diurnal and others of nocturnal habits; some looking for food at dusk, some in the sunshine, and others in the dark of night.

Many live gregariously, others live singly; some attack their prey openly, but the majority stealthily creep up and surprise it, no matter how strong they may be, nor how weak their victim. All carnivorous animals habitually secrete themselves in order not to frighten away their destined prey, and few are in haste to flee at the first signs of danger. The more they like daylight, the livelier, the more sociable and more cheerful they are; the more nocturnal their habits, the more they show themselves distrustfut, shy and sulky.

All Beasts of Prey are flesh-eaters ; and very few of them eat fruit, grain or other regetable food. They are sometimes divided into flesh-eaters and omnivorous animals, but these divisions do not bear close scrutiny, for those classed as omnirorous prefer a juicy piece of meat to anything else, just as do the largest and most ferocious of the flesh-eaters. All members of this order are downright murderers, whether they kill large or small animals, and even those that are fond of vegetable food quickly rise to the occasion when murder is in view and animal food is at stake. There is naturally as much difference in the methods pursued by carnivorous mammais in their selection of food, or rather prey, as there is in their bodily structure, the character of their native country or their modes of life. Few animals are secure from their attacks. The largest and strongest Carnivora give mammals the preference, although not disdaining other animals. Even the Lion does not feed exclusively on mammals, and the other Felida are still less fastidious. The Dogs, which originally were genuine flesh-eaters, extend their hunting still farther; and among the Civets and Weasels there are some which confine themselves to fish and similar food. The Bears are the real omnivorous animals, devouring vegetable food with as much enjoyment as flesh.

Sexes and Some of the Carnivora are supposed to Young of maintain perfect marital relations; but Carnivora. none of them unite for life. Among some Felide and Weasels, both sexes live in close companionship, and may mutually assist in feeding and protecting their young ones; with the majority, however, the father considers his children his lawful prey and has to be driven away by the mother when he discovers their lair. Under such circumstances the rearing of the young devolves solely upon the mother. The number of young at a birth varies greatly, but is rarely as low as one. They are nearly all born blind and very helpless, but develop rapidiy. The mother carefully instructs them in their craft, and accompanies them in their foray's until they are able to shift for themselres. In a few species the mothers carry their young upon their backs or in their arms in times of danger; the remainder take them away in their mouths.

Man wages open war upon nearly all Carnivora. He has tried to tame and domesticate very few of them, though one genus, the Dog, has come into friendlier relations with him than any other animal.

\section{The Cat Jamillp.}

FIRST FAMILY: FELIDE.

If asked to whom the place of honor among the Beasts of Prey belongs, no Man would be tong in doubt as to the fanily he should name. The Iion was crowned king of the beasts at a remote period of time, and so we first turn to his tribe, which is that of the Cats, or Felide.

The Cats are the nost perfect and typical members of the family of Carnivora. No other group presents the sane symmetry of limb and body and the same regularity of structure. Every part of the bocty is lithe and graceful and this is why these animals are so pleasing to our asthetic sense. Wre may safely regard our domestic Cat as representative of the entire family.
Physical We may assume the structure of the Features of body to be known; the strong, yet the Cat Family. graceful body, the round head set on a stout neck, the limbs of moderate length, the long tail, and the soft fur corresponding in color to the surrounding objects, are features with which everybody is familiar. The weapons with which the Felidie are endowed are perfect. The tecth are formidable, the canines being large, strong, very litthe curved and so perfectly adapted to life-destroying action that the small incisors are hardly noticeable beside them. The tongue is thick and muscular, and is supplied with fine, horny thorns, whose points lie towards the throat. The teeth are not the 
only weapons possessed by the feline animals, their claws being no less terrible instruments for seizing their prey and speedily terminating its existence, Their broad, rounded paws are proportionately short; for the last toe-joint is curved upwards. In repose and in ordinary walking two tendons keep the member in its upright position; but when the animal is angry and needs its claws, a strong flexor muscle inserted below draws it down, stretches the paw and makes it an effective weapon. This structure of the feet enables the Cats to walk without leaving any traces of the claws, and the softness of their step is due to pads upon their soles. The Cats are both strong and agile and their every movement displays vigor and lithesome grace. Nearly all members of this family partake of the same physical and moral traits, although some special group may seem to have a particular advantage over the others. force of their spring. They are also capable of carrying considerable burdens, and easily convey to a convenient hiding place animals they have killed, although their prey may be as large as themselves.

Acute Senses Of their senses those of hearing and of the sight are the most acute. The ear cat Family. undoubtedly is their guide on their hunting expeditions. They hear and determine the nature of noises at great distances ; the softest footfall or the slightest noise from crumbling sand is not lost upon them, and they are thus able to locate prey that they cannot see. The sight is less keen, though it cannot be termed weak. Probably they are unable to see distant objects, but at short range their eyes are excellent. The pupil is round in the larger species and dilates circularly when the animal is in a state of excitement : smaller species show an elliptical pupil, capable of great dilation. In the

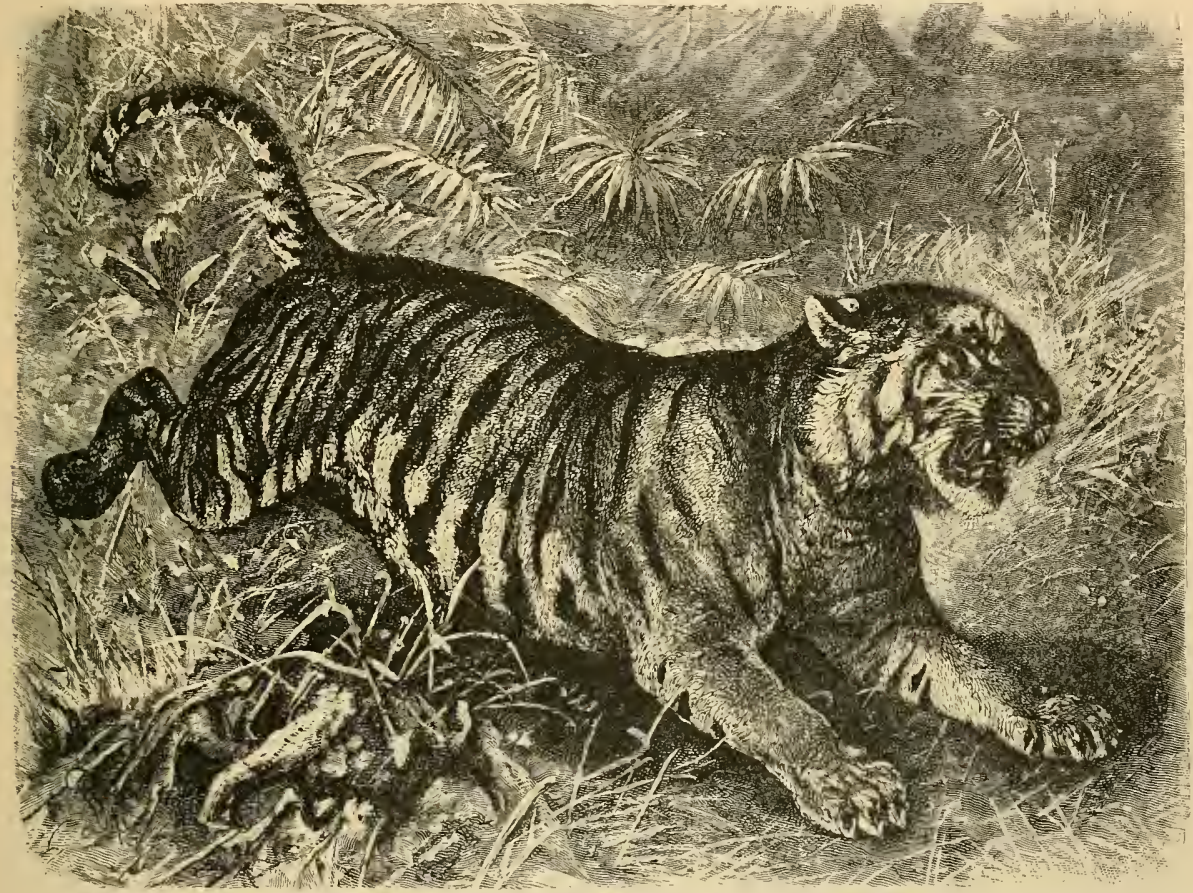

THE ROYAL TIGER.- - Here is presented a faithful portrayal of the scourge of Asia in his native jungle. The flaming yellow hue that forms the approaching it, for the uplifted tail in these animals is a signal of attack, and the whole expression of the face in the picture is one of voracious approaching it, for the uplifted tail in these anmals is a signal of attack, and the whole expression of the face in the picture is one of voracious expectancy, Soon those sharp canin
are well brought out. (Felis tigris.)

All Cats walk well, but slowly, cautiously and noiselessly; they run quickly and can jump distances that exceed many tines the length of their respective bodies. There are only a few of the larger species that are unable to climb; the majority being greatly skilled in this accomplishment. Although as a rule averse to water, they swim well, when necessity compels; at least, none of them can easily be drowned. Each member of this family knows how to curl up its handsome body and reduce its compass, and all are experts in the use of their paws. The large species can strike down animals larger than themselves with one stroke of the paw and the daytime it shrinks to a narrow slit under the influence of the bright light; in darkness or when the animal is excited, it assumes a ncarly circular shape. The sense coming nearest to that of sight in keenness is probably that of touch, which manifests itself in sensibility to pain and other outward conditions as well as in a discriminating faculty of feeling. The most sensitive organs are the whiskers, the eyebrows, and, in the Lynx, probably also the ear-tufts. A Cat with its whishers cut off is in a very uncomfortable plight; the poor thing is at a complete loss to know how to act and shows utter indecision and restlessness until the hairs have grown 
out again. The paws also seem endowed with an exquisite sense of touch. The entire family of Cats is very sensitive; being susceptible to all external impressions; showing decided dissatisfaction under disagreeable influences and a high degree of contentment under agreeable ones. When one strokes their fur they exhibit a great deal of pleasure; while if the fur is wet or subjected to similar repulsive inpressions, they display great discomfort. Their smell and taste are about equal in degree, though perhaps taste may be somewhat the more acute of these two senses. Most Cats appreciate dainty morsels, in spite of their rough tongue. The remarkable predilection of certain species for strongsmelling plants, like valerian, admits only of the conclusion that the sense of smell is very deficient, as all animals with a well-developed organ of smell would shrink from them with disgust: while Cats jump around these plants and act as though they were intoxicated.

Mental En- As to intellect Cats are inferior to dowment of the Dogs, but not to such an extent Cat Tribe. as is commonly supposed. IVe must not forget that when instituting a comparison we always have in mind two species that can scarcely be regarded as fair standards: on the one hand the domestic Dog, systematically bred for thousands of years, and on the other the neglected and often ill-treated domestic Cat. The majority of the Felide show a higher development of the lower instincts than of those that are noble and elevating ; yet even our Pussy demonstrates that the Cat family is capable of education and mental clevation. The domestic Cat often furnishes instances of genuine affection and great sagacity. Man usually takes no pains to investigate its faculties, but yields to established prejudice and seems incapable of independent examination. The character of most species is a blending of quiet deliberation, persevering cunning. blood-thirstiness and foolhardiness. In their association with Man they soon lose many of the charactcristics of the wild state. They then acknowledge human supremacy, are grateful to their owner, and like to be petted and caressed. In a word, they become perfectly tame, although their deeprooted, natural faculties may break out at any moment. This is the principal reason why the Cats are called false and malicious; for not even the human being who habitually torments and ill-treats animals accords them the right of revolting now and then against the yoke of slavery.

The Cats are well distributed throughout the New and the Uld World, except in Australia, where only the domestic Cat is found, many of which have there degenerated into the wild statc. They inhabit plains and mountains, arid localities and marshy districts, forests and fields.

Food and The food of the feline family conHunting Methods sists of all kinds of vertcbrates, pref-

of Felines. erably mammals. Some show a predilection for birds, a few others are fond of Turtles, and some even go fishing. All species pursue the same methods when attaching their destined prey. With stealthy footfall they creep over their hunting ground, listening and looking in all directions. The slightest noise makes them alert and incites them to investigate its origin. They cautiously glide along in a crouching position, always advancing against the wind. When they think themselves near enough, they take one or two leaps, fell their prey by a blow in the neck with one of their fearful paws, seize it with their teeth and bite it a few times. Then they open their mouth slightly but without letting go of the victim; they watch whether any sign of life remains, and then again close the teeth upon it. Many of them utter a roar or a growl at this time, which expresses greed and anger as much as satisfaction, and the tip of the tail wags to and fro. The majority have the cruel habit of tormenting their prey, seemingly giving it a little liberty, sometimes even letting it run a short distance, but only to pounce upon it at an opportune moment, and then repeat the operation over and over, until the animal dies of its wounds. The largest members of the Cat family shun animals which offer great resistance, and attack them only after experience has taught them that they will be victorious in the fight. The Lion, Tiger and Jaguar, at first acquaintance, fear Man and avoid him in a most cowardly manner. It is only when they have seen how easily he is conquered that some of them get to be his most formidable enemies. Though nearly all Felidae are good runners, yet most of them give up their intended prey if they do not succeed in the first attempt. It is only in secluded places that they will eat their prey on the field of capture. Usually they bear away the killed or mortally wounded animal to a quiet hiding-place, where they devour it at their leisure.

The Cat Kind As a rule the female gives birth to and Its several cubs at a litter, but seldom to roung. one. WV may say that the number varies between one and six; although some species are declared to have more than the latter number. The father, as a rule, is indifferent or hostile to the offspring, the responsibility and care resting upon the mother. A feline mother with her young ones is a very pleasing spectacle. Motherly tenderness and solicitude are expressed in every gesture and in every sound, the voice being gentle and soft to a surprising degrce. Her watchfulness is so unremitting that one cannot doubt the absorbing love she has for then. It is very gratifying to observe how carefully she trains then from earliest youth in habits of extreme cleanliness. She cleans, licks and smooths their fur unceasingly, and will tolerate no dirt near the lair. At the approach of a foe she defends her offspring with utter disregard for her own life, and at such times the mothers in all the larger species are most formidable encmies. In many species the dam must protect her little ones from their father, who, if not prevented, will enter the lair and devour them while in their stage of blindness. This, probably, is the origin of the feline habit of mothers hiding their little ones. When the latter have grown somewhat older, the aspect changes, and they have nothing more to fear from the father. Then begins the merry childhood of the little animals, for they arc full of fun and play. Their nature is revealed in the first movements and emotions, thcir play being nothing but a preparation for the serious hunts of their adult life. Everything that moves attracts their notice; no noise escapes them; the slightest rustle makes the little listeners prick up their ears. The earliest delight of these young ones is their mother's tail. They first watch it in its movements, and soon the whole mischievous company tries to catch it. The mother is not in the least disconcerted, but continues to express her moods by the wagging of that member. In a few weeks the little ones are able to indulge in the liveliest romps and the mother joins them, no matter whether she be 


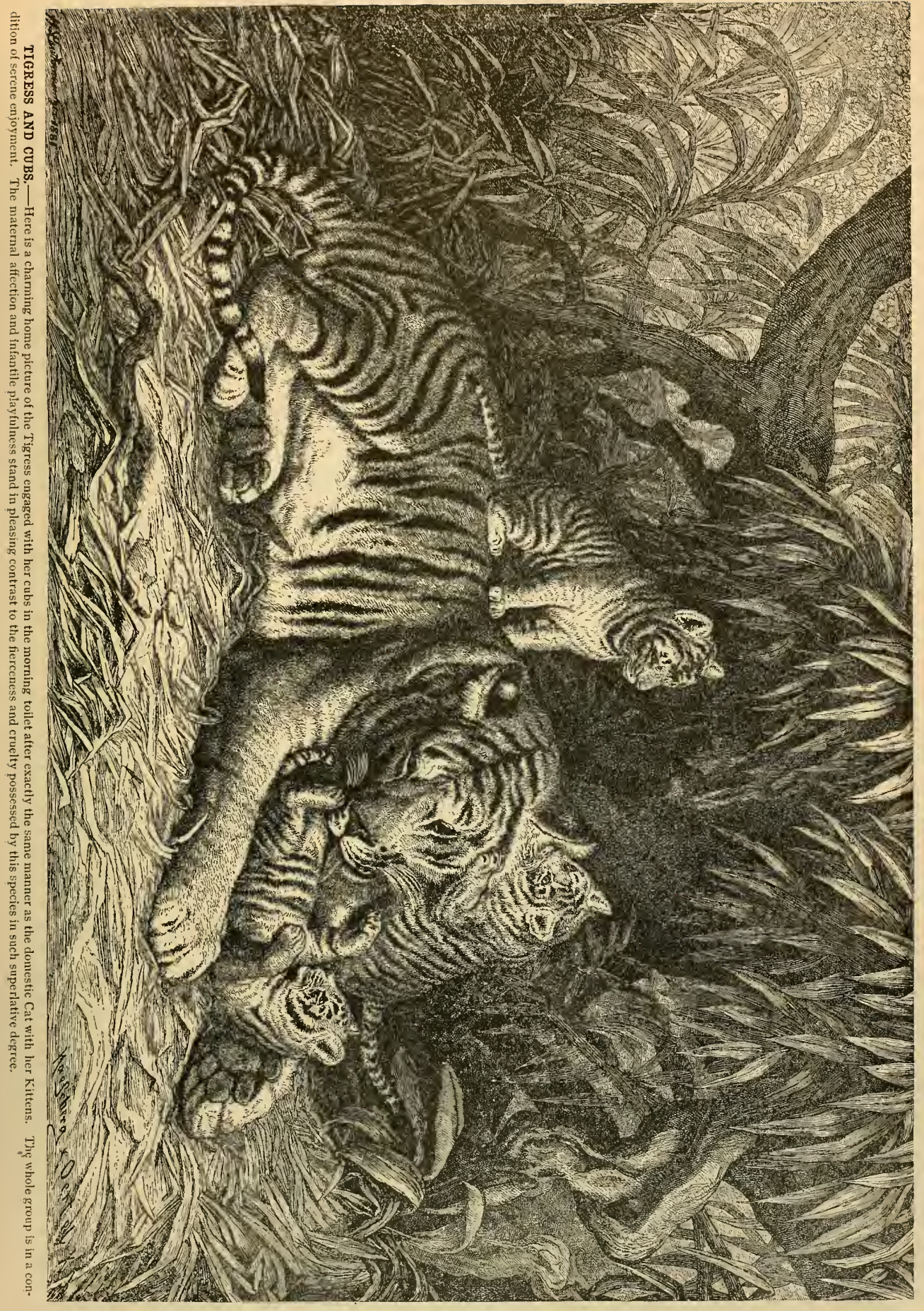


stately Lioness or one of our domestic Pussies. Sometimes the whole family forms a single ball, and each is intent upon seizing the tail of the other. Is they grow, the games become more serious. The little ones learn that their tail is but a part of themselves and long to try their strength on something else. Then the mother brings them snall animals, sometimes alert live ones, then those that are halfexpiring. These she turns loose, and the little fellows practice upon them, in this way learning how to pursue and handle their prey. Finally the mother takes them along on her hunts, when they learn all the tricks-the stealthy approach, the mastery of their emotions, and the sudden attacks. When they become completely independent of parental care they leave their mother, or their parents, as the case may be, and for some time lead a solitary, roaming life.

The harmful species are hunted zealously, and there are men who find the keenest enjoyment in the very danger of this sport.

Subdivisions The classification of the Felidae is very of the difficult; yet we think it proper to di-

Cat Species. vide them into the Cats proper (Filis); the Lynxes (Lynx); the Cheetah (Cynailums) and the Foussa (Cryptoprocta) of Madagascar. A typical specimen of the first group is our domestic Cat and its most highly developed members are the Lion and Tiger. The Lynxes have a shorter tail and longer limbs than the Cats proper and have hair tufts on their long ears. The Cheetah has longer limbs and the claws are not retractile. The last family, the Foussa or Cryptoprocta, has a dentition differing from the other groups, hairless soles and other peculiarities which place it among the distant relatives of the Civets or Viverrida, and stamp it as a being similar to the first original Cat, from whom the others have descended.

\section{THE CATS PROPER.}

We will first consider the Cats proper (Felis), separating the Old World species from those of America. The striped Cats will be treated in one class: the spotted ones and those which are of a uniform color in another.

\section{THE TIGER.}

In the group of the striped Cats the Tiger stands out most prominent, for he is, after the Lion, the most perfect member of the whole family. He is a genuine Cat, devoid of mane, but furnished with large whisker-like tufts, and shows most distinct stripes on his fur. He is the most dreaded of all the feline species, a foe against whom Man, even, is almost powerless. No other beast of prey combines such majestic beauty with so cruel a character; no other better demonstrates the truth of the fable, in which the Mouse admires the Cat for its prettiness and amiability. If fierceness were taken as a standard, he would be counted as first among all mammals, for he has withstood the lord of creation as no other animal has $d$ ne. Instead of retreating as the line of agriculture and civilization advances, he finds himself attracted by human settlements, and has in some instances forced Man to retreat. He does not fight shy of populous localities like the Lion, who secnts danger in them, but boldly opposes Man, not openly, to be sure, but as a stealthy, cunning foe. His cruelty and Man-eating propensities have been greatly exaggerated; or, at least, depicted in very glaring colors.
The Magnificent called Bagh, sher and Nahar by the Hindoos, and Hariman by the Malays, is a magnificent specimen of the Felida, with a wonderfully beautiful color. He is taller and more slenderly built than the Lion. The entire length of a full-grown male, counting from the nose to the tip of the tail, is between nine and ten feet. The female is about one foot, or one foot, four inches shorter. The length of the tail varies from two and onehalf to nearly four feet. The height, at the shoulder, is from three to three and one-half feet. The weight of two female Tigers has been found to be two hundred and sixteen and three hundred and seventeen pounds, respectively, while two males weighed three hundred and twenty-six and three hundred and forty-four pounds. The body is longer than that of the Lion, while the head has a rounder shape; the tail is tuftless, and the hair short and smooth. The female is smaller and her whiskers are inferior to those of the male. All Tigers inluabiting northern regions are clothed during the cold season in thicker and longer hair than those which are natives of the tropical valleys of India. The fur shows a harmonious arrangement of colors, and a vivid contrast between the light flame-color of the groundwork and the dark stripes. As in all the feline animals the tinge of the back is darker than that of the sides; the belly, the inner side of the limbs, the lips and the lower parts of the cheeks are white. The stripes are differently interspaced in individual animals, and run in a slightly slanting direction from the spine backwards and downwards. The tail is lighter than the back and also shows darker ringlets. The whiskers are white. The large eyes have round pupils and are of a yellowish-brown color. The young ones show exactly the same disposition of color, except that the ground tint is lighter. The Tiger, however, shows variations in his coloring: the ground tint may be dark or light, and in a few rare cases it is black or white with dingy stripes.

So brilliantly adorned an animal would seem to be very conspicuous and easily detected by the very animals it pursues; but that is not the case. 1 have already mentioned how the coloring of all animals, and the Felidae in particular, harmonizes with surrounding objects, and I need but recall the fact that the Tiger usually takes up his abode in bushes, reeds and high grass. Frequently even experienced sportsmen entirely overlook a Tiger, as well as other animals that are lying quite close to them

Where the The range of the Tiger is wide, not

Tiger is being confincd to the very warm parts

Found. of Asia, but extending over a portion of that continent equal in area to the whole of Europe. He inhabits the country between the eighth degree of south and the fifty-third degree of north latitude, being found as far north as southeastern Siberia, which has a much colder climate than has that part of Europe which lies in the same latitude. His headquarters are India; and thence he spreads northward through China to the banks of the Amoor and through Afghanistan and Persia to the southern shore of the Caspian Sea. A few scattcred specimens may occasionally be found bevond these boundaries, but certainly not westward to the Caucasus or the Black Sea. On the Malay Islands the Tiger does not live, except in Sumatra and Java, and Ceyton is also free from his presence.

Jungles rich in reeds and bushes harbor the Tiger, as well as stately forests, up to a certain altitude 


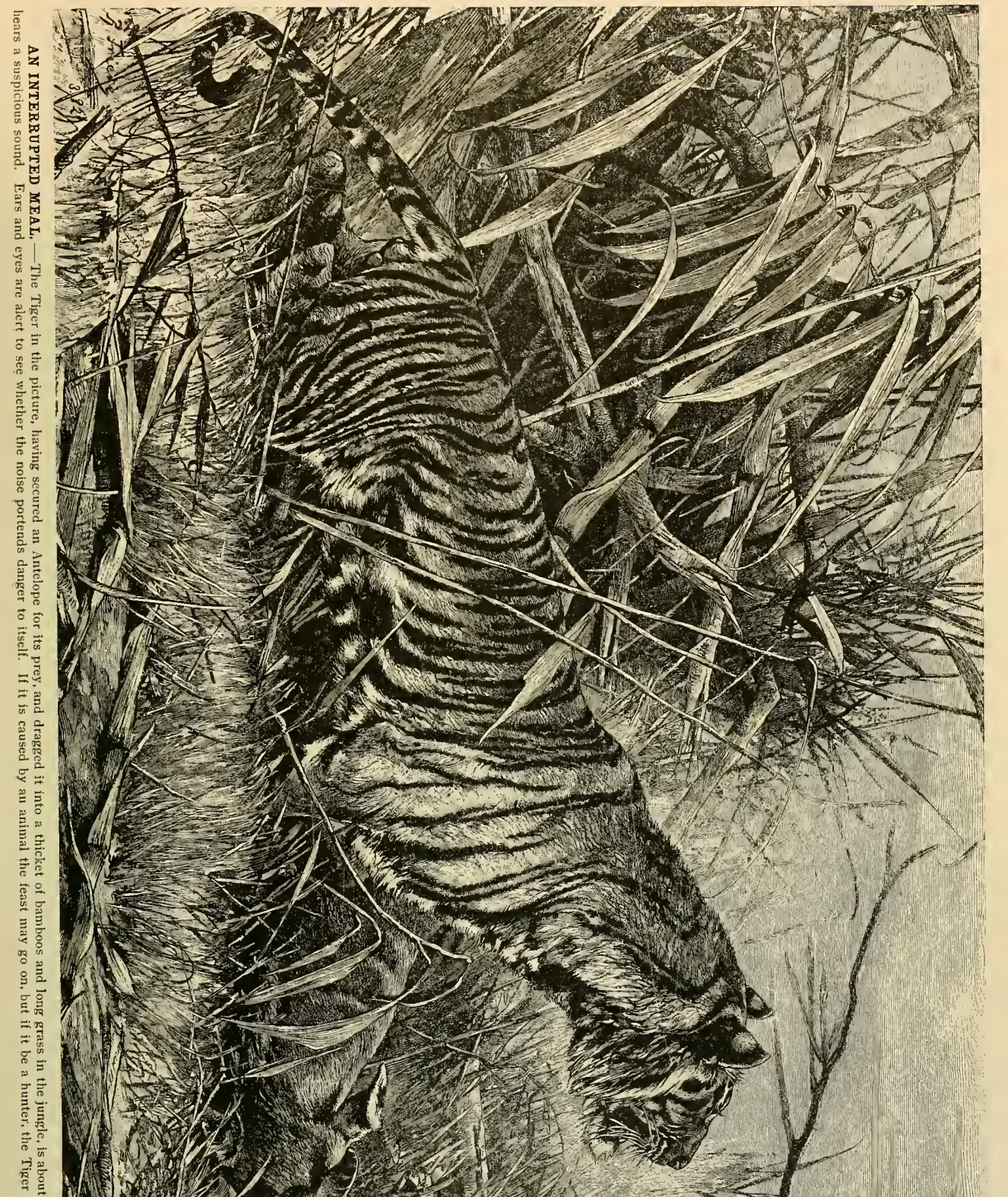

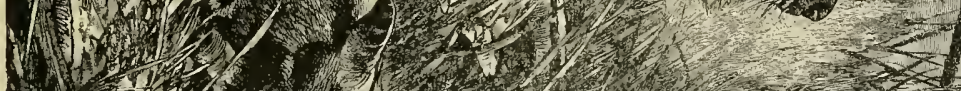

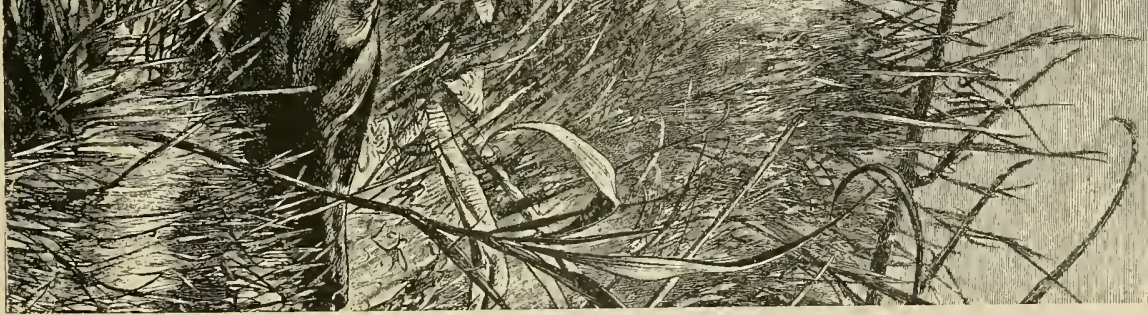


above the sea-level. He does not ascend high mountains, and even in the Himalayas he is not found at a greater elevation than six thousand feet. The banks of rivers thickly grown with reeds, impenetrable bamboo bushes and other thickets are his favorite haunts. He is also fond of ruins, and not infrequently as many as three or four are seen lying on an old wall or on the roof of a deserted temple. All observers agree that he habitually returns to hiding places and lairs that have once been selected, although others just as desirable may be in the immediate neighborhood. Blanford writes: "Some spot grown with high grass or reeds, on the bank of a river or edge of a marsh, some thicket of bushes among a dozen of similar kind, some special pile of rocks among a hundred just like it, continues to be the home of a Tiger for years, and when its inhabitant is killed by a sportsman, another will soon niove into the deserted home."

Habits and The Tiger possesses the same habits Characteristics and customs as all the Cats, but they

of Tigers. are proportioned to his great size. His movements are as graceful as those of the smaller felines, and he is possesscd of wonderful agility and great endurance. . He glides noiselessly along, covering great distances in a short time; he runs swiftly at a gallop and swims excellently. 11 is jumping ability has been much overestimated. The footmarks left by him in the pursuit of game have been measured and the greatest distance covered in a single leap was about seventeen feet. He does not climb trees, unless their trunk is inclined or very gnarled; and he is unable to ascend those that are upright and have a smooth bark. I3ut he somctimes jumps on trees in play, Cat-like, and tears the bark.

The Tiger cannot be said to have exclusively nocturnal habits. Like all Cats he prowls around at any hour of the day or night, but he prefers the period just before or after sunset. He lies in wait for prey chiefly at points where animals go to drink, near roads or along paths through the wood. In southeastern Siberia he nightly visits places where salt is being made: for he, like the natire sportsmen, is well aware that Deer congregate there, attracted by the product of the mines. Often he encounters hunters intent on the same game as hinself. No mammal enjoys immunity from his attacks, except the strongest, like the Elephant, the Unicorn, or the Buffalo. He is said, sometimes, to try his strength on the latter, but usually, and especially if the Buffalo be a male, he cones out worsted. There also are a few reports to the effect that an old and tried IVild lioar occasionally gets the better of him. Now and then the Tiger may pick a quarrel with a Bear, but his favorite game is II ild Boars, Deer and Antelopes. When times are hard he eats any animal that comes along, whether it creeps, flies or walks. The Bengal Tiger, during inundations, lives upon fish, Turtles, Lizards and Crocodiles, Simson found the stomach of a slain Tiger stuffed with Grasshoppers, lle is said not to disdain Frogs: and when, in northern regions, food is searce in winter, he goes Mouse-hunting.

The Tigera Thus all animals, large or small, have Terror to good reason to be on their guard against all Animals. the Tiger. As Crows, or thic smaller animals, make a noise when pursued by a bird of prey, so many animals in the tropics lift up their voices at the alpproach of the Tiger. They know him from experience, and realize what is in store for them when he begins his hunt. Forsyth and others tell us how useful Monkeys may be on a Tiger hunt. "Once," Forsyth tells us, "I followed a Tiger through a dried-out water-course, guided solely by the conduct of numerous Hoonumans, which were plucking fruit on the banks. When the Tiger was passing under them, they fled to the highest trees, shook the branches violently and screamed and chattered so that one could hear them at a great distance. Each troop continued its noise until he was out of sight, and then the next one sounded the alarm: after which the first troop of Monkey's descended and complacently resumed their berry-eating. In this way 1 was kept informed as to the precise whereabouts of the Tiger, and was able, at a bend of the river, to cross it, run ahead of the brute and lic in wait for him. Soon I saw him sneaking along with great, swinging strides, his tail between his legs, the very personification of a guilty murderer. Ilis conscience evidently smote him, for he guiltily looked around and up, as if imploring the IIonkeys to keep still and not betray his presence. A bullet put an end to his career."

Tigers, though On the whole the Tiger is not a couraFierce, not geous animal. He is iist only cautious Brave. and timid, but downight cowardiy, though exceedingly eunning. At a first meeting with Man, the Tiger always seeks safety in flight. Some Tigers are put out of countenance by noises and gestures, and probably none resist a resolute opponent. Some there are, who know by experience that Man is their most easily conquered prey, and these are very dingerous, as they then lie in wait for unsuspecting rictims. Under certain conditions they are not only bold, but impudent. A few districts are so infested with Tigers that communication between given points can only be had in safety by means of large bodies of men, who protect themselves by night by building fires, of which these animals liave great fear. Tigers are known to have carried away people in the neighborhood of villages and even from between huts, and instances are recorded where they have compelled people to desert their homes for places of greater security. Those have most to fear whose occupation demands a rather solitary outdoor life, as shepherds, mail-carriers, wood-choppers and ficld laborers. The first named are also in constant fear for their flocks.

Villages During the latter part of the ' 60 's a

Terrorized by Man-eating Tiger had taken up his

Tigers. abode in Naisur, and attained unenviable notoriety under the name of Benkipur, terrorizing the neighborhood for miles and miles around, until a bullet closed his career of cruclty. Forsyth freed the central provinces of several Man-eaters, of whose deeds he tells us. Onc of them had stopped all communication on several roads, driven away the inhabitants of several villages and compelled others to live in fortified and closed houses. This Tiger was said to have carried away over one hundred people before Forsyth succeeded in killing him. According to Fayrer, a Tiger in the same district, during the years $1867, \mathbf{I} 868$ and 1869 , earried away respectively twenty-seren, thirty-four and forty-seven people; continuing his depredations until he was killed by a spring gun. One Tigress drove away the inhabitants of thirteen different localities, and escaped all pursuit in the most cunning manner. until an Englishman killed her. But because such things happen it must not be concluded that they are of common, every day occurrence. 


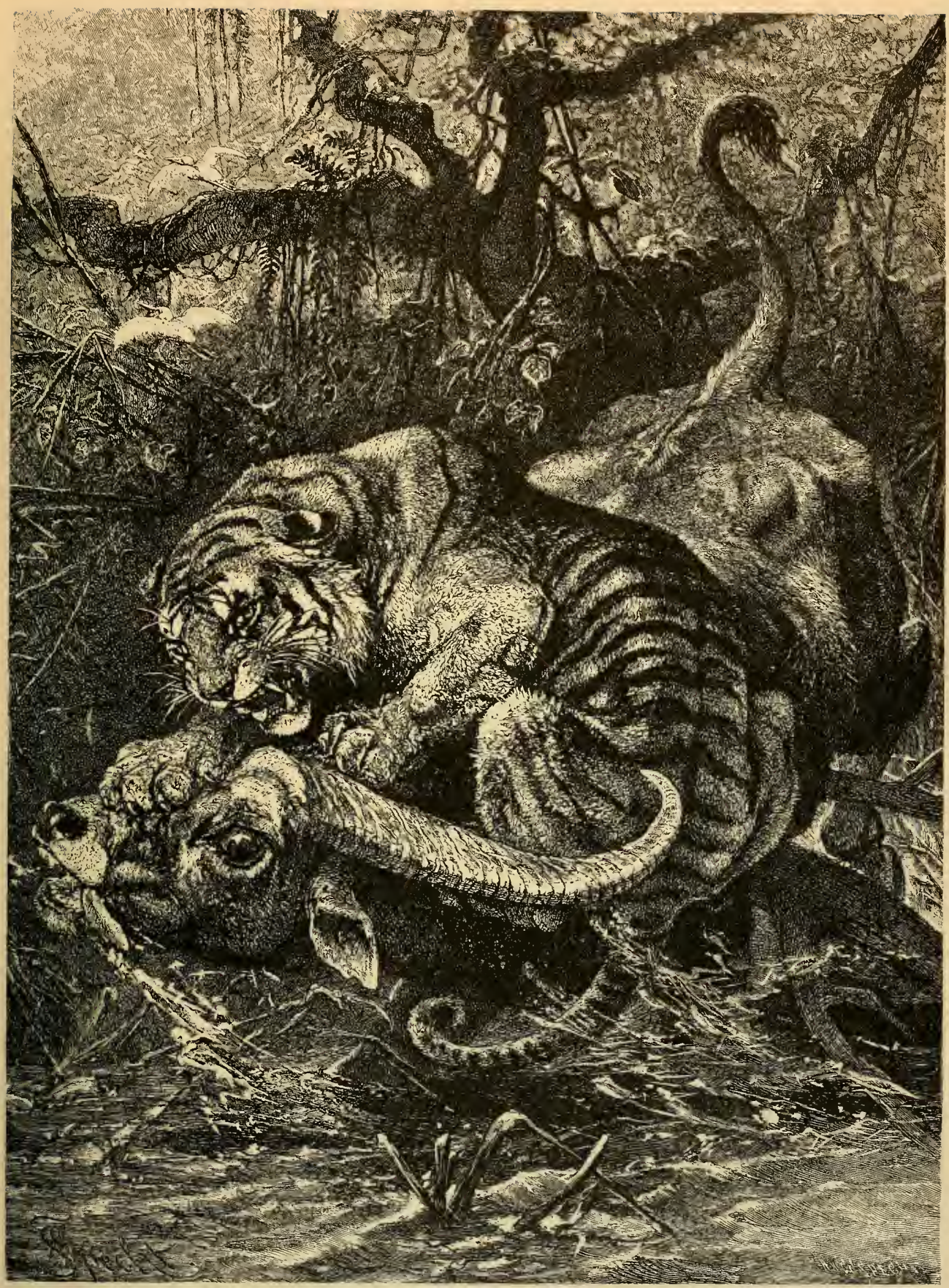

TIGER ATTACKING A BUFFAL0. - Watching by the spot where animals come to drink, the Tiger in the picture has had its stealth rewarded by a victim. The Asiatic Buffalo is one of the most difficult prey with which the Tiger has to do, and under ordinary conditions the Buffalo gets the better of the Tiger that attacks it. In the instance shown in the picture, however, the Buffalo has been taken at a moment
assailant, and is evidently doomed. The method of the Tiger's attack is told in a graphic manner by this picture. 
WTe have an immense stock of information con cerning the life and habits of Tigers, owing to the usually simple mode of hunting them. The number of people addicted to this spurt is very great, comprising even ladies, and the old, terrible stories have lost much credence. It is no longer difficult for us to separate cxtraordinary from everyday occurrences

The character and disposition of Tigers vary in individuals, as might be expected; yet, according to the best authorities, there are in the main three classes of Tigers: those that kill forest animals, those that carry away cattle, and Man-eaters.

The Game-Hunt- A Tiger of the first group shuns the ing Tiger's dwellings of Man, for his real home Habits. is in the wilderness, where he prowls around at all hours of the day and night. He naturally leads more of a roaming life than the others and follows his game from one part of the country to another in the course of the seasons. To the sportsman he proves a most welcome rival, but to the agriculturist he is a good friend, as he drives away Stags and IVild Boars, from whose depradations it is so difficult to protect the fields. These game-killing Tigers as a rule are more slender and agile than the others, though they also boast among their numbers some of more massire build. They are by far the most numerous class of Tigers, and during the hottest and dryest season they gather near the watercourses that have not given ont.

The Cattle- Those Tigers that carry away cattle pre-

Stealing fer the neighborhoud of villages and

Tigers. seck their prey among the herds that are driven to pasturage, or among such stragglers as may be left out for a night. As owners of flocks usually lock them up in secure places before dusk the rapacious Tiger accustums himself to get his food by broad daylight, usually in the latter part of the afternoon. If he is not pursued, he frequents but a few villages; if threatened he extends his wanderings. In Maisur, in a stretch of country twentyfive miles long and thirty-seven miles wide, eight well-known Tigers at one time made their living in this way. Of course they also kill Goats, sheep, Donkeys, Stags, Boars and other game if it crosses their path. An exclusive robber of Cattle is found only among the old, fat and lazy Tigers. Such robbers scelect as their headquarters some locality abundantly supplied with flesh and water. They establish relations of mutual tolerance with the human inhabitants of the village, and every four or five days each Tiger seizes and bears to his lair an unfortunate Cow or Bull.

We must not take our Cattle as a standard and thercby measure the damacre that is done. The Hindoo never kills a Cow, and so there are in every village a multitude of old, decrepit beasts that do more harm than rood, because they aid in spreading the Cattle plague, and these are really best disposed of as Tiger-food. Without the aid of Tigers in kestroying Boars and Deer, it would be utterly impossible in certain districts to obtain good harvests. That is why agriculturists are not greatly pleased, when a sportsman zealously hunts the game-killing and modest Cattle-robbing Tigers, for they serve them as field guards in a certain way. Sanderson once killed a well-known, gigantic Tiger, and the natives, surrounding the corpse, unanimously mourned over his fate; "He never did us any harm; what a pity he is dead," they said.
The Man- The Man-eater usually begins by carryEating ing off Cattle, and loses his dread of Man Tiger. by constant contact with shepherds. Oftener the Man-eater is a female than a male, probably because she has to care for her little ones; and sonctimes it is a wounded or crippled specimen, which cannot support itself in the usual way. Man can be watched and attacked so much more easily than any tame or wild animal, that a Tiger which has once lost the fear of him accepts him as lawful prey, wherever it can safely do so. This has led to the belief that the Tiger prefers human flesh to any other; but this is refuted by many authentic accounts, as also is the belief that the Man-eating Tiger as a rule is a lean, half-starved creature.

Man-eating Tigers are said to predominate in those parts of the country where herds of Cattle are pastured at certain seasons of the year; after their departure the Cattle-robbing beasts are compelled from lack of other food to attack the natives. The Man-eater dues not display any greater courage than other Tigers. He is as cowardly as he is cunning and surprisingly impudent. Running from armed Men, he only attacks those who are alone and defenceless, fully appreciating as he does the difference between the two. In consequence of his Man-hunting habits he is better acquainted with the ways of Men and is therefore much harder to be reached by the sportsman than other Tigers.

Pleas on Sandersun says: "This dreadful plague

Behalf of of the timid and weaponless Hindoo is

the Tiger. becoming rare. Man-eating Tigers of the worst character are now seldom heard of, and when they are they are soon hunted down and killed.

"It is a pity that the Tiger is doomed and is being exterminated in most unsportsmanlike manner. The cause of this lies in the hue and cry, raised mainly in England, over the mischief he does. This belief is without foundation. Let every Man-eating Tiger be pursued and killed; likewise slay the worst among the Cattle-robbers; but ordinary Tigers are useful, they are not dangerous and ought to be spared. Distant be the day when there will be no more Tigers." This explorer is superintendent of the government department for the capture of Elephants and his profession compels him to live in the wilderness among wild beasts. He has an intimate knowledge of every portion of India, its needs and its dangers, and is therefore a most competent judge. His conclusions may well cause serious reflection, especially as they are held by other trustworthy observers. Sherwill sitys very positively: "The Bengal Tiger is, on the whole, it harmless, timid animal, only becoming dangerous when he is wounded. He never molests Men, unless driven to bay, and Maneating Tigers are not found at all in Bengal, except in the marshy forests of the Ganges delta." Fayrer, who appreciates the cruelty of the Tiger, declares that accidents are no more frequent on a Tiger-hunt than in the following of the Fox in England.

Thus it is shown that this generation has a different estimate of the Tiger than was held by our forefathers. He is a beast of prey which, in many districts, at least of India, docs more good than harm, and only upon rare occasions does he become that embodiment of terror which has given a formidable reputation to the whole species.

How the Rarely does the Tiger or the Lion hunt Tiger Hunts prey in the manner that has been usuHis Prey. ally accepted as correct; that is, as if he measured the distance, crouched down and reached 


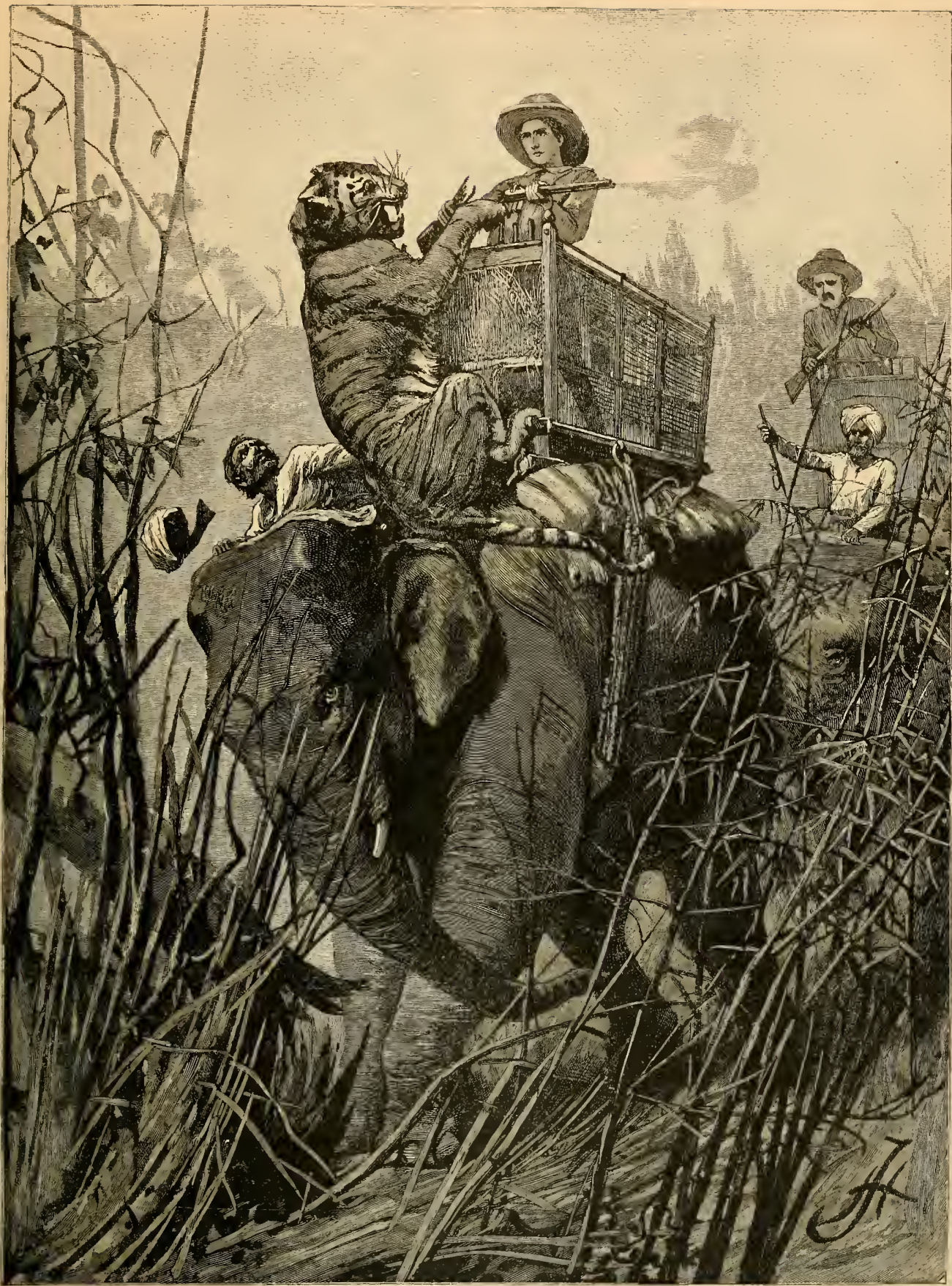

A TIGER HUNT, - When Prince Phillipe of Orleans and his nephew, Prince Henty, were entertained in 1889 by Lord Dufferin, Viceroy of India with a Tiger hunt, they met with the remarkable adventure shown in the picture. A Tigress, whose two cubs had been killed by the party, sprang out of the jungle on the faremost Elephant. The Mahut (Elephant driver) dexterously slid down the side of the Elephant's head in time to save himself, and the Irightened the Tigress, who then made her escape and was next day killed by the party. This picture, which was drawn from the account given by the Prince himsell, is not presented as representing in detail the characteristics of the Tiger, but rather as a valuable illustration of the animal's boldness, and also of an interesting mode of hunting it. 
his victim at one huge bound. The chief success of his attack lies in its surprise. An animal that is close to him, he seizes immediately; one that is farther away he reaches by quick bounds; he pursues a fleeing one, and, if it be a large animal, he tries to tear the muscles and tendons of its hind legs by furious blows of his paw.

The Tiger either drags his prey into a thicket immediately or he waits for dusk; and sometimes he carries it a short distance. Sanderson saw an enormous male Tiger carry an ox weighing about three hundred and sixty pounds a distance of about three hundred paces. When not disturbed the Tiger eats as much as he can, which is nearly sixty pounds. He usually begins with a hind leg; seldom with a flank. While eating, he interrupts his meal at intervals by going for a copious drink of water. He is said to sometimes wade into the water and dip his head in as far as the eyes, lapping and gurgling as if he wished to rinse his huge mouth. After a satisfactory meal, he goes to sleep. He only arouses to procure drink, and, in fact, he attends to his digestion with a great measure of enjoyment. In the evening, generally between four and nine o'clock, he returns to his prey, to cat what he has left, if he can find it; for his table, like the Lion's, is, during his absence, spread for all kinds of hungry beggars, and he not infrequently discovers that the latter have made away with the carcass, even to the bones.

He can endure hunger and thirst for a very long period. Two Tigers were once hemmed in by nets, in an impenctrable thicket about one hundred paces in diameter: they were wounded on the fifth day, but were not killed until the tenth, and then with the assistance of an Elephant. The weather was very hot and they had been, besides, surrounded by fires, and in all this time they had neither food nor water and they suffered from their wounds; yet, they retained their strength to the last.

Methods of There are a great many devices for

Catching catching Tigers. All kinds of traps

the Tiger. are set for them and pitfalls are very efficient. Formerly pointed poles were placed in the center of the latter but an innoccnt human being was impaled on one of them and since that time their use has been interdicted, at least in the neighborhood of Singapore. Hasskarl writes me from Java that large traps are made of tree-trunks, and the bait is a young Kid, whose bleating attracts the beast. After due caution the Tiger creeps into the trap, tries to carry off the prey and thereby pulls a string, which shuts the trap. H. O. Forbes tells us that the natives of Sumatra make a holc in the fence surrounding a village, and attach a spear above the aperture so that when the Tiger crawls through he detaches a spring, which forces the spear into his body. In Assam, O. Flex tclls us, automatic bow's with poisoned arrows are put in the Tiger's path, near the place where he gocs for water. Spring guns are also used to good effect. Lately strychnia has been employed very extensively, but it is said to lose its efficacy when the meat upon which it is strewed begins to decompose

The profits of a successful Tiger-hunter are not to be despised. Besides receiving the bounty offered for killing a Tiger, he can use nearly all parts of its body, especially the fat, which amounts to from four to six quarts, and which is believed by the natives to cure rheumatism and ccrtain diseases of Cattle. In some localities the flesh is catcn, and Jagor declares that its taste is not bad. In somc countries the teeth and claws, the fat and the liver are valued more than the flesh and bones. The teeth are counted by the Shicaris as precious charms which render the wearer invulnerable against attacks of other Tigers. The claws, framed in gold and silver, are worn as ornaments by European and Asiatic ladies. The skins are cured and sold to Europeans and Chinese merchants. The Khirgiz adorn their arrow-cases with them. In Europe a Tiger skin, according to Lomer, may be sold for as much as three hundred dollars.

Tiger Kittens The Tiger seeks his mate at varying

and Their seasons according to his locality, the

Training. breeding period beginning in the northern regions late in the fall or early in the winter; in the southern countries, like India, it is restricted to no particular time. The Tigress gives birth to two or three, sometimes four, and in rare cases five or six cubs, having first selected for her lair some impenetrable spot, surrounded with thick vegetation. The little ones are about half the size of our adult domestic Cat and are charming littlc creatures, as are all Kittens. During the first few weeks the mother does not leave the young ones until she is nearly famished; but as soon as they are somewhat older and require solid food, she begins to prowl around for prey.

Sanderson says: "Little Tigers are extremely pretty and very good-natured. But if one wishes to tame them, they must be captured before they are a month old, and have no linowledge of life in the wilderness, or any dread of Man. They show a great deal of affection for thcir owner, follow him about, lie under his chair, and utter a peculiar, joyous snort when he caresses them. As soon as they taste meat, they do not want anything else to eat and will turn up their little noses at milk. The belief that a raw meat diet renders them wild is totally unfounded, as my own experience with them has shown. That is really the only food on which they thrive, and if they have enough of it they are very tractable. At the age of four months they are alrcady quite strong and stately, but they can be left to run about. for a much longer period. I kept a couple of them at liberty until they were eight months old. They used to play very nicely by themselves and also with Men, and with a tame Bear. My expericnce has taught me that Tigers tamed in this manner are neither malicious nor bloodthirsty, and are not at all subject to savage outbursts if food is furnished in plentiful supply. I once had one of considerable size which had accustomed himself to sleep in my bedroom. After 1 had fallen asleep he would frequently jump upon my bed; but he never took it amiss when I gave him a few cuffs and threw him down again.'

Tigers are Of late Tigers have been traincd to perTeachable but form certain tricks. The trainer enters Treacherous, a cage and causes them to go through a fixed programme, but it always rcmains a risk attended with decided danger. The Tiger is a genuine Cat, and shows affection for those who pet him, sometimes not only tolerating caresses but also returning them. Still his friendship is always doubtful, and he obcy.s in matters that are repugnant to his nature only when he recognizes and fears Man's authority. He never descrves full confidence; it is not so much his malice that is to be dreaded as his consciousness of his own strength. He has as. little malice or treachery as our own Pussy, but is. 
just as intolerant of bad usage, and rebels when he does not like the treatment accorded him by Man.

Combat Between Indian princes still arrange combats Tiger and between Tigers and other animals Elephant. especially the Elephant and Buffalo. Tachard witnessed such a fight in Siam. Three Elephants, whose heads were protected by a kind of harness, were led into an enclosure, fenced in by stakes. The Tiger was already there, but was held by two ropes. He was not very large, and when he caught sight of the Elephants, looked about for a hiding place; but the Elephants at once gave him a few blows with their trunks, which sent him to the floor in a dead faint. He was then untied, soon regained consciousness and, with a roar, rushed at the trunk of one of the Elephants, but the giant lifted it high up and threw the Tiger into the air with his tusks. He did not attempt another attack after this, but ran back and forth near the stakes and tried to escape. The three Elephants were then pitted against him, and they administered such terrific blows that he again fainted. If $\mathrm{the}$ struggle had not ended at this point the enraged Elephants would have killed him.

The ancients did not know the Tiger until a late period. The Bible does not mention him, and the Greeks speak of him but little. Nearchos, Alexander's general, saw a Tiger-skin, but not the animal itself, although the Hindoos informed him that it was as big as the largest Horse and was superior to all other creatures in swiftness and strength. Strabo is the first writer who gives any detailed account of him. The Romans had no knowledge of Tigers up to the time of Varro. Claudius had four of them in his possession. Subsequently Tigers were often brought to Rome, and Heliogabalus had them draw his chariot when performing as Bacchus. Avitus gave, in an amphitheatre, the first performance in which Tigers were killed, five of the beasts being slaughtered.

Description of The Royal Tiger has as few near kinsthe Clouded men as the Lion; his nearest relatives, Tiger. one of which was the Tiger of the Caverns that inhabited central Europe, all being extinct. One South Asiatic species, the Clouded Tiger (Felis nebulosa), approaches him nearest, having like him a long body set on strong, sliort limbs. The head is small, the ears are rounded, and the soft fur resembles the stripes of the Royal Tiger. The greatest points of difference are its smaller size, the very short limbs and the tail, which is as long as the body. The ground color of his fur is a dingy, whitish-gray, sometimes overlaid with a yellow or brownish tinge. The lower parts arc of a tan color. The head, feet and abdomen are adorned with black, round or oblong spots or stripes. The margins of the lips show a black edge, and the ears are black with gray spots. The length of the body is a little more than three feet, and the tail measures a little less than the body. The range of this animal is very extensive, embracing all southcastern Asia.

A few years ago the Clouded Tiger was a very rare animal in collections and zoological gardens, but is now more frequently met with. The natives of Sumatra say that he is anything but ferocious and lives only upon small mammals and birds. Among the latter we must, unfortunately, include Chickens, and the damage he does in poultry yards is considerable. A beautiful specimen of the Clouded Tiger was attached to the London Zoological Garden, and

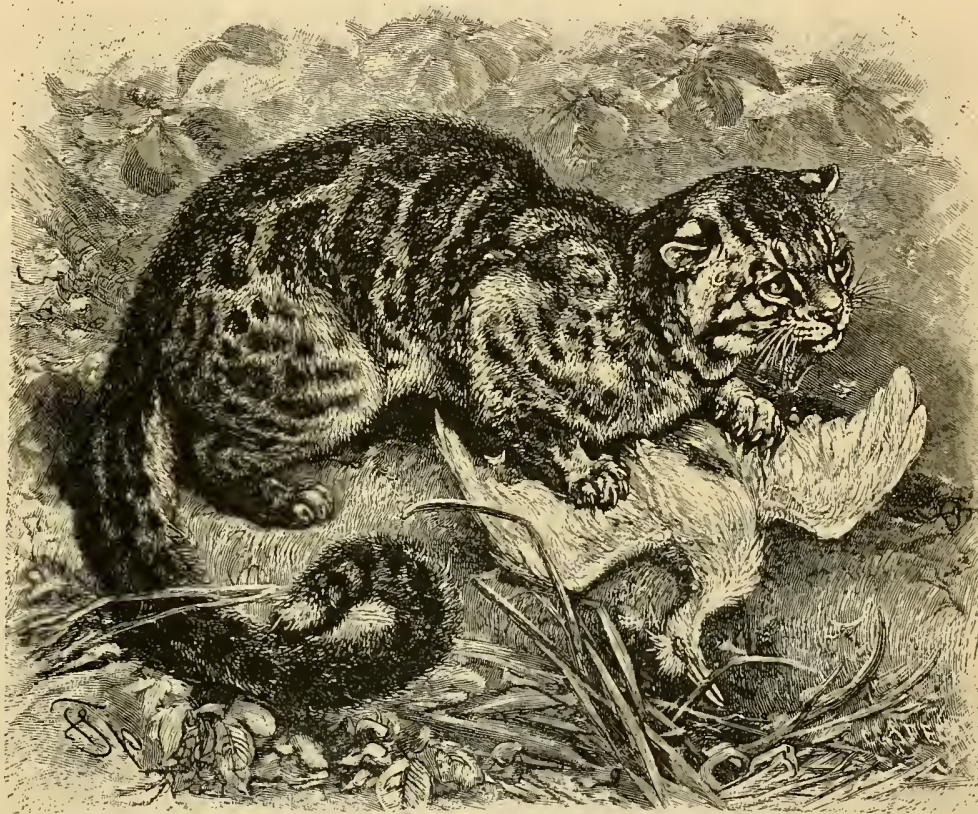

THE MARBLED CAT, - This animal is a little larger than a large house Cat. The ground tint of the fur aries, but is usually of a brownish gray and merges into a black strip which extends along the entire back. On the ides are dark spots, not so sharply defined as those of the Leopard, but still quite prominent. The Marbled Cat a, Java, Sumatra and perhaps Borneo. (Felis mamorata.)

the keeper treated it as he would a good-natured Domestic Cat.

\section{THE COMMON WILD CAT.}

The Common IVild Cat (Felis catus) is the only onc of the family that has not been quite exterminated in the Old WVorld countries, like Germany. For a long time it was thought to be the ancestor of our Domestic Cat, but closer investigation does not support this belief. The Wild Cat is considerably larger than Pussy. It may be distinguished from the latter at a glance by its thicker fur, its larger whiskers, its ferocious look and its stronger teeth; its head is thicker, and its tail is fuller and shorter, does not taper toward the end, and is ringed in gray and black. The throat shows a whitish-yellow spot, and the soles of the feet are black or dark. 
The Wild Cat attains a weight of sixteen or eighteen pounds. Its height at the shoulders is about sixteen inches; its length from snout to tip of tail, forty to forty-five inches, the tail measuring twelve or thirteen inches.

The fur is long and thick, gray in the male, yellowish gray in the female. The face is yellowish, the ears are russet gray on the outside and yellowish white on the inner side. Four black bands run from the forehead backward between the ears, and two of them uniting run along the spine and the upper side of the tail. From this band others of a rather faded dark color proceed downwards, dying away on the abdomen, which has a yellow color, dotted with black spots. The eyes of the animal are yellow.

Where and How The Wild Cat inhabits all parts of

the Wild Cat Europe, with the exception of the Lives. north, or more especially Scandinavia and Russia. In Germany it inhabits all the wooded mountains, though not in very large numbers. The southeast of Europe is particularly well stocked with it. In the lower parts of the Alps it is very common. It is also frequent in Spain and France, and Great Britain has not yet quite exterminated it. Outside of Europe it has only been found in Grusia, south of the Caucasus. Great, thick forests, especially gloomy woods of the pine and fir-tree, are its favorite haunts. The more deserted a district is, the more devoted is the IVild Cat to it. It prefers rocky forests to all others, as rocks afford so many places of concealment. Besides it lives in the holes made by Badgers and Foxes, and in hollow trees.

The Wild Cat lives in company with others of its kind only during the breeding season and while its young ones are dependent on it. At all other times it leads a solitary life. The young separate from the mother at an early age and try hunting on their own account.

The IVild Cat begins its activity at dusk. Endowed with excellent organs of sense, cautious and cunning, noiselessly creeping up to its prey and patiently watching its opportunity, it is a dangerous foe to small and moderate sized animals. It lies in wait for the bird in its nest, the llare on the ground, the Squirrel on the tree. It kills larger animals by jumping upon their backs and severing the carotid artery with its sharp teeth. It also shows its genuine feline nature by renouncing its intended prey, if the first leap is unsuccessful. Fortunately its principal nutriment consists of Mice of all kinds and small birds. It is only occasionally that it seeks for larger animals. Still, it is a fact that it attacks Fawns and Roes, and is strong enough to cope with them. It keeps watch by the banks of lakes and rivers for fish and birds and catches them very adroitly. It

is extremely destructive in parks and game preserves.

Considering its size, the Wild Cat is a very dangerous Beast of Prey, especially as it is guilty of the bloodthirstiness that distinguishes all of its kindred. For this reason hunters detest it and pursue it without mercy. No sportsman gives it due credit for all the Mice it kills. How many of them it destroys may be seen from Tschudi's statement that the remains of twenty-six Mice were found in the stomach of one Cat. Zelebor examined several stomachs of Cats of this species and found them to contain the bones and hairs of Martens, Fitchets, Ermines, Weasels, Marmots, Rats, Nice, Squirrels and birds. Small mammals, therefore, form its principal food, and as Mice are the most frequent among these, we are inclined to think that the good services of the Wild Cat more than compensate for the mischief it does. It exterminates more harmful than useful animals, and if its attributes do not endear it to the hunter, our woods profit by its activity.

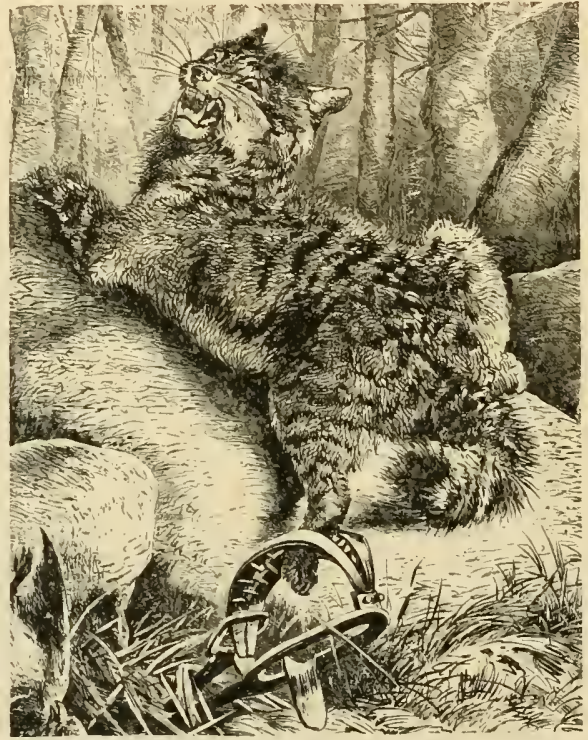

COMMON WILD CAT. - This fierce European animal is thoroughly hated by its human neighbors, who often trap it, like the one in Cat - the arrangement of its strong teeth, the long whiskers, the stunted tail and the gray and black markings of its shaggy coat. (Ficlis ly disabled from moving and even then to give it a finishing stroke before touching it. Wounded Wild Cats driven to bay are very dangerous. Tschudi says: "Take good aim, hunter! If the beast is only wounded, it curves its back, lifts its tail straight up, and makes for the sportsman with a vicious, hissing snort, and buries its sharp claws in his flesh, preferably his breast, so that it can hardly be torn away; and such wounds are extremely slow to heal. It has no fear of Dogs, but will of its own accord, and before it sees the hunter, often come down to them from a tree; and the fight that ensues is fearful. The fierce animal uses its claws to good purpose, always aiming at the Dog's eyes, and fights with desperate energy until the last spark of its tenacious life is extinguished."

We must carefully differentiate the Wild Cat proper from stray domestic Cats that may have 


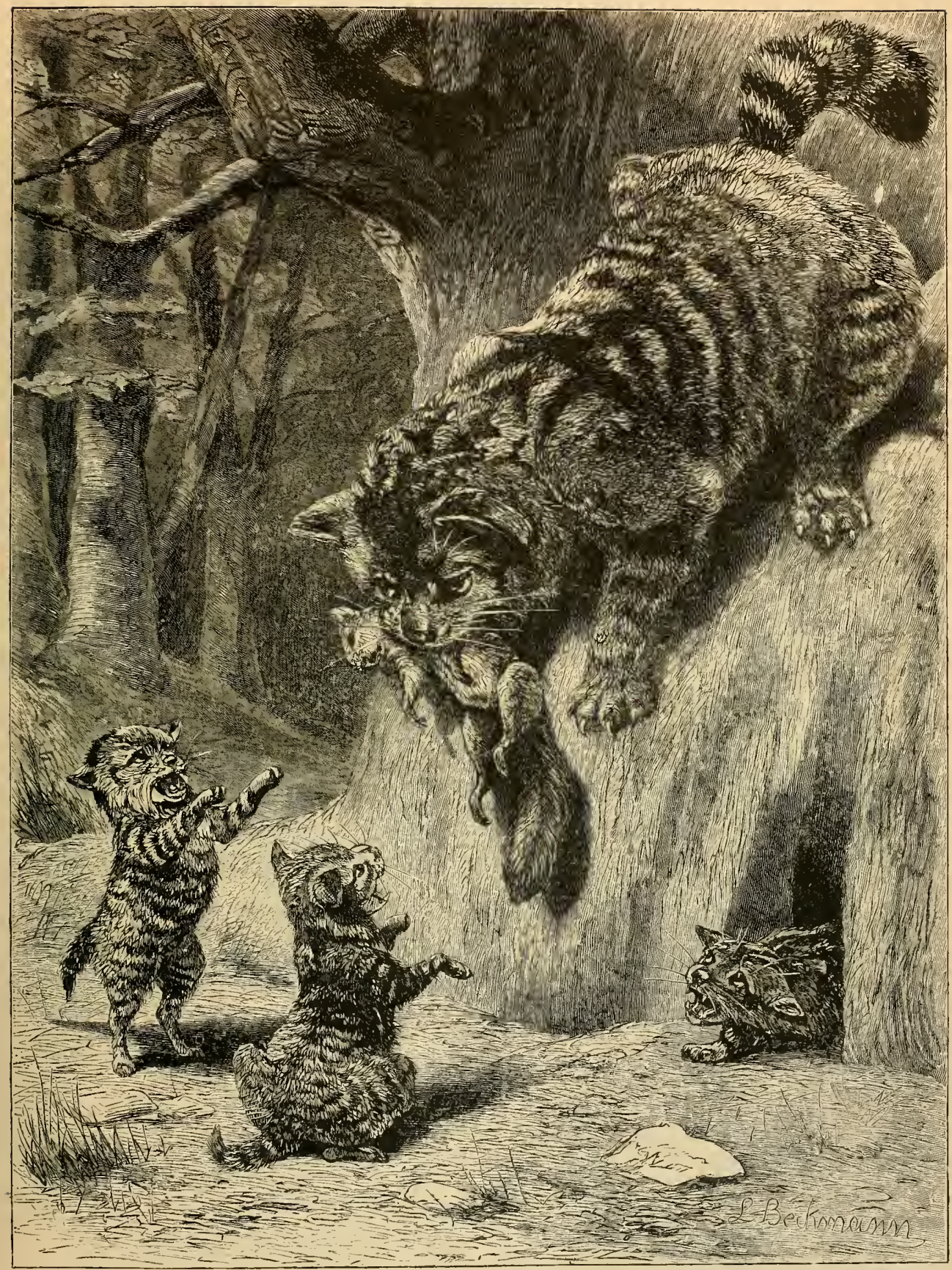

FEMALE WILD CAT AND YOUNG. - In the forests of Europe the Common Wild Cat makes its home. This is not the animal commonly known in America as the Wild Cat, the latter being really the Red Lynx. The European ammal is a true Cat, larger than the domestic species and very fierce and

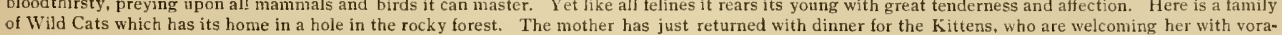
cous expectancy. (Felis catus.)
ciols 
degenerated in the woods. The latter are frequently met with, but they never attain the size of the IVild Cats, though greatly exceeding that of the domestic Cat. They are as ferocious and dangerous as the IVild Cat, and after several generations have been born wild in the forest these animals come to resemble their progenitor, the Egyptian Cat, in color and tint, though they always lack the blunt tail, the light spot at the throat and the dark soles of their ancestor. The animal known as WVild Cat in the United States is very different from the European animal of that name and is in reality a Lynx. (See Red Lynx.)

\section{THE EGYPTIAN CAT.}

The next member of this group is the Egyptian Cat (Felis maniculata). Ruppell discovered it in Nubia, on the western bank of the Nile, in a desert where rocky stretches of country alternated with bushy tracts. Later writers have found it in Soudan, in Abyssinia, in the innermost centre of Africa and in Palestine. The length of its body is about that the Egyptian Cat is more common in the Niam-Niam country than in any other part of Africa that has been fully explored, so that the center of the continent might be considered the point from which it spread. The Niam-Niam do not possess a domestic Cat, in the proper meaning of the word, but their boys capture the Egyptian Cat and wholly or partially tame it. At first they are tied in the vicinity of the huts, and soon become completely at home in the house, where they make it their business to catch the Mice which infest these dwellings in great numbers.

Venerated Fbers in "An Egyptian Princess," by the Ancient says: "The Cat was probably the Egyptians. most sacred of all the sacred animals which the Egyptians regarded with veneration. Herodotus says that when one of their houses was on fire, the Egyptians first thought of saving the Cat and then of putting out the fire, and when a Cat dicd they cut off their own hair as a sign of mourning. When a person wittingly or unwittingly caused

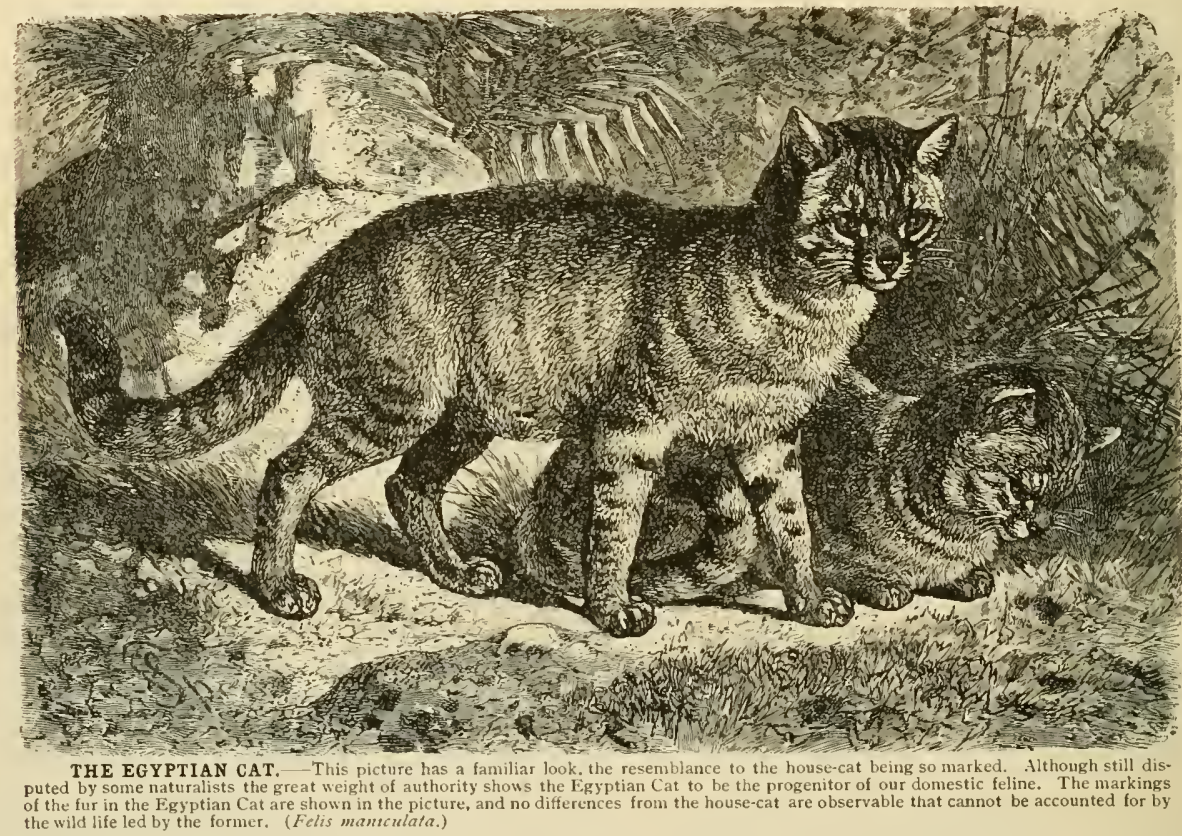

twenty inches and its tail measures a little over ten inches. These are not the exact dimensions of our domestic Cat, but they approximate them closely.

The arrangement of the colors of the fur is much iike that on some of our Cats. The mummies and pictures on Egyptian monunients agree most closely with this species, and evidently tend to prove that this was the domestic Cat of the Egyptians. Perhaps the priests imported it into Egypt from southern Nubia. It probably extended thence to Arabia and Syria, and later to Greece, Italy and the remainder of Europe, and in more modcin times, emigrating Europeans spread it still farther.

The observations of Schweinfurth in the NianNiam country are of great weight as evidence that the figyptian Cat is the original stock from which the race of our domestic Cats descended. Hc says the death of one of these animals, he forfeited his life. Diodorus himself saw a Roman citizen, who had killed a Cat, put to death by a mob, though the government, in its fear of Rome, tricd its best to pacify the people. Dead Cats were artistically embalmed, and of all mummified animals that are found, the Cat, carefully swathed in linen bandages, is the most common."

\section{THE DOMESTIC CAT.}

All researches point to the fact that the Cat was first tamed by the Egyptians, and not by the Hindoos, or any northern people. The old Egyptian monuments speak clearly in pictures, signs and mummies, while the records of other nations do not even give us food for conjecture. The very fact that the mummies of both the domestic Cat and 
the common Jungle Cat are found supports me in my opinion, for this goes to prove that when Egypt was in the meridian of its power, its inhabitants extensively caught and probably tamed the jungle Cats. Herodotus is the first Greek to mention the Cat, and it is but slightly alluded to by even later Greek and Roman writers. IVe may conclude, therefore, that the animal spread very gradually from Egypt. Probably it first went East. We know, for instance, that it was a favorite pet of the prophet Mohammed. In northern Europe it was barely known before the tenth century. The Codex of Laws in Wales contains an ordinance fixing the price of domestic Cats and penalties for their ill-treatment, mutilation and killing. The law declared that a Cat doubled its value the moment it caught its first Mouse; that the purcliaser had a right to require that the Cat have perfect eyes, ears and claws, to know how to catch Mice, and, if a female Cat, to know how to bring up her $\mathrm{K}$ it tens properly. If the Cat failed to meet any of these requirements, the purcliaser had the right to demand a return of one-tlird of the purcliase money.

This law is of $\mathrm{great}$ value as furnishing proof that in those times domestic Cats were held in high estimation, and also because we learn by plain inference from it that the IVild Cat can not have been the progenitor of the domestic species, as Great Britain was overrun with Wild Cats, whose young ones it would have been easy to tame in unlinited numbers.

The Domestic According to Cat Almost Tschudi, the

Universal. Cat now inhabits all parts of the globe except the extreme nortl and the highest altitudes of the Andes, and has established itself wherever civilization, progress and domestication have penetrated. But
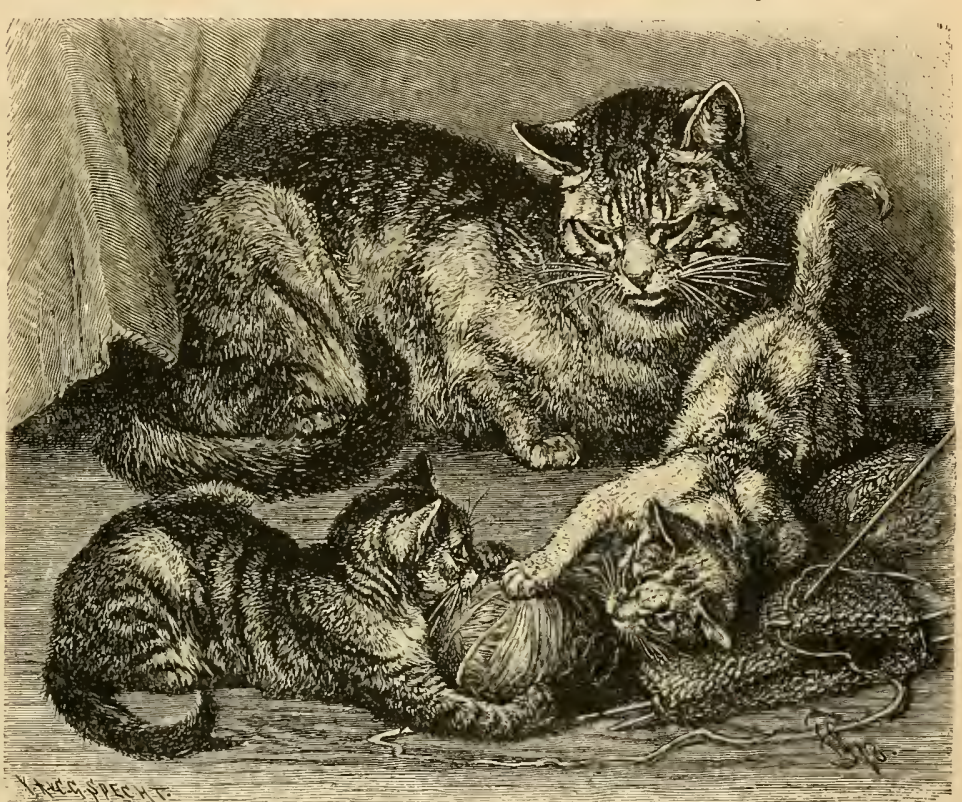

THE DOMESTIC CAT. The animal in the picture is familiar to all, and the playful scene here depicted is a very common one. The mother Cat watches with every indication of pleasure the merry gambols of her offspring.
The methods of a domestic Cat in training her young are much the same as those of the Lioness, the Tigress and The methods of a domestic Cat in training her young are much the same as those of the Lioness, the Tigress and
other larger members of the Cat family, and may therefore be observed with profit by the student, (Felis maniculata other larger
domestica.)

notwithstanding the fact that it is an inmate of human habitations throughout the world, the Cat reserves to itself a large measure of independence and only recognizes Man's authority when obedience suits its inclination. The more it is petted, the greater becomes its affection for the family; the more it is left to its own devices the more its attachment is directed toward the house in which it was reared rather than to the people who live there. Man always determines the degree of tameness and domesticity of a Cat by his conduct towards it. When neglected it is likely to take to the woods in summer. Sometimes it becomes quite wild there, but usually comes back at the approach of winter, accompanied by its Kittens if any liave been born to it during its vacation. It is often the case that after such a sojourn in the woods the Cat shows little liking for people, and this is especially noticeable in warm

clambers up trees or walls easily, but on level ground a Dog can overtake it without difficulty. However a Cat is dropped, it will always alight on its paws, the pads of which soften the violence of the fall. I have never succeeded in causing a Cat to fall on its back, even when 1 have dropped it from close range over a chair or table. As soon as I would let go it would instantly turn over and stand on its feet quite unconcerned. How it is able to accomplish this feat, especially when the short distance is considered, is quite a mystery to me. In falling long distances, it, of course, regulates its position in alighting by means of its tail. The Cat can also swim, but it practices this accomplishment only when there is an urgent need for it, and it probably never enters the water of its own accord, as it even shows a great dislike of rain; but there are exceptions, for Haacke knew a Cat which was in the habit of jumping into a pond 
and catching Goldfishes. In sleeping, the Cat likes to curl up in a soft, warm place, but cannot bear to be covered. I have noticed that Cats show a decided liking for hay as a bed, probably because the fragrance is agreeable to them After a nap on such a bed their fur usually has a very pleasant odor.

Of the senses those of touch, sight and hearing are the strongest in the Cat. The sense of smell is rather dull, as anybody can see when the creature is offered a favorite dainty in such manner as to prevent it from using any other sense in the effort to determine what it is. If the whiskers are used, the result is different, for they are very sensitive organs of touch; so are its paws, but in a less degree. The eyes are excellent and capable of seeing by night as well as by day. But the palm undoubtedly belongs to its sense of hearing. Lenz tells us that he was once sitting outdoors with a Kitten in his lap: suddenly it jumped backwards after a Mouse, which was running unseen on a smooth stone pavement from one bush to another and did not make a particle of noise that a human ear could detect. He measured the distance at which the Kitten had heard the Mouse running behind it and it proved to be fully fourteen yards.

Noteworthy The intellectual capacities of the Cat Qualities are usually quite misunderstood. Peoof the Cat. ple consider it a treacherous, deceitful, sly animal, that is not to be trusted. Nany confess to an unconquerable feeling of antipathy towards it. As a rule it is compared with the Dog, which ought never to be done; and as such comparison shows that the Cat does not possess the Dog's good qualities, the conclusion is frequently drawn that there is no use of any further investigation. Even naturalists are given to pronouncing prejudiced and one-sided opinions against it. I have sympathetically studied the Cat from my childhood, and therefore accept the following description of Scheitlin's, which certainly possesses the merits of originality, understanding and just appreciation: "The Cat is an animal of a high order of intelligence. Its bodily structure alone indicates this. It is a pretty, diminutive Lion; a Tiger on a small scale. It shows the most complete symmetry in its form - no one part is too large or too small. That its every cetail is rounded and beautiful is even shown by an examination of the skull, which is more symmetrical than that of any other animal. Its movements are undulating and graceful to the extent that it seems to have no bones. We value our Cats too slightly because we detest their thievish propensities, fear their claws and love their eneny, the Dug, and we are not able to show equal friendship and admiration for these two opposite natures.

"Let us examine the Cat's qualities. We are impressed by its agility, yet its mind is as flexible as its body. Its cleanliness of habit is as much a matter of mental bias as physical choice, for it is constantly licking and cleaning itself. Every hair of its fur must be in perfect order; it never forgets as much as the tip of its tail. It has a discriminating sensibility as to both color and sound, for it knows Man by his dress and by his voice. It possesses an excellent understanding of locality and practices it, for it prowls through an entire neighborhood, through basements and garrets and over roofs and hay-sheds, without bewilderment. It is an ideally local animal, and if the family moves it either declines to accompany them or, if carried to the new residence, returns at the first opportunity to the old homestead; and it is remarkable how unerringly it will find its way back. even when carried away in a sack for a distance of several miles."

The Mother When the mother Cat gives birth to.

cat and Kittens there are usually five or six her Kittens. in the litter, and they remain blind for nine days. The mother selects for her young ones a secluded spot and hides them carefully, especially from the Tom-Cat, which, if he found them, would make a meal of them.

Young Kittens are beautiful little animals, and their mother's love for them is unbounded. Whenever she scents danger she carries them to some place of safety, tenderly lifting them by compressing the skin of their necks between her lips so gently that the little Pussies scarcely feel it. During the nursing period she leaves them only long enough to forage for food. Some Cats do not know how to take care of their first young ones and have to be initiated into the duties of motherhood by Men or by some old experienced Tabby. It is a proven fact that all mother Cats learn how to care for Kittens better and better with each succeeding litter.

A Cat during the suckling period tolerates no Dog or strange Cat near her Kittens; even her owner is an unwelcome visitor at such a time. At the same time she is particularly open to compassion for others. There are many instances on record where Cats have suckled and brought up young Puppies, Foxes, Rabbits, Hares, Squirrels, Rats and even Mice; 1 my-self have tried similar experiments successfully with my Cats, when I was a boy. Once I brought a little squirrel yet blind to one of my Cats. Tenderly' she accepted the strange child among her own, and from the first cared for it with motherly solicitude. The squirrel thrived beautifully, and after its step-brothers had all been given away, it stayed and lived most harmoniously with its foster mother, and she then regarded it with redoubled affection. The relations between them were as close and tender as possible. They understood each other perfectly, though each talked in its own language, and the Squirrel would follow the Cat all over the house and into the garden. Intelligence It is commonly thought that Cats are and Affection incapable of being educated; but this of Cats. is an injustice. They are also capable of constant affection, and I have personally known some which moved with their owners from onc house to another and never thought of returning to their former home. They were well treated, and therefore thought more of the people than of the house. They will allow those they like, and especially children, to take incredible liberties with them, nearly as much, in fact, as Dogs will. Some Cats accompany. their owners in their walks, and I knew two TomCats which usually followed the guests of their mistress in the most polite manner. They would accompany them for ten or fifteen minutes and then take their leave with many an amiable purr, expressive of their good will. Cats often strike up friendships with other animals, and there are many instances where Dogs and Cats have become fast friends, in spite of the familiar proverb.

Anecdotes There are a great many anecdotes illus-

About trating the intclligence of this excellent
the Cat. animal. Once our Cat gave birth to four charming little Kittens, which she kept carefullyhidden in a hay-shed. Three or four weeks later she came to my mother, coaxingly rubbed against her dress, and seemed to call her to the door. Mother followed her, and the Cat then joyfully ran across 
the yard to a hay-shed. Soon she appeared in the door of the upper story carrying in her mouth a Kitten, which she dropped down upon a bundle of hay. Three other littens followed in like manner and were made welcome and petted. It proved that the Cat had no more milk to give her young ones, and in her dilemma bethought herself of the people who gave her food.

l'echucl-Loesche had a Cat which had struck up a friendship with an old Parrot, and would always go to it when the bird called its name: "Ichabod." When the Parrot interrupted the Cat's slumbers by biting its tail the latter never showed the least resentment. The two friends were fond of sitting together at the window, looking out at the passing sights.

In my native village a friend of mine lost a little Robin Redbreast and in a few days his Cat brought it back in its mouth unharmed. Thus it had not only recognized the bird, but caught it with the intention of pleasing its master. Therefore $I$ also believe the following story to be true: A Cat lived on very good terms with a Canary bird and frequently played with it. One day it suddenly rushed at it, took it in its mouth and growling climbed up on a desk. The terrified owner, on looking around, perceived a strange Cat in the room. Pussy had distrusted her sister and thought it best to rescue her friend from the other Cat's clutches.

$\begin{array}{cc}\text { Great } & \text { From a } 11 \\ \text { Usefulness } & \text { these ac- }\end{array}$ of the cat. counts we must conclude that Cats are deserving of the friendship of Man, and that the time has come at last to correct the unjust opinions and prejudices many people hold against them. Besides, the usefulness of $\mathrm{Cats}$ ought to be taken more into account. He who has never lived in an old, tumble-down house,

overrun with Rats and Mice, does not know the real value of a good Cat. But when one has lived with this destructive plague for years and has seen how powerless Man is against it, when one has suffered day after day from some fresh mischief and has become thoroughly enraged at the detcstable rodents, then he gradually comes to the conclusion that the Cat is one of the most important domestic animals, and deserves not only tolerance and care, but love and gratitude. The mere presence of a Cat in the house is sufficient to render the impudent rodents ill-humored and inclined to desert the place. The Beast of Prey pursuing them at every step, seizins them by the neck before they have become aware of its presence, inspires them with a wholesome terror; they prefer moving away from a locality defended in this way, and even if they remain, the Cat soon gains a victory over them.

Mice of all kinds, notably house and field Mice, are the preferred game of the Cat, and most Cats will also wage war upon Rats. Young and inexperienced Cats catch and kill Shrews, but do not eat them, as their powerful scent repels them; older Cats usually leave these odorous animals unmolested. The Cat finds variety in its dict by hunting Lizards, Snakes and Frogs, May-Bugs and Grasshoppers. The Cat exhibits as much perseverance as dexterity in its hunting. Being a Beast of Prey at heart, it is also guilty of many little depredations. It destroys many an awkward young bird, attacks rather grownup Hares, catches a Partridge once in awhile, lies in wait for the very young Chickens in the yard, and under some circumstances goes fishing. The cook is usually not on speaking terms with it, for it proves its domesticity by visiting the pantry whenever it has a chance. But the sum total of its usefulness by far exceeds all its peccadilloes.

Varieties The Domestic Cat (Folis maniculata doof the mestica) enbraces but few differing Domestic Cat. species. The following colorings are the most common: black with a white star on the breast; white, yellow and red; brown and striped;

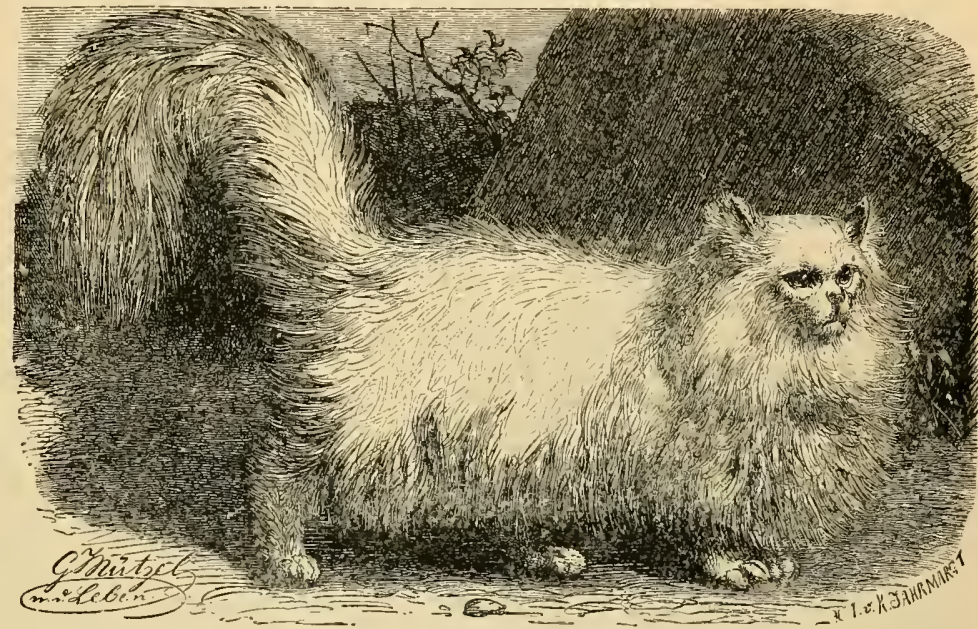

THE ANGORA CAT. Although it is as tame and tractable as any others of the domestic Cats, the animal shown in the picture has such marked differences from the more common type as to be classed as a distinct variety. The fur is just as soft as that of the common Cat, but is remarkably long, and the tail is bushy, and these characteris Felis maniculata domestica angorensis.)

bluish gray; light gray with darker stripes, or tri-colored, with white and yellow or yellow-brownish and coal-black or gray spots. The bluish gray Cats are rare, the light gray ones very common. The most handsome Cats have dark gray or blackish brown stripes like a Tiger. It is a peculiar fact that tricolored Cats, which in some localities are regarded as witches, and for this reason slain, are nearly without exception females.

The Angora The Angora Cat (Filis miniculata domisCat, a Distinct tica angor'nsis ) is usually regarded as a

variety. quite distinct variety of the domestic Cats. It is one of the most beautiful Cats, distinguished by its large size and long silky hair, which is either a pure white or assumes a yellowish, grayish or mixed tinge. The lips and soles are flesh-colored.

\section{THE LION}

A single glance cast at the Lion and particularly at the expression of his face, suffices to make us 
subscribe to the opinion held concerning him from remotest times. The Lion is the king of all Beasts of Prey, a ruler among quadrupeds. The classifying naturalist calls him nerely a Cat of a particularly powerful build, yet the impression produced by the magnificent animal induces even the most scientific to give him a fitting place among his kindred.

Lions are easily distinguished from all other Felide. Their special peculiarities are: a strong, powerful body, clothed in short, sleek hair of a uniform tint; a broad face with small eyes; a mane, resembling the tippet of an emperor, adorning the shoulders of the male; and a tuft at the tip of the tail. In comparison with the other Felidie, the body of the Lion seems short, the flanks retracted, and the whole body produces an impression of power, but not of clumsiness. Hidden in the tuft of the tail is a horny nail, noticed by Aristotle, but denied by many modern naturalists. The eyes have a round pupil, the whisker-hairs are arranged in from six to eight rows. Above all else it is the mane which distinguishes the male Lion and bestows upon him his proud, kingly look.

The mane clothes the whole neck and the breast, but varies so much, that, with or without just cause, it has served as a basis to divide the Lion into a few distinct kinds. I will give a short description of the different species and leave the reader to judge for himself whether these distinctions are justified. Let us first consider the Barbary Lion, for it is he that has, since time immemorial, retained the title of "King of Beasts" by his couragc, strength, bravery, nobility, generosity, gravity and calm deneanor.

The Lion The Barbary Lion (Filis lio barbarms) like

of all his kindred has a strong frame; and the Barbary. front part of his body is much larger than the hind part, because of the broad chest and retracted flanks. The thick and nearly square head is prolonged into a broad, blunt nuzzlc; the ears are rounded, the eyes are of medium size but full of fire, the limbs are very strong, and the paws are the largest among all Felide. The long tail ends in a short thorn, which is covered with a fluffy tuft. The color of this Lion is tawny, inclining to a reddish yellow or dull brown hue, according as some hairs have black tips or are quite black. The mane is very thick. A male Lion may mcasure four fect in height at the shoulder, and about eleven feet in length from the nose to the tip of the tail, the latter occupying from five to six feet. Newborn Lions have a length of about thirteen inches, but have no mane or tailtuft. They are clothed in woolly, grayish hair, which shows markings suggestive of those of the Ocelot to an experienced observer. These brindlings are faint during the first year, but are visible on the legs and under portions for several years, especially in the female Lions; and the exterior marks of adult age make their appearance during the third year. The Lioness always resembles the young Lion to a greater or less degree: her coat is either of the same length on the breast as upon the remainder of the body, or, at most, but a very little longer. The Barbary Lion is confined to the Atlas country.

other The Senegal Lion (Felis lio senegalensis) Varieties has a lighter mane, very little developed of the Lion. on the breast. The South African Lion (Felis leo capensis), and probably also the Abyssinian Lion, are distinguished by their huge size; and they have a dark manc. The Persian Lion (Felis leo persicus) possesses a mane consisting of mixed brown and black hair; and this animal extends over Persia to India; he is still too little known for us to be able to say whether he resembles more closely the Senegal Lion or the Guzerat Lion, which is occasionally maneless.

The Senegal Lion and the South African Lion are distributed all over central and southern Africa, from the western to the eastern coast, and as far north as the 2oth degree of northern latitude. They are regularly met with on the banks of the Blue and White Nile and in the Abyssinian forests; and in the deserts of central and southern Africa they are of common occurrence.

The Guzerat Lion, known to the ancients, and improperly called the Maneless Lion (Folis leo guzcratcnsis), was formerly supposed to be small and maneless, but both these conjectures have been proved to be erroneous. He is of a dull tan color, the tail-tuft and ears being darker.

Decrease in The time when six hundred Lions could

Numbers be brought together in one arena is of the Lion. irremediably past. The King of Beasts has since then retreated farther and farther before the Lord of Creation. Man fights him with all his might and will continue to steadily press him back and ultimately exterminate him. The Lion of Barbary formerly inhabited all Northeastern Africa, and was nearly as common in Egypt as in Tunis, Fez or Morocco; the increase of population and the progress of civilization drove him back farther and farther, until nowadays he is rarcly found in the valley of the Lower Nile or on the southern coast of the Mediterranean. In Algeria and Morocco he is still no rarity, and in Tunis and the oasis of Fessan he is a permanent feature. In Algeria the Lions are much reduced in numbers; the frequent wars between the French and the Arabs have driven them away, and the French Lion-hunters, notably Jules Gérard, have made sad havoc in their ranks. The conditions under which the Lion of Senegal exists are more favorable. The native of central Africa is not sufficiently well armed to rise successfully against his worst tyrant and tax-gatherer. Still cien the Negro presses the Lion into more remote regions.

The Lion's The Lion leads a solitary life, living with Manner his mate only during the breeding season. of Living. At other times every Lion in northern Africa has his own hunting district, although he does not quarrel with others of his kind over such matters. In South Africa it often happens that several Lions unite for a hunt upon a large scale. Livingstone tells us that troops of six to eight Lions will prowl around together. In extraordinary cases the troops may be still more numerous. Selous, one of the latest writers on the subject, also says: "In central South Africa one more frequently meets four or five Lions together than single specimens, and troops of ten or twelve are not extraordinary."

The Lion does not inhabit virgin forests, but likes an open landscape: jungles of grass, interspersed with low, bushy forests, and prairies grown with stunted shrubs and deserts, no matter whether they are mountainous or level. In some secluded spot in Soudan, usually in bushes, or in South Africa in the high reeds growing on the banks of the temporarily flowing rivers of that region, he sclects a shallow place as his den and uses it for a day or more, according as the country is rich or poor, protected or open to attacks. When dawn surprises him on his wanderings, he goes to sleep wherever he happens to be.

On the whole his habits are those of the entire feline species; still he differs in many essentials. Ife 


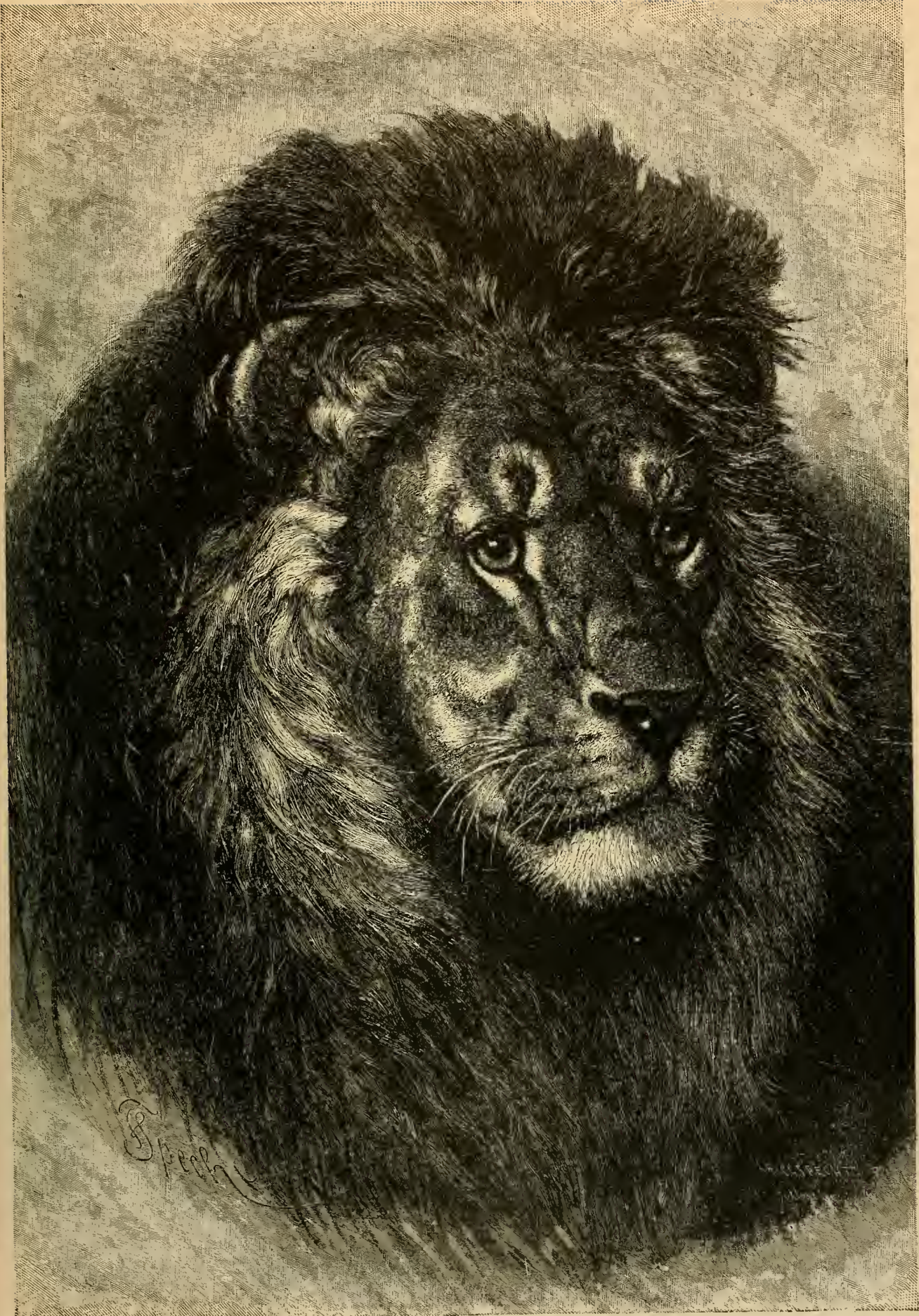

H OF THE BARBA LION — A single glance at this head explains sufficiently why the animal that bears it is called " The King of Beasts." the congucror are depicted in the face, and its expression, and the bold and shaggy mane that covers the head and neck gives to this head an especially impusing appearance. 
is lazier than the rest of the Cat family and asoids extended journeys, trying to make life as easy as possible. Selous' experiences taught him that the South African Lion prefers feasting off the game some hunter has killed to exerting himself to capture his own prey. This is why, in East Soudan, he regularly. follows nomadic tribes wherever they go. He goes with them into the treeless plain and returns with them to the forest; he regards them as his tributary subjects and the taxes he levies on them are indeed of the heaviest kind. His manner of life is nocturnal. He is seldom met with in daytime in the forest; probably only when sought for and disturbed in his lair by Dogs.

He does not visit the ricinity of villages before the third hour of night. The Arabs aver that "he roars thrice to apprise all animals of his coming and warn them to keep out of his way." Unfortunately. this good opinion is based upon rather imaginary premises, for whenever I heard the roar of the Lion, I was alway"s sure to learn that he had previously slunk into the village and stolen an ( $)_{x}$ or Cow: Other writers also concur with me, that he often comes "like a thief in the night."

Vet the Arabs are not wholly wrong, but only put a wrong construction on facts. I have never believed the roar to be a warning, but have been led to think that its purpose is to disturb the whole locality, thus causing the other animals to flee, and perhaps in their confusion to run right into the fangs of either the roaring Lion himself, or a hunting companion of his.

Lion's Attack I am fully persuaded that when a Lion on a Cattle breaks into a roar near an enclosure in Enclosure. which Cattle are guarded, his sole purpose is to render then so mad with fear that they will blindly try to break out. I will attempt to describe the Lion's attack upon such an enclosure.

At sunset the nomad las led his herd into the seriba (camp), elosed in by a fence about nine feet high and three wide, woven out of the thorny branches of the mimosa: the most secure wall that he ean build. The Sheep bleatingly call their young ones; the Cows have been milked and are at rest. A pack of Dogs mounts guard. Gradually all noises die away and the peace of night descends on the scene. The llomen and Children have gone to sleep, and the Men are returning from their work to the huts. Bats come down from the trees and glide over the camp like ghosts. Everything clse is quiet and in repose. Eien the Dogs have ceased their yelping, although still intent on their faithful watch and keep.

Suddenly it seems as if the very earth quakes; a Lion roars in closest proximity. He truly deserves his name of "Essed," that is, "the causer of alarm." for the greatest confusion reigns in the seriba. The Sheep run against the thorny fence as if insane; the Goats bleat loudly; the Cattle gather together with moans; the Camels try to break all fetters in their mad longing for flight, and the courareous Dors, which have been victorious in many a fight with Leopards and Hyenas, howl loudly and plaintively and seek the protection of their masters. With one gigantic leap the powerful animal clears the wall and selects his prey. One blow with his fearful paw fells a young $\mathrm{Ox}$, whose neck the Lion breaks with its huge jaws. With a low growl the robber lies on his prey; his eyes glow and his tail lashes the air. IIe lets go of the dying animal, and again closes his teeth on it until it ceases to move. Then he beats his retreat. He must go back over the wall, but does not intend to leave his victin. All his strength is taxed to take such a leap with the prey in his mouth, but he succeeds. I have seen a Lion with a two-year-old Ox clear a wall over six feet high. I have also seen the deep impress the $O_{x}$ left in the sand, when the Lion dropped it on the other side, previous to taking it up again. The Oxen in those countries are not as heavy as ours. Often one sees the furrow which the animal had made when being dragged to the place at which he was devoured.

The Terrific The fact is well known that all animals Roar which know the Lion will tremble at the

of the Lion mere sound of his voice. let we must not think that the Lion lets his roar re-echo through the wilderness at all times. His usual sounds are a long-drawn tone, like the mewing of a giant Cat, and a deep growl. When frightened he utters a short "huff" or "wau." His real roar is uttered comparatively seldom, and many people who have visited countries inhabited by Lions have never heard it. The roar is characteristic of the whole animal, and may appropriately be called the expression of his power. It is the only one of its kind, and is surpassed in fullness of tone by the voice of no living creature except the male Hippopotamus, according to Pechuel-Loesche. The Arabs have a pertinent expression for it: "raad," meaning "thunder." It seems to come from the very depth of the ehest and to strain it to the utmost.

The effect of the King's voice on his subjects is indescribable. The howling Hyena is stricken dumb, though not for long: the Leopard ceases to grunt; the IIonkey's utter a loud, gurgling sound and mount to the highest tree-tops; the Antelopes rush through the bushes in a mad flight; a bleating flock becomes silent; the laden Camel trembles and listens no longer to its driver's appeal, but throws load and rider off and seeks salvation in flight; the Horse rears, snorts and rushes back; the Dog unused to the chase creeps up to his master with a wail.

The Lion The North African Lion, when within the in Search reach of a village, seeks nowhere else for

of Prey. prey. He is an unpleasant visitor and difficult to get rid of; the more so, as he is possessed of a great deal of eraft. Livingstone also says: "When the Lion is too old to hunt, he frequents the villages in search of Goats, and if a lloman or Child crosses his path, he attacks them instead. The Lions which attack human beings are always old ones, and it is a common saying among the natives, when a Lion has helped himself to a Goat in a village: 'His teeth are used up; he will soon kill a human being."'

In an attack on wild animals the Iion behaves quite differently. He knows that they scent him from afar and are fleet-footed enough to escape. Therefore he lies in ambush for then or slinks up to them, sometimes with others of his own kind, keeping well to lceward of the victims, and hunts them not only at night but even in broad daylight. Still such day hunts are always the exception. Generally he awaits dusk at least before he sets out on his prowlings. He follows wild herds as well as the herds of Cattle, and like other Felide he likes to lie in wait in such places as water-courses in open ground where the animals of the wilderness come to drink.

According to Livingstone the Lion seizes his prey usually in the neck, or in the flanks, where he is most fond of beginning his meal. Selous corroborates the statement that the Lion always begins devouring his victim at the flanks and first eats the intestines 


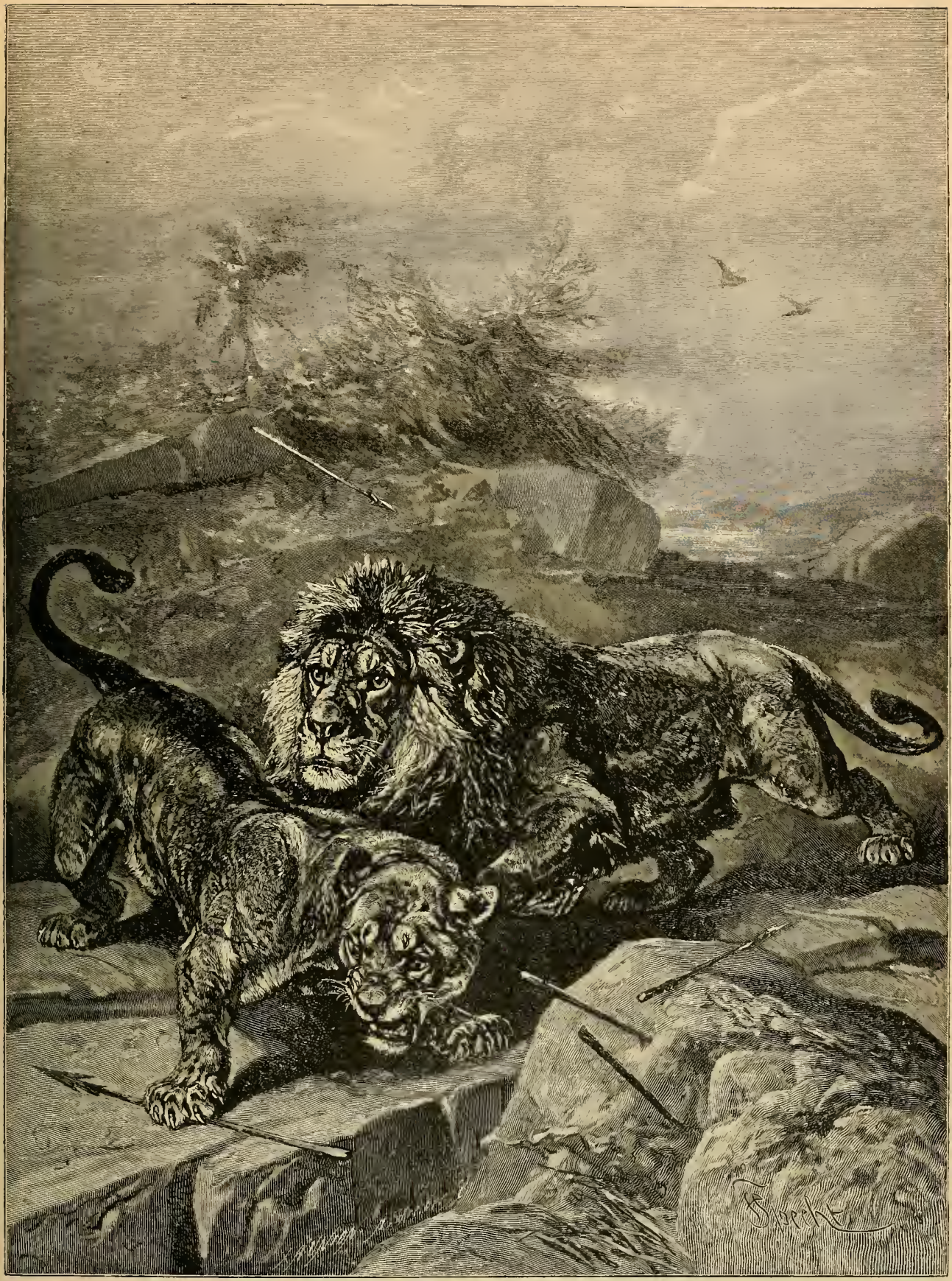

THE BARBARY LION- - Seeking their prey in the afternoon or evening the Lion and Lioness spend the daytime sleeping in their lair. In the picture they are represented as roused from their slumbers by the arrows of secreted foes, one of which has grazed the skin of the Lioness, who is depicted in the act of roaring. Both are bewildered as well as enraged, and will fall an easy victim to the shower of arrows and bullets that will follow. (Felis leo bar. barus.) 
and inner organs. He has also seen Lions take these parts and cover them with earth, doubtless to keep them till the following night and to protect then from the Vultures which are sure to put in an appearance during the day. Concerning their mode of attack he says: "In my experience Lions attack animals in the most varied manner; I have seen a Horse, a young Elephant and two Antelopes killed by bites in the throat; but I have also seen a Horse and several Zebras killed by bites in the nape of the neck. I suppose that Buffaloes sometimes meet their death through dislocation of the vertebræ of the neck, the Lion jumping on their shoulder, taking their nose with his paw and giving it a sudden turn. I have seen and shot a great many Buffaloes which had escaped the Lion in time to save their lives, after being terribly lacerated about the shoulders and neck.

The Lion prefers large game, but in default of it he accepts rather small fry with good grace. It is said that he even eats Locusts. The aim of his hunt is the capture of large prey always, as lie is most frequently found where there is much game, or numerous herds of Cattle. He fincis his principal food among flocks of domestic animals, wild Zebras, Antelopes and wild Boars. Under certain circumstances he even eats animals he finds dead. Selous says: "The South African Lion is often a very dirty feeder and frequently gorges himself with the huge bodies of Elephants in a state of decomposition and craw?ing with worms in the tropic sun; night after night he returns to the feast, until all is gone." Probably a great many other animals help him, and rarely let the opportunity slip of feasting at the King's table. The cowardly, lazy Hyena and the whole genus of Dogs proper think it very convenient to let others do the killing for them; and as soon as the Lion has left they eat their fill and more. The King does not tolerate them and it is said that serious quarrels occur over this matter.

Lions Attack Man is very seldom attacked by the Men Lion, and his tall form seems to in-

but Seldom. spire the latter with fear. In Soudan at least, where His Majesty is met with rather frequently, scarcely any instances of Lions eating Men are known. More frequently Man meets with an untimely death in that country from attacks by Crocodiles and even Hyenas than from Lions. In South Africa the anecdotes about their attacking Nen are common, as they penetrate into camps, in spite of fires, to carry away Cattle, or even human beings sitting near the fire. Probably only senistarvation leads them to the camp fires, as it did that strong Lioness with an empty stomach, of which Selous say's that notwithstanding fires, guards and shots, she thrice came into the camp and attacked a Horse and two natives close to the fire. Each time her nurderous attempts were frustrated, and finally she was killed. " $A$ hungry Lion is like a devil" is a saying in South Africa; and whether old and debilitated or young and strong, by night or by day, a famished Lion will attack MIen, and if such an experience teaches him what an easy prey Man is, he is sure to wish again for such convenient game. Real "Man-eaters" can hardly be developed there though, as most of the South African natives are not the people to stand much from a Lion.

Selous' Nobody has described the South Afri-

Description can Lion in plainer and more perti-

of the Lion. nent language than Selous: "It has always appeared to me that the word 'majestic' is singularly inapplicable to the Lion in the wild state, as when seen by daylight he always has a stealthy, furtive look that entirely does away with the idea of majesty. To look majestic a Lion should hold his head high. This he seldom does. When walking he holds it low, lower than the line of his back, and it is only when he first becomes aware of the presence of Man that he sometimes raises his head and takes a look at the intruder, usually lowering it immediately, and trotting away with a growl. When at bay, standing with open mouth and glaring eyes, holding his head low between his shoulders, and keeping up a continuous low growling, twitching his tail the while from side to side, no animal can look more unpleasant than a Lion; but there is then nothing majestic or noble in his appearance. If the Lion throws his tail twice or thrice vertically upward, it means 'look out'; for this is the sign of an immediate attack. lions met in the daytime nearly always retreat before Man, even when they are disturbed in their meal, and, consequently, hungry. Of course, when they are attacked or wounded they reciprocate. In my experience Lions are more aggressive than any other South African game 1 have ever met. As they are more easily concealed and more rapid and agile in their attack than Elephants, Unicorns or Buffaloes, I consider them nuch more dangerous. Still Lions show as much individuality as Man, and it is not to be supposed that what one does, the next one is also sure to do. I think that nobody has a right to call Lions cowards, because he has shot two or three which happened to be such. There are more accidents happening from encounters with Buffaloes, but this is explained not by the fact that Buffaloes are more dangerous, but because they are more frequently met with. In the ' 70 's one met fifty Buffaloes to a single Lion on a hunt."

The awe-inspiring presence of the Lion, his great power and courage, have always been acknowledged and admired. Though this enthusiasm may at times have been exaggerated and may have resulted in ascribing properties to the Lion which he does not possess, still it is not without foundation. The most prominent naturalists give the Lion credit for qualities which in my opinion include nobility enough. And whoever has become more closely acquainted with that animal; whoever has, like myself, intimately known a captive Lion for years, must think as 1 do; he must love and esteem it as much as a human being can love and esteem any animal.

The Lioness A Lioness gives birth to from one to and six cubs at once, the number usually

Her Cubs. being two or three. The little Lion-cubs have their eyes open at birth and are about half the size of a Cat. The Lioness treats then usually with great tenderness and one can hardly imagine a more beautiful spectacle than the mother with her cubs. They play together like Kittens, and the mother regards them gravely, but yet with infinite pleasure. They may be seen thus in captivity, as a Lioness often gives birth to a litter when a captive. In well managed zoological gardens Lions are now bred as carefully and as systematically as Dogs; and even in circuses, where the animals have but little room and often insufficient nourishment, Lions are born and sometimes grow up.

Lion-cubs are at first rather clumsy. They learn to walk in the second month of their life and their play begins still later. At first they mew like Cats, but later on their voice becomes fuller and stronger. In their play they are at first awkward and clumsy, 
but agility comes in time. Towards the close of the first year they have attained the size of a strong Dog. In the third year the mane begins to appear in the male, but full growth and distinction of sex are onty completed in the sixth or seventh year. The age a Lion attains is in proportion to the slow development. There are cases on record where Lions have lived to be seventy years old in eaptivity; although they lose much of their beauty and show signs of decay rather early, in spite of the best of care.
He needs about eight pounds of fresh meat daily. This will keep him in fine condition and he will grow fat on it.

Experience I have taken care of a Lioness for with a two years. She became accustomed Tame Lioness. to the household in a very short time and enjoyed the freedom of the whole yard. She soon followed me about ilke a Dog, caressed me at every opportunity and annoyed me only by coming to my bed in the night and awakening me with her

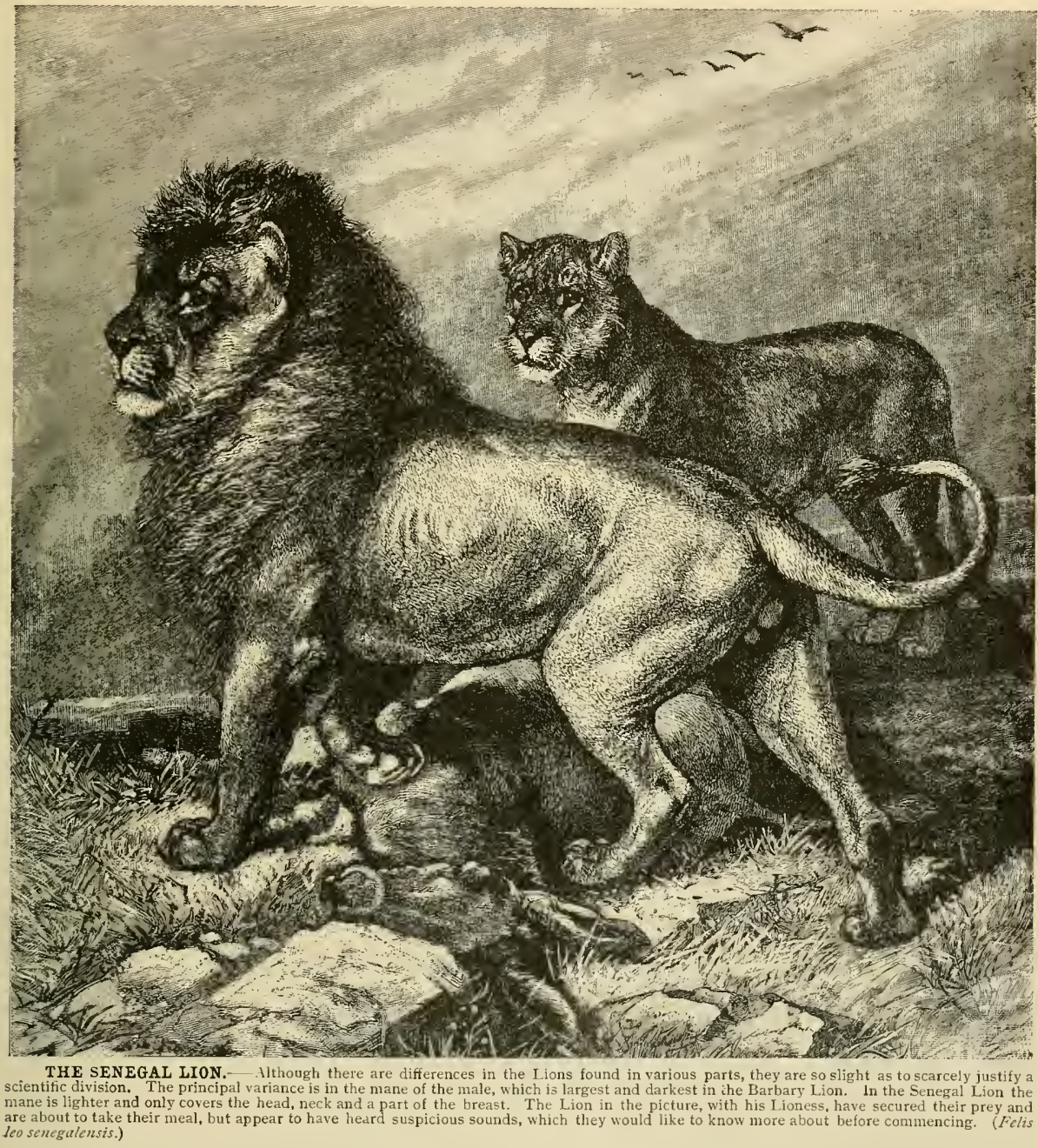

The Lion Lions eaptured young may become very in tame if they receive intelligent care. They captuity. know their keeper and become attached to him in proportion to the attention he bestows on them. One cannot imagine a more amiable creature than a Lion tamed in this way, which has forgotten his freedom, and I might say his Lionhood, and devotes himself to Man with his whole soul. With good food a Lion will live in captivity for years. caresses. A few weeks after her arrival she reigned supreme in our yard. She teased and frightened all the other animals in every imaginable way. The only one that defied her suceessfully was a Marabou. At their first meeting the bird went up to her and gave her so thorough a lesson with its huge beak that atter a prolonged fight she had to give in. She would often lie down like a Cat, and then jump on one of us, like the Cat on a Mouse, her only intention 



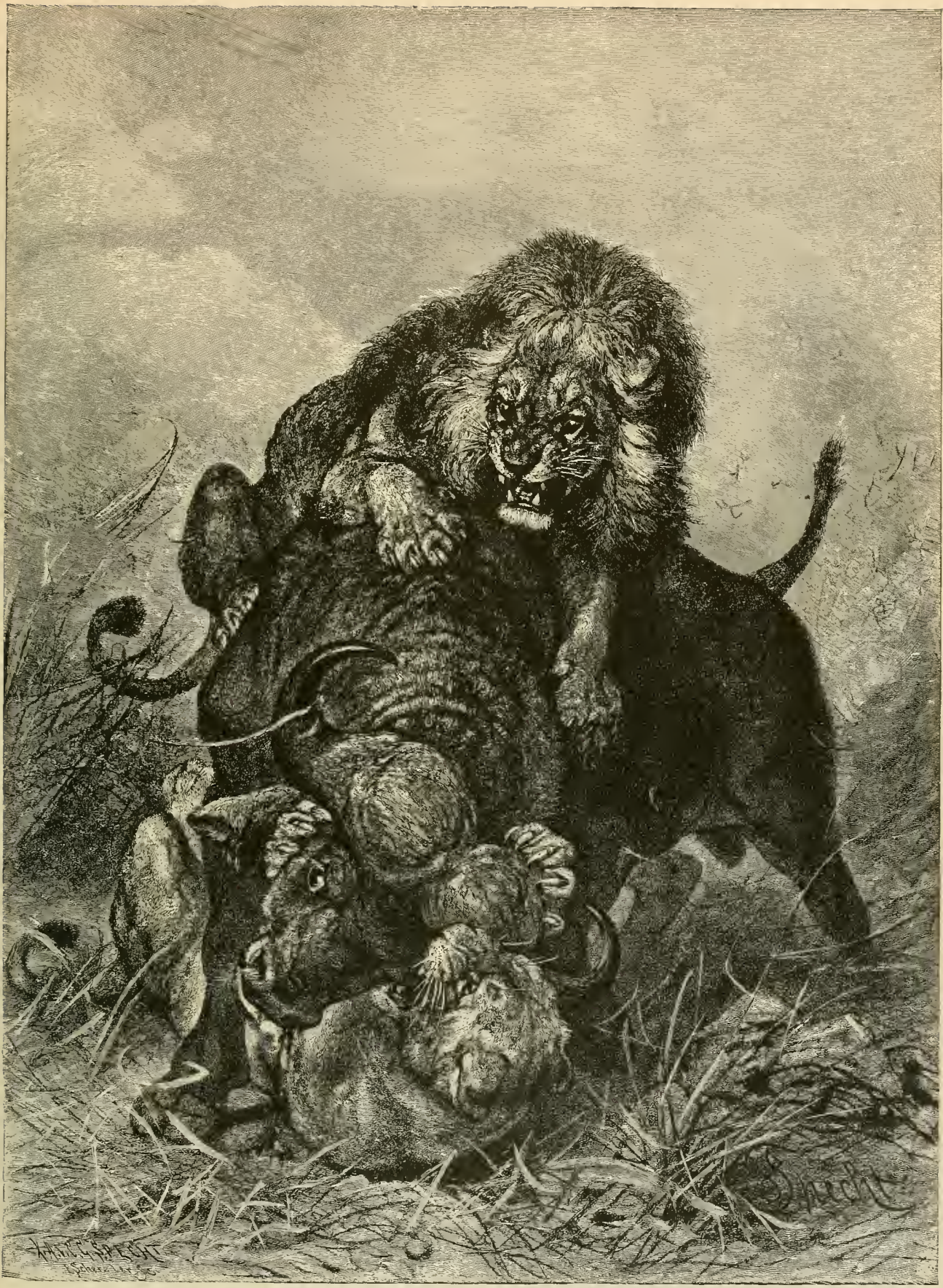

LIONS ATTACKING A BUFFAL 0. - Here is a battle-royal between a South African Lion and Lioness and a Cape Buffalo, The latter is the strongest and wildest animal of his species in . Africa and his horns are large and powerful. A Lion will seldom attack a Buffalo unaided; when one does the Buffalo is as likely to be victor as the Lion. Usually two or more Lions unite to conquer this powerful beast. In the picture the Liopess, who has led the attack, has been thrown to the ground and the Buffalo is about to use his horns to good effect when the male Lion springs on his back, making the contest so uneven that the Buffalo is certain to be vanquished. 
The Long- The Long-tailed Panther (Felis z'arieTailed gatu), inhabiting Sumatra and Java, is Panther. believed to be an entirely distinct species. He has a small oblong head, a long neek, a tail the length of which equals that of the body, and short, strong limbs endowed with powerful paws. His spots are small and dark and are grouped very close together. They give the skin a black-blue lustre, perceived when one looks at the fur from the side. The ground color is a dark clay yellow, and the spots are brownish yellow.

The The Black Panther (Felis molus) differs Black from his kindred only in color; and ac-

Panther. cording to Rosenberg every inhabitant of lava knows that he is found in the same litter with the yellow animals. Sanderson believes them to inhabit only thick, extensive forests, and not to be found everywhere like their yellow kinsmen. Nearly

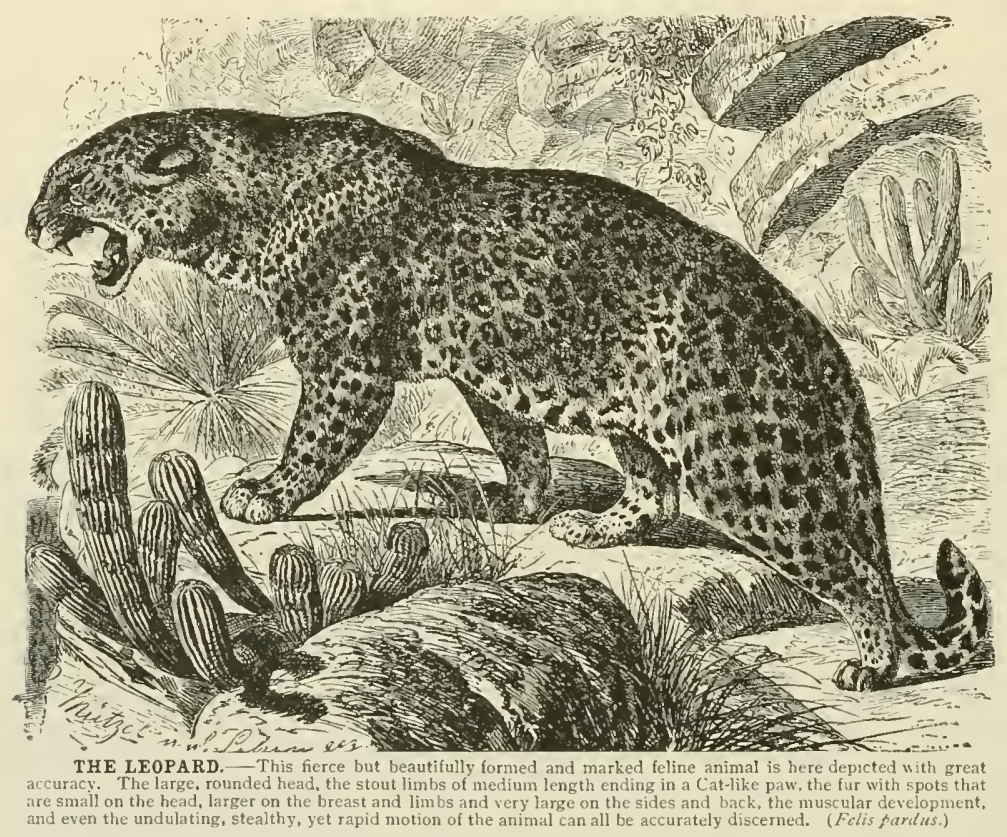

Traits of It is as customary to speak of the Leopards and Panther and Leopard as it is to speak Panthers. of the Panther or Leopard. We will call the African animal, Leopard; the Asiatic, Panther. In their character and mode of life they agree as much as is consistent with their varying strength and size. The former is content with smaller game and smaller domestic animals; the latter enters the ranks against larger gane and Cattle of all kinds, as well as human beings. It comes next to the Tiger in point of rapacity, and in India is often considered more dangerous. We will probably hear similar reports from Africa when that continent has been more thoroughly explored. There is no doubt but that there the size and other features vary much.

The Filis pardus is distributed over the whole of Africa and ali southern Asia. In the west he penetrates much farther north than the Tiger, but in the east he is confined mueh more closely to the south. The Panther extends from Persia, Asia Minor and Armenia to the Caucasus. In southern Daghestan his numbers are much reduced, yet he is stil] a permanent feature there. At the western inclination of the Caucasus to the Black Sea, he is said to range still farther north, but it has not been established how far. In central Asia the middle and lower Oxus are his northern boundaries. Blanford says he is not found in the Punjab nor in some parts of Sinde.

These animals might be called taciturn, for their roice is not loud a $\mathrm{nd}$ is seldom heard. In captivity they have been heard to make plaintive sounds, reminding one of a Cat's cry. Sometimes one hears a hoarse cry from every zoological garden now has Black Leopards, and in some they are systematically bred.

Leopards and Hunters, merchants, etc., readily dis-

Panthers criminate between the smaller, bulk-

one Family. ier Leopard and the larger, more slenderly-built lanther, but in zoology they both belong to one group. The Panther and Leopard are both Filis partus. In Wicst Africa they are called "Ngo," in P'ersia "Palang," in India "Tschita,"

Adnara," "Honiga" and "Kerkal," and on the Malay Peninsula they are termed "Harimau-bintang." The size, the shape of the head, the slender or bulky frame, the length of the tail, the ground color and spots of the shin are subject to the greatest variation. Some are yellow or reddish, others light or dark brown; and black ones, whose spots show only under a ecrtain light, are known; and even white specimens have eome to liwht. The difference in the size is probably due to the difference in age, locality and food. them in the wilderness, repeated three or four times. l'echuel-Loesche represents it by the spelling "Huraak." When frightened, or when attacking they utter the same coughing sound, sometimes blended with the indescribable growl of a ferocious Dog.

Symmetry of The I.eopard or Panther is the most Leopards beautiful of all the Cats. We look and Panthers. upon the Lion as the King of Beasts. The Tiger is considered the most dangerous of this cruel family; the Ocelot's skin show's a greater variety of color; but they are all much inferior to the Leopard in symmetry of bodily structure, in beauty of coloring, in agility, vigor and gracefulness of movement. He unites all the advantages which other Cats possess singly. His velvet paw vies in softness with our Pussy's, but hides a claw that compares with the strongest. His teeth are proportionately much stronger than those of his kingly kinsman. Ile is an ideal Beast of Prey, combining beauty with agility and vigor, and intrepidity with cumning. 


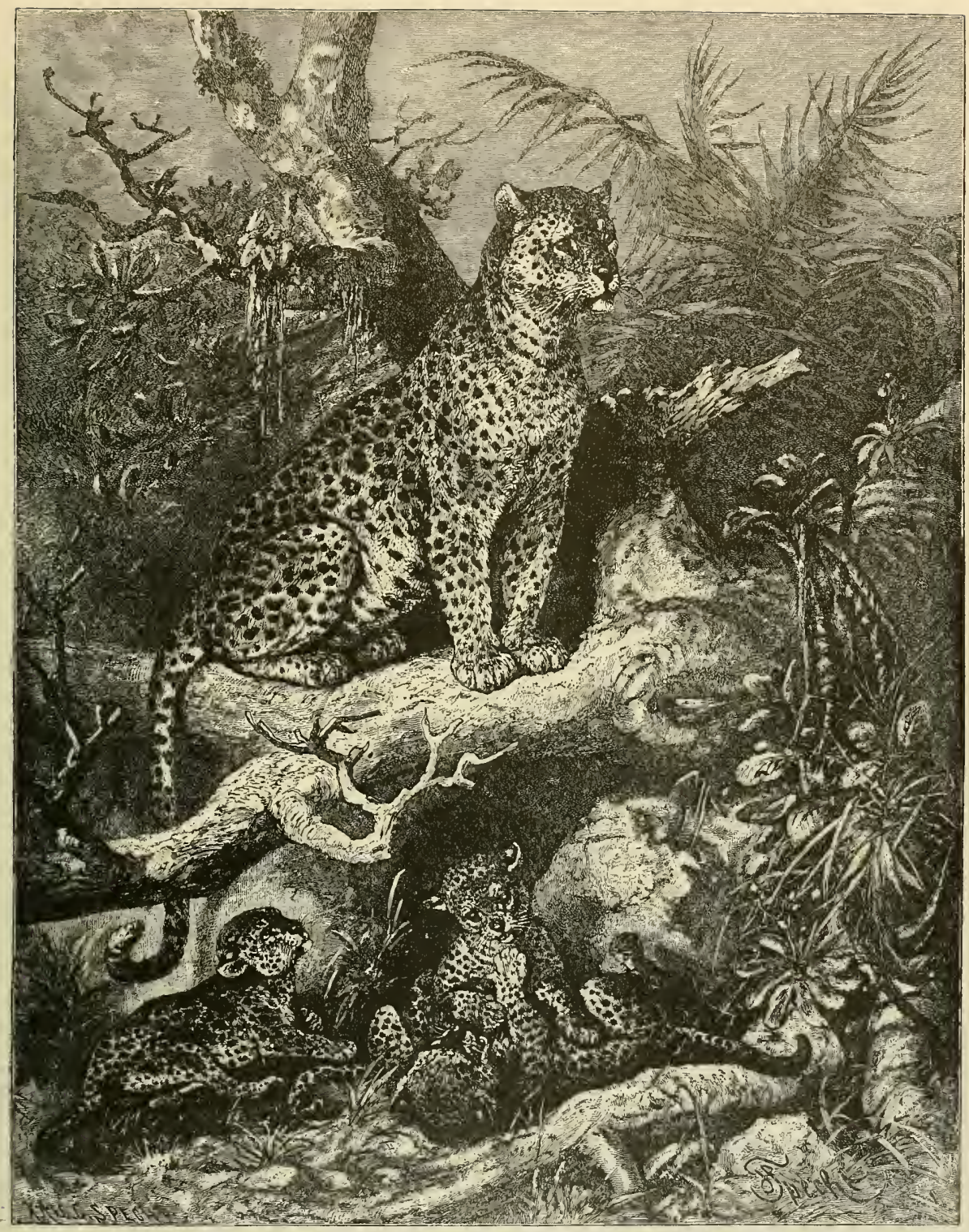

LEOPARDESS AND YOUNG.- - Here is shown a Leopardess in repose, enjoying the playful sport of her young ones, yet keeping watch for anything that may endanger them, and at the same time for any luckless animal that may serve for a converient meal. The spots on the fur are the main distinguishing feature of this animal, extending as they do from the round head and short neck to the tip of the long tail. The youngsters are having a good time, a characteristic of all Kittens whether they belong to Pussy or a stately Leopardess. (Felis pardus.) 
At a cursory glance we might deem the spotted fur of the Leopard much too bright for a suecessful life of rapine, in which the prey must be overpowered by stealthy, unperceived movements. But even a superficial consideration of the native country of the animal dispels these ideas. Whoever has seen his haunts personally, finds it only natural that so brightly clothed an animal should disappear in their vegetation and their roeks. These animals are found in large numbers wherever there are extensive forests with a dense growth of underbrush. They do not like grassy plains, although they are frequently met in other open places and in the plantations and fields surrounding settlements. Mountains are a favorite resort for them, for high elevations abound in game and furnish excellent places of concealment.

The Leopard Notwithstanding his moderate size, the a Terrible Leopard is a truly terrible foe to all anfoe. imals and even to human beings, though he avoids Man as long as possible. He is a master in all athletic accomplishments, and craftier than other Beasts of Prey; so that he catches even the most wary or the fleetest of game. He climbs a pole or tree as well as any Cat, and is quite as often found on trees as on the level ground. In case of necessity he can swim streams of considerable width. It is only in movement that he shows his full beauty. He is so full of lithe, easy gracefulness that one can not fail to enjoy watching him, however one may hate him for his cruelty. Nothing denotes the slightest effort in his soft, rounded movements; lis feet tread as gently as if they carried the lightest of bodies, and the Leopard delights the eye to an extent equaled only by one other much smaller beast of prey the Genette.

Unfortunately his intellectual gifts do not harmonize with his external beauty; at least, not according to our standard. The Leopard is crafty, ill-natured, ferocious, vindictive and by no means cowardly. In Africa he is, like the Jaguar in America, sometimes called Tiger, for this name is thought to designate the embodiment of cruelty, and no other Cat is as worthy of the nanie as lie. He kills all the creatures he can, be they large or small, aggressive or defenseless. His principal food is probably furnished by Antelopes, Jackals, Slieep and Goats, but he also climbs after Monkeys and catches birds of all kinds. Anything in the animal world serves him for prey although, according to Pechuel-Loesche's observation, he also devours the fruit of the oil-palm. The Baboons always have him at their heels. He prevents these animals from becoming too numerous, as may be seen in the mountains where the Leopard does not range, the Dog-headed Monkeys being found there in much larger numbers than elsewhere.

He is said to cause fearful slaughter in herds guarded by enclosures, and will kill a dozen or more Sheep in a single night. That is why the herdsmen fear him more than the other Carnivora, which stop with a single victim. He is also an inveterate Chicken thief.

Exciting En- The Leopard gave me a personal proof counter with a of his intrepidity. One day we were Leopard. riding on horseback through a part of the Bogos mountains. Suddenly we heard the barking of Baboons over our heads and decided to try our guns on them. The servants were left in the valley with the Mules, while we climbed the mountain and, having selected a convenient spot, fired at the Baboons. They were perched at a great elevation, and most of our shots failed to reach them. Some of them did, though, and the victims either fell or eseaped wounded. A very old Baboon came staggering down the mountain-wall, and we thought we would surely find him dead in the valley.

Suddenly there was a terrible uproar among the Monkeys and then sounds of tumult reached us from the valley. All the male Baboons advanced to the edge of their rocks, grunted, growled and roared, and furiously beat the earth with their fists. All eyes looked downward and a few of the strongest males started to climb down. N'e thought they were going to attack us and reloaded our guns with a little more haste. The noise from below grew greater, our Dogs barked, and at last we heard the words: "Help! help! a Leopard!" We looked down and saw a Leopard making straight for our servants. He seemed occupied with something else on the way, but his body conccaled the object from our view. Then two shots followed and all became quiet, except for the barking of the Dogs.

Events had happened so quickly, that we did not know what the matter could be. So we hurried down at once, and found our servants staring at a bush in every possible attitude. "There is the Leopard," they cried. Cautiously I approached the bush, but could see no trace of the beast. Then one of them pointed to a particular spot, and I saw a dead Leopard lying close before me. About ten paces farther off lay a dead Baboon.

Now we had an explanation of everything. In mounting we had probably passed quite close to the leopard. Then we had fired about ten shots, whose report had been re-echoed by the rocks. Upon this, the Leopard had rushed on the wounded, descending Monkey, in spite of the Men he had seen and heard, undeterred by the loud reports of the guns which had frightened all the other animals, and heedless of the broad daylight. Sitting on the Baboon as on a Horse, he rode down into the valley, nothing daunted by the shouts of the servants. The cook said that he then, being "frightened to death," had seized one of my guns and shot at random, the bullet luckily. piercing the Leopard through the chest. Then he had killed the liaboon without being quite clear why he had done so. Investigation brought to light the fact that the Leopard had put his claws into the Monkey's face, tearing deep holes in it, while he had in some places let his hind paws drag.

Destruction In villages and cities lying in the caused woods, the Leopard makes frequent by Leopards. attacks upon dwellings. Before the very eyes of people he seizes upon his prey and drags it away, paying no attention to the shouts and noises of the spectators. Every domestic animal is food for lim. He is fond of Dogs, too, though they object strongly, and resist being carried away. In many localities the natives are compelled to build strong stables for their domestic animals, so as to protect them during the night.

When the female Leopard thinks her cubs are in danger, she rushes at her foes in a mad rage. There are also instances on record, where Leopards have attacked people without any reason. In Abyssinia such things happen every year, especially to children. In Western Africa they also become dangerous to the inhabitants at times.

Government statistics in India show that in the decade from 1876 to $1886,2,368$ people were killed by Panthers, the number killed in a single year ranging from 194 to 300 . It does not say how many of these accidents were caused by wounded or irritated beasts. Sanderson says that he knows of no 


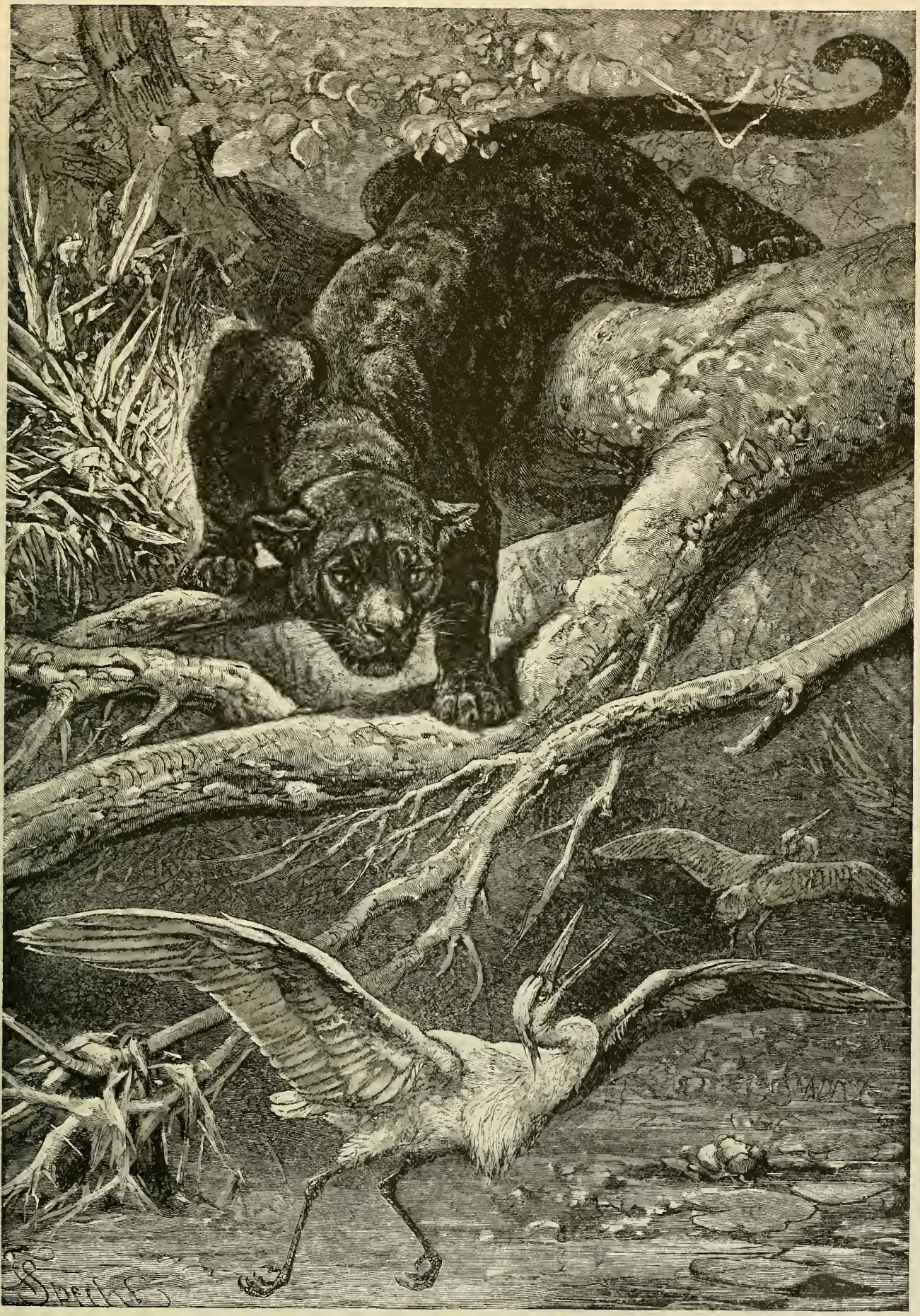

THE BLACK PANTHER. - This member of the Panther species differs from the others principally in the dark hue of its fur and the consequent indistinctness of its spots. It is a restless hunter, killing not only manumals but also birds. The animal in the picture is represented in its native Sumatran jungle, ready to seize an aquatic bird which has become aware, too late, of its enemy's stealthy approach. (Felis melas.) 

or ercome his obstinacy without ill-treating him, for he did not belong to me, and I had to be careful with him. I dared not even use my whip, made of the hide of a Hippopotanus; it was sufficient to cow all the other animals, but it was not long enough to drive this one to the door of his cage. So I took a that the animal is destined to live in colder regions than the Leopard. He is indigenous to central Asia as far as Siberia. A. Walter says: "He takes the place of the Panther in the mountains of Turkestan, and inhabits the Atlas and the South Siberian mountains, southeastern Buchara, the Pamir, Cashmere

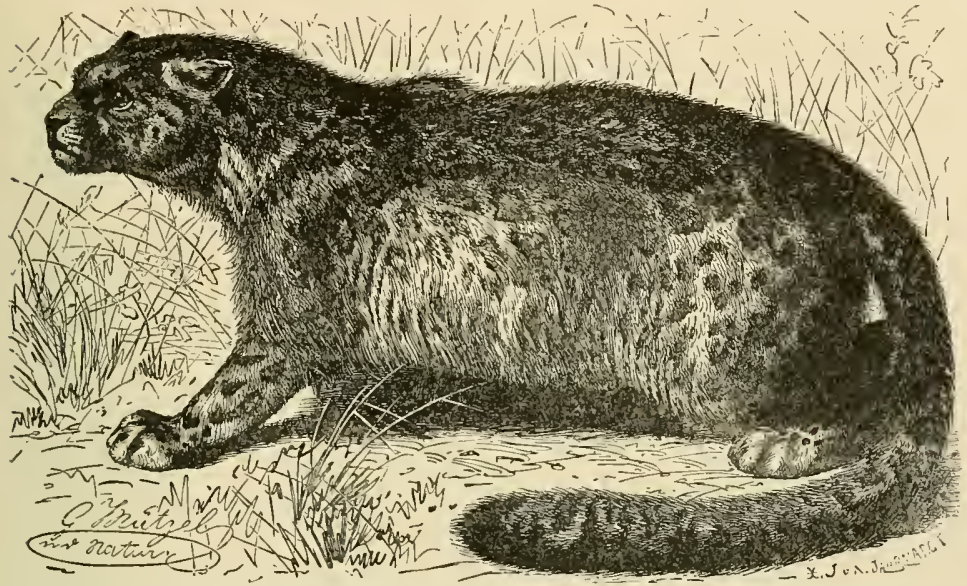

THE OUNCE. - The animal which is shown in this picture in an attitude characteristic of the stealthy movements of the entire family, is especially distinguished from the Leopard and Panther by its thick coat which enables
it to live in cool and nountainous regions. The distinct markings of the spots, small on the head and larger and ring-shaped on the body, are well brought out. It is sometimes called the Snow Leopard, (Felis tuncia.)

new stable-brush and fastened it on a long pole; with this he got his beating, but it did not have the desired effect. Then I hit upon the plan of pouring water over him, and as soon as a pail was emptied upon his head or the hose was turned upon him he made for his cage with all possible speed. Later on I only had to show him the hose to make him decamp.

The Romans frequently used Leopards and Panthers in their amphitheatres. The latter were then plentiful in Asia Minor, and Scaurus sent in one hundred and fifty of the spotted animals. Pompey sent four hundred and ten and Augustus four hundred and twenty.

\section{THE OUNCE, OR SNOW} LEOPARD.

A large-sized Cat of central Asia, the Ounce, probably comes nearest the Leopard. The Ounce, or Snow Leopard (Felis uncia), -attains nearly the same size as the Leopard. The ground color of the skin is whitish gray, the hairs tipped with light yellow whose size is that of our domestic Cat. It is spread

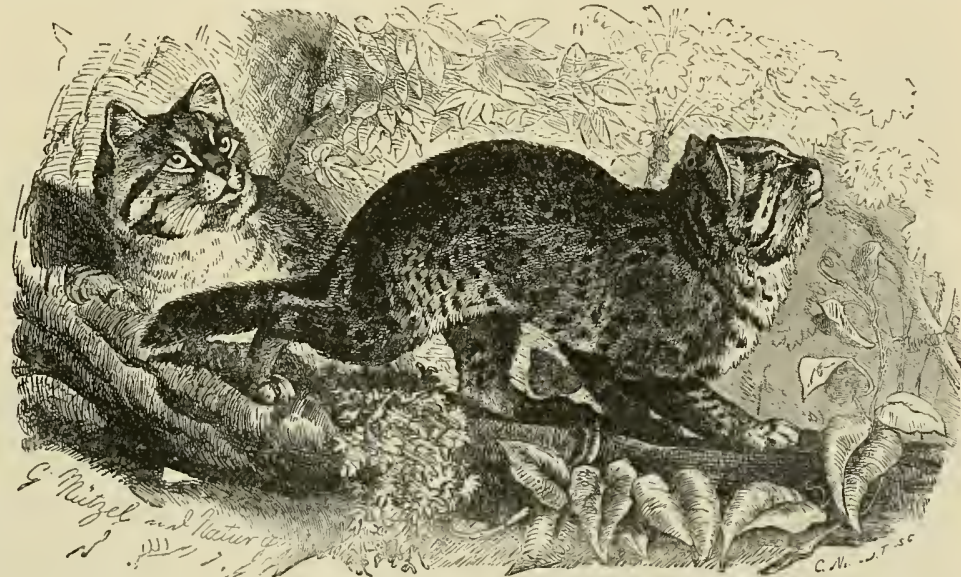

THE LEOPARD CAT. - Fierce, cruel and untamable, this Cat is a terror to small animals and birds in all parts of eastern Asia. It derives its name from the number and shape of its spots, although they are not so sharply defined as those of the Leopard. It is noted for its agility in climbing, and the picture shows it in the appropriate surroundings of its arboreal home. (Felis bengalensis.)

In the Himalayas he feeds on wild Sheep, wild Goats, rodents and birds, and also kills the smaller domestic animals. He is said to attack Horses, but has never been known to attack Man.

\section{OTHER OLD WORLD FELINES.}

There are still a few smaller Old World Felidx which deserve to be mentioned in connection with the preceding group.

The Viverrine Cat ( Fclis aiterrina) is of the same size as the IVild Cat. It has a gray ground color, sity, mand vary in intenblack. It inhabits East India, southern China and the Malay Peninsula, living chiefly near rivers and swamps and feeding upon fish. It is said, also, to attack rather large mammals, like Dogs ard Sheep. The majority of these Cats behave badly in captivity and are very difficult to tame.

Still smaller is the Leopard-Cat (Fclis bcngalensis), the back, as usual in this class of felines, assumes a darker tinge, the under part of the body a lighter hue. The black spots are distinct; they are small and full on the head, larger and ring-shaped on the neck, and form large rings surrounding a dark center on the body. The fur of the Ounce shows clearly

all over eastern Asia, and enjoys the reputation of being a very agile climber and an intensely cruel and ferocious animal. It is said to be tamable only in rare instances.

We may regard the Serval (Filis serial) as a connecting link between Cats and Lynxes. He is of 
slender build, and the head is adorned with large, wide ears, which give it the appearance of being remarkably high. The fur is of a light tan color with black bands on the back and spots on the sides. It is a rather common Cat in South Africa, and is also found in all grassy plains of the continent. Its chief prey is smaller nammals, and especially poultry. When caught young it may be tamed by good treatment, but adults usually retain their ferocity. The fur is sold as "African Tiger-Cat," but does not conmand a ligh price.

\section{AMERICAN FELINE ANIMALS.}

The next of kin to the Lion was formerly supposed to be found among the New IVorld Felidx, to which we will now turn; but their slender body, shorter legs, and small head devoid of beard and mane place the spot. The head is gray and the tip of the tail is: dark. There is no difference in color between male or female, but the cubs are totally different from their parents. The tint of adult Pumas also varies with the locality; those in South America are lighter, being nearly a silver-gray, while those confined to Mexico and the United States are of a dark tan color.

Home and The Puma is very widely spread. He Haunts of the is found not only all over South Amer-

Puma. ica, from Patagonia to New Granada, but he extends over Mexico into the United States and as far as Canada. In some localities the animal is very common, in others it had already been nearly exterminated in the last century, when Azara furnished the first good description of it.

The haunts of the Puma depend upon the nature of the country. In sections well wooded he decidcdly prefers forests to plains; but his favorite spots are edges of forest and plains grown with very high grass, though he apparently visits these latter only for hunting purposes; at least, he al ways malies for a forest when pursued by Men. Still he is constantly found in the pampas of Buenos Ayres, where there are no forests at all, and there he hides very skillfully in the grass. He seems to avoid banks of streams and localities that are subject to in undations. Like many of his family he has no particular den or lair. He spends the day sleeping on trees, in bushes or in the high grass; in the evening and at night he goes forth to hunt. He sometimes covers great distances in a single night, and sportsmen do not always find him near the place where he struck thief. It is therefore appropriately portrayed in the picture with a bird as its victim. The characteristics of this Cat, the down his prey.
slender body, black stripes and spots on the light (tan-colored) fur, and especially the large, long ears, are all well shown in down
the illustration. (Felis seriat.)
Every movement of thief. It is therefore appropriately portrayed in the picture with a bird as its victim. The characteristics of this Cat, the down his prey.
slender body, black stripes and spots on the light (tan-colored) fur, and especially the large, long ears, are all well shown in down
the illustration. (Felis scrical.)
Every movement of uniformly colored New World Felidx on a much lower plane than the Old World Cats.

\section{THE COUGAR, OR PUMA.}

The best known species of the uniformly colored American Felide is the Cougar, Silvery Lion or l'tuma (Filis concolor), commonly called "Panther" in the United States, and having different local names, among which arc those of "Tiger," "Catamount" and "Mountain Lion." His length is about forty inches, the tail measures about twenty-five inches, and the shoulder height is about twenty-five inches. The dense, short, soft fur is more abundant under the body than on the back. The prevailines color is tan-brown, darkest on the spine, whitish on the under parts. Above and below the eye there is usually a white the Puma is full of grace and vigor; he is said to makc leaps of cighteen feet and more. His sight is keenest in the dusk and by night, though bright sunshine does not seem to dazzle him. His sense of smell is deficient, and his hearing extremely acute. He exhibits courage only in the direst neccssity; and as a rulc he flees before Men and Dogs.

Prey All smaller, weak mammals are his prey, of the Deer, Sheep, young Calves, and Colts when Puma. separated from their mothers. Even the fleetfooted Monkeys have no immunity from his attacks, for he holds sway in the trees as well as on the level ground, Renger once observed him hunting Monkeys. The flute-like tones of a few Capuchins had attracted the naturalist's attention, and he seized his gun to kill a few of them. Suddenly the whole troop 


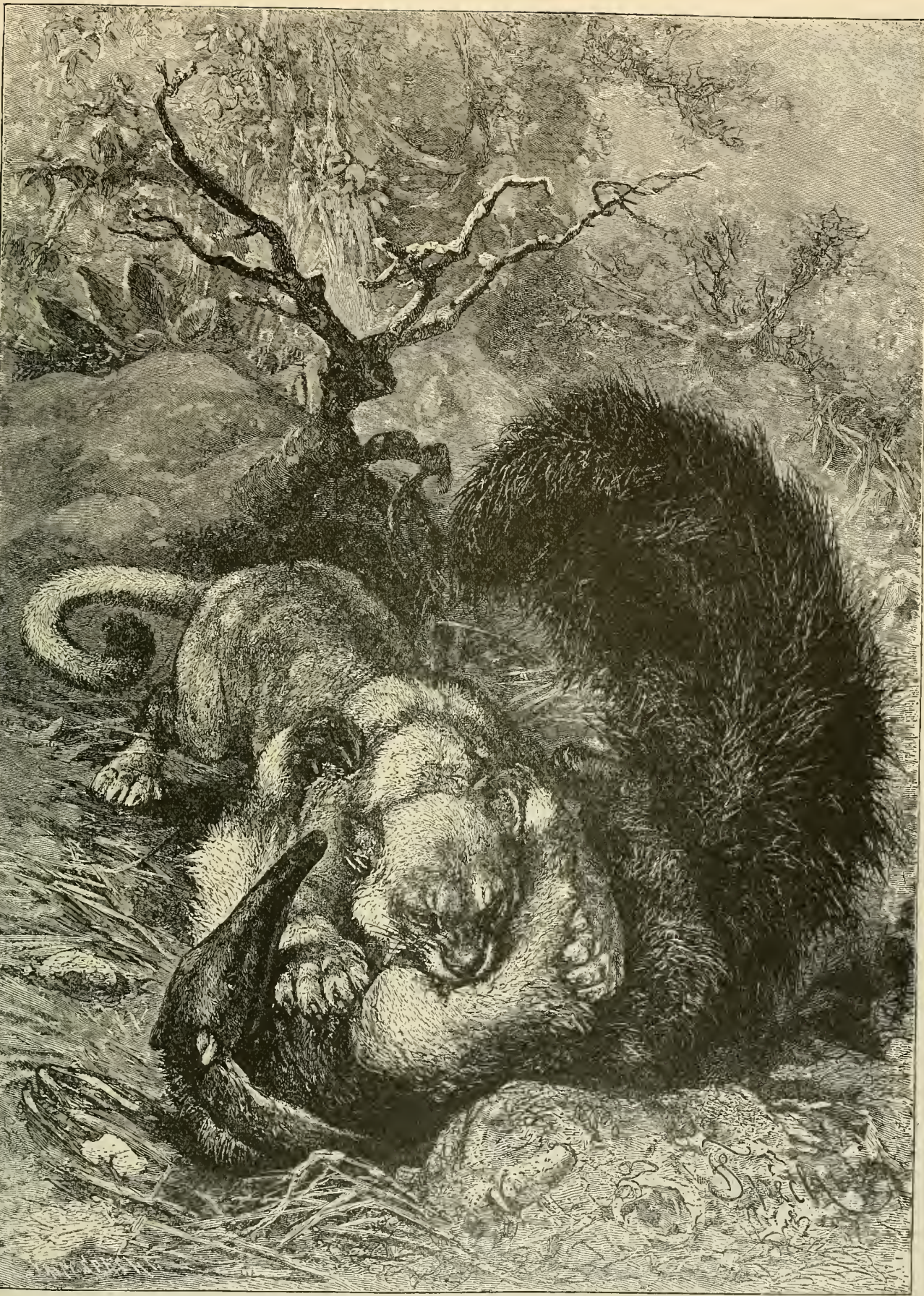

PUMA ATTACKING AN ANT-BEAR. - There is no more harmless creature than the Ant-Bear of South America, when let alone, Butt its fore feet are muscular and its claws are powerful and when a Puma attacks it they are used with such etfect that the fieree foline is often severely wounded, although generally succeeding in making a meal of the Ant-Bear. The Puma is a very bloodthirsty animal, and, whether hungry or not, usually attacks every animal that comes in its way. The savage character of its onslaught is well portrayed in the picture. (Ficiis concolor.) 
of Monkeys broke into a croaking cry and came rushing in his direction. Dexterously the animals swung from branch to branch, from tree to tree, expressing, in plaintive cries, their great terror. A Puma was pursuing them, leaping from tree to tree. lle slipped through the tortuous branches, wound with creeping vines, with most incredible agility, making his way ont on boughs until they bent with his weight, and then jumping to another tree.

When the Puma has seized his victim, he tears open its neck, and laps its blood beforc he begins to eat. He devours every part of a small animal; but larger ones he eats only in part, usually the head, neck and shoulders, and, according to Azara's observations, he covers up the remainder with straw or sand. Frequently the slaughter of a single creature

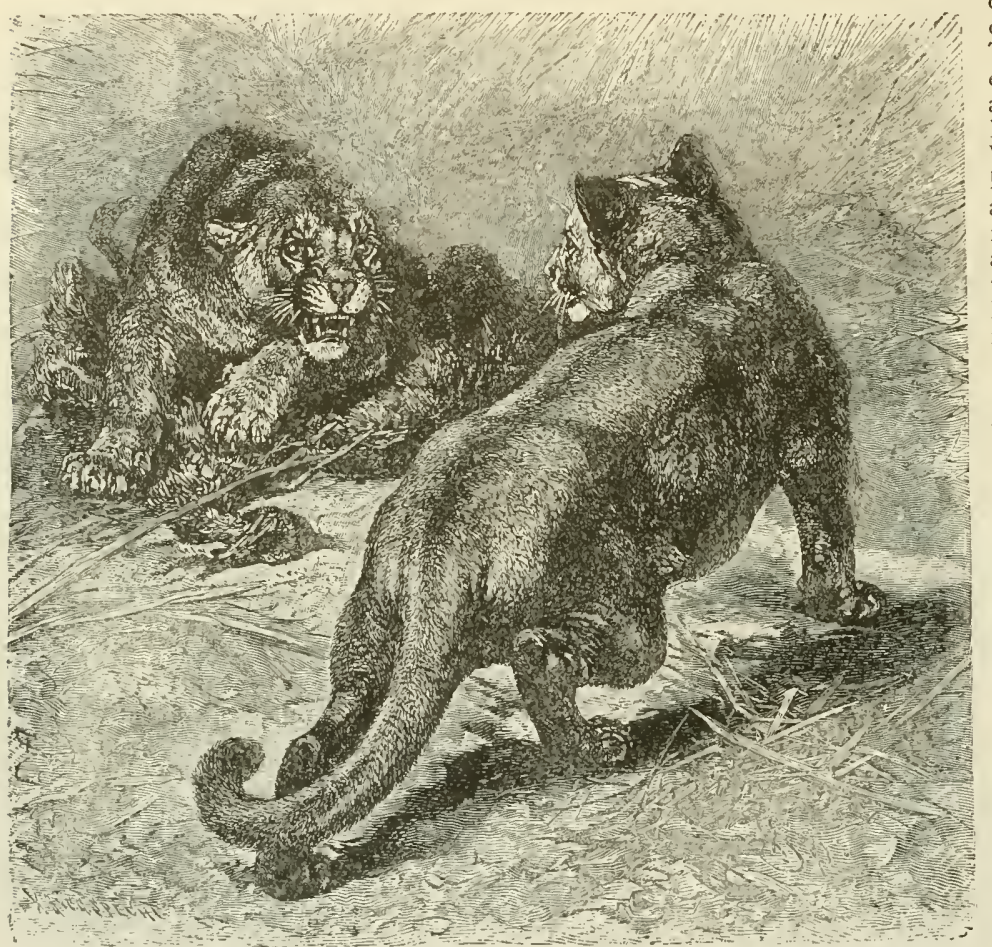

THE COJGAR OR PUMA. - This vicious beast is an American animal ranging from Canada to Patagonia, and in the United states is only found in forests or mountain fastnesses in the West and South. "It is distinguished from others of the Cat tribe by being of one color, with the exception, usually, of white spots above and below the eyes. The picture represents a family row, evidently. The Puma in the background has captured a large bird and
the other wants it. There will be trouble. (Felis concolor.)

does not content this sanguinary animal, and thus he becomes a dangerous enemy to owners of flocks. Ie never carries his victim far from the place at which he killed it He rarely attacks animals larger than Sheep; Horses, Mules and Cows are secure from his attacks, as well as Dogs; although he frequently prowls close to houses.

Hunting (Wwing to his cruelty and the injury he

the does to the property of Man the Puma is

Puma. being energetically exterminated. There is no great danger in hunting him if one is cautious, for even a wounded l'uma is not mucl to be feared.

Among the many stories illustrating the character of this animal, the following seens to me to be very good: An Englishman, hunting wild Duchs in the pampas, was creeping along on the ground towards some birds. He had wrapped his head and body in a poncho, so as to escape the notice of the birds. Suddenly he heard a short, hoarse roar, and nearly simultaneously something touched him. Quickly he threw down his covering and to his great surprise beheld a Puma at arm's length. The animal was just as much astonished as he. It gazed at the sportsman for some moments, siuwly retreated a few steps, stopped again, and then made its escape in huge bounds.

The Puma Pumas captured old sometimes reject all in food and prefer starvation to the loss of Captivity. liberty; when very young cubs are captured they soon become thoroughly tamed. Some of them enjoy the liberty of the whole house. They look for their keeper, lick his hand, rub against his feet and then lie down near him. When petted, they purr like Cats. Probably they also do this when they feel particularly comfortable. When displeased they growl, but a roar $h$ as ncver been heard from them.

Two tame Pumas that 1 took care of al ways greeted their friends with a shrill whistle, the like of which I never heard from any other Cat. There is one drawback to a tame Puma; when he has great affection for his master and likes to play with him, he hides at his approach and then jumps on him unexpectedly, as tame Lions are also wont to do. One may easily imagine how uncomfortable such an ill-timed caress may become.

The skin of the Puma is only used in the northern parts of America. In some localities his flesh is eaten and is said to be very palatable, being similar in taste to that of the Calf.

\section{THE YAGUARUNDI.}

Description Nearest to the Puma stands the Yag of the uarundi (Folis yoguanmili), a slender Vaguarundi. creature nearly resembling a Marten in his long body and tail. The head is small, the eye moderately large, the cars rounded, the fur short, dense and of blackish gray-brown color; each hair is of a gray-black hue at its root, then black and the tip is brown. The female is always lighter in tinge. The size is much smaller than that of the Puma, for the body is only twenty-two inches long; the length of the tail is nearly thirteen inches and the shoulder height fourteen inches. 


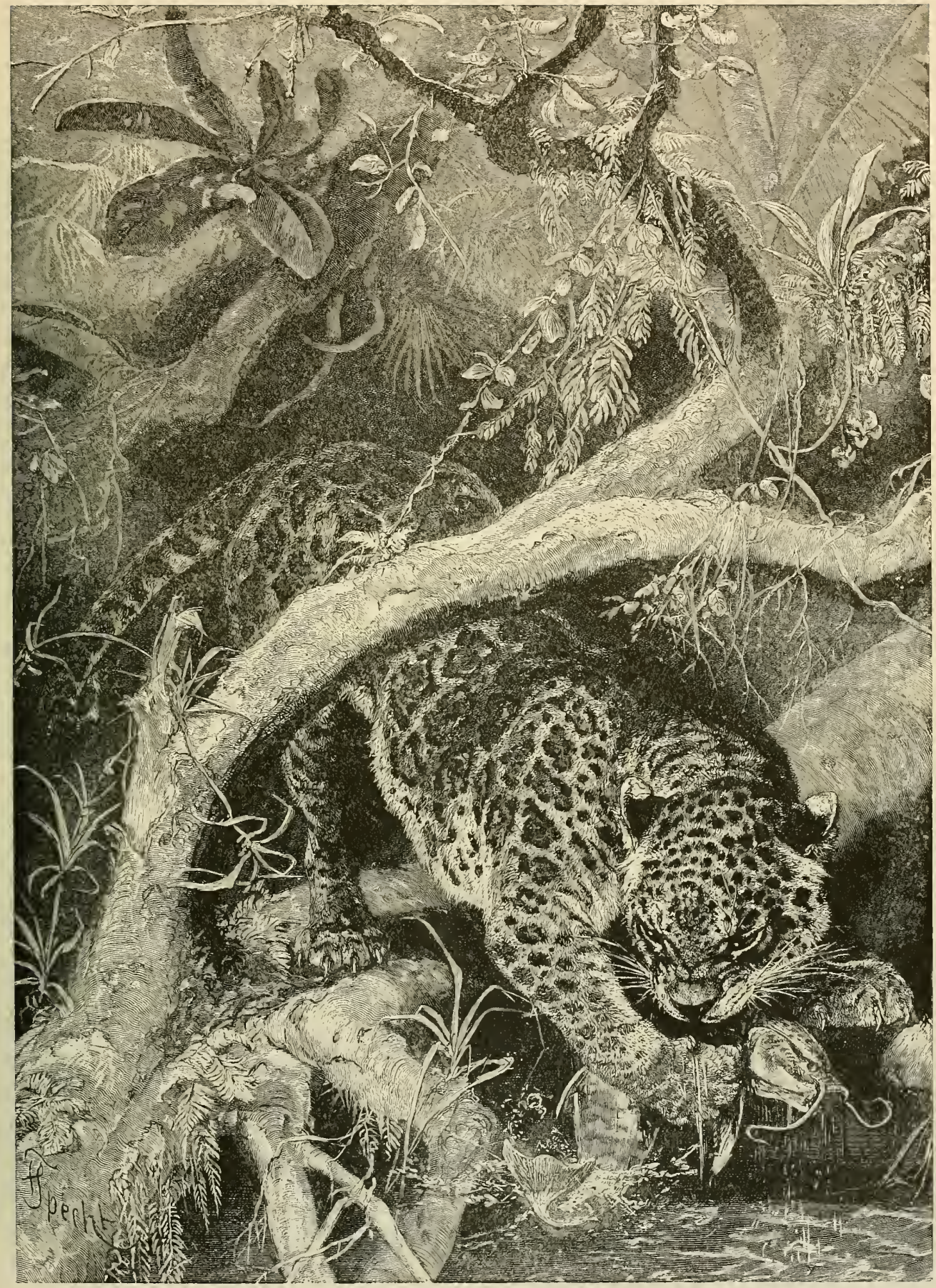

THE JAGUAR. - The most dreaded denizen of the lorests of the New World is the Jaguar. It attacks mammals and birds, from the largest to the smallest; devours Turties, and will lie on a tree branch on the bank of a running stream, watching for big fish which it frequently, succeeds in catching in the seeming to know that its only reward would be a shock. (Felts onza.) 
The Iaguarundi inhabits South America, between Paraguay and Panama, and O. Stoll has also found him in southern Guatemala under the name of Gato del Monte.

Usually the Yaguarundi lives in pairs in a given strip of land, and undertakes short journeys from these headquarters. Not infrequently he shares his hunting grounds with other couples, contrary to the habits of Felidxe in general. Rengger's Dogs once found six Yaguarundis in one hedge. He does not attack Men, and hunting him is not fraught with any danger. He scarcely ever defends himself against Dogs and is also caught in traps.

Rengger kept several Yaguarund is that were captured young. They were as tame as the gentlest of domestic Pussies, but their Poultry-stealing propensities were such that he could not allow them the freedom of the premises.

\section{THE JAGUAR.}

The Jaguar (Fclis onza) is the largest, strongest and most ill-famed of all New IVorld Felida. Evcry traveler has had somc ncw tale to tell about him. although it seems that old accounts exaggerated his ferocity. It is easily explained that many stories were believed to be true that were only founded on current gossip, for the animal was but little known.

The Jaguar shows more vigor than agility in his frame, and his appearance is a little clumsy. The body is not as long as that of the Leopard or Tiger, and the limbs are proportionately shorter than theirs. According to Rengger's statement a full-grown Jaguar mcasures fifty-cight inches from the tip of his snout to the root of his tail, and the length of the latter is twenty-seven inches. A. von Humboldt saw several specimens which were as large as the Royal Tiger. The average shoulder height is thirty-two inches. The fur is short, thick, lustrous and soft, and longer at the throat, on the breast and on the under part than on the rest of the body. The ground color as well as the spots are subjcct to great variations. The najority have a tan colored body, except that the inner side of the ears, the jaws, the throat, the under part of the body and the inner side of the legs are white. The fur is marked all over, either witl small black, circular, oblong, or irregularly shaped spots, or with larger spots and rings edged around with black or tan color, and having one or two black points in the middle. On the inner side of the legs the spots sometimes unite to form bands, and the end portion of the tail shows two or threc full rings. All varieties show a black spot at the corners of the mouth. On the spine the spots merge into an irregular stripe, which divides in two on the buttocks. More exact particulars can hardly be given, as no two or three skins are marked exactly alike. The female shows a paler tint than the male, and her spots are smaller and more dense. Black Jaguars are not a very great rarity. Their skin is so dark that the spots are hardly distinguishable.

The variety in size, ground color and markings must be considerable, and rather uniform in essentials, as many naturalists recognize several distinct species.

Home and The namc of "Jaguar" is taken from Haunts of the the Guaran language, in which "JaguarJaguar, ette" signifies "body of a Dog." "The Spaniards call the animal "Tigre," the Portuguese "Onca." The Jaguar extends from Buenos Ayres and Paraguay all through South America to Mexico and the southwestern part of the United States.
Probably he is most common in the temperate regions of South America, and least frequently found in the United States, where the encroachments of civilization have driven him farther and farther into retirement. He inhabits the wooded banks of streams, edges of marshy woods and marshes grown with grass and reeds over six feet high. He is seldom seen in a field or in the center of large woods, and then only when he transfers his abode from one locality to another. Where dawn surprises him he lies down and spends the day.

The Jaguar ln the morning dawn, or evening dusk, Searching or in broad moonlight, the Jaguar sets for Prey. forth on his travels, but never by daylight, nor during very dark nights. All of the larger kinds of vertebrates that he can get hold of he preys upon. He is a formidable enemy in every respect. His gait appears clumsy, but he moves with the greatest ease and agility when circumstances require it. His strength is exceedingly great for an animal of his size, and may safely be compared to that of the Lion and the Tiger. The senses are acute and are of uniform development, except that the smclling faculty is rather deficient, as is the case with all Felidae; and he seems perfectly endowed for a life of rapine. He is not fastidious in his feeding. Azara found bristles of a Porcupine and Rengger found parts of Rats in stomachs of Jaguars, so that they evidently prey upon the smaller as well as the larger animals. The Jaguar lurks for birds in the reeds, and very skillfully catehes fish in the water. A. von Humboldt says: "The Jaguar is the most formidable foe of the Arrau-turtle, and follows it to the place where it deposits its eggs on the beach. In order to devour it more easily he turns it over on its back. The Turtle is thus rendered helpless, as it cannot regain its feet unassisted, and as the Jaguar turns over many more Turtles than he can eat in one night the lndians often profit by his industry. One cannot too much admire the dexterity of the Jaguar's paw, with which he empties the Turtle's shell, penetrating the double coat of mail with as much adroitness as if the tendons had been cut by a surgical instrument."

"An expcrienced sportsman," says Rengger, "can often observe the Jaguar, especially along watercourses where he may be seen creeping up to the bank in search of Otters. From time to time he stops and looks attentively around; but 1 never saw him follow the spoor of game guided by his scent, his nose on the ground. The patience and circumspection with which he approaches a victim are incredible. His movements are sinuous, like those of a Snake, and he often keeps quite still for a few minutes, or makes wide circuits to approach his prey from another and more advantageous side. I'hen he succeeds in approaching near enough, he jumps on his victim with one, or sometimes two bounds. fells it to the ground, lacerates its neck, and carries the agonized animal into the thicket.

The Jaguar makes great ravages among herds and flocks. He especially preys upon young Cattle, Horses and Mules.

Methods He catches his prey as well in the of the Jaguar's water as on terra firma, but he does Attack. not attack animals on trees, although he climbs very well when pursued. A great many stories have been set afloat about the way he catches fish. Rengger gives us the following report: "I was returning in my canoe from a Duck hunt one sultry summer evening, when my Indian companion 


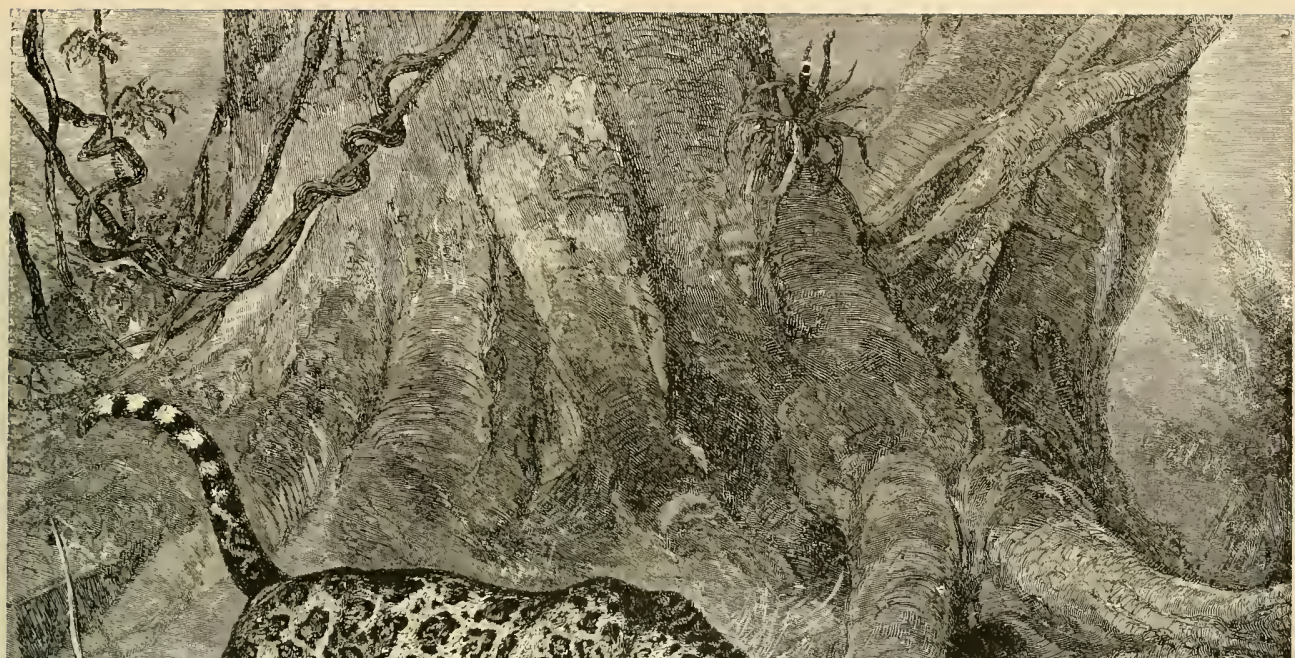

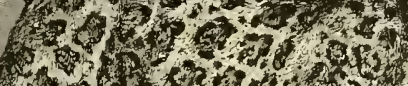

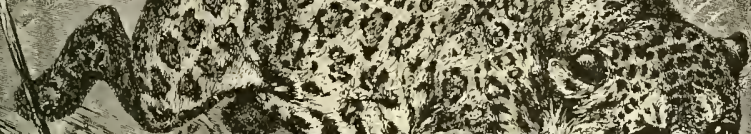

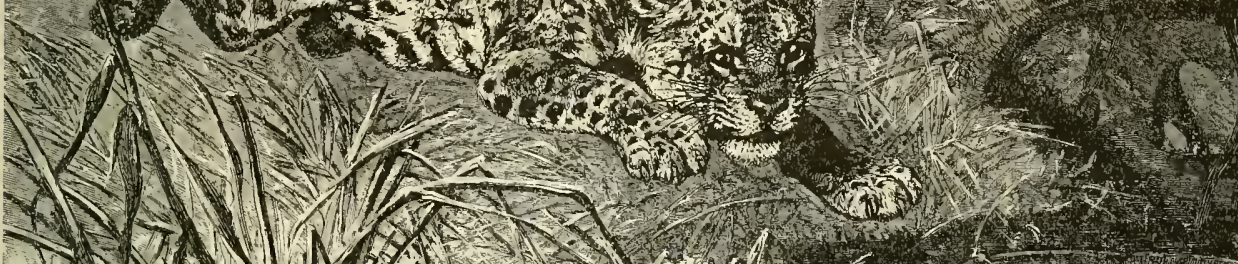

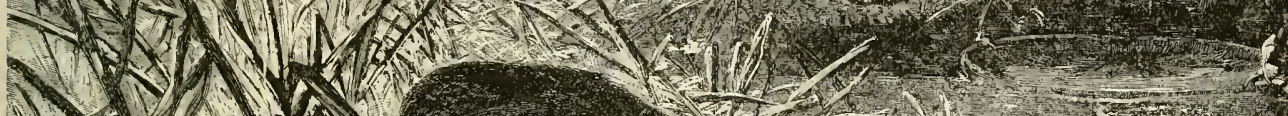

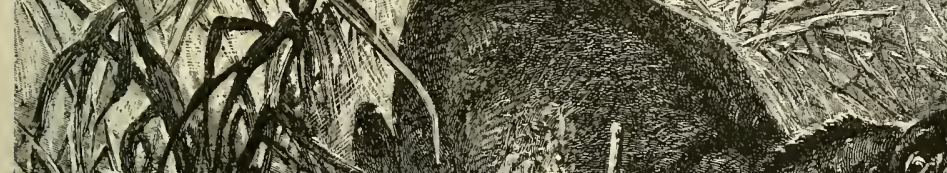

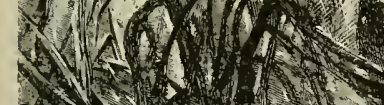

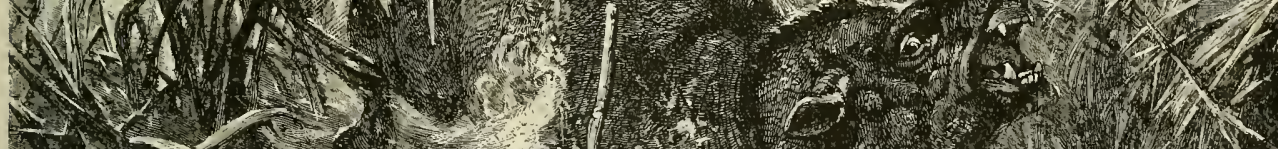

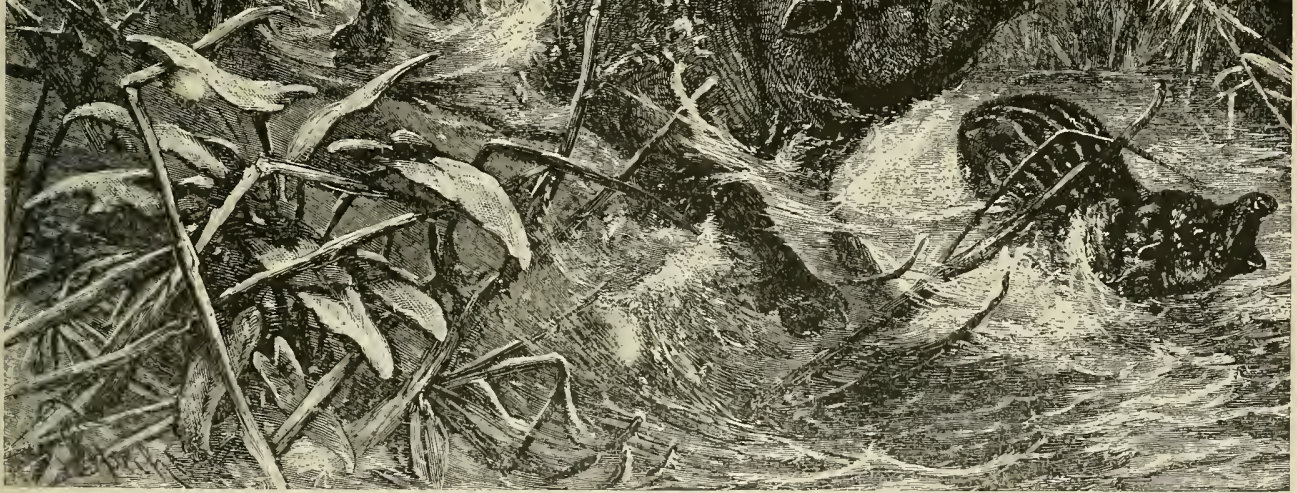
JAGUAR ATTACKING A TAPIR.-and thus the Jaguar is often thrown off. In the case pre- 
perceived a Jaguar on the bank of the river. We approached him and hid ourselves so as to observe what he was about. He had crouched down on a little projection of the bank, where the current was swift, and where a kind of fish called "Dorado" was likely to be found. He did not take his eye off the water, but sometimes bent forward a little, as if he wanted to pry into the very depths of the water. In about a quarter of an hour I saw him strike at something with his paw, and then he threw a fish on the ground. It will be seen, therefore, that he fishes exactly like our domestic Cat.

When the Jaguar has killed a small animal he eats it immediately, including the skin and bones; but of large prey, like Horses and Cows, he eats only a part, without showing special partiality for any particular piece; but he leaves the entrails of these animals untouched. After the meal he retires into the forest, usually not over a mile from the place where he has eaten, and goes to sleep. In the evening, or on the following morning, he returns to his prey, makes another meal from it and leaves the remainder to Vultures.

It is Rengger's opinion that a Jaguar never eats more than twice of an animal he has killed, and never touches the carcasses of animals that are dead when he finds them. He never kills more than one animal at a single onslaught, and in this he distinguishes himself greatly to his advantage, as compared with other large Felidx.

Jaguars not A Jaguar which has not yet made
Usually Danger- the acquaintance of Man, avoids him
ous to Man.
respectfully, and regards him curi-
ously at a distance. There is no instance on record of a Jaguar having killed a Man in a forest. Only those Jaguars living in populated districts, or near rivers on which there is much navigation, lose their fear of Man and attack him. Traditional stories are current that Jaguars have been known to enter boats tied to the bank at night and carry away meat or Dogs, and even kill sailors ; but as a general thing it is only imprudent people who lose their lives from attacks of Jaguars, and cautious ones find it not difficult to save themselves from these animals. It is a noticeable fact that the Jaguar differs from some of the other large feline animals in having no fear whatever of fire.

Sounds Made The much talked of "roar" of the by the Jaguar cannot be a very impressive Jaguar. sound. Former travelers have either selected the word too carelessly, or else they have mistaken the noises made by other animals for his. The unrecognized sounds of a strange and unknown environment also nuay have impressed them in too high a measure. Modern travelers know nothing about this roar. Like the l'anther and Tiger, the Jaguar is a silent animal; it is not often that he growls, grunts, howls, or utters a cry that would appropriately befit a Cat of his size.

Habits and The Jaguar remains in one locality Wanderings of as long as there is anything left for

the Jaguar. him to prey upon and he is not annoyed too much. When food becomes searce, or pursuit waxes hot, he leaves the neighborhood and emigrates to other haunts. His journey is made during the night. He goes through the most densely populated localities and swims across the widest rivers in his migration, claunted by nothing.

Rengger writes: "The yearly swelling of streams and rivers drives the Jaguars away from the islands and wooded shores, and causes them to come nearer settlements; as a consequence they do more mischief during this season. If the inundation is great, one may not infrequently see a Jaguar in a town or a village situated on the high bank of a river. His appearance is not always attended by damage, for the barking of the Dogs and thronging of people bewilder the animal so much that he looks about for a place of concealment. The wounds inflicted by a Jaguar are always dangerous, not only because of their depth, but also because of their character. Neither his teeth nor his claws are very sharp or pointed, and so every wound combines bruising with laceration."

The Female During the greater part of the year the Jaguar and Jaguar, as Rengger's observations show, her Cubs. lives alone, and only in the months of August and September do the two sexes seek each other's companionship. A litter of young Jaguars consists of two or sometimes three cubs, the mother selecting the most impenetrable thicket of the forest or a pit under a half uprooted tree for a den for herself and children. During the first days the mother does not leave her young ones, unless it be for a very short time, and when she believes them to be in danger she carries them in her mouth into another den. Her motherly love is said to be very great; she defends the young ones with a kind of frenzy, and if one of them be killed or captured she pursues their assailant for hours.

loung Jaguars are often brought up in households. For this purpose they must be captured while they still live on their mother's milk, for otherwise it is too late to tame them. They play with Cats and Dogs and show a particular fondness for wooden balls. Their movements are easy and lively: They know their keeper perfectly and after a separation show pleasure in seeing him again. As soon as they become conscious of their power, which is about the third year, they do not fail to use their strength to the great inconvenience of their owner. It is useless to file off their canine and incisor teeth to the roots and to cut their fangs from time to time, for they are so strong that they can do a great deal of mischief without these weapons. While they are young they can be kept in check by blows, but later it is very difficult to master them. Generosity and gratitude are emotions unkwown to the Jaguar; he shows no permanent attachment for his keeper, nor for any animal that has been brought up with him, and therefore there is great risk in keeping him outside of a cage after he is a year old.

Methods The Jaguar is constantly pursued of Hunting the and hunted in all possible ways beJaguar, cause of his harmfulness. In South America the Indians use arrows poisoned with the deadly Urari. Besides this method there is a much bolder proceeding: the sportsman wraps his left arm in a sheep-skin and procures a two-edged knife, about two feet long. Accompanied by two or three Dogs he then sets out in search of the Jaguar, which, when found, attacks the Dogs. Then the sportsman approaches and excites him by words or gestures. The animal makes for the Man with wideopen mouth, approaching on his hind legs like a Bear. The hunter presents his protected arm to the claws of the Jaguar, and, bending a little to the right, thrusts the knife into his left side.

The natives of Paraguay attack the Jaguar on horseback, using a lasso; they throw it around his neck and then gallop away dragging him behind then and sometimes strangling him with the aid of 


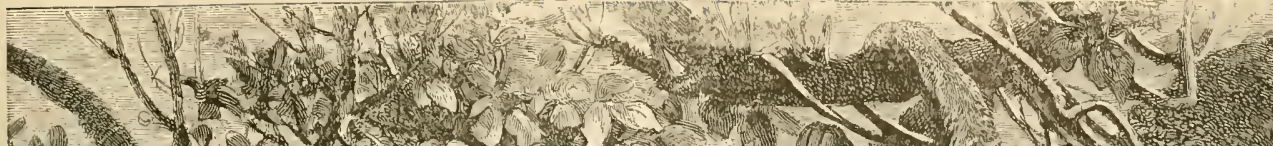

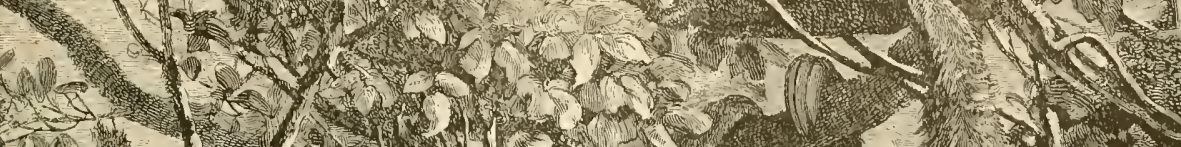

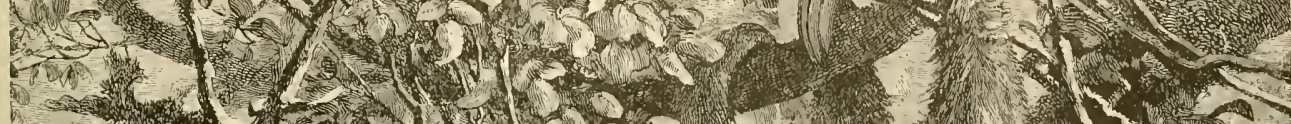

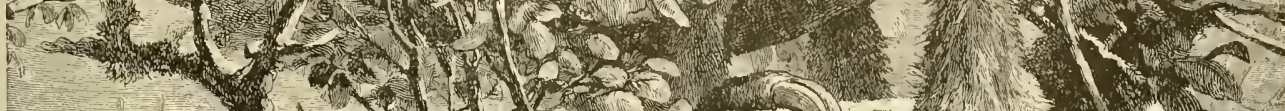

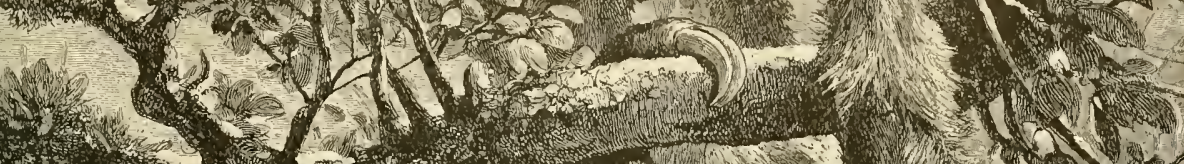
$2 y+5.6250$

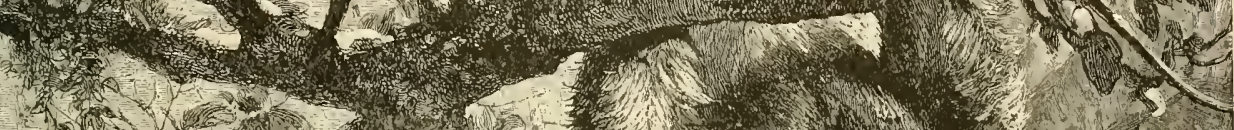

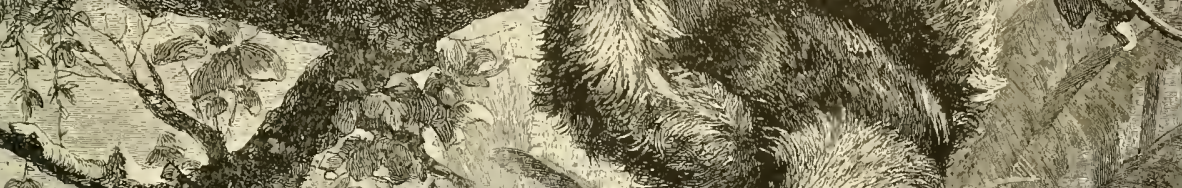

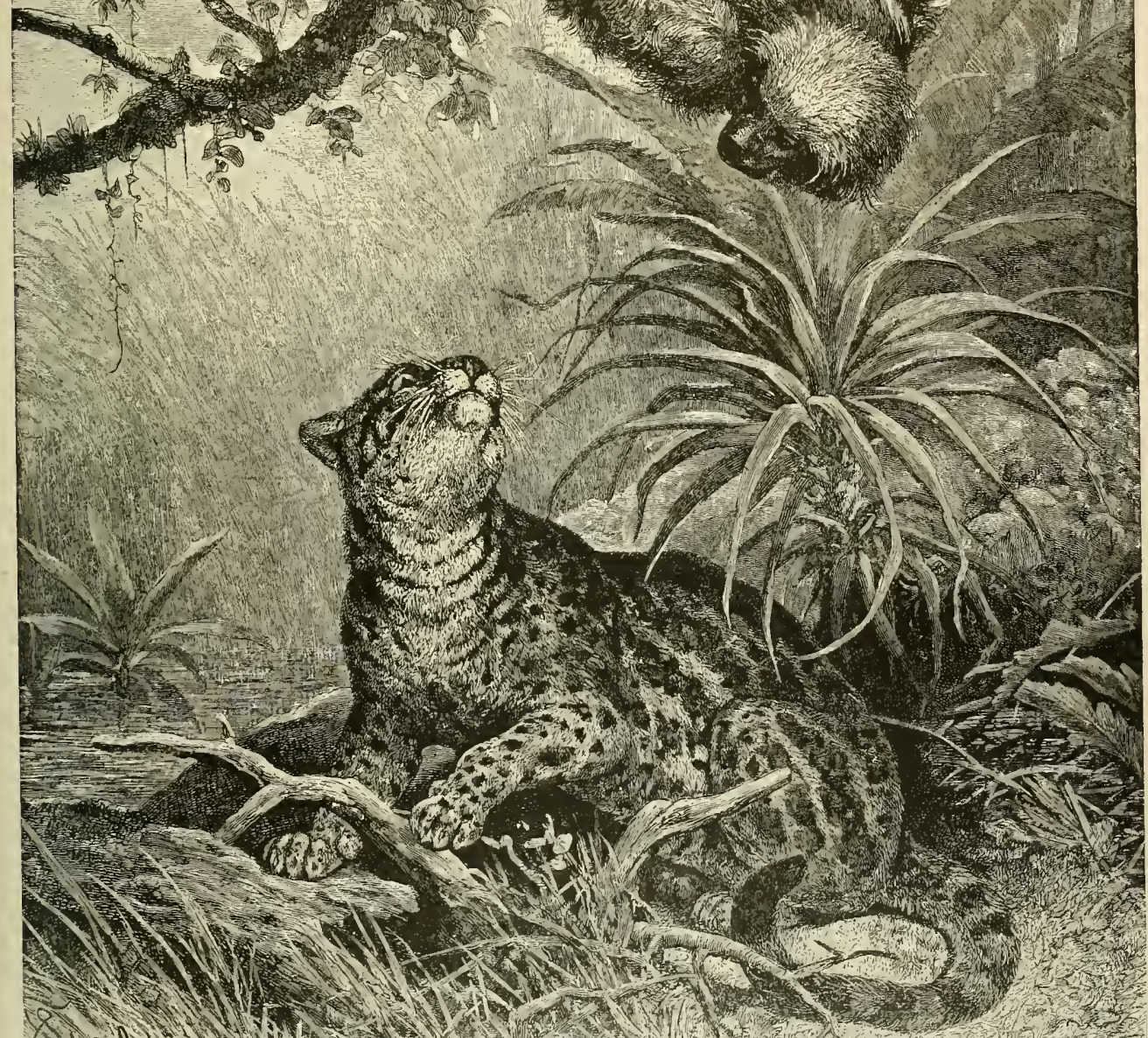

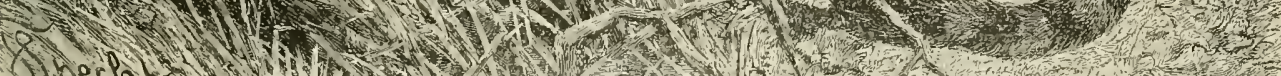

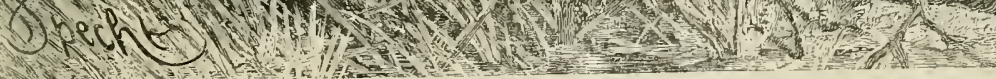

OCELOT AND SLOTH. - In the South American forests there is no more harmless animal than the Sloth, aud none is fiercer than the Ocelot, The about with considerable rapidity. But it is no match for the agile, cruel, 
a second lasso, which is pulled in the opposite direction. Sometimes he is caught in pitfalls or killed with spring guns put near his prey.

The fur of the Jaguar is of slight value and is seldom used in any way except as a rug. Von der Steinen, who has tried Jaguar flesh, says that the first animal was tough, but the second "tasted like roast pork. The cutlets would have been excellent cooked with red cabbage." Certain parts of the Jaguar's body are used as medicines.

\section{THE OCELOT.}

The Ocelot (Felis pardalis) is a smaller American Cat. His length is about four feet, of which the tail takes up about one foot and a half, and his height at the shoulder is about twenty inches. The body is proportionately strong, the head rather large, the tapering tail moderately long, the ears short, broad and rounded, the pupil of oblong, oroid shape; the fur is thick, soft, lustrous and marked with bright, well-harmonized colors. The general color is tawny good as moonlight to him, in fact, he prefers those that are stormy, as he can then slink into farmyards unperceived and work destruction at his own will. In dark nights the farmer has need to lock his poultry yard with extra care, for if the Ocelot succeeds in entering he will work fearful havoc. In the woods his sustenance consists of birds, small mammals, young Roes, Pigs, Monkeys, Rats, Mice, etc.

Ocelots live in couples within a circumscribed territory. When the sportsman has seen one he may look for the other in close proximity, but more than two are never found in one locality. Male and female do not go out for prey together, nor do they help each other in the hunt or in an attack.

The Ocelot does comparatively little mischief to Man; he is too much afraid of Man and of his Dogs to approach human dwellings. Only houses that are very near woods receive an occasional visit from this animal, and even then he has designs only on the poultry; he usually carries away about two Chickens and eats them in the nearest bush. If his

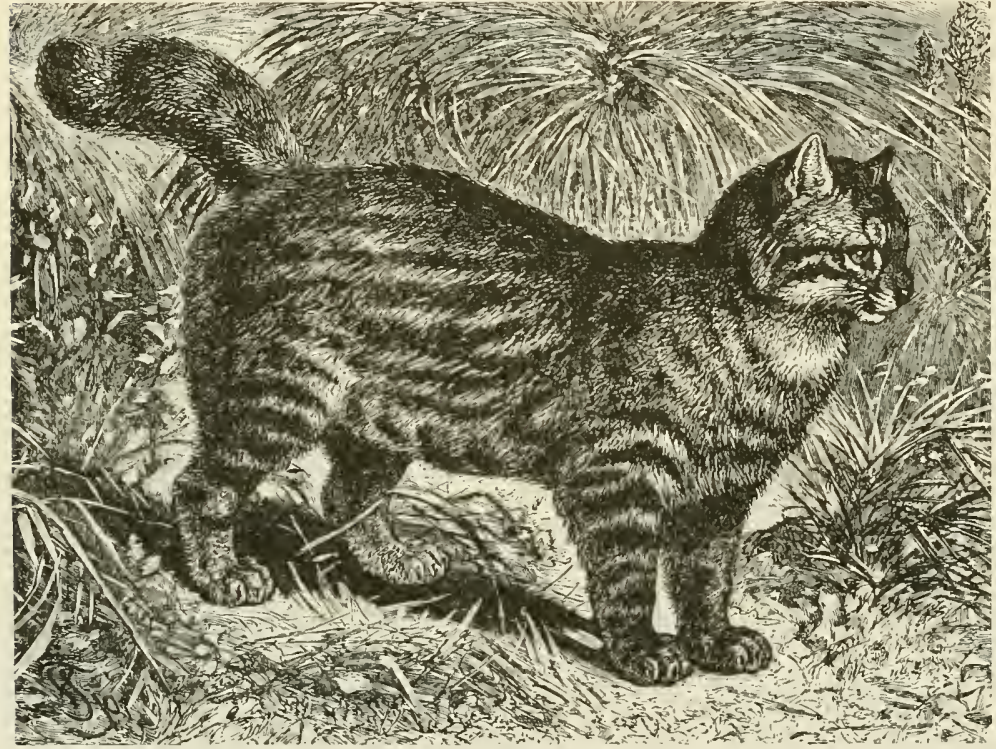

THE PAMPAS CAT_ — This Cat is noted as having more clearly defined stripes than any other feline animal and these markings are accurately shown in the picture, which portrays the animal in its native home amid the cacti and long grass of the South American plains. (Felis pajeros.)

or grayish brown above and yellowish white below. A black stripe runs from the eyes to the ears. The body shows bands and spots of black, and the tail is ringed with black. The markings may vary greatly in the different specimens.

The Ocelot is widely distributed. He is found in the southern parts of North America and in South America south to Peru, Bolivia and Paraguay. $\mathrm{He}$ lives more in the deep, virgin forests than in the vicinity of settlements, although he may also be met with there. He is never found in the open country. but only in the woods, in rocky or marshy situations. He does not seem to have a permanent den. How the Ocelot During the day he sleeps in the most Lives impenetrable part of the forest; at and Hunts. dusk, and particularly at night, he goes forth to prey. Dark or stormy nights are as first raid is successful, he is likely to repeat it for several succeeding nights, until he is captured or the pursuit becomes too hot for him. In Paraguay he is hunted with Dogs or caught in traps. He is very shy and wary, and on moonlight nights he generally manages to see the hunter and make good his escape before he himself is seen.

The Ways Young Oceof Tame lots are often

Ocelots. caught and tamed, and are interesting animals when in captivity. They will play with a little piece of paper, an orange or other trifle like young Kittens. They soon come to know their keeper, will lick his hands, lie down at his feet and climb upon him. They are very susceptible to caresses and purr whenever they are petted, and never show a treacherous disposition. Captive Ocelots will live on very good terms with Dogs and Cats, but cannot overcome their Chickenstealing propensities. Forgetful of all former castigations, they will spring at a Hen at every opportunity and then nothing can keep them from killing the fowl. For this reason they are usually kept in a cage or chained up.

\section{THE PAMPAS CAT}

The Pampas Cat (Felis pajeros) possesses more distinct stripes in the markings of its fur than any other member of the Cat family. Its ground color is a beautiful silvery gray, traversed by paler or darker russet stripes. Each hair is gray at its root, and then yellow, tipped with silver-gray, or in the stripes with a russet yellow. Along the spine black 
and dark red hair is mixed, and the tail shows from four to six dark rings near the tip. Though the colors of the Pampas Cat are rather dull, the disposition of its markings nakes it one of the prettiest members of the Cat tribe. Large Tom-Cats of this species may attain a length of from forty-eight to fifty inches, of which twelve belong to the tail.

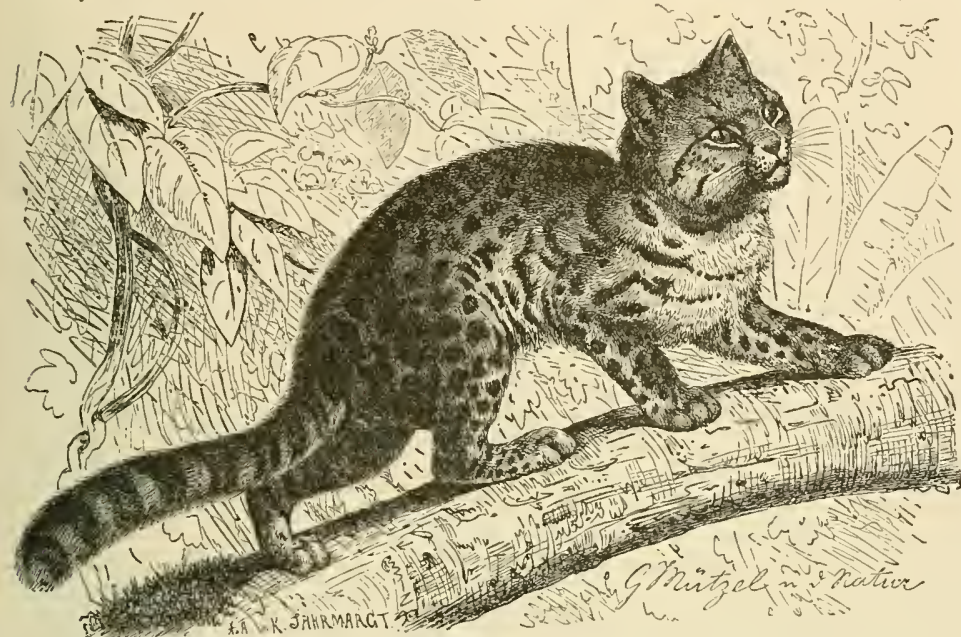

THE MARGUAY, OR TIGER CAT, - This South American feline is rather smaller than the domestic Cat, and has a sott and beautiful tan-colored fur, prettily striped and spotted, and a tail that is thickest at the end. It is an arboreal animal, partial to birds as well as rodents and other small mammals. The Cat in the picture seems to have a bird in view. (Felis tigrna.)

The Pampas Cat, as its name denotes, is indigenous to the pampas or plains of South America, extending through Patagonia as far as the Straits of Magellan, being especially abundant on the banks of the Rio Negro.

\section{THE MARGUAY.}

Two other American species are the Marguay and the Long-tailed Tiger Cat. The Marguay is called Tiger-cat (Felis tigrinis) by naturalists and in commerce; and barely attains the size of our domestic Cat. Its body length is twenty inches, its tail length twelve. Its beautiful, soft, Catlike fur has a pale, tawny color on the upper portion of the body, and is white with dark spots below. The ears are black interspersed with white spots. The tail is bushier at the tip than at its root.

This Cat resembles the Ocelot in its mode of life in all respects. When taken young it becomes a very docile and affectionate animal. WVaterson brought up a young Marguay in Guiana with great care. It soon formed a strong attachment for him and followed him about like a Dog. The house was overrun with Rats and Mice, which had eaten holes in thirty-two doors. The Marguay waged an incessant war against them and in a short time it freed the house from these destructive rodents, and thereby especially endeared itself to its owner. most species is stumpy.
THE LONG-TAILED TIGER CAT

The Long-tailed Tiger Cat (Filis macrura) seems to be more common than the two preceding species in the Brazilian forests. Its dimensions are about the same as those of a large domestic Cat, but its paws are much stronger. Its length is forty inches, inclusive of the tail, which measures twelve or thirteen inches; and its height at the shoulder is about twelve inches. Its distinguishing feat ures are a small head, large eyes, lancet-shaped ears and curved, whitish claws. Its general color is tanbrown on the upper part, white below, and the whole body shows longitudinal rows of dark spots, some of which assume a ring-like shape around a lighter center.

A slender body and beautiful fur make this animal one of the most attractive of the whole Cat family. It inhabits nearly all the great forests of Brazil. The Brazilians call it the Spotted Wild Cat, and often kill it for the sake of its beautiful fur. It climbs very well, and likes to $\mathrm{cl}$ a $\mathrm{mber}$ up creeping vines and search the trees for birds' nests; it also catches and devours all kinds of small animals. It is a dangerous foe to both wild and demestic Chickens and often invades farmyards to steal poultry. It has its lair in hollow trees, rocky holes or caverns.

\section{THE LYNXES.}

Nearly all naturalists agree in assigning the Lynx $(L y n x)$ a place of its own among the Cats. The

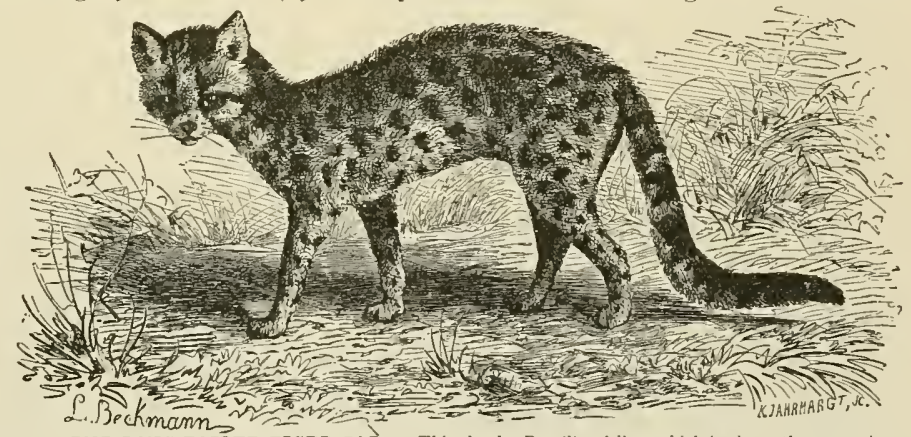

THE LONG-TAILED TIGER CAT. - This slender Brazilian feline, which is about the same size but proportionately longer than the house Cat, has a beautiful fur with almost straight rows of spots leng th-
wise of its body, as shown in the picture. The smallness of the head and the pointed ears are also distinuishing features. (Felis macrura.)

Lynxes are distinguished by a moderately sized head endowed with tufted ears, and most species also possess well-developed whiskers. The body is slender but strong, the legs are long and the tail in

All continents except Catless Australia are well stocked with Lynxes; Europe itself has two distinct 
species of its own. They preferably inhabit dense furests, in which they select the most inaccessible places, but they are also found in plains and deserts and even in districts well settled by Man. They may all be regarded as highly-developed Cats; and they are destructive and dangerous to both wild game and domestic animals.

The The Common Lynx (Lynx a'ulgaris) ranks Common first among this group, by virtue of his Lynx. beauty and strength. The museum of Christiania has revealed to me the dimensions a Lynx may attain; those shown in German collections usually are but of moderate size. A fully grown Lynx is at the least as large as the Leopards we usually see in zoological gardens; only he is a little shorter of body and has longer legs. His length is from three and one-half to four feet; the tail from six to eight inches and his shoulder height is thirty inches. A male Lynx may weigh sixty, aye, even ninety pounds, as I was told in Norway. The animal has an exceedingly strong frame and powerful paws, reminding one of the Tiger and Lion, and reveals his great strength at the first glance. The ears are rather long and pointed, and end in a thick tuft of stiff black hair, about an inch and a half long. The thick upper lip is provided with several rows of stiff, long whisker-hairs. The body is clothed in a thick, soft fur, which is elongated in the face into a beard, hanging down in points from both cheeks, and in connection with the ear-tufts, giving the Lynx face a rather peculiar appearance. The color of the fur is reddish gray above, spotted with reddish brown on the head, neck, back and sides, while the under part of the body, the inner sides of the limbs, the throat, lips and rings around the eyes are white. The tail is covered with hair of uniform length, and has a wide black tip, which occupies nearly half of its entire length; the other half of the tail shows indistinct rings. In summer the fur is short and reddish, in winter the hair is longer and grayish white. The coloring may vary much in different animals. The females, as a rule, are redder than the males and their spots are more indistinct. The young ones are almost white.

The Lynx was known to the Ancients, but was exhibited much more rarely in Rome than the Lion and Leopard, because even then he was so much more difficult to take alive. The one that Pompey exhibited had been imported from Gaul. His life in the wild state was shrouded in a mystery which left room for many fables.

Range and Haunts In the middle ages he was a perof the

Common Lynx. manent occupant of German forests and was universally detested and pursued. His numbers have been steadily reduced since and he may now be considered exterminated in Germany proper.

The present eastern range of this Beast of Prey begins east of the Carpathians. He is found in Russia and Scandinavia, and all the mountainous and wooded parts of eastern Siberia, and his southern Asiatic limit is Turkestan and the Himalayas.

An essential requirement of his existence is a dense forest abounding in inaccessible thickets and game of all kinds. In sparsely wooded sections the Lynx shows himself only in exceptional cases; forest fires may, for instance, compel him to shift his quarters, and he will sometimes search an almost treeless locality for Hares. It may happen that a fire will drive hini as far as the orchards of a village. Unlike the WVolf, the Lynx remains for some time in one locality, searches it in all directions, often traveling miles in one night and using highroads for this purpose, generally returning to his old quarters.

Traits and Habits The Lynx is inferior to none of of the the other Cats in physical and

Common Lynx. mental endowments. He is capable of great endurance in walking, can leap an astonishing distance, climbs fairly well, and seems to be a good swimmer. Of his senses his hearing is probably the most efficient, and he therefore has a full right to the ornamental ear-tuft. His eyesight is probably very keen, although modern observers have given us no proofs in corroboration of the old stories about the Lynx's eye.

Former writers have compared the sounds he makes to the barking of a Dog, but this is by no means a correct comparison. His cry is a sound beginning high on the scale and ending low, resembling more the roar of a bear.

According to Noleken, the Lynx is an entirely nocturnal animal. He hides at the dawn of day and then, if undisturbed, lies still till evening: something the Wolf never does. He selects for his lair a thicket, a cavern, and sometimes holes made by Foxes and Badgers. His choice unfailingly falls on the very densest thicket that is available, like that formed by young fir trees, and then he cares very little whether the environs are much frequented or not.

As the shades of evening fall he becomes active. During the day he seems as rigid as a statue, but at night he sets out, and during the first part of his journey he makes frequent pauses, like those made by a Cat previous to entering an enclosure that appears to threaten danger. Only a very inexperienced person could mistake the spoor of the Linx for that of any other animal. The imprint is very deep, owing to the strength of the paw, which exceeds that of a large Wolf; and it is very round in shape, and, as the claws are hidden, is blunt in front. The pace is short compared with the size of the imprints made, and the spoor takes a form something like that of a row of pearls, and every person who has once seen it is sure to recognize it again.

The peculiar structure of the Lynx invests all of his movements with a certain degree of clumsiness. His step seems heavy; but if he lacks the gracefulness of his feline kindred, he possesses their agility in full measure, and surpasses them in rapidity of movement and endurance. The best illustration of his capabilities in these respects is furnished by a vicw of the ground where he has attacked his prey in freshly fallen snow.

The Common Apparently the Lynx regards as his Lynx rightful prey every animal that he may and His Prey. be able to subdue. There is hardly a living creature, from the smallest nummal or bird up to the Roe, which is secure from him; although it is probable that only the very strong Lynxes will venture to attack large Deer. The Lymx decidedly prefers large to small game and seldom condescends to catch Nice.

In the north the Lynx does comparatively little mischief; but in countries of temperate climate he makes himself equally detested by the flock-owner and the sportsman, as he not only kills much more than he needs for his sustenance, but often only laps the blood of his victim, eating the choicest portions and leaving the remainder to Wolves and Foxes. in these milder climates he seldom returns to feast 


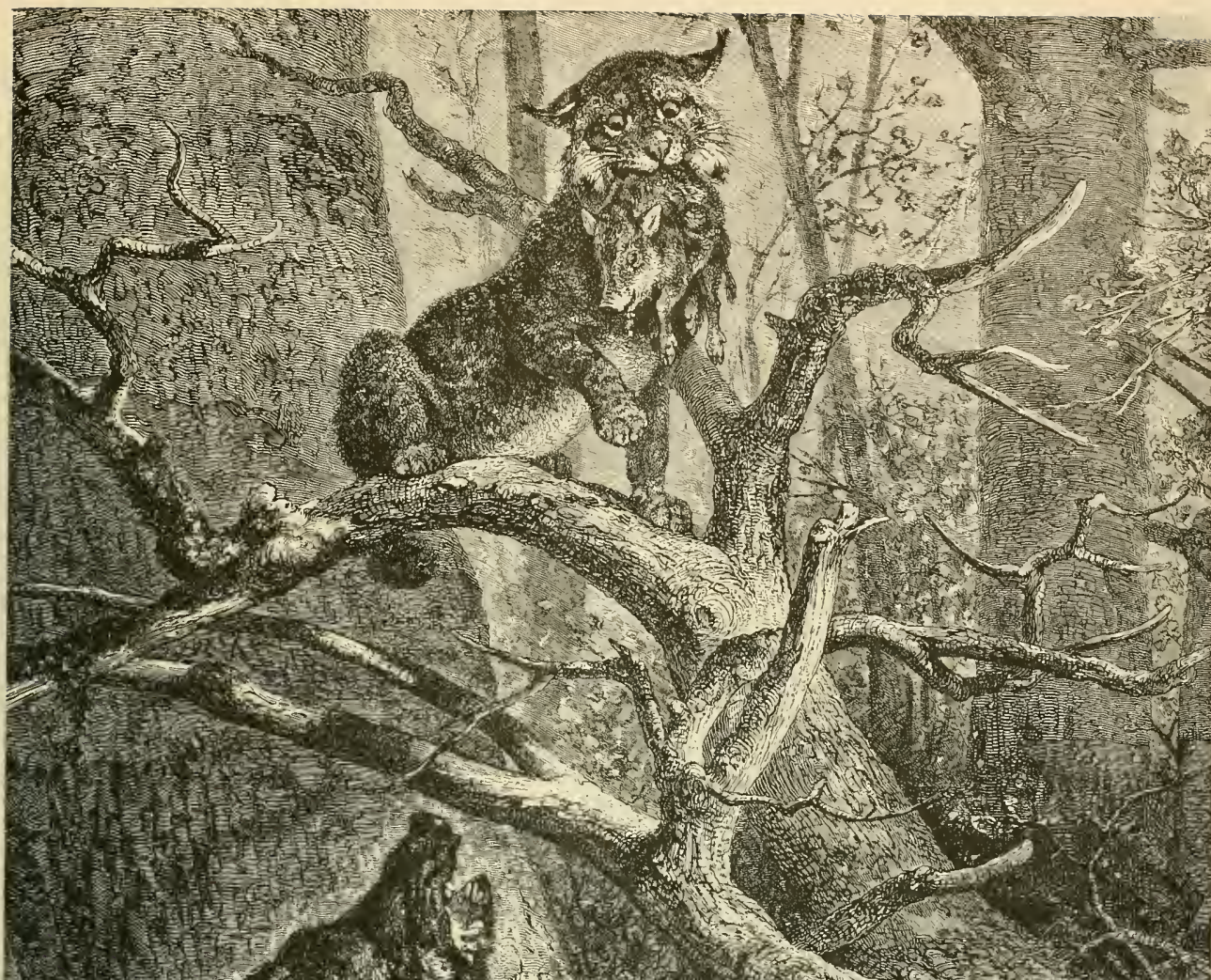

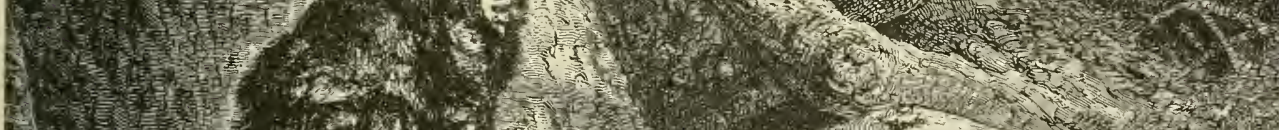

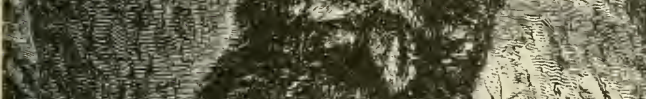

s.t. 4 (0) 
a second time on his prey, but in the north, where game is scarce, he does this habitually and to sueh an extent that he totally gives up the search for other prey and renains near the carcass of his victim until it is all caten. In the Alps he makes his presence felt in quitc another and more emphatic way. According to Schinz, he preys upon Badgers, Hares, Rabbits and Nice, pursues the Roes and Chamois, and makes raids upon herds of Sheep, Goats and Calves. Bechstein says that a Jynx can kill thirty Sheep in one night: Schinz's experience makes the number from thirty to forty and Tschudi tells of a Lynx who in a short time killed more than one hundred and sixty sheep and Goats.

A Tamed Lynx Captive Lynxes may unconditionally

an Attractive be counted among the most attractAnimal. ive of Cats. If they have not received eareful training in youth, they do not always show themselves in their most amiable light, but they never fail to attract very marked attention. her great excitement she always had enough reasoning power to gauge the distance and to approximate the difference between the Hare's speed and her own. She would obey only my brother's or my own summons, and showed no respect toward any othur person. When we were both away for a whole day, nobody could control her and then woe be unto the careless Chicken or the thoughtless Goose! During our absence she would, as soon as it became dusk, climb on the roof, lean against the chimney, and go to sleep. As soon as our carriage came into the yard, late at night, she sprang to the stairs in a few bounds. If I then called her name she would come to me quickly, put her strong fore-paws on my shoulders, and purring and rubbing herself against me like a Cat, she would follow me into the room and prepare to pass the night on the bed or the lounge.

"Unce my brother and 1 were obliged to stay away from home for a whole week. The Lynx in the

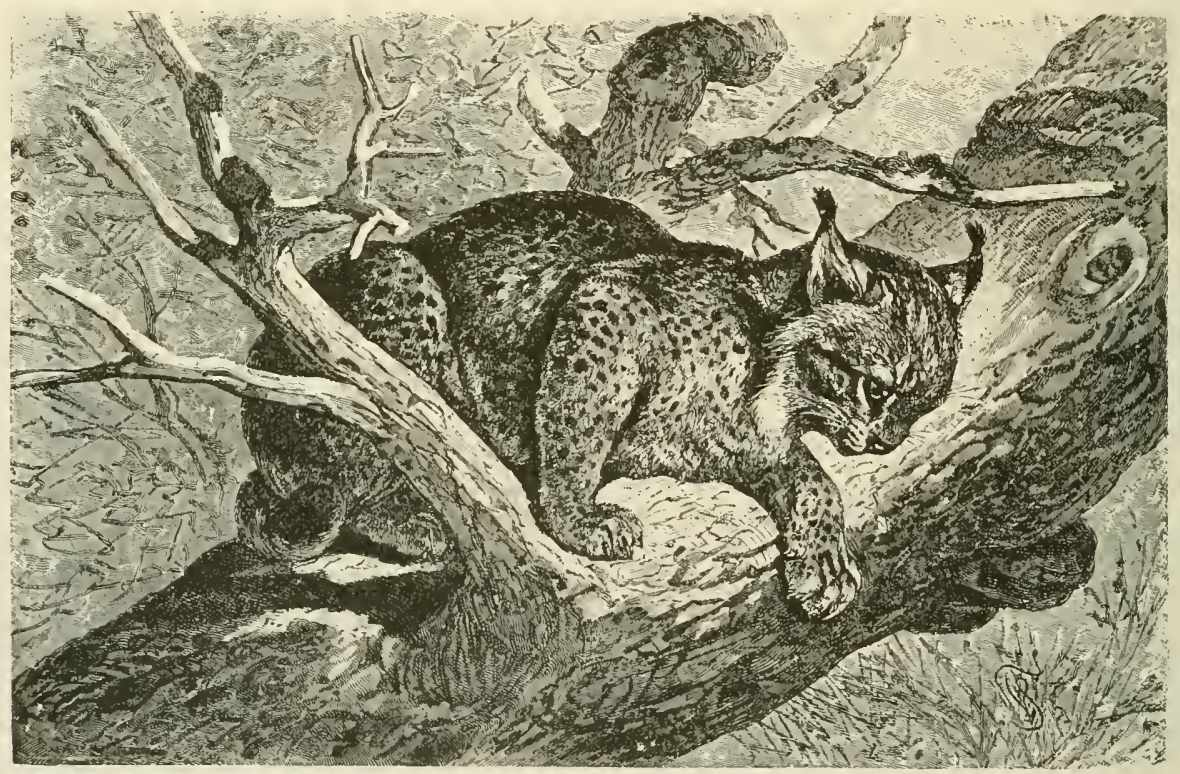

THE PARDINE LYNX. Although one of the smallest members of his family, the Pardine Lymx of southern Europe is as agile and fierce as the largest. The princtpal characteristics of this Lynx, the short and distinctly spotted fur, the long whiskers and ear-tufts are shown
in this picure, which represents him watching for prey from a secure hiding place in a tree. (Lynx fardinus.)

We are indebted to Loewis for an excellent report of a female Lynx that he kept. He says: "A few months sufficed to teach my young Lynx her name, 'Lucy:' W'hen, during a hunting expedition, I would call out this name, together with those of numerous Dogs, she would always respond to her own name, but to no other. Her training had been very easy and had reached such a point that when she was engaged in a passionate but forbidden chase of IIares, Sheep or poultry, and I called her, she would stop instantaneously and come back like a guilty Dog. crouching low on the ground and pleading for mercy. When she was too far away to hear our voices, the report of a gun was sufficient to call her back to us in breathless haste.

"Lucy took part in all my autumnal hunting expeditions. When she eaught sight of a poor Hare, she immediately engaged in a hot pursuit, and in spite of meantime grew to be afraid of Men, made piteous eries while she searched the place for us, and on the second day emigrated to a birch forest near by, without receiving any supplies from the kitchen. Only at night would she go back to her old place on the roof near the ehimney. When we at last returned her joy knew no bounds. With lightning speed she cane down from the roof, and nearly choked my brother and myself in the embrace she gave us. From that time she was reinstated in our house, and every evening, when my mother would read aloud to us, she would resume her place on the lounge, purring, yawning or snoring, and presenting an interesting spectacle. She displayed highly developed sensibility, an illustration of which was furnished by a scene that I onec observed from my window. Our great pond was frozen, but a hole had been cut in the iee for the benefit of the Geese. When the Lynx saw 


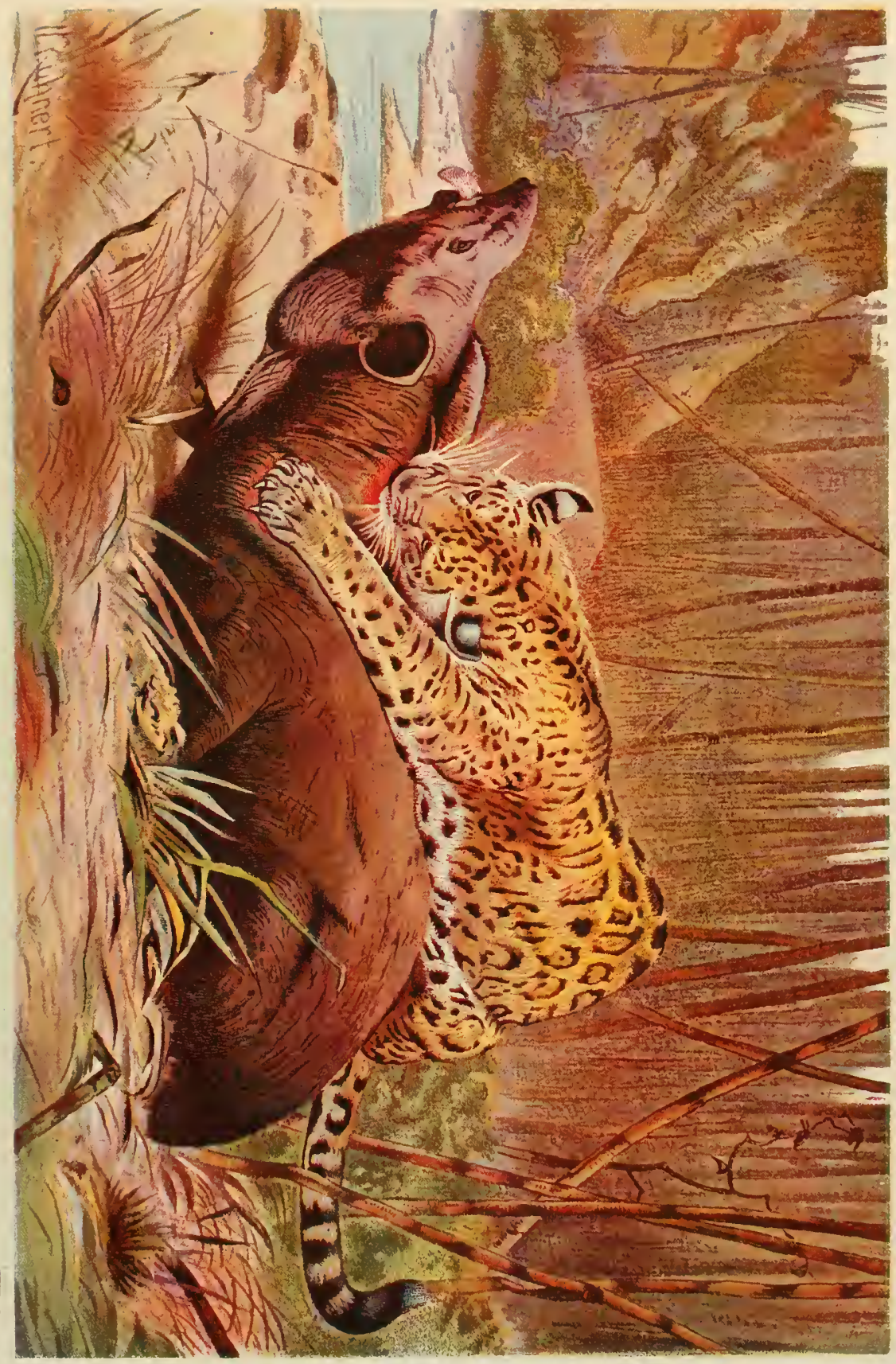



the flock her eyes sparkled, and with cautious movement she slowly crept toward thent. The vigilant descendants of Kome's rescuers grew uncasy, but the Lynx was already near. With one bound she darted like an arrow into the frightened assenbly, but instead of catching a Goose with each paw, as she had evidently intended, she fell into the water. I gave the Geese up as lost, for they stood about on the slippery ice in utter confusion, making no effort to escapc, but the Lynx, dripping wet and completely disconcerted, slunk away through the defenseless crowd with her head lowered, evidently ashaned to be seen after her failure. She hid herself and did not come out again for hours."

Hunting the The Lynx is zealously hunted, not only Lynx-Its because of the mischief he does, but beValuable Fur. cause of the pleasure the sport affords.

The fur of the Lynx is very valuable. The Scandinavian specimens are counted among the finest lynx by the short hairs of his fur, by the proportionately very long whiskers, long ear-tufts and by entirely different markings on his skin.

The Peshoo In North America the Pceshoo or Canaor Canadian dian Lynx (Lynx borealis) takes the place

Lynx. of the above named European species. $\mathrm{He}$ is a little smaller than the European Common Lynx, his length not exceeding forty-six inches. His fur is shorter and thicker than that of the European Lynx. He is spread all over those parts of North America to the north of the great lakes and east of the Rocky Mountains, and lives in forests like the Oid World Iynx.

The Canadian Lynx is, next to the Red Lynx, the most useful wild Cat of America, for his fur serves a variety of purposes. Thousands of skins of this species of Lynx are shipped every year to Europe, where they are assorted according to their differcnt qualities and are given various names in commerce.

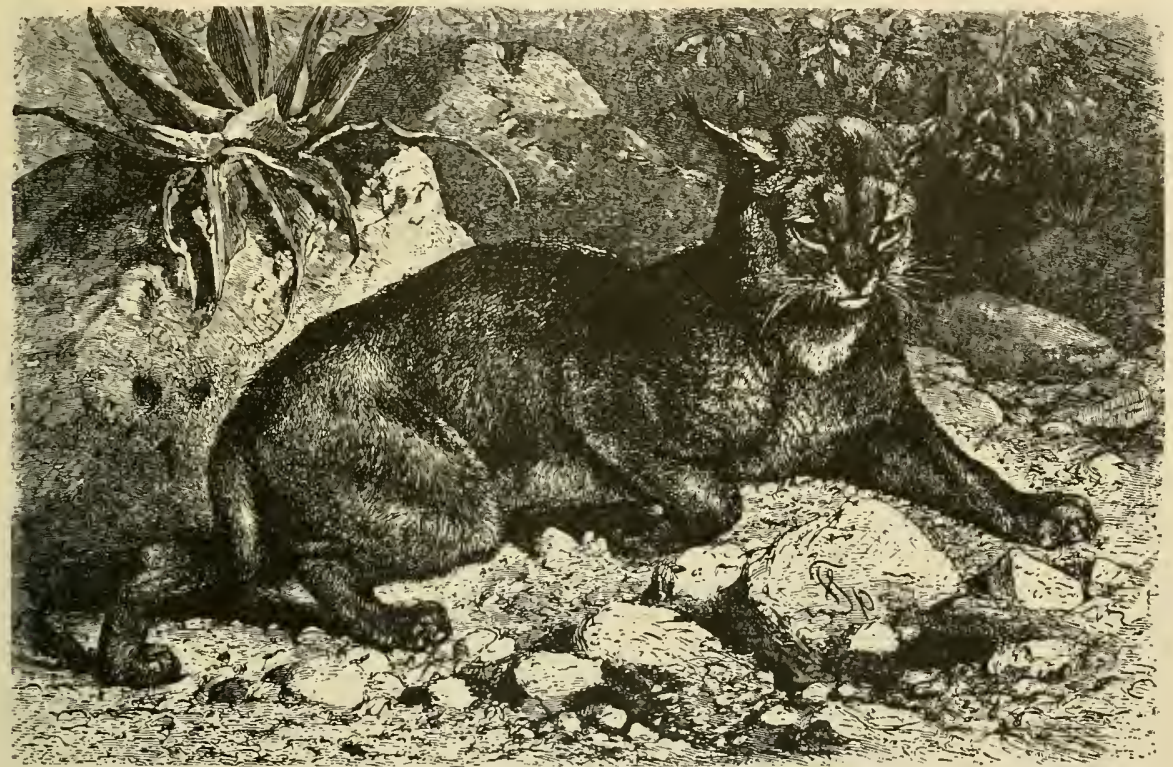

THE CARACAL LYNX. - This animal is the most vicious member of the Lynx group, and the picture well shows the slender body long limbs, and long ear-tufts that are his prominent characteristics. He is fleet of foot, and attacks Antelopes as well as small mammals and birds in the deserts and grassy plains of Atrica and western Asia. (Lyn.r caracal.)

and largest, and these shins command a price of from twenty-five to thirty marks each. Siberia furnishes annually about fifteen thousand, Russia and Scandinavia about nine thousand Lynx furs. The skins of the Lynxes of eastern Siberia are disposed of exclusively in the Chinese markets and bring a high price in Mongolia.

Lynx flesh is said to be very savory. Kobell says that during the Congress at Vienna, in 1814, Lynx roast frequently came on the table of Enperors, and in 1819 the King of Bavaria took a Lynx diet to cure himself of vertigo. The flesh is light colored and tender, like the best veal, and is free from the disagreeable taste so often found in game.

The In the south of Europe the genus Lynx

Pardine is represented by the Pardine Lynx (Lymx

Lynx. pardimus). He is much smaller than his northern kinsman, for his length barely reaches three feet. IIe is also distinguished from the Common
The Red Lynx The species of Lynx found in forests or American in the United States is the Red Lynx Wild Cat. or Bay Lynx (Lynx mufus). It is popularly known as the I'ild Cat, but is a true Lynx, with the ear-tufts characteristic of that group, and differs from the other members of it principally in the color of its fur. It is found all over the United States, from the Atlantic to the Pacific. The general color is usually red, but darker, and sometimes nearly black, along the backbone, while under the body it is whitish and on the breast purc white. The entire fur, except the breast, is covered with spots and streaks of darker fur. The length of the body and head is about fifty-three inches, and the tail is six inches long. The color of the fur is a brighter red in summer and a darker brownisle red in winter. Different writers have classified several species of the American Lynx, including the Texas Lynx ( Lynx maculata), which is found in Texas and Southern Cal- 
ifornia ; the Oregon Lynx (Lynx fasciata), which inhabits northern Oregon and Washington; the Florida Lynx (Lynx floridamus), which is found in Florida, Georgia, Alabama and Louisiana, and the Carolina

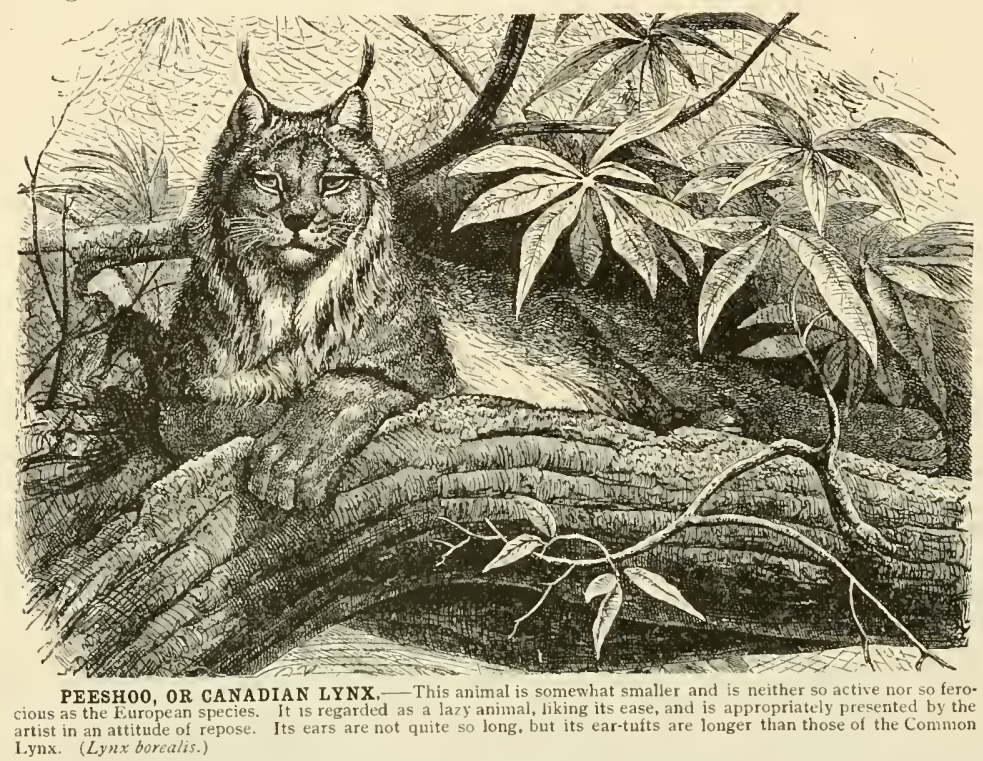

His mode of life is similar to that of his kindred. He preys upon all smaller mammals and birds of the desert, and also attacks Antelopes; at least the Arabs, who call him "Khut el Chala," have assured me that he does. This also agrees with the fact that in Asia, and especially India, he is trained for Antelope, Hare and Rabbit hunting. In my experience the Caracal, proportionately to its size, is the fiercest and wildest member of the Lynx group. No zoological garden has as yet succeeded in taming the ferocious little beast beyond mere toleration of the presence of his keeper in his cage.

The The common Common Jungle-Cat Jungle-Cat. (Lynx chaus) chiefly inhabits the low swanipy woods on the shores of the Caspian and Aral Seas, and also in Persia, Syria, Egypt, Nubia and Abyssinia. He is, like the Caracal, slender and long of limb, but has a longer tail and sliorter ear-tufts. The

Lynx (Lynx carolinensis), found in North and South Carolina. There does not appear to be much justification for these divisions, which are based principally upon the different markings of the fur. In a general way it may be said that the specimens obtained from southern climates are shorter in their fur, more brightly colored and more distinctly spotted than those from the northern regions, but otherwise these animals do not differ in their habits and characteristics, which are those of the Lynx group in general.

The Caracal, Among

a Southern southern Species of Lynx. Lynxes the Caracal ( Lynx caracal or Caracal inclanotis), strikes one as a genuine child of the desert and plain. This animal is smaller than the northern species being from twenty-six to thirty inches long, while its tail attains a length of nearly ten inches.

The range of the Caracal is surprisingly large. He inhabits all Africa, western Asia and India, and lives in deserts as well as on grassy plains, but he is not found in forests. fur is thick, of a yellow or greenish gray, with faded, darker stripes which are not very sharply defined. He attains a total length of thirty-six inches of

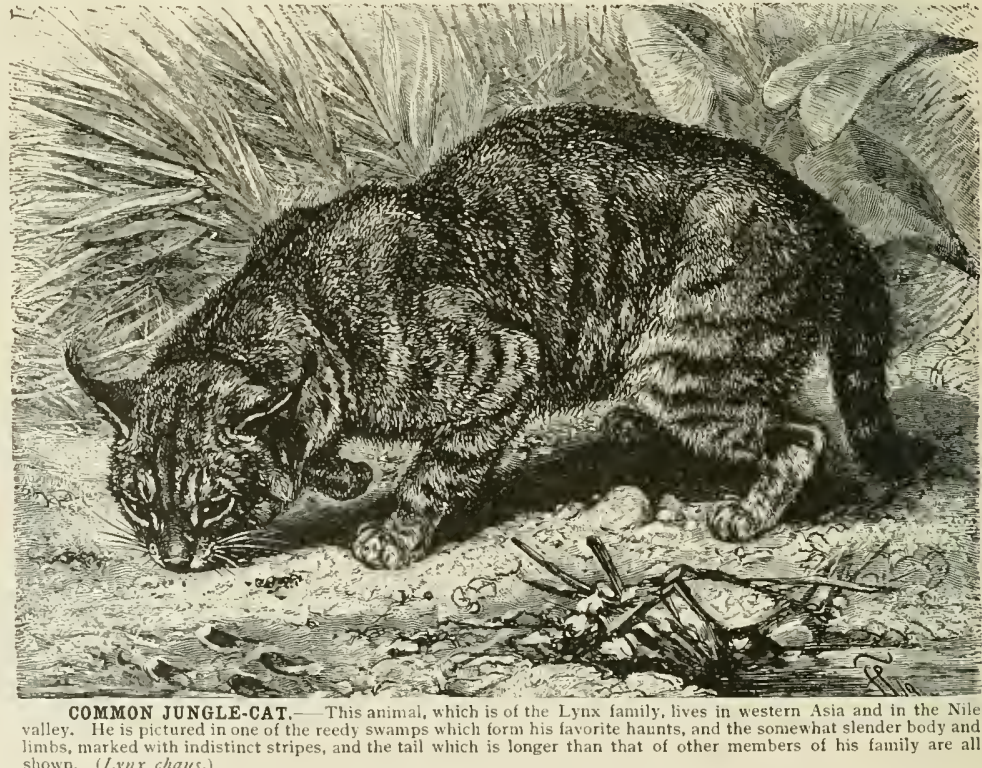

which about ten inches must be allowed for the tail. I have met the Jungle-Cat several times in the Nile valley. He is not rare in Egypt, although he 
is frequently passed unnoticed. In this country there is almost an entire lack of the larger forest in which a Beast of Prey could effectually conceal itself, and therefore the only refuge for such an animal is that furnished by reeds, high grass and corn-fields. The Jungle-Cat prowls around both day and night. He boldly comes up to the very out skirts of villages, and seems even to select orchards in their vicinity as his farorite haunts.

Captive Jungle-Cats are seldom seen, and when taken old, they are of a fierce and unamiable disposition, but young animals may, with kindly care, become very affectionate. The Egyptian explorer. Dumichen, recounts the following story of a young Jungle-Cat which he found half-starved in a subterrancan vault as he was searching the ruin of a temple: "The Jungle-Cat made no attempt at escape when I seized it, but seemed to be meekly resigned the Guepard. It serves to bridge over the chasm between the Cat and the Dor. This animal has a perfect right to its scientific name, Cynailums (DogCat), for he is really half Cat and half Dog. The head and the long tail are Cat-like, but the rest of the body, and especially the long legs, are much like a Dog's. The paws still show, like the Cat's, a pertect arrangement for retracting the claws, but the flexor muscles are so weak and ineffectual that the claws nearly always protrude, and therefore are blunted like those of Dogs. The teeth are similar to those of the other Cats, but the canines are pressed together as they are in Dogs. The mental endowments correspond to the physical attributes : The expression of the face is in the main Cat-like, but the disposition of a Dog, in all its good-natured gentleness, speaks to us through the eyes.

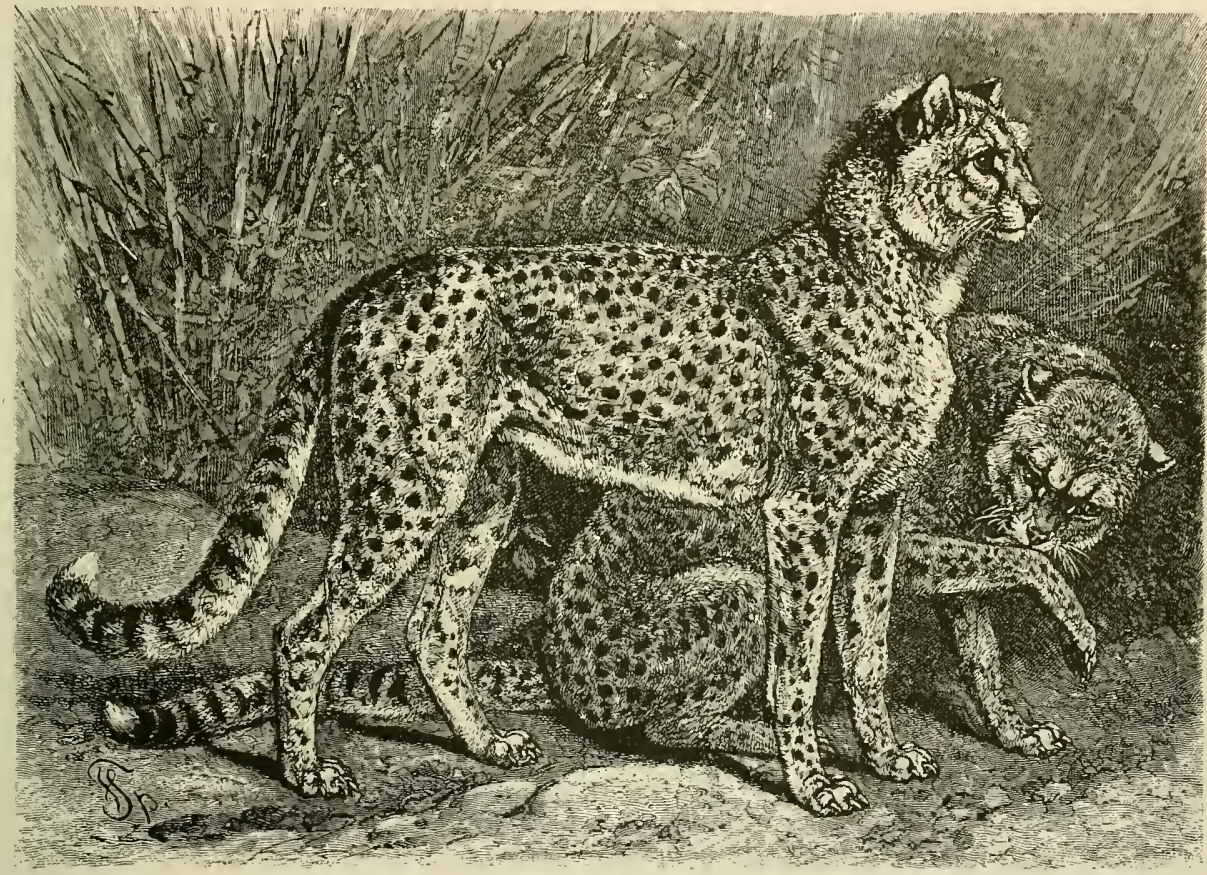

THE FAHHAD, OR AFRICAN CHEETAH.__ A glance at this picture will shnw why the naturalist has given these animals a name which means Dog-Cat. The limbs are Jong like those of the Dog, but the long tail, the head and the paws are Cat-like. The African variety. shown in this picture, differs from the Asiatic species principally in the shortness of the mane on the nape of the neck and different markings of the fur. (Cynailurus guttatus.)

to its fate. It ravenously ate the food I gave it, and allowed itself to be taken up and caressed. Fully appreciating the service I had rendered it, the little animal became my inseparable companion, jumped on my Camel when I set out on a trip, wandered with me through the greater part of Nubia, and when I was copying inscriptions, it would keep near me for hours at a time. It also was on friendly terms with my Dog. The two never quarreled, but often played with each other in the most amiable way:"

\section{THE CHEETAH.}

We now turn to a singular species, the Cheetah or Ilunting Leopard, which is sometimes also called
Character- Our present knowledge is not sufficient istics of the to enable us to decide whether the Chee-

Cheetah. tahs constitute more than one species. Certain naturalists hold the African and Asiatic animals to be identical; others count besides the Asiatic Cheetah, sometimes called the Maned Cheetah (Cyncilurus jubatus), and the Fahluad or African Cheetah (Cmailumis guttatus), the Spotted Cheetal (Cynailums socmmeringii), and the Woolly Cheetah (C)nailums luncus). The Asiatic Cheetah is very slender, and has much longer limbs than the Cats proper. The head is small and elongated in a Doglike way, instead of being round like that of a Cat: the ear is wide and low, and the eve has a round pupil: the fur is long and tangled, especially on the 
back, where it forms a short, though distinct mane. It is of a very light yellowish gray, closely spotted with black or brown, and at the extremity of the tail the spots unite to form a few small rings. The length of the Cheetah's body is about fifty-five inches; the tail measures thirty inches, and the height at the shoulder is from thirty to thirty-three inches. In the Fahhad, or African Cleetah, the mane on the nape of the neck is nearly absent, and the ground color of the fur is orange, except the under portion, which is white and unspotted; the spots on the back are different from those of the Asiatic species, and the tip of the tail is white instead of black.

The Asiatic Cheetah is indigenous to the whole of southwestern Asia, and if we count the Spotted Cheetah as belongring to the same species, also in northeastern Africa. He is a genuine animal of the plains, who has to gain his livelihood by agility more than by strength.

The Cheetah's

Habits in a

Wild State.

His principal prey are the small and medium-sized ruminants which live in the regions he inhabits, and he is very skillful in their capture. His favorite game are Antelopes, and he is most frequently found in the vicinity of the localities preferred by these animals, generally taking up his abode among the rocks of low hills. Experts agree in saying that for short distances the Chcetali is the fastest runner among mammals. Still he also uses cumning to subdue his prey. Whenever he perceives a flock of Antelopes or Deer, he crouches down and creeps forward, stealthy and quick as a Cat. He adapts his morements to the peculiaritics of his gane, always keeping to leeward of it and lying quite still when the leader of the herd lifts its head to reconnoitre. In this way he approaches as near as possible to the most conveniently situated animal; then he makes a rush at it, pursues it when it flees with wind-like rapidity, fells it to the ground with blows aimed at the feet and then seizes it by the throat. When he is within a rifle shot's range of his prey he does not hesitate to enter into the pursuit of the flectest-footed game, confiding in his own quickness.

The Cheetah Such innate cunning and such abilas a Hunting ity for the chase naturally attracted Animal.

the notice of the observing natives of his country and incited them to an endeavor to profit by this animal's hunting ability. A simple training suffices to make the Cheetah an excellent sporting animal, scarcely inferior to the Falcon in its way. All over East India he is considered a very valuable assistant in the chase. The Shah of Persia imports Cheetahs from Arabia and keeps them in a house of their own. In I474 Joseph Barbaro saw a hundred Cheetahs belonging to the Prince of Armenia. In Europe the Cheetah has also been used in the chase.

It is said that packs of these Cat-Dogs are still kept by a few native Indian princes at no small cost. Their training is confided to specialists, and their use in the chase presupposes the direction of expert huntsnuen, occupying a position like that formerly held by falconers; so we may imagine that this sport is not of the cheapest.

In India, when such a chase is in progress, the Cheetah, his head covered with a hood, is set on one of the light, two-whecled carts peculiar to that country. With this vehicle the hunters approach a herd of grazing game as closely as possible, for as is the casc with wild hords everywhere else, even the shyest Asiatic animals will permit a carriage to approach much nearer than people afoot. When the hunters are within two hundred or three hundred paces of the game the hood is removed from the Cheetah's head and the keepers point the game out to him with expressive gestures. All the animal's latent passion for the chase, together with his natural craftiness, are brought into play. Softly but swiftly he slips from the cart, and unseen and unheard he creeps up to the game. When he succeeds in catching his prey, he seizes it by the neck, and then the trainer hurries to it and cuts its throat. The flowing blood is caught in a dish and given the Cheetah to drink, after which his head is again covered with the hood.

It is very surprising that we know so little of the life in the wild state of this animal which is so often domesticated. I have questioned even the African nomads in vain : these people who know the animal so well could only tell me that it is caught in traps and tamed in a very short time in spite of its native fierceness.

The Cheetah That domestication cannot be difficult in is a fact clear to everybody who has

captivity. seen a captive Cheetah. I do not believe that I exaggerate when I say that there is no better-natured animal in the whole Cat family, and I doubt if any other wild Cat becomes so thoroughly tane. Good-nature is the essential trait of the Cheetah's character. A Cheetah, when tied, will never think of biting through the slender cord which holds him. A tame Cheetal never attempts to harm anybody and it is perfectly safe to walk boldly up to him and pet him. Ile accepts caresses with indifference, or at best only acknowledges them by purring a little louder than usual; for when he is awake, he purrs all the time, just like a Cat, except that the tone is louder and deeper. Frequently he will stand for hours dreamily gazing in one direction, complacently purring, and at such periods Chickens, l'igeons, Sparrows, Guats and Sheep may pass him unmolested, for he will not even deign to look at them. It is only other carnivorous animals that can disturb his reverie and upset his goodhumor. A passing Dog immediately excites him ; he ceases purring and turns a keen glance upon the intruder, who usually looks somewhat sheepish at such a moment, and the Cheetah pricks up his ears and sometimes tries to overtake the Dog in a few bounds.

I had a Cheetah which was so tame that I could lead him through the town by a string. So long as we only encountered people, he walked quietly by my side, but whenever he saw Dogs he becane so excited that once I thought 1 would make a trial of what he would do if he had less restricted liberty; so I tied him to a rope fifteen or twenty yards long, wound it around my arm and set out with him. Two large, lazy curs crossed our path. Jack (that was my Cheetah's name) ceased his comfortable purr, looked at them sharply and grew impatient. I quickly unwound the rope so as to let him have free play. Instantly he crouched down and crept toward the Dogs, which looked at the singular creature with a puzzled expression. The nearer he came to the Dogs, the more excited and the more cautious he became. Like a Snake he glided along on the ground until at last he thouglit himself near enough; then with three or four gigantic bounds he reached one of the now flceing Dogs and threw it down. This the Cheetah did in a quite peculiar manner; not trying to bury his claws in the Dog's 


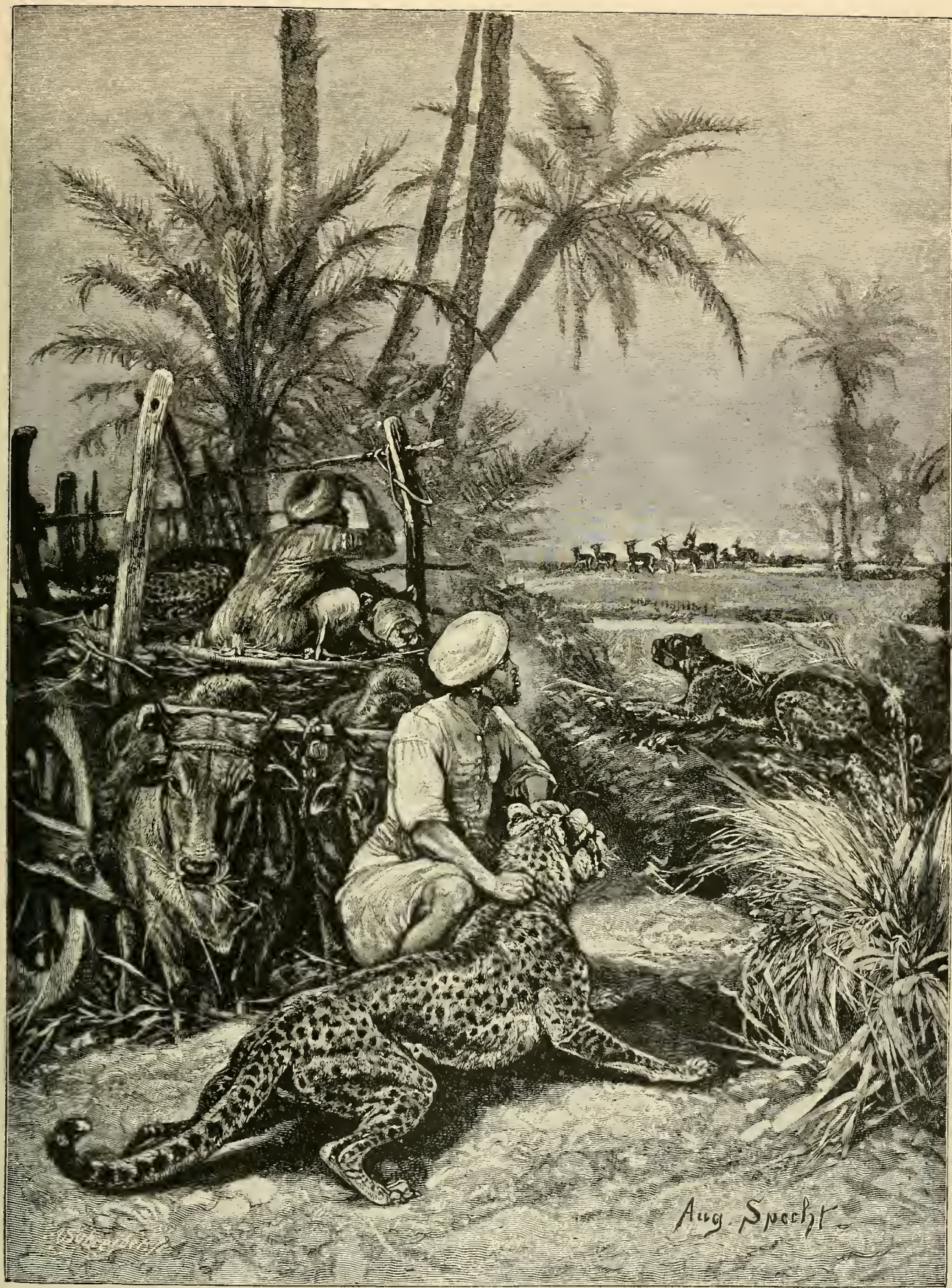

CHEETAF, OR HUNTING LEOPARD. --Of the wild members of the Cat fanily this animal is the most easily tamed. It is sometimes called the when it is turned loose. It approaches the herd with cat-like stealth until near eno 
flesh but beating it with his fore-paws, until it fell. The poor cur was in great terror when it saw the Cat-like face above it, and expressed its fright in a dismal howl which was re-echoed by all the Dogs in the street with demonstrations of compassion and excitement. $A$ large crowd assembled around us, and I was obliged to take my Cheetah and return home without having accomplished my object, which was to see what the Cheetal would finally do with the Dog.

Encounter Between I must confess, to my shame, that a Cheetah I delight in no other spectacle so and a Leopard. much as a fight between animals, and so I arranged one in my yard. I possessed a nearly full-grown Leopard at the time, a demon in Cat's shape: I have already described him. I made his chain longer and let him into the yard. The Cheetah was not tied to anything. He was in an staying in Alexandria, had called on me, expecting to see my animals, but had not found me at home. I promised to show them some of the animals in their own houses, and once, when I knew they were all together, I led Jack by a string and called on them. I pacified the frightened servants, and went up-stairs. There I opened the door slightly and asked whether I could come in with my Dog. Permission was granted and Jack entered the roon. The ladies greeted him with a shriek and then in their despair jumped on a large, round table in the middle of the room. Before they had collected their senses, Jack had followed their example and also stood on the table, purring very good-naturedly and rubbing himself against their dresses. So their terror was soon dispelled, they started to caress and pet him, and he seemed to be very proud of being treated with such distinction by them.

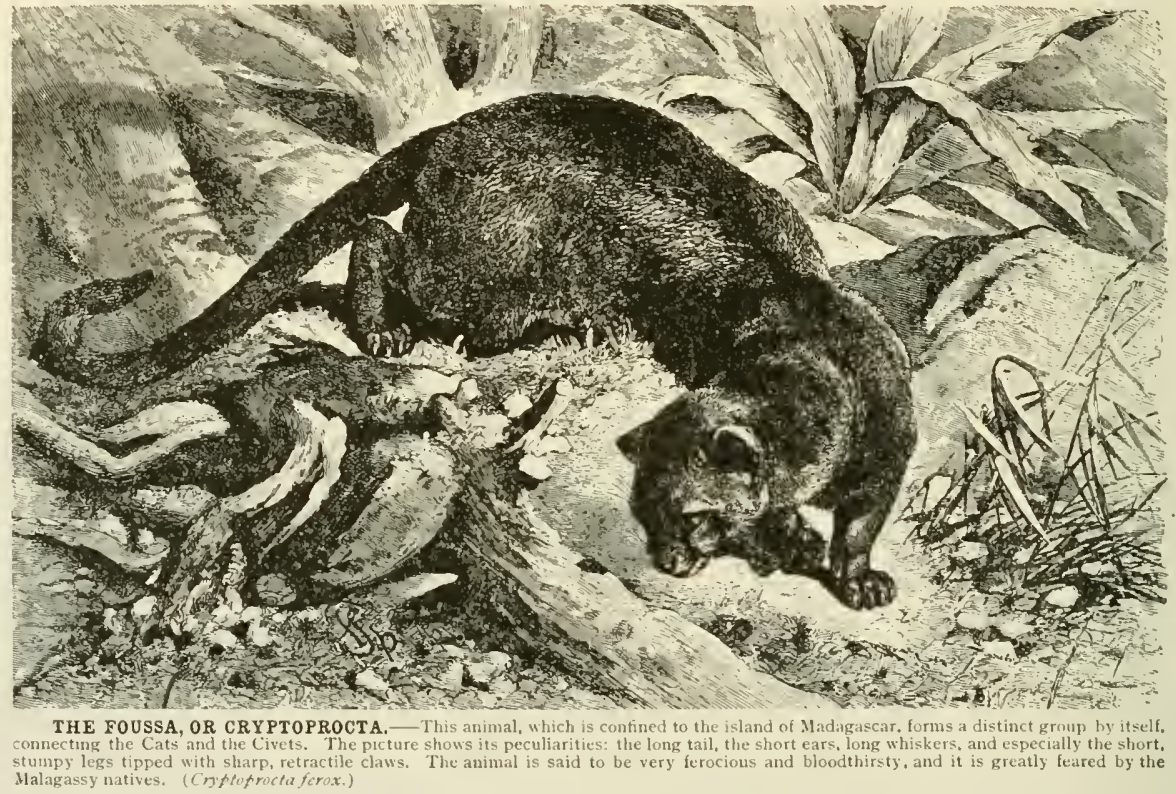

amiable temper when I brought him into the vard, and purred very expressively; but as soon as he caught sight of the Leopard he appeared a different animal. His mane stood on end and he even started to spit (something I had never heard him do before), and courageously rushed at his opponent. Then a fight followed accompanied by such a terrible spitting and "swearing" that I must say I was frightened. The Leapard was soon ranquished and lay on the ground, but still threatening the Cheetah with his mighty paws. Jack would certainly have come out the victor, if I had not poured two pailfuls of water on the enraged warriors. Ther stopped immediately and looked rather sheepishly at each other. Then the Leopard, with his antipathy to his occasional baths rearoused, made for the cage, which I immediately shut. In a few minutes Jack was licking and cleaning his fur and purring as if nothing had happened.

Ilow really amiable my Jack was, may be seen in the following aneculot Several German ladies
THE FOUSSA, OR CRYPTOPROCTA.

Pollen's and Schlegel's investigations have shown that the animal named Foussa, or Cryptoprocta, which formerly was counted among the Viverridae or Civets, really belongs to the Cats, or at least forms a connecting link between the Cats and the Civets. It possesses the gencral structure, the expression of the face and the retractile claws of the Cats, while other features, such as the elongated body, the short legs, the short, egg-shaped ears and the long whisker-hairs point to the Viverrida.

The Cryptoprocta (Cryptoprocta ferox) attains an extreme length of sixty inches, twenty-seven being the length of the tail; but it is far from tall, as the legs are only six inches long. The fur is close and short, having a shorn aspect on the head and legs. It is reddish yellow, and darlier on the mpper part, as there each hair is alternatcly yellow and brown: the cars are of lighter hue, and the whisker-hairs are partly black and partly white. The pupil of the eye 
is of a grayish green color and is similar to that of the Domestic Cat.

The Cryptoprocta is indigenous to Madagascar, where it is called the "Foussa." It is generally known there, and dreaded in a ridiculous way. It is even said to attack human beings and is the hero of a great many stories. Its life in the wild state is very. little known.

\section{The Civet Jfamílp.}

\section{SECOND FAMILY: VIVERRIDF.}

The Cryptoprocta has led us to the family of the Civets (I iverrida). Its members are distinguished from the Cats by their long, round, thin body, which rests on short legs; by a long, thin neck and elongated head and a very long and usually pendant tail. The eyes are generally smail, but the ears vary greatly in size in different species; the feet have either four or five toes, and the claws are retractile in a great many varieties of these animals. Under the tail, where it joins the body, are two or more glands containing a peculiar secretion which has an odor that is not always agreeable; and this secretion is sometimes stored in a special pouch.

The Civets are, in a general way, very much like the Weasels, whose place they take in the southern countries of the Old World. On the other hand many of them remind us of the Cats, and some even bear a slight resemblance to Bears. They are chiefly distinguished from the IVeasels by their sharper and more pointed teeth.

Home and Habits The Civets inhabit the southern part of the of the Old IVorld, preferably Africa

civet Family. and southern Asia. Three species are found in Europe, on the Mediterranean coast, one being found exclusively in Spain. The Civets are distinguished by a great variety of forms, and their haunts are as varied as their species. Some inhabit sterile, high and arid countries, deserts, plains or the unproductive forests of the rainless regions of Africa and central Asia; others prefer the most fertile valleys, especially reed-grown banks of rivers. Some approach the neighborhood of human dwellings, others retire into the depths of dense forests; some lead arboreal lives, while others are only found on level ground. Rocky caverns and crevices, hollow trees and holes in the ground, which they either dig themselves or take possession of, form their abode, and there they rest for the portion of the day which they give up to relaxation.

Most Civets have nocturnal habits, but there are also many which are active only during the day; these latter hunt while the sun shines, except at high noontide, and rest during the night. Very few can be called lazy, slow or clumsy; the majority equal in agility the quickest of Carnivora. Some walk only on thir toes, while others step on the whole sole of their feet; some climb, but most of them remain on the ground.

Their organs of sense are very keen, especially the three higher attributes of sight, smelling and hearing. They are perfectly endowed for a life of rapine and are only equalled in rapacity by the IVeasels. All Civets are bloodthirsty in the extreme, and attack all animals which they believe they can conquer. Their principal food probably consists of small mammals, birds, eges, insects, and in some cases fishes and Crabs. The agility and intrepidity shown by some of these animals in their struggles with poisonous Snakes have earned for them a wide reputation in all countries where they are known, and remarkable fables have been invented in regard to some species. Unceasingly they prowl around during their waking hours and they investigate every crevice or hole in field, forest or rock, which offers the slightest promise of food. When at rest they usually lie curled up like a ball, in quiet, contemplative reserve; and only a few species have a fixed place of abode, to which they constantly return after their forays. The sound emitted by some species is a hoarse, dull growl, while others make a shrill, monotonous, whistling noise, and others have varying cries.

Many species have the singular faculty of giving forth a strong odor of musk, which has its origin in the glands before mentioned, whose secretion is known to us under the name of civet and is of an oily or greasy nature.

As with the other Carnivora, the number of young at a birth greatly varies, being usuallybetween one and six. The mothers are devoted to their offspring, and in some species the father also assumes part of the training of the young. Civets taken young can, as a rule, be easily tamed and then prove as good-natured and familiar as the old ones are fierce and obstinate. They bear captivity well, and several species of these animals are extensively kept for the sake of the secretion of their glands, which is a valuable article of commerce.

On the whole the usefulness of the Civets may be regarded as compensating for the mischief they do. In their native country their depredations are not much noticed, while their useful service in catching harmful insects is recognized, and for this reason one species of this family was declared sacred by the ancient Egyptians, and enjoyed universal veneration among the people of that remarkable nation.

The most prominent members of this group are the Civets proper or Cat-footed Civets (Ailuropoda), which are endowed with retractile claws, like a Cat's, and the Mungooses which have non-retractile claws, like those of Dogs.

\section{THE CAT-FOOTED CIVETS.}

The bodies of the Civets proper ( Iiterra) are light and elongated, the tails long, the legs also long and the soles covered with hair; the feet are provided with five toes and partly retractile claws. Short, broad ears, moderately large eyes with round pupils, a pointed snout and nose, a soft fur and a very perfectly developed pouch for the glands complete the characteristics of this family. 
Structure The African Civet (Iizerra civetta)

of the African attains the size of the average Dog.

Civet. but its looks are feline and its whole appearance reminds one very much of a Cat, although it has also many points of resemblance to a Weasel. The broad, rounded head ends in a rather pointed snout; the ears are also pointed and the eyes, which have round pupils, are obliquely placed in the face. The body is elongated but not particularly slender, being among the stoutest in this group; the tail is about lialf the length of the body; the legs are of medium length and the soles are entirely covered with hair. The fur is not very long, but thick and coarse ; a ratler long mane or crest, which the animal can erect at will, extends along the neck and spine and is still perceptible on the tail. The ground-color is a beautiful ashen-gray nerging into yellow, and shows numerous irregular black-brown spots, which on the hind legs form distinct stripes. The crest or mane is brownish-black, and the under
In captivity it is kept in special stables or cages and is fed with meat and poultry. When taken young it not only bears the loss of its liberty much better than when captured old, but soon gets tame and familiar. The strong odor of musk which captive Civets give forth renders them almost unbearable to people with sensitive olfactory nerves.

African Civets Alpinus saw Civets kept in iron Valued cages by Jews in Cairo. They for their Perfume. Were fed exclusively with meat to increase their production of civet and render them a profitable investment. In his presence some civet was extracted from them and he had to pay an extremely high price for it. These animals were at one time hept for this purpose in European cities also, like Lisbon, Naples, Rome, Venice, and even in Germany, and especially in llolland.

To obtain the perfume, the animal is tied to the stakes of its cage: the pouch is turned out with the fingers and the civet is expressed from all the

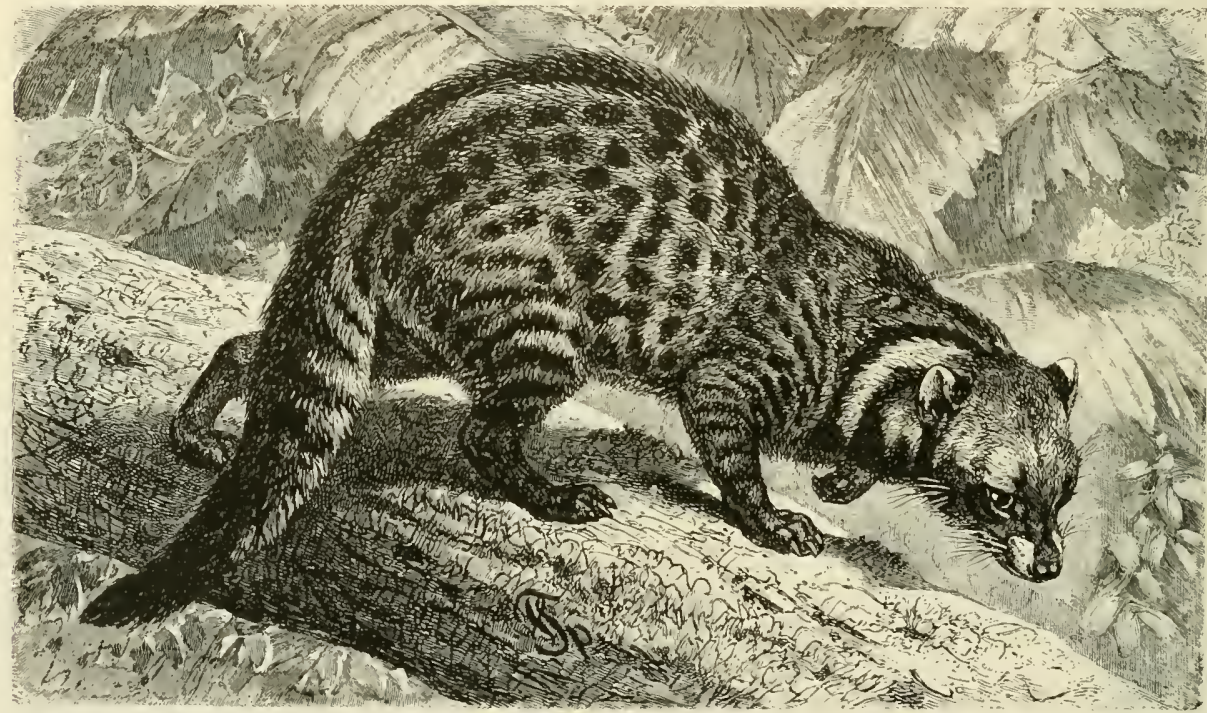

THE AFRICAN CIVET, - This is a typical memher of the Viverrine family of camivorous mammals. He is shown in his native Guinea forest where he frequently climbs trees to rob birds' nests of their eggs. The long hody with spots of brownish black and a crest of long hairs of the same color extending from the nape of the neck along the spine and tail ithe roumded head with its Weasel-like expression and the white
stripe on the side of the neck are characteristic features of the African Civet. (l itera circtio.)

portion of the body is, as usual, lighter. The tail, which is thickly clothed with hairs at its root, show's from six to seven black rings and its extremity is black-brown. On both sides of the neck there is a long, oblong, white stripe running backward. The length of the body is about twenty-eight inches; the tail measures fourteen inches and the shoulder height is about twelve inches.

Home and The native country of this Civet is Habits of Africa, chiefly the western part of the African Civets. Continent; that is, Upper and Lower Guinea. In the eastern half of Africa only a few scattered specimens may be met. Its habits are like those of the majority of the Civet family. mainly nocturnal. It sleeps during the day and starts out in the evening to look for small mammals and birds. It is said that eggs form its favorite food and that it will even climb trees for the sake of securing them. glands terminating in the pouch. As a rule it is taken from the pouch twice a week, but the amount obtained varies very much. Freshly expressed it is a white foam, which, after a time, becomes brown and loses a little of its strength. The perfume offered for sale as civet, is, for the greater part, only initation, and even the genuine civet must go through a series of processes before it is fit for use. The best is said to come from the Asiatic Ciret, and is brought from Boorou. The Javanese Civet is also said to be superior to the Bengalese and African kinds. During recent years the trade in civet has fallen off greatly, for vegetable musk is being more and more substituted for it.

The Asiatic Nearly all I have said about the AfriCivet can Civet may be applied to the Asi-

Described. atic Civet (I iz'cra zibitha), which, for a long time, was taken for a variety of the $A$ frican species. Its color and markings are different; its 
head is more pointed, the body more slender and the ears are longer, and it lacks a mane. Its ground color is a dingy brownish yellow, with dark russet colored spots. On the spine these spots merge into one large, black band: on the sides they fade. A

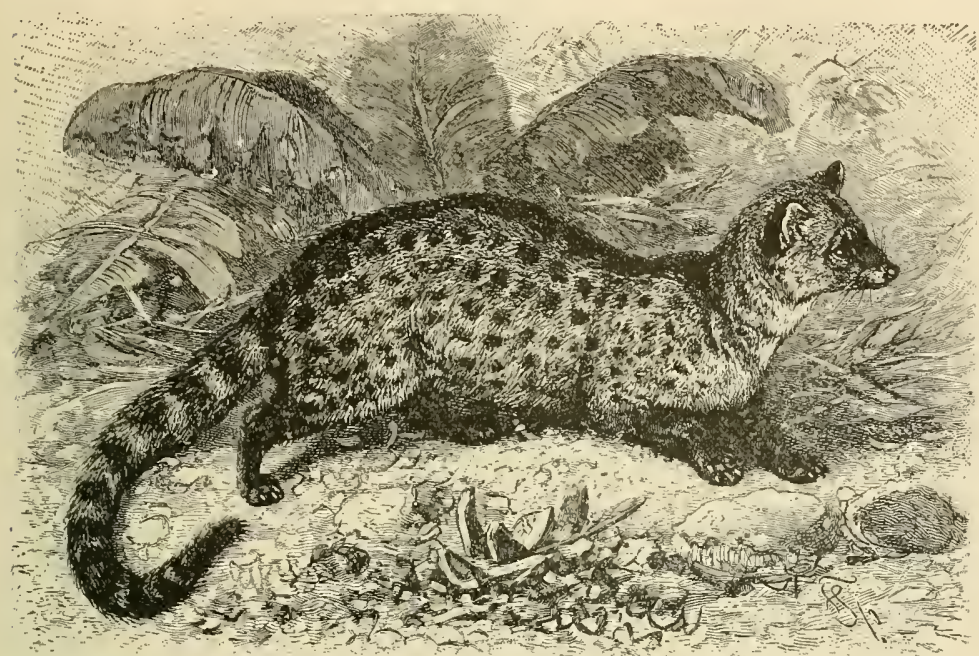

THE LESSER CIVET, OR RASSE.- One of the smallest of the Yiverrine, or musk-bearing fanily. Its markings resenble those of the African more than the Asiatic Civets, but it is much smaller than either of the others, although its tail is proportionately longer. It is an mhabitant of India. (Vizerra malaccensis.)

full-grown animal has a body thirty-two inches long, the tail is twenty-two inches long and the shoulderheight is fifteen inches. It weighs from sixteen to twenty-four pounds.

The Asiatic Civet has been widely spread by the Malays who call it "Tinggalong." According to Blanford it is indigenous to Bengal, Assam, Burmah, southern China and the Malay Peninsula. The Asiatic Civet leads a solitary life and prowls around at night, not infrequently visiting human dwellings and stealing Chickens and Ducks. It also eats fruit and roots, insects, Frogs, Snakes, eggs, birds and all mammals it can subdue.

The Lesser A Civet now

Civet, or frequently

Rasse. seen in zoological gardens is the E.esser Civet or Rasse (Vic'erra malaccensis). It is considerably smaller than the Asiatic Civet. but its tail is $\mathrm{much}$ longer; the length of its body is about twenty-four inches, the tail measuring nearly as much. Its head is narrow and its ears very long. The rough fur is grayish brown, tinged with black, showing rows of dark spots, and the tail has several dark rings.
The Rasse inhabits all India, except the country of the Indus and WVestern Rajputana. It is much valued in its native country for the sake of its civet, which is there put to the most varied uses. This secretion is usually mixed with some other perfume and is not only sprinkled on dresses, but is also used for the scenting of rooms and beds in a manner that is perfectly unbearable by European noses.

$\begin{array}{cc}\text { The Genettes- } & \text { The sub- } \\ \text { The Common order of } \\ \text { Genette. }\end{array}$ ettes (Genettu) is distinguished by a very long body, a hairless stripe on the soles, five-toed fore and hind paws furnished with retractile claws and a long tail. The Genettes also have a shallow civet-pouch at the root of the tail.

The best known species of these animals is the Common Genette (liacra genetta), the only Civet inhabiting Europe. It bears a great resemblance to its relatives which have already been described and even its coloring is similar. The body is twenty inches long, its tail sixteen inches and its beight at the shoulders is from six to seven inches. The body

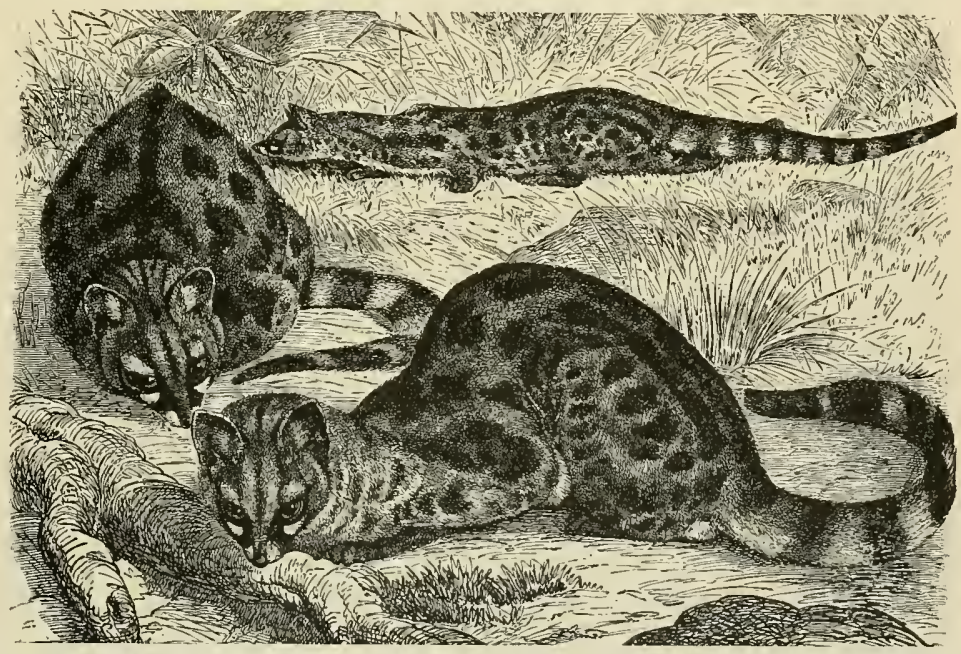

THE COMMON GENETTE.-One of the prettiest of all creatures is the Common Genette, a small, graceful, but bjoodthirsty animal, with a beautifully marked and valuable fur. Its agile but wary movements are well shown in the picture, especially in the Snake-like attitude of the animal in the background. Its quickness as well as stealth rests on extremely short legs and is very slender. The head is small and distinguished by a long snout and wide ears. The pupil of the eye is like that of a Cat, having a slit-like appearance in the daytime. The pouch secretes only a small quantity of a fatty 
matter, having the odor of musk. The general color of its fur is light gray, tinged at the surface with yellow and showing dark spots. The fur is commercially valuable.

This little animal, which, notwithstanding its dainty appearance, is of a cruel, bloodthirsty and audacious disposition, is found most plentifully in the Atlas country, but it also inhabits southern Europe, especially Spain and southern France. It exists in large numbers in the localities that are adapted for its habits in Spain, although one seldom meets it. It lives in forests as well as on plains, but it is most frequently found in damp situations in the vicinity of springs and rivers, woods rich in underbrush, mountains abounding in crevices and similar places. A sportsman may sometimes come across it in such a locality even in the daytime, but usually he has no time to shoot, for its fur is so similar in color to that of the rocks and the ground that it is difficult to keep it in view, and its movements are so wary, and at the same time so agile, that when detected it is already escaping. It slips through plants, grasses, shrubs and stones like an Eel or like a Fox. Its movements are as graceful as they are agile and rapid. I do not know of any other mammal which so completely combines the sinuosity of the Snake with the quickness of the Weasel. Its movements are so perfect as to cause involuntary admiration.

$\begin{array}{cl}\text { An Account } & \text { Pechuel- } \\ \text { of Tame } & \text { I. o s che } \\ \text { Genettes. } & \text { writes from }\end{array}$
Chinchocho, the former station of the Gussfeldt Loango exploring party: "We kept several Civets and Genettes. The former are not possessed of an amiable disposition, can never be trusted and the odor they give forth is insufferable. The Genettes, on the contrary, became exceedingly tame, knew the names we gave them, ran after their keeper like Dogs in broad daylight and their whole demeanor afforded us great pleasure. One half-grown Genette had estabished itself in our main barrack, and seened to find abundant nourishment in the Rats which infested the house. When we sat talking in the large meeting room of an evening it would often come out on one of the rafters of the roof, look down with curious eyes and then jump down on the table with one graceful bound. Then it would keep sliding from one of our party to the other, uttering soft, low sounds, submit to being stroked and teased, and would soon disappear as quietly as it liad come."
The Paradoxures The Civets lead us to the Paradoxures or or Palm Cats (Paradorums). These

Palm Cats. animals are semi-plantigrade, that is, they step on half of their soles in walking. The tail, from which the animal derives its name, Paradoxunis, meaning queer-tailed, can be curled by a few. species of the Palm Cats, but this peculiarity is by no means striking. The paws have claws that are more or less retractile in different species and which are used, Cat-fashion, to seize the prey and to defend their owner.

All species of this group inhabit southern Asia and the adjoining islands. They set out in search of prey after sunset and are agile enough to catch small

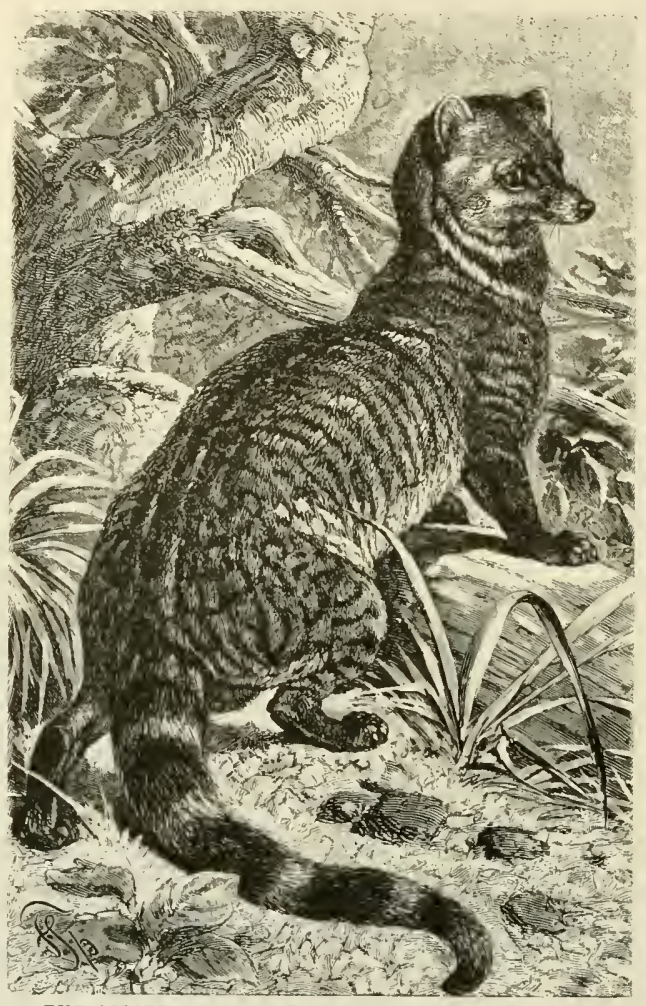

THE ASIATIC CIVET, - This animal is commercially valuable for the "civet," or animal-musk, which is procured from it, in which respect it excels all musk-bearing animals. Its slender body bears distinct markings, with a black stripe along the spine; and the head has keen eyes and a
pointed snout. It is a night prowling animal and very destructive among airds. (I'ichra zibetha.) mammals and birds, although they also eat fruit. Description of The Indian the Indian Paradoxure Paradoxure. (Paradoxilrus niger) resembles the Genettes in shape as well as coloring. His dimensions approximate those of our Domestic Cat, his body being about twenty inches in Jength, and the tail nearly as long. The body is elongated, the legs short and strong, and the long tail can be closely curled downward as well as upward. The eyes, which are very prominent, lhave a brown iris, and a large and exceedingly mobile pupil, which may be retracted until it presents only a slit of a hair's breadth. The general color of the hair is black or brownishgray, marked with dark bands and rows of spots.

The Indian Paradoxure is common on the island of Ceylon, and in India, north to the Himalayas, wherever there are trees, in the jungles as well as in settlements. Not infrequently he takes up his abode in barns or sheds. Like all other members of his family he eagerly hunts small mammals and birds, eating the eggs or young birds in their nests, Lizards, Snakes, and insects; and he is also fond of fruit. He is said to cause great ravages in pineapple plantations, to be an annoying visitor in coffee plantations, and to be very fond of the juice of palnıs, or "palm-toddy." He also makes frequent calls in the poultry-yards of his vicinage.

The Common The Common Paradoxure or Musang Paradoxure (Paradoxumus hemapluratitus), repre-

or Musang. sents the family in Burmah, Siam, the Malay Peninsula, Sumatra, Java and Borneo. His body is about seventeen inches long, the tail a little shorter than the body, and his coloring is subject to great rariations. 


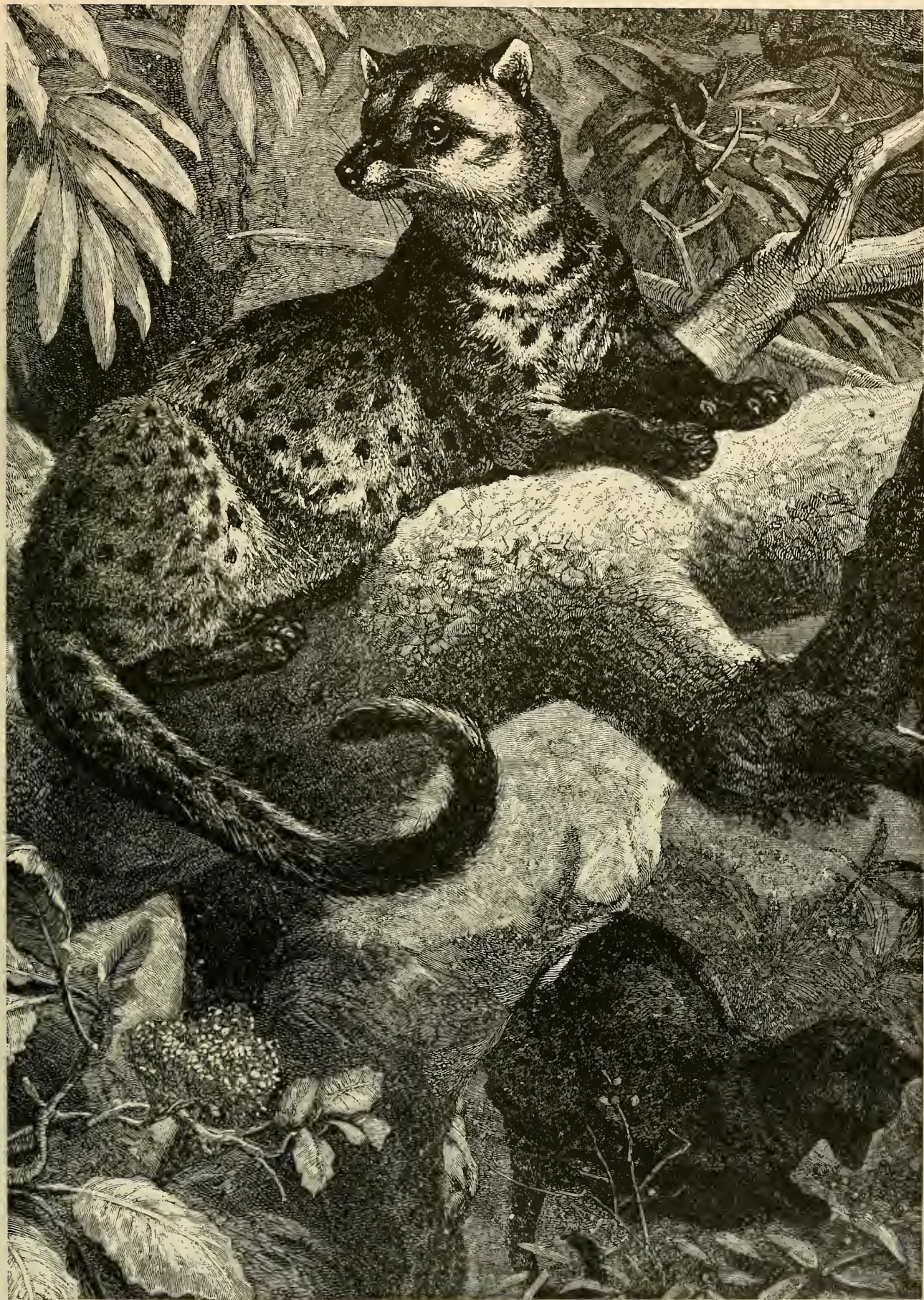

INDIAN PARADOXURE, OR PALM-CAT. - This graceful anmal is about the size of the ordinary house Cat. It is an eager hunter of birds and small mammals but is also very fond of pineapples, bananas and other fruits and coffee berries, and is therefore very destructive to the plantations of India and the Malay Peninsula, where it is found. The handsome head and spotted fur are well depicted here, and its long tail is a prominent characteristic and can be curled by the animal at will, upward as well as downward. The animal in the lower foreground is feeding on small fruit while the other on the tree is resting and watching. (Paradoxurus niger.) 
Junghuhn furnishes much information about his life in the wild state and his visitations of the coffee-plantations. When the coffee-berries begin to ripen and their color becomes a vivid red, at which period adults and childien strip the branches of the red berries and hurry to the drying-grounds with

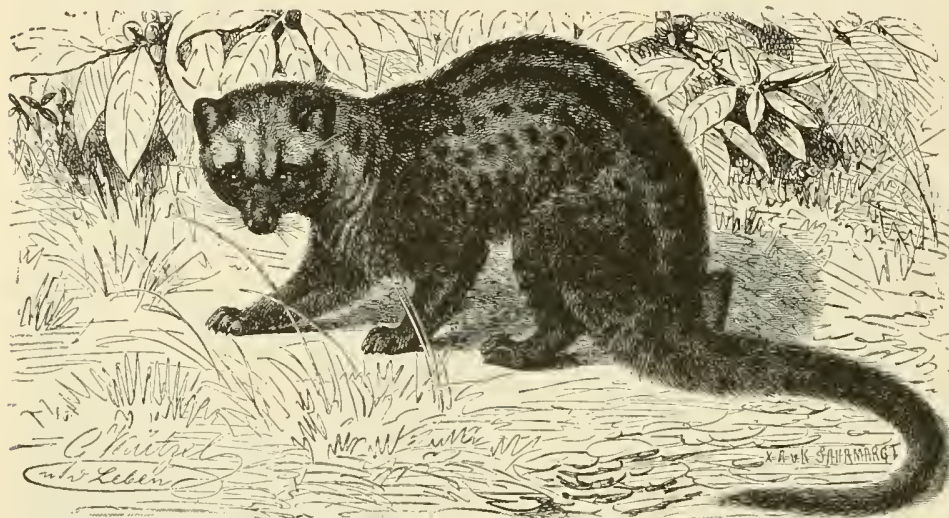

THE COMMON PARADOXURE, OR MUSANG.- - This aninal, which inhabits the Malay Peninsula, Java, Sumatra and Borneo, is smaller than the Indian species, although his habits are much the same. The ferent specinens. He makes such ravages on the plantations in Java when the coffee berries are ripe that the natives call him "Coffee-Rat." (Paradoxurus hermafhroditus.)

their full baskets, then "one often sees on the paths intersecting the coffee-gardens the spoor and signs of the Musang, which enjoys the evil reputation of being a Chicken-stealer in the mountains, but is also fond of fruits, and frequently, when the berries are ripe, visits the coffee-plantations where he is often caught by the Javanese at that season of the year. The Musang also lives on birds and insects, catches wild Chickens, and sucks the eggs of both tame and wild birds. In captivity he is often kept on notbing but pisang for weeks at a time, and gets so used to the house that it is safe to allow him his freedont. The keeper who occasionally presents him with a Chicken egg gains his affection to such a degree that he follows him around like a Dog and submits to being petted and stroked by him."

The Masked Paradoxure (Paradoxurus lariatus) inhabits China and Formosa. His color is principally black on the head, gray on the chceks, lower jaws, throat and neck, and yellowish-gray on the upper part of the body. A whitish band runs from the tip of the nose to the back of the head; another extends under the eyes, and a third above them. The ears, the tip of the long tail and the feet are black. It is sometimes called the Masked Paguma.

\section{THE DOG-FOOTED CIVETS.}

Among the Viverrida with non-retractile claws, or Dog-footed Civets (Cynopoda), we must first turn to the Mungooses or Ichneumons, so widely celebrated in olden times. The Mungooses (Herpestes) have the following distinctive features: the body rests on short legs, and is long and round; the head is of small or medium size; the snout is pointed; the eyes are rather small, and have a circular or elliptical pupil; the ear is short and rounded; the nose is short, hairless, smooth and furrowed in the median line; the feet are five-toed; the tail tapers toward the end, and the fur is rough and long. The leeth are forty in number and are for the most part very strong.

The Ichneumon As is but of Ancient just, we witl Fable. first consid er the Ichneumon, or "Pharaoh's Rat" (Hirpestes ichnetmon), the sacred animal of the ancient Egyptians. Herodotus tells us they were embalmed after their death and buried in sacred ground. Strabo writes that this excellent animal never attacked large Snakes without the aid of several companions and then easily got the better of the most poisonous

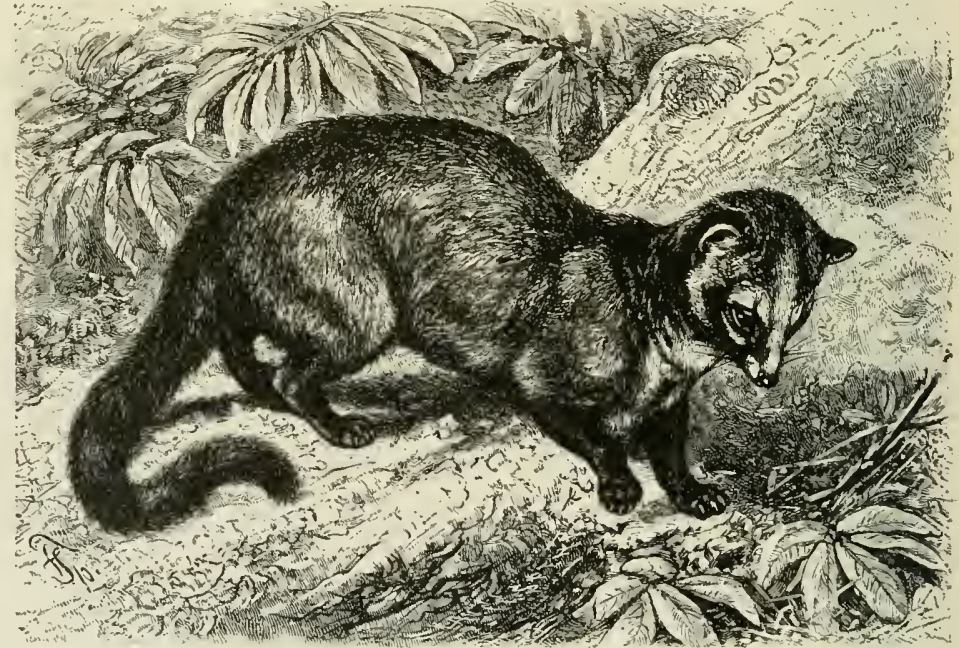

THE MASKED PARADOXURE,-This species of Palm-Cat, which is found in China and Formosa, dif-

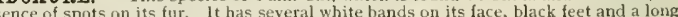
reptiles. Therefore its image stood in the Hicroglyphs as an cmblem of a weak Man who could not get on without the support of others. Elianus, on the contrary, assured us that it chased the Snakes unaicled, but with great cunning, first wallowing in the mud and then drying itself in the sun, so as to 
insure certain protection from the teeth of its opponent, while it protected its face by enveloping it with its tail. Tradition is not content with all this, but according to Pliny it invests this courageous promoter of public welfare with a great many more brilliant qualities. When the Crocodile has eaten its fill, it comfortably lies down on the sand and opens its huge mouth, well garnished with teeth, threatening dire peril to every disturber of its pence. Only one little bird is impudent enough to pick out the shreds of food remaining between the teeth. Besides this little bird all animals dread the monster, except the Ichneumon, which stealthily approaches, enters the Crocodile's mouth with a bold bound, bites its way through the throat to the Crocodile's heart, lacerates it, and in this way kills the huge monster. Then, covered with blood, it works itself out of the dead body with its sharp teeth. Or else it lurks around and finds the place where the dreaded reptile's numerous e g g s are buried; it digs and works until it reaches the treasure in the depths of the earth and in spite of the mother, which carefully mounts guard over the egos, it devours them all in a short time and comes out an inestimable benefactor to mankind. It is not to be doubted that the Egyptians believed all these tales and recounted them to the above mentioned authors; and that these naturalists, ordinarily so accurate, were thus led into complete error in this particular case. All these beautiful stories are wholly without foundation. It is only in modern times that exact data about the life and habits of the Ichneumon has been obtained, but even several centuries ago travellers were led to express grave doubts as to the usefulness of the Ichneumon, and only the strong tendency of humanity to cling tenaciously to all old and well-beloved traditions prevented these ancient tales from being long ago relegated to the category of fable.
Characteristics A full-grown Ichneumon considerof the ably exceeds our domestic Cat in

Ichneumon. size. Its body is about twenty-six inches long, and its tail at least eighteen inches. Its short legs make the animal appear smaller than it is. The body is slender, like that of all Viver-

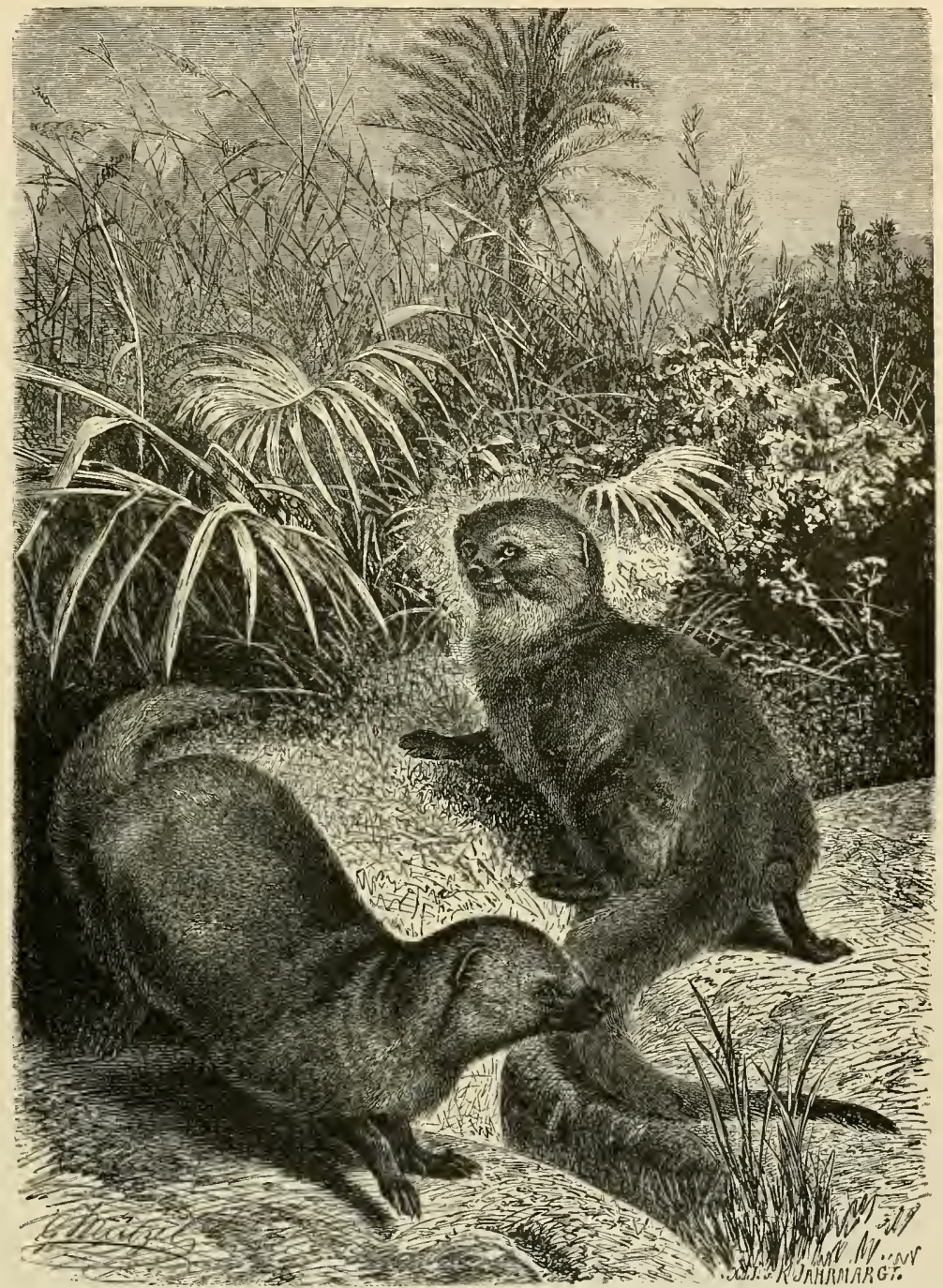

THE ICHNEUMON - This animal is appropriately pictured in the Nile Falley with pyramids in the distance. imes called "Pharaoh's Rat." The animal is very bloodthirsty and kills all animale , the long tail and short, black legs are shown in the picture. (Herpestes zchneumon.)

rida, but is by no means as gracetul as that of the Genette. The leos are short, the soles naked and the toes are connected by membranes for half their length. The long tail appears very thick at its root, owing to its very long fur, presenting almost the appearance of gradually merging into the body, and its extremity is provided with a tuft. The small 
eyes are not surrounded by hair and therefore present the appearance of being even fiercer in expression than they really are. The fur is quite peculiar. It consists of an inner woolly coat of a russet yellow color, entirely covered with hairs which are about two and one half inches long and are alternately black and cream colored, the tip being pale yellow. The resultant general color is a greenish gray which harmonizes perfectly with the environment of the animal in its native home. On the head and back the hue is darker and under the body it is paler. The legs and the tuft of the tail are black.

The Ichneumon's Pharaoli's Rat extends not only all Home over northern Africa and part of

and Haunts. Asia, but may be found in southern Spain, northern Asia, all of Africa and Madagascar; although it may have been imported by Men to the latter place. It never goes far from valley's. Its favorite haunts in Egypt are the thickly-grown banks of rivers and the reed thickets which often surround fields in that country. Here the animal

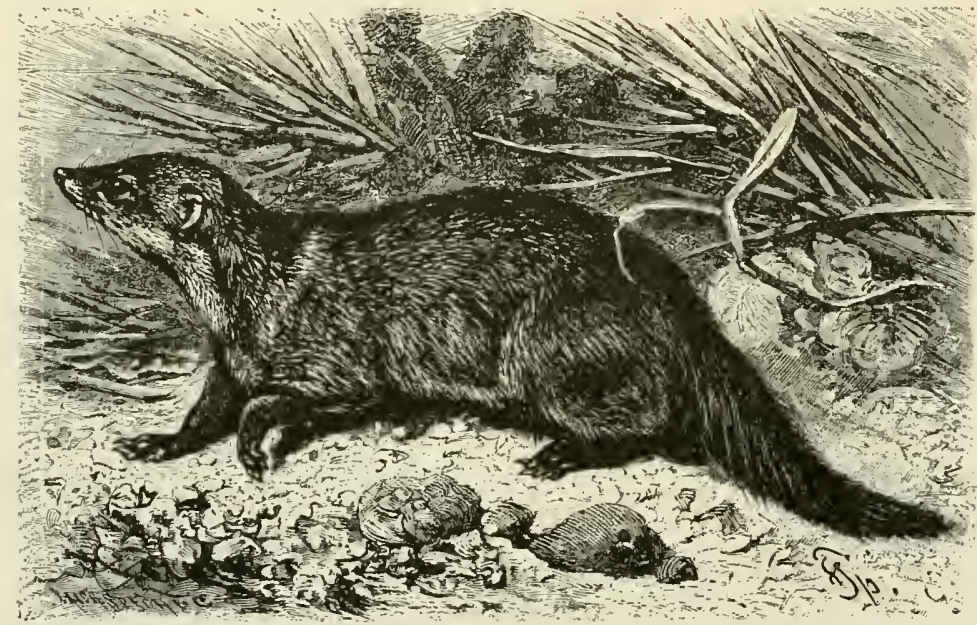

MANGUE OR KUSIMANSE.-A small, burrowing animal of West Anca, torning by itself a distinct group of the Viverrine family. It has a thick, stout body covered with harsl fur of a chocolate brown, and its length from snout to root of tail is fifteen inches. The tapering tail is eight inches long. Its walk is plantigrade, the soles are bare, each foot has five toes and the claws on the fore-feet are long and curved. The snout is long and the ears small. lt lives on mammals, insects and fruits. (Crossarchus obscurus.)

spends the day and lays out for itself, among the reeds, narrow but very carefully kept walks leading to deep, but not very capacious dens. In these the femalc gives birth to from two to four young ones in spring or the beginning of summer. The mother suckles her offspring for a very long time, and both parents care for their yourig for a still longer period. Habits and The name Ichneumon significs "tracker," Traits of and the animal fully justifies this desigIchneumons. nation. He resembles the Weasels in his traits and his mental endowments, for he possesses their disagreeable smell, their cunning, their adroitness in stealing and their thirst for blood. He is shy, cautious and distrustful to the highest degree. He never ventures into an open field, but always sneaks along under cover. He prowls around in the daytime and attachs and eats every animal he can overcome: mammals smaller than the Hare, and birds from the Goose or Chicken downward to the smallest. He also feeds on Snakes, Lizards, insects and worms : and he probably eats fruit also. His thievish propensities have earned him the detestation and contempt of all Egyptian peasants, for he mercilessly plunders their Hen and Pigeon roosts and he is very destructive to the Chickens' nests, which in that country are constructed exactly like those of wild birds. He is of no real use in the present age, unless the extermination of Snakes be counted as a particularly useful achievement.

$H$ is gait is very peculiar, giving the animal the appearance of creeping along on the ground without moving a limb, for the short legs are entirely covered by the long hair of the fur and their movements are barely visible. During the summer months the Ichneumon is seldom met alone, but as a rule is accompanied by his family. The male comes first, then the female, and the young ones bring up the rear. One animal always runs close to the other, in such a manner as to create the impression that the whole chain is composed of but a single being with a shape something like that of a huge Snake. From time to time the father stops, lifts his head and looks around to see if danger threatens, moving his nostrils to all sides and sniffing like a panting animal. If he sees prey, he noiselessly slides up to it through the grass, and when he has approached sufficiently near he will make one or two bounds even after a flying bird. Before a Mouse-hole he mounts silent guard, and after a Rat or a young bird he creeps with amusing gravity.

Probably he tracks as well as the best Dog; and it is an established fact that he is guided by his sense of smell in the chase. If he finds eggs he sucks them; and as a general thing he also sucks the blood out of small mammals and birds and eats only the brain. He kills a great many more than he ean devour.

His voice is only heard when he has been wounded by a bullet, although the Egyptians say that he utters a shrill, monotonous whistle during the breeding season.

Methods of The cliase of the Iclneumon is considHunting the ered a pious deed by all Egyptians. It

Ichneumon. is only necessary to go into a village and announce that one has come to hunt the Icluneumon, or "Nims," and old and young will joyfully render all necessary assistance in the extermination of the detested rogue and pillager. The hunter takes his post at some place grown with reeds, and the Arabs begin to drive the animal out of it. The Ichneumon fully realizes what is going on, and as soon as the people begin their noise, he tries to hide. His efforts are of no avail, for the Arabs poke long poles into the holes and burrows of the ground, and he is compelled to look for an asylum in another field. With the greatest caution he glides along, 
sniffs and looks around; but as the pursuers approach nearer and 1fearer, he attempts at last to run over some place which does not afford absolute shelter. This he does noiselessly and gently, so as not to betray himself by quick movements. It is essential to shoot at a short distance and with very large shot in

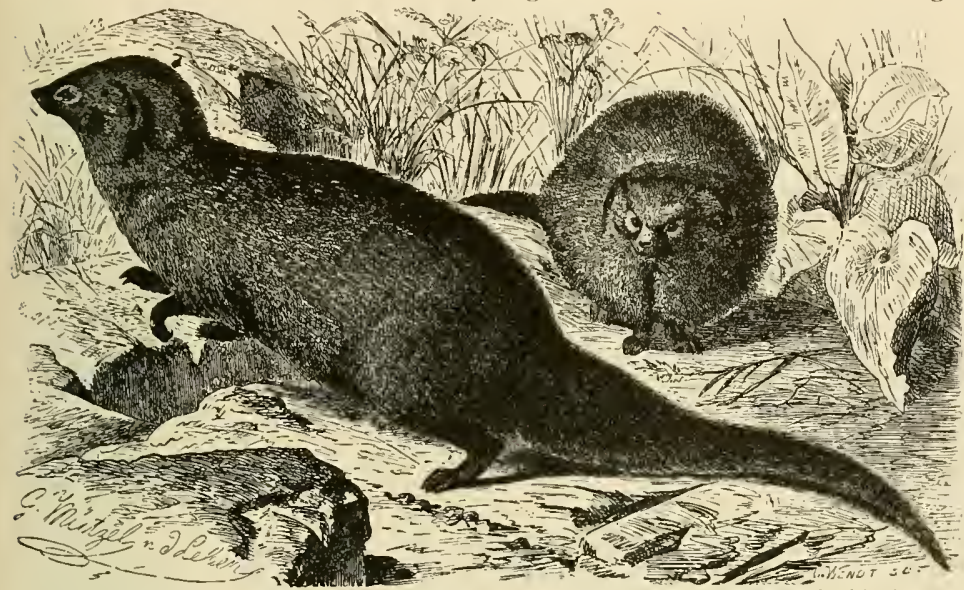

THE MUNG0. - Among the Mungooses the Mungo, which inhabits India, Ceylon and Afghanistan, is especially distinguished because of the skill he exhibits in destroying poisonous Snakes. His long body covered animal in the foreground. (Herpestes mungo.)

order to kill him, for the animal has a wonderful tenacity of life and if he be only wounded he is sure to escape.

French naturalists say that captive lchneumons are easily domesticated, know their owner's voice and will follow him about like Dogs. But they are very restless creatures and cause annoyance by the persistence with which they drag portable articles all over the house and upset everything. In one respect they are useful. A house that harbors an Ichneumon is secure from Rats and Mice, for he pursues these rodents with indefatigable zeal. When he has caught one, he runs with it into a dark corner and expresses his ability to take care of it himself by grunts and grumbling sounds.

The Mungo Mungooses and resemble each Its Habits. other in their shape and mostly also in their behavior. The description of the lchneumon $\mathrm{might}$, therefore, serve our purpose, if there were not a few others deserving of mention. The species representing Pharaoh's Rat in India is the Mungo (Herpestes mungo). It is much smaller than the lchneumon, its body being from sixteen to twenty inches long, and its tail nearly the same length. Its long, coarse hair is gray, with a white band close to the tip of each hair.
It ranges to the East as far as Assam, and westward to Afghanistan and Beloochistan, and on the island of Ceylon.

The Mungo Jikes hedgerows, groves, plantations, rocky forests grown with underbrush, and frequently visits human dwellings, causing great depredations in the Chicken-roosts. His family consists of three or four young ones, born in burrows. He seems to be fond of sweet fruit, but prefers an animal diet. He runs from rock to rock, and from cavern to cavern, and searches his hunting ground so thoroughly that hardly anything edible can be overlooked. Sometimes he hides himself in a small hole, and when he makes his appearance, he is sure to bring with him a Mouse, a Rat, a Lizard or a Snake which he has caught in his own hiding-place.

The Mungo The Mlungo as a Snake is honored Exterminator. and celebrated for his fights with poisonous Snakes. It is his agility which gains him the victory in such encounters. The natives believe that wlsen he has been bitten by a Snake he digs up a plant or very bitter root, known as Manguswail, eats it, and instantly recovers, so that he is able to resume his fight with the Snake. Even exact observers assure us that there is some foundation to this story, inasmuch as the Mungo,

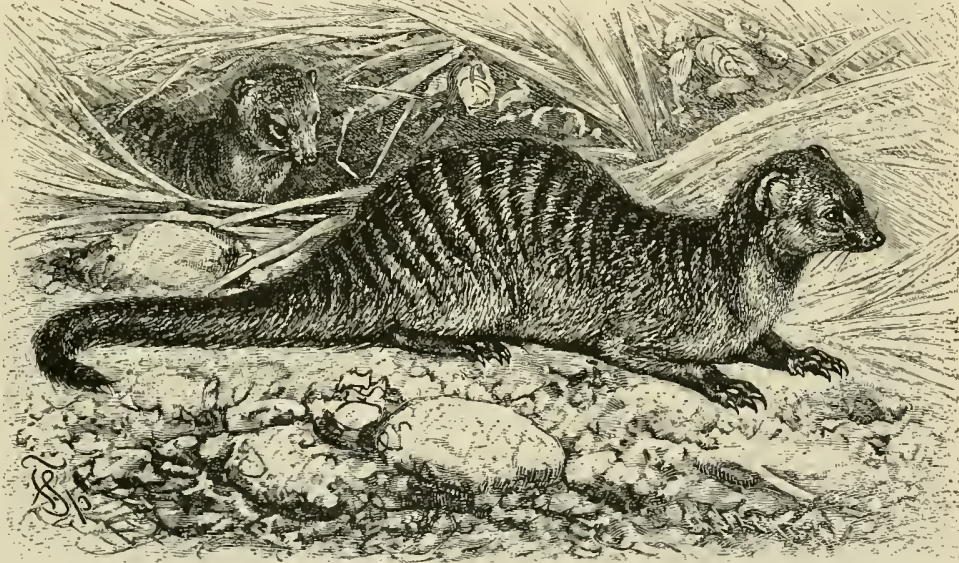

THE BANDED MUNGOOS. This African species of the Mungooses is one of the prettiest as well as one THE BANDED MUNG00S. This African species ot the Mungooses is one of the prettiest as nell as one of the smallest of the group, and is distinguished from the others also by the stripes or bands trom which it derives

when bitten and exhausted, runs away, looks for some plants with which he rehabilitates himself, and then returns ready for the fray. Blanford calls the story about the antidote a fable. If there was any truth in it, it would be difficult to understand why other Snake-hunters, such as the Secretary-bird and some Eagles, should be left defenseless and the 
Mungo alone provided with a prophylactic. Besides ne would think that with the consciousness of security he would be careless about the way he approached the serpent, while the truth is the very thing in this animal that excites admiration is the

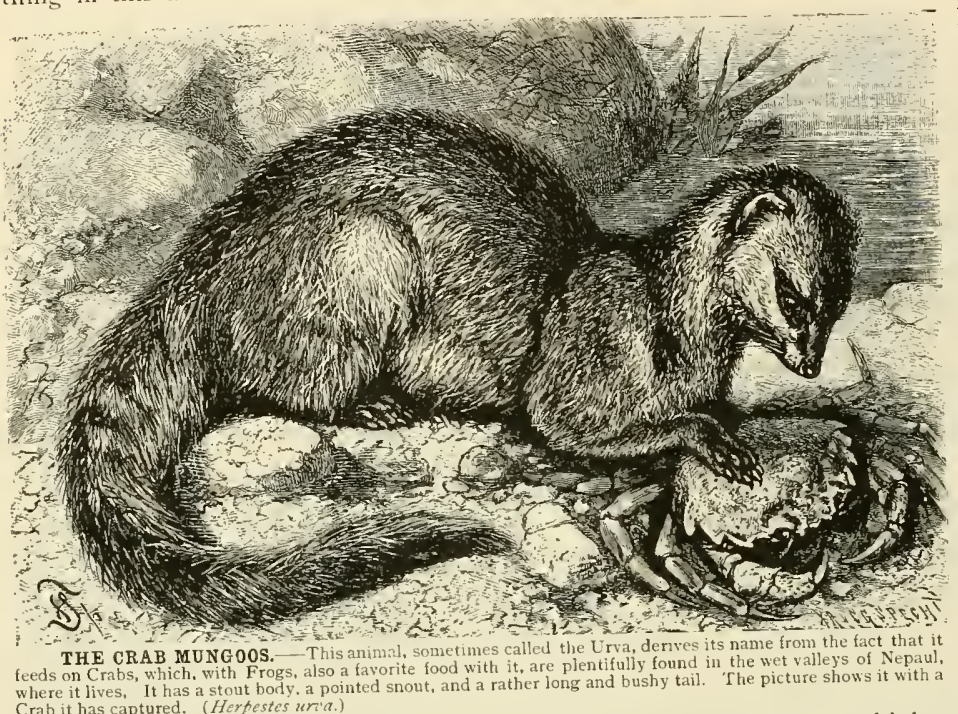
Crab it has captured. (Herpestes un'a.) trepid fellow; once he successfully fought with a big Dog, and at another time killed a bird six times his size He also killed many Snakes. When excited, his hair stood on end and he looked twice as large as usual, but his master only had to lift his finger to make the angry pet desist from his attack. He followed his master to England and was the favorite of all who knew him. He knew a great number of tricks: jumping, turning somersaults, sitting on chairs with a cap on, playing soldier, etc. Pips died of grief. During a temporary absence of his master he refused all nourishment and starved to death.

Besides the Ichneumon there is only one European Mungoos that is worth mentioning, the Meloncillo (Horpestes widdringtonii). This a nimal was well known to Spanish sportsmen long before it fell into the hands of a naturalist. Its chase was profitable, for the hair of its tail is long and especially adapted for making painters' brushes, and therefore the tail,

adroitness with which he escapes the spring of the Snake, and the cumning he exhibits in his methods of attacking it. His thick, coarse hair, bristling with excitement, and his thick skin render it very diffiwhich brought a high price, was the only part that was used and the remainder of the fur was thrown away.

The Meloncillo lives exactly like the Ichneumon, cult for the Snake to bite him, but if he is bitten, the Nungo dies from the wound as well as any other animal, although the effects of the poison seem to be slower in his case.

The Mungo was imported into Jamaica during the ' 70 's, and is said to have exterminated so many of the Rats infesting the sugar-cane plantations on that is land that his usefulness is estimated at several million marks a year

The Mungo The Munas a go is the Domestic Pet. $\mathrm{m}$ e m be $\mathrm{r}$ of his family that is best adapted for domestication, for he is a cheerful, rather good-natured animal of cleanly habits.

Sterndale had a Mungo, which was his steady in a group by itself. (Cynictus penicillata. very well when his owner was going to shoot a bird for him; he danced around when he saw the gun adjusted, and hurried to procure the falling prey. He was very clean, and after eating picked his teeth in

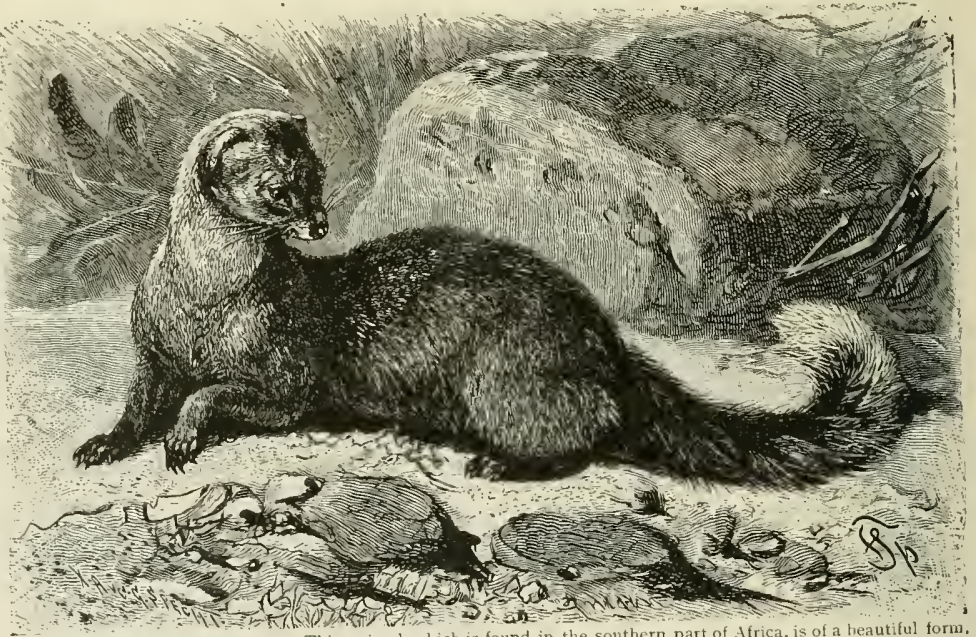

THE FOXY MUNGOOS. - This animal, which is found in the sonthern part of Africa, is of a heautiful form, has a smooth, tan-colored fur and a bushy tail with a white tip. It resembles the caused many naturalists to place it

valleys crossed by rivers, especially in Estramadura and Andalusia. It inhabits almost exclusively the reedy woods and plains grown with Esparto and is not found in mountains, as is generally stated. Its total length is forty-four inches, of which about twenty inches is taken by the tail. The fur is longer 


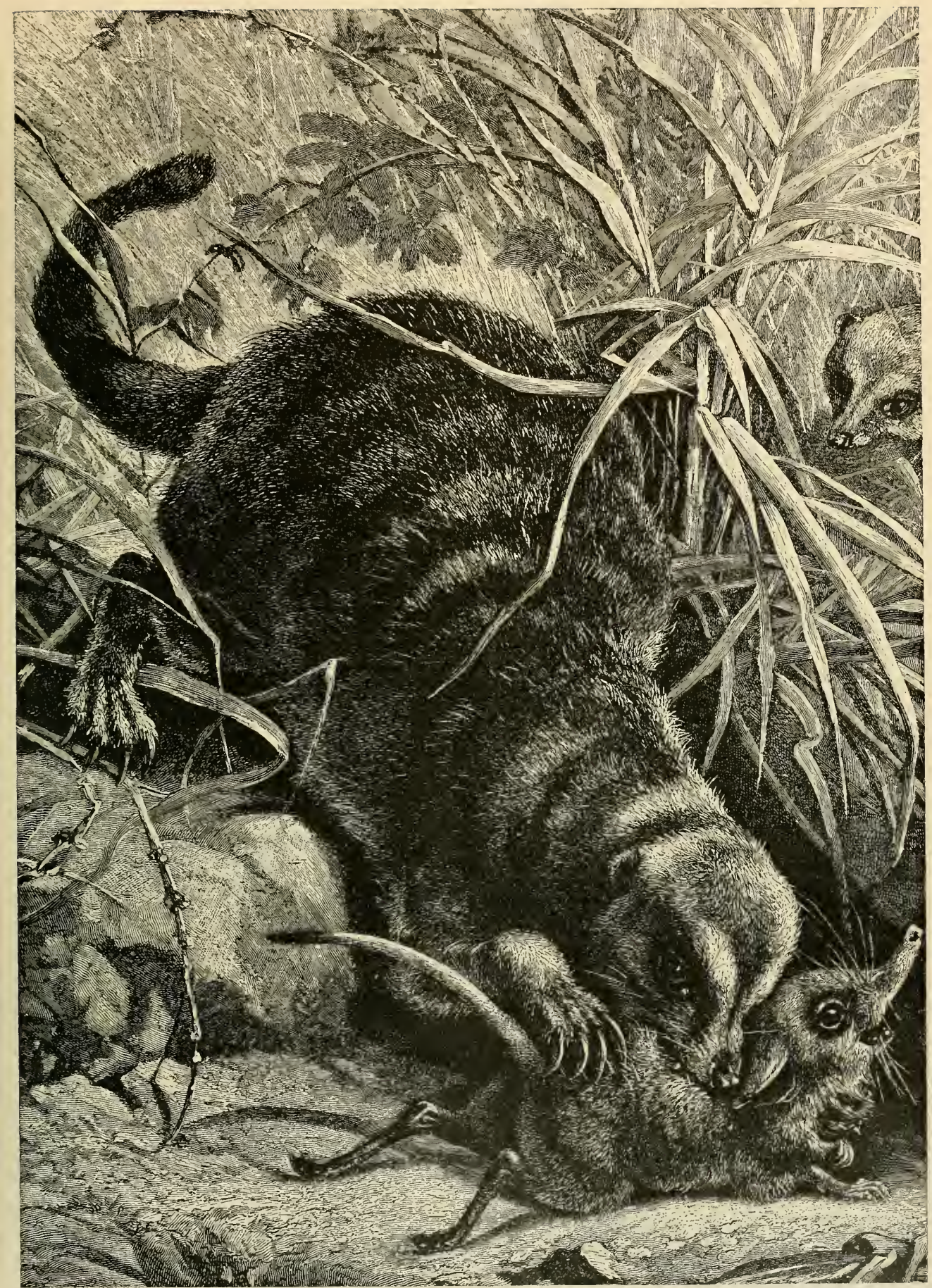

THE SURICATE, - This animal, which lives principally in south. Africa, is distinguished by its rough coat and its strong claws, of which those on the forefeet are particularly long. It is the special enemy of the Elephant-House, a remarkably prolific and destructive rodent of sour
shows it in the act of attacking. The Suricate forms by itself a distinct genus of the Viverrine order. (Suricata tetratactyla.) 
on the spine and the neck and under portion of the body are hairless. Its color is dark gray, sprinkled with lighter hairs.

The Banded Mungoos, an

A distinguished member of the group is the Banded Mungoos Interesting Animal. (Horpestes fasciatus). It is small, the length of its body being given as sixteen inches, and that of its tail as eight inches, but $I$ have seen decidedly larger ones.

The best authorities intimate that this Mungoos inhabits all of eastern Africa, from the Cape of Good Hope to Abyssinia, and also part of western Africa.

This dainty little sneak shows its bloodthirsty disposition plainly in its flashing cyes. Its food consists of all small mammals, birds, insects, eggs and fruit.

In western Africa the Banded Mungoos is often kept in factories, missions and on mail steamers. It is allowed perfect liberty, but never attempts to return to its wild habits. It is a general favorite, but like the domestic Cat, seems to think more of the house than of people, though it sometimes does get attached to persons and will jump into their lap: and it is fond of being petted. It opens eggs with its fore paws, or more frequently by throwing them backwards, between its hind legs, against some hard substance. It treats other small, round objects in the same way, and it is advisable to keep valuables secure from it. Pechuel-Loesche kept mercury, which he used for an artificial horizon, in a strong glass bottle, which he found in pieces near a trunk, and E. Teusz relates how he had a chronometer in Malandje, where another one could not be bought, and his Banded Mungoos had thrown it several times against walls and trunks before its owner discovered what it was that the animal played with so gleefully.

The Crab 1 will mention one other member of this Mungoos or group, the Crab Mungoos or Urva (HirUrva. pesti's ur'a), for it is a peculiar transitional form between the Mungooses proper and the Gluttons. It does not essentially differ from the Mungooses, but its body recalls the Glutton in several respects. The snout is pointed and the body stout. The toes are connected by large webs, and the scent-pouches are highly developed. The back is of a dingy gray color, with an admixture of brown; the under portion of the body and the legs are of a uniform brown tinge. Sometimes it shows darker stripes and a white band runs from the eye to the shoulder. It is a large animal of its kind, measuring from thirty-two to thirty-six inches, of which twelve inches is taken up by the tail.

Hodgson discovered the Urva in the swampy valleys of Nepaul. He thinks that it is rather aquatic in its habits and feeds principally on Frogs and Crabs.

Allied to the Mungooses are a few animals which differ from them mainly by the structure of their feet; the fore paws have five toes, the hind paws only four, and the soles are partly covered with hair.

The Foxy The Foxy Mungoos (Cynictis penicilMungoos, an lata) is about twenty-eight inches in African Species. length, twelve inches of this length being taken up by the tail. The fur is smooth and the tail bushy. The general color is tawny, but the tip of the tail is white, and long, black whisker-hairs stand over the eyes and lips.

It lives north of the Cape of Good Mope, in burrows in the sand, feeds upon Mice, birds and insects, is fieree, cunning and agile, and has hardly ever been hunted; its life and habits have never been observed to any extent.

The Suricate and /ts

The Suricate (Suricata tetradactyla) inhabits Africa from Lake Tsad to

Strong Claws. the Cape of Good Hope. The snout has something of the proboseis in its character, the legs are long and the feet are provided with four toes and long, stout claws. The claws of the fore paws show a higher development than those of any other member of the family. With their aid the Suricate can easily burrow long and deep tunnels in the ground.

The Suricate reminds one as much of the Mungooses as of the Weasels; it is a small, long-legged creature, with a length of from twenty to thirty inches, of which the tail takes up half. Its rough coat is grayish brown, traversed by darker bands.

There are no known species of the Viverrine family in America. The Cacomixle, or Mountain Cat, found in Mexico and California, was formerly considered as forming a group of this family, but it is now placed with the Raccoons, to which it is more closely allied.

\section{The SiDarten Jfamill.}

THIRD FAMILY: MUSTELIDE.

The family of the Martens, or as it is sometimes called, the Wleasel family, shows a greater variety of species than that of the Viverridae or Civets. It is a difficult matter to give a general description of this family, for the structure of the body, of the tecth and of the feet is subject to more variations than those of any other Carnivora. Ne can only say that the members of this family are small or medium-sized Beasts of P'rey, with bodies of very clongated shape resting on verv short legs. The feet have either four or five toes. These animals are provided with secntpouches like the Civets, but the secretion of these glands is by no means an agreeable perfume, and in some cases has an abominably fetid odor. The fur is usually thick and of fine texture, and in this family. we find the most valuable fur-producing animals.

Where and Nembers of the Marten family are How the Marten distributed over all continents ex-

family Lives. cept Australia. They endure all climates, on plains as well as mountains. Their haunts are most often in woods or rocky regions, but they also frequent the open country, gardens and human dwellings. Some live in the water, some on terra firma, those of the latter class being excellent climbers, and they all know how to swim. Some burrow holes in the ground, others take possession of exist- 
ing ones; others again live in hollow trees or seize upon the nests of Squirrels or of birds; in a word, it may be said that this family knows how to take advantage of any kind of retreat, whether it be the natural crevice in a rock or an artificial cavern; a dark nook in a human dwelling or the branches or roots of trees in the heart of the forest. The majority of these animals have a permanent dwellingplace, but many species prowl around. Some of those which inhabit northern regions hibernate; the others are active all the year round.

Physical and Nearly all animals of this family are Mental Traits of remarkably quick, adroit creatures Martens. and adepts in all physical exercises. They walk on the soles of their feet, use their paws and tail in swimming, and climb excellently in spite of their blunt claws. Their organs of sense are all developed in nearly equal degree. Their mental place of concealment to another when she scents danger. When taken young and treated with care, animals of this family attain a high degree of docility and may be trained to follow their master about and hunt and fish for his benefit. The descendants of one species have been domesticated for a period so long that it cannot be specified, and have been bred to serve the purposes of a certain class of sportsmen.

The Marten Fam- Some of these animals work a great ily Destructive deal of mischief through their de-

but Useful. structive, sanguinary instincts, but on the whole their usefulness, direct or indirect, more than compensates for the damage they do. Their services in catching harmful animals should not be underestimated, and though it may be difficult to forgive them their encroachments on human property, it must be admitted that the losses they occa-

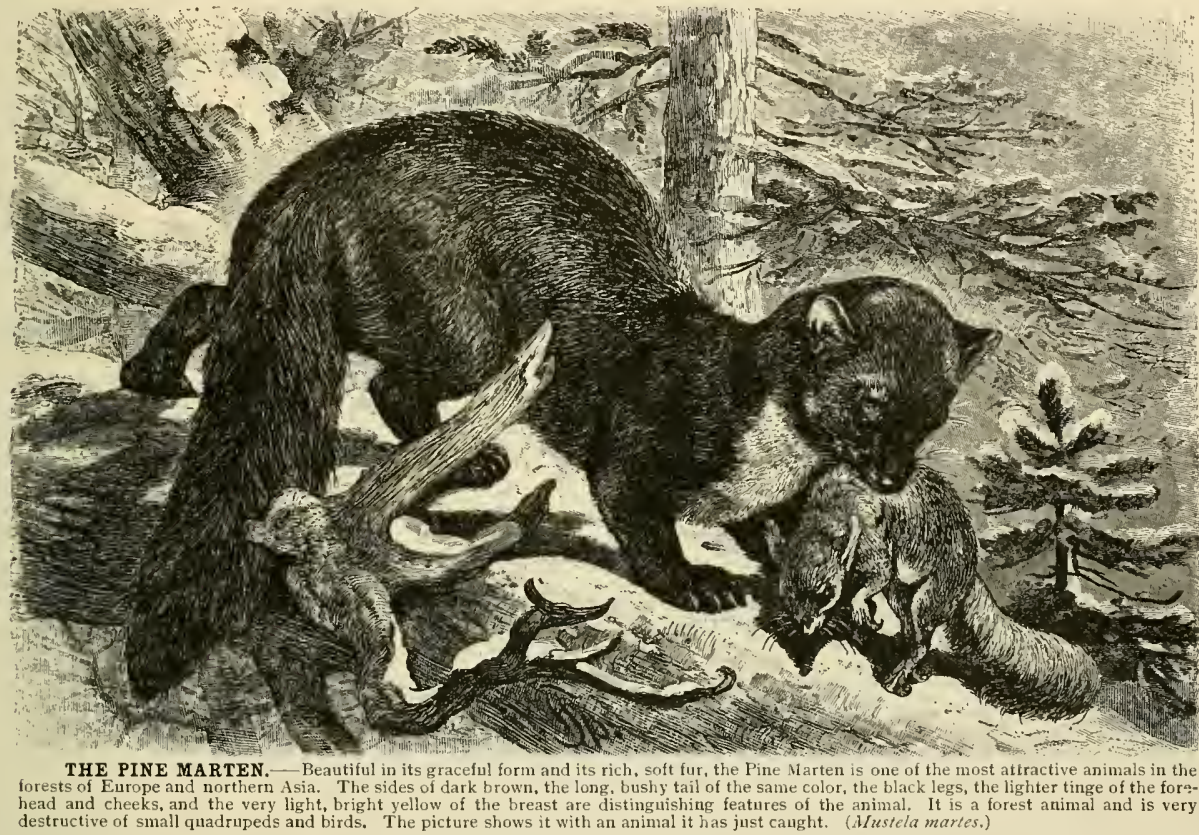

endowments are of a high grade, and some species give evidence of an astonishing amount of reasoning power. They are cumning, distrustful, wary, extremely courageous and sanguinary, but devoted to their offspring. Some are gregarious, others live singly or only temporarily with their mates. Some are active both day and night, but the majority of them are of nocturnal habits, and in populated districts they sally forth only at night. Their principal föod consists of animals. Some eat fish, Crabs and vegetable food, especially sweet, juicy fruit. The thirst for blood that inspires them all is surprising in its intensity. They slay more than they need for their sustenance and some species might be said to intoxicate themselves with the blood they suck from their victims.

The young, whose number varies between two and ten to the litter, are born blind and are under nursing care for a long time. The mother defends them boldly when attacked and carries them from one sion happen only through the carelessness of the involuntary contributors to their appetites.

How great a number of animals of the Marten family are killed annually for the sake of their furs is best seen from the statistics of the commerce of furs. According to Lomer about three million skins are marketed annually, exclusive of those which Indian and Asiatic hunters retain for their own use. Some Indian and Mongol tribes live almost exclusively from the product of their chase of fur-producing animals, and among these the Martens rank first. Thousands of Europeans and Americans owe their living to the fur trade, and many extensive and previously unknown tracts of country have been opened to civilization by hunters and trappers who have ventured into them to seek this game.

Three sub-Fain- We will begin our description with ilies of the the Martens proper and those mem-

Marten Family. bers of the family whose mode of progression is digitigrade, that is, those which walk 
on the tips of their toes. They form the first subfamily, Martide. The second sub-family, Mitide, includes the Badgers and others, whose walk is plantiurade; and the third is formed by the Otters and their relatives, which we separate from the other Martens under the name of Fissipidia, or web-footed.

\section{THE MARTEN GROUP.}

The first place in the first sub-family belongs to the Marten and its group (Mustela). They are of medium size, endowed with a slender, elongated body, short legs, a head that is somewhat narrow in front and ends in a pointed snout. The ears have a transverse position, are rather short, nearly threesided, and somewhat rounded at the tip. The eyes are moderately large and of a vivacious expression, the feet have five toes provided with sharpclaws, and the tail is of moderate length. The Martens all have glands near the root of the tail secreting a peculiar fluid, and their fur is long and soft.

The Pine Marten's The line Marten (.Mustcla martes) is Physical an animal as agile as it is beautiful. characteristics. Its body measures about twenty-two inches, its tail about twelve inches in length. The fur is of a dark brown color in the upper parts, pale on the snout, light brown on the forehead and cheeks and yellowish on the sides and under portion; the legs are a brownish black, the tail dark brown. A narrow, dark brown stripe runs from the ears downward. Between the hind legs there is a tawny spot with dark brown edges, which sometimes is continued as a band of dingy yellow and runs as far as the throat. The lower part of the throat and the breast are of a beautiful yellow tinge and constitute the most prominent distinguishing feature of the animal. The fur is dense, soft and lustrous and consists of an outer coat of rather long, stiff hair and an under fur which is short, fine and woolly, which assumes a whitish tinge in the fore parts and a yellowish hue on the sides. The upper lip is provided with four rows of whisker hairs, and there are also a few bristles under the corners of the eycs, under the chin and on the throat. In winter the general color is darker than in summer. The female is distinguished by a paler hue on the back and a less distinct spot. The throat and lower part of the neck of young animals are of a lighter tint.

The Pine The Pine Marten inhabits all the Marten's Home wooded parts of the northern half and Habits. of the Old Viorld. In Europe it is found in Scandinavia, Russia, England, Germany, France, Hungary, Italy and Spain; in Asia it extends to the Altai, its southern confines being the sources of the Jenisei. Corresponding with such an extensive range, its fur is subject to considerable modifications. The largest specimens are found in Sweden, and their fur is twice as long and thick as that of the German Martens, and grayer in tint. The German furs are more of a yellowish brown or dark brown; and specimens of the latter color are especially found in Tyrol and bear an astonishing resemblance to the fur of the American Sable. The Martens of Lombardy are of a pale gray-brown or yellowish-brown hue; those of the Pyrenecs are large and strong, but also of a light tint, while the Macedonian and Thessalian Martens are of moderate size and a dark color.

The Pine Marten inhabits forests and is found most frequently in lonely, dense and gloomy spots. It is a genuine arboreal animal and has no superior as a climber. Hollow trees, and nests deserted by wild Pigeons, birds of prey and Squirrels are its favorite places of abode, and in rare instances it looks for an asylum in the cleft of a rock. As a rule it sleeps all day; with the approach of night, usually before sunset, it sallies forth and attacks all creatures that it believes it can master. No quadruped between the Mouse and the Hare or young Fawn is secure from it. It stealthily follows its victim, and when near enough, makes a sudden charge and kills it. The Pine Marten has been repeatedly observed to attack weak young Fawns and it is quite as destructive of birds as of quadrupeds. All species of Chickens living in the temperate zone have in it a formidable foe. Stealthily and softly it creeps up to their roosts, no matter whether they are on trees or on the level ground, and before the watchful Hen has the slightest suspicion of its presence, it springs upon her neck, lacerates it with a few bites, or severs the carotid arteries, and eagerly laps the flowing blood. Besides it plunders birds' nests, visits bee-houses and steals the honey, and eats fruit and berries, pears, cherries and plums. When food is scarce in the forest, it becomes bolder, and extreme hunger drives it near human dwellings. When once it succeeds in entering Hen-roosts or Pigeon-houses it causes greater devastations than any other animal, except those of its own group.

Three or four young I'ine Martens are usually found in each litter, the nest being warmly lined with moss, and generally in a hollow tree, but more rarely in a 'quirrel's or Magpie's nest or a cleft of rock. The mother watches over her family with untiring devotion, and never leaves the vicinity of the nest for fear of losing her children. In a few weeks the little ones are able to accompany her on her promenades on the trees, playfully and adroitly climbing and leaping on the branches; and she gives them a thorough training in all physical exercises, warns them of danger and hurries their flight to a place of safety. Young Martens are easily brought up in captivity ; at first they should be fed with milk and bread, but later on they may be kept on meat, eggs, honey and fruit for a long time.

Doings of $\alpha$ "On the 20 th of January," says Lenz,
$\begin{gathered}\text { Captive Pine "I received a young Pine Marten, } \\ \text { Marten. }\end{gathered}$ tree that very day. I soon induced it to lap warm milk, and in a few hours it ate bread soaked in milk. In this little animal I could clearly obscrve the natural development of taste in the species. In the beginning, that is, in June and July, the young Pine Marten is fed certain things by its parents, mostly birds; later it must, according to the season of the year, accuston itself to Mice, fruit, etc.

On the second day I offered it a Frog, but it paid no attention to it; then I gave it a living Sparrow, which it immediately snapped at and devoured, feathers and all. On the fourth day I let it go hungry and then tempted it with a Frog, a Lizard and a Snake. It paid no attention to them: neither did it care for a young Raven. On the sixth day it left its cage and killed a Falcon in its nest, eating the head, ncck and part of the breast. I offered it many kinds of food in the course of time and found that it preferred small birds to everything clse.

"When it had attained three-fourths of its complete growth and showed great voracity, I again offered it a Snake, but although very hungry the Marten approached very cautiously and drew back at every movement made by the reptile. Finally becoming persuaded that the Snake was not danger- 
ous, the Marten gave it a bite that broke off the tail, which it ate. Then it carried the Snake into its nest, from which the reptile escaped and hid in the hay, but was drawn from this retreat by its adversary. The Marten then bit off another piece of the tail, but did not dare take the snake by the neck and kill it until about two hours later, when it carried the dead reptile to the nest and ate it with evident pleasure, but not with avidity. It had not finished this meal when I threw another Snake, twenty-four inches long, toward the Marten, which tried to approach it, but drew back frightened, as the Snake resented its advance and hissed. Then I brought a large Snake of another kind, freshly killed. After it had become convinced that this one was dead, the Marten carried it back and forth and an hour later ate it, head, venomous fangs and all. Then I gave it a Lizard, which was greeted witl a sniff; the little animal hissed hoarsely, nearly like a Snake, opened its mouth and jumped at the Marten about ten times. The Marten evaded its bites, but soon became bolder, as it saw that the Lizard could not harm it, and after an hour killed and devoured the reptile.

"This goes to prove that by nature the Marten has no inclination to kill Snakes and similar animals, yet in the light of this experience it is not improbable, that in winter, when it finds them in a defenseless state, it kills and eats them, for it probably suffers severely from the pangs of hunger at this time of year, as it is extremely voracious.

"I wish to call attention to an erroneous opinion that prevails generally. It is commonly believed that the Martens, in killing any animal, always find the carotid arteries and sever them with their strong

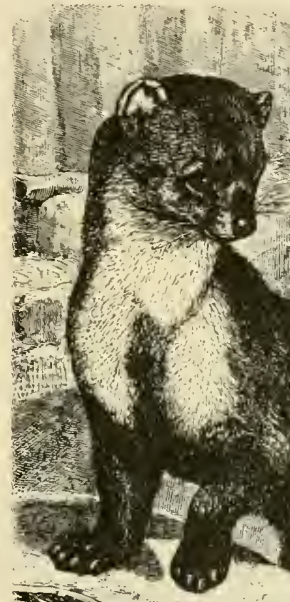

intending to do harm. Once it bit my hand through thick gloves, drawing the blood, although the bite was meant in a friendly way. It does not express real affection in its face and gestures, but it never intentionally harms those with whom it is well acquainted when it is kindly treated. Its black eyes express only avidity and sanguinary proclivities. When it lies comfortably in its nest, it often utters a long, drumming, murmuring sound. I never heard it produce sounds similar to those nade by the Polecat. When it was angry, it growled violently.

Pine Martens The Pine Marten is hunted in all Vigorously Hunted possible way's, not so much with a for their Fur. view to checking its murderous career, as for the sake of its fur. It is most easily pursued on freshly fallen snow, as its spoor may
then be seen not only on the snow-covered ground but also on the branches of trees. Occasionally it may be encountered lying in the wood, usually stretched at full length on $\mathrm{the}$ branch of a tree. When found in this position it is easy to shoot it, for if the first shot misses the gun may be reload. ed and a second shot taken, as the animal does not flee but fixedly looks at its assailant.

In hunting the Pine Marten one needs a good Dog, which will seize it boldly and hold it fast, for the animal is wont to jump at its pursuer and will frighten a Dog that is not very courageous. It is easily caught in traps, which are prepared in a very ingenious way. The bait is usually a piece of bread, fried with a small piece of onion and a little honey in unsalted butter and strewn with camphor. Other baits are ingeniously mixed f rom various strongly scented materials.

The fur of the Pine Marten is the most valuAsiaticanmals and birds, and is particularly partial to poultry, as European and Asiatic rarmers frequently find. A log pile near a dwelling is a favorite resor able to its habits. M.Mustcla forne.

They do seize larger animals by the throat and strangle them, but without touching the carotids; therefore they cannot suck their blood, but content themselves with licking the blood that chances to ooze out, and then eat the animal, beginning at the neck. The larger animals, like Rats of good size, Chickens, etc., do not have the tough, yielding skin of their necks even lacerated by the Narten while it is killing them, but only when it begins to devour them.

"While my captive Marten was little it was very fond of playing with people who started the play, but later on play was not advisable, for when it was grown up it used its teeth rather freely, although without able of European furs, and in quality resembles that of the Sable more than any other found on this continent. The best skins are found in Norway, the next best in Scotland and others are brought from Italy, Sweden, north Germany, Switzerland, upper Bararia, Tartary, Russia, Turkey and Hungary.

The Stone The Stone or Beech Marten (Mustela Marten or Beech foina) is a little smaller than the

Marten. Pine Marten; the legs are proportionately shorter, the head longer notwithstanding the shorter face; the ears are smaller, the fur shorter and of a lighter hue and the throat is white. The total length of a full-grown male is twenty-eight inches, a little over the third of which is taken up by 
the tail. The fur is grayish brown, assuming a darker tint on the legs and tail and merging into dark brown on the paws. The spot on the throat is smaller than that of the Pine Marten and consists of pure white hairs; though in the young animal it is sometimes of a reddish-yellow shade. The margins of the ears are set with short whitish hair.

The Stone Marten is found in nearly all the countries that the Pine Marten inhabits; it is a native of all of central Europe and Italy, excepting Sardinia ; England, Sweden, temperate European Russia bounded by the Ural, the Crimea and the Caucasus; and western Asia, especially Palestine, Syria and Asia Minor. But it also extends over Afghanistan and a great part of the Himalayas, although in this latter region it is not found at a lower elevation than 4,800 feet. In the Alps it mounts higher than the fir-tree belt in summer, and descends in winter. In Holland it seems to be almost exterminated. Nearly everywhere it is more common than the Pine Marten and approaches much more closely to human dwellings ; in fact, one might go so far as to say that vil. lages and eities are its favorite haunts. Isolated barns, stables, garden-houses, old walls and large piles of wood in the vicinity of villages most frequently harbor this dangerous foe of domestic birds.

Habits and Food The mode of life and habits of the of the Stone Marten correspond with those Stone Marten. of the Jine Marten in a great many respects. It is an adept at all physical exercises, and is as lively and agile, as courageous, as cunning and as ferocious as its kinsman ; it climbs perfectly smooth trees and poles, takes long leaps, swims with ease, and ean creep without noise and force itself through extremely narrow apertures.

Its food is nearly similar to that of the Pine Marten, but it is guilty of a considerably greater amount of mischief, for it has larger opportunities of causing damage to property. Whenever it has the slightest chance, it enters the Chicken-coops and slay's the inmates with insatiable ferocity. Besides this it preys on Mice, Rats, Rabbits, birds, and when it is in the forest, on Squirrels and reptiles. Eggs seem to be a favorite dainty with this animal and it also revels in fruit of all kinds, cherries, plums, pears and gooseberries, and hemp seed. It is necessary to proteet valuable fruit from it, and this is best accomplished by painting the tree-trunk with tobacco-juice or kerosene oil as soon as one perceives the mischief. Chicken-coops and Pigeon-houses must be securely locked, and every hole large enough to admit a Rat must be closed up.

Taming the Even specimens that are taken old are Stone capable of a certain degree of domes-

Marten. tication. In Scotland a Stone Marten was once eaught in a peculiar way. The unwelcome guest had taken up his abode near a mountain village and for a long time had been guilty of murders innumerable among the Chicken tribe. With the aid of good Dogs the villagers succeeded in driving him out of an isolated barn, which the robber had appropriated for his den. They drove him to the edge of a precipice, and thought they had him, but he preferred to jump down, falling from a height of ninety feet. The shock proved too violent for him, and he lay motionless, as if dead. Il is pursuers felt assured that he had killed himself and one of them went down, in hopes of obtaining the fur, and took the poor creature up. It suddenly began to move, and gave its reseuer a distinct proof of its returning consciousness by biting him. Still the wounded
Man did not let the animal go, but seized it by the neek and brought it home. The family treated it with kindness and in a short time it became quite tame, either owing to the fall it had taken or from gratitude for the friendly care. Its owner resolved to make use of its abilities in eatching Mice, and therefore the Marten was installed in the stable, where it not only made itself at home in a short time but struck up a friendship with the Horse. WThen any person entered the stable the Marten was found near its friend, whom it seemed to defend with a growl. It would sit on the Horse's back, or run back and forth on it; and sometimes played with the Horse's tail or ears. The Horse seemed to appreciate the affection the little robber had for it, but unfortunately the tie of friendship was severed in a cruel way. While on one of its nocturnal excursions the Marten entered a trap and was found dead the next morning.

The Sable, $a$ The celebrated Sable (Mustela zibclMost Valuable lina) is closely allied to the Martens. Fur Animal. It is distinguished from the Pine Marten, which most resembles it, by its conicallyshaped head, large ears, long, stout legs, large feet and lustrous, silky fur.

The fur is valued aceording to its thickness, softness and uniformity of tint. The woolly coat should show a smoky brown tint merging into bluish gray. The lighter the color of the outer coat, the smaller is the value of the skin; the darker and more uniformly tinted it is, the greater its value. The handsomest pelts are blackish in the upper part, mixed black and gray on the snout, gray on the cheeks, reddish chestnut-brown on neek and flanks, a beautiful yellow on the throat and lower part of the neck, and the ears usually show margins of grayishwhite or pale brown. The yellow color of the throat fades after the animal's death, and the most vividly yellow specimens are the first to fade.

The Sable's Originally the native country of the

Range and Sable extended from the Ural to the

Principal Food. Bering sea and from the southern mountainous boundaries of Siberia to latitude sixtyeight degrees north, and also over a small part of northwestern America, but it has much narrowed during recent times. Incessant persecution has driven the animal to seek refuge in the darkest forests of northeastern Asia, and as eren there Man follows it eagerly, even at the risk of life, it retires farther and farther back and is constantly becoming more rare, While Sable hunters were still reaping golden harvests, they founded associations in Kamchatka, and the decrease of the animal there as well as all over Eastern Asia dates from that time. The principal eause of its extermination is the activity of hunters. The animal undertakes rather prolonged wanderings, following, as the natives say, its favorite gane, the Squirrel. In the pursuit of these rodents it crosses wide streams by swimming, even during the season of drifting ice, although it usually avoids water. Its favorite haunts are forests of fir trees, whose large trunks afford shelter, while the seeds contained in the cones of the tree furnish the animal food.

The Sable seems most to resemble the Pine Marten, partaking of its agility and masterly way of elimbing. Its food consists ehiefly of Squirrels and other rodents, birds and similar prey, but it does not disdain fish, as it is sometimes induced to enter traps in which fish is used as bait; it has also been observed that it is fond of the honey of wild liees. It seems 


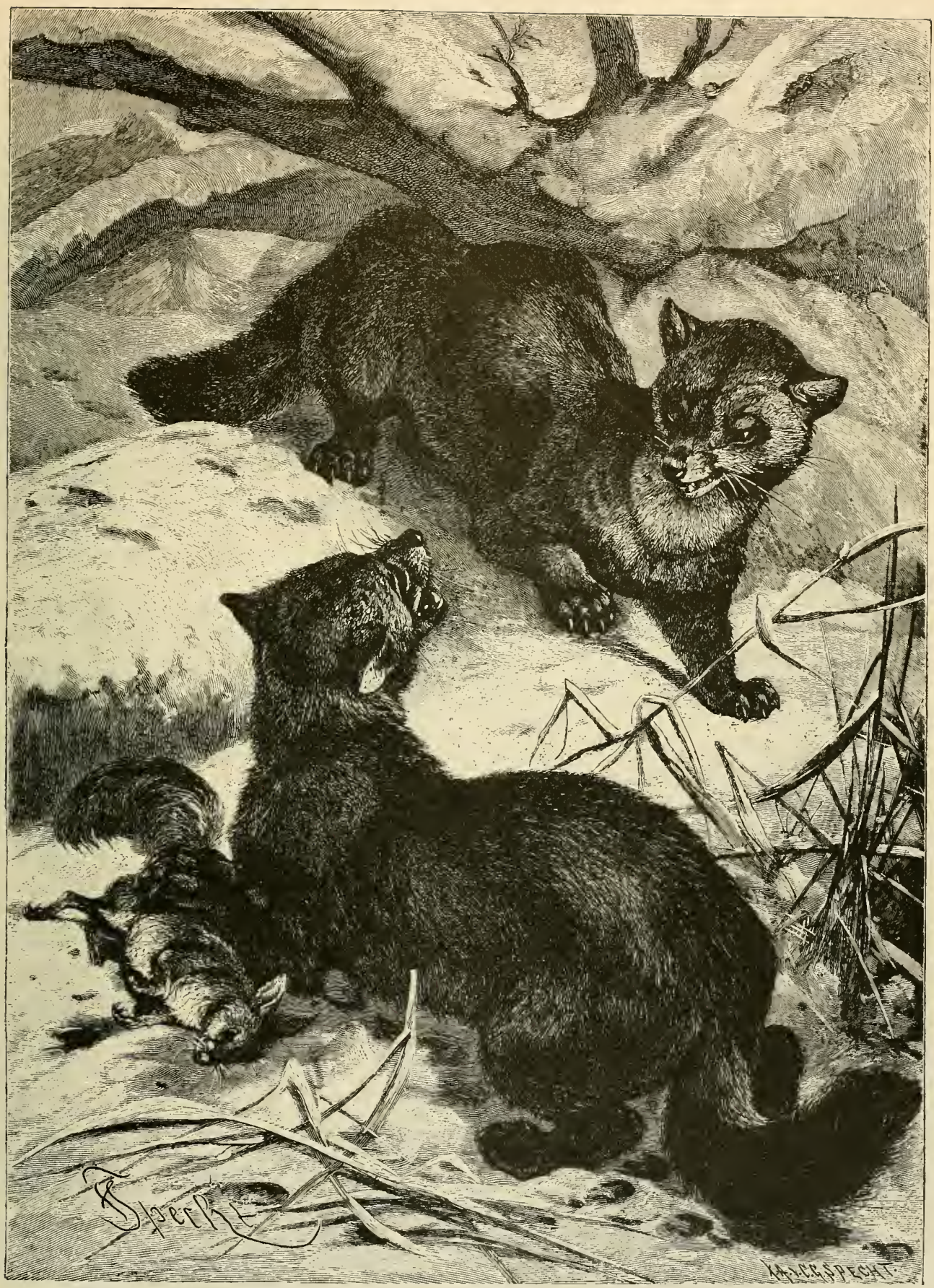

THE SABLE. - This animal, found in the colder portions of Asia and North America, is zealously hunted because of the great value of its fur. It most appropriately depicted in the snow, where one of these aniuals, having killed a Rabbit, seems to be called upon to defend its prey from a hungry brother, which, from the position of its claws, seems inclined to fight for a share of the booty. The animal in the upper part of this picture shows the markings most prized by the Sable hunter: the lower part of the neck yellow, the cheeks gray and the rest of the fur nearly black. (.1/ustela zibellina.) 
to consider cedar nuts desirable food, for the majority of the Sables that Radde caught had their stomachs quite full of these nuts.

Hunting the The hunting and capturing of Sables sable for sets the whole male population of cerits fur. tain tribes annually in motion and causes merchants to travel thousands of miles. Steller, and later the Russian Stshukin, inform us that the largest number of Sables are still found in the gloomy forests between the Lena and the Eastern Sea, and the product of their furs is still the greatest source of income to the natives as well as to the Russian settlers. The hunting season lasts from October to the middle of November or the beginning of December. The hunters assemble in small groups on the hunting grounds, where every association has its own dwelling; and during the journey the Dogs have to draw the sledges, packed with provisions for several months. The hunt is still conducted essentially in the same manner as described by Steller. Traps and nooses of the most varied descriptions are put out the spoor of the siable is followed on snow-shoes, the animal's hiding-place is surrounded by nets, and the fleeing Sable is killed by arrows or with a gun. The most popular method is to use traps that catch the animal without damaging the fur. The hunter and his associates spend several days in constructing all the traps, and often enough, when he looks for a victim on his daily visit, he finds that an impudent Arctic Fox or some other Beast of Prey has eaten the precious booty. Or a storm may come along and compel the poor man to look out for his own safety without thinking of disentangling the captive animal. In this way Sable-hunting is really a series of continuous troubles.

Hou sables There are, even at this late day, very Behave When few accounts about the life of Sables Tamed. in captivity. One specimen was kept in the palace of the archbishop of Tobolsk and was so completely tamed that it was allowed to walk about the town at its own will. Other tamed Sables played very nerrily together, sat upon their hind legs in order to fight more effectually, jumped around in the cage, wagged their tails when they felt comfortable and expressed their anger by grunting and growling like young Dogs.

The American In the northeast and extreme Sable a north of North America the Sa-

Northern Variety. ble genus is represented by the American Sable (Mustila amoricana). It is eighteen inches long, exclusive of the tail, which measures seven inches, and is more closely allied to the Pine Marten than to the Sable. $\mathrm{lts}$ color is a uniform brown, except that the patch on the breast is yellow and the head and ears are gray or white. The hair is considerably coarser than that of the Sable and is of about the same quality as that of the Pine Marten.

The finest pelts of this species come from the shores of the Hudson Bay; the country around the Little and Great Whale rivers, eastern Maine and Labrador. According to Lomer about 100,000 pelts are annually sold from the region named, and from 30,000 to 50,000 come from Alaska, very fine pelts commanding a price of about nineteen dollars each.

The Fisher The Fisher Marten is a native of the Marten, or same region of country. It is called Pekan. Pekan in Canada and Wijack by the Indians, and is also known as Pemnant's Marten (. Hustila pennentii). It is a large, thick-set. Fox-like animal, whose body measures over twenty-four inches; the tail from twelve to fourteen inches. The fur consists of a thick, fine, lustrous outer coat and a long, soft, woolly under fur. Its color is, as a rule, very dark, or even black, and only the head, nape of the neck and back show an admixture of gray; but there are also individual members of this species that are very light, chestnut or light brown or even yellowish white.

The range of the Fisher extends over the whole north of America. In his habits he resembles different species of his relatives. His usual habitations are caverns, which he excavates near river banks. His food is said to consist mainly of quadrupeds living near the water. These animals are hunted by young Indians who find in this viciously. biting creature an antagonist which can test their courage, while at the same time they are not exposed to as much danger as are the Men of their tribe who hunt the grim Bear. Lomer says that there is hardly another fur so well adapted for Men's clothing, and the pelt is highly esteemed in northern American countries as well as in Russia, commanding a price from eight to fifteen or even as high as twenty dollars, a coat made from this fur costing as high as from three hundred to one thousand dollars. Comparatively few of these furs reach the European market; the number may be about twelve thousand annually, and they are known com. nercially under the name of Virginian Polecat.

\section{THE WEASEL GROUP.}

"Putorius" or "Foetorius" (each meaning "foulsmelling") is the name given to another group, in honor of the renowned Polecat, which certainly deserves this designation, while other members of the group do not. The animals belonging to this group are distinguished by a head that tapers in a marked degree toward the sharp snout; short, rounded, three-sided ears; a slender, elongated body; short legs provided with long-toed feet, and a round tail, clothed with rather long hair, which does not attain half the length of the body.

Description The Polecat (Putorizs fatidus) attains a of the lengtll of body of from sixteen to sev-

polecat. enteen inches and a length of tail of six inches. The fur is of a uniform brownish black color below, while the upper parts and the sides are lighter, usually of a dark chestnut tinge; and the upper part of the neck is also lighter, the shorter, yellowish woolly coat being nearer the surface in these parts of the fur. A red-brown band, indistinctly defined, runs lengthwise under the body; and the chin and tip of the snout are of a yellowishwhite tint, with the exception of the dark nose. Above the eyes there is a yellowish white spot, fading at its edges, and uniting with an indistinct band beginning below the ears. There are variations in coloring which have by some been considered as marking distinct specics; and yellow or white Polecats have also been observed. In the female all those parts of the fur which are yellow in the male are of a pure white. The fur of the species is thick, but it is nuch less beautiful than that of the l'ine Marten.

The Tiger Pole- The Polecat has a kinsman, the Tiger cat, a sepa- Polecat (Putorius sumuticus), which in-

rate Variety. habits southeastern Europe, extending as far north as Poland, and several parts of western Asia; and it is of frequent occurrence in southern Afghanistan, especially around Kandahar. Its mode of life is identical with that of the common l'olecat. 
The Polecat's The Polecat inhabits the temperate Range zone of Europe and Asia and even enand Habits. croaches a little upon the arctic zone. It is found throughout all Europe except Lapland and northern Russia. In Asia it ranges from the Caspian sea through Tartary and Siberia to Kamchatka. Every locality holding out a promise of food is adapted for its existence and therefore it frequents plains as well as mountains, forests and ficlds, and is particularly partial to the vicinity of large farms. It takes up its habitation in hollow trees, rocks, old Fox burrows and similar holes which it happens to come across; and, if driven to it, can burrow itself. It establishes itself in fields of highgrown wheat or corn; it also makes its home in fence corners, under bridges, in old walls, the roots of large trees or close hedges; in short, it settles down wherever there is a good chance to do so, but fights shy of work, preferring to let other animals do the digging and burrowing. In winter it shifts its
Polecats, and as the result of his labors, concluded that they devoured lirogs and Snakes with great pleasure, never caring for the bites of venomous Snakes and experiencing no discomfort from them. The Polecat Besides feeding on venomous Snakes a Vigilant the l'olecat, Marten-fashion, attacks Hunter. every creature it holds to be its inferior in strength. It is a deaclly enemy of all Moles, field and house Hice, Rats and Hamsters, Hedgehogs, Chickens and Ducks. Frogs seem to be one of its favorite dainties, for it catches them in great quantities, and keeps them in its burrow by the dozen. When food is scarce it contents itself with Grasshoppers and Snails. It also goes fishing and lies in wait for fish on the banks of rivers, lakes and ponds, jumps after them into the water, dives and seizes them with great adroitness; it is even said to take them from under the ice in winter. It is also very fond of honcy and fruits. Its sanguinary instincts are great, but not so great as those of the Martens

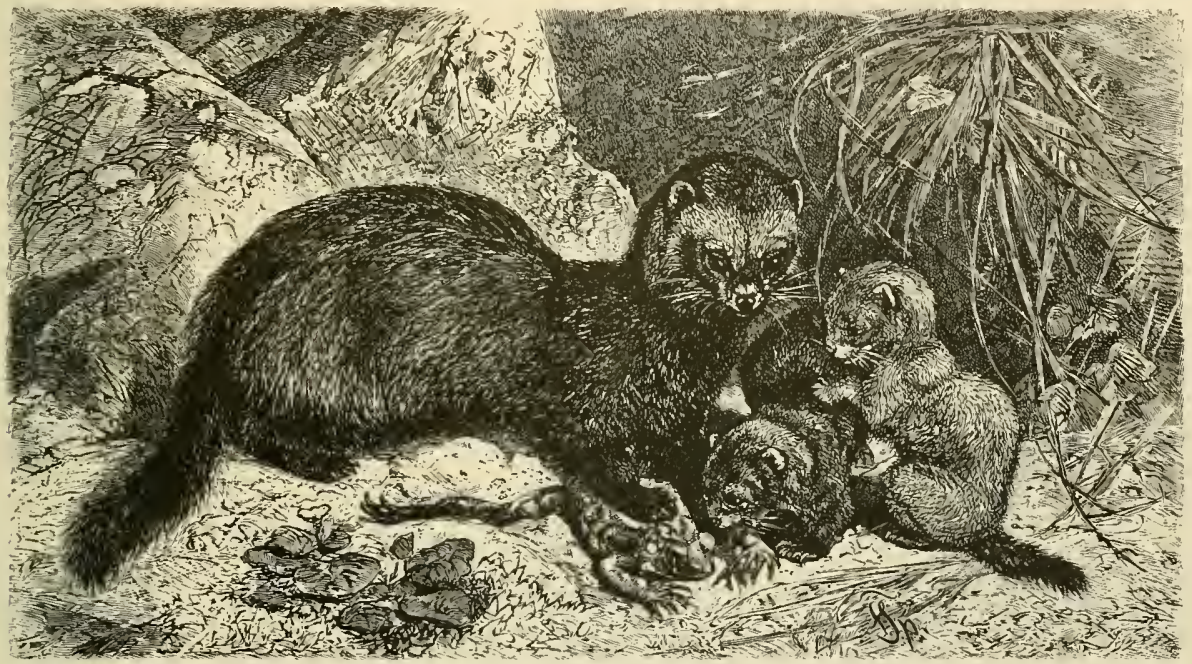

THE POLECAT.- - An animal which is generally avoided by those of sensitive olfactory nerves is the Polecat, which inhabits the greater part of Europe and Asia, where it ravages poultry yards, but also catches Rats. Mice and other rodents. It is also partial to Frogs, and the mother Polecat in the picture is shown in the maternal act of bringing to her young a Frog she has killed. (Putorius fxitus.)

quarters and moves into villages and cities, often encroaching upon the domain of the domestic Cat and the Stone Marten. Occasionally it enters Henhouses, Pigeon-roosts, Rabbit-hutches and similar places, where it displays an activity little calculated to bring joy to their inmates or owners, and only equaled but never surpassed by other members of the Marten family. On the other hand it makes itself useful, and if the farmer is careful of his Hens, Pigeons and Rabbits, he cannot find fault with his guest, for it catches a multitude of Rats and Mice, thoroughly rids the immediate neighborhood of Snakes, and requires nothing for its services but a warm bed in a very dark corner in the hay-loft. There are localities where the Polecat is as welcome as it is detested in others.

The Polecat IVe must agree with Lenz, who advises Useful in the every forester to spare the Polecat. Its

Woods. right place is in the woods, and it does much good by killing Mice and Snakes; its usefulness in destroying Hamsters is also worthy of mention. Lenz experimented a great deal with half-grown proper. As a rule it does not kill all the poultry in a house into which it has effected an entrance, but takes the first fowl that it comes across and hurries with it to its hiding-place; but it repeats this performance several times in one night. More than other members of the Marten family it is in the habit of stocking its larder with provisions, and not infrequently goodly supplies of Mice, birds, eggs and Frogs are found in its burrows. Its agility makes its task of providing for its sustenance an easy one.

All movements of the Polecat are quick, agile and to the purpose. It is past-master in the arts of sneaking and leaping; it climbs, swims, dives, in short, makes use of every movement that may further its purposes. It is crafty, cunning, cautious, distrustful, ingenious and, when attacked, courageous, and addicted to vicious biting; in short, it is perfectly fitted for committing great robberies. Like the Skunk [which in America is frequently called "Polecat"], it defends itself in extremities by ejecting a foul-smelling fluid and thereby deterring the Dogs from pursuing it. Its tenacity of life is incredible. 
It jumps from great heights without injuring itself, bears pain of all kinds almost with equanimity and succumbs only to extremely severe wounds.

A litter of Polecats is composed of four or five, sometimes six young ones, for which a retreat is usually established by the mother in a cavern, or still better, in a heap of wood or dry branches. The mother is excedingly fond of the little ones, cares for them in the tenderest way and defends them against any enemy; sometimes, when she hears a noise in the neighborhood of her nest, she will attack a human being of her own accord. The little ones, after a childhood of about six weeks, aceompany the mother on her hunts, and at the end of the month they are nearly as large as she is herself.

Young Polecats may be suekled by Cat-mothers and tamed, but they do not afford one much pleasure, for thcir sanguinary proclivities revive when they grow up and they pursue every good-natured domestic animal.

Polecats Sometimes Polecats in the wild state someDangerous-

Hunting Them. times conduct themselves in the most audacious manner when they meet human beings and may even become dangerous to ehildren. "In Verna, a village in Hessen," says Lenz, "a six year old boy, who had been given eare of a baby, set it down on the road, near a canal. Suddenly three Polecats made their appearance and attacked the child. One seized it by the nape of the neck, another by the side of the head, the third by the forehead. The baby gave a Joud scream and the brother was coming to the reseue, when still more Polecats emerged from the canal and charged at him. Fortunately two men came to save the children; they killed two Polecats and the others then made their escape."

This animal is pursued in nearly every locality it inhabits beeause of the considerable damage it causes. All the customary weapons and traps are used in its extermination. In those localities that are infested with Mice it would be better to leave the Polceat alone and direct attention to the repairing of the Chieken-coops.

The fur of the Polecat is warm and serviccable, but it is not valued as much as it would be if it were not for the really unbearable odor that clings to it. The long hair of the tail is used for brushes; the flesh is perfectly useless and is disdained even by Dogs.

The Ferret, a All modern naturalists agree in regardDomesticated ing the Ferret (Putorius furo) as a Variety. descendant of the Polecat, having undergone eertain modifications in captivity and domestication.

The Ferret has been known sinee the oldest times, but only in a domesticated condition. Aristotle refers to it under the name of 1ktis, Pliny under the name of Viverra. On the Balearic islands the Rabbits at one time had so increased that the natives appealed to the Emperor Augustus for help. He responded by sending them a few "Viverrx," whose abilities as hunters were great. They were put into the burrows of the Rabbits and drove the harmful roclents out into the nets of their enemies.

The Ferret resembles the Polecat in shape and size. It is a little smaller and weaker, but we observe this phenomenon in many animals that live in dependence upon Man, that is, in captivity. The bocly is eighteen inches long, the tail five inches. These are the rclative measurements of the Polecat; and the Ferret does not differ in any marked degree from the Polecat in the structure of its skeleton. In. Europe the Ferret is usually seen as an Albino, being of a whitish or yellowish color, a little darker in the lower parts, and with pink eyes. A few specimens are darker and look like genuine Polecats. No essential differenees have as yet been found between Poleeats and Ferrets, and the reasons that have been given as suffieient to entitle the Ferret to being ranked as a distinet species do not bear close investigation, as the prineipal distinguishing features of the Ferret have been counted its delicate, ehilly nature, its gentleness and its tameness. In my opinion this is no valid proof, as all Albinos are weakly and delieate. Some naturalists supposed the Ferret to be of African origin and to have extended from Africa to Europe, but they have not been able to support their opinions by any observation.

How Ferrets The Ferret is found only in captivity are $U_{\text {sed }}$ and is kept in continental Europe only and Kept. for Rabbit-hunting. In England the Ferret is also used to exterminate Rats, and the "Ratters" are considered of much higher value than those that hunt only Rabbits. The animals are kept in chests and eages, the hay and straw is frequently changed and they are protected from the cold in winter. Usually they are fed on bread and milk, but a diet of tender flesh of freshly killed animals is much more conducive to their health. Lenz's obscriations show that they ean be very cheaply kept on Frogs, Lizards and Snakes, of which theyare very fond.

Habits and The Ferret resembles the Polecat in Traits of the its temper, except that it is not so Ferret.

lively; its thirst for blood is not inferior to that of its wild brother. Even when it is nearly satiated, it attacks Rabbits, Pigeons and Chickens with a kind of a mad frenzy, seizes them by the neek and does not loosen its hold until the prey is thoroughly clisabled from moving. It laps the blood, oozing out of the wound it has made, with incredible avidity, and appears to consider the brain a dainty morsel. It attacks reptiles with greater eaution and seems to be aware of the danger appertaining to venonous Snakes. It attacks the hamless species of Snakes withont hesitation, even when it sees one of them for the first time, and in spite of its violent writhings, the Ferret seizes it, bites it through the backbone and eats a fairly large piece. But it approaches a renomous Snake with caution. and tries to bite the treacherous reptile in the middle of the body. It does not die from the effects of a Snake bite, but becomes sick and dejected.

Unly in rare instances is the Ferret completely tamed; there are eases on record, however, where lerrets have followed their masters about like Dogs. and could be allowed to roam about at perfect liberty. But in the majority of cases these animals know how to profit by their freedom when once they have made good their escape; they straightway seek the forest, where they make themselves at home in some Rabbit's burrow, which serves them as an asylum during the summer. In a short time they forget Man, and if they are not reeaptured they perish during the winter, as they are much too delicate to withstand the cold.

The voice of the ferret finds expression in a dull growl, or, when expressing pain, in a shriek. It is seldom heard, for the animal usually lies snugly curled up and quite still, and becomes active only when there is some sanguinary feat to be achieved. 
A family of Ferrets includes from five to eight young ones, which remain blind during the first two or three weeks of their lives. They are admirably cared for by the mother and are weaned when about two months old, and when this has been done they are old enough to be separated from maternal care and reared by themselves.

How Ferrets The Ferret is excellent as an assistant

Hunt Rabbits in a Rabbit hunt, but its real usefuland Rats. ness is very slight in comparison with the cost of its maintenance.

The hunt is begun in the morning. The Ferrets are carried in a basket or box lined with something soft or in a game pouch. On arriving at the burrow the hunter looks for all the outlets and places before each of them a net about a yard long and fastened to a large ring; then the Ferret enters the principal outlet and this is also closed against egress in a similar manner. As soon as the Rabbits become aware of the presence of the intruder, they rush out and are caught in the nets and killed. The Ferret itself is prevented from killing them either by a muzzle or by having its teeth filed, and a little bell is suspended from its neck so that its whereabouts may be constantly known. As soon as it reappears at the outlet, it is taken up, for if it should enter the burrow a second time, it would lie down to rest and its master would be compelled to wait for it for hours. It is very important that it be taught to respond to a whistle or a call. If it does not obey this signal, resort is had to coaxing in order to induce it to come out. An effectual expedient, for instance, is to tic a Rabbit to a pole and thrust it into the burrow. No Ferret can withstand such a temptation; its teeth close on the Rabbit, with which it is drawn out of the hole.

In England the Ferret is more frequently employed to exterminate Rats, and still oftener to fight with these biting rodents. A Ferret which is only accustomed to Rabbits cannot be used for Rats, for it is afraid of every large Rat. A "Ratter" has to be specially trained. It is at first made to fight with young, weak Rats, and then becomes gradually accustomed to combats and victories. The innate sanguinary nature of the Ferret asserts itself by degrees, and the courage of the little robber grows until it at last attains such perfect skill in fighting the black game that it accomplishes marvels. A thoroughly trained Ferret can kill fifty Rats in one hour, within a space two or three yards square.

The Ferret, in its search for Rabbits, may meet enemies of its own family which have taken up their abode in a deserted Rabbit's burrow. Then a fright$\mathrm{fu}$ ] struggle takes place between two animals well matched in strength and agility. Such a combat is hardly enjoyed by the owner of the tame member of the tribe, as he has cause to fear for the life of his assistant in the Rabbit-chase.
Weasels and The IVeasels and their next of kin are their Kind of still more slender and attenuated Described. shape than the Martens proper. They all dwell in fields, gardens, burrows, clefts of rock or under stones or wood-piles and then roan about by day as well as by night. They are the smallest lieasts of Prey, but their courage and sanguinary disposition render them model types of the Carnivora.

Characteristics The Weasel (Putorius z'ulgaris) attains of the a total length of eight inches, about weasel. two of which go to the diminutive tail. The body is cxtremely elongated and appears to be longer than it really is on account of the neck and head being of about the same circumference as the body. The animal is of the same thickness from head to tail, and only in adult WVeasels do the loins seem a little retracted and the nose somewhat pointed. The legs are very short and thin and the paws are tender; there is a covering of hair between the balls of the soles, and the toes are furnished with thin, sharp and pointed claws. The 
Runge and The Weasel is of frequent occurrence Habits of the througliout Europe, though perhaps Weasel. not so frequent as in northern Asia; it is also found in British North America, and the northern portions of the United States. It inluabits plains as well as mountains, forests as well as woodless stretehes of eountry, and it frequents populated districts as well as the wilderness. It discovers a suitable dwelling place in any locality, for it adapts itself to circumstances, and always devises for itself a loop-hole of escape from enemies. In this way it inhabits hollow trees, heaps of stone, hollow river banks, Mole's burrow's and the hiding places of Hamsters and Rats, and in winter repairs to barns, cellars, stables, garrets and similar retreats, frequently even in cities. In those localities where its movements are undisturbed it prowls around in the daytime; but in those where it is pursued or harassed it sallies forth only at night, or if by daylight only with the greatest caution.

The observer who noiselessly approaches the hiding place of a IVeasel may easily secure the pleasure of watching it. He may then hear a slight rustle of leaves and see a small, brown creature gliding along. As soon as the IVeascl catelies sight of a human being it stands on its hind legs to obtain a better view. The idea of flight seldom enters this dwarf-like creature's head, but it looks at the world with a pair of bold eyes, and assumes an attitude of defiance. When one goes very near it the Weasel is sometimes bold enough to approach him, putting on an indescribably impudent look, as if it whes to find out what the intruder neans by disturbing it.

Great Courage More than once it has happened that and Audacity the audacious little creature has atof Weasels. tacked Man, and retreated only after a prolonged fight. It has also been known to suspend itself by its teeth from the legs of Horses, and in these cases has only been made to relax its tenacious hold by the joint efforts of Ilorse and rider. With so great a degree of courage the WVeasel combines an incomparable presence of mind. The IVeasel is never at a loss for a way to eseape ; it does not give up hope even in the claws of a bird of prey. A naturalist once saw a large bird swoop down on a field, pick up a small quadruped and fly away with it ligh up in the air. Suddenly the bird staggered in its flight, and then dropped to the ground dead. The surprised spectator hurried to the place and saw a IVeasel tripping merrily away. It had adroitly severed its formidable enemy's neck with a bite and so saved itself.

Animals Preyed It is a natural conclusion that so Upon by courageous an animal must be a terthe Weasel. rible Beast of Prey, and such the Weasel truly is. It wages open war upon all small quadrupeds and causes dreadful ravages among them. Among the mammals it preys upon all Mice, house Rats and water Rats, Moles, young Hamsters, Hares and Rabbits. Among the birds it kills young Chiekens, Pigeons, Larks and others living on the ground; it attacks even those birds it finds sleeping on trees, and plunders their nests. Among the reptiles it lies in wait for Lizards and Snakes, though it cannot withstand the repeated bites of a venomous Snake. It also feeds on Frogs and fishes, in short, on every kind of flesh, including even that of its own species. When it ean get hold of Crabs, it opens their hard shell very adroitly to get at their meat. Its small size and incredible agility stand it in good steaci in its hunts, and it may be said that no small animal possesses immunity from it. It has been observed to hunt in company with others of its species, a fact which is not astonishing, as it lives gregariously, and there are great numbers of these animals in some places. Pechuel-Loesche once saw seven adult Weasels, probably belonging to the same family. They were diligently searching a piece of meadow for game in bright daylight, and they did not seem to be much disconcerted at having a spectator. The lleasel seizes small animals by the nape of the neck or by the head; larger ones it tries to seize by the throat. It will make one or two apertures in the tip of an egg and suck out the entire contents without losing a drop. It is said to carry away large eggs between its chin and breast; smaller ones it carries in its moutl. When it has killed a large animal it does not eat the flesl but contents itself with lapping the blood; but smaller prey it eats upentirely: II hen it has once seized an animal, it never lets the victim go until it is dead. It can often be seen hunting in the immediate neighborhood of human habitations, and it displays scarcely any timidity in its actions.

The Young A litter of IVeasels numbers from three Weasel and to eight blind young ones, the mother Its Mother. usually selecting a hollow tree or a burrow and preparing a nest-like couch for them out of straw, hay or leaves. She is very fond of her offspring, suckles them for a very long time and provides for them for a few months after they are weaned, bringing then live Mice to eat. When she thinks the retreat unsafe, she carries them away in her mouth. In danger the faithful mother defends them with unlimited courage. When the charming little aninals are grown up, they often play with the mother, and it is both curious and pretty to see such a little group romping aronud in the sunshine on a meadow; they prefer one that abounds in subterranean burrows, especially holes made by Moles.

Young Weasels while still following their mother are of the proper age to be domesticated. Buffon was the originator of the belief that the little animal is not capable of domestication, but this is a wrong opinion to hold, though it is not entirely without foundation. Weasels which have been accustomed to people from childhood are remarkably tame and charming little creatures.

Anecdote Of the different anecdotes about Weaof the Tame sels, one, recounted by Wood in his

Weasel. Natural History as coming from a lady, strikes me as the most attractive, and I will here give an extract from it :

"If 1 pour some milk into my hand," says this lady, "my tame IVeasel will drink a good deal, but if I do not pay it this compliment it will scarcely take a drop. When satisfied, it generally goes to sleep. Ny chamber is the place of its residence and I have found a method of dispelling its strong odor by perfumes. By day it sleeps in a quilt, into which it gets by an unsewn place which it has discovered on the edge; during the night it is kept in a wired box or cage which it always enters with reluctance and leaves with pleasure. If it be set at liberty before my time of rising, after a thousand playful little tricks, it gets into my bed, and goes to sleep beside me. If I am up first, it spends a full half-hour in caressing me, playing with my fingers like a little Dog, jumping on my head and my neck with a lightness and clegance which I have never found in any other animal. If I present my hands at the distance of three feet, it jumps into them without ever miss- 


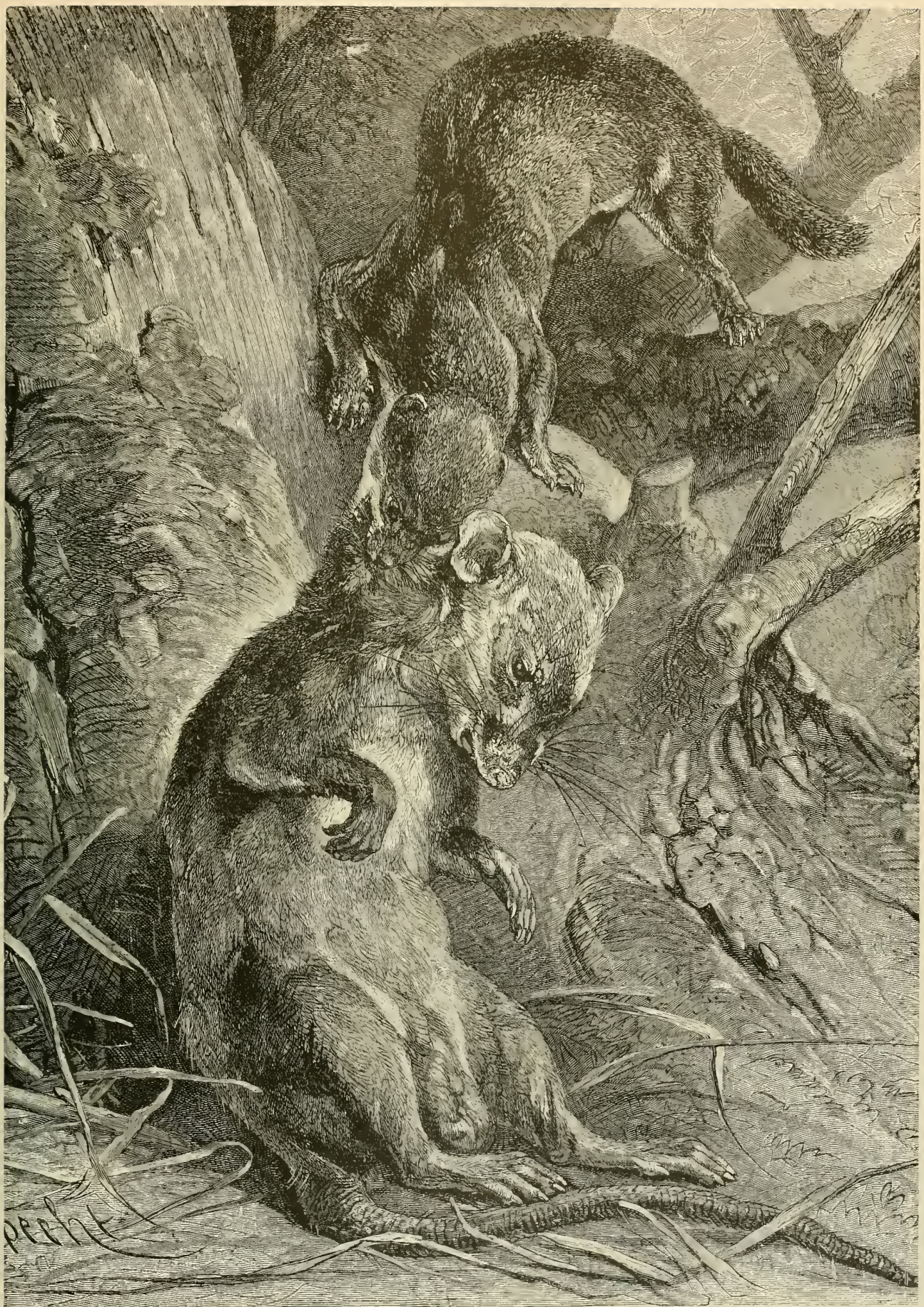

WEASEL ATTACKING A BROWN RAT - During the present century the Brown Rat has greatly increased in numbers in Europe, largely taking the place of the smaller black member of his tribe. This vicious rodent has a most determined enemy in the Weasel, which, although inferior to this Rat in size, pursues it relentlessly and with almost uniform success. The picture shows the Weasel attacking one of these destructive rodents, and illustrates its little amimal. (Putorius z'ulgaris.) 
ing. It exhibits great address and cunning to compass its ends, and seens to disobey eertain prohibitions merely through caprice.

"In the midst of twenty people it distinguishes my voice, seeks me out and springs over all the others to come at me.

"One singularity in this charming little animal is its curiosity. It is impossible to open a dratver or a box, or cven to look at a paper, but it will examine it also. If it gets into any place where I am afraid of permitting it to stay, I take a paper or a book and look attentively at it, on which the Weasel immediately runs upon my hand and surveys with an inquisitive air whatever I happen to hold. I must further observe that it plays with a young Cat and Dog, both of considerable size.

If carefully tended a domesticated Vieasel may live from four to six years ; in its wild state it probably lives from eight to ten years. Unfortunately these small, useful animals are much pursued by malicious people and killed from sheer mischievousness. A Weasel is easily caught in a trap, with bait of an egg, a small bird or a Alouse. On account of its great usefulness, the little animal ought to be thoroughly protected instead of being pursued. It may be safely stated that no other animal is so fitly endowed for hunting Mice.

The Ermine, Closely allied to the Weasel is the Eror Stoat, mine or Stoat (Putorius crminea) which Described. resembles the former in its shape and mode of life, but is of - Jarger dimensions than its little kinsman. The total lengtl of the Ermine is thirteen inches, or a little more in high northern latitudes. The upper part of the body and half of the tail are of a brownish red color in sumnier and white in winter, and the woolly coat is also brownish red, or white, according to the season. The under part of the body is always white with a slight yellow tinge and the extremity of the tail is always black.

changes in The modifications of tint which the the Fur of the Ermine undergoes in the different sea-

Ermine. Sons have given rise to differenees of opinion among naturalists. Some assume that it sheds its hair twice a year; others, with whom I agree, are of the opinion that the summer-hair simply bleaches out at the approach of cold weather, a phenomenon which is also observed in the Arctic Fox and the Alpine llare. The swedish writer, Grill, whose charming descriptions I quote below, has had excellent opportunities of watching the change of color in captive Ermines in the spring. "On the 4th of March," he says, "one could see the first dark hairs between the eyes. On the roth a dark patch had spread over half the forchead, but still showed white spots here and there. Around the eyes and nuse several small dark spots had appeared. When it bent itself, one could see that the roots of the hairs on the middle of the back, the shoulders and on the head were dark. The cliange of color took place very rapidly, especially at first, so much so that its progress could be traced daily or even half-daily. On the $3 \mathrm{~d}$ of $A$ pril the only white places were the lower part of the neck and throat, the whole under portion of the body, the ears, a strip running from the ears to the eyes, which were surrounded by a narrow dark border, a small piece adjoining the black part of the tail, the feet, the inner sides of the legs, and the buttocks. Un the Ioth the cars, with the exception of a small spot, had beeome brown. At first the dark hairs grew to- gether, and before they were as long as the white ones, the latter had fallen out. IVe may say that the real change went on during the first lialf of March ; after the Igth of March the brown coat only spreads more and gradially takes the place of the white one."

Where and The Ermine is spread over a large exHow the tent of country in the north of both the Ermine Lives. Old and New IVorld. It inhabits all Europe to the north of the Pyrenees and the Balkans, and northern and central Asia to the eastern coast of Siberia. It has also been found in Asia Minor, Persia and Afghanistan and even in the. Himalayas. In America it is found from the extreme north southward taking in the northern half of the United States. Wherever it exists, it is rather common, and in Germany it is one of the commonest Beasts of l'rey.

Like the IVeasel, the Ermine is found in any kind of locality, and knows how to make itself at home anywhere. Holes in the ground, burrows of Moles and Hamsters, clefts of rock, holes in walls, crevices, heaps of stone, trees, deserted buildings and a hundred similar hiding places are used by the Ermine during the day, and there it sleeps while the sun shines: though it also frequently happens that it promenades around, boldly exposing itself to human eyes. Its real activity, as a rule, begins at dusk. Toward evening it exlibits a lively disposition, and one who looks in favorable localities at this time will not need to search long before discovering this ingenious little creature with its intelligent eyes. It may be called a master in all physical exercises: runs and leaps with the greatest agility, is an excellent climber and ean swim rapidly across wide rivers. lts mental endowments liarmonize completely with its physical attributes. It possesses as much courage as its small cousin the IVeasel, and has an extremely sanguinary disposition.

The Ermine The Ermine preys upon all small quadand Its Numer- rupeds and birds which it call conquer,

ous Prey. and often attaclis animals greatly its superior in size. It wages constant war on Mice, Moles, Hamsters, Rabbits, Sparrows, Larks, Pigeons, Chickens, Swallows, which it takes from out of their nests; Snakes and Lizards, and even Hares are not secure from it.

It is a very pretty sight to watch an Ermine bent on pursuing one of its favorite prey, a IVater-Rat. This rodent is hunted on the ground and in the water by the little rascal and, unfavorable as the proper element of the Rats seems to be to the Ermine, it succeeds in worsting them. At first it searehes all the holes. Its acute sense of smell informs it accurately whether one or two Rats are taking repose in one of the holes. When the Ermine has found a promising hole, it enters it without further ado. The Rat, full of dismay of course, rushes into the water, and makes for a thicket of reeds; but this does not place it out of the reach of its vigilant pursuer and most ferocious enemy; keeping head and neck above water like a Dog, the Ermine glides on and pursues the Rat with indomitable perseverance. If chance does not come to the rescue, the Rat is lost.

The Ermine is caught in all kinds of traps, sometimes in Rat traps which it chances to enter. Frmines which are caught young may become very tame and afford their keeper a great deal of pleasure. Some specimens are said to have followed their keeper about like a Dog. Even old Ermines may sometimes be domesticated. 


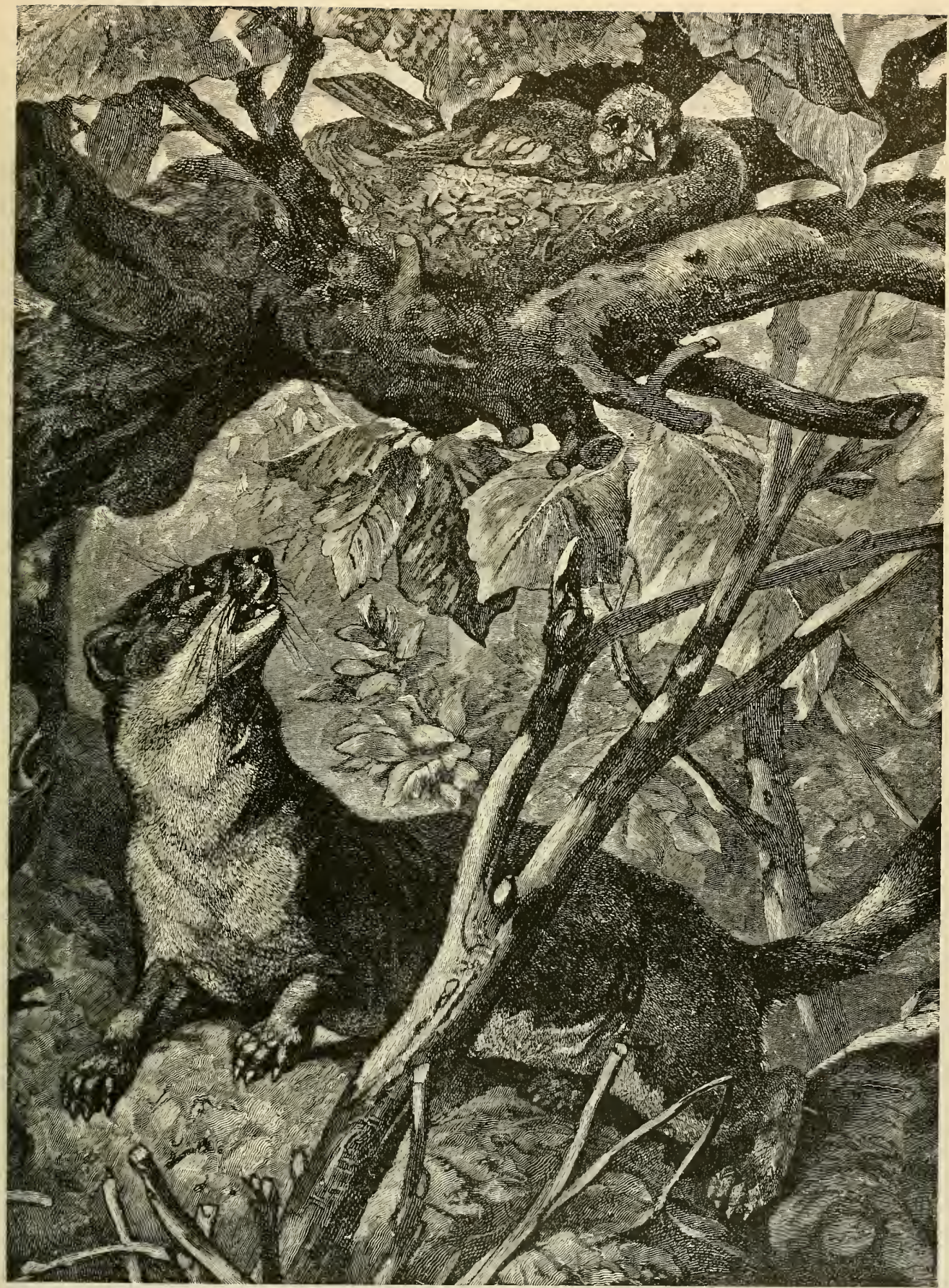

THE ERMINE, OR STOAT- This fierce little Beast of Prey is found in the northern portion of both hemispheres. It preys upon all small mam mals, attacking even Hares, does not despise Snakes or Lizards, and is especially tond of birds. The animal in the picture will find no difficulty in depopulating the nest above him. This animal's fur changes with the seasons. It is shown in this engraving in its summer coat, the upper part brownish-red, the lowe white. In the winter the animal is entirely white, except that the tip of the tail is black at all seasons. (Putorius crminea ) 
Account of "A few days before Christmas, I843," a Captive says Grill, "I was given a male Ermine, Ermine. which had been eaught in a pile of wood. It wore its pure white winter dress. The round black eyes, the red-brown nose, and the black tail-tip stood out in bold relief against the snow-white fur, which only at the root and on the inner half of the tail had a sulphnr yellow tint. It was a pretty, lively little animal. At first I put it in a large, untenanted room, which soon took on the disagreeable odor that characterizes the IVeasel tribe. Its skill in elimbing, leaping and hiding. itself was marvelous. It climbed up window curtains with ease, and if frightened, it would drop down with a scream. On the second day it ran up the stove-pipe and stayed in that grimy retreat a few hours, and came out covered with soot. It often eluded me for hours at a time when I would be looking for it, and then it would issue from some place where 1 thought it least likely to be concealed. As the room was not heated, it soon made itself a nest in a bed, but always left this warm refuge when anybody entered the room. Still the bed remained its favorite hiding place. It would run to it when rapidly approached, but if one came up to it gently, uttering a few kind words, it would stop, crane its long neck and lift one fore-paw. Its fondness for petting is well known, and the peasants often say, 'Little Wleasel likes to be praised.' If its curiosity is aroused, or it scents danger, and wishes to see farther than its small stature permits, it sits up on its hind legs. If one approaches it, it barks before fleeing, in a violent, yelling tone, resembling that of a woodpecker.

"When it was put in a large eage on the third day. and it saw that there was no escape for it, the Frmine did not suffer any one to approach toward the cage without jumping to the bars, biting viciously, and uttering the sound described above in a long trill resembling the ery of the Magpie. It felt itself sccure in the cage, and did not even fear the Dog, and the two animals used to bark into each other's faces, each on its own side of the bars. When 1 put the fingers of a glove through the bars it bit at and tore them. When it was very angry (and so little a cause as disturbing its sleep was sufficient to rouse its ire), all the hairs of its long tail stood on end.

"In general my little Ermine was very wieked. It detested music. If one played on a guitar in front of its eage, it jumped against the bars as if insane, and barked and hissed as long as the playing continued. It nevertried to use its elaws for the laceration of its prey, but always used its teeth.

"On the 7 th of May, when the animal had been four and one-half months in my possession, 1 tried for the first time to pet it, having gloves on. 1t bit into them, but I did not feel the teeth, neither did they leave any traces. At first it tried to evade my caresses, but later it seemed to like them, lying down on its back and closing its eyes. On the following day I repeated the experiment, as I had a firm intention of rendering it as tame as 1 could. Soon I pulled off my glove and stroked it and it did not attempt to bite me. I could pet and stroke it, lift its paws and even open its mouth without maknng it angry, but when 1 took it by its body it slid out of my hands like an E.el. It had to be approached gently, if one lid not wish to seare it, and the rule for the treatment of all wild animals held good for this one also: the trainer must show at the same time that he does not fear the animal and that he does not intend to harm it."
The fur of the Ermine is not very expensive, but is still highly valued for its beauty. In olden times it was used only by princes, but now it is more common.

Special Charac- The Mink and its nearest relatives teristics of are very closely allied to the Polecat the Mink. and differ from it only by a flatter head, larger eanine teeth, shorter legs, the presence of webs between the toes, especially developed in the hind legs, a proportionately longer tail and a lustrous fur consisting of close, smooth, short hair, resembling Otter fur. Its color is a uniform brown. There is a European and an American species. Until very recently little was known about the mode of life of these two animals and even now the published observations are far from satisfactory, especially those relating to the European species. I owe a great deal to the experiences of a Lubeck forester, who has kindly put his observations at my disposal. The American 1 ink has been described by Audubon and Prince de VIied.

The European The European Mink or Nerz (Putorius Mink or (utriola) attains a length of twenty Nerz. inches, about six of which go to the tail. The body is long and slender, the legs are short, and the whole animal resembles the ()tter, except that the head is still more slender. The feet are similar to those of the Polecat, but the toes are connected by webs. The lustrous fur consists of dense, smooth, short and rather hard outer hair, of a brown color, and a grayish, matted, woolly inner coat. The color is darker in the middle of the back, on the nape of the neek and on the buttocks than on the rest of the body, and the tail is usually darjer than the sides. On the under parts the tint merges into grayish brown. The throat shows a small whitish or light yellow spot, the upper lip is white in front and so is the whole lower lip.

The American The American Mink (Putorius e'ison) Mink's shows a similar distribution of colors,

Superior fur. but its fur is much more esteemed, as it is softer and of a more woolly character. It is a little larger than the European Mink.

In their mode of life both animals probably agree in all essentials and, therefore, I will give an account of the most important points in the description of the A merican Nink by the above-mentioned naturalists, before I proceed to describe the European Nerz.

Audubon's Aceording to Audubon the Mink observation of ranks next to the Lrmine in dethe Mink. structive activity, prowling around the farm-yard or duck pond; and its presence is soon deteeted by the sudden disappearance of sundry young Chickens and Ducklings. Audubon had a personal experience with a Mink which had taken up its abode in the stone-dam of a small pond near the home of the naturalist. This pond had been dammed for the benefit of the Ducks in the rard, and in this way afforded the Mink hunting-grounds of ample promise. Its hiding place had been selected with cunning and audacity; very near the house and still nearer the place where the Chickens had to pass on their way to drink: In front of its hole there were two large stones, which served the Mink as a watehtower, from which it could overlook the yard as well as the pond. It would lay in wait for hours every day, and would carry away Chickens and Dueks in broad daylight until the naturalists put an end to its carcer. Audubon found the Mink to be especially plentiful on the banks of the Ohin river and there observed it to be of some use in eatehing Mice 
and Rats. Besides this sport, which is of some benefit to Man, it is unfortunately addicted to poaching and fishing. Audubon observed it to swim and dive with the greatest agility and pursue and attack the quickest of fishes, such as the Salmon and Trout, as successfully as an Otter. When better provender is not procurable it is content with a Frog or a Lizard, but when food is plentiful, it is very fastidious. In swampy regions it preys upon Water-rats, Finches and Ducks; on the shore it preys on Hares, in the ocean it feeds on Oysters and from the bottom of rivers it takes Mussels and other shell-fish ; in short, it adapts itself to the locality and knows how to profit by whatever food supplies it nay be able to find. When frightened, it gives forth a very fetid odor, like the Polecat.

The five or six young to which the female gives birth at the end of April, may be found in holes under projecting banks of rivers or on sinall islands, in moors, or even in hollow trees. If taken young, they get to be exceedingly tame and become genuine pets. Richardson saw one in the possession of a Canadian lady, who used to carry it about with her, in her pocket.

The $\mathrm{Mlink}$ is easily caught in any kind of trap and is as frequently shot as it is caught; but its tenacity of life renders a good aim necessary.

The European The Europe-

Mink now an Mink or Rare. $\quad \mathrm{N}$ e $\mathrm{r} \mathrm{z}$ a s been described much less than the American species. Wildungen wrote in I799 that the Mink was then a rare animal, unknown to most German sportsmen; he had long wished to see it closely and owed the realization of this wish to the indefatigable zeal of Count Mellin. He proceeds to give us a few details, observed by the latter: "The Mink resembles the Marten in its manner of

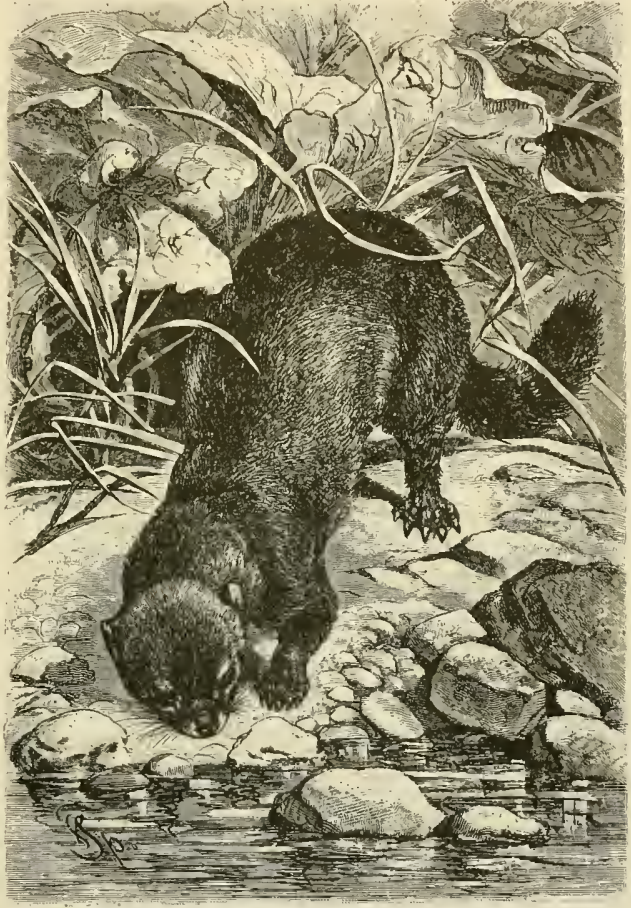

THE EUROPEAN MINK. - This animal, sometimes also called the Nerz, much resembles the American Mink, except that it is somewhat smaller and its fur is coarser. The long, slender body, the webbed feet and the keen, watchful node of waiting for and attacking its prey, are well shown here. It inhabits swampy regions and banks of streams, and is an expert at fishing and catches smali mammals, birds and Frogs, (Putorius lutreola.) bly young Water-hens and Woodcocks also fall victims to it. The high price which its fur brings, even in summer, increases the efforts made to capture this rare animal, and it may soon be exterminated in omerania, where Mellin observed it."

This extract contains really all we have so far kown about the Mink. The fear that it has been exterminated in Gcrmany has become general, but ock the Mink occurs all ove home is eastern liurope, Finland, Poland, Lithuania, Russia. There it is found from the Baltic Sea to the Ural, from the Dwina to the Black Sea, and not very rarely. It also inhabits Bessarabia, Siebenbuergen and Gallicia. In Moravia, Silesia and Holstein it is very rare; yet I received from Holstein the following report from Mr. Claudius, a forester well versed in zoological matters

Habits of the "The Mink
European likes the European likes the
Mink. reedy surroundings of lakes and rivers, and takes up its abode in dam-like eminences in the roots of alder trees, as near as possible to some body of water, and it provides this habitation with several outlets in the direction of the water. Burrows leading away from water are never found. When a Polecat is compelled to desert its hole, it cannot be driven into the water, but invariably looks for safety on land, where it is always able to find innumerable chances for escape; but the Mink, under like circumstances, drops vertically into the water and disappears from view. It is extremely difficult to shoot it in the water, for it stays in a long time, and emerges at a considerable distance from the place at which it dived beneath the surface. When under water, even if the swimming space is very limited, the Mink is perfectly secure from capture by a Dog."

The European For many years Claudius and I had Mink in tried in vain to obtain a living Mink. Captivity. At last, in 1868 , he wrote me that a female Mink had been caught and brought to him. It appeared to thrive on a diet of milk and meat, and, as its temper seemed quiet, he hoped the wound caused by the trap would soon heal. "It is a great deal better-natured than the other Weasels," Claudius writes, "it is only angry when irritated. It prefers to pay no attention to me, but allows me to stroke its fur with a little stick without taking it amiss. All day long it lies curled up on a bundle of hay in the cage. At night it prowls around in its ever, happens only in isolated dwellings, and I have consists of fish, Frogs, Crabs and Snails; and proba- 
spacious dwelling, and several times has left it. The first time it did this, 1 found it hidden in a corner of a room. Later on, whenever it succeeded in freeing itself during the night, I always found it on its hay in the morning, as if it had undertaken its nocturnal wanderings with a view to relaxation rather than with the intention of escape."

After the Mink liad become completely reconciled to its loss of liberty, and so tame that it allowed its owner to take it up and seemed susceptible to caresses, Claudius sent it to me in a chest. Even while I was opening it, I knew that I had to deal with a Mink, for there was no trace of the disagreeable odor a Polecat would have given forth under similar circumstances. I may well say that no other animal ever gave me the joy 1 experienced in seeing this rare specimen, a European Mink. I had been yearning for years to possess one, and this animal, fortunately, has thrived for many years in my care. Late in the evening, never before sunset, it quits its bed and prowls around in the cage. This it does every night, and thus explains the ignorance that prevails concerning its habits; for who can follow the Mink in the dark of night in its favorite haunts - the moors? As far as one can judge in a confined space it seems to resemble the Polecat most in its movements. It possesses the agility of the Martens, but has neither their aptitude at climbing nor their activity. It may be said that the Mink does not make one unnecessary step. The intelligent little head is never at rest; the keen eyes incessantly search the room, and it pricks up its little ears to take in, by its sense of hearing, what might escape the eyes. If it is offered a living prey, it pounces upon it with Weasel-like rapidity, kills it with a few bites and drags it into its hole.

Fish and Frogs seem to be its favorite food, though Claudius thought that it preferred meat and ate fish only in default of it. It astonishes me, that my prisoner rather shuns water than yearns for it. An Otter tries to profit by the friendly element even within the most limited space, but my Mink never thinks of it; it uses the water only for drinking, never to bathe or play in.

\section{THE GLUTTON.}

The Glutton, or Wolverine, is one of the clumsiest members of the Marten or Wieasel family and represents a distinct group, Gulo, whose distinguishing features are as follows: The body is stout and strong, the tail short and very bushy, the neck thick and short, the back arched, the head large, the snout elongated and blunt, the legs are short and stout, the clumsy paws have five toes, and are provided with curved and compressed claws.

Description of The Glutton (Gulo boralis) is a little the Glutton over three feet long, six inches of or Wolverine. which go to the tail. The shoulder height is from sixteen to seventeen inclies. On the snout the hair is short and thin; on the feet it is thick and lustrous; on the body long and shaggy; on the legs, the light side-bands and the tail it is very long and coarse. The top of the head and the back are of a brownish black, with an admixture of gray hairs: the under part and the legs are black. There is a light gray patch between eycs and ears and a light gray band runs from the shoulders along the sides. The woolly under-fur is gray, and beneath the body is brownish.

The Glutton inhabits the north of the globe. From southern Norway and Finland it spreads all over northern Asia and North America to Greenland. Formerly its southern boundaries in Europe were formed by lower latitudes than now; during the Reindeer period it extended to the Alps. Bechstein tells us of a Glutton that was killed in Saxony. Zimmerman of another caught in Brunswick. These two are considered isolated animals, for it seems very improbable that the Glutton is to be found so far south in modern times. Its native range is Norway, Sweden, Lapland, northern Russia, especially the country surrounding the White Sea, Perm, Siberia, Kamcliatka and North America.

The Glutton's Older naturalists relate the most Voracity marvelous tales of the Glutton, and

Exaggerated. it is their fault that the animal bears a name signifying the same thing in all languages. Michow, for instance, says: "In Lithuania and Moscovia there is an animal called Rosomacha (the Russian name for it), which is very gluttonous. It is as large as a Dog, has eyes like a Cat, very strong claws, a body clothed with long brown hair, and a tail like a Fox, only shorter. When it finds a carcass it eats until its stomach is distended and returns to its repast as soon as it is able to eat more, repeating its meals until it has devoured the carcass. It seems to do nothing but eat and drink and eat again." Steller las long since refuted these silly stories, and Pallas gives a correct account of this strange animal.

Range and The Glutton inhabits the mountainous Habits of the parts of the north, preferring, for inGlutton. stance, the barren heights of the Scandinavian Alps to the immense forests of the lower mountains, although it is also found in these latter situations. It has no permanent hiding-place, but changes its lair according to circumstances and hides at the approach of night in any place that is propitious, be it in a thicket, a cleft of rock, a forsaken Fox burrow or a natural cavern. Like all of the Weasel tribe, its habits are essentially nocturnal, still it prowls around at will in its native country, so little inhabited by human beings, and shows itself also in the light of the sun. It would be compelled to do this, anyway, as in the most northerly regions of its native range the sun shines day and night during the summer.

It spends the winter like its nearest relatives among the Weasels without falling into a deep sleep, and its large paws enable it to walk on the snow with ease. As it is not fastidious in its taste it leads a confortable, easy life, without ever being in great straits. Its movements are peculiar, and its walk especially distinguishes it from all other animals of which I have any knowledge. It rolls itself along with large bounds, limping and turning somersaults. Yet, despite its peculiarities of gait, its walk is not slow, and it can easily overtake small quadrupeds and attack larger ones after a longer pursuit. In spite of its clumsiness it can ascend small trees. It lies in wait on the branches, close to the trunk, till some game passes beneath. Its smelling faculty ranks first among its senses, and its sight and hearing are also very efficient.

How the G/ut- Its principal food consists of Mice, and

ton Secures especially Lemmings, of which it exter-

Its Food. minates astonishing numbers. As these animals abound in certain seasons, it does not need to look for other prey. It follows Wolves and Foxes in the hope of obtaining a portion of their prey. When Mice are scarce it is obliged to hunt nobler game. It is an established fact that it attaclis and sometimes kills Reindeer, and even Elks. Thunberg 


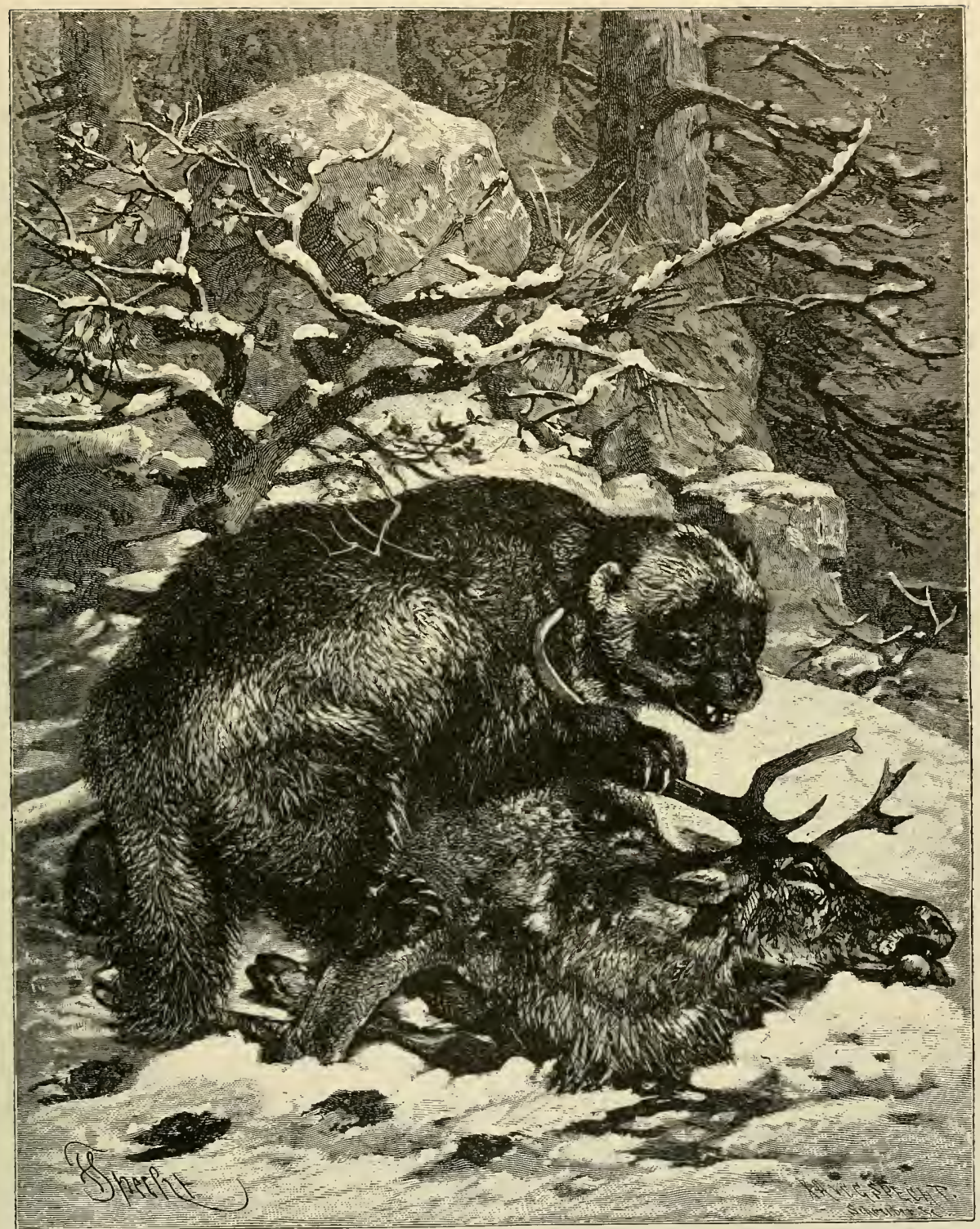

THE GLUTTON, OR WOLVERINE. - This animal, which is found in the cold northern regions of Europe, Asia and America, receives its name from the earlier belief that it was abnormally voracious, but it does not appear to deserve its title. It is a very fierce hunter, however. and kills animals of all sizes from the Mouse to the Elk, the picture describing its attack on the latter animal. It is a clumsy but powerlul animal with a coarse fur which is long and shaggy, except on the snout. (Gulo borealis.) 
was told that it could kill Cows, lacerating their throats. Loewenhjelm, in his "Travels in the North," mentions that it causes ravages among flocks of Sheep, and Erman was informed by the Ustjaks that it would jump upon the neck of Elks and kill them with a few bites. My hunting companion, Eric Swanson, told me that in Scandinavia it gently approaches snow-birds, pursuing them in the burrows which they excavate for themselves, and easily kills them. The Glutton is heartily detested by: the hunters. My companion assured me that whenever, having killed a Reindeer, he neglected to hide the carcass under stones, he would find, on his return, that his game had been partly eaten by the Glutton. Frequently it steals bait from traps or eats a portion of the animals caught in them. It acts exactly in the same way in Siberia and America. It often creates great ravages in the huts of Laplanders. It opens for itself a way into the dwelling through doors or roofs, steais meat, cheese, dried fish or similar things, tears the skins of animals which the inmates have prepared for narket, and often, when famished, eats part of them. It is active day and night in winter, and, when tired, scoops a hole in the snow and rests in comfort. It eats smaller animals on the spot where it kills them, but it carefully buries the uneaten portion of larger animals, to which it returns for a second repast.

Methods of Uwing to the great activity of its depHunting redations the Glutton does not enjoy. the Glutton. the particular esteem of the northern nations, and it is hunted, pursued and lilled in every possible way, though its fur is by no means widely used. Only the natives of Kamchatka value it highly, but they believe that there is no fur superior to the Glutton's pelt.

Although a small animal the Glutton is an antagonist not to be despised, for it is strong, fierce, and has a capacity for resistance out of proportion to its size. It defends itself against Man only when there are no means of escape. Usually it takes to flight at sight of a hunter, and when pursued, it climbs a tree or mounts high rocks, where its enemies cannot follow it. In treeless plains it is soon overtaken by Dogs, but defends itself against them with great intrepidity.

How the A young captive Glutton is very playGlutton Acts ful, nearly like a young Bear. Ithen in Captivity. tied to a pole, it runs back and forth in a semicircle, shaking its head and grunting. When it anticipates an unfavorable change of weather it becomes sulky. Though not quick in its movements, it is in constant motion when awake and lies still only when sleeping. When a tree is brought into its cage, it climbs it with ease and seems to delight in performing gymnastic feats on the branches.

Three Gluttons The real character of the IVolverine is

observed only completely displayed when it is in in Captivity. the society of animals of its own kind. In the Berlin Ticrgarten three Nolverines, an old one and two young ones, shared a cage. It would be difficult to imagine anything merrier than these two young creatures. They were seldom seen at rest; the greater part of the day they spent in play, which at first was good-natured, but soon became more serious and occasionally ended in a duel, in which both fighters made good use of claws and teeth. When the play was over, they tripped through the cage, sniffed in all corners, threw the dishes containing food and water over and vexed the honest washerw oman who had to clean their cage, display- ing a great liking for the investigation of things which did not in the least concern them. Then they again picked a quarrel with each other and resumed their play, keeping people for hours before their cage. When the keeper entered bringing the food, they behaved quite differently. The first time I saw them fed, I suddenly understood why they had been called "Gluttons," Whining, howling, growling, barking, showing their teeth and boxing each other's ears, they ran about the cage in a crazy manner, looking at the meat with aridity. If the leeper did not hand it to them inmodiately, they rolled themselves on the floor in despair, and as soon as a piece was thrown them, they rushed at it with such eagerness, chewed it with such an accompaniment of growling and smacking of lips, devoured and swallowed it so greedily, that one could no more doubt that the older authors had found some foundation for their stories about the Glutton, by observing the animal in captivity.

\section{THE GRISONS.}

The Grisons (Galictis) are members of this family who live in Brazil, and they are of slender, Martenlike build. They have a rather thick head, larger behind, provided with low, rounded ears and relatively large eyes, short legs, moderately large feet provided with five toes connected with webs, bearing sharp, curved claws, and naked, callous soles. The tail is of moderate size, or rather long, the fur is short and the teeth differ from those of the other IVeasels. The secretion of their scent-glands has a strong odor of musk. There are two species known now, both inhabiting forests and bushes. They are very agile, climb well and prey upon small and medium-sized animals; they also share the predilection of the Ratel and the Bears for honey. The names of the two species are the Tayra (Galictis barbara) and the Grison (Gulictis vittata).

\section{THE BADGERS.}

The second sub-order of the Martens is formed by the Badgers (Milite) and numbers among its members the stoutest forms as well as those giving forth the most offensive odors. Their mode of walking is plantigrade.

The Badger is a complete type of a selfish, distrustful, sulky, ill-humored creature. Nearly all observers agree on this point, though they do not depreciate the usefulness of the animal. The Badger is the most harmless of all European larger beasts of prey, yet it is hunted like the Wolf or the Fox, and has not even found defenders among sportsmen, a class of people who usually are fondest of the animals they pursue most. Pcople condemn it, without stopping to consider that it honestly makes its living in its own way, and that only its peculiar mode of life is at the bottom of this dislike. It is really a sulky fellow, avoiding the society of Man or beast, and as lazy withal as it is possible to be. These qualities are not adapted to gain it many friends, but I must confess that I personally am fond of it; its mode of life and its actions amuse me.

The genus Mcles, represented by the liadger, is distinguished by a heavy, stout body, a thick neck, and a long head, the snout tapering like a proboscis, the eyes and ears are small, the soles naked, and the fore-paws are provided with strong claws. The tail is short, the fur coarse and thick, and there is a slit under the insertion of the tail leading into the scentpouch. The teeth are surprisingly strong. 
Characteristics The common Badger (Meles taxus or of the Miles aulgaris) attains a length of Common Badger. thirty inches in its body and seven inches in its tail. Adult males may weigh as much as forty pounds in the fall. The fur is rather long, harsh, nearly bristle-like and glossy. Its color is grayish white mixed with black on the back, reddish on the sides of the body and the tail, black-brown on the under surface and the feet. The head is white, but a faded black stripe runs on each side of the snout, over the eyes and white ears and loses itself in the neck. The females are smaller in size and lighter in color, the whitish woolly under fur coming nearer the surface. White badgers are very rare, and those that are white with chestnut spots are still more rarely found. retain its independence to the most complete degree. Its strength enables it to dig out burrows with ease, and like a few other animals leading a subterrancan life it can bury itself in a few minutes.

Observations of The Badger spends nearly all its life

Badgers in in this burrow and goes a certain dis-

the Wild State. tance away from it only at night. In very solitary woods it may come out for a walk in the afternoon in late summer, and I have net it myself in the daytime, on the Isle of Rugen, but such instances are the exception. Tschudi says: "A sportsman who had the rare chance of observing a Badger in the free state, gives an interesting account of it. He repeatedly visited a Badger's burrow, situated on the edge of a precipice, and which was plainly seen from the opposite side. When the wind

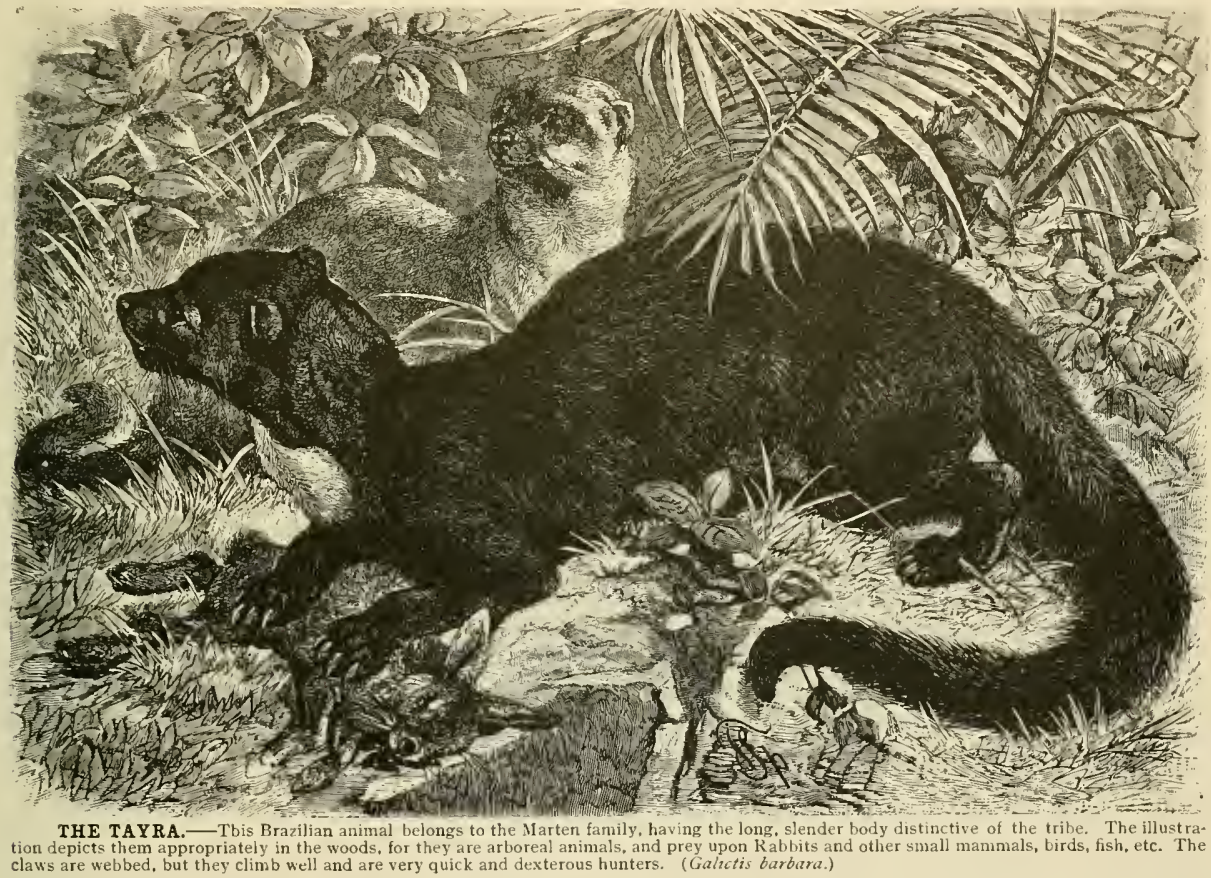

Home and With the exception of Sardinia and Haunts northern Scandinavia, the Badger is of Badgers. found all over Europe ; it inhabits Asia from Syria through Georgia and Persia to Japan, and Siberia as far as the Lena. It leads a solitary life in burrows, which it digs out with its strong, curved claws on the sunny side of hills, provides with from four to eight outlets, and furnishes most comfortably. The round chamber at the bottom, which may be approached through several conduits, is so large that it can hold a soft, large heap of moss, the animal and its young. Few of the conduits are regularly used, most of them serving only as means of escape in danger, or as ventilators. Scrupulous cleanliness is observed throughout, in great contrast to most similar subterranean habitations of other animals. The site selected by the hermit is usually a wood near a meadow, or a meadow on a hill, but always a quiet, solitary spot. The animal is fond of a comfortable, contemplative mode of life, and likes to was favorable, the hunter softly approached the object and soon saw an old Badger, sitting there sulking and lost in its own tiresome thoughts, but seemingly enjoying the warm sunshine. This was no accident, for he often saw it again on bright days, basking in the sun's rays. It spent its time in comfortably doing nothing. Either it sat still, gravely looking around, or rocked to and fro upon its forelegs like a Bear. This comfortable quietude was sometimes interrupted by sanguinary parasites, which it destroyed on the spot with great expedition, after which it would again bask in the sunshine, alternately exposing its broad back or well-nourished stomach to the warning rays of the sun,"

During the breeding season the Badger lives with its mate; the rest of the year it lives alone, holding friendly relations with no other animal. The Fox sometimes forces its society upon it in old and wideextended burrows, but even then the animals care little for each other, the Fox inhabiting the upper 
chambers and conduits, while the Badger is content in the lower ones.

Habits and The movements of the Badger are slow Food of and lazy, its walk is clumsy and its most the Badger. rapid trot is so slow that it is believed a good pedestrian can overtake it. The animal's appearance is so strange that it is often misleading. At first sight of it one is reminded of a Pig rather than a Beast of Prey, and I think that in order to identify it positively one has need to be fairly familiar with its shape and habits. The grunting noise it makes is very suggestive of the Pig.

During the spring and summer its food consists of roots, insects, Snails and Rain-worms ; also, occasionally, young Hares, eggs and young birds. It is very expert in digging out Rain-worms with its sharp, long claws, which it uses likewise in searching for the larve of the May-bug and other destructive insects, which live in the ground, in ficlds and meadows. It also digs up Humble-bees' and Wasps' nests, tribe and does not damage, but helps to preserve, a forest. A forester who exterminates it sins against himself and works detriment to the forest which is in his care.

Hibernation At the end of autumut the Badger is well of the fattened. Then it thinks of the coming Badger. winter, which it intends to spend as confortably as possible, and, therefore, makes its preparations to that end. It carries leaves and grass into its hole and makes a thick, warm bed. Until the approach of cold weather, it lives upon the provisions it has garnered. Then it curls up, lying on its stomach, puts its nose between its fore-paws and goes to sleep. The hibernation is irregular, like that of the Bear. If the cold is not intense, especially if a thaw comes, or there are mild nights, it rouses itself, and sometimes leaves its hole to drink. If the weather is relatively warm, it transiently sallies forth as early as January or February to dig out roots, or, if fortune smiles on it, to catch a

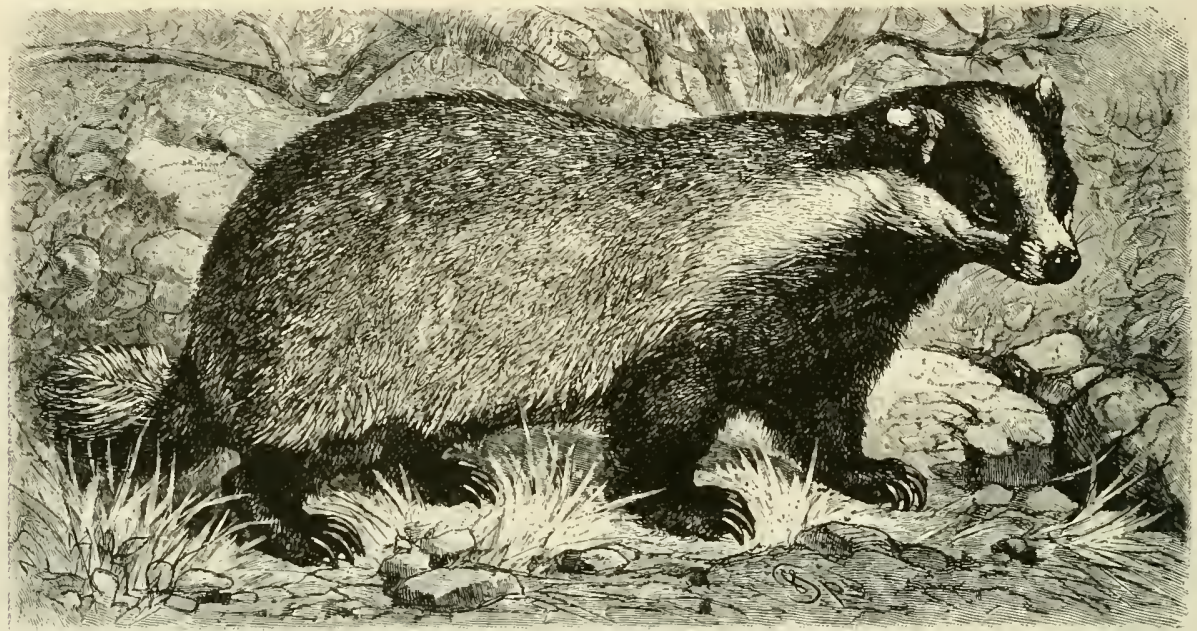

THE COMMON BADGER, — This animal, found in nearly all Europe and a large part of Asia, has a thick, gray fur on its back and sides, dark brown underneath, and a white face with black stripes, as shown in the picture. It is as clumsy as 1 t: looks, but is famous for the carefully

delichting in the honey-combs and caring little for the stings of the angry owners, protected as it is by its rough fur, a thick hide and a goodly layer of fat. snails, and possibly Butterflies and Caterpillars, are picked from trees and eaten with relish.

In autumn it rejects such food as acorns, etc., but enjoys fallen fruit, carrots and turnips; nor does it disdain small quadrupeds, such as Mice, Noles, etc., and Lizards, Frogs and snakes are welcome additions to its bill of fare. Sometimes it ravages vineyards, compressing the ripe fruit with its paws and reveling in enjoyment of this relish. V'ery rarely it steals young Ducks and Geese from farms lying near forests ; for it is exceedingly shy and distrustful, and leaves its abode only when it feels sure it will not be observed. Frequently it feeds upon the carcasses of animals it finds dead. On the whole, it eats little and its winter provisions do not amount to a very large store. The Badger does not cause any perceptible damage in Europe; or when it may do so, it always amply compensates for it by catching and eating all kinds of vermin that infest the forests and fields. It is the most useful member of the IVeasel
Mouse. Still, fasting does not agree with it, and at the approach of spring its roundness has disappeared and its appearance is nearly that of a skeleton; but after the period of hibernation is over it rapidly accumulates flesh and regains its rotundity.

The Female Toward the close of February, or beginBadger ning of March, the female Badger gives and roung. birth to from three to five blind young, for which a soft bed of moss, leaves, ferns and long grass has been carefully prepared. Of course she lives in her own burrow, for the female Badger is as inveterate a hermit as the male. She loves her little ones tenderly, and, after weaning them, brings them worms, roots and small animals, until they are able to provide for themselves. Three or four weeks later the small and pretty animals appear at the mouth of the hole and bask in the rays of the sun. They are very playful and afford a pleasing spectacle, the more so as one rarely has the chance of seeing it. They remain with their mother till autumn, when they leave her and undertake to cater for themselves. They are fully grown in the second year and may attain an age of ten or twelve years. 
Methods of Various devices are employed in catchCatching ing the Badger. Sometimes it is dug or the Badger. bored out of its burrow in a most cruel manner, with an instrument resembling a corkscrew; or it is driven out by Dogs and then shot. Its only chance of escape is by hiding so successfully that not even the Dogs can find it in its burrow, it being so clumsy that it could never escape by flight. When pursued to its burrow it therefore usually seeks to save itself by noiselessly burrowing deeper with great rapidity. Frequently it escapes the vigilance of the Dogs by pursuing this course.

The best time for shooting the Badger is very early in the morning, when it is upon its return home. Waiting for it in the evening is a very tedious task, as the distrustful animal comes out only in the middle of the night and then it sallies forth in the most quiet manner possible.

Old Badgers that are taken from their burrows are most disagreeable creatures, ungrateful for kind treatment and incapable of receiving instruction, being lazy, distrustful, treacherous and malicious. They show their teeth at the slightest provocation, and viciously bite every one who approaches them incautiously. Those that are captured young and handled with care behave differently. They are capable of domestication and affection, especially if they are fed a vegetable, or $\mathrm{ma}$ in $1 \mathrm{y}$ a vegetable diet. They may become so tame as to follow their keeper about and return to their cage at his command.

$\begin{array}{cc}\begin{array}{c}\text { Account of } \\ \text { a Tame }\end{array} & \mathrm{Ludwig} \\ \text { Badger. } & \text { Beckman } \\ & \text { writes to }\end{array}$

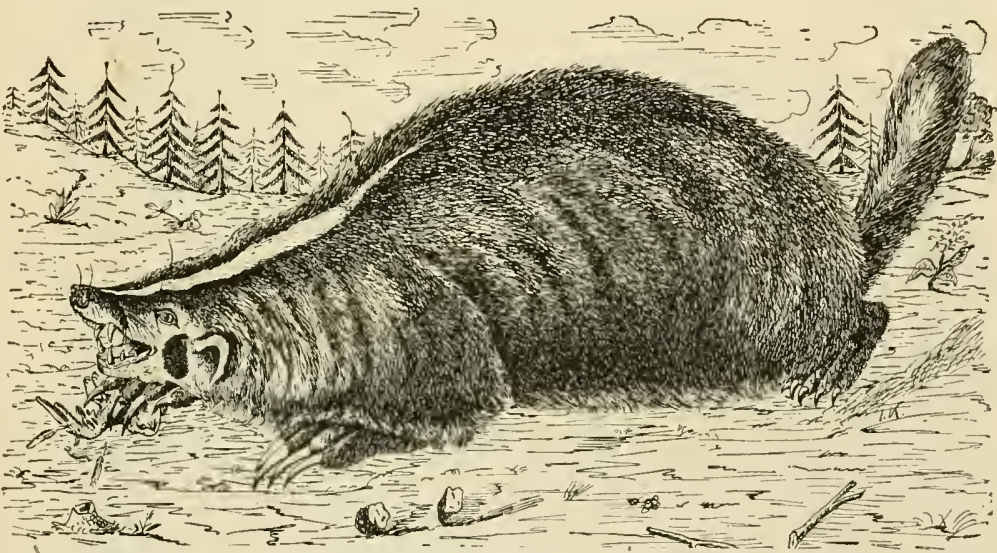

THE AMERICAN BADGER, OR TAXEL. - The American representative of the Badger tamily, distributed al! me as follows about a tame Badger: "I have

ing, with her hair standing on end. In this manner she would trot back and forth before the Dog, like an enraged Turkey. In a few monents her hair would lie flat again, she would put her fore-paws down, and shaking her head with a conciliatory grunt hu hu, gu gu,' she would resume the wild play.

She was allowed the freedom of the whole house, for she had exceedingly cleanly habits, and seemed to take special delight in trotting up and down stairs. Frequently she would trot quietly around in the barn, putting her curious nose into every corner. She estecmed it a special favor when she was allowed to stay with me during a meal; at such times she pushed the Setter unaffectedly aside, put her fore-paws and her sleek, striped head on my lap. and uttering her customary 'hu hu, gu gu,' pleaded for a piece of meat, which she very gently and dexterously detached from the fork with her front teeth. During the winter she liked to lie in front of the stove, turning her broad under surface to the cheerful fire.

In summer she often accompanied me to a little

had a perfectly tame female Badger in ny possession, and I mourn her loss deeply. Kaspar - that was her name-was an honest soul, though not given to refined notions. She desired to live at peace with all the world, but her clumsy tricks often led to misunderstandings and unpleasant experiences. Her best chum was a very agile, sagacious Setter, which I had trained from puppyhood to associate with all kinds of wild animals. The Dog and the Badger gave us, so to speak, veritable tournaments on beautiful evenings, and people who were fond of animals came to see them from miles around. The essential feature of the fight consisted in the Badger's shaking her head like a Wild Boar, and then running at the Eog, trying to hit him sideways with her head in passing. But the Dog would jump over her with a graceful bound; when she proceeded to a second and a third attack. Then he would run into the garden, and if, in the pursuit, she succeeded in catching him by his hind leg, a vigorous fight ensued, which, however, never proceeded to serious results. When Kaspar became angry, she would retreat a short distance, stand on her hind legs, trembling and pant- wood, where she felt completely at home and made new discoveries at every step. Either she caught a Humble-bee or dug a worm out of the ground, or she found some berries, or a Snail on the way. When I was returning, she sulkily trotted at my heels, and usually would begin to pull my trousers with her teeth. If I administered to her a sound kick with niy foot, she regarded it in the light of an encouragement to proceed with her play; but the slightest slap with the hand or a blow with the whip wounded her deeply."
The Alnerican Badger a
The American Badger or Taxel (Taxideu Distinct Variety. its European cousin, is now justly regarded americana), which was formerly classed with stoutly built, has a flattened appearance, and is about twenty- four inches long; the tail six inches. The fur is a grizzled mixture of a blackish tawny-gray and white, and the tail is broad and flattened. The claws on the fore-paws are very large and strong, furnishing the animal excellent tools for dig- ging. The snout is shorter and the over-hair, which projects above the woolly undercoat, is softer than that of the European Badger ; and this soft hair is used for making painters' pencils. Dr. Elliot Coues says that "the Badger, above all our other animals, is notable for its flatness ; even when running it looks broad and flat, and its bodv seems to sweep the ground during 
its rather slow, heavy and awkward progress. Seen when crouching in fancied security, or hoping to escape observation: (and it will sometimes remain long motionless in this posture, permitting near approach), the animal might easily be mistaken for a stone or clod of earth. The very hairs lie tat, as if parted in the middle, and form a fringe along either side, projecting, as one writer has remarked, 'like the shell of a turtle or the eaves of a house

Home and Habits This Badger is found in the greater part of of American the United States, Canada and Mexico. The Badgers. portions of 'Texas and California has been by some authorities classed as a distinct species under the name of the Mexican Badger (Taxidea americana), but the characteristics of the animal do not differ materially from the

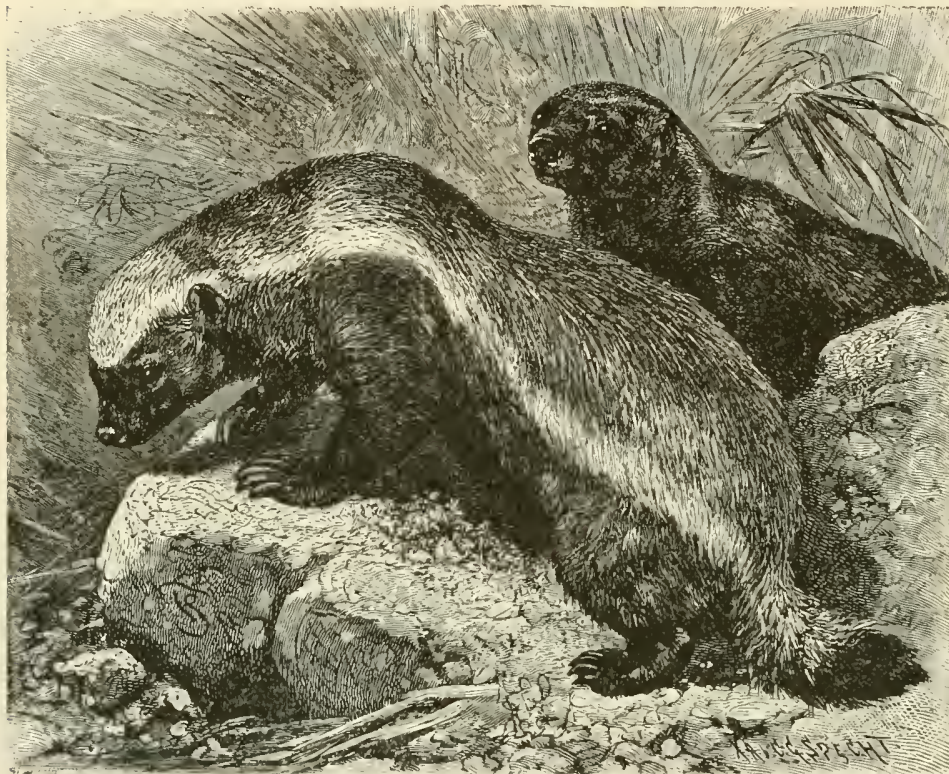

THE RATEL, OR HONEY-BADGER. - This African animal is so peculiar in its narkings as to be at once distinguished from any other. The difference between the light fur which covers the upper part of the body and the dark covering of the lower half is sharply defined as shown in the picture. The strong claws, which are also shown, give it great digging ability, for it eats roots as well as small animals, and excavates itself a burrow with great rapidity. Its predilection for honey gives it the name it bears. (I/Cliturit cafpessts.)

Anserican Badger, of which it is now regarded as being only a local variety.

The American Badger inhabits plains principally; although it is also found in wooded districts, and is especially numerous in the region west of the Mississippi to the Pacific coast, abounding in very large numbers in the plains watered by the Missouri and the arid, sage-brush plains between the Rocky Mountain and the Sierra Nevada ranges, where Badgers'burrows are encountered constantly. The animal itself is not so frequently seen, for it shuns Nan and hastily retreats to its burrow to escape human sight. When attacked by a hunter at close range it shows fight, bristles up its hair until it appears much larger than it really is, and instead of retreating advances open-mouthed and with a great display of ferocity. The hunter who attacks it with a stick will need much caution, for it clings to life tenaciously, and snaps at its assailant viciously, and its bite inflicts a serious wound. It is usually caught in traps, as it is difficult to find, and only a few can be obtained by hunting theur.

The American Batger is more carnivorous than the European species, and its principal prey are the rodents which abound in the region it uccupies. Where Gophers are found the Badger digs them out and kills them, taking possession of their burrows and, according to Dr. Samuel Lockwood, "enlarges the establishment to suit his own ideas of convenience."

\section{THE RATELS.}

Another group is formed by the Ratels, cr Honey Badgers (. Hellizora). They are animals possessed of broad backs, short snouts and short tails; the body is clumsier than that of the Badger and has a flattened appearance, the back being very broad and tlat; the snout elongated; the small ears scarcely visible above the fur; the eyes are small and lie very deep; the legs are short, stout and bare-soled, and the toes of the fore-paws are provided with long claws, adapted for burrowing.

The Ratel The Ratel, or Honey Badger (Melor Honey Badger livora capensis), attains a length of Described. twenty-eight inches, ten of this forming the proportionately long tail. The hair is long and wiry; forehead, back of head and neck, back, shoulders and tail are ashy gray, while the snout, cheeks, ears, throat, breast, underpart and legs are grayish black, the line of demarcation between the two colors being very distinct. Usually a light gray stripe separates the coloring of the back from that of the under surface of the body, distinguishing the African Ratel from its Indian cousin.

Haunts and $\mathrm{T}$ he $\mathrm{R}$ ate Habits lives in subof Ratels. terranean burrows, which it excavates for itself with incredible dexterity. It is so slow and clumsy that it could never escape its enemies, were it not for this ability to bury itself, at least in soft ground, digging a burrow so quickly as to hide before its an tagonist has had time to attack it. Its habits are nocturnal and it seldom sallies forth in the daytime. On our hunting trip to the Bogos country we saw the Ratel twice, both times in the evening, before sunset. At night it prowls around slowly, at its own will, preying on small mammals, especially Mice, or birds, Tortoises, Snails and worms; digging out roots or tubers, and looking for fruit. One preference determines its whole mode of life and gives it a distinguishing name: it is passionately fond of honey and, therefore, is a zealous hunter of Bees.

The Ratel on In the treeless regions of Africa Bees the Hunt settle in all kinds of deserted holes in for Honey. the ground, just like the Humble-bees and $W$ asps. Such a nest is the most welcome thing a Ratel can find, and when discovered the creature proceeds to destroy it with marked satisfaction. The Bees defend themselves as well as they can, seeking to wound the enemy with their stings, but its hairy, thick hide is an excellent shield, for it lies more loosely on the subcutaneotts layer of fat than that of any other animal. The Ratel is said to be really able to turn around in its skin. Bees are utterly powerless before such an enemy, which greedily digs around in their abode and feasts on its contents.

The Ratel is not only fond of honey, but also looks for more substantial food. Carmichael says 
that owners of poultry-yards regard it as one of the most destructive creatures to be found. In Algoa Bay several peasants were once quarreling over some eggs, which Hens had laid outside of their coops, when a Ratel put an end to the contention by killing all the Hens-there were about thirty of them - in a single night, and carrying three away to its den.

Description The Indian Ratel (Mellizora indica) of the is said to have the same habits as the Indian Batel. preceding animal and also to be a destructive visitor of poultry-yards. It is found all over India, to the west and northwest of the Bay of Bengal, to the foot of the Himalayas (with the exception of the coast of Malabar) and Lower Bengal. It is not found in Ceylon.

Ratels when captured young are capable of domestication and afford much amusement by the clumsiness and originality of their movements.

\section{THE TELEDU.}

The Teledu or Stinking Badger (Mydaus meliceps) is a small member of its family attaining a length of nearly fifteen inches, one of which goes to the stumpy jittle tail. The color of the thick, long fur is a uniform dark brown, with the exception of the back of the head and neck. A white or yellowish-white band runs along the spine to the tip of the tail. The under surface of the body is lighter than the upper part. The fur consists of a silky inner coat and a coarse outer one, forming a kind of a mane on the sides and nape of the neck. The Teledu inhabits Sumatra, Java and Borneo, but it is not known whether it is found on the Malay Peninsula and other parts of the continent.

Burrow of Horsfield was the Teledu the first to Described. describe the habits of this peculiar creature. It digs its hole to a slight depth under the surface of the ground with great caution and dexterity. When it has found a place protected by the long and large roots of a tree, it scoops out a hole between the roots, and a central round chamber about three feet in diameter is built right under the tree. Conduits about six feet long lead to the surface in various directions, the entrances being skillfully concealed by twigs and dry grass. During the day it remains in its burrow; but after sunset it sets forth to hunt for larvæ of all kinds, and worms, especially Rain-worms, which it finds in great numbers in the fertile soil. It digs them out like a Pig and thereby does great damage in the fields. According to Horsfield it lives in Java only upon mountains having an elevation of more than 7,000 feet above the sea, and is found there as regularly as certain plants. Modern accounts contradict these statements. Karl Bock avers that in southeastern Borneo, "where the Teledus are as common as Rats," they are found "at an elevation of eighty or one hundred feet. In Sumatra, the highest elevation in which they are found is lower than 1,000 feet and there they occur but rarely."

Traits and The Teledu is a very slow-moving aniHabits of the mal, and is therefore often caught by

Teledu. the natives, who do not fear it in the least, but even go so far as to eat its flesh, for they believe that whoever can bring himself to eat this meat enjoys immunity from disease.

During his stay in the mountains of Prahu, Horsfield asked the natives to bring him a few Teledus for examination and dissection, and they brought him so many that he soon refused to accept any more. "I was assured," says this naturalist, "that the flesh of the Teledu was very savory, if one succeeded in killing the animal quickly and immediately proceeded to remove the tail-glands, before they had time to communicate their abominable odor to the body. My native hunter also told me that the Teledu could not eject its secretion to a longer distance than twenty-four inches. The fluid is of a viscid character, and its effect is produced by reason of its great volatility; it may infect the surroundings of a whole village, and in its immediate neighborhood it is so strong that some people who cannot escape its powerful odor faint away. The various American animals remarkable for their ill odor are distinguished mainly for their ability to eject the fluid to a greater distance.

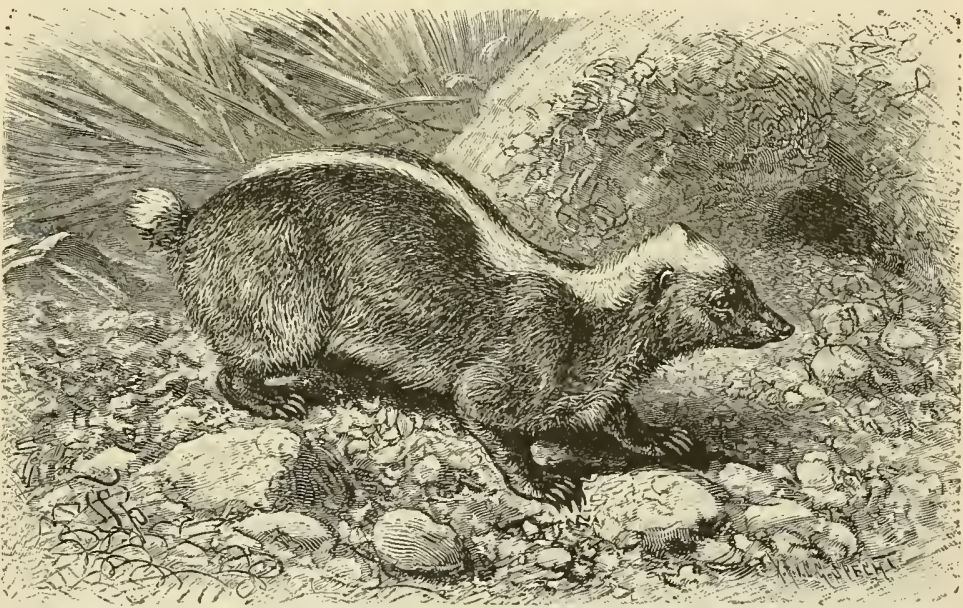

THE TELEDU, OR STINKING BADGER_-This animal, which gives forth an odor fully entitling it to its name, is distinguished by the white stripe that extends from its forehead to the tip of $j$ ts queer, stumpy little tai! as
shown in the illustration. Its strong, curved claws enable it to make its burrowing chamber, and with the aid of its shown in the illustration. Its strong, curved claws enable it to make its burrowing chamber, and with the
strong snout to dig and root for worms and larva in Java and Sumatra, where it lives. (Mydaus meliceps.)

"The Teledu is of a gentle, mild disposition, and when taken young may easily be domesticated. One specimen, which I caught, knew its home and its keeper, and never once enitted its horrid odor."

\section{THE SKUNKS.}

It cannot be averred that any of the IVeasel family give forth an agreeable perfume; there are some. even among the European species, from whose bodies a terrible stench issues forth. But the Polecat cannot vie with some of its American and African relatives, or with the Teledu of the southeast of the Old World, which has just been described. When 
one reads what abominably fetid odors they are capable of spreading, he can understand what a genutravelers and naturalists agree that one cannot portray the effect of the secretions of these animals. No chemical laboratory, no heap of refuse, no foul carcass, in short, no stench on earth is said to be as fetid and unbearable as that which the graceful animals of the genus Mephitis give forth, and with which they impregnate objects for weeks or even months. The odor is said to be pestilential, and a person who has had the misfortune to come in close relations ine scent gland means! All accounts of American

Mode of Life The Mephitis cannot be called genuine of the forest animals, as they prefer grassy or Skunk Group. bushy plains to extensive forests of tall trees. During the day they lie in hollow trees, in clefts of rocks, or in caverns which they dig for themselves, and sleep; at night they rouse themselves and eagerly seek for prey. Their usual sustenance is worms, insects, birds and small quadrupeds, but they also eat roots and berries. They use their fearful secretion only when irritated or persecuted and, consequently, frightened. They make the most sanguinary and predaceous Felidx modestly keep at a distance and find antagonists only in very courageous Dogs, who, after having been tainted by the secretion, rush at their mephitic assailants, evidently caring little, under these odorif erous circumstances, whether they, themselves, live or die. The habits of all known species of the Skunk group are very similar, and it therefore suffices to consider one or two of them only.

The Surilho The Surilho of Brazil of Brazil (MeDescribed. phitis suffocans) inhabits the greater part of South America. It is sixteen inches long, exclusive of the tail, which measures eleven inches. Its color and markings are subject to great variations. The hair is thick and long, short on the snout and may be of any tint, between grayish black, brownish black or lustrous black. The white stripes begin on the forehead and run, separated by a finger's breadth, to secretion which is the nearest approach in foulness of odor to that of its morthern cousin. The broun a mephitic is generally varied with wide. white stripes, from the forehead to the root of the tail, but dividing into two along the spine as shown in the picture. It is a rather handsome animal, with a head somewhat elongated and narrowing toward the snout, and long claws to aid it in scratching up the ground in its search for Beetles. (M/cphitis suft focans.)

with one of those anımals is avoided by every one. as though he had the plague. In spite of their small size, these animals are such powerful enemies of Man, that those whom their terrible secretion has touched are ostracised from human socicty. These creatures can render an entire house uninhabitable, or make valueless a stock of precious goods.

characteristics The Mephitis have a more slender af the body than the Badgers, a long tail,

skunk Group. a large nose, a black ground-color, and white striped markings. The head is small in proportion to the size of the body, and pointed; the small eyes have a sharp, penetrating look, the ears are short and rounded; the short legs have medium sized paws, endowed with five toes alınost completely united, and having rather long, slightly curved nails. The soles of the balls of the feet are naked. The scent-glands are large, and can be compressed by a special muscle. The secretion is a yellow, oily fluid, which, by compressing the muscle, the animal can eject a distance of several yards. Old animals and males are said to produce a stronger odor than young or female specimens. the root of the tail; in some rare instances they are absent and the animal is uniformly black. Hensel says that it would be difficult to find two specimens exhibiting exactly the same markings.

The habits of the Surilho are not essentially different from those of the W'easels. It lives in the Campos country of the valley and the Sierra and shuns dense virgin forests; yet it is confined to the woods, for it is only found in isolated forests of the Campos. Its presence is easily detected by the small, funnel-shaped holes which it makes in the grassy ground near the forest edges in its search for Beetles.

The Skunk The ill-famed Skunk (Meplitis a'arians) of North takes the place of the Suriiho in Nortl

America. America. It is about sixteen inches long, its tail measuring nearly the same. The ground color of the lustrous fur is black. A plain, narrow, white stripe commences at the nose, broadens on the forehead and still more so on the back of the head, and divides at the sloulder into two bands, which run the whole length of the body and unite at the tip of the tail. Small, white spots appear on the 
neck, near the shoulders, on the outside of the legs, and more rarely on the breast and under portion. The tail either shows two broad, white, longitudinal bands or else is irregularly marked with black and white.

The Skunk has been known for a long time on account of the reckless manner in which it insults our sense of smell, and nearly all modern travelers continue to refer to it. Its range is rather extensire; the animal being most plentiful near lludson Bay, from where it spreads southward. Its favorite haunts are the rather elevated portions of country, especially forests and beech-tree woods on riverbanks, or rocky regions, in which it takes up its abode in caverns and clefts of the rocks.

The skunk is so well aware of its formidable weapon, that it is by no means shy or cowardly. It is slow in its movements; it can neither jump nor climb, but only walk or hop. Its walk is nearly plantigrade, and it arches its back and carries its tail in a downward direction. From time to time it burrows in the ground or sniffs around for something eatable. If one happens to meet it, it quietly stops, lifts its tail, turns around and, if the intruder comes too near, ejects its noxious fluid. Hensel says that when it is pursued by Dogs, it lays its tail along its back like a sitting Squirrel, turns its hinder quarters towards the Dogs and performs queer, angry, hopping antics, such as one sometimes sees in the cages of Bears. The Dogs know their opponent's dangerous weapon and kcep at a respectful distance, but few of them having the courage to seize and kill a Skunk. The attacked animal never wastes its secretion by unnecessary haste, but continues to threaten as long as the Dogs are a few yards distant from it

Audubon's Ex. Audubon had a personal experiperience ence with a Skunk. "This snall, with a Skunk. dainty, innocent looking animal," he says, "is capable of putting the greatest braggart to flight with its first shot, so that he will run with cries of misery. I suffered from it myself when I was a school-boy. The sun had just set. I was slowly walking along with a few friends of mine. We perceived a charming little animal, unknown to us; it stopped and looked at us, as if waiting for us to come up and keep it company, like an old friend. The little thing looked so innocent and tempting and it kept its tail lifted up, as if it invited us to take hold of it and carry it home on our arms. I was quite delighted and put out my hand to take it - and the pretty little beast overwhelmed ne with its diabolical secretion. I had my eyes, nose and mouth full of it and dropped the monster as if I had been struck by lightning."

South American Skunks do not differ from their Jorth American relatives in the strength of their secretion.

The Skunk In captivity Skunks do not emit their in $\boldsymbol{a}$ terrible odor, provided one guards carecaptive State. fully against irritating them. They get very tame and tolerably well accustomed to their keeper, though they walk backwards in the beginning, their tails lifted, and ready for assault. Hay is their favorite bed, for they prepare a perfect bed with it and then curl up on it like a ball. After eating, they wipe their snouts with their fore-paws, being very cleanly, and they always keep their fur dainty and dressed. They are fed upon meat, and their favorite food is birds.

\section{THE ZORILLAS.}

In Africa the place of the Skunks is taken by the Zorillas, which are closely allied to them, but have hairy soles and have teeth more closely resembling those of Weasels.

The best known species is the Cape Zorilla (Rhabdogale mustima), which attains a length of fourteen inches, exclusive of the tail which is ten inches long. It extends throughout Africa, reaching into Isia Minor through Suez, and is said to be found eren on the Asiatic side of Constantinople. Rocky regions form its favorite haunts, and it lives either in clefts or burrows, which it digs for itself under trees and

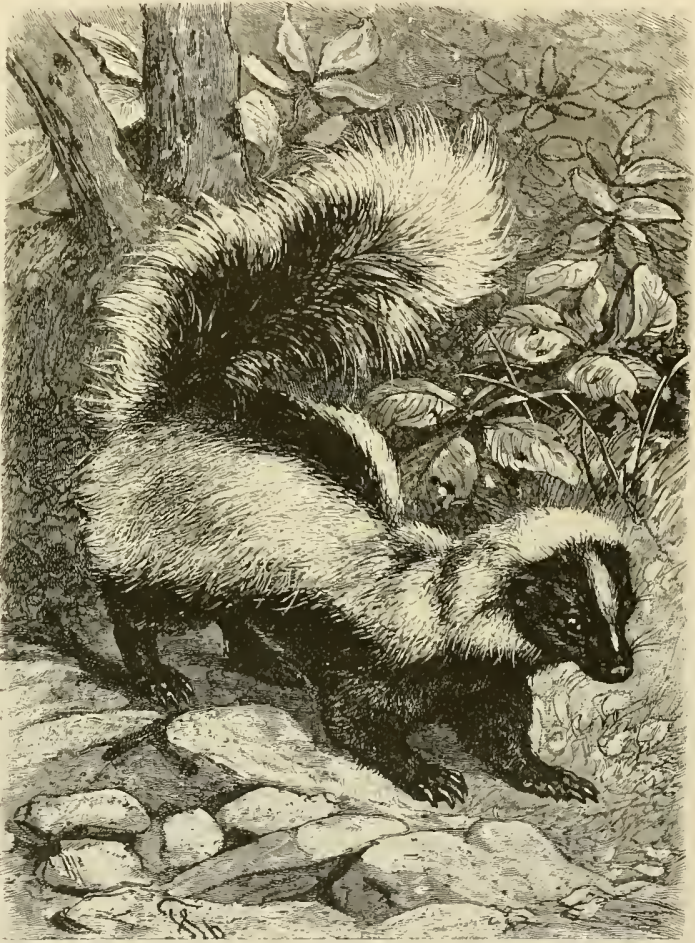

THE SKUNK. - This American animal bears the unenviable distinction of mitting a fetd secretion which, once smelled, makes all other stenches seem perumes. When an enemy approaches, the animal lifts its iong, bushy tail, preparatory emitting its foul secretion; and when a Skunk is seen in the attitude of the one in picture one would do well to retreat. (Wephitis rarians or Mcphitis mefhitua.) bushes. Its habits are thoroughly nocturnal and therefore it is seldom seen. Its food is small mammals, especially Mice, small birds and their eggs, amphibia and insects. It is frequently a menace to poultry, effecting an entrance, Marten-jike, into farmyards and slaying the Chickens like a Polecat.

The Zorilla is not Marten-Jike in its movements, for it is not agile, and may.even be styled lazy. It does not know how to climb and is afraid of water, though it swims fairly well. It uses its abominable weapon exactly like the Skunk, and finds it a very effective means of defense. 


\section{THE OTTERS.}

The third sub-order of the Martens is formed by the Otters (Lutricle), which number about twenty distinct specics that are distinguished by a long, flat body resting on short legs, a flat head with a blunt snout, small, prominent eyes and short, round ears; very well developed webs between the toes; a long, tapering, flattened tail, and short, coarse, sleck, glossy hair. The paws are five-toed, the two middle toes being but slightly shorter than the outer ones. Otiers do not possess a scent-pouch, but have two scentglands terminating at the root of the tail. The structure of the teeth and skeleton resembles that of the other Martens. The most peculiar feature is

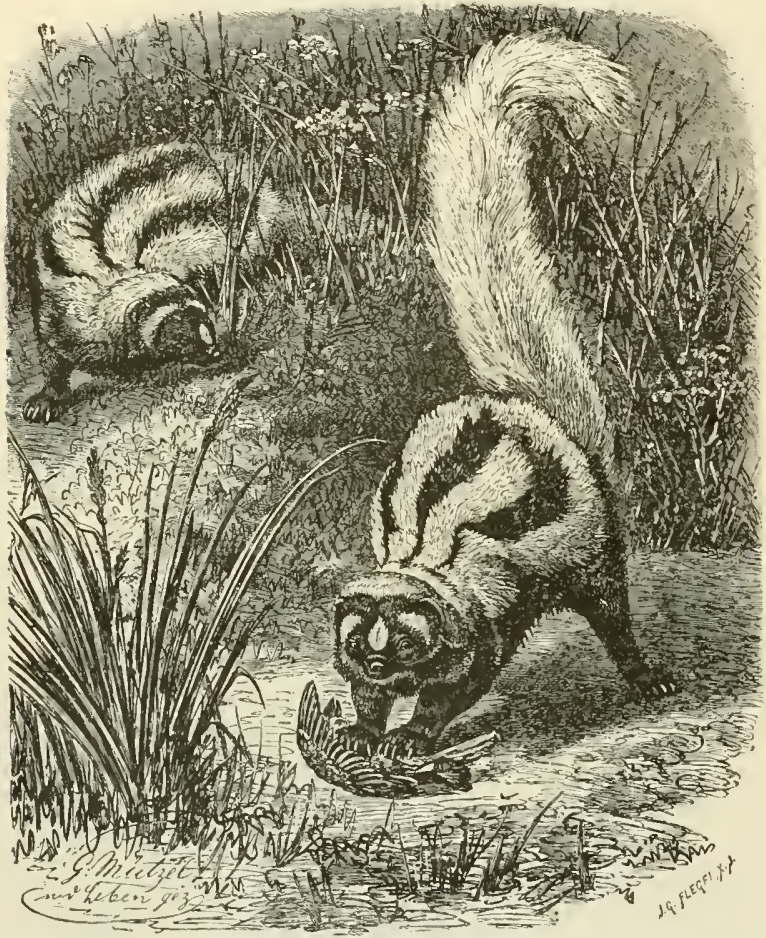

THE CAPE ZORILLA,- While our own American animals of the Skunk group have no rivals in the faculty of emitting offensive odors, the Zorillas of Africa have great ability in that way. The Cape Zorilla is a prettily marked animal with white stripes extending along its body and a long, bushy tail. feathered prey. (Rhabdogale mustelina.)

the strikingly flat skull, with its wide cranial part, its narrow facial one, and a short snout, these characteristics appearing in all the various species.

Aquatic Otters inllabit rivers and oceans, and Nature of the range over nearly all parts of the globe,

Otters. with the exception of Australia and very high latitudes. They leave the water only when compelled to do so, and then solely with a view of finding some other body of water. They swim and dive in a masterly manner, being able to stay under water a very long time; they run tolerably wcll, in spite of their slort legs, and are strong, courageous aninals. They are capable of domestication. Their relations to Man are always strained, for the damage they do is far in excess of the benefit they cunfer by their valuable furs.

Description Europe harbors only one species of this of the Com- sub-order, the Common Otter (Lutra mon Otter. zulgaris). The length of this aninal is forty-eioht inches, sixteen of this going to the tail. The head is oblong and rounded; the ere is small, but has a vivacious expression; the ear is very short, rounded, can be closed by a fold in the skin, and is nearly hidden in the fur: the body is slender but flat; the tail is more or less rounded and tapering toward the end; the legs are very short, webbed up to their claw's and adapted for a plantigrade walk. The fur is thick and fits the body closely; its outer cuat consists of wiry, lustrous hair of a dark brown color; the under surface is of a slightly. lighter tinge, which at the throat and sides of the head nerges into whitish-gray brown, the hidden margin of the ear being light brown; the lower lip show's a patch of faded white, and several other small white spots are distributed over chin and lower jaws. Some animals have a tint inclining to gray ish brown, rather than dark brown.

Where and How The conmon Otter inluabthe Common its all Europe and the Otter Lives. greater part of central and northern Asia, ranging as far as the Amoor to the east, and to the Himalayas on the southeast. It does not seem to extend very far nortl, for Lapland shows only a few scattered specinıens. In India, China and Japan its place is taken by closely allicd species, while those inhabiting Africa and America rank as distinct species. In middle and southern Europe it is found in every body of water offering any promise of food, even in rivers running through densely populated countries. In central Asia it is also common everywhere. The Indian Otter even roes into the sea, lives at the mouth of rivers and oceasionally visits the ocean.

The Otter has a predilection for rivers whose banks are extensively grown to forests. There it lives in subterraneous burrows, constructed in accordance with its tastes and nllode of life. The place of exit is always loeated below the surface of the water, usually at a depth of about eighteen inches; a tunnel about two yards long leads thence, slanting upwards into a spacious cliamber, which is lined with grass and always kept dry. Another narrow tunnel runs from the central chamber to the surface and aids in ventilation. Under all circumstances the Otter lias several retreats or homes, unless fish is exceedingly plentiful and it is not obliged to undertake extended journeys for food. When the water rises and inundates its habitation, it has recourse to trees or hollow trunks, where it spends its leisure hours when not hunting.

Traits and The Otter entails great loss upon the Movements of owners of fisheries and upon entlusithe 0tter. astic anglers, but is extremely attractive to the naturalist. Its life is so peculiar that it has to be observed in a special manner, and therefore must furnish pleasure to every person fond of nature. The Otter is remarkable in every way ; in its aquatic life, as well as in its movements ; in its hunt for food 
and in its mental endowments. It belongs, without question, to the most attractive class of aninals That it is an aquatic animal is seen even when it is on dry land, having a crecping and Snake-like walk, on account of its short legs; but its movements are by no means slow. It moves quite differently in the water, which is its proper element, and to which it flees when danger threatens it on land. Its structure is admirably adapted for swimming and diving. The Snake-like, flat body, the short feet, converted into vigorous oars by large webs, the rather long and powerful tail serving as a very efficient rudder, and the sleek, slippery fur-all these endowments combine to enable it to glide swiftly through the waves. Its sharp, vigorous teeth serve to seize the prey and never let anything they once hate closed upon escape, however slippery it may be. In winter, when the water is frozen over, it looks up holes in the ice and descends, and returns through them to breathe. Unfailingly it finds these holes again and is just as fishes only by night, especially in full moonlight. It sometimes comes quite close to human dwellings during its hunts, and passes villages that lic on the bank, usually without being detected.

Old Otters usually live singly, but the females swim about accompanied by their young, or other females. During the breeding season one may meet males and females fishing together. They always swim up stream from their habitation, and sometimes search a river for miles away, as well as the smaller rivers and ponds that are connected with the large stream.

Skill of the An Otter is as effective and skillful a otter hunter in the water as are a Fox and a as a Hunter. Lynx combined on the land. In shallow water it drives the fishes into a bay to prevent their tlight, or sometimes it beats the surface of the water with its tail, and frightens them so that they seek refuge in holes in the bank or under stones, and thus fall an easy prey.

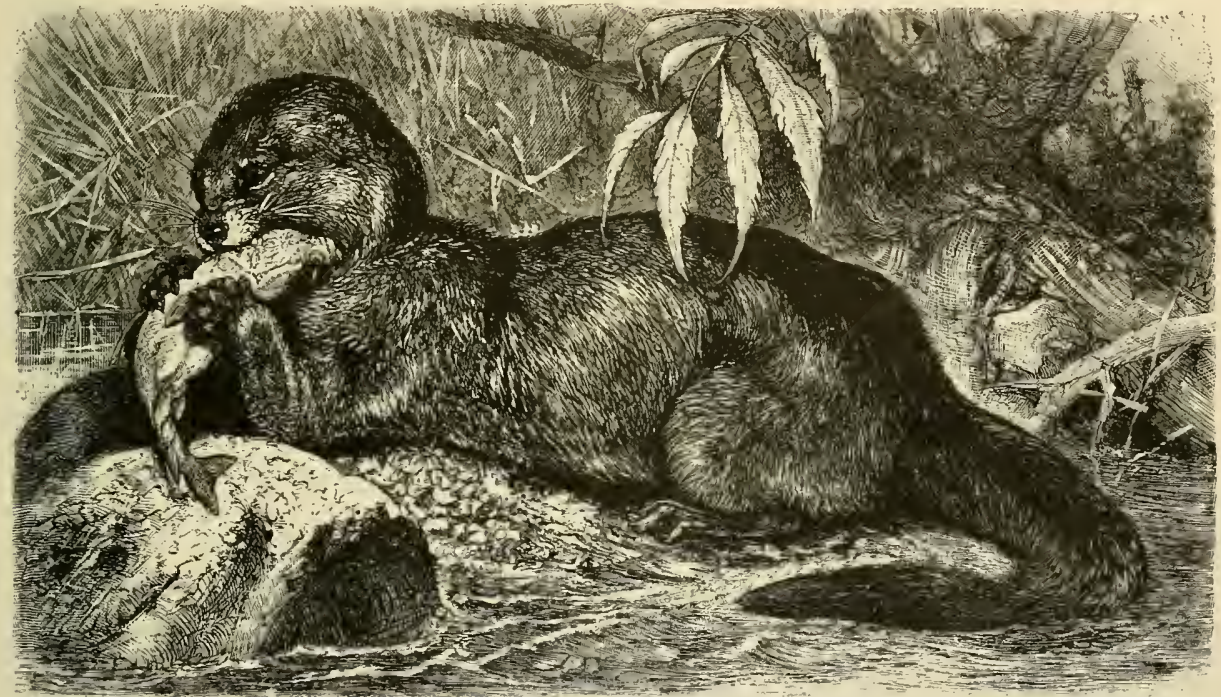

TH COMMON OTTER. The characteristics of the Conmon Otter of Europe and Asia are wel] depicted in this illustration-the rounded head, small ears, tapering tail, short legs, ending in webbed feet, and rough wiry outer fur. The predilection of the animal for fish is also shown, the head, small ears, tapering tail, short legs, ending in webbed feet, and rough wiry outer fur. The predilection of

ingenious in detecting others. The hole need only be large enough to admit its nose for the purpose of breathing ; and where such apertures exist the frozen deep is perfectly adapted for its hunting.

The voice of the Otter is much more rarely heard from animals in the wild state than from those in captivity, which are more easily excited. When the Otter feels comfortable it utters a low chuckle; when it is hungry it emits loud cries, sounding like "girrk" and so loud as to be disagreeable. It signifies its anger by a loud shriek, and its contentment by a shrill, harmonious whistle.

The senses of the Otter are extremely acute. The presence of a Man or Dog is perceived at a distance of several hundred paces, and the approach of either is always deemed a signal for prompt escape into the water. The incessant persecution which it has suffered has rendered it extremely shy and cautious, and one who wishes to see it has to lie in wait for days. As a rule it sallies forth after sunset, and
The Otter also preys upon Crabs, Frogs, IVater voles and small and medium-sized birds, though fishes, especially Trout, are its favorite food.

Young Otters The Otter has no set breeding season, and How for one meets young ones all the They are Tamed. year around. There are from two to four blind young ones in the litter. The mother selects for them a secure place, warmly lining the nest with soft grass. She loves her offspring tenderly and takes great care of them. They reach their full growth by the third year. Otters taken young and kept on milk and bread may become very tame. The Chinese tame one species and train them to catch fish, and in Europe Otters have also repeatedly been trained for the same purpose. A tame Otter is a very pretty and sympathetic animal. It soon comes to know its owner and follows him or her about like a Dog. It prefers a milk and vegetable diet to one of meat, and may be trained not to touch fish at all. 
Story of "A well-known sporting gentleman," a Tame says Wood, "was possessed of an Otter otter. which had been trained with singular success. When called, the Otter immediately answered to the appropriate name of 'Neptune.' The animal early showed signs of docility and in process of time increased in aptitude and sagacity. It ran freely about and could fish at will. Frequently it procured a dish of excellent Trout quite alone, the fishing exploits sometimes occupying the greater part of the night. When morning came it was always to be found at its post and a stranger would have been astonished to see it among several brace of Pointers and Greyhounds. In fact, according to the game-keeper, 'it was the bcst Cur that erer ran.' Its reputation as an angler was advancing rapidly and its master's neighbors intended to borrow it, for
On larger lakes and ponds it is followed in boats and shot when it comes up to breathe. A light ripple on the surface of the water indicates its course to the sportsman and guides him in his action. In deep water this mode of hunting is not practicable, for an Otter when killed falls to the botton like a piece of lead, and when the body finally reappears on the surface it is half-decomposed and the skin is spoilt. In rivers where Otters are plentiful one can employ still another method. Large nets are quietly laid across the river and the Otters are frightened by Dogs. Several people take their post at the nets, armed with guns and spears, or else, if possible, they acconpany the Dogs into the water. Then the predaceous animal is either shot or speared. This is the method of hunting usually pursued in Scotland, and to some extent in Germany. A captured Otter hisses, makes

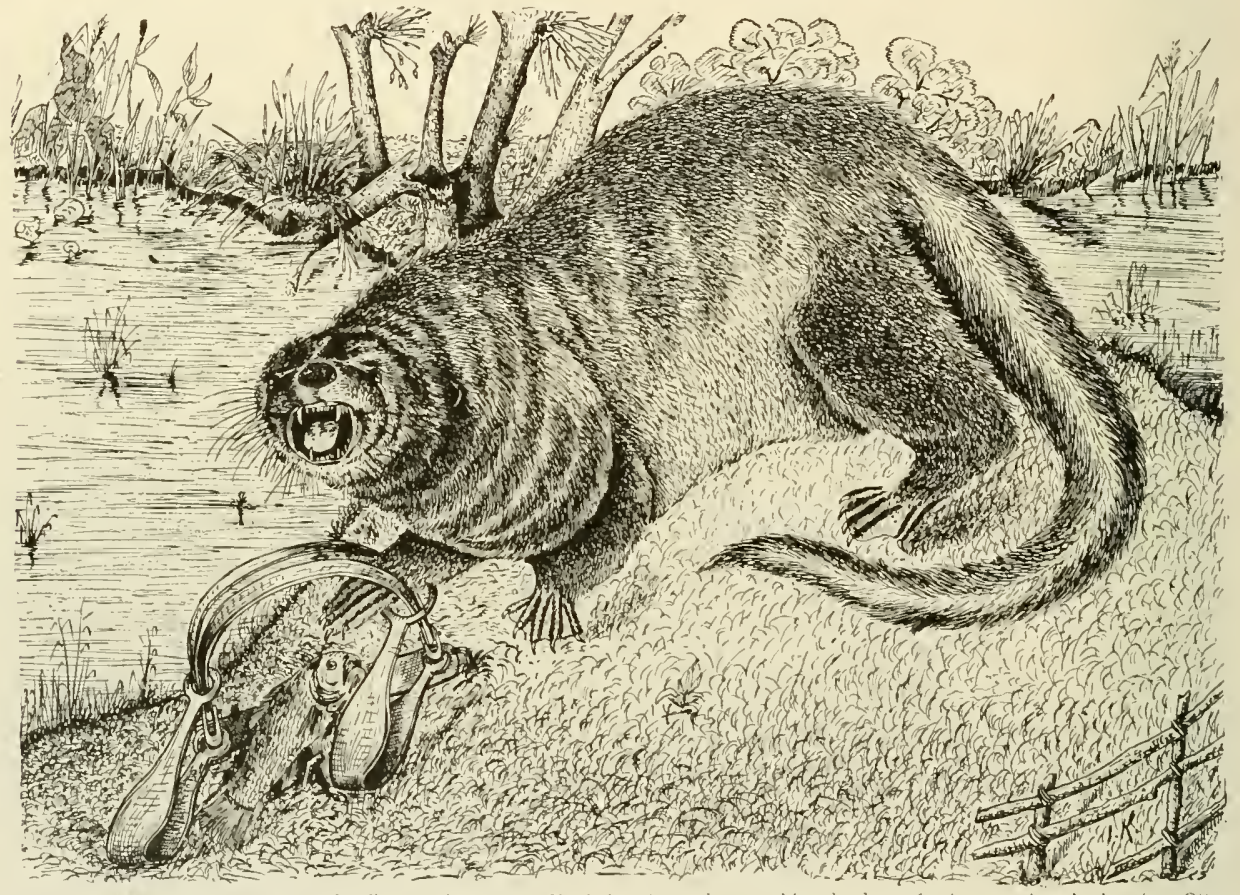

THE AMERICAN OTTER. In all parts of temperate North America, and encroaching closely on the . Irctic region, the American Otter makes its home on the banks of nearly all streams except those from which it has been driven by Man. While it resembles the Enropean Otter, it is
much larger in size, has a longer tail. and has a nasal pad between the nostrils which is larger than that of any other species. The American Otter is vigoronsly hunted for its fur, and for this purpose traps are largely used after the manner shown in this illustration. (Lutra canadensis.)

the purpose of ascertaining the size of the larger Trout in the pools on their estates."

Methods of The Otter is ruthlessly persecuted on Hunting account of the damage it does. Its cun-

the Otter. ning renders many modes of hunting either impossible or tedious in its case. It is very difficult to shoot it, for when it scents the approach of Man it kecps out of sight. In winter the task of finding it is easicr, especially if one lies in wait for it at a hole in the ice. It is most frequently caught in traps set into the water at a depth of about two inches, without any bait. The trap is concealed with moss, and is best put in a ditch which the Otter has to cross on its way from one pool to another. The ditch is for this purpose made so narrow that the Otter must run over the trap to reach its destination. a furious show of resistance and defends itself as long as it has a spark of life left; it is especially dangerous to imprudent Dogs, as it often breaks their legs with a bite. Experienced Otter-hounds know how to avoid such accidents and soon master the animal. When it finds itself overpowered the Otter expresses its agony by a plaintive whine.

The fur is used for trimming winter clothing, for caps and fur collars, and in Kamchatka the most valuable Sable pelts are packed in Otter fur for shipment, as it is supposed that the latter absorb the dampness and preserve the Sable. The hair of Otters' tails is used for painters' brushes and out of the fine, woolly inner fur cxpensive and durable hats are manufactured. In consequence of the demand for its fur, the Otter is persistently hunted, 
The American The American Otter (Lutra canadensis), Otter, $\alpha$ although closely allied to the Common (utLarger Species. ter, has sufficient distinctive differences to It is considerably larger than the European animal, being about four feet in length from the tip of the snout to the root of the tail, and the tail is about two feet long: it has a yad or protuberance on its mose. The soles are covered with hair, and have callosities. 'The fur is of a brownish black color.

The young are born in April in the northern, and earlier in the southern part of the animal's range, and a litter is composed of from one to three young ones, which are the object of most tender care on the part of their mother.

Range and This Otter is found in the greater part of

Habits of the United States and in Canacla north to

American Otters. the Hudson Bay region. Its habits resemAmerican Otters. ble those of its European cousin, but it has one peculiarity that is noticed by all naturalists who have closely observed this animal, and that is its habit of sliding or coasting down hill, in which it displays a zeal and proficiency that a school-boy might envy. In Canada, and other sections where the snow is plentiful, Otters indulge freely in this sport and, as described by Godman, they select in winter the highest ridge of snow they can find, scramble to the top of it, "lie on their riers, but those from Canada are deemed more valuable than those from the more

American Utters may be most successfully tamed, especially when taken young. Audubon had several young otters which he says "became' as gentle as Puppies in two or three days. They preferred milk and boiled cornmeal, refusing fish or meat till they were several months old." They became so tame that they would romp with their owner, and were very good-natured animals.

Besides the American Otter three other American species have been mentioned by some authorities, inclucling the Mexican Otter (Lutra californica), the Peruvian Otter (Lutra filina), inhabiting Central America, 'Peru and Chili, and the Brazilian Otter (Lutra brasilicnis); lut as they are much alike in size and coloration, and differ little, if any, from those alreadly described, it is doubtful if these can be regarded as distinct species. Little is known about them or their habits.

The Sea Otter, The Common Otter and some of its a Marine relatives temporarily visit the ocean,

Variety. but one species belongs to it entircly. The Sea Otter or Kalan (Enhydris lutris) is a representative of a distinct species and is perhaps a tran-

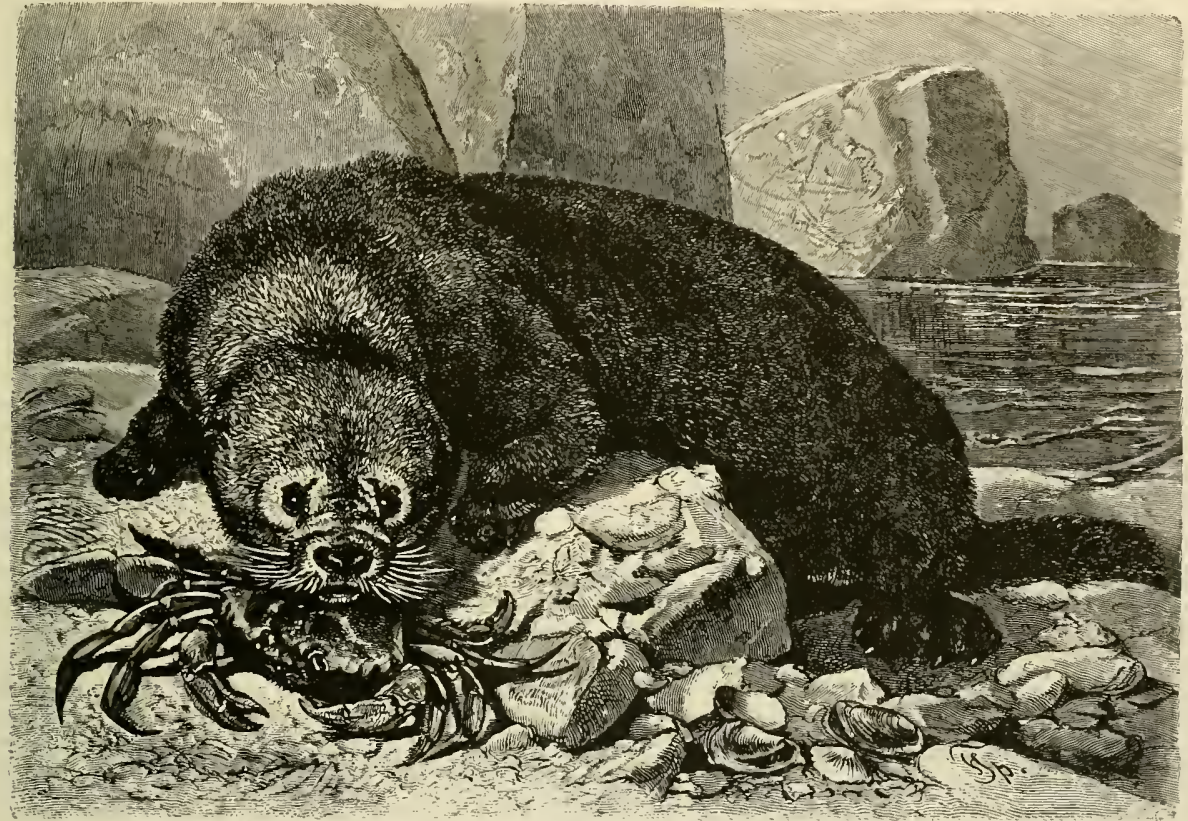

SEA OTTER, OR KALAN. - This is the true marine Otter, for while other species of the group make occasional excursions into salt water the Kalan makes its home in the ocean, and is found on the shores and islands of the North Pacific. The flattened face, rounded head, short tail, flipper-like hind paws, and dense fur are shown in the animal in the picture, which is enjoying a meal of shell-fish on a beach in its

icy, northern home. (Enhydris lutris.)

stomachs with the fore-feet bent backwards and then, giving themselves an impulse with their hind-legs, glide head-foremost down the declivity, sometimes for the distance of twenty yards. This sport they continue, apparently with the keenest enjoyment, until fatigue or hunger induces them to desist."

It is not only in winter that they enjoy this sport. "Otter slides" or places on the clay banks of streams where they pursue this diversion, are well known in the West. Audubon says: "On one occasion we were resting on the bank of Canoe Creek, a small stream near Henderson, which empties into the Ohio, when a pair of Otters made their appearance, and, not observing our proximity, began to enjoy their sliding pastime. They glided down the soap-like, muddy surface of the slicle with the rapidity of an arrow from a bow, and we counted each one making twenty-two slides before we disturbed them,"

Hunting and The number of the Otters is rapidly decreasTraining ing in America, because of the systematic American Otters. way in which they are pursued by trappers American Otter is in high reputation and general use with fur- sition member between the Otters and Seals. The head is somewhat flattened, but rounder than that of the other Otters, the neck is short and thick, the body is uniformly round, the tail is short, thick and compressed, of a conical shape and clothed in thick hair. While the fore-paws differ from those of the Common Otter only in their short toes (which are connected by tough webs, naked on their under surface and provided with small, weak claws), the hind paws are really fin-like, at least as much as a Seal's flippers, from which they differ in having their toes increase in length from the inner to the outer side. In some respects the hind paw of a Sea Otter resembles that of the Beaver, only that it is covered with short, dense, silky hair. The outer fur consists of long, wiry, brownish-black hair with white tips, which 
lend it a grizzled appearance. The under fur is of a fine, woolly texture. Ioung animals have a long, coarse, white or grayish brown fur, entirely covering the under fur. Adult Sea Otters are at least sixty inches long, about twelve of which go to the tail. Their weight is from sixty to eighty pounds.

The Sea Otter is indigenous to the North Pacific, extending as far north as the chain of the Aleutian Isles. It extends farther south on the American than on the Asiatic coast, being confined by the twenty-eighth degree of north latitude, but each year shows a decrease in its numbers.

Steller's Account Wie owe the best description of the of the animal to Steller, who was shipSea Otter. wrecked in $174 \mathrm{I}$, with Bering, and had abundant opportunities for observing the animal. "The fur of the Sea Otter," says he, "whose skin lies loosely on the body and moves all over in running, exceeds that of all Beavers in length, beauty, and in the intense black color of the hair. The best pelts sell for thirty roubles in Kamchatka, forty in Irkutsk, and one hundred at the Chinese boundary, if one takes merchandise in trade. The flesh is tender and savory. The Sea Otter is a beautiful and pleasing animal, merry and play.ful, kindly and affectionate in disposition. When one sees it run, the lustre of its black hair is superior to that of the finest velvet. Otters usually live together in families, male, female, half-grown and little children. The love of the parents for their offspring is so great that they brave death in defending them and at their loss cry very much like human beings. They grieve so that in ten or twelve days they lose all their flesh, become weak and sick and remain dejectedly in one spot. These animals have no special breeding season, but are seen with their young ones all the year round. The female carries her little ones in her mouth, but in the water lies on her back and holds the young one in her fore-paws as a mother holds her child. She also fondles it affectionately, plays 'toss and catch' with it, pushes it into the water to teach it how to swim, and takes it up and kisses it when it is tired.

"The food of the Sea Otter consists of Crabs, shells, small fish, and to a less extent of sea-weed and meat. I do not doubt that if one cared to go to the expense of importing specimens into Russia, they could there be domesticated; they even might breed in a pond or river. In reality they care little for salt water, for ] have seen them spend diys on islands and in rivers. This animal deserves the greatest consideration of our crew at least, for we had scarcely any other food but its flesh for six months, and it was also the only cure for those suffering from scurvy.

"The Otters are very graccful and quick in their movenents; they swim well and run rapidly. One cannot imagine anything more beautiful than this animal running along, clothed in its silky, glossy black fur. It is remarkable that the more beautiful their fur is, the more lively and cunning they are. Those that are perfectly white are probably very old and can be caught only with great difficulty; they are so wary. When they sleep on land, they curl up like Dogs. When they emerge from the water, they shake themselves and dress their fur with the forc-paws, like Cats. In running they proceed at a rapid pace, but make many detours. If a Man bars the way, they stop, arch their backs, hiss and threaten to attack him. One blow on the head is sufficient to make them drop down as if dead and cover their eyes with their paws.
"In July" and August Sea Otters change their coats, but only to a slight extent, and their color becomes browner. The best pelts are taken in March, April and May; the greatest number are shipped to China. In Kamchatka the most gorgeous apparel is supposed to be a dress made from white Reindeer skins and trimmed with Otter, A few years ago, everybody was wearing Sea Otter furs, but this custom has gone out since they have become so dear; besides, Dogs' skins are now thought to be fincr, warmer and more durable in Kamchatka."

Hunters Have In modern times this valuable furMade Sea Otters producing animal is very rare and scarce. has become so shy that it is approached with the greatest difficulty: PechuelLoesche, who observed and occasionally hunted the Sea Utter twenty-five years ago near the Aleutian Isles, says that the wary animal rarely suffered a sailing vessel or boat to approach within gunshot. Animals that do not succumb to the first shot are always lost to the hunter, unless he can shoot them again when they come to the surface. A single boat stands little chance of success, as the animal can easily remain a quarter of an hour under water and often reappears at a place quite distant from that expected.

How the The Otter is hunted in many different Sea Otter is ways. When the sea is calm the peo-

Hunted. ple go out in boats, and as soon as they notice an Otter they surround the place with their boats and kecp a sharp lookout. When the animal reappears it is immediately friglitened back into the water by spear-thrusts, shots and yells, and a new circle is formed around the point where it disappeared, and so on, until the Otter, which is not allowed sufficient breathing time, wearies and falls a prey to the nearest hunter. Such a hunt may be prolonged for two or three hours unless a welltimed spear ends the chase. In this way the hunters, if they have good luck, may kill from forty to fifty Otters in three months, every pelt bringing a price of at least fifty dollars.

Some hunters try to kill the animals from the shore, fur merchants providing them with excellent guns for the purpose. When the sea is rough the hunter wanders around on the cliffs and tries to shoot the Otters (which appear beyond the surf, in the more quict waters), aiming at their heads. The roar of the waves and the flying foam prevent the wary animal from recognizing the danger that threatens it, and a persevering hunter may send out one bullet after another. When one of his shots finally reaches its aim he sits down and waits patiently until wind and waves bear his precious booty ashore. The most exciting method of hunting, on account of the dangers which attend it, is the killing of an Utter by blows from clubs. During a storm the Otters are frightened by the rising fury of the waves, which beat upon the nearly inaccessible cliffs upon which they have taken refuge in order to escape the pursuit of Man. The animals mount bigher on the cliffs to escape the wrath of the wares, and there are foothardy sportsmen who will risk their lives in order to surprise the Otters on their high resting-places. If they succed in landing on the leeward side of the cliffs, they mount and kill the Otters with clubs. The howling of the storn and the roar of the waves deaden all sounds the huntsmen may make, while the rain and fog prevent the more distant animals from seeing the fate that awaits them. Two men once succeeded in this way 


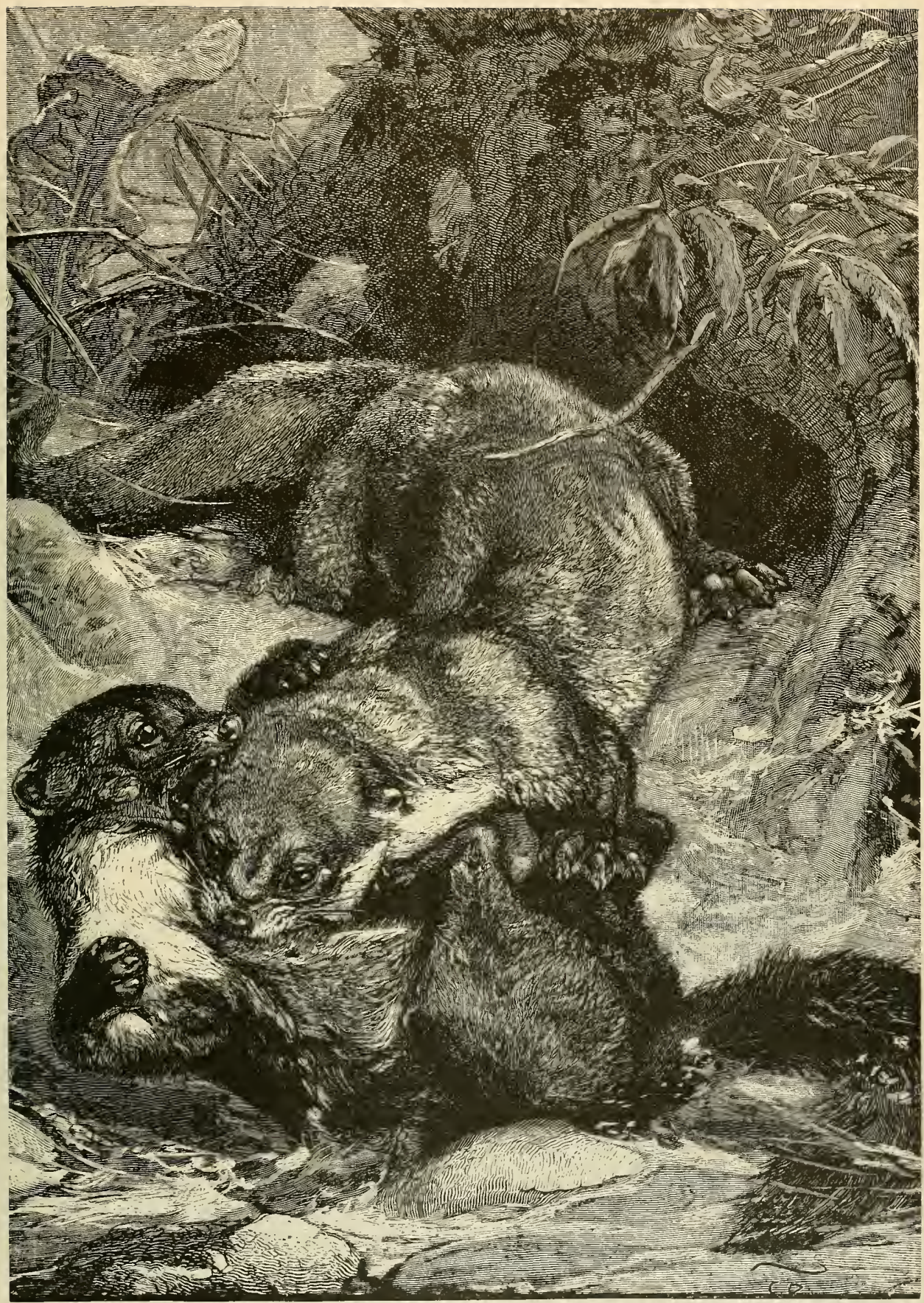

COMBAT BETWEEN AN OTTER AND A STONE MARTEN_-Members of different species of the Marten family sometimes quarrel, and the picture represents an encounter between an Otter and a Stone Marten which was observed at Beilstein in Swabia. Both these animals are persistent hunters of the Water-Rat and it was probably over such a booty that the combat began. The Man who saw the fight approached the animals
unnoticed and killed the Otter, which was on top, with a blow, while the Stone Marten made its escape, although the teeth of the dead animal held a mouthful of Marten-fur. The Marten. how by several severe wounds on the Otter's body. 
in killing seventy-eight of these valuable animals within an hour.

If the hunting of these animals is not restricted by law, the Sea Utter will be exterminated in the near future, and, like Steller's Northern Sea Cow, be among the number of the species we have seen disappear from the earth, so to speak, before qur eyes.

\title{
The Iberina Jfamíly.
}

\author{
FOURTH FAMILY: HYæNIDA:
}

Among the animals exhibited in traveling shows there is one which usually attracts the special attention of the spectators owing to the extravagant explanations of the keeper, who never fails to depict it as a genuine monster and ascribe to it the most dangerous traits. Bloodthirstiness, cruelty and a deceitful, wicked disposition are usually the mildest of the qualities he ascribes to this animal. In addition he accuses it of exhuming the dead bodies of human beings and eating them, in order to further excite the excusable indignation of those spectators who are not well versed in zoology. Science has not been able so far to dispel these unfoundect notions, which kecp their hold on people's minds despite all teachings to the contrary.

Many Fables There are few animals whose history rold About has been adorned with so many fan-

the Hycenas. tastic and horrible tales as that of the Hyznas. The ancients told the most incredible stories about them. Dogs were said to lose their voice and senses if the shadow of a Hyrna fell on them. The hideous animals were alleged to imitate the human voice, in order to decoy people toward thier retreat and then devour them. The most remarkable feature of these tales is that they found credence with all the nations which came in contact with the Hyana. The Arabs especially are rich in stories concerning it. They firmly believe that people who partake of the brain of a Hyana become insane, and the head of a slain Hyxna is always buried, lest it should be used by wicked sorcerers for their diabolical charms. They are even firmly persuaded that Hyrenas themselves are nothing but sorcerers in disguise, which assume human shape by day and prowl around as Hyænas during the night, working destruction upon good people. I have been repeatedly and earnestly warned by my servants not to shoot the llyanas, and fearful stories were told me about these despised creatures and their supposed supernatural powers.

Hycenas Have Tradition always selects its heroes. Many An animal which is the subject of

Peculiar Traits. many marvelous tales must have something peculiar in its appearance. This is confirmed in the Hyanas, which resemble Dogs, yet differ from them in every point. Their appearance is far from pleasing; in fact, is decidedly repulsive. All Iyrenas are ugly. Some naturalists have seen in them a connecting link between Dog and Cat, but we cannot agree with this opinion, for the Hyrenas have a distinctly peculiar shape of their own. The body is stout, the neck and head are thick; the snout is strong and unattractive. The curved fore-paws are longer than the hind paws, the body sloping from the shoulders to the tail, and the feet are all four- toed. The ears are scantily clothed with hair and of ignoble shape; the eyes have a slanting position, and glow with an uncanny, unsteady, repulsive expression. The thick head looks stiff, the bushy tail does not reach lower than the ankle-joint and the long, coarse fur forms a crest on the spine, resembling a Hog's bristles; the color is gloomy and all these features combine to produce an unattractive appearance. Ali Hyænas are nocturnal animals and are possessed of a repulsive, discordant, shrill and even ghostly, laughing voice; they are greedy, gluttonous, give forth an offensive odor and walk in a skulking, nearly limping manner. In fact, these animals have nany oddities in their appearance and the most kindly observer could not call them good-looking. Comparative anatomists credit them with still more marked peculiarities. Their teeth are of an exclusively carnivorous character, and the great strength of the clumsy jaws and teeth enables them to devour what has been left of the carcasses slain by other carnivorous beasts, as they are able to crunch the largest bones. The incisors are well developed, the canines of a blunt, conical shape; the premolars have strongly depressed crowns, and the grinding-teeth are distinguished by their enormous size. Powerful cheek-muscles, large salivary glands, a tongue furnished with horny projections, a wide gullet and peculiar tail-glands are further distinguishing features of the animals under consideration.

Range and The range of the Hyana is very wide, Habits of the comprising all of Africa and southHyoenas. ern Asia as far as the Bay of Bengal, but not extending east of it, and excluding Ceylon. These animals do not frequent close, extensive forests, but prefer the open country grown with grass, bushes, small woods, and even plains or deserts. They are met in the daytime only when they bave been frightened from their hiding places; the sun must have set before they think of sallying forth. Then may be heard the howl of these animals, as they prowl around singly or in small troops, looking for carcasses or live prey. When one of them commences its abominable nocturnal song, all the others usually join in the uncarthly music. The voice of the Striped Hyana is very discordant, but not as disagreeable as common report declares; hoarse sound. alternate with shrill notes, shrieks with murmurs or growls. On the other hand the howl of the Spotted species consists of a really ghostly laughter. He who hears these sounds for the first time cannot refrain from shuddering, and recognizes in them onc of the main reasons for the invention of the many stories concerning these animals. It is very probable that Hyanas call one another by these howls, and the noise immediately ceases when one of them has 

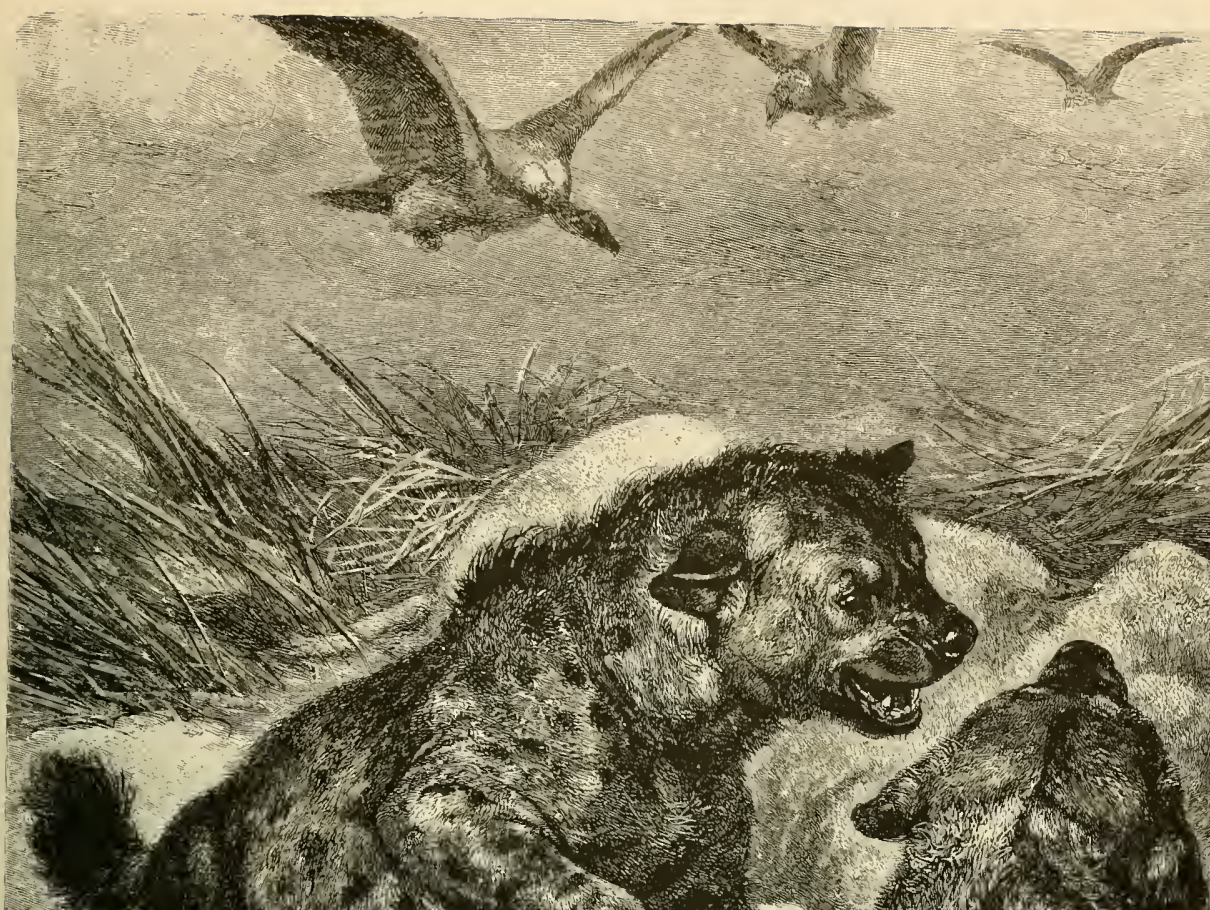

Her.

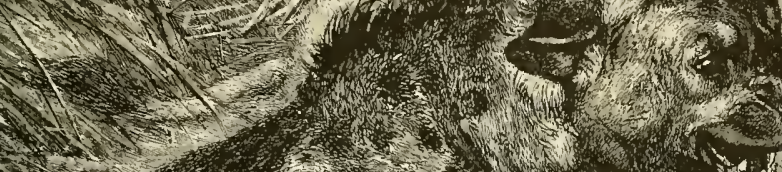
mon mon
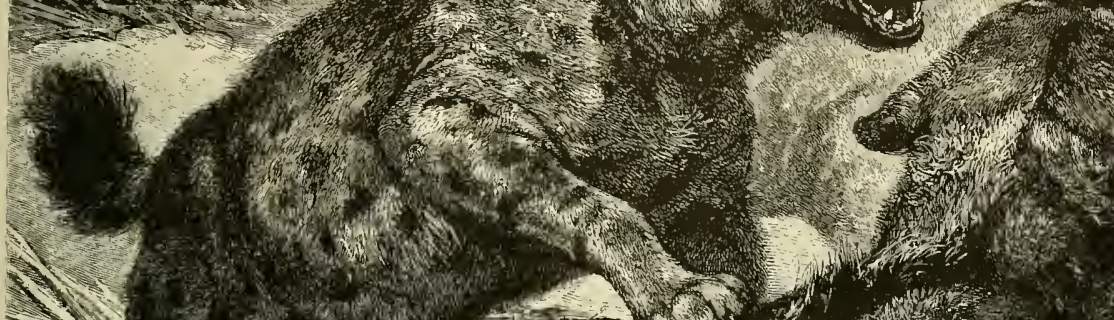

W

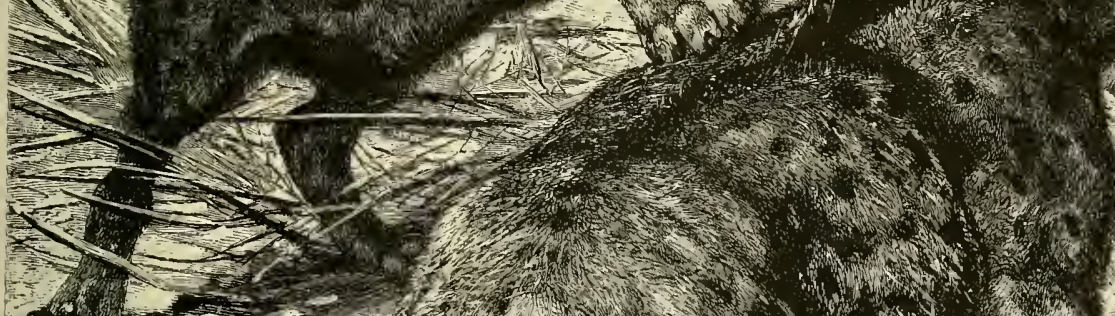

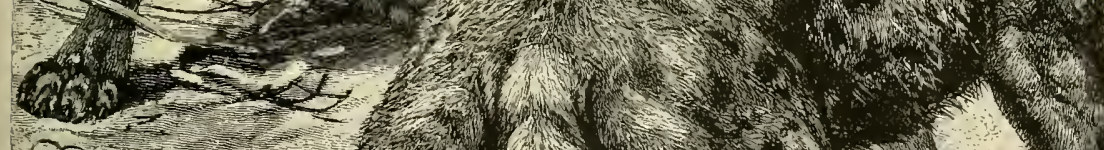
W. (1)

SPOTTED HY ENAS.- - The Hyænas, althongh their vices have been greatly exaggerated by tradition, have much that is repulsive, both in appearance and character. Largest of the family is the Spotted Hyina, deriving its name from the brown spots on its yellowish gray fur. The picture shows the hover above. The stout body, neck and head, the powerful jaws that enable these beasts to crunch large envious wultures, which they have driven away, throat, are all well shown here. (Hyana crocuta.) 
found its prey. The animals prowl around during the entire night, even entering villages and cities, paying no attention to the Dogs, and retiring only towards morning.

How Hycenas Hyxenas are guided in thcir wanderings Prowl by their scent as well as by their sight and Hunt. and hearing. The ugly fellows are as much attracted by any dead beasts, or the body of a dead human being, as by a flock of Sheep or Goats, or by a herd of Cattle, and they will prowl around a fence which is too high for them to climb. As soon as they have scented prey, they cease their howling and silently trot nearer and nearer to their victim, stopping every now and then to look, listen or sniff, and ever ready to flee if danger threatens. The spotted species are a little more courageous than the striped Hyana, but still may be termed exccedingly cow- pleased when they find carrion. Around a carcass that lies in the Hyzenas' range there always assembles a gathering that can hardly be described. They are the Vultures among quadrupeds, and their voracity is really extraordinary. When they find carrion they forget all considerations of prudence, and even the cowardice which they usually display. It is told that feasting Hyxenas engage in violent fights, and there is such a croaking, shrieking and laughing at such times that a superstitious person might really think all the inhabitants of the infernal regions had been let loose. They are useful in removing dead animals, but the loss they entail by attacking flocks is far greater, since the carcasses would, without their assistance, be taken away by far better scavengers among the birds and insects. They follow caravans through the plains and deserts in greater or smaller numbers, as if they knew that out of such bands something would surely fall to their share. How Hycenas Act

Varying opinions have prevailed as Toward Man. to whether or not they attack human beings. The Striped Hyæna has not been convicted of doing this, but there have been so many reports to this effect about the spotted species that its danger to human beings is not to be disputed. It sometimes steals children, but usually does not dare to attack adult people except when sick, overcome by fatigue, or asleep; but in exceptional instances it also attacks armed Men. In some African regions it is therefore looked upon as a scourge to be dreaded, especially where it is plentiful. It is pursued in a rather persistent manner by European settlers as well as by many native tribes. It is shot, caught in nooses, traps and pits, and poisoned with strychnine. If taken very young, Hyænas are easily tamed and frequently become very affectionate. They bear captivity well, but often become blind in old age.

\section{Divisions of ln former ages the Hycena Hyanas were dis- Family. tributed over a} W'olf looks for carrion washed ashore by the tide. The fur is long and thick, and a long mane tends along the back, hanging down on both sides, this mane being in part whitish gray and the remainder
brownsh black. The legs have black stripes on the general brown color. and the long ears are erect.
(Hyana brunnca.)

ardly, when their size is considered. If they do not find any carrion they confine themselves to attacking defenscless prey, and therefore do damage only to the weaker domestic animals, in whose ranks they may make considerable havoc. Hyienas destroyed two strong Asses belonging to the traveler and hunter, Selous, the marauders eating every part but the skulls, and on another occasion they devoured part of a Lioness he had killed in the evening. Probably they attack healthy living animals only when they cannot find sick, exhausted or dead ones

In some rare instances they bccone veritable Beasts of Prey, pursue Antelopes in the night, drag them down as Wrolves do their victims, and kill and devour them. Such hunts, however, must be regarded as exceptions, as they are certainly best much greater part of the globe, and were rather numerous in Germany, as is shown by the many remains of bones. In the present day there are four species belonging to this family, three Hyænas proper and the Aard-Wolf, which nay be considered a connecting link between the Myrnas and the Civets.

\section{THE HYANAS PROPER.}

The Spotted Hyiena (Hyana crocuta) is distinguished by its greater strength and spotted skin from the striped and brown specics which are much oftener seen in Europe. The ground-color is whitish gray, with a surface tinge of yellow; the sides and thiglis show brown spots. The head is brown, with a reddish hue on the cheeks and top; the tail is ringed with brown and its extremity is black; the 
feet are whitish. These colors are liable to show considerable variations, as they may be much darker or lighter. The length of the body is about fiftytwo inches; the height of the shoulder is nearly thirty-two inclies, but much larger specinens are reported to have been killed.

Spotted Hyona's The Spotted Hyana inhabits Haunts and

Mode of Life.

southern and eastern Africa, cxtending from the Cape of Good Hope to about the seventeenth degree of north latitude, and wherever it is plentiful it almost completely crowds out the Striped Hyzena. The two species live together in Abyssinia and East Soudan, but farther south the Spotted Hyana gradually becomes sole possessor of the field. It is tery com- more stupid, and of a more wicked and brutal disposition than its striped relative, though it may be tamed to a certain extent in a short time, with the aid of the whip. Still it seems that it never attains the degree of docility that is reached by the Striped Hyana. The tricks pcrformed in wandering circuses by the Hyana do not furnish us with a standard, and it is only such peripatetic zoologists as these that find pleasure or profit in bestowing much attention upon these animals, which are so ugly, clumsy and unprepossessing in their cage. For hours thcy lie like a $\log$; then they jump up, look at people with a remarkably dull-witted expression, rub thenselves against the bars from time to time and then break out with their abominable laughter.

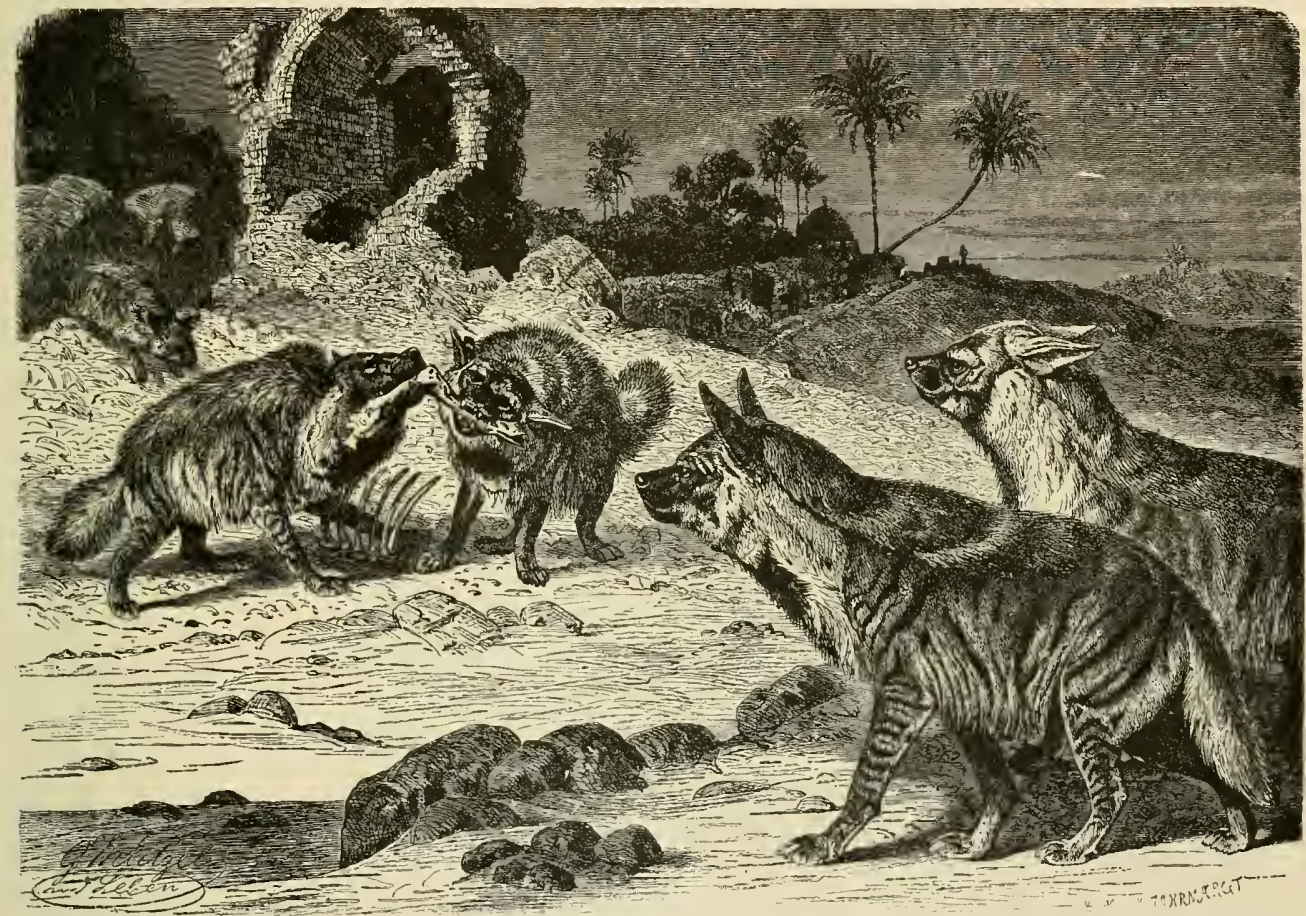

STRIPED HY ENAS. - This species of the Hyæna family is the best known, and derives its name from the markings of its fur as shown in the picture. This is, like the other species, a carrion eating animal, and the dispute over the possession of a bone, as here depicted, is a rery common occurrence on the African and Asiatic plains which form its habitat. The rough, coarse fur and mane, the erect ears and somewhat slender limbs which distinguish the animal, are seen in this group. (Hyana striata.)

mon in Abyssinia; and is found even at an elevation of twelve thousand feet above the sea. Its mode of life is similar to that of the others, but it is much more dreaded because of its large size and strength, and probably it is on this account that it is considered a spirit of eril, bringing misfortune to man. A great many observers agree that it attacks human beings, especially when the latter are asleep or tired. Ruppel says that the Abyssinians declare this to be the case.

character and The Spotted Hyrena is the animal Disposition of that plays the most important part Spotted Hycenas. in tradition. Of all Beasts of Prev it undoubtedly possesses the ugliest and most repulsive shape: and its mental endowments are such as to make the animal still more detestable. It is
The Brown The Brown Hyana or Strand-lVolf

Hycena or (Hyana brumea) is mainly distinStrand-Wolf. guished from its relatives by a long, rough mane on the back and hanging down on both sides. The hair is long over the entire fur, and its color is a general dark brown, diversified by a few spots on the legs of a mixed brown and white hue; the head is dark brown and gray, the forehead black, sprinkled with white and reddish brown. The hair of the mane on the back is whitish gray at bottom and brownish black above. The Brown Hyæna is considerably smaller than the Spotted Hyæna, and at the best only attains the size of the striped species.

This animal inhabits the south of Africa, but probably only the desert-like western regions, and is said to exist usually near the sea-shore. It seems to be 
mucl less plentiful than the Spotted Hyana, but to lave about the same habits, living mainly on carrion, perhaps on that washed ashore by the waves.

The Striped The Striped Hyana (Hycena striata) is

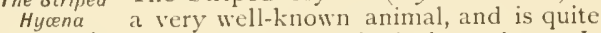

Described. often seen in zoological gardens. It is very frequently shipped to Europe, for it exists nearest this continent. [lt is aiso a very familiar feature of menageries in the United States.] It is, in fact, a very common animal and the one usually trained to perform the ordinary tricks one sees in circuses. A description of its appearance may be limited to a few words, since it is so universally known. The fur is rough, stiff and rather long; the color is a whitish-yellow gray diversified by black stripes. The hair of the mane also has black tips and the throat is not infrequently entirely black. The tail is either of a uniform tint or striped. The head is thick, the snout relatively thin, though still clumsy enough; the ears are erect, large and entirely

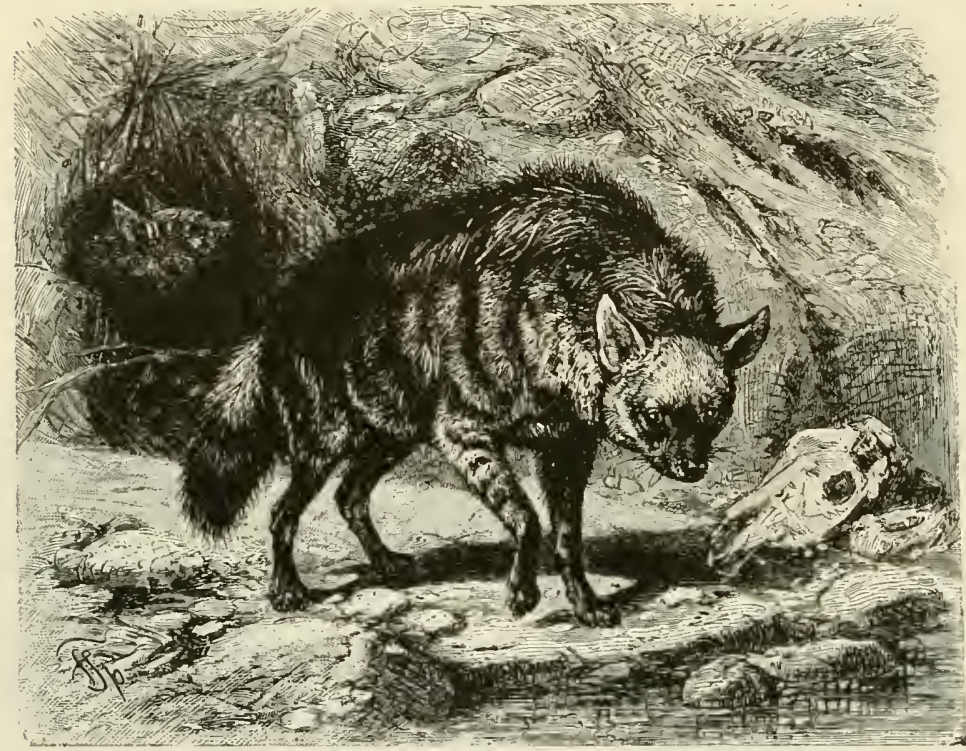

THE AARD-WOLF.- This animal forms a distinct group of the Hyæna family, has at yellow fur with hlack stripes and a rough mane extending along its back. In the picture one Aard-llolf has left the hole from which the other is just emerging, for they are burrowing animals and live gregariously. They are great enemies to the flocks of Sheep in southwestern Africa. (Proteles lalandii.)

devoid of hair. The younger specimens resemble the adults. The average length of the body is about three feet, a little more or less.

Where and How The striped Hyma has the most Striped extensive range of the three species;

Hycenas Live. it is common throughout the northern part of Africa, beginning with the extreme west, and is found over a considerable part of southern Africa and all southern Asia, from the Mediterranean to the Bay of Bengal. Like all Hyrenas it does not affect woods, but delights in the open country. It is the least harmful of the three species of 1 lyanas, and probably is nowhere much feared. There is so much carrion, or bones at least, lying around in its native country, that it is seldom driven by hunger to boldly attack living animals. Its cowardice exceeds all bounds; still it sometimes enters villages, and in Egypt prowls around their outskirts. Carcasses put out by us as a bait to decoy Vultures within range of our guns always attracted Hyænas during the night, and they annoyed us very much. When we were camping out, they often came sneaking up, and even entered the encampment, and several times we were able to fire at them without rising. In spite of this animal's voracious importunity, nobody fears it, and it is really too cowardly to attack even sleeping people. Neither does it dig up the dead, unless the bodies are but thinly corered with a little sand or earth; and it is quite innocent of the ghoulish practices imputed to it by showmen. Its habits are much the same as those of the spotted species, except that it is seldom found in large numbers.

Two striped A few days after our first arrival in Hycenas Trained Khartum we purchased two young as Pets. Hyænas [for a price equal to twentyfive cents in American money]. The animals were about the size of a half-grown Terrier, clothed in a very soft, fine woolly fur of dark gray hue and very spiteful, notwithstanding they had enjoyed human society for some time. We put them in a stable and I visited them daily. At first they were addicted to vicious biting, but repeated sound blows overawed their resistance, and three months after the day of purchase I could play with them as I would with a Dog, without having to fear any mischief on their part. Their affection for me increased every day, and they were overjoyed when I $v$ isited them. When they were more than half-grown they signified their pleasure in a very strange manner. As soon as I entered the room they rushed at me with a joyous howl, put their fore - paws on my shoulders and sniffed my face. Later on I led them by a slight string through the streets of Cairo, to the horror of all good citizens. They were so affectionate that they often paid me a call without being invited, and it made a surprising as well as uncanny impression on strangers to see us at the tea-table. Each of us had a Hyæna at his side, and the animal sat on its haunches as quietly and sensibly as a well-bred Dog, who pleads for a few scraps at table. The Hyrenas did that also, and their genthe request consisted of a low but very hoarse cry. They expressed their gratitude either by the same sounds and actions they used in greeting me as above described, or by sniffing my hands.

They were passionately fond of sugar, but also had a great liking for bread, especially if it was soaked in tea. Their usual food was Pariah Dogs, which we shot for the purpose. My pets were on good terms with each other. if one were absent for any considerable time there was great joy when the two met again; in short, they proved to me quite 
conclusively that even Hyanas are capable of warm attachment.

\section{THE AARD-WOLF}

The Aard-Wolf (Proteles lalandii) forms the second genus of the Hyzna family. In its external appearance this animal, which as yet lias been studied but very little, strikingly resembles the Striped Hyona, and like it, has a blunt snout, long forepaws, a sloping back, a mane on its spine, and a bushy tail ; but its cars are larger and the fore-paws are furnished with a short thumb, after the manner of some Dogs. So far the Aard-IVolf is the only known variety of the species. Its length is fortyfour inches, twelve of this going to the tail. The fur is of a pale yellow color, brindled on the sides with black stripes. The head is black with an admixture of yellow; the under surface has a yellowish white color, and the second half of the tail is black.

The Aard-lVolf is a native of southern Africa, especially of its western portion. From all accounts it would seem that this animal has nocturnal habits and hides in burrows resembling those of a Fox, but more extensive and affording shelter to several individuals. Verreaux saw three Aard-Wolves killed by members of his party, all of them driven out of the same burrow by Dogs, although they issued from separate exits. When they made their appearance the mane or crest on the back was erect with angry excitement, while the cars and tail were pendent. They tried to run away with great celerity, and one of them attenıpted to dig a hole to hide itself, displaying a remarkable dexterity in the act. lnvestigation of the burrow showed that all the conduits communicated with each other and led into a spacious chamber, which probably was temporarily inluabited by all of them. The same observer states that these animals mainly feed on Lambs, but from time to time also kill full-grown Sheep, fron which they usually eat only the fat tail. If this be correct they do not need very strong teeth. In all other respects the life of the Aard-Wolf is quite unknown.

\section{Tbe $\mathbb{P o g}$ Jfamíle.}

FIFTH FAMILY: CANIDE.

The fifth family of the Carnivora comprises the Dogs, and its limits are more or less clearly defined. We have already stated that the Dogs do not differ so widely in their bodily structure from the Cats as a cursory glance would lead one to believe. As marked as their peculiarities are in the external and internal structure, in their mode of life and their habits, the two families still have many traits in common. In point of size Dogs are all inferior to the large species of the Cat tribe, and therefore are deprived of the fear-inspiring strength of those most perfect Beasts of Prey. The body is lean, the head small, the snout pointed; the blunt nose is prominent, the neck rather weak. The body rests on thin or long legs provided with small paws, and is retracted in the flanks; the tail is generally short and frequently bushy. The fore-paws usually show five toes, the hind paws are always limited to four, bearing strong but not retractile claws. The eyes are large and better adapted for bright light than those of the Cat; the ears are usually larger and more pointed; the lacteal nipples are more numerous. The teeth are strong and from thirty-six to forty-eight in number; the incisors, especially the upper ones, are proportionately large, the outer ones being enlarged so as to resemble the canine teeth; the canines or eye-teeth are slender and slightly curved, the premolars are less sharply indented than the Cat's; the molars are rather blunt, adapted to thoroughly grinding the food. The skull, and especially the jaws, are of an elongated shape. The vertebral column is formed by twenty dorsal and lumbar, three sacral and from eighteen to twenty-two caudal vertebra. The chest is formed by thirteen pairs of ribs, nine true and four false. The clavicle is stunted, the shoulder narrow, the pelvis strong. The digestive apparatus is distinguished by a roundish stomach; the intestines proper attain from four to seven times the length of the body.
General Charac- Dogs show in their entire structure teristics of that they are not exclusively animal the Dog Family. feeders, and therefore admit of the inference that they are of a less sanguinary nature than the Felida. This is, indeed, one of the principal distinguishing features between the two. They are unquestionably inferior to the Cats so far as savage, bloodthirsty instincts go, and all show more or less pronounced good-nature. The expression of a Dog's face is as a rule friendly, and never shows much resemblance to the defiant self-reliance and savage disposition expressed by a feline face.

Dogs were widely spread in former periods of the world; it is unquestioned that they made their appearance on earth in very early ages. They now extend all over the globe, and are common nearly everywhere. Their favorite haunts are solitary, quiet regions and the wilderness, be it mountainous or level; gloomy, extensive forests, thickets, plains and deserts. Some prowl around continuously and stay in one locality only as long as a dependent little family keeps them there; others burrow habitations in the earth or use ready made subterranean retreats as a permanent abode. Some are of purely nocturnal habits, others are half-nocturnal, and some are on excellent terms with daylight. The former conceal themselves during the day in their burrows or lonely, secluded hiding places, in bushes, reeds, or fields grown with high cereals, between deserted dark roeks, and prowl around during the night either singly or in packs. Sometimes they cover miles in their wanderings, hunting during these expeditions, visiting even larger villages and cities and retiring at dawn to the first convenient hiding place they come across; these species are hardly less active in the day than at night. Few animals of this family live singly or in couples; for even those species of which the male and female keep temporarily together, sometimes unite into more numerous packs; and it 
may therefore be said that all Dogs are gregarious animals.

Physical In respect to agility the Dogs are very Capabilities of little inferior to the Cats. Their blunt

the Dogs. claws prevent them from climbing and confine them to the ground; neither can they leap so high and far as the Cats; but in all other respects they rather surpass them. They are excellent runners, possessed of nearly incredible endurance; they swim, without exception, and some in a masterly way, and we find veritable aquatic anmals among them: that is, such as really take delight in the water. Their mode of progression is digitigrade, like that of the Cats, but their walk is peculiar, as they do not set their legs straight in this movement. All Dogs have highly developed senses. Their hearing is not inferior to that of the Cats, while the sense of smell

carefully thought-out plans, as to the outcome of which they are tolerably secure in advance. It is the high grade of intellect of the Dog which has allied it so closely to us and puts it above the other animals,

Habits and Their food is mainly animal, consistGeneral Traits of ing of mammals and bircis. They do

the Dogs. nut eat freshly killed meat in preference to carrion, showing in very many cases a considerable predilection for the latter, and some are very fond of bones. Besides, they feed on reptiles, amphibia, fish, Crabs, insects or honey, fruit, the products of the field and garden, even buds, young shoots, roots, grass and moss. Some species are very greedy and kill more than they can devour; but their bloodthirstiness never assumes so formidable a shape as that of some of the animals of the Cat and Marten families. There is no one Dog which de-

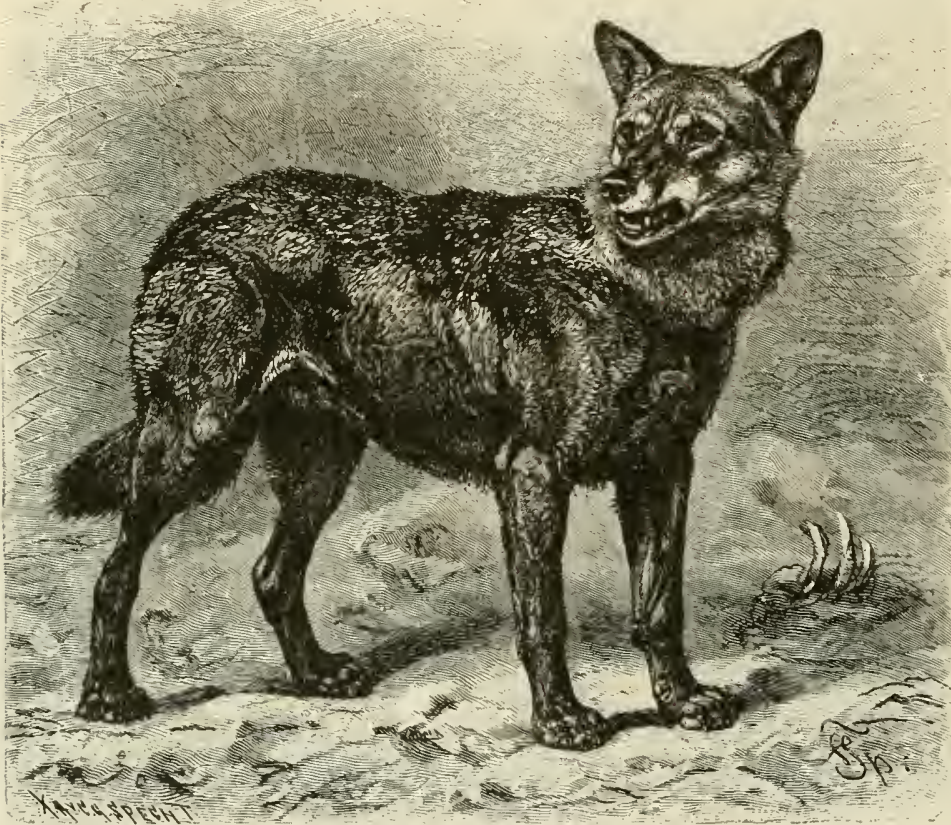

THE WOLF. - The most common of the wild members of the Dog family, lean, long-legged, with erect ears and a bushy tail. This common Wolf is found in Europe. Asia and America, althongh a few minor differences have led certain naturalists to make separate species of some of the varieties. It is a great enemy of flocks and herds, is relentlessly hunted by $\mathrm{M}$ an but is still found in large numbers wherever the country is wild. (Canis lufus.) lights in the blood of his victims to the point of intoxication.

Dogs are more prolific than the Cats, the number of their young in some instances reaching the greatest limit of the reproduction of mammals. On the average a litter consists of from four to nine young ones, but there are instances of record where one female's litter has amounted to eighteen and even twentythree Pups at a birth. It happens not infrequently that the father or some other male Dog pursues the offspring with murderous intent and devours them, if he can, and this is especially the case with Wolves and Foxes, which under farorable conditions do not spare each other. With most species, however, the gregarious instincts also assert themselves in respeet to the little ones; and the mothers always provide for them with a really self-sacrificing affection.

The mischief caused

is developed to a marvelous degree, and their faculty of sight may be said to be better than that of the Cats, for the nocturnal Dogs are equal to the Cats, and those of diurnal habits decidedly surpass them.

Mental Endow- The mental endowments of the Dogs ments of are still more highly developed than the Dog Family. those of the Cats. Those species that stand on the lowest plane show notable cunning and eraft, sometimes at the expense of their courage, a quality possessed by others to a high degree; the higher grade of Dogs, especially those which know Man, or, as I might better term it, are devoted to him body and soul, daily prove to us that their intellect has reached a higher development than that of any other animal. The tame Dog and the wild Fox act with rational deliberation and carry out by Dogs as a family is considerable on account of the fact that some species are very numerous, and those that entail any loss to mankind are ruthlessly pursued everywhere. The smaller species do us good service, as they catch rodents and inseets or devour carrion and other noxious matter, also yielding their shin, fur and teeth for useful purposes.

Divisions The Dogs may be divided into three of the groups, and two of these maybe split up Dog Family. into smaller sub-orders. These groups are formed by the WVolves or wild Dogs (Canis), with

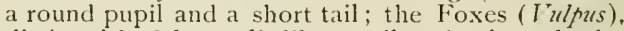
distinguished by a slit-like pupil and a long, bushy tail, and the Long-eared Dogs (Otocyon), animals of the descrt, having a different and much more numerous set of teeth. 


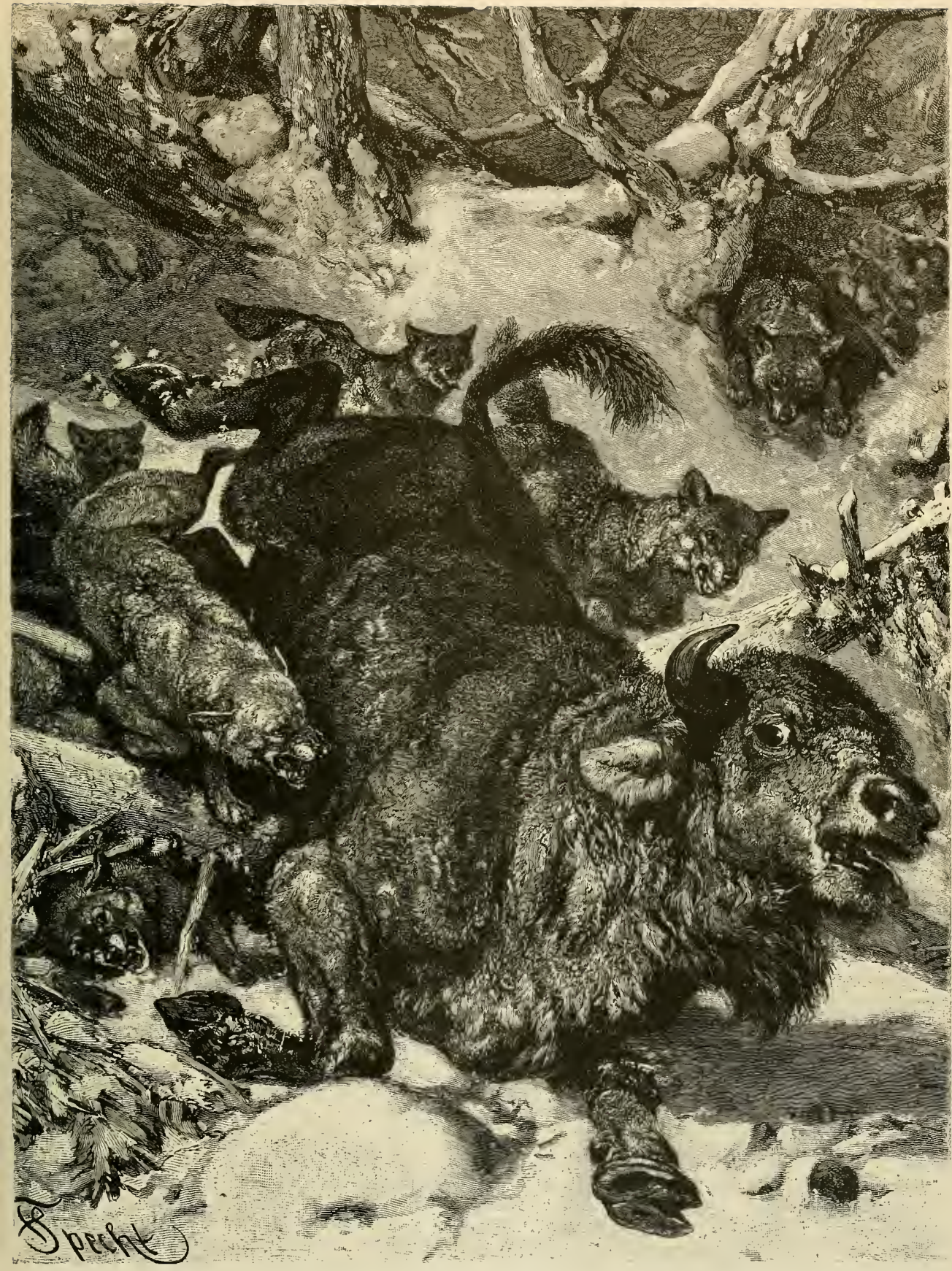

A PACK OF WOLVES.-The common Wolf is a fearful destroyer among the flocks in Europe. The manner in which Wolves assemble in packs and relentlessly attack all animals they come across is well shown in this illustration. The Wolves have pursued their victim until it has finally fallen, and they are now sure of a meal. 
In order to judge correctly of the domestic Dog and his numberless varieties, it is absolutely necessary to become acquainted first with his relatives in the wild state, the lVolves, among which we must look for his progenitors. It also scems but logical to consider the wild Dogs before we turn to the domestic varieties. The former teach us what the Dog originally was before he became the property of Man; in them we see the aboriginal animal, while the tamed Dog represents the changed, or if I may term him such, the humanized animal.

\section{THE WOLVES PROPER.}

The sub-order of Wolves proper ( Lupus) comprises all Wolf-like Dogs except the Hyæna-Dog; they have forty-two teeth, and show a great variety in their external appearance, though thcir head is always moderately large and the snout rather pointed. takes on a yellowish hue; in northern countries it is of a whiter, and in southern regions of a blacker tint. The forehead is whit ish gray, the snout yellowish gray, but always mixed with black; the lips are whitish, the cheeks yellowish and sometimes indistinctly striped with black; the dense woolly under-fur is dull gray.

Here and there one may meet a black Wolf, which as well as some other modified species is only a variety. Wolves inhabiting mountains are in general large and strong, while the Vlolves of the plains are most perceptibly smaller and weaker, but by no means less aggressive or bloodthirsty than their mountain relatives. In Hungary and Galicia a distinction is generally recognized between the Wolf of the forest and the Wolf of the plain.

An adult Wolf attains a length of sixty-four inches, about twenty of which are taken up by the tail; the height at the shoulder is about thirty-four inches. A

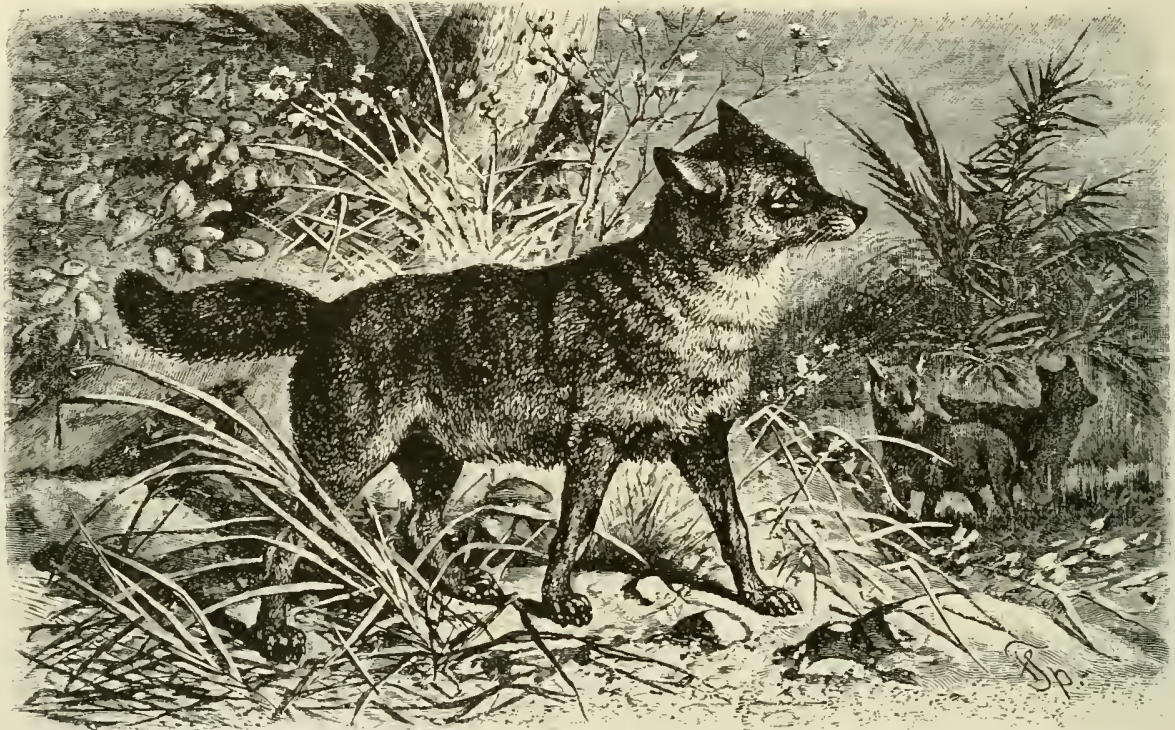

THE JACKAL W OLF. - This is a species of Wolf found in Egypt. Nubia, Abyssinia and the Soudan and called ". Abuel Hossein " by the Arabs. It has a stout body on slender legs, pointed snout, and a general appearance of strength and agility. While generally attacking only smaller animals, the Wolves sometimes hunt in packs, and several of them are often found together, as in the picture. (Canis anthus.)

The Wolf the The Volf (Camis lupus or Lupus a'ulgaris) Most Common has much the shape of a large, long-

Species. legged, lean Dog which lets its tail hang down instead of curling it upward. A closer inspection reveals the following differences: the body is lean, the waist retracted; the legs correspond to this bodily structure; the long-haired tail reaches the ankle-joint ; the snout appears long and pointed in comparison with the thick head; the forehead is sloping; the eyes have a slanting position and the ears are always erect. The fur is subject to changes both in density and color, according to the country the Wolf inhabits. In the northern regions, the hair is long, rough and dense, longest on the under surface of the body and the thighs, bushy on the tail, dense and erect on the neck and sides; in southern countries it is on the whole shorter and rougher. The color is usually a dull, gray ish yellow with an admixture of black; it is lighter, often assuming a whitish gray tint, on the under surface. In summer the general color has more of a reddish tinge, in winter it large specimen may weigh eighty or even one hundred pounds. The female differs from the male by being of a slighter build, and having a more pointed nose and a thinner tail.

Wide Range The Wolf is still spread over a wide Inhabited by area, though his territory has been much

the Wolf. restricted in comparison with former times. He is found throughout nearly the whole of Europe, though he has disappeared from the most densely populated parts of this continent. He is extensively distributed in Spain, being found in all the mountainous sections and even on the larger plains; he is common enough in Greece, Italy and France, more rare in Switzerland, and is extinct in middle and northern Germany and Great Britain. He is common in eastern Europe. The countries in which he is most abundant are Hungary, Galicia, Croatia, Craniola, Servia, Bosnia, the country of the Danube, l'oland, Russia, Sweden, Norway' and Lapland. He has never been found on lceland and the islands of the Mediterranean, but he seems to exist 
in the Atlas country. He also extends all over northeastern and central Asia, throughout Afghanistan and Beloochistan south to the Indus, perhaps to the upper Punjab, and has a so closely allied relative in North America that his range may be said to extend also over the western hemisphere, and the North American and Mexican Wolves may be regarded only as varieties.

The Wolf as The ancients knew the IVolf well. Many

Known to Greek and Roman authors mention him, the Ancients. some not only with the horror which he has always excited, but with a secret terror of the uncanny or ghost-like attributes of the animal. In the old German mythology the Wolf, as the animal consecrated to Woden, is rather venerated than detested; the latter feeling arises, however, later, when Christianity takes the place of pagan mythology. Then Woden became "The Wild Hunter" and the south. It even takes up its habitation in bushy but not very large thickets, in damp forests, in maize fields, and, in Spain, is even found in corn fields, sometimes in the immediate neighborhood of villages. In densely populated districts it shows itself before sunset only in exceptional cases, but in lonely forests it begins its activity in the afternoon, like the Fox under similar conditions, and prowls around, seeking something for its ever famished stomach. During spring and summer it lives singly, in twos or in threes; during the autumn it lives in families, and in winter in more or less numerous packs, varying in size with the favorable or unfavorable character of the locality for such a union.

How the Wolf When Wolves have once gathered

Hunts in into a pack they do everything in Packs or Singly. common, calling each other with a howl, and mutually assisting in the search for food.

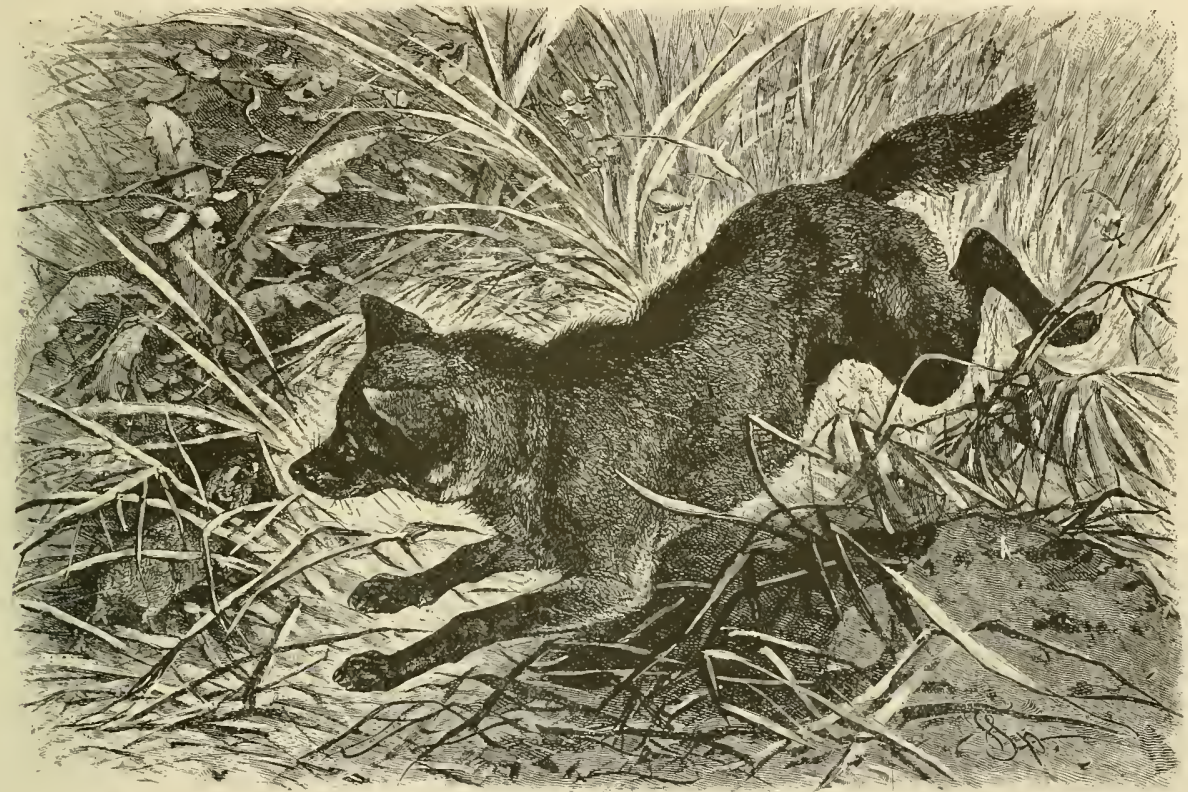

GUARA. - This is the native name of an animal also called the Red Wolf, or Maned Wolf, which has a wide range in South America and is especially plentitul in southern Brazil. Paragnay and the Argentine Republic. 1t differs from other Wolves in its lighter build, more pointed muzzle, shorter tail and elongated feet. The fur is yellowish on the under portion, reddish brown on the sides and a darker brown on the spine, where it forms a mane about five inches long. The hair is short and smooth on the face and teet and longer on the body. Its caution fleeing at his approach. It rarely attack domestic animals, bnt lives principally on small animals, especially rodents, which it finds in the marshes which torm its lavorite haunts, and is also said to eat
small fruits. (Canis jubatus.)

Wolves his Dogs, until finally the animal becomes the ghost-like IVolf of nursery fables, a monster who is alternately Man and Wolf.

The numbers of the IVolf are being more and more reduced, but his last days in civilized Europe are evidently still far off. During the past century this liarmful Beast of Prey existed in every larger German forest, and statistics show that even during this century thousands have been killed. They appeared in great numbers in the wake of the French army fleeing from Russia, that retreat furnishing them so many corpses which served them as food.

Where the The IVolf inhabits lonely, quiet regions, Wolf Makes and spots in the wilderness, delighting His Lair. in dense, gloomy forests, bogs with alternating swampy and dry places, and plains in the
A Wolf prowls around in company with others exactly in the same way as he does singly; he follows chains of mountains, wanders through plains, traverses entire provinces in crossing from one wood to another, and therefore may suddenly make his appearance in localities where he has not been seen for a long time, sometimes for a lapse of several years. It has been proven that he may cover from twenty-five to forty-three miles in a single night on his wanderings. Not infrequently, and always in winter when the snow is deep, packs of Wolves run in single file, like Indians on the warpath, and tread into each other's foot-marks, if possible, so that even an expert finds difficulty in estimating the size of the pack. The agility of the Wolf presupposes a great expenditure of strength, rapid tissue 
change and a disproportionately great supply of food, therefore the dangerous animal causes sad havoc among the flocks that he can reach. His favorite game is among domestic flocks and the larger wild animals, both furred and feathered, but he also contents himself with the smallest, even eating insects; and he does not disdain vegetable food, consuming, it is said, maize, melons, pumpkins, cucumbers, potatoes, etc. The mischief he causes by his hunting might be borne, though it is considerable, if he were not impelled by his wild hunting zeal and indomitable thirst for blood to slay more than he needs for his sustenance. This renders him a curse to the flock-owner and sportsman, and makes him everybody's cordially hated enemy. During the summer he is less harmful than in winter. The forest gives him much food besides his regular game, such as Foxes, Hedgehogs, Mice, various birds and reptiles and vegetable food, so the only domestic animals which fall a prey to him are the smaller ones which graze unsuspectingly near his haunt. He commits fearful ravages among the wild animals, such as Elks, Stags, Fallow Deer and Roes, and he exterminates nearly all Hares in his range, the only prey procurable in winter in the proximity of villages. He does not neglect to profit by opportunities, and enters stables without scruple, slaying all smaller domestic animals he can find. The inhabitants of the localities he infests lose a great number of their Dogs every winter, and the IVolfhunter constantly loses several of his faithful companions in the chase during the summer. When the Wolf hunts in packs, he also attacks Horses and Cattle, though these animals know how to defend themselves. It is said in Russia that hungry packs of W'olves even attack Bears and finally come out victorious in the deadly struggle. It certainly is a fact, that the Wolf hunts every living thing that he thinks he can subdue. However, he always shuns Man, as long as it is possible to do so. The horrible stories which are told about the Tiger as well as the Wolf, and are profusely adorned by the imagination, are to a very small extent based on truth. A pack of Wolves, suffering severely from hunger, may in their desperation attack, kill and devour human beings, even if they are armed Men; but the dangers to which inhabitants of Wolf-infested countries are exposed are not so great as has been supposed.

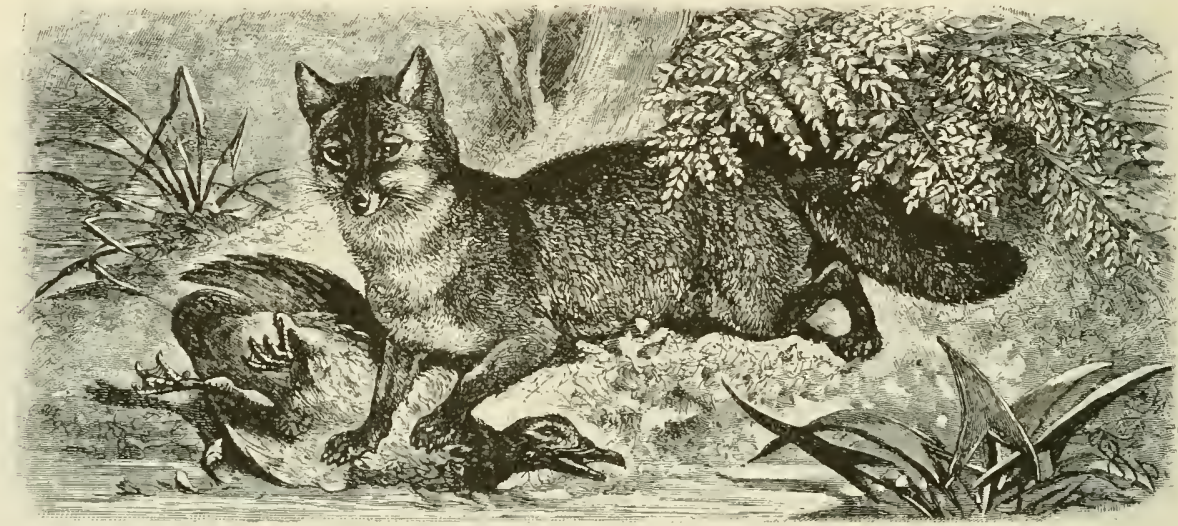

AGUARA, 0R BRAZILIAN FOX.-This animal, which is a species of Wolf with many Fox-like attributes, is found throughout South America. It is a vigorous hunter of birds and small mammals, is very cunning and agile, nocturnal in its habits, and has other indica. tions of the Fox in its nature besides its pointed muzzle and bushy tail. (Canis z'etulus.)

but he attacks larger domestic animals only in exceptional cases. Sometimes he contents himself with following the lowest of prey, pursuing the Lcminings for hundreds of miles, and then feeds only on these Mice, also picking up Lizards, Adders, Frogs and May-bugs. He is passionately fond of carrion, and wherever his range is co-extensive with that of the Lynx, he clears away the remains of his cousin's repasts.

Great Destruction He acts quite differently in autumn Inficted and winter. Then he uninterrupted-

by the Wolf. ly sneaks among the Cattle grazing out of doors and spares neither large nor small animals; refraining from attacking Horses, Cattle and I Hogs only winen they form compact herds, and before he has combined with other Wolves in a pack. At the beginning of winter he approaches nearer and nearer to human habitations. He penetrates to the very outskirts of St. Petersburg, Moscow, and other Russian cities, enters Hungarian and Croatian villages, daring to run through towns as large as Agram, and regularly hunts in small villages, especially pursuing Dogs, which are a favorite game and
Single Wolves hardly ever attack a Man, even if his only weapon is a club, unless circumstances are particularly favorable for the assault, but defenseless Women and Children may be in greater danger.

The preceding accounts show clearly enough how much mischief the Wolf causes. The nomadic tribes, and all those nationalities which breed Cattle, consider him decidedly the worst of all their enemies; and it sometimes happens that he really makes Cattle-breeding in many localities an impossibility. According to Kobell, a single Wolf, whicl prowled around Schliersee and Tegernsee for nine years before he was shot, had, according to government statistics, killed one thousand Sheep and much other game during this time; so that the loss he entailed was considered to amount to from eight to ten thousand florins. In Lapland the word "peace" is synonymous with freedon from Wolves. Only onc kind of war is known there, and that is the one waged against the animals under consideration, which often damage the living property of the poor northern nomads to a considerable extent. In Spain the Wolves also do much harm. In Russia about 
one hundred and eighty thousand head of horned Cattle and three times that number of small domestic animals are annually slain by them; Lazarewski estimates the loss in domestic animals as amounting to fifteen million and that in game to fifty million roubles. Besides all this, IVolves sometimes suffer from hydrophobia, and then are equally dangerous to Man and beast.

Animais that It is easy to understand that these Withstand dangerous animals are dreaded not the Wolf. only by Men but also by other animals, especially where they exist in large numbers. llorses become extremely restless when they scent a Wolf, and the other domestic animals, except the Dog, take to flight when they have the slightest warning of the proximity of their principal foe. Good Dogs, on the other hand, delight in nothing so much as in a IVolf-hunt, it being a characteristic trait of Dogs that they are fondest of the most dangerous hunting. It is difficult to understand, or, at least remarkable, that hatred should become so great between two species as closely allied as the Wolf and Dog.

There are other domestic animals also which know how to defend themselves against the Wolf. In southern Russia Wolves live in burrows which they dig for themselves, sometimes as deep as six feet. At night they continually prowl around the herds of the Russian steppes. They approach the Horses with caution, and try to steal Colts that have strayed too far from the flock; or they attack an isolated Horse, springing at his throat and throwing hin down. If other Horses perceive the Wolf, they immediately go up to him, and if he does not retreat they strike him with their front hoofs, and the Stallions may even seize him with their teeth. He gets into quite as bad a plight when he tries to procure himself a pork roast in the forests of Spain or Croatia. A single Hog may fall a prey to him, but a large, compact herd is always avoided by Wolves. If he mistimes his attack by a moment, he is trampled down by the enraged Hogs and devoured with as much enjoyment as a meal of pork might afford him.

Attributes The Wolf possesses all the Dogs' attriand Traits of butes and traits; he has their strength

the Wolf. and perseverance, their acute senses and their sagacity. But he is much more one-sided and less noble than the domestic Dog, undoubtedly because he lacks the education which Man gires to the Dog. His courage is out of all proportion to his strength. When he is not hungry he is one of the most cowardly and timid animals in existence. He then flees not only before a Man, a Dog, a Cow, or a Goat, but even before a flock of Sheep, if only the animals crowd together and turn their heads towards him.
The Wolf is by no means inferior to the Fox in cunning and caution; if anything he surpasses Reynard in these qualities. As a rule he adapts himself to circumstances, reflects before he acts and knows how to find a loophole of escape in danger. He sneaks up to his prey with as much cunning as caution; and if he is himself pursued he trots along with the utmost deliberation. His sense of smell, sight and hearing are all equally acute. He is said not only to track prey but to scent it at a great distance. When he finds spoor in his path, he knows very well the animal to which it pertains. He follows it and does not suffer anything to divert him from it. His cowardliness, his slyness and the acuteness of his senses are well shown in his methods of attack.

The Mother In the early spring the female Wolf

Wolf and gives birth to from three to nine, usu-

Her Young. ally from four to six young, in some

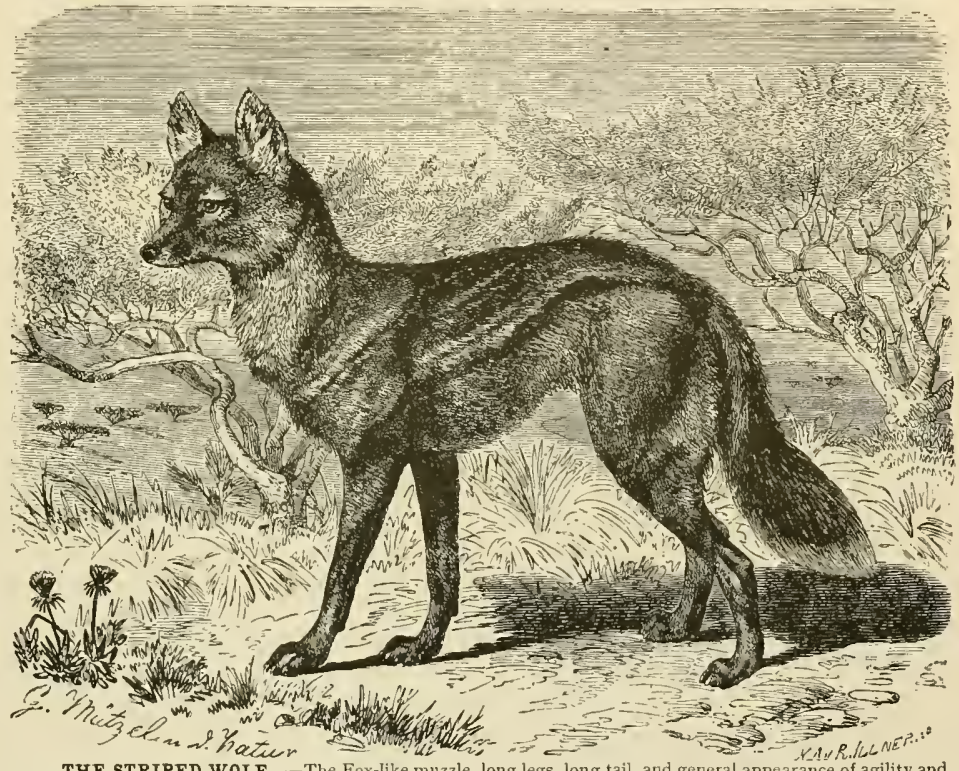

The Fox-like muzzle, long legs, long tail, and general appearance of agility and hidden place in the depth of the forest. The newly born whelps remain blind for twenty-one days, grow very slowly at the first and very rapidly when they are older, and conduct themselves exactly like young Dogs. They are very playful and their howling and yelping during their romps are sometimes heard at a great distance. The mother treats them with all the tenderness of a good canine mother, licks and cleans them, suckles them for a very long time and then procures them ample nourishment, suitable for their age; she is always on her guard lest she betray them, and if her distrust has been aroused or danger threatens, she carries them to another place she deems more secure. The age a Wolf may attain probably reaches to twelve or fifteen years.

It has been sufficiently proven by many experiments that the interbreeding of the IVolf and Dog produces hybrids, capable of further reproduction. These cross-breeds are not always intermediate in character between the Wolf and Dog, and even the 
young of the same litter may differ among themselves. As a rule they are most Wolf-like, though there may be some which more resemble the Dog.

Taming of Wolves taken young and properly the Wolf not treated become very tame and very

Difficult. much attached to their master. Cuvier tells us of a Wolf, which had been brought up like a young Dog and at full growth was donated to the Jardin des Plantes. "There he showed himself very dejected for a few weeks, ate very little and manifested utter indifference towards his keeper. Finally he conceived some affection for those who were enployed about him, and seemed to have forgotten his former master, but when the latter returned to Paris, after an absence of eighteen months, the IVolf heard his voice in spite of the noisy crowd, and being set free, signified his joy most demonstratively."

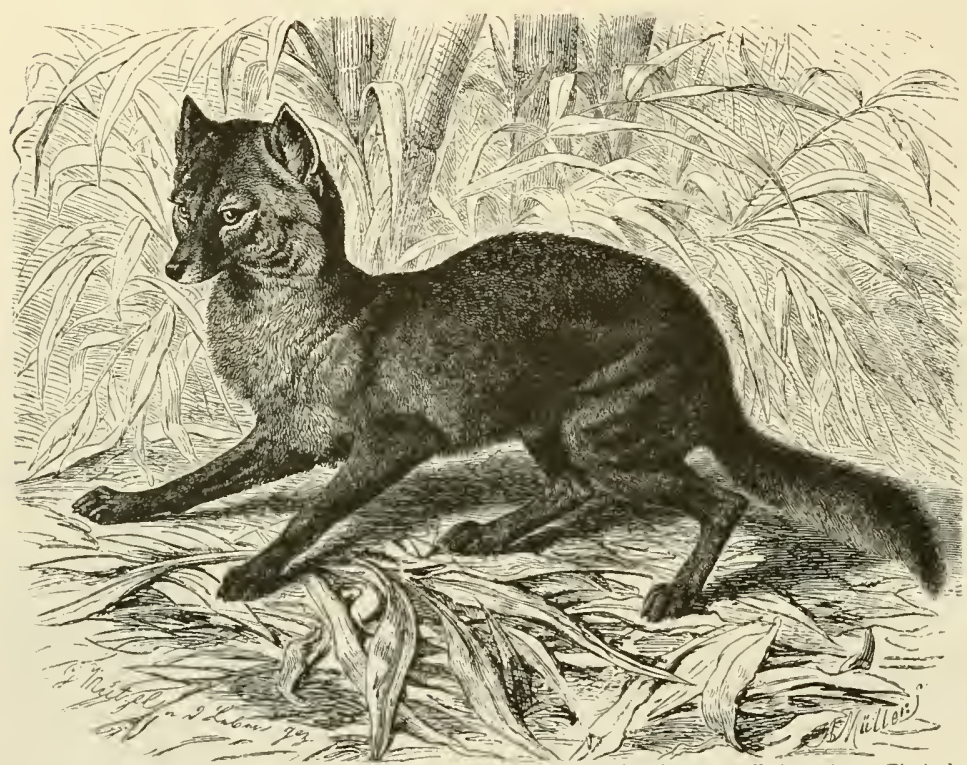

THE JACKAL. - The comely shape of this impudent night prowler of Asia is well shown here. The body is stout but not clumsy, the limbs are long, the muzzle is Fox-like, and the tail is long and bushy. They are noc turnal it their habits and very audacious, invading towns as well as plantations and carrying away everything edible which they can get. They kill many rodents, but they also are insatiable Chicken-thieves. Their howlings make night hideous in the Orient. (Canis aureus.)

The Wolf is The Wolf is killed in every possible Hunted manner; by the bullet, by in idious

With Zeal. poison, by the treacherots noose or trap, by the club and any other obtainable weapon. Most Wolves are probably killed by strychnine. When food begins to be scarce in winter, a slain Sheep is prepared in the following manner: The animal is skinned and the poison sprinkled into little incisions all over the body. Then the skin is put on again and the bait is laid in a place known to be frequented by Wolves. No Wolf eats his fill of an animal poisoned in such a manner, as the poison affects him very quickly and he succumbs to it at once. This mode of extermination probably produces the surest results. Pitfalls are also success$\mathrm{f} u 1$; they are dus about three yards deep and twoand-a-half yards in diameter, are covered with a light roof of small, flexible boughs, moss, etc., and the bait is fastened in the middle. To prevent the Wolf from making too close an investigation before- hand and also to protect people from falling in, the pitfall is surrounded by a high fence, which any one who desires to reach the prey has to clear at a bound.

In populous districts hunts are sometimes arranged on a large scale. The finding of a Wolf's spoor was and still is a signal for the rallying of whole parishes. In the larger forest districts, of Poland, Posen, east Prussia, Lithuania, etc., wide strips have been cleared in the forest, and then divided into smaller squares, for the sole purpose of WVolf-hunting.

The inhabitants of the Russian steppes hunt in a different manner. They deem a gun an entirely secondary feature of the chase; the IVolf is pursued by hunters on horseback, until he can no longer run, and is then slain.

The greatest profit that the Wolf yields is his winter fur, which, as is universally known, may be profitably used. The best and largest pelts are furnished by Scandinavia, northern Russia, Siberia and northern China and are sold at from $\$ 2.50$ to $\$ 8$ apiece. Besides this, many govermments give a fixed premium for every Wolf that is killed.

\section{The North Ameri The North American and lts Habits. Wolf $\{$ Canis occidentalis} (T) common Wolf, and the question whether it is a distinct species is still an open one. As a rule it is a little smaller than the European species, but the hab. its of the two are very similar although the American Wolf is not dangerous to Man exceut when it is made desperate by hunger. There are great vari eties in color among animals of this species in America. Those of a gray color similar to that of the European Wolf are the most common, and are distributed from the Gulf of Nlexico to the arctic latitudes and from ocean to ocean, but in some of the northwestern states there are white Wolves and in Texas a variety is found with a reddish fur. Black Wolves range in Florida and some of the other southeastern states and in the lower Missouri Valley there are some of a dusky drab color. The Wolf is much less numerous in the greater part of the United States than formerly, but it is still quite plentiful on the western plains and in many portions of Canada. Packs of Wolves follow herds of Bisons and when one of the herd hecomes isolated they attack it, and although in the combat which follows some of the pack are often killed the Bison, if it happens to be sick or exhausted, frequently falls a prey to the IVolves. Deer, Antelopes, Foxes, rodents and al small mammals are attacked by Wolves, and those of their own pack that are killed by Bisons are devoured by their companpons. In general, what has been said of the European Wolf as to habits, hunting and feeding, applies to the American Wolf.

The Jackal Wolf, The Jackal IVolf, or the Abu el Hosan African sein of the Arabs (Canis anthus), is Variety. a small, northeast African species, known to the ancient Egyptians and pictured by them on their monuments. His snout is pointed; the ears are large and broad; the body, supported by long legs, is stout and of a dark tawny color, which is subject to considerable variations, according to the locality. Small animals, carrion and fruit forn his nutriment, but sometimes he joins others of his kind 


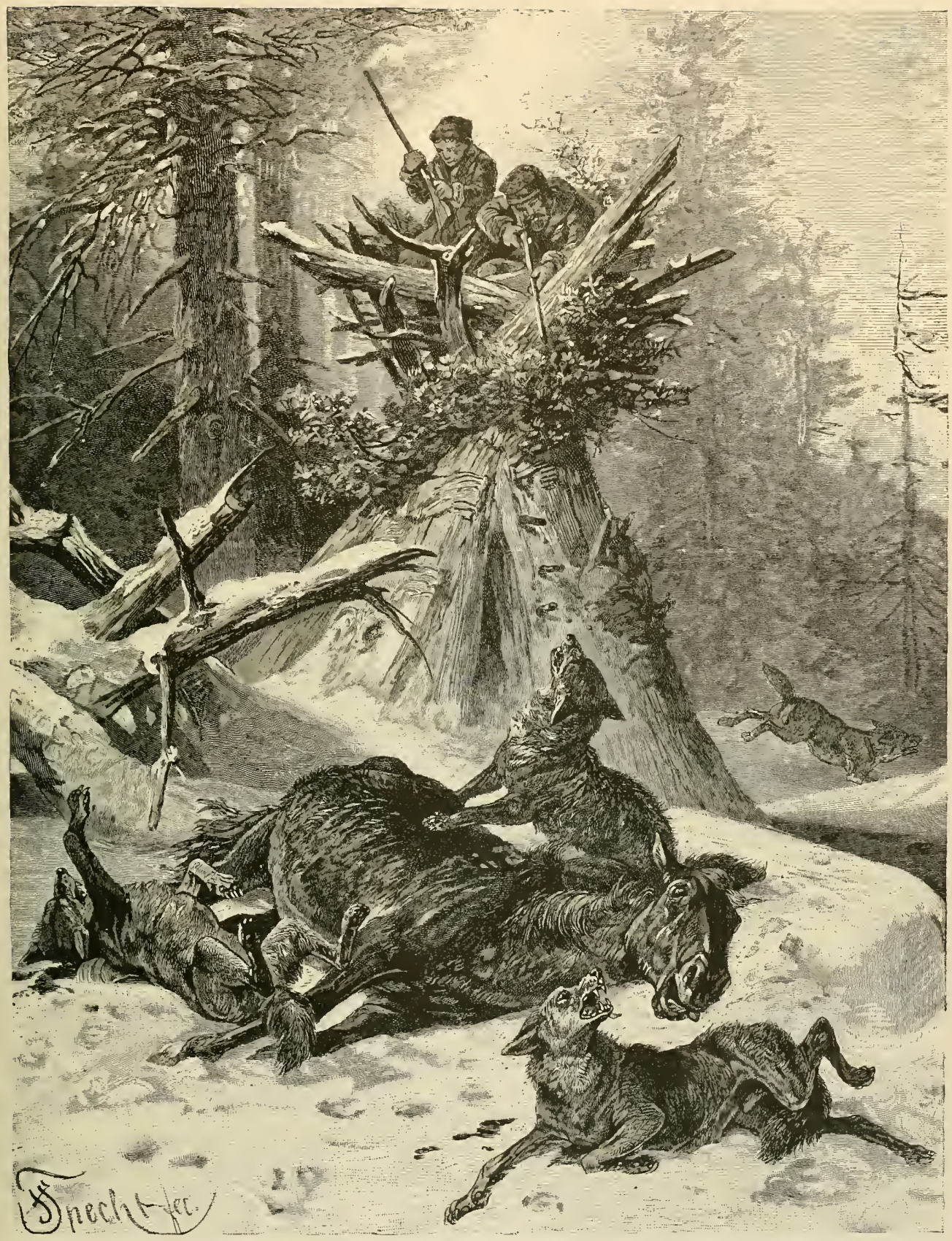

THE WOLF.- There is no other animal of its size and few even among the larger Beasts of Prey which equal a hungry Wolf in fierceness and boldness. In the winter time, especially, when domestic animals are housed and burrowing animals have retired to their winter quarters, the IVolf, enboldened by scarcity of food, becomes dangerous to Man, whose only safe refuge, at such a time, is to climb to a place of satety and with a trusty gun make war on the upine pack until such as are not killed are scared away. The picture represents such a scene and is typical of the dangers which may come in winter in the Wolf-infested regions in the west of our own country, as well as in others where these animals range. 
in a pack and together they attack the Sheep and Goat flocks of the natives.

The Striped A species much resembling these is Wolf, an Inter- the Striped Wolf (Canis adustus), an mediate Species. animal resembling both the Wolf and the Jackal. The body is elongated; the head of a conical shape, pointed toward the snout, not unlike that of the Fox; the eyes have a slanting position; the ears are widely separated, like those of the Jackal, and rounded; the legs are strikingly long and slender. The tail reaches to the ground.

"The Striped Wolf," says Pechuel-Loesche, who observed him in Lower Guinea, especially in Loango, in the wilderness as well as tamed, "is statelier and has longer legs than the Fox. He has the same sly expression of the face, but suggests also a decidedly better disposition and has a more aristocratic bearing. These IVolves are remarkably agile, lithe animals, freedom. Not only did he run around in the enclosure and visit our rooms, but he prowled around for hours in our plantations and the forests of the neighborhood. He searched for Beetles and Grasshoppers, play fully jumping after those that whirred away, and also caught many an unwary little mamnal or bird. Unfortunately he did not catch the Rats which had become quite a plague in our camp. He left the poultry alone after once having received a slight castigation for catching a Hen. When after this he regarded some forbidden dainty with covetous eyes, a mild word or a slight remonstrance was sufficient to turn him from his evil way. Sometimes he strayed from the enclosure and remained away all day, but he always made his appearance in the dining-room at night to receive a few scraps. If he was forgotten for a longer time than he deemed proper, he pushed his nose against the leg of some one present, or, like

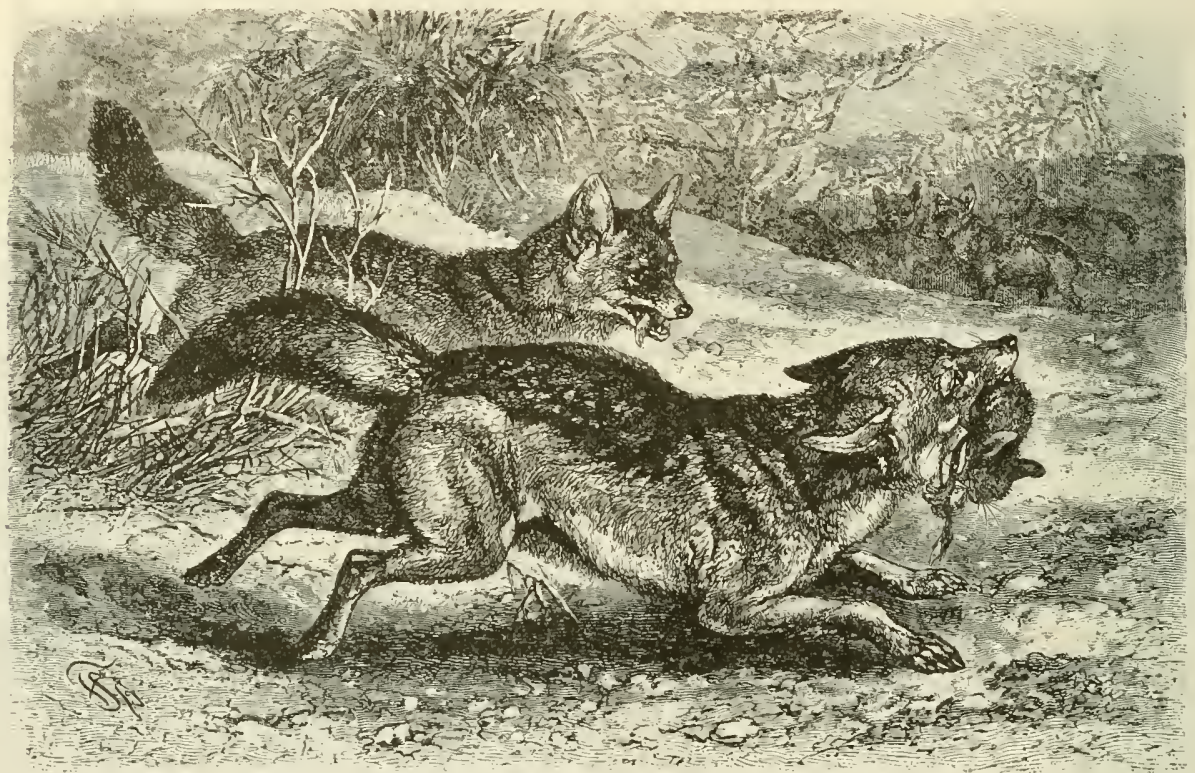

CAPE JACKAL. - Ranging in eastern Africa from southern Nubia south to the Cape, from thence across the continent and for some distance up the western coast is the Cape Jackal. It is especially plentiful in Abyssinia and south Africa, and is found in both plains and forests and is especially abundant in the mountainous regions. It is distinguished from the other Jackals by the Fox-like head, and the long, pointed ears which lie close together. It has a thick, fine, soft tur of a beautiful yellowish gray on the sides, yellowish white on the under portion, while the back is covered with a broad cape of a blackish hue crossed with white lines. Jt is very bold, enteritig villages and even camps, showing no dread of camp-fires. lt steals everything a blackish hue crossed with white lines. J is very bold, entering villages and even camps, showing no dread among poultry and small domestic animals, and is accused by the Somaln natives of eating the fat tails off the live Sheep of their country. (Canis

and it affords one great pleasure to observe their movements. They come quite close to human dwellings, for the village Dogs never think of picking a quarrel with them; neither do the natives, who call them 'Mbulu,' harm them. The Mbulu utters his shrill, long-drawn yelp in the morning and evening all the year round; it is so loud that a newcomer may be quite startled when he hears it in the immediate proximity of a village or encampment. The piteous cries of a Mbulu once brought us to the edge of a bushy little forest just in time to rescue the animal from a huge Snake which was strangling it

The Striped "Wle frequently kept half-grown Striped

Wolf in Wolves in our cnclosure. One of them

Captivity. grew to be a very stately animal, and was so tame and docile that he was given unlimited a Dog, put his head on somebody's knee. He accepted everything thankfully: bread, beans, rice, fish, meat, even raw bananas, or oil nuts; but he could crush only the smallest bones with his teeth. If one of us paid him attention or spoke to him kindly he would look into our eyes with a greatly pleased and affectionate expression, like a Dog, but very seldom wagged his tail. The human voice produced an impression on him such as 1 have seen exhibited only by the Gorilla : it literally scemed to fascinatc him."

character. The Jackal (Camis or Lupus aureus) is

istics of the the animal which the ancients called

Jackal. Thos or Gold-Wolf, and probably the same as the "Foxes" mentioned in the Bible, with which Samson, by setting fire to their tails, burned the wheat fields and vineyards of the Philistines. The 
Jackal is known all over the Orient and his actions are there talked about with the same interest that we give to the deeds of the Fox.

The Jackal is from twenty-six to thirty-two inches long; of this length from nine to twelve inches are taken up by the tail, and the height at the shoulder is from eighteen to twenty inches. $\mathrm{He}$ is of vigorous build, the legs are long, the snout more pointed than that of the Wolf, but blunter than that of the Fox; the bushy hanging tail reaches to the anklejoints. The ears are short, and the light-brown eyes have round pupils. The fur is rough, of moderate length and difficult to describe. The ground color is a dingy tan-color or grayish-yellow, merging into black on the back and sides, or tinged with black in waves or stripes. This color is in sharp contrast to that of the sides, thighs and paws, which is a pale red, and the sides of the head and neck are of the same tint. The pale or grayish-yellow ground color merges into whitish yellow on the throat and the under-waist, reddish yellow on the breast and gray on the lower part of the throat.

Asia must be considered as the native country of the Jackal. From India he extends over the west and northwest of the continent, through Beloochistan, Afghanistan, Persia, the Caucasus, Asia Minor; Palestine, Arabia to northern Africa; but he is also found in Europe, in Turkey, Greece and a few localities of Dalmatia. In India and Ceylon he is found everywhere, in forests as well as in the open country, on plains and in mountainous regions, and in the IImalayas to an elevation of over three thousand feet.

Mode of In his mode
Life of the of lif e the
Jackal. sents an intermediate form between the IVolf and the Fox. He resembles the latter more than the former. In the daytime he keeps in hiding; towards cvening he sallies forth on his hunt, howling loudly to attract others of his kind, in company with which he then prowls around. He is gregarious, though he also hunts alone. He might be termed the boldest and most importunate of all wild Dogs, and is not at all afraid of human settlements, boldly penetrating into villages and even populous towns, and entering yards and houses, taking away what he can find. This boldness renders him a great deal more disagreeable and annoying than do his celebrated nitghtly songs, which he keeps up with admirable perseverance. As soon as night has really set in, one hears a howl of many voices, highly piteous in character, resembling that of our Dogs, but combining a nuch greater variety of sounds. At any rate, these melancholy howlings cannot be regarded as the expression of grief on the part of these animals, for they howl in a manner equally mournful when their food is plentiful, and they have every reason for expressing joyful satisfaction.
There are still other deeds of the Jackals which excite our aversion. The slight amount of useful service they perform is out of all proportion to the destruction wrought by them. They are useful in clearing away carrion and all kinds of vermin, and especially in catching Mice, but they do much harm by their insolent robberies. Not only do they devour everything edible, but they also steal all kinds of non-eatable things in the house and yard, tent and room, stable and kitchen, taking any thing that strikes their fancy. Their thievish disposition is perhaps as great as their voracity. In the poultry-yard they play the part of the Fox, slay with a Mlarten-like greed, and steal with all the insolence, if not the cunning, of the Fox. According to circumstances, they may also attack a stray Lamb or Goat, pursue small game and plunder orchards and vineyards. In India they are said to ravage sugar-cane plantations and maize fields and damage the coffee plantations, devouring a considerable quantity of the ripe berries. Jackals taken young become very tame, much

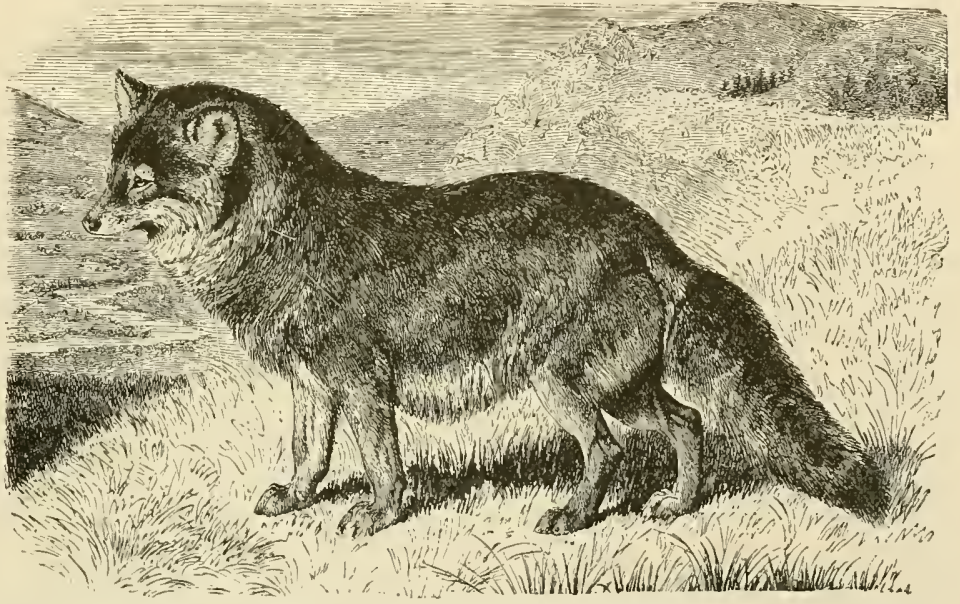

COYOTE, OR PRAIRIE WOLF. Here is an animal familiar to the residents of the western plains. It might aptly be called the Jackal of America, except that it is more cowardly than the Asiatic animal. Its long, thick fur makes the body look somewhat clumsy, but it can run very fast. The head bears a strong resemblance
to that of the Fox. The Coyote prowls at night, like others of the Wolf species, and may most frequently be seen (anis latrans.)

tamer than do Foxes. They become entirely accustomed to their owner, follow him about like a Dog, not only accept but beg for caresses, respond to a call, wag their tails in a friendly manner when petted, and, in short, show all the qualities of domestic Dogs. Even when taken old, they finally recognize Man's supremacy, though they may be addicted to biting viciously in the beginning.

The Coyote, or A well known American Wolf, the Prairie Wolf of Coyote or Prairie IVolf (Canis laAmerica. trans), appears to be an intermediate form between the IVolf and Fox, although his Wolfish traits are unmistakable. He has the body, tail and vigorous limbs of the Wolf, and the pointed snout of the Fox. His strong body appears still stouter than it really is, owing to his thick fur ; the neck is short and strong, the head more slender than that of the Wolf, broader at the top and sharper at the snout; the ears are rather large, wide near the head but not rounded at the tip; the light brown eyes have a round pupil. The color of the fur is a dingy yellowish-gray. 
Range and The Prairie IVolf is spread extensively Habits of the over the central parts of North AmerCoyote. ica, to the west of the Mississippi, and to the south of British America, perhaps as far as Panama; it is especially plentiful in the great plains west from the Missouri to the Rocky Mountains, in California and in British Columbia. Prince de Wied, to whom, as well as to Audubon, we owe the best descriptions of this animal, say's that it lives only singly or in couples, after the manner of European Wolves. It preys upon everything it can subdue and is as sly as the other IVolves and Foxes. At

natured Dog, but only towards acquaintances. His actions were those of a domestic Dog in every respect. When he caught sight of his friends, he used to leap with joy, wag his tail and come to the bars of his cage to be petted. But he never licked anybody's hands; at the most, only sniffing them. When left alone, he was very miserable and relieved his feelings by a pitiful howl; but when he had company, he ill-treated the animals, unless they were better biters than himself.

He was very susceptible to the complainings of other animals. He always joined in the howl of

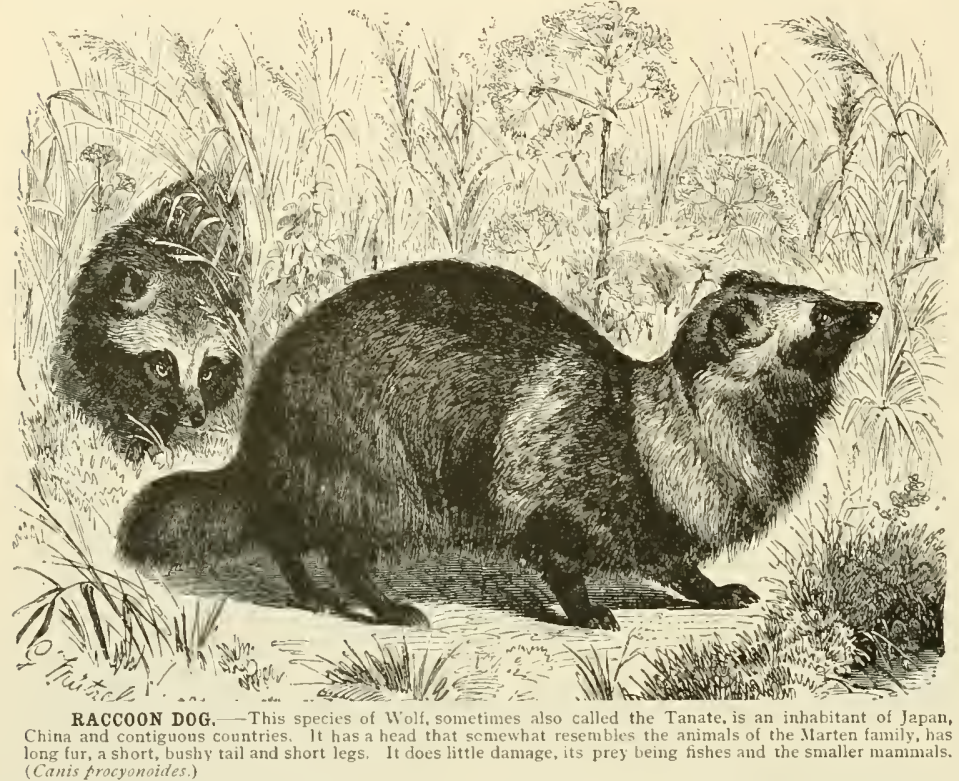
Wolves and even responded to the roar or growl of Bears. If a person talked to him in a plaintive tone. as if pitying him, he howled and whined as some domestic Dogs do under similar circumstances. Music also always moved him to loud outcries, but his howling at such times was evidently not meant to be taken seriously:

\section{The Raccoon As a repre-} Dog of sentative of China and Japan. a low grade of Wolves on the Northern Hemisphere, may be mentioned the Raccoon Dog (Canis procyonoides), a peculiar animal, indigenous to temperate eastern Asia, especially China and Japan; it has a somewhat Martenlike aspect and nocturnal habits, and feeds principally on Mice and fish.

The Wolf According Species of South to modern America. naturalists the Wolf has a few allied night it often goes so far as to enter the Indian villages and in winter, when prey is scarce, it is not infrequently seen to trot around in the daytime, as the IVolf does, in deep snow or during very cold weather.

The traveler on the western plains will seldom see a Coyote in the daytime during the milder seasons of the year, the animal being both crafty and cowardly and nocturnal in its habits. At night, however, it may be frequently seen to prowl quite near to a belated horseman or even in close proxinity to a camp fire, but it is very alert and only a quick shot is likely to be successful. It continues to make its presence known, how ever, for like the Asiatic Jackal, which in its habits it much resembles, it keeps up an incessant lowling during the night until the early morning.

This animal is much despised by the frontiersman, and "as mean as a Coyote" is a proverb in the far IVest, probably because of its howling propensities, and its destruction of Quail and other birds and small game. But the Coyote is not without its redeeming traits. It kills large numbers of destructive rodents, and is an adept at killing Rattlesnakes and other venomous reptiles.

During the breeding season, it inhabits burrows or caverns that it excavates for itself, and there the female gives birth in April to from six to ten young ones. At this time her voice is heard on the prairie. It is a curious bark, ending in a drawn out note, resembling the sound made by Foxes.

Account I can give a personal account of its life of a Captive in captivity, for I took care of a Prairic

Coyote. Wolf for some time. He had been reared in the house and was as gentle as a good- species among the South American wild Dogs, namely the Crab-eating Dog (Canis cancrizons) [an animal with a Fox-like muzzle, conica] ears and a rather long, bushy tail, which hunts in small packs] and the Aguara or Azara's Fox, also called Brazilian Fox (Camis a'ctulus or azara). The latter is a native of all South America, from the Pacific to the Atlantic and from the equator to the southernmost part of Patagonia. This animal is said to be possessed of the curious peculiarity of stealing and hiding all kinds of things for which it has no use. Tschudi found in the cavern of a "Zorra," as the Brazilians call this animal, a stirrup, a spur and a knife.

\section{THE HYANA DOGS.}

A second sub-order of the Wolves is formed by one of the most remarkable as well as most beautifully marked species, the Hyæna-Dogs (Lycaon). The body is slender, but of strong build, the head is moderately large or rather small, the snout is blunt. Hearing and sight are very well developed; the ears are high, wide and nearly devoid of hair, and the large eyes have a circular pupil. The legs are moderately long and the front feet as well as the hind ones have only four toes: differing from other Dogs. The further distinctive features of this species are a moderately long, not very bushy tail and a smooth, short-haired fur, of a very peculiar color. 
The Hycena Dog or Cape Hunting Dog.

The Hyxna Dog or Cape llunting Dog (Canis or Ljecron pictus) is about the size of a lean $1 \mathrm{Wolf}$ or mediumsized domestic Dog, while his aspect more closely resembles the latter. In spite of the slender shape, it produces the impression of a vigorous, strong animal. No two Dogs are marked exactly alike, only the head and nape of the neck exhibit a certain uniformity in tint. The prevailing colors are white black and ochre-yellow. Some have their ground color white, some black, and the lighter or darker spots contrast with these hues in bold relief. The spots are also of irregular shape; they may be small or large, and sometimes are distributed all over the body; but the white and yellow ones ahways have black margins. The snout is black up to the eyes and this color is continued in long stripes between the eyes and ears, along the top of the head and nape of the neck. The ears are black, the eyes brown. The root of the tail is ochre-yellow, the middle black, and the bushy tip white or ochreyellow.

The Hyana Dog is a native of Africa, but his boundaries have not yet been exactly determined. He ranges in south Africa; Boehm saw him in east Africa to the east and also to the southwest of the Tanganyika Lake: Ruppell found him in Nubia, Schweinfurth says that he is abundant in the Bongo country and Nachtigal says the same about Kanem on the Tsad Lake.

Cuminings' Gordon Account of Cummings Hycena Dogs. met Hyæna Dogs in southern Africa. "These Dogs," says he, "hunt in packs, varying in number up to sixty, and by their extraordinary power of endurance are enabled to overcome the largest and most powerful Antelope. They do not attack Buffaloes, as far as my knowledge goes. They pursue their quarry until it is worn out; then it is dragged to the ground and in a few minutes torn to pieces and consumed." In spite of the really beautiful coloring and high stature of the Hyæna Dog, Heuglin calls it " an unclean, evil-smelling animal, addicted to biting and incapable of hiding its false and treacherous disposition," and he says that, when wounded, it does not fear to attack Man. Hunting Abilities However this may be, the multiof the colored Beast of Prey remains a

Hycena Dog. highly attractive creature. It must be a magnificent spectacle to see these beautiful, agile and loud-voiced animals hunting. A large, strong Antelope has been frightened by them : it knows its pursuers and hurries through the grassy plain with all the speed its fleet legs can command.
Behind it is the pack, yelping, howling, whining and uttering indescribable sounds, which might be termed joyous, for they resemble the bright tones of a bell. As the chase progresses, the Antelope forgets all danger except that which is most imminent, and hurries along, heedless of human beings, whom it usually shuns, followed by the close-banded pack of Dogs. The pace of the latter is a long, never-tiring gallop and their discipline is excellent. When the leading Hounds arc fatigued they fall to the rear, and others, which have been rescrving their strength, come up, and so they relieve each other as long as the chase endures. Finally the hunted animal is tired out and brought to bay. Conscious of its strength the Antelope turns around and faces its deadly foes. The slender, pointed horns sweep the sward in wide curves. But, although one or two of the pursuers succumb in the struggle, it is usually but a minute before the unequally matched Antelope lies on the ground in panting agony. Sometimes, but rarely, it succeeds in freeing itself when first brought to bay. Then the hunt begins afresh and the voracious Dogs again rush after the Antelope, their snouts covered with blood. Their thirst for carnage is said to increase with the death of each

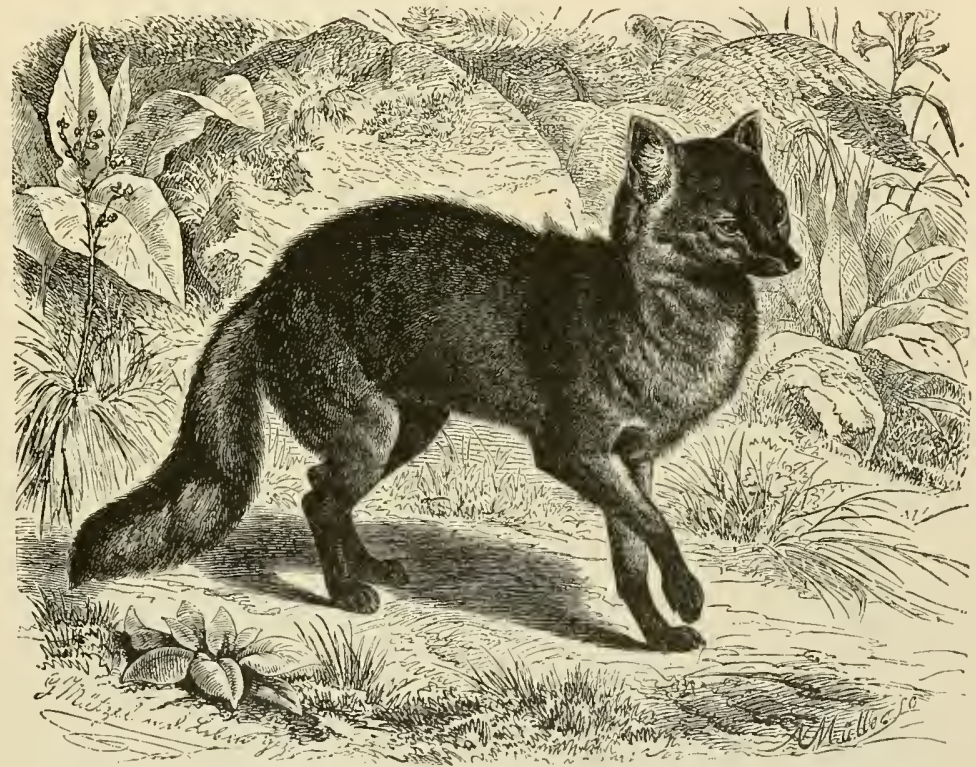

THE CRAB-EATING DOG.-This is a South American species of wild Dog, which is placed by some natualists along with other South American animals in a group under the name of Fox-Wolves. The muzzle is distinctly Fox-like but the remainder of the body, with the exception of the bushy tail, is more like that of the Wolf. Little is known about its habits except the Crab-eating propensity, from which it derives its nane, and the fact that it hunts in victim, and it is also said that they eat only the intestines of the killed game, leaving the rest for other animals of prey. They seem to eat very little of the muscular meat, for Burchell found a freshly killed Antelope, of which these Dogs had eaten only the inner parts, so he made use of the rest in his own kitchen.

Usefulness of The Myrena Dog is a wild animal which Tamed seems to promise a great deal if it only Hycena Dogs. were tamed. It would make an excellent tracker, but an animal of such characteristics is not easily brought under subjection to the will of 
Man. Schweinfurth saw a Iyæna Dog in a Seriba in the Bongo country, "which was thoroughly tamed, and was as docile as a Dog with its master." In I 859 I had the pleasure of finding an admirably kept and nearly full-grown Hunting Dog in Leipzig. I have seen several later and have also kept a few myself. Their distinctive traits scem to me to be a boisterous mischievousness, and an indomitable habit of biting, perhaps without the intention of hurting anybody and only as an outlet to the fidgety liveliness of their ever active spirits. As soon as a Hyæna Dog is excited, its every nerve quivers and moves. Its remarkably active disposition first assumes the semblance of exaggerated mirth, and then, a moment later, strikes one as a savage, sanguinary mania for biting. Grandville represents a lWolf as declaring: "Barking is of no avail ; one has to bite."

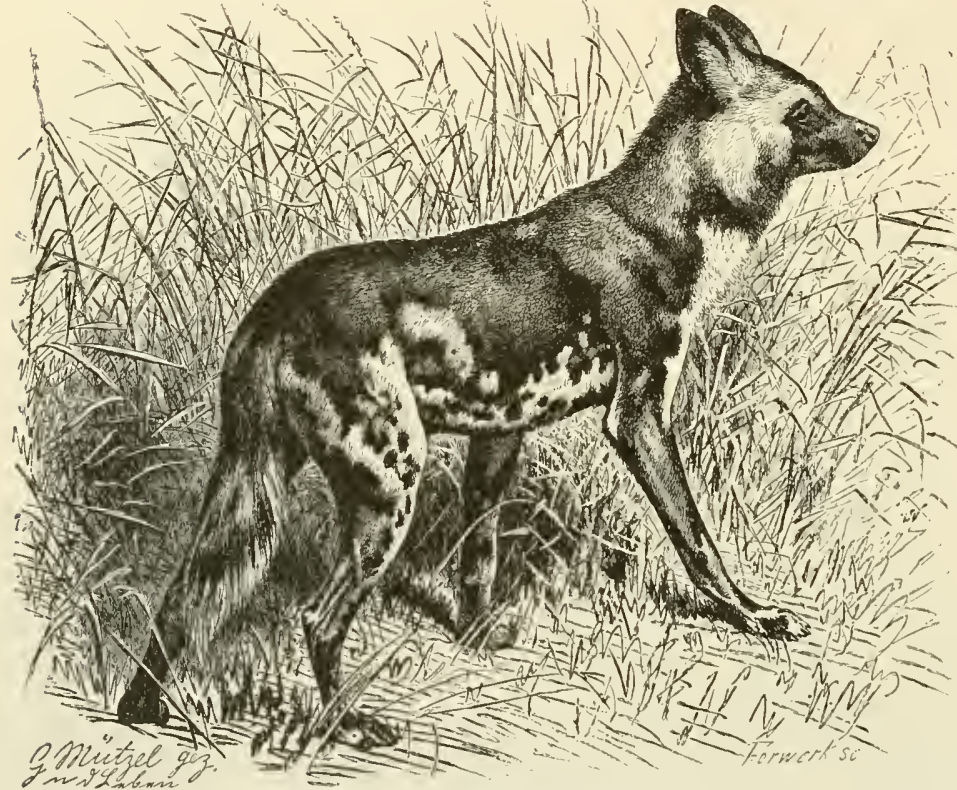

HY ENA DOG. - The slender, leng limbed animal in the picture, sonetimes also called the Cape Hunting Dog. is the representative of a distinct sub-order of the Wolf species. As will be sten from the picture, it is handsomely marked, has long Hound-like limbs, a tail with a bushy tip, and a form that suggests both agility and strength, qualities that are requisite to the tracking of the Antelope, which is the favorite prey of these wild Dogs. (Canss pictus.)

If he had known the Hyæna Dog, he would, doubtless, have ascribed this sentiment to that animal.

The Indian Sykes has described the Indian Wild

Wild Dogor Dog, or Kolsun, which he considered

Kolsun. the progenitor of all domesticated Dogs. This animal bears, according to his account, a greater resemblance to the Greyhound than to the Wolf or Jackal, and belongs to a third sub-order of the Wolves (Cyon), whose range is co-extensive with that of the Tiger. It has much the same proportions as a medium-sized Greyhound and its hair is of uniform thickness, rather short on the body but long on the tail. The color is a beautiful brownish or russet red merging into brownish gray, light on the under surface of the body and dark on the snout, ears, feet and extremity of the tail.

This Dog is called Son-Ram-kutta, Djangli, Kolsun, Kolsa, etc., in India, Buansu, etc., in the Himalayas (Canis or Cyon dukhuncnsis and Primar'us), and is found all over the Himalaya country from the val. ley of the upper Indus and Cashmere as far east as Assam, in eastern Thibet, and in all the woody regions of East India.

The Kolsun or Buansu is a genuine arboreal animal and inhabits principally extensive forests, but sometimes is also found in jungles; while in the northern and elevated portions of his native country, where forests are lacking, he has to content himself with the open country and rocks. He does not seem to be plentiful anywhere, and as he drives the game away and makes it rery restless by his mode of hunting, he does not stay long in one locality. He hunts in packs, which were formerly said to comprise fifty or sixty of these animals, but which, according to modern observers, seldom include twenty, and generally number only from two to twelve. The Indian II ild Dog usually pursues his game noiselessly, and his voice is heard only at rase intervals. He does not bark, but the sound he makes is rather a plaintive whine. All accounts agree as to his exceedingly good hunting qualities. In his mode of hunting he resembles the Hyana Dog. As soon as the pack has found some animal that will serve for prey, they pursue it with the utmost perseverance, and sometimes divide into smaller packs in order to cut off its escape on all sides; and are thus said to be able to overtake even the fleetest-footed Stag. Their chief attack is not made from the front and is not directed at the throat, but rather at the flanks and the soft hinder part of the body, which they tear by rapid bites during the chase, so that the intestines protrude and the animal soon succumbs.

The Malay The Malay Wild Dog, or Wild Dog or

Adjag. Adjag (Canis

or (yon mutilans) is smaller and weaker than his Indian relative and has a yellowish Fox-red color, which is lightest on the under surface of the body. The tail is tipped with black. The Adjag does not seem to differ in any marked degree from the Kolsun, except that there are no accounts to the effect that he preys upon large and strong animals. He is a native of Sumatra and Java, ranging, so far as his haunts are now known, from the sea level to about three thousand feet above, preying on rather peculiar game on the sea beach, as Junghuhn's observations show: "On the I $4^{\text {th }}$ of May, 1846. I came out of the bushes covering the coast of the Tandjung-Sodong. Looking at the wide beach before me, I thought I gazed on a battlefield. II undreds of skeletons of huge Tortoises lay strewn on the sand. Some had been bleached by the sun so as to present nothing but smooth bones, some were still filled with decaying, foul-smelling intestines, and some were yet fresh and bloody ; but all lay on their 
backs. This was the place where the wild Doss attack the Tortoises, which here make nightly journeys to the downs and back to the sea. The Dogs come in packs of twenty or thirty, seize the Turtle at all available parts of its body, and, snapping at

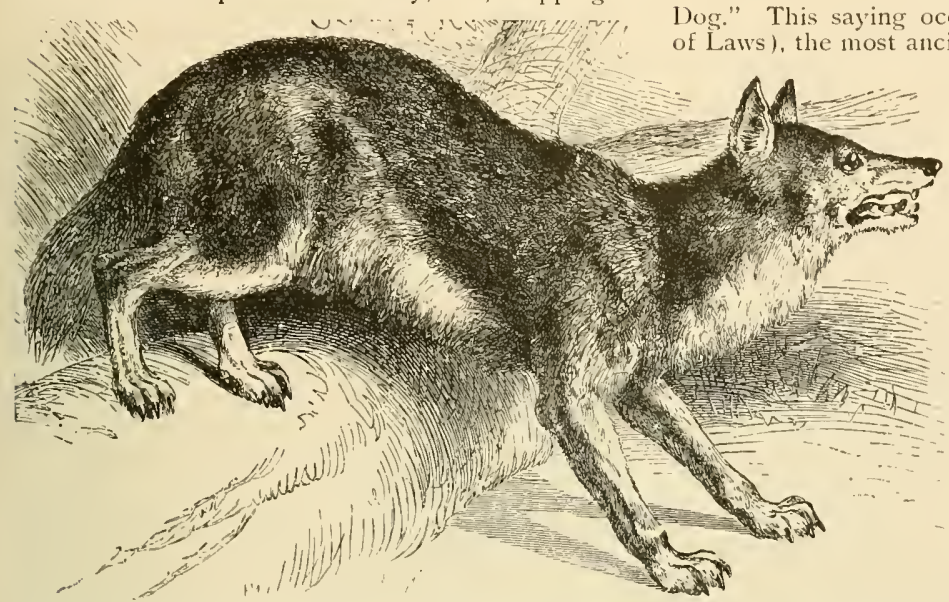

INDIAN WILD DOG, OR KOLSUN. - In exceedingly skillful hunter, keen of eye and fleet of foot is the Indian Wild Dog, or Kolsun, which bears a strong likeness to some domesticated hunting Dogs. The animal in
the picture is shown with ears erect, and eyes watching for game. The strong though not bulky form, the bushy the picture is shown with ears erect, and eyes watching for game. The strong though not buth
tail, and the fur, light below and dark above, are faithfully illustrated. (Canis duklunensis.)

the feet and the head, succeed in turning the animal over by their joint efforts, in spite of its huge size. Then they begin to gnaw, tear up the under shields and proceed to make a bloody meal of the intestines, meat and eggs. Many Tortoises escape these attacks and reach the sea, sometimes dragging the tugging Dogs along with them. But even when the Dogs have secured a Turtle for their prey, they are not always permitted to quietly devour it. On some nights it happens that the lord of the wilderness, the Royal Tiger, leaves the forest, stops for a moment and overlooks the beach with glistening eyes, and then, softly slinking up toward the Dogs, suddenly jumps among the pack with a low growl. They scatter to all sides and hurry to the wood in a mad flight, uttering an agitated sound that more resembles whist $1 \mathrm{ing}$ than growling.

$\mathrm{By}$ this account it is

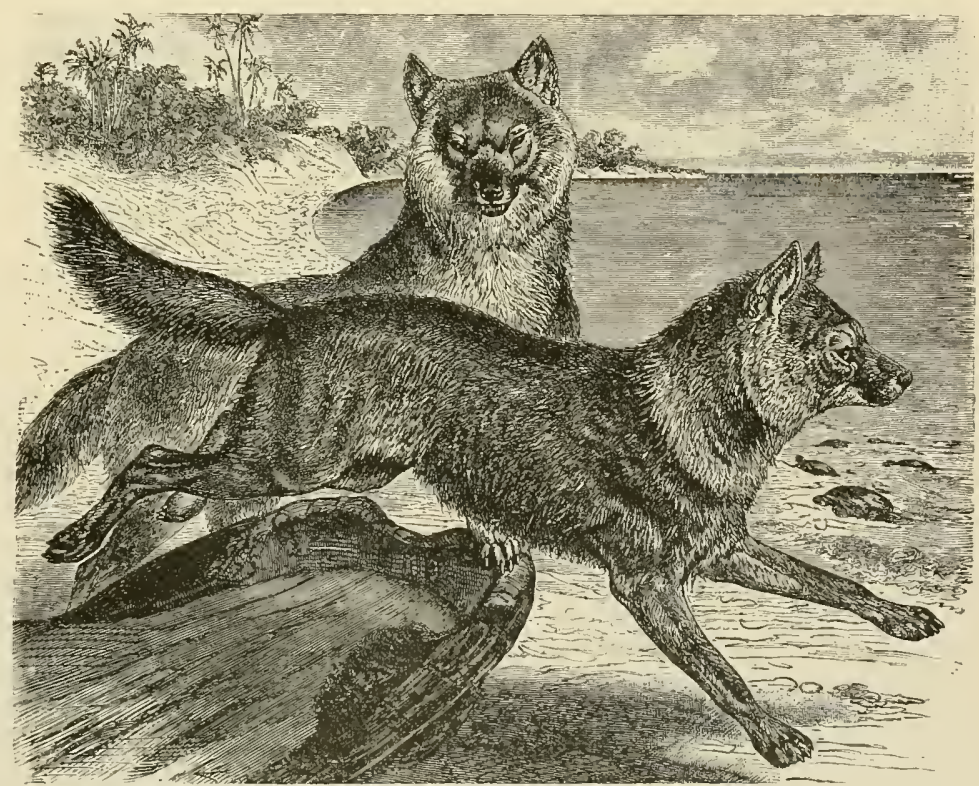

MALAY WILD DOG, OR ADJAG.-On the islands of Java and Sumatra the wild Dog known as the Adjag is found. The artist has appropriately depicted these animals on the sea-shore by the side of the inverted shell of a great Turtle which they have emptied, for the barren coasts frequented by these sea animals is a favorite resort for the llalay Wild Dog in search of food. (Canis rutiluns.)

nized from a distance by the wanderer in the willerTHE DOG. Zendavesta, one of the oldest books of mankind.

Great Merits No animal of

of the the globe is
Dog.

ing of the fullest, most undivided esteem, friendship and love of Man than the Dog. He forms a part of humanity, for he is indispensable to our welfare. "The Dog," say's Cuvier, "is the completest, the most singular, and the most useful conquest that Man has ever made. The whole species has beconle our property, each individual is devoted to Man, his master, adopts his manners, distinguishes and defends his property, and remains attached to him even unto death: and all this springs not from mere necessity, om a true friendship. The seen that these Dogs wage war with the inhabitants of the deep at a place exccedingly gloomy and barren, never visited by the natives of Java, but recog-

power of smelling of the Dog have made him a powerful ally of Man against the other animals, and were perhaps necessary to the establishment of soci- 
The Dog is the only animal which has followed Nitn all over the globe.

The Dog is well worthy of being considered at length, and spoken of with pleasure and love, notwithstanding the fact that he is so well known. Wherever Man has made a habitation the Dog is found, and even the most uncivilized nations possess him as a companion and defender. But neither tradition nor rescarch has given us sufficient ches as to his progenitors, and opinions the most divergent have been pronulgated as to the origin of the most important of all domestic animals. There is no other animal about which so many conjectures and hypotheses have been advanced.

The Dog and "If one wishes to separate the Dog the Wolf from the other Wolves," says Blasius, Compared. "there still remain no further distinguishing features than the curve of the tail to the left, which Linneus mentions. The historic fate of the Dog resembles that of Man. The total subjection of the Dog to Man has ted to consequences for which we find no paratlel in the animal world. The existence of the Dog is so closely allied to that of Man, and the Dog, like Man, has been obliged to adapt himself to the most diverse and antagonistic influences of nature to such an extent, in order to help to conquer and reign over the whole globe, that his original state in nature may only be conjectured theoretically, like that of Man. But this relates only to his physical properties. As to his intellectual nature opinions cannot differ. In the structure of his skeleton, his skull and his teeth, the Dog is a Wolf; still neither his skull nor his teeth serve to identify him with any one species of Wolf, nor disclose any sharp line of demarcation between him and the known species of Wolves. The Furopean Dogs waver in the peculiarities of their skull between the Wolves and the Jackals, but in such manner that the peculiarities either cross, unite or vary.

Universality "The Americans had indigenous Dogs of the before the Spaniards imported the EuDog. ropean specics. In Mexico the Spanjards found dumb Dogs. A. von Humboldt says that the Indians of Jauja and Huanca adored Dogs, before the Inca Pachacutec converted them to the adoration of the sun. Their priests blew on Dogskulls, and the skults as well as nummies of Dogs were found in the oldest Peruvian tombs. Tschudi has inspected these skulls and thinks them to be different from those of European Dogs; he belieres them to come from a distinct species, which he calls Canis inger. The native Dogs in Peru are called Runa-allco, to distinguish then from the European species which have degenerated into the wild state. These Dogs are said to sustain particularly unfriendly relations with Europeans.

"It is surprising that the native Dogs show in their skulls an approximation to the structure of the IVolves of their own country, but it is a matter of still greater surprise that they also show an affinity in their general appearance to the wild species when they have returned to the savage state. This relates not only to the coloring, but also to the shape of the animal, the pointed, erect ears, the hair and other characteristics. Olivier has remarked that the Dogs in the environs of Constantinople resemble Jackals. In southern and eastern Russia there are numberless half savage Dogs running around in packs and bearing a striking resemblance to the Jackal in their color, their bodily shape and the structure of thcir cars. The observation of l'allas, that the Dogs live in decided friendship with these Jackals, is easily understood in the face of such resemblances. It is a known fact that Dogs and Wolves may interbreed to any degree. Crosses between Dogs and Jackals are no rarity. Pallas even mentions that crosses between the Dog and Fox are well known to the Russians, but he evidently does not found this statement on his own observations.

"The question as to whether the Dog is a distinct, separate and independent species, like the Wolf, the Jackal and the Fox, is difficult to settle in the affirmative. No single species of wild animal shows such divergence in the skull, in the structure of the whole body, and in the proportions of actual size. But neither do the domestic animals in which we must suppose the original species to be still unaltered, or only changed by domestication and culture, such as the Horse, Ass, Cow, Goat or Hog, show any such extremes, and still less may it be said that several species are contained in this great variety of forms. It is clear, then, that we cannot speak of one species as being the stock from which the Dog sprang. It is also improbable that such a species would as yet have remained undiscovered by scientific research.

"And so, as long as one wishes to retain these problentatic points in the domain of natural history, there remains but one conclusion, which agrees with the opinion of Pallas: that the origin of the domestic Dog must be sought in the domestication and interbreeding of the different species of Wolves indigenous to the different countries. Naturally this supposition in relation to the point at issue is but a hypothesis, but if it is founded on facts in nature, it will be possible to make it a conviction by direct comparison of the skulls of Dugs with those of Wolves. It is clear that the fact that Dogs interbreed without limits among themselves and with Wolves and Jackals, is most readily reconciled with this hypothesis. The great similarity between Jackals and Dogs which have returned to the savage state, in their shape and coloring, and the ready approximation and friendship of the two is also of great importance. Horses returned to savagery also show an approximation to wild Horses. Goats, which for generations roam at large in the mountains the greater part of the year, as often happens in Dalmatia and some parts of Italy, much resemble the wild Capra agagnis; and colored Rabbits, when given their liberty, after a lipse of several years produce young which cantot be distinguished from the wild species and are themselves perfectly wild." Darwin on the "The reasons," says Darwin, "which Origin have led various authors to infer that of the Dog. our Dogs have descended from more than one wild species are: Firstly, the great difference between the sereral breeds, and secondly, the more important fact that, at the most anciently known historical periods, several breeds of Dogs existed, very unlike each other, and closely resembling or identical with breeds still alive. Youatt gives a drawing of a beautiful sculpture of two Greyhound Puppies from the villa of Antonius. (In an Assyrian monument, dating back to about $640 \mathrm{~B}$. C., an enormous Mastiff is figured, and such Dogs are still imported into the sanie country. On the Egyptian monments from the Fourth to the Twelfth dynasties - that is, from about 3400 to $2100 \mathrm{~B}$. C.- several varieties of the Dog are represented, most of them allied to Greyhounds. At the later of these periods a Dog resembling a Hound is figured, with drooping ears, but with a longer back and more 
pointed head than in our Hounds. There is, also, a Turnspit, with short and crooked legs, closely resembling the existing variety. The most ancient Dog represented on the Egyptian monuments is one of the most singular: it resembles a Grey-hound, but has long, pointed ears and a short, curled tail. A variety closely allied to it still exists in northern Africa, for Mr. E. V. Harcourt states that the Arab Boar-Hound is an eccentric, hieroglyphic animal, such as Cheops once hunted with, somewhat resembling the rough Scotch Deer-Hound. With this most ancient variety a Pariall-like Dog coexisted. We thus see that at a period between four and five thousand years ago, various breeds, namely Pariah Dogs, Greyhounds, common Hounds, Mastiffs, house Dogs, lap Dogs and Turnspits existed, more or less closely resembling our present breeds. But there is not sufficient evidence that any of these ancient Dogs belonged to the same identical subvarieties with our present Dogs.

"In Europe the Dog was kept in a domestic state a long time previous to any historical record. The bones of a canine animał were imbedded in the Danish Kitchen-Middens of the Neolithic or NewerStone period, and probably belonged to a domestic Dog. This ancient Dog was succeeded in Denmark, during the Bronze period, by a larger and somewhat different Dog, which, during the Iron period, was replaced by a still larger kind. A mediumsized, domesticated Dog existed in Switzerland in the Neolithic period, which in its skull was about equally remote from the Wolf and the Jackal, and partook of the characters of our Hounds and Setters or Spaniels. During the Bronze period a larger Dog appeared which, judging from his jaws, resembled a Dog of the same age in Denmark. Schmerling found the remains of two notably distinct varieties of the Dog in a cave, but their age cannot be positively determined.

"The main argument in favor of the several breeds of the Dog being the descendants of distinct wild stocks, is the resemblance they bear in different countries to distinct species still existing there. It must, however, be admitted that the comparison between the wild and domesticated animal has, except in a few instances, been made with sufficient exactness. There is no inherent difficulty in the belief that several canine species have been domesticated. Members of the Dog family inhabit nearly the whole world, and several species correspond, to a considerable extent, in their structure and habits, with our several domesticated Dogs. Sarages keep and tame animals of all kinds, naturally preferring sociable ani- mals, like the Dog. At an extremely ancient period, when Man first entered any country, the native animals had no instinctive or inherited fear of him, and would consequently have been tamed far more easily than now. Foi instance, when the Falkland Islands were first visited by Man, the large Wolf-like Dogs (Canis anturcticus) came to mect Byron's sailors without fear: but the latter fled into the water to avoid them, mistaking the animals' curiosity for ferocity. Even recently a Man, by holding a piece of meat in one hand and a knife in the other, could sometimes stick them at night. At the Galapago Archipelago I pushed Hawks from a branch with the nuzzle of ny gun, and held out a pitcher of water for other birds to alight on and drink. It is a more important point that several canine species evince no strong repugnance or inability to breed under confinement; and the incapacity to breed under confincment is one

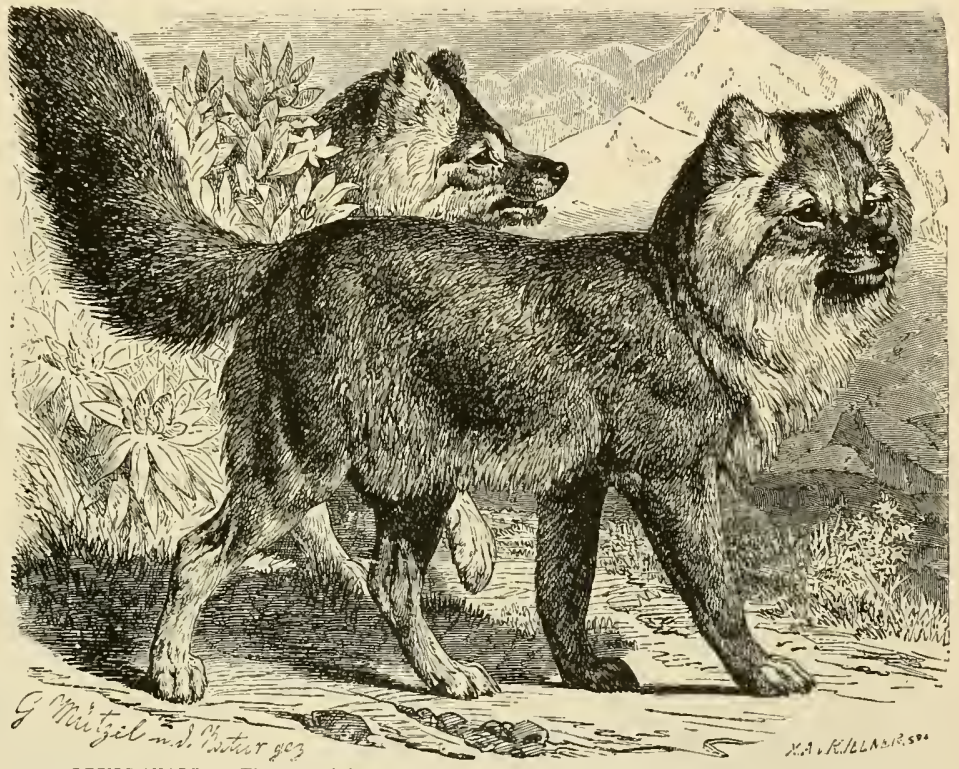

ALPINE WOLF.-This animal, by some accounted a sub-order of the common Wolf, has so many points nches long, exclusive of the bushy tail, which measures fourteen inches, and its shoulder height is eighteen inches. Its long. coarse fur is of russet, or yellowish gray, but of lighter tint and longer about the neck; the head is broad, Ihe niuzze blunt and the ears small. It is found in northern Asia and inhahits mountains surrounding the alleys of the lenesej and Amoor rivers, attacks Deer, especially Roes and Fawns, and the Mountain Goat; uns in packs usually, but sometimes singly and vigorously fights Men and Dogs when they attack it By some ria. (Canis alpunus) (n)

of the commonest bars to domestication. Lastly, savages set the highest value on Dogs even halftamed animals are highly useful to them. North American Indians cross their half-wild Dogs with Wolves, and thus render them wilder than before, but bolder. The savages of Guiana catch and partially tame and use the whelps of two wild species of Canis, as do the savages of Australia those of the wild Dingo. From these several considerations we see no difficuity in believing that Man might have domesticated various canine species in different countries. It would have been a strange fact if one species alone had been domesticated throughout the world.

Points of Simi- "Ile will now enter into details. The larity Between accurate and sagacious Richardson Dog and Wolf. says: 'The resemblance between the North American Wolves and the domestic Dogs is so 
great that the size and strength of the W'olf seems to be the only difference. I have more than once mistaken a band of Wolves for the Dogs of a party of Indians, and the liowls of the animals of both species is prolonged so exactly in the same key that even the practiced ear of the Indian fails at times to discriminate them. Dr. Kane has often seen in his teams of sledge Dogs the oblique eye (a characteristic on which some naturalists lay great stress), the drooping eye and scared look of the Wolf. In disposition the Eskimo Dogs differ little from Nolves, and according to Dr. Hayes they are capable of no attachment to Man, and are so savage that when hungry they will attack even their masters. Aceording to Kane they readily become feral. Their affinity is so elose with Wolves that they frequently cross with them, and the Indians take the whelps of IVolves to improve the breed of their Dogs. Turning to the southern parts of the New World: Columbus found two kinds of Dogs in the W'est Indies, and Fernandez describes three in Mexico. Some of these native Dogs were dumb, that is, did not bark. In Guiana it has been known since the time of Buffon that the natives cross their Dogs with an aboriginal species, apparently the Marcong or Carissi (Camis cancrizoms). A careful observer, Rengger, gives reasons for believing that a hairless Dog was domesticated when America was first discovered by Europeans. Some of these Dogs in Paraguay are still dumb, and Tschudi states that they suffer from cold in the cordillera. This naked Dog is, however, quite distinct from that found preserved in the ancient Peruvian burial places, and deseribed by Tschudi, under the name of the Inca Dog (Canis inge) as withstanding cold well and as barking. It is not known whether these two distinet kinds of Dog are the descendants of native species, and it might be argued that when Man first emigrated into America he brought with him from the Asiatic continent Dogs which had not learned to bark, but this view does not seem probable, as the natives along the line of their march from the north reclaimed, as we have seen, at least two North American species of Canida.

"Turning to the Old IVorld: some European Dogs ciosely resemble the IVolf. Thus the Sliepherd Dog of the Ilungarian plains so much resembles a Wolf that Mr. Paget, who gives this description, says he has known a Hungarian to mistake a IVolf for one of his own Dogs.

"The European Wolf differs slightly from that of North America, and has been ranked by many naturalists as a distinct species. The common IVolf of India is also, by some, esteemed as a third species, and here again we find a marked resenblance between the Pariah Dogs of certain districts of India and the Indian Wolf. With respect to Jackals Isidore Geoffray Saint-Hillaire say's that not one constant difference can be pointed out between their structure and that of the smaller races of Dogs, and they agree elosely in habits. Ehrenberg asserts that the domestic Dogs of Lower Egypt and certain mummied Dogs have for their wild types a species of IVolf (Canis lupaster) of the country; whereas eertain other mummied Dogs have the closest relation to a wild species of the same country, namely, Canis sabbar, which is oniy a form of the common Jackal. Jackals and Dogs sometimes naturaliy cross in the East, and a case is on record in Algeria. I may add that the domestic Dogs on the coast of Guinea are Fox-lilie animals and are dumb. On the east coast of Africa between latitude $4^{\circ}$ and $6^{\circ}$ south and about ten days' journey inland, the Rev. S. Erhardt informs me a semi-domestic Dog is kept, which the natives assert is derived from a similar wild animal. Lichtenstein says that the Dogs of the Bushmen present a striking resemblance even in color with the Brown Hyana. Mr. E. Layard informs me that he has seen a Caffre Dog which closely resembled an Eskimo Dog. In Australia the Dingo is both domesticated and wild. Though this animal may have been introduced aboriginaliy by Man yet it must be considered as almost an endemic form, for its remains have been found in a similar state of preservation and associated with extinct mammals, so that its introduction must have been ancient.

"From this resemblance in several countries of the half-domesticated Dogs to the wild species still living there; from the facility with which they can often be crossed together; from even half-tamed animals being so much valued by savages, and from the other circumstances previously remarked and which favor their domestication, it is highly probable that the domestic Dogs of the world have descended from two good speeies of Wolf (namely, the Common Wolf and the Coyote) and from two or three other doubtful speeies of Wolves (namely, the European, lndian and north African forms); from at least one or two South American canine species; from several races or species of the Jachal; and perhaps one or more extinet species. Those authors who attribute great influence to the action of climate by itself may thus account for the resemblance of the domesticated Dogs and native animals in the same countries; but I know of no facts supporting the belief in so powerful an action of climate. So I conclude the domestic Dog is nothing but the artificial product of Man.'

The Dingo, An instructive example of the stateor Australian ment that donestic Dogs may return Wild Dog. to the wild state, is given us by the Dingo or W'arragal (Canis dingo), the so-called Australian Wrild Dog, which, in view of his mode of life. I nyseif have considered one of the original species of wild Dogs; now that I have seen several specimens of this doubtful tribe, I ean only suppose him to be a domestic Dog run wild. The fact that the Dingo is, with the exception of a few Vinghanded animals and rodents, the only Australian mammal not belonging either to the pouched animals or to the Monotremata, is of great importance in this question. The reasons to the contrary are not valid, unless one considers as such the alleged discovery of Dingo remains in diluvial strata. It is, however, difficult to establish the period and circumstances of the return to savagery, and to do so seems of no great importance in the settling of this question, in view of the general character of the animal, which is that of a domestic Dog, and not that of a wild one.**

Physical The Dingo attains the size of a moderCharacteristics ately large Shepherd Dog. His shape of the Dingo. is thick-set, the head large and clumsy, the muzzle short and blunt. The ear is erect, wide at the root and rounded at the extremity; the tail is bushy and reaches lower than the ankle-joints; the limbs appear museular and are somewhat short; the

* In the latest researches of MacCoy and Nehring the fossil remains of the Dingo have been found in the pliocene and quartenary strata of Fictoria, and therefore the Dingo is proved to be a genuine IVolf, and not a domestic Dog returned to the sayage state. He is allied to the Volf of
India. and immigrated into Australia through the country uniting Australia and southeastern. Asia at a certain period of the pliocene epoch. (Note to
last Girman cotation.) 


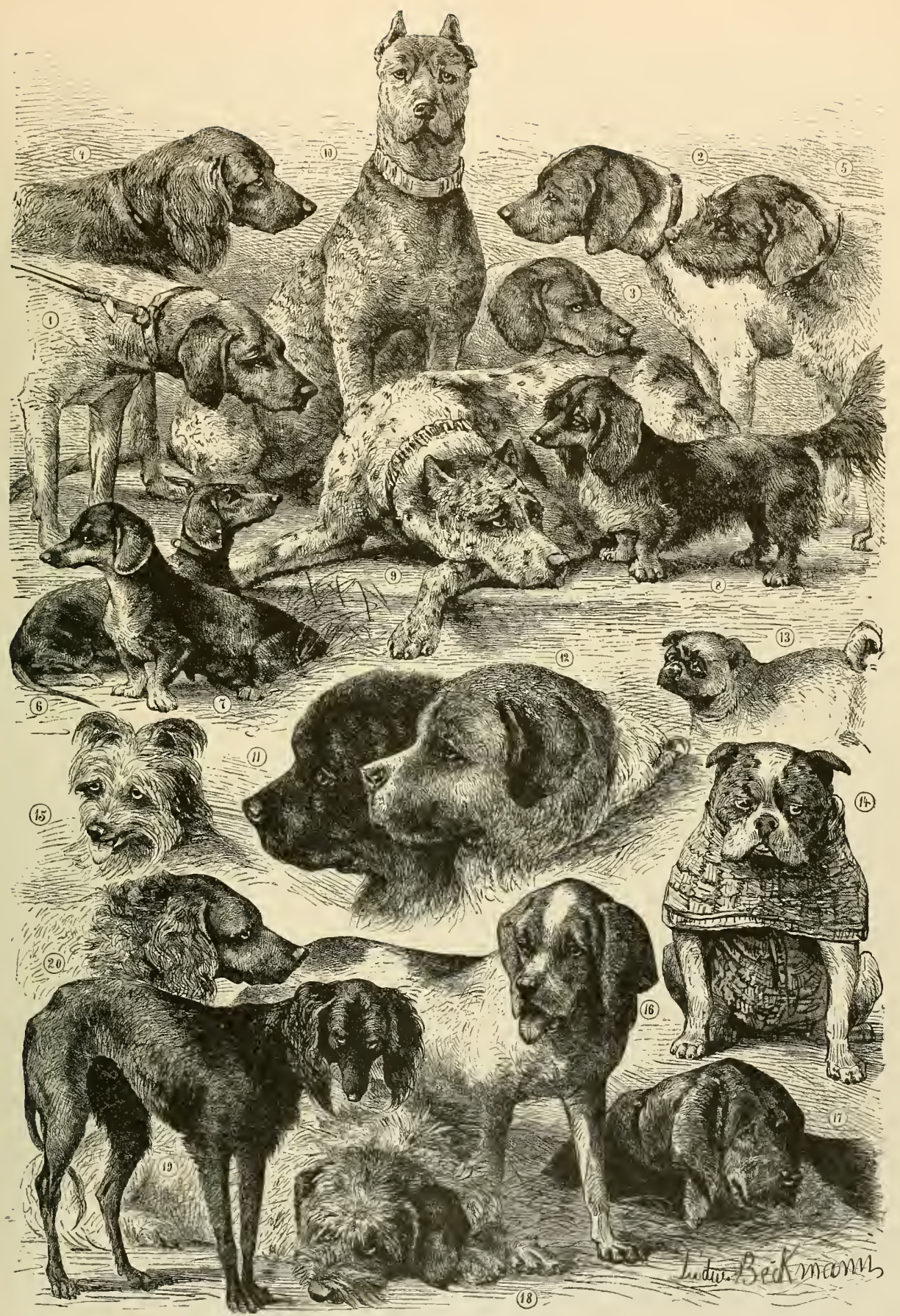

PRIZE DOGS OF THE INTERNATIONAL DOG SHOW IN HANOVER.-1. Saul.-Schweiszhund or German Bloodhound. 2. Hector IV.-German Short-haired Pointer. 3. Runal.-German Short-haired Pointer. 4. Mylord II.-German Long-haired Pointer. 5. Diana.
Rough-nuzzled Dog. 6. Fina.-Female Badger-Dog. 7. Thyra,-Female Badger-Dog. 8. Schnipp,-Long-haired Badger-Dog. 9. Pallas.-Tiger Mastiff, 10 Leo,-German Mastiff. Ir, Conı.-Newfoundland Dog. 12. Cadwallader-Alpine Dog. 13. Zulu Il.-Pug Dog. 14. Lorne.-BullDog. 15. German Sheep Dog 16. Normand.-French Chien Courant. 17. St. Hubert,-French Chien Courant. Is Nivernais.-French Chien Courant. I9. Persian Greyhound, 20. D'Audenter.-Spaniel. 
fur is composed of hairs of uniform length. In most specimens which 1 saw, the color varied between a vague pale yellowish red and a more or less grayish tinge, or even a blackish hue. The chin, throat, lower parts and tail are usually lighter, while the hair of the upper surface is darker. Though these colors prevail, one may meet black Dingos, or some with white paws and other unusual markings.

The Dingo is still found in nearly all the denser forests of Australia, upon the eminences grown with shrubs; in the groves of the park-like plains, and on the plains themselves. He ranges throughout the whole continent and is rather common in all parts of it. He is considered the most dangerous foe of flocks and is hunted in every possible manner.

Habits and In his habits and practices the Dingo Traits of the resembles the Fox more than the IVolf.

Dingo. Like the former he hides all day in his lair, in localities where he is not quite secure, and prowls around at night, threatening all Australian quadrupeds. He also resembles the Fox in the trait that he rarely hunts in great packs. Dingoes are generally seen in troops of five or six, usually a mother with her offspring; but it sometimes happens that a great many Dingoes assemble around a heap of carrion; some settlers state that they have seen as many as eighty or one hundred of these animals together. It is said that Dingo families keep faithfully together, and that each family takes possession of an allotted range, never encroaching on the domain of another pack, nor suffering other Dingoes to cross the boundaries they have appropriated for their own hunting grounds.

Harmful Before the settlers inaugurated a Depredations of determined warfare a gainst this the Dingo. deadly foe of their flocks, they lost an astonishing number of Sheep. It is said that out of one single flock one thousand two hundred head of Sheep and Lambs were lost in three months because of the depredations of the 1)ingoes. Sill greater than the immediate loss that a visit of this predaceous animal entails, are the indirect losses, for upon his appearance the shcep are seized by an insane fear, which causes them to run away into the wilderness, where they fall a prey to other Dingoes, or perish of thirst. The Dingo also preys on Kangaroos of all kinds and other larger and smaller animals of the bush. He attacks every animal indigenous to Australia and fears only domestic Jogs. Shepherd Dogs and I lounds bear eternal enmity to the Dingoes and the wild and tame Dogs pursue each other with eager ferocity. If a number of domestic Uogs see a Dingo, they pounce upon him and tear hini to pieces; the reverse happens when a stray tame Dog is found by Dingoes.

The Dingo When the Dingo meets a human being Holds Man he always tlees, if he has the time to do in Fear. so. In his flight he show's all the cunning of a lox, and knows how to profit by every loophole of escape, but if he is driven to bay, he turns around in a savage manner and defends himself with the frenzy of despair ; yet even then he tries to make good his escape. Bentett relates really wonderful stories about the Dingo's tenacity of life. A Dingo had been surprised by his enemies and had been beaten so severely that it was thought that all his bones must have been broken; so he was left lying where he had been struck down. But hardly had the Men left the supposed corpse, when to their great surprise, they saw the animal get up, shake himself and hurry to the woods. At the present day the Dingo is being exterminated by fair means and foul. Everybody's hand is against him, and he is shot, caught in traps or poisoned with strychnine. It is only by chance that he is shot; for he is too timid and cunning to cross a hunter's path, and even when pursued by Hounds the chances are that he will somehow cunningly elude them.

The Dingo The Dingo has usually been considered in a incapable of domestication; yet he is Tame State. occasionally found, half-tamed, in the keeping of the Australian natives. A great many Dingos which were kept captive in Europe, remained savage and ferocious and their Wolfish nature constantly asserted itself, so that the keepers had always to be on their guard. That opinions as to the character of a whole tribe, when formed from the observation of a few scattered specimens, may be very deceiving, is well illustrated by the Dingoes of the Breslau Zoological Garden. One of them became as tame as a Dog, while the other remained savage. The first named learned to bark ( a not ew orthy accomplishment) and used the newly-acquired language to good advantage; for instance, when a door near the cage was opened, while his untamed companion produced long-drawn, laughing tones, like a Jackal, the tamed animal always joined the duet with a truly Dog-like howl. Schlegel, to whom I am indebted for this account, was, like myself, of the opinion that the progeny of the Dingoes might be trained to be very useful companions to Man.

King has succeeded in bringing up a young Dingo, and training him to assist in guarding Cattle; and Pechuel-Loesche observed a beautiful, strong Dingo on board the English iron-clad ship Defence, which roamed about all over the ship like a Dog, elimbed the steep stairs with sure-footed dexterity, and was on good terms with everybody on board.

The Ouner. From the Dogs run wild let us now turn

less or to those which, though ownerless, yet pariah Dogs. stand in a certain relation of dependence to Man. The English have given them the name of Pariah Dogs, and we may well adopt this designation, for Pariahs they are, indeed: miserable, degenerated animals, cast off by the better classes; they are but poor Curs, in spite of their complete freedom; they lick the hand that imposes the yoke of slavery upon them, and seem happy when Man allows them to serve him and keep company with him.

In the south of Europe the Dogs are kept in a manner quite different from that usual in the north. In Turkey, Greece and southern Russia herds of ownerless Dogs besiege the cities and villages, sometimes entering the streets, but never penetrating into a yard; for, if they did, they would be driven away by the Dogs of the house. They feed chiefly on carrion or occasionally upon small animals, especially Mice and the like. The Dogs kept by peasants in the south of spain are also fed very little at home, and they prowl about at night, secking food. According to Bolle, it has occasionally happened, during recent years, on the Canary Islands, that a Dog has run wild and perpetrated great damage among the flocks of Sheep.

Pariah Dogs All Egyptian cities stand partially of the upon the ruins of fornter towns, that Egyptian Towns. is to say, on lieaps of rubbish. The majority of these cities, and more particularly the largest of them, like Alexandria and Cairo, are surrounded for a considerable distance by veritable 
mountains of debris. These mounds serve as habitations for the Dogs that have run wild. The animals are all of one breed, and are of the size of a Shepherd Dog, but have an ungainly shape and a repulsive expression of countenance. The tail is long, rather bushy, and usually pendent; and the color of their coarse, matted hair is a dingy, reddish brown, sometimes merging into gray or yellow. Other colors, more particularly black and light yellow, are sometimes seen, but not often. These Dogs live on the elevations just described in a condition of complete independence. There they spend the greater part of the day in sleep, and prowl around at night. Each one of these Dogs has his own habitation, which is arranged with peculiar care, his home consisting of two holes, one of which faces east and the other west. If the situation of the mountain is such that the holes on both sides are exposed to the north wind, each of the animals digs for himself another excavation, into which he moves when the cold wind annoys him in his morning and evening retreat. In the morning the Dogs can always be found in the holes that face toward the east until about eleven o'clock, for in these recesses they await the first rays of the sun to warm them after the cold of the night. The sunshine, increasing in intensity, at last becomes too warm, and one Dog after another arouses himself, climbs over the summit and slinks into his hiding place on the other side. When the afternoon sun begins to annoy them in this retreat the colony returns to the holes on the east side and stays there until sunset.

Then life begins in the mountains. Large and small troops and sometimes packs are formed. Sounds of barking, howling, or quarreling are heard, according to the mood the animals are in. A large carcass always causes them to collect in great numbers; a dead Ass or Mule is eaten up even to the largest bones by the hungry pack. If they are very hungry, they go to the carrion even in the daytime, especially if their most disagreeable rivals, the Vultures, should come down, and they fear their competition. They are possessed of professional envy to a high degree, and enter into violent combats with all uninvited guests. Vultures are not easily driven away and of all carrion-eaters offer the most determined and courageous resistance, and therefore it is from the competition of these birds that the Dogs'sustain the greatest loss. Carrion forms the chief part of their food under all circumstances; but these Dogs may sometimes be seen mounting guard before a Mouse-hole like Cats, or to attack a bird, like Jackals or Foxes. When carrion fails them, they undertake long journeys, enter cities and prowl through the streets. As they clear away vast quantities of filth they are tolerated though not welcome guests, and nowadays it is probably very seldom that a pious Moslem mentions them in his will, as is said to have happened not infrequently in former times.

When resting in their proper abode these Dogs are rather cautious and timid, and especially shun people in European attire who may endeavor to approach them. If one of the Dogs is attacked a genuine uproar begins. A head appears at every hole and in a few minutes the tops of the inounds are covered with Dogs, which keep up an uninterrupted yelping. I have hunted these Dogs sereral times, partly for the purposes of observation, partly with a view to procuring their flesh, which I used either as bait for wild Vultures or to feed my cap-

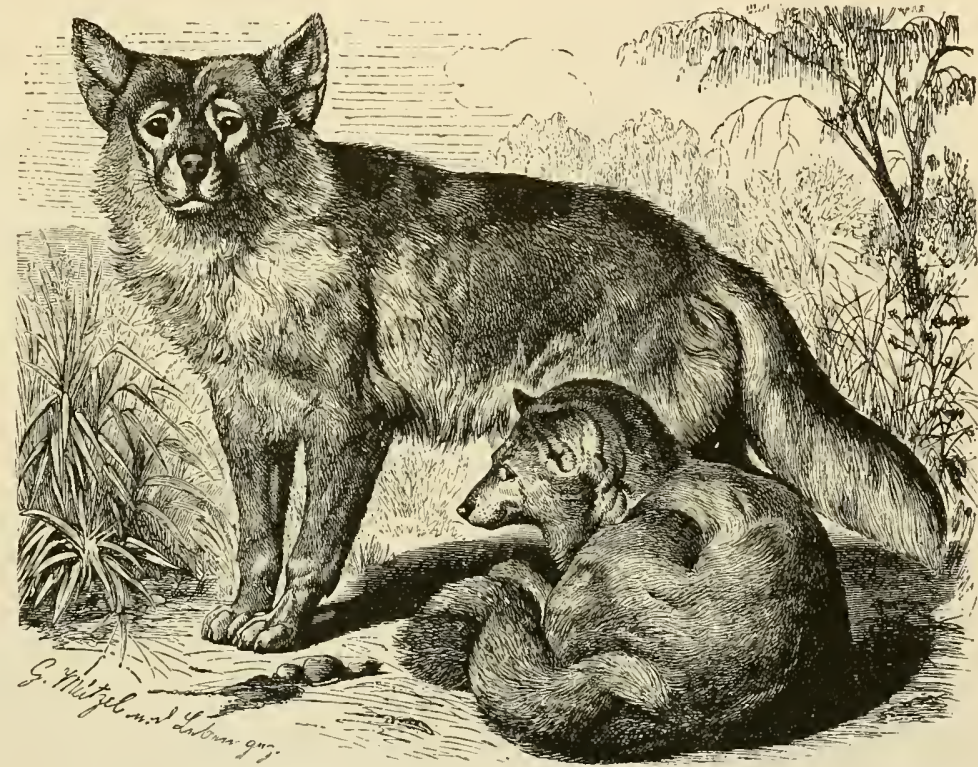

DING0. - The wild Dog of Australia, known as the Dingo, is generally disliked by the present white inhabitants because of the damage it causes among the flocks in the great Sheep ranges. The aborigines, however, frequently amed it sufficiently to make it an important assistant to them in the chase. It is about as large as a medium-sized domestic Dog, has a shaggy coat and a bushy tail, and makes its living by hunting the marsupials and rodents of the tive Vultures and Hyænas. During such hunting expeditions I saw how these animals keep and live together and I also observed the fact that they soon learned to know and fear me. In Khartum, for instance, it was impossible for me to shoot one of these masterless Dogs, as they would not permit me to approach them nearer than four hundred paces, and they were so wary that they baffled every attempt to get within gunshot.

Sometimes the masterless Dogs increase in such numbers as to become a plague. In order to get rid of these pests Mohammed Ali once freighted a ship with them and threw them overboard into the deep sea. Fortunately cases of hydrophobia are extremely rare among these animals, and instances of persons having been bitten by a mad Dog are nearly unknown. 
Ownerless In Constantinople the relation of Man Dogs in to Dog is said to be quite similar. Constantinople. Hacklander says: "Inseparable from the streets of the capital is the thought of their permanent inhabitants, the ownerless Dogs, which one sees in countless numbers. Usually one gets an exaggerated impression of things when he reads of them and is disappointed when brought face to face with the facts. This is not the case with these Dogs. Though all travelers agree in represcnting them as a plague, the majority of these writers are too mild in their description of the nuisance. The animals belong to a quite peculiar breed. In appearance they probably come nearest the Sheplierd Dogs, but their tail is not curled, and the short hair is of a dingy yellow. When one sees them slinking along in a lazy manner, or lying in the sun, he must confess that no animal has a more impudent, I may even say, depraved look. All the streets and squares are full of them; they stand either in a row before the houses, waiting for scraps that may be thrown to them, or they lie in the middle of the street; and the Turks, who carefully avoid harming any living creature, go around them. I have never seen a Moslem kick or beat one of these animals; but, on the contrary, the tradesman throws them the remains of his meal from his shop. The Turkish Kaikshi and the sailors from the ships do not have this tenderness of feeling, and many a Dog ends his life in the Golden Horn.

"Every street of the city has its own Dogs, which hold possession of it, just as beggars have their particular localities in our large cities; and woe to the Dog which enters a strange domain! I have often seen a number of these Dogs pounce upon such a luckless Cur and literally tear him to picces, if he did not make a hurried escape. Every time we bought anything eatable at some corner bazaar, all the Dogs we passed would follow us, and would leave us only when we entered another street, where a similar escort awaited us."

Linneus' The description of the character and Description of life of domestic Dogs is best begun the Dog. by the incomparable characterization given by the father of zoology, Linneus, in his peculiarly succinct and pertinent manner: "Eats meat, carcasses, cereals, no herbs, digests bones, vomits after partaking of grass. Drinks in a lapping manner; the nose is damp, the scent is excellent; runs sideways, walks on toes; perspires very little, lets his tongue hang when he is overheated; before going to sleep goes round the spot where he intends to lic: hearing keen; when asleep, dreams. The litter of Pups numbers from four to eight, the males resembling the father, the females the mother. Very faithful companion of Man; wags his tail at approach of owner; defends him; if owner walks he runs ahead, stopping at crossings; is docile, searches for lost things, makes the rounds of the master's premises at night, announces the approach of peoplc; guards goods, drives Cattle from fields, keeps Reindeer together, defends Cattle and sheep from wild animals, keeps Lions at bay, drives up game, points Ducks, brings killed game to the hunter, turns the spit in France, draws the wagon in Siberia. Pleads for scraps at table; if he has stolen, he timidly hides his tail; eats grecdily. At home he lords it over all ; is the enemy of beggars, and attacks strangers without provocation. Heals wounds, gout and cancers by licking the affected place. Howls when he hears music, bites at stones which are thrown toward him; feels depressed and has an unpleasant odor before a thunderstorm. Suffers from tape-worm; propagates rabies. Finally gets blind and gnaws his own limbs. The American species forgets how to bark. Mloslems abhor him. Victim of dissectors for observing circulation of blood, etc."

Character and This description needs nothing save Life of elaboration. All domestic Dogs are Domestic Dogs. practically alike in their mode of life and conduct, so long as the influence which the habits and customs of human beings exert over them does not change their manner of living.

Dogs are both diurnal and nocturnal animals, are equally well endowed for light or darkness, and are as active and lively by day as by night. When allowed to do so, they hunt in the daytime as well as after nightfall, showing a predilection for uniting into packs. One of the essential traits of their character is love of society, and this has a most decided influence on their habits. They eat all kinds of food that Man eats, both animal and regetable food, and are indifferent as to whether it is cooked or raw. They are most fond of meat, especially if it has begun to decompose a little, and they greedily devour carcasses. Some of the breeds prefer meat to any other food, others esteem it less highly. Of cooked foods they prefer that which is of a wheaten nature, especially if it be sweet; and those Dogs that eat fruit prefer the sweet to that which has an acid flavor. Bones, good broth, bread, vegetables and milk are the best food for a Dog; fat and too much salt are harnful. He can also thrive on an exclusive bread diet if he is trained to eat it at regular times. His food should never be given to him hot, but should always be lukewarm and served to him in a clean dish. An adult Dog receives sufficient nourishment if he eats his fill once a day, but it is better to feed him twice daily, and if he is given enough to eat in the evening he will be a more faithful watch Dog; for a hungry Dog may not infrequently be bribed into treachery by a meal. Dogs drink a great deal of water, lapping it with the tongue, which they bend in the shape of a spoon, curving the tip. A plentiful supply of water is an essential condition to their health.

Physical The Dog can run and swim excellently, Traits of the and can also climb to a limited extent,

Dog. but he finds it difficult to walk on the edge of a precipice without beconıing dizzy. He walks and trots in a peculiar slanting direction. When running quickly, he may take leaps of considcrable length, but is not capable of making sudden turns. Some Dogs are very fond of the water, but those that are spoiled in training are afraid of it. The climbing abilities of Dogs I observed in Africa. They climb walls or the slightly inclined roofs that are common in that country, very adroitly, and run on the narrowest landings with the unfailing security of Cats. In repose the Dog either sits on his hind legs, or lies down on his side or stomach stretching his hind legs sideways and his fore-legs to the front, and putting his head between them. He rarely stretches his hind legs behind him.

All Dogs like to sleep, but only at intervals, and their sleep is very light and restless, frequently disturbed by dreams, which cause them a perturbation which they indicate by wagging their tails, by twitching movements, growling or low barking. They are exceedingly cleanly in their habits; and the place where they are kept, and especially where they sleep, must be kept clean. They perspire very little, even when they have been running for a long time; saliva 


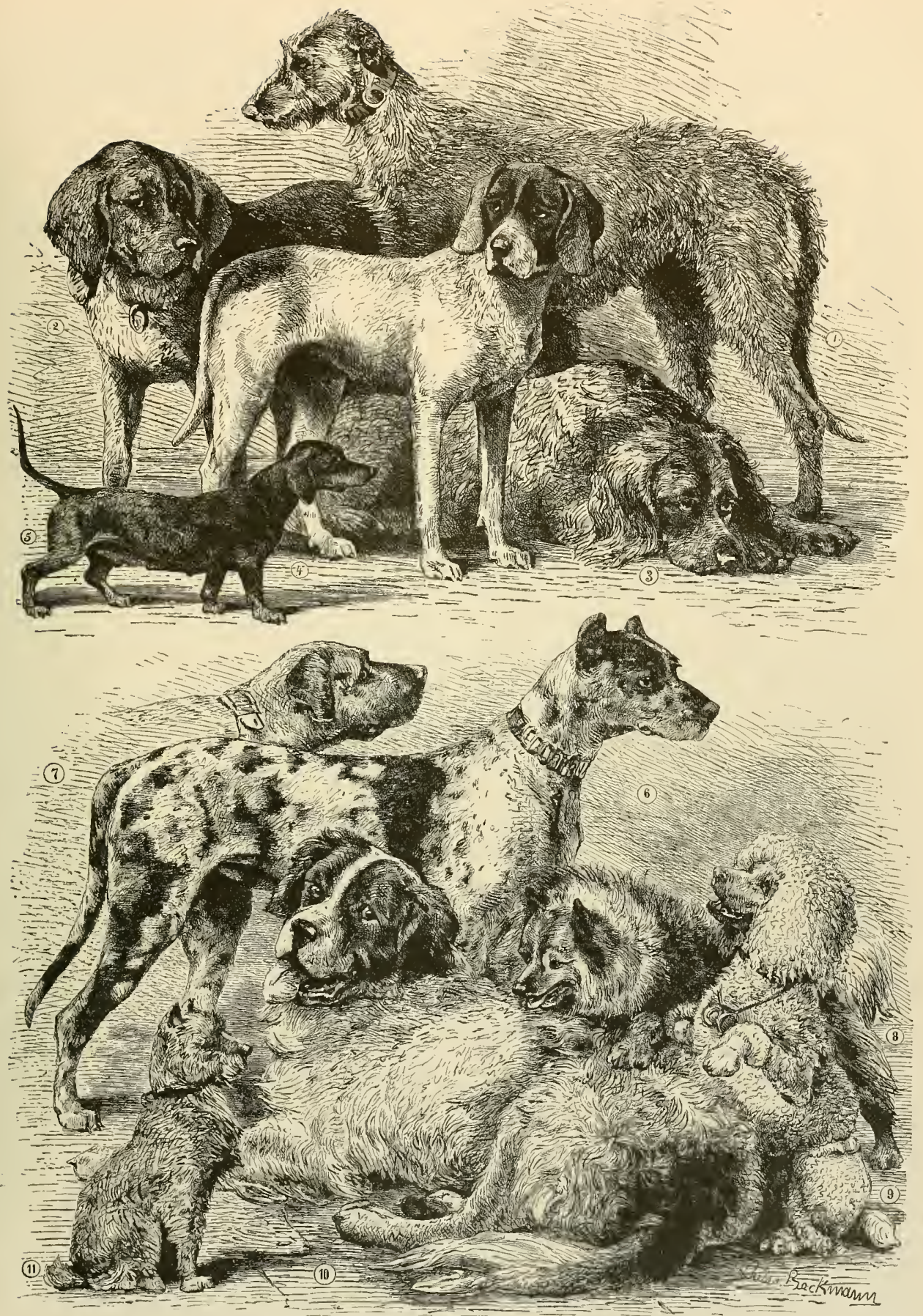

PRIZE DOGS OF THE INTERNATIONAL DOG SHOW AT CLEVE, - I. Druamah,-Scotch Deerhound. 2, Hercules, - English Bloodhound. 3. Job.-German Long-Haired Pointer. 4. Cora,-German Smooth-coated female Pointer. 5. Longa.-Female Badger-Dog. 6. Nero,-German "Tiger" Mastiff. 7. Prince.-English Mlastiff, 8. Mohr-Pomeranian Dog. 0. Solo.-White Poodle, ro. Gessler.-Alpine Dog. 11. Rattler.-German Rough-oated Terrier. 
takes the place of the perspiration, and drops from their tongues, which they let hang from their mouths when they are overheated.

Development The senses of the Dog are acute, but of the not evenly developed in the different Senses in Dogs. breeds. Smelling, hearing and sight seem to rank first, some being distinguished by their scent, some by their keenness of sight. The sense of taste in Dogs cannot be disputed, but it finds expression in a strange manner. Everything that excites their organs of sense too much is distasteful to them. They are least susceptible to light, and most to loud, yelling sounds and pungent odors. Ringing bells and music make them howl. Cologne water, ammonia and ether excite their disgust when held under their noses. The sense of smell is exceedingly well developed in some breeds of Dogs and attains a degree of acuteness which is scarcely comprehensible to a human being.

scheitlin on Books might be written about the Mental Charac- mental characteristics of Dogs; it teristics of Dogs. is very difficult to describe them in a few words. The description of the Dog's mind which has pleased me most, has been given by Scheitlin, and I will here reproduce some portions of it: "As great as may be the physical difference between Dogs," says he, "the mental dissimilarity is still greater; for some breeds are incapable of learning, while others learn all kinds of tricks and duties almost instantly. Some cannot be tamed at all, others become tame very soon, and what some love, others hate. The Poodle goes into the water of its own accord, the Spitz desires to always remain at home. The Mastiff may be trained to attack Man, the Poodle cannot be made to do so. The Hound alone has a perfect scent. The Bear Hound is the only Dog that will attack a Bear by biting at its hind legs; and it is only the long Badger Dog, which seems to need an additional pair of legs in the midule, that is so low in stature and has such crooked limbs that it can easily crawl into a Badger's burrow; a feat it performs with a degree of pleasure equal to that with which the Drover's Dog, describing great curves, compels a drove of Calves and Cattle to hurry onward.

"The Newfoundland Dog does not fear the Wolf, and is therefore fitted for guarding flocks; he digs, swims and dives, and pulls people out of the water. The Drover's Dog, which also contends with the Wolf, is a good guardian of flocks, hunts Wild Boars and all other large animals; shows reasoning powers and affection, but will not go into water unless compelled to do so. $\mathrm{He}$ is used and abused in the chase, and according to a settled psychological law, this renders him a real brute, especially with young Calves, which do not defend themselves with their heels, and which he consequently does not fear. His bloodthirstiness is repellant, and his inclination to bite, to drink blood, and to pull about and devour remains of animals, are his worst qualities. The Greyhound is said to lack nearly all reasoning powers, capability of education and faithfulness, and to be childishly fond of a stranger's caresses; still he may be trained to course Hares. The Setter indicates its most striking trait by its name. The Dog and every other animal must first give an intimation of what it likes, before it can be trained. The King Charles Spaniels seen to have been created for the sole pleasure of being carried in ladies' arms, to sleep on sofas, to lie in people's laps, to growl at strangers, to stay in rooms, to drink out of their mistress' glass and eat out of her plate, and to be kissed. The Hound is praised for his keen scent, his sagacity, docility and faithful affection for his master. The house and Shepherd Dogs are equally sagacious, and are also good watch Dogs. The spitz, or Pomeranian Dog, is said to be clever, docile, lively and agile, to be addicted to biting, and a good watch Dog, but some varieties of this species are treacherous and deceitful. The northern Dog is devoted to Man, but does not know his master, is not afraid of blows, has an insatiable appetite, and yet can endure hunger for a long time. The Nastiff's character is a combination of faithfulness with little sagacity. He is a good watch Dog, a fierce, courageous antagonist of the Wild Boar, Lion, Tiger and Panther, and sets little value on his life. He can be guided by a wink of the eye, a gesture, or still more by a word from his master; and may be trained to attack Man, not fearing to enter into combat with three or four Men. When engaged in an onslaught he pays no attention to shots, stabs or lacerated limbs, and enters into dreadful fights with animals of his own kind. The Mastiff is very strong, being able to pull down the strongest Man and strangle him, or hold him captive and helpless until he is released, and he can hold an enraged IVild Boar by the ear so that it cannot move. The Mastiff is remarkably obedient, and has considerably more sense than is usually accredited to him. The Dog which stands on the lowest plane is undeniably the Pus Dog. He owes his degeneration to mental deterioration, and naturally cannot elevate himself. He does not comprehend the human mind, neither does the human mind understand him.

Great "The body of the Dog has in life so

Capabilities of spiritual an expression that the skin the Dog. of the dead animal cannot be effectually stuffed. The mind of the Dog is undeniably as perfect as an animal's mind can be. Of no other brute creature can it so appropriately be said that the only human quality he lacks is that of speech. Of no other animal have we so many pictures of all his different varieties, such an extraordinary number of anecdotes illustrating his sagacity, his memory, his reasoning powers, his imagination and even his moral qualities, such as faithfulness, affection, gratitude, vigilance, love for his master, patience with human beings, ferocity toward and hatred of his master's enemies, etc., and no other animal is therefore so frequently pointed out to us as a pattern. How much there is to tell of his docility! He can dance, drum, walk a rope, mount guard, take and defend fortresses, shoot off pistols; he turns the spit, drags the wagon; he can be taught to recognize notes, numbers, cards, letters; to take his master's hat off, bring his slippers, and even attempt to take his shoes off; he knows the language of the eyes and of the face and many other things."

"I have known Dogs," says Lenz, "which appeared to understand nearly every word their master uttered, opened and shut doors at his command, brought in a chair, a table or a bench, took off or brought his hat, looked for and brought a hidden handkerchief or such things, sought and found a stranger's hat among a lot of others by scent, etc. It is a pleasure to watch a clever Dog, the manner in which he turns his ears and eyes when expecting his master's command. how pleased he is when he is allowed to follow his master's footsteps, what a miserable face he makes when he is made to remain at home; how, when he has run ahead, he stops at a 
crossing and looks back for an indication as to whether he shall go to the right or to the left; how happy he is when he has done a clever thing, how ashamed when he makes a blunder! How, when he has been up to some mischief and is not certain whether his master has perceived it, he lies down, yawns, makes believe he is half asleep and indifferent in order to put suspicion on a wrong track, and still casts an anxious, tell-tale glance at his master from time to time! He soon know's every friend of the house, easily discriminates between the welcome and unwelcome visitors and harbors a dislike for beggars. It is a pretty sight to see him looking for truffles for his master, though naturally the Dog is not fond of them; or how he helps his master drag a wagon and makes greater efforts when he sees his master do so."

Most Promi- All this goes to show that the several nent Traits species of Dogs differ from each other in Dogs. mentally as much as they do physically. Unwavering faithfulness and affection for his master, unconditional obedience and devotion, alert vigilance, gentleness, an obliging and kind disposition, these are the prominent $t r a i t s$ of their character. No one Dog combines them all in an equally high degree; some of these characteristics will be more and the othcrs less prominent in one Dog than in another. Education has more to do with forming a Dog's character than is generally supposed. Only well disposed human beings can bring up Dogs properly. The Dog is a faithful mirror of his master. The kinder, the more attentive one is to him, the better and cleaner one keeps him, the more reasonably one demeans himself with him, the more sensible and goód he becomes; and exactly the reverse happens if the Dog has received bad treatment. He adapts

himself to all circumstances and is always devoted to Man, body and soul. This high virtue is usually not appreciated and therefore the word "Dog" is still used as an insulting term, while it should, properly, mean the reverse. The great variety of the Dog's capabilities lifts him to the highest plane in animal nature, and his faithfulness makes him Man's most indispensable companion.

The Marked Several peculiarities are possessed by Peculiarities nearly all species. Many Dogs howl of Dogs. and bark at the moon, without any obvious reason. Their nature incites them to quickly follow any moving beings or objects, whether Men or animals, wagons, balls or stones, which they try to seize and impede even when they are well aware that the object of attack is entirely useless to them. They are great enemies of certain animals, without any real cause. For example, Dogs hate Cats and Hedgehogs, and even take pleasure in torturing themselves by biting into the bristles of the latter animals, although they know very well that such an onslaught is sure to prove unsuccessful and result in nothing better than bloody noses and snouts.

The strong presentiment which a Dog possesses of impending change of weather seems worthy of notice. The approach of rain is indicated by an unpleasant odor exhaled by his body at such times.

Dogs rarely live on very good terms with one another. When two strange Dogs meet, they first sniff each other, then they show their teeth and a fight is on, unless tender feelings come into play. The more surprising, therefore, are the very sincere friendships which Dogs sometimes strike up. Such comrades never quarrel, but seek each other's society and assist each other in case of necessity. Similar alliances are sometimes entered into with other animals, and even the popular saying about Cat and

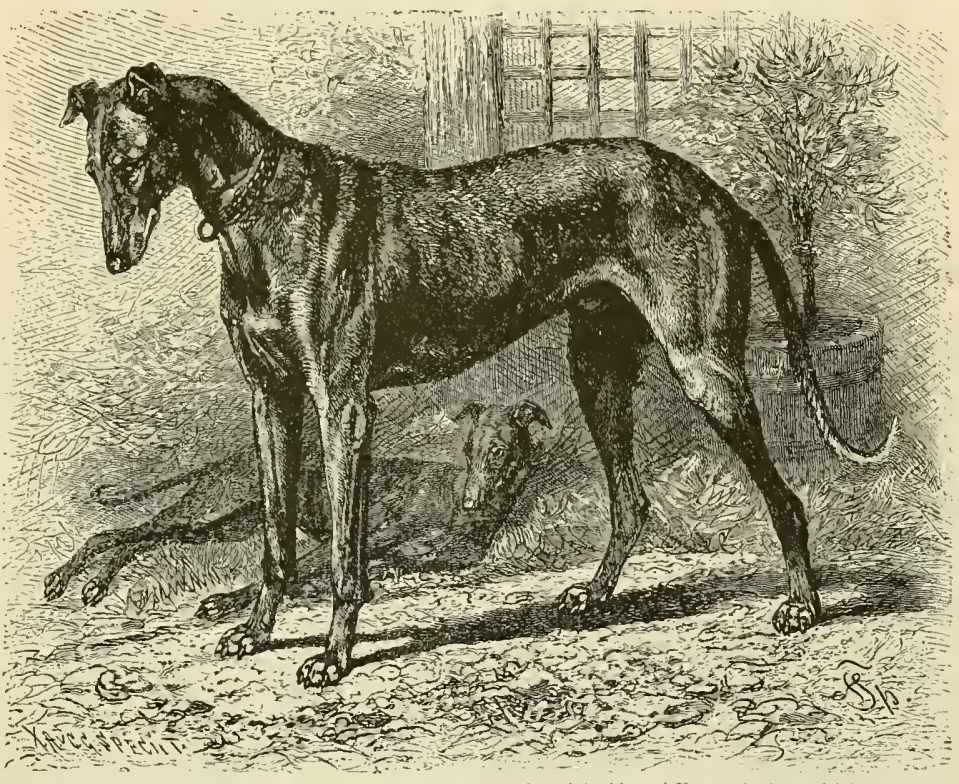

THE GREYHOUND. - Coming originally from the region of Arabia and Egypt, the beantiful Greyhound is admired wherever beauty, grace and fidelity are appreciated. The slender body, long legs and intelligent head with drooping ears, the long thin tail, the short smooth fur, and the graceful bearing of this noble friend of Man are fully Dog may be refuted by exceptional examples.

The Mother The birth of Pups usually takes place Dog and Her in some dark corner, the litter numberPuppies. ing from three to ten, usually from four to six, and in rare instances twenty or more Pups, which are born with incisor teeth already developed, but remain blind for ten or twelve days. The mother is tenderly devoted to her young, suckles and cares for them. licks, warms and defends them, and, not infrequently, changes their place of abode, carrying them gently by the loose skin of the neck. Her love for her offspring is really touching, and there are well-attcsted stories that must incite not only our esteem, but our admiration. Bechstein relates a fact, which seems almost incredible: "A shepherd in Waltershausen was in the lhabit of buying Sheep every spring in Eichsfeld and, of course, his Sheep 
Dog, a female, had to accompany him on the journey, which was a distance of eighteen miles. Once she gave birth to seven Pups in a strange locality and the shepherd had to leave her there. But a day and a half after his return he found the mother Dog with her seven Pups at the house door. She had carried the little ones, one after another, a short space at a time, and in this way made the entire distance thirteen times, in spite of her weakness and

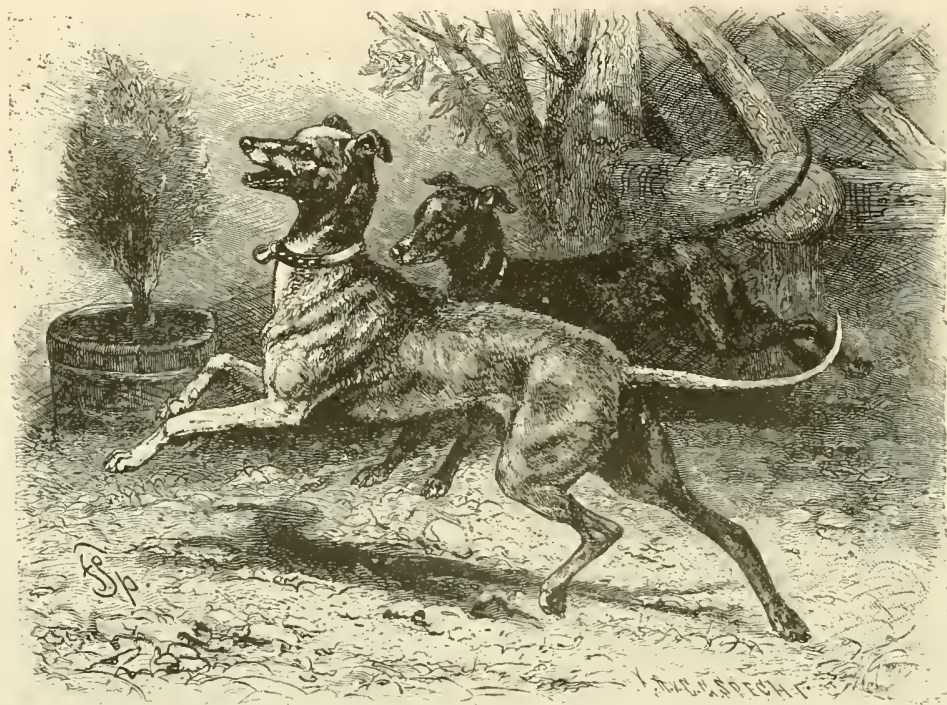

ITALIAN GREYHOUND. Because of its great symmetry of body and limb the Italian Greyhound is highly prized by connoisseurs of Dogs. It is the smallest of the Greyhounds, but its nore delicately shaped ontlines and especially smooth, soft coat make it a great favorite. It resembles the other Greylounds in its general traits. (Canis familiaris grajus italious.)

exhaustion, and had successfully accomplished the difficult task."

How Young It is usual to retain but two or three Puppies Should or at the most four Pups out of a

be Trained. litter, in order not to weaken the mother too much. The little fellows need a great deal of nourishment, and the mother is hardly able to satisfy them. Man, being the animal's protector, ought to feed a suckling mother Dog particularly well. Every thoughtful owner of such an animal prepares for her a soft place in some dark, warm corner, and then helps her to rear the little family as best he can. The mother seems to have a heart capable of great love, and she tolerates strange Pups, or even other animals, such as Kittens and little Rabbits that may be given her. I have often tried this experiment, but think that suckling Cats are still kinder than a mother Dog, which rarely can refrain from wrinkling her nose somewhat disdainfully at foster children. Still they prove excellent wet-nurses for Lion and Tiger Cubs.

Usually the Pups are weaned after six weeks. The mother is then put on short rations, so that her milk will dry up. The young ones are taught to eat light, solid food and trained to be cleanly in their habits. They shed their first teeth during the third or fourth month; at the age of six months they do not care much for the mother. If one wishes to educate or train them, he must not wait much longer before he begins. The opinion prevailing among hunters and Dog breeders of the old school that a Dog is too young and weak to be taught before he is a year old is not correct. Adolph and Karl Mueller, who are distinguished both as naturalists and sportsmen, begin the training of their Hounds as soon as they can run, and their success has been marked. Their pupils do not receive a single illmeant blow, hardly ever an angry word or any correction beyond a slight remonstrance, and they turn out to be the most efficient companions and assistants in the chase. Young Dogs ought to be treated like Children and not like stubborn slaves. They are, without exception, willing and docile pupils, soon listen attentively tô every word of the trainer, and do more and better work when actuated by love than when impelled by fear. Trainers of Dogs who can do nothing without a collar of thorns and a whip are ignorant torturers, and not thinking educators.

Length of Life Dogs enter and Diseases upon old age of Dogs. when they are twelve years old. Instances are on record, however, where they have lived to be twenty, or even as much as thirty years old; but these are rare, exceptional cases. If they do not die of old age their death is caused by one of the many diseases to which they are subject.

A very common Dog disease is the mange, caused by parasites, and not, as was formerly believed, in consequence of improper food, lack of exercise or uncleanliness. Young Dogs often suffer from distemper, consisting of a contagious inflammation of the mucous membranes, occurring oftenest between the fourth and ninth months of their age. It may be said that more than half of the European Dogs succumb to it, or at least have their usefulness spoiled by it. They also suffer from parasites, of which more than a dozen kinds are known. They are often infested with Fleas and Lice, and in certain localities suffer from Ticks. The former are easily got rid of by strewing a layer of ashes on the ground under the straw upon which the animal sleeps, or else by rubbing Persian insect powder into the fur. The Ticks which plague them most may be exterminated by dropping a little brandy, salt-water or tobacco juice on them. It is not advisable to tear thesc insects out by force, as the head is apt to remain in the wound and cause suppuration and abscesses.

Hydrophobia, its The most terrible malady known to Symptoms and Dogs is hydrophobia or rabies, Dangers. which endangers not only other Dogs and domestic animals, but also human beings. Usually this fearful malady occurs in the older Dogs. mostly in summer, when the heat is greatest, or in winter, when the cold is intense. One may recognize it by the Dogs's clianged conduct. He becomes 
deceitfully amiable, or growls at his master, shows an unusual drowsiness and melancholy; constantly looks for warm places, often slinks to his food, but does not eat, drinks water greedily, but in small quantities, and generally behaves in a restless, disturbed manner. Unmistakable signs are also a change in his voice, the bark becoming a hoarse howl, loss of appetite, inability to swallow, flow of saliva, a bleared look; he makes frequent trips out side the house, licks and swallows strange objects, and, as the disease advances, snaps and bites without cause. In the later stages constipation sets in, the ears droop, the tail hangs down, the eye has a dull and squinting look. Then the eye becomes red and inflamed. The Dog ceases to be susceptible to caresses, pay's no attention to his master's command, becomes more and more restless and shy; his look is rigid or fiery, the liead droops, the eyes and cheeks swell, the tongue becomes very red and hangs out of the mouth, from the sides of which viscid saliva runs down. Soon the animal only growls without barking, and ceases to recognize any people, even his master. He pants for a drink, but cannot swallow; the water chokes him and the muscles of the gullet contract convulsively. Then a dread of water and all other fluids begins. He ceases to lie down, but slinks around with drooping tail and squinting eye.

After this stage the malady develops into a quiet or a raging variety. In the former the eyes are inflamed, but rigid and blear; the tongue becomes bluish and hangs out. White foam covers the corners of the mouth, which is always open; the lower jaw becomes paralyzed and droops. IVith his tail between his legs and with deep sunken head the Dog runs for miles, staggering and shivering, biting everything that crosses his path, especially other Dogs. If he encounters an obstacle in his way, which does not allow of his proceeding in a straight direction, he turns around in a circle, falling and snapping.

In the raging variety the eye glistens, the pupil enlarges, the mouth is open but little, is covered with saliva and the bluish tongue hangs out. Even in the first stages

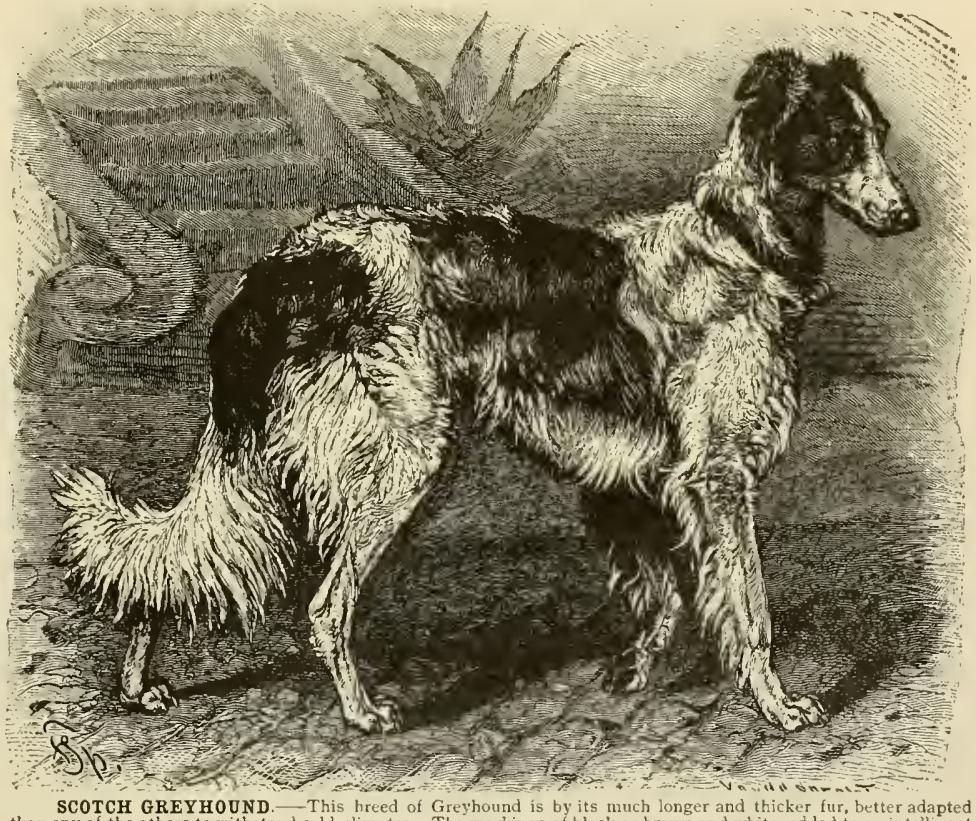

SCOTCH GREYHOUND. - This hreed of Greyhound is by its much longer and thicker fur, better adapted head and a kind disposition, make this Dog both a beautiful and a faithful companion to Man. (Canis famlaaris grajus hibernicus.) a staggering manner, but still may swim across rivers and pools. He bites everything he encounters, even inanimate objects, and if chained up bites his chain.

The ancient Greeks knew hydrophobia, though it is of much rarer occurrence in the southern countries than in somewhat colder latitudes. In the arctic and torrid zones the malady occurs very rarely, or not at all.

Remediesfor Per. Many remedies have been vaunted sons suffering as a cure for rabies, but they have from Rabies. not proved efficacious; and it has been generally found impossible to say whether the animal which had bitten a person was really suffering from rabies or not. The only unfailing remedy was the cauterization of the wound, but it had to be done immediately and thoroughly. If this was neglected, or if the poison had already penetrated into the body, it depended on circumstances over which Man had no control, whether disease, and with it death, would result. Lately Pasteur has tried to save even such cases. His procedure consists in the inoculation of the disease as carly as possible, in the same manner as small-pox is prevented by vaccination. He dries the spinal marrow of rabid animals, rubs it in broth and injects this mixture into the skin several times. By the drying process the spinal marrow is weakened in the intensity of its of this form of rabies, the Dog shows a great deal of obstinacy and deceit, even towards his master; he involuntarily snaps after Flies or anything that approaches him; attacks poultry and tears it to pieces without eating; invites other Dogs to join him and then makes ferocious rushes at them; shows his teeth, distorts his face, whines, licks his lips with his inflamed tongue, watery saliva dropping from his mouth the while. He turıs away from water in 
Signs of Health The best sign of a Dog's health is a and sickness cold, moist nose. If the nose bein Dogs. comes dry and hot, if the eyes become blear and the appetite fails, one may be sure that the Dog is ill. If his condition does not rapidly improve and the remedies prescribed by a good veterinary surgeon have no effect, there is little hope for recovery; for few Dogs live through serious disease. Wounds heal quickly and well, frequently without any assistance; but diseases of the

Even where the Dog is occasionally or regularly used as an article of food, he still is the companion and assistant of Man. In the tropics he serves, in the eapacities of sentinel and assistant in the chase, even those people of the lowest races who have no individual name for him; while the northern nations would be helpless without him, for he drags their sleds over the deserts of ice and snow, or carries the hunter's outfit on lis back, like a beast of burden. In northern Asia Dog furs are manufactured into clothing, and even in Gerniany caps, pouches and muffs are made out of them. The bones and tendons serve to make glue; the tough, thin skin is tanned and made into shoes and gloves, while the hair is used as a stuffing in upholstery. Dog's fat is utilized to make wagon-grease, and was formerly used as a medicine in consumption. On the field of battle in former times, Dogs were also used: not as it is in our day proposed to use them, as trained warners and fleet-footed messengers easily escaping detection, but as real fighters by the side of the warriors. IVhen the Spaniards were subjecting the countries of the New IVorld, the Bloodhounds played no small part as fighting companions, and many of these animals were esteemed for their bravery and distinguished deeds of daring, and were honored as much as any hero among the greedy army of the conquerors. Like all participants in those fights and pillages, these Dogs, or, rather, their masters for them, received their share of booty. Later on, up to very recent times, it was usual to track escaped slaves or subjugated natives, who had deserted the yoke of the Europeans, by Bloodhounds into the very wilderness; [and similar methods were sometimes resorted to in recapturing fugitive Negroes during the days of slavery in the United States].

The usefulness of Dogs was appregroup, is the Danish Dog. The long legs give it great running ability, and thestrong body and limbs confer upon the nnimel great powers ot endurance, while the eyes speak kindness and intelligence. (Canis familiaris molossus danious.)

inner organs generally baffle even experienced physicians, and bunglers still more surely, and such diseases end fatally in a surprisingly short time.

Great $U_{\text {seful- }}$ The usefulness of the Dog can not be ness of the easily overestimated. Every reader

Dog. knows from experience what a part the Dog plays with civilized peoples, but the animal is still more important to savage and uncivilized tribes. $\mathrm{His}$ flesh is eaten on the South Sea Islands, and by sundry African tribes, the Tungus, Chinese, Eskimos, North American Indians, etc. In China one often sees butchers carrying slain Dogs, and those bearing such burdens always have to defend themselves against the attacks of other Dogs, which run about and attack them in packs. Let us here mention another relation between Man and Dog, which may seem to us horrid and uncanny : since Bernardin de St. Pierre gave utterance to the idea that Dog-eating was the first step towards the eating of Man, anthropology has gathered many facts tending to confirm the opinion that the habit of consuming Dog's flesh is either a precursor, an accompaniment, or a remnant of the cannibal habit.

ciated in the oldest times; but the treatment they received and the esteem accorded them varied much. Socrates was wont to swear by the Dog; Alexander the Great was so afflictcd at the early death of his favorite Dog that he built a city with temples in honor of the lamented animal. Homer sings in a touching manner the praises of Odysseus' Dog, Argos. Pliny valued Dogs highly and narrated many things about them; he stated, for instance, that the Colophonians kept great herds of Dogs on account of their constant wars, and that the Dogs were first in the attack and did not scruple to take part in any battle. When Alexander the Great went to India, the king of Albania made him a present of a Dog of immense size, which pleased Alexander very much. He pitted Bears, Wild Boars and other animals against him, but the Dog lay quite still and did not get up. Alexander believed him to be lazy. and ordered him killed. When the king heard of this, he sent another Dog of the same breed, with a message that Alexander should not send weak animals against him, but Lions and Elephants. The king had had only two such Dogs, and if Alcx- 
ander killed this one, his like would not remain upon earth. So Alexander made the Dog fight first with a Lion, then with an Elephant, and both of these animals were killed. The ancient Egyptians used Dogs in the chase, and, as is seen from the monuments left by that interesting people, they thought highly of them. The Hebrews, on the other hand, despised the Dog, as is proven by nuany passages in the Bible, and the Arabs of to-day still hold him in contempt. The ancient Germans honored the Dog highly. When the Cimbri were conquered by the Romans, 108 B. C., the latter still had a hard fight with the Dogs which guarded the baggage of the defeated army. The Canary Islands derive their name from Dogs, as Pliny tells us. Von Humboldt writes that in Peru it was customary to beat Dogs during a lunar eclipse, until the eclipse was over.

It is amusing to read what medicinal uses the Dog could be put to, according to the older authors. The entire Dog was, in their opinion, made up of medicines of varied virtues.

Having considered the Dog in general, let us turn to some of the breeds of this remarkable tribe, selecting only the most important out of the numberless array of species. Reichenbach counts one hundred and ninety-five different kinds!

\section{THE GREYHOUND.}

The distinguishing features of the Greyhound (Canis familiaris grajus) are an extremely slender, graceful body, a pointed, finely shaped head, thin, long limbs, and usually smooth, short hair. The fine, elongated muzzle, the rather long, narrow, pointed ears, half of which stand erect, the other half hanging over and grown with short hair, the short, stiff lips, give the head an extremely graceful appearance and at the same time indicate a different development of the senses. The Greyhound sees and hears excellently, but its sense of smell is deficient, as the nasal bones have but little room for expan-

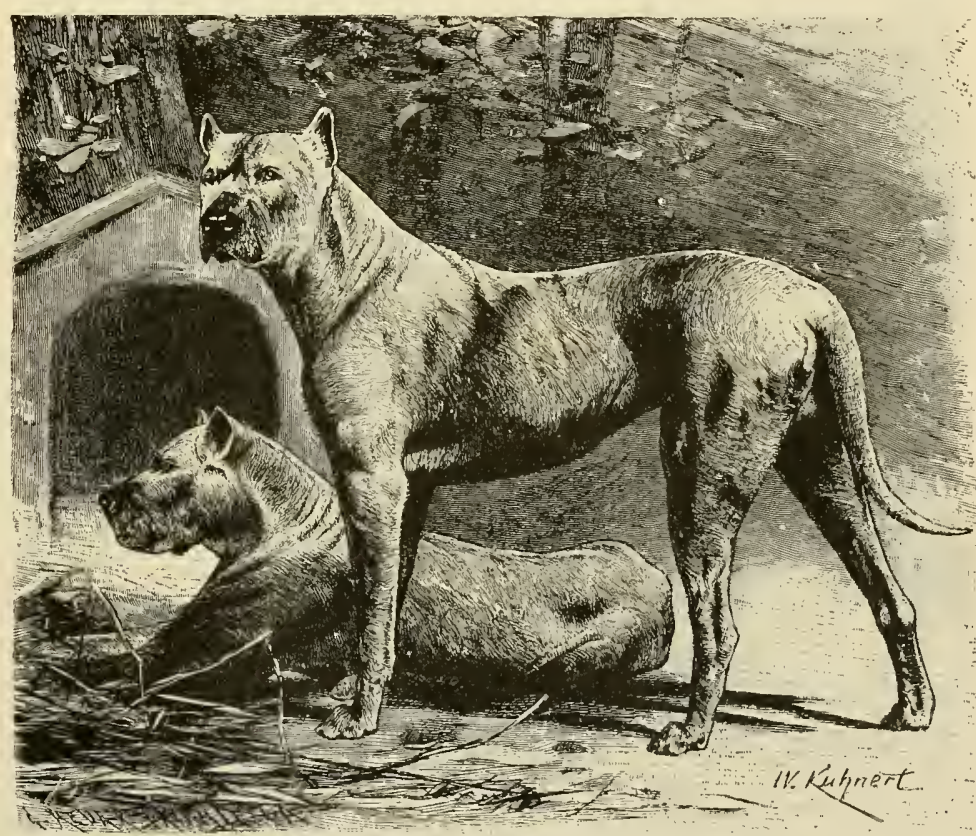

THE GERMAN MASTIFF. - A tamous breed of Dogs, pepular in Germany, of strong and vigorous huild and great sagacity; a kind friend, but a powerful antagonist. Perhaps no animal of modern times is more widely known or has been more written about than Prince Bismarck's "Dog of the Empire," a fine specimen of this breed. (Cants familiuns molossus germanicus.) other animals, always as an ummistakable proof of capacity for swift and enduring motion. The limbs of the Greyhound are exceedingly fine, and every muscle in them, and especially the strong tendons in which the muscles terminate, are plainly visible. But the chest also shows all the intercostal muscles, and some Greyhounds look as if their muscles had already been laid bare by a skillful dissector. The tail is very thin, rather long, reaching below the extencls it horizontally bchind him with a slight upward curve. The hair is usually thick, fine and smooth, but in some varieties it is longer and also assumes a hue different from that of the others, most breeds being of a tawny hue. The most perfect Greyhounds, namely, those of Persia and central Africa, are nearly always of this color. Spotted Greyhounds are more rare and always weaker than those of a uniform color

Traits and The Greyhound differs from other Uses of the Dogs in his mental qualities. He is Greyhound. an exceedingly selfish animal, being, as a rule, not very faithful to his master, but liking and the Cheetah, and we find it in a great many ankle-joints, and either hangs down or the Dog sion in the narrow nose, and the nasal nerves therefore can never attain as high a development as in other Dogs. The chest is the most remarkable part of the body. It is wide and capacious, and contains relatively very large lungs, capable of inhaling enough oxygen to purify the blood, the circulation of which is greatly increased by rapid exercise. The loins, on the contrary, are extremely retracted, as if they were intended to compensate for the extra weiglit of the large chest. We have noticed a similar shape in the Long-armed Apes, or Gibbons, to be petted by everybody and inclining to any one who is kind to him. If his master treats him with unvarying kindness, he is pleased and becomes to a certain extent attached to him; but his unfaithfulness displays itself when somebody else pets him more than his master. This faithlessness is historical. When Edward III, died his Greyhound left hinil at the very instant and went over to his eremies. However, there are praiseworthy exceptons among the Greyhounds, individuals which are scarcely inferior to other Dogs in point of affection 
and faithfulness; and these dutiful animals reconcile us to the breed in this respect.

The Greyhound acts toward other Dogs precisely as he does toward human beings. He does not bear them any love, and adopts a manner almost of indifference toward them; but if a fight is started he is the first to bite and may become dangerous; for in spite of his fine, slender body he is strong, and as soon as the biting stage of a fight is reached he takes advantage of his high stature, holding his opponent by the nape of the neck, tightening his grasp when the other Dog moves, tries to lift him

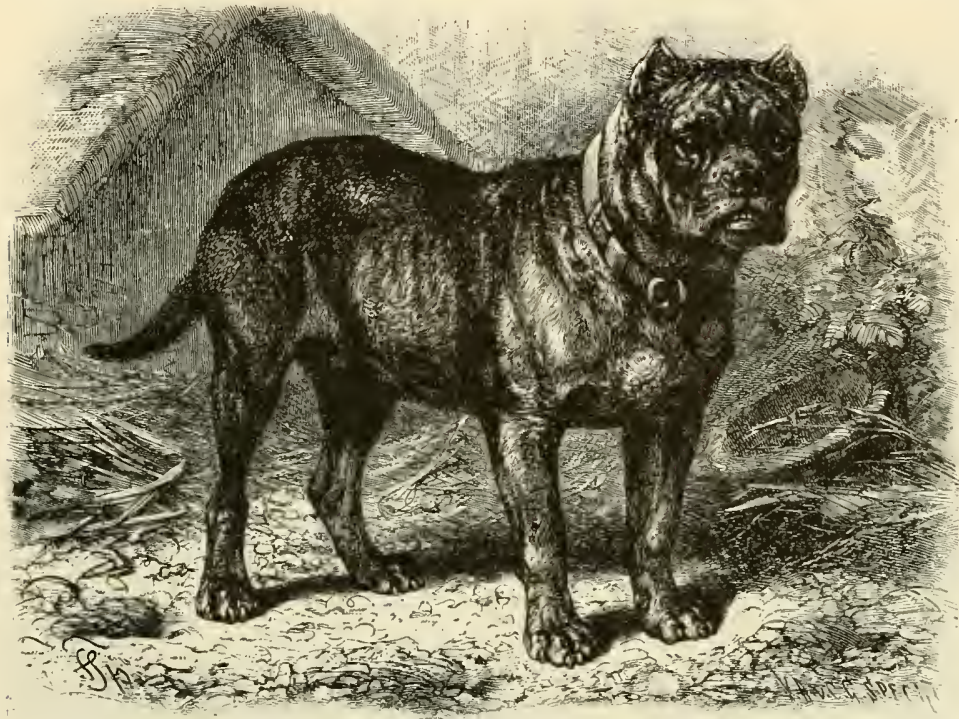

THE BULLDOG. The type of strength, courage and persistent determination, above all other animals, is the Bulldog. The stout body and powerful chest, the blunt muzzle, the upper lip overhinging the lower jaw on both mal. He is a faithful watch Dog, a fearless hunter and a good servant, but a bold and invincible antagonist. (Canis familiars molossus hibernicus.)

and gives him a shake that makes the poor animal lose his senses. All the unsympathetic qualities of the Greyhound cannot diminish his importance, however. Among many nations he is as indispensable as the Pointer to the European sportsman, or as the Collie to the shepherd. In the south, especially in all eountries abounding in plains, he is used to a far greater extent than in the North. The Tartars, the Persians, the inhabitants of Asia Minor, the Bedouns, the Cabyls, the soudanese, the people of India and other tribes of central Africa and Asia put a great value on him, sometimes as great as on a Horse. Among the Arabian tribes of the desert, or rather of the desert-like plains on the border of the Sahara, there is a proverb: "A good Falcon, a swift Dog and a noble Horsc are worth more than twenty Women."

In our temperate climes the Greyhound is not used to any great extent. A level country, through which a flurse may be ridden tnobstructed, is the only one suitable for the hunter who desires to be "in at the death" when a Grevhound has caught a Hare.

The Greyhound Such a chase affords a beatiful specChasing $\alpha$ tacle. The Hare is not as stupid as it Hare. looks and plays an inexperienced Dog many a trick. The Greyhound follows his game with fearful rapidity, making leaps of great distances, sometimes vying with the larger Felida in this respect, clearing two, three or four yards at a bound, so that he soon comes up with the Hare. When he is nearly on the point of seizing it, the hunted animal suddenly turns around and retraces its steps, but the Dog, taking a straight course, rushes ahead and nearly falls to the ground from his sudden halt, when he finds his prey has eluded him. He looks around savagely and, in great anger, again seeks the Hare and sees it running along at probably one hundred and fifty paces distant. He turns about, rushes after it and just as he is ready to seize it, the Hare turns around again and the Dog fails as in the first instance. In this manner the hunt might be continued forever if the hunter did not send two Dogs after one Hare; one pursuing it, the other cutting off its retreat.

The Grey. W'hile Greyhound of the hounds of the

Desert. North differ much in their structure and fur, those of the South secmingly all belong to the same breed, a specimen of which, the Greyhound of the Desert, we will consider. He is as noble as he is graceful, his fur is of silky softness, his color light tawny, sometimes with a whitish tint, frequently merging into a dark roe-brown. This breed of Dogs is found pictured on the Egyptian monuments with other species, especially among spotted Greyhounds.

In IS48 I spent several wecks in the village of Melbes in Kordofan, and had a great many opportunities of watching the Greyhound of central Africa. The natives, although they cultivate the soil, depend chiefly on Cattle-raising and hunting for their livelihood. For this reason they keep only Shepherd Dogs for their flocks and Greyhounds to guard their village. It was a real pleasure to walk through the village, for in front of every house several of these Dogs were sitting, vying with each other in beauty. They were watchful, differing in this respect from other Dogs of their kind. They protect the village from the attack of Hyænas and Leopards, and the Lion is the only animal with which they dare not enter into a contest. During the day they were quiet and it was only after sunset that they became active. One could then see then climbing about on the walls, and even mounting on the conical straw roofs of the round huts, probably to have a better vantage-ground for surveying the neighborhood. Their agility in climbing was well calculated to evolie astonishment.

Every weck there were holidays for these animals. In the early morning one would sometimes hear the sound of a bugle in the village: that was the signal for a hunt. The Men and the Dogs assembled and 
the whole concourse left the village in an orderly manner, presenting a magnificent sight. They seldom went very far, for the nearest woods furnished plentiful game, and, owing to the zeal and skill of the Dogs, the hunt was an easy one for the Men. Arrived at a forest of bushes, the hunters formed a wide circle and let the Dogs loose. The latter entered the thicket and caught nearly every animal it contained. Bustards, Guinea-fowls, and many other birds which the Dogs had captured, were brought to me. An Antelope never escaped them, for from four to six Dogs always united in pursuing it.

Daumas' Account of General Daumas tells us about the the Greyhound of Greyhounds of the western part the Desert. of the desert: "In the Sahara, as well as in all other Arabian countries, the Dog is only a neglected, importunate servant whom one repels, in spite of his great usefulness both in watching the house and guarding the Cattle; and the Greyhound alone enjoys the affection, the esteen and the tender consideration of his master. Rich and poor consider him their inseparable companion in all chivalrous sports, which the Bedouins follow with such zest. The Dog is carefully tended, specially fed, being, as it were, allowed to eat out of the master's dish, and the breed is kept strictly pure.

"When the Greyhound is about three or four months old, his education is begun. The boys let Mice run before him, and pit the young racer against this game. In a short time the noble animal shows great pleasure in such a chase and in a few weeks it can be used against larger rodents. At the age of five or six months it is taught to course the Hare, the teaching of which presents much greater difficulties. Then comes the turn of the young Gazelles. They are approached with great caution when resting by the side of their mother. The Dog's attention is directed to them, they are excited until they grow restless and then are let loose. After some practice the Greyhound becomes passionately fond of hunting, even without much encouragement.

"Such practice continues until the noble animal is a year old and has almost reached his mature development. Still the 'Slugui' is not employed in the chase until he is about fifteen or sixteen months old. From that moment he is expected to do nearly the impossible: and he meets every expectation. When such a Dog catches sight of a herd of thirty or forty Antelopes, he trembles with excitement and pleadingly looks up to his master, who takes his water-pouch and moistens the Dog's back and flanks, knowing that the Dog will be more fortified by this than by anything else. Finally the Greyhound is set free, and with a yelp of joy darts for the prey like an arrow, always selecting the finest, state jiest animal of the herd. As soon as he has caught his "Antelope, he immediately receives his rightful part of the game, namely, the flesh of the ribs; for he would turn with disdain from the intestines.

"The noble Greyhound hunts only with his master, for whom he displays great affection. When the master has been absent for a few days the Greyhound rushes joyously out of the tent upon his return and jumps into the saddle with one bound to caress the Man whom he has missed so mucli. Then the Arab says to him, "My dear friend, excuse me, it was necessary for me to leave you; but I will go with you now, for I need meat; I am tired of eating dates, and you will be kind enough to procure me some flesh.' The Dog, listening to all these kind words, acts as if he understood every syllable. The price of a Slugui, trained to catch the larger kinds of Gazelles, is equal to that of a Camel; a Greyhound which kills the larger Antelopes easily brings a price equal to that of a fine Horse."

The Italian The most graceful of the whole Greyhound, a Grace- Greyhound family is the Italian ful Dog. Greyhound (Camis familiaris grajus italicus), a mere dwarf compared with the others, but a very well-formed dwarf, whose limbs and body display the greatest symmetry. His weight seldom exceeds six or seven pounds and the most valuable Italian Greyhound does not weigh over four pounds, in spite of his height, which reaches sixteen inches. In shape and color he corresponds closely to the Greyhound proper.

The Scotch Grey- The smooth, thin fur and the conhound a Rough- sequent sensitiveness to cold, as Coated Variety. well as their frequent occurrence in Africa and Asia, indicate that the Greyhounds originally came from hot countries. For the greater part these breeds retained all their peculiarities, even after having been transplanted to the north, but some

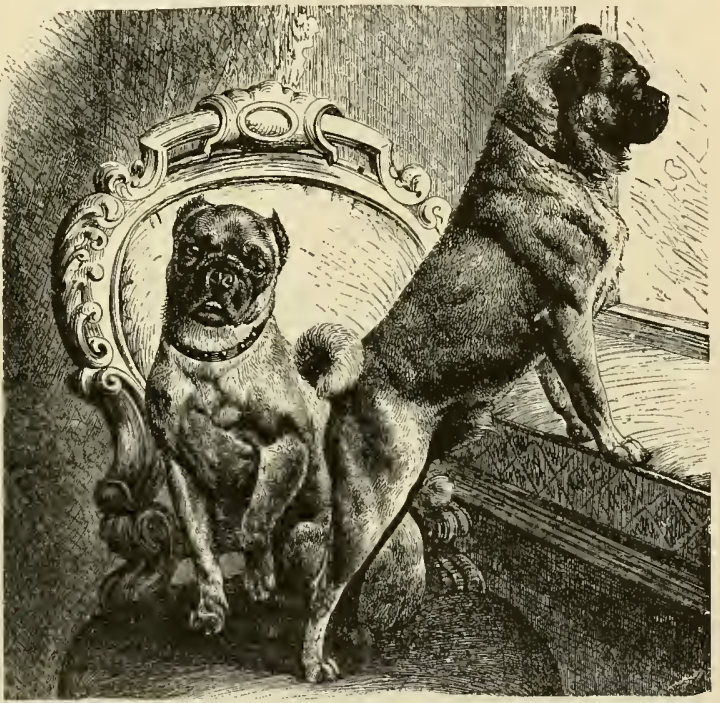

THE PUG DOG.-This very familiar little animal is a sort of a miniature Bull og, which he resemhies in shape, and on a small scale, in disposition. Landseer once $o g$, whec he resemhies in shape, and on a small scale, in disposition. Landseer once che the rest not inapt. Pug-Dogs are easily spolled by too minch pettir

adapted themselves to the rougher climate. To these latter belongs the Scotch Greyhound (Camis familiaris grajus hibernicus) whose fur is about three times as long as that of the common Greyhound, and is so thick as to effectually protect it from cold. The color is black or brown and white, sometimes reddish brown brindled with gray. The pure breed is now perhaps extinct, or at least is rarely met with. let even those now commonly known are among the stateliest of Dogs; they are more affectionate and faithful than other Greyhounds, but hase a quick temper and may become dangerous to other Dogs. 
The Naked Dog An ugly, degenerated type of the of Central Greyhound is the naked Dog found Africa. in central Africa (Camis familiaris africamus). The body is long, slender and much retracted in the flanks. A few hairs are found only near the tail, around the mouth and on the legs; all the rest of the body is entirely devoid of hair, and this is what gives the Dog its ugly appearance. The black hue of the skin, which in our climate after some time merges into gray and here and there shows flesh-colored spots, is not pleasing. The length of the body is twenty-two inches, that of the tail ten, and the shoulder height fourteen inches.

Besides this unclad relative of the Greyhound other hairless Dogs exist, some of them having a

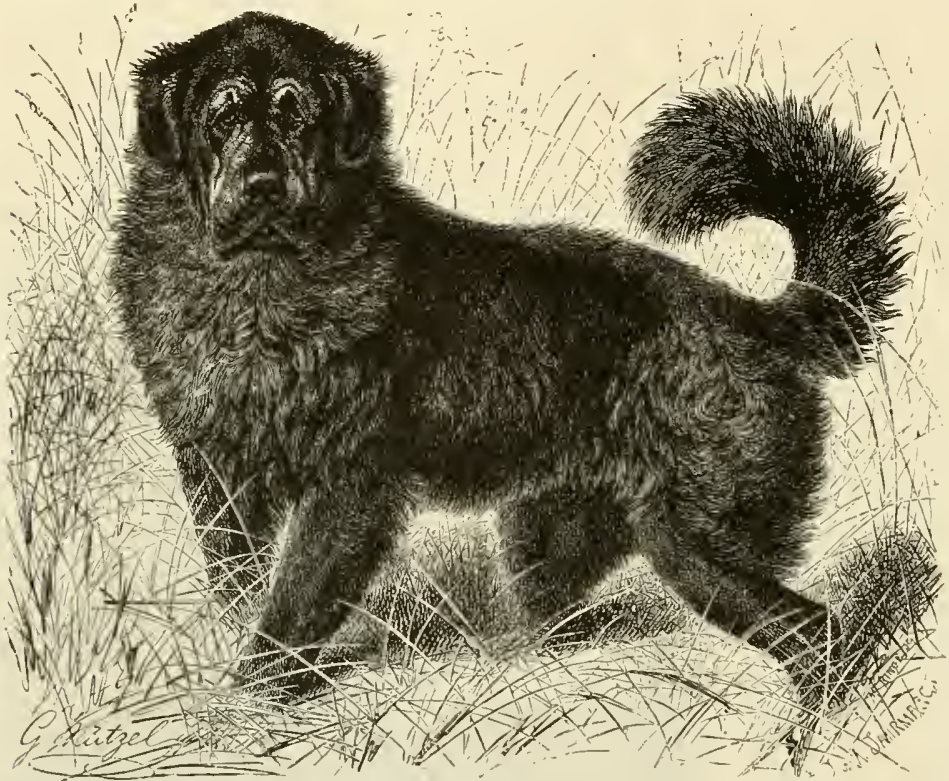

THE DOG OF TIBET.-- One of the largest and noblest Dogs of the Mastiff group is the Dog of Tihet which as a watch Dog and a guardian of flocks makes himself very ustful in the mountain villages of central. Isia. The long, rough, hlack hair, strong, heavy body, courageous and intelligent face and pendent ears shown in the picture. represent his character as a faithful and especially useful servant of Man. (Cams famalaris molossus tzbetcarius.

faded tuft of hair on the forchead. They may be found in China, Central and South America, Manila, the Antilles and the Baháma Islands.

\section{THE MASTIFFS.}

A second group of the Dog tribe is formed by the Mastiffs (Canis familiaris molossus).

The Handsome, To this group belongs, in the first Large Danish place, the Danish Dog (Camis familDog. iaris molossus danicus) though it may be considered a cross between Greyhound and Bulldog. He is a large, handsonc animal of noble shape, has slender legs, a smooth tail and large, beautiful eyes; the muzzle is tapering, but, like the whole body, is of stouter build than that of the Greyhound.

The German Much more common than the Danish Mastiff or Dog is his near relative and descend-

Ulmer Mastiff. ant, the German Mastiff ( Camis familiaris molossus germamicus) distinguished as much for its beaty as its sagacity, and popular in Germany. for still another reason. Who has not heard, or, at least read about, Bismarck's "Dog of the Empire"? The German breeders have been successful in dereloping this breed (which originally bore the title of the parent stock or that of "Ulmer Mastiff") to such an extent that for the last decade it has only borne the name of German Mastiff.

Its fur is short and thick, both on the body and on the tapering, slightly curved tail. The color is a uniform black, light or dark gray, brownish or light yellow. The lighter tints are sometimes brindled with darker hues; and those of a light gray ground-color usually have spots of a darker tinge; while those German Mastiffs that have a fur of uniform color frequently show white marks on breast and toes. The ears are of moderate size, placed high on the head, and are, as a general thing, partially split.

$\begin{array}{cl}\begin{array}{c}\text { Story of a } \\ \text { Large German } \\ \text { Mastiff. }\end{array} & \text { this breed, } \\ & \text { a ccording }\end{array}$
to Grassner's description, had in his third year attained a shoulder height of thirty-seven inches, a total length of seventy inches (including the tail) and a weight of 122 pounds , which is an extraordinary size. His master was director of a school and lived in an unprotected neighborhood at the outskirts of a German manufactur ing town. He deemed it necessary to purchase a strong Dog for the protection of his family and home. "My choice," said he, "fell on a five months" old German Mastiff, whose parents, ow ing to their large size, intelligence and faithfulness, were held in high esteem by the Dogfanciers of the neighborhood, but were also much feared on account of their fierce disposition. When I brought the Dog home, his clumsiness and $h$ is ferocious looks incited very unfavorable comment. But it was only a few hours before he had forgotten his awkwardness and began to feel quite at home in the midst of his new surroundings. Naturally he became my constant companion on my daily walks, during which he displayed an entirely unexpected liveliness and activity. As I paid but little attention to him, he sought out for himself all kinds of amusement after his own fashion, especially observing all human beings with constant attention, and if he disliked their actions, he immediately stepped in to regulate matters more in accordance with his notions. Quarreling, for instance, was highly distasteful to him. Even if persons at a great distance began to exchange loud words, he rushed between them, growling and showing his teeth, and soon quieted the disturbance.

"The sight of a driver maltreating a Horse aroused him to the greatest excitement, and he would at once go to the side of the Horse and assume a threatening attitude. If the driver then persisted in 
striking the Horse the Dog would throw the Man to the ground with such force that he could not immediately recover from the shock. On the other hand, if my Dog saw a Man pushing a very heavy wheelbarrow, he would always run to help, pulling the vehicle from the front with his strong teeth.

"His strength was in keeping with his huge size. It was child's-play for him to carry, for a long

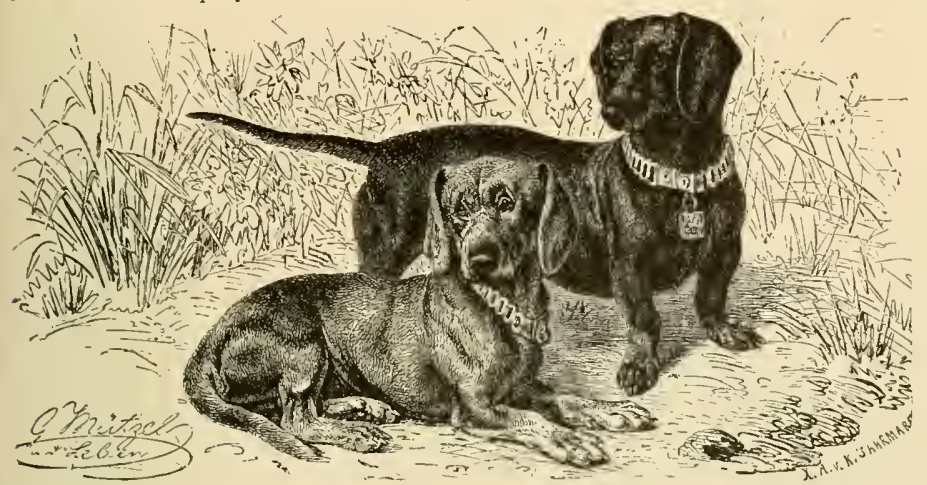

THE BADGER-DOG, OR DACHSHUND _-This animal. largely bred in Germany, is famous for its hunting qualities, its staying powers, courage and keen scent, especially qualifying it for the pursuit of game. The most marked physical characteristics are the large, pendant ears, and the crooked, short legs, which are (

distance, a basket weighing fifty pounds. A Goat which had butted at him as it passed by, was seized by the Dog and brought to me, the Dog clearing two railway fences on his way. A ferocious Bull, which was being driven to pasture with other Cattle, came toward me in a threatening manner. The Dog sprang at the animal's throat and held it until the beast roared with pain, and when its assailant loosened his hold it made a hurried flight. Once Tom (that was the Dog's name) had to be sent away, and the carpenter made a box out of new boards, strong enough, as he said, to hold a Tiger. Tom gnawed the box into splinters before he reached the station. When he was rushing at any object that had excited his wrath, the strongest Man could not have checked him be threw down all who interfered with him and dragged them along on the-iround.

"He participated in all family events. If one of us was sick in bed, he would sit by the bedside

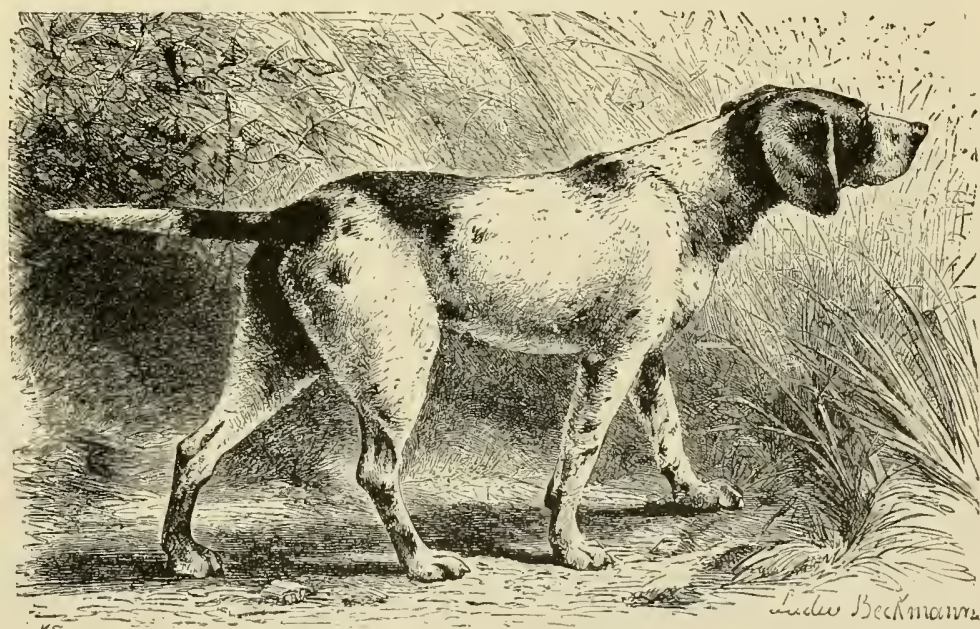

THE PoINTER. - There is no more valuable Dog from the standpoint of the hunter than the Pointer, a smooth-coated animal of the Hound group, endowed with a keen scent, great sagacity, and a capacity lor pertec smooth-coated animal of the Hound group, endowed with a keen scent, great sagacity, and a capacity lor pertect pportunity for a shot has come. It is a symmetrical, shapely animal, and its physical characteristics are admirably pportunity for a shot has come. It is a symmetrical, shapely aning
shown in this illustration. (Canis familiaris sagax aicularius.) and hiding in his huge mouth, some object which my daughters needed for their needlework, such as a skein of wool or a pair of stockings rolled together. If my daughters would then pretend to make diligent search for the missing object, he would assume a very grave demeanor and foolish expression of countenance, to show that he had no idea what the fuss was about, but would give up the missing object with a sly twinkle of his eye, when he was asked the direct question: 'Tom, do you know where it is?' If I happened to be present before this quessaw that the girls were not observing him, he would come to me, open his mouth so that I could see the hidden object, give me a sly, knowing look, and then turn around again and assume his former silly expression of countenance.

It would lead me too far to mention all his tricks unobserved, as he thought, tion was put to him, and he for bours and look at the patient's face, from time to time putting his muzzle or paw gently on the hand held out to him, as if he wished to express his commiseration. If an absent member of the family sent sonte package by mail, the Dog could hardly wait to and qualities, some of which are usually thought to be characteristic traits of certain other breeds only; but I will here relate two more proofs of his intelligence. One day I happened to be near the station at the time a train was arriving. Force of habit 
made me look through the window, to see whether an acquaintance was there. I noticed that Tom kept looking alternately at me and at the train, evidently thinking that I expected somebody. Desirous to know whether I had guessed his thought, I said: 'Yes. Tom, run!' Like a flash of lightning he was off to the station, after the train. 1 hurried there also, and arrived in time to see how he hastily looked over all the alighting passengers, went through all the cars twice and then only, not having found any well-known friend, sadly took his departure. From that time the Dog ahways went to meet or backward, but is usually lifted and bent forward. The ordinary coloring is a pale or brownish yellow, sometimes with a surface tinge of black; the muzzle, the lips and the outer margins of the ears are black. There are many variations in coloring, however, as with all other Dogs.

Life and Princi- The original native country of the pal Traits of the Bulldog is probably Ireland; at Bulldog. least it is there that one finds the best existing types of Bulldog. In keeping with the heavy and clumsy build of these animals their pace is neither swift nor enduring. On the other hand they are possessed of enormous strength, much determination and great courage; and it may be said that, with a few exceptions, they are the most courageous of animals. By virtue of their great strength Bulldogs are especially adapted for a difficult. dangerous chase and for fights with wild animals. Their mental qualities are not as pronounced as those of other sagacious Dogs, but neither are they on as low a plane as is generally supposed; for every Bulldog accustoms hinself to Man and sacrifices his life for him without hesitation. He is particularly adapted for the duties of a watch Dog and defends what is confided to him with really a wonderful intrepidity. As a traveling companion to Man in a dangerous, lonely country he has no equal.
THE RETRIEVER. - The Retriever variety of Hounds includes besides the smooth-coated kind known as the Pointer. the Retriever proper, or Water Spaniel, the beautiful, rough-coated Dog shown in the picture. It has the same traits as the Pointer, but is more fond of the water. Well trained Dogs of this species are not only valuable all our guests who came by rail and whom he knew, and really was the most trustworthy messenger we could send, especially at night time. As soon as the train came into the station, he would make his way through the crowd to the cars, kindly greet the arriving guests, coax them to give him a piece of luggage to carry, and triumphantly lcad the marci home, opening a way through the crowd in an admirable manner, and leading our friends by the most direct route to the place where we stood outside the platform."

Physical Charae- The Bulldog (Canis familiaris molossus teristics of the libermicus) is a sub-order of the MasBulldog. tiffs; he is of a stout, vigorous build, the body being but slightly retracted in the flanks; the back is not arched, the chest is broad, the neck is rather short and thick, the head long and rounded, the forehead is strongly curved; the muzzle is short, narrows somewhat in front and is very blunt. The lips hang down low on both sides, but do not come together in front, and saliva is perpetually dropping from them; the ears are rather long, of moderate width, rounded and semi-erect, the tips hanging over The legs are strong and of medium length. The tail is thick at its root, tapering towards the end and reaches to the ankle-joints; it is seldom held straight
There are anecdotes, relating how he has successfully defended his master against five or six highwaymen, and there are further narratives of victories he has won in such unequally matched fights, in spite of the numerous wounds he received. He is also used to guard herds of Cattle and he knows how to tame the wildest Bull, for he is expert enough to suspend himself by his teeth from the Bull's face, and hold fast until the beast is ready to patiently submit to him. He is easily trained for fights with large Beasts of Prey, such as Bears, Wolves and Wild Boars. He is very forbearing in his behavior to other Dogs; seldom picks a quarrel, and allows smaller Dogs to take liberties with him. He is faithful to his master, but is dangerous to strangers, no matter whether he is chained up or at liberty; and when pitted against people, he is a really formidable foe.

Bulldogs proper are very large and strong animals, with a short, truncated muzzle, whose upper lips, though hanging down low at the sides, do not close in front, so that the teeth are always exposed. The nose is not infrequently split, the fur usually consists of short hair of a plain reddish color; sometimes it shows several colors. In former and less secure times, when protection was more needed, 
Bulldogs were kept in greater numbers than now: for at the present time they are seldom seen, except in the possession of Dog-fanciers.

The Boxer, an The breed of Bulldog known as

Especially Pugna- the Boxer (Canis familianis molos-

cious Bulldog. sustypicus) is most frequently seen in England. More than the Bulldog proper he is regarded as a ferocious, dull-witted animal, though he possesses these qualities only in a limited degree. $\mathrm{He}$ is affectionate and faithful to his master, but he must know him well, and also know that the master's mental powers are superior to his own physical ones; else he thinks he can accomplish with Man what he succeeds in doing with beasts. Ile is extraordinarily imperious and is addicted to vicious biting, and he really enjoys killing other animals. It must be stated to his praise, that his courage is still greater than his really formidable strength.

What the Boxer has once seized, he cannot be easily made to relinquish. If a stick or handkerchief be held out to him, and he closes his powerful jaws upon it, one can lift the Boxer by this tightly held object, swing him or throw him on his back, without succeeding in making him release his tenacious hold.

There are some Mastiffs which are not agreeable companions to Man. Instances are on record where they have placed their own new master in a state of siege, and have refused to permit him to move. It is therefore easy to understand why Bulldogs are not kept to any great extent nowadays. They are not so stupid as they are supposed to be, and there are individuals among them whose sagacity nearly equals that of the Poodle.

I knew such a Dog, which afforded much pleasure by his sagacity. When his master said: "Go, get a cab," he went to the nearest cab-stand, jumped into a vehicle and barked until the driver started; then he either directed him by barking, or ran in front.

The Pug, a Cari- To the Mastiffs becature Among longs that cariDogs. cature of a Dog, if such I may term him, the Pug (Canis fumiliaris molossus fucator), which is really a diminutive Bulldog, with the same peculiarly truncated muzzle and curled tail. His stout, vigorous build and distrustful, grumpy character closely partake of the Bulldog type.

The Pug was widely spread in former times, then became nearly extinct and lately has again become very common. He is easily spoiled and petted, and in consequence becomes capricious and naughty, and is an abomination to a great many people.

Mastiffs Formerly A large species of the Mastiff was Used as Man- used for a brutal practice in former chasers. times. It was trained to catch Men, throw them down and even kill them. At the invasion of Mexico by the Spaniards, such Dogs were used both as fighters and trackers, and one of them, called Becerillo, is celebrated, or rather, notorious. His courage and his sagacity were equally extraordinary. He occupied a high rank among the Dogs and received double rations of food. During an attack he used to rush into the middle of the band of opposing Indians, seize one by the arm and lead him away captive. Such captives as obeyed, he dir not harm, but any Indian who refused to go with him, he threw down and strangled. He knew the conquered Indians from the enemies and never touched the former.

As late as I 798 these Dogs were used for the same purposes, not by the Spaniards but by Englishmen who employed them in the chase of $\mathrm{Men}$.

The Magnificent A Mastiff which was known by Dog of Tibet the Romans, is the Dog of Tibet Described. (Canis familaris molossus tibetanus) a magnificent, beautiful, large animal of really aweinspiring appearance. One glance suffices to show that this Mlastiff is the giant among Dogs and is distinguished as much for his nobility of form as for beauty of color. He is black, for the greater part, but the muzzle and eyebrows are yellowish; the hair is long and rough. In his native country this animal is considered as useful as he is docile; and he is therefore found in all mountain villages of Tibct, as guardian both of flocks and houses.

\section{THE BADGER-DOGS.}

A group very different from that of the Mastiffs is that of the Badger-Dogs or Dachshunds (Camis familiuris vertugus). They are among the most peculiar and remarkable of Dogs. The body is long, round and arched downward, the back being bent in that

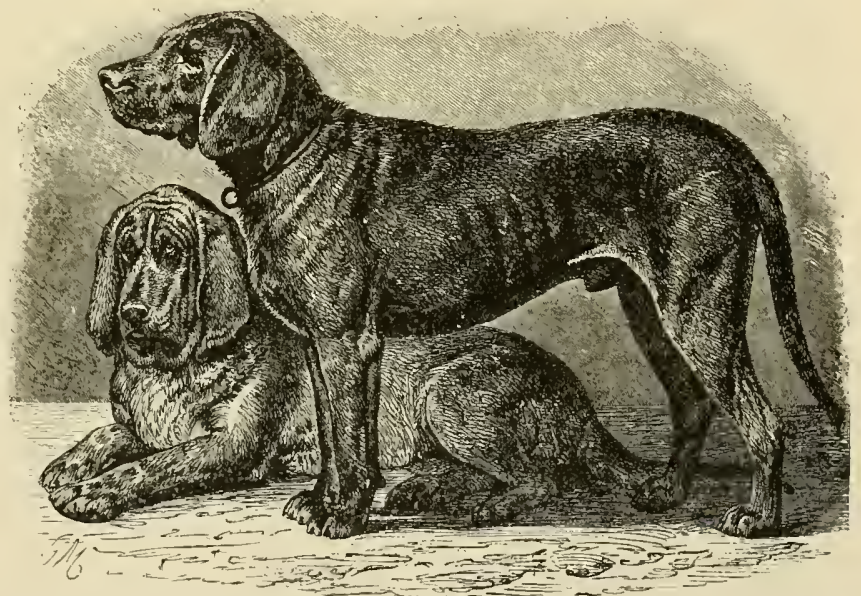

THE SCHWEISZHUND, OR GERMAN BLOODHOUND.-A valuable Hound, principally bred in Germany, stout of body, bold in disposizion, with a keen scent and a cool head, is the Schweiszhund. It is allied to the Pointer and Retriever in its main characterıstics, but its more vigorous build makes it even more valuable than these in the pursut of large game. The very large, pendent ears, the verhanging upper lip, and the great development of the chest, are marked charactersstics shown in this illustration. (Canis famlzars sagax sanguinarus.)

direction; the legs are short and crooked, the head and muzzle large and furnished with a set of good, serviceable teeth, the ears are pendent, the paws large and provided with sharp claws. The hair is short, sleek and coarse. The legs are very short, clumsy and strong; the wrist-joints of the fore legs are crooked inward to such an extent that they nearly touch each other, and from this point they again assume an outward curve; the hind legs have the last toe placed higher than the others and provided with a claw. The tail reaches nearly to the 
ankle-joints and is carried in an upward line, with the end curved toward the thighs, and seldom hangs straight down. The short hair is coarse, but smooth and of varying colors, usually black or brown above, russet below, or it may be, a uniform brown or yellowish hue, or even gray; and these colors may be spotted with colors differing from the ground-tint. As a rule, there are two light russet spots over both eyes.

Senses and All Dachshunds have a very fine

Badger-Dog. ulty of hearing; they possess courage, reasoning power, bravery and endurance to a high degree, and may therefore be used for any kind of hunting. They will even boldly attack IVild Traits of the scent and an exceedingly acute fac-

by any other Dog. He will spend hours in following a Hare, or in digging and burrowing in some hole in which a Rabbit has concealed itself; and indifferent to fatigue, he will hurry after a Deer utterly forgetful of time and space. When he is tired, he lies down, rests and then resumes his hunt. For these reasons the Dachshund is usually employed only for one kind of hunting - to drive animals out of their subterranean burrows.

The English The English Turnspit is bred in France

Turnspit and Great Britain (Canis familiaris

Described. vertagus rectipes). It differs from the brceds common in Germany mainly in its sturdier shape, larger head, shorter snout, straight fore-legs and a longer and thinner tail. It is a true Dachshund in its character, be-

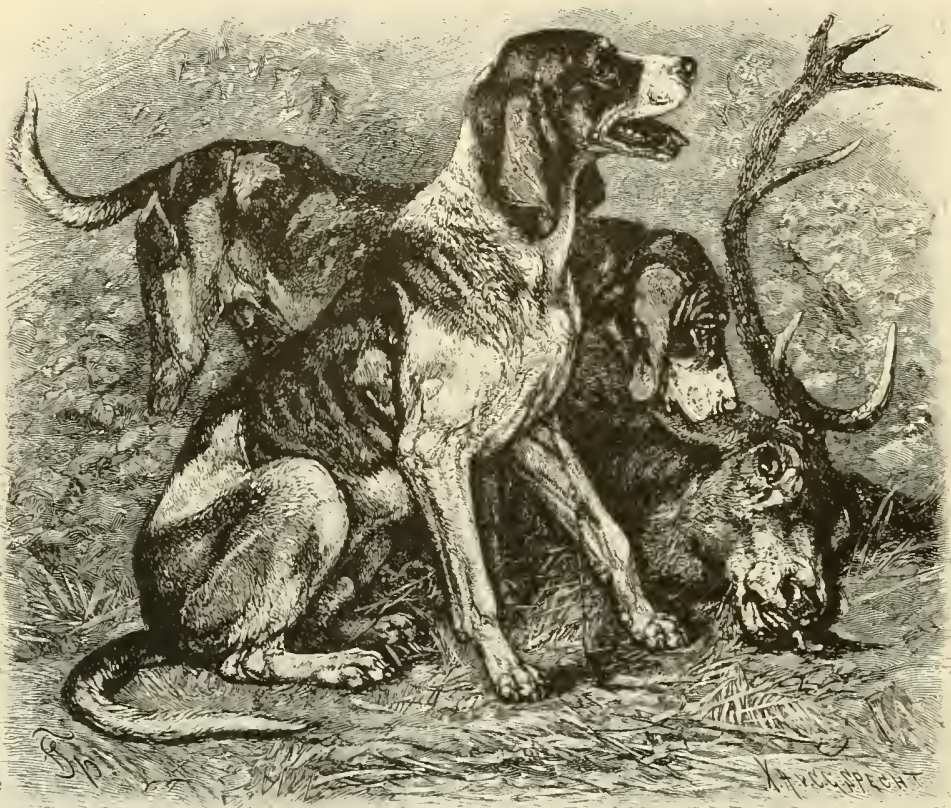

THE STAGHOUND. - A famous but very rare species of Hound, which in its pure breed is now said to be Only tound in the royal kennels of England is the Staghound. It excels all other Dors 11 speed and endurance and is especially adapted for the hunting of fleet-footed game. It is appropriately depicted by the side of a wounded Stag. filiaris sagax accettorius.

Boars, and protect themselves very effectually from the savage onslaught of these animals, as the Boar cannot seize them so easily as he can taller Dogs. They are sagacious, docile, faithful, lively and sympathetic, but arc very vigilant and strangers find it hard to get acquainted with them. Unfortunately it is also true that they are very cunning and thievish. and in old age become sullen, sulky, addicted to bitinc and often treacherous.

During the chase they give one a great deal of trouble. The Dachshund undertakes the pursuit of game with astonishing eagerness, and will enter the most impenetrable thickets. Owing to his excellent scent he soon finds a quarry, and then he forgets everything elsc. Nlthough he may have received, on previous occasions, severe chastisement for his disobedicnce, still he will let the sportsman whistle, call and look for him in vain; as long as he sees the quarry or can track it by scent, he goes his own way with an obstinacy that is hardly equaled the Otter. improvement. ing as eager, lively, violent and pugnacious as its relatives. It is more rarely used for hunting than it is to guard the house and perhaps also to turn the spit. In this latter capacity it is put into a drum which serves as a turning-wheel. It can occasionally be seen at work in restaurants and inns in French towns. It serves its term without grumbling, but neither cheering words nor chastising can compel it to work longer than a certain customary length of time.

$\begin{array}{cc}\text { The Otter- } & \text { The Otter- } \\ \text { Hound a Rare } & \text { Hound, ac- } \\ \text { Species. } & \text { cording to }\end{array}$ some authorities, is a cross breed between the Deer-Hound and Terrier. nearer to the latter than to the former. It is of vigorous frame, has a long head, a pointed muzzle, long, drooping ears, a long body, straight legs and a rough coat of varying colors, the hair being of medium length. It derives its name from its ability as a hunter of

THE HOUNDS.

The group of Dogs, ranged under the common name of Hounds (Canis familiaris sagar ) displays a great varicty of types and forms; they are much more open to instruction than Dachshunds and are indisputably entitled to rank first among the domestic Dogs. The largest number of varicties of Hounds is found in Great Britain, whcre a great deal was accomplished in the brceding of these exccllent Dogs much earlicr than German people bethought themselves of undertaking the work of

All Hounds are born hunters, and if this happens not to be true in exceptional cases, they are good for nothing. Careful breeding is of more inportance with I Iounds than with any other Dogs, and one always finds that good mothers or tried, skillful 
parents bring up excellent Pups. They are strong, sivift, and more than other Dogs are fitted for the chase by the perfect development of their senses, especially by their delicate scent. They are endowed with such smelling powers that they can detect the track of game after hours, nay, after days have elapsed.

The Pointers Among the many breeds we will first and Their Track- consider the best known, the Pointing Abilities. ers. They are of moderate size and rather strong build; the muzzle is long and thick, the nose is sometimes split, the ear is wide, long and drooping; the hair may be long, short or bristly and the color usually is white, spotted with brown or more rarely black; but there are also entirely white, brown, black or yellow varieties.

Pointers are sagacious, docile, obedient animals, eager for the hunt, to the success of which they are quite indispensable. They track the game by following fresh spoors or simply by scent, and, under favorable circumstances, they are able to scent small game at a distance of thirty or even fifty paces.

"For many years past," says Diezel, "I have compared the capabilities of the animals inhabiting Germany, and have persuaded myself that there is one far superior to all others, and that is the Pointer.

Requisites in "To make my Training a assertion hold Pointer. good, the Doo must be of very pure breed and possessed of all his natural endowments, especially a delicate scent. Further, he must not have been brought up isolated, but immediately under the eyes of his trainer, and thus be taught from puppyhood to understand every word and gesture. Then, also, his trainer must possess all the qualifications of a good teacher, among which patience is not of the least importance, and must be a good marksman; for only when all requisite conditions are fulfilled can the Dog reach that admirable degree of obedience, self-control and skill, which I will try to describe A perfectly trained Dog, three or four years old, always looks for the game by natural instinct, holding his nose to the wind and from time to time turning to the right and to the left. Sometimes he stops and looks around at his master, who by a gesture indicates the locality the Dog has to search. These gestures are scrupulously obeyed. If he scents important game, the almost constant motion of the tail ceases at once, and his body is converted into a living statue. Frequently he slinks nearer the object with stealthy tread like a Cat before he stops. After a few moments he turns his head to see whether his master has noticed him and is coming towards him. Some especially sagacious Dogs, when the locality does not permit the master to follow their lead (as a forest, or a field of tall corn where a Dog cannot be seen), leave the quarry for a short time, in order to find their master and lead him to the spot But of the many Dogs which I have had in my possession, few did this, and not at the beginning; they learned it only in after years."

A thoroughly trained Hound is a really admirable animal, and a bad sportsman, when accompanied by a good Dog, runs the risk of being frequently rebuked by the Dog, by actions expressing decided disapproval.

I knew a Pointer, called Basco, which belonged to an excellent sportsman. His owner lent him to a young friend, better accustomed to the use of the pen than to that of the gun. Twice the young hunter slot, and twice he failed. The Dog then approached him, gave him a look of profound contempt and straightway trotted home. This Dog was

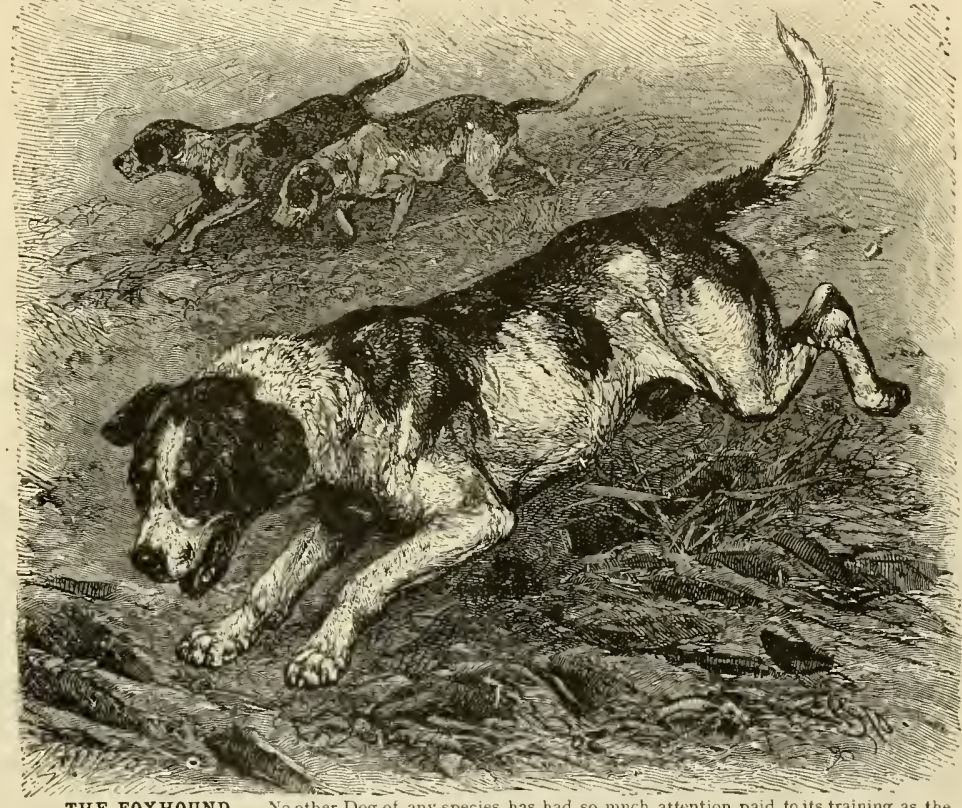
Foxhound. The results are seen in an animal that combines in the most perfect degree the qualities of a hunting Hound. Keen scent, most astonishing endurance and running qualities, courage and sagacily are combined in the
Dog which the picture shows intent on the Fox's trail. Its perfect proportions and vigorous build make it an ideal an enthusiastic hunter, but after somc years he could not be prevailed upon to accompany a bad marksman on a chase, for his contempt for unskillfulness was too decp-rooted.

General observa- It goes without saying that if a tions on the good Dog is to be well trained, Training of Dogs. he must have an excellent trainer. The training of a I og is a difficult matter; patience, earnestness of purpose and affection for the animal are essential qualities of a teacher. In former times those training Dogs proceeded in a more forcible manner, using the whip and a rough collar. A great many trainers still pursue this plan, but others proceed on different and better principles. They do not consider their pupil a slave, but a reasoning 
assistant, and consequently treat him as such even from lis puppyhood.

The Schweisz- Resembling a smooth-coated hund or German Pointer in size and form is the

Bloodhound. German Bloodhound or Schweiszhund (Canis familiaris sagari sanguinarius). Nothing definite is known as to the origin of these Dogs. They are of vigorous build and of a brown, red or pale yellow color, with a blackish tinge on muzzle and ears, and frequently also have a black stripe on the back. The head is wide and only slightly arched; the nose is black or nearly flesh-colored and

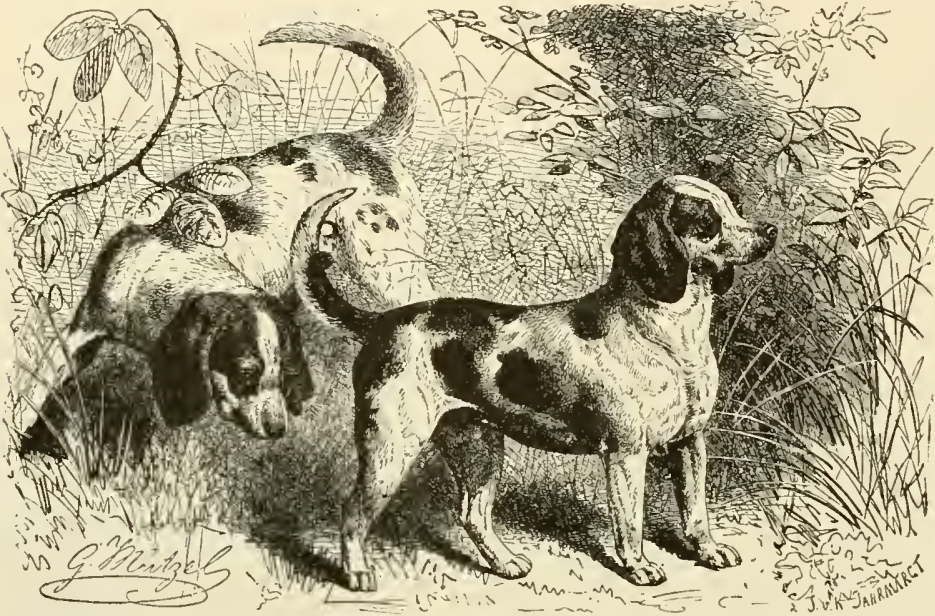

THE BEAGLE.-A small hut valuable Hound, which is especially useful in chasing Hares and other small but fleet-footed game, is the Beagle. Its characteristics are a stout build with a development of the chest especially adapting it for a long chase, large, pendent ears, pointed muzle, short but strong and sinewy legs and rather short tail. (Canis famtiaris sagat irritans.)

much wider than that of other Hounds; the lips of the wide snout hang over and form deep creases at the corners of the mouth. The wide ears are of moderate length and rounded. The expression of the face is grave, intelligent and noble. The tail gradually tapers toward the extremity. The voice is full and deep and the bark is a peculiarly long sound. Whoever lhas heard it once easily recognizes it arain.

The Schweiszliund is a nearly indispensable assistant in the chase of large game; his office is to pursue the track of the wounded quarry. He is held on a line and quietly leads the hunter to the place where the animal has broken down. When he is let loose and has found the game dead he announces it by his bark; but if the hunted animal has fled, he pursues it and "sets" it until his master comes and ends the hunt with a shot

The Staghound Another nember of the group is the

a VeryRare Staghound (Canis familiaris sagax Animal. acceptorius), which is said to be a descendant of the Bloodhound and Grevhound, whose good qualities he is believed to combine. He is distinguished by his keen scent and great speed. There are but few specimens of this brecd left, and they are in the possession of the Queen of England. It was very different in former times. George III. was passionately fond of Stag hunts, in which he frequently took part personally. Not infrequently the hunt was conducted with such zeal that of the one hundred riders who originally set out after the
Stag ten or twenty only were left when the fleet quarry was finally taken by the Hounds. Astonishing distances were covered with wind-like speed, and the hunt was continued so long that a large number of Horses and even many Dogs perished. Now things are different, as the cultivation of the ground offers too many obstacles to this mode of hunting.

The Foxhound An animal of much greater imporGreatest of tance than the Staghound is the FoxHunting Dogs. hound (Canis familiaris sagax a'ulpecaputs). Nany people of distinction have occupied themselves with him more than with other animals or things, and large books have been written about him. He possesses the speed of the Greylound, the courage of the Bulldog, the delicate scent of the Bloodhound, the sagacity of the Poodle, in short, he has, in combination, the superior qualities of all other Dogs. His speed and endurance are extraordinary. A good pack may follow the Fox for half a day, or longer, with untiring zeal. Bell tells us, for instance, that the Hounds of the Duke of Richmond found a Fox at 7:45 o'clock in the morning, and caught up with him only after ten hours' hard running, shortly before 6 in the evening. Several of the sportsmen changed Horses three times, and some of the Horses died from exhaustion; but of the Dogs there were twenty-three present at the end of the chase.

The Beagle Famous The Beagle (Canis familiaris sagax as a Hunter imitans) is an extremely sympaof Hares. thetic little animal. His height at the shoulder does not exceed fourteen inches. He resembles the Foxlound in appearance, fur and ears, but his legs are shorter and stouter, and it therefore would seem plansible that he is a cross between Foxhound and Badger-Dog.

Beagles are used in packs to bait Hares, and on such hunts it is pleasant to hear their harmonious voices, which sound like bells. The scent of the Beagle is extremely acute, and he is capable of prolonged running.

\section{THE SPANIELS.}

Several Dogs which differ a great deal from each other are grouped under the common title of Spaniels (Canis fumiliaris extrarius). All Spaniels are possessed of great speed, but they lack endurance. They have a delicate scent and great intelligence, but are not very docile. Some of them are used in hunting small game, especially birds; but they stand in need of very careful training, for their innate hunting fever is excessive. Even when they have had the best of training they will tremble with excitement at finding a spoor, unable to restrain their joy or zeal, and will yelp and bark almost incessantly. For this reason they are more frequently kept as pets than used for the cliase. They are very 
courageous, however, and they retain their origina! boldness in other climes, even in tropical lndia, which soon spoils the best of other northern Dogs. Captain Williamson says that one of these small, foolhardy animals once boldly went up to a Tiger. The huge beast at first looked with astonishment at the yelping little thing, then got up, disturbed by the noise of the importunate prig, and fled! The narrator assures us that it was an indescribable sight to see these two animals, so ill-matched in size and strength: in front, the big, powerful Tiger with lifted tail, while the courageous little Dog brought up the rear, yelping and growling.

King Charles and The small toy Spaniels are called Blenheim Spaniels, King Charles Spaniels; and the Diminutive Dogs. smallest bear the name of Blenheim Spaniels. The former owe their appellation to the fact that King Charles II. of England was very fond of them and always had a few around. They are of a dark color, which often merges into brown, while the breast is white. The hair is long and silky and the ears large and long. The best and most esteemed specimens weigh but five pounds, and the largest not more than seven pounds. They are popular pets, for they are pretty, lively and docile when treated properly, and are very amusing companions. They are always intent on some prank and are easily taught a number of tricks. They have one disagreeable feature, though - their eyes are always moist with tears, and teardrops are incessantly falling from the corners of their eyelids.

The Noble New. IV hile we foundland may con-

Dog Described. sider the species just mentioned as dwarfs, the Newfoundland Dog i Camis familiaris $e x$ travius terre not'e) is the giant among Spaniels. He is a powerful animal, with a large, long head, a somewhat thickened muzzle, drooping, shaggy ears of moderate size, large ehest, stout neek and rather long, strong legs; the fur is long, dense, shaggy, somewhat curly, and soft, being of an almost silky texture. The tail is rather long and shaggy, and the toes are

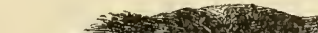

best of all water Dogs, and the water seems to be his proper element. He is exceedingly fond of swimming, dives like an aquatic animal, and can remain in the water a long time. Once one of these Dogs was found in a distant bay, miles from the shore, and it was evident that he had been swimming for hours. A Newfoundland Dog is perfectly indifferent as to the direction he has to take in swimming, and makes his way with equal facility against the stream and waves as with them. Without any preliminary training he will take all kinds of objects out of the water with indefatigable zeal, even during the severest cold weather, and deliver them to his master; in fact, he can be given no greater pleasure than to be afforded the opportunity of disporting himself in the water. His pleasure is considerably enhanced if his master goes into the water with him. The Dog seems to be beside himself with joy to find that Man is also at home in the water, and demonstrates his delight in many ways. The Dog swims around his master, dives under him, makes believe to support him for a little while, and plays around in the water with much glee. When finally the master is weary and turns to the shore, webbed. The color of this Dog is subject to consid. erable variations. Many are black, with a vivid russet spot over each eye, and similar spots on the throat and joints of the feet. Less frequently they are black and white, or brown and white, or uniformly brownish black and white.

Traits and Quali- The Newfoundland is deservedly ties of the considered one of the handsomest Newfoundland Dog. of Dogs, and is much esteemed. His mental qualities correspond with his beauty and prove the excellence of the stock from which he springs. He is affectionate and faithful, intelligent and extremely docile. The Newfoundland is the the Dog tries to invite him to more sport in the water.

This extraordinary fondness of the Newfoundland for water makes him a very useful animal. There are a great many instances on record where he has rescued drowning people. In localities which border on deep water, this Dog can not be surpassed as a nurse for children. One may boldly confide the smallest child to his vigilance and care, and may rest assured that as long as the Dog is near by the child will not be harmed. Besides all these excellent qualities, the Newfoundland Dog has a great fund of good-nature, gentleness and gratitude for 
benefits received; but his memory of injuries and castigations abides for a long time, and he may become dangerous to people who intentionally torment him.

The St. Bernard The St. Bernard Dog (Canis familiaris Dog, the crtravius st. bernardi) resembles the Worthiest of All. Newfoundland. Tschudi says: "The St. Bernards are large, remarkably strong animals, with long fur, short, wide muzzle, and long ears. They are exceedingly intelligent and faithful. Their breed was kept pure during four generations, but is now no longer so, because so many of these Dogs months, when the numerous clefts and precipices are covered with snow, the passage is fraught with much danger and trouble to the stranger. Every year the mountain claims a small number of victims. The wanderer either falls into a cleft, or is buried under an avalanche; or the fog is so dense that he loses his way and perishes in the wilderness with hunger and weariness, or is overcone by a sleep from which there is no awakening. Without the Christian and self-sacrificing activity of the noble monks the Pass of St. Bernard would be available but a few weeks or months of the year. Ever since the eighth century they have devoted themselves to the pious care and rescue of travelers. The latter are entertained at the monastery free of cost. The stone buildings on the hearths of which the fire never goes out, can acconmodate several hundred people in case of necessity. But the most peculiar feature is the regular rescuing service, which is much facilitated by these celebrated Dogs. Every day two servants of the convent go over the most dangerous places of the pass: one goes from the cottage of the Cowkeeper of the monastery (which is much lower down on the mountain) up to the Hospice, the other goes down. In stormy weather, or after an avalanche, the number of searchers is trebled and several priests go with the party, accompanied by the Dogs and provided with spades, poles, biers and refreshments. Every suspicious track is indefatigably pursued, signals are being given all the time, and the Dogs are closely watched Bernard Dog stands foremost among animals in his deeds of mercy and kindness. These are eloquently told in the text; and the physical characteristics of the Dog are faithfully depicted by the artist. The thick, shaggy coat and strong body are needed in the Dog's work of succor in the deep snows that abound in the Pass of the Great St. Bemard, where the Dog lives with his masters, the good nonks whose devoted lives he shares. (Canisfaniuris cxtrarizs st. bernardz.

have perished in avalanches encountered in their faithful service. A closely allied Dog is now being bred, and even young Pups of this breed bring a good price.

Noble Service "The native home of these noble aniof the St. mals is the Ilospice of' St. Bernard, Bernard Dog. situated at an elevation of about seven thousand five hundred feet above the sea, on a desolate mountain crest, in the vicinity of which winter lasts for eight or nine months. It is only in sumner that large snow-flakes fall in this locality; in winter dry, small, brittle crystals of ice fall there: so fine that the wind drives them through every crevice in doors and windows. Near the monastery, especially, the wind often piles these crystals in loose walls of snow, from thirty to forty feet high, covering all roads and the edges of the precipices, and falling down into the latter at the slightest knock.

The journey across this old mountain pass is devoid of langer, even in summer, only cluring clear weather. On stormy days, or during the winter
They are trained to track a human being, and often prowl around all the precipices and roads of the mountains for days. If they find a frozen body, they run back to the convent by the shortest way, bark violently, and lead the ever ready monks to the lost one. If they meet an avalanche, they make diligent search for the track of a human being, and if their keen scent discovers one, they immediately proceed to dig up the snow-buried unfortunate, their strong paws and great strength standing them in good stead at this task. They usually carry a sniall basket with restoratives or a flask of wine tied to their neck, and sometimes they have woolen blankets on their back. The number of people rescued in this way is very great and their names are inscribed in the historical books of the Hospice. The most celebrated Dog was "Barry," the indefatigable creature who saved more than forty pcople."

Scheitlin's Account A poem has been written about of Barry, the this Dog and Tschudi gives it in

Life-Saving Dog. his work; but I know a still finer pocm on the subject, though it is not written in 
verse: I mean Scheitlin's description of Barry. He says: "The most excellent Dog of which we have knowledge is not the one which woke the guardians of the acropolis of Corinth; it is not Becerillo, which tore many hundreds of poor Indians to picces; not the Dog of the hangman, which, at his master's command, guided a stranger safely though a great, gluomy forest; not Dryden's Dracon, which rushed at four highwaymen, killed some of them and saved his master's life; not that one which ran home to give information that the miller's little Girl had fallen into the river; not the Dog in Warsaw which jumped down from the bridge and saved a little Girl's life; not Aubry's Dog, which seized his master's nurderer and would have torn him to pieces before the king; not Benvenuto Cellini's Dog, which woke the goldsmiths when the gems were about to be stolen; but Barry, the saint on the St. Bernard! Barry, the highest among Dogs, the highest among all animals! Jou were a great human Dog, Barry, with a warm heart for the suffering. You saved the lives of more than forty people. With your little basket and a flask of sweet, strengthening wine on your neck, you left the monastery day after day, in snow-storms and in thaw, to search for people buried by the drifting snow or by an avalanche, to dig them out, or, if you could not do so, to run home and bring the monks to help you with their spades. You were the reverse of a gravedigger, for you resurrected people who were buried. Like a sympathizing human being, you must have been able to show your compassion, or else that jittle Bov whom you dug out of the snow would not have dared to sit on your back and suffer himself to be carried to the hospitable monastery! When you arrived with him, you pulled the bell, to give the precious foundling into the care of the merciful monks, and then you hurried back to resume your search! Every success made you more joyful, more compassionate. That is the blessing of a noble deed: that it must go on producing more nobility!

Tschudi says that excellent Dogs are also kept on the St. Gotthard, Simplon, Grimsel and Furka passes and in all other Alpine hospices. These Dogs are possessed of extremely keen powers of scent where human beings are concerned, and are usually Newfoundland Dogs or cross-breeds with Newfoundland blood. The inhabitants of all the hospices agree that these Dogs know the approach of a storm an hour beforehand, especially in winter, and show it by their restlessness. But no other Dog has become as celebrated as Barry.

The Poodle, His The well-known Poodle (Camis famil-

character. iaris cxtrarius genumus) is also a Spanistics and Traits, iel. It does not seem necessary to describe him, as he is so universally known. The stout body thickly clothed in long, woolly, shaggy hair, forming actual curls on some parts of the body, and the long, wide ears, distinguish him from his relatives. A Poodle, to be accounted a fine specimen of the breed, nust be all black or all white, or at most may have a white patch on the forehead and breast, if the rest of the body is black.

The Poodle shows his close relations to the Spaniels by his fondness for water. He not only swims well, but likes to swim, and he may be trained for hunting. He is, however, more fit to be a companion to Man, and such he is to a greater extent than any other animal. To describe him I take the words of Scheitlin, who is one of the warmest admirers of this Dog: "The Poodle has the best built body among Dogs. He has the most beautiful head, the most symmetrical body, the finest shape, a full, wide chest and well-formed limbs; is neither large nor small, long nor short, and has the most dignified bearing. Physically he is well adapted for all exercises. He learns to dance of his own accord, for his half-human nature incites him to stand on two legs and walk erect. He soon sees that he can do it, and does so, whenever he feels like it. His sense of taste is delicate; he discriminates between two different kinds of food and is fastidious. His scent

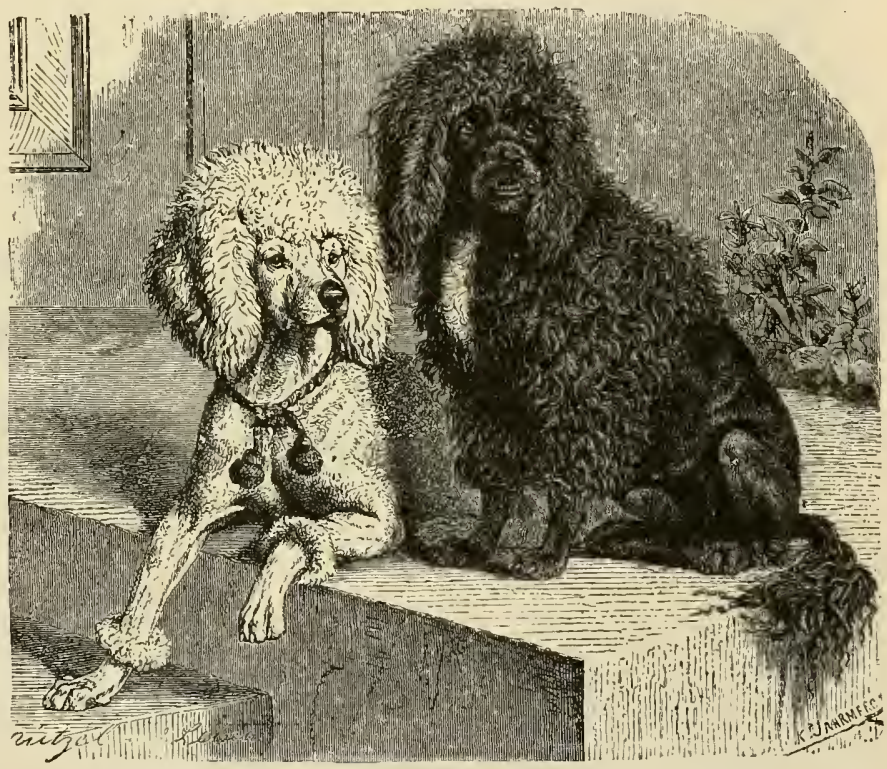

THE POODLE. Everybody is acquainted with the Poodles. Here they are shown, one white, one lack, but both pert, intelligent, shaggy and curly-coated, although the white Dog has been partly shorn. The Poodle is a very sagacious animal, capable of great usefulness if it is not spoiled in training, and a Caus famihares extrarus gomunus.)

is celebrated. If he is given a shoe or any other object belonging to a lost child, he can retain the memory of the smell and, by means of it, find the child. He seldom errs, for his nose is his chief organ of sense. His hearing is excellent. He knows a voice from afar, distinguishes its inflections, recognizes the difference between large and small bells, and knows the sound of the footsteps of the different people living in the house. Of his zenses, only that of sight is defective: he does not see well and recognizes his master by sight only when quite near. but what he lacks in this respect is more than made up by the great acuteness of his other senses. 
Great Sagacity "The sense of locality of the Poodle shown is excellent. He finds his way home by the Poodle. from places that are hours' or even days' walking distance away. He roams about at will in the city or country, and will visit houses where he has been with his master and has been made welcome, even if it has happened but once. Therefore he can be taught to bring the meat from the butcher and the bread from the baker. His perception of time is keen. He knows when Sunday is coming, and knows dinner time like a hungry human being. He discriminates between colors, and by

Two other things are worth mentioning in regard to the Poodle; his tendency to imitate and his ambition or vanity. He is always looking at his master and always wishes to do something for him. As a child thinks that its father is always right and that what the father does it can and must do likewise, so does the Poodle regard his master. If his master takes up a ball, he takes one between his paws and tries to bite it and worries if he does not succeed; if his master is a geologist and looks for stones in the interest of science, the Poodle also looks for stones. If the master works with the spade, the Poodle also digs up the earth with his paws. If the master looks out of the window the Poodle jumps up on the sill, and looks at the beautiful view. He also likes to carry a stick or a basket, because he has seen his master and the cook do so. He carries it carefully, puts it at people's feet, goes from one to another to show off his skill, and complacently wags his tail. While he carries an object, he pays no attention to other Dogs; he seens to despise them as good-fornothings, while they appear to esteem him."

Disposition "The Poodle is of the not the most

Poodle. feared Dog, but he is the most highly valued and popular one, because he is the best natured of then all. $\mathrm{He}$ especially endears himself to children, as he suffers them to tease him, to ride on him and worry him in every way, without even growling, biting or showing signs of annoyance. THE SKYE TERRIER. The shaggy, wiry coat, the short tail, the snub nose and queer little ears of the good-nasured and kind in its demeanor toward its master and friends, but a good watch Dog about a house. (Ciants familuaris gryphus hirsutus.)

their aid distinguishes between objects. The impression which music produces upon him is strange; some instruments he likes, some he does not. He keenly watches all that goes on around him and nothing escapes his notice; therefore people call him sagacious. He is a perfect observer and therefore understands not only the words but also the facial expressions and glances of his master. His memory is exceedingly tenacious. He remembers the shape and color of his master for years; and retains the knowledge of a road for an equally long period. The Dog is called sagacious for his discriminating scent alone, but how much more he deserves the term on account of his memory, for in ordinary life a child, and sometimes even a learned but stupid Man, gets praise for being clever solely because he has a good memory. This faculty is one of the principal reasons for the Poodle's docility, but he also requires patience, good nature and obedience. He can be taught to drum, shoot off pistols, climb ladders, take by assault a hill defencled by other Dogs, and learns to play on the stage with others of his kind. We know that Horses and Elephants have been taught the same tricks.
He is very greedy, but will frequently allow one to take his food out of his mouth, a thing very few other Dogs will do. The Poodle remembers all his life the person who has once shorn him, and if that person enters the house at any future time to shear him, he runs away and hides himself, for he does not wish to be shorn. It is very interesting to see how he looks for his master. He runs along the street, his head held low, then he stops, reflects a little, turns around, stops again at another corner, reflects again, crosses the street obliquely to save time, etc.

"It is strange, that the better-natured, the more sagacious a Poodle is, the less useful he is as a watch Dog and the less readily he will attack a Man. He loves and venerates all human beings; if one pits him against a Man, he only looks at his master and his opponent, as if he thinks it quite impossible for his master to pit him against his own kind. The master might be murdered without his defending him. This Dog is always highly obedient, as he fears not only blows but his master's displeasure, his words, his threatening finger, and this docility makes the Poodle a most amiable companion." 


\section{THE TERRIERS.}

Let us now turn to another remarkable group, the Terriers (Canis familiaris grypluss). Some naturalists rank them among the preceding group, and in fact, a few Terriers much resemble the Poodle in their fur, the structure of their muzzle, ears and tail; in their good nature, faithfulness, and merry, playful disposition; but the structure of skull and skeleton is entirely different and entitles them to be ranked as a distinct species. There are two main sub-orders in this group, the smooth-coated and the roughcoated Terriers. The former rescmblc the BadgerDogs in their structure, but differ from them in having longer and straight legs, and ears that are either entirely erect or have only their tips hanging down. Most Terriers are of a dark color, those that are spotted being less common. The body is somewhat slender, the head is stout, the muzzle long and blunt. The tail is smooth and is either extended straight out behind or curved slightly forward. The legs are straight and of moderate length. The ears and tail are usually docked in puppybood and the animals are thereby. made ugly in an unjustifiable way.

$\begin{array}{cl}\begin{array}{c}\text { General } \\ \text { Traits of the } \\ \text { Terriers. }\end{array} & \text { are exceed- } \\ \text { ingly clever, }\end{array}$
playful creatures, thei eagerness for a hunt surpassing all bounds. They are very fond of catching Rats and Mice and digging out Moles, and are really indefatigable in their pursuit of these small animals. They cannot always be recommended as domestic pets, as their restless temperament sometimes makes them very annoying; but on the other hand they are admirable companions for people who do much riding or driving, for a Terrier is best pleased when he is obliged to run fast. But even when accompanying his master on the swiftest gallop, he finds time to investigate every Mouse-hole and disturb every Mole which is engaged in throwing up its heaps of earth. With his nose high in the air, he looks all around him and whenever he hears a rustling noise he approaches cautiously and softly, stops for a moment, then makes a sudden jump, beats the earth with his fore-paws and in another moment has the subterraneously living creature in his mouth. He hunts Nice in exactly the same manner, displaying such great zeal in hunting them, that, according to Lenz, he will catch from four to five and sometimes fourteen or more Nice during a tolerably long walk. He does not eat the MIoles, but buries them. He eats of Mice until he is satisfied and throws the rest away.

His success in catching Rats has particularly attracted the notice of Englishmen, and great Rat fights in which these Dogs were brought to display their activity were long a popular form of sport in England [but are now rare because these contests are inhibited by law ]. To add to the interest of these Rat fights exceedingly high bets were made upon the Dogs which participated, and the contests thereby assumed the character of gambling.

The mental gifts of all Terriers are worthy of notice. These exhibit a great sagacity and a considerable degree of reasoning power. There are cases on record where they have known the value of money and have procured coins to buy food. 
hang over only at the extremities; as a rule he is of slender build, endowed with a lean body and long, sinewy legs, like those of a Wolf, but he is considerably smaller than a Volf in size. The somewhat elongated head with its pointed muzzle, the lean, straight legs, the moderately long tail which the Dog usually carries hanging downward with the tip curved upward, and the thick, curly and sometimes shaggy fur of gray-brown color, are further distinguishing features that serve to complete his picture.

The Sheep Dog is generally used as a guardian of flocks as early as his first year, but a longer time is requisite for him to learn to do his duty perfectly. It is by no means a matter of indifference to him what kind of animals he has to tend, as he adapts his behavior to their different characteristics. The Dog of a Cow-keeper must constantly observe his master and obey his commands. Cows which do not obey
Like every other Dog, the Sheep Dog is the reflection of his master. The Spanish Sheep Dog is as fierce, the German Sheep Dog as good-natured as his owner. If the latter is a poacher, the Dog will soon equal the best of Hounds; if the master tries to eke out a livelihood by looking for mushrooms or the like, the Dog will help hin gather them; if the master has to encounter two-legged or four-legged robbers, the Dog takes his share in the fray; if the Shepherd lives in peace, there is no gentler being than his Dog. The two resemble and entertain each other. There are Sheep Dogs which really understand every word their master says. A credible observer once told me that he had himself heard one Shepherd tell his Dog to pay special attention to the rape-seed. The animal seened puzzled for an instant, probably because he had never heard the word before. Wheat and rye, barley and oats,

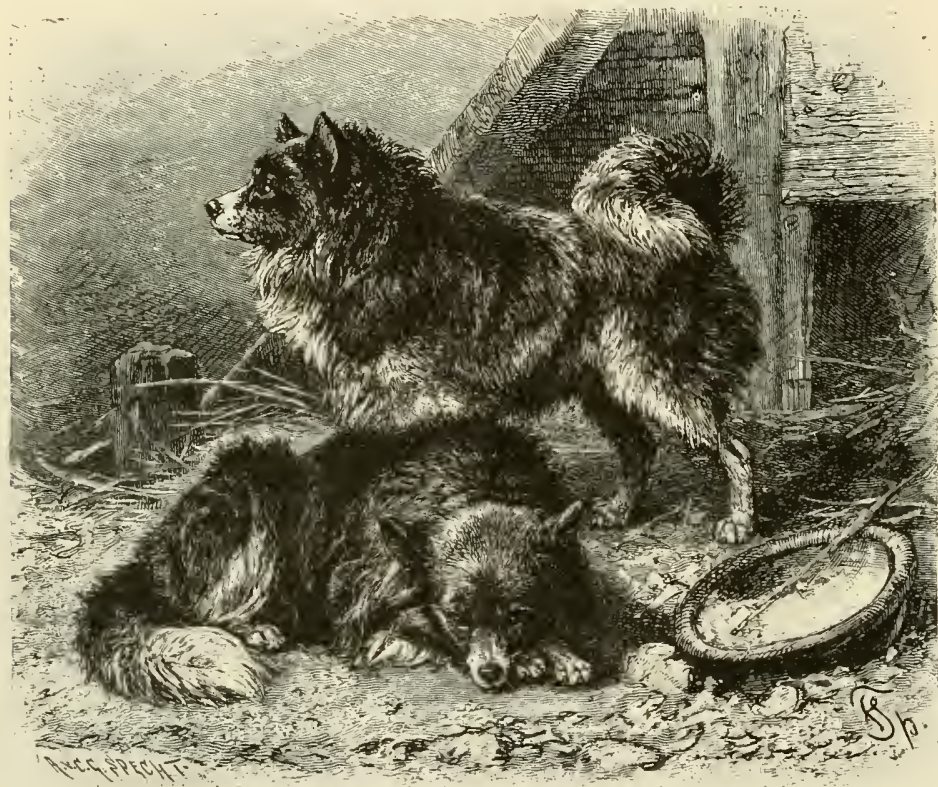

THE POMERANIAN DOG, OR SPITZ.-- Yaluable as a watch Dog, the Pomeranian Dog or Spitzis an special favorite in Germany with farmers, and also with carters whom it accompanies on their journeyings. me have short hair, but those most common have a shaggy, coarse fur on the body and tail like those shown in
ie picture. They are very intelligent and affectionate, and faithful in the highest degree. (Cans famthans t. e picture. They are
d. mesticus pomeranus.)

immediately must be bitten, for otherwise they will stand in no fear of him. When he drives the Cow before him he must bite only her hind-legs, never her tail, flanks or udder. If the Cow kicks, he must take care of himself, but still he must bite; if a Bull or a Cow tries to resist him by resorting to their horns, he will still conne out victorious, if he knows his business, for he will seize the animal's mouth, and suspend himself from it. Spanish shepherds make use of a sling with unfailing security. A Bull which has been punished several times by having a stone flung at his head must beware of the Dog; for the bog soon picks out the fiercest in the flock and allows him a very limited range of movement. Strong he-Goats also have to be bitten by the Dog. but only on their hind legs. He must never bite Lambs or suckling Ewes, however, but must only make believe that he will bite. meadow and field were familiar things to him, but of rape-seed he knew nothing. After some reflection he went around the flock, investigated all the fields and stopped at the one which was grown with something different from the seeds he knew, thinking that that ought to be the rape-seed field, and so it was.

The Pomera. What the nian Dog a Good Sheep Dog Watch-Dog. is to the flocks, the Spitz or Pomeranian Dog (Canis familiaris domesticus poncramus) is to the house. He is small, or at the most of medium size, vigorous and stout, has a narrow head and pointed muzzle, short legs and a long tail, medium-sized ears and keen, intelligent eyes; he is clothed in either long. coarse fur, or short hair of fine texture, and his color may be pure white, yellow, Fox-red, gray, or, very rarely, black, sometimes with light marks on the forehead and feet. Altogether it would be difficult to mistake him for any other breed of Dog.

All individuals of this species are very fond of their liberty and should not be chained up; but when they are allowed to prowl around at will, they can not be equaled as watch Dogs, because they are so faithful and incorruptible.

The Estrimo Dog, The Eskimo Dog (Canis famitiaris

a Very Useful domesticus borcalis) which belongs to Animal. the same family as the Pomeranian Dog, is not less useful than the two last named species and must be regarded as the most important domestic animal of the uncivilized tribes of the whole north of the globe. His height at the shoulder is from twenty to twenty-four inches, though in some localities the average is higher. He differs from the Sheep Dog in having a more Wolf-like aspect, and also because of his erect cars, his thick fur (which in winter assumes quite a woolly texture). 
and his cunning expression of countenance. His demeanor indicates a certain degree of independence and liberty, though he enjoys these privileges but temporarily. He has closely allied relatives all over the north of the Old World, and is employed as much for guarding Cattle as for drawing sleds.

Nearly the whole life of the Eskimo Dog is spent under the yoke, and is employed either in drawing sleds or in carrying burdens. In arctic America and on its islands he is a real beast of burden and the only one which Man has there appropriated. Only during the short summer docs his master give him a limited amount of liberty, but in winter he is a perfect slave.

A well-fed Eskimo Dog may be termed a handsome animal; but unfortunately his food, if he does not procure it himself, is administered to him by his master in such scant proportions, that for many months he resembles a skeleton more than a living being. His relation to Man is peculiar. He knows that he is bound by the chains of slavery, and he tries to break these fetters. He is Wolf-like in a phys. ical as well as mental aspect. He resembles the arctic IVolf so much in his thick fur, his erect ears, the width of the upper part of the head, and the pointed muzzle, that from a distance the two can not be distinguished from each other. The Eskimo Dog is an inveterate thief, but on the other hand is as fawning as only a fear-tormented slave can be. A rather numerous pack is usually put before a sled, and they follow the leadership of an old experienced Dog; there is no semblance of human guidance according to our ideas. The Dogs are fastened to a strap in a primitive manner. In the Hudson Bay country the Dogs are sometimes put in single file. Occasionally a fight ensues during the journey; and then the whole team is huddled together in inextricable confusion; they are all barking, biting, growling and rushing together and not even the powerfully wielded whip of the owner of the sled suffices to restore order in the turbulent

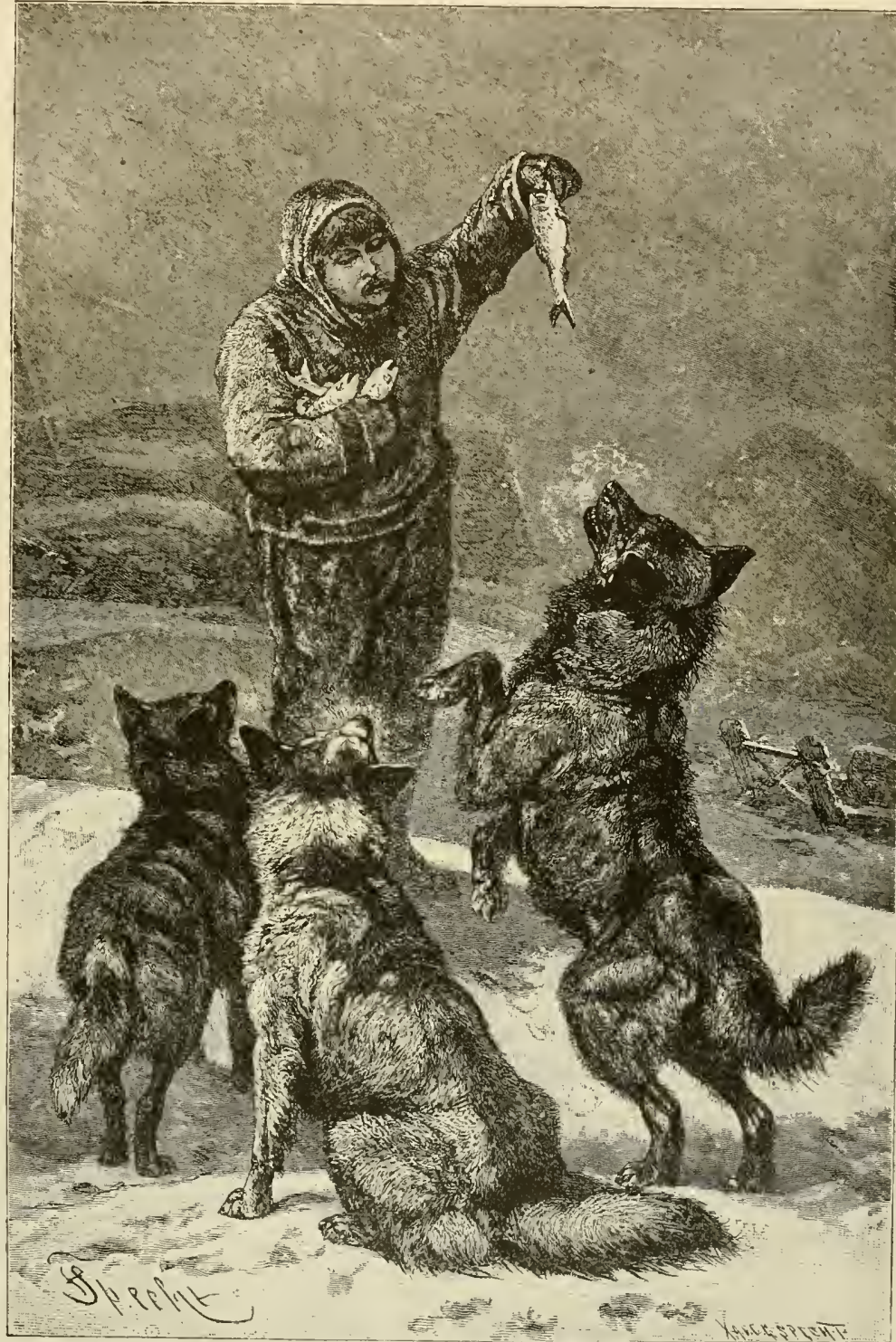

ESKIMO DOG. - Servant and slave of the people of the frozen North, the Eskimo Dog is indispensable in those regions. It is the only beast of burden and a valuable assistant in the chase, very Wolf-like in its build and to a large extent in its disposition. It is scantily fed and usually hungry, and the picture well depicts its eagerness for the fish that is to serve for its dinner. This Dog has a warm, shagry coat, and needs it in the frozen climate thar forms its that is to serve for its dinner. This Dog has a warm, shaggy coat, and needs it in the frozen climate that forms its
home. When the Dog is too old to work it is killed for its fur, which is used for clothing. (Canss familiaris domesticus

pack. Finally the entanglement reaches such a stage that free progress is rendered impossible, and then the journey is interrupted until the driver 
alights, disentangles the animals and harnesses them to the sled afresh.

The arctic nations could not exist without this domestic animal, which renders them innumerable useful scrvices. Carrying a burden of from twenty to thirty pounds, these Dogs accompany their masters on their long protracted hunting expeditions. Fron six to ten Dogs draw a sled with a load of from six to eight hundred pounds, and they are said to cover considerable distances, usually from twentyfive to thirty miles a day. If the load is light, they may traverse fifty miles. If they scent game on their way, they often start, in mad pursuit, after it. They also assist in the chase, mount guard, defend their owner in case of danger, and render a hundred other valuable services.

Steller's Account Steller has given us an excellent of the Life description of how these Dogs and of Eskimo Dogs. their kin are used: "Imong the domesticated animals of Kamchatka the Dogs take first rank because of their remote antiquity as well as their usefulness; and besides, they are the only domestic animals in that country.

"Without Dogs people could not live here, as in other countries they could not do without Horses and Cattle. The Dogs of Kanchatka are of various colors, the white, black and wolfish-gray varicties predominating. The fur is very dense and long. These Dogs live on fish. From spring till late autumn they receive no attention, and prowl around at liberty. Nll day long they lie in wait for fishes on river banks, catching them with great dexterity When they have enough fish, they eat only the heacls, like Bears, and leave the rest. In Octolser every Man collects his Dogs and ties them to his house posts. Then the animals are made to go hungry for some time, so as to lose their fat and be in condition to run without losing breath, and with the first snow-fall their misery begins. They are then heard bewailing their fate, howling and lamenting day and night. Their food in winter is of two kinds. As a dessert and stimulant they reccive putrid fish, which has been stored and soured in pits. The principal food is dry, and consists of mouldy fish, dried in the air. This they get in the morning to brace them up for running. The strength of these Dogs is astonishing. Is a usual thing only four Dogs are harnessed to one sled, but they easily draw thrce adult people and a load of fifty pounds. The load ordinarily given to four Dogs is from one hundred and sixty to two hundred pounds. Although traveling with Dogs is very arduous and dangerous, and more fatiguing than journeying on foot, and the driver becomes thoroughly worn out with the work of guiding these Dogs and the discomforts of this method of traveling, yet it has many advantages. By this means journeys from one place to another can be made over the worst roads, upon which no progress could be accomplished either with Horses or on foot, because of the deep snow."

\section{THE FOXES.}

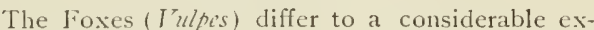
tent from the IVolves. The long body, the long head with its pointed muzzle, the elongated and somewhat oblique pupils of the eyes, the short legs and the very long, bushy tail or "brush" of the Foxes entitle them to rank as a distinct species. In spite of the rescmblance to the customs and habits of other Canida, their behavior and character display many" peculiar traits and are worthy of special mention.
The Common Fox, The Common Fox (I'ulpes inulgaris) the Famous undoubtedly ranks first among Reynard. the wild mammals of Germany. Scarcely any other animal, except, perhaps, the Jackal, enjoys such celebrity and universal indorsement as friend Reynard, the emblem of cunning, slyness, deceit, mischief, and if I may say so, vulgar chivalry. Jle is praised by proverb and tradition, he is glorified by poems; that greatest of poets, Goethe, thought him a worthy subject of an epic. Whether he deserves all this glory is another question. Pechuel-Loesche says: "The Fox of tradition and poetry and the fox in real life are really two very different animals. Whoever observes hin with an unprejudiced mind, fails to discover any extraordinary degrec of that much praised presence of mind, cleverness, cunning and practical sense, or even an unusually keen development of the senses. In my opinion he is by no means supcrior in his endowments to other Beasts of Prey, especially the Wolf. The most that can be truly said in his praise is to admit that, when he is pursued, he knows how to adapt himself to the surrounding circumstances, but scarcely more so than other sagacious animals. Like many other animals, including the harmless species, some old Foxes may have their wits unusually sharpened by expericnee, but every huntsman who has had much to do with Foxes will admit that there are a great many which are not ingenious, and some which may even be called stupid, and this refers not only to young, inexpericnced Foxes, but also to many old ones. The fox is a rascal and knows his trade, because he has to make a living somelow; he is impudent, but only when driven by hunger or when he has to provide for his little family; and in bad plights he shows neither presence of mind nor deliberation, but loses his head completely. He is caught in clumsy traps and this cven repeatedly. In the open country he allows a sled to approach him within a gun's shot; he permits himself to be surrounded in a hunt in spite of the noise and shots, instead of wisely taking to his heels; in short, this animal, which is more relentlessly pursued than any other inllabitant of the woods, still has not learned to sce through all the tricks of Men and shape his actions accordingly. Master Reynard of tradition and the Common Fox of the forest may not very well be regarded as the same animal, for the latter is by no means remarkably clever."

General Descrip. Reynard is the hero of a hundred tion of the stories and pictures, and his image is

Common fox. Well known to everybody. Still he deserves to be specially introduced to those who are not very conversant with nature. His length is fiftysix inches, twenty of which are taken up by the tail; the height at the shoulder is fourteen or at the most fifteen inches. The head is wide, the forehead flat, the muzzle, which tapers abruptly, is long and thin. The eves are oblique, and the triangular ears are erect. The body appears stout on account of the thick fur, but is in reality remarkably slender, though very strong and capable of a great range of movement. The legs are lean and short, the tail is long and bushy, the fur is thick and soft. Reynard and all his noble family are clothed in a way which is excellently adapted to their predaceous life. The color is a pale, grayish red, resembling the color of the ground, and is equally fit for any forest, high or low, for the heath, for a ficld and for a rocky region. The coat of the Fox seems to correspond more closely to his surroundings than that of any other 


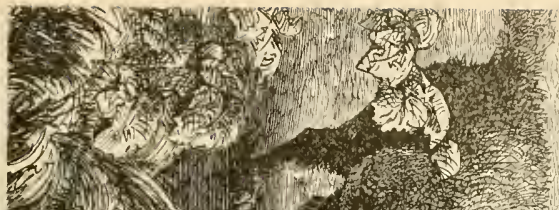

:

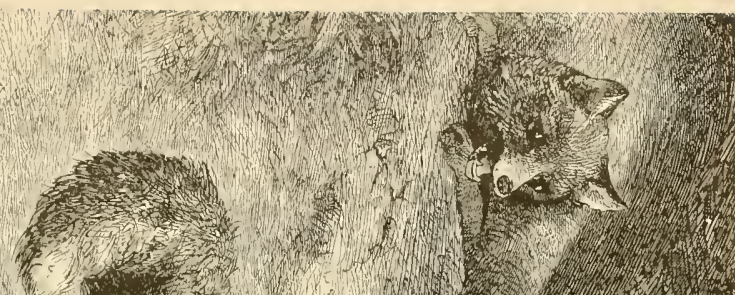

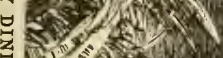

IIn

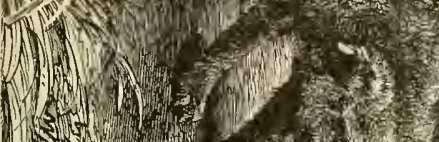

1)

Not

.

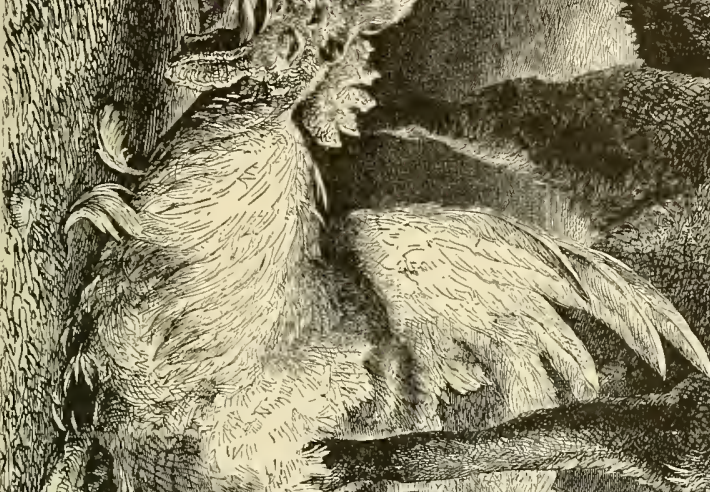

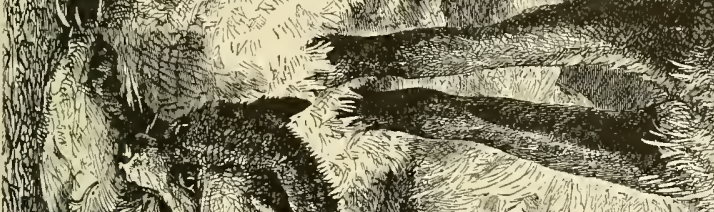

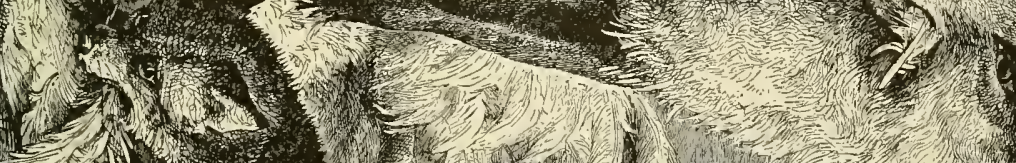

m

$(x+2)$

(1) $8(2)$

-
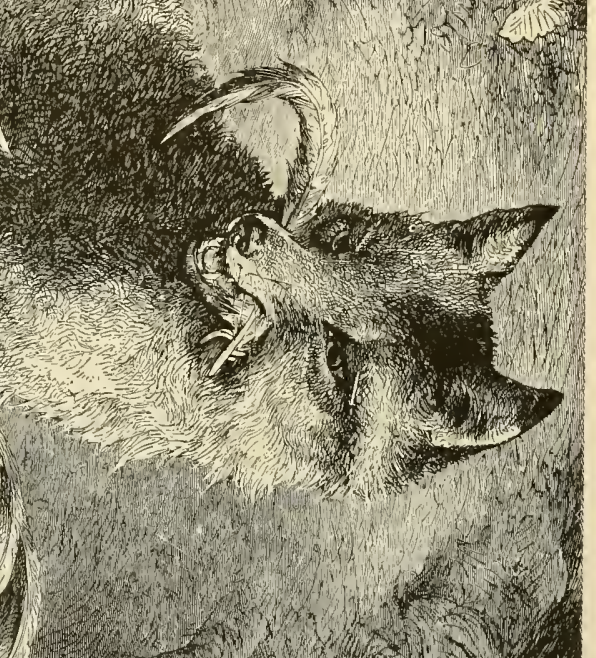

$y^{4}$

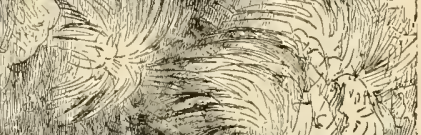

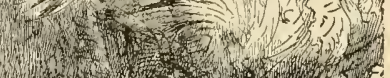

2. 1 -

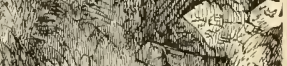

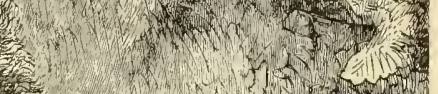

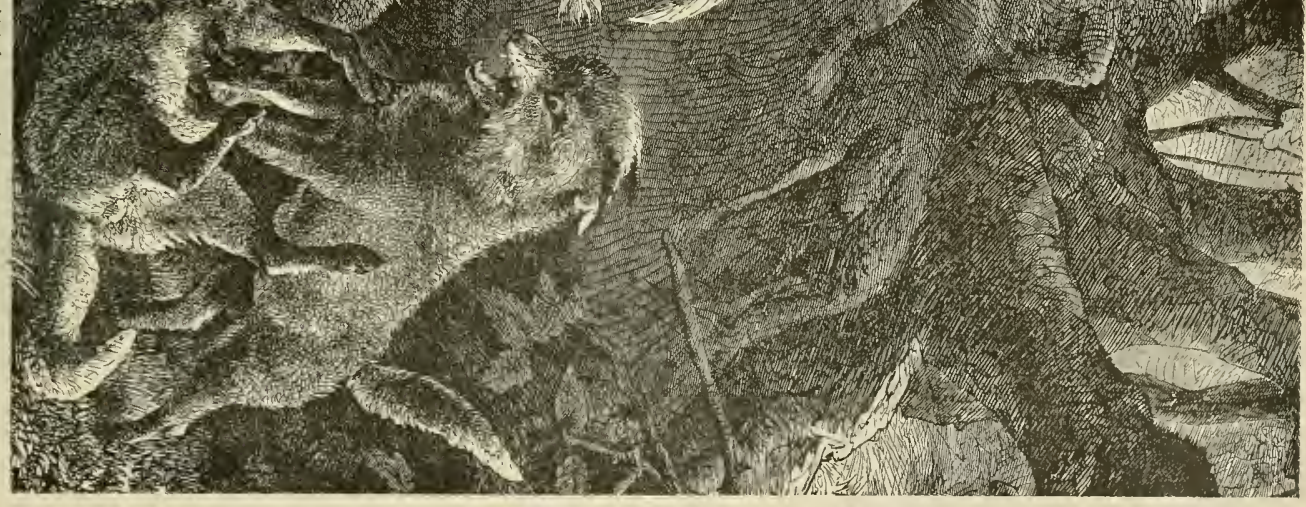


animal, for the southern Fox differs considerably from the northern one, the Fox of the mountains from that of the plains. Those species living on plains and deserts show the similarity of their color with that of the ground still more distinctly. IThen we come to examine the fur closely we find the distribution of the colors to be somewhat like this: the whole upper surface is of a russet or yellowish red hue; the forehead, the shoulders and the buttocks, to the root of the tail, have a surface tinge of white, as the hairs in these parts are tipped with white; the lips, cheeks and throat are white. A white stripe runs along the legs; the breast and the under portion are ashy gray; the flanks are whitish gray, the fore-legs red, the ears and the paws black; the brush is either russet or yellowish red, blackened at the surface, and its tip is either of the same color or white. All these shades imperceptibly merge into each other, none of them being placed in sharp contrast, and that is the reason why the coat is so well adapted for any surroundings.

Where the Foxes Reynard inhabits the greater part Make Their of the Northern Hemisphere of our Homes.

globe. He ranges throughout Europe, northern Africa, western and northern Asia; we may include Afghanistan, the western Himalayas and Tibct in his range, for the species prevailing there can hardly be differentiated as distinct. He is nowhere within this wide expanse entirely absent, and in some localities is rather common. His adaptability aids him in finding habitations where other Beasts of Prey cannot find any, and therefore cannot exist, and his agility and cunning enable him to maintain these habitations with an obstinacy and pertinacity which is without parallel. As the Wolf opposes him as an enemy he is relatively: scarce in the genuine Wolf regions; but his numbers increase in proportion as the Volf is being exterminated.

He always selects his placcs of abode with the greatest caution. Usually they are deep hollows between rocks, covered with branches, or situated between roots of trees or other similar favorable places, and the end is a spacious climber. Whenever he can avoid doing so, he does not dig out these burrow's himself, but establishes himself in some old, deserted Badger's hole or shares it with the Badger in spite of the latter's disinclination to enter into social relations with other animals. Nll the larger Fox burrows or "earths," as they are called, have been originally constructed by Badgers. If it is possible, the Fox excavates his burrows in mountain walls, so that the conduits lead upward, without rumning close to the surface. In perfectly. level ground, the chamber is often situated quite near the surface. During the autumn he likes to make his home in heaps of dead wood or stones, especially on plains; and it sometimes happens that an old tree or even a mere hollow in the ground has to serve as his apartment and as nursery. He is always found at home, when the weather is rainy, stormy or cold, during the breeding season, in summer when the heat is intense or as long as the female nurses little ones; but when the weather is favorable, he roams about his domain and rests wherever he can find a comfortable place. In plains devoid of woods, as for instance in the fertile country of Lower Egypt, the Foxes excavate real burrows only for their little ones, while the parents live outdoors beneath the mild Egyptian sky all the year round.
The Fox a Per- The Fox prefers to prey at night, sistent but in quiet regions he hunts as willBeast of Prey. ingly when the sun shines. During the long summer days, in covered places of his domain, he sometimes sallies forth with his family several hours before sunset; during severe, cold weather or when the snow is deep, he seems to rest only in the morning, for one may then see him roaming in the fields as early as ten o'clock in the forenoon. Like a Dog, he values warmth very much. In fine weather he basks on some old tree or stone and spends nany an hour in the most comfortable mental quietude. When he deems himself secure, he will sometimes go recklessly to sleep in placcs that are little sheltered or entirely uncovered, snoring like a Dog, and slumbers so soundly that an intelligent Dog may succeed in warning the sportsman, who can then surprise and observe him. At dusk, or carlier in the afternoon, he sets out on his predaceous roamings. Very cautiously and leisurely he saunters along, looking and sniffing from time to time, always trying to keep under cover and therefore selecting his way's and passages among the most favorable situations, between shrubs, stones, high grass or similar places. He keeps in the thicket as long as he can, and whenever he has to leave it, he takes care to select a place where isolated shrubs or similar coverings form, so to speak, a bridge to another favorable part of the wood. Experienced hunters therefore know these passages very well and judge of the route Reynard will take under given circumstances with a considerable degree of certainty.

The Fox preys on all animals from a young Roe to a Beetle, but principally on Mice, which probably form the staple ingredient of his repasts. He spares ncither young nor old, and zealously pursues Hares and Rabbits and even attacks young Roes or Deer. He not only plunders the nests of all birds brooding on the ground, devouring both eggs and young, but also tries to overcome the old birds, and not infrequently succeeds in doing so. He swims and wades through swamps and moors, in order to reach the birds which brood on the water, and there are cases on record where he has killed brooding swans. He also attacks tame poultry and effects an entrance into isolated farm-yards at night; and if he is afforded a good cover, he pursues the poultry even in broad day-light. In large orchards and rineyards he is a more frequent visitor than one imagines. There he catches Grasshoppers, May-bugs and their grubs, Rain-worms, etc., or gathers sweet pears, plums, grapes or berries. At the river-bank he tries to surprise a finc Trout or a stupid Crab; at the sea-shore he empties the nets of the fishers; in the forest he robs the nooses spread by the hunter. In this way his larder is always well stocked and he becomes straitencd in circumstances only when the snow is very decp and impairs his opportunities. Then he is satisfied with anything edible, not only with carcasses, which he will feed upon at any scason of the year and seems to like, as all Canidxe do, but even with an old, dried-out bone or a piece of balf-rotten leather. Quite frequently, also, he visits the encampments of wood-choppers to pick up the remains of their repasts. When his hunger is half satisfied, he plays long and cruelly with his prey before dispatching it.

The Fox is Wary, In his prowlings he regards his sebut Some- curity as paramount to cvery other times Bold. consideration. Things he does not understand arouse his suspicion, and when once he 


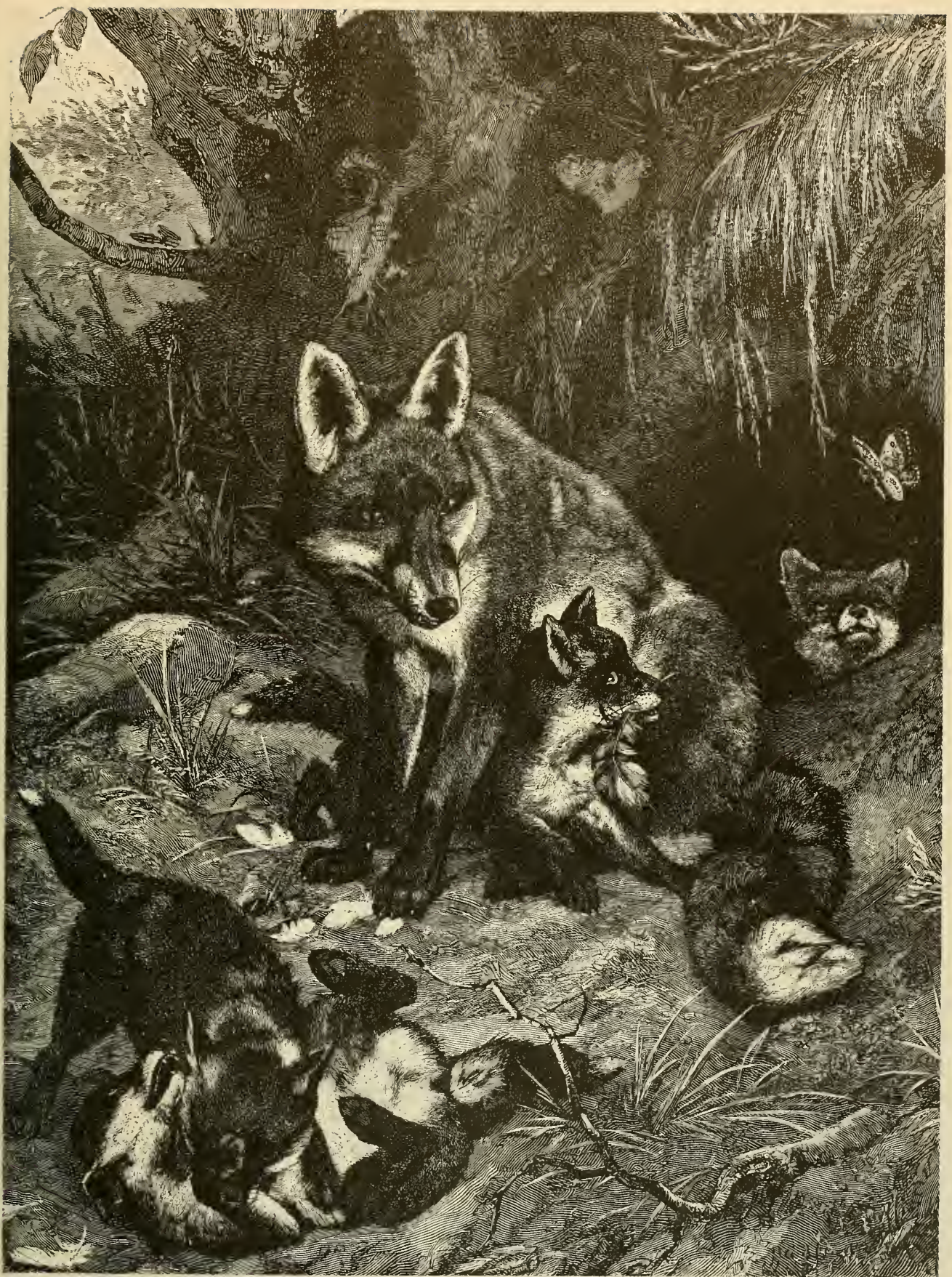

A FAMILY OF FOXES.- Here is a pleasant family scene representing a summer day in a quiet European wood. Madame Reynard and her four little ones have come out of their secluded burrow to enjoy the pleasant air. The mother is calmly content, but watchful. The two little Foxes in the foreground are playing with each other after the manner of young Puppies. Another, nestling by the mother, finds amusement in biting a twig, and the fourth, just emerging from the burrow, is very intent on the movements of a pretty Butterfly, which he will snap at if it comes nearer. The mother is a fine specimen
of the Fox tribe, and her tail is a beautiful "brush" which many a sportsman would like to own. (Vulpes zuclgaris.) 
has become distrustful, only the pangs of hunger can goad him into reckless actions; but when he has been long deprived of food, he becomes downright impudent. In broad daylight the hungry Fox will put in an appearance in a yard, seize upon a Chicken or Goose before people's very eyes, and hasten away with his prey. He is much averse to parting with the booty so arduously procured, and if he is compelled to relinquish it, he repeatedly returns to see whether he still cannot make away with it. The same boldness is occasionally displayed by him under circumstances calling for immediate flight. Once a Fox, which was being hunted by Hounds and had twice heard the shot buzzing by, seized a sick Hare in his flight and carried it with him for a considerable distance. Another was surrounded in a field; he came out, attacked a wounded Hare, killed it before the eyes of the huntsmen, rapidly buried it in the snow, and then thed directly through the line formed by the sportsmen.

The Fox Usu. Reynard does not belong to the greally Lives garious animals, and in this respect, a Lonely Life. also, he differs from the Wolves, It is frequently the case, however, that several foxes are found in one thicket or even in the same burrow. As a rule evcry Fox goes his own way and pays only as much attention to others of his hind as he decms to be profitable. Of friendship with other animals he knows as little as of companionship with his own species. He has been repeatedly observed to be on friendly terms even with his deadly foe, the Dog, but these cases have certainly been rare exceptions. Neither can his relations with his cousin, the Badger, be interpreted as friendly, as Reynard by no means cares for the Badger, but only for lis apartments.

The Mother Litters of young Foxes are born during Fox and the end of April or beginning of May. Her Young. Their number varies betwcen three and twelve; from four to seven is probably the usual count of a litter. The mother treats them with great tenderness, does not leave them during the first days of their life, and afterwards only for a short time during dusk; and appears to be very anxious not to betray their place of abode.

A month or six weeks after birth the pretty little robbers, clothed in reddish gray wool, emerge from their lair at some quiet hour, to bask in the sun and to play with each other and with the obliging mother. She brings them food in abundance, accustoming them to a live diet from the very beginning; she brings Mice, little birds. Frogs and Beetles and teaches her hopeful offspring to catch, torment and eat the prey. She is more cautious than ever at such a time, scents danger for her brood in the most innocent thing, and leads them back into the lair at the slightest noise. If she notices pursuit. she drags them to another lair in her mouth and even when she is hard pressed she still takes one young Fox with her and tries to reach a place of safety. In experienced person can quite frequently succeed in observing the playing family. When the little ones have attained a sufficient size they like to lie at the opening of the lair mornings and evenings and await the mother's coming; if they have to wait too long, they bark and thercby occasionally betray themselves. By July they have grown sufficiently to either accompany their mother or to hunt alone and try to surprise a little Hare, a Mouse, a bird or some other animal, if even it be only a Beetle, in the divtime or at dusk. At the end of July they leave the lair for good and establish themselves with their mother in some corn-field which holds out a promise of abundant prey and perfect security. After the harvest they go into thick bushes, heather and reeds, during this season completing their education as worthy hunters and cunning poachers, and separate from the mother in late autumn to begin life on their own responsibility.

How the Fox Foxes taken young can be easily reared, Behaves in as they thrive on the ordinary diet of

Captivity. Pups. If one plays much with them, they soon become tame and their lively, playful disposition makes them very amusing.

"Of several Foxes which I reared," says Lenz, " the last, a female, was the tamest, because she was smallest when I received her. She was just beginning to eat solid food, but had already become so vicious and so much addicted to biting that she always growled when eating her favorite food and bit right and left into straw and wood, even when nobody was disturbing her. Kind treatment soon made her so tame that she would allow me to take a freshly killed Rabbit out of her bloody mouth and insert my finger in its stead. Even when grown up she liked to play with me, was demonstrative in her joy when 1 visited her, wagged her tail, whined and jumped around. She was just as much pleased to see any stranger; and she distinguished strangers at a distance of fifty paces, when they were turning the corner of the house, and with loud cries would invite them to come up to her, an honor which she never accorded either to me or my brother, who usually fed her, probably because she knew that we would go anyway"

The Fox is Relent- Reynard is detested by all sportslessly Hunted by men, and is hunted all the year Sportsmen. round; there is no season when he is spared. He is shot, caught in traps, poisoned, dug out of his burrow and killed with a common club, baited by Hounds, driven out of the earth with prongs, in short, he is being exterminated in every possible way. Such relentless and almost inhuman persecution may be justified from the point of view of a sportsman, in whose eyes the forest exists only for gamc, but from every other point of view it is very wrong. In hunting-grounds the Fox makes sad havoc; but in forests and fields he is more useful than otherwise; it is therefore easy to understand why the sportsman hates and pursues him and why the asriculturist, who does not hunt, interferes in his behalf.

Naturally a Fox hunt affords great pleasure to the sportsman. Usually Reynard is baited by Hounds; sometimes the hunter lics in wait for him and decoys him by imitating the voice of a young Hare or a Nousc, or shoots him in broad moonlight near a carcass. A very attractive sport is afforded by him in winter on the snow-covered fields. Occasionally he is hunted in the forest with Beagles, the best passages being occupicd by sportsmen. A Fox wounded by a shot seldom complains; and occasionally he performs surprising deeds. Winckell had crushed a Fox's foot with a bullet, and the paw hindered the Fox from running, as it kept flapping against his head. At last he angrily turned his head around, bit off the entire paw and proceeded on his way as if nothing ailed him. The liox, in general, is extremely tenacious of life. There are several instances on record where Foxes, which were left as dead, jumped up and made good their escape. Hunters of the Fox must exercise vigilance if they would secure his "brush" as a trophy. 
The Fox Has Other than Human

Enemies.

The Fox has a number of enemic: besides Man. Not only does the Wolf catch and devour him, but Dogs also have so great a grudge against him that they will tear him to pieces. It is a remarkable fact that female Foxes suckling young are often into villages, where he bit every living thing that crossed his path.

The Red Fox, an Amerox, is the Red Fox ( I ulpes fulwus) of North AmerSpecies.

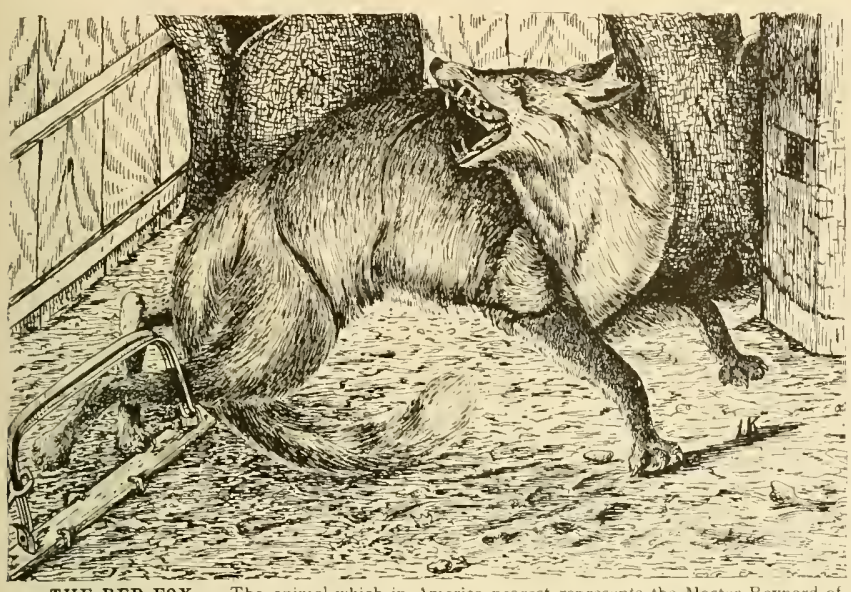

THE RED FOX

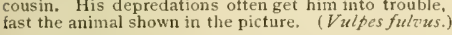

spared by male Dogs, or not pursued at all. Other mammals can not harm Reynard; but he has several very dangerous enemies among the birds. A Hawk carries young Foxes away without hesitation, while the Eagle will even attack the adult, though it sometimes fares badly enough in doing so. Tschudi relates such a case: "A Fox which was running over a glacier, was seized by an Eagle and lifted high up in the air. Soon the robber be. gan to flutter its wings in a strange way and was lost from sight behind a peak of the mountain. The observer mounted the summit, when, to his surprise, the Fox darted past him like an arrow; on the other side he found the Eagle with a lacerated breast. The Fox had succeeded in craning his neck, seizing the predaceous bird by the throat and biting it through. Contentedly he limped away, though the memory of the fearful voyage through the air probably clung to him for life."

Among other classes of animals the Fox has no enemies which could be dangerous to him, but he has-some which greatly annoy him, namely, Fleas. There is a story to the effect that he takes a careful bath with the result of driving them to a bundle of moss which he carries in his mouth, and then gets rid of the unwelcome guests by throwing the bundle away.

It has been proven that the Fox shares all the diseases of the Dog and is also subject to the dreaded hydrophobia. Instances are known where this fearful disease has driven hin in broad daylight of which is thick and fine, three inches long, and varying in color from pale silver to bluish black, but the tail is tipued L sually the fur is given a hoary appearance by the admixture of white tipped hairs with those entirely black. "The fur of the Silver Fox," says M. M. Backus, who is an excellent authority, "is fine and curly; its beauty places it at the head of all fancy furs; the tail is a royal brush. These furs

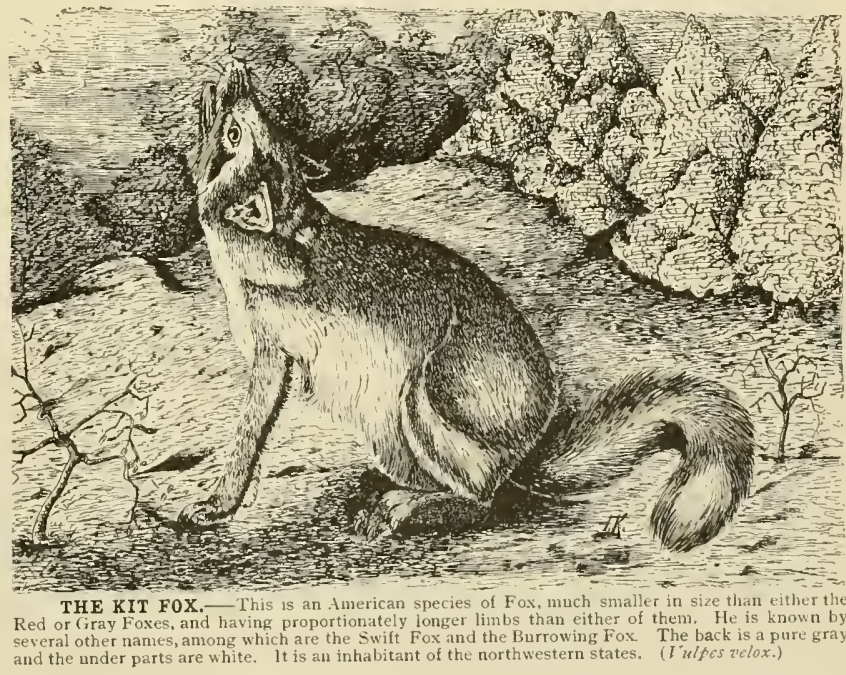

are userl for muffs, boas and linings of robes, and bring from fifty to two hundred dollars each." A large form of the Red Fox, found in Ltah, has been named the Long-tailed Fox (Iulpes macrurus) but is believed to be only a local variety and not a distinct species. In some other sections Red Foxes with peculiar markings are sometimes found, but these, bear ing different local names, are similar in structure and habits. 
Range and Notwithstanding the diversity in the coloring Habits of the of the fur and other minor differences, these Red Fox. varieties may all be safely included in the Forth America except the Pacific coast region, extending south to the gulf states and north to the region in which the Arctic Fox is found, and, like other fur-bearing animals of a similarly wide range, the furs of the northern specimens are thicker and more valuable than those procured from the south. The cluse relation of the Red Fox to the Common Fox of Europe is especially shown in the similarity of the habits of the two, for even Reynard is not more daring or more cunning than his American cousin. Some differences between the two have been noted, however, for Sir J. Richardson says: "The Red Fox does not possess the wind of its English congenor. It runs for about one hundred yards with great swiftness, but its strength is exhausted in the first burst, and it is soon overtaken by a Wolf or a mounted horseman." The Red Fox has the vulpine appetite for poultry to the fullest extent and is a dangerous neighbor to a well stocked barnyard. It is also an adept at catching wild fowls, but probably finds its principal prey among the Rabbits, Rats and rother rodents. This Fox is also very fond of fish, and when ranging near the seashore is said to visit the beach in winter secking Crabs and finny prey. When very hungry it does not disdain Crickets and other insects.

The Red fox The Red Fox needs all his cunning, for he is Persistently persistently hunted, especially in the northern Hunted.
hearing animals is so extensively carried on. This Fox is very wary, and the silver fox variety is particularly shy and difficult of approach, owang to the persistency with which it is sought for its valuable fur.

Some writers hold the opinion that the Red Fox may be descended from individuals of the European species introduced at an early period, and account for the points of difference by the altered conditions. In support of this theory it is argued that no renains of the Red $F(x)$ have been found in the cave deposits of America, while those of the Gray Fox are abundant. However this may have been, it seems certain that the Red Fox has driven out the Gray Foxes from many localities in which the latter were formerly very common.

The Kit Fox One of the smallest of the Foxes is the Kit Fox

The Kit fox (I ulpes r'elox) which is an inhabitant of the

a Western northwestern states and of the western Cana-

Species. dian provinces; covering the region from southeastern Nebraska northwest to British Columbia. Its length is about twenty inclies, exclusive of the tail, which is about twelve inches long. The overhair is fine and the back is a pure gray. the sides yellow and the under parts white. The ears are small and covered with hair and the soles are also hairy. The muzzle is shorter and the head broader, proportionately to its size, than that of the Red Fox. It is sometimes called the Swift Fox and also the Burrowing Fox, getting the latter name for the ability and rapidity with which it makes the holes in the ground in which it lives.

The Arctic Fox, In the animal world we find relations a Northern closely allied in a physical respect variety. but differing at all points in mental characteristics. Such a degenerated fellow is the Arctic Fox, a near relative of Master Reynard, but widely differing from him in manners and customs. $\mathrm{He}$ is one of the simplest and at the same time most importunate, stupidest and yet slyest members of the Fox tribe. The Arctic Fox (I'ulpes lagopus) has short, rounded ears, short legs-the balls of the feet being as thickly grown with hair as the rest of the body - a full, bushy tail and a peculiar color. Ile is perceptibly smaller than the Common Fox, being about thirty-eight inches long, a third of which is taken up by the tail. In summer his fur is of an earthy or rocky color, in winter it assumes either a snow-white or dark bluish hue. Some Foxes there are which do not undergo a white change of coat for winter, but preserve their slate or bluish color. White mothers are often found with both bluish and white young ones, for in the latter the outer coat has notyet reached its full length, and the color is determined by the inner fur, which may be dark or white; but blue-coated mothers are never found with white children. A proof that white and blue Arctic Foxes are constant varieties, is, according to $\mathrm{G}$. Lomer, furnished by the fact that among the furs coming from Alaska, those that are blue are the larger by about a hand's breadth and the hair on them is shorter and coarser than that of the white furs.

Home and As the name indicates, the Arctic Fox Haunts of the inhabits the high latitudes both of the Arctic Fox. Old and New World, being of rarer occurrence on the islands than on the continents. It may be assumed that he became distributed all over the northern part of the globe by means of ice floes; at least Arctic Foxes have often been seen drifting in the ocean on these natural ships and they have been found in great numbers as the only nonaquatic mammals on islands which are quite distant from any others, under such conditions that the only reasonable explanation of their presence was that they had immigrated in former times.

Life and Only before a storm or when he deems Habits of Arc- himself insecure, the Arctic Fox retires

tic Foxes. into caverns in the rocks or into burrows which he has himself scooped out; and then he sallies forth to prey only at night: but in localities where he is not obliged to hide from Man even in daytime, he does not take the trouble to dig burrows or pits, but lies in wait for prey under stones and bushes and in other similar places. He is not fastidious in his feeding but is content with any animal food. Mice are his favorite game; and he often follows the armies of Lemmings for a long distance and pursues them persistently, even if he has to cross rivers and other large bodies of water in doing so. Among the birds he preys on Snow Birds and other birds of the sea and its shore, and is especially destructive to the young broods. He also claims all the animals that are washed ashore.

Arctic Foxes are frequently encountered in packs; yet no great peace prevails among them, as bloody combats often take place which afford an amusing spectacle to the looker-on. One animal will seize another, which he throws to the ground, tramples under foot and keeps down until he thinks he has bitten his antagonist enough. During the whole performance the champions scream like Cats and signify their excitement by shrill howls.

Elliott's H. Elliott, who explored Behring IsObservations of land and investigated the existence of Arctic Foxes. fur-producing animals and the metlods of liunting them, gives us many details about the Arctic Fox. He teils us that the inhabitants of Attu, the westernmost island of the Aleutes, have intentionally imported the blue Fox into their country and breed him there, so to speak, in liberty and in a pure way. The common Red Fox had already been exterminated on Attu when the inhabitants brought the beautiful blue Arctic Foxes from the Pribylow Islands. Other less valuable Foxes cannot reach this remotc island, for not even the ice furnishes them with a bridge; and besides this the inhabitants guard carefulty against the deterioration of the race of their Foxes; consequently no detrimental crossbreeding can take place and the beauty of the furs of their blue Foxes, of which the inhabitants of Attu sell from two to three hundred annually, is beyond reproach and is universally acknowledged.

Arctic Foxes The breeding season of the Arctic Fox

and Their lasts through April and May. In the

roung. middle or latter part of July the female gives birth to from nine to ten or even twelve young ones in some cavern or crevice of a rock. She makes her lair preferably on a mountain or at its edge. The mother Foxes love their little ones 
tenderly, and, in fact, overdo their solicitude, for they betray their presence with the intention of protecting their offspring from danger. As soon as they see a Man, even at a distance, they begin to yelp and bark, probably with the intention of frightening him away.

Hunting and Arctic Foxes are trapped and hunted Taming of ArC- in various ways; they are caught in tic Foxes. nets, nooses and iron traps. These Foxes probably have also dangerous enemies in the Polar Bears, and the sea Eagles also seem to pursue them. Steller saw an Eagle seize a Fox with his talons, lift him up and then drop him on the ground, the Fox being killed by the fall. The fur is really the only thing for which the Arctic Fox is useful to Man. Arctic explorers have been reduced to the necessity of eating its flesh, but all such unfortunates agree that its meat is not a dainty. goes a change according to the season. The summer fur grows afresh and is reddish in tint, while in the winter fur every hair has a wide silver-white ring preceding the dark tip, and in the resulting general color sometimes the reddish and sometimes the white hue will predominate.

The Corsac ranges from the steppes surrounding the Caspian Sea to Mongolia, but the animal inhabits only desert or steppe-like regions, never being found in forests nor in mountainous countries. He has no permanent place of abode, not being addicted to burrowing for himself, but roams about and takes his sleep in the open country; or at times he may utilize a Bobac burrow found by chance, and sometimes, perhaps, may enlarge it for his own occupancy. In such Narmot holes several, or at least two, Corsacs are said to be frequently found together. The Corsac's principal food seems to be

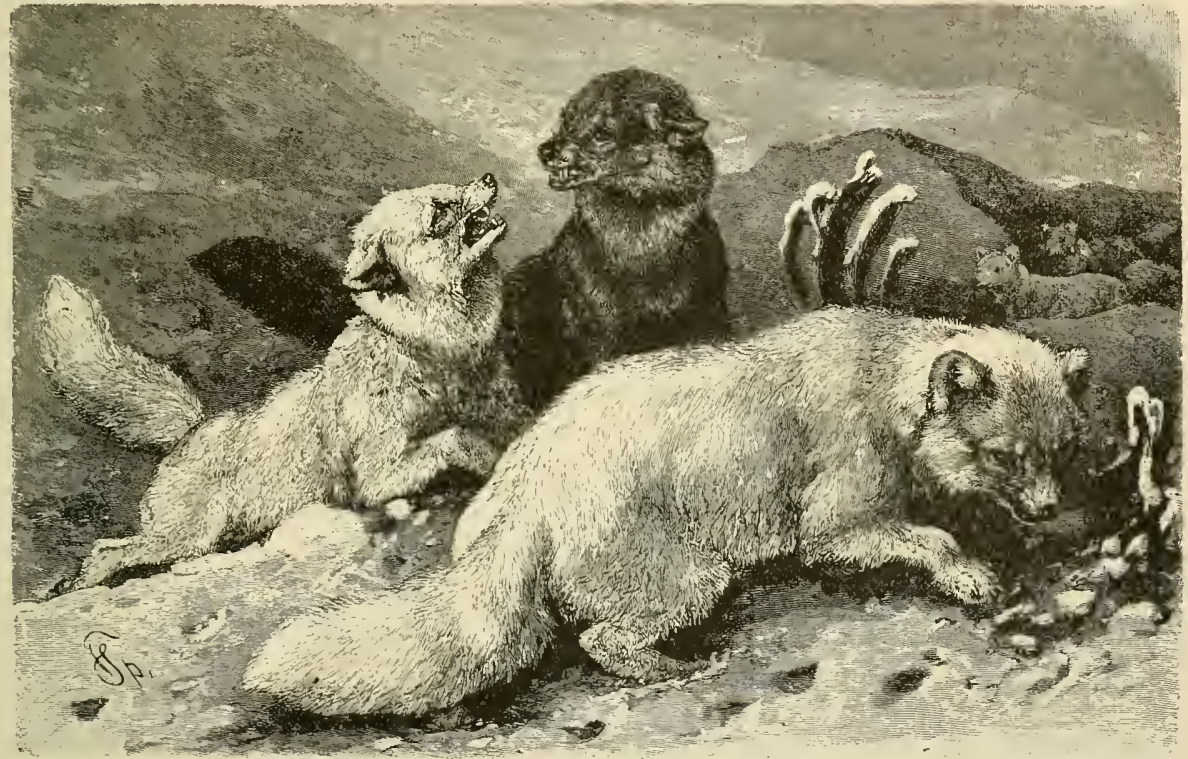

THE ARCTIC FOX. - This inhabitant of the frigid regions of the North is a bold and impudent anmal with all the cumning and slyness of its relatives. This species of the Foxes is vigorously hunted because the fur which nature has given it to withstand the nortlern winter is dense, warm and beautiful. Some are pure white and others have a darker hue of a bluish tinge but all are of the same species and are frequently found in the same pack as shown in the picture. (Vulpos lagopus.)

Arctic Foxes taken young become tolerably tame and may be taught to follow their master like Dogs. As a usual thing they are of an irritable temper. however, and when they are touched they growl like angry Dogs, and their green, flashing eyes assume a ferocious glare. They do not very well tolerate others of their own kind in their cage.

The Corsac, Of the other Foxes I will here only ar Fox of mention those which are distinguished the Steppes. by a peculiar mode of life or a striking color. A small variety is the Asiatic neighbor of the Common Fox, the Fox of the Steppes, or, as he is called by the Russian, the Corsac (I'ulpes corsac). He is much the inferior of Reynard in size, his length being twenty-two or twenty-four inches at the most, exclusive of the tail, which measures fourteen inches. In appearance and manners he much resembles his kinsman. His dense fur shows less variety than the Wolf or Common Fox, but under-
Hares and Mice, but he also preys on birds, Lizards and Frogs, and also, probably, on larger insects, particularly Grasshoppers.

$\mathrm{He}$ is zealously pursued, especially by the Kirghiz people, for his winter fur is soft, thick, warm and handsome. Besides being caught in traps and nooses put in front of his holes, he is baited by Dogs, after having been driven out by smoke. The Tartars have trained more dangerous animals for his chase than Dogs. They use tamed Fagles and Falcons to capture him and the poor fellow can certainly not escape such winged pursuers.

I have kept living Corsacs for a tolerably long time and have often seen other captive Corsacs, but have seen no essential differences between their behavior and that of the Common Fox. A Corsac is one of the happiest inhabitants of a zoological garden, soon feels at home in his cage, does not dread either the heat of summer or the cold of 
winter and endures the burning rayts of the sun with the same equanimity with which he lies down on the stone floor of his cage when there is a hard frost.

The Graceful Some exceedingly pretty, small speFennecs or Large- cies of Foxes inhabit Africa and the

Eared Foxes. contiguous portions of Asia. They are the dwarfs of the Dog tribe in general and the Fox genus in particular; are of graceful build and a pale yellow color. They are principally distinguished by the large ears, which in two species exceed all usual proportions, but in other allied species also are notably larger than those of other Foxes. They have been called Large-eared Foxes or Fennecs, though their teeth are similar to those of the other Foxes.

When the hot day is drawing to its close and all animals of diurnal habits seem revived by the coolness of the evening, another somewhat gloomy but yet dainty tribe thinks only of beginning their day's or rather night's work. I do not mean the aboninable Hyrenas nor the howling Jackals. which loungrily prow] around for food at that time; neither do I mean the Lynx of the desert, the Caracal; but it is another robber, the daintiest and most graceful of them all that 1 wish to introduce. This is the Fennec, or Fox of the Desert (I'ulpis zirdo), an animal more characteristic of the desert than the Gazelle itself. Imagine a Fox's face, delicate and fine of feature, cunning and sly of expression like that of Reynard himself. This face shows a pair of unusually large eyes and both sides of it are surmounted by ears more huge than are found in any other member of the Fox family or even among the rest of the Canidie. The slender body rests on small, extremely delicate and dainty feet, and ends in a thick, long, bushy tail. suffices to suffices to show that it must be extremely quick and agile, besides being most efficient in its organs of sense.

Acute Sometimes, at dusk, there may be heard Senses of the a low, shrieking sound, difficult to deFennec. scribe. Then if one be fortunate, he may see, between heaps of sand or stones, or in the valley grass, the Fennec, gliding along with extreme caution, listening, sniffing and looking to all sides. Nothing could possibly escape the notice of this accomplished robber. Yonder Locust, in performing its final leap for the evening, has made so great a noise that the large ears of the Fennec have easily heard it; and the graceful creature, impelled more by curiosity than hunger, sneaks up stealthily and despatches it; or an agile Lizard has moved, and in an instant the Fennec approaches to see what is going on. His principal food, however, consists of other animals, especially birds. IVoe be unto the Lark which chances to sit near the Fennec's path! It is doomed if it but moves a wing, or, dreamily thinking of its simple song, gives forth but a single note! Woe also to the Prairie Chicken, for it is the prey the Fennec hunts most eagerly! He has no need to catch many; a single one is sufficient to provide him, and perhaps his hungry family also, with a dainty repast. His abilities are shown to the best advantage when his fine nose has scented a sign of these Chickens! Perhaps only one or two have crossed the path the thief is pursuing, but that suffices. The track is carefully investigated and he follows it with his nose to the ground, noiselessly, unheard and unseen. The Fennec knows his birds well and his sight is keener than that of most travelers. He is not deceived elers. He is not deceived
by stones or mounds of earth of a similar color, for his nose and his acute hearing do their part in the tracking. However slight the noise which a bird produces in dressing its feathers, however seemingly invisible the mcrement of a cautious male bird, which looks for enemies even when half asleep, and however imperceptible the odor of a bird's spoor, indiscernible to us, none of them escapes the Fennec. See! he has made sure of the track now and glides along, nearly creeping on his stomach, ind istinguishable by sight or hearing. There, behind the last bush, he stops. The eyes glow, the ears are expanded, he greedily sniffs at the dreaming, slumbering birds. His whole body is full of life, y't one sees no movement; the entire soul of the Fox lies in his face, and yet it seems as rigid as his body, which appears to be made of the sand of the desert. Then-a single
bound, a flutter of wings-the bird is killed. The others rush up, noisily flapping their wings. Unsteadily they roam in the darkness, and soon fall asleep again, perhaps without knowing who their nocturnal foe has been.

Description The Fennec is the smallest of all Foxes. of the Including his tail, which measures about

Fennec, eight inches, his length is barely twentysix and his height at the shoulder eight inches. His frame is exceedingly delicate, the head is very pointed; the pupils of the large eyes are nearly circular and surrounded by a brown iris. The most remarkable features of the animal are undoubtedly the ears. They attain nearly the length of the head, and are about half as wide as they are long. They give the animal a truly adventurous appearance 
and in a certain respect invest it with a Bat-like aspect. The inner margins of the ears are covered with white hair, in such a way that two tufts go up from the aperture of the ear, which unite in one running to the upper tip, where it becomes short and thin. The small snout is adorned by long bristly

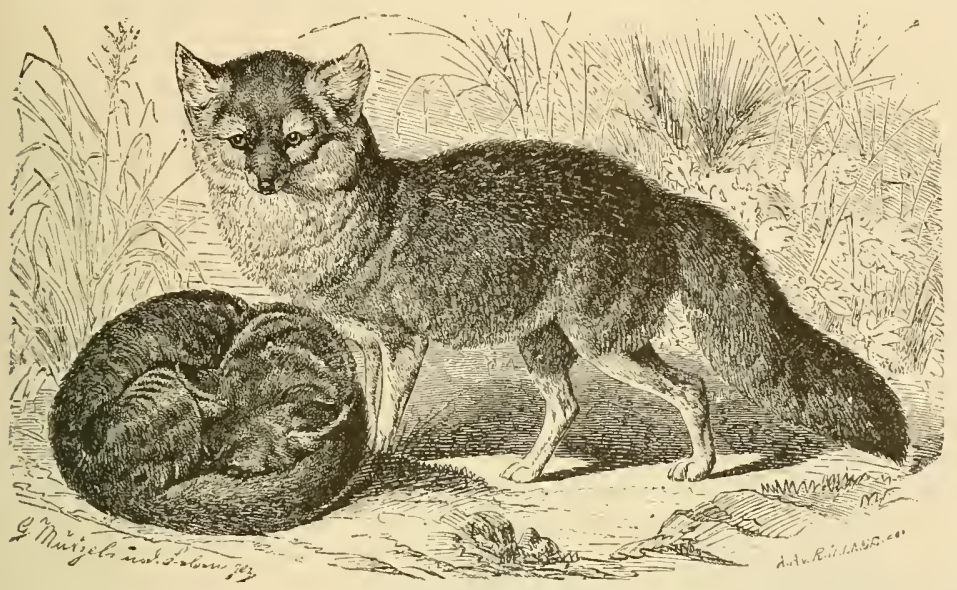

THE CORSAC. - This species of the Fox, which roams about on the broad steppes of Asiatic Russia to the east of the Caspian Sea, is small but active, and seldom makes a burrow for itself, but sleeps with no further
attempt at concealment than is afforded by the vegetation of these treeless plains. The picture shows one of these attempt at concealnent than is afforded by the vegetation of these treeless plains. The picture shows one of these
animals taking a nap, while the other, wide-awake, presents the characteristics of a truc Fox, with a dense fur and animals taking a nap, while the
a bushy tail. ( $V^{\prime} u l p e s$ corsac.)

whisker hairs, which add to the peculiar appearance of the animal. The fur is of silliy softness and in winter is supplemented by a woolly inner coat, which in spring is rubbed off in flakes by brushing the body against branches, etc. One would think that the Fennec did not need a thick fur in the warm country he inhabits; but the little fellow seems to be very sensitive to cold, and to stand in need of more than ordinary protection. The upper surface of the body has a color decidedly similar to that of the sand; the under surface is white: and there is also a white patch over the eyes, while a darker stripe is found beneath them. The tail is very long, bushy and nearly of an ochre yellow tint, but with only black patches at the root and the tip. The fur of the female is of a strawyellow tinge, and the color usually becomes lighter with advancing age.

The Long- The Long-

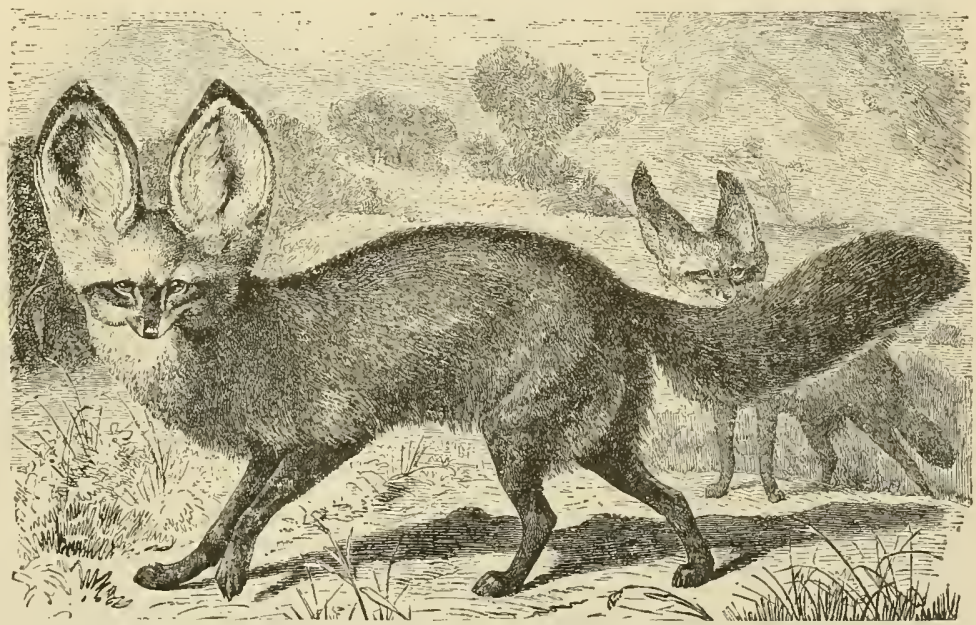

THE LONG-EARED FOX. This animal, which has long ears somewhat similar to those of the Fennec, is a night prowling creature. 1ts proportionately longer legs, larger size and shorter muzzle distinguish it from the Fennec, which it resembles in other respects. The artist has appropriately pictured it amid the surroundings of a high, bushy plain, for it is in such localities in southern Africa that this Fox is principally found. (Otocyon megalofis.) posed of black and silver
gray and covering the forehead, top of the head, back of the cheeks, nape of the neck and the whole upper surface. Each individual hair is white at its base, and then black, and marked with a wide white band near the tip. The cheeks and throat are yel- lowed out by the Earthhog; at night it roams proaches camp fires uttering really doleful wailings. tood consists of small but mainly of Locusts.

The Gray Fox The Gray Fox an American (I'ulpescinireomay be considered a species allied to the Common Fox, but standing on a from the latter by its diforter legs, proportionately longer tail and a more graceful shape in general. Approxfeet including the tail, which is about sixteen inches, and the shoulder height is twelve inches. The prevailing color is a peculiar spotted gray, commuzzle, although the ears are similar to those of the
Fennec and nearly as large.
Its favorite haunts are the bushy, elevated plains of the interior in southern Africa, north of the Orange river. During the day it lies hidden like all its rela-
Eared Fox of eared Fox (Otocyon megalotis) inhabits
Ear South Africa. southern Africa. In appearance it resembles other Foxes especially the Fennec, and has frequently been mistaken for the latter. But it is much larger, has longer legs and a much shorter

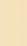


According to Audubon the Gray Fox is more frequent in the southern than in the northern states of North America and it does not seem to exist to the north of Maine. It is of rare occurrence in New England and Canara; in Pennsylvania and New Jersey it is about as frequent as the Red Fox, but in the southern states, excepting the mountains of Virginia, it is the only existing species; and in Florida, Mississippi and Louisiana especially it is quite common. To the west it ranges as far as California.

Traitsand Life It is difficult to say in what respects of the Gray the Gray Fox differs from Reynard and

Fox. his relatives proper. The descriptions known to me, among which the detailed account of Audubon ranks first, resemble the biography of the Common Fox as one egg does another. The Gray Fox is said not to be so rapid and enduring a runner; as to the rest its ways probably do not differ materially from those of its kinsman. Its haunts are thickets difficult of access and impenetrable to large Beasts of Prey, and rocks abounding in hollows and crevices; its hunting-grounds are the surroundings says he, "we caught sight of a Gray Fox, whose gait was exactly similar to that of a Setter. Slinking on against the wind, through the high grass, it suddenly stopped and sat down on its haunches. An instant later it got up, and sneaked on with slow and cautions tread, occasionally lifting its nose high in the air and moving it from side to side. Finally it seemed to be sure of its prey and moved on in a straight direction, though still very cautiously sometimes creeping along the ground and occasionally getting out of our sight, until we noticed it again as it made the last stop. We saw no Cat-like movement of the tail ; but the ears were lowered, the head raised but a few inches from the ground. In this position it remained for about half a minute, and then it jumped on its prey with one powerful bound. The whirr of a rising bevy of Quail and two or three sharp, screaming sounds were heard, and soon afterward the successful thief came into view, with a Ouail in its mouth. We were provided with a gun, and probably could have killed it, but why should we have done so? It had demonstrated to us that it not only belonged to the Dogs, but could match an excellent Hound; and besides, it had procured its food in a lawful way: why should we kill it?" Our judgment is somewhat less mild when we find the nests of Turkers and other useful birds plundered by it or come to a place which plainly shows the traces of a combat between it and a Turkey. We then understand why it is pursued as much as its kinsmen, although we may assume that, like them, its usefulness in diminishing the numbers of harmful rodents outweighs the damage it causes by destroying useful animals, Besides pursuing larger game, especially vertebrates of all classes, the Gray Fox also of its abode, from the sea-shore to the farm-yard. Audubon affirms, that though it is much more rimid and shy than the Red Fox and is driven to flight not only by the bark of a Dog but even by the crackling of a branch; and although one hears little or nothing of inroads made by it on protected poultry yards or flocks of Sheep, yct the animal is detested and pursted in the south to the same extent as the Red Fox in the north. The latter, he says, may be compared to a sly, bold robber, the former to a sneak-thief.

How Gray The females of both species are equally foxes Live impudent, however, when they have and Hunt. young. Like Reynard, the Gray Fox shows a predilection for Mice and Rats, especially the Meadow Mouse and the Cotton Rat, without, however, disdaining anything eatable. Audubon describes in a very graphic way, how the animal. which may be compared to an excellent Hound, sneaks up to a bevy of Quail, pays most careful attention to the wind, and succeeds in carrying off one of the birds. "On a cold, rainy, traveling day," hunts insects, sometimes scratching the half-rotted
bark from trees to get at them, and it likewise feeds on all kinds of vegetable substances. In the state of New York a farmer called Audubon's attention to a maize-field in which several unknown animals had caused considerable damage, feeding on the ripening cobs. The trace of the culprits proved them to be Gray Foxes and the suspicion was shown to be correct by the capture of three of these animals.

Young Gray In Carolina young Gray Foxes are
$\begin{gathered}\text { Foxesand their born during the last days of March } \\ \text { Training. }\end{gathered}$
or in the beginning of April, in the northern states a little later. The young rcmain months and then disperse, as soon as they are independent and able to lead a solitary life. Even when they have attained their full size, the younger Foxes are still easily recognized, by their comparative lack of caution, and if hunted with Hounds, they seek safety in prolonged flight only when compelled to do so, usually trying to climb some conunder the mother's protection for about three 
venient tree, while old and experienced foxes frequently foil their deadly enemies by all kinds of tricks and artifices. Audubon seems to think it surprising that a Fox should climb a trec, while we, who judge from the specimens of skill furnished by Master Reynard, do not share his opinion. So agile an animal as a Fox sees no insurmountable obstacles to climbing a tree with low reaching branches, gnarls and other excrescences while the clumsy Dog is unable to imitate it in this respect.

How the Practically, the same that has been said Gray Fox is about the hunting and other methods Hunted. of extermination of the Common Fox will likewise hold true in respect to the Gray Fox. Traps the most manifold are used in America also, to overpower the annoying rascal, and the hunt is followed as diligently as in England. Captive Gray Foxes behave like their European kinsman in all essentials, but are said never to become completely tame and always to suffer from an unconquerable ycarning after liberty. It is said to be especially difficult to break them of their tendency to bite; at least Audubon affirms that he never saw a captive animal of this species which would have become more than half tame. In one respect the Gray Fox differs from its relatives to its advantage: it is not possessed of their unpleasant odor.

The skin of the Gray Foxes is of slight value, owing to its short and coarse hair, and it is generally used as a lining for traveling coats. According to Lomer about twenty-five thousand skins are sold annually, and they command a price ranging from about a dollar to a dollar and a half apiece.

The Coast One of the lowest forms of the vulpine family
Fox, a Small is shown in the Coast Fox (I I ulpes littoralis), an
Species. American species, found along the Pacific coast
ish Columbia. It has weak jaws, small toeth, short, slender
limbs and a not very stout body. The fur is black on the
back, a cinnamon brown on the sides, and the sides and under
portion of the muzzle are black. There is also a stripe of
black along the upper surface of the tail. Its nearest relative
is the Gray Fox, but it is much inferior to the latter in strength
and agility as well as in size.

\title{
The tbear jfamílp.
}

\author{
SIXTH FAMILY: URSIDA.
}

The last family of the order Carnivora consists of animals which we knew and loved in the days of our childhood. The Bears (Urside) are animals so distinguished that probably everybody can recognize them at a glance; but the smaller species differ from the larger ones in many respects, and with some we are yet doubtful whether we should place them in this family at all.

General The body of the larger bears is thick Characteristics set, while that of the smaller ones is of Bears. sometimes slender; the head is of a rounded, elongated shape, with a pointed and usually truncated muzzle, the neck is relatively short and thick; the ears are short and the eyes comparatively small; the limbs are of medium length, both hind and front paws being five-toed and provided with large, curved, immovable, non-retractile claws, which consequently are frequently much blunted at their tips. The soles of the feet touch the ground for their entire length in walking, and are almost entirely hairless. The teeth are from thirty-six to forty in number and consist of six incisors above and below, four canines or eye-teeth, from two to. four premolars above and below or two above and three below, and lastly two upper and from two to three lower molars. The incisors or cutting teeth are relatively large, and harmonize with the strong canines, which latter are generally provided with edges and ridges. The premolars, on the other hand, are of plain conical shape or furnished with a few insignificant tubercles; the carnassial tooth is very weak, and is even,absent in some species, while with others it is only a strong premolar with an inner tubercle. The grinders are flat, those of the lower jaw being always longer than they are wide. The brain part of the skull is elongated and marked with strong ridges; the cervical vertebra are short and strong, as also are the nineteen or twenty dorsal vertebre, to which fourteen or fifteen pairs of ribs are attached. The sacrum consists of from three to five vertebra, the tail of from seven to thirty-four. The tongue is smooth, the stomach is simple, the small and large intestines do not differ markedly; and the cecum, or blind process, is absent.

Where Bears are Bears existed in former periods. At Found-Their present they extend all over Europe, Habits. Asia and America and part of northwestern Africa. They inhabit the warmest as well as the coldest of countries, higl mountains as well as the coasts of the Arctic Sea. Nearly all species select dense, extensive forests or rocky regions, generally lonely spots. Some delight in watery or damp situations, streams, rivers, lakes, swamps and the sea, while others prefer stretches of dry land. One species is confined to the sea-coast and seldom penetrates the depths of the continent, but still undertakes more extensive migrations than the others, traversing great distances on drift ice, crossing the northern Arctic Ocean and migrating from one continent to the other. All other species roam about within narrower limits. Most Bears live singly, or male and female together only during the breeding season; but some are gregarious and unite into larger bands. Some dig holes in the carth or in the sand, and use them for their lair, others take shelter in hollow trees or in clefts of rock. Mlost species are nocturnal or semi-nocturnal in their habits, go forth to hunt after sunset and spend the day sleeping in their hiding places.

Bearsare More than the other Beasts of Prey,

Omnivorous the Bears seem to be omnivorous in

Animals. the full sense of the word, and able to subsist on vegetable food alone for a long time. They not only devour edible fruit and berries, but also corn. ripe or half-ripe grains, roots, juicy herbs, buds, etc. Captive Bears have subsisted on oats 
for a long time without impairing their health. In youth they are probably vegetable feeders exclusively, and later in life most species continue to prefer vegetable food. They are not fastidious feeders, and also eat animals, namely, Crabs, shell fish, worms, insects and their grubs, fish, birds and eggs, mammals and carcasses of animals, but they eat the latter, probably, only while they are still fresh and give forth no odor. When in the neighborhood of human habitations they do some damage; and the stronger species temporarily become great robbers and, when driven by hunger, attack even larger animals and work destruction among Catte. Some are so bold that they penetrate into the very villages. Vet even the strongest are, as a rule, dangerous to Man only when they are disturbed, frightened or wounded; in short, provoked to do so.

Movements and People who think the movements of Capabilities a Bcar clumsy and slow, are misof Bears. taken. The large species are not, as a general thing, particularly fleet or active, but they are possessed, to an exccptional degree, of endurance; while the smaller species are renarkably swift and agile. The Bears are plantigrade in their walk and deliberately put one foot in front of the other; but when they are cxcited, they can procecd at a great pace, running in a peculiar but rapid gallop: and even the largest species, under such circumstances, display an astonishing speed and agility. Those which are clumsiest know how to stand erect, and can walk a short distance tolerably. well, though with a somewhat staggering gait. They all know how to climb fairly well, though they do not often exercise this ability on account of their heaviness, and totally give it up in old age; at least the large species do. Some avoid the water, while others are excellent swimmers; some can dive deep and long. The Polar Bear is often found miles from shore, swimming in the ocean, and then presents an opportunity for observing his quickness and endurance. Their great strength facilitates the morcments of the Bears, enables them to surmount diffieulties which would put serious obstacles in the way of other animals, and stands them in good stead in their depredations, for they can drag an $0 \mathrm{x}$ away.

Senses of The sulell is the most efficient among the Bears in their senses. The sense of hearing is

Generat. good and in some species excellent, sight is fairly keen, the sense of taste deficient and the sense of touch rather undeveloped, thourh some possess a genuine organ of touch in their elongated muzzles. Some species are sensible and sagacious, and may be trained to a certain extent; but they exhibit no high mental development. Some individuals become very tame, though they display no particular affection for their master and kecper. They always revert to their grosser animal instincts in old age, for then they become wicked, intractable and viojent, and the strong species may be dangerous. The Bears signify their various moods by modulations of their remarkable voice, finding utterance in dull growling, snorting and murmuring, or grunting, whistling and sometimes barking sounds.

Hibernation Ali the larger Bears inhabiting the of the north roam around only in summer Bear Family. and retire into a lair or hiding-place at the beginning of winter. But they do not fall into an uninterrupted hibernation, but sleep, or rather slumber in a half-waking condition, and they are awake as soon as anything suspicious occurs near them. They very seldom go forth during this period, however, and still more rarely do they partake of food. It is surprising that only the Bears of the continent proper hibernate, while the Polar Bears and sea Bears roam around during the severest cold, or, at most, calmly lie down in the worst snow-storm and seek shelter in the snow itself as it falls; that is, they allow it to completely cover them.

The female gives birth to from one to six young ones in a nest-like lair, and feeds, tends and protects then with careful tenderness. The Cubs are born blind, but after they gain their sight and activity they are exceedingly jolly, playful little animals.

The destruction wrought by the Bears is just about compensated for by their usefulness, especially as they, for the greater part, inhabit thinly populated districts where they can hardly do much damage to Man. The fur of nearly every species is used and highly valued. The flesh is also eaten and even the bones, tendons and intestines are put to some use.

\section{THE LARGE BEARS.}

The Bear fanily is divided into three sub-orders, of which the first comprises the Large Bears (Ursinc) which have the bulkiest forms of the whole family. They are endowed with a long snout, small eyes and ears, moderately long limbs, five-toed feet with naked soles, blunt, non-retractile claws, a stub-like tail and thick, shaggy fur. This sub-order numbers two groups; the Bears proper and the Sloth Bear.

\section{THE BEARS PROPER.}

While every person believes he knows the Common Bear fairly well, zoologists hare not yet come to a conclusion whether they are to count his varieties as one species or divide them into several distinct ones.

The Common or If we accept but one species, the Brown Bear Common or Brown Bear (Ursus arc-

Described. tos), we have to admit that there are a great many varietics in it, differing not only in fur and color, but also in shape and form of skull. The fur may be called thick and is longest around the face, on the under portion and behind the legs; it may consist of longer or shorter hairs, which nay be straight or slightly curly; the color may be any shade between brownish black, dark red and yellowish brown, or between blackish gray, silver gray and isabel color. The white collar often found in young animals sometimes remains to old age, or else reappears in the aged animal as distinct as it was in youth. The snout is elongated (in some species very much), the forehead is more or less flattened, the body is either very thick set or somewhat slender, the limbs may be long or short. There are two species living in Europe: the Ursus arctos, which has several varieties and is distinguished by long legs, a long body, a high forehead, a long head and muzzle, and a plain fur of a faded, grayish hue. Secondly, the Ursus formicarius, endowed with shorter, thick legs, a stout body, a wide head, a that forehead and a short muzzle.

This Bear may attain a length of from eighty to eighty-eight inches, and a shoulder-height of from forty to forty-six inches. His weight varies between three hundred and five hundred pounds, but in very large, fat specimens may be as great as seven hundred pounds.

Range and

If all the species be regarded as one, Haunts of the he may be described as being spread Brown Bear. from Spain to Kamchatka, and from Lapland and Siberia to the Atlas, the Lebanon and 


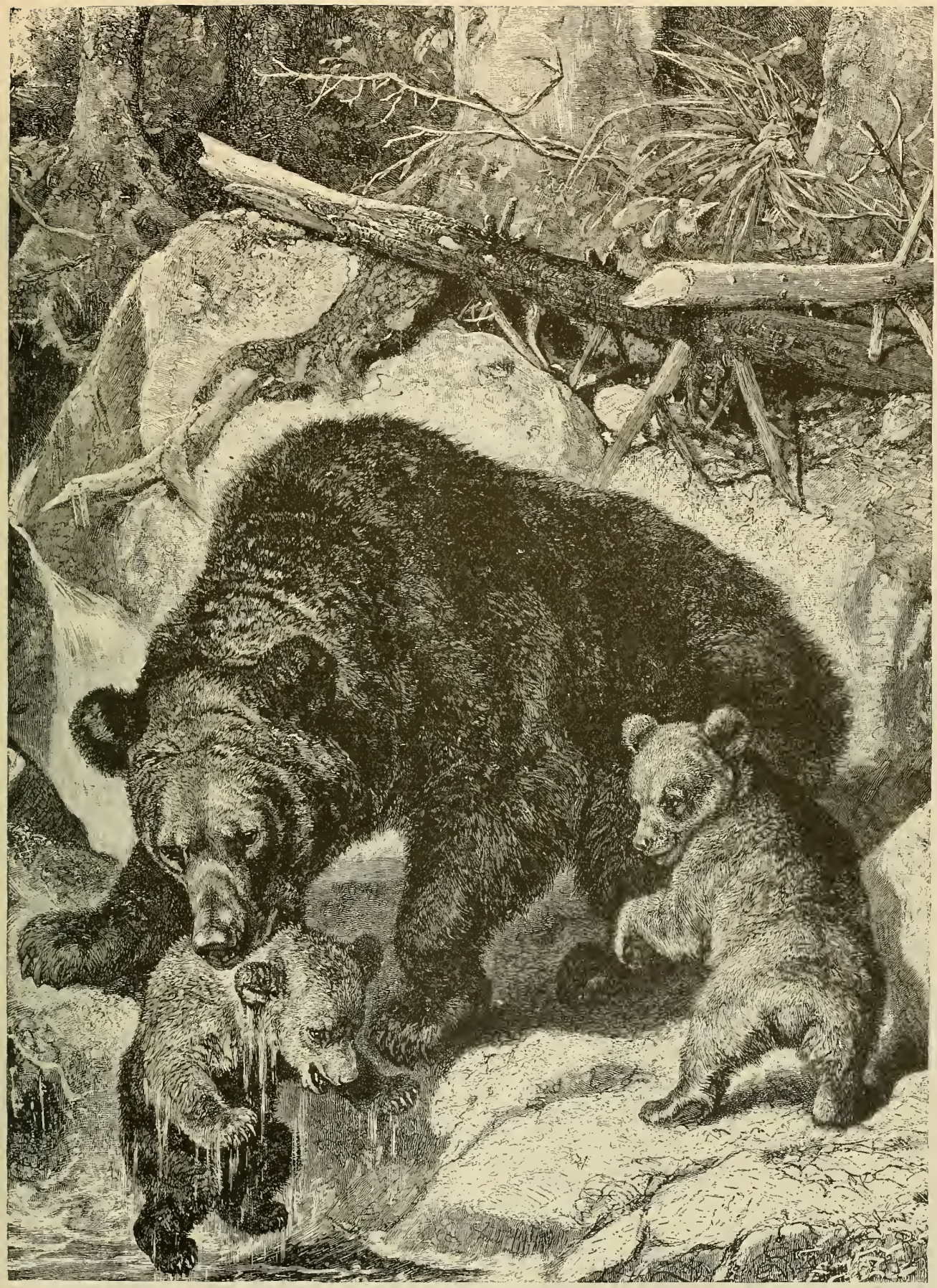

BEAR AND YOUNG BATHING.- - The life of the Beasts of Prey presents constant examples of the universality of maternal affection among favored by these animals. A converien are very attentive to their young, and the picture shows a family of Bears which has its home in the deep forest so much typical specimen of the Brown Bear, with the clumsy appearing body and limbs, shaggy fur, elongated head and muzzle and high forehead belonging to that species. (Ursus arctos.) 
the western Himalaya mountains. Extensive, nearly inaccessible, or at least little frequented forests, rich in berries and other fruits, are a prime condition for his existence. Hollow's in trees or under their roots, caverns, dark, impenetrable thickets and swamps with dry islands afford him shelter and protection from Man, his deadly enemy.

Physical Quali- The Brown Bear, the clumsiest and ties of Brown heaviest of the predaceous animals Bears.

of Europe, is, like most of his near relatives, an unwieldy and rather dull-witted fellow. But he really looks clumsier than he is. He goes at an ambling pace, that is, he lifts both limbs of the same side at once in walking and trotting, his gait in consequence appearing uncouth, waddling and sprawling. When hurried, he goes at a gallop, overtaking Man with ease, and in other respects displays a degree of speed and activity not generally credited to him. Jle is an excellent swimmer and climber, but in old age, when he is large and heavy, he gives up the latter accomplishment; or, at least, does not climb smooth trees devoid of boughs. His powerful muscles and strong, hard talons much facilitate his climbing, and he will sometimes even mount very steep, rocky walls. Of his senses, hearing and smelling seem to be the most acute. His sight is rather deficient, though his eyes cannot be ealled weak. His sense of taste seems to be quite well developed.

Forester

Krementz on

the Bear.

Forester Krementz has lately published his experiences of many years with the Bears living in the Rokitno swamps. His book is very instructive, but he particularly states that he does not know whether his observations will also apply to Bears of other regions. "In general," say's he, "the Bear cannot be called cruel or bloodthirsty. If he were, he would find daily opportunities for exercising his instincts, and taking into account his formidable strength, the question would present itself, as to whether it would not be advisable to persecute him more. I have not met with a single case where he would have taken the offensive in his rencontres with Man on his wanderings. On the contrary, he usually seeks safety in flight on such occasions, or else, in the consciousness of his power, he pays no attention to the miserable inhabitant of the earth, or at the most vents his displeasure by a sham attack accompanied by short growls. The Bear is rather a good-natured animal, though he is not to be trusted under any circumstances. He especially objects to being provoked or disturbed in his rest. He is of a very phlegmatic temper, is exceedingly fond of being comfortable, and his attacks always display a certain frank, open-hearted, chivalrous disposition, which has nothing in common with the cowardly cruelty of the Wolf or the deceiving, treacherous attack of the Lynx. In certain isolated cases he is even possessed of a certain kind of grim humor."

Food and A single glance at the Bear's teeth

Depredations teaches us that he is an omnivorous of Bears. animal and more of a vegetable than an animal feeder. He is best compared to the l'ig: everything edible is wclcome to him. As a usual thing, plants form his principal food, small animals, such as insects, Snails and the like constituting the dessert. For months he may be satisficd with such food, gorging himself witl young, budding rye or juicy grass like a Cow, feeding on ripening grain, buds, fruit, acorns, berrics and mushrooms; digging up an occasional Ant-hill, delighting in the larva or the Ants themselves, whose peculiar acid taste may be to his liking. Sometimes he scents a Bee-hive, which provides him with an exceedingly welcome feast. In southern Carinthia the Bee-hives are carried into the mountains in summer, and according to the season at which the various plants of the Alps bloom, they are placed higher or lower on the mountain. Sometimes a Bear comes over from Craniola and then works sad havoc, breaking the hives and emptying them. A few years ago one such straggler roamed from one Bee-house to another destroying over a hundred of them; eight belonged to the narrator, Forester Wippel. The attacks of Bees are by no means a matter of indifference to him; he growls with pain, rolls on the ground, tries to rub the tormentors off with his paws, and if he can stand it no longer he even makes his escape and retires into the forest or into the water, but only to return sooner or later and resume the struggle for his favorite dainty

How one Brown It is impossible to follow a Bear Bear Spent about on his daily wanderings in His Day. order to watch his doings; and the chance meetings one has with him, even when awaiting him at his favorite resorts or drinking places, are of too short duration to throw much light on the mode of life of the Bears, which as yet is steeped in darkness in many respects. The fresh spoor in dew or hoar frost are of great use as furnishing an insight into the daily life of Bears, so we will here give the result of following such spoor: "A Bear of medium size crussed a meadow early in the morning; at its edge there lay a fallen pine tree, which he turned over, scratching the earth under it in several places in his search for worms, grubs and larva. The bark of the two year old tree had been torn away in a few places, and his soul had been delighted by the fat grubs and Beetles under it. His further progress through the forest was made clear by foliage seratched away, Ant-hills thrown about, wood and bark turned over, and plucked blue-berries, cranberries and mushrooms. In several places he had scratched up the earth on finding fresh sign of Deer. Following the Deer tracks, he had trotted on; then he went in the direction of a swamp, proceeded about one hundred paces, suddenly turned to the left, went back to the wood he had just come from, and made a jump at a few HazelIJens, as was shown by the feathers the birds had lost in their hurried flight from the sudden attack. Then he again turned his face to the swamp and crossed it in a straight direction without any notable incident. He again entered the wood, tore an empty Thrush-nest from a bush, then used his teeth and claws in the endeavor to enlarge the aperture of a hollow oak, in which a swarm of wild Bees had stored their honey, ate some blue-berries, sniffed at the entrance of a Badger's burrow, and made himself conspicuous by running back and forth on a grassy plot. A closer investigation showed the sign of young Woodcocks, whose track he had zealously pursued. From here he crossed a swampy, dense alder-tree forest, then entered a forest of oid pine trees, tore the bark off the lower half of a dead pine, scratched up the earth and sat down on it, the ground also showing a great many imprints of the claws and soles of the forepaws. Then he set his face toward a buckwheat field, which he crossed, and then entered a district of soft-wood trees and pines, situated on low land and abounding in cut trees; he seemed to prefer the parts where the trees were cut, crept 


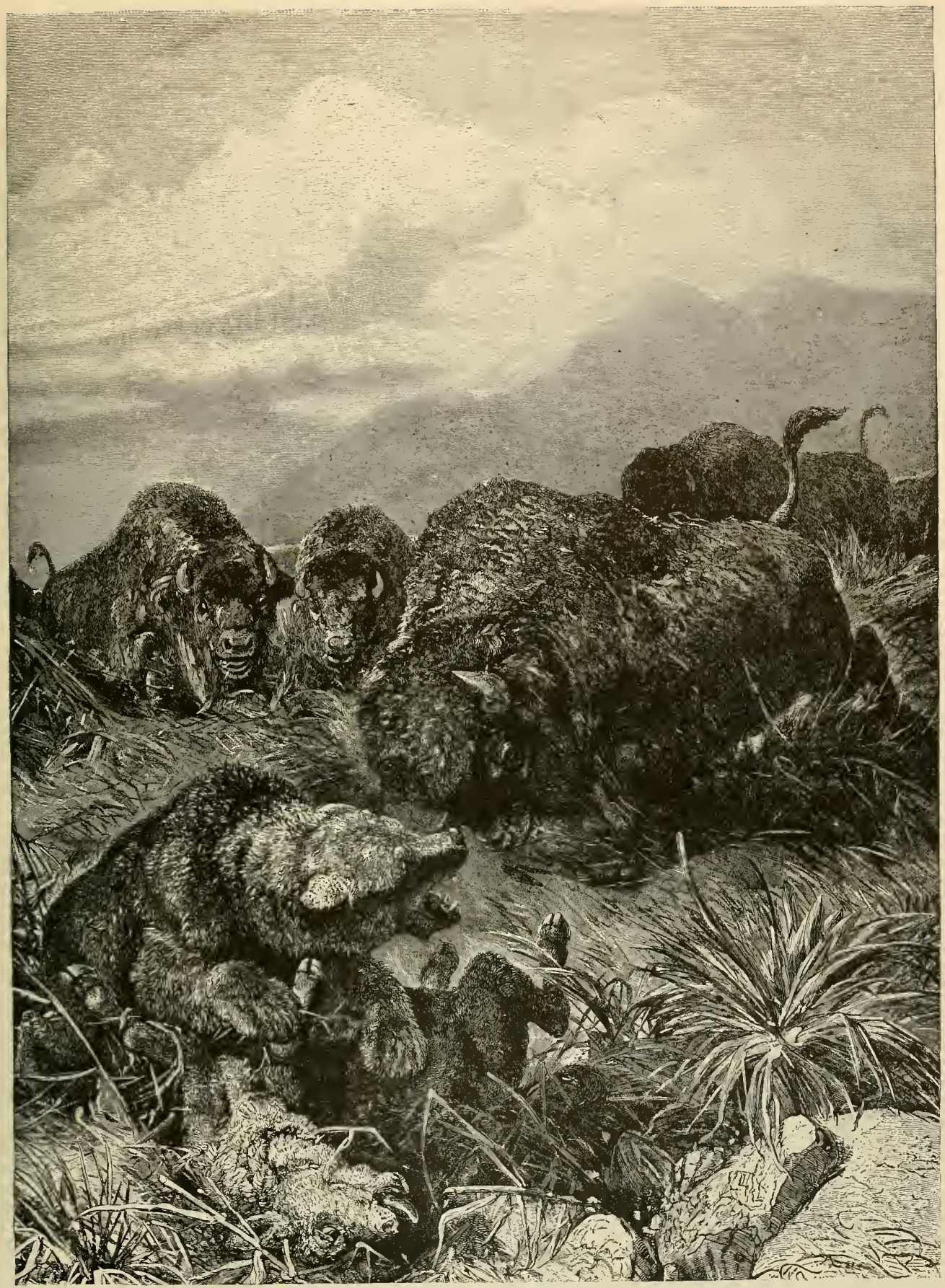

THE GRIZZLY BEAR. AND BISONS.-Except Man, the Bison or American Buffalo has little to fear from any antagonist, for its great strength, courage and endurance oyerawe all Beasts of Prey, except, occasionally, a hungry frizzly Bear. This Bear can sometimes overcone a solitary Buffalo which may becone isolated from the berd. The episode which is illustrated in the picture is one of excitement among the most formidable animals which are found in valleys and foothills of the Rocky Mountain regions. The Grizzly Bear has attacked a Bison Calf which has become separated from the herd. The piteous wail of the dying Calf has brought the herd of Buffaloes to the scene and the Grizzly Bear must now reluctantly abandon his prey and seek safety in flight, or the killed, for he cannot overcome the attack of the herd of infuriated beasts, although his running powers are sufficient to enable him to escape. 
under the root of a fallen pine, slipped over a prostrate aspen tree and his hind quarters had sunk rather deep into the swamp. Finally he made for the drier ground of a pine wood near by and disappeared, his pursuit being abandoned at this point."

The Brown As long as the Bear has regetable Bear in Search food in abundance he confunes himof Prey. self to it; but when driven by necessity, or when he has become accustomed to animal food, he occasionally develops into a predaceous animal in the full sense of the word. He tries to sneak up to his prey; but he is also said to tire out Cattle by pursuit, or, when they graze on high mountains to disperse and drive them over precipices, which he then cautiously descends and eats his fill below. Success increases his boldness. In the Ural mountain region the Bear is accounted the worst enemy of Horses. Drivers and coachmen sometimes refuse to go through a forest at night, though it is probable that it hardly ever happens that a Bear attacks Horses harnessed to a carriage. Those, however, that graze at liberty in the forest are never secure from him. A friend of mine, Von Beckmann, an expert Bear-hunter, told me how the animal proceeds in his attack, having personally witnessed the encounter. Several Horses were grazing near a swampy thicket, in full view of the hidden hunter. A Bear made his appearance in the thicket, and slowly crept up to the Horses, until they noticed him and fled in great haste. The Bear followed then with enormous bounds, overtook one of the Horses in a surprisingly slyort time, gave it a blow on the back with one paw, a blow on the face with the other, threw it down and tore its breast open. When he saw that among the fleeing animals one was lame and could not escape, he left the killed prey, ran after the second victim, easily reached it and killed it also. Both the Horses uttered fearful outcries.

When the Bear llas become bold, he also approaches stables and tries to break the doors, or, as has repeatedly happened in Scandinavia, he uncovers the roofs. He is so exceedingly strong that he can carry even large animals away. Krementz gives several examples of the exceeding strength of the Bears. One Bear broke pine poles that were three and four inches thick; another took a Cow that had just received her death-blow and was still struggling, with his fore-paws and carried her across a small river in a forest, walking on his hind-legs. A kecper of the forest, who was sitting at a fire, was attacked by a Bear, which had been frightened out of his hibernation. The Man had his skull crushed by a single blow from the Bear's fore-paw, so that instant death ensued. A fourth Bear dragged a living Deer out of a pit into which it had fallen. The Deer weighed about six hundred pounds and the Bear dragged it through the swamp for about one-third of a mile. It is probable that Deer often escape a Bear's pursuit by their vigilance and speed; still he often follows even Reindeer in the north of scandinavia for a long distance. He also preys on fishes and follows the course of rivers for miles intent on catching the finny prey.

Hibernation At the approach of winter the Bear of the prepares a resting place between Brown Bear. rocks or in caverns which he either finds ready for his use or excasates for himself ; or in a hollow tree; or frequently chooses a retreat in the thicket, or on a dry island in a swamp. When severe cold weather sets in, the Bear settles down in his winter quarters and then sleeps through the cold season. The time when he begins his hibernation varies according to the climate of the locality and the weather. A female Bear usually retires as early as the beginning of November, but the male Bear, heedless of cold weather and the amount of snow, still roams about in the middle of December, as I saw myself by his spoor in Croatia. According to Russian Bear-hunters, he thoroughly investigates the surroundings of his den before going to sleep, and shifts his quarters if he finds human tracks in different directions. If the snow begins to thaw in the middle of the winter, he leaves his den, even in Russia and Siberia, to drink or eat. It is an established fact, that he lies under the snow for three or four months in Livonia, taking no nourishment whatever, and is found with an entirely empty digestive tract if killed during this period.

If the winter is mild, his rest is perhaps not prolonged more than a few weeks, and beneath gentler skies he probably never thinks of a winter's retreat at all. Observations of captive Bears seem to indicate this, for these Bears do not hibernate, and behave in winter exactly as they do in summer. While they are given their food regularly, they eat nearly as much as at other times, and during a mild winter they sleep only a little more than in summer.

The Mother A litter of young Bears usually num-

Bear and bers two or three, sometimes one or

Her Young. four, and very seldom five Cubs at a birth. As a rule the mother prepares a complete nest for them, but it has also been observed that she occasionally placed them simply on the snow. If danger threatens her offspring, she sometimes carries them far away in her mouth. It is a surprising fact, that the mother often deserts her Cubs, when hard pressed, while they are still very small and helpless, but courageously defends them when they have become larger and stronger. In the latter case she considers herself an autocrat of the whole locality which she has selected as her place of abode, and meets every disturbing element with an immediate attack. Some she-Bears become the terror of all who have to pass through their domain and may even suspend communication on a road and whoever enters their neighborhood without Dogs, risks being wounded or killed. In their fourth montl the Cubs are large enough to follow their mother about; then she diligently teaches them to climb and to find their food, and instructs them in nuany branches of knowledge necessary to a Bear's education.

Young Bears when they are finally deserted by their mother, are said to stay around the old den during the summer, and make use of it in bad weather, until they are driven away; they also like to associate with other young Bears. Accounts of Russian peasants and hunters, first published by Eversmann and yet lacking confirmation, throw a peculiar light on these associations. They affirm that a Bear-mother employs her older children as nurses of the younger ones, if necessary using force, and the two year old Bears which run around with their mother, brothers and sisters are simply called "Pestun," that is, "child's nurse." Eversmann relates the following story of a Bear family which crossed the Kama: "When the mother had reached the other side, she saw that the Pestun was slowly coming after her, instead of helping his younger brother and sister, which still were on the other side. As soon as he reached the shore, the mother 
quietly administered to him a box on the ear. This enlivened his understanding, and he went back and brought one of the Cubs over in his mouth. The mother looked on, and he again went back to bring the other one, which, however, he dropped in the middle of the stream. Then she rushed in, administered another castigation, compelling him to do his duty, and the whole family went on its way in peace." The young peasants and hunters of Russia and Siberia all say that every female Bear has a Pestun to take care of her little Cubs. It is his duty among other things to watch over them in some thicket, when the mother goes out to prey or satiates herself with some prey which she cannot carry away. He shares her den in winter and is left free only when another has been found to take his place. Thercfore one may even find a four year old Pestun in a Bear family.

Amusing An- Young Bear tics of Young Cubs, when Bears. about five or six months old, are very amusing animals. Their liveliness is great and so is their unwieldy clumsiness, and they are constantly playing the drollest antics. Their childishness shows in their every action. They are very playful, climb trees from sheer mischievousness, wrestle with each other like boys, jump into the water, run to and fro without purpose and play a hundred tricks. They show no particular affection for their keeper, but are amiable alike to everybody, making no distinction of persons. Whoever gives them something to eat is the right man for them; whoever rouses their anger, is considered a foe and if possible tręated as such. They are as irritable as children; their love may be won in a moment and lost as rapidly. They are clumsy and awkward, forgetful, inattentive, unwieldy and silly- like their parents, with the only difference that these qualities are more prominent in them. With careful training, however, young Cubs may be taught to perform many amusing feats.
Bear-Hunting A Bear hunt is dangerous sport; is a Danger- still, the formidable stories told in ous Sport. former times are being refuted by cxperienced modern Bear hunters. Good Dogs seem to inspire all Bears with extraordinary terror and under all circumstances are the best assistants

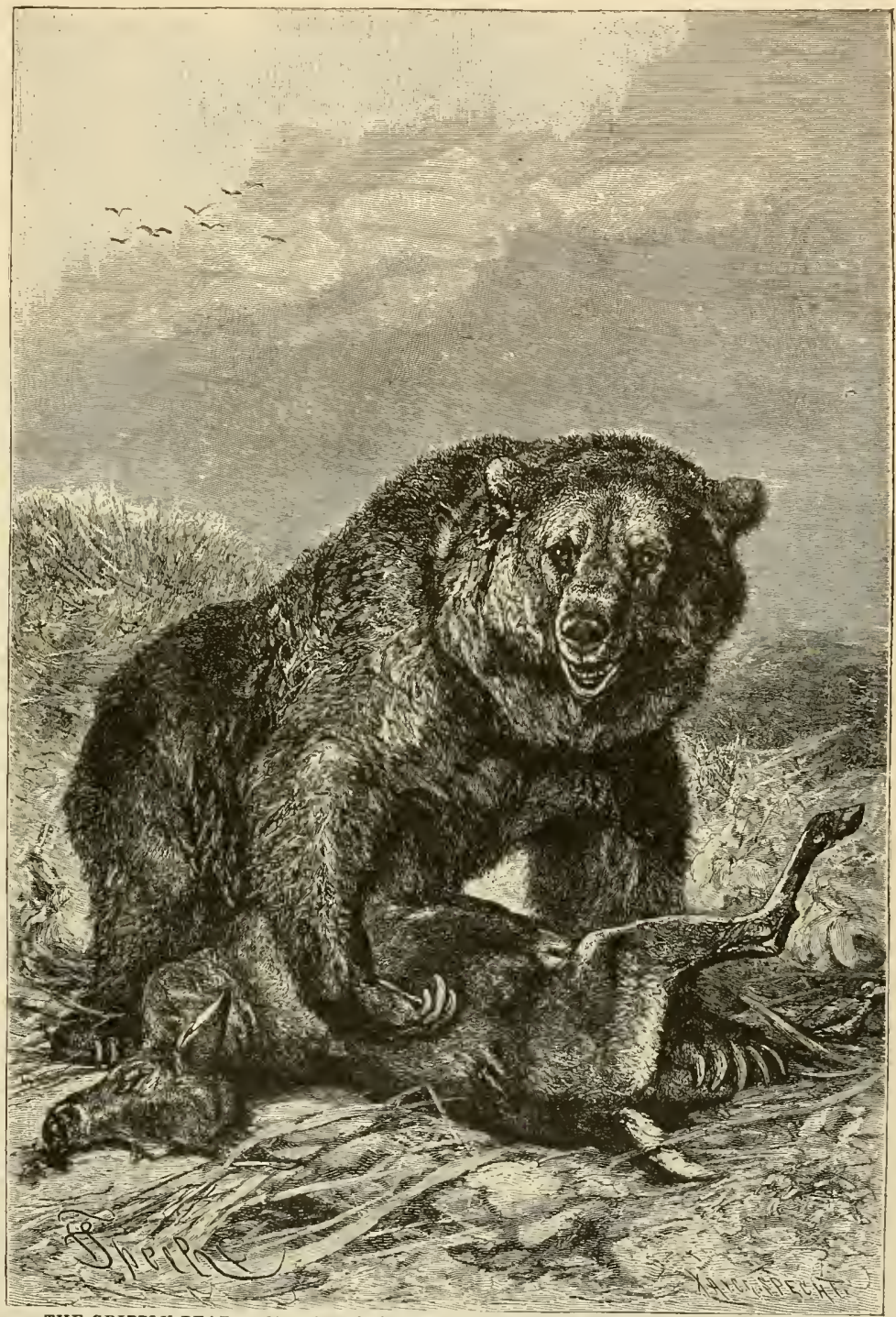

THE GRIZZLY BEAR, - Nost formidable among the Beasts of Prey found in the United States is the Grizzly Bear, the monster of the far lWest, about which more thrilling tales of adventure have been told than any other American animal. The picture shows him just as he has struck down his prey with a blow of his powerful paw and s about to make a meal of it. The ponderous body of the hunter. In southeastern Furope the Bear is ehiefly hunted in a battue during the autumn, rarely by a single huntsman and very rarely in or in front of his winter den; in Russia, however, the latter place is where he is usually sought. As the Bear 
always follows the same daily route, one can count on meeting him with tolerable security, provided one know's his habits. Cool blood, a good, steady aim and good and tried weapons are prime necessities of a Bear-hunter.

Krementz says: "The prevailing opinion, that the Bear always stands on his hind-legs in his attacks and walks up to his antagonist, is an erroncous one. It would be easier to meet his attack if he did. I have personally shot twenty-nine Bears, and seen others shoot about sixty-five; I have been present at the attack of bears of every size and description and have been several times attacked myself; but I saw only one male and one female Bear walk erect toward their antagonist for any considerable distance. I do not wish to assert that the attack, as it is usually pictured in hunting accounts and other scientific works, never happens that way; only that such cases seem to me to be extremely rare. The attack of a Bear is usually sudden and rapid, and he either tries to deal his opponent a blow with a forepaw by executing a rapid and violent motement to the side, or he quickly trots up to his enemy, suddenly lifts himself on his hind-legs in the immediate proximity of his foe whom he tries to knock down with a violent stroke of the front-paw, or else he deals him a sound blow and gives him a quick bite. He never keeps near his victim when Men and Dogs are about, but makes his escape."

Besides being hunted in accordance with all the rules of sport, the Bear is persecuted in all other possible ways, in those countries where it molests people. The purpose is reached by intrepidity combined with cunning. In Galicia and Transylvania strong iron traps are placed in the usual path of the Bear; a cliain is fastened to the trap and to the chain a heary log is tied with a long, strong rope. If the Bear steps into the trap, he tries in vain to free himself from the chain, and finally the long rope entangles him in a tree and he tires himself out by his struggles and perishes. The lounter inspects the road every two days, and the track of the dragged iron, chain or log clearly show him the way taken by the Bear. "The natives of Asia," says Steller, "construct a building of many logs, all of which fall upon the Bears and kill them when they step on the traps, which are carefully concealed in front of the structure. The natives also dig a pit and fasten a pointed, smooth, burnt pole in it, rising several feet high out of the earth; the pit is covered with grass. Then they arrange a sham trap, a spring, fastened to a rope; when the Bear steps on the rope, the spring is loosened and hits the animal, which, frightened out of its wits, incautiously runs on, falls into the pit on the pole and is killed."

In Norway, Russia, Transylvania and Spain there are still to be found experienced and intrepid men who, accompanied by a few Dogs, meet the Bear armed only with a spear and knife, and risk a life and death struggle with him.

Profits of The profit of a successful Bear hunt a Successful is quite considerable. The flesh

Bear Hunt. brings a good price; the fat, which is reputed to be an excellent remedy for promoting the growth of hair, is much sought after and well paid for. Bear-fat is white, never becomes hard, rarely gets rancid if kept in elosed jars, and the repulsive taste it has when fresh disappears on steaming the fat with onions. The flesh of a young Bear is very palatable, the hams of old Bears are considered a dainty, either roasted fresh or cured.
The paws are esteemed the most savory part by gourmands; but one must first get used to their appearance, for when they are skinned and prepared for cooking they resemble a large human foot to a disgusting extent. The head is also said to make an excellent dish. The fur is used in different ways; that of the smaller animals is hardly considered, while that of the larger ones brings, according to Lomer, a price of from twenty to eighty dollars, according to its beauty.

The Romans matelied Bears in the arena, receiving their supply principally from the Lebanon region, although we read that they had some which came from northern Africa and Libya. Their descriptions of the life of this animal are mixed with fables. Aristotle, as usual, gives the most correct account; l'liny borrows from him, but adds a few fables; Oppian gives an excellent account of the magnificent Bear hunts of the Armenians on the banlis of the Tigris: Julius Capitolinus describes the fights in the circus and mentions that Gordian I. brought a thousand Bears to the arena in one day.

The Barren In arctic North America there is a brown Ground Bear, an Bear, which was found in the barren ground Ground Bear, an of the Arctic Zone, by Sir John Richardson, Arctic Variety. who called it the Barren Ground Bear. It has been classed by some naturalists as a distinct species (Lisus richardsonii) but its similarity to the common Brown Bear is so great and its points of difference so few that it can scarcely be regarded as more than a local variety.

The Grizzly The nearest relative of the Brown Bear Bear, an Amer- is the Grizzly Bear (Crsus cinercus or ican Species. (rosus homibilis) known to the Americans under the familiar appellation of "Old Ephraim," and ranging over the whole of northwestern America. He resembles the common Bear in structure and appearance, but is larger, heavier, clumsier and stronger. The color varies greatly, from iron gray to light reddish-brown, the former hue sometimes having a sonmewhat silvery glint, the latter a golden one, produced by the silver-white or yellowish tips of the outer hair. American hunters therefore distinguish between the Grizzly proper, the Brown and the Cimmamon Bear, the latter variety being considered the handsomest. His range comprises the west of North America. In the United States he is found from the southern part of the Rocky Hountain region, thence to the northern part of Dakota. The farther we go to the west, the more frequently he is encountered, especially in mountains. In the south he is also found in the high lands of Mexico; while in the north his range extends as far as the Aretic Circle and farther.

Mode of Life $I_{11}$ his mode of life the Grizzly resemof the bles the common Bear, and also hiber-

Grizzly Bear. nates; but his walk is more staggering and all his movements are clumsier. He is said to be able to climb trees only in youth, not being equal to this accomplishment in old age; on the other hand he swims over wide streams with ease. He is a capable Beast of Prey, and more than sufficiently strong to conquer any ereature living in his native country.

Stories of Former accounts all tend to charEncounters with acterize him as a cruel and formidthe Grizzly. able animal. He was said to have no fear of Man but to boldly attack him, no matter whether the latter was on Horseback or afoot, armed or defenseless, whether he had offended him or never thought of hurting him. For all these reasons, the hunter who had measured his strength with "old Ephrain" enjoyed the admiration and esteem 
of all Men, white or Indian, who heard of him, the latter praising the killing of a Bear as the highest deed of Man. Among all the Indian tribes the possession of a necklace of Bears" claws and teeth invests its wearer with a distinction scarcely enjoyed by a European prince or commander of a victorious army. Only he who has earned the Bear-chain by his own prowess and efforts has a right to wear it. It is further said that the monster, who walks boldly up to other people to kill them, flees when he scents the wearer of such a necklace. To the same degree that the Grizzly fears the scent of such a Man, all other animals are afraid of the Bear. Domestic animals act exactly as if they perceived the odor given forth by a Lion or Tiger, and even the carcass or fur of the Grizzly inspires them with a wholesome terror. Several hunters there are who assert that the American Wild Dogs, so voracious in other respects, show their awe of the Bear by leaving his carcass untouched.
Food and Prey The Grizzly feeds on vegetable mat-

of the Grizzly ter, being fond of fruit, nuts and Bear. roots, but he also kills animals; and he is said to catch fish very dexterously. In Alaski, where he is very common, one frequently sees paths which he has trodden down and walks on regularly, either on banks of rivers, or on desert plains, in marshy or mountainous districts; and the direction and course of these paths are selected with such skill that one only needs to follow them in order to strike the shortest road between two localities. "On the steep slopes of the mountainous coast on the west side of Cook's Inlet," says Elliott, "one can occasionally see troops of twenty or thirty of these unwieldy animals, in quest of berries and roots. But their furs are not very valuable, because they are of coarse, uneven, shaggy texture. As they are also very ferocious, they are not hunted generally, except by the Kenai people, who hold them in high esteem like the rest of the natives and are wont to

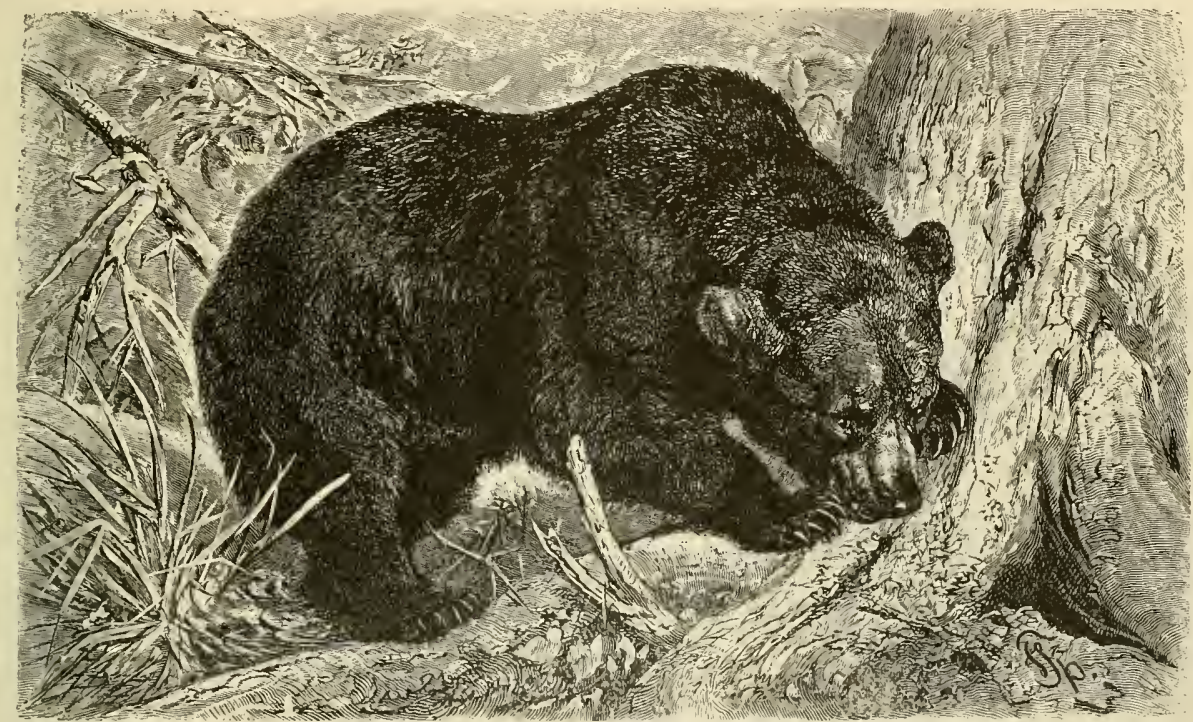

THE BLACK BEAR. - The most common species of Bear found in America is the Black Bear, which inhahits nearly all forest regions of the United States and Canada. The picture well portrays this familiar animal with its fur of almost uniform black, its clumsy body and Jong. somewhat pointed snout. The paws are smaller than those of the Brown Bear. The artist has appropriately pictured the animal in a dense forest. This animal does not often assume the offensive toward Man, but is formidable when attacked. (L'rsus americamus.)

There is no doubt that these as well as other reports are partly incorrect, and in part greatly exaggerated. They were spread and gained credence when the far IVest was as yet little frequented and a monstrous animal was needed, capable of playing the same part in stories of adventures, as the most notorious predaceous beasts played in the Old World. Occasional deeds were thought to be characteristic of the whole species under all conditions, and so the Grizzly became the terror of the unknown far West. Many a Man has perished by Grizzlies, as well as by the common Bear; wounded beasts have defended themselves, and those taken by surprise, especially mothers who thought their Cubs in danger, have also, probably, assumed the offensive; but still the Anerican Bear is no more formidable than his European relative, nor does he show greater courage, but resembles him in all respects. Bears of either species may become dangerous if provoked. address eulogies to a Bear before killing or trying to slaughter him. As the natives are further afraid of entering on places where volcanic influences are at work, the surroundings of craters, hot springs or places where steam is issuing from the ground, form an asylum for wild animals, especially for Bears, which are all well aware of the fact that Man will not molest them there."

Young Grizzly A young Grizzly can easily be tamed Bears are and, like the Brown Bear, is then a

Easily Tamed. companionable, amusing animal for a time. In spite of its length and thickness, his fur is of so fine a texture and so lovely a color that it is very becoming to the little fellow. Palliser, who brought a little Grizzly to Europe, praised his prisoner very much. He ate, drank and played with the sailors, and amused all the passengers, so that the captain of the ship later assured the sportsman that he would like to have a young Bear on board 
on every journey. This animal had struck up a queer friendship with a little Antelope which was its traveling companion, and defended it in the most gallant way on one occasion. When the Antelope was being, led through the streets on its way from the ship, a huge Mastiff pounced on it and seized it in spite of the shouts and the blows which the keeper administered to him with his stick. Fortunately Palliser and his Bear had taken the same road, and when the latter saw what was going on, he tore himself loose; in another instant he had seized his friend's foe by the neck and administered such a castigation to him that he ran away with a piteous howl.

Captive Grizzlies do not differ materially from the European Bears in their customs. In the London Zoological Garden there were two, which once played an important part from a medical point of view. In their youth they suffered from a severe inflammation of the eyes, as a result of which they became blind. It was lecided to cure them. The patients were separated, and the keepers put a strong collar on each, and pulled the head of the gigantic Bear close to the iron bars with ropes so that the sponge saturated with chloroform could be held to his nostrils with safety. The effect was disproportionately rapid and sure. After a very few minutes the huge animal lay like one dead in its cage, deprived of consciousness and movement, and the oculist could enter safely, put the terrible head in position and do his work. Just as the cage had been darkened, the animal awoke, staggered to and fro as if intoxicated, and seemed to become still more unsteady as its conscionsness returned. In time it appeared to realize what had happened to it during its death-like sleep, and when it was examined a few days after, it had become conscious of its regained power of sight and appeared to rejoice in the light of day, or at least to know the contrast between the former perennial night and the actual brightness of the sunlight.

The Cinnamon Bear The Cinnamon Bear (L'rsuscinnamoncus) of the Rocky is by some considered as a distinct sjeMountains. cies, and by others as being only a variety ties class it as a variety of the Grizzly. Bear. It is found in the Rocky . Ilountain region and a portion of the Sierra Nevadas, occupying a part of its range in conmon with the Grizzly and the Black Bear, but is much more numerous than either of these species in southern Utah, Arizona and northern Nexico. It inhabits the mountains principally, although sometimes descending into the valley, and is much more formidable than the Black Bear, though liunters and frontiersmen do not regard it as being so dangerous an antagonist as the Grizzly Bear. The name " Cinnamon" Bear accurately describes the color of its fur, which is nearly of a uniform slade all over the aninal, although the hairs are much paler at the roots than at the rip.

The Musquaw The best-known American Bear, the

or American Musquaw or Black Bear ( $L$ 'rsms am's-

Black Bear. icamus) is a widely spread and comparatively good-natured animal; at least it is much more harmless than the Grizzly or the Brown liear. Its length is at the nost six feet, its height at the shoulder a little over three leet. It differs from the Brown Bear mainly by its narrower head, its more pointed snout, very short soles and in the texture and color of its fur, which consists of long, wiry. smooth hair, which is shorter only on the forehead and around the snout. The hue is a brilliant black, merginer into yellow on both sides of the snout: and a patch of the latter color is atso often found in front of the eyes. More rascly Black Bears are seen whose lips liave white margins, and which have white stripes on the breast and the top of the head.
The Cubs, which at first are light gray, assume the darker hue of their parents at the beginning of the second year, but it is much later before their hair grows long.

Differences of color have led many hunters and others to distinguish other species of Bears. There is, for instance, a Fellow Bear in North and South Carolina, the color of which is yellowish-hrown. But this difference of hue is the only one that separates it from the ordinary Black Bear, of which it is merely a rariety.

The Black The Musquaw spreads all over North Bear's Home and America. He has been found in all Haunts. wooded districts, from the eastern coast to the Californian boundary, and from high latitudes to Mexico. The forest provides for all his wants; but he shifts his quarters from one locality to another, according to the scason and its different products. During spring he is wont to look for his food in the fertile river valleys, and therefore he prowls in the thickets edging the banks of streans and lakes. In summer he retreats into the depths of forests rich in all kinds of fruit ; but in winter he secks out a suitable den in some sechuded place, and either sleeps or really hibernates in it. Opinions differ in regard to his hibernation. Some writers hold that only a few of these Bears hide in their den for weeks and sleep, while the majority of them roam from one place to another in winter as at other seasons, or even migrate from northern regions to more southern ones. Other observers believe that this happens only in mild winters, and that in those that are more severe all Black Bears hibernate. It is a fact that it is most frequently in winter that people sally forth on Bear hunts and find the animal in its den.

Characteristics Notwithstanding his stupid, clumsy and of the Black unwieldy appearance, the Black Bear

Bear. is a watchful, active, vigorous and agile animal of great endurance. He can run so swiftly that a Man cannot overtake hins; he is an excellent swimmor and an adept at climbing. At any rate he is more agile than the European Brown Bear which, in other respects, Je resembles. He attacks Man very rarely, sceking safety in tlight as soon as he catches sight of this his worst foc, and does not even always turn on him when wounded, though he may become dangerous when hemned in by his enemies.

His principal food is of a vegetable nature. consisting chiefly of herbs, leaves, half-ripe and ripe grains, berries and fruit of the most varied kinds. But he also makes inroads on the live stock of the farmers and, like Brown bruin, even dares to attack large Cattle. He is always in the way of the farmer, either by damaging the crops or molesting the Hocks, and therefore he fares like the Brown Bear: he is pursued and exterminated whenever he show's himself near human habitations.

Methods of Hunt. The Black Bear is hunted by variing the Black ous methods. Nany are caught Bear.

in large traps, but more are killed with bullets. Good Dogs are of inestimable service in rousing the Bear or driving him into a tree, thereby giving the sportsman the opportunity to take a good, steady aim and send his bullet to the right spot.

Sone kinds of hunting practiced by the Indians are very peculiar, and still more so are the solemn ceremonies they go through in order to appease the manes of the deceased Bear, the performance partaking somewhat of the character of worship. Alexander Henry, who traveled in the part of the country where fur-producing animals are most 
abundant, relates how his hosts behaved in the presence of a Bear he had just killed. "Directly after his death all the Indians approached him, especially the woman we called 'Old Nother.' She took the animal's head into her hands, patted and repeatedly kissed it and asked forgiveness a thousand times, assuring the dead Bear that it was not the Indians who had killed him, but that an Englishman had been guilty of that evil deed. This ceremony did not last very long, for soon the skinning and dividing of the meat began. Each person in the party took his burden of shin, meat or fat and we started for home. As soon as we arrived, the head of the Bear was adorned with silver bracelets and all the saudy ornaments the family possessed. Then it was put on a stand and a quantity of tobacco was deposited before its nose. On the following morning preparations for a feast were made. The hut was cleaned and swept, the head of the Bear was put on a high place and covered with a new handkerchief which had never been used. After the pipes had been put in order, the Indian blew tobacco smoke into the Bear's nostrils. He asked me to do likewise, assuring me that 1 , who had killed the animal, would certainly appease its ire in this way. I tried to convince my kindly and well-meaning host that the Bear did not live, but I failed in this attempt. Finally my host made a speech, in which he endeavored to glorify the Bear, and after this the repast on the Bear's flesh began.'

The Black All Black Bear in Bears which

Captivity. I have observed differ materially from their kin by their gentleness and good nature. They never make hostile use of their strength in their relations with their keepers, but completely acknowledge human supremacy, and present no difficultics in their training. At any rate they fear the keeper more than he does them. A smail Elephant, which was being led past the cages of several Musquaws wfich 1 took care of, frightened them to such an extent that they hurriedly climbed up a tree, as if they considered themselves to be safe there. They show no desire to fight with other Bears which mav be brought to them, and even a small individual of their own species, if courageous, can acquire the supremacy in the cage.

Captive Black Bears constantly display their agility in climbing. Whenever they are frightened by anything, they jump up to the first boughs of a smooth oak, to the height of about six feet, and then ascend to the top with the greatest security and ease. Once the keeper tried to drive the uld she-Bear into her cell, but she jumped over him, right into the tree. The voice of the Black Bear resembles that of the Brown Bear, but is much weaker and more plaintive. Black liears can be easily spoiled by the liberality of well-meaning friends. They soon come to know a person who makes a practice of feeding them, and when he forgets to give them something, they remind him of it with piteous requests. They accustom themselves to a kind of mendicancy which is irresistible; for their attitudes, with outstretched arms, are so droll, and their whining so pitiful, as to

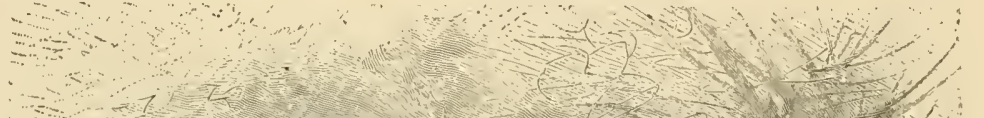

BLACK HIMALAYAN BEA Th having many of the characteristics of the other large Bears, has a less clumsy body, larger ears, a shorter snout and shorter claws than most of the other Bears. It is found in forest regions principally, and the picture, which brings move any heart. A few Musquaws in the possession of Count Goertz would search peuple's pockets for dainties, and they made life a burden for those who brought them nothing

The Black An Asiatic representative of the Himaloyan Bear family is the Black Himalayan Bear

Described. (Crsus torquatus). His body is comparatively slender, the head ends in a pointed snout, the forehead and nose forming a nearly straight line. the ears are round and relatively large, the legs are of medium length; the feet are short, and the toes armed with short, vigorous claws. The fur may vary greatly in texture and color, if the several accounts refer to this animal and not to two distinct species. 
Where the Him- Wallich found this Bear in Nepal; alayan Bear Siebold, in his work on the animal Lives. World of Japan, says that the Himalayan Bear, called Coona by the Japanese, is of frequent occurrence not only in China and Japan. but also in most mountains of the continent and the southern Asiatic islands. In northern India and Cashmere he delights in forest thickets located near fields and vineyards, while in southeastern Siberia he prefers open forests of tall trees. He climbs the highest trees with ease, and Radde says that it is believed by the Birar-Tungus people, that he rarcly comes to the ground; in summer he makes himself little bowers in the tops of the trees by bending and intertwining branches, and in winter he sleeps in some hollow tree in a sitting posture. They also say that he is cowardly and harmless, having a small mouth and being able only to bite, but not to lacerate those whom he attacks. Adams, however, was told the reverse, and affirms that the Black Himalayan Bear is feared by the inhabitants of the mountains of India for very good reasons. Blanford calls him the most carnivorous of all the Bears of India, killing not only small Cattle and Stags, but also large Cattle and Horses, and occasionally feeding on carcasses, although his principal food is of a vegetable nature.

Himalayan Bears Captive Black Himalayan Bears in the Tame

state. are now seen in all larger zoological gardens. They resemble the Musquaw most in their conduct, having nearly all his habits and customs ; their intellectual capacities are about on the same plane as those of the American animal, and the best that can be said of them is that they impress one favorably because of the gracefulness of their movements.

The Malayan Bear, The Malayan Bear or Bruang, or as Its Habitat and Rosenberg gives it more correctly: Traits.

Biruang (irsus malayamis) [which is by some authorities called the Malayan Sun Bear] differs markedly from the species we have so far considered. It is of elongated yet clumsy shape, with a thick head, a wide muzzle, small ears, very small, stupid eyes, comparatively huge paws, long and strong claws and short fur. Its length is about fifty-six inches, its height about twenty-eight inches. The fur is short, but close, and is of a lustrous black huc, with the exception of the pale yellow sides of the snout and a yellow or light mark on the breast in a horseshoe or ring-like form.

The Biruang inhabits Borneo, Sumatra, Java and the Malayan P'eninsula. Very little is known about his life in the free state. He is known to be an excellent climber, perhaps the best among all his family, and is said to live as much in trees as on the ground, and to feed almost exclusively on plants, though he may occasionally devour a quadruped or bird. According to Marsden, he causes great devastations in the cocoa plantations on Sumatra and also ascends cocoa palms to feed on the tender shoots. $\mathrm{He}$ is said to be often kept in captivity in his native country, for he may be allowed to play even with children, being a good-natured, harmless fellow, which may be given the freedom of the rard. Sir Stamford Raffles, who possessed an animal of this species, could let him go into the nursery and never had to punish him by chaining him up, or by blows. More than once the Bear went to the table and asked for something to eat. He also proved to be a consummate gourmand, as the only fruit he would eat were mangoes. He was loved and hon- ored by the whole household and behaved in a model way, never harming the snallest animal. He often took his meals in company with a Dog, a Cat and a small l'arrot, out of the same dish.

In our cages the Biruang proves to be very different, at least in so far as my expericnces go: he seems stupid, though anything but good-natured, rather exhibiting an obstinate, wicked temper. He rarely makes friends with his keeper, in spite of the best of care.

The Polar Bear, If the rather slight differences in a Distinct structure and habits exhibited by species. the common Bears entitle them, in the opinion of some naturalists, to be ranked as distinct species, it is easy to understand why the Polar Bear (Cisus maritimus) is regarded as the representative of an independent species. The first navigators who mention him believed him to be only a variety of Master Bruin, whose fur had assumed the snowy color peculiar to high latitudes; but this error did not prevail long, as the material differences between the Brown and the Polar Bear were soon discovered. The latter is distinguished by an elongated body, a long neck, short, strong legs, with feet much longer and broader than those of the generality of Bears, and which have their toes connected by strong webs nearly to their middle. He is by far the largest of all liears, for his height at the shoulder is from fifty-two to fifty-six inches, while he attains a length of from one hundred to one hundred and twelve inches. He weighs twelve hundred pounds, and, if very fat, even sixteen hundred pounds.

The body of the Polar Bear is much clumsier, though more elongated, and the neck much thinner and longer than those of the Common Bear. The head is long, flattened and comparatively narrow, the back of the head is much elongated, the forehead is flat, the snout is thick at the root, pointed in front; the ears are small, short and rounded; the nostrils are wider and the mouth split less deeply than those of the Brown Bear. The paws are provided with thick, curved claws of moderate length; the tail is very short, thick and stub-like, scarcely protruding from the fur. The long, shaggy, rich and close fur consists of a short inner fur, and of a plain, hustrous, soft outer coat of nearly woolly texture. The hair is shortest on the head, neck and back, longest on the hind quarters, the under portion and the legs. There are a few bristle-like hairs on the lips and over the eyes; but the eyelids have no lashes. IVith the exception of a dark ring around the eyes, the bare tip of the nose, the margins of the lips and the claws, the Polar Bear is of a snowy white color. The hue of young animals is a pure silvery white, while the older individuals assume a yellow ish tinge, supposed to be caused by their oily food. The season of the year has not the slightest influence on the coloring.

The lcy Home The Polar Bear inhabits the highest of the Polar latitudes of the globe, the genuine Bear. ice region of the pole, and is found only there where water is frozen, at least partially, either a great part of the year or perennially. It has not yet been established how far north he penetrates; but as far as Man has gone in those inhospitable regions, he has found the Bear to be a living inhabitant of that zone so inimical to life, while to the south he has been seen only in exceptional cases as far as the 55th degree of North latitude. He belongs to none of the three northern continents 


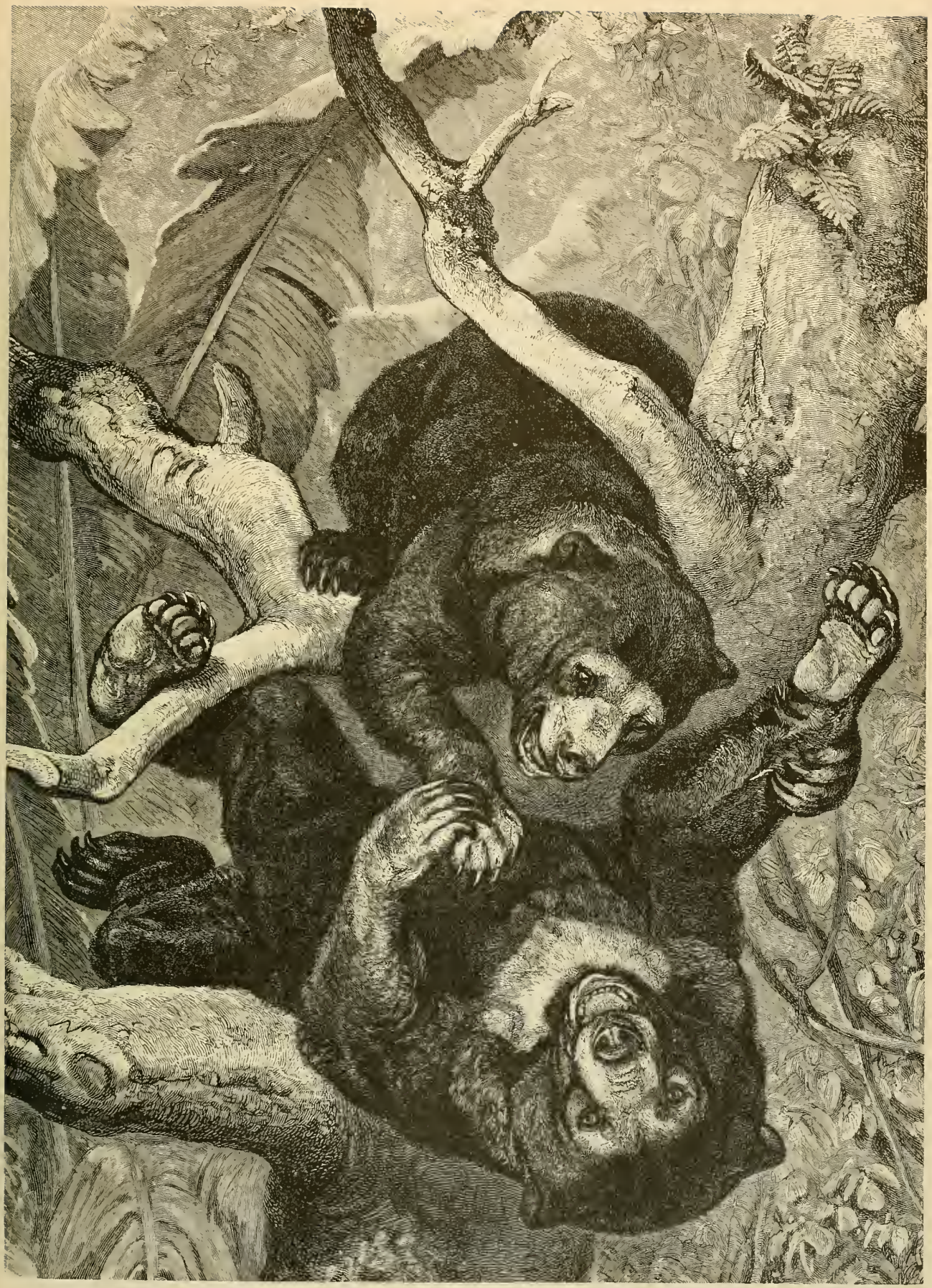

THE MALAYAN BEAR.- - This inhabitant of the Malayan Peninsula and Islands, sometimes called the Biruang, has a clumsy, black body to which he pale yellow markings of the face present a decided contrast. These Bears are of arboreal habits, are expert climbers and like to disport themrselves 
exclusively, but is common to them all. Interfered with and endangered by no other creature, heedless of the severest cold and braving heavy storms, the fierceness of which is almost beyond our power of conception, he roams about through continent and oceans, over the icy covering of the water or through the waves, and the very snow itself may becone his covering and his shelter. He is plentiful on the eastern \merican coast, around Baffin's Bay and Hudson Bay, in Greenland, Labrador and some islands, and is found as well on the land as on drift ice. In \sia, Nova Zembla is his headquarters; but he is also seen in New Sibcria and even on the conttinent, though only when he drifts there on ice-floes. In this way he sometimes lands in Lapland and also in Iceland; and Polar Bears have frequently been seen drifting on ice-floes in water that was otherwise free from ice, at great distances from the shore. Sometimes they roam about by the dozen or in even nore numerous troops. Scoresby say's that he once met about one hundred Polar Bears together on the coast of Greenland, of which twenty were near enough to be killed. The uninhabited island of St. Natthews, in Behring Sea, seems to be a real Polar Bear country, for it is full of them; hundreds of them keep house there, unmolested and secluded from the world. They also abound north of the Beliring Strait and sometimes gather in considerable numbers around some food. Pechuel-Loesche says: "We saw an unusually numerous troop of Polar Bears on an ice field, for which we thought there must be some special reason. It soon became evident to us. On the edge of the field lay the swollen carcass of a whale which had been washed ashore, and the Bears had collected for a repast. It was an interesting sight to see the participants of this feast, some of which had soiled their white fur in a deplorable way in the difficult carving of the mountain of flesh. They seemed very much displeased at our arrival and quite disposed to dispute the right to the prey with those in the approaching boat. lisut when the largest fellow broke down with a shot in his neck, and another was severely wounded, they made their escape with surprising quickness. Like a pack of angry Wolves they then surrounded us at a safe distance and waited for our departure with all kinds of lumbering, threatening gestures."

Physical Traits The movements of the Polar Bear, of Polar on the whole, may be termed clumsy, Bears.

but his powers of endurance are remarkable. He exhibits them to the full in swimming, as he is a masterful adept in this exercise. Scoresby estimates the speed with which a Polar Bear moves in the water, uniformly and without apparent fatigue for hours at a time, at two and a half to three miles an hour. The large amount of fat stands him in very good stead, counterpoising the weight of his body with that of the water. He is therefore enabled to swim across vast expanses of water for days at a time and is often met in the open ocean far from the shore. According to Pechuel-Loesche's observations, he always enters the water hind quarters first, unless he is hard pressed, and he allows himself to glide into the water in a ludicrous, cautious, nearly anxious way. He dives with as much ease as he swims on the surface. He has been obscrved to bring Salmon out of the water, and this is certainly an admirable illustration of his diving powers. On the ground, also, he is by no means as helpless and unwieldy as he looks. His usual pace is slow and deliberate, but when he falls into his seemingly clumsy gallop or trot, he proceeds at a surprising pace, even on uneven ice or ground, and he knows how to pick out the most convenient path with great circumspection. His organs of sense are exceedingly acute, especially those of sight and smell. Scoresby says that in traversing vast ice-fields, he mounts on ice-blocks and looks out for prey. 1le scents a dead Whale or a piece of bacon thrown into the fire at remarkable distances.

Food and Forag. The food of the Polar Bear coning Habits of sists of nearly all the animals Polar Bears. found in the sea or on the unfertile coasts of his native country. His formidable strength (which considerably surpasses that of the other ursine Beasts of Prey) and his agility in the water greatly facilitate his task of providing food for limself. Seals of various kinds are his favorite game, and he is sufficiently cunning and agile to reach these sagacious and quick creatures. When he sces a heal lying on the shore afar off, he noiselessly enters the water, swims to the Seal against the wind, approaching it with the greatest caution and then suddenly emerges from the water near the animal, and, as a rule, overpowers it. In those icebound regions the Seals arc wont to lie ncar holes and crevices in the ice, using them as means of communication with the water. The Polar Bear, swimming under the surface, finds these apertures with unfailing certainty and so the fear-inspiring head of the most terrible enemy of the helpless Seals suddenly makes its appearance, so to speak, in their own home, blocking the only road by which it is possible for them to escape. The Polar Bear catches fish by diving and swimming after them, or driving them into crevices between the ice and catching them there. He attacks land animals only when deprived of other prey; still Reindeer, Arctic Foxes and birds are in no way secure from him. Osborne saw a Polar Bear roll away stone-blocks, to provide her Cubs with Lemmings, and Brown, as well as Kukenthal, noticed that this Bear devours a great many eggs of Eider-Ducks. He is wont to regularly visit even those brooding-places of seabirds which are difficult of access, and levy a tribute on the surplus of eggs and nestlings, occasionally displaying great climbing abilities. He feeds on carrion as well as on fresh meat, and is said not even to disdain the carcass of another Polar Bear. In those regions which are frequented by Seal-hunters and Whalers, the carcasses of Seals and Whales deprived of skin and fat constitute a convenient and plentiful article of his diet. But he is by no means an exclusive animal feeder, and, wherever he can procure it, he eats vegetable food, especially berries, grass and moss, a fact which is well known to those who have often met Polar Bears. With some old fellows, vegetable food seems to be the predominant if not their only food in summer, in favorable localities, the contents of the stoniach of animals which have been killed giving unnistakable proofs to this effect.

Only Female It is highly probable that most Polar Bears Regu- Polar Bears do not hibernate. It larly Hibernate. is an established fact that one may see and hunt them all through the winter. They live on the sea-coast in that season, usually on the brink of the ice. The female Bears retreat for the winter, however, and the Cubs make their appearance during the coldest months. The female Bear prcpares a den under rocks or projecting ice- 


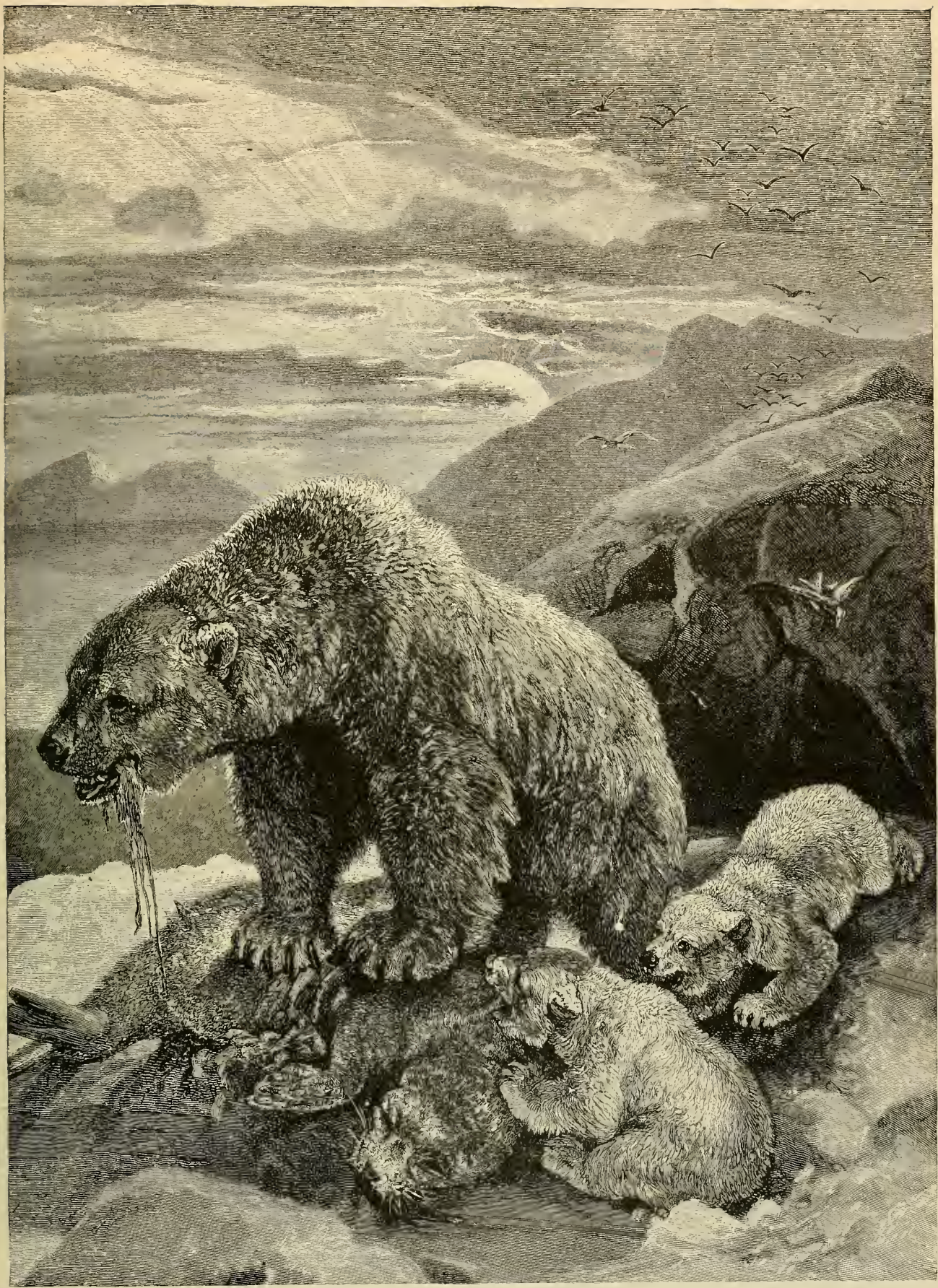

POLAR BEAR AND CUBS. - This presents a scene at sunrise in the frozen regions of the north. The mother Polar Bear and her Cubs are on a great ice floe, above which the Sea Gulls hover, envious of the ursine family, which have secured a Seal for breaktast. The mother has begun her voracious meal: the little ones are not yet accustomed to a meat diet, but are about to try it. The picture well brings out the physical characteristics of the animals and particularly the shaggy fur covering the body and legs, as well as the powerful paws of the larger animal. (U'rsus maritimus.) 
blocks or else digs a pit in the snow and suffers herself to be snowed in. Considering the large amount of snow which falls in those regions, it is not long until her winter quarters are provided with a thick and rather warm covering. Before retiring for the season she lays up a goodly supply of fat. and on this she lives during the winter; for she leaves her den only when the sun of spring stands high above the horizon. During this retircment the Cubs make their appearance. They accompany their mother on her wanderings much earlier than the children of the land Bears. They are most carefully and tenderly fed and protected by her. Even when they have become half-grown or little short of adult age, the mother shares all dangers they incur; she teaches them their craft, consisting of swimming and the catching of fish, in their earliest youth. The pretty little fellows soon know how to do both, but they try to arrange things for themselves as conveniently as possible, and even when they are rather large they comfortably rest on the mother's back when tired.

Female Polar Explorers and whalers have narrated

Bears are Good touching stories of the self-sacrificing Mothers. and loving spirit of Polar liear mothers. Scoresby says: "A she-Bear, which had two Cubs, was pursued by several armed sailors on the ice. At first she seemed to incite the Cubs to greater speed by hurrying on in advance and looking back at them, trying to impart to them a sense of the danger they were in by peculiar motions and a particularly plaintive tone of voice; but when she saiv that her pursuers were drawing too close to her, she endeavored to drive the Cubs on, pushing and shoving them, and thus she succeeded in making good her escape."

Polar Bears A great many accidents are charged

Are Dangerous to the fierce attacks of Polar Bears, as Foes. and many a whaler is said to have lost his life through his foolhardiness in entering into a combat with one. Such narratives are usually found in travelers' descriptions of former times, and rarely in those of more recent date. In order to explain the sharp contradictions, it may be assumed that either the dangerousness of the P'olar Bear was much overrated in the olden times, or that he has since changed his grim temper, perhaps in consequence of a better acquaintance with Man. At any rate, the idea of dangerousness, as applying to the whole species, is not an accurate one. The average experience of those who have hunted and obscrved him a great deal during the last few decades goes to prove the reverse. Lamont, who has undertaken bunting expcditions to the far north in his own ship, writes as follows: "I consider the l'olar Bear the strongest of all Beasts of Prey; but like all other wild animals, he does not attack Man so long as he can aloid him, with very rare exceptions." Nordenskiöld sums up his own and a great many other people's experiences in the following words: "If one meets a Polar Bear unarmed, a few violent motions and shouts suffice to rout him; but if one flees from him, one may rest assured that the animal will very. soon be at his heets. A wounded Bear always flees. Often he puts snow on his wound with his paw, and sometimes, in his agony, he digs a whole in the snow to hide his head. When a ship rides at anchor, a Bear sometimes swims up to it, and when a tent is pitched in some remote region, the occupant often inds a Bear in the morning, which has sniffed at the tent at night, but dared not enter it. Formerly the sight of a Polar Bear used to strike terror to the hearts of Arctic explorcrs, but nowadays hunters, armed with their spears, do not hesitate to attack even great numbers of Bears. They rely less on their guns. Sometimes they have killed as many as twelve Bears with their spears in a short time. I know of one case only, where a Norwegian hunter was severely injured by a Bear."

How Polar Bears In eastern Greenland the Bear acts Act Toward in the same way. "Encounters with Man. Polar Bears," say Copeland and Paver, "have the most varied issues. It not infrequently happens that a sleighing party, obliged to forego a hunt by lack of time or for other reasons, passes by one or several Polar l3ears, which often are at a distance of a few paces only, and display no other emotion by their demeanor than that of curiosity and amazement. Or else they content themselves with going around the sleigh, their heads constantly turned in its direction. One of our sailors, called Klentzer, went through an experience as dangerous as it was ludicrous, in our winter harbor. He was walking along the decline of the Germania mountain, unarmed, and was about two thousand paces away from the ship, when he perceived a P'olar Bear close behind him. He was well aware of the remarkable speed which these creatures may attain, and which renders any attempt at escape futile; he also knew about the frequently successful trick of distracting the Bear's attention by a continuous dropping of objects, while trying to gain the protecting shelter of the ship at a leisurely pace, calling all the while for help. so he gradually divested himself of his hood, gloves, stick, etc., all of which the Bear pulled to pieces with its teeth. Still the animal finally came close up to him and sniffed his hand like a Dog. Then the Man, who had been incessantly shouting for help, resolved upon the desperate and impossible feat of strangling his foc with a strap, if it should attack him. His piercing cry was heard from the ship. We hurriedly armed ourselves, but feared the worst. The great distance we had to traverse gave the Bear enough time to have destroyed his victim ten times over before we could come to the rescue, but he was so slow in making up his mind, that our approach, shots and shouts drove him away. He made his escape over steep rocky inclines and was gone as suddenly as if he had been blown away."

Polar Bears The l'olar Bear is hunted, wherever Are Vigorously he ranges, on account of his flesh, fat Hunted. and fur. He is destroyed with gun, spear and trap; and according to Scemann, some hunters are said also to have recourse to the following trick. They bend a piece of whalebone, about four inches wide and twenty-four inches long, in the form of a spring, wrap it in seal-fat and let it freeze. Then they go in search of a liear, provoke him with an arrow, throw the piece of fat down and flee. The Bear sniffs the piece, and discovering that his find is eatable, he swallows it and perishes; for in the warm temperature of his stomach the fat thaws, the whalebone springs apart and tears his intestines. 1 leave it as an open question, whether such suspicious pieces of fat are really swallowed whole by these distrustful creatures when they have been irritated as described in this story.

Polar Bears are When they decm themselves secure,

Very Destruc- however, they devour the most varied tive. and remarkable objects and have a peculiar and by no means laudable tendency to 
investigate and appropriate the provisions which arctic explorers store away in some part of the icebound solitudes for future use. Sand has been found to be the best protection against their depredations, the stores of provisions being covered with this substance, and water poured on it until the whole is surrounded by a sufficiently thick, frozen covering. but also coffee, sails and the American flag, the only thing which they could not grapple being the chests, which were made entirely of iron. A Polar Bear, which was killed by McClure's men in one of the expeditions sent out to rescue Sir John Franklin, had his stomach stuffed with raisins, corned beef, tobacco and court-plaster, a repast which he could

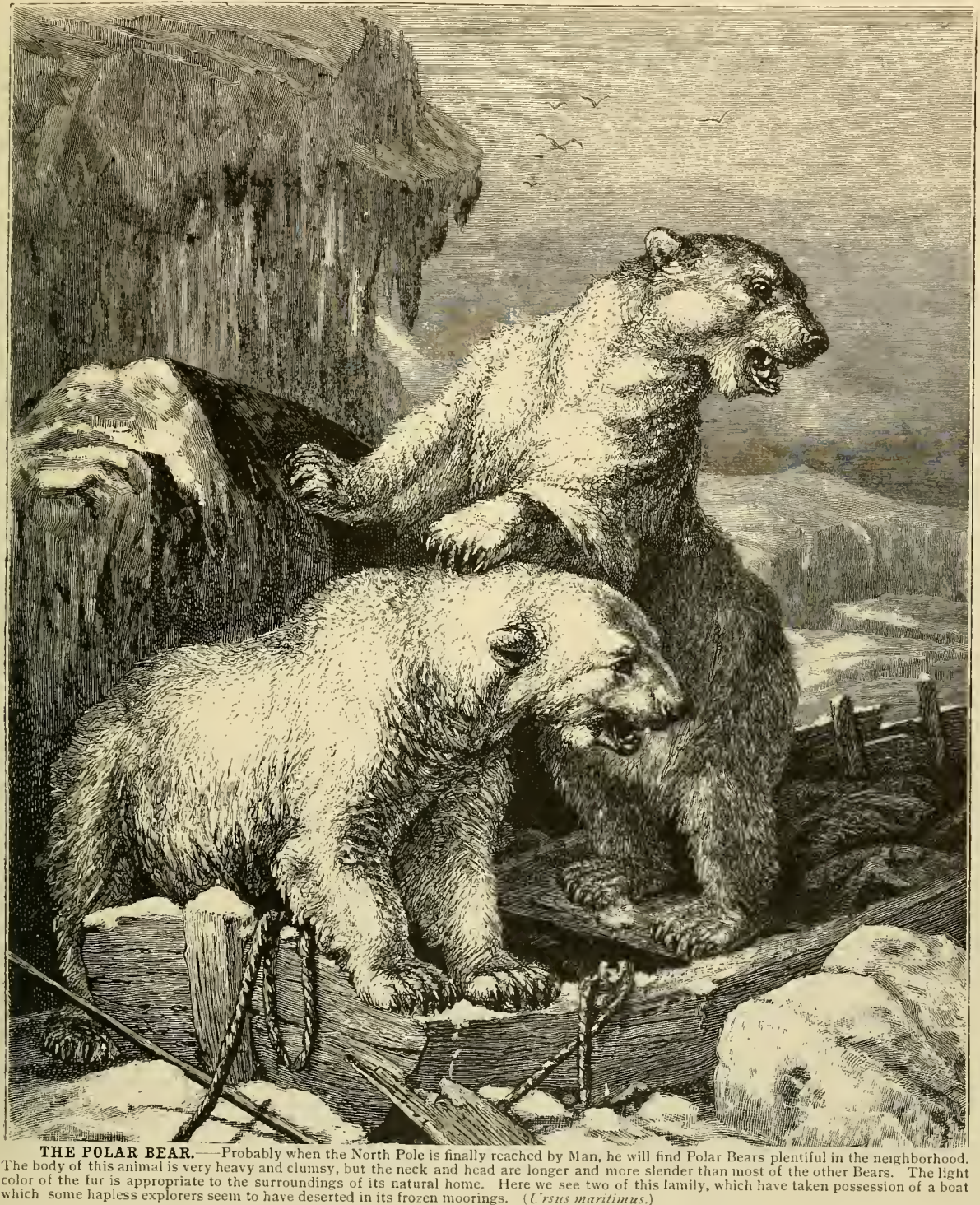

Wooden houses are broken into by the Bears, piles of stone, chests, barrels, etc,, are thrown down or broken to pieces, and then the animals proceed to devour every imaginable item of the contents, swallowing whatever they possibly can. Kane says that the plunderers not only ate his meat and biscuits, have only found in some devastated storehouse in the high north. German explorers had their measuring apparatus and climbing irons carried away by Polar Bears; and when they were away on a sleighing trip, the animals devoured their sugar and their candles, chewed up their rubber bottles and the 
tobacco-pouches, and pulled the cork out of the alcohol bottle; and an important diary had just received the first bites when the mischief was fortunately discovered and the Bears were driven away. Training and Polar Bears taken very young nuay be Taming Young tamed and trained to a certain degree. Polar Bears. They allow their owner to visit their cage, and may on occasions go to the length of romping around with him, but still captivity is never to their taste. Even in their native country they feel uncomfortable when housed, even during their earliest youth, and the greatest pleasure that can be given them is to allow them to roll in the snow and on the ice. In the spacious compartments provided with deep and wide tanks, such as zoological gardens nowadays construct for them, a Polar Bear may be tolerably content and play with companions for hours in the water, or even amuse himself with wooden blocks, balls and similar things. As his age advances he becomes irritable and violent. Toward others of his kind he is sulky and intractable where food is concerned, though a real fight seldom breaks out between two Bears of equal strength, the mutual anger usually venting itself in furious growling. With very good care it is possible to keep Polar Bears for several years.

The flesh and fat of the Polar Bear are much esteemed by all inhabitants of high latitudes. Even European sailors eat the meat, and, after it has been separated from the fat, do not find it unpalatable; but they assert that the flesh frequently disagrees with those who eat it. The liver is said to be especially harmful and some maintain that it is actually poisonous. The fur of the Polar Bear is foremost in vaiue among all Bear skins and brings a price of from fifty to one hundred and twenty-five dollars.

\section{THE SLOTH BEAR.}

The Labiated or Sloth Bear, called "Aswal" in India (Melursus labiatus), is quite different from the Bears proper, which we have so far considered, both in shape and habits, and forms a species by itself. It is distinguished by a short, thick body; short legs, rather large feet, whose toes are armed with immense scythe-shaped claws; an elongated, truncated snout, whose lips may, at will, be very much protruded, and long, shaggy hair, which forms a mane on the neck and falls low down on both sides. Ail these features combine to give the animal so peculiar an appearance as to entitle it to be ranked as a distinct species. How remarkable the animal must be is best seen from the fact that it was first described as the Ursine Sloth (Bradypus ursinus) and in one book was even styled "the Nameless Animal." In Europe the Sloth Bear first became known toward the end of the last century, and in the beginning of the present century the first living specimens were imported.

The length of the Labiated Bear, including the stump-like tail which measures from four to five inches, may be as much as seventy-two inches; his shoulder height is about thirty-four inches. The head is flat, the forehead wide and flat, and ends in a long, narrow, tapering snout, partaking of the proboscis in character and of very peculiar formation. The nostrils are very mobile, and the long extensible lips are still more so. Even when at rest they project to a considerable degree over the jaw, but when circumstances require it, they may be elongated, projected, folded and turned to such an extent as to form a kind of a tube, partaking of nearly all the qualities of a proboscis. The long, flat, narrow tongue, truncated at its extremity, helps to form and use this tube and in this way the animal is not only capable of seizing and drawing to itself alf kinds of objects but, so to speak, to suck them in. The remainder of the head is furnished with short, blunt, erect ears and small, slanting, nearly pig-like eyes. Very little of the head is seen, however, as even the greater part of the snout, which is grown with short hair, is covered by the strikingly long, bristly hair of the top of the head. This kind of fur also clothes the tail and some parts of the body, especially the neck, and is so long as to form a dense, shaggy mane. In the middle of the back the tangled mass of hair usually forms two large, puffy bumps, giving the Bear the appearance of being hump-backed. In this way the front part of the animal has a remarkably clumsy appearance, which is materially enlianced by the heavy, unwieldy body and the short, stout legs. Even the feet are peculiar and the exceedingly long, sharp, curved claws are decidedly remarkable and quite Sloth-like. The incisor teeth are usually lost very early in the animal's life and the jaw thereby gains an aspect which is difficult to describe. The color of the coarse hair is a brilliant black; the snout is gray or dingy white, and the breast shows a horseshoe-shaped white patch. Sometimes the toes also. have a light tinge. The claws are usually of a whitish, horny hue, and the soles are black. The young animals differ from the old ones by a slighter development of the mane on the head and shoulders, the ears therefore protruding and appearing relatively larger: and their claws are darker than those of the older animals. The snout is also usually of a yellowish-brown hue from the point to the forehead, and the horseshoe-shaped mark on the breast is yellowish white.

Habitat and The native country of the Sloth Bear Life of Sloth is India, from near the foot of the Bears. Himalayas to its southern extremity, and Ceylon. He delights in a hilly country, rich in jungles, and though he is much hunted, he is still one of the most common of the large animals of India, though in some parts he may be considered extinct. On Ccylon, according to Tennent, he hides in the densest forests, in the hilly country on the northern and southeastern coast, and he is found as rarely in higher mountains as in the damp valleys. In the region of Kurrachee he was so common during a prolonged drought that the women had to give up their beloved baths and ablutions in the rivers, bccause Bears crossed their way not only on land but in the water also, the latter often unintentionally, for they had fallen into the water while drinking and could not climb back on the shore on account of their clumsiness. During the hottest hours of the day this Bear lies in caverns, either natural or dug out by himself, preferably choosing those between rocks on the sloping sides of hills or in precipices. In spite of his thick, dark fur he is not very sensitive to heat. Usually he spends the hot day in a cool hiding-place, however, and goes forth at night, though he is also often seen in the morning and evening. His senses are not acute, with the exception of his smelling faculty. He hears and sees so badly that no great difficulties are presented in creeping quite close to him. He climbs fairly well in the rocks and is wont, after the fashion of other Bears, to roll head over heels down some steep declivity when frightened or when shot at. 


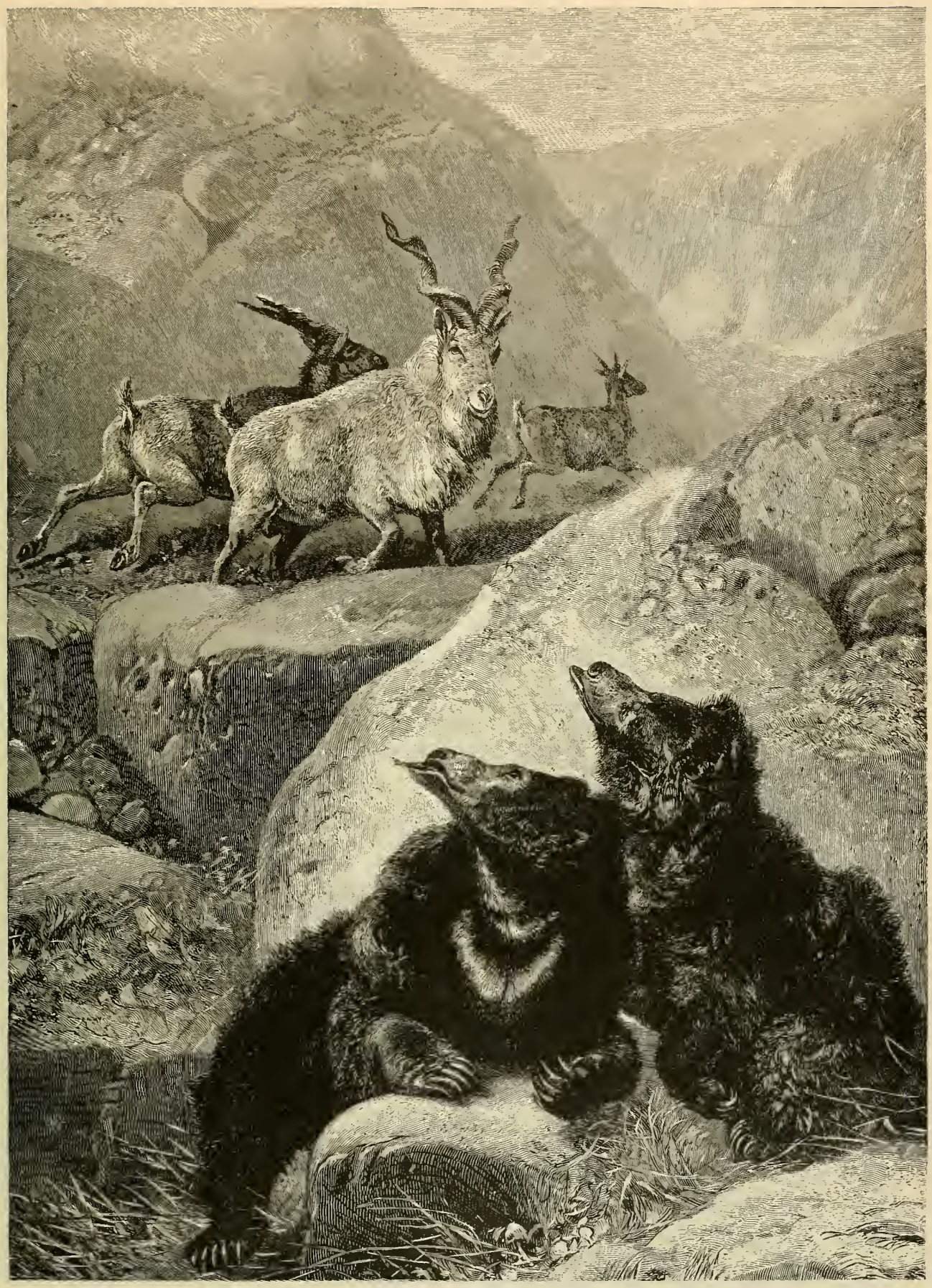

THE LABIATED OR SLOTH BEAR. - One of the most peculiar forms of the Bear family is this animal, which the artist has appropriately pictured in company with the wild Sheep of the Himalayan region. The long, flexible, protruding lip, which gives the animal its name of Labiated, or Lipped Bear, is the most striking feature of the animal, giving it a comical appearance. Its name of Sloth Bear comes from certain superficial resemblances to the Sloth including its long claws, and also because of its slow and clumsy movements. (Melursus labiatus.) 
The Sloth Bears' The food of the Sloth Bear consists Food and How almost exclusively of vegetable subThey Get $/ t$. stances and smaller animals, especially invertebrates, and he is said to eat eggs and small birds only occasionally. All naturalists agree in asserting that he never attacks larger animals with a view to eating them, except that Sanderson and McMlaster tell experiences where Bears had eaten part of a Stag which had been shot, and another time of an $O_{x}$ killed by a Tiger. Cubs reared in captivity willingly eat raw and cooked meat, however. Various roots and fruits of all kinds, the much prized pulpy buds of the Mohra tree or broad-leaved Bassia, Bees' nests, of which the combs and grubs taste as sweet as the honey to him, Caterpillars, Snails and Ants form his principal sustenance, and his long curved claws are of great service to him in searching for and digging out hidden roots or excavating Ant-hills. He even destroys the wonderfully built fastnesses of the White Ants and in such mammals, including Man, in the most cruel way, before eating them. He is said to hug his victims close with his arms and claws and then to break their limbs one after another deliberately and while constantly sucking them with his lips. As a rule he avoids Man; but his slowness not infrequently prevents his flight and then, either from fear or with the instinct of self-preservation, he assumes the offensive. His attacks become so dangerous under these circumstances that the Cingalese consider him the most terrible of animals. Sanderson writes: "Sloth Bears are not harmless to unarmed people. Wood cutters and other people who follow their rocation in the forest and the jungle often fare very badly in their encounters with these Bears. Like all wild animals they are most dangerous when surprised, for then, actuated by fright and fear, they may attack a Man."

The animal is hunted in various ways. His trail is easily recognized in the morning in the dewy grass

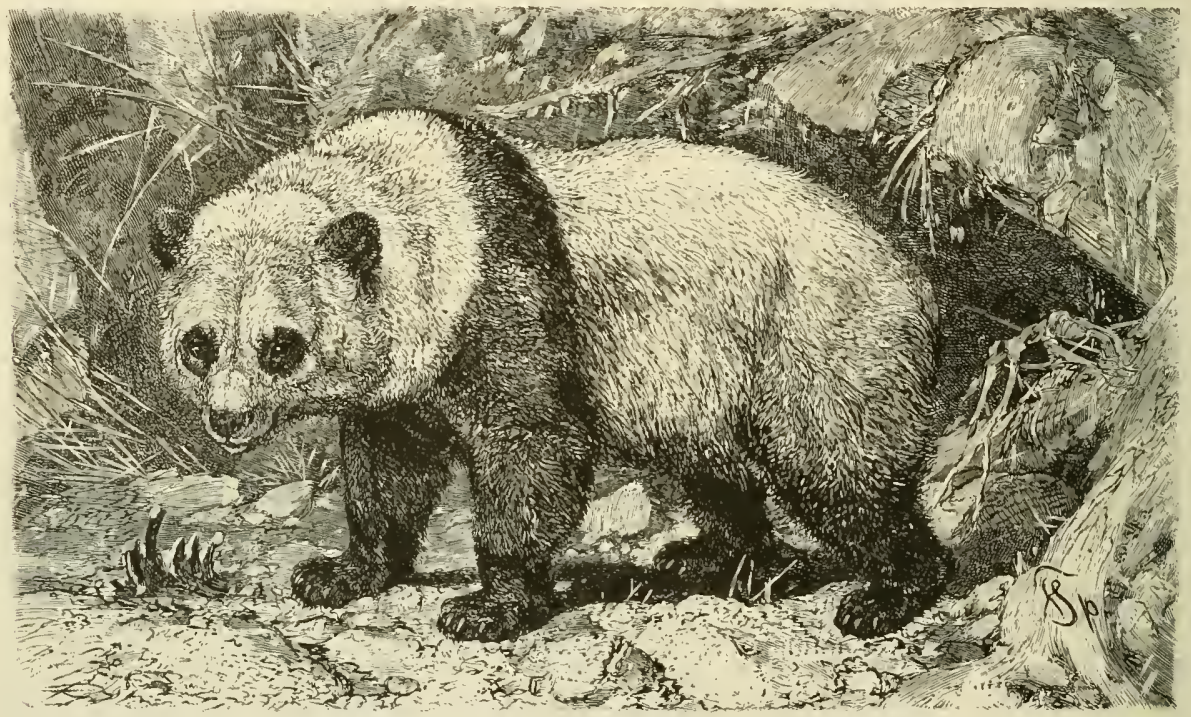

THE AILUROPUS, - This is a very rare animal which was first discovered by Pere David 1 in 860 in eastern Tibet. It has a clums body with very long fur and yery short tail. The fur is for the greater part white, but the black markings are peculiar, the ears, a ring around the eyes and the limbs being black, and a wide strip extending from the front legs up to the shoulders is also black. It is said to feed princi-

a case plays sad havoc among the young brood. Sanderson also relates that in some localities the Aswals visit the groves of wild date-trees, where palm-wine is manufactured. They climb the trunks of the trees, which are from eighteen to twenty-four feet high, up to the very tops, upon which are hung the vessels which catch the outflowing juice; thcy tilt the filled vessels with their paws until they can drink the contents. A few quarts of the liquid might not be begrudged them if they did not break so many vessels while making their clumsy thefts. People who sustain the loss say that the thieves do not go to the trouble of climbing down, but simply let themselves fall to the ground, and further state that they often get fairly intoxicated with the wine.

sloth Bears Tennent's communications concern-

Sometimes Very ing the habits of the Sloth Bear are

Dangerous. not absolutely confirmed by recent accounts. In Easi India the Bear is said to torment and shrubs, and may be readily followed, or one may find his den, and there await his return from his nocturnal prowlings; or may systematically search a stretch of jungle where Bears are sure or likcly to be found, and shoot them when they are driven out into the open ground.

Captive Sloth The Sloth Bear has been repeatedly

Bears Become observed in captivity, in India as well

Very Docile, as in Europe. In his native country his docility is utilized by mountebanks and jugglers, and like Bruin he is trained to perform all linds of tricks. He is kept on milk, bread, fruit and meat, and usually comes to the conclusion that he decidedly prefers bread and fruit to other food. Curled up like a sleeping Dog he rolls from one side to the other, jumps around, turns somersaults, walks erect and makes the queerest faces when food is offered him. He also impresses one as being comparatively good-natured, familiar and honest. 


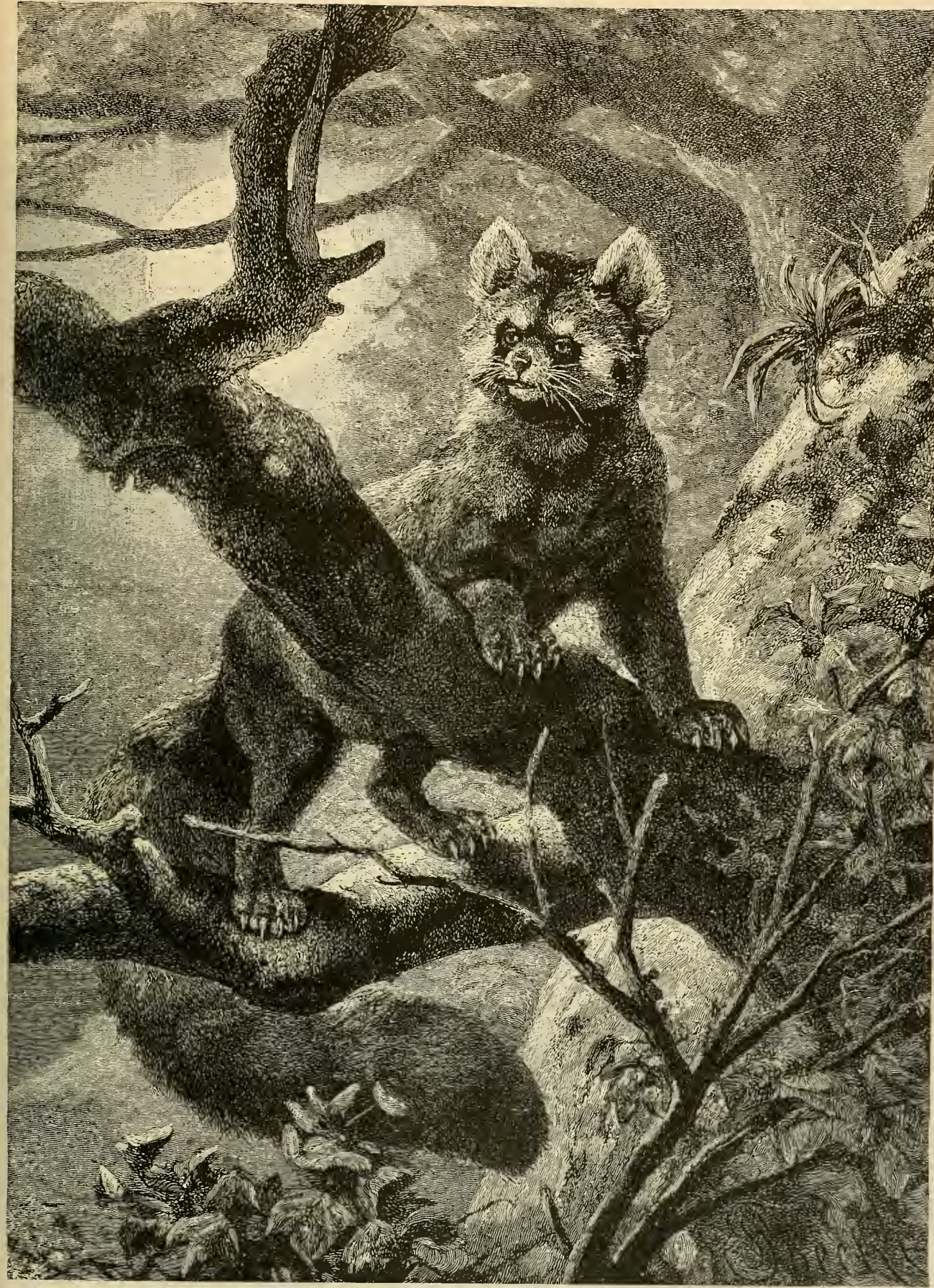

THE PANDA. Here is an anina!, found in the Himalaya region of Asin which well deserrud be classed as a body and stout limbs are Bear-like, while its short, broad face, its whisker hairs and its large, erect, pointed ears reunind one of a Cat. It has a bushy tail nearly as long as its body. It is appropriately pictured in the forest, for it lives much in trees, and feeds principally on fruits and other vegetable substances 


\section{CAT-LIKE BEARS.}

Three remarkable animals of southern Asia constitute the second suborder of the Bears, whose members we will call Cat-like Bears (Ailurino). They are a transitional form between the Large Bears and the Civets and are distinguished by their somewhat Catlike paws, the soles of which are covered with hair and have claws that are slightly retractile.

The Ailuropus The first place in this suborder of the Tibetan belongs to the Ailuropus (Ailuropus Forests. melanoleucus), which was discovered by David about twenty years ago, and which on the one hand resembles the Large Bears, on the other the Panda. He is of smaller size than the common Brown Bear, measuring about sixty inches from the tip of his snout to the end of his tail. His feet, which have hairy soles, are wide and short and he does not walk on the entire sole. The snout is short, and the head proportionately broader than that of any other Beast of Prey. His fur is dense, Bear-like and of a uniform white color, with the exceptions that a ring around the eyes, the ears, the front legs, and a band extending from them up to the shoulder, the hind feet and the tip of the tail, are black.

Next to nothing is known about his life in the wild state. He inhabits the most inaccessible mountainous forests of eastern Tibet.

The Panda, or The representative of the second

Red Cat-like species of this suborder, the Panda Bear. or Red Cat-like Bear (Ailumis ful$g e n s)$, in a certain way holds the middle position between the Ailuropus and the Binturong. On account of his thick, soft fur, his body appears clumsier than it is; the head is covered with long hair and is very broad and short, and the snout likewise. The long tail is pendent and bushy, having the appearance of being very thick; the cars are small and rounded; the eyes arc small; the short legs are furnished with soles thickly covered with hair, and the walk is semi-plantigrade; the toes are short and the claws are strongly curved. The size of the Panda is about that of a large Tom-cat. The fur is dense and long, of a vivid and lustrous dark red on the upper surface, with a light golden tinge on the back, where the hairs are tipped with yellow; the under surface and the legs are lustrous black, with the exception of a dark chestnut transverse band on the front and sides; the tail is of a Foxy red, indistinctly ringed with narrow bands of a lighter hue.

The Panda is a native of the southeastern parts of the Himalayas, where it is found at an elevation of from six thousand to twelve thousand feet. Little is known about the life in the wild state of this beautiful, dainty creature. It lives in the woods either in couples or in families, mounts on the trees, and makes its home in their hollows or in elefts of rocks; it spends much time on the ground in its search for food. It is an almost exclusivcly vegetable feeder, but is also said occasionally to plunder nests and eat insects.

The Binturong, $a$ The last species of the suborder is Southern Asiatic the Binturong (Arctitis binturong). Species. He exceeds the Panda in size; his length is from fifty-four to sixty inches, nearly half of this length being taken up by the very long, prehensile tail. The body is stout, the head thick, the snout elongated; the legs short and thick, the soles are naked, five-toed, armed with tolerably strong, somewhat retractile claws. The body is clothed in a thick, rather rough, loose fur. The ears are short, rounded and surmounted by tufts. Thick, white whisker-hairs on both sides of the snout surround the face as with a halo. The color is a dead black, merging into a grayish tinge on the head and into a brownish shade on the limbs.

The Binturong is a native of Borneo, Java, Sumatra, the Malayan P'eninsula, Tenasserim, Aracan, Assam and siam. Its life in the wild state is also very little known. It is nocturnal in habits, leading a principally arboreal life, and is slow in its motions. It is onnivorous, disdaining neither small mammals, birds, fish. worms, and insects, nor fruit and other vegetable food. Living as it does in lonely forests and hidden from view, it is seldom seen; its voice is said to find utterance in a loud howl. Though wild and fierce in disposition, it soon becomes tame when taken young and is as gentle as it is playful.

\section{THE SMALL BEARS.}

In the third suborder we consider the Small Bears, animals of a moderate size, which are confined to America.

General Fea- The Raccoons (Procyon) are distintures of the guished by the following features. Raccoons. The body is thick-set, the head widens considerably in its posterior part, the snout is short; the large eyes are close together, the large, rounded ears lie quite close to the side of the head; the legs are relatively long and thin; the feet have naked soles and slender toes of medium size; the nails are rather strong and compressed from both sides; the tail is long and the fur consists of rich, long, straight hair.

The Raccoon The Raccoon (Procyon lotor) attains

Proper De- a length of twenty-six inches exclu-

scribed. sive of the tail, which is ten inches long; the height at the shoulders is from twelve to fourteen inches. The fur is yellowish gray with an admixture of black. The fore-legs, a tuft near the ears (which is surrounded by a brownish black patch behind the ears), the sides of the snout, and the chin, have a light yellowish-gray tint. Brownish black stripes run from the forehead to the tip of the nose and around the eyes; yellowish white bands run above the eyes to the temples. The fore and hinder paws are of a brownish yellow-gray tint, while the long hair of the lower half of the limbs takes a deep dark brown tinge. The grayish-yellow tail is ringed with brownish black and ends in a tip of dark brown. No one of these colors contrasts boldly with the others, and so the general coloring, regarded from even a slight distance, becomes of a gray hue, difficult to determine and describe, and harmonizing as marvelously with the color of treebark as with that of the ground, whether grown with fresh or dry grass.

The Raccoon is The Raccoon is indigenous to North a Native America, occurring in the south as American. well as in the north. Nowadays the number of the Raccoons has been greatly reduccd in the more populous districts, in consequence of the relentless pursuit the animals have been compelled to undergo; but they are not quite exterminated cven in thickly settled localities. In the interior of the continent, especially in the wooded regions, they are still numerous. The favorite haunts of the Raccoon are forests bordering on rivers, lakes or small streams. As a rule the Raccoon is wont to go forth on his hunt at dusk only, and sleep during the bright, sunshiny day in hollow trees or on 


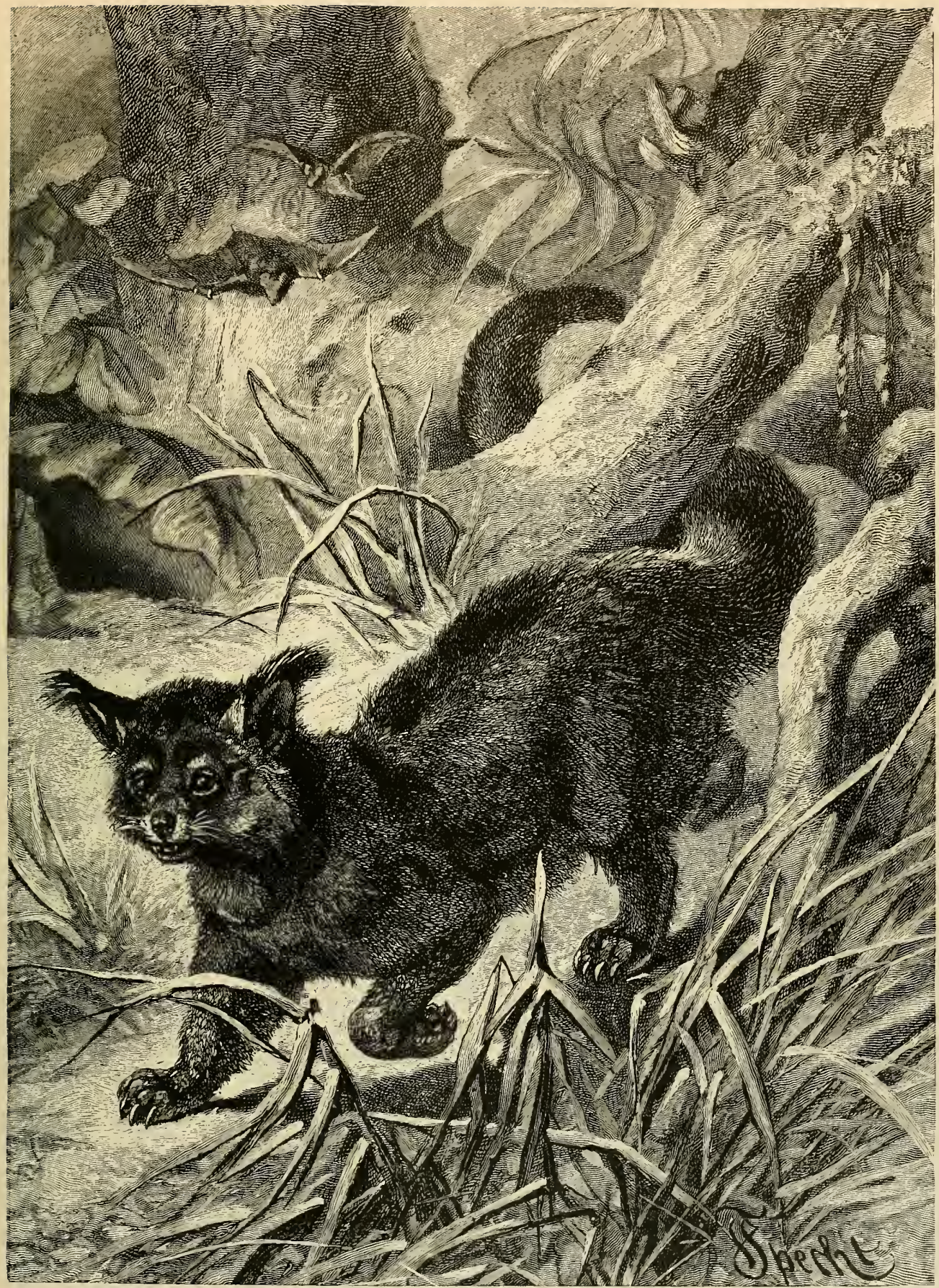

THE BINTURONG. This is an animal of such differing characteristics that it is difficult to classify, It has ear-tufts like a Lynx, its claws are partly retractile like those of a Cat, it has a prehensile tail like some of the American Monkeys, has nuch in its structure that reninds one of the Civet famnly, with which it is placed by some naturalists, but is somewhat clumsy and slow, and has many traits of the Bear family, with which it is generally classed. It is appropriately pictured in a tropical forest, for it is an arboreal animal and is found in southeastern Asia and on the Mlalay Islands. (Arctictzs binturong) 
thick leaf-covered boughs; but in localities where he is entirely undisturbed, he has no particular time of day for hunting but promenades through his vast domain by day as well as by night.

some Notable He is a cheerful, handsome fellow

Traits of the and amusing because of his great Raccoon. activity and liveliness. When he saunters along undisturbed, he lets his head sink, arches his back, permits his tail to droop, and slinks on his way rather slowly and with a sidelong movement; but as soon as he has made a discovery worthy of arousing his interest, as for instance when he finds the trail of a harmless animal, or perceives the animal itself, his demeanor changes entirely. Then the rough fur becomes smooth, he pricks up his wide ears to listen, stands erect on his hind legs, and follows at an agile pace, jumping and running, and he climbs with an agility for which one would scarcely have given him credit, not only on slanting and perpendicular trunks, but also on horizontal branches, with his body upward or downward. Frequently one sees him running on a horizontal branch, like a Sloth or a Monkey, his body hanging downward. He often leaps from one branch to another with unfailing security, and displays a mastery far above ordinary skill in the art of climbing. On level ground he is also thoroughly at home and knows how to procecd at a great pace by executing jumps in which he alights upon all four paws at once. His mental qualities are somewhat Monkey-like. He is chcerful, lively, inquisitive, mischievous and prone to play merry tricks, but is also courageous, and, when necessity demands it, cunning as a Fox in catching his prey. He lives on excellent terms with his own kind and even in old age he plays for hours with like-minded companions, or in captivity with any animal that is moved to play with him.

Raccoons Live on The 'Coon [for so he is familiarly'

Varied Kinds called] eats anything edible, but of food. seems to be rather fastidious, selecting the choicest morsels wherever he can do so. Fruit of all kinds, chestnuts, wild grapes, and sweet corn while the ears are still soft, are articles of diet highly esteemed by him; but he also preys upon birds and their nests, knows how to slyly circumvent a Chicken or a Pigeon, is a master in finding the most carefully hidden nest, and then delights in the eggs, which he knows how to open and empty with marvelous agility, without losing a drop of their contents. Not infrequently he enters gardens or houses with the sole intention of stealing Chickens, or devastating llen's nests, and therefore docs not enjoy a very high place in the favor of farmers. He even levies tribute on the water, for he very adroitly catches fish and Crabs, and during low tide he often travels far out into the sea in search of this favorite dainty. He seems to be extremely partial to the stout grubs of some Beetles and displays great shill in the capture of Grasshoppers. He possesses the peculiarity of dipping his food into the water and then rubbing it between his forepaws, as if to wash it. He does this only when he is not very hungry, however; for, when luunger presses, the demands of his stomach probably leave him no time for the much liked, playful occupation, which has caused the Germans to name him, "WVash-Bear."

The little Raccoons make their appearance in May. They are from four to six in number to the litter and very small. The mother, with considerable carc, prepares a nursery for them in a hollow tree.
Raccoon Hunt- The Raccoon is pursued not only on ing a Favorite account of his fur, but he is also American Sport. killed for mere sport. If one has only his fur in view, he is easily caught in iron and other traps, baited with a fish or a little piece of meat. The lunt is less simple. Americans are passionately fond of this sport. The Raccoon is not hunted by day but by night, with Dogs and torchlights. When the Raccoon leaves his solitary den and glides through the underbrush with low, noiseless steps, and the forest is buried in stillness, the hunters and Dogs set out. A good, experienced Dog finds the trail and the whole pack rushes after the flecing, agile 'Coon, which finally mounts a tree with Monkey-like quickness and tries to hide among the darkest branches. The Dogs surround the foot of the tree, barking and howling, while the pursued animal lies cuddled far up in the branches comfortably at rest, cnveloped by the darkness of night. Then the sportsmen come nigh. The torches are thrown in a heap, dry wood and pine-cones are gathered, and suddenly an immense fire blazes up under the tree, shedding a magic light on the surroundings. Some good climber then mounts the tree, and undertakes the office of the Dogs among the branches. The Man and the Monkey-like Bear race with each other on the tree, till the Coon goes forth on a wavering branch in the hope of reaching another tree in this way. His pursuer follows him as far as he can, and suddenly begins to shake the branch with all his might. Then the poor Raccoon must hold fast, or he will fall to the ground. But all efforts are of no avail. The enemy advances nearer and nearer, the animal's efforts to hold on become more and more strenuous and then he grasps a brittle branch and tumbles down. The Dogs greet his downfall with joyous barks and the chase is rencwed with fresh vigor. The Raccoon tries to escape the Dogs by climbing other trees, but he is doomed to become the prey of his four-footed encmies at last, and their bites end his life.

Raccoons May A Raccoon taken young usually beBecome Very comes tame in a very short time. Tame. His familiarity, cheerful disposition and peculiar restlessness, his never ceasing enjoyment of moving about, and his amusing, Monkeylike temper, render him an agreeable pet. He enjoys being petted very much, but never shows great attachment to any person. He is always ready for play and pranks and testifies his contentment by a little growl, just as Puppies are wont to do. His demeanor reminds one of a Monkey in every respect. He is always busy with something and pays a great deal of attention to all that is going on around him. He causes much mischief on his walks around the louse and yard. He investigates and tastes everything, in the pantry as well as in the yard and garden.

L. Beckmann's "Foremost among the qualities of the
Account of 'Coon," says L. Bechmann, "are his

the Raccoon. unlimited inquisitiveness and greed, his obstinacy, and his tendency to search all nooks and corners. In sharp contrast to these qualities, he also possesses coolness, self-restraint and a marked sense of humor. These contending instincts, naturally, often bring about the quecrest results. As soon as he realizes the impossibility of attaining any special object he has been striving for, the fiercest curiosity immediately gives place to an apathetic indifference, and obstinate perseverance changes into resignation. On the other hand he 


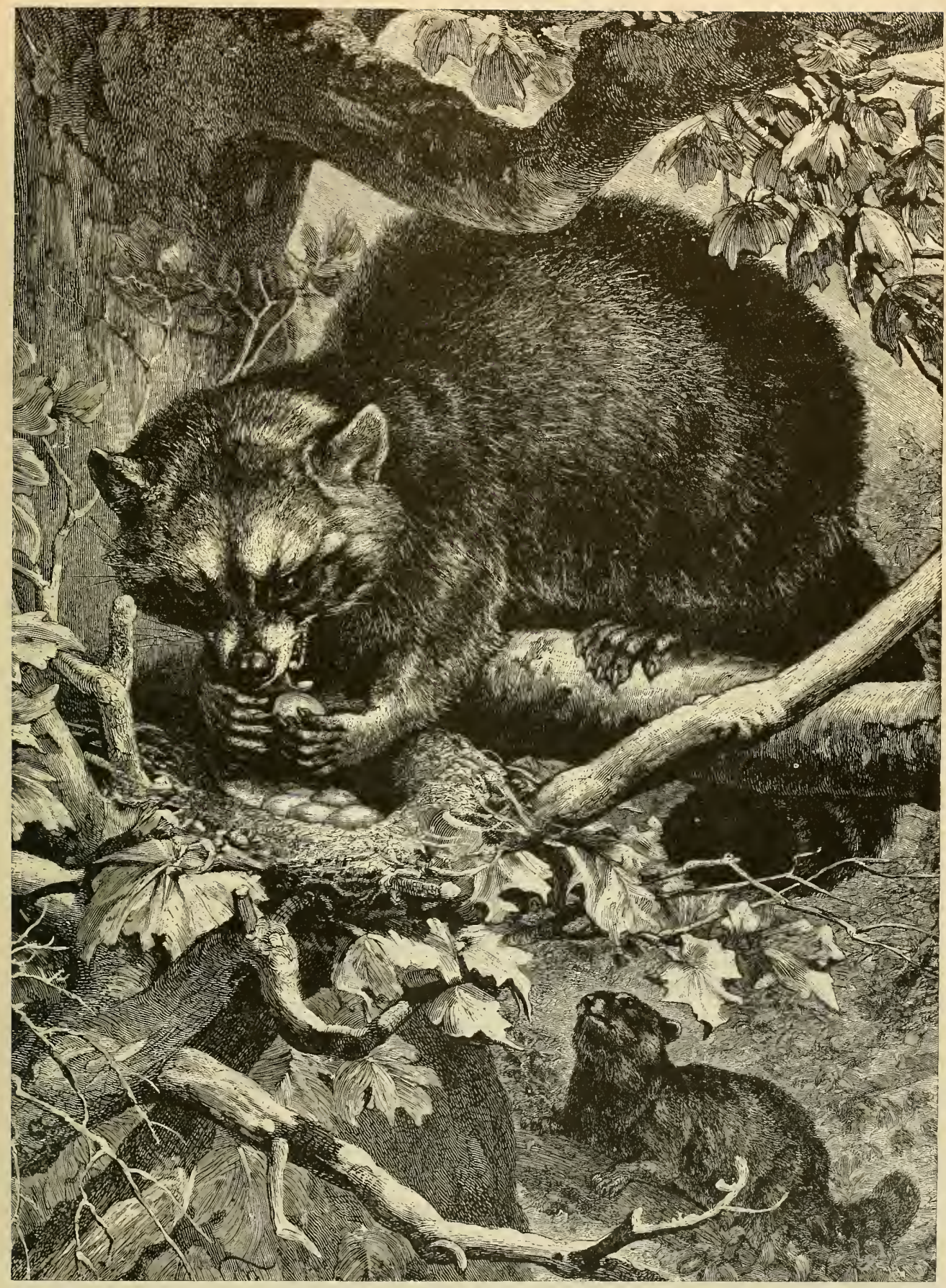

THE RACCOON,- Our American representative of the Small Bears, the famous 'Coon, is very fond of eggs, and many a bird's nest is levied on for these dainties by this sly, keen animal. The Raccoon in the picture has found a feast of this kind, and the little one beneatl, too small to forage for himself, is looking on enviously while his mother is enjoying her delicate repast. (Procyon lotor.) 
often passes quite unexpectedly from lazy sulkiness into the best of spirits by turning a somersault; and in spite of all his self-restraint and sagacity he commits the silliest blunders when once his desires have been aroused.

"In the numerous leisurc hours which fall to the lot of every captive Raccoon, he occupies himself with a thousand things for his amusement. He will either sit erect in a lonely corner and with the utmost gravity try to tie a grass-blade around his nose; or he will play meditatively with the toes of his hind foot, or make dashes at the wagging tip of his long tail. At other times he will lie on his back, pack a large heap of hay or dry leaves on his stomach and try to compress the whole pile by drawing his tail over it with his fore-paws. If lie

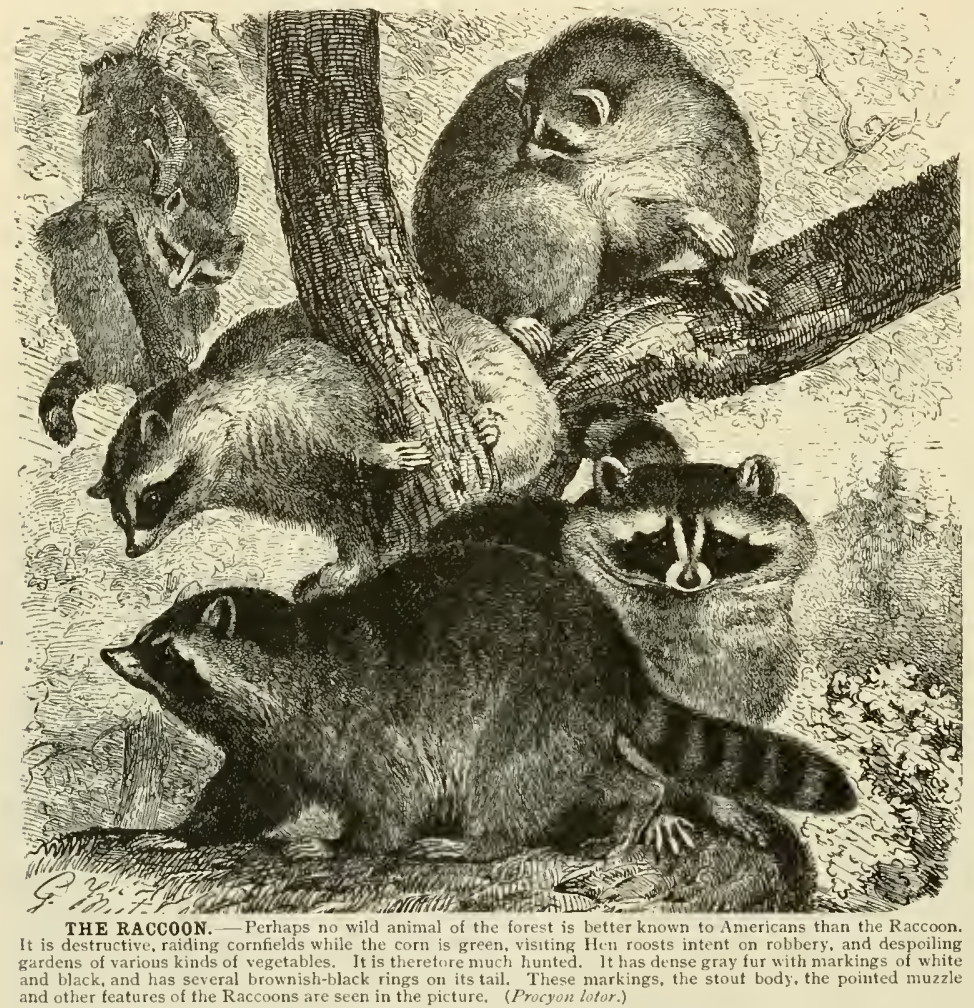

steps into the water with evident delight and gropes on the ground for some washable object. An old pot handle, a piece of porcelain or a snail's shell are welcome finds and are immediately put into use.

"One Raccoon had entered into a covenant with a large Setter. He liked to be coupled with the Dog and then they both followed every step of their owner, while, on the other hand, when the Raccoon alone was led with a rope, he would always try to go his own way. As soon as he was freed from his chain in the morning, he hurried to join his friend with joyous bounds. Standing on his hind feet, he hugged the Dog's neck with his flexible paws, and caressingly put his head close to his companion, and then touched and looked at the body of his fourfooted friend curiously from all sides. It seemed that every morning he detected and admired new beauties in it. If there were any flaws in the hairy covering, he immediately tried to remedy them by licking and stroking the Dog's fur.

He did not care to have any dealings with the small, biting Dachshunds; yet he occasionally tried to embrace one of the crooked-legged creatures from above. If he succeeded in doing this, he would execute a high, backward leap into the air in his delight, try ing to bite his dangling, curled tail between his parted fore-paws, while still in the air.

"He attacked smaller mammals and poultry of all kinds, and it was extremely difficult to make him surrender his victims. Mice, Rats and other such animals he killed with a bite in the neck and ate them skin and all, as he could only partially succeed in skinning them, in spite of all his worrying and pulling."

A Raccoon killed in the chase is fairly profitable game. His flesh is eaten not only by lndians and can reach a stone wall, he scratches the mortar out of the joints with his sharp claws and in a short time causes a sad devastation. Like Jeremiah on the ruins of Jerusalem, he then crouches in the midst of his mound of rubbish, casts grim glances at the surroundings and loosens his collar with his fore-paws, exhausted by the hard labor.

" After a prolonged drought, the sight of a tub filled with water rouses his enthusiasm, and he tries every means of approaching it. Then the first step he takes is to investigate the depth of the water, for he only likes to dip his feet into it in order to wash various objects in it in play, and he decidedly disapproves of standing in the water up to his neck. If the investigation proves satisfactory he
Negroes but also by some white people, and his fur is extensively used: Raccoon fur being popular for clothing. The long hair makes good painters' brushes, the woolly fur is used in the manufacture of hats, and the tails are used entire as boas. Raccoon De- family is the Crab-eating Raccoon or scribed. Aguara (Procyon cancriononis). which represents the genus in South America, where it is principally found on the castern coasts. It is a little taller than its relative, is of a grayish-black or yellowish-gray hue, which is lighter on the under than the upper surface, and the tail is bushy and marked with yellowish rings. The face is dark, and over the eyes there is a light patch.
The Crab-Eating Another member of the Raccoon 
The Coatis and The Coatis (Nasur) naturally follow Their Long the Raccoon and its companion. Noses. They are easily recognized by their long, slender, nearly Weasel-fike body, their short neck and long, pointed head, their tail which equals over the mouth, and has sharp and upturned edges. The ears are short and rounded, the eyes of medium size, and the five toes are united and armed with long and slightly curved claws. The teeth resemble those of the Raccoon, but are more slender.

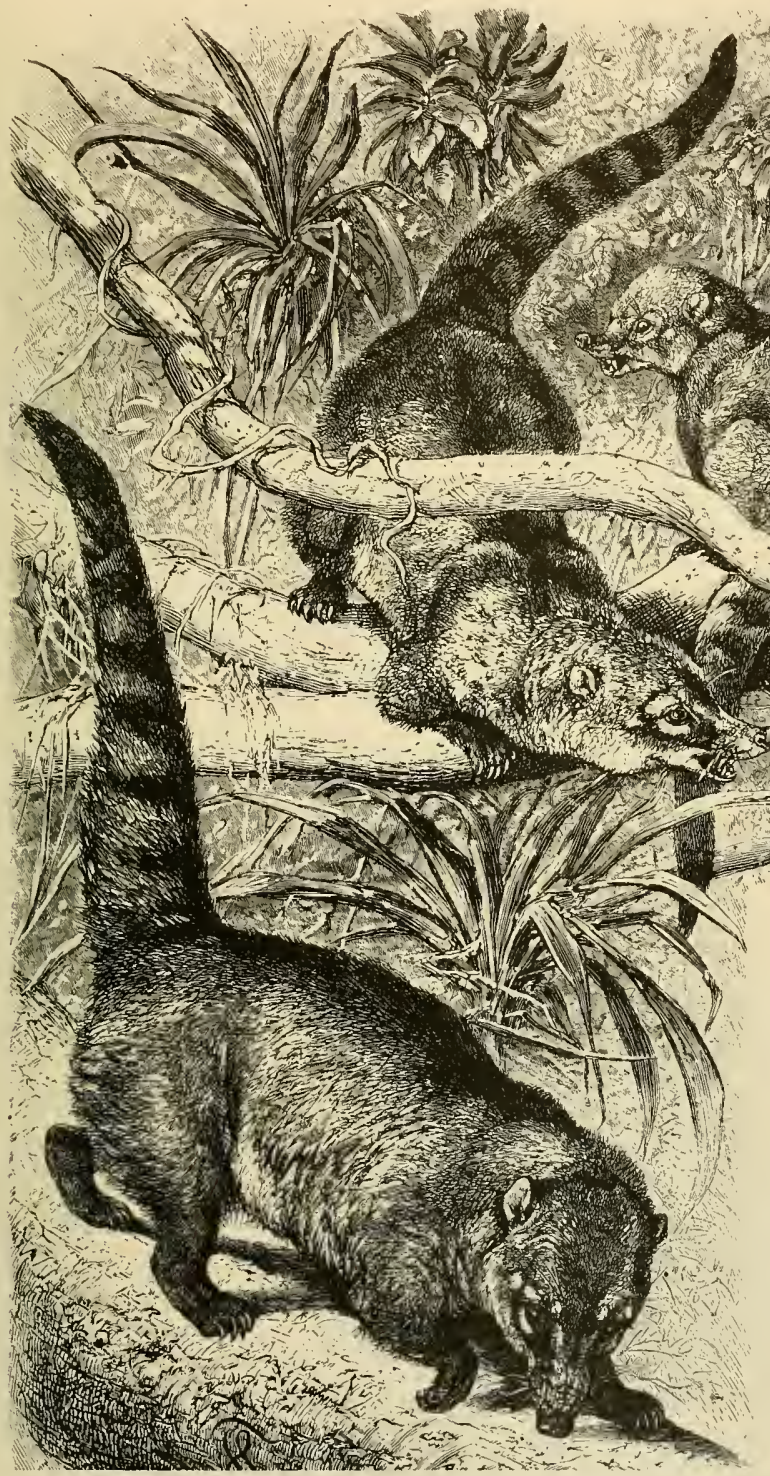

THE COATI_- In South America there is an animal resembling a Raccoon in man A nose. This is the Coati, of which a group is here depicted. They are arboreal in their habits and are appropriately shown disporting themselves on trees, and their method of hescending from the tree head first is also portrayed. (

the body in length and is thickly grown with hair, and their short, vigorous legs, furnished with broad paws and naked soles. Their most prominent feature is the nose, which projects, proboscis-like, far eighteen of which go to the tail. The height at the shoulders is eleven or twelve inches. The thick, long, though not shaggy fur consists of wiry, coarse, lustrous hair, longer on the tail than on the body, and a short, soft, slightly curly, woolly 
inner fur, which is especially densc on the sides and back. The ground color varies on the back between red and grayish brown, and merges into a yellowish tinge on the under surface. The forehead and top of the head are yellowish gray, the lips are white, the ears brownish black behind and grayish yellow in front. A round, white spot is placed above each eye, another on the outer corners of the eyelids, and two, which sometimes merge into one, stand under the eyes; a white band runs down along the root of the nose. The tail is ringed alternately with brownish yellow and brownish black

Description of Hensel considers the Narica ( Nitsue the Narica, a narica) of Central America an enDistinct Species. tirely distinct species. It is about the same size as the Coati and the general coloring also recalls the latter. The upper surface of the fur is more or less dark, according to whether the light or dark hue of the hair-tips prevails in the individual animal. A ring around the eye, a band commencing over the eye and running toward the tip of the nose, and the front part of the snout above and below, are yellowish white; the throat and sides of the neck are slightly darker, the rest of the under surface brownish, the feet of a pronounced brown.

The Coatis in Ve are indebted to Azara, Hensel, His Wild Rengger and Prince von IVied for State. detailed descriptions of the Coati as it is seen in the wild state.

The Coati," says Hensel, "is so common in Brazil that I was enabled to purchase as many" as two hundred skulls. Comparison of these skulls and observation of the Coati in the wilderness lead me to the conclusion that the old males, which have becn considered a distinct species, lead a solitary life. At a certain age they leave the troop of which they have so far been members in conpany with the females, and after that they return to the troop only during the breeding season. Solitary females are scarcely ever seen; and if a single one be occasionally found, it has probably been driven away from the troop by hunters, or the troop has been quite near but has remained unnoticed by the sportsman. The Coatis are diurnal aninals. They rest at night and display an incessant activity from morning till evening. During the day they seem to be perpetually wandering, leaving no place accessible to them unsearched. Their food undoubtedly consists of everything edible in the animal and vegetable world. They also like to enter plantations to plunder the maize fields, especially while the grains are still tender."

The Daily
Life of the their prey; and they seem to regard
Coati. Snails as dainties. When they have scented a worm in the ground or a grub in some rotten wood, they take the greatest pains to possess themselves of this prey; they eagerly dig with their forepaws, put their nose into the excavated hole from time to time and sniff, like Dogs which hunt for Mice in the field, until they have attained their object. The morning is spent noisily in whistling, digging and rooting, climbing and quarreling. When it begins to get hot in the forest, the troop looks out for a suitable place for a map. A well-placed tree or a convenient bush is picked out and each comfortably stretches itself on a branch and takes its ease in sleep. In the afternoon the wandering is resumed, until the task of finding a good sleepingplace at night interrupts it. If Coatis notice a foe, they immediately apprize their companions of it by loud, whistling sounds, and hurriedly climb a tree: all others follow this example and in a minute the whole troop is distributed on the branches at the top. If one ascends after them or only gives the trunk a sound blow with an axe, they go out farther on the branches, jump to the ground and run away. If they are undisturbed, they descend from the tree head first. They turn their hind-paws outward and backward and hold fast with them to the trunk. On branches they proceed cautiously and do not dare to take leaps, as Monkeys do, for instance, from one tree to another, though they could do so if they would try, for their agility is scarcely inferior to that of the Monkeys or Cats. On the level ground they are much clumsier than in the branches of a tree. They either walk, holding their tails vertically upward, or jump in short bounds, always touching the ground with but one half of their soles. It is only when standing or sitting on their haunches that they step on the entire sole. Their running gait looks awkward, but consists really of a gallop, in which much ground is quickly covered. Ther seem to fear the water and enter it only when hard pressed; yet they are sufficiently good swimmers to cross rivers and streams.

Of their senses, that of smell is undoubtedly the most acute; the one next in keenness is the sense of hearing, while sight, taste and touch are relatively weak. At night they do not see, and even by day light their sight is not very keen, and sensibility in the animal seems to be nearly confined to the proboscis-like nose, which is also the principal organ of touch.

According to Rengger the young Coatis make their appearance in October, from three to five in number, in a hollow in a tree or in the ground, a ditch grown with thick bushes, or some other secluded nook. Here the young are kept hidden until they can follow the mother on all her prowlings.

\section{How}

Coatis and Dexico hunt the Coati prinroods with a pacter At sight of the Dogs, the Coatis flee, screaming, to the nearest trees and are shot. It requires a wellaimed shot, if one wishes to get then into one's possession; for those which are wounded lie down on an embranchment and can only be dislodged with much effort. A single Dog cannot cope with this animal. The Coat is which live solitary know especially well how to use their teeth to good purpose, turning courageously on any Dog which may happen to be near, screaming fiercely and biting viciously. The victory is dearly bought, at any rate, for the Coati sometimes incapacitates five or six Dogs before yielding to superior power. The flesh is liked not only by natives, but also by Europeans.

How the Coati In captivity, the Coati becomes at-
Acts in Cap- tached to people, although it never
tivity.
shows any particular preference for its kecper, however tame it may be. It plays with everybody; Monkey-fashion, and also with its animal companions, such as Dogs, Cats, Chickens and Ducks. It is unsafe, however, to disturb it when it eats, for even the most domesticated Coati will bite men or beasts if they try to take its food away. Independent or even fierce traits enter into the composition of its character. It by no means submits to the will of Man, but becomes furious when compelled to obey. Not even blows are of much 
avail, for it courageously resists and bites those who punislı it, be it the keeper or anybody else.

Not much docility can be expected of so irritable and intractable a creature. It is hardly possible to train it for anything. Rengger saw one which stood on its hind legs, like a Poodle, at the command of did the one in Paris. This enigmatical creature was a Kinkajou, an animal really nearly unknown at the time. Sone believed it to be a Lemur; others, considering the teeth, which were entirely different from those of the Half-Monkeys, classed it with the Civets, and called it the Nexican Weasel; but the pre-

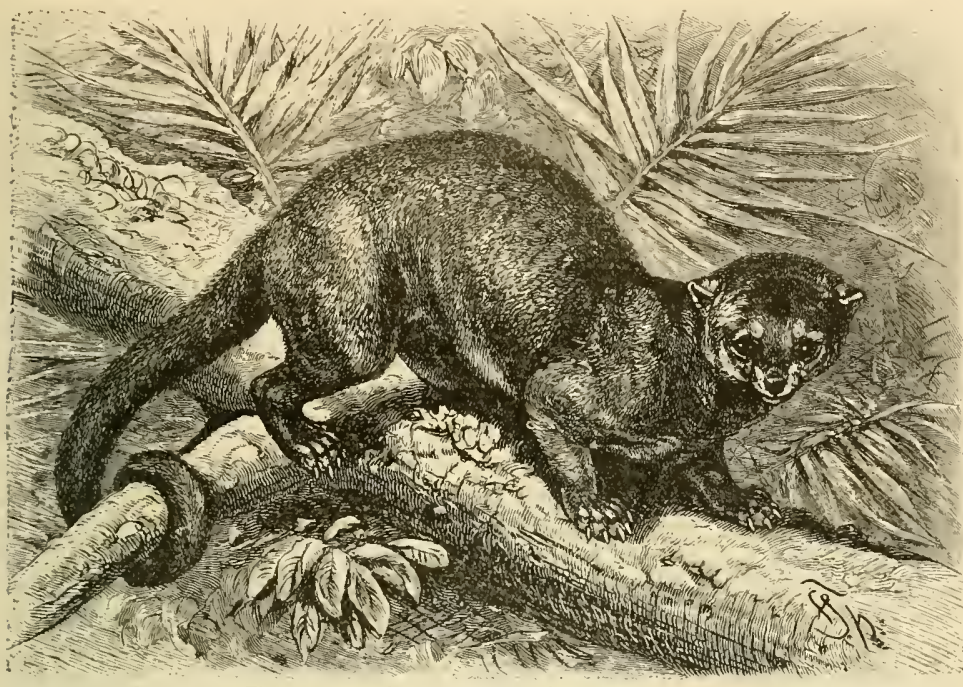

THE KINKAJOU.

scientific world it was classed with the Lemurs, then with the Civets, but is now put with the Bear family, to which it is allied by its anatomical structure, its teeth, jts food and its plantigrade walk. It has a short, Cat-like head, and a tail which is prehensile like the Monkeys, which are its neighbors, for its bome is in South America, although it has been found as far north as Louisiana. (Corcoleptes caudivoliulus.

its master, and shammed death at the report of a gun, but such docile individuals are exceptions to the rule.

If allowed the freedom of the house, the Coati makes itself extremely disagreeable. It digs up or upsets everything with its nose. It is possessed of much strength in this member and of a good deal of agility in its forepaws, and makes good use of both. It leaves nothing untouched. If it can get hold of a book, it turns all the leaves, using its two fore-paws alternately with remarkable rapidity. If it is given a cigar it unrolls it completely by a like movement. If a standing object attracts its attention, it gives it a blow first with the right paw, then with the left, until the object falls down.

The Kinkajou a Som e tim e VeryPeculiar ago the posAnimal. sessor of a zoological garden in Paris had the right to claim that he showed the world an animal as yet unknown to naturalists, and which he had received from America. This happened toward the end of the last century, and another specimen came to London at the same time, interesting the naturalists there as intensely as hensile tail did not fit into this category and the teeth also differed markedly, distinguished as they were by blunt grinders, adapted for a mixed diet. At last it was placed among the Bears, together with several other animals as peculiar as itself.

The Kinkajou, Manaviri or Cuchumbi, as the animal is called in its native country, northern Brazil (Cercoleptes caudivolvulus), seems to be a transitional form between Bear and Civet. The body is very long, but clumsy, and rests on short legs; the head is remarkably short, thick and short snouted; the eyes are of moderate size, the ears small, the toes are fire in number, half grown together and armed with strong claws, and the soles are naked. The tail is longer than the body, and is as completely prehensile as that of some pouched animals or of the Howlers. When full-grown the hinkajou measures thirty-six inches, about nineteen of which go to the tail; the height at the shoulders is six or seven inches. The fur is very thick, rather long, slightly curled, soft, and of vel-

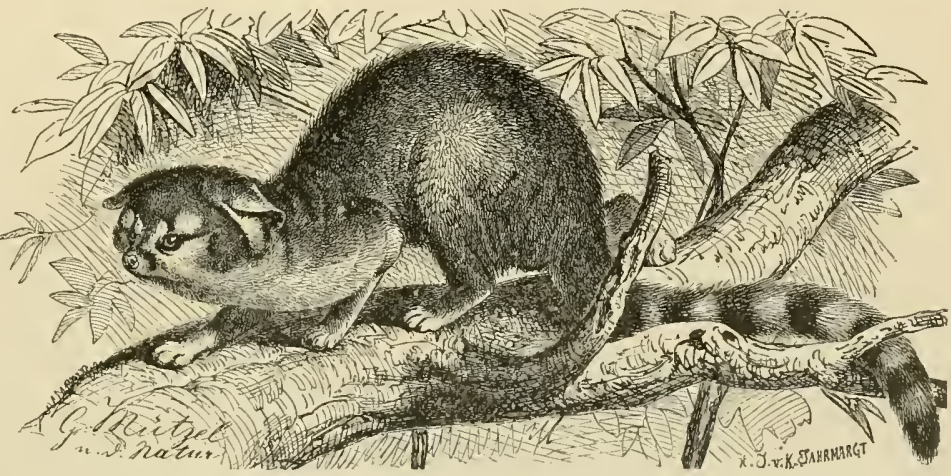

THE CACOMIXLE.-Long erroneonsly thought to belong to the Civet fanily. the Cacomixle is now classed with the Raccoon gromp of the Bear family. 1t is found in Mexico, Texas and California, and has many popular names in the latter state, including "Raccoon-Fox" and "Mountain-Cat." It has a face much like that of vety lustre; the color of the upper and external surface is a light, grayish yellow, with a reddish surface tinge, and shows brownish black waves, especially distinct on the head and back. Its appearance harmonizes excellently with its arboreal surroundings. 
At present we know that the Kinkajou is widely spread. It is indigenous to the whole of northern Brazil, Peru and to the north as far as Mexico, or even solithern Louisiana and Florida. It lives in vircin forcsts, on trees, and delights in the proximity of great rivers. Its habits are completely nocturnal; it spends the day sleeping in hollow trees, but at niglit it display's great activity, climbing with remarkable adroitness about the high tree-tops in search of food. Its prehensile tail is extremely useful in this connection. It is inferior to hardly any Monkey in climbing ability. All its movements are marked by great agrility and security. It can loold fast to branches with its hind legs or tail and grasp a tree so firmly that it is able to climb down head first. Its mode of progression is plantigrade.

Traits of the All those who have so far observed Kinkajou the Kinkajou agree in that it is Described. gentle and good-natured in its relations to Man, and soon becomes as familiar and kind as a 1 og, likes to be petted, recognizes its owner's voice and seeks his company. By actions it invites its kecper to play with it, or to speak to it, and these friendly traits make it one of the most popular domestic puts of the natives in South $/$ Mmerica. In captivity, as well as in its wild state, it sleeps during most of the day. It then covers its body, especially the head, with its tail. It eats anything which is given it: bread, meat, fruit, boiled potatoes, vegetables, sugar or prescrves; drinks milk, coffee, water, and, if permitted, wine or eren brandy until it is intoxicated, which makes it sick for several days. Occasionally it also attacks poultry. kills it, sucks the blood and leaves the rest. Kappler, who observed the Kinkajou in Guiana, says: "It lives only on fruit and becomes extremely tame. I received a young one from Indians, and gave him complete liberty. Nobody knew where he spent the day, but as soon as we sat down to the table in the evening, "Wawa," as we called the creature, arrived and amused us by his funny, caressing actions, one of which consisted in his trying to insinuate his long. slender tongue into my mouth, ears and nose. Hc atc ripe bananas and other fruit. When the house was closed at night, Wawa was put out, and he then mounted the bread-trees, cocoanut palms or Arogato trees, for he did not like to stay on the ground. I kept him over a year, until he suddenly died."

The Cacomixle A small Beast of Prey, which fora small but merly was placed among the Civets, Lively Species. according to recent research belongs to the American Small Bears. IIe mean the Civet, or as Hernandez called it as carly as I65I, the Mexican Cacomixle (Bassaris astuta). An adult male attains a length of about thirty-eight inches, two-fifths of which go to the tail. In shape, the animal reminds one of a small Fox; in coloring, of a Coati.

The Cacomixle inhabits Mexico, Texas [and California, and it has been found as far north as Oregon.] In Mexico it takes up its abode in rocks and deserted buildings, but in Tcxas is found principally in hollow trees. In Mexico it is frequently found in the very capital, and Charlesworth even supposed that it never made its habitation far from human dwellings, as the poultry yards furnished it such favorable hunting grounds.

The Cacomixle is a lively, play'ful and active creature, frequently recalling to mind a Squirrel by its movements and attitudes, and the Mexicans call it "Squirrel-Cat" for this reason. If disturbed in its den, it assumes the same graceful attitudes as the Squirıel and lays its tail upon its back. It is an excellent climber, but can not leap from branch to branch with the agility and sccurity of the Squirrel. When frightened it runs along one branch and tries to reach another from its twigs. Occasionally one may see it lying on some bough basking in the sun. It then lies motionless, half curled up and apparently sleeping; yet at the slightest signal of danger it slips into its hole with all possible speed and reappears only after sunset.

In spite of the slymess and timidity of the Cacomixle, it may become moderately tame, and after it has been kept in a cage for some time, it may be allowcd to run about the house at will. It is frequently kept as a pet in Mexico, and makes itself useful as a mouser. 


\title{
Cbe Feals or Jfin= Jfooted Animals.
}

\author{
FIFTH ORDER: PINNIPEDIA.
}

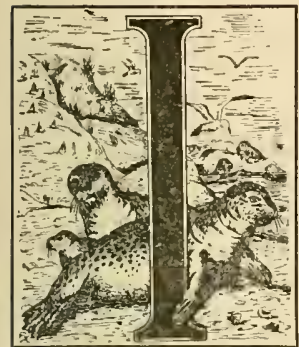

THE Seals we see inhabitants of the sea, which, unlike the Winales, appear to be mammals even to the uninitiated. Though essentially aquatic, they possess four legs, which are distinctly outlined and not joined for their entire length to the body, as in the Whale, although their motion is of a trail ing character, and the feet show the gradation of fingers and toes with some distinctness. With most of the Seals the toes are perfectly mobile and connected only by wcbs, but with a few they are entirely enveloped in the skin of the body and immovable but may, nevertheless, be usually recognized by the little nails, which are fastened externally. There is nothing that should strike us as absolutely strange about these animals except the feet. The structure of the toes is different from that of any animals we have so far considered: the middle toe is no more the longest and strongest, but all the toes are of practically identical conformation. Though the bodily structure of the Seals differs notably from that of all other mammals which we have so far discussed, in other respects comparison may still be drawn between it and that of the beasts of preyespecially the Otter and the Bear - with a fair degree of ease, and some naturalists, who class the Seals among the beasts of prey, are therefore justified in doing so. The head is comparatively small, tolerably distinct from the neck and resembles that of the Otter or the Bear. The nose is provided with oblique, slit-like nostrils, which may be closed; the eye is large and furnished with a lid, the outer ear may be closed, and is developed to an appreciable extent only in one species, the other Seals lacking an ear-conch. The short, thick neck merges immediately into the body, the shape of which is more or less cylindrical and gradually tapers to the buttocks, while the tail has deteriorated into a stub. The thick, firm skin is, for the greater part, covered only with a plain outer fur of uniform length, which sometimes is elongated into a mane, or there may be a somewhat thick, woolly inner fur. The teeth and the inner structure show a distinct character of their own, in spite of the manifold resemblance to the-respective parts of the beasts of prey.

The vertebral column resembles that of the Carnivora; the cervical vertebre are distinct and furnished with well-developed processes. There are fourteen or fifteen dorsal and five or six lumbar vertebrx; from two to seven united vertebræ form the sacrum, and from nine to fifteen go to the tail. The clavicles are absent. The bones of the limbs are very short; the bones of the fore-arm and leg are always separate, the wrist and ankle-joints are of regular formation.

Wide Distribu- The Seals are distributed over all tion of the the oceans of the globe, inhabiting Seals. the higher south as well as the north, and are even found in great inland Asiatic lakes, into which they have either penetrated by way of the rivers flowing from them, or in which they have been left, when the means of communication by water witl the greater ocean were shut off. The north exhibits the most species, the south is stocked with those that are most striking in appearance. Usually Seals delight in the proximity of a coast, and many undertake wanderings from one locality to another, and also often go up rivers.

Seals on the They live on the mainland only on

Ground and in special occasions, namely, during the

the Water. breeding season and in their earliest youth; and the water is their proper element. Seen on the ground they strike one as very helpless creatures, but in the water they proceed with the greatest ease. It is with difficulty that they climb rocks from the beach or drifting ice, and then they comfortably stretch themselves on the firm ground and bask in the sun; at the sound of danger, they seek the friendly depth of the ocean with all possible despatch. They swim and dive in a masterly way. It matters not to them, whether the upper surface of their body lies upward or downward; they are even able to move backward, as I can vouch for from my own experience. In the water they can turn about in any direction, and change their location with the greatest agility.

Haacke's Haacke writes: "We are moved to

observations involuntary admiration when we ob-

of Seals. serve Seals engaged in fishing. At the Frankfort Aquarium, from the dark space reserved for visitors, one may observe the Seals under glass in a spacious tank, hunting live fish for their sustenance. It is astonishing to note the accuracy and speed with which they conform to every rapid movement of the fish and anxiously dart through the water, every movement and turn of each flipper of the Seals being to the purpose and planned with exactness, while they elongate or shorten their necks at will. In a few seconds the fish disappears in the Seal's mouth, as if sucked in. Great, also, is the dexterity with which our Seals, standing erect in the water and looking for the food-bringing keeper, can keep themselves in one place by a gentle movement of their hinder flippers."

Movements of On the ground, on the other hand, Seals on even those species which really walk, Land. hobble along in an awkward way, while all the other species move about in a very odd fashion, peculiar to themselves. Their method of locomotion is nearly the same as that of some Caterpillars. The Seal which wishes to go from one place to another on the ground throws itself on 
its breast, arches its body as a Cat does its back, then rests its weight on the hind quarters, about the loins, and quickly jerks its body forward, throwing its fore part further to the front by this means. It is thus enabled to grovel along at a somewhat rapid pace, by alternately resting its fore and hind parts on the ground, and arching and stretching its body. The legs are, in fact, not called into service in thus moving along the ground, but are only utilized when the animal climbs upward. It also uses its limbs very skillfully for the purpose of dressing and cleaning its fur, or scratching itself, or to grasp something with them; for instance, when clasping its young to the breast

General Traits All Seals are gregarious in a high and Habits of measure, and solitary specimens are

the Seals. hardly ever seen. The more deserted the locality, the larger are the troops and families sides or their under surface to the kindly rays of the sun; they close their eyes almost completely, yawn and generally deport themselves more like dead masses of flesh than living creatures; and the regular opening and closing of the nostrils are the only signs of life they give under these circumstances. When they feel very well, or during the breeding season, they neglect eating for weeks at a time; but at last hunger urges them to rise and return to the ocean, where their lean body soon regains its pristine roundness and sleekness and again acquires its bolsters of fat. According to Haacke's observations in Frankfort they can endure hunger for at least six weeks. The little Seals are lively, playful and cheerful, but old animals are sulky in disposition, and appear to become degenerated in consequence of their laziness. It must be admitted, however, that their helplessness on the

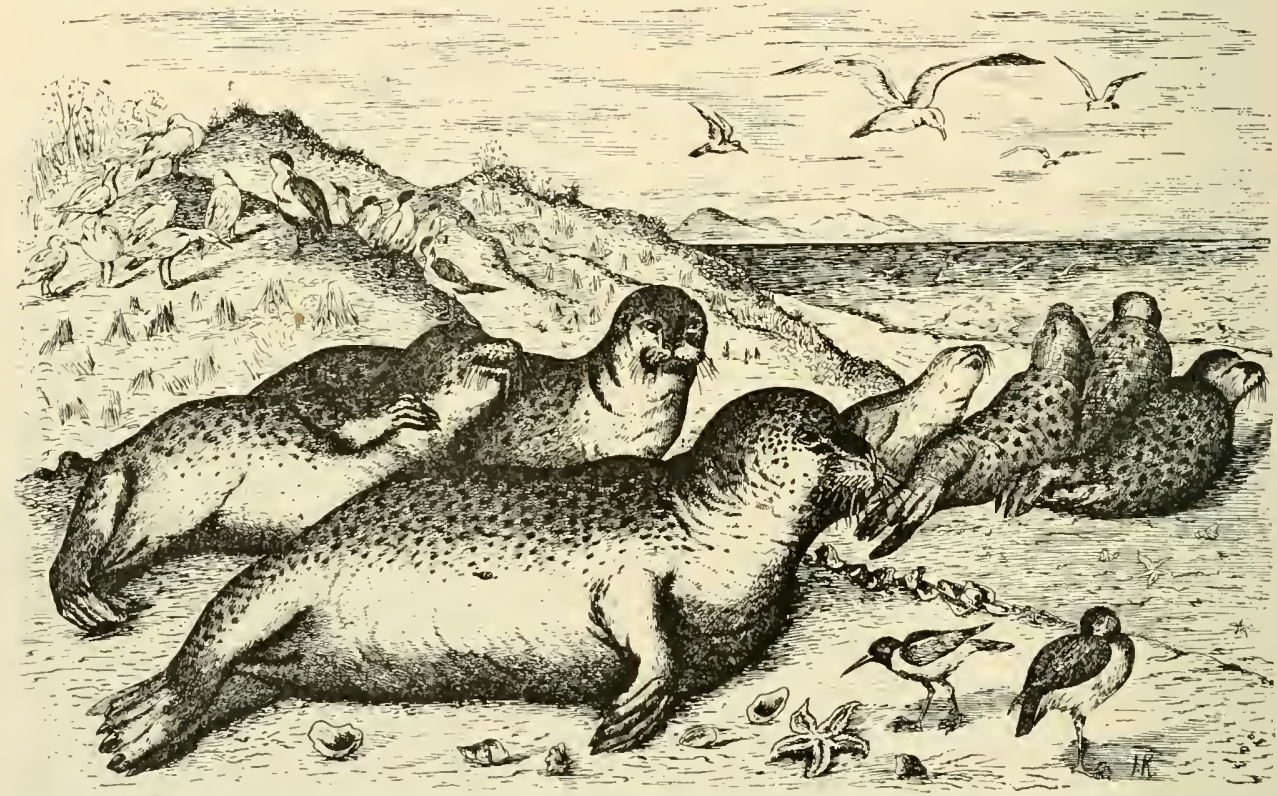

THE COMMON SEAL. - The typical animal among the Ordinary or Earless Seals is the Common Seal, which is sometimes also called the Harbor Seal. It is one of the smallest but best known species of the Seal family, has a fur varying in color with different individuals, but usually brown or brownish yellow with darker spots. It likes to rest on the beach or rocks bordering on the sea. but its movements on land are very slow and awkward. It is the water. It is found on both sides of the Atlantic and north Pacific, and also in the Mediterranean. (Phoca 2'itulina.)

formed by the Seals; and the less they come in contact with Man, the more comfortable and sympathetic become these creatures, which exhibit so much timidity in regions frequented by human beings.

The habits of the Seals are nocturnal. They prefer to spend the day on the mainland, sleeping and basking in the sunshine, and then exhibit characteristics which are the reverse of those they display in the water. When they are on land one perceives no sign of the agility and speed which mark their actions when they are in their proper element, but on the contrary they present a complete picture of laziness. Anything that disturbs their repose is highly distasteful to them; in fact, some species can scarcely be incited to flee. Blissfully they stretch themselves, alternately presenting their back, their ground makes them appear even lazier than they really are. When they see that they are in danger, they speedily enter the water, as 1 said before; but if peril suddenly overshadows them, they become so frightened that they sigh and tremble, and are so excited that their frantic efforts fail to avert their peril. But if they have to defend females and young ones some of them exhibit great courage. On the loneliest islands some species are so indifferent to strange visitors that they calmly permit the intruders to walk around among them and do not flee; but they develop great wariness after they have once become acquainted with Man, the destroyer of the animal world.

Of their senses, that of hearing is excellent, in spite of the absence or small size of the external ear; sight and smell are less strongiy developed. 
The voice consists of hoarse sounds, somctimes resembling the bark of a Dog, sometimes the bleating of a Calf, or the bellowing of a Cow.

$\begin{array}{cl}\text { Family Life Every group of Seals is one family } \\ \text { of the } & \text { A male always unites himself to } \\ \text { Seals. } & \text { several females. From about six to }\end{array}$ twelve months after the breeding season, the female gives birth to one, or more rarely two young Seals, which are pretty and cheerful little creatures.

Old and young love each other with equal tenderness and the mother protects her offspring against any danger at the peril of her own life. The father enjoys the merry play of the little ones, and signifies his approbation by a contented growl, and as his constitution forbids an active participation in the pranks of the young one, he follows its somersaults and rapid movements back and forth, at least with his eyes. After two months at the utmost the young Seals are so far developed that they can be weaned. Their growth proceeds rapidly. After from two to six years they have reached maturity; at the age of from twenty-five to forty they are old and decrepit.

Their food is of an animal character, chictly consisting of fish, crustacea and mollusks. A few species are also said to attack various sea-birds, which smaller Pinnipedia do not annoy, or even other Seals. It has happened in Dusseldorf that Seals which have been peacably inhabiting a tank with Ducks, suddenly dragged all the latter under water and killed them. In order to promote their diges- tion, some Seals swallow stones, after the same manner as certain species of birds.

A Seal-hunt is nothing but merciless slaughter. Therefore the word "sport" is never used in connection with it; Seal-hunters talk of "killing," but never of "sport." Old and young, large and small Seals are, or at least were, all being destroyed without distinction. In this way it has been brought about that nearly all species of Seals are much reduced in numbers and some are on the road to complete extinetion. In many places but few remain of the large herds which during the last contury covered lonely islands. The oil and fat, teeth and skin of the Seals are commodities much sought after, and this explains the zealous pursuit of these animals by Man.

Nearly all Seals may be tamed and sonie nearly become domestic animals. They come and go at will; fish in the ocean and return to their owner's house of their own accord; learn to know him and follow him like Dogs.

Divisions of the The order of the Seals is naturally

Fin-Footed divided into three families. The

Animals. first are the Ordinary Seals, which are entirely devoid of an ear-conch and of the power of walking on their hind feet. In marked distinction from them is the family of Eared Seals, which are posscssed of ears and have the ability to use their hind legs for the purpose of walking. Between these two are placed the Walruses, in which the ears are wanting, but which are able to advance their hind legs under their body.

\section{The Ordinare 5eals.}

\section{FIRST FATILY: PHOCIDE.}

Much more numerous than all other families, the Ordinary Seals populate not only the oceans of the globe, but also large inland lakes, which are connected with the former, or which formed part of them in bygone times, as for instance, the Baikal and the Caspian Seas. They inhabit all the zones of the earth, but are especially abundant in the frigid zones, and divide into a considerable number of species in the north. Off some coasts these muclipursued animals are still plentifully found and, speaking generally, they are not rare on any coast, although their numbers continue to steadily decrease.

Habits of the In their habits they much resemble Ordinary the Eared Seals; in their movements Seals. on the ground they differ from the latter quite materially, because they are not able to walk, but have to propel themselves by a sliding movement. It is only in the water that they show themselves to be the equals of the Fared Seals and display all their swiftness, for they swim and dive in masterly fashion. They dart through the water with the speed of a predaceous fish, turning around with lightning-like rapidity; they also can stay in any particular place as long as they please. For amusement they describe circles, from time to time jump out of the water full length, chase or tease each other, or play quite alone in the water, acting as if they were intoxicated; they come to the surface lying on their back, push themselves along while in that position, turn around and around, and act in the oddest manner, sometimes forgetting themselves to such a degree that a skillful hunter can approach them unnoticed, within a harpoon's throw, and kill them.

Actions of They descend to a great depth and Ordinary Seals occasionally stay under water for a in Water. considerable length of time, but by no means as long as is averred by some writers. If they are not pursued, they come to the surface to breathe, on an average once a nimute. It may happen that Seals, when pursued, will stay three or four tines as long under water; but at any rate they are not capable of spending half an hour there, as has been repeatedly affirmed and believed. Fabricius, who described the Seals living in Greenland at great length, does not believe that a Seal can stay under water longer than seven minutes. Seals really sleep in the water. With a few strokes of their hippers they rise to the surface from time to time with their eyes closed, breathe, go again to the bottom and repeat the performance at every breath of air. That they can sleep lying on the surface is amply proved. The Greenlanders, who intimatcly know this animal which is so important to them, have a special name for each of its attitudes in the water, bccause they decide, from the various positions assumed by the animal, whether they will be able to approach a swimming Seal or not. 
The Ordinary Though the Seals live in the ocean

Seal on the for days and weeks and can dispatch Land. all their business in the water, they are fond of repairing to the land for the purposes of resting, sleeping and basking in the sun's rays. They jerk themselves out of the water to a considerable distance on the shore, by violently flapping their expanded hind feet together. When frightened or in danger all Seals constantly spit water, perhaps in order to make their pathway smoother. Clumsy as their gait may appear, it is a very rapid pace: a running Man must expend some effort in order to overtake a Seal gliding along on land. The hind part of a Seal's body is as mobile as its neck. The Seal can twist itself so as to lie on its back in front and on its under surface behind, or the reverse, and can turn its head in any direction.

In the higher latitudes these animals, even when not compelled to do so, preferably select drift-ice as their resting places, and stay there, quietly stretched out, for periods as long as those in the south lie on the beach warmed by the sun. The possibility of lying for hours on so cold a surface without giving up too much heat or catching cold is afforded them by the layer of fat which spreads between the skin and muscles, and is a very poor conductor of heat.

The voice of the Seals is either a hoarse bark or a whine; when angry they growl like Dogs.

Development Even the ancients described the of the Senses Seals as highly gifted animals. of Seals. Their senses seem to be efficient and of rather uniform development. Nose and ears may be closed and in a living Seal alternately have the appearance of triangular, roundish holes or only of narrow slits. The nostrils are opened at every breath and immediately closed again and stay so, even when the animal is on land, while the ears are shut only in the water and not always even there. In the large and very slightly protruding eyes the light or dark brown iris fills the entire space left open by the lids; the white of the eye is seldom seen. The pupil is neither circular nor elliptical but four-cornered. The expression of a Seal's eye is irorthy of notice, as is also the fact, that when moved by emotions of any kind, all Seals shed tears If we regard sight as the nuost highly developed sense, as we probably have the right to do, we may consider hearing as the next best. The ancients had discovered the fact that Seals are fond of music and singing, and modern observers have noticed that they attentively listen to bells and other lond sounds. Brown affirms that he has frequently seen Seals lift their heads out of the water and listen to the songs of sailors who were hauling in an anchor with a windlass. The church at Hoy on the Orkneys is situated near a narrow, sandy bay, much frequented by Seals, and they find particular attraction, as it seems, not only in its situation but also in the church-bells; for the animals have often been seen swimming straight to the coast when the bells were ringing, their eyes fixed in the direction from which the sounds proceeded, while they listened, with raptured and delighted attention, as long as the bells continued ringing.

Mental It is difficult to pass judgment on

Characteristics the mental qualities of Seals. There of Seals. is no doulst as to their sagacity; but frequently they display such stupidity and clumsiness as to puzzle the observer. Bold in descrted localities, they behave with extreme caution where they know that they are threatened by deadly enemies. It is established that the warnings of older animals are heeded and acted upon by the younger ones. Captive Seals soon make friends with their keeper and some become very tame, respond to the names that are given them, will leave their tank and take fish out of the keeper's hand and show their interest and affection in other respects. There are certainly some which suffer themselves to be touched and stroked by the keeper, shake hands with him, and even allow their friend to put his hand in their mouths.

It seems that Seals are rather indifferent toward all animals which are not classed as fish, mollusk or Crab; but if one were to regard this as a proof of their good-nature, one might be mistaken. They are alway's violent when brought in contact with Dogs; they snort angrily and try to drive the canine intruders away by clapping their teeth together.

Development Like all members of their family

of the roung they make proof of special tenderSeals. ness toward their young. They play with them in many ways, and defend them in peril even against stronger animals.

Varying with the locality in which the Seals live. their young are born during the months of May, June or July, birth being given to one, or more rarely two young Seals, on some lonely, uninhabited island, preferably on a sandy spot on the beach, in caverns, on rocks or on an ice-ficld. The young Seals nake their appearance perfectly developed, but are clothed in a dense, white, tender fur, which hinders them from swimning and still more from diving, but is soon exchanged for the sleek, stiff fur of youth. Until that time the fenale stays on land with the little ones.

In the Zoological Garden of Hamburg a perfectly developed little Seal was born on the 3 oth of June, at an early hour, for the keeper, to whose care I had committed the Seal, saw the little one playing in the water near its mother when he arrived in the morning. On the land I found the whole fur of the newborn, consisting of a not inconsiderable heap of short, wavy hair of silky softness, all of which was lying on a spot of small circumference. The little one wore no trace of the woolly fur; its coloring closely resembled that of its mother, except that the different colors were fresher and brighter. The eyes had a clear and lively appearance. Even the very movements of the young aninal were entirely those of its parent: as agile in the water, as clumsy on land. 1t seemed, that during the first hours of its life it had already acquired all the accomplishments of its race, for it swam on its stomach and on its back, dived easily and long, and, in a word, it acted like an old Seal. But then it had been born as a remarkably developed and strikingly large specimen. On the very day of its birth we succeeded in weighing and measuring the already intractable little fellow. He weighed seventeen and one-half pounds and was thirty-four inches long.

The spectacle the two animals presented was a highly fascinating one to the observer. The mother seemed to rejoice in her offspring, and displayed the greatest tenderness in every respect, while the precocious little one seemed to understand her. From the very first days she played with it in a clumsy" way, at first in the water, then also on land.

Importance To the northern nations the Seals

of the Seals are the most important of all anito Man. mals. The Greenlanders' life is rendered possible by the Seals, and they extract profit 
from every portion of the animal's body. But we also value highly the sleek, beautiful, waterproof fur, and esteem the fat and even the flesh. It is not surprising, therefore, that the Seals are most eagerly hunted in all oceans. Hunt and capture are nearly synonymous in this case, for fire-arms are used but rarely and never on the high sea, for a Seal when killed goes to the bottom like a piece of lead. It is different in particularly favored haunts of the animals on the beach. On the eastern coast of the island of Rugen there is, as Schilling says, a heap of rocks, several hundred paces distant from the extreme point of the high promontory, and at the ordinary height of the water these rocks project over three feet above sea-level. Frequently from forty to fifty Seals lie on them, but they are too prudent to let a boat approach them.
On the Sivedish coast of the Baltic the liunt is followed more regularly and frequently, usually with harpoons only, or more rarely with guns. Some Swedish hunters train Dogs to track the Seals on the ice and keep them busy until their owners arrive. On the Faroe Isles the Seals are mainly hunted during the time they spend on shore with their young.

Among all peoples the Greenlanders seem to be those who not only know how to hunt Seals most successfully, but also how to put the animals to the most manifold uses. "The Greenlanders," says Fabricius, "are great masters of the art of plying their oars easily and neatly, so that one hardly hears a sound. If a Seal rises up in sight the Greenlander watches its actions, in order to proceed with his attack according to its movements. As soon as he has satisfied himself in regard to the whereabouts of

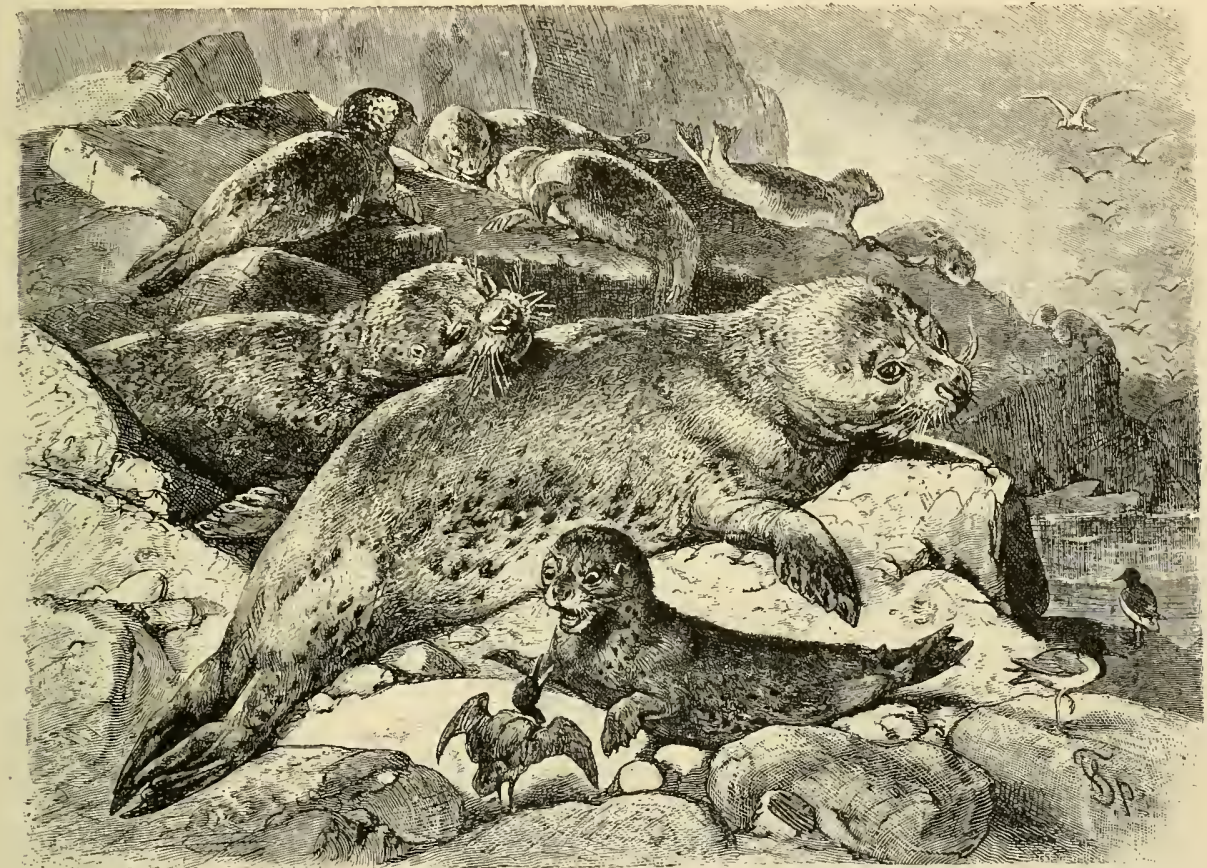

THE SEA LEOPARD_- This animal forms a distinct group of the Ordinary Sea!s, and is widely distributed in the antarctic and southern temperate seas, and frequents the coasts of Australia. New Zealand and the islands of the southern Pacific. The large males attain a length of twelve feet. The ground color is a silver gray, and yellowish or brown spots are distributed over the body. (Stenorhynchus leptonyx.)

Methods of Schilling says that one may someHunting the times succeed in shooting Seals seals. which are seen from a ship, if one with a little sail boat noiselessly sails up to the sleeping animals, keeping half to leeward. During a prolonged frost a hunt on the ice may also yield good results, but it is never sure to do so, and is always fraught with danger. When the Baltic is frozen over, the Seals keep artificial holes in the ice open, in order to reach the outer air, and to creep through on to the ice, where they sleep. Every Seal usually forms such an aperture for itself, and sometimes has several for its own personal use. To these holes a Man creeps up at night, in felt shoes so as to deaden the noise of his steps, but he must pay careful attention to the weather and wind and be constantly on his guard. the Seal, he strives with all means at command to approach it as near as possible, in order not to miss it. The point he must pay most attention to is that neither the movement of the oars nor the darting forward of the boat shall cause any great noise; for this would disturb the repose of the Seal. Not a little dexterity and practice are required for this softened movement, which is accomplished partly by long, deep strokes of the oars, partly by propelling the boat with movements of the hand and body. and some are such experts that they can get the boat alongside the Seal without attracting its attention. But if it should happen to be one of the cautious kind which is always alert, the obstacles in the way are greater; yet the hunter does not give up all hope, but watches it dive and then hurries along. But if its head is above water, he keeps quiet, stoops 
or lies down, to give the boat the appearance of a lifeless object, drifting in the water. If the Seal dabbles in the water and is bewildered in its play, sometimes looking at the hunter, the latter whistles to make it feel more secure. If it still happens to dive before it is within a harpoon's throw, the hunter watches the direction of its course, changes his position slightly, and when it comes to the surface kecps it constantly in view. W'hen he at last approaches sufficiently near to it, he throws the harpoon at it, the line following the spear. As the harpoon has barbed hooks, he sees immediately whether the Seal has been hit or not; for if the animal is struck it camnot easily get off, but drags more and more on the line. No time must then be lost; as soon as the hunter sees that the Seal is hit, he must throw the bladder out of the boat, for otherwise the boat itself would be dragged by the Seal when the line had all been unwound and might easily turn over. These are the causes why Greenland Sealers so often lose their lives; for if a Seal once drags a hunter away and no companion who could come to the rescue is nigh, he can seldom be saved. But if he manages to throw the bladder out in proper time the greatest danger is past. Occasionally so courageous a Seal is met that it charges at the thin boat made of skins, and bites a hole in it, the hunter running the risk of sinking. Therefore this hunt is a perilous one in many respects, and many Greenlanders do not hazard it without reflection.

"But if the Seal drags the bladder, which he can rarely pull beneath the surface, along the course of its flight, the hunter keeps the bladder in sight, follows it and tries to kill the Seal with spears. These spears have no barbed hooks, but slip out of the wound and float on the water, as soon as they are thrown at the Seal. These many wounds, and the dragging of the large, air-filled bladder, tire the Seal out. When the hunter at last approaches close to it, he deals the Seal a mortal blow on its nose with the fist, which stuns it, or, if it be necessary, he stabs it with a knife. Then the animal is prepared before its captor takes it home. All wounds are stopped with little picces of wood, lest the blood should flow out, then air is blown between the skin and flesh, so that the carcass will float better. If several others are caught, they are fastened to the first one, and a lucky sportsman may bring home four or five at once."

All Seals are remarkably tenacious of life and are killed on the spot only when a bullet pierces the brain or the heart. Besides Man, the Seals have an enemy in the quick Killer-Whale, before which all the smaller Seals fly in abject terror. Pursued by this voracious monster, they jump in rapidly succeeding leaps high above the water, resort to all tricks in swimming and diving, try to gain small straits and shallows, hurry to the shore, and in their deadly terror forget even their dread of Man. The Polar Bear also pursues them relentlessly and, as we have seen, he knows how to seize upon them with tolerable skill. Young Seals probably also suffer from the attacks of large fishes.

Manifold The northern nations use the entire

Uses of the Seal, not only oil and skin, as we Seals. do, and the flesh besides, as do the Swedes and Norwegians. The intestines are eaten, or, after they have been thoroughly cleaned and smoothed out, they are manufactured into windows, clothes and curtains. A garment, the capisad of the Greenlanders, is made up out of them and highly valued on account of its excellent waterproof qualities. The blood, mixed with sea water, is boiled and eaten as soup, or after it is frozen, as a dainty, or it is shaped into balls after cooking, dried in the sun and stored away for future use in hard times. The ribs are used to stretch the skins or are manufactured into nails; the shoulder-blades are formed into spades; the tendons are made into thread, etc. Yet the chief profit to the Greenlanders accrues from the skin, oil and meat.

The Common The species whose life has served us Seal, the Typical as the type in the preceding reSpecies. marks, is the Conmon Seal (Phoca vitulina), an animal widely spread over northern seas and also conmon in the German waters. The length of an adult specimen, measured from the snout to the tip of the tail, varies between sixtyfour and seventy-six inches and, strange to say, the fenales are larger than the males. The liead is eggshaped, the snout short, the eye is large, dark and has an intelligent expression; the ear is indicated only by a small, triangular elevation; the upper lip is thick, but very mobile and grown with stiff whisker-hairs; the neck is short and thick, the body tapers almost uniformly from the shoulders to the tail. The fur consists of stiff, lustrous hairs, the general coloring of which is a yellowish gray, relieved by a number of irregular brownish or black spots, distributed all over the upper surface.

Extensive Range The Common Seal ranges through-

of the Com- out all northern parts of the Atlantic

mon Seal. Ocean, including all parts of the Arctic Ocean. Beginning at the Mediterranean, into which it occasionally penetrates through the Straits of Gibraltar, it inluabits the entire Atlantic coast of Europe and the Baltic Sea, where it is almost as plentiful in the Gulfs of Bothnia and Finland as in the Sound and the Little and Great Belt; it also occurs in the White Sea and, according to some accounts, also along the coast of northern Siberia and from Behring Strait to California; it certainly has been observed in Spitzbergen, on botl coasts of Greenland, Davis Strait, Baffin's Bay and Hudson Bay and it goes rather far to the south along the eastern coast of North America, being by no means a rare visitor in the Gulf of Mexico, and in a few cases also of the northern coasts of South America. Not infrequently it goes from the sea for a long distance up some river and is therefore often found far from the seashore.

Different Species The Common Seal is not the only of the Ordi- one frequenting the German coast, nary Seals. for there also are quite regularly found the Gray Seal (Halicharus grypus) and the Ringed Seal (Phoca fottida). The Monk Seal (Stinorhynchus albie'enter) is nlore rarely met with there, being indigenous to the Mediterranean, and the Crested Seal or Hoodcd Seal (Cy'stopliora cristatu), which is a native of ligh latitudes, is also seldom seen so far south as the German shores.

The Caspian Seal (Phoca caspica) is a species closely allied to the Common Seal, and, as its name implies, it lives in the Caspian Sea, cut off from any commurication with the ocean.

Characteristics The Saddle-Back Seal [also called of the Saddle- the Greenland Seal and Harp Seal] Back Seal. (Phoca granlandica) differs from the Common Seal in its longer and narrower head, a flatter forehead and longer muzzle, as well as in the structure of the hand. The prevailing color of an old male is a light or dark tawny gray on the upper 
parts, the under portion being of a dull, russet, silver-gray tint; and the chocolate colored, or blackishbrown face, including forehead, cheeks and muzzle, and the markings of the back, stand out in bold relief against this hue. These markings are more or less sharply defined and of oblong, horseshoe or lyre shape. Some individuals of the species show the saddle narrow like a ribbon, others have it perceptibly wider. The female is smalier and its coloring differs from that of the male to such an extent that it has been considered and described as a distinct species by some writers. The snow white fur of the cubs gradually merges into the tint of their parents during the lapse of several years.

The Saddle-Back is confined to the highest latitudes of the north, though its range perhaps extends through the Straits of Behring into the northern
Adult males attain a length of from ninety-two to one hundred inches; the females lack the hood and are of perceptibly smaller dimensions.

Of the Seals of the northern Arctic Ocean the Crested Seal scems to have a very linited range and occurs in small numbers. According to Fabricius, it is most frequent off the coasts of Greenland and Newfoundland, less so on the western coast of Iceland and a rare visitor, probably only when it has lost its way, farther south.

According to the accounts of many writers this species is one of the most courageous and pugnacious of Seals, and hunting it is not devoid of danger. When it lies on the ice in comfortable repose, it produces the impression of utter indifference to all surroundings, and the far-off look of its large, black eye seenis rather dull; neither does it attack any

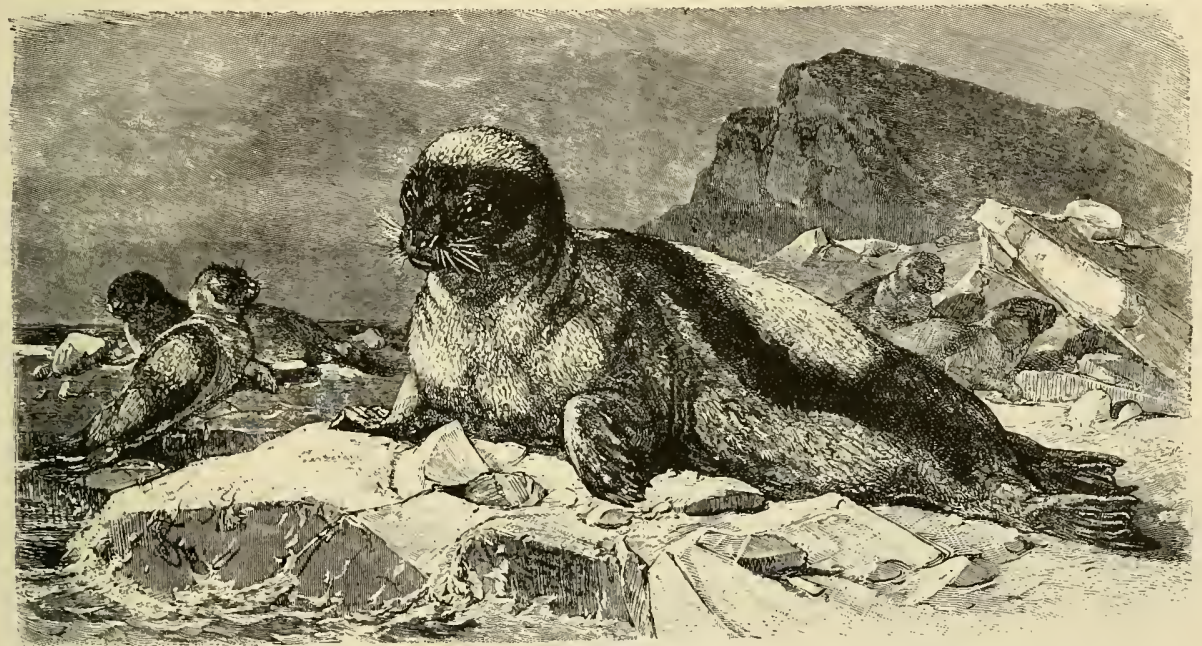

THE SADDLE-BACK SEAL. This member of the Seal family is found in the Arctic latitudes extending as far north in the circumpolar regions as explorers have yet penetrated. It gets its name "Saddle-Back" tron the large patch of white fur on its upper surface, which is in bold contrast to the brownsh-black fur surrounding it. The somewhat narrow head is also a distinguishing feature. The animals in the picture are comfortably resting on a great ice-floe. 'This species is also known by the names of "Harp Seal "and "Greenland Seal." ( $P$ hoca granlandica.)

Pacific. Single specimens have repeatedly been observed on the coasts of Lapland and Norway, and even of Great Britain and Germany.

The Crested or As a representative of the Hooded Bladder-Nose Seals we will consider the Crested Seal. or Bladder-Nose Seal (Cystophore cristata, ) one of the largest Seals of the Arctic Ocean, distinguished above all other things by a bladder which extends over the nose, the whole upper part of the muzzle and nearly the entire upper surface of the head, and which may be distended with air or emptied at will. When filled with air it forms a bag ten inches long and eight inches high and looks like a cap drawn over the front part of the head; when closed it may be compared to a keel dividing the nose into two parts. The head is large, the muzzle is thick and blunt, the body resembles that of all other Seals. Old and young are of different color, but the hue is not affected by sex. The fur consists of a long outer coat and a close woolly inner fur, the upper part as a rule being of a dark nut-brown or black tint, diversified with large or small circular spots of still deeper color; the under surface is of a dark gray or rusty silver-gray, devoid of spots. living being unprovoked, but it is easily excited and then prone to offer resistance.

characteristics The Elephant Seal (Macrorlimus of the lconimus) resembles the other Seals

Elephant Seal. in respect to its general shape but is superior to all in size; the length at least of those of the Californian coast has been found to be a little more than twenty-two feet, though the average length is about fifteen feet. The female attains about half this length, but not even a third of the weight, old males being estimated to weigh more than six thousand pounds. The head is large, wide and elongated, the muzzle of moderate length, tolerably broad, slightiy tapering in front and truncated in a nearly straight direction; the upper lip is grown with stout, dark brown whisker hairs, sometimes $51 \mathrm{x}$ inches long; the eye is relatively large, round and protuberous like a ball; the exceedingly small ear is, properly speaking, only a roundish hole, which is not even surrounded by a margin of skin. The nose differs materially according to the sex. While this significant organ shows no unusual development in the female, it is prolonged into a proboscis in the male, beginning at the corner of the mouth and 
extending forward for about sixteen inches, and sometimes measuring double this length when the animal is excited. The hue of the fur undergoes modifications not only under the influence of age and sex, but also according to the season of the year. Immediately after a change of coat the prevailing color is a bluish gray, which later merges into light brown.

Range and Habits The Elephant Seal inhabits the south-

of Elephant ern regions of the oceans, from about Seals. fifty degrees south latitude, perhaps all over the southern Arctic circle. Formerly it was found on the southern cxtremity of America and the adjacent islands, off the island of Juan Fernandez, and on the southern coasts of Chile; also on New Zealand, Tasmania and many other islands situated in these latitudes, but in most of these localities it is either entirely absent or nearly exterminated.
Their movements on dry land are exceedingly clumsy and weary then greatly. If they are very fat the body shakes at each jerking movement like a huge bladder filled with jelly. They work to propel themselves forward a little way, and then they are tired and have to rest; still in California they slide up inclines from five to ten yards high and reach spots situated upwards of sixty feet above sea-level even on very uneven ground. In the water they are totally different creatures. They are excellent swimmers and divers, execute rapid turnings, calmly lie down to sleep on the waves and let themselves drift, and display great zeal and agility in hunting their food, which consists principally of fish. They also swallow stones. Forster found in the stomach of an Elephant Seal twelve round stones, each of the size of two fists, and so heavy that he could hardly understand how the walls of the stomach could bear the burden.

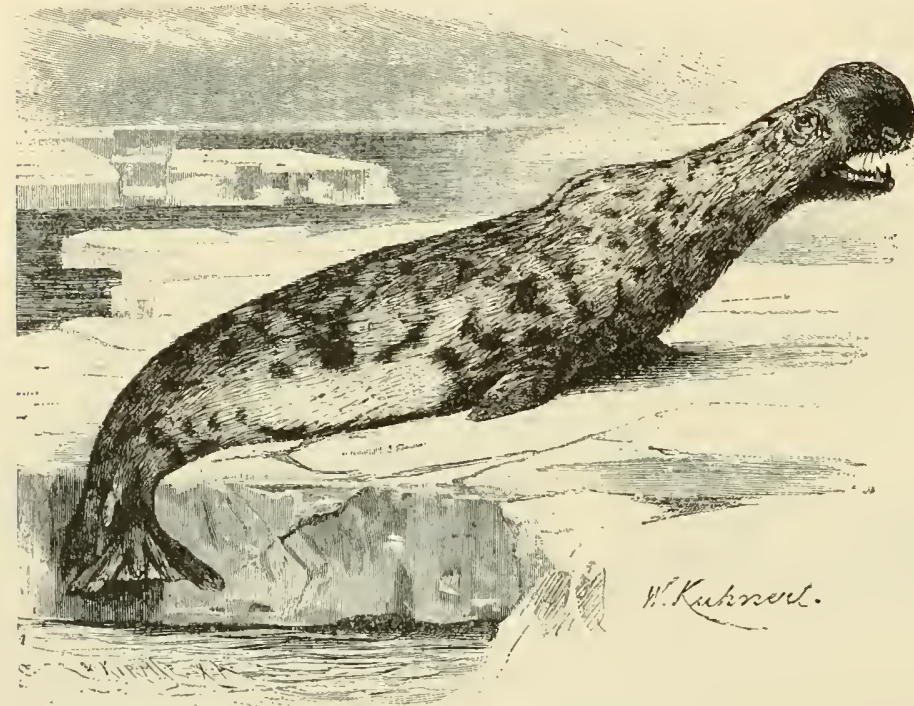

THE CRESTED OR BLADDER-NOSE SEAL. - A glance at this picture will explain the reason for the rame given to this Seal. When filled with air, the bladder at the end of this animal's muzzle gives it a very peculiar appearance. The body does not differ much in shape from that of ordinary Seals, hut the nmmerous dark spots distributed all over the fur, as shown in the illustration, give it a distinctive individnality. (Crystophora cristata.)

The habits of the Elephant Scal remind us of those of the Fur Seal and the Sea Lion. Like them it undertakes annual migrations in its southern range, only diseased and enervated animals staying behind, while the others all make the journey together. They arrive in great numbers in Patagonia in September and October, and sometimes as early as June, and leave again at the end of December to travel in a southerly direction. On the ground they prefer sandy and pebbly spots, but also prowl around in fresh water. Families numbering from two to five members form a separate company in the great herd; and are always found closely huddled together, usually sleeping in the mud or reeds. During a period of intense heat they cool themselves with damp sand, into which they dig a hole for themselves, or which they throw on the upper surface of thcir body with their fore-feet; sometimes they look more like heaps of earth than living animals, and in this respect resemble Thick-skinned animals.
Elephant Seals Their senses of a Peaceable are said to be Disposition. little developed. They are lazy, dullwitted creatures, that rarely suffer themselves to be disturbed in their easy repose. They enjoy the reputation of being of a gentle and peaceable disposition, as they have never been seen to make unprovoked attacks on other mammals or human beings. Small Seals of other species and Men quietly bathing may swim among them with security. Pernetty affirms that his sailors rode astride them, and when their gait was too slow, urged them to more rapid notion by knife thrusts. K. von den Steinen describes their manners as follows: "Usually the males stared at us with their mouths open, but did not stir. The expression of their faces was wonderfully ludicrous, as they gazed at us in their stupid astonishment, wrinkling their thick noses up and down in their discontent. A hypochondriac of the most somber disposition could not have refrained from a woe-begone smile at the sight of the funny physiognomy of one old hooknosed fellow in particular."

Youthful Life of Ten montlis after the breeding sea-

the Elephant son, usually in July or August, but in Seals. Patagonia the beginning of November, and about a month after the arrival of the herd on the islands, the young Seals make their appearance. They are large creatures, about fifty-two or sixty inches long, and weigh about eighty pounds. The mother suckles them for about eight weeks and guards them carefully. In the seventh or eighth week of their lives they enter the sea. The whole herd slowly leaves the shore, and swims farther out each day. The cubs follow the main body of the herd on all these wanderings, but are descrted by their mothers in a very few months after their birth. The proboscis develops in the male in the third year of life. 
The Hunting of The Elephant Seal is pursued by

the Elephant Man wherever it is found. ForSeals. merly these Seals were secure from all enemies on their deserted islands; but since the European sealers have gone out to seek them, or from about the beginning of this century, their numbers have rapidly decreased. The sealers cause merciless havoc among the defenseless creatures.

Scammon says, that the coast of California scarcely furnished any Elephant Seals to the hunters even twenty years ago, and this region therefore is no longer regarded as a hunting ground. In order to count on sure results it is necessary to go to the desert islands on the southern boundary of the Seals, range and remain there for months or years. These islands are uninhabited by human beings, and Ker- with these, and also with good guns, the hunters try to get between the herd on the land and the water. Then they make the greatest possible noise, by shouting, shooting, or in any other way, and slowly advance on the herd, swinging the guns, clubs and spears; and frightened by the unusual din, the herd, as a rule, retreats. If, as not infrequently happens, a male tries to resist and break through the line, a bullet through the brain ends his life, or a spear thrust into his mouth arrests him and forces him down on his hinder quarters. Two men armed with heavy oaken clubs hurry to the spot and stun or kill him by repeated blows on the head. The slaughter of their companions causes such a terror among the animals that they lose all self-possession and climb, roll and fall over each other, if they do not see any

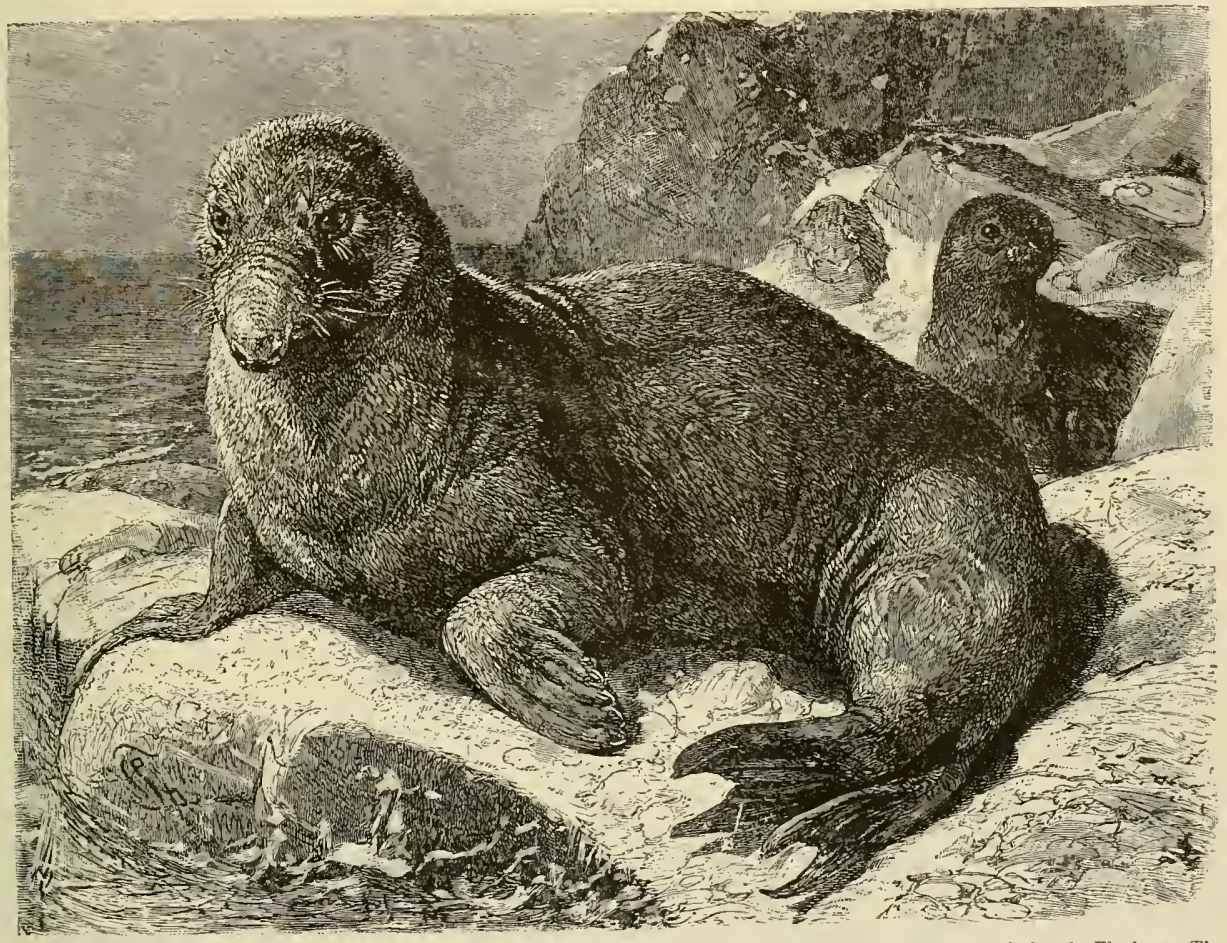

THE FIFPAT SEA heen aptiy named after the Elephant. The

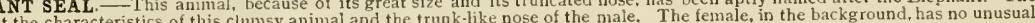
picture well brings out the characteristics of this clumsy animal and the trunk-hike nose of the male, The female, in the background,
development of the nose, for the probocis-like appearance is a purely masculine adornment in the species. (Macrorhinus leonmus.)

guelen is held to be the most important of all for Seal killing, but the shores are full of broken rocks, partly concealed under the water, which render landing difficult and for long distances do not allow even the smallest vessel to cast anchor among them with security. The sealers landing in a boat, even during the calmest weather, are compelled to jump into the water and hold the boat lest it be dashed against the rocks. An angry surf roars around those icy, rocky coasts and inundates them to a considerable depth at every breeze. It was not without reason that Cook called it Kerguelen Land, or Desolation Island.

The hunt of the Elephant Seals is pursued with the help of heavy cudgels and spears about fifteen feet long, provided with strong, sharp tips. Armed other means of escape. Immediately after the killing, the process of cutting off the blubber begins. The various pieces of blubber are tied together, fastened to ropes and dragged to the ship, where they are further divided and rendered in special kettles, the oil which is extracted from them being valued higher than that of the IVhales for lubricating purposes. The flesh of the animal is black, oily and nearly uneatable, and is therefore of little value, but the heart is a favorite dish with the sailors, and the liver is considered a dainty by these not very fastidious people, though it is said that it causes a drowsiness that lasts several hours and can not be overcome. The tongue, salted, is said to be really very savory. The short-haired, stiff skin is manu- 
factured into excellent coverings for large trunks, and made into harness, and would be turned to much greater account if the largest skins were not also the poorest, owing to their many scars. The Elephant Seals will not inhabit the earth long.
They can not even, like the Whales, retreat into the inaccessible parts of the ocean before their cruel enemy: they must endure persecution until the last of them shall have succumbed to the destructiveness of the insatiable beast of prey called Man.

\section{The volalius ffamílp.}

SECOND FAMILY: TRICHECHIDE.

The second family of the Fin-Footed animals consists only of one species (Trichechus), the Walrus or Morse, called Seahorse by English and Rosmar by Norwegian sealers, and Morsk by the Laplanders, and probably contains the most gigantic members of the Seal family.

Physical Struc- When this huge animal reaches comture of the plete maturity it attains a length of Walrus. about fourteen feet, in a few rare cases even fifteen or sixteen feet, and a girth of from nine to ten and sometimes even twelve feet. Its weight is estimated to reach 2,000 pounds. As with the Seals, the elongated body is thickest in the middle, but it does not narrow backward to the same extent as that of the other Seals. From this huge body the limbs project downward and outward like so many large rags, both the elbow and knee joints being distinguishable. The feet are furnished with five toes, which have short, blunt claws placed behind the extremity of each toe. The tail appears like an insignificant rag of skin. But it is not the body which characterizes the Walrus, it is the head, which is proportionately small, round and thickened to deformity by two swollen, ball-like tooth sockets in the upper jaw. The muzzle is very short, broad and blunt, the upper $\mathrm{H}_{\mathrm{ip}}$ is fleshy and arched on the sides, while the lower lip is puffy. On both sides of the muzzle stand rows of round, flattened, horny whisker hairs, longer behind than in front; the stoutest hairs may be as thick as a raven's quill, and four inches long; their number may be several hundred. The nostrils are crescent-shaped, the very deep set eyes are small, brilliant and protected by projecting lids. The ears lack any trace of external conch and lie far back on the head.

The teeth constitute the most remarkable feature. In the front part of the muzzle two powerful tusks, protruding far out of the mouth, crowd out the six incisors and two canines which exist in the very young animals. These tusks attain a length of twenty-four and in very rare instances as much as thirty-two inches, and weigh on an average from five to six pounds each, or even seven pounds; but there are said to have been specimens weighing fourteen and sixteen pounds. The skin is nearly destitute of hair and very thick, and is not merely wrinkled but positively gnarled. The prevailing color of old and young is a more or less vivid tanbrown or skin-brown. Generally, the tusks of the female are thinner, but frequently longer and finer than those of the male, which are usually blunt.

Early Accounts For centuries the IValrus has been of the Wal- known by pictures and descriptions, rus. but not in its true shape or habits. Albertus Magnus in the thirteenth century gave a description of the animal plentifully seasoned with fables and tales, and Olaus Magnus had scarcely anything to add to it three hundred years later. A bishop of Drontheim had a Walrus head salted and sent it to Rome, to Pope Leo X., in 1520 . This head was modeled in Strasburg and old Gessner gives a fairly accurate description from it. Martens of Hamburg lastly, who saw the Walrus personally at the end of the seventeenth century in the Arctic Ocean, gives a good and detailed account, and from that time the number of descriptions increases, and so does our knowledge of the animal through the accurate accounts of its habits and the modes of hunting it.

The Walruses Like so many other animals the IValDiminishing in rus also has been by degrees graduNumbers. ally displaced in regions nearer and nearer to the North Pole by the attacks of Man and now holds its own only in those places where there are difficulties in the way of sealers, which may be overcome only in certain years. We may say, in a general way, that the Walrus occurs in all waters surrounding the North Pole to the present day, but is not found everywhere. It is met all the year round in the northern parts of eastern and western Greenland, in Baffin's Bay and all connecting straits, sounds and gulfs, to Behring Straits, which connect its eastern and western range. It also is found off Nova Zembla and Spitzbergen and along the whole northern cost of Siberia.

A few decades ago Walruses were met with within the described area, at least occasionally, in very considerable numbers, sometimes in herds of many thousands, and their combined weight, according to the assurances of sealers and hunters, pressed large floes of ice, which ordinarily rose high over the surface of the water, down to its level. At present only a few hundreds are seen congregated in a herd and this only under favorable circumstances.

The first impression a VIalrus produces on Man is not a favorable one. The oldest seafarers found it as repulsive and ugly looking as do the sailors and travelers of to-day. German Arctic explorers say that if there is an anmal which is entitled to be termed a mouster, it is the Walrus, equally because of its appearance as on account of its demoniacal voice and unprepossessing character. The life of the Morscs secms to be a very monotonous one, partly, perhaps, for the reason that they procure their food with less pains and in less time than other Seals. In brief, we may say the following of their life and doings in the course of days and years. Haunts and Hab. According to the conformation of its of the the coast, the animals congregate in Walrus. more or less numerous troops. The adults are said to live in separate herds, the males keeping together, and the females keeping apart 


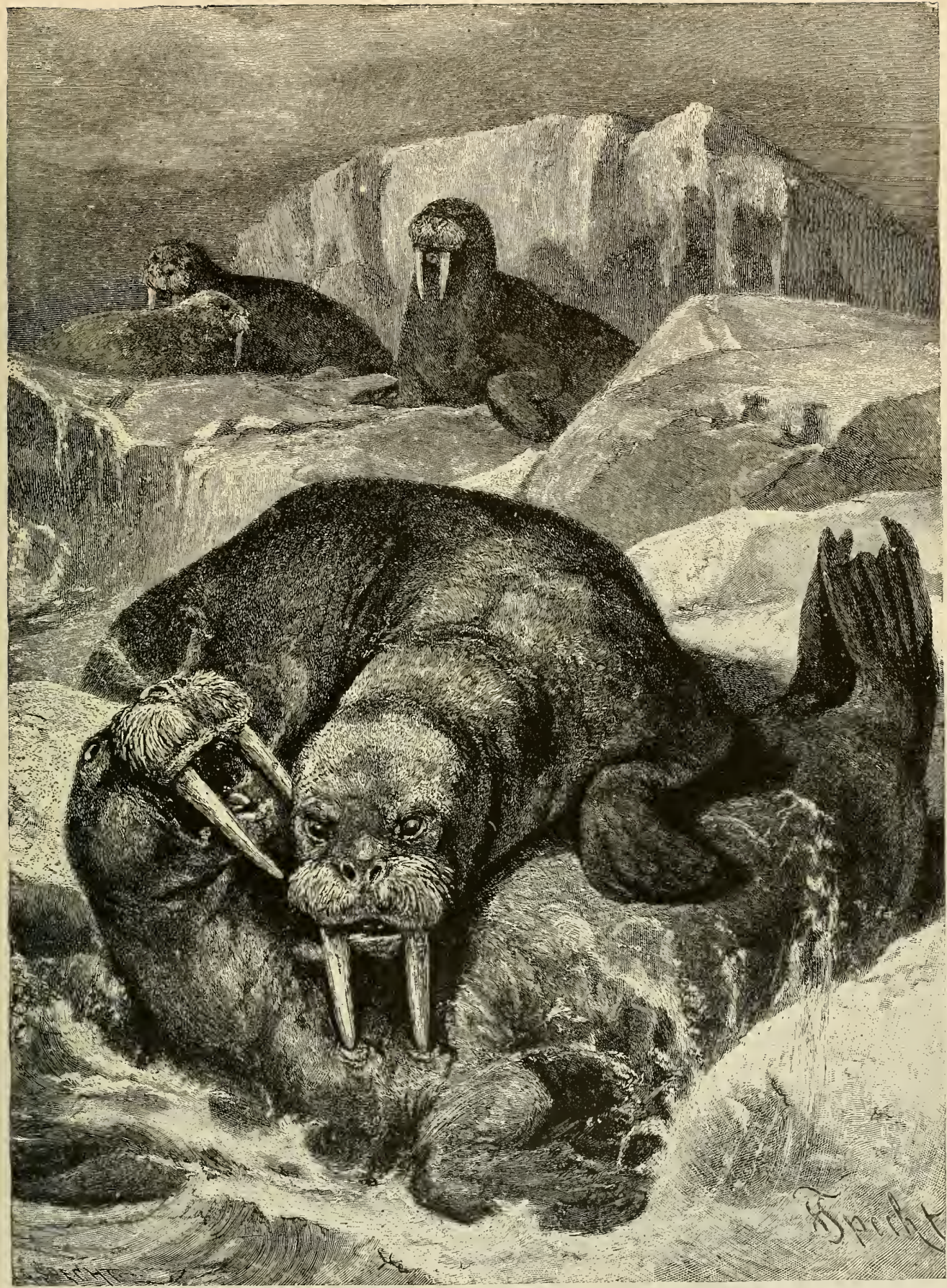

THE WALROS.-This extremely ugly animal lives in the region of perpetual ice in the extreme north, and the group in the picture is appropriately shown growth of horny whiskers on the upper lip and creeks. Some writers divide the family into two species, the North Atlantic and the North Pacific Walruses, but others, while recognizing slight differences, regard the two kinds as being only local varieties of the same species. (Trichechus rosmarus.) 
with their suckling cubs. Arctic explorers say that a single ice floe often carries twenty or more Walruses. Their dark bodies are closely huddled together, the head being inclined to the side on account of the long tusks, or resting on the body of a neighbor; "in this way, bored by the sight of the sun shining for months or by the monotonous noise of the surf, they sleep through the greater part of their existence." At least one Walrus mounts guard as a sentinel among the sleeping ones, and at the sight of danger it wakes the rest with its loud voice, or, if necessary, with a slight push of its tusks, and the whole herd then prepares either for flight or for defense. Where the Morse has not yet made the acquaintance of Man, a strange ship scarcely rouses the attention of the sentinel or the herd in general, and not even the report of a cannon disturbs them. as everybody in the Arctic Ocean is used to such detonations, the ice sometimes bursting on large tracts with a noise as of thunder.

Movements of In regard to the character of their Walruses on Land movements they seem to approach and in Water. nearest to the Eared Seals. (in land the gait of the Walrus is heavy and unwieldy ; still it does not creep, but walks, moving the feet simultaneously crosswise, and differing from other animals of similar gait only in putting the toes of the fore-feet and the heels of the hind-feet to the front. In climbing steep blocks of ice the Walrus is said to have recourse to both of its long tusks, hooking them into clefts and crevices and pulling the heavy body up by them; then it again stretches its neck and repeats the performance until it has reached the desired halting place. Still these tusks ean hardly be considered to be a necessary implement to aid the Walrus in walking, as the Eared Seals, which are not less heavy, make progress in similar localities without then. I believe it to be more probable that the WValrus makes for itself a way through driftice with the help of the tusks. It is not unlikely that by similar efforts it forms the openings in the ice for breathing, which it uses and keeps open as well as do the other Seals. It also surely employs its tusks in rooting up the ground searching for food, and also uses them as a means of defense, sometimes even breaking the planks of a boat with them. The Morse enters the water either by gliding over steep places or by throwing itself into the waves with one leap, like other Seals. After the manner of its kin it is as swift and easy in swimming as it is slow on the ground or on the ice; it dives to a considerable depth and is certainly able to stay under water for several minutes. In swimming, the creature's speed is superior to that of any boat propelled by oars, and it gives evidence of a nearly untiring endurance. The voice of the Walrus resembles the lowing of a Cow, or the deep, hoarse bark of a Dog, changing to a positive bellowing when in anger. During the breeding season the voice is heard so far, that Captain Cook and his sailors always knew, from the noise they made, the proximity of a coast in fog or at night, and were thus enabled to avoid a collision of the ship with the ice.

Mode of Life It is a very difficult matter to pass of the Wal- judgment on the mental qualities of rus. this animal from the observations that have so far been made, though we may suppose that the Walruses are not less sagacious than the other Seals. In regard to the acuteness of their senses, Pechuel-Loesche says : "Their sight is poor ; their hearing is far better, and their sense of smell is extremely keen, as, under favorable conditions, they scent Man at least at a distance of several hundred paces, and one who wishes to approach them must therefore pay careful attention to the wind." In spite of the extreme indifference it assumes towards Man at its first encounter, the Walrus alters its demeanor as it gathers experience, and opposes the Lord of Creation with energy and intelligence. Among its noteworthy qualities we must notice not only the curiosity peculiar to all Seals but also an amount of courage unusual in a Pinniped. Walruses enter into violent combats with each other, as well as with their enemies, but only during the breeding season, which usually occurs during the latter part of spring. At this time the males not only roar and bellow at all hours of the day, but also attack each other, and tear such deep wounds in the hides of their antagonists that they at times afford a scarcely less horrid spectacle than other Seals, which may be said to have been torn in shreds during their duels.

The Fernale Wal- The female gives birth to a single rus and Her cub in a season, and she devotes cub. herself to it with most faithful maternal affection; she looks to its sustenance and education in a self-sacrificing way, and defends it in peril with all the courage and fury of her race. The cub returns her affection tenderly and does not desert its mother even in death. If one kills the cub, he may count on the most obdurate resistance and unquenchable revengefulness of the mother.

Food of the Wal- The researches of MaImgren and rus-How Pro- Brown point to the fact that the cured. Walrus feeds exclusively on animal matter. Both found a shell (Mya truncata), which in the northern parts of the Arctic Ocean covers all banks and cliffs, and another one (Saxicara migosa) to be the principal contents in the stomachs of the individuals which they examined, and chey concluded that the Walrus employs its powerful tusks principally to loosen the shells from the rocks and dig them out of the mud. In doing this it swallows not only other low marine animals, but also the algre which are fastened to the shells and other sea-plants, and also, as do so many other Seals, swallows sand and pebbles. Besides the lower marine animals the creature also eats fish and occasionally even the meat of the larger marine mammals.

Walruses are Walruses lying on the beach or on Formidable in the an ice field are little to be dreaded, Water. as their unwieldiness hinders them from successful attacks, but in the water they command all their agility and strength. Occasionally these courageous and intrepid representatives of the Seal family attack even without provocation, and force sailors into unintended combats. The Arctic explorers, Payer and Copeland, give us an aninated and graphic description of such an encounter: "If such a monster catches sight of a boat, it lifts itself above the surface of the water in sheer amazement, utters its cry of alarm, which consists of oft repeated short barks, and swims towards the boat with all possible speed. Its cries attract others, wake the sleeping animals which the boat has earefully avoided touching, and in a short time there follows in the wake of the frail little vessel a number of these monsters, raging in simulated or real fury. It may be that the animals are inspired by curiosity only; but the way in which this euriosity finds expression is by no means happily selected, and the suspicion that they wish to turn the boat over, in order to examine it more fully, lies very near the 


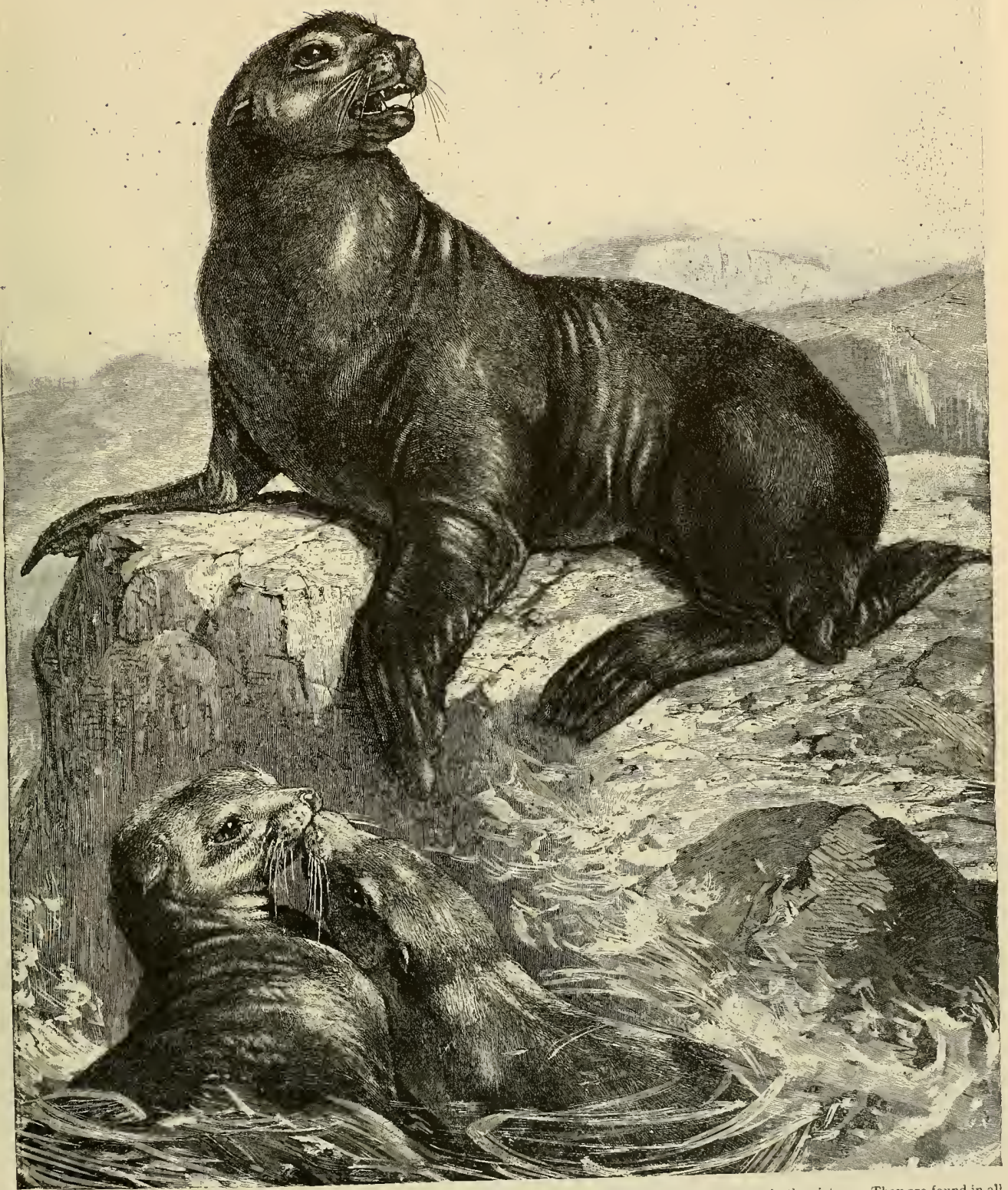

SEA LIONS. - The typical animal of the family of the Eared Seals is the Sea Lion, a group of which are seen in the picture. They are found in all climates in the Pacific Ocean, although they are especially numerous in the remote Arctic regions. The lures of the animal: the small but well defined ear, swim and play together in water near the land or an ice-floe. The picture shows the characteristic
the limbs protruding from the body and peculiar shape of the toes and flippers. (Otaria stelleri.) 
truth. It is therefore necessary to prepare for the fray, especially as the actions of the animals soon convince the observer that it will be impossible to escape them unmolested even with the quickest rowing by five men. The roaring, spurting and diving herd of Morses is soon but a few paces distant. The first shots are fired, and this volley rouses their wrath. The fight waxes hot, some of the Men wield their axes against the fore-flippers of the terrible sphinxes as they threaten to overturn the boat and dash it to pieces; others of the crew defend themselves with spears or deal blows with their oars upon the gigantic, thick heads, or else send indigestible leaden pills down the wide open abysses of the incessantly roaring mouths. A wild din fills the air; the boat's defenders fight hard to keep their balance; the water foams and surges violently ; new monsters suddenly raise their heads out of the the water or swim up to the boat; others, mortally wounded, go to the bottom, their blood imparting its color to the surrounding sea. The impending danger that the boat may be overturned or severely damaged by the tusks of a Walrus, may often be averted only by mortally injuring the leader of these brave and hardy creatures."

Uses to Which Europeans [and Americans] use the the Walrus hide, blubber and tusks of the Walis Put. rus. The lide is tanned, the blubber rendered, the tusks are used as ivory. The flesh is coarse-grained and oily and is eaten by Europeans only when necessity impels, though the tongue is said to be very palatable. With the nations of the high northern latitudes matters are different; they use every part of the Morse. The hide is manufaetured into thongs, ropes and fishing nets, or even summer habitations may be covered with it; a variety of tools are made out of the bones; the sinews are twisted into sewing thread; the flesh is a favorite dish and the blubber is used as shortening in their food or is burned to furnish light.

\title{
The Eared acals.
}

\author{
THIRD FAMILY: OTARIIDE.
}

The members of the third family of the FinFooted Animals, the Eared Seals (Otoriide) differ from their other relatives in the following features. The external ear has a well dereloped, though small, conch. The limbs protrude from the body and are clearly distinguishable; the flippers are large, elongated beyond the toes in a rag-like manner, and the soles are bare; the hind toes are of fairly uniform length, while the fore toes decrease in length toward the outer side. The sexes differ strikingly in size, the males attaining, as a rule, at least double the length and three or four times the weight of the females.

General Traits of All known varieties of this family the Eared resemble each other to such an exSeals. tent that they must necessarily be classed in one species; all lead the same mode of life as regards essentials. Mainly inhabiting the Pacific Ocean, they exist as well off the ice-bound coasts of Behring Straits as on the continent surrounding the Antarctic Pole and its islands, in the temperate zones as well as beneath the horizontal rays of the sun in the equatorial regions. They either undertake journeys of varying extent, or they may remain in the same locality for years. They are incessantly and ruthlessly pursued in most of the regions they inhabit, and in some sections have already been exterminated by the greed of Man, who for centuries has waged war on them and slaughtered and destroyed them by the thousand on account of their skin, flesh and fat.

Structure and The species of Fared Seal, which Characteristics of nearly every visitor to San Francisco SeaLions. mentions, is the Sea Lion of the sailors (Otaria stelleri), a variety well known to us since steller's times. A male Sea Lion may attain a length of more than twelve feet and a girth of about nine feet. The females are much slighter, their length not exceeding nine feet, and their average weight not being more than four hundred pounds.
In its structure this animal differs less from the Ordinary Seals than other groups of this family, but can as little be mistaken for one of the earless Seals as the others; not only because its legs and feet show a different construction, but it may be distinguished at a glance by its elongated head and neck and its proud, domineering attitude when excited. The coloring of an old male is subject to many variations, as one may find, lying on the same rock, black, mottled, or reddish-brown, sombre or light gray specimens. A mature female is usually of a light brown hue; the fur of the cubs is of a slate-gray or grayish-black tint.

The Sea Lion exists in the northern part of the Pacific Ucean, ranging south about as far as the Galapagos Islands.

The Herd of Finsch writes about the well known Sea Lions at San lierd of Sea Lions at San Francisco Francisco. as follows: An extremely wide and no less dusty road leads through deserted downs, grown with scant vegetation, where the sand is in constant motion and from time to time fills the air with a kind of fog; after a walk of three-quarters of an hour one reaches the Cliff House, a hotel situated close to the rocky beach of the Pacific, and representing a favorite picnic site of the inhabitants of San Francisco. Even at a distance the noise of the powerful surf greets the ear of the visitor approaching the Cliff House, but simultaneously he hears a peculiar bark, which gains in volume and variety as he comes nearer. Guided by this bark one perceives a lively activity going on upon three high eonical cliffs, situated at about one hundred and fifty paces from the coast, the lower part of which projects horizontally from the ocean in places, against which the waves dash with deafening noise. About sixty huge Sea Lions lie on the larger steep rocks of the cliff, in groups of as many as fifteen or singly, comfortably stretched out in crevices or on the narrow ledges, ruled over as it were by a power- 


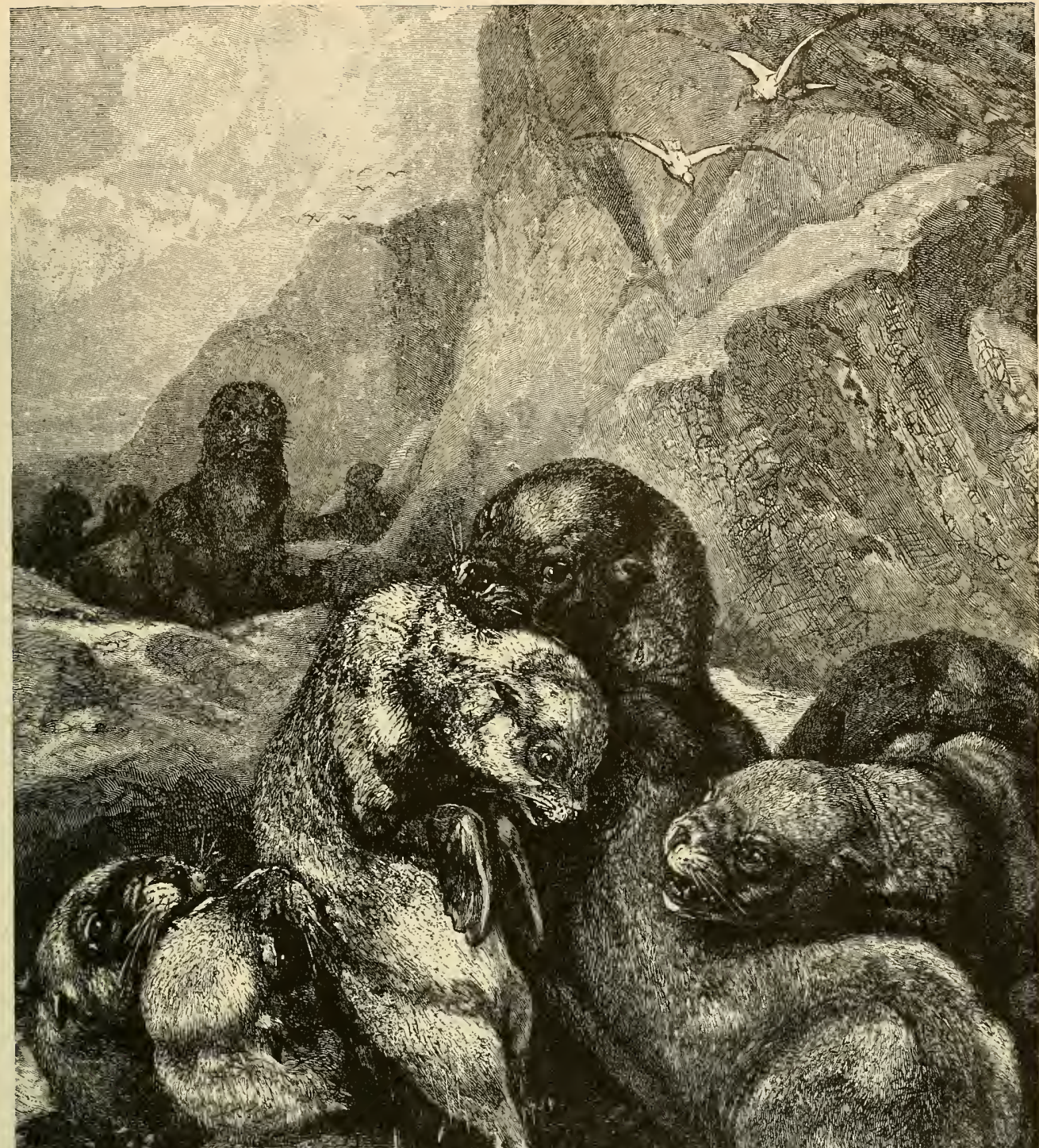

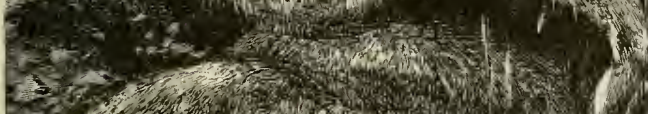

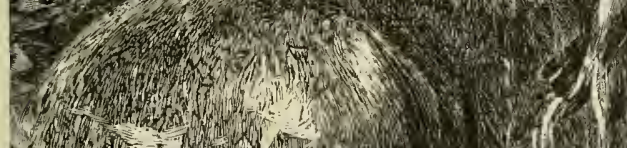

(6)

W. as the Sea Bear. This is the species of Seal which has been the subject of so much international controversy. Its principal home is now on the Pribyloff Islands of the northern Pacific, where it seeks the most inaccessible rocks for its lair. These Seals live in large herds. The picture illustrates a group of them making slow progress over the rocks, while a mother Seal aids her young one to advance by carrying it in her mouth. (Otaria ursina.) 
ful male Sea Lion, enthroned on the highest part and well known to all inhabitants of San Francisco under the name of "Ben Butler." From time to time he lifts his head, inflates his thick neck to a wonderful extent and utters a deep bark, which is joined not only by the weaker, finer, and higher voices of all his mates, but also by the hoarse shriek of the numerous Sea-gulls and the croaking of other aquatic birds which sit in long rows on the rocky ledges and single tops and points of the cliffs, as well as by the dull bass voice of the brown Pelicans. Fascinated by the striking spectacle, even the most indifferent visitor observes the different animals for some time and soon sees to his astonishment how these giants, which are apparently so clumsy and unwicldy, climb to the highest tops of the cliff. Frequently one sees them throwing themselves into the ocean, simply by sliding down the gentle incline of the rock or leaping from some higher point. Dolphin-like they then play about in the water, sometinies literally jumping out of it, pursuing each other and making pretense of being engaged in a furious fight, though in reality these encounters are nothing but mere sham and play. In a seemingly great rage two of them may open their huge mouths and roar at each other as if preliminary to the most earnest combat, but soon they peaccfully lie down side by side and perhaps even begin to lick each other. For hours one may watch the ever varying spectacle, and still continue to observe and find something new."

Sea Lions are easily kept in captivity, are capable of becoming very tame and if taken young they exhibit an extraordinary degree of affection for their keeper.

The Northern Fur The Northern Fur Seal, Sea Bear or Seal or Sea Ursine Seal (Otaria ursina), is of Bear. smaller dimensions than the Sea Lion, the largest males measuring not over six feet or six feet six inches, and the fernales seldom exceeding the half of this. The hair is perceptibly longer on the neck and the fore part of the body and somewhat longer along the spine; it consists of an outer fur which is not very stiff and a close inner woolly fur of exceeding softness and delicate, silky texture. The ground color is dark brown, merging into brownish black in some individuals, having a mottled appearance on the head, neck and fore part, but assuming a lighter tint on the under and inner sides of the limbs. The older females are of a silvery gray tinge and young animals of both sexes have a fur of silvery hue.

Range, Haunts Few Seals have so wide a distribuand Habits of tion as the Fur Seals, as they are Fur Seals. found on the coasts of Patagonia and southwestern Africa, on the Falliland Island, off southern Novia Scotia, on the St. Paul Island in the Indian Ocean, and the Pribyloff. Islands in the Behring Sea. In their natural history the attractive picture Steller drew of them has been greatly added to in recent times.

The observations of all sailors, who know the Fur Seals, tend to show that they visit the islands and rucks on which they appear at regular intervals, for the sole purpose of breeding, and during the other months they live exclusively in the ocean, undertaking very extensive wanderings. Still, as the observations of several consecutive years show, they always return to the same known breeding grounds or "rookeries." When the season of their landing draws nigh, onc first sees a few old males arrive, which seem to do service as explorers. The others follow them, a few at a time. They exhibit great circumspection in selecting their sites, perhaps only because experience has taught them the necessity of guarding as much as possible against their worst enemy, Man. In general they select islands, or stretches of coast on larger islands, against which the surf dashes with special violence, and then they choose the least accessible rocks lying immediately above high-water level, as temporary habitations.

Two or three day's after landing each female gives birth to one, some of them, perhaps, in very rare cases, to two, young ones. The little Sea Bear, like all Seals, very fully developed and with his eyes open, is about fourteen inches long at birth. During the first weeks after birth, the cubs are left by their mothers only for a few minutes at a time at the most, but after awhile they go into the water for a longer time in search of food. " Up to that time the cubs follow every movement their mothers make on land, but are entirely incapable of swimming during the first four or six weeks, and are sure to drown if by any accident they fall into the water. After these early weeks of their lives they gradually and awkwardly learn how to swim, trying to imitate the old ones, but always scrambling back to the shore in a hurry during the first attempts. In time they gain confidence and go farther out, and become quite skillful swimmers by the middle of September.

Great Value of The Sea Bear is a still more valuable the Furs of animal than any of the other mem-

Sea Bears. bers of his tribe, on account of his excellent fur. The natives of the islands which he frequents also kill him for his flesh, which forms an important part of their sustenance and is held to be savory even by Europeans. The main profit of the chase has always accrued from the fur of the young animals: but people have acted in as improvident and scnseless a manner in the chase of the Fur Seals as they have in the hunting of other marine animals in general, and within a few decades such extraordinary numbers of them have been exterminated, that some islands which were formerly populated by them have gradually become descrted. The furs of this species form the most valuable commodity of the entire fur trade.

The Southern Sea The Southern Sea Lion (Otaria jubata)

Lion an Antarc- has a very noticeable distinguishing tic Variety. mark in the smallness of its ears. Full grown males attain a length of seventy-eight inches from the tip of the nose to the end of the short tail. The females are distinguished from the males by their darker coloring and considerably smaller size, which in the majority of cases is not more than half that of the males, the weight being in proportion. These animals are found on the coasts of the southern portion of Soutl America and islands in the same latitudes and south to Graham I and. They are most numerous on the coast of Terra del Fuego and on the Falkland Islands. Their habits and modes of life are similar to those of the northern Sea Lion. Like the latter they undertake extended migrations, and have regularly selected haunts where they make their home until the young have been born and trained to swim and to provide for themselves. During such a sojourn, strange to say, these animals enter the water very reluctantly, for Abbott say's that although he threw stones at a family of these Sea Lions, he could not drive them into the sea. 


\title{
Tbe Tinsect=Leating Intímals.
}

\author{
SIXTH ORDER: INSECTIVORA.
}

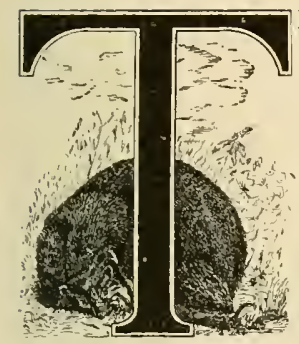

H E Insect - Eating aninals are small creatures, mostly of a striking appearance, whose mode of progression is plantigrade; they are distinguished by an elongated head and a nose prolonged so as to partake of the character of a proboscis. The body, as a rule, is of stout build; the fore limbs are regular, the tail in some species is short, the hind limbs long, the organs of sense may be highly developed or stunted; the texture of the fur includes every variety between velvety softness and a coat bristling with spines. The teeth are of all three kinds; but the incisors differ materially in number and shape in the different groups and varieties; the canines attain an astonishing length in some species, while in others they are smaller than the incisors; only the molars show uniformity to the extent of being single pointed in front and furnished with several tubercles behind. The feet are usually provided with five toes, the development of which, as well as that of the wrist and ankle joints, varies materially. Of the muscles, that which serves to roll the skin (especially developed in some species), is deserving of mention.

General Traits The Insectivora are dull, sulky, disof Insecti- trustful and timid creattres of solivores. tary tendencies and possessed of a violent temper. By far the larger number live under ground, digging and rooting, or at least keeping from view in secluded hiding places; some, however, inhabit the water and some live on trees. Their astonishing activity puts a successful check on the increase of harmful insects and worms, Snails and other animals of low development, and even some small rodents. Therefore, they are all, nearly without exception, useful laborers in the vineyard, but are known and esteemed only by persons well versed in natural history; the mass of people hold them in abomination. These small diggers are pursued, on account of their ugly looks and their habits, wherever they are found, by people who utterly ignore the services these animals render. He who studies their life is certain to act differently. He finds so many attractive and fascinating traits that he soon forgets their lack of good looks and gives them his hearty interest and approval.

Hibernation of Many species of Insectivora hiberthe Insecti- nate and would perish if nature had vores.

not provided for their conservation in this way. At the approach of cold weather, nature, to a certain degree, puts a stop on the lower forms of animal life, and thousands upon thousands of the creatures, which are destined to be the food of the animals now under consideration, doze off either into etcrnal or temporary slecp. In this way earth is rendered desolate for the foes of insect life, and as they cannot migrate like the birds, they are in a certain way conpelled to follow the example set by the insects. So they retire into the best concealed hiding places they can find, or prepare such themselves, and fall into that deep lethargy, which temporarily stops all activity of life and preserves it in their bodies until they wake again. But only those species hibernate which feed on vegetable matter as well as insects, while the most zealous insect hunters ply their craft in winter as well as in summer. Under the snow and earth and in the depth of the water, life, pillage and carnage still go on in winter; and this is also the case, of course, in those countries where there is perennial summer, or where there is no winter that brings freezing cold with it.

The Insect-Eating animals are chiefly found in the temperate countries of the north and are not found in South America or Australia. They delight in watery, or at least damp, forests, groves, plantations and gardens, scarcely ever leaving such situations. Quictly and noiselessly they follow their hunt, by far the larger number being active by night, although some pursue their prey in the bright daylight.

The opinions of scientists as to the division of the Insectivora show some discrepancy. We will admit seven families, including a remarkable animal of the Malayan Islands, the Galcopithecus.

\section{The lbedochogs.}

FIRST FAMILY: ERINACEIDE.

The Hedgehogs, which we put at the head of this order, are such remarkable animals, that the shortest description suffices to characterize them. A set of teeth, thirty-six in number, and a coat of spines are the most important features of the few varicties which we consider as really belonging to this family. All Hedgehogs are of a stout build, and thotigh their heads are not particularly long, the muzzlc part is drawn out into the form of a proboscis; the eyes are moderately large, the ears fairly so, the short thick legs end in clumsy feet, the front pair always having five toes, the hind ones usually having five, and exceptionally four. The tail is short and the wiry fur consists of short spines above and hair below.

$\begin{array}{cl}\text { Habitat } & \text { The family is disseminated over Eu- } \\ \begin{array}{c}\text { and Traits of } \\ \text { Hedgehogs. }\end{array} & \text { rope, Africa and Asia. Forests and } \\ \text { meadows, fields, gardens and exten- }\end{array}$ sive plains are the principal haunts of its members. Here the Hedgehogs take up their abode in the densest of thickets, under hedges, hollow trees, and roots, in rocky crevices, burrows deserted by other animals, or similar places, or they dig short shafts for themselves. The greater part of the year 
they live singly or in couples and lead a perfectly nocturnal life. It is not until after sunset that they wake from their daily slumber and go out in search of food, which, with most of them, consists of plants and animals, and with some only of the latter. Fruit and juicy roots, seeds, small mammals, birds, insects and their grubs, Snails, Rain-llorms, etc., form the ingredients which lavish nature has provided for their meals. In exeeptional cases some of them also dare attack larger animals, such as poultry or young Hares. They are slow, heavy and rather lazy creatures, confined to the ground; and they step on their entire sole in walking. Among their senses smell ranks first; but their hearing is also acute, while sight and taste are very deficient and their sensibility is of a dullness which is really unrivalled. The mental qualities of the Hedgehogs are on a rather low plane. They are timid, shy and stupid, but fairly good-natured, or rather indifferent with regard to the surrounding circumstances, and therefore easily tamed. The young are from three to eight in number and blind at birth; the mother tends them carefully and even exhibits a certain amount of courage in their defense, which she lacks entirely under different circumstances. The majority have the peculiar trait of rolling themselves into a ball at the slightest danger, in order to protect their soft parts against any possible attack. In this attitude, also, they sleep. Those which inhabit northern climes spend the cold season in uninterrupted hibernation, and those which exist in the equatorial regions sleep during the dry season.

The direct usefulness of the Hedgehogs is slight. Nowadays at least one hardly knows what to do with a lledgehog which has been killed. Their indirect use, however, is greater, as they destroy a multitude of noxious animals. For this reason they deserve our fullest sympathy and the most generous protection, instead of the contempt they usually are subjected to.

The Common Of the Common Hedgehog (ErinaHedgehog De- ceus iuropaus), the whole body with scribed.

all its parts is very stout, thick and short, the muzzle is pointed and indented in front, the mouth is slit far back; the ears are wide, the eyes black and small. A few black whisker hairs stand among the whitish or reddish-yellow hair of the face, the fur on the sides of the nose and upper lip being dark brown; a white patch lies behind the eyes. The hair on the neck and under portion is light red with an admixture of yellowish or whitish gray. The spines are yellowish, with dark brown rings in the middle and at the tip; their upper surface shows twenty-four to twenty-five fine longitudinal grooves, which are separated by arched ridges; the center shows a marrow tube filled with large cells. The bodily length of the animal is from ten to twelve inches; the tail measures one inch, the height at the shoulder is about five or seven inches. The female differs from the male by its slightly larger size, a more pointed muzzle, stouter body and lighter, more grayish hue; her forehead is also usually not so deeply set with spines, the head appearing longer because of this arrangement.

The Common Hedgehog is distributed not only over all Europe, with the exception of the coldest parts, but also over the greater part of northern Asia; it is found in Syria as well as in western and southeastern Siberia. It is a quite common animal in Great Britain, especially in the south of England. It is rare, but not entirely absent, in Ireland.
Peculiarities of The Hedgehog is a queer fellow, but: the Hedge- a good-natured, timid one withal, hog. and gains its livelihood as best it can, by means of hard toil and trouble. Having little aptitude for society, it is always found singly or at the most in the society of its mate. Under the densest of thickets, heaps of dry wood or in hedges, each Hedgehog settles down singly and as comfortably as it can. If no ready-made burrow can be found, it digs one out for itself with great labor, and lines it with some appropriate material. The burrow reaches about twelve inches below the surface and is provided with two exits, of which one, as a rule, faces south, the other north. But these doors are subject to change, like those of the Squirrel, especially during a violent northern or southern wind. In high corn the creature usually only makes a large nest.

If our bristled hero, while walking, hears anything suspicious, he stops, listens and sniffs, and one clearly sees that the sense of smell is by far the most acute, especially in comparison with that of sight. It not infrequently happens that a Hedgehog runs right under the feet of a hunter, then suddenly stops, sniffs around and runs away in a hurry, unless it should prefer to resort to its method of defence, that is, to roll itself up into a ball. The former shape of the animal then shows in nothing; it forms an egg-shaped lump, showing an indentation at one place; but the rest is of fairly regular roundness. The indentation leads to the abdomen, and in it lie, closely pressed together, the snout, the fore legs and the little stub-like tail. When the creature moves quietly along, the coat has a rather smooth appearance and the thousand spines lie quite smoothly, arranged like shingles on a roof; they bristle on all sides as soon as the Hedgehog assumes the ballshape and give it the appearance of a terrible ball of spines. A somewhat experienced person, however, even then finds no difficulty in carrying a Hedgehog away in his hands. To do this it is only necessary to place the ball in the position the animal would assume for walking, gently stroking the spines in a backward direction, and then they do not hinder one in the least.

If one of its principal foes, a Dog or a Fox, finds it, the Hedgehog rolls itself together in a hurry, and stays in that attitude under all circumstances. It notices by the furious barking and growling of its pursuers, that their intentions are earnest, and it carefully guards against giving up its inherited privileges. There are, however, many expedients to induce a Hedgehog to give up its ball shape. If water is poured on it, or it is thrown into the water, it unrolls itself immediately; not only Reynard, the rascal, but also many a Dog knows how to profit by this use of water, to the detriment of the little creature. Tobacco smoke blown into its nose through the spines, has the same effect.

The Hedgehog The Hedgehog is by no means an Seeking for unskilled or clumsy hunter; it knows Food. how to perform certain tricks for which one would never give it credit. The principal part of its food consists of insects, though, and this is how it becomes so useful. But it does not content itself with this unsubstantial food, and wages war on other animals also. None of the small mammals or birds is secure from it, and among the animals of the lower orders it plays sad havoc. Beside the multitude of Grasshoppers, Crickets, Cockroaches, Nay-bugs, Beetles of all kinds and their 


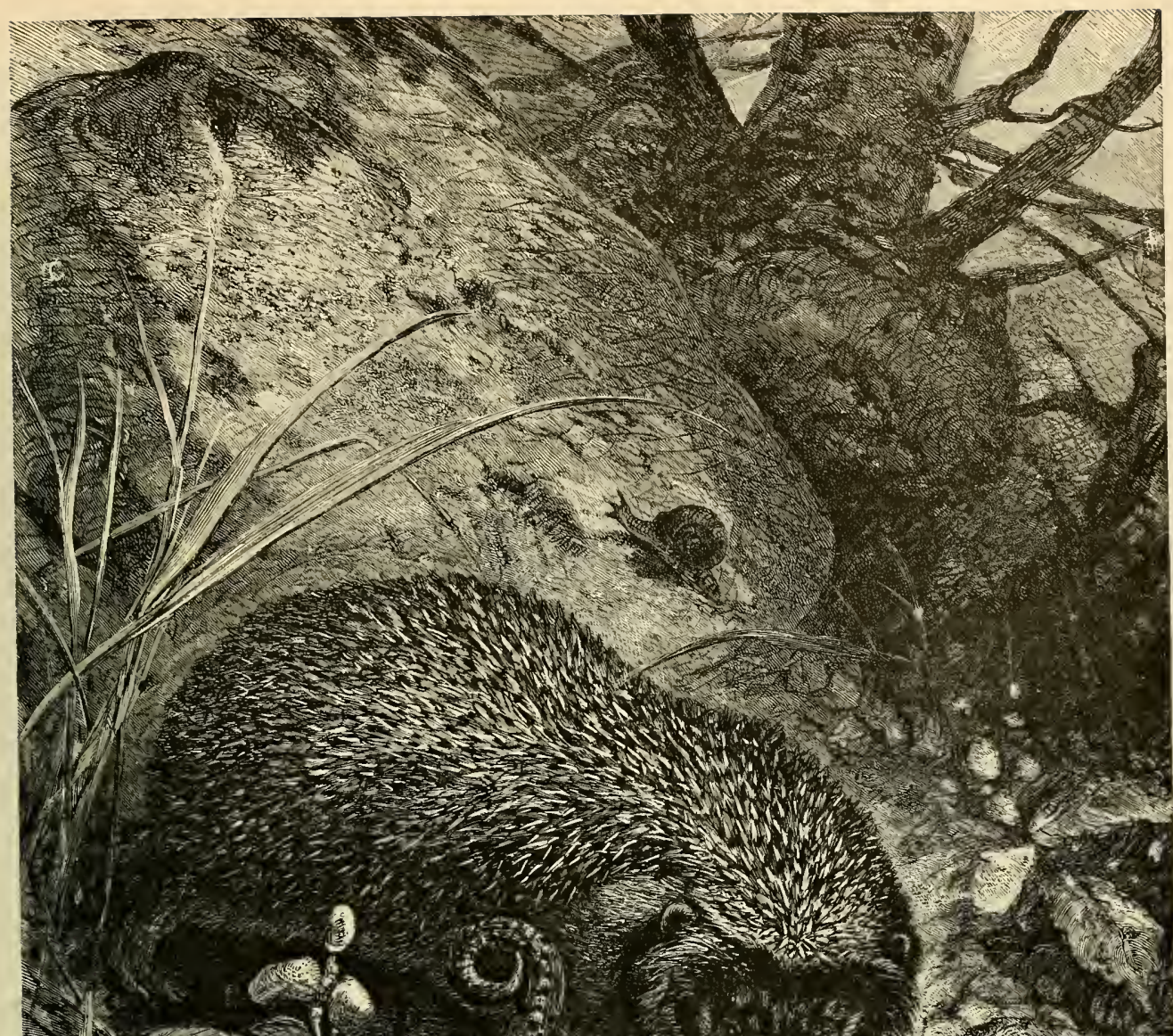

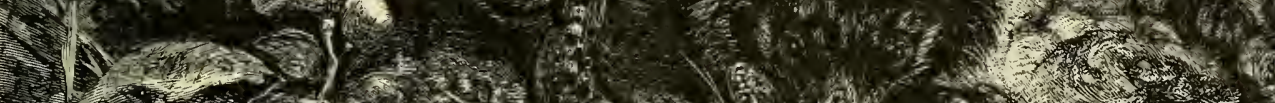

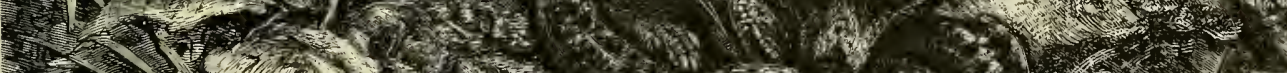

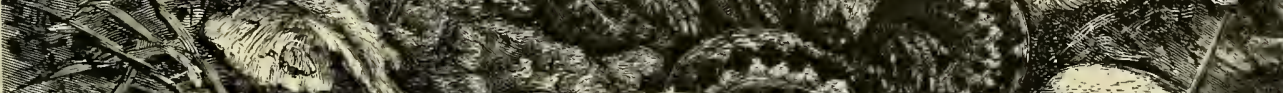

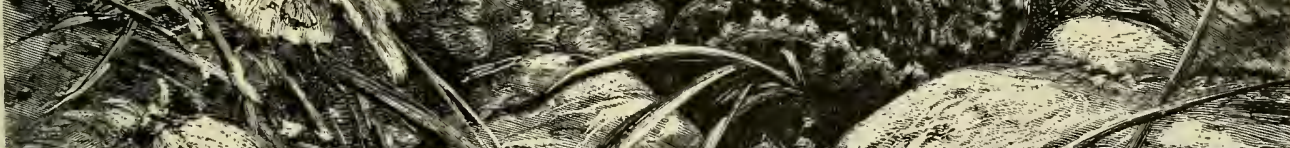
17 - 1 . 2xi I 15

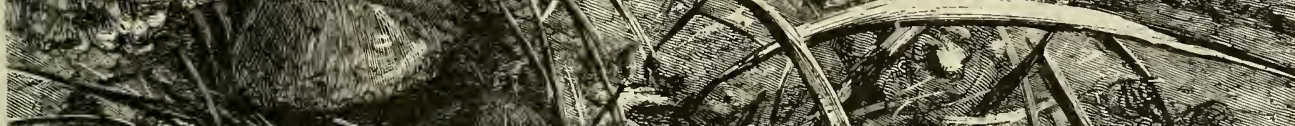

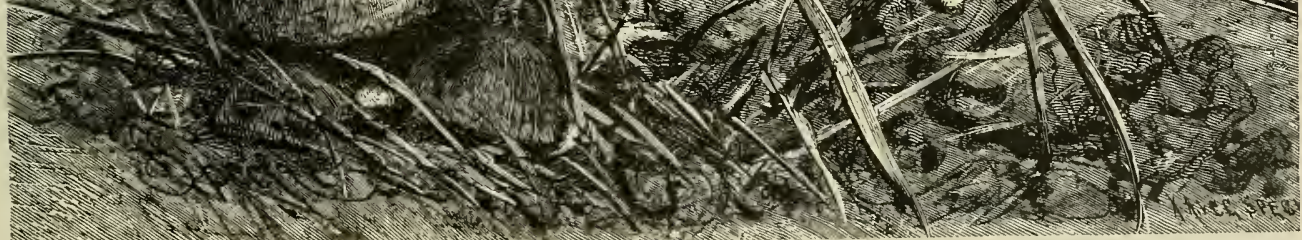

THE HEDGEHOG, An animal very faniliar to Europeans, and possessed of peculiar characteristics, is the Hedgehog. Its method of defending itself against attacks, by rollnng itself into a round ball which presents only sharp spines to the enemies' onslaught, is well known. Another famous and useful trait of the Hedgehog is its boldness in attacking venomous reptiles. The picture shows a Hedgehog busily employed in a fight with an Adder, which it is important gane. (Erinaceus europaus.) 
larve, it devours Rain-worms, Snails, Mice, small bitds aild even the young of larger ones. One really would not think it capable of catching the small, nimble Nice; but it knows its business, and accomplishes this seemingly impossible feat.

Snake Killing Much more important are its comPropensities of bats with Snakes, in which it exhibits Hedgehogs. a courage which it would scarcely be suspected of possessing. Lenz has made excellent observations upon this trait of the animal: "On the 2 th of August," he says, "I put a Hedgehog into a large box, in which, two days later, it gave birth to six little ones, covered with incipient spines. The mother took care of her children with faithful love. To test her appetite I proffered her various kinds of tood, and found that she ate Beetles, Rain-worms, Frogs, and I3lindworms with great gusto, and also ate even Toads, but these not so willingly. Mice were her favorite dainty; fruit she ate only when there was no animal food to be had, and when I once gave her nothing but fruit for two days, she ate so seantily that two of her young starved for want of milk. She exhibited great courage also in contending against dangerous animals.

But let us come to the main point, the fight of our heroine with an Adder. Although it gave us great admiration for the Hedgehog's exploits, we must confess that we would lack the courage to imitate them. On the 30 h of August I put an Adder in the Hedgehog's box, as she was quietly suckling her young. I had previously demonstrated by experiment that this Snake did not lack poison, as it had killed a Mouse very quickly two days before. The Hedgehog soon scented it (the creature was always guided by scent, never by sight,) rose from her bed, earefully groped around the Snake, as it lay stretched out, sniffed at it from the tail to the head, aud paid special attention to the mouth. The Snake hissed and bit repeatedly into the snout and lips of the Hedgehog. Scorning the Snake's impotent rage the Hedgehog comfortably licked her wounds, without flinching, and while so engaged received a sound bite in her tongue. Without being the least confused, she went on sniffing at the enraged, biting Snake, repeatedly touching it with her tongue, without biting, however. Finally she quickly seized the head of the Snake, and, in spite of its resistance, crushed it, poisonous teeth, glands and all, between her teeth, and ate it to the middle of the body. Then she stopped and went back to suckle her young. In the evening she ate the rest of this Snake and also a young new-born Adder. On the following day she devoured three more new-born Snakes, neither the Hedgehog nor her young ones feeling any the worse for these repasts; nor was there any swelling or anything else of the kind to be seen on the wounds. This Hedgehog has since frequently fought with equal success, and she always crushed the head first, while she never paid any attention to this careful selection of the head in killing nonvenomous Snakes. The remains of her repast she was wont to carry into her nest and devour them at leisure."

These observations are undoubtedly remarkable in every respcet. In the light of physiology, one cannot understand how a warm-blooded animal can stand bites which would mean death to others of its class. We must bear in mind that the bite of an Adder kills mammals which are of at least thirty times the size and wcight of the Hedgehog, and apparently ought to be much stronger than it is.
But our bristly hero really seems to be proof against venom; and devours not only poisonous snakes, the venom of which, as everybody knows, is effective only when it enters the blood directly, but also animals the poison of which acts when taken into the stomach, as, for instance, the well-known Cantharides, or Spanish Flies, the bodies of which cause violent inflammation if applied to the external skin, and which taken internally would unfailingly cause the death of other animals.

Birth and Train- Young Hedgehogs are born in litters ing of Hedge- of from three to six, and in rare cases hogs. eight, in a nest which the mother has specially prepared for the occasion, and which is of large, roomy dimensions, warmly lined and situated under thick hedges, heaps of leaves or moss, or in a corn field. The little Hedgehogs, which are blind at birth, are about two and one-half inches long, of a white color in the beginning and have a nearly naked appearance, as the spiues do not develop until later.

\section{Hedgehogs}

in their Winter

Towards autumn the young Hedge-

Retreat. hogs are so far grown-up that each before the cold weather comes, each has stored goodly supply of fat on its little body and thinks of preparing its winter quarters, like the parents. The winter abode is a heap of straw, hay, leaves and moss, earefully lined in the interior. The building materials are brought there by the Hedgehog itself in a very queer manner. It rolls around in the leaves where they lie thickest, in this way pinning a load of them to its spines, and giving itself a quite magnificent appearance. In the same manner it carries fruit home. With the first intense cold the Hedgelog buries itself deeply in its habitation and there spends the cold season in uninterrupted hibernation, which usually lasts till March. Under favorable circumstances a Hedgehog in the free state probably reaches an age of from eight to ten years.

The Hedgehog To tame a Hedgehog it is only nec-

in Captiv- essary to confine it in a convenient

ity. place. It soon becomes accustomed to its captivity and loses its fear of Man. It eats what is offered it without hesitation and even looks for additional food for itself in house and yard, and still more freely in barns and sheds. In some localities it is highly esteemed as a mouser and is extensively employed as such in warehouses where Cats are not desirable. The Hedgehog is admirably adapted for the extermination of obnoxious insects, especially for the devouring of the repulsive Cockroaches, and it does its work with great zeal. If it is only treated kindly and a secluded corner is provided for it, eaptivity causes it no grief whatever.

Enemies of the The Hedgehog has many enemies Hedge- beside ill-natured, ignorant human hog. beings. Dogs hate it with great intensity and signify their enmity by a prolonged, fierce bark, whenever they discover a Hedgehog, and take every means to demonstrate their dislike of the bristle-wearing creature. But the latter remains in a ball-like position, so long as a Dog busies himself with it, and the aggressor gets nothing but a bloody nose as the reward for his violence, for the Dog can do nothing to the animal in its coat of mail, but only harms himself. The Fox is said to pursue Hedgehogs with great zeal and to cause them to unroll, in a mean way, by slowly rolling the ball of spines to the water with his fore-paws and throwing it in. In this way many Hedgehogs perish. 


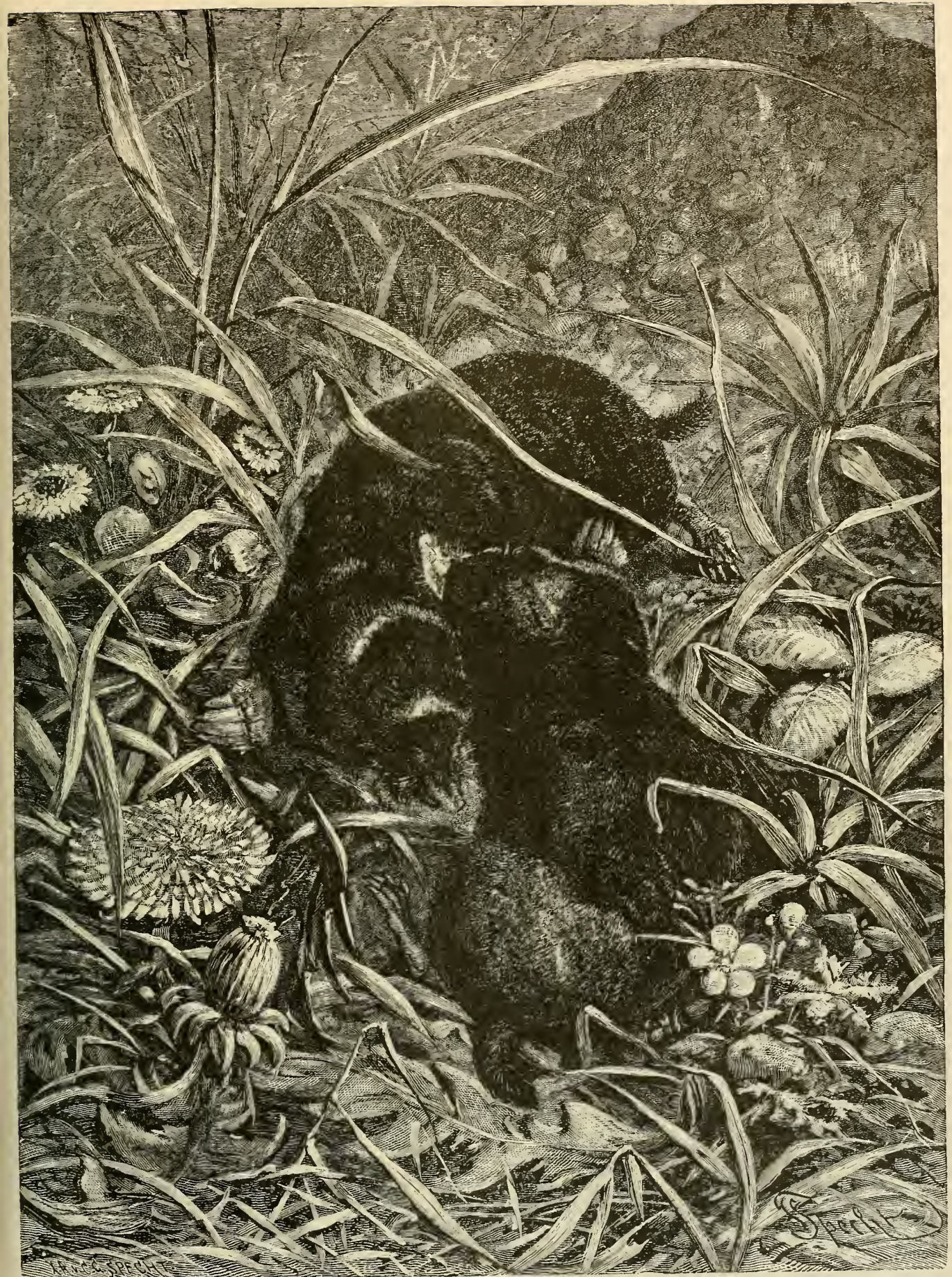

THE COMMON MOLE. - No family of animals is more adapted to a life of digging than the Moles, which have effective spades or scoops in the strong, large laws of their forepaws. The Common Mole, the European animal which is regarded as typical of the entire family, is depicted in the picture. It is a morose, sur and unsocial animal, and when two Moles meet, a combat usually ensues, and therefor 
especially in youth; and they have a still more dangerous enemy in the Screech-Owls which constantly prey upon these animals wherever they can find them.

Uses of the The flesh of the Hedgehog is probaHedgehog in the bly eaten only by Gypsies and simiPast.

lar wandering tribes, who have invented a special mode of cooking it. The "chef" covers the Hedgehog with a thick layer of well kneaded, sticky clay, and puts it into the fire, turning it carefully at regular intervals. As soon as the clay has become hard and dry, the roast is taken out of the fire, set to cool, and then the outer laver is broken off, removing with it all the spines, which are embedded in the earth. The Romans used the bristly skin to card their woollen shawls, and Hedgehog skins were therefore largely employed as an article of commerce, the gains being so considerable that the trade had to be regulated by laws passed by the Roman senate. The skin with its spines was also used as a flax-comb. Even to the present day some farmers are said to make use of a II edgehog skin when they wish to wean a Calf. They tie a piece of the skin to the Calf's nose and leave it to the mother to drive away the young animal, which naturally annoys her extremely when it wears such a nose piece. Occasionally a Hedgehog skin in its natural shape is manufactured into a queer, bristly cap by hatters.

\section{Tbe sinoles.}

\section{SECOND FAMILY: TALPIDXI.}

The Insect-Eating animals which follow the Hedgehors, and which we consider as animals of fairly high order, on account of their forelegs being developed into perfect scoops for digging, live almost completely in underground retreats where they lead a life peculiar in every respect.

General Descrip- The Mloles are disseminated over tion of the nearly all Europe, a great part of Asia, Moles. southern Africa and North America. Their varieties are not numerous, but it is possible, however, that there are still a great many species of Moles as yet unknown to naturalists. The Moles are all shaped and endowed in so striking a manner as to be instantly recognizable. The body is stout and of cylindrical shape, and merges into a small head without the intervention of a distinct neck. The head is elongated and tapers into a kind of proboscis, while the eyes and ears are little developed and from the external view are barely seen, or else entirely invisible. The body is supported on short legs, the forward pair appear to be relatively gigantic digging tools, while the hind limbs are longer and slender and resemble those of the Rat; the tail is short or altogether absent. The teeth are from thirty-six to forty-four in number. The structure and position of the fore legs imply a degree of comparative strength in the upper part of the chest, such as no other animal possesses. The shoulder-blade is the narrowest and longest, the clavicle the thickest and longest found among the Insectivora; the upper arm is exceedingly broad, the lower one strong and stout. The wrist is composed of ten bones. It is evident that these gigantic fore limbs can serve only for digging; they are such effective scoops that it would seem impossible to improve upon them. Particularly strong muscles are attached to these bones, and from this muscular development the remarkable relative strength of the animals' fore part is derived.

Moles all delight in fertile plains, though they are not absent in mountains. Being children of darkness, the effect of light is painful to them. Therefore they seldom, of their own free will, come to the surface and even in the depth of the earth they are more active by night than by day. Their bodily structure is not adapted to a life on the upper surface. They can neither leap nor climb, and can scarcely walk properly, though some of them proceed at a rapid pace, touching the ground only with the soles of their hind feet and the inner edge of the forepaws. Their movements in their underground passages are much more rapid, and the dexterity with which they dig is marvelous. They are also good swimmers, although they resort to this mude of locomotion only when compelled by necessity. Their broad forepaws are effectual oars and the strong arms are less readily wearied in the water than they are by digging.

Physical and Of the senses of the Moles those Mental Traits of of smell, hearing and touch are esMoles. pecially well developed, while that of sight is very deficient. The voice finds utterance in hissing and squeaking sounds. The mental capacity is slight, though not to such an extent as is generally believed. The so-called bad qualities however seem to be much more strongly developed than the good ones, for all Noles are highly quarrelsome, sanguinary creatures, addicted to vicious biting and surpassing even the Tiger in cruelty, devouring thcir own kind with pleasure whencver they encounter them. Their food is exclusively of an animal nature, for they never eat anything of a vegctable character. NIl kinds of insects living underground, worms and the like, form the main portion of their food; but they also feed on small mammals and birds, Frogs and Snails, whenever they can. Their voracity equals their activity, and as they can endure hunger only for a rery short time without injury to themselves, they do not hibernate. For this very reason they beconc useful as exterminators of insects: but their digging propensities cause them to be considered a nuisance. 
Birth Once or twice a year the young and Training of Moles make their appearance, three Moles. to five at a birth, and the mother takes care of them with great solicitude. The little ones grow rather rapidly and stay with their mother for one or two months. Then they become independent and begin digging on their own account. They can only be kept in captivity by bestowing the utmost care upon them, as it is very diffictult to satisfy their great voracity.

The Common The Common Mole (Talpa curopaa), Mole of which is the type of the whole family, is a species confincd to Europe and Asia. Inclusive of the tail, which measures one inch, the length is six, at the utmost seven inches, and the height at the shoulders is about two inches. The body is of cylindrical shape and the very short legs end in short toes of which the middle one is longest. The toes are united by a membrane for nearly their entire length. The eyes are about the size of a poppy seed; they lie midway between the tip of the snout and the ears and are completely covered with the hair of the head; still they are protected by lids and may be projected or retracted at will; therefore they may be used. The ears are small, and have no external conch. The uniform, black fur is very close, short, soft and velvety all over. The animal is covered all over with it with the exception of the paws, soles, tip of the snout and end of the tail. It has a somewhat vivid lustre and sometimes varies from the typical black into a brownish, bluish or even whitish tint. Yellow or white Moles are found very rarely.

This Mole ranges all over Europe and northern Africa and extends through Asia to the Altai, or even into Japan. It goes as far as the Amoor and southward down to the Caucastus; in the Alps it is found at an elevation of 6,000 feet. It is common everywhere within this range and increases in a surprising way in all sections where it is not pursued.

How the It designates its haunts by its own

Mole Digs and handiwork in the surest way, as it is

Makes Hills. obliged to constantiy construct new hillocks in order to earn its living. These hillocks always indicate the direction and extent of its existing hunting grounds. Owing to its extreme voracity, it is compelled constantly to enlarge these little hills and therefore it is forever working at the extension of its underground domain. Incessantly it digs horizontal shafts at a slight depth from the surface and in order to remove the earth it has dug up, it throws up the well known hillocks.

Digging is very easy work for a Mole. With the aid of the strong muscles of its neck and the im- mense spade-like hands, with which it holds itself steady, it bores its snout into the loose ground, loosens the surrounding earth with its fore-paws and throws it backward with cxtraordinary rapidity. Its ears are perfectly protected from the entrance of sand and earth by their ability to close themselves. The loosened earth is left to lie bchind in the passage that is being constructed until the quantity becomes inconvenient. Then the Mole makes its way to the surface and throw's the earth out little by little with its snout. During these operations it is nearly always covered with a layer of loose eath from five to six inches deep. In loose ground the animal works with really admirable rapidity. Oken kept a Mole in a box of sand for three months, and observed the animal work its way in it nearly as rapidly as a fish glides through the water, snout foremost, using the fore-paws to throw the sand to the sicle and the hind limbs to push it backward. In its underground passages the Mole proceeds with still greater speed, as has been demonstrated by very pretty experiments.

Lecourt wished to investigate the speed of a Mole in its conduits, and for this purpose he employed a means as ingenious as it was anusing. He set up in a row a number of heavy straws in the main conduit, arranged so that the Mole cottld not run along the passage withou tonching them. To the tops of these straws he fastened small paper flags, and when the Mole was occupied in its hunting ground, he frightened it with the sound of a bugle, and thus caused it to run into the main conduit. Then the little flags fell down one after another, the instant the Mole touched them, and the observer and his assistants had an opportunity to correctly record for a short distance.

the speed of its course for a sliort distance. Principal The Mole has many foes beside
Foes of the Man. Polecats, Stoats, Owls and Mole. Falcons, Ravens and Storks watch it as it throws up its hillocks; the little IVeasels even pursue it in its conduits, where, as already, mentioned, it also frequently falls a prey to the Adder. Terriers find great pleasure in watching a digging Mole, then throwing it up with a sudden jerk, and killing it with a few bites. Only Foxes, IVeasels, Hedgehogs and the before mentioned birds eat it; the other adversaries only kill it and let it lie.

closely Related The American species of Moles are re American garded as distinct from those of Europe Apecause of differences in dentition and other variations. The Common American Mole (Scalops aquaticus) inhabits the eastern portion of the United States, and in its size, appearance and mode of life so much -esembles the European species that to the ordinary observer the differences are scarcely apjarent. A Mole known as the Silver or Prairie Nole (Scalops argchtatus) is found in Texas and Mexicn, but shows little to distinguish it from the Common 
American Mole beyond the fact that it is usually somewhat Arerer ins

Two other species, showing another difference in dentition, are the Hairy-tailed Mlole (Scapanus breweri), and a blackish purple variety popularly known as the Oregon Mole (Scapazus townsendi), both of these animals being found principally in the western part of the United States.

The Star-Nosed A very peculiar appearance is presented by Mole De- $\quad$ the Star-Nosed Mole (Condy/ura cristata) a scribed. very common species found in all the northour Canada, and from the Atlantic to the Pacific. It receires its generic name "Condylura " or "Lnotted Tail," from the fact that when a specimen is dried the skin of the tail shrinks to such an extent that the bones show through and all the joints are seen through the skin, like a succession of knots. The head and body are together about four and a half inches in length, while the tail is two inches long, which is much longer than that of any other Mole. The specially distinguishing feature of this animal, however, is the long snout and the peculiar adornment of its tip, from which about twenty rosecolored rays of fleshy cartilage radiate around the nostrils, like the tentacles of the sea anemone or the petals of a daisy. The Star-Nosed Nole has a coat of very soft blackish gray fur. Its habits correspond with those of the other species of Mloles.

\section{Tbc Tupaias.}

THIRD FAMILY: TUPAHDE

A third family is formed by the Tupaiidæ. They remind one of Squirrels, though the resemblance can only be regarded as superficial. The head tapers

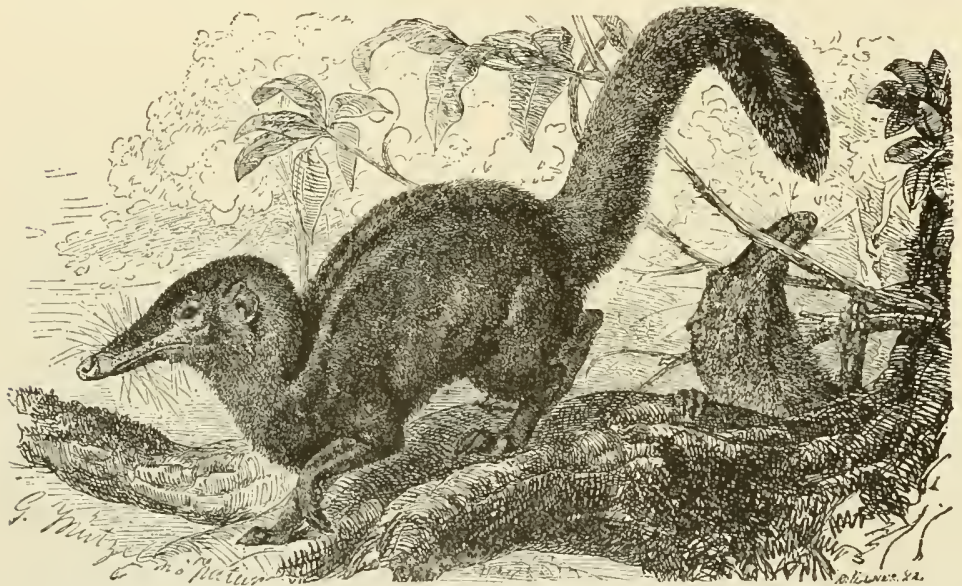

THE TANA - Iively species of the Insect-Eaters is the Tana of India, slender and having a long, bushy tail, and a tapering muzzle. The picture appropriately represents the Tanas in the tre'ts, for they live ou fruit as well as insects and seek for food in the trees as well as on the ground. (Tupaia tana.)

into a muzzle, the blunt extremity of which is usually bare of fur. The body is elongated, the tail, which is long in all species of this family and especially so in some varieties, is bushy, and covered with long hair which is divided by a distinct parting and hangs equally on each side; the fur is dense and soft. The eyes are large, the ears oblong and rounded, the limbs five-toed, the feet have naked soles; the toes have no connecting membranc and are armed with short. scythe-shaped claws. The female has four mamme on the abdomen.

The Tupaiidae inhabit parts of India and the Indian Archipelago. Their habits are truly diurnal and they perform their robberies in the light of day. Their fur and movements rescmble those of Squirrels and the natives of the countries they inhabit have but one name for the two kinds of animals.
The Tana Typ. One of the largest species of the ical of the family is the Tana (Tiupaia tana). Family. It is distinguished from the others not only by its size, but also by its long tail, and it is clothed in a dark brown fur, the tint deepening into black, with a surface tinge of red on the under portion, and showing an admixture of gray on the head and muzzle. In size the Tana comes nearest to our Squirrel; the body is not quite eight inches long, and the tail is of equal length.

The Tana is a nimble and lively creature, though not quite so speedy as our Squirrel; it makes the most of its long, curved nails and climbs nearly as well as a Monkey. Its food consists of insects and fruit.

\section{Tbc $\mathfrak{I}$ ong= Icgaco $5 b r c w s$. \\ FOURTH FAMILY: MACROSCELIDIDE.}

The Long-Legged Shrews are better known to us than the Tupaias, though by no means adequately, for they form one of the most remarkable families of the order. While the Tupaias show an approximation in the structure of their tails to the Jerboas, the Macroscelidida also resemble the latter, as they have long, slender hind legs, nearly devoid of hair, like those of the Jerboa. In addition to this characteristic, which gives them their Latin name, signifying " Long-Legged," they also have a nose longer than that of any other species of Insectivora, and which is elongated into a veritable proboscis. This long snout shows a slight vestige of hair only in the middle, and a rather thick crest of fur at its base, its extremity being quite destitute of hair. Other distinguishing features of the head are the large eyes, the prominent, protruding ears, furnished with inner lobes, and the long whiskers. The rather sliort, thick body is supported by legs, showing a great difference in length between the fore and hind pairs. The two fore legs are not short, but the hind legs are of remarkable length and formed much like those of the Jerboas. The fur is rich, very dense and soft. The teeth are forty in number.

The Elephant The Elephant Shrew (Macroscelides Shrew De- tyficus) is ten inches long, about four scribed. inches being taken by the tail and not quite one inch by the proboscis. Its fur is of a reddish-brown or mouse-gray tint on the back, sides and head, and of a more or less clear white under the body and on the paws.

The I-lephant Shrew has the same habits as the other Macroscelidida, of which hitherto about ten species have been differentiated. All of these species are at home in Africa, especially in the southern and eastern parts, and they enliven the barren, sunburnt stretches of country. These animals delight in rocky mountains, where they seek safety in deep, 
inaccessible holes under stones and in rocky crevices and the burrows of other animals. They are very timid and look upon the most trifling disturbance as foreboding danger. They are true diurnal animals, and might even be termed creatures of the sun which feel most comfortable in the most torrid noonday heat when they follow the chase with the greatest ardor. Their food consists mainly of insects, which they capture very dexterously, and pull out of crevices and slits in the hillside. Nothing is so far known about their node of reproduction and no observations seem to have been made with captive specimens of the species.

\section{The spilly ibcogchogs.}

\section{FIFTH FAMILY: CENTETIDAi.}

The members of the fifth family of the order under consideration are the Centetide, or Spiny Hedgehogs, taking their appellation from an insectivorous, Hedgehog-like inhabitant of Madagascar. They are of elongated build, long-headed and distinguished by a fairly long snout; the eyes are small, the ears of moderate size, the tail either altogether lacking or long and destitute of hair; the legs are short and termmate in fivetoed feet, armed with strong claws. They are clothed partly with quills, partly with stiff hair.

Principal
$\begin{gathered}\text { Traits of the } \\ \text { Tanrec. }\end{gathered}$
(Centetes ec-
(udatus) is
mainly remarkable because of its pointed snout. The entire body is clothed rather thickly with spines, bristles and hairs, which to a certain extent merge into one another or at least distinctly serve to show that the spines are nothing but modified hairs. True and somewhat flexible spines, about half an inch long, are found only on the back of the head and on the nape and sides of the neck. The tip of the snout and the ears are entirely bare, but the feet are covered with short hair.

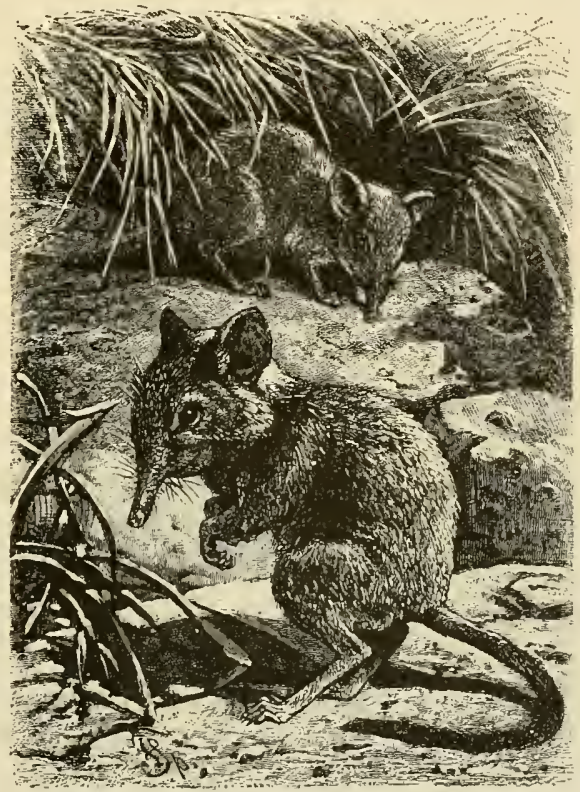

THE ELEPHANT SHREW odd looking animal, with its remarkably long hind-legs and its pro* boscis-like muzzle, adorned with straggling whisker hairs. They roam in the glare of the African sunlight and seek, in the holes and
crevices of stony hillsides, the insects which form their food. (MIacrusceludes typucus.) Quills and hair are of a light yellow color, ringed with brownish black in the middle, this marking being more pronounced on the back than on the sides. The length of an adult animal is about ten or eleven inches.

The Tanrec was originally indigenous only to Madagascar, but has been naturalized also on the islands of Mauritius, Mayotte and Reunion. It delights in mountainous regions abounding in bushes, ferns and moss, and there it excavates the burrows and passages in the ground, which form its hiding place. It is a shy, timid creature, which spends the greater part of the day in the utmost retirement and makes its appearance only after sunset. It shows itself only during the spring and summer of those countries: that is, after the first rain and until the commencement of the dry season. During the greatest drought it retreats into the deepest chamber of its burrow, hibernating from April to November in the same way that the Conmon Hedgehog lies torpid in winter. Its food consists principally of insects, but also of worms, snails, Lizards and various fruits. It seems to have a special predilection for water.

In captivity the Tanrec eats raw meat, boiled rice and bananas. It sleeps through the day and becomes very lively at night.
The Shrews among the Insectivora remind us of the Weasels among the beasts of prey. Like them, they are possessed of all faculties implied by a true predatory life, inhabit the most diverse regions, and exhibit an amount of coura ge, bloodthirstiness a nd cruelty utterly at variance with their small size.

General The Shrews

Account of the belong to Shrews. the smallest of mammals, like the Bats; they are of well proportioned build, their external appearance recalling Rats and Mice. The body is slender, the muzzle elongated, the teeth are complete in number and exceedingly sharp; usually there are two or three cutting teeth, which are sometimes indented, from three to five premolars and from three to four true molars, furnished with four or five tubercles in every row. Canine teeth proper are absent. There are peculiar glands at the base of the tail. The body is clothed in soft, velvety fur; lips, feet and tail are grown with small, stiff hairs; the whisker hairs on the cheeks are long, the sides of the feet are covered with bristly hair, in sharp contrast with the naked soles. Distribution and At present the Shrews are distribTraits of uted over the Old World and North Shrews. America; in Australia and South America they do not occur. They frequent plains as well as mountainous regions and even the Alps, delighting in dense forests and bushes, meadows and pasture-grounds, gardens and houses. The majority give the preference to damp localities; some are remarkable for their water-loving propensities. Many lead a subterranean life, either scooping out burrows and passages for themselves or profiting by already existing retreats, after driving away the rightful owner, in accomplishing which they resort 
to force, when milder means do not avail. Nearly all seek darkness and shadows and shun drought, heat and light, being so sensitive that sunlight frequently kills them. Their movements are exceedingly rapid and nimble, of whatever character they may be. Shrews which only run, skim along the ground with less against strong animals. From our point of view we must consider most of them not only as harmless, inoffensive animals, but acknowledge them to be highly useful creatures, which render us considerable service by exterminating harmful insects. For they seek their food almost exclusively in the

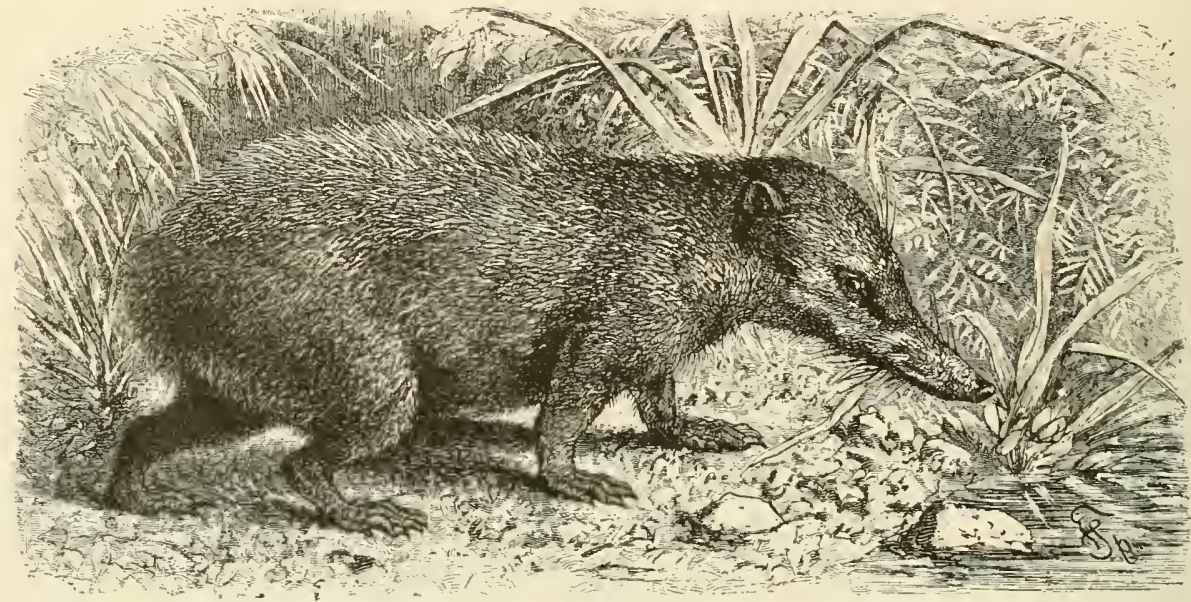

THE TANREC- - This animal has its principal home in Jladagascar, so famous as the home of strange forms of animal life. Its long. taillegs tailless body and elongated snout are distinguishing features, while
Hedgehog's, is a noteworthy peculiarity. (Centecs coaudatus.)

the swiftness of an arrow, while the swimmers among them are inferior to none of the other mammals.

Among the senses of the Shrews that of smell seems to rank first and hearing comes next in efficiency, while sight is more or less deficient. Their intellectual capacity is of a low grade; still it can not be denied that they possess a certain amount of rea- animal world; insects and their larve, worms, small birds and mammals, oceasionally also fishes and their eggs, Shrimps, etc., constitute their prey. Their voracity is remarkable, and what they devour daily is equal to their own entire weight. No one species can bear hunger except for a short time; therefore they do not hibernate, but prowl over the snow cov-

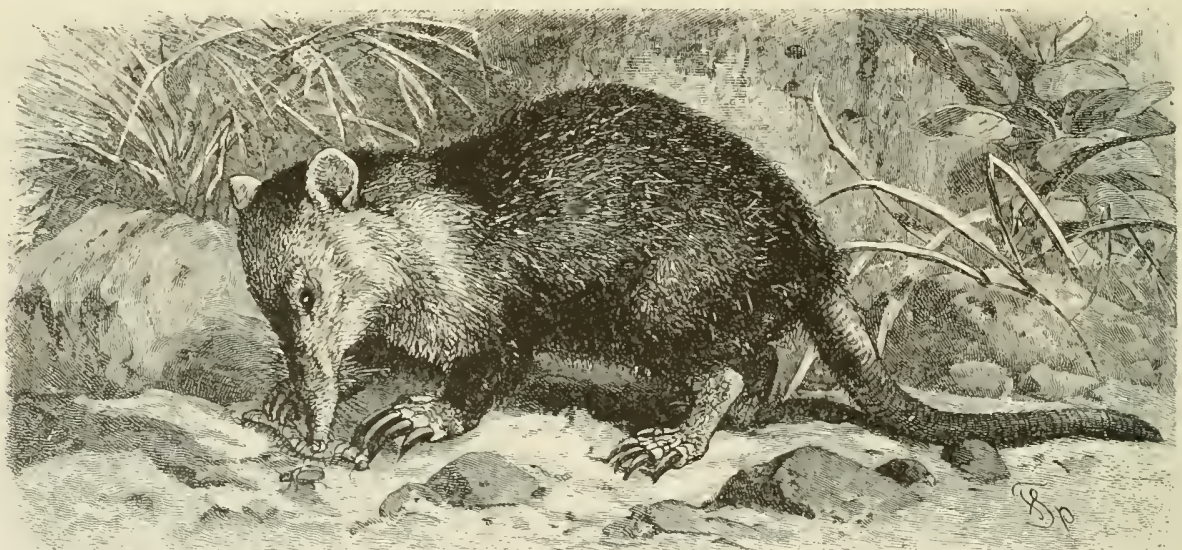

THE ALMIQUI. - In insectixorons animal living on the 1sland of Cuba, principally in the high lands, It measures about nineteen incles, incluing the naked tail, which is eight inches jung. It has a remarkably long, cylindrical snout, feet well formed for runuing or digging.

soning power. They are of a highly predaceous and sanguinary disposition and are really formidable foes to smaller animals, although they usually aroid larger ones. At the slightest noise most species of Shrews will retire into their holes, and they have good reasons for doing so, as they are almest defense- ered ground when the weather is in the least propitious, or seek their nourishment in protected places, as for instance, in human dwellings. The voice of all species consists of high pitched, chirping, squeaking or piping sounds; terror is signified by plaintive tones, and when in danger they all give forth a more or less 
strong odor of musk, which, though it does not protect their life from enemies, renders their thesh unpalatable to all but a few animals, for Dogs, Cats and Weasels usually let killed Shrews lie without eating them while most birds, whose senses of smell and taste are less developed, do not disdain to devour them.

Most Shrews are prolific animals, for the number of their young ranges between four and ten at a birth. They are usually born with closed eyes and

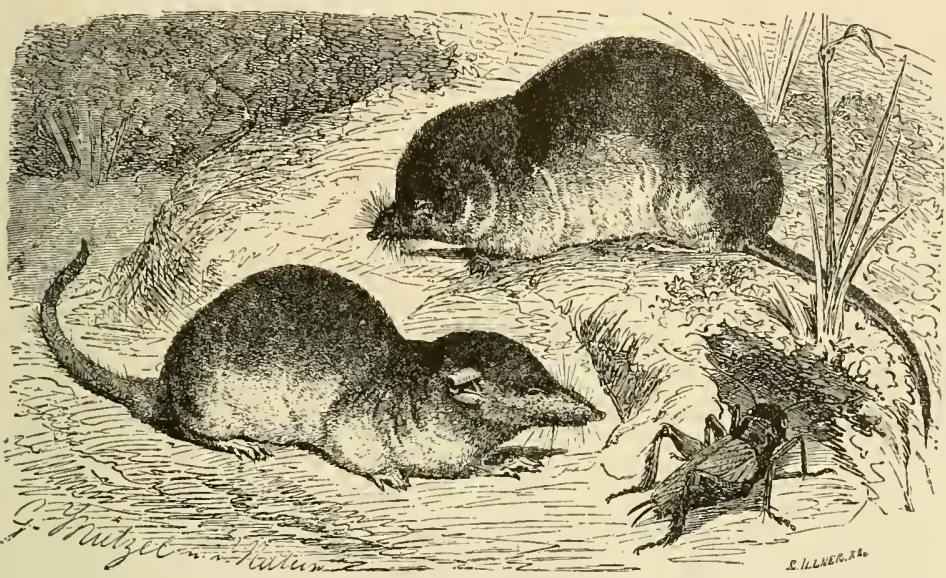

THE COMMON SHREW. - The most numerous family of the Insect-Eating animals is that of the Shrews, and the typical species of this family is the Common Shrew of Europe, which is no larger than a common Mouse, but is a fierce, sanguinary and voracious little creature. The characteristics of the animal are well shown in the picture, and the little insect which is being pursued is evidently doomed. (Sorex rulgars.) destitute of any hairy covering, but they grow apace, and in month they are able to ply their craft.

\section{THE SHREWS PROPER.}

In the first sub-order we include the Shrews proper (Soricine). They constitute the center of the family; their teeth are from twenty-eight to

Description of The Shrews in the narrowest sense

the Common (Sort $x$ ) are distinguished by having

shrew. thirty-two teeth, tipped with dark brown, feet and toes surrounded on all sides with short, soft hair, and a tail clothed in fur of uniform length. Their typical representative is the Common Shrew (Sorex vulgaris). It is somewhat inferior in size to the domestic Mouse; its length is four and one-half inches, one and three-fourths inches of which is taken by the tail. The coloring of the brown and the most lustrous black; the sides always exhibit a lighter tinge than the back, the lower parts are grayish white with a surface tinge of brown; the lips are whitish, the long whisker hairs black, the paws brownish, the tail dark brown on its upper and brownish yellow on its under surface. The various tints have given rise to different classifications, some authorities recognizing several species, others considering them only varieties. Common Germany, Sweden, England, France, shrew. Italy, Hungary and Galicia, and probably also in the adjacent parts of Russia, on heights as well as in low lands, on mountains and in valleys, in fields and gardens, in the neighborhood thirty-two in number, the skull is long and narrow and there are no webs between the toes. fine, velvety fur ranges between a vivid reddisl

Range of the The Common Shrew is found in of villages or in the villages themselves, and usually near water. In winter it seeks refuge in houses, stables and barns. In Germany it is the commonest underground holes, and therefore is prone to take up its abode in the burrows of Moles or in deserted Mlouse holes, if it does not find natural crevices in rocks. In soft ground it scoops out runs for itself with its muzzle and weak fore-paws: the runs always being very near the surface. As with most other species of the whole family. It likes best to live in habits are wholly nocturnal. and it is averse to leaving its underground abode in the daytime. It never does so in the midday sunshine, and there is good reason to believe that the rays of the sun cause it serious discomfort; at least it is supposed that the many dead Shrews which are found on roads and in ditches in the latter part of summer, have been unable to find the entrance of their underground retreats, being dazzled by the glare of the sun, and therefore have perished. Habits and Move. The Shrew ments of Com- is occupied mon Shrews. incessantly

in sniffing in all directions seeking for food, accompanying its explorations with rapid twitchings of its mobile muzzle; and whatever it is able to despatch is devoured, not sparing its own young or the slain of its own species. Lenz says: "I have often kept Shrews in boxes. One can hardly satisfy their appetites with Flies, Mealworms, Earthworms and such food. I had to give to each of them daily a dead Mouse, Shrew or bird equal in size to itself. Small as they were, they invariably ate the entire animal, leaving nothing but the skin and bones. In this way I sometimes succeeded in fattening them; but if Shrews have to endure the slightest fast, they die. I have also tried to keep them alive by feeding them on bread, turnips, pears, hemp seed, poppy

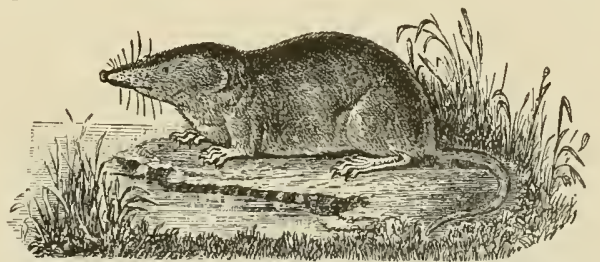

BROAD-NOSED SHREW.-The most common species of the true Shrews which is found in the eastern portion of the United States. and resembles the Common Shrew of Europe more than any othes. American species. (Sorcx platyrinutus.)

seed, rape seed, canary seed, etc.; but they preferred starvation to this food. If I gave them rich cake, they tried to eat it on account of the fat; if they found a Shrew or Mouse caught in a trap, they immediately set to work and cievoured it. With good care, a Slirew may be kept for months."

Welcker tied a string to the hind leg of a living Shrew and let it creep into holes in a field infested 
with Mice. In a short time, from a hole entered by the Shrew, a Field-Mouse came creeping in great terror, with the Shrew on its back. The greedy beast of prey had fastened its teeth to the neck of its victim, and it speedily killed and ate it. The movements of the Shrew are exceedingly rapid and nimble. It whisks along the ground with great speed, takes fairly long leaps, can climb inclined trees, and swims tolerably well when compelled to do so. Its voice consists of a soft chirping or whist-

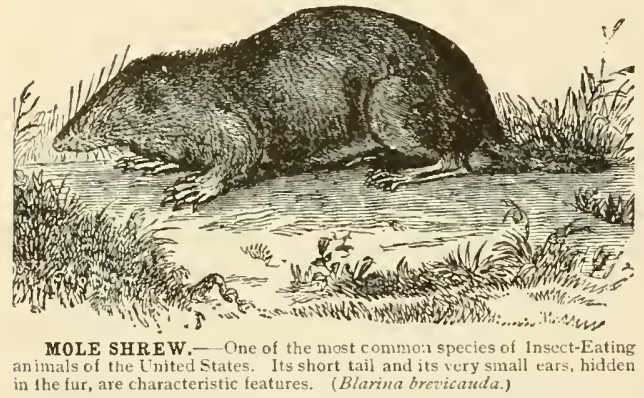

ling sound of high pitch, similar to that heard from the other members of the family. The most acute of its senses is undoubtedly that of smell. It often happens that Shrews caught alive, when let loose, run back into the trap, for the reason that the odor of the Shrew clings to it. It does not seem as if Shrews were guided by sight. Their hearing must also be rather deficient; but their fine scent furnishes almost complcte compensation for the deficicncy of the other two senses.

The Character of There are few other animals that are the common possessed of so unsociable a dispoShrew. sition, or act so atrociously toward their own kind, as the Shrews; the Moles alone can be considered as a match for them in iniquity. Not even the opposite sexes of the Shrews can live together in peace, except during the breeding season. One Shrew will devour the other whenever opportunity offers. Frequently these animals become engaged in combats so fierce that one can casily capture them. In fighting they interlock in close embrace and roll over the ground, their teeth fastened into each other with a fury worthy of the most ferocious bulldog. It is fortunate that the Shrews are not so large as Lions: they would depopulate the earth and ultimately be reduced to starvation. Very rarely do Shrews live together in rcal peace. Cartrey oncc heard a continuous rustle and noise in some dry leaves, and discovered a multitude of these little creatures, which he estimated to number about one hundred; they secmed to play among themselves, running back and forth keeping up a constant chirping and squeaking, without any apparent reason: perhaps it was nothing but a grand wedding. A fenale Shrew builds for her little ones a nest of moss, grass, leaves and stems of plants, if possible in a wall or uncler a hollow tree; she provides the nest with several side entrances, lines it softly, and between May and July from five to ten little Shrews make their appearance, entirely deroid of hair, and with thein eyes and ears closed. At first the mother suckles them with great tenderness, but her solicifude soon flags, and the young ones set out to provide for themselves. After this, as has already bcen stated, all fraternal considerations cease; for even in youth, every Shrew understands food to mean all flesh it can lay its claws on, even if it be the carcass of its own brother or sister.

Enemies of the It is surprising that few animals eat Common Shrews. Cats catch them, probably shrew. because they at first mistake them for common Mice, but only kill them without eating them. The WVasels also seem to disdain them; but the Adder and several birds of prey, like the Stork, devour then unceremoniously and with great gusto. Undoubtedly the aversion to these animals shown by such mamnals as are endowed with fine powers of scent, is to be explained by the disgust with which the odor given forth by the Shrew's excites them. This powerful musk-like odor is produced by two secretory glands, found on the sides of the bocly, nearer to the fore-legs than to the hind ones, and it is imparted to all objects with which a Shrew comes in contact.

It is possible that the superstitious abhorrence with which Shrews are regarded in many parts of Europe derives its origin in part from this odor. In some countries, as for instance England, the inoffensive creature is held by many people in nearly as great dread as a venomous Snake. Everybody is aware of the fact that a Shrew with its fine, thin teeth cannot do the slightest harn to a human being, but still the direst consequences are ascribed to its bite. The mcre touch of a shrew is considered as a certain herald of evil, and animals and Men, who have been

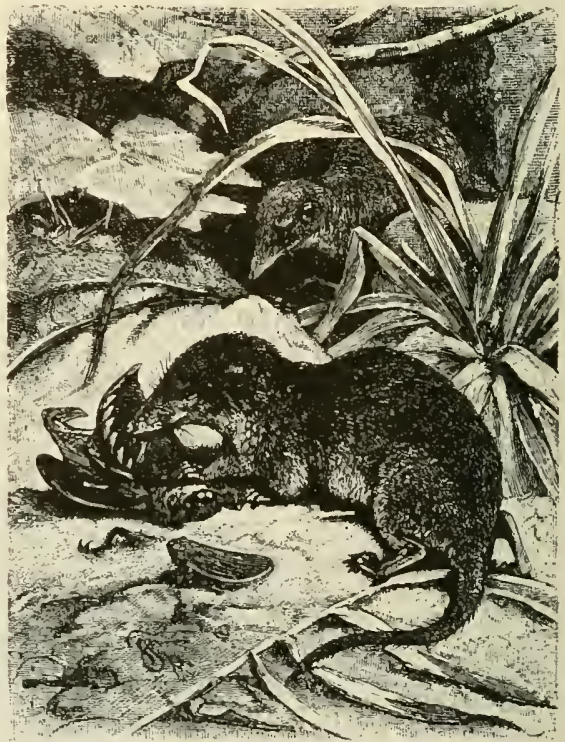

DOMESTIC SHREW, - The sma!l animal known as the Domestic or Honse Shrew derives its name from the fact that it is fond of entering buildings in urder to procure food, besides foraging in fields and gardens. It has a wide range through Europe and Isia. (Crocidura aranea.)

"Shrew-struck," are expccted to fall ill in the ncar future, unless they have recourse to a particular remedy.

American Rela - The Common Shrew has several American tives of the Com relatives, the species which resembles it tives of the Com- most being the Broad-Nosed Shrew (Sorix inon Shrew. Slatyrinus) which is found all over the eastern portion of the United States. It has conspicuous ears 


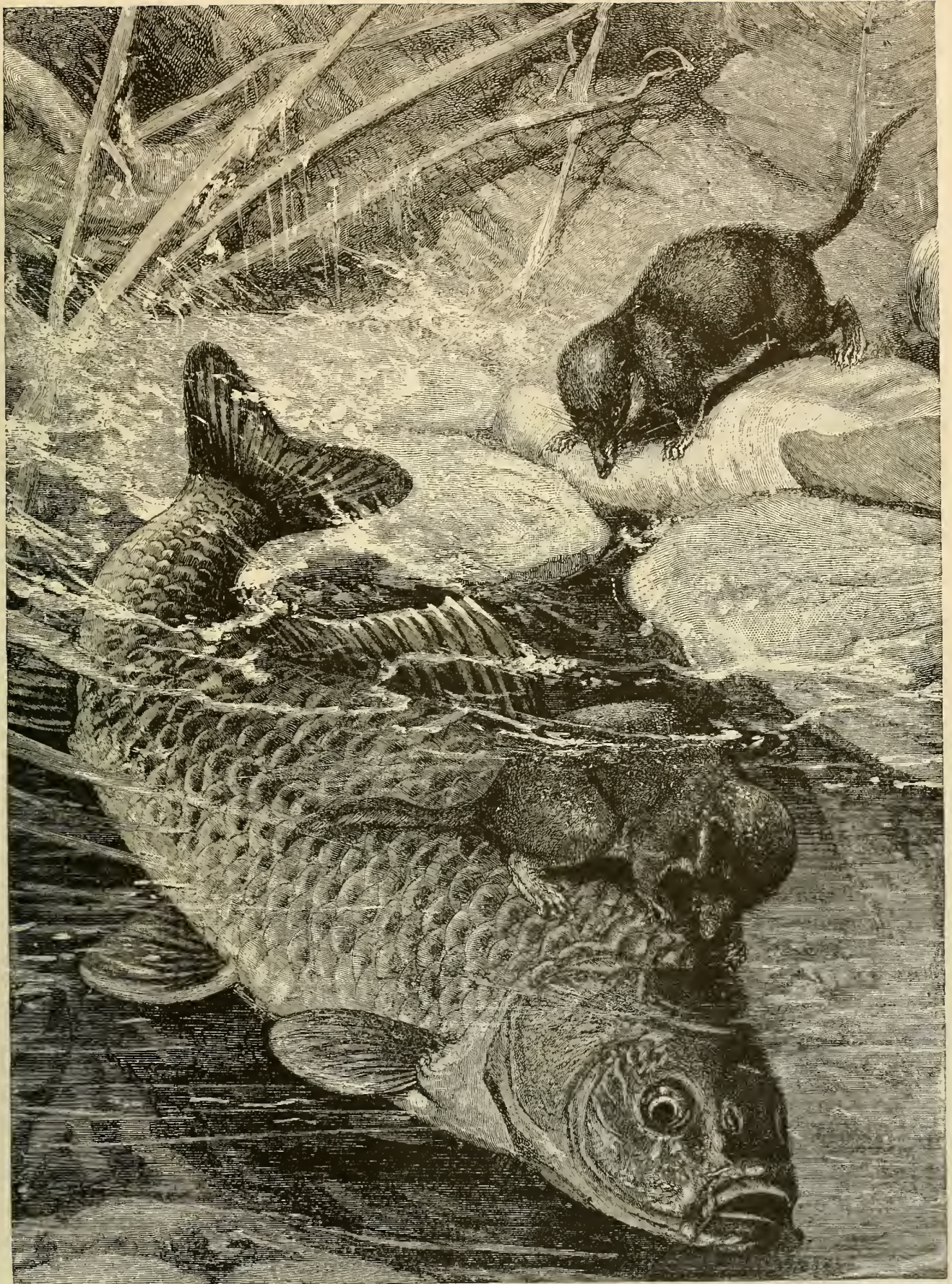

THE WATER SHREW.- These animals, which make their burrows in river banks and lead an emphatically aquatic life, possess all the sanguinary proclivities of their kind, and besides insects they eat any fishes they are able to overcome, and their voracity incites them to attack quite large members of the finny tribe, as is clearly shown by this picture, which was taken from life. The Water Shrew is distributed over nearly all of Europe and part of Asia and is found in abundance in all congenial places. (Crossopus fodicus.) 
and a rather long tail, and its habits are very similar to those of the common species of Europe and Asia.

The Marsh Shrew (Sorex palustris) takes the place of the Water Shrew in the Lnited States, from the Rocky Mountains east to the Atlantic. Its toes have a fringe of stiff hairs; the ears are moderately well developed; the thirty-two teeth are of a brownish red tint: the tail is equal in length to the head and body together. It is as aquatic in its habits as the Water Shrew of Europe, and Professor Cope observed it swimming in a lake in New Hampshire forty feet from the bank. Besides these there are other species of Long-tailed Shrews, among which Sorex bendiri is the largest known species of the Shrew family, while another, Sorex personata, is nearly as small as the Etruscan Shrew.

\section{The Mole-Shrew}

an Eastern

Species.

An eastern American species is the MoleShrew (Blarina bribauda) which derives its Latin name from its extremely short tail. This animal has very small ears, which are concealed in the fur. Dr. Nerriam, who observed the MoleShrew in the Adirondack region says: "The rigors of our northern winters seem to have no effect in diminishing its activity, for it scampers about on the snow during the severest weather, and I have known it to be out when the thermometer indicated a temperature of twenty degrees Fahrenheit. It makes long journeys over the snow, burrowing down whenever it comes to an elevation that denotes the presence of a log or stump, and $\mathrm{I}$ am inclined to believe that at this season it must feed largely upon the chrysalides and larva of insects that are alwavs found in such places." Besides their insectivorous food these animals are also said to eat beech nuts.

quently as this species. Outdoors in the morning and evening hours it preys on small animals of all kinds, ranging from the smaller mammals down to worms; in the house it forages on aninal matter, and oily substances. Its habits are nearly identical with those of the Common Shrew

The Etruscan Another species, possessing thirty Shrew, a Tiny teeth, the Etruscan Shrew (Crocicreature. dura suarcolens, Crocidure itmesca). deserves mention for the fact that, with the exception of one species of Bat, it is the smallest of all known manmals. Its total length is two and one-half inches, one inch of this being included in the tail. The coloring of the velvety fur is a light brownish or reddish gray tint, the tail is brownish above, lighter beneath; the muzzle and paws are flesh-colored, the feet show whitish hair; older individuals look lighter and have a russet hue, while the younger ones are darker and more of a grayish tint. The relatively very large ear-conch is worth notice.

The Etruscan shrew occurs in nearly all countries surrounding the Nediterranean and Black Sea. It has been found in northern Africa, southern France, Italy and the Crimea. Its habits are similar to those

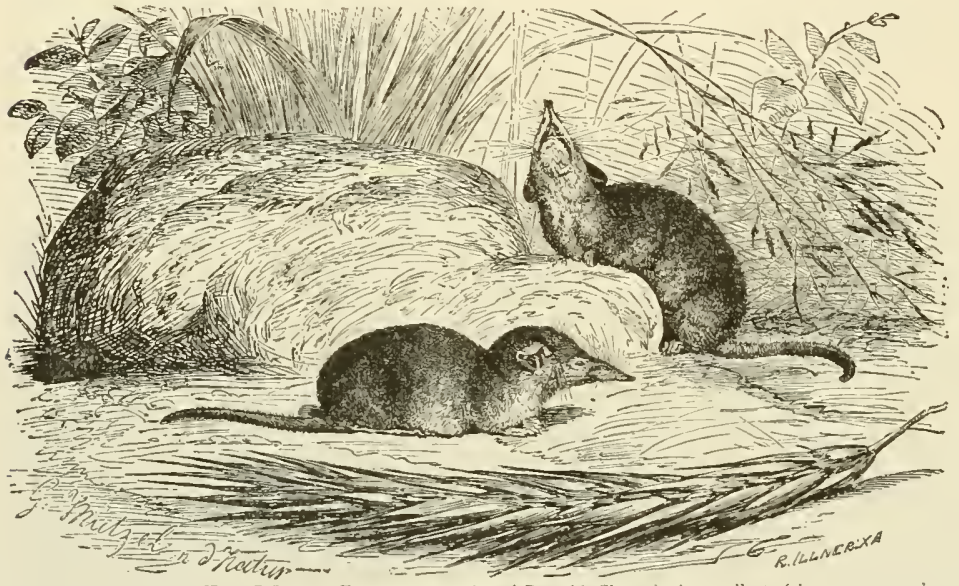

THE ETRUSCAN SHREW - Fxcepl one species of Bat this Shrew is the smallest of known mammals. How sme lound principally in southern Europe, and has all the sanguinary instincts of its race, (Croctura suateolens.)

Characteristics The Field Shrews (Crocidzra) have of the Field from twenty-eight to thirty white Shrews. teeth. In other respects they correspond with the Common Slirew to a great extent.

The Domestic Shrew (Crocidura aranca) is a small creature whose total length is about four and onehalf inches. It is of brownish gray color above, merging into a lighter tint beneath, without a sharp line of demarcation; and the lips and fect are brownish white.

From northeastern Africa the Domestic Shrew spreads over southern, western and central Europe as far as northern Russia; it is also found in central Asia and northeastern Sibcria, but seems to be absent in England, Denmark, Sweden, Norway, and Holland. According to Blasius, it is to a certain extent confined to fields and gardens, preferring them to forests. On the outskirts of forests it is occasionally encountered. None of its kin become so easily accustomed to liuman beings, and none enter buildings, especially stables and barns, so freof its kind already mentioned.

The Water Of the other

Shrew and its Shrews we Habits. will mention only one more species, the Water shrew (Crossopus fodiens). It differs from its relatives principally in hav ing the under surface of its toes edged with stiff, stout and rather long hairs, taking the place of webs.

It seems that the Water Shrew is distributed over nearly all Europe and part of Asia, and is found in abundance in all congenial places. To the north its range is bounded by England and the country surrounding the Baltic Sea; its southern boundaries are spain and I taly. It is found at considerable altitudes, in the Alps at about 6,000 feet above sea-level. It delights in the waters of mountainous countries, especially those which remain unfrozen in the most intensely cold weather, as such streams are indispensable for its unobstructed travel in winter. Small rivers of mountainous, wooded regions, having sandy or pebbly beds, fringed by trees and bordered by gardens and meadows, seem to be its favorite haunts. It finds equal pleasure however, in ponds the water of which is clear and covered with duck-weed, and sometimes astonishingly large numbers of the species congregate in such situations. Frequently it is found in villages, being attracted by the food to be obtained in proximity to mills, granaries, etc. Its range is not entirely confined to water, however, but it runs over the meadows lying on the banks of streams, creeping under hay-stacks, entering sheds and stables, and even houses, and sometimes frequents fields situated far away from the water. In porous soil ncar the water it digs conduits for itself, but it prefers to make use of the runs of Mice and Moles, which it 
finds near its haunts. The essentials of its dweling are that the main conduit shall have several exits, one of which ends in the water, another being higher than the surface of the water and still others terminating inland. Such a burrow serves as a sleeping place and asylum to afford the little creature secure shelter from danger.

In this habitation the IVater Shrew usually spends all day in populous localitics; but where it nced fear no persecution, it is much abroad in the daytime, especially in spring during the breeding season. It rarely swims along the shore, being fond of crossing from one bank to the other. If it wishes to go along the stream, it either runs under the bank or on the bottom of the stream beneath the surface of the water. It is an extremely lively, sagacious and nimble creature, and its movements delight the observer in every respect.

Prey and Foes In proportion to its size, the IVater

of the Water Shrew is a really formidable beast

Shrew. of prey. It not only eats insects of all linds, especially those which live in the water, worms, small crustacea, Shrimps and similar creatures, but also reptiles, fish, birds and small mammals. The Mouse which encounters it underground is lost; the newly-fledged Wagtail, which imprudently approaches too close to the water, is pounced upon with the same avidity with which a Lynx charges at a Roe, and is killed in a few moments; the Frog which heedlessly hops past a conduit, feels itself seized by the hind legs and drawn into the depths in spite of its plaintive cries, and soon has to succumb. Minnows are driven into small creeks and there caught in a peculiar manner; the IVater Shrew roils the water and watches the entrance of the creck; and whenever one of the small fishes is about to swim past it, the Shrew pounces on and usually catches it. Thus it fulfills the proverb, and "fishes in troubled waters." But the WVater Shrew attacks not only small creatures, but also animals the weight of which is over sixty times its own; and it may be said that there is no beast of prey which attacks such large quarry, proportionately, as does the IVater Shrew.

The foes of the IVater Shrews are nearly the same as those of the Common Shrew. During the day they are usually comparatively safe; but when they - venture forth on the bank at night, they frequently fall victims to Owls and Cats; the latter, however, only kill them and then discard the carcasses because of the musky odor which pervades them.

\section{THE DESMANS.}

The few species of the second sub-family, the Beaver Shrews or Desmans (Myogalina), seem to be intermediate forms between the Shrews and Moles. Their bodies are stouter than those of the other Shrews, the neck is exceedingly short, and as thick as the body; the legs are short and the feet have five toes, which are connected with one another by long webs; the tail is of oblong, roundish shape, with its extremity compressed like the blade of an oar, and is ringed and scaly and scantily covered with hair. There are no external ears and the eyes are very small. The most remarkable feature of the animal is its nose, which more nearly resenbles a proboscis than that of the Elephant Shrew. It consists of two long, thin, confluent, cartilaginous tubes, which may be nloved in any direction by two large and three small muscles on each side, and it may subserve the most varied purposes, but more especially that of touching objects. At the base of the tail there is a musk gland, the secretion of which has an extremely powerful odor.

So far only one species of this sub-family is known, but this species has two south European varieties. One inhabits the Pyrences and their spurs, the other southern Russia. The first is the species called Almizilero in Spain (Myogale pyrenaica). It is ten inches long, half of which is included in the tail.

The Desman or Wychochol (Myogale moschata) is, at the first glance, distinguished by its size; for its

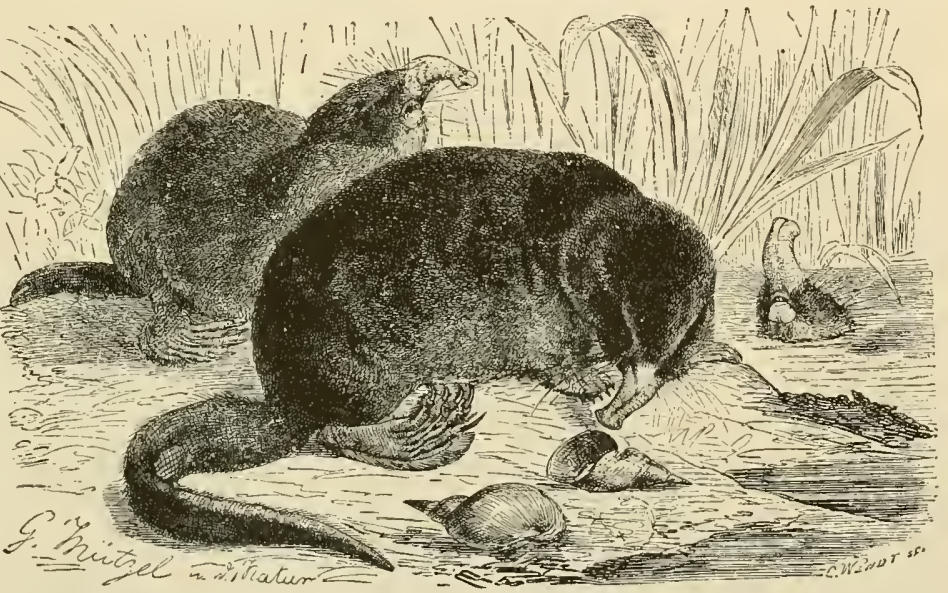

THE DESMAN. - This is an aquatic species of the Insect-Eating animals. It has an elongated snout, a long tail and webbed feet and spends a great part of its time in the water. The group in the picture is shown amid appropriate surroundings: one animal disporting itself in the water, and the others on the bank regaling

total length in some instances amounts to nearly seventeen inches.

The Desman inhabits southeastern Europe, principally the banks of the Volga and Don, but is also found in Asia, in Buchara. Its habits confine it to the neighborhood of water and if it undertakes short journeys from one river to another, it does so most unwillingly. Wherever it occurs, it is found in large enough numbers to render it quite common. Its life is a peculiar one, resembling that of the Otter. It spends half of its time underground, half in the water. It shows a predilection for stagnant or slowly flowing waters with high banks, in which it can easily dig conduits. Its food consists of worms, Leeches, Water-Snails, Water-Snakes, Water-Moths and the larvæ of insects.

Pallas is the only naturalist who gives us information about the Desman in the free state and in captivity. It endures confinement but a very short time, rarely surviving more than three days. It 
amuses by reason of its active and lively disposition, but a captive Desman becomes very disagreeable because of its musky odor, which is so strong that it not only pervades the atmosphere of a room, but any animal eating of the Desman becomes sensibly impregnated with the odor.

American There is an American animal which is a
Relative of the close relation of the Desmans of the Old
Desmans.
an intermediate form between the Desmans two incisors in the lower jaw. This is the Neurotrichus (Neuratrichus gibbsii) only found in western North America, and first discovered in IVashington Territory. Its total length is slightly more than four inches, of which one and one-half inch belongs to the hairy tail. The nose is elongated into a snout, with nostrils at the tip. The animal makes burrows in the ground, lined with leaves or dry grass.

\section{Tbe Colugo, or lliaguang.}

\section{SEVENTH FAMILY: GaLeopithecide.}

The representatives of a distinct family, Galeopithecida, containing but a single species, Galeopithecus, are neither Half-Monkeys, Bats nor Insect-Eaters, but possess distinctive characteristics of all three, and have ever been to naturalists subjects of great perplexity. In accordance with this uncertainty prevailing among naturalists, the best known variety of this species is termed Flying Monkey, Flying Lemur, Flying Cat, Marvelous Bat, etc.

The Galeopithecus is a slender animal, of the size of a Cat; its limbs are of moderate length and are united by wide, thick skin, covered with hair on both sides. The toes are five in number and have retractile, claw-like nails, and no opposabie thumb. The short tail is involved in the membrane. The head is relatively small, the muzzle much elongated, the eyes are mod. erately large, the furcovered ears small. The membrane is not adapted for flying, but is only a parachute, intended to

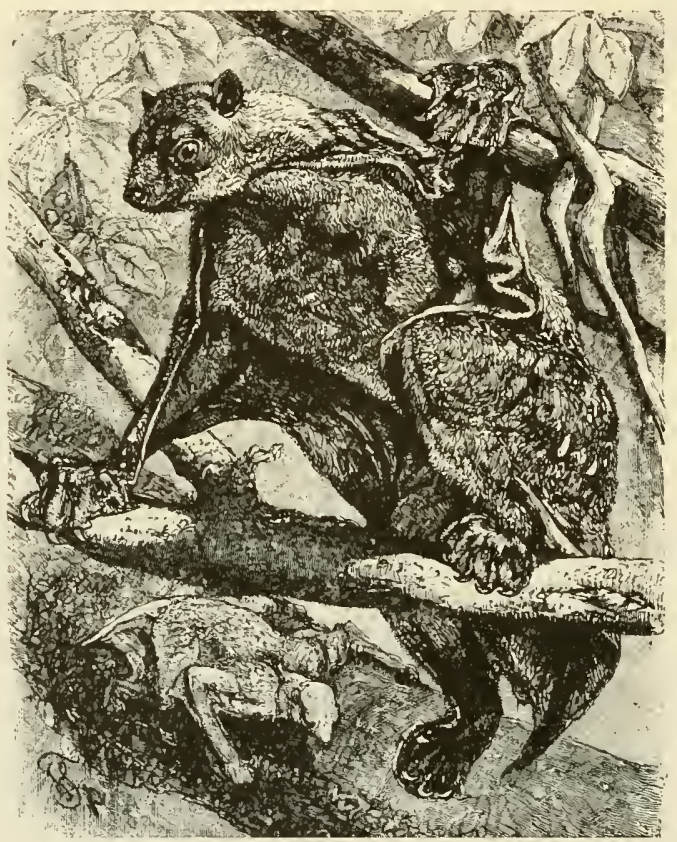

THE COLUGO.- This animal, also known as the Kaguang, has proven a puzzle to zoologists. It was formerly placed among the Bats, then with the Half-Monkey's, and is now ranked as a species of the Insect-Eating animals.
Its notable feature is the membranous formation which it uses as a parachute in jumping long distances from the tops of trees, (Galeopithecus zolans.) twenty-four inches, about four and one-half inches of which go to the tail; the fur is close on the back and scanty on the fore-arms, while the shoulder region and sides of the body are naked. Its upper surface is brownish red, the under one assuming a duskier hue; in youth the upper parts are brownish gray and the sides dark gray, but the limbs and flying membrane are marked with light spots at all periods of life. If we assume the different varieties to form but one species, we may say that the Kaguang is distributed over the Sunda Islands, the Moluccas, the Philippine Islands, and the Nalayan P'eninsula as far as Tenasserim.

Life of the In the daytime the Galeopithecus, scribed. mountainous forests of Jasa, sits so still amidst the branches of trees between forking limbs that it is nearly impossible to detect it. Its sharp claws enable it to climb with agility and immunity from falling, while its progress on the ground is limited to a painful, lumbering crawl. Plucking fruit, and searching for insects, it climbs upward until it has reached the top of a tree, and then launches itself
obliquely downward to another tree-top, "reminding the observer of a paper-kite," as Von Rosenberg has it. W'hen engaged in walking or climbing its flying membrane is lightly folded against the body in such a manner as not to hinder its movements. When it wishes to make use of the membrane, it runs out to the extremity of a bough, leaps off with a vigorous bound, spreading all its limbs in the air and then floats slowly and obliquely down, traversing distances which are said to frequently measure horizontally as mucl as one hundred and eighty feet. It never ascends to a higher plane than the one from which it started on its flight, but always sinks downward at an angle of considerable inclination. During the day it suspends itself from trees, according to Wallace, mainly protected from discovery by its fur, which, with favor longer leaps and slower descent, and does not its irregular whitish spots disseminated on a groundcorrespond to the wing membrane of Bats. It is a continuation of the skin of the body; it begins on each side at the neck, envelops the fore-legs to the paws, extends laterally, in unvarying width, to the hind-legs, which it also envelops to the paws and then continues to an apex at the tip of the tail. In this way the limbs and tail are, to a certain degree, encased in a common membrane.

The Colugo, or Kaguang, called Cubin by the Malays (Galeopithecus solans), attains a total length of work of olive or brown, closely resembles the color of the mottled bark. Its tail is prehensile and it probably makes use of it in its search for food, which consists principally of leaves. "It is said," Wallace further observes, "that the Galeopithecus produces only a single young one at a birth, and my observations confirm this statement; for once I shot a female, which had a very small, tender, naked, wrinkled and blind creature clinging to her breast, reminding one of the young pouched animals." 


\title{
The TRodents or Ginawing Intmals.
}

\author{
SEVENTH ORDER: RODENTIA.
}

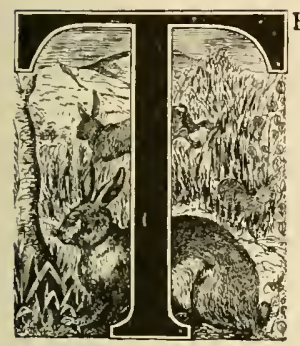

H E order of the Rodents or Gnawing Animals presents a class of animals with clearly defined limits. The creatures belonging to it are perhaps still more entitled to their name than the beasts of prey are to theirs. The distinctive feature, common to all, is found in the fact that two incisors in each jaw are developed into large gnawing teeth, while the canine teeth are lacking. Little can be said about the general appearance of Rodents, as the order is rich in families and species and comprises the most varied forms. The following general characteristics may be said to be found in them. The body, in the majority of cases, is cylindrical and is supported by short legs, usually of unequal length, the hind-legs generally being somewhat the longer, and frequently very much longer, than the fore-legs. The head is set on a short, thick neck; the eyes are large and usually very prominent, and the upper lip, which is adorned with whiskers, is fleshy, very mobile and cleft in front. The front feet, as a rule, have four toes, the hind feet five, the toes being armed with more or less strong claws and occasionally webbed. The fur is nearly always of uniform length, except that it sometimes shows tuft-like elongations at the tips of the ears or becomes bushy at the tail.

Distinctive The gnawing teeth (incisors) are Gnawing Teeth considerably larger than any of the of Rodents. others, the upper ones being always stronger than the lower ones. Both upper and lower incisors are curved, the cutting edge being broad or chisel-shaped; the base is either three or four sided, and they may be flat or arched, smooth or furrowed, of white yellowish or red color. The external or front surface of these teeth is covered with enamel, which has the hardness of steel, and forms the sharp point or the broad, chisel-shaped cutting edge. The rest of the tooth consists of the usual tooth pulp. Being subjected to continuous use, these principal teeth would become blunt and worn out in a short time, if they were not possessed of a great advantage over the teeth of all other mammals: their growth is unlimited. The root of a footh lies in a socket, which pierces deeply into the jaw, and at the open extremity, in a funnel-shaped cavity, the tooth contains a permanent germ, which constantly supplies the tooth with a new growth as it wears off in front. The trenchant sharpness of the edge is preserved by the reciprocal friction of the upper and lower teeth and the grinding effected by it; the jaws have no lateral motion, and the lower jaw can work only vertically or with a slightly projectile or retractile motion from front to rear. In this way these teeth meet all the requirements of the enormous expenditure of material the gnawing process entails. It is easy to demonstrate the constant growth of the gnawing teeth by forcibly breaking one of them in some Rodent, for instance a Rabbit. Then the tooth opposite the broken one, as it is no longer worn off by friction, grows rapidly until it stands out of the mouth in a narrow arch, and curves inward like a horn, thereby mutilating all the other teeth and rendering the sustenance of the animal extremely difficult. With many of the Rodents cheek-pouches open on the inner side of the jaws; they may extend to the shoulders and serve to store away the food as it is gathered. A special muscle pulls these pouches back when they are about to be filled.

Rodents Spread The Rodents are distributed over all alloverthe continents and are found in all cliEarth. mates of any latitude and altitude, as far as there is any vegetation. "In the midst of perennial ice and snow," says Blasius, "where a warm ray of the sun shining but for a few weeks calls forth a short-lived, scanty vegetation in places, on the quiet, lonely, snowy heights of the Alps, in the wide, desolate plains of the north, one still finds Rodents, which do not yearn for a more beautiful sull. The richer and more abundant the vegetation is, however, the more varied and manifold grows the life of this order of animals, which scarcely leaves a spot on earth uninhabited."

Life and These widely distributed animals exHabits of the hibit a great diversity in their ways

Rodents. and habits. Not a few of them lead an arboreal life, many live on the ground; some live in the water, others in underground burrows which they dig for themselves; some in bushes, some in the open field. All are more or less active creatures, and according to the character of their different habitations and modes of life are either excellent runners or climbers, diggers or swimmers. Most of them are inquisitive and lively, but still they do not impress one as sagacious or specially intelligent. The great mass of them form a dull-witted mob, which while timid, are neither cautious nor cunning, and are never distinguished by any prominent intellectual capacity. Some live in couples, some in colonies, and not a few congregate in large com. munities; they are on good terms with other animals, but do not associate much with them. Very few exhibit a wicked, malicious, fierce or impudent disposition, unless excited thereto by some extraneous cause. At the approach of danger they retreat to their places of concealment with all possible. speed; but only a very few species are intelligent enough to baffle pursuit by craft. All Rodents feed mainly on vegetable substances: roots, barks, leaves, buds, fruit of all kinds, plants, grass, farinaceous tubers and even wood fibres are consumed by them; the majority, lowever, eat animal food also, and are 
truly omnivorous. A peculiarity of some, which are too weak to undertake extended wanderings or resist the cold of winter, is that they gather provisions and store them in concealed chambers. The Rodents are the architects among mammals; for some of them construct really ingenious dwellings, which have been admired by men since the earliest times. Not a few Rodents become torpid for the winter. spending the season in a lethargic sleep during which life is maintained by the absorption of the fat abundantly accumulated in their bodies during summer, which is gradually consumed. All voluntary activity pertaining to life is entirely suspended, and even the involuntary functions are, in every respect, at a low ebb during this period of torpor.

Much Harm In proportion to their small size, the

Caused by the importance of the Rodents is very

Rodents. considerable; for they are our most harmful and dangerous enemies. Were it not for the fact that they too have to contend with an innumerable army of foes, and are subject to epidemics and diseases to a great degree, they would reign over the earth and derastate it. The incessant war which is being waged against them does not always counterbalance their amazing fecundity. The assertion seems surprising, but is nevertheless true, that a pair of Rodents can have a progeny of one thousand descendants within one year. It is possible to feel really friendly to only very few members of this numerous order, and of these few still fewer are worthy of domestication. The skin and flesh of the Rodents render them of greater economic importance than any good qualities of character they may possess.

\section{Tbe ฐquirrels.}

\section{FIRST FAMILY: SCICRID.E}

In the first family we place the Squirrels, comprising two sub-orders, the True squirrels and the Marmots. The body of the True Squirrel (Sciurinc) is elongated, the tail is also long with its fur evenly parted lengthwise along the upper surface. The eyes are large and prominent, the ears may be either small or large, scantily covered with hair or furnished with tufts. The fore-legs are perceptibly shorter than the rear pair. The fore-paws have four toes and one rudimentary thumb, the hind paws have five toes. $\begin{array}{cl}\text { Squirrels } & \text { The Squirrels arc found in all parts } \\ \text { ure Almost } & \text { of the globe, with the exception of } \\ \text { Universal. } & \text { Australia; they extend tolerably far }\end{array}$ north and are found in the hottest parts of the south. They live in lowlands and on heights, several species frequenting plains as well as mountains. Natural woods or plantations of trees form their favorite haunts and by far the majority of these animals lead a truly arboreal life, while some take up their abode in subterranean burrows of their own dicysing.

Movements All Squirrels are lively, quick and and Habits of nimble in their movements both in Squirrels. the trees and on the ground. Only the Flying Squirrcls are not at ease upon the surface of the earth, but, on the other hand, they are possessed of the faculty of making exceedingly long leaps, which are, however, only taken in an obliquely descending direction. The mode of locomotion of the majority of the squirrels is a series of jumps, the animals stepping on the entire sole of the foot. Nearly all of the species are excellent climbers, and leap from one tree to another, covering long distances. In sleeping they assume curled up positions, preferably selecting confortable resting places; they therefore find retreat in subterranean burrows or in hollows of trees, or in nests, which they have partially reconstructed or entirely built themselves. Those which live in cold countries migrate at the approach of winter or hibernate uninterruptedly; they therefore gather large or small supplies of provisions, to which they have recourse in case of need. Their vocal expression consists of a whistle and an indescribable growl and hiss.

The Young Mlost species seem to produce young squirrels and more than once a year. During the Parents. breeding scason a male frequently lives for some time with the female and occasionally helps her to build the more or less complicated dwelling, which is expected to harbor the offspring. The number of the young of one litter ranges between two and seven. The little ones make their appearance blind and nearly naked, and stand in need of a warm bed and careful tending. Squirrels taken out of the nest young may be tamed without especial difficulty, but in old age the intractable, sulky temper, which seems peculiar to many Rodents, almost always show's itself, and they become vicious and addicted to biting.

Though all Squirrels have a predilection for vegetable food and at times live exclusively on it, yet, like many other Rodents, they do not disdain flesh, but attack small mammals, zealously hunt for birds and ruthlessly plunder their nests. Though the shins of several species of squirrels are used as fur, and the flesh is frequently eaten, this slight usefulness cannot compensate for the destruction wrought by these animals to our plants and among useful birds.

\section{THE SQUIRRELS PROPER.}

By far the majority of the members of the suborder belong to the species of the Tree Squirrels (Sciums), absent only in Australia. All its varieties correspond so closely in form, structure, habits and character that it is entirely sufficient to describe the Common Squirrel and its habits, in order to gain an insight into the life of the whole tribe.

The Common The Common Squirrel (Sciurus a'ulsquirrel and its garis) is one of the few species of Traits. Rodents with which Man has entered into friendly relations. In spite of many disagreeable qualities, it is a welcome visitor in our houses and impresses even poets as a sympathetic creature. The ancient Greeks were fully cognizant of its attractive qualities, and to them we are indebted for the name by which the Squirrel now goes in science. That Greek name signifies: "he who is under the shadow of his tail," and every one who knows the meaning of the word Sciurus, must involuntarily think of the lively little creature, as it sits on the lortiest branches of the trees. The German poet, Ruckert, has sung about the cheerful little animal in a way that naturalists can not hope to surpass.

Physicalfeatures The body of the Squirrel is about of Common ten inches long, the tail eight inches;

Squirrels. the height at the shoulders is four
s. inches and the weight of an adult animal is a little over one-lialf a pound. The fur is subject to manifold diversification, according to the season - whether summer or winter - and the latitude and consequent 


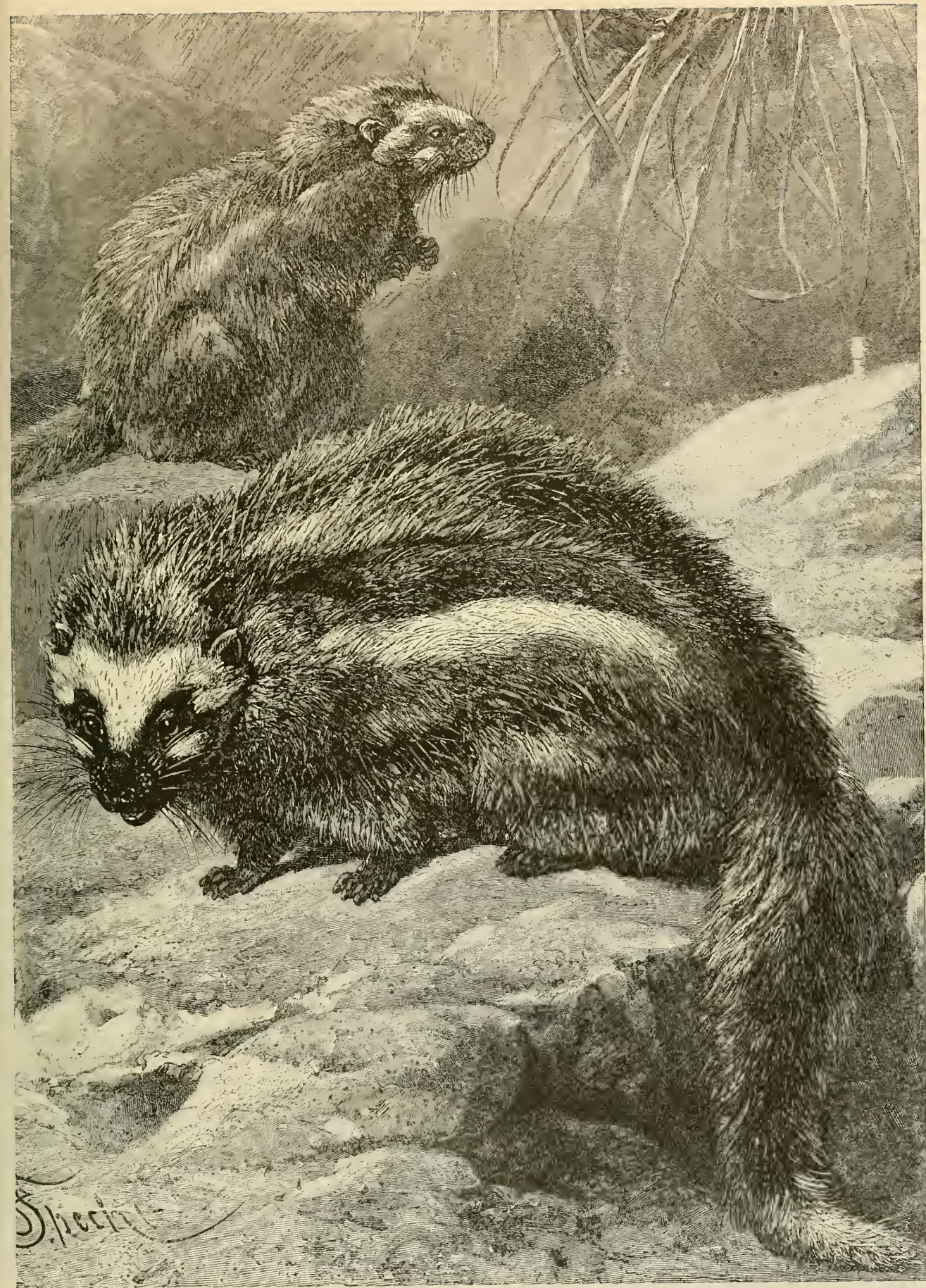

THE SKOLL-CAPS OR LOPHIOMYS. - One of the strangest Rodents ever captured was taken in 1805 to the Jardin d'Acclination in Paris. The long mane along the middle of the back and the tail was found to be erectile like a boar"s, and the Greek name "Lophtionys," signifying " a mouse with boar"s small head is brown and adorned with long whisker hairs, and the general color of the animal is a dark gray, but there are white stripes on the sides and on the forehead. The inner toe of each hind foot is opposable. like a human thumb, and the paw is thus converted into a prehensile hand, which the amimal freely uses in chmbing. After the first specimen was taken to Paris no other
(Lophiomys imhausti.) 
variations of climate. In summer the color of the upper parts is brownish red, with an admixture of gray on the sides of the head; the under parts, be. ginning with the chin, are white. In winter the upper surface is brownish red, mingled with grayish white hair; the lower surface is white, or, in Siberia and northern Europe, frequently whitish gray, while the summer fur in those regions resentbles that of the German squirrel. Black individuals are frequently found in the German forests also; but they by no means belong to a distinct species, for red and black specimens are frequently found together in one litter of young. On very rare occasions one meets white or spotted Squirrels, or such as are possessed of a white or half white tail, and so on. The tail is very bushy and the hair on it is arranged in two lateral rows. The ear is adorned by a tuft of long hair, the soles of the feet are bare.

Home and The Common Squirrel is widely disHaunts of the tributed throughout all of Europe Squirrel. and across the Caucasus and Ural through southern Siberia to the Altai and eastern Asia. But it is not equally common everywhere, or

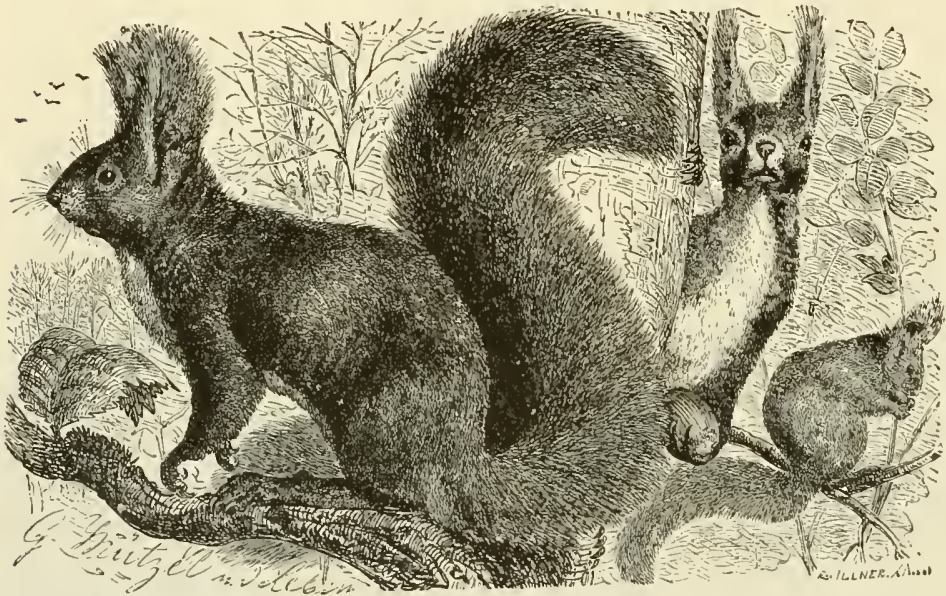

COMMON SQUIRREL. - This European animal is regarded as the typical species among the Tree squirrels, and its character and that of the common species of American Souirrels are very similar. The attitude of the animals in the picture are familiar to all who have watched the antics of Squirels in their arboreal homes. of the animals

every year. Its favorite haunts are dry, shady forests with high trees; and it is as much adverse to dampness as to sunshine. When fruit and nuts are ripe it visits the gardens of villages, but only when they are connected with the forest by small tracts of trees or at least bushes. Where there are many pine cones, it makes its permanent home, and builds one or several habitations, usually in old Crows' nests, which it improves quite ingeniously. If it intends to make a shorter stay, it uses the forsaken nests of Magpies, Crows, or of birds of prey, just as it finds them, but the nests which it intends to serve as a permanent sleeping place, a shelter against bad weather, or a nursery, are built new, though the materials collected by birds are often utilized. It is said that every Squirrel has at least four nests; but nothing has been definitely proven on this score. Hollows in trees, especially hollow trunks, are also frequented by them and occasionally built in. The open-air nests usually lie in a fork, close to the main trunk of the tree; the bottom is built like one of the larger birds' nests, while above there is a flat conical roof, after the manner of Magpies' nests, close enough to be impermeable to the rain. The main entrance is placed sideways, usually facing east; a slightly smaller loop-hole for escape is found close to the trunk. Tender moss forms a soft lining inside. The outer part consists of twigs of various thicknesses, intertwined. The Squirrel especially likes to use the firm bottom of a forsaken Crow's nest, filled with earth and clay, as a base upon which to construct a nest of its own.

The Lively This lively little creature is undoubtWays of the edly one of the principal ornaments squirrels. of a forest. In quict, fine weather it is incessantly active, keeping as much as possible to the trees, which at all times afford it food and cover. Occasionally it will deliberately descend a tree, run to another tree and climb that; doing this often in pure playfulness; for it need not touch the ground at all, unless it wishes to do so. The Squirrel is the Monkey of the woods of temperate climes, and is possessed of many attributes which remind one of those capricious inhabitants of the warmer zone. There are probably few mammals which are possessed of such constant briskness and remain for so short a time in the same place as the Squirrel does in tolerably fair weather. It is ever going from tree to tree, from top to top. from branch to branch; and even on the gromnd it is anything but clumsy or out of place. It never walks or trots, but always proceeds in longer or shorter bounds, and so quickly that a Dog can hardly overtake it, and a human being has to give up the pursuit after a short time. It glides up even the smoothest trees with wonderful ease and speed. The long, sharp claws on the toes stand it in good stead, for it hooks them into the bark, all four feet at once. Then it takes a rumning start for another leap and darts further upward; but one bound succeeds another with such rapidity that the ascent proceeds uninterruptedly, and looks as if the creature glided up the tree. Usually it ascends to the top of the tree without pausing, not infrequently reaching the highest point; then it goes out on some one of the horizontal branches and generally jumps to the tip of a branch of another tree, covering in these jumps distances of four or five yards, always in a downward direction. How necessary the bushy tail is for leaping has been demonstrated by crucl experiments, which consisted in cutting off the tail of some captive Squirrel. It was then seen that the mutilated creature could not leap half so far as one having a tail. The Squirrel is an excellent swimmer though it does not go into the water willingly.

Principal When a . Tquirrel believes itself to be

Food of the unobserved, it is on a constant lookSquirrel.

out for food on its romings. According to the season it eats fruit or seeds, buds, 
twigs, shells, berries, grain and mushrooms. The seeds, buds and young shoots of fir and pine trees probably form its principal food. It bites pine cones off at the stem, comfortably sits down on its haunches, lifts the cone to its mouth with its forepaws, and turning it constantly around, it bites off one little scale after another with its exceedingly sharp teeth, until the kernel is reached; this it takes out with its tongue and puts into its mouth. It presents a very pretty sight when it has plenty of hazel nuts, which are its favorite dainty. Bitter kernels, like almonds, for instance, are poison to it; two bitter almonds are sufficient to kill it

As soon as the animal is provided with food in abundance, it lays by stores for later and less plenteous times. In the crevices and holes of hollow trees and their roots, in holes which it has excavated under bushes and stones, in one of its nests and other similar places it establishes its store rooms, and carries the respective nuts, grains and kernels to them sometimes from a great distance. In the forests of southeastern Siberia, the Squirrels also store away mushrooms, and that in a highly peculiar manner. "They are so unselfish," says Radde, "that they do not think of hiding their supply of mushrooms, but pin them on the pine needles or in larch woods on the small twigs. There they leave the mushrooms to dry, and in times of scarcity of food these stores are of good service to some roaming individual of their kind." By thus guarding against winter the fquirrels show how exceedingly sensitive they are to all influences of temperature. If the sun shines a little warmer than usual, they sleep in their nest during the heat of the day and roam about in the forest only early in the mornings and evenings; but they hold rain showers, violent wind storms, thunder storms and especially snow storms in still greater dread. Their presentiment of temperature to come - cannot be denied. As carly as lialf a day before a storm they signify their restlessness by an incessant hopping about on the trees and by quite pcculiar whistling and clacking noises, which one usually hears from them only when they are greatly excited. As soon as the first presentiments of the storm are felt, they retreat into their nests, a single nest sometimes harboring several Squirrels, and the exit on the side of the wind being carefully stuffed, they comfortably curl up and wait till the tempest has spent itself. A severe autumn is usually very de- structive to them, as they consume their winter stores, and if it is followed by a winter that is in any way severe, a multitude of the animals perish.

The Squirrel's: With the advent of night the SquirWell Developed rel, which stuadily lives in the same Senses. locality, retires into its nest and sleeps there as long as the darkness lasts, but it is by no means helpless, for a suspicious sound wakes it instantly. A frightened squirrel utters a loud "duck, duck"; a sense of comfort or slight anger is testified by a strange murmuring sound which can not very well be rendered by syllables. Special joy or excitement are expressed by a whistle. All senses, and in particular sight, hearing and smell are acute in the Squirrels, and feeling must also be much developed, as their presentiments of changes in the temperature admit of no other explanation; and from observations of captive Squirrels we may conclude that their sense of taste is also decidedly keen. Good mental qualifications may be inferred from the retentive memory the animal possesses and from the slyness and cunning with which it escapes its enemies. Like a flash of lightning it darts to the highest among the surrounding trees, goes up the trunk to the first fork nearly always on the opposite side from its enemy, the most of its body that it shows being the little head, as it conceals itself as much as possible and tries to make good its escape as nearly unperceived as it can.

Four weeks after the breeding season the female gives birth to from three to seven young, in the softest, best jocated nest; the little ones remain blind for nine days and are tendcrly nurtured by their mother. After they have been weaned, the mother, and perhaps also the father, brings them food for several days; then the parents leave the young family to their fate. The young ones remain together for a while, play with each other and soon acquire the habits of their parents. By June the female has another family, and when they also are so far grown up that they can roam around with her, she frequently joins her first litter, and one may see the entire band, sometimes consisting of from twelve to sixteen members, gamboling about in the same part of a wood; and it would be difficult to find a more lively, playful group.

The cleanliness of the Squirrel is remarlable: for it licks and dresses its fur unceasingly. For this reason it is specially adapted to be kept in a room. Half-grown young Squirrels are taken out of the nest for this purpose, and kept on milk and bread, until one can give them grain. 
In youth all Gquirrels are lively, playful and very inoffensive creatures, and delight in being petted. They know and love their keeper and show a certain amount of docility in that they respond to their name. Unfortunately nearly all, even the tamest, become deceitful, or at least addicted to biting, in advanced age.

\section{The Squirrel's \\ Foes are Many.}

The Marten is the most formidable ing rapidly around a tree in a spiral course, when the birds are after it. As the birds have to describe much greater curves in their flight than the Squirrel does in its climbing, it finally succeeds in reaching a hole or dense foliage on the tree-top, where it is safe from further molestation. It is a different matter to escape the Marten. This bloodthirsty beast climbs as well as its victim and pursues it step by step, in the tree-tops as well as on the ground. Young Squirrels are exposed to many more dangers than old ones; and quite young animals can even be overtaken by a human being who is a good climber When we were boys we pursued such young Gquirrels, climbed after them, and the indifference with which they regarled our approach frequently led to their capture. As soon as we could reach the branch on which the young animal sat, it was doomed. We would shake the branch violently up and down, and the thoroughly frightened Squirrel generally thought only of holding tast, lest it should fall. îe would then go farther and farther out, still shaking the branch, until we could seize the little animal with a quick grasp.

The Fur of On the banks of the Lena the peas-
the Common ants are entirely engrossed by the
Squirrel. Squirrel-chase from the beginning of Iarch to the middle of April, and some put out as many as a thousand traps. The Tungus shoot it witl blunt arrows, lest they should spoil the fur, or else they use guns of a small calibre, with bullets the size of a pea, and kill it by shooting it in the head. According to Radde's verbal accounts Squirrel hunting in southeastern Siberia is both entertaining and exciting. The great quantity of the game is a source of satisfaction and revenue to the hunter, for the pelts are much esteemed as fur and a great number of people are engaged in the trade in them. The finest skins come from Siberia, and the farther east they are procured the darker and more valuable they are; west of the Ural they are lighter. The back and uncler-part of the furs are used separately. Russia and siberia annually furnish from six to seven million skins, valued at a little short of a million dollars; only two or three million slins are shipped to western Europe; the rest are manufactured in Russia or exported to China. Besides the skins, the tails are employed as boas, and the hair of the tail makes good painters' brushes. The flesh is white, tender and savory, and is much estecmed by epicures.
The Chicka- Very nearly allied to the Common Squirrel ree or Red of Europe is the Red Squirrel, or Chicharee, Squirrel. (Sciurus hudsonius) a small but quite nuSquirel. merous and very handsome American species, found throughout British North America as far as the forests extend, and also in the most northern states in this country; and a local variety of this Squirrel is found as far south as Coloratlo. The reddish hue of the back may be dark or light, the animal showing great variety in this respect. The under parts are almost always white, but there is a black streak along the flank and the russet tail is fringed with black. The chirping noise made by this animal as it husies itself in the woods gives rise to its name of "Chickaree," which resembles the sound it makes. The lengtb of this animal is about eight inches, exclusive of the tail, which is a little less than that. Its habits are the same as those of the Common Squirrel; in fact, the habits of all species of the true Squirrels are so very sinilar that what has been said of the Common Syuirrel may apply to them all.

Gray squirrels The best known of American squirrels is of Several the Gray Squirrel, a name given to several of Several vies or species which have been differentiated by naturalists. The Gray Squirrel (Sciunus carolinensis) is larger than the Chickaree, being about ten inches long, with a tail that is longer than the body. Thuse of the north are larger than their relatives in the south. The back and flanks of this syuirrel are reddish gray, the under portion being white. It is found in all of the Ailantic states, north and south. In the southwest its place is taken by another Gray souirrel (Simns arizonensis) found in New and Old Mexico and Arizona principally, which is a large variety and has a specially prominent its body. This syurrel is sometimes found at considerable altitudes, especially among the mountain forests of pine, pinon and cedar trees in the northern part of Arizona. A little farther north in the Rocky Nountains is found a very beautiful chestnut-backed Gray Siquirrel (Sciurus aberti) which is of a pure gray on the upper surface, white below, has a chestnut band on the back and a black stripe on the flanks, and which has tufted ears like thuse of the Common and Red Squirrels. Another and very handsume form is that of the California Gray Squirrel (Sciurus fossor) a large variety, which is dark gray above and white below and which has a long and bushy tail.
Traits of the There are several varieties of Squirrels in American Fo the Inited States known as Fox Squirrels. Squirrels. the distinguishing characteristics of these white in all the s]ecies are that the under portion, which is iIt red through intermediate hues to jet black in different varieties. These Fox squirrels have a length of about twelve inches exclusive of the tail, which is of about the same length. The largest variety of this species is the Black Squirrel (5itu"us niger) which inlabits the south $\Lambda$ tlantic and Gulf states. It is about thirteen inches long, has a white nose and white ears. These last distinguishing features are not found in the common Fox Squirrel (Sciurus cinereus) which ranges from a light reddish gray to black in color, although when black it has not the white nose and ears of its southern relative. This variety is found through the New England and Middle states, and south to Virginia. The IVestern Fox Squirrel (Simms ludosicimms) is always of a redclish hue, including the feet and ears, and its bones are red, but its skin is never jet black. This animal inhabits the entire Mississipli Valley region

Pechuel-Loesche's The forests of America, Africa and
Little African India are populated by Squirrels,
Squirrel. ored, and among these are species which by their lively actions sometimes attract observation as much as do the Monkeys. Some of them are easily ciomesticated besides, and amuse their keeper as much as they surprise him by all kinds of peculiar traits, which cannot be observed in those which roam in 
frecdom in the wilderness. A relatively diminutive African Squirrel, the markings of which differed materially from Sciums mimutus, was for a time in the possession and under the observation of PechuelLoesche in Loango. He writes about it: "A charming living squirrel, with a fur of a rusty red color, adorned by two double black and white side bands, was once presented to me. The natives called it Mkaka. It seemed completely grown, though it was only of the size of a large Mouse, so that one could conceal it in one's hand. In a few days it was so tame that we could give it the freedom of the house. With a constant, cheerful 'tak tak,' while the lower one shows but a scanty covering. A bony spur at the first joint of the fore-legs gives especial strength to the membrane. The tail serves as an effective rudder and is always vigorous, though it is not of the same conformation in the different species, one group having it simply bushy, while the other has the hair on it arranged in two lateral rows. There are also slight differences in the structure of the teeth.

The Taguan or The Taguan (Pteromys potamista) is East Indian Fly- the largest nember of the whole ing Squirrel. family, nearly equaling a Cat in size. The flying membrane begins on the fore-legs, ex-

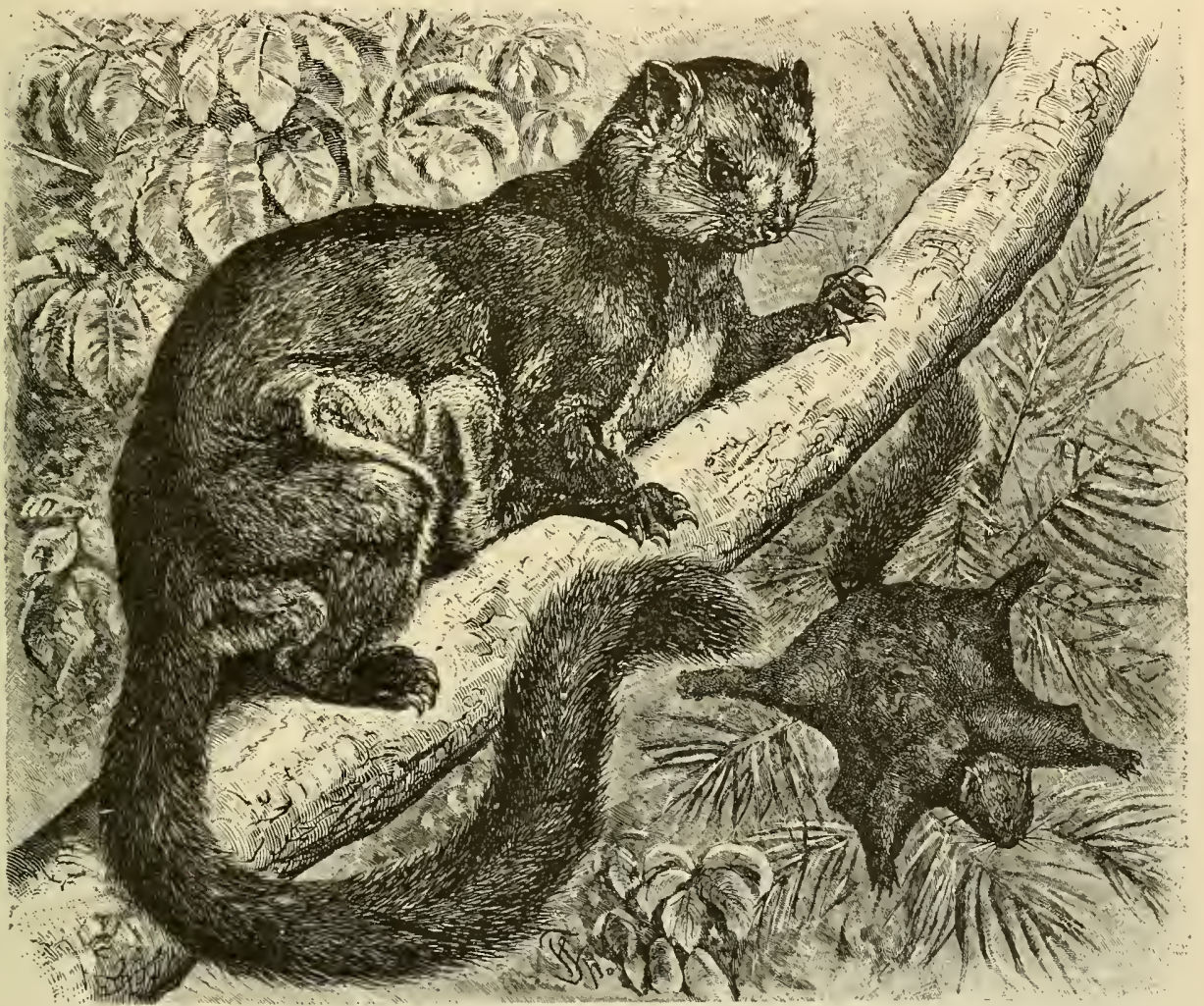

THE TAGUAN. - Of the sub-family known as the Flying Squirrels the largest member is the Taguan, and it is one of the most attractive denizens of the forests and jungles of Hindostan. The very long tail serves as an effective rudder when the animal spreads its membrane to take its long and swift leaps from the tree-tops. These animals, with the membrane spread and folded, are admirably depicted in the illustration. (Pteroinys petaristas)

accompanied by a movement of the wide, bushy tail, it frolicked about at all hours, but was much more active at night than in the daytime."

\section{THE FLYING SOUIRRELS.}

The diurnal Tree Squirrels are followed by the nocturnal Flying Squirrels (Pteromy's). They differ from the foregoing mainly in having their fore and hind legs connected by a wide flying membrane. This membrane acts as a parachute, and enables the Squirrels to execute considerable leaps with ease, in an inclined plane from above downward; it consists of a stout skin, extending along both sides of the body, thickly grown with hair on the upper side, tends down the flanks, and is attached to the hindlegs, whence it is prolonged to the tail by a small fold of skin. In a state of repose the menibrane is folded against the body. On the top of the head, the back and the base of the tail, the color of the fur is a mixture of gray and black. On the whole under surface the fur has a dingy whitish gray tint. The membrane is of a brownish black or maroon color above, edged with light ashy gray and yellowish gray below. The tail is black.

The Taguan is a native of all parts of East India and Ceylon, where there are extensive forests. It lives either singly or in couples, in the densest parts of the woods and preferably on the highest trees. 
In the daytime it sleeps in hollow trees; by night it sallies forth and climbs and jumps about in the tree-tops with exceeding rapidity, agility and prec1sion, executing very long leaps, but always in the obliquely descending line heretofore described. In doing so it stretches its feet horizontally and spreads the membrane. The tail is used as a rudder, and is said to enable the animal to change its course suddenly in the midst of a leap. Sanderson, however, contradicts this statement, saying that when once the animal is launched it cannot deviate from its course, and the natives profit by this inability, as they await the animal at the end of its flight and kill it with sticks. The speed of its bounds and morements generally is said to be so great that the eye can scarcely follow them.

The Liatuga. a The north harbors Flying siquirrels Russian Flying with long, bushy tails on which the

Squirrel. hair is arranged in two lateral rows. One of them, the Russian Liatuga (Pteromys rolans, inlabits the northern part of eastern Europe and nearly all siberia. The animal is considerably smaller than the Common Squirrel, its body measuring only six and one-half inches and its tail four inches. The dense fur is of silky softness and of a dull brown color in summer in its upper part, the fying membrane and the outer face of the limbs being darker grayish white and the under surface white. In winter the fur becomes longer, denser and lighter in color and the upper part and the tail have a silvery gray appearance.

The liatuga inhabits bircl woods or forests in which pines, firs and birches commingle. The birch tree seenis to be a necessity with this animal, and the coloring of its fur also seems to indicate this, as it generally resembles birch bark as much as the fur of the Common Squirrel corresponds to the trunks of firs and pines. These Squirrels are decreasing in numbers, and they bave been nearly exterminated in some localitics where they were formerly plentiful. although it may be that they occur oftener than is commonly believed. The food of the Liatuga consists of nuts and seeds of various trees, principally birch seeds, berries, buds and shoots. With the advent of the cold weather it becomes dull and inactive, sleeping on cold days and running about, for several hours at least, on mild ones.

The Assapan The Assapan, the Flying Squirrel of or American Fly- North America (Pteromys or Silums ing Squirrel. volucillu), is nearly the smallest variety of the whole species. It is only ten inches long. inclusive of the tail which measures four inches. its fur is exceedingly soft and delicate, of a yellowish or brownish gray color on the upper portion, lighter on the sides of the neck, silvery white on the paws and yellowish white on the whole of the under surface. The tail is ashy gray with a surface tinge of brown, the flying membrane is edged with black and white, and the eyes are brownish black. The little animal lives gregariously in the forests of the temperate and warm districts of North Anerica, its habits being similar to those of the Liatuga. It is frequently caught and shipped to foreign lands and bears captivity for years without obvious injury, if adequate care is bestowed on it, and it breeds freely in the cage.

By day, when in captivity, the Assapans lie curled up in their cage, as much hidden from view as possible. Overcome with sleep, they suffer the observer to gently handle them in any way. There is no exhibition of the senseless fury of a disturbed Dor- mouse; one may take them up, turn then over and around and examine them without their making use of their sharp teeth. The most they do is to attempt to escape, and their silky little fur is so sleck and flexible that they slip out of one's hand like quicksilver.

Lively Move. Some time after sunset, rarely before ments of the nine o'clock at night, they bestir Assapan. themselves. On the upper edge of the slecping box, which one must give them as a substitute for their nest, a round little head becomes visible; the body follows and soon one of the little creatures sits on the narrow edge of the box in a graceful squirrel-like attitude, the flying membrane half folded against its hody; half hanging down in a sufr curve. The small, expanded cars move back and forth as does the bewhiskered muzzle, and the large, dark eyes inquisitively scan the cage and surroundings. If nothing suspicious is visible, the Issapan glides down like a shadow, no matter whether the plane is inclined or vertical, always head first, without any noise, without a perceptible movement of the limbs, the sreater part of which is covered witl the membrane. It proceeds on the woven ceiling of the cage, back downward, as if it walked on level ground in a usual gait; it "rope dances" over thin twigs with unsurpassed precision and agility at a uniform speed; over the ground it trips quicker than a Mouse; spreading its membrane to the full, it darts through the whole space of the cage like an arrow, and the next instant it seems glued to a perch as if it were an excrescence belonging to the branch, without having made an effort to regain its balance. During all this moving about it picks up a crumb, a nut, a grain of wheat or a morsel of meat from its dish; drinks, sipping more than it laps, washes its head with saliva, combs its hair with the nails of its fore-feet, smooths it with the soles of its small paws, turning, stretching, stooping al] the while, as if its skin was a bag in which its body sat quite loosely. In the meantime its companions also have left the sleeping box and crouch, sit, cling to, hang from, run and climb in all imaginable positions of a Rodent on the perches, walls, nooks and corners of the cage.

After hunger and thirst are somewhat appeased, and all parts of the fur have been satisfactorily dressed, the desire for freer and more playful movement exhibits itself. For a short time the Assapan sits in one place, as if lost in thought. Then it rouses itself for a leap with its fyring membrane spread, traversing the whole length of the cage. It only remains for an instant on the spot on which it alights; for immediately after reaching it, the Squirrel throws itself backward, making use of any convenicnt object as a fulcrum; then returning to its starting point, it hurries in some other direction. Up and down, head upward or imerted, hither and thither, along the ceiling or the floor, up one wall, down another, through the sleeping box, past the dishes for food and water, from one corner into the other, running, jumping, gliding, soaring, hanging, sitting, the incomparably quick little creature changes every instant, rushing ahead as if it could move a thousand joints at once, and as if there were no such thing as gravity to be overcome. A very keen observation, prolonged for some time, is necessary to follow an $\Lambda$ ssapan at all, to distinguish and understand the purport of its different movements, and if there is a whole band of these creatures (which far surpass all other climbers) running, jumping and soaring 
together, it is entirely impossible to fathom the intention of its evolutions. The suddenness of the changes from one movement to another is what surprises one most The Assapan can suclelenly end the wildest chase at any time it sees fit to do so, and therefore the eye of the observer, in trying to follow

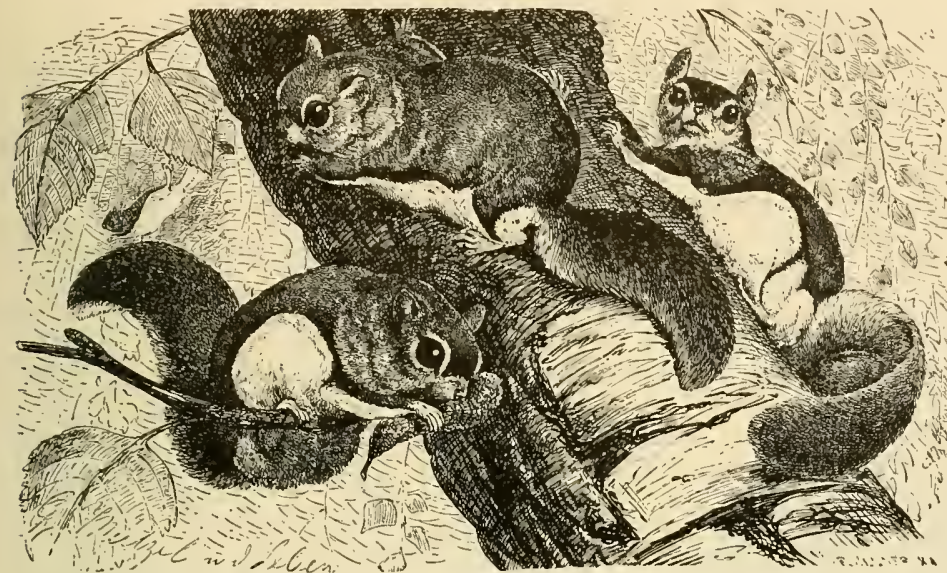

ASSAPANS, OR AMERICAN FLYING SQUIRRELS. - One of the daintiest little animals found in the United States is the Assapan, or Flying Syuirrel, so called because it has a membrane which it can spread to ai it in taking long leaps from a tree-top through the air. It is one of the smallest of the Squirrel family but one of
the prettiest. A typical group of these animals is shown in the picture. It is found all over the United States and the prettiest. A typical group of these an

it, still roams about, while the creature sits on some twig, of a pencil's thickness, as quiet as if it had never moved.

Assapans are The Assapans are very peaceful

Pugnacious and among their own kind, and apparPlucky. ently inoffensive and good-natured, gravish white.
THE GROUND SQUIRRELS.

A genus of this family which is worthy of mention is that of the Ground Squirrels (Tamias). Their possession of cheek-pouches reaching to the back of the head, and their more or less subterraneous habits, characterize them as intermediate links between the irue Squirrels and the Spermophiles, although they agree with the former more than with the latter. The tail of the Ground Squirrels is scantily grown with hair and slightly shorter than the body; the fur is short and not very soft and is usually diversified with a few sharply defined longitudinal stripes on the back. There are few varieties, and they inhabit eastern Europe, Siberia and North America.

The Burunduk or Striped Siberian Ground Squirrel (Tamias striatus), is considerably smaller than the Common Squirrel, but of much clumsier build. The coloring of the short, rough close fur is yellowish, mixed with long, whitetipped hairs on the head, neck and flanks; five black stripes run along the back at unequal intervals, the middle band marking the spine; the next two run from the shoulders to the hind legs, and have a band of pale yellow between them. The whole of the under surface is

but they never hesitate to attack any small animal of another species, especially small birds, and kill them without mercy. Face to face with a victim, they appear as bloodthirsty as beasts of prey, and their indescribable agility and ferocious disposition probably render them quite formidable foes to small animals. They show no fear of mammals in size equaling themselves: other Rodents, for instance. An intruder in their domain is first subjected to an examination by use of their powers of scent; if it be found objectionable it is at tacked, and is scratched, bitten and otherwise annoyed, and if it is not very plucky it is sure to be driven away. So we can not deny that the Assapans are decidedly courageous, besides being bloodthirsty. The little animals are so prepossessing in other respects, however, that one forgets their bad qualities in thinking of the good ones and accordingly declares them to be the most attractive of all Rodents.

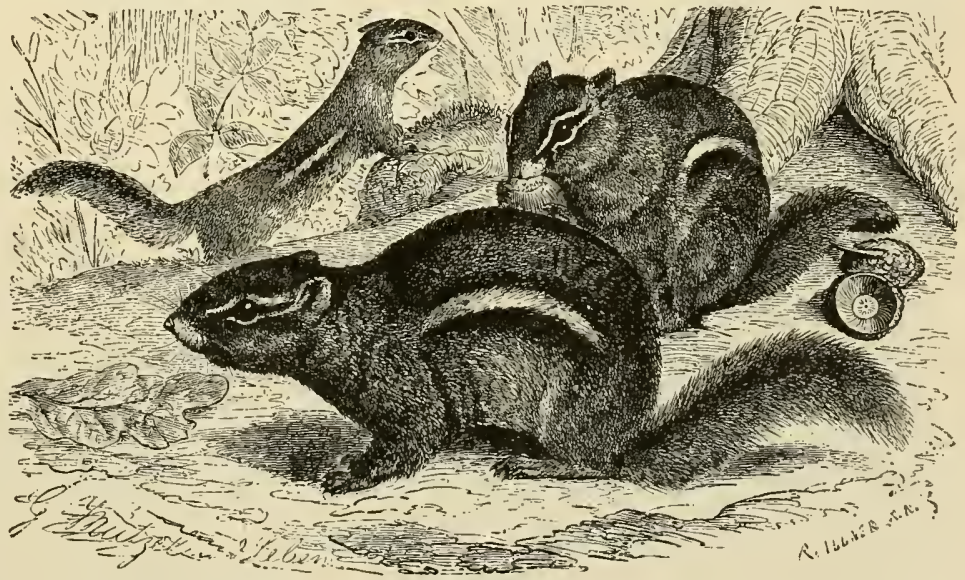

THE CHIPMONK,_ I familiar, lively American animal, which, in some one of its several local varieties, is found all over the United States and the greater part of Canada, Seeds, nuts and grain are its food. and it inhabits the wooded regions and also causes havoc on farms. The picture shows a group of Chipnunks seeking for acorns, and illustrates with fidelity their appearance and the markings of their fur. (Tamias lysteri.)

A large part of northern Asia and a small portion of eastern Europe are the native range of the Old IVorld Ground Squirrel. It lives in forests of firs and pines as well as of birches, but is most frequently found in woods where the stone-pine tree 
abounds. Under the roots of these trees it excavates a rather simple burrow which forks, one passrooms, situated laterally, a long, tortuous passage forming the exit. The food of the animal consists of plant seeds and berries, and preferably cereals and nuts, of which it may carry from ten to sixteen pound. home during a single winter, using its cheekpouches to carry these supplies, and storing them in its larder. Chipmunk Burunduk is the Chipmunk, Hackee, Described. or Chipping Squirrel (Tamias lysteri). It is distributed all over the United States. It is of about the same dimensions as the Burunduk. The face is of a reddish brown tint, with darker spots on the forehead and cheeks; the nape of the neck is ashen gray, the hind quarters reddish brown, the under surface whitish; there is a dark brown stripe on the back, a black stripe over the eye, with white above and below it, and there is a wide white sidestreak edged with blackish brown: the upper surface age leading to the nest and the other to the store

The Familiar The American counterpart of the

to stand in need of food during the whole winter. Audubon dug up a burrow in January, and at the depth of about four feet he found a large nest of leaves and grass in which three Chipmunks were ensconced; others seenied to have retreated to the lateral passages at the approach of the diggers. The animals were overcome with sleep and not very active, but they were by no means as torpid as true hibernating animals are, and they snapped viciously at the naturalist, who tried to handle them. The Chipmunk does not become torpid before November, nor does the Burunduk in central siberia, where the cold begins early; begin its hibernation before the middle of October. Neither of these animals leaves its subterranean residences during the winter, but both keep a passage open, and when the snow thaws, the Burunduk, at least, may be seen very busily occupied in cleaning the entrance of its burrow and protecting it from the water. When the snow melts, both species begin their activity above ground. The young are born in May, and a second litter usually in August. The males engage in fierce combats during the breeding season, and it is said that more pugnacious little creatures than these small, active animals are hard to find. They display an amazing nimbleness and dart between and under hedges like IIrens.

Many Foes of The farmer the Ground regards the Squirrels. Ground Squirrels with by no means friendly eyes. They enter barns, after the fashion of Mice, and if backed by large numbers they cause great devastations. In Siberia the furs of the Burunduk are put to good account and shipped to China where they are principally. used for trimming other furs. The Chipmunk is hog. They form a distinct group of which the Alyssinian aninal, shown in the picture, is typiral it is about twenty inches long. has short ears placed low on the head, and a long tail covered with coarse hair. (Yerus ruilulus.)

of the tail is dark brown, the base being grayish yellow, the tip whitish and the lower surface a ruddy hue.

Many Different Xaturalists, as well as ordinary observers, Varieties of the recognize numerous varieties among the Chipmunks of the L'nited States, founded Chipmunk. princinally on the markings of the fur, for in their habits they are all very similar. Thus there are described by Elliot Coues four varieties found in this country. The first is the Four-Striped Chipmunk (Tamias quadrizitlatus) which inhabits the central region, north and south, comprising the Mlississippi Talley in the larger sense. It is the smallest species, being not longer than five inches, and its name is derived from four white stripes enclosed within five dark or black ones along the back of the animal. Another is the Eastern Chipmunk (Tamits striatus) larger, brighter in color and having on its back five black stripes and also having a white streak on each side of the borly. The Mountain Chipmunk Tamias lateralis) inhabiting the Rocky Mountains, and the Southwestern Chipnunk (Timias harrisi) are other local varieties.

Chipmunks and Late in summer the Chipmunk may Their Hiber- be seen running about, its cheek nation. pouches filled and its eyes beaming with the satisfaction which its riches afford it. According to the different months in which they mature, it gathers its varied stores, for the most part consisting of buckwheat, hazel nuts, maple seeds and corn. It becomes torpid during the winter, but its hibernation is an interrupted one, and it seems hunted to a greater extent than its Siberian cousin. A whole army of enemies is constantly engaged in its pursuit. Boys utilize it to practice the noble sport of hunting: Weasels pursue it both on and under the ground; Cats deem it a prey equally as good as Rats and Mice, and all larger birds of prey carry it off whenever they have a chance. One of these birds has even gained for itself the name of Squirrel-hawk, because of its attacks on these animals. The Rattlesnake, according to the observations of Geyer, also follows the poor Chipmunk with a great deal of perseverance. Winter often causes sad havoc among the numerous voung brood born in summer. Yet they are very plentiful, at least in favorable years, the great fecundity of the female making up for the losses.

The Ground Squir- The pretty color, the gracefulness rels as Tamed and liveliness of the Ground SquirPets. rels recommend them as pets. But they never become quite tame, always remaining timicl and addicted to biting. Their predilection for gnawing everything must also be contended with. They practice this accomplishment with an adeptness equal to that of Rats, and few things in the cage or room can escape defacement or destruction. 
The care of Ground Squirrels presents no difficultics, and they thrive well on the simplest diet of grain and fruit.

\section{THE MARMOTS.}

The Marmots (Arctomyina), which form the second sub-order, differ from the Squirrels proper by having

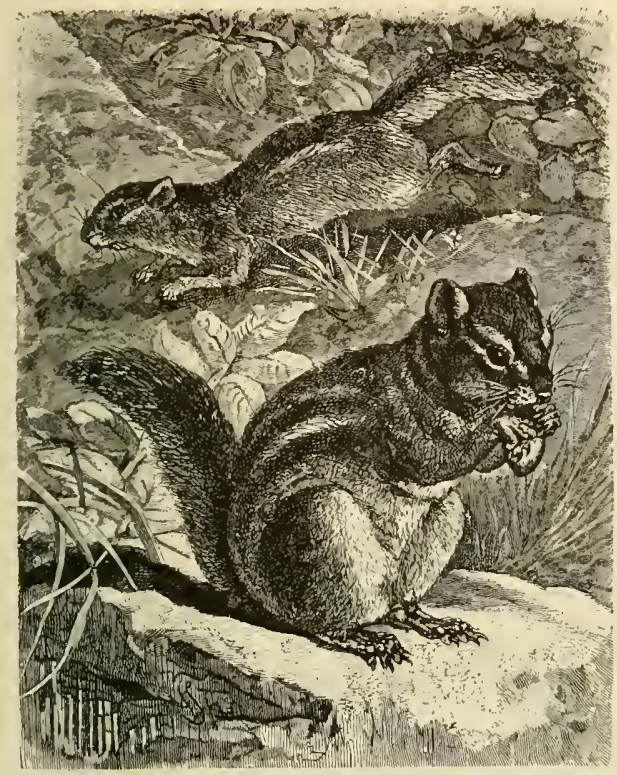

THE BURUNDUK, - This animal, otherwise known as the Striped Siberian Ground Squirrel, is the Old World relative of the American Chipmunk, It lives in the woods and subsists on seeds and berries, which it conveys to its mouth in true Squirrel-fashion. (Tamas struttus.)

a clumsier, stouter body, and a short tail, and also in their dentition.

Range and The Marmots are found in central Habits of the Europe, northern Asia and Nortl Marmots. America, in considerable variets. The majority of them inhabit level country, but some exist in the very highest mountains of their native homes. Their haunts are dry, clayey, sandy or rocky localities, grassy plains and steppes, fields and gardens, and only the mountain Marmots prefer the grazing country beyond the limit of forestgrowth or isolated ravines and rocky valleys between the snow boundary and the forests. All species have permanent residences and never migrate. They build deep, subterranean burrows and live there in communities sometimes composed of astonishingly great numbers. Some have more than onc burrow, according to the season or the business they have on hand, while others stay in the same burrow year after year. They are animals of the ground, lively and quick in their movements, but slower than the Squirrels; several species of Marmots, however, impress one as being very clumsy. Grass, herbs, tender shoots, young plants, seeds, field produce, berries, roots, tubers and bulbs go to form their food, and only those few which can, with much labor, climb trees or bushes, eat young leaves and buds from the trees. Probably they also feed on insects, small mammals and awkward birds, and plunder the nests of the latter. Some Marmots do harm in fields and gardens; but the mischief they do is very slight. While eating they sit on their haunches like Squirrels and lift the food to the mouth with their fore-paws. When the fruit ripens they begin to gather treasures and fill their burrows with grasses, leaves, seeds and grain. At the beginning of winter they bury themselves in their burrows and fall into a deep and uninterrupted lethargy.

The voice of the Marmots consists of a whistle or yelp, louder in some spccies than in others, and a kind of murmur, which, uttered softly, signifies content, but otherwise is an expression of wrath. They are highly cautious, vigilant, shy and timid and many species put out special sentinels, in order to enhance the security of the band, and at the slightest apprehension of danger these watchers hurry to their subterranean hiding placcs. The intelligence of the Marmots shows itself in the fact that they can be tamed to a considerable degree. The majority recognize their kecper and become very familiar. and some get to be quite obedient and docile.

They are very prolific. On the average there is only one litter of young in a ycar, but it numbers from three to ten little ones. The fur of some species and the flesh of others are used; and tamed

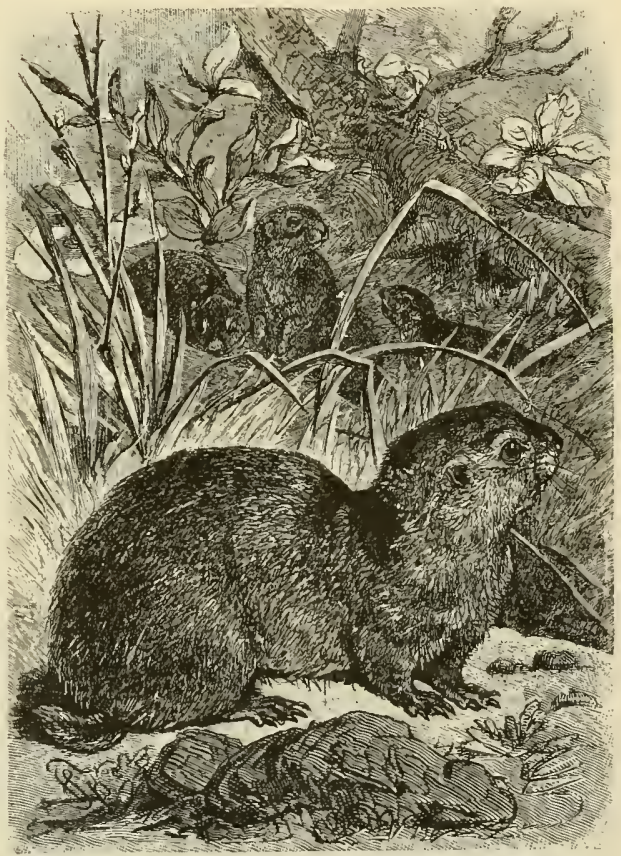

SOUSLIK. - This burrowing animal, found in eastern Europe, delights in grassy localities such as that depicted in the illustration. They are sociable animals, always found in company with others of their kind. (Stomophilus catillus.)

Marmots also make attractive pets, but these are all the uses to which the animals are put.

The first group of the Marmots is formed by the pouched species known as Spermophilus.

The Souslik The Souslik (Spermopliilus citillus). a Russian Sper- occurring in central Europe, is a mophile. pretty little animal, nearly of the size of a Hamster, but more slender and having a 
prettier head. Its fur consists of loose, rather wiry hair; the upper surface is yellowish gray, diversified with irregular waves of russet yellow and small spots; the under parts are reddish yellow, and the chin and throat are white.

The Souslik is mainly found in the east of Europe, its range taking in the northern provinces of the Austro-Hungarian empire and all of southern and tempcrate Russia. In most localities where the Souslik is found it is common, and is occasionally perceptibly prejudicial to agriculture. It selects dry, treeless localities as its haunts; preferring above all others firm sand or clay ground, which is principally fields and grassy plains. According to Herklotz, it has recently paid special attention to railways, the embankments of which facilitate digging and afford a certain shelter from rain showers. The Souslik always lives gregariously; but every animal savory flesh, and he hunts them with nooses, catches them in traps, digs them out or drives them out of their burrows, flooding their retreats with water, and in other ways. In this way the propagation of the Souslik is checked.

Various Species of Of the Spermophiles proper there are sevAmerican Sper. era] species inhabiting North America. In mophiles. the high north is found the species nearest mophiles. to the souslik. It is known as Parry's Marmot Squirrel (Spermophilus empetra). In Illinois, Indiana and south to Kansas, north to Dakota and into Canada, is the snecies variously known as the Gray Prairie Squirrel and the Gray Gopher (Spermophilus franklini). Another is the Thirteen. lined Spermophile, sometimes called "Stars and Stripes" Spermophilus tridecum-lincatus) which has on its dark reddish brown back and sides rows of light spots alternating with from six to eight black, longitudinal stripes. It is found in the eastern states. There are other local varieties in California and Mlevico. Their life resembles that of the Souslik, the northern varieties laying up large stores of provisions for the winter, while those further south do not find so large a stock

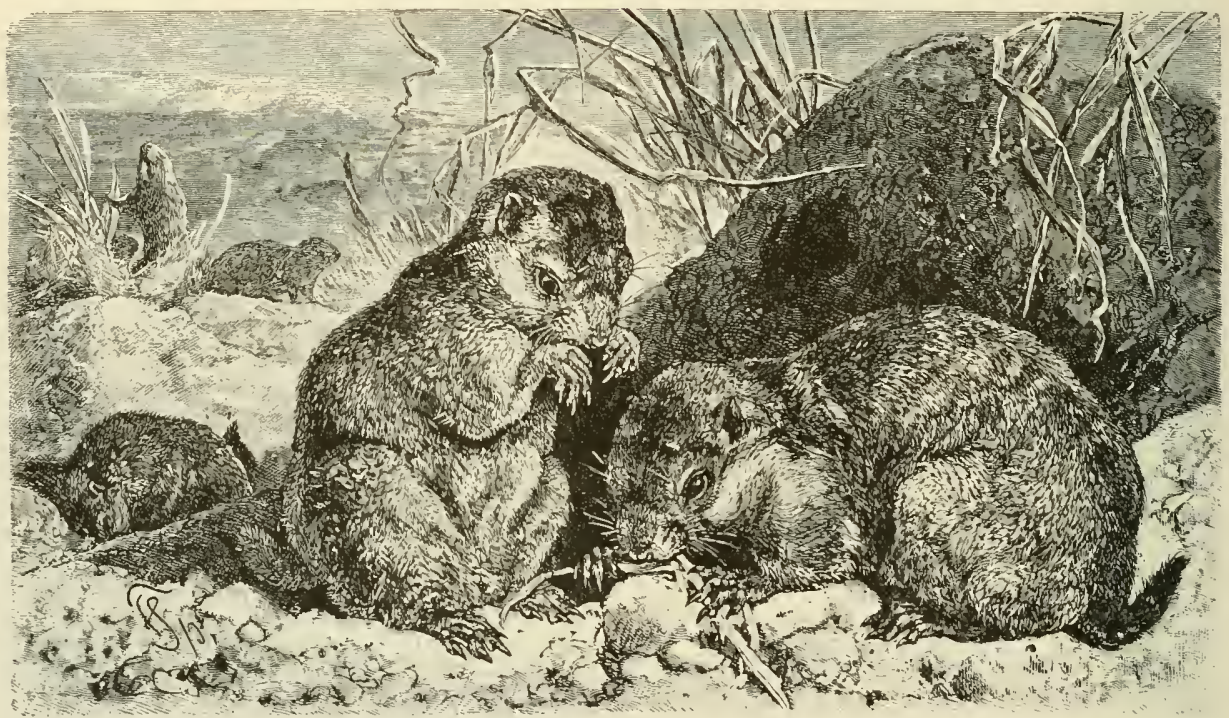

PRAIRIE DOGS — These animals are familiar to all who have lived in or visited the western plains of the United States, or the elevated tablends of out the characteristics of the animals - the stout body, the large head, the alert, watchful eyes and the small ears. (Cynomys ludoricianzs.)

digs its own individual burrow, the malc a shallow one, the female a deeper retreat.

Food and Tender herbs and roots, cereals, Foes of the beans and peas, various berries and Souslik. veretables form the usual food of the Souslik. Towards autumn it gathers provisions, which it carries home in its cheek pouches, Hamster fashion. Besides this the Souslik is a dangerous foe to Mice and birds having their nests on the ground, for it not only plunders the nests, but also attacks the animals themselves, if they are not wary.

The devastation a Souslik perpetrates by its plunderings is noticeable only in places where the animal is numerous. Ermines, Weascls, Polccats and Martens, Falcons, Crows, Herons, Bustards, even Cats, Terriers and other well-known exterminators of Rodents, zealously pursue the Souslik. The Bustard shows great zeal and skill in pursuit, killing the animal with one blow of its beak and eating it, skin and all. Man also pursues the Sousliks, partly on account of their skins, partly on account of their necessary, for the reason that their seclusion is of shorter duration.

The Prairie Dogs' The Prairic Dog (Cynomys ludoviciaLeading Char- mus), living in North America, is in a acteristics. certain sense a connecting link between the Spermophiles and the true Marmots; for though, properly speaking, it belongs to the former, it more resenbles the latter. The body is stout, the head large, the tail short and bushy, the hair of equal length above and on the sides; the cheek pouches are of inferior development. Adult Prairie Dogs attain a total length of about sixteen inches, not quite three inches of which belong to the tail. The coloring of the upper parts is light reddish brown, mixed with blackish gray; the under surface is dingy white and the tip of the short tail shows brown rings.

The appellation of "Prairie Dog," which has been adopted more and more generally, derived its origin from the first discoverers, the old Canadian trappers or hunters who gave the little animal the name on 
account of its barking voice; but the most superficial comparison could not find a point of resemblance between this animal and a Dog in external appearance.

The Prairie Dog The Prairie Dogs' extensive settle-

Towns of the nients, which are called "Dog-towns" West.

on account of their great size, are, as hibernation, usually in the last days of October, it closes all the entrances to its burrow to protect itself from the cold and, as the season advances, it becomes torpid, not emerging from its hole until the warm days of spring awaken it to new, gladsome life. According to the accounts of the Indians, it sometimes opens the doors of its habitation while a rule, found on somewhat low lying prairies, where the grass makes a beautiful natural lawn and at the same time affords the animals convenient food. "The almost incredible proportions which the settlements of these peaceful inhabitants assume," says Baldwin Moellhautsen, "can best be realized by a person who journeys continuously for days among little hillochs of which every one represents the residence of two or more of these animals. These dwellings are usually from five to six yards apart, and each little mound rising in front of their entrances may contain a good cart load of earth, which has been gradually conveyed fron the subterranean passages to the surface by these inhabitants. Some have a single entrance, some have tivo. A well trodden path leads from one divelling to another, and fully justifies the inference that close friendship prevails among the lively, little animals. The selection of a site for their "towns" seems to be determined by proximity to short, crisp grass, which generally grows on high plains, and which, besides one species of root, forms the only food of the little animals. Even on the high plateaux of New Mexico, where not a drop of water is to be found for miles around, there are very densely populated communities
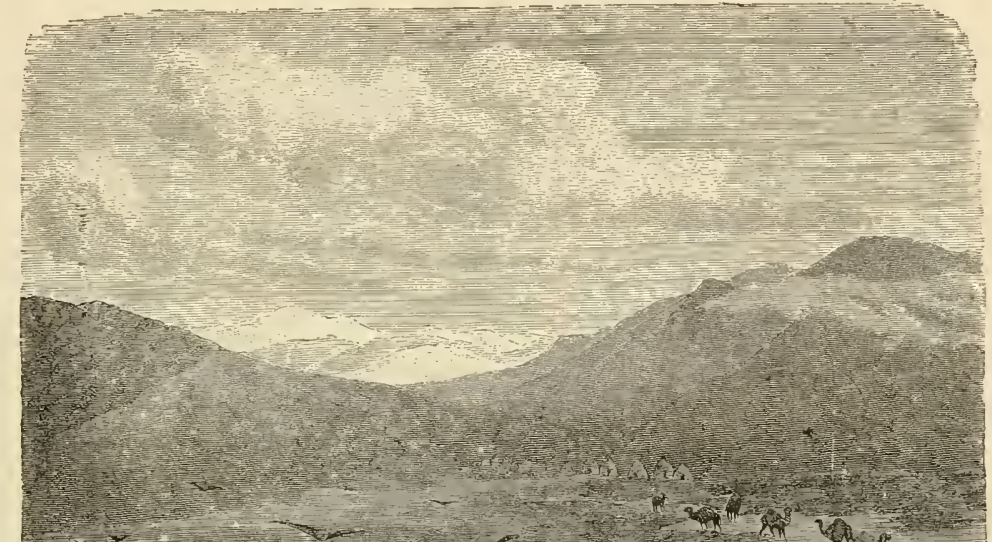

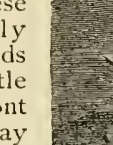
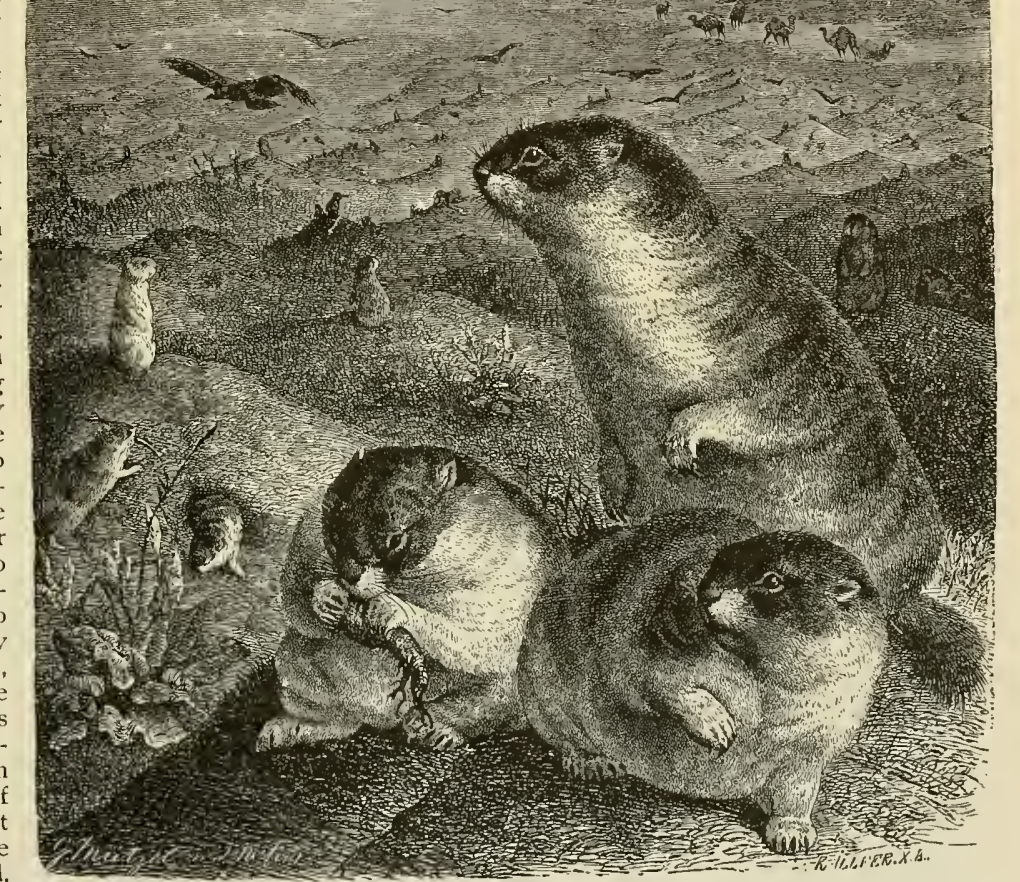

THE BOBAC. - Very similar in appearance and habits to the American Prairie Dog is its Old World relative, the Bobac. In the steppes and valleys of central Asia it throws up mounds at the entrance to its burrows, living in large "towns" with others of its kind, for like the Prairie Dog il is of very sociable disposition. (Arctomys bobac.) of this sort, and as there is no rain for months, and it is necessary to dig to a depth of one hundred feet in order to reach a water vein, there is good reason to believe that Prairie Dogs need but very little water, and content themselves with the moisture which a heavy dew temporarily leaves on the slender grass blades. When the Prairie Dog feels the approach of the time for the days are still cold. This is regarded as a sure sign of the near advent of warm weather.

Appearance of a "Such a settlement affords a remarkPrairie Dog able sight, if one is only luchy

Village. enough to approach it unperceived by the sentinels. As far as the eye can reach, a busy activity prevails: on nearly every mound the 
little, yellow-brown Prairie Dog sits on his haunches like a Squirrel; the erect little tail is in constant motion and the fine, shrill, yelping little voices of many thousands unite to form a peculiar droning sound. If the observer comes a few steps nearer, he hears and distinguishes the deeper voices of the older and more experienced leaders; but as soon as the intruder is observed, a sharp note of warning is uttered, and, as if by magic, every moving creature disappears, plunging head first into its burrow. In places, after a short interval of time, an investigating head, in which is set a pair of eager eyes, protrudes from the entrance of a burrow, while a constant barking warns its friends of the dangerous proxinnity of Man. If the observer lie down and patiently keep quiet and motionless, the sentinel will soon resume its post upon the top of its mound, and communicate the disappearance of danger to its companions by incessant yelping. One by one they leave their dark burrows, and the harmless activities of the sociable little creatures are presently resumed. For hours one could look at the ever clianging spectacle without tiring, and it is no wonder that the observer begins to wish that he could understand the language of the animals; could mingle with them and listen to their private conversations."

It is a remarkable fact, vouched for by various observers, that the burrows of Prairie Dogs are shared by two dangerous foes of smaller Rodents. Not infrequently the Prairic Dogs, Burrowing Owls and Rattlesnakes are seen coming and going through the same entrance.

Comments upon this alleged friendliness and good-fellowship between Prairie Dogs, Owls and Rattlesnakes appear very frequently in accounts of the Prairie Dog, but the belief in the existence of such relations is founded on one of those hal truths which so often lead to erroneous inuressions. The Owls and Rattlesnakes are inhabitants of the same regions as the Prairie Dogs and make use of their burrows, hut, as Elliott Coues says: "Owls and Snakes are enemies of each other, anc both of the Marmots. The birds would devour the young Marmots if they could get at them, and do devour the young Snakes; and the Snakes devour the young Marmots, the Owlets and the eggs of the Owls."

Prairie Dogs Haacke writes as follows about capObserved in tive Prairie Dogs: "There are probCaptivity. ably few animals, the lives of which in captivity so readily become assimilated to their habits in the free state, as the Prairie Dogs, the ingenious habitations of which, together with the attractive activity of the animals themselves, fascinate many visitors to the zoological garden at Frankfort. Scarcely had we put new tenants in our l'rairie Dog park, which had been improved the previous summer by several new arrangements, when the animals commenced their digging. $\mathrm{We}$ put then in the park in the afternoon, and by the following night they were able to sleep in the burrows which they had by that time completed. The P'rairic Dog works with great intelligence when enlarging its burrows. It never begins to dig at the lower end of the tunnel to be excavated, for by so doing it would stop its exit or at least narrow it to a great extent; so it always begins at the upper end. The earth left from former diggings is shoved under the abdomen by the fore-paws, and the hinder paws fling it outside, and so the animal gradually disappears from view, working alternately with its fore and hind paws. But its building operations do not stop short with the digging of tunnels. An important part of its labor is the erection of a dam around the mouth of the tunnel, protecting the burrow from inundations. For this purpose the earth that has been flung out is collected. What has been thrown too far away is flung back near the entrance of the burrow by using the hind legs, and then, as the work has to be exact, the animal carefully pushes the earth with its fore-paws and heaps it around the entrance. Then, to make it permanent, able to resist rain, and form an effective dam, it is thoroughly pressed with the nose; and for this work of puddling the mound and the walls of the entrance, the Prairie Dog selects rainy days as best, and on such days the impressions of the animal's nose can be seen all around the entrance.

According to the weather the Prairie Dog makes temporary clanges in its burrow. When, in October, the weather became cold, our Prairie Dogs closed three of the five entrances of their subterranean residence. The earth around the mounds was utilized, the dams being partially destroyed for this purpose. I have seen them do just the opposite thing in sumner, when the sun would shine warmly after rainy days, and the dwelling had to be dried. Ventilating tunnels, promoting the evaporation of moisture, were then dug. To make the burrow habitable the bed is upholstered with hay and similar substances. When the weather is dry we throw a handful of hay to our Prairie Dogs. Then the animals form bundles of the hay with their forepaws and muzzle, so thick that they can hardly grasp them in their mouths and carry them underground. They utilize paper in a similar way; entire sheets of newspaper are moulded into balls and carried away. Vihen the hay on the bed has become too damp, it is removed and replaced by a fresh supply."

The Bobac, an The Bobac (Arctomys bobac) takes European the place of the Prairie Dog in the Species. Old VVorld; and. like it, is an inhabitant of the plains. It has only recently been generically distinguished from the Alpine Marmot. Its body is fifteen inches long, its tail not quite four; the tolerably thick fur is of a pale russet yellow tint. The young have a darker color than the mature animals.

The Bobac's range extends from southern Poland and Galicia eastward through part of central Asia to the Amoor, and perliaps to Kamchatka, and through the Ifimalayas to sikkim. It inhabits plains and rocky, hilly stretches of country, shunning forests as well as sandy localitics, which do not admit of the burrowing of its deep habitations. Adams found it in the wide valleys and table-lands of Cashmere, at elevations of six thousand or even nine thousand feet above sea level. There it lives in fertile valleys in which a luxuriant but stunted regetation covers the ground during the summer. The Bobac is always gregarious, gathering in rather numerous bands. Its presence impresses a certain peculiar stamp upon the localities it affects. Innumerable mounds, which one notices in the grassy steppes of central Asia, owe their existence principally to these Marmots, which attract the attention of the traveler by their activity, while their flesh renders them an important article of food to the inhabitants of the steppes and to various predaceous lower animals.

Home of the High up in the most elevated rocky Alpine Marmot regions of the Alps, where there Described. grows neither tree nor shrub, where no Cow, and scarcely a Goat or a Sheep can penetrate, even on the small, rocky islands in the very midst of the huge glaciers, where the warm rays of the sun do not melt the snow for more than six 


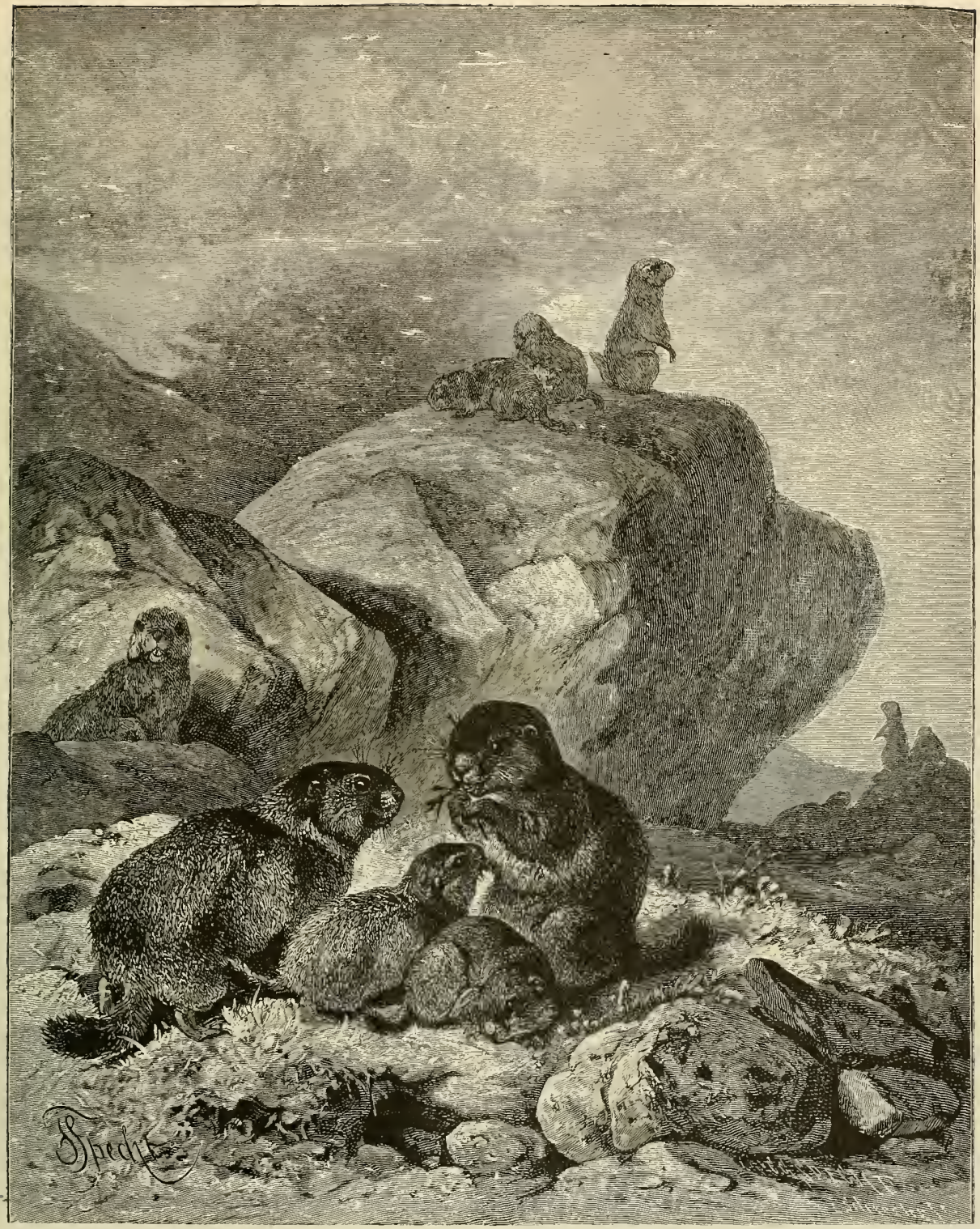

THE ALPINE MARMOT. - In the heights of the mountainous district of Europe is found the typical animal of the sub-family of the Marmots. The summers are short in the region inhabited by this Marmot, and the animals in the picture are shown enjoying themselves during this period. In the winter they disappear, their hibernation lasting from six to eight months. (Arctomys marmota.) 
weeks of the year, there is the home of a member of this family known from remote ages, the habits of which, though resembling those of its previously described relatives in all essentials, still differ in many minor respects in consequence of the character of its native country.

Characteristics of The Common or Alpine Marmot the Alpine (Arctomys marmota) attains a total

Marmot. length of nearly twenty-five inches, its body measuring not quite twenty and one-half inches, its tail four and one-half inches, while its height at the shoulders is ten inches. In appearance and anatomical peculiarities it resembles its kindred. The fur consists of a short woolly under coat and a longer outer one; it is close, abundant and rather long, its color on the upper surface being a more or less brownish black, interspersed with a few whitish

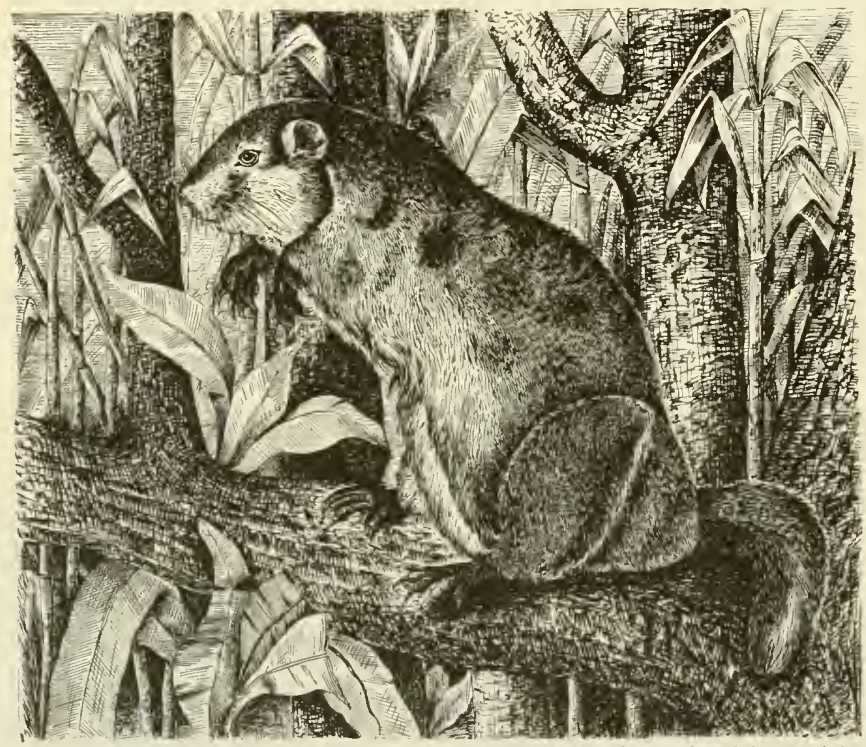

THE WOODCHUCK. This is a familiar American animal found in woods and forests of the northern Uni ted States and Canada, Its stout body and Mousc-like head are well shown ju the picture which represents the animal amid appropriate surroundings. (Arctomy's monax.)

points on the top and back of the head; the nape of the neck, the base of the tail and the whole of the under surface are dark reddish brown, the tint becoming lighter on the legs, the flanks and jowls; the muzzle and fect are rusty yellowish white. The eyes and claws are black, the front teeth are brownish yellow. One may also find entirely black or white individuals, or some that are spotted with pearly white.

Bleak Retreat of Recent investigations have proven

the Alpine that the Common Marmot is con-

Marmot, fined to Europe. The high parts of the Alps, Pyrenees and Carpathian mountains are its favorite homes, and it generally selects the meadows close to the line of perpetual snow, its lowest point of habitation being the forest belt. It selects for its haunts open spots, bounded all around by stecp, rocky walls, or small, narrow, deep valleys between isolated peaks, spots lying as far as possible from human presence. The lonelier the mountain, the more frequently is the Marmot found; and where Man has redeemed the country from its orig- inal wildness the animal has usually become extinct. As a rule it chiefly affects the mountain plains and slopes facing south, east and west, for, like most animals of diurnal habits, it rejoices in the rays of the sun. There it digs its burrows, some small and simple, others deep and more intricate. The former are intended to serve for summer, the others for the winter; the first as shelter from temporary danger and in bad weather, the latter from the terribly severe winter, which in those regions holds sway for six, eight or even ten months. This remarkable creature hibernates and sleeps throughout at least two-thirds of the year, and frequently more; for at the extreme altitudes in which it is found, its life and activity in the waking state and outside of its burrow last scarcely as much as one-sixth part of the year.

Marmot and Their Winter the Marmots dig Quarters. their winter burrow, which is always situated lower down on the mountain than the summer retreat, which is sometimes built as high as 8,000 feet above sea level, while the winter burrow, as a rule, lies in the locality of the highest meadows, and often even in the forest belt. When placed low down it is designed to harbor the whole family, of from five to fifteen members, and is, therefore, very spacious. The sagacious animals begin in August to bite off grass, dry it and carry it to their burrow in their mouths. They amass such a quantity of grass that often one Man cannot carry it away at a single load.

The Marmot's The movements of Peculiar Move- the Marmot are rements. markable, especially the walk, which consists of a peculiar waddle, with legs wide spread and the body nearly or quite dragging on the ground. I never saw any Marmots which 1 kept in captivity jump: they are too clumsy.

Fresh, juicy, Alpine plants, herbs and roots form the food of the Marmot. It seldom drinks during early summer; when it does do so, it takes a great deal of water, and it smacks its lips and lifts its head after every swallow like a Hen or a Goose.

Hunting and Cap. The hunting and capture of Marturing the Alpine mots present manifold difficulties.

marmot. The approaching sportsman is nearly always detected by a member of the colony, which communicates danger signals to its companions by a shrill whistle. Traps of various kinds are used to catch Marmots and they are also lug out of their burrows in the beginning of winter. In many cantons of Switzerland the digging out of Marmots is legally forbidden; for their complete extermination would be accomplished in a short time by this proceeding, while simple hunting is not very disastrous to then. When pressed very hard, the Marmots defend themselves against their enemies with courage and resolution, biting strongly or using their vigorous elaws. A Marmot captured when young may be trained to be so inoffensive and tame that it becomes a source of amusement to both young and old, and its cleanli- 
ness and pretty appearance win for it a great many friends.

The Woodchuck, Very similar in its bodily structure to the The Woodchuck, Alpine Nlarmot is its nearest American relaan American tive, the well-known lloodchuck or Ground Animal. Hog Arctomys mona.x. Its head and body measure about fourteen inches, the tail about four inches The body is stout, the head broad and flat, the legs short and thick. The fur is blackish or grizzled on the upper portion and of a chestnut red on the under surface of the body.

The Woodchuck is found in all parts of the region extending from the Carolinas north to Hudson Bay, and from the Atlantic coast west to Missouri, Jowa and Minnesota. It inhabits woods, prairies and meadows, lives on roots, vegetables, and herbs and is especially fond of red clover. Its burrows are large excavations, and in the early autumm it busies itself in storing provisions for its long winter retreat. It is one of the first hibernating animals to retire to winter quarters and one of the earliest to come forth from its hiding place, the length of its hibernation varying with the locality and being shorter in the south than in the porth. In the northern United States it usually retires about the first of October and reappears about the middle of March. When it begins its hibernation it carefully closes the entrance to its burrow. The winter retreat usually contains a male and female. Dr. Bachmann, who had marked a burrow to which he knew a pair of Woodchucks had retired, caused it to be opened early in November and found the two animals, perfectly dormant, lying coiled up close together in a nest of dry grass, twenty-five feet from the entrance.

The young Woodchucks, of which there are from four to six in a litter, are born about the end of April and are tenderly cared for by the mother until they are old enough to shift for themselves. Woodchucks are vigorously hunted, not only for the harm they do, for where numerous they are very destructive in fields and gardens, but also because they are an easy prey to small boys who, accompanied by Dogs, pursue them or dig them out of their burrows.

Besides the Common Woodchuck there are other American species, notably the Rocky Mountain Marmot (Arctomys faviz'entor) which was first described by Audubon and Bachmann from a specimen brought from California in $18+\mathrm{I}$. It is considerably larger than the Woodchuck, the head and body attaining a length of eighteen inches and the tail ten inches. Still larger is the Hoary Marmot or Whistler (tretomys pruz nosts) which attains a length of from twenty-three to iwentyfive inches and has a tail about twelve inches long. It is an inhabitant of northwestern America, from the Columbia river north to the Arctic circle.

\section{Cbe Doriltice.}

\section{SECOND FAMILY: MYOXIDE.}

The Squirrels are followed by a group of graceful little Rodents, the Dormice (H/yoxide $)$. In appearance and character they exhibit some affinity to the Squirrels, but differ from these latter by peculiarities in their anatomical structure. They have a narrow head with a more or less pointed snout, rather large eyes and large ears, devoid of fur; the body is stout. The limbs are of moderate length; the feet are of delicate mould and the fore-paws have four toes and a flat-nailed thumb mark; the hinder-paws have five toes; the tail is moderately long and very bushy and its fur is arranged in a double row. The fur is rich and soft.

Life and Traits $\mathrm{Up}_{\mathrm{p}}$ to the present time scarcely more

of the Dor- than half a dozen distinct species of mice.

this family are known, and all these are confined to the Old World. Their haunts are in hilly and mountainous localities, in forests, groves and gardens. They live on and in the trees; more rarely in self-dug burrows between roots of trees or in clefts of rocks and walls, and they habitually hide from view as much as possible. By far the majority of these animals sleep through the day and search for food only in the dusk of morning and evening, and for this reason it is rarely and only by chance that they are seen. When they have had enough sleep they are very active animals. They are excellent runners and still better climbers, but cannot leap as far as the Squirrels.

In temperate climes they become torpid at the approach of the cold season and spend the winter sleeping in their nests. Some species lay by provisions for this time and subsist on the stores thus hoarded, which they eat at the intervals of their hibernation, when they awake temporarily. Others do not need even this winter store, as they become so fat before retiring to winter quarters that they can subsist on this adipose accumulation.

The food of the Dormice consists of fruit and all kinds of seeds; the majority also feed on insects, eggs and young birds. While eating, they sit on

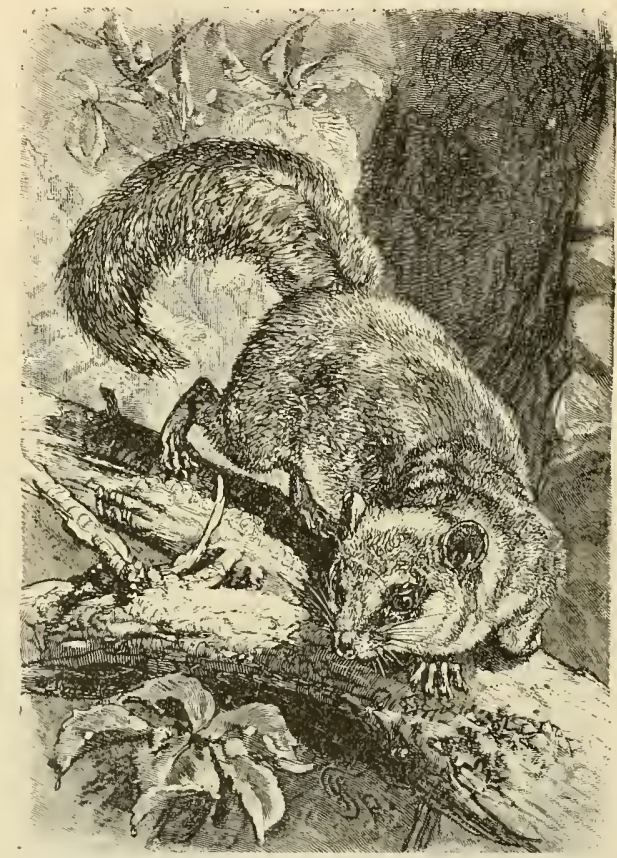

THE LOIR-Cometimes called the Fat Domouse. It is the largest of the Dormouse family and is found principally in southern Europe and in a portion of Asia. It is an arboreal animal, and spends the summer and early autumn seeking for food in the woods, as shown in the picture, preparatory to its long winter hibernation. (1/yoxus g/is.)

their hind legs, like the Squirrels, and lift the food to the mouth with their fore-paws. The Dormice are of no use worth mentioning, while their depredations in gardens may cause considerable harn.

The Loir The first species is formed by the or Fat Dormouse Loir, or Fat Dormouse (MHornis g/is) Described. and an allied variety. The Loir attains a length of six and one-half inches, exclusive of the tail, which is five inches long. The soft and rather close fur is of a uniform ashen grav on the upper surface, with a surface tinge of brownish black; the under surface of the body and the inner surface of the limbs are milk white and of silvery lustre, the line of demarcation being sharply defined.

Haunts and The Loir exists all over southern and

Habits of eastern Europe. Its principal home

the Loir. is in moderately high mountains. preferably forests of oak or becch. It keeps in hid- 
ing during the day and prowls around every night, while the summer lasts, searching for food. It eats acorns and nuts, does not despise sweet, juicy fruit, and attacks, kills and devours any little animal it can overcome. Few Rodents surpass it in voracity, and it eats as long as it can do so. During the autumnal months it amasses provisions and stores them in its hiding place. At this time of the year it becomes very fat, and prepares its winter quarters, making a nest of tender moss in deep holes in the ground, hollow trees, crannies in rocks or old walls. There it curls up, usually in company with several

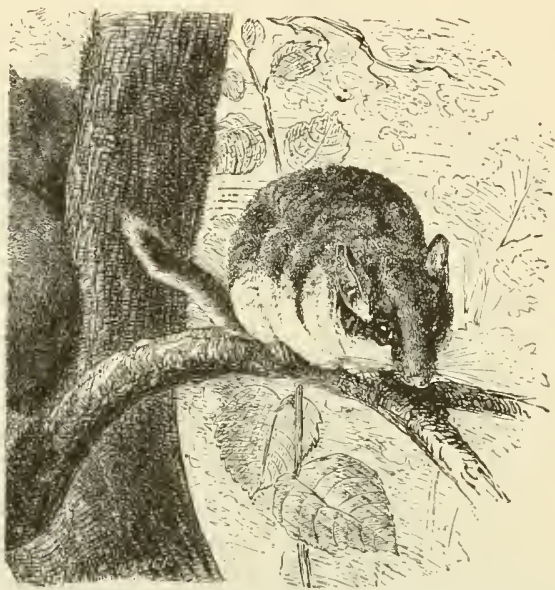

THE LEROT, - This animal is sometimes called the Garden Dormouse, for it enters gardens and is very destructive, devour ing fruit, vegetables and cereals. Its markings are admirably shown in the picture. (Eliomys nitelis.)

others of its kind, and falls into a sleep which is perhaps the soundest experienced by any of the hibernating animals. It begins this sleep early in the fall and rarely wakes before April.

The worst persecutors of the Loir are probably Martens, Polecats, Wild Cats, Weasels and Owls. The little creature defends itself very courageously; though vainly, against the strongest enemies. Where it is common, the Loir is eagerly pursued by Man for its flesh as well as its skin, and is caught in traps of various kinds.

It is seldom seen in captivity, for it is an uninteresting animal, always irritable, and never becomes friendly with its keeper. It ferociously growls, with a peculiar snoring sound, at every person who approaches it. Its only virtue is its cleanliness.

The Lerotin (Hyoxus dryas) is intermediate between the Loir and the Lerot. Its length is seven inches, about half of which is taken by the tail. The body is reddish brown or brownish gray above with a sharp line marking the margin of the white under surface. A black stripe runs between the eyes, broadening out above the eyes so that it reaches the ears. The tail is dark brownish gray above, white below. It is a rare species and ranges in southern Russia, lower Austria and Silesia. Its habits correspond with those of the Loirs and Lerots, as far as they are known.

The Group of The group of the Lerots (Eliomys) the Lerots differs from the preceding mainly Described. in dentition. The teeth of the Loir are ground flat at the crown, while those of the
Lerots become hollow. An external distinguishing feature of the Lerots is in the tail, which is shortluaired at the base and is bushy and of two colors at the tip. The upper and under surfaces are of different colors.

Physical Char- The Lerot (Eliomy's nitela) attains a acteristics of length of body of nearly six inches, Lerots. and a length of tail of nearly four inches. The head and upper parts are of a reddish gray-brown tint, the under parts are white.

The Lerot, which was known to the ancient Romans under the name of Nitela, belongs chiefly to the temperate parts of central and western Europe. Its food is the same as that of the Loir.

Hibernation and For hibernation, the Lerot selects

Food of the dry, sheltered holes in trees and Lerot. Walls, or Moles' burrows, or else it invades farms lying near forests, and creeps into some hiding place in garden houses, barns, hay-lofts, coal men's shanties, or other dwellings. Usually several Lerots sleep in one nest, the entire party nestling close together and nearly rolled into a ball. Their sleep is unbroken, but not so sound as that of other hibernating animals, for whenever the weather is mild they wake up, eat a little of their provisions, and becone torpid again only when the weather again becomes cold.

The Lerot is a detested visitor in gardens, where the finer kinds of fruit are grown. A single animal is sufficient to ruin an entire crop of peaches or apricots. It shows a taste in its depredations which does it great credit, for it selects only the best and juiciest of fruit to eat although it often gnaws into other varieties, to try them, and in this way it ruins much more than it really eats. Therefore, as it works only destruction and is not of the slightest use either for its flesh or its skin, it is zealously pursued by garden owners.

Peculiarities of The third species of the family, which

the Common comprises the Dormice proper (1/us-

Dormouse. cardimns) also differs from the preceding mainly in respect to its teeth. The ears are also smaller. The fur of the tail is rather short and of uniform length throughout.

A single variety of this species exists in Europe. It is the Conmon Dormouse (Muscardimus avellanarius), one of the prettiest, nimblest and most graceful creatures among European Rodents, distinguished as much by its dainty figure and beautiful coloring as by its cleanly habits, pretty ways and gentle temper. The little creature is about as large as a domestic Mouse; its total length is five and onehalf inches, about half of this going to the tail. The fur is of a uniform yellowish red tint; the under surface is a little lighter, and the breast and throat are white. Central Europe is the native country of the little Dormouse, and its haunts are nearly identical with those of its family relations. Low bushes and hedges, especially thickets of hazel nuts, form its preferred places of abode.

All day long the Dormouse lies somewhere in hiding and sleeps. At night it looks for food, which consists of nuts, acorns, hard seeds, juicy fruits, berries and buds; but it is fondest of hazel nuts. It lives in small communities, which can not be said to be closely united. Either singly or two together the Dormice build a soft, warm, ingenious nest out of grass, leaves, moss, small roots and hair, in some dense bush, and from there they set out on their nocturnal prowlings over their domain, nearly always in company with others which live in prox- 
imity to them. Being genuine arboreal animals they are marvelous climbers, even among the thinnest twigs. In August from three to four naked, blind young make their appearance in the ball-shaped sumner nest, which is always built in the thickest of bushes and about three feet from the ground.

Long Hiberna- About the middle of October the tion of Dor- Dormice retire into the hiding-place mice.

where they have stored their winter provisions, and prepare a ball-shaped covering made of twigs, foliage, fir-needles, moss and grass: this they wrap around themselves, curl up into a ball and fall into a still deeper torpidity than do their relatives; for one can take them up and roll them around without their giving a sign of life. According to whether the winter be mild or severe, they sleep through six or seven montlus in a more or less unbroken repose, until the beautiful, warm spring sun awalies them to new life.

\section{Tbe tbcaver.}

\section{THIRD FAMILY: CASTORID.E}

Though corresponding with the preceding Rodents in many respects, the Beaver differs from them and its other relatives in such marked degree that it must be considered as the representative of an entirely distinct family (Castorida).

The Beaver has attracted attention since the earliest times and is frequently mentioned by ancient a uthors under the name of "Castor" and "Fiber" Yet the old observers of nature impart little knowledge in respect to its habits. The Beaver is now distributed over three continents in regions between the thirty-third and sixty-eighth degrees of north latitude. The European countries in which it is most frequently found are Bosnia, Russia, particularly in the northern tributaries of the Pripet in the Government of Minsk, and Scandinavia, especially Norway. It is much more numerous in Asia than in Europe. It

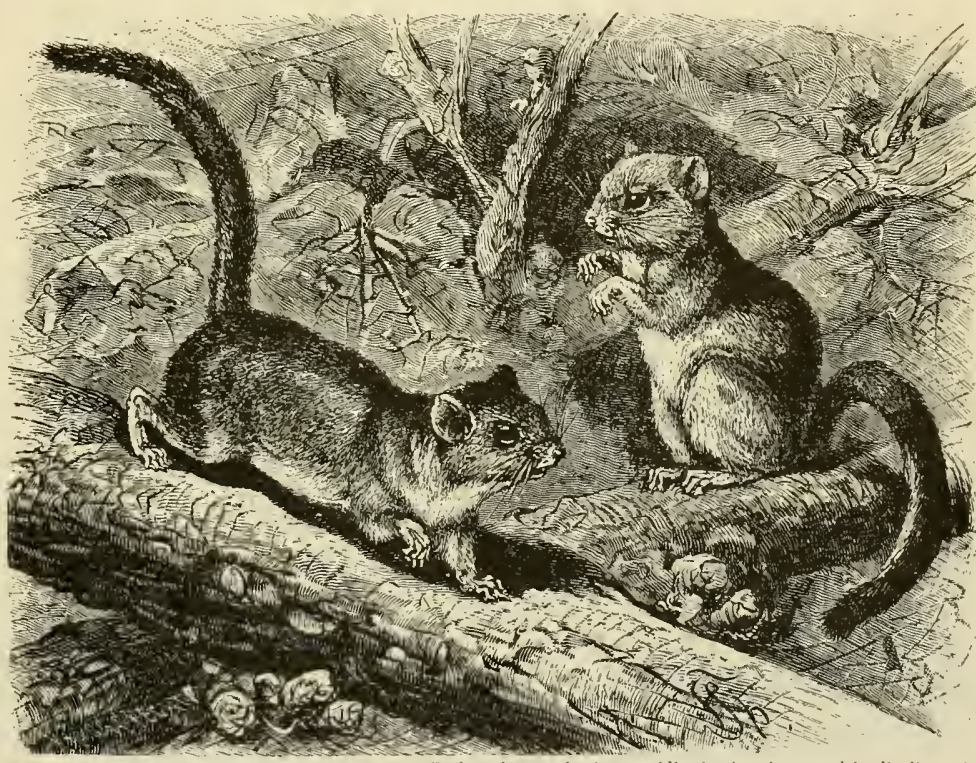

THE COMMON DORMOUSE. - A pretty Rodent fanous for its torpidity in the winter and its liveliness in the summer months. The animals shosn in the picture are appropriately placed amid arboreal surroundings, and the

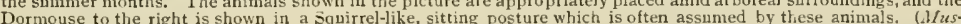
Dormouse to the right

is quite plentiful along the great streams of central and northern Siberia, and is also said to exist along the rivers flowing into the Caspian Sea. It is certainly found along the tributaries of the Kooban on the northern slope of the Caucasus and in Mesopotamia. In America it was formerly common, but its numbers have been greatly diminished by relentless pursuit. Audubon in 1849 mentions only Labrador, Newfoundland, Canada and a few localities in Maine and Massachusetts, as still harboring Beavers, but adds that isolated specimens were still found in vari- ous thinly populated parts of the United States [Since Audubon's time the fauna of the Rocky Mountain regions has become better known, and Beavers have been plentifully found in the western rivers. They still exist in wooded regions on the banks of the Platte and also in other like localities from the Canadian line to Arizona.]

acteristics of the largest Rodents. The body of Beavers. an adult male is from thirty to thirtyeight inches long; the tail measures twelve inches, inches. The weight is from forty to sixty pounds. The body is clumsy and strong, the hinder part being considerably thicker than the fore part; the back is arched, the abdomen pendulous, the neck short and thick, the head broad at the skull and narsow in front, and having a flat top and a short, blunt snout. The legs are short and very sturdy, the hind pair being slightly the longest; the feet are five-toed and the hind ones are furnished with broad webs to the very claws. The tail is round at its root, flattened above and below, and about eight inches wide in the middle, rounded above, and nearly sharp edged at the tip. The ears are small and short, furclad on both sides and can be folded against tine head so as to close the auditory passage almost com-
Physical Char- The Beaver (Castor fiber) is one of and the height at the shoulders is about twelve 
the tip. The tail is grown with very long hair at the base and is naked farther down, being covered with small, elliptical, nearly hexagonal, flat pits, between which grow a few scattered, short, stiff hairs. The prevailing color of the fur is subject to modifications. In a few rare instances white or spotted Beavers have been found.

The large, strong gnawing teeth are flat, and smooth in front, a cross section appearing nearly three-sided; the sides are chisel shaped, and the teeth protrude far out of the jaw. Both sexes possess two peculiar secretive glands, the castoreum bags, in the lower part of the abdomen. The imner walls of these glands secrete the so-called castoreum, a dark reddish brown, yellowish brown or blachish brown salve-like substance, possessed of a peculiarly pungent, strong odor, which strikes few people as agreeable, and is of a bitter, balsamic taste. In former times it was extensively used as a sedative and as a remedy for convulsions, but has come more and more into disuse.

The Canadian The Canadian Beaver (Castor canaBeaver, the Ameri-densis or Castor americamus) differs

can Species. from the European species by hasing the line of its face more arched; its head is narrower, and the skull also shows other peculiarities; the fur is darker and the "scent bags" are differently situated. According to Blasius, its independence as a species can not be doubted.

Home and In the majority of cases the Beavers General Habits of now live in couples, forming more Beavers. or less numerous families only in the most solitary localities. In all populous countries the Beaver lives like the Otter, in simple, subterranean tunnels, and never thinks of building its so-called "lodges' or strongholds. Still some of the latter were found not very long ago on the banks of the Nuthe, near the Elbe, in a lonely spot grown with willow trees, and traversed by the little river, which measures but six to eight paces in width, and has been known under the name of Beaver's I'ool since the oldest times.

From the accounts of observers we extract the following: After mature deliberation the animals select a stream or pool, the banks of which afford them ample provender, and seem specially adapted for the construction of their "lodges." Those which live singly dwell in simple subterranean burrows, after the manner of Otters; societies, which generally consist of families, as a rule construct houses, and, if there should be a necessity for it, dams, in order to hold back the water and preserve it at a uniform height. Some of these dams are from four hundred and fifty to six hundred feet long, from six to nine feet high, from twelve to eighteen feet thick at the base, and from three to six fect at the top. They consist of logs varying in size from the thickness of an arm to that of a thigh, and from three to six feet long. One end of the log or stake is thrust in the ground, the other stands upright in the water; the logs are fastened together by means of thin twigs and made tight with reeds, mud and earth, in such a way that onc side presents a nearly vertical, firm wall to the stream, while the other side is sloped. From the ponds rising above the dams, canals are constructed to facilitate the carrying or floating of the necessary construction materials and food.

Beavers do not forsake a settlement they have founded unless the direst necessity compels them to do so. Beavers' lodges, the origin of which dates very far back, are often found in lonely woods.
How Beavers The working methods of the Beavers Work and Fell are so closely allied to their general Trees. habits that one pictures their life in describing them at work. Like most Rodents they are active at night, and roam about by day only in remote regions, where they have not for a long time encountered any human being. "Shortly after sunset they leave the tunnels, give a loud whistle and drop into the water with loud splashes. For a time they swim near the lodge, going as rapidly against as with the stream and occasionally come to the surface, showing either the nose and forehead or the head and back, according to whether they deem themselves secure or not. When they have taken their bearings, they come to the bank and go as far as fifty paces or more, to fell trees for their food and for their building processes." Branches of the thickness of an inch the Beaver bites off with apparent ease, and it fells trees by gnawing the trumk all around and then more on the side near the river, until the tree inclines to that side and falls into the water. Its work may be traced by innumerable flat, shell-shaped incisions, which appear as smooth and clear-cut as if they had been chopped out with a slightly curved chisel. It is known that the Beaver fells trees thicker than a man's body. Sprigs with plenty of branches are carefully examined before being carried away; occasionally they are split, troublesome stubs of branches are cut off, but all pieces of wood are carried into the water and there the bark is peeled off and stored away for future use. It is not until after a log has been stripped of its bark that the Beaver uses it for construction purposes, takes it out of the water, carries it to the nearest "lodge" and makes use of it there. No regular arrangenient of the logs can be traced. The requirements are met in a deliberate way, but a regular, orderly arrangement of the building materials does not appear to be thought of. Some stakes lie horizontally, some are oblique, some vertical; some protrude to some distance over the walls of the lodge, others are entirely covered with earth; and something is continually being changed or enlarged or improved. All the substances required for stopping the interstices, such as earth, sand, loam or mud, are moved in various ways, but only by means of the mouth and fore-paws; they are worked only with the paws. The tail is, at the most, only used to preserve the animal's balance, and is never made to serve as a trowel, as was formerly believed.

As is the ease with most animals, the female is the real architect, the male being only a helper and understrapper. Both work all the year through, but not alway's with the same zeal. In summer and the beginning of autumn they play more than they advance their work; but just before the cold weather sets in they devote the nights uninterruptedly to their work. They are possessed of a lieen presentiment of impending change of temperature and endeavor to prepare for it as much as possible.

Food and Move The principal food of Beavers is the ments of the barks and leaves of various trees. Beaver. Among all branches, which I threw to my captive Beavers, the first selection always foll on willows; and it was only when these were lacking that they would take poplars, black poplars, aspens, ash trees and birches - alder trees and oaks always being the least liked. Harder branches, which they take in their forepaws and keep turning around, they strip with consummate slill and adroitness; they peel them so neatly that a stripped branch shows no 


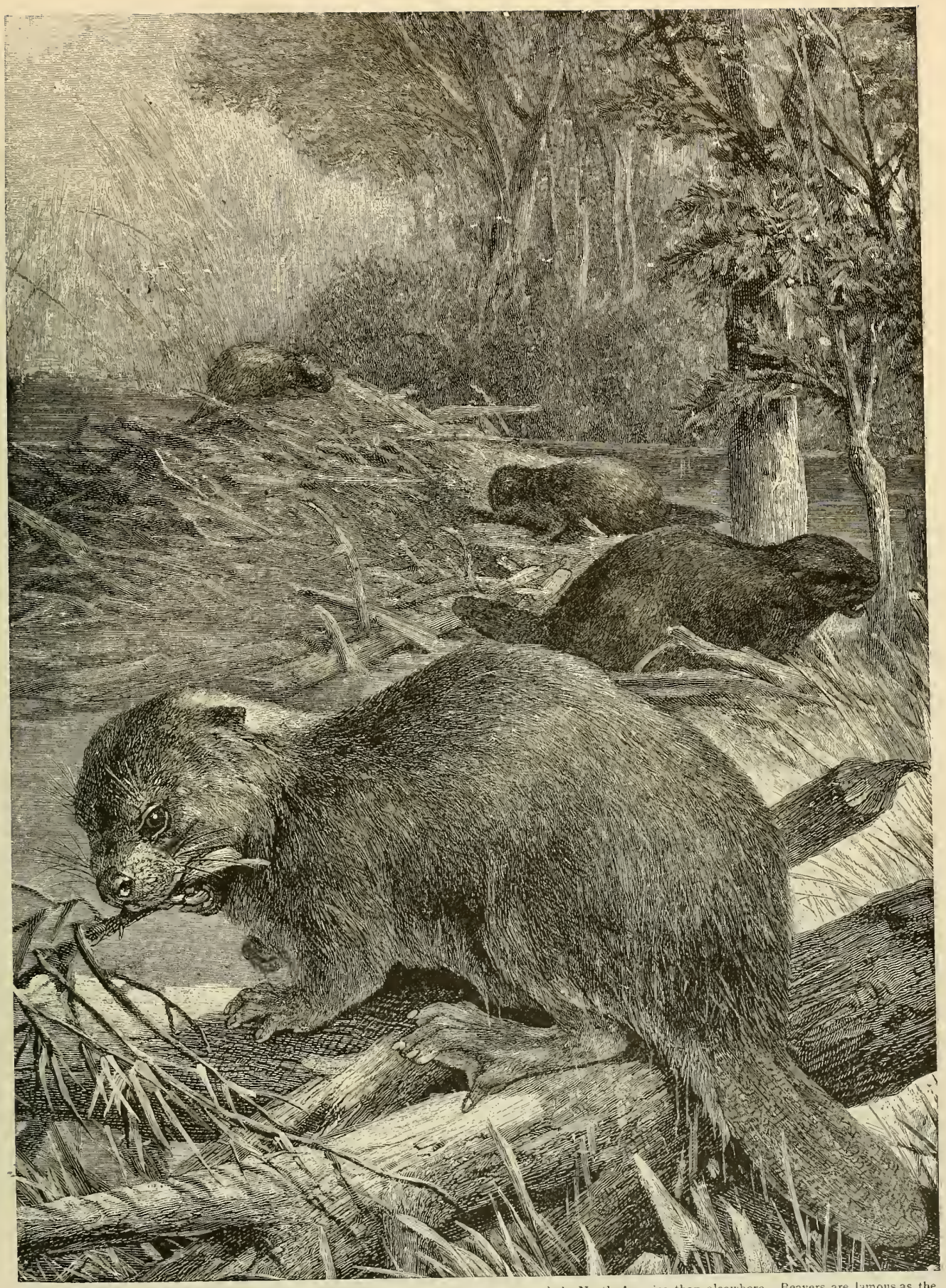

THE BEAYE. - This Rodent is found in three Continents, but more numerously in North America than elsewhere. Beavers are lamous as the most skillful architects amongst the mammals below Mlan, not only because of their well constructed "lodges." but especially because they build with great engineering skill, strong dams in order to secure for themselves a sufficient depthor water (Castor fibcr.) 
trace of their teeth. They soon get used to bread and ship biscuit, apples and carrots, and ultimately become very partial to fruit.

The attitudes assumed by Beavers vary, but on the whole not very much. IWhile sitting, the animal looks like a large, clumsy Mouse. When walking, one leg is moved after another, for the abdomen, which nearly touches the ground, does not admit of rapid, uniform movement. When in a very great hurry the Beaver executes leaps, which in point of clumsiness and awkwardness exceed those of all terrestrial mammals with which 1 am acquainted. These jumps comprise an alternating throwing up of the fore and hind quarters, but in spite of all this they are well directed to accomplish their purpose. In swimming, the Beaver dips its hind quarters so deeply into the water that only the nostrils, eyes, ears and middle of the back remain above the water, the root of the tail being submerged. It proceeds by simultancous, rarely by alternate, strokes of the hind paws; the tail acts as rudder and often moves in vigorous jerks, but the fore-paws take no part in the swimming. The animal can stay submerged for about two minutes, before the want of breath compels it to rise to the surface.

Voice and

Senses of the

The voice of the Beaver is a weak

Beavers.

sound which might most appropriately be styled a moan. This sound is made whenever the animal is excited. And an observer soon learns to understand the different meanings of the various sounds made by these animals. Of their senses, hearing and smell seem to rank first; the small eyes look rather dull, yet the sight is as keen as the taste; neither can some acuteness of sensibility be denied in the animal. As to the degree of reasoning power of a Beaver there may reasonably be different opinions; it must be acknowledged, however, that it ranks high among Rodents. It submits more easily to altered circumstances than other Rodents and learns how best to profit by them; and more than any of the other Gnawing Animals it reflects before acting, deliberates and draws conclusions. Its constructions are not more ingenious than those of other Rodents, but they are always built in conformity with the locality, and any damages to them are always repaired with a careful consideration of the surroundings.

How the Beaver The behavior of captive Beavers is

Acts in Cap- sullen towards other animals and at tivity. least reserved towards human beings. Those which are well treated finally allow themselves to be caressed, and they may go up to their keeper and offer a formal greeting, but they resist any violence. Beavers living in zoological gardens soon find out that women and children are gifted with gentle hearts, and tlierefore they not only appear earlier than is their custom in front of their house, but also, standing up before passing women and children, beg for apples, nuts, sugar and bread. They dexterously take such gifts with their hands and begin to eat; but people who make pretense to give and do not do so, or who tease them, they strike on the fingers.

Beavers caught young may become very tame. Those authors who deal with the American species tell of Beavers which they found in Indian villages, installed, so to speak, as domestic animals, or which they kept themselves. La Hontan says: "I saw nothing more remarkable in these villages than Beavers, as tame as Dogs, in the river as well as running about unmolested in the hedges." Hearne had tamed several Beavers to such an extent that they responded to his call, ran after him like Dogs and received his caresses with joy. They seemed to feel quite comfortable in the society of the Indian women and children; they grew restless in their absence and showed much pleasure on their return.

A litter of Beavers consists of from two to three fur clad, but blind, young, which are born in a dry "lodge." Eight days later they open their eyes and then, or sometimes not until the tenth day, the mother takes her offspring along with her into the water.

Breeding Beavers Except Prince Schwarzenberg, who as an Occupa- exhibited a couple of Beavers at the tion. World's Exposition at Vienna, nobody is nowadays engaged in the breeding of Beavers though it is both an attractive and renunerative occupation; neither is it attended by any special difficulties. A couple of Beavers which had settled in Rothenhof in 1773 had increased to fourteen six years later and to twenty-five after a lapse of ten years; then the breeding was restricted, as the Beavers were allowed free range and they caused too great devastations. In Nymphenburg, in Bavaria, where Beavers were also kept, it was found that some of these animals endured captivity for fifty years.

Methods of The Beaver in the free state has few Catching and Kill- enemies other than Man. Its wari-

ing Beavers. ness frequently baffles even a skillful sportsman. After it has once been alarmed the slightest danger will drive the Beaver into the water, which protects it with tolerable safety. The North American trappers assert that in regions where it is plentiful, it puts out sentinels which are said to apprise their companions of an approaching danger by loudly slapping the surface of the water with their tail. This account may be taken to mean that in a community of cautious animals, like the Beavers, a number is more likely to notice a foe than a single one, and every member of the community becomes a sentinel in this way. As the clapping noise is produced only when a Beaver suddenly dives into the water, and the latter, as a rule, happens when the animal believes itself menaced, of course the otners notice the loud noise and disappear from the surface whenever they hear it. In America, the Beaver is hunted with guns, but is also caught in traps of various kinds. In winter holes are cut in the ice and the Beavers which come to them to breathe are killed; or sometimes the ice is removed from part of the river, a strong net is spread over it, the "lodges" are broken into and the frightened animals are driven into the net.

Usefulness and The usefulness of a Beaver nearly Value of the compensates for the damage it works. Beaver. One must keep in mind that it principally inhabits deserted localities and preferably fells young shoots of trees, which soon grow again. On the other hand the skin and flesh, and still more the castoreum, very amply repay not only the destruction wrought, but also all pains and trouble taken in hunting it. About 150,000 pelts, valued at nearly three-quarters of a million dollars, are taken annually. According to its grade a pelt commands a price of from four to thirteen dollars.

The American Indian tribes hold the Beaver in high estecm. They believe it to be nearly as intelligent as a human being and they affirm that this cxcellent animal is undoubtedly possessed of an immortal soul. 


\section{Tbe Ferboas.}

\section{FOURTH FAMILY: DIPODIDE}

The Jerboas vividly remind us of the Kangaroos in shape and show a disproportionateness of structure similar to that of the latter animals. The hind part of the body is exceptionally strong, and the

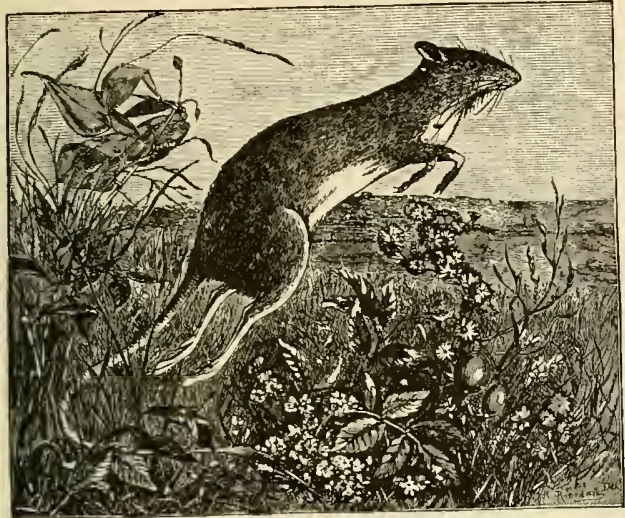

JUMPING MOUSE. - This North American Rodent is famous for its bility to make flying leaps of from eight to ten feet at a bound, although its size is only about that of the Common Mouse. The picture gives a good idea of its jumping ability. (Jaculus hudsonius.)

hind legs are about three times the size of the forelegs; the tail is of proportionate length, but its extremity usually shows a tuft, the hair of which is arranged in a double row. On the other hand, the head of the Dipodidæ differs materially from that of the Kangaroos. It is very thick and adorned with mustaches, which, proportionately to the size of the animal, are the as longest among all mam- and mals, for they are often as long as the body. The eyes are large but have an expression that is vivid and prepossessing to an extent equaled by few other nocturnal animals. The ears are erect and spoon-shaped, and of varying length in different species. In some the ears equal the head in length, in others they are only a third as long, but they are all sufficiently large to show that hearing is a welldeveloped sense with these animals. The neck is thick and immobile, the trunk slender, and the fur is close, soft and of a sandy hue. $\begin{array}{cl}\begin{array}{c}\text { General } \\ \text { Traits of the } \\ \text { Jerboas. }\end{array} & \text { Africa Jerboas principally inhabit } \\ \text { ever, reach over into southern Eu- }\end{array}$ rope, and one species or sub-family is indigenous to North America. They all inhabit dry, open fields, grassy plains or arıd deserts of sand. On clayey or sandy soil, in low-lying situations; sometimes, but rarely, on hills, or amid dense bushes bordering on meadows or near fields, they take up their abode, excavating subterranean burrows which they furnish with plenty of tunnels and with many ramifications, but which are usually very shallow and have numerous exits. By day they stay hidden in their burrows, and after sunset they sally forth and spend the night in a lively manner. Their food consists of roots, bulbs, various kinds of grains and seeds, fruit, leaves, grass and herbs. Some also feed on insects or even on small birds and the decaying flesh of carcasses, and occasionally they kill and devour each other. They take their food in a semi-erect position, supported by their hind quarters and tail, lifting the food to their mouths with their fore-paws. peculiar Move. Their movements are of a peculiar ments of the character. Their usual gait differs Jerboas. from that of the Kangaroo in that they put one foot in front of the other in quick succession, but in a hurried course they proceed by leaps, their vigorous hind feet propelling them high into the air, and the distichous tail regulating the direction and preserving the balance of the body. The fore-legs are either held against the chin or crossed in front of the chest, as a human being when running might place his hands, and at such times these animals produce the impression of possessing only two legs. The larger species may execute immense leaps, and it may be said of all of them that they clear a space amounting to twenty times the length of their body at a bound. One leap rapidly succeeds another, and when one of these animals is in full flight all that can be seen of it is a yellow object shooting through the air in short curves, like an arrow. The dexterity with which they dig in the ground is equally noteworthy, in spite of the weakness of their fore-paws, with

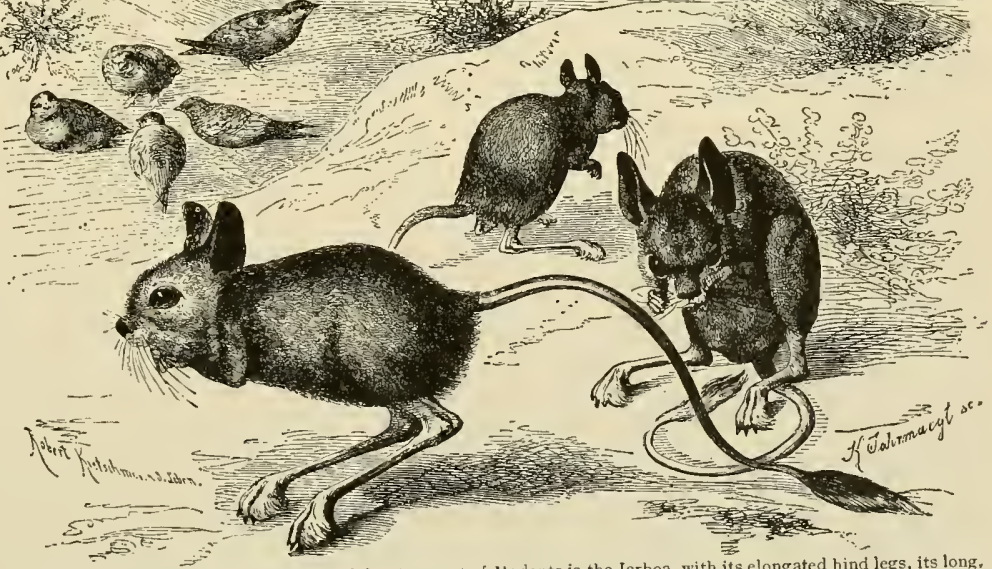

EGYPTIAN JERBOA.- - One of the strangest of Kodents is the Jerboa, with its elongated hind legs, its long, ufted tail and its large ears. The Egyptian species inhabits the deserts of northern Africa and Arabi Desert Larks. has pictured these animais anud such desert surroundings, with no living neighbors save a bevy of Deert which they do this work. While grazing, they walk on all fours, and in this respect also resemble the Kangaroos, but they then move very slowly and maintain this position but a short time. In sitting they rest on the soles of their hind feet and present a somewhat grotesque appearance. 
Senses of the Jerboas are Acute.

All species of this family are endowed with acute senses, their hearing and sight in particular being very good, so that they can easily escape menacing dangers. Being exceedingly shy, timid and fleet, they try to gain their burrows with all possible speed at the slightest alarm, or, if they cannot do this, they seek safety in flight, proceeding with astonishing speed. The largest species, if driven to bay, defends itself with its hind legs, Kangaroo-fashion, while the smaller ones never resort to their natural arms when seized upon. Their voice eonsists of a kind of whine, resembling the cries of young kittens, though some utter a hollow grunting noise; but they seldom make any sound. When the temperature is low: they enter into the hibernating state, or at least beeome torpid for a little while, but they do not lay up a store of provisions, like other Rodents.

Captive Jerboas make exceedingly agreeable and pretty companions; their good-nature and gentle and cheerful disposition render them general favorites.

Nearly all kinds are entirely harmless. The open desert offers them so much provender that they do not make inroads on the property of Man.

\section{THE JUMPING MOUSE.}

The Jumping Mouse of North America (Jaculus hudsomius) represents a distinct species and sub-family. Its strueture shows an affinity to its Old World relatives, but its shape and the fur of the tail also remind one of a Mouse. Its dimensions are about the same as those of the Wood Mouse; its body is about three inches long, its tail about five inches. The fur is smooth and close, and the color of the upper surface is a dark leather-brown, with an admixture of brownish yellow.

The Jumping Mouse is indigenous to the higher latitudes of America. It is found throughout the fur-producing region from Missouri to Labrador. and from the Atlantic to the Pacific. It lives on the borders of meadows thickly grown with bushes and in the proximity of forests, and remains hidden by day but roams about with a large band of others of its kind by night. Its burrows are about twenty inches deep, and still deeper in the cold season. Before the advent of winter it construets a hollow ball of clay, rolls itself up in it, eurls its tail around its body and lies in perfect lethargy till the beginning of spring. A gardener, working out doors in March, is said to have found a lump the size of a child's bouncing ball which astonished him because of its regular shape. When he had split it in two pieces with his spade, he found a small animal curled up in it, nearly like a Chick in an egg. It was a Jumping Mouse which had taken winter quarters in this well enclosed retreat. In summer it is exceedingly nimble and jumps about on its hind legs with extraordinary quickness and agility. It is said to be quite impossible to catch a Jumping Mouse in a forest. It easily clears bushes which a Man cannot readily jump over, and is never at a loss to find a secure hiding place. Audubon doubts whether there is another mammal which can match it in agility. According to many accounts this pretty little animal can be kept in captivity without any difficulty:

\section{THE TRUE JERBOAS.}

The True Jerboas (Dipodince) we regard as types of the whole family, showing all the peculiarities in the most perfect development. Hasselquist aptly remarks that they look as if they were made up from several different animals. "One might say that the little animal had the head of a Hare, the whiskers of a Squirrel, the snout of a Pig, the body. and the fore-paws of a Mouse, the hind feet of a bird, and the tail of a Lion." The head is the most prominent feature: one glance at it shows the Jerboa to be a true inhabitant of the desert. There is ample room for all organs of sense. The ears are large and membranous, and are but scantily covered with hair. The eyes are large and their expression is mild and full of life, like those of some other nocturnal animals of the desert; the nostrils are wide, and whiskers of prodigious length surround the head on both sides, duly representing the sense of touch. The neck is exceedingly short and but slightly mobile. The tail is very long, being either a little or much longer than the body. The portion near the base is round, but the extremity, in most speeies, is adorned with a tuft, which is parted in such a way as to resemble an arrow. The fore feet are of small size, and in leaping they are folded against the body and partly hidden in the fur, in a way which justifies the animal's old appellation of " twofooted." The fore-paws have only four toes, armed with moderately long, curved and sharp claws and a rudimentary thumb, which in some species has a nail, and in others none. The hind legs are in some speeies six times longer than the fore-legs, gaining these proportions not only because of the elongation of the leg bones, but also from that of the instep or metatarsus. The fur is soft and of silky texture, and on the back the hairs are bluish gray at the base, then sand-colored, and have tips of black or dark brown; the under surface is always white, diversified with longitudinal side strealis. 11 is a remarkable fact that in many swift running animals, and anong them the Jerboas, the structure of the feet is of the plainest type and they are but slightly mobile. The junping feet have three, four or five exeecdingly short toes, composed, as a rule, of only two joints. The toes are incapable of lateral motion and can only slightly bend downward, simultaneously. In running only the extreme tip of the nail-joint touches the ground, and that is specially protected by a feathered mass of cartilage.

The Egyptian I select the Egyptian Jerboa (Dipus Jerboa, the Typ- agypticus) as the representative of ical Species. this species. It is an exceedingly pretty little aninal, with a body measuring nearly six inches, while its tail, without the tuft, is nearly eight and one-half inches long. The Jerboas, and probably this very Egyptian species, were well known to the ancients. We frequently find them mentioned by Greek and Roman authors, always under the appellation of "Two-Footed Mice," this being the origin of the present scientific designation of the species.

The Jerboa is distributed over the greater part of northeastern Africa, as well as the adjoining part of western Asia. Open, dry plains, steppes and sandy deserts are its habitation. It populates the most arid, deserted regions and lives in localities which barely seem to afford the possibility of an existence. On those dreary plains, covered with hard grass, one occasionally finds it in large communities. It shares those spots with the Desert Hen and the little Desert Lark, and other birds, and it is difficult to understand low it can find sustenance in competition with the others, which make but a scanty liv- 
ing, although they feed on insects as well as seeds. In the hard, pebbly ground the Jerboa digs tunnels with many branches, but tolcrably shallow, and retires to them on the slightest alarm.

Habits of the In spite of their large numbers these Egyptian pretty animals are rarely seen, for Jerboa. they are restless and timid and at the slightest noise or at the appearance of a strange object they repair to their holes in a great hurry. The movements of these Jerboas succecd each other with a speed bordering on the miraculous; they apparently become birds. No Man can overtake a Jerboa engaged in full flight. Though the Jerboa is a truly nocturnal animal, and begins its wanderings only after sunset, it may sometimes be seen in broad sunlight, sitting at or playing about the entrance of its burrow during the noonday heat. It exhibits an indifference towards the glowing heat of the African sun, which is really admirable; for hardly another animal stirs in the desert at this time, as the burning heat becomes simply unbearable even to the native children of that elevated region. On the other hand the Jerboa is highly sensitive to cold and moisture, and therefore alway's keeps in hiding in its hole when the weather is bad, and it may temporarily enter into a state of torpidity, which resembles the hibernation of northern animals.

There is nothing definite known about the propagation of the Jerboa. The Arabs hunt it diligently, for its flesh is much esteemed by them; they catch it alive without any special trouble, or kill it as it comes out of its burrow.

These animals have few enemies berides Man. The Fennec and the Caracal, and perhaps some few species of Owls are the worst among the foes that

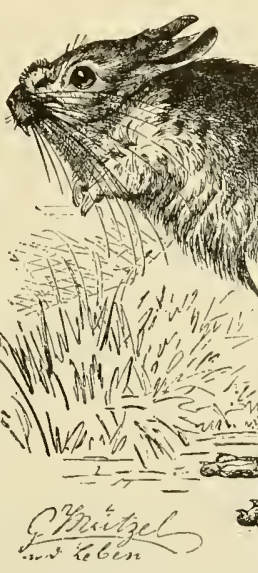

THE ALACTAGA. - This inhabitant of the steppes of Asia and southeastern Europe resembles the Jer boas in many respects, but the stronger thigh bones enable it to run on its two hind legs at a pace even more rapid than that of the Jerboas. (Scirtetes jackus.) fer visibly, and ultimately die. If one gives them wheat, rice, a little milk, and occasionally a grape, a fecl and keep well a long time, and their interesting duings amply repay the slight attentions they need.

\section{THE ALACTAGAS.} from the true Jerboas in the structure of the skull, the teeth and especially the hind-legs. A long and strong metatarsal bone is there, but on both its sides are smaller ones, which support rudimentary toes. This arrangement renders the hind foot five-toed in and each of the lateral bones to one toe.

By the excellent descriptions of Pallas, Brandt and others, the Alactaga of the Mongolians (Scirtetes juculus) is the species that is best known to us. This animal is of about the same dimensions as a Squirrel; its body is about seven inches long, its tail ten and one-half inclies, and its ears are as long as its head. The prominent eyes have circular pupils. piece of an apple, a carrot or some other fruit, they

The sub-family of the Alactagas (Scirtetes) differ reality, for the large bone is connected to three toes lurk for the Jerboas, but the Egyptian Cobra di Capello is probably more dangerous to then. This reptile lives in the same localities inhabited by the Jerboas, easily penetrates into the tunnels which the latter construct, and kills a great number of them.

How Jerboas Europeans versed in zoological matAct in Cap- ters and living in Egypt and Algeria, tivity. often keep Jerboas. I can assert from my own experience that the animal affords great pleasure when kept in a cage or room. During my sojourn in Africa I was often given from ten to twelve Jerboas at a timc. I was wont to give a whole chamber up to these animals, so as to be able to observe their actions. The captive animals would show themselves to be harmless and friendly from the very first. They suffered themselves to be touched, and did not try to evade any person who came near them. When walking in their room care was necessary to avoid stepping on them, for they calmly remained sitting when one approached them. Toward each other the Jerboas preserve an admirably peaceful and sociable temper in captivity. They are accustomed to scanty and dry food, and if entirely denied dry food they lose their spirits, suf-
The hind legs are nearly four times as long as the fore-legs.

Range and Though the Alactaga is found also Habits of the in southeastern Europe, especially Alactaga. in the steppes of the Don and in the Crimea, Asia is its real home. It does not range farther north than fifty-second parallel of north latitude, and in the other direction it is found as far to the southeast as eastern Mongolia.

As the Jerboa inhabits the African deserts, so does the Alactaga exist in the steppes of southern Europe and Asia. It lives gregariously like its kind, but not in great communities. By' day it rests hidden in its artfully constructed burrow, at nightfall it sallies forth, but repeatedly returns to its hole during the hours of darkness. Its movements resemble those of the other members of its family which we have already described. When it is unmolested and engaged in its quest for food, it runs on all fours after the manner of a feeding Kangaroo; but when alarmed or pursued it makes its escape by long bounds, using the hind-legs alone. Its leaps are said to exceed those of the Jerboas; and the animal in full flight proceeds with such speed that the swiftest 
Horse, it is claimed, is unable to overtake it. Shy and timid as it is, it retreats at the slightest alarm; and even when quietly feeding, it frequently rises upon its hinder limbs to look around. When pursued, it does not flee in a straight line, but bounds away, making many doubles and turns until it tires out its pursuers or has found some convenient hole in which to hide.

The Alactarga feeds on all kinds of plants and vegetable substances. Bulbs and roots form its principal sustenance, but it does not disdain insects and it may also devour an occasional Desert Lark, or at least its eggs or young. It gnaws the bark from shrubs, but of the juicy steppe plants it eats only the tenderest shoots. At the approach of severe frost the Alactaga goes into winter quarters. Later in the season it closes the entrances of its tunnels more carefully than before, and together with others of its kind it curls up into a ball, in the softly lined chamber, and begins its winter sleep.

Account
of a Captive deal of pursuit, as the inliabitants of
Alactaga.
The nomads of those regions very rarely keep an Alactaga in captivity, though it endures confinement quite well. It has several times been kept in Europe, not for pleasure only, but for use as well. Strangely enough, we are indebted for the best description of the animal not to a naturalist, but to the antiquary Haym. In order to interpret a gold coin of Cyrene, which on one side presented a Man on horseback and on the other the well-known plant Silphium and under it an Alactaga, Hayn procured one of the little animals, kept it over a year, during which time he carefully observed it and then made public the result of his observations.

For the first three or four months it ate nothing but almonds, pistachios and rough ground corn, abstaining entirely from water; later it fed on apples, carrots and plants, selecting only those having but little odor, such as spinach, lettuce, nettles, etc., and it acquired a taste for an occasional drink of water. It was partial to bread, sugar and similar food, but obstinately refused cheese and all other diet made from or containing milk. Ultimately it preferred hemp seed to anything else. It was free from the disagreeable odor which so often emanates from similar animals, such as Mice, Squirrels and Rabbits. It had so gentle a disposition that one could safely handle it; it never attacked any. one. Timorous as a Hare, it was afraid of even smaller, harmless animals. It suffered much from cold during the winter and it was necessary to keep it near the fire during that season.

\section{THE JUMPING HARE.}

The Jumping Hare (Pidetes caffor), which is regarded as representing a distinct sub-family, materially differs from the other Dipodide in its dentition, and also to a less degree in other characteristics. The body is elongated, gradually growing stouter towards its hinder quarters. The neck is fairly. thick, but distinct from the body and much more mobile than the necks of its relatives. The forelegs are very short, but much stronger than those of the true Jerboas, and the toes of the fore-feet, five in number, are armed with strong, long and sharply curved claws. The hinder limbs are long, vigorous and formed for jumping. The hind feet have four toes attached to distinct metatarsal bones, and provided with strong, broad nails, which are rather short and nearly hoof-like. The middle toe surpasses the others in length; the short outer toe is situated so high upon the foot that it hardly reaches the ground. The tail is very long, strong and bushy; it is slender at its base, but appears larger towards the end by reason of the thickness of the encompassing fur, and it terminates in a blunt-pointed tuft of hair. The fur is long, thickset, copious and soft, its coloring resembling that of the Common Hare, the upper surface being of a dull, rusty, brownish-yellow hue, with an admixture of black, many of the hairs having black tips. The under surface is white. The proportions of the body of the animal are about the same as those of the Hare, it measuring about twenty-four inches from the tip of the nose to the root of the tail; the tail is slightly longer than the body.

Range and Habits The Jumping Hare inhabits sterile

of Jumping regions and even desert-like plains.

Hares. It is distributed over a great part of southern Africa, being found in the western portions of that district as far north as Angola. and in the eastern portions its range extends as far as the Gcrman pussessions of eastern Africa. In Cape Colony it is quite frequently cncountered, occurring in mountainous localities as well as open plains, and sometimes congregating in such numbers as to form considerable settlements. After the manner of the other species of the family it digs long, subterranean tunnels near the surface of the earth leading, after frequent ramifications, to a deeper chamber. Usually several couples or entire families inhabit one burrow:

The Jumping Hare carries its food to its mouth with the fore-paws, after the manner of the true Jerboas. In propurtion to the sloth of its movenients when it proceeds on all fours, is the rapidity of its course when its mode of progression is a series of long and powerful jumps. It springs into the air by means of its long hind legs and alights without falling forward. During flight the forc-legs are folded against the chest. The usual length of its leaps is from two to three yards, but when it is pursued it increases its exertions to such an extent that the average distance covered is from six to ten yards.

In the rainy season it retreats to its burrow and the entire colony remains there curled up and closely huddled together. The Jumping Hare endures captivity well and will live for a long time if it receives proper treatment. It soon becomes tame and famil. iar with its keeper. Its cleanly habits make it a favorite and the procuring of its proper diet is a matter of no difficulty: wheat, bread, lettuce and cabbage are entirely sufficient for its sustenance.

The Dutch settlers of south Africa are very fond of hunting this animal; for its flesh is esteemed for the table and its fur is used in the manufacture of various articles of wearing apparel.

\section{Tbc silice.}

\section{FIFTH FAMILY: MURIDE.}

No other family of the order affords us so advantageous and complete an opportunity to becone thoroughly aequainted with the Rodents as does that which comprises the Mice. This family is not only the richest in species and varieties but also by far the most widely distributed, and, owing to its association with Man, it is constantly gaining a more 
uxtensive range, at least so far as concerns some of its species. The individuals of the family are commonly small, but what they lack in size they nore than compensate in numbers. To outline a general clescription of the whole family it may be said that their distinguishing characteristics arc: a pointed muzzle; large black eyes; wide, deeply concave ears with a scanty covering of hair; a long tail sometimes cuvered with hair or quite as often bare and showing scales; slender legs, terminating in graceful, narrow, five-toed paws; and a short soft fur. Many Mice, however, in the exhibition of some characteristic, show an affinity to other families of the order: thus a bristly, outer fur may recall the l'orcupine; genuine swimming feet, short ears and feet may remind us of the Beavers; a bushy tail of the Squirrels, etc. The structure of the teeth in these aberrant species corresponds more or less with the variations of the typical shape. with but scanty supply of grass and shrubs, furnish then subsistence. Some shun the proximity of human settlements, others intrude upon and follow Man wherever he goes to make his home, even though it be across the ocean. They infest house and yard, barn and stable, garden and field, meadow and forest, carrying devastation everywhere with their destructive teeth. But a small portion of the fanily live singly or in couples, the majority being of gregarious habits, and some species occasionally increase to immense numbers. Nearly all are exceedingly fecund, the number of young in a singic litter ranging between six and twenty-one; the majority have several litters a year, breeding even in winter.

Principal Mice are an especial annoyance to

Traits of the Man, their characteristics appearing Mice. to fit them in an unusual degree for the infliction of damage upon his possessions. Quick

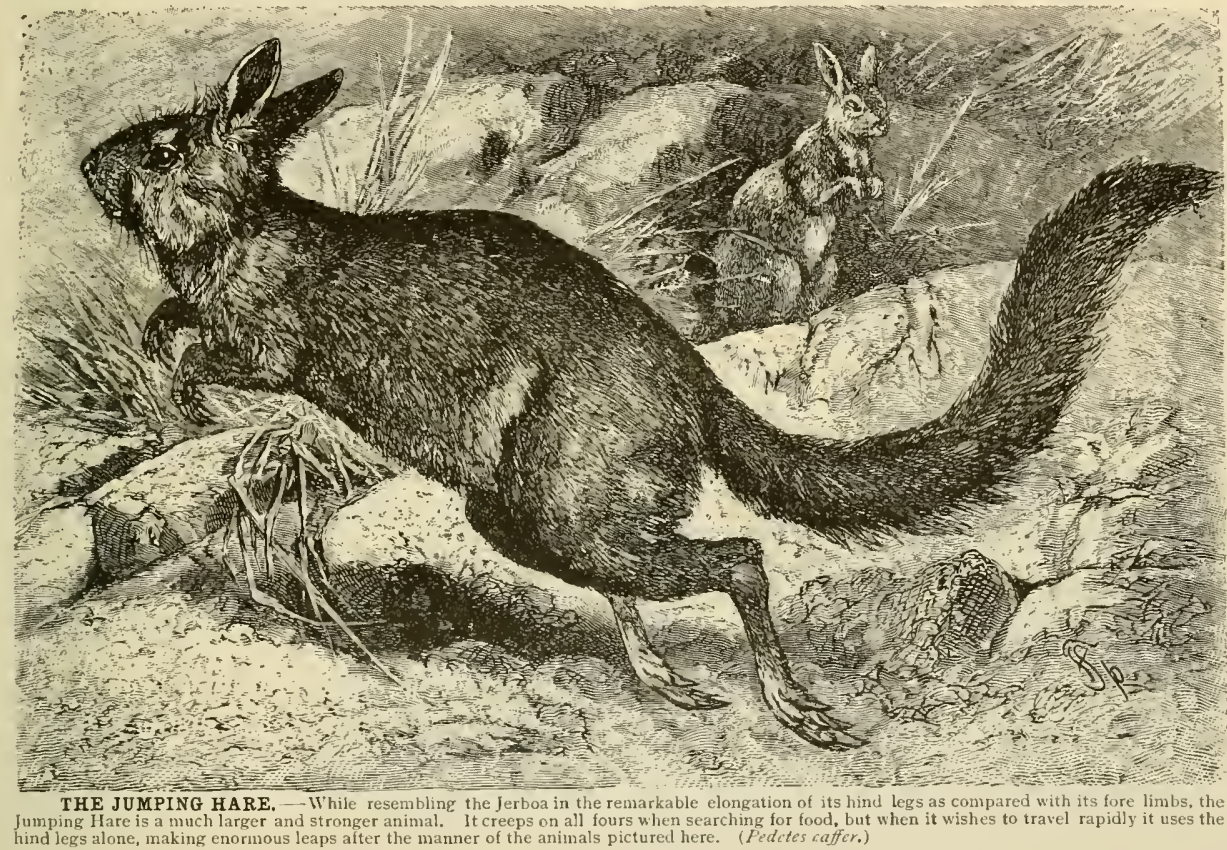

Mice now Distrib- Mice are cosmopolitan, but unfortuuted in all Coun. nately not in a good sense. All contries. tinents are inhabited by members of the family and those happy islands (if such there be) which so far have been spared their visitation, will in course of time be populated by one or other of the numerous species. Mice, by reason of their migratory propensities, have secured foothold in all countries and climes, and though they prefer the balmy breezes of the plains of temperate or warm countries to the rigorous climate of high mountains or the cold of the far north, still they may be found in altitudes marking the boundary line between vegetation and the perpetual snow of the mountains. IVell cultivated localities, fruit fields and gardens undoubtedly are their favorite haunts, but swampy regions, banks of rivers and small streams also afford them food and shelter, and even arid, dry plains, of movement, they are excellent runners, jumpers, climbers and swimmers; they know how to insinuate themselves into the smallest apertures or, if they find no ready made avenue of admission, they open a way by means of their sharp teeth. They are usually moderately sagacious and prudent, but sometimes bold, impudent and cunning; all their senses are well developed, though those of smell and hearing are far superior to the others. Their food consists of all eatable substances of the vegetable and animal world. Seeds, fruits, roots, barks, herbs, grasses and buds, all contribute to their sustenance, and are devoured by them with no less avidity than are insects, meat, tallow, blood and milk, butter and cheese, skin and bones; and whatever substances they cannot eat, they at least gnaw and perforate with their teeth, such as paper and wood. Water they seldom drink; on the other 
hand, they are extremely fond of liquids of a more substantial character and often exercise great ingenuity in obtaining access to them. They destroy much more than they eat, and hence are among the most detested plagues of mankind. I few of them are harmless, innocent animals, and have found favor in our sight by reason of their graceful movements, symmetrical shape and prepossessing habits. These exceptions are principally found among the architects of the family. They construct the most ingenjous nests of any of the inferior mammals and do not annoy Man much, as their numbers are few and they commit little depredation when seeking food. Some species that inhabit cold and temperate countries, hibernate and store away winter provisions; others temporarily migrate in immense numbers, their wanderings usually-leading them to their death.

Few species are eapable of domestication. ()nly a very small number are tractable, or responsive to kindness. The others, even after long eaptivity and continued efforts for their reclamation, remain but treacherous creatures, addicted to biting and badly repaying the friendship and care bestowed upon them. Iice are never really useful; for even though the skin of a few species may be employed for various purposes or the flesh of other species eaten, the benefit derived from both of these uses is not worthy of consideration in comparison with the extreme harmfulness of the entire family:

\section{RUNNING MICE.}

The Running Mice (Mvionidina) are separated from the rest as a distinct sub-family.

They are confined in habitat to Africa, southern Asia and southeastern Europe. They preferably inhabit cultivated districts, but are also found in the most arid plains and steppes, often in extraordinary numbers. The majority dig rather shallow, underground burrows in which they spend the day. Their movements are exceedingly quick and some are said to be able to make jumps of considerable length.

On account of the devastations which the Merionidina cause in the fields, they are detested and pursued to extermination by the inhabitants of those countries which they infest, as are Rats with us.

The Sand Rat, The Sand Rat (Psammomy's obosus)

Common in attains about the same size as the

Egypt. Common Brown Rat, but its tail is much shorter, measuring only five inches, the total length of the animal being nearly thirteen inches. The upper parts are of a ruddy sand color, sprinkled with black; the flanks and under surface are light vellow:

In ligypt this Mouse is seen in the sandy parts of the desert, being particularly frequent on the mounds of rubbish which surround all the cities of the land of the Pharaohs. It burrows out rather deep, branching tunnels and passages, preferably. under and between the low shrubs and the few creeping plants, which afford its habitation a scanty covering and at the same time give it its daily food. As it is not nocturnal in its habits and often emerges from its burrow during the daytime, one can easily observe it. lirequently ten to fifteen are seen frisking about, playing with one another or nibbling at a plant. The Sand Rat is one of the prettiest of the Rodents. It can easily be domesticated and becomes very tame, leaves its cagc, runs fearlessiy about in the presence of Man, and suffers itself to be handled without exhibiting any vicious propensities. Its large and not very prominent eyes and its beautiful fur contribute much to the asrecable impression it produces on the spectator; even its tail, with its close fur and black tuft at the tip, is quite oruamental.

\section{THE MICE PROPER.}

The real types of the family, the Mice proper (Murine), are only too well and too widely known in respect to their habits and their activity. To them belong those species which have spread all over the globe in the wake of Man and are at present established on even the most remote islands. This migration of the animals over the world took place not so very long ago; in many localities the year in which they first made their appearance is yet within menory of living Men; but nowadays they have completed their tour around the world. Nowhere is Man grateful to them for the unalterable attachment they exhibit towards his person and his home; everywhere he detests and pursues them without merey and resorts to all kinds of devices to rid himself of them: and still their predilection remains unchanged, and they cling to him more persistently than a Dog or any other animal. Unfortunately these tenacious domestic friends are detestable thieves which know how to insinuate themselves anywhere with the help of their rascally tools, and cause their host nothing but damage and loss. This is the reason why all true Mice are stignatized as ugly, nasty animals, though in reality they are by no means such, but it must, on the contrary, be confessed that they are good-iooking, graceful and pretty creatures.

The Distinctive Even in common parlance we distinFeatures of Rats guish two main groups, the Rats and and Mice. the Mice, and science adopts this distinction. The Rats are the elumsier and uglier forms, the Mice the lighter and daintier ones. The tail of the former shows between two hundred and two hundred and sixty scaly rings, the tail of the latter only between one hundred and twenty and one hundred and eighty, the fect of the first are thick and stout, those of the second slender and delicate, and the full-grown Rats are considerably larger than their more prepossessing relatives.

Original Whe may assume with tolerable safety.

Home of the that the Rats which at present are Rats.

settled in Europe, were not originally indigenous to the continent, but immigrated. In the works of the ancients there is only one place in which it is probable that the animals mentioned were identical with our Rats; and in this one instance it is not elear which species were meant by Amyntas, whose accounts are quoted by Elian. It has been proven that the Black Rat appeared first in Germany and other parts of Europe; it was followed by the Brown Rat and then quite recently by the Egyptian Rat (Mus alcrandrimus). The Brown Rat, however, being the strongest of all, drove out and almost exterminated the other species and has obtained supremacy nearly everywhere. Let us hope that we may not have to deal with other members of the family, which are given to migration, and in particular that we will be spared the immigration of the Hamster Rat (. M/us or Cricetomy's gambiamus), which by far surpasses our Rats not only in size but also in respect to its activity, and at present worries the merchants of Zanzibar more than all European Rats together. If that animal should elect to visit us, then truly would we know what mischief a Rat can accomplish! 
It is sufficient for the present to describe the two best known species, the Black and the Brown Rat.

The Black Rat The Black Rat (. M/ts rattus) attains a

its Origin and length of body of six and one-half

Peculiarities. inclies, and a length of tail of seven and one-half inches, or a total length of fourtecn

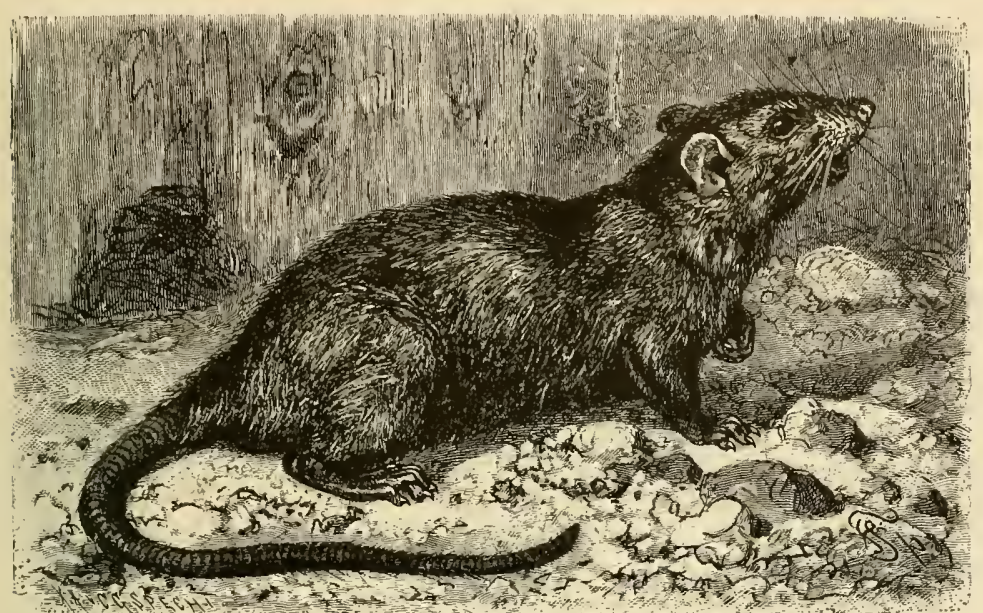

THE BLACK RAT. - This was formerly the most common of the Rats in Europe and until the invasion of the Brown Rat the most formidable. It is still found, not only in Europe, but also in Asia, America and nearly all parts of the world. Its vicious head, coarse fur and scaly, hairless tail are well depicted here. (AIus rattus.)

inches. Its upper surface is dark brownish black, the lower parts being of a somewhat lighter grayish black hue. The feet are of a grayish brown tint, slightly lighter on the sides. The relatively slender tail shows from two hundred and sixty to two hundred and seventy scaly rings. White individuals are not uncommon.

The time when this species first appeared in Europe cannot be definitely determined. Albertus Magnus is the first naturalist to mention it as a German animal; consequently it was a common animal as early as the thirteenth century. Gesner speaks of it as being "an animal that is better known to many than is agreeable to them;" the bishop of Autun excommunicated it from the church in the beginning of the fifteenth century. Possibly it originally c ame from Persia where it still exists in prodigious numbers.

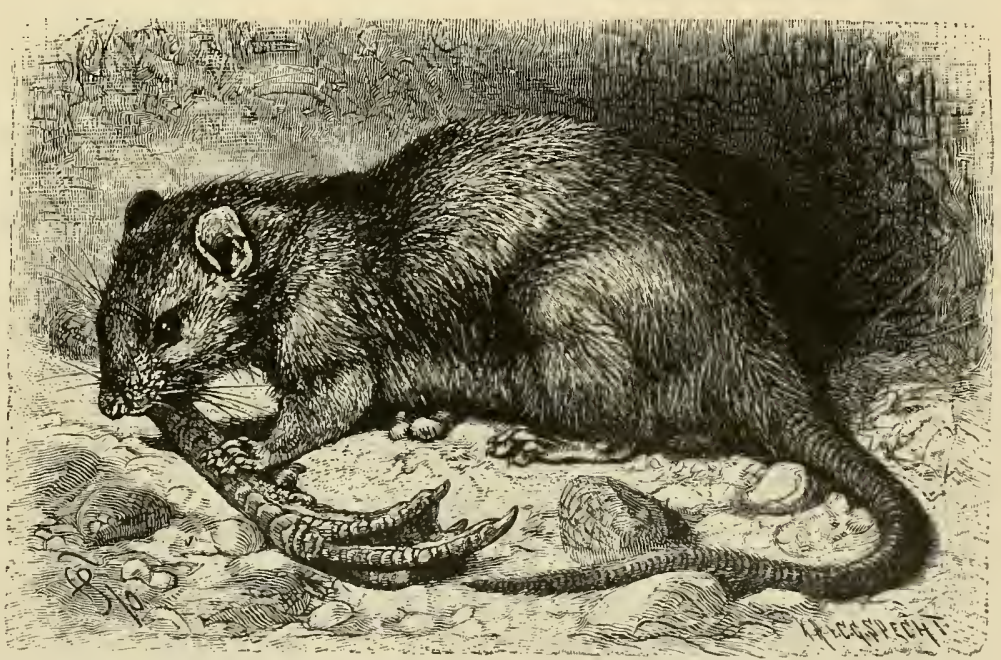

THE BROWN RAT. - The animal shown in the picture is only too familiar. ()riginally a native of India, he has, during the past two centuries overrun all lands, driving out the weaker Black Rat. The animal in the picture has evi is considerably larger, measuring nearly seventeen inches, inclusive of the tail, which is seven inches long. Its color is different on the upper surface from that of the lower parts of the body, the upper parts being a brownish gray; the under parts grayish
Up to the first half of the last century it reigned alone in Europe; since that time the Brown Rat has contested the field and has been so successful that the Black Rat has been obliged to recede. it, such as Bremen and Luneburg in northwestolstadt in Thuringia. It all climes of the globe, wandering through the Undoubtedly it was not Aigenous to America, but ships conveyed it to all coasts and from the coasts it penetrated farAt present it is found in southern parts of in Africa, especially in Egypt, Barbary and the Cape of Good Hope; in tralia and the islands of he Pacific.

The Brown The Brown Rat-its origin, Rat ( Mus etc. decumamis)

It is still distributed sparsely over nearly all parts of compact bodies, existing nearly everywhere it is persed colonies. In Gernany it seems to be nearly persed colonies. In Germany it seems to be ncarly . 
black specimens, white ones with red eyes (true albinos), dull or pied individuals, also occur. The latter are either black and white, or gray and white, and nearly always the head, neck, shoulders and fore-fect, together with a wider or narrower stripe on the back, are black or gray, the rest being white.

The Brown Rat a It is very probable that the Brown

Formidable Rat came to us from some portion Pest. of Asia, namely, India or Persia. Pallas is the first to describe the Brown Rat as an European animal and says that it invaded Europe in immense hordes in the autumn of 1727 after an earthquake, coming from the Caspian country. At that time it crossed the Volga at Astrakhan in enormous numbers and rapidly spread westward. Nearly at the same time, namely in 1732 , it was conveyed to Fingland from East India in ships, and thence it began its tour over the world. In eastern Prussia it appeared in 1750 , in Paris in 1753 , in Germany it was common in 1780 ; in Switzerland it has been known since 1809 , and in Denmark it gained a foothold at about the same time. In I/755 it was carried to North America and there also it multiplied at a wonderfully rapid rate; still it had not spread much farther than Kingston in Upper Canada in 1825 , and more recently still it had not reached the regions about the upper Missouri. It is distributed, however, over all the islands of the Pacific, even the very remotest and most solitary of them. Being larger and stronger than the Black Rat, it invades the localities where the latter formerly lived in peace, and its numbers are on the increase, as those of the latter diminish.

Similar Habits of The two species agree so closely as the Brown and to their mode of life and habits that

Black Rats. the description of one almost exactly fits the other. If it be noted that the Brown Rat settles more in the lower parts of buildings, especially in damp cellars and vaults, in sewers, sluices, cess-pools, drains, and along the banks of rivers, while the Black Rat prefers the upper part of the house, corn-lofts, garrets, etc., little will be left that is not a common attribute of both. Both species of this vermin inhabit all available apartments of a human habitation and all imaginable places holding out a promise of food. They can be found from the cellar to the garret, from the drawing-room to the closet, and in both palace and hovel. Neither fence nor wall, neither door nor lock insures protection from them; where there is no ready-made way they open one; they gnaw and dig passages through the strongest oaken timber or the thickest wall. Only when one sinks foundation walls deep into the ground, closes all crevices between the stones with hard cement and takes the precaution of putting a layer of broken glass between the stones is a building tolerably safe from their intrusion.

Vicious Pro- And yet the destruction of dwellpensities of the ings, the abominable undermining Brown Bat. of and digging through walls, is the smallest of the misdeeds of which the Rats are guilty. The damage they cause by their feeding is much more considerable; anything eatable is acceptable to them. Man eats nothing that Rats will not partake of, and they do not stop short at eating, but go further and share many of his beverages. Were they to become drunk on alcoholic liquors they could be charged with helping to consume all articles of food and drink of which mankind makes use. Not contented with so multifarious a bill of fare, the Rats greedily attack other substances, not sparing living creatures. The foulest offal of the domestic economy is occasionally eaten by Rats, and decomposing carcasses are acceptable to some of them. They eat leather and horn, grain and the bark of trees; no imaginable vegetable substance comes amiss and what they cannot eat they gnaw and destroy. Sometimes they commit serious depredations in plantations of sugar-cane and coffee. There are also authenticated cases on record where they have attacked and attempted to devour small children, and every farmer knows how they prey upon domestic animals. They eat holes into the bodies of very fat Pigs; they eat the webs between the toes of closely penned-in Geese; they drag young Ducklings into the water and drown them. Hagenback, the dealer in animals, had three young African Elephants killed by them, the Rats gnawing through the soles of those powerful animals.

Great Audacity When they abnormally multiply in a of the Rat locality they become very formid-

Family. able, and there are places where they appear in numbers which almost exceed belief. In Paris sixteen thousand Rats were killed in four weeks in a single slaughter-house, and in a place for flaying dead animals near the same city they devoured thirty-five Horses' carcasses to the bones in a single night. As soon as they perceive that Man is helpless against them their audacity increases amazingly. Las Casas tells us that on the 27 th of June, ISI6, Napoleon and his companions on St. Helena were left without breakfast, as the Rats had invaded the kitchen on the preceding night and devoured everything. They existed there in great numbers and were vicious and exceedingly impudent. It usually took them but a few days to gnaw through the walls and planks of the slightly-built houses of the Emperor. During meals they entered the dining-room and at the conclusion of dinner a regular war was waged against them. The Emperor's attendants had to abandon the keeping of poultry, as the Rats would eat the fowls. They even succeeded in stealing the pottlry from the trees on which they perched during the night. In the large depots or repositories of merchandise on the coasts of remote countries they usually make a lodgment coincidently with the removal of goods from the tradingships, and are a grievous nuisance, frequently causing serious damage. All travelers, and especially collectors, complain that many objects, some of them very rare and obtained with great pains, are destroyed by these pests. How effectually they disturb one's sleep at night by their savage conflicts and noisy scamperings over the ground, the walls and the roofs, is well known by every one.

Rats a Source of Sailors, particularly, are badly off in

Annoyance on this respect, for there is no ship

Shipboard. without Rats. On old vessels they cannot be exterminated, and of new ones they take possession when the first cargo is brought on board. On long voyages, especially when they have enough to eat, they increase considerably, and then one can scarcely endure life on board. When Kane's ship was frozen near the 8oth parallel of north latitude on his arctic royage, the Rats increased so prodigiously that they caused grievous damage.

The Rats are experts in all physical exerciscs. They run quiclily, climb excellently, even up tolerably smooth walls, swim in masterly fashion, jump far and with precision, and dig fairly well, though they do not exhibit much endurance in the last accomplishment. The stronger Brown Rat in all 
these regards seems to surpass the Black Rat; at least it is a much better swimmer. It can dive nearly as well as a truly aquatic animal.

Development Among the senses of the Rats, hearSenses of Rats. former is especially excellent, and sight also is highly developed. Their acuteness of taste is but too often exhibited in pantries, where the Rats always select the choicest morsels. As to their intellectual capacities there is little to say. One certainly cannot deny that they are possessed of reasoning power, and, still more, of calculating slyof the Physical ing and sight stand foremost; the

according to the assurances of the servant girl, was always accomplished in the same manner."

Birth and Devel. Rats are exceedingly prolific aniopment of roung. mals. The female gives birth to Rats. from five to twenty-two young Rats, which are charming little creatures, and would please anybody if they did not happen to be Rats. "On the Ist of March, IS52," say's Dehne, "a white Rat in my possession had seven young. She hac built a snug nest of straw in her wire cage. The young were as large as May Bugs and of a bloodred color. At every movement of the mother they uttered a shrill, piping, squeaking sound. On the 8 th their color had already become tolerably white; from the I 3 th to the I6th they ceased to be blind. On the night of the isth they came out for the first time; but when the mother saw that they were observed, she took one after another into her mouth and carried then into the nest. Some of them emerged from another hole, however. Charming little animals they were, of the size of a Harvest Mouse and with tails about three inches long. On the 2 Ist they had already attained the size of Conmon Mice, and on the 28 th that of Wood Mice. They were still occasionally suckled by

THE COTTON RAT. Among the native species of Rats found in this country is the Corton Rat, found in the southern states. Like the Black Rat, its numbers are diminishing as those of the Brown Rat increase. (Sigmodon hispidius.)

ness and a certain craftiness with the help of which they escape from dangers of the most varied kinds. There have been several accounts of the way in which they remove eggs unbroken. Doubts as to their manner of proceedings are no longer justified, since a Man like $K$. von Dalla Torre related the following incident in I880, witnessed by himself: "In the cellar of a house at Innsbruck, eggs, which were kept there, were repeatedly found missing this winter. Suspicion pointed to the servant gir\}, who did all she could to prove her innocence, but in vain. In this plight she bethought herself of watching for the thief and by this means she witnessed the cunning with which the Rats got at the eggs. The eggs lay piled up in a loose heap, and a greedy Rat emerged from a hole, soon followed by another. The first seized an egg with its forepaws, and with the aid of the other Rat, pushed it to one side as far as a few gentle shoves would carry it. Then the first Rat hugged it with its fore-limbs, after the method by which Spiders carry their egg pouches. Of course this Rat could more himself no further, his forelegs being employed in holding the egg. Then the second Rat seized the tail of the first with its mouth ard with apparent ease quickly pulled its companjon toward the hole whence they had issued. The whole proceeding, which, concluding from the number of missing eggs, was the result of considerable practice, lasted barely two minutes; one hour after the thievish couple had first appeared on the scene, they reappeared, undoubtedly with the same intention. By the kindness of the family, in whose house the incident happened, I had the opportunity of being an eye-witness to this mode of theft, which, the mother, played and romped in the most entertaining manner, sitting on their mother's back and letting her carry them about. They were a great deal more amusing to watch than white Mice."

Rats Easily Rats which are closely confined and Domesticated and well cared for become so tame that Tamed. they not only suffer themselves to be touched or used as playthings by children, but become accustomed to come and go in house, yard and garden, follow their keepers about like Dogs, respond to calls, in short, become domestic animals in the true sense of the word.

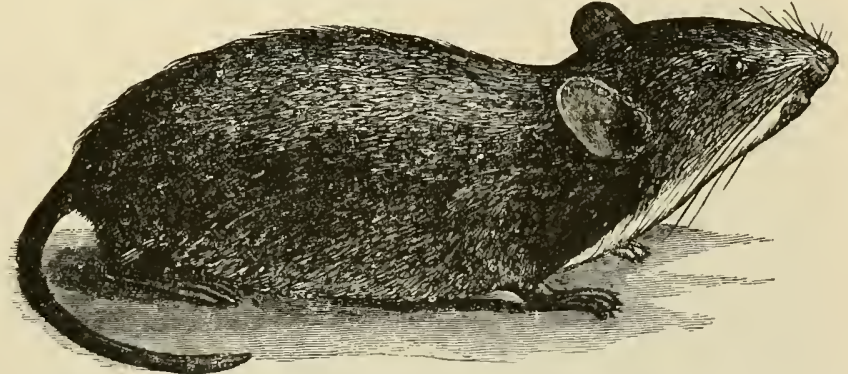

FLORIDA WOOD RAT._-An indigenous species of Rat which, while especially numerous in the south is dis a large Rat, yellowish brown above, white below. (Neofoma floridana.)

Rats Subject to In the natural state Rats are somePeculiar Disease-- times subject to a peculiar disease the "King Rat," which causes the tails of several Rats to grow together and then they form the so-called "King Rat," which was formerly imagined to be something quite different from what it is now known to be. One can occasionally see it in some of the museums. In olden times it was popularly believed that the King Rat, adorned with a golden crown, sat enthroned on a group of Rats thus grown together, 
and thence ruled over a kingdom of Rats. It is true that one sometimes encounters a group of Rats the tails of which are permanently joined together and which, being unable to move, are fed by compassionate individuals of their own kind. It is believed that a contagious disease causes an exudation of serum on the surface of the tails, and, in consequence of the change of this serum into organized cell (or muscle) tissue, the tails roalesce and grow together; but nothing definite has yet been established on this score. In Altenburg, Germany, the remains of a King Rat which is formed of twentyseven Rats is preserved in a collection of curiosities; others have been found in other portions of Germany, notably at Bonn, near Schnepfenthal, in Frankfort, Erfurt and Lindenau near Leipzig.

Means Used to The means used for the extermina-

Exterminate tion of Rats are innumerable. Traps Rats. of many kinds are set for them, and sometimes persistent Rat hunting may bring temporary relief from the annoyance of their presence. If the animals perceive that they are the objects of determined pursuit, it not infrequently happens that they retire from the scene of conflict, returning, however, when the vigilance of their persecutors becomes lax.

Poison to be Given With Ex- against them are various kinds of treme Caution. poison, food being impregnated therewith and deposited near their favorite haunts. But this method of extermination is to be reprobated, for, not to speak of the fact that the poisoned creatures are tortured to death in the most cruel manner, this administration of poison is always dangerous for the reason that the Rats are prone to vomit part of what they have eaten, in this way being likely to poison corn or potatoes, and thus the lives of domestic animals or even of human beings are put in jeopardy. It is less dangerous, though scarcely less cruel, to give them a mixture of malt and unslaked lime; when they have partaken of this they become thirsty and death is brought about as soon as they have clrunk the water required for the slaking of the lime. This method must cause the victims intense agony, by reason of both the generation of hcat and the liberation of the carbonic acid gas of the lime, which inflates the animals to the point of bursting.

Best Extermina- The best extcrminators of Rats under

tors of the all circumstances arc their natural Rats. enemies, particularly Owls, Ravens, IVeasels, Cats and Terricrs. Is among all domestic animals there are particular strains of blood especially fitted for some special use or function, so among Cats there also are families the members of which are passionately fond of Rat-hunting, though at first they have much difficulty in acquiring the art of properly seizing and overcoming the biting Rockents. However, it is not really necessary that a Cat should catch the Rats; it drives them away by merely prowling about in stable and barn, ccllar and pantry. The presence of such an arch encmy is highly distasteful to the Rats, for they are well aware that they have not a moment of safety. Noiselessly the Cat creeps upon them in the dead of night, no sound and hardly a movement betraying its approach; its greenish eyes with their uncanny lustre look into all their holes, and it sits in waiting ncar their most frequented passages; before they know it, it pounces on them and the grasp of the pointed claws and sharp teeth is so firm that escape is well-nigh impossible. Even Rats, audacious as they are, cannot stand this; they are fain to enigrate to places where they can dwell unmolested. In this way the Cat always proves the best helper of Man when Rats or other such annoying vermin have to be driven away. Not less valuable are the services of the Polecat and Weasel, the former working in houses, the latter.in gardens and about stables, barns or granarics.

Several American The Black, Brown and Egyptian Rats, alSpecies of
ready described, have invaded America Species of from the Old World, and here, as well as Rats. there, the Brown Rat has succeeded in driving away other species of its own family.

Besides these there are numerous species which are indigenous to the United States. One which forms a separate subfamily (Sigmodon) is the well known Cotton Rat, or Rice Rat (Sigmodon hispidus). It is widely distributed through the southeru states. It has a stout body four inches in length, a tail over two inclies long, a cuarse fur of blackish yellow-gray above and grayish-white on the under portion.

Still another American sub-family is that of the Wood Rats (Neotoma), which includes many large, handsome species. Especially numerous is the Florida Wood Rat (Neotoma flori(lana) which, while especially plentiful in the southern states, is found in nearly all parts of the country. These Rats when young are of a bluish gray color, but the fur of the mature animal is yellowish brown on the upper portion and white on the under parts and the feet. The Florida Wood Rat is over nine inches long, exclusive of the tail, which is about six inches long.

Another species of the same sub-family is the California Wood Rat (teotoma fuscipes), which resembles the Florida Wood Rat in many respects, but has a longer tail and dark feet.

Uccupying a region between those which form the homes of the two last named species, is the Gray Wood Rat (Neotoma cinerezes) of the Rocky Mountain country, which is distinguished from the others by the possession of a bushy tail. The Indians of the West find the flesh of this animal an acceptable article of food.

Mice Much Better Much more graceful, good-looking

Looking Than and dainty than these ugly, longRats. tailed domestic thieves, are the Mice, though they too are great pests to mankind, in spite of their pretty looks and lively, prepossessing ways, and they are pursued with nearly the same relentless hatred that falls to the lot of their larger, uglier relatives. We may affirm that anybody will find a Mouse in a cage charming, and that even ladies, who are usually seized by a great, although tufounded terror, when a Mouse crosses their path in kitchen or cellar, will declare it to be a pretty creature when they make its closer acquaintance. The possession of pointed gnawing-teeth and the fondness for good things to eat are attributes, however, adapted to inspire wrath and revengeful feelings against them even in the gentle heart of woman.

The Com- The Common Mouse (Mus musculus) mon Mouse and its shows some resemblance to the

Appearance. Black Rat in its appearance, but its structure is much more delicate and symmetrical and it is much smaller. Its total length amounts to about seven and one-half inclies, of which three and one-half inches is occupied by the body. The tail shows one hundred and eighty scaly dermal rings. Its color is nearly uniform: the dark yellowish-gray hue of the upper part of the body and tail gradually merges into the slightly lighter tint of the lower surface; feet and toes are yellowish-gray.

The Wood, or The IVood or Long-tailed Field Long-tailed Field Mouse (Mus syleaticus) attains a Mouse. length of eight inches; the tail which has about one hundred and fifty scaly dermal rings measures nearly four and one-half inches. It is parti-colored, the upper surface of the body and tail being brownish yellow-gray, the under parts and 
the feet and toes being white; the line of demarcation between the two colors is sharply defined.

lioth the foregoing species may be easily distinguished from the third mentioned (the Old World Mleadow Mouse) by the much longer ears. In the latter species the ear attains a size equaling only about one-third of the head and, if deflected forward and folded against the sides of the head, they do not reach the eyes, while the ears of the others attain

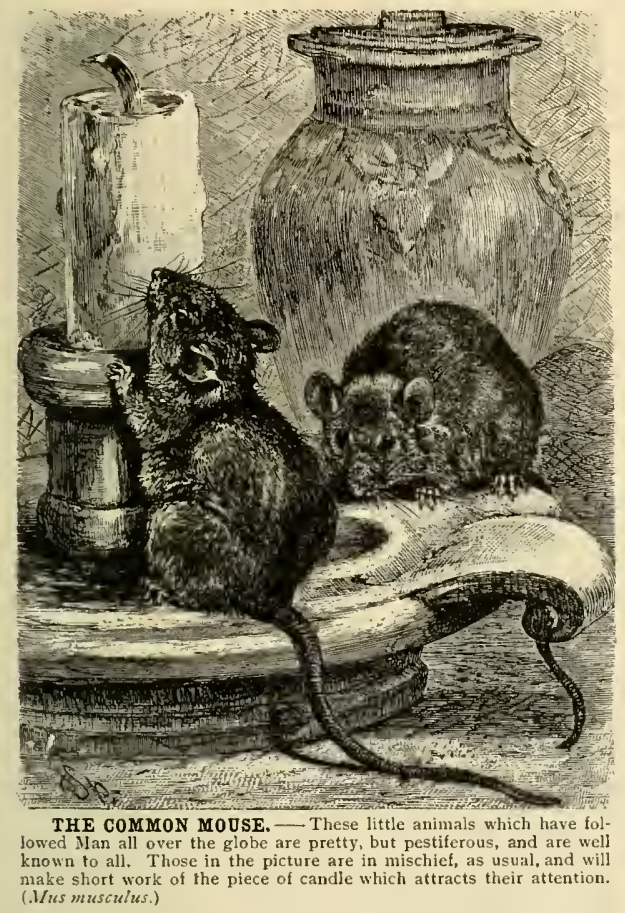

half the length of the head and reach the eye if pressed, in the manner described, to the sides of the head.

The Old World The Old IVorld Meadow Mouse Meadow (Mus agrarius) is seven inches long; Mouse. the tail three inclies. Its fur is tricolored: the upper part of the body is brownish red, diversified on the back with black longitudinal stripes; the sharply defined color of the under surface and feet is white. The tail has about one hundred and twenty scaly dermal rings.

Similarity of All these species of Mice display Tastes and Habits many common characteristics in Among Mice. their selection of haunts, their disposition and their habits, though each may have its individual peculiarities. All three agree in one respect: they show a great predilection for the proximity of human beings, at least at certain intervals. All species, the Common Mouse oftener than the others, are, especially in winter, frequently found in all portions of houses, from the cellar to the garret. None of them is exclusively confined to the localities which its name would indicate as its abode; the Wood Mouse temporarily lives in a barn or a house as well as in the field, and the Meadow Mouse is as little confined to fields as the
Common Mouse to houses, so that one may occasionally see all three species together.

Range and Char- The Common Mouse is said to have acteristics of the been the most tenacious companCommon Mouse. ion of Man from the earliest ages. Aristotle and Pliny mention it and Albertus Magnus was familiar with it. At present it is distributed all over the globe. It has followed Man in his migrations to the farthest north and to the highest cottages on the Alps. There are but few localities at present from which it is absent, and even where it is supposed to be wanting, the supposition is probably founded on the fact that it has escaped observation. On the Sunda Islands, for instance, it is said that there are no Mice, but their advent even there is but a matter of time.

The Nouse takes up its abode in all parts of a human dwelling. In the country it may temporarily live in a garden or in a field or grove; in the city it confines itself to dwellings and outhouses. Every crevice, every hole, in a word, every cranny where it can hide, affords it sufficient shelter and a base of operations from which it sallies fortl on its forays.

$\begin{array}{cc}\begin{array}{c}\text { Physical } \\ \text { It runs with great rapidity, climbs } \\ \text { Pours of the } \\ \text { Mouse. }\end{array} & \begin{array}{l}\text { renarkably well, jumps considerable } \\ \text { distances and sometimes performs }\end{array}\end{array}$ journeys of no small magnitude, proceeding on its way by a series of short leaps. How agile it is in

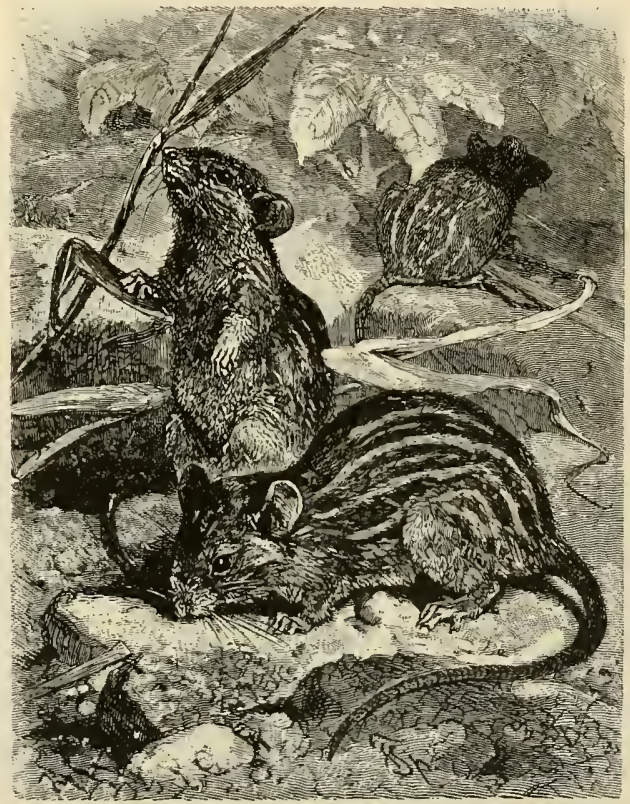

THE BARBARY MOUSE,- This species of Mouse, which is a native of northern Africa, is larger than the Common Mouse, but smaller than the Rats. Its principal distinction is in the markings of whitish-yellow stripes on a dark brown ground color, becoming lighter on the under portion than on the back. (Mlizes barbarus.)

all its movements can be seen by observing a tame Mouse. Even when it sits quiet, it produces the pleasing impression on the mind always awakened by the sight of a pretty animal; but when it sits on its haunches, Rodent fashion, and washes and dresses its fur, it is a really fascinating little creature. It can stand up on its hind legs, like a human being, 
and can even walk a few steps while thus erect, occasionally supporting itself a little with its tail as it moves. It can also swim, though it enters the water only under compulsion. It is good-natured, not treacherous, and does not resemble its vicious, deceitful, biting relatives, the Rats, in the least; it is inquisitive and investigates everything very carefully; it is cunning and intelligent, soon perceiving where it is tolerated, and in such places becomes so used to Man that it runs about its business in human presence, as if nothing menaced or frightened it. Harmonious sounds please and attract it and cause it to forget all timidity and oftentimes to leave its retreat, in order to approach nearer the source of its enjoyment. It appears in broad daylight in rooms in which instruments are played, and rooms regularly devoted to music are favorite haunts with it.

Several periodicals have published articles about so-called singing Mice, and 1 also have received a few accounts of such specimens. All reports agree in that in some places a Common Mouse may be found which utters its natural chirping note in a way which resembles the song of a bird. Some people speak of the song of the Mouse with enthusiasm, and compare it to that of a Canary or even of a Nightingale; others judge less enthusiastically and are probably more nearly right. Herr Schacht, a well-known educator and reliable and well-informed observer, possessed such a singing Mouse for some time. It usually sang at dusk but often only at night. Its song did not bear the slightest resemblance to the bright song of a Canary or the deep trills of a Nightingale. It was nothing but "a twittering, a mixture of long-drawn, squeaking, piping sounds," which in the quiet of night could be heard at a distance of twenty paces. The song of another Mouse, observed by IIerr Mueller, another tutor, consisted of "soft, whistling sounds, uttered slowly or in a more lively manner, in the latter case reminding one distinctly of a bird's song, but being much weaker." This Mouse was excited by music and when listening to it in the daytime would sometimes whistle. Both singing Mice which 1 observed were males, and it therefore appears not improbable that in this case also the sweet gift of song has been bestowed on the male sex alone. Pechuel-Loesche simultaneously and for months observed two singing Mice living at liberty in a kitchen. One of them produced only an irregular chirping and trills, mixed with a low snarling, smacking and occasional deeper murmuring sounds; the other had softer tones at its command, some of which it could prolong for some time, so that it really produced an effect which was melodious in a certain way. It certainly would be more congruous to speak of "twittering" Mice than of "singing" ones. Partiality All agreeable qualities of our do-
of Mice for mestic companion are unfortunately
Dainties. more than countcrbalanced by its fondness for choice and delicate food. One can hardly imagine a daintier feeder than a Mouse which can range at will in a well filled larder. It proves in the most unequivocal way that its sense of taste is highly developed. It gives preference to sweetmeats of all kinds, milk, meat, cheese, fats, fruit and grains, and where it has to choose it takes the best among the good things. Water it does not drink at all if it can procure food containing liquid enough to meet its physical necessities, and even when its diet is dry, it rarely drinks unmixed water, but it sips sweet beverages of all kinds.
Destructive- The damage the Common Mouse enness of tails by the eating of provisions is Mice. slight, on the whole; its principal harmfulness arises from its abominable habit of gnawing all kinds of objects. Mice sometimes work dire destruction among valuable collections of textiles, rare fabrics, books or natural curiosities; if their propensities are not checked by all possible means, they can do incalculable damage.

Fecund- The Common Mouse is excedingly

ity of the prolific. Litters of young Mice in-

Mouse. clude from four to six and often eight young, and each female gives birth to five or six litters a year, so that the immediate progeny from one mother number at least thirty in one year. The young are exceedingly small at birth and quite translucent; their growth is rapid, however; between the seventh and eighth day their hair begins to appear, but their eyes are not opened until the thirteenth day. They remain in the nest but a few days longer, and then proceed to earn their living on their own account.

The Nouse has become a domestic animal in the true sense of the word with the inhabitants of China and Japan, who attain wonderful results in the breeding of animals and the culture of plants. Haacke writes as follows concerning the Mice which of recent years have been exported from these two countries: "From time to time a Hamburg dealer in animals sends me two breeds of Common Mice, which he calls Chinese Climbing Mice and Japanese Dancing Mice. It is true that the first are distinguished only by their differing colors, for their climbing accomplishments are not greater than those of other Mice. The color, hovever, is subject to many variations. Besides individuals of uniform gray, light yellow and white color, I have had specimens mottled with gray and white, black and white, yellow and white, and blue and white. Tricolored Mice secm to be very rare. It is a known fact that we also have white, black and yellow Mice and occasionally also pied ones, and the Chinese have profited by the variations of the Common Mouse also, to satisfy their fancy in breeding animals. The Japanese, however, who are no less enthusiasts on this point, know how to transform the Common Mouse into a really admirable animal. The Japanese Dancing Mice, which perfectly justify their appellation, also occur in all the described colors. But what distinguishes them most is their innate habit of running around, describing greater or smaller circles, or more frequently whirling around on the same spot with incredible rapidity. Sometines two or, more rarely, three Mice join in such a dance, which usually begins at dusk and is at intervals resumed during the night, but it is usually executed by a single individual."

The Natural IWhatever one may say, the direst

Enemies of foe of the Mouse is a Cat. In old Mice. ruins the Owl is the Cat's faithful ally in its warfare against Mice, and in the country, Polecats, Weasels, Hedgehogs and Shrews render good scrvice in the same direction: better aid than any kind of trap, at any rate.

The Wood The Ilood Mouse and the Meadow

Mouse and its Mouse possess most of the characRange. teristics of the Common Mouse. The first named is distributed all over Europe and central Asia, with the exception of very high latitudes, and in mountainous regions it is found at an altitude of 6,000 feet above the sea. It lives in the depths or 
on the edges of forests, in gardens, and more rarely in wide, treeless fields; in winter it enters houses, at first confining itself to cellars and larders, but soon climbs higher and finds its favorite haunts in attics and under roofs. It rivals the Common Mouse in agility, if it does not surpass it, but differs from it in its mode of locomotion-proceeding mostly by jumps. Outdoors it feeds on insects and worms or even small birds or fruit, cherry kernels, nuts, acorns,

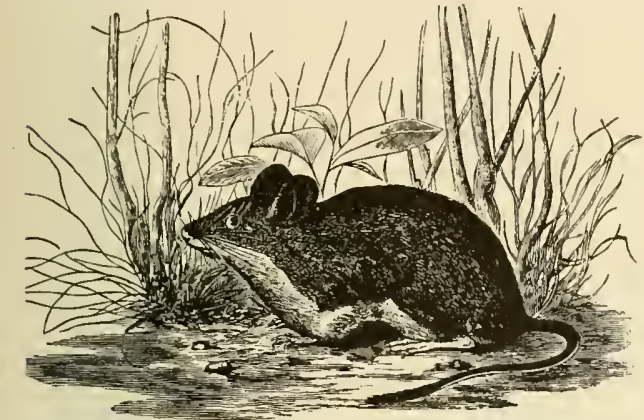

WHITE-FOOTED MOUSE.-The Common Ilouse is thoroughly at home in America, but there are other species which belong to a distinctively American sub-lamily. They are especially represented by the White-tooted Nouse, the pretty graceful animal shown in the picture. (Hesperomys leu copus.)

beech seeds, and in times of scarcity probably also the bark of young trees. It lays up for winter use a store of provisions, but does not hibernate, and draws its sustenance from its gathered treasures only on gloomy or stormy days.

The Range The Meadow Mouse (Mus agrarius) of the Old World has a more restricted distribution Meadow Mouse. than its allied species: it lives between the Rhine and western Siberia, between northern Holstein and Lombardy. It is common in nearly all parts of central Germany and is absent on high mountains. It delights in cultivated fields, forest edges, light shrubbery, and in winter makes its home in granaries, grain stacks or barns and stables. When the grain is being carried from the stacks one sees the little animals scampering through the stubbles in troops. The Meadow Mouse is less agile and much more indolent, passive and better natured than its relatives. Its food mainly consists of corn, seeds, plants, tu. bers, insects and worms. It also lays up winter stores of provisions.

Characteristics of Pretty and neat as all small Mice may

the Harvest be, and charmingly as they conduct Mouse. themselves in captivity, the smallest member of the family, the Harvest Mouse (MIus minutus or messorius), surpasses all the others in these respects. It is livelier, nimbler, in short, a much more prepossessing creature than any other Mouse. Its length is about five inches, one-half of which is included in the tail. The color of the fur is subject to variations. Usually it is parti-colored, the upper parts and the tail being yellowish or brownish red, the under surface and the feet being white; the line of demarcation is sharply defined.

The Harvest Mouse has perplexed naturalists from the earliest ages of zoological research. Pallas discovered it in western Siberia and gave a detailed description and a fairly good picture of it; but nearly every naturalist after him classified it as a new species, and each believed his theory to be right. Continued investigation only gave as a result the irrefragable truth, that the diminutive creature really ranges from Siberia throughout Russia, Hungary, Poland and Germany to France, England and Italy and is absent in only a few regions. It lives in all localities where agriculture is pursued, and by no means always in fields, but preferably in swamps among reeds, rushes, etc. During the summer the pretty little creature is found in the fields in the society of the Wood and Field Mouse; in winter it exists in great numbers in riclis or in barns into which it is conveyed from the field along with the grain. When it spends the winter in the open country, it sleeps through part of the season, but never really hibernates or becomes torpid and therefore lays by stores for winter during the summer.

Peculiarities of The Harvest Mouse is distinguished

the Harvest by its movements from all other

Mouse. species of the family. In spite of its diminutive size, it runs with great fleetness, and climbs with excecding agility and grace. It climbs the smallest twigs of bushes, grass blades so weak and pliable that they bend to the ground under its weight; it ascends nearly as quickly on the trunks

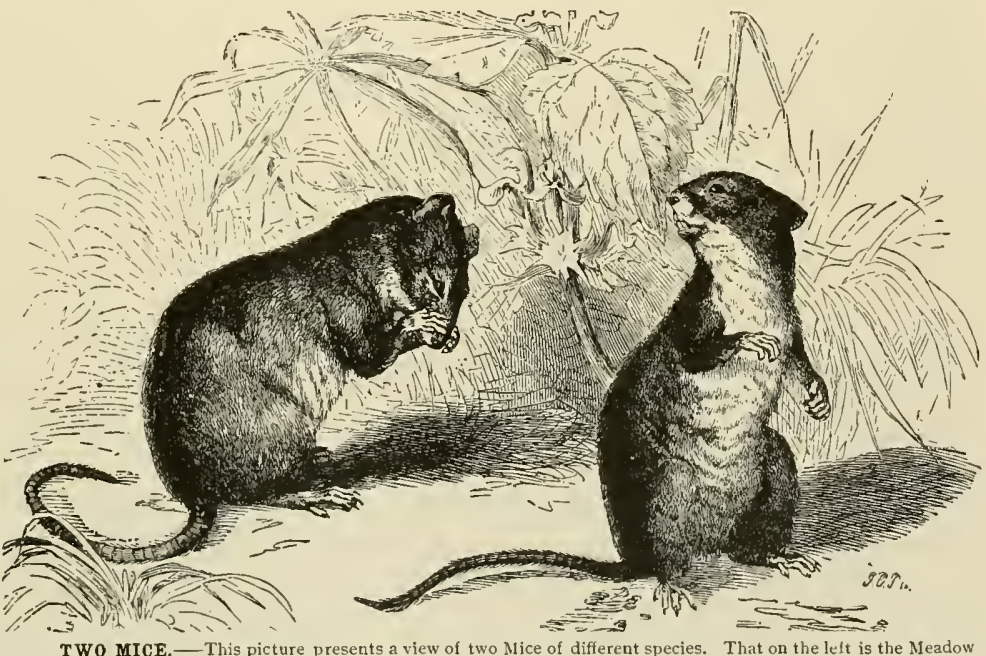

TWO MICE, - This picture presents a view of two Mice of different species. That on the left is the Meadow Mouse of central Europe (W/us agrarius), while on the right is the pretty, white-breasted Wood Mouse, or Long
tailed Field Mouse. (Wus sylvaticus, ) Both delight in outdoor life in summer, but invade dwellings or barns in winter. and amid the branches of trees, and the dainty little tail is skillfully used in this latter operation, being in some degree prehensile. It is also an expert swimmer and proficient in the art of diving, and all its movements are lively and graceful. 
The Harvest The greatest slill of the Harvest Mouse an Mouse is displayed in another direcArtist. tion, however. It is an architect, such an one as has few equals among the lower mammals -an artist which emulates the most accomplished of birds, for it builds a nest which far surpasses all other mammalian nests in point of beauty. The neat construction is so peculiar that it would seem as if the Mouse had been taught its art by a reed Snipe. According to the requirements of the locality, the nest either stands on from twenty to thirty blades of reed grass, the extrenities of which are split and intertwined so as to surround the nest from all sides, or it is suspended from the branches of a bush, or from a reed at a height of two or three feet, looking as if it soared in the air. Its shape most resembles a blunt egg - as, for instance, a particularly round Goose egg - which it also equals in size. The outer covering usually consists of split leaves of the reeds or of reed grass, the stems of which form the foundation of the structure. The Mouse takes every leaf between its teeth and pulls it several times across their points which are sharp as needies, until each leaf has been separated into six, eight or ten parts, or, so to speak, into several distinct threads; then these threads are intertwined and interwoven with utmost care. The inside is lined with various soft substances of woolly or mossy texture, which are supplied by both the regetable and animal kingdoms, the animal sometimes using hair or wool of beasts and sometimes buds and leaves of trees, flowers, etc. A small opening leads into the nest at one side, and if one puts his hand into it he may feel how uniformly smooth and extremely soft the nest is above as well as below. The component parts are so closely interwoven that the nest has a very firm support. If the observer compares the much less serviceable equipment of the Mice for such work with the more useful and available beak of the artist birds, he can not but regard the nest with admiration, and will award the work of the Harvest Mlouse the palm for superiority over the architecture of many a bird. The outside of the nest is alway's formed from the leaves of the plants upon which it is built. As a consequence of this the nest is concealed from all but the closest observation for the reason that its exterior assimilates very closely the color of the foliage by which it is surrounded.

Maternal Affec- If one is fortunate enough to be tion in the present the first time the mother

Species. takes her little ones out, he has the opportunity of witnessing one of the most attractive family pictures in mammalian life. Agile as the members of the little crowd may be they have to receive some instruction, and they are also a great deal too much attached to the mother to wish for immediate independence or to rush out into the dangerous world. Therefore one little creature climbs up this grass stem, another is suspended from the next; again another chirps after the mother, while one may still require lacteal sustenance from her; one washes itself and dresses its fur, another has found a little grain which it daintily holds between its forepaws and cracks open; the weakling restricts its exploits to the inside of the nest, while the most vigorous and courageous male has gone away farthest, and perhaps is already swimming in the water below; in short, the entire family is actively engaged and the mother is the central figure of it all, helping, calling, leading, and protecting the whole society:
Tractable to One can observe this graceful picCaptiv- ture at ease if he takes the whole ity. nest home and puts it in a close wire cage. Harvest Mice are easily maintained on hemp seed, oats, pears, sweet apples, meat and Flies, and the trouble one takes is repaid a thousand times by their many amusing traits. They make a pretty picture when one holds out a Fly to them. All pounce upon it in great bounds, endeavor to seize it with their paws, and lift it to their mouths; and the animal which succeeds in capturing it kills it with all the ferocity of a Lion slaughtering an $\mathrm{Ox}$. Captive young Mice become very tame, but with advancing age their shyness returns, if their owner does not very frequently fondle them, and thus keep a sense of companionship constantly alive in them.

\section{INDIGENOUS AMERICAN MICE.}

The Mlouse family, with the two hundred and fifty or more species, has a number of American representatives in addition to the immigrant Common Mlouse, which has gained a very strong foothold, and is now distributed all over this country. The indigenous American Nice compose a distinct sub-family (Hesperomys) in which are very many distinct species. The typical representative of this family is the White-footed Mouse (Hesperomy's leucopus). It is about three or four inches long, has a fawn colored fur above and is white on the under portion and on the feet; has large eyes with circular pupils, large rounded ears, graceful limbs, cheek pouches to carry its food, and a well shaped head and muzzle on which is a luxuriant growth of long whisker hairs. The movements of this pretty animal are quick and full of grace, befiting the woodland life it leads, but it sometimes invades dwellings and especially outhouses. There are several local varieties of this Mlouse.

An especially handsome species is that of the Golden Mouse (Hesperomys aureolus) with its striking fur of a golden brown above and yellowish white on the under part. This animal is only found in the central and southern states. Many other species are known including the dark colored Michigan MIouse (Hesperomy's michiganensis); the large Californian Nlouse (Hesperomys californicus) with nearly naked tail and ears, which is a large species; and the Missouri Mole Mouse (Hesperomy's leucosaster) a short-tailed variety. The Rice-field Nlouse (Hesperomy's oryzomys) is the largest of American Mice, large specimens of which attain a length of five inches. It has a dark grizzly color on the back and sides, but the under portion and the feet are snow-white. There are numerous other species of American Mice, but those named are the best known. As to habits, the description of those of the Common Mouse is about equally applicable to the indigenous American animals.

\section{THE HAMSTERS.}

The Hamsters comprise the last sub-family ( $\mathrm{Cr}$ cetina). They are Mice of more or less clumsy form and sometimes of large size; their upper lips are cleft and they are provided with large cheek pouches and three molars in each jaw.

The principal anatomic characteristics of the best known species (Cricetus) are: a clumsy, sturdy body. a very short tail scantily covered with hair, and short limbs. There are sixteen tecth and two pairs of remarkably large gnawing teeth. The species usually dwell in corn fields in the fertile parts of temperate Europe, Asia and America. They dig deep burrows composed of several compartments in which they store provisions in autumn, and in these burrows they spend their lives, the joys and sorrows of which we can best ascertain by investigating the habits and occupations of the Cominonin Hamster.

The Common Hamster (Cricetus frumentarius or ''ulgaris) is rather good looking in appearance, but its temper is ugly, sulky and irritable; it is also very pugnacious. The animal attains a total length of about twelve inches, about two of which are included in the tail. The color of the upper parts is usually a light brownish yellow, with a surface tinge of gray. The under parts, the inner and outer sur- 


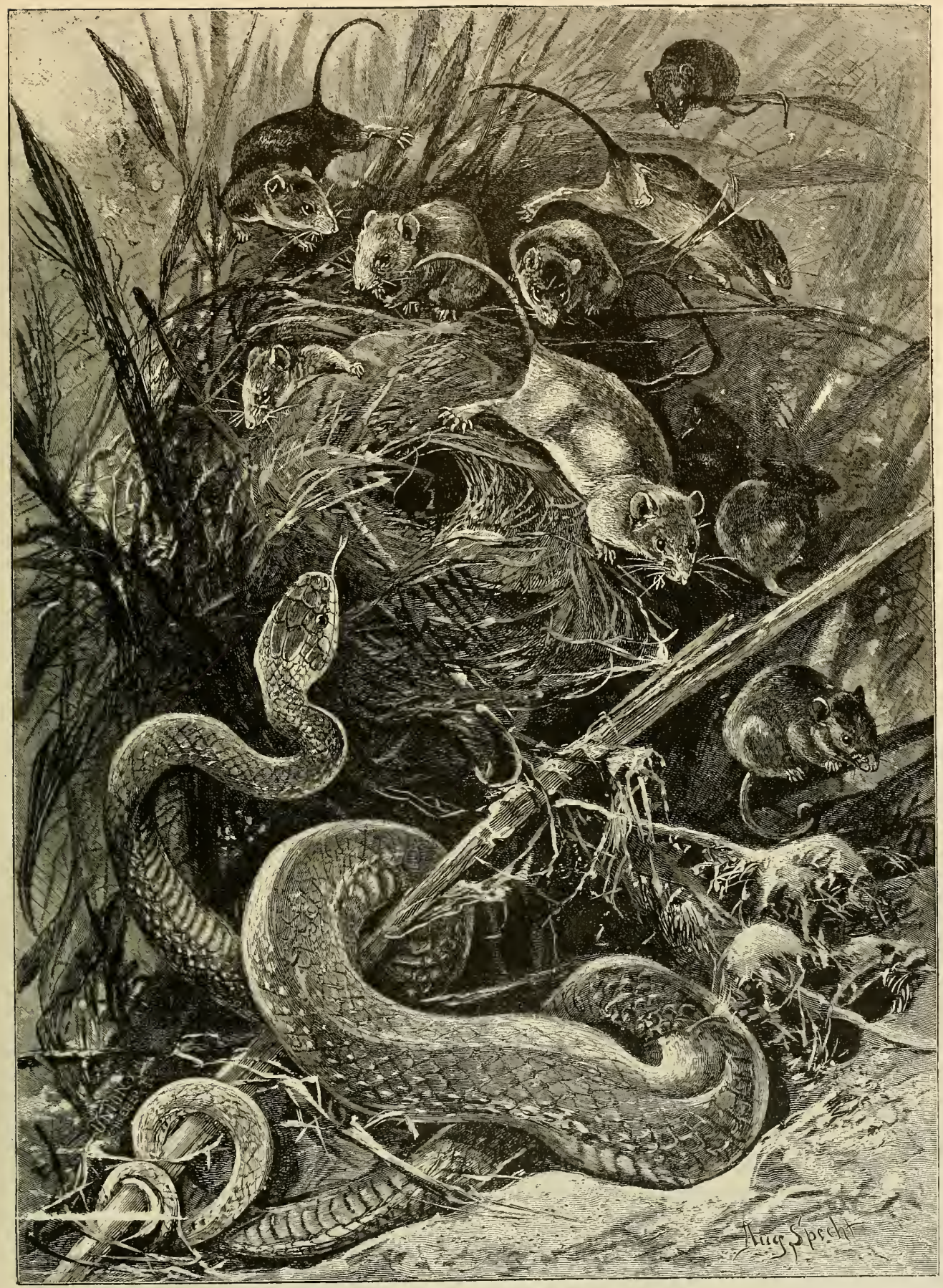

HARVEST MICE ATTACKED BY SNAKE. - Prettiest of all the Mouse family is the little Harvest Mouse. It is also noteworthy for the great cleverness it shows in the construction of its nest, which in compactness and neatness rivals those of some of the best nest-building birds. Such a nest is shown to escape the monster. (.Mus minutus.) 
faces of the fore legs down to the feet, the inner surface of the hind legs, and a band over the forehead are black, while the feet are white. There are, in point of coloration, a great many varieties, however: some are quite black, others are black with a white throat and a gray scalp; others again are pale above and light gray below, with whitish shoulders; completely white individuals are also found occasionally.

The Burrow of Its burrows consist of a large living the Ham- chamber, from three to six feet deep, ster. a sloping tunnel, termed a "creeping hole," and a perpendicular entrance tunnel. The chamber communicates with the store-room by passages. A Hamster's burrow is easily recognized by the heap of earth in front of the creeping hole, which is usually strewn with chaff and pods, the refuse of its food. The entrance tunnel is always perpendicular, sometinjes being so straight that one can thrust a long stick into it; it does not lead straight to the sleeping chamber, however, but diverges from a right line either horizontally or obliquely. The secondary tunnel, on the other hand, seldom runs straight, usually describing a curve. One can easily see by the appearance of the tunnels whether a burrow is inhabited or not. If moss, mould or grass be found in them, or if they have a rougl, unbeaten appearance, it is certain that they are descrted; for every Hamster keeps his house and its doorway remarkably clean and in order. Of the chambers, the smooth-walled living room is the smaller and it is always filled with very fine straw, usually the sheaths of grass blades, which form a soft bedding. Three tunnels converge in it: the one from the entrance tunnel, the other from the creeping hole, and the third leading from the store-room. The storeroom bears a complete resemblance to the first chamber, and is usually filled with the winter store of corn toward autumn. Young Hamsters have only one store-room, but old ones dig from three to five store-rooms, and in each at least a peck of grain may be found.

Formerly it was erroneously believed and asserted that the Hamster piled up different kinds of grain in separate heaps. The fact is that it brings in the grains as it finds, them and the depositing of these grains in separate stores is not due to the sense of order in the Hamster but it is because it finds only one certain kind of grain at a certain time. The burrow of the female differs in some respects from the one we have described; it has only one creeping hole, but from two to eight perpendicular entrances, though only one of them is in constant use as long as her progeny are still young.

Physical Pecul. The Hanster is a comparatively iarities of the agile animal in spite of its apparent Hamster. clumsiness. Its gait is of a creeping character and resembles that of the Hedgehog, the abdomen nearly trailing on the ground; the length of its steps is short. When it is excited or aroused its movenents are more violent and it may then make fairly long and high leaps. It is an expert in digging. If put into a barrel containing earth it immediately sets to work. It usually breaks the ground with its fore-feet, but when the soil is hard it uses its teeth also; the earth is first thrown under the abdomen; from there the hind legs fling it backward. When it reaches a depth too great to thus cast out the loose earth it walks backward and pushes out quite a quantity at once; but it never conveys earth in its mouth or fills its cheek pouches with it, as has been erroneously asserted. Its movements when swimming are not awkward, though it sedulously shuns water. If it is thrown into a vessel filled with a liquid it swims briskly around, growling furiously all the time and generally showing that it feels highly indignant and uncomfortable. When taken by surprise by an enemy it immediately rises upon its hind legs and lets its fore-paws hang down, one usually being a little lower than the other. In this position it glares at the object of its resentment, evidently quite ready for an opportunity of rushing at it and using its teeth on it.

The perceptive faculties of the Hamster seem to be developed pretty uniformly; at least one does not perceive any one of them to be specially keen. Its intellectual endowments are not such as to make it a favorite of Man. The feeling of vicious pugnacity is exhibited by it to an extent unknown among other Rodents of this size, with perhaps the exception of Rats and Lemmings. At the slightest provocation it assumes a defiant attitude, utters a deep, hollow growl, grinds its teeth and opens and shuts them with exceeding rapidity and violence. Its courage equals the violence of its temper. It defends itself against any animal that attacks it as long as it can. It often foils unskilled Dogs; only the cleverest Terriers know how to seize it and then to escape injury themselves they must almost instantly shake it to death. All Dogs detest the Hamster nearly as much as the lledgehog, because it vexes them that they cannot force so small an animal to acknowledge their supremacy. The Hamster defends itself, not only against Dogs, but boldly attacks Man even if the latter does not take the initiative in the combat. It happens not infrequently that a person in quietly passing by a Hamster's burrow suddenly has the ferocious animal hanging from his clothes by its teeth. It also flies at Horses, and if a bird of prey lifts it from the ground it continues to defend itself in the air. Once it has fastened upon something it retains so firm a hold that it must be killed before it lets go.

The Vicious Dis- It is easily understood that so vicious

position of the an animal is not of a sociable disposi-

Hamster. tion. In captivity Hamsters seldom live in peace with each other: old ones probably never do. Young individuals, less than a year old, agree somewhat better. I have kept three in a box for some time; they never quarreled, but, on the contrary, huddled together in a quite friendly manner, one usually sitting upon the other. Young Hamsters from different litters attack each other immediately, however, and the fight is a deadly one. An amusing spectacle is afforded when a Hamster is given a Hedgehog as a companion. At first it looks with curiosity at the queer looking animal, which pays no attention to it, but calmly gocs about its business. The quiet is soon disturbed, however. The Hedgehog happens to come near its fellow-prisoner, an angry growl greets it and the frightened creature rolls up into a ball. Then the Hamster goes on an exploring tour. It sniffs at the bristly ball and a bloody nose teaches it an impressive lesson about the formidable exterior of the Hedgehog. Fiercely it pushes the ball away-alas! the paw is also wounded! Then it gnashes its teeth in rage, hisses, squeaks, jumps on the ball, hops down in anguish, then tries to push the spiny mass with its back and pricks its shoulder; its fury waxes hotter with every fruitless effort to rid itself of the monster; it only reaps new pricks in its feet and lips and finally, 
partly subdued-more amazed than furious--it stands up on its hind legs in front of its bristly antagonist and regards it with a thoroughly ludicrous mixture of trepidation and grim fury, or else it vents its rage on some other object, such as an innocent Hamster fe!low-prisoner, upon which it inflicts the bites originally intended for the Hedgehog. Whenever the Hedgehog stirs the performance is repeated, to the intense amusement of the spectator.

IVitl other smaller animals it naturally agrees still less and even hunts then; for it is predaceous and its food in a great measure consists of living creatures. It is more partial to a diet of small birds, Mice, Lizards, Blindworms, Ringed Snakes, and insects than to vegetable food.

Food As soon as the vegetables and greens

of the Ham- in the fields are mature, the Hamsters. sters are very busy with the harvest. Husks of linseed, lima beans and peas seem to be
Hamsters in In the beginning of October, when Winter Quar- the weather becomes cold and the ters. fields are bare, the Hamster begins earnestly to prepare for winter. Its bed is very small and is closely lined with the finest straw. Then the half torpid animal eats its fill and curls up and goes to sleep. Its circulation is so diminished that its limbs when touched feel ice cold and are so rigid that the joints can only be moved with great effort, and if forcibly bent they imnediately resume their former position, like those of animals which have only recently died. The eyes are closed. Respiration and heart beat are imperceptible. Usually the heart beats fourteen or fifteen times a minute. The first symptom of returning animation before the animal awakes is a diminution of the rigidity. Then respiration increases in activity and the animal stirs; it yawns, uttering a rattling sound, stretches itself, opens its eyes, staggers like a drunken animal, tries to sit up and falls, gets on

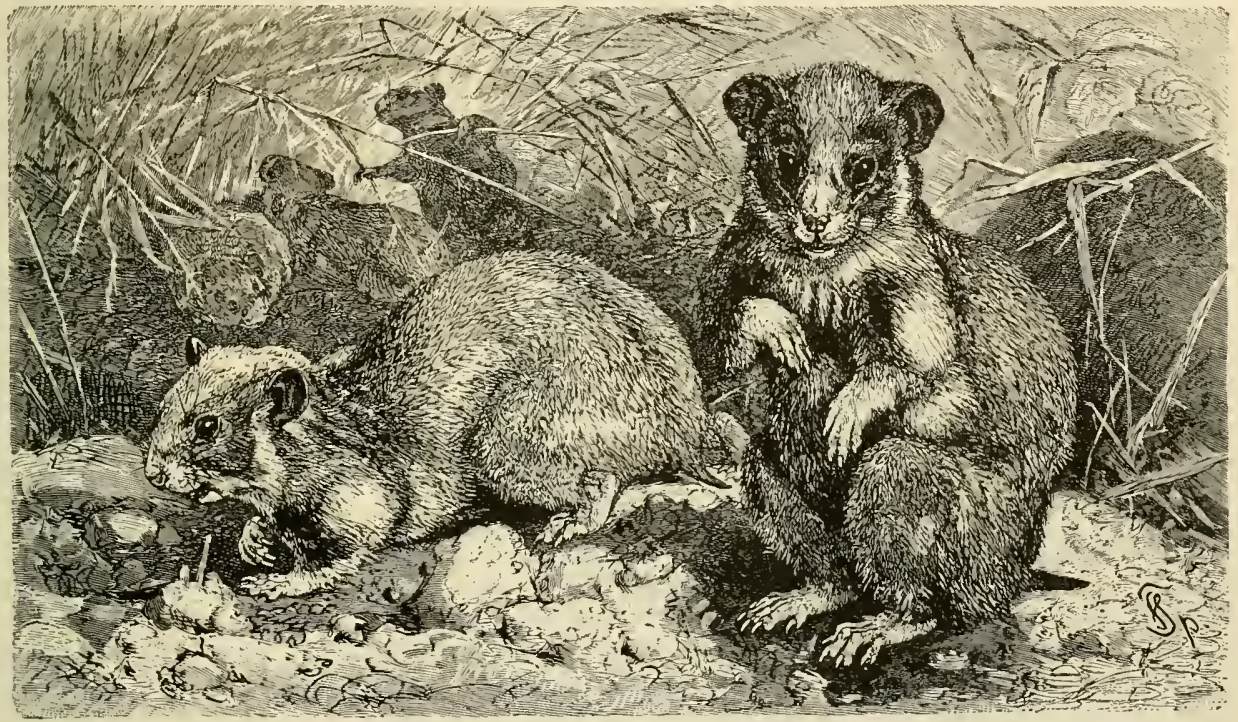

HAMSTERS.- - These Rodents, though nearly related to the Mice, have special characteristics, among which the possession of capacious cheek pouches is noteworthy. They are lively, alert animals which steal grain and store it in large quantities. The animal when approached by an enemy assumes the position shown by the sitting animal on the right hand side of the picture. (Cricetus frumentarius.)

given the preference for winter storage. The Hamster works at its harvesting in the daytime only in those thinly peopled localities where it is entirely undisturbed; its usual working time are the first half of the night and the early morning before sunrise. It bends the high blades of grain with its fore-paws, detaches the ear with one bite, seizes it in its paws and by dint of turning it around a few times, takes all the grains off, and collects them in its cheek pouches. In this way the capacious pouches are stored to plethoric fullness, and some Hamsters may carry a weight of fifty grains home at one time. An animal so heavily loaded has an extremely ludicrous appearance and is one of the clumsiest creatures in the world. One can pick it up without fear, for the crowded pouches prevent its biting; but one must be quick and not give it time, else it empties the pouches and assumes the defensive, and it can then inflict a painful wound. its feet, reflects a little and finally moves slowly about; if food be given it, it devours it immediately, washes and strokes its fur and awakes completely.

The Enemies It is really fortunate for humanity

of the Ham- that the Hamster, the rapid increase sters. of which gives it a prodigious power for evil, has so many enemies. Owls, Ravens and other birds, and even more Polecats and Weasels, are on its trail unceasingly and kill it wherever and whenever they encounter it, and many of these pests are thus destroyed.

In some regions Man wages a relentless war against the Hamster. The principal profit of the chase accrues from the provisions which this singular quarry lays up; the people simply wash the grains, dry and then grind them like other grain. The skins are also put to account; experience has shown that they yield an excellent, light and durable fur. In some localities the flesh is also eaten. 


\section{Tbe volcs.}

\section{SIXTH FAMILY: ARVICOLIDE.}

The family of the Voles (Aricolith) comprises a considerable number of small Rodents, very similar to each other and showing an affinity to the Mice in many respects, for which reason they were formerly counted to be a sub-family of them. Externally they differ chiefly in their clumsy shape, thick head, ears which are entirely hidden in the fur or protrude to a very slight extent, and a short tail which attains a length equal at the most to twothirds of the length of the body.

The Arvicolida inhabit the north of the Old and New Worlds. They frequent plains and mountains, cultivated and rather thinly populated regions, fields, meadows, gardens, banks of rivers, lakes and ponds, and live in holes and burrows dug by themselves. Nearly all shun the proximity of IIIan and but few occasionally enter stables, barns or even gardens. Their burrows usually consist of single or branching tunnels of varying lengths, which often differ from those of others of their genus by reason of their great shallowness; some of them build dome-shaped habitations or other more or less intricately and artfully constructed residences. The majority of the family live singly or in couples; occasionally, however, they herd together in considerable numbers. They take their food mostly from the vegetable kingdom but do not disdain animal substances. Many lay up winter provisions, though they do not hibernate. In nearly all other respects they are similar to the true Mice.

Habits and Pecul. Their habits are nearly identical iarities of the with those of the Mice; their moveVoles. ments are comparatively quick, though not as nimble and agile as those of the true Mice. Few species can climb, but nearly all swim in a masterly way; some live entirely in the water, others at least for months in the snow, where they. excavate long tunnels and build complicated nests. Some species undertake long migrations, probably impelled by scarcity of food, and it is owing to these migrations that several species, which formerly were confined to Asia, have become implanted in Europe. Among their perceptive senses those of smell and sight rank first. Their intellectual capacities are slight. All the species are very prolific, the fecundity of some being well-nigh incredible. Neariy all species are very harmful to Man and have no good qualities compensating for their vices, and are therefore rightly detested and pursued to extermination in every possible manner.

\section{THE MUSKRAT.}

The Muskrat, Musquash or Ondatra (Fiber zibethicus) is the only useful species of the family. Une may term it a large Water-vole with a long tail, broad hind paws, a blunt snout and short, hair-covered cars which nay be closed to exclude water. The tail is rounded only near the base, being near the extremity vertically compressed; the tip is twoedged and scaly. The fur is close, smooth, soft and lustrous, the woolly under fur being extremely delicate, fine and short; the outer coat has a strong lustre and is double the length of the former. The upper surface is either of a brown, or of a yellowish hue; the under surface is gray, with an occasional reddish glint; the tail is black. Adult males attain a total length of twenty-three inches, the tail occupying about half of this.
Range and Habi- The Muskrat inhabits that part of tations of the North America which is included Muskrat. between the thirtieth and sixtieth parallels of north latitude. It is most numerous in Alaska and Canada which are so rich in lakes and rivers. This animal yields a fur which is of considerable use and value. Its favorite haunts are grassy banks of large lakes or wide, slowly flowing streams, quiet rivers and swamps, but it delights most in rather large ponds, grown with reeds and aquatic plants; and there it erects a permanent habitation and dwells either in small colonies or in communities of considerable numbers which form tolerably stable settlements. Its mode of life is in many respects similar to that of the Beaver; for this reason the Indians call the two animals brothers and affirm that the Beaver is the older and more intelligent one, while the Muskrat is the younger and more stupid one. The burrows of the Muskrat are like those of the Beaver, consisting of either plain underground chambers provided with several tunnels, ail terminating under water, or of strongholds or "lodges" above ground. The latter predominate in the north and are of a round and spherical or dome shape; they stand on a heap of mud and rise above the surface of the water. The walls are composed of reeds, reed grass and sedge, cemented with mud; some observers, however, assert that the whole hut originally consisted only of mud and gradually became covered with a thin layer of drifting grass and sedge. "The interior of the "lodge" contains a single chamber from sixteen to twenty-four inches in diameter. A tunnel which opens beneath the water leads to it. Other tunnels, without any opening, run from it for some distance under the ground, being more or less prolonged according to circumstances, their only use being for storage of the roots of aquatic plants. In winter the Ondatra lines its chambers softly witl water lilies, leaves, grasses and reeds and provides for ventilation by loosely covering the centre of the dome-shaped roof with plants, which admit a sufficient quantity of fresh air and let the vitiated air out. As long as the pond or swamp does not freeze to the very bottom it leads a highly comfortable existence in its warm habitation which is additionally protected by a covering of snow.

The Food of The food consists almost wholly of the Musk- aquatic plants, though the empty rat. shells of bivalies have been found in some of their lodges. Audubon saw captive Muskrats which were very fond of Mussels. The species are very lively, playful creatures when in the water, which is their proper element. Sometimes on a calm night many of them may be seen in a mill pond or some other deep, sequestered pool, disporting themsclves, crossing and recrossing in every direction, leaving long, glittering ripples in their wake as they swim, while others stand for a few moments on little tufts of grass, or on stones or logs, from which they can reach their food floating on the water; others sit on the banks of the pond, and then plunge one after the other into the water like Frogs. Should a fowling piece be fired while the Muskrats are thus occupied, a terrible fright and quick dispersion ensues; dozens dive at the flash or disappear in their holes with frantic haste.

The Progeny of About the reproduction of the Muskthe Musk- rat but little is known. Fron three rat. to six young are born in the burrow or in a hole. If they are caught young, they are easily tamed, this species being distinguished by a 
remarkably gentle and equable disposition. Old specimens remain vicious and intractable and can only be kept in boxes which are lined throughout with some metal which can withstand their teeth. They are pursued not so much on account of the damage they cause as owing to the profit they bring. Notwithstanding that some people dislike

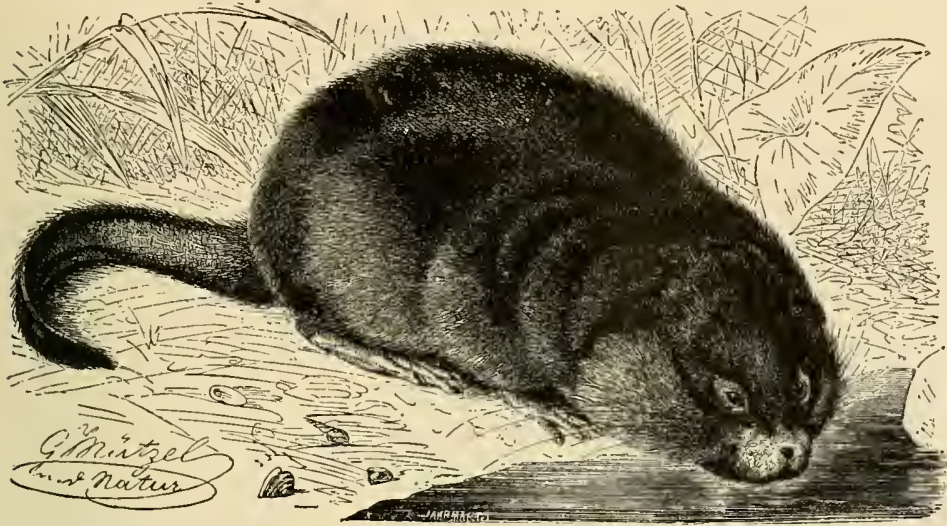

THE MUSKRAT. - Among the Vole tamily of Rodents the most useful is the Muskrat, the American anmal shown in the picture. The fur is very much sought after and is one of the warmest and softest. Muskrats live in burrows near the water's edge for their food consists of aquatic plants. (Fiber zibethicus.)

the fur on account of the odor of musk which clings to it for a long time, it is often used for trimming clothing, or in the manufacture of collars and muffs, especially in America and China. The best pelts are deprived of the long outer fur, dyed a dark brown color and used as a trimming which resembles the true Sealskin. The flesh is eaten only by Indians to whom the odor, which pervades it to such a degree as to render it wholly unpalatable to Europeans, does not seem to be disagreeable.

Methods of The Muskrat Trapping the is caught in Muskrat. traps baited with apples; steel traps are put in front of the holes, or they are sometimes killed in their burrows. The Indians know exactly which "lodges" are inhabited; they noiselessly creep up to those in which the animals remain and with all their might drive a sharp spear through the walls, usually transfixing the inhabitants.

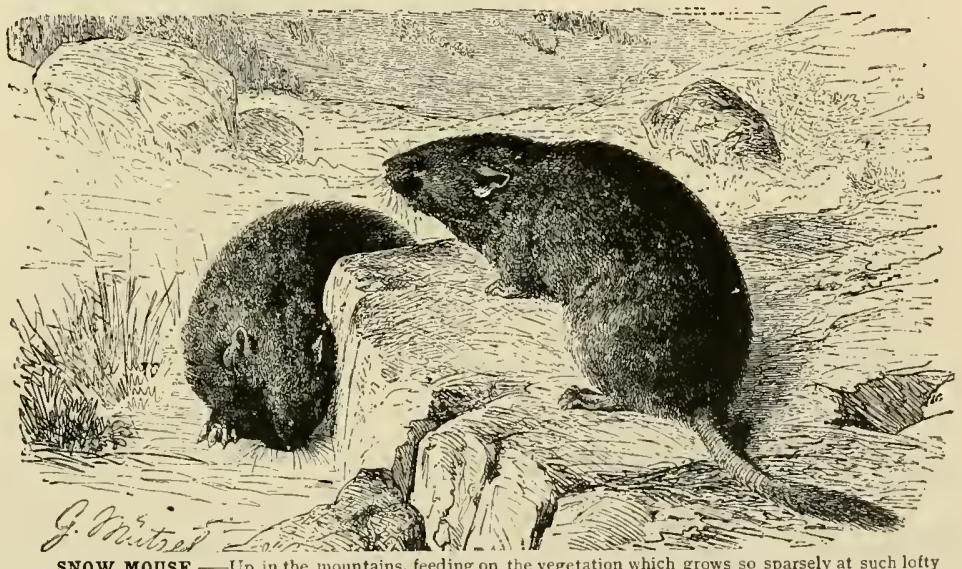

SNOW MOUSE.- Up in the mountains, feeding on the vegetation which grows so sparsely at such lotty elevations, live the animals which the picture appropriately shows seeking for herbs and grass on the snow-1nantied Alps. (Aricola nizalis.)

\section{THE VOLES PROPER.}

After the Muskrats we may consider the Voles Proper (Aricola) and their allies. Description of None of the species renders itself so
the Water conspicuous and obnoxious as the

Vole. Water Vole (Arvicola amphibius), which is one of the most harmful of Rodents, well known to naturalists, among whom it has repeatedly been the object of dissension.
The Water Vole is from eight and one-nalf to nearly ten inches long, the tail measuring from two and one-half to rather more than three inches. The color of the fur may be said to be uniform; for the grayish brown or brownish black of the upper surface gradually merges into the lighter whitish or gray, black or brownish black hue of the under parts. The IV ater Vole may be readily distinguished from the Domestic or Black Rat by its thick, round, short head, with strikingly short ears covered with fur and not attaining a quarter of the length of the head, and its short tail. The color is variable, three variations particularly distinguishable: the Water Rat or Water Vole, the Italian Water Rat and the German Schermouse, the latter a variety often found some distance from water.

The Water Vole is widely distributed and is really nowhere absent within its range, which extends from the Atlantic Ocean to the Sea of Okhotsk, from the White Sea to the Mediterranean, and it frequents alike plains and mountainous regions, occurring even in high mountains.

Water Voles resemble Moles, Muskrats and other aquatic Rodents, in many respects in their habits. The burrows dug by the Vole near the water are alof the typical form being 
that the soil seems to be raised in the digging process, and the upper covering of the tunnel consists of a layer of earth only about an inch thick. Such tunnels are very often destroyed by accident and made impassable; but the Vole is tireless in its work of repairing, even if it has to do the sane work over several times a day. The tumnels may easily be distinguished from those of the Mole, as the hills are more irregular, are composed of larger lumps of earth, do not lie in straight lines relatively to one another and are never open at the apex. In these burrows the Schermice live in couples, but these couples exhibit a tendency to seek locations in the vicinity of others thus mated. The Schermouse is not possessed of great running powers, but it is an excellent digger and swims remarkably well, though not so well as the IVater Shrew. In secluded localities one sees it active by day and night; it is a wary creature, however, and retires into its hole when it notices the presence of an observer. It can be easily watched only when it roams among the reeds. In the park in Leipzig, the Water Voles have become so accustomed to human presence, however, that one can observe them with the greatest ease at any hour of the day, if he brings food for them. A bridge has been built over the narrowest part of the park pond and under this bridge they have taken up their abode; they swim back and forth quite fearlessly, approaching when the children passing or standing on the bridge, throw pieces of bread to them. Probably these morsels were originally intended for fish and Swans, but they attracted the IVater Voles; the nimble swimmers, however, uswally succeeded in catching them, and now they receive them on their own account.

Among the perceptive faculties of the Water Vole

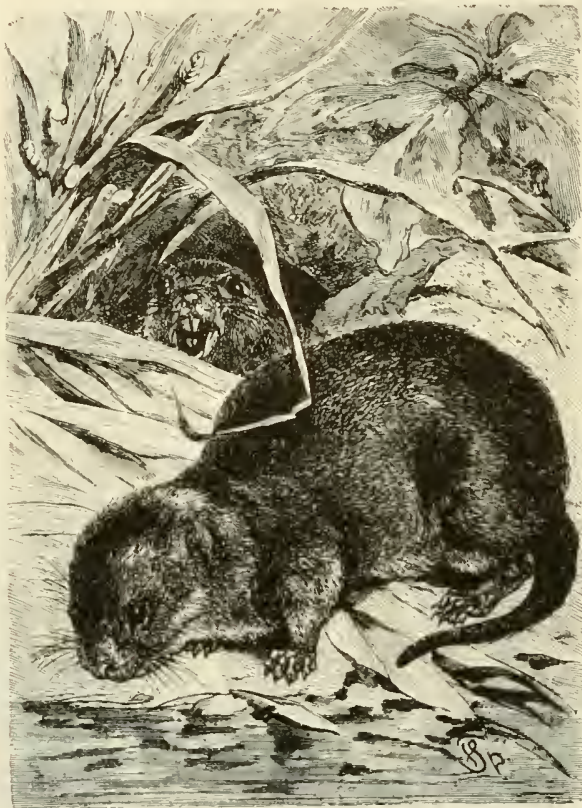

WATER VOLE.-This animal, which is usually known in Eng land as the Water Rat, is found over a very large part of Europe and Asia, and is very mischievous both in the water, where it destroys dams, and in gardens. (Aricola amphibiu.) to soak by tanners, etc. In autumn they enlarge their habitations by building a store-room which is connected with the old nest by tunnels. The storeroom is filled with peas, beans, onions and potatoes from the neighboring fields and gardens and on this they subsist during late autumn and spring or as long as the weather is mild. It is only when the cold is intense that they fall asleep without becoming algid, however.

The fecundity of the Water Voles and Schermice is considerable. Three or four times a year from two to seven young are to be found in the underground warm and soft nest, individuals of various colors sometimes forming one litter. Sometimes their nests are built in a thick shrub, immediately above the surface of the earth and sometimes they are placed on the ground between reeds.

Water Voles The IVater Incapable of Do. Vole is not mestication. suited for confinement. It is rather delicate in its constitution and therefore requires careful attention and its disposition is such that it never becomes really tame.

The Snow Mouse High up in an Inhabitant the Alps, far of the Alps. beyond the limits of other animal life, there exists a second variety of this species, defying the severity of all seasons and never even temporarily seeking shelter in openings in the earth after the fashion of other Rodents in winter. We know as yet nothing of a reliable nature about it, and notwithstanding the fact that the ablest naturalists have tried to obtain an insight into its life, the inhospitable climate of its native country puts too many obstacles in the way of observation.

Physical Charac. The Snow teristics of the Mouse (ArSnow Mouse. vicolar mizin(is) is a rather small creature, the total length being seven inches, of which the sight and hearing seem to be the senses most excellently developed. Its intellectual attributes are superior to those of the Rats. It is inquisitive but rather impassive and fairly good-natured.

Its food is largely of a vegetable nature, and from this fact its presence sometimes becomes extremely harmful to MIan especially if it takes up its abode in gardens. In ponds the IVater Voles are much less destructive, except for the fact that they dig through dams and in this way inadvertently give the water an outlet. In the water they feed mainly on reed stems. But while prefcrring a vegetable diet they do not refuse animal food. In the water, insects and their larvæ, small Frogs, fish and Shrimps form the principal portions of their meals; on the ground they prey upon the various species of smaller Mice, steal the eggs of birds hatching in the grass, and sometimes eat large pieces off animal skins, put out body occupies nearly five inches, the tail not quite two and one-half. Its fur is parti-colored; the upper surface is light brownish gray, the middle of the back being darker than the flanks. The under parts are grayish white and the line of demarcation is fairly sharp. Well-defined variations also occur.

The Bank Vole - The Bank Vole (Aricola glarcolus) Its Home and is a small animal, the body of which Habits. is two inches in length, while its tail is nearly two inches long. It is parti-colored, the upper surface being brownish red, dashed with gray at the hips and the under parts and feet are white, the colors being separated by a sharp line of demarcation.

It is generally found in forests or on-their outskirts, among shrubbery or in groves or park-like gardens. It is known in Hungary, Croatia, Moldavia and Russia. Its diet is more of an animal than 
of a vegetable character, as it mainly subsists on insects and worms and in a wild state may occasionally catch a small bird. When in a state of captivity it is partial to an animal diet. It also eats corn, seeds and bulbous roots and the bark of young trees, especially in winter. When the species is numerous in a forest it can cause untold damage by gnawing the bark of young shoots and it sometimes completely destroys an immense number of newly planted trees. It rarely wanders far away from its forest home but will occasionally visit neighboring fields and there causes great damage after the manner of others of its family.

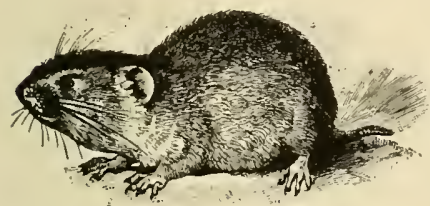

It bears confinement and becomes tolerably tame in a short time. It generally lives peaceably when associated with othRED-BACKED JEADOW Mtouse (Evotomys gapperi.) ers of its own or allied species.

The Red-backed Meadow Mouse (Exotomys gapperi) is the representative of a distinct sub-family of the Poles distinguished from all the other Arvicoles by peculiarities of dentition and cranial development. It is the American congener of the Bank Vole to which it is closely allied. In fact, it is held by several authorities that the Red-backed Meadow Nouse and the Bank Vole are both southern climatic offshoots of a still more northern species, the Red Vole (Arvicola rutilus) which is an inhabitant of northern Europe, Siberia and arctic America.

Field Vole or The Field Vole or Short Tailed Field short Tailed Field Mouse (Arvicola agrestis) is the repMouse. resentative of a distinct sub-species. Its fur is two-colored; the upper parts are dark brownish gray, the flanks somewhat lighter, the abdomen and feet grayish white; the tail is also dark brown above and grayish white below.

The Field Vole inhabits the northern portions of the Old World: Scandinavia, Denmark, Great Britain, northern Germany and France; it usually lives in shrubs, woods, edges of woods, ditches, on dams, etc., but only in localities where there is plenty of water, sometimes co-existing with allied species. Its diet is mainly vegetable. Its movements are so slow and clumsy that one can easily catch it. It is not shy or timorous, but often appears at the entrance of its hole in broad daylight. Its round nest is constructed just below the surface of the earth but is strongly protected from collapse or caving from above by thick tufts of grass and similar materials. Three or four times a year litters containing from four to seven young are born. The offspring grow rapidly and from their birth greatly resemble their parents in appearance and characteristics. They can easily be kept in confinement.

American Species In the United States are very many species of the Field of this family of Rodents related to the Voles. Field Voles, and the Meadow Mice of North this country as are the Voles in Europe. All of the American Arvicolidæ, except the Muskrat, are diminutive creatures, in size comparing most aptly with the Mice proper, but showing marked differences from the latter by their short limbs, short tail, stout form and blunt muzzle.

The American Meadow Mouse (Aricola riparius) is the most common species in this country, and has many local varieties, covering nearly all parts of North Anerica, and is especially plentiful in all of the region from Virginia north to the Hudson Bay country. It is found in many modifications of color and markings, about twenty-five varieties having been distinguished and described by naturalists. The Pine Iouse of the southern states is a near relative of the northern Meadow House, but has a smoother coat and is more highly colored.

\section{THE FIELD MICE PROPER.}

The Field Mice proper, which occur in Europe and northern Asia in several varieties, differ from the preceding species mainly in their dentition. In central Europe there are two kinds of true Field Mice and two kinds of Meadow Mice, one of each variety, not heretofore mentioned, deserving to be described at greater length.

Characteristics The most important member of the

of the Cam. sub-species is the Field Mouse, usupagnol. ally distinguished from the other variety by the name Campagnol (Arricola arialis), the total length of which is nearly six inches. The body is four and one-half inches long, the tail a little over one inch. The fur is indistinctly particolored, the upper parts being yellowish gray, lighter on the flanks, and rusty white on the under parts; the feet are more purely white.

All of central and part of northern Europe, as well as the western part of central and northern Asia, are included in the native country of this small creature, which is of so great importance in the domestic economy of Man. It frequents alike the plain and the mountain, though it is more common in the lowlands. In the Alps it is found at elevations 6,000 feet above the sea. It delights in treeless regions, fields and meadows. It is more rarely met with on the outskirts of forests or in lonely glades; and not only in dry, cultivated land but also in damp, marshy regions. In wet localities it makes its nests with a network of tunnels and runways on the dry tussocks and clods of peat, but in dry situations it builds shallow tunnels with from four to six entrances, connected on the outside by downtrodden, deepened paths. In autumn it retreats under corn ricks or into houses, barns, stables and cellars. In houses it prefers cellars to attics, thereby differing from the true Mice. In winter it digs long tunnels under the snow. Wherever it can, it lays by provisions, consisting principally of corn and seeds; in times of scarcity it emigrates in large bodies, usually going only to a neighboring field, but sometimes it wanders from one locality to another in great numbers, crossing mountain ridges and wide rivers. It is a good runner and an excellent sw im mer, bu t climbs little and a w kwardly. In digging it is an expert. It burrows more quichly than any other Mouse and seems to be tireless in making nests. Its

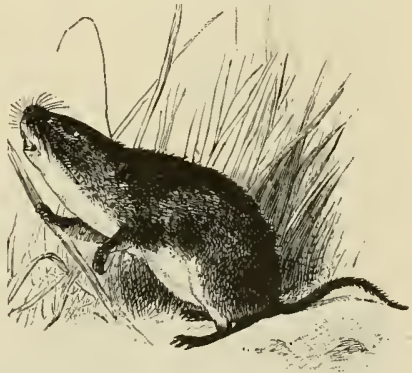

American Meadow Mouse. (Aricola riparius.) habits partake equally of daily and nightly activity. One may see it abroad in the hottest sunshine, though it seems to prefer morning and evening to the hot noontide. A warm and dry temperature are essential conditions for its well-being: continued restriction to damp localities is fatal to it.

$\begin{array}{cl}\text { The Diet of It feeds on all kinds of vegetable } \\ \text { the Cam- } & \text { substances. If it has seeds at its } \\ \text { pagnol. } & \text { disposal it confines its selection to }\end{array}$ them; otherwise it contents itself with fresh grass and herbs, roots, clover, fruit and berries. It com- 
mits great depredations on beech secds and nuts, grains, turnips and potatoes. During the severest cold of winter seasons it hibernates intermittently; in mild weather it awakes and feeds on its provisions. It is remarkably voracious and requires a great deal of food before it is satisfied. It cannot abstain from water.

The Social The Campagnol has the social inInstinct of the stinct highly developed and lives Campagnol. quite peacefully with others of its own kind, the mated couples congregating in large numbers and digging their burrows side by side. Its fruitfulness in the propagation of its species is extremely great, and it may thus become the cause of great damage.

"In favorable circumstances," says Blasius, "the Campagnols increase in a marvelous manner. There are many cases on record where their excessive multiplication has resulted in the destruction of a great part of the harvest over a large extent of country, and where young beech plantations have been ruined on more than a thousand acres by the animals gnawing off the bark. In the second decade of the present century this plague occurred repeatedly on the lower Rhine."

Inadequacy
of Attempts to

of Attempts to
Exterminate.

Unfortunatcly Man is utterly powerless to resist these Mice. All means of extermination, which have so far been devised, appear insufficient in the face of the enormous multiplication of those voracious hordes; only epidemics, breaking out among them and to a certain extent also among the beasts of prey, which in common with the Mice are objects of relentless persecution at the hands of Man, can remedy the evil. The devices for their destruction are numerous. Among others is a kind of earth auger or post hole digger with which one bores holes in the ground, from five to seven inches in diameter and twentyfour inches deep, the result being that the Mice which fall into them devour each other, never attempting to dig tunnels and in this way escape. The annoyed agriculturist throws poisoned grains into their burrows, drives smoke into them, or sprinkles whole fields with a decoction of nux vomica or eupliorbia; in short, he resorts to every expedient to get rid of the abominable plague; but usually all efforts are in vain and some of the methods cmployed (especially that of using poison) are highly dangerous even to human life. The most effective poison fails to destroy all the Campagnols of a field, but may cause the unintended deatl of their relentless enemies - and conscquently our friends-Foxes, Stoats, IVeasels, Buzzards, Polccats, Owls, Crows, to say nothing of the Partridges, Hares and domestic animals, from the Pigeon upwards to the Cow or Horse which may fall victims. This fact alone should be sufficient to induce the utter cessation of the practice of laying out poisons in places accessible to any other animals than those aimed at.

$\begin{array}{cl}\text { The Root } & \text { In Siberia, from the Ob to the Onon, } \\ \text { Vole of Si- } & \text { there exists an Arvicole, which is } \\ \text { beria. } & \text { also worthy of notice, though for }\end{array}$ reasons different from those entitling the Campagnol to notice; it is the Root Vole (Aricicola aconomus). It is somewhat larger than the Field Nouse, being seven inches long, the tail occupying two inches of this length. It is of a light yellowish gray tint above and gray below. It is distinguished from the Ficld Mouse by its shorter head, smaller eyes and short ears, nearly buried in the fur.
Habits

of the Root Vole.

The Root Vole is sometimes found in great numbers in plains and is deemed a benefactor by the inluabitants of those desolate, solitary regions; for it works for the benefit of mankind instead of for its damage. It digs long tunnels under the sod, which lead to a large, round nest, twelve inches in diameter. The nest does not lie very deep underground and is connected with several very spacious siore-rooms; it is softly lined with various kinds of vegetable substances and serves as both couch and nursery; the store-rooms are filled with various roots.

The uncivilized, nomad tribes, who are not given to agricultural pursuits, dig up the treasured stores of the Vole in autumn, when the store-rooms are filled, reject the white roots (which have benumbing properties) and keep the black roots of the meadowbutton, which they use not only as an article of diet but also as a tea. These provisions, taken from the Mice, often last the poor country-folk all through the winter; what is left is given to the wild P'igs, and if a Mouse happens to be taken along with a bundle of the roots it too is eaten as well as the food.

The Vole's Fond. A remarkable trait of this and allied ness for species of Arvicolida is their fondTravel. ness for change of habitation. To the grief of the natives they set out on their migrations in the spring of some years and go westward in hordes, always pushing straight ahead, over rivers and mountains. Thousands of them are drowned and devoured by fish and Ducks, and other thousands are eaten by the Foxes and Sables which alway's accompany these armies.

\section{THE LEMMINGS.}

The Lcmmings (Myodes) are, among the Arvicoles, what the llamsters are among the true Mice, in shape and character: they are the nembers of the family having specially vigorous organization. Short, stumpy tails are their most notable phy'sical characteristic. The head is large in relation to the body and thickly grown with hair; the upper lip is deeply cleft, the roundish ear is small and completely hidden by the fur; the eyes are small. The feet are provided with five toes and even the soles arc fur-clad, and the fore fect in particular are armed with large, strong claws well adaptcd for digging.

Appearance of The typical form of the variety, the the Lem- Lemming (Nyodes lemmus, Limmus ming. noriegricus), attains a total length of six inches, some three-fourths of an inch being included in the little stubby tail. The rich, long fur is marked in a manner very agrecable to the cye of the beholder. The ground color is a brownish yellow, having wavy, shimmering lights on the nape of the ncck, and relieved witl darker spots; two yellow bands run from the eyes to the back of the head. Tail and paws are yellow, and the under parts are also of a plain yellow, nearly sandy color.

An Object of The Lcmming is in many respects

Scientific Per- without doubt the most perpiexing plexity. and mysterious of all Scandinavian animals. The peasants of the mountains believe, despite the civilization of the present day, that it rains down from heaven, thereby explaining its appearance at times in such extraordinary numbers. As an offset to this, and accounting for the'great depletion which often takes place among them, the animals are said to fatally impair their digestion by their voracity, and thus perish. Olaus Magnus says that he saw a grcat many Stoats in the forest in 1518 , the 
animals filling the whole wood with their stench. The cause of this assemblage were four-footed little creatures, called Lemars, which occasionally dropped from heaven during a sudden thunderstorm and rain; whether they had been wafted from distant parts to the place of their discharge to the earth or degree of fear, and if one throws them into a large vessel of water or into a small stream they squeak and growl very angrily and try to regain the dry land as soon as possible. They often betray themselves, for trequently; as they sit in their holes so well hidden that they certainly would not be

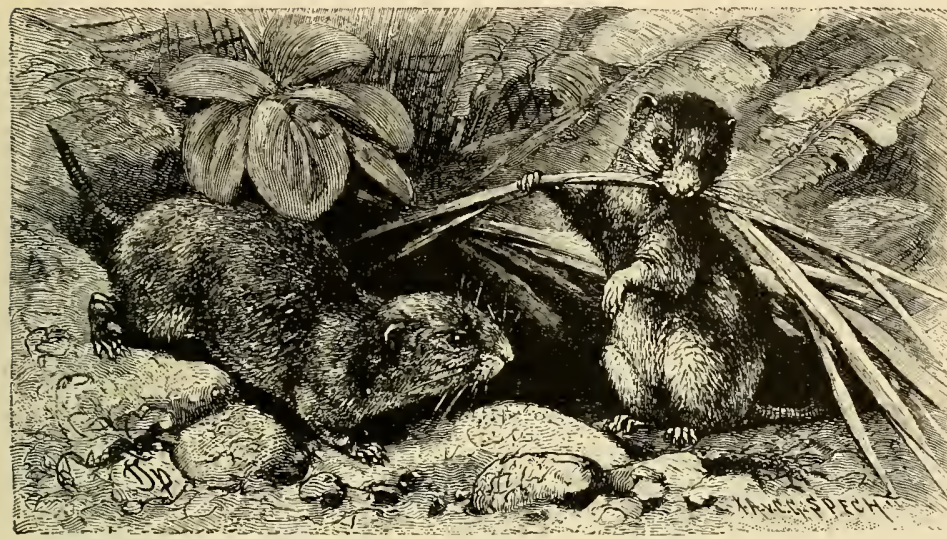

FIELD MOUSE OR CAMPAGNOL. The little Rodents so amusingly depicted in this illustration are so numerous in many parts of Europe and Asia that they work sad havoc in the fields, and frequently destroy a large part of the crops. (Ar

produced in the clouds, was not known. Other authors simply copy the account of the bishop, and Linnzeus was the first who truly described the Lemming (in his Swedish treatise of 1740 ) according to nature and with so many details that there is very little to add to his description. I had the pleasure myself of encountering a great many Lemmings in IS6o especially on the Dovenfjeld, and so have been able to become familiar with them by my own experience.

The Lemming a The aniCharming mals are Animal.

charming

little creatures. They look like small Marmots or Hamsters, resembling the latter particularly in their habits. They take up their abode in the less moist portions of the marshes which cover so large a part of Norway. There they domesticate in small hollows under stones or in the moss; and they may often be seen roaming between the little hillocks which rise out of the swamp. One seldom sees beaten paths extending from one of their holes to an-

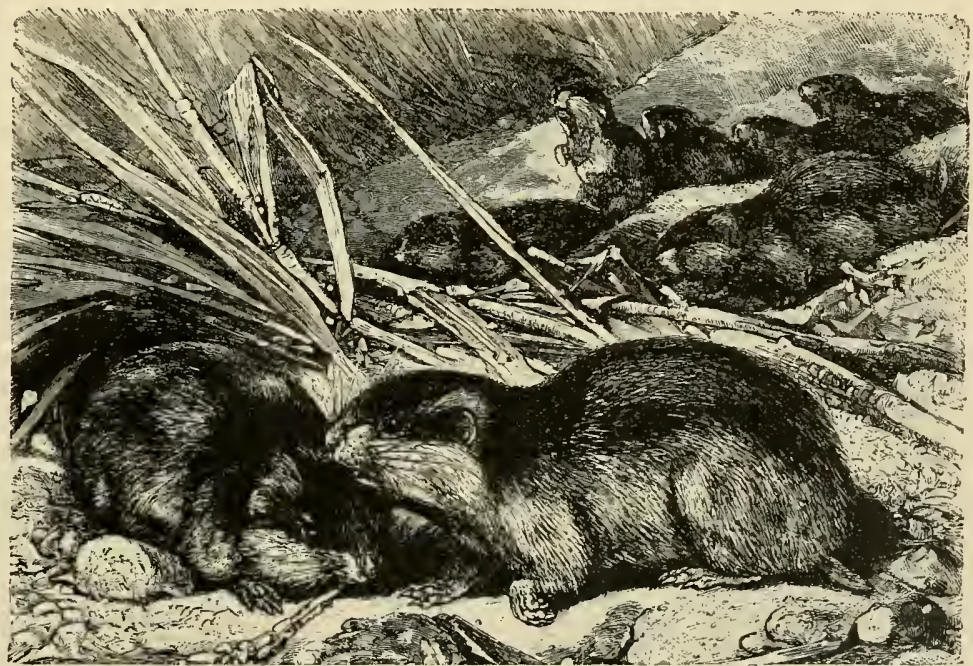

THE LEMMINGS.- Overrunning northern Europe, and sometumes undertaking great migrations in large companies, the Lemmings are among the most interesting of Rodents. They are shown in the picture engaged on one of their journeys, although those in the foreground are picking up a meal on their way. (MIyodes lemmus.) noticed by a passer-by, the appearance of a human being excites them to such main silent. A loud grunting and squeaking, fter the fashion of Guinea into their dom in they wished to forbid his treading on their ground. It is only when they are abroad that they flee from human approach, hurrying to one of their innumerable holes, and secreting themselves in it. Once in there they stay, not stirring or trying to escape, but leaving it to fate, as to whether or not they will be killed or taken away.

The courageous little fellows furnished me coniderable amusement. I never could help provoking them. Once they are driven to bay, they never think of surrender. If a boot be held out to one of them, the animal will bite into it, as it would into a stick or a gun, even though it sees that the latter proceeding avails it nothing. Some Lemmings on one a degree that they can not other; permanent passages are used by them only to avoid wandering through unbroken snow during the winter. They are lively and active during both day and night. Their usual method of locomotion is a rapid tripping walk, though Man can easily outrun and capture them. Water they shun with a certain occasion fastened upon my trousers, so that I could hardly shake them off. Fighting throws them into a great fury, and then they resemble fierce Hamsters. Sometimes they spring up to their antagonist with short leaps, and in general they seem to be afraid of no animal whatever, but offer battle to any 
and every creature in a foolhardy way. Many are run over in the streets by carriages, as they defiantly put themselves in the roadway and do not move. The Dogs on farms kill a great number of them and the Cats probably eat so many that they are never hungry.

Propagation of According to the assurances of my the Lem- old hunting companion, the young ming. are born in the holes in which they in maturer years continue to live. Linnaus says that the animals mostly bear from five to six young at a birth, and Schaffer adds that they have several litters a year. No further particulars as to their propagation are known to me.

The Food of The principal foods of the Lemmings the Lem- are the few mountain plants which ming. thrive in their sterile native country, especially grasses, Reindeer lichen, the buds of the smooth dwarf-birch, and probably also various roots. Lemmings are found as high as lichens grow, and are absent where these are lacking. As far as 1 have been able to discover they do not lay by stores of food for winter, but even then subsist on what they find under the snow. They do not cause any damage, worth mentioning, to Man, for there are no cultivated fields where they live, and they do not enter human habitations. Their native country, sterile and barren as it may appear, is fertile and productive enough to meet their wants, however, and generally supplies them with all they need. In some years, however, this does not seem to be the case; then the Lemmings are obliged to migrate.

Reasons for My opinion is that the cause of such Migration of Lem- migrations must be a temporary lack mings.

of food, brought about by a peculiar combination of circumstances, as happens sometimes with other Arvicolidae. When a mild winter is followed by a good spring and a dry summer, all conditions are fulfilled for a propagation of the species which, like that of some other Arvicolida, may in point of numbers be termed an unlimited one. At the same time the dry weather favors a drying up or at least a stunting of the growth of the principal nourishing plants; when this occurs the diminished pasturage can not satisfy the needs of the hosts of these creatures, voracious like all Rodents, and they are compelled to look for food elsewhere. It is a known fact, that in similar conditions not only Rodents make common cause and troop together, but also other vegetable feeding animals, as for instance Antelopes; they migrate, are joined by others of their kind on the way, and ultimately wander along in an apparently aimless manner, as they neither follow a given direction nor bend their course toward such localitics as will really afford them something to eat. Only after hundreds of thousands have perished from hunger, disease and the fatigue and casualties of traveling, the survivors again try to gain those heights which are their real abode, and then it may happen that instinct resumes its deserted throne and they push on in a straight line. Taking all this in consideration, the migrations of the Lemmings do not strike me as at all more wonderful or less explicable than those of other wandering Mammalia, especially of other Arvicolidx.

The Migration

Fortunate

for Man.

It certainly is fortunate that the creatures have so many natural foes and perish in such immense $10 \mathrm{~mm}$ bers on their journeys; else they would overrun the whole country, and devour everything catable. The climate doubtless is the most effective exterminator of these animals. A wet summer, or a cold, early, snowless autumn kills millions of them, and it is evident that several years are then required to repair the havoc made in their ranks, which in its effects resembles the ravages of an irresistible epidemic. Besides this, an almost countless number of living foes pursue the Lemmings. One may really say that in Scandinavia all species of beasts of prey grow fat on them. Wolves and Foxes follow them for miles and eat nothing else, when Lemmings are to be had; the Wolverine, Polecat, Marten and Ermine hunt no other prey during the Lemming season; the Dogs of the Laplanders, ever hungry beasts that they are, consider a Lemming year a festal season such as is seldom provided for thenı; the Owls follow the migrating hosts; the Buzzards are tireless in their efforts to exterminate these hapless creatures; Ravens feed their young on them and Crows and Magpies also do their best to kill the biting little beasts; even the Reindeer are said occasionally to eat Lemmings, or at least to kill them by stamping upon them with their forc-hoofs.

The Lemming Man attacks the Lemmings only Economically when compelled by the utmost necesUseless. sity. The skin is not worth much and, as is easily conceived, the idea of eating their flesh inspires the natives of the countries they infest with much the same feelings that the thought of a diet of Rat's flesh does us. The Laplanders are frequently driven by hunger to eat the Lemmings, however.

The Lemming A little animal of the United States and
Vole of North Canada, extending from the Ohio Valley to
America. Alaska, is the Lemming Vole or Cooper's
Much resembles the ordinary Field Noopse, but which in its
entition resembles the Lemming so closely as to cause it to
e classified with the latter animal. It makes its home in
elds or grassy plains and woods.

\section{Tbe SMolc Rats.}

\section{SEVENTH FAMILY: SPALACIDE.}

The family of the Mole Rats (Spalacide) consists of ill-shaped, ugly Rodents, which lead subterraneous lives. Reminding one of the Moles, they possess all the disagreeable qualities of the latter but not their useful ones. The body is clumsy and of cylindrical shape, the head is thick and the muzzle blunt; the eyes are exceedingly minute or are entirely hidden under folds of the external skin; the diminutive ears are deprived of an external conch; the tail is either wanting or hidden in the fur. The more prominent anatomical features are the nearly uniformily developed, five-toed feet; as is the case with the Moles, the fore pair are the stronger, and all four paws are armed with very strong claws, well adapted for digging.

The Mole Rats All Mole Rats belong to the Old Peculiar to the WVorld. They generally inhabit dry, old World. sandy plains and dig long, shallow tunnels across extensive tracts of ground, after the manner of Moles. None of the various species are gregarious; each individual lives alone in its burrow and exhibits the sullen, solitary disposition of the Mole. They dig with extraordinary rapidity, some of them being able to descend in even a perpendicular direction. Above the ground they are unwieldy and helpless, but in their subterranean tumnels they 
move forward and backward with nearly equal facility. Their diet is exclusively vegetable, for the most part consisting of roots, tubers and bulbs, which they dig out of the earth; a few of them may in exceptional cases also feed on grass, bark, seeds and nuts. Those that live in cold regions store up winter provisions, but do not hibernate.

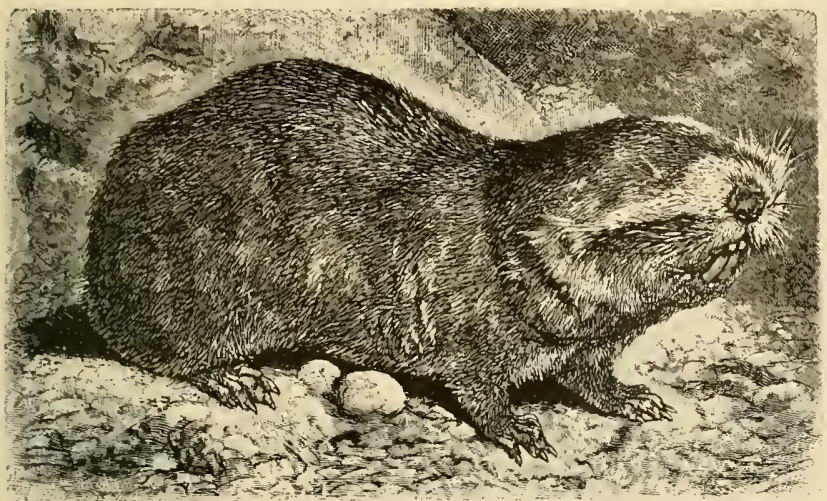

THE MOLE RAT. - The clumsy, almost blind creature, shown in the picture, is the representative of a peculiar deep burrowing family of Rodents. Like the Mole. from which it derives its protruding gnawing teeth are show here. (Spalax typhlus.)

The Common The best known species of the fam-

Mole Rat or ily is the Common Mole Rat or

Slepez. Slepez (Spalax typlilus). The head terminates in a blunt snout and is stouter than the body, while the short, immobile neck is as thick as the tailless body. The short legs terminate in wide paws with strong toes armed with sharp, vigorous claws. The rudimentary eyes are very small, attaining, usually, barely the size of a poppy seed, and lie hidden under folds of the shin so that they are practically useless for purposes of sight. The length of the body is eight inches. Large and powerful gnawing teetl project far beyond the mouth. All the toes of the feet are strong and provided with vigorous claws for digging. The tail is rudimentary, its position being indicated by a slightly protruding wart. The body is clothed in a copious, close, soft fur; rigid, bristly hairs cover the sides of the head from the nostrils to the eyes, and form a brush-like crest. The

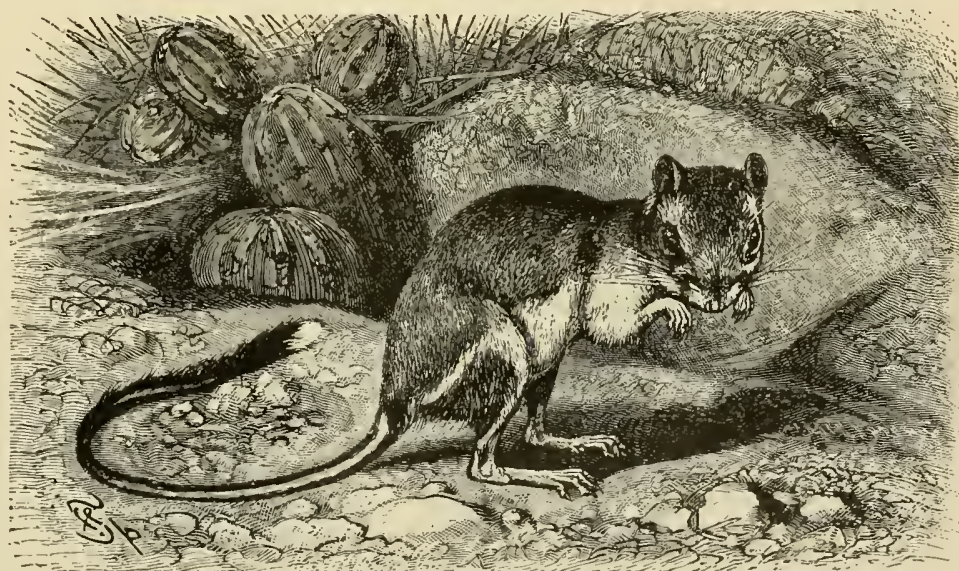

ORD'S POCKET MOUSE. This is the typical animal of the exclusively American family of the Pocket Mice. Its long hind legs, short fore-feet and long-tufted tail remind us of the Jerboas, but its fur lined check pouch form almost the sole vegetation. (Dipodomys philiptiz.) not exclusively, on vegetable food, the plants upon which it feeds put forth decp-reaching tap roots, it sinks tunnels to conground in winter; but if it finds its food nearer the surface, it digs its sluallow passages just below the now. Provisions for winter have not yet been general color is a yellowish brown, tinged with ashy gray; the under parts are of dark ashy gray hue, relieved with white longitudinal stripes on the lower portions of the abdomen, and small, white spots between the hind legs.

The Mole Rat is a native of southeastern Europe and western Asia, principally of southern Russia near found stored in its tunnels, but in many instances nests have been discovered built from the finest of roots. In such a nest from two to four young Mole Rats make their appearance in summer. On the whole the creature does little damage to the possessions of Man; but, on the other hand, its existence does not afford the human species any benefit. 


\section{Tla IDocket SiDicc.}

EIGHTH FAMILY: SACCOMYID.E.

Leaving the Mole Rats we may pass to the consideration of a family, indigenous to North and Central Amcrica, the Pucket Nice (Saccomyide). This division contains Rodents, possessing great diversities in shape, some being graceful and good-looking, others again having an ungainly appearance, and all being little known in respect to cliaracter and habits. They differ from all others by the possession of cheek pouches of variable length or depth, opening externally and lined with fur on the inside. The presence of this inner coat of fur in the cheek pouches suffices to distinguish these species of the order from all their relatives. The external fur of the animal consists of only one wiry or stiff-haired coat.

\section{THE POCKET MICE PROPER.}

The first and typical sub-family commonly bears the name of Pocket Mice (Saccomyina;) their bodies are slender and graceful, the hind legs are elongated, the tail long and the muzzle pointed. Of this subfamily the Dipodomys constitute the most prominent variety. They bear a resemblance to the Jerboas in their outward form; the head is large, wide and flat, the ears rounded, the innermost toe of each foot is rudimentary but armed with a claw; the tail is as long as, or longer than, the body, is fur-clad and terminates in a tuft, the hind legs are distinguished by their length; the teeth contain among their number rootless molars.

Ord's

Pocket Mouse

Described.

Among the few varietics that have so far been differentiated in this species, Ord's Pocket Mouse (Dipodomys philippii) is known best. Its total length is about twelve inches, nearly seven of which are included in the tail; the female is in length nearly an inch shorter than the male. The color is similar to that of the True Jerboas, head and ears, back and thighs are light brown; along the under surface and the flanks and crossing the thighs a stripe of white extends to the root of the tail, as does another from the ears to the shoulders. The tip of the tail is also white; on the sides of the body the white merges into a yellowish tint.

This prettily colored and lively little creature is found in California and from thence east to the Rocky Mountains and south to Mcxico, where it lives in the most solitary and desolate regions, in localities of a desert-like character, sparsely grown with gigantic, wonderfully-shaped cacti. The short description of its habits, which Audubon gives, shows that its traits and character correspond with those of the Jerboas in many respects. It emerges from its hole at dusk only, and trips about amidst the stones, neither knowing nor fearing Wan. In the arid regions which compose its domain, scarcely. a living creature is to be found, exccpt a great many Lizards and Snakes, and hence the question often ariscs in onc's mind, how it is possible for a mammal to cxist there. Most probably Ord's Pocket Mouse subsists also on seeds, roots and grasses, and can go without drinking water for a considerable length of time, like the Jerboas of the desert, or it may be that it contents itself with the tiny dewdrops which are condensed on some of the plants during the night. Authoricative information as to its manner of propagation and habits of life when iil confinement arc still wanting.

\section{Other Species of Pocket Mice.}

This family of Mice with cheek pouches or pockets situated entirely outsicle then nouths includes several other genera, but none which have such elongated hind limbs as thuse which characterize ()rd's Pocket Mouse. These Rudents are called Pocket. Mice, Kangaroo Rats and various other lical names, without much distinction of species by ordinary observers, although science divides them into two genera, each with several species. Of these Perognathus, with three species, show little if any elougation of the hind limbs, the soles of the paws have little hair or are bare and the fur is harsh and coarse. One species (Perognathus penicillatus), which is found in New .lexico, trizona and adjoining states, is about the size of the Common Wlouse, but has a long, tufted tail. A much larger species (Perognathus fasciatus) is about the size of a Chipmunk, is of more ponderous build and has a shorter, tuftless tail. The third species (Perognathus hispidus) is in size intermediate between the other two species and has coarser hair than either of them.

Least Pocket The third genera of this sub-family comMice, Diminutive prises what have been appropriately called Species. These little animals are not quite two inches long, exclusive of the tail, which is of the same length as the body and head together. The hind limbs are longer than the fore legs, though the disparity is not so great as in Ord's Pocket llouse, but the character of their movements is such that thev are known in some localities as Hopping Mice. The typical animal of this species is Crictodipus flavus, which has a soft, silky fur of yellowish red on the upper portion, fading to a fawn colored band along the sides as a dividing line between the ruddy fur of the back and the white of the under portion and legs. There are other species of this group, one of which is scientifically known as Cricetodipus parius. They all live in the West, from Mexico to Canada, and from the Mississipji river to the Pacific coast.

An allied but little known genera of this sub-family is found in the Prickly Pocket Mice (Heteromys) which are found in Mexico, Central America and the West Indies, of which there are several species. These are of stouter build and have spines mingled with their harsh fur.

\section{THE GOPHERS.}

The Gophers (Geomy's) show a furrow in the middle of their upper incisors and their ears are rudimentary. Of the many varieties which recently have been differentiated and classified, the best known may serve us as a typical example.

The Pouched The Pouched Gopher (Giomys bursa-

Gophera vius), is somewhat smaller than a

Type. European Hamster, being fourteen inches long, inclusive of the tail, which measures two and one-half inches. The fur is exceedingly thickset and of a fine, soft texture, reddish on the upper surface and yellowish gray below; the tail and the feet, which show but a scanty covering of hair, have a whitish hue. The name of Gopher is applied in some American localities to various other widely variant Rodents.

Faulty Represen. The zoologists, who first described

tations of the the Gopher, obtaincd their speciGopher. mens from Indians, who had amused themselves by cramming both cheek pouches of the animal full of earth, distending them to such a degree that if the animal had walked the pouches would have trailed on the earth. These artificially: distended pouches obtained for the Gopher its name; the taxidermists who prepared the dead specimens endeavored to give them what was supposed to be a life-like appearance by following the practice of the Indians in distending the cheek pouches, and the artists who delineated the animal followed the models which were accessible to them but too truly in their drawings. Owing to these circumstances, the pictures of Gophers of even recent date represent really monstrous animals, when they honestly intend to familiarize us with the Gopher.

The Gopher is distributed over the country to the east of the Rocky Mountains and to the west of 
the Mississippi, between the thirty-fourth and fiftysecond parallel of north latitude. It leads an underground life, exactly similar to that of the Mole, digging numerous, complicated tunncls in various and most erratic directions and throwing up heaps of earth, resembling Mole's hills.

Tunnels of old standing are packed hard and firm from constant use, while newer ones are not. Lateral passages branch off at intervals. The main chamber is situated under the roots of a tree at a depth of about four and one-half feet; the entrance tunnel is sunk down to it with a spiral direction.

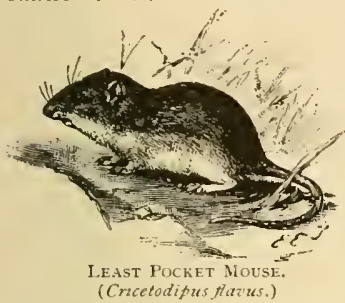

This chamber is of great dimensions, lined throughout with soft grass, not unlike a Squirrel's nest, and serves the animal as a resting and sleeping place. The nest in which the young, numbering from five to seven in each litter, are born about the end of March or beginning of April, is much like the described chamber, but it is lined with the hair of the mother. Like the Mole's nest, it is also surrounded by circular passages from which the tunnels radiate. Gesner found that a passage leads from the nest to a larger hole, the store-room, which is usually filled with roots, potatoes, nuts and seeds. The Gopher works most diligently at the excavation and enlarging of its habitation in the morning hours from four to ten, undoubtedly with the intention of obtaining roots. If the locality has an abundant supply of food, from three to five yards of burrow may be excavated in this time and from two to five mounds are thrown up, but if food be scanty the animal digs for a greater distance and works for a longer time. Sometimes it suspends its work for weeks, apparently subsisting on its stored-up provisions at such times. When throwing up the earth, which it does in a manner resembling that of the Mole, the Gopher exposes itself to view as little as possible and inmediately after accomplishing its purpose, plunges back into the hole. It appears above ground to gather dry grass for its living-room or nest, and also, according to Audubon, to bask in the sun. Its acute sense of hearing and excellent power of scent protect it from surprises; when it apprehends danger it instantly rushes underground, even if it has to secure its retreat by sinking a new shaft.

Peculiari- On the surface of the ground the
ties of the Gopher liobbles along in a clumsy
Gopher. fast as a Man's walk. While eating it often sits on its haunches and uses its fore-paws after the manner of Squirrels. When sleeping, it curls up and reposes its head on the chest, between its fore legs. It fills its cheek pouches, which are of dimensions to excite astonishment in the mind of une unacquainted with the animal, by using its tongue in the process of deposition while grazing, and empties them with its fore paws. As is the case with other Rodents, when they become obese their increase of bulk is altogether lateral, and they become broad, measured across the back; in this condition they assume an oblong ovoid shape, never having hanging-down sacks on the sides of the snout nor the body dragging on the earth. The assertion that they use their cheek pouches to remove the excavated earth from their burrows is based wholly on imagination.

The Gopher The damage done by a Gopher may an Enemy of assume considerable proportions. It Man. sometimes destroys liundreds of valuable trees in a few days, by gnawing their roots, and sometimes destroys entire plots of bulbous or tubcrous plants. For this reason Man is arrayed against it and is really its most dangerous enemy, the only other foes it has to fear besides the agriculturist being water and Snakes.

Audubon's Obser. Audubon kept several Gophers in vations of captivity for weeks, feeding them on Gophers. potatoes. They exhibited an exceedingly voracious appetite, but refrained from drinking, though he offered them not only water but also milk. Their efforts to regain their liberty were incessant, consisting in gnawing their way through boxes and doors. They exhibited an extrenely acquisitive disposition, and constantly dragged clothing and all kinds of similar objects together, utilizing them as bedding, suiting them to such purpose by gnawing them to pieces. One of them, straying into a boot, instead of turning back, simply gnawed its way through the tip. This habit

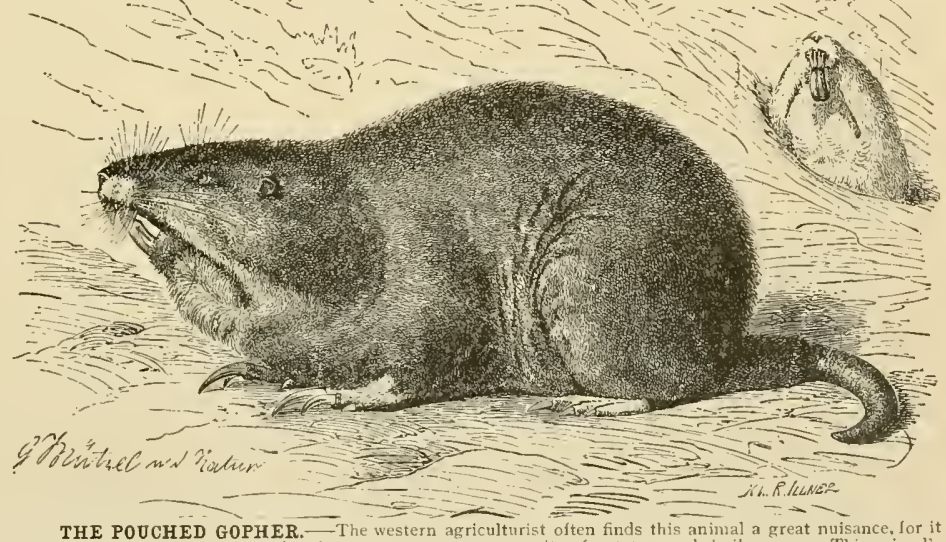
digs up the earth like a Mole, and it destroys an enormous quantity of potatoes and sinilar crops. This animal's digs up the earth like a Mole, and it destroys an enormous quantity of potatoes and similar crops. This animal's
stout, clumsy body, long, strong claws for burrowing and sharp chisel-edged teeth for gnawing, its small ears and tout, clumsy body, long, strong claws for burrowing and sharp chis
lnost bare tail are all well depicted liere. (Geomys bursarizs.) of constantly gnawing, and the noise thereby produced, made the animals unbearable, even to so devoted and self-denying a naturalist as Audubon.

Other Gophers Besides the typical animal just described and Pocket there are the Southern Gorpher or Salaman$\begin{array}{cl}\text { nd Pocket der (Gcomys thaza) which is very much like } \\ \text { Rats. } & \text { the ordinary Pouched Gopher but has its }\end{array}$ tail and feet entirely hare and shows some differences in dentition. It is found in the southern Atlantic states. "Salamander" is its common name in that section, and, curiously enough, the name "Gopher" is there applied to a species of turtle, and in some of the western states various kinds of Spermophiles, or Ground Squirrels, are also erroneously called 
"Gophers." The Chestnut-Cheeked Gopher (Geomys custunops) is a small species, about ten inches long, found in Texas and New Mexico. The fur of this species is soft and glossy. In striking contrast is the harsh, lustreless fur of the Quachil (Geomy's hispidus) of Central America, and the closely allied Mexican Gopher (Geomys mexicanus) both of which are large species about equal in size to the common Pouched Gopher.

Belonging to the same sub-family as the Gophers are the animals known as Pocket Rats (Thomomy's), which differ from the Gophers in having smooth-edged incisors, ears slightly more developed, smaller claws, and relatively larger cheek pouches. The common Pocket Rat (Thomomys talpoides) is about eight inches long, the upper part of the fur varying in color from a gray to a brown or reddish hue. The lower portion is always of lighter tint and quite often white. From the Ilississippi valley west lo California from the Gulf of Mexico to Hudson's Bay these Rodents may he found. Like the Gophers, they are burrowing animals. Other species of Pocket Rats are known, one being the Rocky Iunntain Pocket Kat Thomomys clusius), six inches long, with a tail about one and a quarter inches.

\section{Else Porcupincs.}

\section{NINTH FAMILY: HYSTRICHIDE.}

The Porcupines (Hystriclida) show a much greater development of a defensive coat (its armor being composed of quills) than do other mammals which are simply equipped with bristles. The entire group takes its name from its best known member, and to enable one to recognize any individual, there is not needed a lengthy description of the anatomical peculiarities which characterize the species. The quilis are a common attribute of all animals belonging to the group, though the different species exhibit a great diversity in form.

\section{Range and Habits All Porcu-}

of the Porcu- pines are pines.

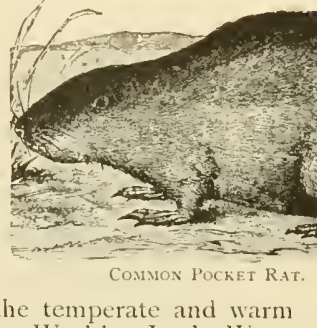
natives of the temperate and warm countries of the Old and New Worlds. In the IV estern Hemisphere one finds the climbing species, in the Eastern the burrowing species predominate. The Old World Porcupines are confined to a life on the ground, and those of the New World to an existence on trees. In accordance with these conditions the former live in thinly grown forests and steppes, hidden during the day in tunnels and holes dug in the hard, compact soil; the latter inhabit extensive forests and pass their hours of retirement curled up in a fork of the branches of a thick treetop, or sitting in a hollow tree trunk. The movements of the species during the day are slow, measured, sluggish. With the advent of night, however, when they have become thoroughly awake, some run along very nimbly on the ground and at a considerable pace, while others climb up and down the branches with considerable agility, although in this respect they do not equal Squirrels. Those inhabiting the ground are most skillful burrowers, and know how to remove all obstructions that the hardness of the ground may occasion. Among their perceptive senses that of the organ of smell seems to be most efficient, the sense of touch being developed to a high degrce in the climbing Porcupines; sight and hearing are more or less deficient in all the species. Their intellectual capacities are on a low plane of intelligence. They are stupid, forgetful, deficient in resources, malicious, violent, shy and timid, though when confronted by an enemy all of them try to intimidate their opponents by erecting their quills and some by producing a rattling noise with the spines on their tails. They are as little inclined to live on amicable terms with creatures of other species as with individuals of their own kind; a choice morsel may provoke a serious quarrel between even male and female. One never sees two Porcupines playing together or engaged in friendly intercourse with each other. They never evince friendship for the keeper who cares for them and apparently never know how to distinguish him from other persons. Their vocal expressions are a dull grunt, a snort, a low moan, or a squeal which is difficult to describe.

$\begin{array}{ll}\text { Food } & \text { The food of the Porcupines consists } \\ \text { the Porcu- } & \text { of all vegetable substances, from } \\ \text { pines. } & \text { roots up to fruit. Nearly all Por- }\end{array}$
cupines seem to be able to abstain from water for a considerable time; probably the dew which is deposited on the leaves, which they eat, is sufficient for their needs.

\section{THE PORCUPINES PROPER.}

The Porcupines proper (Hystrix) are easily recognized by their short, stoutly formed body, their heavy blunt muzzled head set on a stout neck, theis short tail thickly studded with quills, as is the remainder of the body, which is thus incased in a defensive armor of spines developed out of all proportion to the size of the body. Their further characteristics are the small, rould ish ears, the wide upper lips and the cleft between the nostrils.

The Common The Common Porcupine Porcupine c Type. (Hystrix crisThomomys talfuides.)
tions, though not longer than a European Badger, and appears to be much larger than it really is, owing to its cuills. Its length amounts to twentysix inches; the tail measures four and one-half inches, and the height at the shoulder is nine and one-half inches; the weight ranges between thirty and forty pounds. The short, blunt muzzle and the nose are adorned with only a few hairs; the thick upper lip is covered with several rows of lustrous black whisker-hairs and similar bristles grow on small protubcrances above and behind the eyes. Along the neck there is a mane composed of very long, strong, curved quills, slanting when at rest in a backward direction; these may be erected or depressed at will. They are thin and flexible, in part white, in part gray and usually tipped with white. The remainder of the upper surface of the body is overgrown with smooth and sharply pointed bristles of varying lengths, alternately of dark or blackish and white color, implanted but loosely in the skin and thereforc easily pulled out and intermingled in all parts with bristly hairs. On the sides of the body, on the shoulders and near the tail the quills are shorter and blunter than those in the middle of the back. The long and flexible quills attain a length of sixteen inches, while the short, stout ones are only from six to twelve inches long and may be one-fifth of an inch thick. They are all hollow in the middle or else they are filled with a spongelike marrow, the base and tip being mostly white. 


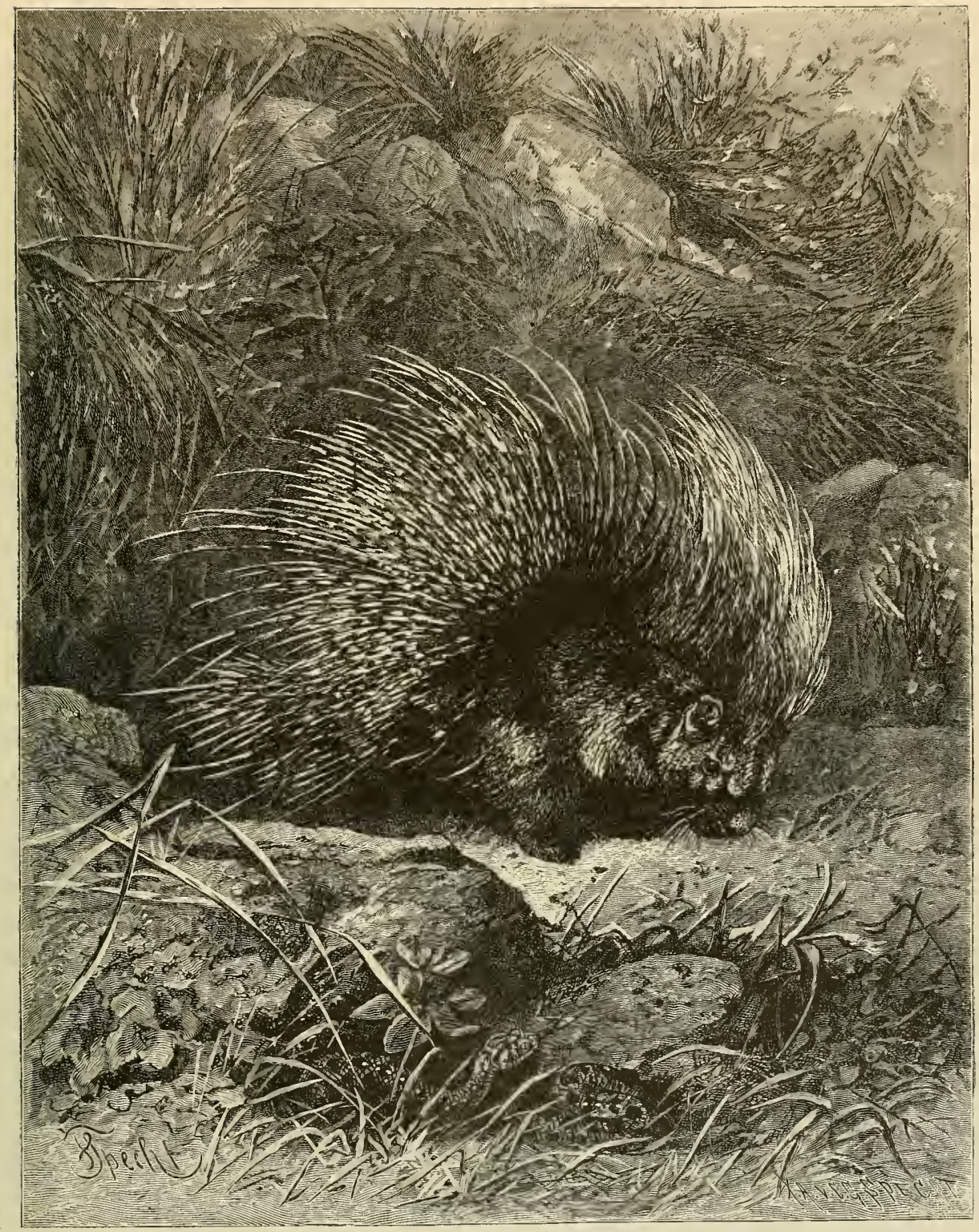

THE COMMON PORCUPINE. - The long spines that clothe this animal have made it known all over the world, although only found in northern Africa and southern Europe. The picture shows a Porcupine with spines erect ready to defend itself. It is very properly shown in arboreal surroundings, and its fighting attitude is doubtjess assumed because of the threatening appearance of the Snake in the foreground. (Hystrix cristata.) 
The shorter quills are blachish brown and ringed, but the base and tip are generally white. The tip of the tail is implanted with quills of a different kind, which are about two inches long and onefourth of an inch thick, and which consist of truncated, thin-walled tubes, with an open extremity resembling the quills of a fowl with their ends cut off, their roots being long, thin and flexible. All the quills of the body may be erected and depressed at pleasure by a large, strong flexor muscle, ramifying bencath the skin of the animal and capable of strong contraction. The under parts of the body are covered with dark brown hair, overshot with a reddish tinge; the throat is encircled by a white band. The claws are darkish, but translucent. The eyes are black.

The European The Porcupines inhabiting Europe Porcupine an $\mathrm{Im}$. are said to be natives of northern migrant. Africa, and to have been imported by the Romans. At present the animal is found in northern Africa along the coasts of the Mediterranean, especially in Algiers, Tripoli, Tunis and as far as Senegambia and the Soudan. In Europe it is frequently found in the Campagna of Rome, in Sicily, Calabria and Greece. In lower Egypt, where it is said to be found, I never saw a trace of it.

Habits of The Porcupine leads a solitary life. the Common Por. During the clay it rests in the long, cupine.

low tunnels which it excavates in the ground; at night it emerges from them and prowls around after food. Its diet consists of plants of all kinds, such as thistles and other herbs, roots and fruit, the bark of many trees and various leaves. Its manner of feeding resembles that of others of its kind. It bites a piece off, seizes it with its front teeth and holds it with its fore-paws while eating. All its movements are awkward and slow; it walks in a lazy, deliberate way and its running capacities are also limited in point of speed. Only in burrowing is the clumsy animal possessed of a certain amount of celerity, which is far from sufficient, however, to enable it to escape a skillful, nimble antagonist. In winter it is said to occupy its burrow morc than at other seasons, and sometimes remains in it sleeping for several days at a time. It does not really hibernate.

The Porcupine's If a Porcupine be taken by surprise Methods of Intim- ontside of its burrow, it threatenidation. ingly rears its head and neck, erects all the spines on its body and rattles them together in a peculiar way, especially those of the tail with which it produces a peculiar rattling sound, quite adapted to frighten an ignorant or timid person. When highly excited it stamps on the ground with its hind feet, and if it be seized it utters a hollow grunt, similar to that of a Pig. Notwithstanding its belligerent demonstrations the animal is perfectly inoffensive, casily frightened, retreating upon the approach of a person and hardly ever making defensive use of its sharp teeth. The quills also are intended more for the defensive than an offensive purpose. Whoever approaches it carelessly may hurt himself, but a dexterons sportsman seizes the creature by the mane and carries it off with case.

Propagation of $A$ litter of young Porcupines num-

the Porcu- bering from two to four is born in

pine. the burrow in a soft nest lined with leaves, roots and herbage. The little creatures make their appearance with open eyes, and have short, soft spines lying close to the body. The spines grow rapidly and soon harden, though they attain their full length only at a more adranced age. As soon as the young are capable of shifting for themselves, they leave their mother.

Method of Hunt. It can scarcely be truly asserted that ing Porcu- the Porcupine causes any damage. pines. Nevertheless it is an object of diligent pursuit. The quills are used in many way's and the flesh is also occasionally eaten. In the Roman Campagna the hunting of the animal is considered a particularly enjoyable sport; there certainly is no denying the fact that the way in which the animal is hunted is somewhat peculiar and attractive. The huntsman sets out in the dark of night, accompanied by a few well trained Dogs, which are set on the trail and left to track the quarry. A loud, furious bark signifies their meeting with the hero of the quills and also serves to guide the huntsman to the spot in which the combat takes place - if the encounter may be called a combat at all. All the sportsmen light the torches which they have kept in readiness and hurry to the scene of action. As soon as the Dogs become aware of their masters' approach, they howl with joy and proceed to furiously attack their antagonist. The Porcupine tries to repel them, rattling its quills, grunting and growling in all tones and protecting itself as much as possible with its quills, which stand out in all directions. Finally the sportsmen form a circle around the game and its pursuers, and the glaring light of the torches enables the sportsmen to view the conflict and renders it possible for the Dogs to subdue the quarry by means of their trained methods of attack. In this way the hunter may either kill the Porcupine or take it home alive.

\section{TREE OR CLIMBING PORCUPINES.}

The Tree or Climbing Porcupines (Corcolabina) are distinguished from other members of the family principally by their slender bodies and tails of greater or less length, prehensile in most of the genera. All varieties comprised in this group are natives of America.

The Uison In the northern half of America the or Canadian Por- Tree l'orcupines are represented by

cupine. the Urson or Canadian Porcupine (Erithizon dorsatum). It, as well as its only known kinsman, differs from the South American Cercolabince in having a stout body, and short, flattened or broadly compressed tail, thickly set with quills on its upper surface and with bristles on the under side. The Urson attains a length of thirty-two inches; seven and one-lialf of which are included in the tail. The head is short, thick and blunt, the muzzle is truncated, the apertures of the small nostrils may be more or less entirely closed by a semi-lunar flap or valve. The fore feet have four toes and no digit analogous to a thumb; the hind feet are five-tocd, the claws are long and strong, the soles destitute of hair, covered with a skin showing a network of furrows. A thickset fur, which attains a length of four and one-half inches on the nape of the neck and changes into sharp spines on the under parts of the body, and the tip of the tail, clothes the animal. Jispersed among the hair and spines, quills rather more than three inches long and for the greater part concealed in the fur, are distributed over the upper surface. The color of the animal is a blending of brown, black and white.

The Canadian Porcupine is a native of the forests of North America, ranging from the sixty-seventh parallel of north latitude south to Virginia and Ken- 
tucky, its eastern and western boundaries being Labrador and the Rocky Mountains. It is not uncommon in the forest regions to the west of the Missouri, but it is nearly extinct in the east. "The Urson," says Cartwright, " is an accomplished climber and probably never descends a tree in winter, before

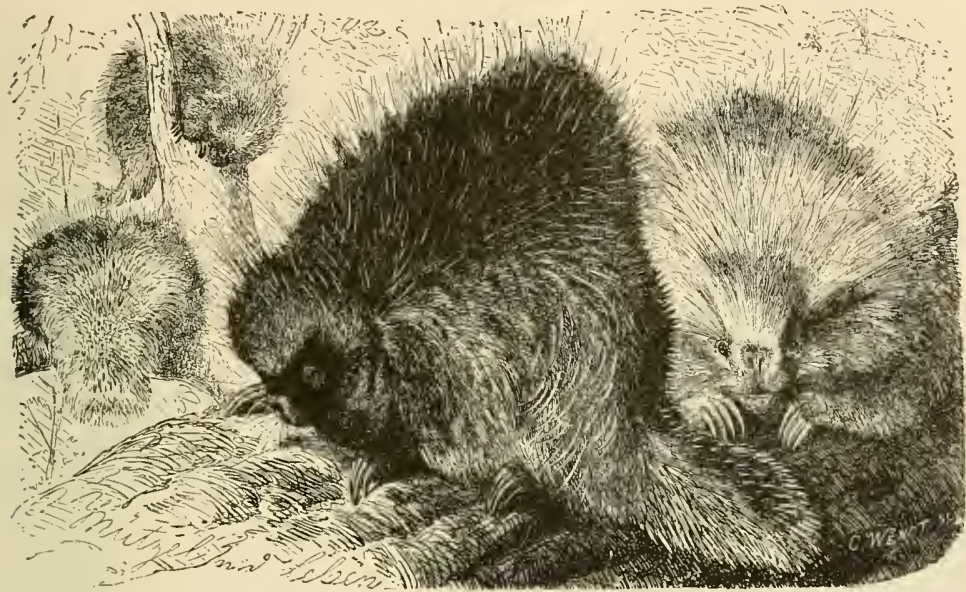
rare in this country, although not so scarce in Canada is the Urson, otherwise called the Canadian Porcupine, of spines, the four strong claws of the fore feet are shown in the animals here portrayed. (Erithizon dorsatum.)
URSON OR CANADIAN PORCUPINE_- Formerly plentiful in the northern United States but now quite

we could occasionally open its cage and afford it the pleasure of a free walk in the garden. It knew us: when we called it, tempting it with a sweet potato or an apple, it slowly turned its head toward us, gave us a gèntle, friendly look and then slowly hobbled up to us, took the fruit out of our hands, sat down on its hind legs and raised the food to its mouth with its fore-paws. Frequently, when it would find the door of our room open, it would come in, approach and rub itself against us, looking at us pleadingly, as if asking for some dainty. We tried in vain to arouse it to an cxhibition of anger: it never used its spines with us. When a Dog came in view, matters were different. Then it instantly assumed the defensive. With its nose lowered, all its quills ereet, and its tail moving back and forth, it was ready for the fray.

"A large, ferocious and exceedingly troublesome Mastiff, belonging to the neighborhood, one day sprang upon the Urson with open mouth. The it has entirely denuded the upper branches of bark. It is most partial to the tenderest shoots or seedling trees. A single Urson may ruin hundreds of them during one winter." Audubon affirms that he has passed through woods, in which all the trees had been stripped by the Urson, producing an appearance similar to that induced when a forest has been devastated by fire. Elms, poplars and firs furnish its favorite food, and therefore usually suffer more than other trees from its destructiveness.

The nest of the Urson is generally found in holes in trees or in rocky hollows, and in it the young, usually. two, more rarely three or four in number, are born in April or May. Those that are taken out of the nest and kept in confinement. unlike the common European Porcupine, soon become accustomed to their master and to their surroundings. They may be fed on all kinds of vegetables and are very fond of bread. If given the freedom of the garden, they

pain. His mouth, tongue and nose were full of Por-
pain

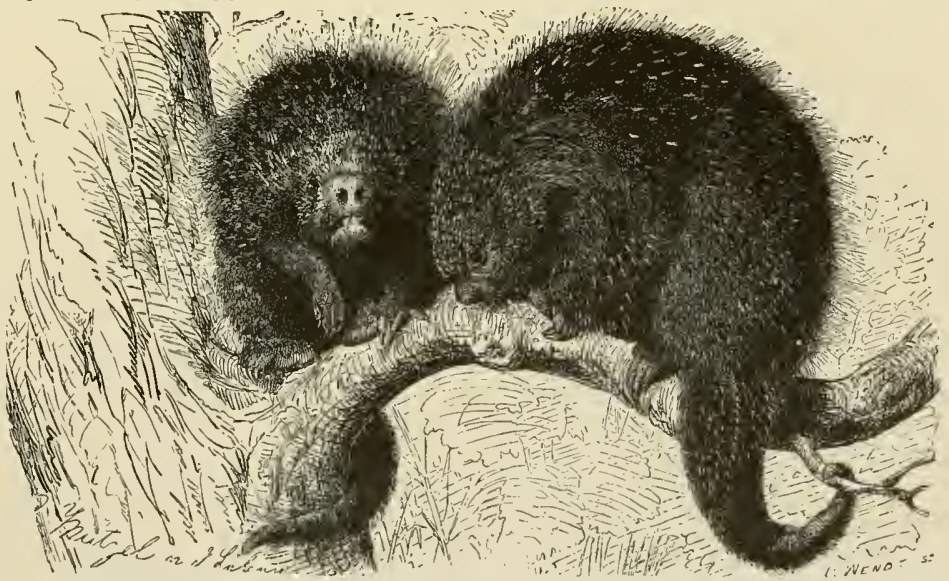

THE MEXICAN PORCDPINE - Among the Tree Porcupines the Mexican species is one of strongly marked physical peculiarities. The long curly hair, concealing to great extent the quills with which the animal bristles, the prehensile tail, the strong claws and queer bewhiskered muzzle are all shown in the picture. (Cercolabes notic hisfanice.) mount trees and eat the bark and leaves. Audubon says that an Urson he had in his possession never exhibited anger, except when some one tried to remove it from a tree which it was in the habit of mounting. "Our Urson had gradually become very tame, and seldom made any use of its nails, so that

cupine quills. He could not close his jaws, but hurried, open-mouthed, off the premises. Aithough the servants immediately extracted the spines from the mouth of the Dog, we observed that his head was terribly swelled for several weeks afterwards, and it was months before he finally recovered." 
The Urson Indians alone know how to utilize Eaten by $\mathrm{In}$ - the Urson. The flesh is much esdians. teemed by them and is said when properly prepared to be quite acceptable to white people also. The skin is of agreeable softness atter the spines have been extracted and therefore can be used in the manufacture of moccasins, shoes, etc; the spines are used by the Indians in the decoration of hunting pouches, head-dresses, etc.

Distinctive Char- The Cercolabes proper comprise the acteristics of the species furnished with a prehensile

cercolabes. tail and four-toed feet. When the fur is so much more copious than the spines that these latter project in places only and are entirely

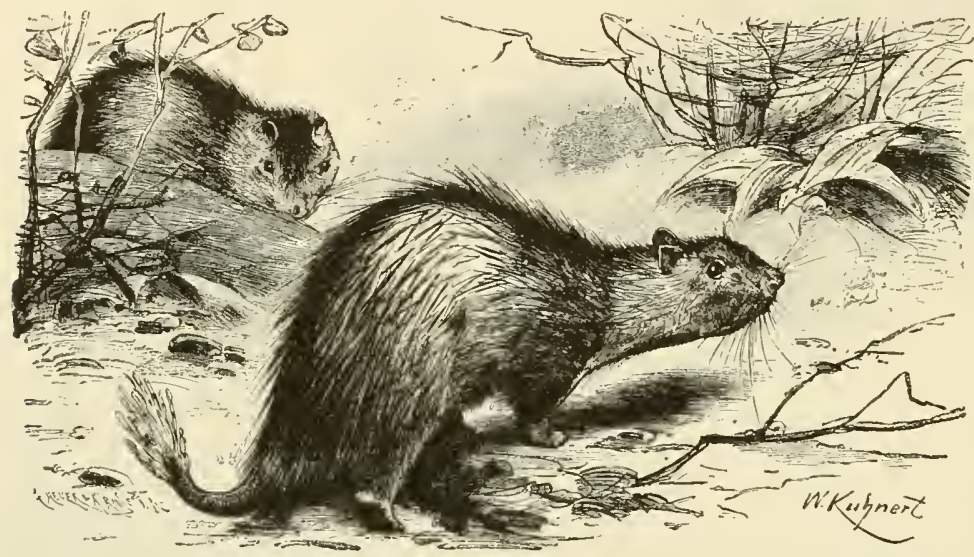

BRUSH-TAILED PORCUPINE. - A separate group of the Porcupine family is formed by two species, one found in west Africa and one in the Mfalay region of Asia. The spines of the back are sharp pointed, and each has a deep groove which extends along its entire length. The tail is the most characteristic feature, the tuft consisting of a bunch of spines so flattened that Buffon compares their appearance to narrow, irregular strips of parchment. The African species is well portrayed in this picture. (Atherura africana.)

absent on the throat, breast and abdomen, the var1eties are placed in the sub-species Sphingurus; those in which the spines prevail are classified as belonging to the sub-species Synetheres.

The Mexican The eastern coast of Mexico is inPorcu- habited by the Mexican Porcupine pine. (Cercolabes nor'e lispanice), a creature of thirty-eight inches total length, the tail oecupying about one-third of this. The glossy hair is very thick and soft, slightly curly and so long as to completely cover many of the spines. The under parts are deficient in spines with the exception of the lower portions of the throat, the inner surfaces of the limbs, the muzzle and the outer half of the tail. This latter organ toward the end is devoid of any covering above, while below it is thickly set with black bristles. Along its flanks the animal display's a yellow coloration. The muzzle is equipped with very long whiskers. The quills are sulphur yellow, tipped with black; thin at the base, of uniform thickness along their middle portions, and then again taper suddenly; the middle part is smooth and polished and the point is sharp as a needle and provided with a barbed hook. So long as the creature is peacefully reposing but very little of the quills is exhibited with the exception of those implanted around the eyes and ears. When it is excited by the presence of an enemy and its blood is up, it erects all its quills so that they stand out in all directions, and if one strokes the fur with one's hand he feels them everywhere. These quills are set so loosely in the skin that they fall out at the slightest touch, and if a person strokes the fur but once, dozens of them are pulled out, some of them invariably sticking to the hand.

The Couiy a Accurate information concerning the South American life in the free state of this and all Species. other species of the Cercolabina is very meager. Whe know most about a closely allied species, the Couiy (Cercolabes zillosus), of which Azara, Rengger, Prince von IVied and Burmeister have written the results of their observations. It is thinly distributed all over Brazil and the country south of it as far as Paraguay, being known everywhere but common nowhere. It usually selects dense forests of high trees as its habitations. The greater part of the year it lives solitary in a fixed location, always keeping to the trees, in the branches of which it moves about with considerable agility. During the day it rests, sleeping in a curled up attitude in its nest in the fork of a limb; during the night it prowls about, climbing slowly and with great circumspection. Hensel lays stress on the fact that it is protected by what Mr. Darwin and other eminent naturalists term "natural imitation," in that it corresponds to its surroundings with regard to shape and coloring. "Nature," says he, "seems to specially favor this Porcupine, for she did not content herself with protecting it from foes among the inferior animals and beasts of prey, but also made provision against the attack of birds of prey. A quantity of long, fine hairs project beyond the quills. When the animal sits quietly and half curled up on the branches of a tree, these long hairs give it a striking and most deceptive resemblance to a lump of a certain kind of gray moss (beard moss), and even a keen-sighted sportsman often readily passes it by, deceived by the long hair flowing in the wind, or occasionally shoots into a piece of that parasitic plant, not being able to exhibit a trophy of his prowess or boast much of his deed afterwards." The attitude assumed by the Cercolabes on trees is peculiar. It sits on its hind legs, keeps its fore-feet close to them, sometimes inverting them so as to support itself on the backs of the fore-paws, instead of the soles; the head is kept to one side, the tail is extended and curved upwards, forming a hook. Usually it assures its holds by coiling its tail round a branch. It sits very securely without this help, however, even on the smallest twigs, as the wide fore-feet, with their inward curve, afford a firm hold. In climbing it presses the broad, fleshy soles of the feet close to the branches and grasps them with the toes which have a prehensile power analogous to that of human fingers.

The food of the Cercolabes consists mainly of fruit, buds, leaves and roots, which it carries to its mouth with its hands. 
The Couiy

in Captivity.

To describe its life in captivity I will quote Azara's observations: "I had a specimen in my possession which had been captured when fully matured; I pernitted it to range my room at will and left it a year without water; for it does not drink. When frightened by anything it ran with comparative agility; I could always overtake it, however, by following at a leisurely pace. All its movements are more or less clumsy; but it readily climbs up and down a stick and grasps it so firmly that it requires considerable effort to loosen its hold. The back of a chair, the point of a perpendicular stake afford it a sufficiently good resting-place upon which to sleep and even recuperate. It is slow-witted and of so quiet and lazy a disposition that it sometimes does not change its place or attitude for twenty-four or forty-eight hours. My prisoner never moved except when it was feeding. Once only did I see it running about at night, nevertheless I believe it to be a nocturnal animal. In the first days of its captivity my Cercolabes would sit down on the back of a chair, but never on anything having a plane surface; one day, however, it climbed up a window and discovered the edge of the window-shutter; it sought no further for a retreat after this. On the shutter it spent all its time, sitting like a statue in its extraordinary position, without the slightest movement. It held on only with its hinder feet, using neither fore feet nor tail to secure its position, crossed its fore legs and put its muzzle into them, as if it wished to kiss its hands. Thus it sat, without moving, without looking about even, till the hour of its meal arrived. It ate very little of the proffered bread, maize, manioc roots, herbs, leaves and flowers, but showed a tendency to vary its diet. It never exhibited vicious tendencies, never bit nor scratched, and never did anybody any harm.

Physical Senses "The sense and Appearance of smell is of the Couiy. the acutest among its senses of perception. I observed my pet raise its head when I drank chocolate or entered the room carrying flowers, so I could safely infer that it perceived odors at considerable distances. Never did I see it exhibit intellectual emotion or signify its grief or pleasure. Sometimes it would recognize the voice of its familiars and turn its head when its name was called."

The external appearance of this species presents so few inviting features that it is but rarely caught and reared by the savage tribes inhabiting the countries of which it is a native. These tribes eat its flesh, however, which is disdained by Europeans on account of its unpleasant odor.

The coendou The Coendou (Cercolabes prilu'nsilis)

a South Ameri- is very similar in appearance to the

can Species. Couiy, so far as relates to its general shape, but is of a perceptibly stronger and larger build. Its length amounts to forty-four inches, eighteen of which are included in the tail. The surface covered by quills begins with the face, continues throughout the entire upper surface, clothes the legs to the ankle-joints, and includes the upper half of the tail and all the lower part of the body. The quills are not habitually depressed, and to not lie close to the body. A few hairs, which intermingle with them, are concealed from view and become visible only when the quills are removed to one side.

The Coendou in Little is known about the life of the a State of Coendou in its natural condition. Nature. The animal is distributed over a considerable part of southern and Central America and is quite plentiful in some localities. After the habit of its relatives it sleeps through the day, perched on the top of a tree in the curled-up attitude already described in connection with the accounts of its kin heretofore given; at night it runs among the branches slowly, but with considerable skill and great surefootedness. Leaves of all kinds constitute its nourishment. The flesh is in great demand with the natives as an article of food and the quills are also put to manifold uses.

\section{Tbe Cavics or Guiltea Dig Jfantílp.}

\section{TENTH FAMILY: CAVIIDE.}

The external distinguishing features of the Cavies (Caviüla) to which our well-known Guinea Pig be-

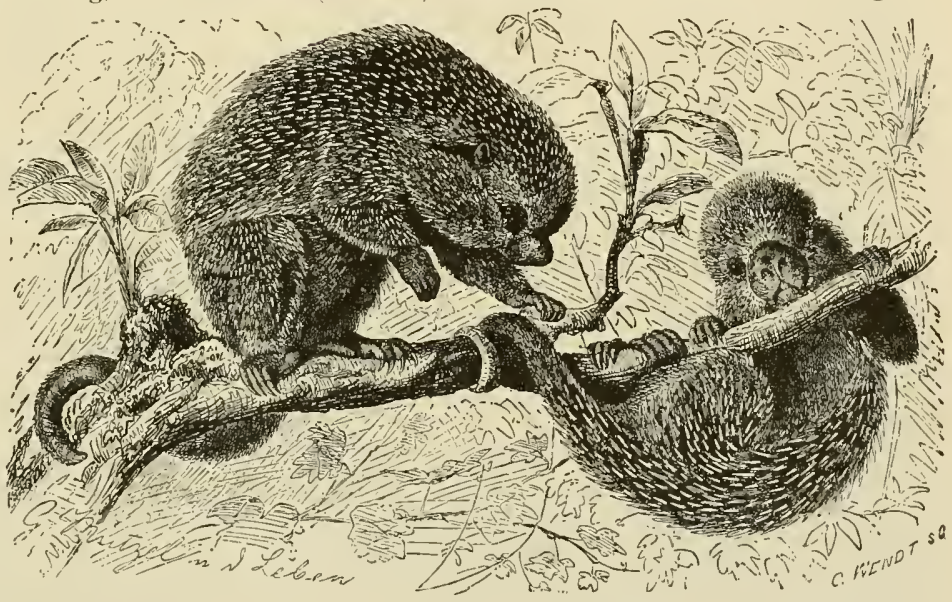

THE COENDOU.-One of the most common of the South American Tree Porcupines is the Coendou. It

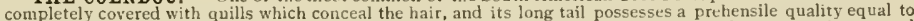
is completely covered with quilis which conceal the hair, and its long tail possesses a prehensile quality equal to the two in the picture amid appropriate surroundings. (Cercolabes prehensilis.) longs, and which occupy an intermediate position between the murine and leponine families, consists of a more or less elongated body, supported by long legs, four-toed fore-feet, and from three to five-toed hind feet, provided with large, hoof-like, triangular nails (resembling those of an $\mathrm{Ox}$ or Goat), and with naked soles; a stub-like tail, ears of varying size and a coarse fur. The teeth consist of four molars in each row of about uniform size and large, broad gnawing teeth, the external surfaces of which are generally of a white color. All Cavies are restricted in habitat to southern and Central America. 


\section{THE GUINEA PIG.}

Our universally known Guinea Pig (Caria porcel(us) has so far, in point of pedigree, shared the fate of many domestic animals; its progenitors can not be traced with accuracy. The record of its genealogy is lost in antiquity. As far as known the little creature was introduced into Europe by the Dutch, soon after the discovery of America, that is, in the sixteenth century. Gesner had even at his early day become acquainted with it, and from that time it has been bred continuously, but until recently the original stock from which it descended was quite commonly (and probably erroneously) thought to be the Brazilian Aperea or Restless Cavy (Caria aperea). Nehring's investigations, however, have proved that it springs from the Peruvian Cary (Carin cutleri), a species closely allied to the Restless Cavy, and kept in that country in a domesticated state as early as the times of the Incas. As

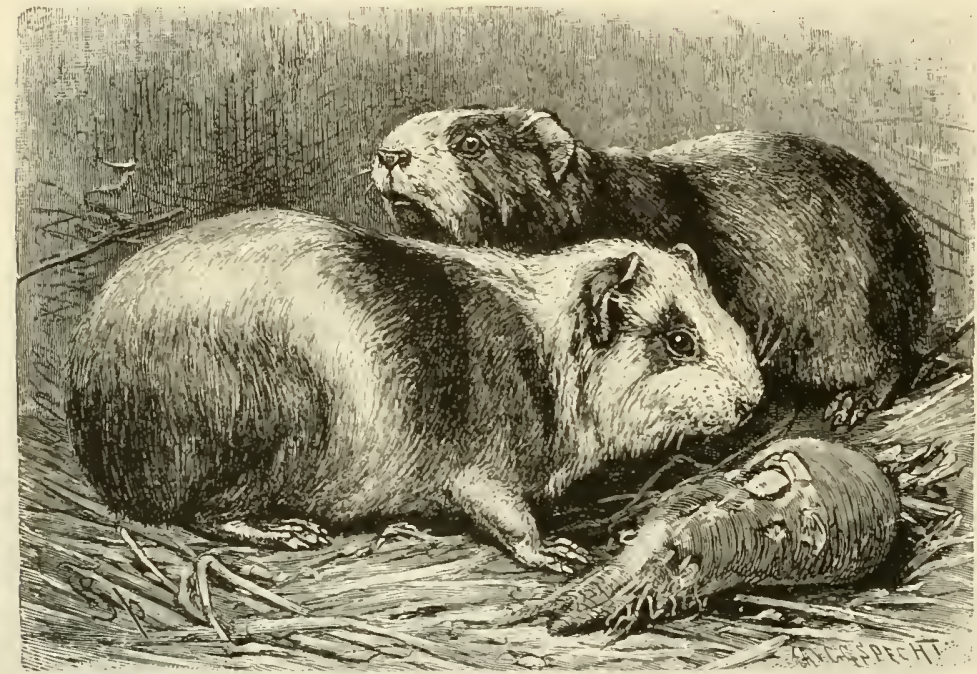

GUINEA PIGS. - The Guinea Pig is indigenous to South America although it has become a not uncommon domestic pet in Europe. Cultivation has developed many variations in their color. The term "Guinea Pig " is prot ably a corruption of "Guiana Pig." are very docile in captivity. (Can'ia As will be soceltos.)

A. Stubel told Nehring, it is even to-day bred and used as an article of diet by the Indians of Peru, Ecuador and Columbia; but it has never been found with the isolated and uncivilized aborigines of Brazil.

Color of the Besides uniformly colored Guinea Guinea Pig a Re. Pigs, among which the white ones sult of Breeding. predominate, one usually sees them of three colors: spotted with white, tawny yellow and black. As a result of Nehring's investigations of the Guinca Pig mummies in the cemetery of Ancon in Peru, it is claimed that the Inca Guinca Pigs showed no black spots. They wcrc either all white, or reddish brown, or, if piebald, spotted respectively with tawny or yellowish white. According to Haacke's observations, tri-colored specimens, with spots of ashy gray instead of black, are not uncommon; the eyes of such individuals are always red. Lately the long-haired Guinea Pig has become very popular; it is a breed which has a long fur, exhibiting peculiar convolutions on different parts of the body.
The Gunea Pig is one of the most popular domestic animals in the entire order of the Rodents, as much on account of the small cost of its maintenance as because of its inoffensive, good-natured disposition. If it has an airy, dry hutch or cage, it is easily kept anywhere. It feeds on the most multifarious vegetable diet, ranging from roots to leaves, on grains as well as fresh juicy plants and requires only a little variety in its food. If it is given juicy fruit it can thrive without drinking water at all, though it is exceedingly fond of milk occasionally. It is naturally very hardy and bears even illtreatment without apparent ill results. For this reason it is a very pleasant pet for children, which are generally the ones that most enjoy the keeping of Guinea Pigs. In its habits and disposition it shows an approximation to the Rabbits in some respects, and to the Mice in others. Its manner of vocal expression is a grunt, which probably gives rise to the appellation of "Pig," and a peculiar murmur, or Cat-like purr and squeal. The murmur seems to be an expression of comfort, while the squeal always signifies excitement.

$\begin{array}{cl}\text { Domestic } & \text { Guinea } \\ \text { Habits of the } & \text { Pigs live } \\ \text { Guinea Pig. } & \text { in pairs }\end{array}$
and the male and female of the species keep together and treat each other with marital affection and tender consideration. Cleanly, like most Rodents, one mate often licks the other, and sometimes uses its fore-feet to comb the other's fur. While one of the couple sleeps, the other mounts guard; if it finds the time tedious and becomes weary itself, it awakes its mate, licking and stroking it, and as soon as it sees it thoroughly awake it lies down to sleep while its mate keeps watch.

Propagation of Few mammals are as prolific as the the Guinea Guinea Pig. In Germany from two Pigs. to three, sometimes four or five young arc born two or three times a year; in hot countries the fecundity of the female is greater and the roung number six or seven. The little ones are highly developed at birth, their eyes arc open and a few hours after they are born they are able to run about with the mother. At the age of five or six months they are capable of breeding themselves, and at eight or nine montlis old they have attained their full size. With good care they may attain an age of six or eight years

Susceptibility to If one pays much attention to the Domestication of Guinca Pigs, he can render them very

Guinea Pigs. tame, though they never lose all their timidity and rarely acquire sufficient intelligence to distinguish their keeper from other people, owing to their slender mental capacitics. There are cxceptions to this rulc, however. "A Guinea Pig belonging to my- children," writes Friedel, "greets 


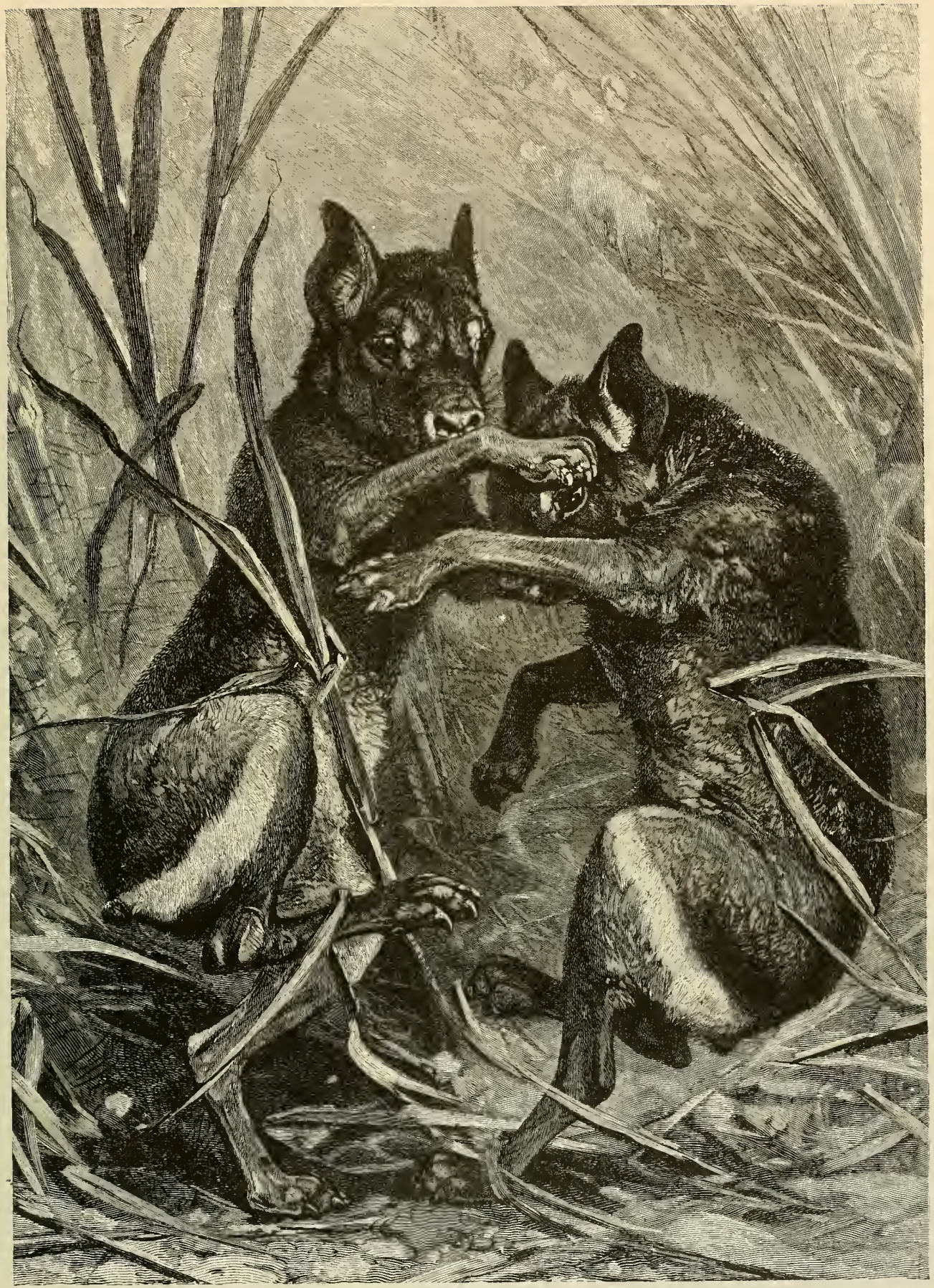

MARA OR PATAGONIAN CAVY.- - Inhabiting the most unproductive regions of a desolate country, living in holes in the barren earth and fleeing at the slightest sound, these animals are seldom seen by investigators. As a usual thing these queer, long-eared, long-legged Rodents are very peaceably disposed and friendly with others of their kind, Occasionally disputes will arise
and fight with their fore-paws, as depicted by the artist. (Dohchotis patagonza.) 
my son with a loud, excited squeal whenever it hears his steps; when he gives it food it utters a loud grateful purring sound; my little daughter is not greeted with a squeal, but with a low murmur; my wife and myself are never saluted with the purring noise. When my wife passes the nest of the animal late at night, a plaintive squeal invariably greets her, while the animal is always silent when 1 go by, for it knows that I never give it anything so late. The creature is then capable of distinguishing between four persons. It also performs tricks, feigns death and jumps up at a word of command." Guinea Pigs are very sensitive to a cold and damp temperature; they become sick when exposed to rough weather and are then likely to die.

Services of The Guinea Pigs have rendered good the Guinea Pig services to science, though, it is true,

to Science, against theirwill. Bischoff has used them in his investigations of animal development and thereby secured them an honorable place in the literature of science. [Pasteur, likewise, in his investigations of the rabies bacillus, has made good use of the species in the propagation of the germs of hydrophobia. Thus, taking all things into consideration, aside from the mere amusement which Guinea Pigs have afforded Man, they have played a not unimportant part in advancement of scientific knowledge.]

\section{THE MARA OR PATAGONIAN CAVY.}

An uncommonly queer animal of the desert, the Mara (Dolichotis patugonica), represents the second species of Cavies. Resembling the llare in many respects, it differs from them very greatly in its long legs and the greater shortness and bluntness of the ears. An adult specimen measures twenty inches, the stub-like tail occupying about two inches of this total; the shoulder height in some individuals may amount to as much as eighteen inches, thus at a first glance giving the animal the appearance of a small Ruminant rather than of a Rodent.

The Range The Mara is not found north of the of the thirty-seventh parallel of south latiMara.

tude. Thestony, arid desert of Patagonia is its native country, and at the point where the Sierra Tapalquen bounds this desert, and the soil becomes damper and more fertile, it disappears. To the west it ranges nearly to Mendoza; reaching then the thirty-third parallel of south latitude. A few decades ago it was much commoner than now, being at present found only where the inhospitable character of the country protects it most from the presence of its enemics. Despite the fact that it is fairly numerous it is not generally easy to obtain a specinen of the animal, for the simple reason that its shy and retiring habits render it difficult to catch. Either it is hidden in its hole, or lies closely and flatly against the ground where it is easily orerlooked by reason of the close assimilation to the ground in the earthy color of its fur. Its tinidity. also protects it from capture. The Mara flees at the slightest alarm. It is entirely diumal in its habits, though it takes refuge in its hole during the noon heat. Its food consists of plants, and their roots and bark, substances usually of a character refused by other mammals. In some parts of Patagonia, where but few dry, thorny shrubs lead a miscrable existence on the stony ground, it is the only living animal to be perceived.

Goering observed an adult Mara for a considerable time in confincment in Mendoza. It was an amiable, good-natured, inoffensive creature. From the first day it showed great confidence in its master, unhesitatingly took the food he proffered out of his hands, and suffered itself to be touched and stroked without exhibiting any sign of uneasiness. It was very responsive to caresses; when one petted it, it arched its back, put its head to one side as if it wished to see the friendly hand, and uttered a highly gratified but indescribable squeal or grunt. Indians and Gauchos are passionately fond of hunting it, especially on account of the skin, of which exceedingly pretty, soft rugs and blankets may be made.

\section{THE AGOUTIS.}

The Agoutis (Dasyprocta) show a striking resemblance to the little Musk-Deer in their shape; they are long-legged, strongly built Rodents, with long heads and pointed muzzles, small, round ears, bare, rudimentary tails, and hind legs which are perceptibly longer than the fore pair. The fore paws have four toes and a small rudimentary thumb, while the hind feet possess only three very long and completely separated toes. All their toes are armed with strong, broad, slightly curved, hoof-like nails, those of the hinder feet being especially developed; the thumb-like protuberances on the fore paws are furnished with small, flat nails. On the whole, the build of the Agoutis is light and elegant, and makes upon the observer an agrecable impression. The teeth are strong; the flat gnawing teeth are especially prominent, and would be conspicuous by reason of their color alone, the upper pair being of a tolerably bright red, the under pair yellowish

The Agoutis are generally found in couples or small communities in wooded plains, the thickest forests of river vallcy's being particularly favored by them: some of then, however, range in mountainous districts as high as 6,000 feet above the sea.

The Common The Common Agouti, sometimes Agouti, or Gold called Gold Hare on account of the Hare. golden color of its pretty fur (Dasyfroctu aguti), is one of the handsomest members of the whole family. It has a thick, heavy, close-set fur; the wiry, coarse, bristle-like hair is very lustrous and is of a reddish lemon-yellow tint, dashed with blackish brown. The general coloring is subject to modifications according to the season, bcing lighter in summer, darker in winter. The length of the body of an adult male is sixteen inches, while the tail measures only about half an inch.

Native Country The Agouti is a native of Guiana, of the Spe- Surinam, Brazil and northern Peru. cies. It is tolerably common in most localities, especially near the low-lying ruver valleys in Brazil. There, as in other places, it inhabits woodlands, frequenting alike the damp unbroken forests and the dricr ones of the interior country; it roams in the adjacent grassy plains, however, taking the place of the llare in those regions. It does not exist in cultivated regions. Usually it is found above the ground, in hollow trees near the ground, and more often solitary than in company with others of its species. By day it quictly lies in its lair and it prowls about only in such localities as afford it security from interruption At sunset, it sallies forth to seek food and spends the whole night in feeding if the weather is good. It is in the habit of leaving and returning to its habitation by a uniform route, and this repeated travel to and fro causes the wearing of a narrow footpath, sometimes one hundred yards long, which betrays the situation of its abode. If a 
Dog be set on the trail, and the lair of the animal is not in the thicket, the hunter nearly always succeeds in catching it. The Dogs give tongue when the game is run to earth, and one can then pull it out of its hole or dig it out. If, however, the Agouti percejves its pursuers in good time, it makes off immediately, and its agility and speed soon put it out of the reach of danger.

Characteristics, The Agouti is an inoffensive, timid Food, etc., of the little animal surrounded by many Agouti.

perils, so that only its extraordinary agility and keen organs of sense can save it from death. In jumping it reminds one of a small Antelope and the little Musk-deer. Its food consists of the greatest variety of vegetation, from roots to buds or the grain. No vegetable substance can resist the sharp gnawing teeth, which easily crack the hardest nuts. In cultivated portions of country to which it sometimes makes incursions, the Agouti becomes annoying by reason of its visits to the sugar-cane plantations and orchards.

About the propagation of the Agoutis in a state of nature we still lack exact accounts. It is known that the animal is rather prolific, the breeding not being restricted to a special season of the year, and that the litters number several young.

Rengger says that when an Agouti is taken young and reared with care, it may become almost completely domesticated. "I have seen several Agoutis," say's he, "that could be permitted to run about promiscuously, never attempting to escape. When once tamed they do not yield to teinptation to abscond, even when liberated in large woods, which are their abode in the free state.

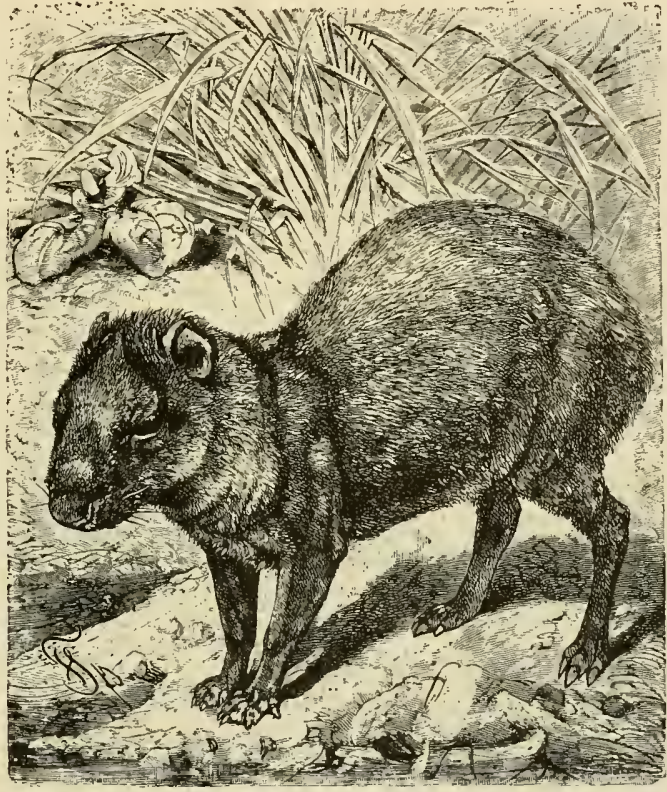

THE COMMON AGOUTI-This long-legged Rodent, sometimes called the Gold Hare, is an inhabitant of South America. Its coarse hair is of a bright yellow, and the tail is a very short naked stump. The hind legs are considerably longer than the fore limbs and the feet have strong claws. (Dasyprocta aguti.) is brought near their domiciles they scent it immediately, and assiduously search for it. Their food is usually taken up with the incisor teeth; then they seize it between the rudimentary thumbs of the forefeet, sitting on their haunches like Squirrels. Sometimes they also eat after the manner of Rats in a crouching position, usually when the morsels are very small or too small to be effectively handled by the fore-paws. I never saw them drink, but they are said to occasionally drink water, lapping it after the manner of a Cat or Dog."

The Agoutian Bodinus justly remarks that the Eligible dainty form, beautiful appearance Pet. and cleanly habits of the animal recommend the Agoutis to fanciers of animal pets, and that their only drawback is their great gnawing propensities. Those kept by Bodinus became, in course of time, so tame as to take proffered dain-
In the forests of northern Paraguay, in the huts of natives, I saw two tame Agoutis which spent the morning and evening in the forest, noon and night with the Indians. Their yearning for liberty is subdued, not so much by their attachment to people as by their growing accustomed to one place. They are but little devoted to human beings, do not distinguish their keeper from other people, seldom respond to the calls of their keeper and look for him only when pressed by hunger. Neither do they like to be fondled by him; they tolerate no restriction, live entirely according to their own wishes and the most they can be trained to do is to look for their food in one particular place. They are fed on everything that is eaten in their owner's house. They are not so fond of meat, however, as Azara has alleged them to be, eating it only when their proper food is wanting. They like to eat roses, and whenever one time as they need it.

\section{THE PACA.}

The Paca (Cologenys paca) is distinguished by a peculiarly thick head, large eyes and small ears, a rudimentary tail, five-toed feet, coarse, stiff hair and especially by the remarkably expanded cheek bone, the expansion being due to an internal molar cavity or hollow. The fur consists of short, thickly set hairs of a yellowish brown color on the upper parts and yellowish white on the under surface of the body and inner portions of the legs. Five rows of yellowish white spots of a circular or ovoid shape extend along both sides from the shoulder to the hinder portion of the thigh. Adult males attain a length of twenty-ejght inches, are about fourteen inches high and weigh as much as eighteen pounds. 
Native Country The Paca is distributed over the of the greater part of South America, from Paca. Surinam in Dutch Guiana throughout Brazil to Paraguay, and is also found among the West Indies on the southern Antilles. The lonelier and wilder the locality the more abundantly is it found; in all cultivated regions its numbers have been greatly reduced. It delights in the edges of forests, wooded banks of rivers or swampy places. There it scoops out a burrow from three to six feet deep and spends the day in it sleeping. At dusk it goes out in quest of food, paying an occasional visit to sugar cane and melon plantations, in which it does considerable damage. At other times it feeds on leaves, flowers and the fruits of various plants. It lives either in couples or singly. The female gives birth to one or at the most two young in the

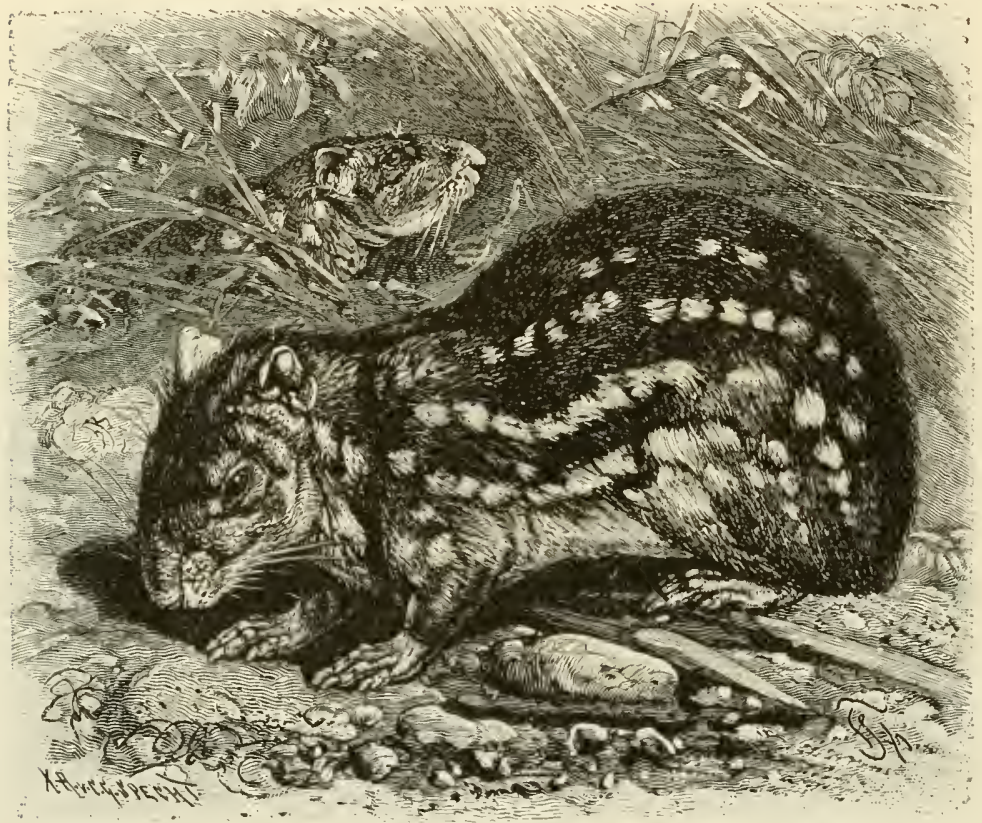

THE PACA.- This is the representative of a distinct sub-tamily among the Cavies. It is a forest animal, preferring damp localities, and a male and female usually live together, so that the picture appropriately shows two of the species. The tail is lacking, the head thick and the coarse hair is marked by five rows of spots as shown in the picture. (Calogenys paca.)

middle of the summer; while they suckle she keeps them hidden in the burrow and even after they are weaned she keeps them near her for a few months longer.

In Brazil the Paca is the commonest forest gane except Agoutis and various species of Armadillos. Prince von IVied often caught it in traps in the forests. It is also hunted with hounds and brought to market as "royal game." There is no possibility of taking it in its burrow, but if the huntsman attentively examines the edge of plantations, he will soon notice the tracks of the animal under the close hedges of reed grass. There the sportsman puts out his noose, baited with an ear of corn, and the next morning he will usually find his trouble well repaid. The Paca is the best game animal of Brazil, probably being surpassed by no other in point of flavor and tenderness. The skin is so thin and tender that it is not pulled off, the entire animal being scalded like a Pig. A Paca prepared in this way and having its head and feet cut off, looks strikingly like a young Pig. According to Kappler a hunted Paca which can not reach its hole sometimes jumps into water, where it dives and remains submerged until its pursuer has withdrawn; he supposes that it swims off under the surface.

The Paca Of late years the aninal has been Well Known to carried to Europe quite frequently.

Naturalists. Buffon had a female Paca, which was quite tame; it took up its abode behind the stove, slept during the day and ran about at night, and when it was shut up in a box, it at once began to gnaw. It licked the hands of friends and allowed them to pet it, stretching itself and signifying its pleasure by a low-voiced, faint sound. Strangers, children and Dogs it tried to bite. When angry, it grunted and gnashed its teeth in a quite ferocious manner. It was so little sensitive to cold, that Buffon believed it could be introduced into and bred in Europe. It is contented with very few comforts, and requires neither specially good food nor a well-equipped stable. I must agree with Buffon in regard to its hardihood in enduring cold; but I do not think that it would be profitable to transplant it to Europe.

\section{THE WATER PIG OR CAPYBARA.}

The Water Pig or Capybara (Hydrochamus capybara) may be considcred the most remarkable of Rodents in one respect; it is the largest and clumsiest member of the whole order. It justifies its name, for its shape and bristle-like pelt remind one quite forcibly of a Pig. Its distinguishing features are: small ears, cleft upper lip, absence of a tail, short webs between the toes and strong hoof-like nails, as well as a very peculiar dentition. The incisors or gnawing teeth are of gigantic proportions, and are at least four-fifths of an inch wide, not very thick and characterized by several shallow grooves on their front faces; among the molars, the rearmost one is as large as the three preceding. The body is strikingly clumsy and thick, the neck is short, the head oblong, deep through from the upper to the lower surface, broad, blunt-muzzled and exhibits a peculiar appearance. The tolerably large, roundish eyes are quite prominent; the ears are rounded at their upper ends, the front edges being turned over and the backs abrupt. The hind legs are much longer than the fore pair, ine fore-feet are four-toed, the hind-feet three-toed. No particular coloring can be ascribed to the thin, coarse fur; an undecided brown with a 
dash of red or brownish yellow is distributed over the body, being nowhere sharply defined. Only the bristles around the mouth are decidedly black. An adult Capybara attains about the size of a year-old Pig and weighs about one hundred pounds. The length is over three feet, the height from the ground to the top of the shoulders about twenty inches.

Distribution of The Capybara is distributed all over

the Capy- South America and is found from the

bara. Orinoco river to the La Plata and from the Atlantic Ocean to the foot of the Andes Mountains. Low, swampy woodland, especially water-courses and the edges of lakes and swamps, are its favorite haunts. It delights in large streams, and never leaves their vicinity unless it should sometimes follow the course of small rivers or ditches emptying into much larger water-courses. In some regions it is quite numerous, and often to be en- plants and the bark of young trees and only where it exists near plantations does it sometimes make inroads on water-melons, maize, rice or sugar canes, and may then inflict considerable damage. The Capybara is a quiet animal. The first glance shows the observer that he has to deal with an extremely dull-witted and stupid creature. One never sees it playing with others of its kind. The members of a herd either graze slowly or they rest in a sitting posture. From time to time they turn their heads in all directions to see whether an enemy is approaching. If a foe be descried they do not hurry but run slowly toward the water IVhen terrified they frantically rush and dive into the water with a cry. If they are not accustomed to the sight of human beings they sometimes gaze curiously at them for a long time before they scamper away. One never hears them utter any other sound than

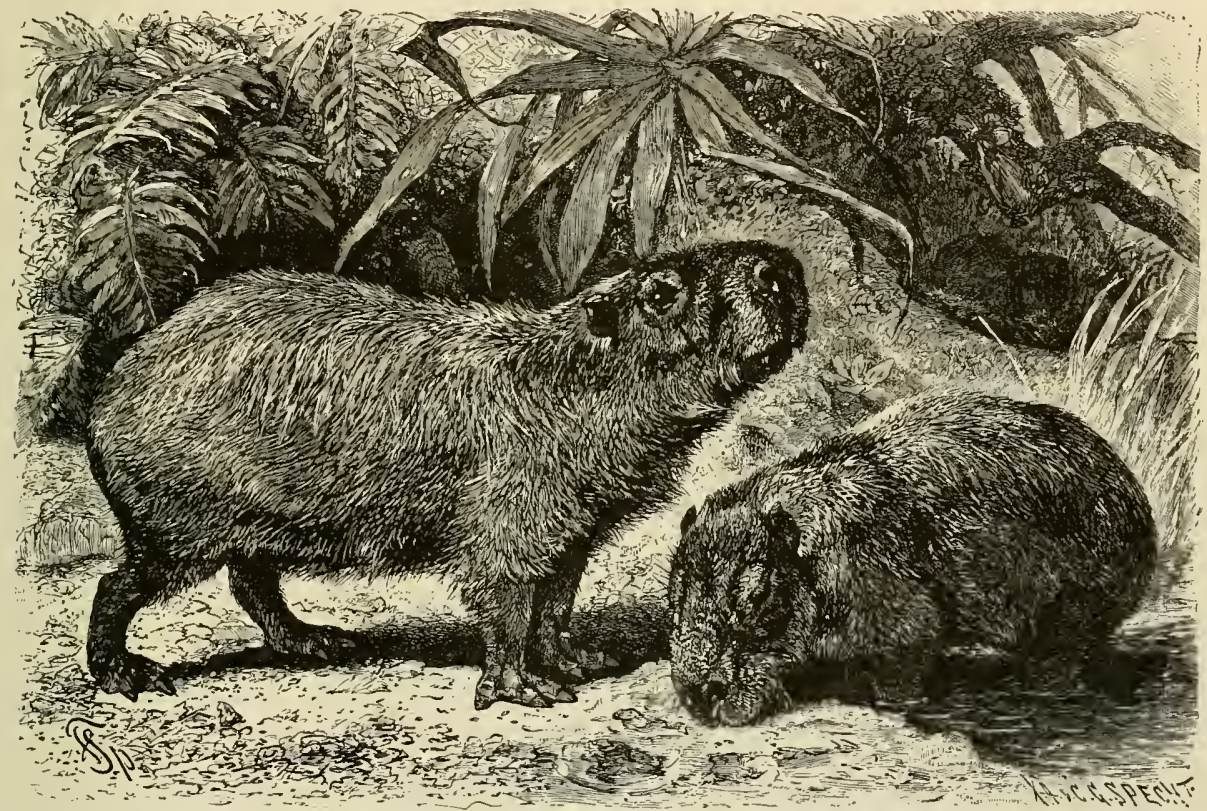

THE CAPYBARA OR WATER PIG.-. This is the largest of all the Rodents. It is a heavy clumsy animal which inhabits low-lying woods in the vicinity of streams or lakes, and although a favorite prey to the Jaguar on land and the Alligator in the water, the Capybaras are sometimes seen in large packs at places remote from settlements. The extremely coarse hair, heavy body and hool-like toes of these animals are well illustrated in the picture. (Hydrocharus cafybart.)

countered. As is easily understood, it is less frequently met with in populous localities than in the wilderness. In the former it is seen only at evening or in the early morning, but one may see large numbers of them, by day also, on the lonely little-frequented banks of rivers, foraging for food or sitting on their haunches like Dogs.

Peculiarities of Its ordinary pace in walking is slow;

the Capy- its running powers of short duration; bara. when hard pressed it sometimes resorts to flight by means of a series of jumps. It is an excellent swimmer, however, and easily crosses streams, though it does so only when pursued or when food has become scarce on the side it occupies. However attached it is to a certain locality, it is sure to leave it when subject to pursuit. It has no real den, though it regularly haunts certain selected spots on the bank. Its food consists of aquatic that cry of alarm, which Azara expresses by the syllable "ap." This cry is so piercing, however, that one can hear it at the distance of more than a mile.

The female has but one litter a year, which numbers five or six young. The little Pigs follow their mother immediately, but do not exhibit feelings of natural affection or even much attachment for her.

The Capybara The animal has of late years been in Captiv- repeatedly brought to Europe. I ity. took care of one of them for some time. It was very much attached to me, knew my voice, came to me when I called it, was much pleased when 1 petted it, and followed me about like a Dog. It did not exhibit the same gentle temper to everybody: when its keeper once was opposing its disposition to wander and endeavoring to drive it home, it jumped on his chest and bit him, fortunately, however, getting more of his coat than 
of his body between its teeth. It could not be called obedient, anyway; it obeyed only when it elected so to do.

Characteristic I can not characterize the moveMovements of the ments of the Capybara as clumsy or

Capybara. lumbering. It seldom runs rapidly, its usual gait consisting of long, deliberately taken steps, but it can easily clear fences three feet high at a bound. It is perfectly at home in the water. It swims across wide streams in a very straight direction, and at the same rate of speed at which a Man walks; it dives like a waterfowl, with one plunge, staying under water for several minutes, and can swim under the surface without mistaking its direction. Its maintenance in captivity causes no trouble at all. It feeds on all kinds of vegetable substances like a Pig and while it requires nourishment in great quantity it is by no means choice as to quality. It is most partial to fresh, succulent grass; but carrots, turnips and bean pods are also much appreciated by it. It crops grass like a Horse, with its

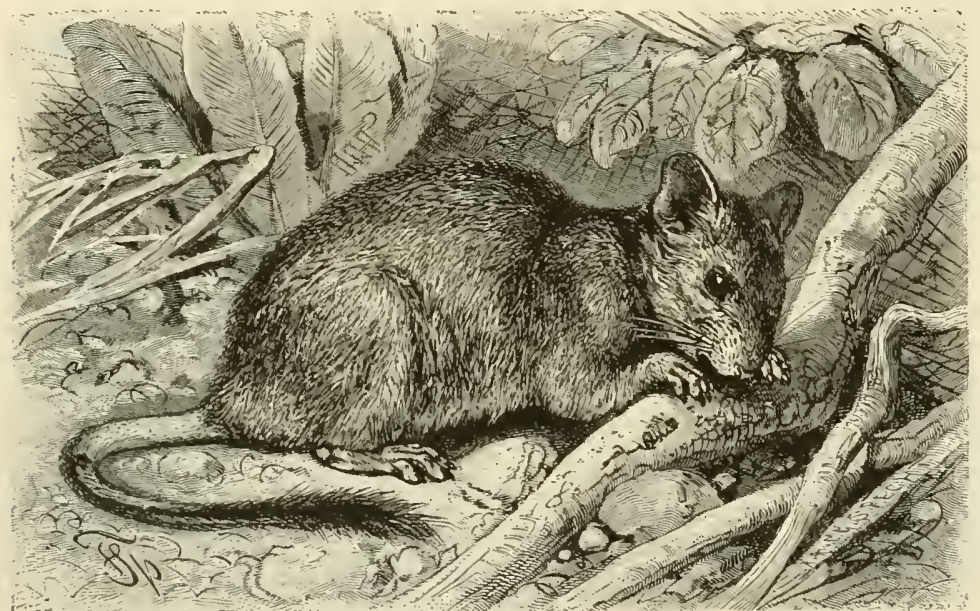

THE OCTODON. - A true Rodent with sharp gnawing teeth which are always ready for business, is the Octodon, shown in this picture. The form of the animal is suggestive of both the Rat and the Squirrel, the tufted tail, especially, being Rat-like. These animals live in South America where their gnawing propensities cause great dam age to vegetation. (Octodon cummingii.)

broad incisors, and also drinks like one, absorbing long draughts at each effort of suction. While it is fond of warmth, it is not very sensitive to cold. It plunges into icy water of streams in winter without any hesitation.

The Flesh According to the accounts of travelof the Capybara ers only Indians partake of its flesh;

Unpalatable. it is unpalatable to Europeans owing to its peculiar, insipid, oily taste. The thick hide, nearly devoid of hairy covering, is exceedingly loose and soft and yields a kind of leather readily permeated by water, and, in consequence, used only for the manufacture of straps, an inferior sort of moccasin and pack-saddles. The Botocudo Indian girls string the incisor teeth of the animal together and use them as bracelets and necklaces. There is no other economic use to which the animal is put.

The South Americans, particularly the Indians, hunt the Capybara for anusement's sake, taking it by surprisc, cutting off its retreat and throwing it down with their lassos. Excepting Man, the Jaguar is probably the worst foe of the Capybara.

\section{The Octodons.}

\section{ELEVENTH FAMILY: OCTODONTIDE.}

This family, not very numerous, but exhibiting great diversity and peculiarity in shape, comprises a group of Rat-like Rodents, inhabiting South America and Africa. The Octodontide to some extent remind us of Rats in their anatomical peculiarities and coloring. The ears are short, broad and scantily covered with hair; the feet have four or five toes, the tail is variable in length and often shows scaly dermal rings, like those of the true Rats; but the resemblance of these animals to Rats ceases with these peculiarities. The fur of some species is soft and of a fine texture; that of others is wiry, bristly or even intermingled with a few flat, longitudinally ringed spines, and the tail is not only hairy, but bushy. The teeth number four or, in exceptional cases, three rooted or rootless molars in each row.

The Octodontida live in forests or in the open country; some prefer hedges and shrubbery; others make their homes in plantations, along roads, between rocks, along the banks of rivers and streams or even on the sea-shore. Generally they live gregariously iu subterranean burrows which they dig and provide with numerous outlets. Some are genuine burrowers, throwing up mounds like those of the Moles and spending nearly all their life underground; others dwell in thickets and nimbly climb about on trees. Most of them are nocturnal in their habits, but a few are quite active in the daytime. Some species are truly aquatic in their habits and are excellent swimmers and divers. Confinement is easily borne by them; they are inquisitive, active, know and follow their keeper, and furnish much amusement by their extremely graceful ways. Their propagation is prolific, for they have from two to seven young at a litter, and their numbers may sometimes increase to such an extent as to enable them to inflict considerable damage in plantations and fields. The slight cconomic advantage and profit which accrue from the use of their flesh and fur are not worthy of any comparison with the loss which they entail through the destruction caused by their ravages.

\section{OCTODONS PROPER.}

The species Octodon, which inhabit Chile, Peru and Bolivia, are as it were, intermediate in character between Squirrels and Rats. Their teeth consist of smooth, ridgeless, pointed incisors (or gnawing teeth) and rootiess molars, the upper surfaces of which nearly simulate in shape the Arabic figure " $\mathrm{S}$ " and from this they derive their name of Octodon or "eight-tooth." 
The Degu and The Degu (Octodon cummingii) is its Peculiari- brownish gray upon its upper surties. face, marked with irregular spots; it is grayish brown below, the breast and nape of neck are darker and the base of the tail is nearly white. The total length is about ten and one-half inches,

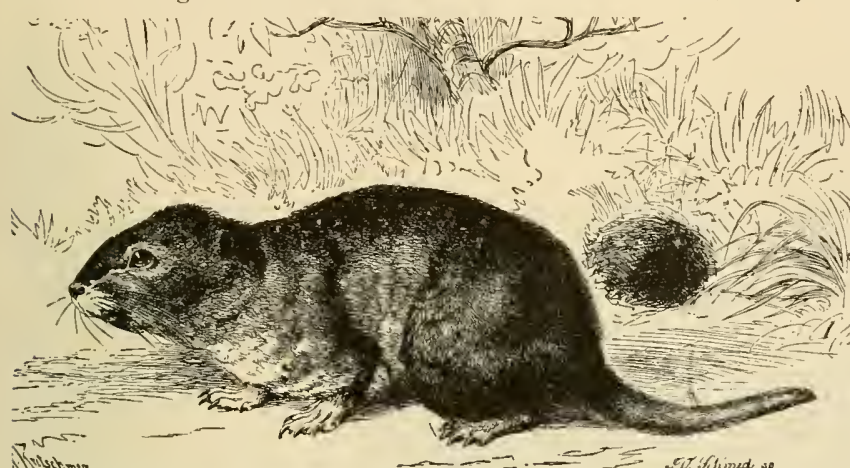

THE TUCO-TUCO. - A member of the Octodon family of Rodents which forms a distinct genus is an inhabitant of Patagonia, called by the native tribes Tuco-tuco. It has five toes on each foot, the innermost toe being much shorter than the other four. It measures about ten inches, of which about two and a half inches belong to the tail. The fur is brownish gray tinged with yellow,
and lighter on the under portion. It inhabits the plains of Patagonia north of the Kio Colorado, where it lives in burrows. (Ctenomys magellanicrs.)

rather more than one-third of this length being occupied by the tail.

The Degu is one of the commonest animals of the middle province of Chile. Hundreds of them in fest the hedges and bushes; even in the immediate neighborhood of populous cities they fearlessly run about on the high roads, boldly invading gardens and orchards, where they cause as much damage by mischievously gnawing (apparently for pastime) at the plants as they do by their voracity. They rarely leave the ground to climb on the lower branches of trees. In respect to their habits these animals resemble Squirrels much more than do the Rats. Notwithstanding the mildness of the climate of the countries in which they live, they lay by provisions but do not hibernate.

\section{THE COYPU OR NUTRIA.}

The Coypu or Nutria of Spanish Americans (.Myopotamus coypu) also bebongs to this family. Its body is stout and plump, the neck short and thick, the head thick, long and broad, blunt-muzzled and flat at the top; the eyes are round and prominent, the ears small and somewhat longer than they are broad; the limbs are short but stoutly fashioned, the hinder pair being slightly the longer; the feet are five-toed, the digits being joined by a wide web and furnished with long, strongly curved, pointed claws, the inner toes of the fore-feet showing a flat nail. The long tail is cylindrical, scaly and rather plentifully overgrown with strong, close bristly hair. The rest of the fur is thick, rather long and soft and consists of a short, soft, downy, woolly coat, nearly impermeable to water and a longer, soft, slightly lustrous outer fur, which determines the color, as it completely covers the inner fur. In regard to its dentition, the enormous, broad, gnawing teeth remind the observer of those of the Beaver.

The Coypu attains to nearly the proportions of a European Otter. Its body is on the average from sixteen to eighteen inches long, and its tail nearly the same in length; one sometimes finds old males, however, which are fully three feet long. The usual color is maroon red on the back, deepening into nearly blackish brown on the under parts, and brightening into a fiery red on the flanks.

Range and
Habits of the important fur-
Coypu. large portion of temperate southern America. The Coypu is known in nearly all the countries south of the tropic of Capricorn. It is exceptionally plentiful all over the country drained by the River La Plata, and in Buenos Ayres, Patagonia and central Chile. Its range extends from Atlantic to Pacific, crossing the mountains, and from the twenty-third to the forty-

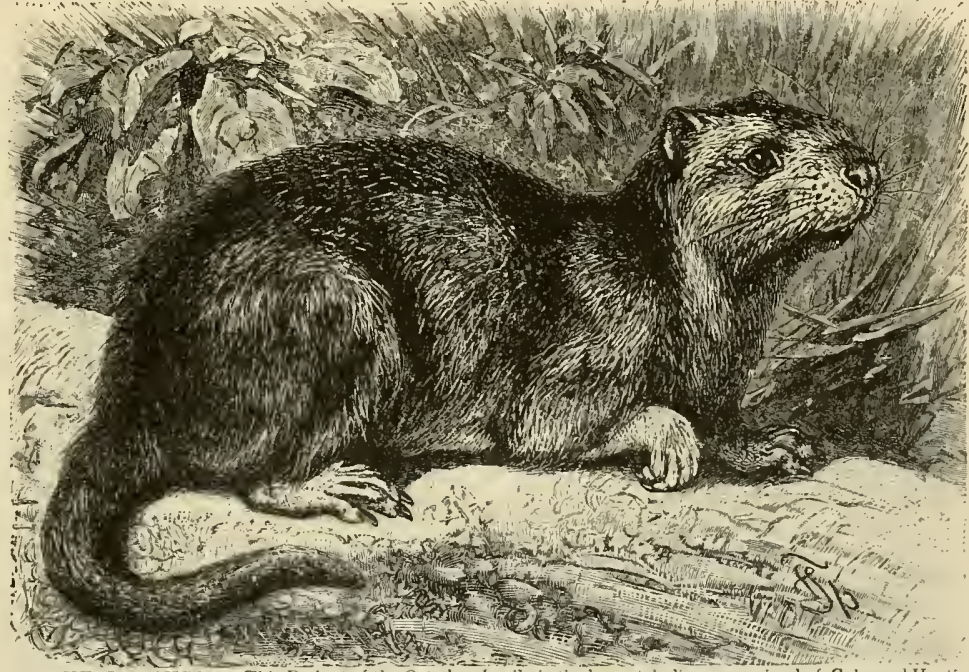

HUTIA TONGA. - This Rodent of the Octodon family is the largest indigenous animal of Cuba and Hayti, ttaining a length of from fourteen to sixteen inches exclusive of the tail. Its fur is of a dull black color. It is arbo-

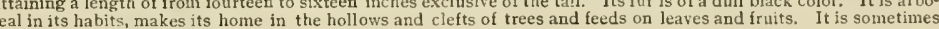
(Caproniys pilorides.)

third parallel of south latitude. It lives in couples on the banks of lakes and rivers, especially near morasses and stagnant waters in which there is a rank enough growth of aquatic plants to form a sufficiently firm surface to the water to hold it up or enable it to pass over on the distended vegetation. 
Every couple excavates a burrow about three feet deep and from sixteen to twenty-four inches wide, in which they spend the night and sometimes also part of the day. In this habitation the female gives birth to from four to six young, which begin to follow her about at a very early age. The Coypu is an excellent swimmer, but an indifferent diver. On dry land its gait is very slow, for its legs are so short as to allow the abdomen to nearly drag on the ground; the animal therefore proceeds by land only when it is crossing the intervening country from one body of water to another. When alarmed it instantly rushes the water, the tail stretched out. The whole labor of propulsion rests with the hind feet, the fore feet being used as little as are those of the Beavers. The voice is a plaintive sound which is not entirely discordant and serves as a call, being responded to by others of the species, which may hear it; it is, therefore, uttered frequently. If the animal is angry or annoyed it utters a petulant growl. Grass is the favorite food of the Coypu, but it also feeds on roots, bulbous plants, leaves, grains, and in captivity on bread; it is quite fond of some kinds of animal food, as for instance, fish; in this respect also showing an affinity with the Rats and not with the

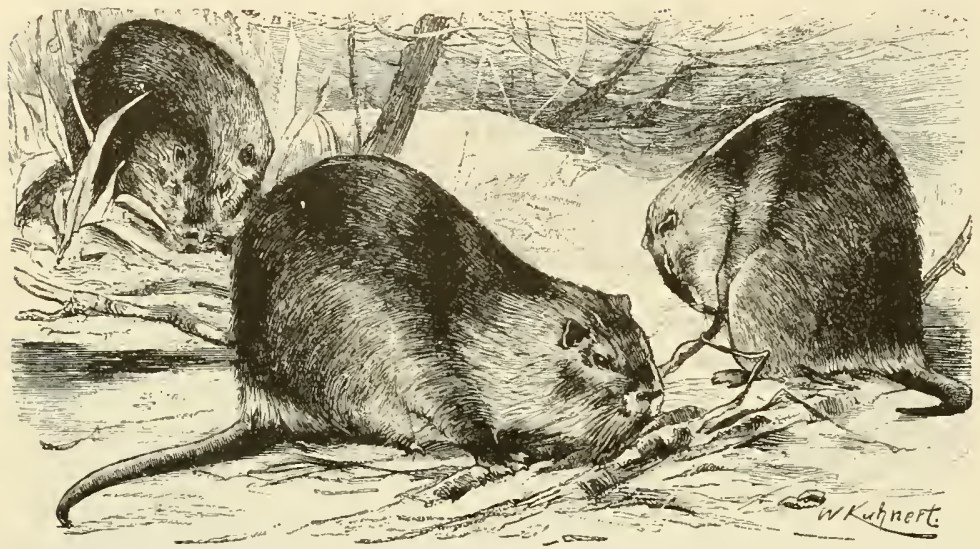

THE COYPU OR NUTRIA. - This Rodent, inhabiting the temperate regions of South America, is aquatic in its habits, frequenting interior streams and bodies of water. As shown by the picture, it has a bare, Rat-like tail and mus coypu.)

and dives into the water; if it be pursued closely it finally retreats into its hole, which it inhabits only at night at times when it is left undisturbed.

Intellectual Char- Its intelligence is slight. It is shy acteristics of and timid and evinces these qualities the Coypu. even when in captivity. It can not be called a teachable animal, though it gradually comes to know its keeper. In the London zoological garden it is a permanent feature and recently it has also been kept in other zoological gardens. "The Coypu," says WVood, "is a quick and lively animal and very amusing in its luabits. I have often watched its funny antics and have been much amused by the manner in which it traverses its domain, and examines everything that seems to be novel. If a tuft of grass is thrown to it. the Coypu picks it up in it.s fore-paws, shakes it violently to get rid of the earth that clings to the roots, and then, carrying it to the water-side, washes it with a rapid dexterity that might be envied by a professional laundress."
Habits
of the
Captive Coypus that I had in my
care spent the entire day, with few

Coypu. intervals, in the water and on the banks, at the most taking a rest at noon; in the evening they were specially active. They sometimes rive evidence of the possession of accomplishments which one hardly expects of them. It is true that their movements are neither rapid nor constant, but they are vigorous and agile enough. In their habits and disposition and in their manner of swimming they resembie Water Voles more than they do Beavers. So long as they are unmolested they are wont to swim straight ahead, the hinder quarters deeply submerged, the head lifted about tivo-thirds above
Beaver. It does not seem to be partial to the bark of trees. The grass is skilltully eaten by it, not being torn to pieces or cut; food thrown to it is seized and carried to the mouth with the forepaws. Towards winter captive Coypus make preparations for more secure shelter, continually digging wherever they can with the intention of building larger burrows. If they are not interfered with they dig deep tunnels in a short time and display great activity in providing a soft bed; for this purpose they carry some of the food given them, especially grasses, into their sleeping chamber.

The care of the Coypus is simple, their feeding easy and cheap, and their breeding presents no difficulties, so that their keeping may be recommended to any person fond of animals and possessing a suitable place for them: I would say more-it would be well worth one's while to try to establish a little colony of some four or five in a sheltered forest, containing a pond or some slowly flowing stream and sufficient herbage. In the light of my experiences I believe that the animals would find sufficient nourishment and would be able to stand the winter of northern climates without inflicting any perceptible damage cither on the trees of the forest or upon the growing crops.

The Fur The animal is an object of eager
of the Coypu pursuit owing to the economic value

valuable. of its fur. In $1 \$ 27$ the province of Entre-Rios exported 300,000 skins, according to the official reports of the custom house in Buenos Ayres, and the export was still on the increase; for in the beginning of the ' 30 's the swamps of Buenos Ayres and Montevideo alone shipped 50,000 skins to England. At present about a million and a half of skins are sold annually, about two-thirds of which are of an inferior quality and are used in the manufacture of felt. Those having long, close hair are used for trimming garments, after the long hair of the outer coat has been pulled out; they are utilized in both their natural color and when dyed. The flesh is white and savory and is eaten by the natives of many localities, but disdained by others.

The Coypu is hunted in Buenos Ayres chiefly with hounds trained for the purpose, which find the 
Coypu in the water and drive it towards the hunter, or else they enter into combat with it, though the large Rodent defends itself couragcously and elfectually. Traps are set out on the shallow places of its favorite haunts and in front of the holes.

\section{THE AFRICAN GROUND PIG.}

An African form, called Ground-Pig by the natives (Aulacodus swinderiames), is a stout animal with a small head, a short, broad muzzle, sniall, naked half-round ears, and short four-toed feet with rudimentary thumbs. The fur consists of smooth, spine-like bristles with a fiexible extremity. The bristles are ashy gray at the base, darker in the middle and black at the tip, which is usually surrounded a short distance from its end by a brownish yellow ring. The GroundPig is, as far as our present information extends, distributed throughout eastern Africa as far to the south as Cape Colony, and in western Africa its range comprises both Upper and Lower Guinea. The animals live near the water and chiefly inhabit banks of rivers, thickly grown with grass, reeds and sedge, or bushes. Their food consists of grass, roots and bulbs. Drummond describes them as very harmful animals that can work great devastations especially on sugar-cane and maize plantations and therefore are diligently pursued in cultivated portions of the country.

The Ground Pig a Another reason for the pursuit of

Choice Food the Ground-Pig at the hands of both

Animal. Europeans and natives is, that its

flesh yields a more palatable roast than any other African mammal.

\section{Tbe Cbincbillas.}

\section{TWELFTH FAMILY: LAGOSTOMIDE.}

It is only in recent times that we have obiained accurate knowledge of the members of a small family of American animals, the pelts of which have been used by the aborigines of South America from time immemorial, and have also been shipped to Europe since the end of the last century. The Chinchillas (Lagostomida) might be classified as an intermediate variety between the Mice and Hares, in respect to their external appearance. The most suecinct description that can be given would consist in calling them Rabbits with a long, bushy tail. Their dentition, however, separates them distinctly from the Hares. The fur of the Chinchilla is the finest of any known mammal. The coloring is a light gray and white, and brownish black or yellow. Habitat The Chinchillas inhabit South Amerof the Chin- ica exclusively, for the greater part chillas. dwelling on mountains at a considerable altitude, among the barren rocks below the line of perpetual snow; only one species is found living in the plains. They take up their abode in natural holes or tunnels excavated by thenselves. They are all gregarious, and sometimes a considerable colony inhabits one common hole. Averse to daylight, like the Hares, they are most active by dusk or at night. They are quick, lively, nimble and timid, and their movenents also partake in character half of those of Rabbits, half of Mlice. Hearing seems to be their best developed sense. Their intellectual capacities are slight. Roots and moss,

bulbs and bark, and probably fruit also are their 
pelts were shipped to Europe by way of Spain and were esteemed extremely valuabie and treasured as great rarities; they have now become common.

Chinchillas The traveler who climbs the CordilNumerous in the leras from the western coast of South Cordilleras. America perceives, when he has reached an altitude of from six to nine thousand feet that the rocks for miles around are frequented by great numbers of this Chinchilla and two varieties of another species of the same family. In Peru, Bolivia and Chile these aninals must be very plentiful, for travelers tell us that they have encountered thousands of them in one day. The Chinchillas are to be seen sitting in front of their holes on bright days, but never on the sunny side of the rocks; they invariably select the densest shade. In the morning and evening hours they are still more frequently to be seen. Then the mountains, and especially the tops of ridges of sterile, stony and rocky regions, where vegetation is scantiest, is fairly alive with them. On the apparently quite barren rocky walls they ship about with the greatest speed and activity. With surprising ease they climb to and fro on walls which appear to offer no hold whatever. They ascend perpendicular heights of from twenty to thirty feet with an agility and rapidity so great that the eye can hardly follow them. Though not exactly shy, they do not suffer people to approach them closely, and they disappear immediately at the first signs of pursuit.

Propagation of No exact knowledge has as yet been the Chin- obtained as to the details of reprochilla. duction of the Chinchilla, though specimens in the London zoological garden have given birth to young. In its untamed state the breeding season seems not to be restricted to any particular time of the year, and the natives say that the number of young varies between four and six. In its native country the Chinchilla is often kept in captivity, but it is still rarely shipped to Europe. The grace of its movenents, its cleanly habits and the resignation with which it accepts its fate, soon make it a favorite pet with people fond of animals. It is so innocent and tame that one can permit it to range the house at will. The only annoying trait it possesses is its inquisitiveness; for it investigates everything it finds, even dishes of food which are put away rather high, for climbing tables and cupboards is but child's play to it. Not infrequently it jumps on somebody's head and shoulders. Its intelligence is of about the same grade as that of the Rabbit or the Guinea I'ig.

The Chinchilla In former times the Chinchilla is

Decreasing in said to have been as often found on Numbers. the lower portions of mountains down to the sea-coast as on the heights. The incessant persecution to which it is subject on account of the value of its fur has driven it upwards into mountain fastnesses. Europeans occasionally kill it with a gun or a cross-bow; but this kind of hunt is always an affair of uncertain result, for if a Chinchilla is not hit in a way which causes immediate death it invariably slips into a crevice between the rocks and is lost to the hunter. The Indians spread wellmade nooses in front of all crevices and take the Chinchillas which have been caught in them during the night out the next morning. Besides this they know perfectly well how to tame the Peruvian Veasel and train it for a Chinchilla hunt; then they proceed in the same manner as the European does when hunting with Ferrets.
The Smaller In northern and central Chile the Chinchilla Smaller Chinchilla (Eriomys laniDescribed. $\quad g_{c}(\tau)$ takes the place of the Common Chinchilla. Its habits are much the same as those of the common species, and its form and coloring are also similar to those of the other. It is nucin smaller, however, for its total length amounts at the most to fourteen or sixteen inches, one-third of which is included in the tail. The fur is close and of silky softness, the hair being less than an inch long on the back and rather more than an inch on the sides. The coloring is a light ashy gray, mottled with a dark hue.

Of this species it was only after repeated efforts on the part of naturalists that a few skulls, and later some living specimens, were brought to Europe, though it had been mentioned in accounts given by travelers of a very early date.

In $I \$ 29$ a living Chinchilla of this variety arrived in London and was described by Bennett. It was a very gentle creature, though it occasionally tried to bite when annoyed or teased. It was rarely in a playful mood and seldom performed its strange antics. It usually sat on its haunches but could also raise itself on its hind legs and retain this erect position; it carried its food to the mouth with its forepaws. In winter it showed great susceptibility to cold.

The observations which I made as to the habits of a captive Smaller Chinchilla tally with Bennett's accounts in all material points. My pet was more of a nocturnal animal, however. It was awake in the daytime only when disturbed. This animal shuns the light and always keeps in the darkest spots. There it settles down with contracted body. Any cranny offers it a place of refuge. Its voice is heard only when some one touches it; then the animal utters a sharp squeak like a Rabbit. It dislikes to be handled and tries to effect its release by sudden spasmodic jerks when taken up, but never resorts to biting. It prefers hay and grass to all other food, disdaining grains and scarcely touching juicy roots. The question, whether it drinks water at all, has not been settled; it, however, seems as if it could entirely abstain from drinking.

Chinchilla's Flesh South Americans are fond of the an Article of flesh of both varieties of Chinchillas, Food. and European travelers also seem to have found it to their taste, though they say it can not be conpuared in excellence to that of the Hare. The flesh is only of secondary consideration from an economic standpoint, however, the principal profit of the chase arising from the value of the fur.

Two Varieties of Two kinds of fur are distinguished Chinchilla in commerce: that of the larger, Fur. true Chinchillas, the hair of which is long and fine, and that of the smaller, short-haired Chinchillas; the former brings from three and onehalf to six dollars apiece, the latter from twenty-five cents up to one dollar and a quarter. About twenty thousand of the former and fwo hundred thousand of the latter are sold annually.

\section{THE LAGOTIS.}

Considerably longer ears, a tail equaling the body in length and bushy along its upper surface, fourtoed feet and very long whiskers distinguish the Lagotis (Lagidium) from the Chinchillas proper. The dentition is very similar in both species and their mode of life is nearly identical. So far only two varieties are definitely known, both living on 
the table-lands of the Cordilleras, just below the line of perpetual snow among the barren rocks, at an elevation of from nine to fifteen thousand feet above sea-level. They are as gregarious, playful and agile as the preceding species, exhibit the same physical and mental peculiarities and feed more or less on the same, or, at least, similar plants. One of two varieties inhabits the table-lands of southern Peru and Bolivia, the other the northern part of Peru and Ecuador.

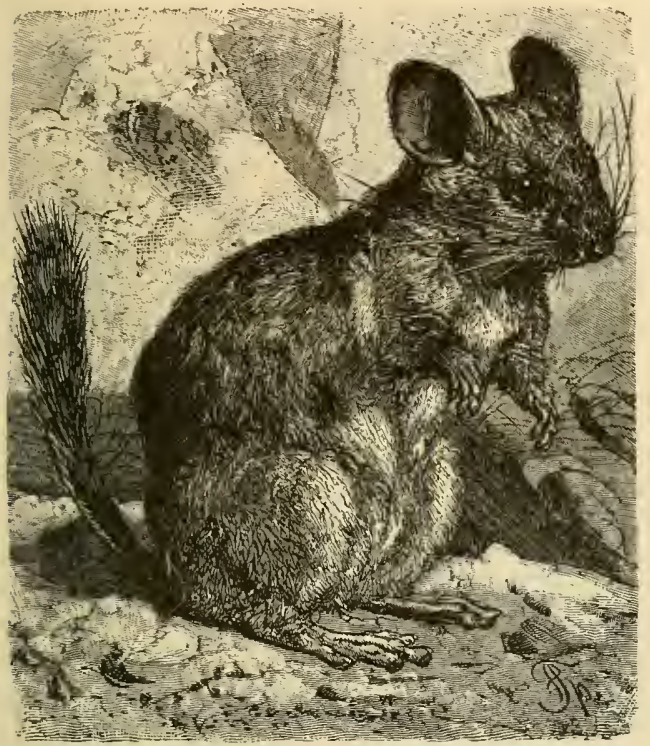

THE COMMON CHINCHILLA. - Sitting in the shadow of a rock in the sterile slopes of the Cordilleras, the little Rodent in the picture is enjoying itself atmidst barren surroundings. It is a very lively, agile animal. and assumes many attitudes, of which that shown in the picture is a contmon one. (Eromys chinchilla.)

The former is the Cuvier's Lagoti (Lagidium curicri) an animal about the size and shape of a Rabbit. The fur is soft and long and of an ashy gray liue, softening into a yellowish tint on the flanks.

\section{THE VISCACHA.}

The representative of the third species, the $V$ iscacha (Lagostomus trichodactylus) assimilates more nearly to the Chinchilla than to the preceding species. Its body is covered by a tolerably thick fur. The upper surface of the pelt consists of uniformly distributed gray and black hairs, the back in consequence appearing rather dark; the whole under surface and the inner portions of the limbs are white. The body measures twenty inches in length, while the tail rather exceeds seven inches.

The Viscacha is the sole representative of its family east of the Andes; it is at present a native of the pampas or vast grassy plains, ranging from Buenos Ayres to Patagonia. Before the general cultivation of the ground in that country it was also found in Paraguay. Wherever it is found at all, it exists in large numbers. In some regions it is so common that one frequently, especially in the dusk of evening, sees groups of them sitting on either side of the road. The very loneliest and most deserted spots are its abode; it comes close to the boundaries of cultivated regions, however, and travelers may generally, with good reason, feel sure that spanish settlements are near when they find a great number of "Viscacharias," as the burrows of these animals are termed.

The Abode of The Viscacha takes up its abode in the Vis- arid plains covered with a scant cacha. vegetation, or even occasionally barren; there it digs extensive underground burrows, preferably near bushes and at a small distance from fields. The burrows are both excavated and inhabited by colonies in common. They are provided with numerous tumnels and holes for escape, often as many as forty or fifty, and are divided into several chambers internally, according to the number of individuals in the family inhabiting it. The number of members of the family may sometimes increase to eight or ten; then some of the innates forsake the old burrow and dic another, if possible close to the former. Now it sometimes happens that the Burrowing Owls, which we know as the companions of the Prairie Dogs, put in an appearance here also, and without further ado take possession of one or the other burrow. The cleanly. Viscachas never tolerate a companion which has not the same strict ideas of orderliness as they and consequently leave the burrow and proceed to dig another for them-

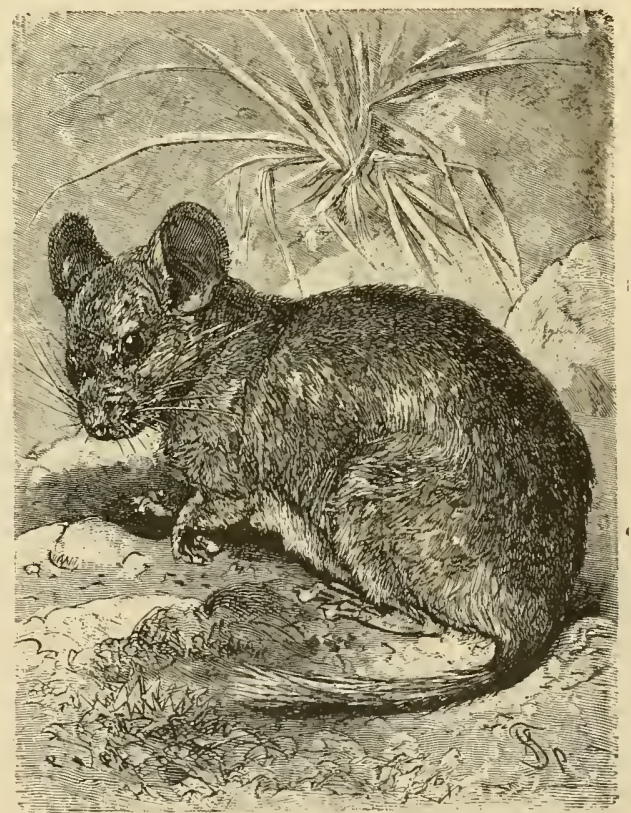

THE SMALLER CHINCHILLA - This species of Chinchilla is smaller than the Common Chinchilla but it differs little Irom that animal in other respects, being as lively and agile as its southern neighbor, which it also resembles in habits. (Enomys lanigeri.)

selves as soon as the intruders annoy them by their uncleanliness. In this way it may happen that the soil is completely unclermined for a space a quarter of a mile square. During the day the family lie hidden in their burrow; towards sunset they emerge. one by one and at the advent of night a more or less numerous company gather in front of the holes. They investigate very carefully to ascertain 
whether or not everything is quiet and safe, and for some time stay near their holes, before they set out in search of food.

Physical Pecul- The movements of the Viscachas reiarities of the semble those of Rabbits; but they Viscacha. are much their inferiors in speed, though they are of a more vivacious and playful disposition. While grazing they play with one another nearly all the time, running, jumping over each other, grunting, showing their teeth, etc. Like Jackals, they carry home the most heterogeneous collection of objects they may find and pile them up in front of their holes in a confused heap, like toys, as it were. One finds bones and nests, and lost articles, which certainly are not of the slightest use to them, piled up before their holes, and when the Gauchos mysteriously lose anything they go to the nearest Viscacherias to look for the missing article.

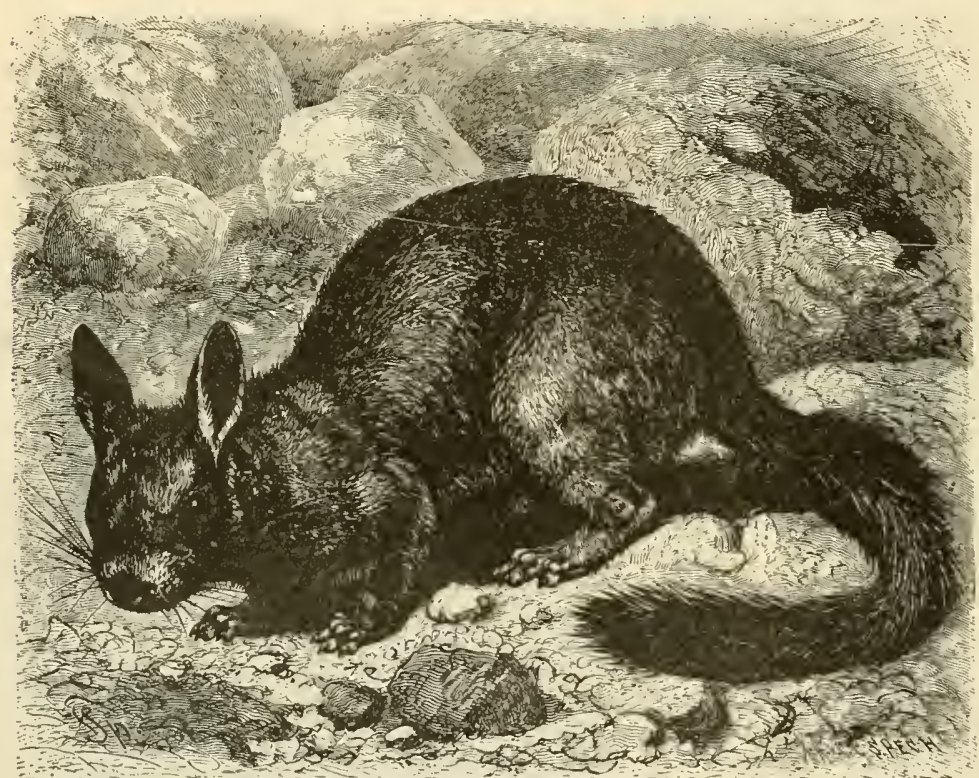

CUVIER'S LAGOTI. - This member of the Chinchilla family is about the size of a Rabbit, but has a long bushy tail, long whiskers that Puss might envy, and very long ears. It is a denizen of the mountains and is therefore here correctly depicted among the boulders of its native Cordilleras. (Lagidum cuiticri.)

From the interior of the burrows, however, the animals remove anything not belonging there, as they also do the dead bodies of their own kind. Whether they gather and store up provisions for winter has not yet been decided. Their method of rocal expression consists of a queer, loud and disagreeable snort or grunt, which can not be described.

Propagation of Nothing definitc is as yet known the vis- about the inethod of their reproduccacha.

tion. The number of young is said to be from two to four in each litter, and they are believed to be fully grown at the age of from two to four months. Goering never saw more than a single young one with one of the old females. It always kept in the closest proximity to its mother, which seemed to be very fond of it and defended it in danger. If the young are captured and carefully tended, they become tame and may be kept as casily as Rabbits
The Viscacha an The Viscacha is pursued less on Annoyance to account of the value of its flesh and Man. skin than it is for the purpose of extermination because of its annoying habits of burrowing. In those places where it is conmon, riding on horseback becomes extremely dangerous, because the Horses often plunge through the roofs of its shallow tunnels, and if they do not fall and throw their riders or break their own legs they usually become very restive and greatly excited over it. The natives know the haunts of the Viscachas from afar by the presence of a small, wild, bitter musk-melon, of which the animals are said to be very fond. This plant is always found where there are many Viscacherias or vice vcrsa-the latter are always established where the plants spread their green tendrils. In this way it serves as a guide and warning for the horseman to avoid the dangerous places.

All expedients for driving the Viscachas from the neighborhood of settlements are resorted to, and even fire and water, literally, are employed for this purpose. The grass around their holes is burned and they are thereby deprived of nourishment; their holes are inundated and they are forccd to go out, straight into the jaws of the waiting Dogs.

The South American Indians eat the flesh of the animal, and may also put the skins to account, though the latter are of much less value than those of the before mentioned kindred species.

\section{Tbe lbares. THIRTEENTH FAMILY:}

\section{LEPORIDE.}

As the last family of this order we consider the Hares (Leporide), a family with characteristics so distinctive that one might regard it as a sub-order.

They are the only Rodents which have more than two front tecth: for the sharp, broad gnawing teeth have on eacl side a true incisor, shaped like a small, blunt, nearly quadrilateral peg. This gives the dentition so peculiar a stamp as to isolate the Hares completely. Each side of both jaws also contains five or six molars, composed of two laminx. The general distinctive anatomical characteristics of the Hares are: an elongated body with long hinder legs, a long skull with large eves and long ears, five-toed fore-fect and four-toed hind-feet, thick, deeply cleft and highly mobile lips, furnished with stout. whiskers on both sides, and a close, nearly woolly fur.

Extensive The family enbraces few species, Distribution of but is distributed over a great cxHares, tent of country. In the Australian belt alone the Hares would be absent were it not for 
the interference of Man. Two imported species are at present widely spread in Australia and New Zealand also. The Hares are tound in all elimates, in plains and on mountains, in the open country and in clefts of rock, above and below the surface of the earth: in short, everywhere, and where one species ceases another commences; the locality which is not adapted for occupancy by the one possesses a contented inhabitant in another. All prefer to feed on tender, juicy plants, but one might say that they really refuse nothing within their reach. They cat all portions of plants from the roots to the fruit, though they are most partial to the leaves of low growing herbs. Most of them live gregariously to a certain extent and rarely forsake their domicile when they have onee selected it, or it has been given them. There they lie hidcten during the day in a depression or hole, and prowl about at night, luoking sion consists of a dull growl, or when frightened a loud, pitiful squeal. The "Crying llares," belonging to this family justify their name. The voice is seldom heard though, and is accompanied and supplemented by a peeuliar flopping of the hind legs, which signifies either fear or anger and is intended to convey a warning. The various species exhibit somewhat wide differences in intellectual capacity. In general the llares do not justify our preconecived ideas of them. They are said to be goodnatured, peaceable, inoffensive and cowardly; they prove, however, that they ean be the very reverse of all this. Cluse observers flatly deny the good-nature and pronounce the Hares malieious and quarrelsome to the utmost. Their timorous disposition, watehfulness and shyness are universally known. while the cunning which they acquire and which reaches really wonderful development in advaneed

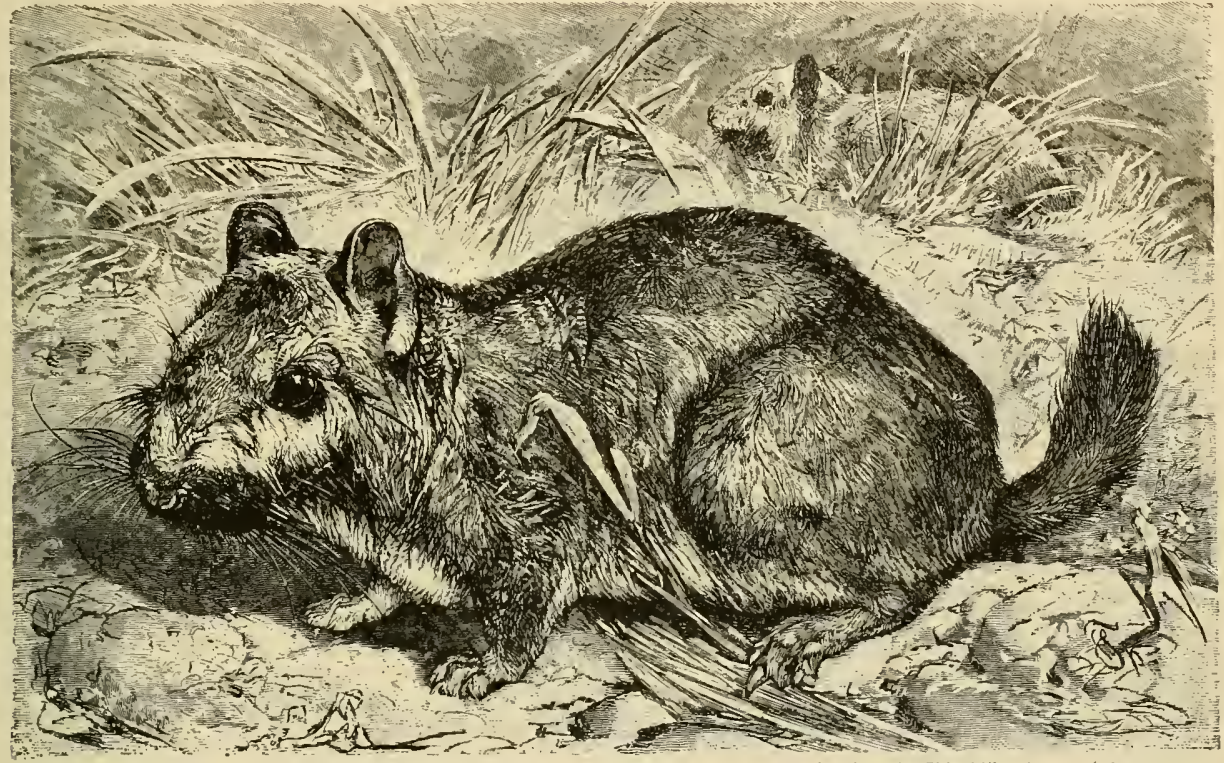

THE VISCACHA. - In the pampas of the Argentine Republic the Viscacha, an animal related to the Chinchilas. is one of the most com-

mon of Rodents. The picture appropriately depicts this species in the high, coarse grass of its native plains, and shows them in company 1or
are gregarious animals. Its actions resemble a Rabbit's but it is not so timid nor so fleet of foot as the latter. (Lagostomus trichodactylus.)

for food. Strictly speaking, when in thinly populated districts they rest only during the noon hours and run about in broad daylight of evenings and mornings if they deen themselves secure from danger. Their movements are very peculiar. The well known speed of the Hares is exhibited only in full course; when their gait is a slow walk they are very clumsy and awkward, owing to the disproportionate length of their hind legs, which renders an even gait difficult. They are able, however, to turn about sharply when in full flight, and give evidence of an avility for which one would not give them credit. They shun water, though they swim across rivers when hard pressed.

Physical and Among their perceptive senses that Mental Character- of hearing certainly ranks first: this istics of Hares. faculty undoubtedly attains among Rodents a development found in few other animals. Their sense of smell is weaker, though not deficient, and their sight is fairly keen. Their vocal expres- age, is much less well known. Neither are they such cowards as is usually believed. One certainly wrongs them in emphasizing this quality in the way Linneus has done, who denounced the Alpine Hare as a coward beyond redemption.

Propagation Though the rate of reproduction of of the the Hare is not as excessive as that Hares. of some other Rodents, it is still great enough, and the old saying of sportsmen that the Hare goes out alone in spring and comes back in autumn in a company sixteen strong, has its full value in localities where life uses our subjeet kindly and pursuit does not wax hot. Most species have several litters a year, each numbering from three to six, nay, even eleven young; but nearly all are deficient in the parental instinct and treat their offspring in an exceedingly careless way; hence many of their progeny perish. In addition to this, a vast army of enemies lie in wait for the savory game, foes of widely variant species in every continent, 
but at no point less in number than elsewhere. No wonder that, beset by so vast a host of enemies, the Jares do not multiply as fast as they otherwise would. It is fortunate for us that such is the case, for else they would lay all our fields completely in waste. As it is, they become a sore pest in all localities where their numbers increase to any considerable extent.

\section{THE HARES PROPER}

The distinctive features of the Jares proper (Lepus) are the ears, equaling the head in Jength, the shortened thumbs of the fore-paws, the very long hind legs, the erect stumpy tail and six molars in the upper jaw.

The Com- The Common Hare (Lepus anlgaris, mon Hare, and its erroneously called Lepus timidus)

Peculiarities. is a stoutly built Rodent of a total length of thirty inches, only three of which are included in the tail; it is twelve inches high and is one of the two species indigenous to Germany. It attains a weight of about ten or twche pounds, but in a few rare instances there are old males weighing fourteen, sixteen or even eighteen pounds. The coloring of the fur is difficult to describe in few words. There is a short woolly inner fur and a long outer one of a genuine eartliy color. The upper surface is brownish vellow dashed with black; the neck is a ycllowish brown mottled with white; the hind parts are whitish gray and the under surface white. The color is subject to regularly recurrent variations in winter and summer, and the female has a more ruddy hue than the male; there are different variations, howeve:, and one meets with dark, piebald and white individuals. In the majority of eases the coloring is excellently adapted to conceal the animal from discovery oy its enemies when it lies on the ground.

The Home of the The Common Hare is indigenous to Common all of central Europe and a small Hare. part of western Asia. In the south it is replaced by the Hare of the Mediterrancan, which is a variety of smaller size and ruddy hue; on the hich mountains by the Alpine llare, and in the north by the Varying Hare, which is perhaps clistinct from the Alpine varicty, but certainly assimilates very close to it. The northern boundary of the Common Jare is Scotland, southern Sweden and northern Russia, to the south it is confined by southern France and the north of Italy. Fertile plains, with or without forests, and the wooded, low-lying spurs or foothills of mountains are its favorite haunts; in the Alps, however, it is found 4.500 feet above the sea and in the Caucasus above 6,000 feet. Habits and Food In general the Hare's habits are more of the Common nocturnal than diurnal, though it is Hare. often seen roaming about in the ficlds before sunset and in the morning on a clear day. It is very averse to leaving the locality in which it has grown up. All kinds of vegetables similar in nature to cabbage and turnips are favorite dainties with it. It seems to be especially fond of parsley.

\section{The Hare}

a Nocturnal Animal.

The Hare spends the main portion of the day sleeping or dozing in its "form." It never goes straisht to the locality where it once occupied an old form or intends making a new one, but runs a little past the place, then turns round, makes a few bounds forward, one to the side and so on, and thus reaches, by an indirect course, the spot where it wishes to remain. In preparing its "form," it digs a depression in the open field from two to three inches deep and slightly curved at the rear end. The size ot this depression is such that when the Hare, lying in this "form," stretches out its fore-legs, puts its head with the folded ears on them and presses the hind leas close to the body, the hind part of the back is all of the animal that is exposed to view. Such a hole is a passably good shelter against storm and rain during the mild season. In winter it hollows out this "form" until only so much of its body as appears to be a small, grayish black dot is seen. speed of The great speed of the Hare in runa Hare in Run- ning is chiefly due to the fact that ning. its hind legs are longer than the fore pair. This is also the reason why it can run better up hill than down. Generally it utters a sound only when it sees itself in danger. This cry resembles that of little children, being a shrill scream or squcak.

Among the perceptive senses of the Hare, hearing is developed best, as is indicated by the large size of the external ear; the smell is fairly keen, but sight is rather deficiont. Among its intellectual qualities an exceeding prudence and vigilance stand out most prominently. The slightest noise, the wind rustling in the leaves, a falling leaf suffice to excite its attention and wake it when it sleeps. The supposed inoffensiveness of the llares is based more on fiction than on truth. Dietrich aus dem Winckell say's outright that the greatest vice of the Hare is its malice, not because it expresses it in biting and scratching, but because it often proves its disposition in the most revolting manner, the female denying her maternal love, the male by his cruelty to the little Leverets.

Propagation of

the Hare Spe.

The first litter in a family of Hares is generally born between the middle cies. and the end of March, the fourth and

last litter in August. The first litter eonsists of one or two, the second of three or four, the third of three and the fourth again of one or two Leverets; in very rare cases there may be five or more young. There are five litters in the twelve months in only very rare, farorable vears. The young are born with their eycs open and certainly in a well developed condition. It is an established faet that the mother spends only five or six days with her progeny and then leaves them to their fate. From time to time she comes back to the spot where she gave birth to the little family, calls them by a peeuliar flopping of the ears and suckles them. It the approach of an enemy she leaves her young, though there are cases on record where old female IJares have defended their offspring against birds of prey and Ravens. The majority of first litters perish.

Many Monstrosi- Among no other animals living in a ties Among state of nature have been observed the Hares. so many deformities as among the Hares. Two-headed indivirluals, or such as have double toncues or projecting tecth, are no rarities.

The True Way Whole books have been writicn of Hunting about the right and wrong methods Hares. of lunting Hares, and it therefore is not my intention to discuss the different modes of hunting at length. In my opinion, the greatest pleasure is derived in looking for the Hare and shooting it. The coursing of the Hare with Greyhounds is highly exciting, but degrades the hunt; the sport where the game is driven into an enclosure may be very gratifying in regions where the animals 
are few, but where there are a great many Hares, coursing in this manner becomes a mere butchery. Shooting a Hare after having successfully stalked the game is the reward of skill and most worthy of a sportsman.

Adaptability of Captive Hares are easily tamed, beHares to Con- come readily used to all kinds of finement. nourishment with which one feeds Rabbits, but are very delicate and apt to die. If they are fed only on hay, bread, oats and water, and never anything green, they live longer. If young Leverets are put with old Hares they are always bitten and killed by the latter. Other weak animals rarely fare any better. I once found a killed and half-eaten Rat in the warren of Hares committed to my care. With Guinea Pigs Hares agree perfectly.

According to an account of the "Jagdzeitung," Mr. Fuchs in lVildenberg had a tame Hare in his itself to the soil and climate according to circumstances; peculiar variations occur, however. The Alpine Hares are of a pure white in winter, only the tips of the ears being black; in summer they are uniformly grayish brown, lacking the mottled appearance of the Common Hare. The Irish Hares, which are very similar, are said never to become white and are therefore considered a distinct species (Lipus hibernicus) by some authorities. On the other hand, the l'olar Hares living in the highest latitudes undergo no modification of color in summer, and are therefore also held to be an independent species (Lepus glacialis). The Scandinavian Hares, all of which belong to this species, are also different: some of them turn white, excepting their black ear tips, while others do not change. The roots of their fur are slate gray, the middle dingy reddish brown and the tips white. This coloring seems to be

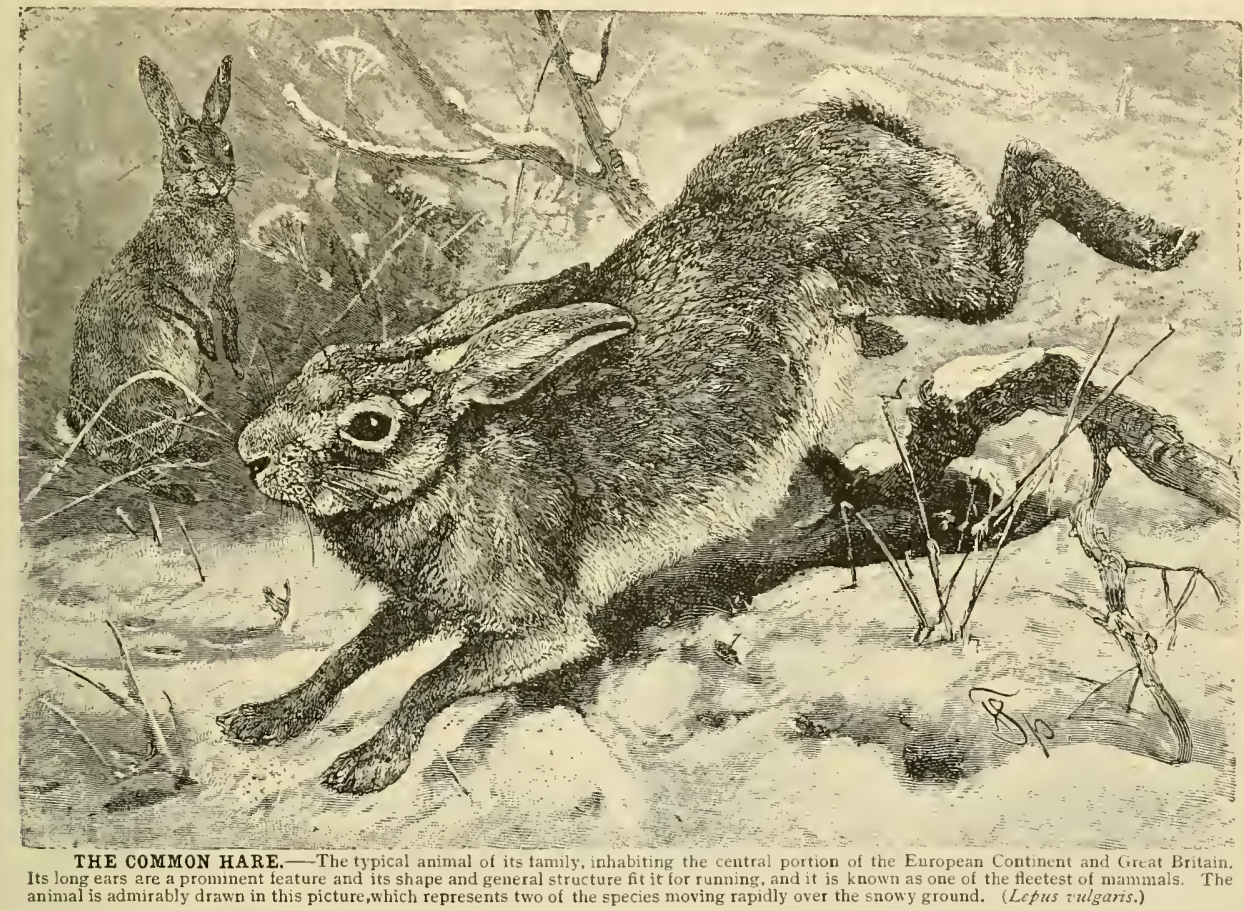

possession which slept and ate with his Dogs and won the special affection of a young Setter. This Hare ate vegetable food only in default of meat: veal, pork, liver and sausage caused it to go into such raptures that it used to execute a regular dance to get at these dainties.

Besides the flesh, which as food is justly esteemed, the fur is also put to account The skin is deprived of its hair, tanned and used in the manufacture of shoes, of one kind of parchment, and of glue; the hair is used in the manufacture of felt.

The Alpine and It is still an undecided question the Polar whether the Varying or Alpine Hare Hares. and the Arctic or Polar Hare of high latitudes are properly of the same variety. In general both prove themselves to be true children of their native country. Their fur accommodates purely fortuitous, however; at least it is maintained that different Hares of one litter often exhibit the two colors indiscriminately.

The Alpine Hare The Alpine or Varying Hare (Lepus -its Pecul- timidus or Lefus i'ariabilis) differs iarities. distinctly from the Common Hare in anatomical structure and in disposition. Tschudi says: "It is more cheerful, livelier, bolder; its head is shorter, stouter, more curved in its outlines; it has a shorter nose, smaller ears, broader cheeks; the hind legs are longer, the soles of the feet more heavily covered with fur; the paws provided with deeply cleft toes capable of much extension, and arned with long-pointed, curved, retractile claws. The eyes are not pink, like those of white Rabbits, white Squirrels and white Mice, but of a darker brown than those of the Common Hare. 
Change of the "WWhen the Alps are buried in snow Fur of the Aipine in December this Hare is as purely Hare. white as the snow itself, only the tips of the ears remaining black. The spring sunshine induces a very remarkable change of color, this change beginning in March. The animal first becomes dark on the back, and gray hairs appear more and more numerously amid the white of the flanks. In April it has a queer, pie-bald appearance. The dark brown hue gains more ground every day, and finally in May the change is complete, the color being uniform and not mottled like that of the Com- and crannies that the spectator can not long remain concealed from the alert animals, or have an opportunity to observe for any length of time their domestic routine. The Alpine Hare "A surprising fact is that the Alpine
Easily Domes- Hare is more tamable than the Comticated. mon Hare; it behaves more quietly and shows greater confidence, but seldom endures long and fails to get fat even with the most abundant nourishment. It misses in the valley below the rarefied air of the upper Alps. It turns white in winter in confinement also. Its fur is not valuable,

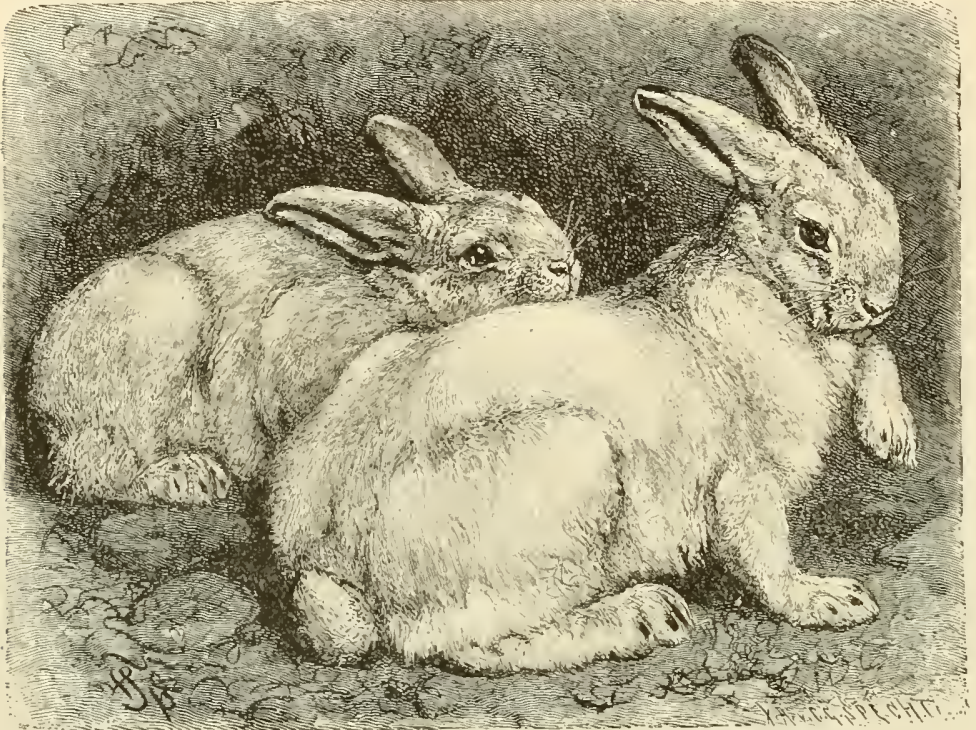

THE ALPINE HARE. - This animal with its white winter coat is a very appropriate inhabitant of the snow regions of the Alps. In the summer the coat is dark brown, but in winter it is all white except the margins of the ears.

mon Hare, the fur of which is of a coarser texture than that of the Alpine Hare. In autumn the first white hairs appear with the first snow; but as winter reaches its climax in less time than does spring in the Alps, the cliange is wrought more rapidly, and is completed sometime during the period extending from the beginning of October to the middle of November. When the Chamois becomes black, its neighbor, the Hare, turns white. The Alpine Hare is commonly found in all the higher Alpine regions, where it is at least as numerous as is the brown Hare in the lower belt. Its favorite country lies between the point at which the fir-trees cease to grow and the line of perpetual snow, at about the same altitude as is favored by the Snow-Hen or Ptarmigan and the Marmot, from 4,800 to 7,800 feet above the sea; it may sometines range much higher, however.

The Propagation "The fenale gives birth to from two
of Alpine to five young, which are no larger
Hares. the forehead. The first litter usually appears in April or May, the second in July or August; there are doubts as to whether there is a third, It is nearly impossible to observe their family life, as the power of scent of these animals is so delicate and the young know so will how to hide in all crevices but its flesh is very toothsome.

The Rabbit (Lepus cumiculus) differs from the Hares proper in its much smaller physical proportions - a more slender frame, shorter head, shorter ears and shorter hind legs. The length of the body of the animal is sixteen inches, nearly three inclies of which are occupied by the tail. The ear is shorter than the head and if pressed forward and downward along the cheek it does not reach to the point of the $\mathrm{muz}$ zle. The tail is black above, white beneath, and the remainder of the body is covered by a gray fur, dashed with yellow-brown above, reddish yellow in front, light rusty on the flanks and thighs and merging into white on the under surface, the throat and the inner sides of the limbs. The upper part of the throat is of a rusty yellow grayish hue, the nape of the neck is palpably of a rusty red color. Variations in coloration seem to occur more rarely than with the Common Hare. Original Nearly all naturalists suppose the Home of the Rabbit. introduced by transplantation into all portions of Europe north of the Alps. Pliny mentions it under the name of Cuniculus, Aristotle calls it Dasypus. All old authors name Spain as its native country,

Present At present the wild Rabbit is dis-

Range of the tributed throughout southern and habbit. central Europe and is quite plentiful in some places. The countries of the Mediterranean are infested by the species in enormous numbers. though it is pursued there all the year round and spared in none of the seasons. In England it was introduced into several localities for sporting purposes and was held in high esteem at first, as late as I 300 a wild Rabbit cost as much as a little Pig. In northern countries it does not thrive. Attempts to introduce it into Russia and Sweden have been futile

Requisites for The Rabbit requires for its domicile the Rabbit's a hilly and sandy country, broken Domicile, by ravines, rocks and shrubbery, in short, offering sheltered spots where it can hide it- 
self. There in suitable locations it establishes rather inconspicuous burrows, if possible, with a sunny exposure. The animals congregate generally in colonies which often seem to have an organized functional govermment. Every burrow consists of a rather deep-lying central chamber from which radiate curving tunnels, each of which is provided with several places of exit. These tunnel mouths usually are more or less enlarged by the frequent passing of the animals in and out; the tunnel proper, however, is so narrow that the inllabitants can just creep through. Every couple has its own domicile, and allows no other animal in it; the tunnels of several burrows often communicate, however. In its bur. row the Rabbit lies hidden all day, unless the bushes around are so thick that it can, entirely screened from observation, obtain its food. As soon as evening draws on it emerges, using a great deal of precaution and carefully reconnoitering before it leaves its hole. If it suspects danger it warns its companions by a vigorous drumming on the earth with its hind legs, and all scramble back into their holes.

The movements of the Rabbit differ materially from those of the Hare. In the first place the Rabbit usually surpasses the Hare in speed and always in agility. It is thoroughly conversant with the art of baffling its pursuers by a series of short doubles, and executes its turns and crooks in a masterly way, requiring an excellently trained Dog or a good marksman to bring it down. Much craftier than the Hare, it very rarely suffers itself to be surprised when feeding and always finds a hole in which to hide. If it were to pursue a line of flight straight ahead, it could be caught in a short time by any moderately swift Dog; but it takes refuge in bushes, crannies, and holes, and usually succeeds in baffling the pursuit of its enemies. The senses of sight, hearing and scent are as acute and perhaps even keener than the same senses in the Hare. The char-

acter of the Rabbit presents many prepossessing phases. It is sociable and gentle, the mothers nurture their young with warm affection and the young hold their parents in great veneration, the patriarch of a whole society being accorded particularly great honor. From early spring until October the female Rabbit gives birth to a litter of from four to twelve young every five weeks, these broods being born in a special chamber, which the mother carefully lines with fur from her own fleece. The little ones remain blind for several days and stay in the warm nest with the mother, who suckles them until the nest litter arrives. The mother is tenderly attached to them and leaves her family alone only when she is forced by hunger to seek food.

Early Fecund-" In warm countries the young are

ity of Rab. capable of reproduction in their bits. fifth month, in cold climates in the eighth, but they do not attain their full growth until a full year old. If we suppose that there are seven litters a year, averaging eight individuals, the progeny of one pair of Rabbits would attain the prodigious number of $1,274,840$ in four years.

The Food of The food of the Rabbit is exactly

the Rab- the same as that of the Hare. But bit. it inflicts a great deal more palpable danage, not only bccause it confines itself in its foraging to a smaller space, but also owing to its fancy for gnawing the bark of trees, through which means it sometimes destroys entire orchards or groves. It is difficult to realize what ravages may be perpetrated by a colony of Rabbits, especially considering the enormous fecundity of the species, if their multiplication be not checked.

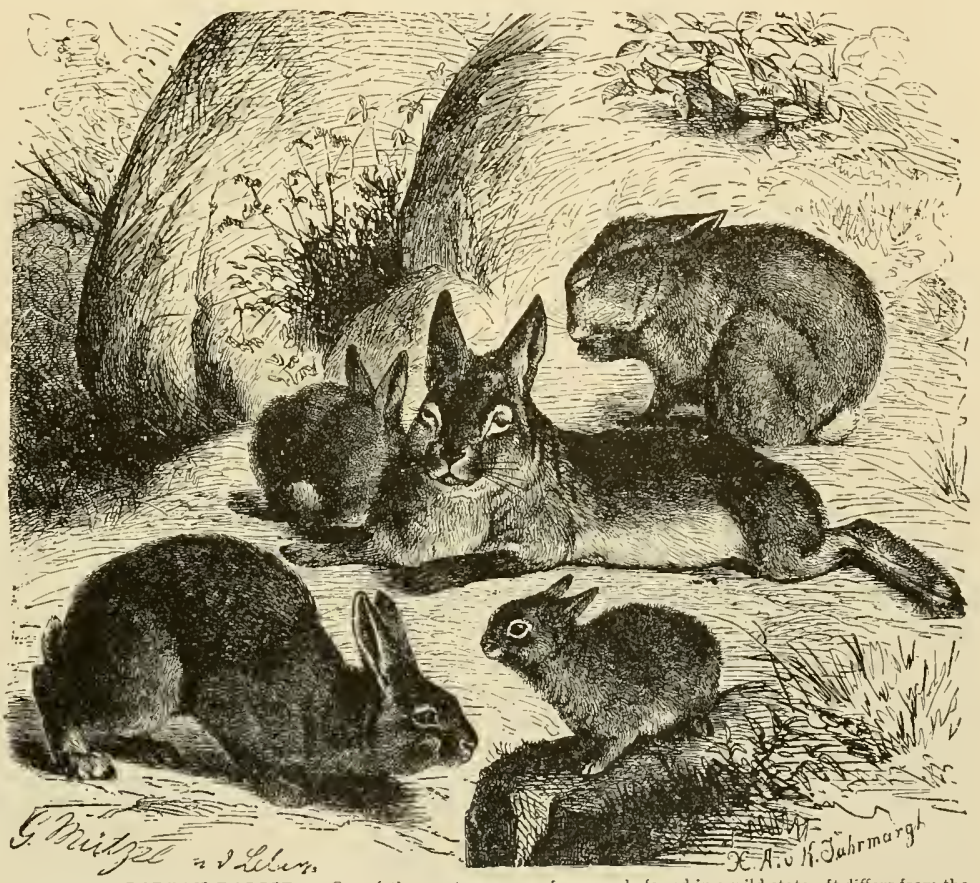

THE EUROPEAN RABBIT. - One of the most common of mammals found in a wild state. ft differs from the Hares in its more slender build, smaller head and shorter ears, and other particulars. The picture shows a happy in fancied security: (Lefus cunculus.)

The Rabbit an Rabbits also drive away other game Undesirable by their restless activity, and Hares Tenant. are seldom found where the Rabbits have gained supremacy. Where they believe themselves secure their impudence assumes incredible proportions. In the Prater at Vienna there formerly were thousands of them that fearlessly ran about by day and did not suffer themselves to be disturbed in their foraging for food either by calls or by missiles thrown at them. They are nowhere protected and are killed even during the close season-the time when no other game is to be molested. Neverthe- 
less they cannot be exterminated without the help of some natural antagonists such as Ferrets. Unless Polecats, Weasels or Martens have multiplied considerably in a particular locality, or there are Screech Owls or other kindred birds of prey to destroy them, a diminution of their numbers is of rare occurrence. Rabbits often a In localities favorable to their mulMenace to Agri- tiplication, Rabbits may become a culture. real pest and exceedingly prejudicial to agriculture. In New Zealand and in Australia, where they have prodigiously multiplied in some localities to such an extent as to entirely

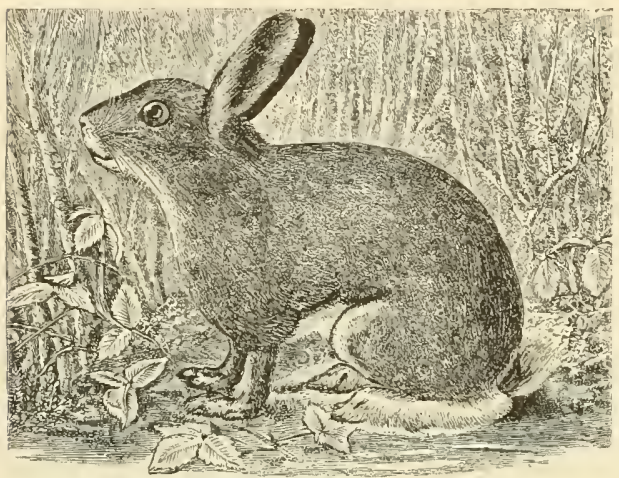

AMERICAN VARYING HARE.-This is the typical American species of the Hare family, of which there are many varieties, the one shown in
the picture being scientifically known as Baird's variety, inhabiting the Rocky mountain region. (Lefus amcricanus bairdii.)

consume the pasturage of domestic Cattle, the attempt to exterminate them has so far been in vain. How seriously damage caused by them is estimated may be seen from the fact that the government of New South IVales has expended over one million pounds sterling in bounties for the killing of the animals during the last decade and finally promised a reward of fifty thousand pounds to the inventor of an effective method of exterminating the pests. Poison, nooses, Ferrets, wire fences, etc., have proved insufficient to check the damage done by these Rodents, An experiment, said to be successful in France at least, lias been made in that country by Pasteur. His plan to exterminate Rabbits quickly and thoroughly is to infect them with Chicken cholera by mixing with their food the germs producing the disease; the experiment has been repeated in Australia on a large scale, but is said to have been unsuccessful.

\section{Origin \\ of the Tame Rabbit.}

The tame Rabbit undoubtedly owes its parentage to the wild one: for while the latter may be tamed in a short time, the former returns to the wild state completely in a few months, if left alone by Man, and in such cases its offspring have the coloring of the wild ones. Tame Rabbits are usually kept in a hutch having a stone or wooden floor, and provided with artificial places for concealment, consisting either of long boxes with several branches or apartments or artificial burrows in the walls; they are given a good supply of straw and dry moss, protected against cold in winter and fed with hay, grass, leaves, etc.

Some Varieties of The Silver-colored, the Russian and

the Domestic the Angora or Silky Rabbit are variPabbit.

eties of the domestic Rabbit. The first is larger than the Common species and usually of a bluish gray hue with a silvery or dark tint. The Russian Rabbit is gray, with brown head and ears, and it is distinguished by a dewlap under the throat. The Angora Rabbit has shorter ears and thickset, soft fur; its long, wavy hair often reaches to the ground and is of a silky lustre. Unfortunately it is of very delicate constitution and requires great care. Attempts to introduce it into other portions of Europe have failed.

North America 'The Hare family has its greatest developNorth America ment in North America, which contains more than twenty species and varieties. Among these are animals that illustrate all the differences in structure and habits known to this family, from the largest slender Hare to the smallest and fattest Rabbit; species that burrow like the Rabbit of Europe, in underground retreats, while others like the Common Hare crouch in shallow "forms" which scarce conceal them from view.

The Polar Hare, Because of its close resemblance to the

a Northern Mountain or Alpine Hare the Polar Hare

Variety. (Lepus glacialis) is considered as the nearthe Old and New Worlds. The northern varieties of the Iountain Hare change their coat with the seasons and except for a brownish tinge on the ears and limbs, turn white in the winter, and these arctic varieties are, by some authorities, separated into a distinct species under the name of the Varying Hare (Lepus a'ariabilis) because of this change of coat. The Polar Hare, however, is white all the year round except the tips of the ears, which are black. It attains a weight of from eight to ten pounds. This Hare occupies a burrow which consists of a hole about four feet in length, extending horizontally into a snowdrift. The number of young composing a litter of these Hares is seven or eight. This species has been found inhabiting the highest latitudes yet visited by Man. Sir George Nares found it on the shores of Grinnell Land, and by observing its footprints in the snow obtained evidence of its

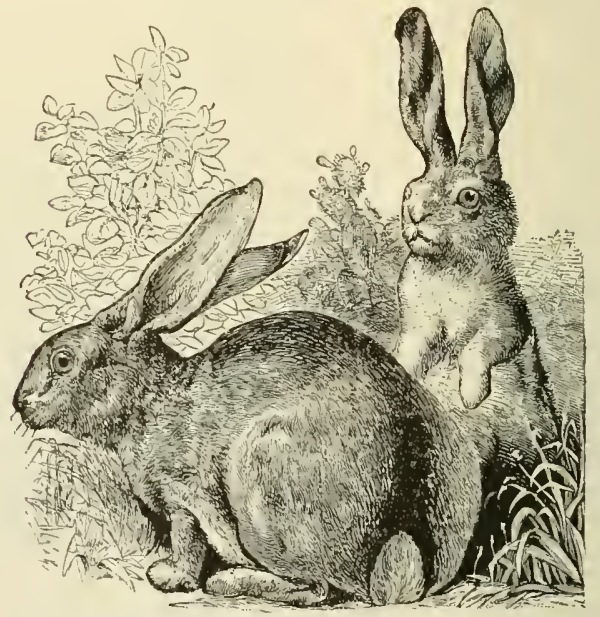

NORTHERN PRAIRIE HARE.-This is the most northern species of the group of Hares, familiarly known in the United States as Jack Rabbits of the group of Hares, familiarly known in the Cnited States as Jack Rabbits
because of their large size and enomous ears. They are lively animals of because of their large size and enormous ears. T
astounding jumping powers. (Lefus camfestris.)

existence in latitude $83^{\circ} 10^{\prime}$, about twenty miles north of the nearest land. In these high northern latitudes this animal "subsists on the stoneworts and other hardy plants which form the scanty vegetation of the circunprolar valleys."

The American A species which has an especially wide dis.

Vorying Hares' tribution is the American Varying Hare

Varying Hares' (Lefus americanus) which is found in all to New Mexico. This species differs from the Mountain Hare of Europe in its relatively snaller ears and smaller size, but like that animal changes its fur during winter. This change is more marked in the more northern varieties, and the nearer the approach is to the arctic regions the more closely the color of this Hares' winter fur approximates to the snow white of the 
Polar Hare. It is especially abundant on the banks of the Mackenzie River, where it is killed in great numbers by the Hare Indians. The typical animal of this species is that of the high north, but there are other varieties of the sanse species which have been named Lipus americanus virginianus, inhabiting the eastern U'nited States; Lepus americanus ziashingtonii, found in Oregon and Washington, and Lepus americamus bairlii, in the Rocky Mountain region south to New Mexico. The principal difference between these varieties is in the coloration of the fur in summer. All are of similar habits and make their resting place in "forms" just large enough to accommodate their bodies, and which are usually situated in long grass. Hunters pursue the Varying Hare for its flesh and fur. This is the species most common in the northern markets in winter. The fur is used by furriers

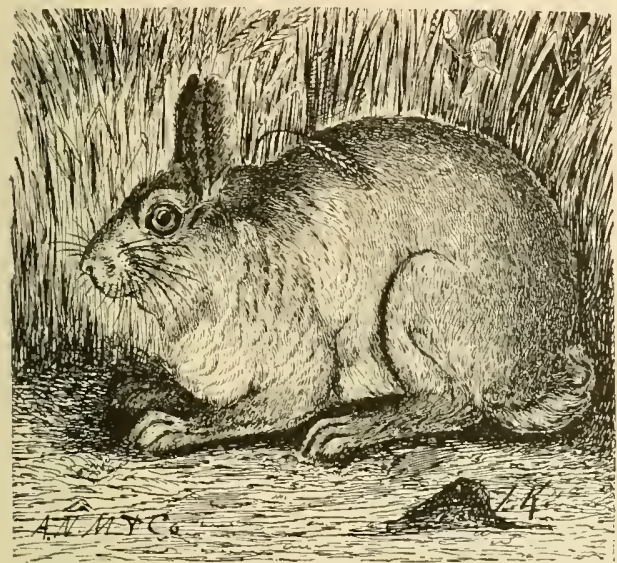

WOOD RABBIT, OR COTTON-TAIL. - A familiar animal in all the forest regions of the United States is the Wood or Cotton-Tail Rabbit, sometimes called "Mlolly Cotton Tail." It is a timid, pretty creature and although it has nuany foes, holds its own in our woods. (Lefus sylvaticus.)

for various purposes and is also used in the manufacture of hats, but is very plentiful, and therefore cheap. Besides Man it has still more dangerous enemies in Wolves, Gluttons and Lynxes, which kill large numbers of these Hares.

The Prairie Hares, In American common parlance there is no or "Jack such distinction between the term "Hare" Rabbits." and "Rabbit" as there is in Europe where in in shallow "forms," are named "Hares," and the smaller and more chubby kind, which digs a deep burrow, is the "Rabbit." In this country no well defined distinction exists. The several species popularly known as Jack Rabbits have none of the distinctive features of the Rabbit (Lepus cuniculus) of Europe. Of these so-called Jack Rabbits the Northern Prairie Hare (Lepus campestris) may be taken as the type. It is one of the largest species of Hares, measuring about twenty inches in length, and it has long, strong and vigorous limbs, and such remarkably long ears that the popular name it bears is fully justified. The general color is yellowish gray with black ear tips. The under portion of the body is of lighter hue, and the tail is white above and below.

This northern species is found on the western prairies from British America to Colorado. It undergoes a winter change of coat, becoming nearly white, but the blanching is never complete and russet streaks or patches remain throngh the winter. Other species of the Jack Rabbits are the Texas Hare (Lcpus callotis) inhabiting Texas, New Mexico and Arizona, and the Californian Hare (Lepus califormicus) of the Pacific Coast. These two do not change their fur with the seasons and their tails are black on the upper surface. The habits of these animals are those of Hares in general, and all the species known as Jack Rabbits are famous for their great speed and for the astounding leaps they make in running. They are the most fleet and agile of American mammals. They are not much pursued for the reason that they are difficult to shoot, and their celerity of movement enables them to elude four-footed foes also.

swamp Hare Two distinct species, both of which are Swamp Hare aquatic in their habits, are found in the
and MarshHare, Aquatic Forms. southern states. These are the Swamp Hare, often called the Marsh Rabbit (Lepus palustris). These have similar habits, take readily to the water, and are said to dive for some distance their legs being less thickly clothed with hair than are the less amphibious species. Both subsist chiefly on aquatic plants, but, although alike in their mode of life, they differ widely in physical characteristics, the Swamp Hare being one of the largest and longest of limb of the American Hares, while the Harsh Hare has short limbs and is small and plump, and is not found so far from the coast as is the Swamp Hare.

The Cotton-Tail a Most abundant of all American species of family is the Wood Rabbit (Lepus sylRabbit-1 vuticus) or Cotton-tail, also called the Gray Species.

Rabbit. It ranges from Hudson's Bay to Florida, and is a small gray species with white fur on the under surface of its tail-from which it derives its popular name. In general form and habits it much resembles the Rabbit of the Old World, although it does not burrow to the extent observed in the European species. In the warmer sections of the country the Cotton-tail does not trouble itself about sheltera shallow excavation by a root or fallen tree serving its purpose. Further north it digs out its refuge to greater depth. It is more gregarious than the larger species and, in the south especially, quite a number of these Rabbits will sometimes congregate in a friendly thicket or convenient briarpatch. In the extreme southern states this animal, as well as other species of the Hares, is much subject to parasitic inflictions, and its flesh is therefore inedible, but farther north it is trapped, not only for its fur but also on account of the damage it does in fields and gardens, and it is subject to the attacks of all carnivorous beasts, birds and reptiles, yet it is so prolific in the propragation of its species that its numbers do not much decrease, and it is common in nearly all sections,

The Sage Rabbit In the prairies of the west and particularly in the valleys and sage brush plains which

$\begin{array}{ll}\text { and Other } & \text { stretch between the Rocky Mountain and } \\ \text { Species. } & \text { Sierra Nevada ranges, is the Sage Rabbit }\end{array}$ (Lepus artemesia) much like the Cotton-tail, of which it seems to be a local variety with such changes as are appropriate to its environment. It exists in very large numbers in spite of the attacks of Coyotes and other predaceous beasts. In size it is about eyual to the Cotton-tail. There are other less prominent forms of the Hare fanily in the United States, mostly in Texas and on the Pacific coast.

THE CRYING HARES OR PIKAS.

The Crying Hares or Pikas (Lagonys) are indigenous to Asia [and western North America]. They differ from the common Hares by their considerably

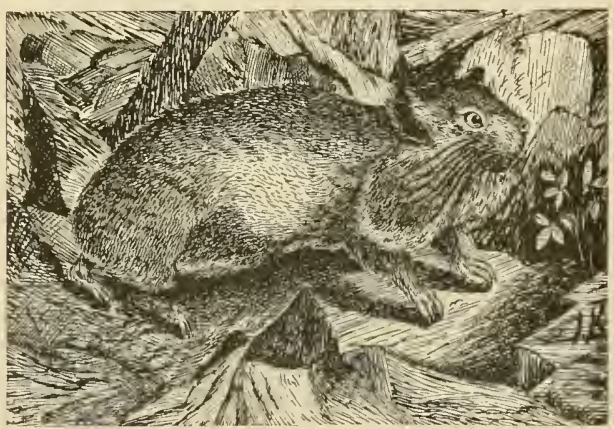

A MERICAN PIKA - This animal, perched on a flat rock in its native Rocky Hountains as shown in the picture, keeps up a squeaking noise, which as many of them are usually together, infallibly attracts the attention of the passer by. It is a peculiar creature and the only representative of the Crying Hares on this continent. (Lagomys princefs.)

shorter ears, only slightly elongated hind legs, a short or a hidden and rudimentary tail, and in their dentition, which exhibits five molars instead of six in each row.

The American or A single species of this sub-family is found The American or in America. It is known as the American Rocky Mountain Pika or the Rocky Mountain Pika (Lugomys Pika. princeps). The scientific name.is borrowed from that given to the animal by the Indians of the western mountain regions, who call it the "Little Chief" Hare. Miners and frontiersmen call it the "Coney" or "Starved Rat," so 
that it will be seen that it does not lack for names. It is from six to seven inches in length. Each hair of the upper parts of this Pika is of a yellowish hue next to the skin, ihen a brownish gray, and black at the tip, the resulting color being a dark grizzly hue. The under portions of the body are of a yellowish or dingy white, and the entire fur is dense and soft. The head, which is two inches long, is ornamented with black whisker hairs and the ears have a blackish tinge with a white margin. The legs are short. A bunch of hairs, less than an inch long, grows out from the rudimentary tail.

Range and Habits In the Rocky Mountain and Sierra Nevada of American ranges from Arizona and New Mexico north $\begin{array}{ll}\text { Pikas. } & \text { no British Columbia and the Canadian } \\ \text { northest, but seldom seen below the timber }\end{array}$ line, these Rodents are found as high up on the mountains as vegetation extends. They are gregarious in their habits and are nsually found in colonies. Their favorite retreats are places where stones, dropping from precipitous heights, have found lodgment. In such localities the attention of an observer may be attracted by squeaking sounds, short, sharp and persistent. Then may be seen these creatures, which are neither Hares, nor Rats, nor Guinea-Pigs, but which have strong resemblances to each of those animals. Slowly the Pika emerges from between the rocks, its body seeming to

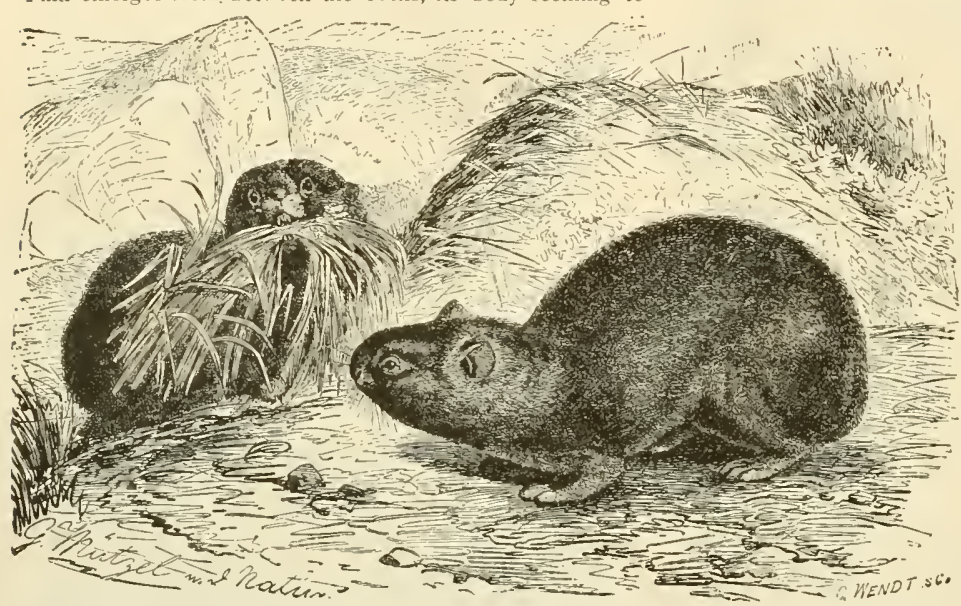

ALPINE CRYING HARES,- - These are Asiatic animals which inhabit the highest altitudes. They lay up piles of hay for food and shelter and the animals in the picture seen to be so engaged. They are burroming Rodents, have shorter ears than the Hares proper, and are practically tailless. (Lagomys alpinus.) and short fur shows a reddish yellow ground color, sprinkled with black on the upper surface, while the flanks and throat are of a plain russet color; the under parts and legs are of an ochre yellow hue. Some individuals are of a deep black color. Adult Crying Hares attain a length of about ten inches.

The Home of All [Old IVorld] Pikas are natives of

the Crying the high mountains of central Asia, Hares. at an altitude of from three thousand to twelve thousand feet above the sea. There they live in the rocky, wild, mountain fastnesses upon the grassy spots abounding near mountain torrents, either singly or in couples, or sometimes in communities of considerable numbers. This species is found throughout the whole of the immense mountain range of the northern edge of central and farther Asia, and also occurs in Kamchatka.

Small holes are excavated by themselves, or natural crevices in the earth or between rocks are chosen as their abodes by the Pikas. On bright days the animals stay hidden until sunset; on cloudy days they are in full activity. For fear of enemies they often expose but half their bodies at the openings of their holes and stretch their heads to see whether or not an enemy is in sight. Inquisitiveness and fear are about equally blended in the composition of their character. Radde characterizes the Pikas as active, peaceable and very diligent Rodents, that gather great supplies of hay, pile them correctly according to orderly rules, and sometimes cover them with broad leaves to protect them from the rain. The heaps of hay collected by them may have a height of six touch the ground as its short legs carry it with jerky, uneven gait. Then it mounis a rock, squats on it and looks around, keeping up its squeaking song, which is echoed by its com panions near by. The chorus may be kept up for a long time unless the observer approaches too near, when the whole party scampers with all possible speed to safe retreats among the rocks and boulders. Sometimes the colony may be seen in grassy spots looking for the food which these animals lay up in large supply, for the time of need, their rocky retreats being kept well stored with hay, roots and herbage of varied kinds.

The female prepares a comfortable, grassy nest among the rocks for her litter of three or four young, which are born in June. The Pika is not a harmful animal, for it lives in localities not susceptible of cultivation, and it is not pursued to any great extent by Man, though it doubtless finds formidable enemies in all the birds and beasts of prey which frequent its mountain haunts.

Peculiarities of The Alpine Crying Hare (Lagomys the Alpine Crying alfimus) is one of the better known Hare. species and recalls to the mind of the beholder a Guinea Pig, by reason of both its shape and physical proportions. The rough, thick, or seven inches and a diameter of from six to twelve inches. Narrow pathways, worn by repeated travel over them, lead to their burrows, on both sides of which the Pikas eat off the grass. During the snowy season of winter they drive tunnels under the snow to their haystacks; these tunnels are curved and tortuous and each has an opening for purposes of ventilation.

The cry of the Pika, which one may hear as late as midnight, resembles the call of the Woodpecker, and is repeated in rapid succession, but rarely over three times.

Unfortunately for them, the little creatures have a great many enemies. Though they are not pursued by the sportsmen of eastern Siberia, they suffer much from the roracity of Wolves, Corsacs and various Eagles and Falcons, and in winter they attract their most dangerous foe, the Snow Owl. 


\title{
The Tootbless Aníntals.
}

\author{
EIGHTH ORDER: EDENTATA.
}

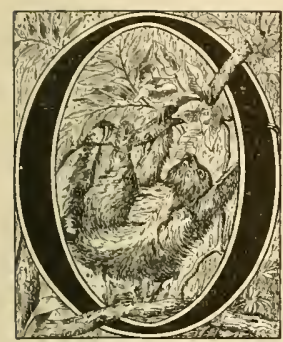

THE mammals comprised in this order, the day of the greatest development is past. In the earlier ages there existed in Brazil edentate animals of physical proportions equal to or greater than those of the Rhinoceros; at the present time the largest members of the order barely equal in size a large lVolf. Among the extinct species there were transitional formsconnecting links--between the now existing families; at present these latter seem in many instances to be separated by wide chasms. And as was the case with their extinct kinsmen some of the species still living are nearing their doom, and their days are numbered.

The Edentata a Variable

The Edentata show little of the harGroup. mony exhibited by other orders. The striking peculiarity of dentition exhibited by all the animals comprised in this group, constitutes the most important characteristic whereby they can be distinguished from other mammals. IVe find animals among the Edentata to which their ordinal name is applicable in its most extended sense, as they do not exhibit the merest vestige of teeth, while the others which are really possessed of teeth, and sometimes a great number of them, at least lack the front incisors. The teeth, which they exhibit and which from their position are strictly called premolars or incisors, because placed in the intermaxillary bone correspond so perfectly with true molar teeth in shape and structure that we cannot apply to them the term incisors in its full meaning. The canine teeth, which are found in extremely rare cases, also differ from the molars only by their considerable length; the molar teeth themselves are of a plain cylindrical or prismatic form and are separated from each other by gaps. They consist only of dentine and cement, being usually destitute of enamel; they are generally produced but once, as but few families shed their teeth. The number of the teeth is subject to considerable variation, not only in the different families but also in the different species of one group; some have only twenty teeth, others about a hundred.

- The Claws In contradistinction to the teeth, the of the Edentates claws show a peculiar development

Peculiar. in these animals. The toes are seldom capable of unrestricted movement, but they always bear claws, which engage and surmount the entire ends of the digits, and for this reason materially differ from other claws. They are either of considerable length, strongly curved and laterally compressed, or else shorter, broad, and nearly spade- shaped, in the former case being adapted for climbing, in the latter for digging and throwing aside earth.

External Cover- These two features exhaust the cataings of Edentates logue of general characteristics; for

Much Varied. in the remainder of their anatomical structure the edentate animals show the widest diversity. The variation of external covering of the body ranges over the greatest latitude that the general description of mammals allows. Some have a thick, soft fur, others a dry, wiry hair; some are covered with bristles, others with scales, and some are enveloped in a large, hard coat of mail, such as is nowhere else found among mammals.

The Home of The members of this family are now the Eden- confined to the Oriental, Ethiopian tates. and South American zones, South America showing the greatest number of species. Asia harbors only Manidida, and Africa has the Aard-varks in addition to these. South America affords a larger variety, the Sloths, Ant-eaters and Armadillos being natives of that continent. The Edentata now extant, as well as the extinct species, exhibit a great diversity in habits as well as in structure.

\section{Tbc জlotbs.}

\section{FIRST FAMILY: BRADYPODIDE.}

At the head of the order we place the family of the Sloths (Bradypodide), though we must confess that they are but poorly developed, dull and sluggish creatures, which excite in us a feeling of pity or contempt.

AnatomicalPecul- Their fore limbs are considerably
iarities of the longer than the hind ones, the feet
sloths. claws; the neck is proportionately long and supports a short, Monkey-like head, with a small mouth, the lips being more or less firm or slightly mobile; small eyes, and ears entirely concealed from sight by the fur; the tail is a barely visible rudimentary stump; the hair is long and coarse, becoming in old age like dry hay, and the direction in which it lies on the skin is the reverse of that of other animals, the "grain" running from the abdomen to the back. Animals living in a state of nature sometimes appear of a green color, owing to the presence of a parasitic plant (chlorococcus) which grows on their hides. The structure of the vertebral column is quite remarkable and unparalleled among mammals. Instead of the seven cervical vertebre which usually form the neck of nammals, some Sloths have but six, others have nine and in exceptional cases even ten; and the number of their rib-bearing vertebræ varies between fourteen and twenty-four. The teeth consist of five 
cylindrical molars in each upper row, the first of which sometimes has a canine shape; the lower jaw usually has but four teeth or rather rudiments of teeth.

The Two-Toed I regard the Two-toed Sloths (ChoSloths De. lapust as standing among all the scribed. Sloth family on the plane of highest development. They have a rather large head, surmounted by a flat forehead, and ending in a blunt smout: the neck is relatively short, the body slender, without a visible tail; the limbs are long and thin, the claws of the fore pair being armed with two and those of the hind pair with three laterally compressed scytheshaped claws. Other peculiar characteristics are the plain. soft fur, having no woolly inner coat; the dentition, and the small number of the cervical vertebra.

The Unau or Twotoed Sloth (Choloprus diductylus), a native of Guiana and Surinam, attains a length of about twent $\mathrm{y}^{\mathrm{y}}$ - eight inches. The long hair on the head points backward, but on the breast and abdomen its direction is toward the back, forming a crest on the spine; it is of a whitish. olive-green gray tint in the face, on the head and the neck; the body is olive-gray, the bachbeing darker than the under parts; the breast, forelegs and shoulders, as well as the lower part of the haunches, are olive brown.

The second species embraces the Threetoed Sloths ( Brad pros). They are of a sturdy physical conformation; have a small head with an obliquely truncated, hard-lipped muzzle and a small moutli, a very long neck, a well developed, laterally-compressed tail, and rather short, stout limbs, the paws of which are furnished both in front and behind with three flatly-compressed, scythe-shaped claws. The hair shows a parting on tie head, and is directed downward; on the rest of the body its line of direction is upward; the soles of the feet are almost entircly covered with fur.

The di or Three-toed Sloth (Fradypus trilactylus) is indigenous to Brazil and attains a total length of nearly twenty-one inches, about one and one-half of which are included in the tail. The fur consists of a fine, short, thick inner coat, which best show's the true markings of the creature, and a long, dry, hard somewhat smooth hay-like outer fur. The color is an ashy gray, dashed with a pale reddish tint, and the abdomen is of a silver gray hue. The claws are rellowish or brownish yellow.

Habits The Sloths are confined to South
$\begin{gathered}\text { and Life of Anerica. Those extensive forests } \\ \text { the Ai. }\end{gathered}$
vegetation reaches its highest development, are the abode of thesc remarkable beasts. The more deserted, sombre and shady a forest, the more impenetrable the thicket, the better is the locality adapted for the life of these helpless animals. They are as truly arboreal animals as the Monkey or the Squirrel; but the latter fortunate climbers reign in the tree-tops, while the Sloths must laboriously and with difficulty crawl from one branch to another. A space that is traversed in play by the agile and mischievous inhabitants of the upper regions, is a journey of great magnitude for the Sloth, and these lazy creatures lead a monotonous quiet life, slowly creeping from branch to branch. In comparison with their movements when on the ground they certainly exhibit great agility in climbing. Their long forelegs pernit them to reach considerable distances and the huge claws enable them, without fatigue, to hang on to branches. They climb quite differently from all other arboreal animals, however; for what is an exception with others is the rule with them. With body hanging down, they reach up with their long arms, hook their claws firmly around a small limb and comfortably drag themselves along from branch to branch. They appear lazier than they really are, however. Being of nocturnal habits they may spend entire days without stirring; but when dusk comes they rouse themselves, and during the night traverse a greater or smaller space, according to their requirements, slowly but not lazily. They feed exclusively on buds, young shoots and fruit and the plentiful dew which they lick off the leaves supplies them with water, which otherwise they would lack. An undeniable slowness of morement is cxhibited in their search for and appropriation of food. They are frugal, easily satisfied, and capable of enduring hunger and thirst for days, some say for weeks, without harm resulting to them. 


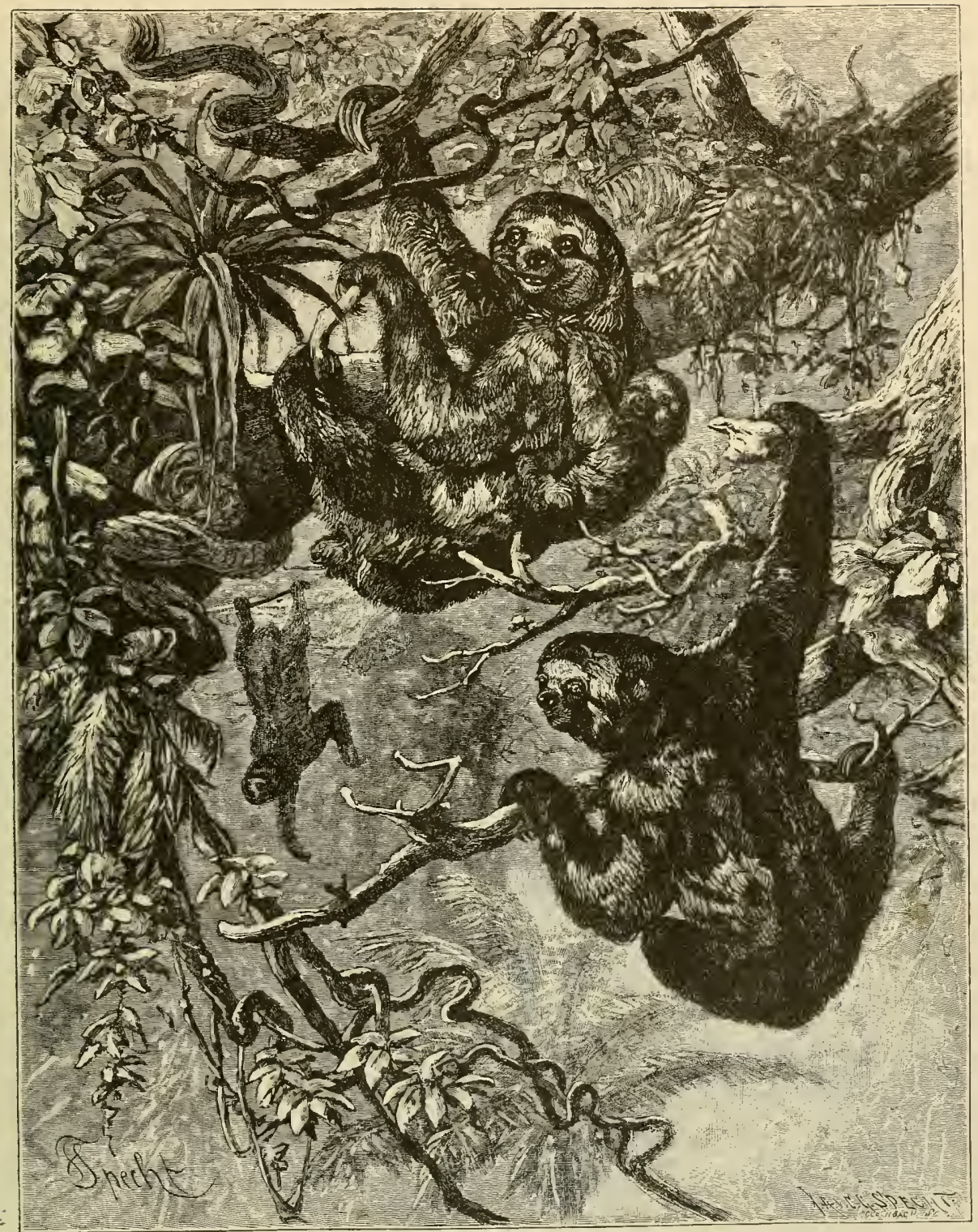

AI, OR THREE-TOED SLOTH.- - These aninals are very appropriately named, for their movements are painfully slow. They have three scrthe-shaped toes on each foot, and move with considerable labor from branch to branch. The positions they assume are well shown in the picture, ard the female with the young one seems to have a specially difficult task in moving about. (Bradypus tridactylus.) 
They do not leave a tree as long as it affords then nourishment; only when the supply of food which it furnishes has been exhausted do they think of migrating. Slowly they descend to the lower branches, seek a point at which the branches of some neighboring tree interlocks with that upon which they are hanging, and then, clinging with their hooked claws, pass over on this aerial bridge.

Movements and On the ground these miserable naPeculiarities tives of the trees are bewildered. of Sloths. Their gait consists of such a painful dragging along of the body as to invariably excite the spectator's pity. In a like manner with the slow Tortoise, the Sloth tries to propel its clumsy bulk. With sprawling limbs, supporting itself on its elbows, slowly describing with its legs segments of a circle, it very gradually pushes itself onward; the abdomen nearly touches the ground, and its head and neck constantly and slowly move from one side to the other, as if their function were to preserve the balance of this extremely awkward animal. One would not readily believe this creature which reels along so miserably, capable of saving itself if by any mischance it fell into the water. The Sloth swims tolerably well, however, moving with even greater speed than in climbing, holding its head high above the surface, breasting the waves with ease and readily regaining the shore. Bates and $\mathrm{V}$ al lace saw a Sloth crossing a river at a place where it was about nine hundred feet wide. This tends to show that the appellation "Sloth," pertinent as it may have been in its original sense of mere slowness of action, really can justly refer only to the movements of this animal when attempting to walk on the ground; for on the trees its laziness, as before stated, does not impress the observer as being so great as one would be likely to believe, judging by the exaggerated accounts of those who first described the animal. The admirable security and certainty with which it climbs is worthy of notice. The Sloth is capable of hooking on to a bough by one foot and remaining suspended from it, not only letting the full weight of the body be borne by the one foot, but also lifting itself up by it.

It is exceedingly difficult to loosen the hold of a Sloth from a branch. While sleeping and resting the animal assumes a position similar to the one ordinarily taken. It puts its four legs close together, curls itself into a nearly spherical ball-shape, and lets its head sink forward over its breast, without letting it rest there, howcrer, or supporting it. In this position it hangs on, always in the same place, during the day, without tiring itself.

Insusceptible as the animal seems to be to hunger and thirst, it is very sensitive to moisture and the resultant sensation of cold. During the rainy season it often hangs in the same place for day's, drooping and miserable, obviously greatly annoyed by the downpouring water.

Very rarely, usually only in the evening or at the dawn of day, or when the Sloth is alarmed, does one hear its cry. The cry is not loud, and consists of a plaintive, long-drawn, short and shrill sound, which is renclered by some as the frequent repetition of the sound of long " $a$ " in Jinglish. Modern observers have never heard the Sloth utter sounds resembling diphthongs, or consisting, as former observers have affirmed, of ascending or descending tones of the scale. The nearest approach to vocal utterance one may hear from a sloth during the day is a deep sigh frequently repeated; on the ground it does not cry.
The Mother Only a single young Sloth appears

sloth and at a birth. It comes into the world

Young. completely covered with hair and even its claws and toes are fairly well developed; immediately after birth it fastens itself to the long hair of the mother by its claws, cla.ping her neck with its forelegs. The mother then carries it about everywhere in this position. At first it would appear as if she regarded her progeny with great tenderness; but the maternal love apparently soon subsides, and then the dull-witted creature barely takes the pains to nourish her infant, cleaning it or attending to the sundry other duties of a nurse.

The indisposition to action of the Sloths, is also seen when they are ill-treated or wounded. It has been sufficiently demonstrated that the lowest animals can endure proportionately the greatest illtreatment, injuries or pain; the Sloths also seem to prove this general rule. The remarkable tenacity of life in these creatures cannot be denied. They bear severe injuries with the indifference of a corpse. Frequently they do not even alter their position after receiving a full charge of shot into the body. Schomburgk says that they are the creatures which are also able to longest withstand the terrible Woorari poison, with which the Indians charge the barbs of the darts from their blow-guns, used in hunting.

The Sloths Not One cannot say that these helpless Much Persecuted animals have many enemies. Their

by Enemies. arboreal life puts them out of the reach of the worst beasts of prey, which are always to be found among the mammalia. Then their fur is so similar in coloring to the branches from which they are suspended, immovable like an excrescence on a limb or the fruit on a tree, that the experienced falcon eye of an Indian is needed to discover a sleeping Sloth. Besides, the animals are not quite so defenseless as would seem at a first glance. They are difficult to orercome on the tree and if they are taken by surprise and attacked on the ground, they throw themselves on their backs with sufficient readiness and seize their assailant with their claws; the strength of their limbs is certainly-considerable. It is difficult for even a strong man to free himself from the clasp of the animal or to tear it from the bough to which it clings; if the would-be captor does not unhook one foot after another and hold it firmly to prevent the animal from regaining its hold, it is impossible to succeed in the latter undertaking.

The Sloth in Cap- Up to a comparatively recent date tivity, an Inter- little was known about the life of

esting Animal. Sloths in confinement. Buffon relates that the Marquis of Montmirail bought a Sloth in Amsterdam, which had been kept on tender foliage in summer and ship's biscuit in winter. Travelers tell us that one can hardly imagine a more inane and insipid creature than a captive Sloth. My joy at finding a living Sloth in Amsterdam will be easily understood, as it gave me the opportunity of personally observing the habits of the animal. Later on 1 succeeded in obtaining several Sloths and in completing my observations. I am not bold enough to affirm that my deductions apply also to the life of the beast in the free state; but I mean to say, that Sloths are not altogether contemptible and tiresome, but interesting and in many respects worthy members of a colleetion of animals.

"Kees" (that was the name of the Amsterdam Sloth) had been an inmate of his cage for nine years and certainly exhibited as much contentment in captivity as any other animal. Whoever has kept mam- 


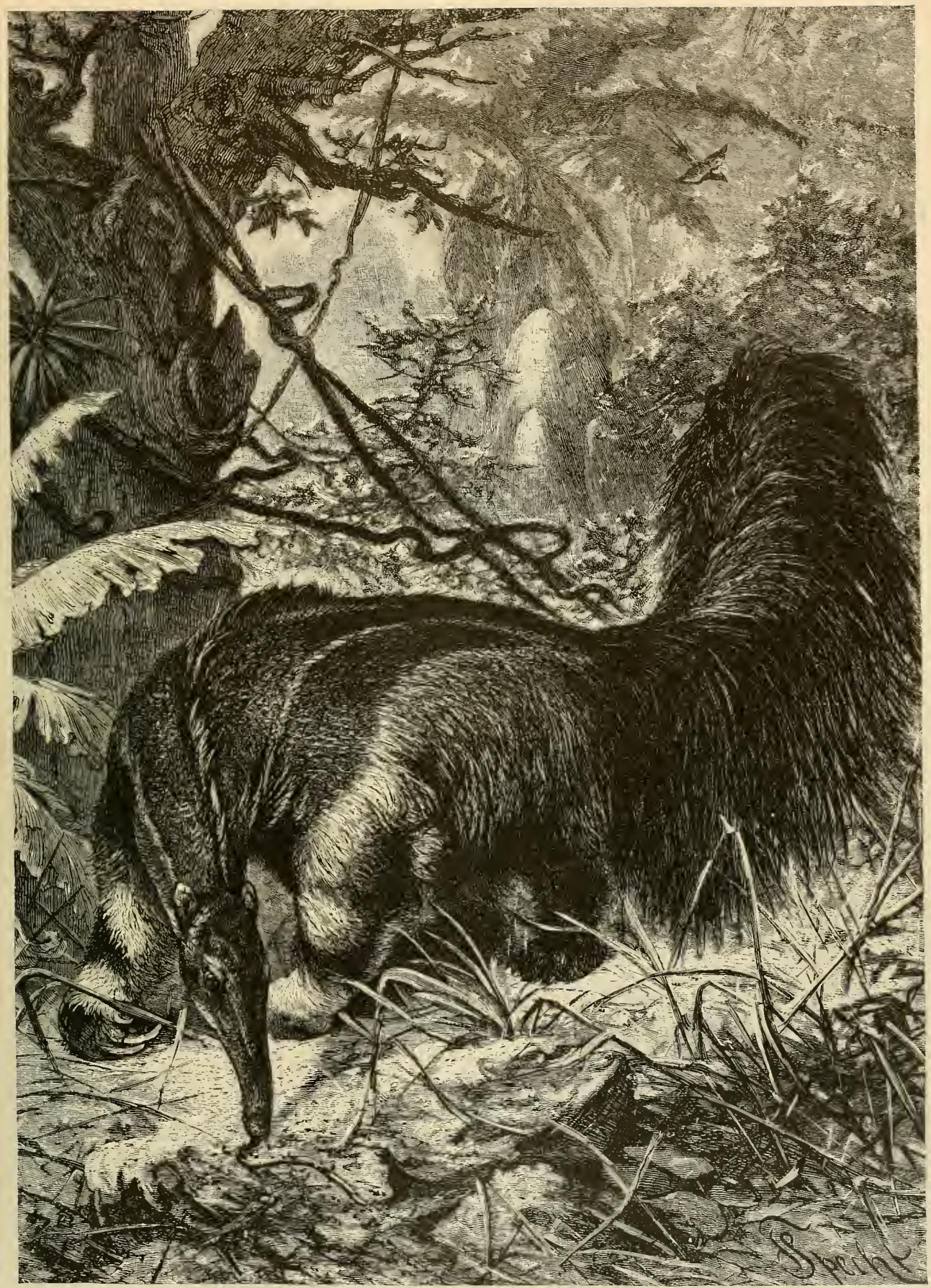

GREAT ANT-EATER OR ANT-BEAR,-One of the strangest appearing of manmals is the Ant-Bear, of which a characteristic picture is her given, depicting the long slender head, the coarse long fur which increases in length toward the fanks and tall, anemies. ulyrmecophaga jubath.) 
mals in captivity knows that he has reason to be well satisfied if his pets survive nine years on the average, and he who has intimate knowledge of the edentates will admit that so long a time is truly a great age for a member of this order. The cage in which liees was confined had a scaffolding of wood in the centre, on which the animal could climb; it had a thick litter of hay on the floor, strong panes of glass formed its sides and it was open above. I have kept my own pets in a similarly constructed cage. He was fed on builed rice and carrots usually, but did not refuse any vegetable food offered him.

Habits of If one pays the animal a visit in the Captive daytime, the only thing to be seen in Sloths. this glass box is a ball, strikingly resembling a heap of reed-grass. This ball presents no particular significance by its shape, as at such times almost nothing of the limbs of the Sloth can be discerned. A closer inspection shows that the limbs have assumed the attitude usual when the animal is at rest or sleeping.

However, the furry ball can be brought to life, if one knows how to proceed; for the Sloth is by no means as dull-witted as it is popularly supposed to be, being on the contrary a nice, honest fellow, only requiring to be handled in the right way. If the keeper simply comes to the cage and calls it, the ball gradually begins to show signs of animation. Deliberately, or as one might say, slowly and somewhat clumsily, it evolves itself and little by little it develops into an animal, which may not be goodlooking, but still is not so hideous as it has been depicted. Slowly and steadily the animal lifts one of its long forelegs, and hooks the sharp claws to one of the cross bars of the scaffolding. If one holds some tidbit, especially a lump of sugar, to the upper bars, it climbs up with moderate rapicity to obtain this choice morsel, sniffs along the wall and opens its mouth as wide as possible, pleading, as it were, to have the sugar thrown in. Then with its eyes closed it eats it, smacking its lips, clearly showing how much it relishes the sweet morsel.

Uses of the The economic value of Sloths to Man

Sloth to is very small. In some regions In-

Man. dians and Negroes eat the flesh, the unpleasant odor and taste of which disgust Caucasians, and in some places coverings and pouches are manufactured out of the tough, strong and durable hide. On the other hand the animals inflict but very little damage, as they retire in the same ratio as man advances. They also are in the list of those animals which are approaching utter extinction. They can maintain their hold on life in only the remotest forest, and no longer than the magnificent trees which give them shelter and food are spared by the axe of the white settlers will their existence be possible.

\section{The Ellt=catcis.}

\section{SECOND FATILY: MYRMECOPHAGIDE.}

The Ant-eaters, which are comprised in the second family, bear but a slight external resemblance to the Sloths. The body is elongated; the head, and especially the snout, are very long and slender; the tail attains nearly half the length of the body. The fur is thick, rough and peculiar, especially on the upper surface. The hinder limbs are slender and wicaker than the fore limbs. The bony structure of the feet shows five toes, not all of which are armed with claws, however. The cavity of the mouth is very small, while the tongue is long, thin and rounded, in appearance resembling a worm. The ears and eyes are very small. The structure of the skull is still more striking. In consequence of the elongation of the facial region the snout is long and tubular; the intermaxillary bone is small and curved and does not properly articulate with the maxillary, but is joined thereto by cartilage only. One looks in vain for teeth, but no vestige of any is found.

The Great Ant. The largest species of the family is eater or Ant- the Great Ant-eater, or Ant-bear, Bear. called Turumi in Paraguay and Tamanoa in Surinam ( Hymecophaga jubata). The fur of this very remarkable animal consists of thick, stifi bristles. prickly to the touch. Short on the head, they become longer on the neck and along the backbone, where they form a mane and may be nine and one-half inches long. The hair of the tail is from ten and one-half to sixteen inches, the fur of the rest of the body and legs being only from three to four and one-half inches long. The coloring of the fur is somewhat variable. The prevailing color of the head is ashy gray mixed with black. Nearly the same hue obtains on the nape of the neck, back, part of the sides, the forelegs and the tail. The throat, neck, breast, abdomen, hind feet and under part of tail are blackish brown. I black band, tapering toward the hind quarters, runs from the head and breast over the back obliquely to the rump and is bounded on each side by a narrow stripe of pale gray, running parallel with it. A black band encircles the end of the fore arm, and the toes of the fore-feet and naked parts of the body are also black. The length of an adult Yurumi is fifty-two inches, the tail without hair measuring twenty-seven inches and with the hair at least thirty-eight inches, and often more than this. That means that the animal attains a total length of ninety-two inches; sometimes one finds old males, however, which are larger.

"The Yurumi is not very common in Paraguay, and inhabits the wholly or partially deserted fields in the north of the country. It has neither a fixed retreat nor other permanent domicile, but roves about the plains in the day and sleeps where night finds it, for this purpose generally selecting a spot where the grass grows very high or where there is a growth of bushes. It is usually solitary in its wanderings, unless it be a female with her young one. Its gait is a slow walk, sometimes, when it is pursued, changing into a clumsy gallop, which, at best, is so slow that a human being, walking, can overtake it. Its sustenance is confined to a diet of Ants, Termites, and the larve of both. In order to obtain access to them it scratches and tears with the long nails of its fore-feet at the heaps of earth which form their domicile, protrudes its long tongue under the insects which pour out from all sides and then draws it into its mouth when it is covered with them. It repeats the performance until it is satisfied or until the Ants or Termites are all exterminated.

$\begin{array}{ll}\text { Propagation } & \text { To the female Sloth a single young } \\ \text { of Ant- } & \text { one is born in spring and she trans- } \\ \text { eaters. } & \text { ports it on her back for a time. It }\end{array}$ is a quiet, peaceable animal, which annoys neither Man nor other mammals in any way, unless it be much provoked."

Uses to Which The flesh and skin of the Yurumi Anteaters are utilized only by the uncivilized

are Put. Indians; still, there are country people in Paraguay who believe the skin to be an unfail- 
ing remedy for lumbago and sciatica and for this purpose place it under their sheets. The Great Ant-eater is rarely lunted; but if one chances to meet it in the field, it is easy to kill it by a few blows on the head. These animals ought to be protected rather than persecuted, however; instead of being

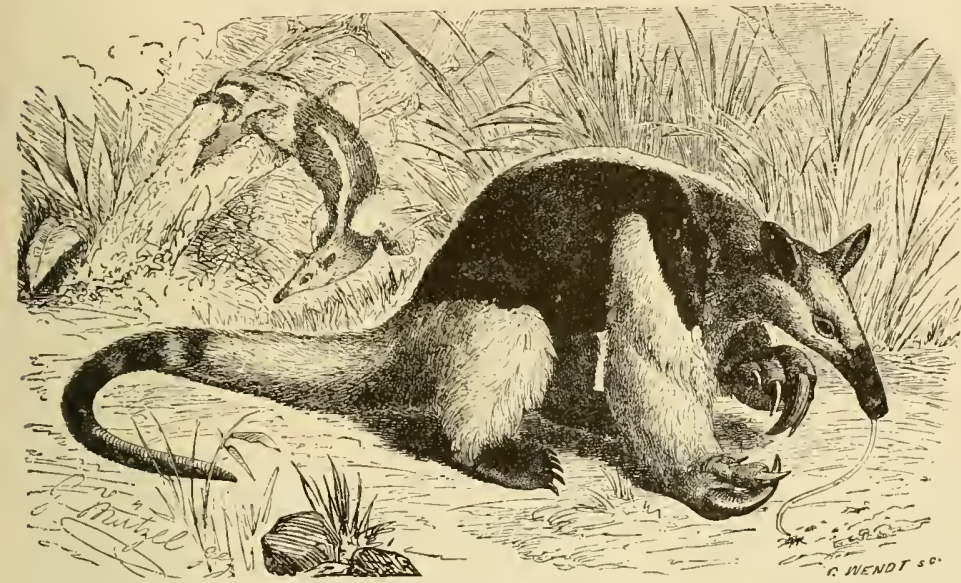

THE TAMANDUA. - This repulsive looking creature, which is also known as the Caguare, is an inhabitant of Sonth American forests and is a species of the Tree-climbing Anteaters. The powerful claws, elongated snout and long, prehensile tail are notable features of the animal here depicted. (Tamandua tctraulactyla,

harmful, they are exceedingly useful in diminishing the numbers of the Termites and Ants, which have multiplied to such an extent in some portions of Paraguay that entire plantations are overrun and devastated by them. The Jaguar and the Cougar probably are the only enemies of the Yurumi, except Man. The fabulous stories of the natives of Paraguay concerning combats between it and the Jaguar, were long ago refuted by Azara."

Home and Habits We learn from
of the Ant- other naturalists eater. that the Ant-eater inhabits nearly the entire east of South America as well as Paraguay and therefore ranges from the La Plata to the Caribbean Sea. It is said to walk holding its head very low, seeking food by scenting the ground. It carries its tail stretched out straight behind and the mane on the back stands erect, so that it produces the impression of being very much larger than it is. Modern observers have found not only Ants and Termites in its-stomach but also considerablè quantities of earth and particles of wood, which the animal swallows with the insects. There is no doubt that the Yurumi, besides its principal food, is fond of devouring chrysallids, millipeds and worms, when these latter are not too large.

Adaptability of Captive Ant-Bears have repeatedly Ant-Bears to been taken to Europe and have been, Captivity. by dint of adequate care, kept living for years. The captive specimens of the London hind paws, both of which are curved so as to make the hold secure, the
which he can take hoid, as shown in the picture. (Cycloturus didactylus.)
Zoological Garden are fed raw, finely shredded meat and rolk of egg; the one that Noll observed in Hamburg was also very fond of a mush made of Indian meal and hot milk and sweetened with a spoonful of molasses, and it was a sight to see the strange-looking animal stancling before its dish, eat-

ing with its queer tongue. The blackish, cylindrical tongue is ejected out of the mouth to a length of about twenty inches, with almost incredible rapidity, its alternations reaching a speed of about one hundred and sixty times a minute; it is revolved in the mush and withdrawn with small particles of food adhering to it.

The Ant-eater is not only a queer-looking creature in human eyes; it excites surprise and even terror in most animals also, as was proven in one case at least, when in one of the German zoological collections $\mathrm{th} \mathrm{e}$ animal was first quartered in the Monkey house. A panic of fright prevailed among the inmates of the house; the Monkeys created such a noise that their cages had to be covered and even a Chimpanzee hid itself in the straw.

\section{THE TREE-CLIMBING ANT-EATERS.}

Among the other Ant-eaters which are of arboreal habits, the Tamandua or Caguare (Tamundua

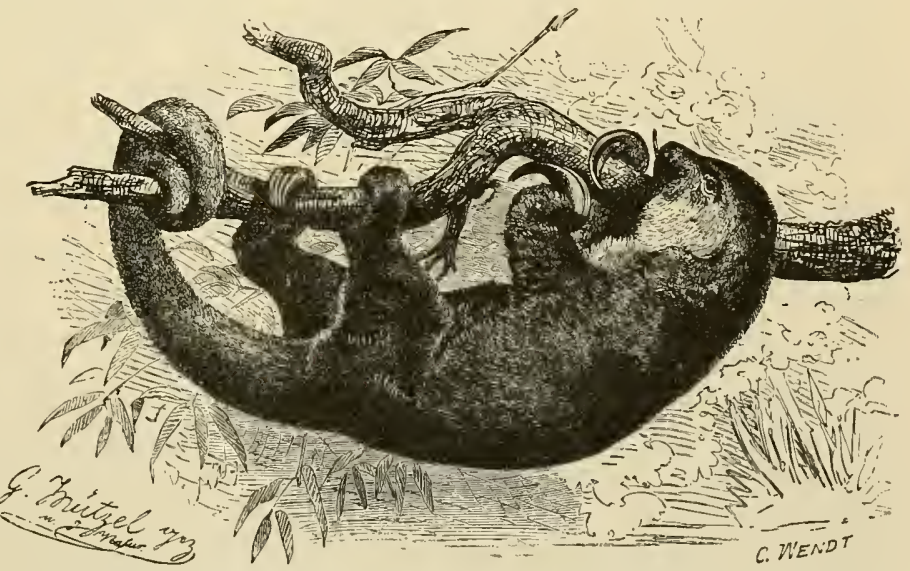

LITTLE ANT-EATER.-This queer little animal, abont the size of a squirrel, is about as well equipped for holding on to a tree as a mammal can well be. Besides his two-toed fore-feet and five-toed
hind paws, both of which are carved so as to make the hold secure, the animal has a prehensile tail by

tctradactyla) most resembles the species already described; nevertheless it is classified as a distinct species, as it has four toes on its fore-feet and five on its hinder ones, and possesses a prehensile tail. It inhabits the same country as the species just described, but extends over a great area of territory, ranging westward to Peru. Its length is about three 
feet, the body measuring about twenty-four inches; the height from the ground to the top of the shoulder is said to average from twelve to fourteen inches.

Habits and Haunts So far we have been able to learn of the Taman- very little concerning the life of this dua. remarkable creature. In Paraguay and Brazil the Tamandua lives everywhere in the lonely forest distriets, affecting the edges of woods and bushes, sometimes being found near human dwellings, It not only lives on the ground, but climbs trees with moderate agility, though its speed does not exceed that of the Sloths; its tail also comes into requisition to render secure its position in sitting. Its food consists mainly of Ants, and especially such as live on trees.

Observations Re- The Tamandua has also been taken garding Captive to foreign lands in recent vears, es-

Tamanduas. pecially to London. Bartlett kept the first specimen in his own room in order that he might be able more accurately to observe its movements. With the help of its powerful, hook-like claws and prehensile tail it quickly climbed upon the different articles of furniture, and finally, becoming more familiar, it jumped thence to Bartlett's shoulder, and in search for food inserted its pointed snout and long, vermiform tongue into all the folds of his clothing, and explored his ears, nose and eyes in a not exactly pleasant manner. As it became more tame, whenever a visitor approached, the Ant-eater quickly came to the front bars of its cage and slipped its investigating tongue over the hand held out to it; one had to be eareful, however, not to let it grasp his fingers with its elaws.

The Peculiar The Taniandua gives forth from Odor of the the scent-glands with which it is ramandua. equipped, a remarkably strong, musk-like odor, especially when it is irritated or excited by the approach of an enemy.

[According to some late authorities there are two species of the Tamanduas: one called the Collared Tamandua (Tamanduca birittata) and the other the Vellow Tamandua (Tamandua longicauda).]

\section{LITTLE OR TWO-TOED ANT-EATER.}

The Little or Two-toed Ant-eater (Cyclotums didactylus $)$ is a little animal of about the size of a Squirrel, being some sixteen inches long, seven inches of which are included in the prehensile tail. There are four toes on the fore-feet, two of which bear stout claws; the hind feet have five toes. The fur is of silky softness and its hue is foxy red above and gray below, some of its hairs are grayish brown at the base, others black, and tipped with yellow brown.

Though the Little Ant-eater is of rather clumsy build, it still may be called a prepossessing creature, especially distinguished by the beauty of its fur. Its distribution is restricted. So far it has been seen only in northern Brazil, Guiana and Peru, embracing countries between the Ioth parallel of south and the 6th parallel of north latitude. In mountainous districts it sometimes ascends as high as I,800 feet above the sea. It is of rare occurrence nearly everywhere. It inhabits, through choice only, the densest woods. Being entirely nocturnal in its habits, it sleeps through the day in trees. Its movements are clumsy; slow and measured; but it climbs fairly' well, though very cautiously and always with the help of its tail. Ants, Termites, Bees, Wasps and their grubs constitute its food.

\section{The Frmadillos.}

\section{THIRD FAMILY: DASYPODIDE.}

The Armadillos (Dasypodida) are, like the Sloths, the survivors of a once larger fanily. In comparison to some of their extinct relations they can at best be considered only dwarfs.

The Glyptodon attained the gigantic proportions of a Rhinoceros; the relatives of some other species were at least as large as an Ox, while the Armadillos of the present time attain an extreme length of sixty inches, or forty inches not including the tail. Armadillos are clumsy creatures with elongated head and muzzle, large, pig-like ears, a stout tail and short legs and strong feet, armed with very stout fossorial (digging) claws. They owe their name to the peculiar nature of their external covering, resembling a coat of mail; this coat is distinguished by rectilinear belts or bands along the middle of the back, and the scales differ from those of other mammals by the arrangement of the scute or shieids. The median zones, which serve to distinguish the species, though they are not always of the same number in the same species, consist of quadrangular, oblong scales or scutes, while the anterior and posterior portions of its armor are formed of transverse rows of four and six-cornered scales, interspersed with others of small, irregular form. The shield on the head is for the most part also composed of five or six-cornered scutes. The animals are protected with a buckler on the upper portions of the body alone, however; the under surface being covered with a more or less coarse, bristly hair; similar bristles also project between the shields.

Home and Habits All Armadillos are natives of the

of Amadil- southern American belt extending los. as far north as Mexico. They live in sparsely grown and sandy plains, in fields, and are found only on the edges of woods, never entering the latter. Only in the breeding season do a few of the same species consort; during the rest of the year every Armadillo leads a solitary life, exhibiting no regard for any other living thing except those that serve it as food.

At dusk the mail-clad creatures appear in front of their deep, subterranean abodes and move about for some time, proceeding at a slow pace from one spot to another. The level ground is their domain and there they are at home as are but few other animals. Slow and lazy as they appear when walking or moving, they are quick and nimble when they have to burrow their way into the ground. When startled, frightened or pursued, they have no better recourse than to entrust themselves to the earth, in the truest sense of that expression. And they are such experts at digying, that they sink very rapidly into the gromind before the gaze of the spectator. Their extraordinary defenselessness would leave them helpless in the face of enemies, if they were not adepts at this method of escape. One kind of Armadillo is able to roll itself into a ball, like the Hedgehog, but does so only in the last extremity when its retreat by burrowing is cut off, and recommences its burrowing and hiding in the earth at the first opportunity. In the water these animals, apparently so unwieldy, also know how to take care of thentselves.

The Armadillos are inoffensive, peaceable creatures, with dull organs of sense and devoid of any prominent intellectual faculty. Their method of 
vocal expression consists in grunting sounds, neither harmonious nor emplatic in the conveyance of any particular meaning.

The Armadillos also, like others of this order, are nearing their complete extinction. Their rate of propagation is slight. It is true that some species have as many as nine young at a birth; but the growth of the animals is so slow, and they are so little able to withstand the many enemies which they have, that their increase in number is a most unlikely contingency.

\section{THE ARMADILLOS PROPER.}

The Armadillos proper (Dasypus) are all more or less of a similar anatomical conformation. The body is supported by short legs, the conical tail is of moderate length, mail-clad and stiff, and the carapace is bony and intimately attached to the dermal processes of the body. There are six or more mo. bile bands along the dorsal median region. All four of the feet are five-toed; the claws of the fore feet are laterally compressed and the outer claws are slightly curved outward. yellow, through the polishing and attrition of surface received by friction against the walls of the burrows. The color of the hair-covered skin of the under surface is similar to that of the outside of the scales on the back. The hair is light, the bare skin brown. The length of the animal is twenty inches, the tail measures nine and one-half inches, and its height is about the same.

The
The Six-banded
Armadillo. to tirenty-four inches long, inclusive of the tail, which measures eight inches, and it is furnished with a shield behind and between the ears, consisting of eight pieces; the anterior and posterior portions of the carapace are separated by six broad transverse zones or bands and is of a brownish yellow hue, the armor part being darker, the skin paler. Armadillos of Mi- Armadillos do not live in any one gratory and Noc- particular locality, but frequently turnal Habits. change their place of abode. Their retreat usually consists of a tunnel-like hole, from three to six feet long and is excarated by them-

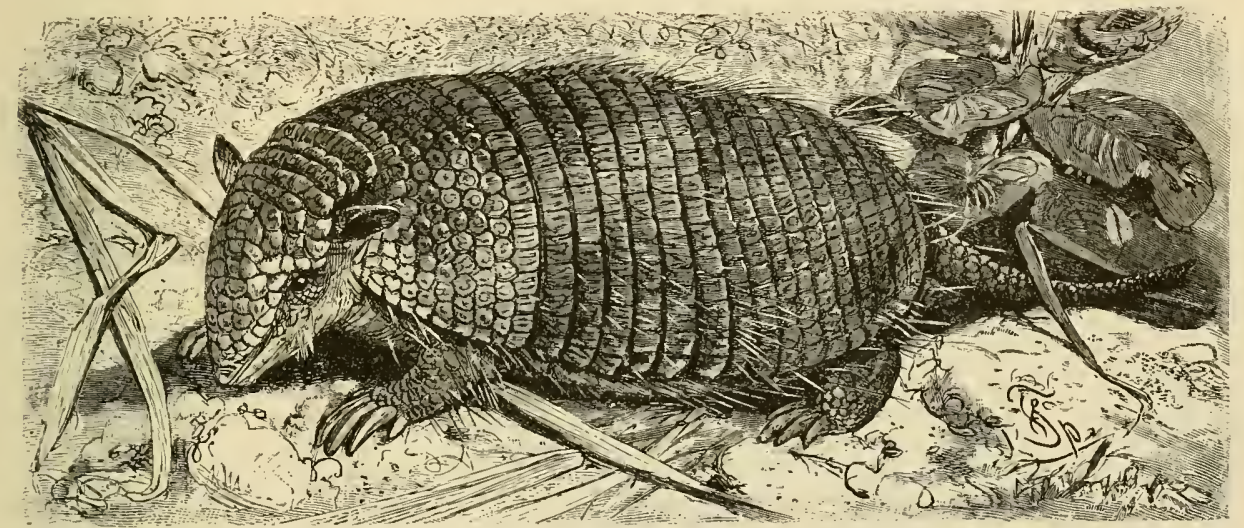

THE SIX-BANDED ARMADILL0,-The animal with the natural coat of mail, of which this is a picture, is especially endowed for a bur rowing, insect-hunting life. Its long strong claws enable it to dig with great agility, not only for purposes of retreat, but also to secure the Ants, Termites, etc., which form its food. (Dasypus sexcinctus.)

All Armadillos bear the generic name of Tatu in the South American Guaran Indian language, a name which also was adopted in the European languages. The name Armadillo is of Spanish origin and literally signifies "the mail-clad," or "the armor-clad." This appellation is given to the Dasypus sexcinctus (the Six-banded Armadillo) in preference, the others of the tribe usually going by their Guaran or other native names.

The Tatupoyu or One of the best-known Armadillos, Yellow-banded the Tatupoyu of the Guarani, which Armadillo. means the Tatu with the Yellow Hand (Dasypus villosus), a native of the Pampas of Buenos Ayres, has the ugliest and clumsiest appedrance of any of its relatives. The nape of the neck is covered with a row of nine oblong, quadrangular scutes or shields, the fore part of the back has seven lateral and five median rows of irregular, hexagonal plates. This shoulder armor is adjoined to the rear by six separate, movable bands or girdles of oblong, four-cornered scutes and then comes the posterior armor, consisting of ten rows of oblong, four-cornered plates. The color of the scales is a brownish yellow, but sometimes they become light selves. At the entrance the hole is circular and has a diameter of from eight to twenty-four inches, according to the size of the animal; towards the lower end the tunnel widens and finally assumes the shape of a chamber so that the animal can comfortably turn around in it. In the wilderness they move about by daylight, when the sky is cloudy and the glaring sunlight does not annoy and daze them; in poptilated localities they do not leave their holes before the fall of dusk and then rove about all night. It appears to be a matter of indifference to them, whether they come back to their holes or not; for if they miss their way, they forthwith dig a new burrow. They have a two-fold purpose in doing so. Azara observed, and other naturalists confirmed his observations, that the Armadillos excavate their burrows chiefly under the hills of Ants or Termites, as this location puts them in a position favorable for gathering their principal food with the greatest convenience by day as well as by night. Besides Ants and Ternites their food consists chiefly of bugs and their grubs. Caterpillars, Locusts and Earthworms. It is also established beyond doubt, that the Armadillos feed on plants, for these latter have 
been found in the stomach of specimens of the animals which have been killed and dissected.

Movements and It is to be expected that their rovPropagation of ings are confined within narrow

Armadillos. limits. The usual gait of all Armadillos is a slow waik and the greatest effort at speed of which they are capable is a slightly accelerated shuffling, which, however, is sufficiently rapid to enable them to distance a human being. Jumping or turning around quickly are feats they can not accomplish. The first is precluded by their stoutness, the latter by the close fit of the armor and rigidity consequent thercon. So, when they wish to accelerate their course to the utmost, they can only proceed in a right line, sometimes slightly trending to an arc of a circle in direction and they would be delivered into the hands of their enemies utterly defenseless, if they had no other tricks at their command. What they lack in agility, they compensate in great muscular power. This latter is particularly shown in the celerity with which they cut their way

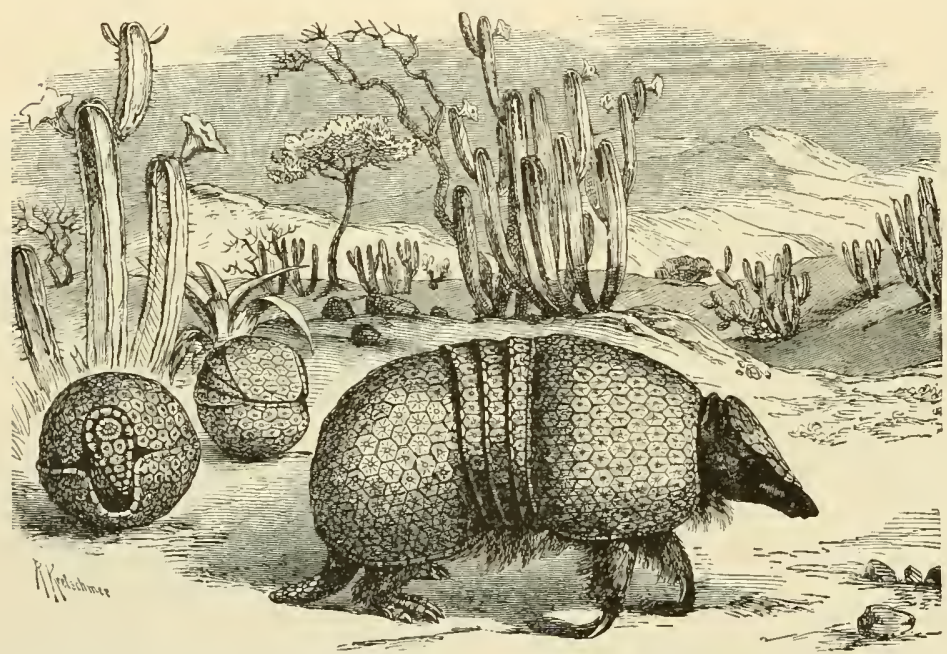

BOLITA OR THREE-BANDED ARMADILL0,- One of the queerest of a peculiar family. The picture presents a view of a gronp of these oddities traversing the cactus-g rown vallevs of their native South America. The three bands which give the animal its name are shown, and the manner in which it rolls itself into a ball when it fears an enemy is'also shown. (Tolypoutes tricmetus.)

into the earth, and that in places which a hoe wielded by a strong man can pierce with difficulty, as for instance the foot of Termites' hills. An adult Tatu, which scents the approach of an enemy, needs only three minutes to crive a tunnel, the length of which considerably exceeds that of its body. As soon as Tatus have dived deep enough into the earth to conceal the entire body, the strongest man is incapable of pulling them out, by the tail. As their holes are only just sufficiently large to admit of their squeezing in, they need but to arch the back a little, and the edges of the scales on the belts above and the sharp claws beneati offer so effective a resistance that nobody can overcome it.

The female gives birth to from four to six young in winter or spring and hides them carefully in her burrow for some time. l'robably they are not suckled long, for they are soon seen running about in the fields. As soon as they are somewhat grown, each goes its own way, and the mother cares no more for her offspring.
Method of The Tatu is usually hunted on moonHunting the lit nights. The sportsman arms him-

Armadillo. self with a stout club of hard wood, pointed or conical at the end and hunts the Tatu by trailing with Dogs. If the Tatu perceives the Dogs in time, it flees forthwith into its hole or digs another as quickly as possible, rather than take refuge in a strange one. If the Dogs overtake it, however, before it gains its asylum, it is lost. As they can not penetrate the carapace of the animal with their teeth, they seize it and prevent its escape by holding it with mouth and paws, until the sportsman arrives and kills it with a blow on the head. Experienced Dogs will overturn the running Tatu with their noses, and attack it from beneath, and as soon as they succeed in doing so, they literally tear it to pieces, the armor crackling between their teeth after the manner of crushed egg-shells. A Tatu in its hole is always secure from Dogs, for their efforts to dislodge it by digging are of no avail. When it is seized by the Dogs, it never defends itself in any way, though it undoubtedly could inflict severe injuries with its claws.

All Armadillos are held in detestation by the South Americans, because they are the cause of many accidents. The bold riders of the plains, who spend the greater part of their lives on horseback, are occasionally brought to grief by plunging into the subterranean workings of the Armadillos. A Horse hurrying on at a gallop, suddenly stepping into a hole, is likely to injure both itself and its rider. Therefore the owners of farms and plantations persecute the poor armor-bearers in the most rutbless and cruel manner. Besides having Man for their arch enemy, they are hunted down by the larger Felidæ, the Brazilian IV'olf and the Jackal Fox.

Armadillos Un- Tatus are rarely domesticated and fit for Domes- reared in Paraguay. They are much tication. too tiresome as companions, and also annoy their keeper too much by their digging propensities to become fayorites as domestic pets. The Armadillos, which are frequently brought to Europe and in some zoological gardens are quartered together with the Monkeys, are fed on worms, insects, grubs, and raw and cooked meat, the latter being fed to them in small pieces, as they can bite nothing from large morsels. They take the food with their lips or their tongue, the latter organ being capable of much extension. If the care bestowed on them is in any way adequate, they preserve their healti for years, serve the Monkeys as beasts of burden or playmates, either willingly or involuntarily, endure everything, become used to taking walks by day and may even bear young. Young Armadillos, born in the London zoological garden, were blind at birth and their soft skin showed all the furrows and divisions of the adult animal. 
Economic Value The usefulness of the Armadillos is of Arma- by no means inconsiderable. The dillos. Indians are exceedingly fond of the flesh of all the species, Europeans eating only that of two kinds. Kappler says that their flesh loses its unpleasant odor of musk if it is soaked over night in a solution of salt and lemon juice. Rengger says that the flesh of an Armadillo, fried and seasoned with Spanish pepper and lemon juice, is one of the most palatable of dishes. The Indians of Paraguay manufacture small baskets out of the shell; the Botocudos make speaking-tubes from the skin of the tail which they strip off in one piece; formerly bodies of guitars were made out of the shields.

\section{THE THREE-BANDED ARMADILLO.}

The still less known Three-banded Armadillos, called Apar or Mataco by the natives and Bolita by the Spaniards (Tolypentes tricinctus), is the representative of another species, the first appellation of which was said to refer to a shell which had been says, in the open country, but Goering could not learn whether or not it excavated burrows. The natives occasionally capture it when out hunting other Armadillos, the flesh of which, as has becn said, constitutes a favorite dish with the Gauchos. But as the Mataco is a pretty creature, it is usually the recipient of merey and is kept as a pet.

The Bolita a Fa. The children play with it, roll it vorite Pet for back and forth or let it run along a children. board and rejoice in the clattering which the contact of its feet with the plank produces. Goering had many visitors who begged to be shown the animal. Though it had not been long in confinement, it showed great docility, and from the first moment it would without any hesitancy take food proffered in one's hand. It would eat all kinds of fruit and leaves, especially peaches, gourds and lettuce, never refusing food when it was offered it. On account of the smallness of the aperture of its mouth, the food had to be cut into small pieces, which it took very daintily. It slept by day as well as by night. When sleeping, it would stretch

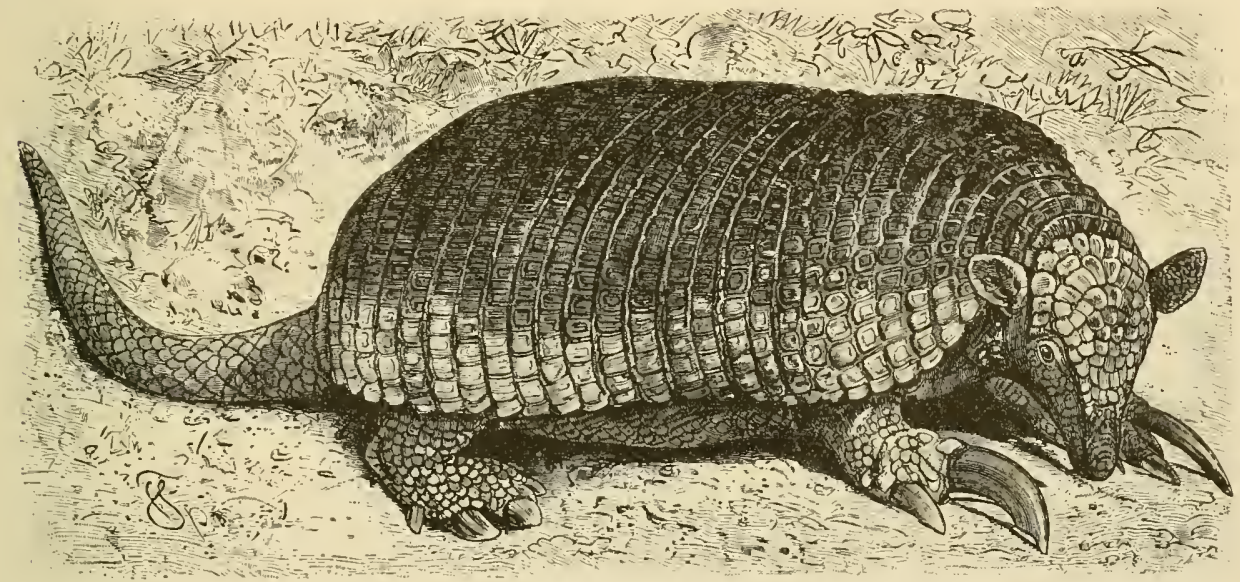

THE GIANT TATU, - This large member of the Armadillo family has other peculiarities besides its great size. It is thoroughly protected by its armor, and other distinguishing features shown in the picture are its long armored tail and its especially long and strong claws. Altogether it is admirably endowed for a digging and insect-hunting life. (Prtodon gigas.)

artificially put together. Azara, however, early gave so clear a description that the existence of the animal could no longer be doubted. He says that the Mataco does not exist in Paraguay, first being found soutl of the 36 th parallel of south latitude. "Some call it Bolita, because it is the only Tatu, which, when it is frightened, or apprehends capture, conceals its head, its tail and its four legs, forming a ball out of its body, which one can roll in all directions without its relaxing itself. One can open this ball only by the exercise of great strength."

Its length from the tip of the snout to the extremity of the tail is eighteen inches; the tail measuives not quite three inches and is round or conical at the tip and compressed horizontally at the base; neither are the scales like those of the others of the species, having somewhat the aspect of stout grains and being very prominent.

Habitat of the Anton Goering obtained a living BoBolita or lita from San Luis in western ArgenMataco. tinia, which is its true native country or at least the country where it occurs most frequently. There the animal lives, exactly as Azara out its fore-legs, draw in the hinder ones, lie down on them and on its abdomen, and hide its head between its fore-legs. The back alway's looked much curved: no matter what attitude it assumed, the animal could not really straighten itself. Though it ate and ran about quietly in the presence of sereral persons, it drew itself together whenever it was touched, and when pressed, it rolled up into an impenetrable ball. When the annoyance ceased, it gradually unrolled itself again and resumed its wanderings.

\section{THE PRIODONS.}

Another specics (Priodon) inhabits the woodland of Brazil and Guiana. P'rnce IVied everywhere was assured of its existence, but nerer could succeed in either seeing or procuring a specimen. He believes that it is distributed over the greater part of Brazil, and perhaps is found throughout all South America. In the extensive virgin torests his hunters often found holes or burrows, especially under the roots of old trees, from the dimensions of which conclusions could be drawn as to the size of the ani- 
mal. The native sportsmen affirmed that it equaled a large P'g in size, and this statement scemed to be borne out by the diameter of the entrance to these burrows and still more by the size of the skins of tails which the prince found among the liotocudos. The Botocurlos of the Rio Grande de Belmonte had speaking tubes, which were plainly called "Tatu tails," and were fourteen and one-half inches lons and three and one-fifth inches in diameter at the larger end.

$$
\begin{gathered}
\text { The Giant Tatu, } \\
\text { a Monster } \\
\text { Species. }
\end{gathered}
$$

Later investigations show that the Giant Tatu (Priodon gigas) attains a body length of three feet or over, the tail measuring about half as much: Kappler gives its weight as ninety pounds. The entire cerebral dome of the skull is covered by very irregular bony plates. The shoulder part of the armor consists of ten bands, another row being interpolated on the luwer portion of the flanks; twelve or thirteen zones consisting of mobile scutes follow; the posterior buckler contains sixteen or seventeen rows. The plates may be square, rectangular, or may have five or six angles, and the hindmost rows of the posterior shield are irregular in shape, the tail is covered by square bony plates of irregular thichness. Probably the most remarkable anatomical feature of the animal, however, is its dentition. The upper jaw on each side contains from twenty-four to twenty-six teeth, the under jaw in each row from twenty-two to twenty-four, of which several are frequently lacking, however. Still there are from ninety to one hundred fully developed tecth or rudimentary organs, performing the office of teeth; but in the anterior portion of the rows they are only thin plates, gradually assuming stouter proportions toward the rear. What use the Giant Tatu finds for all these teeth is quite a mystery, as its food, so far as is at present known, does not differ from that of the other species.

\section{THE BICHOCIEGO.}

Harlan, an American, first discovered a very remarkable member of the family, the Bichocicgo (Chlamydophoms truncatus), in 1824, near Mendoza in the west of the Argentine Republic; the discovery was a surprise to the natives, who had hardly a suspicion of its existence. For a long time two specimens only were known, kept in the collections of lhiladelphia and London, which could fortunately be examined most closely. Later on others were obtained and accounts of the inner anatomical structure and external appearance could be accurately given. The Bichociego is justly regarded as a representative of a distinct species, though it differs from the heretofore described Armadillos more in the peculiarities of its armor than in its inner anatomical structure.

The Bichociego The Bichociego shows the most eran Abnormal ratic deviation of shape and belongs Species. to the most remarkable group in the entire animal world in respect to the horny, nearly leathery armor covering its body. This strange creature is a real dwarf when it is compared with even the smallest of the known Armadillos, while it forcibly reminds one of a mole in respect to its shape, and still more so in regard to its habits. Its head is short, broad in the posterior portion, tapering toward the front and terminating in a rather short, truncated muzzle. The eyes are small and hidden under the hair which falls over them. The ears, which lie close to the head, are devoid of any external conch. The dentition is normal. Incisors and canines are absent, and the molars, eight in number on each side of the upper and lower jaws, are composed of pulp encased in a layer of enamel, devoid of roots and hollow in the lower half; they are of cylindrical shape, and with the exception of the first two in each jaw, which are sumewhat pointed, their grinding surface is flattened. The legs are short: the fore limbs are very sturdy, clumsy and nearly mole-shaped, while the hinder ones are much weaker, ending in long, narrow feet. . 111 its toes bear blunt-pointed claws, those of the fore-feet being very large and stout, forming powerful tools for digging. The tail which is set on at the lower edge of the armor covering the hinder part of the body, in a notch, makes a sudden curve and is folded along the under surface between the hind legs, lying close to the abdomen.

External Appear- The whole upper surface of the body ance of the is covered by a horny shield, some-

Bichocrego. what resembling leather in character, rather thick and less flexible than sole-leather, beginning on the head near the tip of the snout, extending all over the back to the rump, where it ceases abruptly, the animal being thereby endowed with a truncated, and as it were, mutilated appearance. This arnor is composed mostly of regular transverse rows or zones, consisting principally of rectangular shaped and partly of rhombic, or even irregular, hump-shaped shields; it is not connected everywhere so firmly with the skin of the body as the armor of the Armadillos proper, but for the greater part, lies but loosely on it, being fastened along the median line of the back by means of a loose membrane, to the spinous processes of the vertebre; on top of the head the points of attachment are the two semi-circular prominences of the frontal bone through the agency of an integument connecting them with two shields. The effect of this arrangement is that the armor gapes open on the sides of the body and can be raised in a flaplike manner. On the other hand it is securely connected to the bone at the fore part of the head, and likewise at the rump, where it presents an abruptly abcised plane. Though the dermal intervals between the zones are not very wide, they still admit of a considerable degree of movement, which to a certain extent, accounts for the capability of the animal to assume a spheroidal shape. The buckler of the rump is firmly fixed and immobile, connected with the tail by a membrane only; its line of direction forms a right angle with the longer axis of the body and it lies upon the animal perfectiy flat; it consists of five or six semi-circular rows of little shields, some of rectangular, others of rhomboid shape. The armor is nearly destitute of hair and is smooth on the upper parts as well as on the detached under surface; only the lower edses of the carapace show numerous, rather long and silky hairs. The external skin of the animal, however, is covered everywhere, and even that portion bencath the carapace with long, fine, soft, silky hair; only the tail, the soles of the feet, the tip of the snout and the chin are bare. The body rather exceeds five inches in length; the tail measures nearly one and one-half inclies and the height is two inches.

Information as In zoological works we find only the to the Bichociego following data about the life of the Limited. Bichocicgo. The animal lives in sandy plains, and like the Mole, it digs long tunnels under the ground; it carefully avoids leaving this 
subterrancan palace and probably appears on the surface by chance alone. It is said to burrow with the greatest speed and run like the Mole, but is very slow and awkward above ground. Mlost probably it hunts for insects and worms and perhaps also at times contents itself with tender roots. Nothing is known about the details of propagation, except that it is not a prolific animal. The natives believe that the female carries her young hidden under the carapace. We see how scanty the information is and how much of it is yet mere conjecture; hence the greater pleasure did I derive from Goering's communications.

\section{Goering's}

Account of the

"The Bichociego," says he, "lives not Bichociego. only in the province of Mendoza, but also in San Luis. The Spaniards call it Bichociego, because they believe it to be quite blind; some give it the name of Juan Calado (Lacetrimmed Johnny). The little animal inhabits dry, sandy, stony localities, especially such as are overgrown with thorny shrubs and cacti. During the day it keeps hidden in the earth; at night, however, it appears above ground and runs around, and can be seen under bushes on moonlit nights."

The animal is always caught by chance only, usually on such occasions as the digging of channels of irrigation canals where land is to be made cultivable. It has sometimes also been captured along with other Armadillos. Recently a little more pains have been taken to obtain Bichociegos owing to the frequent demand for them; but it must be a very difficult matter to procure them, as Goering, who spent seven months in their native country, could not obtain a specimen either living or freshly killed, in spite of all efforts and promises. The Bichociego is even now an object of wonder and admiration to the natives. If they happen to capture one, they let it live as long as it can, and then preserve it as a great curiosity, in the best way possible; South Americans in general have a peculiar habit of keeping animals that strike them as remarkable, the idea of caring for them not entering their heads, however. As the people do not know how to skin and stuff animals, the Bichociegos one finds in their possession are nothing but mummies.

\section{The pangoling.}

\section{FOURTH FAMILY: MANIDIDE.}

The Pangolins (Manidida) constitute a family quite distinct from the Ant-eaters, notwithstanding the similarity of form and habits. The body of all animals comprised in this group is covered on its upper surface with large, shield-like, horny scales, overlapping each other like shingles on a roof, or rather like the scales on a pine-cone. This covering constitutes the principal distinguishing charac- teristic of the family and is unique among mammals for the shields of the Armadillos and Bichociegos bear but a remote resemblance to these peculiar horny formations, which in their shape partake more of the nature of the scales of a fish or a reptile than of any other dermal adjunct of a mammal.

Physiologicat The following may serve to characPeculiarities of terize the Pangolins more closely: the Pangolins. the body is elongated, the head small, the snout is shaped like a cone, the legs are short, the feet five-toed and armed with strong digging claws. The scales are absent on the throat, the under surface of the body and the inner faces of the limbs, all other portions of the body being enveloped in armor. All scales are attached to the skin at only one point and are of a rhombic shape; their edges are very sharp and they are exceedingly hard and firm. Their arrangement admits of a tolerable facility of movement in all directions; the scales can be moved laterally, as well as erected and depressed. Between the scales and on the naked portions of the body there are thin hairs, which, on the under portion, are often worn away 
observed in Liberia: "Contrary to all accounts in books, this animal runs very swiftly; so fast, indeed, that a man can hardly overtake it, and during its flight it from time to time stands erect upon its hind legs and tail and looks around, letting its fore-legs hang down." He also affirms that two other African species are good runners and agile climbers. In regard to one of the last named species, he says: "It is easily tamed, and can be kept in a house for a long time; it is generally permitted to range the house at will, because it diligently pursues and destroys Ants, Cockroaches and other insect nuisances. They are very agile animals and can climb on the roofs of houses and in tree-tops in play."

The Pangolins With adequate care the Pangolins Readily Adapted can endure captivity for a long time. to Domestication. They readily become accustomed to a diet of milk, bread and even grains, though insects always remain their favorite food. The flesh is eaten by the native Africans and is said to be sa- close upon each other and are thick and firm enough to protect the animal from the claws and teeth of other animals which attack it. The Leopards pursue it incessantly and have no trouble in overtaking it, as it runs much more slowly than they. As neither claws nor teeth furnish it with effectual arms against the formidable teeth and claws of these beasts of prey, when it is overtaken it rolls itself up into a bail and folds the tail against the abdomen, bristling all around with the sharp edges of the scales. The large Cats gently roll it back and forth with their claws, but prick themselves when they handle it more roughly and are compelled to leave it alone. The Negroes kill it with sticks, skin it, sell the hide to white men, and eat the flesh. Its snout might be compared to the beak of a Duck. It possesses a very long, extensile tongue covered with a viscid secretion; this it projects into the holes of Ant-hills or exposes in the vicinity of the usual haunts of Ants; attracted by

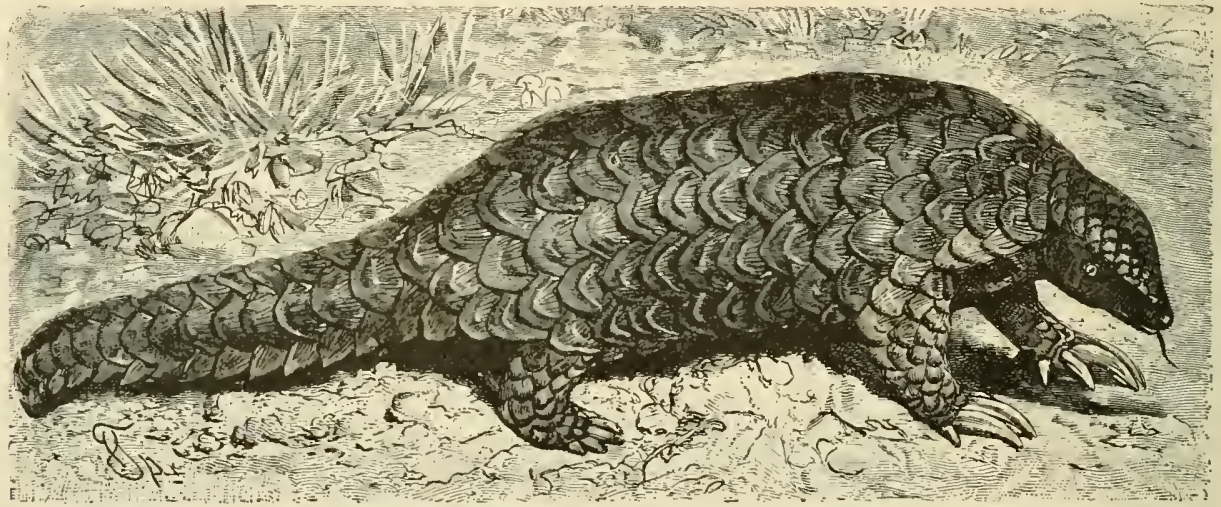

THE PANGOLIN. - This is the typical animal giving its name to a family of queer armored creatures which are mhabitants of Asia and Africa. The species shown here is an inhabitant of India, Ceylon and the Malay country. It is strongly armored and admirably fitted for a burrowing and insect-eating life. (Lianis pentadactyla.)

vory; the shields are used by several tribes as ornaments of various kinds.

Characteristics of The Long-tailed Pangolin (Munis the Long-tailed longicaudata) has a total length of

Pangolin. three or four feet, nearly two-thirds of which is occupied by the tail. The tail of young animals is double the length of the body and becomes shorter in proportion as the growth of the body progresses. With the exception of the inferior external face of the fore-legs, the scales cover the whole upper and external surface of the body and also the under surface of the tail; the scaleless places are grown with stiff bristles. Face and throat appear nearly naked. The scales are exceedingly firm and sharp-edged, and are largest on the middle of the back of the animal. The general color is blackish brown, with a reddish tint; the individual scales are dark brown at the center of the base, edged with yellow at the margins. The bristly hair looks black. The animal is a native of western Africa.

$\begin{array}{cl}\text { Desmarchais' Desmarchais gives the first details } \\ \text { Account of this } \\ \text { Pangolin. } & \text { one fonds a four-footed animal in the }\end{array}$ orest, which the Negroes call Quoggelo. From the neck to the tip of the tail it is covered with scales, which somewhat resemble in shape the leaves of artichokes, only they are more pointed. They lie the odor of the secretion with which the tongue is covered, the Ants rush towards it and adhere to it. When the tongue is loaded with insects it is drawn back into the mouth and the insects are eaten."

The Pangolin The Pangolin (Manis pentadactyla)
Proper De-
scribed. tire family, and which for distinction is sometimes named the Five-fingered Pangolin] possesses a short tail and its shield covers the outer face of the fore-limbs, this peculiarity differentiating it from some of the other species. The animal inhabits India and Ceylon, apparently preferring a hilly country, but is nowhere plentiful. Aelian, even in his early day, mentions that there is an Indian animal which looks like a terrestrial crocodile.

Distinguishing The Pangolin proper differs from Characteristics of the other Manidida, excepting the

the Pangolin. Temminck's Pangolin (Manis t'mminckii), by reason of its size and by having its scales arranged in from eleven to thirteen rows; they are very broad on the back and tail and never externally exhibit the course of the spinal column by the apex or ridge shown in most mammals. An adult male may attain a length of four feet, the body occupying about half of this.

We know as yet very little about the habits of this species. The animals dig burrows, which run ob. 


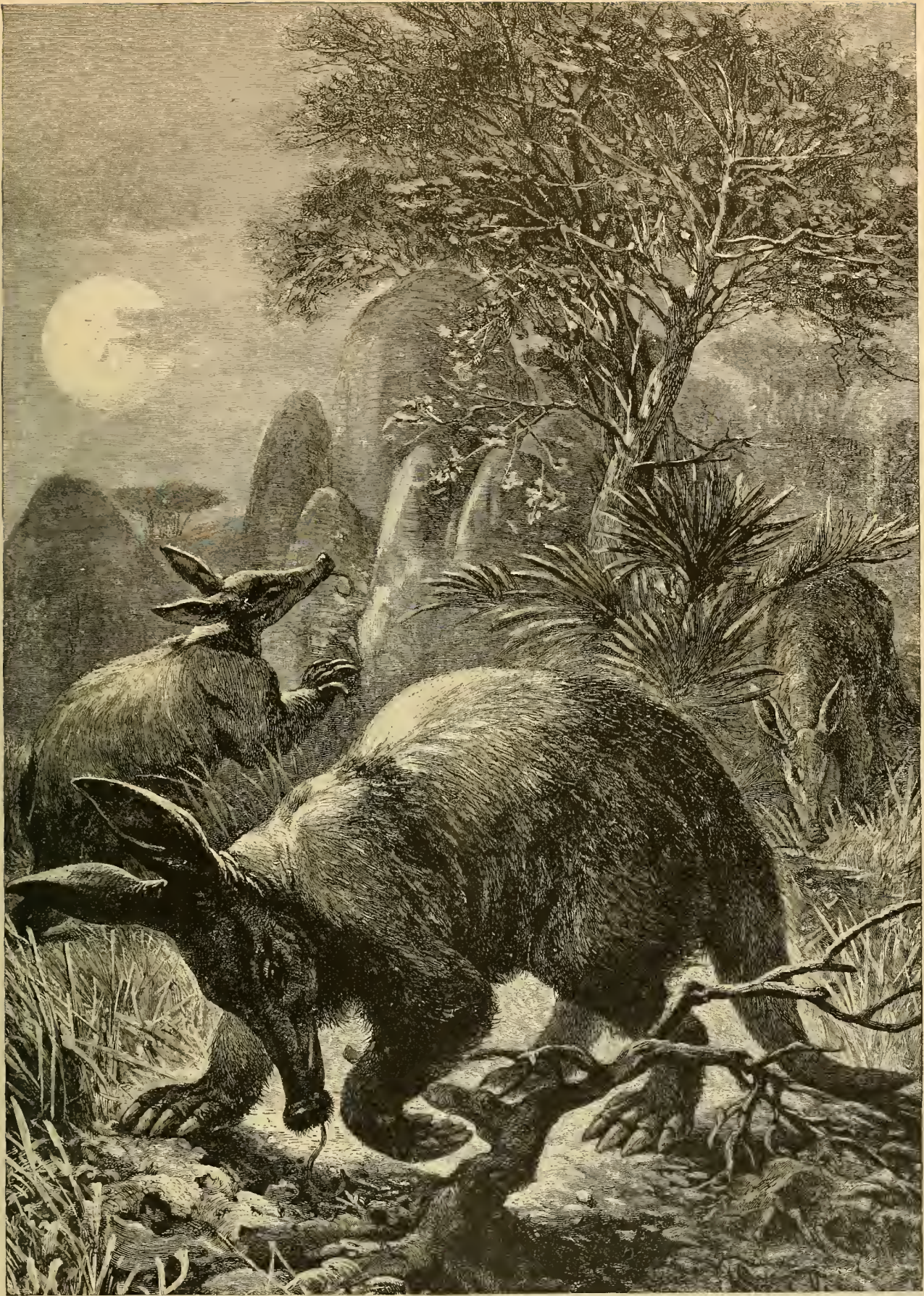

THE AARD.VARK. - Here is one of the most clumsy, odd looking animals in the world. The name, which is Dutch, signifies "Ground-hog," al though the animal is very widely different from that which we know by the same name. It lives in southern and central Africa. Its coarse, bristle-likt hair. long tajl. elongated head and ears, strong claws, and long tongue make a strange picture. (Orycteropus capensts.) 
liquely downward from the surface to the depth of from two to four yards, and terminate in a large, roomy chamber. In this retreat they live in couples, and are found from January to March with one or two young. When they are in their hole they are wont to stop up the entrance with earth in a way which would render it quite difficult to discover their lair if their queer tracks outside did not betray them. Burt says that the Pangolin feeds exclusively on Ants and like insects and destroys a great many of them, but that it can also endure hunger for two months; that it roams about at night, and is very restless in captivity; that it is quite quick in its movements, and when attacked, quietly suffers itself to be taken up by the tail without the least attempt at defending itself against an enemy, etc. The Chinese manufacture a defensive armor out of its skin.

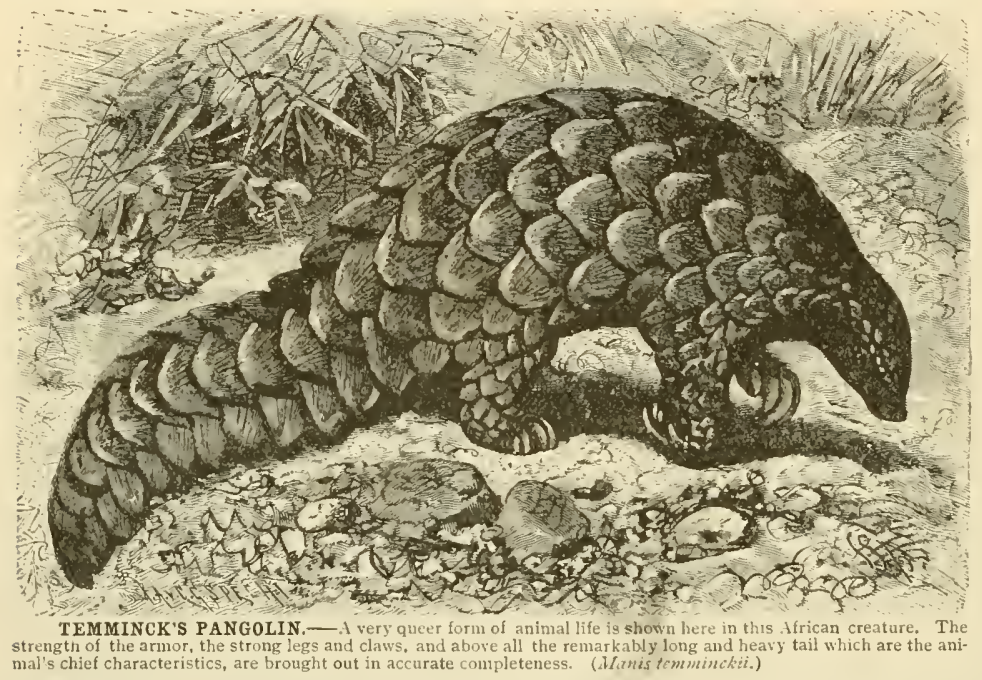
its food. in its habits like that animal, it emerges only after dusk, and as it is neither agile nor fleet, it cannot defend itself against enemies. Ants, Termites, Locusts, Beetles and perhaps also worms constitute

\section{The Gard=varks.}

\section{FIFTH FAMILY: ORYCTEROPODIDE.}

The last family comprises the Aard-varks, clumsy animals, endowed with a stout, short body, sparsely covered with thin bristles, a thin neck, a long, slender head, a cylindrical snout, a conical tail of moderate length, and short, proportionately thin legs; the fore-feet have four toes, the hinder feet five, the toes being armed with strong, nearly straight, flat, hoof-like nails with chisel-shaped edges. The mouth is rather large, the eyes deep-set in the head, the ears are very long. The upper jaw of a young animal contains eight teeth on each side, the lower jaw six. Adult animals, however, usually have only five, and sometimes four teeth on each side, of a crlindrical shape, rootless, fibrous and composed of a great number of fine tubes; the grinding surface is flush with the external edges of the teeth, but the opposite or basal end is hollow.

The Aard-vark (Orycteropus capinsis) attains a total length of nearly six feet, the tail including about thirty-four inches of this total. The weight is from one hundred to one hundred and twenty

Peouliarities of A proportionately short, broad tail, the Temminck's bluntly rounded at the tip, characPangolin. terizes Temminck's Pangolin (1/anis temminckii). In size and shape it assimilates most closely its Indian relative. The tail which attains nearly the length of the body does not decrease in size for the greater portion of its length, and begins to taper at a point near the tip, where it suddenly becomes rounded and abruptly cut off. The body is broad and the head is short and thick. Ovoid scales cover the head; the rest of the scales are very large, marked with fine, longitudinal furrows at the base and smooth at the apex, and arranged in from eleven to thirteen rows on the back, five on the tail and four behind. Adult males attain a total length of thirty-two inches or thereabouts, the tail occupying some twelve inches of this length. This species chiefly inhabits eastern and southern Africa, but is also found in the west.

The Habits of the The Abu-Khirfa or Father of Cattle, Temminck's as the nomads of Kordofan call Pangolin. Temminck's Pangolin, finds sufficient nourishment and the desired solitude in the steppes of Africa abounding in Termites. Holes in the earth form its domicile; but it never buries itself as deeply as does the Aard-vark. Nocturnal pounds. The skin is very thick, sparsely covered with smootl, bristly hair, shorter on the upper parts of the body than on the under surface; at the base of the toes the hair forms tufts. The coloring of the animal is quite uniform. Back and flanks are yellowish brown, dashed with red; the under-surface and the head are light reddish yellow; the buttocks, root of tail and limbs are brown. Newborn Aardvarks are of a pale pinkish or flesh-color.

The Dutch settlers at the Cape of Good Hope gave the animal its name of Aard-vark (Groundhog), because its flesh resembles that of a IVild Boar in taste; they have hunted it extensively and therefore know it well.

Habits and Home The Aard-vark is a native of southof the Aard- ern and central Africa, ranging from vark. the eastern to the western coast, like the Armadillos affecting the plains, desert-like spots and grass-grown table-lands abounding in Ants and Termites. It is a solitary animal, though one sometimes finds it in company with others; strictly speaking, however, every Aard-vark lives alone, resting by day in large burrows excavated by themselves, and moving about by night. It is an expert burrower, a few moments being sufficient for it to completcly bury itself in the ground. 


\title{
Tbe Elepbants.
}

\author{
NINTH ORDER: ProBoscideA.
}

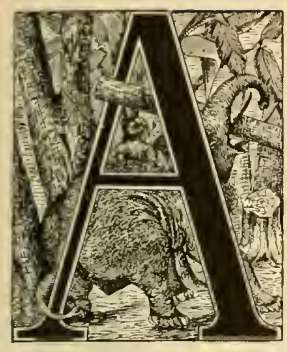

STEADILY decreasing tribe, the last survivors of a formerly numerous group of mamnals, invite our attention in the Proboscidea. They appear to us to be living relics of former periods of creation, as creatures bequeathed by bygone ages. Of all the species of this order, which were formerly numerously and widely distributed over our globe, the representatives of only one family, consisting of two or three species, have come down to our age; but they are the obvious links which connect modern times with prehistoric eras; for to their family belonged the giants, the well-preserved bodies of which the ice of Siberia has retained through the lapse of thousands of years. A glance at the extinct species, with which Neumayr deals in his "I History of the Earth," will facilitate our conprchension of this order.

Characteristics Our Elephants (Elephas), the only of the Elephant living representatives of the family Tribe. Elephantidae, are distinguished by their long, movable proboscis and the peculiar dentition, especially the tusks, which may be designated as exaggerated incisors. The body is short and thick, the neck very short, the head round and protuberant in places on account of the cavities in the upper skull-bone; the legs are tolerably long and pillar-like and the feet are furnished with five connected toes and flat, horny soles.

Importance of The most important organ of an the Proboscis to Elephant's anatomy is its proboscis,

the Elephant. an elongation of the nasal process, distinguished by its mobility, sensitiveness and especially by the finger-like appendage at its extremity: It is an organ of smell, touch and prehension. It is composed of annular and longitudinal muscles, the number of which Cuvier estimates at about forty thousand, and which enable it to turn, extend and contract in all dircctions. It is also a substitute for the absent upper lip, and through its manifold uses life is rendered possible to the animal.

other Physical All other limbs and even the organs Characteristics of of sense of the Elephant appear to

Elephants. be less worthy of notice. The eycs are small and have a dull, but good-natured expression, while the ears are very large and comparable in appearance and texture to leather rags. The toes are so firmly enclosed in the general skin of the body as to preclude their moving against each other. They are covered at the extremities by very small, but strong, broad and flat hoofs.

The dentition is very peculiar. The Elephant has two excessively developed tusks in the upper jaw, but neither incisors nor canines, and usually only one huge molar on each side of both jaws. This tooth consists of a large number of plates of enamel, closely united with each other. When the molar has so far worn away by grinding food that it can no longer perform its office in an efficient manner, a new tooth forms behind it, which gradually advances and assumes its functions contemporaneously with the shedding of the stub. This shedding of teetl has been observed to occur six times, and one may therefore speak of twenty-four molars, which the animal possesses during its lifetime. The tusks which are not shed have an uninterrupted growth and hence can attain a considerable length and an enormous weight.

The Powerful The Asiatic Elephant (Elcplurs asintAsiatic Ele- icus or Elephas indicus), which we phant. are wont to consider the type of its species and family, is a powerful, clumsy, robust animal, with a massive broad-browed head, short neck, powerful body and pillar-like legs. Its head, which is set on the neck at right angles to the spinal column, and usually carried nearly perpendicularly, assists materially in enhancing the overwhelming impression of power the animal makes on the spectator. Huge in all its proportions, it strikes one as being endowed with great mobility of limb, notwithstanding the apparent clumsiness of its shape.

The mcasurements of the size of the Elephant are mostly exaggerated and frequently incorrectly determined. The largest males attain a length of about twenty-one feet from the tip of the trunk to that of the tail, about six feet of which length will be occupied by the proboscis, and the tail may take up as much as five fcet, thus leaving for the body and head a length of eleven feet; the height may amount to nine feet. Larger specimens are rarely found. Sanderson, who was the English government superintendent of the Elephant department in British India for half a lifetime, and who from his experience in that capacity is surely trustworthy authority, measured the largest among hundreds of animals under his care and determined the shoulder height as follows: The two largest males were respectively 120 inches and 118 inches high; the two largest fenales measured respectively 103 and IOI inches. The weight of the heaviest may amount to eight thousand pounds, or perhaps slightly more.

The Hindoo Classi- The natives of India, who are doubtfication of Ele- less the most expert in this line, disphants. tinguish three kinds of Elephants, according to the shape of the animal and the working capacity dependent upon that shape; they call these three grades Kumiria, Dwasala and Mierga. The Kumiria is the most perfect variety, of heavy, symmetrical build, with a capacious chest, a power- 
ful body and head, and a straight, broad, sloping back. Its eye is full, clear and prepossessing. Physically and mentally it is a noble animal, trustworthy and fearless, moving with stately and measured tread, as if expressly created for royal pageantry. The Mierga is its reverse; it is of light, ill-looking build, long-legged, small-headed, pig-eyed, with arched, steep back, narrow chest and full abdomen, a weak, flabby trunk and a thin skin which is easily injured. The Dwasala is a medium between these two widely differing breeds and is aiso the most numerous of the three. It is not human interference that has produced these three breeds so different from each other; they are found in the same wild herd, and we may therefore assume that they are but physical variations of the same species and hence are closely related.

Albinos or White Light-colored or light-spotted speciElephants Very mens, so-called white Elephants, are Rare. rarely seen. In Siam, where albinos of all kinds of animals are much esteemed, as they are believed to be the rulers of their kind, where the white Elephant is held sacred as the most powerful of all animals and one title of the king is "Lord of the white Elephant," it appears that the peoplc have been able to obtain but few light-colored specimens, notwithstanding all possible efforts have been made, and a really white one does not seem to have been found as yet.

Birth and Growth In India the Elephant is full-grown

of the Ele- at twenty-five years of age, though phant. it does not reach its prime until the age of thirty-five. A male is capable of reproduction at about the twentieth ycar. The first offspring is born to a female at about the age of sixteen, and other young ones follow at an average interval of two years and a half. The newborn Elephants are about thirty-six inches high at the shoulder and their average weight on the second day is one liundred and eighty pounds. For six months they feed exclusively on the mother's milk; then they gradually begin to eat some tender grasses, but milk still continues for a few months longer to be their main article of diet. From the hour of birth they appear to be less awkward than other young animals, and strike one as pretty, though droll animals; during the first period of life they preferably keep under the body and between the legs of their mother and do not even leave that place of security when she assumes a quicker gait. It is stated that they are under the mother's protection for several years, at any rate until the birth of a brother or sister ousts them from the first place in maternal care. The first shedding of teeth occurs during the second year, the second in the sixth, the third in the ninth year.

Habitat of the This animal is a native of the greater

Asiatic Ele- part of wooded country of southphant.

eastern Asia, existing in India, from

the foot of the Himalayas to its southern extremity, in Assam, Burmah, Siam, and on the Malayan peninsula, and in smaller numbers on the adjacent islands of Cevlon, Sumatra and Borneo. In some regions it is already extinct or at least its numbers have been greatly diminished, yet it still occurs in all of the larger forests, in mountains and plains within the designated range.

The African There can be no doubt as to the Elephant's Char- specific difference of the African acteristics. Elephant (Elephas africames) from the Asiatic species. It exceeds its Asiatic kinsman in size, but its shape is, on the whole, less sym- metrical, though in the institution of such a comparison we must consider the different breeds of the African species also according to external appearance, and classify them in the same way as is done in India. Its body is shorter, but the legs are longer than those of its relative; its flat head with its thin trunk, large tusks and enormous ears, the arched line of its back, its narrow chest and ugly legs constitute a union of distinctive features, which definitely separate it from the Asiatic Elephant.

The Range of The range of the African Elephant

the African has been considerably restricted

Elephant. within the present century, especially from the south, and now extends from about the latitude of Lake Chad in the north to that of Lake Ngami in the south. There is no invariable boundary line, as the Elephants not only wander over immense distances, but also change their haunts, disappearing in some regions for years or even for decades and as unexpectedly appearing in others.

The Elephant Both species were well known to the known in $A n$ - ancients, and living specimens were cient Times. early brought to Europe. The Median and Persian Emperor Darius, if we accept the records of history, was the first to employ Elephants in battle in his conflicts with Alexander the Great. Aristotle was fortunate enough to see some Elephants taken by the latter and thus was enabled to give a fairly accurate description of the animal. From that time Elephants are frequently mentioned in history. For nearly three hundred years they were employed in Europe in the inccssant wars waged by the various nations for supremacy until the Romans finally emerged victorious from the contest. Besides the Indian Elephant, the African species was also used in warfare, especially by the Carthagenians, who seem to have been adepts in the training of these animals, subscquently declared untamable.

The Romans employed Elephants mainly in their circuses. To what extent the African Elephants were trained may be judged from the fact that the Roman showmen taught them to write letters with pencils, and to walk up and down a slack rope; four of then would carry in a sedan chair a fifth one which pretended to be ill; they could dance to music, eat at a table luxuriousily loaded with gold and silver dishes, observing all rules of etiquette and decorum, and had learned other tricks.

The Chosen Dom- In their native countries Elephants icile of Ele- may be found in extensive forests. phants. The more swampy and unbroken or impenetrable the jungle of woodland, the more frequent is the animal. But one would be greatly mistaken if he entertained the belief that it is to be found only in such forests. It has been affirmed that this largest of terrestrial mammals shunned the cool air of elevated regions, but this is most emphatically disproved by the testimony of conscicntious and reliable observers. In Ceylon, the hilly and mountainous spots are the regions most favored by the Elephants. A similar taste may be affirmed of the African species. In the Bogos country I found signs that Elephants had ranged at an elevation of 6,000 feet, and have been infornzed that in the neighboring regions the animals regularly frequent the highest mountains, which would give then a range certainly extending to an altitude of about 9,000 feet above the sea. Von der Decken found traces of them at this height on the Kilima. 


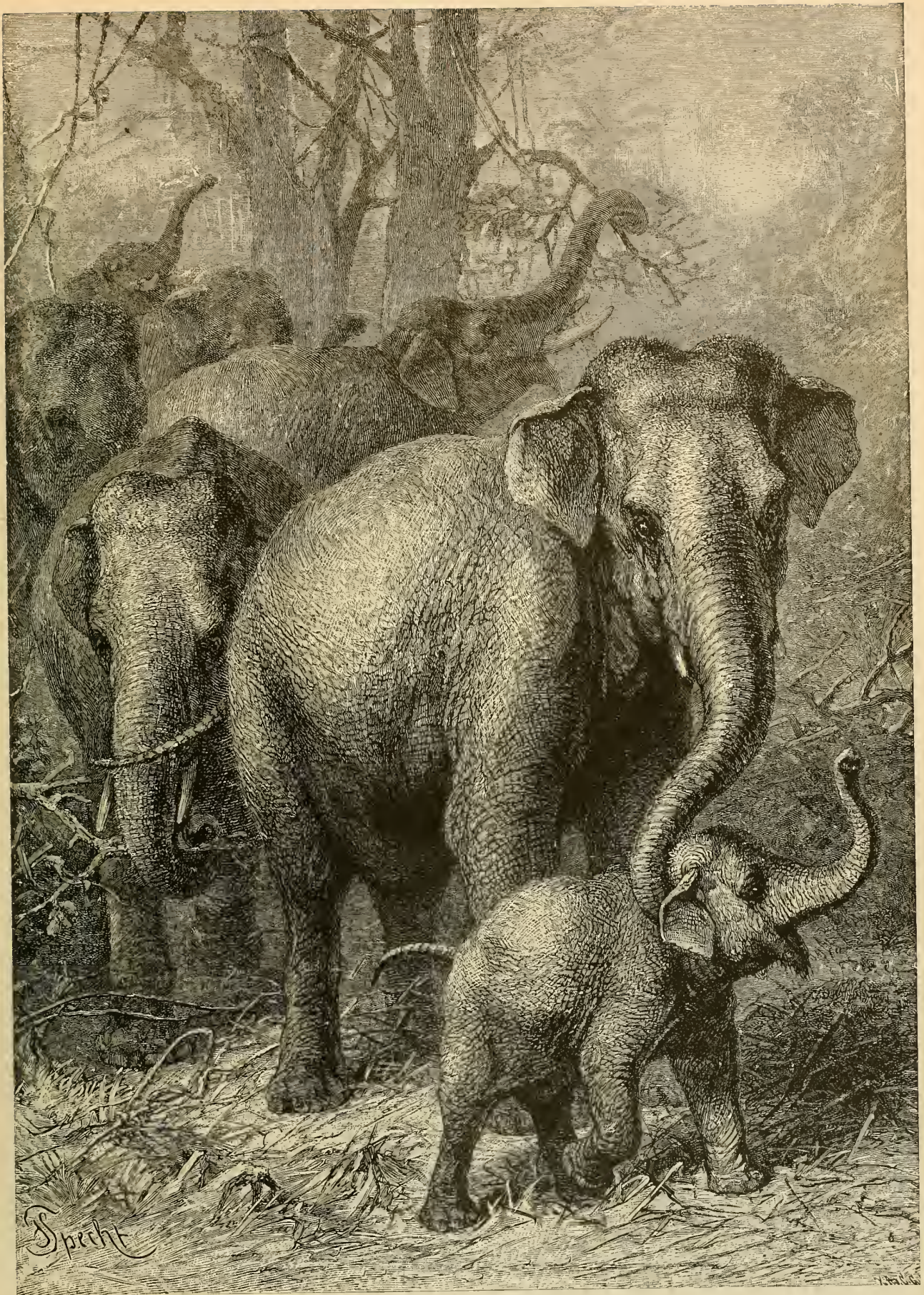

作 used as an animal of state by rajahs, princes, etc, and is also trained for purposes of sport, more particularly for hunting the Tiger. The herd in the illus. tration with the female Elephant and her young one in the foreground is a characteristic group. The small ears and less powerful tusks which distinguish this from the African species will be noted. (Elephas asiaticus.) 
Njaro, and Hans Mever saw them at an elevation of eren 12,000 feet above the sea. Tamed Elephants also give evidence of great skill and untiring endurance in the ascent of high mountains.

The Elephant a Numerous as Elephants may be in Wary Beast the centre of Africa, it is sometimes of Game. exceedingly difficult to discover their exact haunts, as they lead an extremely restless life. While on their journeys from one locality to another they always follow the steps of their leader, choosing either an old path or selecting a new route, always in a direct line, exhibiting a perfeet indifference as to whether the road leads them through forests, bogs, or narrow chasms or over steep heights. It seems as if natural obstacles could offer no impediment to their course: they swim across streams and lakes, easily work their way through the very thickest primeval forests, frequently forming regular roads with firm foundations, because in their migrations they not only march in squads of close formation, but sometimes in single columns, which leave comparatively narrow tracks or paths. Their roads deviate at regular intervals from the dry" regions of the heights to such places as furnish them with water for drinking and bathing purposes.

Peculiarities of The leader of a herd calmly stalks Elephants on through the forcsts, heedless of the the March. underbrush, which it treads down with its broad feet, unmindful of the branches of trees. In the mountains the Elephants select and build roadways as in the forest, display an ingenuity which arouses the admiration of even human engineers. The Elephants always choose for their route the most favorable passes found in the locality through which they journey. Some of these passes are used by them so regularly and for so long a time, that the animals' feet wear off hard stones.

The Muscular The Elephant is elunsy in appearActivity of ance only, being in reality very agile.

Elephants. Its usual gait is a quict, uniform amble, similar to that of the Camel and the Giraffe, covering from two and one-half to three and threefourths of a mile in an hour. This ordinary pace can be accelerated to such an extent, however, that the speed can be doubled for a distance of nine and one-half to twelve and one-half miles. The huge creature is an expert in slinking softly through the woods so as not to be heard at all. "At first," says Sir Emerson Tennent, speaking about the Asiatic Elephant, "a wild herd rushes through the underbrush with a great deal of noise, soon, however, this noise subsides into a perfect silence so that a tyro is led to the belief that the fleeing giants have nade but a few steps and then stopped short." When ascending acclivities of considerable steepness, the Elephant gives evidence of the qualities of a genuine climber. On the ascent of a mountain its progress goes on tolerably well, but in the descent the enormous weight of the animal naturally causes it to labor under greater disadvantage. If the Elephant under these conditions employed its usual gait it would certainly lose its balance, turn a somersault and perhaps lose its life in the fall. But the wary creature does not do so; it kneels down at the edge of the declivity so that its chest rests on the ground, and then it very deliberately pushes its fore-legs on, until they have found a point of support; then it draws its hind legs up and reaches the bottom in this way, gliding and sliding. Yet it sometimes happens that an Elephant gets a bad fall in the course of its nocturnal wanderings.
The old belief that an Elephant cannot lie down is thoroughly refuted by every Elephant we see in a circus. It is true that the giant does not always sleep lying down, but often in a standing position, yet if it wishes to be quite confortable, it lies down. and when it arises does so with the ease characteristic of all its movements. The unwieldy animal is no less proficient in the art of swimming, and throws itself into the water with evident delight, and dives below the surface at will. If it so pleases it swims across broad and swift streams and may even stay under water for a long time, lifting only the tip of the trunk above the surface for the purpose of breathing.

Proficiency of the The proboscis is an organ of high

Elephant's Pro- development, capable of serving a boscis. variety of purposes. Only in exceptional cases is it used to deal a blow or to seize an enemy, for the trunk is a very sensitive organ, and is therefore earefully guarded against all collisions and rough or dangerous operations, by being closely. curled up under the mouth. It is mainly used to take up food, water, etc., and convey them to the mouth, and is also an organ of scent. With the extremely mobile muscular projections at the end of the organ it can easily pick up the smallest objects, such as pins, etc. With its proboscis the animal breaks off branches and uproots small trees, using the feet for pressing down larger ones; for pushing objects it uses that portion of the frontal bone of the skull which is situated just below the eyes and between that point and the base of the trunk. When. in the service of Man, it has to lift heavy burdens, it takes the rope which is fastened to them into its mouth, usually looping it over one of its tusks, if it has any. The tusks are also used in many other ways, but always with the same great caution displayed in using the trunk, and certainly not as levers for the removal of stonc-blocks or pulling up of roots of trecs; they chicfly serve as weapons of defence or attack, and their miscellaneous or careless use is scrupulously avoided, as they are comparatively easily broken.

Development of All the higher perceptive faculties of the Senses of the Elephant are in accord with its Eiephants. before mentioned qualities. Sight does not seem to be highly developed; at least hunters are of the opinion that the range of vision of this animal is very restricted. Smell and hearing are all the better developed, however, while taste and touch are at least proportionately acute, as can casily be ascertained by observation of captive animals. All sportsmen have stories to tell about the acute scnse of hearing of the animal. The slightest noise suffices to rouse an Elephant's attention; the breaking of a small twig is sufficient to put an end to its tranquillity. The sense of smell is exceedingly delicate and is effectual at great distances; no sportsman can approach within reasonable range of this animal if the wind blow from the hunter toward the Elephant. The proboscis is the main organ of the sense of touch, and the finger-shaped appendage at the lower extremity can vie with the trained finger of a blind man in its power of transmission of delicate sensation.

The vocal expression of the Elephant has a wide range and the sounds by which it makes manifest its emotions are manifold. A feeling of comfort is signified by a very low murmur: fright is expressed by powerful, noisy chest sounds rising, when absolute terror is expressed, to short, shrill trumpet-notes, 
coming through the trunk; when enraged it utters an uninterrupted, deep, rumbling, guttural sound; an attack is accompanied by harsh trumpet-tones, the "trumpet" sounds in reality amounting only to a loud squeal of rage.

Elephants of a Every herd of Elephants is a large Clannish Dis- family, and vice versa, every family position.

forms a separate herd. The number of members constituting it may vary a great deal; for a herd may grow from ten, fifteen or twenty members to a band containing hundreds. Some travelers have told of four, five or even eight hundred Elephants, congregated together. Von Heuglin affirms that he met a troup, which he estimates to have numbered at least five hundred, and Sir John Kirk states that he once found eight hundred Elephants together on the Zambesi. They certainly band together to such an extent very rarely. and one may suppose that under such circumstances several herds have come together, meeting by chance while on an extended misration and keeping together for a short time only.

Though each distinct herd forms one family strange Elephants, such as young bulls or females that have escaped from captivity, seem to be admitted into it generally without difficulty, though there may be exceptions. At any rate it would be assuming too much to suppose that the so-called "solitary' Elephants are expelled members which can nowhere find admittance to tribal relations. Sanderson flatly contradicts such a statement. In his opinion the majority of such animals, which oftener happen to be young bulls than old ones, are solitary only in appearance, temporarily keeping aloof from the herd of their own accord, and following the movements of the whole troup. A really solitary Elephant, one that no longer consorts with its own kind, is seldom met with and even then is not necessarily a ferocious fellow or "rogue," as it is technically called. On the other hand it frequently develops into an incorrigible plunderer of plantations, not to be easily scared away by the employment of usual means. It is true, that some of these solitary individuals become dangerous to human beings who chance to disturb or surprise them, suddenly and unexpectedly charging at a man, in their first movement of terror, so to speak, like so many other strong animals.

The Intellect The intellectual capacities of the Eleof the Ele- phant have been greatly overrated, phant. especially by those who have based their conclusions on observations made of it when a pupil of Man and not in its natural condition. Most of the stories of the sagacity and reasoning power of tame Elephants, that one hears so often, are pretty inventions, and are not founded on incidents observed in life. Such is the story of the tailor who administered a prick with his needle to an Elcphant instead of the accustomed sweetmeat; the animal went to the river, and on its return, in revenge squirted a quantity of muddy water on the tailor and bis work; or the story of the animal which lifted the wheel of a cannon over a fallen soldier. to save him from being crushed, and so on. An Elephant in the wild state undoubtedly exhibits far more of simplicity than sagacity, and the trained animal, which apparently sometimes acts on its own ideas, does in reality only what its trainer suggests. Sanderson say's: "Let us see whether the wild Elephant exhibits more intelligence than any other animal. Though its trunk is furnished with an appendage which could protect it very efficiently from a clumsily made pit fall, covered with a few poles and branches, it usually falls easily into the trap. Its companions run away in terror, though they could readily extricate it by treading down the earth at the edges of the pit. If the animal that has fallen in is young, the mother stays near until the hunters arrive, but she has no thought of helping her offspring: she does not even bethink herself of breaking off branches and throwing them to it, to appease its hunger; but storics which ascribe such natural stupidity to the Elephant find far less of credence than those which falsely affirm that the nother assists her young in every way, throws it grass to feed on, fetches water in her trunk for it to drink, or fills the pit with sticlis and branches to aid her infant to escape. Further evidence of stupidity is furnished in the fact that entire herds of Elephants are driven into enclosures surrounded by indifferent fences, into which no other wild animal could be driven, and some are caught by having their legs tied by small parties of Men who creep up together with a few tame Elephants. Escaped Elephants are recaptured in this way with little trouble; even experience does not teach them wisdom. Such facts surely do not harmonize with the assertion that Elephants are uncommonly intelligent animals, and still less, that they are capable of judicious deliberation. I do not believe that I wrong the Elephant by saying that in many respects it is a stupid creature; and I can, without hesitation, affirm that many of the rematkable stories told of its exhibitions of wisdom are only fables, in the main crediting the animal with too high a grade of intelligence, unless, indeed, they refer to tricks of strength or docility; which it accomplishes under the guidance of its trainer.

Elephants are of "Let what has already been said suf-

Amiable Dis- fice as to the intelligence of the Ele-

position. phant. Let us pass to the consideration of its display of emotion in captivity. I think that everybody who has had to deal with Elephants, will agree with me, when I say that hardly enough commendation can be given to their good qualities, while bad traits are to be observed in only exceptional cases. The best qualities of the Elephant are obedience, gentleness and patience. In these respects it is surpassed by no other domestic animal, even under the most trying circumstances. When it has to wait in the glare of the sun or has to endure painful surgical operations, it seldom exhibits any irritation. It never refuses to do anything, when properly guided, unless it is afraid. Elephants, no matter whether they be wild or tame, are exceedingly timorous, and their fear is easily aroused by objects with which they are unfamiliar. Nevertheless many of them indicate dispositions naturally courageous, which only need skillful development to render them invincible; this is proven by the behavior of many Elephants on a Tiger-hunt."

Caution and Tim- Timidity is exhibited by wild Eleidity of Ele- phants in all their actions and habits; phants. whether they are in search of food; whether they go to the natural licks to procure salt, of which they are very fond, or to their drinking pools or bathing places, they always proceed with the utmost caution; but once assured of their safety they seem to extract from life the greatest comfort. They break branches off the trees, as if only bent on pleasure, fan themselves with them, drive away annoying Flies and then leisurely proceed to eat the twigs, after having previously prepared them by 
breaking into small fragments. But though their repasts are usually accompanied with all the comforts to be derived from leisurely deliberateness they do not pass off noiselessly, but are on the contrary sometimes accompanied by a frightful din, as Heuglin witnessed near the upper Nile. The breaking of twigs, the crash of the boughs and trees, often broken through the united efforts of several individuals, the chewing and breathing, the dull, roaring or growling sound caused by the circulation of air or friction in their huge intestines, the thumping of the ponderous feet as they are stamped upon the soil, usually working it into a semi-fluid condition; the squirting of water over the body through the trunk, the flapping of the huge ears, which are often extended as sunshades, the rubbing of the massive bodies against thick tree-trunks, and the high-pitched, trumpet-like sounds uttered from time to time, all these unite to create a deafening concert of sound. In like proportion to such noise is the indescribable devastation which a herd of Elephants is capable of inflicting on a forest. "What the powerful foot does not tread into the ground is overthrown, the strongest trees are uprooted, their branches are broken; the underbrush is heaped in wild confusion, as if torn down by a raging whirlwind; trees which have defied the storms of more than a hundred years, are snapped short off like reeds." Boughs, of a circumference greater than that of a human arm, are swallowed by an Elephant without difficulty. Tery large limbs they denude of leaves and branches entirely or partially, leaving the wood. In dry, desertlike regions they also dig up the soil, to reach the succulent roots.

Methods of
Hunting Ele-

Hunting Ele
phants.

In the open country, for instance in southern $A$ frica, where one can circle about on a well-trained Horse at any desired distance from the Elephant, the sportsman generally uses a magazine gun, often choosing a military rifle, such as the Sharp, Nartini-Henry or Spencer, or the heavicr calibers of the Winchester pattern, the rapid fire of these arms rendering them capable of hitting the aninal with a great many bullets in quick succession until it falls. Wherever the prevalence of the pestiferous Tsetse Fly renders the use of Horses impossible, or where by reason of the obstructions of forests or undergrowth the movenients of a mounted huntsman are impeded, the Elephant hunter generally travels on foot and uses a smooth-bore gun of heavy caliber, or else a ponderous double rifle. As the hunter generally approaches close to the quarry in the thicket and fires at short range, usually at a distance of some thirty paces, aiming with unerring precision at the most vulnerable part of the body (ordinarily, if the position of the game allows, midway between the ear and eyer, a single bullet of heavy weight propelled by a strong charge of powder usually suffices to fell the most gigantic Elepliant.

Perils of Ele- The perils and privations met with phant Hunt- on such hunts are so serious that ing. only the hardiest Men can endure them; but the danger for the sportsman is not as great as one would be apt to imagine. It does happen though that sometimes an enraged or wounded Elephant rushes at his destroyer; and it is also true that occasionally hunters have breathed their last under the feet of one of these forest giants. When such a monster is in a rage the sight of it produces an indelible impression, even aside from that left by the swift movements of its huge bulk which make the ground tremble. With trunk rolled up, and ears slightly extended on each side, swinging its tail in a circle, it fiercely charges at the enemy; its fore part seems to grow, or at any rate strikes the observer, especially if he be the object of attack, as higher and more powerful than ever before; the long folds of skin on its linder quarters shake and protrude; the huge mass pushes on rapidly and relentlessly; angry snorts alternate with cries of rage, the like of which he who has never heard such sounds, can not realize. If the enraged beast reaches its victim under these circumstances, that object of its wrath is lost - griven over beyond rescue, a sacrifice to the wild fury of the maddened brute.

The extermination of the Indian Elephants is not so near at hand. The regulations of thinking officials have modified and restricted the modes employed by the natives, of capturing these animals, by which so many of them were crippled, and the wild Elephants now enjoy complete inmunity, not only in the Western Ghauts, but also in the dense jungles and forests extending along the foot of the IImalayas to Burnah and Siam. The number of those which are annually caught by the government is small, and there is no doubt that the wilderness which has been given over to the thick skinned creatures is at present populated as densely as is either expedient or desirable.

Methods of Trap- In Africa the natives still pursue their ping African hunt of the gigantic quarry as cruelly

Elephants. and rutlilessly as they did in the ancient times. In the west of Africa, in the Ogowe regrion, the Negroes twine creepers from tree to tree in the form of hurdles, drive the Elephants into those parts of the forest which they have thus enclosed, and when the animals stop in indecision in front of the barrier formed by the interlaced creepers, they thrust hundreds of spears into the bodies of the strongest and largest, until they fall. It is more usual, though, to construct such a fence in a wide circular course, leaving a point open for the entrance and then, with all possible speed, to complete the enclosure, when some of the Elephants have inadvertently wandered in or have been driven in. Sientinels are then posted all around, and fires are lighted in order to frighten back those animals which have come too near the fence. Though the smallest Elephant could easily break through the loose and weak enclosure and escape from the poorly armed natives, the captive animals do not dare to try to escape. They are completely starved by the patient hunters, shot at, made targets of a constant shower of spears, and finally succumb either from wounds or hunger, having reached a state of utmost exhaustion. Method of Domes- The mode of procedure for the capticating Asiatic ture of living Elephants with a view

Elephants. to taming them and training the wild beast to the service of Man, is much more attractive and liumane than any other kind of hunt. The Indians have perfectly mastered this art. Among them are regular professional Elephant catchers, called "panikis," who follow the trail of an Elephant as a good Hound tracks a Stag; traces imperceptible to other eycs are to them distinctly legible pasces of a book to be unerringly construed. Their only appliance is a strong, elastic noose of Deer or Buffalo hide, which the hunter, if he be alone, casts around the Elephant's foot. Sometimes a couple wil] follow the animal with noiseless tread and ensnare it at an opportune moment, or even wind the noose thenselives around two of its legs as the Elephant 


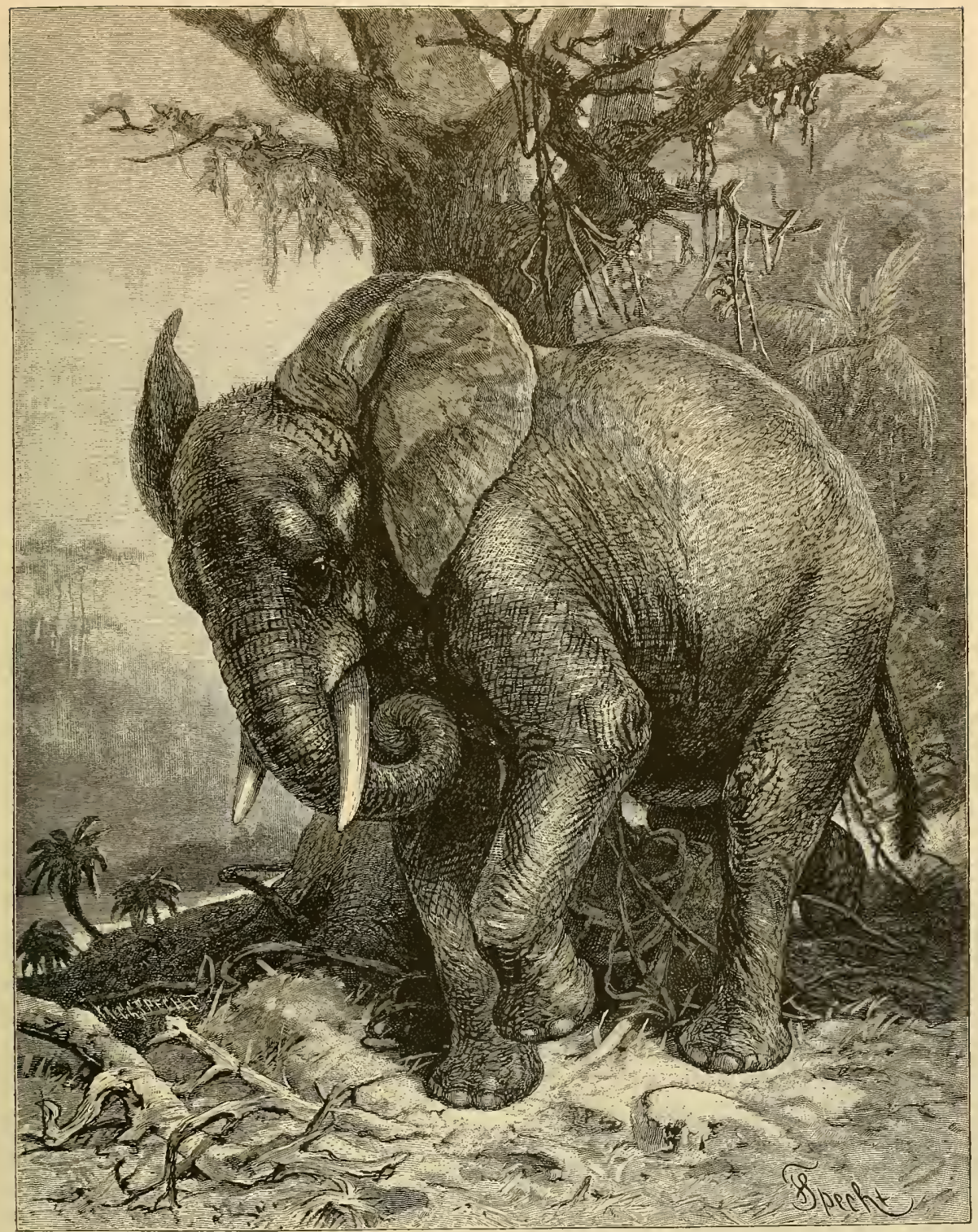

THE AFRICAN ELEPHANT. - This species of the Elephant family differs from the other or Indian species by its larger ears, nore The eager pursuit of the ivory hunters is constantly thinning the herds. This picture brings out the characteristics of this great anima! with wonderful fidelity. (Elcphas africanus.) 
stands quietly. How they manage to get up, unperceived, to the wary animal is a mystery. A European cannot follow them on such a trip, as his presence would spoil everything; so he must content himself with the accounts the hunters themselves give of their exploits. That mode of capture which delivers entire herds into the power of Man, is an undertaking of much grander proportions and more profitable results. For this purpose the beginning of the dry season is usually sclected. Then the head huntsman repairs to the Jocality where a numerous herd of wild Elephants has been ascertained to exist, accompanied by a few hundred trained natives, and as many tame Elephants as possible. The wild herd is first noiselessly surrounded by a double line of sentinels, the circumference of the circle extending over a distance of from three to six miles, and the sentinels are posted from sixty to one hundred paces apart, according to the nature of the locality. As a rule, a herd surrounded in this manner can effect its escape only through gross carelessness of the guards. Within a few hours the huntsmen have silently fenced in the whole area with split bamboo. and have created for themselves shelters made of branches and heavy foliage. In this manner a large portion of the forest is completely enclosed, due care being taken to provide an abundance of food and water from natural sources. The Elephants are thus nominally confined, but are usually restless only for the first few nights, when any attempt to break through the barricr is easily defeated by means of torches, rifle shots and shouting. This enclosure is maintained for from four to ten day's, or, until the time that a strong pale, or pen, the "Khedda," begun simultancously with the larger outside circle, is completed at some favorable spot within the first enclosure. The solid pale is constructed of trunks and posts, and is about twelve fect high; it encloses a circular space of from twenty to fifty yards in diameter, leaving free an entrance about four yards wide, which can be closed by a heavy portcullis or trapdoor of logs, two lines of palisades, forming two sides of a triangle of which this gate is the apex, leading from it like wings to the distance of about one hundred yards. As soon as these arrangements are completed, the circle around the herd is contracted.

The nearest sentries are posted at the ends of two wing-palisades, while the more distant ones advance against the Elephants, slowly and prudently at first, then increasing in spced; finally, when the animals have reached the wide funnel-shaped opening of the Khedda, a general assault takes place, accompanied by shouts and discharge of firearms, the animals effecting their retreat between the two converging lines of palisades and entering the inner paling by the narrow gate. The portcullis drops down, as the rope which holds it is cut in two, and the herd is taken. This driving-in process is not always unattended with risk and danger, for the huge animals often take alarm, and in their wild rush at the huntsmen, break through the lines and escape. They must then either be encircled once more or else be given up entirely. As a rule, however, the hunters succeed in driving the surrounded herd into the pen and keeping them there in spite of their restlessness and occasional attempts to break through the paling. When the first tumult loas subsided, tame Ele-

phants, together with their trainers and the huntsmen, are sent into the Khedda. Here the operation of individually securing the wild Elephants, one by one, is slowly pursued. As each animal is sufficiently subjugated, it is chained and led into the adjacent forest to be firmly secured to a tree, and held for further disposition. This ends the work of the huntsmen, and that of the trainer begins. The wild Elephants at first exhibit a more or less refractory temper, but as soon as they have become used to Man and to their tame associates they are taken to the government training parks or to the place of residence of their captors, where their training is completed.

African Elephants Bear Captiv. ity Well.

tile in devices for meeting its wants under circumstances which correspond little to its natural environments; for instance, where it lacks sufficient space for frec exercise or a large enough bath tub, it compensates for the want of the former by walking up and down or by lifting and setting down its feet, and for the absence of the latter by squirting water over its body with its trunk. Its excellently developed organs of the perceptive senses, its docility and its gentle temper are patent to every observer. It learns to play and "works" willingly and with pleasure, and therefore constitutes one of the most prominent features of every menagerie, as it also becomes the favorite pet of the visitors to a zoological garden. The amount of food it consumes is very large. Haacke says that an Asiatic Elcphant in the Frankfort Zoological Garden, about forty-three years old, received daily sixteen pounds of wheat bran, sixteen pounds of rye bread, four pounds of rice and fifty pounds of hay, not counting the straw of his bedding which he occasionally ate and the tidbits of the visitors, which usually assumed the shape of wheat and rye bread, sugar, fruit and similar things. The same animal drank about sixteen pails of water daily:

Flesh of African The flesh of the African elephant Elephants as an has the taste of beef, but is much Article of Food. tougher and of coarser grain. The Negroes cut the muscles into long strips, dry them in the sun or over the fire and grind them to a coarse powder before using, which they mix with their other plain dishes. During the hunts of the Niam-Niam a sufficient number of Elephants are sometimes killed to supply several villages with meat for months. "Often did I see people," says Schwcinfurth, "walking towards their huts, carrying what I believed to be large bundles of fire-wood, these being their portion of Elephant flesh, which, cut in long strips and dried over the fire, had assumed an appearance closcly resembling that of wood and dry branches."

Economic Value For the world's commerce the only of the Elephant part of importance in the make-up Product. of the Elephant is the ivory, but that is of very considerable value. The total movement of the ivory of now existing species of Elephants which was handled in commerce during a period of five years recently noted, gave an annual average of about $1,736,000$ pounds. Ceylon and Sumatra furnished 4,000 pounds, the Indies 36,000 pounds, and Africa $1,696,000$ pounds. 


\title{
The 0 dod= Toed intumals.
}

\author{
TENTH ORDER: PERISSODACTYla.
}

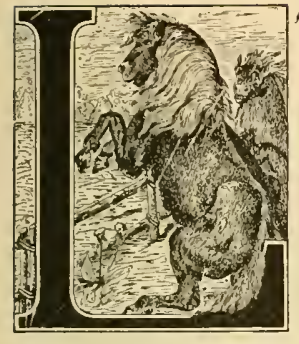

XE that of the Elephants. the order of the Odd-Toed Animals contains only the few survivors of a tribe of a formerly extensive development: they are large animals, moving on hoofed toes, the toe equivalent to the third in five-toed animals being of greater development than all the others. With the Horses it is the only one that is developed at all. The dentition of the Perissodactyla is distinguished by the small size or absence of canines and the tubercles of the molars connected by ridges. Both jaws contain incisors.

There are about twenty-five species of Odd-Toed Animals, and they are indigenous to well-nigh the entire globe, with the exception of Australia; they may be divided into four sharply-defined families: the one-toed llorses, the Tapirs with four toes in front and three behind, the three-toed Rhinoceroses and the Hyracide or Coney family, possessing four toes on their fore-feet and three on the hinder pair. A general description of the order can not be given, as the four families have very little in common with each other, even in their modes of life.

\section{The thorses.}

\section{FIRST FAMILY: EQUIDE.}

All the now existing Horses form so clearly distinguishable a group and are so similar to each other in anatomical development and general peculiarities that one can not help uniting them all in one species.

\section{THE HORSES PROPER.}

The Horses proper (Equus) are of moderate size, have a beautiful form, relatively vigorous limbs and a lean, elongated head with large, lustrous eyes, moderately large, pointed, mobile ears and wideopen nostrils. The neck is strong, the body is rounded and fleshy, the hair soft and short, not erect, but lying close to the body, growing into fong waving strands in the mane and tail. The one daintily hoofed toe on each foot suffices to distinguish the Horses from all other odd-toed animals. Each side of the jaws above and below contains three incisors, six long, quadrilateral molars exhibiting intricate and tortuous convolutions of enamel on the grinding surface and one small, hooked canine tooth of a blunt, conical shape, which may in individual cases be absent. Among the digestive organs the narrow gullet, the communication of which with the stomach is closed by a valve, is deserving of notice. The stomach itself is a simple, undivided, oblong and proportionately rather small sac.

$\begin{array}{cl}\text { Native } & \text { We must regard the greater part of } \\ \text { Country of } & \text { the northern hemisphere as the orig- } \\ \text { the Horse. } & \text { inal native country of the Horses, }\end{array}$ the fossil remains of which are first met with in the strata of the tertiary period. In Europe the wild Horses seem to have become extinct not very long ago; in Asia and Africa they still roam in herds over high table-lands and mountains. In America, where they were extinct, descendants of imported stock have reverted to the wild state; Australia, also, has become inhabited by Horses that have returned to savagery. Herbage and other vegetable substances form their food; in confinement they have learned to consume even animal food, such as flesh, fish and Locusts.

Goneral Attri- $A l l$ Horses are lively, active, intellibutes of the gent animals; their gait is graceful Horse. and stately. The usual pace of the untamed varieties is a tolerably brisk trot, their faster gait being a relatively light gallop. They are peaceful and good-natured to other animals which do not harm them, but anxiously shun Man and the larger beasts of prey; when hard pressed, they courageously defend themselves, however, by striking with their feet and biting. Their rate of propagation is small, the mare giving birth to only a single infant, called a "colt," in any one year.

The Domestic At least two and probably three vaHorse an Animal rieties have been subjugated by Man.

of Antiquity. History does not record, nor does tradition tell us of the time when they were first won to our service; no one can with certainty affirm upon which continent the Horses were first tamed. The tribes of central Asia have been generally believed to be the ones to whom we are indebted for the first subjugation of the Horse; the half-savage former inhabitants of central Europe also reduced the Horse to a state of domestication. But we lack any definite knowledge about the times in which the subjugation was accomplished and in regard to the nations to whom we should turn in gratitude for it.

Various Breeds of Even at the present time the steppes

Wild Horses of southeastern Europe contain herds

known. of Horses which roan over them and are regarded by some as the progenitors of our domestic animal and by others as springing from the latter and having reverted to the savage state. These Horses, called Tarpans, have all the characteristics of unregenerated wild animals, and are considered such by the Tartars and Cossacks. The Tarpan is a small Horse, with thin but strong, enduring legs, a rather long, thin neck, a relatively thick, blunt-muzzled head, pointed ears inclined in a forward direc- 
tion, and small, lustrous, fiery, wicked eyes; in summer its hair is thick, short and wavy, especially on the hinder quarters, where it becomes almost curly; in winter it is thick, coarse and long, especially on the chin, where it nearly reaches the proportions of a beard; the mane is short, thick, bushy and curly; the tail is of moderate length. The prevailing color in summer is a uniform pale brown, yellowish brown or sorrel tint; in winter the hair becomes lighter, sometimes even white, and the mane and tail look uniformly dark. Piebald specimens are never seen, and black ones very rarely.

Habits of the The Tarpan is always found in herds, Wild Horse of which may number several hundred.

Tartary. Usually the herd is subdivided into smaller, family-like groups, each led by a stallion. These herds inhabit wide, open and high table-lands or plains and wander from one spot to another, usu- their fore-hoofs. The story which represents them as forming a circle and kicking with their hind legs has been disproven long ago.

The Tarpan Diffi. The Tarpan is difficult to tame; it cult to Domes- seems that the animal cannot endure ticate. captivity. His lively temper, his strength and savage disposition, defy even the Mongols, well acquainted as they are with the breaking of Horses. The Tarpan is hunted to its death with zeal and passion on account of the considerable damage it causes among herds of domesticated Horses by enticing them away whenever they are left to run at liberty.

These accounts leave the question as to the origin of the Horse unsolved; opinions oppose each other. The characteristics of the Tarpan offer no decisive evidence as to its original character, for Horses revert to the wild state easily and rapidly. The herds

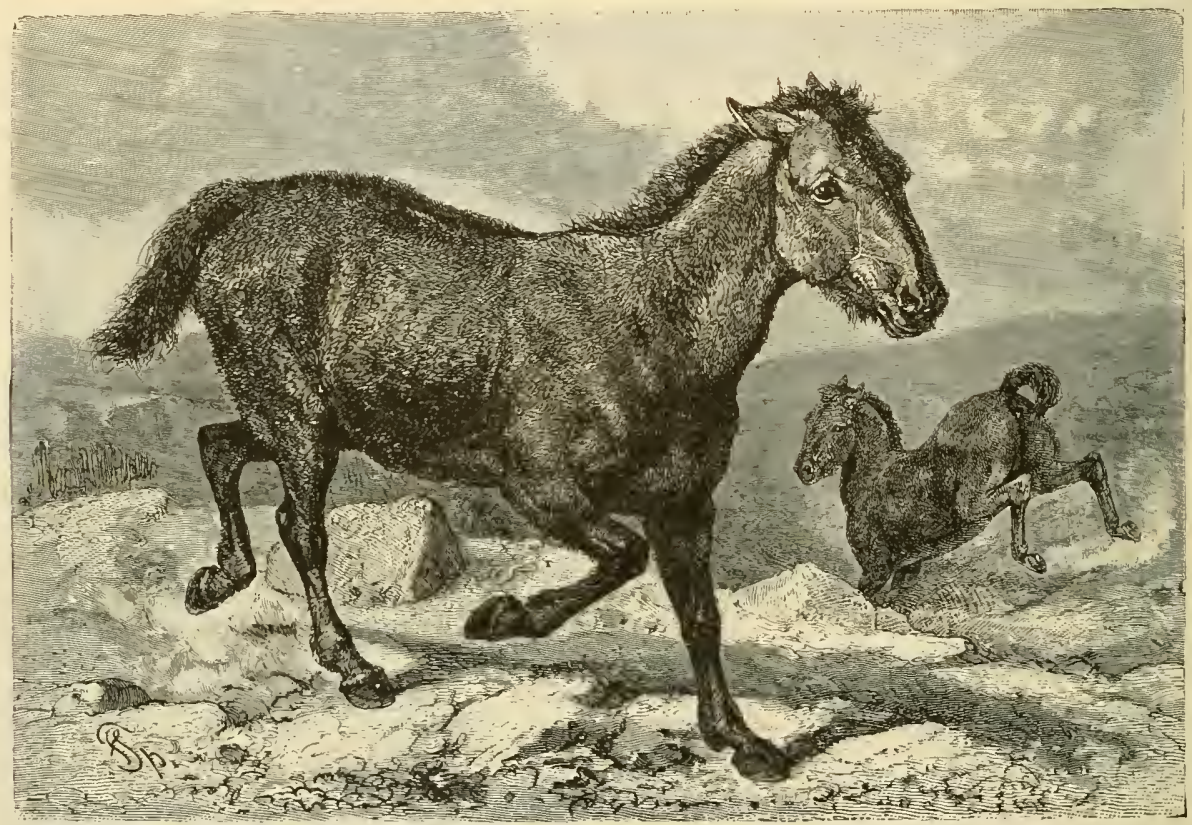

THE TARPAN, - In the steppes north of the Sea of Azof, are large herds of these wild Horses which are made up of numerous families led by a stallion. These Horses are small, of dun color, have short manes, rather short tails, and are very fieet and timid. (Equus tarpan.)

ally pursuing their course against the wind. They are exceedingly wary and shy, look around with high, uplifted heads, snort, whinny, prick their ears, expand their nostrils, and as a rule perceive any menacing danger in good time. The stallion is the sole ruler of the society. He cares for their security but tolerates no irregularity among his subjects. As soon as something arouses his attention, this patriarch begins to snort and quickly erects his ears; with head held high he trots in one particular direction, neighing violently if he perceives any danger and the whole herd scampers off at a frenzied gallop. Sometimes the animals disappear from sight as if by magic. This occurs when they conceal themselves in some deep depression to await further developments. Beasts of prey do not intimidate the courageous and pugnacious stallions. Against Wolves they sally forth, neighing, and beat them down with inhabiting the pampas of South America are an effective example of this. Let us cast a glance at them.

Origin of the "The town of Buenos Ayres," says Wild Horse of the Azara, "founded in 1535, was subsePampas. quently abandoned. The emigrating inlabitants did not even go to the trouble of collecting all their Horses and about five to seven of them were left behind, free to follow their own devices. When the same city was again taken possession of and populated in 1580 , a number of wild Horses were found, the progeny of those which had been left behind. As early as 1596 everybody was allowed to capture those Horses and use them. This is the original stock from which sprung the innumerable herds of Horses which now rove south of the Rio de la Plata." The Cimarrones, as these Horses are called, notv live in all parts of the pampas in enormous 
herds, some of which arc occasionally composed of thousands of individuals. They are a nuisance because they not only consume good pasturage, but also lead away domestic Horses. Fortunately they do not come by night. The natives of the pampas eat the flesh of the Cimarrones, especially that of colts and mares. They also capture some with a view to taming them; the Spaniards, on the other hand, make 110 attempt to use them. Very rarely does a European capture a wild specimen and tame it.

In Paraguay no wild Horses are found, but the condition of the domestic Horses of this country does not differ materially from that of the wild ones. The animals called Mustangs are so neglected that they really degenerate. They are of medium height, have with their mothers until they are three or four years old, and as long as they are not weaned the mothers are greatly attached to them and sometimes defend them even against the Jaguar. When the animals are a little over two or three years old, one of the young male colts is selected and given some fillies, with which he has been accustomed to graze in one particular spot. The Horses belonging to one herd never associate with those belonging to others, and they keep so faithfully together that it is difficult to separate a grazing Horse from the main body of his clan or group. If two or more herds are put together, as for instance when collecting all the Horses belonging to one farn, they inmediately seek their customary companions and

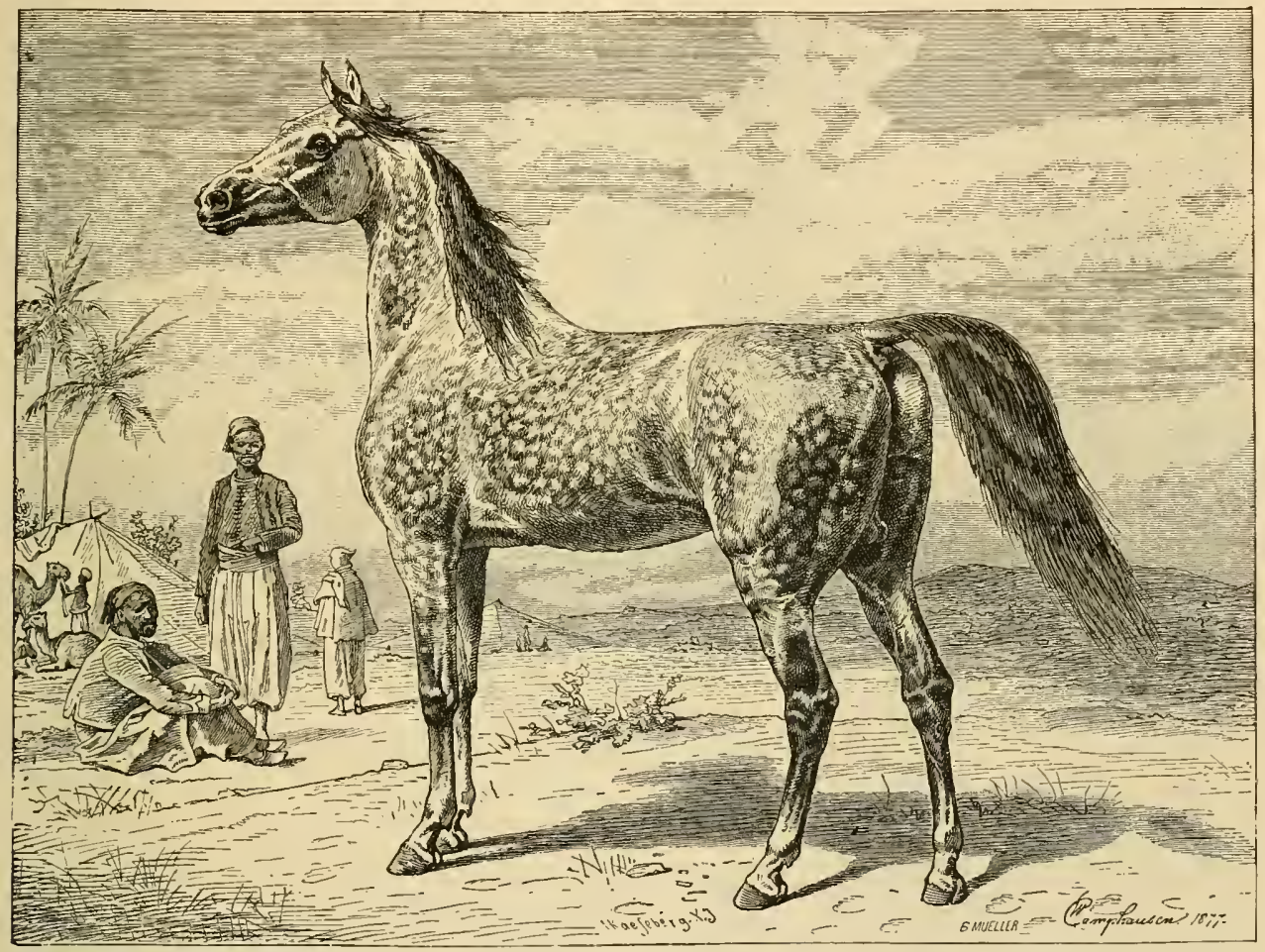

THE ARABIAN STEED.-The Horse has been the most prized of animals with the Arabs from an early period. The Arabian Horse, though not very tall in stature, is of beautiful form. It is fleet, docile and of great endurance and is treated with great consideration by the Arabs.

a large head, long ears and large heavy joints; only the neck and body are of tolerably regular build. The hair is short in summer, long in winter, and the mane and tail are always thin and short.

The Domestic The Horses of South America live Horse in South out of doors all the year round. America. Every week they are collected, to prevent their going altogether astray; their wounds are looked after and cleansed, and the manes and tails of stallions are cut about every three years. Nobody thinks of improving the breed. "Usually," says Rengger, "the Horses live in small herds or groups in some locality, to which they have been accustomed from birth. Each stallion is given from twelve to eighteen mares, which he keeps together and defends against strange Horses. The colts live divide themselves into their original groups. The animals not only show great attachment to each other, however, but also to their pasturage. I have seen some that returned to their old haunts from a distance of eighty hours' travel. Yet more strange is the fact, that sometines the Horses of a whole region set out upon a migration, either singly or in troops. This happens most frequently when a violent rain falls after a season of dry weather, and they are probably actuated by the fear of hail, which often accompanies the first thunderstorm."

Senses of Wild The senses of these nearly wild
Horses Highly animals seem to be more acute than
Developed. hearing is extremely delicate. At night the movements of their ears show that they hear the slight- 
est noise, even when it is unperceived by their riders. Their sight is rather deficient, like that of all Horses; but their free life gives them wide experience in distinguishing objects at a great distance. Their sense of smell helps them to a closer and more thorough knowledge of their surroundings, for they carefully sniff everything that is strange to them. Through this organ of scent they learn to know their riders, their harness, the barn in which they are saddled, etc.; by it they recognize bottomless quagmires in marshy regions, and readily find their way in the darkness of night, or in a dense fog, to their domicile or their pasturage. Good Horses sniff at their riders at the moment of mounting, and 1 have seen some that would not let a person mount at all, or resisted his guidance, if he did not carry a poncho or cloak, such as the natives wear who break in the Horses. Their power of smell does not extend to a great distance, however. I rarely saw a Horse which could scent a Jaguar at the distance of

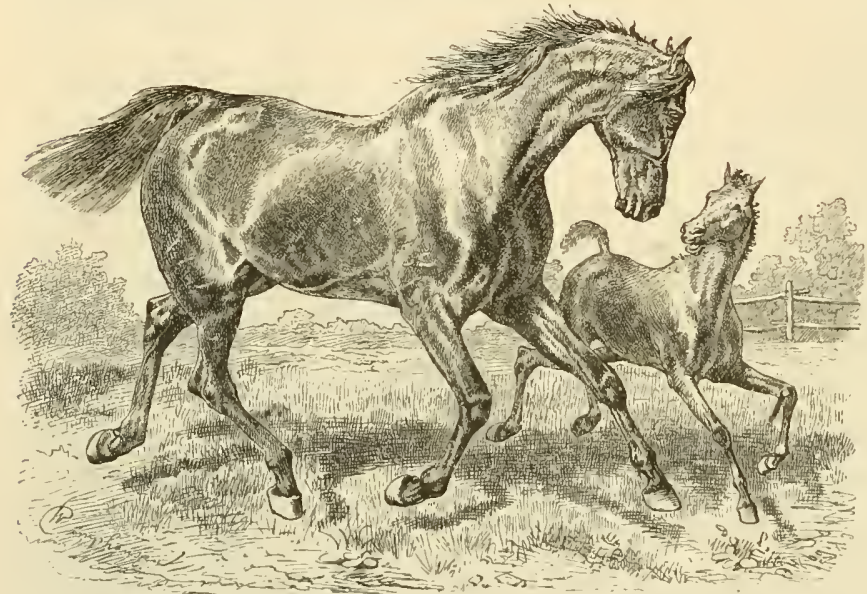

THE TRAKEHNEN HORSE. - I famous (ierman breed of fine Horses, receiving this name from the noted stables in which its excellent faculties and fine running qualities were developed. Next

fifty paces. Therefore they are the most frequent victims of this beast of prey in the populated districts of Paraguay.

Wild Horses A. von Humboldt has given us in a Described by Von few words a masterly description of Humboldt. the manncr of life of the wild Horses in the llanos lying more to the north: "When the grass of those immense plains becomes charred and resolves into dust in summer, under the perpendicular rays of the never-clouded sun, the soil gradually cracks, as if it were torn by powerful earthquakes. Enveloped in dense clouds of dust and pressed by hunger and a burning thirst, the Horses and Cattle roam about, the former with their heads lifted high up, against the wind, snorting and inflating their nostrils, trying to discover by the dampness of the air-current the location of some pool that has not yet all evaporated. The Mules try to quench their thirst in another way more deliberate and showing a higher order of intelligence. A spherical and spinous-coated plant, the melon cactus, encloses a watery pulp in its prickly exterior. The Mule beats these thorns aside with its fore-feet in order to drink the cool juice. But the drawing of water from this living, vegetable source is not devoid of danger; for one often sees animals which are severely wounded in the hoofs and lamed by these cactus-thorns. When the coolness of night at last succeeds the glaring heat of day, the Horses and Cattle are still deprived of their rest. The Vampires disturb them in their sleep and fasten on their backs to suck their blood."

Many Wild Horses When finally the protracted drought Perish During the is followed by the beneficent rainy Rainy Season. season, the scene clianges. Now the surface of the soil is barely permeated by water and the prairie becomes covered with the most magnificent verdure. Horses and Cattle graze in the full enjoyment of life. The Jaguar hides in the high grass and destroys many a Horse and colt. Soon the rivers swell, and those same aninals which languished with thirst during part of the year, now have to live like amphibious creatures. The mares, together with their colts, retreat to the knolls and elevations of the plains, which emerge above the watery surface like islands. But the dry space becomes more contracted every day. For lack of food the half famished animals swim about for hours and miserably subsist on the leaves of the water-rushes which float and wave on the surface of the brown, muddy, seething water. Many of the colts are drowned, while others are caught by Crocodiles, crushed by blows from the tails of these Saurians, and then devoured. Not infrequently one sees 11 orses which bear marked traces of encounters with Crocodiles. Among the fish they also have a dangerous encmy. The sloughs or pools left by the receding waters are filled with innumerable Electric Eels. These remarkable fish can kill the largest animals by mcans of their powerful discharges if their efforts are concentrated upon certain portions of the body. The road near the Uri Tucu had to be abandoned, because these Eels increased and congregated to such an extent in a little river crossing the route that every year many Horses were drowned while stumned from shocks administered to them as they attempted to ford the stream.

Panic-Stricken Another element, yet more dangerous Herds Destroy to the lerds, is found in the frantic

Themselves. terror which sometimes takes possession of them. When struck by a panic, hundreds and thousands of them rush on in a frenzy of fright; stopped by no obstacle, running against rocks and dashing themselves to pieces by falling over precipices. They suddenly appear in the camps of travelers spending the night in the open country; rush on between the fires, over tents and vehicles, inspire with their own fears the beasts of burden, which tear themselves loose and are borne along in the irresistible current to certain destruction or irretrievable loss. Farther north the lndians swell the number of foes which embitter the life of the wild creatures. They catch them to use in hunting, and in breaking them torment them so badly that the boldest and most refractory llorse must succumb in a short time. As with the Bedouins of the Sallara, the Horse is often the cause of the bloodiest com. 
bats among the Indians. He who owns no Horses tries to steal a few. Horse-stealing is considered an honorable occupation by the Red-skins. Gangs of thieves follow wandering tribes or caravans for weeks, until they find an opportunity of stealing all the saddle Horses. The Horses of America are also zealously pursued on account of the value of their skins and flesh.

$\begin{array}{cl}\text { Half-Wild Horses } & \text { The Horses in the United States and Can- } \\ \text { in North } & \text { varieties, there being no species of Horse } \\ \text { America. } & \text { indigenous to this continent. In Texas, }\end{array}$
Mexious Spanish breeds, as well as the I ustang proper, are kept in large numbers: and being allowed to range at large over sparsely populated regions, have reverted to practically a wild state. 1t is true that these Horses are the property of various owners, but many of the Horses in the larger herds are only seen by their masters at the time of the annual or semiannual "round-up," when the Horse owners combine their forces to drive to a "corral" or enclosure, all the Horses within their range, in order that the colts may be branded. It is necessary, in order to settle the question of ownership, that the colt be brought to the branding pen while it is still following its mother, otherwise it is regarded as a "gread" or orphan, and any Horse owner may brand it.

The breaking of these Horses to harness is usually a very difficult feat. Most of them are given to what is popularly known as "bucking." The Horsc pulls vigorously at the bridle, plants its four feet nearly together, and with its back arched keeps up a vigorous and jerky jumping up and down which only experts can overcome. Even the most accomplished riders will often be thrown by these wild creatures. There are great differences in the animals, however, and not infrequently a Horse of this kind will prove as easy to break to saddle or harness as the most docile of ordinary colts.

The description, or even a mere catalogue, of the various, almost innumerable, breeds of the Horse (Equas cuballus) is not within the scope of this book; besides many excellent, comprehensive works have been devoted to the Horse.

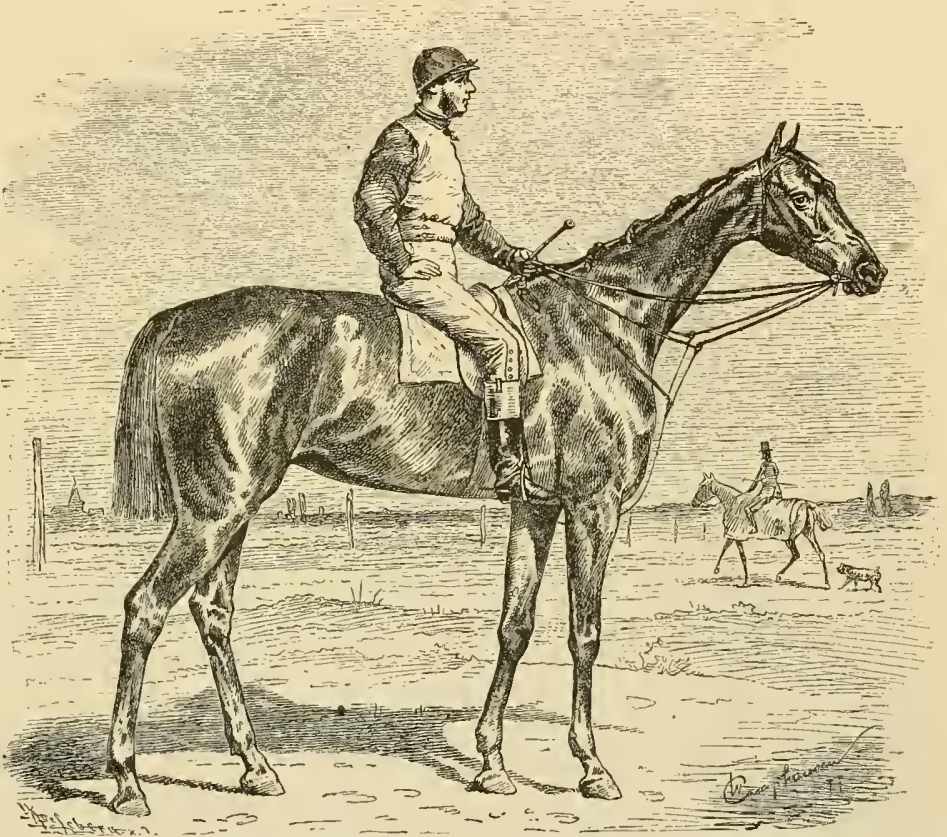

ENGLISH THOROUGHBRED HORSE. - Largely but not solely descended from the Arab steed, the English Thoroughbred represents the results of two centuries of cultivation of the qualities of endurance and speed. The American racing stock is practically of this breed, descended from Horses imported from England within the past century.

It will suffice if we mention the most important breeds, which lave become distinguished for their high development under careful training.

The Arabian Horse The Arab steed ranks first among the Type of the Horses. "The thoroughbred Excellence. Horse," says Count IVrangel, "has no nobler representative than the Arabian Horse of pure descent, which stands on the boundary line between the natural breeds and those of civilization, ańd is praised as the noblest animal of creation by the naturalist, the expert and the poet." According to the standard of requirements set for the Horse by the code of the Arabs, a pure-bred Horse nust combine a symmetrical frame, short and nervously mobile ears, heavy but at the same time symmetrical bones, a fleshless face, nostrils "as wide as the mouth of a Lion," beautiful, dark, prominent eyes, "with an expression like that of a loving woman," a long, arched neck, a broad chest and broad crupper, a narrow back, rownd thighs, very long true ribs and with muscles "like those of the Camel"; a black, unspotted hoof, a fine, scanty mane and an abundant tail, thich at the root and thin at the extremity. Four parts must be broad: the forehead, the chest, the hips and the limbs; four must be long: the neck, the upper part of the limbs, the abdomen and the flanks; and four short: the crupper, the ears, the frog of the foot and the tail. These physical characteristics prove that the Horse conzes of good stock and is swift; for its sliape then resembles "the Greyhound, the Pigeon and the Camel." very short false ones, a compact cylindrical body, long thighs and hams, the latter, with the hocks, forming a slight angle "like those of the Ostrich," 
The Arabs distinguish many strains of blood among their Horses and every locality, every tribe, boasts of its special breed. At present there are twenty-one tribes or families distinguished in Arabia, the five best of which are ranged under the title of "Khamsa," and are said to be descended from the five mares of Solomon. [The Arab always reckons the breeding of the colt by that of the female ancestors.] The oldest and noblest of these families is the "Kehilan" or "Kohlani." Bestowed on their on blue-blooded Horses are very Horses by Arabs. amusing. "Do not tell me that this animal is my Horse; say" that it is my son. It runs than the glance that sweeps the plain. It is pure as gold. Its eye is clear and so keen that it sees a
Bombastic Praise The eulogies bestowed by the Arabs more quickly than the wind of a storm, more swiftly

The English Thor- The noblest relative of the Arab in oughtred Europe is the English thoroughbred Racer. racer. Many experts are of the opinion that the difference between these two breeds lies only in the diversifications caused by altered environment of climate and system of breeding, and that consequently the English racer has pure oriental blood in his reins. The genealogy of the racer, however, furnishes an irrefragable proof that there is no one thoroughbred, the pedigree of which can be traced to exclusively oriental ancestors, either on the father's or mother's side. At the present day the English thoroughbred is nothing but a product of the racer, its selection, breeding, feeding and training, being all rendered subservient to the production of the two indispensable attributes of speed and endurance. The race Horses of today surpass their ancestors in every respect, in shape as well as in capability of performance, and comprise among their ranks many excellent Horses, attaining a height of seventy inches or more. Their shape has become nobler and more symmetrical in its proportions. The Fnglish racer is exported to all countries of the globe, inhabited by Europeans, to improve the breed. A third rcpresentative of the noble breeds is the AngloArab, produced by the imnediate interbreeding of the English and Arab Horses, effected in recent times only.

The thoroughbreds are followed by the much more numerous half-bloods. Many crossings with oriental Horses and especially with English thoroughbreds have gradually produced the Trakehnen, a well-shaped and very capable animal of great powers of endurance, which one at present might term the German Horse, especially as the Trakehnen

PERCHERON HORSE. An especially fine breed of draft Horses, of great strength and endurance. The picture shows the strong and well developed nuscles and powerful limbs of this animal which has become especially popular in this country during recent years.

hair in the dark. It overtakes the Gazelle in its course. To the Eagle it says: I hurry on like you! When it hears the shouts of girls, it neighs with joy, and the whistling of bullets rejoices its heart. From the hands of women it begs for alms; the enemy it beats in the face with its hoofs. When it can run to its heart's desire, it weeps tears. It recks not whether the sky be clear or the blasts of the desert obscure the light of the sun with dust; for it is a noble stecd and despises the rase of the storm. There is no other in this world that could vie with it. Swift as a Swallow, it courses on; so light is its weight that it could dance on the breast of your beloved and not annoy her. Its pace is so gentle that you could drink a cup of coffee on its back, when its speed is highest, and not spill a drop. It understands all like a son of Adam, and all it lacks is spcech."
Horse farm and kindred institutions have exerted and are still exerting the most important influence on the breeding and improvement of all Prussian Horses, and are factors of the grcatest moment in promoting the efficiency of the German cavalry.

Various Other Other half-bloods are bred in Ger-

Half-Breed many, in Hanover, Oldenburg. Horses. Mecklenburg and Holstein. Yet other members of this group are: in Austria, the Lippizaner and Kladruber, which are closely allied to the Spanish half-blood, the Andalusian Horse; in France the Anglo-Norman and Anglo-Breton Horse; in Russia the Orloff trotters, as well as cerland different breeds of highly improved Horses, known as Hunters, Hacks and Roadsters, as well as the powerful Cleveland Bay Horse, now become comparatively rare; in America certain brceds of tain breeds of Don and Circassian Horses; in Eng- 
fast trotters. As may be expected, the Horses descending from all these mentioned half-bloods vary widely in appearance and capacity of performance. They may be light, medium or heavy, and serve as excellent saddle, carriage or strong working Jorses; some are distinguished by their immense draughtpower.

The American

Trotting Hors

Although allied by ties of close relationship to the English thoroughbred, the American trotting Horse has been developed upon the Best. lrotting Horse has been developed upon
lines so peculiarly its own as to be entitled to classification as a national variety. It has been shown by
several writers that fast trotting is not natural to the Horse several writers that fast trotting is not natural to the Horse
family. If the Horse wishes to go quickly it runs or gallops, and only trots when inclined to leisure.

In an early day in New England there was a prejudice against Horse racing, and Horses were encouraged to trot.
The Shetland Horses of the largest breeds often Pony the Smallest attain a height of seventy-two inches of the Horses. and over at the withers; the antitypes of them are the ponies, which are often but half this size. The smallest Horse, the Shetland Pony, has a full, long, shaggy mane and a bushy tail, and is frequently only thirty-six inches high, and sometimes only thirty-four or even thirty-three inches in height, and having no greater physical proportions that those of a large Dog.

Distribution of Nowadays the tame Horse is distrib-

the Domestic uted nearly all over the globe. It is Horse. absent in only the coldest regions and on several islands, where as yet, by reason of lack of use, it has not been introduced. It is bred in

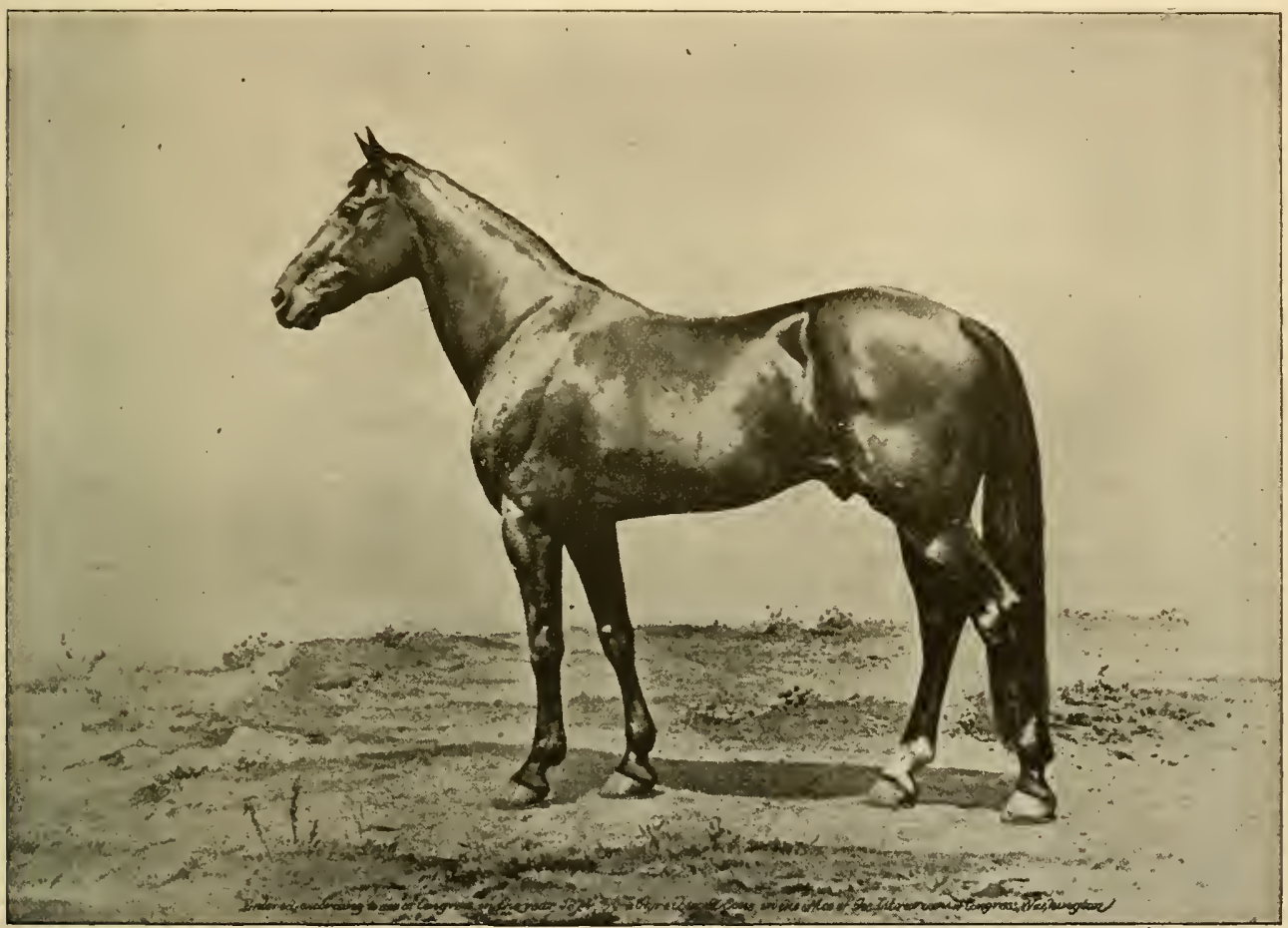

THE AMERICAN TROTTING HORSE. - This is a portrait of "George Wilkes" the famous American trotter. He was foaled in r 856 and died in 1882 and was regarded as a typical representative of the American Trotting Horse, having himselt a record of a nile in two minutes, twenty-two seconds. and being the sire of a numerous progeny of celebrated trotters and pacers.

Later it was a matter of neighborhood pride to own the fastest trotter in the vicinity, and trotting became the favorite gait for Horses. Finally some imported thoroughbreds and their progeny were trained to trot in hamess, and in 1818 a Horse named Boston Blue was matched to trot a mile in three minutes - a feat then deemed impossible, but which he accomplished. This was the beginning of the contests against time, which have since reduced the trotting record second by second down to the last record made by the mare Alix, who trotted a mile in 2:03\% at Galesburg, Ill,, September 19, 1894.

In no other country have trotting races become so popular as in the United States, and with the exception of Russia, no distinctively fast-trotting variety of Horses has been developed outside of those of the United States.

Of the third group, comprising the sluggish, slowpaced draught breeds, we will mention here only the following heavy ones: the English Clydesdale and Dray Horse, the Percheron, the Ardenner, the Pinzgauer, the Jutlander and the Russian Bitjug. wild, half-wild and tame studs. In the wild studs of Russia the herds are left to their own devices all the year round. The Horses born under these conditions are very hardy, vigorous and frugal, but never attain the beauty of those which are born and bred under the supervision of Man. Half-wild studs are those in which the herds of Horses roam over extensive grazing ranges from spring to autumn under supervision; in tame studs the breeding is conducted under the strictest supervision of Man.

$\begin{gathered}\text { Reproduc- } \\ \text { tion of the mare usually gives birth to a } \\ \text { Horse. }\end{gathered}$ is fully covered with hair, and in a few
Holl, which has its eyes open, minutes is able to stand and walk. It is allowed to suckle, play and romp for about five months, after which it is usually weaned. In the first year its coat 
consists of a mixture of wool and hair; its mane is short, erect and curly, and the hair of the tail also partakes of a crinkly, curly character. During the second year the hair becomes more lustrous, mane and tail grow longer and less inclined to kink. After this the age may be determined from the appearance of the incisor teeth with tolerable correctness. From eight to fourteen days after birth the two central teeth, the so-called "nippers," make their appearance; two or three weeks later another breaks through at each side of the nippers. After five or six months the lateral incisors pierce the gum and then the colt has its full complement of milk-teeth. These are in course of time replaced by the permanent teeth. At the age of two and one-half years the "nippers" are shed and replaced by new teeth; a year later the next pair are supplanted, and after another year the outermost incisors are changed. Simultaneously with this last alteration the canines break through, and this indicates that the development of the animal is completed. After the fifth year a person wishing to judge of the age of a Horse, looks at the hollows on the grinding surface of the teeth: blackbrown marks of the size of a small pea. They begin to disappear in the lower jaw at the age of five or six years; in the middle incisors they are obliterated in the seventh year, in the canines in the eighth year; then the upper teeth are developed in like order of succession, until all the marks have vanished by the eleventh or twelfth year. As age advances the teeth also gradually assume a different shape; they become narrower as they grow older. Another plyysical change noticeable in the animal is the variation of its coat with the seasons. With the access of the warm weather, usually beginning in the spring of the year, the shaggy, furry coat of long winter hair covering its body commences to fall out, and is shed so rapidly that the bulk of it disappears within a month or so. Gradually the hair is replaced and it becomes perceptibly longer in the beginning of September or October. The mane and tail remain unchanged through all seasons.

Diseases to Unfortunately the noble Horse is Which the Horse subject to many diseases. The most is Subject. important and serious of these are the spavin, a swelling on the leg (generally induced by a violent sprain) which affects the joint of the knee or of the hock, and usually results in stiffness of the leg; the farcy or "button," a swelling and hardening of the glands beneath the jaw; the mange, a dry or moist eruption, which causes the hair to fall out; the glanders, a violent inflammation of the nasal mucous membrane which also causes a hardening of the glands beneath the jaw, and is extremely infectious, and which may be communicated to human beings; the mad staggers, an acute inflammation of the brain, and the blind staggers, a somewhat similar, though less violently manifested disease, induced by apoplexy (or congestion of blood in the brain); the gray and black cataract and others. Besides all this the animal is subject to the torments of internal and external parasites.

A Horse may attain an age of forty years and over, but frequently is so ill treated that it is old at the age of twenty; as a general rule it may be affirmed that it is only in very rare cases that it lives to be thirty years old.

Scheitlin'sEulogy I leave to Scheitlin the pleasant of the Horse's task of speaking of qualities, habits Endowments. and peculiarities, in short, of the mental characteristics of Horses: "The Horse," says he, "has the power of discrimination in matters pertaining to food, domicile, space, time, light, color, shape, his family, his neighbors, friends, foes, animal companions, people and objects. He has the gift of perception, imagination, memory and manifold sensations induced by a number of conditions of body and mind. Circumstances strike him as agreeable or disagreeable, and he is capable of either being satisfied with given surroundings or else desiring different environment, and even of love and hatred. His great intelligence is easily changed to skill; for the Horse is exceedingly docile. His memory and good-nature render it possible to teach him all the tricks of the Elephant, Ass or Dog. He can solve riddles, answer questions, say "yes" and "no" by moving his head, designate the time on a clock by striking his foot, etc. He correctly interprets movements of his teacher's hands and feet, understands the swinging of a whip and the meaning of words, really having a small dictionary by heart. He feigns death, first stands listless, with widespread legs and hanging head, then staggers, slowly sinks down, falls like a $\log$ and lies upon the ground as if dead; one may sit on him, stretch his legs, pull his tail, poke a finger into his sensitive skin without result; but if a hint be given that the poundmaster is to be sent for, he jumps up and is quite lively and animated again. One can not see that he likes the trick he has to repeat so often; he delights only in running and jumping. How long will he have to be taught until he learns how to jump through two large hoops, covered with paper and placed at a distance from each other? We are not surprised that a human being can and will learn, but we wonder that a Horse can learn. One really must not say: 'What can he learn?' but: 'What can he not learn?'

"He who wishes to teach a Horse anything human must, in the beginning at least, teach hin humanely, that is, not by blows, threats or hunger, but with kind words, exactly as a kind, intelligent Man treats another kind, intelligent Man. As a rule Horses are perfect prototypes of children in their good and bad qualities. Besides his sense of locality, the Horse also has an idea of time. He learus to walk to music, to trot, gallop and dance. He also knows the greater divisions of time, whether it is morning, noon or night. He does not even lack a perception of harmony. Like a warrior, he is fond of the exciting clangor of the trumpet. Joyfully he paws the ground with his fore-feet when the trumpet resounds as a signal for a race or a battle; he also knows and understands the signals given by the drum and all sounds which present an association of ideas to his courage or his fears. He knows the thundering noise of cannon, but when he sees the lacerated carcasses of companions killed in battle, he evinces dread and repugnance.

"The Horse is very susceptible to fear, in this respect resembling a human being. He starts at a sudden sound, an unusual object, a waving flag, a garment hanging in a window. He carefully looks at the ground covered with stones, and treads cautiously when entering a river. He is thoroughly awed by lightning. During a thunderstorm he perspires from fear, perhaps the dread of being struck. When two are harnessed together and one attempts to run away, the other, if he be not also frightened, can hold him back; usually, however, both are simultaneously seized by terror, and run in ever increasing panic, rushing over and through every possible 
thing, sometimes dashing into a wall in their insane career.

"The one real enjoyment of a Horse is running. $\mathrm{He}$ is a traveler by nature. Horses grazing in the Russian steppes run merely for the pleasure of it. They will drag coaches at a gallop, and thus accomplish a day's journey, without misgivings about finding the long way home again. On the pasturage they romp and play all kinds of antics, such as running races and biting each other. There are some which constantly annoy the others. The animal which measures his strength with Man must feel himself near to humanity; must, in fact, believe himself nearly, if not quite, Man's equal.

"The stallion is a terrible animal in every way. His strength is immense, his courage surpasses our understanding, and hence is generally underestimated; his eye is full of fire. The mare is much
THE ASSES.

The second sub-specics of the Horses is formeci by the Asses and Zebras (Asimus). They differ from the Horses proper by having only the extremity of the tail covered with long hair, and by the absence of the rudimentary nail at the top of the fetlocks on the fore-feet.

Physical Charac- The Koulan of the Khirgiz or Dzigteristics of the getai of the Mongols (Equus [Asimus] Koulan. hemiontes) is possessed of certain points of beauty which place it, in the elegance of its appearance, far above the Ass. An exceedingly light body, slender limbs, a wild, fleet appearance and the beautiful color of its hair are its strong points. It is somewhat larger than the small variety of Mules, nearly equaling a small Horse in size. The head is somewhat heavy, the chest large, angular in its lower

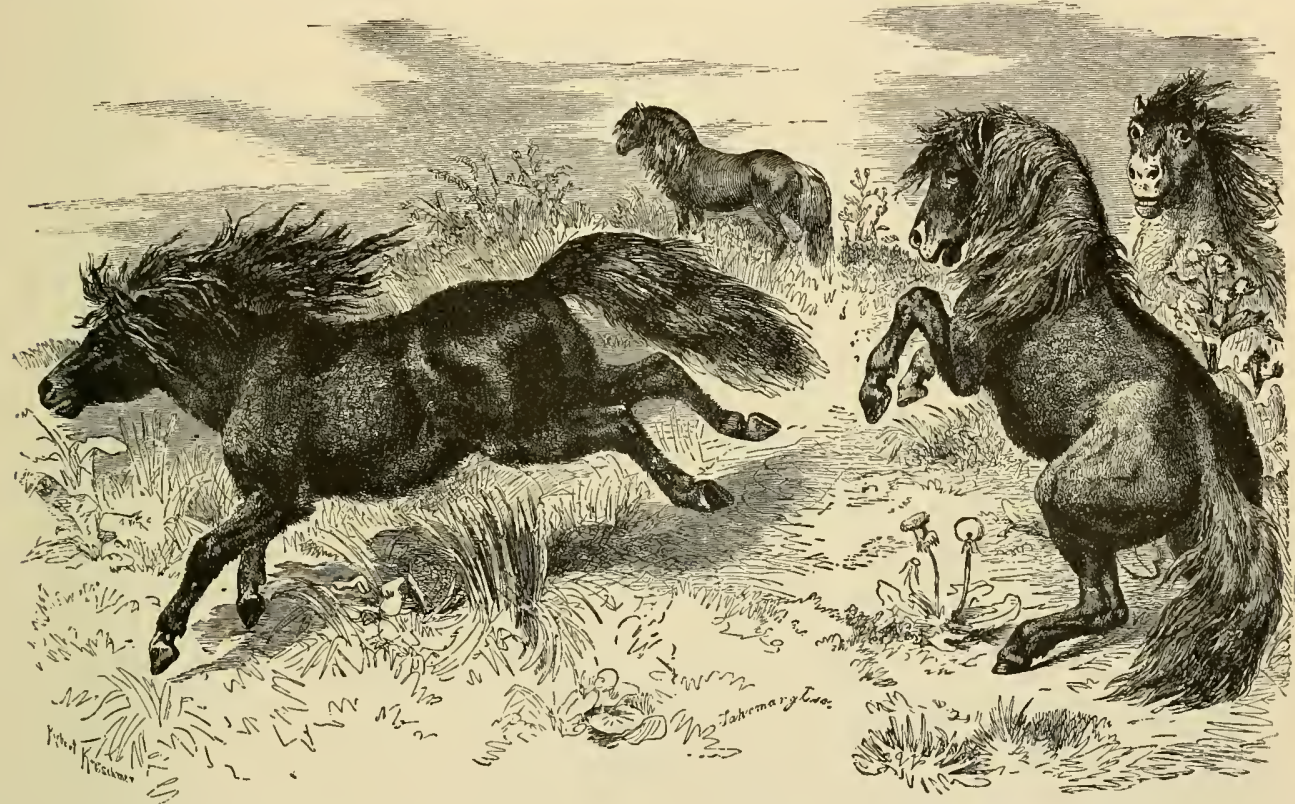

THE SHETIAND PONY,-Although all varieties of the domestic Horse are of one species, training and environment have produced widely diversified types. One of the extremes is the Shetland Pony, which owes jts dwarfed form to centuries of breeding in the uncongenial climate of Shetland. Though the smallest variety it is very strong and has great endurance. The flowing mane and tail contribute much to this animal's beauty.

gentler, more good-natured, obliging, obedient, docile; hence she is generally preferred to the stallion. The Horse is susceptible of almost every mental emotion. He loves and hates, feels the promptings of envy, revenge, caprice, etc. No two Horses are alike. The one is vicious, treacherous and false, the other is docile and gentle. Either nature or training, or both, have made them what they are.

"How different are the various periods in the life of Horses; the fate of most is to be petted, pampered and kept in clover when young, and to be despised and neglected cart Horses fed on the coarsest hay, and plentifully treated to blows when old. Many a favorite steed has been mourned with sorrowful tears and has justly had a marble monument erected in his honor. Horses, like Men, have their infancy for mischief, their youth for beauty, their maturity for work, their old age in which they grow lazy and weak: they bloom, mature and fade!' part and slightly compressed. The ears are longer than those of the Horse, but shorter than those of common Mules. The mane is short and erect, similar to that of the Ass, and the tail and hoofs also resemble those of that animal. The chest and upper parts of the fore-legs are narrow and far from being as muscular as those of the Horse; the hinder quarters are also thin, and the limbs are exceedingly light and fine and moderately long. The prevailing color of the Dziggetai is a right yellowish brown; the nose and inner faces of the limbs are of a pale yellow color; the mane and the tail are blackish, and a dainty brown-black stripe runs along the spine, broadening on the croup and then again becoming quite narrow near the tail. The total length of the animal amounts to about one hundred inches, the head occupying twenty inches of this, and the tail sixteen, exclusive of the tuft; the height at the top of the shoulders varies between fifty-two and sixty inches. 
The Range The Dziggetai or Koulan is a child of the Kou- of the steppes. Though it preferIan. ably affects the environs of lakes and rivers, it does not shun the arid, waterless, desert-like regions; neither does it avoid mountains, provided that the open country continues to prevail, and the region is not overgrown with forests. It is not the rarefied air of the heights in the mountain, the glaring heat of the sun in summer, nor the icy cold of the low plains in winter; not the piercing snowstorms of the heights, nor the hot cloud of sand whirling in the valley below, which bounds the domain of this hardy animal of the steppes. It is solely Man, who determines, or at least dominantly influences, its range of territory and manner of existence. When the wide country has been in the least
Traits and Habits A fondness for the society of its kind of the Kou- or even of other species of animals, lan. is one of the main traits of the character of this wild Horse, as well as of the solidhoofed animals in general. As the Zebra, Quagga and Dauw join the herds of African Antelopes and Ostriches, one also sees the Dziggetai in the mountains in company with various kinds of wild Sheep, the Antelope of Tibet and the Grunting $O \mathrm{x}$ in the lowlands, or grazing together with the Saiga or others of the numerous family of Antelopes. It is also on friendly terms with stray Horses.

A person who has seen Koulans in their native country and at full liberty, will not hesitate to declare them highly-endowed animals. The eye of the observer, fascinated by their movements, regards the

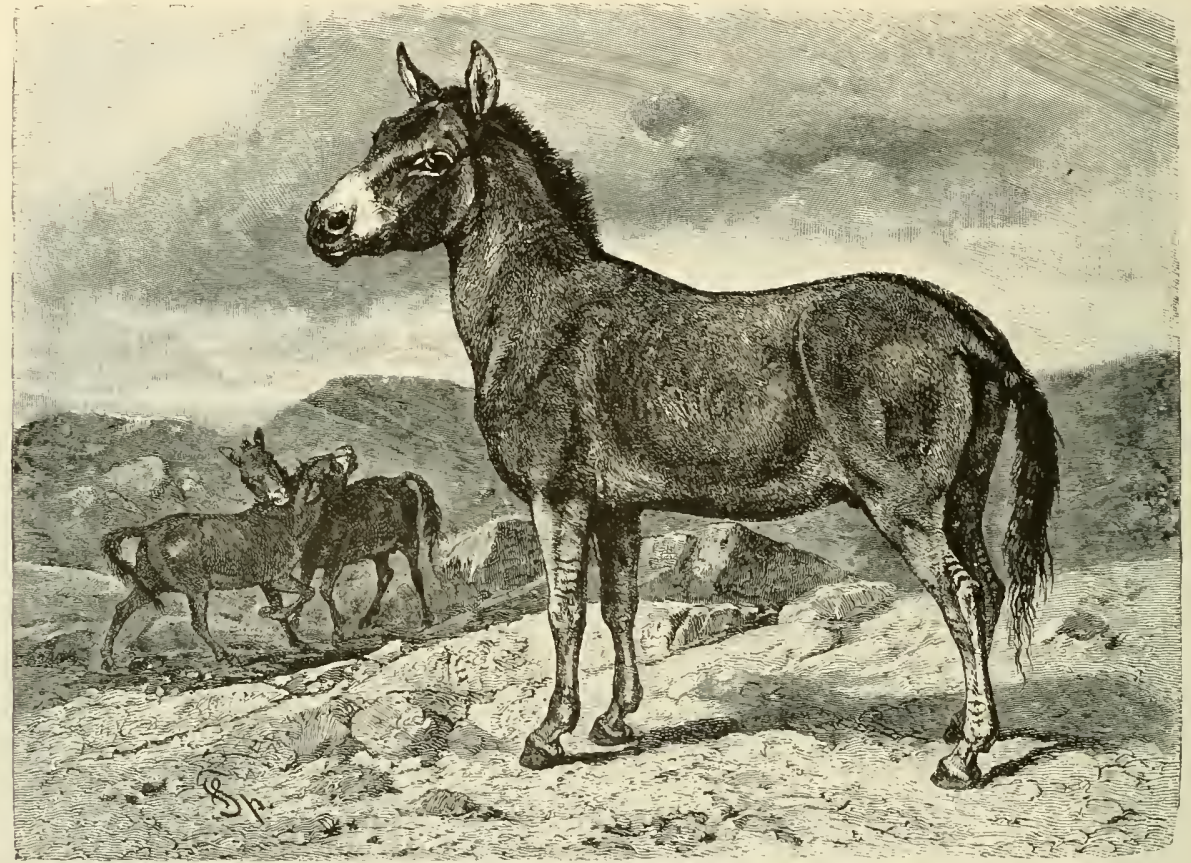

THE KOULAN. - The largest and one of the wildest and swiftest of the wild Asses of Asia is this animal, which is here appropriately depicted in its hign home in the table-lands of Tibet. It has more the aspect of a Horse than an Ass, although the shape of the body and tail are Ass-like. It looks so much like the Mule that it has been given a scientific name meaning " half-Ass." (Equtus hemionus.)

invaded by nomad tribes, or where the wandering shepherd regularly goes back and forth at long intervals with his herds, the Koulan is driven away. Where, in the midst of abundant pasturages, there are strips of country so poor, so desolate and so barren that even that precursor of civilized Man, the shepherd, never enters but sedulously shuns them: there one is sure to find this wild Horse led thither by its unquenchable thirst for unbounded freedom, enjoying itself amid the general desolation.

It still inhabits several districts of Akmolinsk in tolerably large numbers, a strip of steppes between the Altai and the Saisan Lake, and is found in all congenial places to the south and east of that region, in southern Siberia and Turkestan, though in less numbers than in the wide, deserted plains of Mongolia and northwestern China, or on the mountains of Tibet. incomparable agility of the swift creatures with delighted amazement. "It is the most wonderful spectacle," says Gay, "to see with what rapidity they climb the mountains, with what skill they pick their way down without stumbling. Koulans which we pursued, scoured over the hills and dales of the steppes, as if they were amusing themselves with the exercise of their indefatigable strength."

An animal of this kind easily escapes the pursuit of the larger beasts of prey. In the steppes of western Asia there is none which possesses the temerity to attack Koulans; even Wolves in that country do not dare attack healthy wild Horses, as these latter make excellent use of their vigorous hoofs in warding off their enemies. IVeak and diseased Koulans, which stray away from the herd, are probably the only ones attacked by Volves. In the southern and southeastern portion of its range the Tiger may oc- 
casionally secure one of them as a trophy of his might. Man is a more dangerous foe to them. The wandering native shepherds are passionately fond of hunting the Koulan-the more so as the chase calls all of the hunter's ability into play. In zoological gardens the Koulan is as yet a rarity, though it has been repeatedly introduced within the last twenty years, and has frequently bred in captivity, Paris alone having a record of the birth of sixteen young. It also has been successfully crossed with the Ass, the Quagga, the Zebra and recently also with the Horse.

The Onager an Another wild Horse of Asia, perAsiatic Wild haps in reality being but one and Horse. the same animal with the Koulan, is the Onager of the ancients, which is also repeatedly mentioned in the Bible. According to Sclater's comparisons of living wild Horses, it is more than prob- exceedingly smooth and delicate. The mane stands erect and consists of soft, woolly hair about four inches long; the tuft on the tail measures from seven to twelve inches. The mode of life of the Onager resembles that of the Koulan. A stallion is the leader of each herd, the other members of which are nuares and foals of both sexes. In point of activity the Onager is not surpassed by the Dzigsretai.

The perceptive senses of the Onager, especially those of hearing, sight and smell, are so well devel oped that it is impossible to surprise it in the open plain. Its habits being very frugal, it comes to drink, at the most, every other day, and one who thinks to surprise it while drinking, therefore usually lies in wait for it in vain. Plants containing salt are its preferred food, and those it likes next best are the bitter, juicy kinds, such as the dandelion, the flag,

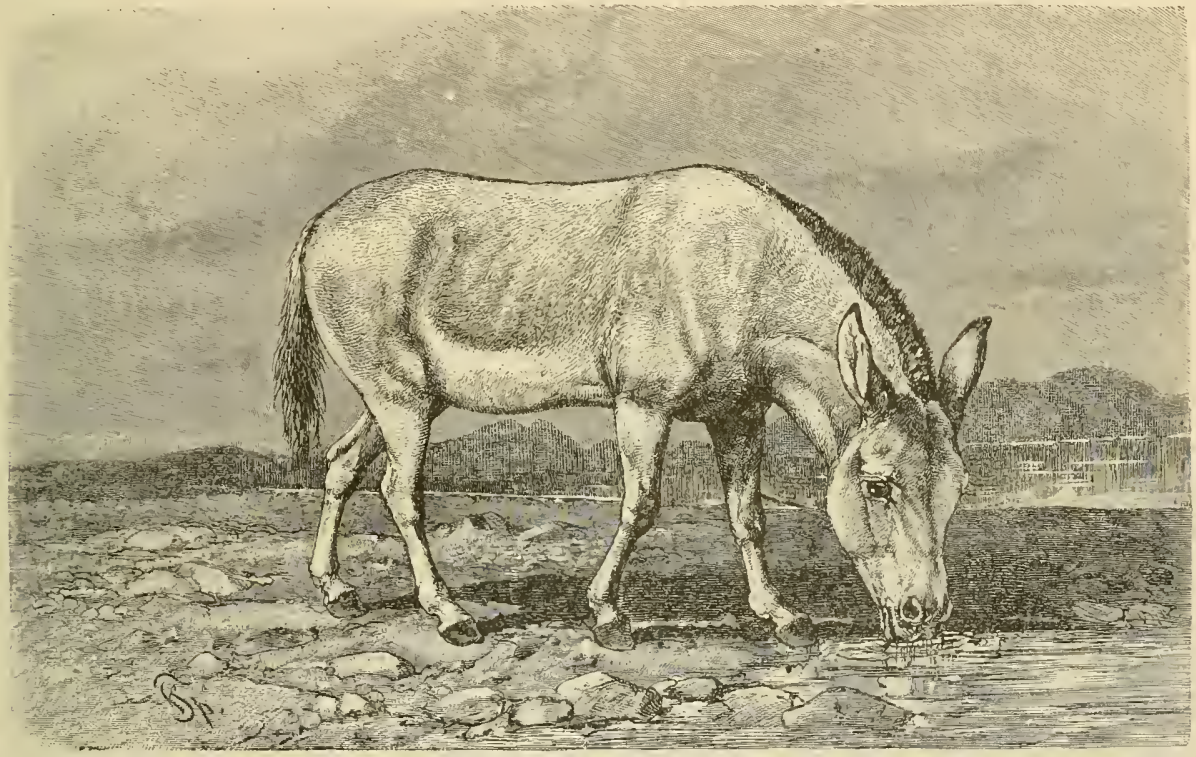

THE ONAGER_- - I wild Ass of central Asia, which is larger than the domestic species. It has a short, stiff mane, has great speed and endurance, and is found throughout an extensive range in central Asia. (Equus onager.)

able that the wild Ass of the deserts of India does not differ from the Onager. Thus it would range from Syria, across Arabia, Persia and Beluchistan to India.

The Onager (Equns [Asinus] onagor) is perceptibly smaller than the Dziggetai, although it is taller and possessed of finer limbs than the common Ass. The head is proportionately longer and larger than the Koulan's; the fleshy lips are thickly covered with stiff, bristly hair to their very margins; the ears are tolerably long, though shorter than those of the Ass. The prevailing color is a beautiful white with a silvery lustre, merging into a pale sorrel tint on the upper part of the head, the sides of the neck and body and the hips. On the side of the withers a white stripe of a hand's breadth runs down; a second stripe runs along the backbone and down the back of the hind legs; in its centre is a smaller brown stripe. The hair is softer and silkier than that of the Horse. The winter hair may be compared with Camel's wool, while the summer hair is and kindred vegetation. It does not disdain varieties of clover and lucerne or any kinds of cereals. On the other hand it dislikes all aromatic, balsamic plants, marsh herbs, buttercups and prickly plants, including the thistle. It is more partial to brackish or salty water than to fresh, but the liquid must be clear; it never drinks muddy or turbid water.

Varieties and Char-The progenitors of our Ass (Equus acteristics of [Asimus] asimus) live in Africa, reprethe Ass. sented by two sub-species. The first of these, the Ass of the Plains (Equinus asimus africamus) resembles its tamed offspring in Egypt in physical proportions and appearance, while its demeanor and habits recall its wild Asiatic kinsman. It is large, slender and of pleasing contour, brownishyellow colored, lighter on the under surface, with a distinct stripe on the back crossed by another at the shoulders, and several more or less well-defined transverse stripes on the outer surface of the lower limbs. The mane is erect and short, the tail-tuft long and stout. 
The Appearance The Somal Ass (Equns asinus somuland Habits of the icus) differs from the Ass of the Somal Ass. Plains in its greater size and longer. pendent mane. It is gray with an indistinct stripe on the back. The shoulder cross is absent; the legs, however, show numerous distinct black transverse bands. It is a native of the Somal country, while the more widely known Ass of the Plains is found in the deserts of Upper Nubia. It is plentiful near the Atbara, the main tributary of the Nile, and also in the plains of Barka. Its range extends to the coast of the Red Sea. There it exists under circumstances

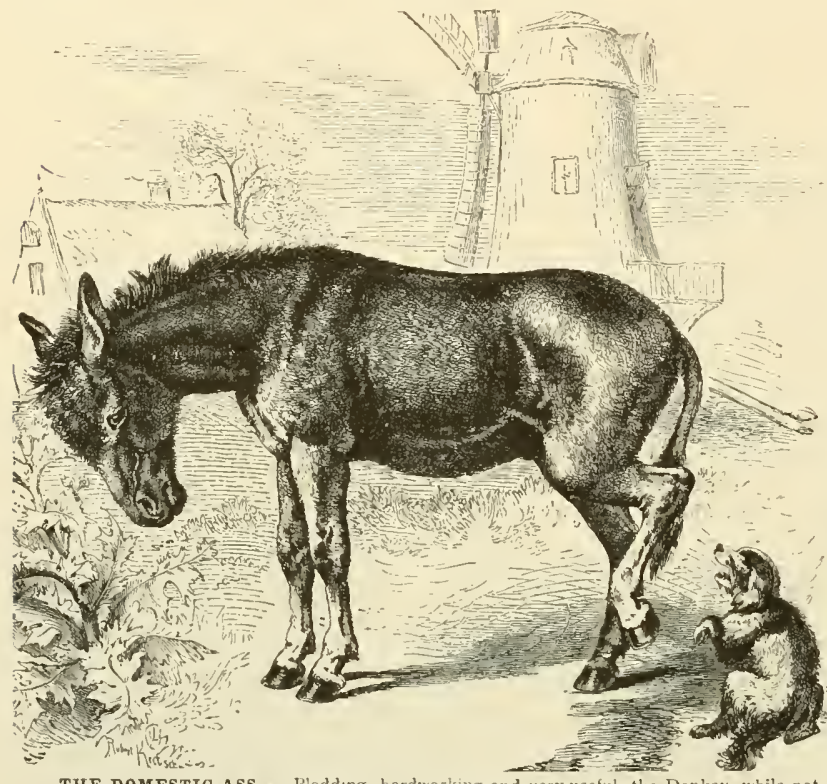

THE DOMESTIC ASS, - Plodding, hardworking and very useful, the Donkey, while not much used in the northern and eastern parts of the L'nited States, is a principal beast of burden in many foreign countries and also in the sonthwestern mountain regions of our own country. The many foreign countries and also in the Southwestern mountain regions of our own country. The
hind foot is the favorite weapon of the Domestic Ass, and the little Dog in the picture is in great hind foot is the favorite weat
danger. (Equus asinus.)

quite similar to those of the Dziggetai and Onager. Every stallion is the leader of a herd of from ten to fifteen mares, over which he watches and which he defends. It is extremely shy and wary, and very difficult of pursuit. All tame Asses employed in the south, and probably also in Abyssinia, appear to descend from this stock, for the Arabs declare that they strikingly resemble the wild Asses. The striped feet of southern Asses, especially those of the Somal Ass, are a noteworthy feature: for they prove that the Ass is a link between its Asiatic relatives and the Zebras.

The Ass of the Plains has been domesticated from the earliest times, and wild specinuens have been continually used to improve the brecd. The ancient Romans expended large sums of money on its improvement, and the Arabs still make great efforts to constantly improve the blood of the domestic variety. It is only in some parts of Europe that the tame Ass has degenerated into a mere cripple through constant neglect.

Asses of Northern If wi compare the German \ss, conEurope Sadly veying the flour to the mill or dragDeteriorated. ging the milk-cart, with his southerm brothers, we are sometimes almost tempted to regard the two as different animals, so slight is the resemblance they bear to each other. The northern Ass is everywhere known to be a lazy, self-willed and often an especially obstinate fellow, though wrongly believed to be the embodiment of dullness and stupidity; the southern Ass, on the other hand, especially the Egyptian Ass, is a handsome, lively, exceedingly diligent animal of great endurance, with a working capacity very little less than that of the Horse, which latter, indeed, in some respects the Ass surpasses. But it is subjected to very much more careful treatment than its northern brother. In many parts of the Orient the best breeds are kept as pure as those of the noblest Horses; they are well fed, not overworked in youth, and an adult Ass can therefore do work the Ass of northern Europe could never accomplish. The nations of the East are perfectly right to bestow much attention on the breeding of Asses, for with them it is a domestic animal in the full meaning of the word. It is found attached to the establishments of the rich and in the huts of the poor, and is the most indispensable domestic of every southerner. In Greece and Spain one may see very beautiful Donkeys, though they are much inferior to the average Ass of the Orient, especially of Persia, Turcomania and Egypt. The Greek and Spanish Asses are of about the size of a small Mule; their hair is sleek and soft, the mane is tolerably long, and the tail-tuft proportionately very long; the ears are long, but fine; the eyes are lustrous. The great power of endurance, the easy, traveling pace and gentle gallop of the Ass render it an animal unsurpassed in good qualities for riding.

The Arabian Ass The Arabian Asses, the Finest especially those bred Variety. in Jemen, are even superior to the other varieties of oriental Asses. There are two breeds; one is large, courageous, swift, well adapted for travel under the saddle; the other is smaller and weaker and is generally used to carry burdens. The large Ass has probably been improved by successive crosses with the Onager. Quite similar breeds are found in Persia and Egypt, where a good Donkey commands a high market price. A saddle Donkey fulfilling all requirements is more expensive than an indifferent Horse and it is by no means seldom that its price amounts to as much as three hundred and fifty dollars. Bogumil Goltz speaking of the Egyptian Donkey says: "One really can not imagine a more serviceable and honest creature than this Donkey. Some large fellow throws himself on a little Donkey, the size of a six weeks old calf, and urges it on at a gallop. These slenderly built creatures proceed at an excellent amble; but their possession of the strength necessary to enable them to drag an adult person around for hours, trotting and galloping even during the great heat of midday, seems to me beyond the possibilities of nature, and might be called a Donkey mystery." The saddle Donkeys have their hair very carefully clipped short over all portions of the body, except on the thighs where the liair is 
?eft long and rarious designs and arabesques are cut in it, giving the animal quite a peculiar aspect.

In former times half-wild Asses were found on some islands of the Grecian archipelago and in Sardinia, and even now they are to be found in South Anerica. Wherever individuals of the species escape from the restraint and training of Man, they soon revert to all the habits of their wild progenitors.

The preceding data have already indicated the extensive range of the Ass. The eastern part of western and central Asia, northern and eastern Africa, south and central Europe and South America are the countries in which it thrives best. The dricr the soil the better its health and development. Damp and cold agree less with it than with the Horse.

Importance of the Riding on Donkeys is probably noDonkey in where so nuch in vogue as in Egypt. Egypt. The willing animals are really indispensable as a complement of the conveniences and comforts of life in all greater cities. They are hired in the same way that our cabs are, and therefore no dignity is forfeited by employing them. Such conditions are brought about by the narrowness of Egyptian streets, that Donkeys alone are fit to render easy and practicable the necessary journeys one takes about town. Therefore they are seen everywhere, as for instance in Cairo, mingling with the continuous stream of people filling the streets. The Donkey drivers of Cairo constitute a distinct profession, a genuine caste, which forms as much an integral part of the city as do the minarets and palms. They are indispensable to the natives and to foreigners; every day a person lives in Cairo he has occasion to be thankful to them, although at the same time they frequently arouse one's ire. "It is a genuine pleasure and a real misery," says Bogumil Goltz, "to deal with these Donkey boys. One is at a loss to decide whether they are good-natured or morose, obstinate or obliging, lazy or active, cunning or impudent; they are a mixture of all possible qualities.

"'Look, sir,' says one, 'see this locomotive of a Donkey, which I offer you, and compare it with those of the other boys! Why, they must fall down under you; for they arc miserable creatures and you are a stout man! But my Donkey! He will run away with you like a Gazelle, in pure play.' "Ehis is a Donkey of Kahirin," says another. 'His grandfather was a Gazelle, and his great-grandmother a wild Horse. Run, you son of Kahirin, prove my words to the gentleman! Be a credit to your parents: go in the Lord's name, my Gazelle, my Swallow!' The third does still better, praising his Donkey as a Bismarck or a Von Moltke of his species, and so on, until the visitor mounts a Donkey, which is then urged into a gallop by a series of ininitable jerks, blows, pushes, and pricks administered with the goad, and the boy runs after, calling, screaming, urging, chattering abusing his own lungs as much as he does the Donkey. Thus the rider is hurried through the crowd of animals, street carts, loaded Camels, carriages and walking people, and the Donkey never loses courage for a moment, but rushes on at a very agreeable gallop, until he has reached his destination. Cairo is a veritable training school at which to accustom one to the use of Donkeys, and the only place where one learns to fully know, appreciate, esteem and love this excellent creature."

Traits and Capabil. Oken's words apply perfectly to ities of Tame the north European Ass, however: Asses. "The tame Donkey has degenerated to such an extent through prolonged ill-treatment that it has lost nearly all resemblance to the parent stock. Not only has it becone much smaller, but it has also a duller, ashy color and longer, flabbier ears. Courage in it has turned to obstinacy, speed to slowness, vivacity to dullness, love of liberty to patience, sturdiness to endurance of blows."

All the perceptive senses of the tame Ass are well developed. Hearing ranks highest; sight comes next and then smell; it seems to possess little ner.

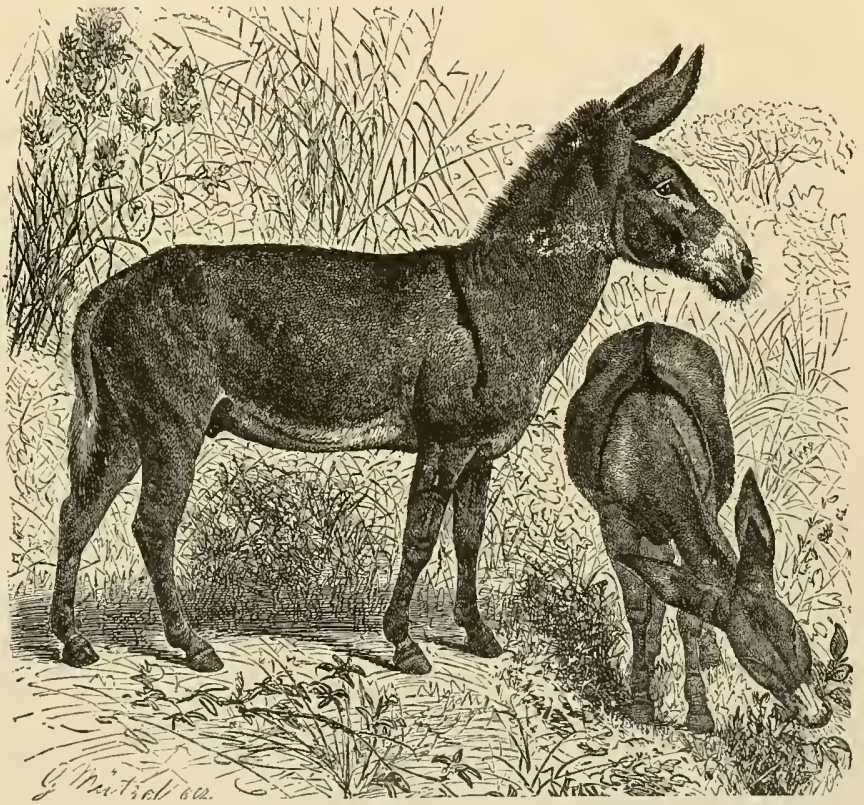

AFRICAN WILD ASS - In the northern part of Africa is found, in its wild state, the animal shown in the picture. It is a symmetrical, active animal of a uniform reddish cream tinge except for the marked black stripes placed along the back and transversely across the shoulders. (Equws asivous sensibility, and the sense of taste is probably also not particularly well developed, else it certainly would be more exacting in its diet than the Horse. Scheitlin tells us that its mental capacities are not so slight as is generally believed. It has an excellent memory and easily finds its way again over any road which it has once traveled; in spite of its stupid looks, it is sometines possessed of no small cunning; neither is it always so good-natured as people think. Occasionally it even displays an abominable viciousness. It may suddenly stop on the road, oblivious of blows, and may even throw 
itself down, carrying its burden with it and biting and kicking the while. Some people believe that its delicate hearing is the cause of all this, as every noise dazes and frightens it, though as a rule, it is not timid, but only capricious.

The Iss contents itself with the most indifferent quality and the scantiest quantity of food. Grass and hay from which a well-bred Cow would turn with a snort expressive of disgust, and which a Horse would disdain, are dainties to it, and it even accepts thistles and thorny bushes and prickly herbage. It is only fastidious in the selection of its drink; for it touches no turbid water. The liquid may be salty or brackish, but it must be clear. In traveling through deserts an Ass sometimes gives its master a great deal of trouble, for in spite of the greatest thirst it will not drink the roily water in the leather water bottles.

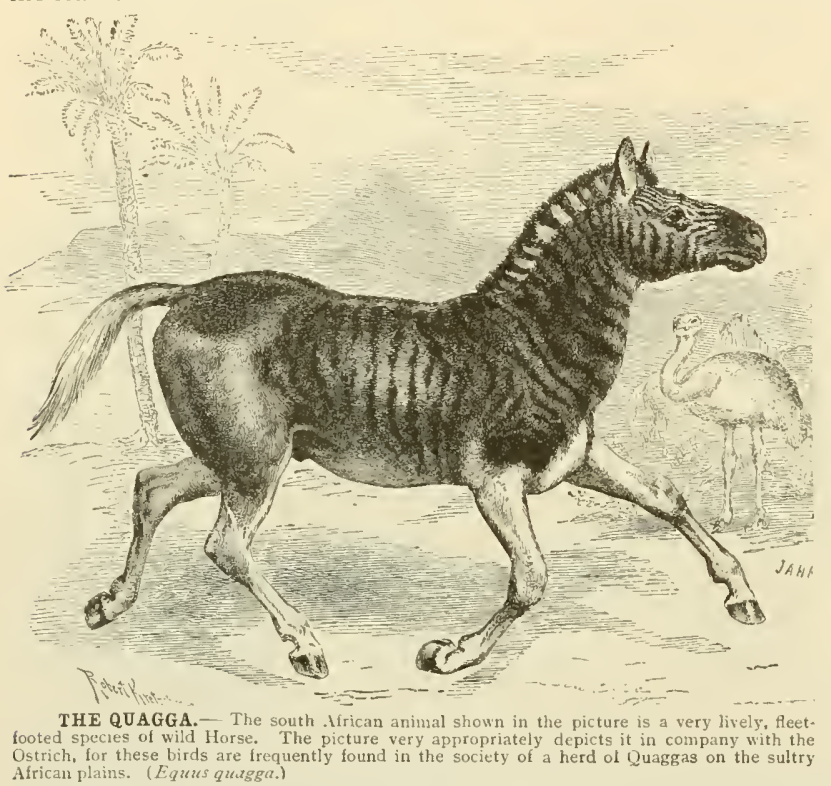

father's, while their traits resemble those of tixe male progenitor.

The Mule and The Mule (Equus mulus) attains the Hin- nearly the physical proportions of ny. the Horse, and resenbles it somewhat in appearance also, but differs from it by the shape of the head, the length of the ears, the tail covered with short hair at its root, the thin, but powerful thighs, and the narrower hoofs, which show an affinity to the Ass. The coloring, as a rule, is that of the mother. It brays like its father.

The Hinny (Equus himmus) conserves the insignificant form, the small size and the long ears of its mother, showing only the thinner and longer head, the fuller thighs, the hairy tail and the neighing voice of the llorse. From the mother it also inherits its laziness, besides its external appearance.

The newborn Mule foal is stronger and stands on its legs much sooner than a young Horse does; on the other hand the period of its growth is much more protracted. No Mule ought to be pur to work before it is four years old; but to compensate for this delay, its strength lasts into its twentieth and thirticth and sometimes to its fortieth year.

On account of their greater usefulness Mules are nearly exclusively bred. Only in Spain and Abyssinia did 1 see Hinnies; there seemed to be no Mules there. The Nule combines the good qualities of both parents. Its frugality and endurance, its gentle, sure pace are inherited from the Ass: its strength and courage can be traced to its nother. In all mountainous countries Mules are regarded as indispensable; in South Amcrica they are as important as the Camel to the Arab. A good Mlule carries a burden of three hundred pounds and covers a distance of from twelve and onehalf to seventeen and one-half miles daily. At this rate of progress one hardly perceives a decrease of power after a quite prolonged journey, even when its food is but scarce and so bad that a Horse would not eat it at all.

Even in the most recent times it has repeatedly been asserted that Mules or Hinnics are sterile. This is not always the case, however. Instances are on record dating from the remotest antiquity, where crosses between Ass and Horse gave birth to young in their turn. Several observations of more recent times also put the capability of reproduction of the Mule beyond doubt; thus Mules have propagated themselves to the second generation in the Jardin d'acclimation in Paris, within the last two decades.

\section{STRIPED HORSE OR ZEBRA GROUP.}

An old Iatin author relates how in the year $2 \mathrm{II}$ Caracalla, besides fighting with a Tiger, Elephant and Rhinoceros, also had a Hippotigris brought forward, which he killed with his own hands. There is hardly a doubt that the author meant by "TigerIlorse" one kind of the striped African wild Horses. Five species of striped Horses have bccn classified, but whether this classification has a justifiable foundation is an open question, for the points of difference are, in some cases, very slight. 
Characteris- The Quagga (Equns quagga) shows a tics of the greater similitude to the Horse than Quagga. to the Ass in its outward appearance, though it is much inferior in beauty to the Dauw. The body is of very pleasing outline, the head is moderately large and graceful, the ears are short, the legs strong. A short, erect mane adorns the whole length of the neck; the tail is hairy from the root and longer than that of the other varieties of the Zebras, though considerably shorter than that of the Horse. In respect to the rest of its hairy covering the Quagga resembles the latter-the hair is short and lies close to the body. The ground-color is a brown tint, dark on the head, lighter on the baek, the crupper and the flanks; the abdomen, the inner face of the thighs, and the hair of the tail are pure
The Dauw Nearest Burchell's Zebra, or the Dauw Kinsman of the (Equits burchellii), is undoubtedly the Horse. noblest member of the whole family, because it shows the greatest resemblance to the Horse in appearance, being scarcely smaller than the Quagga. The soft, sleek coat is of a sorrel color above, and white underneath. Fourteen small black stripes commence at the nostrils. Along the spine runs a black band edged with white; the neck is marked by ten broad, black and sometimes forked stripes; the legs are usually of a plain white color.

Peculiarities The Zebra (Equzs sebra) has much of the Ze- the same physical proportions as the bra. Dauw, but is striped all over the body, and thereby readily distinguished from that animal. Its conformation is approximate to that of

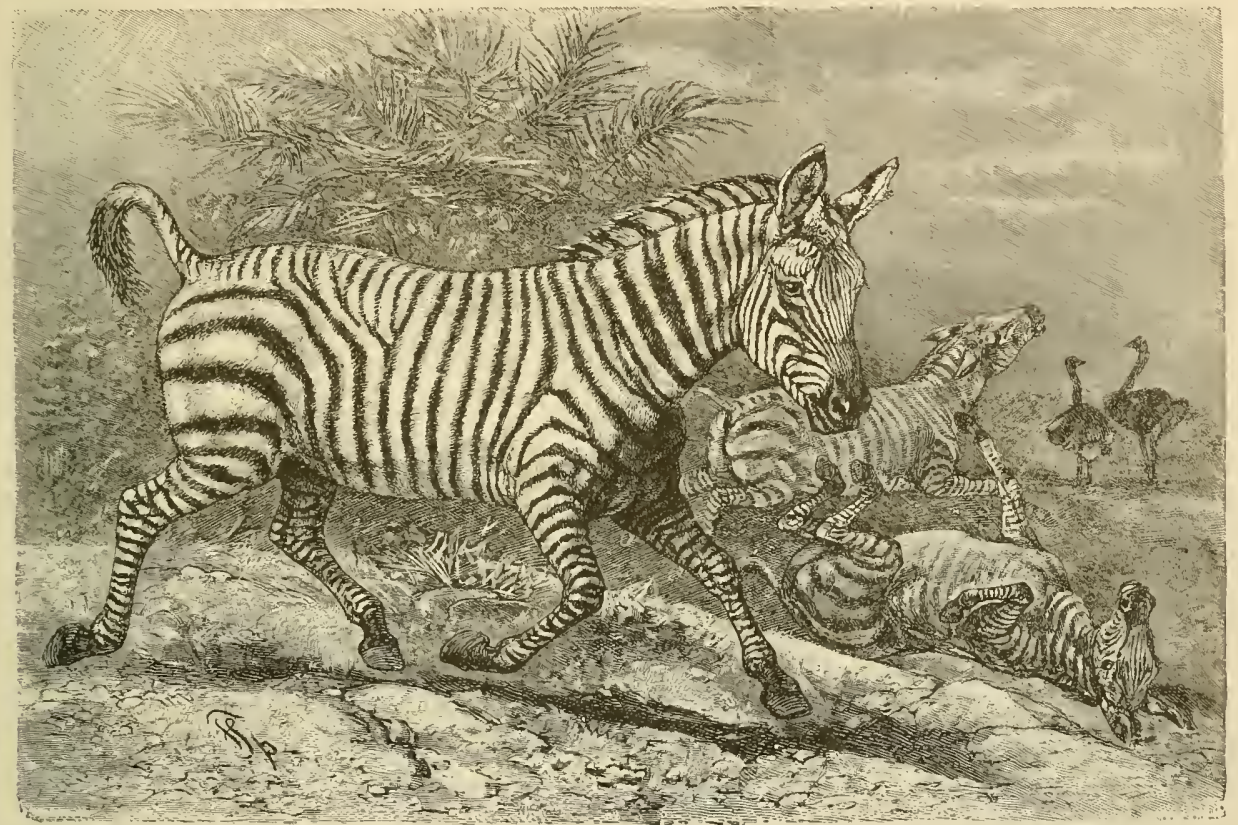

THE ZEBRA. This species of the Horse family, once common in south Africa, is now found there in much decreased numbers. It is the most perfectly striped of all the family, not only being marked on the body but also on the legs, down to the hoofs. The group in the picture is shown running, rolling and romping in true Horse fashion. (Equzs zcbriz.)

white. Grayish white stripes, dashed with a reddish tint, run across the head, neck and shoulders; on forehead and temples they are longitudinal and lie close together, and on the cheeks they run transversely and at greater intervals. Between the eyes and the mouth they form a triangle. The neck contains ten such stripes which are continued in the mane also; the shoulders have four and the body a few more, which -become shorter and paler as they approach nearer the hind quarters. Along the entire spine, back to the tail, runs a blackish-brown band, bordered along its edges with reddish gray. The ears are covered with white hairs on the inside, the outside being yellowish white and marked with one dark brown band. The sexes resemble each other very much, the female being somewhat smaller and possessed of a shorter tail. The adult male attains a length of eighty inches, or one hundred and four inches including the tail; the height at the withers is about fifty-two inches. the Ass rather than to the Horse, reminding one most of the Dziggetai. The body, supported on slender, well-shaped limbs, is stout and vigorous, the neck is arched, the head short, the muzzle large and somewhat obtuse, the tail of moderate length, for the greater part overgrown with short hair but having long hair only toward its lower extremity, thus resembling an Ass' tail; the mane is thick, but very short. Transverse stripes of a lustrous black or reddish brown hue run on a white or light yellowish ground, from the muzzle to the hoofs; only the posterior part of the abdomen and the inner sides of the upper parts of the legs are free from stripes. The dark, brown-black, longitudinal stripe on the back is also conspicuous.

Range and Habits The real native country of the Ze-

of the $Z_{e-} \quad$ bras is southern and eastern Africa; bras. they are not found within the narrower equatorial regions of the western half of 
Africa nor any part of the Congo district, with the exeeption of the remotest southeastern portion. The ()uagga is found to the north of Cape Colony, in the Kalahari and German possessions in southwestern Africa to the Cunene, as well as in the Transvaal. Burchell's and Chapman's Zebras occur nearer to the Zambesi and the Cunene. The Zebra, on the contrary, preferring a mountainous country, has a far wider range than its relatives: in Cape Colony it maintains its foothold to the present day and to the north it penetrates as far as Benguela in the west, and to about the twelfth parallel of south latitude in the east.

The Zebras live gregarionsly. Generally they are seen in groups of ten to thirty; but there are many accounts of herds of them numbering hundreds which when seen were probably in the act of migrating. Every different species is always met apart from other species of the same family. Perhaps one species of Zebra fears the other; but it is not afraid of other animals. Thus all observers agree that Quagga herds nearly alway's contain Spring-boks, Gnus, Ostriches and also Buffalos. Ostriches in particular are said to be the constant companions of this species of wild Horse, doubtless because the latter derive greater benefit from the wariness and vigilance of those gigantic birds.

All Zebras are exceedingly fleet, wary and timid animals. They scour over hill and dale with windlike rapidity. A well-mounted rider finds it not so very difficult to overtake a compact body of fleeing Zebras, though a single individual easily escapes the swiftest rider. It is said that when the pursuer suceeeds in scattering the herd and separating the foals from their mothers, the young Quaggas become willing eaptives and follow the Horses as they did their mothers. There seems to exist a certain friendship between the Zebras and the onehoofed domestic animals, for it is said that the Quaggas and Burchell's and Chapman's Zebras sometimes follow the Horses of traveling parties and quietly graze among them.

Traits and Capa- The Zebras are not very fastidious bilities of in the elooice of their food; yet they Zebras. are more exacting than the Asses. Their native country offers them sufficient nourishment, and if food becomes scarce in one place, they set out in search of more productive localities.

The vocal expression of the Zebras is as different from the neighing of the llorse as it is from the braying sounds of the Ass. Cuvier says, that the Quagga reiterates the syllables "oa oa" some twenty times in succession, while other travelers describe its cry with the words "qua qua;" or "quaha," which also aceount for the origin of the llottentot name of the animal. The Dauw utters short sounds, something like "yu, y'u," which, in captivity at least, are rarely uttered more than three times in succession. All the perceptive senses of the /ebras are acute. The slightest noise fails to escape their ear, and their eye is exceedingly keen and very rarely deceived. In their mental attributes all are about on a common plane. An unlimited love of freedom, a mischievous disposition, a certain wildness, even some malice and much courage are common characteristics of them all. They valiantly defend thenselves against the attacks of beasts of prey by kicking and biting. Hyenas prudently let them alone. Perhaps the powerful Lion is the only brute foe which succeeds in overcoming a Zebra; the impudent Leopard probably attacks only weak speci- mens. The worst enemy of the Zebras is Man. The diffieulty of the pursuit and the beautiful shin of the animal, which serves a variety of purposes, prompt Europeans to vigorously lunt this quite harmless quarry. Europeans kill Zebras with bullets, natives with javelins; more frequently, however, the dainty creatures are taken in pitfalls and then either killed with little trouble or consigned to captivity.

The Zebras have been wrongly held to be untamable. The people who are properly qualified for the undertaking have not occupied themselves sufficiently with the subjugation of these magnificent animals. A few attempts have been erowned with success, others have failed. Quaggas have been repeatedly trained to convey burdens and draw carts. In England a couple of the beautiful animals are recorded to have been tamed to such an extent that they could be harnessed to a light carriage and used like llorses. Other accounts, however, are to contrary effect. Sparmann relates the first attempt of a rich settler in Cape Colony to break Zebras to harness. He had reared several young Zebras and seemed to be satisfied with their eonduct and had confidence in their docility. One day he bethought himself of harnessing the pretty animals to his carriage. He took the lines himself, and set out with his racers. The trip must have been accomplished in a very short time; for the happy owner of the Zebras presently found himself in their stable, together with the remnants of his carriage. This and a few similar attempts rendered the settlers of Cape Colony thoughtful, and convinced then that the taming of Zebras is impossible. All intelligent observers do not doubt, however, that we will win the Zebras to our service in the course of time. Barrow affirms that success would be assured if people proceeded with more patience and circumspection than do the peasants of the Cape.

How the Zebra All species of Zebras bear confine-

Acts in Cap- ment in other than their native countivity. tries without harmful results. They enjor the best of health if they receive good food; and if they are properly managed they propagate their young even if kept within narrow confines. It has been demonstrated that the Zebras may produce cross-breeds with others of the one-hoofed tribe also. So far the following cross-breeds have been produced: Zebra and female Ass; male $\Lambda$ ss and Zebra; half Ass ( Mulc or Hinny) with Zebra mare; half $\Lambda$ ss with Ouagga, and Ouagga with female Ass; also offspring of Zcbra and female Ass, and offspring of Ass and Zebra mare both breeding with a Pony. These eases luave proved the possibility of hybrids possessing the power of propagating the species.

\section{The Tapits.}

\section{SECOND FAMILY: TAPIRIDA.}

We regard the Tapirs (Tapirida) as the family most elosely allied to the Horses, for though relatively small animals, of a clumsy organization, their kinship to the Jlorse tamily is instantly recognized by eyes observant of natural affinities. They are distinguished by a tolerably well-shaped body, with long, slender head, a slender neek, a short, stub-like tail and proportionately long, stout legs. The erect ears are short and rather broad, while the slanting eyes are sniall. The upper lip is elongated into a prehensile proboscis or trunk, which hangs down far 


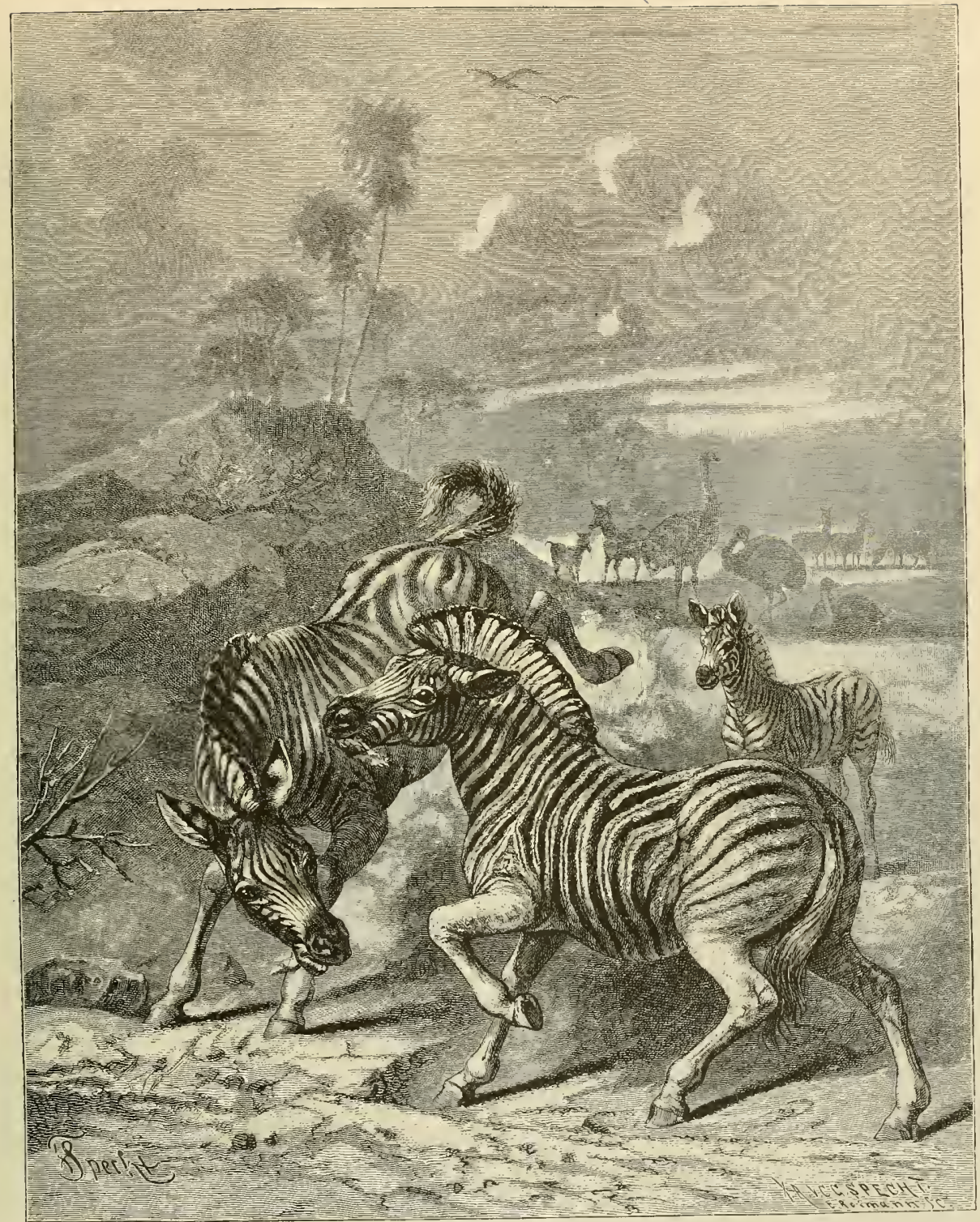

THE DAUW OR BURCHELL'S ZEBRA. - The commonest species of the Horse family found in the great plains of Africa. Its symmetrical form, regular stripes, novel mane and graceful bearing make it one of the handsomest of quadrupeds. It associs 
beyond the lower lip. The stout feet are equipped with four toes on the front pair and three on the hinder pair. The strong hide has no wrinkles and lies smoothly on the body. The hair is short, but thick, and in the American species it is prolonged into a mane from the middle of the head to the withers. The dentition exhibits six incisors and one canine tooth in each side of both jaw's, seven molars in each side of the upper, and six in the corresponding portions of the lower jaw. The bony structure of the animal is distinguished by its comparative lightness. (If the species of this family, for the most part American, at least one has been known to us for a considerable length of time, the others having been discovered, described and classified only in a recent period. It is rather surprising that the American Tapir was the first enrolled in the books of natural sciunce, while the earliest definite information concerning the Malayan Tapir came to the knowledge of the white races in the beginning of this century; though it was known a long time before, not to us, but to the Clinese, whose natural histories and school books mention it. In the Tapirs the same physical comparison may be instituted which is al most invariably justified when a family has representatives in the Old and New Vorld: the Uld WVorld species are of nobler physical organization, and, so to speak, more perfeet anmals than those living in the New World.

\section{Distinctive Features \\ of the Malay}

Tapir.

The MIalayan Tapir (Tapirus indicus or Tapimus malayeamus) is casily distinguished from its American kinsman by its greater size; its proportionately more slender shape; its head, thinner in the facial parts and morc curved in the skull portion; its stronger and longer trunk; its stouter feet; the absence of a mane, and lastly by its color. The difference in structure of the trunks of these animals seems to me to be of special importance. While the trunk of the American Tapir is abruptly projected from the upper lip and lias a rounded, tubular shape, tile upper half of the muzzle of the Malayan Tapir almost imperceptibly graduates into the trunk, the cross-section of which is similar to that of an Elephant's trunk, rounded in its upper half, but flattened in its lower portion.

The color of the hairy coat which envelops the entire body is highly characteristic. A pure, deep black may be regarded as the ground-color; a grayish white caparison stands out on it in bold relief. The exact bodily measurements of an adult female were: the total length amounted to one hundred inches, inclusive of the tail, which was nearly two and onchalf inches long; the height from ground to shoulder was forty inches, the height at the buttocks fortytwo inclies. The animal is a native of Tenasserim and Siam, south of about the fifteenth parallel of north latitude, the Malayan peninsula, Sumatra and Borneo.

It is a striking fact that despite our active commerce with lndia and southern $\Lambda$ sia nothing definite was known of this Tapir until ISI9, when the animal was introdueed to the notice of the western world through the publication of the rescarches of Cuvier. In 1820 the first skin, skelcton and various internal parts of the yet very little known creature arrived in furope. We have recived more information about it since, but still we eannot boast of a perfect knowledec concerning it. There is yet no authentic account given of the life of the animal in the free state; neither do the observations of its life in captivity entirely comprehend the subject. Sterndale charae- terizes it as a shy animal, living in seclusion, which, if taken roung, can be easily tamed and is capable of great affection.

Description of the A short mane on the neck and a American shin of one color characterize the Tapir. American Tapir (Tapirus amcricamus or Tapinus terrestris) which is also called Anta or Danta in Brazil. It is that species of the family with which we first becone acquainted. A few years after the discovery of the American continent travelers began telling tales of a large animal, which they believed to be a Hippopotamus, and the European naturalists therefore bestowed the appellation of Hippopotumus terrestris on it. The famous Marcgrav of Liebstad first gave a detailed description and picture of it about the middle of the eighteenth century: Later travelers and explorers completed the first description, and at present there are few animals about which we are better informed than about this species of Tapir. The body shows a rather uniform eovering of hair, which is elongated into a stiff but short mane from the middle of the upper part of the head along the neck to the shoulders. The color is a blackish gray-brown, assuming a lighter tint on the sides of the head, especially on the neck and breast; the feet and tail, the spine and nape of the neek are usually darker; the ears are edged with whitish gray. Various modifications in the color of the coat of hair oceur. There are pale gray, yellowish or brownish individuals. Joung animals show only on the back the ground color prevalent all over the bodies of the old ones. The upper surface of the head is closely besprinkled with circular, white spots; and along each side of the body run four continuous lines of dots of a light hue, extending also over the limbs. As age adrances, these spots coalesee into each other, forming bands, and disappear entirely at the end of the second year. lecording to Tschudi's measurements, the Tapir may attain a length of eighty inches and a height of sixty-eight; Kappler, however, finds that with this length the height of the animal at the shoulder is barely forty inches. It is a strange fact that these measurements apply to the female Tapir, she as a rule being the larger of the two.

Range of the Recent investigations show the range American of the Tapir to be restricted to the Tapir. south and east of siouth America, whilc in the north and in the west of the southern half, as well as in Central Amcrica, it is replaced by closely allicd but distinct species.

The accounts of the Tapirs given in this work are based on the communications of Azara, Rengger, Prince of Vied, Tschudi, Schomburgk and others, regarding the American species; for we lack any detailed accounts of the life of the Asiatic Tapir. liesides, all species are so similar that it suffices to examine closely into the life and doings of the one.

All species of Tapirs inhabit woodlands, and sedulously shun gaps or open land. For this reason they are the first to recede before the strides of human civilization and retreat into the depth of the forest, while, as Hensel says in speaking of South America, the remaining animals of the tropics press to those parts of the wood which border on the lands which have been made arable. In the brushwood of the South American forests the Tapirs make well defined, beaten roads, which are with difficulty distinguished from the paths of the Indians and an inexperienced person is often induced to follow them to his detriment and confusion. The 
animals use these paths as long as they are not molested; when alarmed or pursued, however, they plunge through the most tangled thicket with ease.

Habits and Move. The Tapirs are mainly animals of ments of the the darkness. Tschudi says: "For

Tapir. months we roamed through the dense forests, containing hosts of Tapirs, but we never saw one during the day, for in the daytime they seem to remain concealed in the dense brushwood, in cool, shady places, affecting the proxinity of stagnant water, in which they like to wallow. In quite undisturbed and very dense forests, however, they also rove about by day. It is true, that they are averse to moving about in the sunshine, and in the middle of the day they always seek in dense shades shelter from the fatiguing heat and from Mosquitoes, which annoy them to an extent almost unbearable." Prince IVied says: "If one
In their movements the Tapirs remind the onlooker of Hogs. Their walk is slow and deliberate; one leg is leisurely put in front of the other, the head is bent to the ground and only the sniffing trunk, constantly moving back and forth, as well as the restless ears, enliven the lazy aspect of the creature. The Tapir is an excellent swimmer and a still better diver, and crosses the widest rivers with apparent ease, not only when compelled to swim by pursuit, but whenever occasion offers.

The Senses and Among the perceptive senses of the General Traits of Tapir those of smell and hearing deTapirs. cidedly rank highest, and are probably of equal keenness; sight is comparatively weak. This deficiency is, however, partially compensated by an exquisitely susceptible sense of touch, especially in the trunk, in which it is very delicate, and is used in manifold ways. The vocal expression is

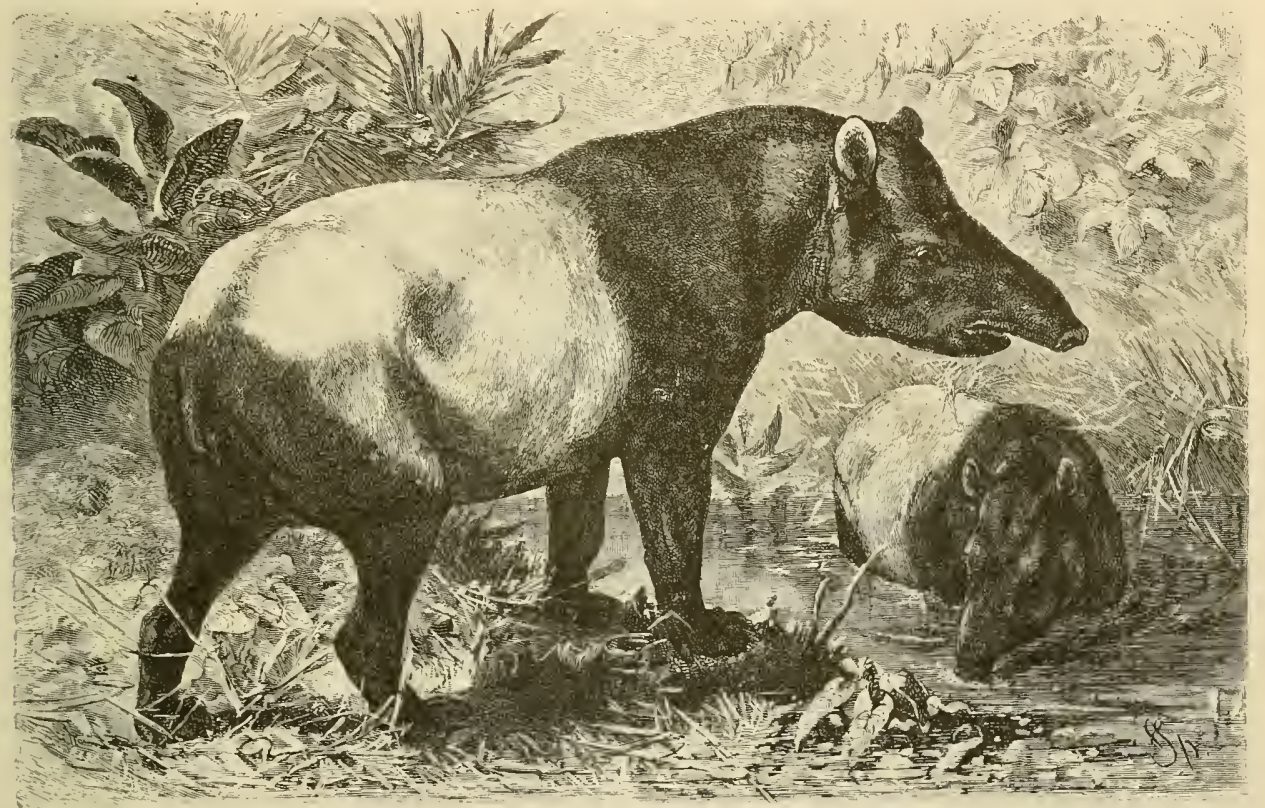

MA AYAN TAPIR. - Though so far from its Anerican cousin the Malayan Tapir closely resembles it in physical characteristics and habits. It is longer and not quite so clumsy as the American Tapir, but the special distinguishing nark of the Asiatic species is the large white patch on the rear portion of the back and sides, as indicated in this picture. (Tufincindicus.)

goes to a river in the early morning or in the evening, softly and noiselessly, he may frequently see Tapirs bathing, for the purpose of cooling themselves or of getting rid of the torments of Mosquitoes. No animal knows better how to protect itself from these annoying insects; every mud-pool, every creek or pond is utilized by them with this end in view." Towards evening the Tapirs sally forth in qưtest of food, and probably they are active all night. Their habits show a resemblance to those of the IVild Boar, but they do not herd together in such numbers as do Hogs, but live singly, like the Rhinoceros. The males especially are said to possess solitary habits and join the females only during the breeding season. Herds or groups are seldom met with, and bands numbering more than three have been observed only where a particularly good, rich pasturage had attracted several Tapirs. a peculiar, shrill whistle, out of all proportion to the bulk of the animal.

All Tapirs seem to be good-natured, timid and peaceable creatures, which have recourse to the use of their natural weapons only in dire necessity. They flee from every foe, even from the smallest of Dogs, but most anxiously from Man, of whose superior might they are well aware. This is shown by the mere fact of their being much more wary and shy in regions near plantations than in the untrodden forest. This rule of extreme timidity has exceptions, however. Occasionally they defend themselves and when aroused are by 110 means despicable antagonists. They rush at the eneny in blind fury, try to run over him, and sometimes they may use their teeth after the manner of enraged Hogs. In this way the mothers defend their young, when the latter are menaced by a sportsman. Then they brave any dan- 
ger and heed no wound. Anv one who has dealt with captive Tapirs for any sufficient length of time knows that they are mentally much above Rhinoceroses and Hippopotami, and about on the same level of intelligence as Pigs. "A Tapir taken young," says Rengger, "accustoms itself in a few days to human beings and habitation, not leaving the latter after once becoming thoroughly acquainted with the surroundings. It becomes restless if its keeper leaves it for any considerable time, and seeks him, if it is at liberty. It allows anybody to touch and stroke it." Kappler, who frequently reared young Tapirs, says that he always used to make somebody a present of them while still young, because they became so annoyingly familiar; an adult specimen once pulled the cloth off a set table with everything that was on it. Those that 1 have taken care of justified thesc statements. Both specics proved to be very goodnatured creatures. They were quite tame, possessed of peaceable intentions toward all animals, perfectly agrecing among themselves, and affectionate toward their friends. Keller-Lewzinger is persuaded that the Anta could be reduced to a domestic state. He says that those which are taken young become as tame as Dogs in a few days, and never think of escaping. "In Curitiba, the capital of the province of Parana," he says, "a tame, ownerless Tapir used to run about in the streets for several years; from morning to night Negro boys would ride on it. A temperature of two or three degrees below zero, centigrade, as happens there quite frequently in June and July, seemed to affect it very little."

Tapirs in the free state feed exclusively on vegetable substances, such as leaves of trees. In Brazil they are partial to young palm leaves; not infrequently, however, they invade plantations and prove that they are also fond of sugar cane, mangoes, melons and other vegetables.

Tapirs Vigorously All species of Tapirs are vigorously Hunted by hunted by the natives of the counNatives. tries ther inhabit, as both their flesh and skin are utilized. The flesh is said to be tender, juicy and savory; the thick hide is tanned and cut into long strips, which are rounded, made flexible by repcated rubbing in of hot lard, and then made into whips or bridles.

In America the Tapir is usually hunted with Hounds. The Dogs eagerly pursue tle fleeing animal, until, as is always the case, it reaches the nearest body of water. There a hunter is hidden in a light boat near the bank, and he helps the Dogs to run down the swimming and diving quarry. Unless the water surface be so small that the Tapir can cross it quickly and obscure the trail, it is soon overtaken and killed by a bullet or a long hunting knife. Von den Steinen graphically describes a Tapir hunt, which happened during his trip on the Xingu: "Valentin discovered a Tapir swimming near the bank; everybody came hurrying up to assist in the chase. Irineo hit it with two bullets, one lodging in the flanks, the other in the trunk; Valentin sent a charge of small shot whistling by its ears - still it scampered into the forest. The Dogs rush on in pursuit and we row with all our might; then follow fresh reports from the guns and the Tapir disappears into the thicket. The Dogs look stupiclly into the water, completcly at fault. Soon a little Pomeranian Dos regains the trail, traces the animal and the others help it. Then, at a distance of a third of a mile, the Tapir reappears in the water; an excitine race and indescribable confusion follow. It dives and comes up again; Pedro shoots at a distance of five paces and misses; he sends off an arrow, which rebounds from the tough hide; Nerelles also misses it at a close distance, while somebody else hits it. The boats nearly upset each other. as we try to seize it: our boat careens over and is filled with water. We stick knives into the Tapir; the Iuruma pricks it with an arrow, the Woman waves her arms in excitement and screams that we ought to lasso the creature. Antonio's knife thrust is followed by a jet of blood, the animal again plunges under water, but, coming up between two boats, it is seized by a leg, killed and dragged to the nearest rock, It is a huge beast, a 'regular Mule,' and is covered with large, brown ticks. The short, stiff mane is rather good-looking, appearing like that of the Greek Horses of the gods."

\section{Tbe IRbinoceroses.}

THIRD FAMILY: RHIXNCEROTIDE.

Even purely superficial consideration and comparison reveal some of the common anatomical features which cause Horses, Tapirs and Rhinoceroses to be classified within the same order; but a still closer analysis is necessary in order to recognize the comparatively near kinship of the families represented by them.

General Character. The Rhinoceroses ( $R$ hinocerotid $\mathscr{C})$ istics of Rhi. are stout, unwieldy animals of rather noceroses. bulliy proportions, distinguished by a strikingly elongated head, the lower or nasal portion of which supports a horn, or two horns standing one behind the other; a short neck, a thick, rotund body, covered with a tough, armor-like skin, almost entirely, or for the greater part, devoid of hairy overgrowth: a short tail, and short, sturdy, but by no means clumsy legs, the feet of both the front and hinder pair having each three hoofed toes. Every individual nember of the body appears queer and peculiar, eren if compared with the corresponding portion of other members of the family of the Perissodactyla. The head is much elongated, the facial part in particular being disproportionately lengthened, while the skull part is greatly compressed from front to rear, so that the forehead recedes abruptly, giving rise to a deeply indented saddle or ridge between it and the perceptibly higher nasal portion. The mouth is disproportionately small, and the upper lip is drawn out at its center, into a gradually tapering, trunk-like appendage. The lower lip is slightly rounded, or else its extremity presents a flattened, chopped-off appearance. The eyes are strikingly small; the ears are rather large and rounded on their outer margins. The short, wrinkled neck, which is thicker than the head, merges into the bulky body without any perceptible line of demarcation. The body is characterized by a peculiar formation of the backbone, the spines of which are sharp and grow longer and more prominent toward the middle of the back; the buttocks are slightly higher than the shoulders; the abdomen is "paunchy" and pendulous; the short tail is either much compressed laterally toward its extremity, in which case its width from root to tip is nearly uniform, or else it is long and tapering. The legs, down to the ankle joints, crook inward like those of a German Badger Dog, but below that point are straight. The feet broaden out equally on all sides, down to the soles, which are of ovoid shape. 
Of the three toes on each foot the width of the middle one is nearly double that of cither of the others. The skin is very thick, and in most species of the family is of an almost armor-like toughness. It either envelops the body snugly, with the exception of a few not very prominent folds, or else it is divided into several distinct shields, separated by deep furrows. The loose skin of these interstices affords the only means of mobility, for the shields may be made to touch or even overlap each other at these furrows, which are composed of a thinner and much more flexible skin than that which forms the shields. Decp wrinkles surround the eyes and mouth, and in the latter instance impart an unexpected degree of flexibility to the clumsy appearing, but actually very mobile lips. A network of shallow depressions cross in individual instanees and not as a general rule, the superficial skin exhibits horny excrescences attaining the height of an inch or thereabouts, on different portions of the body, but usually on the head.

The bony skeleton is of a clumsy, vigorous structure. In respect to dentition it may be said that the canines are absent; the African species also lack the incisors in both jaws, but the Asiatic species usually show them during their entire life. The remaining teeth consist of seven molars on both sides of each jaw.

The Rhinoceroses, which at present inhabit the Oriental and Ethiopian belts, were more widely distributed in former times, their earlier range including southern Germany, France, England, Russia and Siberia. Among the extinct species which

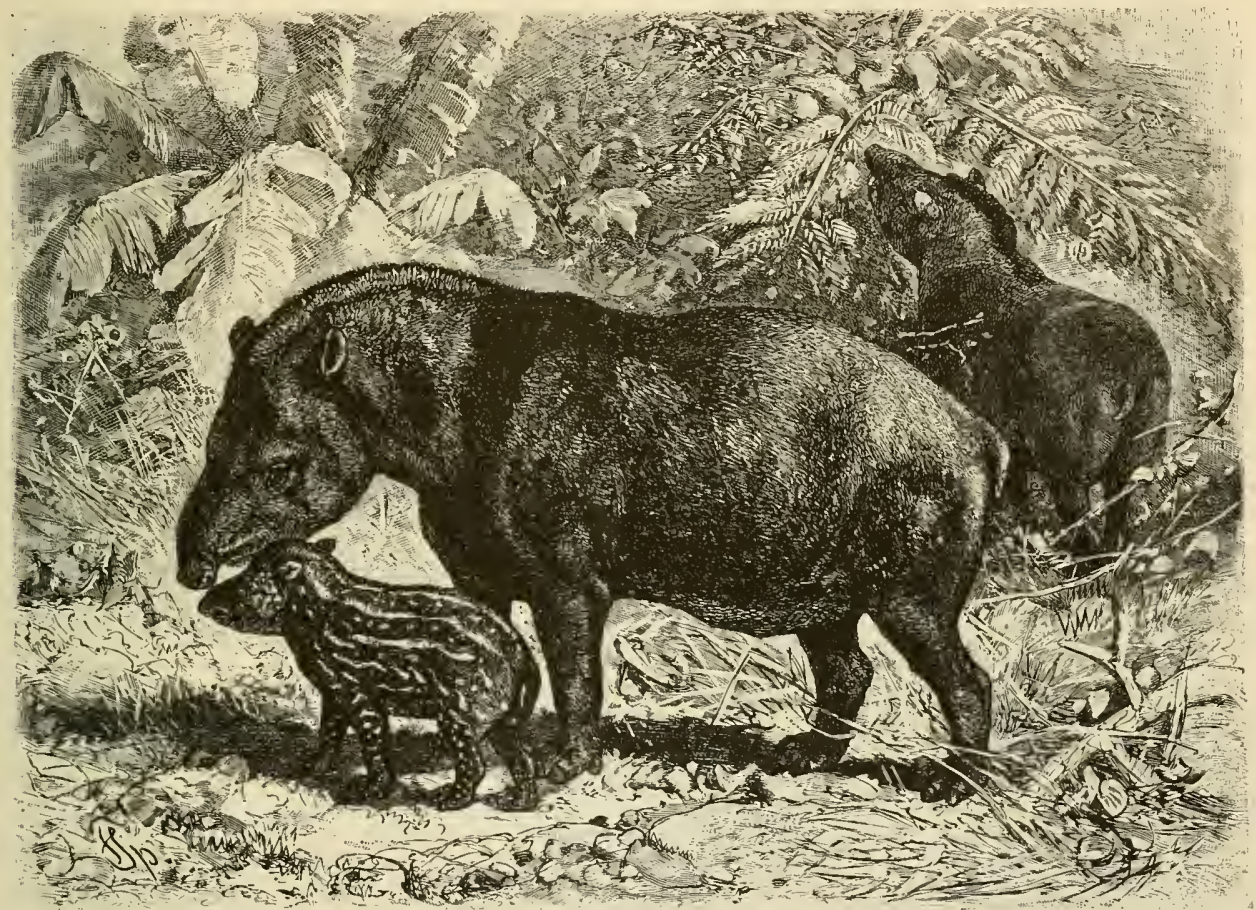

AMERICAN TAPIRS. - Here is a group of these South American animals luxuriating in the native swanps which furnish them plentifully with the leaves, shoots and fruits which form their food. The clumsy body, head and proboscis-like snont of the adults are shown, and the peculiar spots and stripes of the infant Tapir are also portrayed. These markings disappear with naturity. (Tapirus amcreanus.)

each other on the skin, separating it into elevations of very uniform shape, apparently arranged into a pattern of regular design; and which forms, on the thick, shield-like portions of the hide, an especially odd but attractive adornment. The hairy covcring of the Rhinoceroses is usually restricted to a moderately long fringe upon the ear margins and upon the broadly-compressed extremity of the tail, but in a few varieties it also extends to several spots on the skin. The horns, which have their foundations in, and are really developments of the superficial skin, consist of extremely fine, round or angular fibres of horny tissue arranged in parallel lines and forming hollow eones; and their broad, rounded bases are attached to the thick skin which covers the nasal portion of the face. Not infrequently, though only have been classified, one particularly deserves to be mentioned - the two-horned prehistoric Rhinoceros, with a bony nasal partition (Khimociros tichorhinus) because its remains have been found preserved not alone in a few separate bones, but quite complete with skin and hair. In northern Asia, from the $\mathrm{Ob}$ to the Straits of Behring, there is no river in the open country on the banks of which the fossil remains of prehistoric animals, especiatly of Elephants, Buffaloes and Rhinoceroses, can not be found.

Flower's Classifica. Our knowledge of the existing spetion of the Rhi- cies has been materially extended noceroses. during recent times, but is even yet far from satisfactory. Flower, in the year 1876. subjected the family to a new revision and consideration. This naturalist distinguishes three main groups 
of the family, arranged in accordance with their dentition and the folds of the skin. The first group comprises all species, the skin of which is divideci into shields; the second embraces those, the shin of which shows less folds, and in the third group the skins do not exhibit any permanent folds.

One horn and well developed folds on neck and loins, which bound the coat of mail formed by the skin anci surround shield-like areas, characterize the Shielded Rhinoceroses (Rhinoccros), represented by two living varieties.

Description of the The Rhinoceros or Unicorn, usually Indian Rhi. called the Indian Rhinoceros (Rhinoceros. noceros umicomis) attains a total length of twelve and one-half fect, including the tail, which is two feet long; the height at the shoulders is five feet, eight inches, and the weight amounts to 4,000 pounds or thereabouts. Of sturdy and strong build, it is distinguished from its relatives by its comparatively short, broad, thick head, and the character of the margins of the shiclds, which is peculiar to this species. The range of this Rhinoceros now extends throughout the northern part of India.

The Javan or The other variety of this sub-species Wara Rhi- is the II ara Rhinoceros, commonly noceros. known as the Javan Rhinoceros (R/inoceros sondaicus). Is far as our knowledge goes, this species appears to have a much more extensive range than the Indian Rhinoceros.

The African Rhinoceros (Atlodus) is characterized by either the absence or rudimentary character of incisors in its dentition. Its snooth, even and hairless skin is marked by distinct folds only at the base of the neck and is divided neither into shields nor zones. Its defensive weapons consist of two slender horns, placed one behind the other.

Black Rhinoceros The best known representative of the Best Known this sub-specics is the Two-horned Variety. Rhinoceros (Rlinociros bicormis), called the Black Rhinoceros by the Poers and English hunters, Borele by the natives of south Ifrica, and Keitloa, if its posterior horn is very long. Its color varies between a uniform dark, slaty gray, and a dingy, reddish brown. Iull-grown bulls have a total length of thirteen feet, four inches, inclusive of the tail, which is usually about two feet long; the height at the shoulders is five feet, four inches. The horns are inclined in a backward angle, and are from twenty-eight to thirty-two inches long. In rare cases the rear horn is as long or slightly longer than the foremost one, but in the majority of cases it does not attain half the length of the anterior horn and often appears as a mere stub. The range of the animal has been considerably restricted, especially from the south, but it is still quite extensive, as it comprises a large part of Africa, especially its eastern half, south from about the fifteenth parallel of north latitude.

The Rhinoceros The ancients were familiar with the Well Known to Rhinoceros. Pliny records that

the Ancients. Pompey introduced the first Unicorn at the games in Rome in the year 6 I B. C., at the same time that he imported the Lynx from Gaul and the Baboon from Ethiopia. Agatharchides was the first to speak of these inimals; Strabo, who saw a Rhinoceros in Alexandria, was the second. Pausanias refers to it under the name of "Ethiopian Ox," Martial also mentions it in one of his verses. Early Arabian authors speak about both varieties and discriminate between the Indian and African species, and in their folk-lore tales the animals fie- quently play the part of magical beings. Marco Polo, that renowned traveler and author, who plays so important a part in respect of the ancient records of zoology, was the first to break the silence after the long lapse of time, during which nothing had been heard about the Rhinoceros. He saw it on his journey to the East Indies, namely in Sumatra, in the thirteenth century. Jn I $_{5} \mathrm{I}_{3}$ the King of Portugal received a living Rhinoceros from the East Indies. Its fame resounded throughout the European countries. Albrecht Durer published an engraving, which he had made after a poor picture he received from lisbon. It represents an animal which appears as if it were clothed in a suit of armor, the feet being also incased in scales of mail, and the shoulder being surmounted by a small horn. For nearly two hundred years that engraving of the famous master was the only existing European picture of the khinoceros. Chardin, who saw the animal in Ispahan early in the eighteenth century, was the first to give an approximately correct picture of this animal. Bontius had corrected the description of its life about the middle of the seventeeth century.

On the whole, all Rhinoceroses have much in common in their mode of life, their character, their qualities, their movements and their food; yet every variety seems to have its inclividual peculiarities. The Asiatic varieties of the Rhinoccros, for instance, are thoursht to be exceedingly vicious animals. The Javan varicty is described as mucl better natured, and that of Sumatra (R/hinoceros sumatronsis) is said to be guite inoffensive. The same variation in characteristics holds good in regard to the African Rhinoceroses. The Two-horned Rhinoceros is said to be the fiercest of all African animals, despite its small size; while the larger "white" variety exhibits a much milder and comparatively harmless disposition. There is probably some truth in this account, but the whole truth may be that every Rhinoceros shows good nature at its first acquaintance with Man, and while it is not provoled, but becomes vicious when taught by experience that Man is an enemy, or when its enmity is aroused by provocatioll.

Favored Haunts The favorite haunts of the Rhinocof the Rhi- eros are watery localities such as noceros. marshy districts, rivers which overflow the comntry adjacent to their banks to a great distance; lakes with bushy, muddy banks, in the proximity of which there is rich pasturage; woodlands through which flow creeks, and similar localities. The African varicty is also very comfortable in rather dry stretches of country, rich in grass and buslies, provided there are pools within its reach. Even the most tangled thicket, inaccessible to other creatures, opens its innermost recesses to these bulky animals, for against their coats of mail the most penetrating thorns are powerless. Therefore nearly all species of Rhinoceroses are most frequently encountered in forests, stretching inland from the seacoast, others of them occurring more regularly and frequently in the hilly country than in the plains. Every Rhinoceros probably visits the water once a day to drink and wallow in the mud.

A mud bath is an actual necessity to all thickskinned animals living on dry land; for appropriate as the adjective "thick" is in regard to their skins, they are exceedingly sensitive to the stings of the various specics of Flies, Gnats and Mosquitoes, and obtain some degree of relief only by incasing them- 


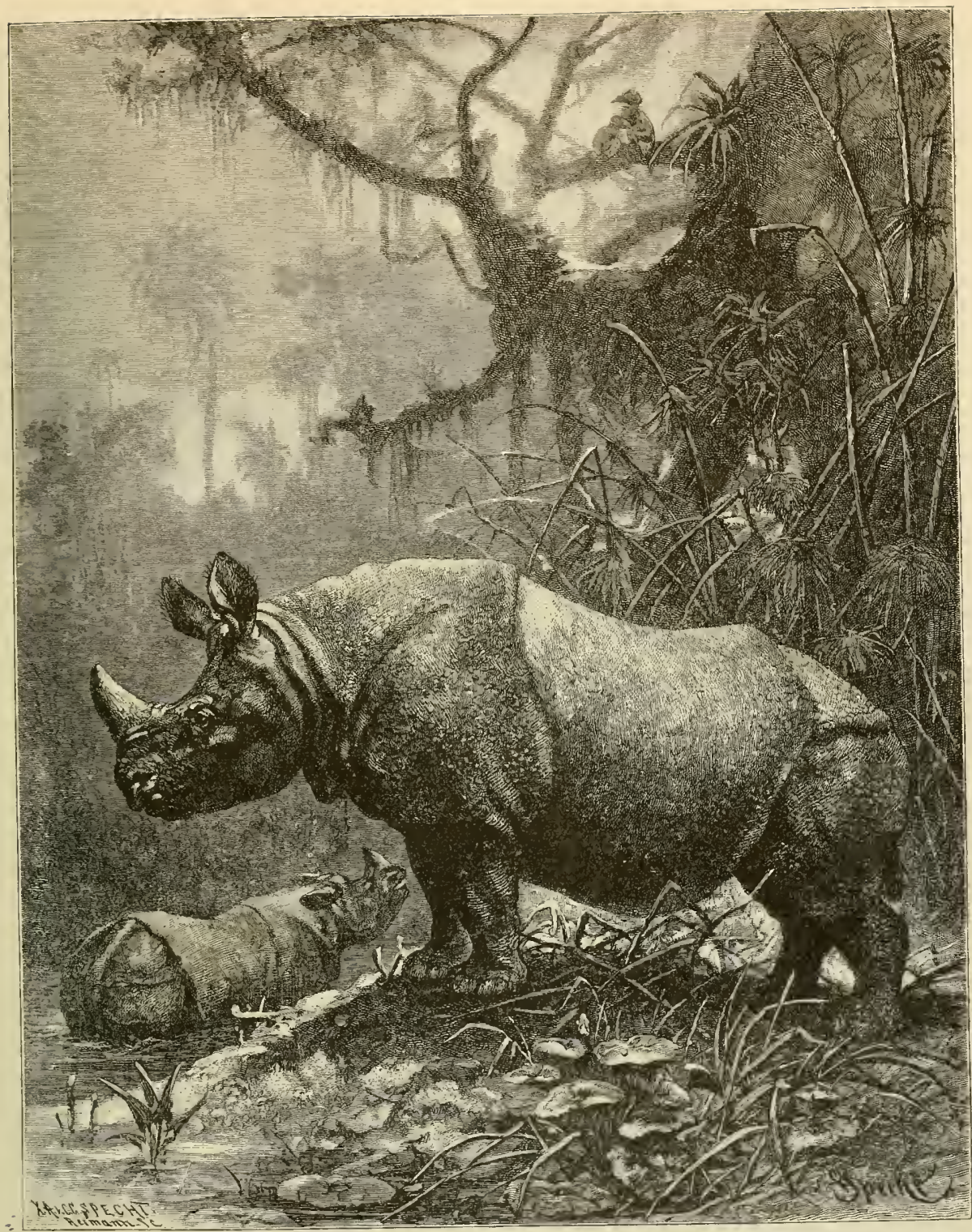

in a deep, danip part of the jungle, where a convenient stream invites to aquatic exercise, are two Rhin strange, wrinkled neck, and the single horn, surmounting the muzzle, combine to give this animal an especially formidable appearance. (Rhinoceros unicornis.) 
selves in a thick crust of mud. Before even going in search of food, the animals hurry to the soft banks of lakes, pooks and rivers, dig a hole in the marshy soil and wallow and turn about in it, until their backs, shoulders, sides and abdomen are covered with mud. This wallowing in the mire is so grateful to them that they utter loud grunts of satisfaction and may even be entranced and occupied by the comfortable bath to such an extent as to forget their usual wariness.

The Rhinoceroses are more active by night than by day. Great heat is distressful to them; for this reason they sleep through the warmer part of the day in some shady place, lying recumbent, half on the side, half on the abdomen, the head stretched out upon the ground between their forelegs, or resting on those members, or sometimes they lazily stand in some quiet place in the wood, where the thick foliage of the larger trees protects them from the burning rays of the sun. All observers agree that the sleep of these animals is very deep. Frequently one may approach sleeping Rhinoceroses without special caution, for they lie apparently as lifeless as blocks of stone. Generally one hears the resounding snore of a sleeping Rhinoceros at quite a distance and has his attention attracted even if he fail to see the creature. It sometimes happens, however, that a Rhinoceros breathes quietly when asleep, and that one suddenly confronts one of these monsters without having had a suspicion of its proximity.

Feeding Grounds At the approach of night, and in and Food of the many localities as early as the after-

Rhinoceros. noon, the unwieldy creature rises, takes a mud-bath, luxuriously stretching its limbs in it and then goes forth to forage. It feeds in dense forests, hardly accessible to other animals, as well as in the open country; in the water and pens and thickets of the swamps, no less than in high dry lands of the mountains and valleys. In the jungles of India the traveler frequently observes long and perfectly straight roads made by Rhinoceroses, all vegetation along the way being crushed aside, and the soil being trampled compactly and much worn. In the center of Africa similar paths may be seen.

In regard to its food, the Rhinoceros occupies about the same relation to the Elephant as the Ass to the Horse. It browses on branches and dry, hard shrubbery of all kinds, eats thistles, broom-grass, underbrush, reeds, prairie-grass and so on, without, however, being averse to more succulent food. In Africa the main sustenance of some individuals consists of branches, especially those of the widely plentiful thorny mimosas; others confine themselves principally to a diet of tuft-grass. Occasionally the animals commit considerable depredations in the cultivated fields of the districts in which agriculture flourishes. They trample down and destroy a great deal more in plantations than they eat. The food is gathered with the wide mouth or seized and broken with the prehensile extension of the upper lip, which fulfills the functions of a hand-like appendage, when the animal eats. The Indian Rhinoceros can extend the trunk-like projection of the upper lip to the extent of about six inches, and seize a thick tuft of grass with it, pull it up and convey it to the mouth. Whether the grass is clean or whether some earth adheres to the roots, secms to be a matter of indifference. It is true that the animal beats a pulled-up bush against the ground once, in order to shake off the bulk of the carthy matter adhering to the roots, but after that one effort it conveys the plant into its huge mouth with the utmost complacence, and swallows it without evincing any discomfort or making any obvious effort. It is also partial to roots; these it is able to obtain with great shill and ease. When in a playful humor, it amuses itself by digging a small tree or shrub out of the ground, for purc pastime, sweeping its powerful horn about under the roots, until it can finally seize the bush and lift it up; then the roots are broken off by successive blows and consumed.

Mental Character-The character of the Rhinoceros is istics of Rhi- not very attractive. Its entire time noceroses. is passed in eating and sleeping, and it seems to be unaware of the existence of the rest of the world. Unlike the Elephant, the Rhinoceroses do not live in herds, but usually singly or at the utmost in small bands numbering from four to ten. There is little connection between the members of such a herd; as a rule each lives for itself and acts as it likes. Tet it cannot be truthfully affirmed that one regards the other with dull indifference; for, leaving a mother and her young out of consideration, friendly, and even affectionate relations often exist between the two sexes, which may be of a very tender and lasting character, sometimes ending only with death. Their mental faculties appear as sluggish as their bodies, but in reality neither are so. A Rhinoceros generally strides along with a ponderous and somewhat clumsy gait, and when it lies down and wallows, it seemingly does so as awkwardly as possible; but these movements appear more clumsy than they really are. The Rhinoceros does not pace or amble like the Elephant, but strikes out with the opposite fore and hind legs simultaneously, after the manner of a trotting Horse. Every Rhinoceros indulges in swimming, but generally remains on the surface of the water, and does not dive unless it is absolutely necessary.

Senses and Mental Among the perceptive senses of the Attributes of Rhi-Rhinoceros, that of hearing ranks noceroses. first; smell comes next and then touch. Sight is very weak. The sense of hearing must be extremely acute, for the animal is cognizant of very slight sounds proceeding from a great distance. The presence of the sensation of taste can not be denied; at least I observed that sugar was an article considered highly desirable by tame specimens, and consumed by them with special delight. The vocal utterance of the Rhinoceros consists of a dull growl, changing into a ferocious snorting and panting in anger. In a state of natural freedom these snorts may be frequently hcard; for the rage of a Rhinoceros is easily excited and its habitual indifference toward everything that does not come under the classification of food, may very soon turn to the direst anger. It is then absolutely reckless of the number or strength of its enemies, and blindly rushes straight at the object of its wrath. The frenzied animal seems to care very little whether a troop of armed Nen oppose it, or whether the object of its ire is perfectly inoffensive and insignificant. Red objects are said to irritate it, as they do a Bull; at least it has been known to attack pcople attired in bright colors, who had done nothing to provoke it. Fortunatcly escape from a Rhinoceros rushing on in blind rage is not difficult. An cxperienced hunter allows it to approach to within ten or fifteen paces distance and then suddenly jumps aside out of its pathway; the frenzied beast rushes past him, unable to turn until it has gone too far to scent its foe any longer, and continues its mad chasc at 


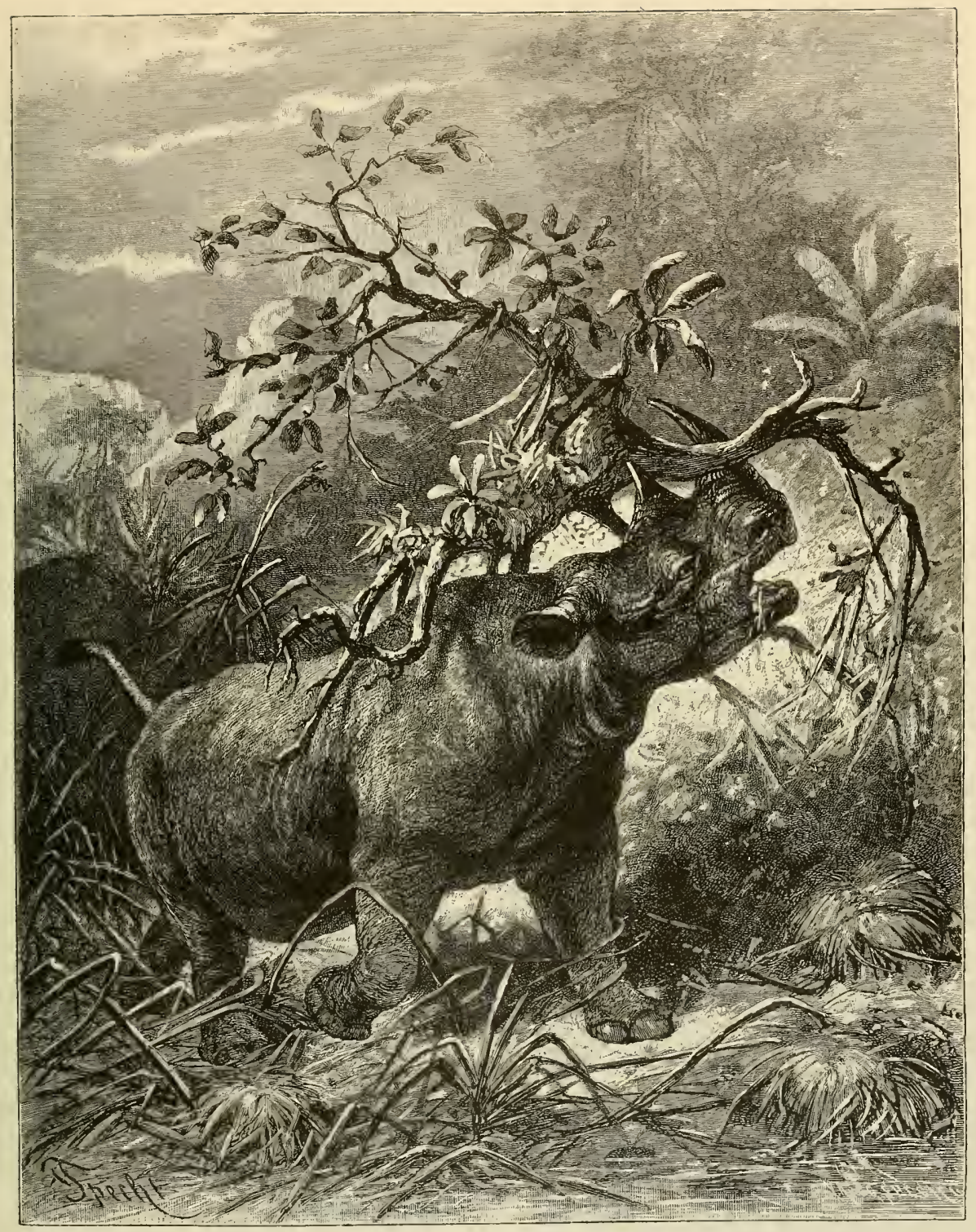

TWO-HORNED RHINOCEROS. - This is an African species, very much at home in the dense forest, which amply supplies it with the leaves and young shoots which form its food. Once very common throughout Africa, its numbers are decreasing yearly because of the vigor with which it is hunted. (Rhinoceros bicornis.) 
haphazard, perhaps venting its rage on another and imnocent object which it may chance to meet.

Reproduction and The female Rhinoceros gives birth Growth of the to only a single young one in any Rhinoceros. one year. It is a small, clumsy beast about the size of a half-grown Pig, and born with open eyes. Its ruddy skin is devoid of folds, but a rudiment of the horn is already to be discovered. It is not known how long the young Rhinoceros remains under the care of its mother; neither is the relation of the father toward his offspring known. The growth of the young animal progresses rapidly during the first few months. A Rhinoceros which measured about twenty-four inches in height and forty-four inches in length on the third day, grew five inches in height and six inches in length in one month. By the time it is thirteen months old it has usually attained a height of forty-eight inches, a length of eighty and a girth of eighty-four inches.

Relations Between In former times many tales were Rhinoceroses and current relative to the friendships Other Animals. and animosities of the Rhinoceros. Especially was the Elephant said to be in continuous strife with it and to be always defeated. These stories, descending to us from the days of Pliny, are occasionally warmed over by some traveler, but doubtless should be regarded as fables. The stories recounting the friendly relations existing between this animal and weaker creatures are more correct. Anderson, Gurdon Cumming and other noted tralelers and writers, nearly always found the Twohorned as well as the large IIhite Rhinoceros attended by a friendly bird, to which the animal has lent its own name, and which faithfully accompanies its giant friend throughout the day, in a certain way performs the services of a sentinel and feeds on the vermin with which the animals swarm. It therefore keeps in the immediate neighborhood of the animals or perches on their very bodies. These birds are the best friends of the Rhinoceros and rarely fail to apprize it of an impending danger. Naturally the faithful attendance of these birds is appreciated, for the most dull-witted mamnal would feel grateful for the great benefit they render it by picking off the tormenting insects. Yet I will leave it an open question whether or not, at the approach of an enemy, especially Man, the birds peck at the ears of the animal upon the body of which they find their favorite food. I incline to the belief that the general restlessness which the feathered sentinels exhibit at the sight of anything suspicious, is sufficient to put the Rhinoceros on the alert. We know beyond peradventure, that certain specially cautious or timid birds are appreciated by other animals as sentinels and warners, and encouraged by them to cultivate intimate social relations. The Rhinoceros probably encounters few willing antagonists besides Man. Lions and Tigers shun the animal, because they know that their claws are too weak to inflict deep or effective wounds upon it because of the protection afforded by its ithick coat of mail, but they may occasionally menace a calf separated from its mother. The Rhinoceros fears other small animals much more than it does the large beasts of prey, and finds most annoying foes especially among some kinds of Gad-flies and MIosquitoes.

Man the Arch Ene. Man is undoubtedly its most danmy of the Rhi- gerous foe. The people of nations noceros.

within whose domain the unwieldy creature lives, as well as European sportsmen, pur- sue it must diligently. It was formerly erroneously believed that the thick hide was bullet-proof; there is no doubt, however, that a knife, a spear or even an arrow projected from a strong bow can pierce it. The native hunters endeavor to approach the Rhinoceros against the wind during its sleep, and thrust their spears into its body or apply the muzzles of their guns very close to some vulnerable part in order that it may receive the full impetus of their bullets. The Abyssinians employ javelins, sometimes flinging as many as fifty or sixty at one Rhinoceros. When it is somewhat exhausted with the loss of blood, one of the boldest approaches it and tries to hamstring it by severing the main tendon of the hind-leg with a sharp sword, in order to paralyze the movements of the animal and render further resistance impossible. In India Elephants are employed in the chase, but even they are sometimes endangered by the attacks of the infuriated animal. The African species are hunted by Europeans in the same way that Elephants are: the sportsman lies in wait for them at night at their drinking place; they are stealthily approached in the thicket where they lie asleep by day, or the hunters ride up to them in the open country, in order to secure an opportunity to send bullets of large caliber, propelled by heary charges of powder, into the most vulnerable region of their bodies from the nearest possible distance.

Various Methods of The capture of the beast alive is Capturing the attended by greater difficulties than Rhinoceros. the hunt. The Vara Rhinoceros is taken mainly on account of its horn, which brings a high price among the Chinese. In order to capture it deep, narrow pits are dug in the course of its paths; these pits are planted with stout, sharp-pointed poles intended to pierce and impale the heavy animal as it falls; they are then carefully covered with branches of trees. The Rhinoceros pursues its usual pathway. breaks through the branches and tumbles into the pit, and even if it escapes being injured, it is still unable to climb out and effect an escape. The young Rhinoceroses, which are occasionally sold in the various markets of the world, are caught in Africa by hunting parties during the breeding season. Old cows with calves are sought; the mothers are killed and the young are then easily captured.

Selous recounts a remarkable case of helpless confidence shown by a young Two-horned Rhinoceros. One morning as he was setting out for a hunt with his compantion, Mr. Wood, they unexpectedly met an old Rhinoceros near a fence, and immediately shot it, hitting it with two bullets. The animal was seriously wounded and fled, and then only did they discover that it was a cow, and that a calf a few days old was vainly endeavoring to follow it. The little creature desisted from its purpose and crept under Wood's Horse, while Selous despatched the mother with a final shot. "On returning to my friend," says he, "I found him sitting under a trce, and the calf standing close to his Horse, which did not seem to be at all afraid of the little monster. The little calf was hardly larger than a half-grown Pig, and showed no sign of fear when we or our native attendants came up to it and stroked it. Onc circumstance struck me as odd; it perspired violently all over its back, something which I never saw an adult Rhinoceros do. Is the untamed little orphan followed IVood's Horse, as if it were its mother, we concluded to take it along to our vehicles, which were some six miles away, and to try to rear it. So we set ont and the little creature followed us like a Dog. The hot 
sun seemed to inconvenience it greatly, for it stopped at every shady bush; but as soon as we would advance about thirty paces ahead, it would wave its little tail, squeal and trot on to join its Horse. Finally we reached the wagons and then the behavior of the confiding little creature underwent a sudden change. Whether it was due to the presence of the Dogs, which jumped around it barking, or to the unfamiliar appearance of the carts, the general aggregation of human beings, smells and miscellaneous objects which go to make up a camp, I do not know, but our protege was suddenly transformed into a veritable little devil, furiously charging at Men, Dogs and even cart wheels. We secured it by means of a strap around its neck and shoulders, but it proved very refractory during the operation, jumping into the air, rushing at me and furiously thrusting at my knee with its nose. IVe fastened it to a cart-wheel, and it began to quiet down, but whenever approached by Man or Dog it relapsed into its former savagery. As I liad feared, it took none of the nourishment prepared and offered to it by us; milk would probably have proven acceptable, but unfortunately we could not get it, as we had no cows. As all attempts to induce it to eat failed, and we could foresee that if we set it free, it would either miserably starve or breathe its last between the teeth of some Lion or Hyana, I decided to shoot the forlorn creature, which it would have given me so much pleasure to rear."

In our zoological gardens the majority of Rhinoceroses are goodnatured and tame, suffer themselves to be petted, driven back and forth, and generally managed without offering any resistance, and gradually become strongly attached to every keeper who treats them judiciously. There is only one case on record in which a captive Rhinoceros exhibited a vicious disposition, and that was where one of these animals attacked and killed two Men.

\section{The contics.}

\section{THIRD FAMILY: HYRACIDE.}

At many places in the wild, desolate, mountain regions of Africa and western Asia, the arrival of Man induces a great display of activity. Lively animals about the size of Rabbits, which have been basking in the sunshine, are frightened from their stony beds by the unusual invasion, whisk about on the rocks, disappear in the innumerable crevices, and then return to the openings and watch their strange invaders with a quaint air of harmless curiosity. These are the Conies, the smallest and daintiest of all the existing species of Odd-toed animals.

Classification and Naturalists have held widely diver-

Characteristics gent opinions as to the classification

of Conies. of these pretty cliff-dwellers. Pallas, because of their habits and outward appearance, classed them as rodents; Oken thought them to be related to the marsupials, or pouched animals; Cuvier placed them in his order of "Many-toed animals." Lately his classification has also been disputed, and Huxley has raised them to the dignity of representatives of a distinct order. We regard them as belonging to the order of the Odd-toed animals, without entering into a discussion as to whether our doing so is the correct solution. They constitute only one family.

The distinctive features of the Conies (Hyracide) are as follows: the body is of elongated, cylindrical

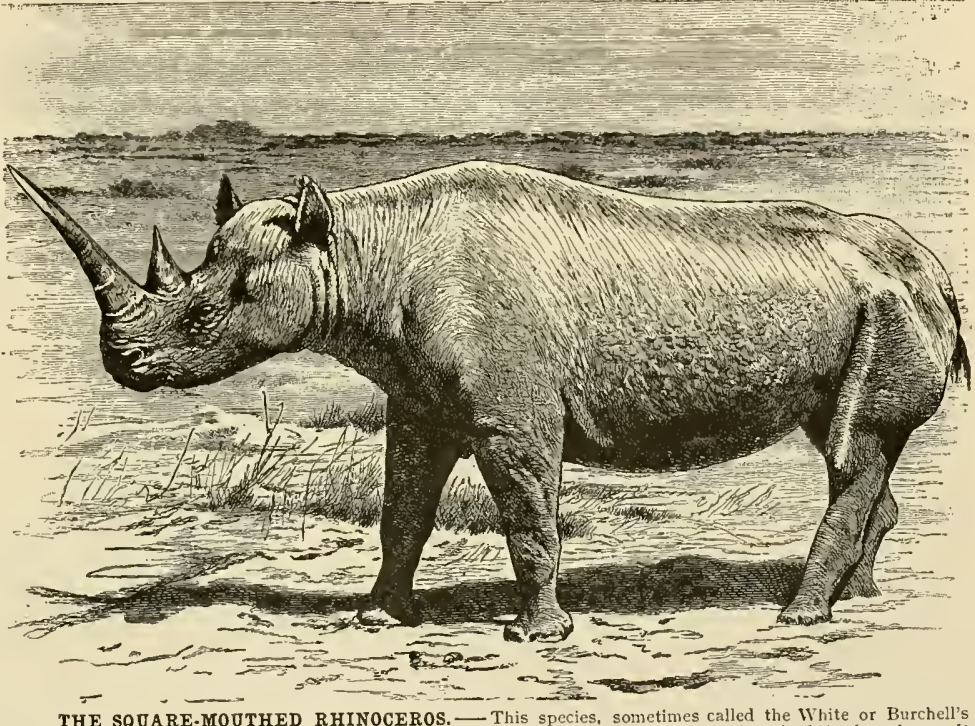
THE SQUARE-MOUTHED RHINOCEROS. - This species, somet the great length of the front horn. It lives by dist Africa south of the Zambesi, and its flesh being of excellent flavor it has been hunted until it is very scarce. No speciAfrica south of the Zambesi, and its flesh being of excellent flavor it has

form; the head is comparatively large and clumsy, tapering toward the front and much compressed laterally; the upper lip is cleft, the top of the nose fine and delicately shaped; the eye small, but prominent, the ear, nearly buried in the fur, is short, broad and round, the neck short and stout, the tail a barely perceptible stump; the legs are moderately long and somewhat weak, the delicate feet are rather long, and there are four toes on each of the front pair, and three to each of the hinder feet, the toes being joined together to the last joints by a web of skin, all being provided with flat, hoof-like nails, except the innermost toes of the hind feet, which are each surmounted by a claw-shaped nail. The naked soles consist of several flexible, callous pads, divided by deep fissures. A copious, soft fur, consisting of one coat only, covers the body and limbs.

The Cony an Ani. The Conies are mentioned by various mal of Ancient writers as well-known animals in days Prestige. of remotest antiquity. The variety inhabiting Syria and Palestine seems to be referred 
to in the Hebrew text of the Bible under the name of Laphan, which Luther translated by the word "Rabbit," and in the authorized and revised versions is rendered "Cony." The Conies may for the greater part be considered characteristic animals of mountainous regions of the deserts and of elevated table-lands. Represented by several varieties, they inhabit all the mountains of Syria, Palestine and Arabia, perhaps also of Persia, the Nile country, east, west and south Africa alike, frequenting elevations of 6,000 or 9,000 feet above sea level, and the peaks and cones that rise like islands sheer above the surface of the plains - the presence of the little animals constituting one of the characteristic features of the high table-lands of northeastern Africa.

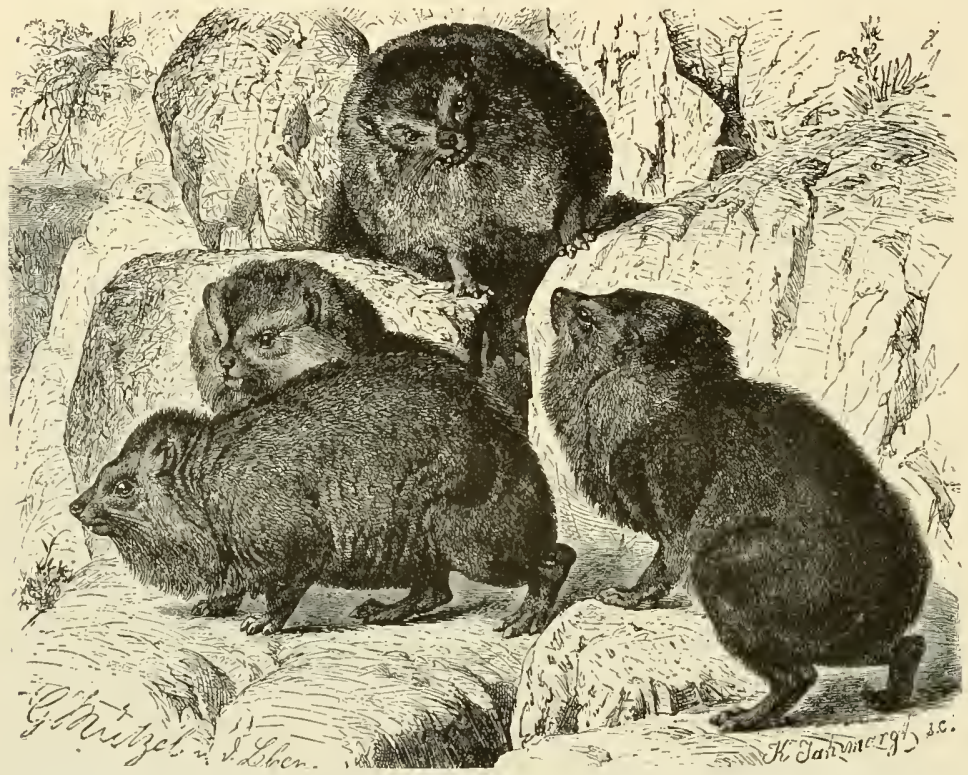

THE CONY. - The Book of Proverbs, enumerating four animals which it describes as "exceeding wise," says "the Conies are but a feeble folk, yet they make their houses in the rocks." These are the animals in the picture, which are timid and wary, and congregate in large numbers in the mountains of northern Africa and western Asia. (Hyrax abyssinicus.)

The Abyssinian For the purpose of our description

Cony, or Ash- we select the Abyssinian Cony, or koko. Ashkoko (Hyrax abyssinicus) as it is the variety best known to us. The animal measures from ten to twelve inches in length; the fur consists of moderately long, fine hairs, gray-brown at the base, lighter gray in the middle portions, merging into a dark brown surmounted by a light colored tip, the resulting general color of this combination being a mottled pale gray. Modifications of tint seem to be of rather frequent occurrence.

The more fissures and crannies there are among the rocks, the more numerous these animals are. If the observer quietly passes through the valleys he sees them sitting, or more frequently lying, in rows on the projecting ledges; for they are a lazy, comfort-loving tribe, which like to bask in the warm sunshine. A rapid movement or a loud noise disperses them instantly; the whole assemblage quickens to life, all flee with an agility like that usual among rodents, and almost instantly disappear. In the neighborhood of villages, where they are also to be found, sometimes in immediate proximity to houses, they show scarcely any fear of the natives, and boldly attend to their various affairs as if they understood that nobody thinks of molesting them; but when approached by people whose color or attire differs from that of their usual human neighbors, they immediately retreat to their holes in the rocks. A Dog or other animal of the lower orders inspires them with much greater fear than does a human being. When startled by a canine foe, even after they have become hidden, safe from pursuit, in their rocky crevices, they continue to give utterance to their curious, tremulous yell, which resembles the cry of small Monkeys.

We must confirm the observation of a former traveler, who called attention to the striking fact that the peaceable and defenseless IIyrax lives in the permanent society and on the best of terms with a by no means despicable beast of prey, a variety of Mungoos (Herpestes zibra). A Lizard, probably one of the species of the Star Lizard (Stillio cyanogaster) also joins the two. It would seem that the prudent Cony fills the office of sentinel in this triple alliance, for as soon as it utters its shrill whistle the entire collection disappears in the crevices between the stones.

The Conies are averse to leaving their mountainous, rocky domicile. When the grass growing between the boulders has been eaten off, they descend for food to lower regions, but they always post sentinels on the most prominent peaks of rock, and a warning signal from one of these guards suffices to incite a hurried flight of the entire body.

Traits, Reproduc- In regard to their movements and tion and Hunt. mental characteristics, the Conies ing of Conies. seem in certain particulars to be intermediate in position between the unwieldy Rhinoceroses and the nimble Rodents. They are excellent climbers. A close investigation of the soles of their feet, which are as elastic and springy as rubber, reveals the fact that the Hyrax is able to contract and distend the middle cleft or fissure of its solepad at will, and thereby to secure a hold on a smooth surface by means of suction. The behavior of the Conies indicates great gentleness, and even simplicity, combined with excessive timidity. The social instinct is highly developed in them and they are rarely met singly. 


\title{
The Cloven=ilbooted Inimals.
}

\author{
ELEVENTH ORDER: ARTIODACTYLA.
}

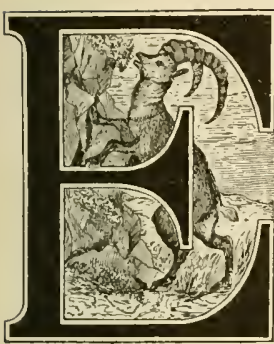

SPECIALLY conprehensive is the order of the Artiodactyla or Cloven-hooted Animals, which inchudes all hoofed aninats which have only two fully developed toes on each foot, or in which these two at least greatly exceed the three other toes in size. The third and fourth toes, corresponding to the middle and ring-finger in the human hand, are the digits which are especially large and are of equal development one with the other, while the others are more or less stunted or merely rudimentary. The first toe, corresponding to the human thumb, is entirely wanting in all Artiodactyla. The bony skeleton is remarkable for the great uniformity existing among all the species in the number of dorsal and lumbar vertebra which together always amount to ninetcen, except in the case of some domestic breeds, and by the absence of the clavicle or collar-bone. If we add further, that the molar teeth or "grinders" seldom exhibit internal convolutions of enamel, but have a filling of dental pulp alone, we will have entmerated all the common peculiar features in the bony structure of the Artiodactyla, not taking into consideration resultant peculiarities of development. In regard to their mode of life all Artiodactyla resemble each other in that the majority of them are exclusively herbivorous, while the remainder are, to say the least, chiefly vegetable feeders. In all other regards the order shows widely different forms, corresponding to its abundance of species.

The Artiodactyla are not indigenous to New Zealand and the continent of Australia, but are natives of all other countries in which terrestrial mammalia are to be found. Prehistoric fossil Artiodactyla are first met with in Tertiary geological formations and of some families there are many fossil genera nearly related to existing forms.

The abundance and variety of species of the Artiodactyla render it desirable for convenience in classification to divide the order first into suborders. We distinguish two of these: the Manyhoofed, in the individuals of which the second and fifth toes are more or less developed in addition to the two principal toes, and the Ruminants or Twohoofed, in which the toes other than those developed into the two hoofs have either entircly or for the greater part disappeared. In the former the metatarsal and metacarpal bones are separate, but jointed together in a manner similar to those of human fingers and toes, but in the Two-hoofed species these bones are fused together, or ankylosed, forming in each foot a solid bone.

\section{TRuminants or $\tau$ wo=lboofco Elnimals.}

\section{FIRST SUBORDER: BHACTYLA.}

The Ruminants, or Two-hoofed animals (Bidactyla). are all closely allied to each other, notwithstanding the fact that they exhibit a great variety in their external structure and appearance. They may possess horns or entirely lack those appendages, may be beautiful or ugly, of graceful or clumsy form, and they also show great diversity in size. Speaking generally, the following may be enumerated as distinctive features of the animals of this suborder. The neck is long and very mobile, the head broadens considerably across the forehead or frontal region, and is frequently adorned by horns or antlers. The eyes are large, lustrous, and are frequently exceedingly beautiful, the erect ears are well shaped, the lips are mobile, often naked and nearly always devoid of whisker hairs or bristles. The tail is usually short, rarely reaching to the ankle-joints. The hair, which is for the greater part short and thickset, lies close to the body; but sometimes grows into a mane or tuft on the neck, on the lower part of the under jaw or chin, on the back and at the tip of the tail. The hair is never bristly, and is often of fine texture, woolly and curly, and its color varies very widely in different species. In all species the structure of the skeleton and of the teeth shows great similarity. Of incisors there are from six to eight in the lower, and none, or in rare cases, two in the upper jaw. There are either no canines or only one on each side of both jaws. There are from three to seven molars on each side of the upper and from four to six molars on each side of the lower jaw. The incisors are usually sharp, broad and spade-shaped, but those of the upper jaw have a shape similar to the incisors of a Dog. The canine teeth of such Ruminants as possess them are conical, and in a few species protrude laterally from the mouth. The molars consist of two pairs of crescent-shaped pillars, the surfaces of which exhibit protruding folds or convolutions of enamel. The skull is elongated and tapers toward the extremity of the muzzle; the orbits of the eyes are separated from the temples by a bony bridge formed by the temporal and molar or cheek bones; the brain cavity of the skull is small. In the spinal column the unusually long, narrow mobile cervical or neckvertebræ attract the anatomist's attention. In all Ruminants, without exception, only two toes, the third and fourth, are perfectly developed. The mouth is characterized by strong labial or lip muscles and numerous papille or minute excrescences on the inside; the salivary glands are comparatively large; the stomach consists of four, or at least three different compartments; the paunch, the honeycomb bag. the manyplies and the reed or rennet. The first is in immediate communication with the gullet or 
resophagus, the last with the intestinal canal. The paunch receives the coarsely masticated food, and by muscular action pushes it in small quantities into the honeycomb bag, the network of folds in which accomplishes preliminary digestion and forms the food into pellets, which arc again brought up into the mouth, finely ground by the molars, thoroughly mixed with saliva, and then sent into the manyplies through two folds of the gullet, which form a channel; and thence the food passes to the rennet, in which it is finally digested.

Horns a Factor in The horns or antlers possessed by Classification of many Ruminants are of some im-

Ruminants. portance in the grouping and classification of species. In general they are divided into two groups: The Two-hoofed animals wearing horns, and those possessed of antlers. By the use of the term horns are indicated those formations of horny substance which are articulated with or rest on a bony basis of the elongated frontal bone, and are really mere hollow, conical, horny shells; they are never shed and renewed, but only increase in size as the animal develops. Antlers, on the other hand, are horns, rooted in comparatively small prominences of the frontal bonc, and which consist of solid, bony tissue throughout, and as the age of the animal increases, branch more and more until they attain a certain point of development. The antlers are shed every year and replaced by new ones in the course of a few months. As a rule, only the nrale animals have antlers; while horns are common to both sexes of the animais bearing them. The hoofs are subject to much variation in shape and size.

Distribution and The Ruminants are indigenous to all

Habits of Ru- continents with the exception of

minants. Australia. There does not seem to be a uniform distribution of the main groups. The horned animals or bovine group and the Deer have the widest range, while the Giraffe and Musk Deer group have the most restricted distribution; the Deer are wanting in the Fthiopian belt, being on the other hand the only Ruminants in the South American belt; the Musk Deer are indigenous to central Asia only, the Giraffes only to Ethiopia; and the Cherrotains are wanting in America.

Nearly all Ruminants are shy, fleet, peaceably inclined animals, well-endowed in most physical respects, but equipped to only a limited extent with intellectual attributes. Many live in herds, all collect into bands or troops. Some inhabit the mountains, some the plains; no species is really aquatic, though some prefer swampy lowlands to dry plains. They are exclusively vegetarian in diet. They are fond of herbage, leaves, young shoots and roots, some also of grains, and others of lichens. The young of the Ruminant species are usually born singly, although in rare cases there are two and in exceptional instances three at a birth. In the case of most Ruminants their usefulness to Man outweighs the damage they inflict upon his possessions, whether we consider the species that have been domesticated or those yet in a free state, although a few species are great annoyances to the people of certain countries in which agriculture has yet attained to but an inferior phase of development. The flesh, hide, horns, hair and bones of both wild and tame species are put to almost innumerable uses. That the Ruminants furnish materials for the manufacture of the greater part of our clothing, is well known. As domestic animals they do not exhibit any remarkable sagacity, but are docile, patient and easily maintained, and for these reasons have become indispensable to Man. The four families of the Chevrotains, Musk Deer, Pronghorns and Giraffes, which exhibit such a paucity of species, are the only ones which have not been employed as domestic animals; of all the other families one or more species have become the servants and allies of Man. The majority of the species living in a wild state have always been considered the choicest quarry of sportsmen, and thus have been the recipients of regal honors.

The evidence of geological strata, dating from the remote period of the Tertiary formation, goes to show that the Ruminants have not undergone many radical changes, and that in a majority of cases the prenistoric species are identical with those now in existence.

Division of the IVe divide the Ruminants into seven Order of Ru- families: the Giraffes (Camclopartaminants. lide), the Camels (Camelide), the Horned Animals (Borida), the Prong-horns (Antilocapride), the Deer (Ceritide), the Musk Deer, (Moschide), and the Chevrotains (Tragulide), of the characteristics of each of which we will speak when we reach their respective divisions.

\section{Tbe Giraffes.}

\section{FIRST FAMILY: CAMELOTARDALIDE.}

Among existing Ruminants we still find forms which present characteristics peculiar to themselves, and suggest an affinity to no other creatures of the present day, but rather reminding us of the creatures described in the fairy tales of a by-gone age. The most striking of these anomalies is the Giraffe. Varro is not so very far wrong in defining this strange animal as a "mixture of Panther and Camel," and those who lived at a much later date were certainly excusable when they scornfully pronounced the pictures of the animal (of which commercial stagnation had made them ignorant, but which in the revival of intercourse they had found again on Egyptian monuments) the dream-fancies of an unbridled artistic imagination. And as the Romans wondered at the Giraffes which they beheld at the games of Julius Casar and on several subsequent occasions, so do we, the enlightened generation of the nineteenth century, marvel when we first see the curious creature that we know so well from having often seen its pictures.

Peculiarities of The Giraffe is the representative ot

the Giraffe a distinct family (Camelopardalide)

Family. distinguished by the most character istically developed structure of the foot. In the present stage of evolution of original species the Giraffe or, as would be most correct, "Serafe" (Camelopardalis giraffa) is the only member of the family. It is characterized by a neck the length of which exceeds all normal measurements, very long legs, a stout body with a sloping back, a delicate, fine head with large, beautiful, clsar eyes and two queer, horn-like projections of bone arising from the frontal region and covered with skin. The long legs and neck combine to render the Giraffe the tallest and at the same time comparatively the shortest of all mammals, for its body measures only ninety inches in iength, while the height at the shoulders is ten feet, and the head is from sixteen and one-half 


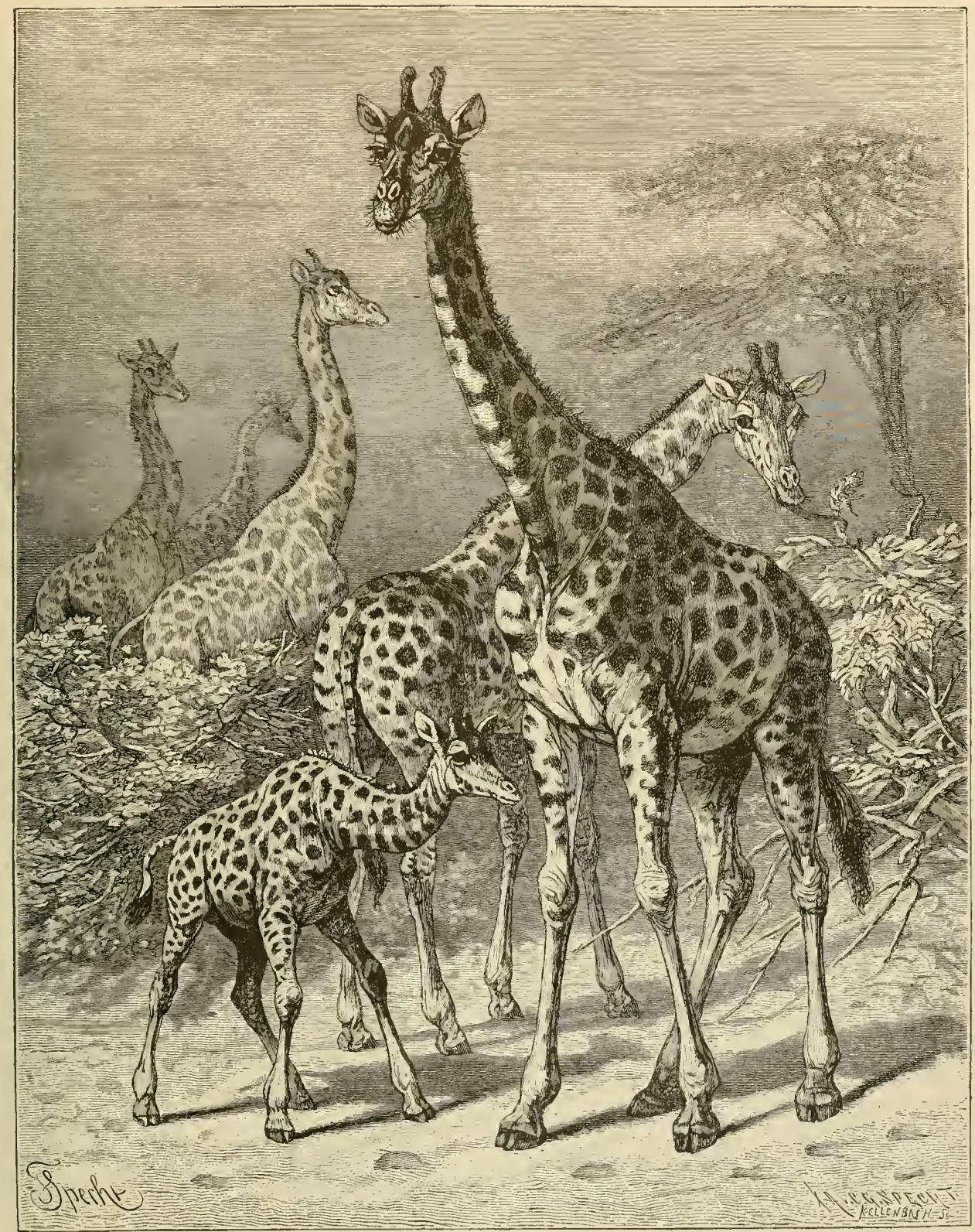

THF GIRAFFE - The tallest of all animals, deriving its exceptional height from its great length of neck and limbs. The group in this picture is shown with its native surroundings, among the mimosa trees of its native Africa. The spotted coat and tufted tail are here seen, and the aninial hav
ing its head most to the right in the pictnre also exhibits another pecnliarity of these animals-the long and elastic tongue. (Camelopardalis giraffa.) 
to twenty feet above the ground. The tail measures forty-four inches, including the tuft of hair at the end and thirty-two inches without it. The distance from the tip of the muzzle to the base of the tail amounts to thirteen and one-third feet; the weight is $I, 000$ pounds. These external measurements alone serve to show that the Giraffe deviates in its shape from all other mamnals; but its anatomical structure is so remarkable as to require a detailed description. The Giraffe appears, as we said before, not only as a queer compromise between the Panther and the Camel, but seems to have been fabricated, as it were, out of the component parts of the bodies of different animals. Head and body seem to be taken from the Horse, neck and shoulders from the Camel, the ears from the $O x$, the tail from the Ass, the legs from the Antelope, while the coloring and markings of the slcek skin remind one of the spots of a Panther. Such a combination can not fail to produce an animal of abnormal shape, and nobody is likely to be inclined to call a Giraffe beautiful. The short body is entircly out of proportion to the long legs and neck; the precipitously sloping back must be pronounced ugly from an artistic standpoint, and the immense height of the animal does not contribute to its beauty by any means. The lines of the head are magnificent, the eye of wondrous beauty and the markings of the skin are attractive, but all the rest is queer and striking, making the Giraffes veritable oddities.

special char- The elongated head of the Giraffe acteristics of the appears longer than it really is, on Giraffe.

account of its rather thin muzzle; it has very large eyes of an exceeding brightness, and yet extremely gentle in expression, large, delicate and excessively mobile ears about six inches long; and two projections on the forehead, which faintly resemble horns, and are somewhat shorter than the ears. Between the two there is a third roundish protuberance of the bone, a third horn, as it were. The neck is as long as the fore-legs, thin, laterally compressed and adorned with a pretty crest of hair on the upper posterior surface. The body is broad across the eliest, much higher at the withers than at the crupper; and somewhat depressed along the middle line. It is strongly characterized in the fore part of its structure by the shoulder-blades, which protrude at nearly right angles to the axis of the body; and as the animal's body is greatly narrowed toward the buttoclis it follows that on a front view of the animal, the observer does not see the hinder quarters at all. The legs are comparatively slender and nearly of equal length; the hoofs are of dainty shape. A naked callosity, like that of the Camel, covers the knees of the fore-legs and the hock-joints of the hind-legs. The hide is very thick and its hairy covering is uniform throughout, except upon the callous pads just mentioned, the crest of the neck and the tuft of the tail. A faded sandy yellow forms the ground-color, darkening on the back, and merging into a whitish hue on the under part. It is marked by rather large irregularly shaped russet-brown spots of varying shades, whicli are so close together as to give the light ground an appearance resembling a network. On the neck and legs the spots are smaller than on the remainder of the body. The abdomen and the inner surfaces of the limbs are free from spots. The mane is of a pale tint and banded with brown; the ears are white in front and at the base, and brownish behind, and the hair-tuft is of a deep black tint.
The Distribution The present range of the Giraffe exof Existing tends in a wide curve over the eastGiraffes. ern half of Africa, from about the sixteenth parallel of north latitude to the twentythird parallel of south latitude; in the Kalahari alone it may extend somewhat farther southward, but by no means as far as the Orange River. In the whole of the Congo region the Giraffe seems to be absent, being also unknown in Upper and Lower Guinea and the country further to the interior. In former times its range extended to the coasts of the Atlantic ocean in southwestern Africa. It was exterminated, however, all along the coast more than a generation ago.

In its native woods the Giraffe certainly produces a different impression from that made by it when confined within the narrow enelosure of a zoological garden. The curious but frequent correspondence of the shape and general appearance of an animal with the other natural objects of the locality in which it lives, is also seen in this case. Gordon Cumming says: "IThen a herd of Giraffes is seen dispersed in a grove of the picturesque, umbrella-shaped mimosas, which adorn their native plains, and on the topmost branches of which their immense height enables them to browse, the observer would be really deficient in appreciation of natural beauty, if he failed to find the sight a very attractive one." The Giraffe is frequently encountered in stretches of country abounding in old, half-decayed, weather-beaten trees, the branches of which sometimes, owing to the moss covering them, strikingly resemble the long necks of Giraffes. The above-mentioned sportsman says: "I was often in doubt as to the presence of a whole troop of Giraffes, until I had recourse to my spyglass. Even my half-savage companions had to acknowledge that their keen, experienced eyes were deceived sometimes; either they mistook those weather-beaten trunks for Giraffes, or else they confounded the real Giraffes with the old trees."

Habits and Mode Giraffes are most often seen in groups of Life of of from six to eight. Where they Giraffes. are undisturbed, however, they frequently congregate in greater numbers. Cumming mentions herds of thirty and forty, but believes sixteen to be the average number.

All the movements of the Giraffe are curious. It looks best when proceeding at a quiet walk, as it then presents a dignified and graceful appearance. Its usual gait is a slow, measured amble, and both legs of one side move simultaneously, after the manner of a pacing Horse. Its running gait is a remarkably uncouth, halting and ponderous gallop rendered ludicrous by the striking disproportion between its height in front and that behind, as well as between its height and length. Still, as every individual leap is very long, the animal is enabled to traverse distances at a very rapid rate. The great size and weight of the fore part of the body render it impossible for the animal to clear the ground of its fore feet by mere muscular strength. It is therefore neeessary for it to arch backward its long neck and thus shift the centre of gravity of the body farther toward its hind quarters, in order to make it possible for the animal to raise its fore quarters from the earth and leap. The Giraffe leaps without bending the fore-legs, lifting them stiffly, with a simultaneous movement of the neck; then follows the springing motion of the hind legs, attended by another niovement of the neck. Thus as Lichtenstein has it, "the neck of a leaping Giraffe moves steadily, swinging, 
back and forth like the mast of a ship dancing on the top of high waves." One requires a very good Horse to overtake a fleeing Giraffe, and it is especially difficult to pursue it to the end, as nearly all other animals tire out sooner than it does.

The attitude the animal assumes when desirous of picking up some object from the ground, or of drinking, is very peculiar. Old descriptions assert that the Giraffe kneels down for this purpose, and in exceptional cases it may do so. As a rule, however, it lowers its fore-quarters by straddling its fore-legs to such an extent as to enable it to reach the ground conveniently with its long neck. People who have not witnessed this feat believe it to be impossible. While sleeping it lies on its side and folds both or only one of its fore-legs. Its sleep is not very profound, and lasts but a short time.

Peculiarities of It stands to reason that the food of the Diet of the Giraffe harmonizes with its shape Giraffes. and other characteristics. The animal is entirely unfitted for devouring grass from the surface of level ground, but is far better able to break the foliage from trees. Its remarkably mobile tongue is of the greatest help to it. Most Ruminants use the tongue for the plucking of their food, but none of them use it so much and so effectually as the Giraffe. What the trunk is to the Elephant, the tongue is to the Giraffe. It can pick up the smallest objects with it, pluck the tenderest leaf and convey it to its mouth. "In our zoological garden," say's Oken, "more than one lady, while gazing at the Giraffes, has been deprived of the artificial flowers adorning her hat. It seems as if the Giraffe is guided by its eye rather than by its nose in the selection of its food, and thus it frequently happens that the animal deceives itself, as in the cases where it tears the artificial flowers from a hat." In the free state the branches, buds and leaves of the mimosas furnish the principal diet of the Giraffe; but it is also fond of browsing on the creepers, which envelop the forest trees of northern Africa in such profusion. As the above-mentioned trees do not grow to be much higher than the animal, the latter obtains its sustenance without difficulty. In the dry season, when the majority of the trees are bare of foliage, and the tall, dry grass affords it but scant fare, it sonetimes travels for miles to drink from some pool or the puddles which remain from the streams that only flow during the rainy season.

Development of The perceptive senses of the Giraffe, the Senses of especially those of sight and hearing,

the Giraffe. are acutely developed; and its mental capacity is of a very high order. It is clever, intelligent and extremely gentle, and in proportion to its size it is a highly good-natured, peaceable creature, living on amicable terms not only with its own kind, but also with other animals, as long as the latter do not annoy or persecute it. In case of necessity it knows full well how to defend itself effectually, not with its horns, which seem to be merely ornamental, -but by dint of vigorous kicks administered by its long, sinewy legs.

Methods of The hunting of the Giraffe is a pasHunting the time of which the African natives as Giraffe. well as Europeans are passionately fond. The former hunt it with the aid of a Camel or a Horse, pursuing the Giraffe until it is thoroughly exhausted, when the pursuers first hamstring it to disable it from kicking, and then kill it. The flesh of the animal is in great demand as an article of food, and other parts of its body are put to va- rious uses. Europeans in hunting it employ firearms, but as a rule succeed in despatching the wary animal only after a prolonged chase, even when possessed of long range arms. According to Selous" experiences, one can overtake a flecing Giraffe with even an indifferent Horse, sufficiently at least to allow the sportsman to dismount and send a well-aimed bullet after it, for it develops its highest speed only in the last extremity. The different parts of the carcass of a Giraffe are put to good use in many ways. The hide is tanned into an excellent durable leather, the tail-tuft is used for fly brushes, the hoofs furnish a good quality of horn, and the flesh is excellent food. Tet the natives especially rejoice when they can possess themselves of a living Giraffe. The striking animal is liked everywhere and everybody is pleased to own one. In the villages in the interior of Africa the traveler frequently sees a couple of Giraffes' heads looming up and peering over the high walls of a garden; and not infrequently one meets tanle specimens coming and going at will in the environs of a settlement. At our arrival in Karkodj, a hamlet on the Blue River, a Giraffe was the first inhabitant to come up to our barge to greet us. It fearlessly and confidingly approached quite close to the boat, ate bread and grains of durra out of our hands, and demeaned itself toward us as if we were old friends. It soon appreciated how great a pleasure it was giving us; for during our sojourn in the place it came several times daily to be caressed. The Arabian name "Serafe," "the lovely one," which has been corrupted into Giraffe, became thoroughly appreciable to me at that time.

Unfortunately the Giraffes exported to other countries endure confinement for a protracted time only with the best of care. The majority die of a peculiar disease of the bones, which has been termed "Giraffe disease." Lack of exercise and inappropriate diet may be the causes of this fatal malady.

\section{Tbe camels.}

\section{SECOND FAMILY: CAMELIDE.}

The family of the Camels (Camelide) are distinguished by callous foot-soles; by the absence of horns and of rudimentary toes; by a cleft upper lip, and by their peculiar dentition. In regard to the latter the Camel differs from all other Ruminants by the possession of two (and in earliest youth six) incisor teeth in both the upper and the lower jaws. The hoofs are very small, being really only ungulate toe-nails of the callous soles. The stomach has only three compartments, as the manyplies is so small that it is usually considered one with the rennet.

Physical Charac- The Camels are very large Rumiteristics of the nants, with long necks, elongated camels. heads, bodies cylindrically compressed in the region of the loins, and shaggy fur of nearly woolly texture.

North Africa, central Asia and southwestern America are the homes of these animals. The few species which this family contains have been almost entirely domesticated in the Old World and partly in the New. In the latter they inhabit the mountains up to elevations of 13,000 feet above sea level; in the former they preferably range over the hot, parched plains. Herbage, leaves and branches of trees, thistles and thorns constitute their food. They are very frugal feeders, and are able to endure hun- 
ger and thirst a long time. Their usual gait is a heavy, jerky amble, and their course appears wavering and awkward in the extreme, although it is really adapted to the speedy traversing of long distances. The wild species are all gregarious and live in herds; Their mental endowments are on a rather low plane, and their moral attributes worse yet. They can not be termed gentle, good-natured, sagacious or patient animals, though they assume the yoke of servitude and acknowledge human supremacy with a certain exhibition of resignation. There is only a single young one at a birth, and the mother bestows much loving care on it.

\section{THE CAMELS PROPER.}

The true Camels (Camelus), all Old-IVorld forms, are distinguished by their large size and by the presence of either one or two humps on the back; they possess two more molars in each jaw than the Llamas or New World species. Their form is ungainly, the head being especially ugly; the hair is very uneven, longer in some places on the body than in others, but on the whole woolly. Callosities are found on the chest and the joints of the legs wherever they come in contact with the ground as the animal kneels to receive a load or when it lies down to rest. There are two species, one predominating in Africa, the other in Asia. They are the Dromedary and the Bactrian Camel, respectively.

Traits and Char- The Dromedary is doubtless the most acteristic of useful of all African domestic aniDromedaries. mals; but it is also the most una. miable, stupid, obstinate and disagreeable creature imaginable; certainly those with which I came in contact deserve such an arraignment. It is indebted for its good reputation solely to its physical attributes; its mental qualities have not been praised even by an Arab, though hundreds of that race could not live without this animal.

The Dromedary, or one-humped Camel (Camelus dromedarius), called Djemmel in Arabia, is a very large Ruminant, averaging in heiglit from six feet, eight inches, to seven feet, eight inches, and a length of from ten to eleven feet, counting from the tip of the muzzle to the end of the tail. Though the Camel does not exist in such a variety of breeds as does the Horse, yet it is subject to numerous artificial modifications. In general it may be asserted that the Camels of the plains or the desert are slender, tall, long-legged creatures, while those indigenous to fertile countries, especially to northern Africa, are clumsy, heavy animals. Between a "Bisharin," that is, a Camel bred by the Bisharin wandering tribes, and an Egyptian baggage Camel, the difference is as great as that between an Arab steed and a cart Horse. The former Camel is excellent for riding purposes, while the latter is one of the strongest beasts of burden in the service of Man.

The Arabs enumerate over twenty different breeds of the "ships of the desert," for there is a science of the breeds of Camels as there is of those of Horses, and in speaking of the Dromedary, one also uses the terms "noble" or "thoroughbred" or "common." In the typical specimen of the Dromedary the following are the salient points: The head is rather short, but the muzale is long and bulging; the eyes are large and of dull expression, the ears very small but mobile. The neck is long, laterally compressed and thickest in the middle. The body is protuberant and rounded on all sides. The hump stands erect but is subject to great modi- fications in size at different seasons of the year. The more abundant the nourishment of the Camel, the larger the hump; the more its fare is restricted the more the hump shrinks. With fat, well nourished animals it is conical in shape and covers at least one-fourth of the back; but in quite lean specimens it almost entirely disappears. During the rainy season, which implies succulent pasturage, the hump, which during the dry months of hunger had been barely visible, grows at an astonishing rate, and its weight may then amount to as much as thirty pounds, while under the contrary circumstances it can diminish to four or six pounds. The legs are awkwardly placed, and the hinder thighs, especially, protrude so far from the body that they accentuate the uncouth appearance of the animal. The tail has a thin tuft of hair at its extremity and descends to the ankle joint. The hair is soft and woolly, and is much longer on the top of the head, on the neck beneath the throat, on the shoulders and on the hump, and greatly thickened in the tail tuft. Another peculiarity is to be noted in the callosities on the breast and joints of the legs, which grow larger and harder with advancing age. The callosity on the chest projects like a hump beyond the other portions of the skin of the breast, and forms a cushion for the body to rest upon when the animal lies down.

The color of the animal varies widely and constantly. A light sandy color is the hue most frequently met with, and there are also gray; brown or quite black Camels, or individuals with paler or lighter feet, but no pied ones.

The Range of At present the Dromedary is known the Drome- only as a domestic animal; it is dary. found in all African countries from the Mediterranean to about the twelfth parallel of north latitude, in the somal country to the fifth parallel, and in southwestern Asia. It ranges from Bokhara and Turcomania, in the extreme east, where the Two-humped Camel begins, throughout Persia, Asia Minor, Syria, Arabia and northern Africa to the Atlantic Ucean. But it is also found on the Canary Isles, and has been introduced into Australia, North America, Italy and southern Spain. It thrives fairly well in the dry stretches of northern India. Hans Meyer informs us that the Dromedary is employed in the oil-mills of the sultan of Zanzibar, but that it suffers greatly in health and comfort from the effects of the climate. It seems to have originally come from Arabia, and it probably was introduced into northern Africa in comparatively modern times. But of its origin nothing is certainly known. The old Egyptian monuments show no picture of this notable animal, neither do the Roman and Greek authors who traveled in Egypt allude to the Camel as an indigenous product. In the Bible the animal is frequently mentioned under the name of Gamal. Job is said to have possessed at one time three thousand, and later six thousand Camels; the Midianites and Amalekites had as many "as the sands of the sea." The animal was used in precisely the same way as it is now. It was distributed through northern Africa, being probably introduced by the Arabs. Its domestication took place in prehistoric times. Wild Camels, or such as have reverted to savagery. are nowhere to be found at present.

The Camela The Camel is a genuine animal of Son of the the desert and thrives only in the Desert. driest and hottest portions of the globe, while it languishes and perishes away in cul- 


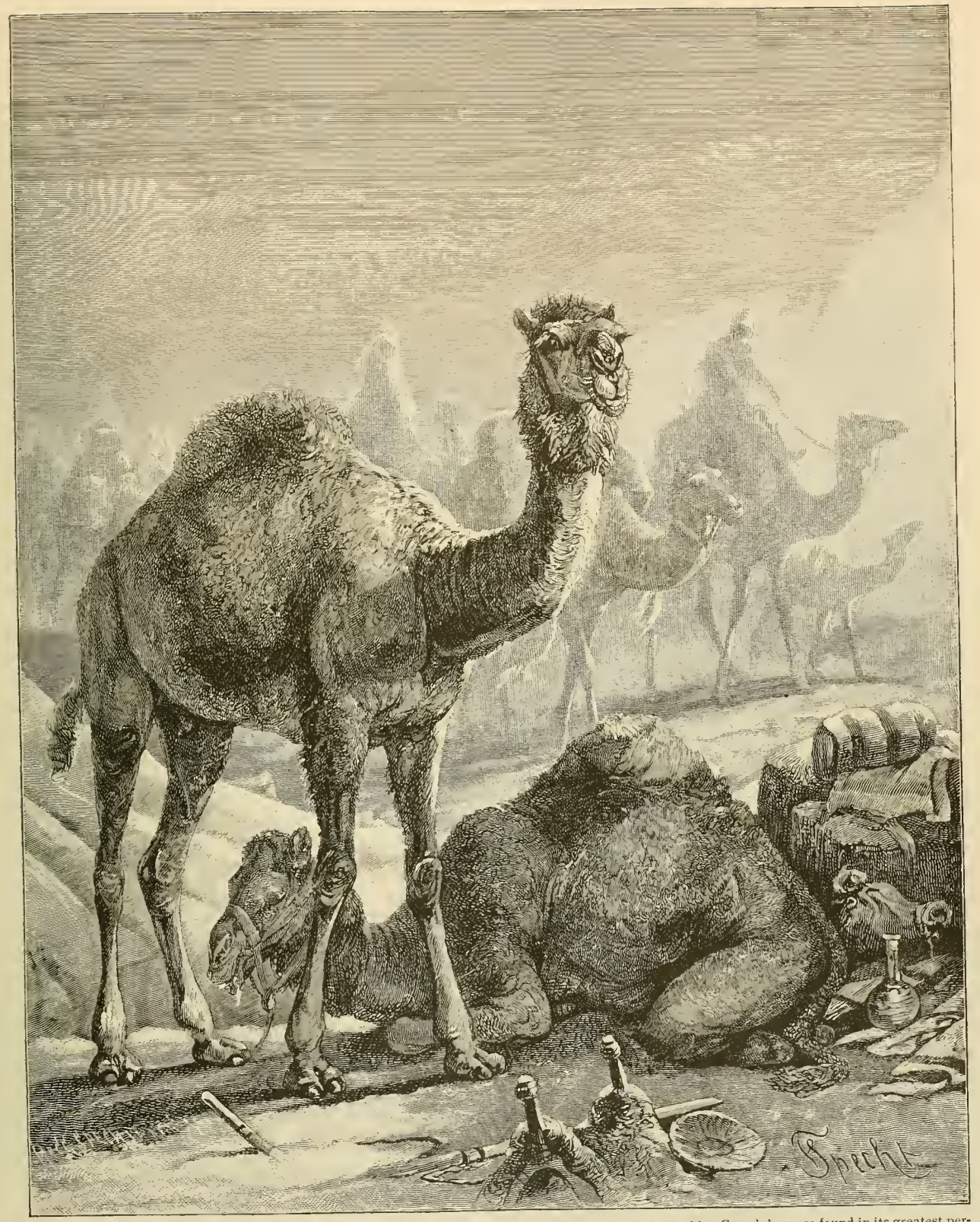

THE DROMEDARY, - The single-humped species of the Camel tribe is sometimes called the Arabian Camel, because found in its greatest perfection in Arabia, It is an ungainly animal, but is indispensable where great deserts are to be traversed, its capacity for traveling long distances the Red Sea water and its great powers of endu 
tivated and damp countries. In Egypt very large, heavy varieties have been bred, probably by giving them more abundant food; but they have lost several of their most valuable qualities, such as the light, even pace, endurance and frugality; these strains are therefore held in slight esteem by the Arabs of the desert. In the equatorial portions of Africa, where the vegetation grows more abundant, the Camel does not thrive. Repeated attempts to penetrate to the interior of the continent with it, have been attended by failure. Within its natural range the animal enjoys sound health and attains its highest physical development; if taken to the south it becomes sickly and finally succumbs without any evident reason, notwithstanding it has received good care and the most abundant food.

As yet no effort has been made to transplant the animal to the regions north of the great tract of the desert; but there is scarcely any doubt that it would thrive there also in countries not too much unlike its native home. In I622 Ferdinand de Medicis (the second) introduced Dromedaries into the province of Tuscany in Italy, and this breed has survived to the present day. In the district of San Bossore near Pisa, a few Camels appear to enjoy life with comfort in a large sandy plain, their habits there being exactly the same as those they possess in their native habitat. In ISIO there were onc hundred and seventy Camels, and in 1840 the herd had increased in numbers only one more. In Sicily Camels were also introduced, with a view to being employed as beasts of burden in the sulphur mines, but they all perished. In southern Spain the experiment of breeding Camels has been tried with favorable results.

Experiment with In 1856 the government of the United Camels in the States purchased seventy-five DromUnited States. edaries at Smyrna, through Henry C. Wayne; they were to be utilized as beasts of burden in Texas, Arizona and other portions of the arid regions. Secretary S. Langley, of the Smithsonian Institution, Washington, has very kindly informed us as to the result of this experiment: "At the beginning of the war of secession all the Dromedaries went into the hands of the authorities of the Southern Confederacy. At the end of the war they again came into the possession of the government of the United States, but the attention the officers had bestowed on the animals was relaxed as a consequence of the war. In I866 the government sold them at auction and people soon ceased to occupy their attention with them. Some died, some were turned loose, and it is said that one or two of these animals still roam about the Llano Estacado. At the time of the auction some were transported to California, where they were intended for carrying burdens between Ingo in California, and Carson in Nevada. As the result was by no means adequate to the expectations, they were set free. Some survivors are said to still live in the desert portions of southern Arizona and California. In January, I 889 , one of these wild Dromedaries was caught in Arizona near Gila Bend. This is the last information we have had of thesc animals."

John IV. Leonard, who lived for several years in Arizona, says that he saw at one time, in 1877, six of these Dromedaries in the valley that stretches several miles north of the Gila River. One of the herd was a young animal still following its mother. At that time there were certainly many more than the six mentioned, for the same authority says that he frequently conversed with people who had often encountered the herds, and the estimates as to the total number of the animals, made by the prospectors and hunters who most frequented that section of Arizona, never ran less than forty, while others claimed that there were fully one hundred Camels in the Gila valley.
The Dromedary All over the north and east of Africa Bred Extensively the Dromedary is bred in great in Africa. numbers. Immense hosts of them traverse the great roads of the desert between the Niger countries and the north of Africa. The number of Camels that perish yearly along the trails of caravans through the desert can not be estimated; how great it is, however, can best be comprehended by traveling through the desert. In the Nubian desert as well as in the Bajuda, at the entrance and outlet of these roads, I found one skeleton after another in rapid succession for miles, so that the road was plainly mapped out by these blanched bones. The desert is not only the home and place of birth of the Camel, it is also its deathbed and tomb. The numbers of Camels that are slaughtered are insignificant when compared with the numbers which perish while on duty.

The Camel an Ex. The Camel chooses its sustenance clusively Vegeta- exclusively from the vegetable world ble Feeder. and is far from being fastidious in its choice. It may be truthfully asserted that its frugality is its greatest virtue: the worst quality of food satisfies it. When it is but scantily provided with the driest regetation of the arid regions it can hold out against the hardships of desert travel for weeks. In adverse circumstances, when other food is laching, an old basket or a mat woven out of the split leaves of the date-palm furnishes it with an acceptable meal. In East Soudan the huts of the natives, which consist of a frame-work of slender poles thatched with grass from the plains, have to be protected from the Camels by a dense outer coating of thorns, else the voracious animals would devour the whole house to its very foundations. It is really wonderful that the sharpest thorns and spines do not wound their callous mouths. If Camels are allowed a juicy meal once in awhile, they accept it with evident enjoyment; in cultivated fields they are sometimes guilty of perpetrating the most annoying havoc, devastating entire districts of country. They are very fond of small beans, peas and vetches, and scem to look upon grains of all sorts as dainties. On journeys through the desert where the load must be as small as possible, every Arab takes only a little durra or barley along for his Camel, and feeds the animal a few handsful of it every evening, generally from the only apology for a handkerchief which he possesses, which is furnished by the lap of his burnoose or robe.

The Dromedary's If given moist juicy food, the Drom. Ability to With- edary can go without drinking water

stand Thirst. for weeks, provided it is not heavily loaded or especially overworked, and is allowed to select its plant food after its own desire. It has been said that Camels could go without water for from fourteen to twenty days cven under conditions imposing hard labor upon it; but such accounts smack of the fabulous in flavor and always elicit a smile from the initiated. In the glaring heat of the African dry season, a traveling Camel must have sufficient nourishment, water, and fully thirty or forty hours of complete rest at least every four days in order to endure the fatigue its work imposes upon it.

Stories of a Camel's In former times this abstemiousAbility to With- ness of the Camel in the matter of stand Thirst Fa/se. water drinking, was explained by the peculiar structure of its stomach. People believed that the large cells in the first two compartments of the stomach might be regarded as reser- 
vorrs, and one reads in many an old book of travel how the travelers in the desert in their last extremity could still find a store of the much needed water in the stomachs of their Camels. Though I have always doubted these stories, I have expressly questioned experienced drivers of Camels, grown old in the desert. None of them knew anything about such a story; none of them had ever as much as heard this enormous falsehood. Later on, as I was present at the killing of Camels which had drunk the day before, I convinced myself personally that it is quite impossible to drink water which has been mixed for days with the food accumulating in the stomach and with the gastric juices. The whole body exhales a repulsive smell; and such a mush in the stomach is calculated to inspire even a person as no other domestic animal can accomplish. All Camels when proceeding at a pace more rapid than a walk exhibit a gait that is apparently a very clumsy amble, whether they run slowly or rapidly; the amble of a trained riding Camel, however, is a very easy and pleasant one for the rider. The usual walking gait is a queer, stiff kind of stalk, the Camel moving its head back and forth in a very peculiar manner at every step, so that one can hardly imagine anything uglier than the appearance of such a slowly noving monster. If a Camel accustomed to that gait and belonging to the good breeds, which keep up a uniform pace without interruption, is brought to a trot, the cumbersome creature appears graceful and good-looking. In the beginning of a race the speed of a trotting Horse may surpass that

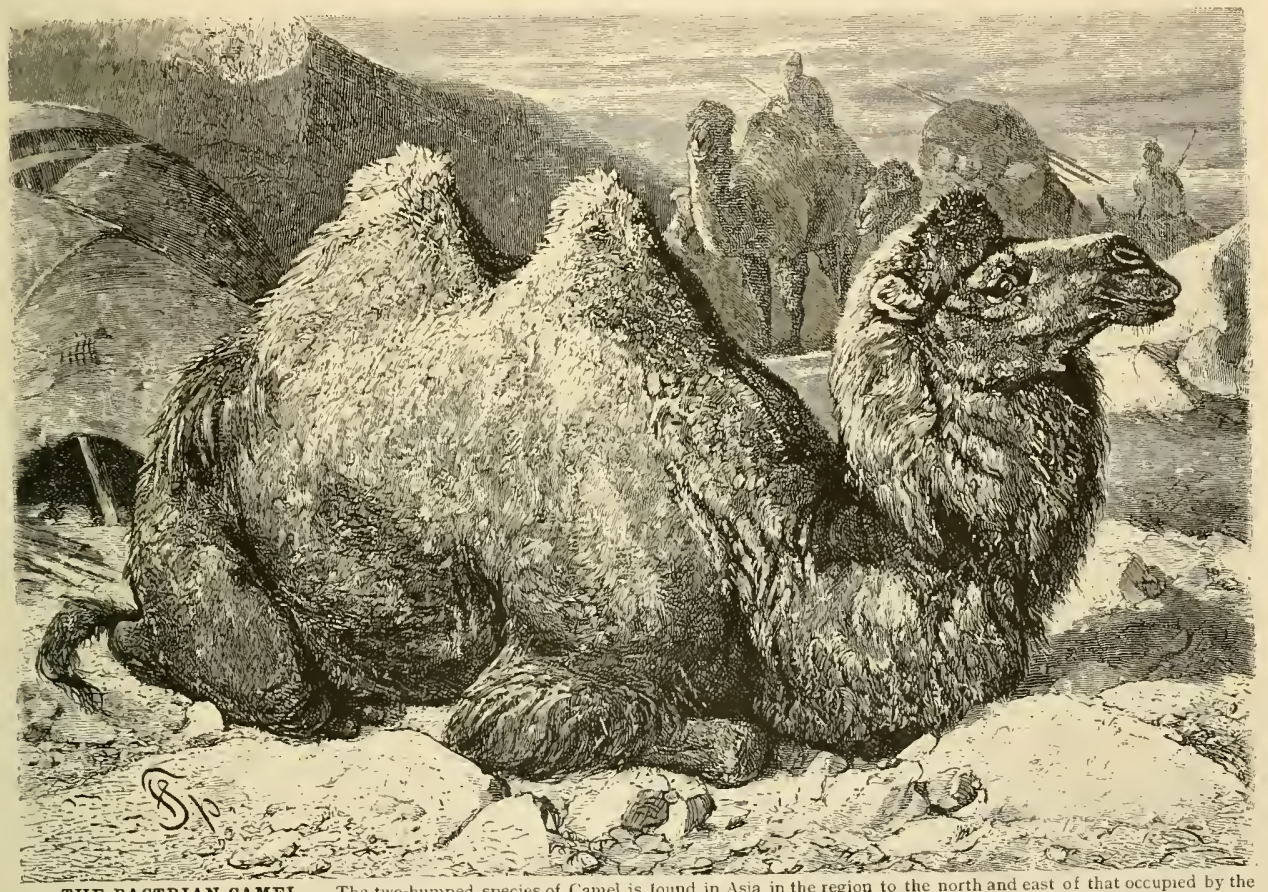

THE BACTRIAN CAMEL. - The two-humped species of Camel is lound in Asia in the region to the north and east of that occupied by the Dromedary. It is larger and more robust than the lat ter animal. plentiful than that of the other species. (Camelus bactrianus.)

half dead with thirst with feelings of unconquerable disgust. The stench from the freshly opened stomach of a Camel is simply unendurable.

It is a really interesting sight when thirsty, tiredout Camels draw near to a well or a river. They lift their heads high in the air, inhale long breaths with half-closed eyes, lay their ears back and then start to run, so that one has to sit firmly in the sad"dle if he does not wish to be thrown out. When the beasts finally reach the well they crowd to the water and give themselves up to the enjoyment of drinking.

Dromedaries as If one looks at a Dromedary in reSaddle and Pack pose he will hardly be willing to

Animals. believe that this animal can nearly equal the Horse in speed. And yet such is the case. The Camels born in the desert or upon the plains are excellent runners in many respects, and are able to cover distances without intervals of rest, such of a Camel, if the two go at the same gait; but the Horse soon lags behind while the Camel trots on uninterruptedly at its initial rate. If a rider gives a saddle Camel a rest at noon, during a ride from early morning till late at night, the animal will trot for sixteen hours and in that time easily cover a distance of eighty-seven and one-half miles. A good Camel that receives abundant food and water may sustain such a strain for three or even four days without an intervening day's rest, and cover upwards of three hundred and twelve miles in the longer period.

The work of the average or common variety, and that of the baggage Camel conform to a different standard. The former at best covers but half the distance that the best saddle animals do, as a rule averaging only about thirty miles a day; the latter travel on the average two and one-half miles an 
hour, carrying a load of three lundred pounds, and able to march for twelve hours, or even longer, ithout a rest.

\section{Requisites for a Good Saddle Camel.}

The Arab requires three things from a good Dromedary: it must have a soft back, must not require a whip, and must not cry when getting up or lying down. Unly he who has had experience with Camels knows what this means. An ordinary baggage Camel is the most disagreeable of all animals to ride. The uneven, jolting, pacing gait causes the rider to be jerked up and down, back and forth, describing curions curves, comparable to the lines of a figure described by a Chinese pagoda set in motion. As soon as the Camel begins to trot, matters assume a different aspect. The steady alternating movement of the legs on the opposite side stops the sidewise jolting motion, and if the rider skillfully lies back in the saddle, he experiences no more inconvenience from the still somewhat violent shaking-up than he would if he were on Horseback. A Camel in a fit of rage always goes at a gallop, but it is not capable of keeping this pace up for any length of time; neither does it need to, for usually the rider who lias not a very firm seat in his saddle, lies on the ground within the few very first minutes, while the Camel gallops on at its sweet will and soon resumes its usual gait. For these reasons the Arabs have accustomed their riding Camels to gro only at a trot.

I Dromedary reared on the plains can be used to only a limited extent in a mountainous country, as it climbs with great difficulty. In the water the animal is at a still greater clisadvantage. Even when driven into a small stream or pool to drink it acts as if insane; but when it has to cross a wide stream it becomes much worse. As it can not swint, and the ferry-boats are usually too small to accommodate the unwieldy creature, the driver compels it to enter the water, alongside of the boat, prevents it from sinking by keeping hold of its head and tail, and thus drags it over to the place of lancling.

Mental and Phys. The vocal utterance of the Dromeical Characteris- dary is indescribable. Gurgling tics of Camels. and moaning, grunting, growling and roaring alternate in the most curious way. Among the perceptive senses that of hearing is probably best developed, for the sight seenis to be much less acute and the sense of smell is certainly weak. The sense of touch, however, seems to be delicate and that of taste is occasionally manifested. On the whole the Camcl nutist be regarded as a creature of poorly developed physical senses. A judgment of its mental faculties is not much more favorable. It can not be denied that the Dromedary possesses a really surprising faculty for annoying a person incessantly and in almost unheard of ways. Stupidity and a vicious disposition are generally found together; but if they are combined with cowardice, obstinacy, a sulky temper, an aversion to everything sensible, hatred or indifference toward the keeper and benefactor, and a hundred other vices, all possessed by the same brute and practiced by it to perfection, it is enough to drive insane the person who has to deal with sucl a creature. He thoroughly understands and appreciates this, who has been thrown from the back of a Camel, trampled on by it, bitten, forsaken in the wilderness and mocked at, after the creature has vexed him hourly for days and weeks with inexhaustible perseverance, and after all means of improvement and castigation have been in vain applied to the beast. It is of no moment in this connection -and we do not hold the facts in malice against it that the Camel exhales an odor, compared with which the stench of a Billy-goat is perfume, that it tortures the ear by its roar-as much as it does the nose by its stench and the eye by the foreced sight of its unspeakably stupid head on its long, ostrich-like neck; what gives it so low a place in my opinion is that it always deliberately acts contrary to its master's will. Among the thousands of Camels which I observed in Africa, I saw only one that displayed anything approaching affection towards its master. These remarks apply to the Dromedary only within certain restrictions, however. Many travelers have not undergone such unpleasant experiences, and the J Jomedaries of other and much more extensive regions than that to which my observation was confined are judged much more leniently. According to popular report those of southwestern Asia, the Somal country, and the Sahara, must be animals of an entirely different stamp.

Reproduction of The female gives birth to a single Camels and Appear- young one. It is true that the infant ance of young. is a misshapen little creature from the very" first day of its life, but it has something droll and playful about it, like all young animals. It is born with open eyes and covered with long, thick, soit woolly hair. The hump is very small and the callosities are barely indicated. In size it considerably surpasses a newborn colt; for it is rather more than three feet high and much taller after the lapse of onc weck. With advancing growth the wool becomes much thicker and longer and the young Cancl clevelops a really striking resemblance to its American relative, the Alpaca. Almost immediately after its birth it begins to follow its nother about, sile caring for it with great solicitude. If two mothers with their colts happen to meet, the latter play with each other in the most amiable way, while the mothers grunt in approbation. The Camel suckles her young upwards of a year and shows unusual courage during this time, defending her offspring to the extent of her strength if circumstances require it. But she only cares for her own infant, never for a strange one.

Economic J. Williams pronounces the flesh of
Value of the young Camels one of the greatest camel. delicacies. The hide is manufactured into teut covering and various utensils, though the leather is not very durable while the hair is woven into strong textures. The milk of the animal is so thick and rich in fat as to be repulsive to the taste of Man, and is therefore but little used.

The Two Humped The part which the Dromedary or Bactrian plays within its range is almost simCamel. ilar to that of the Bactrian Camel (Camelus buctriamus) in east and central Asia. It is to be distinguished from the Dromedary by its two humps, one rising on the withers, the other in front of the croup. In form it is lumbering and clumsy; the bulk of the body being greater and the hair much more copious than that of the Dromedary; the color also is generally darker, usually a deep brown, with a ruddy tint in summer.

I have become doubtful as to whether or not the Bactrian Camel ought to be considered a species distinct from the Dromedary. The two readily breed together, and their hybrid offspring may in turn continue the mixed species by breeding with each other with cither variety of the parent stock. If we admit their identity of species, we would have to regard 
the Bactrian Camel as the original stock and the Dromedary as a breed produced by selection; for the Kirghiz and Mongols describe the wild Camels as being two-humped. Prshewalski has proven within the past forty years that there are numerous troops of Bactrian Camels in central Asia, which are, and always have been, really wild, and have not merely reverted to the wild state. They possess smaller humps than those bred in a state of domesticity, callosities on the knees of the fore-legs, and a somewhat different structure of the skull, and as far as is now known, they range from southern Dzungaria over eastern Turkestan to Tibet.

The Bactrian Camcl is bred in all level countries of central Asia, and is especially useful in the traffic of mercliandise carried on between China and southern Siberia and Turkestan. In Bokhara and Turcomania the Dromedary gradually supersedes it, and replaces it entirely where the plains become more barren and at last merge into the desert.

Traits of the Though it may be asserted that the Bactrian Bactrian Camel shows in its charCamel.

acter and qualities an affinity to the

Dromedary, it can not be denied that it is better natured than the latter. It readily allows itself to be approached and caught, and willingly obeys its master's commands without causing a great deal of commotion. But it is still a Camel in all that the name implies. Its mental faculties are on the same low level as those of the Dromedary; it is just as stupid, listless and cowardly as the latter animal. A Hare springing up between its feet may throw it into a panic. It starts aside in terror, and then rushes on like a senseless creature, and its fellows, moved by common impulse, follow without knowing why. A large, black stone lying by the roadside, a heap of bones, a fallen saddle, in fact, any unfamiliar object may frighten it to such an extent that it completely loses its wits and causes rout and confusion in the entire caravan.

The Bactrian Camel, like the Dromedary, can not thrive on rich pasturage; it requires the coarse vegetation of the sterile plains, which would barely satisfy other animals; its favorite food consists of wormwood, garlic, shoots of all kinds of shrubs, and especially plants containing salt, which are indispensable to the maintenance of its good health, and to its recuperation if it becomes debilitated from any cause.

To the female Bactrian Camel is born a single young one-usually at the beginning of the spring season. The little creature is very helpless during the first few days of its life, but soon becomes strong enough to follow the mother about, and she evinces for it a most tender maternal affection. A few weeks after birth it begins to eat vegetable food, and then is temporarily separated from the mother, the latter being milked, as is every other female animal belonging to the herds of the inhabitants of the Asiatic plains. In the second year the colt has its nose pierced, and the bridle-stick is put through the aperture, for at this age its training commences. In the third year of its life it is used for short rides, in the fourth to convey light burdens; in the fifth year it is looked upon as fully developed and capable of working. 11 ith good treatment it may continue to work until its twenty-fifth year.

Great Usefulness A strong Bactrian Camel can daily of the Bactrian travel from nineteen to twenty-five Camel. miles, carrying a burden of four hundred and forty pounds, and a very strong one can carry one hundred pounds more; with half this load it is able to cover nearly double the distance at a trot. In summer it can abstain from water for two or three days, in winter from five to eight, and endures abstinence from food from two to four days without suffering material harm or discomfort. On trips of considerable length it requires a day's rest at intervals of every six or eight days. In the Kirghiz plains it is not used exclusively as a beast of burden, but also as a draught animal in single and in double harness, and on tracts of country liable to the contingencies arising from the ever cluanging sand drifts, it even takes the place of Horses in the mail service.

Nothwithstanding all its faults, the Bactrian Camel must be acknowledged to be one of the most useful creatures that Man has subjugated to his service. It well fulfills all the tasks required of it, and could not be replaced by any other domestic animal. Its hair, milk, skin and flesh are all put to account, and it is harnessed to carts and used as a beast of burden. With its help Man is enabled to traverse the waterless, treeless wastes of wilderness in which Horses would succumb to the hardships incident to their passage; with its help its owner climbs mountains upwards of thirteen thousand feet high, to points of elevation which the $\mathrm{rak}$ is the only other animal able to endure. The Horse is the companion of the inhabitant of the steppes, the Bactrian Camel is his servant.

\section{THE LLAMAS.}

The New Vorld Camels include those numerous American animals which appear but dwarfs in size when compared with their Old World family or generic relations. The Llanas (Auchenia) are Camels, but they are much smaller than the Old World species. True, the American Camels are inhabitants of the mountains and for this reason alone they can not attain the same size as their Old World relatives which belong to the fauna of the plain. The Llamas differ from the true Camels not only by reason of smaller size, however, but also by the relatively large head, the frontal region of which recedes sharply and connects at a considerable angle with a pointed muzzle; by their large ears and eyes, their thin, lean neck, long, slender legs with hoofs more deeply cleft; by their smaller callosities and their long, woolly fleece. The hump is lacking, and the loins are still more contracted than those of the true Camels.

Four Species of The Llamas are divided into four Llamas Now species, which have been well known Existent. from remote ages under the names of Huanaco or Guanaco, Llama, Paco or Alpaca and Vicugna. Authorities are not yet agreed as to whether all four animals are to be regarded as original species or not. Some consider the Guanaco to be the progenitor of the Llama and Alpaca, and base their chief ground for this opinion in the fact that the Llania and the Guanaco may interbreed and produce offspring capable of continuing the species; others deem the slight differences in outward form important enough to regard the four Llamas as distinct species, as the natives have always done. Tschudi, who has been able to observe all the Llamas on their native ground, agrees with the natives, and his opinion has long been regarded as decisive. Let us consider, however, how potent in inducing variation of form is the influence of domestication on animals, and we will then also find the contrary opinion to be based on reasonable grounds, and will hardly be pre- 
pared to acknowledge the Llamas and Alpacas to be anything but the domesticated offspring of the Guanaco.

The Guanaco and Vicugna have remasned untamed to the present day, while the Llama and Alpaca have been domesticated from time immemorial. The first discoverers of America found the two already in a state of subjection to Man. Peruvian tradition supposes the taming of the animals to have taken place in the earliest stage of human existence, and connects them with the terrestrial appearance of their demigods. The Spaniards, who landed first, found everywhere considerable herds of Llamas in the possession of the mountaineers, and described the animals in a somewhat confused manner, yet with sufficient accuracy of detail to enabie us to recognize and distinguish the various forms. Pedro de Cieza clearly discriminated between the four species as early as $154 \mathrm{I}$, by an account which serves to show beyond a doubt that the four different kinds of Llamas have not undergone any change within the last three hundred years.

Home and All Llamas are indigenous to the Haunts of the table-lands of the enormous mounLlama. tain chains of the Cordilleras or Andes. They thrive only in cold regions and therefore descend to the pampas or great plains of Patagonia only in the extreme south near the Antarctic regions. Near the equator their usual haunts lie between thirteen thousand and fifteen thousand feet above the sea, and they do not thrive below an altitude of 6,600 feet in the warm parts of the country, while Patagonia, being a colder country, affords them suitable haunts below this level. Those of the species living in the wild state retreat to the highest crests and ridges of the mountains in the rainy season, and descend into the fertile valleys during the dry season. They are gregarious, sometimes living in flocks of several hundred, and are assiduously hunted by natives.

Description The Guanaco (Anchenia huanaco)

of the Guan- claims, together with the Llama, the aco. distinction of being the largest South American mammal, and though it occurs only in an untamed state, is one of the most important. In size it about equals a European Stag or Red Deer; as regards its shape it is a queer conmpound of Camel and Sheep. In a full-grown individual the total length of the body is seven and a half feet, the tail occupying about nine and a half inches; the height at the withers is three feet ten inches, and the height from the ground to the top of the head, five fect four inches. The female is smaller, but of exactly the same shape and hue as the male. A tolerably long, copious, but loose fur covers the body. This coat consists of a short, woolly layer of fine texture and a thinner, longer outer fur. The general color is a dingy reddish brown, while the middle of the breast, the abdomen and the buttucks, as well as the inner surface of the limbs, are whitish.

The Guanaco is distributed over the Cordilleras, from the wooded islands of Terra del Fuego to northern Peru. It is specially plentiful in the southern part of the mountain range, and is gregarious in its habits. Meyen saw flocks numbering from seven to one hundred grazing near rivers. A herd usually consists of many females and only one fullgrown male.

All the movements of the Guanaco are quick and lively, though the animal is not as swift in flight as one might suppose. Over level ground a good
Horse soon overtakes a fleeing herd, but ordinary Dogs have some difficulty in keeping up with them. The usual gait of the Guanacos is a short, halting amble; and when fleeing at the top of their speed they extend their necks forward, somewhat after the manner of a Goose. The Guanaco is an excellent climber; it runs like a Chanois along the steepest crags and precipices, even where the most experienced mountaineer fails to gain a foothold, and fearlessly looks down into the abyss. When at rest the animal lies on its breast and legs, Camel-fashion, and its method of lying down and arising is very similar to the action of the Camel under the same circumstances. During its rest it dreamily clews the cud.

The Guanacos are generally very wild and shy. The leader nearly always stands a few paces from his flock and mounts guard with the utmost vigilance, while the herd grazes in peace. On the slightest alarm he utters a loud, neighing bleat; instantly all the members of the herd raise their heads, sharply look around, and then betake themselves to flight.

The female gives birth to one perfectly developed infant during the season. The newborn Guanaco is covered with hair and has its eyes open. The mother suckles it for four months, guards it carefully, displays toward it great tenderness and keeps it near herself until it is completely matured.

Peculiar Methods The Guanaco defends itseif against of Defence Prac- its own kind by kicking and biting, ticed by Guanacos. but timorously takes refuge in flight without so much as making a pretence of defending itself against an enemy which it fears. IVhen the Guanacos have become accustomed to Men and domestic animals, they become bolder, sometimes courageously charging at an opponent, trying to bite and kick hin, and in other cases resorting to a mode of defence peculiar to all Llamas. They allow their antagonist to approach quite closely, then put their ears back, assume a surly expression of countenance and then suddenly and violently spit upon the eneny, the discharge consisting of saliva and the herbage that is either held at the time in the mouth, or which they have procured expressly for this purpose out of the stomach by retching.

Man is under all circumstances the worst foe of these animals; their fleetness protects them against other assailants. Whether the Condor really causes among them such havoc as has been ascribed to that bird of prey remains an open question. The South Americans are passionately fond of hunting the Guanaco, both on account of the sport which it affords, and the economic value of the carcass, for the profit accruing from the flesh and skin is not to be despised.

In mountainous regions, as well as on plains, Guanacos are not infrequently taken with a view to domestication. While they are young they exhibit no vicious tendencies, and altogether conduct themselves in a pleasing manner. They are tame and affectionate, follow their master about like Dogs, and may be treated as Lambs; but the older they grow, the more their love and affection for Man diminishes. They are easily maintained on hay, grass, bread and grains, even in Europe, where they propagate their species if they are well taken care of.

The Llama The Lama, or more properly Llama

a Domesticated (Auchenic lama), is found principally

Species. in Peru, and there thrives best on the tabie-lands. Its physical proportions are slightly 
larger than those of the Guanaco, and it is characterized by callosities on the breast and on the external surface of the first joints of the fore-legs. The head is narrow and short, the lips are hairy, the ears short and the soles of the feet large. The coloring is very variable; it may be white, black, pied, reddish-brown spotted with white, dark brown, ochre-ycllow, grayish-red, or of other hues. The adult animal attains a height of from eight feet eight inches to nine feet four inches from the soles of its feet to the top of its head; at the withers it is about four feet high.

Acosta relates that the Indians lead entire herds of "these Sheep," loaded like beasts of burden, over the mountains, the herds often numbering from three such a hard task is imposed only on those animals belonging to poor soldicrs wandering through Peru. All these animals prefer cold air and thrive in the mountain, while they succumb to the heat of the plain. They are often entirely covered with hoarfrost and ice and yet remain in good health. The short haired specimens often furnish the beholder with cause for merriment. Ever and anon they suddenly stop on the road, lift their heads and fixedly stare at people, standing still a long time without showing any sign of fear or displeasure. At other times they suddenly take fright and shy at something, and run up on the top of the highest crags taking with them their burdens, and they often have

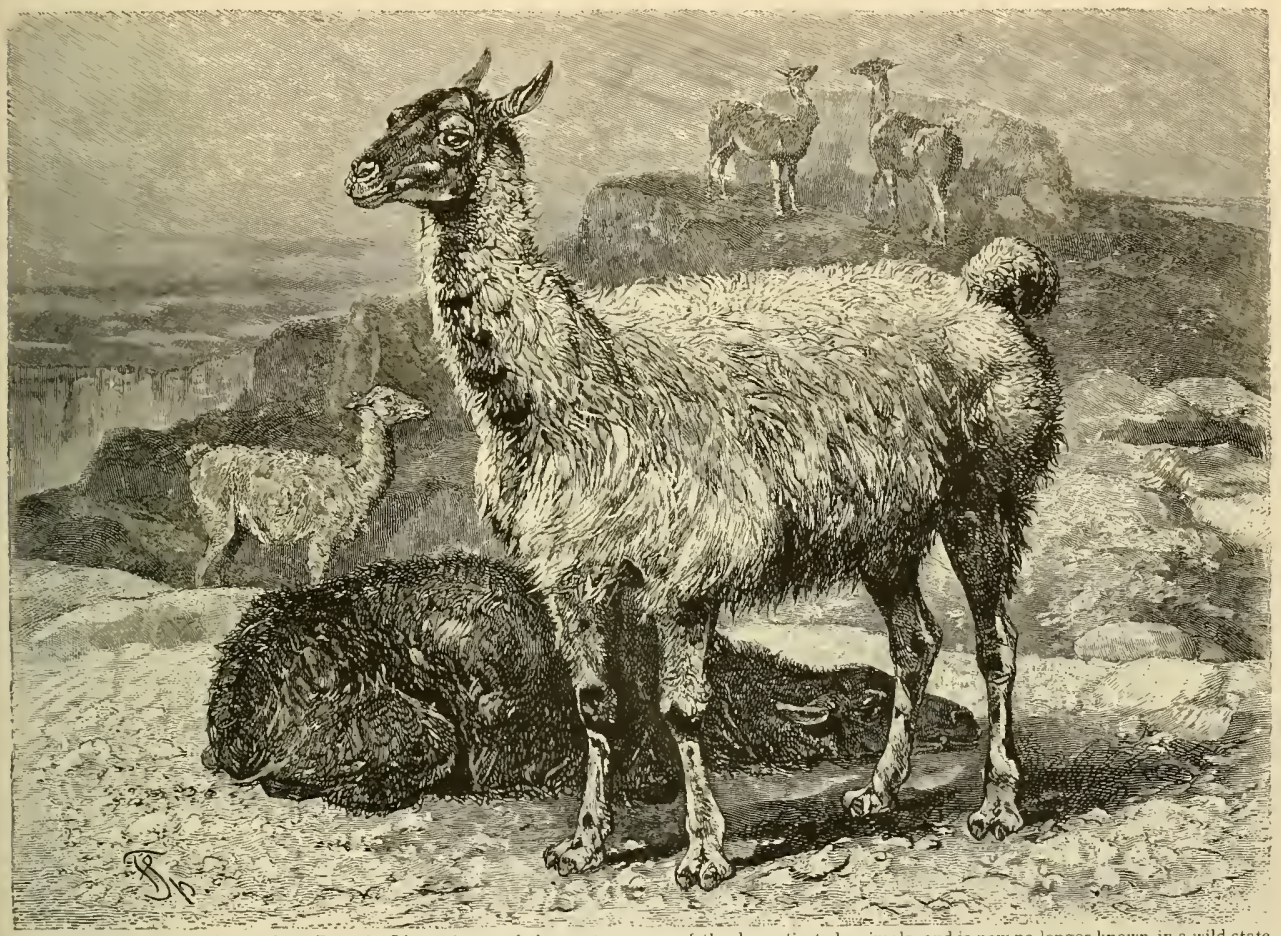

THE LLAMA. In southern Peru the Llama is one of the most common of the domesticated animals, and is now no longer known in a wild state. It is the typical species of the New World animals of the Camel family, though much smaller than the Camels proper. It was formerly much used as a ished. fts hairy covering is long and woolly. (Auchenta lama.)

hundred to five hundred, or even one thousand. "I have been astonished," says he, "to see these herds of Sheep loaded with two or three thousand bars of silver, of the value of about three hundred thousand ducats, accompanied only by a few Indians who guide, load and unload the Sheep, the escort at the most being supplemented by a few Spaniards. They sleep all night in the fields and yet so great is public security in Peru that nothing has ever been lost by robbery on these long journeys. In suitable resting places, where there are rivers and pasturage, the leaders unload their animals, put up tents, cook meals and take their ease despite the long journey. If the trip requires only one day's travel, those Sheep carry eight arrobas (about two hundred pounds) and traverse from eight to ten leguas (eighteen to twenty-two and one-half miles); but to be shot down in order to prevent the loss of the goods they carry."

Only the males are used for conveying burdens, the females serving exclusively for breeding purposes. "There is nothing more beautiful," says Stevenson, "than a caravan of these animals, as they march one behind the other, in the greatest order, each with its burden of a hundred weight or so. They are guided by a leader, adorned with a tastefully decorated halter, a little bell and a flag on its head. Thus they travel along the snow-covered peaks of the Cordilleras or by the side of the mountain, along roads where Horses and Mules would pick their way with difficulty; and they are so tractable that their drivers need neither goad nor whip to guide or urge them forward. Quietly and without interruption they move on toward their goal." 
The Llama of Meren estimates the importance of Great Value to the the Llama to the Peruvians as equal

Peruvians. to that of the Reindeer to the Laplander. The animals are kept on the table-lands in enormous herds. All species of Llamas produce at a birth only a single young one, which is by mothers of most species suckled for about four months, and for a period somewhat longer by females of the Llama species proper.

The same naturalist informs us that the importance and also the price of the Llama have considerably diminished since the introduction of animals of the II orse tribe, and further that the herds of Llamas are occasionally ravaged by terrible plagues, and stricken down in appalling numbers.

Peculiarities of At present the Llama is seen in Temper of the nearly all zoological gardens. If it Llama. is kept in company with others of its kind, it seems to be much more amiable than when say that I never knew one to be gentle or good. natured.

Characteristics The third form of the group, the of the Al- Paco or Alpaca (Auchenia pacos), is paca. smaller than the Llama, and shows a similarity to the Sheep in physical structure, but has a longer neck and a more delicate head. Its flecce is very long and of exquisite softness; on some spots, as for instance, on the sides of the body, the hair attains a length of from four to five inches. The color is usually entirely white or black, but there are also pied or mottled specimens.

The Alpacas are kept in large herds, which graze on the high plains all the year round; they are driven to the huts or booths of the owners for shearing only. There is, perhaps, no other animal that has so refractory a temper as the Alpaca. If one is separated from the herd, it throws itself on the ground, and neither coaxing nor blows can persuade it to

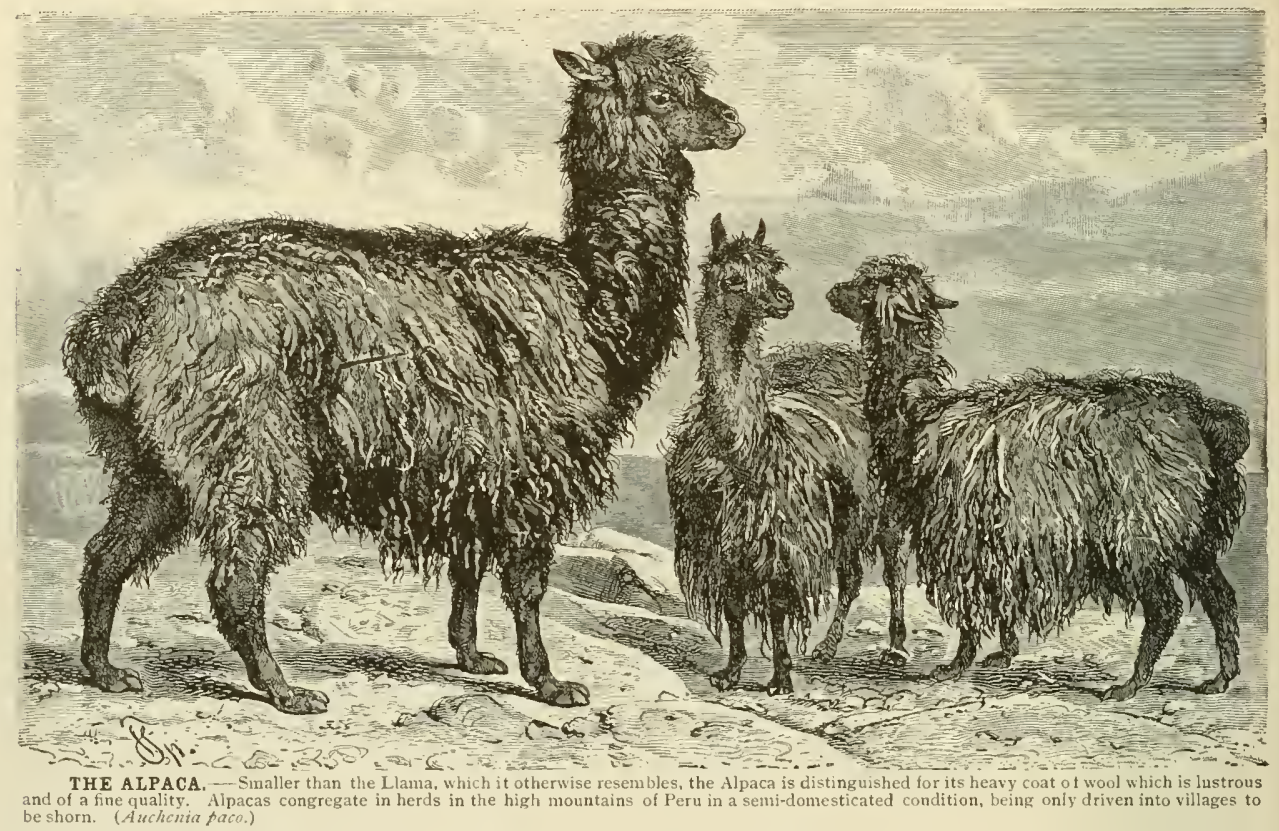

it is alone, and has nothing to claim its attention. It agrees peaceably with its generic and family relations, and mated couples especially are tenderly attached to each other. They learn to know their kecper and act tolerably well toward him, but toward strangers they exhibit the ugly disposition of true Camels, being constantly in an ill humor, and exceedingly irritable. In the Berlin Tiergarten there was a Llama which was endowed with an especially unpleasant temper; a placard was attached to its cage, asking visitors to refrain from provoking the Llama, the natural result being that everybody did his best to irritate the animal. Consequently it was in a state of perpetual agitation. Whenever a visitor approached, its comfortable rumination instantly ceased; it laid its ears back, stared at the stranger, then suddenly walked up and spit at him. The other Llamas, which I have seen, or have had under my charge, behaved in a similar manner, and I can truly get up. It prefers the severest castigation, and even the most painful death to obedience. A single individual can be induced to move only by making it join a herd of Llamas or Sheep. From time immemorial the Indians have manufactured blankets and cloaks out of the wool of the Alpacas and Llamas.

Value of the The attempt to transplant Alpacas
$\begin{gathered}\text { Alpaca to } \\ \text { Man. }\end{gathered}$
in Europe has been repeatedly made, ure, and like attempts to colonize them in Australia have met with no better success, although the experiments of that kind in the latter country have been on a larger scale than those in Europe. The Alpacas possess great powers of endurance, can be maintained with but little care, and propagate rapidly. Besides being valuable for their wool, which sells for about seventy dollars per hundred weight on the western coast of South America, the flesh of the Al- 
paca is very palatable. In their native country they are not used as beasts of burden, but are bred exclusively for their wool and flesh. From their wool the Indians manufacture artistic table-covers and other valuable articles, which are noteworthy for their beautiful lustre and their wearing qualities.

The Vicugna, its "The Vicugna (Auchemia ricugnt) is Home and more graceful than the Llama," says

Haunts. Tschudi. "In size it holds the mean between Llama and Alpaca, but is distinguished from both by its wool, which is much shorter, more curly and of an exquisitely fine texture. The top of the head, the upper part of the neck, the body and the thighs are of a peculiar reddish yellow hue known as Vicugna color; the throat and the inner faces of the limbs are light ochre yellow; the breast-hair, which is nearly five inches long, and the abdomen are white.

"During the rainy season the Vicugnas live on the ridges of the Cordilleras, which afford but scant vegetation. As the hoofs are soft and the soles sensitive, the animals always remain on the grass plots, and even when pursued, they rarely retreat to the craggy, bare peaks and still less to the glaciers and snowfields, as is the habit of the Chamois. During the hot season they descend to the valleys. The apparent contradiction of habits that induces the animals to keep in cold regions in winter and in warm ones in summer, is explained by the fact that the crest of the Cordilleras is quite parched during the dry scason, and vegetation capable of affording them sufficient nourishment can be found only in the valleys, where there are rivers and morasses.

"The female usually gives birth to a single young one, which immediately after it is born exhibits extraordinary powers of endurance and great fleetness. The young male Vicugnas remain under the protection of their mothers until they are fully grown; then a large number of females unite and drive the males away by dint of biting and kicking. These discarded individuals unite to form their own herds, eventually joining others, so that they sometimes number from twenty to thirty."

The Vicugna Vicugnas caught young are easily Easily Domes- tamed and become very familiar, atticated.

taching themselves to their keeper and following him like well-bred domestic animals. With advancing age, however, they become vicious, like their wild relatives, and unbearable by reason of their unpleasant habit of continually spitting. The experiment of taming them is seldom tricd, and their freedom is disturbed only to procure their wool.

As early as the times of Acosta the Indians used to shear the Vicugnas and use their wool to manufacture a fabric of great value, which had the appearance of white silk, and was very durable, as it did not require dyeing or the usual process of bleaching and finishing. Clothing made from this stuff was especially adapted for hot weather. Even now the finest and most durable materials are woven out of this wool, and felt made from it is used for making strong, soft hats.

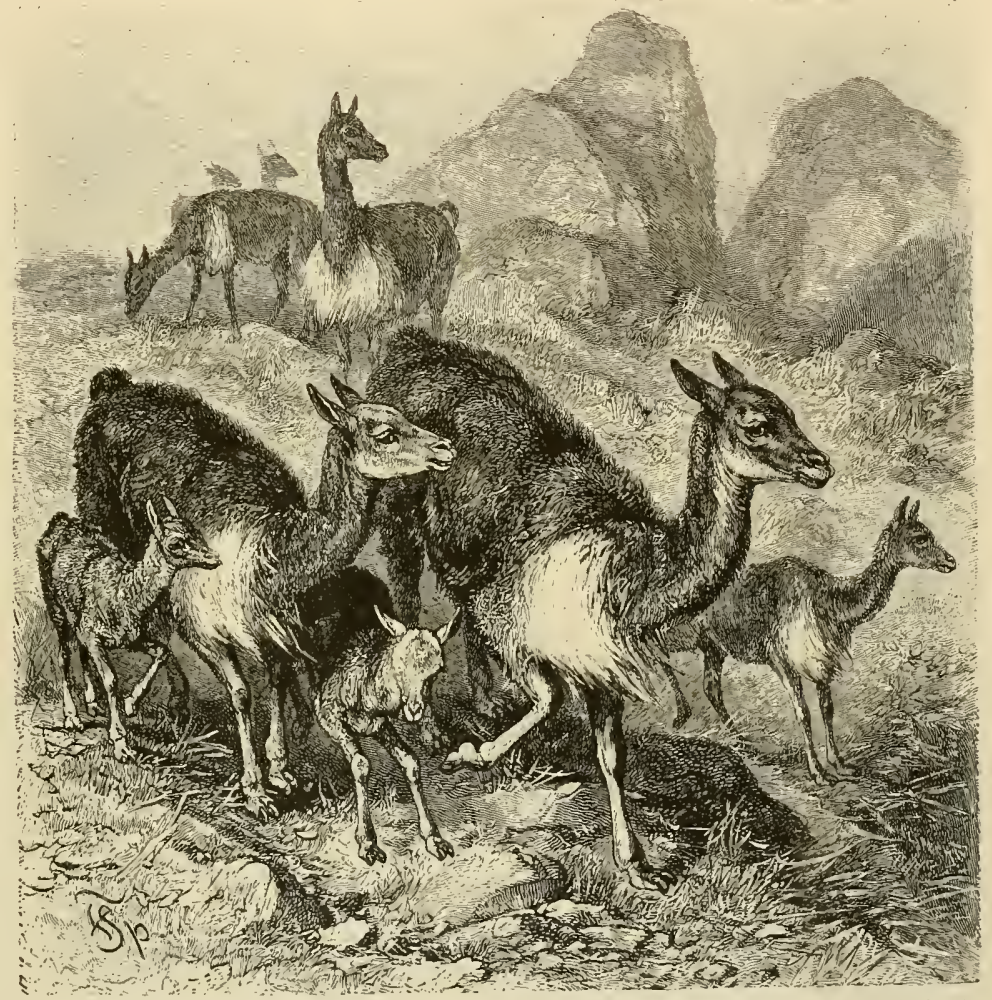

THE VICUGNA.- Inhabiting the most elevated localities of Bolivia and northern Chili, the Vic ugnas live in

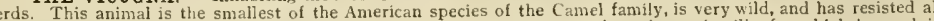
herds. The are pretty animals with a soft, silky fur which is much in

\section{The tbornco Elnimals.}

THIRD FAMILY: BOVIDÆ.

The third main section of the Ruminants contains the Horned Animals (Bovide), which constitute a single, clearly defined family, separated into five subfamilies. Closely allied to the hollow-horned animals as the Deer may appear to be, they differ from them decidedly in shape and structure, as well as in the manner of the growth of their horns, the development and progression of those members being a constant one. The Horned Animals have conical projections on the forehead, which remain enclosed 
in the horn; the bony projection forms the core of the horn and grows uninterruptedly from the base, and thereby extends in length and also in thickness at the root. As it grows, new horny mass is developed on this bony projection along its whole length, the old continually forming a firm sheath around it. With the hollow-horned animals also the existing older external horny coat is separated from the inner bony core by the newly formed horny process, but it is not shed mechanically, as with the Deer, the conical shape of the parts by which union is formed with the frontal bone of the head, and the firm sheath of the previously grown external horny coat preventing the falling off of the horns. Further particular characteristics of the family are, that all animals belonging to it have six incisors and two canine teeth in the lower jaw, and twelve molars six on each side-in both upper and lower jaws, incisors and canines, however, being absent in the upper jaw, the family showing great uniformity in dentition.

The Horned Family Nothing general can be said about Have Few Features the Horned Animals, except in rein Common. gard to their horns and dentition. The structure of the body is very variable, as the family contains clumsy, bulky forms as well as light and graceful ones. The shape of the horns and hoofs, the length of the tail, the hairy covering and color vary to a great extent. WVidely different as is their outward appearance, the mode of life of the Bovide presents an equally great diversity of habit. Indigenous to nearly all parts of the globe, with the exception of South America and Australia, they divide into many species and live in all latitudes and heights, in all regions and fields, from the lonely desert to the forest gorgeous in its tropical splendor, from the swampy plain to the glaciercovered mountains. By far the majority of them live gregariously, not a few herding in considerable numbers, some at least temporarily collecting in bodies, the number of the individuals composing which is not approached by any similar collection of mammals unless we except the gatherings of the rodents. As is to be expected from their varying shape, some move with a clumsy, lumbering gait, while the others exhibit great speed and agility; again, adapting thenselves to the environment of their customary haunts, some are as excellent swimmers as the others are climbers.

Importance to Man To Man the Bovidæ are of a higher of the Horned and greater importance than all other Animals. Ruminants, with the single exception of the Camels. From their number humanity has reclaimed the most important domestic animals so far as regards nourishment and use; to them we are indebted for a material part of our usual diet and our clothing; without them we would be incapable of prolonging our existence. Even the untamed species, enjoying unlinited freedom, are as a rule more useful than otherwise, as their inroads on what we term our property do not injure us as much as the ravages of other large animals, and as they, by giving up to our use their palatable flesh for food, and other portions of their bodies for various pur poses, on the whole even more than repay for all the clamage they inflict, and as game no animals are more popular than those of this family.

The five sub-families, into which we divide the Buvida, we will call Caprina, comprising the Goats and Sheep; Ovibovinz, or Musk Oxen; Bovine, or the Ox tribe; Aplocerine, or Mountain Goats, and Antilopina, or Antelope tribe.

\section{THE SHEEP AND GOAT TRIBE.}

The two kinds of Caprina, namely the Goats and the Sheep, exhibit so close an affinity to each other that it seems scarcely possible to decide on special distinctive features between them.

All species of this family attain what is to be considered but a moderate size when compared with other Ruminants; they are of sturdy and sometimes even of clumsy organization, have short necks and generally stout, coarse heads, low, sturdy legs with comparatively obtuse hoofs, a round or broad tail naked on its under surface, short or moderately long ears, tolerably large eyes with obliquely placed oblong pupils, more or less compressed and angular horns curving backward and outward, not infrequently spirally twisted, and more rarely conforming to a lyre-shaped outline. These horns are often very bulky and possessed by both sexes, though those of the female are considerably shorter than those of the male. The pelt, which is usually of a subdued, neutral color, is very thick, and consists of a long outer fur and a copious woolly inner layer.

The Sheep and Goat tribe is for the greater part indigenous to the regions of the north of the Old World; they were originally absent in the South American, Ethiopian and Australian Zones, and are represented by only one native species in the North American and Oriental belts, respectively.

\section{THE GOATS.}

The sturdy, vigorous body of the Goats (Capra), to which we unhesitatingly concede the first place in their sub-family, have a sturdy, vigorous body which rests upon strong and comparatively short legs; the neck is stout and the head proportionately short and broad at the forehead. The tail, which is usually carried erect, is triangular and devoid of hair on its under surface. The eyes are large and lustrous, the ears erect, acutely pointed and very mobile. The horns are quadrilateral with rounded edges, or twoedged with an elliptical cross-section distinctly marked by rings denoting the growth of each succeeding year, broad and flattened on their anterior surfaces and possessed by both sexes. The direction of the horns is either backward, with a simple, crescent-shaped sweep, or they curve outwardly at the tips producing a lyre-shaped contour. Those of the he Goats are always much heavicr than those of the she Goats. The fur consists of two layers, the finer woolly coat being concealed by the coarse outer hair. With some species the outer fur lies tolerably. close to the body, with others it grows into a mane on certain parts of the body, with most species it forms a stiff beard on the chin. The hue of the fur is always dull and neutral, either earthy or rockcolored, brown and gray tints prevailing. Another feature characteristic of these animals, is the powerful, rank odor, with which all Goats afflict our sense of smell.

Goats in a free state inhabit central and southern Asia, Europe and northern Africa. Domesticated species are distributed over the entire globe. They are as a rule inhabitants of mountains, especially of high ranges, where they affect lonely spots inaccessible to Man. The majority of species range higher than the line of perpetual snow. Sunny spots with dry pasturage, thinly grown woodland glades and craggy walls, as well as bare cliffs and rocks, louming straight above the eternal snow and ice, are their favorite haunts. All species are gregarious. They are active, lively, restless, intelligent and sportive 


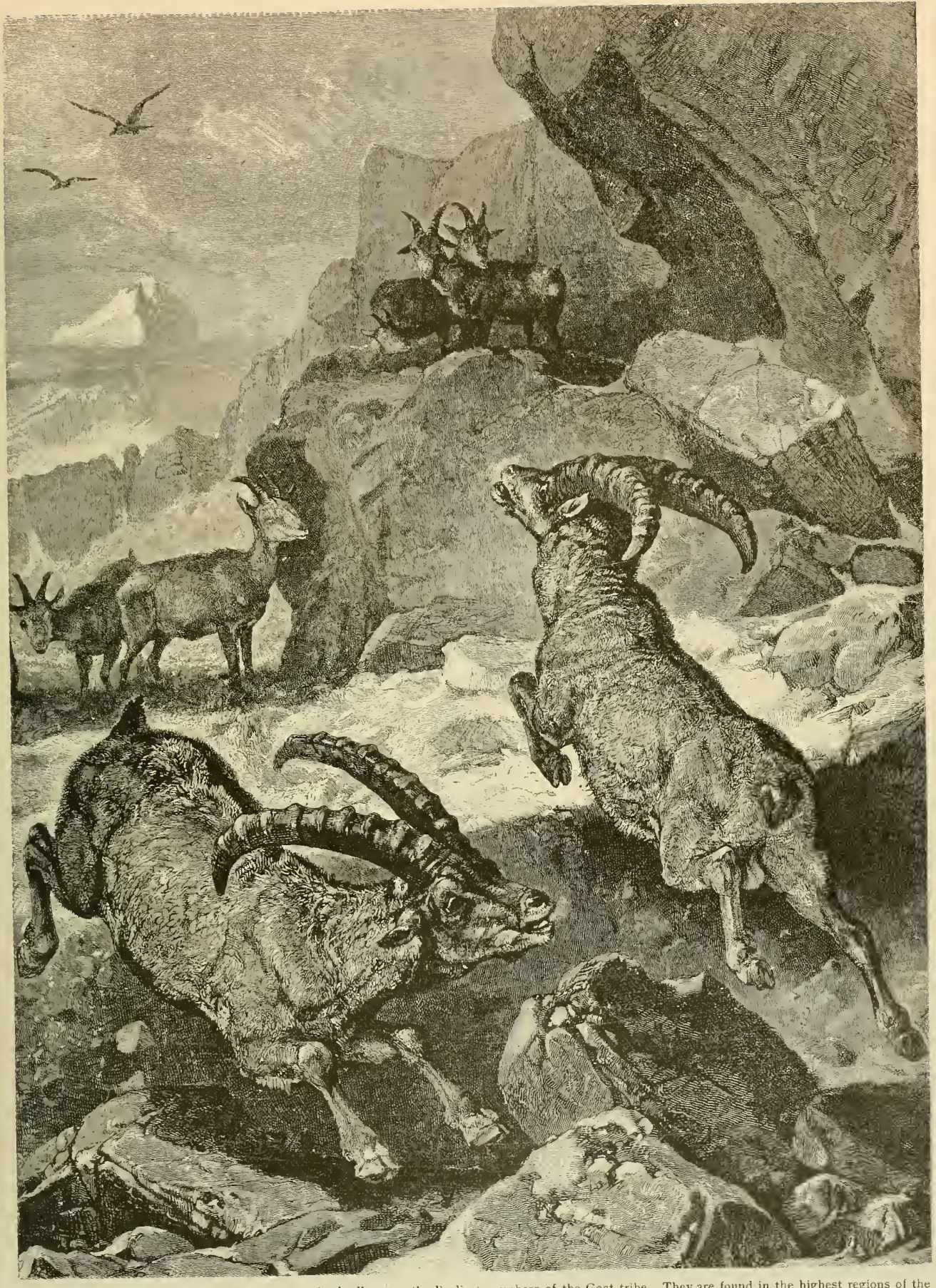

IBEX OR STEINBOCK.- These mountain dwellers are the liveliest members of the Goat tribe. They are found in the highest regions of the European Alps, spending the day in localities above the line of perpetual snow. At night they descend to the highest woods to graze, retiring at sunrise to their snowy fastnesses. They jump from crag to crag with great security and facility. They live in small herds and the picture shows them as they appear in their Alpine home. (Capra ibex.) 
animals, which incessantly run and gambol, and only lie quictly on one spot when engaged in chewing the cud. Old males are the only individuals which lead solitary lives, and they but seldom; others always tenaciously keep together. Though they are active by day and by night, they give the preference to the day. Their peculiarities are displayed at every opportunity. They are exceedingly good climbers and jumpers and in the exercise of these accomplishments they display an amount of courage, intelligence and resolution which redounds greatly to their credit. They are remarkably sure-footed, and traverse the most dangerous spots in the mountains. They are free from dizziness, and they stand on the narrowest ledges and with apparent indifference gaze into the most terrible abysses. With foolhardy carclessness they graze on nearly vertical walls. In proportion to their physical stature they are possessed of enormous strength and of wonderful powers of endurance and thus are perfectly adapted to inhabit a sterile domain, in which every leaflet. every little blade of grass has to be acquired by labor, and existence must be maintained by dint of incessant struggle. Sportive and playful toward each other, they are wary and shy in all their relations toward other beings and generally flee at the slightest noise; though one can not ascribe such action entircly to fear, for in case of necessity they fight with much courage and determination, and exhibit a certain pugnaciousness which is certainly entitled to respect.

Diet and Prop- Succulent mountain herbs of all agation of kinds furnish the fare of the Goats. Goats.

Fastidious to a high degree, they always select the choicest morsels. Water is an essential with them, and therefore they shun regions where there are no rivers or creeks.

The number of young brought forth at a birth ranges between one and four. With wild species the number reaches two at the most; with tame ones, in rare cases, four. The kids are perfectly developed at birth, have their eyes open and are able to follow the mother about at once. Those of wild species run about the mountains on the first day of their life, exhibiting as much boldness and being as sure of foot as their parents.

Great Value of IVe may truly assert that all Goats

Goats to are eminently useful animals. The Man. damage they inflict is of slight account generally, and is to be noticed in but few countries, while their usefulness is considerable, especially in regions where the animals are used to extract, for the benefit of man, profit from localities which would otherwise lie waste. The desolate mountains of the south of Europe are covered with herds of Goats, which browse the grass from precipices where no human being could gain a foothold and thus turn into food for man through the medium of their own flesh, vegetation that otherwise would be lost. Nearly every portion of the carcass of the wild species is useful to man, such as flesh, skin, horn and hair, and the tame Goats are not only the most valuable friend of the poor, but also come very near being the only producers of milk in the south, where they are regarded as animals of great utility.

The classification and identification of the wild Goats is a difficult matter, because the species are so very similar and there are so many obstacles in the way of observing their life. There are several varietics among them, of which we will now consider the Ibex and the Goats proper.
The Ibex, and its The Ibex or Steinbock (Ibcx) inhabPeculiari- its mountains, at an altitude so great ties. that other large mammals ranging there would fail to find sufficient food and hence would be stunted. Few Ruminants follow them into the high altitudes, where they roam about from year to year, descending but slightly lower during only the severest winter weather. It is in accordance with this mode of life, that every species of Ibex has a very restricted distribution. Some naturalists admit only one species, not only tor Europe, but in general. IVe, however, prefer to consider the various forms as species, for the time being. In doing so, we regard the lbex as a sub-genus rich in species. Europe alone possesses three different varieties: one, the Ibex proper (Capra Ibex), inhabits the Alps, the second, the Pyranean Ibex (Capra pyrenctica), dwells among the Pyrenees and other Spanish mountains, the third, the Caucasan lbex (Capre caucasica), finds its domicile in the Caucasus. Then there is a fourth species in Siberia, a fifth in Arabia, a sixth in Abyssinia and a seventh in the Himalayas. All these animals are very similar in anatomical shape and the color of their coats and differ mainly in the formation of their horns and in their beards. Intermediate forms have as yet not been discovered, and thus we must regard them for the time being as distinct species.

Description of the The Ibex of the Alps, Bouquetin or

Alpine lbex or Steinbock (Capra ibcx), is a handsome,

Steinbock. stately creature, the body of which measures from five feet to five feet four inches in length. Its height at the shoulder is from thirty-two to thirty-four inches, and it weighs from one hundred and fifty to two hundred pounds. The animal's appearance produces upon the observer the impression that it possesses great strength and endurance. The body is sturdy, the neck of medium length, the head is proportionately small, but strongly arched on the forchead. The legs are vigorous and moderately long, the horns, possessed by both sexes, attain a comparatively large size and great strength in the case of old males, and they curve obliquely backward in either a straight direction or in a crescent shape. At their bases, where they are thickest, the horns stand nearest to each other. From that point they diverge widely, and gradually taper toward their extremities. Their cross-section forms an oblong quadrangle slightly depressed on the hinder surface of the horn, and becoming flatter toward the upper extremity. The rings produced by growth, protrude especially in front, forming bulky knots or tubercles, and then run along the sides of the horn, being much less prominent there, however, than in front. Toward the base and the extremity the rings diminish in width; toward the middle of the horn they are widest and are found most closely together. The horns may attain a length of from thirty-two to forty inches, and a weight of twenty or thirty pounds. The horns of the female bear a greater resemblance to those of a domestic she Goat than to those of the male Steinbock.

The fur is rough and thick, undergoing modifications in the different seasons, being longer, coarser, curlier and of duller tint in winter, shorter, finer and more lustrous in summer, and during the cold season it is mixed with a thick under wool, which is shed as the temperature becomes warmer. The hair is erected into a kind of mane on the back of the neck, and in old males it also becomes longer on the back of the head and on the lower jaw. In the latter sit- 
wation the hair forms a short beard, not over two inches long and absent in the young males and all females. The color of the beard slightly differs with age and season. In summer a reddish gray tint prevails, in winter it is yellowish gray or of a pale tint.

Habits and Pecul- The Bouquetins form herds of variiarities of the ous sizes, the old makes joining them steinbock. only during the breeding season, however, and leading a solitary life during the remainder of the year. The she Goats and kids always live in a lower belt of mountain region than do the males, in whom the yearning for the highest altitudes is so powerful that only lack of food and the severest cold can compel them to descend. According to Berthoud von Berghem, whose accounts are still accepted as authentic, all males that are over six years old retire to the highest spots in the mountain, lead a more and more solitary life and finally become so insensible to the severest cold that they will sometimes stand on the highest peaks with their faces turned against the storm, motionless as statues, as a result of which they not infrequently get the tips of their ears frozen. Like the Chamois, the Ibex also grazes during the night in the forests nearest the line of vegetation, in summer never descending lower than a quarter of an hour's journey from the perpetual snow limit. At sunrise they begin to climb upwards, grazing, and finally settle down to rest on the highest and warmest places, facing east and south; in the afternoon they descend again, grazing, to spend the night in the forest, if possible.

No other Ruminant seems to be so well fitted to climb mountains as the wild Goats in general and the Ibex in particular. All the movements of the latter are quick, vigorous and yet easy. It runs with great speed, climbs with admirable facility and exhibits a truly astonishing security and speed in going along almost perpendicular walls of rock where it alone can gain a foothold. An uneven spot or indentation in the wall, which a human eye barely sees when quite close to it, affords it sufficient support; minute crevices and small holes constitute for it the steps of a convenient ladder. It plants its hoofs so firmly and securely that it can keep its hold upon the smallest spots of standing room. Schinz has observed and interestingly recorded with what precision these ani- mals reach the spots at which they aim. A young Bouquetin in Berne sprang voluntarily and without having been pursued, alighting on the head of a tall Man, and kept its place there with all four hoofs. Another was seen to stand on all four feet on the top of a pole, a third stood on the narrow upper edge of a door and mounted a vertical wall without any other support than that formed by the projections of the bricks, at such joints as had been denuded by the falling off of mortar. Running along this wali, it scaled it to the top with three bounds. It took its stand opposite the goal it had selected and measured the distance with its eye; then it trav-

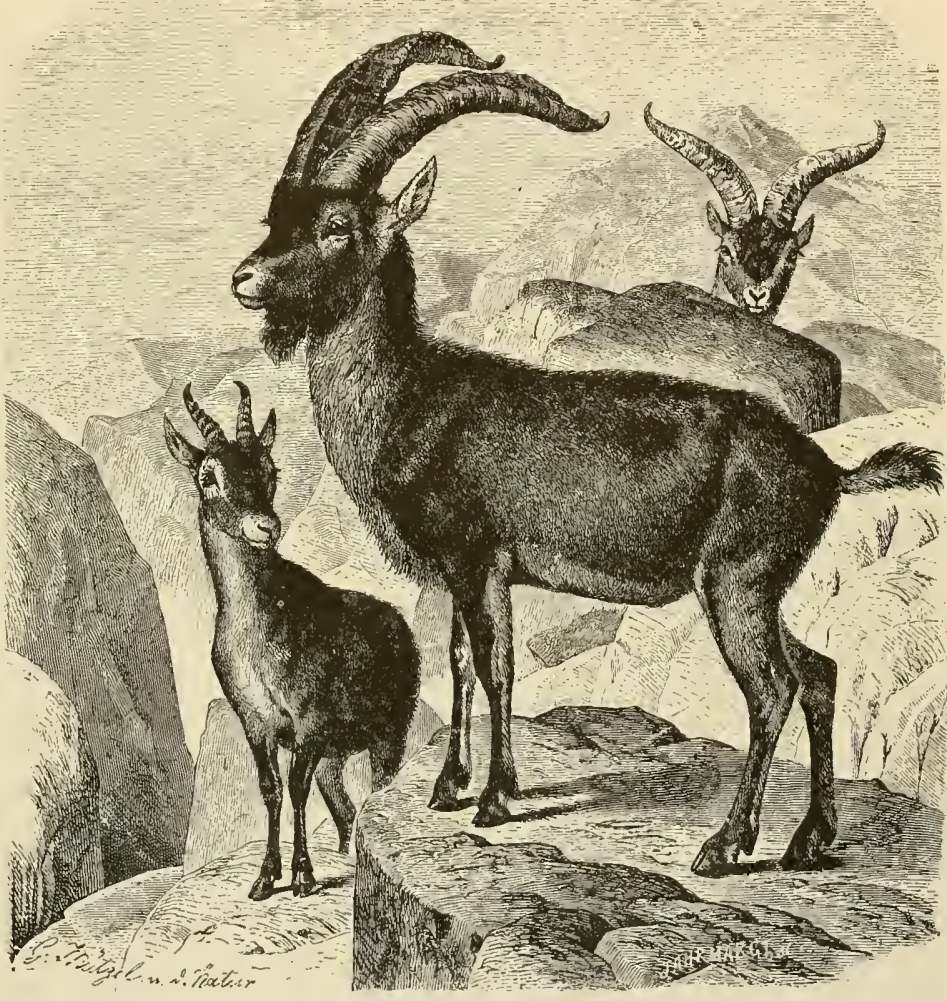

PYRENEAN IBEX_-Closely allied in its nature to the Steinbock is the Pyrenean Ibex, which is distinin guished from its. Alpine relative by a more gracelul form and by differently shaped and twisted horns. It inhabits )

ersed an equal horizontal space taking short steps, repeatedly coming back to the starting point; it swayed to and fro on its legs as though trying their elasticity, then jumped and reached the top in three bounds. They scarcely seem to touch the rocks or walls in leaping, and their bodies bound upwards like balls. The ease and security with which the Ibex crosses the deepest and most dangerous erevasses and abysses are also truly wonderful.

sensory and Mental The vocal expression of the Ibex Attributes of resembles the whistle of the lbexes.

Chamois, but is longer drawn-ont

Among the perceptive senses that of sight ranks first. The eye of an Ibex is much keener than that 
of a Chamois, while its scent is much weaker; the faculty of hearing is excellent, the mental capacity is probably on a level with that of the Goats in general. The Ibex proves its sagacity by the judicious selection of its haunts and walks, by its calculating caution, skillful avoidance of danger and easy resignation to altered circumstances.

In quiet, elevated valleys the Ibex feeds in the forenoon and afternoon; in regions where it fears molestation it selects as its meal-tmmes the hours of dawn and twilight and perhaps the night. Its food consists of the juicy, delicate Alpine herbs, grass, buds of trees; leaves and tips of branches, especially varieties of fennel and wormwood, thyme, the buds and branches of the dwarf-birch, birches, Alpine roses, gentian and in winter also dry grass and moss.

Propagation Usually at the end of June or at the of the beginning of July the females give lbex. birth to one or two young, equaling newborn kids in size. A few hours after birth the little creatures prove themselves to be nearly as bold mountain-climbers as their mother. She loves her young exceedingly, licks them clean, guides then, talks to them, through the medium of her kind bleating calls them, keeps hidden with then in caverns while she sucliles them, and never leaves them unless the greatest danger thruatens her, and she must save her own life, without which that of her infant would also be lost. In such a case she runs along dizzy precipices and seeks safety in rocky crevices and crannies. The kids, however, very adroitly conceal themselves behind stones and in holes, lying quite still and motionless, looking, listening, sniffing in all directions. The gray fur of the young Ibex is so similar in coloration to the rocks and earthy matter surrounding it that the keenest Falcon's eye could not diseern it and distinguish it from the rock, which thus takes a mother's place and shelters it for the time being. Large birds of prey, especially the Golden Eagle and perhaps also the Golden Vulturc, are a menace to the safety of young kids, but owing to the mother's vigilance, they probably are rarely successful in their attempts to seize her young. The older animals are probably preyed upon by the Lynx, Wolf and Bear. More fatal than all these foes combined are the severe clinte and the accidents concomitant with the inhospitable nature of their haunts in winter and spring. But the worst foe of the Ibex is Man, especially the poacher. Probably no more difficult and dangerous undertaking can be conceived than the lbex hunt as conducted by a poaeher. All that can be said of the dangers of a Chamois hunt obtains in this instance only in a higher measure. On account of the scarcity of the game, the hunter must be prepared to live from eight to fourteen days far away from all human habitations, braving the perils of outdoor life in the high mountains; he must endure frost, snow, hunger, thirst, fog and storm, often spend several nights on a hard rock, without shelter from the ice-cold wind, and very often he has to return home empty-handed after many trials of his patience. In the event of the most favorable result he must shun all frequented paths with his dearly bought prize, in order to avoid detection by the forest guards; he must be able to walk the edges of the most frightful precipices without dizziness, and have strength to carry heavy burdens in order to be able to convey the reward of his efforts home at all. Thus it happens but too often that he brings poverty and misery into his lut instead of the carcass of his game, not to speak of the fact that he daily runs the risk of falling into an abyss and being dashed to pieces, or of ending his life by the bullet of a guard.

lbexes Very Sus- Bouquetins taken young, as a rule, ceptible of Do- thrive well, if they are given a Goat mestication. as wet-nurse. They soon become tame, though they lose this quality with advancing age. They are as full of curiosity, fun and frolic as kids of other species, and so playful and droll that they can not but amuse the observer. They make friends with their foster-mother in a few days, and with their keeper after some time, distinguishing him from other people and showing nuch joy if they see him again after a prolonged separation. They are highly susceptible to caresses, but do not brook any vioience, and defiantly and most amusingly resist even their keepers attempting to move their heads by means of their short horns. If scratched between the horns, they remain as motionless as Lambs, but not infrequently requite such benefits by a thrust of the head meant in play but not always devoid of painful results. The older they grow, the more selfconscious and presumptuous do they become.

Stories of a Bernese There are some difficulties and unHalfbred pleasant consequences in the way of
Ibex. lbex. letting crosses between the Ibex and domestic Goat run free. This was proven by the result of experiments made at Berne about seventy ycars ago. The Bouquetins and their hybrid offspring were turned loose on part of the ramparts of the town, where they received their food and propagated themselves in the lesired manner. But the half-bloods, as well as the Bonquetins themselves, soon forgot all the benefits received and finally displayesl tleither affection for, nor fear of, Man. One hybrid male found great pleasure in attacking a sentinel on the ramparts, and displayed a perseverance in this occupation, which soon caused him to become highly unpopular. Once he interrupted the observations of the astronomer working in his tower and tore his coat-sleeve. Later he amused himself by joining the promenades of honest citizens, and causing the people to flec before him. Finally he bethought himself of mounting on the roofs of houses and demolishing the bricks of the chimmeys. Numerous complaints were lodged against him, and the wise and mighty city government was obliged to respond to them; the mischievous buck was solemnly banished and transported to a mountain near Unterseen, together with his female Goats. The latter soon became accustomed to their allotted heights but the buck preferred the inhabited parts of the nountain to the proximity of glaciers. He began by visiting the huts on the Alps, and he there struck up a closer friendship with the domestic Goats of the vicinity than was agrceable to the Goat herds, and finally became so regular and importunate a visitor that he could not be driven away, as he made very free use of his horns.

Such decds of violence and various other pranks at last made his removal imperative. The task of taking him higher up in the mountain to the Saxetenthal devolved on four strong Men. The wild creature was fastened to a strong rope, and he succecded more than once in throwing all his leaders to the ground. Then a strong Chamois hunter undertook the supervision of the intended Bouquetin removal. He also had a hard time of it, for the buck seemed to be utterly devoid of gratitude. Once he challenged his guardian to a duel, the Man being 
compelled from motives of self-preservation to accept it, as it occurred on the edse of a precipice. For a whole hour he had to struggle with the animal betore he subdued it. Besides these chivalrous exploits the buck was guilty of greater deeds of mischief. He continued to be the terror of the goatherds, whom he frequently attacked and ill-treated, coming down from the heights to visit their huts. The people living on the mountains again began handing in petitions to the government, and the consequence was another removal of the buck. The Grimselalpe was allotted to him; but there also he evinced his old disposition; he picked quarrels with all Dogs with which he came in contact, even with the largest; and if they stood their ground he simply threw them over his head, sending them through the air in a bold curve. He defiantly put himself in the formation of its horns. The favorite haunts of the Pyrencan Ibex are as inaccessible as those of the Stcinbock, and it is equally as difficult to hunt.

General Character. The Goats proper (Hircus) are, on an istics of Domes- avcragc, of a smaller size than the tic Goats. Ibex. The horns are more or less compresscd, those of the male having longitudinal angular ridges or "keels," while those of both male and female are marked by wriukles or transverse rings, each depression indicating a deposit of borny matter acquired during the growth of the horn. In all other respects the Goats resemble the lbex.

Ancestry of the As is the case with the other domesDomestic tic animals we do not know which Goat. species of wild animals was the original progenitor of the domestic Goat. Our information about the wild Goats, which are especially nu-

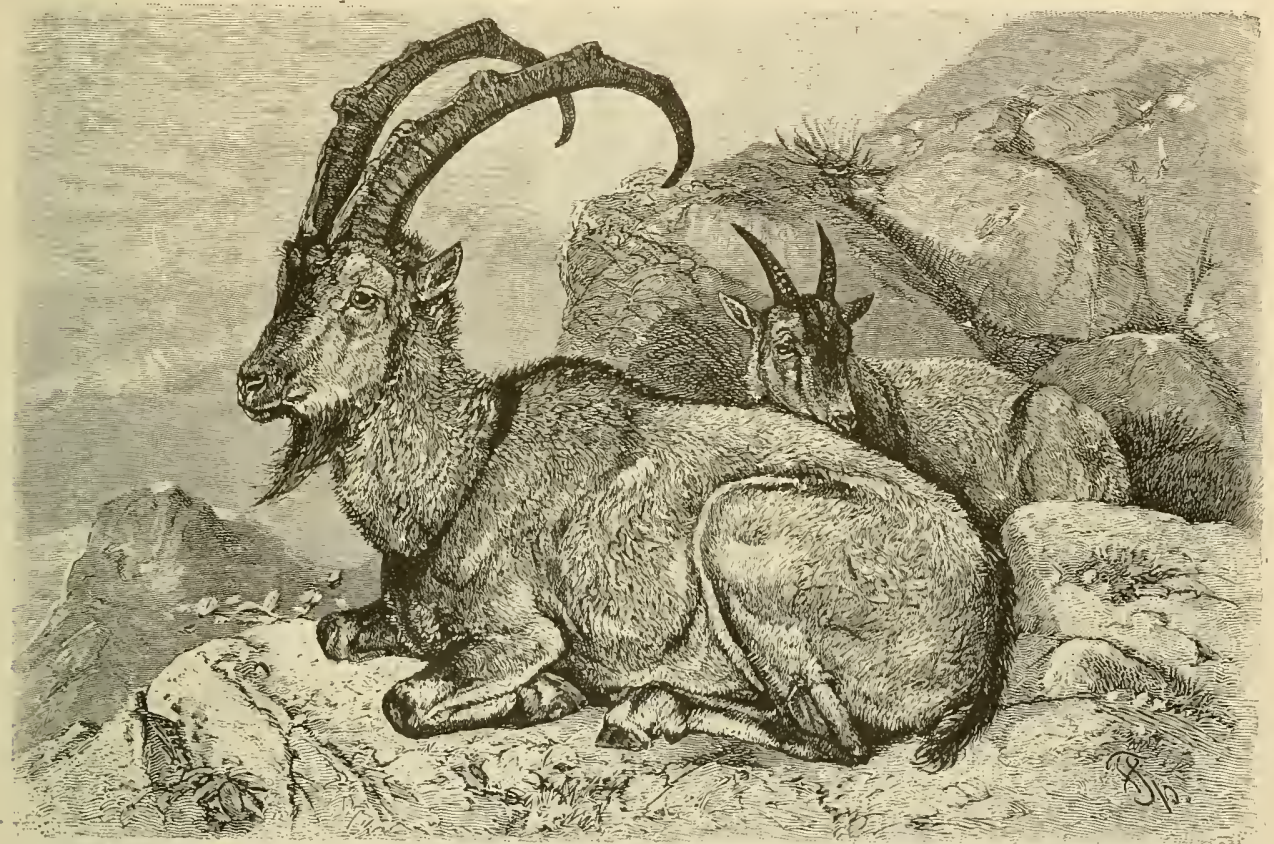

THE EGAGRUS GOAT. - The wild Goat, called Paseng by the Persians, is believed by many naturalists to be the original stock from which the domestic breeds are descended. The long horns of the male, transversely ridged, are proportionately longer than those of any other Ruminant animal. 1 inhabits the remote heights of all Asiatic mountain ranges from the Caucasus to the Himalayas. (Capra agagrus.)

way of climbing travelers and spread terror and panic wherever he appeared. So the government at last was obliged to take extreme measures against him and the freedom-loving, vigorous fellow was sentenced to die. His offspring were distinguished by a particularly savage disposition, which manifested itself as they grew older. While they were young, they diverted the goatherds by their mischievous pranks and antics; but when they grew older and stronger, they became a burden to their owners and were slaughtered, one and all. Such was the termination of the Bouquetin breeding at Berne, the intended object being found impracticable, or if not impracticable was certainly not achieved in this attempt.

The Ibex of the Pyrenees (Capra pyrencica) attains exactly the same dimensions as the Steinbock of the Alps, but differs materially from it in the shape and merous in Asia, is so meager that we have no means of forming even an approximate estimate of the number of their species. Many naturalists believe that to the Egagrus more than any other wild species of Goat is due the honor of having enriched us with so useful a domestic animal. The Figagrus and the domestic Goat are alike in all physical essentials except in the direction and twist of their horns.

Description of the The IEgagrus or Paseng (Capra agagAgagrus or ris) is smaller than the European Wild Goat. Bouquetin, but perceptibly larger than the domestic Goat. The length of a full-grown male is about five feet; the height at the shoulder is thirty-eight inches and at the croup nearly an inch more. The female is perceptibly smaller. The horns are very large and strong, much compressed laterally, sharp-edged in front and behind 
and rounded or arched on the outer side. In medium sized animals they often measure upward of sixteen inches and more than double this size in old individuals. Beginning from the base they swcep backward in a bold, direct curve, and in old males describe almost a semicircle. They are set close together at their bases, gradually diverge for more than half their lensth, and for the remainder of their length to their extremities curve boldly forward and inward. The knots or transverse rings on the horns, between which are numerous smaller ridges, number defined black-brown stripe runs along the course of the backbone to the black tail.

Range and The Hogarus is a native of an exten-
Habits of the Sive portion of western and central
Agagrus. Asia, It is found on the southern slope of the Caucasus, and in the Taurus and other mountains of Asia Mlinor and Persia, and from thence far south through Afghanistan and Beluchistan. It is also found on the islands of the Mediteranean, especially among those of the Grecian Archipelago, and perhaps even on the higher parts of the Greek

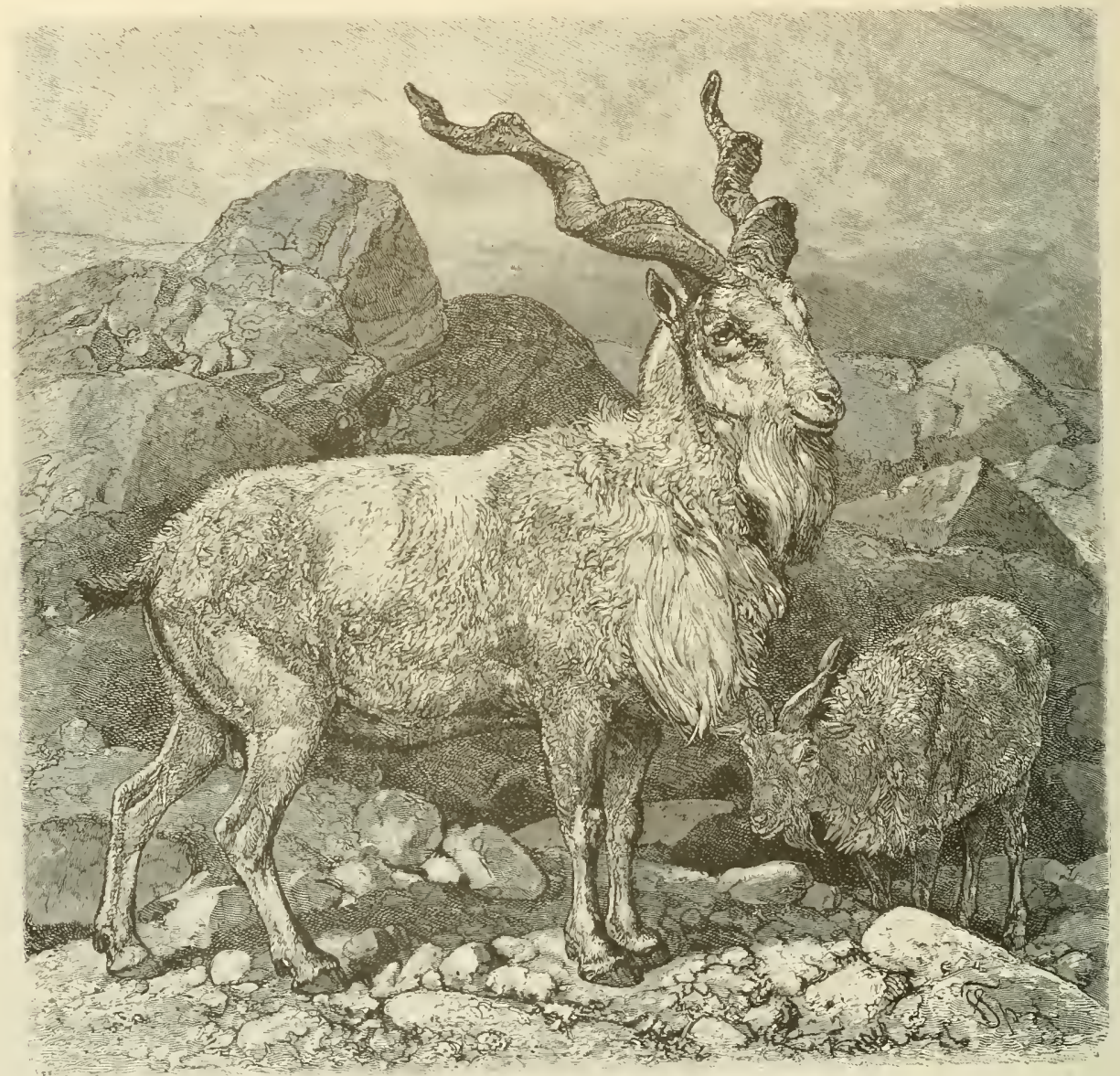

THE MARKHOOR. - The lofty mountains which enclose the famous valley of Cashmere in Asia form the favorite home of the Markloor or Narkhor, populy loor. Me Markhoors have bred several times in the gardens of the \%oulugical Society. London. (Cafrafalioneri.)

from tem to twelve in old individuals. Euragus Goats of both sexes have coarse beards; the remain der of the hairy covering consists of a rather long. smooth, wiry outer fur, and a short, woolly inner coat of a medium desree of softness. The coloring is a brimht reddisli-gray, or a rusty hue of brownishvellow, assuming a lighter tint upon the sides of the neck and the flanks. The breast and throat are blackish-brown, the abdomen and the inner and rear surfaces of the thighs are white. I sharply peninsula. Investigation has demonstratud, alnost to a certainty, that the Egagrus is the same animal mentioned by Homer in his description of the $\mathrm{C}_{\mathrm{y}}$ clopean Island:

"A wooded isle, wherein do roam wild Goats unnumbered;

For lath of Man, or presence there, affrights them not."

The actions and habits of the Egagrus strikingly resemble those of the Ibex. With heedless fleetness it runs along the most perilous paths or stands for hours, entircly free from vertigo, looking down into 
deep gulfs which yawn below. It is an cxcellent climber, and executes dangerous leaps with sreat courage and skill. It is execedingly wary, and generally succeeds in avoiding the most insidious dangers.

The little ones of this species appear in April or May. The younger mother Goats sive birth to one or two kids, older mothers always to two and not rarely three at a time The newborn kids follow their mother about immediately after birth, and after the third day are able to tread with facility the most difficult paths. Their growth is rapidand they are always inelined to play and eaper.

There are but few living specinens of the Egagrus Goat now to be found in zoologieal gardens, though the transportation of animals of this kind, tamed from infancy; would present few difficulties. with a taste something like that of venison. It is cither caten fresh or is cut into long, marrow strips and dried in the air for future use. The long-haired fur obtined in winter is used by the Moslems as it carpet on which to say their prayers and is highly valued, as its pungent odor is much liked by those Orientals. The short-haired summer fur is manufactured into bags, the horn into sabre-handles, powder horns, ete., and thus the earcass of a buck is put to account in a good many ways.

The Evolution of Neither tradition nor history furnish

the Domestic us any aid in the attempt to sulve Goat. the prublem of the descent of our domestic Goat (Capro hircus) and its exceedinsly numeruus breeds. IVe are unable to decide at what time onc or the other of the wild species was reduced to a state of domesticity, when any crossing of the

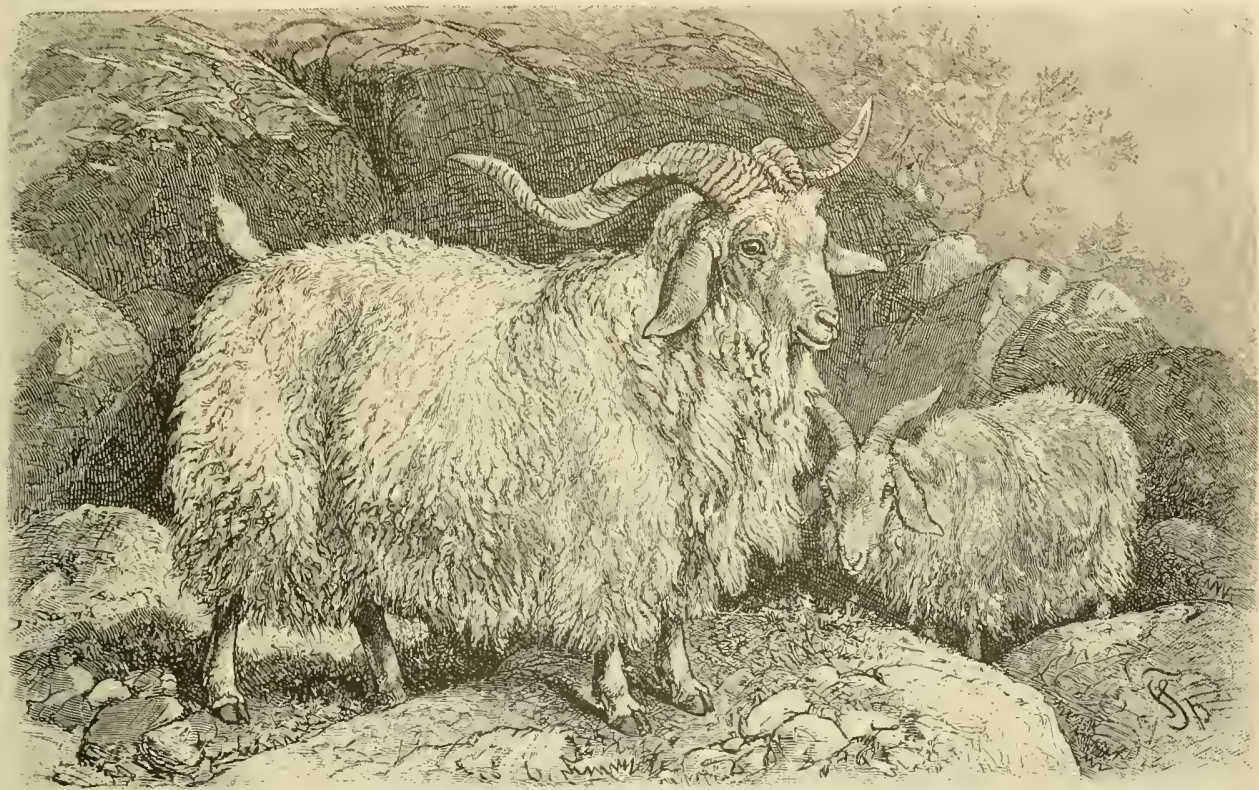

THE ANGORA GOAT. of Asia linor of which the town of Augora is the principal market. Its tong fleece furoishes the textile staple known as mohair, used in making fine fabrics. The horns of the male are spirally twisted, as shown in the picture. (Capra hurcus angarensis.)

Vigorous Pursuit A superstitious belief is still widely of the Agag- prevalent among the unenlightened rus Goat.

peoples of the world, that the bezoar stones, or eartlyy concretions found in the intestines of the Ruminant aninuals, are of miraeulous medicinal value, particularly as antidotes to poisons. Though the supposed virtues of bezoar stones have long since been shown to be non-existent, the erroneous belief that these concretions are oftener contained in the stomachs of the Egagrus Goats than in those of óther Ruminants is the cause of a relentless, exterminating war, waged against these froliesome denizens of the mountains by people who still believe in the magical powers of bezoar stones. This charlatan belief is unknown on the Grecian isles, in the Caucasus and in the Cilician Taurus region, and in those portions of their range these wild Goats are pursued solely on account of their flesh, fur and horns.

The profit aceruing from the chase is not inconsiderable. The flesh is exceedingly savory and tender, breeds oceurred, if it occurred at all, or how the peculiarities of breeds that have been proven to cxist for thousands of years have been developed.

The Angora Goat We may call the Angora Goat (Capro and its Native hircus angorensis) the noblest of all Home. the domestic breeds. It is a beautiful, farge animal of sturdy organization, with strong legs, short neck and head, curiously twisted horns and a remarkable coat of hair. Both sexes have horns. Those of the buek are much eompressed, not twisted, sharply edged longitudinally, and bluntly. pointed behind; they usually stand out at a vertical angle from the head, describe a wide double spiral curve and have their extremities directed upward, appearing to make three curves. The she Goat has smaller, weaker, round and directly curved horns. Only the face, the ears and the lowest parts of the legs are covered with short, sleck lair; the other portions of the fleece are extremely rich, thick and long; fine, soft, lustrous, silky and curly. Both sexes 
are adorned with a rather long beard, composed of wiry or stiff hair. $\lambda$ dazzling, uniform white is the prevailing color of this breed of Goats; individuals showing dark spots on a light ground are of rarer occurrence. In summer the hair pulls out or is shed in large locks or bunches, but soon grows again. French brecders have found that one fleece weighs from two and one-half to five pounds.

This Goat derives its name from the small town of Angora, now in the Turkish pashalic of Anadoli in Asia Minor, but which was once the commercial town Ancyra, famous among the ancients. The native country of the animal is dry and hot in summer, but very cold in winter, though this latter season lasts only three or four months. In times of great scarcity, or when there is no food to be found in the mountains, the Goats are sheltered in miserable stables, but they are left to graze outdoors for the remainder of the year. During the hot season the fleece is washed and combed several times a month, to preserve its beauty.

Great Value The number of these Goats kept in of Angora Goat's Anadoli is estimated at half a milHair. lion, and there are is hundred or more female Goats to every male. Angora alone furnishes nearly two million pounds annually of the hair of these Goats [ which is the mohair of commerce], the value of this quantity amounting to about $\$ 900,000$. Part of the product is locally woven into strong fabrics for Men's wear, and finer ones for the use of Women, as well as into stockings and gloves, and the residue of the product is shipped to the English markets.

Ever since the value of mohair became known in civilized lands attempts have been made to iutroduce this Goat into Europe and other portions of the globe, and the results so far leave no cause for complaint. It is even said that the wool of the animals born in France is finer than that of the parents. In Cape Colony, South $A$ frica, the Angora Goat has been introduccd with espccially excellent results, the demand for thesc Goats in that colony increasing to such an extent that in 1880 a consignment of bucks commanded prices ranging from five hundred to two thousand dollars each. The animals throve excellently, and the export of mohair increased at a surprising rate. In 1862 the amount exported barely amounted to one thousand pounds, while in $18 S_{5}$ it aggregated four million eight hundred pounds, the value of which was officially given at over one million dollars; so that the Cape Colonists are not without warrant for their expressed hope that they will soon outdo the Asiatic producers in the quantity as well as the quality of their product of mohair.

The Cashmere The Cashmerc Goat (Cupra hircus Goat and its Value laniger) is scarcely less valuable than to Man. the Angora. It is a rather small animal, of graceful build, measuring nearly five feet in total length, and twenty-four inches in height at the shoulder. A long, stiff, fine and straight outer fur covers the short, soft, down-like wool of an exquisitely fine texture; only the face and ears are covered with short hair. The color of the coat is variable. Usually the sides of the head, the tail and the upper portions of the body are of a silver white or a faint yellowish hue.

The range of this beautiful Goat extends from Tibet, throtighout Bokhara to the Kirghiz country. It has been introduced into Bengal, but it is especially numerous in the mountains of Tibet, among which it ranges even during the severest cold. fior a long time doubt prevailed in Europe as to what animal furnished the hair which is used in the manufacture of the finest of all woolen fabrics, until a French physician, lBernier, visited Tibet in I664, accompanying the Great Mogul, and was informed that two varieties of Goats furnished such wool, one being a wild and the other a tame species. The pure white is in greatest request, really possessing the lustre and beauty of silk. (One animal yields from three-fifths to four-fifths of a pound of downy wool fit for use.

Forty thousand establishments for weaving shawls are said to have existed in Cashmere during the reign of the Great Mogul; but gradually this important branch of industry was neglected to such an extent that thousands of the sixty thousand weavers who earned their living by their craft were forced to emigrate for lack of work. Even yet the weaving industry has not been restored to its former flourishing condition.

The Cashmere Goat Naturally, the idea of introducing Successfully Ac- this profitable animal into Europe climated in Europe. was entertained years ago. Ternaux, who was the pioneer of the weaving of fine shawls in France, bethought himself of procuring Cashmere Goats, and the celebrated Jaubert offered his services for the realization of this plan. He sailed for Odessa in 1818 , and was there informed that the nomad tribes in the steppes between Astrachan and Orcnburg kept Cashmere Goats. He joined these people, convinced himself of the genuineness of the animals by a close examination of the down, and bought one thousand three hundred of them. This flock he brought to Kaffa in the Crimea, embarked with it and landed in Marseilles in April, I819. Unly four hundred of the Goats had lived through the long, troublesome journey, and they had suffered so much hardship that there was little hope that they would be able to propagate themselves. The bucks especially were very weak. Fortunately the lirench naturalists, Diard and Duraucel, sent a strong Cashmere buck to the zoological garden in Paris, at nearly the same time, having received the animal as a present in India. This Goat became the male ancestor of all the Cashmere Goats now living in France, which yicld an annual income of from threc million to four million dollars. From firance the Cashmcre Goat was imported into Austria and 11 urtemberg, but unfortunately the breed did not prosper there.

Various 0ther The Syrian Goat (Capra hircus mamBreeds of Domes- brica) somewhat resembles the Cashtic Goats. mere Goat on account of its long hair, but differs from it in having extremely long, pendulous ears: no other variety of Goat having ears of such size and shape. At present it is very numerous in the territory near Aleppo and Damascus. Beginning in Asia Minor, it seems to range over a great part of the Asiatic continent. The Kirghiz Tartars keep these Goats in large herds.

Next to this variety the Egyptian or Nile Goat (Capra hircus aguptica), the animal which is so frequently scen represented on the ancient monuments of Egypt, seems to me to bc the most worthy of note. It is somewhat smaller in its physical structure than our domestic Goat, but has longer legs and shorter horns and is especially characterized by its small head and disproportionately large, flat muzzle. Egyptian Goats of both scxes are either devoid of horns or else these appendages are small, thin and stubby, and none of the Goats of this breed which 1 
observed had beards. The usual color of the animal is a vivid, reddish brown. This Goat is extensively bred in all the lower Nile valley as far up as central Nubia, where another breed supplants it.

The Dwarf Goat This is the Jwarf Goat / Cafra lirens

of Northern reiersal, which measures at most Africa. twenty-eight inches in length and twenty inches in height at the withers, and cloes not exceed fifty pounds in weight. It is one of the most graceful in plysical forn of the entire group. It has a stout body, short, vigorous legs, and a iroad head. Dwarf Goats of both sexes have short horns, barely as long as a Man's finger. The fur is composed of rather short but thickset hair of dark color, the prevailing hues being black, mingled with hair of a subdued red tint. This breed is probably indigenous to the country lying between the IThite Nile and the Niger.

Because their usefulness has been recognized by people of all nations, the domestic Goats are now found in nearly all parts of the globe, and are sure to be included among the domestic animals of all nations, the people of which lead settled lives. Goats exist under the most varied circumstances, though the majority of species live in flocks which graze at will during the day and are kept under human supervision at night. Goats that have reverted to a wild state are probably found only on some of the mountains of southern $A$ sia and a few of the least frequented islands of the ilediterranean.

The far-famed Goats of the Pacific island of Juan Fernandez imade famous by Defoe as the scene of the adventures of Robinson Crusoe) are the descendants of a few Goats which were left there by Juan Fernandez, the discoverer of the island, in 1563. Their new mountainous home seemed to fully meet the requirements of these Goats, which multiplied exceedingly.

Traits and Attri- The Goat is especially adapted to butes of the mountain life. The wilder a mountGoats. ain is, and the steeper and rougher its surface, the better a Goat seems to thrive on it. In. southern Europe and in the temperate portions of other continents scarcely a mountain range can be visited without encountering flocks of grazing Goats.

The attributes of the Goat greatly differ from those of the Sheep, to which it is so closely allied. The Goat is a lively, capricious, inquisitive, playful creature, disposed to indulge in antics and cut capers which are amusing to the unprejudiced observer. Lenz has depicted its character in an admirable way: "Even a small kid, only a few weeks old, display's a propensity for embarking in perilous undertakings, in addition to indulging in many odd pranks. An innate longing ever impels the Goats upward, and their greitest pleasure is to climb heaps of wood or stones, walls, rocks or stairs. Frequently it is barely or not at all possible for a Goat to desecnd from an eminence to which it has laboriously climbed. It knows no dizziness, and without eoncern walks or lies down by the edge of the most frightful precipices. The fights in which, on first meeting, horned males or even she Goats engage are ficree enough to inspire spectators with uneasiness."

Likes and Dis- The Goat has a natural affection for
likes of the human heings, and it is of a vain
Goat. caresses. In the high mountains it importunately 
swers to propounded questions, without having been previously trained to do so. My mother used to licep Goats and was very fond of them, and therefore paid great attention to their care. She could always tell whether her proteges were satisfied or not; for she had only to question them from her window, to receive an intelligible answer. When the Goats heard the voice of their mistress and felt themselves in any way neglected, they immediately gave a loud cry; if they were satisfied, they remained silent.

Uses and Care On the high mountains of Spain of Domestic Goats are, because of their great Goats. sagacity, employed as leaders of flocks of Sheep. The better breeds of Sheep graze there during the entile summer on the mountain heights, and in the south often ascend to altitudes between six thousand and seren thousand five hundred feet above sea level. There the shepherds could not accomplish their mission without the aid of Goats; vet they regard these useful animals only as a necessary evil, because they entice the sheep on perilous climbing expeditions. In Greece Goats are about the only animals kejt in herds. They populate the mountains and make known their presence to the traveler from a great distance by reason of the pungent odor arising from their bodies. In many countries Goats are largely left to follow their own devices, as, for instance, is done in the Alps. They are driven, in the spring, into some particular, entirely isolated pasturage. In autumn the herd is collected, but sometimes many of the Goats are found to be missing when the flock is recounted. Some owners send a little salt to their Goats, daily or weekly, by one of the farm hands, whose visits. made regularly to the same spot at the same hour of the day, the Goats learn to eagerly look for.

In central Ifrica also, the Goats are left to graze at their own discretion during the day, but at night they collect in the enclosure of thorny hedge, called the seriba, where they are protected from wild beasts. In western Africa they also run about at will, climb the trunks of low, sloping trees, and mount even the cross railed fences, but are carefully stowed away for the night in those districts where Leopards exist, for these beasts of prey are the worst enemies of the Goats.

America received the Goat from Europe, and it is now distributed over the northern and the southern divisions of the continent, but it is not always carefully bred, On the contrary, it seems to be much neglected in some South American countries, as for instance in l'eru, Paraguay, Brazil and Surinam, while more attention is bestowed on it in Chile. In Austratia the useful creature has also been introduced and has attained an extensive distribution.

The Goat an Om. Observation show's that in Germany nivorous the Goat eats four hundred and fortyFeeder. nine kinds of plants out of five hundred and seventy-six. Its variable, capricious disposition shows itself distinctly when the animal is eating. It is ever eager for a novelty. plucking a little everywhere, investigating and nibbling at this and that and not stopping long even at the best. It is especially fond of the foliage of trees and therefore is liable to commit considerable devredations in nurseries. It is a remarkable fact that it feeds without harmful results to itself on some plants whicl are very pernicious to other animals; thus it consumes spurgewort, spurge-olive, celandine and carlinethistle, the acrid stonecrop, coltsfoot, sage, hemlock, the common balm and similar herbs, also partaking of smoking-tobacco, cigar-stubs and so on, with pleasure. The digestive powers of the Goat are enormous, and some of the food it eats seems almost impossible for reception into the stomach of an animalas for instance, print paper, brown straw-board, etc. Jt is most partial to young leaves and buds, pods of peas and beans, leaves of cabbage and turnips and of most trees; it thrives best on vegetation which grows on dry, sumny, fertile, elevated spots. Goats grazing in pastures get only water to drink, while Goats kept in stables are usually given a lukewarm mixture of rye-bran, with a little salt and water.

Kids of the domestic Goat are usually born one or two, more rarely three, and only in exceptional cases four or five, at a birth. The next day after birth they run about and after four or five days they follow their mother everywhere. They grow rapidly: during the second month the little horns begin to sprout; in about a year the young ones have attained their full growth.

Great Economic The Goat may in many countries be Value of truly called the friend of the poor. Goats. and its usefulness is undoubtedly great. It is maintained at trifling cost the greater past of the year and in summer at really none at all. On the other hand it provides the household with milk and furnishes the fertilizer for the piece of land of its poor owner. Lenz kept a careful account and found that a Goat which is well fed will furnish about eight hundred and eighty-five quarts of milk a year.

Besides the milk and the cheese, as well as the butter - which play an important part in some countries-the Goat is very valuable on account of the usefelness of its flesh, skin, bones and horns. The flesh of young kids is very savory, though perhaps a little too tender, and that of older Goats is good. The skin is manufactured into Spanish leather, morocco and more rarely into parchment; the Orient is still the chief source of the two former kinds of leather. The skins of the bucks are made into brecches and strong glores; in Greece wine-bags and in Africa water-bags are made of Goat skins. The skin of the common Goat of Cape Colony is valued most for the manufacture of leather. The coarse hair is occasionally used for brushes or twisted into ropes. The horns fall to the use of turners, and in the Orient and among many so-called savage tribes they are appropriated by physicians, who use them as cupping glasses. Thus the estimable animal is useful both while living and when dead.

\section{THE SHEEP.}

When an anatomical comparison is made it is seen that the Sheep ( Oris) are closely allied to the Goats, but in point of intellect only the wild species of the two groups bear any rescmblance to each other. The Sheep differ anatomically from the Goats in the possession of tear pits, a flat forchead, triangular, somewhat spirally twisted horns marked with transverse furrows, and by the lack of a beard. On the whole, the Sheep is slenderly formed, with a lean body, long legs, a short tail, a head the facial portion of which tapers sharply, moderately large eyes and cars, and a double, shasgy or woolly fur.

Range and All wild Sheep inhabit mountains of Habitat of Wild the northern hemisphere. Their Sheop. range extends from Asia to southern Europe, Africa and the northern part of America. Every group of mountains in Asia possesses one or 
more species peculiar to it, while lirope, Africa and Anerica appear poorly endowed, and so far as is now known possess only one indigenous species apiece. Several species are very closely allicd to each other and are dependent for their distinctive features mainly on the difference of the horns, the shape, size and twist of which are considered decisive. One variety has the right horn twisted to the left from its base to its extremity; while the left horn is twisted to the right; the extrenities diverge in an outward direction; in the others the twist of the right horn is a right curve, of the left horn a left curve; then the extremities point backward and the horns recall to the mind of the observer those of the Goats.

All wild Sheep are natives of the mountains; and seem to thrive only at a considerable altitude. For the greater part they ascend beyond the line of mountain vegetation, in winter of moss, lichens and dry srass. Sheep are fastidious when they have a choice of food, and frugal to a marked degree when but little is offered them. Dry grass, shoots, bark of trees and similar things constitute their only fare in winter, without their showing any signs of cletriment from insufficient nourishment.

The sheep De- More than other doncestic aniteriorated by Do- mals, perhaps with the sole excep-

mestication. tion of the Reindeer, do the sheep show the degenerating effects of slavery: The tame sheep is a mere shadow of the wild one. The Goat retains its independent spirit to a certain degrce in ciptivity as well as in freedom, but the sheep becomes a weak slave in the service of Man. No other animal suffers itself to be more easily restrained and mastered than a tame sheep; it seems to be glad when another creature relicves it of the burden of

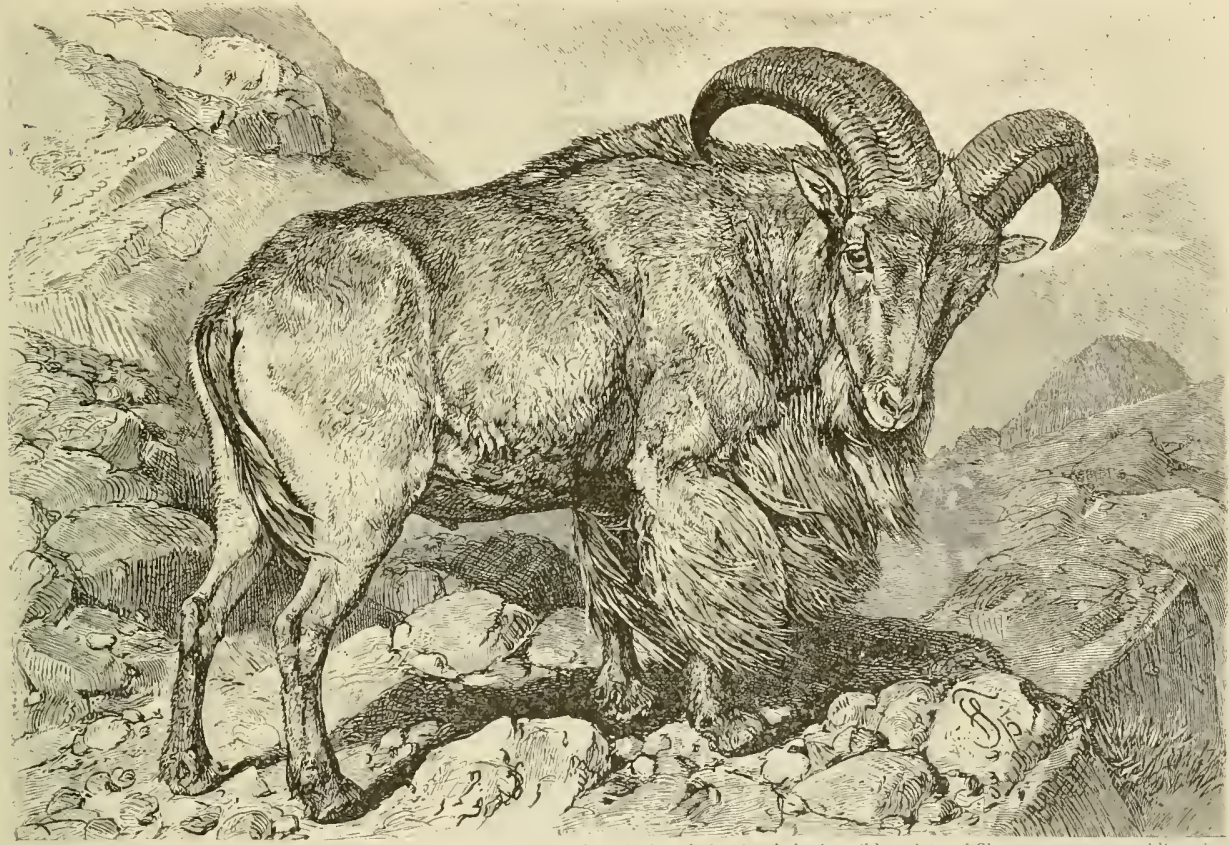

THE AOUDAD. - In the great mountain ranges of north Mfrica is found the Aoudad, the wild variety of Sheep nearest resembling the

Goats. $1 \mathrm{t}$ ascends to lofty elevations and avoids Man as much a

perpetual snow, some of them going as high as from twenty thousand to twenty-three thousand feet above sea level, where no other creatures can live except Goats, the Musk Ox and a few birds. Only tame Sheep inhabit the plains, and those that are bred in mountainous regions show clearly enough bow much they enjoy existence in a locality which assimilates their natural requirements. Abundant pasturages or light forests, rocky, precipitous mountain slopes, which bear but here and there a small sprouting plant, form the haunts of the wild Sheep. According to the season they wander from the higher regions downward or vice versa: summer invites them to go higher, winter drives them into more hospitable regions, for it clears away their table in the heights, and they must seek food elsewhere. In summer their food consists of fresh and succulent caring for its own welfare. It ought not to surprise us that such creatures are good-natured, gentle, peaceable, inoffensive; their mental qualities have their origin in stupidity and dullness, and a lamb is for this very reason not a very happily selected prototype of innocent, virtuous people. In southcrn countrics, where the Sheep are left more to their own devices than they are in more northerly regions, their mental qualities are better developed and they appear more independent, bold and courageous.

The multiplication of the Sheep is rapid. The ewe gives birth to one or two and more rarely three or four young in a season, which are able to walk and follow their mother about soon after birth. The wild ewes defend their young at the peril of their own lives and evince for them an extraordinary affection. 
Wild Sheep Nearly all wild species may be tamed

Easily Domes- without special truuble, and retain ticated. their lively disposition at least through several generations, and as a rule breed in captivity. They become sincerely attached to those persons to whom they must look for their sustenance and care, respond to their calls, are fond of caresses and may become so thoroughly tame that one can send them to pasture with other domestic animals, without their attempting to profit by such favorable opportunities to regain their freedom. The tame fur, and an undercoat of fine, curly wool, completely investing the body. The hair is longer on the neck and withers, forming a short, erect, mane-like ridge or comb; on the breast and sides it develops into a rich mane, beginning at the throat and nearly reaching the ground, and covering the forelegs and a portion of the neck.

Various naturalists from Caius Brittanicus, who mentioned it in I56I, have described the animal as an inhabitant of Morocco, Algiers, Egypt, Abyssinia and the upper Nile. Buvey says: "The Aoudad is generally called Arui by the natives of southern Algiers. Undoubtedly it occurs with still greater frequency in the loftier mountain levels in the Atlas range in Morocco than it does in A]giers, as the immunity from human invasion which characterizes that part of the mountain range can not but be agreeable to a Ruminant.

"The Arui is fond of the highest mountain ridges, which can be reached only by penetrating through barriers of bowlders and masses of stone, and therefore its pursuit is extremely difficult and often very perilous. Nor does it, even if successful, hold out a promise of much gain, for the loudad lives solitarily, and only at certain periods, generally in November, can several Sheep be found congregated. They keep together for a time, and then they disperse again, each going its own way. The Arabs are very fond of the flesh of these wild Sheep, the mutton closely resembling the flesh of Deer. The Heeces are made into rugs by the Arabs: the skin is sometimes tanned and used as Norocco leather.

"Though the Arui is classified among the rarer animals, it is sometimes caught in nooses by the inhabitants of the mountains and is then usually disposed of to the commander of the nearest military post at a low price. In the gardens of the clubrooms at Biskra there was a young Arui, which was accustomed to surmount a wall sixteen feet high; surrounding the enclosure in which he was kept; he would climb it with a few nearly vertical bounds apparently as easily as if he ran along level ground, and then maintain his hold on the top, which was barely a hand's breadth in width, with a security which warranted the belief that he felt himself entirely at home on it."

The Mouffion the Only two degrees of latOnly Wild Sheep itude separate the AouNative in Europe. dad from the Moufflon (Oris musimon), the only wild sheep inhabiting Europe, and which ranges in flon, a species of wild sheep now much reduced in numbers. It is a very agile, timid animal, an excellent climber. sure-tooted and climbing to great heights inaccessible to Man. The male has broad, boldly curved horns as shown in the picture. (Oizs musimon.)

Sheep have been under Man's supervision for thousands of years and are now distributed all over the globe and everywhere held in high esteem on account of their surpassing usefulness.

The Aoudad We place the Aoudad (Oris tragcla.

its Range and phus) foremost among the wild Habits. Sheep to be described; it is an animal markedly characterized by its long, hanging mane. The fleece consists of a strong, rough outer the mountains of the islands of Sardinia and Corsica. It is more or less generally believed that the Moufflon in former times existed also in other parts ic Islands and in Greece, but there is no positive proof upon which to base this belief. At present the Mouftion is found in herds that may sometimes rise in number to half a hundred, but are ustrally much smaller. of southern Europe, as for instance on the Balear- 
We see in the writings of old-time authors that these wild sheep were formerly found in great numbers. Sometimes from four to five hundred were slain in one single great hunt; nowadays huntsmen are satisfied if they succeed in killing or capturing several of them; on hunting expeditions which are organized at great expense, and with much attention to completeness of equipment, it very rarely happens that one or two score of the animals are bagged.

The Moufflon one The Mouftion belongs among the of the smallest of smaller species of wild sheep, the Wild Sheep. though its length may anlount to fifty inches, inclusive of the tail, which at most measures four inches; the height at the withers is twentyeight inches and the weight ranges between eighty and one hundred pounds. The horns, measured along their line of curvature, are about twenty-six inches long and weigh from eight to twelve pounds. The structure of the body has the sturdy character common to all wild Sheep. There is a dark brown on the discovery of some suspicious object give a note of alarm which arouses their companions, upon which the whole party instantly takes refuge in tlight. At certain seasons the herds separate into smaller troops, each band consisting of one ram and several ewes, which the brave ram has attracted by his exhibition of prowess during a prolonged series of fierce fights. During the months of December and January the passer-by may hear, echoing through the mountains, the noise which the horns produce in clashing against each other, and if he cautiously and quietly follows the guidance of the sound he may see the strong rams of the herd take opposing positions and then charge against each other with such violence that it is almost incomprehensible how the fighters can retain their places on the ground.

roung Mouffons In April or May onc or two young and Their Char- ones make their appearance. After acteristics. a few days they follow their mother about on the most dangerous break-neck paths with

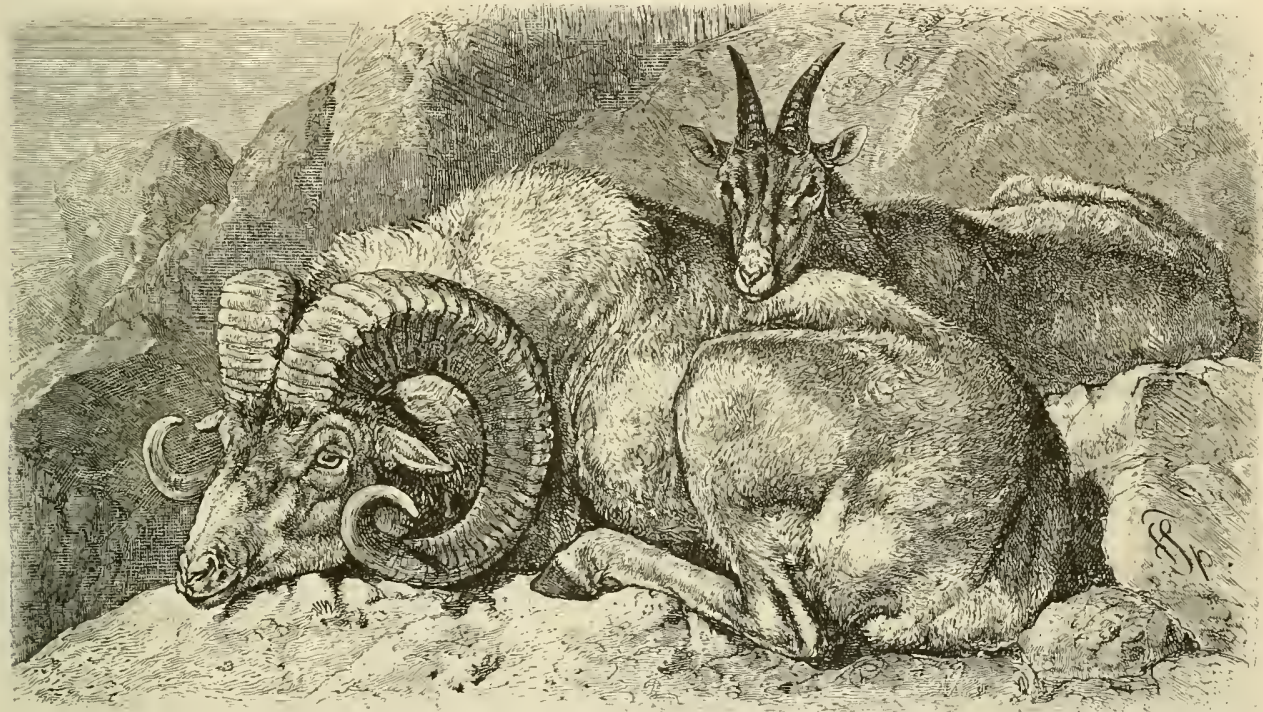

THE KRATSCHKAR OR WILD SHEEP OF TURKESTAN.-Interesting because it is by many authorities conjectured to be the ancestor of our common Sheep is this animal, living in Turkestin, where its range is contined to the Pamir plateau, where it breeds by thousands. It climbs the highest ridges, which it prefers to the valleys, and is a magnificent animal, with homs only less prominent than those of our Americas Big Hom. It was first made known to Europeans in the thirteenth century by the famous Venetian traveler, Marco Polo, from whom it derives its scientific name. (Ozis polii.)

line along the course of the spinal column, while the prevailing color is a foxy red, dashed with ashy gray on the head and merging into white on the muzzle, the croup, the sides of the tail, the ends of the feet, and the abdominal surface. The horns of the ram are strong, long, very thick at the base and triangular in their cross-section. The ewe is perfeptibly smaller, and is easily distinguished from the ram by her more subdued color, and the horns, as a rule, are absent or occur only in rare cases.

The Mouffon a In contradistinction to the Aoudad Gregarious the Moufflon lives in herds, the guidAnimal. ance of which devolves on some strong adult ram. These herds select the loftiest mountain-peaks for their haunts, establishing their quarters on steep and more or less inaccessible precipices. As is the habit of cther gregarious Ruminants, a few individuals keep a careful lookout, and apparently the utmost security and soon match her in all her accomplishments.

The Mouffon is lively in its movements, agile, quick and sure-footed; but not capable of enduring continued exertion, at least on level ground. Climbing is its specialty. Cetti says that it is very timorous and trembles with fear on hearing the slightest unusual noise, taking refuge in flight as quickly as possible.

Methods of Men have recourse to various means Hunting the to enable them to obtain this valua-

Mouffon. ble quarry: It is said that sometines rams may be attracted by sportsmen concealed in the bush imitating the bleating of the shcep, but the usual mode of hunting is to shoot with a rifle, though it rarely gives favorable results.

Strong, fully developed Moufflons are probably never caught, and young ones can be captured only 
after the mother has been killed. They soon become used to their keeper. but in spite of the high degree of docility which they usually exhibit, they always retain the lively disposition and vivacious manners characteristic of them in the free state; a passive attachment to their accustomed companions and an affection for their young-these are the sole signs of mental activity which l observed in them.

The Argali Central Asia and North America the Largest of contain the largest wild Sheep char-

the sheep. acterized by powerful horns and long legs. The Argali of the Mongols ( Oris argali) is a huge Sheep equaling a nine-months-old calf in size. The powerful, triangular, broad horns stand closely together at their bases; they first turn backward and outward, then downward and outward and the tip again curves backward and upward. They are covered from their very roots with transierse ridges, entirely encircling the horn in a scries of intricately intertwined convolutions. Thickset, wavy hair and fine, short wool cover the body, the pelt being very uniform all over. The prevailing color is a dull, pale gray, merging into a darker brownish gray tint on the face, the thighs, the upper part of the legs, on the margins of the buttocks and the posterior portion of the abdomen, and into grayish white on the fore-part of the muzzle, on the upper portion of the hams and on the lower half of the legs.

The Range and The Argali ranges from the mountHabitat of the ains of the district of Akmolinsk to Argali. the southeastern boundaries of the Mongolian tableland, and from the Altai to the Alatau, and possibly still farther southward.

The Argali shuns damp, wooded mountains and localities of great altitude. It prefers mountain ranges from two thousand to three thousand three hundred feet above sea-lerel, abounding in barren crags, with scantily wooded slopes and wide valleys. There it lives winter and summer on approximately the same territory, at the most moving only from one mountain range to another.

Diet and Mental During the summer the Argali Development of the feeds on the same kind of vegetaArgali.

tion as is appreciated by the domestic Sheep; in winter it contents itself with moss, lichens and dried grass, and such other scanty provender as its range affords at that season.

The senses of the Argali secm to be excellently and uniformly developed. It sees, hears and smells remarkably well, is fastidious in its food, whenever there is a possibility of choice; neither has its sense of touch apparently been slighted. The demeanor of the Argali is expressive of deliberation and selfcomplacency, and these animals also give evidence of a certain amount of reasoning powers and judesment. Whenever constant pursuit has made them Wary, they display much caution, though they are not excessively shy; but where they are habitually ummolestcd they are surprisingly trustful. Their foolish and sometimes dangerous curiosity is worthy of note. Steller recounts how the hunters of Kamchatka occupy the attention of the Big llorn Sheep, or the closely allied variety living on the mountains in that region, by dressing up a dummy to attract the attention of the animals, and then cautiously steal up to within shooting distance of the sheep by circuitous routes. Prejevalsky heard the same story. about the Argali and tested the truthfulness of the Mongolian statement by hanging his shirt on a ramrod and thereby arresting the attention of a fleeing flock of wild Sheep for a quarter of an hour.
Argali Sheep a Notwithstanding such devices the Favorite Game pursuit of Argali Slicep requires an Animal. experienced sportsman, and still more a good marksman. The nutton is highly estecmed by the Kirghiz and is really excellent, though sonewhat strong in flavor. In addition to being pursued by Man the adult Argali sometimes falls a victim to the Tiger, the common Wolf and the Alpine IVolf, though the eiforts of these beasts to capture it are rarely successful. The beasts of prey may oftener succeed in taking a lamb, but the most dangerous foe of the young Sheep, probably, is the Golden Eagle.

If Man could succeed in taming these Sheep he would win in them domestic animals which would be of great economic value and importance. It would be hard to find another animal as suitable to be introduced into other countries as this one, which defies alike the severe cold of the winter and the burning heats of the summer of the steppes.

Kanchatkan wild A wild Sheep, inhabiting KamSheep Related to

chatka (Oz'is nizicolu), is thought the Big Horn. to belong to the same species as the Big Horn or Rocky Mountain Sheep (Oris montama) though it differs from the latter in the structure of its horns, which are similar in external appearance to those of the Big Horn but much weaker.

Range and Habits The Big Horn inhabits the Rocky of Rocky Mount- Mountains and the country west of

ain sheep. it, ranging from the sixty-eighth parallel of north latitude south to about the fortieth parallel and existing only in the willest and most inaccessible stretches of mountain country.

The information we possess about the Big Horn, especially regarding its habits, is very scant. Adult rams attain a length of six feet four inches, only four and four-fifths inches being occupied by the tail and the height at the shoulder is forty-two inchcs. The ewe measures from fifty-six to sixty inches in length and from thirty-six to thirty-eight inches in height. The males attain a weight of three humdred and sixty pounds, the horns alone sometimes wcighing as much as fifty pounds; the females weigh from two hundred and sixty to two hundred and cighty pounds. The physical organization is sturdy and muscular and the head resenbles that of the libex. The length of the enormous horns, measwred along the curvature, may be as much as twentyeight inches. The hair bears no resemblance to wool and is of firm texture, though soft to the touch, slightly way and at the most two inches long. Its prevailing color is a dingy, grayish brown, deepening into a darker tint along the course of the spine.

In their habits the Big Iforns do not differ from their relatives, nor even materially from the Ibex. Like the latter, they are matchlessly adept at climbing. $\Lambda$ s soon as they perceive anything strange or suspicious they seek refuge among the most inaccessible heights and there take up a position on some projecting ledge which orcrlooks their domain. Wherever they have come in contact with Man, they fear him as much as their arcli enemy, the Wolf. The mutton is eaten by white people as well as by Indians, but has a peculiar shecp-like odor, especially perceptible in the meat of the ram. The skin is clurable and strong, but also solt and flexible and is in great request among the Indians for the manufacture of leather hunting shirts.

It has alway's becn esteemed a very difficult feat to capture young Big Horns, as they casily follow 
their mothers into the most inaccessible spots. The attempt has recently met with success, however, and in the west young rams have not only been tamed to such an extent that they could be safely lett to run free with the domestic flocks, but they have also been successfully crossed with the common sheep. The flesh of the mixed breed is said to be excellent.

Origin of the $\mathrm{We}$ have as little definite knowledge Domestic about the origin of the domestic Sheep.

Sheep (Oits aries) as about the descent of other Ruminants that have entered our service and have beconte completely domesticated. Opinions of naturalists concerning this subject diverge widely. Some believe that all breeds of Sheep spring from one common wild parent species, which presumably became entirely extinct in prehistoric times or else was completely exhausted by the complete domestication of all the individuals compris-
In the light of recent investigations, the opinion seems justified that the different breeds of Sheep are nothing but artificial products of the efforts of Man, variable in shape and size, formation of horns and fleece, liabits, behavior and all other qualities. The varieties of the domestic Sheep are numerous, but from the naturalist's standpoint are mucl alike. The Merino sheep The Merino Sheep (Ozis aries hisa Profitable panica) is at present by some auVariety. thorities considered to be the most profitable of all domestic Sheep. It has been proven that it acquired its peculiar character in Spain and it has gradually been used for the improvement of nearly all European breeds. Of moderate size and plump, stout build, it is distinguished by a large head with a flat foreliead, arched nose and blunt muzzle, small eyes and large tear-pits and moderately long, acutely pointed ears. The horns are

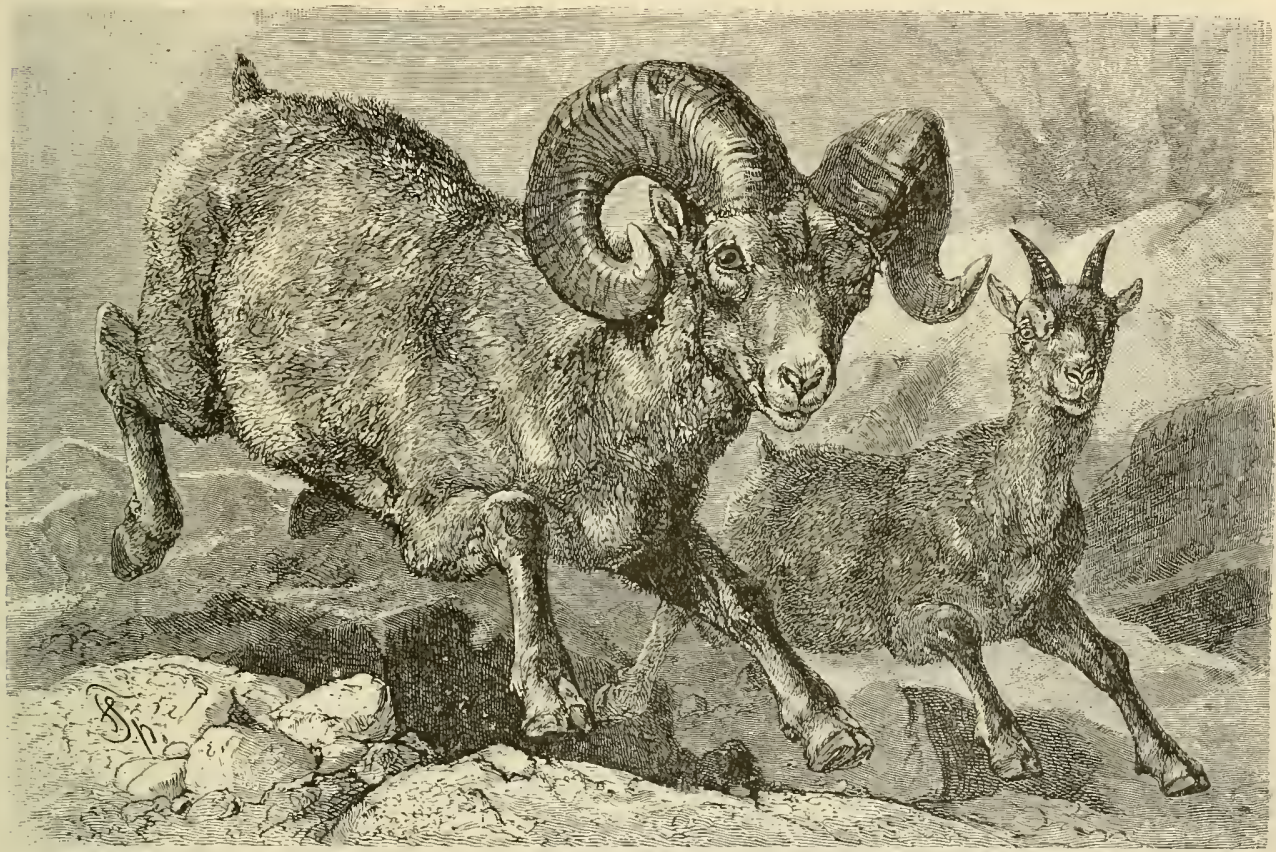

THE BIG HORN in She the males of this species. (Oris montana.)

ing the species, and is therefore nowhere to bc folnd in a state of nature at the present time. Others, however, hold that several species of wild Sheep must certainly be considered as factors in this evolution, and that the almost numberles. breeds of domestic Sheep must be regarded as produets of continued interbreeding of those species and their offspring. Some regard the Moufflon as the original stock, others the Arrali; some the Aondad, a few the Sha (Oris rignei) of Little Tibet; some, whose ranks I join, admit their ignorance frankly and honestly, and justly emphasize the fact that mere suppositions cannot aid in the solution of the question. The difference between the breeds consists mainly in the convolutions or twistings of the substance of the horns, the length and anatomical structure of the tail and texture of the fleece. strong and curve laterally and backward from their base; then they turn forward and upward in a double spiral curve. As a rule horns grow only on the head of the ran. The neck is short and thick, the skin usually lying on it loosely and being deeply wrinkled and furrowed, and a dewlap usually depends from its lower portion, while the muscular and fatty tissue about the upper part of the throat proper bulges out in a goitre-like fashion. The legs are comparatively short, but strong and stout, and the hoofs are obtusely pointed. The fleece is a short, soft, fine wool, which is quite uniformly curly. Merino sheep have been introduced with great success into Cape Colony, North and South America and Australia, in some of these countries being raised as separate herds and in others they have been used to improve native breeds. 
The Persian Besides the Merino Sheep 1 will also Sheep a Pecul. mention the Persian Sheep (Oris iarspecies. aries steatopyga). This is a fat-buttocked breed of sheep which in several varietics closely allied is found in innumerable quantities in central Asia and northeastern central Africa; all the wandering tribes of the northern and interior portions of the country, as well as the free Neyroes, breed it. This Sheep is an animal of rather large physical proportions, with small horns, and differs from most other tame species by reason of the fact that its fleece consists entirely of hair instead of

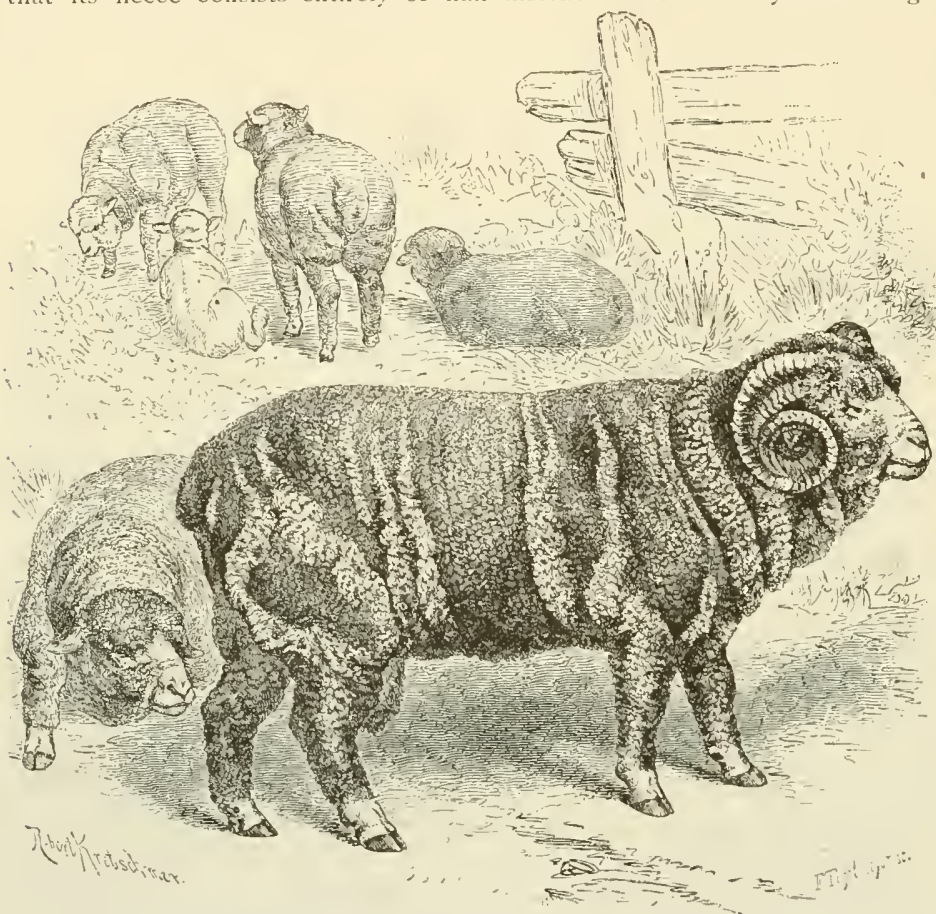

MERINO SHEEP. - A famous species of the domestic Sheep, which is found in its greatest punty in Spain. It is valuable for the quality of its wool and it las been used very largely to improve many breeds of Sheep in Europe, Australia and America. It has the mild, inoffensive qualities of domestic Sheep in general. (Ories arics hisponica.)

wool. Its pelt resembles that of the wild Sheep, bearing no resemblance to the genuine woolly fleece; and the hairy covering of adult specimens is not suitable for spinning and weaving. The lambs have a woolly coat, which is of exquisitely fine texture.

Mental Character The domestic Sheep is quiet, paticnt,

of the Domes- gentle, simple-minded, servile, weak,

tic sheep. timid and cowardly, in short, an uninteresting creature. One hardly can ascribe any particular qualities to it, for it is characterless. It understands and learns but little and is therefore unable to shift for itself. If selfish humanity did not accord to it particular protection, it would shortly cease to exist. Its timorous disposition is ridictlous and its cowardice piteous. Nny mysterious or unusual noise startles the cntire flock, thunder and lightning completely unsetties them, and not infrequently foil all human efforts to render them quiet.

In the steppes of Russia and Isia the sliepherds often have the most arduous tasks in preserving their charges. During a snow-storm or thunder storm the panic stricken flocks, disperse in a wild stampede, rushing out into the wastes of the steppe like senseless creatures and then resignedly suffer thenselves to be snowed under or to freeze, without making any attempt to shelter themselves from the sturm or even to seek for food. Sometimes thousands perish in a single day. In Russia a Goat is generally used as a leader for a flock of sheep; but even a Goat is not always able to keep the stupid animals under proper guidance. During a thunder storm they huddle together and can not be made to move. "If lightning strikes into the Hock," say's Lenz, "many are killed at once; if fire breaks out in the sheepfold, the Sheep do not run out but on the contrary may sometimes even rush into the fire. I once saw the charred ruins of a large fold full of roasted carcasses of Sheep; in spite of all efforts the attendants had succeeded in rescuing but a few." The best manner of rescuing Sheep from a burning fold or structure is to let the Sheep Dog, to which they are accustomed, drive them out.

To a certain degree, however, the sheep exhibits mental capacity. It learns to know its keeper, obeys his call and displays a certain amount of affection and docility towards him. It seems to have a liking for music, or at least it patiently and passively listens to the bagpipe playing of the shepherd, and it has evidently some premonition of impending changes in the weather.

The Sheep prefers and ranges in dry and high localities more than in low and damp ones. According to Linneus it feeds on three hundred and twenty-seven of the common central furopean plants, refusing to eat one hundred and forty-one. Ranunculus, cypress spurge, meadowsaffron, shave-grass, wild cabbage or skunk cabbage and rushes are poison to it. It thrires best on a diet of various dried plants; a grain diet fattens it too much and has a deteriorating effect on the wool. It is very fond of salt, and fresh trinking water is indispensable to its welfare.

The ewe ustually gives birth to only one lamb, though there are sometimes two and very rarely three at a birth. The little creatures must at first be carefully protected from the influence of suclden and marked changes in the temperature, but later they are allowed to follow their dam to pasture. They cut their milk teeth in their first month; the first permanent molar comes out in the sixth month; during the second year the two first incisors drop out and are replaced by permanent teeth: the anterior milk molars are shed cluring the fifth year only and 
this completes the dentition. All breeds affiliate readily with each other and for this reason they may easily be improved.

Foes Dangerous In Germany this valuable domestic to the Domes- animal has few foes; in the north and tic Sheep. south of Europe, however, the Wolf is prone to hang about the outskirts of flocks. In Asia, Africa and America the larger species of the Cat tribe and larger kinds of wild Dogs pursue the defenseless creature, and in Australia the Dingo and the Tasmanian Wolf prey upon it. Bruin, the Bear, may also occasionally regale himself with a Sheep. Eagles and Horse-kites are dangerous foes of lambs. On the other hand those Sheep which suffer most from these enemies possess greater immunity from the ravages of diseases and so the damage is about equalized. The most frequent of all diseases in Sheep is staggers, which is most common among young Sheep; it is caused by the presence of a parasitic worm (Tania comumus) in the brain. Other intestinal worms, the so-called Flukeworms (Distoma hepaticum), cause consumption of the liver, and Threadworms cause consumption of the lungs. Sheep are also tormented by external parasites, such as the Sheep-ticks (belonging to the genus Hippoboscida) and the Mites. Then they are subject to hemorrhage of the kidneys, to a distemper in the feet, known as the hoof-rot, to the smallpox, wind colic, and other diseases which are often fatal.

A Slleep may become fourteen years old; but it loses most of its teeth as early as the ninth or tenth year of its life. This renders it unable to maintain itself by grazing and then, if it is to be used for food purposes, it has to be fattened and killed with all possible speed.

\section{THE MUSK-OX.}

In the high latitudes of the far north, in those desolate regions where the ground thaws but partially in summer, where dwarfed trees endure a miserable existence, wherever the patches of moss and lichen extend, there the Reindeer and Musk-ox roam through the inhospitable couritry. Formerly these Kuminants ranged much more to the south. The Musk-ox has, as Duncan says, had a hard struggle for life, as we can sce by the fragnents of bone it has left in many an old river bed of Europe and Asia. The southern boundary of its range lay over fifteen degrees of latitude more southward, while it now begins beyond the sixtieth parallel of north latitude in America, the only continent it still inhabits, and in which it is numerously found.
Physical Pecul. The Musk-ox (Oribos moschatus), iarities of the Musk-ox. called Uningarok by the Eskimos, combines the peculiarities of Sheep and Oxen in a curious way, and it therefore seems justifiable to consider it as a representative of a distinct sub-family. The absence of a dewlap under the throat, the peculiarity of its facial conformation, the sliortness of the stub-like tail, the peculiarly shaped hoofs and the presence of only two mamnz: all these features serve to differentiate the animal as decidedily from the other Oxen, as they suggest an affinity to the Sheep. The total length amounts to about eight feet two inches, inclusive of the tail, which occupies nearly three inches; the height at the shoulders is three feet eight inches. The bulky body is supported by short, vigorous legs, the neck is short and thick, the tail really nothing but a stub buried in the fur; the head is very clumsy and pro-

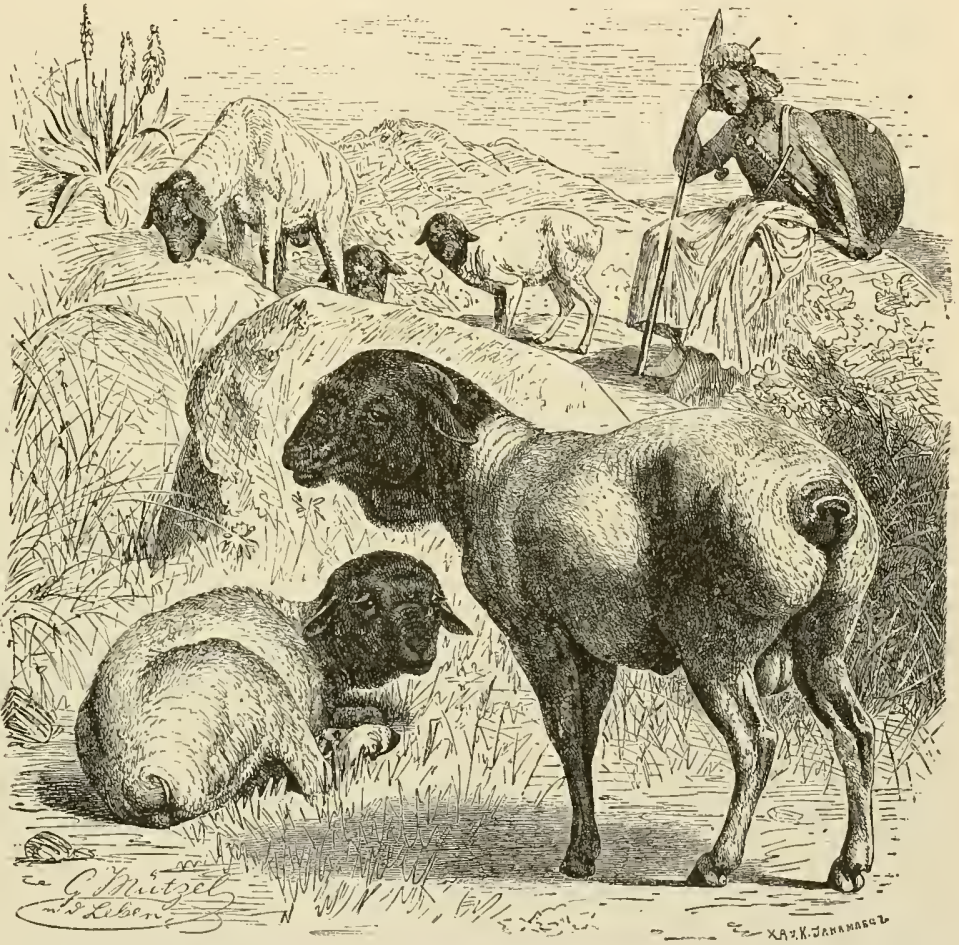

PERSIAN DOMESTIC SHEEP. - The variety of domestic Sheep found in Persia and adjacent countries especially noted for the accumulations of fat which are secreted on the posterior part of the body around the portionately narrow and high; the forehead is for the greater part covered by the horns; the eye is small, the mouth large and ill-shaped, and equipped with thick lips. The horns are ridged longitudinally from their base to their middle. Their manner of growth is peculiar; after emerging from the forehead they first curve slightly backward, lying close to the head; then they sweep straight downward, then turn forward and outward and their pointed tips finally curve upward again. An exceedingly thick fur clothes the body, being of surprising density on the face and legs. The relatively strong outer fur becomes longer from the lower portion of the under 
lip to the breast and forms a mane which nearly reaches the ground; on both flanks the hair liangs to the hoofs, and it also grows in profusion on the withers, its appearance resembling a cushion-like saddle, which begins behind the horns and covers both sides of the neck to the extent of concealing the ears. The general color of the animal is a dark unber brown, merging into lighter brown on the face and the hair of the breast and foreparts and becoming yet lighter on the saddle-like tuft which extends along the crest of the neck and slioulders.

Range and Food IVithin its wide domain the Musk-ox of the Musk- inhabits all localities which afford it $0 x$. at least temporary shelter and sustenance. Collected into herds of varying numbers it takes up its abode preferably in valleys and low lands. It seems to be more numerous in the more remote regions that lic far toward the north than it is further south and closer to Man. The members of the second German Polar expedition from their experience believe that this theory is true at least in regard to eastern Greenland. They met herds of twenty or thirty Oxen. On the remotest islands of the northeast, however, Mecham saw one hundred and fifty individuals of the species distributed over a strctch of country which it would take but a short day's journey to traverse, and at another time he counted about seventy Oxen grazing within sight. During the summer the herds in the north of continental Inerica delight in the proxinuty of rivers, moring southward in the fall of the vear. At the same time they also keep closer to one another and begin to congregate in larger herds, having previously grazed in more scattered and smaller groups. If the ice is firn enough to bear their weight, one can sce them wandering in long trains from one island to another, in order to find a range affording for the time being sufficient pasturage. Their extreme hardiness and frugality alone enable them to endure the terribly severe winter. In a slow, deliberate manner they traverse the endless waste of snow, in order to reach a spot which holds out a promise of food. At the malting of the snow the time of plenty commences for them, which while it brings with it an abundance of food, yet has its accompaniments which inflict on them great suffering. In winter they have to seck and dig for their miserable food deep under the snow; in sumner they can easily feed on the low-growing regetation which with the advent of warmer weather and sunshine sprouts up in rank profusion, at least in spots; but they are greatly annoyed by swarms of Gnats which sometimes accompany them in astonishing numbers, and to the attaclis of which they are peculiarly subject while they are undergoing a cliange of coat. It does not seem as if the shedding and renewal of the coat is an easy or agreeable process, for they frequently waliow in muddy pools and quagmires, probably with the intention of obtaining a crust which will shicld them from the attacks of their tormentors. The shedding process scems also to affect their strength, for they appear to confine their wanderings to narrower limits during this time. ()nly after they have completed their change of coat do they resunc their paticnt, persevering journeys across the vast stretches of their dreary and sparsely inhabited native country

The cow gives birth to one calf: a small and attractive little creature, which is nost tenderly loved and cared for, and if necessary courageously defenderl by its mother.
The Musk-0x an Notwithstanding their awkward lookAgile, Active ing shape, the Musk-oxen move Animal. With admirable ease and with the agility and nimbleness of Antelopes. Goat-like they climb about the rocks; without any apparent great effort they ascend steep walls and look down, entirely free from dizziness. Confronted by Man, those Musk-oxen that have seen little or nothing of the arch-enemy of animals act in an undecided and perplexed nimner. It is not long, however, before they acquire a correct idea of the formidable qualities of this adversary so suddenly appearing in their native fields, which have before been frequented only by the IVolf or Polar Bear. Recognizing the menacing danger arising from the presence of Man, they take timely refuge in flight.

Methods of If several hunters stealthily approach

Hunting the a quietly grazing herd of Musk-osen

Musk-0x. simultaneously from different directions, the animals sometimes huddie closer together instead of fleeing and dispersing, and thus the sportsmen are afforded the opportunity of firing several shots. Under these conditions the hunting of the Musk-ox certainly answers the description of Payer and Copeland, who style it a pursuit perfectly devoid of danger, saying that such a hunt presents no more difficulties than would the shooting down of a herd of Goats or Cattle grazing around a cowkeeper's cottage present to a hunter who has taken his position on the cottage. I believe it, however, wrong to deduce from this the unqualified statement that hunting the Musk-ox has in it no element of danger, the more so as the experiences of former observers emphatically discredit the truth of such statements. II ounded anmals are likely to become enraged, and when aroused do not hesitate to charge fiercely and desperately at the hunter, and the latter has a fortunate escape if he is not run over or gored with the pointed liorns.

The Economic The flesh of the Musk-ox is always Value of the permeated with a palpable odor of Musk-Ox. musk. In the carcasses of cows, however, it is by no means strong enough to render the dressed meat unpalatable, as is said to be the case with bulls, especially those killed during the breeding season. The wool and hair are in great request with the Indians and the Eskimos. The wool is so fine that excelient cloth could be woven out of it if one could only get enough of it. The tails are nanufactured into fly-brushes by the Eskimos and the hide furnishes good shoes.

\section{THE OX TRIBE.}

The Ox tribe (Botina), which forms the third subfanily of the Horned Animals, is comprised of large, strong and heavy Ruminants, the principal distinctive physical characteristics of which are: more or less round, smooth horns, a broad nuzzle with nostrils widely separated, a long tufted tail, reaching to the heel-joint, and a lack of tearpits and digital protuberances for the support or reception of claws. The majority are also distinguished by a pendent dewlap under the throat. The skeleton slows an organization in which strength rather than agility or grace of movement has been the prine consideration. The horns, which expand at the base, may involve and occupy the entire forchead, but in the great majority of instances leave it free; they are smooth, rounded or in some cases transversely furrowed or ringed at the base, and curve outward or inward, backward or forward, upward or downward. 
The hair is generally short and sleek, but is sometimes devcloped into a mane on certain parts of the body

The Ox Tribe All Europe, Africa, central and Widely Distributed southern Asia, as well as the northOver the Earth. ern portions of America may be regarded as the native country of the Ox tribe; at present the species which have been subjected to the dominion of Man, are distributed over all parts of the globe. The wild species inhabit the most widely variant localities, some affecting dense woodland; others, open grassy spots, some delighting in plains, others in mountains, where they may ascend to a height of sixteen thousand or twenty thousand feet. Some prefer swampy situations and moors, others dry regions. Very few live habitually in one place; nearly all lead a roving life. Those which swinmers, and cross the widest streams without hesitation. Their strength is uncommonly great, their endurance wonderful. Among the perceptive senses that of smell rainks first; hearing is also acute, but sight is not so well developed. The mental capacities are of a low order; the wild species, however, display much more intelligence than the tame ones. The character of the $\mathrm{Ox}$ tribe is manifold and widely at variance in the different species. On the whole, they are gentle and trustful toward creatures which are not dangerous to them or do not annoy them; but they also may upon occasion become exceedingly fierce, pumnacious and courageous. If they are irritated, they charge at the strongest beasts of prey, regardless of any peril, and know how to employ their weapons with such skill and effect that they frequently come out victorious. In general

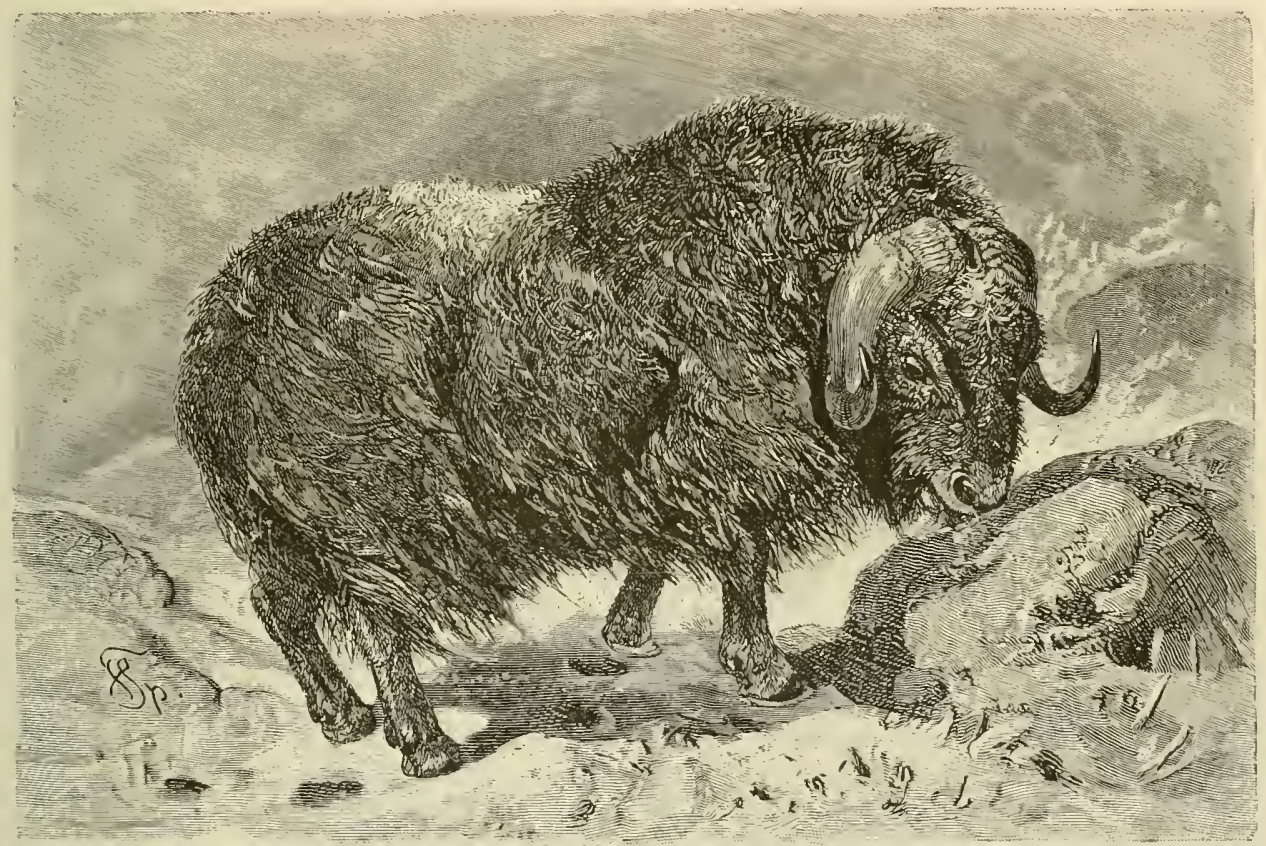

THE MUSK-0X. - This inhabitant of the arctic regions of America is an intervening genus between the Sheep and the $O x$. It is clothed with brown hair, nearly a yard in length, covering the thick, woolly under fur. The horns of the adult male meet in the middle line of the forehead, as shown in the picture. It is heavily built, with short legs, but climbs rocks and precipices with ease. (Ozibos mosihatus.)

inhabit mountains descend into the valleys in winter; those living in the north move southward; others migrate, urged by lack of food, seeking more abundant pasturage. The species are, without exception, gregarious and congregate in herds, under the leadership of strong, experienced animals. Some species band together by thousands. Old males occasionally segregate themselves from the herd and lead the life of hermits.

Physical Attri- All Oxen in their movements appear butes of the lumbering and slow, but they are perox Tribe. fectly well able to travel at a rapid rate; and they display a great many more accomplishments than one would give them credit for. Their usual gait is a slow walk; but they can also trot and occasionally break into a remarkably awkward but swift gallop. The species inhabiting mountains are masterly climbers. All are accomplished their disposition one toward another is peaceable, though they fight with a decided ferocity at certain times. The usual vocal expression of the species consists of a bellowing or "lowing" of a variable pitch, or of a grunt and growl, generally emitted under the influence of excitement.

$\begin{array}{cl}\text { The Diet } & \text { Plants of a great variety constitute } \\ \text { of the } & \text { the food of the animals of the Ox } \\ \text { Tribe. } & \text { tribe. They consume foliage and }\end{array}$ tender buds, shoots and branches of the greatest variety of trees, herbage, bark of trees, moss and lichens, aquatic plants and those growing in bog and swamps, even sharp reed-grass and reed-like plants. In the domestic state or in captivity they feed on all kinds of vegetables. They are all very fond of salt, and water is indispensable for them; some delight in wallowing in muddy pools or lie in rivers or ponds for hours. 
Prcpagation of the Species of the Ox Tribe.

The cow gives birth usually to a single young one, or very rarely to two. The calf is always perfectly developed and able to follow its mother almost innediately after birth. The mother gives evidence of the strongest maternal love and treats her calf with great tenderness, suckles, cleans, licks and caresses it and defends it against any dangerous attack with the most reckless courage. The bulls of some species assume the office of protector and guardian of the calves when they have grown sufficiently to be weaned by their mothers.

The Entire Tribe of All species of Uxen may be more Oxen Adaptable or less readily tamed and trained to to Domestication. devote themselves to the service of Man; they soon become accustomed and attached to their keeper, respond to his calls and yield obedience even to weak children; but they do not evince a special preference for their master above others, deporting themselves toward every one with equal kindness when once they are tamed.

Hunting of 0 xen The hunting of the wild species of an Exciting and Oxen is a dangerous pursuit; an Noble Pursuit. irrit ated bull especially is an adversary not to be lightly regarded, and one to be approached with the utmost caution. But in this very element of danger is to be found the reason which renders this sport popular to the true huntsman and for the fact that among some nations this kind of sport is regarded as truly noble and surpassing all others of its kind.

Physical Pecul- The lak or Grunting Ox (Bos gruniarities of the nicns) has a body of sturdy build and rak. a moderately lizge and very broad head which tapers uniformly from the long, flat forchead to the club-shaped muzzle. The eyes are small and of a dull expression, and the ears are small and rounded. The horns are set on the rear portion of the dome of the skull, one on each side of the frontal ridge. In shape they are horizuntally compressed, rounded in front but ridged on the back surface. They curve first backward, then again forward and upward, and the tips point outward and backward. The neck is short, like that of the common bull. The outline of the back shows prominent projections and depressions in the region of the shoulders and then slopes gently toward the tail. The tail itself is long and tipped with a bushy tuft which reaches to the ground. The outer covering of the body consists of uniformly colored, long hairs of fine texture, which sometines fall all over the face and also form a heavy, wavy, mane-like appendage which falls, curtain-like, on the withers and along both sides of the body. Adult Yaks are of a beautiful deep black, tinted with brown on the back and sides; but the muzzle is of a grayish hue, and a silvery gray stripe extends along the back. Old Bulls attain a total length of fourteen feet two inches; the height from the ground to the top of the hump is six feet four inches, and the horns are from thirty-two to thirty-six inches long. A fullgrown cow, however, barely attains a length of nine feet four inches, and a height of fire feet four inches.

Range and The plateaus and mountain ranges of

Habits of the Tibet and adjacent countries harbor rak.

the Iak; table-lands of from thirteen to twenty thousand feet elevation are its farorite haunts. The barren soil of its bleak home is covered with wiry grass only in those spots which raging storms bury under the snow in winter. Anid such wastes the lak satisfies its frugal wants, secures pro- tection from human atracks and thus succeeds in its struggle to matntain its existence nore easily than one would suppose.

Notwithstanding its great strength, the $Y^{\top}$ ak is inferior, in physical endownents, to the other animals of the mountains. It is true that it vies with the wild Sheep and the Ibex in climbing, and is equally as sure-footed among the loftiest and wildest crags, ridges and steep declivities; but when it runs over level ground any Horse can overtake it. Among its perceptive senses that of smell surpasses all others in keenness. That its intelligence is of a low grade is attested not only by its disproportionately small brain, but still more by its behavior in danger. The most notable characteristic of the $I^{\top}$ ak is its laziness. Early in the morning and at night it seeks its food; the remainder of the day it devotes to rest, which it takes either standing or lying down. The only sign of life it then gives is the chewing of its cud, but for which it might, from its motionless attitude, be easily taken for a stone monument.

A single calf is born to the cow of this species, and is suckled and kept under its mother's care for presumably over a year, as the Mongols say that the lak cow gives birth to young only once in two years. In its sixth or eighth year the lak is said to be full grown, and in its twenty-fifth year it dies of old age, unless its life be prematurely ended by disease or a sportsman's bullet. No other enemy which might prove fatal to it climbs to the heights where the Iak nukes its home.

rak Hunting a The pursuit of the lak is as attract-

Dangerous ive to a bold and well armed hunter sport. as it is dangerous. The powerful animal, if not mortally wounded, is apt to charge at the sportsman without hesitancy, and even if the latter has courage, skill, presence of mind and the best of arms, he can never count with certainty upon felling with a second shot the beast which, mad with rage and pain, rushes at him. A bullet from the most powerful rifle can only inflict a mortal wound in the head when it penetrates the small area occupied by the brain and lacerates that organ; and a body-shot is fatal only when it pierces the heart. For these reasons the Mongols fear the Iak as they would a demon, and go out of their way to avoid it. If they do summon up the courage to hunt it, they do so in parties of from eight to twelve or more, and fire at the Iak only from ambush.

Kenlock praises the excellent Havor of the Yak's flesh, though he always found it very lean, and he esteems the tongue and marrow bones as delicacies. The rak In all those countries which liarbor

Is Extensively the $\mathrm{Yak}$ in their high mountains, this

Domesticated. beast is also found in a state of bondage as a useful and important domestic aninal. The tame Vak differs little from the wild one in respect to shape and hair, but it varies from the parent stock in the matter of coloring. Yaks of a pure black hue are rare; generally even those nost resembling the wild ones show white spots. Brown, red and mottled individuals are frequently to be seen. Several strains have already been artificially produced perhaps by crossing with other species of Oxen. Occasionally tame laks liave reverted to the wild state and after a few generations have regained their original color. The tame herds, like their wild kinsmen, thrive only in cold, lofty mountainous regions, and sicken and perish in countries where the climate is hot, while they bear intense cold with great indifference. 


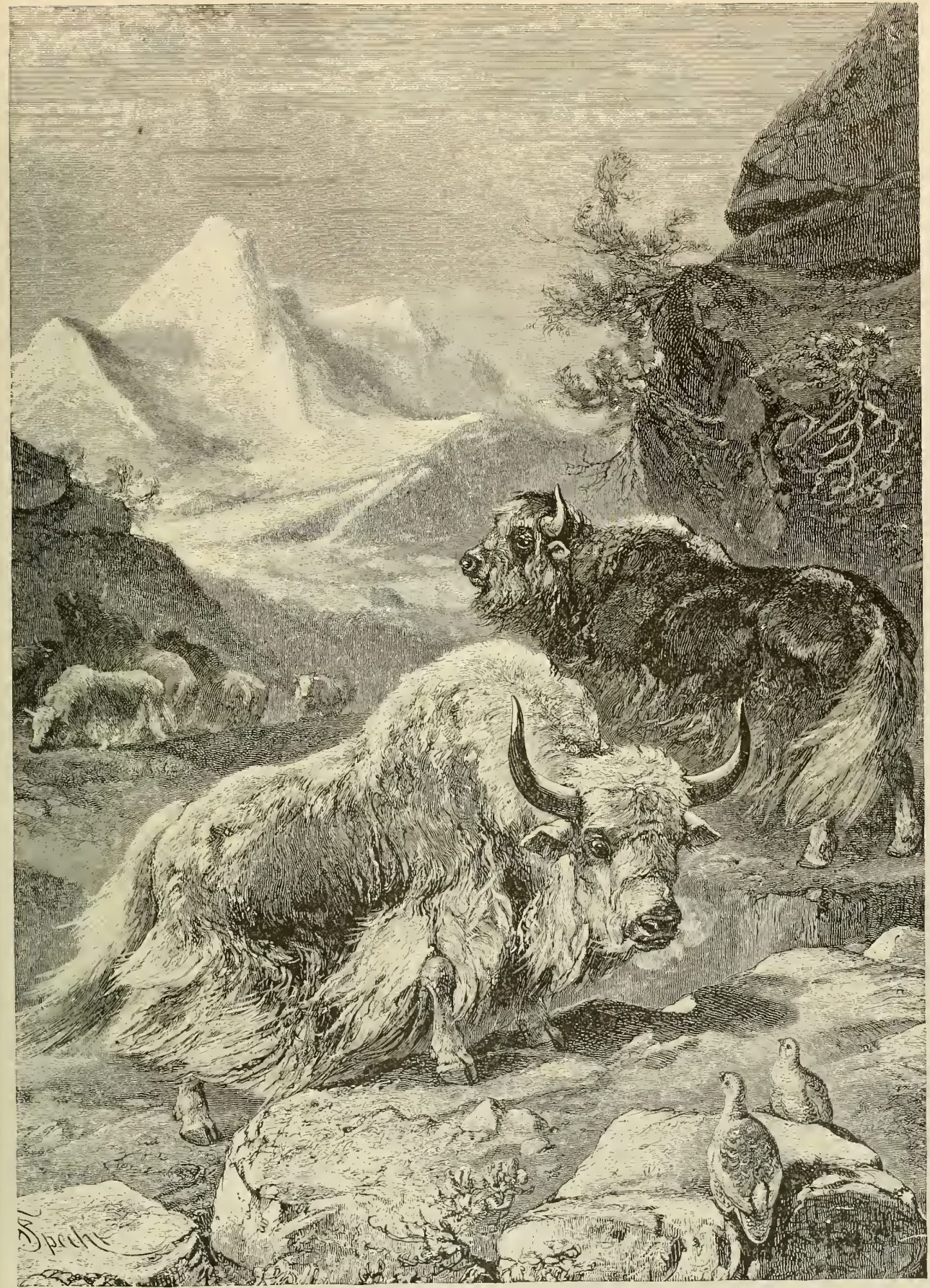

THE YAK, The wld variety of the Yak loams in the high platcaus and mountains of Tibet near the line of perpet ual snow. The anmal which is also called the Grunting Ox because of its Hog-jike method of vocal expression, is about the size of the common Ox, to which it bears a general resemblance but it has a remarkable covering of long, silky hair. (Bos grunuens.) 
The Tibetan employs the Yak as a beast of burden and as a saddle animal. The disposition of the Yak toward its friends and familiars is one of conparative gentleness, as it allow's itself to be handied, groomed and led by a rope secured to a ring put through its nose. Towards strangers it behaves differently, as a rule: it expresses uneasiness, lets its head drop to the ground and acts generally as if it intended to challenge an antagonist. It always retains a certain amount of its natural fierce disposition.

Yaks Especially The Vak easily carries on its back Useful in Mount- from two hundred to three hundred ain Country. pounds, and that over the most difficult, rocky paths and snow fields. It may be used to convey burdens across very high mountain passes, for it retains its vitality and strength there also, in spite of the rarefied air which so exhausts and oppresses other creatures. It can not be employed on roads interrupted by boulders and wide fissures, for a heavy burden hinders it from jumping over high rocks or wide crevices.

The milk and the flesh of the tame Yak are equally valuable as food for Man. The hide is tanned into leather and the hair is twisted into ropes. The most valuable part of the beast in the eves of the warlike tribes of its neighborhood is the tail, which furnishes them with those famous insignia of war or decorations borne before persons of rank, the "horse tails" so frequently mentioned in works treating of Oriental subjects.

The Yak Easy of The Yakswhich have been taken to Acclimation in For- Europe have th riven bctter than eign Lands. was expected. The suggestion was thus made that this beautiful $O x$ might be successfully acclimated in foreign lands and the rearing of the animals in a domestic state might be expected to yicld abundant profit; for the Tak furnishes excellent wool, palatable Hesh and rich milk; is a strong and indefatigable worker and contents itsclf with cheaper food than other Cattle. The Grunting $O_{x}$ is certainly useful in all these respects on the tablelands of Tibut and Turkestan, and there proses to be an almost invaluable animal. But beyond the mere suggestion nothing has ever been done in the mitter, is in Europe it was thought that the ranges of mountains are sufficiently stocked with mountain Cattle and Alpine Goats and it was contended that the lak would certainly not render greater service or prove of more value than they.

The Home of the A game prescrve of a peculiar kind Europeun is found in western Russia, in the Bison.

southern portion of old Lithuania.

It is the famous forest of Bialowitch, a genuine northern virgin forest of an area of 2,000 square kilometers. It is cntircly unconnected with any other forest and it may be compared to an island, surrounded by fields, villages and treeless heaths. 11 ithin the boundaries of the forest there is only one-village, the name of which is identical with that of the forest; this settlement is inhabited not by farmers but by foresters alone. About four-fifths of the trees are pines, which cxist to the exclusion of other species over extensive stretches; in the damper spots they are interspersed with oaks, linden trees, hornbeams, birches, alder trees, poplars and willows. This forest still harbors the greatest mammal of the European continent, the Europcan Bison. This huge animal nowadays exists only there and in a few forests on the Caucasus and in the woods of Mezerzitz in Silesia; on the remainder of the globe, if we except a kindred American species, it is extinct. Stringent laws protect it in the forest of Bialowitch. and if the successive owners of this remarkable game park had not fostered it during several hundred rears, the European Bison would now be found only in small numbers in the Caucasts.

In former times this was different: for the Bison ranged all over Europe and a large portion of Asia, but in spite of efforts to preserve it the attacks of poachers and finally a general epizootic, which destroyed the grater portion of the herds in the begimning of the eighteenth century, reduced their numbers most materially.

The Bisons (Bomyssus) are considered the representatives of a distinct sub-genus of the Oxen and are characterized by small, round horns, which are placed well to the front and curve upwards; a very broad, arched forehead, soft, long hair and the great number of their ribs. The Furopean Bison or Wisent has fourteen pairs of ribs, the American Bison fifteen.

Description of the Though we may safely assume that European the European Bison (bos bison or Bison. Bonassus bison) has diminished in size, it is still a lugge animal. A specimen of the species slain in Prussia in I 555 was seven feet high and thirteen feet long, and weighed over nineteen hundred pounds. Nowadays the nost gigantic bulls rarely grow higher than five fect eight inches or longer than eleven fect four inches, nor do they weirh more than one thousand to one thousand four hundred pounds. The Bison impresses the beholder as the incarnation of rude strength and vigor. Its heact is moderately large and well shaped, the forehead is high and very broad, the facial portion tapers uniformly towards the extremity; the muzzle is blunt and broad, the ears short and rounded and the eye may be called small. The neck is rery stout, short, and thick through from upper to lower surface, and is encased in a loose skin which derelops into a dewlap, extending from the throat down to the breast. 'The body' is supported by stout legs and has a bulky appearance, and the shoulders are stronsly arched from the rear of the withers to the middle of the neck. The tail is short and thick. The horns are set on very much to the sides of the frontal bone of the skull and are comparatively small, round and pointed; they first curve outward, then upward and at the same time slightly forward, and then inward and backward, so that the tips stand nearly vertically above the bases. The fur is dense and long all orer the body, and consists of a thickset, curly outer coat and a woolly matted shurter under fur. On the back of the head the hair grows into a broad tuft, and along the spine rises into a moderately ligh crest; on the chin it forms a beard which hangs down after the manner of a queue and on the lower part of the throat it derelops into a wide mane, covering the whole of the dewlap. The prevalent color is a light brown, dashed with a faded yellow tint; on the sides of the head and on the beard it deepens into black-brown, on the legs into dark brown, on the tail-tuft into black, and on the tuft of hair overhanging the top of the head it sottens into a light brownish-yellow. The cow is of a perceptibly smaller and more graceful build than the bull; her horns are weaker and the mane is much less developed, but she is of the same colorings as the male.

In summer and autumn the Bison lives concealed in damp spots of the wood, usually in thickets; in 


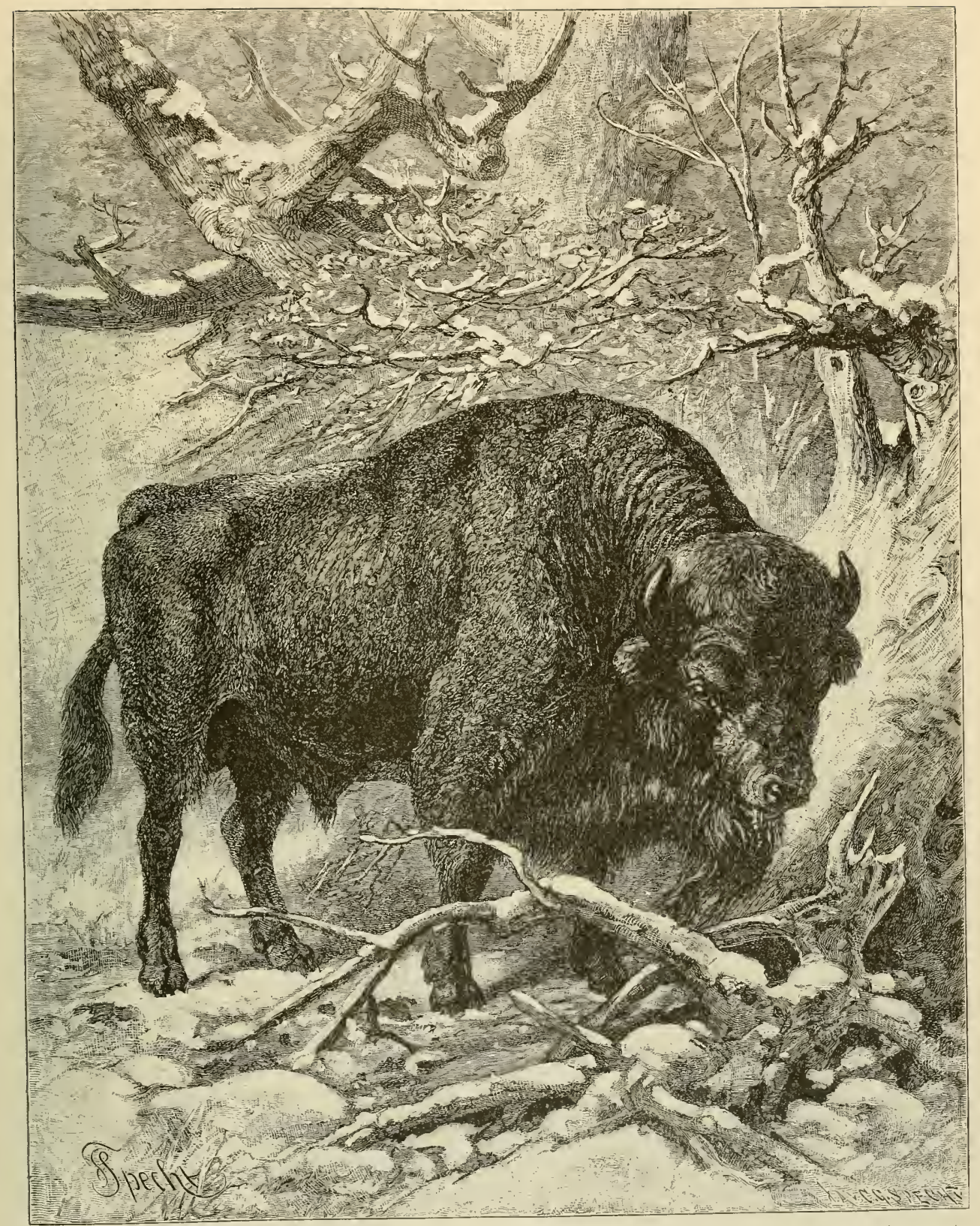

THE EUROPEAN BISON. - This large and powerful animal which once inhabited nearly the whole of Europe is now almost extinct, except herd which is kept under the protection of the Russian czar in the forest of Bialowitch, in Lithuania. It much resembles the Amerimal in its forest home, (Bos brson.) 
winter it prefers higher and drier regions. Very old bulls live in solitude but the younger members of the herd consort in companies of fifteen or twenty in summer and of thirty to fifty in winter. Every herd occupies its permanent domicile and always returns to it when the search for food has terminated.

The Bison Semi- The Bisons are active both by day

Nocturnal in and by night, but like best to graze in

its Habits. the evening and morning hours, and sometimes also by night. Herbage, leaves, buds and bark constitute their food; they strip the trees as high as they can reach, and bend young, flexible trees down, by straddling them, in order to reach the top, which they generally destroy entirely. The ashtree furnishes their favorite diet, as they seem to prefer its succulent bark to that of any other species; trees with spiny or thorny foliage are avoided by them. In winter they feed almost exclusively on bark, twigs and buds of the trees within their reach and also probably on lichens and dry grass. The hay crop of the meadows in the forest of Bialowitch is stored away for them, and they sometimes possess themselves of that belonging to farmers on the outshirts of the wood by breaking down the fences. Fresh water is a necessity with them.

The Bison an Ani- Though the Bisons produce upon the mal of speed beholder the impression of heavy and and Endurance. lumbering animals, they appear sufficiently active, when their movements can be fairly seen. Their ordinary gait is a rapid walk; their running pace is an awkward but speedy gallop, the head being carried very low, and the tail uplifted and stretched out bchind. They wade and swim through bogs and rivers with ease. Among their senses of perception that of smell ranks highest; sight and hearing are less acute; taste and touch attain ordinary development. Their disposition and character change with age. Young Bisons are lively and playful creatures; they are moderately good-natured, and though they are not exactly gentle and peaceable, they are not vicions. Old Bisons, however, especially old bulls, are dignified if not sullen in their bearing, of an irritable, violent temper and averse to trifling or play. Generally they ignore those who do not annoy them, but the slightest cause may arouse their ire and render them formidable. In summer they always shun Man, but in winter they do not give way to anybody, and it has sometimes happened that travelers through their haunts have had to wait a long time before it pleased a Bison to remove from the path he occupied and which the wayfarer wished to travel, there being no room to pass by the animal. A fierce, defiant, violent temper also characterizes this species of wild $O x$. Younger individuals are always more timid than the old bulls, some among which, especially those leading a solitary life, may develop into serious plagues of the neighborhood which they infest. It seems to afford then a special pleasure to provole battles with the hunıan species.

At certain seasons the bulls engage in fights, perhaps beginning in play, but ending in a very serious manner. The animals rush frantically at each other and clash their horns with so much violence that it seems surprising that they do not break from the force of the collision.

Propaga. The calves of the Bison species are
tion of the born singly, generally in May or
Bison. her calf the cow separates from the herd and selects a suitable secluded spot in the thickest of the wood or in some quiet, peaceful locality. There she keeps herself and her calf in hiding during the first few days after its birth, and defends the little one with extraordinary courage in case of danger. During its early youth the calf, in the presence of an enemy seelis safety by crouching close to the ground; it pricks and nervously twitches its ears, dilates its nostrils and eyes, and anxiously watches the foe, while the mother prepares for the encounter. The Man or beast that approaches a Bison cow at such a moment does so at his peril, for she rushes upon an adversary without hesitation. The calves are pretty, prepossessing animals, though they very early exhibit indications of what they will become in old age. Their growth is very slow, and they probably attain their full size only in their eighth or ninth year. The age to which Bisons may usually attain is believed to range between thirty and fifty years. Cows die about ten years younger than bulls, but with the latter blindness generally supervenes in old age; they lose their teeth, become unable to bite off and masticate young twigs or otherwise provide for their sustenance, waste away and finally succumb to the lack of nourishment.

Hunting the These powerful animals are perfectly

Bison a Royal able to defend themselves from their Pastime. adversaries. Bears and Wolves may endanger the life of a calf, but only when the mother has lost her life by some accident, and the calf is unprotected.

In former times Bison hunting was the favorite sport of kings, and many such royal hunts have taken place in the forest of Bialowitch, and as late as I860 the Emperor of Russia gave a hunt in which he himsclf shot six, and the Princes Charles and Nibrecht of Prussia killed eight Bisons.

I have secn and closely observed several European Bisons in different zoological gardens, and have informed myself in regard to them. These animals are all alike, and however kindly may be their demeanor in youth their natural ferocity breaks out in advanced age and then even their keepers dare not trust them. Even at their best they are obstinate and difficult to manage, though they gradually come to treat their friends with some degree of toleration. Red is said to excite these animals, to anger, and hence a person clad in bright colors runs some risk of being attacked by them.

Several naturalists have advanced the opinion that the Bison was a factor in the origin of several of the domestic breeds of Cattle, but recent experiences seem to show this theory to be fallacious. A violent animosity exists between the Bison and domestic Cattle, and even where young Bison calves and tame Cattle are kept together, as has been done in the forest of Bialowitch, their relations are anything but friendly.

The American The same fate which overtook the Bison also Almost European $\mathrm{B}$ is on in the course of Extinct. centuries, befell its only relative, the Imerican Bison, in an incredibly short time: one might say, during a single decade. Only one generation ago, millions of these huge animals roved over immense tracts of land in North America-to-day there are but a few hundreds of them left at various points throughout the country, and even those few now in existence would soon disappear did not the general government strenuously protect them. History knows no other instance like this, nor will it have to record one in its future annals, of harmless, useful animals being methodically shot down and 


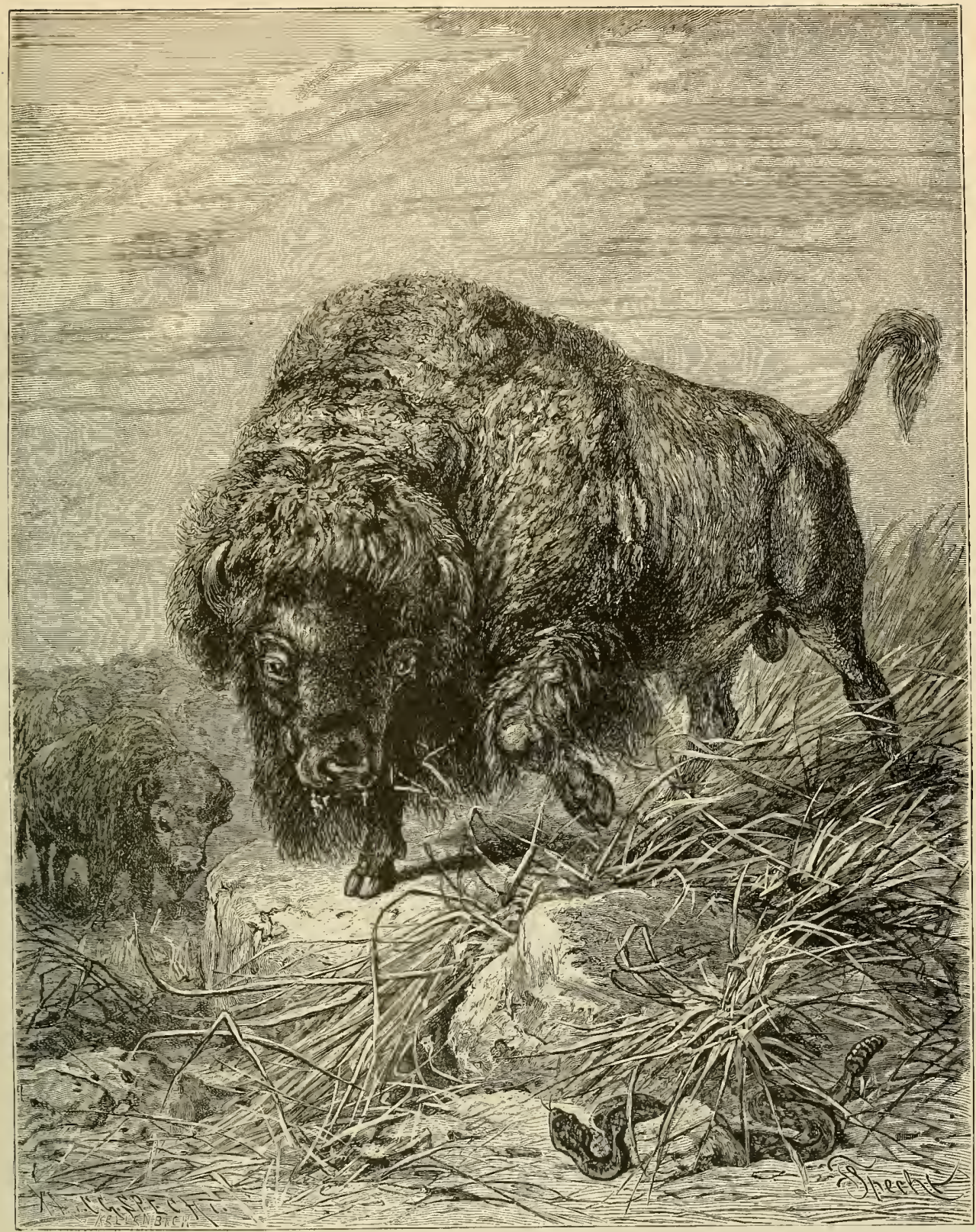

The western plains in countless thousands. Relentless pursuit has nearly exterminated them, and they are now only represented by a herd protected by the United States government and a few smaller herds in zoological collections. This Bison popularly but erroneously called the Buffalo, is a large and powerful
shoulders and a shaggy mane. It is pictured here as it formerly lived in large herds on the great plains. (Bos americanus.) 
ruthlessly slaughtered in enormous numbers for a slight profit, and until entirely too late left utterly unprotected by law. The only traces of the once innumerable herds of Buffaloes are to be seen in the blanched bones dispersed in the vast solitudes of the great plains of the Ilest. The result of the close investigation of IVilliam $\mathrm{T}$. Hornaday gives the number of the survivors on January I, 1889, as eight hundred and thirty-five, inclusive of the two hundred then living in Irellowstone Park under the protection of the government. This extermination of the Bisons has in the main been accomplished sinee the beginning of the seventies, and principaily through the agency of the railways tratersing the far West. Over fifty thousand Indians whose subsistence, like that of their ancestors, was either entirely or partly dependent on the existence of the Buffaloes, are exposed to privations and the danger of starvation if the government of the United states does not always provide for their maintenance in due time.

Former Range of When the first Furopeans settled in
the American North Anerica the range of the
Bison. Atlantic coast westward to the boundaries of Nevada and Oregon, southward to the twenty-fifth parallel and to the northwest to about the sixty-fifth parallel of north latitude, comprising woodland as well as prairie country.

If there had been laws in any way judicious and timely regulating the hunting of the animal, there might have been shot antually about half a million of young bulls, the product of the carcasses of which would have yielded a profit of about two million five hundred thousand dollars, and the enormous herds would not have been perceptibly decreased; now the most strenuous efforts are necessary to preserve the few hundred sturviving animals.

From the foregoing remarks it will be seen that the following description deals with the life and habits of creatures which populated the wilderness of North America in enormous herds about twenty or more years ago but now are practically extinct.

Description of The American Bison or Buffalo,

the American (Bos amiricumus) oecupies the same Bison. relative position in regard to the North American animals, that the European Bison does to the various Furopean species - that of the giant of all terrestial mammals of its native country. The bull measures from nine to ten feet in length, exclusive of the tail, which is twenty inches long, or, including the hair-tuft, twenty-six inches; the height at the withers varies from five feet eight inches to six fect four inches; the weight ranges between one thousand two hundred and two thousand pounds. The cows are always consiclerably smaller than the bulls. The differenees between the American and European Bison are greater than those between any other so elosely allied species of Oxen. The head of the American Bison is very large-proportionately much larger-has a broader brow, is clumsicr and heavier than that of its European relative; the nose is more strongly arched and the ears longer. The dull eyes are of moderate size and a dark brown color-the whites having a vascular, reddish, inflamed appearance. The short, deep, narrow neek ascends abruptly to the shapelessly high withers; the legs are comparatively short and very slender. The horns curve backward, outward and upward and the tips do not materially converge. The hair resembles that of the European Bison. The head, neck, shoulders, fore-parts of body and upper parts of the fore-legs, the fore-parts of the hams and the extremity of the muzzle are clothed with long hair; the withers and slooulders have a large mass of mane-like fur; the chin and throat show an appendage of beard-like hair; the forehead and back of the head are covered with curly, matted hair and all the other parts of the body are clothed with short, thick hair. In winter the hair grows to a considerable length; in the beginning of spring the winter fur is shed in large locks. As a result of this shedding, the color of the beast is modified. That of the new coat is a uniform grayish-brown, decpening into black-brown in the mane, which covers the top part of the head, forehead, neck and the under surface of the throat. The horns and hoofs, as well as the naked muzzle, are of a lustrous black hue.

Range and Habits In contradistinction to the European of American Bison, which is invariably a forestBisons. dweller, the liuffalo must, at least since its lange has been restricted by advancing cisilization, be regarded as an animal peculiar to the inmense western plains of North America. There it lived gregariously, though the herds were not organized in compact form but were somewhat loosely divided into numerous, smaller groups. A plain overgrown with succulent herbage, if viewed from a distance, may seem to be literally packed witl Buffaloes, but on a nearer view one soon sees how the apparently compact mass resolves itself into numerous smaller herds of varying size; and each of these, though but a few hundred paces distant from the other, possesses a leader of its own and preserves, as it were, its right of independent aetion.

The Bisons used to undertake annual migrations with greater or less regularity. Beginning in July, they moved southward; at the advent of spring they returned to the north, clistributed into smaller troops or herds. Evidences of these migrating hosts could be seen even when the Buffaloes themselves could not be perceived; for packs of lean Wolves followed in their wake upon the surface of the earth while flocks of Vultures, Eagles and Buzzards followed them in the air, the former as well as the latter heing well assured of prey. Wherever the Buffaloes had taken up a permanent abocke, they went back and forth over the same paths with great regularity, espceially in going from their abundant pasturage to the rivers, which they frequented to drink or to take cooling baths, and on these journeys they wore the roads, known in the language of the prairie frontiersman, as "Buffalo-trails." These Buffalo-trails generally ran in absolutely direct lines hundreds in number, parallel to one another and crossing rivers at points convenient for entering and leaving the water. They closely resembled the paths trodden down and regularly frequented by our domestic Cattle, wherever they unrestrainedly graze in large numbers in forests and pastures.

European Travel- In I 55 I Moellhausen saw hundreds ers and the of thousands of Bisons in the prairies Buffalo. to the west of the Missouri; in IS5S Froebel traveled with a train of wagons from $M$ issouri to Mexico and was surrounded by herds of Buffaloes for eight days. As Hepworth Dixon deserites it: "in bands, in masses, in hosts, the shaggy, black creatures thunder along in front of us, sometiues from north to south, sometimes from south to north; for forty consecutive hours we had them in sight, thousands upon thousands, tens of thousands upon tens of thousands, an innumerable mass of un- 
intellects are capable of development. On the other hand, wild specimens by their actions clearly prove that they discriminate between innocuous and harmful things. They are not intractable to domestication, readily entering into friendly relations with individuals who treat them kindly; at least they learn to recognize their keeper and to love him to a certain degree. It is true, however, that it takes a long time to overcome their innate shyness and alter their preconceived opinions.

During the summer the coarse looking, but nutritious grass of the prairies furnishes the grazing Bisons with ample provision, but in winter they must content themselves with scanty fare.

The Bison's Life The perils by which a Bison's life is Encompassed with surrounded are many and serious.

Many Perils. Winter, which is usually severe in the prairie, destroys hundreds of its tribe after first starving and weakening them. Their end is still more sudden in winter when they trust the ice covering the rivers more than they are, by its thickness, warranted to do. Their habit of galloping in column abreast with thousands, one behind another, frequently proves fatal to them in such a case. The ice breaks bencath the enormous weight of the Bisons: the animals in front of the long column fall into the water; they vamly endeavor to get out, being pushed forward and trampled under by the hundreds which erowd after them and thus they miserably perish. Many Bisons are destroyed in a similar way when crossing rivers in summer, intcnding to land at a spot where quicksand or mud render the ascent of the bank difficult.

Living Enemies of The American Bison has as little

the American lack of living cnemies as have others Bison. of its tribe. It is said that the Grizzly Bear enters into combat even with a strong bull, and that the Wolf becomes dangerous at times to the younger Buffaloes. The direst foc, however, is Man, especially the white Man, the devastations of whose hunting rifle assumed serious proportions as early as the third or fourth decade of this century. "In former times," says Moellhausen, writing sometime during the fifties, "when the Buffalo could, in a certain sense, be considered a domestic animal of the Indians, no diminution of the innumerable herds could be noticed; on the contrary, they throve and multiplied on the rich pastures. Then the white people came into that part of the country. "The large skins with their rich covering of hair pleased them, the savory Buffalo flesh was to their taste, and both promised them rich gain. The lust for the glittering baubles or the stupefying and intoxicating liquors of the white Man was first kindled in the breast of the red-skinned natives of the prairies, and then a very small price was offered them for the produce of their chase, and the devastation commenced. Thousands of Buffaloes were slain for the sake of securing their tongues, and more frequently still for their shaggy skins, and in a few years a surprising diminution was perceived. The improvident lndian thinks not of the future; he lives only in the present, and its pleasures. He needs no further encouragement; he will hunt the Buffalo until the last one shall have left its skin in his hands. Surely, the time is not far off, when the enormous herds will live only in the memories of the people, and three hundred thousand Indians will be deprived of their sustenance, and urged by hunger they will, together with millions of Wolves, become the pests of the adjoining civilization."
Value of the The dried flesh is said to be palataCarcass of the ble and nourishing; especially that Buffalo. preparation of it which is dried in the sun, minced or pounded and mixed with fat, and known under the name of "pemmican." When used for expeditions on which much nourishment must be compacted in small space it is generally also mixed with raisins and pressed into cakes. The tongue of the Bison is esteemed a great delicacy. The flesh of the cows is richer than that of the bulls and that of the calves is exceedingly tender. Out of the skin the Indians used to make warm articles of clothing, tents and beds, saddlcs, belts, etc., and occasionally would cuver the frames of their canoes with it. The bones furnished them with saddle-trees and scalping knives, with which they then would deprive their enemies of their scalps. The sinews were made into strings for their bows and thread for sewing; and out of the feet and hoofs they manufactured a durable glue, boiling the gelatine out of them. The strong hair of the head and neck were twisted into ropes; the tails were made into flybrushes. The white Man also prizes the Buffalo hides. The leather is excellent, though somewhat porous and coarse in grain, the shin with the hair may be used for all kinds of coverings, and skins without blemish, whicl commanded a price of from seven to twelve dollars thirty years ago, are now three or tour times as high, and soon will entirely disappear from the market. The wool, of which a single flecce may furnish as much as eight pounds, can be used as well as Sheep woul and was in some localities utilized for the manufacture of warm and very durable materials.

The Buffalo Capa. Imerican Bisons have been seen in

ble of Trans- Furopean zoolosical gardens for the

plantation. last few decades unly. I received a conmunieation from London to the effect that an English lord had introduced several couples from America and bred a herd numbering from fifteen to twenty on his estates in Scotland. After his death, however, they were sold. They propagate normally and easily if given adequate care. The calves born in confinement are most vigorously defended by their mothers against any kind if interference, and grow up as readily as do the offspring of our domestic Cattle. Nevertheless, the Ancrican Bisons in the European zoological gardens arc also becoming extinct.

The Oxen proper (Bos), to which species our domestic Oxen belong, form a group by themselves, characterized by a long and broad flat forehead, large horns, not very much expanded at their bases, and set on the head in a line with the frontal ridge. and a comparatively thick, short covering of fur; they are also anatomically characterized by thirteen or fourteen rib-bearing vertebre, six not supporting ribs and four sacral articulations. We will first cast a cursory glance at sercral Asiatic spccies living in the wild state.

Peculiarities and The Gayal (Bos frontalis), attains a

Habits of the total length of twelve feet, about Gayal. thirty-two inches of which are included in the tail; the height at the shoulder is from five fect to five feet four inches. The proportions of its body show the most pleasing symmetry, every part being strong and full, without appearing clumsy; the bull thus produces the impression of the higliest vigor and perfect, harmonious beauty and nobility. The horns are very large in diameter, of a conical shape and show a slight curve outward and back- 
ward. The fur is short, thick, sleek and lustrous, and is uniform in length nearly all over the body; it becomes only slightly longer at the throat, forms a rich tuft on the lower portion of the tail and also pendent curly tufts or fetlocks on the anliles of the fore-legs. The prevailing color is a leep black; the hair of the forchead is grayish or fallow brown, the tufts on the forc-legs are of a rich sepia brown, and the under portion of the lower lip, the corners of the mouth and a narrow margin on the upper lip are white.

The Gayal is a native of the mountainous regions to the east of the Braliniaputra river as far as Burmah; and it is possessed of nearly as good climbing powers as the Yak. It is usually found in herds, millk of the Gayal is said to be very rich and the flesh of the animal is exccilent.

The Gaur a Near The Gaur or Gour (Bos saumus) cxKinsman of the hibits a great affinity to the Gayal, Gayal. but scems to differ from it always in various internal and external anatomical features, especially in the number of ribs. Sir Walter Elliot, in describing a Gaur slain by himself, says that it differs materially from the ordinary Cattle of India, rather showing a elose approach to the Bison, by which name English sportsmen are wont to call it. The head is shorter than that of the common $\mathrm{Ox}$, the forehead very broad, the frontal outline of the face curved, the eye and ear smaller than those of the Buffalo, the neck short, thick and stocky, the

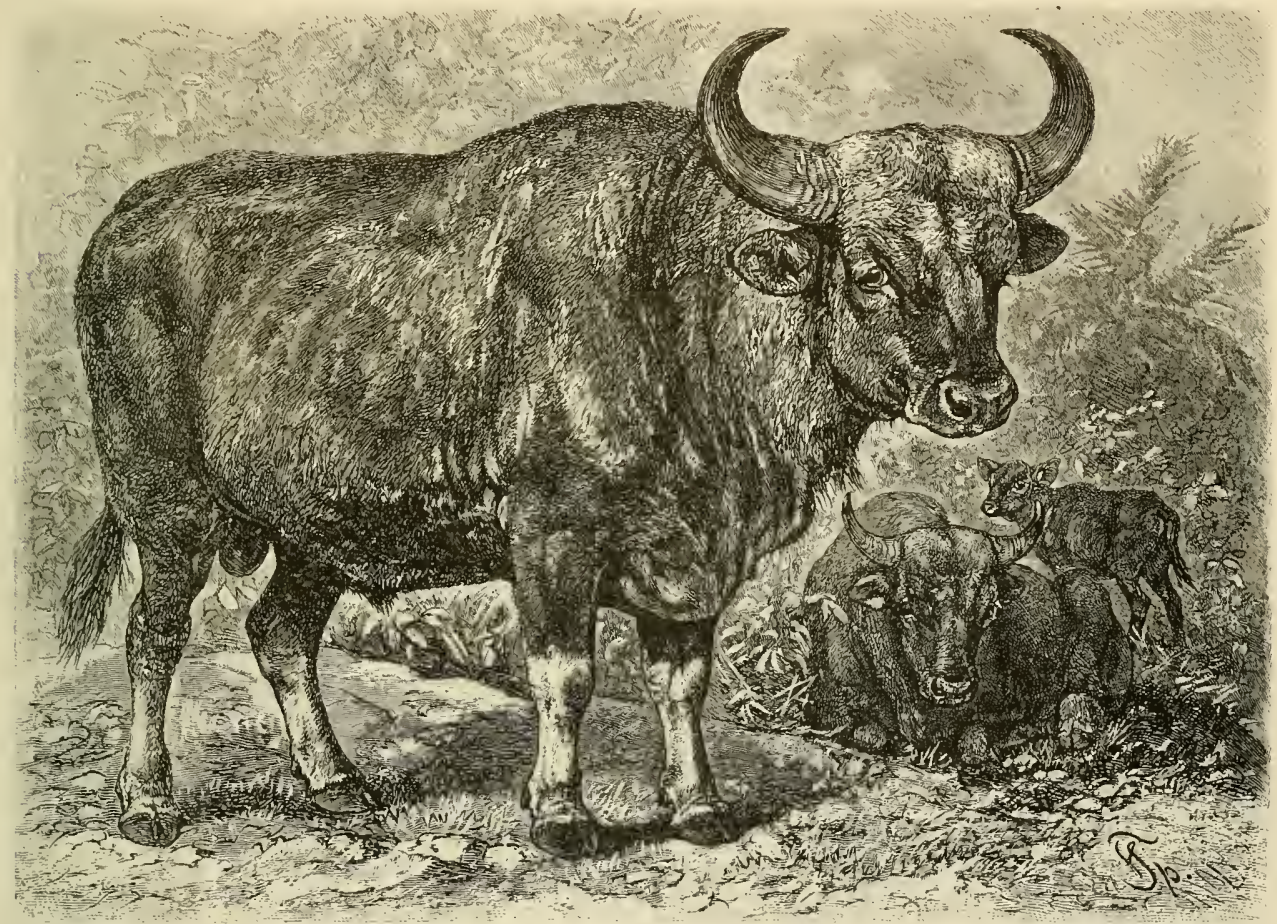

THE GAUR.-Inhabiting India, Burmah and the Malay Peninsula, the Gaur is one of the handsomest and largest of the Ox tribe. The broad forehead, stout figure and strong horns are prominent physical characteristics of the animal. (Bos ganerus.)

goes forth to graze in the morning, evening and on moonlit niglits; and during the oppressive noonday heat it retreats into the innermost recesses of the woods, and rests there in the shade, chewing the cud. It is fond of water, but not of mud, and therefore shans swamps, but likes to cool itself in clear mountain waters. Its temper is described as gentle and trustful. It never attacks human beings, but rather sedulously and anxiously shums them. It defends itself from the attack of beasts of prey with great courage, however, and is said to put to flight even the Tiger and Panther. If it does itself flee from an enemy its keen senses and its agility and speed secure its safety:

The natives have domesticated the Gayal or Mithun from time immemorial, and either breed it pure or cross it with other breeds of Oxen. The body stout, the chest broad. The horns are very much expanded at thcir bases and taper to a point; they are set on laterally and curve backward and upward. The skin is unusually thick on the upper part of the neck and shoulders as well as on the thighs, and is clothed with short, dense hair, which grows slightly longer on the throat and chest and forms a curly tuft between the horns. The prevailing color is a beautiful dark brown, brightening into a decp ochre yellow on the under surface, then changing into a dingy white on the legs, into light grayish brown on the forchead and deepening into grayish black around the eyes. According to Elliot's measurements the tolal length of a full grown bull of this species would be fourteen feet four inches, the tail measuring thirty-four inches; the heirht at the shouldicr is about six feet two inches. 
The Domicile The range of the Gaur is greatly exof the tended. Whercier the country is of Gaur. Wooded, monntainous or hilly eharacter, lowever rugged the district may be, it is found over all the territory extending from the southern extremity of India to the Himalayas, and eastward through Assam and Chittagong to Burmah, and on the Malayan peninsula. A thickly grown wilderness consisting of impenetrable thickets of wild vines and ferns and brakes of bamboo, as well as grassy, dense primeral forests, are hiding places adapted to the taste of the Gaur, especially when incorporating among other features deep ravines abounding in water, stecp walls covercd with frag. ments of rock, and rugged, barcly accessible peaks. can hardly be driven away. Towards morning it re turns from pasture and hides in the ficlds of tall grass or the brakes of bamboo, to rest, sleep and ruminate,

Methods of In hunting the Gaur, rifles of very

Hunting the heavy caliber are used, as is generally Gaur. the case with large quarry. It is hunted by following its tracks, stalking and shooting it or occasionally by having one driven by beaters or hounds within shot. Good sportsmen in general do not hunt herds, but on]y old bulls which live solitarily and, next to the Elephant, are considered to be the Jargest gane one can slay. That the perils of the chase have been greatly exaggerated, all recent authors agree, though they also admit that a wounded

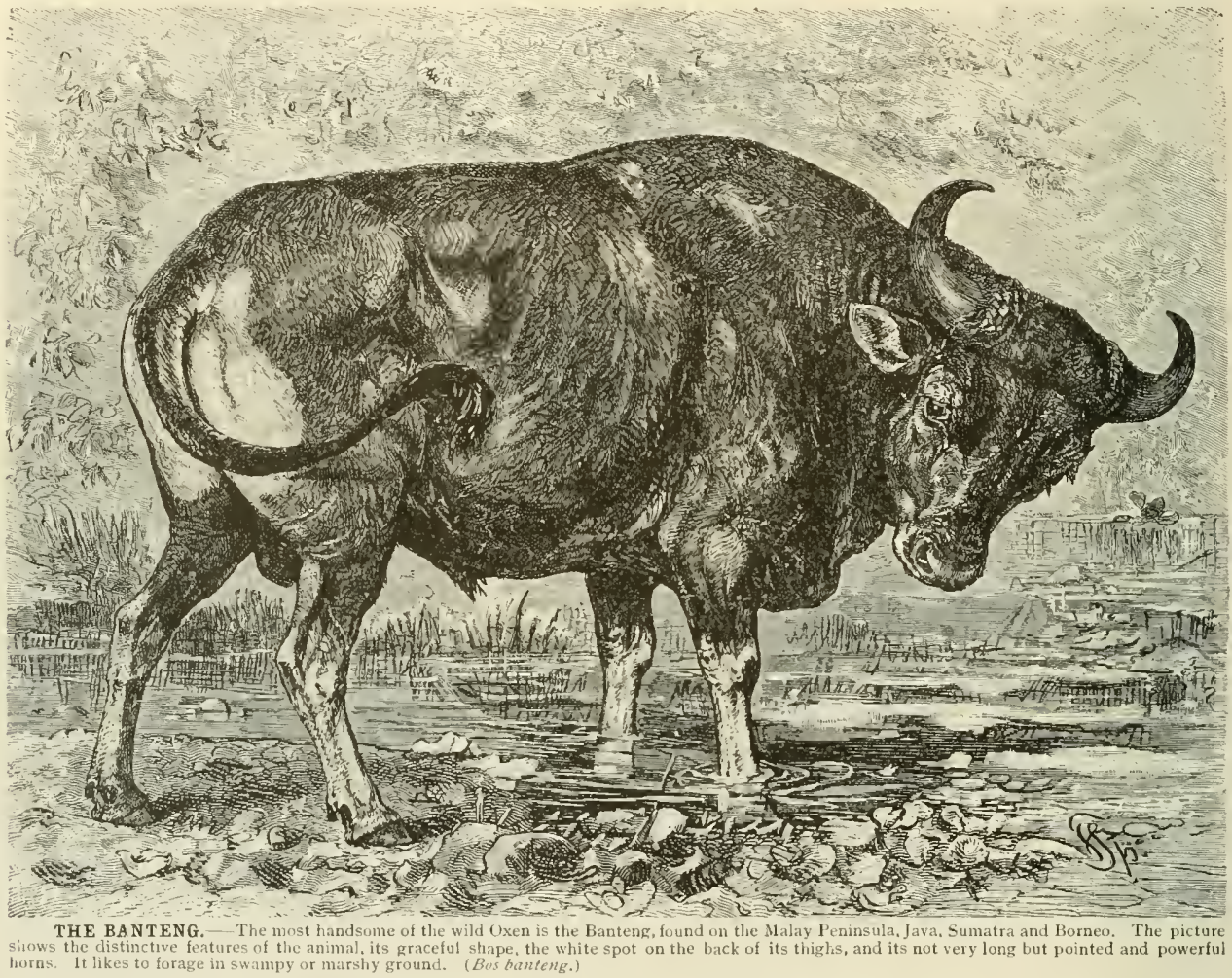

Yet it descends occasionally into the low-]ying valleys, attracted by newly sprouting, tender, verdant grasses. Its capacity for locomotion over the most difficult paths is said to be little slort of marvelous. The heary animals tear along, on the broken surface of an almost perpendicular acclivity, with a speed and facility that almost equal those of the Deer, or descend into the valley with a rush, in a good round trot or a swift gallop.

The Gaur Noc- Gencrally the Gaur grazes only by turnal in its night, delighting in spots where Habits. roung, juic erass is sprouting, as it wrefers this and tender bambou sloots to any other frod. If, however, it lives in the neighborhood of cultivated fields, it makes incursions into them and sionally becomes so bold and persistent that it bull brought to bay may prove himself to be a far from despicable antagonist.

The Banteng, I must award to the Banteng of the Handsomest of Malayan peninsula (Bos bantong) the the $0 x$ Tribe. meed of praise as the most beautiful of all known wild Oxen. In gracefulness of form it can vie with the Antelope, and its coloring is remarkably attractive. The horns are expanded at the bases and irregularly ridged for about the first third of their length; from this point they are smooth, with very sharp tips. They first curve outward and backward, then moward and forward, and their ends point upward and inward; they are from sixteen to twenty inches loner. The hair is uniform theuchout and lies close to the body; its color is dark gray-ishbrown, tinted with red in the hinder parts. A wide 
white mark on the buttocks may be considered the most conspicuous distinctive feature; the lower half of the legs and the upper surface of the tips of the ears are also white.

The Habitat, Range The banteng is a native of Java, and Habits of Borneo and the eastern portion of the Banteng. Sumatra; but it also inhabits portions of the Asiatic continent, namely, the Malay Peninsula, Tenasserim and Pegu, and probably also Burmah. It delights in damp or marshy woodland, in watery situations in general, low lying valleys traversed by slowly flowing rivers being more to its taste than any other linds of forest country.

The retiring yet courageous disposition of this wild Ox renders its pursuit both perilous and difficult. It is true that it gencrally flees on perceiving an approaching human being, but if brought to bay and wounded, it exhibits little fear of the sportsman, not infrequently turning on him and using its pointed horns with great skill and effect.

Adult Bantengs cannot be tamed, but calves may become completely domesticated, as the temper of this animal seems to be more tractable and responsive to kindness than that of any other known species of wild Oxen.

\section{DOMESTIC OXEN.}

None of the Oxen that have so far been described have probably had any part, or at the most only a small one, in the production of our domestic Cattle. The darkness beclouding the origin of these extremely useful creatures, which have been subject to Man from the earliest ages, does not seem so dense as that which conceals from view the history of the descent of other domestic animals; yet a decision on the subject is no less difficult in this case than in that of any of the others. Authorities nearly all agree that the origin of Oxen won to domesticity at nearly the same time in all three continents of the Old World must be traced not to one but to several different primary species. Which were these original species, however, not even the boldest conjectures, based on the skeletons of extinct animals, can suffice to approximately determine. As has been seen from the preceding descriptions, several different kinds of wild Oxen are even at the present day being trained and won to domesticity, or at least used to improve existing domestic breeds; but the period at which Man first mastered the wild Ox or, as is more probable, formed a herd of its offspring taken young, lies outside the pale of all history and tradition. The earliest legends mention herds of tame Cattle; on the oldest monuments of the countries which we consider the nurseries of civilization we find the effigies of domestic Cattle; we dig their anatomical remains out of the alluvial soil around the fomer sites of lacustrine dwellings. Not without warrant do we lay special stress on the importance of these relics; but the most careful exanination of them sheds as little light on this (in more than one respect) mysterious question, as does the comparison of the ancient monumental images with the breeds of Cattle of to-day, and by no means solves the mystery of their ancestry

The ancient animal pictures of the Egyptian monuments are drawn with great skill and show us distinctly three breeds of Cattle: first, a long-horned variety, the most common breed, which had the great honor of furnishing the sacred bull, $A_{\mathrm{p}}$ is; sec-

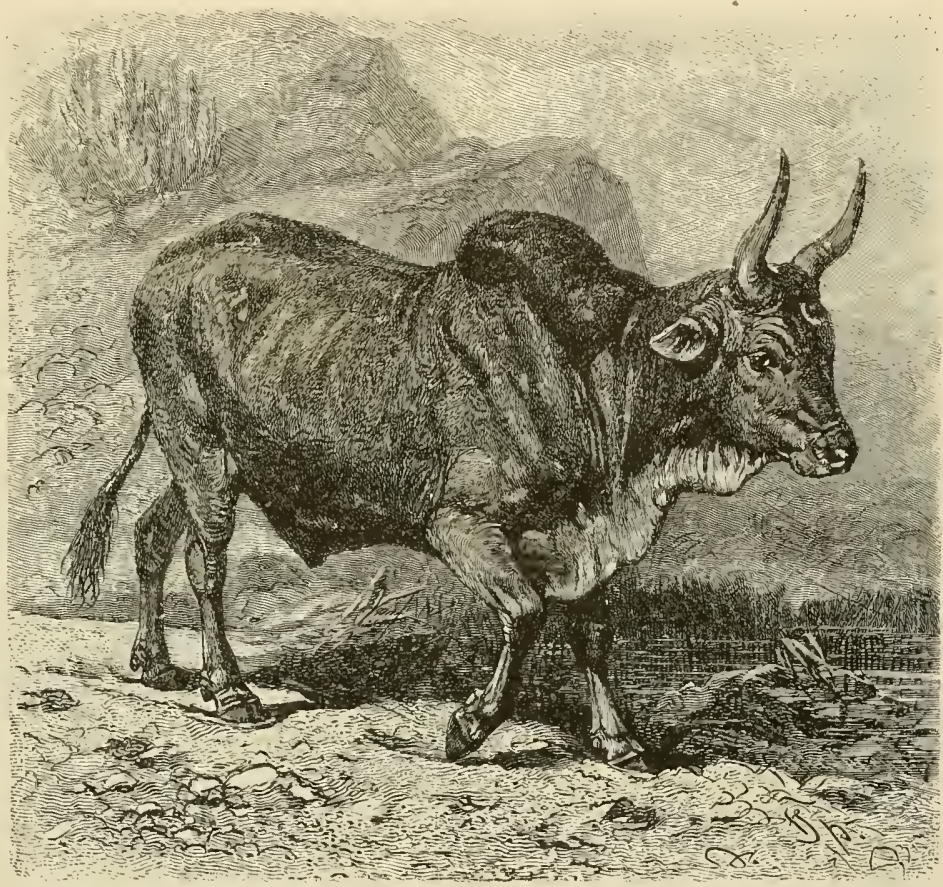

THE SANGA. - This Abyssinian variety of domestic Ox has a well developed hump and long and pecul 1) $y$ shaped horns, hut is otherwise a well shaped animal. Its limbs and tail are loug. In habits it does not difter ondly, a short-horned breed, quite similar to the former, but with short horns describing il curve of a quarter of a circle; and thirdly, humped Oxen, ustually represented among the tribute brought to the Egyptian rulers by the tribes of the Soudan.

The delineation of the anatomical structure of the head in all these representations shows features having a close resemblance to those of a Zebu head. The humped Ox, which is even at the present day distributed all over central Africa, is the progenitor of both the ancient and modern strains of Egyptian domestic Cattle, which are and have always been of the humped breeds. If one travels from Lower Egypt up the Nile, through Nubia and Dongola to Sennaar, he can but observe how the high-neclied Egyptian domestic $O x$ is gradually superseded by the genuine humped $\mathrm{Ox}$ of central Africa. The 
old Egyptian long-horned breed, especially the one with the lyre-shaped horns, very decidedly resembles the Abyssinian Sanga.

Humped Oxen - The Sanga (Bos africamus) may prob-

The Sanga and ably be regarded as the most beautiZebu. ful breed of all humped Uxen. It is large, slender, yet vigorous, long-legged and rather lons-tailed and the hump is well developed. The horns are very strong, and differ materially from those of most European species; they are fully forty inches long, stand rather close together at their bases and curve first outward, then straight upward, in the last third inward, and the tips again turn outward. The hair is straight and fine and the general color is chestnut brown.

The Zebu ( Bos indicus) must be regarded as closely allied to the Sanga, though it markedly differs from it and also is divided into a series of sub-breeds. It definitely settle the problem. According to Rutimeyer three different specics of wild Oxen took part in the production of the forty or fifty breeds of domestic Cattle now existing and classified in Europe and America; first the Bos primogenius, which probably belonged to the same specics as the Urus or Aurochs described by ancient authors; second the Bos longifrons and the Bos frontosus, the remains of which have been found in different parts of Europe.

Rutimeyer gives it as his opinion that direct lineal descendants of the Bos primogenins, although much degenerated, still live in a half wild state in some of the larger forests of the north of England and Scotland. An animal the description of which is very similar to that of the Park Ox, existed in Wales as early as the tenth century. Four hundred head of white Cattle with red ears were sent to King John,

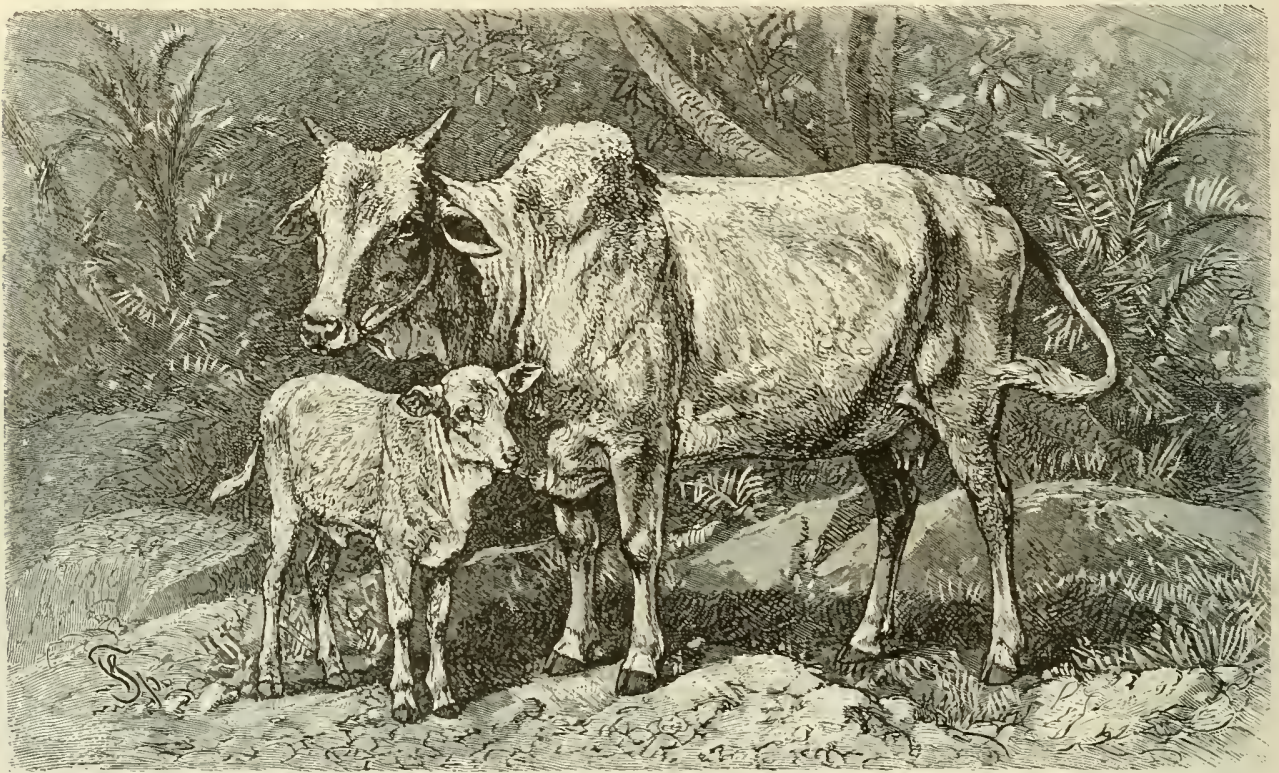

THE ZEBU, This East Indian animal, which is one of the humped varieties of domestic Cattle, is noticeable for its short, straight horns and its long ears. The cow and calf in the picture are of the lighter breed, although there are also Zebus of other colors, and some that are pied. (Bos indicus.)

attains in some regards about the same physical proportions, but is comparatively stouter and shorter legged than the Sanga. The ears are long and pendent; the horns are very short. The coloring is less uniform than that of its African relative, the usual reddish or yellowish brown frequently merging into a dingy yellow or a white hue, pied Zebus being no rarity. In India individuals of this species are not infrequently true dwarfs, barely attaining the size of a small Donkey. The zoologist still searches in vain for a species to which he can positively ascribe the most active agency in the production of the Zebu breeds. Various experiments have clearly proven that the Zebus readily propagate with other breeds of domestic Cattle, and that the hybrids are fertile to the most remote relationship.

Probable Ancestors The solution of the question as to

of Humpless the origin of the humpless EuroCattle.

pean breeds seems to be somewhat easier, though in this case also we can not hope to and one bundred were required of culprits as a penalty for some misdemeanors, according to an old statute. It has been proven that the animal then lived in a wild state in a virgin forest, extending transversely all over the north of England and south of Scotland from Chillingham to Hamilton; and in the two parks bearing these two names, lying on the margins of the larger main forest, the Cattle are still preserved. As early as I 260 IVilliam of Farrars caused Chartley Park in Staffordshire to be guarded by an enclosure, with a view to preserving the wild Oxen on that stretch of swampy woodland, and this example found followers. As the $\mathrm{Ox}$ became rarer, other owners of large estates acted on the hint, and thus the Park $\mathrm{Ox}$ was seen only in enclosures even at a period antedating the Reformation. Fourteen of these parks were still in existence in the beginning of the present century, and five are preserved to the present day, each of then stocked with herds of these British wild Oxen. 
The Park Ox, or The Park Ox (Bos scoticus) is of midWild $0 x$ of dle stature, and of strong but not Britain. clumsy structure. The hair is short and lies close to the body; on the neck and top of the head it is longer and curly; it is uniformly of a milk white hue, except on the muzzle, the ears, horns and hoofs. The ears are reddish-brown on their inner surface, the fore part of the muzzle is brown, the eyes are bordered with black, the hoofs black and the horns are grayish white with black tips. The latter are moderately long, rather thin, slender and sharply pointed, and curve from their bases outward and upward, while the tips turn very slightly inward again.

The aristocratic owners of the parks still existing in Scotland take a certain pride in extending their especial protection to these animals, the relics of peculiarities with the exception of the white color, being generally a plain black, brown, red or yellowish brown-a black ring encircling the eyes and mouth.

The Freiburg or In describing a few breeds of the swiss $0 \times$ De- humpless domestic Ox, 1 will briefly scribed. mention three specially prominent breeds. The $\mathrm{Ox}$ of Freiburg or Swiss $\mathrm{Ox}$ (Bos tamms friburgensis) may be taken as a type of the Alpine Cattle, which are bred in a great many strains, showing a marked variety among themselves. It is a well-shaped animal with a moderately large head, a broad forehead, a short thick neck, a prominent dexwlap, a long, broad-backed body, sturdy limbs and a long tail terminating in a large tuft. It has relatively short, rather weak, but very pointed horns, which curve outward and upward,

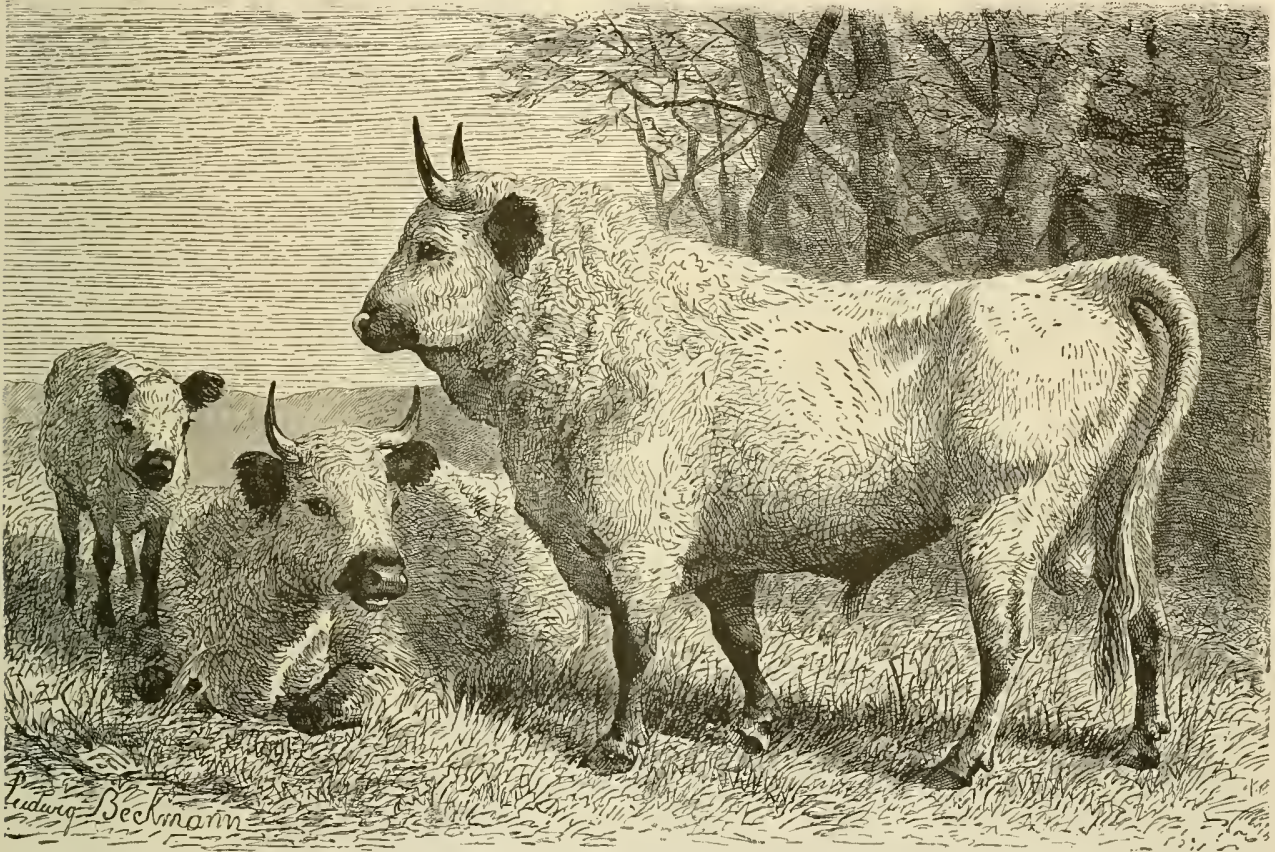

THE PARK OX. The wlld C. Tttle of Britan are still preserved in several British parks, and are believed by some authorities to approach neares to the ancient Urus, or Aurochs, which are by many supposed to hase been progenitors of the humpless breeds of domestic Cattle. The Park Ox is of stout form and is of white color except the tips of the horns, the ears and the muzzle. (Bos scoticus.)

olden times, and they are preserved at a considerable expense. Special guards watch over them, try to ward off all danger from them and finally segregate the Bulls which have become vicious on account of their old age, or otherwise useless. These Cattle have all the characteristic attributes of the wild animals of the present. They hide their young, graze furing the night, sleep and bask in the sun by day. They are fierce only when driven to bay; on all other occasions they are very shy and flee before the most insignificant of humanity, even when but remotely menaced.

Descendants of the Among the distinctively Scotch Park Ox Frequent breeds of Cattle there are occain Scotland. sionally to be found single individuals or entire breeds, which seem to have descended directly from the Park Ox. They display all its in the shape of a crescent, the tips turning outward and either forward or backward. The hairy coat is sleek and shows black or brownish red spots on a white ground. This $\mathrm{Ox}$ is bred especially in Freiburg and the adjacent cantons of Switzerland; it yields both excellent beef and extremely rich milk.

Peculiarities and The most widely distributed breed Merits of the of marsh Cattle is probably the Dutch 0x. Dutch Ox (Bos taunis hollandicus) which, in Fitzinger's opinion, is a direct descendant of the Aurochs. Stately proportions marked by a graceful uniformity in the development of all parts of the body, and very uniform coloring and markings, comprise its most prominent features. The head is long, tapering towards the muzzle; the neck long and thin the abdomen barrel-shaped; that is, long and pendent; the withers are narrow, the croup 
broad, and the tail moderately long. The legs are especially stoutly and strongly developed, long, but not clumsy. The horns are short, weak, and usually turn outward and forward; the coloring is pied, the white or grayish white ground showing black or sonetimes brown or red spots, of varying size and shape. In Holland this $U \mathrm{x}$ has been bred for centuries. It is distinguished for its abundant yield of milk, and is easily fattened.

The Durham or The Durham or Short-horned breed English Short- of England (Bos tumms dumilnensis) horn. may be mentioned as a not exactly handsome product of continued systematical breeding. It is, in fact, an Ox with no symmetry of proportions-a shapeless animal-with a small head, really the recipient of no care at all Only occasionally does some person commissioned to inspect the herd visit its haunts. It is not of particularly large stature, though a beautifully proportioned and uncommonly strong creature, characterized by tolerably long and very pointed horns, curving outward; the color is a dark red or bay, or a black-ish-brown, as a rule, but there are exceptions.

America the Par-In the New World circumstances adise of Reverted have always favored the reversion of Cattle. Cattle to the wild state. Columbus first imported the useful creature on his second trip to San Domingo. There it multiplied with such rapidity that a few years later calves of both sexes could be distributed all over the island, and twenty-

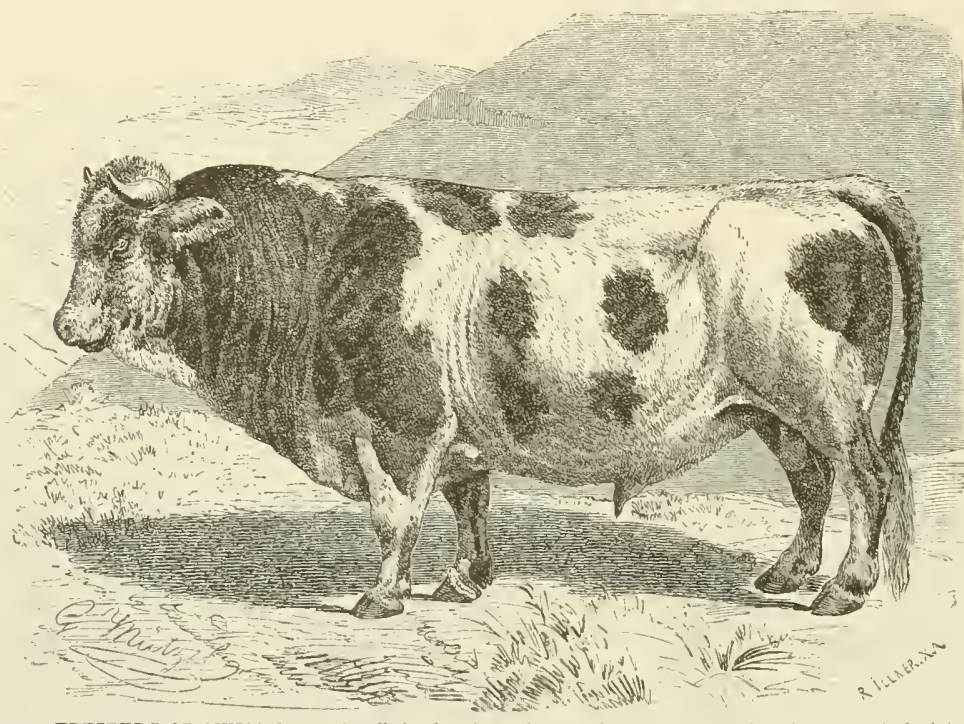

FREIBURG OR SWISS 0X. - A well developed, sturdy animal is the Freiburg Ox, which is typical of the Alpine Cattle. It is a short-horned variety, has a thick neck with a prominent dewlap, a small head and the white ground color of its sides shows several dark spots. (Bos tuurus frourgensis.)

very weak horns, a straight back and short legs, a thick neck and unwieldy body, bred especially to furnish the greatest possible amount of beef when fattened and butchered. The coloring of the short, smooth hair is subject to much variation. ()riginally the Durham was bred almost exclusively in the eastern coast counties of England; now it is to be seen in all the counties of England and Ircland and occasionally in Germany, Holland and France [and is also numerous in the United States]. In the yield of milk it is inferior to many of the other breeds, but in the production of beef it surpasses tinem all.

oxen Easily Re. With as much ease as that with which

vert to a wild a wild $\mathrm{Ox}$ is tamed and reduced to a

State. state of domesticity, the domestic Ox reverts to the habits of the original species, when it escapes from the supervision and carc of Man. Oxen which have reverted to complete or partial savagery are found mainly in those countries over which Spaniards once ruled or which are still subject to their dominion. The bull which is so highly esteemed in Spain because it is indispensable to the conduct of bull-fights, descends from Cattle which once were tame. It leads the life of wild Oxen, never entering a stable the whole year round, and is seven years after the discovery of Domingo herds of four thousand head were of common occurrence. In 158 thirty-five thous an d skins were exported from this island alone. About 1540 Oxen werc transported from Spain to the southern portions of America. They found the climate of the New World so favorable to their well-being that they shortly emancipated themselies from human protection. A century later they inhabited the pampas in such enormous numbers that people in those regions pursued the sanze course in regard to them that the hunters of North America did later with regard to the Bisons: that is, slaughtered the animals solely for the sake of their skins. The flesh and fat were left for the consumption of the tame and wild Dogs and of the Vultures. Such indiscriminate slaughter soon thinned the numbers of even these enormous herds, and only recent improvements in the manner of utilizing all parts of the carcasses of the beasts led to a change in the methods of slaughter and saved these wild Cattle from utter extinction.

wild Cattle in In Texas, California and some of the westthe United em states and territories there are immense herds of what are known as "range" Cattle. States. These are the direct descendants of the Spanish Cattle brought to America in the early days of Spanish dominion on this continent. A few decades ago the care of Cattle in Texas was very lax, all of the animals being left to follow their own devices on a common range. Now the stock owners largely use fenced-in pastures, so as to restrict the travels of their Cattle within proper bounds. Some of these pastures enclose many thousands of acres within one fence.

Cattle belonging to smaller owners are still turned out on the prairie and allowed to wander about promiscuously. Each owner has a brand, which he can register with the county clerk. such registry making the brand the indisputable property of the one in whose name it is entered. With this brand he marks all the Cattle he owns. At least once a year there is a general "round-up" of the Cattle, the owners in a county uniting to drive all the Cattle to a corral, or enclosure. From there the calves following their mothers are driven into the branding pen, and the brand of their owner is placed on them and they remain his until rebranded. 
In Texas it was formerly quite frequently the case that many Cattle would wander away or conceal themselves so effectually that the vigilance of the cowboys was eluded, the result being that there would be next year a number of two-year-old calves unbranded. The rule for these calves was that the first Cattle owner who caught such an outcast could brand it. A shrewc stockman named Nlaverick, seeing a chance of profit in it, made a special feature of capturing these ownerless yearlings and branding them, doing the business so successfully that it

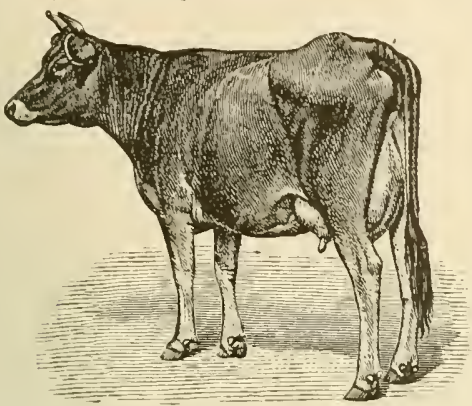

JERSEY COW.-The breeds of Cattle from the British Channel Islands bear the palm for choice quality of cream and butter obtained from their milk. The Jersey is the type of these animals and is a favorite dairy cow in America and Great Britain.

became the custom for the other stockmen to call unbranded yearlings "Nlavericks," and they are known by that name to this day. Such opportunities as those of Maverick are not now open. Closer attention is paid to the Cattle and it is seldom that a calf escapes being branded. The Cattle raising industry is one of great importance in the IVest, where there are large areas not fitted for cultivation, which are admirably adapted for Cattle raising.

On the Falkland Islands the Oxen have completely returned to savagery and are entirely emancipated from the yoke of Man, being but occasionally hunted by sailors whose provisions of meat have run out. On the Galopagos Islands, the Philippine and Sandwich Isles and on the Celebes, Oxen having reverted to a wild state are also found, and the same may be said of Australia and New Zealand. In the high mountainous regions of central Asia Cattle which have resumed their wild habits also occur, especially in instances in which herds have become ownerless in consequence of wars. In Colombia, as in most other countries of South America, they live in unrestrained freedom, not in the low lands, however, but on the heights of the Cordilleras. Manner of Life of A glimpse at

Cattle in Vari- the manner of

aus Nations. life of the domestic Cattle of various countries is instructive as well as fascinating. In order to begin our consideration in historical fashion, let us turn our attention first to those herds which still lead the same manner of existence as did those belonging to the patriarchs. The wandering tribes of eastern Soudan are herdsmen, who attend to their duties in exactly the same way as their ancestors did thousands of years ago. Herds of Cattle constitute their only riches. Their wealth is estimated by the number of their Sheep and Cattle, as that of the Laplander is estimated by the number of his Reindeer.

The greatest of European land-owners and cattlebreeders, including those of Holland and Switzerland, can hardly realize the vast numbers contained in the herds of those nomads. Near the village of Melbess, which I have already mentioned once, the plain shows a deep depression, at the bottom of which a number of wells have been dug, one beside the other, for the sole purpose of watering the herds congregating there during the noon hours. Beginning in the afternoon and during the whole night, far on towards noon of the next day nearly a hundred people are busy hauling water from the wells and pouring it into pools in which a little salty earth is added to it. From all sides innumerable herds of Sheep, Goats and Cattle draw near, first the Sheep and Goats, then the cows. In a few minutes the valley is filled with them. One sees nothing but an unbroken herd of animals pressing back and forth, a dark human form looming up between them at intervals. Thousands of sheep and Goats keep arriving, while as many are departing, satisfied. I believe it impossible to count the number of Cattle; for one soon gives up as hopeless the task of counting in the cunfusion of the throng; yet 1 believe I do not exaggerate if I put down the number of the animals daily congregating at the spot as sixty thousand.

In the south of Africa the Oxen are of great importance, as without them the extended trip necessary for purposes of trading and hunting through the vast wastes in parts entirely devoid of water and grass would be impossible.

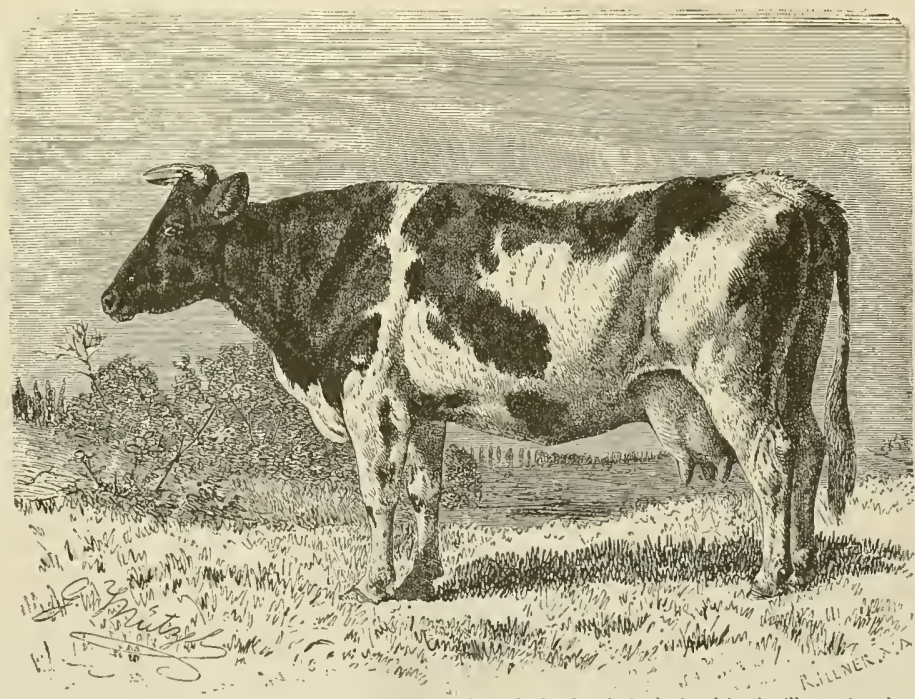

DUTCH cow - The breed of Dotch Oren, of which the female is depicted in the illustration, has been bredin Holland for hundreds of years, and is especially adapted to marshy regions. It is a rather handCattle Life in Tem- In southern Russia, Tartary, and perate and North- probably also a great portion of ern Lands. central Asia, considerable herds of Cattle are kept. All of the steppes of southern Russia are covered with herds of Horses, Sheep and Cattle. In summer all these animals live outdoors; 
during the severe, long winter they find some protection arainst the storms on the lee side of a mound of earth thrown up to break the force of the freezing winds prevailing. If such a mound is provided with a miserable piece of roof on one side, it is considered an excellent stable. Among these herds the Cattle rank first in point of number, and have naturally many advantages over the others: they are hardier and do not perish so easily in the snow storms which play such dire havoc among the Horses and Sheep, as they do not lose their instinct of locality and become bewildered, but hurry straight home to shelter-unless, indeed, as sometimes happens, the storm is too high. In most of these regions the herds are left to roam at will. The animals had to shift for themselves, and were given neither shelter nor food. Some of them were so wild that they would let no human being approach them. The calves were suckled as long as they craved milk, and herdsmen never thought of

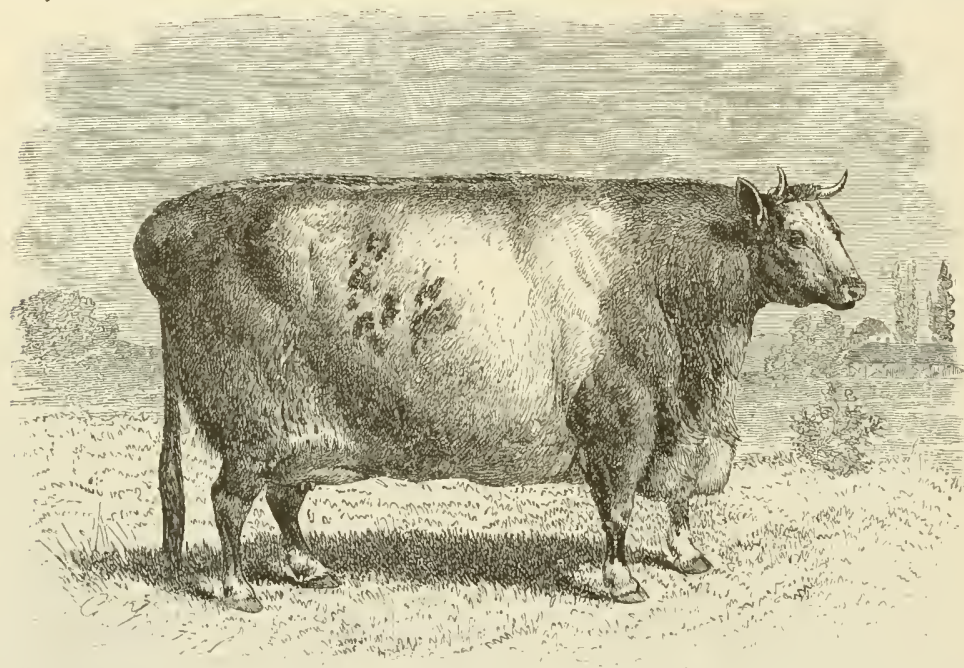

DURHAM OR SHORT-HORN COW.-The Durhan breed of Cattle is a famous English variet $y$ now common also in the United states. Its large, unwieldy body, straight back, and small head and horns. make it an ungainly looking animal but it is famous for the quantity and quality of beef it furnishes. (Bos taurus dunelmensis.)

separating them from their mothers until they had reached their second year. This method of Cattle raising has been greatly changed in recent years, however.

Even in Italy there are still Cattle living in a halfsavage condition. In the Maremmas, those strips of coast country between Pisa and Naples, which are nearly perfectly level, fertile in spots and marshy throughout the remainder of their extent, ill-famed for their unhealthy, miasmatic climate and thinly populated, numerous herds of Cattle rove about, living outdoors year after year, migrating over extensive tracts of territory, and guarded only by the hardiest Men. In Wallachia, Servia, Bosnia, Bulgaria and Syria similar conditions of life prevail among the Cattle.

In the mountainous countries of central Europe, especially in the Alps, the valuable domestic animal receives quite a different sort of care, though there is yet much left to be desired. Tschudi says: "Usually there is no provision made for a suitable stable, or even for any shelter at all. And yet these badly protected beasts apparently thoroughly enjoy the beautiful, calm period of their existence in the Alps. One has only to bring the large bell, which in spring sounds the signal for the departure to and the return from the Alps, among the Cattle in the valley, and it will excite immediate and general attention. The cows collect, lowing and jumping with joy, thinking they hear the signal for departure, and when they set out, and the finest cow has the largest bell hanging from a gay ribbon around her neck and a bouquet of flowers between her horns; when the beast of burden is packed with cheesekettles and provisions, when the milk stools are set between the horns of the Cattle, and the neat herdsmen begin their Alpine songs and the yodling resounds through the valleys, then, indeed, one ought to see the manifestations of pleasure with which the good-natured and mischievous creatures take their places in the procession, and, lowing, shape their course towards the mountain. Cows left in the valley often escape the vigilance of their owners and follow their mates to distant mountains."

In the very high northern latitudes winter is a particularly hard time for Cattle. The short summer of Norway and Lapland does not produce enough veretation to supply the Cattle with winter provender, therefore they are fed in winter not only hay and straw, leaves and birch branches, reindeer-moss, aquatic plants, algre and so on, but also fish and especially the heads of Haddocks, which are caught in great quantities during the time forage is scarcest.

In most other countries of Europe, the cow is a miserable slave of man; in Spain, however, the bull is esteemed of some importance, and may become the hero of the day and occasionally arouse a great deal more sympathy than anything else in the brcast of a Spaniard. This is because the Spaniards both those dwelling in their own country and those living abroad, especially in the warmer parts of the New World - are passionately fond of spectacles such as were in vogue in ancient Rome, but are not now in favor with any other civilized nation; and every bull passing under the observation of a Spaniard is mentally estimated by a standard the highest excellences of which are great capacity and invariable inclination for fighting.

Mental Attributes After all that has already been said, and Capacities I need not further predicate much of the $0 x$ about the intellectual qualities of the domestic $\mathrm{Ox}$. The animal undoubtedly occupies a low plane of intelligence: for it is certainly the most stupid of our domestic animals except the Sheep. It learns to know its keeper and evinces a certain 
amount of affection for him; it obeys his summons and follows his call and exhibits a certain degree of fellowship with the person who comes nuch in contact with it. Habit seems, however, to have nore to do with this than conscious knowledgre.

Various plants, whether fresh or dried, such as vetches, peas, young grains and succulent herbage, seem to constitute the favorite foods of the Ox tribe. Plants and vegetable substances inimical to their well being are: flax, leaves of the yew-tree, waterhemlock, louse-wort, bent-grass, pond-weed, meadowsaffron, spurge, monkshood, young oak-leaves and walnut tree leaves, wet clover and sinilar things. l'arsley, celery, garlic and onions, when eaten, are said to decrease the production of milk. Thyme, ranunculus and plantains are eaten in times of scarcity of food, while cows of all breeds are pas- ever, they may again slightly turn forward or describe a gentle curve downward, and assume a slightly outward direction.

The Fierce and Among the animals belonging to Powerful Cape this group, we assign to the Cape Buffalo. Buffalo (Bos or Bubalns caffer) the first place; it is the fiercest and most powerful member of the sub-genus and particularly characterized by its curious horns. It is of a sturdier organization than other Buffaloes; the head is proportionately small and the neck rather thick; the withers are slightly raised, the tail is long and thin and decorated with a strong, copious tuft, occupying half its length. The horns are curved outward and backward at the roots, then up and backward, and the tips again show a marked inward curve. In the cases of old bulls they are greatly expanded at the

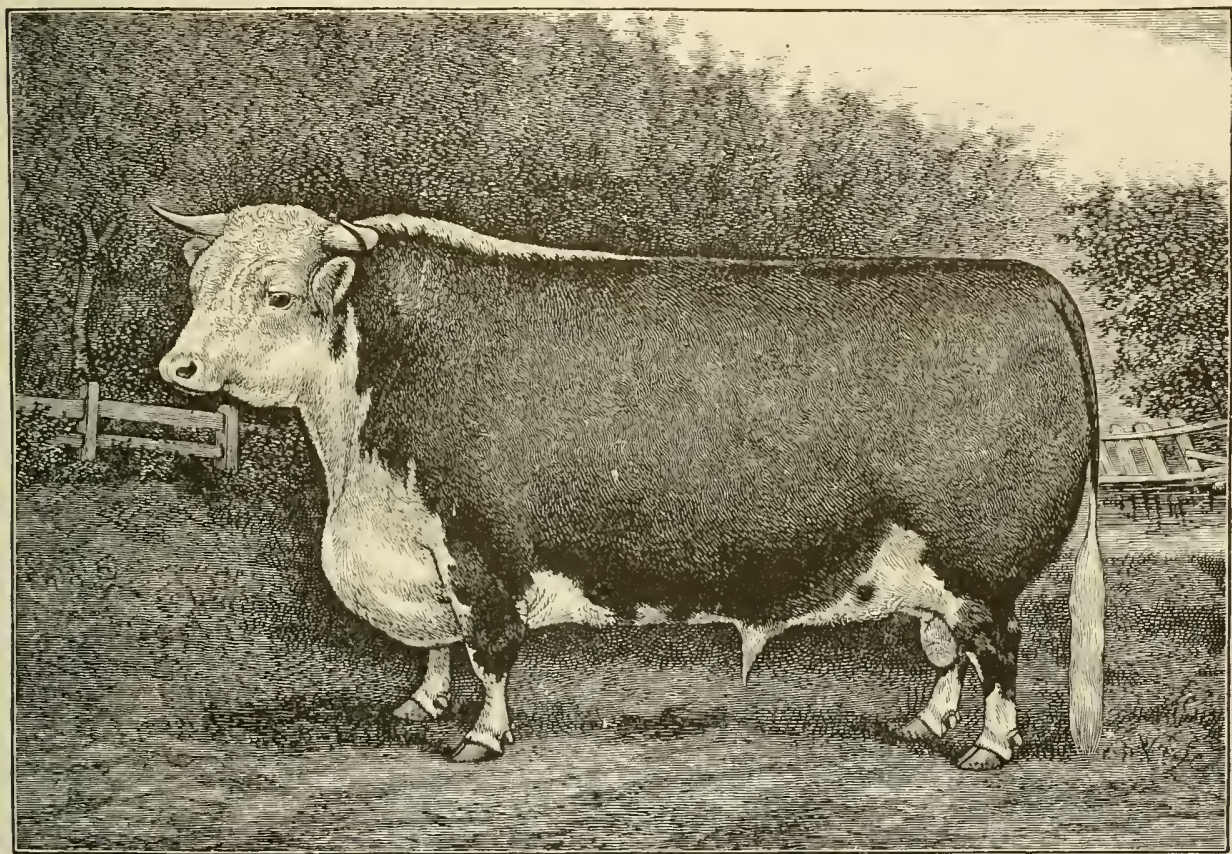

HEREFORD BULL. The Hereford breed is one especially favored by graziers because of its large size, its sturdy constitution, the ease with which it is fattened and the large yield and excellent quality of its beef. It leads among the heavy English breeds and has become a favorite with Cattle raisers in the United States.

sionately fond of all kinds of fruit and most vegetables, such as potatoes, carrots, squashes, turnips, etc.; salt is necessary for their continuance in health. The cow is justly held to be the most profitable of all domestic animals.

\section{THE BUFFALOES}

The Buffaloes (Bubalus) are clumsily built Oxen with a heavy, ungainly body, rather short, stout legs, a broad head with a strongly convex low forehead, dull, sinister-looking eyes, and laterally projecting ears, which are usually large and wide. The horns are set on the apices of the extreme upper posterior angles of the skull and are generally disproportionately enlarged in diameter at their bases; their direction is at first downward and backward, then outward and finally upward; occasionally, how- roots, and covered with thick, annular furrows; they overshadow the whole forehead so that a narrow strip in the middle only is left uncovered. With the exception of the ears and the extremity of the tail, the growth of hair is extremely scant, so that some places have an almost naked appearance, and a truly hairy covering can be properly spoken of only in connection with the head and legs. The color of the animal is produced less by the black hair, tipped with a lighter tint, than by the dark brownish-gray hide. The height of a Cape Buffalo at the shoulder varies between five and six feet, according to sex and the development of the animal. The horns, which in the female are more slender and cover the forehead only half as broadly and buikily as in the male, may in both sexes attain a spread of from forty to nearly forty-five inches. 
Range and Habits The range of the Cape Buffalo comof the Cape prises, like that of the Giraffe, the Buffalo. greater part of the eastern half of Africa. In Cape Colony it has, together with the few surviving Elephants of that country, only a restricted and quite isolated habitat between the bays of Mossel and Algoa. The southern boundary of its present range might be described by a line running along the Cubangu to the Ngami lake: thence eastward to the Limpopo and to the east of the Transvaal; thence it would run south to about the bay of St. Lucia. To the north of this line it is found in most of the African territory, up to about the sixteenth parallel of north latitude. It affects the plain more than the mountains, and for its permanent abode it always selects a locality where water is plentiful.

The Cape Buffalo is gregarious by nature, and constantly lives in association with its own kind, in bands of from thirty to sixty in regions where it is pursued, and in herds numbering hundreds or even thousands in those localities in which it is little or not at all molested.

During the hot hours of the day the Cape Buffalo lies in its retreat still and motionless, sleeping or sometimes ruminating; it not infrequently makes its resting place in a pool of water or a mud-hole, for this reason often appearing covered with a goodly crust of mud. In the late afternoon or toward evening it rises, and grazes at intervals from that time till early morning, not in leisurely comfort, like other Oxen, but by fits and starts. With a restless haste, driving away the obnoxious Flies, and often uttering its dull growl, it sways from side to side its ever damp, thick muzzle, pricks up its broad ears, deeorated with a bristly fringe of hair, and lashes its flanks nervously with its tufted tail. Apparently ever sulky and completely inaccessible to any mollifying influence, grim and vicious, it carries its broad, bulky head partly concealed by its horns halfway lowered, as if ever ready to make an attack, and the large, blue-black eyes glare wildly from under the huge horns, so that the animal can not avoid producing upon the beholder the impression of unrestricted fury and deliberate malice.

Without being really timorous, the Buffaloes flee at the approach of Man, and, especially if they have been repeatedly pursued, they shun the proximity of their most formidable enemy' as much as possible; but if driven to bay or provoked, they turn against him without scruple and then heed neither spear nor bullet in their blind rage. A wounded Buffalo, which does not immediately charge at his enemy, never flees far, but hides in ambush in the high grass and there awaits the approach of his pursuers, witl the intention of rushing at them with lightning-like rapidity. If its enemies flee or hide, it follows them snorting, trying to trail them by its powers of scent. The old solitary bulls separated from their herds are said to be simply terrible. Drayson says: "It is well known that it is the habit of nearly all animals to flee from Man, provided he does not wound them or intrude on them at an unsuitable time; these old hermits, however, certainly do not wait for such excuses, but meet the sportsman half way, and pick a quarrel with him."

The Pursuit of Selous, who shot several hundred the Cape Buffaloes in south Africa, says: "I Buffalo. did not find the old solitary bulls any more dangerous than the animals living in a herd. Unless they are wounded, they generally flee from Man; and even when injured, they are no worse than any Buffalo out of a herd under similar circumstances." He further relates, to indicate the strength of an old bull, that he once was charged at, while on horseback, by a wounded bull, which threw the Horse into the air "as if it were a Dog."

Thus one may conclude that the chase of the Cape Buffalo is not devoid of danger; the animal probably is not usually felled by the first shot, hence generally has time and strength enough to confront its antagonist.

The beef of the Cape Buffalo vies with that of fattened Oxen in its savory taste. It is tougher and of coarser grain, but is very juicy in spite of the lack of fat: hence it is an object of zealous pursuit among African huntsmen. But Man is not the only dangerous enemy of the Buffalo; the Lion also dares attack the powerful creature and sometimes succeeds in killing it by breaking its neck. At any rate it is nothing uncommon for hunters in south Africa to encounter Buffaloes which have succeeded in shaking off, and perhaps in killing, the beast of prey, but bear deep wounds on neck and shoulders received during their struggle.

The Cape Buffalo The first living Cape Buffaloes were Capable of Do- taken to Europe by Th von Heug-

mestication. lin. He says: "Notwithstanding its ferocious temper in the wilderness, it seems that the animal may be easily tamed and then probably put to excellent use."

Cape Buffaloes have propagated themselves in various zoological gardens; but those which are born in confinement differ little or not at all from those which are imported from Africa. Both grow as rapidly as other Oxen; but the huge horns of the bulls are very slow in development, and extended observations lead to the belief that many years are needed for their growth before they assume their characteristic shape and size.

The Indian Buf- The ancestor of the completely falo's Physical tamed and domesticated Buffaloes, Peculiarities. which are to be frequently seen in the valley of the Danube and in Italy and in much greater numbers in Egypt and India, is not the Cape Buffalo, but an animal still living in southeastern Asia.

The Indian Buffalo (Bos or Bubulus armi) attains, according to its breed, a total length of from nine feet four inches to ten feet, including the tail, which measures from twenty to twenty-four inches. The height at the shoulder ranges from four feet eight inches to six feet. The head is slıorter and broader than that of the $\mathrm{O} x$, the forehead large, the facial portion short, the neck short and stout, longitudinally wrinkled in front, but destitute of a dewlap. The abdomen is slightly elongated, but full and rounded. The body shows a hump-like elevation on the withers, and a depression along the back. The chest is narrow, and the flanks are retracted; the tail is rather short; the sturdy legs are proportionately short and the feet are equipped with broad hoofs, capable of a remarkable degree of lateral extension. The small eyes have a ferocious, defiant expression; the ears are long and broad covered with short hair on the outside, and decorated with long tufts of hair on the inner surface. The horns are long and strong, expanded at their roots, then tapering and ending in blunt points; on their two anterior surfaces they show deep transverse furrows from their bases up to their middles; from that point to their extremities, as weil as along the entire 


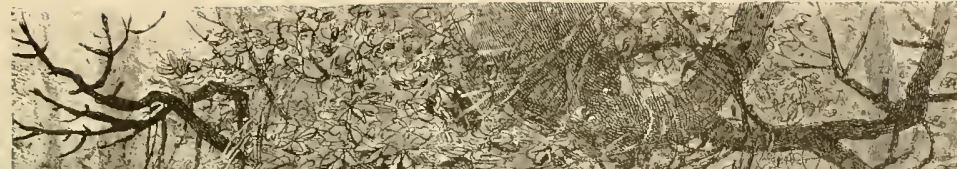

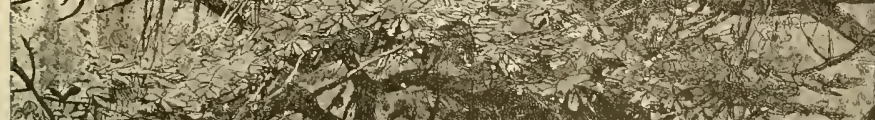
1)

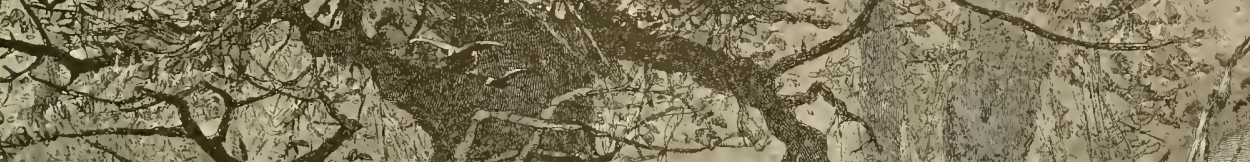

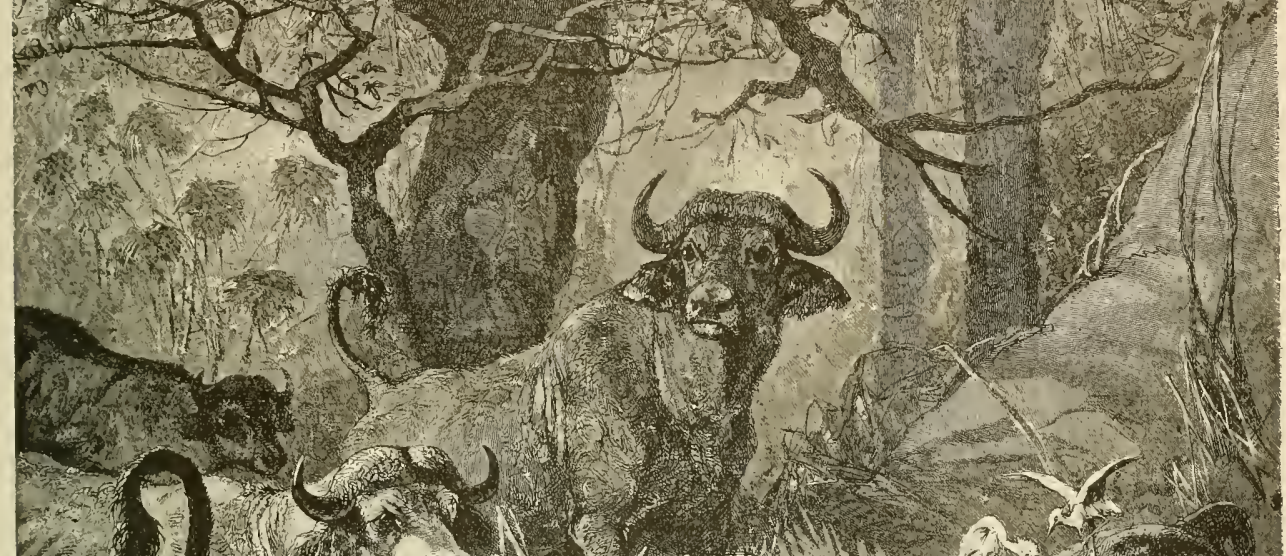
(1) 1.20

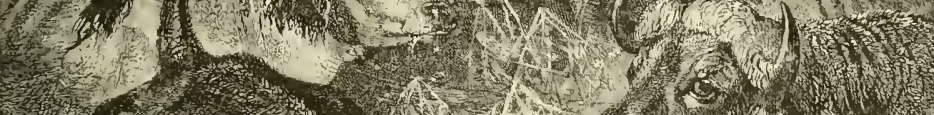

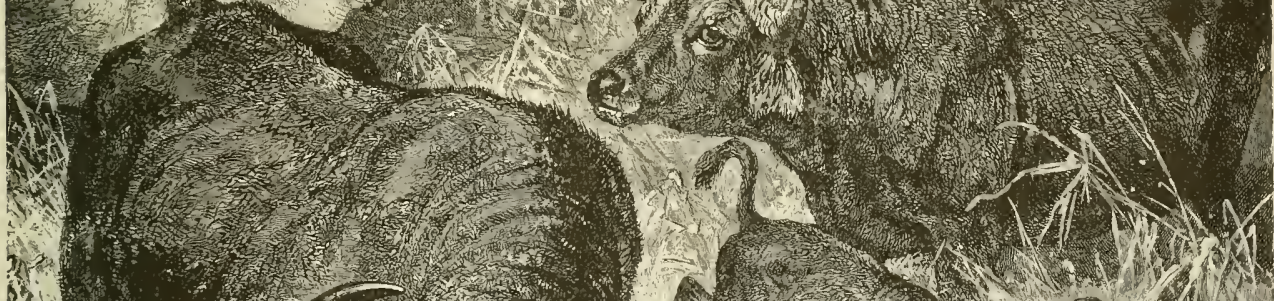

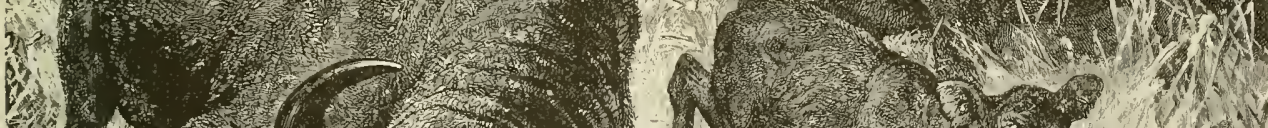

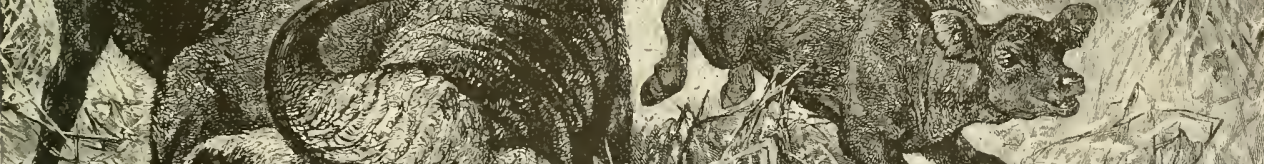

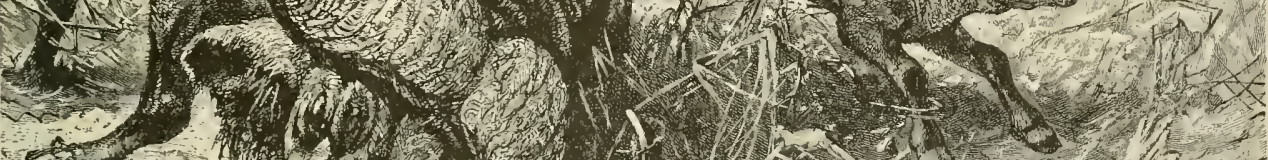
s.t.

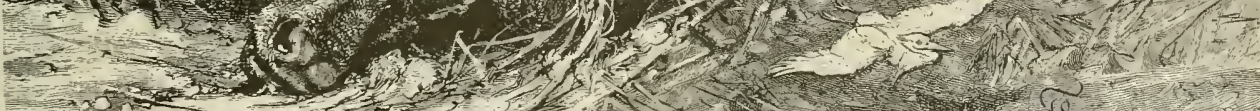

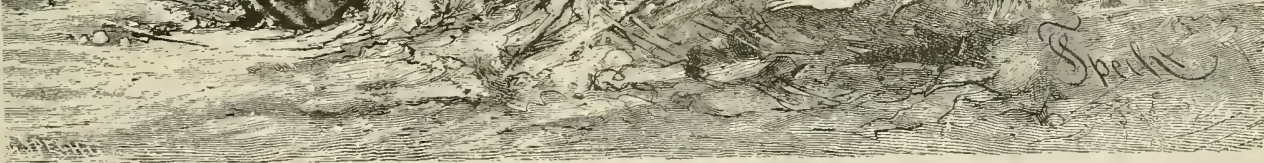

THE CAPE BUFFALO. These wild and ferocious animals inhabit eastern Africa from Abyssinia to Cape Colony Where they are little disturbed (n) gerous antagonists of the sportsman who hunts them. (Bosiaffer.) 
posterior surfaces, they are perfectly smooth; their cross-section is an irregular triangle. The hairy covering is scant, stiff and brist]y, growing a trifle longer only on the forehead, the shoulders, along the entire front of the throat and on the tail-tuft, while the hinder part of the back, the buttocks, breast and abdominal surface, the thighs and the greater part of the legs have a nearly naked appearance; thus the coloring of the hide, which as a rule is dark blackishgray or black, is a greater factor in producing the general color than the bluish-gray hair, tinged with brownish or red-brown. There also are white or mottled individuals, but they are rare. The cow differs from the bull only by its smaller proportions. Range and Habits The range of this wild Buffalo ex-

of the Indian tends from the foot of the Himala-

Buffalo. yas, through Bengal and the eastern portions of central India southward about to the Godavari, and eastward, through Assam and Burmah, at least as far as northwestern Siam. It is also a native of Ceylon.

Being as fond of water as all other members of its tribe, the Indian Buffalo is found only in the wetter portions of its range, either near rivers or in the immediate neighborhood of small lakes, which may contain water only at certain times, or else around shallow lagoons on the shores of the occan. It is clumsy in its novements, but is strong and possesses great endurance, and in swimming it is particularly proficient. Anong the perceptive senses those of smelling and hearing rank first; sight and susceptibility to sensation of touch appear to be little developed, neither does the sense of taste seen of a high order, as the animal contents itself with the worst quality of food, such indecd as other Oxen disdain. The liutfaloes graze especially during the night and in the early morning; they are given to incursions into plantations and sometimes comnit great depredations in them.

The temper of the Indian Buffalo is said to be sulky and uncertain; its strength and courage are said to be so great that Hindu poctry places the animal on a level with the Tiger. "The bull," says Hodgson, " is so strong and pugnacious thet it not only dares attack a full-grown Elephant, but occasionally subdues it." Jerdon also states that an enraged Buffalo will sometimes turn and charge straight against a hunting Elephant, and he adds: "The Buffaloes are anything but shy, except in those regions in which they have suffered much from constant pursuit, and one can approach them within easy range even on Elephants, without the aid of which the chase can not very well be successfully conducted."

The vocal expression of the Buffalo is a deep, rumbling bellow: Hodgson says that the bull seeks his mate in the fall; then the larger herds generally resolve themselves into smaller bands, one of which each bull collects around himself.

The Indian Buffalo is, in a certain sense, the natural enemy of the Tiger, and nearly always issues victorious from its combats with that beast. IV. Rice relates that adult Buffalo bulls are occasionally attacked by Tigers, but frequently succeed in quieting the beast of prey forever. When one Buffalo is attacked the others fly to its rescue and, as a rule, succeed in despatching or driving off the assailants. Herdsmen tending tame Buffaloes may, without fear of molestation from beasts of prey, spend their time in the jungle, riding one of the animals. Johnson relates how a Tiger attaclied the rearmost Man of a caravan. A herdsman, who was guarding Buffaloes near by, flew to the rescue and wounded the beast of prey. The Tiger inmediately relinquished its first victim and seized the herdsman; but the Buffaloes, seeing the danger their master was in, rushed at the Tiger and assailed it so furiously that it soon lay dead upon the ground.

Distribution and IVe do not know when and how the Life of the Tame tame Buffalo has been distributed, Buffalo. but we suppose that it was probably brought to Persia in the train of great armies or of migrating tribes, as the companions of Alexander the Great found it there. Later the Moslems may have transported it to Egypt and Syria. In the year 596, during the reign of Agilulf, it landed in 1taly, to the great surprise of Europeans. At first it seems to have spread very slowly; it is now found from southern China, throughout India and Farther India, Afghanistan, Persia, Armenia, Syria, Palestine, Turliey, Greece, and the valley of the Danube, Italy, and very commonly also in Egypt, but not in Nubia. Like all of its relatives, it most delights in hot, swampy or watery situations. The Nile Delta is a paradise for it. On the lower Danube it apparently feels very comfortable; in the Italian swamps it is the only member of its family to be found, as all others succumb to the noisome atmosphere of the unhealthful climate. In Lower Egypt it is plentiful everywhere, and, except the Goat, is the only source of supply for milk and butter. Every village in the Delta and most of the villages in Upper Egypt have a large pool between the huts, the sole purpose of which is to afford the Buffaloes a convenient bathing place. One sees them much oftener in the water than on the pasturage, and if possible, they submerge themselves so deeply that only the head and a small portion of the back protrude above the surface.

The Buffalo's One cannot sufficiently admire the Actions and mastery by the Buffaloes of the art Movements. of swimming. They act as if water was their proper element, for they dive, lie on their sides or half on their backs, and either permit themselves to comfortably float without stirring. or swim straight across a stream, except for the slight distance they are drifted down by the current. On land the Buffalo impresses one as being much clumsier than it appears in the water. Its walk is shambling and lumbering and its running gait, though tolerably swift, is also an awkward, halting mode of progression.

When one first meets tame Buffaloes, he is apt to become really frightened. The expression of their faces indicates ineradicable defiance and smouldering ferocity; the expression of their eyes seems to signify a deceitful, base disposition. The observer soon becomes convinced, however, that it would be totally wrong to judge a Buffalo by its external appearance. In some countries, certainly in Egypt, it is an extremely good-natured animal, which every peasant will unhesitatingly and safely trust to the guidance of the weakest child. Buffaloes appear indifferent to everything except food or drink.

Propagation and $\mathrm{ln}$ the more northern regions, in Economic Value of Fcbruary or March, the Buffalo cow the Buffaloes. usually gives birth to a calf. The little one is an ungainly creature, but the mother loves it tenderly and defends it from harm with the well-known heroic courage of the Ox tribe. In its fourth or fifth year the Buffalo is mature and it may live for about eighteen or twenty years. 
The Buffalo is relatively more protitable to Man than our domestic Ox, as it requires next to no care and is satisfied with food which all other domestic animals disdain. In marshy localities it is highly useful in tilling the fields also, for what it lackis in intelligence it more than compensates by its enormolls strength.

The Hesh of the adult Buffalo is not eaten, at least by white Men of other than its native countries, on account of its toughness and the odor of musk which clings to it. The flesh of the calves is said to be very good, however, and their fat to be almost equal to pork in taste and tenderness. The strong hide yields excellent leather and durable and useful articles of many kinds are made from the horns. formerly sometimes classified with the Antelopes, sometimes with the Goats.

Description of the The Rocky Mountain Goat, called Rocky Mountain Nane by the Canadians (Aplocems Goat. montamus or amoricamus), has the general shape of a domestic Goat, but apjears sturdier and shorter-necked in consequence of its rich, long fleece, though the body itself nust be considered slender. The head is elongated, the eye is large, and the ears are moderately large and sharply pointed. The short tail is bushy on the upper surface and the sides; the legs are sturdy and look still more so because of their profuse covering of hair. The hoofs, the upper parts of which are covered with wiry hair, do not difter materially from those of wild

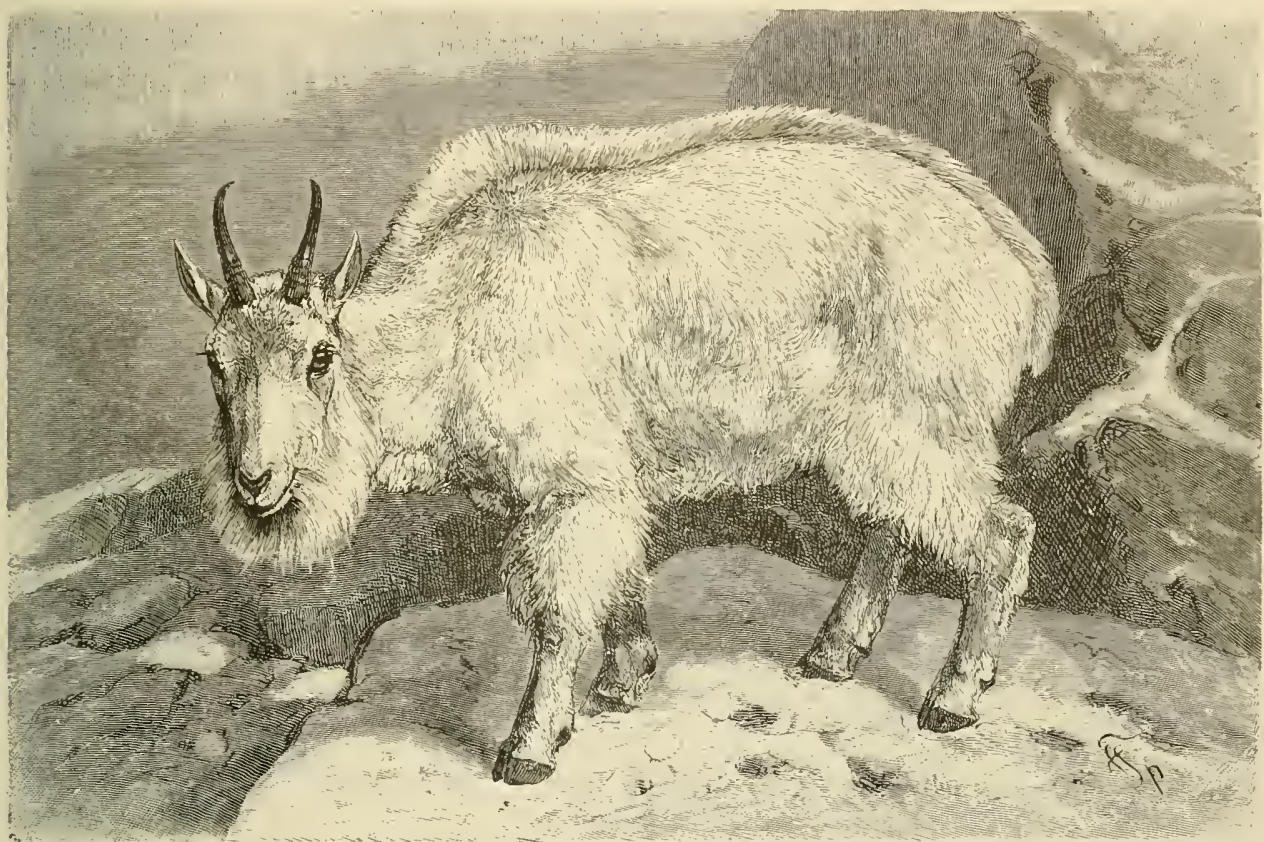

THE ROCKY MOUNTAIN GOAT. With its home in the highest parts of the Rocky Mountains this animal is not much molested. 1ts body is shaped much like that of a domestic Goat, but the two differ in their horns so much that they are placed in distinct sub-fanilies. Rocky Mountain Goats are very lively, agile and wary animals. (Afloconts montunzs.)

The Natural Ene. The Buffalo has enemies which mies of the might prove fatal to it only in India Buffalo. and perhaps in Persia. It is probably rarely the case that a pack of 11 olves attack a Buffalo in the Danube country, and then the animal must be either debilitated or fatigued if they are to be successful. The conditions are similar in India, though there the tame Buffalo encounters the same enemy as the wild one, namely the Tiger. It is true that this formidable beast of prey secures an occasional victim from among the Buffaloes, but it seems to hold equally true that a herd of Buffaloes are able to invariably rout any Tiger.

\section{THE ROCKY MOUNTAIN GOAT.}

On the high mountains of North America there lives a Horned Animal which deviates so considerably from its family relations in the formation of its horns, that we recognize in it the representative of a distinct sub-family, the Aplocerine, It was
Goats. The fleece is uniformly white all over the body and consists of a long, hard outer coat and a fine, long, straight, woolly immer fur, the two kinds of hair occurring singly in some and together on other parts of the body. On the face and forehead appears nearly exclusively the thick, fine, curly wool; on the neck, abdominal surface and thighs both kinds of hair are found; on the nape and sides of the neck, back, tail and in the mane-like covering of the throat, breast, shoulders and front part of the hams the wool is entirely absent. On the back of the head there is a thick, long tuft of hair, which falls down on all sides and merges into the mane of the upper part of the neck and back. From the chin and lower jow the rich beard hangs down in thick curls, which look as if they were intentionally divided and artificially twisted. The neck is covered by a drapery of long hair, which falls down over the shoulder-blade and is continued into a kind of mane on the shoulders and thighs and nearly envelops the 
fore-legs, leaving only abcut one-third of those members bare. A similar appendage covers the forepart of the hind-legs. The tail is decorated with a long, thick tuft of the outer hair. The face is entirely covered by the wool, as are also the eyes up to the edges of the lids and the nose to the margin of the nostrils. The ear, however, is covered with stiff hair on both sides. The fleece feels soft and pliable to the touch, like Sheep's wool, and the individual hairs are somewhat matted and adhere perceptibly to each other. The length of the animal is from forty-eight to fifty-six inches, the tail taking up rather less than four inches of this total: the height at the withers is from twenty-seven to twenty-nine and one-half inches, the height at the croup varies between twenty-nine and thirty-one inches. The horns, which are borne by both sexes, but are slightly stronger in the buck, attain a length of from eight to nearly eleven inches and turn upward, backward and outward in a direct slight curve. They are nearly round at the base and slightly ringed on the lower half; in the middle section they are a little compressed laterally and the tip is again rounded.

Range of the The range of this atimal is reRocky Mountain stricted to the northern part of the Goat. Rocky Mountains and extends northward to the sixty-fifth parallel of latitude. According to Baird, it is commonest in the elevated portions of the state of IVashington, and the Prince of IV ied says that it exists in greatest profusion near the sources of the Columbia river. Some information as to its mode of life has been obtained, but only in recent times, It inhabits such lofty heights that it finds no other food than lichens, mosses and mountain plants of the hardiest kind, or in exceptional cases a few stunted shrubs of a kind of pine (Pinus contorta) and similar scant bushes. Nevertheless it leads a rather comfortable life most of the time, and care and trouble beset it only when winter drives it away from its high pasturage. In summer it climbs up to an elevation of over thirteen thousand feet and there selects its headquarters, generally choosing the lower edge of the melting snow fields. In winter it is wont to descend to a somewhat lower level, whthout, however, leaving the high mountains proper. In such a mountainous wilderness, which is trodden by human feet in exceptional cases only, it goes on its intricate paths with careless speed, jumping from one rock to another with the precision peculiar to its tribe and climbing about the most inaccessible looking walls. Differing from other Goats, the bucks are said to undertake the leadership, and the she Goats and kids follow them in single file. When the herds are alarmed or frightened by a shot, they shim along the edges of the most frightful precipices at a full gallop, or cross an abyss, stepping on the same spots one after another, showing more of the lightness and grace of winged creatures than the actions of even the most agile quadrupeds. Being exceedingly wary, and endowed with extremely keen senses of hearing and smell, the Rocky Mountain Goat usually thwarts any attempt of Man to approach it, and is therefore as difficult of obscrvation as of pursuit. From the beginning of June little kids are seen following their mothers, usually one behind each Goat, but sometimes there are twins. The kids are extremely pretty.

The Rocky Mount. Excepting a few naturalists and ain Goat Rarely hunters addicted to this sport, the Molested. Indians alone engage in the chase of these wary inhabitants of those desolate heights; and the latter do not display any special zeal in the pursuit. The flesh of this Goat is not esteemed, for it is tough and impregnated with the strong, rank smell which usually characterizes the male Goat, and which in this species is not absent even in the kid. It is for this reason repulsive even to the Indians, whose taste is by no means fastidious. The Rocky Mountain Goat is therefore pursued only for the sake of its fur, which is either disposed of to the white fur traders at the trading posts or made into plain rugs by the Indians.

As far as my knowledge goes, this Goat has never been tamed and is to be seen in very few museums.

\section{THE ANTELOPE TRIBE.}

The Antelopes (Antilopinc) constitute the subfamily among the Horned Animals which is richest in forms, but also stands on the lowest plane of development. Speaking in a general way this sub-family comprises the most graceful and elegant of the Horned Animals, but this statement is only true in the wide sense, for among the Antelopes are included several species which conform but little to the commonly entertained notion of an Antelope. As a rule the animals of this tribe bear the characteristic of the family, as it includes the most dainty and slender of all the hollow-horned animals; but there are also included in the sub-family some clumsy, lumbering creatures which at first glance one would be inclined to classify with the Oxen. Therefore great difficulties attend the effort to make a general characterization of these animals, nor is it easy to set the line of demarcation for the subfamily, as some Antelopes show much greater affinity to the Oxen or the Goats than to the original type, which we consider to be the Gazelle, world famed from the earliest ages.

Characteristics and lin general, the Antelopes are Range of the slender, Deer-like animals, with Antelopes. short and nearly always thickset hairy covering and more or less twisted horns, which are usually borne by both sexes. The different species show much similarity in bodily structure, and the only marlied distinctive features are found in the formation of the horns, the hoofs and the tail, as well as sereral modifications of the hairy covering. But the number of species of Antelopes is so great that the members placed at either extremity of the group bear little resemblance to each other.

The Antelopes inhabit the whole of Africa, southern, western and central Asia, southern and central Europe. Each species seems to have its favorite food, which determines its place of abode so long as human interference does not drive the shy, fleet animals to pastures new. The majority inhabit the plains, but some decidedly prefer the high mountains to the valleys, and ascend to the lower limits of perpetual snow. Some inhabit open country covered with a sparse vegetation, others are found in thin ranges of scrubby bushes; some in the thickest of forests, a few species even in marshes and bogs.

Food and Their food consists exclusively of Uses of the vegetable substances, mainly of Antelopes. herbage, leaves, buds and young shoots. Some content themselves with the coarsest food, others are exceedingly fastidious and feed only on the most succulent and dainty of plants. If provided with fresh, green provender, the majority can abstain from water for a long time, and those that live in arid deserts can go entirely without water for days and even weeks. 
One may call the Antelopes, with hardy an exception, useful and valuable animals. In the localities which they inhabit, they seldom work any considerable damage; and they are of use on account of their flesh, their horns and their excellent hide. Therefore they are invariably objects of the chase with people of all races who share their natire countries. Some Antelopes of great reputation from the earliest ages have had their praises sung by poets and travelers; and in the pursuit of others the hunter risks his life a hundred times. In various ways Man feels himself attracted by all Antelopes. The majority of species easily bear confinement, at least in their native country; they propagate themselves and delight their keeper by their tame and trustful ways. Some of them literally become domestic animals, and in many instances were so regarded and treated in former times.

IVe will mention only the most important forms of this sub-family, the richest in variety among the Ruminants.

\section{THE ANTELOPES PROPER.}

I will begin the description of the series of animals thus classified with an account of the Antelopes proper (Antilopi). The group comprised under this name is characterized by physical proportions approaching the Roebuck in size, elongated horns the outlines of which resemble those of a lyre or which may be spirally twisted, tear-pits which are large as a rule and small only in exceptional cases, the existence of inguinal glands, and a hairless muzzle of small extent generally restricted to a spot on the upper lip.

Account The Sasin (Anof the Sasin tilope ceraica-

Antelope. pral plays an important part in Hindu mythology, and is sacred, along with many other species, to the goddess Chandra or the moon. It is smaller, and more slender and elegant than the Fallow Deer. Its body is from forty-eight to fifty-two inches long, the tail measures six inches and the height at the withers is thirty-two inches. The color varies in accordance with the sex and age. Dark brownish-gray tints prevail among old bucks. The female is much lighter and of a sorrel tint. Young females are said to differ from the old ones by the exhibition of a reddish hue. The horns, which are borne only by the bucks, attain an average length of from sixteen to twenty inches, and in some rare cases from twentyfour to twenty-six inches, and are generally bent in a slight spiral of three or four and sometimes five turns. At the roots both horns stand close together, but at the extremities they are from twelve to sixteen inches apart; they are stouter or more slender according to the age of the animal and are ringed nearly to the tip, which is smooth. Bucks of ad- vanced age sometimes show as many as thirty such rings, though their number does not stand in a direct proportion to age and growth.

The Sasin inhabits the open, flat territory of India with the exception of lower Bengal and the coast of Malabar. It usually lives in bands of twenty or thirty and frequently even from forty to sixty. It affects the open country in all cases and shuns thickly grown regions, for it exercises great watchfulness. Williamson is authority for the statement that a few young males or old females are always posted as sentinels, when the herd is occupied in grazing on some favoritespot. These sentinels keep a particularly watehful eye on bushes behind which a hunter might creep up and hide. The same observer says it would be foolish to let Greyhounc's course them, for the hunter can expect to be suc- 
Gazelle in the desert forms an exceedingly attractive picture, and one which has inspired Oriental poets with enthusiastic songs from the remotest times. Even the stranger from the Occident, if he sees them in a state of liberty, can understand why it is that they appear to the Oriental the personification of grace and loveliness; for he also feels a breath of that enthusiasn which inspires the words and sentiments of those glowing songs of praise. The son of the desert compares the bright eye of the maiden who moves his heart to its very depths, with that of the Gazelle; he know's no more fitting designation for the slender white neck of his beloved, than to call it the neck of a Gazelle. The pious man finds in this graceful daughter of the desert an emblem to aptly typify the yearning of his heart after everything sublime. The Gazelle exercises a fascination over everybody. The Egyptians dedicated it to the suprene goddess Isis on account of its gracefulness, and sacrificed its young to the queen of the gods; its beauty serves as an enblem to the poet in the "Song of Solomon;" for in that book it is the Roe and the young Hart with which the beloved is compared. The Arabian poets of all times fail to find words sufficiently laudatory in which to picture it; the oldest books of this nation are full of its praises, and the singers on the Arabian streets glorify it to-day.

Physical Pecu/. The Gazelle (Antilopi dorcas) is ratlier iarities of the smaller than the European Roe, but Gazelle. is of a much more delicate and slender build and has more beautiful markings. Old bucks are forty-four inches long, or fifty-two including the tail, and are twenty-four inches high at the withers. The body is sturdy, though it looks slender on account of the long legs; the back is somewhat arched, higher at the croup than at the withers, the tail is tolerably long and thickly grown with hair at the tip. The legs are extremely delicate, slender and terminate in very shapely hoofs. The neck is elongated and the head of moderate length, broad and high above the eyes, tapering below, and slightly rounded at the muzzle. The ears are about three-fourths as long as the head. The large, softly lustrous eyes show a nearly round pupil; the tearpits are of moderate size. The prevailing color is a sandy yellow, warming into a more or less dark reddish brown on the back and legs. A still darker stripe runs along both flanks and separates the dazzlingly white under surface from the darker upper parts. The horns vary in size and appearance according to the sex. In the case of the buck they are larger and the rings of growth are always much more prominent. In both sexes the horns curve upward and backward, the tips again curving forward and somewhat converging, so that their front view bears a resemblance to the lyre of ancient nations.

The Range and The range of the Gazelle extends

Food of the from Barbary to Arabia and Syria, Gazelle. and from the coast of the Mediterranean to the mountains of Abyssinia and the plains of central Africa. The entire territory of the desert and the plains adjoining it may be properly regarded as its native country. In the Abyssinian mountains it ascends to an elevation of about five thousand feet. The more abundant the vegetation of the wilderness, the more frequent the animal is in it; but it must be borne in mind that an abundant vegetation from a north African point of view is very different from what is meant by the expression in regard to our country. It would be a mistake to suppose the Gazelle to be a permanent inhabitant of really fertile valleys; it pay's but flying visits to such regions, and probably enters them only if compelled by hunger to do so. It is true that it prefers the cooler climate and shade of the lowlands to the hot glare of the table-lands, but only of the lowlands of the wilderness; in valleys traversed by rivers it is found as rarely as in high mountains. Its favorite haunts are groves of mimosas, or better still, those sandy stretches where hills alternate with valleys and mimosas are found uniformly distributed all over the country without forming isolated groves or patches of woods, for the mimosa must be regarded as its principal food. In the plains it also occurs, and that quite numerously in some localitics; but in such situations also it prefers thinly grown tracts of brush to fields of waving grass. In the plains of Kordofan there are bands of forty or fifty which extend their wanderings to considerable distances, though they perhaps do not continue them the whole year round. In their favorite haunts, however, they are only seen in small groups, numbering from two to eight, and often singly.

The Gazelle at The Gazelle is indisputably a highly

Liberty and gifted animal, as active and agile as

Tamed.

any other Antelope and remarkably graceful besides. Its step is exceedingly light, and it seems, in running, to barely touch the ground. A fleeing herd affords a truly magnificent spectacle, for even when danger is quite near they seem to be at play. One Gazelle often leaps over another in pure sportiveness, making leaps of from three to six feet in leinght. With like playfulness it leaps over stones and bushes in its path, even when it appears much easier to go around them. The Gazelles perceptive senses are excellently developed: that of smell is acute, the eye is keen and the sense of hearing delicate. The animal is intelligent, cunning and even shy, is possessed of an excellent memory, and where it gathers experience it becomes more and more sensible. Its behavior is really charming. It is an inoffensive and somewhat timid creature, but by no means so devoid of courage as is usually believed. There is always a certain amount of quarreling and fighting going on in a herd, especially among the bucks. IVith all other animals the Gazelle lives in peace; therefore it is often seen in companionship with other nearly allied species of Antelopes.

Gazelles taken into houses while yet young become tame in a few days, and bear confinement well and for a long time, especially in their native country. In the European households of the larger cities of northern and eastern Africa there are always to be seen tamed Gazelles, and among them are many which have become so accustomed to human companionship that they can be regarded as genuine domestic animals.

The Gazelle The Gazelle is, in its native country, Esteemed as a the object of a diligent and most en-

Game Animal. thusiastic chase. It is shot, caught by Falcons or coursed to death by Greyhounds. The second mode requires a great number of people, Dogs and Falcons, thus entailing great expense, and is engaged in only by the great people of the world. Quietly and slowly, as much as possible from the leeward, the huntsmen approach a herd of Gazelles, profiting by all natural advantages for concealment which the ground may offer. At a suitable distance from the lierd the hood is talien off a trained Falcon, and as soon as the bird has 
caught sight of the Gazelle, it is set free. The Falcon rises high up in the air, like an arrow, swoops down on the Gazelle and tries to fasten its claws upon the animal's head near its eyes. The surprised beast endeavors to rid itself of the bird of prey by shaking and rolling itself, and the Falcon eventually loosens its hold on the head of the victim but instantly fastens on to it again, usually selecting the hind leg for its point of attack. Though the Dogs have as yet seen nothing of the Gazelles, they know by experience that the hunt commences with the removal of the Falcon's hood. They become uneasy, pull at their leashes, and finally can not be kept back any longer. They are let loose and follow the Falcon, keeping it in sight, and behind them the hunters hurry on their Horses. If the Falcon is a good onc, it can stop any
The hunter made as good use of his time as lie could, and in the majority of cases was able to obtain a successful shot from one of the thicker bushes, usually at a distance not exceeding from ninety to one hundred and fifty paces. The surviving Gazclles would make off with all possible speed after the report, generally trying to gain the nearest hill, to the top of which they would climb. There they would stop, however, exactly as if they wished to inform themselves of what had taken place, and more than once we succeeded in creeping up near to the place where they were posted like sentinels. In some localities the higher hills would gradually all become covered with Gazelles, which, alarmed by the reports of our shots, had drawn near from all sides to survey the ground from their watch-towers. I may well say that those mountains, which are for

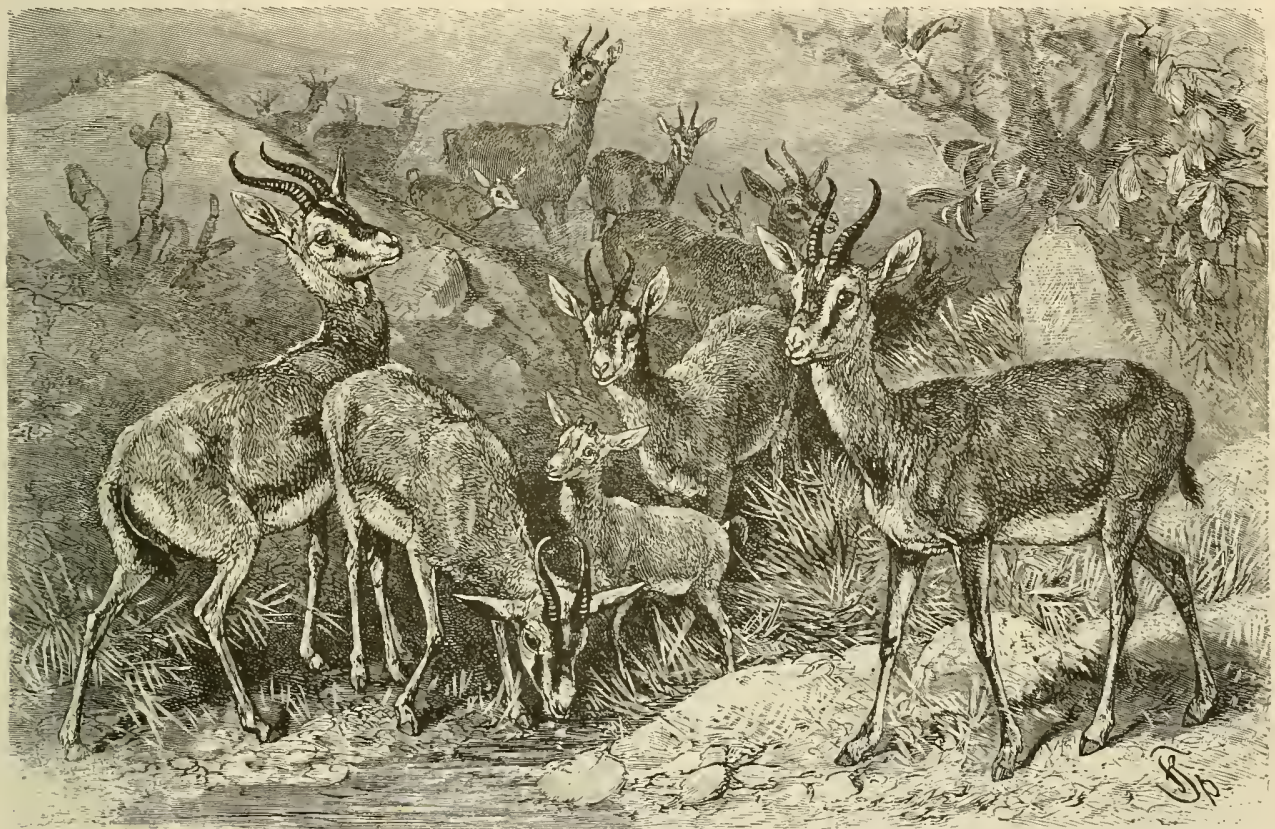

THE GAZELLE. - Long the favorite theme of Oriental poets, the Gazelle, or Barbary Antelope, is one of the wrost graceful and agile of animals The slender, black horns surmount a beautiful head which is further adorned by long but symmetrical ears, and the entire contour of the animal is delicate and shapely. (Antilope dorcas.)

Antelope that is not too large, until the Dogs come up and tear it to pieces.

Methods Employed The hunt with a gun yields very in Shooting good results. Whenever we, my Gazelles. companion Van Arkel and myself, saw a troop of Gazelles, we would cautiously continue on our way, making at the most a small detour and approach the Gazelles as closely as we deemed advisable. Then one of us would jump down from his Mule and hide behind a bush, surrendering the Mule to the servant who accompanied us. Then the dismounted hunter would creep up to the quarry, carefully keeping to the leeward and occasionally crouching on the ground; the other one continued his journey. Generally the leader of the herd would curiously follow the latter with its eyes, forgetting to examine the rest of its surroundings, and thus exposed the herd to attack. the greater part bare of trees, were in this way decorated in a wonderfully beautiful fashion. The fine forms were so clearly outlined on the deep blue sky that one could distinctly perceive every limb, even at a great distance. It also happened frequently that the frightened Gazelles would go over one of the numberless hills and stop as soon as they had passed down the other side and lost the hunter from view. In the beginning they deceived me several times by this strange conduct. I would climb the hill with the greatest caution and look for my quarry in the distance, while it stood right beneath me. A rolling stone or some other noise which I occasioned would alarm them and they would start away with windlike rapidity. But 1 never saw Gazelles pursued by Men have recourse to their utmost speed, which they display only when Dogs are at their heels. I can not describe the spectacle then afforded by 
these two animals; the most I could say being that rather than to run: but that statement would still fall short of describing its fleetness.

Peculiarities and The Springbols (Antidorcus) exhibit Structure of the a great affinity to the Gazelles, but

springbot. differ from them and all other relatives by reason of one important feature, peculiarly their own. Hong the back, beginning about its middle, runs a furrow formed by a doubling of the skin and covered with very long hair; it is usually closed, but opens in response to violent movements, especially in bounding. The horns, which are borne by both sexes, rise vertically from the forchead and form an outline similar to that of a Grecian lyre. The organization is both vigorous and graceful, the head is moderately large, the neck slender, the tail of medium length, the feet somewhat long from the a Gazelle, skimming over the ground, seems to $\mathrm{fl}$.

cially in the northwestern parts, but is plentiful principally in the endless, desolate and desert-like plains, extending from the Orange river to the Ngani region. The majority of the Springboks probably populate the Kalahari and some strips of territory in German Southwestern Africa. They are found there ranging from groups of twos and fives up to herds from thirty to fifty in number, and sometimes exen one hundred and two hundred. They change their places of abode, disperse over their vast territory or aggregate in large herds, according to the amount of pursuit to which they are subjected, the abundance or scarcity of food, and the filling or drying up of water places. When the south African regions are visited by great droughts, as happens at variable intervals, the suffering Antelopes are obliged to desert their haunts, to evacuate vast regions and migrate to others. The wandering bands of animals are joined by other troops and herds; growing in to thousands they form hosts, and are followed by the various beasts of prey which feast on the weary and dead animals. Keeping closely or loosely together, the sprngboks push on in a direct course, destroying the scanty remains of vegetation and finally invading more favored localities like swarms of Locusts. In recent times these migrations, or "trekbolien," as they are called by the Boers, have 'ost much of their magnitude. and also occur mucl less frequently, not because the times of scarcity are no more, but evidently because the numbers of springboks have greatly decreased.

Gordon Cumming thus writes, speaking of a period about forty years ago: "Every traveler, "ho like myself has seen the large hosts which the Spring-

bolis form in their pilgrimages, and gives an accurate hut frequently undertake migrations when seasons of drought and scarcity make their accustomed range undesirable On these occasions they assemble in bands of thousa

soles to the ankles, the ears long and pointed, the eyes very large, lustrous and long-lashed, the tearpits small and obscure.

The only representative of this sub-genus is the Springbok (Antilope tuchore), a wonderfully beautiful Antelope, measuring five feet in length, the tail occupying eight inches of this total; the height at the shoulders is thirty-four inches. The color is a lustrous, dark cinnamon-brown; a stripe running from the roots of the horns across the eyes towards the nose, and another broad one extending along the flank from the fore-thighs to the hams, are nut-brown; all other parts are white. The horns are black, and measured in a straight line they may attain a length of from eleven to twelve inches in the case of the buck; measured along the curvature, they are from twelve to sixteen inclies long and show about twenty complete transverse rings, the tip being smooth.

The range of the Springbok is restricted to southern Africa. It is still found in Cape Colony, espeand true description of what he has seen, must fear that he will encounter disbelief, so wonderful is the sight of the migrating hordes. They have justly and pertinently been likened to the devastating swarms of Locusts with which the wanderer in this land of wonders is so familiar; like them they devour all verdure on their way in a few hours, and destroy in a single night the fruits of a farmer's years of toil.

"On the twenty-eighth of December I first had the pleasure of seeing a 'trek-boken.' In respect to animals, this was, I believe, the grandest spectacle I ever witnessed. For about two hours before the day dawned, I had been lying awake in my wagon, listening to the grunting of the bucks within two hundred yards of me. I imagined that some large herd of Springboks was feeding beside my camp. But upon rising when it was clear, I beheld the ground to the northward of my camp actually covered with a dense living mass of Springboks, marching slowly 
and steadily along, extending from an opening in a long range of hills on the west, through which they continued pouring like the flood of some great river, to a ridge about a mile to the east, over which they disappeared. I stood upon the fore-chest of my wason for nearly two lours, lost in wonder at the novel and beautiful seene. Immense and astonishing as was the herd of Springboks which I saw that morning, it was far surpassed by the one I saw the same night; for when we had erossed the range of hills, througl the opening of which the Springbols had poured, I saw the plain and even the slopes of the hills which extended all around, covered not with herds, but with one continuous mass of Springbolis. As far as eye could see, the country swarmed queer, perpendicular leaps, bounding into the air with folded legs, the long, snow white hair upon the back waving in the air and giving the animal a truly fairy-like appearance, which distinguishes this Antelope from all others. They sometimes leap higher than six feet, and elear from thirteen to sixteen feet at a bound, apparently without the slightest exertion. Before leaping, they bend their heads towards the fore-legs, then bound up, using all four feet, rise to the given height, their backs strongly eurved and the fold of skin expanded like a fan. For one monsent they literally seem to soar, then they come down on all four feet at once and again go up in the air.

springboks soon become tame when talien young. Those which I saw were shy and cautious towards

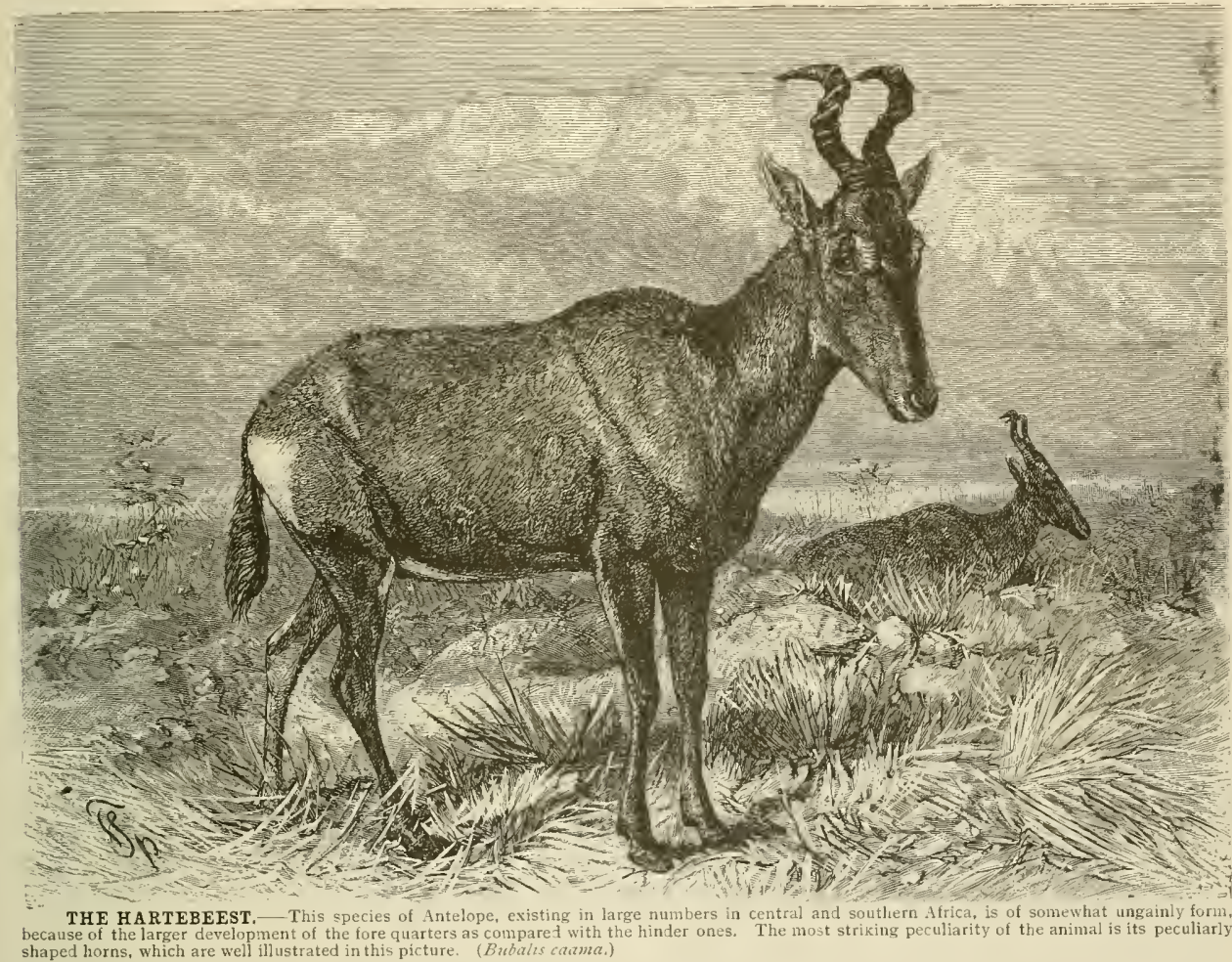

with them, until they merged into an indistinet confusion of living creatures." Le Vaillant also speaks about herds numbering from ten to fifty thousand, pursued by Lions, Leopards and Hyanas, and E. Kretschmar tells of masses, which he estimated to contain millions. The density of such a moving herd is sometimes simply wonderful. Harris tells us-that a herd of Sheep, which once happened to mingle with the wandering Springboks, were compelled to go along with them; even the powerful Lion, which diligently pursues these Antelopes, is said to be sometimes taken prisoner and compelled to move in their midst.

The Springbok's The Springbok is well entitled to Traits and Move- the name which the Dutch settlers ments. bestowed on it-namely, the Jumping Buck. When fleeing, it executes a series of strangers, but full of sport when in the presence of friends. If several are kept in the same enclosure, they do not always agree; the bucks especially are quarrelsome fellows that torment or at least mildly tease even their female mates. With the exception of this quarrelsome disposition, captive Springboks are charming animals. Their soft, magnificently colored fur, their elegant form and graceful movements fascinate everybody, even in the small space of an enclosure where they can not be justly appreciated. Unfortunatcly few living specimens arrive in foreign countries.

\section{THE OX-ANTELOPES.}

We will let the Gazelles be followed by the OxAntelopes (Bubalis), as they, in a certain sense, are transitional forms between the true Antelopes and 
the heavy bovine forms of the family. This group comprises larye, stout, almost clumsy Antelopes, with high withers and sloping backs, shipeless, elongated, broad-muzzled heads, short necks, stout limbs and doubly curved horns, placed on the frontal ridge and existing in both sexes.

The Hartebeest The south African Hartebeest of the of South Africa Boers, called Kama by the Bechuanas Described. (Bubalis caama), is distinguished from its relatives by its longer head and the stronger horns, bent in more acute angles, its proportionately smaller ears and its color. The horns are very stout at their roots, short, and marked by knotty excrescences about sixteen in number; from their bases they at first ascend parallel to each other, then they curve slightly forward, and in the last third of their length again turn outward and backward at nearly hours, standing in the shadow cast by tree trunks or the gigantic Ant-hills which are situated invariably in sunny spots, and thus the animal may long escape the detection of watchful eyes by its persistent repose and the choice of a background similar in color to itself." Notwithstanding the ungainly shape and the ugly, shapeless head, which give the Kama a striking and clumsy appearance as it strides along, it still produces a majestic impression, which is at its best when the animal falls into a gallop. Active, like any other Antelope, it often delights in queer leaps and antics and not infrequently indulges in strange pranks.

Hartebeests which are under human care from early youth become extremely tame; they follow their keeper about, take bread and tidbits out of his hand and signify their affection for him in various

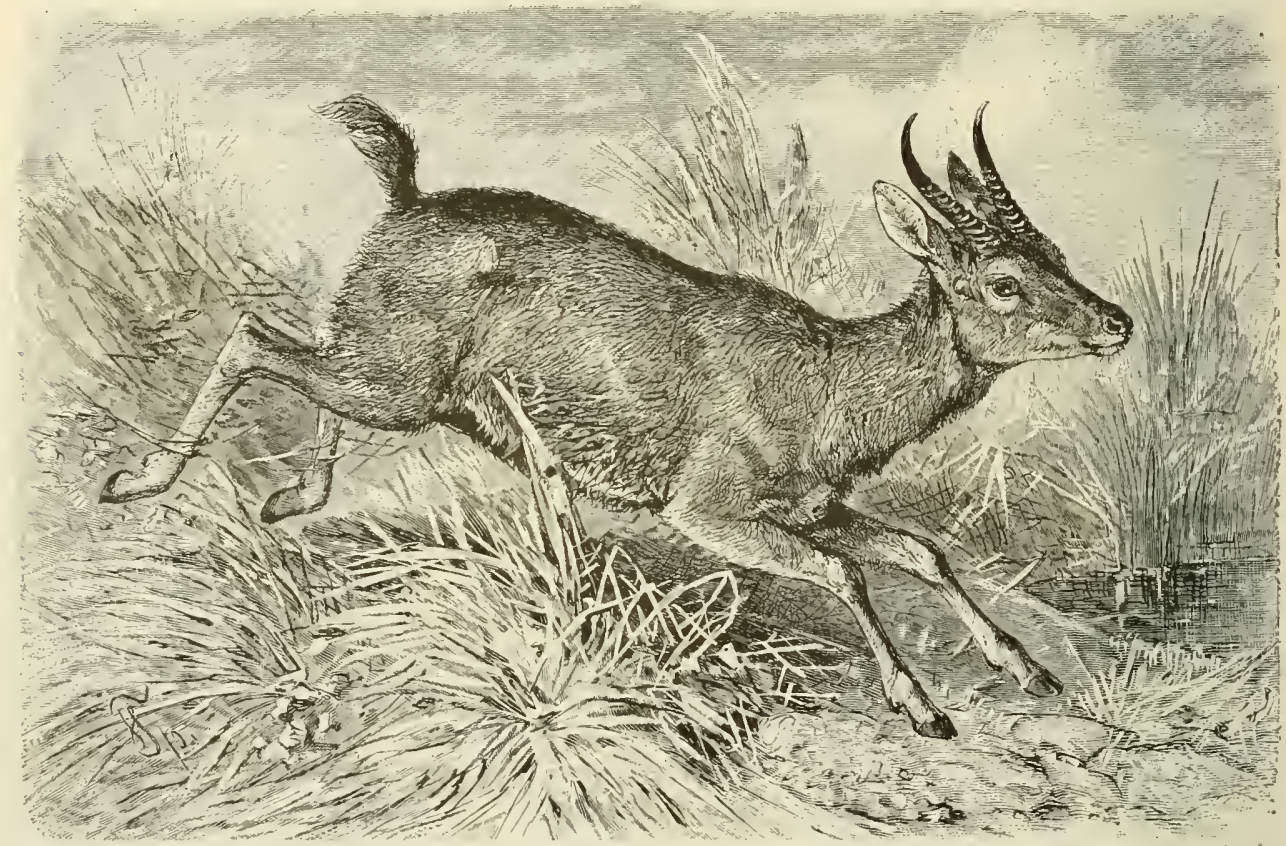

THE RIETBOK, OR REED ANTELOPE, - This African species of the intelope sub-family derives its name from its preference for reed-grown marshes, such as shown in the picture. It is of strong build, fleet of foot and has curved horns the tips of which point forward. (Reduncus eleotragus.)

right angles; the horns have very sharp points. The color of this Antelope is a beautiful, light cinnamonbrown. In former times the Hartebeest was frequent in northern Cape Colony, but incessant persecution has caused it to retreat across the Orange river. It is found in considerable numbers only to the north of settlements or beyond the localities frequented by hunters; and in the interior of the eastern half of Africa in suitable regions it is among the commonest of the Antelopes. Schweinfurth found it to be one of the most frequent inhabitants of the Bongo and Niam-Niam country. "Most frequently," says he, "one meets troops from five to ten in number in the uninhabited wildernesses of the frontiers. In cultivated countries the animal prefers the light forests of bushes in the neighborhood of river valleys, rarely, however, entering the open lowlands. It is in the habit of resting during the noon and manifold ways. Unfortunately, these beautiful relations between Man and beast do not last long; for as soon as they become conscious of their strength, the animals, especially the bucks, exhibit the innate pugnacity of their tribe and generally display a special animosity and the greatest viciousness against those to whom they have previously been most attached. Their flesh is esteemed, as it is among the most savory meats yielded by the Antelope family. The fur is made into rugs, the tanned hide into straps and harness, and the horns, on account of their hardness and lustre, into all kinds of vessels and ornaments.

\section{THE REED ANTELOPES.}

The Reed Antelopes (Redunca), like the preceding species, also resemble both the Gazelles and the Oxen in some respects. They have large or medium- 
sized forms, are of sturdy organization, and have a comparatively large tail. The male alone is possessed of horns, which are round, ringed at the base and curved forward at the tips.

The Riet-Bok Typ- The Rict-bok (Redunca cleotragus) is ical of the Reed the best known species of this geAntelopes.

nus. This beautiful animal attains a length of from four feet eight inches to five fect, inclusive of the tail; it is about thurty-eight inches high at the withers and thirty-two at the croup). On the whole the Rict-bok resembles the Roe-buck, but is of a more slender organization. The Riet-bok is a native of south Africa, as well as of the eastern parts of central Africa. It is found only beyond the great swamps of the upper Nile and lives in couples in the developed, and the animals have glands between the digits of their hoofs and are ormamented with a long tail-tuft.

The Water-buck's The Watcr-buck (Kobus cllifsiprymRange and mus) is a stately animal of nearly the Habits. same physical proportions as the larger species of Deer. Its total length is six feet eiglit inches, the length of the tail being twenty inches, and the height at the cromp four feet four inches. The prevailing color is gray. The horns attain a length of thirty-two inches, measured along the curvature, and usually show thick, triangular, transverse rings, except near their cxtremities.

A. Smith found the WVater-buck in south $\Lambda$ frica in small herds, numbering from eight to ten, their favo-

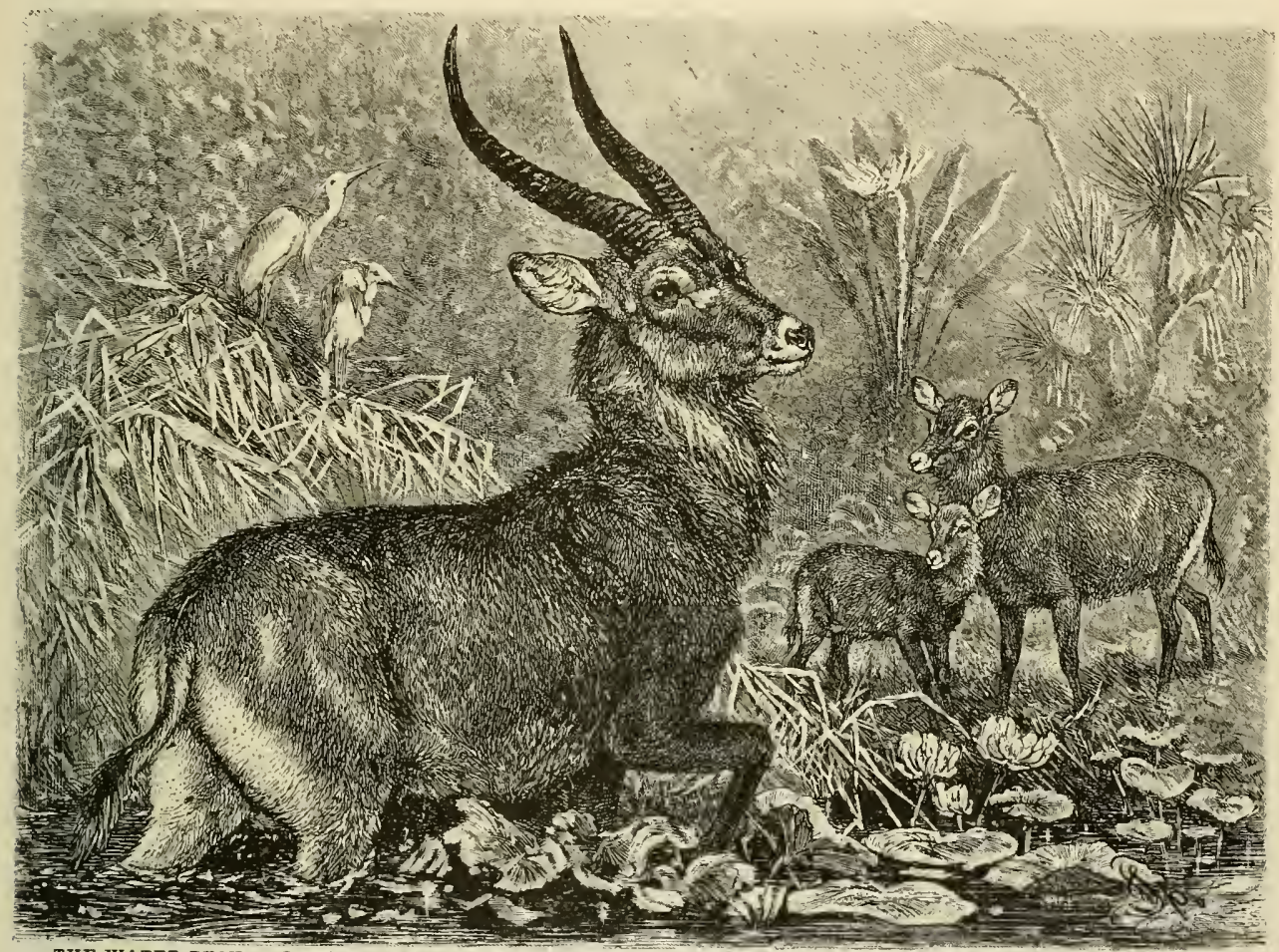

THE WATER BUCK. One of the best known of the African species of Antelopes is the Water-buck, which has been given its name from its habit of requenting rivers and its abilities as a swimmer. The large curved horns are borne only by the male. The picture appropriately shows these animals, thick brush-wood in the neighborhood of watercourses or bogs, as well as in the rush-banks and cane brakes and the high sedge grass along the margins of swampy, periodically inundating or temporarily flowing rivers. In consequence of its secluded mode of life one sees it much more rarely than its frequency would seem to warrant.

\section{THE WATER-BUCKS}

The Water-bucks (Kobus) are regarded as nearly allied to the Reed Antelope. They are large Antelopes of symmetrical shape, long-haired, and often having manes, the males being equipped with long, pointed, ringed horns, which bend backward and then forward in a soft curve, and lastly in an upward and outward direction. The muzzle is moderately

rite haunts being the banks of rivers. Von Heuglin, and later Schweinfurth, met it in the northeastern part of central Africa, and Pechuel-Loesche found it to be plentiful in some localities on the western Congo. Despite its almost clumsy appearing form the Water-buck produces a favorable impression on the spectator. Its eyes are lustrous and expressive, reflecting an independent, if not fierce spirit, and its movements are comparatively graceful. According to Heuglin's observations it is by no means a genuine habitual swamp-dweller, but delights in spots which are overgrown with reeds higher than a Man's head. Like the Black Antelope it is wont to ascend Ant-hills, and assuming a statuesque attitude, survey its swampy domicile from them. If the leader scents danger, it hurries off at a frenzied 
gailop, followed by the whole herd. The flight is always directed toward the water and the frightened beasts plunge into the waves with a splash.

The flesh of these beasts is said to be almost entirely uneatable, being tough, coarse-grained and pervaded with a disagreeable, rank odor, sufficiently strong to disgust even a hungry Caffre.

\section{THE ORYX ANTELOPES.}

The genus of Antelopes classed as Oryx includes animals which have been known from early ages. At least one species has been found frequently depicted on the Egyptian and Nubian monuments, in various positions: usually with a rope around its neck, betokening that the animal has been pursued, caught and subdued. In the chambers of the great pyramid of Cheops the same animal is portrayed, being sometimes represented witl only one horn. On this evidence some naturalists have based a belicf that the Oryx was the original of the fable of the Unicorn, whereas the truth is that only the Khinoceros can be meant by the name "Rem," which is translated "Unicorn" in our Bible.

The Passan The Passan, ealled "Gemsbok" by or Gemsbot of the Dutch and Kukama by the licchSouth Africa. uanas (Ory capensis) is generally regarded as the type of the genus. It is eight feet long, counting in the sixteen-inch tail, and its height is four feet from the ground to the top of the shoulders. The back, sides, flanks and nape of the neck are yellowish white, merging into a snowy white on the head, the ears, the under portion of the body, the upper parts of the thighs and the legs from the pastern joint downwards. There are black markings on the head, including a stripe on the forehead, a broad patch on the nose, a band extending from the horns across the eyes to the lower jaw, and another running parallel with it, and a black stripe bordering the external margins of the ears, which give the Gemsbok the appearance of IIearing a halter on its head, and there are other black patches and stripes on various parts of the body. The stately lorms, whicl are borne by both sexes, are bent very little, and oftentimes are perfectly straight. are ringed on the lower half, smooth on the upper portion and end in sharp points. So far as is known the Gemsbok is only found in southern Africa, but is represented in the northeast by a closely allied species.

The Beisa of The latter is the Beisa (Oryxy bcisar), Northeastern probably the genuinc Ory $\mathrm{x}$ deAfrica.

scribed by ancient writers. It is not inferior to the Passan in size, and like that animal has horns which are straight, or only slightly curved, and which are borne by both sexes and slightly exceed three feet in length. In markings and general coloring the Beisa resembles the Passan. It inhabits northeastern $\Lambda$ frica up to about the twentieth parallel of north latitude.

The Algazel or Wild The third species of this group, the cow of the Algazel, called by the Arabs the Arabs. Wild Cow, or the Cow of the Plains (Ory $x$ leucory $x$ ), is of a more clumsy build than its relatives, and bears horns of the same length as those of the heisa, runged, and gently curved in an outward and backward direction, the tips inclining downward. The ground color of the short, sleek outer coat is an almost pure yellowish white, lighter on the under surface of the body and the innes faces of the limbs, and deepening into a russet color on the neck. Six patches of a dull brown tint mark the head. Old bucks attain a length of six feet eight inches, or more, the height at the shoulders being four feet four inches.

The range of this intelope extends throughout the northeastern part of central Africa. It is frequently encountered in Sennaar and Kordofan, more rarely in central and western Soudan, but occurs in the north and in a few desert valley's of Nubia.

Characteristics The Oryx Antelopes are generally of the Oryx seen in pairs or in very small bands, Antelopes. the company frequently consisting of only a mother with her young. Their walk is light, their trotting uneven and hard, their gallop very heavy, but enduring and sieady; yet a wellmounted hunter can occasionally capture the Passan without firing a single shot, simply pursuing the animal until it is exhausted and ceases its flight. The l'assan of south Africa is apparently fond of the society of its kind, as one frequently sees it grazing in perfect harmony with other Antelopes. The Algazel, howerer, sometimes proves to be a highly intractable animal, as I have observed myself, and it often severely ill-treats other animals while in a fit of ill-humor. When Antelopes of this species are provoked, they are said to turn upon their assailant in a great rage and attack him in a most vicious manner. Liclitenstein relates how one of his companions found the slieletons of a Lcopard and an Ury lying beside each other in the Larroo country: The buck had killed its dangerous eneny by a thrust with its horns, but had succumbed to the injuries it had rceeived. Harris thinks it not improbable that a Lion may occasionally meet its doom in a similar war.

The pursuit of all Oryx Antelopes is usually undertaken on horseback: Gordon Cumming describes a hunt in a graphic manner and relates how he followed a wounded Passan a whole day, until the animal stopped from sheer exhaustion. No other Intelope is said to afford a more magnificent spectacle than a fleeing Oryx buck.

The wandering inhabitants of the African plains frequently catch some one of the species of Oryx of their native regions and bring it to town to dispose of it to some native aristocrat or to a European. From such a source I obtained several during my sojourn in Africa. I can not say anything in praise of my captives. They are lazy, uninteresting and quarrelsome. They easily bear confinement and readily recognize their keeper; but he can never trust them, as they sometimes, apparently in play, make use of their horns in a most dangerous manner. They can not be kept together with other animals, as they soon assert their mastery and atrociously ill-treat their companions. They also pick quarrels among themselves and viciously engage in combats with one another. They are very obstinate and can be transported only with the greatest clifficulty.

The skin and flesh of the Oryx Antelopes are utilized for food and leather. The straight horns of the Passan and the Beisa are often employed by native warriors as spear tips. The Europeans at the Cape often have the horns polished, decorated with silver knobs and use them as canes.

\section{THE ADDAX.}

The Addax Antelopes are most nearly allied to the Orys, as their horns, which are well developed in both sexes, form the sole distinctive feature. These mentbers are light, twisted either spirally or in a 


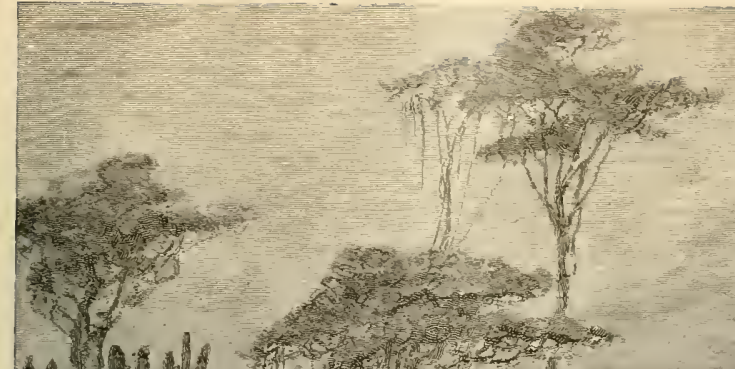

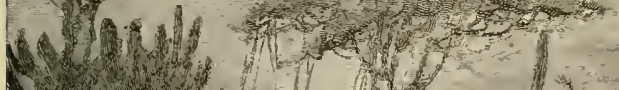
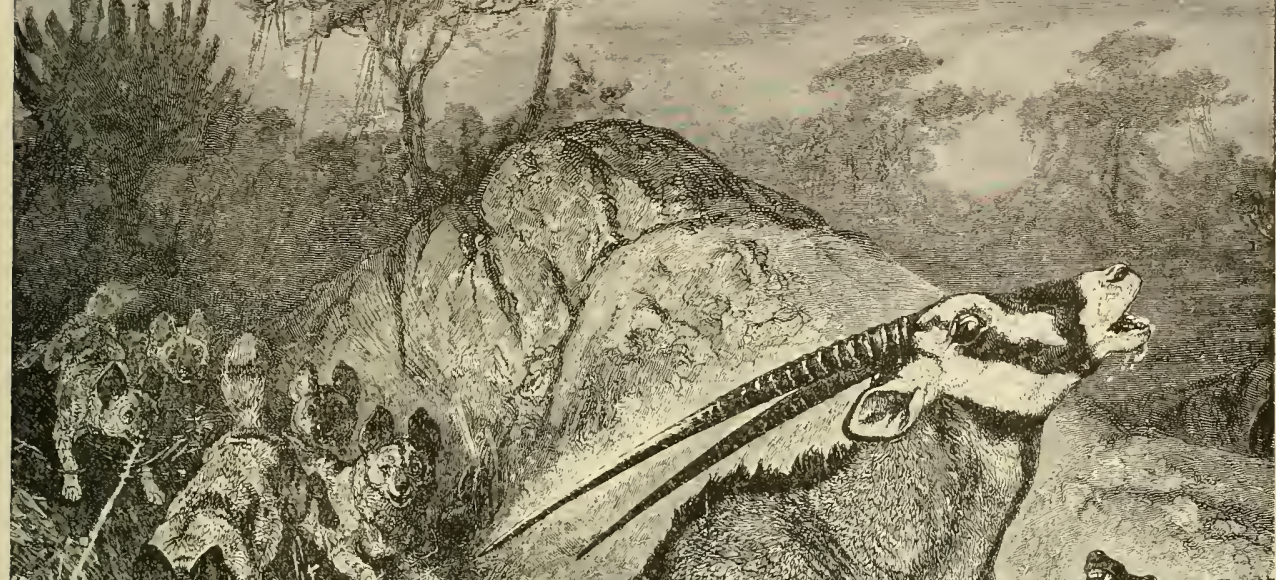

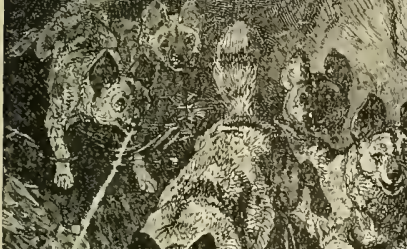

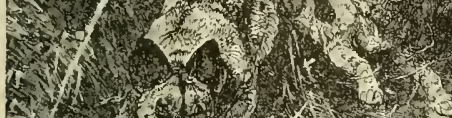

s.

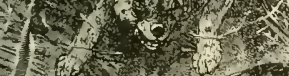

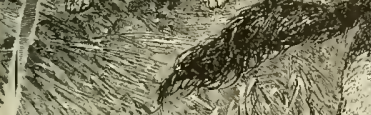

ation

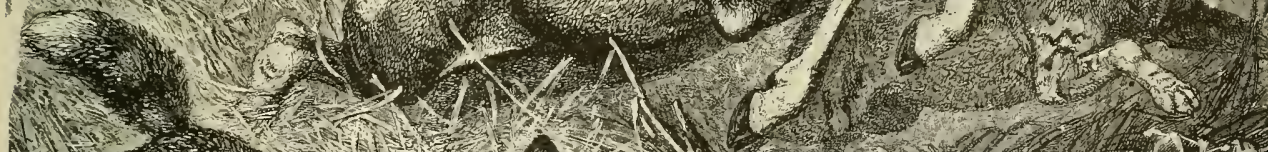

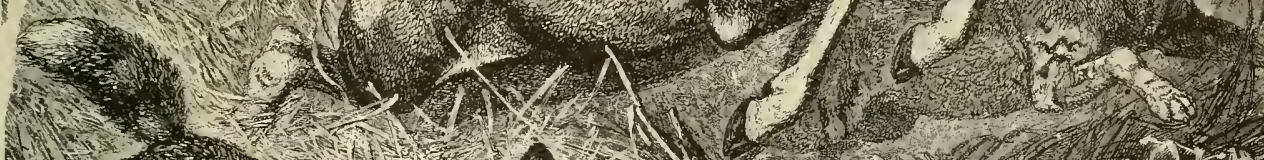

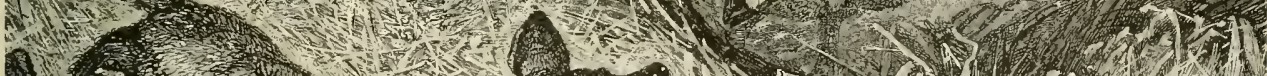

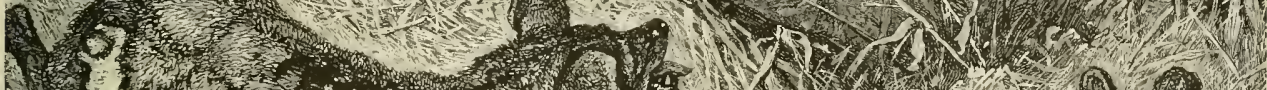


lyre shape, ringed along their whole length, slender and long. The Addax is repeatedly found depicted on Egyptian monuments. The horns which adorn the head of the sculptured images of the gods, of the priests and kings of ancient Egypt, are patterned after the horns of this Antelope. From Egypt the reputation of the animal spread and the Greeks and Romans were familiar with it.

The Addax (Addax nasomaculatus) is of rather clumsy physical proportions. The hairy coat is thickset and, with the exception of that covering a few places about the body, is short and coarse. In front of the base of the horns there is a tuft hanging over the forehead; a strip of rather long hair extends from the ear to the back of the head; the chiefs of the wandering tribes of Bedouins regard it as being one of the noblest animals that can be hunted, and pursue it partly for the sake of its flesh, partly to tcst the speed of their Horses and Greyhounds, and partly to capture the young, which they rear.

Living specimens have repeatedly been kept and observed in various zoological gardens. Their conduct shows how nearly allied they are to the Oryx; for they are just as capricious and quarrelsome as the latter. Exeeptions have been observed, however. If kept on plain food, these Antelopes bear long captivity casily and propagate themselves without any special difficulty, as the animals are by nature fitted to bear privations.

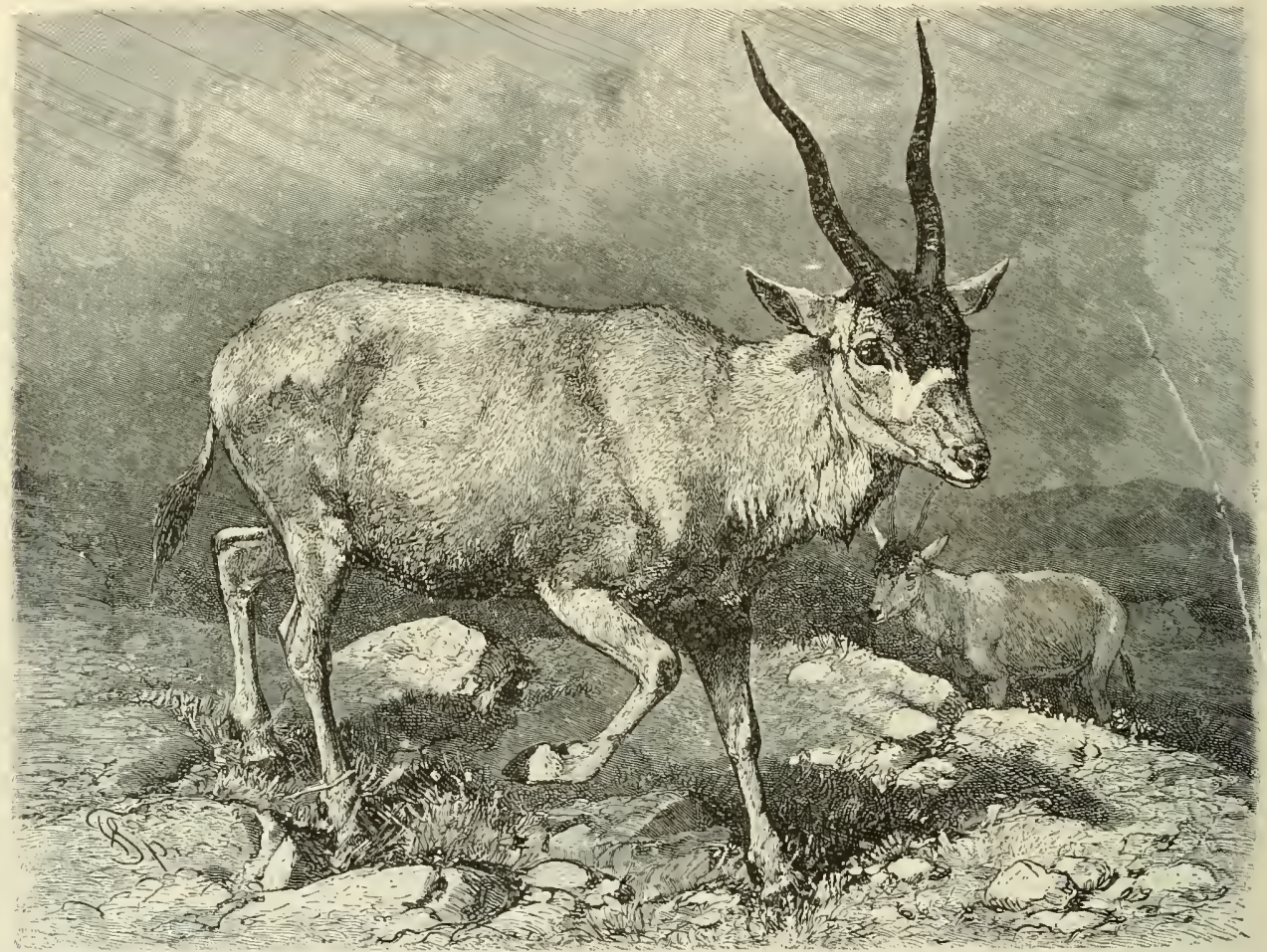

THE ADDAX. A heavy and rather ungainly specjes of Antelone is the dddax, which is an inhabitant of northern Alrica. Besides the peculiar twist of the horns this animal is specially marked by a tuft of long dark hair on the foreliead and a lighter one on the neck. (Addax $n$ asomaculatus.)

fore part of the neck is adorned by a long mane. During the cool season the yellowish white hue gradually merges into gray. Young animals are of a pure white color. The body measures six fect eight inches in length, and the height at the withers rather exeeeds forty inches.

The range of the $\Lambda$ ddax embraces the heart of northern Africa, lying south of the eighteenth parallel of north latitude, from the Nile country to the Lake Tchad region. It inhabits the most arid regions, in which, as the nomads say, not a drop of water can be found for miles around. If the stories of these people are to be believed, the animal can abstain from water for months. It is shy and timid, like the rest of the Antelopes, agile and hardy, but exposed to a great deal of persecution. The

\section{SPIRAL HORNED ANTELOPES.}

The Spiral IIorned Antelopes (Strepsiceros) comprise large Antelopes with spirally twisted, compressed and acutely-angled horns, borne only hy the males, and a fur relieved by stripes or otherwise marked in light colors.

The Koodoo a $\triangle$ representative of this group is the Large, Stately statcly Koodoo (Strepsiceros liudu).

Animal. an Antelope surpassing the European Stag in size. Adult males measure about ten feet in length, from the nose to the tip of the tail, the latter organ being about twenty inches long. The height at the withers is five fect eight inches, and the weight ranges from six hundred pounds upwarts. The doe is considerably smaller. In its bodily structure the Koodoo resembles the Stag in 


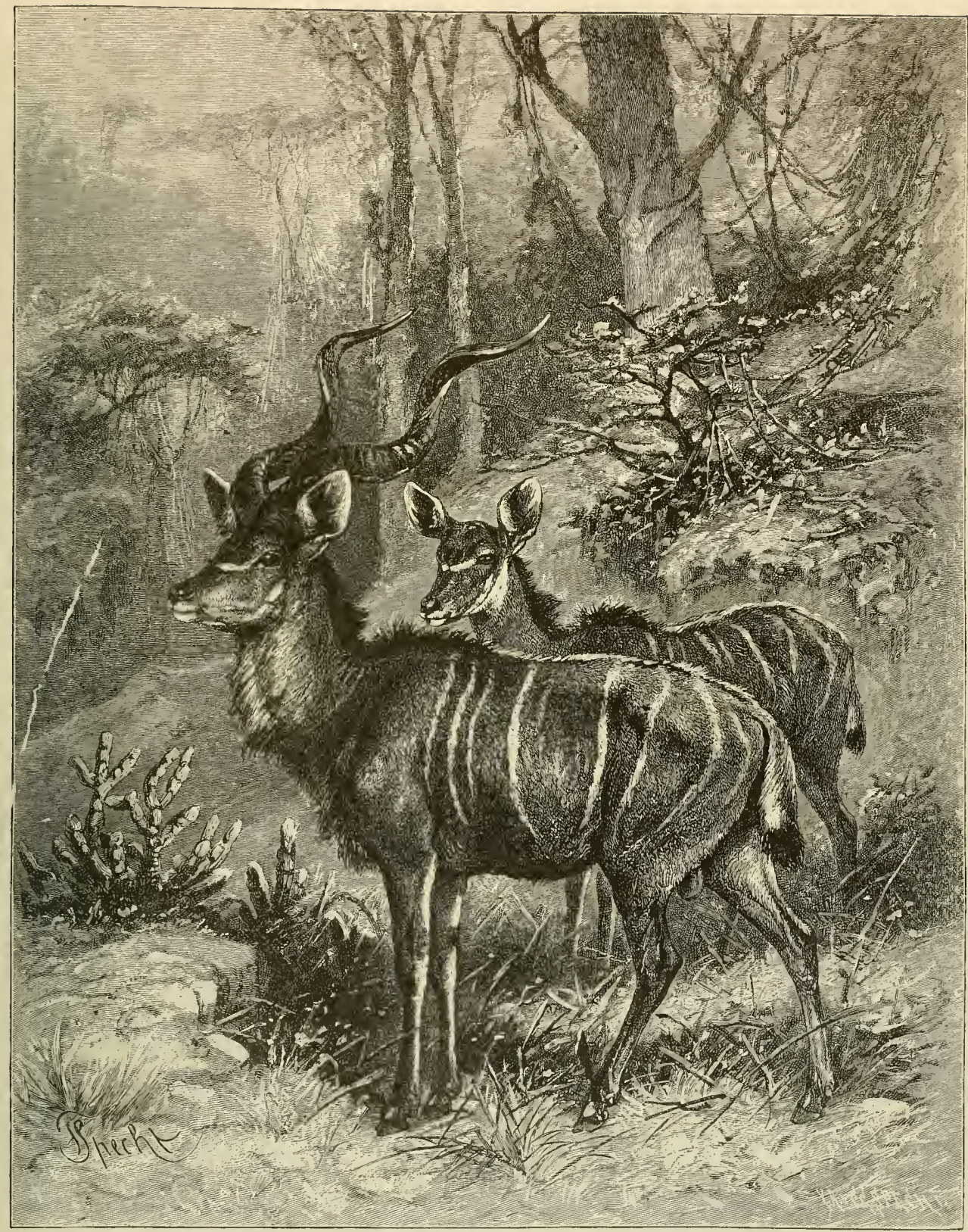

THE KOODO0.- This animal, belonging to the group of Spiral-Harned Intelopes, is large, symmetrical and prettily marked, the white stripus on ts sides being a specially prominent feature. The female resembles the male except that the latter bears on his head a magnificent pair of spiraliy twisted horns, over three feet in length. It ranges through all of eastern Africa, from the Nile to Cape Colony. (Strepsiccroskudu.) 
many respects. The ground color of its coat is a reddish brown-gray tint, difficult to deseribe, which merges into whitish gray on the hinder parts of the abdomen and the inner surfaces of the limbs. This color is relieved with white stripes, usually from seven to nine in number. The horns are a magnificent adornment of the buck, being eertainly the stateliest members of their kind found among the Antelope group. They attain a height, measured in a direct line, of from thirty-six to forty or even forty-two inches, their tips diverging to the extent of from twenty-eiglit to thirty-two inches. It is difficult to understand how the animal is able to carry the weight of such horns with the ease and majesty it displays in its bearing.

Range and Hunt. The Koodoo, called Agasen and ing of the Tigrish in Abyssinia, has a wide Koodoo. range, extending from Cape Colony, throughout the eastern half of Africa, to the Nile regions. It seems to be absent in the middle portions of the western half of Africa. that is, in the Congo region. The Koodoo probably chiefly inhabits rocky and mountainous regions, but it occurs also on the plain, at least in southern Africa it ranges over the plains overgrown with bushes and trees and is also at home among thorny bushes growing in jungle-like thickets, but cannot be consiclered a forest dweller in the common sense of the term. In the Bogos country we found it at an elevation as low as one thousand eight hundred feet above the sea, ascending to an altitude of six thousand feet, always among the precipices, along the brinks of which, among the green mimusas, it stalked in a majestic manner. Full-grown bucks live solitarily, but the does assemble in small bands of from four to six.

In all countries where the stately, beautifully marked Koodoo is found, it is subject to the most zealous pursuit. Its flesh is really excellent, as I have convinced myself personally, its taste being similar to that of the venison of the European Stag. The marrow of the bones is consickered a rare delicacy by many of the south African tribes. The Caffres, especially, have no more pressing business on hand, when they have killed a Koodoo, than to strip the flesh off the bones and break the larger bones, and suck the marrow out, raw as it is. The hide is also much valued in south Africa and is considered unsurpassable for some purposes. In Abyssinia the skin is tanned, and of the horns, after their internal cancellated structure has been removed by decay, are made receptacles for honey, salt, coffee and other articles.

\section{BOVINE ANTELOPES.}

The group of the Bovine Antelopes (Busclaphus) represents in a certain measure an intermediate link between the Antelopes and the Oxen. The anatomical proportions of all the species comprised in this group are cumbersome and clumsy; the body and neck are short and stout, the head large, the tail resembles that of a cow, the skin of the throat is elongated into a low, pendulous dewlap, the horns, which are characteristic of both sexes, are slightly curved backward from the line of the face, are triangular in shape and exhibit several spiral turns of the seam produced by the union at acute angles of the three sides.

The Eland a Fa- The Iiland (Buscluphus orcus) attains mous African a total length of nearly thirteen fect Antelope. four inches, twenty-eight inches of which are included in the tail. The height at the withers ranges between five feet and six feet four inches, and the weight is 1,000 , or, according to Harris, even 2,000 pounds. The color undergoes various modifications aecording to age and also the locality which the animal inhabits. Adult bucks are light brown or yellowish gray on their upper surface, with a surface tinge of rusty red; the flanks are whitish yellow, the under parts and the outer faces of the lower portions of the thighs are yellowish white, the head is light yellow-brown. Some individuals show bold and usually transverse stripes upon the body; with others the stripes are faint, and some have none at all. The largest horns which Selous measured attained a direct length of thirty and cne-half inches in the males, in which, by reason of use, they are generally worn or broken, and thirty-four and onehalf inches in the female.

Habitat and The Eland is distributed over a much Habits of the larger portion of Africa than was Eland. formerly believed. Prior to the investigations of Heuglin and Schweinfurth the animal was thought to inhabit only the south of the continent; at present we know that it occurs in all available parts of the southern half and the eastern half to a point far north of the equator. In the last century it was found in Cape Colony; at present it has retreated far into the interior. Its favorite pastures are the high grassy plains scantily overgrown with mimosas, from which it descends into the damp lowlands in times of drought. A strange fact concerning it is that it is also found in mountainous localities, and that on the roughest places, most difficult of access. Hans Meyer observed several troops on the high plain of the Kilimanjaro, at an altitude of I 4,000 feet, and saw the spoor of the stately animals at a height of upwards of 15,000 feet. Seen from a distance a herd of lilands resembles a herd of domestic Cattle to such an extent as to often mislead the observer. If they are pursucd, they proceed at a gallop, which does not seem to be very swift but in reality rapidly puts distance between them and their enemies. If pressed hard, they quicken their pace to a steady swinging gallop.

The Eland in Cap- The Eland Antelopes at one time tivity-Profita- were familiar features of European ble Game. zoological gardens, but are now becoming rare. Weinberg says that all specimens existing in them now are the descendants of two conples, introduced into England in 1840 and 1851 . London first furnished the gardens and parks of Great Britain with these animals and then the zoological gardens of the rest of Europe. The descendants of these animals show the docility and stupidity of domestic Cattle and readily propagate themselves. Once a choice young bull was killed and its flesh was served at the royal table at IVindsor, at the Tuileries of Paris, and also at a banquet of the Houses of Lords and Commons, and the correct proportion of fat and lean in the meat was thought to be particularly excellent.

The profit of a successful Eland hunt is considerable. The flesh is dried or salted; the fat, of which there is not infrequently a large quantity, is mixed with a little beef-suet and alum and made into good candles, while the uncommonly thick and tough hide is manufactured into excellent straps.

\section{THE NYLGHAU.}

In reccnt years an Indian Antelope, which travelers often mentioned under the name of Blue-bull, the Nylghau (Portax pictus) has frequently been taken 


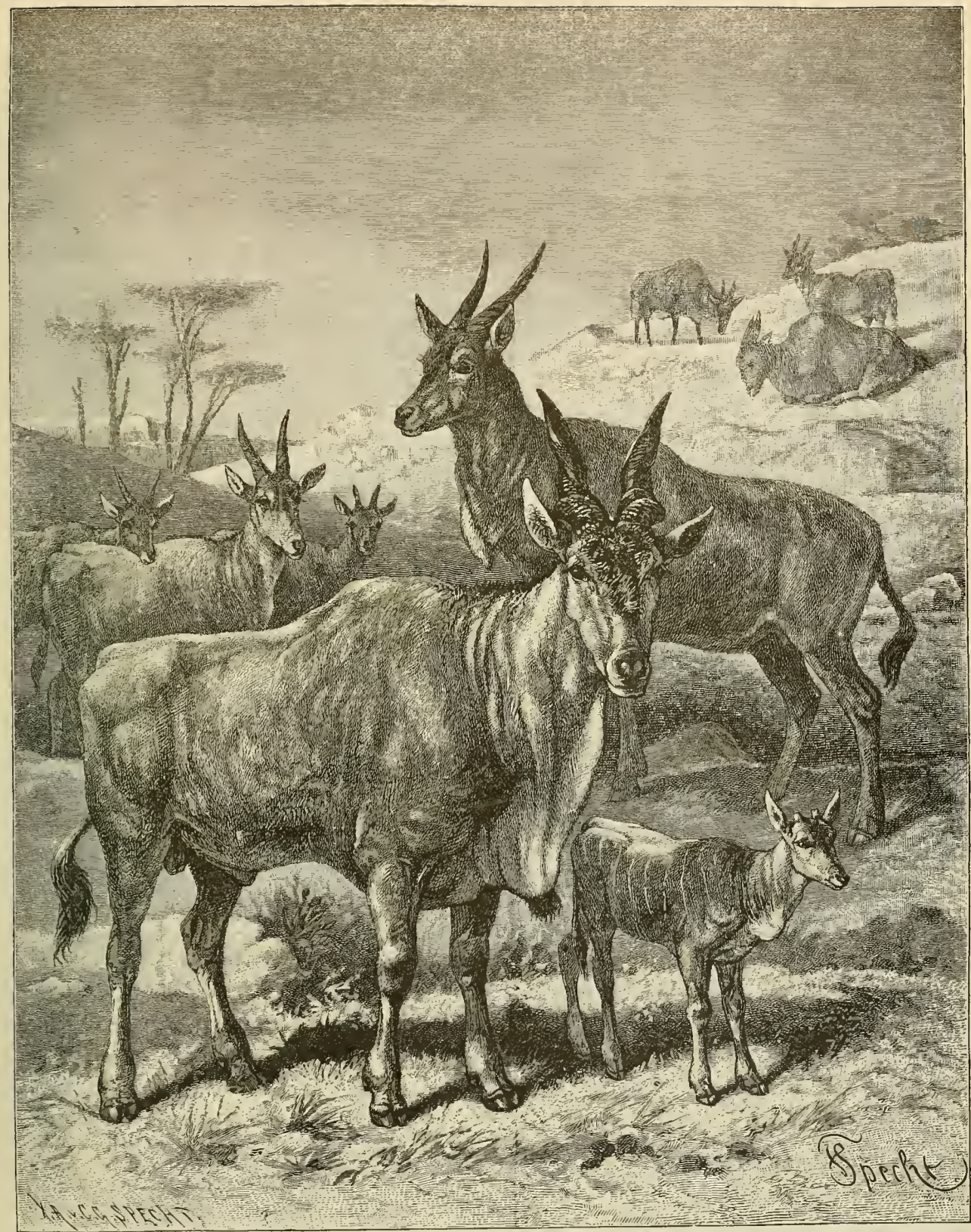

The Eland is a favorite game animal in a large portion of Africa, its flesh being the me Oxen, and resemble the latter in many particulars, notably in the dewlap hanging from their throats. Both sexes have horns. (Buselaphus oreas.) 
to Europe and the same animal anciently was sometimes kept in captivity in India itself. The Nylghau is one of the most noticeable species of the whole sub-family on account of its shape and color, and appears in a certain way to be intermediary between Deer and Ox. The horns, which adorn both sexes, are nearly erect, of conical shape, gently curving in the form of a crescent and from eight to ten inches in length; those of the female are nuch shorter or may be altogether absent. The prevailing color is a roan - a mixture of dark brown and ashy gray, with a faint bluish tint. The fore part of the under surface, the fore legs and the outer surface of the hind legs are blackish-gray, the hind legs black, the middle and hinder part of the under surface and the inner faces of the thighs are white. Two transverse stripes of the same hue run across the lower portions of the legs, surrounding the pastern joint like a ring; a large, crescent-shaped patch marks the throat. Old females are of a more fallow, often deer-like, gray-brown hue. Adult bucks attain a total length of from eight feet to eight feet eight inches, from eighteen to twenty inches of this being included in the tail; the height at the shoulders ranges between fifty-two and fifty-six inches. The animal is indigenous to India, ranging from the foot of the Himalayas to Maisur.

The Nylghau does not usually prefor mountainous regions, but sometimes inhabits them, provided they are overgrown with light woods and not very dense jungles. Occasionally it also enters the open, bushgrown country, if it is not entirely devoid of water, for, as Sterndale assures us, it drinks cvery day. Generally one sees these animals in herds of from six to twenty in number, but old bucks sometimes lead a solitary life. Nothing else is known of their life in the tree state, except that they graze less during the night than in the morning and evening hours and rest during the hottest part of the day.

The movements of the Nylghau are somewhat peculiar on account of the queer attitudes which the animal assumes. Its ordinary pace is similar to that of other Antelopes, but as soon as it becomes excited, it arches its back, draws in its neck and creeps slowly along, casting gloomy looks about through lialf closed eyes. The tail is then drawn in between the legs. In full flight the bearing of the Nylghau is stately and dignified and affords a handsome spectacle, especially if the animal lifts its tail erect in the air.

The hunt of the Nylghau is not a sport of which European sportsmen are passionately fond; the hunter usually approaches cautiously and shoots down the largest and nearest buck, or pursues it on horseback, for it is not very difficult to overtake, if it be pursued hotly from the very beginning and made to exhaust itself more rapidly. The subjects of Indian princes have from remote times taken great pleasure in presenting this species of Antelope to their lords and masters; it therefore may yet be seen in parks owned by aristocrats. In 1767 only the first pair were taken to England, and at the close of the century others came to France, Holland and Germany. At present the Nylghau is seen in nearly all European and American zoological gardens, where it propagates seasonably and regularly.

\section{FOUR-HORNED ANTELOPE.}

Before we leave India to return to Africa, the country most abounding in Antelopes, we will call to mind one of the most remarkable species of the whole family, nay, of all Ruminants, the Four-horned Antelope (Tetraccros quadricomis). Among the domesticated Ruminants we may sometimes find individuals possessed of four or even eight horns; but they are never at the foundation of a distinct species, but rather to be regarded as singular exceptions or freaks of nature. No other wild animal shows a growth of horns similar to that of this Antelope. Thus it stands completely isolated, at least so far as our present experience extends.

The Four-horned Antelope is a small, dainty animal. Its length amounts to from twenty-eight to thirty-two inches, the tail measuring nearly five inches of this total. The height at the withers varies between twenty-four and twenty-six inches. The female is hornless. Of the horns of the buck the fore pair are set on above the inner corners of the eyes, and incline slightly backward; the hinder pair are placed above the outer corners of the eyes, slightly curved forward and are ringed at the base and smooth at the tip. The hinder pair may be from four to five inches long, the fore pair rather more than an inch or an inch and a half in length. The animal is apparently found throughout all India, being quite frequent in places where wooded or bush-grown hills afford it a compatible abode, and it lives either singly or in pairs.

\section{THE BUSH-BUCKS.}

Under the name of Bush-bucks (Ceplatoloplus) we comprise several small species, with short horns which are straight or slightly curved forward, and are usually borne only by the males, but sometimes are also developed in the female. There is a furrow between eye and nose, and a long tuft of hair between the horns, which may be crected at will.

The Duyker The Duyker or Diver (Ccplarlolophlus
or Diver An- mergins) is one of the largest species
telope. forty-four inches, of which about eight inches are included in the tail; the height at the shoulders is twenty-two inches. Its straight, awl-shaped horns show from four to six not very prominent rings and attain an averasse length of frum three to four and in some rare cases five inches; they nearly disappear among the hair of the tuft when that appendage is erected by the animal. The color is very variable, but generally is a grayish olive tint on the upper surface, or dark yellow-brown in case of the male, fading into white on the under surface. The animal mainly inhabits south Africa, where it is still common in forests of trees of second growth or of small underbrush.

The Duyker is one of the first Antelopes a newcomer meets in Cape Colony, as it inhabits the thickets of bushes along the sea-coast in probably greater numbers than are to be found in the wooded inland country. Like all smaller or dwarf-like Antelopes, one meets it either singly or in pairs. It is never seen outside of the bushes in which it habitually conceals itself.

"At the approach of a Man or some other enemy," says Drayson, "it will lie still, watching him attentively, until it is sure that it is discovered. It will then jump up and start off, making a series of sharp turns and plunges resembling the motions of a diver. sometimes over bushes and at others through them. It crouches and crawls in the long grass or between the bushes, so softly as to make the pursucr think it has disappeared or lain down. But the latter supposition is never correct, for the Duyker simply pro- 
ceeds under cover of the foliage, until it has gained a start: then it again bounds away. The cleverest hunter and the best Dog are often baffled by the Duyker; if the course of the buck can be traced and the place in which it lies down, after its erratic nat neuvering, discerned, it can easily be approached from the leeward side. The irregular course which it pursues necessitates great accuracy and quickness of aim in shooting it, however. The Duyker is not very swift; an old l'ointer, which served me as a Dog of all work, frequently caught and held a Duyker until I came up and despatched it. The skin of

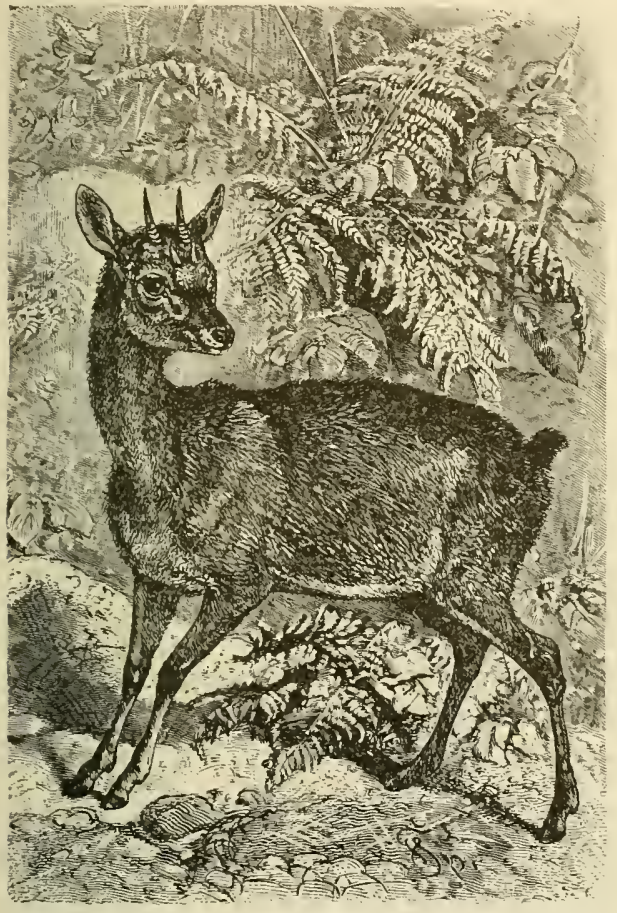

THE FOUR-HORNED ANTELOPE,-One of the most peculiar of he Antelopes is the Four-horned species shown in the picture. The animals are found in India. The most characteristic feature of this Antelope is the small, extra pair of horns in front of the main pair borne by every male. (Tetraceros quadricornis.)

the Duyker is used for the thongs of long wagon whips; the flesh is highly esteemed for making good soup. As a general rule the venison of South African Antelopes and Deer is very inferior, being dry and tasteless, but to the epicurean sportsman I can recommend the liver of all the small Antelopes as a great delicacy. The Dutch grease and baste the flesh of the Duyker with fat taken from the Eland or the Hippopotamus and greatly improve the flavor of the venison."

\section{DWARF ANTELOPES.}

The smallest species of the family are ranged under the title of Dwarf Antelopes (Neotragus). They are exceedingly elegant little animals, exhibiting great similarity among themselves, and only the males bear horns, those members being very small thin and erect. The roundish head and the pointed nose, with its small muzzle, are further distinctive features. All known species strongly resemble each other in their habits and demeanor, so that it will suffice if I draw a pen picture of one observed by myself and comnet what is known of other species with this description.

The Greyhound The Greyhound Antelope (NeotraAntelope of gus hempricliii), called Beni Israel

East Africa. by the inhabitants of Massowal, is one of the daintiest of Ruminants. The buck has a pair of small horns with from ten to twelve rings extending half around on the lower half of the outer side and with tips which curve forward; these horns are nearly covered by the strongly developed hair-tuft and entirely overshadowed by the very long ears. The body is sturdy, the tail a shorthaired stump; the legs are of moderate length, but extremely weak; the hoofs are long, narrow and pointed, the rudimentary toes barcly perceptible. The hair is very fine and rather long. The color appears reddish-gray or bluish-gray. On the back the hue warms into reddish-brown; the thighs of the fore-legs are often mottled, the under parts and inner surfaces of the legs white. A broad band above and below the cyes is white; the ears are edged with a blackish tint; the horns and hoofs are black.

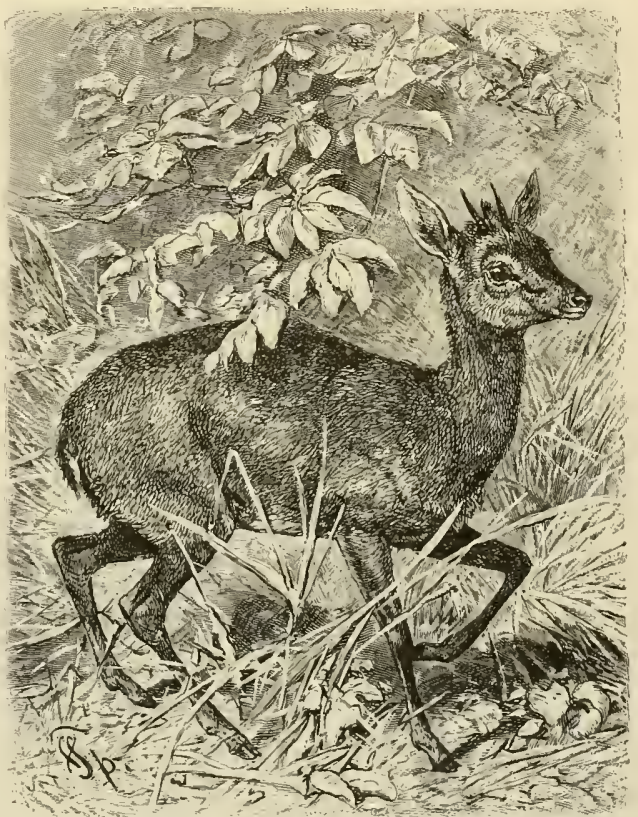

THE BUSH.BUCK. This Antelope, which is also called the Duyker or Diver, is especially numerous in the southern part of Africa. Although not large it is a very agile animal, and on its head it bears in addition to its short horns a tuft of hair which it can erect at will. (Cephaddition to its short

In Abyssinia one can hardly miss the Beni Israel, in suitable places, beginning from the sea-coast to an elevation of six thousand feet. Nearly all Dwarf Antelopes are inhabitants of the forests of underbrush so abundant in Africa. Thickets which would be impenetrable for other larger Antelopes provide these Lilliputians with magnificent residences. They find a path among the densest of tangles and an exit 
between the sharpest of thorns. The Beni Israel decidedly prefers the valley to the heights. It delights most in the green woods bordering the course of those streams flowing only during the rainy season. There it revels in a profusion of hiding-places, for in these localities, mimosas, thorns, cypress, spurge bushes and other larger plants are interwoven and intertwined by a genuine network of creepers; and there it finds grateful retreats in bushes entirely closed from the outside, while the inside is liabitable and completely hidden from view, or else there are narrow thickets which are connected on long stretches. Farther away from the vivifying watercourse, the shrubs become fewer in number and green, succulent grass can grow unhindered. There one is sure to meet the little Antelope. Like the majority of its relations, about which we have acquired any information, it lives invariably in pairs, never in larger companies unless there has been an addition to the family, and the offspring still requires motherly care. In such instances the young one trots along behind the parents.

Method of Hunting At first the hunter experiences some the Greyhound difficulty in discovering the little Antelope. creature; but when he has become familiar with its habits and haunts he knows how to find it, for he needs but to proceed logically. The tints of the animal's fur, which correspond almost exactly with those of the surroundings and really appear to merge into them, contribute materially to hide these dwarfs.

Reproduction and Very meagre accounts have so far Capture of Grey. reached us as to the reproduction of hound Antelopes. the Dwarf Antelopes. Ehrenberg mentions the month of May as the usual time when the little ones are born; but I have seen kids following couples in March and more frequently in April.

The Caffres put into the way of the dwarf bucks nooses which, when the animal steps into them, are drawn tight and hold fast one of the legs of the Antelope; or, if the natives only wish to obtain the venison of the animals they put out snares, which catch them by the throat and strangle them. The venison of this animal is rather hard and tough, but still is a somewhat palatable dish. It may be nore suitable to make soup than to serve as a roast. Keeping Drayson's advice in mind, I have mainly confined my gastronomic experiments to the liver of the Dwarf Antelope and agree with that observer that it is truly a delicacy.

Dwarf Antelopes Outside of its native country, the Easily Tamed- Dwarf Antelope soon succumbs to

Their Foes. the influences of a foreign climate and it is therefore very difficult to bring it to Europe. At the Cape and in other parts of Africa, however, it has been kicpt for a long time in houses or in yards. It is said that specinens which are taken young soon bccome warmly attached to their keeper, follow his call, suffer themselves to be fondled, petted and to be carried about and generally resign themselves to human domination without offering any resistance; therefore their exceeding good-nature, gentleness and amiable temper are greatly praised.

Next to Man the most deadly enemy of the Dwarf Antelopes is probably the Leopard. Smaller Felidæe may also prey on the unresisting dwarf and most probably the Eagle occasionally snatches away a kid. Jackals, Foxes and other members of the band of marauders also figure ainong the enemies of the Beni Israel and its relations.

\section{THE MOUNTAIN ANTELOPES.}

All the Mountain Antelopes are to be distinguished from the others of their family by their stout, bulky, short bodies. They are comparatively thick and pudgy in body and short of leg, and they are digitigrade animals, that is, their hoofs are so formed that the entire weight of the animals rests on the tips. A more or less dense and wiry fur is no less a characteristic feature of the inhabitants of the cooler heights. Such a bodily structure is common to all; but there are differences in regard to the horns, sometimes both sexes being endowed with them, sometimes only the males.

Physical Formation The Goral of India, an animal beand Habits of longing to the genus Nemorhoedus, the Goral. is possessed of a remarkable faculty for climbing. Both sexes bear horns, resembling thopse of Goats. So far few species of that genus are known, and that but imperfectly.

The Goral (Ncmorticedus goral) has about the same proportions as a Goat. Its range is restricted to the Himalayas, and that to a belt between three thousand and seven thousand eight hundred feet of altitude. Kinloch says that it is gregarious, sometimes living in great herds, but generally widely dispersed in small troops or even singly and in pairs. It dwells in forests as well as among barren crags and stony walls, apparently preferrmg steep cliffs thinly overgrown with bushes and small trees. The inhabitants of Nepal believe it to be the speedicst of all creatures. No living Goral has as yet been taken to Europe or America and even the skins of these animals are classified among the rarities in a museum.

These Oriental Antelopes are followed in the category by the European Chamois, the graceful, much pursued child of German mountains. It is held to be the representatives of a distinct genus (Capella), the main distinctive features of which are erect horns, with tips curved backward like hooks.

Physical Peoul- The Chamois (Capella nipicapra), the

iarities of the only species of the genus, averages

chamois. a length of forty-four inches, about three inches of which are included in the tail; the height at the withers is thirty inches, at the croup thirty-two, and the weight ranges between eighty and ninety pounds. The horns are about ten inches long, measured along the curvature, and are not only farther apart in the buck than they are in the doe, but also stouter and more decidedly hooked. In all other respects Chamois of the two sexes resemble each other, though the bucks are as a rule larger than the does. The fur undergoes modifications according to the season. In summer the prevailing color, a dingy reddish brown, or rusty red, fades into a light reddish yellow hue on the lower surface; a black brown stripe runs along the course of the spine; the throat is of a yellowish, fallow tint and the nape of the neck yellowish white. This hue deepens on the shoulders, thighs, breast and flanks: a stripe on the buttocks shows a tint of yellow which fades almost into white. A narrow blackish longitudinal band runs from the ears across the eyes, standing out in bold relief on the fallow ground color. In winter the Chamois is of a dark brown or lustrous brown-black'hue above and white below; the legs are lighter in the lower than in the upper portions and their color warms into a faint red; the feet are yellowish white, like the head, which somewhat darkens on top and on the muzzle. Both summer and winter coat change so gradually that they are in their entirety worn but a very short 


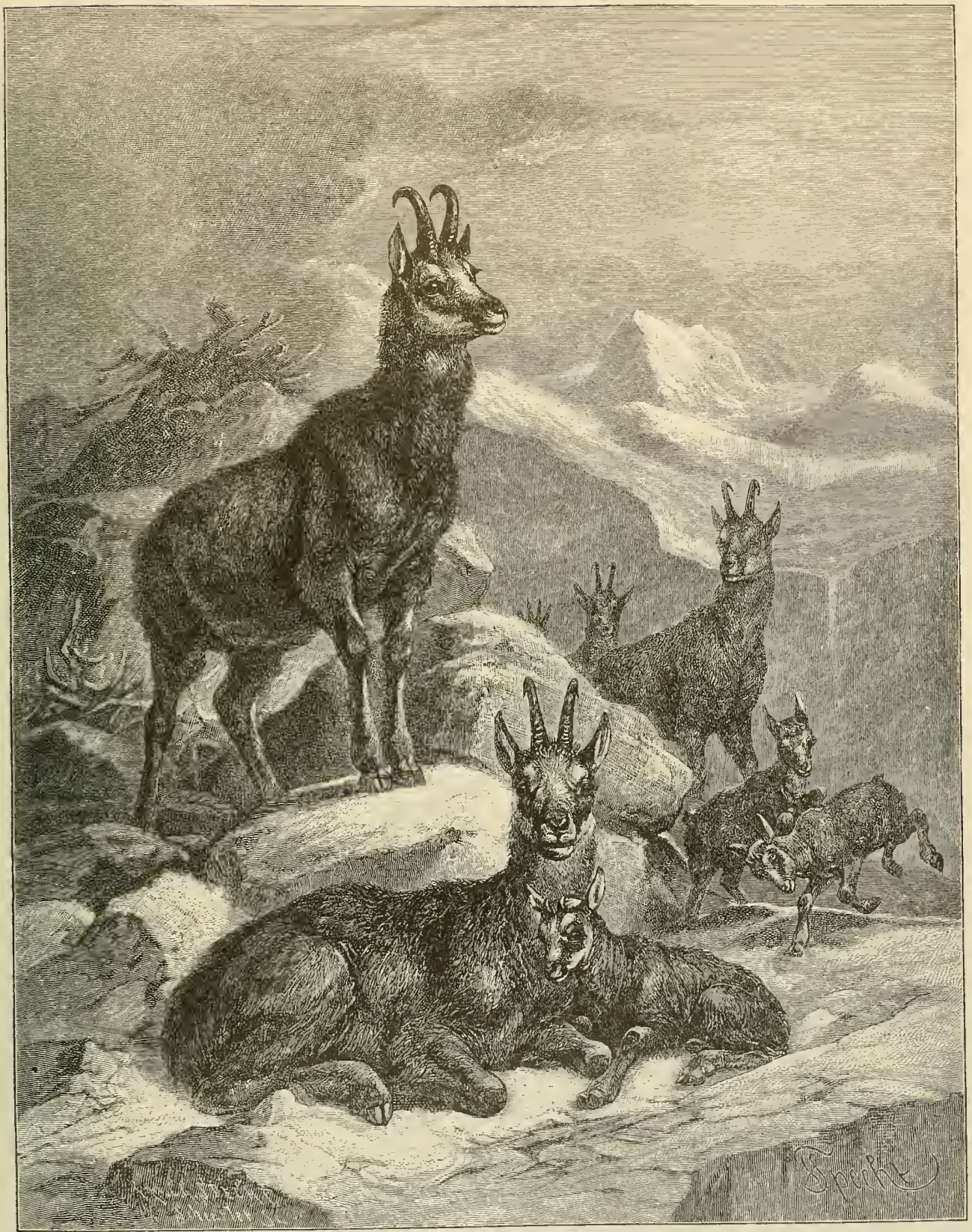

THE fame the line of perpetual snow. The picture shows a family of these animals amid characteristic surroundings. (Capellat nupicapra.) 
time. loung animals are reddish brown and lighter around the eyes. Light varieties or white individuals are seldom seen.

Range and The Alps may be termed the true Habits of the home of the Chamois. Its range Chamois. really extends much farther, as the Chamois is also found in the Abruzzi, the Pyrenees, the mountains of the Cantabrian coast, of Dalmatia and Greece, on the Carpathian mountains, especially on the peaks of the high Tatra, the Transylvanian Alps, and lastly on the Caucasus, in Taurida and Georgia. In the Swiss Alps it is at present of comparatively rare occurrence, being much less numerous there than in the eastern Alps, where it exists in considerable numbers espccially in upper Bavaria, Salzburg and the Salzkammergut, Strria and Carinthia, cared for and protected by wealthy and judicious land-owners or people who rent the hunting privileges. The steep, inaccessible heights of the middle Carpathian mountains also harbor it in numbers satisfactory to sportsmen, though it is not protected there.

The current belief that the Chamois is an Alpine animal in the narrowest sense of the term, that is, that it roams invariably above the forest belt, in the immediate neighborhood of the glaciers, is an erroncous one; for it unreservedly belongs to the family of the forest Antelopes. Wherever it is protected, it shows a decided preference for the upper forest belt. In summer it does ascend in greater or smaller numbers to the higher belts of the mountain, and remains for weeks and months in proximity to the snow and glaciers, selecting the highest meadows and treeless crags as its temporary abode; but the majority of the Chamois of a district are found in summer, as well as winter, in the upper forest belt.

The Chamois is wont to rest at night. At dawn it rises and begins to feed, as a rule descending the mountain slowly. The latter part of the forenoon it spends in ruminating in the shade of a projecting rock or under the branches of an old fir tree, usually lying, confortably stretched out, on its folded legs. At about noon it begins to slowly ascend the mountain, feeding as it goes, and in the afternoon again rests for a few hours under trees, on projecting, smooth ledges of rock, or snow, or some similar spot selected at random. It feeds again towards evening and retires at the approach of dusk. It is said to occasionally vary this history of its day by feeding during moonlit summer nights.

Being in high degree gregarious, the Chamois associate in flocks, which often consist of great numbers. These societies are formed by the does, their kids and the young bucks, up to their second or at most their third year. The old bucks, except at certain seasons, live solitary, or they join one, two or three others of their own sex. It seems, however, that these animals never associate closely for any long time. Of the larger flocks an old, experienced doe assumes the leaderslip and usually, but not invariably, guides the actions of the flock, which, however, does not rely entirely on her vigilance.

The Chamois' In regard to its movements the Movements on the Chamois vies with the other mountMountains. ain-climbing members of its family already known to us. It is a skillful climber, a surefooted jumper and a bold and indefatigable ascender of mountains, moving rapidly and nimbly about on the most dangerous places to which no Goat dares attempt to climb. When it proceeds slowly its gait is lumbering and clumsy and its bearing ungainly; but as soon as its fear is aroused and it takes to fight, the animal changes completely. It then impresses one as far livelier, bolder, nobler and stronger, as it bounds away, every one of its movements characterized by vigor and grace. Some definite observations have been made about its extraordinary leaping powers: Von Wolten measured the leap of one Chamois and found it to have covered a distance rather exceeding twenty-three feet. The same observer saw a tame Chamois jump up a wall thirteen feet high, and leap down on the other side, alighting on the back of a servant girl who was cutting grass. The Chamois can gain a foothold on the smallest projection, and in scaling an eminence, it looks more like a bird in flight than an animal climbing. It takes a run and generally ascends obliquely. It goes uphill more easily than downhill, and sets its mobile and sensitive forefeet on the ground with extreme caution, lest it should loosen some of the stones over which it passes. Even when severely wounded it rushes up the most dangerous paths; nay, even when deprived of a leg, it exhibits scarcely less agility than when it is sound.

The Chamois proceeds with the utmost caution when crossing snow-covered glaciers, and carefully aroids all snow filled crevices even though it can not distinguish them by its sight. It also shirts the edges of an abyss very carefully and slowly. Some members of the flock concentrate their attention on the path, while the others incessantly look out for any other danger. "We have seen," says Tschudi, "how a flock of Chamois crossed a dangerous and very steep ledge of rock, which was covered with loose, rolling stones, and it was a pleasure to observe their patience and sagacity. One of them took the lead and walked gently upwards, while the others waited their turn, until it had reached the height, and only when all the loosened stones had ceased rolling, the second followed, then the third and so on. Those which had arrived at their destination showed not the slightest inclination to disperse on the pasturage, but stood watching on the edge of the chasm until the last companion had joined them in safety." An untsual sense of locality stands the Chamois in good stead on its bold wanderings. It never forgets a road it has once traveled and one might say it knows every stone in its domain; this is just why it is so thoroughly at home on the high mountain and seems awkward when it leaves it.

The Perceptive The senses of the Chamois are un-

Senses of the equal in acuteness, but not weaker Chamois. than those of its relatives. Those of smell and hearing seem to be developed best, while that of sight is less keen. The delicacy of the first is manifested not only by their commonly demonstrated keen scent, but also by their surprisingly good powers of trailing which enable them to take up the track of each other and unerringly follow it. He who wishes to observe Chamois or to approach them, must pay careful attention to the direction of the wind and approach them from the leeward, as the shy animals will certainly otherwise escape. At what distance their scnse of scent is efficient, cannot be determined definitely, but it may be confidently asserted that it considerably exceeds the range of a rifle-shot. At any rate the sense of smell is the one which apprises a Chamois first and most unmistakably of an approaching danger and consequently incites it to flight. Their sense of hearing deceives them much oftener, though it is very delicate. They usually pay very little attention to the noise of falling 
stones; for they are accustomed to it in the mountains. Even the report of a gun does not always excite their attention; but when once Chamois recognize the sound and know what it portends, they hurriedly scamper off. In many cases, how'crer, the report perplexes them and the sportsman has an opportunity of sending another shot at them. This may be partly explained by the fact that even a Man often finds it very difficult, on account of the echoes in mountain regions, to judge from what direction a shot was fired or whether the noise was produced by the report of a gun or only by concussion of a rolling stone dashing against a boulder. The sense of sight of the Chamois is undoubtedly efficient at long distances, but does not enable them to distinguish enemies who remain quictly under cover Like most other animals they do not seem to recognize an enemy in a quiet human being, and see in him an object of fear only when he moves.

The Chamois a Towards the middle of November, Courageous, Pugna- the strong bucks join the flocks and cious Animal. remain with them for two or three weeks. Taciturn and silent as they are during the remainder of the year, they then exercise their voices, emitting a dull, hollow bellow or grunt, hard to be described. At the appearing of the old males the young bucks disperse in alarm; old warriors, however, that encounter each other in a flock, always refuse to retreat, and at once enter into combat, a strong buck never tolerating the presence of another one in his flock, even if the latter consists of thirty or forty females. The little Chamois appear during the last days of May or at the beginning of June. Old does sometimes have two, or even three, young at a birth; young does only one.

Infancy and Train- The young kids are lovely little ing of Cham- creatures with a thick woolly coat ois Kids. of a pale fallow red hue; they follow their mothers everywhere and in a very few days display the same agility as is possessed by older animals. The does treat them with the greatest maternal tenderness for at least six months, exercising great rigilance in their behalf and teaching them all that is necessary to enable them to fill their mission in life. The mother guides her offspring with a bleat, bearing a slight resemblance to that of a Goat; she teaches them to climb and jump, and sometimes executes some leap for that purpose a great many times, until they can accomplish it themselves. The kids are sincerely attached to their mother and do not, while they are young, desert her even in death. Their growth is very rapid, for, as Kobell, who is well versed in these matters, says, they are the only aninals which suffer comparatively little from the severe weather of winter. They still find some food on the steep rocky precipices from which the silow is usually blown away, or under the shelter of rocks and trees, which lieep it away to some extent, while Deer are driven into the. valleys and, if not fed by man artificially, frequently succumb.

Food of the Cham-In summer the Chamois feeds on the ois in Summer best and most succulent of Alpine and winter. herbs, especially on those which grow near the snow line, and also on tender young shoots of the bushes and dwarf trees of that altitude, its bill of fare ranging from the rose of the Alps to the young seed cones of pines and firs. In late fall and winter, however, it must content itsclf with the long grass protruding above the snow, and with moss and lichens. Salt seems to be an essential to its well being, as it is to most Ruminants; as to water, however, it does not seem to need it and probably quenches its thirst by licking the dewy leaves. It is fastidious from choice and frugal from necessity and rapidly increases in tat, bulk and weight when it feeds on good food, but scanty fare soon reduces it. Flocks of Chamois often gatler around the hay-riclis which are piled up in some districts of the Aips, and they gradually eat such deep holes or tunnels into the pilcs that they can go into the hay to shelter themselves from the storms. In other localities where such hay-ricks are unknown, they accept no food from the hands of Man even in the severest of weather of winter, but suffer and pine.

Winter for the Chamois not only implies great scarcity of food, but it also menaces then with avalanches, which sometimes bury entire flocks. The animals know this danger and confine themselves to places where they are safest; but even then their doom often overtakes them. Rolling masses of earth and boulders also sometimes kill them; diseases and epizootics thin their numbers, and an array of foes, chief among which are the Lynx, IVolf, Bear and Eagle, are constantly at their heeis. Lynxes lie in wait for them in the forests in winter, and commit great ravages among them; Wolves follow them, especially when the snow lies deep, and Bears also inflict great losses on their ranks. In the Engadine it is said to have happened that a Bear pursued a Chamois into a village, in which the animal was saved by entering a barn. Eagles are no less dangerous, as they swoop down on them as unexpectedly as a flash of lightning coming from a clear sky, take up a young kid without the least ado and try to drag larger ones into some abyss, despite their resistance. These assailants are, fortunately, nearly extinct in all protected localities, but their number is everywhere augmented by the most deadly foe-Man--unless the government has established definitc hunting rules and customs which warrant or tend to attain a regulated protection of this noble game.

The Chamois a The hunting of the Chamois has

Favorite Game cver been held to be a sport worthy Animal. of practice by the highest in the land, and at the present day has become almost exclusively a sport for princes. The greatest abundance of Chamois are found in the game preserves owned by the Emperor of Austria, the King of Bavaria, various arclidulies and wealthy noblemen of the Austro-Hungarian empire; they are guarded by experienced forest guards, usually living right in the midst of the hunting district, and therefore the chase of the animals in these regions is both attractive and generally rewarded with success.

Von Kobell's Ac- "A great deal has been written count of a Chamois about the Chamois hunt," says Hunt. Franz von Kobell, "and there are some people who have but barely seen a few hunts, and yet have taken to writing and have, according to their humor and the experiences of the expeditions in which they have talien part, either made it out to be the most dangerous of all sports or else described it as if it were not more perilous than the coursing of Hares or the chase of Deer. That this hunt is more romantic than others, is implied by the character of the scenery amidst which it must occur, but as regards the perils of the hunter, they depend upon the methods used and the conditions surrounding the hunt. He who has hunted many 
Chamois will hardly have been spared the feelings of inward terror, as he climbed over a precipice or threaded his way through a chasm and was suddenly aware of a rolling of stones above him, caused by a fleeing flock and he could barely save himself by crouching behind a boulder or ledge; or as he followed a wounded Chamois and unexpectedly found himself in spots where the consequences of a mistake in a step or leap, which had to be made, were but too obvious. One certainly must not think that both Chamois and hunter always have to crawl about rocky precipices like Flies on a wall. The locality often is so favorable that the hunter can obtain his prey without the exercise of special skill and with little trouble, as, for instance, when the spoor follows the course of a road or extends through a wood or valley. There is scarcely any variety of hunt in which the conditions differ so widely.

The Usual Method "To shoot a good buck with a rifle of Hunting the is usually a difficult feat; but as Chamois. chance in some instances spoils opportunities, so is it favorable in others. One sometimes has chances for a shot where he does not expect them at all. The paths which Chamois may select when driven by beaters are very uncertain and present a thousand aspects, for precipices, chasms and crags alternate in the most variable manner. Over the face of steep precipices the flock nearly alway's takes the same road, unless driven off by a shot. Over a chasm they all spring; sometimes they go down the rocky inclines, jumping from point to point, in a zigzag direction, without stopping. They like to hide in the heaps of wood, which have been cut and piled for the charcoal burners, and it is almost incredible how quickly they work their way through the intricate tangle of trunks and limbs. If the wind is good-that is, blows from the hunter toward the game-they are usually urged forward easily; but the main thing is to make them see the beater, for while stones thrown down the mountain side startle them, they do not disturb them enough to put them to flight. The Chamois know whether the stones are dangerous to them or not; so if they are under cover of a rock, they calmly wait, in spite of all the stones that may come bounding down over it. If the atmosphere is foggy the huntsman can be successful only when there are a great many beaters, and they proceed in close order. When a flock approaches, one can frequently observe with interest and pleasure how frivolous and unconcerned a crowd a herd of Chamois is. For the main body leaves all care to the leading doe, and while she stops to listen and watch the others butt against each other and fight, unless the beaters are too near.

"As regards distance, especially across a chasm, it is easy to be deceived, and many a Chamois owes its escape to miscalculation in this respect. There is a rule among experienced hunters that the distance is too great for successful shooting when one can not easily distinguish the horns. A badly wounded Chamois soon lies down; but if it is pursued, or a Dog is set upon its trail, it resumes its flight and generally mounts on a crag where a Dog can not follow it-and then the hunter must shoot it down. In craggy, precipitous mountains a Dog is useless, for the trail of the wounded Chamois can be easily traced by the blood drops on the gray stones. Sometimes, however, the hunter loses his gane because of inability to reach the spot where the animal lies dead."
Chamois in Ma- The flesh of the Chamois can vie terial and Poetical with that of any other animal in Aspects. flavor and excellence, in my opinion far surpassing even that of the Roe, which is deemed the tenderest and most palatable of all indigenous European kinds, the Chamois venison being distinguished by a savory taste, which can not be compared to anything else. The hide which is manufactured into excellent leather, is nearly as valuable as the venison. The horns are also put to account and the hair taken in a strip running along the course of the backbone serves as an ornament on the hats of professional as well as amateur hunters.

The Chamois plays the same part in the poetry of the inhabitants of the Alps, as the Gazelle does in the literature and folklore of the Orient. Hundreds of songs describe it and its pursuit in an interesting and poetical manner; numerous and widely varying traditions and fables are intertwined with its natural history, so far as it has become known to the common people.

The Chamois

in a State of

Chamois taken young are capable of herbs, cabbage, turnips and bread. If the owner have some good-natured Goats in his possession he may install them as foster parents, and the small, light-hearted natives of the mountain will thrive all the better for it. They merrily play with the kids and saucily romp with the Dogs; they follow their keeper about trustfully and come up to him to beg for food. They always exhibit their natural inclination for the highest attainable points and objects upon which they may mount. Blocks of stone, piles of any sort of material in the yard, walls and other eminences are their favorite haunts, on which they sometimes remain standing for hours. They never become as strong as Chamois in the natural, untamed state, but seem to bear confinement quite well. In some individuals a certain fierceness of temper makes itself apparent in old age and they sometimes use their little horns in quite a bellicose and resolute manner. Their frugality in the matter of food renders captivity more easy for them to bear. In old age they are still less fastidious about their food than in youth. In respect to bodily endurance and indifference to hardship one might say that they are born bardy. In winter a little straw under a small open shed is sufficient provision for them. They do not appear to be comfortable in a stable; space for exercise and a supply of fresh air are essentials for their continued well being. Those individuals that are taken old always remain timid and shy.

Chamois seldom propagate themselves in captivity: In IS63, however, Schoepff had the pleasure of having his captive Chamois give birth to a healthy kid. The nurture of the little one was entrusted to a Goat, and it grew and throve so well that it nearly equaled its mother in size when one and a half years old. After two years the old Chamois gave birth to another kid.

\section{THE SAIGA.}

The Saiga (Colus tataricus) differs so considerably from all other known Antelopes in some important peculiarities, that it is justly regarded as the representative of a distinct species. It exhibits some affinity to the Sheep in shape and action, in other respects, however, resembling Reindeer. Its body is very short and thick, the fur consists of extremely 


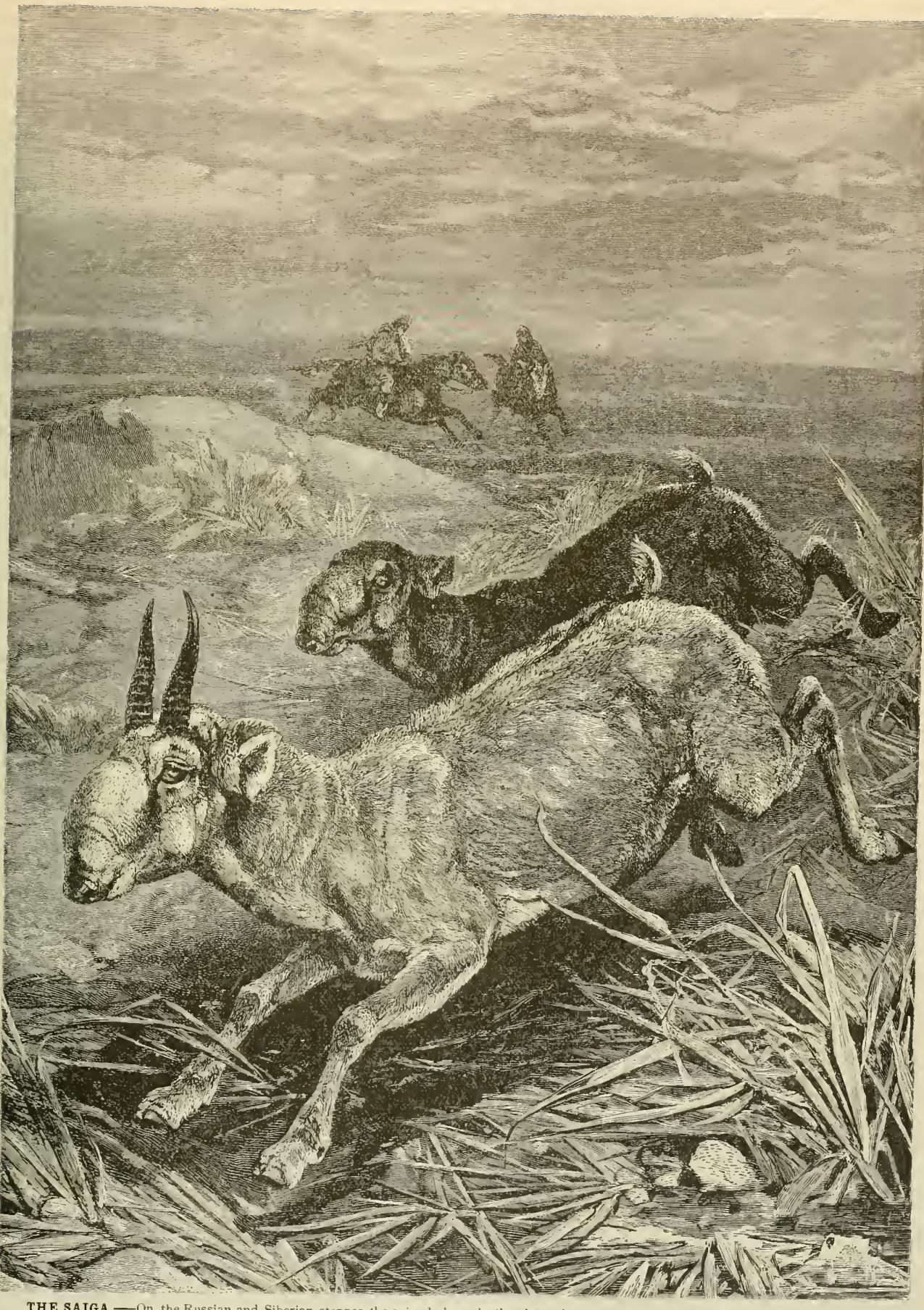

THE SAIGA.- On the Russian and Siberian steppes the animal shown in the picture is very common, frequently assembling in large herds, Its gait is speedy but awkward as it endeavors to escape from the Kirghiz Tartars who pursue it over the arid , frequently assembling in large herds. Its Saiga has horns, but both sexes are marked with the distinguishing feature of the species, the large projecting nose which gives these animials so odd an
appearance, (Colus tartaricus.) 
long filaments and is so close as to resemble a rug of smooth wool. More than by any other feature, however, the Saiga is characterized by the anatomical structure of its muzzle and especially of the nose. This latter organ projects beyond the lips, is divided by a longitudinal furrow, and is composed of thin, almost membrane-like cartilage, with a wrinkled surface and furnished with delicate retractile muscles, and therefore very mobile, the whole forming a somewhat wel]-developed snout or trunk, so that the group might properly bear the name of "proboscis Antelopes." The buck alone has horns, and they stand sonewhat far apart, are lyrate in the contour of their curves, pale in hue and transparent. The color of the back and sides is grayish yellow in summer; the limbs below the knee are darker, the sides of the neck and under surface of the abdomen. as well as the inner surfaces of the limbs are white; forehead and top of the head are ashy gray, a lancet-shaped patch on the croup is beset with coarser, longer hair and appears to be blackish brown. Towards winter the fur becomes lighter and fades into a yellowish gray, with a whitish surface tinge. The length of an adult buck is fifty-two inches, four and a half inches of which are included in the tail; the heiglit at the withers is barely thirtytwo inches, the horns, measured along the line of curvature, are from ten to twelve inches long.

The Range and The Saiga is a native of the steppes Habits of the of eastern Europe and Siberia, rangSaiga. ing from the Polish boundary to the Altai mountains. It always lives in flocks, gathering together in the fall of the year in great herds, consisting of several thousand in number, which undertake periodical migrations and return to their former haunts in troops towards spring. It is very rarely that one sees a solitary Saiga; for the old bucks remain with the flocks throughout the year. They manifest but little agility, their perceptive senses exhibit on an average but a slight degree of acuteness and their mental capacities are not of a high order. The speed of adult animals is so great that neither Horse nor Greyhound can overtake them, but younger ones soon get out of breath and the old animals also fall victims to the united efforts of beasts of prey, sucl as Vilves.

The food of the Saiga consists chiefly of saline plants and herbs, which grow in enormous masses in some places of the sunny, arid Tartar steppes which are also intersected by many streams flowing from saline springs. The does give birth to a single young one, which is very helpless at first, and generally makes its appearance towards the middle of May.

Notwithstanding the fact that their venison is bad, the Saigas are persistently and extensively hunted by the natives of the steppes. They are pursucd on horseback and with llounds and are, as a rule, overtaken, if the chase extends over a long distance. IVolves also commit great depredations among them and completely devour those that they kill, leaving only the skull and horns. These remnants are picked up by the Kirghiz or Cossacks and sold for a small price to Chinese merchants.

\section{THE GNU.}

The Gnus (Catoblepas) are probably the most striking in appearance of all Antelopes; they are very queer looking Ruminants, intermediate links, if such we may term them, between the Antelopes, Oxen and Horses, and true caricatures of the more noble and graceful members of their families. When one sees a Gnu for the first time, he is uncertain what kind of a creature he really confronts. The animal impresses one as a Horse with cloven hoofs and a bovine head, and its whole demeanor is in perfect harmony with its hybrid shape. It is inpossible to call the Gnu a beautiful animal, exquisitely delicate as the anatomical structure of some of its parts may be, because of the oddity of its general appearance.

Physical Fea- The genus $c_{1}$ the Gnus is poor in tures of the species and its distinctive features Gnus. are as follows: The body, supported on moderately long legs, is stout, the head nearly square, the muzzle broad, the nostril appears as if it were closed by a valve, the eye is surrounded by a circular, radiating wreath of white bristles and is wild and fierce in expression. Both sexes have horns, which are set on the frontal ridge of the skull, flatly compressed, very broad and have their tips hooked upward. The tail is ornamented with a long tuft like a Horse's tail. The median portion of the face, the upper surface of the neck, the back, throat and cliceks are furnished with a stout mane, while the rest of the hairy covering is smooth.

The Gnu, called WVildebeest by the Boers (Catoblipas gnu), averages a total length of nine feet four inches, inclusive of the tail, which measures twenty inches without the hair, and from thirty-two to thirty-six inches with the hair; the height at the shoulders is four feet. The prevailing color is a dark grayish brown, lighter in some parts, darker in others, and assuming a yellowish, reddish or blackish tint. The female is smaller in body and its horns are also smaller than those of the male, but the hue in both sexes exactly corresponds.

Habitat and The Gnu is a native of South Africa;

Habits of the it lias been exterminated in Cape Gnu. Colony. According to accounts of trustworthy observers it migrates annually, actuated, in our opinion, by the want of food. It is a very active, sportive animal, and enlivens the wide plains to a wonderful degree.

Gordon Cumming was informed that the WVildebeest does not retreat from its domicile, even when attacked by a large number of hunters. Incessantly describing circles, pawing and capering in the most eccentric manner, the shaggy herds of these remarkable and queer looking Antelopes surround their pursuers. While the latter ride towards them, intending to kill a few, they run in circles on either side and take up their positions on the places the hunters have vacated a few minutes previously. Sometimes one sees on the plains old IVildebeest bucks, singly or in troops of four or five, standing short distances apart and motionless during a whole forenoon, gazing at the movements of some other aninal, and continually emitting a loud, grunting noise and a peculiar short, sharp nasal snort.

The movements of the Gnu are quick and spirited, and its fondness for play and sport is cqualed by no other Ruminant. In serious combats males and females exhibit equal courage. Their rocal cxpression resembles the lowing of Oxen. In captivity the animals often prove wild and intractable, insusceptible to petting and domestication, but also rather indifferent as to the loss of their freedom. The young Gnus are born singly at various seasons of the year, the little one a few day's after birth exhibiting its delight in the execution of the same capers and antics as its parents and, on account of its small size, appearing still more droll than they. The mother 
apparently loves it tenderly and perils her life in defense of it without hesitation.

Difficulty and The pursuit of adult Gnus is rendered Profit of a Gnu difficult by reason of the extreme Hunt. speed and endurance of the animal. Gnus when pursued exhibit a striking resemblance to fleeing wild Oxen. Occasionally Gnus are caught in pitfalls or snares. Those which are taken when already old act as if mad; young ones, however that are reared on cow's milk and caressed and fondied become accustomed to Man and so tame that one can send them to pasture with the flocks and allow them the liberty accorded a domestic animal

The profit accruing from the carcass of a slain Gnu is about the same as that arising from any other wild African Antelopes. The flesh is eaten, being juicy and tender, the hide is used as leather, and the horns are made into knife handles and other articles.
Horns of Prong. This Ruminant, the Pronghorned horns Not Those of Antelope, differs from all its relaan Antelope. tives of the entire order, by having hollow, pronged horns, which do not increase by a continuous growth, as do those of the 11 orned Animals, but are shed and formed anew from time to time, as are those of Deer, but in a totally different manner. Other peculiarities, such as the existence of special glands, the resemblance of the hoofs to those of the Giraffe, the texture and appearance of the hair, etc., induced Nurie, who dissected the animal, to describe it as "an Antelope with a head like a Deer, hoofs like a Giraffe, glands like a Goat, hair like a Sheep," which can mean nothing else but that the l'ronglorn is no Antelope. All characteristics of the Ruminant in question are of so peculiar and important a character that the animal cannot be united with any other family of its order, but must

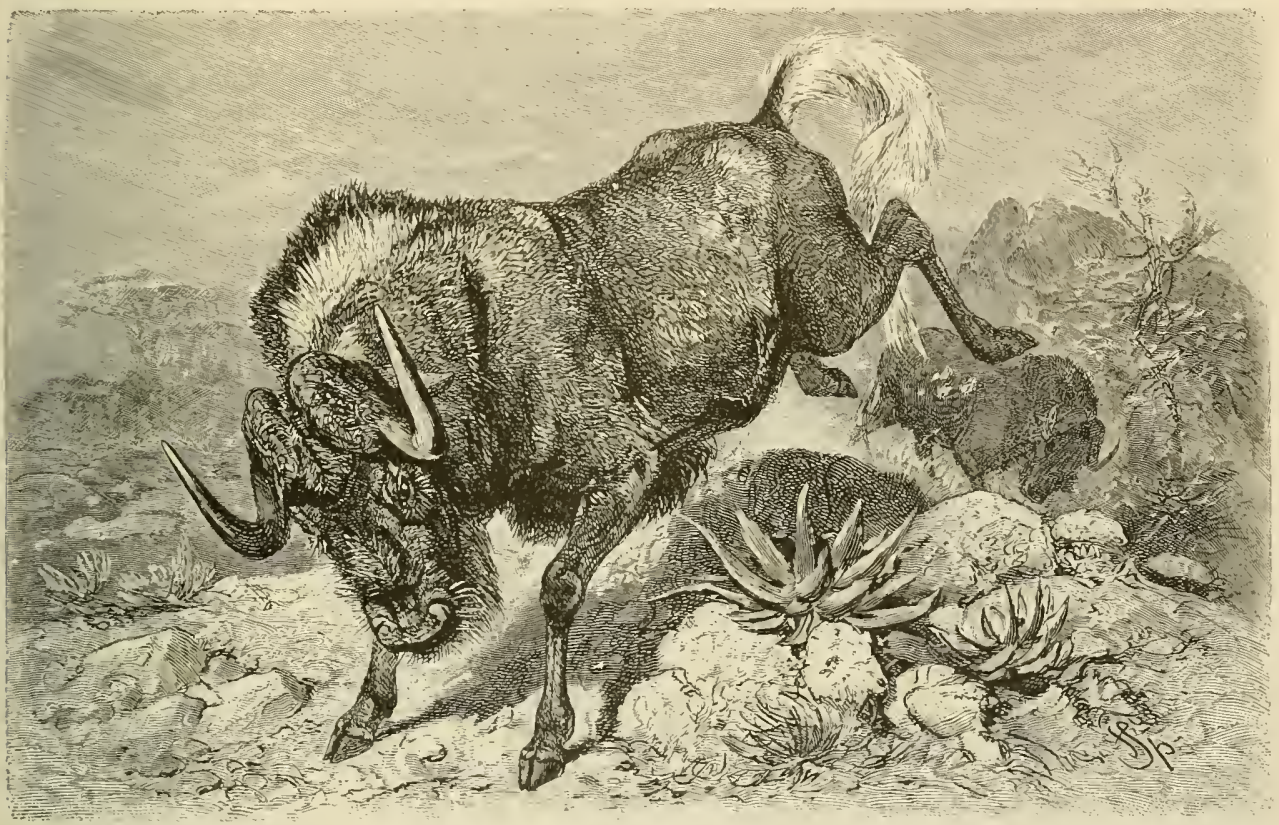

THE GNU. - This species of the dntelope, which is an inhabitant of south Africa. has many peculiarities, among which the shape of the horns, the bristles around the strangely formed snout, the manes on the neck and withers and the horse-like tail, are sonie of the most noteworthy. (Catoblcpas gnu.)

\section{Tbe pronghornco Entumals.}

\section{FOURTH FAMILY: ANTILOCAPRIDE.}

We let the hollow-horned animals be followed in our consideration by a Ruminant which was, until recently, classified among the Antelopes, although the distinctive difference in the formation of its honis from those of all other Horned Animals made such a classification manifestly incorrect. This is probably the animal mentioned by old Hernandez as existing in Mexico, under the name of "Teutlamazame," but as the scientific description of this remarkable Ruminant dates back only to the year ISI5 it was reserved for the naturalists of our own time to correct a scientific error which had been obstinately persisted in, and to give the animal its true position in its order. be classified as the representative of a distinct family which we will call the Pronghorned Animals.

Description and The Pronghorn, or, as it is variously Range of the called the Pronghorned Antelope, Pronghorn. Prongbuck, Cabree or Cabrit (Antilocapra amcricana or Antilope furcifir) has, on the whole, the shape of a vigorous Antelope, measuring about five feet in length, from seven to eight inches of which total are included in the tail; and the height at the shoulders is thirty-two inches. The head is ungainly, sheep-like and elongated, the eye large, dark and expressive; the ear is rather long and is acutely pointed. The neck is of moderate length, and the body appears more slender than it really is, for it is supported on very lelicate legs of more than medium length. Three different and usually sharply contrasting tints-a rusty sorrel, white and dark brown-make the coat one of very gay appearance. 
The hair is long, wavy and brittle. The lorns and hoofs are black. Both sexes have horns, but only those of the bucks are pronged; they rise vertically. from the head and their tips are sharply curved inward and backward; in the old buck thoy are nearly doubly as wide as they are thick, peculiarly rough and uneven and beset at irregular intervals with short, pointed excrescences. The horns of the buck attain a length of from ten to twelve inches, those of the female only from three to nearly five inches.

The Pronghorn is an inhabitant of western North America, ranging from the Saskatchawan river in the north to the Rio Grande in the south, and from the Missouri to the shores of the Pacific. It does not by any means confine its domicile to the plains, as has been supposed, but has been found in the wild, sterile, high valley's of the Rocky Mountains up to an altitude of 8.300 feet. Finsh believes it to be plentiful in the wide prairies of Kansas, and down to Texas, as well as in the prairies between the Rocky Mountains and the Sierra Nevada, or in the western territory between the latter and the sea.

Daily Life The daily life of the Pronghorns, as

of the Prong- well as the modifications which they horns.

undergo in the course of the year,

have been described most minutely, and probably also most correctly, by Canfield, who claims to have become as familiar with them as other people are with Goats and Sheep. He says: "From the first of September to the first of March one always sees them in larger groups composed of bucks, does and yearlings. Shortly afterward the does individually retire from these herds and give birth to their young. After a short interval they again unite with other suckling does and their little calves, possibly with a view to common defense against the WVolf and Coyote. The adult bucks roan about singly or two together, leaving the mothers with their latest progeny to their fate, the young Pronghorns in the meantime gathering in groups of their own apart from the older animals. Apparently tired of the world and bored by society the old bucks wander about for one or two months, frequenting localities in which they are not ordinarily seen. Two or three montlis subsequently the adolescent bucks again join the old does and their calves, and finally the old bucks also put in an appearance, so that one can observe herds numbering hundreds, or sometimes even thousands, after the first of September. A herd never leaves its native locality or roams over more than a few miles of range. In dry summer weather they seek water and go to drink regularly once a day or twice in three days; but if the grass is fresh and green, as is the case during the greater part of the year, the Pronghorns do not drink at all."

Food Movements The food of the Pronghorns consists and Faculties of mainly of the short succulent herb-

Pronghorns. age of the prairie, of moss and perhaps of young and tender branches of trees and shrubs. They are exceedingly fond of saline water and pure salt, like most other Ruminants, and they often take up their abode in the neighborhood of saline deposits, and also rest for hours around salty outcroppings, after they have licked to satisfaction. With sufficient pasturage they become very fat in fall, but often suffer greatly from hunger in winter, when the snow covers the ground to the depth of a foot or more and they are obliged to content themselves with the scantiest food. They soon decrease in flesh, for running in the snow wears them away, and too often they perish in a miserable way.
All observers agree in their admiration of the speed and agility of the Pronghorns. They may, perhaps, in this regard be inferior to some of the Old World Antelopes, but stand unequaled among the animals of the prairies of the New IVorld. Agile and light, reaching far with the bold stride of their long legs and, moreover, putting to shame every other American mammal in point of endurance, "they scour over the plain like the wind." Finsh says that "a fleeing herd of Pronghorns affords an incomparable and never-to-be-forgotten spectacle." Skimming over the hills, the animals display the same agility in going either up or down hill as on the level ground and, as Audubon says, they move their four legs along the ground with such celerity that one can no more distinguish the limbs than he can the spokes of a rapidly revolving wheel.

The perceptive senses of the Pronghorns are acute. They can see at great distance, hear excellently, and scent an enemy approaching with the wind at several hundred paces. They are wary and shy, to a certain degree intelligent and certainly cautious, and judiciously select their abode, especially the spots in which they are wont to rest and chew the cud about noon-time, always taking care that they have an unobstructed view, profiting by the wind in a most ingenious way and moreover putting out special sentinels. They carefully avoid human settlements, but pay little attention to herds of domestic animalseven of Horses and Cattle-and quietly graze in their proximity. Several observers lay stress on the fact that they do not always flee from an approaching railway train, sometimes escorting it and apparently testing its speed by running beside it for awhile. Audubon and others assure us that they can easily swim across wide rivers.

The Growth and The growth of young Pronghorns is Horn Shedding of relatively very rapid, as is that of all the Pronghorn. Ruminants. The horns appear in both sexes towards the end of July, first as short, bluntly conical tips, which attain a length of one to two inches by December; for the first year they do not grow farther, but are shed and renewed. This process, however, differs so completely from the shedding of antlers by Deer, and is so remarkable in itself, that I must describe it at greater length.

The first to observe and describe the shedding of horns was Canfield; but as his paper relating to this subject and sent to Baird in September, is 58 , was published by the latter naturalist only in 1886 , the fame of having given to science the first account of the strange fact belongs to Bartlett, who had the care of captive Pronghorns in the London Zoological Garden. The accounts of both agree perfectly and have recently been substantiated by other observations. Bartlett says that the Pronghorn he took care of had little horns which, towards the middle of October, suddenly seemed to grow very rapidly, not only increasing in length, but also increasing in circumference. On the morning of the 7 th of November, the keeper informed him rather excitedly that the Pronghorn had lost one of its horns. In consequence of this message Bartlett repaired to the stable and arrived just in time to see that the second horn had also been shed. A closer examination of the animal revealed to his astonishment two new horns in place of the old ones, the new embryo members being clothed with long, straight, soft hair and having their bony core enveloped with a horny substance. There was no trace of bleeding, such as always attends the loss by fracture of the true hollow 
horns or the shedding of antlers by the Deer. The ncw horns seemed to be of larger diameter than the hollow space of the old ones, a circumstance explained by the fact that the hair at their bases had concealed the gradual shedding of the old sheaths. The rapid growth of the new horns led to the conchusion that the process was an entirely natural one: the animal in accordance with its nature had to shed its horns in this manner. This supposition received a complete confirmation in the account of the $\mathrm{Anuer}$ ican naturalist Canfield, published in conscquence of Bartlett's report. A Pronghorn which was kept by Canfield attained an age of nearly threc years, regularly shedding its horns during this time, thus affording the naturalist an opportunity of observing not only a double shedding of the horns, but also of the ncously with the beginning of the shedding process, and thus pushes the old horns out of place. From November till January no strong line of demarcation can be noticed between the hairy covering and the horn proper, the entire new formation being closely covered with a sheath of hair, which is not rubbed off as is the case with the Deer, but gradually falls off as the growing of the horny substance progresses. In summer the line of demarcation between hair and horn is very distinct.

The Pronghorn's Pronghorned Antclopes, when taken Behavior in in old age, do not scem to become

Captivity. reconciled to the loss of their freedom. Such as could be captured in winter during the prevalence of a deep snow, and were then turned loose in an enclosure, proved to be very tractable and

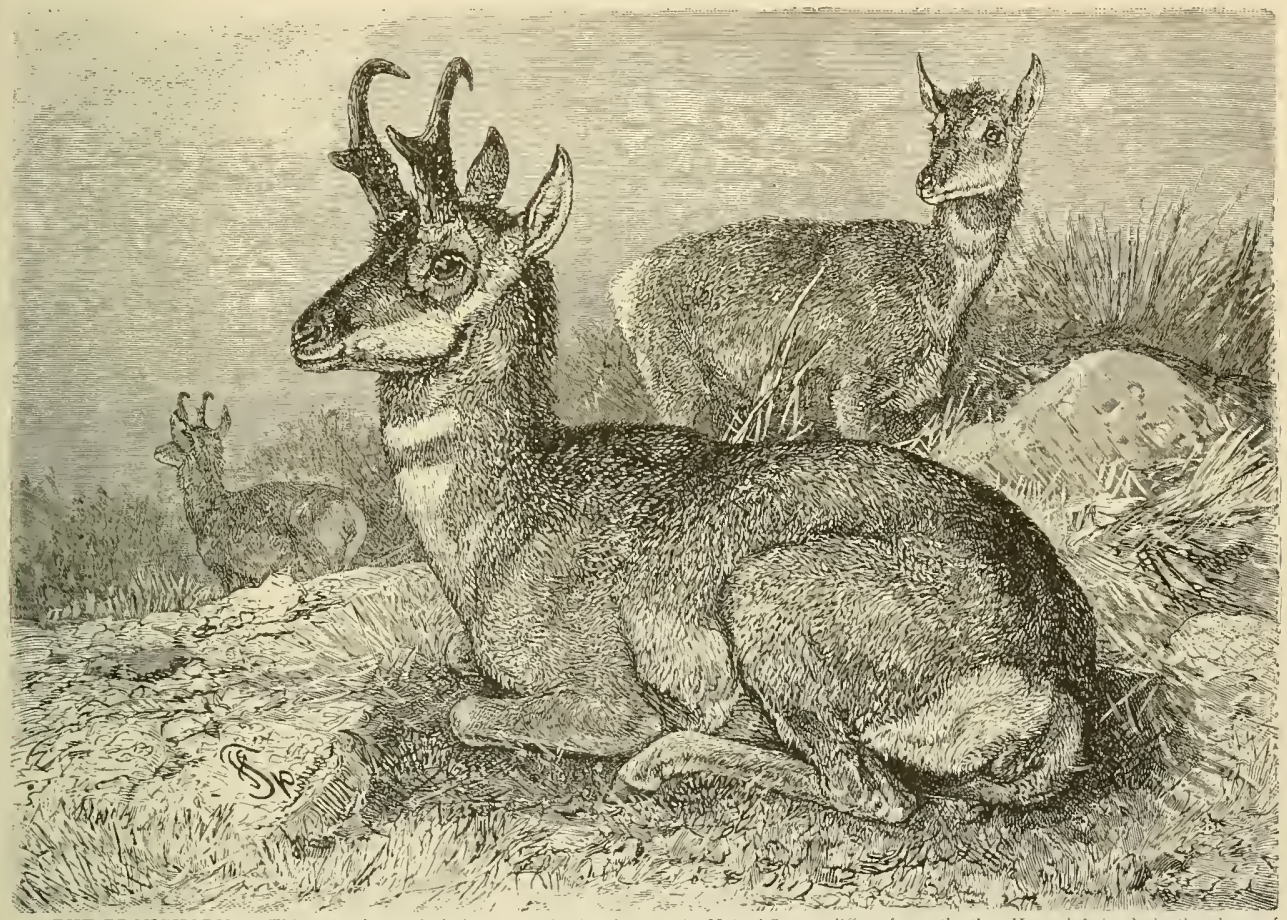

THE PRONGHORN - This anmal, popularly known as the Antelope in the United States, differs from all other Horned Animals in the shape of its horns and the manner in which it sheds and renews them. It is a familiar fenture of the region west of the $M$ issouri and noted as the most fleetfooted of the larger American mammals, having no rival in this respect except its neighbor, the Jack-rabbit. (Antilocupra americana.)

further development of those members. The third year's horns exhibit a modification of form, no longer having a circular but an ovoid cross-section rudimentary development of the prong. On the forehead, at the root of each horn there forms a second excrescence, at first separated from it, thus forming a second pair of tubercles as it were, which soon unites permanently with the older bony core, however, and only serves for the attachment of the prong. The complete horn is developed by the following June and hencetorth remains more or less the same after each shedding, only increasing a little in size. IVe may fairly assume that the new horny substance is formed by the fusion of the capillary substance between the cancellated matter of the bony core and the horny sheath, which begins to grow simulta- good-natured, or even trustful, but only while their exhausted and weakened condition lasted. As soon as the effects of starvation had been overcome, the yearning after freedom would assert itself and they 'shibited their natural savage disposition. They would run and butt against the fence of the enclosure as if they were mad and give vent to their rage until they sustained some mortal injury.

Kids taken soon after birth also generally die very early, unless special care is bestowed on them. Of about twenty little kids, which Canfield took in the course of three summers, he succeeded in rearing only two. Nearly all of them suffered from diarrhcea, probably in consequence of the diet of cow's milk, which is not suitable for them. If they succeeded in overcoming this, they would live for 
two or three months longer, then fall ill of pyremic sores or inflammations of the limbs and die. Mr. Canfield might have had more favorable results if he had given the wild young creatures a robust. good-natured Goat as a wet nurse, for, as he says himself the milk of the Pronghorns is so rich and sweet, that it can not possibly be substituted by cow's milk.

The Pronghorn buck, in the case of which Canfield observed the shedding of the horns, was as pretty and playful as he was bold and restless. He always ranged in sight of the house while grazing in the daytime and slept near by at night. IJe was fond of hunting with the Hounds, however, and as none of them could equal hin in speed he always touk the lead of the pack, when they tracked a Coyote by night. IJe liked to go hunting with his master, and if he happened to lose sight of $\mathrm{Mr}$. Canfield or of the Dogs, he straishtway betook himself home, once doing so from a distance of twelve miles. He would often join his wild kin, when they crossed the valley or came to Irink, but he always left them and came back home. He willingly let people scratch his head or play with his horns, but would let nobody touch any other part of his body. Unfortunately he received a kick from a Mule, which broke his leg; he was bandaged and braced and soon recovered, but lost his former agility and shortly after fell a prey to the Wolves. All Pronghorns brought to Europe have experienced ill health, and have succumbed to various diseases.

The Pronghorn Diffi- About twenty or twenty-five years cult to Gapture ago the Pronghorn was not often or Kill. hunted, and as Prince of Wied says, "only when no Bison flesh was to be had." At that time the Indians were still the most deadly foe of the animal, but they have since been superseded by the white Man.

There are, however, few people who habitually engage in the difficult pursuit of this animal, even where the Antelopes are plentiful. The sportsman has to depend on his skill in stealthily approaching the quarry unperceived by it, and he who is familiar with the western prairies, devoid of trees and shrubs, knows what this means.

The profit of the chase is not slight. The venison of the animal is distasteful to some on account of its strong, repulsive odor; most people, however, find that it has an exceedingly fine gamy flavor, entirely different from that of the European Stag or Roe, and therefore it may justly be ranked among the most excellent dishes of the lVest. The fat is noted for its hardness and is made into excellent candles; the fur is light and soft but not durable and is used by the Indians in the manufacture of their shirts and by white people in the making of gloves.

\section{Tlx Dect.}

\section{FIFTH FATILY: CHRIID.E.}

No other group of the order is so easily distinguished as the fanily of the Deer 1 (imide). They are Ruminants with antlers. These words describe them sufficiently; for everything else appears to be of minor consideration when contrasted with this peculiarity.

The antlers are generally borne only by the males. They are a double, bony, branching development of horns, which is deciduous, that is, cast annually and renewed. At the sixth or eighth month of age a bony projection makes itself apparent, attended by an elevation of the outer table of the frontal bone, this projection being retained through life, and the antlers being attached to it. At first they are straight and pointed; later they branch more and more, the branches sprouting from each main shaft and sometimes numbering as many as twelve.

Process of Growth Blasius says: "As the age of Deer of Deer's Ant- increases, the antlers undergo a great lers. modification. The first and generally very striking change that takes place is that in the bony projections at the bases, which expand every year to a greater extent and approach a junction with each other in the mididle of the forehead. They seem to appropriate the osseous matter of the head, for other portions of the sliull annually diminish in size, as the thickness of the frontal ridge increases. The changes in the shape of the antlers and the number of branches are still more striking. The young horns, in the incipient development of which lies the reason for the casting of the old ones, are at first surrounded by a hairy integument, abundantly supplied with blood-ressels and glandular, and soft and flexible to the touch. The lower spurs sprout first from the main horn, then the higher ones follow, and after all have attained their ultimate proportions the circulation of blood ceases and the animal feels the need of rubbing off the skin or 'velvet' which then begins to peel off of its own accord." The further development of the antlers then proceeds in the following manner: Before the Deer completes its first year, horns (which are the immediate continuation of the bony projections on the frontal ridge) are formed. These may be shed by some species of the family, but they are always replaced in the same manner, while the antlers succeeding these horns and constituting the decoration of the head during the second year, show one or two branches in most of the Deer. In the spring of the third year the same process is repeated; but the new horn contains one more spur than that of the preceding year, and so it goes on until the greatest possible development of the animal has been attained. Diseases, or insufficient nutrition, sometimes cause a retrogression, the new horns numbering one or two spurs less than those of the preceding year, and, on the other hand, the formation of the antlers may be accelerated by abundant nourishment and a quiet manner of life, devoid of trouble or hardship. The antlers are fastened to the bony projections at their bases by articulation, that is, by liaving smaller or larger projections of the roots of the horns interlocking and fitting into corresponding depressions on the upper surface of the bony projection, and vice versa. A few days before casting their antlers most Deer show a swelling of the edges of the skin surrounding the projections and the roots of the antlers; the animal takes care not to strike its antlers so as to hurt them and thereby proves that it experiences an unusual sensitivencss at this place.

The casting itself is occasioned cither by the weight of the horns themselves or by a slight external collision. It happens very rarely that both antlers are cast simultaneously; there is usually an interval ranging from a few minutes to several days, between the casting of the first and second horn. At this period the whole demeanor of the Deer, especially the carriage of the head and the drooping of the ears, is cxpressive if not of pain, yet of an uncomfortable feeling. A few days previously 


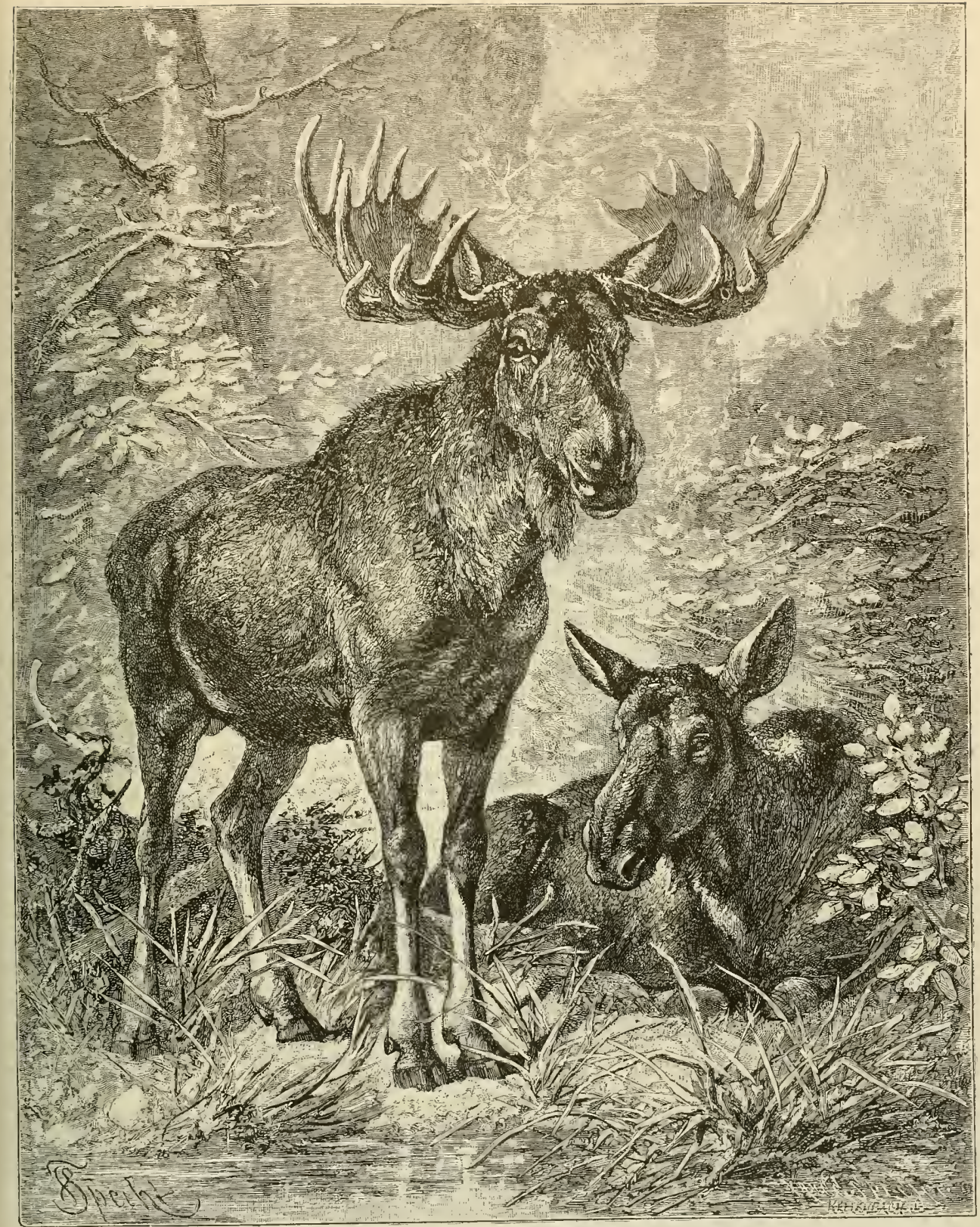

Tur stout hoofs and the niale is crowned with antlers which attain an enormous size. The Elk, notwithstanding the great expanse of these antlers, manages to go thro the female is without horns. (Alces palmatus.) 
it ceases thrusting with its horns, and defends itself by strikins with its forelegs, after the manner of the doe. When one horn has been cast, the unbalanced weight of the renaining horn causes the animal to carry its head inclined to one side, and to frequently shake it, as if to hasten the casting of the annoying member.

Distribution and The Deer were originally distributed General Traits over a large part of the globe. At of Deer. present they inliabit all continents, with the exception of the Fthiopian belt and lustralia; they exist in nearly all climates, in plains and in mountains, in the open country and in woods. All Deer are lively, timid and fleet creatures, quick and agile of movement and keen of sense, but endowed rather poorly mentally. The method of vocal expression consists of short, dull grunting or roaring sounds in the male and a shrill bleating in the female.

The food of the Deer is of an exclusively vegetable nature; at least it has never been proven whether or not, as has been affirmed, the Reindeer eat Lemmings. Herbage, buds, leaves, the needles of the fir and pine, blossoms, cereals, fruit, berries, young shoots and branches, bark, moss, lichens and mushrooms are their main articles of food. They are very fond of salt and require water.

The young Deer make their appearance, one or two, or in rare cases three at a birth, perfectly developed, and they follow their mother about within a few days after birth. With a few species the father as well as the mother shows a kind regard for the offspring. The fawns take great pleasure in receiving the caresses which their mothers bestow on them, and the mothers take the utmost care of the fawns and valiantly defend them when in danger.

In localities where agriculture and forestry are pursued according to the requirements of modern times, Deer can not be tolerated. The damage wrought by these beautiful animals exceeds the slight use which they are to Man. Unquestionably they are inimical to the cultivation of the ground and the proper keeping of the forest. If it were not for the chase, which is justly considered to be one of the noblest and manliest of sports, all Deer would long ago have been exterminated in every densely peopled agricultural country. This point has not yet been reached; but all the members of this family, distinguished as it is in so many respects, are nearly everywhere approaching their doom and probably will soon be seen only in parks and zoological gardens.

Domestication of The taming of Deer is not as easy as Deer Somewhat is usually supposed. Those which Difficult. have been from early times in possession of Man, and have become accustomed to him, exhibit an amiable, trustful and affectionate temper when they are young. As age increases, however, all these qualities gradually disappear and nearly all old Deer are cross, vicious and pugnacious creatures. Even the one species that lias been domesticated for a great length of time, the Reindeer, is no exception to this rule. Its domestication is by no means a perfect one, such as we see in other Ruminants, but is only partially successful.

\section{THE ELKS.}

We will place the giants of the family at the head. The Elks (Alces) at present have only one representative, or, if the American Moose is regarded as a distinct species, two. They are huge, clumsy, long-legged animals; their antlers broadly expand, somewhat like spades, and are marked by finger-like indentations with many spurs; they have small tear-pits, hair tufts on the inner side of the tarsus and glands between the toes, but no canine teeth. The head is ugly, the hairy upper lip projects over the lower; the eyes are small, the ears long and broad; the tail is very short.

The European Elk The Elk (Alces palmatus or Corrus Known in Early alces) has enjoyed a wide celebrity Ages. from early ages. The origin of the name is not quite clear: some hold that it has been corrupted from the old word "elent," which signifies strong; others believe it to come from the Sclavic word "jelen" (Deer). The old Roman authors speak of the Elk as a German animal. Julius Casar said: "There are Alces in the Hircynian forest, animals resembling Goats in shape and variety of color, but larger, devoid of horns and with jointless feet. Never do they lie down to rest, nor can they get up, when once they have fallen. They lean against trees, when sleeping: therefore the hunter undermines the trees or chops them nearly in two so that they fall down, along with the animals, which lean against them." In writings of the middle ages the animal is mentioned quite frequently, also in the song of the Nibelungen, in which it is called Elk.

Diminished Range IVithin the last few hundred years of the European the number of Elks in Europe has Elk. undergone a very rapid and consider-

able decrease. Elks are now kept in small herds in Germany in forest preserves, under the strictest supervision; and the Elk is found in the free state in the higher latitudes of all wooded countries of Europe and Asia. In Europe it is confined to the lowlands about the Baltic, meaning Lithuania, Corland and Livonia, except eastern Prussia, as well as in Sweden, Norway and a few regions of Russia. In Asia the Elk is much more common; it spreads there north of the fifticth parallel orer the entire north to the Amoor and occurs wherever there are extensive forests.

The Elk is a powerful animal. The length of body of an adult Elk ranges between eight feet eight inches and nine feet eight inches; the tail is about four inches long and the height at the withers averages six feet four inches. Very old animals may weigh as much as one thousand pounds; the average weight, however, varies between six hundred and eight hundred pounds. The body of the Elk is comparatively short and stout, broad in the chest; high, with an incipient hump on the withers; straight along the back, low at the croup. It is supported by very long, vigorous legs of equal length, terminating in narrow, straight, deeply-cloven hoofs, which are joined to one another by an elastic connecting membrane; the rudimentary toes slightly touch the ground. The short, stout, strong neck supports a large, elongated head, narrowing in front of the eyes and terminating in a long, thick, bulbous snout, abruptly flattencd in front. The antlers of the male each consists of a large, plain, expanded, triangular, flat, spade-shaped and furrowed blade, serrated with numerous spurs along its outer edge, and supported by a short, thick, rounded shaft; both these shafts are marked with small knob-like protuberances, and are set on short, bony prominences at the upper exterior angles of the skull, and curve laterally from their bases. The antlers nay weigh as much as forty pounds. The hair of the Elk is long, thick and 
straight. The color is a rather uniform reddish brown, deepening into a brilliant black-brown on the crest of the neck and sides of the head, and fading into gray at the extremity of the snout; the legs are whitish ashy-gray, the rings around the eyes gray. The doe is of slightly smaller proportions, but has no antlers.

The Domicile, Hab- The Elk delights in wild, lonely its and Diet of forests, abounding in grassy swamps the El/. and inaccessible marshes, especially those grown with willows, birches, aspens and other thickly leaved woods. Bogs and marshes seem to be essential to its well-being and confort. The awkward, stupid-looking creature confines itself to the lower, watery situations in summer, and in winter to the higher ones, which are not exposed to inundations and are not covered with ice. In serene weather it prefers forests of ordinary leaved trees; in rain, snow and fog, thick growths of trees with needle-like foliage, such as pines and firs. It readily changes its place of abode if disturbed or urged by want of food.

In its habits the Elk differs from the ordinary Deer in many respects. Like the latter it gathers into troops of variable numbers and it is only towards the time that the young are born that the old males separate from these herds and consort in societies of their own.

The Elk dislikes being disturbed in any way, even more than do other Deer. It requires absolute freedom from molestation and forsakes the locality in which it has been annoyed. IVherever it knows that it is secure, it rests only in the morning and afternoon hours, except, perhaps, a few short intervals, and roams about in quest of its food from four o'clock in the afternoon, and during the early night and early morning; under different circumstances it sometimes chooses the night for its search for food. The Elk's principal diet in the forest uplands consists of leaves and shoots of the sizamp-willow, birch, ash, aspen, mountain ash, maple, linden, oak and pine; on the heath of young reeds and sedge, supplemented with sprouting corn and flax. When taking its food from the tree it drives its incisor teeth in like a chisel, peels a piece of bark a little distance, seizes the loosened end with its teeth and lips and then tears long strips off in an upward direction. Trees of medium growth it bends down with its head and breaks off their tops; as is easily explained, it prefers trees and shrubs, the bark of which contains a large amount of sap, such as the aspen, ash, willow and poplar, sometimes completely stripping very stout aspen trees. Peculiar Modes of The movements of the Eilk are much

Locomotion of less uniform and lighter than those the Elk, of the Stags or Red Deer. It is not possessed of great powers of endurance, but is capable of trotting along rather rapidly for a long time; sone authorities aver that it can at this gait travel thirty miles a day.

Whangenlein describes a very quecr node of locomotion of the Elks over swampy districts. Where the soil will not bear a running Elk, the animal crouches down on its body, flexing the strong tendons of its hind legs; then it stretches out its fore-

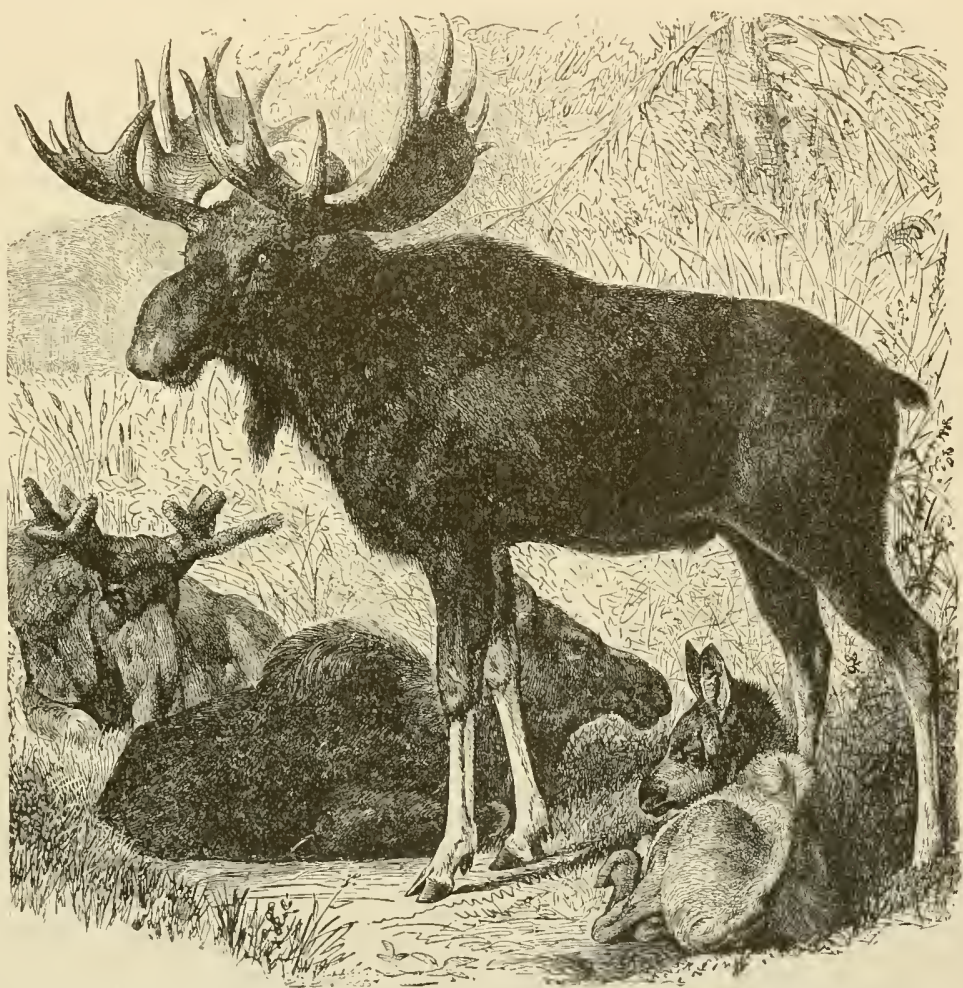

THE MOOSE.--The Moose of North America and the Elk of Europe and Asia are so nearly related that they can scarcely be regarded as nore than varieties of the same species. The Moose shows slight variations in horns and fur from the Elk, and is restricted in its habitat to British America, and is most plentiful in the northern legs, hooks its hoofs on some point of resistance, such as a grass tuft or partly submerged log or branch, pushes with its hind legs and pulls with its fore feet, and thus glides over the muddy surface; where the ground is quite qualy, it sometimes lies down on its side and works its way along by kicking and beating the mud with its legs. In the art of swinming the $F / k$ is an adept. It enters the water not only from necessity, but, like many of the bovine species, for its own comfort and pleasure, to bathe and cool itself. In eastern Siberia it seeks the deeper gorges in the mountains, in which the snow lies for a long time, and there wallows in the cooling element. It can not long proceed on smooth ice, uncovered by snow, and if it once falls on the slippery 
surface, it is very difficult for it to rise. When it runs, one hears distinctly a clicking, rattling noise produced by the clattering of the rudimentary toes against the heel of the hoof. An Elk which has started to run can not be made to swerve from a direct course, but proceeds straight through the thickest of the wood, through lakes, rivers, and bogs, which may lie before it

Physical and Men- The sense of hearing of the Elk is tal Faculties of acute, while its faculties of sight and the Elk. smell are inferior. In $r$ egard to mental capacity it does not seem to belie the indications of its lumpish, stupid appearance. Its actions indicate very little intelligence. It possesses little shyness and still less caution, and hardly learns to discriminate between real and imaginary danger. A firm bond of union between the members of a herd does not seem to exist, but each indiridual acts according to its own judgment. It is true that the fawn follows its mother, but the herd does not invariably follow its leader, as is the case with other Deer. During the mating season the males are very much excited, challenging each other and fighting with great obstinacy and ferocity. They readily attack Mlan at this time and continually wander around, day and night, apparently possessed of a feeling of vague disquiet and unrest. The affection of the Elk mother for her fawn is very great. she defends even her slain young one, and if her infant be taken from her she roams about the place of its capture searching for it for day's.

The Elk's In spite of the Ell's strength, it has Enemies and to fear other enemies besides Man, Uses. especially the Wolf, Lynx, Bear and Glutton. The VIolf usually tears an Elk down in winter in deep snow; the Bear is prone to sneakingly approach only solitary animals and refrains from attacking a troop; the Lynx and occasionally the Glutton spring on an Elk passing under the tree which shelters them, fasten their claws into its neck and bite through its arteries. They are the most dangerous enemies of the strong Elks. Wolves and Bears, however, need to proceed cautiously in attacking an Elk, for the latter knows how to ward off an attack successfully, even when deprived of its vigorous antlers, using the hard, sharp hoofs of its forelegs with much skill and vigor.

Elks taken young may be tamed and even allowed to wander about at liberty; in Germany, however, they rarely survive captivity for a long time. In Sweden they are said to have been trained to draw sleds, but a law was passed prohnbiting this practice, "for the speed and endurance of the Elks would have rendered the pursuit of criminals impossible." Later attempts to domesticate the Elk have failed. The young appear to thrive at first, but subsequently they become reduced in condition and die.

The profit to Man of the carcass of an Elk is considerable. Venison, hide and antlers are all put to account, like those of the other Deer. The flesh is tougher, but the hide is firner and better than that of the Red Deer. Elk hide was highly esteemed and brought a high price, in the middle ages especially. But all the profit of the Elk is far from compensating for the damage it inflicts. The animal is most clestructive to the trees in woods which it inhabits and is so great a menace to the existence of well kept forests that it ought not to be cared for or protected in those regions in which there is any attempt made to practice forestry after modern and improved methods.
Difference Between The Moose or Moose Deer of Eng. the Moose and Eu- lish-speaking Americans, and called ropean Elk. Orignal by French Canadians (Alces americanus, or alces malchis) differs from its Old IVorld relative in the deeply indented blades of its antlers, with separate spur sprouts, its dewlap scantily grown with hair and its darker color. Opinions about this animal are as yet by no means settled, though some naturalists have clained to find point of distinction not only in the texture of the fur but also in its darker color, particularly on the hams of the animal. I have seen living animals of both hemispheres beside each other, and have not been able to find any considerable difference, so that I hardly believe that they can be considered distinct species. The antlers of the Moose are stronger and heavier than those of the European Flk and may attain a weight of sixty to eighty pounds. Hamilton Smith gives the following description: "The Moose Deer is the largest species of Deer, for it is taller than a Horse at the withers. If one were to deny the grand impression this animal produces on the spectator, it would be probable that he had seen only stuffed females or young individuals. We had the opportunity of beholding Moose Deer in the prime of their development, with completed antlers and in their wild state, and we must confess that no animal makes a more magnificent appearance. The head is over two feet long, but has a clumsy appearance; the eye is proportionately small and deep-sunken; the ears resemble those of a Donkey and are long and hairy; the spurs of the antlers may sometimes number as many as twenty-eight."

The Range of the The Moose Deer is still found in Moose and Method the northern portions of North of Hunting it. America, especially in Canada, New Brunswick and on the shores of the Bay of Fundy. Franklin found it at the mouth of the Mackenzie and eastward along the Coppermine river at the sixty-fifth parallel. Mackenzie also found it on the heigluts of the Rocky Mountains and along the sources of Elk River. The Moose Deer casts its antlers later than does the European Elk, usually in January and February, and in severe winters as late as March. The food of the Noose is probably identical with that of the Elk.

The northern Indians hunt the Moose extensively and in various ways. One of their principal devices consists in driving the animal into the water, where they approach it in their canoes and slay it without difficulty. These people affirm that after partaking of the flesh of the Elk, they can travel three times as far as after a meal consisting of other meat. They make large spoons out of the antlers and utilize the hide for corering their canoes. Toung Moose Decr can easily be tamed, for they learn to know and trust their keeper after a few days captivity. But with increasing age they, like their relatives, become savage, hasty-tempered and dangerous.

\section{THE REINDEER.}

Among the Reindeer (Rangifer) both sexes have antlers, which rise from a short bony protuberance on the frontal ridge, describe first a backward and then a forward curve, expand in a blade-like manner at their extremities, have finger-shaped indentations and are slightly furrowed. Very broad hoofs and rather long, bluntly pointed rudimentary toes distinguish this species of Deer. Their shape is rather cumberous, the head being specially ungainly; the legs are relatively short; the tail is very short. The 
old males sometimes, but not uniformly, have small canine tecth in the upper jaw; the females never liave them.

The Reindeer may be styled the most useful of Deer. Entire nations owe their existence to it; for they would cease to be did they not possess this strangcly chosen domestic animal. To the Laplander or Finlander the Reindeer is much more of a necessity than the $U_{\mathrm{x}}$ or Horse is to $\mathrm{ts}$, or the Camel and Goat to the Arab; for it must perform the aggregated services of nearly all other domestic animals. The tame Reindecr yiclds fesh and skin, bones and tendons, to furnish its master with fooc and raiment; it yields its mill; it scrves as beast of burden and drags the family and the houschold groods from one place to another on a light sled; in short, the Reindeer renders the nomad life of the northern tribes possible.

I know of no other animal in the life and treatmant of which the burden of servitude, the curse of slavery, is expressed so clearly as in the case of the $\mathrm{R}$ eindecr. There is no doubt that the wild Scandinivian Reindeer is the ancestor of the domestic animal of that country. Tame ones, released from the restraint and protection of Man, revert to savagery in a very short time and become entirely assimilated to the wild ones after a few generations. Yet there hardly exist two creatures differing so very widely in shape and temper as the tame and wild Reindeer. The former is a miserable slare of a poor, miserable master, the latter a proud monarch of the lofty mountains, a Chamois-like Deer, possessing all the noble qualities pertaining to so beautiful a creature. He who has seen free Reindeer in troops and tame ones in herds and compared them, can hardly believe that both are children of the same ancestor.

Description The Reindeer (Rangifoturamdus) is
of the Rein- a stately creature of Stag-like pro-
deer.
height. Its length varics between five feet eight inches and six feet eight inches; the tail measures five inches, the height at the withers is three feet seven inches. The antlers are inferior in size and still more in beauty to those of the Stag, yet constitute a stately ornament. The body of the Reindeer differs from that of the Stag, perhaps only by the greater breadth of the hinder quarters; but the necli and head are much clumsier and less beautiful, the legs considerably shorter and the hoofs much more unsightly than those of the Red Deer. The Reindeer also lacks the proud bearing of the Stag: it carries itself much less haughtily than that noble animal. The neck has about the same length as the head; it is sturdy and laterally compressed and barcly curves upwards; the head is slightly narrower in front, with a blunt, bulbous snout, straight along the nasal ridge. The ears are shorter than those of the Stag, but of similar formation; the eyes are large and beautiful; the tear-pits small and covered with tufts of hair. The thighs are thick, the legs stout and short, the hoofs very large, broad, flatly compressed and deeply cloven; the rudimentary toes reach to the ground. In tame Reindeer the hoofs increase so much in width that one would have to separate the wild and tame ones into different species, if he considered the structure of the hoofs alone. The wild Reindeer are generally of a much more dainty and attractive appearance than the tame ones, which by contrast seem deformed and plain.

The coat is closer than that of any other Deer The lower portion of the neck is adorned with a mane, which sometimes reaches to the chest, and the latir on the cheels is also longer than on other parts of the body. In winter the hair is nearly thrce inclies long all over, and as the hairs lie very close together they form a coat of over one and a half inches in thickness, which explains the fact that the Reindecr can easily bear an exceedingly cold temperature. The general color saries in the different individuals and also according to the season. The wild Reindeer change their coat and its bue, rather regularly, twice a year. In spring the copious winter inair is shed and is replaced by a short, gray coat; then other hair gradually mingles with it, its white tips entirely overshadowing the gray hair, until the whole animal appears whitish gray, strikingly resembling the tint of melting, dirty snow. The tame Reindeer is of a dark brown huc in summer. In winter the brown color disappears, and the white hair predominates; but there are many Reindeer which are characterized in winter only by a greater length of hair, the hue remaining unchanged. The antlers of the female are snialler and have lewer spurs than those of the male.

Early History and Some naturalists regard the AmcriPresent Range of can Reindeer as a distinct species,

the Reindeer. and base their opinion on the fact that the European Reindeer is also found on the American continent and differs from the other in dimensions, hue and liabits. The Caribou (Rangifer caribu) is said to be larger than the Reindeer, to have smaller antlers and a darker color and live more solitarily, and mainly in woods.

The high north latitudes of the Old World, and if the American Caribou is counted as belonging to the same species, also the northmost habitable regions of the New, are the native country of the Reindeer. It is gencrally found north of the sixticth parallel in all countries; in some localities descending as far south as the fifty-second parallel and ranging northward invariably beyond the eighticth parallel. One finds it wild in the glacial mountains of Scandinavia and Laplancl, in Finland, in the whole of northern Siberia, in Grecnland and on the northmost mountains of continental America, and it also lives on Spitzbergen. It was introduced into Iceland over a century ago, and it las completely reverted to the wild state on that island and has spread in considerable numbers over all of its mountains. In Norway 1 found it in considerable numbers on the Dovrefjeld. It also occurs on the lofty mountains of Bergen and ccrtainly descends there as far south as to the sixtieth parallel of north latitude.

The Domicile and The Reindeer is a genuine mountain

Habits of the child, like the Chamois, and is found Reindeer. only on the broad, treciess ridges of the northern mountains, called by the natives fjelds, and overgrown with moss and a few mountain plants. "In Norway the belt betwcen three and six thousand feet of altitude forms its usual place of abode. It never descends in those regions to the forest belt, anxiously avoiding woods in general. The barren table-lands and slopes, between the rocks of which grow some straggling plants, or those vast elevated plains, which are thinly covered with reindeer-moss, nust be regarded as the home of these animals, and it is only in migrating from one range of mountains to another, that they traverse the boggy, morasslike, low plains; and even during such changes of location do they anxiously shun the forest. Pallas states that the Reindecr is occasionally to be found 
in the woods of northern Siberia, and Von Wrangel confirms this statement. Both these writers inform us that it undertakes extensive and regular migrations in Siberia. "Towards the end of May," says Von Wrangel, "the wild Reindeer leaves the woods in large herds, having sought shelter there against the severe cold during the winter; it wends its way towards the northern plains, partly because it finds there on the surface more abundant nourishment of moss, but partly, also, to escape the Gnats and Flies, which abound in such enormous swarms at the commencement of spring as to darken the air. The migration in spring is not profitable to the natire defined, beaten roads. In crossing a river, they select a spot where a firm, stable road from the valley leads to the point of entrance on one bank and a hard sandy bottom facilitates their landing on the opposite shore. Each separate herd crowds closely together and the whole surface is covered with swimming animals." On the continent of America the animals migrate, as do their kin in Siberia, from the mountains to the coast and back. Sir John Franklin says that they leave the lowlands with their young (which have been born there) in July and August; in October they have reached the boundary of the cold tracts of country and seek shelter and

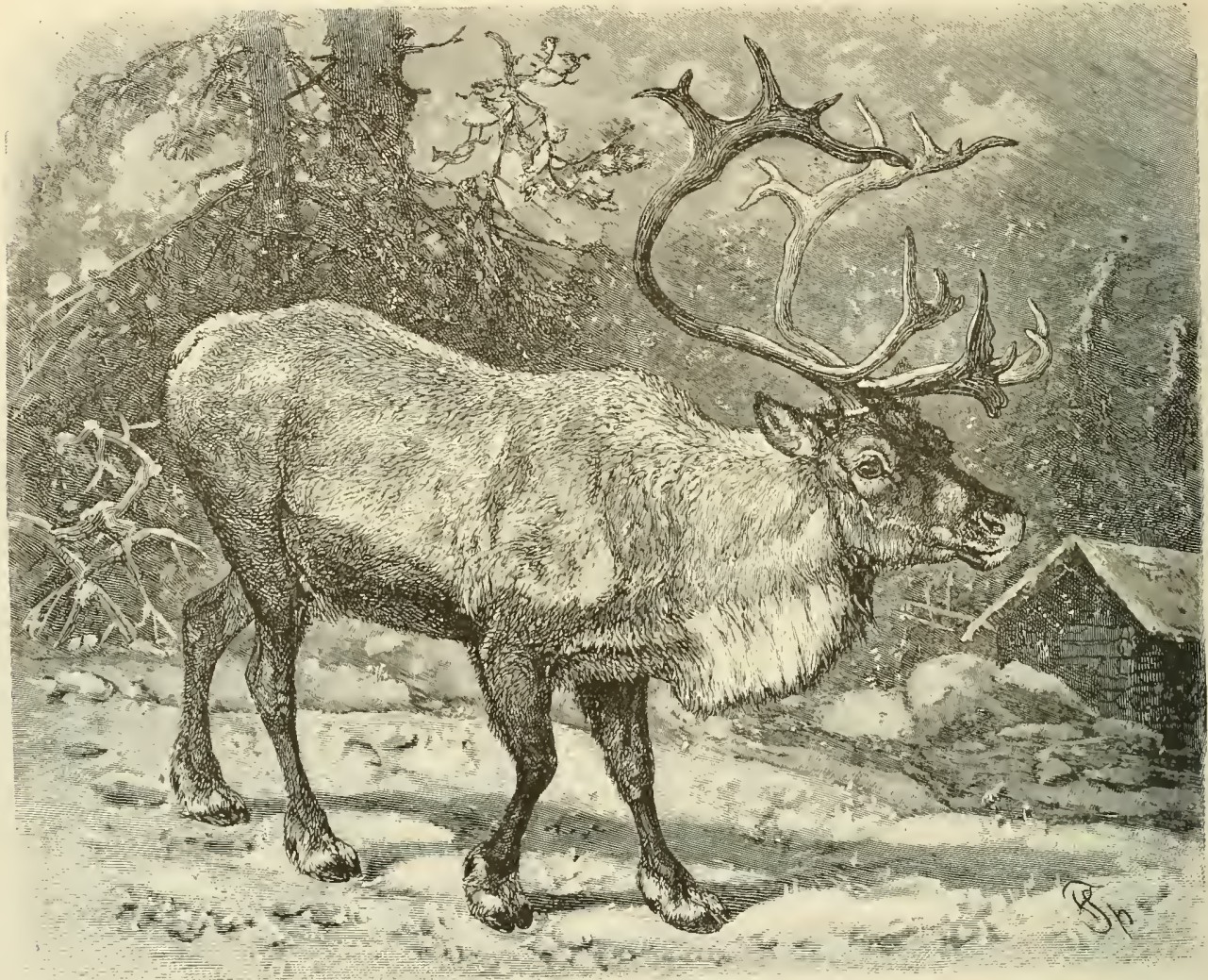

THE REINDER. - The most useful of all species of the Deer family is the Reindeer, which, in the countries of the frozen uorth is the principal draught animal. The tame breed is somewhat deteriorated in size, but the number of the wild species is much diminished on account of the manner in which they are trapped and domesticated by the natives. The antlers, which are borne by both sexes, grow to great size and branch in a peculiar manner, as shown in the picture. (Rangifer tarandies.)

tribes; for at that season the animals are lean and quite covered with lumps and wounds from the poisonous stings of insects. In August and September, however, when the Reindeer again returns from the plain to the forest, they are sound and well nourished and their venison is palatable and wholesome. In favorable years the herds consist of several thousand in number, which may be resolved into smaller flocks of two and three hundred each, kecping rather close together, however, so that the whole makes up one immense, tolerably compact mass. In their migrations they always travel over the same route, making in their wanderings well- sustenance in the forests in winter. As soon as the snow begins to melt on the mountains, they again lcave the elevated woodiands and gradually descend to the plains. Packs of Wolves, which seize many a victim, follow their footsteps, and bands of Indians lie in wait for them along their established "runs," which the animals traverse with the greatest regularity.

Physical and Men- The Reindeer are admirably adapttal Development of ed to inhabit those northern regions, the Reindeer. which in summer are really only one stretch of morass and in winter only one continuous snow-field. Their broad hoofs cnable them to trav- 
crse the fenland and the surface of snow as well as to climb up the slopes. The gait of the Reindeer is a rather quick pace or a rapid trot, and nearly every step is attended by a peculiar crackling sound, comparable to that produced by an electric spark. When walking slowly over a marshy surface the Reindeer expands its hoofs to such an extent that the footprint resembles that of an $O \mathrm{x}$ much more than that of a Deer, and walks over the snow in a similar manner, not sinking into it after the snow has settled down in any measure. Swimming comes very easily to a Reindeer.

Wll the perceptive senses of the Reindeer are excullent. Its power of smell is extremely acute, beingr efficient at a distance of five or six hundred paces, as I have personally convinced mysclf. Its hearing is at the least as sensitive as that of the Stag, and its sight is so quick that a huntsman, if he wishes to be successful, has every reason to hide most carefully, even if he approaches against the wind.

In summer the wild Reindeer feeds on juicy mountain plants, especially on the leaves and flowers of the snow-ranunculus, the Reindeer sorrel, the common crowsfoot, and the fescul-grass, in winter on lichens.

Reproduction, In Norway the little ones make their Chase and Value of appearance towards the middle of the Reindeer. April. Wild Reindeer are said never to give birth to more than onc fawn, which is a trim little creature, and the mother apparently loves it tenderly and suckles it a long time.

The chase of the wild Reindeer requires a sportsman passionately fond of it or a true naturalist who does not mind hardships and privations. The first shot throws a troop into such confusion that the Reindeers stand still in utter astonishment, and flee only after they have descried the hunter. The Norwegian hunters are aware of this peculiarity of the animal, and like to hunt alone or in small parties. They cautiously approach a troop, take aim at some particular animals, and one of them fires first; then the others shoot also. The chase of the Reindeer is of the utmost importance to many Siberian tribes.

"The Yukaghirs and the other inhabitants of the country along the Anyui riter in Siberia," says Von IVrangel, "depend entirely" on the Reindeer, which furnishes them almost exclusively with food, raiment, means of locomotion and houses, just as it does for the people of Lapland. The results of the Reindeer chase determine whether faminc or confort shall prevail, and the season of the Reindeer migration is the most important part of the year. When the animals reach the rivers in their periodical migration, and prepare to swin over, the hunters, who have been skulking behind bushes and rocks, dart forward in their little boats, surround the herd and endeavor to stop it, while two or three of the most skillful row among the swimming crowd and succeed, in an incredibly short time, in slaying, or severely injuring, a great number of animals that, as a result of their wounds, are scarcely able to reach the shore where they fall into the hands of the women, girls and children. The hunt is exceedingly perilous, however, for the small, light boat easily capsizes in the midst of the enormous throng of animals swimning, one closely beside another, and moreover the pursued animals defend themselves in every possible way: the males with their antlers and teeth, the females with their forelegs with which they are wont to jump on the gunwale of the boat. If the boat capsizes the hunter is usually lost, for it is well-nigh impossible for him to work his way out of the throng."

The Indians of the extreme northern parts of North America hunt the Reindeer in a similar manner, King says. These people are also almost entirely dependent on this animal for everything which contributes to their comfort or permits their existence. Vast herds - many thousands in number migrate northward to the Arctic Ocean in spring and southward again in the fall. At the time of this last migrition they have a layer of fat from three to five inclues in thickness under the skin of the back and croup and therefore they are the main object of the chase. They are shot with fire-arms, causht in snares or killed with spears while crossing rivers; deep pitfalls are dug for them, or the trapper constructs two fences of branches and shrubs, and leaves narrow gaps in each, provided with snares; the herd is driven between the fences and the people capture those which try to break through, or stab them when they come out.

Economic Value The Indians make similar uses of

of the Rein- the carcasses of the wild Reindeer as deer. do the Laplanders of those of their tame herds. The antlers and bones are made into fish-spears and hooks; the meat, fat and hair are scraped off the hides with the split shin bones; the skin is rubbed with the brains, to render it pliant; the leather is tanned by being smoked with rotten wood and is then hung around the tent-poles; the raw hides are made into bow-strings and nets; the tendons of the back are split into fine thread; the soft. fur-like skins of the fawns must provide the Indians with clothing. They wrap thomselves in Reindeer skins from head to foot, throw a soft tanned skin on the snow, cover themselves with another, and thus are cnabled to bid defiance to the severest cold. No part of the Reindeer is left unutilized, not even the partiy digested food found in the stomach, which when it has lain for some time and undergone a certain fermentation, is reckoned to be a very dainty dish.

The wild Reindeer has many enemies besides Man. The most dangerous of all is the llolf. This beast of prey always hangs on the outskirts of the herds, but is most dangerous in winter. In Norway the attempts at Reindeer breeding which werc made in the southern mountains had to be abandoned on account of the Wolves. The Wolverine, I,ynx and Bear also prey on the Reindeer. Next to these large predaccous animals, small and apparently insignificant insects must be counted their most annoying if not their worst foes.

Reindeer taken young bccome tamc very soon; but one would err greatly if he were to place Reindeer, in regard to tractability, on a level with other animals recluced to a statc of domesticity. Not even the descendants of those which have been in captivity from time immemorial, are as tame as our common domestic animals, but they always remain in a half savage condition. Only Laplanders and their Dogs are able to guide and rule such herds.

Characteristics and Laplanders are not the only race Habits of Domes- to occupy themselves with Reindeer tic Reindeer. breeding, in which pursuit the Finlanders and many Siberian tribes also engage. The tame Reindeer is the stupport and the pride of the Laplander; it is alike his pleasure and wealth, bis burden and his torment. In his opinion he who numbers his Reindeer by the hundred, has reached the pinnacle of human bliss. Some few Laplanders 
possess from two to three thousand, but the majority do not exeeed five hundred. The fjeld Laplander, who is the genuine Reindeer breeder, looks proudly down on alt other members of his tribe, who have given up nomad life and have either settled on the shore as fishermen or gone ont in service among the Scandinavians; he believes himself alone to be truly independent and he knows nothing more desirable than his Reindeer herd.

Such a herd presents a curious and highly interesting spectacle. It really resembles a wandering forest assuming of eourse the forest to have been deprived of its leaves for the time being. The Reindecr proceed in close ranks like Sheep, but at a brisk. even pace, skimming over the ground more rapidly indeed than any of our domestic animals. The heeper with his Dogs walks on one side, busily engaged in keeping the herd together.

If there is good pasturage near, the Laplanders build a penfold, to facilitate milking, and drive the animals into it every evening. Reindeer remind one of shecp by their restlessness and their continual bleating, though the sounds which they utter are more like the grunting of swine. The great majority of those kept in herds are very small: one sees but a few large animals among hundreds. The irregularity of the size of the antlers also impresses one disagreeably. In approaching the penfold, one first hears the constant bleating and then a sharp, crackling noise, as if hundreds of electric batteries were active, due to the perpetual moving to and fro of the animals and the castanet-like action of their hoofs. In the middle of the penfold lie several large trunks of trees, to which the Reindeer are fastened while they are being milked. No keindeer suffers itself to be robbed of its milk without being first secured with a lasso, and therefore every Laplander of either sex always carries a long strap or a rope. In use as a lasso this is lightly coiled, held by both ends and thrown so as to fall around the neck or antlers of the animal; then the milker gradually pulis it nearer until he has drawn it up quite close; a sailor-knot is next hitched and put around the animal's mouth, thus securely bridling it and compelling complete obedience. Then the end of the lasso is fastened to the tree trunk and the business of milking begins. While this lasts, the Reindeer makes various efforts to run away; but the Laplanders know how to foil them and draw the noose around the nose of especially refractory animals so close as to compel then to stand still. The milker approaches the Reindeer from behind, and gives the udder a few slaps with the hand, which empties it. The milk has a pleasing swectish taste and is as rich as cow's cream. As soon as the milling is accomplished, the penfold is opened and the animals go out to pasture, no matter whether they have been collected in the early morning or late at night, for they graze both day and night.

The Great Useful- The entire value of tame Reindecr ness and Value of to their owners can not be estimated

the Reindeer. at all, when we reflect that it furnishes to them almost every necessity of life. Every thing the animal produces is put to account, not only the milk and the palatable cheese made from it, but also the flesh, the blood and every single part of the body. The horns in their carly eartilagenous state are caten with as much gusto as are those of the Elk when in the same condition. The soft skins of the fawns are made into garments; the woolly hair is spun and woven; the bones furnish materials for various tools; the tendons are utilized as thread. Then the animal must supply the motive power for conveying the entire family with all their chattels from one place to another, especially in winter. In I apland the Reindeer is mainly used for purposes of draught and less for carrying burdens on its body, as the latter mode of conveyance is very hard upon it on account of its weak back and loins. The Tungus and Koryak tribes in Siberia, however, ride on the strongest male Reindeer, placing a saddle over the shoulder blades, and sitting astride of the queer looking saddle animal. In Lapland nobody rides on Reindeer and it is only the strongest inales or "oxen" as the Norwegians say, that are employed for driving. Good beasts of draught easily bring a price of from eight to twelve dollars, while the ordinary Reindecr costs from three to four and a lialf dollars at the most. A Reindeer is never previously trained or broken; but a strong animal is selected out of the herd and harnessed to a sled, which is higlly suitable for the purpose, being perfectly adapted to the nature of the country and to the powers of draught of the Reindecr. It is very different from the sleighs in use elsewhere and resenbles a boat. It consists of very thin birch boards which are nailed to each other, curved in boat shape, beginning at a broad keel, thus forming a trough, the front part of which is covered. Naturally only a single person can sit in such a boat-like sled. 1 or luggage or merchandise the traveler employs sleds which can be covered on top with sliding lids, but are similar to the passenger sleds in all other respects. A good Reindeer travels about six miles an hour, dragging a load of from two hundred and forty to two hundred and eighty pounds; but usually the load is much lighter. In summer it is not used in the capacity of a beast of drauglit in Norway. If one is careful with strong, well-fed Reindeer-that is, if the beasts are permitted to work only a few hours in the morning and evening, and are allowed to graze at noon and night-he can travel over astonishingly great distances with them, without overtaxing their strength.

Close captivity is very distasteful to a Reindeer: yet it thrives fairly well in zoological gardens if tended with proper care, and it usually propagates in eaptivity. The warm temperature of the low country in summer does not agree with its health, while it is perfectly indifferent to the severest winter cold. Correspondingly it would be more adapted than any other Deer for introduction into forcign countries on woodless high table-lands among mountains where the Reindecr-lichen grows. It would be very comfortable there, would soon become used to its surroundings, propagate its species and become an object of the chase. I mentioned this fact years ago, and tried to demonstrate that it must necessarily thrive on the high mountains of Germany. The attempts that have been made have fulfilled my predictions if not my desires. It is only necessary now to proceed to further experiments with due earnestness and the proper knowledge, and consequent success cannot fail to follow.

\section{THE FALLOW DEER.}

The Reindeer are naturally followed by the Fallow Deer (Demul). The genus is known by their horns, which are round and furnished with two spurs on their lower portion and cxpand above into an elongated blade with spurs on the margins, directed upward and backward. 


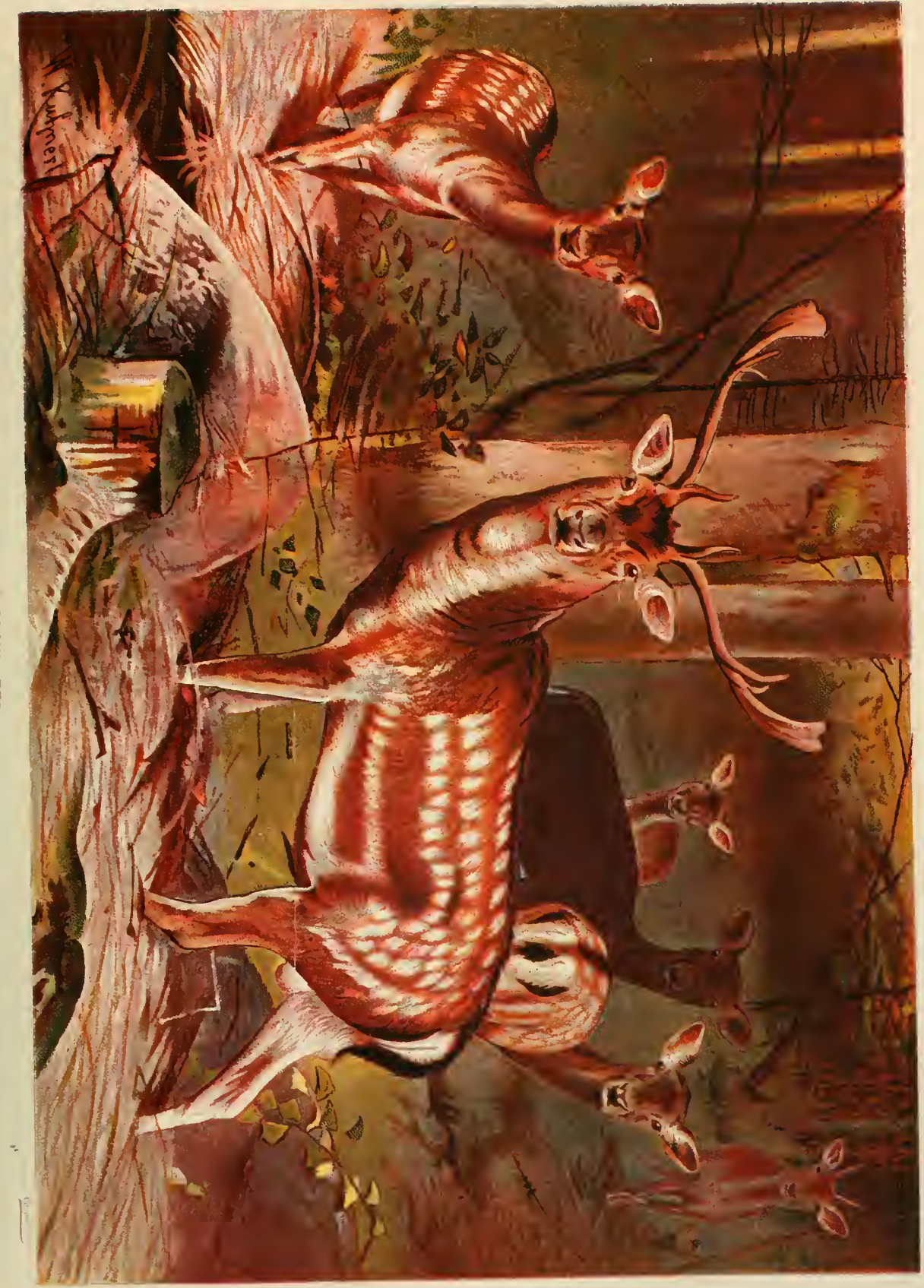





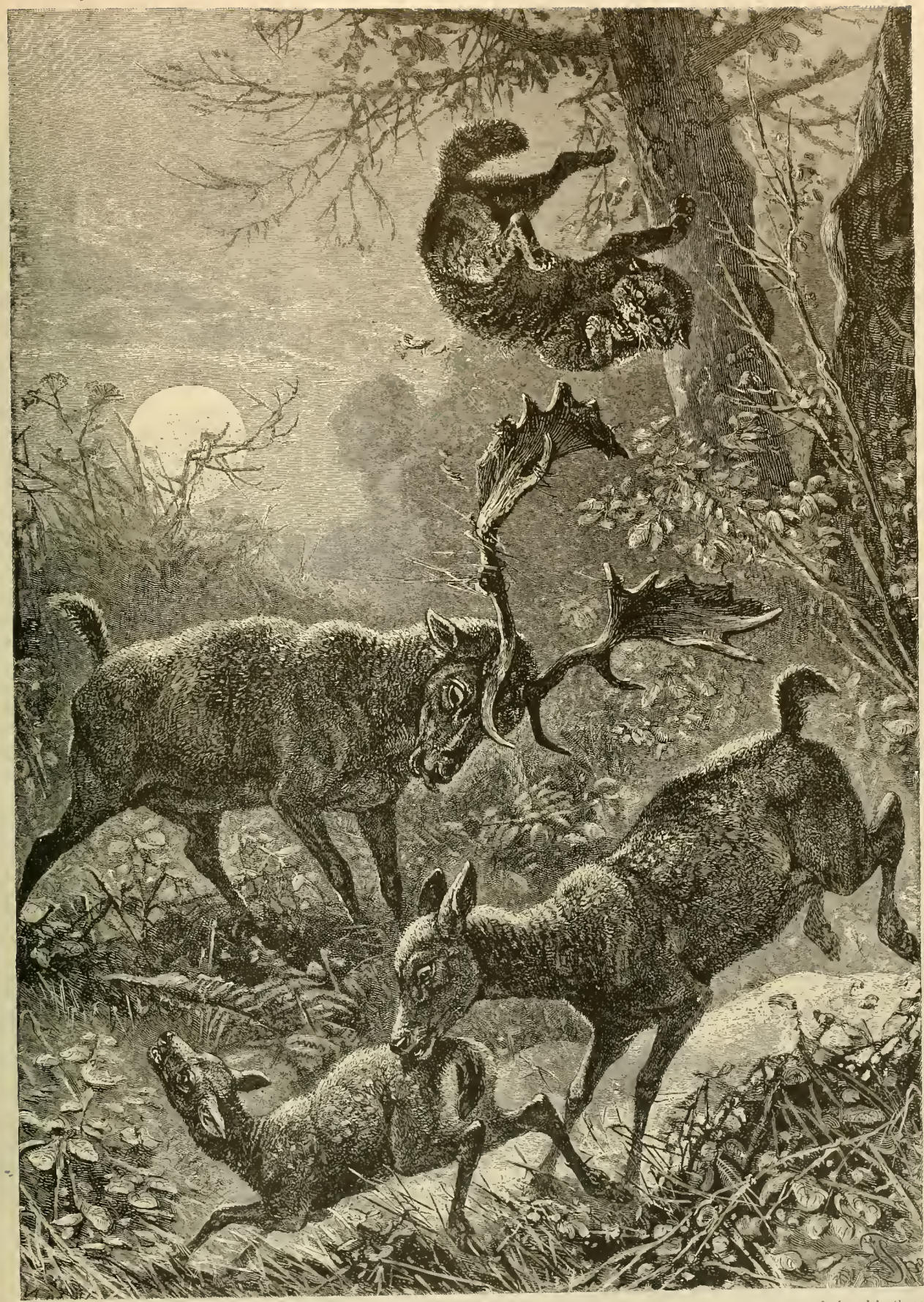

FAILW Dis in all northern and central Europe, but now only found in those countries in parks and preserves, although it still occurs wild in western Asia. The picture presents an exciting forest scene. The family has been disturhed by a feline intruder intent on making a the 
Pange and History The Fallow Deer affects temperate of the fallow climes more than cold ones and Deer. therefore has always been frequent along the Mediterranean. Its range extends southward to the northern margin of the Salara, northward to the southern portions of Sweden and Norway. It is probably most plentiful in England, where it is bred in great numbers in the parks of the large land-owners. It especially delights in a rolling country where gentle slopes alternate with low hills, groves, underbrush and forest trees and where the soil is grown with short grass. It seems created for parks and one can hardly imagine a better ornament for large pleasure-grounds than the Fallow Deer.

Physical Pecul- The Fallow Deer (Dama inlgaris) is iarities of the Fal-greatly the inferior of its noble kins. low Deer. man, the Stag, in size. Inclusive of the tail, which is from six to eight inches long, it measures about five feet four inches in length; its height at the shoulders varies between thirty-four and thirty-six inches and the height at the croup between thirty-six and thirty-eight inches; its weight probably seldom exceeds from two hundred to two hundred and forty pounds. The doe is smaller. But few of the other Deer show such modifications in color as the Fallow Deer, according to the season and the age. In summer the upper surface, the thighs and the tip of the tail are reddish brown, the under parts and inner sides of the legs being white; blackish rings surround the mouth and the eyes; the hair of the back is whitish at the base, reddish brown in the middle and black at the tip. In winter the head, neek and ears are brownish gray, the back and sides blackish, the lower surface ashy gray, sometimes tinged with red. White indivichuals are not very uncommon. They do not ehange their color at any season and are distinguished in winter only by the greater length of their hair. Some Deer also have a yellowish coat in youth; black specimens are rarer.

Habits and Mental The Fallow Deer is less shy and Attributes of Fal- cautious than the Stag, neither can low Deer. it by its sense of smell detect the presence of Man at so great a distance, but only for about three hundred paces. It often roams about in clear spots in the woods in bright daylight, but does not undertake its journeys so regularly or for so great a distance as its relative. It is inferior to the Stag in fleetness, leaping power and agility; it lifts its legs higher in trotting and jumps in bounds, after the manner of Goats, elearing the ground simultaneously with all four feet. If not engaged in full flight the tail is lifted when running. It can clear obstacles of over six feet in height, swims fairly well, but never wallows like the Stag. The food of both Deer is the same; but the Fallow Deer does more stripping of bark and thereby renders itself a nuisance. It is a surprising fact that this Deer sometimes eats poisonous plants, which eause its death.

Reproduction and The doe gives birth to one or, more Development of the rarely, two fawns, generally in June.

Fallow Deer. The little one is very helpless in the first days of its life and receives from its mother careful protection and shelter. Smaller predaceous animals that may exhibit intentions inimical to the bright colored little fawn are driven off by the mother by striking them with her fore-legs; larger and more dangerous beasts she decoys away from the place where her infant rests by walking slowly away, inducing the beast of prey to follow her as an intended victim; when she has accomplished this object, she completes the stratagem by fleeing rapidly from the presence of the enemy and returning to the spot where the young one lies, after innumerable detours and doubles. When the fawn is six months old an elevation can be noticed on the bony projections of the frontal ridge of the skull in the male, out of which the horns sprout by the end of February and go on developing till August, when they are shed. It is not until the fifth year that the blades of the antlers begin to develop, and they increase with time in size and in the number of marginal spurs. The old Deer shed their horns in May, the young ones in June, usually not both antlers simultaneously, but with an interval of two or three days between the periods of denudation. The new antlers are developed by August or September.

The Fallow Deer The Fallow Deer is either "stalked" as a Game and shot with a rifle, or hunted with Animal. a great number of hounds; sometimes Men are employed as beaters to rouse the game. Success generally rewards one who has patience to lie in wait for it, as it invariably passes along its regular "runs," as its paths are technically called. The skin is valued more than that of Red Deer on account of its softness and pliability. The venison is very savory, especially when the animal is killed during the season, from July to the middle of September, the Deer accumulating much fat during that period.

This Deer is better adapted for parks than any other species; it readily becomes familiar with mankind, frequents spots cleared of trees in the day, thus allowing itself to be seen, and is of a playful or even mischievous disposition. In one respect it can also be considered a weather prophet: when it is especially restless and capricious, unpleasant or stormy weather may be looked for with a considerable degree of confidence. The Fallow Deer preserve their cheerful temper in closer confinement also, easily becoming accustomed to it. They seem to be especially fond of music; even those in the free state approach to listen when they hear the sounds of a bugle.

\section{THE RED DEER}

Among the Deer in the narrowest sense, are the Red Deer (Cornus) which belong to both northern belts; the males alone have antlers, with round branches. Of the more or less numerous spurs, at least three are directed forward. The outer face of the hinder ankles are furnished with hair tufts. The tear-pits are distinct. In old males, and more rarely with very old females, the canines in the upper jaw protrude far beyond the others.

Description of One of the stateliest and noblest the Stag or Red forms of this sub-genus is the Stag Deer. or Red Deer (Cerins claphus). Not-

withstanding its slenderness it is of vigorous and handsome organization, and its bearing is noble and proud. Its physical proportions vary considerably, according to the country in which it is indigenous. It attains a total length of from six feet two inches to seven feet two inches, some six inches of this being included in the tail. The height at the shoulders varies between four and five feet and the weight between three hundred and twenty and five hundred and forty pounds; but there also occur uncommonly large specimens, which may weigh six hundred pounds and upwards The female is considerably smaller and is differently colored. In respect 


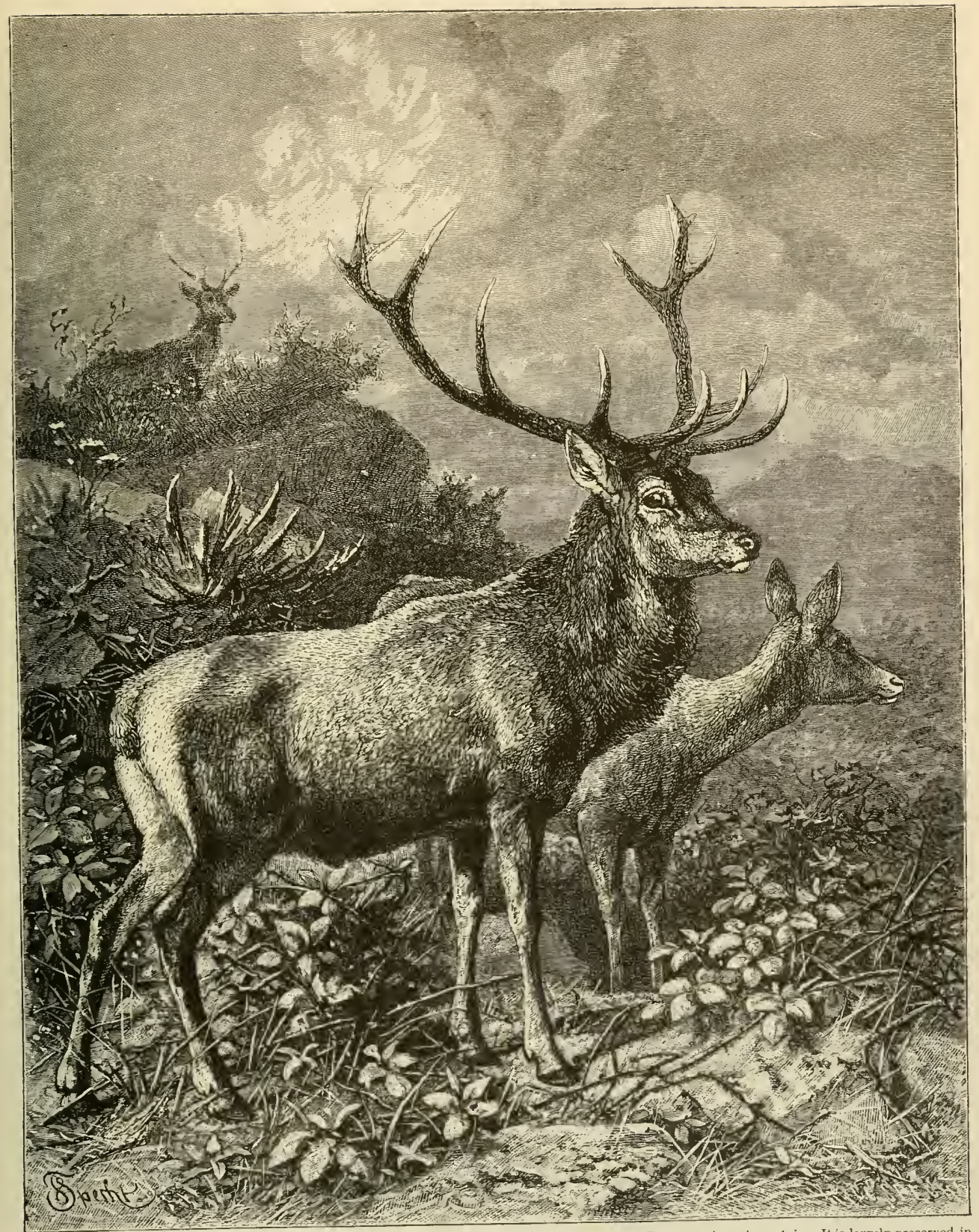

ST - This is a noble species of Deer, found in the temperate regions of Europe and northern Asia. It is largely preserved in forests in Scottand, where a Stag which has more than twelve points or tines on its antlers is known as a "Royal Stag." This number is, however, trequently exceeded. The (Cervus elephas.) 
to size the Stag is inferior only to the Wapiti and the Persian Deer, exceeding the other known species of its genus. It has an elongated body, retracted in the flanks, with a broad chest and strongly projecting shoulders, a straight, flat back, which is somewhat high at the withers and rounded on the croup, and a long, slender, laterally compressed neck. It has a long head, high and broad at the back, strongly tapering in front, with a flat forehead and with depressions between the eyes and along the nasal region from the eyes to the muzzle. The eyes are of moderate size, and are bright and animated in expression, with long, round pupils. The tear-pits are placed obliquely towards the corner of the mouth; they are rather long and form a narrow, oblong depression, the walls of which secrete a fatty mucous matter, which the animal presses out by rubbing against trees. The body is supported on slender legs of moderate length, and the toes are encased in straight, pointed, narrow and slender hoof-like nails; the rudimentary digits are rounded and lons, cut off squarely at the extremity and hang straight down, without touching the ground, however. The tail is of conical shape, tapering towards the tip. A fine woolly coat and a coarse outer-fur cover the body and lie rather smooth and close, becoming considerably longer at the throat. The stiff upper lip, which does not hang over, is beset with three rows of thin, long bristles; similar hairs stand out above the eyes. The color of the animal is subject to modification according to the season, sex and age. In winter the outer-fur has more of a grayish brown tint, in summer more of a reddish brown; the woolly coat is ashy gray with a brownish tip. The fawns alone show white spots on a red-brown ground color, during the first months of their lives.

The antlers of the Stag are set on short shafts, and are very pronounced in their branching, bearing many spurs and standing erect. They curve from the base in a strongly arched outline, directed, in relation to the planc of the forehead, backward and outward; toward the upper extremities they again curve inward and turn their tips slightly towards each other. There is a spur at the base in front, directed up and forward; above this is another, and others spring from the middle of the horns; the extrenities form the crown, the spurs of which differ in position and size according to the age of the Stag, varying in different individuals. The horns are round, rough and more or less burred, especially in the lower parts, and have numerous straight or convoluted longitudinal furrows. The tips of the spurs are smooth, polished, of a dingy white or yellowish color, while the color of the main portions of the antlers themselves ranges from a light tan to blackish brown, according to the coloring effects of the juices of the plants which have stained them. Large antlers weigh from ten to sixteen pounds, and may in exceptional cases attain a weight of from twenty to twenty-four pounds, or even more. The horns may measure from thirtytwo to forty-eight inches along the curvature, or even more in some rare cases.

In the language of hunters, especially as expressed in the ancient "art of venery," the fawn of the Red Deer is called a "hind-calf;" in its second year it is called a "pricket," in its third a "brocket," in the fourth a "stagon," in the fifth a "stag," and from its sixth year the name of "hart," is applied. Other authorities use the term "brocket" for the second year, "spay" for the third and "staggard" for the fourth year. The female is known as a "hind."

Range and Move. The Stag still inhabits nearly all Euments of the rope, with the exception of the highstag. est northern latitudes, and closely allied species inhabit a large part of Asia. The northern limit of its range reaches to about the sixty-sixth parallel in Europe and the fifty-fifth in Asia. To the south its range is restricted by the Caucasus and the mountains of Manchuria. Its numbers have greatly decreased in all populous countries and in some it has become extinct. It is most plentiful in the Caucasus and the vast forests of southern Siberia. The Red Deer prefers the mountainous regions to the plains and especially delights in large tracts of umbrageous forest. These Deer assemble in large or small herds which divide off with reference to their age and sex. The hinds and young fawns usually remain together; the old females form small troops of their own, and the old males usually live solitarily. In winter the Red Deer descends from the mountains to the plain; in summer it ascends to the summits of the secondary ranges [the mountains which are intermediate between the foothills and the highest snow-capped peaks]. It adheres to its established range unless pursued, and only strays away of its own volition during the mating season, or while the new antlers are growing, or when impelled by lack of food to seek new pastures.

The movements of the Stag are all light and graceful, but at the same time its bearing is proud and majestic, the male, especially, being an animal of noble carriage. The ordinary gait is a rapid walk. In trotting the Stag moves with great swiftness, and in running attains remarkable speed. In play it takes cnormous bounds, clearing obstacles of great height. It is a fearless swimmer, entering deep and broad streams, and in Norway even arms of the ocean, straits and fjords are crossed with ease.

Mental Traits Of the perceptive senses of the Stag

and Habits of those of hearing, smelling and sight Stags. are very acute. It scents a human being at a distance of six hundred paces; and not a sound in the forest escapes its keen ears. It is very timid and shy, but is neither sagacious nor clever. Its memory appears to be weak and its powers of comprehension slight; but yet it gradually learns to profit by experience. IVhen, however, its passions are aroused, it often forgets the consideration of safety, which is usually uppermost with it. Its usual timidity is undoubtedly the result of its experience that Man is its most deadly foe; but when it is fully conscious of protection, it becomes very familiar. When kept in close confinement, or even when at liberty during the mating season, the Stag frequently becomes irritated from the most trifling cause, and may attack human beings. Both ancient and modern books of hunting contain many stories of Stags which have, without any apparent provocation, made injurious or fatal attacks upon people. Between old Stags, during the mating season, most determined battles occur, the combatants using their antlers as weapons. There are instances on record where the antlers of the two participants in such combats have become so firmly interlocked that the animals have been unable to scparate and have died in consequence. In some such cases even human ingenuity and strength have been unequal to the task of separating, without injury to the antlers, the bodies of animals which have died in this manner. 
Fawns of the Red Deer make their appearance one, or in rare cases two, at a birth, at the end of May or in June in some loncly, quiet spot in the woods where the vegetation is most dense. The little ones are so weak and helpless during the first three day's of life that they cannot move from their place. One may even take them up in his hand. The mothers leave them but rarely and only for a short time during this period, and even when driven away, move only just far enough to ward off the real or imaginary danger by decoying the enemy by means of a sham flight. After the fawn is a week old, it is worse than useless to attempt to capture it without nets. It follows its mother everywhere, and immediately crouches in the tall grass whenever she gives a sound of alarm or stamps her fore-foot on the ground. It suckles until the next pairing season, and the mother instructs it from early infancy in the choice of proper food. The female attains maturity in its third year; but the male has to pass through several years more before it attains the right to rule as the "antlered monarch of the forest." Its first horns grow in its seventh month; after that its head decoration changes annually. As a usual thing the spurs of the antlers increase in number annually, but antlers with over twenty regularly shaped spurs have probably been found very rarely. Antlers with eighteen spurs are included in every considcrable collection; and on living Stags antlers with sixteen spurs are no rarity.

The natural enemies of the Red Deer are the Wolf, the Lynx and the Glutton, and rarely the Bear. The IVolf and Lynx are probably the worst. The former, in packs, pursues the Deer in the deep snow, worries and exhausts it; the latter jumps on its neck from the branches of a tree when it unsuspectingly passes under them. The most deadly foe under all circumstances, however, is Man, though now he does not longer pursue and kill the Red Deer in the former reckless and reprehensible manner. I believe I may leave the mode of hunting undiscussed, as a detailed description would lead us too far, and those who are interested in the matter can find full accounts of it in other books. At present this noble sport has been greatly restricted, and the majority of the professional hunters of to-day have never shot a Stag: such quarry is reserved for more aristocratic people.

"The Red Deer is also grievously tormented by some kinds of Gad-flies. These disgusting insects hatch their pestiferous progeny úpon the body of the Deer, exactly as they do on the Reindeer, perforating holes almost entirely through the skin of the poor animals. A species of Louse, which settles in the hair, and Mosquitoes and Gnats also torment this Deer to a great extent.

Unfortunately the damage wrought by the Red Deer is much greater than the profit it brings; not- withstanding the fact that the venison, skin and antlers bring a high price, and one may highly appreciate the pleasure of the hunt, the harm causcd by the Deer is not compensated.

The Barbary In northwestern Africa there is a Deer Related to Deer, which has been separated from the Stag. the Stag under the name of the Barbary Deer (Cervus barbants), but it has by no means been acknowledged as a distinct species by all authorities, rather being considered only a varicty, for it comes nearest the Stag in all respects. () the other species of the sub-genus, the largest of all, the IVapiti of North America (Corrus canadensis) rcmains to be mentioned.

The Wapitia The American representative of the genus Noble American Cerzus, to which the Stag also belongs, is Deer. the Wapiti (Cera'us inaclinsis), sometimes, but erroneonsly, called the American Elk or Gray Moose, and which is named Wawaskeesh by the Cree Indians and La Biche by the French Canadians. There is no more noble species in the
nontire Deer family than this

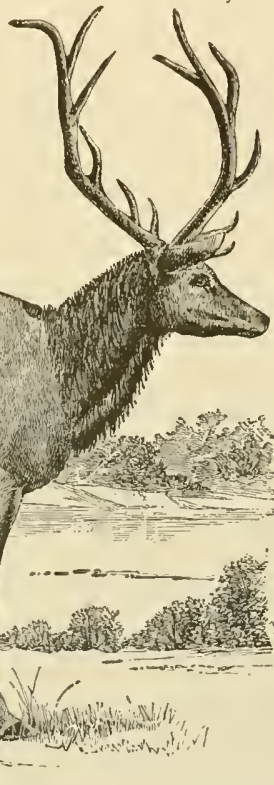

American species of Deer nearly reated here. (Corcus canudensis.) anim which is larger than the Stag, to which it bears a close resemblance in many respects. The antlers of the two animals are much alike but those of the VYapiti are heavier, corresponding to the greater stature of the animal which stands considerably ligher than the Stag, its shoulder height being about fifty-four inches. The hoofs are semi-circular in shape and broader than those of the Stag, and the tail is shorter. The general color of the summer coat is a light chestnut red, which deevens into a brownish hue on the neck and legs, and almost into black on the throat and along the median line of the under surface of the animal. The buttocks are yellowish white bordered by a dusky band which extends down the posterior surface of the hindlegs. The winter fur is dense and soft and its hues are grayer than those of the summer coat.

Like its Old World relative the Wlapiti has retreated from its former haunts in those sections where human beings have become numerous. Its former range in cluded all of the northern and middle states, and in the western part of the continent it extended south to New Mexico; but it is now found in few places east of the Rocky Mountains, such as in Nontana and the Dakotas. It is still by no means rare in northern California, Oregon and Washington, but it is much more frequent in Canada, where its range extends north to Hudson's Bay. It frequents low grounds, preferably well wooded tracts in the vicinity of marshes, and is quite numer ous in the clumps of wood bordering on the upper Mlissouri and its tributaries, and on the Saskatchewan and other Canadian rivers; and it feeds on grasses and the young shoots of the willow and poplar. During the mating season the males have fierce combats similar to those made by the Stag under like conditions, and at this time the male IVapiti emits a peculiar noise, resembling the braying of an Ass, beginning with a loud shrill tone and ending in a deep, guttural note. The growth and shedding of the horns is about the same as with the Red Deer, the horns reaching their full growth about the sixth year. In Nay or June the female, in some convenient thicket, gives birth to a fawn, or in rare cases to two. The development of the young IVapiti is not different from that of the fawns of the European Red Deer.

The Wapitis, in regions where little molested, associate in large herds, but as such localities are few they are usually 
scen in small families of six or seven, for which the older females act as sentinels. The gait of these animals is a swinging, easy trot, or, when pursued, a clumsy gallop. They are not difficult to hunt, but their principal utility is for their skin and antlers. The flesh is coarse and the fat is excessively hard, and the meat is not held in great esteem.

\section{THE AXIS DEER.}

Among the Deer of India we must first mention the Axis, called by the Hindus, Chital, and by the English, the Spotted Deer (Axis axis). It represents a distinct sub-genus, and attains a length of body of from fifty-four to sixty inches, the beight at the shoulders being only from thirty-six to thirtyeight inches. So far as color is concerned it may be called one of the handsomest, if not the handsomest. plentiful and collects in great herds, which graze in the open places during the night, and seek the shade of the forest in the day. The Axis is the object of persistent pursuit by the natives and by Englishmen; this continual pursuit may be the reason why it is as shy as the common Deer in localities where experience has familiarized it with being hunted. A captive Axis soon becomes entirely docile, however. It was introduced into England many years ago and it thrives excellently in the mild English climate.

\section{THE RUSINE GROUP.}

Most other Deer of India bear a peculiar stamp, which distinguishes them from their European or American relatives, but can better be appreciated on

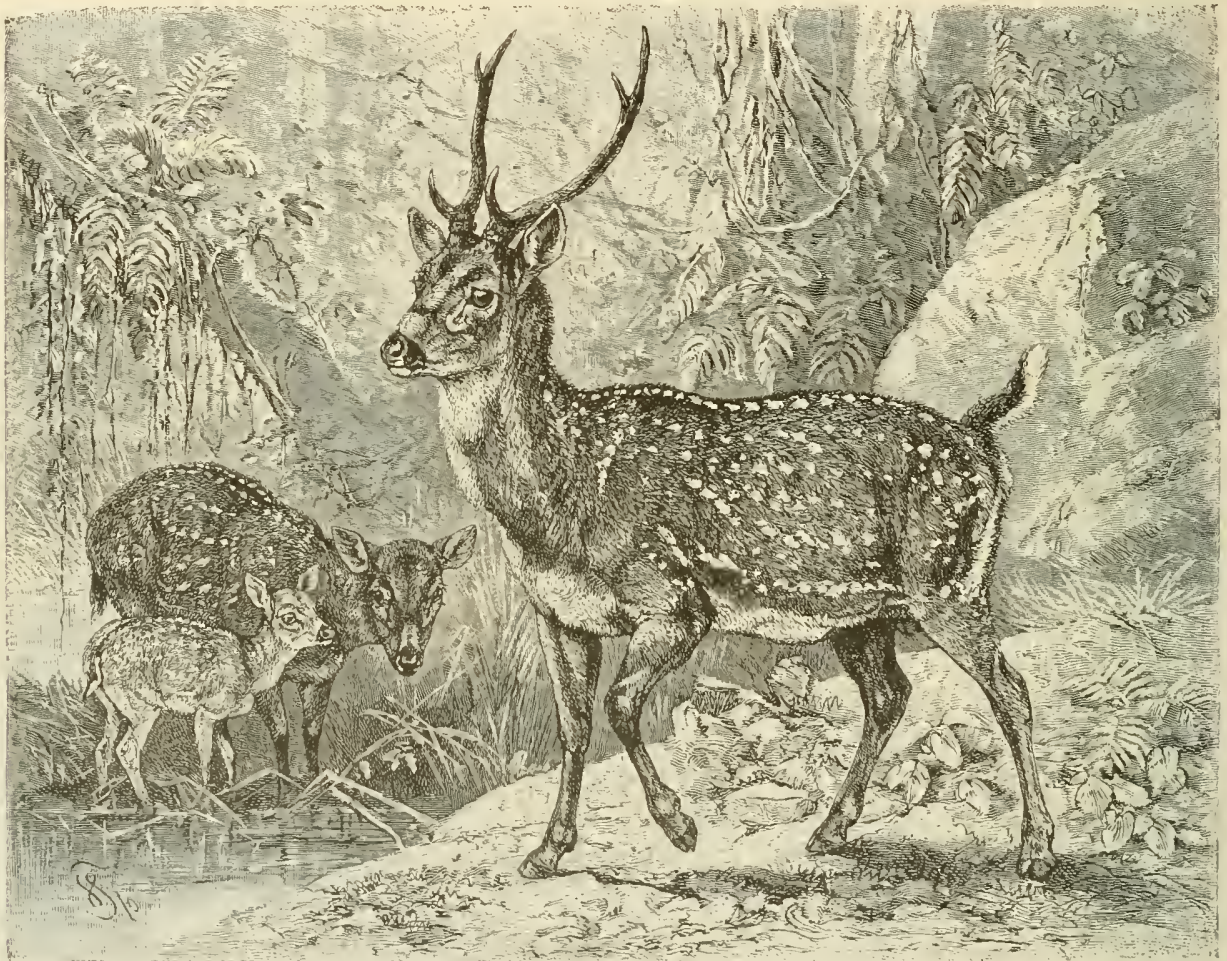

THE AXIS DEER.

animal, in both sexes and at all seasons, is distinctly spotted. "The antlers ground color; the stripe on the back appears very dark, nearly black on the withers; the throat, abdomen and inner faces of the limbs are yellowish. white, the outer surfacc of the limbs yellowishbrown. Seven rows of white, rather irregularly placed spots, conspicuously adorn each side.

Range and Peoul- The Axis is a native of all India, iarities of the with the exception of the Punjab. Axis.

and of the country east of it to Cochin China and is also found in the island of Ceylon. The animal inhabits the level as well as the hilly country and is found at the foot of the Himalayas and in the Sundarbans, in stately forests as well as in the jungle, but generally near water. Wherever the surroundings are to its taste, it is quite personal inspection than described. In general one may say that these Indian Deer, which form the subgenus Rusa, are of more or less compact organization, with stout limbs, short head and neck, but with a proportionately long tail, and are thinly covered with coarse, brittle hair. Only the males have horns and the horns have, as a rule, no more than six spurs.

In my opinion the Sambhar (Rusa aristotclis), which was described by Aristotle under the name of "Hippelaphus" in a manner leaving no doubt as to its identity, may be designated as the stateliest and noblest Deer of this group.

The Great Rusa - The Great Rusa (Rusa lippelaphus) Its Physical Propor- is little inferior to the Stag and tions, Range, etc. Sambhar in size, and measures fully six feet eight inches, twelve inches of which are in- 
cluded in the tail; the height at the withers is about forty inches. The female is considerably smaller. In general the distinctive characteristics of this Deer are those of its group. A notable fearure is the strong mane, which is developed at the throat and chin, the hair composing which hardly differs in character from the hair of other portions of the body.

As far as is now known the Great Rusa is a native of Java; to Borneo it is said to have been imported by Man. Travelers say that this Deer gathers into very numerous troops, which frequent open grasscovered plains more than they do woodlands. During the heat of the day the animals lie hidden in the grass and reeds or in the bushes; before sunset they set out for a pool and at the advent of evening they begin grazing. They are exceedingly fond of water, and this trait can be observed in captive specimens, which always display great eagerness for a mud-bath.

The movements of the Rusa deserve a short description. No other Deer that I know struts along with so much dignity as this one. Its gait exactly resembles an artificial pace, the so-called "Spanish walk" of a trained saddle Horse. Every one of its movements is like those which a Horse executes under the direction of his rider.

On the grand hunts held by the Malayan princes, in which the animals are driven by beaters, many hundreds of this species of Deer are sometimes slain; though the hunters do not employ fire-arms, but use only swords and spears to slay them or nooses to capture them alive. Junghuhn says that this Deer is hunted only for its flesh, which is cut into thin slices, rubbed with salt, dried in the sun and called "jendeng." It is considered the most palatable accompaniment of the various rice-dishes, which are never absent from the table of Javanese chiefs, and is also esteemed as an excellent dish in the menu of Europeans. The skin is not used.

Physical Propor. The Hog Deer (Rusa tions and Habitat porcimus) is one of the of the Hog Deer. commonest species in India and exhibits the nost awkward and ungainly forms of the whole family. It is of a moderately heavy organization, thickbodied, short-legged, short-necked and short-headed. The general color, usually, is a coffee-brown, which deepens into blackish-brown in the male and fades into tan color in the female. The antlers of the male, as a rule, bear six spurs; the horns are weak, stand on rather high cranial protuberances and attain a length of from fourteen to sixteen inches.

The Hog Deer is a native of the greater part of British India and Burmah. It is commonest in the Ganges country, and rarer in central India. Generally the animals live singly, but sometimes one finds two or three together. They prefer grassy spots thinly grown with bushes to the jungle or to a forest of tall trees, though they occasionally also occur in the latter in large glades. They lie hidden by day and feed by night; when alarmed, they flee in a curious and rather awkward manner, with the head held low, their name being derived from this gait.

The majority of the Hog Deer which are found in zoological gardens are exported from Bengal. The climate of temperate Europe agrees tolerably well with them, but they require a sheltered place to which they can retreat in rough weather. They breed readily, and increase considerably even when kept in a narrow enclosure.

\section{NORTH AMERICAN DEER.}

The Mazama Deer (Cariacus) live in North America and northern parts of South America; they are delicately formed, graceful Deer, distinguished as much by their structure as by the antlers of the male. Their shape is very slender, and the neck and head are long; the legs are of moderate length,

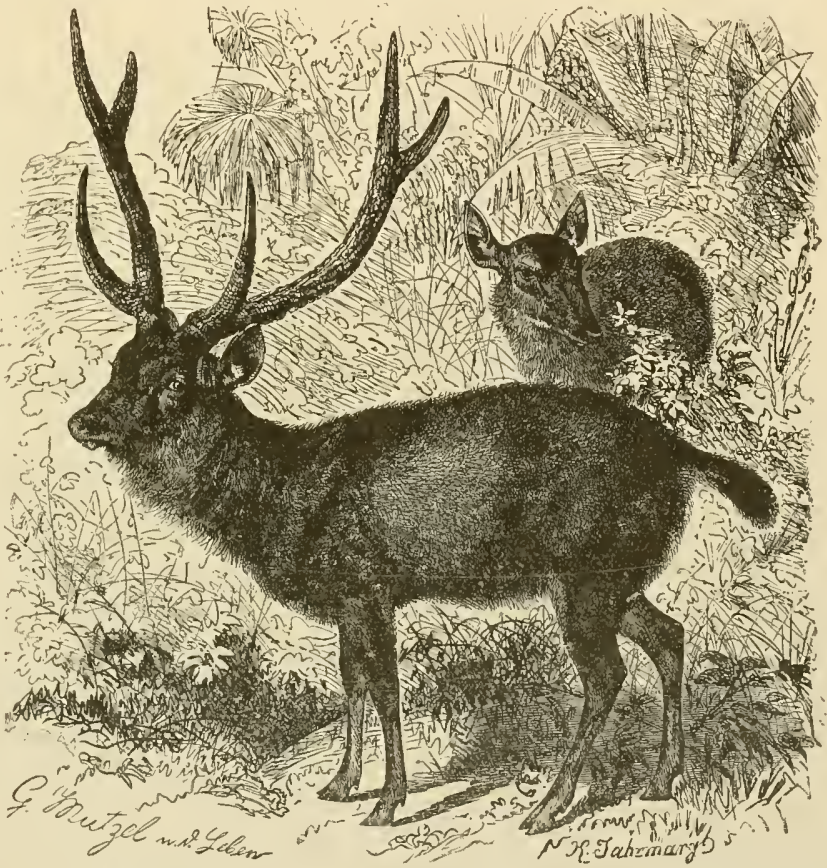

THE SA is an Indian species of Deer which derives its scientific name from THE SAMBHAR,-This is an Indian species of Deer which derives its scientific name from

but slender, and the tail rather long. The antlers are either forked or bent in one curve from behind outward and forward and branch in from three to seven spurs, which are all directed inward. These antlers have a basal spur, but the two other anterior spurs, found in Old World species, are absent. The coat is formed of close, soft, glossy hair. It develops into a mane in the male and into a tuft on the tail of both sexes.

Structure and The best known species is the VirRange of the Vir-ginia Deer or Carjacou (Cariacus ginia Deer. virginianus) which exhibits an affinity to the Fallow Deer in many respects, about equaling it in size, but differing markedly from it by reason of its graceful form and especially the elongated, fine head, which one may, with some justice, call the most beautiful head belonging to any of 
the Deer. The Prince of Wied says, however, that the animal often exceeds the Fallow Deer in size and is but little inferior in that respect to the Stag. The color varies according to the season of the year. The prevailing color of the summer coat is a beautiful, uniform reddish yellow, deepening on the back, but becoming lighter on the flanks; the abdomen and inner faces of the limbs are paler. In winter the upper surface is grayish brown, the under parts pure white. The length of a male of average size is six feet, the tail measures twelve inches, the height of the antlers is twelve inches, and the length of each horn, taken along the curvature, is about twenty inches. The height of the buck at the withers is about forty inches. The doe is considerably smaller, bcing only four feet four inches long and not over thirty-two inches high. The fawn is spotted very

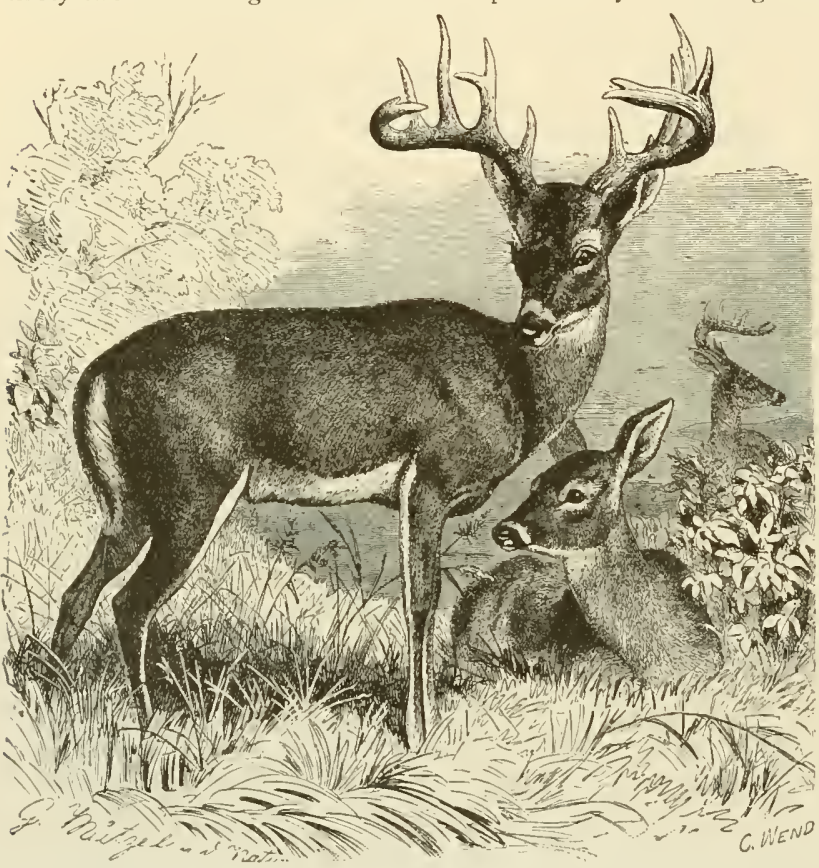

VIRGINIA DEER - Here is our common American Deer, Iamous as one of the mos beautifu] of the entire family. Its range includes all of the United States east of the Mlissour River, and all the southern states including Texas. In the far weslern region it is replaced by River, and all the southern states inclinding T
closely allied species. (Cariacus virginianus.)

daintily with white or yellowish white, on a dark brown ground, resembling the parents in other respects.

From the accounts of American naturalists this beautiful Deer is distributed through all forests of North America, with the exception of those of the extreme north. It is said not to be usually found in the sub-arctic regions, but it occurs in Canada. It ranges from the eastern coast of North America to the Rocky Mountains and southward to Mexico. In former times it is said to have been plentiful everywhere in its native country; at present it has been nearly exterminated in the more densely populated parts and has retreated to the forest country or the fastnesses of the mountain regions. In general its habits coincide with those of the Red Deer, allowing for differences in environment.
Audubon's Account Audubon says: "The Deer has a of the Virginia strong attachment to the locality it Deer.

has selected as its domicile and always returns to it when it has been driven away. It does not rest on the same bed on different days, however, but still is found in the same locality, sometimes at a distance of less than fifty paces from the spot on which it has been molested. Its favorite haunts are fallow fields, which have partly reverted into bushland again, the underbrush on which conceals it and affords it shelter. In the southern states it often selects brushwood along the boundaries of plantations, especially in summer, when in most states it is protected by law from molestation. There it reposes during the day, in a gloomy thicket of canes, wild grapes, thorn bushes, etc., always selecting the place of its domicile in the closest possible proximity to its feeding ground. The fancy for similar localities is not general, however, for one often finds its tracks in fields, which can have been invaded only by animals coming from a great distance. In mountain regions the traveler sometimes sees one lying on a rocky projection, reminding the observer of a Bonquetin or a Chamois, but it generally hides among low bushes, beside fallen tree trunks, or in similar places. In the cold season it prefers protected, dry spots, often standing and basking in the sunshine. In summer it retreats into shady parts of the woods during the day and ranges in the vicin. ity of small rivers or cool streams. To escape the attacks of Mosquitoes it often takes refuge in a river or pond, and submerges itself in the water up to its nostrils.

The food varies with the time of year. In winter the Deer devours the branches and leaves of bushes, in spring and summer it selects the tenderest herbage, exhibiting great fastidiousness, and often enters fields in quest of young Indian corn and other grain. It is very partial to berries of various kinds, nuts and the smaller fruits. One would think that such variety of food would tend to keep it always in good physical condition; but such is not the case, for, with the exception of certain seasons, these Deer are very lean. They are fat from August to November. We have slain some ourselves, which weighed about one hundred and sixty pounds each, and have been informed that some attain a weight of upwards of one hundred and eighty pounds.

"The docs are fattest from November to January; then their condition is reduced until the fawns are born, but they become fatter again while they are suckling their young. The young fawns are born in April in the south Atlantic states, and when but few days old, sometimes sleep so soundly that they can be surprised and taken before they are aware of the approach of Man. They are very easily tamed, and become greatly attached to their keepers after several hours of captivity. A friend of ours possessed a female fawn, which was brought to a Goat after its capturc and adopted by her, and we have 
seen others reared by cows. They readily endure confinement, but we have found them to be troublesome pets. A couple which we kept for some years acquired the habit of risiting our study by way of the open window, and continued their visits when the window was closed, heedless of broken glass. The animals seemed to have a destructive disposition in general, licked and nibbled at the covers of our books, and scattered our papers in sad confusion. No bush in the garden, however valuable to us, was sacred to them; they even gnawed our carriage harness and finally took to biting off the heads and feet of our young Ducklings and Chickens, leaving the mutilated bodies.

"The venison is the most savory of any that we have tasted. It is more delicate than that of the Wapiti or of the European Deer; but it possesses its best flavor only during the nonths when it is fat.
The Virginia Deer Mazama Deer, which I took care of, Easily Domes- would trustfully approach their ticated. friends and would not only accept proffered dainties in a friendly manner, but also gratefully lick the giver's hand. Unfortunately there is one drawback to the keeping of these Deer in small enclosures: they frequently break their delicate legs, and injure themselves so severely that a cure is difficult or impossible.

"Fire-Hunting" In portions of the southern states, partic-
for Deer in the ularly in the regions known as the "piney-
South. long-leaf yellow pine forests extend for many miles with little undergrowth, the Virginia Deer was formerly very plentiful, and is still found, though in reduced numbers. In those sections a peculiar mode of hunting was formerly resorted to. A party of hunters, with their Dogs, would start out after dark, frying pan but larger and with a longer handle. Into this

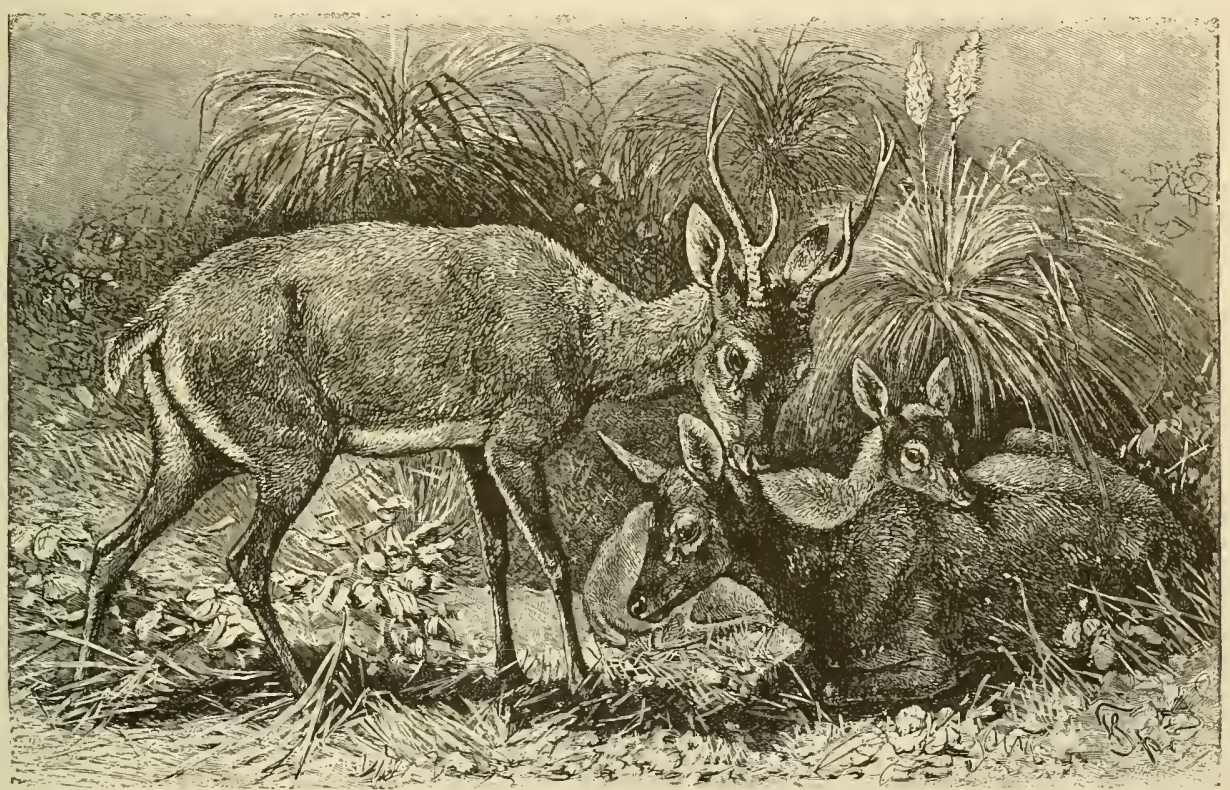

THE PAMPAS DEER_- In the extensive grassy plains of South America ranges the species of Deer shown in the picture. It is smaller than the V'irginia Deer, but, like the latter, is a graceful and agile animal. (Cariacus or Blastoccrus campestris.)

"The chase of this Deer required all the cunning and patience of the Indians, before the pale-face entered the hunting grounds with his rifle, his Horse and his Dogs. The Indian disputed the prey with the Wolf and the Puma, and the most varied modes of hunting were brotght in requisition. The Deer was oftenest slain after it had been deccyed to the vicinity of the hidden hunter by an insitation of the cry of the young or that of the buck. Sometimes an Indian would dress in the skin of a slain Deer, the antlers of which he fastened on his head; he would faithfully imitate the gait and movements of the Deer, succeed in approaching close to the herd and then kill several with his bow and arrows, one after another, before the animals would become alarmed and take flight. Since the introduction of fire-arms, however, most of the Indian tribes have laid aside the bow and arrow for the rifle, in the use of which they have become quite adept." vessel, known as a "fire-pan", the hunters placed and ignited from time to time, pine-knots, which are plentifully found in those forests. This hard and resinous fuel burns easily and with a bright light. As the fire-pan was behind the hunter, the handle being carried on the shoulder, the blaze did not dazzle his eyes, and yet brought into bold relief every object for a long distance ahead of him. Deer tracks were followed until at last the hunter saw before him two balls of lustrous, bluish-red light, reflected by the eyes of the mystified Deer, which, although dazzled and amazed by the bright glare of the resinous torch, stood still. The hunter could approach within easy shot of the animal, before the latter comprehended the necessity of flight, and by aiming at the spot between the eyes secured his game. Adepts in this method of sport learned to discriminate between the eyes of Deer and those of colts and calves, which much resemble those of Deer when seen by firelight, and which beginners sometimes shot by mistake. It was claimed that each animal inhabiting the woods had a distinguishable gleam of its eyes, differing from all others in size, shape or color; and other animals besides Deer, including Raccoons, Opossums, the Red Lynx and other nocturnal animals were hunted by the same method of "shining their eyes," as it was called. A kind of lamp to wear on the hat was invented and sold for fire-hunting purposes to replace the fire- 
pan, but this method of hunting has become almost obsolete. The White-Tailed The nea rest relative of the Virginia Deer is the White-tailed Deer (Cariacus leucurus. West. In size it is very much the same as the Vir ginia Deer, but the tail is longer and is white with a reddish tinge on the upper surface, and the under portion of the muzzle is also white. The legs and hoofs are more slender than those of the Virginia Deer and the general color is paler. From the western portions of Nebraska and Dakota to the Pacific coast, through the northern part of California and all portions of Oregon and Washington the Whitetailed Deer make their home amid the trees and bushes on the borders of rivers and swamps. The vallevs immediately east of the Cascade range harbor them most abundantly. In their habits they resemble other species of the family. They are lively, and, when alarmed, make their escape with remark able speed, and are sufficiently wary usually to keep out of range of any but long-distance shooting.

Another species quite common in the far west is the Black-tailed Deer (Cariacus co Tailed Deer Iumbianus). The upper surface of the tail Described. is black, the under portion white. The antlers branch out in prongs, the number of branches increasing with age. From the western slope of the Cascade Mountains this Deer extends southward through Oregon and California and is especially a familiar feature of the redwood forests of those states, although to the south the thick growths of the manzanita and chapparal afford it a convenient shelter. Its flesh is not much esteemed, and it is therefore not hunted so vigurously as some other species. Not much success has at tended the effort to domesticate Black-tailed Deer. They seem to be sufficiently amiable and friendly, but the changed conditions do not agree with them, and they soon die.

The Mule Deer, The Mule Deer (Cariacus macrotis) is neighbor of the two last mentioned species, as it inhabits the mountains of Washington, Oregon and ldaho. This animal never decies. scends to the valley unless it is driven by very severe weather in double prongs and constitute a striking adornment; another marked characteristic is the ears, eight inches long, which give the animal its name. The color of the coat is a dingy brown, changing to gray in winter. There is a black stripe along the back which, according to some authorities, can be erected by the animal at will. The margins of the large ears and the tuft of the tail are black. The remainder of the tail, which is about eight inches long, and the buttocks are white. Its movements are not so lively as those of the Virginia Deer.

The venison of the Mule Deer is excellent, and it is therefore a favorite game animal. A single fawn is born to the doe in May or June. The little creature, which is of.a pale yellow hue with white spots, is very pretty, and is cared for with great tenderness by the doe until it is old enough to be weaned and even after that remains with its mother for a considerable period. The males of the Mule Deer species shed their horns in March.

There is a variety of the Mule Deer found in southern Califormia, Arizona and northern Sonora which is smaller that those of the more northern region. Its general color is more of a reddish hue, and the upper surface of the tail is black. It is not found east of the Sierra Nevada range.

The Mexican A small species, inhabiting Mexico, Central

America and a part of Texas is known as the Nlexican or Sonora I)eer (Cariacus me. icanus). Its size varies with locality, for those living in the northern part of the range are, the largest, the smallest being found in Central America. This animal has a short tail, broad and short hoofs and its coat is of a grayish brown color, resembling the winter coat of the Virginia Deer, but the Mlexican Deer does not change color with the seasons. Its habits are similar to those of the I"irginia Deer.

\section{SOUTH AMERICAN DEER.}

In the Blastocerus genus, which succeed the Virginian Deer and its relatives, and the native country of which is South America, the antlers are erect and forked; the main anterior branch is always less developed than is the main posterior branch; the anterior nember is sometimes forked; the posterior always.

Description of the Pampas Deer or Guazuy.

The best known species of this genus, the Pampas Deer or Guazuy (Blastocens campestris) is of moderate proportions compared with other nembers of the family; its body is from forty-four to fifty-two inches long, the length of the tail being four inches; the height at the withers is twenty-eight inches; at the croup thirty inches; and both the shape and color of the animal are decr-like. Its antlers resemble those of the Roe buck, but they are more slender and the spurs are longer.

This Deer is plentiful in Paraguay, Uruguay and northern parts of the Argentine Republic. Rengger says that it ranges chiefly in the open, dry country in thinly-populated regions and shuns the neighborhood of swamps and forests even when hotly pursued. It lives in pairs and in small troops; old males live in solitude. During the day the Deer rests in the high grass and keeps so still that one can go by on horseback without arousing it. After sunset it goes in quest of food and roams about all night. The doe produces only one fawn at a birth, either in spring or in autumn.

A Pampas Deer taken young becomes exceedingly tame. It soon learus to know all members of the household, follows them about, responds to their calls, plays with them and licks their faces and hands; with Dogs and Horses it is not only on peaceable terms, but even goes so far as to tease them with playful butts and thrusts; it shuns strange people and Dogs. Its sustenance consists of raw and cooked vegetables of all kinds; it is specially fond of salt, as are all its relatives. In fine weather it disports itself in the open air; during the noon hours it chews the cud, and when it rains it betakes itself to shelter.

\section{THE ROE.}

The Roe represents a special genus (Caproolus), the horns of which are round, but slightly branched, forked, rough and have no basal spur.

The Roe buck (Caproolus caprea) attains a length of fifty-two inches and a height of thirty inches at the croup; the small stub-like tail is not an inch long. The weight ranges between forty and fifty, in some rare cases sixty, pounds; the doe is of smaller proportions. Compared with the Stag, the Roe is of sturdy build, and its head is short and blunt. The antlers are characterized by large, bulbous expansions or "burrs" and relatively large shafts beset with quite broad protuberances, technically called "pearls." Generally the main shaft of the horn has only two spurs, but the full development of Roe's antlers does not stop short at this. Blasius says that ten spurs form the highest regularly developed form of the Roe buck antlers. Malformations are remarkably frequent in Roc buck's horns. One can see antlers of the most abnormal shape in collections: some show a whole series of the usual spurs, others are enlarged into blades, and beset with marginal spurs. There are Roe bucks with three horns and three cranial protuberances for them, while others have only one horn, the so-called "wig horn."

The close hair of the Roe clianges with the season. The upper surfaces of the body and the outer surfaces of the limbs are dark rusty red in summer, brownish gray in winter; the under parts and the inner surfaces of the limbs are lighter.

The Range and With the exception of the extreme Favorite Haunts of north, the Roe is distributed all the Roe.

over Europe and the greater part of Asia. In the latter continent its range northward includes middle and southern Siberia as far as the forests extend, eastward to the mouth of the Amoor, southward to the lofty mountains of India and Man- 


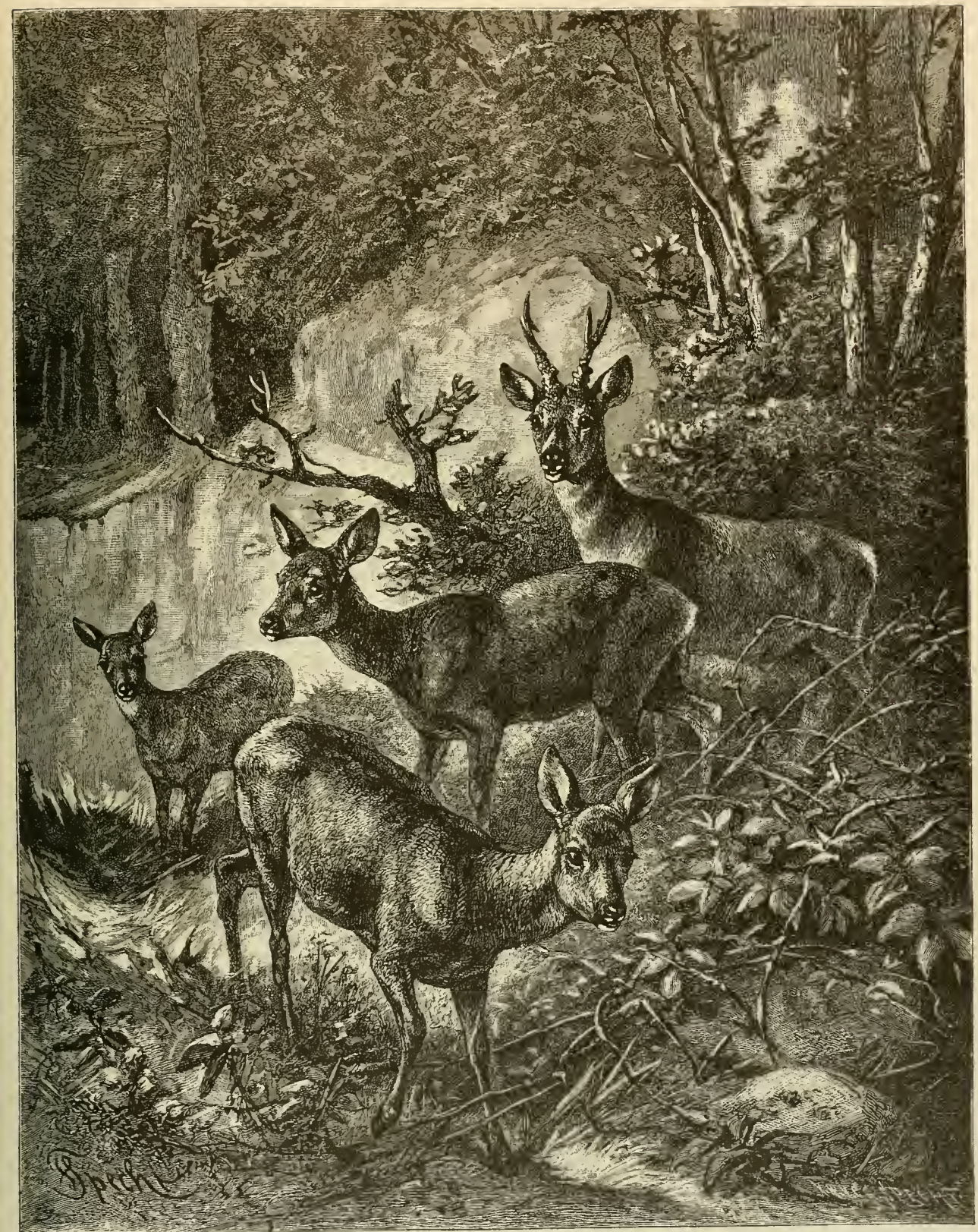

THE upricht a and it is every where fond of large, dense forests. (Cafrolus cafraa.) 
churia, but it is quite scarce in the barren, treeless table-lands.

In general one may say that, within its range, the Roe is found alike in young forests and in older ones, provided they abound in underbrush, no matter whether they are situated on mountains or in plains or whether they consist of deciduous or evergreen trees. The Roe seems to delight in the latter, especially in a marshy country. In winter it descends from the heights, in summer it mounts higher. In agricultural countries it often rests in the fields of tall grain during the day.

characteristics The Roe is nimble and graceful in and Habits of its movements. It can cover considthe Roe. erable distances in its agile bounds, leaping over wide ditches, high hedges and shrubs without any obvious effort, and it is also a good swimmer and an adept at climbing hills and mountains. Its senses of hearing, smell and sight are acute; and it is cunning and cautious. While the animal is young it is remarkably amiable, but in old age it is very obstinate, defiant and vicious.

Roes never form as large troops as do the Red Deer. During the greater part of the year they live in families, consisting of one buck and one, or more rarely of two or three does and their fawns. During the day the Roe remains hidden in a quiet, secluded spot of its temporary domicile; towards evening (and in quict localities in the late afteruoon) it goes out to graze in young forests, in glades or in fields; towards morning it betakes itself back to the thicket or into high grain, and beats away the moss or sod with its fore-paws, thus preparing itself a lair for resting. It usually pertinaciously frequents the neighborhood in which it has once established its, domicile, but not invariably. Its food is nearly the same as that of the Stag; only the Roe selects more of the tenderer plants, being more fastidious.

Only a single fawn is, as a rule, born to a young doe; old ones give birth to two, or in rare cases even to three. The mother conceals her offspring from an approaching enemy with great care, and at the slightest premonition of danger she gives signals of alarm. During the first days of life, when the fawns are yet too weak and awkward to run, the mother resorts to dissimulation and tries to decoy the enemy away from the vicinity of the little ones. If a fawn be taken away fron her, and she can not rescue it, she follows the robber, whether Man or beast, for a long time and expresses her distress by constantly running to and fro and bleating. About eight days after their birth, the fawns accompany the doe when she is grazing, and after ten or twelve days they are strong enough to run after her. Then she returns with them to her old quarters, with the intention, as it were, of introducing the offspring to their father.

Hunting the Roe, The Roe is hunted in nearly the and the Profit same manner as are other Deer, Therefrom.

thougli shotguns are now used more extensively than are rifles in districts which are not under the restriction of game laws. The Roe is also pursued by Lynxes, Wolves, Wild Cats and Foxes, the first preying upon large and small alike, the last chiefly selecting the fawns; the very young fawns are said also to fall victims to the diminutive but bloodthirsty Weasel.

The profit that accrues to Man from the Roe is inconsiderable; the harm it does is not slight, and outweighs the profit. It works sad destruction in young forests especially, and sometimes destroys the painstaking labor of years in a few days.

The Roe Difficult The Roe is more difficult to keep to Keep Cap- than other Deer, either in parks, in tive. zoological gardens or in smaller inclosures, for its liberty-loving mind rebels at all restriction. It proves to be a very fastidious, capricious creature, difficult to satisfy; it is frail and weak, does not always breed in a cage and often dies in consequence of some insignificant cause. If reared from early youth, it is readily tamed, is on friendly terms with Man and beast, acts like a true domestic animal and affords one great pleasure. In the long run, however, the doe alone is satisfactory; the buck ends by exhibiting his true nature; he becomes bold and importunate, while the doe as a rule retains her gentle disposition.

\section{THE MUNTJAK DEER.}

In conclusion, we will cast a glance at the genus of the Muntjak Deer (Cernulus), which are characterized by their small size, their short, imperfect antlers, their strikingly large canine teeth, their deep, wide tear-pits and lack of a hair-tuft on the hinder ankles. The species ranged in this group are natives of the southern and southeastern parts of Asia, up to south China, and of the adjacent islands.

Description of the The Muntjak or Kidang, sometimes

Muntjak or called "Wrinkle-face" by English-

Kidang. men (Comulus muntjac), is the best known form; it is somewhat smaller than a Roe, being from forty-six to forty-nine and one-half inches in length, from six to seven inches of which are included in the tail; the height at the shoulders ranges betwecn twenty-six and twenty-eight inches. The hair is short, smooth and close, the color on the upper surface being a warm, yellowish brown, sometimes deepening into maroon; the hinder part of the abdomen and the inner surfaces of the limbs, the back part of the cheeks and the lower part of the tail, are white; the fore part of the abdomen and the chest are more yellowish. The horns are set on very high basal protuberances, are directed obliquely backward, and bend at first slightly outward and forward, then curve boldly backward and inward. The basal prominences, which are from thrce to four inclies in length, are very peculiar; they are covered with a hairy skin up to the "burr," as the bulbous protuberance at the beginning of the horn proper is called; the margin near the burr is decorated with tufted hair, and the burr is composed of a single row of large "pearls" or button-likc excrescences. The female has hair-tufts in the place of horns.

The Range and The Muntjak is a native of Sumatra,

Habits of the Java, Borneo, Banca and Hainan, as Muntjat. well as of the Malayan peninsula, Burmah and British India. A country that is not too high and shows alternating hills and dales, or still better, which lies at the foot of high mountains or near extensive forests, seems to unite all the conditions that are essential to the wellbeing of this Decr. It is found singly or in pairs. Spots which moreover have an abundance of water and are unfrequented by Man, form the clioicest abode for the Muntjak. With its head held low, it slips through matted thickets and among broken trees like a Weasel, and nimbly threads its path through the smallest gaps. Day and night it utters its sharp cry, a hoarse, sharp, resounding bark, which has caused it to be known in some places as "the "Barking Decr." The Muntjak is a very courageous 
beast and uses its small horns and its canine teeth with much vigor and skill. Many Dogs are wounded in attacking it and they sometimes sustain injuries on neck, throat or abdomen, which end in death.

The Muntjak endures confinement very well in its own country and fairly well in Furope. It is often found in the possession of Europeans and natives. The venison is said to be savory, but lean.

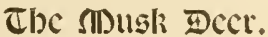

\section{SIXTH FAMILY: MOSCHIDE.}

Some naturalists have placed among the Decr several small and very dainty Ruminants, which among others include the dwarfs of the entire order, namely, the Musk Deer and the Chevrotain. We regard them as distinct families, however.

The Musk Deer (Moscliide) have no antlers, no tear-pits, no hair-tuft on the hinder legs, and a rudimentary tail. The males are, like male Chevrotains, distinguished from other Ruminants by the possession of long, protruding canine teeth in the upper jaw, projecting downward from the mouth. The lofty mountains of China and Tibet constitute the native habitat of these animals. There they live in the rockiest portions of the mountains - seldom ranging in the valleys, into which they descend only when a severe winter drives them from their heights and lack of food compels them to turn toward more favored regions.

The family is represented by one genus and one species only, the Musk Deer (Moschus moschiferus). It is a graceful Ruminant, from thirty-six to forty

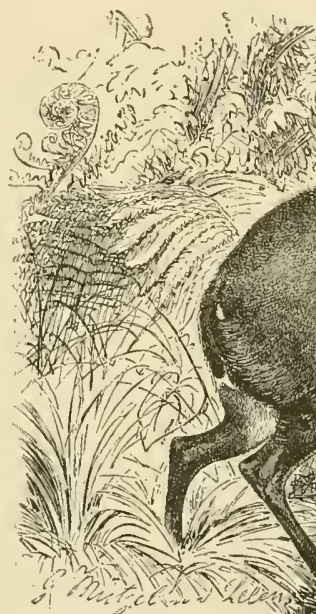

THE MUNTJ K - The species The of the pedestals which comect the antlers of the male with the frontal bones. (Cervulus muntjac.)
Description of the The musk pouch lies in the hinder Pouch of the part of the abdomen and has the apinent, roundish pouch rather exceeding two inches in length, one inch in width and about two inches in height. On both sides it is beset by a margin of stiff hair, the direction of the growth of which on one side is opposed to that of the other side, a circular spot in the middle being left uncovered. This spot contains two little apertures, onc bchind the other and connected with the pouch itself by short canals. Small glands within the pouch secrete the nusk, and when the pouch becomes too full it is emptied by means of the anterior canal. The pouch attains its full dimensions and normal contents of musk only in the adult animal. The average quantity of the valuable substance is little short of an ounce, but nearly double that amount has been found in some pouches. Young bucks yield about one-eighth of this quantity. In the living animal the Musk Deer. pearance of a sac-like, slightly prom- inches in length, and from twenty to twenty-two inches in height at the shoulders. It is of sturdy build; higher at the croup than in front, slenderlegged, short-necked. It has a rather long head, obtusely rounded at the muzzle; its eyes are of moderate size with long lashes and a very mobile pupil; and it has ears of ovoid shape which are half as long as its head. The toes are encased in rather small, long, narrow and pointed ungulate nails; but the feet can be expanded considerably by means of a fold of shin connecting the hoofs with the rudimentary toes, which reach to the ground. This arrangement enables the animal to walk sure-footed and without difficulty on snow-fields or glaciers. By all accounts the color of the coat of the animal must be very variable; some individuals are very dark above, dingy white below; others are reddish brown; some yellowish brown above, white beneath; others again show a longitudinal row of light spots on the back. The canines protrude from the mouth of the male two or three inches, and show first a gentle bend outward, then a scythe-shaped curve backward. The female also has canine teeth, but they do not protrude beyond the lips. musk has the consistency of a salve; when dried it is a granulated or pulverized substance, which is at first of a red-brown hue, but later darkens and may become coal-black.

Neither the Greeks nor the Romans knew anything of the Musk Deer, notwithstanding their foolish fondness for perfumed ointments, and the fact that they obtained most of them from India and Arabia. The Chinese, on the other hand, have been using musk for thousands of years. We obtained the first information concerning the Musk Deer from the Arabs.

Range and Attri- The Musk Deer is distributed over butes of the the region from the Amoor to the

Musk Deer. Caspian Sea and from the sixtieth parallel of north latitude to China and Farther India. It is most abundant around the Lake of Baikal and in the mountains of Mongolia, as well as in the Himalayas, where it is said rarely to descend below seven thousand five hundred feet in summer. In parts of these regions it is yet so plentiful that professional hunters can slay several hundred in one winter. The craggy slopes and tangled forests are the proper haunts of these noted animals, and there 
they are found usually singly, but sometimes in couples. Kinloch compares the habits of the Musk Deer to those of the Hare, as it prepares itself "forms" like those of the latter animal and lies in them during the day. When grazing it selects slopes, where grassy pastures alternate with patches of low underbrush. It enters the open, uncovered pastures only at dusk or in the early morning hours. Its movements are quick and sure. It runs with the speed of an Antelope, jumps with the precision of a Bouquetin, and climbs with the boldness of a Chamois. Over the soft surface of snow-fields, in which a Dog sinks and a Man can bardly move, Musk Deer proceed quite comfortably, barely leaving a trace. When pursued, they jump just like the Chamois from a considerable height, without sustaining any injury, or they run along precipices which barely afford a possibility of gaining a foothold. In case of necessity they do not hesitate to swim across broad rivers.

Their perceptive senses are excellent, but their mental capacity is slight. The Musk Deer is shy, but neither sagacious nor prudent. When an accident befalls it, it is frequently at a complete loss how to act, and runs about as if it were deprived of its senses. A newly captured individual behaves in the same manner.

Reproduction, Pur- The female gives birth to one or suit and Value of two brightly mottled young ones,

the Musk Deer. and guards them faithfully till the next pairing season, at which time she casts them off. At the end of the third year the young have completed their growth.

The pursuit of this important and profitable: creature is very difficult, at least in Siberia. Its shyness seldon allows a hunter to approach within shooting distance. The course usually pursued is to lay snares on its way. The plans of the trapper for the capture of the Deer are often nullified by the Glutton, the Siberian Weasel and the Ravens. The furred beasts of prey follow the trail of the animal and cat the captives out of the snares. The Golden Vulture and the Eagle also prey on the young Musk Deer, the Panther and Cheetah on the old ones. English sportsmen kill the Deer in the Jimalayas with a rifle, and either stalk it alone or have it driven out by beaters.

The venison is much esteemed by Europeans in India; the musk pouch is worth from $\$ 2.50$ to $\$ 7.50$. The greater part of the musk is shipped to England from China; but it is seldom unadulterated, for that crafty, long-cued nation has been zealously studying the art of adulteration of the precious substance for ages. Old travelers relate queer things concerning the strength of the odor of musk. Tavernier and Chardin say that hunters are obliged to stop their noses and mouths before cutting off the pouch, for incautious inhalation of the odor causes fatal hemorrhages. Chardin affirmed that he had never been able to nearly approach dealers in musk, and had to make his purchases from them through the intervention of commercial friends. According to his assertion the odor is unbearable and really dangerous to Juropeans who are not used to it.

We still lack detailed accounts of the life of this animal in confinement. In the year i 772 a Musk Decr reached Paris, after a journey of three years, and it lived there for three more years. It died from the effects of a ball of hair, which had formed in its stomach from the hair the animal had licked off itself. and had become attached to the wall of the stomach in such a manner as to prevent the passage of food from that organ to the smaller intestines. It had always been well prerious to the accident causing its death, and this fact led French naturalists to believe that this important animal might be introduced into high European mountains.

\section{Tbc Cbcurotains.}

\section{SEVENTH FAMILY: Tragulide.}

The last family of the Ruminants comprises the Chevrotains or Pigmy Musks (Tragulida), and forms the connecting link between the Ruminants and the Swine. The animals classified under this title inhabit western Africa and south Asia and are exceedingly pretty creatures. If one imagines a roe-like, dainty little animal, with a rather stout body, a slender, well-shaped head, beautiful, lustrous eyes, and legs which are scarcely thicker than a lead pencil, with extremely neat hoofs, a sinall, trim, stub tail and a soft, close fur of attractive hue, he will have a correct idea of a Chevrotain.

Appearance and The Kanchil or Pigmy Musk (TraHabitat of the gulus kanchil or Tragulus pygnaaus) Kanchil. is about eighteen inches in length, less than two inches of which are included in the tail; the height at the withers is eight inches, the croup being nearly an inch higher. The hair is of rather fine texture, and of reddish fallow hue on the head, lighter on the sides, and nearly black on the top. The upper surface of the body is reddish yellow-brown, strongly mingled with black along the back, lighter on the flanks, spotted with white on the upper part of the neck, and the under surface is white. The older males have strongly curved canine teeth, which protrude rather more than an inch beyond the gums. The small, fine hoofs are of a light brown horn color. Young animals do not differ from the old ones in these particulars.

Java, Singapore and the Malayan peninsula are the chief regions constituting the home of this lovely little creature; in Sumatra, Borneo, Ceylon, as well as in India, from its southern extremity to the Himalayas, up to an altitude of eighteen hundred feet, it is represented by allied species. In Java it inhabits the mountains more than it does the plains, existing along the lower edges of the primeval forests covering all mountain ranges, selecting for its retreat the brushwood forming the forest boundaries; from its domicile it can easily reach the grassy slopes below in a few minutes. One never encounters it in herds, for it usually lives singly, or, at the most, in pairs during the mating season. During the day it lies hidden, resting and ruminating, in the thickest part of the bushes; at dusk it sallies forth to graze upon various leaves, herbage and berries. IVater is indispensable to it.

Physical and Men- All movements of the little animal tal Endowments are extremely light and graceful, of the Kanchil. and lively withal. In proportion to its size it is capable of executing long leaps, and it skillfully surmounts all obstacles in its way. But its delicate limbs are not gifted with great endurance, and it would soon fall into the hands of its enemies if it did not possess a means of defense in the execution of a peculiar trick. Generally it endeavors to escape pursuit by hiding in a bush; but as soon as it sees that it can no longer do so, it calmly lies down and feigns death, as the Opossum does under similar 
circumstances. The enemy approaches, thinking the prey is his for the taking, but before he has reached it, the little creature gives a bound and scampers off like a flash.

In modern times specimens of this or the other species of Pigmy Musk have frequently been taken to foreign lands and kept in confinement for a considerable time. Wandering menageries also have occasionally shown some one of the species all over the country. The appearance of the animal is neat and trim; it keeps itself exceedingly clean, and is continually licking and dressing its fur. The large,

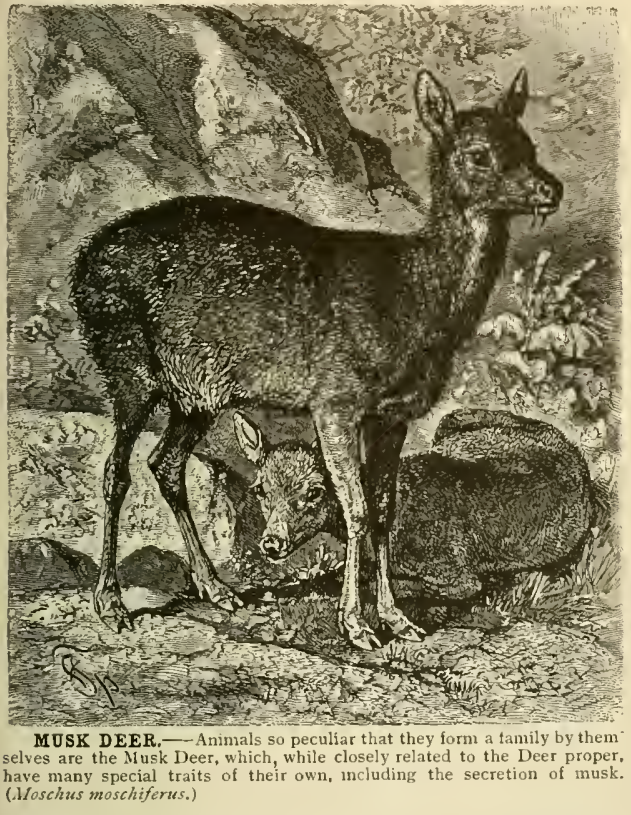

beautiful eyes seem to indicate that it is an animal highly gifted mentally; but such is not the case, for it gives no proof whatever of superior intellectual powers: being a dull, uninteresting creature. It spends its day sleeping, ruminating and eating. One seldom hears the sound of its voice-a soft, low gurgle, resembling somewhat a note of the tremolo stop of an organ.

\section{Cloven= SECOND SUBORDER: SU1NE}

The second suborder of the Artiodactyla comprises the non-ruminating Swine and Hippopotami, which may be collected into two families.

\section{Tbe swinc.}

\section{EIGHTH FAMILY: SUIDE.}

The Swine have a laterally compressed body; the head is nearly conical in shape with a truncated muzzle, the tail is thin, long and curly, the elongated snout is broadened in front nto a disc, which con- tains the nostrils; the ears are of moderate size and are generally erect; the aperture of the lids of the eye is oblique and proportionately small; the legs are slender and thin, the toes stand in pairs, the middle ones, which support the body, being materially larger than the outer ones. A more or less dense coat of bristles covers the body. The female has numerous mamme placed in two parallel rows on the abdomen. The skeleton shows light, graceful formations. All Swine have three kinds of teethincisors, canines, and molars - in the upper and lower jaws. The number of the incisors varies between two and six in the upper jaw, and four and six in the lower; these teeth frequently drop out in old age, however. Canines exist always and are of very characteristic shape-three-edged, strongly curved and bent upwards. The remaining, or molar, teeth, the number of which is variable, are more or less compressed, the grinding surface being broad and beset with many cusps, or projections. Among the muscles, the set that moves the lips is particularly noticeable; the muscles of the upper lip are especially strong and mobile, and furnish the trunk with the strength necessary for rooting in the earth.

Distribution and With the exception of Australia, the

Attributes of Swine are natives of nearly all coun-

the Swine. tries of the remaining continents. They affect extensive, damp, marshy forests in mountainous or lowland countries, thickets, bushes,

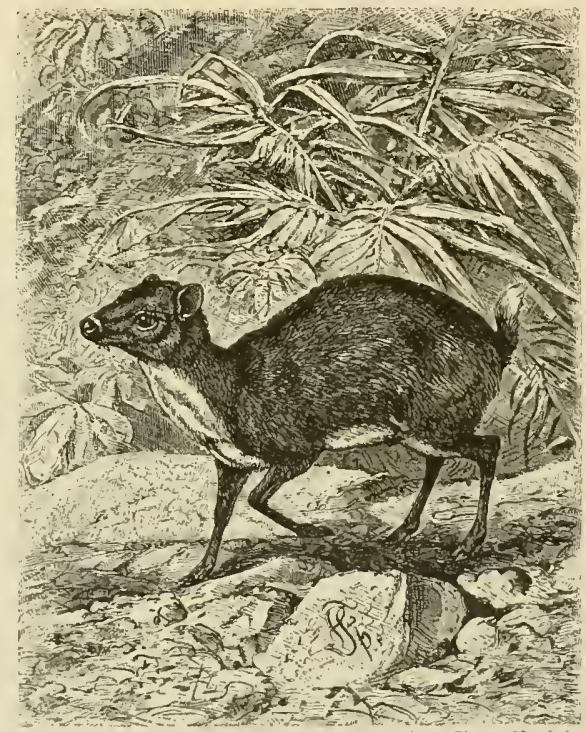

THE KANCHIL. - This is the smallest of all the Cloven Hoofed animals, and is very agile and wary. It is snared by the Mlalays for the sake of its flesh. (Tragulus kanchil.)

damp plains and fields grown with high grass. They all delight in water, in bogs, pools, and the banks of rivers and lakes. In such places they make a bed in the mud or marsh and spend their time of rest in it, often lying half in the water. Some species seek shelter in large holes between the roots of trees. The majority are gregarious; but the herds which they form seldom attain to great numbers. Their mode of life is nocturnal; for even in localities where they are unmolested they begin active operations 
only at dusk. They are by no means as clumsy and helpless as they seem, their movements being comparatively light. Their walk is somewhat swift, their running rapid; their gallop consists of a series of peculiar bounds, each of which is accompanied by an expressive grunt. They are all excellent swimmers, and even cross straits in order to pass from one island to another. The perceptive senses of the Swine are also well developed, those of smell and hearing being especially acute. The small, dull eye, on the contrary, does not seem to be very keen, neither do taste and sensitiveness to touch seem to be well developed. They are wary and shy, and flee, as a rule, from all danger, but when they are hemmed in, they bravely take up the defense and often furiously charge against their antagonists. In doing so they try to knock down and overrun the enemy and rip him with their sharp tusks, and they use these formidable weapons with so great skill and vigor that they sometimes becone very dangerous. The males defend their mates, and the mothers protect their young with great devotion. They seem but slightly amenable to instruction, of an obstinate disposition, and not capable of domestication of a high degree, their qualities in general not being very attractive. Their vocal expression is a queer grunt, expressive of a great deal of self-content and a comfortable state of mind and body. Old males also utter a deep growl.

Dietand Repro. The swine are omnivorous in the duction of the most extended sense of the word. Swine.

Whatever is in any way edible is acceptable to them. A few Hogs feed cxclusively on vegetable food, such as roots, herbs, cereals and fruit, onions, mushrooms, etc.; the others consume insects and their larre, Snails, worms, reptiles, Mice nay, even fish - and show a great liking for carrion. Their voracity is so well known that nothing need be said about it; all other qualities are really absorbed and overshadowed by it, with the sole exception of the unparalleled uncleanliness which has made them the objects of the aversion of mankind.

In few species does the female give birth to but a single young one or a small litter; the others bring forth a large number at a time, often more than any other mammal, the number occasionally rising as high as twenty-four. The little ones are charming, playful, active creatures, that would delight anybody, if they did not display the uncleanly predilections of their parents, from the first day of life. Their growth is surprisingly rapid, and they are capable of reproduction when they are a year old. For this reason all countries in which they thrive swarm with them, and they are exterminated with difficulty even where they are in nowise protected.

Their exceeding fecundity and indifference toward a change of environment render them highly suitable for a state of domesticity. Few animals are tamed so easily; but few revert again to the wild state so readily as they do. A young Wild $\mathrm{Hog}$ usually soon becomes used to confinement and to the filthiest of stables, while a domestic Hog, born in such quarters, becomes a savage, fierce animal after a few years in the free state, being scarcely different from its ancestors, and (if it be a female) as a rule producing young at her first litter which are in every respect similar to wild specimens.

The Enemies All wild Swine are so destructive to of the agriculture that they must be reSwine. garded as enemies to the cultivation of the ground. They are therefore most diligently pursued wherever Man assumes sovereignty. The chase of the IVild Hogs is counted one of the noblest of sports and has many attractive features, for they are animals which occasionally offer a desperate resistance.

Man, however, is the worst enemy of the Wild Hogs in the northernmost countries only. In the equatorial regions the larger species of the Cat tribe and of the Dogs pursue them and often make sad inroads on their ranks. Foxes, smaller Felide and birds of prey dare attack only young Swine, and always display great caution when doing so, as the mother vigorously protects her litter of little ones.

\section{THE SWINE PROPER.}

All Swine of the globe display great affinity to each other in structure and character. The slight differences which may be established are based on the greater slenderness or bulkiness of structure, the number of toes and teeth and the formation of the tusks. Forty-four teeth, four toes on each foot, and usually ten or at least eight mamma on the abdo men of the female, elongated oval liairy ears and a tail of moderate size, terminating in a tuft; such are the characteristics of the Swine proper (Sus), which are adequately represented in the common or Wild Hog or Boar (Sus scrofa). This strong, stout and by no means defenseless animal is tully eighty inches in total length, including from eight to ten inches for the tail. The height at the shoulders is thirtyeight inches and the weight averages from three to four hundred pounds, size and weight being subject to considerable modifications, however, according to the locality, season and food. The llild Boars living in swampy regions are always larger than those which live in dry forests; those which exist on the islands of the Mediterranean never equal in size those of the continent. The IVild Boar much resembles its tamed descendant in slape, though the body is shorter and sturdier, the legs are stouter, the head is somewnat longer and slenderer, the ears are more erect, slightly longer and more acutely pointed; the tusks are also larger and sharper than those of the domestic Swine. The hue is variable, but is usually black; gray, rusty white or mottled IVild Hogs are rare. The young display yellowish stripes on a reddish gray ground, running rather straight from the fore parts to the hindquarters and fading out in the first months of life. The hairy covering consists of stiff, long, pointed bristles, frequently split at the top; rather short fine woolly hair is mingled with them, according to the season; a kind of crest or mane forms on the back. Rusty-colored, white spotted individuals and such as are half black, half white, are generally considered to be descendants of degenerated domestic Sivine, set free at some former period to increase the number of Wild Boars.

The Ancient and In former times the IVild Boar was Present Range of spread all over Europe, being equally the Wild Boar. plentiful in the central and in the southern part of this continent; at present, to the delight of all agriculturists and foresters and to the regret of all sportsmen, it is extinct in several countries and in many others it exists only in a few parks protected by game laws. Its range does not extend northward beyond the fifty-fifth parallel. In Germany it still exists in a completely wild state in greater numbers than is agreeable to the agriculturist. Still more numerously than in Germany does it exist in some of the mountain forests of France and Belgium, and also in Poland, Galicia, Hungary, 
the Danube valley, southern Russia, on the Balkan and the Spanish peninsula. In Asia it ranges from the Caucasus to the Amoor and from latitude fiftyfive degrees north to the northern slope of the Himalayas: in Africa it inhabits all suitable localities along the entire northern coast. Beyond the given boundaries it is represented by other species, in part still to be examined by naturalists and thus not yet conclusively defined. Such are the Maned Hog of continental India (Sus cristatus), the Andamanese Hog of the Andamans (Sus andamancmsis), the Bearded Hog of Borneo (Sus barbatus), the Striped Hog (Sus rittutus) of Java, Amboina and Bangka, the Javan IVild Hog (Sus z'cmecosus) of Java and Ceram, the Celebes Hog, found on Celebes (Sus celebensis), the Timor Hog on Timor (Sus timorensis), the New Guinea Hog (Sus pafucnsis) and the Black Hog (Sus nigrr) on New Guinea, the White-bearded Hog (Sus leucomysta.r) in Japan and Formosa, and finally the Sennaar Hog (Sus semmarmsis) in the centre of northeastern Africa. A strong Indian Boar is by no means afraid of a combat with a Tiger, and not infrequently proves itself master of the field.

The Preferred Damp and swampy localities are Domicile of the often the abode of the IVild Boar. Wild Hog. no matter whether they are covered with extensive forests or only a swampy growth; it shows a great predilection, however, for extensive, young and dense forests of fir, pine, and other trees with needle-like foliage. In many localities of Egypt the Wild Boars live all the year around in sugar-cane fields, without ever leaving them; they feed on the canes, wallow in the water which is conducted through the fields, and feel so thoroughly satisfied there that they can not be driven away by any means. In constructing its bed the Boar roots out a depression, just large enough to take in its body; if the material is obtainable it lines this lair with moss, dry grass and foliage, and rests in it quite comfortably. Herds of IVild Boars prepare their lairs in a similar manner, but in lying down so dispose of themselves that the heads of all are directed toward a common centre.

omnivorous Pro- Being very gregarious, the Wild pensities of Hogs are wont to gather into herds, wild Hogs. the sows with the young, by themselves. The mature males not infrequently form troops of their own; but males of seven years or older live solitary and join the herds only during the breeding season. During the day the members of the herd lie in their lairs, quietly and lazily; towards evening they rise and start in search of food. At first they root up the earth in the woods or in the fields, or they run to a pool, and wallow in it for half an hour or so. Such a cooling bath seems to be indispensable to them, for sometimes they run miles to obtain it. Only when complete quiet prevails do they attack the fields and from any place upon which they then settle they are driven away with extreme difficulty. When the heads of grain are filling out it is very hard to drive them out of the fields and to protect the crop from damage. They eat much less than they trample down or uproot, and this is why they are so exceedingly destructive. In the woods and on the meadows the Hogs look for worms and insects and their grubs and truffles, or in fall and winter for acorns, hazel-nuts and chestnuts; in the cultivated fields they take potatoes, turnips, cereals, peas and beans. One may say in general, that they eat all imaginable kinds of plants and various animal substances, even dead beasts, slain Deer and car- casses of their own kind, and occasionally they may become truly beasts of prey, for they attack fawns, pursue Red or Fallow Deer or Roes which are wounded or weak from scant food, and in times of scarcity they eat their own young. According to whether food is plentiful or the winter a severe one, they may temporarily change their quarters and even undertake considerable migrations.

General Mental II'ild Hogs are wary and ever on the Characteristics of alert, though not exactly shy, as they

the Wild Hog. can depend on their own strength and weapons. Their character is a queer blending of a preference for comfortable repose, inoffensive good-nature, impetuosity and uncommon irritability. The strongest Boar will not molest a person if it is not provoked: but it always attacks a Dog and endeavors to kill it. No sow, however, and still less an old male will endure insult, or even teasing. If a person quietly goes his own way the IVild Boar pays no attention to him, or else makes off; but if it is provoked, it will turn even upon an armed Man. Dietrich aus dem IVinckell relates how, when an inexperienced youth, he once gave a Pig, which ordinarily was quite a good-natured fellow, a blow with his whip when riding past it, after which he was obliged to ride as fast as he could to escape it. He says: "Even a hunter must be on his guard when confronted with wounded Swine. IVhen a Hog attacks Man or beast, it rushes at its antagonist with great rapidity. It deals powerful, dangerous blows with its tusks; it rarely ceases the aggressive and still less frequently does it retreat. If one does not lose his presence of mind in such cases he lets the Hog approach quite close and then jumps quickly behind a tree; or, if this is not feasible, simply aside; thus the animal, not being very agile, rushes past. But he who has no time or opportunity for the execution of these maneuvres for safety, can only throw himself flat upon the ground; for a fighting Hog can strike only in an upward direction, never downward." The female is not of so hasty a temper as the male, but is little inferior to it in courage. She can not inflict severe injuries with her tusks, but this fact only results in making her still more dangerous than the male, for she stops near the object of her wrath, tramples on it with her feet and tears out pieces of flesh with her teeth. Even half-grown sows or young Pigs attack human beings; little ones are defended by older animals with indomitable courage. Sows which have Pigs do not easily give up the pursuit of any person who has robbed them of a little one.

If one looks at the tusks of a large Hog he realizes that they may become formidable weapons. Both tusks are white and lustrous and extremely sharp and pointed, and as age increases, they become more so through constant mutual friction. The tusks of the male increase in length and size and become more strongly curved as the animal grows older.

Birth and Infancy The weaker sows give birth to from of Wild four to six, the stronger ones to Pigs. $\quad$ eleven or twelve Pigs at a litter, in a lair which the mother has previously prepared in some lonely thicket and lined with moss, pine or fir needles, or other foliage. In this retreat she hides her little ones during the first two weeks, leaving them for short intervals only when she goes in search of food.

A group of these handsomely marked, young animals affords a pleasing spectacle, for the little Pigs are lively and extremely amusing creatures. Their 
markings are very becoming to them, and the playful, mischievous disposition of youth presents a perfect contrast to the laziness and fierceness of the animal in old age. The sow advances gravely, the pigs rum back and forth, squealing and grunting, dispersing and then collecting again, stopping, per-

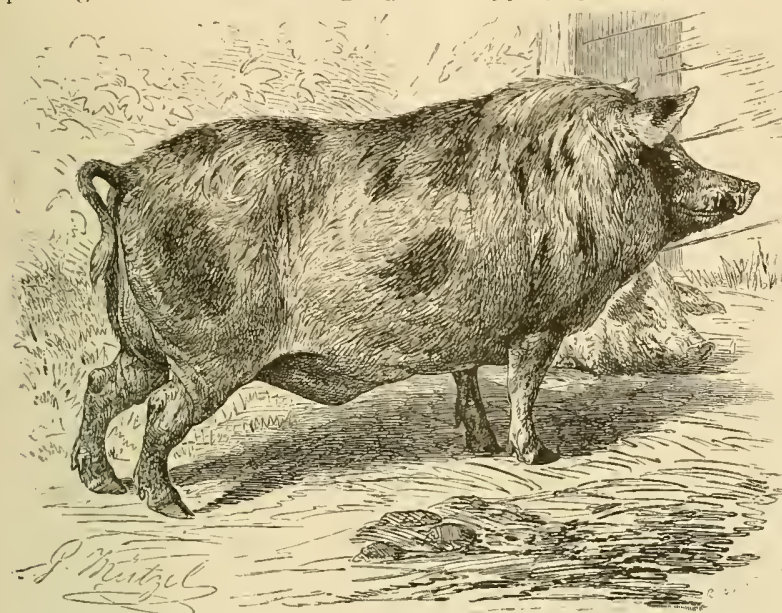

THE BERKSHIRE HOG. - This is a favorite English breed of domestic Swine, distinguished by a stout body, pointed, erect ears, comparatively short limbs and early maturity of growtis. (Sies scrofa.)

petrating some clumsy little joke, surrounding the mother and stopping her to suckle, and again merrily trotting on. So it goes all night: and even by day the restless brood can scarcely bear the restraint of the lair, continually moving to and fro. The age a Wild Boar may attain is estimated at twenty or thirty years. A tame Hog never becomes so old; lack of exercise and dearth of suitable food shorten its life. The wild Sivine are probably subject to few diseases. In central Europe their principal foes are the IVolf and Lynx and probably also the sly Fox, which catches at least an occasional little pig. In more southern regions the larger nembers of the Cat tribe, especially the Tiger, pursue this choice game extensively. The greatest foe of the animal, however, is Man.

The Boar a Favor. The chase of the IVild Boar

ite Game $A n-$ has ever been held to be a imal. gallant, manly sport; at present, however, it has become morc of a farce-a travesty on the old hunts-than an equal struggle between hunter and animal. In olden times matters were certainly seriously different, especially when the only arms in common use were the bow and the spear.

A Wild Boar defends itself against Dogs with unyielding rage. In former times people used in hunting IVild Hogs only the so-called Boar-hounds, strong, fleet and courageous animals, which were kept in a half-savage state and used only in Boar hunts. One breed of Dogs was used to follow the trail of the quarry and the other kind fought it. Before they would be able to seize the Boar and hold it fast by the ears, many a Dog had his body ripped open or sustained some other injury. When once seized by the ears the Boar would be held until the liunters came up and dispatched it.

The flesh of the Wild Boars is justly much esteemed, for it has not only the taste of pork but a genuine gamy flavor besides. The skin is also utilized and the bristles are in great request. But however great the profit may be, it can never outweigh the damage the animal inflicts on the agricultural districts it may infest.

Origin of the Com- Not only the European mon Domestic Wild Boar, but also sevHog. eral of its Indian, Malayan and eastern Asiatic relatives seem to have been reduced to the domestic state fron the earliest ages. In Julien's opinion domestic Pigs were bred in the Celestial Empire about 4,900 years before Christ; Rutimcyer's investigations of the lake dwellings show two different breeds of the useful domestic animal in Switzerland. "The ancient Egyptians," says Dumichen, "kept the Hog as a domestic animal. The monumental inscriptions mention it and it is pictured singly and in herds. I et it seems to have been kept for the sole purpose of being offered as a sacrifice on certain feasts of the year." It is frequently mentioned in the Bible; the Odyssey speaks of it as of a universally known and generally cared for animal.

Innumerable breeds have arisen and become extinct since those times and even now, as a result of the requirements of necessity or fashion, or by chance, new breeds originatc and older ones die out. Fitzinger and Von Nathusius assume that all breeds now living may be traced back to two different

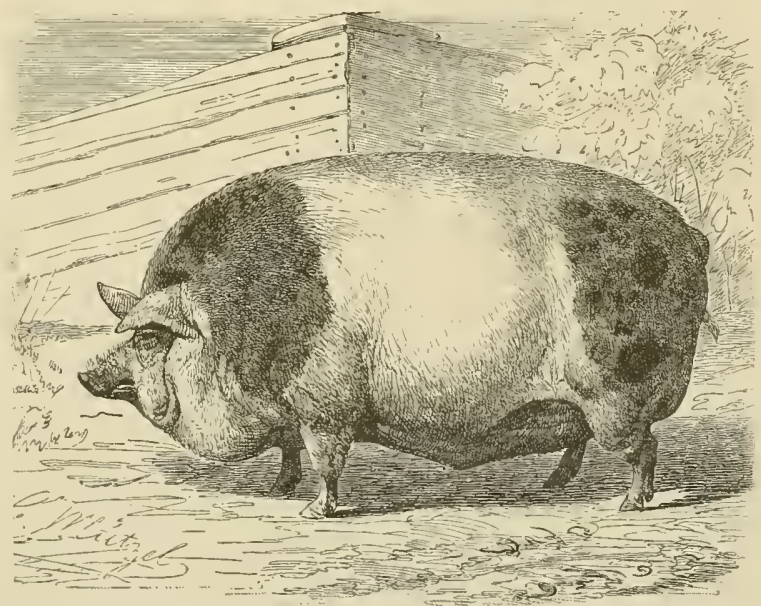

THE HARRISSON HOG, A variety of domestic Swine with pointed, sent. pendent ears, short legs, and tapering muzzle. It becomes excessively fat and is valuable pendent ears, short legs, and tap.
or pork purposes. (Sus sirofa.)

forms or species: the European Wild Boar and one south Asiatic species (Sus cristatus). This, however, does not preclude the fact that other Indo-MalayChinese species have also taken part in the evolution of the domestic species. Great as the difference be- 
tween these breeds may be, their existence as well as the origin and dying out of forms bred under the influence of Man are explained by independent or compelled selection in breeding and also by the variable conditions of climate, food, etc., surrounding domestic Hogs. All the popular and admired breeds of modern times are only artificial products of Man: the sturdy Berkshire, the fat Harrisson, and the compactly built Runt Hog. The Masked Hog is also an artificial production and owes its existence to the caprice of Japanese breeders. We leave it to others to describe that, as well as all other breeds, and will only cast a cursory glance at the habits and qualities of the domestic Hog in general.

Distribution of The domestic Hog is at present disthe Domes- tributed all over the globe. As far tic Hog. north as agriculture is pursued it lives in a state of, domesticity; in the southern countries it is kept in herds more or less remote from human companionship. As swampy countries constitute its natural and preferred range it undergoes

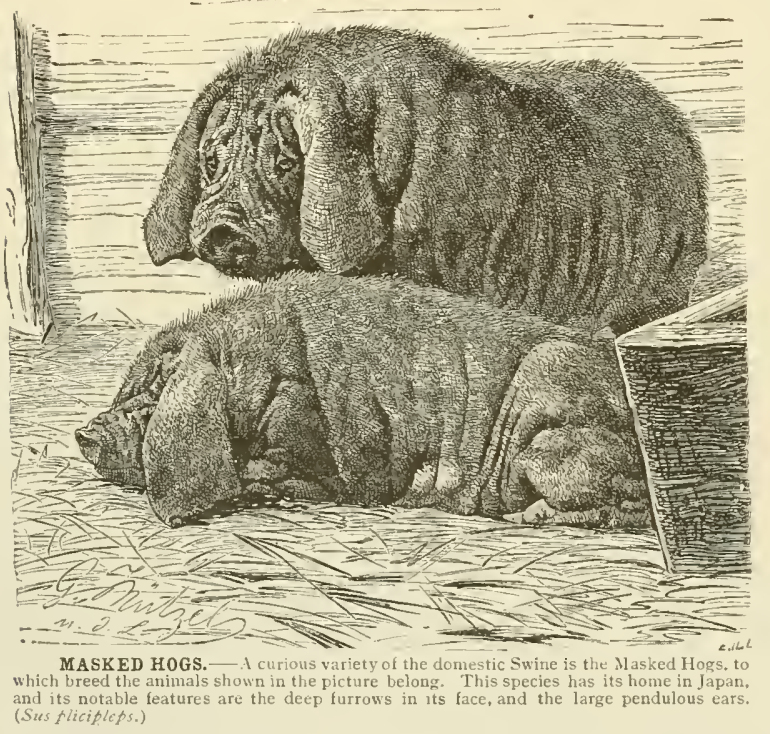

than those which spend the greater part of their lives outdoors; these latter are usually somewhat longer-legged and leaner, but much stronger physically and mentally; and more independent and courageous than the former. This forest breeding, if such I may term it, is followed not only in America, but also in most provinces of Russia, in the Danube valley, in Greece, Italy, southern France and Spain. In Scandinavia the Hogs run at large at least during the whole summer, each having a small triangular wooden collar around its neck, which prevents it from entering fenced-in land, but does not hinder it in the least in other respects. In traveling through Norway one sees Hogs running along the high roads very leisurely and contentedly, seeking all kinds of refuse and procuring other food by vigorous exploration of the ground by rooting. In southern Hungary, Croatia, Slavonia, Bosnia, Servia, Turkey and Spain, they are left to their own devices all the year round, and are cared for only sufficiently to keep them from rumning away. They appear to appreciate their surroundings in the forest and find very suitable feeding and fattening grounds, especially in the oak woods. In spain they ascend high up in the mountains, in the Sierra Nevada, for instance, as high as 7,500 feet, and seem contented and thrifty in localities in which other animals could not find enough to sustain them. Life in the free state greatly develops all their physical and mental qualities. They are good runners and elimbers and are amply able to protect themselves. In some instances, particularly in the colder teinperate climates, the Hogs are kept in forests in summer and in folds in the winter.

It has been held, but quite erroneously. that a Hoy needs mud and dirt for its pluysical welfare. Recent investigations have demonstrated that this animal thrives much better when it is kept clean, than when it constantly wallows in the mud; therefore well informed and progressive breeders no longer coop up their Pigs in the abominable prisons, called pig-sties, but give them spacious, airy premises, that can easily be cleaned, and there they rear much healthier and stronger domestic Pigs than they formerly did in the small, dirty sties. The best plan is to have the floor of the swine-fold made of stone slabs.

Mental Attribute The domestic Hog is voracious, reof the Domes. fractory and awkward, and displays tic Hog. little attachment to humanity. There are exceptions, however. Domestic Hogs, which from early youth have lived more in contact with the family than by themselves, as not infrequently happens in rural regions, exercise their intellectual powers and prove themselves much more intelligent than others of their kind. A forest guard told me, that he at one time had a little Pig of the so-called Chinese breed in his possession. It followed him like a Dog, knew its name, always came when it was called, went up the stairs with him, behaved quite decently in the house, obeyed orders and performed tricks. It had been taught to look for morels in the woods and performed its duty with great zeal. In France especially are Hogs trained to seek truffles: They also acquire many other accomplishments. When Louis XI was sick, nothing could cheer the melancholy king until a troop of well-trained little

fatter, but are weaker and more subject to diseases 
Pigs were brought to hin; they were attired in queer clothing and danced to the music of a bagpipe. Other l'igs have been trained to form words of large printed letters, to indicate the time after looking at a clock, etc. An Englishman had a l'ig trained to hunt. The animal was called "Slut;" it was very fond of the sport and would follow any hunter. It would point at any kind of game with the exception of the Hare, which it never seemed to notice. So sensitive was its nose that it would frequently point at a bird at a distance of forty yards. "Slut" was employed in the capacity of pointer for several years, but was at last killed, because it had become a dangerous neighbor to the Sheep. Other l'igs have been trained to run in harness. A farmer near St. Albans, England, often came in with a team of four Hogs, drove once or twice around the market-place, fed his team, and then drove back to his cause its death: as to the rest it eats anything Nan eats and a hundred things beside. It selects its food indiscriminately from the vegetable and animal kingdoms. It makes itself very useful on fallow land and in stubble-fields, as it destroys Mice, Maggots, cnails, Earth-worms, Grasshopjers, chrysalids of Butterflics, and various weeds, and as a result gets very fat while it is rooting up the earth. Black Hogs are said to enjoy the advantage of being able to consume poisonous plants of all kinds without injury to themselves, and therefore they are liept in some countries to either partial or total exclusion of all others.

While one tries, as much as possible, during the fattening process to keep domestic Hogs from taking exercise, he must allow some space for recreation to those destined for breeding. They also require clean, warm folds. The pairing usually occurs twice

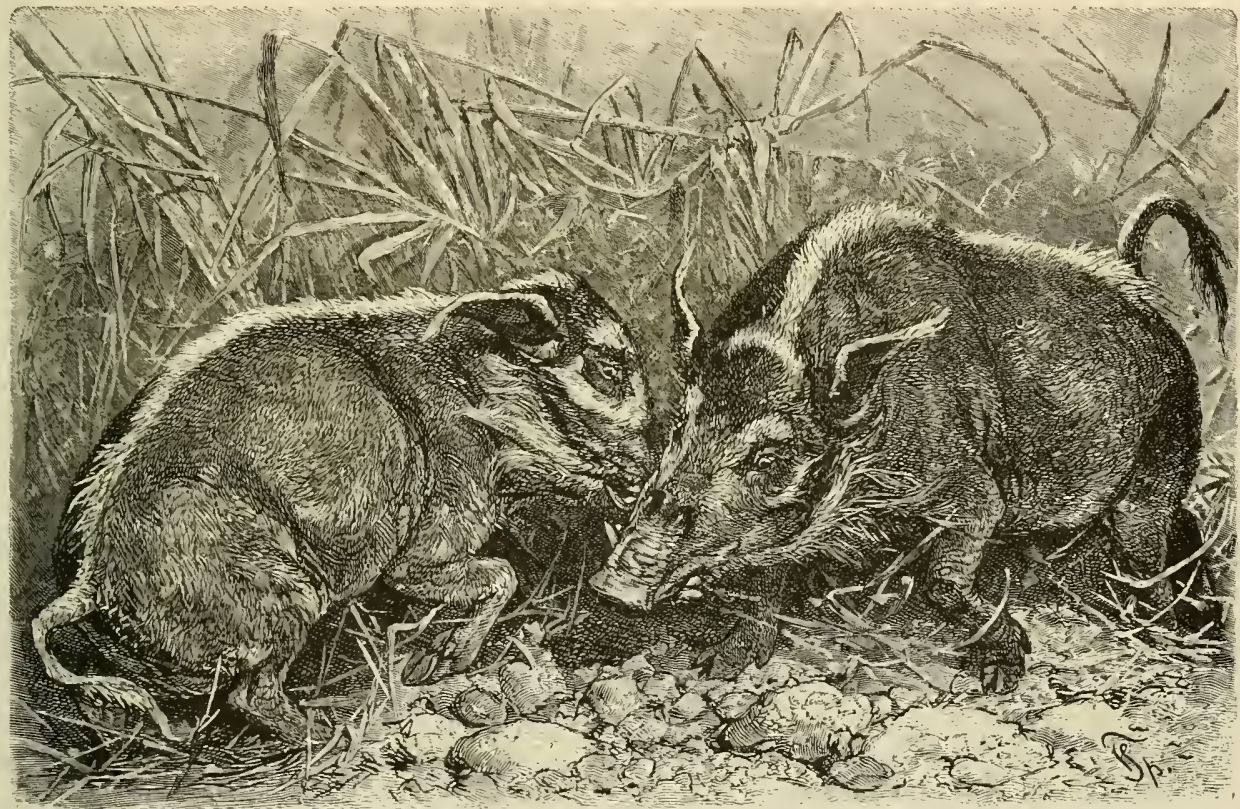

THE TUFTED HOG _- This animal, sometimes known as the Red River Hog, is noted for its vivid coloring, its somewhat humped back and light-colored mane, and above all for its long, penciled ears. It is a native of west ifrica, where it runs wild in the forests. (Potamocharus porcus.)

house. Another farmer laid a wager that he would in one hour ride his Pig from his own house to Nor. folk, a distance of four miles, and he won his wager.

These stories prove that Hogs are docile and carry with them the corollary that we ought not to underrate their mental capacity. It is a queer fact that Hogs always display a certain aversion towards Dogs. Tame and wild Hogs have no scruples anginst eating all other sorts of carrion, but are said never to touch Dog-flesh; on the other hand strange Dogs are often attacked by a gang of village Hogs, and sportsmen and promenaders, who, with their Dogs, visit villages where Hogs are allowed to run abroad, do well in being cautious.

Feeding and Uses In general 'a tame $\mathrm{Hog}$ is almost of the Domes- absolutely omnivorous. There really tic Hog. is hardly a nutritive substance which this animal would scorn. Some plants are not touched by it and acrid, pungent spices sometimes a year, in the beginning of April or in September From sixteen to eighteen weeks later, the sow produces from four to six, sometimes from twelve to fifteen, and in rare cases from twenty to twenty-four young. The mother displays little maternal solicitude for her Pigs, often not even preparing a bed before their arrival. It happens not infrequently, when the number of her progeny annoys her, that she eats some of them, this usually happening after she has smothered them by rolling over the Pigs accidentally. Some sows have to be watched and denied animal food a long time before the little ones make their appearance. If the mother is patient and careful with them, the young are left to suckle for four weeks, and require no other attention. Then they are taken away and reared on light, easily. digested food. Their growth is very rapid and a $1 \mathrm{Hog}$ is capable of reproduction at the early age of eight months. 
1 need say nothing about the utilization of the carcass of the animal; for everybody knows that absolutely no part of the body is wasted.

\section{THE HUMPED HOGS.}

The Hogs that have so far been considered are followed by the Humped llogs (Potrmochamis), which are undoubtedly the handsomest members of the entire family: Their distinctive features consist in a bony protuberance situated between eye and nose, an elongated face, a moderately long and finely shaped muzzle, large, narrow, pointed ears, decorated with hairy tufts, a mockerately long, bushy tail and four mammit in the female.

\section{Description of The Tufted Hog (Potamocharns por- the Tufted (us) the most beautiful of all Swine, Hog. has been known since the middle of} the seventeenth century. This animal is considerably smaller than the IVild Boar, though it attains, at full growtl, a length of from five feet to five feet four inches, inclusive of the tail, which is ten inclies in length; the height at the shoulders ranges from twenty-two to twenty-four inches. The skin is covered with short, soft bristles, which are elongated into a weak mane along the course of the spine and develop into tufts beneath the eyes, into stout whiskers on the checks and into a bushy tuft at the extremity of the tail, the remaining portion of which is naked along the greater part of its Iength. The prevailing color of the animal is a fine lustrous brownish red, dashed with yellow. The animal abounds mainly in west Africa, but Boehm mentions having seen it several times in eastern Africa.

We still have very scanty information concerning the life of the Tufted Hog in a wild state. The Gussfeldt Loango exploring party obtained several young Tufted Hogs. One of then was installed in the Monkey cage, was on excellent terms with its fellow-prisoners and was very amusing by reason of its cheerful, active disposition. Pechuel-I oesche says, in speaking of the wild specimens: "They are lively and very fleet; judging from their trails, they always roam about in considerable herds, especially in damp forests, near rivers, though they are not rare in the mountains. Occasionally one may be heard grunting in the thicket, quite near the traveler, or still more frequently they growl in quite a peculiar, contented way. When they are alarmed, they seldom give a sound, but retreat noiselessly, hoping to remain unseen. They are tenacious of life and may go quite a long distance after being struck by a well-aimed bullet. The flesh is savory."

Like all Wild Boars, they endure the change from a torrid to a temperate climate fairly well and usually survive if protected during the severe weather of the winter; they would excite great hopes of successful propagation in captivity if they would only take better care of their young than they have so far done under human supervision.

The Bush Hog A second species of the genus, the of Southern and Bosch Vark or Bush Hog (Potamo. Eastern Africa. charus africanus), it is believed, inhabits only southern and eastern Africa. It is somewhat larger than the Tufted IIog, has a uniform growth of hair, except a recumbent mane on the neck and rather stout whiskers. The beard and mane are whitish gray, the face is fallow gray, the rest of the body reddish grayish-brown.

\section{THE BABIRUSA.}

A very curious Hog lives on Celebes and the adjacent islands cast of it, especially on Sulu, Man- gola and Buru. It is much slenderer and has longer legs than all the others of its kin, but is chiefly distinguished by its tusks, which have the appearance of horns, for they attain such great length that they may quite appropriately be compared to those members, Europeans have simply accepted the original native name, Babirusa, which is equivalent to BoarDeer. The Babirusa differs from all other members of the family by reason of its canines and is justly regarded as the representative of a distinct genus (Porcus.)

Description of The Babirusa (Porcus babyrassa) is an
the Babi-
rusa. report having seen male Babirusas as large as medium-sized Jonkeys. The average length of body of an adult animal amounts to forty-four inches, the tail is eight inches in length, the height at the whers and croup is thirty-two inches. The body is elongated, the back slightly arched, the head comparatively small, the legs are long and quite vigorous, each having four toes, and the tail is slender and pendent. The canine teeth of the upper jaw of the male Babirusa are extremely long, thin and pointed, rounded on their front face, laterally compressed, blunt-edged behind, and directed upwards and at the same time strongly curved backwards, so that they sometimes penetrate into the skin of the forehead when the animal is of an advanced age; they pierce the root of the mouth and curve backward in a crescent shape or even still more markedly. The shorter and thicker tusks of the lower jaw are directed upwards in a straighter manner. The canines of the female are very short. The hairy covering consists of sparse and rather short bristles, which are thichset along the course of the spine, between the numerous wrinkles of the skin and at the extremity of the tail, where they form a small tuft. The skin is thick, hard, rough, greatly wrinkled and deeply furrowed on the face, around the ears and on the neck. A dingy, ashy gray on the upper and exterior surface and a rusty red on the inner faces of the limbs are the prevailing colors; a brownish yellow band, formed by the tips of the bristly hair, extends along the middle line. The ears are blackish.

History, Range and It seems that the Babirusa was Habits of the known to the ancients. Skulls of Babirusa. the animal have been known to naturalists for several hundred years, but skins have ever been rare in Europe, and are so still; the pictures have been caricatures and the natural history of the animal consisted of a series of the most insipid fables.

Celebes must be regarded as the real native country of the Babirusa, for it is only found there and on the previously mentioned adjacent islands, being absent from the other islands of the Australian Archipelago and also on the Asiatic and Australian continents. Its habits are similar to those of other Swine. Swampy forests, cane-brakes, moors and lakes grown with a profusion of aquatic plants are its favorite haunts. There it assembles into greater or smaller societies, slecping by day and roaming about by night in search of food, accepting anything in the line of provender. The Babirusa avoids Man as long as it can, but when driven to bay, it defends itself with the resolute courage common to all male Hogs, and its lower canine teeth are such effective weapons that they may well inspire the most courageous Man with a sentiment of cau- 
tion. The natives are said to kill it with spears and sometimes to organize hunts in which the animal is driven by beaters, under which circumstances it ustially seeks safety in flight.

The sow is saici to give birtl to one or two young, in February. They are pretty little creatures, from seven to eight inches in length, and are loved and defended by their mother with great devotion. If the young are taken early, they gradually acquire a certain degree of tameness; they become used to Man, occasionally follow their keepers about and express their gratitude by shaking their ears and tails. One sometimes finds a living Babirusa in the possession of a native chief, for the people of the islands which it inhabits regard it in the light of a queer creature and keep it in confinement as a curiosity. This, however, happens quite seldom, and a high price is asked for a Hog of this kind. the London Zoological Garden, and some of them throve quite well, and propagated in captivity, under the careful treatment accorded to them.

\section{THE WART HOGS.}

Besides the Humped Hogs (Potamocharus), Africa harbors genuine monsters of the same family, the Wart llogs (I'lacocharus). They are the clumsiest and ugliest of all known Swine, distinguished above all by the ungainliness of their heads and the peculiarity of their dentition. The body is of cylindrical shape, the neck short, the head bulky, with a low, broad forehead, the nasal area being perceptibly broadened all over and disproportionately so in the front part of the upper lip. On the sides the head is disfigured by three wart-like growths; one of these is over an incli high, pointed and mobile and is situated below the eye; another, a smaller one, stands

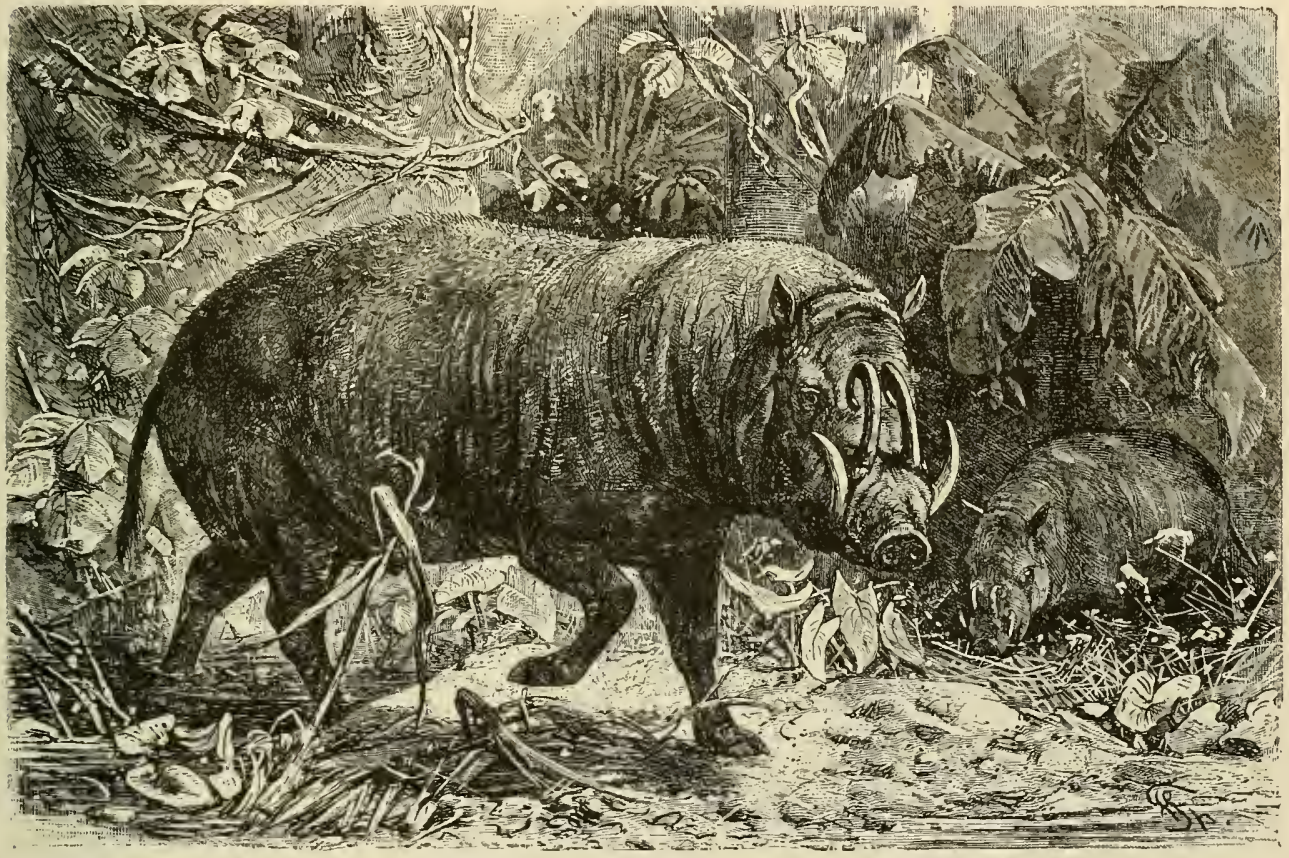

THE BABIRUSA _ A peculiar species of the Swine family found in some of the islands of the Malay Archipelago. The tusks of the lower jaw are long and sharp, but the upper pair grow very long and curve backward. Only the male Babirusa has these tusks. (Porcus babyrussa.)

Markus, the Dutch governor of the Moluccas, made a present of a couple of Babirusas to the French naturalists, Quoy and Gaimard, when they visited him on their tour around the world. These two Babirusas were the first that were brought to Europe alive, arriving in 1820 . Both animals became tolerably tame. They proved to be extremely sensitive to cold. In March the female gave birth to a young one and immediately became very irritable and vicious. She allowed nobody to touch her offspring, tore the clothes of the keepers and snapped violently at those who approached her. Unfortunately the animals did not long survive, for the cold climate proved fatal to them. The little Pig, a male, grew rapidly and attained to a considable size in a few weeks. It died before it was two years old. Later, other living Babirusas reached erect on the fore part of the side of the upper jaw, and the third, which is long at the root, begins on the lower jaw and extends along it to the mouth. The small eyes are prominent, like those of the Hippopotamus; the disk on the snout is enlarged and is of an ovoid shape, the longest diameter being horizontal. The skin is covered with very short and thinly set bristles, with the exception of whiskers and a spinal mane-like crest. The dentition consists originally of six incisors above and below, gigantic, longitudinally furrowed tusks, which bend directly upward, as they do with the Hogs, and six molars in each row, above and below. Thus there are forty teeth, of which, however, not only the molars, but also a majority of the incisors, usually drop out, although the loss of the teeth is not uniform but varies in different individuals. 
Physical Charac- The Wart Iog (Phacocharusafricants) teristics of the attains a total length of six feet four Wart Hog.

inches, inclusive of the tail, which measures eighteen inches; the height at the shoulders is twenty-eight inches; the appearance of the animal is also characterized by the very elongated, broad snout somewhat furrowed along the center, the erect excrescences and the tusks which are but very slightly, if at all, bent laterally. The hairy covering of the sides and under parts of the body is short and thin, even during the cold season. On the other hand a mane, which begins on the forehead, broadens on the back, and extends to the croup, attains so considerable a length that it falls down to the abdomen along the sides. The range of the Vart Hog extends principally over the eastern parts of central Africa. ish brown, mingled with white, on the sides [and there is an oblique whitish stripe on the neck and shoulders, from which it derives its name of Collared Peccary]. The inguinal gland secretes a fluid of pungent odor, offensive to human nostrils, but which seem to be a grateful perfume to the animals themselves, for they frequently rub their muzzles over each other's glands, and seem to derive a considerable degree of satisfaction from the act.

The White Lipped The second species of the genus, the

Peccary De- White-lipped Peccary (Dicotyles labiscribed. atus) is perceptibly larger than its relative, from which, also, it differs in color: and it has a large white patch on the lower jaw. Its general color is grayish brown, rather uniform on the entire body, the light patch on the muzzle standing out in bold relief.

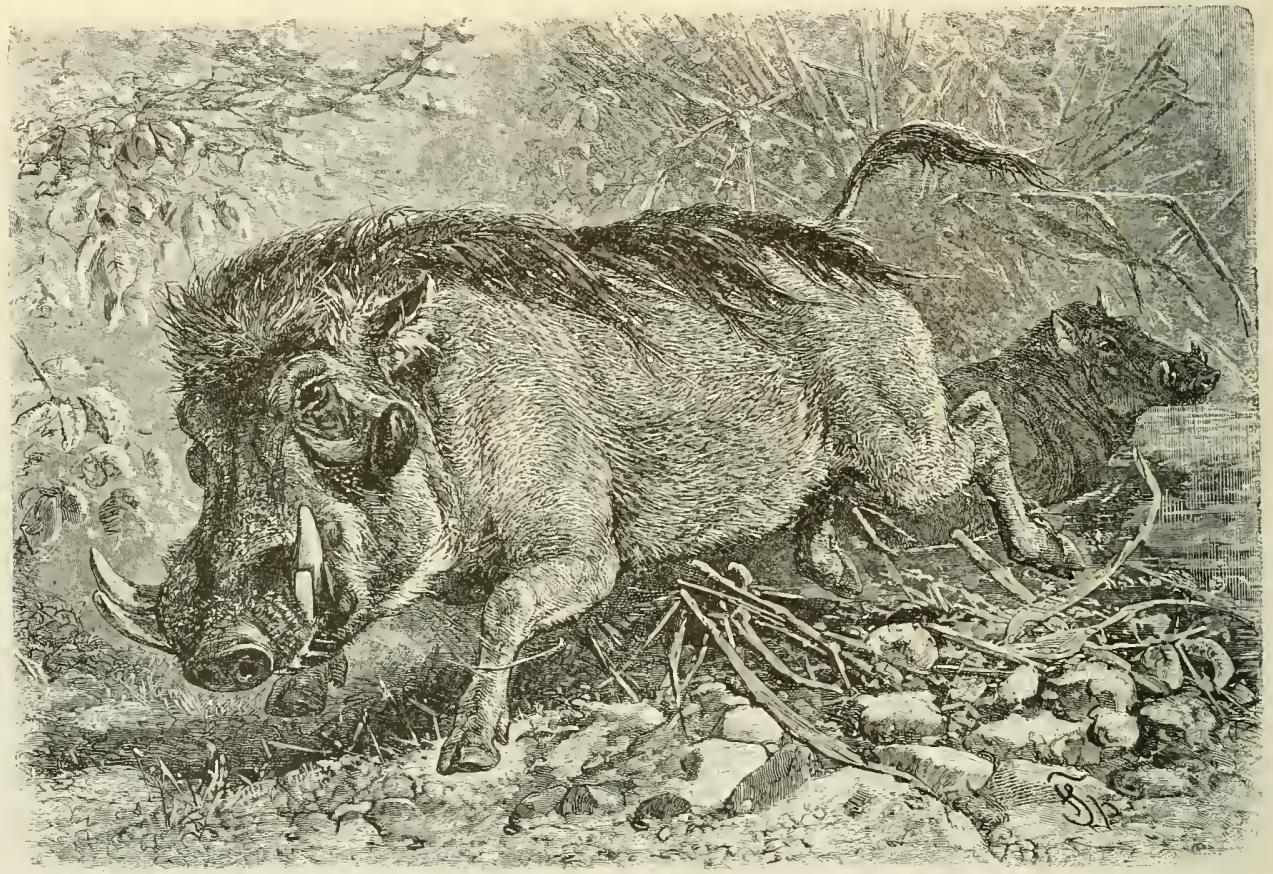

TH WAT its face, It is a very strong animal and its back is surmounted by long bristles forming a mane. (Phaiocharus afrianus.)

\section{THE PECCARIES.}

Among the distinctive characteristics of the Peccaries (Dicotyles) are, first, their dentition: the teeth are thirty-eight in number and the tusks do not curve upward, nor do they pierce the upper lip. These animals are further characterized by a compact structure; a short head and short, slender snout, and rather small ears; by the lack of an outer digit on each hind foot, the rudimentary tail, the cutaneous gland opening near the loins, and the mamme of the female, which are two in number.

Description of The Collared Peccary (Dicotyles torthe Coltared quatus) is a small Hor measuring not Peccary. more than thirty-eight inches, with a tail less than an inch long, and the height at the shoulders is from fourteen to sixteen inches. The general color is a blackish brown, fading into yellow-
Range and Habits The Peccaries are of common occurof the Pec- rence in all wooded regions of South caries. America, up to an altitude of about three thousand feet above the sea. [The range of the Collared Peccary extends also northward through Central America, Mexico and Texas, the Red River in Arkansas being the northeastern boundary of its range.] The White-lipped Peccarics roam through the woods in large lierds numbering thousands, under the leadership of the strongest males. The Collared Peccarics form into troops only numbering from ten to fifteen, and they daily change their place of abode and are continually migrating. Rengger affirns that one may follow them for days without seeing them. "In their wanderings," says this naturalist, "ncither the open country (which ordinarily they seldom frequent) nor water can stop them. If 
they reach a field, they cross it at a run, and if they arrive at the banks of a river, they do not hesitate an instant, but swim across it. I saw them crossing the Paraguay River at a place where it required about half an hour to do so. The herd keeps together in a close throng, the males in advance, each mother female having her young bchind her. The noise made by the herd can be heard from afar, not only on account of the dull, hoarse sounds made by the animals, but still more by reason of the crackling of the branches which they break in their impetuous progrcss."

The Peccaries search for food both day and night, and it is probably the lack of suitable food which actuates them in their more cxtensive wanderings. All kinds of arboreal fruit and roots furnish their usual fare. Their teeth are so strong that, as Schomburgk says, they can easily open the hardest of palm-seeds. In inhabited countries they frequently make inroads on plantations and do great mischief to the crops. They are said also to eat Snakes, Lizards, worms and grubs, besides vegetable food. In their movements and character thcy exhibit an affinity to the Wild Boars, but show neither the voracity nor uncleanliness of the latter; for they never eat more than they require and seek water only during periods of the most intense heat, and then they wallow only in pools. During the day tley hide in hollow treetrunks or between loose roots; when they are hunted, they always flce to such hiding places. Their perceptive senses are weak, their mental capacity slight. The senses of hearing and smell scem to be best developed, but that of sight is very poor.

"The White-lipped Pecca ries," says Rengger, "are extensively hunted, partly for the sake of their flesh, and partly. because they are so hurtful to the crops. They are usually tracked in the woods by Dogs and killed with fire-arms or spears. If they are in the habit of invading a certain plantation, the planter digs a pit, which may bc as deep as nine feet, on that portion of his possessions through which they are wont to pass as they take their departure. He then waits for them to put in an appearance, and when they come he drives them towards the pit, with the help of Dogs and Men, who raise a great outcry; if the herd is numerous, the pit is sometimes half filled with them. The Indians catch them with snares.'

The female gives birth to a single young one, or in some rare cases two; the little ones follow their mothers perhaps as early as the first day, but certainiy in a very short time after their birth. These little Peccaries do not grunt, but cry somewhat like Goats. They are tamed without trouble and become true domestic animals if accorded good treatment.

The skin of the Peccaries is principally used for bags and thongs, the flesh being eaten by the poorer classes. It has an agrecable taste which has, however, no resemblance to pork.

\section{Tbc 1bippopotamí.}

\section{NINTH FAMILY: HIPPOPOTAMID.E.}

The Hippopotamus (Hippopotamus amphibius) is very much clumsicr than any of the other Artiodactyla and is, besides one much smaller relative (the Liberian Iippopotamus, which is yct little known, and occurs in $\mathrm{U}_{\text {pper Guinea) the only living repre- }}$ sentative of a distinct family, the Hippopotami (Hippopotamide). The ancient Egyptians, who called the uncouth giant "River-Hog," were much more correct in their appellation than the Greeks, who called it "River-llorse," or the Arabs, who call it "Water-Buffalo;" for if the Behenoth mentioned in the Bible can be compared to any animal, that animal is the Swine.

General Character- From a purely external consideraistics of the Hip- tion the head differs more than anypopotamus. thing else from all others mammals. It is distinguished by its nearly rectangular shape, and by the small ears and eyes, as well as the ob-

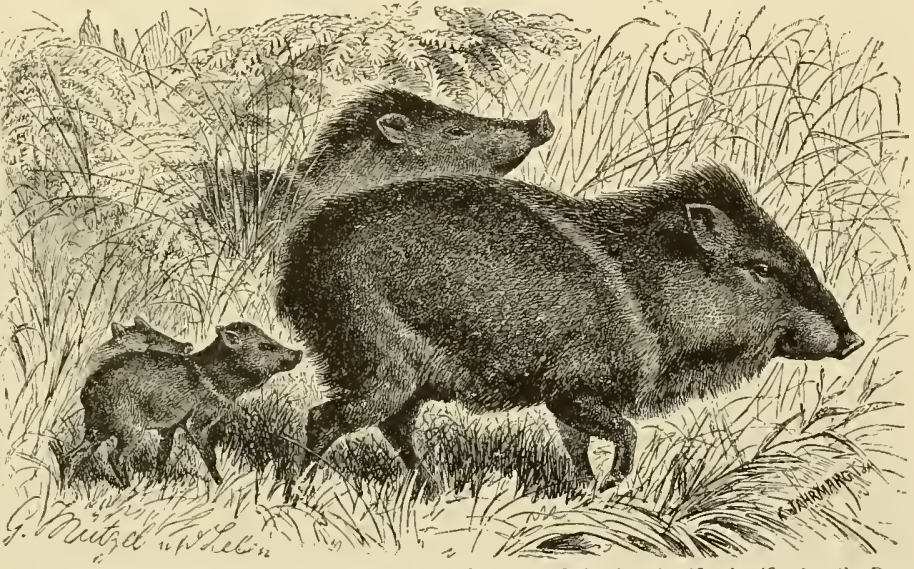

ARY. - Though placed with the Swine in scienlific classification, the Pecst characteristic features. (Dicotyles torquatus.)

liquely placed, large nostrils of a curved, slit-like shape, which, together with the other organs of sense, form the highest points of a plane, below which lie the forehead and facial part. The hoad is also characterized by the shapeless muzzle, the thick, smooth upper part of which is rather narrow posteriorly, broadens and becomes thicker in front, and is abruptly cut off, giving to the beast a thick upper lip which covers and closes the hideous mouth from all sides. The neck is short and stout, the body long, but at the same time thickened out of all proportion and therefore inordinately clumsy; the back is higher at the croup than at the withers, and depressed in the middle, and the abdomen is full and round, and so pendulous as to touch the earth when the animal walks on muddy ground. The tail is short and thin, and towards the extremity laterally compressed; and the disproportionately short, shapeless legs have broad, four-toed feet, the digits being joined by short webs and all directed forward. The extremity of the tail alone has short, wiry bristles. The remainder of the hide, which is nearly an inch thick and is characterized by several deep folds, especially on the neck and chest, is very 
sparsely covered by short, bristly hair. Furrows, which cross each other, divide the shin into scalelike plates, which may be of large or small size. The color is of a peculiar coppery brown, which merges into a dark, dirty-looking red on the upper surface and into a bright, purple-brownish tint beneath. Brownish and bluish spots, placed with a considerable degree of regularity, give the rather uniform mass a certain diversification in coloring. The hue changes, however, with reference to whether the Hippopotamus is dry or wet. On just leaving the water, its upper parts appear brownish blue, and the lower surface nearly flesh-colored, but when the skin dries, it becomes darker, nearly blackish brown or slate-colored, or when the sun shines on its back, it looks uniformly bluish gray. The total length of an adult male Hippopotamus is from fourteen feet to fifteen feet, inclusive of the tail, which is eighteen inches long; the height at the shoulders is five feet. The weight of the animals may average from four thousand to five thousand pounds, and probably may rise as high as six thousand in an old bull. The head alone of such a giant weighs fully four hundred pounds.

The dentition of the Hippopotamus differs from that of the Swine, with which it most nearly corresponds, less in the number of teeth than in their formation. Each jaw contains four incisors, two canines and fourteen molars: thus the teeth are forty in number. The two central incisors of the lower jaw are separated from each other by a gap, are considerably larger than the lateral ones, and are in a certain sense similar to canine teeth. Those of the upper jaw are smaller, curved and placed perpendicularly to the jaw. The canine teeth of the lower jaw are enormous tusks, averaging twenty inches in length and eight pounds in weight; they are threesided, curved in a crescent shape, beveled at the extremity, and marked with deep longitudinal furrows; the upper ones, which are directed downward, are perceptibly smaller and weaker than the lower pair, but are also curved and beveled. The skeleton is exceedingly bulky in all its parts; the skull is nearly rectangular, flat and compressed, the cerebral area is small, the orbit is surrounded by a high ridgc formed by the frontal and malar bone, the remainder of the bony framework is thick, clumsy and heavy.

The Range of At present one must penetrate rather the Hippo- deeply to the interior, coming from potamus. the north, if he wishes to encounter a Hippopotamus in Africa. The noted animals have receded far towards the center of the continent along the Nile. Only when one reaches the very heart of Africa do the sculptured effigies in the Egyptian temples, which date four thousand years back, become living pictures before one's sight. There the same animals are found to-day, among the unchanged people; there we meet the Baboon and the Crocodile, the sacred Ibis and the Tantalus, and beside them what remains of the Elephant, the Rhinoceros and the Hippopotamus. Wherever Man rules undisputed the latter have succumbed to the terrible firearms; but where he is armed only with a spear or bow, they still confront him as living enemies. The Hippopotamus is now extinct in all parts of Egypt and also in Nubia, where Ruppell found it in considerable numbers as late as the beginning of this century.

In east, south and west Africa the llippopotami descend much lower towards the coast than in the northeru half of the continent, and not infrequently. even swim out to sea. They likewise go up a river, as far as the force of the current permits them, and thus it happens that they are found in the lake of Tana in Abyssinia, which is situated 6,460 teet above the sea.

General Traits of The River Horse is confined, more the Hippopot- closely to the water than any other amus. thick-skinned animal; for properly speaking it comes to the shore only in exceptional cases: when the stream itself does not abound in the plants which form the animal's customary food, it leaves the water for the purpose of feeding. Sometimes, however, it seeks the bank during the day, to bask in the sun's rays.

in favorable spots along a watercourse an expert can soon discover the whereabouts of these gigantic animals. At intervals of three or, at the most, four minutes, during calm weather, one may see a jet of spray rising to the height of about eighteen inches, and may hear a rushing, puffing or snorting sound. This means that a Hippopotanus has just risen to the surface to breathe, and then, if the observer is near enough, he may also sce a part of the animal's head: a shapeless, red or brownish red mass, upon whlch may be distinguished two points-the ears: and four little hillocks the eyes and nostrils. It is seldom that more than the upper part of the head of a Hippopotamus is seen in the water, and even this portion can be easily mistaken for something else, when it is seen for the first time. By keeping to the leeward and remaining quiet, it is easy to observe the animal swimming up and down as if in play.

The Hippopotamus is gregarious, only the old males living a solitary life. A large pool is sometimes utilized for a somewhat protracted sojourn of a herd of these animals. When they inhabit narrow, shallow waters which, in many places, dry up during the arid season, it can be observed that the animals do not leave certain favorable spots during any part of the day. They are also wont to hollow out for themselves pits in the middle of the beds of shallow rivers: long, deep depressions-the longest diameter of which follows the same direction as the currentin which they can dive conveniently and hide when they are pursued. These depressions are sometimes connected by channels, hollowed out like ditches, which form submarine pathways for the animals.

The Hippopotami In places where they deem them-

by Day and selves free from danger of molestaNight. tion the animals seek, during the day, some spot near the bank, either in shallow water or on the shore, and bask in the sunshine, abandoning themselves to a dreamy, half-dozing condition, during which they display a degree of blissful contentment equaling that exhibited by wallowing Swine or bathing Buffaloes. At intervals the male animals grunt like Hogs, or one of them lifts its head a little to look around, but otherwise pay little attention to the surroundings except in those localities where they have learned to dread Man and his terrible firearms.

Toward evening the group shows signs of life. The grunting of the male becomes louder and the entire herd dive up and down the stream in play and sometimes indulge in a merry chase. They seem to like the neighborhood of vessels, and often accompany boats on evening trips for considerable distances. Sometimes they make such a terrible noise, with their snorting, grunting, roaring and surgling that they become veritable nuisances. They 


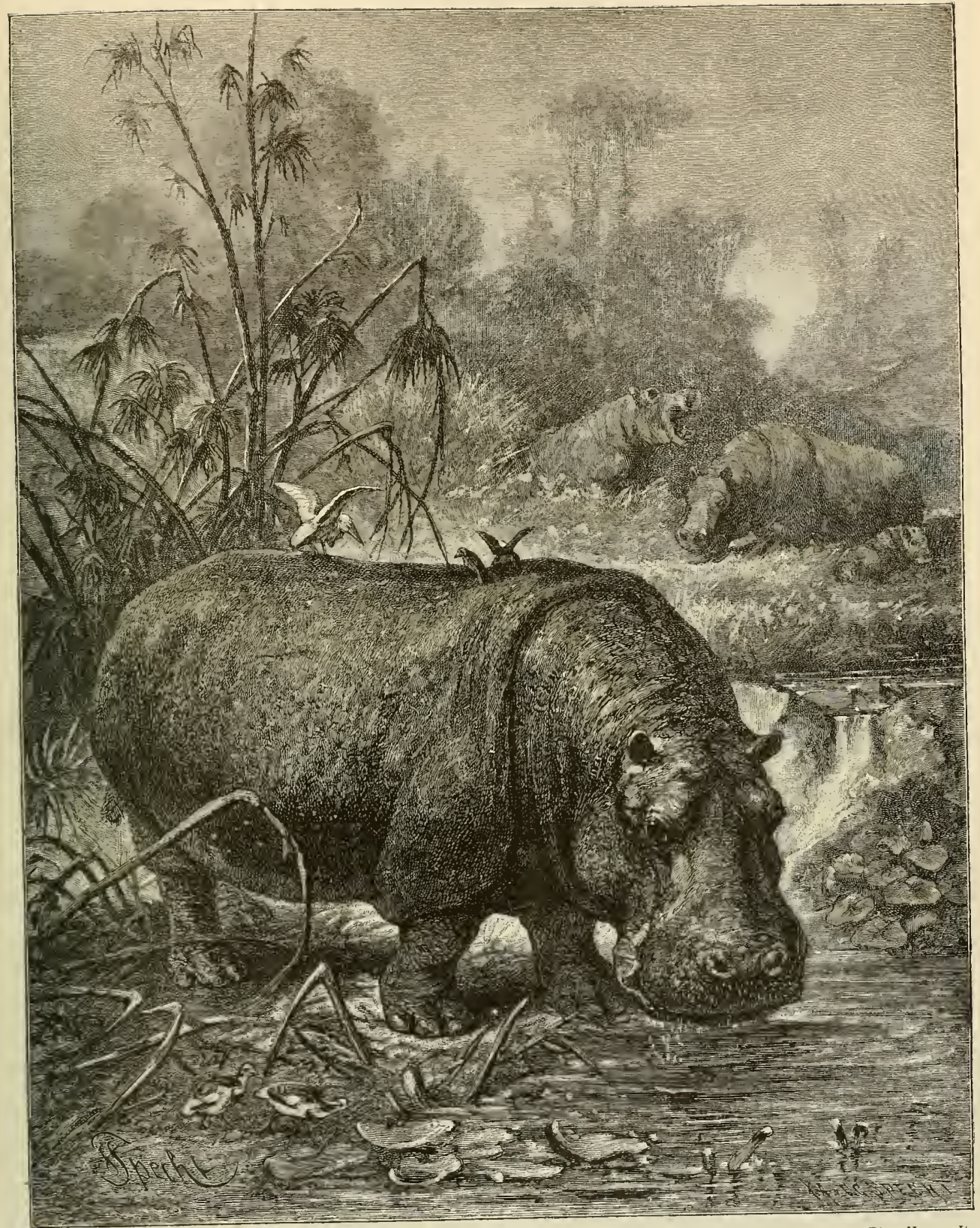

THE The mest peculiar and repulsive possessed by any animal; the neck is short clumsy legs bear a body of groat bippopotanus is in the large rivers of short and verv thick. The expression olferocity in its face is a tiue) (Hiptoputamus amplizius.) 
swim in any depth of water with a degree of ease and agility that is amazing and they go through the water as swiftly as a row-boat, without making a ripple, when they swin quietly. When, on the contrary, a Hippopotamus is enraged and charges at an enemy, or blusters about after having been wounded, it jerks its hind legs backward with extreme violence, shoots forward with powerful bounds, and may trouble the waters of an cntire lake, causing high waves on the whole of its surface. The force of its movements under such circumstances is such that it has been known to lift boats of considerable size and dash then to pieces.

"To describe the vocal utterance of these giants with even approximate accuracy," says Heuglin, quite truly, "is beyond the power of words. It consists of a roar, bearing some resemblance to that of a Buffalo. Its tone is a deep, reverberating bass, which sounds as if it came from the recesses of a large, hollow barrel. The roar of a number of males, each striving to outdo the others, suddenly resounding through the quiet loneliness of night combined with the rushing, blowing and puffing of the diving Hippopotami, produces an infinitely majestic impression, which does not seem to be lost even on the animals of the wilderness; for the Jackal, the Hyzena, and even the Lion, are silent and listen, when, like the rolling of an earthquake, the thundering voice of Behemoth booms over the watery surface, resounds through the distance, and is lost in the vast virgin forcst." The voice of the Hippopotamus surpasses that of all other animals in volume, but is seldom heard in full force.

Habits of Feeding In the broad lagoon-like spots of the

of the Hippo- upper Nile, abounding in vegetation,

potamus. the Hippopotamus does not leave the stream even at night, or does so very rarely. It feeds in such places day and night on the plants growing in the water.

Such is not the case in localities where it must ascend the bank to graze. About an hour after sunset it emerges from the water, listening and watching with the greatest caution; in the neighborhood of cultivated localities it shapes its course towards the plantations. There it works great devastation, sometimes laying waste an entire ficld in one night. Its voracity is enormous, and if its numbers increase to any extent, it may become a serious plague, in spite of the fertility of its native country; for a much greater quantity than the amount consumed is trodden down under its huge feet or broken when it wallows contentedly, like a Hog, in some shallow depression after it has satisfied its wants. It consumes all kinds of grain and all vegetables which are raised in the country.

The Hippopot. The Hippopotamus, however, is not amus a Danger- only hurtful to the crops on its foragous Foe.

ing expeditions, but may become a monster perilous to the life of Man and beast. The four powerful tusks are formidable weapons when used against other animals. Ruppell tells us of a case, in which a Hippopotamus crushed four draught Oxen, which were quictly standing near a waterwheel. "On the Kingani," says Boehm, "two women who were loudly talking to each other, as they passed by several fceding Hippopotami, were suddenly attacked by one of the animals and injured so severely by a few bites, that both dicd." The Hippopotami are not, however, regarded everywhere as uncommonly dangerous; in some regions they are not feared when on land, but only in the water.
They seldom molest large vessels, but light boats sometimes fare rather badly from their attacks. "Lieutenant Vidal," says Owen, "had just started on his trip on the river Tembi in southwestern Africa, in a light boat, when he suddenly felt an exceedingly powerful thrust from beneath, so that the stern of the boat was nearly lifted above the water and the pilot was precipitated overboard. The next instant a gigantic Hippopotamus rose out of the water, and, open-mouthed and with a fierce, menacing look, rushed at the boat. It seized the craft between its fearful jaws and tore seven boards off it at one bite. Then it disappeared, but soon came up again to renew its attack and was made to desist from its purpose only by a shot fired at its face. The boat, which immediately filled with water, was fortunately so near the shore that its occupants could gain the land before it sunk. Probably the little vessel had grazed the back of the animal and thus provolied the attack."

Similar stories, with manifold additions and multiplications, are current in many of the regions inhabited by the thick-skinned fellows, if not in all, and he who hears them is led to the belief that they relate to everyday occurrences. Hippopotami are quite frequently to be seen on some African rivers, and in some special localities exist in large numbers, and if they were as dangerous as they are sometimes represented to be, all travel and traffic on water-courses frequented by them would cease, or at least would be greatly impeded. In reality, however, numberless irail craft ply along those streams, past the huge creatures or between them, and are not molested.

Birth and Youth The Hippopotamus is dangerous

of the Hippo- only when it is defending its young. potami. It is only during modern times that, by watching captive animals which have bred in confinement, observations concerning the pairing of these animals and the birth of their young have been made. In the free state, the young are born about the first third of the rainy season, which period always affords them the most abundant quantity and succulent quality of food. This season of tropical spring varies greatly in different parts of Africa. The maternal Hippopotamus is tenderly solicitous for her progeny, seeing impending danger in the most harmiless-objects. Probably the father also guards his offspring, but the mother is easily recognized, never losing sight of her infant for an instant, watching it with truly maternal care and sometimes playing merrily with her pet. She suckles it under water, but Theodor von Heuglin says that the female gives birth to her young on the land, or in some swamp, in a secluded lair. After birth she does not always lead it straightway to the river, but sometimes puts it into a pit, which the little beast can not leave without her aid

Dangers of Hunt- The blind rage of an infuriated 1 Iiping the Hippo- popotamus indicates clearly that the potamus. pursuit of the animal without firearms of heavy calibre and great power is a sport not exactly suitable for amateur hunters. Light rifle bullets, even when fired at short range, seldom have any effect. Ruppell says: "With one Hippopotamus which we killed we fought for four hours, and it came very near destroying our large canoe and all of us along with it. The twenty-five bullets we fired at the monster's head, from a distance of about six feet, pierced only the skin and the bone near the nosc. All other bullets lodged in the thick hide. 


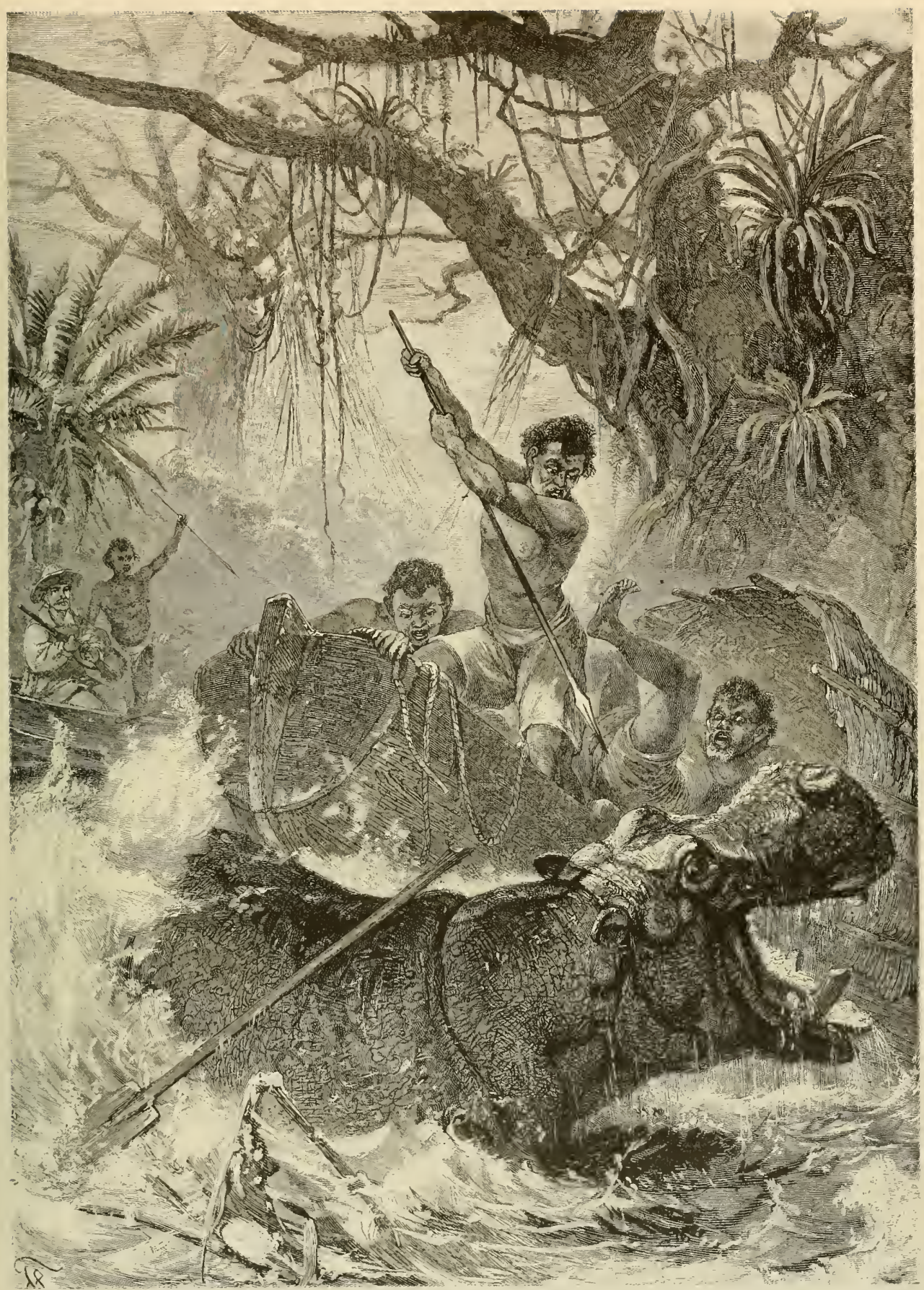

ATTACK ON A HIPPOPOTAMUS. The hunting of the llippopotamus is fraught with great danger, and the scene depicted here represents a moment of peril. The huge beast, compelled to take the defensive, has broken the rude paddle used by the natives to propel the canoe, One of the boat-
men is endeavoring to give the monster such a thrust with the spear as will either end its life or cause it to retreat and expose sone vital spot to the ain of the white Man's gun. If this fails, the frail craft may readily be crushed by the animai's vicious attack. (Hippopotamus amflubus.) 
At every snort the beast squirted copious jets of blood over the boat. Then we finally made use of a large stationary swivel gun which we had deemed unnecessary, considering the short distance. But only after five of its balls, fired at the distance of several yards, had inflicted the most terrible wounds in its head and body, did the giant breathe its last. The darkness of night still increased the ghastliness of the struggle."

But without such weapons of offense, the native hunter has fron time immemorial attacked the monster with javelin and spear and followed the sport as successfully as these arms permitted. In all essential respects the African sportsman proceeded and still proceeds after the fashion of the ancient Egyptians, with whose Hippopotamus hunts we are familiar through the pictures on the monuments, and the accounts given in the writings of several of the old authors. The spear and a suitable harpoon provided with a line and a buoy are the only weapons which the inhabitants of the upper Nile country use against the Hippopotamus even in the present day. At about midnight the harpoon caster creeps along the shore to the place at which the animals issue from the water. He hides in the bushes to the leeward of this place of egress and waits until an animal, returning from pasture, has about half entered the river. Then he throws the harpoon into its body with all his force, and flees, hoping that the friglitened animal will rush into the water. This is what usually happens; but on the other hand the monster generally turns upon its assailant if attacked when going up the shore. After the harpoon throwing, either immediately or on the next morning, the sportsman and his assistants enter one of the boats held in readiness, and go in search of the wounded animal, looking first for the spear-end protruding above the water or the floating wooden buoy. As soon as they have found these traces of the animal they cautiously row near, with javelins and spears ready for instant use, and the line is taken up. The slightest pull causes the Hippopotamus to rise to the surface in a paroxysm of pain and rage; it rushes at the canoe, but is greeted by a shower of spears, which frequently compels it to retreat. Yet it not infrequently happens that it reaches the boat and destroys it with its tusks. In a fortunate case, however, the beast is assailed with all the weapons, until it succumbs to the wounds.

Economic Value The profit of the chase is not slight. of the Hippo- The flesh of the monster, particularly potamus. the fatter portion, is esteemed and eaten by everybody. In the good old times the settlers of Cape Colony could hardly imagine a greater treat than a Hippopotamus hunt. The flesh and fat were cut off the body of the slain gigantic creature on the spot, and transported home by the cart-load. Young animals are said to yield especially savory meat and the fat of the old ones is reputed to be preferable to fat pork; the tongue is considered a delicacy, either fresh or smoked. This latter statement nearly all sportsmen agree upon, but many are of a different opinion concerning the flesh, which some think insipid, soft and tasteless. In east Africa the fat is considered the best ointment for the hair or the body. The thick hide is manufactured into excellent riding-whips, canes and shields; the teeth are, according to Westendarp, in great request for the manufacture of a number of fine turner's articles, as the composition of the tusks surpasses the genuine Elephant's ivory in fineness of texture, hardness and whiteness. The capture of the monster alive requires a patient, skillful chase. Every Hippopotamus seen in captivity has, almost without exception, been taken while young, and it is scarcely necessary to say that the mother of the little animal must be first killed, before such a capture is possible. The unreasoning affection of the clumsy, little creature for its mother facilitates the capture, however; it follows its wounded mother anywhere and does not even desert her dead body. A harpoon is then thrown at some sensitive spot of its body, or the hunter entangles it in a net, and thus it is pulled ashore. At first it endeavors to free itself, uttering yelling, piercing cries, like a $\mathrm{Hog}$ about to be killed, and offers a great deal of resistance: but it soon becomes used to Man and follows its keeper about.

The Hippopota- All experiments show that the Hip-

mus Easily popotamus endures confinement Tamed. readily and for a long time in the various temperate climates. When a couple of the animals are installed in a place, where they can move about in accordance with their natural propensities, that is, can go into the water or be on shore as the fancy takes them; and one may count on their having offspring. They are satisfied with any kind of food, especially with anything that is usually fed to domestic Hogs, During my stay in Cairo J saw the first captive Hippopotamus which has been shipped to Europe in modern times. It had become so used to its keeper, that it ran after him like a Dog and allowed itself to be easily managed. [Since then many Hippopotami have been taken to Europe and America.]

Age and Develop- Behemoth hardly has another enemy ment of the Hip- besides Man that could seriously impopotamus. peril its safety. In those places which "Man does not reach with his torment" the Hippopotamus probably attains a very great age. Though its growth is comparatively rapid, it requires many years before it attains its full size. Probably it is capable of reproduction in its second year and is certainly so in the third; but, as observations of captive specimens have demonstrated, it continues to grow steadily for several years, even after it has borne young, and when the body has at last attained its full size, the teeth at least continue to increase in length and bulk. It is not known when the decay incident to old age begins, nor is it known how old it may become in the free state.

The Liberian Hippo. The second existing representative potamus a smaller of the family, the Liberian HippoSpecies. potamus, or, as it might be termed also, the Dwarf Hippopotamus (Hippopotamus or Charopsis liberiensis) is very much smaller than the preceding species, and is apparently restricted to a small range in $\mathrm{U}_{\text {pper Guinea. It differs from its }}$ gigantic kinsman not only by reason of its much smaller proportions but also by the lack of two incisor teeth in the lower jaw. Buttikofer, who has seen freshly killed specimens, says that the back is of a slate-black hue, the abdomen a dingy, greenish white, the sides a greenish slate-gray. An adult female, which he obtained, weighed, according to his estimate, only eight hundred pounds, its height at the shoulders was thirty and a half inches, its total length seventy-four inches, nearly seven of which were included in the tail. 


\section{The Fea Cows.}

TWELFTH ORDER: SiRENIA.

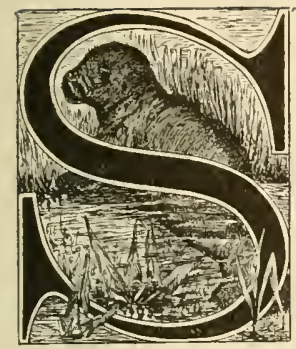

TUDENTS reading the name "Sirenia" in zoology would naturally think of the fabulous creatures of antiquity which were said to be half Woman and half fish, which inhabited the crystal waves of the ocean and by their wonderful $\mathrm{s}$ we $\in \mathrm{t}$ singing and still more enticing gestures, by the stately poise of their heads and their glowing glances, lured the poor sons of the earth to follow them to the ocean's depths and be lost; but if he should expect in this connection an account of such beings, he would be greatly mistaken. Naturalists have in this case only proven their predilection for adopting poetical names, without having fulfilled the requirements of poetry. The name of Sirenia has been about as appropriately chosen for the oceandwellers in question as has been that of the Greek wood-nymphs (Hamadryas) which has been bestowed upon the queerest of Monkeys, which, indeed, is beautiful only in the eyes of a naturalist, and neither in its looks nor its actions has any suggestion of a nymph.

General Charac- The Sirenia or Sea Cows form an teristics of the order by themselves. In their inteSirenia. rior anatomical structure they show the greatest affinity to the hoofed animals and may be regarded as a branch of them, which has adapted itself to an aquatic life. Many naturalists place them among the Whales as a special division or family, but the differences between them and the latter animals are so great that the plan of placing them apart is well justified. They are distinguished by a small head, separated by distinct demarcation from the body and furnished with a bulbous snout, bristly lips, and nostrils opening at the extremity of the muzzle; by the clumsy, peculiarly articulated body, sparsely covered with short, bristle-like hair, and by their peculiar dentition. They have only two limbs, namely, the anterior pair, but they are genuine fin-limbs. The general integument incases the toes so completely that all independent mobility of the individual parts is destroyed. Only the traces of nails indicate externally the digital divisions of the hand. The tail, which performs the functions of the hinder limbs, terminates in a fin. It requires a vivid imagination to see mermaids in these animals, even if they should show themselves at a great distance; the only thing these lumbering, uncouth creatures have in common with the beautiful body of a human female is that their mamma are also placed on the chest, between the fore limbs, and are more prominent than those of other aquatic mammals, but these animals are nevertheless very interesting.

\section{The SiDanatees.}

\section{SOLE FAMILY: MANATIDE.}

This order has only one family (Manatide), which is divided into three genera, of which one, composed of the Sea Cow proper, can no longer be classified among the living ones, however. The genera differ so materially in their dentition that it does not seem suitable to discuss it here and at the present time. While the Sea Cow or Stellerine possessed, instead of teeth, only a horny plate for mastication, which was developed on the inner side of the lower jaw and on the palate, the rest of the Sirenia have toothed jaws. Upon this difference have been based the genera, which, if one follows the more recent classifications of Dollos (who regards the Stellerine, which has not been long extinct, as a Halicore that has lost its teeth) would be limited to the Dugong (Halicore) and the Manatees (Manatus).

Habitat and The Sirenia inhabit shallow banks
Habits of the and gulfs of tropical countries, estu-
Sirenia. shoaly waters of the latter. They seen to occur only in exceptional cases in the temperate zone, but nothing definite can be said in regard to this subject, as they usually baffle observation. We know, however, that their abode is not always the same: they often wander for many miles, sometimes penetrating far inland, entering the lakes which are connected with great rivers. They are to be seen either in couples or in small societies; yet it is affirmed that they live in strict monogany and that a male alway's keeps faithfully to his mate. They are much more aquatic than the Seals. In exceptionally rare cases only do they thrust their bulky bodies above the surface of the water. They lack the agility of other aquatic mammals, for, though they are excellent swimmers and divers, they shun very deep waters, probably because they are too awkward for a constant ascent and descent. On dry land they drag themselves along for short distances with the greatest difficulty; their finny limbs are much too weak to move the great bulk of the body, the more so as the latter does not seem to possess any of the flexibility of the body of a Seal.

Diet and Atri- The food of the Sirenia is composed

butes of the of marine plants, alge and grasses

Sirenia. which grow in shoaly water or close to the bank, as well as of various aquatic plants which grow luxuriantly in shallow spots of rivers.

Like all voracious creatures the Sirenia are lazy, dull-witted beings with weak senses. They are called peaceable and harmless for the reason that they do nothing but eat and rest. They are neither shy nor bold, and live in peace with all other animals, caring for nothing but their food. Their intellectual power is exceedingly slight, but there is no doubt of 
the existence of some intellect. The sexes exhibit great affection for each other and endeavor to protect one another; the mothers tend their children lovingly and are even said to carry them, when they are suckling, as Women carry their babes, using one of their fins as an arm to press the little ones to the breast. The vocal expression of the Manatees consists of a weak, dull moan. In breathing, they make a noise much resembling a loud snore.

It is worthy of notice that these clumsy creaturis not only endure confinement, but may be tamed to a high degree of docility.

Their flesh, fat, hide and teeth are used; but, so far as known, no other portions of their carcass are put to account in any way.

\section{THE MANATEES PROPER.}

In the Manatees (Manatus) the tail-fin is rounded; the somewhat shapeless, fish-like body is very and a weight of six hundred or, according to Kappler, sometimes of eight hundred pounds. Ameri. cans assert, however, that they have seen much larger individuals, measuring seventeen or even twenty feet in length. The skin is nearly destitute of covering, having only short bristles, which stand about fourfifths of an inch apart. The coloring is a rather monotonous bluish gray, darker on the back and sides than on the under surface. The bristles have a yellowish tint.

We owe the first exact account of the animal to A. von Humboldt. In dissecting a Lamantin, which was ten feet long, in Carrichana, on the lower Orinoco, he found the following: The upper lip, which is clothed with a very tender skin and serves as an antenna, or feeler, when coming in contact with objeets, protrudes greatly, and the cavity of the mouth, which has an abnormally warm temperature in a freshly killed animal, shows a very curious organiza-

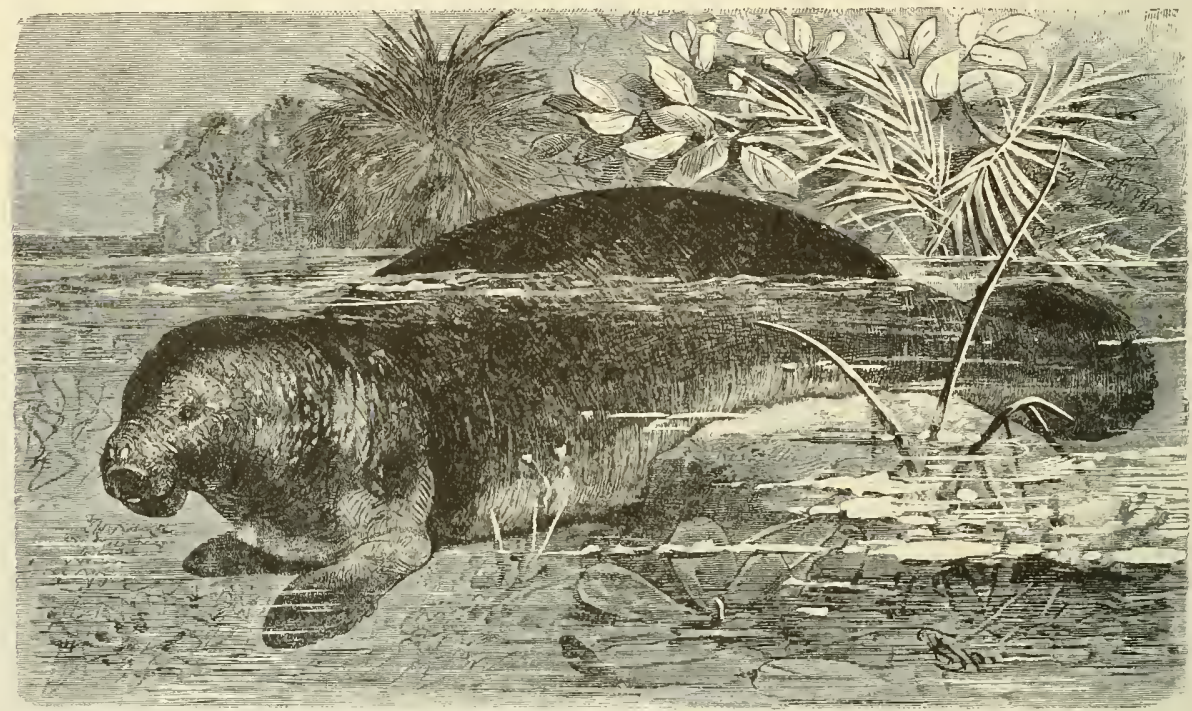

LAMANTIN OR AMERICAN MANATEE.-From Florjda to Brazll and in the Gull of Mexico this strange aquatic mammal frequents creeks, lagoons and the estuaries of rivers, and ascends many of the latter to a considerable distance. Its head is of moderate size, oblong, with a blunt, truncated muzzle. It has only one pair of limbs, which are flattened, oval paddles, and it has a flat, horizontal tail, with rounded edges. (. Hanatus americanus or latirostris.)

sparsely covered with short hair, which becomes more thickset only on the snout, where it changes into bristles. On the toes of the rounded pectoral fins can be discerned four small flat nails. Only. young animals exhibit incisor teeth, as the incisors fall out very soon and only the molar teeth are left in the mouths of old animals. The two American species of this genus occur in the rivers flowing into the Atlantic and the adjacent sea-shore between the twenty-fifth parallel of north latitude and the nineteenth parallel of south latitude. The African suecies (Manatus sonegalensis) inhabits the Tchad lake, the uppr parts of the great western rivers and the small rivers of the coast which flow into the Atlantic Ocean between the twentieth parallel of north latitude an the tenth parallel of south latitude.

The Lamantin The Lamantin, called Ox-fish by the and Other Portuguese (Manatus latirostris). is Species. the species that has been observed most closely. It attains a length of about ten fect tion. The tongue is nearly immobile, but in front of it there are, on both sides of the jaws, a fleshy excrescence and a cavity covered with hard skin, one fitting into the other. If the back of the animal is laid open, the dissecter is astonished at the size, shape and length of the lungs; for they are about a yard long, have exceedingly large cells and resemble huge floats; they admit an enormous quantity of air. The stomach is divided into compartments, and the intestine is over one hundred feet long. The other American species [which, from its principal habitat, may be termed the Amazonian Manatee] (Mlanatus immgnis) differs from this Lamantin by its narrower skull, which also has more delicate bones. This species is so far definitely known to exist only on the upper Amazon and the Orinoco rivers.

Habitat and The Lamantin inhabits the eastern Habits of the coast of Florida, the coasts of the Lamantin. Greater and Lesser Antilles, the Magdalena River and the eastern coast of South Amer- 
ica and its rivers as far south as Cape North, occur ring principally in Surinam. Probably it is the only member of the order to be found in the Gulf of Mexico. A. von Humboldt observed that the Lamantins prefer those places in the sea in which there are fresh water inlets or springs; in rivers they penetrate far inland and in times of inundation they also wander into lakes and swamps. "In the evening," says A. von I Iumboldt, "we passed the estuary of the Cano del Manati, which derives its name from the enormous number of Lamantins or Nanatis which are anuually caught there. They are plentiful on the Urinoco below the waterfalls, in the Meta and the Apure."

The habits of the lamantin are much like those of other Sirenia. Several travelers have affirmed that it sometimes leaves the water to graze on land; but as early as the last century others most decidedly refuted this. It browses only on the grass arrows, which have ropes and light wooden floats fastened to them to indicate the direction the animal takes, or he harpoons and kills and then flays and dresses it in one of those light, raft-like boats, whicl are used for travel on South American rivers. This latter operation is sometimes done in the middle of the stream, the hunters first filling the boat two-thirds full of water, pushing it under the Lamantin and then causing it to float by baling the water out with a gourd. The thick hide of the beast is cut into strips and used for whips and cords, the latter are of no service in the water as they soon rot.

\section{THE DUGONG.}

The Chinese and Arabs have for centuries known one of the most important representatives of the family of which we received but scant, occasional information up to the beginning of the present century; we mean the Dugong (Halicor' dujong)

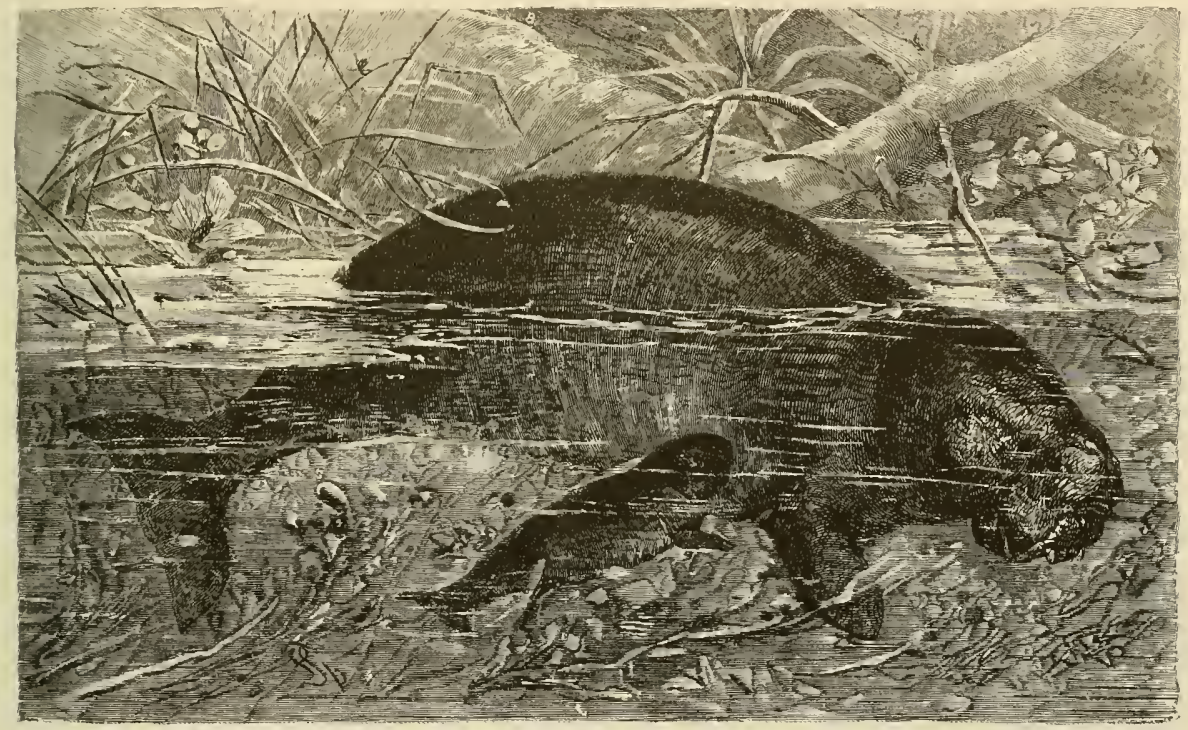

THE DUGONG. - In the Red Sea and on the eastern coast of Africa and all coasts of southern Asia, the Indo-Malayan Archipelago and Australia, the Dugong is numerously found, living on seaweed in shallow harbors, hays and mouths of rivers. The tail is fish-like, but the head is of oblong shape, and the only limbs are two nailless flippers. (Halicore dugong.)

which grows in the water. As all southern rivers in quiet places abound in aquatic plants of all kinds it does not suffer from want, nor is it obliged to swim far to procure its food. It eats enough to completely fill the stomach up to the cesophagus, but when its appetite is satisfied it often lies down in shallow places, in such a way that the snout projects above the water, so that it does rot need to be constantly rising to the surface to breathe and thus it sleeps through several hours of the day. When it is awake it can be seen above the water only when it comes up to breathe; this, however, happens very often, notwithstanding the capacious lungs, and it is probably for this reason that it prefers the shallower spots in rivers.

Hunting and The method of hunting this animal

Taming the $L a$ - is rather simple. The hunter apmantin. proaches the grazing-place of the Lamantins in a boat and waits until one of them comes up to breathe. He either shoots it with
Description of The Dugong attains a length of from the Du- ten feet to sixteen feet eight inches. gong. The short, thick neck, which exhibits distinct demarcation from the head, merges almost imperceptibly into the body, which is uniformly rounded, gradually becoming thicker from the head to the middle and then tapering towards the tail. The pectoral fins are placed at a short distance behind the apertures of the ears, in the lower third of the perpendicular thickness of the body; they are not particularly long; but broad, rounded at the anterior margin, sharper at the posterior; the toes may be recognized only by touch, for no trace of claws exists. The tail is formed by a flattened, crescent-shaped fin. The most striking feature in the short, thick snout is the flat upper lip, sloping from above backwards and downward, and beneath which projects a thick piece of flesh, truncated below. This projection communicates behind with a peculiar plate in the mouth, which covers the inter- 
maxillary bone. A similar plate is placed on the lower jaw. The lower lip forms a thick bulbous roll, sharply defined behind. The nostrils lie on the upper surface of the snout, are placed close together and form two crescent-shaped slits; the eyes are small, of ovoid shape, but strongly arched and of black hue; they lie in an oblique slit, surrounded by lashes along its upper margin, devoid of true lids, but furnished with a winking membrane, and can be closed at will by a muscle which produces contraction of the skin; the ears are only indicated by small roundish apertures. The skin is of a dull leaden or bluish gray color, marked with dark longitudinally arranged spots; it is smooth and shining, wrinkled only on the abdomen and overgrown with short, thin and stiff bristles, which nearly develop into spines on the upper lip. The fins are perfectly naked. The dentition consists of rootless incisors and molars, part of which fall out in old age. Canine teeth are lacking; the male, however, develops two of its front teeth into tusks, measuring from eight to ten inches in length and nearly an inch in thichness; they are covered by the gums for about seven-eighths of their length.

Habitat and Habits It seems that the Dugong is caught of the Du- in all parts of the Indian Ocean and gong.

the regions communicating with it. It occurs all over the southern Chinese seas, and off the coasts of Sulu, Banda and Sunda; towards the north it extends to about the middle of the Red Sea. In this last locality it is a very well-known animal. All sailors have seen it, and one will hardly question any of them in vain about the Nakhe el Bahr (Camel of the water). In the east it inluabits the coast of New Guinea and Queensland, as far southward as Moreton Bay.

The Dugong frequents the sea, and in exceptional cases the fresh water of the estuaries, but not the rivers themselves; it prefers the neighborhood of coasts and proceeds only as far from shore as the submarine vegetation extends. Its favorite haunts are shallow inlets in which the sun shines through the calm waters to the very bottom and the profuse vegetation of the sea can develop with particular luxuriance. It does not frequent the land; at least it may be inferred that Dugongs found lying on the shore have been left by the ebb-tide, and being too lazy to push their heavy bodies back into the water, prefer to wait until the next high tide. From the bottom of shallow creeks the Dugong rises to the surface about once a minute, thrusts out its nose or sometimes half its body, breathes and slowly sinks back into the deep.

The fishermen say that the Dugongs usually live in couples and rarely in small families; but this statement applies better to the Arabian Gulf than to other parts of the Indian Ocean, where they are said sometimes to have been seen in schools. The Arabian fishermen say that one always finds at least two Dugongs together in the Red Sea, but not infrequently as many as ten.

\section{THE SEA COW}

"Along the whole beach of the island, especially where little streams flow into the sea and all kinds of sea-plants are most plentiful, one finds at all seasons great herds of Sea Cows, which our Russians call Morskaia Korova. As the Sea Otters had been scared away from the northern coast and the obtaining of provisions began to become difficult, we thought of catching these animals and using them for food as presenting an easy way out of our difficulty, because they were near to us. To this end the jolly-boat was repaired towards the end of June, as it had been badly damaged on the rocks in fall; a harpooner, a steersman and four oarsmen were placed in it; and each was given a harpoon and a rope, coiled as are ropes used in whaling, the other end being held on the beach by the remaining forty Uen. The sailors quietly rowed up to the animals, which were grazing in herds along the banks at the bottom of the sea, deeming themselves in perfect security. As soon as the harpooner had securely buried his weapon in the body of one, the Men on the beach gradually pulled it ashore; those in the boat approached it in the meanwhile, exhausting it still more by the wounds they inflicted, and when it seemed quite spent they dealt it other wounds with large knives and spears, so that it lost nearly all its blood, which streamed out of the wounds in jets; then it could be pulled ashore during flood tide and there secured. When the ebb came, and the animal lay on dry land, we cut the flesh and fat off in pieces and carried them to the dwelling-places, amidst great rejoicing, the flesh being stored away in large barrels and the fat hung on high posts. It was not long before we saw ourselves surrounded by such plenty of food that we could uninterruptedly go on with the construction of our new boat, which was to be our means of escape."

The naturalist, Steller, who was shipwrecked in November, I74I, on the previously unknown Bchring Island, where he spent ten dreary months, thus begins his description of one of the most remarkable of marine mammals, a creature which seems to have been completely exterminated, and has been named the Sea Cow, Rhytina, or after its discoverer, Stellerine (Halicore stcllerii). Allured by the accounts of the Russian exploring party to which Steller belonged, whalers and foolhardy adventurers flocked to Behring Sea in great crowds and there commenced so terrible a slaughter among the defenseless dwellers of the ocean that the Sea Cows were exterminated from the face of the globe. All later endeavors to procure at least one of these animals have been in vain. Every ship bound for Behring Sea has had its instructions concerning them, but none has brought one back with it. It is supposed that the last was killed in 1,68 by an expedition under Popoff. Nordenskjold, however, who visited Behring Island in 1879 , is inclined to place the date of the final extinction of the tribe in the year 1854 .

Steller believed the Sea Cow to be the Lamantin discorcred by Hernandez. His description shows clearly, however, that the Sea Cow was a very different creature from the remaincler of the Sirenia. The jaws were covered with grinding plates, instead of teeth connected only with the gums. This feature alone suffices to characterize the animal. "The largest of these animals," says Steller, "are from twenty-four to thirty-three feet long, and about twenty-three feet in girth at the stoutest place. I estimate the weight to be about forty-eight thousand pounds. The fat is not oily or flabby, but hard and glandular, white as snow, and after lying a few day's in the sun it assumes an agreeable yellowish tint like that of Dutch butter. Boiled, it surpasses the best beef suet in sweetness and flavor; when melted, it is like fresh olive oil in hue and freshness, and like sweet almond oil in taste." 


\section{The Toubales.}

\section{THIRTEENTH ORDER: CETACEA.}

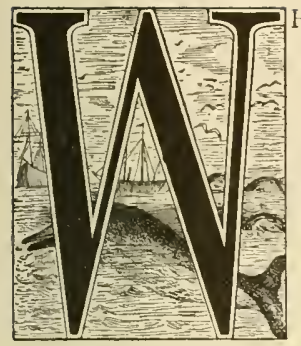

HAI.E.S are among the mammals what the fish are among the vertebrates: creatures belonging exclusively to the water and anatomically constructed in accordance with the necessities of such a mode of life. Their size is an indication of this: for the water alone admits of the easy progress of such giants, and only the infinite abundance of the sea affords

them the required nourishment.

The Whales exhibit the warm blood, the breathing through the lungs, the suckling of the young and all other essential features of the manmalia, along with the other orders of the class. In every other respect, however, they deviate from the higher mammalia still more than do the Sirenia. Slightly educated persons, and nations in the childhood of civilization, have invariably classed them among the fishes, and only the close modern investigation of their character has assigned them their proper place.

General Descrip- The body of the Whales is bulky,

tion of the clumsy, and devoid of any external

Whales. joints. The head is frequently monstrously large and as a rule unsymmetrical, and merges into the trunk of the body without distinct demarcation of a neck region; the trunk tapers backwards, and terminates in a broad, horizontal tail-fin. The hinder linbs, which distinguish all other mammalia, with the exception of the Sirenia, are absent; the fore pair have become fins: one has to examine these with the dissecting knife, if he wishes to discover the digits in them, and even then he finds peculiarities of structure. An occasional dorsal fin, which extends along the spine, still further increases the resemblance of these animals to fish. Otherwise the IV'hales are characterized externally by the wide-gaping mouth, devoid of lips, and provided either with an abnormally large number of teeth or barbs; by the thin, smooth, soft, greasyfeeling skin, velvety to the touch, and scantily overgrown with bristles in a few small spots. The color is sombre, and the skin contains a thick layer of fat, the entire integument forming a strikingly thickened hide, between the cells of which the fat is deposited.

The Anatomical The inner anatomical structure of

Structure of these giants of the sea also exhibits Whales. peculiar features. The bones of the skeleton are distinguished by their loose, porous formation, and they are so pervaded by a fluid fat, that the liquid can hardly be eradicated and they preserve a fatty, yellowish appearance even after prolonged bleaching; on the other hand no bone contains a cavity for marrow. The huge skull bears a regular proportion to the body in a few species only; the bones of the head are found in queer malpositions: put loosely together if articulated, or are connected with other bones only by soft cartilage; some of them appear stunted, others strikingly enlarged and there seems to be no vestige of order or regularity. In the vertebral column the formation of the neck part is most striking. The number of the individual vertebre is normal, seven, but they are similar in shape to thin, flat rings and not infrequently are partly ankylosed or fused together, producing, in consequence, the little mobility characteristic of the necks of such species as possess this formation of the cervical region. It is owing to this fact that one often recognizes the seven articulations only by the foramina or apertures in the bony substance through which the pairs of nerves emerge from the spinal cord. Besides the cervical vertebre the Whales possess from eleven to fourteen dorsal, from ten to twenty-four lumbar and from twenty-two to twenty-four caudal vertebre. It must be remarked, however, that strictly speaking, one mav talk only of pectoral or dorsal vertebrit, and of lumbar-caudal ones, as a developed pelvis is absent and no sacral bone exists. The number of true ribs is very small; the true Whales have only one, and more than six do not seem to occur in any nember of the order. False ribs alway's occur in greater number than true ones. The fore limbs are characterized by their shortness and the flatness of all bones, and the strikingly great number of joints in the digits; for while other mammals have thrce joints in the phalanges all Whales have more, with the exception of the first and sometimes of the fifth phalange, and the number of joints in one phalange may rise to thirteen.

The dentition of the Whales not only differs from that of all other mammalia but also materially diverges between the two main divisions of the order. According to Carus, teeth germs form in longitudinal pits of the mucous membrane of the jaw in all Whales, but they do not develop into permanent teeth, which are not shed, except in the case of the Toothed Whales. They disappear in the IVhalebone Whales and in their stead there develops an armament of the upper jaw and of the palate peculiar to these animals. In transverse furrows there are formed horny plates or laminxe suspended by one edge perpendicularly to the plane of the cavity of the mouth; the outer ones, fastened to the upper jaw, are the longest, those on the palate the shortest; they are the baleen, which forms whalebone.

The epiglottis is not adiapted for producing a harmonious voice, but for the passage of a great quantity of air at once. The windpipe is very wide, the lungs have considerable capacity, and all branches of the bronchial tubes communicate with one another, so that from either one both lungs may be filled. 
The muscles are simple, in accordance with the proportions of the animal, and exceedingly vigorous. The bulk of the brain and nerves is very small. In a Whale of twenty feet in length and ten thousand pounds in weight, the brains did not weigh four pounds: that is, not more than the weight of those of a human being, who seldom attains a weight of two hundred pounds! The development of all organs of sense is apparently deficient. The eyes are small, the ears barely perceptible externally, being, so to speak, rudimentary. Yet onc cannot suppose the senses of sight and hearing to be inadequate. All Whales prove that when they are submerged their sight is not only very keen, but is effective at great distances, and also that they hear noises of all kinds. It is only when they are above the water, in the rarer medium of the air. that these senses appear weak. The sense of smell is very deficient. We camnot judge of the taste, but we know that the sense of touch is somewhat developed.

The Whate Emi- It is hardly necessary to explain that nently Fit for such an organization is eminently.

Its Habitat. fitted for the aquatic life of the

Whales. The horizontal tail-fin admits of easy diving or ascent, or the exploration of regions of varying depth. The smoothness of the skin facilitates the progress of the enormous mass through the water, the layer of fat diminishes the weight, compensates for the lack of warm, hairy covering and also offers the necessary resistance to the almost incalculable pressure that a Whale has to endure in descending into the depths of the ocean. The extremely capacious lungs permit a prolonged stay under water.

The Whales shun the proximity of coasts as much as possible: for peril assails them from land. Only. a few Dolphins live in fresh water: others occasionally penetrate into rivers, but do not usually proceed farther than the influence of the tide is felt. No other Whales leave the salt water, but traverse shorter or greater distances of the ocean with more or less regularity. Eschricht gives the following arcount of these migrations:

\section{General} raits of the no single species has a permanent Whales. place of abode anywhere, having. apparently, certain favorite haunts for summer, and others, perhaps very remote, for winter; and after the fashion of migratory animals in general, they traverse more or less definite routes, in spring, from one to the other, and back again in the fall of the year. Like most migratory animals, the Whales are gregarious. Where food is plentiful one often finds hundreds or over a thousand congregated together, not only of one but of different species; and according to the testimony of inhabitants of coasts, the numerous migrating 'schools' are sometimes joined by a few animals of entirely different orders."

All Whales are highly active animals. They are masterly swimmers, evincing in the action not the slightest effort, and some displaying incomparable speed. When they wish to do so, they exhibit such an extraordinary strength of the powerful tail-fin that they can jerk thenselves above the water, in spite of the enormous weight of the body, and take long leaps. Generally they keep near the surface of the water, and perhaps they descend into great depths only when wounded. The upper stratum of the water is their proper element, as they have to expose their heads and parts of their backs to breathe. This latter process is accomplished in the following manner: the Whale blows up the water which has entered the imperfectly closed nostrils, with a snorting noise and such force that it is separated into fine drops, and yet is thrown to a height of five or six yards. This breathing jet may best be likened to a column of vapor, escaping from a narrow pipe; the snorting also resembles the noise caused by eseaping steam. A jet of water such as is given forth by a fountain is never thrown up by a Whale, though most artists thus represent the spouting of the animals, and many naturalists still thus describe it. Immediately after the spouting of the water, the animal inhales the air which it requires, with a rapid inspiration, emitting an audible. moaning sound, and sometimes it breathes three, four or five times a minute, but the jet is thrown up only at the first time of breathing after rising, though one may, in cool weather, often see lingering in the air the mist produced by the breatl. The nostrils are so placed that the Whale, in rising, elevates them above water first, and thus breathing is as easy to it as to other animals. A large Whale, swimming undisturbed, may pass continuously along the surface from five to fifteen minutes, breathing uniformly, or it may sink slightly below the water after every breath, but sometimes it goes on in this way mueh longer, until it has satisfied its desire for air. Then it may plunge down and remain invisible for ten or twenty minutes or even longer. The large species may remain under water for from thirty to fifty minutes, when they are pursued. A harpooned Sperm Whale remained under water for nearly an hour, according to the observation of Pechuel-Loesche; another, which was also injured, remained there for eighty minutes, diving down about three thousand nine hundred feet. When the breathing is stopped, a Vhale is asphyxiated just as is any other mammal, and that, too, as the observations of whalers show, in a very short time. The animals also die in a contparatively brief period when they are on dry land.

The Diet and All Whales subsist on animal food, Reproduction of and probably take in plants only by Whales. chance; at least more exact observation is required before we can positively assert that one species, namely, the Razorback, browses on the sea-weeds which are often found in its stomach in great quantities, and that a Dolphin eats the fruit fallen into a river. Larger and smaller aquatic animals are the prey after which they strive. The very largest species feed on the very smallest animals, and, vice versa, the smaller ones are the most inveterate beasts of prey.

The young Whale is at birth very well developed and is from one-fourth to one-third as long as its mother. The mother tends it with touching tenderness, risking any danger for its sake and never forsakes it while it lives. The growth of the young one seems to be comparatively slow. How long the life of the IVhale lasts is not known.

The Enemies and The IVhales also have their enemies, Pussuit of especially during the early portion Whates. of their lives. Several species of Sharks, and the Killer-whale are said to regularly hunt for young Whales in the same way in which they attack older ones and then feast on the gigantic carcass for days. But Man is a much more deadly enemy to the W'hales than any monster of the sea. It is he who has, for over one thousand years, systematically pursued many species of the order, and has nearly exterminated some of them. The Invericans became the most diligent whalers. 
During the period from 1835 to $I 872$, that is, covering thirty-eight years, $19,9+3$ ships wore engaged in the Whale industry; they secured $3,6,1,772$ barrels of spermacet 1 as well as $6,553,014$ tons of oil, and realized from them the sum of $\$ 272,274.916$. In Scammon's estimation they must have killed annually. 3,865 Sperm Whales and $2,8-5$ IThabone $11 \%$ hales to which must be added onc-fifth of this amount as the proportion of wounded which escaped final capture, so that one nust count the total number of the Whales caught or in any way destroyed within this period to be no less than 202,714 .

\section{Methods of The capture of the llhate, though \\ Hunting the accidents happen during the hunt, is, Whale. on the whole, less dangerous than} the voyage in itself, it it leads into ice-bound parts of the sea. During many years the commerce sustains heavy losses. Fortunately human lives are seldom lost in the shipwrecks, as the sea is usually calm and the crew have sufficient time to make their way to another ship. Whale-fishing is not only a dangerous and arduous undertaking, however, but also a very uncertain one. $\mathrm{Up}$ to a few decades ago the fishing was mainly done by ships fitted out for long cruising, and they hunted principally three of the largest species: the Greenland Whale, the Right IV hale and the Sperm Whale, which represented a value of from $\$ 3,750$ to $\$ 10,000$ apiece, according to its condition and the state of the market. The method of capture is as follows When the ship has reached the whaling grounds, it cruises back and forth, and two Men are usually on the lookout on the mast. When Whales are sighted the call, "There they spout!" throws the entire crew into excitement. "The behavior of the animals under inspection," says Pechuel-Loesche, "the manner of the spouting, the shape of the back and tail-fin, enable experienced whalemen to recognize with tolerable certainty, whether they have met the species of Whale that they have been seeking, or any other Whale the capture of which is at all remunerative. When this question has been settled, the captain gives the order for lowering the boats, of which the large whaler usually has four. These boats are from twenty-one to twenty-seven feet long and about six feet broad, of light but perfect build, devoid of keel and pointed at both ends, so that they can go backwards and forwards with equal facility, and may be quickly turned. The weapons include about four harpoons, several lanees, a very heavy gun, which shoots wedge-shaped grenades, a short blubber-spade, a hatchet and a strong knife, which are placed in the stern of the boat within convenicnt reach of the harpooner. The compass, a ladle, and a small cask containing ship's biscuit, a lantern, candles and matehes, are placed in the stern locker; another small keg with drinking water usually lies in the middle of the boat. The most important part of the capturing implements is the line, about an inch in thickness, about three hundred and fifty fathoms in length and made out of the best quality of hemp. It is coiled in spiral form in two flat tubs behind the row-benches, with the most conscientious care, as any tangle, occurring while it is being run out, would entail an accident. From the end of this rope left outside of the tub the harpooner takes a length of five to eight fathoms and affixes two harpoons to it. These an experienced thrower hurls against the Whale, at its first approach, in rapid succession: and to enable him to grasp them securely, they are placed on a low stand to his right.
A good harpooner must be sure of his aim at a distance of four or five fathoms. Generally, however, he goes much nearer the Whale, sometimes even lettiug the boat touch it, so that the harpoon is thrown insteact of being thrust into its body. This intrepid mode of attack leaves nothing to be desired in regard to precision of stroke, but it is the most dangerous. As soon as the harpoon is fast, the boat is rowed backwards, away from the Whale, with all possible speed. This moment is always fraught with peril; by chance or intentionally the wounded animal may capsize the boat with its huge tail, or hurl it intu the air or smash it from above as if it struck down upon the frail craft with a gigantic flyfopper. If the frightened IVhale flees (in a deep part of the sea it usually dives perpendicularly, in shallow water it swims off at a slight depth), the line rolls off the next instant; sometimes from one hundred to one hundred and fifty fathoms are unreeled in one minute. The crew has to be on a sharp lookout then, for whoever is entangled by the line is generally lost. After this the boat is "fast." Steersman and harpooner change places; the latter had the task of attacking the Whale, but the prerogative of killing it belongs to the former. Then only begins the real struggle and the greater danger. Naturally nobody thinks of stopping a diving Whale; any large Whale would pull the boat down with it, as a fish does the light piece of cork which forms the float of a fishing line. If the animal dives very deep, the next boat is called upon, and its line is added to that already attached to the harpoons; if the Whale does not come up quickly enough, the last fathom of line may go overboardand then the Whale is free. It is very seldon that the boatsmen succeed in regaining possession of the line, by rowing in the direction which the animal has taken and fishing up the dragging line after its reappearance.

"In most cases the line of one boat is sufficient, however. The Whale may dive to the depth of one or two hundred fathons and stay there, scarcely moving. If the line begins to be loose it is pulled up with joint efforts, to incite the prey to rise. If the uncouth fellow takes this proceeding amiss, however, it baffles any attempt to bring it to the surface with irresistible force and goes deeper down. Thus the struggle back and forth goes on according to the size and species of the animal for ten, twenty or thirty minutes, and in some rare cases for double this time, until the Whale begins to realize the need for air and rises. The direction of the line shows whereabouts it will appear and a second boat endeavors to surprise and engage it there, planting additional harpoons in its body: only when this has been accomplished does success seem assured. At this point the wounded aninal either turns upon its tormentors or makes an effort to escape by darting along the surface, as it can not dive immediately for lack of breath. Then begins a mad pursuit, the animal only drawing out a few fathoms of the line which is securely hitched to the boat but ready to be cast off in an instant. The dark, gigantic body shoots through the waves, puffing and snorting, while the water parts and is hurled up in milk-white masses as the animal, by furious strokes of its tail, endeavors to free itself. Two or three boats, filled with intrepid salors, fly in pursuit of the Whale. They disappear anong the foaming, splashing, towering waves, often seeming to sink during their mad course over and through the surging waters, but 
thes contimue their course over the 'vasty deep' no matter whether it be day or night. An unprepared observer might inagine he saw in them a gathering of the maddest of water spooks. At last the Whale stops, exhausted, and either rolls in the water in a tired and sluggish manner or rages and beats around. Then the boats can approach it, and this they do, cautiously keeping out of reach of the animal's dangerous tail. The crew then try to kill the Whale either with a gun-harpoon or a liand lance, the thin iron blade of which is thrust behind the fin to the depth of about six feet. If the Whale dives again or makes off, the performance is repeated, until it is finally killed or its pursuers are obliged to set it free by cutting the line. If a gun-harpoon or a lance pierces the lungs the IVhale spouts blood-it 'hoists the red flag'- and dies in a comparatively slort time, though sometimes only after the exhibition of a powerful agony called by whalers 'the flurry,' during which all boats wait at a safe distance."

If a Whale is killed and the ship can not conveniently approach it, it must be taken in tow by the boats. On its arrival at the ship it is secured by a strong chain around the root of the tail and also fastened near the head; it is made fast to the starboard side of the ship so that it floats with its head directed backward. Two powerful pulleys are secured to the main mast, the rumning tackle of which has its free ends coiled around the capstan. At the side of the ship a frame-like scaffolding is lowered. and swings horizontally above the II hale, serving as a running stage for the blubber-cutters, who prepare for cutting off the blubber with sharp spades. An incision is made on three sides of the fin, to which the tackle of a pulley is fastened; then the fin is torn away, and a continuous strip of "blubber," follows as it is raised up the ship's side, the width of the strip being from fifty-two to seventy-six inches. When this has been hoisted to the height of the lower mast, a second tackle is fastened to it at the level of the deck, the strip of blubber is cut off just above it and the piece is lowered into the hold. while the second pulley in turn winds the ribbon of blubber again up to the lower mast. The hoisting of the blubber is hard work and progresses only by inches; by the slow but powerful traction the strip of blubber, the width of which is determined by the distance apart of the incisions made by the cutting spades, is torn off the carcass of the Thale and wound up in about the same manner as an apple is pared or the wrapper is peeled off a cigar. The body of the animal slowly revolves around its longer axis; in the very beginning, when the opportune moment arrives, a Man secured by ropes and arned with an axe descends to the body of the Whale and cuts off the upper jaw of a Whalebone Whale or the lower jaw of a Sperm Whale, which is taken directly on deck, to have the Whalebone taken from the former and the beautiful teeth from the latter. The huge upper part of the head of a Sprem IThale is also taken on deck in two pieces, in orter to secure the spermaceti. The taking off of the blubber lasts from four to eight hours, according to the size and species of the IVhale and the state of the weather: the process is technically termed "flensing.' IV'hen all valuable parts have been stored away, the mass of flesh is cast adrift.

Process of Render. The enormous strips of blubber let

ing sperm down into the hold are there cut Oil. with short spades into small, oblong pieces, which are thrown back on the upper deck and are deeply incised br a machine provided with a sharp knife and rum by hand; then they go into the "rendering pot," or boiler. The boiling is done in huge iron liettles, walled in on deck, and the hearth of which is surrounded by water. At first wood is used as fuel, but later on only the "cracklings" or residue of the blubber, which possess enough heating power to "try out" the entire remaining supply. The oil is cooled in a cooling-pan and then poured into barrels. "Attired in their worst clothes," writes Pechuel-Loesche, "half-naked, dancing and singing. running after one another and brandishing their tools, dripping with fish-oil and sooty like devils, the crew disport themselves about the hearth. An intensely active life prevails on board. The sight of this activity is doubly striking by night when a mass of the cracklings is hoisted up in an iron basket. This strange torch burns merrily, casting a weird light on the scene as the blazing flames throw glaring, fitful rays on the deck and bring out in bold relief the black clouds of smoke and the masts with their sails, the reflection extending far out over the sea. By day huge masses of smoke on the horizon betray the presence of a Whaler which "tries out" the blubber, long before one catches sight of the ship itself."

Proper Division of the

The Whales are naturally divided Whales. into two main vroups, which one may justly call suborders: the Toothed Whales and the Whalebone Whales. In the former both jaws, or at least one, is furnished with teeth which are not generally shed, but may in some instances be partially or entirely cast. This feature suffices to distinguish them trom the Whalebone Whales in any case. As Kuekenthal has recently denonstrated, the Whalebone and Toothed Whales ought to be classified in two independent orders, as the Toothed IVhales derive their origin from a much older group than the Whalebone Whales. The attributes they have in common are only sinilarities which may be traced back to the common adaptation of the two groups to a life in the water.

\section{The rubalcbonc rubalcs.}

FIRST SUBORDER: MYSTICETE.

The Whales belonging to the suborder of the Whalebone Whales (. Mysticcte) are few in species; they are mainly distinguished by the lack of teeth in both jaws, the upper jaws and palate being furnished with plates of baleen or whalebone. These plates do not stand in the stead of teeth, neither do they resemble them in their organization, their mode of connection with the jaw nor their shape. In very young Whalcs the jaws have been found to contain small, bone-like corpuscles, which might be thought to be tooth-germs; the baleen, however, appears much later and does not proceed from the jaws at all, but from the palate, and the plates are not connected immediately with the bone. Their transverse position in the vault of the cavity of the mouth resembles that of the palate-teeth of fish. The balcen is a horny but not bony formation of the integument and consists of triangular or, more seldom. of square plates, in which may be distinguished thin external layers of horn and an inner substance formed of close-lying parallel filaments which terminate in bristly fibers that form the split portions which com- 
pose the extremity of the plate. Curved layers of horn coalcsce with the individual plates at the roots, connecting them with the skin of the roof of the mouth, from which they derive their nourishment. This skin, which is four-fifths of an inch thick, is abundantly supplied with blood-vessels. The total number of plates is from two hundred and fifty to four hundred, the longest being found in the middle of the jaw, while the shortest are at the ends and at the curve, as they grow rather uniformly shorter from the middle to the two sides. When the Whalebone Whale closes its nouth the lower jaw adjusts itself to the entire upper jaw, the plates touch the tongue around the edges, thus entirely closing the cavity from the outside and, like a sieve, holding fast the smallest and most slippery prey beyond the possibility of escaping. phants or from one hundred and fifty to one hundred and seventy Oxen. Over seven thousand five hundred gallons of oil have sumetimes been rendered from the blubber of such a giant.

In spite of a Whale's enormous bulk it moves with great speed and agility in the water, swimming straight ahead, but in constant vertical curves, coming up to the surface or appearing above it and then again plunging to the depths beneath.

Food of the The food of this largest animal
Whalebone on earth consists of small, insignifiWhale. cant mollusks, crustaceans, cephalopods, sea-nettles and worms, many species of which are barely visible to the eye. But it swallows millions of these creatures at once. With its huge, widely-gaping mouth open the Whale traverses the ocean, fills the great cavity with water, together

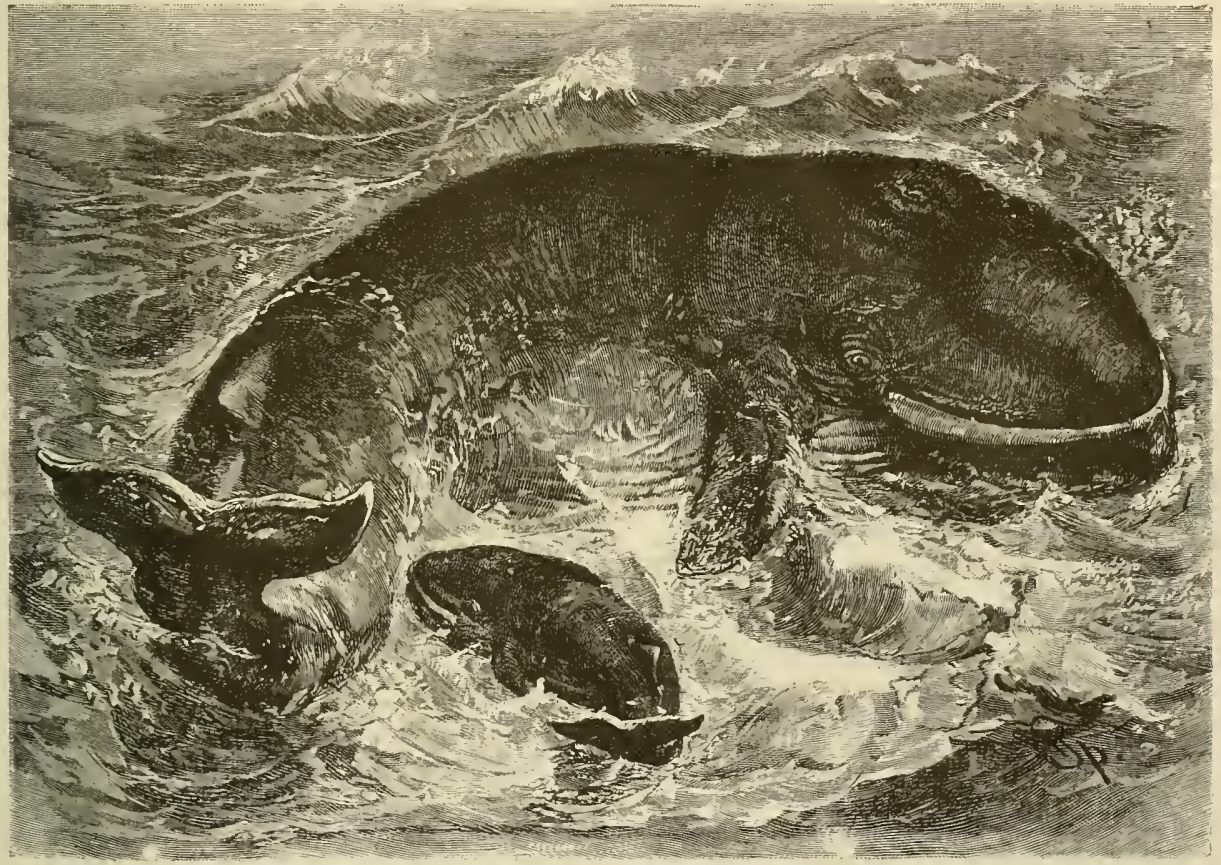

RAZORBACK WHALE. - One of the longest species of the Whales is the Razorback, which makes its home in the north Atlantic and Arctic Oceans. It attains a length of oser eighty feet, and besides being a powerful, is also an agile animal, moving through the water with great rapidity and devouring great numbers of Haddocks, Herrings and other fish. (Physalus antiquorum.)

Physical Charac- The Whalebone IVhales are enorteristics of Whale- mous creatures with huge heads, a bone Whales. wide gape of the mouth, double nostrils and blowing-holes, valved apertures for the ears which the animal can close at will, and very small eves. The spinal column consists of seven cervical, fourteen or fifteen dorsal, eleven to fifteen lumbar and twenty-onc or nore caudal vertebre. The tongue is grown fast in the mouth, and is inmobile, the gullet is narrow, and the stomach has three compartments.

Adult Whalebone IThales attain a lengtl of from sixty to one hundred feet and a weight of from forty thousand to three hundred thousand pounds. They are therefore the largest animals now found on the globe. The bulk of body of a large Whale corresponds to that of about thirty or thirty-five Ele- with the little animals that exist in it, and when the tongue, which is not devoid of sensibility, feels their presence, the giant closes the trap. All the fibers of the baleen are directed perpendicularly downward, thus forming a sieve through which the water can escape, but which retains all the small creatures. A single muscular action of the clumsy and scarcely mobile tongue drives the jelly-like mass through the gullet into the stomach.

Noteworthy Traits In the Whalebone Whales the senses

of Whalebone of sight, hearing and touch are Whales. those best developed. Their intellectual faculties seem to be weaker than those of the Toothed Whales. All Whalebone Whales are fearful, shy and fleet, and therefore probably live in peace among themselves and with most other aquatic mammals. When they are attacked their 
natural courage sonetimes awakes, however, and may develop into fierceness, and they defend themselves with violence and not infrequently with success, but on the whole they do little harm, even to their most formidable enemy. Their principal weapon is the tail, the enormous force of which can be realized when it is considered that it is the organ which propels the huge body through the waves with the speed of a steamboat. A single blow of the tail suffices to smash the strongest boat to pieces or to hurl it into the air, and to kill a strong animal, or a human being.

IVe know very little about the reproduction of the Whalebone Whale; only that the female gives birth to one, or in rare cases two very large young, which have from a third to a fourth of their mother's length and are far progressed in development. The mother suckles them for a very long time, defends them with courage and persistence, hides them under her fins in case of danger, and leads them about until they become independent.

\section{TRorquals or ffurrowco robalcs.}

\section{FIRST FAMILY: BAL.ENUPTERIDE.}

The Furrowed Whales or Rorquals (Balenopterite) owe their name to deep, parallel, longitudinal furrows, which extend over the throat, breast and part of the abdomen; they are of comparatively slender build, furnished with a distinct dorsal fin and lancetshaped pectoral fins of variable length, and their baleen plates are short, but wide.

\section{THE HUMP-BACK WHALES.}

Very long pectoral fins or flippers, which attain at least one-fifth and often one-fourth of the total length, distinguish the Hump-back IVhales (Migaptera).

Description of the This genus is represented by the Hump-Back Hump-back of English and AmeriWhale. can sailors, the Rorghval of Norwegians and Keporkak of the Greenlanders (Megaptera longimama). This Whale is widely distributed, occurring in all of the oceans; it is about fifty feet in length; its flippers are about three feet wide and from nine to twelve feet long and the tail fin has a spread of about twelve feet. It is one of the clumsiest members of the family. Compared with other Rorquals it is decidedly ugly, its body being short and thick, its flippers almost disproportionately long and its tail-fin excessively developed. In the last quarter of the total length the back shows a fat-fin, the hump, which may be of very variable shape and formation. The color of the skin is subject to many modifications. A more or less uniform, deep black hue generally prevails on the upper surface, while the lower surface of the body and the flippers is diversified by whitish, marbled markings.

Habitat and Habits Few Whalebone Whales are seen of the Hump- oftener or in greater numbers than Back Whale. the Hump-back, occurring as it does in all latitudes between the equator and the polar oceans of the north and south, in the high seas and near the coast, in all larger gulfs and bays; and it seems to migrate regularly every year from the poles to the equator. Off the coast of Greenland it is seen only during the summer months, while it is found all the year round off the western coasts of America and Africa, though not in the same places every month.
Though the profit of a slain Hump-back is not small, it is greatly inferior to that derived from a Sperm Whale or a Greenland Whale, as its blubber yields proportionately far less oil than one would naturally believe. For this reason the Hump-back is molested by whalers only when there is no better to be procured, at least off the Greenland coast. Along the American and African coasts, however, it is pursued, with some regularity and a considerable degree of profit by the coast-dwellers.

\section{THE RAZORBACK WHALE.}

In Gray's classification the Fin-fish, which is so frequently spoken of and often mistaken for some other of the Rorquals, has only recently been placed in its proper position, and represents a genus (P/y)salus) the special features of which are as follows: the head takes up about a quarter of the total length, the dorsal fin is placed in the last quarter of the middle line; the joints of the flippers are close behind the head; the tail-fin is indented in the middle and divided into two more or less distinct flukes.

Description, Habi- The Fin-fish or Razorback, called tat and Habits of Sildror in Norway and Tunnolik in the Razorback. Greenland (Physalus antiquomum), is one of the slenderest forms among the Whales, and may attain a length of eighty-three feet. The flippers are one-tenth as long and one-fiftieth as wide, and the dorsal fin is one-fifth as long as the entire length of the animal.

The northernmost part of the Atlantic and the Arctic Oceans are the usual haunts of the Razorback. At the beginning of fall it migrates into more southern waters, and thus it is also met in the seas of the temperate and torrid zone; and is said even to have been found in the Antaretic Ocean.

As one may conjecture from its slender form, the Fin-fish is rapid and agile in its movements. It is considered one of the swiftest of all Whalebone Whales. In swimming quietly it proceeds in a straight direction and rises very frequently to breathe: every ninety seconds, according to my observation. I could hear the noise made by it in blowing at the distance of one knot. The Razorback often appears in the immediate proximity of sailing vessels, swims around them, sometimes faithfully follows them for several hours.

The food of the Razorback consists principally of fish, which it often drives before it in shoals, and of which it eatches great numbers at once in its vast mouth. When it finds an abundance of prey, it remains in one place for days and even weeks, notably off the coast of Greenland, where it devours astonishing numbers of Haddock and Codfish, or other fish which assemble in large "schools."

The Razorback The capture of the Razorback is Difficult of more difficult than that of the Green-

Capture. land Whale on account of the great speed and violence of the animal, but the profit derived from its carcass is much less. In comparison with the Greenland Whale it is considered nearly valueless by the cruising whalers. It is different in those localities where the pursuit may be engaged in from the coast, for in these instances, all parts of the body being put to account, a much higher profit may be derived from it than is possible to accrue to the whalers, as, for instance, off the northern coast of Norway: Kuekenthal says that the value of a large individual of this species is estimated there to amount to $\$ 625$, of which only $\$>5$ represents the value of the short whalebone. 
THE BEAKED WHALES.

The last genus of the family comprises the Beaked Whales (Balanoptera) which are, as far as is now known, the smallest and most gracefully built of all Whalebone Whales.

The Pike Whale the The best known representative of smallest of its this genus is the Pike Whale (BalceFamily. noptera rostrata), the smallest known member of its family, for its length hardly exceeds thirty-three feet. A sombre slate black is the hue of the entire upper surface, from the extremity of the upper jaw to the angle of the flippers of the tail, including the pectoral fin; a more or less reddish white color prevails on the lower surface; the flippers have the same hue as that of the back above, relieved by a white transverse stripe in the middle; their under surface is white like the abdomen. The range of the Pike Whale extends over all oceans surrounding the north pole. From there it wanders southward at the commencement of winter and then appears also on the European, east and west American and east Asiatic coasts.

In respect to habits and mode of life it greatly resembles the Razarback. Generally it lives singly very rarely in couples, and hardly ever consorts in greater numbers. It feeds preferably if not exclusively on small fish, perhaps also on cephalopods, and pursues its prey with such avidity that it often strands itself in the act of pursuit and in many cases loses its life in this way.

Along the American coast the Pike Whale is not generally hunted, and along the coasts of north or central Europe only when it shows itself near the shore.

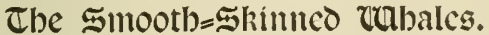

\section{SECOND FAMILY : BALFNIDE.}

The Smooth-skinned Whales (Balanida), which form the last family of the suborder, are of heavier and at the same time more awkward organization than any of the Furrowed Whales; they possess neither dorsal fin, nor furrows in the skin; their flippers are broad and truncated, their baleen plates long and narrow.

\section{THE GREENLAND WHALE.}

IVe must consider the most important of all Whales, the Greenland Whale (Balana mysticitus), as the type of this family; it is a shapeless creature, which exhibits a lack of proportion in all its parts and members.

Pechuel-Loesche gives the proportions of a specimen caught north of Behring Straits as follows: Length, fifty-four feet eight inches, spread of tail. twenty-two feet four inches; length of the largest plate of whalebone, ten feet ten inches. Yet it can not be denied that larger specimens have been found and still exist in remote parts of the sea. Karl Giesecke tells of a Whale, taken in 1813 , which was sixty-eight feet long, and in the commencenient of this century one was killed near Spitzbergen, which was of about the same length and had whalebone sixteen and one-half feet long.

Proportions of the A Whale sixty feet in length is really Greenland an awe-inspiring monster. On an Whale. average, the shapeless head includes one-third of the total length of the animal; the mouth might easily admit a boat of moderate size with her crew, being from sixteen to twcnty feet long and from eight and one-third to ten feet wide. 
The upper skin is thin, of dense texture and velvety softness, comparable to leather saturated with oil, and under it lies the layer of blubber, from eight to eighteen inches in thickness.

Range and Habits The Greenland I'hale inhabits the of Greenland highest latitudes of the Atlantic and Whales. Pacific Oceans and the Arctic Ocean proper, but takes up no permanent abode. It is attracted by the ice to a greater extent than any other species of Whale, and of its own accord selects its haunts in the immediate neighborhood of the ice fields, and wanders south or north in seasons coincident with the formation or thaw of the ice. It not only leaves a locality where the ice melts, but undoubtedly also travels through great distances under the ice, as it has been found amidst immense icefields, in which, in order to breathe, it was obliged to rise to one of the few crevices formed by the ebb and flow of the tide.

The Greenland Whale is gregarious. Generally it is found associated only in small groups of three or four, but during its more extended migrations it may collect into schools composed of large numbers. Experienced Whalers report that generally Whales of the same age consort, young and old forming separate troops.

Physical and men- The movements of these animals are tal Attributes of of an irregular character, but by no Greenland Whales. means slow or heavy. "Clumsy as the IVhale's body apparently is," say.s Scoresby, "its movements are quick and agile; it can put itself beyond the reach of its pursuers in five or six seconds. So great a speed, however, can be maintained only for a few minutes. Sometimes it darts upwards to the surface of the water with such force that it springs beyond it; sometimes it stands on its head, lifting its tail into the air, and lashing the water with terrific violence. The noise which this lashing causes may be heard at a great distance in calm weather, and the circles made in the water expand to a considerable width. When it is pierced by a harpoon, it dives toward the bottom, as straight as an arrow, and though this direction can be maintained for only a few minutes, the action is performed with a speed and force that sometimes, in shallow places, causes it to break its jaws in a collision with the ground."

There is not much to say about the higher attributes of this IIhale. Among the perceptive senses those of sight and touch alone seem to be fairly developed; but it may be reasonably supposed that the organs of sense are sufficiently effective so long as the animal remains under water, and are deficient only when called on to perform their functions in the air.

In serene weather this IVhale has been observed in its sleep. It lies then on the surface of the water, like a dead body, without moving, the extremity of its head lifted above the waves; it breathes quietly, without throwing up a jet, and keeps its balance with its flippers.

As a rule, the female gives birth to one, or in rare cases two young, usually in March or April. The infant IVhale nurses for a long time, perhaps a whole year, the mother lying on her side while suckling it. Its growth is exceedingly rapid, and a nursing IVhale attains a length of at least twenty feet, a girth of thirteen feet four inches and a weight of twclve thousand pounds. According to all accounts the mother is devotedly attached to her progeny and tends and defends it with solicitude.
Economic Value of The value of the carcass of a the Greenland slain Green land Whale is very Whale.

great. The average production of the animal is from 12,000 to 15,000 quarts of oil and from 1,400 to 2,000 pounds of baleen. According to the very variable prices of oil and whalebone, the average value of a Greenland Whale amounts to five thousand dollars; a large Whale, however, may bring in double that sum. The greater part of the profit generally comes from the baleen, which no other species of IVhale possesses in such excellent quality. The flesh can not be said to be altogether uneatable; French ship-cooks know how to prepare it remarkably well. The people of the high northern latitudes have no scruples about eating it, and they habitually consume the blubber.

Enemies of the Besides Man the formidable GramGreenland Whale pus or Killer Whale is probably the and their Inroads. only other foe to attack a Greenland Whale. It is apparently greatly annoyed, however, by various parasites, which prey upon its body. The so-called Whale Lice, a genus of crustaceans, sometimes take up their abode on it by hundreds of thousands and cause such ravages on its back that one might think it suffered from a malignant disease. sea acorns or Barnacles also sometimes cover it in large numbers and form suitable points of attachment for various aquatic plants, so that there are Whales which are obliged to carry a miniature world of animals about on themselves.

Though a constant decrease in the number of Whales can not be denied, we are hardly warranted in believing that the Greenland Whale will be exterminated for some time. Its inhospitable native waters still contain a number of refuges inaccessible to ships and preserve the species from the total extinction which would otherwise be its lot.

\section{The Tootbed rabales.}

\section{SECOND SUBORDER: DENTICITE.}

The remarkable difference in dentition between the Whales has led to the division of the Cetacea into two suborders, one of which, as we have seen, comprises animals which are toothless, having the place of the teeth supplied by a substance, baleen, popularly known as "whalebone," which is peculiar to themselves. The other suborder is known, by eontradistinction, as that of the Toothed Whales (Denticete), including four families: the Dolphins (Delplimide), the Narwhals (Monodontide), the Bottle-nosed Whales (Hyperoodontida), and the Sperm Whales (Catodontidr).

\section{Tlse Dolpbins.}

\section{FOURTH FAMILY: DELPHINIDE.}

The first family of the Toothed Whales comprises the Dolphins, which are medium sized or small Whales having both jaws, either for their whole length or partly, beset with more or less conical teeth, nearly uniform in shape. The body is proportionately long, the head comparatively small, the snout in several species is elongated and pointed, and there is usually a dorsal fin.

Range and Gen- The Dolphins inhabit all oceans, un-

eral Traits of dertake great migrations, but are the Dolphins. only. Whales which frequent rivers or even spend their whole lives in them or in the lakes 


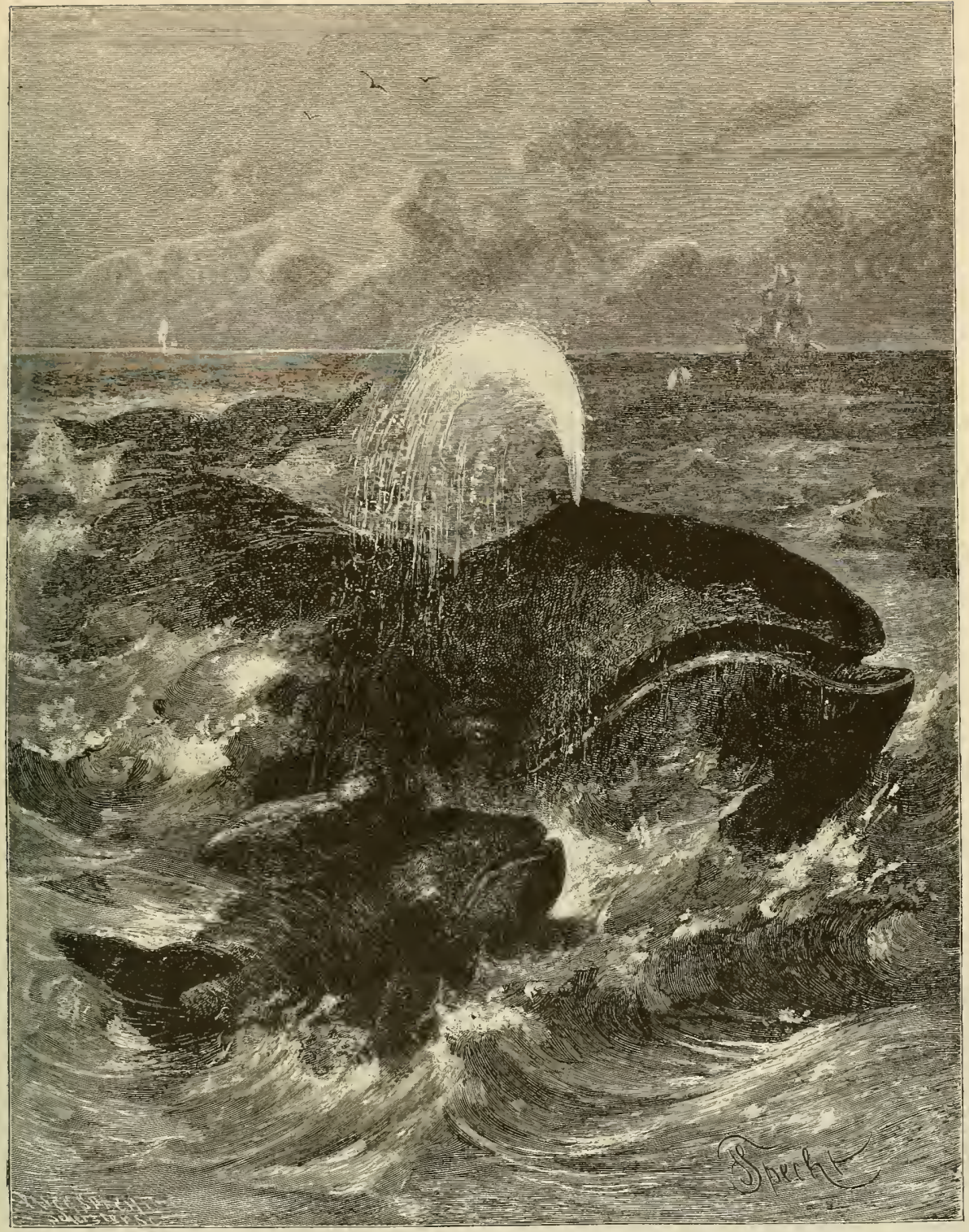

THE GREENLAND WHALE. - This marine monster is the most important of its order, yielding both oil and whalebone in large quantities and of the best quality. In the northern parts of the Atlantic and Pacific Oceans and the Arctic seas this giant of the mighty deep makes its home, and is sometimes found in large numbers, although it is zealously hunted. The picture shows a female of the species attended hy her young. The older animal is shown in the act of "blowng." (Baluna mysticetus.) 
connected with them. They are all gregarious, some of them collecting in very large shoals and roaming about the sea together for days and weeks. Their liveliness, playfulness and lack of shyness have earned them the friendship of sailors and poets from the most remote ages.

Nearly all Dolphins swim with remarkable speed and agility, and are therefore highly adapted for catching fish, and among their numbers are some of the most formidable and predaceous beasts of the ocean. Some species even dare attack the largest of Whalebone Whales, and often conquer them by dint of perseverance. The food of the Dolphins consists principally of cephalopods, mollusks, crustaceans and minute sea organisms, but some are also said to consume sea-weeds and even fruits of trees, plucking the latter from the branches that hang over the water. They are all voracious, greedy and cruel, consuming every eatable thing which they can procure and not even disdaining the young of their own are eaten; the skin and intestines are utilized, and the blubber yields a very fine oil, which is in great request.

\section{THE GRAMPUS.}

Among the numerous species, of which this family consists, the Grampus or Killer Whale, known from the earliest ages and notorious for its voracity, deserves to be mentioned first. It represents a genus of the same name (Orad). The most prominent feature is the exceedingly long, erect dorsal fin. The body is stout, the head short, the forehead sloping, the snout rather broad and the teeth are few in number, but very strong.

Characteristics and The Grampus or Killer IVhale (Orca Range of the gladintor) may sometimes attain a Grampus. length of thirty feet, but averages a smaller size, usually from thirteen to twenty feet. The color seems to be very variable. A more or less deep black extends over the greater part of the

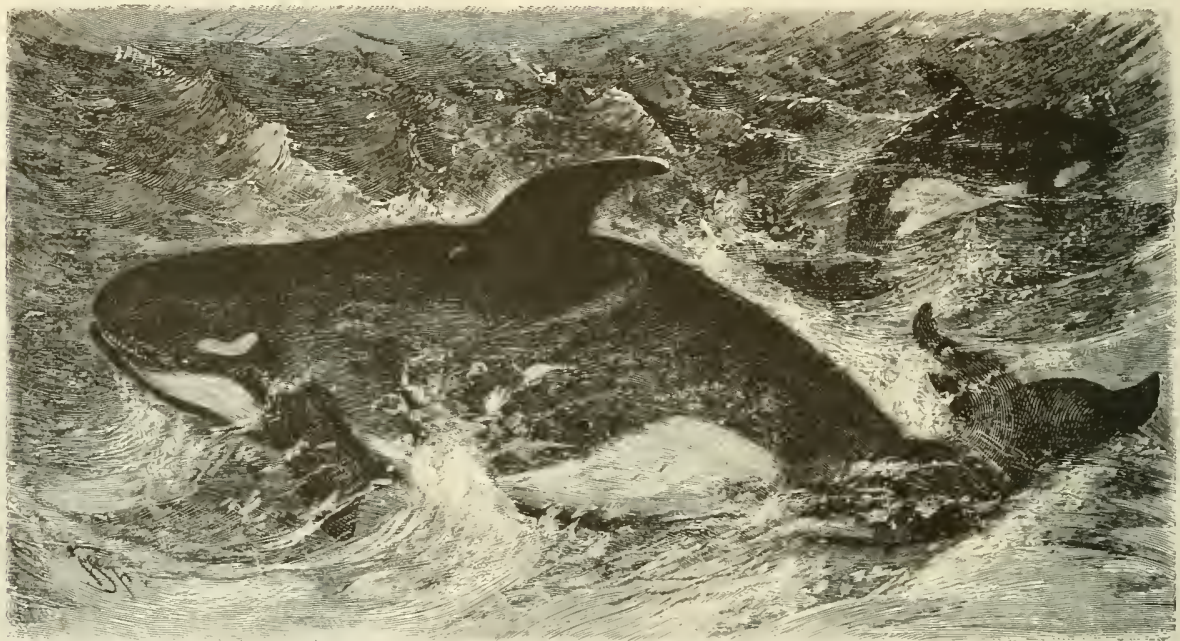

THE GRAMPUS, - This animal, also known as the Killer Whale, has, because of its ferocious and voracious nature, been aptly termed "the Wolf of the Seas," Several of them sometimes unite in attacking the great Greenland Whacious and voracious nature, been aptly termed Seals are killed by the Grampus singly. A stout body and short head, powerful jaws beset with strong teeth, and a long, dorsal fin, are prominent features in this species. (Orca ghaliator. A st

kind or of their nearest relatives. The females give birth to one or two young, suckle them for a long time, carefully protect and tend them and defend them in danger. It is believed that the young grow very slowly.

Pursuit of the All Dolphins are pursued very much Dolphins and its less by $M$ an than are the other Profits. Whales. Their worst foes are the nembers of their own family; but their own indiscrect zeal is still more fatal to them than are the attacks of any of their enemies. They pursue their 1)rey with such greed and eagerness that they often allow it to lead them to disaster on the treacherous shore: they run aground, can not swim back, and thus perish on the dry land. Fishermen sometimes find dozens of them lying on the beach. In their agony some of them utter moans, a few shedding copious tears at the same time.

Man derives considerable profit from many species, for nearly all parts of the body are put to account. The flesh, fat and some of the internal parts upper surface, a rather pure white over the lower surface, with the exception of the extremities of head and tail. It inhabits the northern Atlantic, the Arctic Ocean and the northern Pacific, permanently frequenting the coasts of England, France and Germany. An odd feature in connection with its migrations is that it appears in the southern waters in the summer months, being wont to arrive in May and disappear in the late fall.

The Grampus is numerous nowhere, but is found in mid-ocean as well as near coasts, not infrequently entering bays or even ascending rivers.

It hunts not only small fish, but also the giants of the occan, for it is not only the largest but also the greediest and the most predaceous of all Dolphins. Wherever it appears it is the terror of all creatures to which it is an enemy, and if possible they leave its dangerous vicinity: Its voracity often compels it to live near the coast, where it generally frequents the mouths of rivers, teeming with fish; but when in pursuit of larger prey it swims out into 
the high seas for miles and avoids the coast for days or even weeks. Wherever Greenland Whales, White Whales and Seals are found, one will never miss seeing this their tireless enemy. The White Whale and the Seal rush toward the coast in terror at the sight of it; the former always and the latter usually endangering their safety in such flight. All whalers hate the sight of the Grampus, for its arrival is an indication that all other Whales will at once forsake that part of the sea, even if they have to hide between the ice to escape pursuit. Eschricht took out of the stomach of a Grampus over thirteen fect long the remains of thirteen P'orpoises and fourteen Seals. The fifteenth Seal had stuck in its throat and cholied it.

Scammon says: "The attack which these Wolves of the ocean make on so gigantic a prey as the Greenland Whale recalls to mind a Stag pursued and run down by a pack of Hounds. Some fasten on to the hcad of the IVhalc, others attack it from below, while a few seize it by the lips and hold it and placed in the middle of the body, and the teeth are numerous and sharp-edged.

The Porpoise and The Porpoise (Phocena communis) its Habits De- attains a length of five feet to six scribed. feet eight inches, or perhaps in rare cases of ten fect. The skin is naked, soft, smooth and glistening; the color is a lark blackish brown or black with a grecnish or violet lustre above, and pure white beginning narrowly at the tip of the lower jaw and from thence broadening backward; below, the flippers are of a more or less dark brown tint. The tceth are from forty to fifty in each jaw, thus numbering in all from eighty to one hundred.

It is the Porpoise that one so frequently sces on every journey through the North Sea; that prowls about the mouths of western European rivers and, swimming against the current, not infrequently penetrates to a considerable distance inland. Thus it has been repeatedly found in the Rhine and lilbe and killed in the Seine at Paris and the Thames at London.

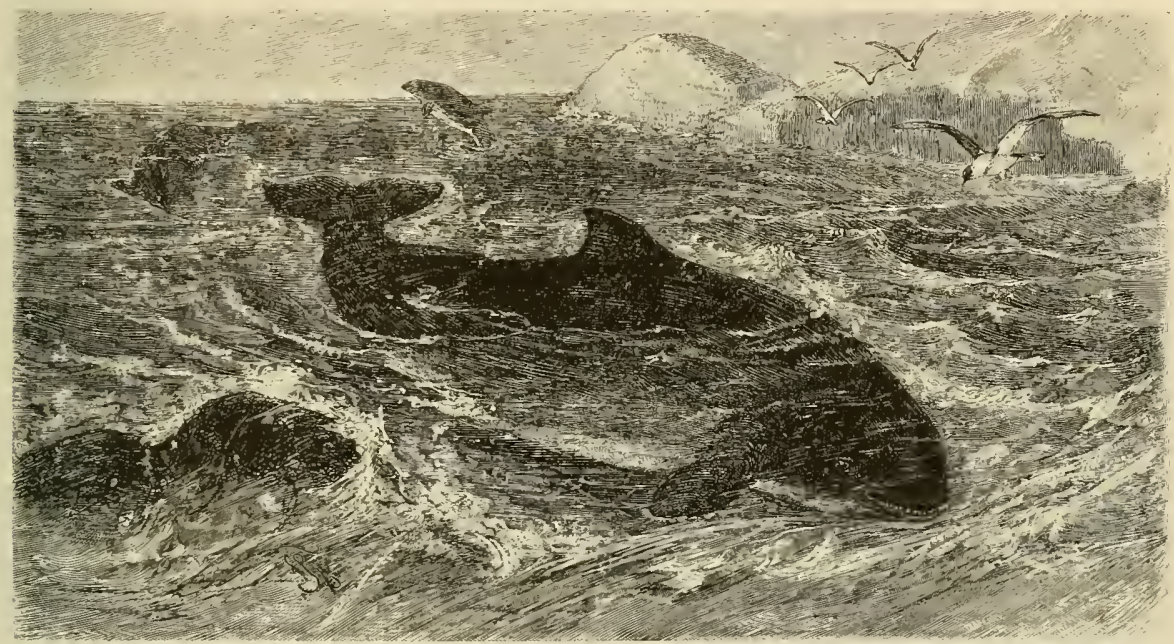

THE PORPOISE. - One of the smallest animals among the Whales is the Porpoise, which is very common in all parts of the North Atlantic. It follows vessels of all kinds, has no difficulty in keeping up with the fastest steamships, but specially likes to play around sailing vessels, as long as they are near the coast. It has a broad tail, a short, dorsai fin and a short body. (Phocana commznis.)

under water or tear its tongue when it opens its huge mouth. In the spring of 1858 I was a witness to such an attack made by three Killers on a female Gray Whale and her young." After so many accounts, tallying in all particulars, there call hardly be a doubt of the truth of the stories told of the ferocity and voracity of these bcasts.

The Grampus of Though the body of the Grampus Little Value possesses hardly any flesh, as Steller to Man. Says, but consists of fluid fat, still it is nowhere generally hunted. Grampuses are occasionally caught in rivers; and there are on record three instances of Killer Whales having been harpooned in the Thames.

\section{THE PORPOISES.}

The commonest Dolphin of the northern Atlantic seas is the Porpoise or Sea Hog, a representative of the genus Pliocana, so poor in species. Its body is short and spindle-shaped, the forehead gently sloping, the dorsal fin is low, broad-rooted, triangular
The native region, proper, of the Porpoise may be considered to be the whole north of the Atlantic, from Greenland to north Africa, inclusive of the Baltic Sea. It seems that it also goes north in summer and turns its face south in winter. In spring it goes in the wake of the Herrings and pursues them so diligently that it often annoys the fishermen. Its voracity is proverbial; it digests its food very quickly and requires a considerable quantity of sustenance to meet its needs. Fishermen detest it, as in a general way it injures their trade, and sometimes inflicts upon them actual personal loss; for it easily tears the weak nets in which they have captured fish of the smaller varieties and then leisurely eats up the prisoners. Strong nets, however, are often fatal to it, as it entangles itself in them and cliokes.

\section{THE WHITE WHALE.}

Martens, who visited Spitzbergen in I67I, as a barber on board a whaler, and gave an account of northern marine animals, first mentions one of the 
most remarkable Dolphins: the White Whale or Beluga, which represents the genus beluga. The lack of a dorsal fin may be considered as the most important distinctive physical feature of the animals of this genus. The strongly-arched forehead terminates abruptly in the broad, truncated muzzle, the jaws of which are armed with a few conical teeth, which usually fall out in old age. The short, blunt flippers, which are placed in the first quarter of the total length, are of an ovoid shape.

characteristics of The Beluga or White Whale (Bcthe White luga leucas) averages a length of Whale. from thirteen to twenty feet. The color is a yellowish white in old animals, brownish or bluish gray in young individuals, and later is mottled until it gradually fades into the hue of maturity.

The Beluga ranges throughout all waters around the north pole, but does not usually roam far south. In rare cases it may stray into southern seas, having ships and gambols joyfully up and down in their immediate proximity; yet it always remains timid, and flees at the slightest noise. The principal reason, however, why whalers do not hunt the animal, which yields more or less profit, is, that the Beluga often baffles pursuit in the open sea by its great speed and agility; and its hunt requires too much time to be profitable for civilized whalers. It is different with the natives of the high north: for them the Beluga is the most important of Whales, on account of its oil and flesh. The majority are caught in nets, which are set at the mouths of ocean creels or the inlets of bays, or in straits between islands. The flippers and tail are esteemed as special delicacies, if they are well prepared. The skin is dried and tanned and serves a varicty of purposes. In Kamchatka, for instance, thongs are made out of it, which are highly esteemed on account of their pliability and strength.

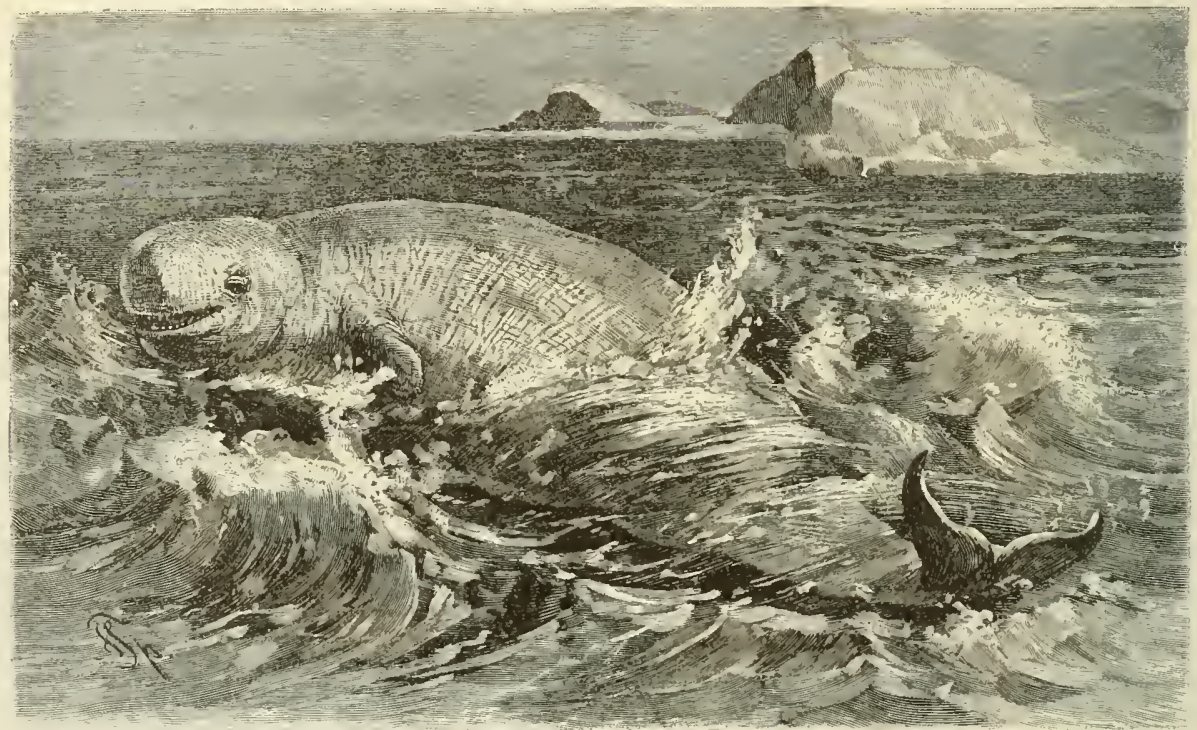

THE WHITE WHALE.-Besides the peculianty of it white body this animal is notable as having no dorsal fin, wlile its blunt muzzle. its short, oval flippers and broad, forked tail are also notable characteristics. As it ranges in polar seas, the artist has appropriately depicted
it in the vicinity of an iceberg. (Belugalencas.)

several times descended to the coasts of central Europe. Small fishes, Shrimps and cephalopods form their food, and besides these animals sand is invariably found in their stomachs, a fact which has led to the joke, common among the Greenlanders, that it can not swim without ballast.

In its demeanor and character the Beluga differs in nearly every respect from the impetuous Grampuses, and likewise from the Porpoises. White Whales are hardly ever seen singly, but generally in groups, which may grow into immense schoo!s. The sight of such a school is said to afford a truly mag. nificent spectacle, as the dazzlingly white animals sometimes, as they rise to brcathe, lift their bodies half above the dark waves.

The Beluga of Great The whalers grect the Beluga with Value to the Arc- joy, as they see in it the precursor tic Dwellers. of the large Whale, and they often sail on in its company, without molesting it. Under these circumstances this Dolphin comes cluse to

\section{ROUND-HEADED WHALES.}

Among all the gifts of the sea none is more important for the northern native than the one proffered in the shape of an animal belonging to the family which we have now under consideration.

The Ca'ing Whate, I mean the Ca'ing or Pilot Whaie its Haunts and (Globiocephalus milas), a representaHabits. tive of the genus of the Roundheaded Whales (Globiocephalus). The Ca'ing Whales [which name is a Scotch contraction of "Calling" Whales] are characterized by the almost globular head, which has a swollen appearance; the crescent shaped flippers, placed well under the body; the dorsal fin, erect in the middle of the back, and the wide intermaxil lary bones of the lower jaw. The body is not spindle-shaped, but compressed laterally. In each jaw, placed at tolerably wide intervals, there are from twelve to fourteen rather long, nearly conical, interlocking tecth, the sharp points of which are curved slightly backward and inward. The naked, 
shining skin is deep black above, grayish black below, marked with a broad, heart-shaped, white patch on the lower part of the neck. Very old males attain a length of from twenty feet to twenty-three feet four inches. The Ca'ing Whale inhabits the Arctic Ocean and also the northern part of the Pacific. From the Arctic Ocean it prowls throughout the northern part of the Atlantic, occasionally penetrating as far south as the latitude of Gibraltar, but it docs not follow definite routes as do other Whales. More gregarious than others of its family and order, it always lives in schools and herds, which may swell from ten and twenty to one thousand or more. lt seems that they are led by old, experienced males, which they follow with the same indifference, or rather stupichity, that Sheep exhibit in following their leading ram, even if it be to their own peril.

The diet consists principally of various varicties of Cuttle-fish; yet the stomach of a Ca'ing Whale which was killed was found to contain Haddocks, Herrings and other small fish, and several kinds of mollusks. pers are placed squarely on the sides, 11 about the first fifth of the length of the body; the dorsal fin is situated nearly in the middle of the upper surface; the tail-fin is proportionately very larese and of an almost exact crescent shape.

The Dolphin De- The Dolphin (Dilphimes dilphis) atscribed-Its tains an average length of six feet Wide Range. cight inches. The skin is cxceedingly smooth, and not only shining but varied in color. It is greenish brown or grecnish black abovc, dazzlingly whitc below, with a sharp but not straight linc of demarcation; the sides are irregularly spotted with a grayish or blackish tint. The number of tectl is subject to considerable variations. Usually there are from eighty-four to one hundred in each jaw, but there also have been found Dolphins which had fifty-three teeth on each side of the jaws above and below: that is, the amazing number of two hundred and twelve in all. The teeth stand at regular intervals, the upper ones interlocking between the lower ones; they are long, conical and very pointed.

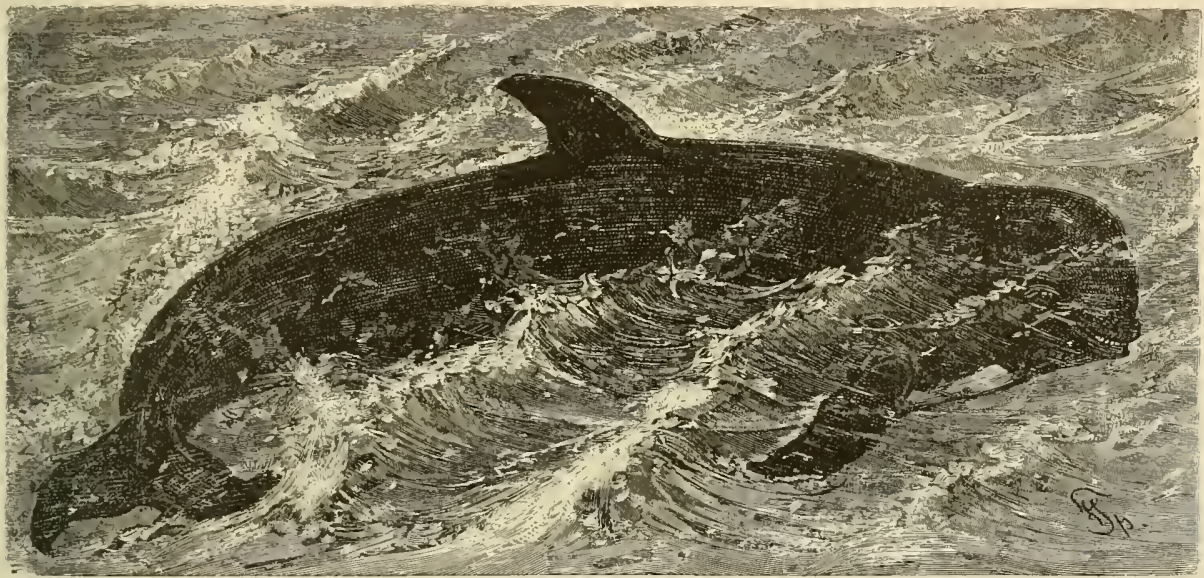

CA'ING OR PILOT WHALE. - Relonging to the genus of the Round-headed Whales is the Ca'ing or Pilot Whale which inhabits the Arctic and the gorthern portions of the Atlantic and Pacific Oceans. The head is almost round and its dorsal fin is rather large and of crescent shape. These animals often pursue their prey to the shore and get lost on the shallow banks. (Globioccphalus melas.)

The Ca'ing Whale No other Whale is stranded so freFrequently quently and in such numbers as the Stranded. Ca'ing Whale, the gregarious habits of which lead it into fatal danger; perhaps it is not going too far to say that this IVhale does not meet with death in the sea, but almost invariably on land. Hardly a year passes, but that a greater or smaller number of Ca'ings are stranded in some place. In 1779 a herd of two hundred met with this fate, in I 805 another of three hundred was stranded on the Shetland Isles; and in I809 and 1810 eleven hundred Whales were cast ashorc in a bay called Walfjord in Iceland. On all northern islands the inhabitants have endeavored, from ancient times, to strand all Ca'ing Whales which show themselves in the neighborhood, in order to take advantage of the very considerable profit which results from their capture.

\section{THE DOLPHINS PROPER.}

The Dolphins, and several species closely allied to them, represent a distinct genus (Delplimus). The comparatively small head tapers in front into a snout, clongatcd in a beak-like manner and armed with a great number of conical permanent teeth; the flip-
All the seas of the northern hemisphere are included in the habitat of this celebrated animal, which contributes so much to the amusement of seafarers and travelers. In its habits and ways the Dolphin exhibits, if possible, a still more playful, capricious oisposition than its relatives. Sometimes it prowls about the high seas, sonetimes it ascends far towards the sources of rivers. Dolphins approach ships in schools and play around them for a long time before they shape their course in another direction; they plunge up and down incessantly, lift their heads above the water for a few moments, blowing with a snorting noise, and then disappear again in the deep. They swim with such extraordinary speed, that they not only follow the course of the swiftest steamer with ease, but gambol near it on their way, circling around it at will, without being left behind. Occasionally one of them jerks itself up into the air and, turning a somersault, falls noisclessly back into the water and hurricdly resumes its former position.

The tecth show clearly enough that the Dolphin belongs among the most predaceous and voracious animals of the sea; it is said to even turn upon its 
wounded companions. Its food consists of fish, Shrimps, cephalopods and other marine animals. Its favorite prey are Sardines, Herrings and Flyingfish.

Dolphins are born singly: the young one is from twenty to twenty-four inclies in length, and the mother nurses it very tenderly for a long time.

The Dolphin encounters a worse foe in the Killer Whale than it does in Man; for the latter pursues it only when the lack of the fresh meat of land animals forces him to supply his need with the flesh of the Dolphin. This fact is to be attributed to a certain reverence on the part of Man which the animal enjoys up to the present day.

As eally as ISI0 A. von Humboldt published an account of a Dolphin inhabiting the fresh waters of South America, without, however, giving a detailed description of it. The painstaking German naturalists, Spix and Martens, published a more accurate description in $1 \& 3 \mathrm{I}$, but the final account is due to the Frenchman, 1)' Orbigny. and in the Orinoco. It is said to differ from the ocean Dolphin in that its movements are slower and less active; it swims more quietly, often rising to the surface to breathe and generally gathers only into small groups.

Bates tells us that the Amazon River is inhabited by at least three different kinds of Dolphins and that Whales are numerous everywhere but surprisingly plentiful in some places. "On the wider parts of the riverbed," says this observer, "from its mouth upward for lifteen hundred miles, some one of the species can be constantly heard to roll, blow or snort, especially at might, and it is these very sounds which contribute not a little to inspire the traveler with the conception of oceanic vastness and solitude." The food of these Dolphins consists nuainly of small fish; but they are said not to disdain various fruits which fall from the trees into the river. The Inias show the greatest preference for the clear, deep estuaries formed by those waters at the junctions of tributaries with the main streams, evidently

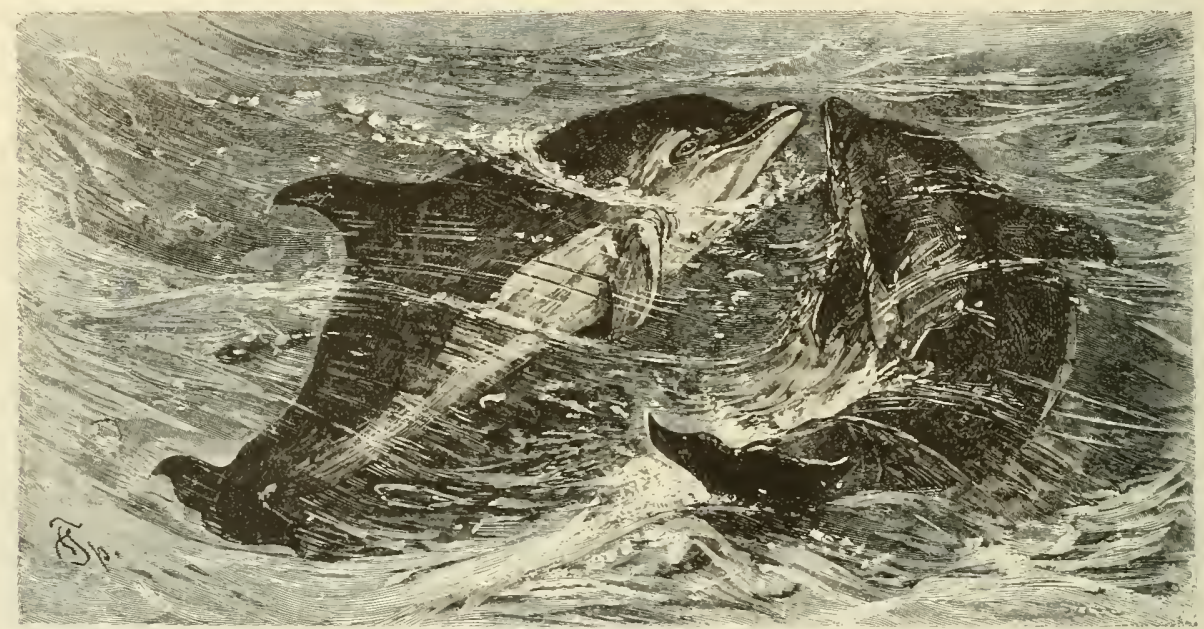

THE DOLPHIN. - The smooth-skinsed, lively and voracious Dolphin which finds itself just as much at home in the decp ocean as near shore, is a familiar sight to all who go to sea, lor it follows in the wake of vessels sometimes for days. It is a smootin-shinned, compact aninal, and its muzzle is elongated into a beak-like projection. (Delphumus delphus.)

The Inia, or The Inia or Bonto (Inia amazonica) Bonto, of South represents the genus of the Long-

America. beaked Dolphins (Inia). Its muzzle is elongated into a narrow, roundisl, obtuse beak, overgrown with stiff hair, and each jaw has sixtysix or sixty-eight pointed teeth with curved, strong crowns. The slender body is equipped with long flippers, notched at the upper ends and tapering in creseent shape towards the extremities; the tail-fin has no flukes and the dorsal fin is very low. The length of the male varies between six and ten feet. The female is said to be only half as large. The Inia is of a pale bluish color on its entire upper surface and pinkish red beneath: but there are many deviations; sometimes one finds individuals of a pronounced reddish or even blackish tint. Recently naturalists have differentiated and classified several allied species.

As far as is now known, this Dolphin inhabits nearly all South American rivers between the tenth and serenteenth parallels of south latitude. It is well known in the Amazon River and its tributaries, because such places harbor the greatest number of fish.

The Inia is not pursucd by the natives. Its flesh is said to be tough, its blubber small in quantity, and its skin suitable for scarcely anything but the manufacture of shields, the capture thus being remunerative only in very slight degree.

\section{THE SOOSOO.}

Pliny mentions a 1)olphin under the name of Platanista, which lives in the Ganges River in India, and according to his description is twenty-three feet long. The animal really exists, but is much smaller than the celebrated old author say's, being only six feet eight inches long. This Whale is the Soosoo of the Ganges (Plataniste sangetica) and is specifically characterized by a very slender body, a crescent shaped, forked tail-fin, and a long, beak-like snout curving upward, the upper jaw of which forms a crest projecting in front and surrounding the blowholes. The jaw's contain thirty or thirty-two strons. conical, pointed tecth. The fin on the back is indi- 
cated only by an elevated, fatty skin, the color is grayish black above, grayish white beneath.

This remarkable Dolphin, which, however, recent investigations have shown to be by no means the only representative of the order living in the rivers of southeastern Asia, exists not only in the Ganges and its tributaries, but has also been found in the Brahmaputra and the Indus. The food of this species consists chiefly of fish and Shrimps: occasionally grains of rice and remains of insects are also found in its stomach, but they are said to come from the intestines of fish it has devoured.

\section{The Nharwbal.}

FOURTH FAMILY: MUNODONTIDE.

Important distinctions separate the Narwhal or Sea Unicorn (Monodon monoceros), the representative of the genus of the same name, so widely from the behind. The tail-fin is very large and branches into two large flukes. The hue of the shining, soft, velvety shin seems to be subject to considerable modifications according to the sex and age.' In the male the white or yellowish white ground color is diversified with numerous, irregularly shaped, dark brown spots set closest together on the back, widest apart on the abdomen, and merging into one another on the head; young animals are darker than old ones. There are also nearly purely white and grayish, unmarked individuals. The total length of the Narwhal is said to sometimes be as great as twenty feet, not averaging, however, more than from thirteen to sixteen and one-half feet.

Superstitions and We must not be astonished at the Facts Concerning fact that marvelous stories concernthe Narwhal. ing the Narwhal were rife among our ancestors. An animal so remarkable in shape necessarily arouses the wonder of mankind, and so long as science had not yet spoken a decisive word, there was food for imagination. The tusk especially

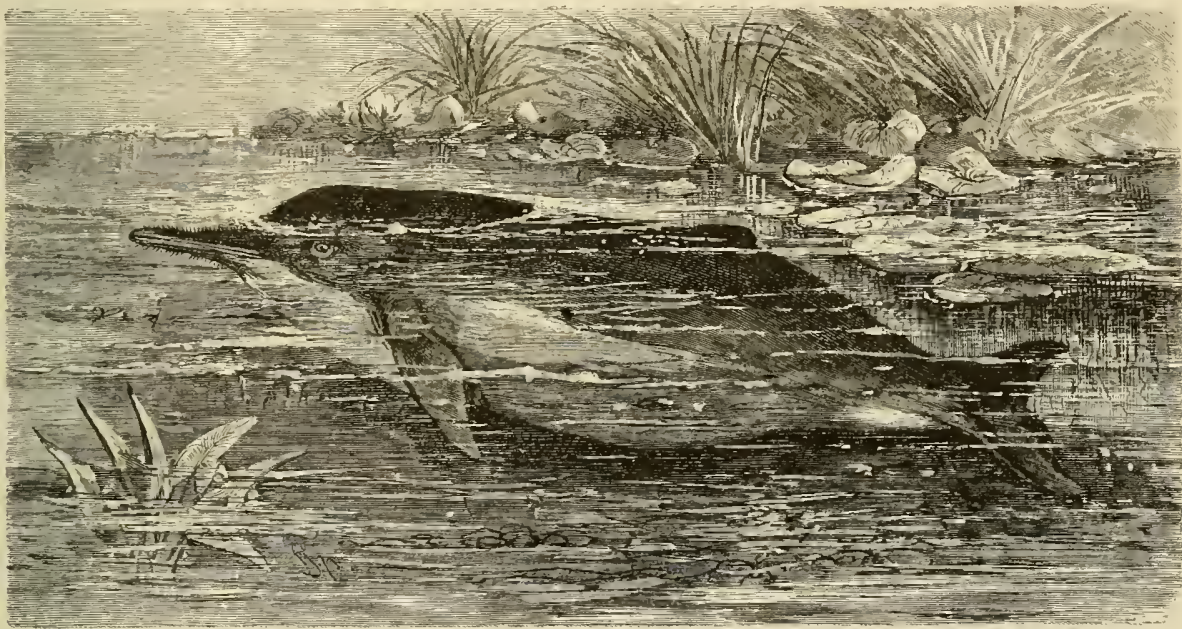

THE INIA. - This animal, sometimes called the Bonto, is quite common in the larger rivers of South America. Its muzzle is elongated into a beak and its flippers are long. It is especially prominent in the Amazon and Orinoco Rivers. Its movements in the water are quite lively. It lives on fish and is very voracious. (Inta amazontca.)

other Toothed Whales that a distinct fanily has been based on the animal. The dentition differs from that of all other Whales in the development of two enormous tusks, which are from six and onehalf to ten feet long, comparatively weak, twisted from right to left, hollowed inwardly and projected horizontally from the upper jaw. The right tusk is stunted as a rule, and in the female both tusks attain but a limited development. There are two small incisors and one molar besides, in the upper jaw, but they are invariably found only in young animals. The cylindrical head is rounded in front and occupies about one-seventh of the total length of the elongated, spindlc-shaped body; the snout is very short, broad, thick, somewhat shortened on the right side and is not differentiated by any line of demarcation, from the flat forehead, but is abruptly truncated, being cut off almost perpendicularly in front. There is no fin on the back, its place being supplied by a fold of skin. The pectoral fins are situated in about the first fifth of the length of the body. They are short, of oval outline and thicker in front than has given rise to manifold conjectures. Albertus Magnus speaks of this animal as a fish, which has a horn on its forehead, with which it can pierce fish and frail ships, but says it is very slow in its movements, and the objects of its attacks can easily escape. On our part we regard this tusk as a weapon, such as is often given the male sex alone.

The Narwhal is an inhabitant of the northern seas and is oftenest found between the seventieth and eightieth parallels of north latitude. It is plentiful in Davis' Straits and Baffin's Bay, in the Arctic Ocean between Greenland and Iceland, around Nova Zembla and farther in the north Siberian seas, and it is rare south of the Arctic Circle. In its native latitudes it is nearly always seen in schools containing large numbers, for in point of gregariousness it is inferior to none of its relatives. "During its migrations," say's Brown, "I have seen schools numbering many thousands. With tusks and tails aligned, they swam beside each other, going north, their movements recalling to the mind of the observer those of a cavalry regiment; bobbing up and 
down with seeming greatest regularity, pursuing their course in wavy lines. Such schools are not always composed of individuals of the same sex, but consist of males and females mixcd."

Disposition, Food Modern seafarers describe this IVhate and foes of the as a very lively, agile animal, which

Narwhal. gives the sea an aspect of animation by reason of its extraordinary speed and repeated divings and reappearances, and enchains the attention of the observer. It certainly does not wage such bloody wars with other Whales as have been fabled, and it lives on amicable terms with its own kind.

Sea cucumbers, mollusks and fish form the food of this notable creature.

Manifold dangers and many foes menace the life of the Narwhal. Of no other Whate does one find so many remains as of this one. Winter, which often arrives with surprising abruptness, binding the seas of the high north in fetters of ice, endangers and renders difficult the existence of all air-breathing marine animals, puts an end to the lives of hundreds and thousands of this species, and when the than they are now, for we see in them only an ivorylike mass. About one hundred and fifty years ago there were still very few Narwhals' tusks in Europe and those that seafarers chanced to find met with a ready sale. They were held to be the horns of the Unicorn of the Bible, and that is why Englishmen place this member on the fabulous Unicorn of their national coat-of-arms. Emperors and kings had them made into rods, adorned with the daintiest carvings, for the purpose of being carricd behind these monarchs on state oceasions, and valuable crosiers for bishops were also manufactured out of them. As late as the sixteenth century four Narwhals' tusks were preserved in the Baireuth museum on the Plassenburg as extraordinary curiosities. One of then had been accepted by two margraves of Baireuth as payment of a debt owed by King Charles $V$, and for the larger one the Venetians offered the cnormous sum of 30,000 sequins, as late as 1559 , without succecding, however, in obtaining possession of it. One tusk, which was suspended by a golden chain in the electoral collection of Dresden, was valued at $\$ 100,000$.

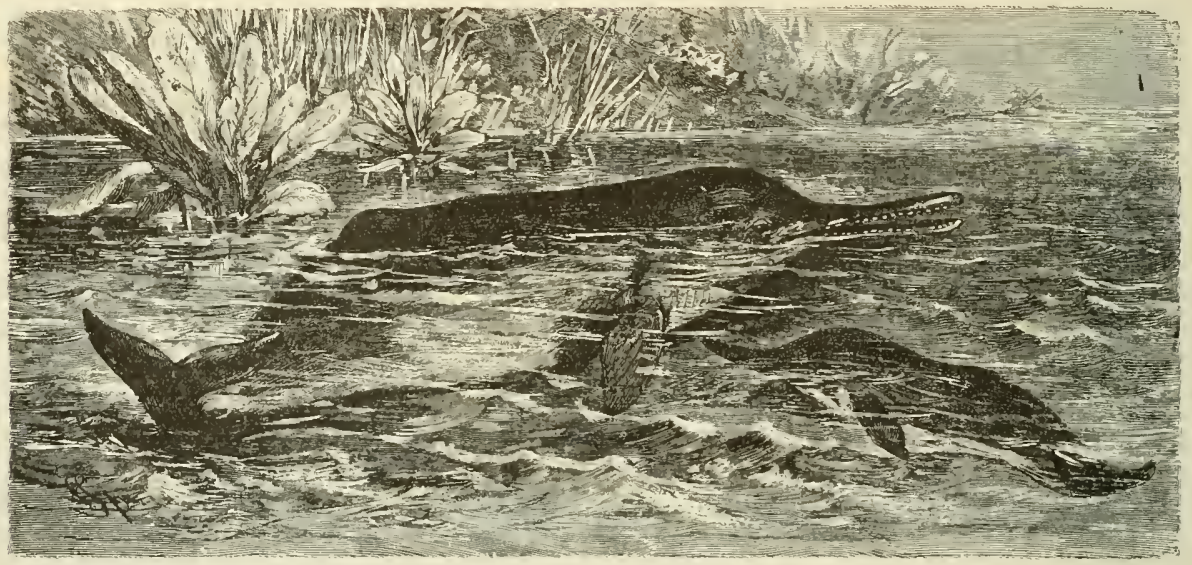

THE SO0S00.-W'ith a long, slender body ending in a Iorked tail at one end and a long beak in another, the Soosoo is one of the strangest members of the Dolphin Iamily. It is found in the Ganges and other principal rivers of India, where it lives on fish. (Platanista gangctra.)

ice fields break the sea washes their dead bodies or fragmentary remains ashore. Small parasites torment the Narwhal, large enemies menace it, and Man in many localities also pursues it. Some are harpooned in the high seas; on the whole, however, the extent of the chase is nowhere considerable, the results therefrom not being remunerative according to the European or American standard of profitable adventure. Flesh and oil are equally esteemed. When the Danish ladies living in Greenland bring the flesh on the table, boiled or fried and served in the jelly made of the fat shin of the same animal, they are filled with the consciousness that the most fastidious forcigner will soon learn to appreciate the dish. Native Greenlanders eat the flesh boiled and dried, the skin and blubber raw; they burn the oil in lamps, make thread out of the sinews and air-bag floats out of the stomach, which they use in fishing; they even know how to put the intestines to account. Tusks and Teeth of In former times very large sums the Narwhal Highly were paid for the tusks. Ill kinds Valued. of oceult powers were ascribed to Hem, and they were put to far more varied uses

\section{Tbe Jbottle= ihosco rabalcs.}

FIFTH FAMILY: HyPEROODONTID.s.

For the sake of completeness I will bricfly mention the third family of the suborder, which comprises the Bottle-nosed Whales (Hyperoodontida) and is represented by several species, chiefly in southern seas. The Whales belonging to this family differ from the Dolphins as much by the snout which is prolonged into a more or less beak-like formation as by the dentition, the peculiarity of which is that the lower jaw has on each side only one or two developed teeth, and besides them, if any at all, but few rudimentary ones, which do not project beyond the gums.

Characteristics and One of the hetter-known members Habitat of the Bot- of this family is the Bottle-nosed tle-Nosed Dolphin. Dolphin (Hyperoodon bidens) a sturdily framed II'hale ranging in length between twenty feet and twenty-six feet eight inches. The snout is prolonged like a beak and protrudes to the extent of from twelve to twenty-four inches; a short but deep fold of skin extends from the middle of the lower 
jaw backward on each side of the nouth; a similar furrow is found farther back at the throat; the rest of the skin is smooth and glistening, of a more or less uniform black tint, but as a rule clarker on the upper than on the lower surface.

The range of the Bottle-nosed Dolphin scems to be restrieted to the Arctic Ucean and the north of the $\Lambda$ tlantic: but it undertakes regular migrations thence, which lead it into waters that are a considerable distance south of its usual range. It makes an annual appearance near the laroe lslands and not infrequently appears off the coasts of Great Britain and even ascends some of the favorably situated British rivers. Cuttle-fish, nollusks and small fish form its diet. Of the former it consumes enormous numbers: the remains of over 10,000 of these animals have been found in the stomach of a captured specimen. Kuckenthal affirms that its div- greater part of their length, and are beset with an array of conical teeth of nearly equal length, while the dental formations of the upper jaws hardly deserve the name' of teeth.

Description of The sperm Whale is inferior in size

the Sperm only to some of the largest Whale-

Whale. bone Whales. There are statement to the effect that some old males have been encountered which mensured one hundred feet, but one will probably come nearer the truth, when no exact measurements are given, if he accepts the length to range between sixty-six and seventy-six feet, the circumference between thirty and forty feet and a width of tail of sixteen and onc-half feet. This holds good for malc or "bull" Whales, for the females are, without exception, considerably smaller, not even attaining half the length of the males. In proportion to the dimensions of the body the pectoral fins

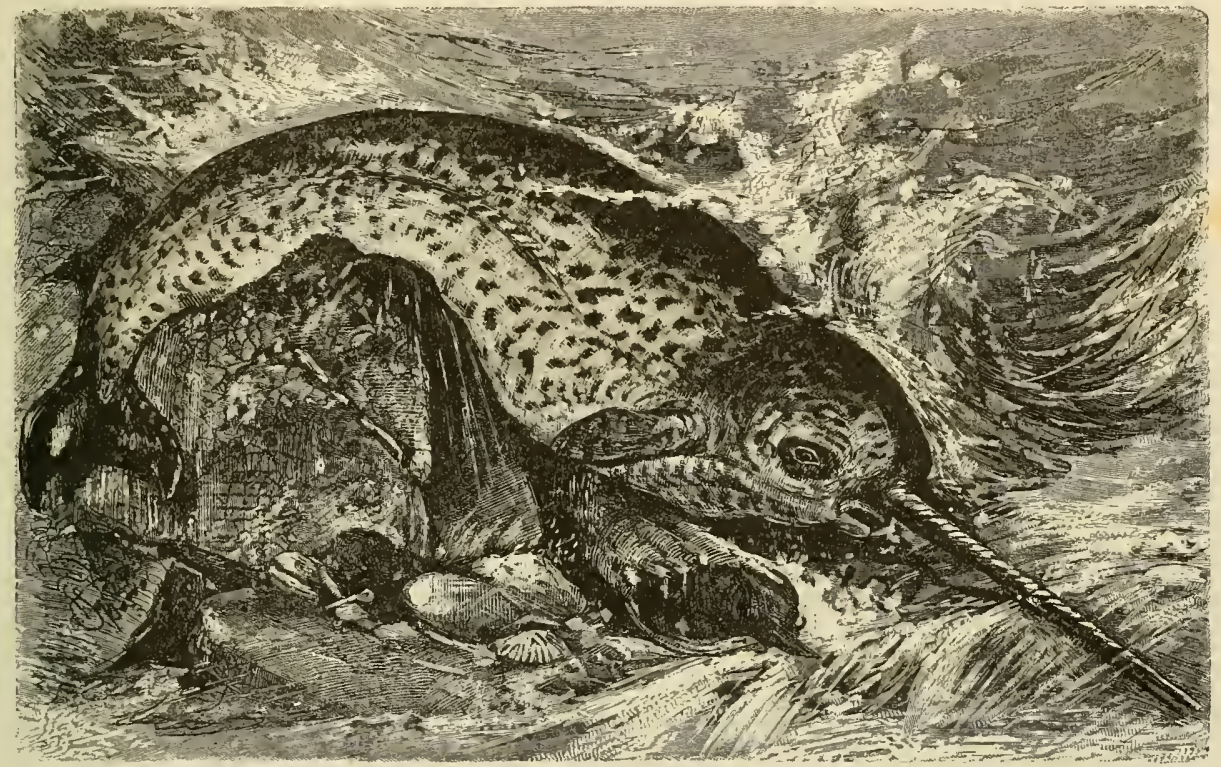

THE NARWHAL. - This species difters so greatly from all other members of the order of the Whales that it is classed alone in a separate gerius. Its most characteristic feature is found in the long tusks which project from six to ten fect; and another is the numlerous spots which mark its sides. It is plentiful in all the seas of the north, but is rarely seen south of the Arctic circle. (Monodon monocerus.)

ing powers are remarkable considering its comparatively small size: a harpooned IBottle-nose took off three hundred fathoms of line and remained fortyfive minutes under water.

\section{The spcrm rabalcs.}

\section{SIXTH FAMILY: CATODONTIDE.}

The fourth family of the Toothed Whales (Catodontide) is represented by the Cachalot, Spermaceti Whale or Sperm IVhale (Catodon or Pliyseter macrocepizalus), the type of the genus of the same name (Catodon), the most uncouth member of the whole order. It is characterized by its enormous head, protuberant at the extremity of the snout and abruptly cut off; by the possession of a single blowholc, placed somewhat to the left, and by the peculiar formation of the lower jaw, the two halves of which lic close together and almost parallel for the are remarkably small. In the largest of the Sperm Whales they measure only six and onc-half feet in length and forty inches in width. The huge, blocklike head, which is abruptly truncated in front, has the same height and breadth as the body, into which it merges without distinct demarcation or the interposition of a neck. The body is very thick in the anterior two-thirds and then tapers towards the tail. In the last third there is a low, humpy bulbous, immobile dorsal fin, which sometimes has a cut-off appearance belind and gradually merges into the body in front. The short, broad, thick pectoral fins are placed immediately behind the eyes and have five longitudinal furrows on the upper surface, corresponding to the five phalanges or fingers encased in the integument, while the lower surface is smooth. The tail-fin is not deeply forked and has two flukes, the margins of which are indented in youth. The blow-hole is a slit of from eight to twelve inches,

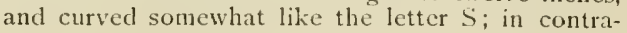


distinction to its position in other Whales it is placed quite in front on the head, somewhat to the left of the median line. The small eye lies far back; the ear, a small longitudinal slit, lies a little below the eye. The gape of the mouth is very wide, the jaws opening back nearly to the eyes. The lower jaw is considerably narrower and shorter than the upper onc, into which it fits when the mouth is closed, and, like it, is beset with rootless, conical teeth, the number of which varies considerably, as some drop out in old age and others become nearly covered by the gums. Only the teeth in the lower jaw, from thirtynine to fifty-two in number (sometimes more numerous on one side of the jaw than on the other) are proportionately large. The skull is remarkable for its lack of symmetry, the head for its bulk and uniform thickness. Beneath the layer of blubber, which on the head is several inches thick, spread layers of cartilage, which serve as a covering for a large cavity which a horizontal wall divides into two compartments, connected by several apertures. The entire cavity is filled with an oily, light substance, the spermaceti, which is also found in a tube running from the head to the tail, and in many little sacs interspersed in the flesh and blubber. The flesh is tough and coarse-grained and interwoven with many thick, stiff, cartilaginous integuments. Over it lies a layer of blubber, variable in thickness and enveloping all is the naked, nearly smooth, glistening skin, of a dusky black or deep dark brown hue, lighter in places on the abdomen, the tail and the lower jaw, and in very old Whales also on the top of the head. The tongue is fixed along its entire under surface to the lower jaw. The stomach has four compartments and the bladder is filled with an orange colored, oily fluid which sometimes contains ball-shaped lumps from three to twelve inches in diameter and twelve to twenty pounds in weight, probably products of disease, similar to the stones or calculi found in the bladders of other animals. These balls furnish the well-known and valuable substance known as ambergris.

Habitat and Habits The Sperm IVhale is almost cosmoof the Sperm politan in range. All oceans of the Whale. globe, with the exception of the Arctic and Antarctic, harbor it. Pechuel-Loesche considers the waters between the fortieth parallels of north and south latitude as the proper range of the Sperm Whale, and from this region it makes irregular excursions to the north, following warm currents and also south to the fiftieth parallel and occasionally beyond it. All specimens which have been observed between the fifty-fifth and sixtieth parallels of north and south latitude and still farther from the equator can only be regarded as stragglers. Certainly no experienced and trustworthy whaler has ever found or hunted groups or so-called "schools" of the animals in these regions.

After the fashion of Dolphins this gigantic Whale traverses the ocean in compact groups or schools of greatly varying numbers, selecting the deepest waters as its haunts. It is fond of prowling near those coasts washed by deep water but it carefully shuns dangerous shoaly water, though it may occasionally accidentally appear in it. The schools usually consist of twenty or thirty members; at certain times, however, several schools are said to unite and journey along together.

In respect to its movements the Sperm Whale is little inferior to the swiftest members of its order. In quiet swimming it travels from three to six knots an hour, but when excited it rushes through the waves, plowing them up like a steamer. One can recognize it from afar by its morements. When moving calmly; it glides lightly under the surface, but when hurrying it violently strikes its tail up and down, so that its head alternately goes up high and down low. Not infrequently it assumes a perpendicular position, holding either its head or its tail high above the surface: differing in this from most other Whales. When playing it stretches out one of its flippers and beats the water with great force; or it lashes the waves with its tail so that the splash can be heard far away and huge white sheaves of water shoot up which can be seen at a distance of ten knots on clear day's and serve as good signs to experienced whalers. On calm days Sperm Whales lie in the water quite motionless and let themselves be rocked by the waves, or they put their heads high up in a ludicrous way, assuming an erect position in the water. One might take them for the ends of huge tree-trunks or the necks of gigantic bottles, gently rocking to and fro on the waves.

Various kinds of Cuttle-fish form the principal food of the Sperm Whale. Small fish that stray into its large mouth, are naturally swallowed likewise, but the Whale does not hunt them. Occasionally it also indulges in vegetable food, devouring the various fruits of trees, which the rivers take into the sea.

The Sperm Whale The Sperm Whale has been hunted an Object of Vigi- from remote times, but more extenlant Pursuit. sively since the end of the seventeenth century, the precedence in this form of enterprise belonging to the Anericans. Since the beginning of this century the South Sea has been the principal hunting ground for these Whales, and even now they are nearly exclusively Englishmen and North Americans who engage in this pursuit. During the years from I 820 to I 830 English whalers took 45.933 barrels of spermaceti, giving an annual average of nearly 4,600 barrels; in I831 and 1832 the yield grew to 7,605 and 7,165 barrels. During the last thirty or forty years, owing to the development of the petroleum industries, the profit of Sperm Whale hunting has decreased considerably. An adult male Whale yields from eighty to one hundred and twenty barrels of oil; the value of such a specimen varies, according to the exceedingly unstable condition of the market, between $\$ 2,200$ and $\$ 5,000$; the females are not worth half so much, being much smaller.

The pursuit of the Sperm Whales is fraught with greater danger than that of other WVhales. A Whalebone Whale endeavors to injure its enemy only in exceptional cases, while the Cachalot defends itself when attacked, turns courageously upon its adversary and makes use not only of its tail, but also of its formidable teeth. That it defends itself with its teeth against other enemies than Man is substantiated by various observations. Thus, sometimes an old male, with a totally mutilated lower jaw, is killed, the animal evidently having been engaged in a fight with one of its own species, or some yet unknown Leviathan of the deep; besides this, whalers also know from hard experience, that not only does a fighting Sperm Whale sometimes run its head against a boat or smash it with its tail, but really takes it into its mouth and crushes it quite easily. Definite observation has shown that it can adjust its tooth-studded lower jaw at alnost a right angle 
to the upper one, and also move it laterally to a remarkable extent. When it is harpooned, it sometimes remains lying quite still in the water for a few moments as though it were paralyzed, thus giving a vigilant whaler opportunity to despatch it quickly. As a rule, however, it engages in a desperate conflict for its life and by no incans always seeks safety in flight, but retaliates for the injury received, with stern fury. All experienced seafarers have stories to tell about accidents, caused by it; some of these tales may be exaggerated or invented, but others have been thoroughly proven.

Adventure of What- The ship Nantucket was made a ers with Sperm complete wreck, in the year $\mathrm{fSO}$, Whales. by a Sperm IVhale, off the coast of Massachusetts. In IS2O the boats of the ship Essex hunted a school of Sperm IVhales in the South Sea, while the ship was following under shortened sail. A gigantic bull appeared in proximity to the ship and leisurely swimming up to it, struck itself against it, as it seemed, quite accidentally. The ship was severely shaken and the Whale also appeared to be seriously injured, for it rolled furiously about in the water; soon, however, it recovered and made off -at least such was the belief of the crew, who were working at the pumps, for a considerable leak had been sprung in consequence of the collision. The Whale was seen to suddenly halt at a distance of about one hundred fathoms, turn around and charge full at the vessel; it struck one side of the bow and crushed it to such an extent that the ship immediately began to sink. Some old bulls are well known to the whalers, and have acquired a kind of celebrity as "fighting Whales," or "biting Whales," as for instance "New Zealand Tom," a gigantic fellow, named after its favorite waters. It is said to have its wits sharpened to such an extent that it meets any attack half way and smashes or bites through the boats which do not escape in time. The ships themselves it leaves unmolested. It is immortalized in songs and in tales; its back is said to be studded with harpoons, resembling that of a Porcupine. At any rate one may regard the Sperm Whale as the most gallant or the noblest of all Whales; it is the type of a genuine monster of the sea.

The gain to be expected from the pursuit of the Sperm Thale, however great it may be, is too little to compensate for the serious dangers with which the undertaking is fraught. Besides the blubber, which yields very good oil, spermaceti and ambergris are also taken from the Cachalots. The spermaceti which is baled out of the cavity in the head, is fluid, transparent and nearly colorless in its fresh state; it coagulates in a cold temperature and then assumes a white color. It is used in medicine and in the manufacture of candles, which are preferred to all others. Of still greater value is the ambergris, about which so many fables were current from ancient times, until it was recognized to be an excretion of the Cachalot; it is a light, wax-like substance of very variable color, and possessed of a very agreeable odor; it softens in heat, changes into an oily liquid

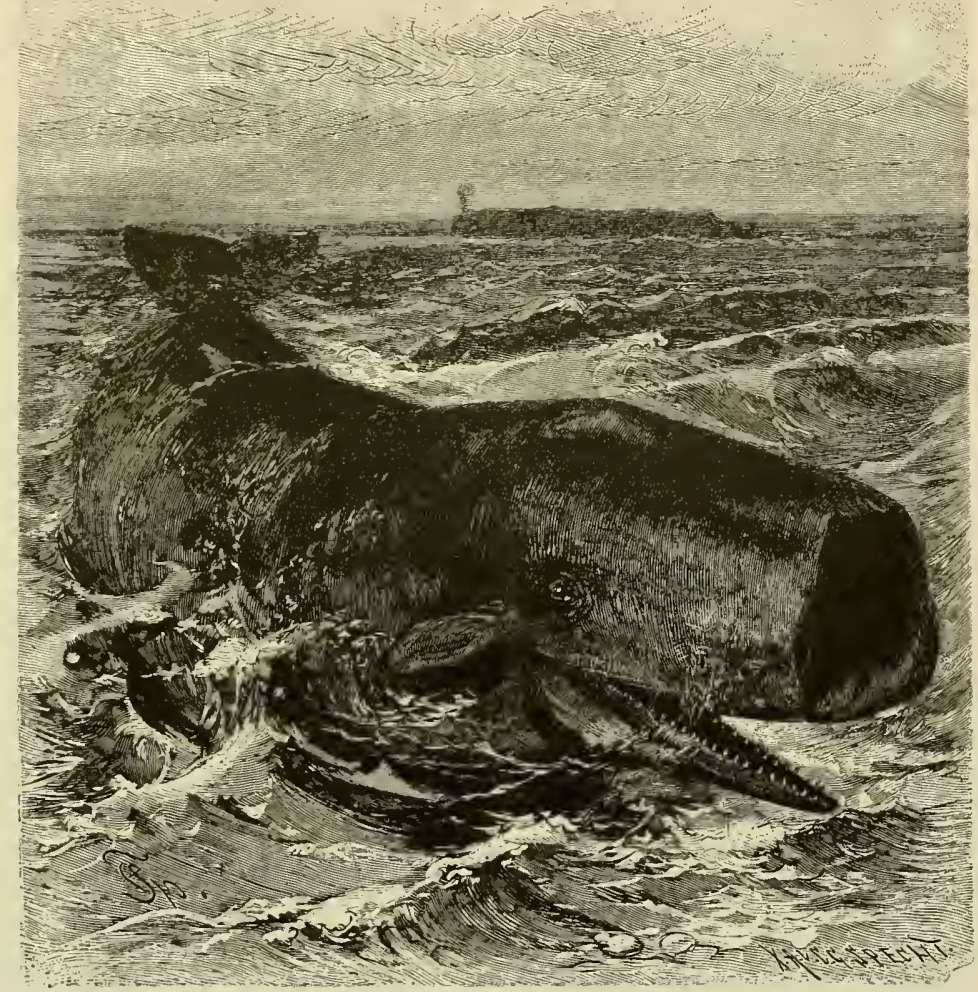

THE SPERM WHALE. This great monster, which frequently exceeds seventy feet in length, has a heavy, THE SPERM WHALE. This great monster, which frequently exceeds seventy feet in length, has a heavy,
This Whale is Which is a valuable article of commerce. (Catodnmacrocephalus.)

in boiling water, and evaporates when subjected to great heat. It is largely used for fumigating purposes and is also mixed with perfumed oils and soaps. It is more frequently found floating in the ocean than in the body of a Whale. There is no doubt that pieces one hundred and eighty pounds in weight, five feet in length and over twenty inclies in thickness have been found floating on the water.

Besides these substances the teeth of the Sperm Whale are also put to account. The pulp is somewhat yellowish, but firm and durable, and the teeth are extensively used for buttons and chips; one pound is worth from half a dollar to one dollar. 


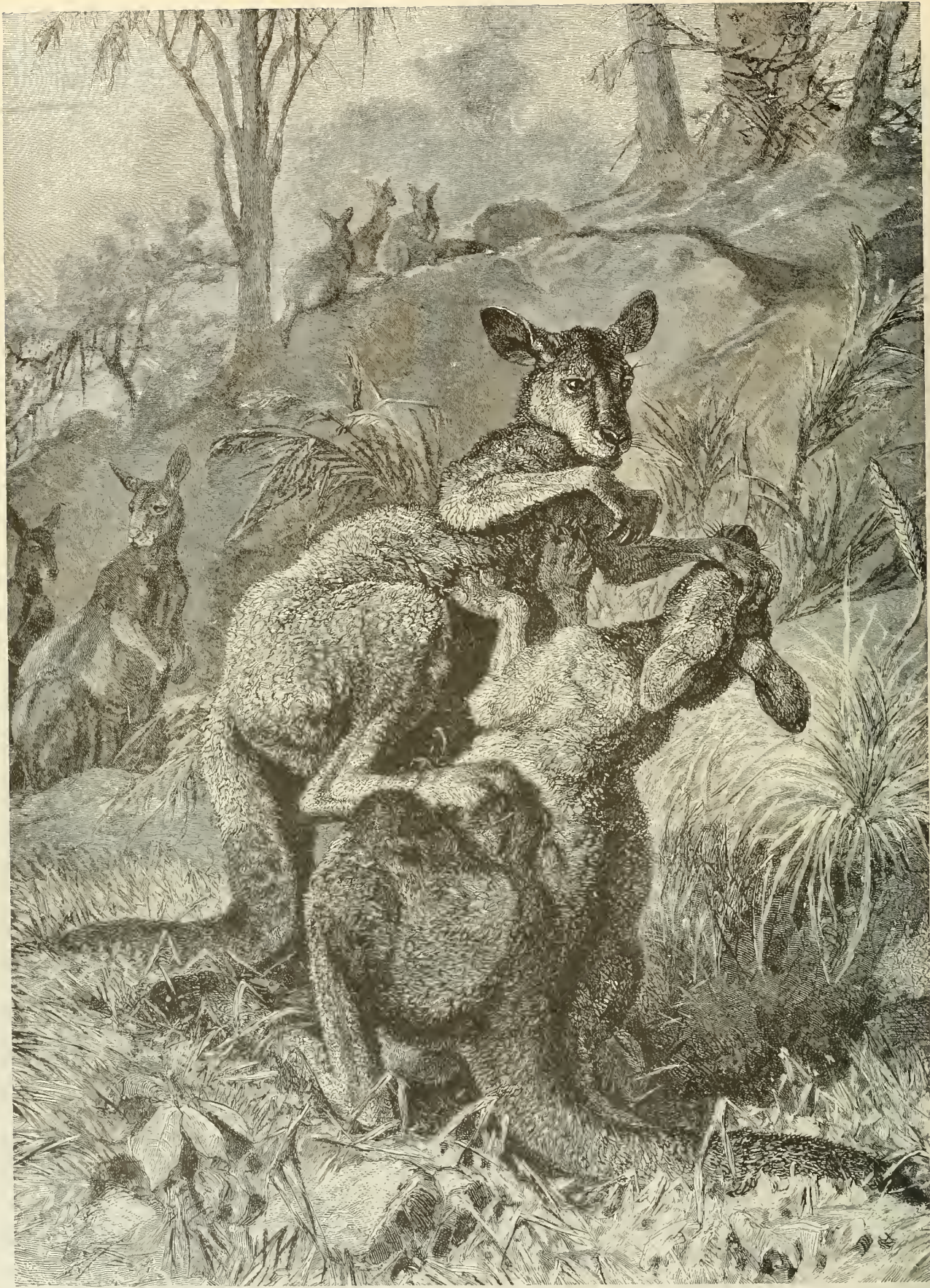

THE GIANT KANGAR00, - One of the most interesting of mammals is the Kangaroo, a typical Pouched Animal, which is also noteworthy for the disproportionate size and strength of its hnd limbs. When moving about on all fours, grazing, it presents an awkward appearance, but it makes rapid
progression by great bounds, using its powerful hind limbs only, after the manner of a Jerboa. When the Kangaroo is at rest it often assumes a perfectly opright position; the tail aiding the two hind legs to form a sort of supporting tripod for the body. When two of these ammals fight, which sometimes sustaining itself meanwhile upon its tail. (Macropus gigantcus, 


\title{
Tbe [poucbed Inímals.
}

\author{
FOURTEENTH ORDER: MARSUPIALIA.
}

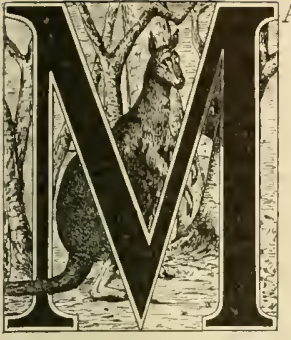

AMMALIA, except those of the Apes, the Whales and the Momotremes, includes no order which is equally important, or more worthy of the attention of naturalists and students, than that of the Pouched Animals, or Marsupials. Close consideration of the latter order shows that under this classification a re ranged families which have little in common except the pouch and the mode and organs of propagation, and which could be, not inaptly, grouped as independent orders of a distinct sub-class of mammals.

Examination of these animals leads involuntarily to the opinion that we have before us a group which was in the palmy period of its existence in the ages when lived and thrived the shapeless amphibia of the mainland, the Flying Lizards of the air, and the marine Dragons of the sea. Tery weighty evidence indicates that the Pouched Animals are only slightly modified offspring of mammals of bygone periods of creation and development.

By comparing a Pouched Animal to a beast of prey or to a rodent, the dullest eye will instantaneously perceive that the Pouched Animal is in all respects much less developed and perfected than the corresponding predaceous or gnawing mammal. This shortconing of the Pouched Animal is found either in the formation of the body, or in the construction of some of the limbs, or in the dentition. IVe speak with pleasure of the graceful frame of many carnivores or rodents, but it is seldom that we experience the same feeling in regard to a Pouched Animal. At best some one species may excite our wonder, but not our pleasurable emotions; another our sense of the ludicrous; a third simply repels us. Something is alway's wanting in a Pouched Animal to meet the sense of propriety of one accustumed to other animal forms. In examining the dentition, our opinion of the importance of the animal is no more favorable; for the teeth, also, seem imperfect and deficient, compared to those of the corresponding carnivores and rodents. The predaceous Pouched Animal has a sufficient number of teeth in its mouth, and they are arranged in a manner similar to those of the beasts of prey, but they are always less developed. What holds good in respect to the predaceous Pouched Animals may also be said of the others, and thus the impression that the Marsupials are imperfect and insufficiently developed beings seems thoroughly justified.

General Charac- Little can be said of the bodily formteristics of Pouched ation of the Marsupials in general.

Animals. The various members of the order, as to physical characteristics, differ more from one another than do those of any other order. Naturally, the formation of the digestive organs and, in a certain sense, also the articulation of the supporting bony skeleton, harmonizes with the dentition, and as the order of the Pouched Animals contains genuine carnivorous forms as well as true vegetable feeders, and even groups recalling to mind the traits of the ruminants, we would hardly be justified in speaking of a prevailing type among the members of this order. Without considering the size, which ranges between that of a medium-sized Deer and that of a Shrew, no other order comprises such a variety of animals, and it seems unnecessary to say anything in this place that would have to be repeated in the course of description. A common characteristic of all membets of the order is the structure of the organs of reproduction and the possession of marsupial (or pouch) bones. These latter are formed from the tendons of the external oblique abdominal muscle, which are inserted in front into the pubis, ossify and thus become the so-called marsupial bones, found also in the male, but in the female probably serving to protect, by strengthening the abdominal wall, the young placed in the pouch from the pressure exerted by the abdominal viscera. The mamme, to which the newborn young attach themselves, are situated in the pouch. This pouch may be a perfect pocket, or degenerate into nierely two folds of skin, or be entirely rudimentary. The young are born under conditions not found existing in any other higher mammal. They are small, naked and blind and their limbs are mere stubs.

Birth and Devel- The female Pouched Animal gives opment of Mar- birth to its young in an immature supials. state of development, takes them up in its mouth and puts them to the mamme. There they remain until the organs of sense and the limbs have developed, and, in the forms possessing a developed pouch, this latter is, during this time, not only a nest and refuge for the young, but also the place in which it develops into a perfect infant. Thence the young one undertakes excursions later, which it gradually extends; but it spends its entire infancy suckling, and with more than one member of this remarkable order the embryonic period preceding birth lasts only a month or little more, while its development during pouch-life extends through a period lasting from six to eight months. In the case of the Giant Kangaroo, the little animal puts its head out of the pouch about nine weeks before it first leaves it, and for about nine weeks more the young creature lives part of the time in the pouch and the remainder outside of it. The number of young may be quite large.

Habitat and Attri. The Marsupials at present inhabit

butes of the Australia and a few adjacent islands,

Marsupials. South and North America. In America the members of one family only are found, and the majority of species exist in the southern 
parts. In accordance with their great diversity in physical structure, the Pouched Animals have little in common in their mode of life: some are carnivorous, others are vegetable feeders; many live on the ground, others on trees, some temporarily even in the water; the majority have nocturnal habits, but some are active by day also.

In 1888 Thomas differentiated six families, thirtyseven genera and one hundred and fifty-one species of Marsupialia, which may all be classified according to their dentition into two suborders, the carnivorous and the herbivorous forms.

\section{Therbivorous Ipoucbed Ennimals.}

\section{FIRST SUBORDER: DIPROTODONTIA.}

In the suborder of the Herbivorous Pouched Animals there.are three incisors in the upper and ouly one in the lower jaw, but the latter is particularly long and strong. The premolars are always smal! and weak, especially those in the lower jaw, which usually fall out early in life and are generally absent in the adult animal. The molars are blunt, but strong, and the entire dentition adapts the animals of this suborder to a diet of fruit and grass. The suborder includes three families: The Leaping Pouched Animals, the Climbing Marsupials, and the Wombats.

\section{Icaping $\mathbb{P}$ poucbed Entimals.}

\section{FIRST FAMILY: MACRUPODIDE.}

The first family of the vegetable feeders comprises the Leaping Pouched Animals (Macropodide), distinguished by their dentition and by their peculiarities of form, which in most species are very markea. The upper jaw normally contains three incisor teeth, the anterior one being largest, and a canine tooth being present only in exceptional cases; in the lower jaw there is only one wide, chisel-shaped incisor tooth and the canine tooth is always absent; there are besides four premolars and eight molars in each jaw. The mode of locomotion of the Leaping Pouched Animals is by a series of leaps; some species, however, know how to climb trees.

\section{THE KANGAROOS.}

The sub-family of the Kangaroos (Macropodine) contains, besides the giants of the order, creatures of a Rabbit's size, but all possess a highly characteristic structure. The body of the Kangaroo increases in girth from the throat toward the buttocks; and the most largely developed part of the body is the loin region, on account of the great muscular proportions of the hinder limbs. On the other hand, the head and chest are almost rudimentary in development. The locomotion of the Kangaroo is almost exclusively performed by the hinder part of the body, and thus the great development of that portion is explicable. The Kangaroo can use its weak fore legs only in a very insignificant way for locomotion and for the grasping of food, while the greatly lengthened hinder legs and the powerful tail enable it to proceed by leaps. The hinder legs and the tail are undoubtedly the most characteristic feature of the animal's structure. The legs have strong thighs, long shins and a disproportionately lengthened foot region with strong, long toes, the fourth of each having a huge, hoof-like nail. The number of toes is only four, as the thumb is lacking. The tail is proportionately thicker and longer than that of any other mammal, and extremely muscular. The fore feet of the Kangaroo, which have five toes, each furnished with round, moderately and equally developed nails are used by the animal after the fashion of hands. The head partakes of the character of that of a Deer and also bears some resemblance to the head of a Hare.

Range and Australia and its adjacent islands are
Habits of the the home of the Kangaroo; the wide,
Kangaroo. grassy plains in the interior of the continent form its favorite haunts. Some species prefer bushy localities, others the rocky mountains to the lawn-like, grassy plains, and still others have taken up their abode in almost impenetrable thickets, through which they must make passages and paths by breaking limbs and branches; or else they live on the rocks and trees themselves, incredible as this may seem. Most species are active by day; the smaller species, however, are nocturnal animals, hiding by day in shallow depressions, which they make their permanent abodes. A few also permanently inhabit rocky crevices.

The Kangaroos undoubtedly take rank among the most remarkable of mammals. Everything about them is really extraordinary: their movements and their attitudes when at rest, the way they seek their food, their reproduction, their development and their mental qualities. Their ordinary gait, which they assume principally when they are grazing, is a heavy, awkward hobble. The animal supports its fore feet on the ground and then pushes the hinder legs on between them. While doing so, it must also support itself on its tail, as else it could not lift its long hinder legs high enough to render such movements possible. But the Kangaroo remains in this inconvenient position no longer than is absolutely necessary. When browsing upon bushes or trees it always sits on its hinder legs and tail and lets the fore legs hang down limply. Whenever it has plucked some favorite plant, it assumes the erect position to consume it. It supports its body on the soles of its hind feet and on its tail, which is firmly planted on the ground behind, the body thus resting securely and conveniently as if on a tripod. In their sleep the smaller species adopt a position similar to that of a Hare in its form: closely crouched to the ground, they squat down on all fours, the tail being extended at length behind the body. This position enables them to take flight instantly.

When a Kangaroo's suspicion is aroused, its first impulse is to flee. Then it displays all its agility. When its gait is faster than its ordinary grazing hobble, it leaps only on its hinder legs, but its bounds surpass those of any other animal in length. It presses its fore limbs tightly against the chest, stretches the tail straight backwards, thrusts the long and slender hind legs against the ground with all the force of the powerful thigh muscles, and darts like an arrow through the air in a low curve. The leaps follow in immediate succession, and each is at least nine feet, but the larger species cover, not infrequently, from twenty to thirty-three feet at a bound, the height of each leap being from six to ten feet. Even captive specimens take leaps of twenty-six feet, if chased back and forth in a large enclosure. It takes quite an excellent Dog to keep pace with a Kangaroo, and indeed there are few 
Hounds that can do so. When there is any cover, such as brushwood, the pursuit has soon to be given up; for the agile Kangaroo easily clears the bushes in its way by leaping over them, while the Dog has to go around. On uneven ground its speed is less, and it experiences great difficulty in going down hill, as it is apt to fall forward in its violent bounds.

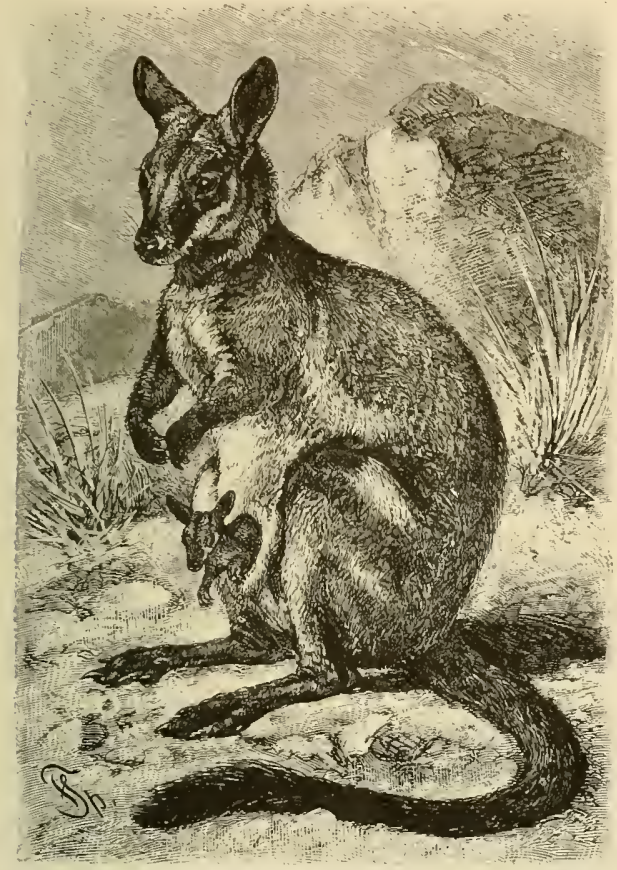

YELLOW-LEGGED KANGA R00. - The Mountain or Rock Kangaroos make their retreat in caverns and crevices and leap with agility from one ledge to another. The Yellow-legged Kangaroo, shown in the picture, with the little baby Kangaroo which rests in her pouch, belongs to this genus. (Petrogale xanthopus.)

A running Kangaroo may hold out for hours, without tiring.

Mental Capacity Among the perceptive senses of the and Propagation of Kangaroo that of hearing probably

Kangaroos. rankis highest: at least there is a continual movement of the ears in captive specimens, just as in other captive large game animals. Sight is less keen, and smell, probably, is rather deficient. Some observers, however, aver that the animals see, hear and scent excellently. They are very dull in intellect: even Sheep are far superior to them in this regard. Anything out of the accustomed order confuses them, for they are not capable of a rapid comprehension of new surroundings. The brain works slowly; every impression they receive becomes clear to them only gradually. A captive Kangaroo becomes used to MIan in general, but I doubt whether it discriminates between its keeper and other people.

The reproductive powers of all Kangaroos are slight. The large species rarely give birth to more than one young one at a time. When the young one is born the mother takes it up with her mouth, opens the pouch with both fore teet, and attaches the insignificant little creature to the breast. Twelve hours after birth the young Giant Kangaroo has a length of only a little over one and one-fifth inches. It can be compared only to the embryos of other animals, for it is quite immature, transparent, soft and worm-like; its eyes are closed, the ears and nostrils are only indicated, the limbs yet unformed. There is not the slightest resemblance between it and the mother. The fore legs are one-third longer than the hinder ones, It hangs from the breast in a strongly curved position, its short tail bent upwards between the hinder legs, without a noticeable movement; it is even incapable of sucking. As soon as it has been attached to the nipple, the latter swells so considerably that it completely closes the mouth of the little one. As before indicated it is supposed that the young Kangaroo does not suck at all, but is provided with milk without making any effort of its own, the milk squirting into its mouth in response to contraction of the lacteal muscles of the mother. For nearly eight months it is nourished exclusively in the pouch; it sometimes protrudes its head slightly a little before this period expires, but it is not yet capable of moving independently.

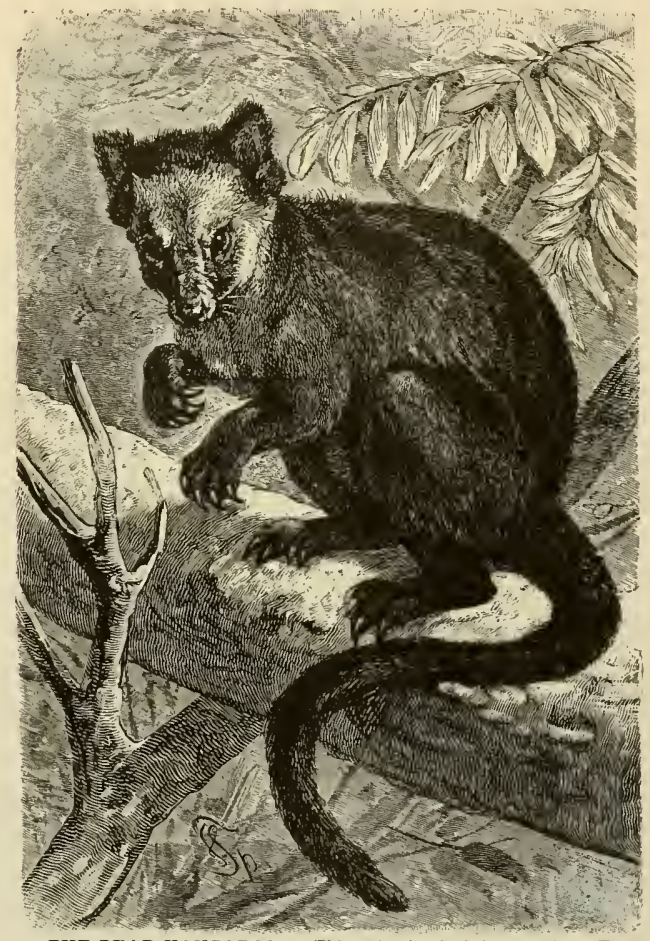

THE BEAR KANGAR00.-This aninal, which is one of the Tree Kangaroos, has its home in New Guinea. It climbs with facility and feeds on the fruit, bark and leaves of trees. Its hind limbs are proportionately shorter than those of the Kangaroos proper, although still longer than the fore pair. (Dendrolagus ursinus.)

A considerable time after it first peeps out of the pouch, the young one occasionally leaves its refuge and roams about near its mother, but for a long time it flees back to the pouch whenever it apprehends any danger. It approaches its mother with long bounds and dives headlong into the half-open pouch of the quietly sitting female. 
Kangaroos The Kangaroos are the most imporImportant Game tant objects of the chase in their naAnimals. tive country and are hunted very extensively by beasts of prey as well as by Men, natives or whites. The white Men, however, cause much greater havoc in the ranks of the Kangaroos than do the natives. Numerous methods are employed to exterminate the animals; they are shot with fire-arms, or coursed to death by Hounds: and that for very wantonness, for the slain bodies are left to rot in the woods. "That is the reason," says an anonymous writer, "why the Kangaroos are already exterminated in the environs of all larger cities and settlements; and if this savage chase is permitted to continue, it will not be long ere they will be numbered among the rarer mammals in the interior also."

Kangaroos Easily Tamed and $A c$ climated.

All species of Kangaroo readily resign themselves to confinement, and are easily maintained on hay, green fodder, turnips, grain, bread and similar articles of food; they do not require a specially warm shelter in winter and breed readily if given proper care.

\section{THE GIANT KAN GAROO.}

The Giant Kangaroo (Mucropus giganteus), known by the appellation of "Boomer" among the Australian settlers, belongs to the largest species of the family. Very old males have, when in a sitting position, nearly the height of a human being. Their total length amounts to about ten feet, about three feet of this being included in the tail; the weight ranges between two and three hundred pounds. The female is, on an average, one third smaller than the male. The fur is copious, thick, smooth and soft, nearly woolly in texture. The coloring is a brown that can hardly be described, mixed with gray. The forelegs, and the hind shins and ankles are white or grayish white, the toes are blackish; the head shows the color of the back with dark stripes on the sides; the tail is brownish, gradually darkening towards the extremity, being entirely black at the tip.

Traits of the Cook discovered this species of KanGiant Kan- garoo in I770 on the coast of New garoo. South Wales and described it under the name in use among the natives. The animal lives in grassy pastures or in the sparsely grown scrubby woods, such as are often found in Australia. It retreats to the bush especially in summer, seeking shelter from the hot noonday sun. At present it has been driven far into the interior of the country by incessant pursuit, and even there it is becoming rare. It lives in groups, but is not as gregarious as we were formerly led to believe by reports that many different families unite. Usually only three or four are seen together, and they regard the social bond so loosely, that one cares very little for the other, but goes its own way independently. A particularly good pasturage may cause a larger number of the animals to congregate, but they separate again when they have exhausted the resources of the locality. Formerly it was believed that males were leaders of the bands, probably because their large size seemed to render them fit for this office; but this supposition has been proven to be incorrect. All observers agree that the Giant Kangaroo is exceedingly shy and timorous and seldom allows a person to approach it. At present it is more rarely scen in confinement in Furope and America than when it was more numerous and casier to capture in its native country. With good treatment it survives a long time; specimens have lived in Europe from ten to twenty-five years.

\section{MOUNTAIN KANGAROOS.}

The Mountain Kangaroos (Petrogale) are animals fitted for a life in mountainous regions; to them belong the Yellow-legged Kangaroo (Pctrogale xanthopus) and the South Australian Rock Kangaroo (Petrogale penicillata). The latter attains a length of fifty inches, inclusive of the tail, which is as long as the body and has a tuft of hair at its end. The prevailing color is purple-gray, merging into a whitish brown hue on the sides, black behind, brown or yellowish beneath.

Home and Habits The mountains of South Australia of the Rock harbor the Rock Kangaroo in conKangaroo. siderable numbers; yet it is not often seen, as it is a lover of the night and very rarely comes out of the dark caves and gulches between the rocks before sunset. The agility which it displays in climbing along the rocky precipices would do credit to a Monkey. By its climbing accomplishments it is protected much more effectually than its relatives from pursuit by Man and other foes. In modern times Rock Kangaroos have been repeatedly brought alive to Europe and they may be frequently seen in zoological gardens. They do not differ from their relatives in their habits or behavior, except in their climbing propensities.

\section{THE TREE KANGAROOS.}

The climbing powers of the Macropodine are brought to the highest point of development in the four species constituting the Tree Kangaroos (Den(trolagus), of New Guinea and north Queensland. The large, strong fore legs are but little inferior to the hinder limbs and are a very characteristic feature of this genus. The Bear Kangaroo (Dendrolagus ursimus) of New Guinea is a medium large animal, fifty inches in length, a little more than half of which is included in the tail.

All observers agree that one can hardly imagine a more remarkable creature than a Tree Kangaroo, merrily moving about among the branches and displaying nearly all climbing abilities that have been observed in mammals. The animal climbs up tree trunks with the greatest ease, going up and down with the security of a Squirrel; yet it looks so strange in the tree tops that every spectator is much amazed when, for the first time, he sees the dark-haired, long-limbed creature. hopping from the ground to the tree and moving about the waving branches. In accordance with the nature of its haunts, it feeds principally on leaves, buds and shoots of trees; probably it also eats fruit. One seldom sees it in captivity.

\section{THE KANGAROO RATS.}

The small leaping forms are called Kangaroo Rats (Potoroince). They generally resemble their large relatives greatly, but differ from them not only by reason of their small size, but also in the long nails on the middle toes of the fore limbs and especially in their dentition. This sub-family is restricted to the continent of Australia and Tasmania.

\section{THE OPOSSUM RAT.}

One of the largest species of the Kangaroo Rats is the Opossum Rat (Bittongia ponicillata), an animal of the size of a Rabbit, with very short, round ears and rather long hair. The color of the upper sur- 
face of the body is grayish brown, sprinkled with black and white: the under surface is dingy white or yellowish. The Opossum Rat is especially distinguished by a brush of long, black, bushy hair, covering the last third of the tail; it is nearly twentyseven inches long, twelve and one-half of which are included in the tail. It is indigenous to the whole

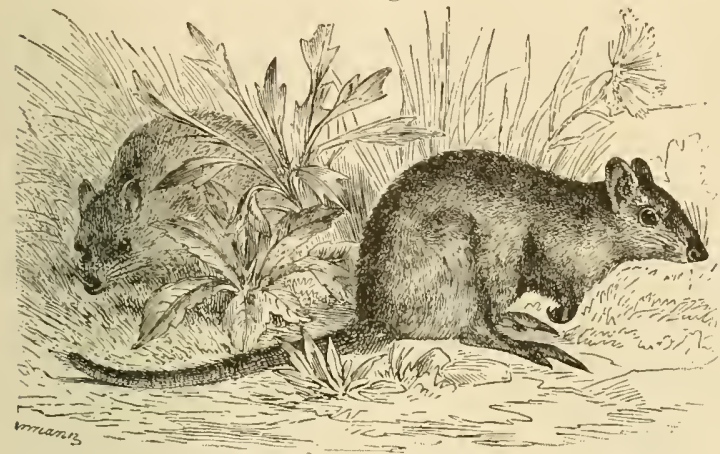

KANGAR00 RAT. - This Australian animal well deserves its name, because of the rat-like appearance of its head and tail. The other portions of the body are formed like those of the Kangaroos. (Potorous tridactylus.)

of continental Australia with the exception of the northernmost region.

Gould says: "Like the other species of the genus, the Opossum Rat scoops out a hollow in the ground for the reception of its thick-walled, grassy nest, the appearance of which is so thoroughly in harmony with the surroundings, that one is surc to overlook it, except by the most careful examination. The way the dwarf Kangaroo transports the dry grass for the construction of its nest is very peculiar. It is done by means of the tail, which is quite prehensile. The animal seizes a tuft of grass with the tail and drags the material to its destination; one may imagine how queer and curious a sight is presented when, in confinement, it gathers the material for its lair in a similar way."

\section{THE KANGAROO RAT.}

The Kangaroo Rat (Potorous tridactylus) may be recognized by its oblong head, its short legs and its rat-like tail. Its body is sixteen inches long, its tail ten inches, the body is of short, sturdy organization, and the neck is thick. The tail is long, flat, and distinctly ringed and scaly; it is covered very sparsely with short, stiff hairs. The long, loose, feebly-glistening fur is dark brown above, dingy or yellowish white beneath.

The Kangaroo Rat is a native of the colonies of New South Vales, Victoria, South Australia and Tasmania. It affects localities sparsely grown with bushes, and shuns an open prairie country. It scoops out a hole in the ground between tufts of grass, carefully lines it with dry grass and hay and there it spends the day. sleeping, usually in conpany with others of its kind; it is of truly nocturnal habits, appearing abroad only towards sunset.

The hangaroo Rat differs very markedly from the other Kangaroos in its movements. It runs quite differently and much more swiftly than they, more after the manner of the Jerboas; that is, it moves the hind legs alternately and not both at once. In respect to diet it also differs from its heretofore described relatives. It digs chiefly after tubers, plants and rocts and therefore sometimes causes considerable damage in cultivated fields. Since the establishment of zoological gardens the Kangaroo Rat has not infrequently been taken alive to Europe and America. It thrives excellently on plain food and requires no particular shelter. A box lined with hay or a small earth-house suffices; if it is given no place of abode it digs out a lair for itself and lines it carefully with grass, leaves and hay, in the same manner that it prepares a nest when free in its native country

\section{Ebc Climbing SDatsupials. \\ SECOND FAMILY: PHALANGERIDE.}

In the family of the Climbing louched Animals (Phalangeride) we range three sub-families, the members of which are mostly herbivorous, and seldom

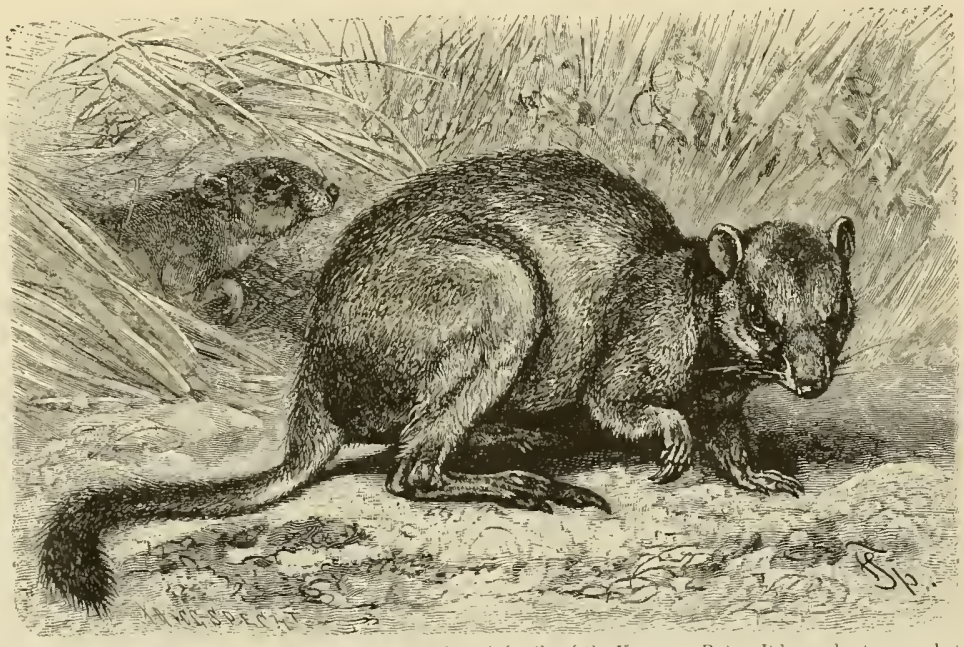

OPOSSUM RAT_-This animal belongs to the sub-family of the Kangaroo Rats. It has a short, somewhat road head, a long tail with tufted end, and strongly developed hind quarters and limbs. lts movements are very road head, a long tail with tufted end, and strongly developed hind quarters and limbs, 1 (Mettongia ponicillata.)
fleet, as it jumps about on its hind feet, but slow when on all fours. (Betto

carnivorous or insectivorous; they lead an arboreal life, have five toes on each foot, a single-chambered stomach and a well developed pouch, opening in front. On the hinder feet the second and third toe are grown together, while the fourth is the longest and the nailless great-toe (corresponding to the thumb of Man) is opposable to the others; the toes of the fore feet are of more or less equal size. 


\section{KOALA OR AUSTRALIAN BEAR.}

The first sub-family is formed by only one genus and species, and presents to us one of the most remarkable of all the Pouched Aninals, the Koala or Australian Bear (Pllascolarctus cincreus). The tailless body is stout, the head very thick and shortsnouted, the mouth is provided with cheek-pouches, the ear is large and overgrown with bushy hair, the fore and hinder paws have five toes and are genuine hand-feet, or feet capable of seizing and holding an object. On the fore paws the two inner toes are opposed to the three others: the hinder feet have a strong, nailless, opposable thumb and toes of very

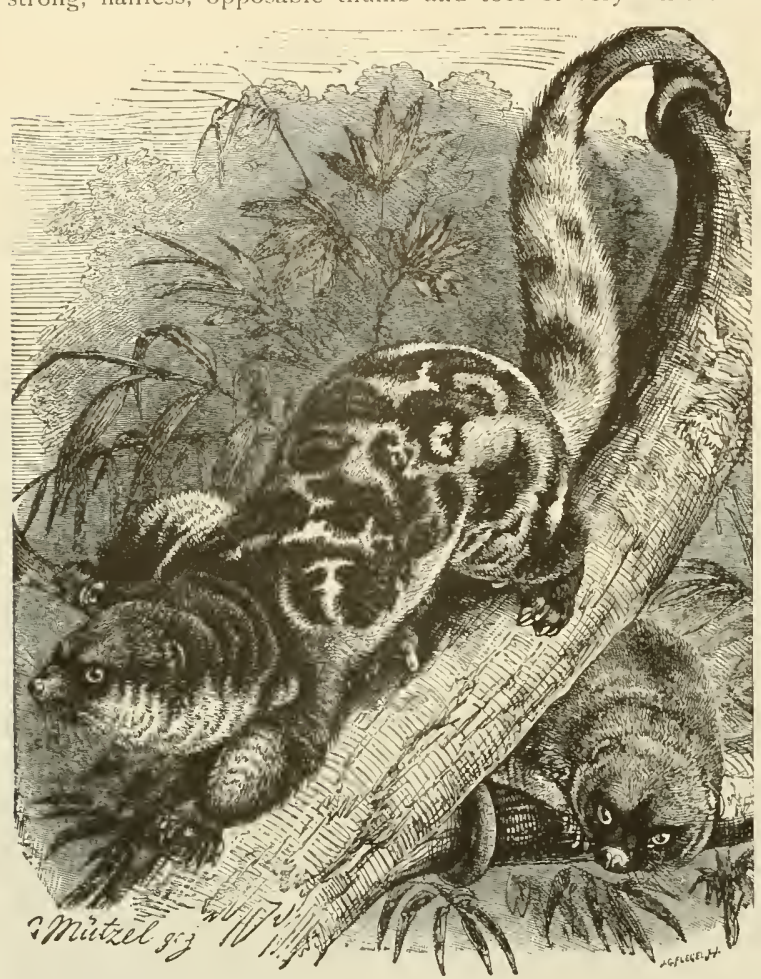

THE SPOTTED CUSCUS. - One of the handsomest of the Marsupials is the Spotted Cuscus, which makes its home in the northern part of Australia, New Guinea and the islands north to the Celebes. The prehensile tail is long and is naked and scaly for its terminal half. The animal is a tree-dweller and lives on vegetable food and also on such terminal half. The animal is a tree-dweller and lives on vegetab)
birds and mammals as it can overcome. (Phalanger maiulatus.)

unequal size, armed with sharp, long and curved nails, thus being eminently adapted for climbing. In respect to dentition, the unequal upper incisors, of which the first is the largest and strongest, the small canine teeth, and the grinders, provided with cusps, are worthy of notice, as special characteristics in which this animal differs from its relatives.

The name of "Pouched Bear" is characteristic, for the Koala bears a striking likeness to a young Bear in shape, gait and general behavior. Its length is about twenty-four inches, the height at the withers about half as much. The color of the upper part of the body is reddish ashy gray, the under surface is yellowish white; the outer sides of the ears are blackish gray.
The Koala is indigenous to east Australia from Queensland to Victoria. It is nowhere common and is therefore little known as yet. In pairs it moves about the loftiest trees with a slowness which has also gained for it the name of "Australian Sloth." The animal is of semi-nocturnal habits, sleeping at least through the greatest heat and light of the day, deeply hidden in the tops of gum-trees, which form its favorite haunts. Towards evening it begins its quest for food. Quietly and unmolested by any other creature of the wilderness, it proceeds leisurely to browse off the young leaves and shoots of branches, holding them with its fore paws and biting them off with its front incisors or cutting teeth.

Being of dull senses it suffers itself to be taken with little trouble and resigns itself with equanimity to the inevitable, including confinement. It not only quickly becomes very tame, but in a short time learns to know its keeper and even displays a certain attachment for him.

So far as is known, the female gives birth to only one young one. After the infant has outgrown the pouch, she carries it around on her back and shoulders for a long time, and treats it with great care and affection. Europeans have known the Koala only since ISO3; the natives, who call it Goribum, have always regarded it as a valuable object of the chase. They hunt it diligently for its flesh, climbing after it on trees.

\section{SMALL POUCHED ANIMALS.}

The sub-family richest in species is formed by the Small Pouched Animals (Phalangerina), which attain, at the most, the size of large Martens. The tail is generally long and prehensile, ths snout is short and broad.

\section{THE CUSCUS.}

In the forests of Celebes, the Moluccas, New Guinea, the Timor group and north Queensland are found the members of a peculiar genus of this sub-family, the Cuscus (Phalanger). They are of clumsy, awkward structure, with moderately long ears, perpendicular pupils of the eyes and a thick, more or less woolly fur: the tail is hairy only around the root, the terminal half being naked and nearly covered with warts.

The Spotted The Spotted Cuscus, known Cuscus the Hand- to the inhabitants of Aru as somest Species. Wangal (Phalanger maculatus), is one of the handsomest species of the genus; it attains a total length of forty-four inches, the tail including about nineteen inches of this. A thick, woolly fur of silky softness clothes the body. The color is subject to many modifications. The upper surface is generally white, dashed with yellow or with gray, relieved by large, irregular, rusty red, deep brown or black spots; the outer faces of the limb are lighter. The under parts are always spotless and of a pure white hue.

The Spotted Cuscus inhabits the islands east of Celebes to New Guinea and North Australia. We are indebted to the Dutchman, Valentyn, for the first accounts of the life and habits of these animals. He relates that the Cuscus or Kusus, as the Malay's call 
them, are among the queerest members of the Weasel tribe on Amboina. "The head bears much resemblance to that of a Rat or a Fox. The end of the tail is bare and prehensile; with it they cling so firmly to branches that one can pull them off only with a great effort. On the Moluccas also they do

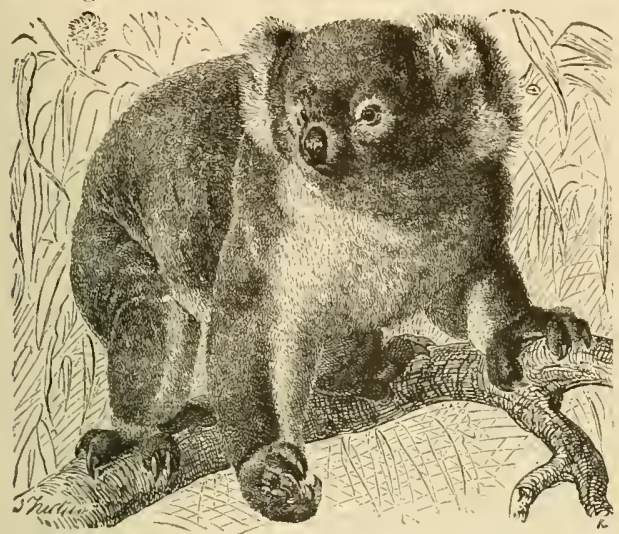

KOALA OR AUSTRALIAN POUCHED BEAR. - Combining many characteristics of the Bear and hie Sloth, although a true Marsupul, the Koala, with its short. tirickset body, short snout and large lie.t is one of the most singular and interestung arboreal animals of Australia and Tasmania, (Phascolarctus cinereus.)

not live in burrows, but on the trees, in the woods, especially where there are tree-nuts. There are more of them on Ceram and Buru than on Amboina, for on the latter island they fear the people, who catch them in a peculiar way and eat them; for they are a delicacy for the natives, and when tried, the flesh tastes like that of a

Rabbit. To capture one of these animals the hunter must stare fixedly at it when it is suspended by its tail; this will cause it to let go in fear and it will fall from the tree. However, it is not given to every one to be able to "look a Cuscus off a tree.' The animals eat green leaves, the outer shells of canary nuts, pisang and other succulent fruits. While eating they sit like Squirrels. Between the hinder legs is a pouch, in which from two to four young are kept." In the forests all known species feed on fragrant fruit; in confinement they also eat raw meat, in default of vegetable food. Their conduct in the cage or in a room is as little prepossessing as their looks.

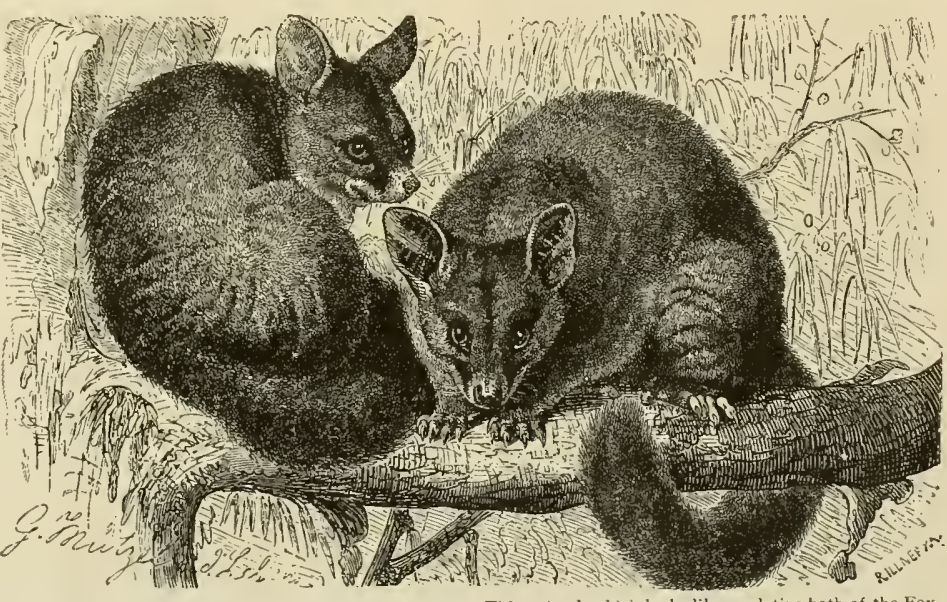

THE VULPINE PHALANGER OR C00S00.- - This animal, which looks like a relative both of the Fox and the Squirrel, is one of the most common of the tree-inhabiting Marsupials of Australia, It sleeps during the day but is liveiy at night, although its food is principally vegetable, with a preference for fruit. (Trichosurus vulfecula.)

They are slow, quict, sleepy and peevish; they eat greedily and drink very much. They do not live at peace with each other, but often strike one another, accompanying the blows with growls and yelling cries; they spit like Cats, hiss and pull one another about. During the day their large carmine-red eyes, the pupils of which contract into narrow slits, look particularly stupid and dull; at night the eyes glow like those of other nocturnal animals: then they resemble the Loris in many respects.

\section{THE COOSOOS.}

The Coosoos (Trichosurus) are seen mich more communly in Europe; they are nearly allud to the Cuscus, have a similar dentition and are distinguished from the latter by reason of the roundish pupils, large ears, smooth fur, and a tail which is hairy for its entire length, except on the us.der sur-

The Vuipine Pha- Une of the best-known specits of langer-Its Habits, this genus is the Vulpine Phalanger

Range, etc. (Trichosurus a'ulpecula or Phalangista oulpina), an animal which appears to combine the graceful form of the Squirrel with that of the Fox. The body is twenty-four inches long, the tail eighteen inclies. The upper surface of the body is of a brownish gray hue, with a fallow reddish tinge, very marked in places; the under parts are light ocluse yellow, the throat aud chest are generally of a rusty red, and the back, tail and whisker-hairs are black.

The Vulpine Phalanger inhabits Australia and Tastrailian Jouched Animals, Like its relatives, it lives exclusively on trees in the woods and its habits are thoroughly nocturnal. Its food is for the most part of a vegetable nature, but it by no means despises a little bird or some other vertebrate.

Only two young ones are born to the female and they are carried in her poucl for a considerable time, but later she carries them on her back, unti] the little ones can dispense with maternal care. They are readily tamed. Of late, living Vulpine Phalangers have frequently been exported to foreign countries, and most zoological collections posface of the tip. mania, and is one of the most common of all Aus- 
They wear a mantle of Coosoo fur with the same gratification of vanity which we derive from a gar. ment of Sable or Marten.

The Pouched Squirrels (Petanroides) bear such a striking resemblance to the better known Flying Squirrels in their physical conformation, that they were not so different from that of those rodents.

\section{THE POUCHED SQUIRRELS.} might easily be mistaken for them, if their dentition

brought to bay, and to make equally good use of both teeth and claws. The flesh is considered a delicacy, and, as the animal attains a considerable size, it is eagerly pursued on this account both by the biaci aborigines and by the white Man.

When the Pouched Squirrel is wide awake, it is distinguished by the agility and precision of its moventents. It seems to fly from one branch to the other, leaping across considerable spaces, elimbing to the top with exceeding speed and going from

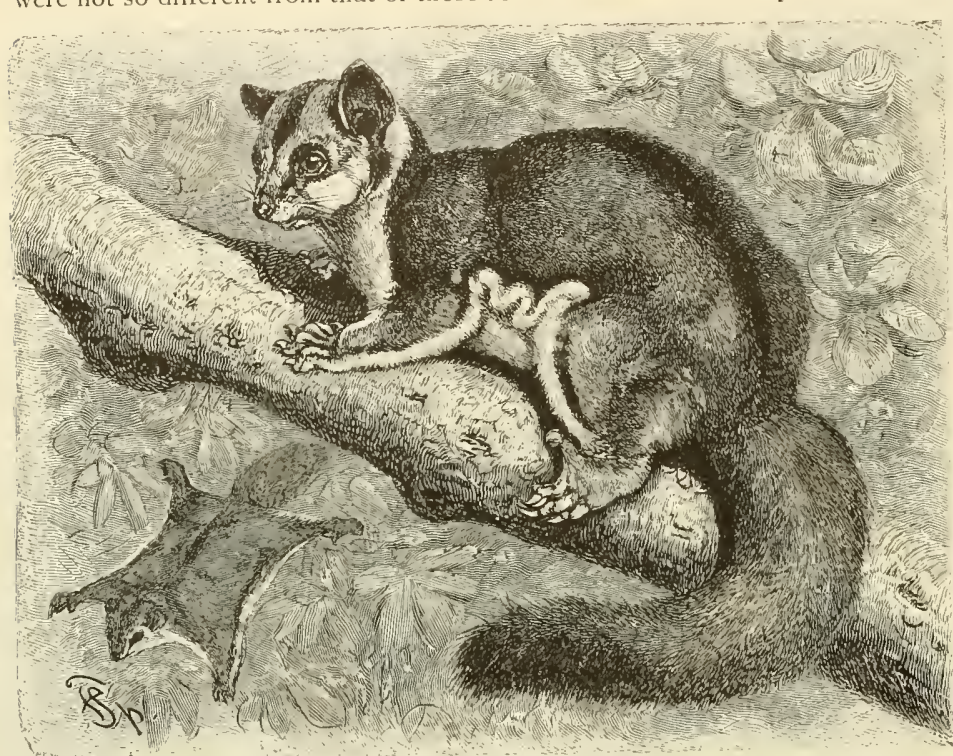

SUGAR SQUIRREL. - Tnis pretty, agle animal makes its home in erstem tustralia in the dense for ests of encalyptus trees, the bark of which contains a kind of sugar, kno like the American Flying Squirrel and food the Sugar squirtel gets its popular name. It has a

The Pouched Squir- The single species of the genus, the rel, its Haunts Pouched Squirrel (Pitauroidis z'oand Habits. lans), possesses a flying membrane extending from the top of the fore leg to the base of the large toe of the hind foot. It attains a length of body of twenty inches; the tail, which is bare on the under side of the tip, being of about the same length. The head is small; the snout short and pointed; the eyes are very large and the ears are broad and grown with thick, bushy hair. The feet have strong, curved and sharp nails. The fur is very long, soft, bushy on the tail and subject to great modifications in point of hue. Generally the upper surface of the animal is brownish black, the head a more decided brown; the flying membrane is marked with whitish spots; the snout, chin and paws are black, and the throat, chest and abdomen are white.

The Pouched Squirrel inhabits Australia, from Queensland to Victoria, especially the extensive forests between Port Philip and Moreton Bay, and is said to be common throughout that region, though it is rarely seen in confincment. Nocturnal, like all its relatives, it hides towards morning in the hollows of large dead trees and spends the day sleeping, secure from any enemy, with the sole exception of the ever-hungry and ever-watchful Australian native. It is said to fight desperately when treetop to treetop. Its long, soft hair has a silky lustre and becomes iridescent in its leaps, and the pale moonlight glints on it with a really beautiful effect, the rays being reflected by the shining hair in a peculiar way.

The food of the Pouched Squirrel consists of leaves, buds and young branches, and perhaps also of roots. scends to the ground for food. It is said to endure confinement for a considerable time; but hunters suceed very rarely in capturing it.

\section{SUGAR SQUIRRELS.}

The Pouched Squirrels are followed by the Sugar Squirrels (Petaurus), the tail of which is hairy over its entire surface. The best known species is probably the Sugar Squirrel (Petannis sciurcus), the very name indicating that the species must be a well-known one. The animal resembles a Squirrel, and still more a Taguan, not only in shape but also in size.

Habitat and Char- The Sugar Squirrel is found from acteristics of the Queensland to Victoria. It is truly Sugar Squirrels. arboreal, and nocturnal in its habits, like most creatures of a similar physical structure. It climbs about the trees with the agility of a Squirrel, always from below upwards, and is capable of executing exceedingly long leaps, changing its direction at will. Even when jumping from a height of thirty feet, it is capable of reaching a tree from sixty to ninety feet distant.

All observers are unanimous in their admiration of its movements when flying, and affirm that the animal displays a grace and daintiness which hardly have an equal. The Sugat Squirrel is a prepossessing animal in general, for it is readily tamed, though not entirely inoffensive, and is extremely lively, active and cheerful at night, but unfortunately it is always somewhat timid. It is frequently found in the houses of settlers, who take great care of it. Its intelligence is not great, but its merry ways, its gentleness and grace to a certain extent atone for its lack of mental powers. It readily becomes accustomed to any diet, though fruit buds and insects are most favored by it, these forming its natura! food. It is specially fond of cucalyptus honcy; insects, probably, also form a not inconsiderThe animal rarely de- 
able portion of its food. Captive specimens in the London Zoological Garden have been observed to devour dead Sparrows and pieces of meat with great pleasure, and therefore naturalists have been led to believe that they noiselessly approach sleeping birds and other small animals at night, after the manner of a L.oris, and kill them. In some regions they work considerable destruction among the peaches and oranges.

The social instincts are very pronounced in the Sugar Squirrel, for it is always found in the woods in company with others of its species.

\section{THE OPOSSUM MOUSE.}

The pigmy among the Climbing Marsupials is the Opossum Mlouse (Acrobates pygmeas), which is properly classified as a distinct genus. 1ts broad flying membrane extends to the lower joints of the legs. The tail, which is thickly covered with hair, is distichous: that is, the hair grows parted into a double row. The ears are moderately large. The pretty little animal has about the physical proportions of a domestic Mouse, and when it sits on a branch, with its elastic membrane folded against the body, it might be mistaken for one of our dainty, though detested, rodents. The Opossum Mouse attains a length of about five and one-half inches, of which a little more than half is the length of the tail. The short soft fur is gray-brown above, and yellowish white beneath

The Opossum Mouse is indigenous to eastern Australia from Queensland to Victoria. Like its relatives, it feeds on leaves, fruit, buds and other tender parts of plants; and will generally devour a small insect, when it happens to come across one. It is scarcely inferior to its relatives in liveliness and activity, and few surpass it in ability to leap or fly over long distances with the help of the outstretched flank membrane. The little creature is said to be a great favorite with the natives as well as with the immigrants in the vicinity of Port Jackson, and is frequently kept tame in a cage. It is lively and good-natured, and soon becomes tractable in captivity, but likes freedom and will escape if possible.

\section{vrombats or TRodcnt=like SiDarsupials.}

THIRD FAMILY: PHASCOLOMYIDE.

"The third family of the herbivorous Pouched Anjmals comprises the Wombats (Phascolomyide) and introduces to us the Rodent-like Marsupials. So far three species of Wombats are known, all of which are very similar in form and habits. These animals are of exceedingly clumsy frame, the body heavy and stout, the neck thick and short, the head uncouth, the tail a small, nearly bare stub; the limbs are short and crooked, the feet five-toed and armed with long strong, curved claws, which are lacking only on the big toes of the hind fect; the soles are broad and devoid of fur. All the toes of the hind feet, except the largest one on each, are partly grown together. The dentition is very remarkable, the broad front incisors, of which there are two in each jaw, corresponding to the gnawing teeth of the rodents. Besides them there are one premolar and four long curved molars on each side above and below.

Description of The Tasmanian Wombat (Phascolo-

the Tasmanian my's ursimis) reaches a length of

Wombat. about thirty-eiglit inches and has short, rounded ears. The color is a spotted, dark, graysh brown.

This specics is a native of Tasmania and the islands of Bass' Strait, while the Broad-fronted Wombat (Pluascolomiys latifrons) is indigenous to South Australia. All species live in dense woodland; they dig large caverns and very deep tunnels in the ground and spend the day sleeping in them. Only when night has completely set in, does the Wombat hobble out to look for food. Its diet consists chiefly of a hard, rush-like species of grass, which covers vast tracts of land, and also includes various kinds of herbage and roots, the latter being secured by vigorous digging.

The Wombat appears even clumsier than it really is. Its movements are slow, but persistent and vig-

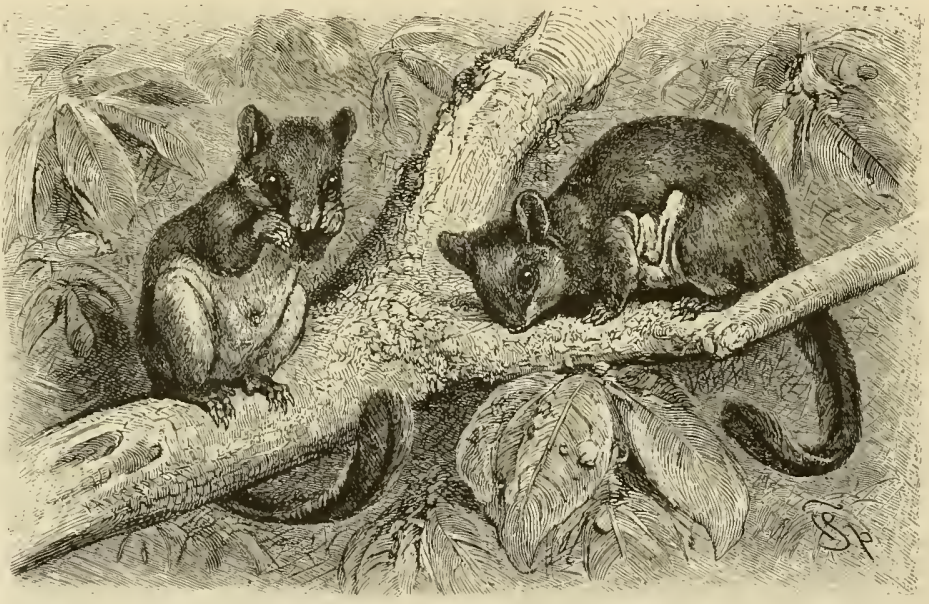

THE OPOSSUM MOUSE - This small animal, about the size of a common Mouse, is a pretty little crea-

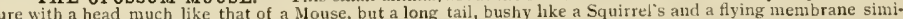
ar to that of the Assapan or Taguan. (Acrobates fygmazs.)

orous. It is so dull-witted and indifferent that it can only be roused to action with great difficulty. It pursues its way without stopping and never shrinks from any obstacle, but endeavors to accomplish whatever it has decided to do, in spite of all difficulties. If it has commenced digging a burrow, a person may fill up the excavation over and over again, but the Wombat will a hundred times or more resume its work and repair all the damage, with the equanimity of a philosopher.

In captivity, if given proper food, the Wombat enjoys good health and becomes so accustomed to contact with Man that it may safely be allowed the range of the house. It can be kept without difficulty on green fodder, carrots, turnips, fruit and various kinds of grain. 


\section{The Carnívorous Marsupials.}

SECOND SUBORDER: POLYPROTODONTIA.

The second suborder of the Pouched Animals is constituted by the carnivorous forms (Polyprotodon(ii) which are distinguished from the members of the first suborder by reason of the great number of incisor teeth - from fourteen to eighteen - of which eight or ten are found above and six or eight below. These teeth are small and of nearly uniform size, and are greatly surpassed in size by the long, pointed canine teeth.

\section{Tbe tsandicoots.}

\section{FOURTH FAMILY: PERAMELID.E.}

Even an inexperienced, amateur naturalist will readily recognize the members of the first family of the Carnivorous Marsupials, namely the Bandicoots (Prramilide). The considerably lengthened hinder peculiar and tolerably quick, as their pace consists of a series of leaping steps of varying length. Their diet consists mainly of plants, especially of succulent roots and tubers; but they also eat insects, worms and seeds.

The Long-nosed The Long-nosed Bandicoot (PeramBandicoot and its cles masuta) belongs to the BandCharacteristics. coots proper, indigenous not only- to Australia but also to New Guinea. It is an animal of peculiar physical structure, having many points of resemblance to a Rabbit and also to a Shrew. Adult animals measure rather more than twenty inches, including the tail, which is nearly five inches long.

\section{Tbe preoaccous SIDatsupials. FIFTH FAMILY: DASYURIDE.}

The predaceous Pouched Animals (Dasyzride) form the second family of their suborder. Fore and

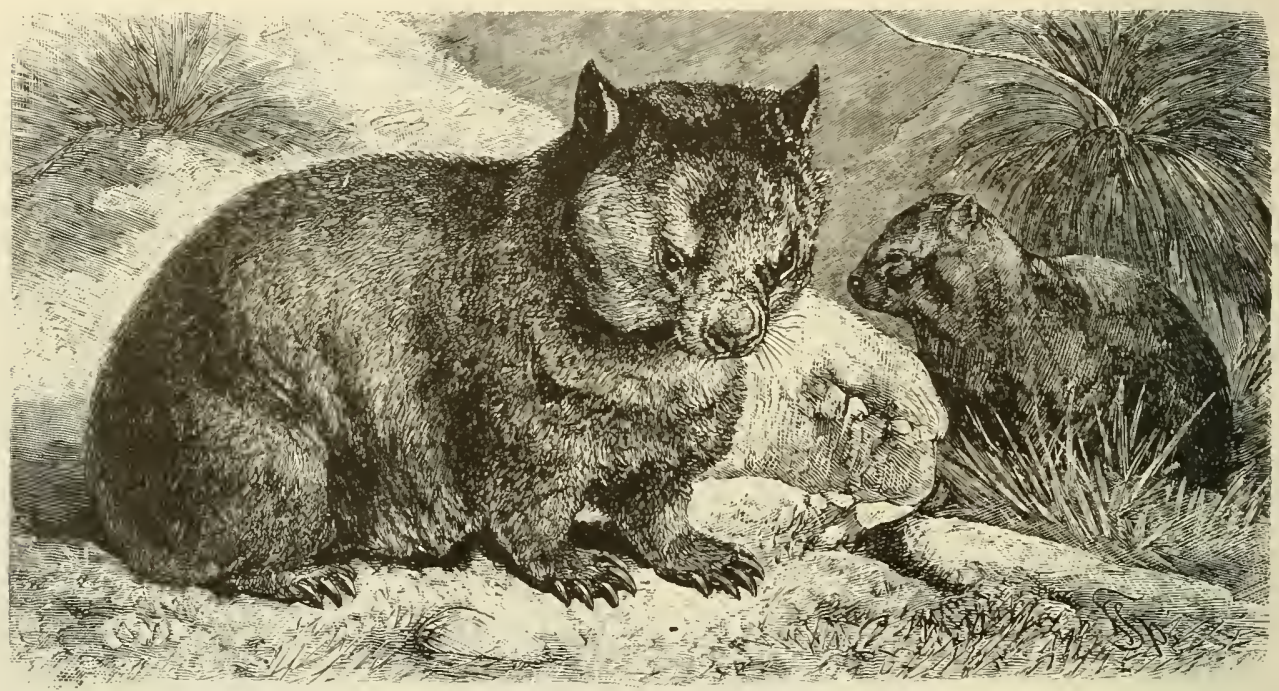

THE BROAD-FRONTED WOMBAT. - This inhabitant of the forests of South Australia subsists on grass, herbage and roots. It lives in deep burrows which it makes lor tself and is a persistent digger. and when it is not scooping out a home it is generally busy digging for roots. (Phascolom) latifrons.)

legs and the deviating toe formation constitute features likely to be noticed by anybody. Of the five fore toes only the two or three middle ones are large and well developed, and they are armed with strong, curved claws. The second and third toes of the hinder feet are grown together; the great toe is absent or rudimentary; the fourth toe is very long. The body is, on the whole, stout, the head very pointed, especially the nasal extremity; the tail usually very short and sparsely grown with hair, but in exceptional cases long and bushy; the ears are strikingly large in some species.

The Bandicoots live in Australia and New Guinea, in burrows which they excavate in the ground, and to which they repair in great haste on the slightest alarm. Occasionally they are found in the vicinity of plantations or settlements, but generally they. kecp aloof from the arch-enemy of all animals: Mlan. Most species seem to be gregarious and to have exclusively nocturnal habits. Their movements are bind legs are of nearly the same length, the former bearing five toes, the latter sometimes five, or only four. The hairy tail is long and not prehensile.

\section{THE DASYURINES.}

The sub-family of the Dasyurines (Dasyurina) occupies the first rank among the animals of this group. All species belonging to it now live only in the Australian belt, from New Guinca to Tasmania.

General Charac- The Dasyurines inhabit woodlands as ter of the Dasy. well as rocky localities or the shores urince. of the ocean, and live either in deep burrows and holes, under roots of trees, in rocky clefts, or in hollow trees. Some move only on the ground, others are excellent climbers and some live exclusively on trees. Their tread is stealthy and deliberate, and they are classed among the plantigrades, as they step on the entire sole.

Nearly all are nocturnal animals, sleeping by day in their holes and sallying out to prey by night. On 
their raids they go to the sea beach and devour all animals cast ashore, both fresh and putrid. Those that live on trees subsist mainly on insects, their largest prey being small mammals, and birds and their eggs. The largest species may occasionally visit human habitations and kill all the poultry of a coop in one night; after the fashion of Martens, or like the impudent Foxes of the north, they despoil granaries and larders, stealing meat and bacon. The smaller species are able to squeeze through the smallest apertures, and render themselves as detested as Martens and Polecats; the largest of them attack flocks of Sheep and oceasionally make off with a victim. Many take their food up to their mouths in their forepaws. Their vocal expression consists of a peculiar growl and a yelping bark. The larger species are very savage, untamable and addicted to biting, and defend themselves furiously with their sharp teeth, when attacked, while the smaller ones seem gentle and good-natured. Some may be easily kept in confinement, and tamed without great trouble, but never show any signs of affection for their keepers. The females give birth to four or five young in spring.

The harm inflicted by the members of this sub-family far outweighs the profit derived from them, and justifies persistent pursuit.

\section{THE ZEBRA.WOLF.}

The Zebra-wolf or Pouched Dog (Thylacimus cynoceplualus), the only living representative of a distinet genus, did not come by its name wrongfully, for it really resembles a wild Dog. Its elongated body, the shape of the head, the strong demarcation of the snout, the erect ears, the eyes, the tail, which is carried extended straight behind, all are similar to the

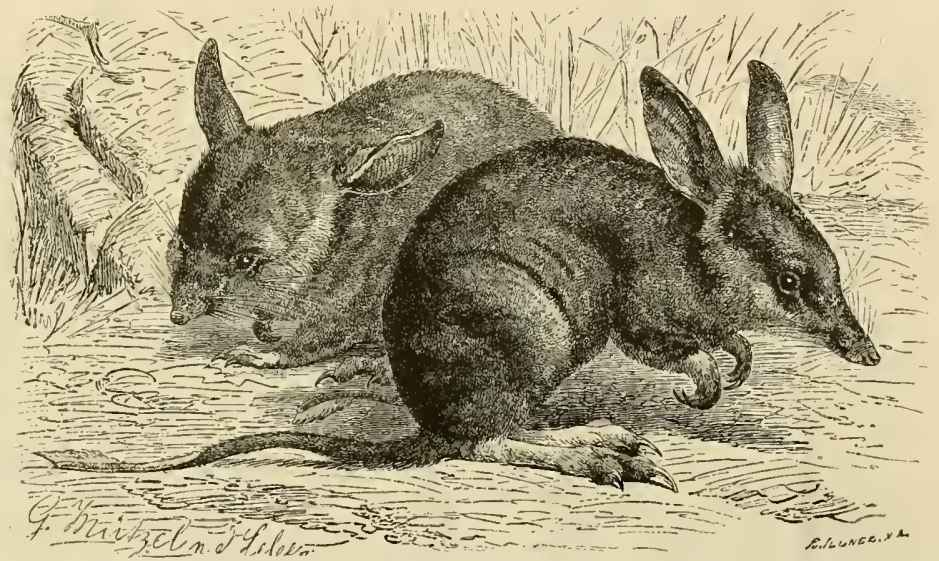

LONG-NOSED BANDICOOT, — This peculiar animal with ears like a Rabbit, muzzle like a Shrew, tail like a Rat and hind quarters like a Kangaroo, is also distinguished by the queer elongation of two or three toes on each fool, especially the middle toe of the hind foot. It belongs to the suborder of Carnivorous Marsupials. (Perameles nasuta.) corresponding members of the Dog; the limbs are proportionately short, however, and the dentition differs markedly from that of the Dog.

The Pouched Dog is the largest of all carnivorous Pouched Animals. Its body is over forty inches long, the tail measures twenty inches and old males are said to become still larger, measuring in all about six feet four inches. The fur is close and loose, of gray-brown hue and marked with twelve or fourteen black transverse stripes on the back.

Habitat and Habits The Pouched Dog is a native of of the Pouched Tasmania. In the first period of Dog. European settlements it was very common, to the great detriment and vexation of the cattle breeders, to whose sheep-folds and poultryyards it pasd frequent visits. Later, however, firearms caused it to retreat more and more, and it is now restricted to the interior, where it still exists in considerable numbers in mountainous districts, being most frequently found at an altitude of about three thousand feet above the sea level. During the day it seeks refuge in clefts of rock in dark, deep gulches, nearly inaccessible to Man, or in natural retreats, or deep burrows which it digs for itself, and from which it undertakes its raids. It is a nocturnal animal and to a great extent shuns light. Even if it is not the most savage of all predaceous Pouched Animals, it still exceeds all its family relations in strength and courage and deserves its name for this reason also.

The food of the Zebra-wolf consists of all smaller animals that it can subdue, vertebrates or imertebrates, from insects and mollusks to domestic animals. When it is especially hungry, it despises no kind of food and is not even frightened by the sharp. spinous weapons of the Echidna. When the animal extends its raids to the settlements, it is caught in traps or hunted with Dogs. It knows how to take eare of itself in an encounter with the latter and displays a savage disposition.

\section{THE TASMANIAN DEVIL.}

The nearest relative of the Pouched Dog, the Tasmanian Devil (Surcophilus ursinus), is very much uglier, and is repulsive and filthy in the highest de- 
of Martens it would invade the poultry-yards, and massacre with a bloodthirstiness equaled only by that exhibited by one of the Weasel tribe. It therefore became an object of general execration and vindictive pursuit from the very outset, the more so as its Hesh was found to be savory, or at least eatable. Traps of all kinds were put out, and thus it came about that it also soon learned to know and fear the reign and intelligence of Man, and retreated to the densest and least accessible forests in the mountains. In many localities it has already been exterminated, and even where it still exists, it is now seen but rarely. It is a genuine nocturnal animal, and as shy of daylight as the l'ouched Dog or one of the Owl-tribe. on the head than on the body. A mature animal attains a body length of sixteen inches, with a tail twelve inches long, the height at the withers being six inches. The menbers of the species are distributed over New South Wales, Victoria, South Australia and Tasmania.

The Spotted Dasyure delights in forests along the sea coast. By day it hides in burrows under trees and stones or in hollow trunks. After nightfall it prowls far around in its search for food. It feeds principally on dead animals cast ashore by the sea, but preys also on smaller mammals or birds nesting on the ground in the woods, not even disdaining insects. The number of young ranges between four and six. The Dasyure is pursued with as

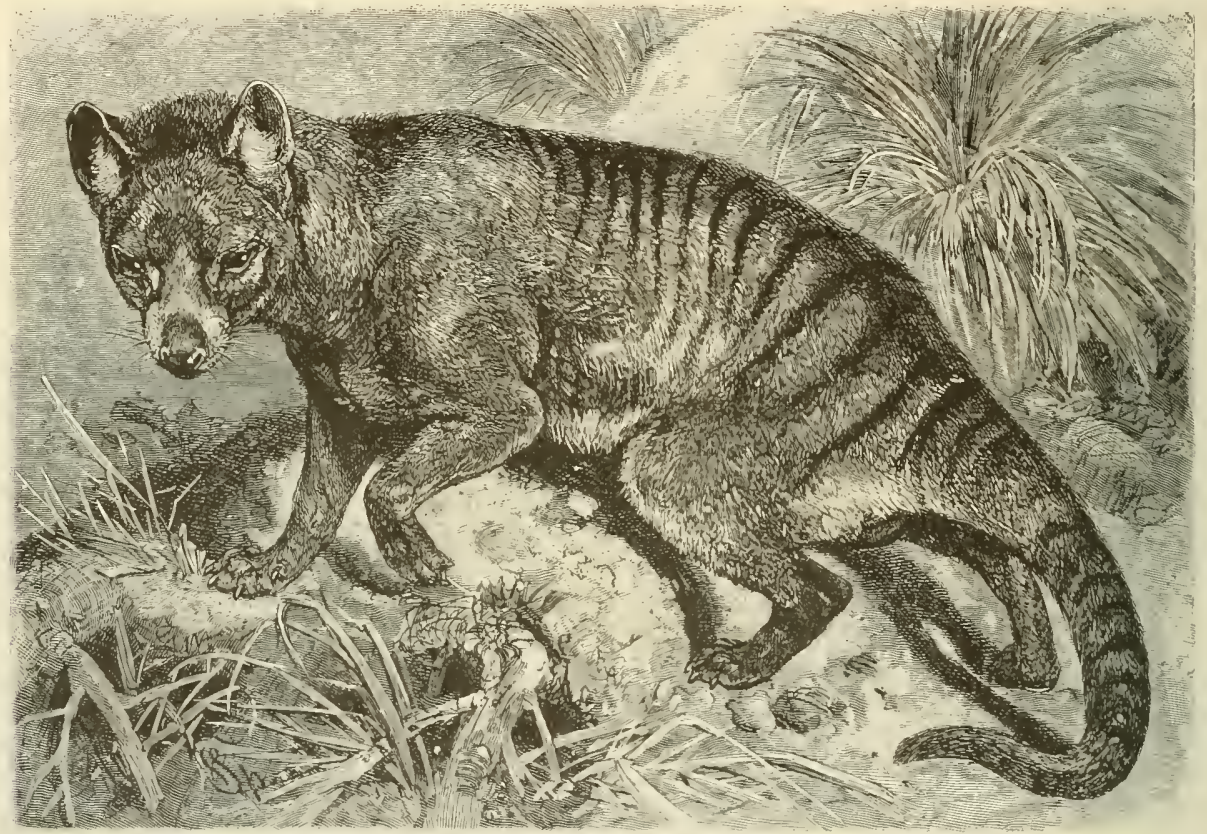

ZEBRA.WOLF OR POUCHED DOG.-This animal, the largest of the Carnivorons Marsupials, makes its home in the interior of Tasmonia, mostly in the mountain districts. It bears a great resemblance, superficially, to the Dog, but differs in dentition and the stripings of the

coat and is a typical Pouched inimal. (Thyluimus cyucephalus.

\section{THE DASYURES.}

The Dasyures, sometimes called the Brush-tailed Opossums (Disynums), constitute a distinct genus. In their appearance they partake of the character of both Foxes and Martens, without, however, showing a striking resemblance to either of them. The body. is slender and elungated, the neck comparatively. long, the head pointed in front. The tail is long, non-prehensile and covered with thick, bushy hair; the legs are short and of medium stoutness, the hind limbs being somewhat longer than the fore pair, and the hind feet distinguished by the lack of a great toe; the toes are separated and armed with strong, curved, pointed claws.

Habitat and Char- () ne of the best known species, the acter of the Spotted spotted Dasyure (Dusyinis airimiDasyure. mus), is usually of a fallow brown hue, although some individuals are lighter; the lower parts of the body are white. The entire upper surface is studded with irregular, white spots, smaller much pertinacity as are the preceding predaceous Pouched Animals, It is frequently caught in great numbers in steel traps baited with some kind of animal food. It is not to be recommended as a pet. for it is one of the most uninteresting of creatures.

THE BANDED ANT-EATER.

The Banded Ant-eater (Mymecobius fasciatus) is the only representative of the second sub-fanily of the predaceous Pouched Animals (I/ymucobiince). Its body is long, the head very pointed, the hinder feet four-toed, the fore feet five-toed, the hinder legs somewhat longer than the fore legs, the soles bare, the toes separated. The tail is non-prehensile, long and shagry. The female has no pouch. The great number of teeth is notable, being greater than that of any other mammal, and ranging from fifty to fifti-four.

The Ant-eater is justly considered to be one of the handsomest and most striking in appearance of any 
of the Marsupials. Its proportions are about the same as those of a common Squirrel. The coloring is very peculiar. The ochre yellow tint of the anterior upper part, which appears lighter by reason of being interspersed with white hair, gradually deepens into black on the greater part of the posterior half of the body and is diversified with white or reddish transverse stripes. The principal food of the Ant-eater is implied by its name. Hence, it is mainly found in those woodlands in which Ants occur in large numbers. It stretches out its tongue into the teeming heap, after the fashion of the Antbear, and quickly withdraws it, as soon as a multitude of the enraged insects have fastened on to it. It is also said to consume other insects and occasionally it eats the resin which exudes from the branches of the eucalyptus, or even grass.

Quite unlike the preceding carnivorous forms, the Ant-eater is entirely inoffensive. It readily resigns itself to captivity, which usually proves fatal to it, as ring chiefly in the South American belt, since only one species, also represented in the southern continent, is found in North America. Nearly all of the species live in the forest or in the underbrush, taking up their aboctes in hollow trees, holes in the ground, among thick grass and in bushes. One species inhabits the banks of small river's, being an excellent swimmer, and it seeks shelter in burrows. All are nocturnal in their habits and lead a solitary, roving life. Their gait when walking on level ground is rather slow and unsteady, and the mode is plantigrade. Most species of this family can climb on trees, suspend themselves by neans of their prehensile tails and remain in that attitude for hours. Among their perceptive senses that of smell seems to be best developed. The mental faculties are of a very low grade, though it can not be denied that they possess a certain degree of cunning, and they are especially skillful in evading any kind of trap. Their food consists of small mammals, birds and

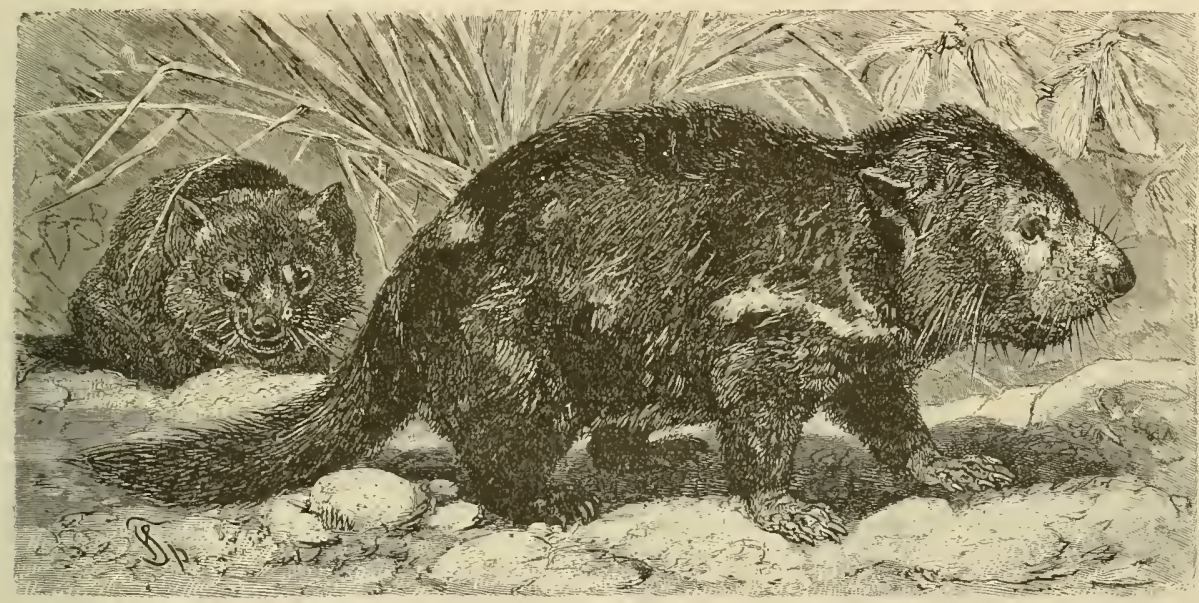

TASMANIAN DEVIL. - This animal of diabolical name is ugly enough to deserve it, is savage and untamable, ferocious and destruc 11.e. It became so formidable an enemy in the poultry yards of the Tasmanian colonists that they have nearly exterminated it, except in a few relreats in the interior of the island. (Sarcophilus urrsinus.)

the necessary food is procured with difficulty in sufficient quantities. The number of young at a birth is said to range between five and eight.

\section{The Doucbed TRats.}

\section{SIXTH FAMILY: DIDELPHYIDE.}

The Pouched Rats constitute the third family of the suborder; they attain at most the size of a Cat, but often do not exceed that of a Mouse. The body is stout, the head more or less pointed at the snout. The tail is usually long, bare at the tip and prehensile; sometines it is short and more or less hairy; the hinder legs are slightly longer than the fore pair, the paws are five-toed, webbed in one genus, and the hinder great toes are opposable to the other digits of the feet. The females of some species are destitute of pouch; in others it exists, and opens more frequently backward than forward. The dentition is of a decidedly carnivorous character.

In former periods Pouched Rats were also found in Europe, but now only inhabit America, being arranged in two genera and twenty-four species, occur- their eggs, and probably also includes small reptiles, insects and their grubs and worms; in times of scarcity they also feed on fruit. The aquatic forms feed principally on fish, while the larger species frequent human habitations and slay al] the weaker animals they can get hold of, reveling in their blood and really intoxicating themselves with it. Their voices are heard only when they are ill-treated, and then they utter peculiar, hissing sounds. When pursued they never defend themselves, but resort to dissimulation, when they can no longer hide themselves. When in anguish they give forth a disgusting, garlic-like odor.

\section{THE COMMON. OPOSSUM.}

The Common or Virginian Opossum (Didelphy's marsupialis) is probably the best known of the Pouched Rats. Neither its hue nor any grace or charm of manner distinguishes the animal, and thus it is justly held to be a repulsive looking creature. The length of body is nearly nineteen inches and the tail measures about seventeen inches. The latter is quite thick, round and tapering, hairy only at the base, and naked from that point to the end; it is 
surrounded by rows of fine scales, between which protrude a few short, straggling hairs. The female has a perfect pouch.

The Opossum is a native of America, from the northern United States to Chile and southern Brazil. In the central parts of this vast territory it is found in abundance, and that by no means to the pleasure of Man. It inhabits forests and bushes, and the denser the foliage the more the Opossum delights in its haunts.

Audubon's Ac

count of the

Opossum.

Andubon says: "Methinks I see one at this moment slowly and cautiously trudging over the melting snow, scenting as it goes for the fare its ravenous appetite prefers. Now it has come upon the fresh track of a Grouse or Hare and it raises its muzzle and sniffs the pure air. At length it has decided on its course, and it speeds onward at a rate equaling the speed of a Man's ordinary walk. It stops and seems at a loss in which direction to go, for the object of its pursuit has either taken a considerable leap or has and juicy stems it gladly feeds. The matin calls of the wild Turkey-cock delight the ear of the cunning creature, for it well knows that it will soon hear the answering cry of the female and thus be enabled to trace her to her nest, when it will suck the eggs with delight. Traveling through the woods, perhaps on the ground, perhaps aloft, from tree to tree, it hears a cock crow, and its heart swells as it remembers the toothsome food on which it regaled itself last summer in the neighboring farmyard. Thither then the hungry rogue bends its way, and if the opportunity is favorable, it sneaks into the clichen coop."

\section{Life and Habits \\ of the Opos.}

sum.

The Opossum is an arboreal animal, as is shown by its entire equipment, and on the ground it is rather slow and awkward. Its mode of walking is plantigrade. All its movements are apparently lazy and even its running gait is slow, though it consists in a series of ambling leaps. In the tops of trees, on the other hand, the animal climbs with great precision and

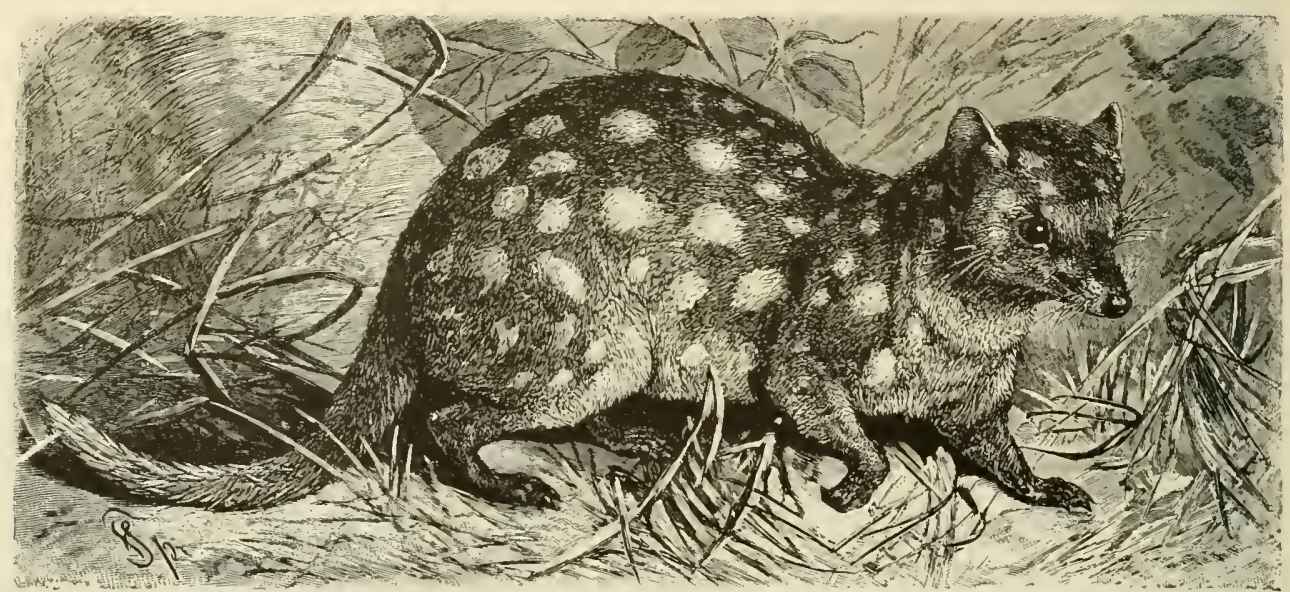

SPOTTED DASYURE. - This animal, which is quite common in Australia and Tasmania, has a fox-like head, a stout body the coat of which is studded with white spots on a groundwork of soft brown. It is a burrowing animal, hiding by day, and at night living on animals it kills, and also on carstudded with white spots on a
rion. (Dasyurus itiverinus.)

doubled backward upon its track before the Opossum entered. It raises itself up, stands for a while on its hind feet, looks around, sniffs the air again and then proceeds; but now, at the foot of a noble tree, it comes to a full stop. It walks round the base of the large trunk, over the snow-covered roots and among them finds an aperture, which it at once enters.

"Several minutes elapse, after which it reappears, dragging along the carcass of a Squirrel, and with it in its mouth begins to ascend the tree. Slowly it climbs until it gains a cluster of branches intertwined with grape-vines, and there, composing itself, it twines its tail round one of the twigs and with its sharp teeth devours the unlucky Squirrel which it holds all the while with its fore paws.

The Omnivorous "The pleasant days of spring have Propensities of arrived and the trees vigorously

the Opossum. shoot forth their leaves; but the Opossum seems nearly exhausted by its enforced abstention from food. It visits the margins of crecks and is pleased to see the young Frogs, which afford it a tolerable repast. Gradually the pokeberry and the nettle shoot up and on their tender tolerable speed. The great toes, or thumbs, of its hind paws enable it to grasp and hold the limbs of trees, and its prehensile tail greatly assists in securing for the animal stability of position and inımunity from falls. Not infrequently it suspends itself by means of its tail and stays in that position for hours.

In the vast, dark woods the Opossum prowls about day and night, though it prefers darkness to light. But when it apprehends danger, or even when daylight annoys it, it appears only by night and sleeps through the day in earth holes or hollow trees. It lives with its mate only during the pairing time, lcading a solitary life during the rest of the year, like all its kin. It has no fixed habitation, but uses any cranny which it descries in the morning after having completed its nocturnal wanderings. If fortune favors it particularly and it finds a burrow in which lives some weak rodent, it is naturally the more pleased; for then the original inhabitant of the dwelling furnishes it with a ready-prepared meal As we can infer from Audubon's description, it feeds on all the smaller mammals and birds it can capture, also on eggs, various reptiles, larger insects and 


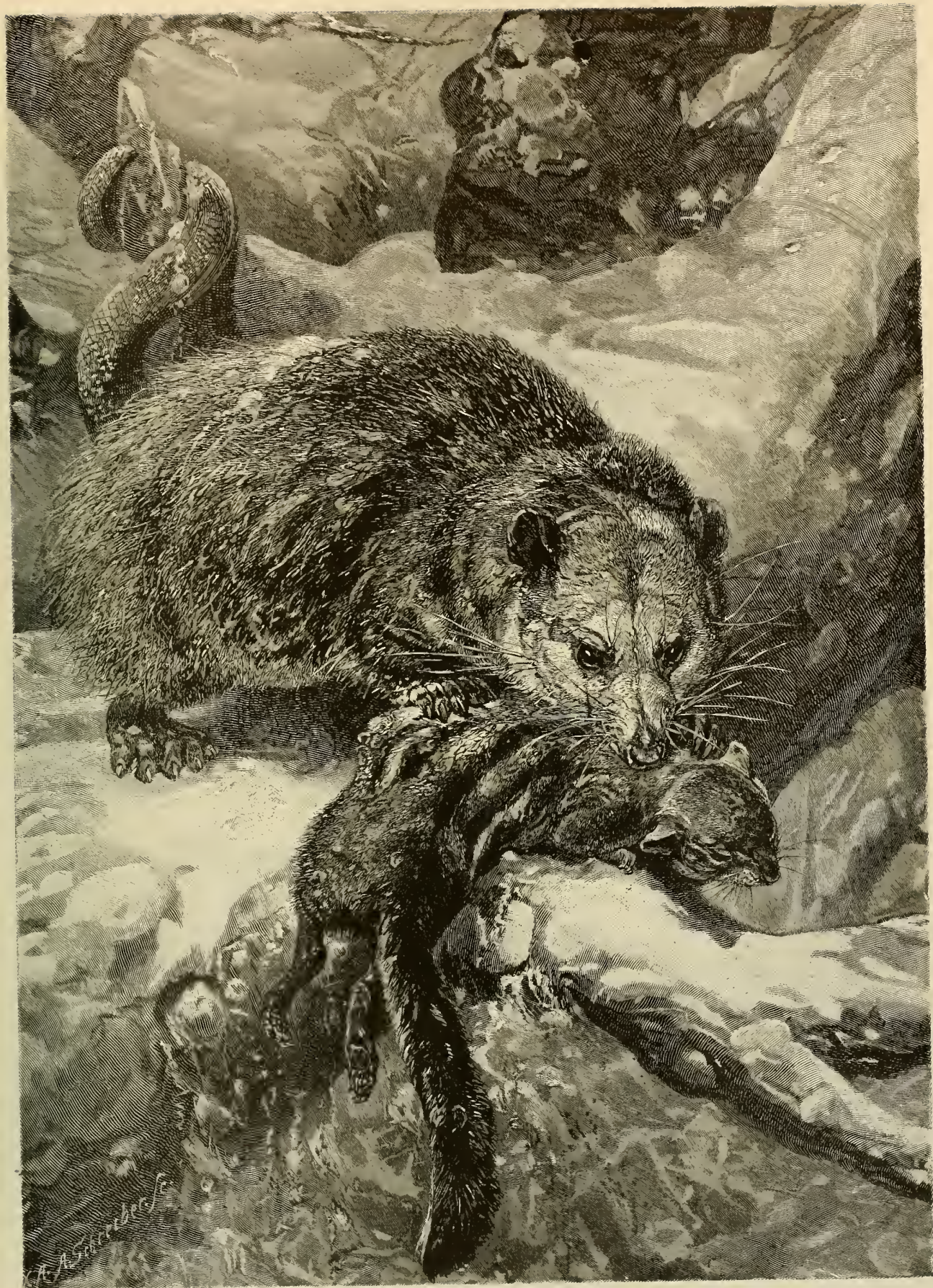

OPOSSUM AND CHIPMUNK. - The only American Marsupial is a carnivorous animal, always hungry and untiring in pursuit of prey. It possesses acute powers of scent, and is very persistent in following the trail of any sing. This picture shows the manner in which it holds on to limbs by its tail Culd is an excelleut portrait of this predaceous Marsupial. (Didelphys marsufialis.) 
their grubs, even worms; and in default of animal food it contents itself with vegetable substances, such as maize and nourishing roots. It prefers blood to any other food and therefore it slays with indescribable bloodthirstiness whenever it can do so. In the poultry yards it often kills all the fowls and then sucks their blood only without touching the flesh. It is said to become so gorged with the blood, as Martens do, that one sometimes finds it in the morning, sleeping among the dead fowls. Cautious in general, it becomes blind and deaf when it can assuage its thirst for blood; forgetting all danger and without desisting from its nurderous purpose, it unresistingly suffers itself to be killed by Dogs or by the enraged farmer.

The Opossum as It is not easily killed, however, for an Expert in an Opossum is very tenacious of life, Deceit. and resorts to dissimulation when very hard pressed. "Conscious of its inability to resist," says Audubon, "it rolls up like a ball. The more the farmer rages the more reluctant is the animal to manifest resentment; at last there it lies, not dead but exhausted, its jaws open, its tongue extended, its eyes dinmed; and there it would lie until the Bottle-fly slould come to deposit its eggs in its carcass did not its tormentor walk off. 'Surely, says he to himself, 'the beast must be dead.' But no, reader, it is only ' 'possuming, and no sooner has the enemy withdrawn, than it gradually gets on its legs and once more makes for the woods."

The Upossum is extensively hunted chiefly on account of the havoc it works among poultry. 'The Negroes are particular enemies of the animal and kill it whenever and wherever they can. The flesh is unpalatable to most white persons, for two glands impart an exceedingly strong and repellant odor of garlic to it, but the Negroes seem to like it and the flesh repays them for the trouble of the pursuit.

The ways of a captive Opossum are hardly interesting to the observer. I must say from my own experience that the animal is even more tiresome than other predaceous Pouched Animals. Rolled up and motionless, it lies in its cage all day, and only when one provokes it, does it make the slightest movement. It opens its mouth as wide as possible, and for as long a time as one stands before it, as if it suffered from lock-jaw. It is lazy and sleepy and appears to be disgustingly stupid.

\section{THE PHILANDERS.}

The subgenus Philander differs from the (Opossums proper mainly by reason of the imperfect pouch of the female. This pouch is formed by two cutaneous folds, which are laid over the unformed young attached to the mamnax.

Description of the The largest species of this subgenus Crab-Eating and one of the largest Opossums in Opossum. general, is the Crab-eating Opossum (Plitander plitirnder). The body is nine and onehalf inches long, and the tail nearly thirteen inches. The thick, soft, woolly hair is dingy, yellowish or reckish gray, yellow beneath. The pale gray face is marked with a brown median line and dark circles around the eyes, while the terminal half of the tail has a whitish appearance.

The Crab-eating Opossum has a wide geographical range, extending perhaps throughout all of trop. ical America. It is numerous in the woods of Brazil, affecting the proximity of swamps, which furnish it with Crabs. It lives almost exclusively on trees, and descends to the ground only when it wishes to forage. Its tail is prehensile and entirely naked, aiding it in climbing. Un the ground it proceeds slowly and awkwardly; yet it knows how to entrap smaller mammals, reptiles and insects, and especially Crabs, its favorite food. In the trees it preys on birds and their nests; but it also eats fruit, like the Opossum and its kin. It is said to also visit poultry yards occasionally and cause great devastations among Chickens and J'igeons. The young of the Crab-eating Opossum differ in color from the old animals. They are completely naked at birth, but when they are sufficiently developed to leave the pouch, they grow a short, silky fur of a shining nutbrown color, which gradually deepens into the dark brownish black color of maturity. All observers agree that the little creatures escape from the pouch and, moving around and upon the mother's body, afford a charming spectacle.

\section{THE WATER OPOSSUM.}

The second genus of the family is represented by the only Pouched Animal, which so far is known to have aquatic habits, the Vater Opossum or Yapock (Chironectis minimus).

Character and Do- The animal has, on the whole, the ings of the Water appearance of a Rat. The tail is opossum. nearly as long as the body, and prehensile, though it probably is not used for grasping objects. The fur is of a beautiful asliy gray hue on the back, sharply defined from the white under surface Six black, broad transverse stripes mark the back. $\Lambda$ dark band runs along the course of the spine from one stripe to another. The ears and tail are black. The body of an adult animal is about sixteen inches long, and the tail measures the same.

The Water Opossum is distributed over a great part of the South American belt. It is found from Guatemala to southern Brazil, but seems to be everywhere of rare occurrence, or at least to be obtained with difficulty, and is therefore found in few collections. It is said to prosecute its search for food by day as well as by night, to swim with ease and to proceed quickly and readily on land. The food is said to consist of small fish and other small aquatic animals and of spawn; yet the large clieek-pouches seem to indicate that the Yapock does not disdain vegetable food.

The female gives birth to about five young, which complete their development in the poucli; she leads them to the water rather early and instructs then for some time in swimming, diving and the art of acquiring food. 


\title{
The $\mathbb{E} \mathfrak{g g}=$ Taying Silsammals.
}

\author{
FIFTEENTH ORDER: MONOTREMATA
}

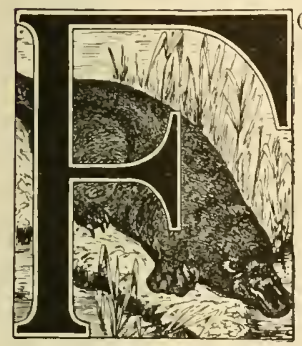

OR a long time the point has been eagerly argued, as to the order in which the Monotremes or Figglaying Nammals ought to be placed; but now this question has been settled. The opinion of older zoologists, who saw a distinct class of the animal world in the Monotremes, had certainiy, temporarily at least, lost its sway, yet it has now partly regained it, and no zoologist of the present time places the Duck-mole and the Echidna (both of which might justly be regarded as representing distinct subclasses among mammals) among the pouched animals, or still less among the edentates.

Physical Peculiar. That the Monotremes really suckle ties of the Mono- their young has long been estabtremes. lished beyond a doubt; yet the close investigations of Gegenbaur were necessary to acquaint us with the true nature of the organs of lactation. The glands, which are situated on the sides of the abdomen, open in many fine ducts of the skin, which in these places is covered with hair. As many male mammals have similar glands in the same places, the first dissectors did not take these to be real organs of lactation until Meckel proved that these glands were not developed in the male Duck-mole, and Baer noticed that the lacteal glands of Whales were similarly constructed. Owen examined the glands in $I_{3} 2$ and found each to have about one hundred and twenty openings in the skin, secreting a nutritive fluid, which he found in the stomach of the young in a coagulated state. Therefore he classified the Monotremes among the mammals. But on the second of September, 1884, Haacke reported to the Royal Society of South Australia, in Adelaide, that he had a few weeks previously found an egg, which he produced at the meeting, in a so far unknown brooding pouch of a living Echidna, and on the same day a cablegram was read in Montreal, which informed the assembled members of the British Association that another naturalist, Caldwell, who was at that very time working in Australia, had found that the Monotremes lay eggs. These discoveries again rendered the closer relation of the Monotremes to other mammais more questionable, the more so, as Gegenbaur proved, in 1886 , that the glands which furnish nourishment to the young do not correspond in their structure with the scbaccous glands, as do the lacteal glands of all other mammals, but represent modified sweatglands. If one further considers that, according to the discovery made by Thomas as late as ISSS, the Duck-mole has, during a considerable time of its iife, teeth, which are true teeth but differ greatly from those of any other living mammal, and that the blood-heat of the Monotremes amounts to twentyeight degrees Celsius (sixty degrees Fahrenheit) at the most, differing in this from all other warmblooded animals, one would think the action justified if we werc to separate the Monotremes as a second main division of mammals from the first, in which arrangement we would classify the pouched animals and higher Mammalia as genuine manmals; or it would not be erroneous even it we were to place them as a distinct class among the vertebrates. Such a division will perhaps be decided on finally; but up to the present we classify these animals as the last and lowest order of mammals, composed only of themselves.

The Monotremes have an outer envelope of skin similar to that of other mammals. The Duck-mole is clothed in fur and the Echidna has its covering of spines and bristles; but in other respects they differ markedly from the other known forms of the class in external appearance as well as intcrnal structure. A hard beali, similar to that of an aquatic bird, stands them in stead of a mouth, and the intestines, the urinary and genital organs all terminate in one orifice, the so-called "cloacal aperture." This is a formation we find again in the birds, which the Monotremes also resemble by reason of their largeyolked eggs, the possession of a single forked sternal bone, formed by the two ankylosed or conjoined collar bones or clavicles, and the partially developed condition of the right ovary. While for these reasons their relation to both birds and reptiles can not be denied, they exhibit an affinity also to the pouched animals by reason of their possession of marsupial bones.

The Monotremes are small mammals, with a sturdy, somewhat flattened body, very short legs, beak-shaped jaws covered with a dry skin, small eyes, a short tail, fect placed at a diverging angle in regard to one another, armed with strong claws and a hollow spur upon the heel of the malc, this spur communicating with a special secretory gland. The outer ear-conch is absent; teeth exist only in the Duck-mole and consist of flat, disk-like, laminæ or "plates" furnished with tubercles or cusps along the edges of their upper surfaces, and articulated loosely superficially with the jawbone, rather than having inserted roots.

Besides the bones of an extinct Echidna, teeth of prehistoric animals, similar to those of the Duckmole have been found; but at present this peculiar order is limited to the two families of the Echidnidx and the Duck-moles. 


\section{Tbe Ent=catcrs.}

\section{FIRST FAMILY: ECHIDNIDE,}

The family of the Ant-eaters (Echidnide) consists of two genera, containing one species each. They are distinguished by their clumsy body, covered by a bristly fur which is for the greater part interspersed with spines; by their cylindrical and absolutely toothless beak, slit at the lower end; their short, stub-like tail, their free, imperfectly mobile teeth and their long, thin, worm-like tongue, which is freely protractile in a manner analogous to that characterizing the motion of that organ in other Ant-eaters. In their external appearance the Ant-eaters differ from the Duck-mole much more than they do in their internal anatomical structure. The two lacteal glands have hundreds of opening canals and lie laterally on the abdomen of the female in shallow depressions, which at least in the Porcupine Anteater, according to the authority of Haacke, are enveloped in the lateral folds of a brooding-pouch, developing as required for the purpose of the reception, incubation and hatching of the egg, later sheltering the young and becoming more spacious as the growth of the young advances, and then again disappearing by process of absorption after the weaning of the progeny. This pouch opens in front and is, even at the beginning of the process of reproduction, large enough to admit a watch. The depressions form shortly before the laying of the eggs, and may become entirely obliterated temporarily. $R$ von Lendenfeld found that during the incubation of the eggs the heat in the pouch was higher than that in any other part of the body, and that the skin forming it appears greatly reddened, and, so to speak, congested, on account of the increased local circulation of the blood. The Porcupine Ant-eater seems to lay only one small, large-yolked, parchment-covered egg. The duration of the period of incubation has not yet been established. The young, when first hatched, is like that of the pouched animals-very tiny, naked and blind and differs from its parents especially by reason of its short snout. It is not definitely known how it is nourished. It seems that it remains in the maternal pouch for a long time.

The Ant-eaters range from New Guinea over Australia to Tasmania.

The Australian The Australian Porcupine Ant-eater Porcupine Ant- (Echidna aculcatatypica), the physical eater. proportions of which are intermediate between those of the Papuan and the Tasmanian Ant-eater, possesses a comparatively long beak. The face and the region around the ears are either completely, or for the greater part, beset with smooth spines, leaving a strip on the forehead and on either cheek bare. The spines on the back are long, stiff and strong, often attaining a length of two and onehalf inches and usually completely overgrowing the hair interspersed among them. Their color is a pale yellow at the base, orange yellow in the middle and black at the tip. The hair on the back is black or deep brown, but is often entirely absent, occasionally, however, protruding above the spines of the hind quarters, this phenomenon perhaps occurring at certain seasons only. The legs, and the entire under surface, are covered by a dark brown fur, plentifully mingled with smooth spines. The animal is about sixteen inches in length, about half an inch of which is included in the tail. This sub-species is distributed over the entire continent of Australia, and also occurs on Kangaroo Island, off the southern coast of Australia.

The Papuan and The Papuan Porcupine Ant-eater Tasmanian Porcu. (Echidna aculcata lawesi) differs from pine Ant-eaters. the Australian sub-species by reason of its smaller size, shorter dorsal spines, between which the hair is visible, a greater number of spines on the head, the legs and the under surface of the body, and by a comparatively longer beak. This sub-species is known only from specimens taken near Port Moresby in southeastern New Guinea.

The Tasmanian Porcupine Ant-eater (Echilna aculeata sctosa) differs from the Australian variety by reason of its greater proportions, as it attains a length of twenty irches, and by the lack of spines on the head, sides, abdomen and legs. The hue of the head is generally lighter than that of the rest of the body.

Habitat and Habits The Porcupine Ant-eater affects of the Porcupine mountanous regions more than it Ant-eaters. does plains, sometimes ascending to an altitude of 3,000 feet above the sea. It particularly delights in dry woodland, where it can excavate burrows and holes under the roots of the trees. There it hides during the day; at night it sallies forth and searches for food, sniffing and digging. Its movements are lively, especially when digging, as it is an adept at this cmployment. Insects and worms, but especially the various kinds of Ants and Termites, constitute its principal food. It finds them with the help of the very sensitive tip of its snout, which is probably less adapted to smelling purposes than it is as an organ of touch It eats after the fashion of other animals with a vermiform tongue, protruding that member, and, when it is covered with Ants, retracting it quickly. Like all other Ant-eaters it apparently involuntarily mixes much sand and dust or dry wood with its food, for its stomach is always filled with such substances. Occasionally grass is also found in the digestive organs.

When an Echidna is menaced with capture it instantly rolls up into a ball, and it is then very hard to obtain a hold upon it, as the sharp spines usually inflict wounds which cause great pain to its assailant. The muscular contraction of the animal in rolling up is sufficient to insert the spines. A rolled-up Fchidna is not easy to transport, the best way being to grasp it by the hinder legs, disregarding its efforts and strugglings. When an Echidna has dug for itself a burrow of moderate elepth, it is extremely difficult to pull the animal out of its subterranean retreat. It first relaxes and then enlarges itself, after the manner of Armadillos, and presses its spines so closely against the circumference of its burrow that it really seems to be glued in it. The assertion of the natives of the regions which it inhabits, that the male wounds its assailant with the spur on its hinder leg, and injects a poisonous fuid through the hollow weapon into the wound, must be regarded as untrue in the light of the results, of all the experiments that lave been made in this dircetion.

The vocal expression of this queer creature, which is heard when it is very uncasy, consists of a weak grunt. Of its perceptive senses those of hearing and sight rank first; the others are less developed.

Haacke's Observa- IIaacke has repeatedly kept Echidtions of the ne in Nustralia and made observaEchidnce. tions, especially concerning their climbing ability, endurance of hunger and method of 
propagation. "The first Echidna which I received," says he, "I put under a box in my study; but that treatment did not seem to please it at all. It persistently and continuously endeavored to escape from its prison, and where there was enough space between the floor and the edge of the box, it constantly put out its long tongue in an exploring way. Finally it succeeded, during the night, in lifting the heavy box and liberating itself. For a long time I looked for it in vain. At last, to my great surprise, I found it in another box about sixteen inches high, which was open above and half filled with pieces of gold quartz the size of a Man's fist, and wrapped in paper; this seemed to impress it as a more fitting sleeping place than the level surface of the ground. Keeping this experience of the climbing ability of the animals in mind, I put two other Porcupine Anteaters in a barrel about three feet high and twenty inches wide, and placed it in the spacious basement of the museum building in Adelaide. An escape from this prison, having the usual shape of barrels, secmed impossible. Fet one of the animals succeeded in escaping. After days of search I found it, again in the barrel with its companion. It may have heard the latter, and worked its way up to the edge of the barrel between that receptacle and the wall and then dropped down into it. As I intended dissecting the animals, and therefore wished to free them from all interferinc fat, I starved them, and found that they could fast at least a month without any visible impaiment of their health. I found the intestinal tract of one of them, killed after a six weels' fast, filled exclusively with sand, to which the animal had access. This was a hint in regard to the preparation of food for these animals when in confinement. If it be given a diet of a fine grained, mixed food, consisting of equal parts of powdered dry meat, scraped yolk of egg, finely ground hemp seed, crumbs of crackers, grated carrots and pure sand, an Echidna may, in my opinion, thrive for a long time, and possibly propagate its species. An addition of Ints, grubs and Meal-worms will make the food still more wholesome. The animal must be treated exactly as are insectivorous birds. The majority of Echidnidae could fast through the time occupied by the journey from Australia to Europe, the fast steamers having shortened the duration of the trip."

\section{THE WOOLLY ECHIDNA.}

The second genus, with its one species, of the Echidnidx is constituted by a recently discovered animal of New Guinea, which we will call Woolly Echidna (Proeclictna brijmii), in contradistinction to the Porcupine Ant-eater. The genus can not be sharply differentiated from the preceding and is principally distinguished from it by the number of toes, there being only three on each foot. The beak, which is curved downward, is nearly double as long as the remainder of the head. The animal is about twenty inches long and is covered on head, body and limbs by a dense, coarse dark brown or black woolly fur, with which a few bristles are mixed and scattering spines are hidden in the hair.
The Woolly Echidna is so far known to exist only in the northwest portion of New Guinea; nothing has been written of its mode of life.

\section{Tbe Duck=moles.}

\section{SECOND FAMILY: ORNITHORHYNCHIDE.}

The Duck-mole (Ornithorhynchus anatimus or paradoxus) is the only known member of the second family of this order. We are indebted to Dr. George Bennett for the first good description of this really striking animal, which continued to be an object of wonder to naturalists and the public at large long after its discovery. Its form and habits were so queer, that Bennett traveled to Australia for the sole purpose of observing the animal. $U_{p}$ to that time only indefinite information had reached us. We simply knew that the Duck-mole lived in the water and was persistently hunted by the natives, for it yielded a savory flesh and laid eggs. The assertion

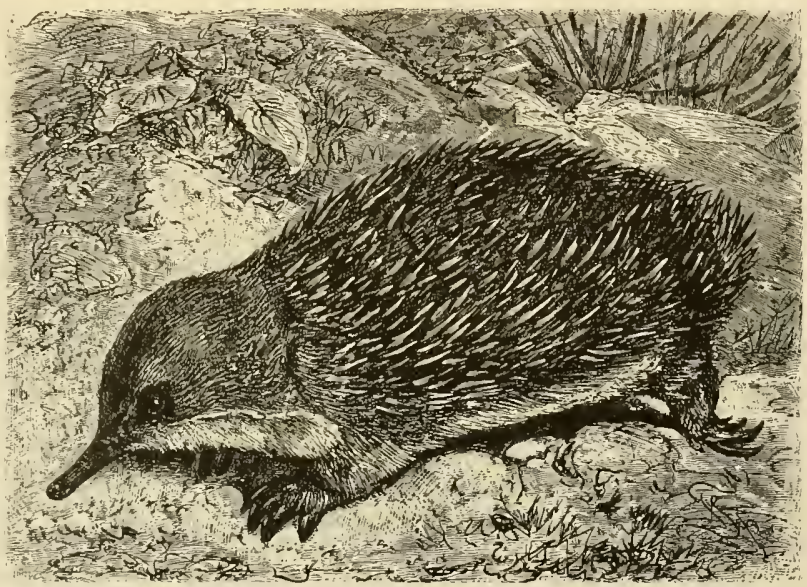

THE PORCUPINE ANT-EATER. - Belonging to the last and strangest order of mamThe Porcunine Ant-eater has many physical peculiarities, It has a bird-like head and beak. mals, the Porcupine Anteater has many physical peculiarities. It has a bird-like head and beak; a of the latter fact was considered untrue until Caldwell reported his discovery of its eggs in 1884 .

Description of The Duck-mole is somewhat larger the Duck- than the Echidna, being about two mole. feet in length, six inches of which are included in the tail. The males are considerably larger than the females. The flattened body shows a certain similitude to that of a Beaver or an Otter. The legs are very small, all four feet being five-toed and webbed. In the fore feet, which possess greater muscular power than the hind pair and serve for swimming as well as for digging, the webs extend slightly beyond the claws, are very flexible and elastic and are retracted from the claws when the animal is engaged in scratching or burrowing in the earth. All the toes are very strong, blunt and excellently adapted for digging. The two middle digits are the longest. The slort hinder paws are directed backward and resemble those of a Seal, and are most effective when exerted in a backward and outward direction. The first toe on each hind foot is very short; the nails are all curved backward and 
are longer and sharper than those of the fore feet; the web extends only to the base of the toes. The male has on each hind foot a pointed, mobile spur, which can be rotated either on its own axis or around the leg to a considerable extent. It is placed a little above the toes and directed inward. The tail is flat and is broad at the end, the extremity being formed by long hairs. It is abruptly cut off, and in old animals is either entirely naked beneath or covered with a few coarse hairs. In young animals it is quite hairy, the fur in the older specimens probably being worn away by long continued friction. The head is rather flat, small and so markedly characterized by its broad duck-like beak as to be without an equal in point of singularity among manmals. Both jaws are elongated, and are surrounded along their entire length by a horny envelope, which is continued backward in a curious shield. The adult animal has only four horny teeth in its two jaws, of which the upper front tooth is long. narrow and sharp, while the posterior tooth is broad and flat, and resembles a grinder. Before the Duckmole attains one third or a half of its size, it has, in the place of these horny teeth, eight true teeth which have the appearance of flat, irregularly rounded disks, beset at their edges with larger or smaller cusps or protuberances. These teeth, which have been discovered only recently, resemble those of the small fossil mammals of the Jurassic group. After they have been almost entirely worn away and cast, the horny formations replace them, being developments of mucous membrane which has become indurated and horny in character. The orifices of the nostrils are situated on the upper surface of the beak, near its extremity; the small eyes are placed high in the head; the aperture of the ear, which may be closed by a special muscle acting as a valve, is situated near the outer corner of the eye. The fold of integument, which projects like a shicld from the beak over the front of the head and the throat, is of great use to the animal, as it keeps the inud off the adjacent fur during the search for food and shelters the eyes when the Duck-mole is digging. The tongue is fleshy but beset with callous projections and is supplemented with a curious bulbous organ behind, which completely closes the mouth. Thus the beak is an excellent sieve, cnabling the animal to examine the water, separate the eatable substances from others, and to store them away in the capacious cheek-pouches extending along the sides of the head.

The fur of the Duck-mole consists of a thick, coarse outer coat of dark brown color with a silvery white surface tinge, and a very soft, grayish inner fur, similar to that of the Scal and Otter. A peculiar fish-like odor, probably due to some oily secretion, is given forth by the fur, especially when it is wet. The Australians, however, are very fond of the flesh of the animal in spite of this disgusting odor.

Habits and Dom- The Duck-mole is fondest of calm icile of the spots in rivers filled with an abunDuch-mole. dance of aquatic plants and the banks of which are shaded by the dense foliage of trees; and it constructs more or less complicated burrows in the banks. A tortuous tunnel, usually about eighteen feet long, terminates in a spacious chamber: both the chamber and its approaches being strewn with dry aquatic plants. Gencrally, however, every chamber has two entrances, one below the surface of the contiguous water, the other about twelie inches above.
The Duck-moles are seen at all times in the rivers of Australia, but most frequently during the spring and summer, and the question has been propounded whether they might not hibernate. Their habits usually induce them to emerge from their retreats at dusk, though they sometimes also appear on the surface of the earth in the daytime, searching for food. When the water is very clear, the observer can follow with the eyes the movements of the animal as it dives and reappears above the surface. He who wishes to observe it must be quiet and motionless; for not the slightest movement eludes its keen eye, nor does the least noise escape its delicate sense of hearing. It rarely remains above water over one or two minutes at a time; then it dives and reappcars at a short distance. As Bennett saw exemplified in his captive specimens, the Duckmole likes to stay near the shore, amidst the mud, searching for its food between the roots of the aquatic plants, which form the main abode of insects. The diet which it obtains during its forays consists mainly of small aquatic insects and mollusks; it stores them temporarily in its cheekpouches and then consumes them ar greater leisure. Bennett's Anec- "On a beautiful summer evening," dote of a Duck- says Bennett, "I approached a small mole. river in Australia, and as I knew the predilection of the Duck-mole for the hour of dusk, 1 tried to obtain a glimpse of one. WVith a constant grasp on our guns, we patiently stood on the shore. It was not long before we saw a black object appear near us on top of the water, the head being raised but little above the surface. We stood motionless, lest we should scare the animal, carefully observing and following its movements, for one must be rcady to shoot just as the Duck-mole reappears after diving. Only a shot in the head is effective, as the loose, thick fur will not allow a bullet to penetrate it readily. We wounded one which gave evidence of severe injury and sank immediately, but soon rose again. When the Dog brought it to us we found it to be a fine male. It had not yet expired, for it made an occasional movement; but no noise, except a frequent stertorous breathing through the nostrils, escaped it. Several minutes after it had been brought out of the water it apparently revived, and, instantly rising to its feet, staggered towirds the river. About twenty-five minutes later it turned over seieral times and then died. As I had heard much about the danger of being pierced by its spur, even when the animal is mortally injured, I put my hand near the so-called "poisonous" spur at the first grasp. In its violent exertions to escape the animal scratched me slightly with its hind paws and also with its spur, but despite the roughness with which I seized it, it did not wound me intentionally. I had also been further told that the Duck-mole lay on its back when it wished to use the spur, which statement will not be received as at all probable by any one who knows the animal in ever so slight a way. I put it into this position, but it only strove to regain its feet without attenspting to wound me by using its spur. In short, I tried in cvery way to induce the animal to make use of its spur as a weapon, but in vain; and I am perfectly convinced that the spur has another function than that of a weapon; the more so, as later experiments with wounded animals have always yielded the same result. The natives characterize the spur as "mischievous," that being with them a word which in general conveys the idea of dangerous or poisonous 
character; yet they use the same expression in speaking of the scratches inflicted by the animal with the hinder feet, and they are not at all afraid of seizing a living Duck-mole. When the queer creature runs along the ground, it produces an iu1pression of something umnatural, and its strange shape easily startles a timid person. Cats instantly take flight at its appearance, and even Dogs, which are not specially trained, stare at it, prick their ears and bark, but are afraid to touch it, so strongly are they impressed by the strange appearance and oddities of this animal.'

Bennett had many burrows explored and thus had the advantage of observing several Duck-moles in captivity. "I had one burrow dug up," says he, "in spite of all dissuasions of a lazy native, who could not understand why I wished for Duck-moles, since I possessed an abundance of Cattle and Sheep. The entrance of the burrow was large in proportion to the width of the tunnel, for the latter became narrower as we advanced, until it only permitted the passage of the animal. IVe had followed it to a depth of nine feet, when suddenly the head of a Duck-mole appeared below, just as if it had been awaked from sleep and had come to sce what we wished. It seemed to recognize the fact that our noisy work was not conducive to its welfare; for it retreated quite hurriedly. As it turned around it was seized by the hind leg and pulled out. It seemed to be very uneasy and astonished at $t$ his treatment. We placed our prisoner, which was a full-grown female, in a barrel full of grass, river-mud, water, etc. It scratched all around the sides of the barrel trying to escape from its prison; but as it found all its labor vain, it became quiet, curled up and seemed to sleep. During the night it was very restless and again scratched with its fore paws, as if it were intent on burrowing a tunnel. In

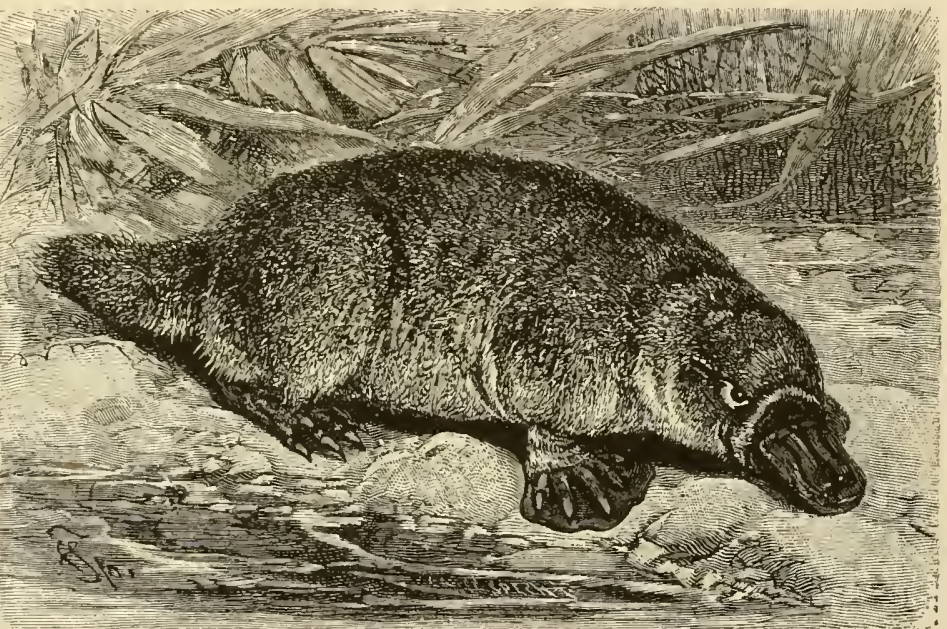

DUCK-MOLE___ Last among the known mammals is the strange and aptly named Duck-mole. It is webfoted and lays eggs, like a Duck, and burrows in river banks like a Mlole or a Beaver, but spends most ol its waking moments in the water searching lor the aquatic insects and Mollusks which constilute its food. (Ornithorhyuchus anatinus.)

the morning I found it fast asleep, the tail turned in, head and beak under its chest, the body curled up. When I disturbed its slumber it growled, somewhat like a Dog, only a little more gently and perhaps more harmoniously. During the day it was usually quiet, but during the night it renewed its atternpts to escape and growled continuously. All Europeans of the neighborhood, who had often seen the dead animal, were glad of the opportunity to observe a living specimen, and I believe that this was the first time a European had taken a living Duck-mole and had examined its burrow.

"When I left I put my 'Mallangong' into a little box lined with grass, and took it with me. To afford it some recreation I woke it after a sliort time, tied a long string to one of its hind legs and set it ashore. It soon found its way into the water and swam up the stream, evidently most delighted with such spots as were thickly covered with aquatic plants.
After the animal had enough of diving, it crept ashore, lay down on the grass and gave itself up to the luxury of scratching and combing itself.

A few days later I allowed it to take another bath in a clear river, in the water of which 1 could see its movements distinctly. It quickly dived to the bottom, stayed there for a little while and then rose again. It roved along the bank, guided by the sense of touch in its beak, which seemed to be very frequently used, and also to be a very sensitive organ of touch. Its appetite was probably quite well satisfied, for whenever it withdrew its beak from the mud, something eatable was undoubtedly in it, as its jaws were then working laterally with a movement peculiar to its method of chewing. Various insects, which hovered closely about it, were unmolested by it, either because it did not see them or because it preferred the food which the mud afforded it. After its repasts it would sometimes lie down on the crassy bank, half out of the water, or it would bend backward, combing and cleaning its fur. It returned to its prison very unwillingly, and this time it did not quiet down at all. During the succeeding 
-I could allow the young animals the liberty of the room, but one old one scratched the wall so incessantly that I had to shut it up. Then it lay quietly all day, but always renewed its attempts to escape during the night. When I disturbed the animals in their sleep, there was always a murmuring.

"My little Duck-mole family lived for some time longer and thus I could observe their habits. The little animals appeared frequently to dream of being in the water: for their fore-paws were often seen to move as they would in swimming. When I placed them on the ground by day, they sought a dark resting-place and in such a spot or in their prison they soon fell asleep, their bodies being disposed of in a curled-up attitude; but they preferred their usual resting place to any other.

"At evening my two little pets emerged from their cage at dusk and usually ate their food; then they began to play like a couple of young Dogs, attacking each other with their beaks, lifting their fore paws and climbing over each other. They were extremely lively; their little eyes gleamed and the apertures of their ears opened and closed in remarkably rapid succession. As their eyes stand quite high in their heads they can not see very well straight ahead, and therefore are apt to come into collision with contiguous objects.

"Soon after my arrival in Sydney the animals, to my great regret, lost much of their flesh, and their shins lost their fine, shining appearance. Their ill health was plainly seen in all their actions, and their appearance could only excite pity. On the 29th of January the female died and was followed on the $2 \mathrm{~d}$ of February by the male. I had kept them alive only about five weeks."

Incubation and The Duck-mole lays several softDevelopment of the shelled eggs, in which, according to

Duck-mole. Caldwell's discoveries, the embryos before being hatched, are developed to about the same stage of growth as are those in a Hen's egg which has been incubated for thirty-six hours. The eggs are hatched in the nest. The newly-hatched young are small, raked, blind and as helpless as those of the Echidna or of the pouched animals. Their beaks are short.

In the zoological garden at Melbourne Duckmoles have occasionally been kept of late years, but none have, so far, reached Europe alive.

\section{TWO OTHER MONOTREMES.}

The already deseribed Monotremes should perhaps be followed by a recently discovered, unnamed animal of the interior of Australia. Its fur has a metallic lustre and it lives subterraneously. So far only one-and that, unfertunately, mutilated-specimen is known, and it still awaits a detailed description.

A still more important acquisition to the natural history of the lowest forms of mammals, however, would probably be the description of the sole indigenous terrestrial mammal of New Zealand. This animal resembles an Otter in general appearance; it lives near and in the water like that animal and is now probably restricted to the elevated lakes of the New Zealand southern mountain ehain. It has been seen several times, and once so near that the observer dealt it a blow with a whip, after which it disappeared in the water, uttering a shrill cry. Julius von Haast saw the aninal's tracks in the snow, but no one has yet succeeded in obtaining a specimen. New Zealand possesses the lowest forms of bird life of any country of the globe; and it is very possible that its single living, indigenous mammal stands as much below the Monotremes in development as the Monotremes are below the pouched animals, and thus would furnish important and perhaps surprising disclosures concerning the origin of the highest class of vertebrates, which includes Man. 


\title{
TABLE OF CONTENTS.
}

\author{
MAMMALS.
}

\section{Finst Order: THE APES AND MONKEYS. Pitheci. 1.}

FIRST FAnILy: The Narrow-Yosed

Apes (Catarrhini) ...... 8

MAN-SHAPED APES (Anlhropomorpha.)

I.-Genus : Gorillas (Gorilla)

Gorilla (G. gina)

2.-Gemus: Chimpanaes (Simia)

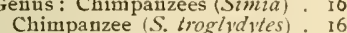

3.-Genus: Orang-utans (Pithecus) is Orang-Utan $(P$. satyrus $) . .18$

4.-Genus: Gibbons (Hylobates). 23 Siamang (H. sindactyius) : 23

Hoolock (H. hulock) .... 23

Lar or White-handed Gibbor (H. lar).... 23 Ungko (H. raflesii) . . 23

Wau-wau or Oa (H. varicgatus) 23

DOG-SHAPED MONKEYS (Cynopilhecini).

5.-Genus : Slender or Sacred Monk eys (Semnopilhecus)

Hoonuman (S. entellus)

Budeng ( $S$ (mantis)

6udeng (S. maurus)..... 27 Genus : Proboscis Monkeys ( $\mathrm{N}$ i

salis) . 2S

Proboscis Monkey or Kahau (N. lavvatus) .....2s

7.-Genus: Thumbless Moukeys (Colobus) . 28

Guerezas (C. gucreza) : . 25

Ursine Colobus (C. wrsinus) . 30

Black Colobus (C. satanas) 30

8.-Gellus : Guenous: (Cercopithecus) 30 Green Monkey (C. sabcus) . . 32 Diana Moukey (C. diana). . 34 Blue-faced Guenon (C. cephins) 34

*Red or Patas Moukey (C. ruber) 34

*Sooty Mangabey (C. fulgginosus)

9.-Genus: Macaques (MacaCus) Common Macaque (M. cynomotgus) _... 36 Bhunder, or Rhesus Monkey (.1T, rhesus $) \ldots \ldots$

\section{PAGE}

*Bounet Monkey (M. sinicus) 36 *Pig-tailed Macaques $(M$. nemestrinus) . . . . 39 Magot or Barbary Ape $(M$.$) s { }^{2}$ ianus) .......... 39

Io.-Genus : Baboons (Cynoctphalus) $4 \mathrm{I}$ Black Baboon (C. niger)... 43 Common Baboon (C. babuin) 43 Chacusa Baboon (C. porcarius) 44 Sphinx $(C \cdot \operatorname{sphin} x)$. . . 44 Hamadryas or Sacred Baboon (C. hamadryas) .... 46 Gelada Baboon (C.gelada) : 48 Maııdr"l] (C. monnon) . . . 49 Drill (C.lcucophaus) . . . 49 Wanderoo (C. silenus) . . 5

SECOND FAMILY: American or Broad. Yosed Moukeys. (Platyrhini) . . 50 PREHENSILE-TAILED MONKEYS (Cebid $a$ ). I.-Genus: Howlers (Mycetes) . . 52 Aluate or Red Howler ( $M$. sen-

Caraya or Black Howler (M. ${ }^{53}$ niger) 2.-Genus : Spider Monkeys (Ateles) 54 Coaita (A.paniscus) . . . 55 Marimonda or Aru (A. beelze. buth $) \ldots . . .55$

Chameck $(A$. pentudactylus $) \quad 55$ Miriki (A.hypoxanthus). . . 55 Gold-Faced Monkey ( $A$. bart. lettii) . . . 55 3.-Genus: Woolly Monkeys (Lagothrix) . . 55

*Humboldt's Lagothrix Moukey (L. inumboldtii) ... 55

4.-Genus: Capuchins (Cebus) : 56

Cai or Sai (C. capucinus) . . 56 Apella or Brown Capuchin (C. apella)

*White-Bearded Capuchin $\left\langle\dot{C}^{5}\right.$ leucogenys) ...... 55 uin $\{C . h y$ -

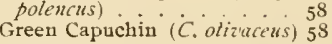

NON-PREHENSILE TAILED AMERICAN MONKEIS (Pitherida)

5.-Genus : Sakis (Pithecia) . . 58 Cuxio (P. satanas) . . . . 58 White-headed Saki ( $P$. tcucocephala) . . . 55 *Hairy Saki (P. hirsula) . . 59

6.-Genus: Short-tailed Monkeys (Brachyurus) $\therefore 59$ Black-headed Saki ( $B$. melanocophalus) . . . . . 59

*Short-tailed Monkey (B. cal$\left.{ }^{\prime} \prime u s\right) \ldots 6 \mathrm{r}$

7.-Genus: Callithrix (Callithrix) 59 Widow Monkey (C. lugens) . 59

*Lovely-Haired Monkey (C.per. sonata) . . . 6r

S.-Genus : Samaris (Chrosothrix) 59 Squirrel Monkey (C. sciurea). 60 9.-Geuus: Owl Monkeys (Nyclipithecus) . . . 60 Mirikina Monkey ( $N$. irizer: gatus $\ldots . .6 \mathbf{r}$

Third Fanily: The Marmosets. (Arclopitheci) . . . . . 62

I.-Geuus : Marmosets (Hapale) . . 62 * Silky Tamarine (H. rosalia) 62 Silver Monkey (II,argentalit) 62 Liou-like Monkey (IT. lconina) 63 Silky Monkey (H.pjomaa). 63 Common Marmosets (H. jac chus)

Patuted Marmoset ( $H$. ponicil

lata) 6 Pinche Marmoset ( $H_{\text {. }}(\alpha d$ ipus $) 64$ Golden Marmoset ( $H$. chryso-

(cucus) . . . . . 64

Second Orden: THE HALF=MONKEYS OR LEMUROIDS. Prosimii. (i).

First Fanits: The Lemurs (Lemu) idce)....... 65

$\mathrm{x}-$ Genus: Indris (Lichanotus). Babacoto (L. brevicaudatus)

2.-Genus: Nakis (Lemur) Ruffed Themur (t. varius) : Catta (L.catta) Mongoose (L. Mongoz). . 67 Black Maki $(L$ macaco)

3.-Genus: Loris (Stenops) Slender Loris $(S$. gracilis $\}$. . . 6S Slow Loris (S. tardigradus). . 69 4.-Genus: Gentle Lemurs (Hapa *Gray Lemur (H. griseus)
5.-Genus: Prehensile-Handed Leunur (Chirogalezs) . . . . 69 *Fork-Crowned Lemur $(C$. furcifer)........ 60 6.-Gellus: Large-Eared Makis (Otolicnus). . . . . . 70 Common Galago (O. galago) . 7 I Comba (O. agisymbanus). . 71

7.-Genus: Stump fingered Lemurs

(Perodicticus)
* Potto Lemur (P.

Totto Letnur (P. polto) . . 72

S.-Genus : Bear-like Lemurs (Aricto. cebus)

*Angwántibo Lemur id calaba 72 rensis) .... 72 rebus) Lemurs (Micro-

*Little Galago Lemur (ji inyoi 73 inus) . . . . . . . 73

SECoxd Fayrly : The Tarsiers ( Tar-

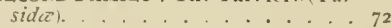
I.-Genus: Tarsier (Tarsius) . . . 72 Spectre Tarsier (T. spictrum). 72

THIRD FAMrLY : The Bare-fingered Animals (Liptodactyla) . . . 73

I.-Genus: Queer-Handed Animals (Chiromys) ..... 73 Aye-Aye (Madagascariensis). 73

*Not mentioned in text except iu description accompanying illustration 


\section{THIrd Order: THE WING=HANDED ANIMALS. Chimpter,. 75.}

First Division: Flyiug Dogs (Ptor opina)

I.-Geuus: Filying Dogs (Pteropus) 79 The Kalong ( $P$. edulis). . . . So 2.-Geuus: Night-Dogs (Cynonveteris) 79 Egyptian Flying-Dog (C. ag.p tiacus).

SECOND DIVISION: The Simooth-Tosed Bats (Gymnoritina). . . . . . Si

I.-Genus: Long-eared Bats (Pleco- $\mathrm{S}_{2}$ (us)

Long-eared Bat ( $P$. auritus) . \$2 2.-Genus: Night.Flyers (Vesper. tilio)

Fucrtil Oruer:

PAGE

First Famila: The cat Fanily (Fe(idc)

I.-Genus : Cats Proper (Felis) . . 92 Royal Tiger ( $F$. ligris). $\quad 9^{2}$ Clouded Tiger ( $F$. nebulosa) .99 Common Wild Cat (F. catus). 99 * Marbled Cat (F. mammorata). 99 Egyptian Cat ( $F$. municulata) 102 Domestic Cat $(F$. maniculata domestica) ...... 105 Angora Cut ( $F$. manicutala domestica angorensis) . . . . 105 Barbary Lion ( $F$. leo barbarus). 106 Senegal Lion ( $F$. lco sencgalensis)

South African Lion ( $F$ leo ca. pensis) . 106 Persian Lion ( $\dot{F}_{\text {. }}$ ico persicus) 106 Guzerat Lion ( $F$. leoguzeratensis) .

Leopard $(\vec{F}$. pardus) Pauther ( $F$. panthera) . . II Long-tailed Panther ( $F$. z' $(?-$ ricgata).

Black Panther $(\dot{E}$. Snow Leopard or Ouuce $(\dot{F}$. uncia)

Viverrine Cat ( $F$ vizerrina) I Leopard Cat ( $F$. bengalensis). 119 Serval (F. serval) ..... IIg Cougar or Puma $(\dot{F}$. concolor $)$. 120 Yaguarundi ( $F$. yaguarundi) . I22 Jaguar $(F$. onza $)$. . . I 24 Ocelot ( $F$. pardalis). . . 12 Pampas Cat (F. pajeros). 128 Marguay (F.tigrinis) . . I I29 Long-tailed Tiger Cat $(F$. ma(rura)

2.-Genus: Lyuxes (Linx) 129 Common Lynx (L. zulgaris). 130 Pardine Lynx (L.pardinus) 133 Peeshoo or Cauadian L, y $11 \times(l$. borcalis) . . 133

Red or Bay Lynx (L. rufus) 133 Texas Lynx (L. maculata) 133 Oregou Lynx (L.fasciata). .134 Florida Lynx (L. tloridanus) 134 Carolina Lynx (L. carolinensis)

Caracal (L. caracal) . . 134 Common Jungle Cat ( $L$. chaus). I 3

3.-Genus : Cheetahs (Cynailums). I 35 Asiatic Cheetali ( $C$ jubatus) . I 35 Fahhad, or African Cheetah (C. guttatus) ...... 135

Spottel Cleetah (C. soemincringii) . . . . . . . . . 135 Woolly Cheetah (C. lancus). I35 4.-Genus: Foussa (Cryptoprocta) . 133 Cryptoprocta (C. fero.t) . . I3s

Second Family: Civat Family (liacrida)

CAT-FOOTED CIVETS. (Niluropoda). 139
*Danbenton's Bat ( $l$. daubcn. Ionii) Colored or Common Bat ( I muinus)

3.-Genus: Noctules (l'esperngo)

*Pipistrelle ( $l$. pipistrellus). . T9

Noctule or Great Bat $(I$. noctula)

4.-Genus : Pug-Dog Bats (Synolus) S2 Barbastelle or Pug-Dog Bat $(S$. barbastellus).

THIRD DIVISION : Leaf-Nowed or Blootsucking Bat (Istiophora). . . . $8_{3}$ 1.-Genus : Tampires (Fhyllostoma). $\mathrm{S}_{4}$

THE BEASTS OF PREY.

I.-Genus : Civets Proper (Iižcrra) 139 Africau Civet $(I$. civctia). Ito Asiatic Civet ( $I$. zibctha) . I40 Lesser Civet ( $V$. malaicensis) It Common Genette ( $l$. genetla) I $4 \mathrm{I}$ 2.-Genus: Palm Cats (Paradoxurus) I.t2 It diau Paradoxure ( $P$. niger) It 2 Common Paradoxure ( $P$. hermaphroditus)

Masked Paradoxure (P. iq) vatus)

DOG-FOOTED CIVETS. (Cynopoda). . 14

3.-Genus: Mungooses (Herpestes) r 44 Ichneunou ( $H$. ichneumon). I 44 Mungo (H. mungo). . . I47 Meloncillo (I/. widdringtonii) 1.48 Bauded Mungoos (II. fascia(us)

Crab Miuggons (H. urza). 150 4.-Geuus: Dog-like Mungooses (C)nictusi).

Foxy Muugoos (Cं penicillata) 150 5.-Genus : Mangues (Crossarchus) 146 Mangue ( $C$.obscurus) . . 146 6.-Genus: Suricates (Suricata). 150 Suricate (S. tetradactyla) . . I50

Third Fanily: The Marten Family (Mustelide) . . . . . . I50 THE MARTENS. (.Martidac) . . . I I52

1.-Genus : Martens Proper (Mustela) 152 Pine Marten ( $H$. mantes) . . . I52 Stone Marten $(\mathrm{H}$. foina) . 153 The Sable (.1\%. zibcllina). . . 154 American Sable (.1. amirica$\begin{aligned} \text { Fislier Marten ( } M \text {. pinnatii) } & 156\end{aligned}$ 2-Genus: Fonl Martens (Putorius) I 56 Polecat ( $P$. fotidus) . . . . I56 Tiger Polecat ( $P$. samaticus) I 56 Ferret $(P$. furo $) .. . .158$ Wease] (P. rulgaris) ...... I59 Frmine ( $P$. crminca) . . . I62 Mink or Nerz (P. lutreola $) .164$ American Mink (P. zison). . I6

3.-Genus: Glutions (Gulo) ... I66 Glutton $G$.borealis $). .166$

4.-Genus: Grisons (Calictis). . I68 Tyra (G. barbara)... 168 Grison (G. irittata)..... I68

THE BADGERS. (Ilid $\sigma$ ) . . . 168

5.-Genus : Badgers (Meles) . . . I 68 Common Badger (1Y. laxus). I69

6.-Genus : New World Badgers (Taridca)....... I7 American Badger ( $\dot{T}$. Americana) ......... I 7 Mexican Badger ( $\dot{T}$. bribandicri). . . .

7.-Genus : Honey Badgers (iclli-

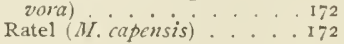

Vampire Rat $(P$ specturum PAGE 2.-Genus: Horseshoe Bats (Rhinolophus) . . . . 85 Lesser Horseshoe Bat (R. hippocrepis). Greater Horseshoe Bat (R.fer-
mu-cquinum). . . . . 86 3.-Genus: Nose-leaf Bats ( $M e g a$ -

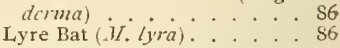
4.-Geuns: Rhinopomes (Rhinopoma) 86 Egyptian Rhinopome (K. microphy(tum)

5.-Genus : Scotophiles (Scotophilus) 56 Welwitch's Bat (S. aclwitchii 86

Currizora. ST.

Indian Ratel ( $\boldsymbol{M}$. indica). 8.-Genus: Stinking Badgers (i/y- ${ }^{173}$ daths)

Teledu ilinelo . . . 173

9.-Genus : Skuuks (d/cphitis) 173

Genus : Skuuks (M/cphitts) . . 173
Surilho (.I. suffocans)

Skunk (1. z'arians)... . . 174

Io.-Geuus : Zorillas (Rhabdogale) . I75 Cape Zorilla (R. mustelina) .175

THE OTTERS. (Lutridc). . . . . I76

II.-Genus : Otters (Lutra). . . I 76 Common Otter $(L$. vulgaris) . 176 American Otter ( $L$. canadensis). $\cdot$. . . 179 Mexian Otter (L. califonica). 179 Peruvian Otter (L. fclina). 179 Brazilian Otter ( $L$. brasilicnis) I 79 12.--Genus : Sea Otters (Enhydris) . I79 Sea Otter (E. lutris) . . . 179

Fourti Family: The Hyana Family (Hyanida)

I.-Genus : Hyæenas (Hyana) . . . I 82 Spotted Hyana ( $H$. crocula). I $S_{4}$ Browu Hyæna (H. bruntea) . 185 Striped Hyxna (H. striata). IS6

2.-Genus : Aard-Wolfs (Proteles). I 87 Aard-Wolf (P. lalandii) . . 187

Fifth Fanily: The Dog Family (Canidnce). . . . . . . . 187

I.-Genus: Wolves (Canis) . . . I88 Wolf (C. Iupus). . . . . 190 Guara ( $C$. jubatus). . . . I91 Nortl American Volf $(C$. occidentalis)..... . 194 Jackal Wolf (C. anlhns) . 194 Striped Wolf (C. adustus) . 196 Jackal (C. aureus) . . . . . . 196 Cape Jackal(C. mesomelas) . . 196 Coyote $(C$. latrans) . . . 197 Raccoon Dog ( $C$. procyonoides). 198 Crab-eating Dog (C. cancrivortus) Aguara ( $C$. velulus) * * . 19 Hyana Dog (C. pictus) . . . 199 Kolsun (C. dukhunensis) . . . 200 Adjag (C. mtilans) . . . . 200 *Alpine Wolf (C. atpinus). . 203 Dingo (C. dingo) . . . . 204 Pariah Dog. . . . . . . 206 DOMESTIC DOGS (Canis familiaris) 207 1.-Group: Greyliounds (C.f.grajus).215 Greyhound ..... . . 215 Greyhound of the Desert . 216 *Scotch Greyhound . . . 217 Italian Greyhound . . . . 217 African Naked Dog $\left(C \cdot f \cdot a f r i-{ }^{21}\right.$ canus) ........ 2 Is 2.-Group: Mastiffs ${ }^{\circ} C^{\circ}$ fam. mo- $^{\circ}$ lossus) . . . . . . $2 \mathrm{IS}$ Danish Dog. 
PAGE

German Mastiff . . . . 2IS

Bullfog . ? 220

Boxer. . . . . . 22

Pug . . . . . . . . . 221

Dog of Tibet . . . . . . 221

3.-Group: Badger Dogs (Cunisfumilitris i'trlagus). . . . . 221

English Turmspit . . . 222

Otter-Hound . . . . . . 222

4.-Group : Hounds (Canis fim saga.r).... 222

Poiuters 223

* Retriever 220

Germau Bloodhonid : . . 224

Staghound . . . . . . . . 224

Foxhound . . . . . 224

Beagle . . . . . . 224

5.-Group : Spauiels ( Canis fam. $\mathrm{C}^{\circ}$ -

Fing Charles... 225

Blenheim . 225

Newfoundland . . . . 225

St. Bernard . . . . . . . . 226

Poodle.

6. - Gromp: Terriers (Canis fam. gryplutus)

Skye Terrier

7--Group: Domestic Dogs Proper

(Canis familiaris domesticus) 220

Sheep dog .

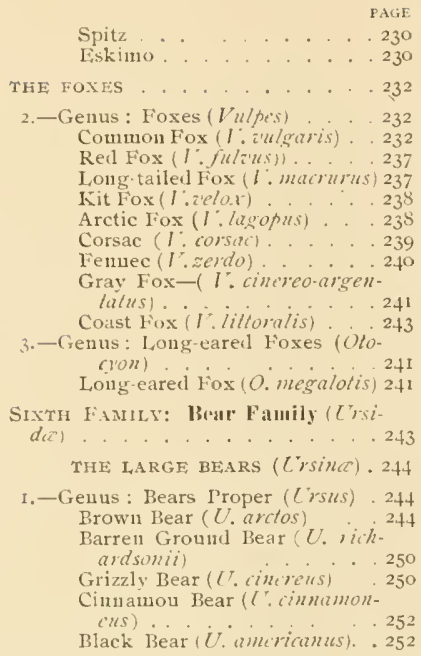

Black II imalayan Bear-( Torquutus)

Malayau Bear $(U$. 2.-Genus : Sloth Bears (Melursus) . 260 Sloth Bear (.T. labiatus). . . . 260

CAT-LIKE BEARS (Allunine) . 264

3.-Genus : Cat-Pawed Bears ( Niluropus)........ 264 Ailuropus 1.4. melanoliucus) 264 4--Genus : Cat-Bears Proper (-tilu-

. . . 26t

Panda (. i. fulginis) 264

5.-Genus: Binturongs (.tritis) 264 Binturong (.1. binlurong) . . 264

THE SMALI, BEARS (Procyoninc). 264 6.-Genus : Raccoous (Procyon) . . 264 Raccoon (P. lotos) . . . 264 Crab-eating Raccoon ( I'. iun'rii'orus) . . . . . . 268 7.-Genus: Long-nosed Bears ( $\mathrm{Na}$ sul ( ) $(i, r) .269$ Coata (i.rifir) . 269 Narica (.1. narica) . . . 270 8.-Genus: Kinkajous (Cerroliptes) $27 \mathrm{I}$ Kinkajou (C. candizolunlus) . 27 I 9.-Genus: Cacomixles (Bassaris) . 272 Cacomixle (B. astuta)

Fifti Onin: THE SEALS OR FIN=FOOTED ANIMALS. I'innipedie. 273.

FIRST FAmLY: Orliuary Simls (Phocide) . . . . . 275

1.-Genus : Common Seals (Phoca) 278 Commou Seal ( $P$. vitulina) $\cdot 2-5$ Caspian Seal ( $P$. caspicia) . . . 27s Sardle-Back seal (P. gronlandical

2.-Genus: Hooded Seals (C.ystophora)

\section{Sixtil Order: THE}

First Famil: Hedgelongs (Erina ceide).

$2 S 9$

Genus: Hedgehogs (Erinacius) . . . 289 Coumon Hedgehog (E. ilrop(Tus)........ 290

SECOND FAMILY : Moles (Talpide) . 294

I.-Geuts: Moles ( Tulpa)

Common Mole ( $T$. erropica) 295

2.-Genus : Shrew-Mfoles (Scalops) . 295 Americau Mole (S. aqualicus) 295

Prairie Mole (S. argentalus) . 295

3.-Genus: Spade footed ShrewMoles (Scapanus) . . 296

Hairy-tailed Inle (S. brenteri) 296 Uregon Mole (S. lownsenti). 296

4.-Genus: Star-Nosed Moles (Condylura)... 296 Star-Nosed Mole (C. cristala) . 206

ThIRd FAMis : Tupaias ( Tupaide') 296

Genus: Tupaias (Tupaia). . .296 Tana $(T . \operatorname{tana}) \ldots .296$
Crested or Bladder-Nose Seal (C. (r)islatu). . . . . 279

3.-Genus : Elepliant Seals (. Marror. $\begin{array}{ll}\text { limus) } & \\ \text { Elephant Seal (.1\% lioninus) } & 279 \\ 279\end{array}$

4.-Genus : Narrow-nosed Seals f. Stinorkynchus)..... . 277

* Sea Leopard (.S. leptony $\left.x^{*}\right) .277$

Mouk Seal (S. albiz'tuler) . . 278

SECOND FAMUIY : Walruses (Triche PAGE chidec) . . . . . . $2 \mathrm{S2}_{2}$

Genus : Walruses (Trichcchus) . 282 Walrus (T. rosmarus) . . . 282

Third Faurly: Eared seals (Olariida) ......... . 286

Genus: Eared Seals (Oturii) Sea Liou (O stcllcri) ., 286 Sea Bear: (0. ursina) . . . 258 Southern Sea Lion (O.jubuta) 288

\section{INSECT $=$ EATING ANITIALS. Insectionm. 22s.9.}

FOURTH FAMIrY : Lomer-Legred Sllorems Mucrosiclidide) . . . . . . . 296

Genus : Elephant Shrews (Macros. Elephaut Shrew (i/. (ypicus) 296

FIFTH FAMIL: Finy Hedrehous: (Cintitide)....... . . . 297 Genus: Spiuy Hedgeliogs (Cinletes)...... . . . 297

Tanrec (c: coundalus) . . 297

SIXTH FAaILY: Nhrews Soricide . 297 SHREW'S PROPER (Soricina) . . . 299 I.-Geuus : Shrews (Sorer) . . . . 299

Commou Shrew (S. zulgaris) 299 Broad-Nosed Shrew is. plulyrhinus.

Jarsh Shrew (s palustris) Dwarf Shrew (S. personala) . 302 2.-Genus: VVest Indian Shrews ( $\mathrm{Sol}$ (noderl). . . . . . 29S
3.-Genus : Mole Shrew's (Blarina) 295 Short-tailed Nole Shrew $(B$ brevicauta). . . . . . 300 4.-Genus: Field Shrewsiciocidura) 302 Domestic Shrew (C. aranca) . 302 Eitruscan Shrew (C. swarolens) 302

5.-Genus: Water Shrews (Crossopus). . . . 302 Water Shrew $(\dot{c}$ fodiens $) .302$

THE DESAIAS (. HOgalinet) . . . . 303

6.-Genus: Beaver Shrews ( $1 / 1 \%$ gale $) .303$ Aluizilero ( $\%$ pirenaica) .303 Desman $(. \%$. Woschata) . . 303 7.-Genus: Neurotrichus (Nimo(richus). . . . 304 Neurotrichus (T. gibbsii) $\begin{array}{ll}304 \\ 304\end{array}$

SEVENTH FAIII, : ('olugos (Galeopi-

(hecide). . . . . . . . . 304

Genus : Colugos (Galeopilhecus) 304 Colugo (G. zolans).... . 304

Serenti Onen: THE RODENTS OR GNAWING ANITIALS. lintentin. 305.

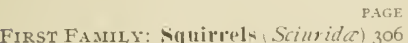
THE TRUE SQU1RREIS (Sciurinc) . . 306

1.--Genus : Tree Squirrels (Sciurus) 306 Coumon Squirrel (S. anlgaris) 306 Chickaree Squirrel ( $S$. hudson-

ius) . . . 310 Gray Squirrel (S. carolinensis) 3 ro
Arizona Gray Squirrel (S. arizonensis) . . . 310 Chestuut-backed Gray Squirrel (S.aberti) . . . . 310 California Gray Squirrel $(\dot{S}$. fossor) . . 310 310 Black Squirrei (S niger) . . 310 Fox Squirrel ( $S$. cincreus) . 310
VVesteru Fox Squirrel (S, ludosicianus) . . . . 310 Little Africau Squirrel $i \dot{S}_{-}$ minutus) ...... 3II 2.-Genus: [lying Squirrels (Pterom $1 s)$. . . . 3 $3^{\top}$ Taguan (P. pitarista) . . . 3 I Liatuga ( $P$. 2'olans) 


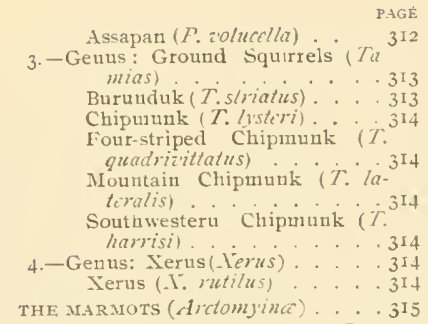

5.-Genus: Pouched Marmots (Spermophilus)

Souslik (S. cilillus) $\because \dot{S}^{315}$

Parry's Narmot Squirrel $(\dot{S}$. empetra) ....... 316

Gray Irairie Squirrel $\left(S_{3}\right.$
fronllini) Tranklinil ${ }_{\text {Thirteen-lined Spermophile }}^{3 \mathrm{I}}$ (S. tridecum-lintatus) $\cdot 316$

6.-Genus: Prairie Dogs (C 1 nom 15$) 316$ Prairie Dog (C. Iudoincuanus) 316 7.-Genus: Marmots Proper ( $d r$ lomys)

Bobac (t. bobute

Alpine Narnot $(A$, marmota) 320 Woodchuck $(\%$ mona $x)$. 321 Rocky Mountain Marmot $(.$. .

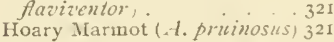

SECOND FAMIL: Dormice (JIyoxida).

1.-Genus: Fat Dormice (,1/yo.1'us) 321 Loir (M. glis)

Lerotin ( $1 / . d r$ ritzs) . . 3 32

2.-Genus : Lerots (Eliomy's). . . 322 Lerot (E. nitela) . . 322

3.-Geuns: Dorasice Proper (Mus

cardinus) Douse (ir. aiel- ${ }^{322}$ lanarius)

Third Fanily: Beavers (Caslorid $a$ ) 323

Genus: Beavers (Castor) . . 323

Beaver (C. fiber) . . . . 323

Canadian Beaver ( $C$. conaden. sis).

Fourth Fanil,: Jerboas (Dipodida 327 JUMPING MIICE (Jaculina) . . . . . 32

1.-Genus: Jumping Mice (Jaculus) Jumping IIouse (J. hudsonius) $32 \mathrm{~S}$ TRUE JERBOAS (Dipodinc)

2.-Genus: Jerboas Proper (Dipus) Egyptiau Jerboa (D.agypticus) $32 \mathrm{~S}$

3.-Genus : Alactagas (Scirtetes) 329 Alactaga (S.jaculus) . . . 329 JUMPING HARES (Podetina) ... . . 328 4.-Genus: Jumping IIares (Pedele's) Jumping Hare (P. caffir) . . 330 Fifth Famil: Mice (.Muida) . .330 RUNNIXG MICE (.ITERonidina) . . 332

I.-Genus: Saud Rats( / Pammomysi 332 Sand Rat $(P$.obesus $) .. \quad 332$ THE MICE PROPER (MUNinC) . . 332 2.-Genus: Mice $($ Mus $)$, alexandri- ${ }^{332}$
Egyptiau Rat (.W. ale nus) . 332 Hamster Rat (1. gambianus) 332 Black Rat (.1\% rallus) . . . . 333 Brown Rat (.M. decumanus) .333 Common Alouse $(1 /$, musculusi 336 IYood Mouse (.1\%. sylizaticus) . 336 old World Meadow Mouse ( $i{ }^{3}$. agrarius)

Harvest Mouse (ji, minutus) 333 Barbary Mouse (. H. barharzus 337

3.-Geuus : Cotton Rats (Sigmodon) 336 Cotton or Rice Rat (S. hispidus)

4--Genus : Wood Rats (Veotoma) .336 I'lorida Wood Rat (.V. floriduna)
California Wood Rat (.V. fusci-

pess) . . . . 336 Gray Woud Rat (v. cincreus) 336 INDIGENOTS AMIERICAN MICE . 340 5.-Genus: Western Mice (Hespero. mys)
white-footed louse $(H$. leucopus) ilouse (H. aureolins) 340 Michigan Nouse (H. michiganensis)

California Uonse (Hi califun $34^{3}$ (us) 340 Missouri Mole Mouse $(H$. lethcogas(er)

Rice.field Mouse $\left(H\right.$. ory $\approx 0^{3+0}$ $m: s)$

THE HAMSTERS (Cricetina). . . . . 340

6.-Geuus: Hausters (Cricelus) . . 340 Common Hamster ( $C$. frumen(arius)

Srxth Fanrly: Volex (Arvicolida) $3+4$ -Geuus: Muskrats (Fibcr) . . . 3H Musktat ( $F$. zibethicus) 34

2.-Genus: Voles Proper (trvicola) 345 Water Vole (A. amphibius) . . 345 Snow Jouse (A, nirulis) $3+6$ Bank Vole (A glareolus) . . 3 $3+6$ Field Vole (.t. agrestis) . . 347 Red Vole $(1$. mililus) . . 347

American Meadow Mouse $(A$. riparius)

Campaguol (1. arvalis) 347

Root Vole (.t. aconomus) . . 34

3.-Genus: Lemmiugs (Mvodes) $3+5$

Lemming $(1 /$. lcmmus) 348

4.-Genus: Lemming Voles (Symaptomyst

Lemming Vole (S. cooperi) 350

Seventh Famis: Mole Rats (Spa-

lacida

Geuus : Nole Rats (Spalar) ... 35 Common دole Rat (S. typhins) 35

Eigutr Family : Poeket Mice (. Sac-

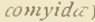
POCKET MICE, PROPER (SACCOMJinC).

t.-Genus: I eaping Pocket Mice (Dipodomys)....... in 352 Ord's Pocket Mouse (D. phi. lipp:il

2.-Genus : Kangaroo Rats (Perognathus)

Brush Tailerl Pocket Mouse ( $P{ }^{352}$ penicillatus) ciatus)

Coarse-haired Pocket irouse 35 ( $P$. hispidus)

3.-Geuus: Least Pocket A u us : Least Pocket Mlice ( $\mathrm{ri}-$
celodipus)

Hopping MLouse (C. fluz'us) . 352 Little Hopping Mouse (C. $f a)_{\text {- }}$ ז'tus).

THE GOPHERS (Gcomida)

.352

. . 352

4.-Genus: Gophers (Geomys) . . 352 Pouched Gopher (G. bursarius) 352 Southern Gopher (G. (uza) . 353 Chestunt-Clieeked Gopher ( $c_{r}$. costanops)

Quachil (G. hispidus).

Uexican Gopler $(6)$. 354 nus)

5.-Genus : Pocket Rats (Thomom irs) 354 Common Pocket Rat ( $\%$, ialpoides)

Rocky urint a 354 (T. clusius). . . . Rat

Niath Family: Porempines (Hys-

(richida) . . . . . . 35t

I.-Genus: Porcupines Proper ( $H_{1}$ 'sConix) Porcupine (H. Cris. lala)
2.-Genus: Brush-tailed Porcupines (Atherwa) .... 35 "Brush-tailed Porcupine ( $A$. africana) . . . . . 35 s

TREE OR CLIMIING PORCUPINES ( $\mathrm{Cer}$ colabin $(c) \ldots . .356$

3.-Genus: Climbiug Porcupines (Erithizon) ..... 356 Urson (E. dorsatum) . . . 356

4.-Prehensile-tailed Porcupiues (Cercolabes).

Mexicau Porcupiue $(C$. noze hispania)

Coniy $\{C$ villosus $) \cdot 35$

Coenduu (C. prehensilis)... . 359

TENTH Fanily: Cavies, or fininea

Pig Family (Caziida). . . . . . . . 359

I.-Geuus: Guinea Pigs (Cazia) . 359 Guinea Pig (C.porcellus). . . 360 Aperea (C.aperea) . . . . 360 Peruviau Cavy (C.culleri) .360

2.--Genus: Maras (Dolicholis). . . 362 Mlara (D.petagonica) . . 362

3 -Genus : Agoutis (Dasyprocta) $\cdot 362$ Common Agouti (D. agut $) \ldots 362$

4-Genus: Pacas (Coelogenj's). . . 363 Paca $\left(C_{\text {. paca }}\right.$. 363 5.-Genus: Water Pigs (Hydrochu: rus)

Water Pig (H. capybara) . . 364

ELEVENTH FaMILY: Oetodons (Oclodontide

I.-Genus: Octorlons Proper (Oclodon Degu $(0$ cummingii) $\cdot 36$

2.-Genus: Nutrias (1Yjoptamus) $36^{-1}$ Coypu $(3 \%$ cospu) ? 367

3.-Genus: Grouud Pigs (Aulaiodus) 369 Ground Pig (A. swinderianus) 369

TWELFTH FAMILY : Chinchillas ( $\mathrm{La}$.

gostomida)

I. -Genus: Chinchillas Proper $\left(F_{r}: 36\right.$ omys). C 360 Common Cliuchilla $(E$. chiviShilla) Chinchilla (E. Tani- ${ }^{360}$ gera) Ch 369

2.-Genus : Lagotis (Lagidium) . 370 Cuvier's Lagoti (L.cuz'ieri) . 371

3.-Genus : Viscachas (Lagoslom usi3j I Viscacha (L trichodacty/us) . 371

THIRTEEXTH FAMILY: Hares ( Lcporid $a)$

1.-Genus: Hares (Lcpus).

Commion Hate ( $L$ andravis)

Alpine Hare (L timidus)

Irish Hare (I hibentis)

Polar Hare (L. placialis) ? 375

Rabbit (L. cuniculus) . . . . 3-6

American Varying Hare $(i$. amerianus)... . . .

Virgiuian Varying Hare $(L$. amer. virginianus) . . . 379 Washingtonii Varying Hare $(L$ amer, iitshinclonii).

Northern Prairie Hare (L. cam- 37 pestris) . . . . . 379 Texas Hare (L. callolis) . . . 379 Californiau Hare ( $L$. califomi-

$\begin{array}{ll}\text { Cus) } & 379 \\ \text { Swamp Ifare (L. aquaticus) } & 379\end{array}$

Marsh Hare (L. palustris) 379

Cotton Tail (L. syliaticus) . 379

Sage Rabbit (L. arle'mesia) . . 379

THE CRYIAT HARES OR PIKAS.

2.-Genus : Crying Hares (Lagomss) 379

American Pika (L. princcps) 379

Alpine Cryiug Hare (L. al." pinus)

FOURTEENTH FAMILF: Bristled

Hive , Lophiomyida) . . . . 30\%

Genus: Bristled Mice (Lephlit. omyss) . . . . . 307 "Skull-cap (L. imhansii) . ${ }_{307}^{307}$ 
Eirititi Oruer: THE TOOTHLESS ANIMALS. Eidentutu. : 381.

First Famils: Nloths (Bradypo. did $(\bar{c})$.

I.-Genus: Two-toed Sloths ( $\mathrm{Cho}$ licpus) 2.-Genus: Three-toed Sloths (Bra. ${ }^{3 \mathrm{~S} 2}$ dipus)

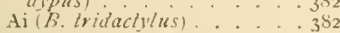

SECOND FAMILY: Int-Eaturs (.Mj). mecophagida)

r.-Genus: Aut Bears (.Mrrmeco. phagal

Nixtil ORER:

Fanily: Elephants Elcphantida.

Genus: Elephants (Elephas)

\section{E.AGE}

Great Ant-Eater ( $M$. jubata)sS6

2.-Genus: Tree-Climbing Aut-Eat-

ers (Tumandua) $\cdot \cdot \cdot \cdot 387$

3.-Genus.-Iittle Ant-Faters ( $\mathrm{Cy}^{3}$

cloturus)

Two-toed Aut-Eater $(\dot{C}$. didac-

tylus)........ . 388

THIRD FanIry : Iruadillos (D)asy'-

podida) . . . . . . . . . 358

I.-Genus : Armadillos Proper ( $D a$ sypus)

THE ELEPHANTS. Probustiten. $: 39$ -

Tatmpoyu ( $D$. illlosus)
Six-bauded
Armadillos
${ }^{3 S g}$ Six-bauded Armadillos ( $D$.
sexcinclus) . . . . . . 389

2.-Genus : Three-handed Armadillos (Tolypeutes). dive i 391 (ricinctus) . . 39

3.-Genus : Priodons (Priodon) . 391 Giant Tatu ( $P$. gigus) . . . 392 4.-Geuns: Cloaked Aruadillos (Chlamydophorus)... . 392 Bichociego (C. truncatus) : 392

African Eleplaant (E. ufricanus).......... 395

\section{Texth Orden: THE ODD=TOED ANIMALS. Perisodutylu. t05.}

First FaMill: Horses (Equida) . . 105 Genus: Horses (Equns). . . 405

Tarpan..........406

Cimarrones . . . . . . . 106

Mustang. . . . . . . . . 409

Arabian ...... . 409

Trakehnen. . . . . . 410

English Thoroughbred . . .410

Anglo-Arab . . . 410

American Trotting Horse . . 4 41

Percheron . . . . . . 4 41

Slietland Pony . . . . . . . .41 I

Koulan (E.henionusi. $\quad 413$

Onager (E. onager) . . . 415

Domestic Ass ( $E$. asinus) _. . 115

African Wild Ass ( $E$, asinus uficanus

Eleterth ( Triet: THe

FIRST SUborder: Ruminamts or

Two-hoofid Inimals (Fidactyla) . 433

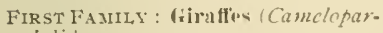

dalider)

434

Genus : Giraffes (Camclopardalis) . 434 Giraffe (C. givuffu) . . . . 434

SECOND Famiry: (amels (Camelida) 437

1.-Genus: Camels (Camelus) . . . 438 Dromedary ( $C$ dromedarius) $43 \mathrm{~S}$ Bactrian Cansel (C. bactrianus) 4.12

2.-Genus: Llamas (-Inchenia). 4.43

Guanaco (-1. huanuco) . . . 44

Llama $(.4$. lama) . . . . . 4

Alpaca (.1. paco) . . . 446

Vicugna (.t. zisugna). . . .47

THIRD FAMIL: Ilomed Inimals

(Bovida) . . . . . . 447 GOATS AND SHEEP ( aprina) + $44 \mathrm{~S}$

I.-Genus: Goats (Capra) . . . 45s Alpine Ibex $\left(C\right.$. $i$ ire. $\left.^{2}\right) \quad . \quad .450$ Pyrenean Ihes ( $C$. pyrenaica) 450 (ucasian Ibex (C.cancasica) 450 Aigagrus (C. cerugms). . . .453

* Marklioor (C. fixlconeri) . . 454 Domestic Goat (C. hircus) . .455 Angora Goat ( $C$.h. angon'nsis) 455 Cishmere Goat (C. h. laniger) 456 irian Goat (C. $h$ nambrica) 456 Egyptian Goat ( C.h. agyptica) 456 Dwarf Goat ( $C$. h. rezcrsa) . .457 *Talır ( $C$ jemlaica). . . 457

2.-Genus Sheep (Otis). . 45s Aoudad i O. (ragelaphus\}. . . 459 Mouflon (0. musimon). . . 460 *Kratichkar $(O$. polii) . . . .46 Argali ( 0 . argali)
Somal Ass (E. asinus somali-

(us). . . . . . 416

Mule (E. inulus) ......41S

Hinny $(E . / t n n u)$. . . . . 418

Quagga (E quagga). Surchel. $^{+19}$

(ii)...... 419

Zebra $(\dot{E}$. zebra). . . $\quad 419$

SECOND FAMIL': : Tapirs (Tapiridac) 120

Genus: 'Tapirs (Tapirus)... 422

Malayan Tapir ( $T$, indicus . .422

Anerican Tapir ( $T$. america-

nus).......... 422

THIRD FAMILY: Rhilloceroses ( Rhi.

nocerotidét . . . . . . 424
Genus: Rlunoceroses (Rhinoc. eros). 424 Indian khinoceros (R. unicorWara Rlinoceros ( $\dot{R}$ sondai. Two-liorned kbinoceros ( R. bi- ${ }^{426}$ cornis). 426 Sunatran Rhinoceros ( $R$. sil- ${ }^{+26}$ malrensis). 426 -Square - monthed Rhinoceros
$(R$. simus)... . . . . . . 43

Fourh FAMILx: (onies (IIracida) 431 Genus : Conies (Hyrax) . . . $43^{2}$ Abyssinian Cony (H. abysini(us) ....... . 432

\section{CLOVEN HOOFED ANIMALS. Lrtiortutylu. 433.}

Kamchatkam Wild (O.nivicola) 46

Big Horn (O. Montana) . . 462

Merino ( $O$, avies hispanica) 463

Persian (O) aries steatopyga pirsita)

THE MUSK-OXEN (Or'iborino)

3.-Genus: Musk-Oxen (Oribos)

IIusk-Ox (O). moschatus)

THE OX TRIBE (Böina)

4 Genus: Oxen (Dos).

Yak (B. grunnicus).

Furopean 468

American Bison ( $B$. amcri-

canus). . . . . . . . 47t

Gayal $B$. fiontalis) . . 476

Gaur (B. gaurus) . . . . . 477

Banteng (b'. bunling). . . . 47s

Sanga ( $B$, africanus). . . . 479

Zebu (B. indicns) . . . . 45o

Park Ox (B. scoti(us) . $48 \mathrm{I}$

Freiburg $O x\left(B\right.$. tam ${ }^{2} i-$ burgensis) . . . . 48 $\mathrm{I}$

Dutch $\mathrm{Ox} B$. $\mathrm{t}$. hollandicus $48 \mathrm{~s}$

Short-Horn (B.t. dunelemen-

sis) . . . . . . . $4^{8_{2}}$

United States Wild Cattle. . 4\$2

Jersey Cow

Hereford 131111.

Cape Buffalo $\left(h^{\circ}\right.$. caffer $\ldots .45$

Iudian Buffalo ( $\left.B . a^{*} n i\right)$. . . .

MoENTAIN GoATS (Aploccrine) . . . 4isg

5.--Genus: Mountain Guats (AploRocky ilonntain Goat $i^{489}$ montanus) ....... fig
ANTELOPE TRIBE (Antilotina).

6.-Genus : Antelopes (.tntilope) . 49I Sisan (-1. cerricapra). . . 49I Gazelles ( 1 . dorcts) . . . 492 Springhok (A. cuchorc) . . 494

7.-Genus: Ox-Autelopes (Bubalis) 495 Hartebeest ( $D$. caama). 496

8.--Genus: Reed Antelopes ( $\mathrm{R}$ :

$\begin{array}{cc}\text { dunca) } & 496 \\ \text { Riet-bok (R. cleotragus) } & 497\end{array}$

9.-Genus: Water-bucks (Fobus). . 497 Water-buck ( $K$. ellipsiprim. nus..... . 497

Io.-Geus : Oryx Antelopes $\left(\sigma \gamma \cdots x^{-}\right) .498$ Passan (O. capensis) . . . . 498 Besia $(O$. besia) . . 498 Algazel (O. (cucorj'x) . . 49S

11.-Genus: Aldax Antelopes (.1uda.r. ...........49s Addax (.1. navomactialus) 500

12.-Genus : Spiral Horned Antelopes (Slripsiceros) 500 Foodoo (S. kudu). . . . . 500

I3. -Genus : Bovine Autelopes (Buse. laphus). Fland $B$ oreas $) .502$

14.-Genus : Nylghaus (Forta $x$ ) . 502 Nylghau (P. pictus) ... 502

15.-Genus: Four-Horned Antelopes (Te'raieros\} . . . 504 Four-Horned( $T$. quadricornis) 504 15.-Genus: Bush-Bucks (C Cphalolo. pirus)

Duyber i : . . . . 504

17.-Genus: Dwarf Antelopes ( 1 co- 504 tragus) 505 Greyhound Antelope $(\mathrm{I}$. hen. prichii). . . . . 505 
IS. - ienus: Mountain Antelopes (Nemurhatus). Goral ( Y goral).

9.-Geuus: Chamois (Capella). Chamois (C. rupicapra).

20.--Genus : Saigas (Co/us).

Saiga (C. futaricus).

21.-Genus: Guus (Citoblcpas) Gnu (C. $g n u)$

Folrth FaAny: Proms-horned

Inimals t.-Antilocapribs

Genus: Pronghorns (AntilocaPra)

Fifth Faurli : Deer (Ceride) . .516

1.-Genus : Elks 1.tllces)

Elk t t palmatus)

Ioose $(-1$ americana

2.-Geuns : Reindeer ( Riunsifir Reiudeer IR. $t a$ rundus Caribou ( $R$ caribu)

3.-Geuns: Fallow Deer (Dama Fallow Deer ID. inlsaris

4.-Genus : Red Deer (Cirus) Stag i $C$ elaphus Barbary Deer (C. birturus) Wapiti ( $C$. camadensis)

5.--Genus : Axis Deer $(-1$. 7 is Axis Deer (A. a.1 i )

6.-Genus: Rusine Deer ( Rusa) Great Rusa th trippelapin Sambhar ( $R$. aristotelis). . 53 Hog Deer ( $R$. porcinus)
-Genus: North American Deer (Cariacns) . . . . . 53 Virginia Deer (C. airginianus) 531 White-Tailed Deer ( $C$. lencuBlack-Tailed Deer (C. colum. 534 bianus). 531 Inle Deer (C. mairotis) . 534 Mexican Deer (C. mexicanus) 534 -Genus: Pampas Deer (Blastocerus) Pampas Deer ( $B$. cimporstrist 5 . 9.-Genus: Roe Deer (Capreolus) . 534 Roe Deer (C. Caprca) . . . 534

1o-Genus : Muntjak Deer (CirizInuntjak Deer (C. mintjac) $\begin{array}{r}536 \\ 5,36\end{array}$

Sixtu Faujl: Huh Wrej (.Mosihid(a)

Genus: Misk Deer (.Mosihns) . 537 Musk Deer ( K. moschifirus . 537

SETENTH Famer: Chevrotaius (Tragulides)

Genus: Chevrotains (Tiagu(us) $53 \mathrm{~S}$ Kanchil (T. kunchil). . . . 53i

SECOND SUBORDER: Clovell-houfod

Yon-runiuats (Suine) . . . . . 539

EIghth FAмrLy : Awine (Suide) . 539

1.--Geuus : Swine (Sins) ... . .539

Maned Hog (S. cristatus) . . . 5t2

Andamanese $\operatorname{Hog}$ is. andiman-

$5+2$
Hog (S, barbatus) . 542 Striped Hog (S. vitlatus). . $5+2$ Javan Wrild $\operatorname{Hog}$ (S. a'crucosus) $5+2$ Celebes Hog (S. ciele'nsis) . $5+2$ Timor $1 \log (S$. timorensis) $\quad 5+2$ New Guinea $\operatorname{Hog}(S$. papucnSis) . . $5+2$

Black Hog (S. nigCr) . . . 542

IThite-bearded Hog (S). lcu-

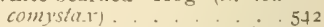
Semuaar $\operatorname{Hog}(S$, simarisis $) .5+2$ IVild Hog (S. So(fiz) + . . 542

Birkshire Hog . . . . 543

II arrison Hog .543

Masked $\operatorname{Hog}$ (S. plicipleps) . . 544

2.-Genus: Humped Hogs (Pola-

mocharus) ...... $54^{6}$

Tufted Hog i P. porcus) . . 576

Bush Hog (P.africanus) . .546

3.-Genus: Babirusa (Por(us) . . . 546 Babirusa ( $P$. baby ussa) . . . 546

4.-Genns: Wart Hogs (Ihacoific)$\begin{array}{ll}\text { Wh } & 547 \\ & 545\end{array}$ 5.-Genus : Peccaries (Dicolyles) . . 548 Collared Peccary $1 \mathrm{D}$. lorqua(us) 548

White-lipped (D. labiatus) $54 \mathrm{~S}$

NiNTH Famis: Hippopotami (Hip.

popotamide ). . . . . . . 549

Geuus: Hippopotami (Hippopo-

Hippopotamus (H. amphibins) 549

Hippopotamus $(H$. amphibins liberiensis.

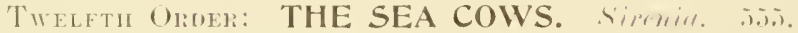

First FAmby: Manalees (Manatider) (renus: Manatees (.Manatus) $\quad .555$

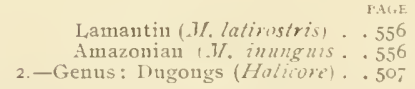

Ingong $\mid H$. dusong $\mid . .557$ Sea Cow $1 H$. stellerii).$\cdot 55 \mathrm{~S}$

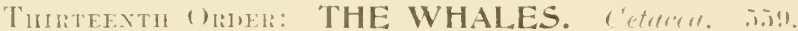

First Family : Firvowid Whales (Balchopterides).

1.--Geuus : Hump-back Whales (.T/esaplera) Hump-back whale ( $1 \%$ iong $i^{564}$ mana)

2. -Genus : Razorback Whales $\left(P / y^{\prime-}\right.$ snlus)

Razorback Illale $P$ antiqumum) .. . . . 564

3.-Genus: Beaked Wbales (Balcn. optirit

Pike Whale ( $D$. irstrata 565

SECOND FAMII : Smouth-skinnel

Whalus lialcentite) . . . . . 565 Geus : Greeuland Whales ( $\mathrm{Bal}$ (') .565
FIRST SUBORDER: Heririrelous Punched Inimals (I)iprofulontia) 579 First Fanily. Lenpina Ponched Inimals (. Macrop-dide)

THE KANGAROOS (.1/aropodilla") . . 5SO

1.-Geuns: Giant Kaugaroos 1. 1/acroGunlkangaroo $1 / .5 \mathrm{~s} 2$ 2.-Geuns : Nountain kangaroo

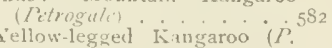
ranthopus). Rork liangaroo ( $P$ pinicillata) $5 \mathrm{Si}_{2}$
Greenland Whale (B. mysti(ist 11,5$)$

THuke FaArs: : Dolphius (Dilphinillis

\section{1.-Genus : Grampus ( () ra)} Grampus $(0$. oludiutor

2.-Genus: I'orpoi-es (Mhoicina) 569 Porpoise (\%: commnnis). 569

3-Genus: White Whales ( Di:lugu) 569 Beluga ( $B$. lincas). 570

4.-Genus: Roumb headed whales (Glohiociphatus).... . . 570 pilot Whale (G. mitas) . . 570

5.-Genus : Dolplinins (De (phinus) . 5, 1 Dolphin (D). delphis) . . . . 571

6.-Geuns: Long-lueaked Dolplinius (Inia) Inia $(L$ amaromica) . $5,5,2$

7.-Genus : Soosoos (Plalanisia) .572

Soosou $(P . g a n g e t i(a) \ldots .572$

Fockth liamly; Xajwhal ( Monodontide . . . . . . . . 573

Genus: Narwhals (.Monodon) . . 573 Narwhal (.1\%. monoicros). . . 573

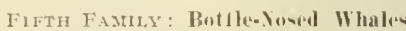
(Hyporoodontida). . . . . . .574

Geuus: Bottle-noscd Whales (Hypcoodon) Bottle-nosed Dolphiu (H. bi. (cns)............57t

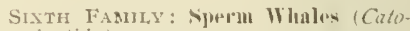
dontid, . . . . . . 575

Genus: Sperm Whales (Citodon) 575 Sperm Viliales $(C$ : macoocephalus).

THE POUCHED ANIMALS. Masmpintiu. 5it!

3.-Geuns: Tree Kaugaroos ( $\left.D_{c}\right)^{\mathrm{PT}}$ drolagns)........... 5\$2 Bear Kangaroo (D. Mrimus) ${ }_{5} \mathrm{~S}_{2}$

KANGAROO RATS (Potoroinc) . . . . 5 $\mathrm{S}_{2}$

4.-Genus: Opossum Rats (Btiton.

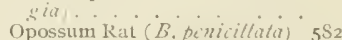

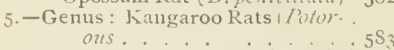
Kaugaruo Rat ( $P$. tritadilus) ${ }^{5 \mathrm{~S}_{3}}$

SECOND FAMr1, : ('limbine Mar×upials (Phatangeride). . . . . 583
ALSTRALIAN BEARS ( Phas-colurdi-

$n(C) . . . . . . . .554$

1.-Geuus: I'ouched Rears (Phascolarctus. . . . . . . . 5s Iioala ( $P$. cinerins). . . . . 584 SMALL POLCIIED ANIAIAL ( Phalangerincl............. . . . 5S 2.-Genus: Cuscus (Phalanger). . 55t Spotted Cuscus ( $P$. macmlains) $5 \mathrm{St}$ 3.-Genus: Coosoos (Ti-ichosm?s) . 585 vulpine Plialanger ( $T$. F'ultiecirlat) 
4.-Genus : Pouched Squirrels ( $P^{P}$ tanrvides)........ . . 586 Pouched squirrel ( $P$ irolans) 556

5.-Genus : Sugar Squirrels (Pitutmes) ......... . 556 Sugar Squirrel ( $P$. scinrits) 556 6.-Genus: Opossum Monse (.tcrobates). . . . . . . . 587 Opossum Mouse (A. pleméns) $5 \mathrm{~S}$ 7

THIRD FAMrLY: Wombats or Rodunt-

like Yar-mpials (Phascolompidac).

Genus: Wombats (Phascolomys) 58 ? Tasmauian ITombat (P. ursi-

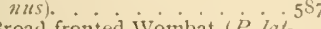
Broad-fronted IVombat (P latifrons). . . . . . . . $5^{57}$

SeCONd Suborder: Carnivornus

Marsilpials (Polyprolodonlia) . . 5SS

\section{Fiftefexti Ordie:}

First Fanily: Int-eaters (Echidnid(c) . . . . . . . . . . 596 1.-Genns: Porcupine Ant-eaters (Echidna) . . . . . . . . 596 Australian Porcupine Ant-eater (E. aculcata tipica) . . . 596
FOURTH FAaILY: Bandienots (Pi): amelide) . . . . . . . . . 588

Genus: Baudicoots (Perameles)'5ss Long-nosed lBandicoots ( $I$. no suta) ...58s

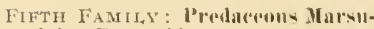
pials (Dasyzuride) . . . . . . . 588 THE DASYURIXES (DiSyurina).

1.-Geuns: Zebra-wolves (Thylacinus). . . . . . . 5S Zebra-wolf ( $T$, ejroccphalus) 589 2.-Genus: Tasmaniat Devil (Surco philus)....... . . 58 Tasmauian Devili $S$. ursinus. 589 3.-Genus: Dasyures (Dasymus) . . 590 Spotted Dasyure (D. "itc\%inus). .........590

EGG=LAYING MATIMALS.

Papuan Porcupine Ant-eater (E. aculeata laácsi) . . . . 596

Tasmanian Porcupine Anteater ( $E$. aculeata sctosa) .596 2.--Genus . Woolly Echidna (Proechidna) . . . . . . . 597
THE BANDED ANT-FATERS ( $M y r$ mecobiina). . . . . . . 590

4.-Genus : Banded Ant-eaters $(M / y, r$ mecobius) . . . . . . . 590 Bauded Ant-eater $(\dot{M}$. fascialus $) 590$

Srxth Family: Ponched liats ( $D i$ -

delplyyide) . . . . . . . 59

1.-Genus: Pouched Rats (Didelphys)......... . 59I Commou Opossum ( $\bar{L}$. marsupialis) 59

2.-Genus: Philanders (Philander). 594 Crab-eating Opossum ( $P$. philander)....... 594

3.-Genus : Water Opossums (Chironectes) . . .

Wonotremate. 595.

Woolly Echidtra ( $P$. bruijuii) 597 SECOND FAMILy: Duck-moles (Ornithorhynchide) . . . . . . 597

Genus: Duck - moles (Ornilhorhynchus) . . . . . 597 Duck-mole ( $O$ ancinus) .597 



\section{INDEX TO TEXT.}

Aard-vark, 396

Aard-Wolf, is

Abyssinian Cony or

Ashkoko, 432

Abyssinian Lioli, 106

Acrobates, $5^{5} 7$

Addax, 495

$$
\text { pygmieus, } 5^{8} 7
$$

anteloves, 498

nasoniaculatus, 500

Adjag, 200

Aegagr us or Wild Goat, 453

African Cheetah, I35

Árican Ciret, Ito

Africau Elephant, $39 \mathrm{~S}$

African Ground Pig, 360

Afircan Hartebeest, 496

African Naked Dog, 218

Africau Rhinoceros, 426

African Wild Ass, +15

Agoutis, 362

Aguara or Azoras Fox, $19 \mathrm{~S}$

Ailuropoda, I 39

Ailuropus, 26

Ailurinæ, 264

Ailurus, 261

" fulgens, 26,

A lact agas, 329

Albinos, $39^{\circ}$

Alces, 5 Is

"“ americaua, 520

" palusatus, 518

Algazel or Wile Cow, $49 \mathrm{~S}$

Alimizilero, 303

Alpaca, 446

Alpine Crying Hare, 380

Alpine Hare, 375

Alpine Ibex or Steiubock, 450

Alpine Marmot, 320

Alpine Wolf, 203

Alunqui, 295

Aluate or Red Howler, 53

American Badger or Taxel, I7

Americau Bisou, 472

American Feline Animals, I20

American Fox Squirrels, 310

American Mleadow Mlouse, $3+7$

American Mink, 16

American Mole, 295

Americall or Broad-Nosed

Nonkeys, 50

Aurerican or Rocky Mountain

Pika, 379

American Otter, 179

Anterican Sable, I56

American Skunk, 171

American Spermophiles, 316

American Tapir, 122

American Trotting Horse, 4II

Anerican Varying Hare, $37 \mathrm{~S}$

Anerican Wrild Cat, I.33

Andanianese Hog, 5.12

Angora Cat, 105

Angoria Goat, 455

Angwántibo L,emur, 72

Ant-bear, 386

- Ant-ezters, 356

Ant-eaters, 596

Autelopes, 490

Autilocapra, 513

anericana, $5 \mathrm{I} 3$

Antilocapridix, 513

Antilope, 491

$$
\begin{array}{ll}
\text { “. } & \text { carvicapra, } 491 \\
\text { dorcas, } 472 \\
\text { euchore, } 494
\end{array}
$$

Antilopinæ, 490

Anthropomorpha, 5

Aoudad, 460
Apella or Brown Capuchin, 57

Apes aud Monkeys,

Aplocerinæ, 489

A piocerns, 459

montanus, 459

Ara'ian Ass, 416

Arabian Horse, fog

Arctic Fox, 23 S

Arctitis, 264

binturong, 264

Arctocebus, 72

Arctocelus c.tlabarensis, 72

Arctoms in:e, 315

Arctomys, 315

$$
\begin{array}{ll}
\because & \text { bubac, 3IS } \\
\because \quad \text { flaviveutor, 32I } \\
\because \quad \text { monax, 32I } \\
\because \quad \text { marmota, 320 }
\end{array}
$$

Arctopit pruitiosus, 32

Argali, 462

Armadillos, 388

Artiodactyla, 433

Aru, 55

Arvicola, 345

agrestis, 347

amphibius, $3+5$

arvalis, 347

“ glareolus, 3.6

“ nivalis, 3.6

“ aeconomus, 349

“ rip $₫$ rius, 347

Arvicolidxe, $3+4$

Ashkoko, 432

Asiatic Cheetah, I35

Asiatic Civet, Ito

Asiatic Elephant, 397

Ass, 4I5

Ass of the Plains, 415

Assapau, 312

Aises, 413

Ateles, 54

"' bartlettii, 55

" beelzebuth, 55

“ hypoxanthus, 55

" paniscus, 55

" pantadactylus, 55

Atherura, $35^{\circ}$

Atherura africana, $35^{\mathrm{s}}$

Auchenia, +43

" huanaco, 444

“ lama, 444

“ pacos, 446

vicugua, 447

dngwántibo, $7^{2}$

Aulacodus, 369 swinderianus, 360

Australiau Bear, 58

Australian Porcupine Anteater, 596

Australiau Wild Dog, 204

Axis, 530

"' axis, 530

Axis Dear, 530

Aye-Aye, 73

Babirusa, 546

Baboons, $4 \mathrm{I}$

Bactrian Camel, 412

Badger Dogs, 221

Badgers, : 68

Balæmida, 565

Balæena, 565

mysticetus, 565

Balænoptera, 565 rostrata, 565

Balæuopteridæ, 56

Bauded Aut-eater, 590
Banded Mungoos, I5o

Bandicoots, 5 SS

Bank Vole, 3.6

Banteng, 475

Barbary Ape, 39

Barbary Deer, 520

Barbary Lion, 106

Barbastelle or Pug.Dog Bat, $\mathrm{S}_{2}$

Barren Gronnd Bear, 250

Baslıful Billy, 69

Bussaris, 272 astuta, 272

Bay Ly'nx, 133

Beagle Dogs, 224

Beaked Whales, 565

Bearded Hog, 542

Bear Fanıly, 2.13

Bear Kangaroo, $5^{\mathrm{S} 2}$

Beasts of Prey, 87

Beaver, 323

Beaver Sbrews, 303

Beech Martin, I53

Beisa, 495

Beluga, 569

leucas, 570

Bettongia, $5 \mathrm{~S}_{2}$

persicilata, $5 \$ 2$

Bhunder, or Rhesus Moukey, $3 \mathrm{~S}$

Bichociego, 392

Big Horn Rocky Mountain Sheep, 462

Binturong, 264

Black Baboon, 43

Black Bear, 252

Black Colobus, 30

Black Fox, 237

Black-headed Saki, 59

Black Himalayan Bear, 253

Black Ilog, 542

Black Howler, 53

Black MIaki, 67

Black Pauther, I I4

Black Rat, 333

Black Rhinoceros, 426

Black Squirrel, 310

Black-tailed Deer, 534

Bladder-llose Seal, 279

Blarina, 300

" brevicauda, 300

Blastocerus, 534 caupestris, 534

Blenheim Spaniels, 225

Blood-sucking Bats, 83

Blue-faced Guenon, 34

Brachyurus, 59

$$
\text { " calvus, 6I }
$$

melanocephalus, 59

Bradypodida, $38 \mathrm{I}$

Bradypus, $3 \mathrm{~S} 2$

$$
\text { tridactylus, } 3 \mathrm{~S}_{2}
$$

Braziliau Otter, I79

Broad-fronted Niousbat, 587

Broad-nosed Monkey, 50

Broad-nosed Shrew, 300

Brown Bear, 21

Brown Capuchiu, 57

Brown Hy:ena, IS5

Browti Rat, 333

Brush-tailed Opossum, 590

Brush tailed Porcupine, $35^{S}$

Bobac, 3 IS

Bonnet Monkey, 36

Bos, 468

" africanus, 479

" americauus, 474

" arui, 4 S6

" banteng, 478

" bison, 470

Bos, caffer, is 5

froutalis, 476

ganrus, 477

grumniens, 468

"iudicus, 480

"scoticus, 4 is

taurus friburgensis, $48 \mathrm{r}$

" ". dunelemensis, 4 s

" hollandicus, 48

Bottle-11osed Dolphin, 574

Bottle-uosed Whales, 574

Bouquetins, 450

Boville, $4+7$

Boviua, 466

Bovine Alitelopes, 502

Boxer, 221

Bubalis, 495 caanua, 496

Budeng or Negro Monkey, 27

Buffaloes, 485

Bulidog, 220

Burchell's Zebra, 119

Burnnduk, or Striped Siberian

Ground Squirrel, 313

Bush.bucks, 504

Bush Hog, 546

Buselapkus, 502 oreas, 502

Cacajao, 59

Cachalot, 575

Cacomixle, 272

Ca'iug Whale, 570

Cai or Sai MIonkey, 56

California Gray Squirrel, 3 10

California IVood Rat, 336

Californiau Mouse, 340

Califorviau Hare, 379

Callithrix, 59

$$
\text { “ lugens, } 59
$$

personata, 6

Camelidæe, 437

Camels, 437

Camielus, $\div 38$

$$
\text { ". bactrinaus, } 4.12
$$

Iromedarius, 435

Canieloparclaliclac, 434

Camelopardalis, 13.1

Campagno1, 347 giraffa, 434

Canadian Beaver 
Capra, caucasica, 450 falconeri, 454 hircus, 455 h. egyptica, $45^{6}$

"h. angorensis, 455

، 1. laniger, 456

“ h. nuambrica, 456

" h. reversa, 457 ibex, 450 jemlaica, 457 pyrenaica, 450

Capreolus, $53 t$ Caprine, $4+8$ capraz, 534

Caprbara, 30

Capuchins, 56

Caracal, 134

Carasa or Black Howler, 53

Cariacus, 531

columbianus, 534

lencurus, 534

macrotis, 531

mexicanus, 53.4 virginianus, 531

Carjacou; 53

Carnivora, 87

Carnivorous Mlarsupials, 5 SS

Caroliua Lyux, I34

Cashmere Goat, 456

Caspian Seal, $27 \mathrm{~S}$

Castor, 323

" canadensis, 324 fiber, $\hat{3}^{2} 3$

Castoridx, 323

Catarrhini, $\mathrm{S}$

Cat Family, SS

Cat-Footed Civets, 139

Cat-like Bears, 264

Catoblepas, 512

Catodour, $5 \div \frac{5}{5}$ guu, 5I 2 macrocephalus, 575

Catodontidice, 575

Cats Proper, 92

Catta Leminr, 67

Cavia, 360

aperea, $3^{\text {rio }}$

" cutleri. 360 porcellus, 360

Caries or Guinea Pig Family, 359

Caviidae, 359

Cebidic, 52

Cebus, 56

. apella, 57

. capucinus, 56

" cucogeny's, 58

". hypolencus, $5 \mathrm{~S}$

" olivaceus, $5 \mathrm{~S}$

Celebes Hog, 542

Centetes, 297

$$
\text { ecaudatus, } 297
$$

Centelidxe, 297

Cephalolophus, 5c

$"$ mergeus, 504

Cercopithecus, 30

Cercolabes, $35^{\circ}$

$$
\begin{aligned}
& \text { " nova hispaniae, } 35^{\mathrm{S}} \\
& \because \quad \text { prehensilis, } 359 \\
& \text { villosus, } 35^{\mathrm{S}}
\end{aligned}
$$

Cercolabinae, 356

Cercoleptes, 271

Cercoleptes caudivol vulus, 27 I

Cercopithecus diana, 34 cephus, 34 fuliginosus, 35 ruber, 34
sabxus. 32

Cervidise, 516

Cervus, 526

barbarus, 529

canadeusis, 529
elaphus, 526

Cervulus, 536

$$
\text { mıutjac, } 536
$$

Cetacea, 559

Chacma, 44

Chameck, 55
Chamois, 506

Clueetah, 135

Chestuut-backed Gray Squir

Iel, 3 IO

Chestrut-Cheeked Gopher, 354

Cherrotains, $53 \mathrm{~S}$

Chickaree or Red Squirrel, 310

Chimpanzee, 16

Chipmunk, 3I 4

Chinchillas, 369

Chirogaleus, 69

Chiromys, 73 furcifer, 69 marlagascarienis, 73

Chironectes, 594 mimimns, 594

Chiroptera, 75

Chlamydophorus, 329

Cholcepus, $3 S_{2}$ truncatus, 392 didactylus, $3^{32}$

Chrysothrix, 59 sciurea, 60

Cinuamon Rear, 352

Civet Fauily, 139

Climbing Marsupials, $5 \mathrm{~S}_{3}$

Climbing Porcupines, 356

Clouded Tiger, 99

Cloven-hooferl Animals, 433

Cloven-hoofed Non-Ruminants, 539

Coaita, 55

Coast 1:0x, $2+3$

Coatis, 269

Coelogenys, 363

". paca, 363

Condou, 359

Collared Peccary, 518

Colobus, $2 S$

$$
\text { guereza, } 2
$$

satanas, 30 ursiuus, 30

Colugo or Kaguang, 304

Colus, 510

tataricus, 510

Comba, 71

Common Agouti, 362

Common Baboon, 44

Common Badger, 160

Common Bat, $\mathrm{S}_{2}$

Common Brown Bear, 24

Common Chinchilla, 360

Common Jormouse, 322

Conmulu Fox, 232

Common Fox Squirrel, 3 ro

Common Galago, 71

Common Genette, 141

Common Ilamster, 3.10

Common llare, 371

Conmon lledgeliog, 290

Common Jungle Cat, 134

Conmon Ly ux, I30

Common Macaque, 36

Common Marmoset, 63

Common Marmot, 320

Common Mole, 295

Common Mole Rat or Slepez, 351

Conımon Mouse, 336

Common Opossum, 591

Common Otter, $1-6$

Conmmon l'ocket Rat, 354

Common l'aradoxnre, I42

Contmou Porcupine, 354

Conmon Seal, $2-5$

Common Shrew, 299

Coummon Squirrel, 306

Common [Wile] Cat, 99

Condylura, 296 cristata, 296

Conies, 431

Cooper's Mlouse, 350

Coosoo, 5 S5

Corsac or Fox of the Steppes, 239

Cotton or Rice Rat, 336
Cotton-tail or Wood Rabbit, 379

Cougar or Puma, I20

Couiv, $35 \mathrm{~s}^{\circ}$

Coyote, 197

Coypu or Nutria, $36 \%$

Crab-eating Dog, 195

Crab-eating Raccoon, 265

Crab-eating Opossum, 594

Crab Mnngoos or Urva, 150

Crested or Hooked Seal, 278

Cricetinx, 340

Cricetodipns, 352

flavus, 352

Cricetus, 340 parvus, 352

". frumentarius, 430

Crocidura, 302

aranea, 302 suaveolens, 302

Crossarchus, I 46 obscura, 146

Cross Fox, 237

Crossopus, 302 fodiens, 302

Crying Hares or Pikas, 379

Cryptoprocta, I 3 ferox, $13 \mathrm{~S}$

Cuscus, 584

Cnvier's Lagoti, 371

Cuxio MLonkey, 5 is

Cycloturus, 38

didactylus, 388

$$
\begin{array}{ll}
\text { ، } & \text { guttatus, } 135 \\
\text { jubatns, 135 } \\
\text { laneus, 135 }
\end{array}
$$
soenmeringii, I 35

Cruictus, 150 peuicillata, $15^{\circ}$

Cynocephalus, 4 I labuin, 44

gelada, 48

hamadryas, 46

leucophieus, 49

timortuon, 49

niger, 43

porcarins, 4

sileuus, 50

Cymontss, 336

splıiux, 44

ludoviciauus, 316

Cymopitheciui, 25

Cyuoporla, 144

Cyuonycteris, 79

Cron, 200

logptiacus, S1

Crstophora, 279

cristata, $2-9$

Daclislinuds, 221

Dama, 52. vulgaris, 526

Davish Dog, 2 เ8

Dasypodidie, 388

Dasy proct: $x, 362$

Dasypus, 3 sig aguti, 362

sexcinctus, $3 \mathrm{Sg}$ villosus, 359

Dasyuridae, 558

Dasyurina, 588

Dasyurines, 585

Dasyurus, 590 viverrinus, 590

Daubenton's 13at, 79

Dauw, 419

Deer, 516

F) gu, 367

Delphinida, 566

velphinus, 57

" delplis, $57 \mathrm{I}$

Dendrolagus, $5 \mathrm{~S}_{2}$

Desmaus, 303 ursinus, 582

Diana Mlonkey, 3

Dicotyles, $5.4 \mathrm{~s}$

labiatus, 548

Dicotyles torquatus, 548

Didelphyidee, 59.

Didelphys, 591 marsupialis, 59

Dingo, 204

Dipodidæe, 327

Dipodinae, 327

Dipodomys, 352

philippii, 352

it agyplicus, $32 \mathrm{~S}$

Dog, The, IS7

Dog-footed Civets, 144

Dog-shaped IIonkey's, 25

Dog of Thibet, 221

Dolphin, 57 I

Dolphins, 566

Dolphins Proper, 57

Dolichotis, 362 patagonica, 362

Domestic Ass, 416

Domestic Cat, I02

Domestic Dogs, 229 
Elinaceus, 290

europæus, 290

" chinchilla, 369 langera, 369

Ermine or Stoat, 162

Eiskimo Dog, 230

Etruscan Slirew, 302

European Bison, 410

Europeau Elk, 518

European Mink or Nerz, 164

European Porcupine, 356

Fahhad or Africau Cheetah, 135

Fallow Deer, 524

Felidae, 88

Felis, 92

“ bengalensis, 3 I9

" catus, 99

" concolor, 120

" leo barbarus, I06

" leo capensis, 106

" leo guzerateusis, 106

" leo persicus, Io6

، leo senegalensis, Io6

or niacrura, 129

" maniculata, 102

“ maniculata domestica 105

" maniculata domestica augorenesis, 105

" marmorata, 99

“ maniculata, Io

" melas, 1 i 4

nebulosa,

" onza, 124

" pajeros, I28

" panthera. I I

"pardalis, I 28

" pardus, II

" serval, 119

" tigrinis, 129

" tigris, 92

" uncia, II

“ variegata, 114

"viverrina, 119

- yaguarundi, I22

Fennec, 240

Ferret, 158

Fiber, 344

is zibethicus, 34

Field Shrew, 302

Field Vole or Short Tailed

Field Mouse, 347

Fisher Marten, 156

Florida lytix, 134

Florida Wood Rat, 336

Fiving Dogs or Fruit-Eating

Bat $\div, 79$

Flying Squirrels, 3 I I

Fork-crowned Lemur, 69

Four-horned Antelope, 504

Fisur-striped Chipmunk, 314

Foussa or Cryptoprocta, ${ }_{3} 8$

Foxhouud, 224

Foxes, 232

Fox Squirrels, 310

Foxy MIungoos, I5o

Freiburg $\mathrm{Ox}, 48 \mathrm{I}$

Fruit-eating Bats, 79

Galagos, 70

Galeopithecidae, 304

Galeopithecus, 304

Galictis, I 68 volans, 304

" barbara, 168

vittata, I68

Gaur. 477

Gaval, 476

Gazelle, 491

Gelada Baboon, 48

Genettes, 14 I

Gentle Lemurs, 69

Geoniys, 352

" bursarius, 352

castanops, 354
Geomys hispidus, 354 mexicanus, $35 t$ tuza, 353

German Bloodhound, 224

German Mastiff, 2I8

Giant Kaugaroo, 582

Giant Pangolin, 393

Giaut Tatu, 392

Gibbons, 23

Giraffes, 434

Globiocephalus, 570 melas, 570

Glutton or IVolverine, 166

Guu, 5 I2

Goats, 448

Gold-haired Monkey, 60

Golden Marmoset, 64

Golden Mouse, 340

Gold-faced Moukey, 55

Gophe's. 352

Goral, 506

Gorilla, 9

" girua, 9

Grampus, 568

Gray Fox, 241

Gray or Geutle Lemur, 69

Gray Gopher, 316

Gray Lemur, 69

Gray Prairie Squirrel, 316

Gray Seal, 278

Gray Squirrel, 310

Gray Wood Rat. 336

Great Ant-eater or Ant-bear, $3^{56}$

Great Bat, 8

Great Rusa, 530

Greater Horseshoe Bat, 86

Greevland Whale, 565

Green Moukey, 32

Greyhound, 215

Greyhound Autelope, 505

Grison8, 168

Grizzly Bear, 250

Ground Squirrels, 313

Grunting Ox, 468

Guauaco, 444

Guara, 19?

Guenons, 30

Guereza, 28

Guinea Pigs, 360

Gulo, 16

borealis, I 66

Guzerat Iion, 106

Gymuorhiua, 81

Hairy Saki, 59

Hairy-tailed Mole, 296

Half-monkeys or Lemuroids, 65

Halicore, 557 “ dugong, 557

Hamadryas, 46

Hamsters, 340

Hapale, 62

* argentata, 63 chrysoleucus, 64

jacchus, 63

leonina, 63

cedipus, 64

penicillata, 64

pygmæa, 63

rosalia, 62

Hapaleuıur, 60

Hares, 372 griseus, 69

Harrison $\mathrm{Hog}, 543$

Hartebeest, 496

Harvest Mouse, 339

Hedgehogs, 289

Hereford Bull, 485

Herpestes, I 44

$$
\begin{array}{ll}
\text { " } & \text { ichneumon, I50 } \\
\text { " } & \text { mungo, I47 } \\
\text { " urva, I50 } \\
\text { widdringtonii, I48 }
\end{array}
$$

Hesperomys, 340
Hesperomys aureolus, 340 californicus, 340 leucogaster, 340 leucopus, 340 michiganeusis, $3+0$

Hinuy, 418 oryzomys, 340

Hippopotami, 549

Hippopotamidæ, 549

Hippopotanus, 549

$$
\text { " amphibius, } 549
$$

Hoary Marmot, 321

liberiensis, 55

Hog Deer, 531

Honey Badgers, 172

Hooded Seal, 278

Hoolock, 23

Hoonuman, 25

Hopping Mice, 352

Horned Animals, 447

Horses, 405

Horseshoe Bats, 85

Hounds, 222

Howlers, 52

Hulman, 25

Humboldt's Lagothrix Monkey, 55

Hump-back IVhales, 564

Humped Hogs, 546

Hunting I,eopard, 135

Hutia Tonga, 367

Hyæna, 182

“' bruunea, 185

" crocuta, 184

striata, Is

Hyena Family, 182

Hyæuidx, $\mathrm{I}_{2}$

Hydrochcrus, 36

Hylobates, 23 capybara, 364

$$
\text { ". hulock, } 23
$$$$
\text { " lar, } 23
$$$$
\text { "، rafflesii, } 23
$$$$
\text { " syudactylus, } 23
$$

Hyperoodon, 574 variegatus, 23

Hyperoodontidaens. 574

Hyrax, 432

" abyssinicus, 432

Hyracida, 431

Hystrichidxe, 354

Hystrix, 354

$$
\text { cristata, } 354
$$

Ibex or Steinbock, $45^{\circ}$

Ichneumon, 144

Indian Buffalo, 486

Indian Paradoxure, 142

Indian Ratel, I 73

Indian Rhinoceros, 426

Iudiau Wild Dog, 200

Indris, 67

Inia or Bonto, 572

Inia amazouica, 572

Insect-Eating Animals, 289

Insectivora, 289

Introductory Preface, iii

Irislı Hares, 375

Istiophora, 83

Italian Greyhound, 2I7

Jackal, Ig6

Jackal Wolf, I94

Jack Rabbit, 379

Jaculina, 328

Jaculus, 328

" hudsonius, $32 S$

Jaguar, 124

Javan or Wara Rhinoceros, 426

Javan Wild Hog, 542

Jerboas, 327

Jersey Cow, 483

Jumping Hare, 330

Jumping Mouse, 328

Jungle Cat, 134

Kalan, 179

Kalong, So

Kamchatkan IVild Sheep, 462

Kanchil, 53

Kaugaroos, 5 so

Kangaroo Rats, 583

King Charles Spaniels, 225

King Rat, 335

Kinkajou, 27

Kit Fox, 235

Koala or Australian Bear, 584

Cobus, 497

Kolsun, 200

Koodoo, 500

Koulan, 413

Labiated or Sloth Bear, 260

Lagıdium, 370

Lagomys, 379

" alpinus, 380

priuceps, 379

L,agostomidre, 369

Lagostomus, 27 I

trichodactylus, 37

agothrix, 55

I.agotis, $37^{\circ}$ humboldtii, 55

lamantin, 556

Lar, 23

Large-eared Foxes, 240

Large-eared Makis, 70

Leaf-nosed Bats, 83

Leaping Pouched Animais, 
Long-nosed Bandicoot, 588 Loug-nosed or Proboscis Monkey, 2 S

Loug-tailed Fox, 2.37

Long-tailed Pangolin, 394

Loug-tailed Pauther, II 4

Long-tailed Tiger Cat, I2O

Lophiomyide, 307

Lophiomys, 307

imhausii, 307

Lovely-Haired Mlonkey, 6 I

Lupus, 190

Lutra, 176

" brastlienis, 179

" californica, 179

" camadensis, I79

" felina, 179

" vulgaris, 176

Lutrida, 1,6

Lycaou, 198

Lyux, I 29

" borealis, I33

" caracal, I34

" caroliueusis, I34

“ chaus, I3t

" fascinta, 134

" floridaulus, I34

، maculata, I 33

“ pardinus, 133

“ rufus, 133

"vulgaris, I3o

Lyuxes, 129

Lyre Bat, $\$ 6$

Macaco, 67

Macacus, 36

$$
\begin{array}{ll}
\text { " } & \text { memostrinus, } 39 \\
\text { " } & \text { rhesus, } 38 \\
\text { "Sinicus, } 36
\end{array}
$$

sylvauns, 39

Macaques, 36

Iacropodidac, 580

Macropodinae, $5^{80}$

Macrorhiuus, 279 leoniuus, 279

Macroscelides, 296 typicus, 296

Macroscelidiclec, 296

Macropus, $5 \mathrm{~S}_{2}$ gigauleus, $5^{82}$

II 7 got Monkey, 39

Makis, 67

Malay Wilk Dog or Adjag, 200

Malayan Bear, $25 t$

Malayan 'Tapir, 422

Mianatees, 555

Manatida, 55.5

Manatus, 556

$$
\text { " inunguis, } 556
$$

Maudrill, 49 latirostris, 556

Ianed Cheetah, I35

Ianed Hog. $5 t^{2}$

Maveless Lion, Io6

Iangue or Kusimanse, I 46

Manididæe, 393

IIanis, 393

" gigantea, 393

" Jongicaudata, 394

" pentadactrla, 394 tenumiuckii, 394

Ian-sliaperl Apes, $\$$

Mara or Patagonian Cary, 362

IIarbled Cat, 99

II 1 rguay, r 29

Marimonda or Arn, 55

II atkat Monkey, 38

Markhoor, 454

MI trul osets, 6

II armots, 315

IIrsh Rablit, 379

Iarsh Slurew, 302

Iarsupialia, 579

Marten I'amily, 150

Marten Group, 152

Martid: , 152
Masked Hog, 544

Masked Paradoxure, I 44

Mastiffs, 218

Mazama Deer, $53^{\text {t }}$

Megaderma, S6

" lyra, S6

Megaptera, 564

longimana, 564

Meles, 168

$$
\text { taxus, I } 69
$$

Melidæe, 168

Mellivora, 172

$$
\begin{array}{ll}
\text { " } & \text { capensis, } 172 \\
\text { indica, } 173
\end{array}
$$

Meloncillo, I 48

Melursus, 260

"i labiatus, 260

Mephitis, 173 suffocans, 174

“ varıus, 174

Merionidiuæe, 332

Merino Sheep, 463

Mexican Badger, I72

Mexican Caconnixle, 272

Mexican Gopher, 354

Mexicau Otter, 179

Mexicau Porcupine, 358

Mexicau Deer, 53

Mice, $33^{\circ}$

Michigan Mlouse, 340

Microcebus, 73

Mink, 164 myoxints, 73

Miriki, 5

Mirikina MIonkey, 61

Missouri Mole Mouse, 340

Mole Rats, $35^{\circ}$

Mole Shrew, 302

Moles, 294

Moose, 520

Mougoose Lemur, 67

Monk Seal, 275

Monkeys,

Monodon, 573 monoceros, $5 \pi 3$

Mouodontidæ, 573

Monotremata, 595

Mowotremes, 595

Moschidæ, 537

MIoschus, 537

$$
\text { moschiferus, } 537
$$

Ioufflon, 460

Mountain Antelopes, 506

Mountain Chipmunk, 3if

Mountaiu Kangaroos, 582

Mouse-colored Bat, $\mathrm{S}_{2}$

IIule, fis

Itule Deer, 534

II uugo, I47

Mungooses, I4t

I untjak Deer, 536

Muridae, 330

Murinze, 332

IIus, 332

" agrarius, 337

“ alexaudriuus, 332

" barbarus, 337

c. decumanus, 333

" gambiauus, 332

" minutus, 339

" musculus, 336

* rattus, 333 sylvaticus, 336

IItsaing. $1+2$

Iuscardinus, 322

avellanarius, 322

Musk Deer, 537

Musk-Oxea, 465

Muskrat, 344

Misquaw, 252

Mustela, 152

$$
\text { americana, } 156
$$

foina, I53

martes, I 52

pennantii, I56

zihelliva, I54

Niustelidre, 150

Mycetes, 52
Mycetes viger, 53 seniculus, 52

Mrdaus, I 73

“. meliceps, 173

Myodes, 34 S

IIyodes lemmus, 348

Iyogale, 303

moschata, 303 pyrenaica, 303

Mrogalinæ, 303

Myoxidæ, $32 \mathrm{I}$

Mroxus, 32 I

" dryas, 322 glis, $32 \mathrm{r}$

Myoptamus, 367

" coypu, 367

Iyrmecobiinae, 590

Iyrmecohiuus, 590

fasciatus, 590

Myrmecophaga, 396 jubata, $3^{56}$

Myrmecophagidae, 386

Naked Dog, 2 IS

Narica, 270

Narrow-nosed A pes, 8

Narwhal, 573

Nasalis, $2 S$

" larvatus, 28

Nasua, 269 uarica, 270 rufa, 269

Negro Moukey, 27

Nemorhcedus, 506

Neotoma, 336 goral, 506

$$
\text { ". cinereus, } 336
$$
fuscipes, 336

Neotragus, 504

"1 hemprichii, 505

Nerz, 164

Neurotrichus, 304 gibbsii, 304

Newfoundland I $\log , 225$

New Guinea Hog, 542

Nilbhandar or Wanderoo Monkey, 50

Noctule, 82

North American Deer, 53

North Auerican Wolf, I9.

Northeru Fur Seal. 28s

Northern Prairie IIare, 379

Npetipithecus, 60

Ny lghau, 502 trivirgatus, 6I

Ocelot, I 28

Octorlou, 367

Octodoutida

Odd-Toed Animals, 405

old World Mearlow Mouse, 337

Onager, 415

Opossum, 591

Opossum MIouse, 587

()possum Rat, 5S2

Orang-utan, Is

Orca, 568

" gladiator, 568

Ordinary Seals, 275

Ord's Pocket MIonse, 352

Oregou Lynx, I34

Oregon Mlole, 296

Oruithorbynclidie, $59^{-}$

Ornitborhynchus, 597

Ory $x, 49$ anatiuus, 597

". besia, 498

" capeusis, 498 lencoryx, 498

Oryx Antelopes, 49

Orycteropodidxe, 396

Orycteropus, 396

Otaria, 286 capensis, 396

jubata, 258

Otaria stelleri, 286 ursina, $2 S S$

Otariidee, 286

Otocyou, 24 megalotis, $24 I$

Otolicnus, 70

$$
\text { agisymbanus, } 71
$$

galago, $7 \mathrm{I}$

Otter Honud, 222

Otters, 176

Ounce, IIg

Ovibos, 465

" moschatus, 465

Ovibovinæ, 465

Oris, $45^{5}$

" argali, 462

" aries hispanjca, 463

“ aries steatopyga persica 464

" noutana, 462

" musimon, 460

“ nivicola, 462

" polii, 46I

tragelaphus, 459

Owl Mloukeys, 60

Ownerless or Pariah Dogs, 206 
Phalaugerida, $5^{84}$

Pharaoh's Rat, I 44

Phascolarctina, 583

Phascolarctus, 594

cinereus, $5^{8}$

Phascolomyidae, $5^{87}$

Phascolomys, 587

$$
\text { " latifrons, } 587
$$

Philander, 59 ursinus, 587

Phoca, 278

" caspica, 278

4. grcenlandica, 278

“ vitulina, 278

Phocæna, 569

"communis, 569

Phocide, 275

Phyllostoma, 84

Physalus, 564 spectrum, 84

" antiquorum, 564

Pigmy Musk, 538

Pikas, 379

Pike Whale, 565

Pilot Whale, 570

Pinche Marmoset, 64

Pine Marten, 152

Pıuipedia, 273

Pipistrelle Bat, 79

Pitheci, I

Pithecia, 58

" hirsista, 59

"s leucocephala, $5^{8}$

Pithecidæe, 58 satauas, $5^{5}$

Pithecus, 18

" satyrus, I8

Platanista, 572

gangetica, 572

Platyrruini, 5

Plecotus, 82

auritus, 8

Pocket Rats, 354

Pointer Dogs, 223

Polar Bear, 254

Polar Hares, 375

Polecat, 156

Polyprotodontia, 587

Pomeranian or Spitz Dog, 230

Poodle Dog, 227

Porcupines, 354

Porcus, 546

$$
\text { babyrussa, } 546
$$

Porpoises, 569

Portax, 502

" pictus, 502

Potamochcerus 546 africanus, 546

Potamochœerus porcus, 546

Potorous, $5^{8_{3}}$ tridactylus, 583

Potto Lemur, 72

Pouched auimals, 579

Pouched dog, 589

Pouched goplier, $35^{2}$

Pouched rats, 59I

Pouched squirrels, $5 \$ 6$

Prairie dogs, 316

Prairie hares, 379

Prairie mole, 295

Praire wolf, 197

Predacious Marsupials, 588

Prianuus moukey, 25

Prickly pocket mice, 352

Prioton, 39

Proboscidgas, 392

Proboscidea,
Procyon, 264

" cancrivorus, 268

lotor, 264

Procyonina, 264

Proechidna, 597

bruijuii, 597

if lalandii, 18 -

Pronghorned Animals, 513
Prosimii, 65

Psammomys, 332 obesus, 332

Pteromys, 3 I I petaurista, $3 \mathrm{II}$

، volaus, 3 I2 volucella, 312

Pteropina, 95

Pteropus, 79 edulis, so

Pug Dog, 22 I

Puy-Dog Bat, 82

Puma, I 20

Putorius, 156

" erminea, 162

"r foetidus, I56

if furo, $15^{8}$

"I lutreola, I6

" sarmaticus, I56

" vison, I64

"t vulgaris, 159

Pyrenean Ibex, 45I

Quachil, 354

Quagga, 419

Rabbit, 376

Raccoon, 264

Raccoon Dog, I98

Rangifer, 520

caribu, 521

Rasse, 141

Ratel or Honey Badger, I72

Razorback IVhale, 564

Red Backed Meadow Mouse, 347

Red or Bay-Lynx, I 33

Red Coati, 269

Red Deer, 526

Red Fox, 237

Red Howler, 53

Red or Patas Monkey, 34

Red Squirrel, 310

Redunca, 496 eleotragus, 497

Reed Antelopes, 496

Reindeer, 520

Rhabdogale; 175 mustelina, 175

Rhesus Monkey, 3

Rhinoceros, 424

$$
\text { " bicornis, } 426
$$
simus, 431 soudaicus, 426 sumatrinsis, 426 unicornis, 426

Rhinocerotidæ, 424

Rhiuolophus, $\mathrm{S}_{5}$ ferrum - equin - Sea Unicorn, 573

Semnopithecus, 25

Rhinopoma, 86

Rhinopomes, 86 microphyllum, $\$ 6$

Rice-field Mouse, 340

Rice-Rat, 336

Riet-bok, 497

Ringed Seal, 2-8

Rock Kangaroo, $5 \mathrm{~S}_{2}$

Rocky Mouutain Goat, 489

Rocky Mountain Marmot, 321

Rocky Mountain Pika, 379

Rocky Mouutain Pocket Rat 354

Rocky Mouutaiu Sheep, 462

Rorlentia, 305

Rodents or Guawing Animals, 305

Roe, 534

Root Vole, 348

Rorquals or Furrowed Whales, 564

Round-Headed Whales, 570

Royal Tiger, 92

Ruffed Lemur, 67

Ruvinauts, 433

Ruuving Mice, 332 entellus, 25

Rusa, 530

Rusa aristotelis, 531 hippelaphus, 530 porciuus, 531

Russian Flying Squirrel, 3 I2

Rusine Group, 530

Sable, 154

Saccomyina, 352

Sacred Baboon, 46

Sacred Moukeys, 25

Saddle-Back Seal, 278

Sage Rabbit, 379

Saguin ouistiti marmoset, 63

Saiga, 510

Saint Bernard Dog, 226

Salamauder, 353

Sambhar, 53I

Sand Rat, 33

Sanga, 480

Sarcophilus, 589

ursinus, 589

Sasin Antelope, 49 r

Sasyures, 590

Scalops, 295

argentatus, 295

aquaticus, 295

Scapanus, 296

" breweri, 296

Scirtetes, 320

nsendi, 296

Sciurida, 306 jaculus, 329

iurinæ, 306

Sciurus, 306

" aberti, 3 ro

" arizonensis, 310

carolinensis, 310

cinereus, 510

fossor, 310

hudsonius, 310

Iudoviciauus, 3 Io

minutus, 3 I

niger, 3 Io

vulgaris, 306

Scotch Greyhound, 2 I

Scotophiles, 86

Scotophilus, 86

Sea Bear, 288 welwitchii, 86

Sea Cow, 555

Sea Cows, 555

Seals or Fin-Footed Animals, 273

Sea Hog, 560

Sea Leopard, 27

Sea Lion, 286

Sea Otter, 179$$
\text { “ entellus, } 25
$$

Senegal Lion, 106 maurus, 27

Sennaar Hog, 542

Serval, I 9

Sharmindi Billi, 69

Sheep, 458

Sheep Dog, 229

Sheep and Goat Tribe, 4.4

Shetland Pony, 4 II

Shielded Rhinoceroses, 426

Short Horn Cow, $4 \mathrm{~S}_{4}$

Short-tailed Iudris Lemur, 67

Short tailed MIonkey, $6 r$

Short-tailed Saki, 59

Shrews, 297

Siamang, 23

Sigmodon, 336

Silky Tamarin, 63

Silver Fiox, 237

Silver MIoukey, 6

Silver or Prairie MLole, 295

Simia, 16

troglodytes, 16

Sirenia, 555

Six-banded Aruadillo, 389
Saccomyidxe, 352

Skunks, 173

Skye Terrier, 229

Slender L,oris, 68

Sleuder or Sacred Monkeys, 25

Slepez, 35 I

Sloth Bear, 260

Sloths, 381

Slow Loris, 69

Small Bears, 26

Smaller Chinchilla, 370

Small Pouched Animals, 584

Smooth-nosed Bats, 8I

Smooth-skinned Whales, 565

Snow Leopard, I I9

Snow Mouse, 346

Solenodon, 298

cubanus, 298

Somal Ass, 416

Soosoo, 572

Sooty Manghahey, 35

Sorex, 299

" bendiri, 302

، palustris, 302

" personata, 302

" platyrhinus, 300

Soricida, 297

vulgarus, 299

Soricinte, 299

Souslik, 315

South African Lion, I06

South American Deer, 534

South Australian Rock Kan- 
Sugar Squirrel, 586

Surilho, I7

Sus, 539

andamanensis, 542

" barbatus, 542

"“ celebensis, 542

" cristatus, 542

“ leucomystax, 542

“ uiger, 542

"papuensis, 542

“plicipleps, 544

" scrofa, 5.42

"' seunarensis, 542

" verrucosus, 542

"timorensis, 542

" vittatus, 542

Swamp Hare, 379

Swine, 539

Swiss Ox, 481

Synaptomys, 350

Synotus, cooperi, 350

"“ barbastellus, 82

Syrian Goat, 456

Taguan Squirrel, 3 I I

Tahr, 457

Tailless Ape, 39

Talpa, 295

europæa, 295

Talpidae, 294

Tamandua or Caguare, 387

Tamaudua, ${ }_{3}{ }_{7}$

Tamarins, 63 tetradactyla, 387

Tamias, 3 I 3

$$
\begin{array}{ll}
\text { " } & \text { htriatus, 3I3 } \\
\text { " } & \text { lysteri, 3I4 } \\
\text { " } & \text { quadrivittatus, 3I4 } \\
\text { lateralis, 3I4 }
\end{array}
$$

Tana, 296

Taurec, 297

Tapiridæ, 420

Tapirs, 420

Tapirus, 422

$$
\text { " americanus, } 422
$$

arpan, 406

Tarsidæ, 72

Tarsier, 72

Tarsius, 72 spectrum, 72

Tatnpoyu, 389

Tasmanian Devil, 589

Tasmauiau Vombat, 587
Tasmanian Porcupine Anteater, 596

Taxel, I7 I

Taxidea, I7 I

“ americana, I7I

" berlandieri, 172

Tayra, I68

Teledu or Stinking Badger, 173

Temminck's Pangolin, 394

Terriers, 229

Tetraceros, 504 quadricorvis, 504

Texas Hare, 379

Texas Lynx, 133

Thirteen-lined Spermophile, 3 I 6

Thomomys, 354 " clusius, 354 talpoides, 354

Three-banded Armadillo, 39 I

Three-toed Sloths, $3 \mathrm{~S}_{2}$

Thumbless Monkeys, 29

Thylacinus, 589

Tiger, 92 cynocephalus, 5 S9

Tiger Polecat, $I=6$

Timor Hog, 542

Tolypeutes, 391 triciuctus, 39

Toothed Whales, 566

Toothless Animals, $38 \mathrm{I}$

Tragulidæ, 538

Tragulus, 538

kanchil, $53^{8}$

Trakehuen Iforse, 408

Tree-Climbing Ant Fiaters, 387

Tree or Climbing Porcupine, 356

Tree Kangaroos, 582

Tree Squirrel, 3 II

Trichechidre, $2 \mathrm{~S}_{2}$

Trichechus, 282

" rosmarus, $28_{2}$

Trichosurus, 585

$$
\text { vulpecula, } 5^{85}
$$

True Jerboas, 328

Tuco-Tuco, 367

Tufted $\mathrm{Hog}, 546$

Tupaia, 296

Tupaias, 296

Tupaiidæ, 296

Two-Horned Rhinoceros, 426
Two Humped Camel, 442

Two-toed Ant-eater, 388

Two-toed Sloth, $38_{2}$

Ulmer Mastiff, 2 I 8

Unau or Two-Toed Sloth, $3 S_{2}$

Ungko, 23

Ursidæe, 243

Ursinæ, 2.44

Ursine Colobus, 30

Ursine Seal, 288

Urson or Canadian Porcupine, 356

Ursus, 244

". americanus, 252

“ arctos, 244

“ cinereus, 250

" cunamoneus, 252

" malayanus, 25

" maritimus, 254

" richardsonii, 250

Urva, I50 orquatus, 253

Vampire Bat, $\mathrm{S}_{4}$

Vari or Ruffed Lemur, 67

Varying Hare, 375

Vespertilio, 82

$$
\text { ". } \quad \text { murinus, } \mathrm{S2}_{2}
$$

Vesperugo, $\mathrm{S}_{2}$

$$
\text { "، pipistrellus, } 79
$$

Vicugna, 447

Virginia Deer, 531

Virginian Opossum, 59

Viscacha, $37 \mathrm{I}$

Viverra, I 39

" civetta, 140

“ genetta, I4I

“ malaccensis, IfI

Viverridæ,

Viverrine Cat, Is

Voles, 344

Vulpes, 232

"i cinereo-argentatus, 241

" corsac, 239

"fulvus, 237

- lagopus, 238

a littoralis, 2.43

“ macrurus, 237

" velox, 238

vulgaris, 232

"c zerdo, 240
Vulpine Phalanger, 585

Walrus Family, 28

Wanderoo Moukey, 50

Wapiti, 529

Wara Rhinoceros, 426

Wart Hogs, 547

Water-buck, 497

Water Opossum, 594

Water Pig or Capybara, 364

Water Slirew, 302

Water Vole, 345

Wau-wau, 23

Weasel Group, 156

Weasels, I59

Welwitsch's Bat, 86

Western Fox Squirrel, 310

IVbalebone IVhales, 562

IVhales, 559

White-Bearded Hog, 542

White Footed Monse, 340

White-handed Gibbou, 23

White-Headed Saki, 58

White Lipped Peccary, 548

White-Tailed Deer, 534

White Whale, 569

Vidow Monkey, 59

Wild Boar, 540

Wild Cat, 99

IVild Dogs, I 88

IVild Horse, 406

Wild Pigs, $54^{2}$

IVild Sheep, 548

Ving Handed Animals 75

Volverine, I66

Wolves Proper, I9o

Vombats, 587

Voodchuck, 32 I

Wood Mouse, 336

Wood Rabbit, 376

Wood Rats, 336

Woolly Echidna, 597

Woolly Cheetah, I35

Xeriss, 3I 4

"rutilus, 5 I4

Yaguarundi, I22

Yak, or Gruntiug Ox, 468

Yapock, 594

Yellow-legged Kangaroo, $58 z$

Zebra, 4Ig

Zebra-wolf, $5^{89}$

Zebu, 480

Zorrillas, 175 . 


\section{INDEX TO ILLUSTRATIONS.}

Lion and Lioness, Frontispicte Gorilla

Family of Gorillas

The Gorilla and the Leopard

Face of a Chimpanzee.

Profile of a Chimpanzee

The Gorilla

Orang-utan

Family of Chimpanzees

Champanzees at School

Feurale Oraug-utan and Child

Young Orany-utan

Baboons (colored) opp

White-hauded Gibbons

The Wau-Wau

Ursine Colobus

Black Colobus

Hoonuman Monkeys

Budeng or Negro Monkey

IIoonuman Moukey's

Long-nosed Monkeys .

Diana Monkeys . .

Guereza Monkeys :

Green Monkey's.

Red or Patas Monkey

Sooty Mangabey. .

Bomnet Monkey

Common Macaque

Bhunder or Rhesus Monkey

Pig-taiied Macaques

Black Baboon

Magot-Barbary or Tailless Ape

Common Baboon .

Cliacma Baboon...

Sacred Baboon or I1 amadryas

Gelada Baboon . . . .

Mandrill.

Drill

Wanderoo.

Red Howlers

Black Howler Mlonkeys

Miriki Spider Monkey .

Coaita Spider Monkey

Chameck Spicler Monkey

Gold-Faced Monkey

Humboldt's Lagotlirix ionkey.

Cai Weeper Capuchin Monkeys

A Group of Capuchius .

Cuxio Monkey ... .

Hairy Sakj

White Headed Saki Monkey

Short-tailed Monkey

Lovely Haired Monkey. .

Squirrel Monkeys

Silky Tamarin..

Night Monkeys. .

Common Marmosets.

Piuche Narmoset .

Vari, or Ruffed Lenumr.

Short-tailed Indris Lemur

Cat-like Lemur.

Mongoose Lemur

Macaco or Black Lemur.

Grav or Geutle IJeniur.

Fork-Crowned Lemur

Sleuder Loris

Stender Loris Iemur.

Stow Loris Lemur.

Potto Lemur

Angwántibo Lemur

Little Galago Lemur.

I,arge-eared Galago Lemur

Aye-Aye .

Barbatelle or Pug-Dog Bat

Kaloug Bats . .

Kalong Bat

Pipistrelle Bat.

Daube ston's Bat.

Long-eared Bat.
Noctule Bat

Egyptian Rhinoporue

Vaupire Bat

Greater Ilorseshoe Bat

Greater IIorseshoe Bat

Velwitsch's Bat

Royal Tiger

Royal Tiger

Tigress and Cubs

An Interrupted Meal

Tiger Attacking a Buffalo

A Tiger llunt

Marbled Cat

Common Wild Cat

Female Wild Cat and Young

The Egyptian Cat

The Domestic Cat

The Angora Cat

Head of the Barbary I,ion

The Barbary Lion

Fenale Panther and Young (colored) opp

The Senegal Lion

Lions Attacking a Buffalo

The Leopard

Leopardess and Young

The Black Panther

The Long-tailed Panther

The Ounce

The Leopard Cat

The Serval

Puma Attacking an Ant Bear.

The Cougar or Puma

The Jaguar

Jaguar Attacking a Tapir

Ocelot and Sloth.

The Pampas Cat

The Marguay or Tiger Cat

The Long-tailed Tiger Cat

The Common Lyix.

The Pardine Lynx .

Leopardand Tapir (colored) opp

The Caracal Lynx

Peeshoo or Canadiau Lyux

Common Jungle Cat

The Fabliad or African Chectal

Cheetals or Hunting Leopard.

The Fonssa or Cryptoprocta.

The African Civet

The Lesser Civet or Rasse

The Common Genette

The Asiatic Civet

Indian Paradoxure or Palm Cat

The Commou Paradoxure or MIusang I4

The Masked Paradoxure - Mrest.

The Ichnemunon

Mangue or Kusimanse . . . 146

The Mungo ....... I47

The Banded MIungoos . . . . . . . It7

Crab Iungoos

The Foxy Mrungoos . . . . . 14

The Suricate . . . . . . . I49

The Pine Marten . . . . . . . . 151

The Stone Marten. . . . . . . . 153

The Sable . . . . . . 155

The Polecat . . . . I57

The Ferret

Weasel attackiug a Brown Rat

The Errmine or Stoat

The Europeau Mink

The Glutton or Wolverine

The Tayra

The Common Badger :

The Anierican Badger or $\mathrm{T}$ axel

The Ratel of JIoney-Badger

The Teledn or Stinking Batger,

The Suritho.

The Skunk.

The Cape Zorrilla
The Common Otter

The American Otter.

Sea Otter or Kalan

Otter and a

Stone Marten . . . . . . . I81

Spotted Hyæusas . . . . . . $18_{3}$

Brown Hyænes . . . . . . . . 184

Striped Hyienas........ 185

The Aard-WoIf . . . . . 186

... ISS

A Pack of Wolves . . . . . . I IS9

The Jackal Wolf . . . . . . . 190

Guara . . . . . . 191

Aguara or Brazilian Fox . . . . 192

The Striped Wolf ....... 193

The Jackal ......... I94

The Wolf. . . . . . . . . . 195

Cape Jackal . . . . . 196

Coyote or Prairie Wolf . . . . . 197

Raccoon Dog. ......... 198

The Crab-eatiug Dog . . . . 199

Ilyæua Dog . . . . . . 200

Indian Wild Dog or Kolsul _... 20I

Malay Wild Dog or Adjag . . . . 201

Alpine Wolf Prize Dogs of the International Dog

Show in Hanover. . . . . . 205

Diugo . . . . . . . 207

Prize Dogs of the International Prize

Sliow at Cleve

The Greyhound . -

Italian Greyhound . . . . 2I2

Scotcl Greyhound . . . . 213

1)anisl Dog. . . . . . . . 214

The German Mastiff . . . . 215

The Bulldog . . . . . . . 216

The Pug-Dog . . . . . 217

The Dog of Tibet . . . . . 218

Badger Dog or Dachshund . . . . 219

Poluter...... 219

Retriever . 220

The Schweiszhuud or German Blood-

hound

The Staghound. . .

The Foxhoutd … $\ldots 223$

The Beagle . . . . . . 224

The Newfoundland Dog . . . . . 225

The St. Berıard Dog . . . . . . . 226

The Poodle. . . . . . . 227

The Skye Terrier . . . . $22 \mathrm{~S}$

The Sheep Dog . . . . . . . 229

The Pomeranian Dog or Spitz . 230

Eskimo Dog . . . . . 23I

A Fox Family Diniug . . . . 233

A Fanily of Foxes. . . . . . 235

The Red Fox. . . . . . . 237

The Kit Fox . . . . . . . 237

The Arctic Fox . . . . . . 239

The Fermnec . . . . . . . 240

Corsac . . . . . 24I

Long-eared Fox $\cdots 2+1$

The Gray Fox . . . . . . . . 242

Bear and Young Bathing . . . . 245

Grizzly Bear and Bisons . . . . . 247

The Grizzly Bear . . . . . . . . 249

The Black Bear. . . . . . . . 251

Black Himalayan Bear . . . . 253

Mralayaı Bear . . . . . . 255

I'olar Bear and Cubs . . . . . 257

The Polar Bear . . . . . . 259

Laliated or Sloth Bear . . . . 26

Ailuropus ......... 262

Panda . . . . . . . 2 263

Binturong . . . . . . . 265

Raccoon ......... 267

Raccoon . . . . . 268

Coati . . . . . 269 26

Kinkajou . . . . . . . 27I

Cacomixle . . . . 27I 
Common Seal

The Sea Leopard

Saddle-Back Seal

Crested or Bladder-Nose Sea

Elephant Sea

valrus.

Sea Iions

Fur Seal or Sea Bear

The Hedgehog

Common MIole

Common American Mole

Star-Nosed Mole

The Tana

Elephant Slirew

Tanrec

The Alniqui

Common Slurew

Broad-Nosed Slirew

Mole Slirew

Domestic Shrew

Water Shrew

Etruscan Slirew

Desman

Colugo

Skull-Caps or Lophiourys

Common Squirıel

Gray Squirrels

Chickaree or Red Squirrel

Taguan

Assapans or Americau Flying Squir rels

Chipmuik"

Cerus

Burmuduk

Souslik

Prairie Dogs

Bobac

Alpine Maruot

Woodchuck

Loir .

Common f)arumonse . 323

Beaver. . . . . . . . . . 325

Jumping Mouse . . . . . . . . 327

Egyptian Jerboa . . . . . . . . .327

Alactaga . . . . . . . . 329

Jumping liare. . . . . . . 33r

Black Rat . . . . . . . . . 333

Browil Rat........... 333

Cotton Rat .......... . . 335

Florida Wood Rat. . . . . . . . . 335

Coumon Mlouse . . . . . . . . . . 337

Barbary Mouse . . . . . . 337

White-Footed Mlouse . . . . . . 339

Mfearlow Nlouse
Wood Mlouse or Long-tailed field 339

Mlouse
Ilarvest Mice Attacked by Suake. 339
341

Hansters............ 343

Muskrat . . . . . . . . 345

Suow Mlouse. . . . . . . . 345

Water Vole . . . . . . 346

Red-Backed Meadow Mlouse . . . 347

American Meadow Mouse . . . . 347

Field Mouse or Campagnol . . . 349

lenmiugs. . . . . . . . . . 349

Mole Rat

Or's's l'ocket Miouse

Least Pocket Mouse . . . . . . . 353

Pouched Gopher. . . . . . . . . . 353

Common Pocket Rat. . . . . . . . 354

Common Porcupine . . . . . . . . 355

Urson or Cauadian Porcupine. . . . 357

Mexican Porcupine . . . . . . . . 357

Brush-tailed Porcupine . . . . . 35 S

Coendou

Guinea Pigs.

Mara or Patagonian Cavy. . . . . . 361

Conmon Agouti . . . . . . . . 363

Paca ............. 364
Capybara or WVater Pig .

Octodon

Tuco-'Tuco

liutia Tongo.

Coypu or Nutria

African Ground Pig .

Common Cininchilla

Smaller Chinchilla

Cuvier's Lagoti.

Viscacha

Conmmon Hare.

Alpiue Hare

European Rabbit

American Varyiug IIare

Northern Prairie Hare.

Wood Rabbit or Cotton-tail

Americau Pika

Alpine Crying Hares.

Unau or Two-toed Sloth

Ai or Three-toed Slotlı

Great Ant-eater or Ant-liear

Tamandua

I,ittle Ant-eater

Six-baniled Armadillo

Bolita or Three-banded Armadillo.

Giant Tatu

Bichociego

Pangolin

Aark-vark

Temminck's Paugolin

Indian Elephant

African Elephant

Tarpan

Arabiau Steed.

Traklieen Horse

English Thorouglibreil ilorse

Percheron Ilorse

American Trotting Horse

Shetland Pony.

Koulan

Onager

Domestic Ass

Africau Wild Ass.

Quagga .

Dauw or Burclicil's Yulura

Malayan 'Tapir

Americen Tapir.

Indian Rluinoceros.

Two-liorued Rhinoceros.

Square-mouthed Rhinoceros..

Cony .

Drouncelary

Bactrian Canel

I,lama

Alpaca

Vicugua.

Ibex or Steinlock. . . . . 410

Pyrenean Ibex.

Aegagrus Goat

llarklioor.

Angora Goat.

Tahr

loudad.

Moufflon

Kratsclikar or IVild sheep.

Bic Ilord

Merino Slieep

Persian Domestic Slicep.

Musk-Ox

liuropean Bisol1

Yak

American Bison

Gayal

Gaur

Banteng

Sanga

\%ebu

Park $\mathrm{Ox}_{\mathrm{x}}$.
Freiburg or Swiss $\mathrm{Os}, \quad 4 \mathrm{Sz}_{2}$

Jersey Cow . . . . . . 483

Dutch Cow.

Durham or Short-horn Cow. . . . 454

Hereford Bull . . . . . . . . 485

Cape Buffalo . . . . . . . . 457

Rocky Mountaiu Goat . . . . . 459

Sasiu . . . . . . . 49

Gazelle . . . . . . . . . 493

Springhok .. . . . . . . . . 494

Hartebeest ... 495

Rietbok or Reed Antelope . . . . . 496

Water-Buck . . . . 497

Passan Pursued by Hyaena Dogs . . 499

Addax ... 500

Foodoo . . . . . . . . 501

Eland .... 503

Four horned Antelope. . . . . . 505

Bush-Buck . . . . 505

Clramois . . . . . . 507

Saiga . . . . . . . . 511

Guu

Croughor ............. 515

Elk ........... 517

Moose ...... 519

Reindeer . . . . . . . . 522

Fallow Deer (colored) opp. . . . . 524

Fallow Deer . . . . . . . 525

Stag or Red l)er . . . . . . . 527

IVapiti........ . . 529

Axis Deer . . . . . . . . 530

Sambhar ......... . . 531

Virgiuia Deer. . . . . . . 532

Cawpus Deer . . . . . . . . 533

Roe Deer . . . . . . . . . . . 535

Muntjak .......... . 537

Mlusk l leer . . . . . 539

Kanchil ...... . . 539

I'emale Wild Boar and Youug. . . 54 r

Berkshire $\mathrm{Hog}$. . . . . . . . . . 543

Harrisson Ilog . . . . . . . . . 543

Maskerl Ilogs. . . . . . . . . 544

Tufted Hog. . . . . . . . . . 545

Babirusa . . . . . . , 547

Wart llog . . . . . . . . . . 548

Collared l'eccary . . . . . . . 549

Ilippopotamus ....... 551

Attack on a llippopotamus . . . 553

Lamintin or Anerican Manatee . 556

1)ugrons . . . . . 557

Razor-back Whale ...... 563

Pike Whale. . . . . . . . . . 565

Greenland Trliale....... . . 567

Grampus. ...... 568

l'orpoise . . . . . . . . 569

White Whale. . . . . . . 570

Ca'ing or Ptlot Whale . . . . . 571

Jolpliin . . . . . . . . 572

Inia . . . . . . . . 573

Soosoo . . . . . . . . . 574

Narwbal . . . . . . . . 575

Sperril Whale........ . . 577

Giant Kaugaroo ....... 578

Vellow-legged Kaugaroo..... . . 5 SI

Bear Kangaroo . . . . . . . $5 \mathrm{SI}$

Kangaroo Rat . . . . . . . $5^{\mathrm{S}_{3}}$

Opossim Rat . . . . . . . $5 \mathrm{~S}_{3}$

Spotted Cuscus ..... . 584

Koala or Anstralian Pouched Bear . $5 \mathrm{~S} 5$

Vulpine Phalanger or Coosoo... . 585

Sugar Squirrel . . . . . . . . 5 S 6

Oppossum Mionse. . . . 581

Lonc nosed Bandicoot...... 589

Zebra-wolf or Pouched Dog. . . . . 590

Tasnanian Devil . . . . . . . 591

Spotterl Dasyure... . 592

Opposum and Chipmunk . . . . 593

l'orcupim Ant-eater . . . . . . 597

Duck-mole . . . . . . . 599 




